ORP-56320

Revision 0

\title{
Final Report - IHLW PCT, Spinel T1\%, Electrical Conductivity, and Viscosity Model Development, VSL-07R1240-4
}

Prepared for the U.S. Department of Energy

Assistant Secretary for Environmental Management

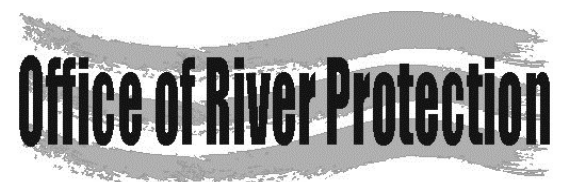

P.O. Box 450

Richland, Washington 99352 
ORP-56320

Revision 0

\section{Final Report - IHLW PCT, Spinel T1\%, Electrical Conductivity, and Viscosity Model Development, VSL-07R1240-4}

\author{
A. A. Kruger \\ Department of Energy - Office of River Protection \\ G. F. Piepel \\ Pacific Northwest National Laboratory \\ S. M. Landmesser \\ Pacific Northwest National Laboratory \\ I. L. Pegg \\ The Catholic University of America
}

\author{
A. Heredia-Langner \\ Pacific Northwest National Laboratory \\ S. K. Cooley \\ Pacific Northwest National Laboratory \\ H. Gan \\ The Catholic University of America \\ W. K. Kot \\ The Catholic University of America
}

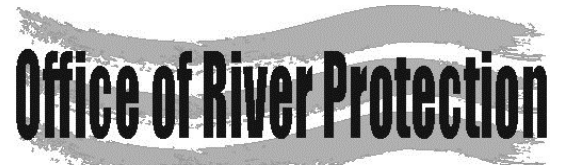

\section{P.O. Box 450}

Richland, Washington 99352 
ORP-56320

Revision 0

TRADEMARK DISCLAIMER

Reference herein to any specific commercial product, process, or service by tradename, trademark, manufacturer, or otherwise, does not necessarily constitute or imply its endorsement, recommendation, or favoring by the United States Government or any agency thereof or its contractors or subcontractors.

This report has been reproduced from the best available copy.

Printed in the United States of America 
VSL-07R1240-4

\title{
Final Report
}

IHLW PCT, Spinel $T_{1 \%}$, Electrical Conductivity, and Viscosity Model Development

\author{
prepared by
}

Greg F. Piepel, Scott K. Cooley, Alejandro Heredia-Langner, and Samantha M. Landmesser ${ }^{(a)}$

\author{
Statistical Sciences \\ Pacific Northwest National Laboratory \\ Richland, WA 99352 \\ and
}

Wing K. Kot, Hao Gan, and Ian L. Pegg ${ }^{(\text {b) }}$

Vitreous State Laboratory

The Catholic University of America

Washington, DC 20064

${ }^{\text {(a) }}$ For the River Protection Project-Waste Treatment Plant

Support Program for Bechtel National, Inc.

${ }^{(b)}$ For Duratek, Inc. and Bechtel National, Inc.

January 23, 2008

Rev. 0 
The Catholic University of America

Vitreous State Laboralory
IHLW PCT, Spinel T Tr, Electrical Conductivity, and Viscosity Model Development Final Report, VSL-07RI240-4, Rev 0

Document Title: $\quad$ IHLW PCI, Spinel $T_{1 \%}$, Electrical Conductivity, and Viscosity Model Development

Document Number and Revision: VSL-07R1240-4, Rev. 0

Issue Date:

January 23, 2008

Performing Organization: Vitreous State Laboratory, The Catholic University of America (VSL), Pacific Northwest National Laboratory (PNNL)

Test Specifications: 24590-HLW-TSP-RT-01-006, Rev. 1 (VSL)

24590-WTP-TSP-RT-02-001, Rev. 0 (PNNL)

Test Exceptions: $\quad$ 24590-WTP-TEF-RT-03-078, Rev. 0 (VSL)

24590-WTP-TEF-RT-03-040, Rev. 0 (PNNL)

24590-WTP-IEF-RT-07-00017, (PNNL and VSL)

Test Plans: $\quad$ VSL-02T7800-1, Rev 1 (VSL)

TP-RPP-WTP-179, Rev. 1 (PNNL)

R\&T Focus Area(s): $\quad$ HLW Waste Form Qualification

Test Scoping Statement(s): VSL-13, HLW Product Properties Modeling (VSL)

VSL-14, HLW Processing Properties Modeling (VSL)

PNWD B-72, Demonstrate Compliance with Glass Durability Requirements for HLW (PNNL)

\section{Completeness of Testing:}

This report describes the results of work and testing specified by the above-listed Test Specifications, Test Plans, and Test Exceptions.. The work and any associated testing followed established quality assurance requirements and were conducted as authorized. The descriptions provided in this report are an accurate account of both the conduct of the work and the data collected. Results required by the Iest Plans are reported Also reported are any unusual or anomalous occurrences that are different from the starting hypotheses. The test results and this report have been reviewed and verified

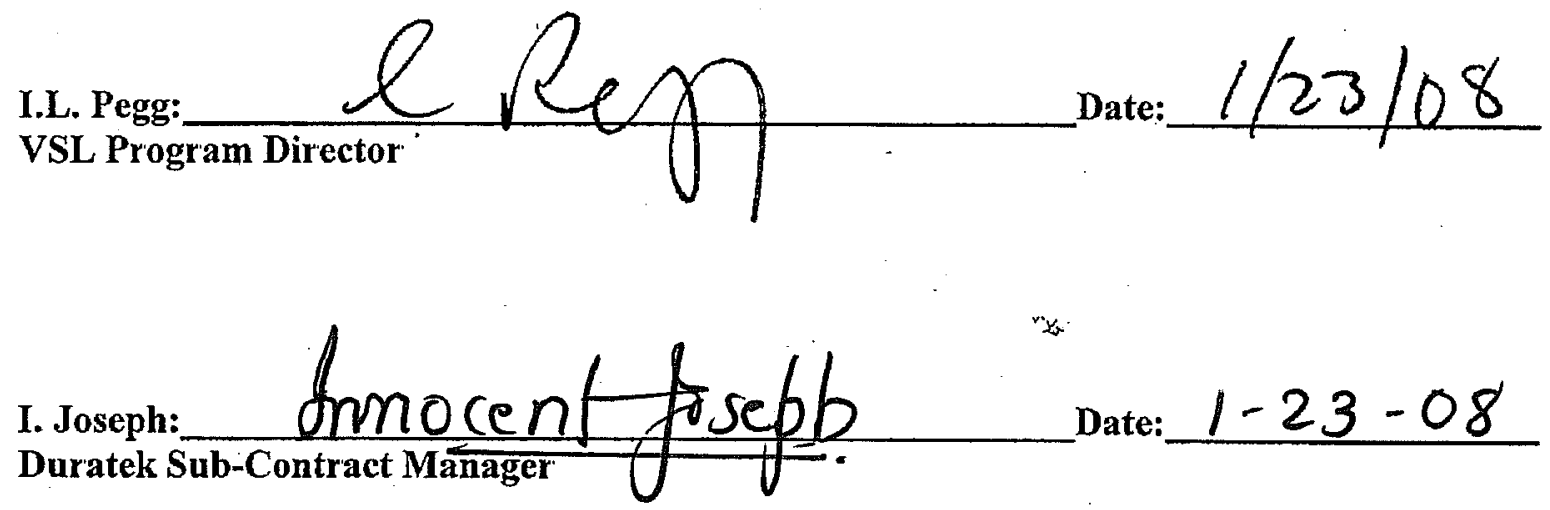




\section{TABLE OF CONTENTS}

\begin{tabular}{|c|c|}
\hline & \\
\hline & \\
\hline & \\
\hline & KY UF IESTINU \\
\hline CTION & J 1 INTRODUCTION \\
\hline 1.1 & Test Objectives...... \\
\hline 1.2 & Test Overview...... \\
\hline 1.3 & How Test Objectives Were Achieved.. \\
\hline ECTION & J 2 DATA FOR DEVELOPING AND VALIDATING HLW GLASS PROPERTY \\
\hline & MODELS . \\
\hline 2.1 & Data Available for Modeling HLW Glass Properties . \\
\hline 2.1 .1 & Phase 1 Initial Test Matrix (HLW02) Glasses...... \\
\hline 2.1 .2 & Phase 1 Augmentation Test Matrix (HLW03) Glasses........................... \\
\hline 2.1 .3 & HLW04 Glasses for Actual-Waste (AY-102/C-106) Testing Support.... \\
\hline 2.1 .4 & 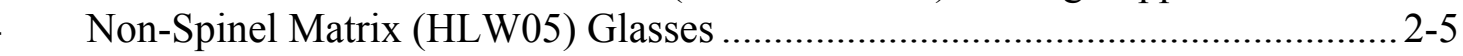 \\
\hline 2.1 .5 & 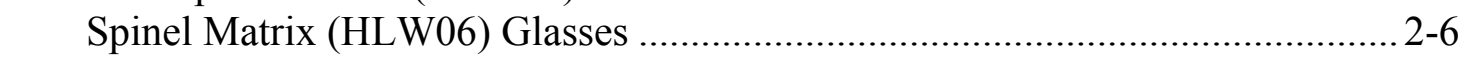 \\
\hline 2.1 .6 & HLW07 Test Matrix Glasses . \\
\hline 2.1 .7 & HLW-ALG Glasses... \\
\hline 2.1 .8 & HLW98 \\
\hline 2.1 .9 & Actual HLW Glasses.... \\
\hline 2.1 .10 & Summary of HLW Glasses Available for Property Modeling. \\
\hline 2.2 & Data Available for Validating PCT and Spinel $\mathrm{T}_{1 \%}$ Models for HLW Glasses...... \\
\hline 2.2 .1 & 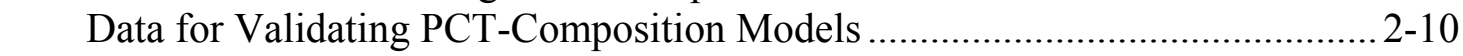 \\
\hline 2.2 .2 & Glasses for Validating Spinel $\mathrm{T}_{1 \%}$-Composition Models.......... \\
\hline SECTION & J 3 EXPERIMENTAL PROCEDURES AND CALCULATIONS... \\
\hline 3.1 & Glass Batching and Melting. \\
\hline 3.1 .1 & Batching of Starting Mate \\
\hline 3.1 .2 & Glass Melting. \\
\hline 3.2 & Analyses of Glass Compos \\
\hline 3.3 & Product Consiste \\
\hline 3.4 & Fraction Temperature $\left(\mathrm{T}_{1 \%}\right) .$. \\
\hline 3.5 & Electrical Conductivity Testing ..... \\
\hline 3.6 & Viscosity Tes \\
\hline 3.7 & Canister Centerline Cooling. \\
\hline ECTION & J 4 PCT, $\mathrm{T}_{1 \%}$, ELECTTRICAL CONDUCTIVITY, AND VISCOSITY RESULTS .. 4-1 \\
\hline 4.1 & 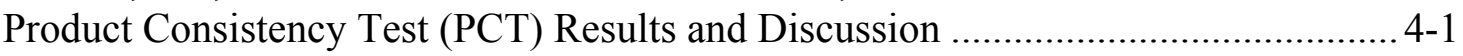 \\
\hline 4.1 .1 & PCT Results . \\
\hline 4.1 .2 & Discussion of PCT Re \\
\hline 4.2 & One-Percent Crystal Fraction Temperature $\left(\mathrm{T}_{1 \%}\right)$ Results and Discussion . \\
\hline 4.2 .1 & $\mathrm{~T}_{1 \%}$ Results. \\
\hline 4.2 .2 & Discussion of $\mathrm{T}_{1 \%}$ Results \\
\hline 4.3 & Electrical Conductivity Results a \\
\hline 4 & Electrical Conductivity Results.................... \\
\hline
\end{tabular}


4.3.2 Discussion of Electrical Conductivity Results............................................ 4-7

$4.4 \quad$ Viscosity Results and Discussion .................................................................. 4

4.4.1 Viscosity Results............................................................................... 4-8

4.4.2. Discussion of Viscosity Results................................................................. 4-9

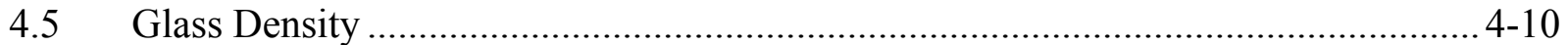

SECTION 5 MODELS RELATING PCT BORON, LITHIUM, AND SODIUM

RELEASES TO HLW GLASS COMPOSITION ........................................... 5-1

5.1 PCT Release Data Used for Model Development and Validation............................. 5-1

5.1.1 Model Development Data for PCT Releases ............................................. 5-1

5.1.2 Primary Model Validation Approach and Data ..............................................5-5

5.1.3 Secondary Model Validation Approach and Data .......................................... 5-6

5.1.4 Separate Data for Validating PCT Models .................................................. 5-7

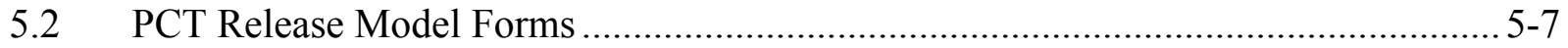

5.2.1 Mixture Experiment Model Forms .............................................................. 5-8

5.2.2 Normalization and Transformation of PCT Release Values...............................5-8

5.3 Property-Composition Model Results for PCT-B Release ..................................... 5-10

5.3.1 Results from Full Linear Mixture Model for IHLW PCT-B ............................. 5-10

5.3.2 Results from Reduced Linear Mixture Model for IHLW PCT-B..................... 5-12

5.3.3 Results for 18-Term Partial Quadratic Mixture Model for IHLW PCT-B ....... 5-16

5.3.4 Results for 15-Term Partial Quadratic Mixture Model for IHLW PCT-B ....... 5-19

5.3.5 Recommended IHLW PCT-B Models......................................................... 5-20

5.4 Property-Composition Model Results for PCT-Li Release .................................... 5-20

5.4.1 Results from Full Linear Mixture Model for IHLW PCT-Li ........................... 5-20

5.4.2 Results from Reduced Linear Mixture Model for IHLW PCT-Li .................... 5-22

5.4.3 Results for 18-Term Partial Quadratic Mixture Model for IHLW PCT-Li ....... 5-25

5.4.4 Results for 15-Term Partial Quadratic Mixture Model for IHLW PCT-Li ....... 5-28

5.4.5 Recommended IHLW PCT-Li Models ......................................................... 5-29

5.5 Property-Composition Model Results for PCT-Na Release .................................... 5-29

5.5.1 Results from Full Linear Mixture Model for IHLW PCT-Na .......................... 5-30

5.5.2 Results from Reduced Linear Mixture Model for IHLW PCT-Na................... 5-32

5.5.3 Results for 18-Term Partial Quadratic Mixture Model for IHLW PCT-Na ...... 5-35

5.5.4 Results for 15-Term Partial Quadratic Mixture Model for IHLW PCT-Na ...... 5-38

5.5.5 Recommended IHLW PCT-Na Models...................................................... 5-39

5.6 Comparison and Down Selection of PCT-B, PCT-Li, and PCT-Na Models for HLW Glasses............................................................................................. 5-39

5.7 Recommended and Second-Choice Models with Bias-Correction for PCT-B, PCT-Li, and PCT-Na Releases from HLW Glasses............................................. 5-41

5.8 Example Illustrating PCT Model Predictions and Statistical Intervals ...................5-43

5.9 Suitability of the Recommended IHLW PCT-B, PCT-Li, and PCT-Na Models for Application by the WTP Project............................................................. 5-46

SECTION 6 MODELS RELATING ONE-PERCENT CRYSTAL FRACTION

TEMPERATURE $\left(\mathrm{T}_{1 \%}\right)$ TO HLW GLASS COMPOSITION ............................. 6-1

$6.1 \quad \mathrm{~T}_{1 \%}$ Data Used for Model Development and Validation ........................................ 6-2

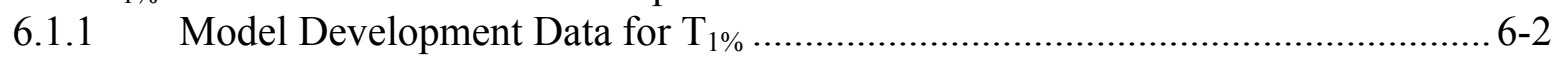

6.1.2 Primary Model Validation Approach and Data ............................................. 6-5

6.1.3 Secondary Model Validation Approach and Data ........................................ 6-6 


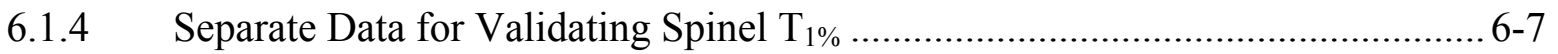

6.2 Spinel $\mathrm{T}_{1 \%}$ Model Forms.................................................................................. 6-8

6.3 Property-Composition Model Results for Spinel $\mathrm{T}_{1 \%}$ Linear Mixture Models ........... 6-9

6.3.1 Results from Full Linear Mixture Model for IHLW Spinel $\mathrm{T}_{1 \%}$.................... 6-10

6.3.2 Results for Reduced Linear Mixture Models for IHLW Spinel $\mathrm{T}_{1 \%} \ldots \ldots \ldots \ldots \ldots . . . . .6-12$

6.3.3 13-Component Reduced Linear Mixture Model for IHLW Spinel $\mathrm{T}_{1 \%} \ldots \ldots \ldots . . .6-15$

6.4 Results for Partial Quadratic Mixture Models for IHLW Spinel $\mathrm{T}_{1 \% \ldots \ldots \ldots . . . . . . . . . . . . .6-15}$

6.4.1 First 20-Term Partial Quadratic Mixture Model (PQM1a) for

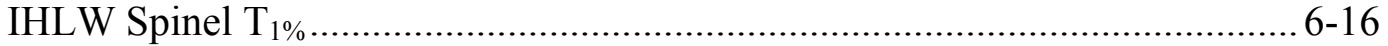

6.4.2 Second 20-Term Partial Quadratic Mixture Model (PQM1b) for

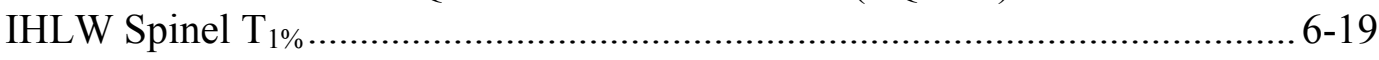

6.4.3 18-Term Partial Quadratic Mixture Model for Spinel $\mathrm{T}_{1 \%}$ Derived from the

13-Component Reduced Linear Mixture Model.............................................. 6-22

6.5 IHLW $\mathrm{T}_{1 \%}$ Model Results Based on 144 Spinel-Only Glasses ............................... 6-22

6.6 Recommended and Second-Choice Spinel $\mathrm{T}_{1 \%}$ Models for HLW Glasses ............... 6-24

6.7 Example Illustrating Spinel $\mathrm{T}_{1 \%}$ Model Predictions and Statistical Intervals........... 6-25

6.8 Suitability of the Recommended IHLW Spinel $\mathrm{T}_{1 \%}$ Model for Application by the

WTP Project

SECTION 7 MODELS RELATING ELECTRICAL CONDUCTIVITY TO HLW GLASS

COMPOSITION AND TEMPERATURE .................................................... $7-1$

7.1 Electrical Conductivity Data Used for Model Development and Validation .............. 7-1

7.1.1 Electrical Conductivity Model Development Data......................................... 7-1

7.1.2 Primary Electrical Conductivity Model Validation Approach and Data ............ 7-5

7.1.3 Secondary Electrical Conductivity Model Validation Approach and Data ......... 7-5

Electrical Conductivity Model Forms................................................................ 7-6

7.2.1 Temperature Dependence of Electrical Conductivity ..................................... 7-7

7.2.2 Model Forms for the Temperature and Composition Dependence of Electrical

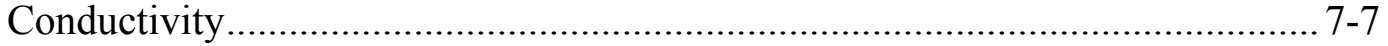

7.2.3 Transformation of Electrical Conductivity ................................................. 7-8

7.3 Model Results for IHLW Electrical Conductivity with the Truncated-T2 Equation

Parameters Expanded as Linear Mixture Models............................................... 7-9

7.3.1 Results for 44-Term Electrical Conductivity Model with the Truncated-T2 Equation Parameters Expanded as 22-Component Linear Mixture Models........ 7-9

7.3.2 Results for a 27-Term Electrical Conductivity Model with the Truncated-T2 Equation Parameters Expanded as Reduced 14-Component Linear Mixture Models........................................................................................................ 7-11

7.3.3 Results for 27-Term Electrical Conductivity Model with the Truncated-T2 Equation Parameters Expanded as 14-Component Reduced Linear Mixture Models........................................................................................... 7-12

7.4 Investigation of Adding Crossproduct Terms to, and Eliminating CompositionTemperature Terms from, the 27-Term Truncated-T2 Linear Mixture Model........ 7-14

7.5 Results for the Recommended 22-Term Electrical Conductivity Model.................. 7-15

7.5.1 Results for the Recommended 22-Term Electrical Conductivity Model Fitted to the 208-Glass Modeling Dataset ................................................... 7-15

7.5.2 Validation Results for the Recommended 22-Term Electrical Conductivity Model 
7.6 Example Illustrating Electrical Conductivity Model Predictions and Statistical

Intervals ........................................................................................ $7-18$

7.7 Suitability of the Recommended Electrical Conductivity Model for Application

by the WTP Project ....................................................................................... 7-20

SECTION 8 MODELS RELATING VISCOSITY TO HLW GLASS COMPOSITION

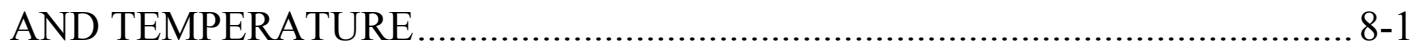

8.1 Viscosity Data Used for Model Development and Validation ................................ 8-1

8.1.1 Viscosity Model Development Data ............................................................. 8-1

8.1.2 Primary Viscosity Model Validation Approach and Data ................................ 8-5

8.1.3 Secondary Viscosity Model Validation Approach and Data ............................ 8-6

8.2 Viscosity Model Forms........................................................................................ 8- 8

8.2.1 Temperature Dependence of Viscosity ................................................... 8 8 -

8.2.2 Model Forms for the Temperature and Composition Dependence of Viscosity . 8-7

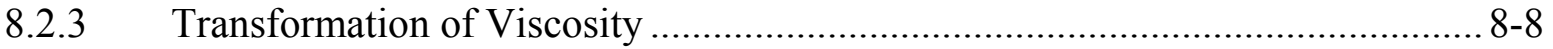

8.3 Model Results for IHLW Viscosity with the Truncated-T2 Equation Parameters

Expanded as Linear Mixture Models ..................................................................... 8-9

8.3.1 Results for 44-Term Viscosity Model with the Truncated-T2 Equation

Parameters Expanded as 22-Component Linear Mixture Models ...................... 8-9

8.3.2 Development of Viscosity Models with the Truncated-T2 Equation Parameters Expanded as Reduced Linear Mixture Models ............................. 8-11

8.3.3 Results for 27-Term Viscosity Model with the Truncated-T2 Equation

Parameters Expanded as 15-Component Reduced Linear Mixture Models ...... 8-13

8.4 Investigation of Adding Quadratic Terms to, and Eliminating Composition-

Temperature Terms from, the 27-Term Truncated T2-Linear Mixture Model ......... 8-14

8.5 Results for the Recommended 29-Term Viscosity Model...................................... 8-15

8.5.1 Results for the Recommended 29-Term Viscosity Model Fitted to the

197-Glass Modeling Dataset.................................................................... 8-16

8.5.2 Validation Results for the Recommended 29-Term Viscosity Model.............. 8-17

8.6 Example Illustrating Viscosity Model Predictions and Statistical Intervals............. 8-18

8.7 Suitability of the Recommended Viscosity Model for Application by the WTP

Project............................................................................................................ 8-20

SECTION 9 REGIONS OF VALIDITY FOR HLW GLASS PROPERTY MODELS.............9-1

9.1 Single-Component Composition and Temperature Constraints ............................... 9-2

9.2 Multiple-Component Composition and Temperature Constraints............................. 9-3

9.2.1 Multiple-Component Constraints on Primary HLW Glass Properties ................9-4

9.2.2 Constraints on Pairs of Correlated HLW Glass Components ............................. 9-6

9.2.3 Constraints on Other HLW Glass Properties and Composition Expressions ...... 9-6

9.3 Summary and Discussion of HLW Glass Property Model Validity Regions .............. 9-7

SECTION 10 SUMMARY AND CONCLUSIONS FOR HLW GLASS PROPERTY-

COMPOSITION MODELS ........................................................................ 10-1

10.1 Summary of IHLW PCT Modeling ........................................................... 10-2

10.2 Summary of IHLW Spinel $\mathrm{T}_{1 \%}$ Modeling ..................................................... 10-4

10.3 Summary of IHLW Electrical Conductivity Modeling ........................................ 10-6

10.4 Summary of IHLW Viscosity Modeling.......................................................... 10-7

10.5 Summary of Model Validity Regions for Recommended HLW Glass Property

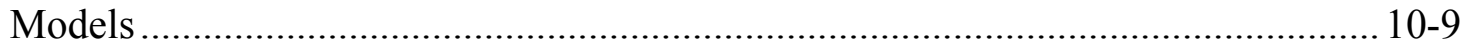


10.6 Suitability of Recommended HLW Glass Property Models for Use by the WTP Project.

SECTION 11 RECOMMENDATIONS FOR ANY FUTURE IHLW PROPERTYCOMPOSITION DATA COLLECTION, MODEL DEVELOPMENT, OR MODEL VALIDATION WORK

11.1 Recommendations for IHLW PCT

11.2 Recommendations for IHLW $\mathrm{T}_{1}$

11.3 Recommendations for IHLW Electrical Conductivity and Viscosity.

11.4 Recommendations for IHLW TCLP-Cd Release $11-6$

11.5 General Recommendations

11.5.1 Recommendation for Additional Work to Assess Suitability of the

Recommended HLW Glass Property Models

11.5.2 Recommendations for Replication.

11.5.3 Recommendation to Investigate Local As Well As Global Modeling Approaches

11.5.4 Recommendation for Space-Filling Experimental Design ............................... 11-8

SECTION 12 QUALITY ASSURANCE

SECTION 13 REFERENCES.

Appendix A Selection of Test Matrices to Support Development of Phase 2 PropertyComposition Models for WTP HLW Glasses

Appendix B Compositions and PCT Release Data for HLW Glasses Used to Validate PCT Models

Appendix C Statistical Methods Used to Develop, Evaluate, and Validate Property-Composition Models

Appendix D Variance-Covariance Matrices Associated with Coefficients of PCT, Spinel $\mathrm{T}_{1 \%}$, Electrical Conductivity, and Viscosity Models for HLW Glasses

Appendix E Calculating Estimated $\mathrm{T}_{1 \%}$ Values and Corresponding Standard Deviations Appendix F Normalized Target Compositions (in mol\%) of 305 Simulated and Actual HLW Glasses

Appendix G Glass Melt Electrical Conductivity and Viscosity Values at a Temperature of $1150^{\circ} \mathrm{C}$ Calculated Using Vogel-Fulcher Equation Fits 
The Catholic University of America Vitreous State Laboratory
IHLW PCT, Spinel $T_{1 \%}$ Electrical Conductivity, and Viscosity Model Development Final Report, VSL-07R1240-4, Rev. 0

\section{LIST OF TABLES}

Table 2.1. Components with Lower and Upper Limits (wt\%) for Groups of IHLW Glasses.........T-1

Table 2.2. Composition of "Spike" Components for IHLW Initial Matrix (HLW02) and

Augmentation Test Matrix (HLW03) ……..............................................................T-2

Table 2.3. Composition of Others1 and Others2 Components for HLW Study Glasses ................T-3

Table 2.4. Composition of "Constant" Component for IHLW Study Glasses................................

Table 2.5. Least-Restrictive Component Lower and Upper Limits (wt $\%$ ) for IHLW Test Matrices HLW02, HLW03, HLW05, HLW06, and HLW07 .....................T-5

Table 2.6. Multi-Component Constraints for WTP IHLW Test Matrices HLW02, HLW03, HLW05, HLW06, and HLW07 .................................................................6

Table 2.7. Model-Based Glass Property Constraints for the IHLW Initial (HLW02) and Augmentation (HLW03) Matrices.......................................................

Table 2.8. Target Glass Compositions (wt \%) for the IHLW Initial (HLW02) and Augmentation (HLW03) Test Matrices Expressed in the Original Oxide Forms.

Table 2.9. Composition Expansions of the Spike and Constant Components for the IHLW Initial (HLW02) and Augmentation (HLW03) Test Matrices Expressed in the Original Oxide Forms ……......................................................... 12

Table 2.10. Original and Revised Oxide Forms for IHLW Glass Compositions............................T-16

Table 2.11. Target Glass Compositions Expressed in Revised Oxides (wt\%) for the Initial (HLW02) and Augmentation (HLW03) Test Matrices

Table 2.12. Expanded Compositions in Revised Oxides of Spike and Constant Components for the Initial (HLW02) and Augmentation (HLW03) Test Matrices.

Table 2.13. Target Glass Compositions (wt\%) Expressed in Revised Oxides for the HLW04 Glasses

Table 2.14. Target Glass Compositions Expressed in Revised Oxides (wt\%) for the Non-Spinel (HLW05) Test Matrix

Table 2.15. Expanded Compositions in Revised Oxides (wt \%) of "Others" and Constant Components for the Non-Spinel (HLW05) Matrix

Table 2.16. Target Glass Compositions Expressed in Revised Oxides (wt \%) for the Spinel (HLW06) Test Matrix .

Table 2.17. Expanded Compositions in Revised Oxides (wt $\%$ ) of "Others1,"

"Others2," and Constant Components for the Spinel (HLW06) Matrix

Table 2.18. Target Glass Compositions Expressed in Revised Oxides (wt\%) for the HLW07 Test Matrix

Table 2.19. Expanded Compositions in Revised Oxides (wt\%) of "Others1," "Others2," and Constant Components for the HLW07 Test Matrix .....

Table 2.20. Expanded Compositions in Revised Oxides (wt\%) of "Remaining" Components for the HLW07 Test Matrix

Table 2.21. Target Glass Compositions (wt\%) Expressed in Revised Oxides for the HLW-ALG Series $\mathrm{T}-36$

Table 2.22. Target Glass Compositions (wt\%) Expressed in Revised Oxides for the 40 HLW98 Glasses Having PCT, $\mathrm{T}_{1 \%}$, Electrical Conductivity, or Viscosity Data $\mathrm{T}-40$

Table 2.23. Target Glass Compositions (wt\%) Expressed in Revised Oxides for the Actual HLW Glasses T-46

Table 2.24. Groups and Numbers of HLW Glasses ...............................................................

Table 2.25. Summary of Data Sets for Validating PCT Models on HLW Glasses........................T-48 
The Catholic University of America Vitreous State Laboratory
IHLW PCT, Spinel $T_{1 \%}$ Electrical Conductivity, and Viscosity Model Development Final Report, VSL-07R1240-4, Rev. 0

Table 2.26. Compositions of HLW Glasses Expressed in Revised Oxides (wt $\%$ ) for

Validating Spinel $\mathrm{T}_{1 \%}$ Models $\mathrm{T}-49$

Table 3.1. HLW Canister Centerline Cooling (CCC) Temperature Profile $\mathrm{T}-52$

Table 4.1. HLW Glasses Having Data for PCT, Spinel $\mathrm{T}_{1 \%}$, Viscosity, and Electrical Conductivity.... $\mathrm{T}-53$

Table 4.2. $\quad$ PCT Results for 268 Simulated and Actual HLW Glasses ... T-58

Table 4.3.

Temperature and Volume \%-Crystallinity Data for 247 Simulated

HLW Glasses $\mathrm{T}-68$

Table 4.4. Primary Crystalline Phase, Estimated One-Percent Crystal Fraction

Temperature $\left(\mathrm{T}_{1 \%}\right)$, and Estimated Standard Deviation of $\mathrm{T}_{1 \%}$ for 247

Simulated HLW Glasses $\mathrm{T}-75$

Table 4.5. Melt Electrical Conductivity Data for 210 Simulated HLW Glasses ............................ -82

Table 4.6. Melt Viscosity Data for Simulated HLW Glasses .....................................................

Table 5.1. List of HLW Glass Compositions with PCT Data Having Outlying

Values for One or More Components

Table 5.2. Normalized 25-Component Compositions (mass fractions) of 266

HLW Glasses Used for PCT Model Development ...................................................T-94

Table 5.3. PCT Releases and Data Splitting Validation Sets of HLW Glasses

Used for PCT Model Development.

Table 5.4. PCT Release Data, \%RSDs, and Standard Deviations for Replicate

Sets of HLW Glasses

Table 5.5. Coefficients and Performance Summary for the 25-Component Full Linear

Mixture Model on the Natural Logarithm of PCT-B for HLW Glasses

Table 5.6. Coefficients and Performance Summary for the 13-Component

Reduced Linear Mixture Model on the Natural Logarithm of PCT-B

for HLW Glasses.

Table 5.7. Coefficients and Performance Summary for the 18-Term Partial Quadratic

Mixture Model on the Natural Logarithm of PCT-B for HLW Glasses

Table 5.8. Coefficients and Performance Summary for the 15-Term Partial Quadratic

Mixture Model on the Natural Logarithm of PCT-B for HLW Glasses $\mathrm{T}-128$

Table 5.9. Coefficients and Performance Summary for the 25-Component Full Linear

Mixture Model on the Natural Logarithm of PCT-Li for HLW Glasses ...

Table 5.10. Coefficients and Performance Summary for the 13-Component Reduced Linear Mixture Model on the Natural Logarithm of PCT-Li for HLW Glasses .........T-130

Table 5.11. Coefficients and Performance Summary for the 18-Term Partial Quadratic Mixture Model on the Natural Logarithm of PCT-Li for HLW Glasses

Table 5.12. Coefficients and Performance Summary for the 15-Term Partial Quadratic Mixture Model on the Natural Logarithm of PCT-Li for HLW Glasses ... $\mathrm{T}-132$

Table 5.13. Coefficients and Performance Summary for the 25-Component Full Linear Mixture Model on the Natural Logarithm of PCT-Na for HLW Glasses

Table 5.14. Coefficients and Performance Summary for the 13-Component Reduced Linear Mixture Model on the Natural Logarithm of PCT-Na for HLW Glasses.......T-134

Table 5.15. Coefficients and Performance Summary for the 18-Term Partial Quadratic Mixture Model on the Natural Logarithm of PCT-Na for HLW Glasses $\mathrm{T}-135$

Table 5.16. Coefficients and Performance Summary for the 15-Term Partial Quadratic Mixture Model on the Natural Logarithm of PCT-Na for HLW Glasses T-136

Table 5.17. Terms in Selected Models for PCT-B, PCT-Li, and PCT-Na Releases from HLW Glasses. T-137 
Table 5.18. Fit and Validation Statistics for Selected PCT-B, PCT-Li, and PCT-Na Models for HLW Glasses T-138

Table 5.19. Coefficients and Performance Summary for the Recommended 19-Term Model (18-Term Partial Quadratic Mixture Model with Bias Correction) for the Natural Logarithm of PCT-B for HLW Glasses $\mathrm{T}-139$

Table 5.20. Coefficients and Performance Summary for the Second Choice 16-Term Model (15-Term Partial Quadratic Mixture Model with Bias Correction) for the Natural Logarithm of PCT-B for HLW Glasses $\mathrm{T}-140$

Table 5.21. Coefficients and Performance Summary for the Recommended 19-Term Model (18-Term Partial Quadratic Mixture Model with Bias Correction) for the Natural Logarithm of PCT-Li for HLW Glasses

Table 5.22. Coefficients and Performance Summary for the Second Choice 16-Term Model (15-Term Partial Quadratic Mixture Model with Bias Correction) for the Natural Logarithm of PCT-Li for HLW Glasses

Table 5.23. Coefficients and Performance Summary for the Recommended 19-Term Model (18-Term Partial Quadratic Mixture Model with Bias Correction) for the Natural Logarithm of PCT-Na for HLW Glasses

Table 5.24. Coefficients and Performance Summary for the Second Choice 16-Term Model (15-Term Partial Quadratic Mixture Model with Bias Correction) for the Natural Logarithm of PCT-Na for HLW Glasses

Table 5.25. Fit and Validation Statistics for Recommended and Second-Choice Models Without and With Bias-Correction for PCT-B, PCT-Li, and PCT-Na Releases from HLW Glasses.....

Table 5.26. HLW03-06 Composition in Formats Needed to Illustrate the Use of PCT Model for HLW Glasses. $\mathrm{T}-146$

Table 5.27. HLW06-15 Composition in Formats Needed to Illustrate the Use of PCT Model for HLW Glasses...............................................................................................

Table 5.28. Predicted PCT Releases and Corresponding 95\% UCIs and 95\% SUCIs for the HLW03-06 Composition Used in PCT Models for HLW Glasses..................T-148

Table 5.29. Predicted PCT Releases and Corresponding 95\% UCIs and 95\% SUCIs for the HLW06-15 Composition Used in PCT Models for HLW Glasses. T-149

Table 6.1. Normalized 25-Component Compositions (mass fractions) of 168 HLW Glasses with Spinel as the Primary Crystalline Phase and Used in Spinel $\mathrm{T}_{1 \%}$ Modeling.... $\mathrm{T}-150$

Table 6.2. Temperature and Volume \%-Crystallinity Data for 168 HLW Glasses with Spinel as the Primary Crystalline Phase and Used in Spinel $\mathrm{T}_{1 \%}$ Modeling..... $\mathrm{T}-162$

Table 6.3. Number of Temperature vs. Vol\%-Crystallinity Points, Intercepts, Slopes, Estimated $\mathrm{T}_{1 \%}$ Values, and Standard Deviations of $\mathrm{T}_{1 \%}$ Values for $168 \mathrm{HLW}$ Glasses Having Spinel as the Primary Crystalline Phase and Used for Spinel $\mathrm{T}_{1 \%}$ Modeling.... $\mathrm{T}-167$

Table 6.4. Spinel $\mathrm{T}_{1 \%}$ Data and Standard Deviations for Replicates of HLW Glasses Used for Modeling $\mathrm{T}-173$

Table 6.5. Compositions of 39 HLW Glasses (Mass Fractions of 25 Normalized Components) for Validating Spinel $\mathrm{T}_{1 \%}$ Models $\mathrm{T}-174$

Table 6.6. Temperature and Volume \%-Crystallinity Data for 39 HLW Glasses with Spinel as the Primary Crystalline Phase and Used in Validating Spinel $\mathrm{T}_{1 \%}$ Models 
The Catholic University of America Vitreous State Laboratory
IHLW PCT, Spinel $T_{1 \%}$ Electrical Conductivity, and Viscosity Model Development Final Report, VSL-07R1240-4, Rev. 0

Table 6.7. Intercepts, Slopes, Predicted Spinel $\mathrm{T}_{1 \%}$ Values, Standard Deviations of Spinel $\mathrm{T}_{1 \%}$ Values, and Number of Temperature vs. Vol\%-Crystallinity Points for 39 HLW Glasses Used to Validate Spinel $\mathrm{T}_{1 \%}$ Models $\mathrm{T}-179$

Table 6.8. Coefficients and Performance Summary for the 25-Component Full Linear Mixture Model on Spinel $\mathrm{T}_{1 \%}$ for HLW Glasses .... T-180

Table 6.9. Coefficients and Performance Summary for the 15-Component Reduced Linear Mixture Model on Spinel $\mathrm{T}_{1 \%}$ for HLW Glasses T-181

Table 6.10. Coefficients and Performance Summary for the First 20-Term Partial Quadratic Mixture Model (PQM1a) on Spinel $\mathrm{T}_{1 \%}$ for HLW Glasses. T-182

Table 6.11. Coefficients and Performance Summary for the Second 20-Term Reduced Partial Quadratic Mixture Model (PQM1b) on Spinel T ${ }_{1 \%}$ for HLW Glasses ............T-183

Table 6.12. Fit and Validation Statistics for Selected Spinel $\mathrm{T}_{1 \%}$ Models Based on 144 Spinel-Only HLW Glasses.... $\mathrm{T}-184$

Table 6.13. Fit and Validation Statistics for Selected Spinel $\mathrm{T}_{1 \%}$ Models Based on 168 HLW Glasses in the Modeling Dataset.....

Table 6.14. HLW03-06 Composition in Formats Needed for Use in Spinel $\mathrm{T}_{1 \%}$ Models for HLW Glasses $\mathrm{T}-186$

Table 6.15. Predicted Spinel $\mathrm{T}_{1 \%}$ Values and Corresponding 90\% UCIs and 90\% SUCIs for the HLW03-06 Composition Used in Spinel $\mathrm{T}_{1 \%}$ Models for HLW Glasses T-187

Table 7.1. HLW Glass Compositions with Data for Electrical Conductivity and

Viscosity Having Outlying Values for One or More Components $\mathrm{T}-188$

Table 7.2. Normalized 22-Component Compositions (mass fractions) of 208 HLW Glasses Used for Electrical Conductivity Model Development.

Table 7.3. Temperature and Electrical Conductivity Observations and Data-Splitting Validation Sets for Each of the 208 HLW Glasses Used for Electrical Conductivity Model Development

Table 7.4. Variation in Electrical Conductivity Values for Replicate Glasses at Actual Temperature Measurements.....

Table 7.5. Variation in Electrical Conductivity Values for Replicate Glasses Interpolated at Nominal Temperatures.

Table 7.6. Coefficients and Performance Summary for the 44-Term Truncated T2-Linear Mixture Model on the Natural Logarithm of Electrical Conductivity for HLW Glasses

Table 7.7. Coefficients and Performance Summary for the 27-Term Truncated

T2-Linear Mixture Model on the Natural Logarithm of Electrical Conductivity for HLW Glasses.

Table 7.8. $\quad$ Summary Statistics for Various Models Fitted and Validated Using IHLW Electrical Conductivity Data for HLW Glasses . T-206

Table 7.9. Coefficients and Performance Summary for the 22-Term Truncated T2-Linear Mixture Model with One Crossproduct Term on the Natural Logarithm of Electrical Conductivity for HLW Glasses.

Table 7.10. HLW03-06 Composition in Formats Needed for Use in Electrical Conductivity Models for HLW Glasses. T-208

Table 7.11. Predicted Electrical Conductivity, Standard Deviation, and Statistical Intervals for HLW03-06 Composition Used in IHLW Electrical Conductivity Models T-209

Table 8.1. $\quad$ Normalized $^{(\mathrm{a})}$ 22-Component Compositions (mass fractions) of 197 HLW Glasses Used for Viscosity Model Development. T-210 
The Catholic University of America

Vitreous State Laboratory
IHLW PCT, Spinel $T_{1 \%}$ Electrical Conductivity, and Viscosity Model Development Final Report, VSL-07R1240-4, Rev. 0

Table 8.2. Temperature and Viscosity Observations and Data-Splitting Validation Sets for Each of the 197 HLW Glasses Used for Viscosity Model Development

Table 8.3. Variation in Viscosity Values for Replicate Glasses at Actual

Temperature Measurements ....

Table 8.4. Variation in Viscosity Values for Replicate Glasses Interpolated at Nominal Temperatures

Table 8.5. Coefficients and Performance Summary for the 44-Term Truncated T2-Linear Mixture Model on the Natural Logarithm of Viscosity Fitted to Data on 197 HLW Glasses

Table 8.6. Coefficients and Performance Summary for the 27-Term Truncated T2-Linear Mixture Model on the Natural Logarithm of Viscosity Fitted to Data on 197 HLW Glasses....

Table 8.7. Coefficients and Performance Summary for the 24-Term Truncated T2-Linear Mixture Model on the Natural Logarithm of Viscosity Fitted to Data on 197 HLW Glasses

Table 8.8. Coefficients and Performance Summary for the 29-Term Truncated T2-Linear Mixture Model With Five Quadratic Terms on the Natural Logarithm of Viscosity Fitted to Data on 197 HLW Glasses

Table 8.9. Summary Statistics for Various Viscosity Models Fitted and Validated Using Data from HLW Glasses

Table 8.10. HLW03-06 Composition in Formats Needed for Use in Viscosity Models for HLW Glasses.

Table 8.11. Predicted Viscosity, Standard Deviation, and Statistical Intervals for HLW03-06 Composition Used in Viscosity Models for HLW Glasses

Table 9.1. Minimums and Maximums of HLW Glass Components (in Mass Fractions) for Compositions in the Modeling Datasets for Each HLW Glass Property

Table 9.2. Minimums and Maximums of HLW Glass Components (in Mass Fractions) Included in the Others Group in Table 9.1 for Compositions in the Modeling Datasets for Each HLW Glass Property ....

Table 9.3. Lower and Upper Bounds on HLW Glass Components (in Mass Fractions) that Partially Define the Composition Validity Regions for IHLW Property Models

Table 9.4. Minimum and Maximum Temperatures at Which Electrical Conductivity and Viscosity were Measured for HLW Glass Compositions in the Modeling Datasets Along with the Lower and Upper Bounds on Temperature that Partially Define the Validity Regions for IHLW Electrical Conductivity and Viscosity Models..

Table 9.5. Minimums and Maximums of Measured Property Values for HLW Glass Compositions in the Modeling Dataset for Each HLW Glass Property....

Table 9.6. Multiple-Component and Multiple-Variable Constraints that Partially Define the Composition Validity Regions for IHLW Property Models $\mathrm{T}-236$

Table 9.7. Minimum and Maximum Values of Multi-Component Constraint Expressions Calculated for 302 HLW Glasses

Table 9.8 Summary of Constraints Specifying the Model Validity Region for each HLW Glass Property $\mathrm{T}-238$ 
The Catholic University of America Vitreous State Laboratory
IHLW PCT, Spinel $T_{1 \%}$ Electrical Conductivity, and Viscosity Model Development Final Report, VSL-07R1240-4, Rev. 0

\section{LIST OF FIGURES}

Figure 3.1. HLW Canister Centerline Cooling (CCC) Temperature Profile F-1

Figure 4.1. Ranges of Normalized PCT Releases (B, Li, and Na, in $\mathrm{g} / \mathrm{L}$ ) for the 268

HLW Glasses with PCT Data, by Sub-Groups of Glasses.

Figure 4.2. Distribution of Normalized PCT Releases of Boron, Lithium, and

Sodium for the 268 HLW Glasses with PCT Data....

Figure 4.3. Comparison of Normalized PCT Releases of Sodium and Lithium with

Normalized PCT Release of Boron for the 268 HLW Glass with

HLW Glasses with PCT Data

Figure 4.4. Measured pH of the PCT Leachates versus Alkali Oxides for the

268 HLW Glasses with PCT Data

Figure 4.5. Normalized PCT Releases of Boron versus pH of PCT Leachates

for the 268 HLW Glasses with PCT Data F-6

Figure 4.6. Normalized PCT Releases of Sodium versus pH of PCT Leachate for the 268 HLW Glasses with PCT Data.

Figure 4.7. Normalized PCT Boron Release versus Alkali Content $\left(\mathrm{Na}_{2} \mathrm{O}+\mathrm{Li}_{2} \mathrm{O}+\mathrm{K}_{2} \mathrm{O}\right)$ for the $268 \mathrm{HLW}$ Glasses with PCT Data F-8

Figure 4.8. Normalized PCT Sodium Release versus Alkali Content $\left(\mathrm{Na}_{2} \mathrm{O}+\mathrm{Li}_{2} \mathrm{O}+\mathrm{K}_{2} \mathrm{O}\right)$ for the $268 \mathrm{HLW}$ Glasses with PCT Data

Figure 4.9. Normalized PCT Boron Release versus the Molar Ratio of (Alkali Oxides + Alkaline Earth Oxides) $/\left(\mathrm{Al}_{2} \mathrm{O}_{3}+\mathrm{B}_{2} \mathrm{O}_{3}+\mathrm{Fe}_{2} \mathrm{O}_{3}+\mathrm{SiO}_{2}+\mathrm{ZrO}_{2}\right)$ for the 268 HLW Glasses with PCT Data... F-10

Figure 4.10. Volume \% of Crystalline (Spinel) Phase in Heat-Treated HLW Matrix Glass (HLW02-01) and Replicate (HLW02-52)...

Figure 4.11. Volume \% of Crystalline Phase in Heat-Treated HLW Matrix Glass (HLW02-04) and Replicate (HLW02-54)

Figure 4.12. Distribution of Estimated One-Percent Crystal Fraction Temperature $\left(\mathrm{T}_{1 \%}\right)$ for 172 HLW Glasses with Spinel as the Primary Crystalline Phase.

Figure 4.13. Estimated $\mathrm{T}_{1 \%}$ versus Molar Ratios of $\mathrm{Fe}_{2} \mathrm{O}_{3}$ and $\left(\mathrm{Cr}_{2} \mathrm{O}_{3}+\mathrm{Fe}_{2} \mathrm{O}_{3}+\mathrm{NiO}\right)$ to (Alkali Oxides + Boron Oxide) for 172 HLW Glasses with Spinel as Primary Crystalline Phase F-14

Figure 4.14. Distribution of Temperature Values for Each of 210 HLW Glasses with Electrical Conductivity Data.

Figure 4.15. Temperature Dependence of Electrical Conductivity for Each of 210 HLW Glasses

Figure 4.16. Glass Melt Electrical Conductivity (in $\mathrm{S} / \mathrm{cm}$ ) at $1150^{\circ} \mathrm{C}$ Calculated by Vogel-Fulcher Equation Fit as a Function of the Sum of Major Alkali Oxides $\left(\mathrm{Li}_{2} \mathrm{O}+\mathrm{Na}_{2} \mathrm{O}+\mathrm{K}_{2} \mathrm{O}\right)$ for $210 \mathrm{HLW}$ Glasses with Electrical Conducitivity Data F-16

Figure 4.17. Glass Melt Electrical Conductivity (in $\mathrm{S} / \mathrm{cm}$ ) at $1150^{\circ} \mathrm{C}$ Calculated by Vogel-Fulcher Equation Fit as a Function of the Sum of Major Alkali Oxides and Alkaline Earth Oxides $\left(\mathrm{Li}_{2} \mathrm{O}+\mathrm{Na}_{2} \mathrm{O}+\mathrm{K}_{2} \mathrm{O}+\mathrm{CaO}+\mathrm{MgO}+\mathrm{SrO}\right)$ for $210 \mathrm{HLW}$ Glasses with Electrical Conductivity Data. F-17

Figure 4.18. Glass Melt Electrical Conductivity (in S/cm) at $1150^{\circ} \mathrm{C}$ Calculated by Vogel-Fulcher Equation Fit as a Function of the Sum of Major Valence III, IV, and V Components $\left(\mathrm{Al}_{2} \mathrm{O}_{3}+\mathrm{B}_{2} \mathrm{O}_{3}+\mathrm{Fe}_{2} \mathrm{O}_{3}+\mathrm{SiO}_{2}+\mathrm{ZrO}_{2}+\mathrm{P}_{2} \mathrm{O}_{5}\right)$ for 210 HLW Glasses with Electrical Conductivity Data. F-18

Figure 4.19. Distribution of Temperature Values for Each of 210 HLW Glasses with Viscosity Data. F-19 
The Catholic University of America Vitreous State Laboratory
IHLW PCT, Spinel $T_{1 \%}$ Electrical Conductivity, and Viscosity Model Development Final Report, VSL-07R1240-4, Rev. 0

Figure 4.20. Temperature Dependence of Viscosity for Each of 210 HLW Glasses. Also shown is an Arrhenius equation fit for each glass for comparison purposes

Figure 4.21. Glass Melt Viscosity (in P) at $1150^{\circ} \mathrm{C}$ Calculated by Vogel-Fulcher Equation Fit as a Function of the Sum of Major Alkali Oxides $\left(\mathrm{Li}_{2} \mathrm{O}+\mathrm{Na}_{2} \mathrm{O}+\mathrm{K}_{2} \mathrm{O}\right) 210 \mathrm{HLW}$ Glasses with Melt Viscosity Data.

Figure 4.22. Glass Melt Viscosity (in P) at $1150^{\circ} \mathrm{C}$ Calculated by Vogel-Fulcher Equation Fit as a Function of the Sum of Major Alkali and Alkaline Earth Oxides $\left(\mathrm{Li}_{2} \mathrm{O}+\mathrm{Na}_{2} \mathrm{O}+\mathrm{K}_{2} \mathrm{O}+\mathrm{CaO}+\mathrm{MgO}+\mathrm{SrO}\right)$ for $210 \mathrm{HLW}$ Glasses with Melt Viscosity Data

Figure 4.23. Glass Melt Viscosity (in P) at $1150^{\circ} \mathrm{C}$ Calculated by Vogel-Fulcher Equation

Fit as a Function of the Sum of Major Alkali Oxides, Major Alkaline Earth

Oxides and Boron Oxide $\left(\mathrm{Li}_{2} \mathrm{O}+\mathrm{Na}_{2} \mathrm{O}+\mathrm{K}_{2} \mathrm{O}+\mathrm{CaO}+\mathrm{MgO}+\mathrm{SrO}+\mathrm{B}_{2} \mathrm{O}_{3}\right)$ for 210

HLW Glasses with Melt Viscosity Data.....

Figure 4.24. Glass Melt Viscosity (in P) at $1150^{\circ} \mathrm{C}$ Calculated by Vogel-Fulcher

Equation Fit as a Function of $\mathrm{Al}_{2} \mathrm{O}_{3}+\mathrm{Fe}_{2} \mathrm{O}_{3}+\mathrm{P}_{2} \mathrm{O}_{5}+\mathrm{SiO}_{2}+\mathrm{ZrO}_{2}$

for $210 \mathrm{HLW}$ Glasses with Melt Viscosity Data.

Figure 4.25. Glass Melt Viscosity (in P) at $1150^{\circ} \mathrm{C} \mathrm{Calculated} \mathrm{by} \mathrm{Vogel-Fulcher} \mathrm{Equation} \mathrm{Fit}$ as a Function of the Molar Ratio of the Sum of Alkali Oxides, Alkaline Earth Oxides and Boron Oxide $\left(\mathrm{Li}_{2} \mathrm{O}+\mathrm{Na}_{2} \mathrm{O}+\mathrm{K}_{2} \mathrm{O}+\mathrm{CaO}+\mathrm{MgO}+\mathrm{SrO}+\mathrm{B}_{2} \mathrm{O}_{3}\right)$ to Glass Forming Oxides $\left(\mathrm{Al}_{2} \mathrm{O}_{3}+\mathrm{Fe}_{2} \mathrm{O}_{3}+\mathrm{P}_{2} \mathrm{O}_{5}+\mathrm{SiO}_{2}+\mathrm{ZrO}_{2}\right)$ for 210

HLW Glasses with Melt Viscosity Data

Figure 5.1. Ranges and Distributions of Component Mass Fractions (x-axes) for 268

HLW Glass Compositions with PCT Data. The vertical lines (when present) are the lower and upper limits for each component varied in statistically designed test matrices

Figure 5.2. Ranges and Distributions of Component Mass Fractions (x-axes) for 266 HLW Glass Compositions with PCT Data after Removing Two Outliers. The vertical lines (when present) are the lower and upper limits for each component varied in statistically designed test matrices

Figure 5.3. Scatterplot Matrix of 18 Components (mass fractions) for 266 HLW Glasses in the Initial PCT Modeling Data Set

Figure 5.4. Scatterplot Matrix of Natural Logarithms of PCT-B, PCT-Li, and PCT-Na Normalized Releases (g/L) for Initial PCT Modeling Dataset of 266 HLW Glasses

Figure 5.5. Predicted Versus Measured Plot for the 25-Component Full Linear Mixture Model for PCT-B Fitted to Data from 264 HLW Glasses F-31

Figure 5.6. Standardized Residuals Plot for the 25-Component Full Linear Mixture Model for PCT-B Fitted to Data from 264 HLW Glasses.

Figure 5.7. Predicted Versus Measured Plot for the 25-Component Full Linear Mixture

Model on IHLW PCT-B Fitted to the Data-Partition Modeling Subset of 162

Glasses and Applied to the Validation Subset of 102 Glasses.

Error bars are $95 \%$ prediction intervals (PIs)

Figure 5.8. Predicted Versus Measured Plot for the 25-Component Full Linear Mixture Model for PCT-B Applied to the 556-Glass Separate Validation Set. Error bars are 95\% prediction intervals (PIs) F-32

Figure 5.9. Response Trace Plot for the 25-Component Full Linear Mixture Model for PCT-B Fitted to Data from 264 HLW Glasses. 
Figure 5.10. Predicted Versus Measured Plot for the 13-Component Reduced Linear Mixture Model for PCT-B Fitted to Data from 264 HLW Glasses

Figure 5.11. Standardized Residuals Plot for the 13-Component Reduced Linear Mixture Model for PCT-B Fitted to Data from 264 HLW Glasses F-34

Figure 5.12. Response Trace Plot for the 13-Component Reduced Linear Mixture Model for PCT-B Fitted to Data from 264 HLW Glasses

Figure 5.13. Predicted Versus Measured Plot for the 13-Component Reduced Linear Mixture Model on IHLW PCT-B Fitted to the Data-Partition Modeling Subset of 162 Glasses and Applied to the Validation Subset of 102 Glasses.... F-35

Figure 5.14. Predicted Versus Measured Plot for the 13-Component Reduced Linear Mixture Model for PCT-B Applied to the 556-Glass Separate Validation Set. F-35

Figure 5.15. Predicted Versus Measured Plot for the 18-Term Partial Quadratic Mixture Model for PCT-B Fitted to Data from 264 HLW Glasses. F-36

Figure 5.16. Standardized Residuals Plot for the 18-Term Partial Quadratic Mixture Model for PCT-B Fitted to Data from 264 HLW Glasses. F-36

Figure 5.17. Response Trace Plot for the 18-Term Partial Quadratic Mixture Model for PCT-B Fitted to Data from 264 HLW Glasses.

Figure 5.18. Predicted Versus Measured Plot for the 18-Term Partial Quadratic Mixture Model on IHLW PCT-B Fitted to the Data-Partition Modeling Subset of 162 Glasses and Applied to the Validation Subset of 102 Glasses.

Figure 5.19. Predicted Versus Measured Plot for the 18-Term Partial Quadratic Mixture Model for PCT-B Applied to the 556-Glass Separate Validation Set.............F-38

Figure 5.20. Predicted Versus Measured Plot for the 15-Term Partial Quadratic Mixture Model for PCT-B Fitted to Data from 264 HLW Glasses...............................F-38

Figure 5.21. Standardized Residuals Plot for the 15-Term Partial Quadratic Mixture Model for PCT-B Fitted to Data from 264 HLW Glasses...............................F-39

Figure 5.22. Response Trace Plot for the 15-Term Partial Quadratic Mixture Model for PCT-B Fitted to Data from 264 HLW Glasses.

Figure 5.23. Predicted Versus Measured Plot for the 15-Term Partial Quadratic Mixture Model on IHLW PCT-B Fitted to the Data-Partition Modeling Subset of 162 Glasses and Applied to the Validation Subset of 102 Glasses...........................F-40

Figure 5.24. Predicted Versus Measured Plot for the 15-Term Partial Quadratic Mixture Model for PCT-B Applied to the 556-Glass Separate Validation Set...........................F-40

Figure 5.25. Predicted Versus Measured Plot for the 25-Component Full Linear Mixture Model for PCT-Li Fitted to Data from 250 HLW Glasses. F-41

Figure 5.26. Standardized Residuals Plot for the 25-Component Full Linear Mixture Model for PCT-Li Fitted to Data from 250 HLW Glasses. F-41

Figure 5.27. Predicted Versus Measured Plot for the 25-Component Full Linear Mixture Model on IHLW PCT-Li Fitted to the Data-Partition Modeling Subset of 154 Glasses and Applied to the Validation Subset of 96 Glasses F-42

Figure 5.28. Predicted Versus Measured Plot for the 25-Component Full Linear Mixture Model for PCT-Li Applied to the 480-Glass Separate Validation Set. F-42

Figure 5.29. Response Trace Plot for the 25-Component Full Linear Mixture Model for PCT-Li Fitted to Data from 250 HLW Glasses. F-43

Figure 5.30. Predicted Versus Measured Plot for the 13-Component Reduced Linear Mixture Model for PCT-Li Fitted to Data from 250 HLW Glasses. F-43

Figure 5.31. Standardized Residuals Plot for the 13-Component Reduced Linear Mixture Model for PCT-Li Fitted to Data from 250 HLW Glasses. F-44 
The Catholic University of America Vitreous State Laboratory
IHLW PCT, Spinel $T_{1 \%}$ Electrical Conductivity, and Viscosity Model Development Final Report, VSL-07R1240-4, Rev. 0

Figure 5.32. Response Trace Plot for the 13-Component Reduced Linear Mixture Model for PCT-Li Fitted to Data from 250 HLW Glasses F-44

Figure 5.33. Predicted Versus Measured Plot for the 13-Component Reduced Linear Mixture Model on IHLW PCT-Li Fitted to the Data-Partition Modeling Subset of 154 Glasses and Applied to the Validation Subset of 96 Glasses............................F-45

Figure 5.34. Predicted Versus Measured Plot for the 13-Component Reduced Linear Mixture Model for PCT-Li Applied to the 480-Glass Separate Validation Set............................45

Figure 5.35. Predicted Versus Measured Plot for the 18-Term Partial Quadratic Mixture Model for PCT-Li Fitted to Data from 250 HLW Glasses................................46

Figure 5.36. Standardized Residuals Plot for the 18-Term Partial Quadratic Mixture Model for PCT-Li Fitted to Data from 250 HLW Glasses................................46

Figure 5.37. Response Trace Plot for the 18-Term Partial Quadratic Mixture Model for PCT-Li Fitted to Data from 250 HLW Glasses................................47

Figure 5.38. Predicted Versus Measured Plot for the 18-Term Partial Quadratic Mixture Model on IHLW PCT-Li Fitted to the Data-Partition Modeling Subset of 154 Glasses and Applied to the Validation Subset of 96 Glasses............................F-47

Figure 5.39. Predicted Versus Measured Plot for the 18-Term Partial Quadratic Mixture Model for PCT-Li Applied to the 480-Glass Separate Validation Set..........................F-48

Figure 5.40. Predicted Versus Measured Plot for the 15-Term Partial Quadratic Mixture Model for PCT-Li Fitted to Data from 250 HLW Glasses.................................48

Figure 5.41. Standardized Residuals Plot for the 15-Term Partial Quadratic Mixture Model for PCT-Li Fitted to Data from 250 HLW Glasses................................49

Figure 5.42. Response Trace Plot for the 15-Term Partial Quadratic Mixture Model for PCT-Li Fitted to Data from 250 HLW Glasses F-49

Figure 5.43. Predicted Versus Measured Plot for the 15-Term Partial Quadratic Mixture Model on IHLW PCT-Li Fitted to the Data-Partition Modeling Subset of 154 Glasses and Applied to the Validation Subset of 96 Glasses............................F-50

Figure 5.44. Predicted Versus Measured Plot for the 15-Term Partial Quadratic Mixture Model for PCT-Li Applied to the 480-Glass Separate Validation Set..........................F-50

Figure 5.45. Predicted Versus Measured Plot for the 25-Component Full Linear Mixture Model for PCT-Na Fitted to Data from 266 HLW Glasses.............................F-51

Figure 5.46. Standardized Residuals Plot for the 25-Component Full Linear Mixture Model for PCT-Na Fitted to Data from 266 HLW Glasses. F-51

Figure 5.47. Predicted Versus Measured Plot for the 25-Component Full Linear Mixture Model on IHLW PCT-Na Fitted to the Data-Partition Modeling Subset of 163 Glasses and Applied to the Validation Subset of 103 Glasses ... F-52

Figure 5.48. Predicted Versus Measured Plot for the 25-Component Full Linear Mixture Model for PCT-Na Applied to the 554-Glass Separate Validation Set. $. F-52$

Figure 5.49. Response Trace Plot for the 25-Component Full Linear Mixture Model for PCT-Na Fitted to Data from 266 HLW Glasses .... F-53

Figure 5.50. Predicted Versus Measured Plot for the 13-Component Reduced Linear Mixture Model for PCT-Na Fitted to Data from 266 HLW Glasses. F-53

Figure 5.51. Standardized Residuals Plot for the 13-Component Reduced Linear Mixture Model for PCT-Na Fitted to Data from 266 HLW Glasses. F-54

Figure 5.52. Response Trace Plot for the 13-Component Reduced Linear Mixture Model for PCT-Na Fitted to Data from 266 HLW Glasses F-54

Figure 5.53. Predicted Versus Measured Plot for the 13-Component Reduced Linear Mixture Model on IHLW PCT-Na Fitted to the Data-Partition Modeling Subset of 163 Glasses and Applied to the Validation Subset of 103 Glasses.... 
Figure 5.54. Predicted Versus Measured Plot for the 13-Component Reduced

Linear Mixture Model for PCT-Na Applied to the 554-Glass Separate

Validation Set. Error bars are 95\% prediction intervals (PIs) F-55

Figure 5.55. Predicted Versus Measured Plot for the 18-Term Partial Quadratic Mixture Model for PCT-Na Fitted to Data from 266 HLW Glasses. F-56

Figure 5.56. Standardized Residuals Plot for the 18-Term Partial Quadratic Mixture Model for PCT-Na Fitted to Data from 266 HLW Glasses F-56

Figure 5.57. Response Trace Plot for the 18-Term Partial Quadratic Mixture Model for PCT-Na Fitted to Data from 266 HLW Glasses

Figure 5.58. Predicted Versus Measured Plot for the 18-Term Partial Quadratic Mixture Model on IHLW PCT-Na Fitted to the Data-Partitioning Modeling Subset of 163 Glasses and Applied to the Validation Subset of 103 Glasses

Figure 5.59. Predicted Versus Measured Plot for the 18-Term Partial Quadratic Mixture Model for PCT-Na Applied to the 554-Glass Separate Validation Set F-58

Figure 5.60. Predicted Versus Measured Plot for the 15-Term Partial Quadratic Mixture Model for PCT-Na Fitted to Data from 266 HLW Glasses.

Figure 5.61. Standardized Residuals Plot for the 15-Term Partial Quadratic Mixture Model for PCT-Na Fitted to Data from 266 HLW Glasses

Figure 5.62. Response Trace Plot for the 15-Term Partial Quadratic Mixture Model for PCT-Na Fitted to Data from 266 HLW Glasses

Figure 5.63. Predicted Versus Measured Plot for the 15-Term Partial Quadratic Mixture Model on IHLW PCT-Na Fitted to the Data-Partition Modeling Subset of 163 Glasses and Applied to the Validation Subset of 103 Glasses.... F-60

Figure 5.64. Predicted Versus Measured Plot for the 15-Term Partial Quadratic Mixture Model for PCT-Na Applied to the 554-Glass Separate Validation Set F-60

Figure 5.65. Predicted Versus Measured Plot for the Recommended 18-Term Partial Quadratic Mixture Model for PCT-B Fitted to Data from 264 HLW Glasses, With Bias Correction for Predicted Values Above $0.5 \ln (\mathrm{g} / \mathrm{L})$.

Figure 5.66. Predicted Versus Measured Plot for the Second Choice 15-Term Partial Quadratic Mixture Model for PCT-B Fitted to Data from 264 HLW Glasses, With Bias Correction for Predicted Values Above $0.5 \ln (\mathrm{g} / \mathrm{L})$.... F-61

Figure 5.67. Predicted Versus Measured Plot for the Recommended 18-Term Partial Quadratic Mixture Model for PCT-Li Fitted to Data from 250 HLW Glasses, With Bias Correction for Predicted Values Above $0.5 \ln (\mathrm{g} / \mathrm{L})$.

Figure 5.68. Predicted Versus Measured Plot for the Second Choice 15-Term Partial Quadratic Mixture Model for PCT-Li Fitted to Data from 250 HLW Glasses, With Bias Correction for Predicted Values Above $0.5 \ln (\mathrm{g} / \mathrm{L})$.... F-62

Figure 5.69. Predicted Versus Measured Plot for the Recommended 18-Term Partial Quadratic Mixture Model for PCT-Na Fitted to Data from 266 HLW Glasses, With Bias Correction for Predicted Values Above $1.0 \ln (\mathrm{g} / \mathrm{L})$....

Figure 5.70. Predicted Versus Measured Plot for the Second Choice 15-Term Partial Quadratic Mixture Model for PCT-Na Fitted to Data from 266 HLW Glasses, With Bias Correction for Predicted Values Above $1.0 \ln (\mathrm{g} / \mathrm{L})$.... F-63

Figure 5.71. Standard Deviations of Predictions Considered as Mean Values versus Predicted Values over the HLW Glass Compositions in the PCT-B Modeling Dataset for the Recommended 19-Term Partial Quadratic Mixture Model with Bias-Correction Term 
The Catholic University of America Vitreous State Laboratory
IHLW PCT, Spinel $T_{1 \%}$ Electrical Conductivity, and Viscosity Model Development Final Report, VSL-07R1240-4, Rev. 0

Figure 5.72. Standard Deviations of Predictions Considered as Mean Values versus

Predicted Values over the HLW Glass Compositions in the PCT-Li

Modeling Dataset for the Recommended 19-Term Partial Quadratic

Mixture Model with Bias-Correction Term

Figure 5.73. Standard Deviations of Predictions Considered as Mean Values versus

Predicted Values over the HLW Glass Compositions in the PCT-Na

Modeling Dataset for the Recommended 19-Term Partial Quadratic

Mixture Model with Bias-Correction Term

Figure 6.1. Ranges and Distributions of Components Mass Fractions (x-axes) for 169

HLW Glass Compositions with Spinel $\mathrm{T}_{1 \%}$ Values Judged Acceptable for

Model Development

Figure 6.2. Ranges and Distributions of Components Mass Fractions (x-axie) for 168

HLW Glass Compositions with Spinel $\mathrm{T}_{1 \%}$ Values Selected for

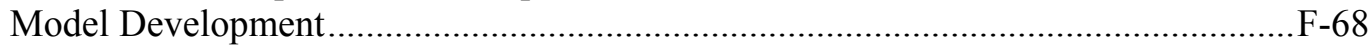

Figure 6.3. Scatterplot Matrix of 18 Components (mass fractions) for $168 \mathrm{HLW}$

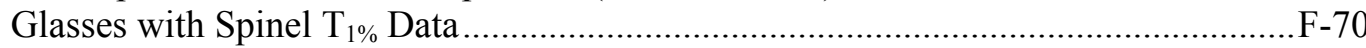

Figure 6.4. Histogram of Estimated Spinel $\mathrm{T}_{1 \%}$ Values for $168 \mathrm{Model}$

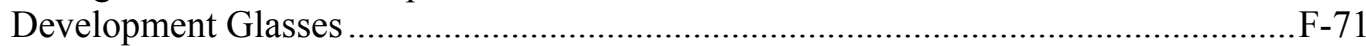

Figure 6.5. Histogram of Estimated Spinel $\mathrm{T}_{1 \%}$ Values for 38 Validation Glasses.........................

Figure 6.6. Predicted Versus Measured Plot for the 25-Component Full Linear Mixture

Model for Spinel $\mathrm{T}_{1 \%}$ Fitted to Data from 168 HLW Glasses.....................................F-72

Figure 6.7. Standardized Residuals Plot for the 25-Component Full Linear

Mixture Model for Spinel $\mathrm{T}_{1 \%}$ Fitted to Data from 168 HLW Glasses

F-72

Figure 6.8. Predicted Versus Measured Plot for the 25-Component Full Linear

Mixture Model for Spinel $\mathrm{T}_{1 \%}$ Fitted to the Data Partition Modeling Subset

of 124 Glasses and Applied to the Validation Set of 44 Glasses

Figure 6.9. Predicted Versus Measured Plot for the 25-Component Full Linear

Mixture Model for Spinel $\mathrm{T}_{1 \%}$ Applied to the 38-Glass

Separate Validation Set .....

Figure 6.10. Response Trace Plot for the 25-Component Full Linear Mixture Model

for Spinel $\mathrm{T}_{1 \%}$ Fitted to Data from 168 HLW Glasses......

Figure 6.11. Predicted Versus Measured Plot for the 15-Component Reduced Linear

Mixture Model for Spinel $\mathrm{T}_{1 \%}$ Fitted to Data from 168 HLW Glasses..

Figure 6.12. Standardized Residuals Plot for the 15-Component Reduced Linear Mixture

Model for Spinel $\mathrm{T}_{1 \%}$ Fitted to Data from 168 HLW Glasses. F-75

Figure 6.13. Response Trace Plot for the 15-Component Reduced Linear

Mixture Model for Spinel $\mathrm{T}_{1 \%}$ Fitted to Data from 168 HLW Glasses.

F-75

Figure 6.14. Predicted Versus Measured Plot for the 15-Component Reduced Linear Mixture

Model on IHLW Spinel $\mathrm{T}_{1 \%}$ Fitted to the Data-Partition Modeling Subset of

124 Glasses and Applied to the Validation Subset of 44 Glasses

Figure 6.15. Predicted Versus Measured Plot for the 15-Component Reduced

Linear Mixture Model for Spinel $\mathrm{T}_{1 \%}$ Applied to the 38-Glass

Separate Validation Set.

Figure 6.16. Predicted Versus Measured Plot for the 20-Term Partial Quadratic Mixture

Model (PQM1a) for Spinel $\mathrm{T}_{1 \%}$ Fitted to Data from 168 HLW Glasses.

Figure 6.17. Standardized Residuals Plot for the 20-Term Partial Quadratic Mixture

Model (PQM1a) for Spinel $\mathrm{T}_{1 \%}$ Fitted to Data from 168 HLW Glasses.

Figure 6.18. Response Trace Plot for the 20-Term Partial Quadratic Mixture

Model (PQM1a) for Spinel $\mathrm{T}_{1 \%}$ Fitted to Data from 168 HLW Glasses 
The Catholic University of America Vitreous State Laboratory
IHLW PCT, Spinel $T_{1 \%}$ Electrical Conductivity, and Viscosity Model Development Final Report, VSL-07R1240-4, Rev. 0

Figure 6.19. Predicted Versus Measured Plot for the 20-Term Partial Quadratic Mixture Model (PQM1a) on IHLW Spinel $\mathrm{T}_{1 \%}$ Fitted to the Data-Partition Modeling Subset of 124 Glasses and Applied to the Validation Subset of 44 Glasses F-78

Figure 6.20. Predicted Versus Measured Plot for the 20-Term Partial Quadratic Mixture Model (PQM1a) for Spinel $\mathrm{T}_{1 \%}$ Applied to the 38-Glass Separate Validation Set F-79

Figure 6.21. Predicted Versus Measured Plot for the 20-Term Partial Quadratic Mixture Model (PQM1b) for Spinel $\mathrm{T}_{1 \%}$ Fitted to Data from 168 HLW Glasses

Figure 6.22. Standardized Residuals Plot for the 20-Term Partial Quadratic Mixture Model (PQM1b) for Spinel $\mathrm{T}_{1 \%}$ Fitted to Data from 168 HLW Glasses

Figure 6.23. Response Trace Plot for the 20-Term Partial Quadratic Mixture Model (PQM1b) for Spinel $\mathrm{T}_{1 \%}$ Fitted to Data from 168 HLW Glasses F-80

Figure 6.24. Predicted Versus Measured Plot for the 20-Term Partial Quadratic Mixture Model (PQM1b) on IHLW Spinel $\mathrm{T}_{1 \%}$ Fitted to the Data Partition Modeling 124 Glasses and Applied to the Validation Subset of 44 Glasses

Figure 6.25. Predicted Versus Measured Plot for the 20-Term Partial Quadratic Mixture Model (PQM1b) for Spinel $\mathrm{T}_{1 \%}$ Applied to the 38-Glass Separate Validation Set.

Figure 6.26. Prediction Standard Deviations versus Predicted Values over the HLW Glass Compositions in the Modeling Dataset for the Recommended 20-Term Partial Quadratic Mixture Model (PQM1a) on Spinel $\mathrm{T}_{1 \%}$ F-82

Figure 7.1. Ranges and Distributions of Components Mass Fractions (x-axes) for 210 HLW Glass Compositions with Electrical Conductivity Data.

Figure 7.2. Ranges and Distributions of Components Mass Fractions (x-axes) for 208 HLW Glass Compositions with Electrical Conductivity Data After Deleting Two Outliers from the Initial 210 Glasses

Figure 7.3. Scatterplot Matrix of 18 Components Mass Fractions for 208 HLW Glass Compositions with Electrical Conductivity Data After Deleting Two Outliers from the Initial 210 Glasses

Figure 7.4. Predicted Versus Measured Plot for the 208 HLW Glasses in the Electrical Conductivity Modeling Dataset Constructed Using the 44-Term Truncated T2-Linear Mixture Model. F- 88

Figure 7.5. Standardized Residuals Plot for the 208 HLW Glasses in the Electrical Conductivity Modeling Dataset Constructed Using the 44-Term Truncated T2-Linear Mixture Model. F-88

Figure 7.6. Predicted versus Measured $\ln (\mathrm{EC}, \mathrm{S} / \mathrm{cm})$ Values for each of the Five Data-Splitting Validation Subsets of the 208 HLW Glasses in the Electrical Conductivity Modeling Dataset Constructed Using the 44-Term Truncated T2-Linear Mixture Model.

Figure 7.7. Predicted Versus Measured $\ln (\mathrm{EC}, \mathrm{S} / \mathrm{cm})$ Values for each of the Five DataSplitting Validation Subsets of the 208 HLW Glasses in the Electrical Conductivity Modeling Dataset Constructed Using the 44-Term Truncated T2-Linear Mixture Model.Error bars are 95\% prediction intervals (PIs). The number of glasses whose $95 \%$ PIs do not include the measured values (represented by the $45^{\circ}$ line) is shown F-89

Figure 7.8a. Response Trace Plot for IHLW Electrical Conductivity at $950^{\circ} \mathrm{C}$ Constructed Using the 44-Term Truncated T2-Linear Mixture Model. F-90

Figure 7.8b. Response Trace Plot for IHLW Electrical Conductivity at $1050^{\circ} \mathrm{C}$

Constructed Using the 44-Term Truncated T2-Linear Mixture Model F-90 
The Catholic University of America Vitreous State Laboratory
IHLW PCT, Spinel $T_{1 \%}$ Electrical Conductivity, and Viscosity Model Development Final Report, VSL-07R1240-4, Rev. 0

Figure 7.8c. Response Trace Plot for IHLW Electrical Conductivity at $1150^{\circ} \mathrm{C}$

Constructed Using the 44-Term Truncated T2-Linear Mixture Model

Figure 7.8d. Response Trace Plot for IHLW Electrical Conductivity at $1250^{\circ} \mathrm{C}$

Constructed Using the 44-Term Truncated T2-Linear Mixture Model

Figure 7.9. Predicted Versus Measured Plot for the 208 HLW Glasses in the Electrical Conductivity Modeling Dataset Constructed Using the 27-Term Truncated T2-Linear Mixture Model

Figure 7.10. Standardized Residuals Plot for the 208 HLW Glasses in the Electrical Conductivity Modeling Dataset Constructed Using the 27-Term Truncated T2-Linear Mixture Model.

Figure 7.11. Predicted versus Measured $\ln (\mathrm{EC}, \mathrm{S} / \mathrm{cm})$ Values for each of the Five

Data-Splitting Validation Subsets of the 208 HLW Glasses in the Electrical Conductivity Modeling Dataset Constructed Using the 27-Term Truncated T2-Linear Mixture Model.

Figure 7.12. Predicted Versus Measured $\ln (\mathrm{EC}, \mathrm{S} / \mathrm{cm})$ Values for each of the Five DataSplitting Validation Subsets of the 208 HLW Glasses in the Electrical Conductivity Modeling Dataset Constructed Using the 27-Term Truncated T2-Linear Mixture Model. Error bars are 95\% prediction intervals (PIs). The number of glasses whose $95 \%$ PIs do not include the measured values (represented by the $45^{\circ}$ line) is shown

Figure 7.13a. Response Trace Plot for IHLW Electrical Conductivity at $950^{\circ} \mathrm{C}$ Constructed Using the 27-Term Truncated T2-Linear Mixture Model

Figure 7.13b. Response Trace Plot for IHLW Electrical Conductivity at $1050^{\circ} \mathrm{C}$ Constructed Using the 27-Term Truncated T2-Linear Mixture Model

Figure 7.13c. Response Trace Plot for IHLW Electrical Conductivity at $1150^{\circ} \mathrm{C}$ Constructed Using the 27-Term Truncated T2-Linear Mixture Model

Figure $7.13 \mathrm{~d}$. Response Trace Plot for IHLW Electrical Conductivity at $1250^{\circ} \mathrm{C}$ Constructed Using the 27-Term Truncated T2-Linear Mixture Model

Figure 7.14. Predicted Versus Measured Plot for the 208 HLW Glasses in the Electrical Conductivity Modeling Dataset Constructed Using the 22-Term Truncated T2-Linear Mixture Model

Figure 7.15. Standardized Residuals Plot for the 208 HLW Glasses in the Electrical Conductivity Modeling Dataset Constructed Using the 22-Term Truncated T2-Linear Mixture Model

Figure 7.16a. Response Trace Plot for IHLW Electrical Conductivity at $950^{\circ} \mathrm{C}$ Constructed Using the 22-Term Truncated T2-Linear Mixture Model. F-97

Figure 7.16b. Response Trace Plot for IHLW Electrical Conductivity at $1050^{\circ} \mathrm{C}$ Constructed Using the 22-Term Truncated T2-Linear Mixture Model F-97

Figure 7.16c. Response Trace Plot for IHLW Electrical Conductivity at $1150^{\circ} \mathrm{C}$ Constructed Using the 22-Term Truncated T2-Linear Mixture Model F-98

Figure 7.16d. Response Trace Plot for IHLW Electrical Conductivity at $1250^{\circ} \mathrm{C}$ Constructed Using the 22-Term Truncated T2-Linear Mixture Model F-98

Figure 7.17. Predicted versus Measured $\ln (\mathrm{EC}, \mathrm{S} / \mathrm{cm})$ Values for each of the Five Data-Splitting Validation Subsets of the 208 HLW Glasses in the Electrical Conductivity Modeling Dataset Constructed Using the 22-Term Truncated T2-Linear Mixture Model

Figure 7.18. Predicted Versus Measured $\ln (\mathrm{EC}, \mathrm{S} / \mathrm{cm})$ Values for each of the Five DataSplitting Validation Subsets of the 208 HLW Glasses in the Electrical Conductivity Modeling Dataset Constructed Using the 22-Term Truncated T2-Linear Mixture Model. F-99 
Figure 7.19. Prediction Standard Deviations versus Predicted $\ln (\mathrm{EC})$ Values over the HLW Glass Compositions in the Modeling Dataset and Temperatures $950,1050,1150$, and $1250^{\circ} \mathrm{C}$, Obtained Using the Recommended 22-Term Electrical Conductivity Model

Figure 8.1. Ranges and Distributions of Components Mass Fractions (x-axes) for 210 HLW Glass Compositions with Viscosity Data

Figure 8.2. Ranges and Distributions of Components Mass Fractions (x-axes) for 208 HLW Glass Compositions with Viscosity Data After Deleting Two Outliers from the Initial 210 Glasses

Figure 8.3. Scatterplot Matrix of 18 Components Mass Fractions for 208 HLW Glass Compositions with Viscosity Data After Deleting Two Outliers from the Initial 210 Glasses

Figure 8.4. Predicted Versus Measured Plot for the 197 HLW Glasses in the Viscosity Modeling Dataset Constructed Using the 44-Term Truncated T2-Linear Mixture Model

Figure 8.5. Standardized Residuals Plot for the 197 HLW Glasses in the Viscosity Modeling Dataset Constructed Using the 44-Term Truncated T2-Linear Mixture Model F-106

Figure 8.6. $\quad$ Predicted Versus Measured $\ln ($ Viscosity, poise) Values for each of the Five Data-Splitting Validation Subsets of the 197 HLW Glasses in the Viscosity Modeling Dataset Constructed Using the 44-Term Truncated T2-Linear Mixture Model F-107

Figure 8.7. Predicted Versus Measured $\ln ($ Viscosity, poise) Values for each of the Five Data-Splitting Validation Subsets of the 197 HLW Glasses in the Viscosity Modeling Dataset Constructed Using the 44-Term Truncated T2-Linear Mixture Model. Error bars are 95\% prediction intervals (PIs). The number of glasses whose $95 \%$ PIs do not include the measured values (represented by the $45^{\circ}$ line) is shown

Figure 8.8a. Response Trace Plot for IHLW Viscosity at $950^{\circ} \mathrm{C}$ Constructed Using the 44-Term Truncated T2-Linear Mixture Model. F-108

Figure 8.8b. Response Trace Plot for IHLW Viscosity at $1050^{\circ} \mathrm{C}$ Constructed Using the 44-Term Truncated T2-Linear Mixture Model. F-108

Figure 8.8c. Response Trace Plot for IHLW Viscosity at $1150^{\circ} \mathrm{C}$ Constructed Using the 44-Term Truncated T2-Linear Mixture Model.

Figure 8.8d. Response Trace Plot for IHLW Viscosity at $1250^{\circ} \mathrm{C}$ Constructed Using the 44-Term Truncated T2-Linear Mixture Model.

Figure 8.9. Predicted Versus Measured Plot for the 197 HLW Glasses in the Viscosity Modeling Dataset Constructed Using the 27-Term Truncated T2-Linear Mixture Model

Figure 8.10. Standardized Residuals Plot for the 197 HLW Glasses in the Viscosity Modeling Dataset Constructed Using the 27-Term Truncated T2-Linear Mixture Model

Figure 8.11. Predicted versus Measured $\ln$ (Viscosity, poise) Values for each of the Five Data-Splitting Validation Subsets of the 197 HLW Glasses in the Viscosity Modeling Dataset Constructed Using the 27-Term Truncated 
The Catholic University of America Vitreous State Laboratory
IHLW PCT, Spinel $T_{1 \%}$ Electrical Conductivity, and Viscosity Model Development Final Report, VSL-07R1240-4, Rev. 0

Figure 8.12. Predicted Versus Measured $\ln ($ Viscosity, poise) Values for each of the Five Data-Splitting Validation Subsets of the 197 HLW Glasses in the Viscosity Modeling Dataset Constructed Using the 27-Term Truncated T2-Linear Mixture Model. Error bars are 95\% prediction intervals (PIs). The number of glasses whose $95 \%$ PIs do not include the measured values (represented by the $45^{\circ}$ line) is shown

Figure 8.13a. Response Trace Plot for IHLW Viscosity at $950^{\circ} \mathrm{C}$ Constructed Using the 27-Term Truncated T2-Linear Mixture Model .

Figure $8.13 \mathrm{~b}$. Response Trace Plot for IHLW Viscosity at $1050^{\circ} \mathrm{C}$ Constructed Using the 27-Term Truncated T2-Linear Mixture Model .

Figure $8.13 \mathrm{c}$. Response Trace Plot for IHLW Viscosity at $1150^{\circ} \mathrm{C}$ Constructed Using the 27-Term Truncated T2-Linear Mixture Model

Figure $8.13 \mathrm{~d}$. Response Trace Plot for IHLW Viscosity at $1250^{\circ} \mathrm{C}$ Constructed Using the 27-Term Truncated T2-Linear Mixture Model

Figure 8.14. Predicted Versus Measured Plot for the 197 HLW Glasses in the Viscosity Modeling Dataset Constructed Using the 29-Term Truncated

T2-Linear Mixture Model

Figure 8.15. Standardized Residuals Plot for the 197 HLW Glasses in the Viscosity Modeling Dataset Constructed Using the 29-Term Truncated T2-Linear Mixture Model.

Figure 8.16a. Response Trace Plot for IHLW Viscosity at $950^{\circ} \mathrm{C}$ Constructed Using the 29-Term Truncated T2-Linear Mixture Model

Figure $8.16 \mathrm{~b}$. Response Trace Plot for IHLW Viscosity at $1050^{\circ} \mathrm{C}$ Constructed Using the 29-Term Truncated T2-Linear Mixture Model.

Figure 8.16c. Response Trace Plot for IHLW Viscosity at $1150^{\circ} \mathrm{C}$ Constructed Using the 29-Term Truncated T2-Linear Mixture Model

Figure 8.16d. Response Trace Plot for IHLW Viscosity at $1250^{\circ} \mathrm{C}$ Constructed Using the 29-Term Truncated T2-Linear Mixture Model.

Figure 8.17. Predicted versus Measured $\ln$ (Viscosity, poise) Values for each of the Five Data-Splitting Validation Subsets of the 197 HLW Glasses in the Viscosity Modeling Dataset Constructed Using the 29-Term Truncated T2-Linear Mixture Model

Figure 8.18 Predicted Versus Measured $\ln ($ Viscosity, poise) Values for each of the Five Data-Splitting Validation Subsets of the 197 HLW Glasses in the Viscosity Modeling Dataset Constructed Using the 29-Term Truncated T2-Linear Mixture Model. Error bars are 95\% prediction intervals (PIs). The number of glasses whose $95 \%$ PIs do not include the measured values (represented by the $45^{\circ}$ line) is shown

Figure 8.19. Prediction Standard Deviations Versus Predicted $\ln$ (Viscosity, poise) Values over the HLW Glass Compositions in the Modeling Dataset and Temperatures $950,1050,1150$ and $1250^{\circ} \mathrm{C}$, Obtained Using the Recommended 29-Term Viscosity Model F-118

Figure 9.1. Illustration of How the PCT-B Model Validity Upper Bound was Determined for the Recommended 18-Term PQM Model with Bias Correction. F-119

Figure 9.2. Model Validity Constraints on HLW Glass Electrical Conductivity as Functions of Temperature F-120

Figure 9.3. Model Validity Constraints on HLW Glass Viscosity as Functions of Temperature 


\section{LIST OF ABBREVIATIONS}

AA

ACED

AES

ANL

BNFL

$\mathrm{CCC}$

CI

CSLM

CUA

CVS

DCP

DOE

DWPF

EA

EDS

EGCR

EPA

GLS

HLW

HWVP

ICP

ID

IHLW

ILAW

LAW

LCI

LM

LOF

LRM
Atomic Absorption

Algorithms for the Construction of Experimental Designs (commercial software used to select a mixture experiment design from a set of candidate points)

Atomic Emission Spectroscopy

Argonne National Laboratory

British Nuclear Fuel Limited

Canister Centerline Cooling

Confidence Interval (two-sided)

Component Slope Linear Mixture

Catholic University of America

Composition Variation Study

Direct Current Plasma

United States Department of Energy

Defense Waste Processing Facility

Environmental Assessment

Energy Dispersive X-Ray Spectroscopy

Experimental Glass Composition Region

United States Environmental Protection Agency

Generalized Least Squares

High Level Waste

Hanford Waste Vitrification Plant

Inductively Coupled Plasma

Identification

Immobilized High Level Waste

Immobilized Low Activity Waste

Low Activity Waste

Lower Confidence Interval

Linear Mixture

Lack-of-Fit

Low Activity Waste Reference Material 
MAXR

MIXSOFT

MSE

NCAW

NQA

ORP

$\mathrm{P}$

PCM

PCT

PI

PNNL

PNWD

PQM

PvM

QA

QARD

$R^{2}$

$R_{A}^{2}$

$R_{P}^{2}$

$R_{V}^{2}$
Maximum R-squared improvement

Commercial software used to design mixture and other constrained region experiments

Mean Squared Error (from regression)

Neutralized Current Acid Waste

Nuclear Quality Assurance

Office of River Protection

Poise

Partial Cubic Mixture

Product Consistency Test

Prediction Interval

Pacific Northwest National Laboratory

Battelle-Pacific Northwest Division

Partial Quadratic Mixture

Predicted versus Measured

Quality Assurance

Quality Assurance Requirements and Descriptions Document

This statistic is referred to as $R$-squared, and is the proportion of variation in values of a response variable over a model development dataset that is accounted for by a fitted model. The $R^{2}$ statistic takes a value between 0 and 1.

This statistic is referred to as adjusted R-squared, and is the proportion of variation in values of a response variable over a model development dataset that is accounted for by a fitted model after adjusting for the number of fitted coefficients in the model. The $R_{A}^{2}$ statistic takes a value between 0 and 1 , and $R_{A}^{2} \leq R^{2}$

This statistic is referred to as predicted R-squared, and is the proportion of variation in values of a response variable over a model development dataset that is accounted for by a fitted model, where each data point is in-turn left out of the fitting process and thus not used to obtain the predicted value of the response variable for that data point. Generally $R_{P}^{2} \leq R_{A}^{2} \leq R^{2} \leq 1$, although $R_{P}^{2}$ can take negative values in cases where there are one or more highly influential data points in the model development dataset.

This statistic is referred to as validation $R$-squared, and is the proportion of variation in values of a response variable over a model validation dataset that 
is accounted for by a fitted model. Generally $R_{V}^{2} \leq R_{P}^{2} \leq R_{A}^{2} \leq \mathrm{R}^{2} \leq 1$, although $R_{V}^{2}$ can take negative values and can take values larger than $R_{P}^{2}, R_{A}^{2}$, or $R^{2}$.

R\&T Research \& Technology

RCRA Resource Conservation and Recovery Act

RMSE Root Mean Squared Error

RMSE $_{V} \quad$ Root Mean Squared Error for Validation

RPD Relative Percent Difference

RPP River Protection Project

RSD Relative Standard Deviation

SD Standard Deviation

SEM Scanning Electron Microscopy

SRNL Savannah River National Laboratory

SSE Sum of Squared Errors

SUCI Simultaneous Upper Confidence Interval

$T_{1 \%} \quad$ One-Percent Crystal Fraction Temperature

$T_{L} \quad$ Liquidus Temperature

TCLP Toxicity Characteristic Leaching Procedure

TFCOUP Tank Farm Contractor Operations and Utilization Plan

THERMO Thermodynamic Hydration Energy Reaction Model

TWRS Tank Waste Remediation System

UCI Upper Confidence Interval

ULS Unweighted Least Squares

VSL Vitreous State Laboratory

WAPS Waste Acceptance Product Specification

WASRD Waste Acceptance System Requirements Document

WLS Weighted Least Squares

WTP Hanford Tank Waste Treatment and Immobilization Plant

WVDP West Valley Demonstration Project

WVNS West Valley Nuclear Services

XRF X-ray Fluorescence 


\section{SUMMARY OF TESTING}

\section{A) Objectives}

This report is the last in a series of currently scheduled reports that presents the results from the High Level Waste (HLW) glass formulation development and testing work performed at the Vitreous State Laboratory (VSL) of the Catholic University of America (CUA) and the development of IHLW property-composition models performed jointly by Pacific Northwest National Laboratory (PNNL) and VSL for the River Protection Project-Waste Treatment and Immobilization Plant (RPP-WTP). Specifically, this report presents results of glass testing at VSL and model development at PNNL for Product Consistency Test (PCT), one-percent crystal fraction temperature $\left(\mathrm{T}_{1 \%}\right)$, electrical conductivity (EC), and viscosity of HLW glasses. The models presented in this report may be augmented and additional validation work performed during any future IHLW model development work. Completion of the test objectives is addressed in Table S.1.

Table S.1. Completion Status of Test Objectives.

\begin{tabular}{|c|c|c|}
\hline Test Objective & $\begin{array}{l}\text { Objective } \\
\text { Met }(\mathbf{Y} / \mathbf{N})\end{array}$ & Discussion \\
\hline $\begin{array}{l}\text { Develop property-composition models and } \\
\text { supporting data that relate IHLW performance } \\
\text { on the PCT to IHLW composition and are } \\
\text { suitable for predicting the PCT performance } \\
\text { of IHLW glasses to be produced in the WTP. }\end{array}$ & Yes & $\begin{array}{l}\text { The PCT models developed are } \\
\text { described in Section } 5 . \text { The } \\
\text { supporting data and experimental } \\
\text { methods are described in Sections } 2 \text {, } \\
\text { 3, and } 4 \text {. }\end{array}$ \\
\hline $\begin{array}{l}\text { Develop models for liquids temperature }\left(\mathrm{T}_{\mathrm{L}}\right) \\
\text { suitable for predicting the primary liquidus } \\
\text { phase in RPP-WTP glasses. This phase is } \\
\text { expected to be spinel for AZ-101, AZ-102, } \\
\text { and AY-102/C-106 wastes, and thorium- } \\
\text { containing phases for AY-101/C-104 wastes. }\end{array}$ & $\begin{array}{c}\text { Yes; } \\
\text { partially }\end{array}$ & $\begin{array}{l}\text { As directed by WTP, instead of } \\
\text { models used to predict } \mathrm{T}_{\mathrm{L}} \text {, models } \\
\text { were developed for prediction of } \mathrm{T}_{1 \%} \\
\text { (see Section } \mathrm{B} \text { below), which are } \\
\text { described in Section } 6 \text {. The } \\
\text { supporting data and experimental } \\
\text { methods are described in Sections } 2 \text {, } \\
3 \text {, and } 4 \text {. The models developed are } \\
\text { for predicting } \mathrm{T}_{1 \%} \text { only in glasses with } \\
\text { spinel as the primary crystalline } \\
\text { phase. Models to predict } \mathrm{T}_{1 \%} \text { for other } \\
\text { primary phases such as thoria in } \\
\text { AY-101/C-104 waste were not } \\
\text { developed. }\end{array}$ \\
\hline
\end{tabular}




\begin{tabular}{|c|c|c|}
\hline $\begin{array}{l}\text { Develop property-composition models that } \\
\text { relate viscosity and electrical conductivity of } \\
\text { glass melts to IHLW composition and are } \\
\text { suitable for predicting the properties of IHLW } \\
\text { glasses to be produced in the WTP. }\end{array}$ & Yes & $\begin{array}{l}\text { The electrical conductivity models are } \\
\text { described in Section } 7 \text {. The viscosity } \\
\text { models are described in Section } 8 \text {. } \\
\text { The supporting data and experimental } \\
\text { methods are described in Sections } 2 \text {, } \\
3 \text {, and } 4 \text {. }\end{array}$ \\
\hline $\begin{array}{l}\text { Develop property-composition models and } \\
\text { supporting data that relate IHLW performance } \\
\text { in the TCLP to IHLW composition and are } \\
\text { suitable for predicting the TCLP performance } \\
\text { of IHLW glasses to be produced in the WTP. }\end{array}$ & Yes & $\begin{array}{l}\text { Toxicity Characteristic Leaching } \\
\text { Procedure (TCLP) data were } \\
\text { collected on } 118 \text { statistically designed } \\
\text { HLW glasses. Of these, } 102 \text { were } \\
\text { available for modeling TCLP } \\
\text { cadmium release (TCLP-Cd). Two } \\
\text { were declared outliers, so data for } 100 \\
\text { glasses were used to develop a TCLP- } \\
\text { Cd model. The data, model, and } \\
\text { model validation results have been } \\
\text { reported by Kot el al. (2004). }\end{array}$ \\
\hline $\begin{array}{l}\text { Develop property-composition models that } \\
\text { relate density of IHLW glasses to composition } \\
\text { in order to predict overall volumes of IHLW } \\
\text { that would be produced from a given waste } \\
\text { feed. }\end{array}$ & No & $\begin{array}{l}\text { Limited density data were collected } \\
\text { for HLW glasses but were insufficient } \\
\text { to develop models. Per WTP Test } \\
\text { Exception, no systematic data } \\
\text { collection was undertaken and no } \\
\text { model development was attempted. } \\
\text { Based on the currently available data } \\
\text { and information, an HLW glass } \\
\text { density model would be needed only } \\
\text { for a very limited number of unlikely } \\
\text { cases. The density property- } \\
\text { composition model may be developed } \\
\text { and reported at a later date if so } \\
\text { directed }\end{array}$ \\
\hline
\end{tabular}

Section 1 of this report provides further discussion of the test objectives and references to the relevant Test Specifications, Test Plans and previous reports.

\section{B) Test Exceptions}

One of the initial test objectives was to develop models for predicting the liquidus temperature $\left(\mathrm{T}_{\mathrm{L}}\right)$ of the primary liquidus phase in HLW glasses, which addresses a WTP process requirement to avoid formation and subsequent settling of crystals in the melter. However, in practice, all HLW glasses are in fact produced below the liquidus temperature because of the presence of noble metals in the wastes. In addition, a strict application of the liquidus temperature for phases other than noble metals also is overly restrictive on waste loading. In 
view of these considerations, the WTP has instead adopted an operational definition of the original liquidus temperature requirement: the glass melt must contain less than $1 \%$ by volume of crystalline phases at $950^{\circ} \mathrm{C}$. Accordingly, WTP Research and Technology (R\&T) directed the change from modeling $\mathrm{T}_{\mathrm{L}}$ to modeling $\mathrm{T}_{1 \%}$, which was documented in Test Exception 24590WTP-TEF-RT-03-078 (Westsik 2003b).

Test Exception 24590-WTP-TEF-RT-03-040 (Westsik 2003a) applies to the PNNL Test Specification (Swanberg 2002) and Test Plan TP-RPP-WTP-179, Rev. 0. The Test Exception specifies that PNNL modeling of viscosity and EC will only occur in Phase 2 (which is covered in this report), rather than both Phase 1 and Phase 2 as had been previously planned. The Test Exception was addressed by Rev. 1 of the Test Plan (Piepel and Cooley 2003).

Test Exception 24590-TEF-RT-07-00017 (Abel 2007) applies to the VSL Test Specification 24590-WTP-TSP-RT-01-006, Rev. 1 (Swanberg 2001), VSL Test Plan VSL02T7800-1, Rev. 1 (Gan and Pegg, 2002), and PNNL Test Specification 24590-WTP-TSP-RT02-001, Rev. 0 (Swanberg 2002). The Test Exception directs that the development activity for an HLW glass density versus composition model be deleted from the relevant Test Specifications and Test Plan. Development of models that relate HLW glass density to composition was not attempted because it was determined that, based on the latest information and data, such models would be needed only for a very limited number of unlikely cases.

\section{C) Results and Performance Against Success Criteria}

This report summarizes and discusses the results for (i) property-composition data, (ii) model development, model validation, and model prediction uncertainty, and (iii) model validity regions for PCT, spinel $\mathrm{T}_{1 \%}$, EC, and viscosity of HLW glasses. Section 2 summarizes the design, background, and target compositions of HLW glasses used in development and validation of the property-composition models; it also identifies the property data collected for the HLW glasses. Section 3 describes experimental procedures and calculations. Section 4 describes the data collected and used in model development. Sections 5 through 8 discuss the propery-composition models developed to predict the PCT releases of boron (B), lithium (Li), and sodium (Na) (Section 5); spinel $\mathrm{T}_{1 \%}$ values (Section 6); melt EC (Section 7); and melt viscosity (Section 8). Table S.2 summarizes the locations within the report of the key modeling results for the recommended and second-choice models for each property. Section 9 discusses the validity regions for the recommended and second-choice PCT, spinel $\mathrm{T}_{1 \%}, \mathrm{EC}$, and viscosity models developed in this report. Section 9 also discusses the validity region for the recommended model for $\mathrm{Cd}$ release from the Toxicity Characteristic Leaching Procedure (TCLP-Cd). That model was discussed by Kot et al. (2004). 
Table S.2. Locations of Results for Recommended HLW Glass Property Models.

\begin{tabular}{|c|c|c|c|c|c|}
\hline \multirow{2}{*}{$\begin{array}{c}\text { HLW Glass } \\
\text { Property }\end{array}$} & \multicolumn{2}{|c|}{ Recommended Model } & \multicolumn{2}{|c|}{ Second-Choice Model } & \multirow{2}{*}{$\begin{array}{c}\text { Example } \\
\text { Calculation }\end{array}$} \\
\hline & $\begin{array}{l}\text { Model } \\
\text { Results }\end{array}$ & $\begin{array}{c}\text { Variance- } \\
\text { Covariance } \\
\text { Matrix } \\
\end{array}$ & $\begin{array}{l}\text { Model } \\
\text { Results }\end{array}$ & $\begin{array}{c}\text { Variance- } \\
\text { Covariance } \\
\text { Matrix } \\
\end{array}$ & \\
\hline PCT-B & Table 5.19 & Table D. $2^{(\mathrm{a})}$ & Table 5.20 & Table D. $3^{(\mathrm{a})}$ & Section 5.8 \\
\hline PCT-Li & Table 5.21 & Table D. $5^{(\mathrm{a})}$ & Table 5.22 & Table D. $6^{(a)}$ & Section 5.8 \\
\hline PCT-Na & Table 5.23 & Table D. $8^{(\mathrm{a})}$ & Table 5.24 & Table D. $9^{(\mathrm{a})}$ & Section 5.8 \\
\hline Spinel $\mathrm{T}_{1 \%}$ & Table 6.10 & Table D.11 & Table 6.11 & Table D.12 & Section 6.7 \\
\hline $\begin{array}{c}\text { Electrical } \\
\text { Conductivity }\end{array}$ & Table 7.9 & Table D.14 & Table 7.7 & Table D.13 & Section 7.6 \\
\hline Viscosity & Table 8.8 & Table D.16 & Table 8.7 & Table D.15 & Section 8.6 \\
\hline
\end{tabular}

(a) The variance-covariance matrices in Appendix D are only for the partial quadratic mixture (PQM) model terms in the recommended and second-choice models for PCT-B, PCT-Li, and PCT-Na. The standard error of the bias-correction constant in each of these models is given in the "Model Results" table.

\section{Property-Composition Data for Modeling IHLW Properties}

Of the 305 simulated and actual HLW glasses included in this work, 268 have PCT data. Normalized PCT releases were calculated from the analyzed data using target glass compositions and they covered relatively wide ranges: $0.007 \mathrm{~g} / \mathrm{L}$ to $21.903 \mathrm{~g} / \mathrm{L}$ for boron, $0.006 \mathrm{~g} / \mathrm{L}$ to $10.675 \mathrm{~g} / \mathrm{L}$ for lithium, and $0.050 \mathrm{~g} / \mathrm{L}$ to $11.819 \mathrm{~g} / \mathrm{L}$ for sodium. Only one glass (HLW-ALG-03) was found to have normalized PCT-B and PCT-Li releases greater than the WTP contract limits. Specifically, HLW-ALG-03 had (i) a PCT-B release of $21.903 \mathrm{~g} / \mathrm{L}$ vs. the contract limit of $16.695 \mathrm{~g} / \mathrm{L}$ and (ii) a PCT-Li release of $10.675 \mathrm{~g} / \mathrm{L}$ vs. the contract limit of $9.565 \mathrm{~g} / \mathrm{L}$. The vast majority of the normalized PCT data were below $2 \mathrm{~g} / \mathrm{L}$, confirming the previous observation that PCT is not a particularly constraining requirement in HLW glass formulation. In general, the PCT releases were considerably lower in the actively designed simulated glasses and in the actual waste glasses. This was mostly a consequence of the statistically designed test matrices, which covered much broader compositional regions. Additionally, the PCT constraint was not applied in the design of two statistically designed matrices (HLW06 and HLW07) because it was deemed desirable for the purpose of model development to have glasses that exceed the contract limits in terms of PCT releases. In spite of these considerations, there was a relative deficiency of data in the higher PCT release region, which impacted the validity regions for the PCT models.

As expected, qualitative correlations were evident between the PCT data and glass compositions. Specifically, increased PCT releases were observed with higher concentrations of alkali oxides and lower concentrations of glass network formers. 
Heat treatment of HLW glasses conducted at temperatures from $650^{\circ} \mathrm{C}$ to $1200^{\circ} \mathrm{C}$ resulted in formation of various crystalline phases. The measured vol\% crystallinity data ranged from trace values to over $40 \mathrm{vol} \%$. The primary crystalline phases were spinel, zircon, zirconia, and thoria. The typical relationship observed between crystal vol\% and heat treatment temperature was linear and linear regression of the (vol\% crystallinity, temperature) data resulted in estimates of $\mathrm{T}_{1 \%}$ values. Estimates of $\mathrm{T}_{1 \%}$ were obtained for 229 simulated glasses, of which 172 precipitated spinel as the major crystalline phase. The 172 estimated spinel $\mathrm{T}_{1 \%}$ values span a range of $554^{\circ} \mathrm{C}$ to $1279^{\circ} \mathrm{C}$, with a median of $944.6^{\circ} \mathrm{C}\left(\right.$ mean $=931.8^{\circ} \mathrm{C}$ ), which can be compared with the WTP processing requirement of $\mathrm{T}_{1 \%} \leq 950^{\circ} \mathrm{C}$. This indicates a good distribution of data for modeling spinel $\mathrm{T}_{1 \%}$ and being able to predict well at $950^{\circ} \mathrm{C}$. Gross compositional trends in the estimated spinel $\mathrm{T}_{1 \%}$ values, however, were less apparent than for the PCT data and no simple correlations between HLW glass compositions and spinel $\mathrm{T}_{1 \%}$ were evident.

Of the 305 simulated and actual HLW glasses included in this work, 210 simulated glasses have EC results. EC was measured at four temperatures (in the vicinities of nominal temperatures of $950,1050,1150$, and $1250^{\circ} \mathrm{C}$ ) for each $\mathrm{HLW}$ glass and the measured EC increased with increasing temperature. The measured EC values ranged from $0.034 \mathrm{~S} / \mathrm{cm}$ to $1.376 \mathrm{~S} / \mathrm{cm}$. The current WTP requirement for glass melt EC is that it be within $0.1 \mathrm{~S} / \mathrm{cm}$ to 0.7 $\mathrm{S} / \mathrm{cm}$ in the temperature range of 1100 to $1200^{\circ} \mathrm{C}$. Of the $210 \mathrm{HLW}$ glasses with EC measurements taken in this temperature range, only eight glasses had EC measurements outside of this range, with 7 above and 1 below the respective limits. In correlating EC with glass composition, alkali oxides had the strongest effect on EC, which increased with the alkali oxide concentration. This is an expected relationship since EC in the HLW glasses is mostly ionic and alkalis provide the most mobile ions.

Viscosity was measured for 210 simulated HLW glasses. With a few exceptions, viscosity was measured at four temperatures (in the vicinities of nominal temperatures of 950 , 1050,1150 , and $1250^{\circ} \mathrm{C}$ ) for each HLW glass and the measured viscosity decreased with increasing temperature. The measured viscosity ranged from $3.60 \mathrm{P}$ to $3166 \mathrm{P}$, which can be compared with the WTP processing limits of $10 \mathrm{P}$ to $150 \mathrm{P}$ (at $1100^{\circ} \mathrm{C}$ ). Forty-three glasses had fitted viscosities at $1100^{\circ} \mathrm{C}$ that exceeded the limit of $150 \mathrm{P}$, ranging from $151 \mathrm{P}$ to $572 \mathrm{P}$. In contrast, there were no glasses with fitted viscosities beneath the lower limit of $10 \mathrm{P}$ at $1100^{\circ} \mathrm{C}$. The viscosity of the simulated glasses decreased with increases in the concentrations of alkali, alkaline earth, and boron oxides and with decreases in the concentrations of glass network formers.

\section{$\underline{\text { Property-Composition Model Development, Validation, and Performance }}$}

The data in the modeling dataset for a given property were used after initial assessment to develop models for that property. The HLW glass property-composition models were obtained by estimating model coefficients using least squares methods. Model validation was accomplished by data-splitting, data-partitioning, and by applying the models to calculate the properties of separate validation glasses where available. Separate validation glasses were 
available for PCT and spinel $\mathrm{T}_{1 \%}$, but not $\mathrm{EC}$ and viscosity. In the data-splitting approach, the modeling dataset was split into five sets of modeling and validation subsets, using roughly $80 \%$ of the data for modeling and $20 \%$ for validation in each split of the dataset. In the datapartitioning approach, the modeling dataset for a given property was partitioned into a modeling dataset and a validation subset. Note that the modeling subset for the data-partitioning approach was comprised primarily of statistically designed glasses, whereas most or all of the glasses that remained in the data-partition validation subset were actively designed. Based on the performance of the models that were investigated, recommended models were selected.

The test objectives were achieved by developing, validating, and quantifying uncertainty in property-composition models for HLW glasses. The recommended models for each property, being the best of the models considered in the development and validation process, are judged suitable for predicting properties of HLW glasses. However, it is outside the scope of work in this report to completely assess the suitability of the recommended property models. Ultimately, the WTP project needs to assess whether the recommended models, along with their corresponding uncertainties, are suitable for their various intended uses (e.g., glass formulation, addition of glass-forming chemicals to waste during HLW vitrification operations, and compliance with WTP contract specifications and processing constraints). Such assessments are within the scopes for algorithm development and verification (work being conducted by WTP project staff) and statistical compliance methodology development and demonstration (work under separate PNNL scope). Initial statistical compliance methodology development and demonstration work was conducted for earlier versions of property-composition models (Piepel et al. 2005). That work is tentatively planned by the WTP project to be updated by PNNL in FY2009 for the models presented in this report.

\section{$\underline{\text { PCT Modeling for HLW Glasses }}$}

The PCT modeling datasets contained 264 glasses for PCT-B, 250 glasses for PCT-Li, and 266 glasses for PCT-Na. The PCT results in these final modeling datasets vary from 0.104 to $21.903 \mathrm{~g} / \mathrm{L}$ for PCT-B release, 0.141 to $10.675 \mathrm{~g} / \mathrm{L}$ for PCT-Li release, and 0.050 to $11.818 \mathrm{~g} / \mathrm{L}$ for PCT-Na release. Assessment of the ranges and distributions of the component values over the HLW glasses with PCT data led to identifying 25 components as having sufficient support for separate model terms in initial PCT property-composition modeling. These 25 components are $\mathrm{Al}_{2} \mathrm{O}_{3}, \mathrm{~B}_{2} \mathrm{O}_{3}, \mathrm{CaO}, \mathrm{CdO}, \mathrm{Cr}_{2} \mathrm{O}_{3}, \mathrm{Fe}_{2} \mathrm{O}_{3}, \mathrm{~K}_{2} \mathrm{O}, \mathrm{La}_{2} \mathrm{O}_{3}$. $\mathrm{Li}_{2} \mathrm{O}, \mathrm{MgO}, \mathrm{MnO}, \mathrm{Na}_{2} \mathrm{O}, \mathrm{NiO}, \mathrm{PbO}, \mathrm{Sb}_{2} \mathrm{O}_{3}$, $\mathrm{SeO}_{2}, \mathrm{SiO}_{2}, \mathrm{SrO}, \mathrm{ThO}_{2}, \mathrm{TiO}_{2}, \mathrm{Tl}_{2} \mathrm{O}, \mathrm{UO}_{3}, \mathrm{ZnO}, \mathrm{ZrO}_{2}$, and Others (the sum of all remaining components).

Several model forms were investigated for PCT-B, PCT-Li, and PCT-Na releases as functions of HLW glass composition, including linear mixture (LM) models, partial quadratic mixture (PQM) models, and partial cubic mixture (PCM) models. Based on model fitting and validation results, the 19-term models (consisting of $18 \mathrm{PQM}$ terms and a bias-correction term applied for higher predicted PCT releases) are recommended for predicting PCT-B, PCT-Li, and PCT-Na releases from HLW glasses. These models contain 13 linear terms $\left(\mathrm{Al}_{2} \mathrm{O}_{3}, \mathrm{~B}_{2} \mathrm{O}_{3}, \mathrm{Fe}_{2} \mathrm{O}_{3}\right.$, $\mathrm{Li}_{2} \mathrm{O}, \mathrm{MnO}, \mathrm{Na}_{2} \mathrm{O}, \mathrm{SiO}_{2}, \mathrm{SrO}, \mathrm{ThO}_{2}, \mathrm{UO}_{3}, \mathrm{ZnO}, \mathrm{ZrO}_{2}$, and Others), which are for the same in each of the PCT-B, PCT-Li, and PCT-Na PQM models. The five quadratic terms in the PCT-B 
model are $\left(\mathrm{Al}_{2} \mathrm{O}_{3}\right)^{2}, \mathrm{UO}_{3} \times \mathrm{ZnO},\left(\mathrm{MnO}_{2}\right)^{2}, \mathrm{Fe}_{2} \mathrm{O}_{3} \times \mathrm{ZnO}$, and $\mathrm{Al}_{2} \mathrm{O}_{3} \times \mathrm{ZrO}_{2}$. The five quadratic terms in the PCT-Li model are $\left(\mathrm{Al}_{2} \mathrm{O}_{3}\right)^{2}, \mathrm{UO}_{3} \times \mathrm{ZnO}, \mathrm{Fe}_{2} \mathrm{O}_{3} \times \mathrm{LiO}_{2}, \mathrm{SrO} \times \mathrm{ZrO}_{2}$ and $\mathrm{Al}_{2} \mathrm{O}_{3} \times \mathrm{ZrO}_{2}$. The five quadratic terms in the PCT-Na model are $\left(\mathrm{Al}_{2} \mathrm{O}_{3}\right)^{2}, \mathrm{Al}_{2} \mathrm{O}_{3} \times \mathrm{ZrO}_{2}, \mathrm{Fe}_{2} \mathrm{O}_{3} \times \mathrm{LiO}_{2}, \mathrm{SiO}_{2} \times \mathrm{ZnO}$, and $\mathrm{SiO}_{2} \times \mathrm{UO}_{3}$. Results for the 18-term PQM models on PCT-B, PCT-Li, and PCT-Na, without and with bias-correction terms, are discussed in Section 5.

Models with 16 terms (13 linear terms, two quadratic terms $\left[\left(\mathrm{Al}_{2} \mathrm{O}_{3}\right)^{2}\right.$ and $\left.\mathrm{Al}_{2} \mathrm{O}_{3} \times \mathrm{ZrO}_{2}\right]$, and a bias-correction term for higher predicted PCT releases) were suggested as second-choice models for each of PCT-B, PCT-Li, and PCT-Na. The two quadratic terms are the same for each PCT release, and were the only ones appearing in all three of the 19-term recommended models for PCT-B, PCT-Li, and PCT-Na. This may provide some protection against the 19-term models over-fitting the modeling data, at a possible cost of not predicting PCT releases as well.

Because of the magnitudes of uncertainties in the PCT data (i.e., from making simulated HLW glasses, PCT testing, and chemical analysis of leachates), as well as significant lack-of-fit (LOF) of the recommended PCT-B, PCT-Li, and PCT-Na models, prediction uncertainties for the models are relatively large (see Table S.3). The LOFs of the recommended and secondchoice PCT models with bias-correction terms are attributed to more complicated relationships between PCT-B, PCT-Li, and PCT-Na releases and HLW glass compostion (over the relatively large HLW glass composition region of interest) than can be approximated by quadratic or cubic polynomial-type models. PCT models without bias-correct terms had a tendency to under-predict

Table S.3. Prediction Uncertainties of Recommended Models for HLW Glasses.

\begin{tabular}{|l|c|c|}
\hline \multirow{2}{*}{$\begin{array}{l}\text { Property } \\
\text { Recommended } \\
\text { Model) }\end{array}$} & \multicolumn{2}{|c|}{$\begin{array}{c}\text { Range of Prediction Standard Deviation Values } \\
\text { Over the Corresponding Modeling Dataset }\end{array}$} \\
\cline { 2 - 3 } & $\begin{array}{c}\text { Prediction Considered } \\
\text { as Mean Property Value }\end{array}$ & $\begin{array}{c}\text { Prediction Considered as an } \\
\text { Individual Property Value }\end{array}$ \\
\hline PCT-B & $0.05-0.24 \ln (\mathrm{g} / \mathrm{L})^{(\mathrm{c})}$ & $0.21-0.31 \ln (\mathrm{g} / \mathrm{L})^{(\mathrm{c})}$ \\
\hline PCT-Li & $0.04-0.21 \ln (\mathrm{g} / \mathrm{L})^{(\mathrm{c})}$ & $0.18-0.27 \ln (\mathrm{g} / \mathrm{L})^{(\mathrm{c})}$ \\
\hline PCT-Na & $0.03-0.21 \ln (\mathrm{g} / \mathrm{L})^{(\mathrm{c})}$ & $0.19-0.28 \ln (\mathrm{g} / \mathrm{L})^{(\mathrm{c})}$ \\
\hline Spinel T & & $27-40^{\circ} \mathrm{C}$ \\
\hline EC & $5-30^{\circ} \mathrm{C}$ & $0.16-0.19 \ln (\mathrm{S} / \mathrm{cm})^{(\mathrm{c})}$ \\
\hline Viscosity & $0.02-0.11 \ln (\mathrm{S} / \mathrm{cm})^{(\mathrm{c})}$ & $0.12-0.15 \ln (\text { Poise })^{(\mathrm{c})}$ \\
\hline
\end{tabular}

(a) Prediction considered as the true mean property value for batching and melting a given HLW glass composition and measuring its property (PCT and spinel $\mathrm{T}_{1 \%}$ ) or measuring its property for a given composition-temperature combination (EC and viscosity).

(b) Prediction considered as an individual property value for batching and melting a given HLW glass composition and measuring its property (PCT and spinel $\mathrm{T}_{1 \%}$ ) or measuring its property for a given composition-temperature combination (EC and viscosity).

(c) Standard deviations in natural logarithm units are approximately equal to the relative standard deviation (standard deviation divided by the mean) in original property units. For example, $0.24 \ln (\mathrm{g} / \mathrm{L})$ can be interpreted as an approximate relative standard deviation of 0.24 (or a percent relative standard deviation of $24 \%$ ). 
moderate-to-large PCT releases (especially the PCT-B and PCT-Li models). Adding biascorrection terms to the recommended and second-choice models for PCT-B, PCT-Li, and PCT$\mathrm{Na}$ releases removed this aspect of model LOF. Still, significant LOFs remained, which are reflected in larger prediction standard deviations. However, unless higher waste loadings are pursued, it is relatively easy to formulate HLW glasses with PCT-B, PCT-Li, and PCT-Na releases substantially below the contract limits associated with the DWPF-EA glass. Hence, the larger prediction uncertainties may not overly restrict WTP HLW vitrification operations.

\section{Spinel $\mathrm{T}_{1} \%$ Modeling for HLW Glasses}

A total of $168 \mathrm{HLW}$ glasses with spinel $\mathrm{T}_{1 \%}$ values was included in the modeling dataset. Over these $168 \mathrm{HLW}$ glasses, the component ranges and distributions of 25 components $\left(\mathrm{Al}_{2} \mathrm{O}_{3}\right.$, $\mathrm{B}_{2} \mathrm{O}_{3}, \mathrm{CaO}, \mathrm{CdO}, \mathrm{Cr}_{2} \mathrm{O}_{3}, \mathrm{Fe}_{2} \mathrm{O}_{3}, \mathrm{~K}_{2} \mathrm{O}, \mathrm{La}_{2} \mathrm{O}_{3}, \mathrm{Li}_{2} \mathrm{O}, \mathrm{MgO}, \mathrm{MnO}, \mathrm{Na}{ }_{2} \mathrm{O}, \mathrm{NiO}, \mathrm{PbO}, \mathrm{Sb}_{2} \mathrm{O}_{3}, \mathrm{SeO}_{2}$, $\mathrm{SiO}_{2}, \mathrm{SrO}, \mathrm{ThO}_{2}, \mathrm{TiO}_{2}, \mathrm{Tl}_{2} \mathrm{O}, \mathrm{UO}_{3}, \mathrm{ZnO}, \mathrm{ZrO}_{2}$, and Others) were sufficient to support separate model terms if needed. These were the same 25 components selected for initial PCT modeling.

Several model forms were investigated for modeling spinel $\mathrm{T}_{1 \%}$ as a function of HLW glass composition, including a 25-component LM model, a reduced 15-component LM model and a series of PQM models, in which the reduced 15-component LM model was augmented using statistical variable selection methods with between two and nine quadratic terms.

Based on comparison of model fitting, validation, and other results (see Section 6), a 20-term PQM model (denoted PQM1a) consisting of 15 linear terms $\left(\mathrm{Al}_{2} \mathrm{O}_{3}, \mathrm{~B}_{2} \mathrm{O}_{3}, \mathrm{Cr}_{2} \mathrm{O}_{3}, \mathrm{Fe}_{2} \mathrm{O}_{3}\right.$, $\mathrm{Li}_{2} \mathrm{O}, \mathrm{MnO}, \mathrm{Na}_{2} \mathrm{O}, \mathrm{NiO}, \mathrm{SiO}_{2}, \mathrm{SrO}, \mathrm{ThO}_{2}, \mathrm{UO}_{3}, \mathrm{ZnO}, \mathrm{ZrO}_{2}$, and Others) and 5 quadratic terms $\left[\left(\mathrm{ZrO}_{2}\right)^{2}, \mathrm{MnO} \times \mathrm{Na}_{2} \mathrm{O}, \mathrm{Li}_{2} \mathrm{O} \times \mathrm{MnO}, \mathrm{MnO} \times \mathrm{NiO}\right.$, and $\left.\left(\mathrm{SiO}_{2}\right)^{2}\right]$ was recommended for predicting the spinel $\mathrm{T}_{1 \%}$ of HLW glasses. A different 20-term PQM model was chosen as the second-choice model, with the main difference being that quadratic terms involving $\mathrm{ZrO}_{2}$ and $\mathrm{ThO}_{2}$ were not allowed. That 20-term PQM model (denoted PQM1b) consists of the same 15 linear terms and 5 quadratic terms $\left(\mathrm{Cr}_{2} \mathrm{O}_{3} \times \mathrm{SiO}_{2}, \mathrm{Al}_{2} \mathrm{O}_{3} \times \mathrm{MnO}, \mathrm{MnO} \times \mathrm{Na}_{2} \mathrm{O}, \mathrm{Li}_{2} \mathrm{O} \times \mathrm{MnO}\right.$, and $\mathrm{Na}_{2} \mathrm{O} \times \mathrm{SiO}_{2}$ ). Results for these two PQM models are discussed in Section 6. These two PQM models performed better than the 25-component and 15-component LM models for the 168-glass modeling dataset, data-splitting validation, and data-partitioning validation. The 15-component reduced LM model had the best performance on the 38-glass separate validation set, but owing to the limited nature of those data, the advantages of the 20-term PQM models out-weighed this advantage of the 15-component reduced LM model.

The recommended 20-term PQM model (PQM1a) for spinel $\mathrm{T}_{1 \%}$ appears to yield unbiased predictions over the full range of measured spinel $\mathrm{T}_{1 \%}$ values in the modeling dataset. However, the model does have moderately large scatter in data points about the fitted model. This scatter is a result of (i) relatively large uncertainties in the estimated spinel $\mathrm{T}_{1 \%}$ values, and (ii) significant LOF of the recommended PQM1a model. Because of these reasons, prediction uncertainties for the model are relatively large (see Table S.3). It is unclear whether the magnitudes of uncertainties in spinel $\mathrm{T}_{1 \%}$ model predictions are small enough to avoid overly restricting the formulation and processing of HLW glasses in the WTP facility. 
Modeling of $\mathrm{T}_{1 \%}$ for the 59 simulated glasses with non-spinel primary crystalline phases was not attempted because there were an insufficient number of glasses with any given primary crystalline phase. Also, the tank waste anticipated to generate HLW glasses with primary phases high in Th and $\mathrm{Zr}(\mathrm{C}-104)$ will be blended to significantly change its composition (Kirkbride et al. 2007).

\section{Electrical Conductivity Modeling for HLW Glasses}

The EC modeling dataset included data for 208 HLW glasses, after excluding two outliers (HLW98-96A and HLW98-96) from the 210 glasses with EC data. Each of the 208 HLW glasses had measured EC values at four temperatures. Actual temperatures at which EC was measured ranged from $909^{\circ} \mathrm{C}$ to $1277^{\circ} \mathrm{C}$. The $\mathrm{EC}$ results varied from 0.034 to $1.376 \mathrm{~S} / \mathrm{cm}$. Over these $208 \mathrm{HLW}$ glasses, the component ranges and distributions of 22 components were sufficient to support separate model terms if needed. These 22 components are $\mathrm{Al}_{2} \mathrm{O}_{3}, \mathrm{~B}_{2} \mathrm{O}_{3}$, $\mathrm{CaO}, \mathrm{CdO}, \mathrm{Cr}_{2} \mathrm{O}_{3}, \mathrm{Fe}_{2} \mathrm{O}_{3}, \mathrm{Li}_{2} \mathrm{O}, \mathrm{MgO}, \mathrm{MnO} \mathrm{Na}_{2} \mathrm{O}, \mathrm{NiO}, \mathrm{PbO}, \mathrm{Sb}_{2} \mathrm{O}_{3}, \mathrm{SeO}_{2}, \mathrm{SiO}_{2}, \mathrm{SrO}, \mathrm{ThO}_{2}$, $\mathrm{Tl}_{2} \mathrm{O}, \mathrm{UO}_{3}, \mathrm{ZnO}, \mathrm{ZrO}_{2}$, and Others (the sum of all remaining components).

Investigation of three equations (Arrhenius, truncated T2, and T2; see Section C.2.1 of Appendix C) for the temperature dependence of EC showed that the truncated-T2 equation was sufficient for the vast majority of the 208 HLW glasses in the EC modeling dataset. Several property-composition-temperature model forms for EC were developed by expanding the two parameters of the truncated-T2 equation as linear or partial quadratic mixture experiment models.

Based on model fitting and validation results, a 22-term truncated T2-LM model was selected as the recommended model. This model has 14 linear composition terms of the form $x_{i}$ (involving $\mathrm{Al}_{2} \mathrm{O}_{3}, \mathrm{~B}_{2} \mathrm{O}_{3}, \mathrm{Fe}_{2} \mathrm{O}_{3}, \mathrm{Li}_{2} \mathrm{O}, \mathrm{MgO}, \mathrm{MnO}, \mathrm{Na}_{2} \mathrm{O}, \mathrm{SiO}_{2}, \mathrm{SrO}, \mathrm{ThO}_{2}, \mathrm{UO}_{3}, \mathrm{ZnO}, \mathrm{ZrO}_{2}$, and Others), the $\mathrm{Li}_{2} \mathrm{O} \times \mathrm{Na}_{2} \mathrm{O}$ quadratic term, and 7 composition-temperature terms of the form $x_{i} /(T / 1000)^{2}$ with $x_{i}=\mathrm{B}_{2} \mathrm{O}_{3}, \mathrm{MnO}, \mathrm{SiO}_{2}, \mathrm{SrO}, \mathrm{UO}_{3}, \mathrm{ZnO}$, and $\mathrm{ZrO}_{2}$. The temperature $(T)$ is scaled by 1000 so that the model coefficients for those terms are of comparable magnitudes to those of the linear composition terms. Results for the recommended EC model are discussed in Section 7. Methods for making EC predictions and quantifying the uncertainties in the predictions are also illustrated in Section 7.

The recommended EC model for HLW glasses provides unbiased predictions over the full range of measured EC values in the modeling dataset. The predicted versus measured plot has relatively tight scatter for most data points, moderate scatter for some data points, and outlying data for two glasses (HLW07-28 and HLW07-40). The recommended EC model does not have a significant LOF, so that EC predictions can be expected to be within the uncertainty of what would be obtained by batching and melting HLW glasses and measuring the EC. The magnitudes of uncertainties in EC model predictions (see Table S.3) should be small enough that they will not overly restrict the formulation and processing of HLW glasses in the WTP facility. 


\section{Viscosity Modeling for HLW Glasses}

The viscosity modeling dataset initially included data for 208 HLW glasses, after excluding two outliers (HLW98-96A and HLW98-96) from the 210 glasses with viscosity data. Viscosity was generally measured at four temperatures for each HLW glass. Actual temperatures at which viscosity was measured ranged from 931 to $1281^{\circ} \mathrm{C}$. The viscosity results varied from $3.60 \mathrm{P}$ to $3166 \mathrm{P}$. It was further decided to eliminate data for 11 glasses having viscosity at fewer than four temperatures. Hence, the viscosity modeling dataset consisted of viscosity values at four temperatures for each of 197 HLW glasses. Over these 197 HLW glasses, the component ranges and distributions of 22 components were sufficient to support separate model terms if needed. These 22 components are $\mathrm{Al}_{2} \mathrm{O}_{3}, \mathrm{~B}_{2} \mathrm{O}_{3}, \mathrm{CaO}, \mathrm{CdO}, \mathrm{Cr}_{2} \mathrm{O}_{3}, \mathrm{Fe}_{2} \mathrm{O}_{3}, \mathrm{Li}_{2} \mathrm{O}, \mathrm{MgO}, \mathrm{MnO}$ $\mathrm{Na}_{2} \mathrm{O}, \mathrm{NiO}, \mathrm{PbO}, \mathrm{Sb}_{2} \mathrm{O}_{3}, \mathrm{SeO}_{2}, \mathrm{SiO}_{2}, \mathrm{SrO}, \mathrm{ThO}_{2}, \mathrm{Tl}_{2} \mathrm{O}, \mathrm{UO}_{3}, \mathrm{ZnO}, \mathrm{ZrO}_{2}$, and Others (the sum of all remaining components). These were the same 22 components selected for initial EC modeling.

Investigation of three equations (Arrhenius, truncated T2, and T2; see Section C.2.1 of Appendix C) for the temperature dependence of viscosity showed that the truncated-T2 equation was sufficient for the vast majority of the 197 HLW glasses in the modeling dataset. Several property-composition-temperature model forms for viscosity were developed by expanding the two parameters of the truncated-T2 equation as linear or partial quadratic mixture experiment models.

Based on model fitting and validation results, a 29-term truncated T2-LM model with five additional quadratic terms is the recommended model for viscosity of HLW glasses. This model has 15 linear composition terms of the form $x_{i}$ (involving $\mathrm{Al}_{2} \mathrm{O}_{3}, \mathrm{~B}_{2} \mathrm{O}_{3}, \mathrm{CaO}, \mathrm{Fe}_{2} \mathrm{O}_{3}, \mathrm{Li}_{2} \mathrm{O}$, $\mathrm{MgO}, \mathrm{MnO}, \mathrm{Na}_{2} \mathrm{O}, \mathrm{SiO}_{2}, \mathrm{SrO}, \mathrm{ThO}_{2}, \mathrm{UO}_{3}, \mathrm{ZnO}, \mathrm{ZrO}_{2}$, and Others), five quadratic terms of the form $x_{i} x_{j}$ or $x_{i}^{2}\left[\mathrm{Al}_{2} \mathrm{O}_{3} \times \mathrm{SiO}_{2}, \mathrm{~B}_{2} \mathrm{O}_{3} \times \mathrm{Na}_{2} \mathrm{O}, \mathrm{Li}_{2} \mathrm{O} \times \mathrm{ZnO}, \mathrm{Na}_{2} \mathrm{O} \times \mathrm{ThO}_{2}\right.$, and $\left.\left(\mathrm{Li}_{2} \mathrm{O}\right)^{2}\right]$, and 9 composition-temperature terms of the form $x_{i} /(T / 1000)^{2}$ involving $\mathrm{Al}_{2} \mathrm{O}_{3}, \mathrm{Fe}_{2} \mathrm{O}_{3}, \mathrm{Li}_{2} \mathrm{O}, \mathrm{Na}_{2} \mathrm{O}$, $\mathrm{SiO}_{2}, \mathrm{SrO}, \mathrm{ThO}_{2}, \mathrm{UO}_{3}$, and $\mathrm{ZrO}_{2}$. The temperature $(T)$ is scaled by 1000 so that the model coefficients for those terms are of comparable magnitudes to those of the linear-composition terms. Results for the recommended 29-term viscosity model are discussed in Section 8 . Methods for making viscosity predictions and quantifying the uncertainties in the predictions are also illustrated in Section 8.

The recommended viscosity model for HLW glasses provides unbiased predictions over the full range of measured viscosity values in the modeling dataset. The predicted versus measured plot has relatively tight scatter for all viscosity data on the 197 glasses in the modeling dataset. The recommended viscosity model does not have a significant LOF, so that viscosity predictions can be expected to be within the uncertainty of what would be obtained by batching and melting HLW glasses and measuring the viscosity. The magnitudes of uncertainties in viscosity model predictions (see Table S.3) should be small enough that they will not overly restrict the formulation and processing of HLW glasses in the WTP facility. 
$\underline{\text { Model Validity Regions for HLW Glass Property Models }}$

The WTP project has developed models for five HLW glass properties (PCT, spinel $\mathrm{T}_{1 \%}$, melt EC, melt viscosity, and TCLP-Cd). These models were fitted to experimental data using regression methods. In general, models obtained in this way should only be applied within appropriate composition regions of validity (PCT, spinel $\mathrm{T}_{1 \%}$, TCLP-Cd) or compositiontemperature regions of validity (viscosity and $\mathrm{EC}$ ). For the recommended PCT, spinel $\mathrm{T}_{1 \%}, \mathrm{EC}$, viscosity, and TCLP-Cd models on HLW glasses, it was decided in consultation with the WTP Project to (i) specify the model validity regions as the regions covered by the modeling datasets, but (ii) exclude any subregions in which models yield unacceptably biased predictions. Bias corrections were applied to PCT models to correct for the tendency of models to under-predict higher PCT releases. Applying bias-corrections to PCT models permitted setting less restrictive model validity constraints for those models.

The model validity regions for the recommended HLW glass property models are specified using (i) single-component constraints on HLW glass composition, (ii) single-variable constraints on HLW glass melt temperature (for EC and viscosity models), and (iii) multiplecomponent constraints for PCT, spinel $\mathrm{T}_{1 \%}$, and TCLP-Cd properties. Some single- and multiplecomponent constraints are specified directly on HLW glass compositions. Other multiplecomponent constraints involve limits on HLW glass and melt properties, and are implemented using the recommended or second-choice property models. Such multiple-component constraints are indirect constraints on HLW glass compositions. In general, each property (i.e., PCT-B, PCT-Li, PCT-Na, spinel $\mathrm{T}_{1 \%}$, EC, viscosity, and TCLP-Cd) has its own model validity region. For a given property, the model validity regions for the recommended and second-choice models are the same. The model validity regions are discussed in Section 9. The constraints that specify the validity regions for the HLW property-composition models are summarized in Table 9.8.

\section{D) Quality Requirements}

The portions of this work performed at VSL were conducted under a quality assurance program compliant with NQA-1 (1989), NQA-2a (1990) Part 2.7, and the Quality Assurance Requirements and Description (QARD) document (U. S. DOE-RW 2004). This program is supplemented by a Quality Assurance Project Plan for WTP work (VSL 2003) that is performed at VSL. Test and procedure requirements by which the testing activities are planned and controlled are also defined in that plan. The program is supported by VSL standard operating procedures that were used for this work (VSL 2006).

All simulated HLW glasses were prepared and characterized at VSL as part of the contract work under Bechtel National, Inc. The QA program as described above was in place during all of this work. Five actual waste glasses were prepared and characterized at PNNL and SRNL. The following QA programs were implemented for the preparation and testing of the actual waste glasses, which have been reported previously:

- AZ-101 glass at PNNL (Hrma et al. 2004): This work was performed to the quality requirements of NQA-1 (1989), NQA-2a (1990) Part 2.7, and QARD (2004). A matrix 
that cross-references the NQA-1, 2a and QARD requirements with the procedures at PNNL was given by Hrma et al. (2004), including justification for those requirements that were not implemented.

- AZ-102 glass and C-104 glass at PNNL (Smith et al. 2001): Feed preparation and glass fabrication work was conducted under the quality requirements of the Standards-Based Management System as described in the document BNFL Phase B-1 Support Quality Assurance Planning Document. The work elements relating to glass product testing were conducted to meet the requirements of QARD and the Nuclear Quality Assurance Requirements and Description Manual.

- C-106 glass at SRNL (Schumacher et al. 2002): The QA program for this work was in compliance with the applicable elements of QARD for areas affecting IHLW development, qualification, characterization, and certification.

- AY-102/C-106 glass at SRNL (Crawford et al. 2005): This work was conducted in accordance with the SRNL QA program which complied with NQA-1 (1989), NQA-2a (1990) Part 2.7, and QARD (2004). The Task Technical and Quality Assurance Plan (Crawford 2003) provided the specific quality requirements.

The QA requirements for PNNL work were met through the Quality Assurance Plan (PNNL 2007a) for the River Protection Project-Waste Treatment Plant Support Program (RPP-WTP Support Program). The RPP-WTP Support Program implementing procedures (PNNL 2007b) comply with the requirements of NQA-1 (1989), NQA-2a (1990) subpart 2.7, and QARD (U. S. DOE-RW 2004).

The following specific areas of this work are subject to the QARD: glass preparation, glass compositional analysis, statistical experimental design development, PCT testing, and PCT model development. All work in these areas was performed according to VSL and PNNL QA programs and implementing procedures that are compliant with QARD.

Although not directly relevant to the applications described in this report, it is noted that the glass preparation in this work also was subject to the requirements in Blumenkranz (2001), which describes the application of requirement in EPA (1993) and EPA (2001).

\section{E) R\&T Test Conditions}

The datasets used to develop HLW property-composition models included data collected at VSL for the WTP project since 2002 that satisfy the applicable QA requirements. The datasets also contained results for five actual waste glasses that were prepared and characterized at PNNL and SRNL. The data collected at VSL involved testing of simulated glasses only, the formulations of which were designed either statistically or actively. The statistically designed glasses belonged to one of five test matrices (HLW02, HLW03, HLW05, HLW06, HLW07), each of which was developed to meet a set of specific design constraints. A staged approach was adopted in developing these matrices to allow continual incorporation of evolving information and data on waste compositions and process knowledge, whereby updates and improvements to 
the property-composition models will help define the most appropriate compositional space for study. The modeling datasets comprise 207 glasses from statistically designed matrices. Table S.4 summarizes the locations in the report where the compositional ranges of the five statistically designed HLW glass matrices are listed. Section 2 describes the HLW glass compositions for each of the statistically designed matrices. The compositions of another 40 simulated glasses were calculated with the preliminary IHLW formulation algorithm (denoted HLW-ALG glasses). Preparation and testing of these 40 glasses was intended as an assessment of the IHLW formulation algorithm to identify potential deficiencies and areas for possible improvements before its implementation at the WTP. Finally, the datasets included 53 glass compositions that were actively designed to support melter testing and actual waste testing. Formulation of these glasses was based on waste data either from inventory or actual waste analysis. Of the 305 simulated and actual HLW glasses in the datasets, 268 have PCT data, 229 have estimated $\mathrm{T}_{1 \%}$ values (of which 172 are with spinel as the primary liquidus phase), and 210 each have EC and viscosity data.

Table S.4. Locations of Compositional Ranges of Statistically Designed HLW Glasses.

\begin{tabular}{|c|c|}
\hline Glass Components & Locations in Report \\
\hline Major Oxides & Table 2.1 \\
\hline $\begin{array}{c}\text { "Others" or "Spike" Oxides } \\
\text { (Minor components that were varied) }\end{array}$ & $\begin{array}{c}\text { Table 2.2 (HLW02- and 03-) } \\
\text { Table 2.3 (HLW05- 06-, and 07-) }\end{array}$ \\
\hline $\begin{array}{c}\text { "Constant" Oxides } \\
\text { (Components not varied) }\end{array}$ & Table 2.4 \\
\hline
\end{tabular}

Crucible melts of the simulated HLW glasses (about $420 \mathrm{~g}$ ) were prepared by melting mixtures of reagent grade or higher purity chemicals in platinum-gold crucibles at $1150^{\circ} \mathrm{C}$ for 120 minutes. Mixing of the batched chemicals was accomplished by dry blending while mixing of the melt was accomplished mechanically using a platinum stirrer. Samples of the resulting glasses were then analyzed by x-ray fluorescence (XRF) on solid samples. This analysis was supplemented by Direct Current Plasma-Atomic Emission Spectroscopy (DCP-AES) on solutions from microwave-assisted acid dissolution of the glass samples. Actual HLW glass samples were prepared at PNNL and SRNL by mixing actual tank waste samples with LAW pretreatment products (either actual waste or simulant) and glass forming chemicals based on target compositions formulated at VSL. The blended wastes were dried and melted in crucibles inside shielded cells. The resulting glasses were recovered and dissolved by fusion $\left(\mathrm{Na}_{2} \mathrm{O}_{2}-\right.$ $\mathrm{NaOH}$ or $\mathrm{KOH}-\mathrm{KNO}_{3}$ ) and/or heated digestion with a mixture of acids, followed by chemical analysis using Inductively Coupled Plasma-Atomic Emission Spectroscopy or Mass Spectroscopy (ICP-AES or ICP-MS).

The PCT (based on ASTM 1285) was performed at $90^{\circ} \mathrm{C}$ for seven days on 263 simulated and 5 actual HLW glasses. The glass samples were ground and sieved (-100 to +200 mesh, or 
$0.074 \mathrm{~mm}$ to $0.149 \mathrm{~mm}$ ) before leaching with deionized water. Testing of the 263 simulated glasses was performed at VSL and the leachates were analyzed by DCP-AES. Actual glass samples were tested at PNNL or SRNL and the leachates were analyzed by ICP-AES.

The statistically designed, simulated HLW glasses (247) were heat-treated isothermally between $650^{\circ} \mathrm{C}$ and $1200^{\circ} \mathrm{C}$ (after a pre-melt temperature of $1200^{\circ} \mathrm{C}$ for 1 hour to establish a common starting point) at selected temperatures for 70 hours. The heat-treated samples were examined by Scanning Electron Microscopy and Energy Dispersive X-ray Spectroscopy to identify the crystalline phases and to estimate their volume fraction. Linear regression of the (volume $\%$ crystallinity, temperature) data was used to estimate $\mathrm{T}_{1 \%}$ values. No $\mathrm{T}_{1 \%}$ values were estimated for the HLW04 glasses, the HLW98 glasses, or the actual waste glasses.

The melt viscosities of the simulated HLW glasses were measured, typically in the temperature range of $950-1250^{\circ} \mathrm{C}$. A rotating spindle viscometer was used, with the viscosity determined from the relation between torque and rotation speed. The EC of a glass melt was determined by measuring the resistance as a function of frequency using a calibrated platinum/rhodium probe attached to an impedance analyzer (Hewlett-Packard model 4194A or an Agilent 4294A). Measurements were performed over temperature ranges similar to those employed for the viscosity measurements, with the results extrapolated to zero frequency to obtain the direct current conductivity. Both the measured viscosity and EC data were fitted to the Vogel-Fulcher equation to give, respectively, interpolated values of viscosity and EC at standard temperatures (e.g., $1150^{\circ} \mathrm{C}$ ). Actual waste glasses were not characterized with respect to melt viscosity or EC.

\section{F) Simulant Use}

Waste simulants were not used at VSL in the preparation of simulated HLW glasses. All of the simulated HLW glasses were prepared from reagent grade chemicals in combinations designed to achieve the target compositions.

For the preparation of HLW glasses from actual waste samples, simulants were prepared for the Sr/TRU removal waste streams from LAW pretreatment. These Sr/TRU removal simulants were blended with actual Envelope D waste samples in the preparation of AZ-102 (at PNNL) and C-106 (at SRNL) glasses.

\section{G) Discrepancies and Follow-On Tests}

There are no discrepancies to note. The models presented in this report may be augmented and additional validation work performed during any future IHLW model development work, especially if significant changes are anticipated in the compositions of the HLW streams or target glass compositions to be used in HLW processing. Also, additional work may be needed if 1) the model validity constraints are found to be too restrictive, or 2) the model prediction uncertainties are too high for the desired applications of the models. 


\section{SECTION 1 INTRODUCTION}

The United States Department of Energy's (DOE's) Hanford site in the state of Washington is the current storage location for about 50 million gallons of high-level mixed waste. This waste is stored in underground tanks at the Hanford site. The Hanford Tank Waste Treatment and Immobilization Plant (WTP) will provide DOE with a capability for treating this waste by vitrification for subsequent disposal. The tank waste will be partitioned into Low Activity Waste (LAW) and High Level Waste (HLW) fractions, which will then be vitrified, respectively, into Immobilized Low Activity Waste (ILAW) and Immobilized High Level Waste (IHLW) products. The ILAW product will be disposed of in an engineered facility on the Hanford site while the IHLW product will be directed to the national deep geological disposal facility for high-level nuclear waste. The ILAW and IHLW products must meet a variety of requirements with respect to protection of the environment before they can be accepted for disposal.

This report is the last in a series of currently scheduled reports for the WTP project that presents the results from HLW glass formulation development and testing work performed at the Vitreous State Laboratory (VSL) of the Catholic University of America (CUA), and the results from development of IHLW property-composition models performed jointly by Pacific Northwest National Laboratory (PNNL) and VSL. This report presents the datasets and results of work to develop models for the following HLW glass and melt properties:

- Product Consistency Test (PCT) responses (i.e., releases of boron, lithium, and sodium)

- $\quad$ spinel $\mathrm{T}_{1 \%}$, which is the temperature at which the volume fraction of spinel crystals in equilibrium with glass melt equals $1 \%$

- electrical conductivity (EC)

- viscosity.

Models for the PCT responses and spinel $\mathrm{T}_{1 \%}$ relate those properties to HLW glass composition. Models for EC and viscosity relate those properties to HLW glass composition and melt temperature. The data, model development, model validation, and model uncertainty results presented in this report are the last of this type of work currently scheduled for predicting properties of HLW glass. However, if the current HLW glass property-composition database is augmented with additional data in the future, additional model development and/or validation work could be performed at that time.

This report is responsive to the applicable Test Specifications (Swanberg 2001, Swanberg 2002), Test Exceptions (Westsik 2003a, Westsik 2003b, Abel 2007), and Test Plans (Gan and Pegg 2002, Piepel and Cooley 2003) for IHLW property-composition modeling. The purpose of the work described in these documents is to develop property-composition models to support 
HLW waste form qualification, processing, and compliance. The models are intended to provide the basis for defining operating ranges, developing target glass compositions, making operating decisions (e.g., glass former additions), and demonstrating compliance with applicable specifications during HLW vitrification operations at the WTP.

The test objectives, test overview, and discussion of how the objectives were met are presented in Sections 1.1, 1.2, and 1.3, respectively. The IHLW composition region of interest and the HLW glass data covering this compositional region are described in Section 2. Experimental procedures used in glass preparation, as well as sample preparations and measurements of PCT, $\mathrm{T}_{1 \%}, \mathrm{EC}$, and viscosity are described in Section 3. The PCT, $\mathrm{T}_{1 \%}, \mathrm{EC}$, and viscosity data and general features of their relationships to HLW glass composition are discussed in Section 4.

Models relating PCT boron, lithium, and sodium releases to HLW glass composition are presented and discussed in Section 5. Models relating spinel $\mathrm{T}_{1 \%}$ to HLW glass composition are presented and discussed in Section 6. Models relating EC and viscosity to HLW glass composition and melt temperature are presented and discussed in Sections 7 and 8, respectively. The validity regions for the IHLW property models are presented in Section 9. A summary and conclusions from the IHLW PCT, spinel $\mathrm{T}_{1 \%}$, EC, and viscosity model development and validation work are presented in Section 10. Recommendations for future property-composition data development, modeling, or validation are discussed in Section 11. The quality assurance requirements applied to the work presented in this report are described in Section 12. References are listed in Section 13.

Appendix A discusses the development of two test matrices that generated part of the data used for modeling in this report. Appendix B contains the compositions and PCT release data for glasses used to validate PCT-composition models. Appendix C discusses the statistical methods applied in the main body of the report. Appendix D presents the variance-covariance matrices for selected IHLW property-composition models, which are required to calculate uncertainties of model predictions. Appendix E contains an example illustrating the use of equations for calculating estimated spinel $\mathrm{T}_{1 \%}$ values and corresponding standard deviations. Appendix F presents the HLW glass compositions in mole percent (mol\%). Appendix G contains the glass melt EC and viscosity values at a temperature of $1150^{\circ} \mathrm{C}$ calculated from Vogel-Fulcher fits for each of $210 \mathrm{HLW}$ glasses for each property.

\section{$1.1 \quad$ Test Objectives}

The objectives of the HLW glass property-composition modeling work as given in the Test Plans (Gan and Pegg 2002, Piepel and Cooley 2003) and Test Exception (Westsik 2003b) are listed below along with what has been done to address them.

- Develop property-composition models and supporting data that relate IHLW performance on the PCT to IHLW composition and are suitable for predicting the PCT performance of IHLW glasses to be produced in the WTP. 
- Develop property-composition models that relate viscosity and electrical conductivity of glass melts to IHLW composition and are suitable for predicting the properties of IHLW glasses to be produced in the WTP.

Data, model development, model validation, and model uncertainty results for PCT, viscosity, and EC property-composition models are presented in this report. Previous model development results have been reported by Kot et al. (2005a) for PCT and by Gan et al. (2004) for viscosity and EC. The modeling results in this report for PCT, viscosity, and EC supersede the results in these previous reports.

- Develop models for liquidus temperature $\left(T_{L}\right)$ suitable for predicting the primary liquidus phase in RPP-WTP glasses. This phase is expected to be spinel for AZ-101, AZ-102, and $A Y-102 / C-106$ wastes, and thorium-containing phases for $A Y-101 / C-104$ wastes.

As directed by a Test Exception (Westsik 2003b), instead of liquidus temperature $\left(\mathrm{T}_{\mathrm{L}}\right)$ models, models to predict one-percent crystal fraction temperatures $\left(\mathrm{T}_{1 \%}\right)$ have been developed and are presented in this report. The change to modeling $\mathrm{T}_{1 \%}$ instead of $\mathrm{T}_{\mathrm{L}}$ was made because WTP has adopted an operational definition of liquidus temperature and corresponding limit. Specifically, the amount of crystalline phases that are present in equilibrium with the glass melt at $950^{\circ} \mathrm{C}$ must be less than 1 volume $\%$. The less-conservative operational definition is adopted in recognition of the fact that all HLW glasses are, in actuality, produced below the liquidus temperature of the glass melt as a result of the presence of sparingly soluble species such as noble metals in the wastes. A strict application of the liquidus temperature criterion (for phases other than noble metals) is also overly restrictive on waste loading.

As discussed subsequently, the difference in compositions between (i) AZ-101, AZ-102, and AY-102/C-106 wastes and (ii) AY-101/C-104 wastes was addressed by the development of different test matrices of glass compositions, each focusing on the expected characteristic compositions of the two groups and incorporating compositional and process information available at the time. Additionally, HLW glasses were formulated for melter testing and other testing with data available for each of the four waste groups (i.e., AZ-101, AZ-102, AY-102/C-106, and AY-101/C-104). The data available included inventory data and analytical data for samples of actual wastes. Testing of these glasses confirmed that the primary liquidus phase was spinel for AZ-101, AZ-102, and AY-102/C-106 wastes. By comparison, both zirconium- and thorium-containing phases were important for AY-101/C-104 waste. Note that spinel was the only primary crystalline phase with sufficient data to develop property composition models (see Section 4.2 for further discussion).

Data, model development, model validation, and model uncertainty results for spinel $\mathrm{T}_{1 \%}$ models are presented in this report. Previous IHLW Phase 1 model development results for spinel $\mathrm{T}_{1 \%}$ have been reported by Kot et al. (2005a). Those results were updated by PNNL in 2005 using Phase 1a data and documented in a revision of Section 6 of Kot et al. (2005) ${ }^{1}$. The spinel $\mathrm{T}_{1 \%}$ modeling results in this report supersede the results in these previous documents.

1 The revised report section was provided to the WTP project for project use, but was not issued as a technical report or letter report, and thus it cannot be referenced. 
- Develop property-composition models and supporting data that relate IHLW performance in the TCLP to IHLW composition and are suitable for predicting the TCLP performance of IHLW glasses to be produced in the WTP.

Toxicity Characteristic Leaching Procedure (TCLP) data were collected on 118 HLW glasses (including replicates). Of these, 102 were available for modeling TCLP cadmium (TCLPCd) release. Data for two of the glasses were declared outliers, so that data for 100 glasses were used to develop a TCLP-Cd model. The TCLP data, model, and model validation results have been reported by Kot el al. (2004).

- Develop property-composition models that relate density of IHLW glasses to composition in order to predict overall volumes of IHLW that would be produced from a given waste feed.

Limited density data were collected for selected simulated HLW glasses. However, these data were collected to support other testing. Per direction of the WTP Research and Technology (R\&T) (Abel, 2007), development activity for an HLW glass density versus composition model was deleted from the relevant Test Specifications and Test Plan. No systematic data collection was undertaken for the development of IHLW density models and no model development was attempted because it was determined that such models would be needed only for a very limited number of cases. The only technical need for a density model is to ensure that a filled IHLW canister will not exceed the weight requirements. Based on the available information and data, it is very unlikely that the weight requirements will be exceeded except for extreme glasses that incorporate high concentrations of thorium and/or waste from Sr/TRU removal. These extreme glasses will most likely not be produced according to current projections of waste compositions and waste blending. The density property-composition model may be developed and reported at a later date if it is determined to be needed, and if so directed by WTP R\&T.

\subsection{Test Overview}

Databases of simulated and actual HLW waste glass compositions and property values have been compiled for the purpose of model development, model validation, and development of model uncertainty expressions for the following properties:

- PCT boron (PCT-B), lithium (PCT-Li), and sodium (PCT-Na) releases, in units of g/L

- Spinel $\mathrm{T}_{1 \%}$, in units of ${ }^{\circ} \mathrm{C}$

- EC, in units of $\mathrm{S} / \mathrm{cm}$

- viscosity $(\eta)$, in units of $P$.

All HLW glass data developed under the WTP project dating back to 1998 that satisfy the relevant QA requirements have been included in a separate database for each of these four properties. The data included in these databases are discussed in Section 2. 
The focus of the "testing" documented in this report was the development and validation of HLW glass property models for (i) PCT-B, PCT-Li, and PCT-Na releases, (ii) spinel $\mathrm{T}_{1 \%}$, (iii) EC, and (iv) viscosity. An additional focus was the development of expressions to quantify the uncertainty in property predictions made with the models. The work to develop, validate, and quantify prediction uncertainties for the PCT, spinel $\mathrm{T}_{1 \%}, \mathrm{EC}$, and viscosity models is discussed, respectively, in Sections 5, 6, 7, and 8. In addition to model development, the PCT, $\mathrm{T}_{1 \%}, \mathrm{EC}$, and viscosity data for the HLW glasses were analyzed to determine their dependences on glass composition in terms of the contribution of different constituents to the structure of the glass. These analyses are presented in Section 4. The generation of glass composition test matrices and measurement of glass properties have been documented in previous reports, as discussed subsequently in Sections, 2 and 3. Appendix A discusses the development of test matrices not previously discussed in separate reports.

Toxicity Characteristic Leach Procedure (TCLP) testing and modeling, which are part of the work scopes in the Test Specifications (Swanberg 2001, 2002) and Test Plans (Gan et al. 2002, Piepel and Cooley 2003), were completed and reported earlier using a separate composition matrix (Kot et al. 2004). Additional TCLP testing of HLW glasses for regulatory compliance with Land Disposal Restrictions was also completed and reported (Kot et al. 2003a).

The development of HLW property-composition models adopted a phased approach that ran from 2002 to 2006. During that time, five test matrices of glasses were developed and tested, each of the matrices with its own focus. This approach has the important advantage of continually incorporating the updated information into the test matrix design, including revised waste compositions and process knowledge. The collected data for the earlier test matrices were also important in refining constraints and WTP glass composition region for subsequent test matrix designs such that sufficient data would be available to cover the appropriate glass composition region. In addition to the 207 simulated HLW glasses from the five test matrices, glass formulation work at VSL to support other testing (e.g., melter testing) developed and tested over 100 HLW glasses. Not only did testing of these glasses directly supply data to the databases for model development, it also provided valuable guidance in the design of the test matrices.

\subsection{How Test Objectives Were Achieved}

The test objectives in Section 1.1 were achieved by developing, validating, and quantifying uncertainty in property-composition models for HLW glasses. Recommended models are presented for PCT response ( $\mathrm{B}, \mathrm{Li}$, and $\mathrm{Na}$ releases), spinel $\mathrm{T}_{1 \%}, \mathrm{EC}$, and viscosity. The recommended models for each property, being the best of the models considered in the development and validation process, are judged suitable for predicting properties of HLW glasses. However, it is outside the scope of work in this report to completely assess the suitability of the recommended property models. Ultimately, the WTP project needs to assess whether the recommended models, along with their corresponding uncertainties, are suitable for their various intended uses (e.g., glass formulation, addition of glass-forming chemicals to waste during HLW vitrification operations, and compliance with WTP contract specifications and processing constraints). Such assessments are within the scopes for algorithm development and verification (work being conducted by WTP project staff) and statistical compliance methodology 
development and demonstration (work under separate PNNL scope). Initial statistical compliance methodology development and demonstration work was conducted for earlier versions of property-composition models (Piepel et al. 2005). That work is tentatively planned by the WTP project to be updated by PNNL in FY2009 for the models presented in this report 


\section{SECTION 2 DATA FOR DEVELOPING AND VALIDATING HLW GLASS PROPERTY MODELS}

The databases used in the development of models for high-level waste (HLW) glass properties [Product Consistency Test (PCT), spinel one-percent crystal fraction temperature (spinel $\mathrm{T}_{1 \%}$ ), electrical conductivity $(\mathrm{EC})$, and viscosity] include all data developed under the WTP project since 1998 that satisfy the applicable quality assurance (QA) requirements. Some of the data are from statistically designed ${ }^{2}$ composition matrices to cover the HLW glass composition region or subregions of interest. Other data are from actively designed ${ }^{3}$ glass formulations that relied on glass science rather than statistical methods to develop glass compositions with desired properties. Although melter test glass compositions were selected from actively designed glass formulations that meet all Hanford Tank Waste Treatment and Immobilization Plant (WTP) processing and product quality requirements, no glasses made during melter tests were included in the modeling datasets because they did not meet all the applicable QA requirements. A limited number of data are included from tests on glasses made from actual HLW samples. The model development data are discussed in Section 2.1.

Two databases previously developed and used to validate Immobilized High Level Waste (IHLW) Phase 1 models for PCT and spinel $\mathrm{T}_{1 \%}$ were also used to validate Phase 2 models for those properties in this report. These model validation databases are discussed in Section 2.2.

\subsection{Data Available for Modeling HLW Glass Properties}

The following subsections provide the identifications and target compositions of HLW glasses in the databases compiled for developing property models. Each subsection describes a series or group of glasses for which data on some or all of the properties were collected. The glasses were divided into groups according to how they were formulated and the objectives that their testing supported. The groupings included five statistically designed test matrices, two series of actively designed glasses, one series of glasses calculated with the IHLW formulation algorithm, and one set of glasses prepared with actual waste samples. Glasses produced from HLW melter campaigns were not included in the modeling datasets because they did not meet all the applicable QA requirements. It should be noted, however, that the target glass compositions for all melter tests were previously prepared in crucible melts, with compliance to the relevant QA requirements. Data available for those crucible glasses were included in the modeling datasets. In the following summary, references to the corresponding test matrix development reports and/or data summary reports are provided. The property data that were collected from

\footnotetext{
2 "Statistically designed" refers to a set of glass compositions designed using statistical experimental design methods to cover a composition space.

3 "Actively designed" refers to glasses developed to meet certain specified requirements such as a glass composition to treat a HLW tank waste stream that has to meet all product quality and processing requirements. In this approach, information from characterization of one set of glasses is used to guide formulation of future glass compositions, with little or no intent to cover a composition space.
} 
each set of glasses are identified in each subsection. Section 3 describes the experimental procedures used in data collection, while Section 4 presents the property data for the HLW glasses and discusses those data from a glass science perspective.

\subsubsection{Phase 1 Initial Test Matrix (HLW02) Glasses}

A set of 57 glass formulations specified by a statistically-designed test matrix (Piepel et al. 2002a) was prepared and tested to support Phase 1 of IHLW property-composition modeling. These 57 HLW glasses are referred to as the Initial Matrix and also as the HLW02 series (because the glasses are labeled HLW02-01 to HLW02-57).

The IHLW Initial Matrix focused on glasses corresponding to AZ-101, AZ-102, and AY-102/C-106 wastes with blended LAW pretreatment products. The waste composition information considered in the development of the Initial Matrix included Tank Farm Contractor Operation and Utilization Plan (TFCOUP) Rev. 3A (CH2M Hill 2001), TFCOUP Rev. 2 (CH2M Hill 2000), waste compositions estimates and flow-sheet impacts for HLW streams provided by the WTP (Perez 2002), prior VSL assessments of HLW waste composition (Kot and Pegg 2001), and LAW Sr/TRU pretreatment product compositions (Smith et al. 2001).

Design of the IHLW Initial Matrix began with the selection of glass components and the development of constraints to define the HLW experimental glass composition region (EGCR) to be covered by the test matrix. The glass components and constraints were developed using information on Hanford HLW compositions, pretreatment and recycle assumptions, existing WTP glass formulation data, glass science knowledge and experience, and statistical input. A total of $16 \mathrm{HLW}$ glass components were chosen as experimental design variables (including a Spike component and a Constant component), as shown in the HLW02 portion of Table 2.1. The compositions of the Spike and Constant components in the HLW02 series are shown in Tables 2.2 and 2.4, respectively. Major oxides that significantly affect glass properties were treated as individual design variables while minor constituents were treated as design constants. The Spike components primarily consisted of Resource and Conservation Recovery Act (RCRA) constituents, which were the subjects of TCLP studies (Kot et al. 2004).

The constraints used to define the EGCR for the Initial Matrix were initially developed by VSL and then iterated based on inputs from the WTP Project and Pacific Northwest National Laboratory (PNNL) ${ }^{4}$ - see Piepel et al. (2002a). The IHLW Initial Matrix single-component constraints are listed in the HLW02 portion of Table 2.1, while the multiple-component constraints are listed in the HLW02 portion of Table 2.6. The multiple-component constraints include waste-loading constraints and glass property constraints. The specific numerical constraints used to implement the glass property constraints for the Initial Matrix are listed in Table 2.7.

\footnotetext{
${ }^{4}$ Portions of the work in this report were conducted under Battelle's government contract as Pacific Northwest National Laboratory (PNNL), while other work was conducted under the use permit of that contract as Battelle-Pacific Northwest Division (PNWD). For simplicity, all Battelle work will be referred to as being conducted at PNNL.
} 
The IHLW Initial Matrix was developed by PNNL (with input from VSL and WTP) using a layered design approach (Piepel et al. 1993, 2002b). The design had one outer layer (containing 26 glasses), one inner layer (24 glasses), a center point, and 6 replicate glasses for a total of 57 glasses. The MIXSOFT (Piepel 2003, 2006) and ACED (Welch 1987) software packages were used to construct the Initial Matrix. Additional details of the test matrix development are discussed in a previous technical report (Piepel et al. 2002a). The target compositions of the Initial Matrix HLW glasses expressed in the original oxides are given in Tables 2.8 and 2.9. However, it was subsequently decided to revise the list of primary oxide forms (see Table 2.10). The target compositions of the Initial Matrix HLW glasses expressed in the revised oxides are listed in Tables 2.11 and 2.12.

VSL prepared the Initial Matrix HLW glass samples, collected the PCT, $\mathrm{T}_{1 \%}$, EC, and viscosity data on all 57 of the glasses, and documented the results (Gan et al. 2004, Kot et al. 2005a). Section 3 discusses the methods used to measure properties of HLW glasses, while Section 4 presents and discusses the resulting data.

\subsubsection{Phase 1 Augmentation Test Matrix (HLW03) Glasses}

A set of 45 glass formulations specified by a statistically-designed test matrix (Piepel et al. 2002a) was prepared and tested to augment data from the Initial Matrix to support Phase 1 of IHLW property-composition modeling. These $45 \mathrm{HLW}$ glasses are referred to as the Augmentation Matrix and also as the HLW03 series (because the glasses are labeled HLW03-01 to HLW03-45).

The IHLW Augmentation Matrix focused on glasses associated with AY-101/C-104 wastes as well as AZ-101, AZ-102, and AY-102/C-106 wastes, all with blended LAW pretreatment products. The waste composition information considered in the development of the Augmentation Matrix included TFCOUP Rev. 3A (CH2M Hill 2001), TFCOUP Rev. 2 (CH2M Hill 2000), waste compositions estimates and flow-sheet impacts for HLW streams provided by the WTP (Perez 2002), data on WTP actual waste samples (Smith et al. 2001, Kot and Pegg 2003, 2004) prior VSL assessments of HLW waste composition (Kot and Pegg 2001), LAW $\mathrm{Sr}$ /TRU pretreatment product compositions (Smith et al. 2001), and WTP guidance information (Musick 2002, Pegg 2002).

Design of the IHLW Augmentation Matrix began with the selection of glass components and the development of constraints to define the HLW EGCR to be covered by the test matrix. The glass components and constraints were developed using information on Hanford HLW compositions, pretreatment and recycle assumptions, existing WTP glass formulation data, glass science knowledge and experience, and statistical input. A total of $20 \mathrm{HLW}$ glass components were chosen as experimental design variables (including a Spike component and a Constant component), as shown in the HLW03 portion of Table 2.1. New components varied as design variables in the Augmentation Matrix but not in the Initial Matrix included $\mathrm{Cr}_{2} \mathrm{O}_{3}$ (removed from the Spike component in the Initial Matrix), $\mathrm{ThO}_{2}, \mathrm{UO}_{3}$, and $\mathrm{ZnO}$ (removed from the Constant 
component in the Initial Matrix). The compositions of the Spike and Constant components in the HLW03 series are shown in Tables 2.2 and 2.4, respectively.

The constraints used to define the EGCR for the Augmentation Matrix were initially developed by VSL and then iterated based on inputs from the WTP Project and PNNL (Piepel et al. 2002a). The IHLW Augmentation Matrix single-component constraints are listed in the HLW03 portion of Table 2.1, while the multiple-component constraints are listed in the HLW03 portion of Table 2.6. The multiple-component constraints include waste-loading constraints and glass property constraints. The specific numerical constraints used to implement the glass property constraints for the Augmentation Matrix are listed in Table 2.7.

The IHLW Augmentation Matrix was developed by PNNL (with input from VSL and WTP) using a layered design approach (Piepel et al. 1993, Piepel et al. 2002b). The design had one outer layer (containing 20 glasses), one inner layer (20 glasses), a center point, and 4 replicate glasses for a total of 45 glasses. The MIXSOFT (Piepel 2003, 2006) and ACED (Welch 1987) software packages were used to construct the Augmentation Matrix. Additional details of the test matrix development are discussed in a previous technical report (Cooley et al. 2003). The original target compositions of the Augmentation Matrix HLW glasses are given in Tables 2.8 and 2.9. However, it was subsequently decided to revise the list of primary oxide forms (see Table 2.10). The target compositions of the Augmentation Matrix HLW glasses expressed in the revised oxides are listed in Tables 2.11 and 2.12.

VSL prepared the Augmentation Matrix HLW glass samples, collected the PCT, $\mathrm{T}_{1 \%}$, EC, and viscosity data on all 45 of the glasses, and documented the results (Gan et al. 2004, Kot et al. 2005a). Section 3 discusses the methods used to measure properties of HLW glasses, while Section 4 presents and discusses the resulting data.

\subsubsection{HLW04 Glasses for Actual-Waste (AY-102/C-106) Testing Support}

The HLW04 series contains 12 simulated HLW glasses. These glasses were formulated and characterized to support the testing of actual AY-102/C-106 Envelope D waste blended with the cesium-removal product from treatment of actual AW-101 actual low level waste (Kot and Pegg 2004). Actual C-106/AY-102 waste solid and AW-101 cesium-removal eluate were analyzed at Savannah River National Laboratory (SRNL) and the analytical data formed the bases for developing HLW04 glasses at VSL. The blending ratio of the two waste streams was determined from the WTP dynamic process flow-sheet model G2 (Deng 2004, Vora 2004). The formulation work at VSL resulted in a recommended glass formulation to be used as the target for vitrifying the actual wastes at SRNL (Crawford et al. 2005). A total of eight HLW glasses were formulated and characterized to support actual-waste testing (i.e., HLW04-01 through HLW04-09; HLW04-05 was formulated but not prepared). The other four simulated glasses in this series were slight variations of the glass HLW04-07. The variations included addition of small amounts of noble metals and glasses that had undergone canister centerline cooling (CCC) heat-treatment. The principal crystalline phase that resulted from heat treatment was spinel for all HLW04 glasses. 
Only 10 of the 12 glasses in the HLW04 series have data for at least one of the four properties of interest (PCT, spinel $\mathrm{T}_{1 \%}$, viscosity, and EC). The target compositions of these 10 HLW04 glasses are listed in Table 2.13 using the revised oxides (see Table 2.10). Of the 12 glasses: 8 have PCT data, none have spinel $\mathrm{T}_{1 \%}$ data, 4 have viscosity data, and only 1 has EC data. VSL prepared the HLW04 glass samples, collected the property data, and documented the results (Kot and Pegg 2004, Kot et al. 2005c). Section 3 discusses the methods used to measure properties of HLW glasses, while Section 4 presents and discusses the resulting data.

\subsubsection{Non-Spinel Matrix (HLW05) Glasses}

A set of 30 glass formulations specified by a statistically-designed test matrix (Kot et al. 2005b) was prepared and tested to supplement data from the two Phase 1 test matrices (i.e., HLW02 and HLW03). These 30 simulated HLW glasses are referred to as the Non-Spinel Matrix and also as the HLW05 series (because the glasses are labeled HLW05-01 to HLW0530). The EGCR of this matrix was designed to address the crystallization of non-spinel phases, primarily for AY-101/C-104 wastes. Compared to the Phase 1 Augmentation Matrix (HLW03), this matrix covered a considerably broader EGCR. The expansion of the EGCR was directed by the WTP to include higher concentrations of $\mathrm{Al}_{2} \mathrm{O}_{3}$ and $\mathrm{Na}_{2} \mathrm{O}$ (Musick 2004). The increase in $\mathrm{Al}_{2} \mathrm{O}_{3}$ was based on the projected decrease in caustic leaching efficiency and/or elimination of leaching as HLW pretreatment for some waste batches. Revised estimates of waste compositions also suggested that glasses with higher $\mathrm{Na}_{2} \mathrm{O}$ would be more prevalent during the initial processing at WTP. In addition, interim HLW models suggested that increased $\mathrm{Na}_{2} \mathrm{O}$ concentration would allow for more favorable properties and higher waste loadings (Musick 2004). The constraints used to define the EGCR for the Non-Spinel Matrix were developed by VSL with guidance from the WTP. The compositional ranges for the design of the HLW05 matrix are given in Tables 2.1, 2.3, 2.4, and 2.5. The compositions of the Non-Spinel Matrix glasses are easily distinguishable from those of the Initial Matrix and Augmentation Matrix by their considerably extended ranges in $\mathrm{Al}_{2} \mathrm{O}_{3}$ and $\mathrm{Na}_{2} \mathrm{O}$. Note, for example, that the maximum $\mathrm{Al}_{2} \mathrm{O}_{3}$ in the HLW05 series of glasses is $13 \mathrm{wt} \%$, compared with only $8.5 \mathrm{wt} \%$ for HLW03 glasses. The increases in both oxides are expected to greatly impact various properties of the glasses.

Kot et al. (2005b) described the design and development of the Non-Spinel Matrix at VSL. In general, the matrix development followed the same approach as that used for the HLW02 and HLW03 matrices, employing a layered design. The design had one outer layer (containing 12 glasses), one inner layer (13 glasses), a center point, and 4 replicate glasses for a total of 30 glasses. The glass compositions of both layers were generated by VSL using the commercially available experimental design software Design-Expert (2000). The multivariate constraints imposed in the design calculation are listed in Table 2.6. It is worth noting that the spinel $\mathrm{T}_{1 \%}$ constraint in Table 2.6 was set to below $850^{\circ} \mathrm{C}$ so as to avoid the complication of coprecipitation of both $\mathrm{Zr} / \mathrm{Th} / \mathrm{U}$ phases and spinel phases in the temperature region of $>850^{\circ} \mathrm{C}$. Additional details of the test matrix development are discussed in a previous technical report (Kot et al. 2005b). Design of the HLW05 matrix was conducted using the revised oxide forms (Table 2.10) and therefore conversion of the glass compositions from the original oxide forms was not necessary. 
Since the HLW05 matrix was designed primarily to study the crystallization of non-spinel crystalline phases, PCT was not performed on the HLW05 glasses while EC and viscosity were measured on only selected HLW05 glasses. Consequently, only 13 of the 30 glasses in the HLW05 series have data for at least one of the four properties of interest (PCT, spinel $\mathrm{T}_{1 \%}$, viscosity, and EC). The target compositions of these 13 HLW05 glasses are listed in Tables 2.14 and 2.15 together with the other glasses in the matrix using the revised oxides (see Table 2.10); they are distinguished in Tables 2.14 and 2.15 from the glasses with no modeling data as those not shaded. Of the 13 glasses: none have PCT data, 9 have spinel $\mathrm{T}_{1 \%}$ data, 5 have viscosity data, and 5 have EC data. Originally viscosity and EC were not measured for any of the HLW05 glasses. Subsequently, five HLW05 glasses were selected to have these properties measured, as discussed in Section A.3 of Appendix A. VSL prepared the HLW05 glass samples, collected the property data, and documented the results (Kot et al. 2005b). Section 3 discusses the methods used to measure properties of HLW glasses, while Section 4 presents and discusses the resulting data.

\subsubsection{Spinel Matrix (HLW06) Glasses}

While the Non-Spinel (HLW05) Matrix was developed to address crystallization of nonspinel phases within an expanded EGCR, a separate test matrix was statistically designed to enlarge the database of spinel crystallization and PCT responses in simulated HLW glasses. This test matrix consists of 35 glasses. It is termed the Spinel Matrix and also the HLW06 series because the glasses are labeled HLW06-01 to HLW06-35. The WTP directed that sufficiently broad composition ranges be covered such that the collected data could be used to determine the boundaries of the EGCR for the HLW07 study (Musick 2005). Compared to the Initial Matrix (HLW02), the Spinel matrix encompasses significantly wider composition boundaries. Tables 2.1, 2.3, 2.4, and 2.5 summarize the compositional ranges of the Spinel Matrix. Of particular interest are $\mathrm{Al}_{2} \mathrm{O}_{3}, \mathrm{Na}_{2} \mathrm{O}, \mathrm{SO}_{3}$, and other minor components (e.g., $\mathrm{Cr}_{2} \mathrm{O}_{3}$ and $\mathrm{NiO}$ ). The layered design structure was again used in the development of Spinel Matrix glasses. The inner layer consisted of extended ranges of $\mathrm{Al}_{2} \mathrm{O}_{3}$ and $\mathrm{Na}_{2} \mathrm{O}$ while the outer layer included wide ranges of all major components to reach the prescribed minima and maxima (Musick 2005). Note that, in addition to the major glass oxides and $\mathrm{Cr}_{2} \mathrm{O}_{3}$, three oxides relevant to spinel crystallization (i.e., $\mathrm{MnO}, \mathrm{NiO}$, and $\mathrm{ZnO}$ ) were introduced as $\mathrm{HLW}$ glass components to be varied in the test matrix. There were two composite variables ("Others 1" and "Others2") and a "Constant."

Details of the Spinel Matrix development have been discussed in a previous technical report (Kot et al. 2005b). Briefly, the matrix consists of a center point, an inner layer with 18 unique glasses with two replicates, and an outer layer with 14 unique glasses. The multivariate constraints imposed in the design calculation are listed in Table 2.6. Note that the inner layer was designed to suppress crystallization of non-spinel phases (e.g., $\mathrm{ThO}_{2}$ and $\mathrm{ZrSiO}_{4}$ ), primarily by limiting the maximum concentrations of $\mathrm{ThO}_{2}$ and $\mathrm{ZrO}_{2}$ while extending the ranges of $\mathrm{Al}_{2} \mathrm{O}_{3}$ and $\mathrm{Na}_{2} \mathrm{O}$. The outer layer encompassed wide ranges of all major glass components to reach the prescribed minima and maxima (Musick 2005). The spinel liquidus constraint had a range of $650^{\circ} \mathrm{C}$ to $1200^{\circ} \mathrm{C}$, the upper limit being higher than those used previously. The performance related constraints, such as PCT and TCLP, were not used because of their relative 
ineffectiveness in restricting the data placement in compositional space. Matrix glasses were generated by VSL using the commercial experimental design software Design-Expert (2000). As is the case with the Non-Spinel Matrix, the Spinel Matrix consists of glasses that have considerably extended compositional ranges, effectively expanding the database for development of property-composition models.

The target compositions of the 35 HLW06 glasses are listed in Tables 2.16 and 2.17 using the revised oxides (see Table 2.10). Design of the HLW06 matrix was conducted using the revised oxide forms and therefore conversion of the glass compositions from the original oxide forms was not necessary. Of the 35 HLW06 glasses: 35 have PCT data, 25 have spinel $\mathrm{T}_{1 \%}$ data, 5 have viscosity data, and 5 have EC data. Originally, viscosity and EC were not measured for any of the HLW06 glasses. Subsequently, five HLW06 glasses were selected to have these properties measured, as discussed in Section A.3 of Appendix A. VSL prepared the HLW06 glass samples, collected the property data, and documented the results (Kot et al. 2005b). Section 3 discusses the methods used to measure properties of HLW glasses, while Section 4 presents and discusses the resulting data.

\subsubsection{HLW07 Test Matrix Glasses}

The HLW07 series contains 40 simulated HLW glasses selected to satisfy two main objectives. The principal objective for the HLW07 test matrix was to augment the existing HLW glass property-composition data to reflect an updated understanding of the waste feed compositions to the WTP HLW vitrification facility. A secondary objective included filling in any HLW glass composition subregions that had limited data with respect to both composition coverage and property coverage. The purpose of these objectives was to ensure that the combined data set (existing data plus the HLW07 test matrix) provides an adequate region of validity for the final property-composition models for HLW glasses. Section A.4 of Appendix A contains detailed discussion of the HLW glass components selected to be varied, the composition constraints defining the HLW07 EGCR, and the statistical experimental design methods used to construct the HLW07 test matrix.

The target compositions of the 40 HLW07 glasses are listed in Tables 2.18, 2.19, and 2.20 using the revised oxides (see Table 2.10). Design of the HLW07 matrix was conducted using the revised oxide forms (Table 2.10) and therefore conversion of the glass compositions from the original oxide forms was not necessary. Of the 40 glasses: all 40 have PCT data, 23 have spinel $\mathrm{T}_{1 \%}$ data, 38 have viscosity data, and all 40 have EC data. VSL prepared the HLW07 glass samples, collected the property data, and documented the results (Kot et al. 2006b). Section 3 discusses the methods used to measure properties of HLW glasses, while Section 4 presents and discusses the resulting data.

\subsubsection{HLW-ALG Glasses}

The HLW-ALG series contains 40 simulated HLW glasses selected to assess the performance of the preliminary IHLW formulation algorithm (Vienna and Kim 2007). The 
IHLW formulation algorithm is being developed at the WTP to calculate glass formulations that are acceptable with respect to various product quality, processability, and waste loading requirements. The final IHLW formulation algorithm will be used in an automated fashion in time scales of a few minutes for each batch of waste transferred to the HLW vitrification facility. The algorithm will be needed because current projections predict that the HLW feed composition will change continuously and the processing schedule will not allow sufficient time to formulate glasses using an active-design and testing-based process. The preliminary IHLW formulation algorithm employs interim property-composition models to predict selected properties of HLW glasses. Assessment of the IHLW formulation algorithm with the HLW-ALG series of glasses was intended to identify potential deficiencies and areas for possible improvements before its implementation at the WTP.

Preparation and testing of the HLW-ALG glasses were reported previously (Kot et al. 2006a); a brief summary follows. The WTP project calculated target glass compositions for a series of example waste compositions using the preliminary IHLW formulation algorithm. The waste compositions originated from (i) dynamic flow-sheet model runs, (ii) characterization data of actual waste samples, and (iii) "made-up" wastes that were far from expectations in order to challenge the boundaries of acceptable glass formulations. The calculated algorithm glass compositions were supplied to VSL, where 40 glasses were chosen for testing. The selection of glasses was based on considerations of the calculated properties and glass compositions (i.e., glasses that occupy previously untested compositional regions were selected). For example, one example waste contained very high concentrations of both $\mathrm{MnO}(19.2 \mathrm{wt} \%)$ and $\mathrm{SrO}(27.5 \mathrm{wt} \%)$ and the calculated glass (HLW-ALG-05) was consequently high in both components $(6.98 \mathrm{wt} \%$ $\mathrm{MnO}$ and $9.96 \mathrm{wt} \% \mathrm{SrO})$.

It should be noted that although the calculated HLW-ALG glasses were not actively designed, their compositions could be effectively adjusted by changing the various constraints and weightings used in the formulation algorithm. The constraints are expected to be revised and refined continually until the final IHLW formulation algorithm is verified and validated.

The target compositions of the 40 HLW-ALG glasses are listed in Table 2.21 using the revised oxides (see Table 2.10). Of the 40 glasses: all 40 have PCT data, 22 have spinel $\mathrm{T}_{1 \%}$ data, 39 have viscosity data, and all 40 have EC data. VSL prepared the HLW-ALG glass samples, collected the property data, and documented the results (Kot et al. 2006a). Section 3 discusses the methods used to measure properties of HLW glasses, while Section 4 presents and discusses the resulting data.

\subsubsection{HLW98 Glasses}

The HLW98 series contains 140 simulated HLW glasses tested at VSL from 1998 to 2003 (Fu and Pegg 1998; Kot and Pegg 2001, 2003; Kot et al. 2003b). All of these glasses were actively designed rather than statistically designed and, therefore, compositional correlations are almost certainly present in the data. The HLW98 glasses were formulated and tested for a variety of purposes. In the early work (Part A) to support WTP, the HLW98 glasses were designed to address "envelope maximums" and feasibility issues (Fu and Pegg 1998). Subsequent 
formulation work (Part B1 and Part B2) was performed around specific tank wastes (or blends of tank wastes) to identify target glasses to support melter tests using simulants and to support actual waste testing (Kot and Pegg 2001, 2003; Kot et al. 2003b). In order to support melter testing, HLW98 glasses were formulated using inventory waste data (e.g., TFCOUP data) and the latest available process information. The design constraints in formulating HLW98 glasses were based on requirements in waste loading, product performance (e.g., PCT), and melter processing (e.g., melt viscosity). In the case of formulations to support actual waste testing, actual waste samples from tanks AZ-101, AZ-102, C-106 (without blending of AY-102 waste), and C-104 (without blending of AY-101 waste) were analyzed at SRNL or PNNL. The resulting analytical data formed the bases for formulating HLW98 glasses.

Most of the HLW98 glasses were formulated and tested during Part A and Part B1 of the contract under British Nuclear Fuel Limited (BNFL) when work was performed under a different set of QA requirements. A smaller subset of HLW98 glasses was tested during Part B2 of the contract when the current QA requirements were applied. As a result, only 40 of the 140 glasses in the HLW98 series have data that meet the applicable QA requirements for at least one of the four properties of interest (PCT, spinel $\mathrm{T}_{1 \%}$, viscosity, and $\mathrm{EC}$ ). These $40 \mathrm{HLW}$ glasses were formulated and tested primarily to support melter testing using simulants and to provide target compositions for vitrifying actual waste samples (actual waste testing at PNNL and SRNL). The target compositions of these 40 HLW98 glasses are listed in Table 2.22 using the revised oxides (see Table 2.10). Of the 40 glasses: 38 have PCT data, none have spinel $\mathrm{T}_{1 \%}$ data, 18 have viscosity data, and 17 have EC data. Spinel $\mathrm{T}_{1 \%}$ values were not estimated for the HLW98 glasses because the glasses were formulated and tested before the change directed by WTP to develop $\mathrm{T}_{1 \%}$ models instead of liquidus temperature $\left(\mathrm{T}_{\mathrm{L}}\right)$ models (Westsik 2003b). Heat treatment of HLW98 glasses was performed to determine whether they met the "operational liquidus temperature" constraint rather than to estimate $\mathrm{T}_{1 \%}$. The "operational liquidus temperature" was deemed to be met if less than $1 \mathrm{vol} \%$ of crystals resulted from heat treatment at $950^{\circ} \mathrm{C}$. Consequently, no $\mathrm{T}_{1 \%}$ data were available for the HLW98 glasses. Section 3 discusses the methods used to measure properties of HLW glasses, while Section 4 presents and discusses the resulting data.

\subsubsection{Actual HLW Glasses}

A set of 5 glasses made from actual HLW tank samples, blended with products of LAW pretreatment, were included in the database to consider for use in developing propertycomposition models. Preparation and testing of these glasses were conducted at either PNNL or SRNL (formerly Savannah River Technology Center) with the target glass compositions developed at VSL. Specifically, glasses were prepared and tested for actual waste samples from the following tanks:

- AZ-101: The HLW solid was blended with AP-101/AZ-101 Cs- and Tc-removal eluates before vitrification at PNNL using the target glass composition HLW98-95 (Hrma et al. 2004). 
- AZ-102: Two melts were prepared at PNNL using the target composition HLW9861. The washed HLW solid was blended with either actual or simulated AN-107 $\mathrm{Sr}$ /TRU precipitate, an actual Cs-removal eluate composite, and actual AN-107/AW101 Cs- and Tc-removal eluate (Smith et al. 2001).

- C-104: The HLW solid was blended with actual and simulated AN-107 Sr/TRU precipitate, and an actual Cs-removal eluate composite. Eluates from Tc-removal were not added. Vitrification at PNNL was based on the target composition HLW9851R (Smith et al. 2001).

- C-106: Caustic leached C-106 sludge was blended with cesium-removal eluates (from pretreatment of AN-102, AN-103, and AZ-102 LAW) and a simulated Sr/TRUremoval product before vitrification at SRNL. The target glass composition was based on HLW98-67 (Schumacher et al. 2002).

- AY-102/C-106: The caustic leached HLW slurry was vitrified at SRNL with blended Cs-eluate from pretreatment of AZ-101 LAW. The target glass composition was HLW04-09 (Crawford et al. 2005).

The target compositions of the Actual HLW glasses are listed in Table 2.23. Of the 5 glasses in this subset, all 5 have PCT data, but none have spinel $\mathrm{T}_{1 \%}$, viscosity, or EC data. The PCT data for these glasses are presented subsequently in Section 4.

\subsubsection{Summary of HLW Glasses Available for Property Modeling}

As described in Sections 2.1.1 to 2.1.9, there are nine groups of HLW glasses available for developing property-composition models. Table 2.24 summarizes the groups of glasses, the group IDs, and the number of glasses in each group. In total, there are $305 \mathrm{HLW}$ glasses from the nine groups. However, as described in Section 4, only 285 of the 305 glasses have data for at least one of the four properties that are being modeled.

\subsection{Data Available for Validating PCT and Spinel $\mathbf{T}_{1 \%}$ Models for HLW Glasses}

Several approaches can be used to validate property-composition models, including data-splitting and data-partitioning of the modeling dataset, and using separate validation datasets. The approaches used to validate the PCT, spinel $\mathrm{T}_{1 \%}, \mathrm{EC}$, and viscosity models in this report for HLW glasses are discussed in detail in Sections 5, 6, 7, and 8. This section provides brief summaries of the separate validation databases available to validate PCT and spinel $\mathrm{T}_{1 \%}$ models.

\subsubsection{Data for Validating PCT-Composition Models}

Several waste glass property-composition databases from earlier studies are the source of separate data used in this work for validating the PCT models for HLW glasses. These datasets, 
which have been used previously to support the development of interim property-composition models (Vienna et al. 2002) and to validate WTP IHLW Phase 1 models (Kot et al. 2005a), are summarized in Table 2.25 and described in the following paragraphs. Validation glass compositions and PCT data are provided in Appendix B.

TWRS Part A and WTP Part B1 HLW Glass Formulations (Kot and Pegg 2001, Fu and Pegg $\underline{1998)}$

These studies included the results of HLW glass formulation development with Tank Waste Remediation System (TWRS) simulants during TWRS Part A and during Part B1 of the WTP Project. Both studies were conducted at VSL. The Part A glasses were formulated based on the HLW Envelope D composition specifications provided by the TWRS contract. The Part B1 work built on the Part A results and employed two approaches in formulating HLW glasses, including a matrix of glass compositions designed statistically. Twenty of the glasses in this group used for validating the WTP IHLW Phase 1 PCT models (Kot et al. 2005a) were included in the modeling dataset in this report (because they met the QA requirements for modeling data). Hence, this group contains 20 fewer glasses in this report than it did as discussed by Kot et al. (2005a). See Appendix B for additional discussion.

\section{HWVP Composition Variation Study (CVS) 1 and 2 (Hrma et al. 1994)}

These studies were performed at PNNL for the Hanford HLW vitrification program and included 146 glasses from five statistically designed experimental phases. The design strategy involved defining a glass compositional region expected to contain glasses that might be made from the neutralized current acid waste (NCAW) and expected to be processed by the previously planned Hanford Waste Vitrification Plant (HWVP). Specific compositions were selected for study so as to appropriately cover the defined glass composition region.

\section{Defense Waste Processing Facility (DWPF) PCT Modeling (Jantzen et al. 1998)}

This study was used to develop the Thermodynamic Hydration Energy Reaction Model (THERMO) to predict glass PCT releases based on estimated glass hydration free energy. The THERMO model is used in DWPF to assess product consistency and quality. The glasses examined in this study were fabricated under a variety of laboratory and pilot-scale conditions by various researchers and vendors.

\section{West Valley Demonstration Project (WVDP) Support (Olson 1993)}

Two studies were conducted as part of glass-composition variability testing under the PNNL West Valley Support Program to support the establishment of a glass-composition control strategy by West Valley Nuclear Services (WVNS). Results of PCT releases for 20 glasses were available. 


\section{WVDP Composition Variation Study (CVS) (Olson et al. 1994)}

The PCT method was used to evaluate 44 West Valley glasses to support WVDP. These glasses were fabricated as sets of CVS glasses by the West Valley Support Task at PNNL and were initially tested with a modified Materials Characterization Center-3 test method. They were retested with the PCT method after Waste Acceptance Product Specifications (WAPS) (DOE-EM 1996) included the PCT in an acceptance specification.

\section{WVDP Waste Form Qualification Report (Barnes 1995)}

West Valley Nuclear Services (WVNS) developed a dataset consisting of PCT data for 58 HLW glass compositions. The data were used to develop PCT release models for use in the WVDP. The glasses were selected to evenly cover a glass compositional region centered on the WVDP target glass composition with the boundary taken to be three times the expected process variation. Nine components known to influence PCT releases were varied in these glasses. Out of the 58 glasses, 10 glasses of the alkali series were from the WVDP Composition Variation Study (see above) and thus were included only once in the validation database.

\section{$\underline{\text { RPP-WTP LAW Glass Formulation (Muller et al. 2001) }}$}

This study was performed at VSL to develop LAW glass formulations in support of the Part B1 phase of the RPP-WTP privatization project. An iterative approach was adopted in developing glass formulations such that glasses were formulated, prepared, and characterized to obtain the required property-composition information, followed by analyses of the results and revision of the glass compositions to optimize the important glass properties. No statistically designed glasses were included.

The studies described above together included PCT (and other) data on 554 glasses not included in the PCT modeling dataset. However, most of the glasses have compositions that are outside the constraints used to define the EGCRs of interest for WTP HLW glasses. For example, the WTP LAW glasses (included in the validation dataset) may contain up to $24 \mathrm{wt} \%$ of $\mathrm{Na}_{2} \mathrm{O}$ (Muller et al. 2001), compared with design maximum of $15 \mathrm{wt} \%$ for HLW glasses (see Table 2.1). Hence, these data are appropriate only for assessing the extrapolative prediction capability of PCT models for HLW glasses. The approaches used to validate PCT models are described more fully in Sections 5.1.2 to 5.1.4.

\subsubsection{Glasses for Validating Spinel $\mathbf{T}_{1 \%}-$ Composition Models}

In contrast to the relatively large data set available for validating the PCT models, there are only limited data suitable for spinel $\mathrm{T}_{1 \%}$ model validation. Published data on volume $\%$ crystallinity versus temperature are scarce, especially when interest is restricted to spinel crystals. Additionally, the WTP project has only recently chosen $\mathrm{T}_{1 \%}$ as the appropriate property to be modeled (Westsik 2003b), which is a less conservative approach compared to precedents employed at WVDP and DWPF. The validation dataset was taken from the literature and 
contains a total of 39 glasses, including 11 WTP-TL glasses that belonged to a test matrix that was statistically designed to develop and evaluate liquidus-temperature $\left(\mathrm{T}_{\mathrm{L}}\right)$ and $\mathrm{T}_{1 \%}$ models for WTP HLW glass melts (Vienna et al. 2003). The other 28 literature glasses were also used in the same study (Vienna et al. 2003). Compositions of the 39 validation glasses (in revised oxides, see Table 2.10) and the corresponding spinel $\mathrm{T}_{1 \%}$ values are given in Table 2.26. It can be seen that the validation glasses do not contain $\mathrm{UO}_{3}$ or $\mathrm{ThO}_{2}$. They also have lower maximum values of $\mathrm{ZnO}$ and $\mathrm{ZrO}_{2}$, with much narrower concentration ranges for the TCLP-relevant elements. In general, however, the lower and upper bounds of most major glass components found in the validation set have comparable ranges for spinel $\mathrm{T}_{1 \%}$ as those for the modeling dataset. Data from the 39 validation glasses therefore allowed for a reasonable validation of the prediction performance of the spinel $\mathrm{T}_{1 \%}$ models that were developed.

The validation data were converted from weight percent crystals to volume percent crystals using the density data provided in Vienna et al. (2003). The volume percent versus temperature data were then regressed to determine the $\mathrm{T}_{1 \%}$ values. These data are presented and discussed in Section 6.1.4. 


\section{SECTION 3 \\ EXPERIMENTAL PROCEDURES AND CALCULATIONS}

The experimental procedures used in the preparation and characterization of the simulated HLW glasses discussed in Section 2.1 are presented in this section. The procedures used in preparing and testing glasses made from actual HLW samples are discussed briefly.

For the simulated HLW glasses, the following subsections discuss the preparation of batches, crucible glass melting, glass composition analysis, and test procedures for the Product Consistency Test (PCT), one-percent crystal fraction temperature $\left(\mathrm{T}_{1 \%}\right)$, electrical conductivity (EC), and viscosity.

\subsection{Glass Batching and Melting}

A total of 305 glass samples (some having the same target compositions) were prepared and characterized to support property-composition modeling for HLW glasses. Of the 305 samples, 5 are actual HLW glasses prepared at SRTC (now SRNL) or PNNL, as discussed in Section 2.1. All other samples were prepared at VSL using reagent grade or higher purity chemicals. Batching recipes were prepared to target the glass oxide compositions given in Tables 2.11 to 2.22 in Section 2.1. A technical procedure (VSL 2002) describes the details of crucible preparation of HLW glasses. Section 3.1.1 describes the batching of starting materials, while Section 3.1.2 discusses glass melting.

\subsubsection{Batching of Starting Materials}

Glass preparation began with a batching sheet that provided information on the required starting materials and their weights. The information included the chemicals needed, identification of the chemicals according to the vendors and catalog numbers, the associated purity, together with the amount required to melt a given amount of glass. Chemicals were weighed and batched according to the batching sheets. The batching and preparation of some of the HLW glasses was repeated as a result of the need for a larger amount of glass for extended testing and occasionally as a result of minor batching errors. Consequently, some glasses were prepared multiple times and are identified with an extension $\mathrm{Rx}$ (where $\mathrm{x}$ identifies the repetition number) before they were submitted for PCT, $\mathrm{T}_{1 \%}$, electrical conductivity, and viscosity analyses However, since all "re-melts" had identical target compositions to the original HLW glass formulations; the compositions of all "re-melts" of a given glass used in testing are given in this report under the identification of the original formulation. The use of "re-melts" in collecting data for modeling is not identified in this report.

The information found in the batching sheets, including actual weights of chemicals used and their associated purities, can be used to calculate the composition of the glasses. The 
batching chemicals are determined such that the calculated compositions are equal to the target compositions. The target compositions of the simulated HLW glasses in the property-composition databases are listed in Tables 2.11 to 2.22 in Section 2.

Calculation of the required amounts of starting materials in the batching sheets took into account not only purity information, but also volatility characteristics of the chemicals. Specifically, thallium (III) oxide is relatively volatile, with a boiling point of $875^{\circ} \mathrm{C}$, and substantial loss is expected at the glass-melting temperature of over $1000^{\circ} \mathrm{C}$. Previous glass formulation work at VSL has accumulated a database of thallium-containing glasses (Fu and Pegg 1998, Kot and Pegg 2001), which suggested that thallium loss may vary with concentration and glass composition. On the average, however, those data showed that only $54 \%$ of the starting thallium (III) oxide was retained in glass. Consequently, thallium (III) oxide was "over-batched" by a factor of 1.85 in the batching sheets. Another component, selenium (IV) oxide, which melts at about $350^{\circ} \mathrm{C}$ and sublimes at high temperatures, was also over-batched in the HLW glasses by a factor of 2.29. Note, however, that the database of selenium- and thallium-containing glasses was not available during preparation of most of the HLW98 glasses (which, in fact, constituted that database). Adjustments for volatility were made for all the statistically designed glasses (i.e., HLW02, HLW03, HLW05, HLW06, and HLW07) but not the HLW04, HLW98, and HLW-ALG series. The primary reason for "over-batching" volatile oxides was to support TCLP models development by ensuring that volatile Resource Conservation and Recovery Act (RCRA) metals would be present in the prepared glasses at concentrations close to the targets (which were normally relatively low). The only "over-batched" oxides in crucible melts were $\mathrm{SeO}_{2}$ and $\mathrm{Tl}_{2} \mathrm{O}$. For all other oxides, either they were unimportant in TCLP testing or the existing data did not support "over-batching."

In batching recipes for preparing the statistically designed HLW glasses, up to 41 components might be needed. However, it was possible to take advantage of the fact that, within a selected series of glasses (e.g., HLW02), many of those components were present in constant concentrations. Glass frits, whose compositions varied and were dependent on the test matrix being studied, were therefore prepared with reagent grade chemicals and employed as a starting material in the batching of the HLW matrix glasses in order to reduce the number of components required. After the starting materials were weighed and batched, a blender was used to mix and homogenize the starting materials. A pre-weighed noble metal solution (which consisted of ruthenium $(\mathrm{Ru})$, rhodium $(\mathrm{Rh})$, and palladium $(\mathrm{Pd})$ in nitric acid) was then added and blended with the chemicals. Addition of the noble metals as a solution instead of as a solid (typically less than $0.5 \mathrm{~g}$ of oxide was required) was found to aid in the dispersion of noble metals in the glasses.

Batch sizes of 350 to $450 \mathrm{~g}$ were loaded into platinum-gold crucibles that were engraved with individual identification numbers corresponding to the Glass IDs. 


\subsubsection{Glass Melting}

After the batching of starting materials was completed, the loaded platinum-gold crucible was placed inside a Deltech DT-28 (or DT-29) furnace, the heating of which was controlled by a Eurotherm 2404 temperature controller. The melting temperature was $1150^{\circ} \mathrm{C}$, at which the melt was kept for 2 hours. Mixing of the melt was accomplished mechanically using a platinum stirrer, beginning 20 minutes after the furnace temperature reached $1150^{\circ} \mathrm{C}$ and continuing for the next 90 minutes. The molten glass was poured at the end of 120 minutes onto a graphite plate to cool before recovery.

For preparation of the statistically designed glasses where the target compositions of all glasses were defined once the matrix design was completed, glass melting was performed in a random order. The exact sequence of melts was determined by assigning a random number to each HLW glass and then placing the glasses in ascending order according to the associated random number.

\subsection{Analyses of Glass Compositions}

Compositions of the prepared simulated HLW glasses were analyzed with x-ray fluorescence (XRF) spectroscopy. Powdered glass samples were analyzed with an ARL 9400 wavelength dispersive XRF spectrometer, which was calibrated over a range of glass compositions using standard reference materials. Standard reference materials traceable to NIST, as well as waste glasses such as Argonne National Laboratory-Low Activity Waste Reference Material (ANL-LRM) and Defense Waste Processing Facility - Environmental Assessment (DWPF-EA) glass (Jantzen et al. 1993) were used. XRF analysis provides data for most glass components of interest, except lithium and boron, which are analyzed by direct current plasma atomic emission spectroscopy (DCP-AES), as described below.

Glass samples selected for DCP-AES analysis were subjected to microwave-assisted total acid dissolution in Teflon vessels according to VSL standard operating procedures. Twenty milliliters of a 1:5 mixture of concentrated $\mathrm{HF}: \mathrm{HNO}_{3}$ were diluted to $50 \mathrm{ml}$ and used for the dissolution. This procedure is similar to the ASTM Test Method C1412-99, which also employs a mixture of concentrated $\mathrm{HF}$ and $\mathrm{HNO}_{3}$ in microwave digestion of pulverized glass samples. However, supplemental use of $\mathrm{HCl} / \mathrm{H}_{3} \mathrm{BO}_{3}$ is not included in the VSL procedure because boron is normally one of the analytes. The resulting solutions were analyzed by DCP-AES. These results complement XRF, particularly for boron and lithium. DCP-AES was the only method of glass analysis used for early Part B1 glasses (Kot and Pegg 2001).

Glasses prepared from actual HLW radioactive samples were analyzed by inductively coupled plasma atomic emission spectroscopy (ICP-AES) and atomic absorption (AA) spectroscopy using solutions from acid dissolution of ground glass or $\mathrm{KOH}-\mathrm{KNO}_{3}$ or $\mathrm{Na}_{2} \mathrm{O}_{2}-\mathrm{NaOH}$ fusion according to SRNL or PNNL operating procedures. If boric acid is one of the reagents used in acid dissolution, the analysis will not provide boron concentration in the glass. Similarly, if sodium or potassium salt is used as a reagent for fusion, or nickel and 
zirconium crucibles are used to hold the mixture, the analysis will not provide concentrations of the corresponding constituents. Hence two different digestion procedures were used.

The XRF detection limit for most components is about $0.01 \mathrm{wt} \%$. The accuracy of the analysis is about \pm 10 relative percent for major components ( $>3.0 \mathrm{wt} \%$ in the glass) or $1.0 \mathrm{wt} \%$ absolute, whichever is smaller. However, with the exception of volatile components such as selenium and thallium, the batched (target) glass compositions are expected to be more accurate than the analyzed compositions because the batched compositions are derived from simple weighing of pure chemicals. Hence, the target compositions for all major constituents are believed to provide the best compositional representations of the tested glasses. For the oxides that were "over-batched" (i.e., $\mathrm{SeO}_{2}$ and $\mathrm{Tl}_{2} \mathrm{O}$ ), the analyzed concentrations showed similar deviations from the targets as those for the other minor components. Target concentrations were used for $\mathrm{SeO}_{2}, \mathrm{Tl}_{2} \mathrm{O}$, and other minor oxides in PCT testing and development of all models (see below). The principal role of the compositional analyses is, therefore, to confirm the target compositions. Chemical compositions of all HLW glasses have been reported previously.

\subsection{Product Consistency Test}

The PCT (ASTM 2002) was conducted using $4 \mathrm{~g}$ of crushed glass (100-200 mesh, $75-149 \mu \mathrm{m}$ ) placed in $40 \mathrm{ml}$ of test solution (de-ionized water) inside 304L stainless steel vessels. These test conditions result in a ratio of the glass surface area to the solution volume of about $2000 \mathrm{~m}^{-1}$. The PCT was performed at $90^{\circ} \mathrm{C}$ for 7 days according to ASTM (2002), as required in Specification 1 of the WTP contract (DOE-ORP 2000). All tests were conducted in triplicate (or quadruplicate in the case of glasses made from actual HLW samples) in parallel with the DWPF-EA standard glass that was included in each test set. The leachates were sampled after 7 days. One $\mathrm{ml}$ of sampled leachate was mixed with $20 \mathrm{ml}$ of $1 \mathrm{M} \mathrm{HNO}_{3}$ and the resulting solution analyzed by direct current plasma atomic emission spectroscopy (DCP-AES). Another $3 \mathrm{ml}$ of the sampled leachate was used for $\mathrm{pH}$ measurement.

In addition to the leachate concentrations themselves, it is convenient and conventional to also consider the normalized leachate concentrations. The normalization is performed by dividing the concentration measured in the leachate for any given component by its fraction in the glass. Target mass fractions in glass are used in this work. Thus, the normalized concentration $C_{i}$ of element $i$ (in $\mathrm{g} / \mathrm{L}$ ) is calculated from the elemental concentration $c_{i}$ measured in the leachate (in ppm) as:

$$
C_{i}=\frac{c_{i}}{f_{i}}
$$

where $f_{i}$ is the target mass fraction of element $i$ in the glass.

The surface area of the glass sample tested and the volume of leachant used will also affect the measured leachate concentrations and, therefore, a standard value of their ratio $\left(2000 \mathrm{~m}^{-1}\right)$ is specified in the PCT method (ASTM 2002). A further normalization for this effect 
is often considered by dividing the normalized concentration by the ratio of the surface area of glass exposed to the solution volume $\left(\mathrm{S} / \mathrm{V}\right.$, in $\left.\mathrm{m}^{-1}\right)$. The normalized mass loss $\left(\mathrm{in} \mathrm{g} / \mathrm{m}^{2}\right)$ is then obtained from:

$$
L_{i}=\frac{C_{i}}{(S / V)}
$$

where $S / V$ is the ratio of the glass surface area to the volume of the leachant, which for the standard PCT is $2000 \mathrm{~m}^{-1}$. Assuming this value of $S / V$, if $C_{i}$ is expressed in $\mathrm{g} / \mathrm{L}$, one need only divide by two to obtain $L_{i}$ in $\mathrm{g} / \mathrm{m}^{2}$ (because $1 \mathrm{~g} / \mathrm{L}=1000 \mathrm{~g} / \mathrm{m}^{3}$ ). Except where indicated, the work in this report is performed in terms of the normalized concentration $\left(C_{i}\right.$, in $\left.g / L\right)$.

Specification 1 of the WTP contract (DOE-ORP 2000) requires that the normalized mass losses of PCT-B, PCT-Na, and PCT-Li be below the respective values for the DWPF-EA glass. The nominal values for normalized leachate concentrations from the DWPF-EA glass are 16.695, 9.565, and 13.346 g/L for PCT-B, PCT-Li, and PCT-Na, respectively (Jantzen et al. 1993).

\subsection{Determination of One-Percent Crystal Fraction Temperature $\left(\mathbf{T}_{1 \%}\right)$}

Glass samples (about 3 to 5 grams each) were melted in a platinum, platinum-gold, or platinum-rhodium crucible at a temperature of $1200^{\circ} \mathrm{C}$ for 1 hour to establish a common starting point before heat treatment for 70 hours at prescribed temperatures between $650^{\circ} \mathrm{C}$ and $1200^{\circ} \mathrm{C}$. At the end of the heat-treatment period, the glass samples were quenched by contacting the crucible with cold water. This quenching freezes in the phase assemblage in equilibrium with the melt at the heat-treatment temperature. The sample was then prepared for Scanning Electron Microscopy/Energy Dispersive X-ray Spectroscopy (SEM/EDS) examination to determine the volume fraction of crystalline phases and for identification of the major crystalline phases. The SEM/EDS was performed using a Scanning Electron Microscope JEOL Model JSM-35C (equipped with Noran Vantage Integrated EDS) or Model JSM-5910LV (equipped with Oxford Instruments INCAEnergy 300 system). For each glass, a sufficient number of heat treatments were performed to obtain non-zero vol\% crystallinity data for at least three temperatures in order to reasonably constrain the $\mathrm{T}_{1 \%}$ value. Effort was also made to bracket the $\mathrm{T}_{1 \%}$ temperature so that it could be obtained by interpolation rather than extrapolation, which was the case for 177 of the 229 glasses for which $\mathrm{T}_{1 \%}$ values could be determined (see Section 4 for a discussion of the $\mathrm{T}_{1 \%}$ data).

For the HLW02 and HLW03 glasses, the crystalline phases found in the heat-treated samples were characterized by SEM/EDS. The volume percents were obtained as the average of 4 to 10 viewing area counts from glass sub-samples collected at different locations in the crucible (e.g., near the bottom, center, side of the crucible, etc.). The selection of the glass fragments and viewing areas was intended to provide a representative measure of the overall crystal fraction in the sample. For the HLW05, HLW06, HLW07, and HLW-ALG heat-treated samples, the glass chunks were ground and sieved $(-18 \mathrm{mesh}$, or $\leq 1 \mathrm{~mm}$ ) before SEM/EDS 
analysis. The volume percent data were obtained as the average of 4 viewing area counts from the powdered glass samples.

The $\mathrm{T}_{1 \%}$ value for each glass was obtained by linear regression of the heat-treatment temperature $\left({ }^{\circ} \mathrm{C}\right)$ as the dependent variable versus crystal fraction (vol\%) as the independent variable. The choice of vol\% (which has the larger measurement error) as the independent variable, rather than the temperature (which has the smaller measurement error), is contrary to the selection that would normally be made for regression. However, as discussed in Section E.1 of Appendix E, there are advantages to using this "inverse regression" approach in the present application. The differences in the $\mathrm{T}_{1 \%}$ values estimated using either choice of independent variable were generally small with respect to the standard deviations obtained for the replicates (see discussion in Section 4.2.1).

The data used to support model development in this report were collected over a period of many years. Before the WTP made the change from developing liquidus temperature $\left(\mathrm{T}_{\mathrm{L}}\right)$ models to $\mathrm{T}_{1 \%}$ models (Westsik 2003b), heat treatment was performed to determine whether the simulated HLW glasses met the "operational liquidus temperature" constraint rather than to estimate $\mathrm{T}_{1 \%}$. The "operational liquidus temperature" was deemed to be met if less than $1 \mathrm{vol} \%$ of crystals resulted from heat treatment at $950^{\circ} \mathrm{C}$. Consequently, $\mathrm{T}_{1 \%}$ values were not estimated for the HLW98 and HLW04 glasses.

\subsection{Electrical Conductivity Testing}

The electrical conductivity (EC) of each HLW glass was determined by measuring the impedance of the glass melt at temperatures around 950,1050, 1150 and $1250^{\circ} \mathrm{C}$ as a function of AC frequency using a calibrated platinum-rhodium electrode probe attached to a Hewlett-Packard model 4194A or an Agilent 4294A impedance analyzer. The collected impedance data were analyzed to obtain the DC electrical conductivity. The probe (analyzer along with the crucible to assure that the geometry is replicated) was calibrated and checked using NIST traceable standard material periodically, as required by VSL technical procedure.

The current WTP requirement for glass melt EC limits is 0.1 to $0.7 \mathrm{~S} / \mathrm{cm}$ at 1100 to $1200^{\circ} \mathrm{C}$ (Casassa 2005).

\subsection{Viscosity Testing}

The melt viscosity $(\eta)$ of each HLW glass was measured using a Brookfield viscometer with a platinum-rhodium spindle and crucible. The relative torque of a rotating spindle immersed in molten glass was measured as a function of rotational velocity (revolutions per minute (RPM)) at temperatures around $950,1050,1150$ and $1250^{\circ} \mathrm{C}$. The viscosity of the molten glass was then calculated from the collected data of torque versus RPM. The equipment was calibrated using viscosity standard oils and checked using a NIST traceable standard glass periodically, per VSL technical procedure. 
Per current WTP requirements glass melts should satisfy the viscosity limits of 10 to 150 poise at $1100^{\circ} \mathrm{C}$ (Casassa 2005).

\subsection{Canister Centerline Cooling}

Selected HLW glass samples underwent canister centerline cooling (CCC) heat treatment before additional testing (e.g., PCT) was performed. These samples were distinguished from the original glass samples by adding the extension "CCC" or "CG" to the sample identifications. The CCC temperature profile was provided by the WTP project (Petkus 2003). Table 3.1 reproduces the HLW CCC temperature profile and Figure 3.1 is a graphic representation of the profile. As in the case of isothermal heat-treatment, the glass samples (about $5 \mathrm{~g}$ to $350 \mathrm{~g}$ ) in platinum or platinum alloy crucibles were maintained at a "pre-melt" temperature of $1200^{\circ} \mathrm{C}$ for 1 hour before initiation of the $\mathrm{CCC}$ treatment. 


\section{SECTION 4 \\ PCT, T $_{1 \%}$, ELECTTRICAL CONDUCTIVITY, AND VISCOSITY RESULTS}

Product Consistency Test (PCT), one-percent crystal fraction temperature $\left(\mathrm{T}_{1 \%}\right)$, electrical conductivity (EC), and viscosity results for the simulated and actual high-level waste (HLW) glasses introduced in Section 2.1 are presented and discussed in this section. In addition, general compositional trends observed in the property data are discussed. Quantitative statistical modeling of the respective property datasets are discussed in Sections 5, 6, 7, and 8.

\subsection{Product Consistency Test (PCT) Results and Discussion}

The PCT results are presented in Section 4.1.1 and discussed in Section 4.1.2.

\subsubsection{PCT Results}

Of the 305 simulated and actual HLW glasses discussed in Section 2.1, Table 4.1 shows that 268 glasses have data on PCT-boron (PCT-B) and PCT-sodium (PCT-Na) releases. However, only 253 of these 268 glasses have PCT-lithium (PCT-Li) releases because 15 of the glasses do not contain $\mathrm{Li}_{2} \mathrm{O}$. The PCT was performed and results obtained for these $268 \mathrm{HLW}$ glasses using the procedure described in Section 3.3. Specifically, unnormalized concentrations (ppm) of (i) PCT-B and PCT-Na releases were obtained for the 268 HLW glasses, and (ii) PCT-Li releases were obtained for the 253 glasses. The PCT normalized concentration values (in $\mathrm{g} / \mathrm{L}$ ) and normalized mass loss values (in $\mathrm{g} / \mathrm{m}^{2}$ ) were calculated from the PCT elemental concentrations (in ppm) using Equations (3.1) and (3.2), respectively, and the normalized HLW glass compositions listed in Table 5.2.

The PCT-B, PCT-Li, and PCT-Na releases are given in Table 4.2 for the simulated and actual HLW glasses discussed in Section 2.1. Normalized PCT concentrations (g/L) and mass losses $\left(\mathrm{g} / \mathrm{m}^{2}\right)$ were calculated using target mass fractions of boron, lithium, and sodium in glass per Equations (3.1) and (3.2). The PCT-B releases (normalized concentrations) vary from $0.007 \mathrm{~g} / \mathrm{L}$ to $21.903 \mathrm{~g} / \mathrm{L}$, PCT-Li releases vary from $0.006 \mathrm{~g} / \mathrm{L}$ to $10.675 \mathrm{~g} / \mathrm{L}$, and PCT-Na releases vary from $0.050 \mathrm{~g} / \mathrm{L}$ to $11.819 \mathrm{~g} / \mathrm{L}$. These ranges of PCT releases can be compared to the WTP contract (DOE-ORP 2000) limits of

$$
\begin{array}{lr}
\text { PCT-B: } & 16.695 \mathrm{~g} / \mathrm{L} \\
\text { PCT-Li: } & 9.565 \mathrm{~g} / \mathrm{L} \\
\text { PCT-Na: } & 13.346 \mathrm{~g} / \mathrm{L} .
\end{array}
$$

Of the 268 HLW glasses with PCT-B results, only HLW-ALG-03 has a PCT-B release greater than the $16.695 \mathrm{~g} / \mathrm{L}$ limit. Of the $253 \mathrm{HLW}$ glasses with PCT-Li results, again only HLW-ALG-03 has a PCT-Li release greater than the $9.565 \mathrm{~g} / \mathrm{L}$ limit. Of the $268 \mathrm{HLW}$ glasses 
with PCT-Na results, none have PCT-Na releases greater than the $13.346 \mathrm{~g} / \mathrm{L}$ limit. Previous WTP HLW glass formulation work has repeatedly shown that PCT is not a particularly constraining requirement and that the vast majority of all HLW glasses, and all of the actively designed HLW glasses, consistently surpass the performance limits set by the DWPF-EA reference glass.

Figure 4.1 shows the ranges and median values of normalized PCT-B, PCT-Li, and PCT-Na releases (g/L) measured on 268 glasses from 8 of the 9 groups of HLW glasses discussed in Section 2.1. No PCT data were collected on the Non-Spinel Matrix (HLW05) glasses. Figure 4.2 shows the distributions of normalized PCT-B, PCT-Li, and PCT-Na releases for the 268 glasses. Figure 4.1 shows that a vast majority of the glasses have PCT releases beneath the respective contract limits. In fact, only one glass (HLW-ALG-03) has normalized releases that exceed the PCT-B and PCT-Li contract limits. The HLW-ALG glasses have the widest ranges of releases in $\mathrm{B}$ and $\mathrm{Li}$, with many of the more extreme results coming from the glasses calculated for "made-up" wastes, which were deliberately intended to challenge the boundaries of acceptable glass compositions (Kot et al. 2006a). For glasses with outlying PCT releases, detailed review of the fabrication and testing processes was conducted, which did not reveal any irregularities. If sufficient glass samples remained after testing, this review included examination of the samples for phase separation that might lead to formation of some amount of a more leachable phase, depending on the precise cooling history. No secondary phases that were more leachable were found. It should be noted that the IHLW formulation algorithm included interim PCT models that were developed with data collected for the Initial Matrix (HLW02) and Augmentation Matrix (HLW03) glasses (Vienna and Kim 2007). All glasses from these two matrices, as seen in Figure 4.1, outperformed the reference DWPF-EA glass. While previous WTP HLW glass formulation work has repeatedly shown that PCT is not a particularly constraining requirement (as shown in Figure 4.1 by the PCT performances of the actively designed HLW98 and HLW04 glasses), it is desirable for the purpose of model development to include HLW glasses that span a wider range of PCT performance. This was achieved in part by the design of the Spinel Matrix (HLW06) and the HLW07 Matrix. Glasses from these matrices indeed show broader ranges of PCT-Li and PCT-Na releases. Both matrices were designed to include a broader EGCR, especially for $\mathrm{Na}_{2} \mathrm{O}$ and $\mathrm{Al}_{2} \mathrm{O}_{3}$. Further, PCT constraints were not applied to the design of the Spinel Matrix. It is of interest to note that all actual waste glasses met the contract limits by considerable margins, as was intended and expected based on the corresponding simulant glasses.

\subsubsection{Discussion of PCT Results}

Statistical modeling of the PCT results is discussed in Section 5. The following provides a review of the PCT results with respect to glass composition and a discussion on the general compositional trends of the collected data. The principles that control leaching of glasses in water are relatively well known. The important mechanisms are hydration, diffusion of alkali ions and their exchange with hydrogen ions, hydrolysis of the glass network, secondary phase formation, and the formation of modified layers at the glass surface (Doremus 1979, Hench and Clark 1978). Glass compositions have a profound effect in determining the relative importance of these mechanisms. However, with over 40 component oxides in the matrix glasses and with 
many of these components being varied simultaneously in the statistically designed groups of glasses (see Section 2.1), it is possible only to identify general trends between the PCT results and glass compositions. The many components in HLW glasses can generally be divided into glass formers and glass modifiers. Depending on glass compositions, components including $\mathrm{SiO}_{2}, \mathrm{~B}_{2} \mathrm{O}_{3}, \mathrm{Al}_{2} \mathrm{O}_{3}, \mathrm{Fe}_{2} \mathrm{O}_{3}$, and $\mathrm{ZrO}_{2}$ generally act as glass formers and strengthen the glass network. In contrast, alkali oxides such as $\mathrm{Li}_{2} \mathrm{O}, \mathrm{Na}_{2} \mathrm{O}$ and $\mathrm{K}_{2} \mathrm{O}$ act as network modifiers by breaking Si-O-Si bonds and de-polymerizing the network structure. Alkaline earth oxides play a similar role to the alkali oxides, but generally to a lesser extent because their higher field strength and higher valence lead to more covalence in the glass network. Glasses that are high in glass formers are normally more durable, while those high in modifiers are expected to be more leachable.

Although both boron and silicon are considered structurally as network formers in borosilicate glasses, boron is significantly more soluble than silicon during PCT leaching. In addition, boron forms few secondary phases that precipitate from the leaching solution. These factors suggest that boron concentration in the leachate will be a good indicator of the extent of reaction of the glass with the leachant. In many attempts to explain the leaching results of borosilicate glasses, boron oxide content and its fraction in the glass network are two of the most important parameters (for example, see Kinoshita 1991). For glasses that show little leaching, the observed lithium and sodium releases are generally congruent with the boron release, as seen in Figure 4.3. As leaching increases, sodium and lithium dissolution behavior deviates from being congruent with boron release, which can be explained in part by the formation of sodium- and lithium-containing secondary phases. Exceptions such as HLW06-26 are seen in Figure 4.3 where the release of sodium (and lithium) is higher than that of boron. The glass HLW06-26 contains $20 \mathrm{wt} \%$ of $\mathrm{Na}_{2} \mathrm{O}$ and relatively low concentrations of $\mathrm{Al}_{2} \mathrm{O}_{3}(1.88 \mathrm{wt} \%)$ and $\mathrm{SiO}_{2}$ (33 $\mathrm{wt} \%$ ). Sodium and other alkalis can be released into the solution by ion exchange and diffusion processes, in addition to hydrolysis of the glass matrix. Depending on the relative rates of these processes for a given glass, the normalized concentration of sodium can be higher than that of boron in the leachate. This general relation between PCT releases of alkalis and boron is common and has been observed previously in the testing of WTP IHLW (and ILAW) glass formulations (Kot and Pegg 2001).

The properties of the leaching solution, such as temperature and $\mathrm{pH}$, are also important in determining the rate and mechanism of leaching in borosilicate glasses. Release of alkali ions from the glass matrix rapidly increases the leachate $\mathrm{pH}$, which in turn increases the rate of hydrolysis of the silicate network. Hench and Clark (1978) have classified the interaction of glasses containing high alkali contents with basic solution as the most reactive (the least reactive being silica in neutral-to-acidic solution), with the results often being total dissolution. De-ionized water is the leachant used in PCT and the leachate $\mathrm{pH}$ is another good indicator of extent of leaching. The data in Table 4.2 show that the $\mathrm{pH}$ values range from 8.96 to 12.18 . Note that the leachate $\mathrm{pH}$ values for actual waste glasses are generally lower than those found for the simulated glasses because of radiolysis. Figure 4.4 shows the relationship between leachate $\mathrm{pH}$ and the amounts of alkali oxides in the HLW glasses, while Figures 4.5 and 4.6, respectively, relate the normalized PCT boron and sodium releases to the leachate $\mathrm{pH}$. As expected, the leachate $\mathrm{pH}$ increases with the alkali concentrations in the glasses. The releases of both boron 
(Figure 4.5) and sodium (Figure 4.6) show a general increase with pH but there are fair amounts of scatter in the data.

As previously stated, the extent of PCT leaching can also be compared to the compositions of the glasses in terms of glass network formers and modifiers. The general effects of alkalis on PCT releases are shown in Figures 4.7 (boron) and 4.8 (sodium). While there is again significant scatter in the displayed data, the overall trend shows an increase in PCT releases with higher alkali content. This is expected because less durable glasses would result as the content of glass network modifiers is increased. Figure 4.9 compares PCT boron release to a ratio of glass modifiers to glass formers (i.e., $\left(\mathrm{Li}_{2} \mathrm{O}+\mathrm{Na}_{2} \mathrm{O}+\mathrm{K}_{2} \mathrm{O}+\mathrm{MgO}+\mathrm{CaO}+\mathrm{SrO}\right) /\left(\mathrm{Al}_{2} \mathrm{O}_{3}\right.$ $\left.+\mathrm{B}_{2} \mathrm{O}_{3}+\mathrm{Fe}_{2} \mathrm{O}_{3}+\mathrm{SiO}_{2}+\mathrm{ZrO}_{2}\right)$ ). While there is also a general trend of increase in the releases of boron as the ratio is increased, the correlation is not as evident. Statistical modeling of these results with respect to glass compositions is described in Section 5.

\subsection{One-Percent Crystal Fraction Temperature $\left(T_{1 \%}\right)$ Results and Discussion}

The $\mathrm{T}_{1 \%}$ results are presented in Section 4.2.1 and discussed in Section 4.2.2.

\subsection{1 $T_{1 \%}$ Results}

Heat treatment of $247 \mathrm{HLW}$ glasses was conducted between $650^{\circ} \mathrm{C}$ and $1200^{\circ} \mathrm{C}$, at regular temperature intervals of $50^{\circ} \mathrm{C}$ (measurements were also performed on some glasses at $875^{\circ} \mathrm{C}$ ). The measured crystal vol\% data are tabulated in Table 4.3 . It can be seen that the vol\% crystallinity of the heat-treated glass samples covered a very wide range, from trace to over $40 \mathrm{vol} \%$. The typical relationship observed between crystal vol\% and heat treatment temperature is relatively simple and can be adequately described by a linear relationship. One example is given in Figure 4.10, which shows the heat treatment results of HLW02-01 and its replicate, HLW02-52. In a few cases, the temperature dependence of vol\% is non-linear. For example, the data for the replicate pair HLW02-04 and HLW02-54 show an abrupt slope change at about $850^{\circ} \mathrm{C}$, characteristic of the appearance of a second phase (Figure 4.11). It is, however, still straightforward to estimate $\mathrm{T}_{1 \%}$ based on the linear trend defined by spinel crystallization.

Methods discussed in Section E.1 of Appendix E were applied to the (temperature, vol\% crystals) data in Table 4.3 to calculate estimated $\mathrm{T}_{1 \%}$ values for the HLW glasses and the corresponding standard deviations of the estimated $\mathrm{T}_{1 \%}$ values [denoted $\mathrm{SD}\left(\mathrm{T}_{1 \%}\right)$ ]. The estimated $\mathrm{T}_{1 \%}, \mathrm{SD}\left(\mathrm{T}_{1 \%}\right)$, and primary crystalline phase for each HLW glass are given in Table 4.4. The uncertainty for the estimated spinel $\mathrm{T}_{1 \%}$ values based on replicate HLW glasses is assessed in Section 6.1 . The pooled $\mathrm{SD}$ of spinel $\mathrm{T}_{1 \%}$ is $26.89^{\circ} \mathrm{C}$ and the average relative standard deviation (RSD) is $2.5 \%$, which is comparable to the average RSD (1.6\%) for the spinel liquidus temperature $\left(T_{L}\right)$ previously estimated for a smaller set of replicate glasses (Hrma et al. 1994). The similar uncertainties in experimental measurements of $\mathrm{T}_{1 \%}$ and $\mathrm{T}_{\mathrm{L}}$ suggest that the prediction errors of $\mathrm{T}_{1 \%}$ models and $\mathrm{T}_{\mathrm{L}}$ models should be comparable when they are developed for the same glass dataset. It is therefore expected that adoption of the $T_{1 \%}$ model over the $T_{L}$ model should realize the intended gains in waste loading. 
Overall, $\mathrm{T}_{1 \%}$ was estimated for 229 of the 247 HLW glasses for which (temperature, volume percent crystallinity) data were collected. The other $(247-229)=18$ glasses did not result in enough crystallization data even at low heat-treatment temperatures to allow estimation of $\mathrm{T}_{1 \%}$. Most of these 18 glasses belonged to the Non-Spinel Matrix (HLW05) and the HLW07 Test Matrix. Of the 229 glasses for which $\mathrm{T}_{1 \%}$ values were estimated, 172 precipitated spinel as the primary crystalline phase upon heat treatment. The other 57 glasses with estimated $\mathrm{T}_{1 \%}$ values precipitated $\mathrm{ZrO}_{2}, \mathrm{ThO}_{2}, \mathrm{ZrSiO}_{4}$, or other crystalline phases as the primary crystalline phase (see Table 4.4) after heat treatment. Examples of the other primary crystalline phases included strontium phosphate, uranium oxide, and parakeldyshite $\left(\mathrm{Na}_{2} \mathrm{ZrSi}_{2} \mathrm{O}_{7}\right)$. Of the 172 glasses with estimated spinel $\mathrm{T}_{1 \%}$ values, one (HLW02-10) was an extreme outlier with the $\mathrm{T}_{1 \%}$ $\left(554^{\circ} \mathrm{C}\right)$ estimated by far extrapolation, the lowest heat-treatment temperature being $700^{\circ} \mathrm{C}$. Selection of glasses for inclusion into the final modeling dataset is discussed in Section 6. The $172 \mathrm{~T}_{1 \%}$ values span a range of $554^{\circ} \mathrm{C}$ to $1279^{\circ} \mathrm{C}$, with a median of $944.6^{\circ} \mathrm{C}$ (mean $=931.8^{\circ} \mathrm{C}$ ), which can be compared with the WTP processing requirement of $\mathrm{T}_{1 \%} \leq 950^{\circ} \mathrm{C}$. Figure 4.12 shows the distribution of the estimated spinel $\mathrm{T}_{1 \%}$ for the 172 HLW glasses. A large proportion of the glasses with high spinel $\mathrm{T}_{1 \%}$ values belonged to the Spinel Matrix (HLW06). For example, 10 of the 17 glasses with spinel $\mathrm{T}_{1 \%}$ above $1100^{\circ} \mathrm{C}$ were HLW06 glasses. This resulted from the expanded compositions and the constraint for spinel liquidus temperature (to $1200^{\circ} \mathrm{C}$ ) used in the design of the HLW06 matrix. It should be noted, however, that the expanded EGCR in the design of the Spinel Matrix also resulted in 10 HLW06 glasses with non-spinel primary crystalline phases.

For the 57 glasses that had non-spinel primary crystalline phases, the estimated $\mathrm{T}_{1 \%}$ covered a wide range of $650^{\circ} \mathrm{C}$ to $1511^{\circ} \mathrm{C}$. The principal crystalline phases after heat-treatments were $\mathrm{Zr}$-containing species $\left(\mathrm{ZrO}_{2}, \mathrm{ZrSiO}_{4}\right.$, and $\left.\mathrm{Na}_{2} \mathrm{ZrSi}_{2} \mathrm{O}_{7}\right)$ for 39 glasses, $\mathrm{ThO}_{2}$ for 14 glasses, and "others" (e.g., $\mathrm{UO}_{3}$ ) for 6 glasses. Modeling $\mathrm{T}_{1 \%}$ for primary crystalline phases other than spinel requires considerably more data and was not attempted. In addition, these glasses were not used in developing the spinel $\mathrm{T}_{1 \%}$ model (see Section 6).

\subsubsection{Discussion of $T_{1 \%}$ Results}

Previous HLW glass formulation work for AZ-101, AZ-102, and AY-102/C-106 wastes identified spinel crystallization as the primary constraint that prevented attainment of higher waste loadings (Kot and Pegg 2001). The iron contents in these wastes were comparatively high such that extensive use of additive components to effectively suppress spinel formation was required. These components included $\mathrm{Li}_{2} \mathrm{O}, \mathrm{Na}_{2} \mathrm{O}$, and $\mathrm{B}_{2} \mathrm{O}_{3}$ (Kot and Pegg 2001). Attempts have been made to qualitatively correlate the estimated $\mathrm{T}_{1 \%}$ values with glass compositions, as was performed for the PCT data in Section 4.1. Any trends observed for the $\mathrm{T}_{1 \%}$ data, however, are not as noticeable as those observed for PCT. Figure 4.13 provides one such example, which relates the $\mathrm{T}_{1 \%}$ data to the molar ratio of $\mathrm{Fe}_{2} \mathrm{O}_{3}$ to (alkali oxides $+\mathrm{B}_{2} \mathrm{O}_{3}$ ). Data for outliers and glasses with non-spinel primary crystalline phase are not included in Figure 4.13. While glasses with higher iron concentrations generally do tend to have higher $\mathrm{T}_{1 \%}$ values, the data show a good deal of scatter and the trend is less obvious than the trends found for PCT data. Many other similar attempts did not result in better correlations. For instance, adding chromium and nickel, 
two components known to greatly promote spinel formation, did not significantly reduce the scatter in the data (see Figure 4.13). This might suggest that $\mathrm{T}_{1 \%}$-composition modeling may be more complicated than PCT-composition modeling in the sense that additional modeling terms may be required.

Analyses show that spinel from HLW glasses is a solid solution whose composition varies with glass composition but primarily consists of trevorite $\left(\mathrm{NiFe}_{2} \mathrm{O}_{4}\right)$, nichromite $\left(\mathrm{NiCr}_{2} \mathrm{O}_{4}\right)$, and magnetite $\left(\mathrm{Fe}_{3} \mathrm{O}_{4}\right)($ Mika et al. 1997). Design of the Spinel Matrix (HLW06) and the HLW07 Test Matrix expanded the compositional ranges for $\mathrm{Cr}_{2} \mathrm{O}_{3}, \mathrm{Fe}_{2} \mathrm{O}_{3}$, and $\mathrm{NiO}$. Because of the spinel property constraint (i.e., spinel $\mathrm{T}_{1 \%}$ between $650^{\circ} \mathrm{C}$ and $1200^{\circ} \mathrm{C}$ ), the design maximum of $\mathrm{NiO}=1.2 \mathrm{wt} \%$ was not attained for the Spinel Matrix and the HLW06 glasses have a maximum $\mathrm{NiO}$ of only $1.0 \mathrm{wt} \%$. For $\mathrm{Cr}_{2} \mathrm{O}_{3}$ and $\mathrm{Fe}_{2} \mathrm{O}_{3}$, however, the design maxima were reached in both HLW06 and HLW07 matrices. A total of 9 HLW06 and HLW07 glasses have the maximum concentration of $\mathrm{Cr}_{2} \mathrm{O}_{3}(0.6 \mathrm{wt} \%)$ and/or $\mathrm{Fe}_{2} \mathrm{O}_{3}(15 \mathrm{wt} \%)$. Of these 9 glasses, all but one have estimated $\mathrm{T}_{1 \%}$ values above the recommended limit of $950^{\circ} \mathrm{C}$. While this again demonstrates the large single-component effects of $\mathrm{Cr}_{2} \mathrm{O}_{3}$ and $\mathrm{Fe}_{2} \mathrm{O}_{3}$ in determining spinel $\mathrm{T}_{1 \%}$, as stated above, no simple correlations were apparent between the estimated $\mathrm{T}_{1 \%}$ values and the glass compositions.

Recent IHLW glass formulation efforts have developed performance and process compliant glasses with increased waste loadings of up to $14 \mathrm{wt} \% \mathrm{Fe}_{2} \mathrm{O}_{3}$ (Kot and Pegg 2004), compared with a maximum of $12.56 \mathrm{wt} \%$ in earlier work (Kot et al. 2003b). The 168 glasses (after removal of four outliers, see Section 6.1) used in spinel $\mathrm{T}_{1 \%}$ modeling include only 12 glasses with $\geq 14.00 \mathrm{wt} \% \mathrm{Fe}_{2} \mathrm{O}_{3}$. It is of interest to note that, of these 12 glasses, 4 have an estimated $\mathrm{T}_{1 \%}$ of $\leq 950^{\circ} \mathrm{C}$, indicating that even higher waste loadings, corresponding to $\mathrm{Fe}_{2} \mathrm{O}_{3}>$ $14 \mathrm{wt} \%$, may be achievable for HLW glasses.

\subsection{Electrical Conductivity Results and Discussion}

The electrical conductivity (EC) results for HLW glasses are presented in Section 4.3.1 and discussed in Section 4.3.2.

\subsubsection{Electrical Conductivity Results}

Of the 305 simulated and actual HLW glasses discussed in Section 2.1, 210 simulated glasses have EC results as summarized in Table 4.1. Of these 210 glasses, 206 also have viscosity results, with the remaining four (HLW03-08, HLW07-08, HLW07-14 and HLW-ALG24) having EC but not viscosity data. As described in Section 3.5, EC was generally measured at four temperatures for each HLW glass. The EC versus temperature values are given in Table 4.5 for the 210 simulated glasses. Each row of Table 4.5 provides the EC data for a given glass and four temperatures. There are four columns of data for each glass corresponding to the four temperatures at which EC was measured. 
The current WTP requirement (Casassa 2005) for HLW glass melt EC is that it be within 0.1 to $0.7 \mathrm{~S} / \mathrm{cm}$ in the temperature range of 1100 to $1200^{\circ} \mathrm{C}$. For $210 \mathrm{HLW}$ glasses with EC measurements taken in this temperature range, the $\mathrm{EC}$ values were mostly within the acceptable range of 0.1 to $0.7 \mathrm{~S} / \mathrm{cm}$. Eight glasses had EC measurements outside of this range with values from 0.086 to $1.023 \mathrm{~S} / \mathrm{cm}$. The ECs of seven melts (HLW03-08, HLW03-10, HLW07-05, HLW07-16, HLW07-17, HLW07-19, and HLW-ALG-23) were above the WTP recommended upper limit of $0.7 \mathrm{~S} / \mathrm{cm}$, although most of them were only slightly above the limit. The only melt with a EC value lower than the recommended lower limit of $0.1 \mathrm{~S} / \mathrm{cm}$ was HLW02-20 (0.086 $\mathrm{S} / \mathrm{cm})$.

Figure 4.14 shows the distribution of temperature values at which data were collected for each HLW glass with EC data. This figure shows that EC was measured at temperatures not too far from the four nominal values $\left(950,1050,1150\right.$, and $\left.1250^{\circ} \mathrm{C}\right)$ for most $\mathrm{HLW}$ glasses. There are a few aspects of Figure 4.14 worth commenting on. First, the HLW02 glasses (indices 1 to 57) have fairly consistent temperature values at which EC was measured. These glasses were generally measured closely around the nominal temperatures of $950,1050,1150$, and $1250^{\circ} \mathrm{C}$. The HLW03 glasses (indices 58 to 101) were generally measured at nominal temperatures $20-30^{\circ} \mathrm{C}$ lower. The temperatures at which EC were measured for the other groups of glasses (HLW04, HLW05, HLW06, HLW07, HLW-ALG, and HLW98) vary considerably, with the nominal values not being readily apparent from the data. However, any impact of this variation on model development would be expected to be small. The differences in temperature values in Figure 4.14 can be explained by the fact that the HLW02 glasses (those with indices 1 to 57) are non-radioactive glasses, while the rest are radioactive. With radioactive glasses tested remotely, it is harder to achieve specific target temperatures.

The EC versus temperature values in Table 4.5 for the 210 HLW glasses with EC data vary from 0.034 to $1.376 \mathrm{~S} / \mathrm{cm}$, with smaller EC values generally corresponding to lower temperatures and larger electrical conductivity values corresponding to higher temperatures. Figure 4.15 shows the EC values plotted against $1 / T$ (with $T$ in Kelvin), with a line corresponding to the fit of the Arrhenius equation

$$
\ln (\mathrm{EC})=A+B(1 / T)
$$

for each HLW glass (where $A$ is the fitted intercept and $B$ is the fitted slope of the line). The purpose of this figure is not to assess the adequacy of the Arrhenius equation for representing the temperature dependence of EC, but to identify glasses that have different EC versus temperature data or relationships. Figure 4.15 shows that all 210 HLW glasses have temperature dependences occurring within the same band, with no substantially different data or EC-temperature relationships. Section 7.2.1 discusses the work performed to select the best equation to represent the dependence of electrical conductivity on temperature.

\subsubsection{Discussion of Electrical Conductivity Results}

The EC results were reviewed in terms of the molar concentrations of glass network formers and modifiers in the glass composition to examine the extent to which general trends or 
relationships may be evident. In view of the differences in the temperature of measurement, the EC was calculated at the nominal operating temperature of $1150^{\circ} \mathrm{C}$ for the WTP HLW glass melter using the Arrhenius relationship given in Equation (4.1). Appendix F provides the glass compositions in $\mathrm{mol} \%$, and Appendix $\mathrm{G}$ presents the values of electrical conductivity calculated at $1150^{\circ} \mathrm{C}$.

Figure 4.16 shows the $\mathrm{EC}$ at $1150^{\circ} \mathrm{C}$ as a function of the alkali oxide concentration of the glass. A strong correlation is observed, which is not surprising, given that ionic conduction dominates the EC of alkali borosilicate glasses. Also, alkalis are the most mobile ions and as such are expected to contribute most to the EC of the melt. Figure 4.17 shows the calculated EC at $1150^{\circ} \mathrm{C}$ as a function of the sum of the alkali and alkaline earth oxide concentration. Note that while the concentrations of $\mathrm{CaO}$ and $\mathrm{MgO}$ in the $\mathrm{HLW}$ glasses are relatively low (up to $1.36 \mathrm{wt} \%$, or $2.3 \mathrm{~mol} \%$ ), SrO can be present at rather more substantial concentrations (up to $10.3 \mathrm{wt} \%$, or $7.8 \mathrm{~mol} \%$ ). There is also a clear correlation in Figure 4.17 between the EC results and the sum of the alkali and alkaline earth oxides, which is also expected since the alkali oxides are present in quite higher concentrations than the alkaline earth oxides. However, there is considerably more scatter in the data in Figure 4.17 when compared to Figure 4.16, which is consistent with the much lower contribution of the alkaline earths to the EC as compared to the alkalis. The scatter in data is even more noticeable in Figure 4.18 where the EC results are shown as a function of the major glass network former oxide concentrations.

\subsection{Viscosity Results and Discussion}

The viscosity results for HLW glasses are presented in Section 4.4.1 and discussed in Section 4.4.2.

\subsubsection{Viscosity Results}

Of the 305 simulated and actual HLW glasses discussed in Section 2.1, 210 simulated glasses have viscosity results, as summarized in Table 4.1. Of these 210 glasses, 206 also have EC results, with the remaining four (HLW04-03, HLW04-06, HLW04-07 and HLW98-87) having viscosity but not EC data. As described in Section 3.6, viscosity was generally measured at four temperatures for each HLW glass. However, exceptions are glasses HLW03-10, HLW0301 and HLW-ALG-38 (with measurements at three temperatures each), HLW03-13, HLW06-04 and HLW-ALG-13 (with measurements at two temperatures each) and HLW03-32 (with a single viscosity measurement). The viscosity values at measurement temperatures are given in Table 4.6 for the 210 simulated HLW glasses. Each row of Table 4.6 provides the viscosity data for a given glass and up to four temperatures. There are four columns of data for each glass corresponding to the four temperatures at which viscosity was measured. Of the 210 glasses listed in Table 4.6, 197 were included in the final development of HLW viscosity models after exclusion of some glasses with incomplete data (i.e., fewer than four measurement temperatures) and glasses that exerted too much influence on model coefficients (see Section 8.1). 
Forty-three simulated HLW glasses had viscosities exceeding the recommended WTP upper limit of 150 poise at $1100^{\circ} \mathrm{C}$ (Casassa 2005), with interpolated values in the range of 151 to 572 poise. However, it is desirable for developing viscosity models to have some data beyond acceptable processing limits. By contrast, there were no glasses with viscosities beneath the lower processing limit of $10 \mathrm{P}$ at $1100^{\circ} \mathrm{C}$.

Figure 4.19 shows the distribution of temperature values at which viscosity was measured for each HLW glass with viscosity data. This figure shows that viscosity was measured at temperatures not too far from the four nominal values $\left(950,1050,1150\right.$, and $\left.1250^{\circ} \mathrm{C}\right)$ for most HLW glasses. Selected glasses that have measurement temperatures much different than the nominal $950,1050,1150$, and $1250^{\circ} \mathrm{C}$ values are marked with the Glass ID in the figure. Only one temperature value is marked for each glass even if some/all temperature values differ much from the nominal values. For example, HLW03-07 had viscosity measured at four temperatures higher than the four nominal temperatures. Also HLW07-13 $\left(1014^{\circ} \mathrm{C}\right), \mathrm{HLW} 07-25\left(1020^{\circ} \mathrm{C}\right)$, and HLW07-21 $\left(1016^{\circ} \mathrm{C}\right)$ were measured at the temperatures shown in parentheses between the nominal temperatures of $950^{\circ} \mathrm{C}$ and $1050^{\circ} \mathrm{C}$. These observations are noted but they do not affect the suitability of the associated data for developing viscosity models.

The viscosity versus temperature values in Table 4.6 for the $210 \mathrm{HLW}$ glasses with viscosity data vary from 3.60 to 3165.51 poise, with smaller viscosity values generally corresponding to higher temperatures and larger viscosity values corresponding to lower temperatures. Figure 4.20 shows the viscosity values plotted against $1 / T$ (with $T$ in Kelvin), with a line corresponding to the fit of the Arrhenius equation (given previously in Equation (4.1)) for each HLW glass. The purpose of this figure is not to assess the adequacy of the Arrhenius equation for modeling the temperature dependence of viscosity but to assess any glasses that appear to have "different" viscosity at temperature data or relationships. Figure 4.20 does not show any glasses with greatly different data or different viscosity-temperature relationships, although the relationship for HLW07-21 is somewhat different than for most glasses. Section 8.2.1 discusses the work performed to select the best equation to represent the dependence of viscosity on temperature.

\subsubsection{Discussion of Viscosity Results}

As previously noted for EC, because viscosity data were collected at different temperatures, it is convenient for comparison purposes to use the viscosity at $1150^{\circ} \mathrm{C}$, calculated using the Arrhenius relationship given above in Equation (4.1). The glass compositions in mol\% are provided in Appendix $\mathrm{F}$ and the calculated viscosity values at $1150^{\circ} \mathrm{C}$ are provided in Appendix G.

Figure 4.21 shows the calculated melt viscosity at $1150^{\circ} \mathrm{C}$ as a function of the alkali oxide concentration and Figure 4.22 as a function of the sum of alkali and alkaline earth oxide concentrations. Both figures show qualitatively that melt viscosity decreases with increasing concentration of alkalis and alkaline earth oxides. A better correlation is observed with the sum of alkali and alkaline earth oxide concentration than with the sum of alkali oxide concentration. This indicates that the combined effect of alkali and alkaline earths, both contributing 
non-bridging oxygens in the glass structure, is responsible for much of the decrease in melt viscosity. Although less mobile (as evident in the electrical conductivity data), alkaline earth metals play an important role in the creation of non-bridging oxygens, and consequently affect the melt viscosity.

The role of boron in the glass structure is more complicated and has been often described as "anomalous" because of its changing coordination from triangular to tetrahedral with glass composition, especially with alkali concentration. Details of the structural role of boron in borosilicate glasses can be found elsewhere (Pye et al. 1978). Because of the unique role of boron, the viscosity of the glass melt was examined as a function of the sum of concentrations of alkali, alkaline earth, and boron oxides. The plot of melt viscosity at $1150^{\circ} \mathrm{C}$ as a function of the sum of the alkali, alkaline earth oxide and boron oxide concentrations given in Figure 4.23 shows significantly better correlation than was found in Figures 4.21 and 4.22, indicative of the role of boron along with alkali and alkaline earth oxides in decreasing the viscosity of glass melts. Conversely, the plot of melt viscosity as a function of glass former oxide concentrations was adjusted in this case by eliminating boron from this group so that Figure 4.24 shows melt viscosity as a function $\mathrm{SiO}_{2}+\mathrm{ZrO}_{2}+\mathrm{P}_{2} \mathrm{O}_{5}+\mathrm{Al}_{2} \mathrm{O}_{3}+\mathrm{Fe}_{2} \mathrm{O}_{3}$ (mol\%) concentration. Figure 4.25 shows melt viscosity as a function of the ratio (alkali oxides + alkaline earth oxides + boron oxide) $/ \mathrm{SiO}_{2}+\mathrm{ZrO}_{2}+\mathrm{P}_{2} \mathrm{O}_{5}+\mathrm{Al}_{2} \mathrm{O}_{3}+\mathrm{Fe}_{2} \mathrm{O}_{3}$ in mol\%. Both figures show the expected trends with good correlations: the viscosity increases with increasing concentration of network formers (Figure 4.24) and decreases as the magnitude of the molar ratio in Figure 4.25 increases.

\subsection{Glass Density}

One of the original properties to be modeled for HLW glasses was glass density (Gan and Pegg 2002). However, per direction of the WTP Project (as described in Section 1.1), development of density models for HLW glasses was discontinued because such models would be needed only for a very limited number of cases (Abel 2007). The only technical need for a density model is to ensure that a filled IHLW canister will not exceed the weight requirements. Based on the available information and data, it is very unlikely that the weight requirements will be exceeded except for extreme glasses that incorporate high concentrations of thorium and/or waste from Sr/TRU removal. These extreme glasses will most likely not be produced according to current projections of waste compositions and waste blending.

Of the 305 simulated and actual HLW glasses discussed in Section 2.1, density data are available for only two glasses: $2.77 \mathrm{~g} / \mathrm{cc}$ for HLW98-61 and $2.89 \mathrm{~g} / \mathrm{cc}$ HLW98-51AW (measurement made with glass HLW98-51R, which has an essentially identical composition) (Kot and Pegg, 2001). Limited density data are also available for about 20 other HLW glasses not discussed in Section 2.1 and they cover a range of $2.64 \mathrm{~g} / \mathrm{cc}$ to $3.15 \mathrm{~g} / \mathrm{cc}$ (Kot and Pegg 2001). These values are higher than those found for LAW glasses, for which more extensive density data are available (Piepel et al. 2007). Higher density values are expected for HLW glasses since they typically contain more oxides of heavy elements than do LAW glasses. Significant expansion of the density database will be necessary if development of a HLW density model is needed in the future. 


\section{SECTION 5 \\ MODELS RELATING PCT BORON, LITHIUM, AND SODIUM RELEASES TO HLW GLASS COMPOSITION}

This section documents the development and validation of property-composition models and corresponding uncertainty expressions for predicting the PCT-Boron (PCT-B), PCT-Lithium (PCT-Li), and PCT-Sodium (PCT-Na) releases from high level waste (HLW) glasses. Specification 4.8.1.2 of the Waste Acceptance System Requirements Document (WASRD), Rev. 4 (DOE-RW 2002) requires that HLW glasses have PCT normalized releases of boron, lithium, and sodium lower than the corresponding releases from the DWPF-EA glass (Jantzen et al. 1993). The property-composition models and corresponding uncertainty expressions for PCT-B, PCT-Li, and PCT-Na releases from HLW glasses presented in this section were developed and validated using composition and PCT release data collected on simulated and actual HLW glasses.

Section 5.1 summarizes the data used to develop and validate the PCT-composition models for HLW glasses. Section 5.2 presents the model forms for PCT-B, PCT-Li, and PCT-Na releases that were investigated. Sections 5.3, 5.4, and 5.5 summarize the results for PCT-B, PCT$\mathrm{Li}$, and PCT-Na models, respectively. Section 5.6 summarizes the results for various PCT-B, PCT-Li, and PCT-Na models and selects the ones to form the basis for the recommended and second-choice models. Section 5.7 discusses applying bias-correction to obtain the recommended and second-choice models for PCT-B, PCT-Li, and PCT-Na releases of HLW glasses. Section 5.8 illustrates for selected models the calculation of PCT-B, PCT-Li, and PCT-Na release predictions for HLW glasses and the uncertainties in those predictions. Section 5.9 briefly discusses the suitability of the PCT-B, PCT-Li, and PCT-Na models recommended for use by the WTP project. Appendix $C$ discusses the statistical methods and summary statistics used to develop, evaluate, and validate the several model forms investigated, as well as statistical equations for quantifying the uncertainties in PCT release predictions made with the selected models.

\subsection{PCT Release Data Used for Model Development and Validation}

The data used for developing PCT-B, PCT-Li, and PCT-Na release models are discussed in Section 5.1.1. The three approaches and data used for validating the models are discussed in Sections 5.1.2 to 5.1.4.

\subsubsection{Model Development Data for PCT Releases}

The data available for developing property-composition models for PCT-B, PCT-Li, and PCT-Na releases consist of composition and PCT release $(\mathrm{g} / \mathrm{L})$ data from 268 HLW glasses. These glasses are discussed and their target compositions are presented in Section 2.1. The 
corresponding PCT-B, PCT-Li, and PCT-Na releases are presented in Table 4.2. The PCT data for HLW glasses are discussed in Section 4.1.

\section{$\underline{\text { Assessment of Available Glasses with PCT Releases }}$}

The database of 268 HLW glasses with PCT releases contains statistically-designed as well as actively-designed glasses. Some actively-designed glasses are outside the composition region covered by the majority of the HLW compositions. Such glasses are not ideal for inclusion in a modeling set because they can be influential when fitting models to data. Hence, it was decided to (i) graphically assess the 268 simulated and actual HLW glass compositions and (ii) remove from the modeling set any compositions considered to be outlying or non-representative of HLW glasses of interest for the WTP.

Figure 5.1 displays plots of the mass fraction values for 57 components in the 268 HLW glasses with PCT data. On each plot in Figure 5.1, the x-axis represents the mass fraction values of an HLW glass component. The y-axis shows an index value representing each HLW glass composition, which aids in spreading out the data points to avoid over-plotting. The plotting symbols correspond to the nine groups of HLW glass data discussed in Sections 2.1.1 to 2.1.9. For comparison purposes, the vertical bars in Figure 5.1 represent the ranges over which 18 "main" components $\left(\mathrm{Al}_{2} \mathrm{O}_{3}, \mathrm{~B}_{2} \mathrm{O}_{3}, \mathrm{CdO}, \mathrm{Cr}_{2} \mathrm{O}_{3}, \mathrm{Fe}_{2} \mathrm{O}_{3}, \mathrm{Li}_{2} \mathrm{O}, \mathrm{MnO}, \mathrm{Na}_{2} \mathrm{O}, \mathrm{NiO}, \mathrm{Sb}_{2} \mathrm{O}_{3}, \mathrm{SeO}_{2}\right.$, $\mathrm{SiO}_{2}, \mathrm{SrO}, \mathrm{ThO}_{2}, \mathrm{Tl}_{2} \mathrm{O}, \mathrm{UO}_{3}, \mathrm{ZnO}$ and $\mathrm{ZrO}_{2}$ ) were varied in one or more of the statistically designed test matrices included in the dataset.

Figure 5.1 shows several glasses have components with outlying mass fraction values compared to the remaining glasses and/or to the ranges of the 18 "main" components. Figure 5.1 shows outlying observations in the reported compositions for $\mathrm{Ce}_{2} \mathrm{O}_{3}, \mathrm{Gd}_{2} \mathrm{O}_{3}, \mathrm{HfO}_{2}, \mathrm{Nd}_{2} \mathrm{O}_{3}$ and $\mathrm{SnO}_{2}$. In most cases, it is a single observation that causes the range for the component to increase considerably from the bulk of data. Table 5.1 lists the HLW glasses with one or more outlying component values. In some cases, outlying values of minor components would not be expected to impact models for PCT releases from HLW glasses. Hence, a column in Table 5.1 indicates whether the outlying glass was removed from the PCT modeling dataset. Only two outlying glasses (HLW98-96A and HLW98-96B) were selected for removal.

Figure 5.2 shows plots of component distributions for the 266 HLW glasses remaining after the two outlying glasses were removed from the PCT dataset. Figure 5.2 shows that 24 HLW glass components (the first 24 of the 25 components listed subsequently) have sufficient ranges and distributions of values within those ranges to support model terms. Hence, based on Figure 5.2, it was decided to use 25 components for initial PCT modeling work. These are $\mathrm{Al}_{2} \mathrm{O}_{3}$, $\mathrm{B}_{2} \mathrm{O}_{3}, \mathrm{CaO}, \mathrm{CdO}, \mathrm{Cr}_{2} \mathrm{O}_{3}, \mathrm{Fe}_{2} \mathrm{O}_{3}, \mathrm{~K}_{2} \mathrm{O}, \mathrm{La}_{2} \mathrm{O}_{3} . \mathrm{Li}_{2} \mathrm{O}, \mathrm{MgO}, \mathrm{MnO}, \mathrm{Na}_{2} \mathrm{O}, \mathrm{NiO}, \mathrm{PbO}, \mathrm{Sb}_{2} \mathrm{O}_{3}, \mathrm{SeO}_{2}$, $\mathrm{SiO}_{2}, \mathrm{SrO}, \mathrm{ThO}_{2}, \mathrm{TiO}_{2}, \mathrm{Tl}_{2} \mathrm{O}, \mathrm{UO}_{3}, \mathrm{ZnO}, \mathrm{ZrO}$, and Others (the sum of all remaining components).

Figure 5.3 shows a scatterplot matrix of the 266 glasses remaining in the PCT modeling dataset after removing the two outlying compositions. Besides the outlying HLW glass compositions, two other patterns in any given scatter plot are of interest. First, any pattern that shows a strong positive or negative correlation between components is important to note. We 
defer discussion of strong correlations between pairs of HLW glass components until pairwise correlation coefficients are discussed subsequently. Second, any "hole" in a scatterplot indicates lack of data for those combinations of pairs of components. The main "holes" seen in Figure 5.3 are for $\mathrm{SeO}_{2}$ against most other main components and $\mathrm{Tl}_{2} \mathrm{O}$ against most other main components. Pair combinations that include these two main components mainly show large bands of empty space where there are no observations.

An additional way of assessing strong correlations between pairs of HLW glass components is through the calculation of correlation coefficients. These can vary from -1.0 (perfect negative correlation) to 0 (no correlation) to 1.0 (perfect positive correlation). Correlation coefficients equal or larger than 0.6 (in absolute value) indicate a strong linear relationship among the two components involved. Correlation coefficients were computed for all pairs of the 25 components selected for initial PCT-composition modeling. The component pairs with correlations larger (in absolute value) than 0.60 are

$\begin{array}{ll}\mathrm{CaO} \text { and } \mathrm{MgO} & 0.62 \\ \mathrm{CaO} \text { and } \mathrm{TiO}_{2} & 0.62 \\ \mathrm{~K}_{2} \mathrm{O} \text { and } \mathrm{MgO} & 0.70 \\ \mathrm{~K}_{2} \mathrm{O} \text { and } \mathrm{PbO} & 0.66 \\ \mathrm{~K}_{2} \mathrm{O} \text { and } \mathrm{TiO}_{2} & 0.88 \\ \mathrm{MgO} \text { and } \mathrm{TiO}_{2} & 0.87\end{array}$

Note that none of these pairwise correlations involve any of the 18 "main" components varied in one or more of the statistically designed matrices. Thus, the components involved in these high pairwise correlations were varied in groups in the statistically designed matrices. This accounts for why all of the preceding pairwise correlations are positive. Such high pairwise correlations can make it difficult for regression methods to properly separate the effects of the components on the response variable (e.g., PCT releases). Thus, these high pairwise correlations need to be kept in mind in developing PCT-composition models for HLW glasses.

\section{$\underline{\text { PCT Modeling Dataset }}$}

Table 5.2 lists the Glass ID, Group ID, and normalized glass compositions for the 266 simulated and actual HLW glasses in the 25-component forms used for PCT model development. The Group ID column of Table 5.2 indicates the subset of data that each glass is associated with (see Sections 2.1.1 to 2.1.9). The glass compositions in Table 5.2 are the normalized mass fractions $(\mathrm{mf})$ of the 25 components previously identified as having sufficient data to support a separate model term if needed. These components are $\mathrm{Al}_{2} \mathrm{O}_{3}, \mathrm{~B}_{2} \mathrm{O}_{3}, \mathrm{CaO}, \mathrm{CdO}, \mathrm{Cr}_{2} \mathrm{O}_{3}, \mathrm{Fe}_{2} \mathrm{O}_{3}$, $\mathrm{K}_{2} \mathrm{O}, \mathrm{La}_{2} \mathrm{O}_{3} . \mathrm{Li}_{2} \mathrm{O}, \mathrm{MgO}, \mathrm{MnO}, \mathrm{Na}_{2} \mathrm{O}, \mathrm{NiO}, \mathrm{PbO}, \mathrm{Sb}_{2} \mathrm{O}_{3}, \mathrm{SeO}_{2}, \mathrm{SiO}_{2}, \mathrm{SrO}, \mathrm{ThO}_{2}, \mathrm{TiO}_{2}, \mathrm{Tl}_{2} \mathrm{O}$, $\mathrm{UO}_{3}, \mathrm{ZnO}, \mathrm{ZrO}_{2}$, and Others.

Table 5.3 contains columns of normalized PCT-B, PCT-Li, and PCT-Na releases (given in $\mathrm{g} / \mathrm{L}$ units) for the 266 glasses in the PCT modeling dataset for HLW glasses. Of these 266 glasses, all have data for PCT-B and PCT-Na releases, while only 251 have data for PCT-Li releases. The normalized PCT-B, PCT-Li, and PCT-Na releases were calculated as described previously in Section 3.3. It is desirable to have some glasses in the modeling dataset that have 
PCT releases ranging from somewhat below to somewhat above the limits. This allows for more confident use of the model in discerning between glasses with acceptable and unacceptable PCT releases. However, only one glass (HLW-ALG-03) has a PCT-B release above the DWPF-EA glass limit of $16.695 \mathrm{~g} / \mathrm{L}$ and a PCT-Li release above the DWPF-EA glass limit of 9.565 g/L. No glasses in the dataset have PCT-Na releases above the DWPF-EA limit of $13.346 \mathrm{~g} / \mathrm{L}$, although HLW-ALG-03 has a PCT-Na release $(11.819 \mathrm{~g} / \mathrm{L})$ that approaches the DWPF-EA limit.

Figure 5.4 shows a scatterplot matrix of the PCT-B, PCT-Li, and PCT-Na normalized releases $(\mathrm{g} / \mathrm{L})$ for the $266 \mathrm{HLW}$ glasses with PCT-B and PCT-Na data and the $251 \mathrm{HLW}$ glasses with PCT-Li data. Two glasses (HLW03-13 and HLW-ALG-26) stand out as having very low PCT-B releases, whereas one glass (HLW98-94) stands out as having very low PCT-Li release. These glasses were ultimately removed from the modeling datasets for PCT-B and PCT-Li, as discussed subsequently in Sections 5.3.1 and 5.4.1. The final modeling datasets contained 264 glasses for PCT-B, 250 glasses for PCT-Li, and 266 glasses for PCT-Na.

\section{Replicate and Near-Replicate PCT Data}

Table 5.4 lists the sets of replicate (or near replicate) glasses in the PCT modeling dataset for HLW glasses and the corresponding PCT-B, PCT-Li, and PCT-Na normalized releases. Near-replicate sets involve glasses that were intended to be replicates in composition but that have very slight differences for some component values. The differences are typically due to round-off or renormalization when the glasses involved are from different studies. Near-replicates were treated as true replicates for model development and evaluation purposes. In some cases, replicate sets include PCT results from canister centerline cooled (CCC) heat-treatments (e.g., HLW98-96CG), redox-treatments (e.g., HLW98-96RE7), or heat- and redox-treatments (e.g., HLW98-96RE7CCC) of a base glass (e.g., HLW98-96). Table 5.4 also lists estimates of standard deviations $(\mathrm{SD})$ in $\ln (\mathrm{g} / \mathrm{L})$ units and percent relative standard deviations (\%RSDs) for each replicate set as well as pooled estimates over all the replicate sets. A pooled SD or $\%$ RSD combines the separate SD or $\% \mathrm{RSD}$ estimates from each replicate set, so that a more accurate combined estimate of the SD or \%RSD is obtained. These pooled SDs and $\%$ RSDs include uncertainties due to fabricating glasses, performing the PCT, and chemically analyzing leachates to determine elemental releases.

As noted in the previous paragraph, PCT results for CCC-treated and redox-treated glasses were considered as replicates of standard-treated glasses. To assess whether this might inflate the estimate of PCT testing and measurement uncertainty, the replicate sets in Table 5.4 were divided into two groups: "not including" and "including" a CCC-treated or redox-treated glass. Pooled SDs and \%RSDs were calculated for each of the two groups, with the outcome being that the "including" replicate sets actually had smaller pooled SDs and \%RSDs than the "not including" replicate sets. This indicated that (i) the CCC and redox treatments did not increase the variation in PCT results within replicate sets, and thus (ii) it was acceptable to treat CCC-treated and redox-treated glasses as replicates of standard-treated glasses for purposes of calculating PCT testing and measurement uncertainties.

The magnitudes of the overall pooled \%RSDs for PCT-Li and PCT-Na in Table 5.4 are only slightly larger than the approximately $10 \% \mathrm{RSD}$ values for PCT-Li and PCT-Na reported in 
Table F.5 of Hrma et al. (1994). However, the overall pooled \%RSD for PCT-B in Table 5.4 is more than twice as large as the approximately $10 \%$ RSD value for PCT-B in Table F.5 of Hrma et al. (1994). The results from that Table F.5 were based on replicate sets of the same glasses fabricated and tested several times over several years. Hence, the approximately $10 \%$ RSD values for PCT-B, PCT-Li, and PCT-Na reported by Hrma et al. (1994) include an additional long-term source of variation not included in the replicate data of Table 5.4. This suggests that the PCT-B data for the HLW glasses in Table 5.3 were subject to more experimental, testing, and measurement uncertainty than in the Hrma et al. (1994) HLW glass composition variation study. It is not clear why the uncertainty in the PCT-B releases for this dataset is larger, but as discussed in Section 4.1, phase separation could be a possible cause. The estimates of replicate uncertainty for PCT-B, PCT-Li, and PCT-Na releases in Table 5.4 are used subsequently to statistically assess lack-of-fit (LOF) of the various models considered.

\subsubsection{Primary Model Validation Approach and Data}

The primary model validation approach for PCT modeling was based on splitting the PCT-B modeling dataset (264 glasses), the PCT-Li modeling dataset (250 glasses), and the PCT-Na modeling dataset (266 glasses) into five modeling subsets and five corresponding validation subsets. The five modeling/validation splits of the HLW glasses in the PCT-B, PCT$\mathrm{Li}$, and PCT-Na modeling datasets were formed as follows.

- The 57 glasses in the 26 replicate sets were set aside so they would always be included in each of the five model development subsets for each of PCT-B, PCT-Li, and PCT-Na. This was done so that replicate sets would not be split between modeling and validation subsets, thus negating the intent to have validation glasses different than model development glasses.

- The PCT-B, PCT-Li, and PCT-Na releases $(\mathrm{g} / \mathrm{L})$ for the remaining glasses $(264-57=$ 207 for PCT-B, $250-57=193$ for PCT-Li, and $266-57=209$ for PCT-Na) were ordered from smallest to largest. For each of PCT-B, PCT-Li, and PCT-Na, the remaining data points were numbered 1, 2, 3, 4, 5, 1, 2, 3, 4, 5, etc. All of the 1 's formed the first model validation set, while all of the remaining points formed the first model development dataset. Similarly, all of the 2's, 3's, 4's, and 5's respectively formed the second, third, fourth, and fifth model validation sets. In each case, the remaining non-2's, non-3's, non-4's, and non-5's formed the second, third, fourth, and fifth model development datasets. Accordingly, the validation subsets for each of the five splits contained 41 or 42 glasses for PCT-B, 38 or 39 glasses for PCT-Li, and 41 or 42 glasses for PCT-Na.

- The 57 replicate glasses were added to each of the five split modeling subsets for each of PCT-B, PCT-Li, and PCT-Na. For PCT-B, this resulted in two splits containing 222 glasses for modeling and 42 glasses for validation, and three splits containing 223 glasses for modeling and 41 glasses for validation. For PCT-Li, this resulted in two splits containing 211 glasses for modeling and 39 glasses for validation, and two splits containing 212 glasses for modeling and 38 glasses for validation. For PCT-Na, this 
resulted in four splits containing 224 glasses for modeling and 42 glasses for validation, and one split containing 225 glasses for modeling and 41 glasses for validation. The last three columns of Table 5.3 specify the validation subsets for the five modeling/validation splits in the primary validation approach for PCT-B, PCT-Li, and PCT-Na model development.

Data splitting was chosen as the primary validation approach because the PCT modeling dataset contains all the HLW glass compositions that (i) are in the HLW glass composition region of interest, (ii) meet quality assurance (QA) requirements, and (iii) have PCT data. Having a separate validation dataset covering the composition region of interest but not used for modeling is desirable, but that desire was over-ridden by wanting PCT models developed with all appropriate data.

\subsubsection{Secondary Model Validation Approach and Data}

The secondary model validation approach consisted of partitioning the PCT-B modeling dataset (264 glasses), the PCT-Li modeling dataset (250 glasses), and the PCT-Na modeling dataset (266 glasses) into a modeling subset and a validation subset. The modeling subset for each of PCT-B, PCT-Li, and PCT-Na contained (i) the HLW02, HLW03, and HLW07 glasses corresponding to statistically-designed groups of the data, (ii) two HLW05 glasses (HLW05-20 and HLW05-21), (iii) two HLW06 glasses (HLW06-04 and HLW06-32), and 19 HLW-ALG glasses (HLW-ALG-01, -03, -04, -10, -11, -15, -16, -17, -20, -21, -22, -23, -24, -25, -27, -28, -29, $-33,-34)$. Together, these yielded modeling subsets of 162 glasses for PCT-B, 154 glasses for PCT-Li, and 163 glasses for PCT-Na. The remaining 102 glasses for PCT-B, 96 glasses for PCT-Li, and 103 glasses for PCT-Na (which consist of actively-designed glasses and glasses made from actual HLW samples) were used as validation subsets.

The data-splitting approach discussed in Section 5.1.2 is considered the primary validation approach because it comes closer to validating the PCT models of interest, namely those fitted to all glasses used for modeling (264 for PCT-B, 250 for PCT-Li, and 266 for PCT-Na). The primary (data-splitting) validation approach fits PCT models using modeling subsets of 222 or 223 glasses for PCT-B, 211 or 212 glasses for PCT-Li, and 224 or 225 glasses for PCT-Na. The secondary (data-partitioning) approach fits PCT-B, PCT-Li, and PCT-Na models with 162, 154, and 163 glasses, respectively.

The secondary validation approach is desirable because it uses the statistically-designed glasses to fit models, and actively-designed glasses to validate the models. Actively-designed glasses tend to be more clustered in composition space, and can have strong or even perfect correlations between glass components. These aspects make actively-designed glasses somewhat less desirable for model development, but reasonable for model validation. 


\subsubsection{Separate Data for Validating PCT Models}

There were 556, 480, and 554 glasses not used for developing PCT-B, PCT-Li, and PCT-Na models of HLW glasses that were hence available for validating the models. These validation glasses are discussed in Section 2.2.1. However, the majority of these validation glasses had compositions outside the constraints that defined the EGCR of interest for WTP IHLW property-composition model development. Hence, the validation dataset is useful for assessing the extrapolative prediction performance of PCT models for HLW glasses. Extrapolations of empirical property-composition models often result in less accurate property predictions than would result if the models were applied to compositions within the glass composition region of interest.

The compositions for the 556 validation glasses (for PCT-B, the validation sets are subsets of these glasses for PCT-Li and PCT-Na) are given in Table B.1 of Appendix B. The compositions are listed as mass fractions (which sum to 1.0) of the 25 components identified previously for use in initial PCT model development. The corresponding PCT-B, PCT-Li, and PCT-Na release data (unnormalized and normalized) are given in Table B.2 of Appendix B. Note that all 556 glasses were used to validate PCT-B models, 554 were used to validate PCT-Na models, and 480 were used to validate PCT-Li models. See Section 2.2 and Appendix B for further information.

Besides the vast majority of the 556 validation glasses being outside the EGCR for HLW glasses, some of them do not satisfy the full QA requirements (QARD, U. S. DOE-RW 2004). Hence, the validation results based on these data for models presented in Sections 5.3, 5.4, and 5.5 are considered less important than the data-splitting and data-partitioning validation results.

\subsection{PCT Release Model Forms}

Ideally, a property-composition model for PCT would utilize known mechanisms of PCT release as a function of glass composition and other aspects of the PCT. Several mechanistic modeling approaches have been investigated for predicting PCT releases. However, all are either reduced forms of a linear mixture model or can be well-approximated by such a model. Empirical model forms with parameters estimated from model development data have been shown to perform as well or better than the mechanistic modeling approaches. The empirical model forms used are from the general class of mixture experiment models (Cornell 2002), which includes models linear in composition as well as non-linear in composition. Section C.1 of Appendix $\mathrm{C}$ discusses mixture experiments and several general forms of mixture experiment models. Section 5.2.1 discusses the forms of mixture experiment models used for PCT responses of HLW glasses. Section 5.2.2 discusses the choice between modeling unnormalized and normalized PCT releases and transformations thereof. 


\subsubsection{Mixture Experiment Model Forms}

Linear mixture (LM) and partial quadratic mixture (PQM) model forms introduced in Section C.1.1 of Appendix C were chosen for use in modeling PCT-B, PCT-Li, and PCT-Na releases. For modeling these releases, the specific LM model form is given by

$$
\ln \left(C_{B}\right), \ln \left(C_{L i}\right), \text { or } \ln \left(C_{N a}\right)=\sum_{i=1}^{q} b_{i} x_{i}+E
$$

while the specific PQM model form is given by

$$
\ln \left(C_{B}\right), \ln \left(C_{L i}\right), \text { or } \ln \left(C_{B}\right)=\sum_{i=1}^{q} b_{i} x_{i}+\text { Selected }\left\{\sum_{i=1}^{q} b_{i i} x_{i}^{2}+\sum_{i<j}^{q-1} \sum_{i j}^{q} b_{i j} x_{i} x_{j}\right\}+E
$$

In Equations (5.1) and (5.2): $\ln \left(C_{B}\right)$ denotes the natural logarithm of the normalized PCT-B release (in $\mathrm{g} / \mathrm{L}) ; \ln \left(C_{L i}\right)$ denotes the natural logarithm of the normalized PCT-Li release (in $\left.\mathrm{g} / \mathrm{L}\right)$; $\ln \left(C_{N a}\right)$ denotes the natural logarithm of the normalized PCT-Na release (in $\left.\mathrm{g} / \mathrm{L}\right)$; the $x_{i}(i=1,2$, $\ldots, q)$ are normalized mass fractions of $q$ glass oxide or halogen components such that $\sum_{i=1}^{q} x_{i}=1$; the $b_{i}(i=1,2, \ldots, q)$, the $b_{i i}$ (selected), and the $b_{i j}$ (selected) are coefficients to be estimated from data; and $E$ is a random error for each data point. Many statistical methods exist for developing and evaluating prediction models in the case where the $E$ are independent (i.e., not correlated) and normally distributed with mean 0 and standard deviation $\sigma$. Some of these methods (discussed in Sections C.3 and C.4 of Appendix C) were used in developing PCT models. In Equation (5.2), "Selected" means that only some of the terms in curly brackets are included in the model. The subset is selected using standard stepwise regression or other variable selection methods (Draper and Smith 1998, Montgomery et al. 2001). PQM models are discussed in more detail and illustrated by Piepel et al. (2002c).

Cornell (2002) discusses many other empirical mixture model forms that could have been considered for PCT-composition modeling but were not investigated because of time constraints. However, models of the form in Equations (5.1) and (5.2) are widely used in many application areas (including waste glass property modeling) and often perform very well.

\subsubsection{Normalization and Transformation of PCT Release Values}

A transformation to "normalized" concentrations is widely employed in the data analysis and modeling of leaching data (Hrma et al. 1994, Gan and Pegg 2001a, Kot et al. 2005a). The normalized PCT-B releases $\left(C_{B}\right)$ were calculated according to the formula

$$
C_{B}(\mathrm{~g} / \mathrm{L})=\frac{c_{B}(\mathrm{mg} / \mathrm{L})}{[1000(\mathrm{mg} / \mathrm{g})]\left[x_{B_{2} O_{3}}\left(\mathrm{~g} \mathrm{~B}_{2} \mathrm{O}_{3} / \mathrm{g} \text { glass }\right)\right]\left[0.3106\left(\mathrm{~g} \mathrm{~B} / \mathrm{g} \mathrm{B}_{2} \mathrm{O}_{3}\right)\right]},
$$


where $c_{B}$ is the non-normalized boron release (concentration) from the 7-day PCT, and $x_{B 2 O 3}$ is the normalized mass fraction of $\mathrm{B}_{2} \mathrm{O}_{3}$ in the glass.

Similarly, normalized PCT-Li releases $\left(C_{L i}\right)$ were calculated according to the formula

$$
C_{L i}(\mathrm{~g} / \mathrm{L})=\frac{c_{L i}(\mathrm{mg} / \mathrm{L})}{[1000(\mathrm{mg} / \mathrm{g})]\left[x_{L i_{2} O}\left(\mathrm{~g} \mathrm{Li}_{2} \mathrm{O} / \mathrm{g} \text { glass }\right)\right]\left[0.4645\left(\mathrm{~g} \mathrm{Li} / \mathrm{g} \mathrm{Li}_{2} \mathrm{O}\right)\right]}
$$

and normalized PCT-Na releases $\left(C_{N a}\right)$ were calculated according to the formula

$$
C_{N a}(\mathrm{~g} / \mathrm{L})=\frac{c_{N a}(\mathrm{mg} / \mathrm{L})}{[1000(\mathrm{mg} / \mathrm{g})]\left[x_{\mathrm{Na}_{2} \mathrm{O}}\left(\mathrm{g} \mathrm{Na}_{2} \mathrm{O} / \mathrm{g} \text { glass }\right)\right]\left[0.7419\left(\mathrm{~g} \mathrm{Na} / \mathrm{g} \mathrm{Na}{ }_{2} \mathrm{O}\right)\right]} .
$$

The notations in Equations (5.4) and (5.5) are defined similarly as the notations in Equation (5.3).

As seen in Equations (5.3), (5.4), and (5.5), normalizing involves dividing the measured leachate concentration for a given element by the corresponding mass fraction of that element in the glass. Mechanistically, this crudely takes into account the fact that, for a given amount of glass reacted, the concentration of a specific element in the leachate should be proportional to the mass fraction of the element in the glass. This is an approximation for a number of reasons, including the fact that the mass fraction of the element in question affects the amount of glass reacted, and not necessarily all of the constituents in the reacted glass are released to the solution. Nevertheless, factoring out this dependence by normalization is often empirically observed to improve model fits to leaching data and to further reduce the need for non-linear composition terms in the model.

In describing preliminary modeling work for IHLW PCT releases, Perez-Cardenas et al. (2003) found little difference in predictive performance for models based on normalized PCT elemental releases versus unnormalized PCT releases. Because contract specifications (DOE-ORP 2000) are stated in terms of normalized PCT releases, Perez-Cardenas et al. (2003) focused on normalized releases for their preliminary model investigations. Likewise, the model development work summarized in this report was conducted based on PCT normalized elemental releases.

In modeling PCT elemental releases (unnormalized or normalized), it is advantageous to transform the PCT release concentrations in the leachate to the natural logarithm of the concentrations. The advantages of this transformation include:

- The PCT-B unnormalized releases for the 264 simulated and actual HLW glasses used for modeling range from 1.62 to $586.30 \mathrm{ppm}$, while the normalized releases range from 0.104 to $21.903 \mathrm{~g} / \mathrm{L}$ The PCT-Li unnormalized releases on $250 \mathrm{HLW}$ glasses range from 
0.227 to $151.60 \mathrm{ppm}$, while the normalized releases range from 0.141 to $10.675 \mathrm{~g} / \mathrm{L}$. The PCT-Na unnormalized releases for 266 HLW glasses range from 1.373 to $1663.000 \mathrm{ppm}$, while the normalized releases range from 0.050 to $11.819 \mathrm{~g} / \mathrm{L}$. These ranges generally involve more than an order-of-magnitude difference. In such cases, typically the uncertainty in making glasses, performing the PCT, and analyzing the leachate leads to smaller absolute uncertainties for smaller releases and larger absolute uncertainties for larger releases. Hence, the unweighted least squares (ULS) regression assumption of equal variances for all response variable values (see Section C.3 of Appendix C) is violated. After a logarithmic transformation, variances of response values tend to be approximately equal as required for ULS regression.

- A logarithmic transformation tends to linearize the compositional dependence of leach test data and reduce the need for non-linear terms in the model form.

- A natural logarithm transformation is preferred over a common logarithm (or other base logarithm) transformation because of the approximate relationship

$$
\mathrm{SD}[\ln (y)] \cong \operatorname{RSD}(y)
$$

where SD denotes standard deviation, RSD denotes relative standard deviation (i.e., the standard deviation divided by the mean), and $y$ denotes PCT-B, PCT-Li, or PCT-Na release. Equation (5.6) results from applying the first-order variance propagation formula [Equation (7-7) of Hahn and Shapiro (1967)] to the function $z=\ln (y)$. The relationship in Equation (5.6) is very useful, in that uncertainties of the natural logarithm of the response variable $y$ can be interpreted as RSDs of the untransformed response variable $y$.

For these reasons, natural logarithmic transformations of PCT normalized releases $(\mathrm{g} / \mathrm{L})$ were used in modeling PCT-B, PCT-Li, and PCT-Na releases.

\subsection{Property-Composition Model Results for PCT-B Release}

This section discusses the results of fitting several different models using natural logarithms of IHLW PCT normalized boron release $(\mathrm{g} / \mathrm{L})$ as the response variable. Sections 5.3.1 and 5.3.2 present the results of modeling PCT-B using a 25-component LM model and a 13-component LM model, respectively. Sections 5.3.3 and 5.3.4 present the results of modeling PCT-B using 18-term and 15-term PQM models based on the reduced set of 13 mixture components. Section 5.3.5 refers to Sections 5.6 and 5.7, which compare the results from various models and select recommended and second-choice PCT-B, PCT-Li, and PCT-Na models for future use and evaluation by the WTP project.

\subsubsection{Results from Full Linear Mixture Model for IHLW PCT-B}

As the initial step in PCT-B model development, a full LM model in the 25 components identified in Section 5.1.1 was fit to the modeling data (266 glasses) with the response being the 
natural logarithm of PCT-B normalized releases $(\mathrm{g} / \mathrm{L})$. This model form was a reasonable starting point based on the previous work modeling IHLW PCT releases (Gan and Pegg 2001a, Kot et al. 2005a) and provided a basis for appropriate model reductions. The two glasses with very low PCT-B releases (HLW03-13 and HLW-ALG-26) discussed in Section 5.1.1 were substantial outliers. Hence, these two glasses were removed from the PCT-B modeling dataset and all subsequent models used the dataset for the remaining 264 HLW glasses.

Table 5.5 contains the results for the 25-component full LM model fit to the PCT-B data for 264 HLW glasses in the modeling dataset. Table 5.5 lists the model coefficients, standard deviations of the coefficients, and model performance summaries for the full LM model using the modeling dataset, the data-splitting approach (see Section 5.1.2), the data-partitioning approach (see Section 5.1.3), and the separate extrapolative validation dataset (see Section 5.1.4).

The upper right corner of Table 5.5 contains the summary statistics that describe how well the 25-component LM model fits the 264-glass modeling data for PCT-B. The $\mathrm{R}^{2}=0.727$, $\mathrm{R}_{\mathrm{A}}^{2}=0.700$, and $\mathrm{R}_{\mathrm{P}}^{2}=0.659$ statistics (see Section C.4 of Appendix C) indicate that the full 25-component LM model fits the PCT-B data in the 264-glass modeling dataset fairly well. However, the root mean squared error $(\mathrm{RMSE})=0.486$ is noticeably larger than the glass batching and PCT-B measurement uncertainty $(\mathrm{SD}=0.2515$ in $\ln (\mathrm{g} / \mathrm{L})$ units) estimated from replicates in Table 5.4. This indicates the full LM model for PCT-B has LOF, which was confirmed as statistically significant with $p=0.001$ as shown in Table 5.5 (see Section C.4 for discussion of the statistical test for model LOF).

The predicted versus measured plot in Figure 5.5 shows that the full 25-component LM model tends to under-predict PCT-B release above approximately $0.50 \ln (\mathrm{g} / \mathrm{L})$ [approximately $1.65 \mathrm{~g} / \mathrm{L}]$. Figure 5.6 displays the standardized residuals plotted versus the data index (a sequential numbering of the modeling data points) with different plotting symbols representing the different groups of glasses discussed in Sections 2.1.1 to 2.1.9. Figure 5.6 shows that the 25-component, full-LM model tends to over-predict ${ }^{5}$ PCT-B for the HLW04 and HLW98 glasses.

In the data-splitting portion of results at the bottom of Table 5.5, the columns are labeled DS1, DS2, DS3, DS4, and DS5 to denote the five modeling/validation splits of the data as described in Section 5.1.2. The last column of this part of Table 5.5 shows the averages for the different statistics over the five splits. The average statistics over the five data-splits are very close to the statistics obtained for fitting the full LM model for PCT-B to all 264 glasses. This indicates that the model, despite its statistically significant LOF, maintains its performance for data not used to fit the model.

The statistics for the 25-component full LM model on PCT-B from partitioning the 264-glass modeling set into subsets of 162 modeling glasses and 102 validation glasses (see Section 5.1.3) are given on the right side of Table 5.5. The fit statistics of $\mathrm{R}^{2}=0.794, \mathrm{R}_{\mathrm{A}}{ }^{2}=$ 0.757 , and $\mathrm{RMSE}=0.464$ for the 162-glass modeling subset are all better (i.e., larger, larger, and

\footnotetext{
${ }^{5}$ Based on long-term statistical practice, a residual in standardized residual plots is defined as the measured value minus the predicted value. Hence, model over-predictions appear as negative values.
} 
smaller, respectively) than the corresponding statistics for the full 264-glass modeling dataset. However, $\mathrm{R}_{\mathrm{P}}^{2}<0$ is worse for the 162-glass modeling subset, because there are insufficient data to estimate the LM model coefficients for all 25 components. (See Section C.4 of Appendix C for additional discussion of $\mathrm{R}_{\mathrm{P}}^{2}$ and why it can be negative.) For the 102-glass validation subset from data-partitioning, $\mathrm{R}_{\mathrm{V}}^{2}$ is negative and $\mathrm{RMSE}_{\mathrm{V}}=0.464$. This poor validation performance for the 25-component, full-LM model on PCT-B is because there is insufficient support in the 162-glass modeling subset to estimate the LM model coefficients of all 25 components.

The predicted versus measured plot for the validation subset from data-partitioning is given in Figure 5.7. This figure confirms that the full 25-component LM model for PCT-B fitted to the 162-glass modeling subset has relatively poor predictive performance for the 102-glass validation subset. The PCT-B release is moderately to severely over-predicted for many of the 102 validation glasses. Also shown in Figure 5.7 are 95\% prediction intervals (95\% PIs) representing the model prediction uncertainty of single PCT-B determinations for each glass (see Sections C.6 and C.7 of Appendix C). If the 95\% PI for a validation point overlaps the $45^{\circ}$ line, the predicted and measured $\ln (\mathrm{PCT}-\mathrm{B})$ values are within model and measurement uncertainty of each other. Of the 102 validation glasses from the data-partition, 39 have $95 \%$ PIs that do not overlap the $45^{\circ}$ line.

The summary statistics from applying the 25-component full LM model for PCT-B to the separate validation data are also given on the right side of Table 5.5. The negative $\mathrm{R}_{\mathrm{V}}^{2}$ and very large $\mathrm{RMSE}_{\mathrm{V}}=1.599$ for the 556 separate validation glasses with PCT-B data indicate the full LM model for PCT-B does not have very good extrapolative predictive performance. This is confirmed in the predicted versus measured plot for the separate validation data shown in Figure 5.8. The 25-component LM model tends to under-predict PCT-B releases except for the two very small measured releases and a narrow band of moderate releases. However, extrapolative prediction performance is not a primary consideration in selecting a PCT-B model.

Despite the statistically significant LOF of the 25-component full LM model for PCT-B, the model fits the 264-glass modeling dataset well enough to provide guidance for reducing the model (i.e., removing separate terms for components that do not significantly influence PCT-B release). Hence, the full LM model was used to produce the response trace plot (see Section C.5.1) shown in Figure 5.9. The response trace plot shows that $\mathrm{K}_{2} \mathrm{O}, \mathrm{Li}_{2} \mathrm{O}, \mathrm{Na}_{2} \mathrm{O}, \mathrm{B}_{2} \mathrm{O}_{3}$, and $\mathrm{MnO}$ tend to increase PCT-B release, while $\mathrm{Al}_{2} \mathrm{O}_{3}, \mathrm{ZrO}_{2}$, and $\mathrm{SiO}_{2}$ tend to decrease PCT-B release. The response traces for several minor components have steep positive or negative slopes but smaller ranges, and thus they may not have significant effects on PCT-B. This was confirmed by fitting a component slope linear mixture (CSLM) model and verifying the slopes (representing effects) of the components were not statistically significant (see Section C.5.1 of Appendix C).

\subsubsection{Results from Reduced Linear Mixture Model for IHLW PCT-B}

The 25-component full LM model presented in Section 5.3.1 likely contains components that do not significantly contribute to predicting PCT-B release, so model reduction was the next step of the model development approach. Thus, LM models for PCT-B involving fewer than the 25 components were considered. The sequential F-test model reduction approach (see Section 
C.5.1 of Appendix C, Piepel and Cooley 2006) was used to develop a reduced LM model. Option (ii) was used to combine components with nonsignificant effects on PCT-B into the Others term.

The sequential F-test model reduction algorithm was run with the main components $\mathrm{Al}_{2} \mathrm{O}_{3}, \mathrm{~B}_{2} \mathrm{O}_{3}, \mathrm{Fe}_{2} \mathrm{O}_{3}, \mathrm{Li}_{2} \mathrm{O}, \mathrm{MnO}, \mathrm{Na}_{2} \mathrm{O}, \mathrm{SiO}_{2}, \mathrm{SrO}$, and $\mathrm{ZrO}_{2}$ forced to remain as separate terms in the reduced LM model for PCT-B. The resulting reduced LM model included linear terms for these 9 components, plus a linear term for the new Others component obtained by combining the other 16 components involved in the 25-component LM model. However, the new Others component had mass fractions ranging from approximately 0.024 to 0.218 (2.4 to $21.8 \mathrm{wt} \%$ ). Such a high mass fraction of the Others component was considered undesirable. Therefore, the model reduction algorithm was re-run, this time with $\mathrm{ThO}_{2}, \mathrm{UO}_{3}$, and $\mathrm{ZnO}$ being forced to remain as separate components in the reduced LM model. Among the components included in the Others component of the 10-term reduced $\mathrm{LM}$ model, $\mathrm{ThO}_{2}, \mathrm{UO}_{3}$, and $\mathrm{ZnO}$ had the largest maximum values. The resulting 13-component reduced LM model included linear terms for $\mathrm{Al}_{2} \mathrm{O}_{3}, \mathrm{~B}_{2} \mathrm{O}_{3}, \mathrm{Fe}_{2} \mathrm{O}_{3}, \mathrm{Li}_{2} \mathrm{O}, \mathrm{MnO}, \mathrm{Na}_{2} \mathrm{O}, \mathrm{SiO}_{2}, \mathrm{SrO}, \mathrm{ThO}_{2}, \mathrm{UO}_{3}, \mathrm{ZnO}, \mathrm{ZrO}_{2}$, and the new Others component. The Others component of this 13-component reduced LM model had mass fractions ranging from approximately 0.013 to $0.118(1.3$ to $11.8 \mathrm{wt} \%)$. This was considered to be a reasonable range for the Others component, so the 13-term reduced LM model was selected for investigation.

Numerical Results for the 13-Component Reduced Linear Mixture Model on $\ln ($ PCT-B)

Table 5.6 gives the coefficients and coefficient standard deviations for the 13-component reduced LM model for $\ln (\mathrm{PCT}-\mathrm{B})$, as well as performance statistics for the (i) modeling data, (ii) data-split modeling data, (iii) 162/102 partition of the modeling data into modeling and validation subsets, and (iv) 556 separate validation HLW glasses with PCT-B data.

In Table 5.6, $\mathrm{R}^{2}=0.700$ indicates that the reduced LM model for PCT-B accounts for roughly $70 \%$ of the variation in $\ln \left(C_{B}\right)$ values in the 264 -glass modeling dataset. While this is a reasonably large number, a larger value would be preferable. The value of $\mathrm{R}_{\mathrm{A}}^{2}=0.685$ is close to $\mathrm{R}^{2}$, indicating that the model reduction was successful in removing unneeded components. The value for $R_{P}^{2}=0.659$ is not very far below the $R^{2}$ and $R_{A}^{2}$ values, indicating that there are not any highly influential data points in the PCT-B modeling dataset. In any case, $\mathrm{R}_{\mathrm{P}}^{2}=0.659$ provides an estimate of the fraction of variation in $\ln \left(C_{B}\right)$ values for future glasses in the same glass composition region that might be accounted for by this reduced LM model.

Over the five data splits of the PCT-B modeling data, Table 5.6 shows that the 13component reduced LM model has average modeling statistics $\mathrm{R}^{2}=0.694, \mathrm{R}_{\mathrm{A}}^{2}=0.676, \mathrm{R}_{\mathrm{P}}^{2}=$ 0.643 , and $\mathrm{RMSE}=0.497$ that are all close to their values from the 264-glass modeling dataset. The average validation statistics $\mathrm{R}_{\mathrm{V}}^{2}=0.710$ and $\mathrm{RMSE}_{\mathrm{V}}=0.508$ from data-splitting are only slightly worse (i.e., smaller and larger, respectively) than $\mathrm{R}_{\mathrm{P}}^{2}=0.659$ and $\mathrm{RMSE}=0.497$ for the 264-glass modeling dataset. Hence, the data-splitting validation results for the 13-component reduced LM model on PCT-B are generally similar to those from fitting the model to the 264glass dataset. 
The 13-component reduced LM model for PCT-B yielded somewhat different results for the partition of the modeling data into a modeling subset of 162 glasses and a validation subset of 102 glasses. As seen in Table 5.6, the fit statistics $\mathrm{R}^{2}=0.759, \mathrm{R}_{\mathrm{A}}{ }_{\mathrm{A}}=0.739$, and $\mathrm{R}_{\mathrm{P}}^{2}=0.710$ for the 162-glass modeling subset are all better (i.e., larger) than the corresponding statistics for the full 264-glass modeling set. Also, RMSE $=0.481$ is better (i.e., smaller) for the 162-glass modeling subset. For the 102-glass validation subset, the $\mathrm{R}_{\mathrm{V}}^{2}=0.473$ and $\mathrm{RMSE}_{\mathrm{V}}=0.552$ statistics are notably worse than the $\mathrm{R}_{\mathrm{P}}^{2}=0.659$ and $\mathrm{RMSE}=0.497$ statistics from fitting the PCT-B model to the 264-glass modeling dataset. The relatively poor validation results from datapartitioning compared to data-splitting are attributed to non-representative partitioning of the modeling dataset.

For the set of 556 separate validation glasses with PCT-B data, the 13-component reduced LM for PCT-B has $R_{V}^{2}=0.524$, which is notably less than $R_{P}^{2}=0.659$ from crossvalidation with the 264-glass modeling dataset. This indicates that the extrapolative prediction ability of the model is relatively poor. The $\mathrm{RMSE}_{\mathrm{V}}=0.935$ for these 556 glasses is significantly worse than the average $\mathrm{RMSE}_{\mathrm{V}}=0.508$ for the five data-splits of the modeling data and the $\mathrm{RMSE}_{\mathrm{V}}=0.552$ for the partitioned modeling data. Additional explanation of the extrapolative predictive performance of the 13-component reduced LM model for PCT-B is given subsequently when Figure 5.14 is discussed.

The RMSE in Table 5.6 is an estimate of the uncertainty [in $\ln \left(C_{B}\right)$ units] in fabricating simulated HLW glasses and measuring $C_{B}$ if the 13-component reduced LM model for PCT-B does not have statistically significant LOF. To judge the LOF, the RMSE value can be compared to uncertainty estimates based on replicate PCT-B release data. The RMSE $=0.497$ is much larger than the historical replicate $\mathrm{RSD}^{6}$ of $\sim 0.10$ (from Appendix F of Hrma et al. 1994) in fabricating simulated waste glasses and measuring PCT-B release. It is also much larger than the $\ln (\mathrm{PCT}-\mathrm{B})$ replicate $\mathrm{SD}=0.2515 \ln (\mathrm{g} / \mathrm{L})$ in Table 5.4 (which is discussed in the last subsection of Section 5.1.1). These observations suggest that the 13-component reduced LM model for $\ln (\mathrm{PCT}-\mathrm{B})$ has a substantial LOF, which is confirmed by the LOF test $\mathrm{p}$-value $=0.001$ included in Table 5.6. This p-value indicates that the model LOF is significant at the $99.9 \%$ confidence level. See Section C.4 of Appendix C for further discussion of the LOF test.

\section{Graphical Results for the 13-Component Reduced Linear Mixture Model on $\ln$ (PCT-B)}

The predicted versus measured plot in Figure 5.10 for the 13-component reduced LM model for PCT-B is similar to the one in Figure 5.5 for the 25 -component full LM model. Figure 5.10 shows that the 13-component reduced LM model tends to under-predict PCT-B release above approximately $0.50 \ln (\mathrm{g} / \mathrm{L})$ [approximately $1.65 \mathrm{~g} / \mathrm{L}$ ]. The standardized residual plot in Figure 5.11 shows that the model also tends to over-predict PCT-B for the HLW04 and HLW98 glasses. Diagnostic plots for the reduced LM model (not included in this report) support the assumption of normally distributed errors in the PCT-B data (see Section C.3 of Appendix C).

\footnotetext{
6 Per Equation (5.6), RSD values calculated from replicate PCT-B releases approximate SDs calculated from natural logarithms of PCT-B releases.
} 
Figure 5.12 displays the response trace plot (see Section C.5.1) for the 13-component reduced LM model for PCT-B. The figure shows that (i) $\mathrm{Li}_{2} \mathrm{O}, \mathrm{Na}_{2} \mathrm{O}, \mathrm{B}_{2} \mathrm{O}_{3}$, and $\mathrm{MnO}$ tend to increase PCT-B release, (ii) $\mathrm{Al}_{2} \mathrm{O}_{3}, \mathrm{ZrO}_{2}$, and $\mathrm{SiO}_{2}$ tend to decrease PCT-B release, and (iii) the remaining components have moderate to negligible effects on PCT-B release.

Figures 5.13 and 5.14 show the predicted versus measured plots when the 13-component reduced LM model for PCT-B is applied to two validation datasets. Figure 5.13 results from fitting the reduced LM model to a subset of 162 out of 264 modeling glasses, and then applying the resulting model to the remaining subset of 102 validation glasses (see Section 5.1.3). Figure 5.14 results from fitting the reduced LM model for PCT-B to all 264 glasses in the modeling set and then applying that model to the 556 separate validation glasses with PCT-B data (see Section 5.1.4). As discussed in Section 5.1.4, the separate validation dataset consists primarily of glasses with compositions outside the EGCR for WTP HLW glasses, so that the model predictions are mostly extrapolations. Also shown in Figures 5.13 and 5.14 are 95\% PIs representing the model prediction uncertainty of single PCT-B determinations for each glass (see Sections C.6 and C.7 of Appendix C). If the $95 \%$ PI for a validation point overlaps the $45^{\circ}$ line, the predicted and measured $\ln (\mathrm{PCT}-\mathrm{B})$ values are within model and measurement uncertainty of each other.

Figure 5.13 shows that the 13-component reduced LM model for PCT-B fitted to the 162glass modeling subset from data-partitioning has varied predictive performance for the 102-glass validation subset. The PCT-B release tends to be (i) over-predicted for releases up to approximately $0 \ln (\mathrm{g} / \mathrm{L})[1 \mathrm{~g} / \mathrm{L}]$, (ii) fairly accurately predicted for releases between 0 and 0.75 $\ln (\mathrm{g} / \mathrm{L})[1.0$ to $2.1 \mathrm{~g} / \mathrm{L}]$, and (iii) under-predicted for releases above $0.75 \ln (\mathrm{g} / \mathrm{L})$ [approximately $2.1 \mathrm{~g} / \mathrm{L}]$. However, the $95 \%$ PIs overlap the $45^{\circ}$ line (i.e., contain the measured values) for all but 10 of the 102 glasses in the validation subset from data-partitioning. Failure of $100(10 / 102)=$ $9.8 \%$ of the $95 \%$ PIs to include the corresponding measured values is more than the $5 \%$ expected by chance. The $95 \%$ PIs are relatively wide, which are partly due to: (i) the LOF of the 13 component reduced LM model, and (ii) the inherent experimental uncertainty in fabricating glasses, performing the PCT, and analyzing B in the PCT leachates. Separate work to assess the consequences of LOF and prediction uncertainty for this PCT-B model is discussed in Section 5.9 .

Figure 5.14 shows that the 13-component reduced LM model for PCT-B fitted to the 264glass modeling dataset and applied to the 556-glass separate validation dataset (i) significantly over-predicts the two lowest PCT-B releases, (ii) tends to accurately predict releases between -2 to $0 \ln (\mathrm{g} / \mathrm{L})$ [approximately 0.14 to $1.0 \mathrm{~g} / \mathrm{L})$, and (iii) tends to under-predict above $0 \ln (\mathrm{g} / \mathrm{L})[1.0$ $\mathrm{g} / \mathrm{L}]$. The $95 \%$ PIs do not contain the corresponding measured values for 125 of the 556 separate validation glasses with PCT-B data. However, extrapolative prediction performance is not a primary consideration in selecting a PCT-B model.

\section{Summary of the 13-Component Reduced Linear Mixture Model for $\ln ($ PCT-B)}

The 13-component reduced LM model for $\ln (\mathrm{PCT}-\mathrm{B})$ is given in Table 5.6 and the variance-covariance matrix associated with the model coefficients is given in Table D.1 of Appendix D. The 13-component reduced LM model performs similarly to the 25-component full LM model (see Table 5.5). The reduced LM model is also expected to yield smaller uncertainties 
of PCT-B predictions because unnecessary terms have been removed from the model. However, the reduced LM model for PCT-B has significant LOF compared to the inherent uncertainty in batching and melting glasses, performing the PCT, and analyzing the leachate for B release.

\subsubsection{Results for 18-Term Partial Quadratic Mixture Model for IHLW PCT-B}

In an effort to improve on the 13-component reduced LM model for PCT-B of HLW glasses, PQM models (see Section 5.2.1) were also considered. Specifically, selected quadratic terms (squared and two-component crossproduct terms) were added to the linear terms of the reduced LM model for PCT-B to include important nonlinear blending effects of the glass components. PQM models are discussed in detail by Piepel et al. (2002).

All possible quadratic terms were formed using the 13 components of HLW glass in the reduced LM model for PCT-B. The MAXR selection method (see Section C.5 of Appendix C) was used to identify "best" subsets of quadratic terms to include in PQM models. Different PQM models for PCT-B were obtained depending on the number of quadratic terms specified for addition. The MAXR method was coded in R (Ihaka and Gentleman 1996, R Core Development Team 2006), but yields the same results as the MAXR option of PROC REG in SAS (2005).

PQM models were generated using the MAXR criterion to select from 2 to 9 quadratic terms to augment the 13 linear terms from the reduced LM model. Although statistical significance tests indicated up to 9 quadratic terms were statistically significant, past experience with developing and validating PQM models has indicated adding too many quadratic terms tends to over-fit the model development dataset and degrade predictive performance for new glasses. Ultimately, the 18-term PQM model with 13 linear terms and 5 quadratic terms was chosen as including enough quadratic terms to improve the PCT-B model fit, hopefully without significantly over-fitting the model development data.

Numerical Results for the 18-Term Partial Quadratic Mixture Model on $\ln ($ PCT-B)

Table 5.7 contains the coefficients of the 18-term PQM model for $\ln$ (PCT-B), coefficient standard deviations, and performance statistics for the (i) modeling data, (ii) data-split modeling data, (iii) 162/102 partition of the modeling data into modeling and validation subsets, and (iv) 556 separate validation glasses with PCT-B data.

In Table 5.7, the PCT-B model evaluation statistics $\mathrm{R}^{2}=0.788, \mathrm{R}_{\mathrm{A}}=0.774, \mathrm{R}_{\mathrm{P}}^{2}=0.751$, and $\mathrm{RMSE}=0.422$ for the 18-term PQM model are substantial improvements over the corresponding statistics for the 13-component reduced LM model (see Table 5.6). The small drop in values from $\mathrm{R}_{\mathrm{A}}^{2}$ to $\mathrm{R}_{\mathrm{P}}^{2}$ suggests that the PCT-B modeling dataset does not have any highly influential data points for the 18-term PQM model. In any case, $\mathrm{R}_{\mathrm{P}}^{2}=0.751$ provides an estimate of the fraction of variation in $\ln \left(C_{B}\right)$ values for future datasets over the same glass composition region that might be accounted for by this PQM model.

Over the five data splits of the PCT-B modeling data, Table 5.7 shows that the 18-term $\mathrm{PQM}$ model has average modeling statistics $\mathrm{R}^{2}=0.786, \mathrm{R}_{\mathrm{A}}^{2}=0.768, \mathrm{R}_{\mathrm{P}}^{2}=0.739$, and $\mathrm{RMSE}=$ 
0.421 that are all close to their values from the 264-glass modeling dataset. The average validation statistics $R_{V}^{2}=0.764$ from data-splitting is slightly better (i.e., larger) than $R_{P}^{2}=$ 0.751 for the 264-glass modeling dataset. However, the average validation statistic $\mathrm{RMSE}_{\mathrm{V}}=$ 0.453 from data-splitting is slightly worse (i.e., larger) than the RMSE $=0.422$ for the 264-glass modeling dataset. Hence, the data-splitting validation results for the 18-term PQM model on PCT-B are generally similar to those from fitting the model to the 264-glass dataset.

The 18-term PQM model for PCT-B yielded somewhat different results for the partition of the modeling data into a modeling subset of 162 glasses and a validation subset of 102 glasses. As seen in Table 5.7, the fit statistics $\mathrm{R}^{2}=0.826, \mathrm{R}_{\mathrm{A}}{ }^{2}=0.806$, and $\mathrm{R}_{\mathrm{P}}^{2}=0.772$ for the 162-glass modeling subset are all better (i.e., larger) than the corresponding statistics for the full 264-glass modeling set. The RMSE $=0.415$ is also slightly better (i.e., smaller) for the 162-glass modeling subset. For the 102-glass validation subset, $\mathrm{R}_{\mathrm{V}}^{2}=0.618$ and $\mathrm{RMSE}_{\mathrm{V}}=0.470$ indicate the 18 term PQM model predicts less well than indicated by the statistics from fitting the 264-glass modeling dataset. The poorer validation results from data-partitioning compared to data-splitting are attributed to non-representative partitioning of the modeling dataset.

For the set of 556 separate validation glasses with PCT-B data, the 18-term PQM model for PCT-B has $\mathrm{R}_{\mathrm{V}}^{2}=0.623$, which is notably less than $\mathrm{R}_{\mathrm{P}}^{2}=0.751$ from cross-validation with the 264-glass modeling dataset. This indicates that the extrapolative prediction ability of the model is worse than the interpolative prediction ability. The $\mathrm{RMSE}_{\mathrm{V}}=0.832$ for these 556 glasses is significantly worse than the average $\mathrm{RMSE}_{\mathrm{V}}=0.439$ for the five data-splits of the modeling data and the $\mathrm{RMSE}_{\mathrm{V}}=0.470$ for the partitioned modeling data. Additional explanation of the extrapolative validation performance of the 18-term PQM model for PCT-B is provided subsequently when Figure 5.19 is discussed.

The RMSE in Table 5.7 is an estimate of the uncertainty [in $\ln \left(C_{B}\right)$ units] in fabricating simulated HLW glasses and measuring $C_{B}$ if the 18-term PQM model for PCT-B does not have statistically significant LOF. Although RMSE $=0.422$ for the 18-term PQM model is smaller than the corresponding value for the 13-component reduced LM model, it is still much larger than the historical replicate RSD of $\sim 0.10$ (from Appendix F of Hrma et al. 1994) in fabricating simulated waste glasses and measuring PCT-B release, as discussed at the end of Section 5.1.1. The RMSE value is also much larger than the $\ln (\mathrm{PCT}-\mathrm{B})$ replicate $\mathrm{SD}=0.2515 \ln (\mathrm{g} / \mathrm{L})$ in Table 5.4. These observations suggest that the 18-term PQM model for $\ln$ (PCT-B) has a substantial LOF. This indication is confirmed by the $p$-value $=0.014$ of the LOF test (see Section C. 4 of Appendix C) for this model in Table 5.7. This p-value indicates that the model LOF is significant at the $98.6 \%$ confidence level.

\section{Graphical Results for the 18-Term Partial Quadratic Mixture Model on $\ln ($ PCT-B)}

Figure 5.15 displays the predicted versus measured plot for the 18-term PQM model for PCT-B applied to the 266 glasses of the PCT-B modeling dataset. The distribution of points around the $45^{\circ}$ line is improved compared to the distribution for the 13-component reduced LM model in Figure 5.10. However, Figure 5.15 shows that the 18-term PQM model still tends to under-predict PCT-B releases above approximately $0.50 \ln (\mathrm{g} / \mathrm{L})$ [approximately $1.65 \mathrm{~g} / \mathrm{L}$ ]. The standardized residual plot in Figure 5.16 shows that the 18-term PQM model still tends to over- 
predict PCT-B for the HLW04 and HLW98 glasses. Diagnostic plots for the PQM model (not included in this report) support the assumption of normally distributed errors in the PCT-B data (see Section C.3 of Appendix C).

Figure 5.17 displays the response trace plot (see Section C.5.1) for the 18-term PQM model for PCT-B. The figure shows that (i) $\mathrm{Li}_{2} \mathrm{O}, \mathrm{Na}_{2} \mathrm{O}, \mathrm{B}_{2} \mathrm{O}_{3}$, and $\mathrm{MnO}$ tend to increase PCT-B release, (ii) $\mathrm{Al}_{2} \mathrm{O}_{3}, \mathrm{ZrO}_{2}$, and $\mathrm{SiO}_{2}$ tend to decrease PCT-B release, and (iii) the remaining components have moderate to negligible effects on PCT-B release. Curvature effects are apparent for $\mathrm{Al}_{2} \mathrm{O}_{3}$ and $\mathrm{MnO}$ as a result of the $\left(\mathrm{Al}_{2} \mathrm{O}_{3}\right)^{2}$ and $(\mathrm{MnO})^{2}$ terms in the 18-term PQM model.

Figures 5.18 and 5.19 show the predicted versus measured plots when the 18-term PQM model for PCT-B is applied to two validation datasets. Figure 5.18 results from fitting the 18term PQM model to a subset of 162 out of 264 modeling glasses, and then applying the resulting model to the remaining subset of 102 glasses for validation (see Section 5.1.3). Figure 5.19 results from fitting the 18-term PQM model for PCT-B to all 264 glasses in the modeling set and then applying that model to the 556 separate validation glasses with PCT-B data (see Section 5.1.4). Also shown in Figures 5.18 and 5.19 are 95\% PIs representing the model prediction uncertainty of single PCT-B determinations for each glass (see Sections C.6 and C.7 of Appendix C). If the 95\% PI for a validation point overlaps the $45^{\circ}$ line, the predicted and measured $\ln ($ PCT-B) values are within model and measurement uncertainty of each other.

Figure 5.18 shows that the 18-term PQM model for PCT-B fitted to the 162-glass modeling subset from data-partitioning has varied predictive performance for the 102-glass validation subset. The PCT-B release tends to be (i) over-predicted for releases up to approximately $0 \ln (\mathrm{g} / \mathrm{L})[1 \mathrm{~g} / \mathrm{L}]$, (ii) fairly accurately predicted for releases between 0 and 0.75 $\ln (\mathrm{g} / \mathrm{L})[1.0$ to $2.1 \mathrm{~g} / \mathrm{L}]$, and (iii) under-predicted for releases above $0.75 \ln (\mathrm{g} / \mathrm{L})$ [approximately $2.1 \mathrm{~g} / \mathrm{L}]$. However, the $95 \%$ PIs overlap the $45^{\circ}$ line (i.e., contain the measured values) for all but 8 of the 102 glasses in the validation subset from data-partitioning. Failure of $100(8 / 102)=7.8 \%$ of the $95 \%$ PIs to include the corresponding measured values is somewhat more than the $5 \%$ expected by chance. The $95 \%$ PIs are relatively wide, which is partly due to: (i) the LOF of the 18-term PQM model, and (ii) the inherent experimental uncertainty in fabricating glasses, performing the PCT, and analyzing B in the PCT leachates.

Figure 5.19 shows that the 18-term PQM model for PCT-B fitted to the 264-glass modeling dataset and applied to the separate 556-glass validation dataset tends to (i) over-predict for releases below approximately $-1.75 \ln (\mathrm{g} / \mathrm{L})[0.174 \mathrm{~g} / \mathrm{L}]$, (ii) accurately predict releases between approximately -1.75 to $0 \ln (\mathrm{g} / \mathrm{L})[0.174$ to $1.0 \mathrm{~g} / \mathrm{L})$, and (iii) under-predict above 0 $\ln (\mathrm{g} / \mathrm{L})[1.0 \mathrm{~g} / \mathrm{L}]$. However, the under-prediction above $0 \ln (\mathrm{g} / \mathrm{L})$ is less than for the 13 component reduced LM model. The $95 \%$ PIs do not contain the corresponding measured values for 131 of the 556 separate validation glasses with PCT-B data. However, extrapolative prediction performance is not a primary consideration in selecting a PCT-B model. 
$\underline{\text { Summary of the 18-Term Partial Quadratic Mixture Model for } \ln (\text { PCT-B) }}$

The 18-term PQM model for $\ln (\mathrm{PCT}-\mathrm{B})$ is given in Table 5.7 and the variance-covariance matrix associated with the model coefficients is given in Table D.2 of Appendix D. The 18-term PQM model fits the 264-glass modeling dataset better than the 13-component reduced LM model, but still has significant LOF. The 18-term PQM model also performs better on the datasplitting, data-partitioning, and extrapolative validation assessments than does the reduced LM model.

\subsubsection{Results for 15-Term Partial Quadratic Mixture Model for IHLW PCT-B}

Although all five of the quadratic terms in the 18-term PQM model for PCT-B are statistically significant (see Table 5.7), the $\mathrm{UO}_{3} \times \mathrm{ZnO},(\mathrm{MnO})^{2}$, and $\mathrm{Fe}_{2} \mathrm{O}_{3} \times \mathrm{ZnO}$ quadratic terms are hard to explain from a glass science perspective. Because of correlations among quadratic terms, such terms may increase the predictive ability of the model without being justified by glass science. On the other hand, it is possible that such terms are a result of over-fitting. Hence, PQM models containing fewer than five quadratic terms were investigated. Ultimately, a 15-term PQM model containing the same 13 linear terms (as the models in Sections 5.3.2 and 5.3.3) and two quadratic terms $\left[\left(\mathrm{Al}_{2} \mathrm{O}_{3}\right)^{2}\right.$ and $\left.\mathrm{Al}_{2} \mathrm{O}_{3} \times \mathrm{ZrO}_{2}\right]$ were selected for each of PCT-B, PCT-Li, and PCT-Na releases. This model form has the advantage of having the same two quadratic terms for PCT-B, PCT-Li, and PCT-Na releases.

Table 5.8 presents the results from the 15-term PQM model for PCT-B release (i) fitted to the 264-glass modeling dataset, (ii) fitted and validated using the data-splitting approach (see Section 5.1.2), (iii) fitted and validated using the data-partitioning approach (see Section 5.1.3), and (iv) validated for extrapolative performance using the separate validation dataset (see Section 5.1.4). The variance-covariance matrix associated with the coefficients of this model is given in Table D.3 of Appendix D. The results in Table 5.8 for the 15-term PQM model are all somewhat worse than the results in Table 5.7 for the 18-term PQM model, but not substantially so. Figures 5.20, 5.21, and 5.22 contain evaluation and validation plots for the 15-term PQM model on PCT-B fitted to the 264-glass modeling dataset. The predicted versus measured plot in Figure 5.20 and standardized residual plot in Figure 5.21 are similar but slightly worse than the corresponding plots (in Figures 5.15 and 5.16) for the 18-term PQM model. The response trace plot in Figure 5.22 for the 15-term PQM model is generally similar to the one in Figure 5.17 for the 18-term PQM model. However, the curvature effect of $\mathrm{MnO}$ is gone and the $\mathrm{Al}_{2} \mathrm{O}_{3}$ curvature effect is stronger.

Figures 5.23 and 5.24 show the predicted versus measured plots when the 15-term PQM model for PCT-B is applied to two validation datasets. Figure 5.23 results from fitting the 15term PQM model to a subset of 162 out of 264 modeling glasses, and then applying the resulting model to the remaining subset of 102 glasses for validation (see Section 5.1.3). Figure 5.24 results from fitting the 15-term PQM model for PCT-B to all 264 glasses in the modeling set and then applying that model to the 556 separate validation glasses with PCT-B data (see Section 5.1.4). Also shown in Figures 5.23 and 5.24 are 95\% PIs representing the model prediction uncertainty of single PCT-B determinations for each glass (see Sections C.6 and C.7 of 
Appendix C). Some 95\% PIs that do not contain the corresponding measured values occur in Figure 5.23 for 6 of 102 partition validation glasses, and occur in Figure 5.24 for 148 of 556 separate validation glasses with PCT-B data. These numbers are respectively better and worse than the corresponding numbers in the plots for the 18-term PQM model.

\subsubsection{Recommended IHLW PCT-B Models}

The selection of recommended and second-choice models for PCT-B releases from HLW glasses is discussed in Sections 5.6 and 5.7. These sections also discuss the selection of recommended and second-choice models for PCT-Li and PCT-Na releases from HLW glasses.

\subsection{Property-Composition Model Results for PCT-Li Release}

This section discusses the results of fitting several different models using natural logarithms of IHLW PCT normalized lithium release $(\mathrm{g} / \mathrm{L})$ as the response variable. Sections 5.4.1 and 5.4.2 present the results of modeling PCT-Li using a 25-component LM model and a 13-component LM model, respectively. Sections 5.4.3 and 5.4.4 present the results of modeling PCT-Li using 18-term and 15-term PQM models based on the reduced set of 13 mixture components. Section 5.4.5 refers to Sections 5.6 and 5.7, which compare the results from various models and select recommended and second-choice PCT-B, PCT-Li, and PCT-Na models for future use and evaluation by the WTP project.

\subsubsection{Results from Full Linear Mixture Model for IHLW PCT-Li}

As the initial step in PCT-Li model development, a full LM model in the 25 components identified in Section 5.1.1 was fit to the modeling data ( 251 glasses) with the response being the natural logarithm of PCT-Li normalized releases $(\mathrm{g} / \mathrm{L})$. This model form was a reasonable starting point based on the previous work modeling IHLW PCT releases (Gan and Pegg 2001a, Kot et al. 2005a) and provided a basis for appropriate model reductions. One glass with very low PCT-Li release (HLW98-94) discussed in Section 5.1.1 was a substantial outlier. Hence, this glass was removed from the PCT-Li modeling dataset and all subsequent models used the dataset for the remaining $250 \mathrm{HLW}$ glasses.

Table 5.9 contains the results for the 25-component full LM model fit to the PCT-Li data for $250 \mathrm{HLW}$ glasses. Table 5.9 lists the model coefficients, standard deviations of the coefficients, and model performance summaries for the full LM model using the modeling dataset (250 glasses), the data-splitting approach (see Section 5.1.2), the data-partitioning approach (see Section 5.1.3), and the separate extrapolative validation dataset (see Section 5.1.4).

The upper right corner of Table 5.9 contains the summary statistics that describe how well the 25-component LM model fits the 250-glass modeling data for PCT-Li. The $\mathrm{R}^{2}=0.670$, $\mathrm{R}_{\mathrm{A}}^{2}=0.635$, and $\mathrm{R}_{\mathrm{P}}^{2}=0.578$ statistics (see Section C.4 of Appendix C) indicate that the full 25component LM model fits the PCT-Li data in the 250-glass modeling dataset moderately well. 
The root mean squared error $(\mathrm{RMSE})=0.386$ is noticeably larger than the glass batching and PCT-Li measurement uncertainty ( $\mathrm{SD}=0.1317 \mathrm{in} \ln (\mathrm{g} / \mathrm{L})$ units) estimated from replicates in Table 5.4. This indicates the full LM model for PCT-Li has LOF, which was confirmed as highly statistically significant with $p<0.0001$ as shown in Table 5.9 (see Section C.4 for discussion of the statistical test for model LOF).

The predicted versus measured plot in Figure 5.25 shows that the full 25-component LM model tends to under-predict PCT-Li release above approximately $0.25 \ln (\mathrm{g} / \mathrm{L})$ [approximately $1.28 \mathrm{~g} / \mathrm{L}]$. Figure 5.26 displays the standardized residuals plotted versus the data index (a sequential numbering of the modeling data points) with different plotting symbols representing the different groups of glasses discussed in Sections 2.1.1 to 2.1.9. Figure 5.26 shows that the 25component, full-LM model tends to over-predict ${ }^{7}$ PCT-Li for the HLW04 and HLW98 glasses.

In the data-splitting portion of results at the bottom of Table 5.9, the columns are labeled DS1, DS2, DS3, DS4, and DS5 to denote the five modeling/validation splits of the data as described in Section 5.1.2. The last column of this part of Table 5.9 shows the averages for the different statistics over the five splits. The average statistics over the five data-splits are very close to the statistics obtained for fitting the full LM model for PCT-Li to all 250 glasses. This indicates that the model, despite its statistically significant LOF, maintains its performance for data not used to fit the model.

The statistics for the 25-component full LM model on PCT-Li from partitioning the 250glass modeling set into subsets of 154 modeling glasses and 96 validation glasses (see Section 5.1.3) are given on the right side of Table 5.9. The fit statistics of $R^{2}=0.751, R_{A}^{2}=0.705$, and $\mathrm{RMSE}=0.368$ for the 154-glass modeling subset are all better (i.e., larger, larger, and smaller, respectively) than the corresponding statistics for the full 250 -glass modeling set. However, $\mathrm{R}_{\mathrm{P}}^{2}$ $<0$ is worse for the 154-glass modeling subset, because there are insufficient data to estimate the LM model coefficients for all 25 components. (See Section C.4 of Appendix C for additional discussion of $\mathrm{R}_{\mathrm{P}}^{2}$ and why it can be negative.) For the 96-glass validation subset from datapartitioning, $\mathrm{R}_{\mathrm{V}}^{2}$ is negative and $\mathrm{RMSE}_{\mathrm{V}}=1.359$. This poor validation performance for the 25component, full-LM model on PCT-Li is because there is insufficient support in the 154-glass modeling subset to estimate the LM model coefficients of all 25 components.

The predicted versus measured plot for the validation subset from data-partitioning is given in Figure 5.27. This figure confirms that the full 25-component LM model for PCT-Li fitted to the 154-glass modeling subset has relatively poor predictive performance for the 96glass validation subset. The PCT-Li release is moderately to severely over-predicted for many of the 96 validation glasses. Also shown in Figure 5.27 are 95\% prediction intervals (95\% PIs) representing the model prediction uncertainty of single PCT-Li determinations for each glass (see Sections C.6 and C.7 of Appendix C). If the 95\% PI for a validation point overlaps the $45^{\circ}$ line, the predicted and measured $\ln (\mathrm{PCT}-\mathrm{Li})$ values are within model and measurement uncertainty of each other. Of the 96 validation glasses from the data-partition, 30 have 95\% PIs that do not overlap the $45^{\circ}$ line.

\footnotetext{
${ }^{7}$ Based on long-term statistical practice, a residual in standardized residual plots is defined as the measured value minus the predicted value. Hence, model over-predictions appear as negative values.
} 
The summary statistics from applying the 25-component full LM model for PCT-Li to the separate validation data are also given on the right side of Table 5.9. The negative $\mathrm{R}_{\mathrm{V}}^{2}$ and very large $\mathrm{RMSE}_{\mathrm{V}}=1.757$ for the 480 separate validation glasses with PCT-Li data indicate the full LM model for PCT-Li does not have very good extrapolative predictive performance. This is confirmed in the predicted versus measured plot for the separate validation data shown in Figure 5.28. The 25-component LM model (i) over-predicts PCT-Li releases for four glasses with the smallest releases, (ii) has very wide scatter over the majority of the PCT-Li range, and (iii) under-predicts the highest PCT-Li releases. However, extrapolative prediction performance is not a primary consideration in selecting a PCT-Li model.

Despite the statistically significant LOF of the 25-component full LM model for PCT-Li, the model fits the 250-glass modeling dataset well enough to provide guidance for reducing the model (i.e., removing separate terms for components that do not significantly influence PCT-Li release). Hence, the full LM model was used to produce the response trace plot (see Section C.5.1) shown in Figure 5.29. The response trace plot shows that $\mathrm{K}_{2} \mathrm{O}, \mathrm{Li}_{2} \mathrm{O}, \mathrm{Na}_{2} \mathrm{O}, \mathrm{B}_{2} \mathrm{O}_{3}$, and $\mathrm{MnO}$ tend to increase PCT-Li release, while $\mathrm{Al}_{2} \mathrm{O}_{3}, \mathrm{ZrO}_{2}$, and $\mathrm{SiO}_{2}$ tend to decrease PCT-Li release. The response traces for several minor components have steep positive or negative slopes but smaller ranges, and thus they may not have significant effects on PCT-Li. This was confirmed by fitting a CSLM model and verifying the slopes (representing effects) of the components were not statistically significant (see Section C.5.1 of Appendix C).

\subsubsection{Results from Reduced Linear Mixture Model for IHLW PCT-Li}

The 25-component full LM model presented in Section 5.4.1 likely contains components that do not significantly contribute to predicting PCT-Li release, so model reduction was the next step of the model development approach. Thus, LM models for PCT-Li involving fewer than the 25 components were considered. The sequential F-test model reduction approach (see Section C.5.1 of Appendix C, Piepel and Cooley 2006) was used to develop a reduced LM model. Option (ii) was used to combine components with nonsignificant effects on PCT-Li into the Others term.

The sequential F-test model reduction algorithm was run with the main components $\mathrm{Al}_{2} \mathrm{O}_{3}, \mathrm{~B}_{2} \mathrm{O}_{3}, \mathrm{Fe}_{2} \mathrm{O}_{3}, \mathrm{Li}_{2} \mathrm{O}, \mathrm{MnO}, \mathrm{Na}_{2} \mathrm{O}, \mathrm{SiO}_{2}, \mathrm{SrO}$, and $\mathrm{ZrO}_{2}$ forced to remain as separate terms in the reduced LM model for PCT-Li. The resulting reduced LM model included linear terms for these 9 components, plus a linear term for the new Others component obtained by combining the other 16 components involved in the 25-component LM model. However, the new Others component had mass fractions ranging from approximately 0.024 to 0.218 (2.4 to $21.8 \mathrm{wt} \%$ ). Such a high mass fraction of the Others component was considered undesirable. Therefore, the model reduction algorithm was re-run, this time with $\mathrm{ThO}_{2}, \mathrm{UO}_{3}$, and $\mathrm{ZnO}$ being forced to remain as separate components in the reduced LM model. Among the components included in the Others component of the 10-term reduced $\mathrm{LM}$ model, $\mathrm{ThO}_{2}, \mathrm{UO}_{3}$, and $\mathrm{ZnO}$ had the largest maximum values. The resulting 13-component reduced $\mathrm{LM}$ model included linear terms for $\mathrm{Al}_{2} \mathrm{O}_{3}, \mathrm{~B}_{2} \mathrm{O}_{3}, \mathrm{Fe}_{2} \mathrm{O}_{3}, \mathrm{Li}_{2} \mathrm{O}, \mathrm{MnO}, \mathrm{Na}_{2} \mathrm{O}, \mathrm{SiO}_{2}, \mathrm{SrO}, \mathrm{ThO}_{2}, \mathrm{UO}_{3}, \mathrm{ZnO}, \mathrm{ZrO}_{2}$, and the new Others component. The Others component of this 13-component reduced LM model had mass fractions ranging from approximately 0.013 to 0.118 ( 1.3 to $11.8 \mathrm{wt} \%)$. This was considered to be a 
reasonable range for the Others component, so the 13-term reduced LM model was selected for investigation.

Numerical Results for the 13-Component Reduced Linear Mixture Model on ln(PCT-Li)

Table 5.10 gives the coefficients and coefficient standard deviations for the 13component reduced LM model for $\ln (\mathrm{PCT}-\mathrm{Li})$, as well as performance statistics for the (i) modeling data, (ii) data-split modeling data, (iii) 154/96 partition of the modeling data into modeling and validation subsets, and (iv) 480 separate validation HLW glasses with PCT-Li data.

In Table 5.10, $\mathrm{R}^{2}=0.641$ indicates that the reduced LM model for PCT-Li accounts for roughly $64 \%$ of the variation in $\ln \left(C_{B}\right)$ values in the 250 -glass modeling dataset. This is below what is generally desirable as a minimum. The value of $\mathrm{R}_{\mathrm{A}}^{2}=0.623$ is close to $\mathrm{R}^{2}$, indicating that the model reduction was successful in removing unneeded components. The value for $\mathrm{R}_{\mathrm{P}}^{2}=$ 0.590 is not very far below the $\mathrm{R}^{2}$ and $\mathrm{R}_{\mathrm{A}}^{2}$ values, indicating that there are not any highly influential data points in the PCT-Li modeling dataset. In any case, $\mathrm{R}_{\mathrm{P}}^{2}=0.590$ provides an estimate of the fraction of variation in $\ln \left(C_{B}\right)$ values for future glasses in the same glass composition region that might be accounted for by this reduced LM model.

Over the five data splits of the PCT-Li modeling data, Table 5.10 shows that the 13component reduced $\mathrm{LM}$ model has average modeling statistics $\mathrm{R}^{2}=0.641, \mathrm{R}_{\mathrm{A}}^{2}=0.619, \mathrm{R}_{\mathrm{P}}^{2}=$ 0.579 , and $\mathrm{RMSE}=0.388$ that are all close to their values from the 250 -glass modeling dataset. The average validation statistics $\mathrm{R}_{\mathrm{V}}^{2}=0.619$ and $\mathrm{RMSE}_{\mathrm{V}}=0.423$ from data-splitting are slightly better (i.e., larger) and worse (i.e., larger), respectively, than $\mathrm{R}_{\mathrm{P}}^{2}=0.590$ and $\mathrm{RMSE}=0.392$ for the 250-glass modeling dataset. Hence, the data-splitting validation results for the 13-component reduced LM model on PCT-Li are generally similar to those from fitting the model to the 250glass dataset.

The 13-component reduced LM model for PCT-Li yielded somewhat different results for the partition of the modeling data into a modeling subset of 154 glasses and a validation subset of 96 glasses. As seen in Table 5.10, the fit statistics $\mathrm{R}^{2}=0.704, \mathrm{R}_{\mathrm{A}}{ }^{2}=0.679$, and $\mathrm{R}_{\mathrm{P}}^{2}=0.637$ for the 154-glass modeling subset are all better (i.e., larger) than the corresponding statistics for the full 250-glass modeling set. Also, RMSE $=0.384$ is better (i.e., smaller) for the 154-glass modeling subset. For the 96-glass validation subset, the $\mathrm{R}_{\mathrm{V}}^{2}=0.331$ and $\mathrm{RMSE}_{\mathrm{V}}=0.435$ statistics are notably worse than the $\mathrm{R}_{\mathrm{P}}^{2}=0.590$ and $\mathrm{RMSE}=0.392$ statistics from fitting the PCT-Li model to the 250-glass modeling dataset. The relatively poor validation results from data-partitioning compared to data-splitting are attributed to non-representative partitioning of the modeling dataset.

For the set of 480 separate validation glasses with PCT-Li data, the 13-component reduced LM for PCT-Li has $R_{V}^{2}=0.507$, which is notably less than $R_{P}^{2}=0.590$ from crossvalidation with the 250 -glass modeling dataset. This indicates that the extrapolative prediction ability of the model is relatively poor. The $\mathrm{RMSE}_{\mathrm{V}}=0.866$ for these 480 glasses is significantly worse than the average $\mathrm{RMSE}_{\mathrm{V}}=0.423$ for the five data-splits of the modeling data and the $\mathrm{RMSE}_{\mathrm{V}}=0.435$ for the partitioned modeling data. Additional explanation of the extrapolative 
predictive performance of the 13-component reduced LM model for PCT-Li is given subsequently when Figure 5.34 is discussed.

The RMSE in Table 5.10 is an estimate of the uncertainty [in $\ln \left(C_{L i}\right)$ units] in fabricating simulated HLW glasses and measuring $C_{L i}$ if the 13-component reduced LM model for PCT-Li does not have statistically significant LOF. To judge the LOF, the RMSE value can be compared to uncertainty estimates based on replicate PCT-Li release data. The RMSE $=0.392$ is much larger than the historical replicate $\mathrm{RSD}^{8}$ of $\sim 0.10$ (from Appendix F of Hrma et al. 1994) in fabricating simulated waste glasses and measuring PCT-Li release. It is also much larger than the $\ln (\mathrm{PCT}-\mathrm{Li}$ ) replicate $\mathrm{SD}=0.1317 \ln (\mathrm{g} / \mathrm{L})$ in Table 5.4 (which is discussed in the last subsection of Section 5.1.1). These observations suggest that the 13-component reduced LM model for $\ln (\mathrm{PCT}-\mathrm{Li})$ has a substantial LOF, which is confirmed by the LOF test p-value $<0.0001$ included in Table 5.10. This p-value indicates that the model LOF is significant at greater than $99.99 \%$ confidence level. See Section C.4 of Appendix C for further discussion of the LOF test.

\section{Graphical Results for the 13-Component Reduced Linear Mixture Model on $\ln$ (PCT-Li)}

The predicted versus measured plot in Figure 5.30 for the 13-component reduced LM model for PCT-Li is similar to the one in Figure 5.25 for the 25-component full LM model. Figure 5.30 shows that the 13-component reduced LM model tends to under-predict PCT-Li release above approximately $0.25 \ln (\mathrm{g} / \mathrm{L})$ [approximately $1.28 \mathrm{~g} / \mathrm{L}$ ]. The standardized residual plot in Figure 5.31 shows that the model also tends to over-predict PCT-Li for the HLW04 and HLW98 glasses. Diagnostic plots for the reduced LM model (not included in this report) support the assumption of normally distributed errors in the PCT-Li data (see Section C.3 of Appendix C).

Figure 5.32 displays the response trace plot (see Section C.5.1) for the 13-component reduced LM model for PCT-Li. The figure shows that (i) $\mathrm{Li}_{2} \mathrm{O}, \mathrm{Na}_{2} \mathrm{O}, \mathrm{B}_{2} \mathrm{O}_{3}$, and $\mathrm{MnO}$ tend to increase PCT-Li release, (ii) $\mathrm{Al}_{2} \mathrm{O}_{3}, \mathrm{ZrO}_{2}$, and $\mathrm{SiO}_{2}$ tend to decrease PCT-Li release, and (iii) the remaining components have moderate to negligible effects on PCT-Li release.

Figures 5.33 and 5.34 show the predicted versus measured plots when the 13-component reduced LM model for PCT-Li is applied to two validation datasets. Figure 5.33 results from fitting the reduced LM model to a subset of 154 out of 250 modeling glasses, and then applying the resulting model to the remaining subset of 96 validation glasses (see Section 5.1.3). Figure 5.34 results from fitting the reduced LM model for PCT-Li to all 250 glasses in the modeling set and then applying that model to the 480 separate validation glasses with PCT-Li data (see Section 5.1.4). As discussed in Section 5.1.4, the separate validation dataset consists primarily of glasses with compositions outside the EGCR for WTP HLW glasses, so that the model predictions are mostly extrapolations. Also shown in Figures 5.33 and 5.34 are 95\% PIs representing the model prediction uncertainty of single PCT-Li determinations for each glass (see Sections C.6 and C.7 of Appendix C). If the 95\% PI for a validation point overlaps the $45^{\circ}$

\footnotetext{
8 Per Equation (5.6), RSD values calculated from replicate PCT-B releases approximate SDs calculated from natural logarithms of PCT-B releases.
} 
line, the predicted and measured $\ln (\mathrm{PCT}-\mathrm{Li})$ values are within model and measurement uncertainty of each other.

Figure 5.33 shows that the 13-component reduced LM model for PCT-Li fitted to the 154-glass modeling subset from data-partitioning has varied predictive performance for the 96glass validation subset. The PCT-Li release tends to be (i) over-predicted for releases up to approximately $0.0 \ln (\mathrm{g} / \mathrm{L})[1.0 \mathrm{~g} / \mathrm{L}]$, (ii) fairly accurately predicted for releases between 0.0 and $0.75 \ln (\mathrm{g} / \mathrm{L})[1.0$ to $2.1 \mathrm{~g} / \mathrm{L}]$, and (iii) under-predicted for releases above $0.75 \ln (\mathrm{g} / \mathrm{L}$ ) [approximately $2.1 \mathrm{~g} / \mathrm{L}$ ]. However, the $95 \%$ PIs overlap the $45^{\circ}$ line (i.e., contain the measured values) for all but 8 of the 96 glasses in the validation subset from data-partitioning. Failure of $100(8 / 96)=8.3 \%$ of the $95 \%$ PIs to include the corresponding measured values is more than the $5 \%$ expected by chance. The $95 \%$ PIs are relatively wide, which are partly due to: (i) the LOF of the 13-component reduced LM model, and (ii) the inherent experimental uncertainty in fabricating glasses, performing the PCT, and analyzing Li in the PCT leachates.

Figure 5.34 shows that the 13-component reduced LM model for PCT-Li fitted to the 250-glass modeling dataset and applied to the 480-glass separate validation dataset (i) significantly over-predicts the four lowest PCT-Li releases, (ii) tends to accurately predict releases between -2 to $0 \ln (\mathrm{g} / \mathrm{L})$ [approximately 0.14 to $1.0 \mathrm{~g} / \mathrm{L}$ ), and (iii) tends to under-predict above $0 \ln (\mathrm{g} / \mathrm{L})[1.0 \mathrm{~g} / \mathrm{L}]$. The $95 \%$ PIs do not contain the corresponding measured values for 123 of the 480 separate validation glasses with PCT-Li data. However, extrapolative prediction performance is not a primary consideration in selecting a PCT-Li model.

Summary of the 13-Component Reduced Linear Mixture Model for $\ln$ (PCT-Li)

The 13-component reduced LM model for $\ln (\mathrm{PCT}-\mathrm{Li})$ is given in Table 5.10 and the variance-covariance matrix associated with the model coefficients is given in Table D.4 of Appendix D. The 13-component reduced LM model performs similarly to the 25-component full LM model (see Table 5.9). The reduced LM model is also expected to yield smaller uncertainties of PCT-Li predictions because unnecessary terms have been removed from the model. However, the reduced LM model for PCT-Li has highly significant LOF compared to the inherent uncertainty in batching and melting glasses, performing the PCT, and analyzing the leachate for Li release.

\subsubsection{Results for 18-Term Partial Quadratic Mixture Model for IHLW PCT-Li}

In an effort to improve on the 13-component reduced LM model for PCT-Li of HLW glasses, PQM models (see Section 5.2.1) were also considered. Specifically, selected quadratic terms (squared and two-component crossproduct terms) were added to the linear terms of the reduced LM for PCT-Li model to include important nonlinear blending effects of the glass components. PQM models are discussed in detail by Piepel et al. (2002).

All possible quadratic terms were formed using the 13 components of HLW glass in the reduced LM model for PCT-Li. The MAXR selection method (see Section C.5 of Appendix C) was used to identify "best" subsets of quadratic terms to include in PQM models. Different PQM 
models for PCT-Li were obtained depending on the number of quadratic terms specified for addition. The MAXR method was coded in R (Ihaka and Gentleman 1996, R Core Development Team 2006), but yields the same results as the MAXR option of PROC REG in SAS (2005).

PQM models were generated using the MAXR criterion to select from 2 to 9 quadratic terms to augment the 13 linear terms from the reduced LM model. Although statistical significance tests indicated up to 9 quadratic terms were statistically significant, past experience with developing and validating PQM models has indicated adding too many quadratic terms tends to over-fit the model development dataset and degrade predictive performance for new glasses. Ultimately, the 18-term PQM model with 13 linear terms and 5 quadratic terms was chosen as including enough quadratic terms to improve the PCT-Li model fit, hopefully without significantly over-fitting the model development data.

Numerical Results for the 18-Term Partial Quadratic Mixture Model on $\ln$ (PCT-Li)

Table 5.11 contains the coefficients of the 18-term PQM model for $\ln$ (PCT-Li), coefficient standard deviations, and performance statistics for the (i) modeling data, (ii) data-split modeling data, (iii) 154/96 partition of the modeling data into modeling and validation subsets, and (iv) 480 separate validation glasses with PCT-Li data.

In Table 5.11, the PCT-Li model evaluation statistics $\mathrm{R}^{2}=0.742, \mathrm{R}_{\mathrm{A}}^{2}=0.723, \mathrm{R}_{\mathrm{P}}^{2}=$ 0.694, and RMSE $=0.336$ for the 18-term PQM model are substantial improvements over the corresponding statistics for the 13-component reduced LM model (see Table 5.10). The small drop in values from $\mathrm{R}_{\mathrm{A}}^{2}$ to $\mathrm{R}_{\mathrm{P}}^{2}$ suggests that the PCT-Li modeling dataset does not have any highly influential data points for the 18-term PQM model. In any case, $R_{P}^{2}=0.694$ provides an estimate of the fraction of variation in $\ln \left(C_{L i}\right)$ values for future datasets over the same glass composition region that might be accounted for by this PQM model.

Over the five data splits of the PCT-Li modeling data, Table 5.11 shows that the 18-term PQM model has average modeling statistics $\mathrm{R}^{2}=0.745, \mathrm{R}_{\mathrm{A}}^{2}=0.722, \mathrm{R}_{\mathrm{P}}^{2}=0.687$, and $\mathrm{RMSE}=$ 0.331 that are all close to their values from the 250 -glass modeling dataset. The average validation statistic $R_{V}^{2}=0.691$ from data-splitting is similar to $R_{P}^{2}=0.694$ for the 250 -glass modeling dataset. However, the average validation statistic $\mathrm{RMSE}_{\mathrm{V}}=0.378$ from data-splitting is slightly worse (i.e., larger) than the RMSE $=0.336$ for the 250 -glass modeling dataset. Hence, the data-splitting validation results for the 18-term PQM model on PCT-Li are generally similar to those from fitting the model to the 250 -glass dataset.

The 18-term PQM model for PCT-Li yielded somewhat different results for the partition of the modeling data into a modeling subset of 154 glasses and a validation subset of 96 glasses. As seen in Table 5.11, the fit statistics $\mathrm{R}^{2}=0.800, \mathrm{R}_{\mathrm{A}}{ }^{2}=0.775$, and $\mathrm{R}_{\mathrm{P}}=0.731$ for the 154-glass modeling subset are all better (i.e., larger) than the corresponding statistics for the full 250-glass modeling set. The RMSE $=0.322$ is also slightly better (i.e., smaller) for the 154-glass modeling subset. For the 96-glass validation subset, $\mathrm{R}_{\mathrm{V}}^{2}=0.467$ and $\mathrm{RMSE}_{\mathrm{V}}=0.388$ indicate the 18 -term PQM model predicts less well than indicated by the statistics from fitting the 250 -glass modeling dataset. The relatively poor validation results from data-partitioning compared to data-splitting are attributed to non-representative partitioning of the modeling dataset. 
For the set of 480 separate validation glasses with PCT-Li data, the 18-term PQM model for PCT-Li has $\mathrm{R}_{\mathrm{V}}^{2}=0.543$, which is notably less than $\mathrm{R}_{\mathrm{P}}^{2}=0.694$ from cross-validation with the 250-glass modeling dataset. This indicates that the extrapolative prediction ability of the model is worse than the interpolative prediction ability. The $\mathrm{RMSE}_{\mathrm{V}}=0.834$ for these 480 glasses is significantly worse than the average $\mathrm{RMSE}_{\mathrm{V}}=0.378$ for the five data-splits of the modeling data and the $\mathrm{RMSE}_{\mathrm{V}}=0.388$ for the partitioned modeling data. Additional explanation of the extrapolative validation performance of the 18-term PQM model for PCT-Li is provided subsequently when Figure 5.39 is discussed.

The RMSE in Table 5.11 is an estimate of the uncertainty [in $\ln \left(C_{L i}\right)$ units] in fabricating simulated HLW glasses and measuring $C_{L i}$ if the 18-term PQM model for PCT-Li does not have statistically significant LOF. Although RMSE $=0.336$ for the 18-term PQM model is smaller than the corresponding value for the 13-component reduced LM model, it is still much larger than the historical replicate RSD of $\sim 0.10$ (from Appendix F of Hrma et al. 1994) in fabricating simulated waste glasses and measuring PCT-Li release, as discussed at the end of Section 5.1.1. The RMSE value is also much larger than the $\ln (\mathrm{PCT}-\mathrm{Li})$ replicate $\mathrm{SD}=0.1317 \ln (\mathrm{g} / \mathrm{L})$ in Table 5.4. These observations suggest that the 18-term PQM model for $\ln$ (PCT-Li) has a substantial LOF. This indication is confirmed by the $p$-value $<0.0001$ of the LOF test (see Section C. 4 of Appendix C) for this model in Table 5.11. This p-value indicates that the model LOF is significant at greater than the $99.99 \%$ confidence level.

Graphical Results for the 18-Term Partial Quadratic Mixture Model on $\ln$ (PCT-Li)

Figure 5.35 displays the predicted versus measured plot for the 18-term PQM model for PCT-Li applied to the 250 glasses of the PCT-Li modeling dataset. The distribution of points around the $45^{\circ}$ line is improved compared to the distribution for the 13-component reduced LM model in Figure 5.30. However, Figure 5.35 shows that the 18-term PQM model tends to underpredict PCT-Li releases above approximately $0.50 \ln (\mathrm{g} / \mathrm{L})$ [approximately $1.65 \mathrm{~g} / \mathrm{L}$ ]. The standardized residual plot in Figure 5.36 shows that the 18-term PQM model still tends to overpredict PCT-Li for the HLW04 and HLW98 glasses. Diagnostic plots for the PQM model (not included in this report) support the assumption of normally distributed errors in the PCT-Li data (see Section C.3 of Appendix C).

Figure 5.37 displays the response trace plot (see Section C.5.1) for the 18-term PQM model for PCT-Li. The figure shows that (i) $\mathrm{Li}_{2} \mathrm{O}, \mathrm{Na}_{2} \mathrm{O}, \mathrm{B}_{2} \mathrm{O}_{3}$, and $\mathrm{MnO}$ tend to increase PCTLi release, (ii) $\mathrm{Al}_{2} \mathrm{O}_{3}, \mathrm{ZrO}_{2}$, and $\mathrm{SiO}_{2}$ tend to decrease PCT-Li release, and (iii) the remaining components have moderate to negligible effects on PCT-Li release. A curvature effect is apparent for $\mathrm{Al}_{2} \mathrm{O}_{3}$ as a result of the $\left(\mathrm{Al}_{2} \mathrm{O}_{3}\right)^{2}$ term in the 18-term PQM model.

Figures 5.38 and 5.39 show the predicted versus measured plots when the 18-term PQM model for PCT-Li is applied to two validation datasets. Figure 5.38 results from fitting the 18term PQM model to a subset of 154 out of 250 modeling glasses, and then applying the resulting model to the remaining subset of 96 glasses for validation (see Section 5.1.3). Figure 5.39 results from fitting the 18-term PQM model for PCT-Li to all 250 glasses in the modeling set and then applying that model to the 480 separate validation glasses with PCT-Li data (see Section 5.1.4). 
Also shown in Figures 5.38 and 5.39 are 95\% PIs representing the model prediction uncertainty of single PCT-Li determinations for each glass (see Sections C.6 and C.7 of Appendix C). If the 95\% PI for a validation point overlaps the $45^{\circ}$ line, the predicted and measured $\ln (\mathrm{PCT}-\mathrm{Li})$ values are within model and measurement uncertainty of each other. The $95 \%$ PIs are relatively wide, which is partly due to: (i) the LOF of the 18-term PQM model, and (ii) the inherent experimental uncertainty in fabricating glasses, performing the PCT, and analyzing Li in the PCT leachates. Separate work to assess the consequences of LOF and prediction uncertainty for this PCT-Li model is discussed in Section 5.9.

Figure 5.38 shows that the 18-term PQM model for PCT-Li fitted to the 154-glass modeling subset from data-partitioning has varied predictive performance for the 96-glass validation subset. The PCT-Li release tends to be (i) over-predicted for releases up to approximately $0 \ln (\mathrm{g} / \mathrm{L})[1 \mathrm{~g} / \mathrm{L}]$, (ii) fairly accurately predicted for releases between 0 and 0.75 $\ln (\mathrm{g} / \mathrm{L})[1.0$ to $2.1 \mathrm{~g} / \mathrm{L}$ ], and (iii) under-predicted for releases above $0.75 \ln (\mathrm{g} / \mathrm{L})$ [approximately $2.1 \mathrm{~g} / \mathrm{L}]$. However, the $95 \%$ PIs overlap the $45^{\circ}$ line (i.e., contain the measured values) for all but 7 of the 96 glasses in the validation subset. Failure of $100(7 / 96)=7.3 \%$ of the $95 \%$ PIs to include the corresponding measured values is slightly more than the $5 \%$ expected by chance. The 95\% PIs are relatively wide, which are partly due to: (i) the LOF of the 18-term PQM model, and (ii) the inherent experimental uncertainty in fabricating glasses, performing the PCT, and analyzing $\mathrm{Li}$ in the PCT leachates.

Figure 5.39 shows that the 18-term PQM model for PCT-Li fitted to the 250-glass modeling dataset and applied to the 480-glass separate validation dataset tends to (i) over-predict for releases below approximately $-1.0 \ln (\mathrm{g} / \mathrm{L})[0.368 \mathrm{~g} / \mathrm{L}]$, (ii) accurately predict releases between approximately -1.0 to $0 \ln (\mathrm{g} / \mathrm{L})[0.368$ to $1.0 \mathrm{~g} / \mathrm{L}$ ), and (iii) under-predict above 0 $\ln (\mathrm{g} / \mathrm{L})[1.0 \mathrm{~g} / \mathrm{L}]$. However, the under-prediction above $0 \ln (\mathrm{g} / \mathrm{L})$ is less than for the 13 component reduced LM model. The $95 \%$ PIs do not contain the corresponding measured values for 129 of the 480 separate validation glasses with PCT-Li data. However, extrapolative prediction performance is not a primary consideration in selecting a PCT-Li model.

Summary of the 18-Term Partial Quadratic Mixture Model for $\ln$ (PCT-Li)

The 18-term PQM model for $\ln (\mathrm{PCT}-\mathrm{Li})$ is given in Table 5.11 and the variancecovariance matrix associated with the model coefficients is given in Table D.5 of Appendix D. The 18-term PQM model fits the 250-glass modeling dataset better than the 13-component reduced LM model, but still has highly significant LOF. The 18-term PQM model also performs better on the data-splitting, data-partitioning, and extrapolative validation assessments than does the reduced LM model.

\subsubsection{Results for 15-Term Partial Quadratic Mixture Model for IHLW PCT-Li}

Although all five of the quadratic terms in the 18-term PQM model for PCT-Li are statistically significant (see Table 5.11), the $\mathrm{UO}_{3} \times \mathrm{ZnO}, \mathrm{SrO} \times \mathrm{ZrO}_{2}$, and to a lesser extent $\mathrm{Fe}_{2} \mathrm{O}_{3} \times \mathrm{Li}_{2} \mathrm{O}$ quadratic terms are hard to explain from a glass science perspective. Because of correlations among quadratic terms, such terms may increase the predictive ability of the model 
without being justified by glass science. On the other hand, it is possible that such terms are a result of over-fitting. Hence, PQM models containing fewer than five quadratic terms were investigated. Ultimately, a 15-term PQM model containing the same 13 linear terms (as the models in Sections 5.4.2 and 5.4.3) and two quadratic terms $\left[\left(\mathrm{Al}_{2} \mathrm{O}_{3}\right)^{2}\right.$ and $\left.\mathrm{Al}_{2} \mathrm{O}_{3} \times \mathrm{ZrO}_{2}\right]$ were selected for each of PCT-B, PCT-Li, and PCT-Na releases. This model form has the advantage of having the same two quadratic terms for PCT-B, PCT-Li, and PCT-Na releases.

Table 5.12 presents the results from the 15-term PQM model for PCT-Li release (i) fitted to the 250-glass modeling dataset, (ii) fitted and validated using the data-splitting approach (see Section 5.1.2), (iii) fitted and validated using the data-partitioning approach (see Section 5.1.3), and (iv) validated for extrapolative performance using the separate validation dataset (see Section 5.1.4). The variance-covariance matrix associated with the coefficients of this model is given in Table D.6 of Appendix D. The results in Table 5.12 for the 15-term PQM model are all somewhat worse than the results in Table 5.11 for the 18-term PQM model, but not substantially so. Figures 5.40, 5.41, and 5.42 contain evaluation and validation plots for the 15-term PQM model on PCT-Li fitted to the 250-glass modeling dataset. The predicted versus measured plot in Figure 5.40 and standardized residual plot in Figure 5.41 are similar but slightly worse than the corresponding plots (in Figures 5.35 and 5.36) for the 18-term PQM model. The response trace plot in Figure 5.42 for the 15-term PQM model is very similar to the one in Figure 5.37 for the 18-term PQM model.

Figures 5.43 and 5.44 show the predicted versus measured plots when the 15-term PQM model for PCT-Li is applied to two validation datasets. Figure 5.43 results from fitting the 15term PQM model to a subset of 154 out of 250 modeling glasses, and then applying the resulting model to the remaining subset of 96 glasses for validation (see Section 5.1.3). Figure 5.44 results from fitting the 15-term PQM model for PCT-Li to all 250 glasses in the modeling set and then applying that model to the 480 separate validation glasses with PCT-Li data (see Section 5.1.4). Also shown in Figures 5.43 and 5.44 are 95\% PIs representing the model prediction uncertainty of single PCT-Li determinations for each glass (see Sections C.6 and C.7 of Appendix C). Some 95\% PIs that do not contain the corresponding measured values occur in Figure 5.43 for 7 of 96 partition validation glasses, and occur in Figure 5.44 for 134 of 480 separate validation glasses with PCT-Li data. These numbers are respectively the same and worse than the corresponding numbers in the plots for the 18-term PQM model.

\subsubsection{Recommended IHLW PCT-Li Models}

The selection of recommended and second-choice models for PCT-Li releases from HLW glasses is discussed in Sections 5.6 and 5.7. These sections also discuss the selection of recommended and second-choice models for PCT-B and PCT-Na releases from HLW glasses.

\subsection{Property-Composition Model Results for PCT-Na Release}

This section discusses the results of fitting several different models using natural logarithms of IHLW PCT normalized sodium release $(\mathrm{g} / \mathrm{L})$ as the response variable. Sections 
5.5.1 and 5.5.2 present the results of modeling PCT-Na using a 25-component LM model and a 13-component LM model, respectively. Sections 5.5.3 and 5.5.4 present the results of modeling PCT-Na using 18-term and 15-term PQM models based on the reduced set of 13 mixture components. Section 5.5.5 refers to Sections 5.6 and 5.7, which compare the results from various models and select recommended and second-choice PCT-B, PCT-Li, and PCT-Na models for future use and evaluation by the WTP project.

\subsubsection{Results from Full Linear Mixture Model for IHLW PCT-Na}

As the initial step in PCT-Na model development, a full LM model in the 25 components identified in Section 5.1.1 was fit to the modeling data (266 glasses) with the response being the natural logarithm of PCT-Na normalized releases $(\mathrm{g} / \mathrm{L})$. This model form was a reasonable starting point based on the previous work modeling IHLW PCT releases (Gan and Pegg 2001a, Kot et al. 2005a) and provided a basis for appropriate model reductions. No data were identified as outliers in initial PCT-Na modeling work, so all subsequent models used the dataset for the 266 HLW glasses.

Table 5.13 contains the results for the 25-component full LM model fit to the PCT-Na data for 266 HLW glasses. Table 5.13 lists the model coefficients, standard deviations of the coefficients, and model performance summaries for the full LM model using the modeling dataset (266 glasses), the data-splitting approach (see Section 5.1.2), the data-partitioning approach (see Section 5.1.3), and the separate extrapolative validation dataset (see Section 5.1.4).

The upper right corner of Table 5.13 contains the summary statistics that describe how well the 25-component LM model fits the 266-glass modeling data for PCT-Na. The $\mathrm{R}^{2}=0.804$, $\mathrm{R}_{\mathrm{A}}^{2}=0.784$, and $\mathrm{R}_{\mathrm{P}}^{2}=0.746$ statistics (see Section C.4 of Appendix C) indicate that the full 25component LM model fits the PCT-Na data in the 266-glass modeling dataset fairly well. However, the root mean squared error $(\mathrm{RMSE})=0.378$ is noticeably larger than the glass batching and PCT-Na measurement uncertainty $(\mathrm{SD}=0.1318 \mathrm{in} \ln (\mathrm{g} / \mathrm{L})$ units) estimated from replicates in Table 5.4. This indicates the full LM model for PCT-Na has LOF, which was confirmed as statistically significant with $p<0.0001$ as shown in Table 5.13 (see Section C.4 for discussion of the statistical test for model LOF).

The predicted versus measured plot in Figure 5.45 shows that the full 25-component LM model tends to under-predict PCT-Na release above approximately $1.0 \ln (\mathrm{g} / \mathrm{L})$ [approximately $2.72 \mathrm{~g} / \mathrm{L}]$. Figure 5.46 displays the standardized residuals plotted versus the data index (a sequential numbering of the modeling data points) with different plotting symbols representing the different groups of glasses discussed in Sections 2.1.1 to 2.1.9. Figure 5.46 shows that the 25component, full-LM model tends to over-predict ${ }^{9}$ PCT-Na for the HLW04 and HLW98 glasses.

In the data-splitting portion of results at the bottom of Table 5.13, the columns are labeled DS1, DS2, DS3, DS4, and DS5 to denote the five modeling/validation splits of the data

\footnotetext{
${ }^{9}$ Based on long-term statistical practice, a residual in standardized residual plots is defined as the measured value minus the predicted value. Hence, model over-predictions appear as negative values.
} 
as described in Section 5.1.2. The last column of this part of Table 5.13 shows the averages for the different statistics over the five splits. The average statistics over the five data-splits are very close to the statistics obtained for fitting the full LM model for PCT-Na to all 266 glasses. This indicates that the model, despite its statistically significant LOF, maintains its performance for data not used to fit the model.

The statistics for the 25-component full LM model on PCT-Na from partitioning the 266glass modeling set into subsets of 163 modeling glasses and 103 validation glasses (see Section 5.1.3) are given on the right side of Table 5.13. The fit statistics of $\mathrm{R}^{2}=0.874, \mathrm{R}_{\mathrm{A}}=0.852$, and $\mathrm{RMSE}=0.341$ for the 163-glass modeling subset are all better (i.e., larger, larger, and smaller, respectively) than the corresponding statistics for the full 266-glass modeling set. However, $\mathrm{R}_{\mathrm{P}}^{2}$ $<0$ is worse for the 163-glass modeling subset, because there are insufficient data to estimate the LM model coefficients for all 25 components. (See Section C.4 of Appendix C for additional discussion of $\mathrm{R}_{\mathrm{P}}^{2}$ and why it can be negative.) For the 103-glass validation subset from datapartitioning, $\mathrm{R}_{\mathrm{V}}^{2}$ is negative and $\mathrm{RMSE}_{\mathrm{V}}=1.515$. This poor validation performance for the 25 component, full-LM model on PCT-Na is because there is insufficient support in the 163-glass modeling subset to estimate the LM model coefficients of all 25 components.

The predicted versus measured plot in Figure 5.47 shows that the full 25-component LM model for PCT-Na fitted to the 163-glass modeling subset from data-partitioning has relatively poor predictive performance for the 103-glass validation subset because of significantly overpredicting PCT-Na for some of the glasses. The PCT-Na release tends to be over-predicted for most of the other 103 validation glasses as well. Also shown in Figure 5.47 are $95 \%$ prediction intervals (95\% PIs) representing the model prediction uncertainty of single PCT-Na determinations for each glass (see Sections C.6 and C.7 of Appendix C). If the 95\% PI for a validation point overlaps the $45^{\circ}$ line, the predicted and measured $\ln (\mathrm{PCT}-\mathrm{Na})$ values are within model and measurement uncertainty of each other. Of the 103 validation glasses from the datapartition, 38 have $95 \%$ PIs that do not overlap the $45^{\circ}$ line.

The summary statistics from applying the 25-component full LM model for PCT-Na to the separate validation data are also given on the right side of Table 5.13. The negative $\mathrm{R}_{\mathrm{V}}^{2}$ and very large $\mathrm{RMSE}_{\mathrm{V}}=1.561$ for the 554 separate validation glasses with PCT-Na data indicate the full LM model for PCT-Na does not have very good extrapolative predictive performance. This is confirmed in the predicted versus measured plot for the separate validation data shown in Figure 5.48. The 25-component LM model tends to under-predict PCT-Na releases except for a narrow band of small-to-moderate releases. However, extrapolative prediction performance is not a primary consideration in selecting a PCT-Na model.

Despite the statistically significant LOF of the 25-component full LM model for PCT-Na, the model fits the 268-glass modeling dataset well enough to provide guidance for reducing the model (i.e., removing separate terms for components that do not significantly influence PCT-Na release). Hence, the full LM model was used to produce the response trace plot (see Section C.5.1) shown in Figure 5.49. The response trace plot shows that $\mathrm{K}_{2} \mathrm{O}, \mathrm{Li}_{2} \mathrm{O}$, and $\mathrm{Na}_{2} \mathrm{O}$ tend to increase PCT-Na release, while $\mathrm{Al}_{2} \mathrm{O}_{3}, \mathrm{ZrO}_{2}$, and $\mathrm{SiO}_{2}$ tend to decrease PCT-Na release. The response traces for several minor components have steep positive or negative slopes but smaller ranges, and thus they may not have significant effects on PCT-Na. This was confirmed by fitting 
a CSLM model and verifying the slopes (representing effects) of the components were not statistically significant (see Section C.5.1 of Appendix C).

\subsubsection{Results from Reduced Linear Mixture Model for IHLW PCT-Na}

The 25-component full LM model presented in Section 5.5.1 likely contains components that do not significantly contribute to predicting PCT-Na release, so model reduction was the next step of the model development approach. Thus, LM models for PCT-Na involving fewer than the 25 components were considered. The sequential F-test model reduction approach (see Section C.5.1 of Appendix C, Piepel and Cooley 2006) was used to develop a reduced LM model. Option (ii) was used to combine components with nonsignificant effects on PCT-Na into the Others term.

The sequential F-test model reduction algorithm was run with the main components $\mathrm{Al}_{2} \mathrm{O}_{3}, \mathrm{~B}_{2} \mathrm{O}_{3}, \mathrm{Fe}_{2} \mathrm{O}_{3}, \mathrm{Li}_{2} \mathrm{O}, \mathrm{MnO}, \mathrm{Na}_{2} \mathrm{O}, \mathrm{SiO}_{2}, \mathrm{SrO}$, and $\mathrm{ZrO}_{2}$ forced to remain as separate terms in the reduced LM model for PCT-Na. The resulting reduced LM model included linear terms for these 9 components, plus a linear term for the new Others component obtained by combining the other 16 components involved in the 25-component LM model. However, the new Others component had mass fractions ranging from approximately 0.024 to 0.218 (2.4 to $21.8 \mathrm{wt} \%$ ). Such a high mass fraction of the Others component was considered undesirable. Therefore, the model reduction algorithm was re-run, this time with $\mathrm{ThO}_{2}, \mathrm{UO}_{3}$, and $\mathrm{ZnO}$ being forced to remain as separate components in the reduced LM model. Among the components included in the Others component of the 10-term reduced $\mathrm{LM}$ model, $\mathrm{ThO}_{2}, \mathrm{UO}_{3}$, and $\mathrm{ZnO}$ had the largest maximum values. The resulting 13-component reduced $\mathrm{LM}$ model included linear terms for $\mathrm{Al}_{2} \mathrm{O}_{3}, \mathrm{~B}_{2} \mathrm{O}_{3}, \mathrm{Fe}_{2} \mathrm{O}_{3}, \mathrm{Li}_{2} \mathrm{O}, \mathrm{MnO}, \mathrm{Na}_{2} \mathrm{O}, \mathrm{SiO}_{2}, \mathrm{SrO}, \mathrm{ThO}_{2}, \mathrm{UO}_{3}, \mathrm{ZnO}, \mathrm{ZrO}_{2}$, and the new Others component. The Others component of this 13-component reduced LM model had mass fractions ranging from approximately 0.013 to 0.118 (1.3 to $11.8 \mathrm{wt} \%)$. This was considered to be a reasonable range for the Others component, so the 13-term reduced LM model was selected for investigation.

\section{Numerical Results for the 13-Component Reduced Linear Mixture Model on $\ln (\mathrm{PCT}-\mathrm{Na})$}

Table 5.14 gives the coefficients and coefficient standard deviations for the 13-component reduced LM model for $\ln (\mathrm{PCT}-\mathrm{Na})$, as well as performance statistics for the (i) modeling data, (ii) data-split modeling data, (iii) 163/103 partition of the modeling data into modeling and validation subsets, and (iv) 554 separate validation HLW glasses with PCT-Na data.

In Table 5.14, $\mathrm{R}^{2}=0.791$ indicates that the reduced LM model for PCT-Na accounts for roughly $79 \%$ of the variation in $\ln \left(C_{N a}\right)$ values in the 266 -glass modeling dataset. While this is a reasonably large number, a larger value would be preferable. The value of $\mathrm{R}_{\mathrm{A}}^{2}=0.781$ is close to $\mathrm{R}^{2}$, indicating that the model reduction was successful in removing unneeded components. The value for $R_{P}^{2}=0.761$ is not very far below the $R^{2}$ and $R_{A}^{2}$ values, indicating that there are not any highly influential data points in the PCT-Na modeling dataset. In any case, $\mathrm{R}_{\mathrm{P}}^{2}=0.761$ provides an estimate of the fraction of variation in $\ln \left(C_{N a}\right)$ values for future glasses in the same glass composition region that might be accounted for by this reduced LM model. 
Over the five data splits of the PCT-Na modeling data, Table 5.14 shows that the 13component reduced $\mathrm{LM}$ model has average modeling statistics $\mathrm{R}^{2}=0.795, \mathrm{R}_{\mathrm{A}}^{2}=0.784, \mathrm{R}_{\mathrm{P}}^{2}=$ 0.760 , and $\mathrm{RMSE}=0.375$ that are all close to their values from the 266-glass modeling dataset. The average validation statistics $\mathrm{R}_{\mathrm{V}}^{2}=0.731$ and $\mathrm{RMSE}_{\mathrm{V}}=0.424$ from data-splitting are only slightly worse (i.e., smaller and larger, respectively) than $\mathrm{R}_{\mathrm{P}}^{2}=0.761$ and $\mathrm{RMSE}=0.381$ for the 266-glass modeling dataset. Hence, the data-splitting validation results for the 13-component reduced LM model on PCT-Na are generally similar to those from fitting the model to the 266glass dataset.

The 13-component reduced LM model for PCT-Na yielded somewhat different results for the partition of the modeling data into a modeling subset of 163 glasses and a validation subset of 103 glasses. As seen in Table 5.14, the fit statistics $\mathrm{R}^{2}=0.848, \mathrm{R}_{\mathrm{A}}{ }_{\mathrm{A}}=0.836$, and $\mathrm{R}_{\mathrm{P}}^{2}=0.817$ for the 163-glass modeling subset are all better (i.e., larger) than the corresponding statistics for the full 266-glass modeling set. Also, RMSE $=0.358$ is better (i.e., smaller) for the 163-glass modeling subset. For the 103-glass validation subset, the $R_{V}^{2}=0.616$ and $R_{M S E}=0.423$ statistics are notably worse than the $\mathrm{R}_{\mathrm{P}}^{2}=0.761$ and $\mathrm{RMSE}=0.381$ statistics from fitting the PCT-Na model to the 266-glass modeling dataset. The poorer validation results from datapartitioning compared to data-splitting are attributed to non-representative partitioning of the modeling dataset.

For the set of 554 separate validation glasses with PCT-Na data, the 13-component reduced $L M$ for PCT-Na has $R_{V}^{2}=0.367$, which is substantially less than $R_{P}^{2}=0.761$ from cross-validation with the 266-glass modeling dataset. This indicates that the extrapolative prediction ability of the model is relatively poor. The $\mathrm{RMSE}_{\mathrm{V}}=0.996$ for these 554 glasses is significantly worse than the average $\mathrm{RMSE}_{\mathrm{V}}=0.424$ for the five data-splits of the modeling data and the $\mathrm{RMSE}_{\mathrm{V}}=0.423$ for the partitioned modeling data. Additional explanation of the extrapolative predictive performance of the 13-component reduced LM model for PCT-Na is given subsequently when Figure 5.54 is discussed.

The RMSE in Table 5.14 is an estimate of the uncertainty [in $\ln \left(C_{N a}\right)$ units] in fabricating simulated HLW glasses and measuring $C_{N a}$ if the 13-component reduced LM model for PCT-Na does not have statistically significant LOF. To judge the LOF, the RMSE value can be compared to uncertainty estimates based on replicate PCT-Na release data. The RMSE $=0.381$ is much larger than the historical replicate $\mathrm{RSD}^{10}$ of $\sim 0.10$ (from Appendix F of Hrma et al. 1994) in fabricating simulated waste glasses and measuring PCT-Na release. It is also much larger than the $\ln (\mathrm{PCT}-\mathrm{Na})$ replicate $\mathrm{SD}=0.1318 \ln (\mathrm{g} / \mathrm{L})$ in Table 5.4 (which is discussed in the last subsection of Section 5.1.1). These observations suggest that the 13-component reduced LM model for $\ln (\mathrm{PCT}-\mathrm{Na})$ has a substantial LOF, which is confirmed by the LOF test p-value $<$ 0.0001 included in Table 5.14. This p-value indicates that the model LOF is significant at a greater than $99.99 \%$ confidence level. See Section C.4 of Appendix C for further discussion of the LOF test.

10 Per Equation (5.6), RSD values calculated from replicate PCT-B releases approximate SDs calculated from natural logarithms of PCT-B releases. 
Graphical Results for the 13-Component Reduced Linear Mixture Model on $\ln (\mathrm{PCT}-\mathrm{Na})$

The predicted versus measured plot in Figure 5.50 for the 13-component reduced LM model for PCT-Na is similar to the one in Figure 5.45 for the 25-component full LM model. Figure 5.50 shows that the 13-component reduced LM model tends to under-predict PCT-Na release above approximately $0.75 \ln (\mathrm{g} / \mathrm{L})$ [approximately $2.12 \mathrm{~g} / \mathrm{L}$ ]. The standardized residual plot in Figure 5.51 shows that the model also tends to over-predict PCT-Na for the HLW04 and HLW98 glasses. Diagnostic plots for the reduced LM model (not included in this report) support the assumption of normally distributed errors in the PCT-Na data (see Section C.3 of Appendix C).

Figure 5.52 displays the response trace plot (see Section C.5.1) for the 13-component reduced LM model for PCT-Na. The figure shows that (i) $\mathrm{Li}_{2} \mathrm{O}$ and $\mathrm{Na}_{2} \mathrm{O}$ tend to increase PCT$\mathrm{Na}$ release, (ii) $\mathrm{Al}_{2} \mathrm{O}_{3}, \mathrm{ZrO}_{2}$, and $\mathrm{SiO}_{2}$ tend to decrease PCT-Na release, and (iii) the remaining components have moderate to negligible effects on PCT-Na release. It is also noteworthy that $\mathrm{B}_{2} \mathrm{O}_{3}$ does not have a significant increasing effect on PCT-Na as it did for PCT-B and PCT-Li.

Figures 5.53 and 5.54 show the predicted versus measured plots when the 13-component reduced LM model for PCT-Na is applied to two validation datasets. Figure 5.53 results from fitting the reduced LM model to a subset of 163 out of 266 modeling glasses, and then applying the resulting model to the remaining subset of 103 validation glasses (see Section 5.1.3). Figure 5.54 results from fitting the reduced LM model for PCT-Na to all 266 glasses in the modeling set and then applying that model to the 554 separate validation glasses with PCT-Na data (see Section 5.1.4). As discussed in Section 5.1.4, the separate validation dataset consists primarily of glasses with compositions outside the EGCR for WTP HLW glasses, so that the model predictions are mostly extrapolations. Also shown in Figures 5.53 and 5.54 are 95\% PIs representing the model prediction uncertainty of single PCT-Na determinations for each glass (see Sections C.6 and C.7 of Appendix C). If the 95\% PI for a validation point overlaps the $45^{\circ}$ line, the predicted and measured $\ln (\mathrm{PCT}-\mathrm{Na})$ values are within model and measurement uncertainty of each other.

Figure 5.53 shows that the 13-component reduced LM model for PCT-Na fitted to the 163-glass modeling subset from data-partitioning has varied predictive performance for the 103glass validation subset. The PCT-Na release tends to be (i) over-predicted for releases up to approximately $0 \ln (\mathrm{g} / \mathrm{L})[1 \mathrm{~g} / \mathrm{L}]$, (ii) fairly accurately predicted for releases between 0 and 0.75 $\ln (\mathrm{g} / \mathrm{L})[1.0$ to $2.1 \mathrm{~g} / \mathrm{L}]$, and (iii) under-predicted for releases above $0.75 \ln (\mathrm{g} / \mathrm{L})$ [approximately $2.1 \mathrm{~g} / \mathrm{L}]$. However, the $95 \%$ PIs overlap the $45^{\circ}$ line (i.e., contain the measured values) for all but 9 of the 103 glasses in the validation subset from data partitioning. Failure of $100(9 / 103)=8.7 \%$ of the $95 \%$ PIs to include the corresponding measured values is more than the $5 \%$ expected by chance. The 95\% PIs are relatively wide, which are partly due to: (i) the LOF of the 13component reduced LM model, and (ii) the inherent experimental uncertainty in fabricating glasses, performing the PCT, and analyzing $\mathrm{Na}$ in the PCT leachates.

Figure 5.54 shows that the 13-component reduced LM model for PCT-Na fitted to the 266-glass modeling dataset and applied to the 554-glass separate validation dataset tends to (i) under-predict PCT-Na releases below $-1.5 \ln (\mathrm{g} / \mathrm{L})$ [approximately $0.22 \mathrm{~g} / \mathrm{L}$, (ii) accurately 
predict releases between -1.5 to $0 \ln (\mathrm{g} / \mathrm{L}$ ) [approximately 0.22 to $1.0 \mathrm{~g} / \mathrm{L}$ ), and (iii) under-predict above $0 \ln (\mathrm{g} / \mathrm{L})[1.0 \mathrm{~g} / \mathrm{L}]$. The $95 \%$ PIs do not contain the corresponding measured values for 196 of the 554 separate validation glasses with PCT-Na data. However, extrapolative prediction performance is not a primary consideration in selecting a PCT-Na model.

Summary of the 13-Component Reduced Linear Mixture Model for $\ln (\mathrm{PCT}-\mathrm{Na})$

The 13-component reduced LM for $\ln (\mathrm{PCT}-\mathrm{Na})$ is given in Table 5.14 and the variancecovariance matrix associated with the model coefficients is given in Table D.7 of Appendix D. The 13-component reduced LM model performs similarly to the 25-component full LM model (see Table 5.13). The reduced LM model is also expected to yield smaller uncertainties of PCT$\mathrm{Na}$ predictions because unnecessary terms have been removed from the model. However, the reduced LM model for PCT-Na has significant LOF compared to the inherent uncertainty in batching and melting glasses, performing the PCT, and analyzing the leachate for Na release.

\subsubsection{Results for 18-Term Partial Quadratic Mixture Model for IHLW PCT-Na}

In an effort to improve on the 13-component reduced LM model for PCT-Na of HLW glasses, PQM models (see Section 5.2.1) were also considered. Specifically, selected quadratic terms (squared and two-component crossproduct terms) were added to the linear terms of the reduced LM model for PCT-Na to include important nonlinear blending effects of the glass components. PQM models are discussed in detail by Piepel et al. (2002).

All possible quadratic terms were formed using the 13 components of HLW glass in the reduced LM model for PCT-Na. The MAXR selection method (see Section C.5 of Appendix C) was used to identify "best" subsets of quadratic terms to include in PQM models. Different PQM models for PCT-Na were obtained depending on the number of quadratic terms specified for addition. The MAXR method was coded in R (Ihaka and Gentleman 1996, R Core Development Team 2006), but yields the same results as the MAXR option of PROC REG in SAS (2005).

PQM models were generated using the MAXR criterion to select from 2 to 9 quadratic terms to augment the 13 linear terms from the reduced LM model. Although statistical significance tests indicated up to 9 quadratic terms were statistically significant, past experience with developing and validating PQM models has indicated adding too many quadratic terms tends to over-fit the model development dataset and degrade predictive performance for new glasses. Ultimately, the 18-term PQM model with 13 linear terms and 5 quadratic terms was chosen as including enough quadratic terms to improve the PCT-Na model fit, hopefully without significantly over-fitting the model development data.

\section{Numerical Results for the 18-Term Partial Quadratic Mixture Model on $\ln (\mathrm{PCT}-\mathrm{Na})$}

Table 5.15 contains the coefficients of the 18-term PQM model for $\ln (\mathrm{PCT}-\mathrm{Na})$, coefficient standard deviations, and performance statistics for the (i) modeling data, (ii) data-split modeling data, (iii) 163/103 partition of the modeling data into modeling and validation subsets, and (iv) 554 separate validation glasses with PCT-Na data. 
In Table 5.15, the PCT-Na model evaluation statistics $\mathrm{R}^{2}=0.873, \mathrm{R}_{\mathrm{A}}^{2}=0.864, \mathrm{R}_{\mathrm{P}}^{2}=$ 0.848 , and $\mathrm{RMSE}=0.300$ for the 18-term PQM model are substantial improvements over the corresponding statistics for the 13-component reduced LM model (see Table 5.14). The small drop in values from $\mathrm{R}^{2}$ to $\mathrm{R}_{\mathrm{P}}^{2}$ suggests that the PCT-Na modeling dataset does not have any highly influential data points for the 18 -term PQM model. In any case, $\mathrm{R}_{\mathrm{P}}^{2}=0.848$ provides an estimate of the fraction of variation in $\ln \left(C_{\mathrm{Na}}\right)$ values for future datasets over the same glass composition region that might be accounted for by this PQM model.

Over the five data splits of the PCT-Na modeling data, Table 5.15 shows that the 18-term PQM model has average modeling statistics $\mathrm{R}^{2}=0.874, \mathrm{R}_{\mathrm{A}}^{2}=0.864, \mathrm{R}_{\mathrm{P}}^{2}=0.845$, and $\mathrm{RMSE}=$ 0.298 that are all close to their values from the 266 -glass modeling dataset. The average $\mathrm{R}_{\mathrm{V}}^{2}=$ 0.838 validation statistic from data-splitting is slightly worse (i.e., smaller) than $R_{P}^{2}=0.848$ for the 266-glass modeling dataset. However, the average $\mathrm{RMSE}_{\mathrm{V}}=0.328$ validation statistic from data-splitting is slightly worse (i.e., larger) than the RMSE $=0.300$ for the 266-glass modeling dataset. Hence, the data-splitting validation results for the 18-term PQM model on PCT-Na are generally similar to those from fitting the model to the 266-glass dataset.

The 18-term PQM model for PCT-Na yielded somewhat different results for the partition of the modeling data into a modeling subset of 163 glasses and a validation subset of 103 glasses. As seen in Table 5.15, the fit statistics $\mathrm{R}^{2}=0.918, \mathrm{R}_{\mathrm{A}}{ }^{2}=0.908$, and $\mathrm{R}_{\mathrm{P}}{ }^{2}=0.896$ for the 163-glass modeling subset are all better (i.e., larger) than the corresponding statistics for the full 266-glass modeling set. The RMSE $=0.268$ is also better (i.e., smaller) for the 163-glass modeling subset. For the 103-glass validation subset, $\mathrm{R}_{\mathrm{V}}^{2}=0.729$ and $\mathrm{RMSE}_{\mathrm{V}}=0.356$ indicate the 18 -term PQM model predicts somewhat less well than indicated by the statistics from fitting the 266-glass modeling dataset. The poorer validation results from data-partitioning compared to data-splitting are attributed to non-representative partitioning of the modeling dataset.

For the set of 554 separate validation glasses with PCT-Na data, the 18-term PQM model for PCT-Na has $\mathrm{R}_{\mathrm{V}}^{2}=0.516$, which is substantially less than $\mathrm{R}_{\mathrm{P}}^{2}=0.848$ from cross-validation with the 266-glass modeling dataset. This indicates that the extrapolative prediction ability of the model is worse than the interpolative prediction ability. The $\mathrm{RMSE}_{\mathrm{V}}=0.870$ for these 554 glasses is significantly worse than the average $\mathrm{RMSE}_{\mathrm{V}}=0.328$ for the five data-splits of the modeling data and the $\mathrm{RMSE}_{\mathrm{V}}=0.356$ for the partitioned modeling data. Additional explanation of the extrapolative validation performance of the 18-term PQM model for PCT-Na is provided subsequently when Figure 5.59 is discussed.

The RMSE in Table 5.15 is an estimate of the uncertainty [in $\ln \left(C_{N a}\right)$ units] in fabricating simulated HLW glasses and measuring $C_{N a}$ if the 18-term PQM model for PCT-Na does not have statistically significant LOF. Although RMSE $=0.300$ for the 18-term PQM model is smaller than the corresponding value for the 13-component reduced LM model, it is still much larger than the historical replicate RSD of $\sim 0.10$ (from Appendix F of Hrma et al. 1994) in fabricating simulated waste glasses and measuring PCT-Na release, as discussed at the end of Section 5.1.1. The RMSE value is also much larger than the $\ln (\mathrm{PCT}-\mathrm{Na})$ replicate $\mathrm{SD}=0.1318 \ln (\mathrm{g} / \mathrm{L})$ in Table 5.4. These observations suggest that the 18-term PQM model for $\ln (\mathrm{PCT}-\mathrm{Na})$ has a substantial LOF. This indication is confirmed by the $p$-value $<0.0014$ of the LOF test (see Section C. 4 of 
Appendix C) for this model in Table 5.15. This $p$-value indicates that the model LOF is significant at a greater than $99.99 \%$ confidence level.

Graphical Results for the 18-Term Partial Quadratic Mixture Model on $\ln (\mathrm{PCT}-\mathrm{Na})$

Figure 5.55 displays the predicted versus measured plot for the 18-term PQM model for PCT-Na applied to the 268 glasses of the PCT-Na modeling dataset. The distribution of points around the $45^{\circ}$ line is significantly improved compared to the distribution for the 13-component reduced LM model in Figure 5.50. Figure 5.55 shows that the 18-term PQM model still tends to under-predict PCT-Na releases above approximately $1.0 \ln (\mathrm{g} / \mathrm{L})$ [approximately $2.72 \mathrm{~g} / \mathrm{L}$ ], but the under-prediction is not as large as for the 13-component reduced LM model. The standardized residual plot in Figure 5.56 shows that the 18-term PQM model still tends to overpredict PCT-Na for the HLW04 and HLW98 glasses. Diagnostic plots for the PQM model (not included in this report) support the assumption of normally distributed errors in the PCT-Na data (see Section C.3 of Appendix C).

Figure 5.57 displays the response trace plot (see Section C.5.1) for the 18-term PQM model for PCT-Na. The figure shows that (i) $\mathrm{Li}_{2} \mathrm{O}$ and $\mathrm{Na}_{2} \mathrm{O}$ tend to increase PCT-Na release, (ii) $\mathrm{Al}_{2} \mathrm{O}_{3}, \mathrm{ZrO}_{2}$, and $\mathrm{SiO}_{2}$ tend to decrease PCT-Na release, and (iii) the remaining components have moderate to negligible effects on PCT-Na release. A curvature effect is apparent for $\mathrm{Al}_{2} \mathrm{O}_{3}$ as a result of the $\left(\mathrm{Al}_{2} \mathrm{O}_{3}\right)^{2}$ term in the 18-term PQM model.

Figures 5.58 and 5.59 show the predicted versus measured plots when the 18-term PQM model for PCT-Na is applied to two validation datasets. Figure 5.58 results from fitting the 18term PQM model to a subset of 163 out of 266 modeling glasses, and then applying the resulting model to the remaining subset of 103 glasses for validation (see Section 5.1.3). Figure 5.59 results from fitting the 18-term PQM model for PCT-Na to all 266 glasses in the modeling set and then applying that model to the 554 separate validation glasses with PCT-Na data (see Section 5.1.4). Also shown in Figures 5.58 and 5.59 are 95\% PIs representing the model prediction uncertainty of single PCT-Na determinations for each glass (see Sections C.6 and C.7 of Appendix C). If the $95 \%$ PI for a validation point overlaps the $45^{\circ}$ line, the predicted and measured $\ln (\mathrm{PCT}-\mathrm{Na})$ values are within model and measurement uncertainty of each other. The 95\% PIs are relatively wide, which is partly due to: (i) the LOF of the 18-term PQM model, and (ii) the inherent experimental uncertainty in fabricating glasses, performing the PCT, and analyzing $\mathrm{Na}$ in the PCT leachates. However, note that the 95\% PIs in Figures 5.58 and 5.59 are narrower for the PQM model than for the reduced LM model in Figures 5.53 and 5.54. Separate work to assess the consequences of LOF and prediction uncertainty for this PCT-Na model is discussed in Section 5.9.

Figure 5.58 shows that the 18-term PQM model for PCT-Na fitted to the 163-glass modeling subset from data-partitioning has generally unbiased predictive performance for the 103-glass validation subset, although with some scatter. The $95 \%$ PIs overlap the $45^{\circ}$ line (i.e., contain the measured values) for all but 12 of the 103 glasses in the validation subset from datapartitioning. Failure of $100(12 / 103)=11.6 \%$ of the $95 \%$ PIs to include the corresponding measured values is somewhat more than the $5 \%$ expected by chance. The width of the $95 \%$ PIs is 
due to: (i) the LOF of the 18-term PQM model, and (ii) the inherent experimental uncertainty in fabricating glasses, performing the PCT, and analyzing $\mathrm{Na}$ in the PCT leachates.

Figure 5.59 shows that the 18-term PQM model for PCT-Na fitted to the 266-glass modeling dataset and applied to the separate 554-glass validation dataset (i) tends to over-predict somewhat for releases below approximately $-1.5 \ln (\mathrm{g} / \mathrm{L})[0.223 \mathrm{~g} / \mathrm{L}]$, (ii) goes through a trend of under-predicting, accurately predicting, and over-predicting PCT-Na releases between approximately -1.5 to $0 \ln (\mathrm{g} / \mathrm{L})[0.223$ to $1.0 \mathrm{~g} / \mathrm{L})$, and (iii) tends to under-predict above $0 \ln (\mathrm{g} / \mathrm{L})$ $[1.0 \mathrm{~g} / \mathrm{L}]$. However, the under-prediction above $0 \ln (\mathrm{g} / \mathrm{L})$ is similar to that for the 13 -component reduced LM model. The 95\% PIs do not contain the corresponding measured values for 199 of the 554 separate validation glasses with PCT-Na data. However, extrapolative prediction performance is not a primary consideration in selecting a PCT-Na model.

Summary of the 18-Term Partial Quadratic Mixture Model for $\ln (\mathrm{PCT}-\mathrm{Na})$

The 18-term PQM model for $\ln (\mathrm{PCT}-\mathrm{Na})$ is given in Table 5.15 and the variancecovariance matrix associated with the model coefficients is given in Table D.8 of Appendix D. The 18-term PQM model fits the 266-glass modeling dataset better than the 13-component reduced LM model, but still has significant LOF. The PQM model also performs better on the data-splitting, data-partitioning, and extrapolative validation assessments than does the reduced LM model.

\subsubsection{Results for 15-Term Partial Quadratic Mixture Model for IHLW PCT-Na}

Although all five of the quadratic terms in the 18-term PQM model for PCT-Na are statistically significant (see Table 5.15), the $\mathrm{SiO}_{2} \times \mathrm{ZnO}$ and $\mathrm{SiO}_{2} \times \mathrm{UO}_{3}$ quadratic terms are hard to explain from a glass science perspective. Because of correlations among quadratic terms, such terms may increase the predictive ability of the model without being justified by glass science. On the other hand, it is possible that such terms are a result of over-fitting. Hence, PQM models containing fewer than five quadratic terms were investigated. Ultimately, a 15-term PQM model containing the same 13 linear terms (as the models in Sections 5.5.2 and 5.5.3) and two quadratic terms $\left[\left(\mathrm{Al}_{2} \mathrm{O}_{3}\right)^{2}\right.$ and $\left.\mathrm{Al}_{2} \mathrm{O}_{3} \times \mathrm{ZrO}_{2}\right]$ were selected for each of PCT-B, PCT-Li, and PCT-Na releases. This model form has the advantage of having the same two quadratic terms for PCT-B, PCT-Li, and PCT-Na releases.

Table 5.16 presents the results from the 15-term PQM model for PCT-Na release (i) fitted to the 266-glass modeling dataset, (ii) fitted and validated using the data-splitting approach (see Section 5.1.2), (iii) fitted and validated using the data-partitioning approach (see Section 5.1.3), and (iv) validated for extrapolative performance using the separate validation dataset (see Section 5.1.4). The variance-covariance matrix associated with the coefficients of this model is given in Table D.9 of Appendix D. The results in Table 5.16 for the 15-term PQM model are all somewhat worse than the results in Table 5.15 for the 18-term PQM model, but not substantially so. Figures 5.60, 5.61, and 5.62 contain evaluation and validation plots for the 15-term PQM model on PCT-Na fitted to the 266-glass modeling dataset. The predicted versus measured plot in Figure 5.60 and standardized residual plot in Figure 5.61 are similar but slightly worse than 
the corresponding plots (in Figures 5.45 and 5.46) for the 18-term PQM model. The response trace plot in Figure 5.62 for the 15-term PQM model is very similar to the one in Figure 5.57 for the 18-term PQM model.

Figures 5.63 and 5.64 show the predicted versus measured plots when the 15-term PQM model for PCT-Na is applied to two validation datasets. Figure 5.63 results from fitting the 15term PQM model to a subset of 163 out of 266 modeling glasses, and then applying the resulting model to the remaining subset of 103 glasses for validation (see Section 5.1.3). Figure 5.64 results from fitting the 15-term PQM model for PCT-Na to all 266 glasses in the modeling set and then applying that model to the 554 separate validation glasses with PCT-Na data (see Section 5.1.4). Also shown in Figures 5.63 and 5.64 are 95\% PIs representing the model prediction uncertainty of single PCT-Na determinations for each glass (see Sections C.6 and C.7 of Appendix C). Some 95\% PIs that do not contain the corresponding measured values occur in Figure 5.63 for 12 of 103 partition validation glasses, and occur in Figure 5.64 for 207 of 554 separate validation glasses with PCT-Na data. These numbers are respectively the same and worse than the corresponding numbers in the plots for the 18-term PQM model.

\subsubsection{Recommended IHLW PCT-Na Models}

The selection of recommended and second-choice models for PCT-Na releases from HLW glasses is discussed in Sections 5.6 and 5.7. These sections also discuss the selection of recommended and second-choice models for PCT-B and PCT-Li releases from HLW glasses.

\subsection{Comparison and Down-Selection of PCT-B, PCT-Li, and PCT-Na Models for HLW Glasses}

The main model evaluation and validation results for several models of PCT-B, PCT-Li, and PCT-Na releases from HLW glasses are summarized in Tables 5.17 and 5.18. The evaluation and validation results are based on

- $\quad$ PCT modeling datasets of simulated and actual HLW glasses

- data-splitting approach to model validation

- partition of the modeling dataset into modeling and validation subsets

- separate validation dataset of glasses

where the numbers of HLW glasses for these investigations are summarized in Table 5.18.

Four of the six models included in Tables 5.17 and 5.18 are the ones discussed in Sections 5.3.1 to 5.3.4 for PCT-B, in Sections 5.4.1 to 5.4.4 for PCT-Li, and in Sections 5.5.1 to 5.5.4 for PCT-Na. In addition, for each of PCT-B, PCT-Li, and PCT-Na the tables contain results for: 
- An 18-term partial cubic mixture (PCM) model composed of the 13 linear terms plus 5 quadratic and/or cubic terms involving the 13 components that were selected using the MAXR criterion (see Section C.5 of Appendix C).

- A 16-term PQM model composed of the 13 linear terms plus 3 quadratic terms selected using the MAXR criterion.

The 18-term PCM models were investigated for PCT-B, PCT-Li, and PCT-Na in the hope that they would better fit the corresponding modeling datasets and provide better validation performances for the data-splitting, data-partitioning, and separate dataset approaches to validation. Table 5.17 shows the 18-term PCM models did fit the PCT-B, PCT-Li, and PCT-Na datasets better and perform better for the data-splitting and data-partitioning validation approaches. However, the improvement over the 18-term and 15-term PQM models was marginal. The performance of the 18-term PCM models for the PCT-B, PCT-Li, and PCT-Na separate validation datasets was worse than for the 18-term and 15-term PQM models. Hence, the 18-term PCM models are not recommended for use.

The 16-term PQM models were investigated along with the 15-term PQM models as the two most reasonable choices for models having the same quadratic terms for PCT-B, PCT-Li, and PCT-Na releases. However, the third quadratic term $\left(\mathrm{UO}_{3} \times \mathrm{ZnO}\right)$ is hard to explain from a glass science perspective. Further, this additional quadratic term did not substantially improve the fit or validation results of the 16-term PQM models compared to the 15-term PQM models. Hence, the 15-term PQM models were preferred.

Table 5.18 shows that the PCT-Na models fit best (highest $\mathrm{R}^{2}$ statistics), followed by the PCT-B and PCT-Li models. The difference in fits of the PCT-B, PCT-Li, and PCT-Na models presumably results from the increasing divergence in PCT-B, PCT-Li, and PCT-Na release values for the same glass as the releases decrease in magnitude (see Figure 5.4).

Based on the summarized results in Table 5.18 and discussions in Section 5.3 for PCT-B, Section 5.4 for PCT-Li, and Section 5.5 for PCT-Na, the 18-term PQM models were selected as the basis for the eventual recommended models (presented in Section 5.7) for predicting PCT-B, PCT-Li, and PCT-Na releases of HLW glasses. The model coefficients and results are given in Table 5.7 for PCT-B, Table 5.11 for PCT-Li, and Table 5.15 for PCT-Na. Some of the quadratic terms that appear in these models (see Table 5.17) are hard to understand based on glass science knowledge and experience. However, quadratic terms can be highly correlated with each other. This can lead to quadratic terms in PQM models that may not correspond to glass science knowledge and experience, but still improve the predictive performance of the models.

It is possible that the 18-term PQM models for PCT-B, PCT-Li, and PCT-Na over-fit the corresponding modeling datasets. Thus, the 15-term PQM models for PCT-B, PCT-Li, and PCT$\mathrm{Na}$ (listed in Tables 5.8, 5.12, and 5.16) were selected as the basis for the eventual second-choice models (presented in Section 5.7). These models have the advantage of including the same 15terms (13 linear and 2 quadratic) for PCT-B, PCT-Li, and PCT-Na releases. These models also have the advantage of the two quadratic terms $\left(\mathrm{Al}_{2} \mathrm{O}_{3} \times \mathrm{Al}_{2} \mathrm{O}_{3}\right.$ and $\left.\mathrm{Al}_{2} \mathrm{O}_{3} \times \mathrm{ZrO}_{2}\right)$ being understandable from a glass science perspective. 
The 13-component reduced LM models for PCT-B, PCT-Li, and PCT-Na under-predict higher PCT releases somewhat worse than the recommended and second-choice models. Hence, the reduced LM models were not selected as the recommended or second-choice models. However, the 13-component reduced LM models could be used as a baseline in assessing the recommended and second-choice models during future HLW glass formulation and waste form qualification work.

\subsection{Recommended and Second-Choice Models with Bias-Correction for PCT-B, PCT-Li, and PCT-Na Releases from HLW Glasses}

The 18-term PQM models for PCT-B, PCT-Li, and PCT-Na (discussed respectively in Sections 5.3.3, 5.4.3, and 5.5.3) and the 15-term PQM models for PCT-B, PCT-Li, and PCT-Na (discussed respectively in Sections 5.3.4, 5.4.4, and 5.5.4) were selected in Section 5.6 as firstand second-choice models for predicting PCT releases of HLW glasses. However, these models tend to under-predict PCT releases above the following values

$$
\begin{aligned}
& \text { PCT-B: Approximately } 0.5 \ln (\mathrm{g} / \mathrm{L}) \sim 1.65 \mathrm{~g} / \mathrm{L} \\
& \text { PCT-Li: Approximately } 0.5 \ln (\mathrm{g} / \mathrm{L}) \sim 1.65 \mathrm{~g} / \mathrm{L} \\
& \text { PCT-Na: Approximately } 1.0 \ln (\mathrm{g} / \mathrm{L}) \sim 2.72 \mathrm{~g} / \mathrm{L}
\end{aligned}
$$

as seen in Figures 5.15, 5.35, and 5.55 for the first-choice models, and in Figures 5.20, 5.40, and 5.60 for the second-choice models.

The relationships between PCT-B, PCT-Li, and PCT-Na releases and HLW glass compositions apparently are more complicated than can be represented by a global model (i.e., a single mathematical equation) of the linear, quadratic, and cubic forms considered over the whole WTP HLW glass composition region of interest. It was beyond the scope of the model development effort to investigate more advanced modeling methods that might provide solutions to this problem. Hence, an ad-hoc solution was adopted that modified the first- and secondchoice models from Section 5.6 to include bias-correction terms for PCT predictions above the values in Equation (5.7). Other possible solutions that would be more likely to develop unbiased models from the start are discussed in Section 11.1.

Three forms of equations were investigated to estimate the bias-correction

$$
\begin{gathered}
\hat{b} c_{i}=a_{0} \\
\hat{b} c_{i}=a_{0}+a_{1} y_{i} \\
\hat{b} c_{i}=a_{0}+a_{1} \hat{y}_{i}
\end{gathered}
$$


where $y_{i}$ is the natural logarithm of the measured PCT-B, PCT-Li, or PCT-Na release $[\ln (\mathrm{g} / \mathrm{L})]$ for the $i^{\text {th }}$ HLW glass in the modeling dataset; $\hat{y}_{i}$ is a model-predicted value $[\ln (\mathrm{g} / \mathrm{L})]$ for the $i^{\text {th }}$ HLW glass; $\hat{b} c_{i}$ is the estimated bias-correction for the $i^{\text {th }}$ HLW glass; $b c_{i}=y_{i}-\hat{y}_{i}$ is the "measured" bias-correction for the $i^{\text {th }}$ HLW glass; and $a_{0}$ and $a_{1}$ are regression coefficients estimated from the modeling data subset with measured PCT-B, PCT-Li, or PCT-Na values above the cutoff values in Equation (5.7). Equation (5.8c) had the worst bias-correction performance for PCT-B and PCT-Li. The slope in Equation (5.8b) was not statistically different from zero for PCT-B and PCT-Na, indicating that Equation (5.8a) should be used. For PCT-Li, Equation (5.8b) had the best bias-correction performance, but the performance of Equation (5.8a) was good. Hence, Equation (5.8a) was chosen to implement the bias-correction for PCT-B, PCT$\mathrm{Li}$, and PCT-Na models based on these observations, as well as its simplicity.

In summary, the bias-correction approach adopted was to add a bias-correction constant to (i) the 18-term PQM models to form the recommended 19-term PCT-B, PCT-Li, and PCT-Na models, and (ii) the 15-term PQM models to form the second-choice 16-term PCT-B, PCT-Li, and PCT-Na models. The bias-corrected forms of these models are given by

$$
\begin{gathered}
\ln \left(C_{B}\right), \ln \left(C_{L i}\right), \text { or } \ln \left(C_{B}\right)=\left\{\begin{array}{cc}
\hat{y} & \text { if } \hat{y} \leq \mathrm{PCT}-\mathrm{B}, \mathrm{Li}, \text { or Na cutoff } \\
\hat{y}+a_{0} & \text { if } \hat{y}>\text { PCT }-\mathrm{B}, \mathrm{Li}, \text { or Na cutoff }
\end{array} .\right. \\
\text { with } \hat{y}=\sum_{i=1}^{q} b_{i} x_{i}+\text { Selected }\left\{\sum_{i=1}^{q} b_{i i} x_{i}^{2}+\sum_{i<j}^{q-1} \sum_{j}^{q} b_{i j} x_{i} x_{j}\right\}
\end{gathered}
$$

which is a modification of the PQM model form given in Equation (5.2). The modification involves adding the bias-correction constant $\left(a_{0}\right)$ when the predicted PCT-B, PCT-Li, or PCT$\mathrm{Na}$ value before bias-correction $(\hat{y})$ is above the corresponding PCT-B, PCT-Li, or PCT-Na cutoff in Equation (5.7).

Tables 5.19 and 5.20 give the PCT-B model coefficients (including the bias-correction constant), coefficient standard deviations, and selected model fit and separate validation summary statistics for the recommended 19-term and second-choice 16-term models, respectively. Tables 5.21 and 5.22 give similar results for the PCT-Li recommended and secondchoice models. Tables 5.23 and 5.24 give similar results for the PCT-Na recommended and second-choice models. Table 5.25 compares selected summary statistics from fitting and validating the recommended 18-term PQM models and second-choice 15-term PQM models for PCT-B, PCT-Li, and PCT-Na without and with the bias-correction terms. The fit statistics summarized are $\mathrm{R}^{2}$, RMSE, and LOF $\mathrm{p}$-value, while $\mathrm{R}_{\mathrm{V}}^{2}$ and $\mathrm{RMSE} \mathrm{V}_{\mathrm{V}}$ are summarized for the separate validation sets. Other statistics from model fitting (i.e., $R_{A}{ }_{A}$ and $R^{2}$ ), data-splitting validation, and data-partitioning validation were not calculated because of the large amount of computation time that would have been required given the nature of the conditional biascorrection terms in Equation (5.9). Table 5.25 shows that the bias-corrected models have similar or slightly-improved model fit statistics, and marginally improved validation statistics for the separate validation sets. These outcomes are reasonable, given that the numbers of glasses with 
under-predicted PCT-B, PCT-Li, and PCT-Na releases are small enough that major changes in model fit and validation statistics were unlikely. Still, there is considerable value in having substantially corrected the tendency of the models to under-predict higher PCT releases, because this permits setting larger model validity constraints for PCT-B, PCT-Li, and PCT-Na (see Section 9).

Figures 5.65 and 5.66 show $\ln$ (PCT-B) predicted vs. measured plots for the recommended 19-term model and the second-choice 16-term model, each with bias-correction. Similar plots are shown in Figures 5.67 and 5.68 for the PCT-Li recommended and secondchoice models with bias correction, and in Figures 5.69 and 5.70 for the PCT-Na recommended and second-choice models with bias correction. These figures can be compared to the corresponding figures for recommended and second-choice models without bias correction (Figures 5.15 and 5.20 for PCT-B, Figures 5.35 and 5.40 for PCT-Li, and Figures 5.55 to 5.60 for PCT-Na). The comparisons show that the bias-correction terms are generally successful at removing the tendency for under-predicting larger PCT-B, PCT-Li, and PCT-Na releases. The scatter around the $45^{\circ}$ line for higher releases is similar in magnitude to that for lower releases.

Note in Figures 5.65 to 5.70 that the bias-corrected models still under-predict PCT-B, PCT-Li, and PCT-Na releases for the HLW-ALG-03 glass (which has measured PCT-B and PCT-Li releases above the corresponding DWPF-EA glass limits, and PCT-Na release close to the DWPF-EA glass limit). These observations are referred to in Section 9.2.1 in selecting the model validity upper bounds for applying the recommended and second-choice PCT-B, PCT-Li, and PCT-Na models with bias-corrections.

When the bias-correction term in the PCT-B, PCT-Li, or PCT-Na model is needed, its uncertainty must be accounted for along with the uncertainties of the remaining model coefficients in calculating the uncertainties of model predictions. Section C.7.5 in Appendix C discusses the calculation of statistical intervals to quantify uncertainties of the PCT models containing bias-correction terms.

\subsection{Example Illustrating PCT Model Predictions and Statistical Intervals}

This section contains examples to illustrate the use of selected models for PCT-B, PCT$\mathrm{Li}$, and PCT-Na to obtain predicted PCT releases for two specific HLW glass compositions (one each that requires and does not require applying the bias-correction terms). The models selected to illustrate for each of PCT-B, PCT-Li, and PCT-Na include (i) the 13-component reduced LM model (without bias correction), (ii) the recommended 19-term model (18-term PQM model with bias-correction term), and (iii) the second-choice 16-term model (15-term PQM model with biascorrection term). This section also describes how corresponding $90 \%$ UCIs and $90 \%$ SUCIs are calculated. The 90\% confidence levels associated with 90\% UCIs and 90\% SUCIs were chosen for illustration purposes only. The WTP project can use an appropriate confidence level depending on the use of the PCT-composition model and the type of statistical uncertainty expression. 
The first glass composition used in this example is HLW03-06, which was used previously in the Phase 1 IHLW models report (Kot et al. 2005a). The HLW03-06 composition yields PCT release predictions that do not require bias correction. The second glass composition used in this example is HLW06-15, which does require bias correction of predicted PCT releases. The 25-component compositions of HLW03-06 and HLW06-15 for PCT modeling are given in Table 5.2 in mass fraction format. To apply the PCT models to these compositions, the mass fractions of the 25 components must be converted to mass fractions (that sum to 1.0) of the 13 components appearing in the PCT-B, PCT-Li, and PCT-Na models. Mass fractions of the relevant components are then multiplied to obtain the quadratic terms of the 18-term and 15-term PQM models. Tables 5.26 and 5.27 contain the compositions of HLW03-06 and HLW06-15 prepared for use in the different PCT-B, PCT-Li, and PCT-Na models for HLW glasses.

For each of the PCT-B, PCT-Li, and PCT-Na models, predicted $\ln$ (PCT releases) are obtained by multiplying the composition in the format needed for the specific model by the coefficients for that model, then summing the results. The coefficients for the 13-component LM models (without bias correction), the recommended 19-term models with bias-correction term, and the second-choice 16-term models with bias-correction term are given in Tables 5.6, 5.19, and 5.20 for PCT-B, in Tables 5.10, 5.21, and 5.22 for PCT-Li, and in Tables 5.14, 5.23, and 5.24 for PCT-Na. Using vector notation, the predicted values are calculated by

$$
\hat{y}(\boldsymbol{a})=\boldsymbol{a}^{\mathrm{T}} \boldsymbol{b},
$$

where $\boldsymbol{a}$ is the composition of HLW03-06 from Table 5.26 or HLW06-15 from Table 5.27, formatted to match the terms in a given model, the superscript $\mathrm{T}$ represents a vector transpose, and $\boldsymbol{b}$ is the vector of coefficients for a given model. The predicted $\ln$ (PCT release) values from each of the nine IHLW PCT models (three each for PCT-B, PCT-Li, and PCT-Na) are listed in the third columns of Tables 5.28 and 5.29 for the HLW03-06 and HLW06-15 compositions, respectively. The predicted $\ln (\mathrm{PCT}$ releases $)$ in $\ln (\mathrm{g} / \mathrm{L})$ units are easily converted to the usual PCT release units of $\mathrm{g} / \mathrm{L}$ by exponentiation. The fourth columns of Tables 5.28 and 5.29 contain the predicted PCT releases in $\mathrm{g} / \mathrm{L}$ units for the HLW03-06 and HLW06-15 compositions, respectively. However, as discussed in Section C.7 of Appendix C, these back-transformed PCT release predictions in $\mathrm{g} / \mathrm{L}$ units should be considered estimates of the true median (not the true mean) of the distribution of PCT releases that would result if the PCT were repeated multiple times using separately batched and melted samples of the HLW03-06 or HLW06-15 glass.

Equation (C.31a) in Section C.7.1 of Appendix C can be used to calculate a CL\% upper confidence interval (CL\% UCI) for the true mean of $\ln$ (PCT releases) for the HLW03-06 and HLW06-15 glass compositions for each of the PCT models for HLW glasses. A CL\% UCI is of interest because the contract requirements are that PCT releases must be less than the DWPF-EA glass limits, namely PCT-B $\leq 16.695 \mathrm{~g} / \mathrm{L}, \mathrm{PCT}-\mathrm{Li} \leq 9.565 \mathrm{~g} / \mathrm{L}$, and PCT-Na $\leq 13.346 \mathrm{~g} / \mathrm{L}$. For the illustrations to follow, we use $\mathrm{CL} \%=90 \%$. In the notation of Equation (C.31a):

- $\mathrm{CL} \%=100(1-\alpha) \%=90 \%$, so that $\alpha=0.10$. 
- Vector $\boldsymbol{a}$ contains entries corresponding to the terms in a given PCT model, which are calculated using the compositions of HLW06-03 and HLW06-15 in Tables 5.26 and 5.27.

- Matrix $\boldsymbol{A}$ is formed from the data matrix used in the regression that generated a given PCT model. Matrix $\boldsymbol{A}$ has the number of rows in the PCT-B, PCT-Li, or PCT-Na modeling dataset $(264,250$, and 266, respectively) and the number of columns corresponding to the number of terms in a given PCT-B, PCT-Li, or PCT-Na release model. Each column is calculated according to the corresponding term in the model using the HLW glass compositions in the PCT modeling dataset.

Equation (C.36) is used to calculate an $90 \%$ UCI on $\ln ($ PCT release) in units of $\ln (\mathrm{g} / \mathrm{L})$, with the specific formula depending on whether the predicted value before bias correction is above or below the cutoff value for applying the bias-correction. The cutoff values are listed in Equation (5.7). The $\boldsymbol{C}_{U}$ portion of Equation (C.36) is the variance-covariance matrix for the estimated model coefficients, as discussed near the end of Section C.7 of Appendix C. The variance-covariance matrices for the PCT models used in the illustrative example are listed in Tables D.1 to D.9 of Appendix D. The quantity $\sqrt{\boldsymbol{a}^{T} \boldsymbol{C}_{U} \boldsymbol{a}}$ is the standard deviation of a model prediction considered as a mean value when the bias-correction term is not needed. The value of this quantity for each model applied to the HLW03-06 composition is given in the fifth column of Table 5.28. The quantity $\sqrt{\boldsymbol{a}^{T} \boldsymbol{C}_{U} \boldsymbol{a}+\hat{\sigma}_{a_{0}}^{2}}$ is the the standard deviation of a model prediction considered as a mean value when the bias-correction term is needed. The value of this quantity for each model applied to the HLW06-15 composition is given in the fifth column of Table 5.29.

The $90 \%$ UCI values for the true mean $\ln (\mathrm{PCT}$ release) in units of $\ln (\mathrm{g} / \mathrm{L})$ for the HLW03-06 and HLW06-15 compositions based on the IHLW PCT-B, PCT-Li, and PCT-Na models are given in the sixth columns of Tables 5.28 and 5.29 for the HLW03-06 and HLW0615 compositions, respectively. Exponentiating the resulting 90\% UCIs on the true mean value in $\ln (\mathrm{g} / \mathrm{L})$ units yields $90 \%$ UCIs for the true median in $\mathrm{g} / \mathrm{L}$ units. For example, the recommended 19-term model (18-term PQM model plus bias-correction term) for PCT-Na has $-1.6247 \mathrm{ln}(\mathrm{g} / \mathrm{L})$ as the upper limit of the 90\% UCI on the true mean $\ln$ (PCT-Na release) for HLW03-06. However, note that the bias-correction is not applied for HLW03-06. Then $\mathrm{e}^{-1.6247}=0.197 \mathrm{~g} / \mathrm{L}$ is the upper limit of the $90 \%$ UCI on the true median PCT-Na release. The seventh columns of Tables 5.28 and 5.29 contain 90\% UCIs for the true median PCT releases from the HLW03-06 and HLW06-15 glass compositions, respectively, based on the different IHLW PCT models. Note that the 90\% UCI values in $\mathrm{g} / \mathrm{L}$ units using the different IHLW PCT models for both HLW03-06 and HLW06-15 are well below the PCT release limits for DWPF-EA glass (i.e. $16.695 \mathrm{~g} / \mathrm{L}$ for PCT-B, $9.565 \mathrm{~g} / \mathrm{L}$ for PCT-Li, and $13.346 \mathrm{~g} / \mathrm{L}$ for PCT-Na).

As discussed in Section C.7 of Appendix C, there are times when a CL\% simultaneous confidence interval (CL\% SUCI) may be preferred rather than a CL\% UCI. This is particularly true when the regression model (property-composition model) is to be used a large number of times for various glass compositions from a specified composition region. Equation (C.38) in 
Section C.7.5 of Appendix C can be used to calculate a 90\% SUCI for the true mean of $\ln (\mathrm{PCT}$ release) for each of any number of glass compositions in the model validity region. Then, the resulting SUCIs for those glass compositions simultaneously have $90 \%$ confidence for containing their true mean values. The $90 \%$ SUCI values for the true mean $\ln$ (PCT release) in units of $\ln (\mathrm{g} / \mathrm{L})$ for the HLW03-06 and HLW06-15 compositions based on the IHLW PCT models are given in the eighth columns of Table 5.28 and 5.29, respectively. Note that the calculations for HLW03-06 did not require bias-correction whereas the results for HLW06-15 did require bias-correction. The corresponding portion of Equation (C.38) was used for the calculations without and with bias-correction. Exponentiating the resulting $90 \%$ SUCIs for the mean in $\ln (\mathrm{g} / \mathrm{L})$ units yields $90 \%$ SUCIs for the median in $\mathrm{g} / \mathrm{L}$ units. The ninth columns of Tables 5.28 and 5.29 contain 90\% SUCIs for the true median PCT release from the HLW03-06 and HLW06-15 glass compositions based on the IHLW PCT models. Note that the 90\% SUCIs are larger than the corresponding $90 \%$ UCIs, because of the simultaneous confidence protection for multiple uses of the same model. However, the 90\% SUCI values in $\mathrm{g} / \mathrm{L}$ for both HLW03-06 and HLW06-15 using the different IHLW PCT models are well below the PCT release limits for EA glass mentioned above.

\subsection{Suitability of the Recommended IHLW PCT-B, PCT-Li, and PCT-Na Models for Application by the WTP Project}

The 19-term models (18-term PQM models each with a bias-correction term) for PCT-B, PCT-Li, and PCT-Na discussed in Section 5.7 are recommended for use by the WTP project as the best models currently available for predicting PCT releases from HLW glasses. Also, 16term models (15-term PQM models with bias-correction terms) were suggested as second-choice models in Section 5.7. The recommended and second-choice PCT models appear to yield generally unbiased predictions after bias-correction, although the predictions still have considerable uncertainty. However, the PCT-B, PCT-Li, and PCT-Na models still noticeably under-predict releases for HLW-ALG-03 even with the bias-correction terms applied. HLWALG-03 is the only glass in the PCT modeling dataset that had measured PCT-B and PCT-Li releases greater than the corresponding limits of the DWPF-EA glass. HLW-ALG-03 also had measured PCT-Na release below but close to the corresponding limit of the DWPF-EA glass.

Because the recommended and second-choice models with bias-correction for PCT-B, PCT-Li, and PCT-Na still under-predict for HLW-ALG-03 (which has PCT releases beyond or near the DWPF-EA glass limit), restrictions must be placed on the validity regions for these models. The model validity region constraints are discussed in Section 9.

Because of the magnitudes of uncertainties in the PCT data (i.e., from making simulated HLW glasses, PCT testing, and chemical analysis of leachates), as well as LOF of the recommended PCT-B, PCT-Li, and PCT-Na models, prediction uncertainties for the models are relatively large. Figures 5.71, 5.72, and 5.73 display the prediction standard deviations versus predicted values [both in $\ln (\mathrm{g} / \mathrm{L})$ units] for the HLW glass compositions in the PCT-B, PCT-Li, and PCT-Na modeling datasets. The prediction standard deviations for modeling dataset glasses range approximately from 0.05 to $0.24 \ln (\mathrm{g} / \mathrm{L})$ for the recommended PCT-B model, from 0.04 to $0.21 \ln (\mathrm{g} / \mathrm{L})$ for the recommended PCT-Li model, and from 0.03 to $0.21 \ln (\mathrm{g} / \mathrm{L})$ for the 
recommended PCT-Na model. Note that these are standard deviations of model predictions considered as the mean PCT release value for a given glass. Standard deviations of predictions considered as individual determinations of PCT release are larger, ranging from approximately 0.21 to $0.31 \ln (\mathrm{g} / \mathrm{L})$ for the recommended PCT-B model, from 0.18 to $0.27 \ln (\mathrm{g} / \mathrm{L})$ for the recommended PCT-Li model, and from 0.19 to $0.28 \ln (\mathrm{g} / \mathrm{L})$ for the recommended PCT-Na model. Note also that prediction standard deviations will be larger for HLW glass compositions as their distance from glasses in the PCT modeling datasets increases. Finally, the total uncertainty in predictions with the recommended PCT-B, PCT-Li, and PCT-Na models will depend on the type of statistical interval used (see Section C.7 of Appendix C).

Unless different glass compositions (e.g., with higher waste loadings) are pursued, it is relatively easy to formulate HLW glasses with PCT-B, PCT-Li, and PCT-Na releases substantially below the WTP contract limits associated with the DWPF-EA glass. The model validity upper bounds for the recommended and second-choice PCT-B, PCT-Li, and PCT-Na models are 6.61, 4.27, and 5.53 g/L, respectively (see Section 9.2.1). These model validity upper bounds should not be overly limiting for glass formulation, product control, and product compliance during WTP HLW vitrification operations. It is unclear whether the relatively large prediction uncertainties for PCT models will overly restrict WTP HLW vitrification operations. The ultimate suitability of the recommended PCT-B, PCT-Li, and PCT-Na models for HLW glass formulation, glass former addition decisions during production, and demonstrating compliance with WASRD Specification 4.8.1.2 (DOE-RW 2002) will be decided by separate, future WTP project work.

The impact of prediction uncertainties for IHLW Phase 1 PCT-B, PCT-Li, and PCT-Na models (Kot et al. 2005a) on the ability to demonstrate compliance with the WAPS 1.3 specification was previously addressed in Section 6.3 of Piepel et al. (2005). In that work, the HLW glasses expected to be produced in the WTP HLW vitrification plant were shown to have PCT-B, PCT-Li, and PCT-Na releases sufficiently below the DWPF-EA glass limits, even after accounting for conservative composition and model uncertainties. The impact of HLW glass composition uncertainties and model uncertainties for the recommended PCT-B, PCT-Li model, and PCT-Na models (Section 5.7) on satisfying WASRD 4.8.1.2 is planned to be addressed as part of the Technical Scoping Statement (TSS) B-6270 work scope of the River Protection Project-Waste Treatment Plant Support Program at PNNL. The impacts are also planned to be addressed as part of the second iteration of HLW glass formulation algorithm development work planned by WTP project staff. The first iteration of that work (Vienna and Kim 2007) utilized the IHLW Phase 1 PCT-B and PCT-Na models (Kot et al. 2005a). 


\section{SECTION 6 \\ MODELS RELATING ONE-PERCENT CRYSTAL FRACTION TEMPERATURE (T $\left.{ }_{1 \%}\right)$ TO HLW GLASS COMPOSITION}

This section documents the development and validation of property-composition models and corresponding uncertainty expressions for predicting the temperature at which the equilibrium crystal fraction is one volume percent (vol\%) of the molten high level waste (HLW) glass $\left(\mathrm{T}_{1 \%}\right)$. For operation of the WTP HLW vitrification facility, the processing constraint is $\mathrm{T}_{1 \%}$ $\leq 950^{\circ} \mathrm{C}$ for all crystalline phases (Kot and Pegg 2001). This constraint will be implemented using $\mathrm{T}_{1 \%}$ property-composition models and corresponding uncertainty expressions. A preliminary $\mathrm{T}_{1 \%}$ model for spinel crystalline phases was developed during Phase 1 of the IHLW modeling work (Kot et al. 2005a). A revised spinel $\mathrm{T}_{1 \%}$ model was later developed during what

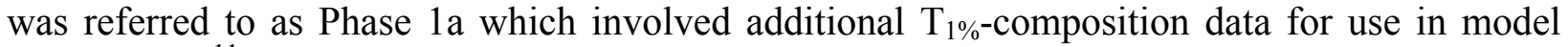
development ${ }^{11}$. The $\mathrm{T}_{1 \%}$ models and uncertainty expressions presented in this section were developed as part of the Phase 2 IHLW property modeling efforts. They were developed and validated using composition and $\mathrm{T}_{1 \%}$ data collected on simulated HLW glasses. Some of these glasses were included in the Phase 1 and Phase 1a modeling work, but others are from studies conducted before and after the Phase 1 and Phase 1a work. The simulated HLW glasses used for Phase 2 model development and model validation are discussed briefly in Section 6.1 (because they have already been described in detail in Section 2.1). Because of the compositional space defined for the test glasses, the primary crystalline phase is spinel, with other phases (e.g., zirconia and thorium-containing phases) occurring less frequently. In fact, there were only sufficient data to develop a spinel $\mathrm{T}_{1 \%}$-composition model. Section 11.2 provides

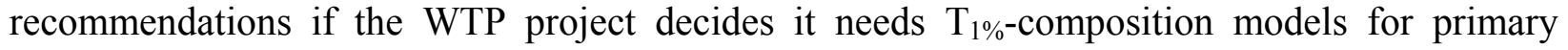
crystalline phases other than spinel.

Section 6.1 summarizes the data used to develop and validate the spinel $\mathrm{T}_{1 \%}$-composition models for HLW glasses. Section 6.2 presents the model forms for spinel $\mathrm{T}_{1 \%}$ that were investigated. Section 6.3 summarizes the results for full and reduced linear mixture (LM) models. Section 6.4 summarizes the results for two partial quadratic mixture (PQM) models. Section 6.5 presents results from models fitted to a subset of the spinel $\mathrm{T}_{1 \%}$ data without any secondary crystalline phases in addition to spinel. Section 6.6 summarizes and compares the results of all models considered and selects recommended and second-choice models. Section 6.7 illustrates for selected models the calculation of spinel $\mathrm{T}_{1 \%}$ predictions and the uncertainties in those predictions. Section 6.8 briefly discusses the suitability of the spinel $\mathrm{T}_{1 \%}$ models recommended for use by the WTP Project. Appendix C discusses the statistical methods and summary statistics used to develop, evaluate, and validate the several model forms investigated, as well as statistical equations for quantifying the uncertainties in spinel $\mathrm{T}_{1 \%}$ predictions made with the selected models.

11 The Phase 1a spinel $\mathrm{T}_{1 \%}$ model was only documented in an informal report provided to the WTP project and other project participants, and hence cannot be referenced. 


\section{1 $T_{1 \%}$ Data Used for Model Development and Validation}

The data used for developing spinel $\mathrm{T}_{1 \%}$-composition models are discussed in Section 6.1.1. The approaches and data used for validating the models are discussed in Sections 6.1.2 and 6.1.3.

\subsubsection{Model Development Data for $\mathbf{T}_{1 \%}$}

The data available for developing $\mathrm{T}_{1 \%}$-composition models consist of (i) glass compositions, (ii) volume percent (vol\%) crystallinity values, and (iii) primary (and secondary crystalline phases, if any) for 247 HLW glasses heat-treated at various temperatures. For each HLW glass, heat-treatment temperatures were selected to generate vol\% crystallinity values below and above 1 vol\%. These (temperature, vol\% crystallinity) data pairs then provided a basis for estimating the $\mathrm{T}_{1 \%}$ value for each glass (using the method described in Section E.1 of Appendix E). The 247 glasses with crystallinity data included the simulated HLW glasses denoted HLW02, HLW03, HLW05, HLW06, HLW07, and HLW-ALG. The glass groups denoted HLW04, HLW98, and Actual (glasses made from actual HLW samples) did not have crystallinity data. Further details concerning these studies and the respective datasets are given in Section 2.1.

As discussed previously, Table 4.3 contains the (temperature, vol\% crystallinity) data for the 247 HLW glasses. Table 4.4 shows the primary crystalline phase (and any secondary phases) in the heat-treated glasses, as well as $\mathrm{T}_{1 \%}$ values. It is seen from Table 4.4 that the spinel is the primary phase for the majority of HLW glasses. However, there were many glasses with other primary phases, or in some cases insufficient data to estimate $\mathrm{T}_{1 \%}$. The Vitreous State Laboratory (VSL) recommended 78 glasses for removal from the $\mathrm{T}_{1 \%}$-composition database for purposes of modeling spinel $\mathrm{T}_{1 \%}$. These 78 glasses typically had primary crystalline phases that were not spinel, or they had observed crystallinity levels sufficiently below $1 \mathrm{vol} \%$ such that it was not possible to accurately determine $\mathrm{T}_{1 \%}$ values. Hence, the tentative database for developing spinel $\mathrm{T}_{1 \%}$ models as functions of HLW glass compositions consisted of data for $247-78=169$ glasses. Note that Table 4.1 shows 172 HLW glasses have a $\mathrm{T}_{1 \%}$ value with spinel as the primary crystalline phase. However, three of these glasses (HLW02-10, HLW07-07, and HLW07-35) were identified by VSL to be excluded from the spinel $\mathrm{T}_{1 \%}$ modeling dataset. The glass HLW02-10 was excluded because the $\mathrm{T}_{1 \%}$ value was estimated by large extrapolation (i.e., $554^{\circ} \mathrm{C}$ vs. $700^{\circ} \mathrm{C}$, the lowest heat-treatment temperature). The other two glasses (HLW07-07 and HLW07-35) were excluded because of the presence of substantial amounts of crystalline phases other than spinel.

\section{Assessment of 169 Available Glasses with Spinel $\mathrm{T}_{1 \%} \underline{\text { Data }}$}

Prior to the start of model development, the $169 \mathrm{HLW}$ glasses with spinel $\mathrm{T}_{1 \%}$ data were graphically assessed to determine (i) if any glasses had outlying compositions, and (ii) which components had sufficient ranges and distributions of values to support separate model terms. Figure 6.1 displays plots of the mass fraction values for 57 components in the 169 HLW glasses 
with $\mathrm{T}_{1 \%}$ data. On each plot in Figure 6.1, the $\mathrm{x}$-axis represents the mass fraction values of an HLW glass component. The y-axis shows an index value representing each HLW glass composition, which aids in spreading out the data points to avoid over-plotting. The plotting symbols correspond to the nine groups of HLW glass data discussed in Sections 2.1.1 to 2.1.9. For comparison purposes, the vertical bars in Figure 6.1 represent the ranges over which 18 "main" components $\left(\mathrm{Al}_{2} \mathrm{O}_{3}, \mathrm{~B}_{2} \mathrm{O}_{3}, \mathrm{CdO}, \mathrm{Cr}_{2} \mathrm{O}_{3}, \mathrm{Fe}_{2} \mathrm{O}_{3}, \mathrm{Li}_{2} \mathrm{O}, \mathrm{MnO}, \mathrm{Na}_{2} \mathrm{O}, \mathrm{NiO}, \mathrm{Sb}_{2} \mathrm{O}_{3}, \mathrm{SeO}_{2}\right.$, $\mathrm{SiO}_{2}, \mathrm{SrO}, \mathrm{ThO}_{2}, \mathrm{Tl}_{2} \mathrm{O}, \mathrm{UO}_{3}, \mathrm{ZnO}$ and $\mathrm{ZrO}_{2}$ ) were varied in one or more of the statistically designed test matrices included in the dataset.

In assessing Figure 6.1, several components appear to have outlying values, but essentially all of these cases are for components with the largest mass fraction of approximately $0.005(0.5 \mathrm{wt} \%)$ or less. Many such components (except ones involved in spinel such as $\mathrm{Cr}_{2} \mathrm{O}_{3}$ and $\mathrm{NiO}$ ) are generally not expected to significantly impact spinel crystallinity. Hence, outliers for minor components not expected to affect spinel crystallinity are not identified and discussed. Figure 6.1 shows that of all the components with maximum values near or above $1 \mathrm{wt} \%$, only $\mathrm{La}_{2} \mathrm{O}_{3}$ has a clear outlier. Glass HLW06-31 has $\mathrm{La}_{2} \mathrm{O}_{3}$ at $1.234 \mathrm{wt} \%$ while all other glasses in the spinel crystallinity dataset have $\mathrm{La}_{2} \mathrm{O}_{3}$ compositions of $0.53 \mathrm{wt} \%$ or less. Hence, HLW06-31 was excluded from the spinel $\mathrm{T}_{1 \%}$ modeling dataset, thereby leaving 168 glasses for spinel $\mathrm{T}_{1 \%}$ modeling.

It is also worthwhile to note from Figure 6.1 that substantial portions of the ranges of $\mathrm{F}$, $\mathrm{K}_{2} \mathrm{O}, \mathrm{MgO}, \mathrm{Nd}_{2} \mathrm{O}_{3}$, and $\mathrm{TiO}_{2}$ result from HLW06 glasses. This could impact the ability to properly account for the impacts of these components on spinel crystallinity during $\mathrm{T}_{1 \% \text { - }}$ composition modeling.

Figure 6.2 is similar to Figure 6.1, except it only shows the distributions of component values for the 168 remaining HLW glasses in the spinel $\mathrm{T}_{1 \%}$ dataset. As part of the data assessment, 24 of the initial 57 components have sufficient ranges and distributions of mass fractions to support separate terms in spinel $\mathrm{T}_{1 \%}$ models. Thus, 25 components were identified for initial spinel $\mathrm{T}_{1} \%$ modeling: $\mathrm{Al}_{2} \mathrm{O}_{3}, \mathrm{~B}_{2} \mathrm{O}_{3}, \mathrm{CaO}, \mathrm{CdO}, \mathrm{Cr}_{2} \mathrm{O}_{3}, \mathrm{Fe}_{2} \mathrm{O}_{3}, \mathrm{~K}_{2} \mathrm{O}, \mathrm{La}_{2} \mathrm{O}_{3}, \mathrm{Li} 2 \mathrm{O}, \mathrm{MgO}$, $\mathrm{MnO}, \mathrm{Na}_{2} \mathrm{O}, \mathrm{NiO}, \mathrm{PbO}, \mathrm{Sb}_{2} \mathrm{O}_{3}, \mathrm{SeO}_{2}, \mathrm{SiO}_{2}, \mathrm{SrO}, \mathrm{ThO}_{2}, \mathrm{TiO}_{2}, \mathrm{Tl}_{2} \mathrm{O}, \mathrm{UO}_{3}, \mathrm{ZnO}, \mathrm{ZrO}_{2}$, and Others (the sum of all remaining minor components).

Figure 6.3 shows a scatterplot matrix of the 18 "main" components of the 168 glasses remaining in the spinel T1\% modeling dataset after removing the one outlying composition. Two patterns in any given scatterplot within the scatterplot matrix are of interest. First, any pattern that shows a strong positive or negative correlation between components is important to note. We defer discussion of strong correlations between pairs of HLW glass components until pairwise correlation coefficients are discussed subsequently. Second, any "hole" in a scatterplot indicates lack of data for those combinations of pairs of components. The main "holes" seen in Figure 6.3 are for $\mathrm{SeO}_{2}$ against most other main components and $\mathrm{Tl}_{2} \mathrm{O}$ against most other main components. Pair combinations that include these two main components mainly show large bands of empty space where there are no observations.

An additional way of assessing strong correlations between pairs of HLW glass components is through the calculation of correlation coefficients. These can vary from -1.0 
(perfect negative correlation) to 0 (no correlation) to 1.0 (perfect positive correlation). Correlation coefficients equal or larger than 0.6 (in absolute value) indicate a strong linear relationship among the two components involved. Correlation coefficients were computed for all pairs of the 25 components selected for initial spinel $\mathrm{T}_{1 \%}$ modeling. The component pairs with correlations larger (in absolute value) than 0.60 are

$\begin{array}{ll}\mathrm{CaO} \text { and } \mathrm{MgO} & 0.71 \\ \mathrm{CaO} \text { and } \mathrm{TiO}_{2} & 0.63 \\ \mathrm{~K}_{2} \mathrm{O} \text { and } \mathrm{MgO} & 0.91 \\ \mathrm{~K}_{2} \mathrm{O} \text { and } \mathrm{PbO} & 0.76 \\ \mathrm{~K}_{2} \mathrm{O} \text { and } \mathrm{TiO}_{2} & 0.95 \\ \mathrm{MgO} \text { and } \mathrm{TiO}_{2} & 0.98 \\ \mathrm{PbO} \text { and } \mathrm{TiO}_{2} & 0.72\end{array}$

Note that none of these pairwise correlations involve any of the 18 "main" components varied in one or more of the statistically designed matrices. Thus, the components involved in these high pairwise correlations were varied in groups in the statistically designed matrices. This accounts for why all of the preceding pairwise correlations are positive. Such high pairwise correlations can make it difficult for regression methods to properly separate the effects of the components on the response variable (e.g., spinel $\mathrm{T}_{1 \%}$ ). Thus, these high pairwise correlations need to be kept in mind in developing spinel $\mathrm{T}_{1 \%}$-composition models for HLW glasses.

\section{$\underline{\text { Spinel } \mathrm{T}_{1}} \underline{\text { Modeling Dataset }}$}

Table 6.1 lists the Glass ID, Group ID, and normalized glass compositions for the 168 simulated HLW glasses in the 25-component forms used for spinel $\mathrm{T}_{1 \%}$ model development. The Group ID column of Table 6.1 indicates the subset of data that each glass is associated with (see Sections 2.1.1 to 2.1.9). The glass compositions in Table 6.1 are the normalized mass fractions (mf) of the 25 components previously identified as having sufficient data to support a separate model term if needed. These components are $\mathrm{Al}_{2} \mathrm{O}_{3}, \mathrm{~B}_{2} \mathrm{O}_{3}, \mathrm{CaO}, \mathrm{CdO}, \mathrm{Cr}_{2} \mathrm{O}_{3}, \mathrm{Fe}_{2} \mathrm{O}_{3}, \mathrm{~K}_{2} \mathrm{O}$, $\mathrm{La}_{2} \mathrm{O}_{3} . \mathrm{Li}_{2} \mathrm{O}, \mathrm{MgO}, \mathrm{MnO}, \mathrm{Na}_{2} \mathrm{O}, \mathrm{NiO}, \mathrm{PbO}, \mathrm{Sb}_{2} \mathrm{O}_{3}, \mathrm{SeO}_{2}, \mathrm{SiO}_{2}, \mathrm{SrO}, \mathrm{ThO}_{2}, \mathrm{TiO}_{2}, \mathrm{Tl}_{2} \mathrm{O}, \mathrm{UO}_{3}$, $\mathrm{ZnO}, \mathrm{ZrO}_{2}$, and Others.

Table 6.2 contains the data relating temperature of heat-treated glass samples to the volume $\%$ of crystallinity (vol \%) at equilibrium for each of the 168 glasses of the spinel $\mathrm{T}_{1 \%}$ modeling dataset. The cells in Table 6.2 shaded gray were excluded from use in the process for estimating $\mathrm{T}_{1 \%}$, which is described and illustrated in Appendix E.

Table 6.3 lists the intercept and slope [ $a_{0}$ and $a_{1}$ from Equation (E.1) in Appendix E] for each of the $168 \mathrm{HLW}$ glasses in the spinel $\mathrm{T}_{1 \%}$ modeling dataset, as well as the estimated $\mathrm{T}_{1 \%}$ value obtained using Equation (E.1), the standard deviation of the estimated spinel $\mathrm{T}_{1 \%}$ value, and the number of data points involved in the development of Equation (E.1) for each glass. Figure 6.4 is a histogram of the estimated spinel $\mathrm{T}_{1 \%}$ values for the 168 glasses in the spinel $\mathrm{T}_{1 \%}$ modeling dataset. This histogram shows that the estimated spinel $\mathrm{T}_{1 \%}$ values are well distributed about the $\mathrm{T}_{1 \%}$ processability limit of $950^{\circ} \mathrm{C}$ (marked with a vertical red line), and that the distribution includes glasses with estimated spinel $\mathrm{T}_{1 \%}$ values below, close to, and above the 
specified property limit. Such a distribution is desirable because models generated using a given dataset are typically more accurate within the range of response values used for model development than they are when extrapolated beyond the range of responses used for model development. Thus, models developed using data that are well distributed around a specified property limit are generally better able to discern between glasses that satisfy the property limit versus those that do not.

Of the 168 glasses listed in Tables 6.1 and 6.3, 144 were identified as having spinel as the primary crystalline phase, with the remaining 24 glasses having spinel as the primary crystalline phase plus some secondary crystalline phase. Model development for spinel $\mathrm{T}_{1 \%}$ was primarily conducted using all 168 HLW glasses listed in Table 6.1. However, as a way of comparing model performance among the contending model forms, some modeling work was conducted using just the 144 spinel-only glasses. Resulting models were then applied to the 24 spinel-plusother-crystal glasses to further assess model performance. A column in Table 6.3 identifies the primary crystalline phase as well as any secondary phases for each glass. This column thus indicates which glasses were spinel-only versus spinel-plus-other-crystals.

\section{$\underline{\text { Replicate and Near-Replicate Spinel } \mathrm{T}_{1}} \underline{\underline{\text { Data }}}$}

Table 6.4 lists the sets of replicate (or near-replicate) glasses, based on compositions, in the spinel $\mathrm{T}_{1 \%}$ modeling dataset for HLW glasses. Near-replicate sets involve glasses that were intended to be replicates in composition but that have very slight differences for some component values. The differences are typically due to round-off or renormalization when the glasses involved are from different studies. Near-replicates were treated as true replicates for model development and evaluation purposes. A total of 15 replicate sets (14 pairs and one set of three) were identified in the spinel $\mathrm{T}_{1 \%}$ modeling dataset and are represented in Table 6.4. Also listed in Table 6.4 are the corresponding estimated spinel $\mathrm{T}_{1 \%}$ values, an estimate of the standard deviation (SD) for each replicate set, and a pooled estimate of SD based on the replicate sets. A pooled SD combines the SDs over the replicate sets so that a more accurate, combined estimate of the $\mathrm{SD}$ is obtained. The pooled $\mathrm{SD}=26.89^{\circ} \mathrm{C}$ is an estimate of the uncertainty in estimated spinel $\mathrm{T}_{1} \%$ values. This pooled SD includes uncertainties due to batching and melting the glasses, measuring melt temperatures and vol\%-crystallinity, as well as developing and applying the fitted versions of Equation (E.1) to obtain estimated spinel $\mathrm{T}_{1 \%}$ values. These sets of replicate glasses also allowed for model lack-of-fit (LOF) tests, conducted in connection with model development regressions (discussed subsequently).

\subsubsection{Primary Model Validation Approach and Data}

The primary model validation approach for spinel $\mathrm{T}_{1 \%}$ modeling was based on splitting the 168 glasses of the spinel $\mathrm{T}_{1 \%}$ modeling dataset into five modeling subsets and five corresponding validation subsets. The five modeling/validation splits of the HLW glasses in the spinel $\mathrm{T}_{1 \%}$ modeling dataset were formed as follows.

- The 31 glasses in the 15 replicate sets were set aside so they would always be included in each of the five model development subsets for spinel $\mathrm{T}_{1 \%}$. This was done so that 
replicate sets would not be split between modeling and validation subsets, thus negating the intent to have validation glasses different than model development glasses.

- The remaining $168-31=137$ data points (glasses) were ordered from smallest to largest according to their estimated spinel $\mathrm{T}_{1 \%}$ values in Table 6.3. The 137 ordered data points were numbered $1,2,3,4,5,1,2,3,4,5$, etc. All of the 1's formed the first model validation set, while all of the remaining points formed the first model development dataset. Similarly, all of the 2's, 3's, 4's, and 5's respectively formed the second, third, fourth, and fifth model validation sets. In each case, the remaining non-2's, non-3's, non4's, and non-5's formed, respectively, the second, third, fourth, and fifth model development datasets. Accordingly, two of these splits contained 28 glasses for validation and 109 glasses for modeling, and three of the splits contained 27 glasses for validation and 110 glasses for modeling.

- The 31 replicate glasses were added to each of the five modeling subsets, yielding two splits with 140 glasses for modeling and 28 glasses for validation, and three splits with 141 glasses for modeling and 27 glasses for validation. The last column of Table 6.3 specifies the validation subsets for the five modeling/validation splits for the primary validation approach for spinel $\mathrm{T}_{1 \%}$ model development.

Data splitting was chosen as the primary validation approach because there was a limited amount of other temperature vs. vol\%-crystallinity data available for model validation purposes (see Section 6.1.3). Furthermore, not all of the separate validation glasses had compositions that satisfied all of the constraints defining the WTP IHLW composition region and meeting quality assurance $(\mathrm{QA})$ requirements.

\subsubsection{Secondary Model Validation Approach and Data}

The secondary model validation approach was based on partitioning the 168-glass spinel $\mathrm{T}_{1 \%}$ modeling dataset into a modeling subset and a validation subset. The modeling subset included all glasses used in statistically-designed groups of the data plus other glasses selected by VSL. These included 53 glasses from the HLW02 data matrix, the 37 glasses from the HLW03 data matrix, 2 glasses from the HLW06 data matrix, 23 from the HLW07 data matrix, and $9 \mathrm{HLW}-\mathrm{ALG}$ glasses. Together, these yielded a modeling subset of 124 glasses. The remaining $(168-124)=44$ glasses (which consist of actively-designed glasses) were used as the validation subset.

The data-splitting approach discussed in Section 6.1.2 is considered the primary validation approach because it comes closer to validating the spinel $\mathrm{T}_{1 \%}$ models of interest, namely those fitted to all 168 modeling data points. The primary validation approach fits spinel $\mathrm{T}_{1 \%}$ models using 140 or 141 of the 168 modeling data points and validates with the remaining 28 or 27 data points, and does so five times. The secondary approach (data partitioning) fits models with 124 glasses and validates with 44 glasses. Hence, the primary validation approach comes closer to validating the spinel $\mathrm{T}_{1 \%}$ models of interest, namely those fitted to all 168 data points. 
The secondary validation approach is desirable because it uses mostly statisticallydesigned glasses to fit models, and actively-designed glasses to validate the models. Activelydesigned glasses tend to be more clustered in composition space, and can have strong or even perfect correlations between glass components. These aspects make actively-designed glasses somewhat less desirable for model development, but reasonable for model validation.

\subsubsection{Separate Data for Validating Spinel $\mathbf{T}_{1 \%}$}

There were 39 glasses not used for developing spinel $\mathrm{T}_{1 \%}$ models of HLW glasses that were hence available for validating the models. These validation glasses are discussed in Section 2.2.2. The full compositions for the 39 validation glasses are given in wt\% values in Table 2.26. The compositions of these 39 glasses listed as mass fractions of the 25 components selected for initial spinel $\mathrm{T}_{1 \%}$ model development are given in Table 6.5. One of these glasses (SPA-18) had a composition whose mass fractions summed to only 0.9121 over the 19 components of the IHLW Initial and Augmentation Matrices (consisting of HLW02 and HLW03 glasses) used for model development during Phase 1. Therefore, this glass was dropped from the spinel $\mathrm{T}_{1 \%}$ model validation set for Phase 1 (Kot et al. 2005a). For this Phase 2 modeling work, this glass was also found to have an unusually large difference between its estimated spinel $\mathrm{T}_{1 \%}$ value (see Table 6.3 ) and the predicted spinel $\mathrm{T}_{1 \%}$ value obtained using a linear mixture model (involving the 25 main components specified in Section 6.1.1) developed during early stages of the Phase 2 modeling work. Therefore, this glass was again dropped, thereby leaving 38 glasses in the separate validation set for Phase 2 . All of the 38 separate validation glasses except one were within (or very close to being within) the component minimum and maximum values from the 168-glass modeling dataset. The exception was MS7-H-Ni with mass fraction of $\mathrm{NiO}=0.018$ $(1.8 \mathrm{wt} \%)$, whereas the largest value in the modeling dataset was $0.01002(1.002 \mathrm{wt} \%)$. The compositions of the 38 separate validation glasses would have to be compared to multicomponent constraints to assess whether they are inside the model validity region (see Section 9) or involve extrapolations of the modeling dataset. However, for discussion purposes in this section, the 38 separate validation glasses will be considered as involving interpolations of spinel $\mathrm{T}_{1 \%}$ models developed from the 168-glass modeling dataset (except for the MS7-H-Ni glass with high $\mathrm{NiO}$ ).

The compositions for the 39 available glasses for validating spinel $\mathrm{T}_{1 \%}$ models are given in Table 6.5 listed as normalized (over the 25 main components specified in Section 6.1.1) mass fractions summing to 1 . Table 6.6 contains data relating temperature to volume $\%$-crystallinity of spinel for each of the 39 available validation glasses. Table 6.7 lists the intercept and slope $\left[a_{0}\right.$ and $a_{1}$ from Equation (E.1) in Appendix E] for each of the 39 available validation glasses, as well as the estimated spinel $\mathrm{T}_{1 \%}$ value, the standard deviation of the estimated $\mathrm{T}_{1 \%}$ value, and the number of data points involved in the fitting of Equation (E.1) for each validation glass. Tables 6.5 and 6.7 include columns to identify the 38 glasses actually used for the spinel $\mathrm{T}_{1 \%}$ model validation.

Figure 6.5 is a histogram of the estimated $\mathrm{T}_{1 \%}$ values from Table 6.7 for the 38 glasses used for spinel $\mathrm{T}_{1 \%}$ model validation. This histogram shows that the estimated $\mathrm{T}_{1 \%}$ values for the 
validation data are well distributed about the processability limit of $950^{\circ} \mathrm{C}$ (marked with a vertical red line), and that the distribution includes glasses with estimated spinel $\mathrm{T}_{1 \%}$ values below, close to, and above the specified property limit.

Use of these 38 validation glasses was considered a separate model validation approach because the glasses were not part of the spinel $\mathrm{T}_{1 \%}$ model development dataset. The data-splitting approach discussed in Section 6.1.2 and the data-partitioning approach discussed in Section 6.1.3 are considered internal validation approaches because the data used by that approach are from the spinel $\mathrm{T}_{1 \%}$ model development dataset and satisfy the full QA requirements. The datasplitting and data-partition validation approaches are considered primary and secondary, respectively, for model evaluation and comparison purposes. The separate validation dataset provides additional validation statistics that can be used to conduct final screening among contending models that otherwise have similar performance results.

\subsection{Spinel $\mathbf{T}_{1 \%}$ Model Forms}

Ideally, a property-composition model for spinel $\mathrm{T}_{1 \%}$ would utilize known mechanisms of crystal formation as a function of temperature to obtain spinel $\mathrm{T}_{1 \%}$ values, and known mechanisms of spinel $\mathrm{T}_{1 \%}$ dependence on HLW glass composition. However, there is insufficient information available to support such fundamental models for the complex HLW glass system with the large numbers of components faced by the WTP project. Hence, several empirical model forms with parameters (coefficients) to be estimated from model development data were considered. These model forms are from the general class of mixture experiment models (Cornell 2002).

Three different mixture experiment model forms were investigated as part of the spinel $\mathrm{T}_{1 \%}$ model development process. These include the linear mixture (LM) model form, the partial quadratic mixture (PQM) model form, and the partial cubic mixture (PCM) model form. These three model forms are discussed in Section C.1.1 of Appendix C, and are the same model forms used in modeling PCT-B, PCT-Li, and PCT-Na releases, as discussed in Section 5. For modeling spinel $\mathrm{T}_{1 \%}$, the specific LM model form is given by

$$
\text { spinel } T_{1 \%}=\sum_{i=1}^{q} b_{i} x_{i}+E
$$

the specific PQM model form is given by

$$
\text { spinel } T_{1 \%}=\sum_{i=1}^{q} b_{i} x_{i}+\text { Selected }\left\{\sum_{i=1}^{q} b_{i i} x_{i}^{2}+\sum_{i<}^{q-1} \sum_{j}^{q} b_{i j} x_{i} x_{j}\right\}+\varepsilon \text {, }
$$

and the specific PCM model form is given by 


$$
\text { spinel } T_{1 \%}=\sum_{i=1}^{q} b_{i} x_{i}+\text { Selected }\left\{\begin{array}{l}
\sum_{i=1}^{q} b_{i i} x_{i}^{2}+\sum_{i=1}^{q-1} \sum_{j=i+1}^{q} b_{i j} x_{i} x_{j}+\sum_{i=1}^{q} b_{i i i} x_{i}^{3} \\
+\sum_{i=1}^{q-1} \sum_{j=i+1}^{q} b_{i i j} x_{i}^{2} x_{j}+\sum_{i=1}^{q-2} \sum_{j=i+1}^{q-1} \sum_{k=j+1}^{q} b_{i j k} x_{i} x_{j} x_{k}
\end{array}\right\}+E \text {. }
$$

In Equations (6.1) to (6.3): spinel $T_{1 \%}$ represents the estimated spinel $\mathrm{T}_{1 \%}$ values in ${ }^{\circ} \mathrm{C}$, obtained by using the process described and illustrated in Appendix $\mathrm{E} ; x_{i}(i=1,2, \ldots, q)$ are normalized mass fractions of $q$ glass oxide or halogen components such that $\sum_{i=1}^{q} x_{i}=1 ; b_{i}(i=1,2, \ldots, q), b_{i i}$, $b_{i j}, b_{i i i}, b_{i i j}$, and $b_{i i k}$ (selected) are coefficients to be estimated from data; and $E$ is a random error for each data point. Many statistical methods exist for developing and evaluating prediction models in the case where the $E$ are independent (i.e., not correlated) and normally distributed with mean 0 and standard deviation $\sigma$. Some of these methods (discussed in Sections C.3 and C.4 of Appendix C) were used in developing spinel $\mathrm{T}_{1 \%}$ models. In Equations (6.2) and (6.3), "Selected" means that only some of the terms in curly brackets are included in the model. The subset is selected using standard stepwise regression or other variable selection methods (Draper and Smith 1998, Montgomery et al. 2001). PQM models are discussed in more detail and illustrated by Piepel et al. (2002c).

Cornell (2002) discusses many other empirical mixture model forms that could have been considered for spinel $\mathrm{T}_{1 \%}$-composition modeling but were not investigated because of time constraints. However, models of the form in Equations (6.1) to (6.3) are widely used in many application areas (including waste glass property modeling) and often perform very well.

Sections 6.3 to 6.6 discuss the results of fitting, evaluating, and validating several spinel

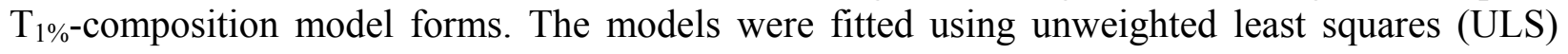
regression using the modeling glass compositions in Table 6.1 and the estimated spinel $\mathrm{T}_{1 \%}$ values from Table 6.3. Model development using weighted least squares (WLS) regression was considered unnecessary even though the $\mathrm{SD}\left(\mathrm{T}_{1 \%}\right)$ values spanned a range involving roughly one order of magnitude. WLS regression was investigated in the Phase 1 modeling work (Kot et al. 2005a) and found not to add any value compared to ULS regression.

\subsection{Property-Composition Model Results for Spinel $\mathbf{T}_{1 \%}$ Linear Mixture Models}

This section discusses the results of fitting full and reduced LM models using data from all 168 glasses in the spinel $\mathrm{T}_{1 \%}$ modeling dataset. Section 6.3.1 presents the results of modeling spinel $\mathrm{T}_{1 \%}$ based on compositions involving all 25 of the components identified in Section 6.1.1. Section 6.3.2 discusses the results from two reduced LM models. 


\subsubsection{Results from Full Linear Mixture Model for IHLW Spinel $\mathbf{T}_{1 \%}$}

As the initial step in spinel $\mathrm{T}_{1 \%}$ model development, a full LM model in the 25 components identified in Section 6.1.1 was fit to the modeling data (168 glasses) using ULS regression with the response being spinel $\mathrm{T}_{1 \%}\left({ }^{\circ} \mathrm{C}\right)$. The full $\mathrm{LM}$ model form was a reasonable starting point based on previous Phase 1 (Kot et al. 2005a) and Phase 1a (informal report) work modeling spinel $\mathrm{T}_{1 \%}$.

Table 6.8 contains the results for the 25-component full LM model fit to the spinel $\mathrm{T}_{1 \%}$ data for 168 HLW glasses in the modeling dataset. Table 6.8 lists the model coefficients, standard deviations of the coefficients, and model performance summaries for the full LM model using the modeling dataset, the data-splitting approach (see Section 6.1.2), the data-partitioning approach (see Section 6.1.3), and the separate validation dataset (see Section 6.1.4).

The upper right corner of Table 6.8 contains the summary statistics that describe how well the 25-component LM model fits the 168-glass modeling data for spinel $\mathrm{T}_{1 \%}$. The $\mathrm{R}^{2}=$ $0.852, \mathrm{R}_{\mathrm{A}}^{2}=0.827$, and $\mathrm{R}_{\mathrm{P}}^{2}=0.783$ statistics (see Section C. 4 of Appendix C) indicate that the full 25-component LM model fits the spinel $\mathrm{T}_{1 \%}$ data in the 168-glass modeling dataset fairly well. However, the root mean squared error $(\mathrm{RMSE})=51.991$ is noticeably larger than the spinel $\mathrm{T}_{1 \%}$ data uncertainty $\left(\mathrm{SD}=26.89^{\circ} \mathrm{C}\right)$ estimated from replicates in Table 6.4. This indicates the full LM model for spinel $\mathrm{T}_{1 \%}$ has LOF, which was confirmed as statistically significant with $p=$ 0.001 as shown in Table 6.8 (see Section C.4 for discussion of the statistical test for model LOF).

The predicted versus measured plot in Figure 6.6 shows that the full 25-component LM model has moderately high scatter (representing prediction uncertainty) and tends to over-predict spinel $\mathrm{T}_{1 \%}$ below approximately $850^{\circ} \mathrm{C}$. Figure 6.7 displays the standardized residuals plotted versus the data index (a sequential numbering of the modeling data points) with different plotting symbols representing the different groups of glasses discussed in Sections 2.1.1 to 2.1.8. This figure shows well-distributed prediction errors for the modeling dataset, including for the glasses from each of the studies included in the modeling dataset.

In the data-splitting portion of results at the bottom of Table 6.8 , the columns are labeled DS1, DS2, DS3, DS4, and DS5 to denote the five modeling/validation splits of the data as described in Section 6.1.2. The last column of this part of Table 6.8 shows the averages for the different statistics over the five splits. The average statistics over the five data-splits are very close to the statistics obtained for fitting the full LM model on spinel $\mathrm{T}_{1 \%}$ to all 168 glasses. This indicates that the model, despite its statistically significant LOF, maintains its performance for data not used to fit the model.

The statistics for the 25-component full LM model on spinel $\mathrm{T}_{1 \%}$ from partitioning the 168-glass modeling set into subsets of 124 modeling glasses and 44 validation glasses (see Section 6.1.3) are given on the right side of Table 6.8. The fit statistics of $\mathrm{R}^{2}=0.832, \mathrm{R}_{\mathrm{A}}^{2}=$ 0.791 , and $\mathrm{RMSE}=47.664$ for the 124-glass modeling subset are all similar to the corresponding statistics for the full 168-glass modeling set. However, $\mathrm{R}_{\mathrm{P}}^{2}<0$ is worse for the 124-glass modeling subset, because there are insufficient data to estimate the LM model coefficients for all 25 components. (See Section C. 4 of Appendix C for additional discussion of $\mathrm{R}_{\mathrm{P}}^{2}$ and why it can 
be negative.) For the 44-glass validation subset from data-partitioning, $\mathrm{R}^{2} \mathrm{v}$ is negative and $\mathrm{RMSE}_{\mathrm{V}}=332.415$. This very poor validation performance for the 25-component, full LM model on spinel $\mathrm{T}_{1 \%}$ is because there is insufficient support in the 124-glass modeling subset to estimate the LM model coefficients of all 25 components.

A predicted versus measured plot for the data-partition validation subset is given in Figure 6.8. This figure confirms that the full 25-component LM model for spinel $\mathrm{T}_{1 \%}$ fitted to the 144-glass modeling subset has very poor predictive performance for the 44-glass validation subset. Also shown in Figure 6.8 are 95\% prediction intervals (95\% PIs) representing the model prediction uncertainty of single spinel $\mathrm{T}_{1 \%}$ determinations for each glass (see Sections C.6 and C. 7 of Appendix C). If the $95 \%$ PI for a validation point overlaps the $45^{\circ}$ line, the predicted and estimated spinel $\mathrm{T}_{1 \%}$ values are within model and estimation uncertainty of each other. Of the 44 validation glasses from the data-partition, 33 have 95\% PIs that do not overlap the $45^{\circ}$ line.

The summary statistics from applying the 25-component full LM model for spinel $\mathrm{T}_{1 \%}$ to the separate validation data are also given on the right side of Table 6.8. The $\mathrm{R}^{2} \mathrm{~V}=0.353$ and large $\mathrm{RMSE}_{\mathrm{V}}=94.771$ for the 38 separate validation glasses with spinel $\mathrm{T}_{1 \%}$ data indicate the full LM model does not have very good validation predictive performance. This is confirmed in the predicted versus measured plot for the separate validation data shown in Figure 6.9. The 25component $\mathrm{LM}$ model tends to over-predict spinel $\mathrm{T}_{1 \%}$ below about $800^{\circ} \mathrm{C}$ and under-predict from about 975 to $1100^{\circ} \mathrm{C}$. This relatively poor validation performance may be a result of the 25 component full LM model over-fitting the data, being an inadequate model form, or the relatively small size and HLW glass composition region coverage of the validation dataset. Figure 6.9 also shows one glass (MS7-H-Mg) as having a much wider 95\% PI than the other glasses. This is a result of that glass having a high $\mathrm{MgO}$ mass fraction of approximately 0.03 (3 $\mathrm{wt} \%$ ), when all other separate validation glasses have $\mathrm{MgO}$ mass fractions of 0.01 or less. In spinel $\mathrm{T}_{1 \%}$ models discussed subsequently, $\mathrm{MgO}$ is combined into the new Others component, and the much larger 95\% PI does not appear.

Despite the statistically significant LOF of the 25-component full LM model for spinel $\mathrm{T}_{1 \%}$, the model fits the 168-glass modeling dataset well enough to provide guidance for reducing the model (i.e., removing separate terms for components that do not significantly influence spinel $\mathrm{T}_{1 \%}$ ). Hence, the full LM model was used to produce the response trace plot (see Section C.5.1) shown in Figure 6.10. The response trace plot shows that $\mathrm{NiO}, \mathrm{Cr}_{2} \mathrm{O}_{3}, \mathrm{ZnO}, \mathrm{Fe}_{2} \mathrm{O}_{3}, \mathrm{Al}_{2} \mathrm{O}_{3}$, and $\mathrm{MnO}$ tend to increase spinel $\mathrm{T}_{1} \%$, while $\mathrm{Li}_{2} \mathrm{O}, \mathrm{Na}_{2} \mathrm{O}, \mathrm{B}_{2} \mathrm{O}_{3}, \mathrm{SrO}$, and $\mathrm{SiO}_{2}$ tend to decrease spinel $\mathrm{T}_{1 \%}$. The response traces for several minor components have steep positive or negative slopes but smaller ranges, and thus they may not have significant effects on spinel $\mathrm{T}_{1 \%}$. The response traces for $\mathrm{ThO}_{2}$ and $\mathrm{UO}_{3}$ are close to horizontal, suggesting that they may have little effect on spinel $\mathrm{T}_{1 \%}$. The minor components as well as $\mathrm{ThO}_{2}$ and $\mathrm{UO}_{3}$ having non-significant effects was confirmed by fitting a component slope linear mixture (CSLM) model and verifying the slopes (representing effects) of the components were not statistically significant (see Section C.5.1 of Appendix C). 


\subsubsection{Results for Reduced Linear Mixture Models for IHLW Spinel $\mathbf{T}_{\mathbf{1}} \%$}

The 25-component full LM model presented in Section 6.3.1 likely contains components that do not significantly contribute to predicting spinel $\mathrm{T}_{1 \%}$, so model reduction was the next step of the model development approach. Thus, LM models for spinel $\mathrm{T}_{1 \%}$ involving fewer than the 25 components were considered. The sequential F-test model reduction approach (see Section C.5.1 of Appendix C, Piepel and Cooley 2006) was used to develop a reduced LM model. Option (ii) was used to combine components with nonsignificant effects on spinel $\mathrm{T}_{1 \%}$ into the Others term.

\section{5-Component Reduced Linear Mixture Model for IHLW Spinel $\mathrm{T}_{1 \%}$}

An initial run of the model reduction algorithm for $\mathrm{LM}$ models was conducted with the components $\mathrm{CdO}, \mathrm{MgO}, \mathrm{Sb}_{2} \mathrm{O}_{3}, \mathrm{SeO}_{2}, \mathrm{PbO}, \mathrm{Tl}_{2} \mathrm{O}, \mathrm{K}_{2} \mathrm{O}, \mathrm{La}_{2} \mathrm{O}_{3}, \mathrm{CaO}, \mathrm{TiO}_{2}$, and Others being allowed to combine. Using a typical specified significance level such as 0.01 for the algorithm stopping criterion, this model reduction run resulted in multiple combined components rather than a single combined component as desired. However, the separate sets of combined components appeared to have relatively small effects on spinel $\mathrm{T}_{1 \%}$, and so they were forced into a single combined component (the new Others component) in the reduced LM model. The resulting 15-term reduced $\mathrm{LM}$ model included terms for $\mathrm{Al}_{2} \mathrm{O}_{3}, \mathrm{~B}_{2} \mathrm{O}_{3}, \mathrm{Cr}_{2} \mathrm{O}_{3}, \mathrm{Fe}_{2} \mathrm{O}_{3}, \mathrm{Li}_{2} \mathrm{O}, \mathrm{MnO}$, $\mathrm{Na}_{2} \mathrm{O}, \mathrm{NiO}, \mathrm{SiO}_{2}, \mathrm{SrO}, \mathrm{ThO}_{2}, \mathrm{UO}_{3}, \mathrm{ZnO}, \mathrm{ZrO}_{2}$, and Others.

Numerical Results for the 15-Component Reduced Linear Mixture Model on Spinel $\mathrm{T}_{1 \%}$

Table 6.9 contains the coefficients of the 15-component reduced LM model for spinel $\mathrm{T}_{1 \%}$, coefficient standard deviations, and performance statistics for the (i) modeling data, (ii) data-split modeling data, (iii) 124/44 partition of the modeling data into modeling and validation subsets, and (iv) 38 separate validation glasses with spinel $\mathrm{T}_{1 \%}$ data.

In Table 6.9, the model evaluation statistics $\mathrm{R}^{2}=0.813, \mathrm{R}_{\mathrm{A}}{ }^{2}=0.796, \mathrm{R}_{\mathrm{P}}^{2}=0.766$, and $\mathrm{RMSE}=56.417$ for the 15-component reduced LM model on spinel $\mathrm{T}_{1 \%}$ are somewhat worse but still similar to the corresponding statistics for the 25-component full LM model (see Table 6.8). The small drop in values from $\mathrm{R}^{2}$ to $\mathrm{R}_{\mathrm{P}}^{2}$ suggests that the spinel $\mathrm{T}_{1 \%}$ modeling dataset does not have any highly influential data points for the 15-component reduced LM model. In any case, $\mathrm{R}_{\mathrm{P}}^{2}=0.766$ provides an estimate of the fraction of variation in spinel $\mathrm{T}_{1 \%}$ values for future datasets over the same glass composition region that might be accounted for by this reduced LM model.

Over the five data splits of the spinel $\mathrm{T}_{1 \%}$ modeling data, Table 6.9 shows that the 15component reduced LM model has average modeling statistics $\mathrm{R}^{2}=0.819, \mathrm{R}_{\mathrm{A}}{ }^{2}=0.798, \mathrm{R}_{\mathrm{P}}^{2}=$ 0.762 , and $\mathrm{RMSE}=56.235$ that are all close to their values from the 168-glass modeling dataset. The average validation statistics $\mathrm{R}_{\mathrm{V}}^{2}=0.752$ and $\mathrm{RMSE}_{\mathrm{V}}=59.364$ from data-splitting are slightly worse (i.e., smaller and larger) than $\mathrm{R}_{\mathrm{P}}^{2}=0.766$ and $\mathrm{RMSE}=56.417$ for the 168 -glass modeling dataset. Hence, the data-splitting validation results for the 15-component reduced LM model on spinel $\mathrm{T}_{1 \%}$ are generally similar to those from fitting the model to the 168-glass dataset. 
The 15-component reduced LM model for spinel $\mathrm{T}_{1 \%}$ yielded somewhat different results for the partition of the modeling data into a modeling subset of 124 glasses and a validation subset of 44 glasses. As seen in Table 6.9, the fit statistics $\mathrm{R}^{2}=0.766, \mathrm{R}_{\mathrm{A}}^{2}=0.736$, and $\mathrm{R}_{\mathrm{P}}^{2}=$ 0.668 for the 124-glass modeling subset are all somewhat worse (i.e., smaller) than the corresponding statistics for the full 168-glass modeling set. The RMSE $=53.552$ is slightly better (i.e., smaller) for the 124-glass modeling subset. For the 44-glass validation subset from datapartitioning, the $\mathrm{R}_{\mathrm{V}}^{2}=0.794$ is close to the $\mathrm{R}^{2}=0.813$ from fitting the 15 -component reduced LM model to all 168 glasses in the spinel $\mathrm{T}_{1 \%}$ modeling dataset. The $\mathrm{RMSE}_{\mathrm{V}}=76.235$ from the 44-glass validation subset is somewhat worse than the RMSE $=56.417$ from fitting the model to all 168 glasses.

For the set of 38 separate validation glasses, the 15-component reduced LM model for spinel $\mathrm{T}_{1 \%}$ has $\mathrm{R}_{\mathrm{V}}^{2}=0.421$, which is substantially less than $\mathrm{R}_{\mathrm{P}}^{2}=0.766$ from cross-validation with the 168-glass modeling dataset. The $\mathrm{RMSE}_{\mathrm{V}}=89.674$ for these 38 glasses is significantly worse than the average $\mathrm{RMSE}_{\mathrm{V}}=59.364$ for the five data-splits of the modeling data and the $\mathrm{RMSE}_{\mathrm{V}}=76.235$ for the partitioned modeling data. Additional discussion of the poor validation performance of the 15-component reduced LM model for spinel $\mathrm{T}_{1 \%}$ is provided subsequently when Figure 6.15 is discussed.

The RMSE in Table 6.9 is an estimate of the uncertainty in estimated spinel $\mathrm{T}_{1 \%}$ values for simulated HLW glasses if the 15-component reduced LM model does not have statistically significant LOF. The RMSE $=56.417$ for the 15 -component reduced LM model is much larger than the replicate $\mathrm{SD}=26.89$ in Table 5.4. This observation suggests that the 15 -component reduced LM model for spinel $\mathrm{T}_{1 \%}$ has a substantial LOF. This indication is confirmed by the $p$ value $<0.001$ of the LOF test (see Section C.4 of Appendix C) for this model in Table 6.9. This p-value indicates that the model LOF is significant at greater than the $99.9 \%$ confidence level.

\section{Graphical Results for the 15-Component Reduced Linear Mixture Model on Spinel $\mathrm{T}_{1 \%}$}

Figure 6.11 displays the predicted versus measured plot for the 15-component reduced LM model for spinel $\mathrm{T}_{1 \%}$ applied to the 168 glasses of the spinel $\mathrm{T}_{1 \%}$ modeling dataset. The distribution of points around the $45^{\circ}$ line is very similar to the plot for the 25 -component full LM model in Figure 6.6. Figure 6.11 shows a tendency for the 15-component reduced LM model to over-predict spinel $\mathrm{T}_{1 \%}$ values below approximately $850^{\circ} \mathrm{C}$, as well as moderately high scatter representing prediction uncertainty. The standardized residual plot in Figure 6.12 shows some tendency for the model to over-predict spinel $\mathrm{T}_{1 \%}$ for HLW05 and HLW-ALG glasses and to under-predict for HLW07 glasses. Diagnostic plots for the 15-component reduced LM model (not included in this report) support the assumption of normally distributed errors in the spinel $\mathrm{T}_{1 \%}$ data (see Section C.3 of Appendix C).

Figure 6.13 displays the response trace plot (see Section C.5.1) for the 15-component reduced $\mathrm{LM}$ model for spinel $\mathrm{T}_{1 \%}$. The figure shows that $\mathrm{NiO}, \mathrm{Cr}_{2} \mathrm{O}_{3}, \mathrm{ZnO}, \mathrm{Fe}_{2} \mathrm{O}_{3}, \mathrm{Al}_{2} \mathrm{O}_{3}$, and $\mathrm{MnO}$ tend to increase spinel $\mathrm{T}_{1} \%$, while $\mathrm{Li}_{2} \mathrm{O}, \mathrm{Na}_{2} \mathrm{O}, \mathrm{B}_{2} \mathrm{O}_{3}, \mathrm{SrO}$, and $\mathrm{SiO}_{2}$ tend to decrease spinel $\mathrm{T}_{1 \%}$. The response traces for $\mathrm{ThO}_{2}$ and $\mathrm{UO}_{3}$ are close to horizontal, suggesting that they may have little effect on spinel $\mathrm{T}_{1 \%}$. 
Figures 6.14 and 6.15 show the predicted versus measured plots when the 15-component reduced LM model for spinel $\mathrm{T}_{1 \%}$ is applied to two validation datasets. Figure 6.14 results from fitting the 15-component reduced LM model to a subset of 124 out of 168 modeling glasses, and then applying the resulting model to the remaining subset of 44 glasses for validation (see Section 6.1.3). Figure 6.15 results from fitting the 15-component reduced LM model for spinel $\mathrm{T}_{1 \%}$ to all 168 glasses in the modeling set and then applying that model to the 38 separate validation glasses with spinel $\mathrm{T}_{1 \%}$ data (see Section 6.1.4). Also shown in Figures 6.14 and 6.15 are $95 \%$ PIs representing the model prediction uncertainty of single spinel $\mathrm{T}_{1 \%}$ determinations for each glass (see Sections C.6 and C.7 of Appendix C). If the 95\% PI for a validation point overlaps the $45^{\circ}$ line, the predicted and estimated spinel $\mathrm{T}_{1 \%}$ values are within model and estimation uncertainty of each other.

Figure 6.14 shows that the 15-component reduced LM model fitted to the 124-glass modeling subset from data-partitioning yields roughly unbiased predictions above approximately $850^{\circ} \mathrm{C}$, but has a tendency to over-predict spinel $\mathrm{T}_{1 \%}$ below $850^{\circ} \mathrm{C}$. However, it is clear that the 15-component reduced LM model does a far better job than the 25-component full LM model (see Figure 6.8) of predicting spinel $\mathrm{T}_{1 \%}$ for the 44 validation glasses from data-partitioning. The 95\% PIs in Figure 6.14 overlap the $45^{\circ}$ line (i.e., contain the measured values) for all but 7 of the 44 glasses in the validation subset from data-partitioning. Failure of $100(7 / 44)=15.9 \%$ of the 95\% PIs to include the corresponding estimated spinel $\mathrm{T}_{1 \%}$ values is somewhat more than the 5\% expected by chance. This is a result of the over-prediction for lower spinel $\mathrm{T}_{1 \%}$ values and significant model LOF that results in increased scatter in spinel $\mathrm{T}_{1 \%}$ predictions. The $95 \%$ PIs are relatively wide, which is partly due to: (i) the LOF of the 15-component reduced LM model, and (ii) the inherent uncertainty in the process of estimating spinel $\mathrm{T}_{1 \%}$ values.

Figure 6.15 shows that the 15-component reduced LM model for spinel $\mathrm{T}_{1 \%}$ fitted to the 168-glass modeling dataset and applied to the 38-glass separate validation dataset tends to (i) over-predict for spinel $\mathrm{T}_{1 \%}$ below $800^{\circ} \mathrm{C}$, and (ii) under-predict above $800^{\circ} \mathrm{C}$. These over- and under-predictions are slightly better than those for the 25-component full LM model (see Figure 6.9). The 95\% PIs do not contain the corresponding measured values for 7 of the 38 separate validation glasses with spinel $\mathrm{T}_{1 \%}$ data. It is not clear whether the relatively poor prediction performance of the 15-component reduced LM model for spinel $\mathrm{T}_{1 \%}$ applied to the separate validation data is because of something different about the validation data related to being collected at a different time, the limited composition region covered by this relatively small subset of validation data, or whether it is an indication of limitations in the 15-component reduced $\mathrm{LM}$ model for spinel $\mathrm{T}_{1 \%}$.

$\underline{\text { Summary of the 15-Component Reduced LM Model for Spinel } \mathrm{T}_{1 \%}}$

The 15-component reduced LM model for spinel $\mathrm{T}_{1 \%}$ is given in Table 6.9 and the variance-covariance matrix associated with the model coefficients is given in Table D.10 of Appendix D. The 15-component LM model fits the 168-glass modeling dataset nearly as well as the 25-component full LM model, while removing several minor components from the model not expected to influence spinel $\mathrm{T}_{1 \%}$. However, the 15-component reduced LM model has a 
significant LOF, corresponding to a tendency to over-predict lower spinel $\mathrm{T}_{1 \%}$ values and relatively large scatter of data about the fitted model.

\subsubsection{3-Component Reduced Linear Mixture Model for IHLW Spinel $\mathbf{T}_{1 \%}$}

Because $\mathrm{UO}_{3}$ and $\mathrm{ThO}_{2}$ appeared to have non-significant effects on spinel $\mathrm{T}_{1 \%}$, the model reduction algorithm described in Section 6.3.2 was re-run with $\mathrm{UO}_{3}$ and $\mathrm{ThO}_{2}$ included in the set of components that were allowed to combine. None of these model reduction runs led to a reduced LM model having just a single combined component to serve as the Others component in the reduced model. This was true even when an extremely small specified significance level was used for the algorithm stopping criterion. Therefore, another model reduction approach was considered. This model reduction approach involved (i) repeated sampling of 120 (selected at random) of the $168 \mathrm{HLW}$ glasses in the spinel $\mathrm{T}_{1 \%}$ modeling dataset, (ii) generating a full 25component LM model using the compositions and estimated spinel $\mathrm{T}_{1 \%}$ data for those 120 glasses, (iii) calculating the p-values associated with the t-tests for estimated slopes ${ }^{12}$ of the 25 components, and (iv) counting the number of times each component had a highly significant slope (where slope represents the component effect on spinel $\mathrm{T}_{1 \%}$ ). Based on this approach, 13 of the 25 main components were consistently found to be significant in the models generated with the random sets of 120 glasses. These 13 components were $\mathrm{Al}_{2} \mathrm{O}_{3}, \mathrm{~B}_{2} \mathrm{O}_{3}, \mathrm{Cr}_{2} \mathrm{O}_{3}, \mathrm{Fe}_{2} \mathrm{O}_{3}, \mathrm{Li}_{2} \mathrm{O}$, $\mathrm{MnO}, \mathrm{Na}_{2} \mathrm{O}, \mathrm{NiO}, \mathrm{SiO}_{2}, \mathrm{SrO}, \mathrm{ZnO}, \mathrm{ZrO}_{2}$, and Others. Consequently, the other 12 components were combined into an Others component to determine a 13-term reduced LM model.

Summary statistics for the 13-component reduced LM model for spinel $\mathrm{T}_{1 \%}$ are presented and compared to the statistics for other models in Section 6.6. The model coefficients, standard deviations of the coefficients, and various diagnostic plots are not provided for the 13-component reduced LM model, because the 15-component reduced LM model is preferred as discussed in Section 6.6

\subsection{Results for Partial Quadratic Mixture Models for IHLW Spinel $\mathbf{T}_{1 \%}$}

In an effort to improve on the 15-component reduced LM model for spinel $\mathrm{T}_{1 \%}$ of HLW glasses, PQM models (see Section 6.2.1) were also considered. Specifically, selected quadratic terms (squared and two-component crossproduct terms) were added to the linear terms of the 15component reduced LM model for spinel $\mathrm{T}_{1 \%}$ to include important nonlinear blending effects of the glass components. PQM models are discussed in detail by Piepel et al. (2002).

The MAXR selection method (see Section C.5 of Appendix C) was used to identify "best" subsets of quadratic terms to include in PQM models. Different PQM models were obtained depending on the number of quadratic terms specified for addition. The MAXR method was coded in R (Ihaka and Gentleman 1996, R Core Development Team 2006), but yields the same results as the MAXR option of PROC REG in SAS (2005).

${ }^{12}$ See the discussion of component slope linear mixture (CSLM) models in Section C.5.1 of Appendix C. 
Preliminary PQM models were developed based on adding from 2 to 9 quadratic terms to the 15-component reduced LM model described in Section 6.3.2. While model performance generally improves as more quadratic terms are added, it often happens that later quadratic terms selected involve components that are not expected to have a significant impact on the response of interest (spinel $\mathrm{T}_{1 \%}$ in this case). Including a large number of such terms can resulting in overfitting the modeling dataset and degrade predictive performance when the resulting models are applied to new data. This can occur even when all of the higher-order terms added appear to be statistically significant. For these reasons, it was decided to form PQM models by adding 5 quadratic terms to the 15-component reduced LM model described previously. Sections 6.4.1 and 6.4.2 present the results for each of two 20-term PQM models developed by adding different subsets of 5 quadratic terms to the 15-component reduced LM model from Section 6.3.2.

\subsubsection{First 20-Term Partial Quadratic Mixture Model (PQM1a) for IHLW Spinel $\mathbf{T}_{1 \%}$}

The first PQM model considered for spinel $\mathrm{T}_{1 \%}$ was obtained by using the MAXR selection approach to select 5 quadratic terms from the set of all possible quadratic terms formed using the 14 non-Others components in the 15-component reduced LM model discussed in Section 6.3.2. This approach produced a 20-term PQM model consisting of 15 linear terms and 5 quadratic terms, namely $\left(\mathrm{ZrO}_{2}\right)^{2}, \mathrm{MnO} \times \mathrm{Na}_{2} \mathrm{O}, \mathrm{Li}_{2} \mathrm{O} \times \mathrm{MnO}, \mathrm{MnO} \times \mathrm{NiO}$, and $\left(\mathrm{SiO}_{2}\right)^{2}$. Subsequently, this first 20-term PQM model is referred to as PQM1.

Numerical Results for the First 20-Term Partial Quadratic Mixture Model (PQM1a) on Spinel $\mathrm{T}_{1 \%} \%$

Table 6.10 contains the coefficients of the 20-term PQM1a model for spinel $\mathrm{T}_{1 \%}$, coefficient standard deviations, and performance statistics for the (i) modeling data, (ii) data-split modeling data, (iii) 124/44 partition of the modeling data into modeling and validation subsets, and (iv) 38 separate validation glasses with spinel $\mathrm{T}_{1 \%}$ data.

In Table 6.10, the model evaluation statistics $\mathrm{R}^{2}=0.880, \mathrm{R}_{\mathrm{A}}^{2}=0.865, \mathrm{R}_{\mathrm{P}}^{2}=0.841$, and $\mathrm{RMSE}=45.934$ for the 20-term PQM1 a model on spinel $\mathrm{T}_{1} \%$ are substantive improvements over the corresponding statistics for the 15-component reduced LM model (see Table 6.9). The small drop in values from $\mathrm{R}_{\mathrm{A}}^{2}$ to $\mathrm{R}_{\mathrm{P}}^{2}$ suggests that the spinel $\mathrm{T}_{1 \%}$ modeling dataset does not have any highly influential data points for the 20-term PQM1a model. In any case, $\mathrm{R}_{\mathrm{P}}^{2}=0.841$ provides an estimate of the fraction of variation in spinel $\mathrm{T}_{1 \%}$ values for future datasets over the same glass composition region that might be accounted for by this PQM model.

Over the five data splits of the spinel $\mathrm{T}_{1 \%}$ modeling data, Table 6.10 shows that the 20term PQM1a model has average modeling statistics $\mathrm{R}^{2}=0.885, \mathrm{R}_{\mathrm{A}}^{2}=0.866, \mathrm{R}_{\mathrm{P}}^{2}=0.837$, and $\mathrm{RMSE}=45.810$ that are all close to their values from the 168 -glass modeling dataset. The average validation statistics $R_{V}^{2}=0.832$ and $R_{M S E}=49.753$ from data-splitting are slightly worse (i.e., smaller and larger) than $\mathrm{R}_{\mathrm{P}}^{2}=0.841$ and $\mathrm{RMSE}=45.934$ for the 168-glass modeling 
dataset. Hence, the data-splitting validation results for the 20-term PQM1a model on spinel $\mathrm{T}_{1 \%}$ are generally similar to those from fitting the model to the 168-glass dataset.

The 20-term PQM1a model for spinel $\mathrm{T}_{1 \%}$ yielded somewhat different results for the partition of the modeling data into a modeling subset of 124 glasses and a validation subset of 44 glasses. As seen in Table 6.10, the fit statistics $\mathrm{R}^{2}=0.852, \mathrm{R}_{\mathrm{A}}{ }=0.825$, and $\mathrm{R}_{\mathrm{P}}^{2}=0.776$ for the 124-glass modeling subset are all slightly worse (i.e., smaller) than the corresponding statistics for the full 168-glass modeling set. The RMSE $=43.665$ is slightly better (i.e., smaller) for the 124-glass modeling subset. For the 44-glass validation subset from data-partitioning, the $\mathrm{R}_{\mathrm{V}}^{2}=$ 0.881 is very close to the $\mathrm{R}^{2}=0.880$ from fitting the 20 -term PQM1a model to all 168 glasses in the spinel $\mathrm{T}_{1 \%}$ modeling dataset. The $\mathrm{RMSE}_{\mathrm{V}}=57.989$ from the 44-glass validation subset is somewhat worse than the RMSE $=45.934$ from fitting the model to all 168 glasses.

For the set of 38 separate validation glasses, the 20-term PQM1a model for spinel $\mathrm{T}_{1 \%}$ has $R_{V}^{2}=0.255$, which is substantially less than $R_{P}^{2}=0.841$ from cross-validation with the 168 glass modeling dataset. The $\mathrm{RMSE}_{\mathrm{V}}=101.728$ for these 38 glasses is significantly worse than the average $\mathrm{RMSE}_{\mathrm{V}}=49.753$ for the five data-splits of the modeling data and the $\mathrm{RMSE}_{\mathrm{V}}=$ 57.989 for the partitioned modeling data. Additional discussion of the poor validation performance of the 20-term PQM1a model for spinel $\mathrm{T}_{1 \%}$ is provided subsequently when Figure 6.20 is discussed.

The RMSE in Table 6.10 is an estimate of the uncertainty in estimated spinel $\mathrm{T}_{1 \%}$ values for simulated HLW glasses if the 20-term PQM1a model does not have statistically significant LOF. Although RMSE $=45.934$ for the 20 -term PQM1 a model is smaller than the corresponding $\mathrm{RMSE}=56.417$ for the 15-component reduced LM model, it is still much larger than the replicate $\mathrm{SD}=26.89$ in Table 5.4. These observations suggest that the 20-term PQM1a model for spinel $\mathrm{T}_{1 \%}$ has a substantial LOF. This indication is confirmed by the $p$-value $=0.006$ of the LOF test (see Section C.4 of Appendix C) for this model in Table 6.10. This p-value indicates that the model LOF is significant at the $99.4 \%$ confidence level.

\section{Graphical Results for the First 20-Term Partial Quadratic Mixture Model (PQM1a) on Spinel $\mathrm{T}_{1} \%$}

Figure 6.16 displays the predicted versus measured plot for the 20-term PQM1a model for spinel $\mathrm{T}_{1 \%}$ applied to the 168 glasses of the spinel $\mathrm{T}_{1 \%}$ modeling dataset. The distribution of points around the $45^{\circ}$ line is improved (less scatter) compared to the distribution for the 15 component reduced LM model in Figure 6.11. Figure 6.16 gives no indication of biased prediction over the range of spinel $\mathrm{T}_{1 \%}$ values in the modeling dataset. Further, the standardized residual plot in Figure 6.17 gives no indication of any tendency for biased predictions for any of the six groups of data represented in the modeling dataset. Diagnostic plots for the PQM1a model (not included in this report) support the assumption of normally distributed errors in the spinel $\mathrm{T}_{1 \%}$ data (see Section C.3 of Appendix C).

Figure 6.18 displays the response trace plot (see Section C.5.1) for the 20-term PQM1a model for spinel $\mathrm{T}_{1 \%}$. The figure shows that $\mathrm{NiO}, \mathrm{Cr}_{2} \mathrm{O}_{3}, \mathrm{ZnO}, \mathrm{Fe}_{2} \mathrm{O}_{3}, \mathrm{Al}_{2} \mathrm{O}_{3}$, and $\mathrm{ZrO}_{2}$ have the largest increasing effects on spinel $\mathrm{T}_{1 \%}$, while $\mathrm{Li}_{2} \mathrm{O}, \mathrm{Na}_{2} \mathrm{O}$, and $\mathrm{B}_{2} \mathrm{O}_{3}$ have the largest decreasing 
effects on spinel $\mathrm{T}_{1 \%}$. Curvature effects are apparent for $\mathrm{SiO}_{2}$ and $\mathrm{ZrO}_{2}$ as a result of the $\left(\mathrm{SiO}_{2}\right)^{2}$ and $\left(\mathrm{ZrO}_{2}\right)^{2}$ terms in the 20-term PQM1a model for spinel $\mathrm{T}_{1 \%}$. The response traces for $\mathrm{ThO}_{2}$, $\mathrm{SrO}, \mathrm{UO}_{3}$, and Others are the closest to horizontal, indicating these components may have negligible effects on spinel $\mathrm{T}_{1 \%}$.

Figures 6.19 and 6.20 show the predicted versus measured plots when the 20-term PQM1a model for spinel $\mathrm{T}_{1 \%}$ is applied to two validation datasets. Figure 6.19 results from fitting the PQM1a model to a subset of 124 out of 168 modeling glasses, and then applying the resulting model to the remaining subset of 44 glasses for validation (see Section 6.1.3). Figure 6.20 results from fitting the PQM1a model for spinel $\mathrm{T}_{1 \%}$ to all 168 glasses in the modeling set and then applying that model to the 38 separate validation glasses with spinel $\mathrm{T}_{1 \%}$ data (see Section 6.1.4). Also shown in Figures 6.19 and 6.20 are 95\% PIs representing the model prediction uncertainty of single spinel $\mathrm{T}_{1 \%}$ determinations for each glass (see Sections C.6 and C.7 of Appendix C). If the $95 \%$ PI for a validation point overlaps the $45^{\circ}$ line, the predicted and estimated spinel $\mathrm{T}_{1 \%}$ values are within model and estimation uncertainty of each other.

Figure 6.19 shows that the 20-term PQM1a model fitted to the 124-glass modeling subset from data-partitioning yields roughly unbiased predictions above $800^{\circ} \mathrm{C}$ approximately, but has a tendency to over-predict spinel $\mathrm{T}_{1 \%}$ below $800^{\circ} \mathrm{C}$. However, this tendency to over-predict is improved compared to the 15-component reduced LM model. The 95\% PIs in Figure 6.20 overlap the $45^{\circ}$ line (i.e., contain the measured values) for all but 6 of the 44 glasses in the validation subset from data-partitioning. Failure of $100(6 / 44)=13.6 \%$ of the $95 \%$ PIs to include the corresponding estimated spinel $\mathrm{T}_{1 \%}$ values is somewhat more than the $5 \%$ expected by chance. This is a result of the over-prediction for lower spinel $\mathrm{T}_{1 \%}$ values and significant model LOF that results in increased scatter in spinel $\mathrm{T}_{1 \%}$ predictions. The $95 \%$ PIs are relatively wide, which is partly due to: (i) the LOF of the 20-term PQM1a model, and (ii) the inherent uncertainty in the process of estimating spinel $\mathrm{T}_{1 \%}$ values.

Figure 6.20 shows that the 20-term PQM1a model for spinel $\mathrm{T}_{1 \%}$ fitted to the 168 -glass modeling dataset and applied to the 38-glass separate validation dataset tends to (i) over-predict for spinel $\mathrm{T}_{1 \%}$ below $800^{\circ} \mathrm{C}$, and (ii) under-predict above $800^{\circ} \mathrm{C}$. These under- and overpredictions are actually worse than for the 15-component reduced LM model (see Figure 6.15). The 95\% PIs do not contain the corresponding measured values for 16 of the 38 separate validation glasses with spinel $\mathrm{T}_{1 \%}$ data. It is not clear whether the poor prediction performance of the 20-term PQM1a model for spinel $\mathrm{T}_{1 \%}$ applied to the separate validation data is because of something different about the validation data related to being collected at a different time, the limited composition region covered by this relatively small subset of validation data, or whether it is an indication of limitations in the 20-term PQM1a model for spinel $\mathrm{T}_{1 \%}$. The poorer validation predictive performance of the 20-term PQM1a model relative to the 15-component reduced LM model could be an indication that the quadratic terms in the PQM1a model are to some extent a result of over-fitting to the modeling dataset, and that those terms are not as important to spinel $\mathrm{T}_{1 \%}$ prediction in general. 
$\underline{\text { Summary of the First 20-Term Partial Quadratic Mixture Model (PQM1a) for Spinel T }} 1 \%$

The first 20-term PQM model (PQM1a) for spinel $\mathrm{T}_{1 \%}$ is given in Table 6.10 and the variance-covariance matrix associated with the model coefficients is given in Table D.11 of Appendix D. The PQM1a model fits the 168-glass modeling dataset better than the 15component reduced LM model, but still has significant LOF. The PQM1a model also performs better on the data-splitting and data-partitioning validation assessments than does the 15component reduced LM model. However, the 20-term PQM1a model performs noticeably worse that the 15-component reduced LM model when applied to the separate validation dataset of 38 HLW glasses.

\subsubsection{Second 20-Term Partial Quadratic Mixture Model (PQM1b) for IHLW Spinel $\mathbf{T}_{1 \%}$}

The selection of the $\left(\mathrm{ZrO}_{2}\right)^{2}$ term in the PQM model discussed in Section 6.4.1 was not supported by glass-science knowledge and experience, which indicated that $\mathrm{ZrO}_{2}$ should have a relatively minor effect on spinel formation. Therefore, a second stepwise regression run was conducted to select quadratic terms from a set excluding terms containing Others and $\mathrm{ZrO}_{2}$. Thus, the available quadratic terms were those formed from 13 components remaining after excluding Others and $\mathrm{ZrO}_{2}$ from the 15 components represented in the 15-term reduced LM model. Among the 5 quadratic terms selected during this second stepwise regression application was $\left(\mathrm{ThO}_{2}\right)^{2}$. The selection of this term in a spinel $\mathrm{T}_{1 \%}$ model was also not supported based on glass-science knowledge and experience. Hence, a third stepwise regression run was conducted, this time selecting 5 quadratic terms from the set of quadratic terms formed from the 12 components remaining after excluding Others, $\mathrm{ZrO}_{2}$, and $\mathrm{ThO}_{2}$. The 5 quadratic terms selected in this third stepwise regression application involved components that seemed reasonable based on glass science knowledge. Thus, a second 20-term PQM model was formed that involved the 15 components represented in the 15-component reduced LM model as well as the quadratic terms $\mathrm{Cr}_{2} \mathrm{O}_{3} \times \mathrm{SiO}_{2}, \mathrm{Al}_{2} \mathrm{O}_{3} \times \mathrm{MnO}, \mathrm{MnO} \times \mathrm{Na}_{2} \mathrm{O}, \mathrm{Li}_{2} \mathrm{O} \times \mathrm{MnO}$, and $\mathrm{Na}_{2} \mathrm{O} \times \mathrm{SiO}_{2}$. Subsequently, this second 20-term PQM model is referred to as PQM1b.

Numerical Results for the Second 20-Term Partial Quadratic Mixture Model (PQM1b) on Spinel $\mathrm{T}_{1 \%}$

Table 6.11 contains the coefficients of the second 20-term PQM1b model for spinel $\mathrm{T}_{1 \%}$, coefficient standard deviations, and performance statistics for the (i) modeling data, (ii) data-split modeling data, (iii) 124/44 partition of the modeling data into modeling and validation subsets, and (iv) 38 separate validation glasses with spinel $\mathrm{T}_{1 \%}$ data.

In Table 6.11, the model evaluation statistics $\mathrm{R}^{2}=0.870, \mathrm{R}_{\mathrm{A}}^{2}=0.854, \mathrm{R}_{\mathrm{P}}^{2}=0.827$, and $\mathrm{RMSE}=47.782$ for the 20-term PQM1b model on spinel $\mathrm{T}_{1 \%}$ are slightly worse than for the PQM1 model (see Table 6.10), but again substantive improvements over the corresponding statistics for the 15-component reduced LM model (see Table 6.9). The small drop in values from $\mathrm{R}_{\mathrm{A}}^{2}$ to $\mathrm{R}_{\mathrm{P}}^{2}$ suggests that the spinel $\mathrm{T}_{1 \%}$ modeling dataset does not have any highly influential data points for the 20-term PQM1b model. In any case, $\mathrm{R}_{\mathrm{P}}^{2}=0.827$ provides an 
estimate of the fraction of variation in spinel $\mathrm{T}_{1 \%}$ values for future datasets over the same glass composition region that might be accounted for by this PQM model.

Over the five data splits of the spinel $\mathrm{T}_{1 \%}$ modeling data, Table 6.11 shows that the 20term PQM1b model has average modeling statistics $\mathrm{R}^{2}=0.875, \mathrm{R}_{\mathrm{A}}^{2}=0.855, \mathrm{R}_{\mathrm{P}}^{2}=0.823$, and $\mathrm{RMSE}=47.669$ that are all close to their values from the 168-glass modeling dataset. The average validation statistics $\mathrm{R}_{\mathrm{V}}^{2}=0.817$ and $\mathrm{RMSE}_{\mathrm{V}}=51.715$ from data-splitting are slightly worse (i.e., smaller and larger) than $\mathrm{R}_{\mathrm{P}}^{2}=0.827$ and $\mathrm{RMSE}=47.782$ for the 168-glass modeling dataset. Hence, the data-splitting validation results for the 20-term PQM1b model on spinel $\mathrm{T}_{1 \%}$ are generally similar to those from fitting the model to the 168-glass dataset.

The 20-term PQM1b model for spinel $\mathrm{T}_{1 \%}$ yielded somewhat different results for the partition of the modeling data into a modeling subset of 124 glasses and a validation subset of 44 glasses. As seen in Table 6.11, the fit statistics $R^{2}=0.837, R_{A}{ }^{2}=0.808$, and $R_{P}^{2}=0.759$ for the 124-glass modeling subset are all somewhat worse (i.e., smaller) than the corresponding statistics for the full 168-glass modeling set. The RMSE $=45.725$ is slightly better (i.e., smaller) for the 124-glass modeling subset. For the 44-glass validation subset from data-partitioning, the $\mathrm{R}_{\mathrm{V}}^{2}=$ 0.862 is very close to the $\mathrm{R}^{2}=0.870$ from fitting the 20 -term PQM1a model to all 168 glasses in the spinel $\mathrm{T}_{1 \%}$ modeling dataset. The $\mathrm{RMSE}_{\mathrm{V}}=62.364$ from the 44-glass validation subset is somewhat worse than the RMSE $=47.782$ from fitting the model to all 168 glasses.

For the set of 38 separate validation glasses, the 20-term PQM1b model for spinel $\mathrm{T}_{1 \%}$ has $\mathrm{R}_{\mathrm{V}}^{2}=0.040$ and $\mathrm{RMSE}_{\mathrm{V}}=115.453$, which indicate very poor validation, worse even than the 20-term PQM1a model. Additional discussion of the poor validation performance of the 20term PQM1b model for spinel $\mathrm{T}_{1 \%}$ is provided subsequently when Figure 6.25 is discussed.

The RMSE in Table 6.11 is an estimate of the uncertainty in estimated spinel $\mathrm{T}_{1 \%}$ values for simulated HLW glasses if the 20-term PQM1b model does not have statistically significant LOF. Although the RMSE $=47.782$ for the 20-term PQM1b model is smaller than the corresponding RMSE $=56.417$ for the 15-component reduced LM model, it is still much larger than the replicate $\mathrm{SD}=26.89$ in Table 5.4. These observations suggest that the 20-term PQM1b model for spinel $\mathrm{T}_{1 \%}$ has a substantial LOF. This indication is confirmed by the $p$-value $=0.004$ of the LOF test (see Section C.4 of Appendix C) for this model in Table 6.11. This p-value indicates that the model LOF is significant at the $99.6 \%$ confidence level.

Graphical Results for the Second 20-Term Partial Quadratic Mixture Model (PQM1b) on Spinel $\mathrm{T}_{1} \%$

Figure 6.21 displays the predicted versus measured plot for the second 20-term PQM1b model for spinel $\mathrm{T}_{1 \%}$ applied to the 168 glasses of the spinel $\mathrm{T}_{1 \%}$ modeling dataset. The distribution of points around the $45^{\circ}$ line is improved (less scatter) compared to the distribution for the 15-component reduced LM model in Figure 6.11. However, the distribution of points is slightly worse than for the 20-term PQM1a model in Figure 6.16. Figure 6.21 gives no indication of biased prediction over the range of spinel $\mathrm{T}_{1 \%}$ values in the modeling dataset. Further, the standardized residual plot in Figure 6.22 gives an indication of some tendency to over-predict spinel $\mathrm{T}_{1 \%}$ for the HLW05 and HLW-ALG groups of data represented in the modeling dataset. 
Diagnostic plots for the PQM1b model (not included in this report) support the assumption of normally distributed errors in the spinel $\mathrm{T}_{1 \%}$ data (see Section C.3 of Appendix C).

Figure 6.23 displays the response trace plot (see Section C.5.1) for the 20-term PQM1b model for spinel $\mathrm{T}_{1 \%}$. The figure shows that $\mathrm{NiO}, \mathrm{Cr}_{2} \mathrm{O}_{3}, \mathrm{ZnO}, \mathrm{Fe}_{2} \mathrm{O}_{3}, \mathrm{Al}_{2} \mathrm{O}_{3}, \mathrm{MnO}$, and $\mathrm{ZrO}_{2}$ have the largest increasing effects on spinel $\mathrm{T}_{1 \%}$, while $\mathrm{Li}_{2} \mathrm{O}, \mathrm{Na}_{2} \mathrm{O}, \mathrm{B}_{2} \mathrm{O}_{3}, \mathrm{SrO}$, and $\mathrm{SiO}_{2}$ have the largest decreasing effects on spinel $\mathrm{T}_{1 \%}$. Curvature effects are not apparent in Figure 6.23 for the PQM1b model as they were for the PQM1a model in Figure 6.18. This is because the PQM1b model for spinel $\mathrm{T}_{1 \%}$ does not contain any squared terms as did the PQM1a model. The response traces for $\mathrm{UO}_{3}$, Others, $\mathrm{ZrO}_{2}$, and $\mathrm{ThO}_{2}$ are the closest to horizontal, indicating these components may have negligible effects on spinel $\mathrm{T}_{1 \%}$.

Figures 6.24 and 6.25 show the predicted versus measured plots when the 20-term PQM1b model for spinel $\mathrm{T}_{1 \%}$ is applied to two validation datasets. Figure 6.24 results from fitting the PQM1b model to a subset of 124 out of 168 modeling glasses, and then applying the resulting model to the remaining subset of 44 glasses for validation (see Section 6.1.3). Figure 6.25 results from fitting the PQM1b model for spinel $\mathrm{T}_{1 \%}$ to all 168 glasses in the modeling set and then applying that model to the 38 separate validation glasses with spinel $\mathrm{T}_{1 \%}$ data (see Section 6.1.4). Also shown in Figures 6.24 and 6.25 are 95\% PIs representing the model prediction uncertainty of single spinel $\mathrm{T}_{1 \%}$ determinations for each glass (see Sections C.6 and C. 7 of Appendix C). If the $95 \%$ PI for a validation point overlaps the $45^{\circ}$ line, the predicted and estimated spinel $\mathrm{T}_{1 \%}$ values are within model and estimation uncertainty of each other.

Figure 6.24 shows that the 20-term PQM1b model fitted to the 124-glass modeling subset from data-partitioning yields roughly unbiased predictions above $900{ }^{\circ} \mathrm{C}$ approximately, but has a tendency to over-predict spinel $\mathrm{T}_{1 \%}$ below $900^{\circ} \mathrm{C}$. This tendency to over-predict is improved compared to the 15-component reduced LM model, but is somewhat worse compared to the 20term PQM1 model. The 95\% PIs in Figure 6.24 overlap the $45^{\circ}$ line (i.e., contain the measured values) for all but 6 of the 44 glasses in the validation subset from data-partitioning. Failure of $100(6 / 44)=13.6 \%$ of the $95 \%$ PIs to include the corresponding estimated spinel $\mathrm{T}_{1 \%}$ values is somewhat more than the $5 \%$ expected by chance. This is a result of the over-prediction for lower spinel $\mathrm{T}_{1 \%}$ values and significant model LOF that results in increased scatter in spinel $\mathrm{T}_{1 \%}$ predictions. The 95\% PIs are relatively wide, which is partly due to: (i) the LOF of the 20-term PQM1b model, and (ii) the inherent uncertainty in the process of estimating spinel $\mathrm{T}_{1 \%}$ values.

Figure 6.25 shows that the 20 -term PQM1b model for spinel $\mathrm{T}_{1 \%}$ fitted to the 168 -glass modeling dataset and applied to the 38-glass separate validation dataset tends to (i) over-predict for spinel $\mathrm{T}_{1 \%}$ below $800^{\circ} \mathrm{C}$, and (ii) under-predict above $800^{\circ} \mathrm{C}$. These under- and overpredictions are actually worse than for the 15-component reduced LM model (see Figure 6.15). Compared to the 20-term PQM1a model, the over-predictions for the 20-term PQM1b model are not as bad, but the under-predictions are worse. The 95\% PIs do not contain the corresponding measured values for 19 of the 38 separate validation glasses with spinel $\mathrm{T}_{1 \%}$ data. It is not clear whether the poor prediction performance of the 20-term PQM1b model for spinel $\mathrm{T}_{1 \%}$ applied to the separate validation data is because of something different about the validation data related to being collected at a different time, the limited composition region covered by this relatively small subset of validation data, or whether it is an indication of limitations in the 20-term 
PQM1b model for spinel $\mathrm{T}_{1 \%}$. The poorer validation predictive performance of the 20 -term PQM1b model relative to the 15-component reduced LM model could be an indication that the quadratic terms in the PQM1b model are to some extent a result of over-fitting to the modeling dataset, and that those terms are not as important to spinel $\mathrm{T}_{1 \%}$ prediction in general.

Summary of the Second 20-Term Partial Quadratic Mixture Model (PQM1b) for Spinel $\mathrm{T}_{1 \%}$

The second 20-term PQM model (PQM1b) for spinel $\mathrm{T}_{1 \%}$ is given in Table 6.11 and the variance-covariance matrix associated with the model coefficients is given in Table D.12 of Appendix D. The PQM1b model fits the 168-glass modeling dataset better than the 15component reduced LM model, but still has significant LOF. The PQM1b model also performs better on the data-splitting and data-partitioning validation assessments than does the 15component reduced LM model. However, the 20-term PQM1b model performs noticeably worse that the 15-component reduced LM model when applied to the separate validation dataset of 38 HLW glasses. The 20-term PQM1b model performs somewhat worse than the PQM1a model in data-partition validation, and has no advantage over the PQM1a model in the separate data validation.

\subsubsection{8-Term Partial Quadratic Mixture Model for Spinel $T_{1 \%}$ Derived from the 13-Component Reduced Linear Mixture Model}

Another PQM model considered for $\mathrm{T}_{1 \%}$ was obtained by using the MAXR selection approach to select 5 quadratic terms from the set of all possible quadratic terms formed using the 12 non-Others components in the 13-component reduced LM model discussed in Section 6.3.2. This model is denoted PQM2, given that it is based on the second reduction of the 25-component full LM model.

The 5 quadratic terms selected for the resulting 18-term PQM model were $\left(\mathrm{ZrO}_{2}\right)^{2}$, $\mathrm{Al}_{2} \mathrm{O}_{3} \times \mathrm{MnO}, \mathrm{MnO} \times \mathrm{Na}_{2} \mathrm{O}, \mathrm{Na}_{2} \mathrm{O} \times \mathrm{SiO}_{2}$, and $\mathrm{Li}_{2} \mathrm{O} \times \mathrm{MnO}$. Note that this PQM model involved a $\left(\mathrm{ZrO}_{2}\right)^{2}$ term. However, additional stepwise regression iterations based on the 13-term reduced LM model but excluding quadratic terms involving $\mathrm{ZrO}_{2}$ and $\mathrm{ThO}_{2}$ (as well as Others) were not conducted. Less effort was made to generate additional PQM models based on the 13-component reduced LM model for two reasons: 1) the Others component for the 13-component reduced LM model ranged to a mass fraction of over 0.14 (14 wt $\%$ ), which is undesirably high, and 2) models based on the 15-term reduced LM model showed slightly better performance than similar models that were based on the 13-term reduced LM model (see discussion in Section 6.6). Hence, preference was given to PQM models based on the 15-term reduced LM model.

\subsection{IHLW $\mathrm{T}_{1 \%}$ Model Results Based on 144 Spinel-Only Glasses}

As discussed in Section 6.1.1, 24 of the 168 glasses in the spinel $\mathrm{T}_{1 \%}$ modeling dataset had one or more secondary crystalline phases in addition to the spinel primary phase. Several of these glasses had secondary phases involving $\mathrm{Zr}$ and $\mathrm{Th}$, thus potentially explaining why the PQM models discussed in Section 6.4 sometimes had quadratic terms selected involving $\mathrm{ZrO}_{2}$ 
and $\mathrm{ThO}_{2}$. Thus, it was decided to investigate whether the 24 glasses in the spinel $\mathrm{T}_{1 \%}$ modeling dataset (with secondary crystalline phases in addition to the spinel primary phase) degrade spinel $\mathrm{T}_{1 \%}$ models. The investigation consisted of taking the model forms previously fitted using all 168 HLW glasses in the modeling dataset, and fitting them using the 144 spinel-only glasses (see Table 6.3. This means that mixture model regression methods were used to generate new model coefficient estimates for models having the same terms as those described in Sections 6.3 and 6.4 , but based on the 144 spinel-only glasses.

One additional model was considered based on the 144 spinel-only glasses: a 20 -term PQM model containing linear terms for the 15 components involved in the 15-term reduced LM model plus 5 quadratic terms. For this model, the 5 quadratic terms were selected using stepwise regression with the MAXR selection criterion from the set of all possible squared and pairwise cross-product terms formed from the 14 non-Others components included in the 15-term reduced LM model. In this sense, this new 20-term PQM model (denoted PQM1c) is similar to the 20term PQM model denoted PQM1a in Section 6.4.1. However, because the selection of quadratic terms in PQM1c was based on just the 144 spinel-only glasses, a different set of quadratic terms was selected than in PQM1a. The quadratic terms selected for this new 20-term PQM1c model did not involve $\mathrm{ZrO}_{2}$ or $\mathrm{ThO}_{2}$, presumably owing to the fact that the glasses with secondary phases containing $\mathrm{Zr}$ and $\mathrm{Th}$ were not included in the 144 spinel-only dataset. The quadratic terms selected for the 20-term PQM1c model were very similar to the quadratic terms selected for the 20-term PQM1b model in Section 6.4.2. The 20-term PQM1c model includes the quadratic terms $\mathrm{Al}_{2} \mathrm{O}_{3} \times \mathrm{MnO}, \mathrm{Na}_{2} \mathrm{O} \times \mathrm{SiO}_{2},\left(\mathrm{Na}_{2} \mathrm{O}\right)^{2}, \mathrm{Cr}_{2} \mathrm{O}_{3} \times \mathrm{SiO}_{2}$, and $\mathrm{MnO} \times \mathrm{ZnO}$.

Table 6.12 contains summary statistics for the different spinel $\mathrm{T}_{1 \%}$ model forms discussed in Sections 6.3 and 6.4, but developed using the 144 spinel-only glasses. The statistics in the upper section of Table 6.12 summarize performance for models fitted with the 144 spinel-only glasses. In general, these results are similar to corresponding performance statistics based on models developed using all 168 glasses in the spinel $\mathrm{T}_{1 \%}$ model development dataset (see upper section of Table 6.13). This indicates that including the 24 spinel-plus-other-crystal glasses in the dataset used to generate the models (the 168 glasses) did not substantially degrade model performance. Thus, by retaining these 24 glasses in the modeling dataset, the resulting models should be more robust for application to compositions that involve secondary crystalline phases in addition to the spinel primary crystalline phase.

The middle section of Table 6.12 contains summary statistics obtained by applying the models generated with the 144 spinel-only glasses to the 24 spinel-plus-other-crystal glasses. These performance statistics are noticeably worse than those for the models fitted to the 144 spinel-only glasses (the upper section of Table 6.12). This indicates that the robustness of the model forms is considerably degraded for predicting spinel $\mathrm{T}_{1 \%}$ of glasses with spinel-plus-othercrystal phases when spinel-only data are used to fit the models. Of the models represented in Table 6.12, the first 20-term PQM model (PQM1a) performs best when applied to the 24 spinelplus-other-crystal glasses.

The bottom section of Table 6.12 contains performance statistics that describe predictive performance when the various models (fitted to the 144 spinel-only glasses) are applied to the 38 separate validation glasses. Again, these results are considerably lower than the corresponding 
statistics that describe model performance based on the 144 spinel-only glasses (the upper section of Table 6.12). This was also the case for the models developed using all 168 glasses in the spinel $\mathrm{T}_{1 \%}$ modeling dataset (see Table 6.13). However, the models fitted to all 168 glasses noticeably outperform those fitted to the 144 spinel-only glasses for the separate validation data.

In conclusion, the results in Table 6.12 compared to the results in Table 6.13 show that the models fitted to all 168 glasses in the spinel $\mathrm{T}_{1 \%}$ modeling dataset are more robust in predicting $\mathrm{T}_{1 \%}$ of glasses with secondary crystalline phases (in addition to spinel as the primary phase) than the models fitted to the 144 spinel-only glasses.

\subsection{Recommended and Second-Choice Spinel T $_{1 \%}$ Models for HLW Glasses}

Table 6.13 summarizes results for the various spinel $\mathrm{T}_{1 \%}$ models discussed in Sections 6.3 and 6.4. These include the various linear mixture models discussed in Section 6.3 and the various PQM models discussed in Section 6.4. Results are summarized for the (i) 168-glass modeling dataset, (ii) data-split modeling data, (iii) 124/44 partition of the modeling data into modeling and validation subsets, and (iv) 38 separate validation glasses with spinel $\mathrm{T}_{1 \%}$ data. Based on these results, the results in Table 6.12 from fitting models to the 144 spinel-only glasses, and discussions in Sections 6.3 to 6.5 , recommended and second-choice models were selected.

The 20-term PQM model (denoted PQM1a) was selected as the recommended model for spinel $\mathrm{T}_{1 \%}$. It was discussed in Section 6.4.1, with coefficients and other information contained in Table 6.10 and its variance-covariance matrix given in Table D.11 of Appendix D. Recall that this model (i) was generated using all 168 HLW glasses in the spinel $\mathrm{T}_{1 \%}$ modeling dataset and (ii) had quadratic terms selected from among all possible second-order terms formed from the 14 non-Others components involved in the 15-term reduced LM model. One of the quadratic terms in this model being $\left(\mathrm{ZrO}_{2}\right)^{2}$ appears to partially be a result of some of the 168 glasses in the modeling dataset containing Zr-containing crystalline phases in addition to the spinel primary phase. However, this PQM1a model performed better than did the PQM1b model (which disallowed quadratic terms containing $\mathrm{ZrO}_{2}$ and $\mathrm{ThO}_{2}$ ). This PQM1a model form also performed better than the PQM1b model form when fitted to the 144 spinel-only glasses, both for the 24 spinel-plus-other-crystals data and the separate validation data (see Table 6.12). The recommended PQM1a model performed better in these regards than even the PQM1c model, whose quadratic terms were selected and the whole model fitted to the data from the 144 spinelonly glasses (see Table 6.12). Hence, even though the recommended 20-term PQM1a model has a statistically significant LOF, it is a result of larger prediction uncertainty. The PQM1a model yields relatively unbiased predictions of spinel $\mathrm{T}_{1 \%}$ (see Figure 6.16).

The 20-term PQM model (denoted PQM1b) was selected as the second-choice model for predicting spinel $\mathrm{T}_{1 \%}$ of HLW glasses. It was discussed in Section 6.4.2, with coefficients and other information contained in Table 6.11 and its variance-covariance matrix given in Table D.12 of Appendix D. This model was also generated using all 168 HLW glasses, but its quadratic terms were selected from among all possible second-order terms formed from the 12 components of the 15-term reduced LM model after excluding $\mathrm{ZrO}_{2}, \mathrm{ThO}_{2}$, or Others. 
The full 25-term LM model (Section 6.3.1) and the 15-term reduced LM model (Section 6.3.2) also have coefficients included in this report. These models are included mainly to serve as baselines for comparison and as fall-back models if future applications of the recommended and second-choice PQM models indicate that the linear models provide better predictive performance. In some cases, past property-composition modeling activities have shown that linear models outperform higher-order models when applied to new compositions. This suggests that higher-order terms may tend to over-represent the data used for model development. The results in Table 6.13 indicate that the PQM models could suffer from some over-representation of the modeling data. Although the PQM models formed by augmenting the reduced LM models with quadratic terms had statistically significant improvements over the LM models for the modeling data, data-splitting, and data partitioning investigations, these improvements were not evident for the separate validation data. In fact, the statistics describing models applied to the separate validation glasses are worse for the PQM models than for the full or reduced LM models (see Table 6.13).

It is not clear how much the lack of improved prediction performance by the PQM models for the separate validation data was due to the limited nature of that data within the compositional region of interest and other factors (e.g., lab-to-lab and long-term variations). Furthermore, the spinel $\mathrm{T}_{1 \%}$ modeling dataset for Phase 2 included many more glasses than what were available during Phases 1 and 1a. The additional glasses in the Phase $2 \mathrm{~T}_{1 \%}$ modeling dataset expanded the ranges represented in the HLW glass composition space for some components compared to the spinel $\mathrm{T}_{1 \%}$ modeling data used during Phases 1 and 1a. Because of the improved confidence concerning how well the Phase 2 spinel $\mathrm{T}_{1 \%}$ modeling dataset represents the HLW composition space (compared to the spinel $\mathrm{T}_{1 \%}$ data used for Phases 1 and 1a), it was decided to select the PQM models denoted PQM1a (recommended) and PQM1b (second choice) based on their improved performance over the LM models for the modeling dataset, data-splitting, and data-partitioning. It was also decided to provide the model coefficients and summary statistics for the spinel $\mathrm{T}_{1 \%}$ 25-component full and 15-component reduced LM models as baselines for comparison with (and to provide justification of) the PQM models, particularly when these models are applied to future data.

In conclusion, the recommended model for spinel $\mathrm{T}_{1 \%}$ prediction is the 20-term PQM model in Table 6.10, with variance-covariance matrix given in Table D.11 of Appendix D. The second-choice model for predicting spinel $\mathrm{T}_{1 \%}$ is the 20-term PQM model in Table 6.11, with variance-covariance matrix given in Table D.12 of Appendix D. It is suggested that both these spinel $\mathrm{T}_{1 \%}$ models for HLW glasses be applied and their performances compared during future IHLW glass formulation and waste form qualification work.

\subsection{Example Illustrating Spinel $T_{1 \%}$ Model Predictions and Statistical Intervals}

This section contains examples to illustrate the use of selected spinel $\mathrm{T}_{1 \%}$ models to obtain predicted spinel $\mathrm{T}_{1 \%}$ values for a specific HLW glass composition. The models selected include (i) the 15-component reduced LM model, (ii) the recommended 20-term PQM model (denoted PQM1a), and (iii) the second-choice 20-term PQM model (denoted PQM1b). This 
section also describes how corresponding 90\% UCIs are calculated. The $90 \%$ confidence levels associated with $90 \%$ UCIs were chosen for illustration purposes only. The WTP project can use an appropriate confidence level depending on the use of the spinel $\mathrm{T}_{1 \%}$-composition model and the type of statistical uncertainty expression.

The glass composition used in this example is HLW03-06, which was used previously in the Phase 1 IHLW models report (Kot et al. 2005a). The 25-component composition of HLW0306 for spinel $\mathrm{T}_{1 \%}$ modeling is given in Table $6.1 \mathrm{in}$ mass fraction format. To apply the spinel $\mathrm{T}_{1 \%}$ models to this composition, the mass fractions of the 25 components must be converted to mass fractions (that sum to 1.0) of the 15 components appearing in the spinel $\mathrm{T}_{1 \%}$ models. Mass fractions of the relevant components are then multiplied to obtain the quadratic terms of the 18term and 15-term PQM models. Table 6.16 contains the composition for HLW03-06 prepared for use in the different spinel $\mathrm{T}_{1 \%}$ models for HLW glasses.

For each of the spinel $\mathrm{T}_{1 \%}$ models, predicted spinel $\mathrm{T}_{1 \%}$ values are obtained by multiplying the composition in the format needed for the specific model by the coefficients for that model, then summing the results. The coefficients for the three spinel $\mathrm{T}_{1 \%}$ models included in the example are given in Tables 6.9, 6.10, and 6.11. Using vector notation, the predicted values are calculated by

$$
\hat{y}(\boldsymbol{a})=\boldsymbol{a}^{\mathrm{T}} \boldsymbol{b},
$$

where $\boldsymbol{a}$ is the composition of HLW03-06 (from Table 6.14) formatted to match the terms in a given model, the superscript $\mathrm{T}$ represents a vector transpose, and $\boldsymbol{b}$ is the vector of coefficients for a given model. The predicted spinel $\mathrm{T}_{1 \%}$ values $\left({ }^{\circ} \mathrm{C}\right)$ from each of the 15 -component reduced LM model and the two 20-term PQM models (PQM1a and PQM1b) are listed in the second column of Table 6.15. The predicted spinel $\mathrm{T}_{1 \%}$ values in Table 6.15 can be considered as estimates of the true mean of the distribution of spinel $\mathrm{T}_{1 \%}$ values that would result if the process for making $\mathrm{T}_{1 \%}$ determinations (see Section E.1 of Appendix E) were repeated multiple times for the HLW03-06 glass.

Equation (C.31a) in Section C.7.1 of Appendix C can be used to calculate a CL\% upper confidence interval (CL\% UCI) for the true mean spinel $\mathrm{T}_{1 \%}$ value for the HLW03-06 glass composition for each of the spinel $\mathrm{T}_{1 \%}$ models for HLW glasses. A CL\% UCI is of interest because the processing constraint is spinel $\mathrm{T}_{1 \%} \leq 950^{\circ} \mathrm{C}$. For the illustrations to follow, we use $\mathrm{CL} \%=90 \%$. In the notation of Equation (C.31a):

- $\mathrm{CL} \%=100(1-\alpha) \%=90 \%$, so that $\alpha=0.10$.

- Vector $\boldsymbol{a}$ contains entries corresponding to the terms in a given spinel $\mathrm{T}_{1 \%}$ model, which are calculated using the composition of HLW03-06 in Table 6.14.

- Matrix $\boldsymbol{A}$ is formed from the data matrix used in the regression that generated a given spinel $\mathrm{T}_{1 \%}$ model. Matrix $\boldsymbol{A}$ has 168 rows corresponding to the number of glasses in the modeling dataset and the number of columns corresponding to the 
number of terms in a given spinel $\mathrm{T}_{1 \%}$ model. Each column is calculated according to the corresponding term in the model using the HLW glass compositions in the spinel $\mathrm{T}_{1 \%}$ modeling dataset.

To calculate an $90 \%$ UCI for the mean spinel $\mathrm{T}_{1 \%}$ in ${ }^{\circ} \mathrm{C}$, the quantity $t_{1-\alpha, n-p} R M S E \sqrt{\boldsymbol{a}^{T}\left(\boldsymbol{A}^{T} \boldsymbol{A}\right)^{-1} \boldsymbol{a}}$ is added to the predicted spinel $\mathrm{T}_{1 \%}$ value $\hat{y}(\boldsymbol{a})$ described above, as indicated by Equation (C.31a). The $\operatorname{MSE}\left[\left(\boldsymbol{A}^{T} \boldsymbol{A}\right)^{-1}\right]$ portion of this expression is the estimated variance-covariance matrix for the estimated model coefficients, as discussed near the end of Section C.7 of Appendix C. The variance-covariance matrices for the three spinel $\mathrm{T}_{1 \%}$ models used in this illustrative example are listed in Tables D.10 to D.12 of Appendix D. The quantity $M S E$ is the mean squared error from regression, and $R M S E$ is the root mean squared error (i.e., the square root of $M S E$ ). Note that the MSE (RMSE squared) is included in the variancecovariance matrices in Appendix D, and thus does not have to be separately included in the statistical interval calculations. The quantity $R M S E \sqrt{\boldsymbol{a}^{T}\left(\boldsymbol{A}^{T} \boldsymbol{A}\right)^{-1} \boldsymbol{a}}$ is the standard deviation of a model prediction; the value for each model is given in the third column of Table 6.15.

The 90\% UCI values for the true mean spinel $\mathrm{T}_{1 \%}$ value for the HLW03-06 composition based on the various spinel $\mathrm{T}_{1 \%}$ models are given in the fourth column of Table 6.15 . Note that the $90 \%$ UCI values for HLW03-06 are somewhat above and hence fail the $\mathrm{T}_{1 \%}$ processing limit of $950^{\circ} \mathrm{C}$. However, as discussed in Section 6.1.1, it is desirable for the modeling dataset to contain glasses with property values below, close to, and above the property limit. In this case, HLW03-06 has a spinel $\mathrm{T}_{1 \%}$ value close to the limiting value.

As discussed in Section C.7 of Appendix C, there are times when a CL\% simultaneous upper confidence interval (SUCI) may be preferred rather than a CL\% UCI. This is particularly true when the regression model (composition-property model) is to be used a large number of times for various glass compositions within a specified composition region. Equation (C.35a) in Section C.7.4 of Appendix C can be used to calculate a 90\% SUCI for the true mean spinel $\mathrm{T}_{1 \%}$ value for each of any number of glass compositions in the model validity region. Then, the resulting SUCIs for those glass compositions simultaneously have $90 \%$ confidence for containing their true mean values. The $90 \%$ SUCI values for the true mean spinel $\mathrm{T}_{1 \%}$ (in ${ }^{\circ} \mathrm{C}$ ) for the HLW03-06 composition based on the spinel $\mathrm{T}_{1 \%}$ models for HLW glasses are given in the fifth column of Table 6.15. Note that the 90\% SUCIs are larger than the corresponding 90\% UCIs, because of the simultaneous confidence protection for multiple uses of the same model.

\subsection{Suitability of the Recommended IHLW Spinel $\mathbf{T}_{1 \%}$ Model for Application by the WTP Project}

The 20-term PQM model (PQM1a) for spinel $\mathrm{T}_{1 \%}$ discussed in Section 6.4.1 was recommended for use by the WTP project as the best model currently available for predicting spinel $\mathrm{T}_{1 \%}$ for HLW glasses. This model appears to yield unbiased predictions of spinel $\mathrm{T}_{1 \%}$ over the full range of values represented in the modeling dataset. However, the PQM1a model has a statistically significant LOF that results in larger uncertainties of spinel $\mathrm{T}_{1 \%}$ model predictions. 
Thus, the relationship between spinel $\mathrm{T}_{1 \%}$ and HLW glass compositions apparently is more complicated than can be represented by a global model (i.e., a single mathematical equation) having the linear and quadratic polynomial forms considered over the whole WTP HLW glass composition region of interest. It was beyond the scope of this model development effort to investigate more advanced model development methods that might yield a model that can better represent the relationship represented in the modeling dataset. Possible solutions are discussed in Section 11.2.

Because of the magnitudes of uncertainties in the spinel $\mathrm{T}_{1 \%}$ data (i.e., from making simulated HLW glasses, heat treatments and vol\%-crystallinity determination, and the process of estimating spinel $\mathrm{T}_{1 \%}$ from temperature-vol\% crystallinity data), as well as LOF of the recommended model, prediction uncertainties for the model are relatively large. Figure 6.26 displays the prediction standard deviations versus predicted values (both in ${ }^{\circ} \mathrm{C}$ ) for the $168 \mathrm{HLW}$ glass compositions in the spinel $\mathrm{T}_{1 \%}$ modeling dataset. The prediction standard deviations for modeling dataset glasses range from approximately 5 to $30^{\circ} \mathrm{C}$ for the recommended spinel $\mathrm{T}_{1 \%}$ model. Note that these are standard deviations of model predictions considered as the mean spinel $\mathrm{T}_{1 \%}$ value for a given glass. Standard deviations of predictions considered as individual determinations of spinel $\mathrm{T}_{1 \%}$ are larger, ranging from approximately 27 to $40^{\circ} \mathrm{C}$ for the recommended spinel $\mathrm{T}_{1 \%}$ model. Note also that prediction standard deviations will be larger for HLW glass compositions as their distance from glasses in the spinel $\mathrm{T}_{1 \%}$ modeling datasets increases. Finally, the total uncertainty in predictions with the recommended spinel $\mathrm{T}_{1 \%}$ model will depend on the type of statistical interval used (see Section C.7 of Appendix C).

It is unclear whether the relatively large prediction uncertainties for the recommended spinel $\mathrm{T}_{1 \%}$ model will overly restrict WTP HLW vitrification operations. The ultimate suitability of the recommended spinel $\mathrm{T}_{1 \%}$ model for HLW glass formulation, glass former addition decisions during production, and verifying compliance with processing requirements will be decided by separate, future WTP project work.

Piepel et al. (2005) previously addressed the impact of composition and model uncertainties for IHLW compliance properties (e.g., PCT) using the Phase 1 IHLW PCT models discussed by Kot et al. (2005a). However, it was not part of the scope of that work to address the impact of uncertainties for processing properties such as spinel $\mathrm{T}_{1 \%}$. The impact of HLW glass composition uncertainties and model uncertainties for the recommended spinel $\mathrm{T}_{1 \%}$ model (Section 6.4.1) on satisfying the $\leq 950^{\circ} \mathrm{C}$ processing limit may in the future be addressed as part of the Technical Scoping Statement (TSS) B-6270 work scope of the River Protection Project-Waste Treatment Plant Support Program at PNNL. The impacts are also planned to be addressed as part of the second iteration of HLW glass formulation algorithm development work planned by WTP project staff. The first iteration of that work (Vienna and Kim 2007) utilized the IHLW Phase 1 spinel $T_{1 \%}$ model (Kot et al. 2005a). 


\section{SECTION 7 \\ MODELS RELATING ELECTRICAL CONDUCTIVITY TO HLW GLASS COMPOSITION AND TEMPERATURE}

This section documents the development and validation of property-compositiontemperature models and corresponding uncertainty expressions for predicting the electrical conductivity (EC) for high-level waste (HLW) glasses. Because EC is a property of a glass melt, it is a function of glass melt temperature as well as glass composition. The propertycomposition-temperature models and corresponding uncertainty expressions for EC presented in this section were developed and validated using glass composition, temperature, and EC data collected on simulated HLW glasses. Electrical conductivity was not measured on any of the glasses made from actual waste samples that are discussed in Section 2.1.9.

The 208 simulated HLW glasses used for EC model development and validation (from the database of 210 glasses) are discussed in Section 7.1. Section 7.2 lists the model forms for EC that were investigated. Section 7.3 presents the results for EC models with the two parameters of the truncated-T2 equation (for temperature dependence) expressed as linear mixture models in composition. Section 7.4 studies the results of adding composition crossproduct terms to EC models. Section 7.5 presents the model fit and validation results for the recommended EC model. Section 7.6 illustrates the calculation of EC predictions and the uncertainties in those predictions using selected EC models and corresponding uncertainty equations. Section 7.7 discusses the suitability of the recommended EC model for use by the WTP project. Appendix C discusses the statistical methods and summary statistics used to develop, evaluate, and validate the several EC model forms investigated, as well as statistical equations for quantifying the uncertainties in EC models.

\subsection{Electrical Conductivity Data Used for Model Development and Validation}

The data used for developing EC models are discussed in Section 7.1.1. The approaches and data used for validating the models are discussed in Sections 7.1.2 to 7.1.4.

\subsubsection{Electrical Conductivity Model Development Data}

The data available for developing EC-composition-temperature models consist of composition, temperature, and EC data from $210 \mathrm{HLW}$ glasses (see Section 4.3). These glasses are discussed and their target compositions are presented in Section 2.1. The corresponding EC $(\mathrm{S} / \mathrm{cm})$ at temperature values are presented in Table 4.5. The HLW EC data are discussed in Section 4.3.

The EC and viscosity datasets contain results for 210 HLW glasses each. The EC and viscosity datasets consist almost entirely of data for the same $206 \mathrm{HLW}$ glasses. There are four 
additional glasses (HLW03-08, HLW07-08, HLW07-14 and HLW-ALG-24) in the EC dataset but not in the viscosity dataset. Similarly, there are an additional four glasses (HLW04-03, HLW04-06, HLW04-07 and HLW98-87) in the viscosity dataset but not in the EC dataset.

\section{Assessment of Available Glasses with Electrical Conductivity Data}

The database of 210 glasses with EC results contains statistically-designed as well as actively-designed glasses. Some actively-designed glasses are outside the composition region covered by the majority of the HLW compositions. Such glasses are not ideal for inclusion in a modeling set because they can be influential when fitting models to data. Hence, it was decided to (i) graphically assess the 210 simulated HLW glass compositions and (ii) remove from the modeling set any compositions considered to be outlying or non-representative of HLW glasses of interest for the WTP.

Figure 7.1 displays plots of the mass fraction values for the components in the 210 HLW glasses with EC data. On each plot in Figure 7.1, the x-axis represents the mass fraction values of an HLW glass component. The y-axis shows an index value representing each HLW glass, which aids in spreading out the data points to avoid over-plotting. The plotting symbols correspond to the eight groups of HLW glass data discussed in Sections 2.1.1 to 2.1.9. Electrical conductivity was not measured on any of the actual waste glasses discussed in Section 2.1.9. For comparison purposes, the vertical bars in Figure 7.1 represent, when shown, the lower and upper limits for statistically designed IHLW test matrices.

Figure 7.1 shows several glasses have components with outlying mass fraction values compared to the bulk of the glasses, but the values and ranges of those components are small and hence the glass compositions were not considered to be outliers. Table 7.1 lists the 10 HLW glasses identified as outliers in the IHLW EC and viscosity modeling sets, and whether each glass was excluded from the final EC and viscosity modeling datasets. Only the first 2 of the 10 glasses were excluded because of having outlying component values compared to the rest of the glasses. The other glasses in Table 7.1 were selected for viscosity and EC measurement and were therefore retained for modeling purposes.

Figure 7.2 shows plots of component distributions after the two outlying glasses were removed from the 210-glass set having EC data. Figure 7.2 shows for the remaining $208 \mathrm{HLW}$ glasses that all 18 of the main HLW glass components ${ }^{13}\left(\mathrm{Al}_{2} \mathrm{O}_{3}, \mathrm{~B}_{2} \mathrm{O}_{3}, \mathrm{CdO}, \mathrm{Cr}_{2} \mathrm{O}_{3}, \mathrm{Fe}_{2} \mathrm{O}_{3}, \mathrm{Li}_{2} \mathrm{O}\right.$, $\mathrm{MnO} \mathrm{Na} 2 \mathrm{O}, \mathrm{NiO}, \mathrm{Sb}_{2} \mathrm{O}_{3}, \mathrm{SeO}_{2}, \mathrm{SiO}_{2}, \mathrm{SrO}, \mathrm{ThO}_{2}, \mathrm{Tl}_{2} \mathrm{O}, \mathrm{UO}_{3}, \mathrm{ZnO}$, and $\mathrm{ZrO}_{2}$ ) have sufficient ranges and distributions of values within those ranges to support model terms. Similarly, Figure 7.2 shows that $\mathrm{CaO}, \mathrm{MgO}$ and $\mathrm{PbO}$ have sufficient ranges and distributions of values within their ranges to support model terms for those components. Based on Figure 7.2, it was decided to use 22 components for initial $\mathrm{EC}$ and viscosity modeling work. These are $\mathrm{Al}_{2} \mathrm{O}_{3}, \mathrm{~B}_{2} \mathrm{O}_{3}, \mathrm{CaO}, \mathrm{CdO}$, $\mathrm{Cr}_{2} \mathrm{O}_{3}, \mathrm{Fe}_{2} \mathrm{O}_{3}, \mathrm{Li}_{2} \mathrm{O}, \mathrm{MgO}, \mathrm{MnO} \mathrm{Na}_{2} \mathrm{O}, \mathrm{NiO}, \mathrm{PbO}, \mathrm{Sb}_{2} \mathrm{O}_{3}, \mathrm{SeO}_{2}, \mathrm{SiO}_{2}, \mathrm{SrO}, \mathrm{ThO}_{2}, \mathrm{Tl}_{2} \mathrm{O}, \mathrm{UO}_{3}$, $\mathrm{ZnO}, \mathrm{ZrO}_{2}$, and Others (the sum of all remaining components).

\footnotetext{
13 The "main HLW glass components" are the ones that were directly varied in one or more test matrices associated with the series of glasses discussed in Section 2.1.
} 
Figure 7.3 shows a scatterplot matrix of 18 main components of the 208 glasses remaining in the EC modeling dataset after removing the two outlying glasses. Because high correlations between some pairs of components may be present and could affect modeling results, pairwise correlation coefficients were calculated. These can vary from -1.0 (perfect negative correlation) to 0 (no correlation) to 1.0 (perfect positive correlation). There are no correlations exceeding 0.6 (in absolute value) between pairs of the 22 components selected for initial modeling work. Among other pairs of components (which may include one of the 22 components selected for modeling) there are 61 that have correlation higher than 0.6 in absolute value. High-correlated pairs (those with correlations equal or greater than 0.6 in absolute value) that include one of the 22 components selected for initial modeling are

$\begin{array}{llll}\mathrm{Rh}_{2} \mathrm{O}_{3} \text { and } \mathrm{Sb}_{2} \mathrm{O}_{3} & 0.63 & \mathrm{CoO} \text { and } \mathrm{PbO} & 0.74 \\ \mathrm{MgO} \text { and } \mathrm{TiO}_{2} & 0.65 & \mathrm{TeO}_{2} \text { and } \mathrm{Tl}_{2} \mathrm{O} & 0.62 \\ \mathrm{CuO} \text { and } \mathrm{PbO} & 0.81 & \mathrm{As}_{2} \mathrm{O}_{5} \text { and } \mathrm{SeO}_{2} & 0.60 \\ \mathrm{Ce}_{2} \mathrm{O}_{3} \text { and } \mathrm{Sb}_{2} \mathrm{O}_{3} & 0.64 & \mathrm{Cl}_{3} \text { and } \mathrm{Sb}_{2} \mathrm{O}_{3} & 0.71 \\ \mathrm{Cs}_{2} \mathrm{O} \text { and } \mathrm{Sb}_{2} \mathrm{O}_{3} & 0.78 & \mathrm{Pr}_{2} \mathrm{O}_{3} \text { and } \mathrm{Sb}_{2} \mathrm{O}_{3} & 0.73 \\ \mathrm{Rb}_{2} \mathrm{O} \text { and } \mathrm{Sb}_{2} \mathrm{O}_{3} & 0.75 & \mathrm{Sb}_{2} \mathrm{O}_{3} \text { and } \mathrm{WO}_{3} & 0.63 \\ \mathrm{Sb}_{2} \mathrm{O}_{3} \text { and } \mathrm{Y}_{2} \mathrm{O}_{3} & 0.77 & & \end{array}$

High pairwise correlations can make it difficult for regression methods to properly separate the effects of the components on the response variable (e.g., EC or viscosity). Note however that, of the 22 components selected for initial EC modeling, only five $\left(\mathrm{SeO}_{2}, \mathrm{Sb}_{2} \mathrm{O}_{3}, \mathrm{Tl}_{2} \mathrm{O}, \mathrm{MgO}\right.$ and $\mathrm{PbO})$ are involved in high-correlation pairs and none of the high-correlated pairs involve two of these 22 components simultaneously. None of these five components $\left(\mathrm{SeO}_{2}, \mathrm{Sb}_{2} \mathrm{O}_{3}, \mathrm{Tl} 2 \mathrm{O}, \mathrm{MgO}\right.$ and $\mathrm{PbO}$ ) are expected to significantly affect EC of HLW glasses. The other 48 component pairs with high correlations do not involve any of the 22 components selected for EC modeling. Hence, these high-correlated pairs are not expected to significantly influence the results from modeling work.

\section{Electrical Conductivity Modeling Dataset}

Table 7.2 lists the Glass ID, Group ID, and glass compositions for the 208 simulated HLW glasses in the 22-component forms used for EC model development. The Group ID column of Table 7.2 indicates the data series that each glass is associated with (see Sections 2.1.1 to 2.1.8). The glass compositions in Table 7.2 are the mass fractions ( $\mathrm{mf}$ ) of the 22 components previously identified as having sufficient data to support a separate model term if needed. These components are $\mathrm{Al}_{2} \mathrm{O}_{3}, \mathrm{~B}_{2} \mathrm{O}_{3}, \mathrm{CaO}, \mathrm{CdO}, \mathrm{Cr}_{2} \mathrm{O}_{3}, \mathrm{Fe}_{2} \mathrm{O}_{3}, \mathrm{Li}_{2} \mathrm{O}, \mathrm{MgO}, \mathrm{MnO} \mathrm{Na} \mathrm{N}_{2} \mathrm{O}, \mathrm{NiO}, \mathrm{PbO}$, $\mathrm{Sb}_{2} \mathrm{O}_{3}, \mathrm{SeO}_{2}, \mathrm{SiO}_{2}, \mathrm{SrO}, \mathrm{ThO}_{2}, \mathrm{Tl}_{2} \mathrm{O}, \mathrm{UO}_{3}, \mathrm{ZnO}, \mathrm{ZrO}_{2}$ and Others.

Table 7.3 contains the measured EC-at-temperature pairs for the 208 glasses in the EC modeling dataset. It also includes a column designating the data-splitting validation subsets for EC modeling and validation. These subsets and the data-splitting validation approach are discussed in Section 7.1.2. Values of EC were generally measured at temperatures around 950, 1050,1150 , and $1250^{\circ} \mathrm{C}$. Actual temperatures ranged from 908 to $1277^{\circ} \mathrm{C}$. The values of EC in Table 7.3 range from 0.034 to $1.376 \mathrm{~S} / \mathrm{cm}$. Smaller values of EC tend to occur at lower temperatures and larger values tend to occur at higher temperatures. 
The last column in Table 7.3 identifies the glasses that were used for creating and validating EC models. Of the $210 \mathrm{HLW}$ available glasses with EC data, two glasses (HLW98-96 $\mathrm{A}$ and $\mathrm{B}$ ) were eliminated from both the $\mathrm{EC}$ and viscosity modeling efforts due to their outlying nature (see Table 7.1). Hence, these two glasses are not included in Tables 7.2 and 7.3.

\section{$\underline{\text { Replicate and Near-Replicate EC Data }}$}

Tables 7.4 and 7.5 list the sets of replicate (or near replicate) glasses, based on compositions, in the IHLW EC modeling dataset and the corresponding EC values at four temperatures for each glass. Near-replicate sets involve glasses that were intended to be replicates in composition but that have very slight differences for some component values. The differences are typically due to round-off or renormalization when the glasses involved are from different studies. Near-replicates were treated as true replicates for model development and evaluation purposes. Table 7.4 lists the EC values corresponding to actual temperature values, which differ somewhat from the nominal values of $950,1050,1150$, and $1250^{\circ} \mathrm{C}$ within replicate sets. Table 7.5 lists interpolated values of EC at the four nominal temperature values. The interpolated values were obtained by fitting the truncated-T2 equation to the (temperature, EC) data for each glass (see Section C.2.1 of Appendix C) and then calculating EC at the nominal temperature values.

Tables 7.4 and 7.5 also list estimates of \%RSDs [calculated using EC values in original $\mathrm{S} / \mathrm{cm}$ units] and SDs [calculated from $\ln (\mathrm{EC})$ values in $\ln (\mathrm{S} / \mathrm{cm})$ units] for each replicate set and nominal temperature. Pooled estimates of \%RSDs and SDs are given over the (i) temperatures for a given replicate set, (ii) replicate sets for a given temperature, and (iii) all replicate sets and temperatures. A pooled $\%$ RSD or SD combines the separate \%RSD or SD estimates so that a more accurate combined estimate of the \%RSD or SD is obtained. These pooled \%RSDs and SDs include uncertainties due to fabricating glasses and measuring EC. As discussed in Section 7.2.2, EC data are subject to two sources of uncertainty whose standard deviations are denoted $\sigma_{G}$ and $\sigma_{T}$. These parameters are expressed in $\ln (\mathrm{S} / \mathrm{cm})$ units because natural logarithms of EC values are modeled (see Section 7.2.2). The SDs given in Tables 7.4 and 7.5 are estimates of $\sqrt{\sigma_{G}^{2}+\sigma_{T}^{2}}$, the total standard deviation of an EC determination for a given glass and temperature.

The \%RSD and SD values in Table 7.4 may over-estimate the uncertainty in EC values because the EC values of replicate sets are not measured at exactly the same temperature values. The \%RSD and SD values in the Table 7.5 may under-estimate the uncertainty in EC values because the interpolated EC values may "remove" some of the natural variation in the data that is the basis for uncertainty estimation. The overall pooled estimate of uncertainty from Table 7.4 $[0.154 \ln (\mathrm{S} / \mathrm{cm}]$ is more conservative (i.e., larger) than the one from Table $7.5[0.127 \ln (\mathrm{S} / \mathrm{cm})]$. Hence, the overall pooled estimate of replicate uncertainty for EC of $0.154 \ln (\mathrm{S} / \mathrm{cm})$ in Table 7.4 is used subsequently to assess LOF of the various models considered. Table 7.4 shows that this roughly corresponds to a $15 \% \mathrm{RSD}$ experimental uncertainty (from batching, melting, and measuring EC of HLW glasses). 


\subsubsection{Primary Electrical Conductivity Model Validation Approach and Data}

The primary model validation approach for EC modeling was based on splitting the 208-glass dataset for model development into five modeling subsets and five corresponding validation subsets. The five modeling/validation splits of the $208 \mathrm{HLW}$ glasses in the EC modeling dataset were formed as follows.

- The 27 glasses in the 13 replicate sets (12 replicate pairs and one triplicate set) were set aside so they would always be included in each of the five model development subsets. This was done so that replicate sets would not be split between modeling and validation subsets, thus negating the intent to have validation glasses different than model development glasses.

- The remaining $208-27=181$ glasses were ordered from smallest to largest according to their average EC values across the four temperatures. The 181 glasses were numbered 1 , $2,3,4,5,1,2,3,4,5$, etc. All of the 1 's formed the first model validation set, while all of the remaining points formed the first model development dataset. Similarly, all of the 2's, 3's, 4's, and 5's respectively formed the second, third, fourth, and fifth model validation sets. In each case, the remaining non-2's, non-3's, non-4's, and non-5's formed the second, third, fourth, and fifth model development datasets. Because 181 is not evenly divisible by 5 , the five modeling and validation subsets did not all contain the same numbers of glasses. Four of the five splits contained 36 glasses for validation and 145 glasses for modeling. The fifth split contained 37 glasses for validation and 144 for modeling. Note that the 145 or 144 glasses in the modeling subsets do not include the replicates.

- The 27 replicate glasses were added to each of the split modeling subsets. Including the replicates, four splits contained 172 glasses for modeling and 36 for validation, while the fifth split contains 171 glasses for modeling and 37 for validation. The last column of Table 7.3 specifies the validation subsets for the five modeling/validation splits in the primary validation approach for EC model development.

Data splitting was chosen as the primary validation approach because the EC modeling dataset contains all compositions that (i) are in the IHLW composition region of interest, (ii) meet quality assurance (QA) requirements, and (iii) have EC data. Having a separate validation dataset not used for modeling is desirable, but that desire was over-ridden by wanting EC models developed with all appropriate data.

\subsubsection{Secondary Electrical Conductivity Model Validation Approach and Data}

The secondary model validation approach consisted of partitioning the 208-glass EC modeling dataset into a modeling subset and a validation subset. Two different partitions were investigated. In the first one (denoted V1), 142 glasses in the series HLW02, HLW03 and HLW07 were chosen for the modeling subset, with the remaining 66 glasses in the validation 
subset. However, this data partition resulted in under-predicted EC values for all models considered (discussed subsequently). The under-prediction resulted from a lack of representation in the modeling subset of certain compositions present in the complete dataset. Hence, it was decided to supplement the HLW02, HLW03 and HLW07 modeling subset with some additional glasses in an attempt to solve this problem. The second data partition was then formed by adding selected glasses to the modeling subset. Glasses HLW-ALG-01, -03, -04, -10, -11, -15, -16, -17, $-20,-21,-22,-23,-24,-25,-27,-28,-29,-33,-34$ (19 glasses), HLW05-20, -21 (2 glasses) and HLW06-04, -32 (2 glasses) were added to all available HLW02, HLW03 and HLW07 glasses to create the modeling subset of 165 glasses used for fitting each of the selected models (discussed subsequently). The remaining 43 glasses from HLW04 (1 glass), HLW05 (3 glasses), HLW06 (3 glasses), HLW-ALG (21 glasses), and HLW98 (15 glasses) were used as a validation subset (denoted V2). Despite having solved some of the under-prediction problems encountered when using the V1 data partition, the V2 partition still showed problems for every one of the candidate models employed.

The V2 data partition solved the problem of biased prediction for some of the models investigated but not all. Under-prediction remained a problem for the models that include a crossproduct term. This may be the result of certain combinations of $\mathrm{Na}_{2} \mathrm{O}$ and $\mathrm{Li}_{2} \mathrm{O}$ (the components involved in the crossproduct term) being depleted in the validation subset after augmenting the modeling subset. Ultimately, it was decided that results from data-partition (V1 or V2) validation of EC models would not be reported in this document.

The data-splitting approach discussed in Section 7.1.2 is considered the primary validation approach because it comes closer to validating the EC models of interest, namely those fitted to all 208 glasses with EC data in the modeling dataset. The primary validation approach fits EC models using 171 or 172 of the 208 glasses in the modeling dataset and validates with the remaining 37 or 36 glasses, and does so five times. The secondary approach fits models with 165 glasses and validates with 43 glasses (for the V2 data partition). Hence, the primary validation approach comes closer to validating the EC models of interest, namely those fitted to data on all 208 glasses. The primary validation approach also avoids the representativeness problems in the secondary validation approach discussed previously.

\subsection{Electrical Conductivity Model Forms}

Ideally, a property-composition-temperature model for EC would utilize known mechanisms of EC as a function of glass composition and melt temperature. No such mechanisms are known, although there is considerable experience regarding the temperature dependence of EC over the range of 950 to $1250^{\circ} \mathrm{C}$. Section 7.2.1 discusses the investigations performed to select an equation to represent the temperature dependence of EC. Sections C.1 and C.2 of Appendix $\mathrm{C}$ discuss mixture experiments and several general model forms in which mixture experiment models are used to expand the parameters of EC-temperature equations. Section 7.2.1 discusses the forms of EC-temperature models investigated. Section 7.2.3 discusses the use of transformed EC values as the response variable for EC modeling. 


\subsubsection{Temperature Dependence of Electrical Conductivity}

Three equations discussed in Section C.2.1 of Appendix C were considered for representing the temperature dependence of EC. These are the Arrhenius equation [Equation (C.9)], the T2 equation [Equation (C.10)], and the truncated-T2 equation [Equation (C.11)]. The EC at temperature observations for each of the 208 glasses in the EC modeling dataset were used to fit each of these three equations. Goodness of fit statistics were calculated and compared. The truncated-T2 equation (which represents a linear relationship between $\ln (\mathrm{EC})$ and $1 / T^{2}$ (where $T$ is temperature in Kelvin) was better than the Arrhenius equation for nearly all the glasses under consideration. The T2 equation was better than the truncated-T2 equation for only a few glasses. There were only 7 (out of 208) HLW glasses that showed statistically significant coefficients for all three of the parameters in the T2 equation. The truncated-T2 equation proved to have better values in several goodness-of-fit statistics (RMSE, correlations among equation coefficients) compared to the other two candidates and was therefore selected to represent the temperature dependence of EC for HLW glasses.

\subsubsection{Model Forms for the Temperature and Composition Dependence of Electrical Conductivity}

The model forms considered for EC start with a slightly modified version of the truncated-T2 equation and expand its two parameters as functions of HLW glass composition. Linear mixture (LM) model forms and a partial quadratic mixture (PQM) model form (see Section C.1.1 of Appendix C) were considered for use in expanding the parameters of the truncated-T2 equation.

The EC model form with the parameters of a modified truncated-T2 equation expanded as LM models is given by

$$
\ln (E C)=\sum_{i=1}^{q} a_{i} x_{i}+E_{G}+\sum_{i=1}^{q} b_{i} \frac{x_{i}}{(T / 1000)^{2}}+E_{T}
$$

The modification to the truncated-T2 equation is that temperature ( $T$ in Kelvin) is divided by the scaling factor of 1000 so that the $b_{i}$ coefficients are similar in magnitude to the $a_{i}$ coefficients. Except for the scaling factor, this equation is the same one given as Equation (C.15) and discussed in Section C.2.2 of Appendix C. The remaining notation is discussed following the subsequent model forms.

The EC model form with the composition-only parameter of the modified truncated-T2 equation expanded as a PQM model is given by

$$
\ln (E C)=\sum_{i=1}^{q} a_{i} x_{i}+\text { Selected }\left\{\sum_{i<}^{q-1} \sum_{j}^{q} a_{i j} x_{i} x_{j}\right\}+E_{G}+\sum_{i=1}^{q} b_{i} \frac{x_{i}}{(T / 1000)^{2}}+E_{T}
$$


Equation (7.2) would be appropriate if there are quadratic compositional effects on EC that are not temperature dependent. Previous work (Feng et al. 2004) showed that the $\mathrm{Li}_{2} \mathrm{O} \times \mathrm{Na}_{2} \mathrm{O}$ crossproduct term was beneficial in modeling EC for LAW glasses. Gan et al. (2004) investigated selected crossproduct terms for modeling EC of HLW glasses, although their recommended model did not contain such terms. Several crossproduct terms were considered in the current modeling work (discussed subsequently) but were found not to have any beneficial impact or statistical significance on the modeling of EC for HLW glasses. Temperature (in Kelvin) is scaled by 1000 in Equation (7.2) for the reason discussed previously for Equation (7.1).

In Equations (7.1) and (7.2) $\ln (\mathrm{EC})$ denotes the natural logarithm of EC [in units of $\ln (\mathrm{S} / \mathrm{cm})]$; the $x_{i}(i=1,2, \ldots, q)$ are mass fractions of $q$ glass oxide or halogen components such that $\sum_{i=1}^{q} x_{i}=1$; the $a_{i}$ and $b_{i}(i=1,2, \ldots, q)$, and the $a_{i j}\left(i j=\mathrm{Li}_{2} \mathrm{O} \times \mathrm{Na}_{2} \mathrm{O}\right)$, are coefficients to be estimated from data; $E_{G}$ is a random error associated with determining EC for each HLW glass; and $E_{T}$ is a random error associated with determining EC at the temperature values of a given glass melt. The random errors $E_{G}$ and $E_{T}$ are assumed to be normally distributed with zero means and standard deviations $\sigma_{G}$ and $\sigma_{T}$, respectively. These standard deviations and the model coefficients are estimated simultaneously using generalized least squares (GLS) regression. See Section C.2.1 in Appendix $C$ for additional discussion of $E_{G}$ and $E_{T}$. See Sections C.3.2 and C.3.3 for additional discussion of GLS regression.

\subsubsection{Transformation of Electrical Conductivity}

In modeling EC, it is advantageous to use the natural logarithm of the $\mathrm{EC}$ values. The advantages of this transformation include:

- The EC values for the 208 HLW glasses in the EC modeling dataset range from 0.034 to $1.376 \mathrm{~S} / \mathrm{cm}$. This is a range of approximately 1.5 orders of magnitude difference. Typically in such cases, the uncertainty in making glasses and measuring EC leads to smaller absolute uncertainties for smaller EC values and larger absolute uncertainties for larger EC values. Hence, the unweighted least squares (ULS) regression assumption of equal variances for all response variable values (see Section C.3 of Appendix C) is violated. After a logarithmic transformation, variances of response values tend to be approximately equal as required for ULS regression.

- A logarithmic transformation tends to linearize the compositional dependence of EC data and reduce the need for non-linear terms in the model form.

- A natural logarithm transformation is preferred over a common logarithm (or other base logarithm) transformation because of the approximate relationship

$$
\mathrm{SD}[\ln (y)] \cong \operatorname{RSD}(y)
$$


where SD denotes standard deviation, RSD denotes relative standard deviation (i.e., the standard deviation divided by the mean), and $y$ denotes EC. Equation (7.3) results from applying the first-order variance propagation formula [Equation (7-7) of Hahn and Shapiro (1967)] to the function $z=\ln (y)$. The relationship in Equation (7.3) is very useful, in that uncertainties of the natural logarithm of the response variable $y$ can be interpreted as RSDs of the untransformed response variable $y$.

For these reasons, the natural logarithmic transformation was employed for all EC model forms.

\subsection{Model Results for IHLW Electrical Conductivity with the Truncated-T2 Equation Parameters Expanded as Linear Mixture Models}

This section discusses the results of fitting two truncated T2-LM models using natural logarithms of EC for HLW glasses, denoted $\ln (\mathrm{EC})$, as the response variable. These models are of the forms given in Equation (7.1). Section 7.3.1 presents the results from fitting a 44-term EC model consisting of the truncated-T2 equation with its parameters expanded using LM terms for each of the 22 components determined to have sufficient support in the 208-glass modeling set. Section 7.3.2 presents the results from fitting a 27-term EC model resulting from expanding the parameters of the truncated-T2 equation using reduced 14-component reduced LM models.

To perform the GLS model fits (see Section 7.2.2 and Section C.3.2 of Appendix C), PROC MIXED in SAS (2005) was used. For each model considered, output files produced by SAS were used in Excel (2003) to perform the remaining model evaluation and validation calculations and in Matlab (2006) to create the plots shown in this section.

\subsubsection{Results for 44-Term Electrical Conductivity Model with the Truncated-T2 Equation Parameters Expanded as 22-Component Linear Mixture Models}

As the initial step in EC model development, the truncated T2-LM model in Equation (7.1) with $q=22$ components identified in Section 7.1.1 was fit to the modeling data (208 HLW glasses). The response was the natural logarithm of EC $(\mathrm{S} / \mathrm{cm})$. This 44 -term model form was a reasonable starting point and provided a basis for appropriate model reductions.

Table 7.6 contains the results for the 44-term truncated T2-LM model for EC of HLW glasses. Table 7.6 lists the model coefficients, standard deviations of the coefficients, and estimates of the $\sigma_{G}$ and $\sigma_{T}$ error standard deviations (see Section 7.2.2). Table 7.6 also contains the model performance summaries for the 44-term model using the modeling dataset (208 glasses) and data-splitting modeling and validation subsets (see Section 7.1.2).

The summary statistics that describe how well the 44-term truncated T2-LM model fits the 208-glass EC modeling dataset are given in the upper right corner of Table 7.6. Only the $\mathrm{R}^{2}$, sum of squared errors (SSE), and root mean square error (RMSE) statistics were calculated because of using GLS regression (see Section C.4 in Appendix C). The $\mathrm{R}^{2}=0.899$ statistic indicates that the 44-term truncated T2-LM model fits the EC modeling data reasonably well. 
For GLS regression, the SSE $=33.428$ and RMSE $=0.206$ statistics do not directly indicate the performance of the 44-term model. However, the values of these statistics can be compared to values for subsequently discussed models. The quantity $\hat{\sigma}_{\text {Total }}=\sqrt{\hat{\sigma}_{G}^{2}+\hat{\sigma}_{T}^{2}}=$ $\sqrt{(0.2058)^{2}+(0.0494)^{2}}=0.2116$ is an estimate of the total uncertainty in an EC determination for a given glass and temperature, under the assumption that the 44-term model does not have a significant LOF. A significant model LOF would inflate $\hat{\sigma}_{\text {Total }}$ and it would over-estimate the true total uncertainty in an EC determination. The value of $\hat{\sigma}_{\text {Total }}$ is about $37 \%$ larger than the overall pooled estimate of uncertainty $\mathrm{SD}=0.154$ (in the bottom right corner of Table 7.4) calculated from replicate data that is not impacted by model LOF. Hence, the 44-term EC model may have some LOF, but it does not appear to be highly significant given the uncertainty inherent in the EC data.

Performance statistics for the 44-term EC model when applied to the five modeling/validation splits formed from the 208-glass modeling set are given in the bottom part of Table 7.6. The columns are labeled DS1, DS2, DS3, DS4 and DS5 to denote the five modeling/validation splits of the data as described in Section 7.1.2. The last column of this part of Table 7.6 presents averages of the modeling $\left(\mathrm{R}^{2}, \mathrm{SSE}\right.$ and $\left.\mathrm{RMSE}\right)$ and validation $\left(\mathrm{R}_{\mathrm{V}}^{2}\right.$ and $\mathrm{RMSE}_{\mathrm{V}}$ ) statistics over the five data-splits. The average modeling statistics $\mathrm{R}^{2}=0.901$ and $\mathrm{RMSE}=0.203$ are close to their values from the 208-glass modeling dataset. The average validation statistics $\mathrm{R}_{\mathrm{V}}^{2}=0.871$ and $\mathrm{RMSE}_{\mathrm{V}}=0.229$ from the data-splitting approach are slightly worse (i.e., smaller and larger, respectively) than the $\mathrm{R}^{2}$ and RMSE values from fitting the EC data using all 208 glasses in the modeling set. This indicates that the performance of the 44-term EC model is not significantly degraded in any of the five validation subsets.

The predicted versus measured plot and the standardized residual plot for the 44-term truncated T2-LM model are given in Figures 7.4 and 7.5, respectively. Figure 7.4 shows moderate scatter about the $45^{\circ}$ line representing perfect prediction, with noticeably outlying data for HLW07-28 and HLW07-40. Figure 7.5 shows a pair of lesser outliers corresponding to glasses HLW02-14 and HLW03-01. Figures 7.4 and 7.5 do not show any strong biased prediction tendencies of the 44-term EC model for groups of the modeling data discussed in Sections 2.1.1 to 2.1.8 or any other significant departures from modeling assumptions.

Figure 7.6 shows the predicted versus measured plot when the 44-term EC model is applied to the five validation sets obtained using data-splitting (see Section 7.1.2). The scatter of the validation predictions around the $45^{\circ}$ line in Figure 7.6 is only slightly worse than for the fitted predictions in Figure 7.4. No strong biased predictions are seen in Figure 7.6. Figure 7.7 is similar to Figure 7.6, except that it also contains $95 \%$ prediction intervals (PIs) representing the model prediction uncertainty of single EC determinations for each glass in the validation subsets at one temperature (see Sections C.6 and C.7 of Appendix C). If the 95\% PI for a validation point overlaps the $45^{\circ}$ line, the predicted and measured $\ln (\mathrm{EC})$ values are within model and measurement uncertainty of each other. Note that the $95 \%$ PIs include the estimated uncertainties $\hat{\sigma}_{G}$ and $\hat{\sigma}_{T}$ resulting from the structure of the EC data. The 95\% PIs for the 44-term model overlap the $45^{\circ}$ line (i.e., contain the measured values) for all but 23 of the 724 (=5 validation subsets, four with 36 and one with 37 glasses, with EC measurements at four temperatures per 
glass) observations. Failure of $100(23 / 724)=3.2 \%$ of the $95 \%$ PIs to include the corresponding measured values is slightly lower than the $5 \%$ that would be expected by chance for a model with no LOF. Hence, it does not appear that the 44-term EC model has significant LOF based on the statistical performance on this data-splitting approach. As a result of this, the width of the 95\% PIs should be due primarily to the experimental uncertainty in fabricating glasses and measuring EC (and model uncertainty that results).

The 44-term truncated T2-LM model for EC fits the 208-glass modeling dataset reasonably well and thus can provide guidance for reducing the model (i.e., removing separate terms for components that do not significantly influence EC). Hence, this model was used to produce a response trace plot (see Section C.5.1) at each of the four nominal temperatures at which EC was measured $\left(950,1050,1150\right.$, and $1250^{\circ} \mathrm{C}$ ), as shown in Figures 7.8 a to $7.8 \mathrm{~d}$. Note that the $\mathrm{y}$-axis [predicted $\ln (\mathrm{EC}, \mathrm{S} / \mathrm{cm})$ ] does not have the same scale and tic marks on each of the four plots. Using the same scale would have greatly condensed the individual plots and made it even more difficult to differentiate response traces of individual components. The response trace plots in Figures 7.8a to 7.8d show that $\mathrm{Li}_{2} \mathrm{O}$ and $\mathrm{Na}_{2} \mathrm{O}$ have dominant increasing effects on $\mathrm{EC}$, while $\mathrm{SiO}_{2}$ has the strongest decreasing effect on EC. The response trace for $\mathrm{MgO}$ has a steeper slope than the response trace for $\mathrm{Li}_{2} \mathrm{O}$, but $\mathrm{MgO}$ has a short range and its effect is not significant. The response trace for Others has a slope similar to the response trace for $\mathrm{SiO}_{2}$, although it is not clear why that grouping of minor components should have a decreasing effect on EC. Several minor components have steep (but short) response traces-the effects of those components are not statistically significant. Figures 7.8 a to $7.8 \mathrm{~d}$ also show that temperature changes have very little effect on (i) which components are important or (ii) the magnitude of the effect that model components have on EC.

\subsubsection{Results for a 27-Term Electrical Conductivity Model with the Truncated-T2 Equation Parameters Expanded as Reduced 14-Component Linear Mixture Models}

In the 44-term truncated T2-LM model presented in Section 7.3.1, some of the 22 components likely do not significantly contribute to predicting EC. Hence, model reduction was the next step of the model development approach. Two approaches were considered in reducing the full 44-term viscosity model discussed in Section 7.3.1. Each of these approaches and brief summaries of results are discussed in turn.

The first approach was to compare summary statistics from the split-plot modeling (using the PROC MIXED routine in SAS 2005) for progressively reduced models to assess how much model reduction was appropriate. For this approach, at each iteration the minor component (among $\mathrm{CaO}, \mathrm{CdO}, \mathrm{Cr}_{2} \mathrm{O}_{3}, \mathrm{NiO}, \mathrm{PbO}, \mathrm{Sb}_{2} \mathrm{O}_{3}, \mathrm{SeO}_{2}, \mathrm{Tl}_{2} \mathrm{O}$ ) that appeared to have the least significance in the model was sequentially removed (moved into the Others component) until all of the minor components had been removed. The components $\mathrm{CdO}, \mathrm{Sb}_{2} \mathrm{O}_{3}, \mathrm{SeO}_{2}$, and $\mathrm{Tl}_{2} \mathrm{O}$ were varied for modeling TCLP releases, but are not expected to affect EC results. Similarly, $\mathrm{Cr}_{2} \mathrm{O}_{3}$ and $\mathrm{NiO}$ were varied for purposes of modeling spinel $\mathrm{T}_{1 \%}$, but they are not expected to affect $\mathrm{EC}$ results. Finally, $\mathrm{CaO}$ and $\mathrm{PbO}$ were never chosen as components to vary in any of the HLW glass studies, but had sufficient ranges and distributions in the modeling dataset to include in the full 
model. However, $\mathrm{CaO}$ and $\mathrm{PbO}$ are not expected to affect $\mathrm{EC}$ results. Model terms involving all the minor components mentioned above were eliminated without significantly impacting prediction performance or other goodness-of-fit statistics. At the end of this process 14 components (including the new Others) remained, resulting in a 28-term truncated T2-LM model. Only the temperature-composition term $\mathrm{MgO} /(\mathrm{T} / 1000)^{2}$ was statistically non-significant and was therefore eliminated, yielding a reduced truncated T2-LM model with 27 terms.

The second reduction approach used to develop reduced model forms for EC of HLW glasses involved expanding each of the two parameters of the truncated-T2 equation using LM models in fewer than all 22 components. The sequential F-test model reduction approach (see Section C.5.1 of Appendix C, Piepel and Cooley 2006) was used to develop reduced LM models for each of the two truncated-T2 equation parameters treated as a separate response variable. Option (ii) discussed in Section C.5.1 of Appendix C was used to develop the reduced LM model for each parameter. A significance level of 0.05 was used for the F-tests conducted by the model reduction algorithm. An option available with the F-test approach is to allow only certain terms to combine during the reduction process. For $\mathrm{EC}$, only the minor components (among $\mathrm{CaO}, \mathrm{CdO}$, $\mathrm{Cr}_{2} \mathrm{O}_{3}, \mathrm{NiO}, \mathrm{PbO}, \mathrm{Sb}_{2} \mathrm{O}_{3}, \mathrm{SeO}_{2}, \mathrm{Tl}_{2} \mathrm{O}$ ) were eligible for reduction for each of the two truncatedT2 equation parameters. That is, they were the only components that could be combined with other components. These minor components were allowed to combine if having the combinedcomponents term in the model rather than the separate component terms did not significantly decrease model performance. Running the model reduction algorithm with each of the two truncated-T2 equation parameters used in turn as the response variable yielded the same reduced model form in which all of the components that were eligible for combining were combined into a new Others component. That is, the same 14-component reduced LM model form was chosen for each of the two truncated-T2 equation parameters for the dependence of EC on temperature. The 14 components were $\mathrm{Al}_{2} \mathrm{O}_{3}, \mathrm{~B}_{2} \mathrm{O}_{3}, \mathrm{Fe}_{2} \mathrm{O}_{3}, \mathrm{Li}_{2} \mathrm{O}, \mathrm{MgO}, \mathrm{MnO}, \mathrm{Na}_{2} \mathrm{O}, \mathrm{SiO}_{2}, \mathrm{SrO}, \mathrm{ThO}_{2}, \mathrm{UO}_{3}$, $\mathrm{ZnO}, \mathrm{ZrO}_{2}$, and Others. Note that Others is the sum of all remaining components, and thus differs from the Others in the 44-term truncated T2-LM model discussed in Section 7.3.1.

The results of the two model reduction approaches agreed, yielding a 28-term truncated T2-LM model of the form given in Equation (7.1) with $q=14$. However, the $\mathrm{MgO} /(\mathrm{T} / 1000)^{2}$ term was statistically non-significant and thus removed, resulting in a 27 -term model that is the first reduced model to be more fully investigated.

\subsubsection{Results for 27-Term Electrical Conductivity Model with the Truncated-T2 Equation Parameters Expanded as 14-Component Reduced Linear Mixture Models}

Table 7.7 gives the coefficients, coefficient standard deviations, and estimates of the $\sigma_{G}$ and $\sigma_{T}$ error standard deviations (see Section 7.2.2) for the 27-term truncated T2-LM model for EC. This model was fitted to the EC data for the 208 glasses in the modeling set using the PROC MIXED procedure in SAS (2005). Table 7.7 also provides performance statistics for the (i) modeling data and (ii) five pairs of modeling and validation subsets that result from data-splitting (see Section 7.1.2). 
The statistics from fitting the 27-term truncated T2-LM model to the EC data from 208 glasses are given in the upper right corner of Table 7.7. The $\mathrm{R}^{2}=0.891$ and $\mathrm{RMSE}=0.212$ statistics are only slightly worse than those for the full 44-term model.

The statistics from fitting and validating the 27-term EC model using the five modeling and validation subsets that result from the data-splitting procedure are given in the bottom part of Table 7.7. The average modeling statistics $\mathrm{R}^{2}=0.892$ and $\mathrm{RMSE}=0.210$ are close to their values from the 208-glass EC modeling dataset. The average validation statistics $\mathrm{R}^{2} \mathrm{v}=0.879$ and $\mathrm{RMSE}_{\mathrm{V}}=0.222$ from the data-splitting approach are not much worse than the $\mathrm{R}^{2}=0.891$ and $\mathrm{RMSE}=0.212$ statistics from fitting the data from all 208 glasses. The average $\mathrm{R}_{\mathrm{V}}^{2}=0.879$ and $\mathrm{RMSE}_{\mathrm{V}}=0.222$ across the five validation subsets are slightly better than the average $\mathrm{R}_{\mathrm{V}}^{2}=$ 0.873 and $\mathrm{RMSE}_{\mathrm{V}}=0.228$ obtained using the 44-term model for the same five subsets. Hence, the 27-term EC model appears to predict as well as the 44-term EC model, even though it has many fewer terms.

From entries in Table 7.7, the quantity $\hat{\sigma}_{\text {Total }}=\sqrt{\hat{\sigma}_{G}^{2}+\hat{\sigma}_{T}^{2}}=\sqrt{(0.2094)^{2}+(0.0501)^{2}}=$ 0.2153 was calculated. It is an estimate of the total uncertainty in an EC determination for a given glass and temperature, under the assumption that the 27-term model does not have a significant LOF. A significant model LOF would inflate this quantity and it would over-estimate the true total uncertainty in an EC determination. For the 27-term model, $\hat{\sigma}_{\text {Total }}=0.2153$ is only slightly larger than $\hat{\sigma}_{\text {Total }}=0.2116$ for the 44 -term model. However, it is about $40 \%$ larger than the overall pooled estimate of uncertainty $\mathrm{SD}=0.154$ (in the bottom right corner of Table 7.4) calculated from replicate data that is not impacted by model LOF (see Section 7.1.1). Hence, the 27-term EC model may have some LOF, but it does not appear to be highly significant given the uncertainty inherent in the data. Together, these results indicate there is little consequence to reducing the EC model from 44 terms to 27 terms.

The predicted versus measured plot and the standardized residual plot for the 27-term truncated T2-LM model for EC are given in Figures 7.9 and 7.10, respectively. Figure 7.9 shows moderate scatter about the $45^{\circ}$ line representing perfect prediction, with moderately outlying data for HLW07-28 and HLW07-40. Figure 7.10 shows that glasses HLW02-14 and HLW03-01 also have outlying values (these same glasses appeared as outlying when the 44-term model was used). Figure 7.9 does not show any tendency to over- or under-predict EC within the range of values available. In general, Figures 7.9 and 7.10 are very similar to the ones for the 44-term model in Figures 7.4 and 7.5.

Figure 7.11 shows the predicted versus measured plot when the 27-term EC model is applied to the five validation sets obtained using data-splitting (see Section 7.1.2). The scatter and bias of the validation predictions around the $45^{\circ}$ line in Figure 7.11 is only slightly worse than for the fitted predictions in Figure 7.9. It is also only slightly worse than the corresponding data-split validation plot for the 44-term model in Figure 7.6. Figure 7.12 is similar to Figure 7.11, except that it also contains 95\% PIs representing the model prediction uncertainty of single EC determinations for each glass in the validation subsets at one temperature (see Sections C.6 and C.7 of Appendix C). If the 95\% PI for a validation point overlaps the $45^{\circ}$ line, the predicted 
and measured $\ln (\mathrm{EC})$ values are within model and measurement uncertainty of each other. Note that the $95 \%$ PIs include the estimated uncertainties $\hat{\sigma}_{G}$ and $\hat{\sigma}_{T}$ resulting from the structure of the EC data. The $95 \%$ PIs for the 27 -term model overlap the $45^{\circ}$ line (i.e., contain the measured values) for all but 16 of the 724 (= 5 validation subsets, four with 36 and one with 37 glasses, with EC measurements at four temperatures per glass) observations. Failure of 100(16/724) $=$ $2.2 \%$ of the $95 \%$ PIs to include the corresponding measured values is slightly lower than the $5 \%$ that would be expected by chance for a model with no LOF. Hence, it does not appear that the 27-term EC model has significant LOF based on the statistical performance on this data-splitting approach. As a result of this, the width of the $95 \%$ PIs should be due primarily to the experimental uncertainty in fabricating glasses and measuring EC (and model uncertainty that results).

To understand the effects of HLW glass components on EC at different temperatures, the 27-term EC model was used to produce a response trace plot (see Section C.5.1) at each of the four nominal temperatures at which $\mathrm{EC}$ was measured $\left(950,1050,1150\right.$, and $\left.1250^{\circ} \mathrm{C}\right)$. These response trace plots are shown in Figures 7.13a to $7.13 \mathrm{~d}$. Note that the y-axis [predicted $\ln (\mathrm{EC}$, $\mathrm{S} / \mathrm{cm})$ ] does not have the same scale and tic marks on each of the four plots. Using the same scale would have greatly condensed the individual plots and made it more difficult to differentiate response traces of individual components. The response trace plots show that $\mathrm{Li}_{2} \mathrm{O}$ and $\mathrm{Na}_{2} \mathrm{O}$ have dominant increasing effects on $\mathrm{EC}$, while $\mathrm{SiO}_{2}$ has the strongest decreasing effect on EC. The response trace for $\mathrm{MgO}$ has a slope similar to the response trace for $\mathrm{Li}_{2} \mathrm{O}$, but $\mathrm{MgO}$ has a short range and investigations showed that $\mathrm{MgO}$ does not have a significant effect on EC. Figures $7.13 \mathrm{a}$ to $7.13 \mathrm{~d}$ also show that temperature changes have very little effect on (i) which components are important or (ii) the magnitudes of the effects that model components have on EC.

\subsection{Investigation of Adding Crossproduct Terms to, and Eliminating Composition- Temperature Terms from, the 27-Term Truncated-T2 Linear Mixture Model}

Preliminary model development work conducted at VSL (Feng et al. 2004) indicated that crossproduct effects represented by the terms $\mathrm{CaO} \times \mathrm{Li}_{2} \mathrm{O}, \mathrm{CaO} \times \mathrm{Na}_{2} \mathrm{O}$, and $\mathrm{Li}_{2} \mathrm{O} \times \mathrm{Na}_{2} \mathrm{O}$ could help improve models for EC of LAW glasses. In fact, the recommended model for EC of LAW glasses (see Section 7 of Piepel et al. 2007) included all three of these crossproduct terms. Hence, it was decided to investigate whether crossproduct terms of these three components could improve the predictive performance of the 27-term truncated-T2 model for HLW glasses. Also, it is possible that some of the remaining $x_{i} /(T / 1000)^{2}$ terms in the model, although statistically significant, are not practically significant for EC prediction purposes and can therefore be eliminated, providing for a simpler model. The following models, all of the form represented by Equation (7.2), were investigated:

- Model 3: A 28-term model consisting of the 27-term truncated T2-LM model plus the term involving $\mathrm{Li}_{2} \mathrm{O} \times \mathrm{Na}_{2} \mathrm{O}$ (the only statistically and practically significant crossproduct term from among the three considered). 
- Model 4: A 27-term model consisting of Model 3 but with the term involving Others/(T/1000) $)^{2}$ removed.

- Model 5: A 22-term model that removes the terms corresponding to $\mathrm{Na}_{2} \mathrm{O} /(T / 1000)^{2}$, $\mathrm{Li}_{2} \mathrm{O} /(T / 1000)^{2}, \mathrm{Al}_{2} \mathrm{O}_{3} /(T / 1000)^{2}, \mathrm{ThO}_{2} /(T / 1000)^{2}$ and $\mathrm{Fe}_{2} \mathrm{O}_{3} /(T / 1000)^{2}$ from Model 4.

Models 4 and 5 were arrived at by deleting terms in Model 3 according to their level of statistical significance. Table 7.8 summarizes key results for Models 1 to 5. Note that Model 1 is the 44term model in Table 7.6, and Model 2 is the 27-term model in Table 7.7. The top part of Table 7.8 summarizes the results from fitting the models to the EC data from all 208 glasses. The bottom part of Table 7.8 shows goodness-of-fit statistics across the five subsets resulting from data-splitting for Models 1 to 5.

In the model development work, reductions of terms still present in Model 5 were considered but it was found that all the goodness-of-fit statistics investigated worsened regardless of the term chosen for deletion. For this reason, Model 5 was considered the stopping point for model simplification.

Based on the results from model development and reduction presented in this section, Model 5 is recommended for EC prediction, with Model 2 recommended as a possible secondchoice model. The recommendation of Model 5 for EC prediction is based both on its relatively small size (22 total terms) and its level of performance (which is presented in more detail in Section 7.5). From results in Table 7.8, Model 5 has either the best or close to the best goodnessof-fit performance among all models explored and maintains this level of performance when applied to the five data-splitting subsets created for validation purposes (as shown in the bottom part of Table 7.8). Because a larger, less simplified model may prove useful for EC prediction for glasses created in the future, Model 2, which has no cross-product terms and maintains all the statistically significant composition-temperature terms, is recommended as a second-choice model.

\subsection{Results for the Recommended 22-Term Electrical Conductivity Model}

Section 7.5.1 presents the results for the recommended 22-term EC model fitted to the 208-glass modeling dataset. Section 7.5.2 presents the validation results for that model.

\subsubsection{Results for the Recommended 22-Term Electrical Conductivity Model Fitted to the 208-Glass Modeling Dataset}

The 22-term model of the form in Equation (7.2) was fitted to the EC data for the 208 glasses in the EC modeling dataset. The PROC MIXED procedure in SAS (2005) was used to perform the GLS regression required for the EC data structure. Table 7.9 lists the fitted model coefficients, the coefficient standard deviations, and estimates of the $\sigma_{G}$ and $\sigma_{T}$ error standard deviations for the 22-term model. 
The upper right portion of Table 7.9 shows that the 22-term EC model fits the 208-glass modeling dataset with $\mathrm{R}^{2}=0.907$, meaning that nearly $91 \%$ of the variation in $\ln (\mathrm{EC})$ values is accounted for by the model. The $\mathrm{R}^{2}=0.907$ for the 22 -term model is a slight improvement over the $\mathrm{R}^{2}=0.891$ for the 27-term model in Table 7.7, even with the 22-term model containing five fewer terms. The RMSE $=0.195$ for the 22-term model is also an improvement over the $\mathrm{RMSE}=$ 0.212 for the 27 -term model.

Performance statistics for the 22-term IHLW EC model when applied to the five modeling/validation splits formed from the 208-glass modeling dataset are given in the bottom part of Table 7.9. The columns are labeled DS1, DS2, DS3, DS4, and DS5 to denote the five modeling/validation splits of the data as described in Section 7.1.2. The last column of this part of Table 7.9 presents averages of the modeling $\left(\mathrm{R}^{2}, \mathrm{SSE}\right.$, and $\left.\mathrm{RMSE}\right)$ and validation $\left(\mathrm{R}_{\mathrm{V}}^{2}\right.$ and $\mathrm{RMSE}_{\mathrm{V}}$ ) statistics over the five data-splits. The average modeling statistics $\mathrm{R}^{2}=0.908$ and $\mathrm{RMSE}=0.193$ are close to their values from the 208-glass EC modeling dataset.

From the entries in Table 7.9, the quantity $\hat{\sigma}_{\text {Total }}=\sqrt{\hat{\sigma}_{G}^{2}+\hat{\sigma}_{T}^{2}}=$ $\sqrt{(0.1919)^{2}+(0.0553)^{2}}=0.1997$ was calculated. This is an estimate of the total uncertainty in an EC determination for a given glass and temperature, under the assumption that the 22-term model does not have a significant LOF. A significant model LOF would inflate this quantity and it would over-estimate the true total uncertainty in an EC determination. For the 22-term model, $\hat{\sigma}_{\text {Total }}=0.1997$ is about $30 \%$ larger than the overall pooled estimate of uncertainty SD $=0.154$ (in the bottom right corner of Table 7.4) calculated from replicate data that is not impacted by model LOF. Hence, the 22-term EC model may have a slight LOF, but it does not appear to be too significant given the uncertainty inherent in the data.

A histogram and normal probability plot of the standardized residuals for the fit of the 22-term model in Table 7.9 to the 208-glass EC modeling dataset for HLW glasses were generated, although they are not shown in this report. These two plots show that only the outlying observations from glasses HLW07-28 and HLW07-40 (mentioned throughout the EC model-development work) depart from the ideal normal behavior which is required to utilize the statistical interval formulas for model prediction uncertainties that are discussed subsequently.

The predicted versus measured plot and the standardized residual plot for the 22-term $\ln (\mathrm{EC})$ model are given in Figures 7.14 and 7.15, respectively. Figure 7.14 shows relatively tight scatter about the $45^{\circ}$ line representing perfect prediction, with only moderately outlying data for glasses HLW07-28 and HLW07-40. Figure 7.15 shows no significant problems with the residuals obtained using this model or with the modeling assumption of constant variance (see Section C.3.1 of Appendix C).

To understand the effects of HLW glass components on EC at different temperatures, the 22-term EC model was used to produce a response trace plot (see Section C.5.1) at each of the four nominal temperatures at which $\mathrm{EC}$ was measured $\left(950,1050,1150\right.$, and $\left.1250^{\circ} \mathrm{C}\right)$. These response trace plots are shown in Figures 7.16a to 7.16d. Note that the y-axis [predicted $\ln (\mathrm{EC}$, 
$\mathrm{S} / \mathrm{cm}$ )] does not have the same scale and tic marks on each of the four plots. Using the same scale would have greatly condensed the individual plots and made it even more difficult to differentiate response traces of individual components. The response trace plots show that $\mathrm{Li}_{2} \mathrm{O}$ and $\mathrm{Na}_{2} \mathrm{O}$ have dominant increasing effects on $\mathrm{EC}$, while $\mathrm{SiO}_{2}$ has the strongest decreasing effect on EC. The response trace for $\mathrm{MgO}$ has a slope similar to the response trace for $\mathrm{Li}_{2} \mathrm{O}$, but $\mathrm{MgO}$ has a short range and investigations showed that $\mathrm{MgO}$ does not have a significant effect on EC. Figures 7.16a to 7.16d also show that temperature changes have very little effect on (i) which components are important or (ii) the magnitudes of the effects that model components have on EC.

\subsubsection{Validation Results for the Recommended 22-Term Electrical Conductivity Model}

The statistics from using the 22-term model to predict EC values for the five validation subsets that result from the data-splitting procedure described in Section 7.1.2 are given in the bottom part of Table 7.9. The average validation statistics $\mathrm{R}_{\mathrm{V}}^{2}=0.894$ and $\mathrm{RMSE}_{\mathrm{V}}=0.210$ from the data-splitting approach are only slightly worse (i.e., smaller and larger, respectively) than $\mathrm{R}^{2}$ $=0.907$ and $\mathrm{RMSE}=0.195$ when fitting the EC data from all 208 glasses in the modeling set. The average validation statistics $\mathrm{R}_{\mathrm{V}}^{2}=0.894$ and $\mathrm{RMSE}_{\mathrm{V}}=0.210$ are slightly better than the average statistics $\mathrm{R}_{\mathrm{V}}^{2}=0.879$ and $\mathrm{RMSE}_{\mathrm{V}}=0.222$ obtained using the 27 -term model for the same five validation subsets. Hence, the recommended 22-term model validates as well as the 27-term EC model for the five validation subsets.

Figure 7.17 shows the predicted versus measured plot when the recommended 22-term EC model is applied to the five validation subsets obtained using data-splitting (see Section 7.1.2). No strong biased predictions are seen in Figure 7.17. The scatter of the validation predictions around the $45^{\circ}$ line in Figure 7.17 is only slightly worse than for the fitted predictions in Figure 7.14. The scatter for the recommended 22-term EC model in Figure 7.17 is smaller than for the second-choice 27-term model in Figure 7.11. In general, the data-splitting results show that the 22-term model in Table 7.9 maintains the level of its predictive performance when applied to validation data within the same composition region as used to develop the model.

Figure 7.18 is similar to Figure 7.17, except that it also contains 95\% PIs representing the model prediction uncertainty of single EC determinations for each glass in the validation subsets at one temperature (see Sections C.6 and C.7 of Appendix C). If the 95\% PI for a validation point overlaps the $45^{\circ}$ line, the predicted and measured $\ln (\mathrm{EC})$ values are within model and measurement uncertainty of each other. Note that the $95 \%$ PIs include the estimated uncertainties $\hat{\sigma}_{G}$ and $\hat{\sigma}_{T}$ resulting from the structure of the EC data. The 95\% PIs for the 22-term model overlap the $45^{\circ}$ line (i.e., contain the measured values) for all but 15 of the 724 (= 5 validation subsets, four with 36 and one with 37 glasses, with EC measurements at four temperatures per glass) observations. Failure of $100(15 / 724)=2.1 \%$ of the $95 \%$ PIs to include the corresponding measured values is lower than the $5 \%$ that would be expected by chance for a model with no LOF. Hence, it does not appear that the 22-term model has significant LOF based on the statistical performance on this data-splitting approach. As a result of this, the width of the $95 \%$ PIs should be due primarily to the experimental uncertainty in fabricating glasses and measuring 
EC (and model uncertainty that results). Separate work to assess the consequences of LOF (if any) and prediction uncertainty for this recommended EC model is discussed further in Section 7.7 .

\subsection{Example Illustrating Electrical Conductivity Model Predictions and Statistical Intervals}

This section contains examples to illustrate using the recommended 22-term truncated T2-LM model and the second-choice 27-term truncated T2-LM model, to obtain predicted EC values and corresponding 90\% lower confidence intervals (LCIs), 90\% upper confidence intervals (UCIs), and two-sided 90\% confidence intervals (CIs) as described in Section C.7 of Appendix C. The 22-term model is the one recommended in Section 7.4 and discussed in detail in Section 7.5. For comparison purposes, calculations are also performed in this section for the second-choice 27-term model discussed in Section 7.3.2. The 90\% confidence levels associated with LCIs, UCIs, and CIs were chosen for illustration purposes only. The WTP project can use an appropriate confidence level depending on the use of the EC-composition-temperature model and the type of statistical uncertainty expression desired.

The glass composition used in this example is HLW03-06, which was used previously for PCT and spinel $\mathrm{T}_{1 \%}$ examples in Sections 5.7 and 6.7. The 22-component composition of HLW03-06 for EC modeling is given in Table 7.2 in mass fraction format. To apply the 22-term and 27-term EC models to this composition, the mass fractions of the 22 components must be converted to mass fractions (that sum to 1.0) of the 14 HLW glass components contained in both models. Mass fractions of the relevant components are then multiplied to obtain the single crossproduct term present in the 22-term model. Table 7.10 contains the composition of HLW0306 prepared for use in the two IHLW EC models.

For each of the EC models, predicted $\ln (\mathrm{EC}, \mathrm{S} / \mathrm{cm})$ values are obtained by multiplying the composition in the format needed for that model by the coefficients for that model, then summing the results. That is, the predicted values are calculated by

$$
\hat{y}(\boldsymbol{a})=\boldsymbol{a}^{\mathrm{T}} \boldsymbol{b}
$$

where $\boldsymbol{a}$ is a vector with entries corresponding to terms in a given model based on the HLW0306 composition and a specific temperature value (in Kelvin), the superscript $\mathrm{T}$ represents a matrix transpose (or vector transpose in this case), and $\boldsymbol{b}$ is the vector of coefficients for a given model. The predicted $\ln (\mathrm{EC})$ values for HLW03-06 at $1140^{\circ} \mathrm{C}^{14}$ using each of the IHLW EC models are listed in the second column of Table 7.11. The predicted $\ln (\mathrm{EC})$ values in $\ln (\mathrm{S} / \mathrm{cm})$ units are easily converted to EC values $(\mathrm{S} / \mathrm{cm})$ by exponentiation. The third column of Table 7.11 contains the predicted EC values $(\mathrm{S} / \mathrm{cm})$. However, as discussed in Section C.7 of Appendix $\mathrm{C}$, these back-transformed EC predictions in $\mathrm{S} / \mathrm{cm}$ should be considered estimates of the true median (not the true mean) of the distribution of EC values that would result if EC measurements

14 The temperature of $1140^{\circ} \mathrm{C}$ was chosen because it was one of the temperatures at which the EC of HLW03-06 was measured. This facilitates comparison of the predicted and measured values. 
at the specific temperature were repeated multiple times on separately batched and melted samples of the HLW03-06 glass composition.

The predicted EC values for HLW03-06 at $1140^{\circ} \mathrm{C}$ in Table 7.11 are $0.262 \mathrm{~S} / \mathrm{cm}$ for the recommended 22-term EC model and $0.226 \mathrm{~S} / \mathrm{cm}$ for the second-choice 27-term EC model. The predicted value using the recommended 22-term model is closest to the measured value of 0.302 $\mathrm{S} / \mathrm{cm}$ for HLW03-06 at $1140^{\circ} \mathrm{C}$.

Equations (C.31c), (C.32c), and (C.33c) from Sections C.7.1 and C.7.2 of Appendix C can be used to calculate, respectively, a CL\% upper confidence interval (CL\% UCI), a CL\% lower confidence interval (CL\% LCI), or a two-sided CL\% confidence interval (CL\% CI) for the true mean of $\ln (\mathrm{EC})$ values for the HLW03-06 glass composition at a specific temperature with each of the IHLW EC models. For the illustrations to follow, we use CL $\%=90 \%$. In the notation of these equations:

- $\mathrm{CL} \%=100(1-\alpha) \%=90 \%$, so that $\alpha=0.10$ for a $90 \% \mathrm{UCI}$, a $90 \% \mathrm{LCI}$, and a $90 \% \mathrm{CI}$ in Equations (C.31c), (C.32c), and (C.33c), respectively.

- The vector $\boldsymbol{a}$ contains entries corresponding to the terms in a given EC model, which are calculated using the composition of HLW03-06 in Table 7.10 and a specific temperature value.

- Matrix $\boldsymbol{A}$ is formed from the data matrix used in the regression that generated a given EC model. Matrix $\boldsymbol{A}$ has the number of rows in the EC modeling dataset $(832=208 \times 4$ temperatures each) and the number of columns corresponding to the number of terms in a given EC model. Each column is calculated according to the corresponding term in the model using the HLW glass compositions and the actual (not nominal or intended) temperatures in the EC modeling dataset.

- Matrix $\hat{\boldsymbol{V}}$ is the estimated variance-covariance matrix for the vector of EC-attemperature data used to fit an EC model. This matrix accounts for the two sources of uncertainty, as discussed in Section C.3.3 of Appendix C.

To calculate a $90 \%$ UCI or LCI in $\ln (\mathrm{EC})$ units of $\ln (\mathrm{S} / \mathrm{cm})$, the quantity $t_{1-\alpha, n-p} \sqrt{\boldsymbol{a}^{T}\left(\boldsymbol{A}^{T} \hat{\boldsymbol{V}}^{-1} \boldsymbol{A}\right)^{-1} \boldsymbol{a}}$ is added to (UCI) or subtracted from (LCI) the predicted $\ln (\mathrm{EC})$ [denoted $\hat{y}(\boldsymbol{a})$ ] described above. The calculations are given by Equation (C.31c) for an UCI and Equation (C.32c) for a LCI. To calculate a $90 \%$ two-sided CI, the quantity $t_{1-\alpha / 2, n-p} \sqrt{\boldsymbol{a}^{T}\left(\boldsymbol{A}^{T} \hat{\boldsymbol{V}}^{-1} \boldsymbol{A}\right)^{-1} \boldsymbol{a}}$ is subtracted from and added to the predicted $\ln (\mathrm{EC})$ [denoted $\hat{y}(\boldsymbol{a})]$, as indicated by Equation (C.33c). The $\left(\boldsymbol{A}^{T} \hat{\boldsymbol{V}}^{-1} \boldsymbol{A}\right)^{-1}$ portion of these expressions is an approximate estimate of variance-covariance matrix for the estimated model coefficients, as discussed near the end of Section C.7 of Appendix C. The variance-covariance matrices for the recommended 27-term and second-choice 22-term EC models are respectively listed in Tables 
D.13 and D.14 of Appendix D. The quantity $\sqrt{\boldsymbol{a}^{T}\left(\boldsymbol{A}^{T} \hat{\boldsymbol{V}}^{-1} \boldsymbol{A}\right)^{-1} \boldsymbol{a}}$ is the standard deviation of a model prediction; the value for each model is given in the fourth column of Table 7.11.

The $90 \%$ LCI, 90\% UCI, and $90 \%$ CI values for the true mean $\ln (\mathrm{EC})$ in units of $\ln (\mathrm{S} / \mathrm{cm})$ for the HLW03-06 composition at a temperature of $1140^{\circ} \mathrm{C}$ based on the recommended and second-choice IHLW EC models are given in the fifth, seventh, and ninth columns of Table 7.11. Exponentiating the resulting $90 \%$ LCIs, UCIs, and CIs for the mean EC values in $\ln (\mathrm{S} / \mathrm{cm})$ units yields 90\% LCIs, UCIs, and CIs for the median EC $(\mathrm{S} / \mathrm{cm})$. These values are in the sixth, eighth, and tenth columns of Table 7.11. For example, the recommended 22-term EC model has $(-1.457,-1.222) \ln (\mathrm{S} / \mathrm{m})$ as the two-sided $90 \%$ CI on the true mean $\ln (\mathrm{EC})$ for HLW03-06 at $1140^{\circ} \mathrm{C}$. Then $\left(\mathrm{e}^{-1.457}, \mathrm{e}^{-1.222}\right)=(0.233,0.295) \mathrm{S} / \mathrm{cm}$ is the two-sided $90 \% \mathrm{CI}$ on the true median $\mathrm{EC}$ for HLW03-06 at $1140^{\circ} \mathrm{C}$. The second-choice 27 -term model has $(-1.609,-1.367) \ln (\mathrm{S} / \mathrm{m})$ as the two-sided $90 \%$ CI on the true mean $\ln (\mathrm{EC})$ for HLW03-06 at $1140^{\circ} \mathrm{C}$. Then $\left(\mathrm{e}^{-1.609}, \mathrm{e}^{-1.367}\right)=$ $(0.200,0.255) \mathrm{S} / \mathrm{cm}$ is the two-sided $90 \% \mathrm{CI}$ on the true median EC for HLW03-06 at $1140^{\circ} \mathrm{C}$. Rounding accounts for the differences between the values in $\ln (\mathrm{S} / \mathrm{cm})$ units and the corresponding EC values expressed in $\mathrm{S} / \mathrm{cm}$ units.

Note that neither of the $90 \%$ CIs (in the last column of Table 7.11) based on the recommended and second-choice models contains the measured value of $0.302 \mathrm{~S} / \mathrm{cm}$ for EC at $1140^{\circ} \mathrm{C}$. However, this is not a fault of the $90 \% \mathrm{CIs}$, which are statistical confidence statements about the true mean $[\ln (\mathrm{S} / \mathrm{cm})]$ or median $(\mathrm{S} / \mathrm{cm})$ value of $\mathrm{EC}$ at $1140^{\circ} \mathrm{C}$. The appropriate type of statistical interval to compare to a single measured EC determination is a prediction interval (PI). The formula for calculating a two-sided PI on an individual EC value for a given HLW glass composition and temperature is given in Equation (C.34c) of Section C.7.3 of Appendix C. The calculation of a two-sided $90 \%$ PI is not illustrated in Table 7.11 because PIs are not the appropriate type of statistical interval for verifying that EC constraints are satisfied during WTP HLW vitrification operations.

\subsection{Suitability of the Recommended Electrical Conductivity Model for Application by the WTP Project}

The 22-term model for EC discussed in Section 7.5 is recommended for use by the WTP project as the best model currently available for predicting EC of HLW glasses. This model appears to yield unbiased predictions of EC over the full range of measured EC values in the modeling dataset. There is relatively tight scatter for most data points around the fitted model with moderate outliers for only two HLW glasses (see Figure 7.14). The recommended EC model may have a slight LOF, so that EC predictions can be expected to be within the uncertainty of what would be obtained by batching and melting glasses and measuring the EC plus a small additional uncertainty corresponding to the LOF.

The magnitudes of uncertainties in EC predictions using the recommended 22-term model should be small enough that they will not overly restrict the formulation and processing of HLW glasses in the WTP facility. Figure 7.19 displays the $\ln (\mathrm{EC})$ prediction standard deviations versus predicted values [both in $\ln (\mathrm{S} / \mathrm{cm})$ units] for the HLW glass compositions in the EC 
modeling dataset at temperatures of $950,1050,1150$, and $1250^{\circ} \mathrm{C}$. The $\ln (\mathrm{EC})$ prediction standard deviations for EC modeling dataset glasses at these temperatures range from approximately 0.02 to $0.11 \ln (\mathrm{S} / \mathrm{cm})$ for the recommended EC model. Note that these are standard deviations of model predictions considered as the mean EC value for a given glass. Standard deviations of predictions considered as individual determinations of EC are larger, ranging from approximately 0.16 to $0.19 \ln (\mathrm{S} / \mathrm{cm})$ for the recommended EC model. Note also that prediction standard deviations will be larger for HLW glass compositions as their distance from glasses in the EC modeling dataset increases. Finally, the total uncertainty in predictions with the recommended EC model will depend on the type of statistical interval used (see Section C.7 of Appendix C).

Work to assess the impact of HLW glass composition and model uncertainties for the recommended $\ln (\mathrm{EC})$ model (Section 7.5) on satisfying WTP IHLW processing requirements is planned to be addressed as part of the Technical Scoping Statement (TSS) B-6270 work scope of the River Protection Project-Waste Treatment Plant Support Program at PNNL. The impacts of these uncertainties on glass formulation and processability are also planned to be addressed as part of the second iteration of the HLW glass formulation algorithm development work being conducted by WTP project staff. The first iteration of that work (Vienna and Kim 2007) utilized a preliminary EC model (Gan et al. 2004). 


\section{SECTION 8 \\ MODELS RELATING VISCOSITY TO HLW GLASS COMPOSITION AND TEMPERATURE}

This section documents the development and validation of property-compositiontemperature models and corresponding uncertainty expressions for predicting the viscosity (denoted $\eta$ ) for high-level waste (HLW) glasses. Because viscosity is a property of a glass melt, it is a function of glass melt temperature as well as glass composition. The propertycomposition-temperature models and corresponding uncertainty expressions for viscosity presented in this section were developed and validated using glass composition, temperature, and viscosity data collected on simulated HLW glasses. Viscosity was not measured on any of the glasses made from actual waste samples that are discussed in Section 2.1.9.

The 197 simulated HLW glasses used for viscosity model development and validation (from the database of 210 glasses) are discussed in Section 8.1. Section 8.2 lists the model forms for viscosity that were investigated. Section 8.3 presents the results for viscosity models with the two parameters of the truncated-T2 equation (for temperature dependence) expressed as linear mixture models in composition. Section 8.4 presents the results for viscosity models of the form considered in Section 8.3 plus quadratic (squared and crossproduct) terms. Section 8.5 presents the model fit and validation results for the recommended 29-term viscosity model. Section 8.6 illustrates the calculation of viscosity predictions and the uncertainties in those predictions using selected viscosity models and corresponding uncertainty equations. Section 8.7 discusses the suitability of the recommended viscosity model for use by the WTP project. Appendix C discusses the statistical methods and summary statistics used to develop, evaluate, and validate the several viscosity model forms investigated, as well as statistical equations for quantifying the uncertainties in viscosity models.

\subsection{Viscosity Data Used for Model Development and Validation}

The data used for developing viscosity models are discussed in Section 8.1.1. The approaches and data used for validating the models are discussed in Sections 8.1.2 to 8.1.4.

\subsubsection{Viscosity Model Development Data}

The data available for developing viscosity-composition-temperature models consist of composition, temperature, and viscosity data from 210 HLW glasses (see Section 4.4). These glasses are discussed and their target compositions are presented in Section 2.1. The corresponding viscosity (poise, P) at temperature values are presented in Table 4.6. The HLW viscosity data are discussed in Section 4.4.

The EC and viscosity datasets contain results for 210 HLW glasses each. The EC and viscosity datasets consist almost entirely of data for the same $206 \mathrm{HLW}$ glasses. There are four 
additional glasses (HLW04-03, HLW04-06, HLW04-07 and HLW98-87) in the viscosity dataset but not in the EC dataset. Similarly, there are an additional four glasses (HLW03-08, HLW0708, HLW07-14 and HLW-ALG-24) in the EC dataset but not in the viscosity dataset.

\section{Assessment of Available Glasses with Viscosity Data}

The database of 210 glasses with viscosity results contains statistically-designed as well as actively-designed glasses. Some actively-designed glasses are outside the composition region covered by the majority of the HLW compositions. Such glasses are not ideal for inclusion in a modeling set because they can be influential when fitting models to data. Hence, it was decided to (i) graphically assess the 210 simulated HLW glass compositions and (ii) remove from the modeling set any compositions considered to be outlying or non-representative of HLW glasses of interest for the WTP.

Figure 8.1 displays plots of the mass fraction values for the components in the 210 HLW glasses with viscosity data. On each plot in Figure 8.1, the x-axis represents the mass fraction values of an HLW glass component. The y-axis shows an index value representing each HLW glass, which aids in spreading out the data points to avoid over-plotting. The plotting symbols correspond to the eight groups of HLW glass data discussed in Sections 2.1.1 to 2.1.9. Viscosity was not measured on any of the actual waste glasses discussed in Section 2.1.9. For comparison purposes, the vertical bars in Figure 8.1 represent, when shown, the lower and upper limits for statistically designed test matrices.

Figure 8.1 shows several glasses have components with outlying mass fraction values compared to the bulk of the glasses, but the values and ranges of those components are small and hence the glass compositions were not considered to be outliers. Table 7.1 lists the 10 HLW glasses identified as outliers in the IHLW EC and viscosity modeling sets, and whether each glass was excluded from the final viscosity and EC modeling datasets. Only the first 2 of the 10 glasses were excluded because of having outlying component values compared to the rest of the glasses. The other glasses in Table 7.1 were selected for viscosity and EC measurement and were therefore retained for modeling purposes.

Figure 8.2 shows plots of component distributions after the two outlying glasses were removed from the 210-glass set having viscosity data. Figure 8.2 shows for the remaining 208 HLW glasses that all 18 of the main HLW glass components ${ }^{15}\left(\mathrm{Al}_{2} \mathrm{O}_{3}, \mathrm{~B}_{2} \mathrm{O}_{3}, \mathrm{CdO}, \mathrm{Cr}_{2} \mathrm{O}_{3}, \mathrm{Fe}_{2} \mathrm{O}_{3}\right.$, $\mathrm{Li}_{2} \mathrm{O}, \mathrm{MnO} \mathrm{Na}_{2} \mathrm{O}, \mathrm{NiO}, \mathrm{Sb}_{2} \mathrm{O}_{3}, \mathrm{SeO}_{2}, \mathrm{SiO}_{2}, \mathrm{SrO}, \mathrm{ThO}_{2}, \mathrm{Tl}_{2} \mathrm{O}, \mathrm{UO}_{3}, \mathrm{ZnO}$, and $\mathrm{ZrO}_{2}$ ) have sufficient ranges and distributions of values within those ranges to support model terms. Similarly, Figure 8.2 shows that $\mathrm{CaO}, \mathrm{MgO}$ and $\mathrm{PbO}$ have sufficient ranges and distributions of values within their ranges to support model terms for those components. Based on Figure 8.2, it was decided to use 22 components for initial $\mathrm{EC}$ and viscosity modeling work. These are $\mathrm{Al}_{2} \mathrm{O}_{3}$, $\mathrm{B}_{2} \mathrm{O}_{3}, \mathrm{CaO}, \mathrm{CdO}, \mathrm{Cr}_{2} \mathrm{O}_{3}, \mathrm{Fe}_{2} \mathrm{O}_{3}, \mathrm{Li}_{2} \mathrm{O}, \mathrm{MgO}, \mathrm{MnO} \mathrm{Na}_{2} \mathrm{O}, \mathrm{NiO}, \mathrm{PbO}, \mathrm{Sb}_{2} \mathrm{O}_{3}, \mathrm{SeO}_{2}, \mathrm{SiO}_{2}, \mathrm{SrO}$, $\mathrm{ThO}_{2}, \mathrm{Tl}_{2} \mathrm{O}, \mathrm{UO}_{3}, \mathrm{ZnO}, \mathrm{ZrO}_{2}$, and Others (the sum of all remaining components).

\footnotetext{
15 The "main HLW glass components" are the ones that were directly varied in one or more test matrices associated with the series of glasses discussed in Section 2.1.
} 
Figure 8.3 shows a scatterplot matrix of 18 main components of the 208 glasses remaining in the viscosity modeling dataset after removing the two outlying glasses. Because high correlations between some pairs of components may be present and could affect modeling results, pairwise correlation coefficients were calculated. These can vary from -1.0 (perfect negative correlation) to 0 (no correlation) to 1.0 (perfect positive correlation). There are no correlations exceeding 0.6 (in absolute value) between pairs of the 22 components selected for initial modeling work. Among other pairs of components (which may include one of the 22 components selected for modeling) there are 61 that have correlation higher than 0.6 in absolute value. High-correlated pairs (those with correlations equal or greater than 0.6 in absolute value) that include one of the 22 components selected for initial modeling are

$\begin{array}{llll}\mathrm{Rh}_{2} \mathrm{O}_{3} \text { and } \mathrm{Sb}_{2} \mathrm{O}_{3} & 0.63 & \mathrm{CoO}_{3} \text { and } \mathrm{PbO} & 0.74 \\ \mathrm{MgO} \text { and } \mathrm{TiO}_{2} & 0.65 & \mathrm{TeO}_{2} \text { and } \mathrm{Tl}_{2} \mathrm{O} & 0.62 \\ \mathrm{CuO} \text { and } \mathrm{PbO} & 0.81 & \mathrm{As}_{2} \mathrm{O}_{5} \text { and } \mathrm{SeO}_{2} & 0.60 \\ \mathrm{Ce}_{2} \mathrm{O}_{3} \text { and } \mathrm{Sb}_{2} \mathrm{O}_{3} & 0.64 & \mathrm{Cl}_{3} \text { and } \mathrm{Sb}_{2} \mathrm{O}_{3} & 0.71 \\ \mathrm{Cs}_{2} \mathrm{O} \text { and } \mathrm{Sb}_{2} \mathrm{O}_{3} & 0.78 & \mathrm{Pr}_{2} \mathrm{O}_{3} \text { and } \mathrm{Sb}_{2} \mathrm{O}_{3} & 0.73 \\ \mathrm{Rb}_{2} \mathrm{O} \text { and } \mathrm{Sb}_{2} \mathrm{O}_{3} & 0.75 & \mathrm{Sb}_{2} \mathrm{O}_{3} \text { and } \mathrm{WO}_{3} & 0.63 \\ \mathrm{Sb}_{2} \mathrm{O}_{3} \text { and } \mathrm{Y}_{2} \mathrm{O}_{3} & 0.77 & & \end{array}$

These are the same pairs of components, and the same correlation coefficient values (to two decimal places) that also exceeded 0.6 (in absolute value) for the EC dataset. High pairwise correlations can make it difficult for regression methods to properly separate the effects of the components on the response variable (e.g., EC or viscosity). Note however that, of the 22 components selected for initial viscosity modeling, only five $\left(\mathrm{SeO}_{2}, \mathrm{Sb}_{2} \mathrm{O}_{3}, \mathrm{Tl}{ }_{2} \mathrm{O}, \mathrm{MgO}\right.$ and $\left.\mathrm{PbO}\right)$ are involved in high-correlation pairs and none of the high-correlated pairs involve two of these 22 components simultaneously. None of these five components $\left(\mathrm{SeO}_{2}, \mathrm{Sb}_{2} \mathrm{O}_{3}, \mathrm{Tl}_{2} \mathrm{O}, \mathrm{MgO}\right.$ and $\mathrm{PbO})$ are expected to significantly affect viscosity of HLW glasses. The other 48 component pairs with high correlations do not involve any of the 22 components selected for viscosity modeling. Hence, these high-correlated pairs are not expected to significantly influence the results from modeling work.

\section{$\underline{\text { Viscosity Modeling Dataset }}$}

Initially there were 208 simulated HLW glasses with viscosity data available for model development. However, glasses HLW03-01, HLW03-10, HLW03-13, HLW03-32, HLW06-04, HLW-ALG-13 and HLW-ALG-38 were excluded from the modeling dataset because of not having viscosity data at four temperatures. This elimination left 201 glasses with enough data available to create viscosity models that depend both on temperature and chemical composition of the glasses involved. After initial modeling efforts, four more glasses (HLW02-06, HLW0214, HLW07-28, and HLW07-40) were found to exert too much influence on model coefficients and goodness-of-fit statistics and were therefore eliminated from the modeling dataset. Eliminating these glasses resulted in a final dataset of 197 HLW glasses used to develop and validate predictive viscosity models.

Table 8.1 lists the Glass ID, Group ID, and glass compositions for the 197 simulated HLW glasses in the 22-component forms used for viscosity model development. The Group ID 
column of Table 8.1 indicates the data series that each glass is associated with (see Sections 2.1.1 to 2.1.8). The glass compositions in Table 8.1 are the mass fractions $(\mathrm{mf})$ of the 22 components previously identified as having sufficient data to support a separate model term if needed. These components are $\mathrm{Al}_{2} \mathrm{O}_{3}, \mathrm{~B}_{2} \mathrm{O}_{3}, \mathrm{CaO}, \mathrm{CdO}, \mathrm{Cr}_{2} \mathrm{O}_{3}, \mathrm{Fe}_{2} \mathrm{O}_{3}, \mathrm{Li}_{2} \mathrm{O}, \mathrm{MgO}, \mathrm{MnO} \mathrm{Na}_{2} \mathrm{O}, \mathrm{NiO}, \mathrm{PbO}$, $\mathrm{Sb}_{2} \mathrm{O}_{3}, \mathrm{SeO}_{2}, \mathrm{SiO}_{2}, \mathrm{SrO}, \mathrm{ThO}_{2}, \mathrm{Tl}_{2} \mathrm{O}, \mathrm{UO}_{3}, \mathrm{ZnO}, \mathrm{ZrO}_{2}$ and Others.

Table 8.2 contains the measured viscosity-at-temperature pairs for the 197 HLW glasses in the initial viscosity modeling dataset. The last column designates the data-splitting validation subsets for viscosity modeling and validation. These subsets and the data-splitting validation approach are discussed in Section 8.1.2. Values of viscosity were generally measured at temperatures around $950,1050,1150$, and $1250^{\circ} \mathrm{C}$. Actual temperatures ranged from 931 to $1281^{\circ} \mathrm{C}$. The values of viscosity in Table 8.2 range from 3.60 to 3165.51 Poise. Smaller values of viscosity tend to occur at higher temperatures and larger values tend to occur at lower temperatures.

\section{$\underline{\text { Replicate and Near-Replicate Viscosity Data }}$}

Tables 8.3 and 8.4 list the sets of replicate (or near replicate) glasses, based on composition, in the IHLW viscosity modeling dataset and the corresponding viscosity values associated with the four temperatures at which viscosity was measured for each glass. Nearreplicate sets involve glasses that were intended to be replicates in composition but that have very slight differences for some component values. The differences are typically due to round-off or renormalization when the glasses involved are from different studies. Near-replicates were treated as true replicates for model development and evaluation purposes. Table 8.3 lists the viscosity values corresponding to actual temperature values, which differ somewhat from the nominal values of $950,1050,1150$, and $1250^{\circ} \mathrm{C}$ within replicate sets. Table 8.4 lists interpolated values of viscosity at the four nominal temperature values. The interpolated values were obtained by fitting the truncated-T2 equation to the (temperature, viscosity) data for each glass (see Section C.2.1 of Appendix C) and then calculating viscosity at the nominal temperature values.

Tables 8.3 and 8.4 also list estimates of \%RSDs [calculated using viscosity values in original P units] and SDs [calculated from $\ln (\eta)$ values in $\ln (\mathrm{P})$ units] for each replicate set and nominal temperature. Pooled estimates of \%RSDs and SDs are given over the (i) temperatures for a given replicate set, (ii) replicate sets for a given temperature, and (iii) all replicate sets and temperatures. A pooled \%RSD or SD combines the separate \%RSD or SD estimates so that a more accurate combined estimate of the \%RSD or SD is obtained. These pooled \%RSDs and SDs include uncertainties due to fabricating glasses and measuring viscosity. As discussed in Section 8.2.2, viscosity data are subject to two sources of uncertainty whose standard deviations are denoted $\sigma_{G}$ and $\sigma_{T}$. These parameters are expressed in $\ln (\mathrm{P})$ units because natural logarithms of viscosity values are modeled (see Section 8.2.2). The SDs given in Table 8.2 are estimates of $\sqrt{\sigma_{G}^{2}+\sigma_{T}^{2}}$, the total standard deviation of a viscosity determination for a given glass and temperature. The pooled estimates of replicate uncertainty for viscosity in Table 8.2 are used subsequently to assess lack-of-fit (LOF) of the various models considered. 
The \%RSD and SD values in Table 8.3 may over-estimate the uncertainty in viscosity values because the viscosity values of replicate sets are not exactly at the same temperature values. The \%RSD and SD values in Table 8.4 may under-estimate the uncertainty in viscosity values because the interpolated viscosity values may "remove" some of the natural variation in the data that is the basis for uncertainty estimation. The \%RSD and SD values in Tables 8.3 and 8.4 are very similar. In Table 8.3 , the overall pooled $\mathrm{SD}=0.109$ [calculated from $\ln (\mathrm{P})$ values] and $\% \mathrm{RSD}=10.81$ [calculated from $\mathrm{P}$ values]. In Table 8.4 , the overall pooled $\mathrm{SD}=0.113$ [calculated from $\ln (\mathrm{P})$ values] and $\% \mathrm{RSD}=11.16$ [calculated from $\mathrm{P}$ values]. These indicate that the relative uncertainty in viscosity measurements over replicate glasses is very close to 11 $\mathrm{RSD} \%$. In the subsequent discussion, the value of $\mathrm{SD}=0.113$ is used to assess the LOF of the various models considered. Table 8.4 shows that this roughly corresponds to an $11 \% \mathrm{RSD}$ experimental uncertainty (from batching, melting, and measuring viscosity of HLW glasses).

\subsubsection{Primary Viscosity Model Validation Approach and Data}

The primary model validation approach for viscosity modeling was based on splitting the 197-glass dataset for model development into five modeling subsets and five corresponding validation subsets. The five modeling/validation splits of the $197 \mathrm{HLW}$ glasses in the viscosity modeling dataset were formed as follows.

- The 27 glasses in the 13 replicate sets (12 replicate pairs and one triplicate set) were set aside so they would always be included in each of the five model development subsets. This was done so that replicate sets would not be split between modeling and validation subsets, thus negating the intent to have validation glasses different than model development glasses.

- The remaining $197-27=170$ glasses were ordered from smallest to largest according to their average viscosity values across the four temperatures. The 170 glasses were numbered $1,2,3,4,5,1,2,3,4,5$, etc. All of the 1 's formed the first model validation set, while all of the remaining points formed the first model development dataset. Similarly, all of the 2's, 3's, 4's, and 5's respectively formed the second, third, fourth, and fifth model validation sets. In each case, the remaining non-2's, non-3's, non-4's, and non-5's formed the second, third, fourth, and fifth model development datasets. Because 170 is evenly divisible by 5, the five modeling subsets have 136 glasses and the validation subsets all contain 34 glasses. Note that the 136 glasses in the modeling subset do not include the replicates.

- The 27 replicate glasses were added to each of the split modeling subsets. Including the replicates, all five splits contained 163 glasses for modeling and 34 for validation. The last column of Table 8.2 specifies the validation subsets for the five modeling/validation splits in the primary validation approach for viscosity model development.

Data splitting was chosen as the primary validation approach because the viscosity modeling dataset contains all compositions that (i) are in the IHLW composition region of interest, (ii) meet quality assurance (QA) requirements, and (iii) have viscosity data. Having a separate 
validation dataset not used for modeling is desirable, but that desire was over-ridden by wanting viscosity models developed with all appropriate data.

\subsubsection{Secondary Viscosity Model Validation Approach and Data}

The secondary model validation approach consisted of partitioning the 197-glass viscosity modeling dataset into a modeling subset and a validation subset. Two different partitions were investigated. In the first one (denoted V1), 131 glasses in the series HLW02, HLW03 and HLW07 were chosen for the modeling subset, with the remaining 66 glasses in the validation subset. However, this data partition resulted in under-predicted viscosity values for all the models considered (discussed subsequently). The under-prediction resulted from a lack of representation in the modeling subset of certain compositions present in the complete dataset. This same problem first appeared when using the V1 partition to validate models for electrical conductivity and, for that property, it was decided to form a second data partition (denoted V2) by adding selected glasses to the modeling subset. Glasses HLW-ALG-01, -03, -04, -10, -11, $15,-16,-17,-20,-21,-22,-23,-25,-27,-28,-29,-33,-34$ (18 glasses) and HLW05-20, -21 (2 glasses) were selected by VSL to augment the modeling portion of the dataset for viscosity. This produces a subset of 152 glasses used for modeling viscosity, with the other 45 glasses reserved for validation. A nearly identical set of glasses were used to form a V2 partition set for electrical conductivity with the exception of three glasses that had insufficient or no viscosity data. Despite having solved some of the under-prediction problems encountered when using the V1 data partition, the V2 partition still showed problems for every one of the candidate models employed. The problems were attributed to non-representative partitioning of the complete modeling dataset into modeling and validation subsets. For this reason, results from datapartition (V1 or V2) validation of viscosity models are not reported in this document.

The data-splitting approach discussed in Section 8.1.2 is considered the primary validation approach because it comes closer to validating the viscosity models of interest, namely those fitted to all 197 glasses with viscosity data in the modeling dataset. The primary validation approach fits viscosity models using 163 of the 197 glasses in the modeling dataset and validates with the remaining 34 glasses, and does so five times. The secondary approach fits models with 152 glasses and validates with 45 glasses (for the V2 data partition). Hence, the primary validation approach comes closer to validating the viscosity models of interest, namely those fitted to data on all 197 glasses. The primary validation approach also avoids the representativeness problems in the secondary validation approach discussed previously.

\subsection{Viscosity Model Forms}

Ideally, a property-composition-temperature model for viscosity would utilize known mechanisms of viscosity as a function of glass composition and melt temperature. No such mechanisms are known, although there is considerable experience regarding the temperature dependence of viscosity over the range of 950 to $1250^{\circ} \mathrm{C}$. Section 8.2.1 discusses the investigations performed to select an equation to represent the temperature dependence of viscosity. Sections C. 1 and C. 2 of Appendix C discuss mixture experiments and several general 
model forms in which mixture experiment models are used to expand the parameters of viscosity-temperature equations. Section 8.2.2 discusses the forms of viscosity-temperature models investigated. Section 8.2.3 discusses the use of transformed viscosity values as the response variable for viscosity modeling.

\subsubsection{Temperature Dependence of Viscosity}

Three equations discussed in Section C.2.1 of Appendix C were considered for representing the temperature dependence of viscosity. These are the Arrhenius equation [Equation (C.9)], the T2 equation [Equation (C.10)], and the truncated-T2 equation [Equation (C.11)]. The viscosity at temperature observations for each of the 197 glasses in the viscosity modeling dataset were used to fit each of these three equations. Goodness of fit statistics were calculated and compared. The truncated-T2 equation (which represents a linear relationship between $\ln (\eta)$ and $1 / T^{2}$ (where $T$ is temperature in Kelvin) was better than the Arrhenius equation for nearly all the glasses under consideration. The T2 equation was only slightly better than the truncated-T2 equation. However, estimates of the three parameters in the T2 equation were simultaneously significant for only 13 of the HLW glasses. The coefficients for the truncated-T2 equation obtained for glasses with sufficient viscosity data showed less correlation than those for the other two temperature-dependence equations. The truncated-T2 equation proved to have better values in several goodness-of-fit statistics (RMSE, correlations among equation coefficients) over the other two candidates and was therefore selected to represent the temperature dependence of viscosity for HLW glasses.

\subsubsection{Model Forms for the Temperature and Composition Dependence of Viscosity}

The model forms considered for viscosity start with a slightly modified version of the truncated-T2 equation and expand its two parameters as functions of HLW glass composition. Linear mixture (LM) model forms and partial quadratic mixture (PQM) model forms (see Section C.1.1 of Appendix C) were considered for use in expanding the parameters of the truncated-T2 equation.

The viscosity model form with the parameters of a modified truncated-T2 equation expanded as LM models is given by

$$
\ln (\eta)=\sum_{i=1}^{q} a_{i} x_{i}+E_{G}+\sum_{i=1}^{q} b_{i} \frac{x_{i}}{(T / 1000)^{2}}+E_{T}
$$

The modification to the truncated-T2 equation is that temperature ( $T$ in Kelvin) is divided by the scaling factor of 1000 so that the $b_{i}$ coefficients are similar in magnitude to the $a_{i}$ coefficients. Except for the scaling factor, this equation is the same one given as Equation (C.15) and discussed in Section C.2.2 of Appendix C. The remaining notation is discussed following the subsequent model forms. 
The viscosity model form with the composition-only parameter of the modified truncated-T2 equation expanded as a PQM model is given by

$$
\ln (\eta)=\sum_{i=1}^{q} a_{i} x_{i}+\text { Selected }\left\{\sum_{i=1}^{q} a_{i i} x_{i}^{2}+\sum_{i<}^{q-1} \sum_{j}^{q} a_{i j} x_{i} x_{j}\right\}+E_{G}+\sum_{i=1}^{q} b_{i} \frac{x_{i}}{(T / 1000)^{2}}+E_{T} .
$$

Equation (8.2) would be appropriate if there are quadratic compositional effects on viscosity that are not temperature dependent. Temperature (in Kelvin) is scaled by 1000 in Equation (8.2) for the reason discussed previously for Equation (8.1).

In Equations (8.1) and (8.2): $\ln (\eta)$ denotes the natural logarithm of viscosity [in units of $\ln (\mathrm{P})]$; the $x_{i}(i=1,2, \ldots, q)$ are mass fractions of $q$ glass oxide or halogen components such that $\sum_{i=1}^{q} x_{i}=1$; the $a_{i}$ and $b_{i}(i=1,2, \ldots, q)$, and the $a_{i i}, a_{i j}$, are coefficients to be estimated from data; $E_{G}$ is a random error associated with determining viscosity for each HLW glass; and $E_{T}$ is a random error associated with determining viscosity at the temperature values of a given glass melt. The random errors $E_{G}$ and $E_{T}$ are assumed to be normally distributed with zero means and standard deviations $\sigma_{G}$ and $\sigma_{T}$, respectively. These standard deviations and the model coefficients are estimated simultaneously using generalized least squares (GLS) regression. See Section C.2.1 of Appendix $C$ for additional discussion of $E_{G}$ and $E_{T}$. See Sections C.3.2 and C.3.3 for additional discussion of GLS regression.

\subsubsection{Transformation of Viscosity}

In modeling viscosity, it is advantageous to use the natural logarithm of the viscosity values. The advantages of this transformation include:

- The viscosity values for the 197 HLW glasses in the viscosity modeling dataset range from 3.60 to $3165.51 \mathrm{P}$. This is a range of nearly 3 orders of magnitude difference. In such cases, typically the uncertainty in making glasses and measuring viscosity leads to smaller absolute uncertainties for smaller viscosity values and larger absolute uncertainties for larger viscosity values. Hence, the unweighted least squares (ULS) regression assumption of equal variances for all response variable values (see Section C.3 of Appendix C) is violated. After a logarithmic transformation, variances of response values tend to be approximately equal as required for ULS regression.

- A logarithmic transformation tends to linearize the compositional dependence of viscosity data and reduce the need for non-linear terms in the model form.

- A natural logarithm transformation is preferred over a common logarithm (or other base logarithm) transformation because of the approximate relationship

$$
\mathrm{SD}[\ln (y)] \cong \operatorname{RSD}(y)
$$


where SD denotes standard deviation, RSD denotes relative standard deviation (i.e., the standard deviation divided by the mean), and $y$ denotes viscosity. Equation (8.3) results from applying the first-order variance propagation formula [Equation (7-7) of Hahn and Shapiro (1967)] to the function $z=\ln (y)$. The relationship in Equation (8.3) is very useful, in that uncertainties of the natural logarithm of the response variable $y$ can be interpreted as RSDs of the untransformed response variable $y$.

For these reasons, the natural logarithmic transformation was employed for all viscosity model forms.

\subsection{Model Results for IHLW Viscosity with the Truncated-T2 Equation Parameters Expanded as Linear Mixture Models}

This section discusses the results of fitting two truncated T2-LM models using natural logarithms of viscosity for HLW glasses [denoted $\ln (\eta)$ ] as the response variable. These models are of the forms given in Equation (8.1). Section 8.3.1 presents the results from fitting a 44-term viscosity model consisting of the truncated-T2 equation with its parameters expanded using LM terms for each of the 22 components determined to have sufficient support in the 197-glass modeling set. Section 8.3.2 discusses the methods used to develop truncated T2-LM models with reduced numbers of HLW glass components. Section 8.3.3 presents the results from fitting two models consisting of the truncated-T2 equation with its parameters expanded using 15component reduced LM models.

To perform the GLS model fits (see Section 8.2.2 and Section C.3.2 of Appendix C), PROC MIXED in SAS (2005) was used. For each model considered, output files produced by SAS were used in Excel (2003) to perform the remaining model evaluation and validation calculations and in Matlab (2006) to create the plots shown in this section.

\subsubsection{Results for 44-Term Viscosity Model with the Truncated-T2 Equation Parameters Expanded as 22-Component Linear Mixture Models}

As the initial step in viscosity model development, the truncated T2-LM model in Equation (8.1) with $q=22$ components identified in Section 8.1.1 was fit to the modeling data (197 HLW glasses). The response was the natural logarithm of viscosity (P). This 44-term model (denoted Model 1) form was a reasonable starting point and provided a basis for appropriate model reductions.

Table 8.5 contains the results for the 44-term truncated T2-LM model for viscosity of HLW glasses. Table 8.5 lists the model coefficients, standard deviations of the coefficients, and estimates of the $\sigma_{G}$ and $\sigma_{T}$ error standard deviations (see Section 8.2.2). Table 8.5 also contains model performance summaries for the 44-term model using the modeling dataset (197 glasses) and data-splitting modeling and validation subsets (see Section 8.1.2). 
The summary statistics that describe how well the 44-term truncated T2-LM model fits the 197-glass viscosity modeling dataset are given in the upper right corner of Table 8.5. Only the $\mathrm{R}^{2}$, sum of squared errors (SSE), and root mean square error (RMSE) statistics were calculated because of using GLS regression (see Section C. 4 in Appendix C). The $\mathrm{R}^{2}=0.987$ statistic indicates that the 44-term truncated T2-LM model fits the viscosity modeling data quite well. For GLS regression, the SSE $=19.479$ and RMSE $=0.162$ statistics do not directly indicate the performance of the 44-term model. However, the values of these statistics can be compared to the values for subsequently discussed models. The quantity $\hat{\sigma}_{\text {Total }}=\sqrt{\hat{\sigma}_{G}^{2}+\hat{\sigma}_{T}^{2}}=$ $\sqrt{(0.1471)^{2}+(0.0764)^{2}}=0.1658$ is an estimate of the total uncertainty in a viscosity determination for a given glass and temperature, under the assumption that the 44-term model does not have a significant LOF. A significant model LOF would inflate $\hat{\sigma}_{\text {Total }}$ and it would over-estimate the true total uncertainty in a viscosity determination. The value of $\hat{\sigma}_{\text {Total }}$ is about $50 \%$ larger than the compromise overall pooled estimate of uncertainty SD $=0.113$ (see Section 8.1.1) calculated from replicate data that is not impacted by model LOF. Hence, the 44-term viscosity model may have some LOF, but it does not appear to be highly significant given the uncertainty inherent in the viscosity data.

Performance statistics for the 44-term viscosity model when applied to the five modeling/validation splits formed from the 197-glass modeling set are given in the bottom part of Table 8.5. The columns are labeled DS1, DS2, DS3, DS4 and DS5 to denote the five modeling/validation splits of the data as described in Section 8.1.2. The last column of this part of Table 8.5 presents averages of the modeling (SSE, RMSE and $\left.\mathrm{R}^{2}\right)$ and validation $\left(\mathrm{R}_{\mathrm{V}}^{2}\right.$ and $\mathrm{RMSE}_{\mathrm{V}}$ ) statistics over the five data-splits. The average modeling statistics $\mathrm{R}^{2}=0.988$ and $\mathrm{RMSE}=0.159$ are close to their values from the 197-glass modeling dataset. The average validation statistics $\mathrm{R}_{\mathrm{V}}^{2}=0.980$ and $\mathrm{RMSE}_{\mathrm{V}}=0.193$ from the data-splitting approach are slightly worse (smaller and larger, respectively) than the $\mathrm{R}^{2}$ and RMSE values from fitting the viscosity data using all 197 glasses in the modeling dataset. This indicates that the performance of the 44-term viscosity model is not significantly degraded in any of the five validation subsets.

The predicted versus measured plot and the standardized residual plot for the 44-term truncated T2-LM model are given in Figures 8.4 and 8.5, respectively. Figure 8.4 shows tight scatter about the $45^{\circ}$ line representing perfect prediction, with no significantly outlying data apparent. Figure 8.4 shows what may be a slight tendency to under-predict viscosity at higher values but this may be due simply to the relative lack of data at the high-end of viscosity values. Figure 8.5 shows, in general, no apparent trends in the residuals or violations in the assumption of constant variance (although nearly all points for the few available HLW05 glasses are underpredicted).

Figure 8.6 shows the predicted versus measured plot when the 44-term viscosity model is applied to the five validation sets obtained using data-splitting (see Section 8.1.2). The scatter of the validation predictions around the $45^{\circ}$ line in Figure 8.6 is only slightly worse than for the fitted predictions in Figure 8.4. No strong biased predictions are seen in Figure 8.6. Figure 8.7 is similar to Figure 8.6 except that it also contains $95 \%$ prediction intervals (PIs) representing the model prediction uncertainty of single viscosity determinations for each glass in the validation 
subsets at one temperature (see Sections C.6 and C.7 of Appendix C). If the 95\% PI for a validation point overlaps the $45^{\circ}$ line, the predicted and measured $\ln (\eta)$ values are within model and measurement uncertainty of each other. Note that the 95\% PIs include the estimated uncertainties $\hat{\sigma}_{G}$ and $\hat{\sigma}_{T}$ resulting from the structure of the viscosity data. The $95 \%$ PIs for the 44-term model overlap the $45^{\circ}$ line (i.e., contain the measured values) for all but 20 of the 680 (= 5 validation subsets, each with 34 glasses with viscosity measurements at four temperatures per glass) observations. Failure of $100(20 / 680)=2.9 \%$ of the $95 \%$ PIs to include the corresponding measured values is lower than the $5 \%$ that would be expected by chance for a model with no LOF. Hence, it does not appear that the 44-term viscosity model has significant LOF based on the statistical performance on this data-splitting approach. As a result of this, the width of the 95\% PIs should be due primarily to the experimental uncertainty in fabricating glasses and measuring viscosity (and model uncertainty that results).

The 44-term truncated T2-LM model for viscosity fits the 197-glass modeling dataset very well and thus can provide guidance for reducing the model (i.e., removing separate terms for components that do not significantly influence viscosity). Hence, this model was used to produce a response trace plot (see Section C.5.1) at each of the four nominal temperatures at which viscosity was measured $\left(950,1050,1150\right.$, and $\left.1250^{\circ} \mathrm{C}\right)$, as shown in Figures $8.8 \mathrm{a}$ to $8.8 \mathrm{~d}$. Note that the $y$-axis [predicted $\ln ($ Viscosity, P)] does not have the same scale and tic marks on each of the four plots. Using the same scale would have greatly condensed the individual plots and made it even more difficult to differentiate response traces of individual components. The response trace plots show that $\mathrm{Li}_{2} \mathrm{O}$ and $\mathrm{Na}_{2} \mathrm{O}$ have dominant decreasing effects on viscosity, while $\mathrm{SiO}_{2}$ and $\mathrm{Al}_{2} \mathrm{O}_{3}$ have the strongest increasing effects on viscosity. Figures $8.8 \mathrm{a}$ to $8.8 \mathrm{~d}$ also show that $\mathrm{ZrO} 2$ and $\mathrm{B}_{2} \mathrm{O}_{3}$ have increasing and decreasing effects, respectively, on viscosity, with the effects getting weaker as temperature increases. Figures $8.8 \mathrm{a}$ to $8.8 \mathrm{~d}$ show that no other components have response traces with large positive or negative effects.

\subsubsection{Development of Viscosity Models with the Truncated-T2 Equation Parameters Expanded as Reduced Linear Mixture Models}

In the 44-term truncated T2-LM model presented in Section 8.3.1, some of the 22 components likely do not significantly contribute to predicting viscosity. Hence, model reduction was the next step of the model development approach. The two parameters of the truncated-T2 equation were expanded using LM models involving fewer than the 22 components. Two approaches were considered in reducing the full 44-term viscosity model discussed in Section 8.3.1. Each of these approaches and brief summaries of results are discussed in turn.

The first approach was to compare summary statistics from the split-plot modeling (using the PROC MIXED routine in SAS 2005) for progressively reduced models to assess how much model reduction was appropriate. For this approach, at each iteration the minor component (among $\mathrm{CdO}, \mathrm{Cr}_{2} \mathrm{O}_{3}, \mathrm{NiO}, \mathrm{PbO}, \mathrm{Sb}_{2} \mathrm{O}_{3}, \mathrm{SeO}_{2}, \mathrm{Tl}_{2} \mathrm{O}$ ) that appeared to have the least significance in the model was subsequently removed (moved into the Others component) until all of the minor components had been removed. The components $\mathrm{CdO}, \mathrm{Sb}_{2} \mathrm{O}_{3}, \mathrm{SeO}_{2}$, and $\mathrm{Tl}_{2} \mathrm{O}$ were varied for modeling TCLP releases, but are not expected to affect viscosity results. Similarly, $\mathrm{Cr}_{2} \mathrm{O}_{3}$ and $\mathrm{NiO}$ were varied for purposes of modeling spinel $\mathrm{T}_{1 \%}$, but they are not expected to affect 
viscosity results. Finally, $\mathrm{PbO}$ was never chosen as a component to vary in any of the HLW glass studies, but had sufficient range and distribution in the modeling dataset to include in the full model. However, it is not expected to affect viscosity results. Model terms involving all the minor components mentioned above were eliminated without significantly impacting prediction performance or other goodness-of-fit statistics. Hence, 15 components (including the new Others) remained, resulting in a 30-term truncated T2-LM model. That model had three composition-temperature terms $\left[\mathrm{B}_{2} \mathrm{O}_{3} /(T / 1000)^{2}, \mathrm{CaO} /(T / 1000)^{2}\right.$, and $\left.\mathrm{MgO} /(T / 1000)^{2}\right]$ that were statistically non-significant. Those terms were therefore eliminated, yielding a reduced truncated T2-LM model with 27 terms.

The second reduction approach used to develop reduced model forms for viscosity of HLW glasses involved expanding each of the two parameters of the truncated-T2 equation using LM models in fewer than all 22 components. The sequential F-test model reduction approach (see Section C.5.1 of Appendix C, Piepel and Cooley 2006) was used to develop reduced LM models for each of the two truncated-T2 equation parameters treated as a separate response variable. Option (ii) discussed in Section C.5.1 of Appendix C was used to develop the reduced LM model for each parameter. A significance level of 0.05 was used for the F-tests conducted by the model reduction algorithm. An option available with the F-test approach is to allow only certain terms to combine during the reduction process. For viscosity, only the minor components (among $\mathrm{CdO}, \mathrm{Cr}_{2} \mathrm{O}_{3}, \mathrm{NiO}, \mathrm{PbO}, \mathrm{Sb}_{2} \mathrm{O}_{3}, \mathrm{SeO}_{2}$, and $\mathrm{Tl}_{2} \mathrm{O}$ ) were eligible for reduction for each of the two truncated-T2 equation parameters. That is, they were the only components that could be combined with other components. These minor components were allowed to combine if having the combined-components term in the model rather than the separate component terms did not significantly decrease model performance. Running the model reduction algorithm with each of the two truncated-T2 equation parameters used in turn as the response variable yielded the same reduced model form in which all of the components that were eligible for combining were combined into a new Others component. That is, the same 15-component reduced LM model form was chosen for each of the two truncated-T2 equation parameters for the dependence of viscosity on temperature. The 15 components were $\mathrm{Al}_{2} \mathrm{O}_{3}, \mathrm{~B}_{2} \mathrm{O}_{3}, \mathrm{CaO}, \mathrm{Fe}_{2} \mathrm{O}_{3}, \mathrm{Li}_{2} \mathrm{O}, \mathrm{MgO}, \mathrm{MnO}$ $\mathrm{Na}_{2} \mathrm{O}, \mathrm{SiO}_{2}, \mathrm{SrO}, \mathrm{ThO}_{2}, \mathrm{UO}_{3}, \mathrm{ZnO}, \mathrm{ZrO}_{2}$, and Others. Note that Others is the sum of all remaining components, and thus differs from the Others in the 44-term truncated T2-LM model discussed in Section 8.3.1.

The results of the two model reduction approaches agreed, yielding a 30-term truncated T2-LM model of the form given in Equation (8.1) with $q=15$. As mentioned previously, the $\mathrm{B}_{2} \mathrm{O}_{3} /(T / 1000)^{2}, \mathrm{CaO} /(T / 1000)^{2}$, and $\mathrm{MgO} /(T / 1000)^{2}$ terms were statistically non-significant and thus removed, resulting in a 27 -term model that is the first reduced model to be more fully investigated. 


\subsubsection{Results for 27-Term Viscosity Model with the Truncated-T2 Equation Parameters Expanded as 15-Component Reduced Linear Mixture Models}

Table 8.6 gives the coefficients, coefficient standard deviations, and estimates of the $\sigma_{G}$ and $\sigma_{T}$ error standard deviations (see Section 8.2.2) for the 27-term truncated T2-LM model for viscosity (denoted Model 2). This model was fitted to the viscosity data for the 197 glasses in the modeling set using the PROC MIXED procedure in SAS (2005). Table 8.6 also provides performance statistics for the (i) modeling data and (ii) five pairs of modeling and validation subsets that result from data-splitting (see Section 8.1.2).

The statistics from fitting the 27-term truncated T2-LM model to the viscosity data from 197 glasses are given in the upper right corner of Table 8.6. The $\mathrm{R}^{2}=0.986$ and $\mathrm{RMSE}=0.168$ statistics are only slightly worse than those for the full 44-term model.

The statistics from fitting and validating the 27-term viscosity model using the five modeling and validation subsets that result from the data-splitting procedure are given in the bottom part of Table 8.6. The average modeling statistics $\mathrm{R}^{2}=0.986$ and $\mathrm{RMSE}=0.167$ are nearly identical to their values from the 197-glass viscosity modeling dataset. The average validation statistics $\mathrm{R}_{\mathrm{V}}^{2}=0.982$ and $\mathrm{RMSE}_{\mathrm{V}}=0.186$ from the data-splitting approach are not much worse than the $\mathrm{R}^{2}=0.986$ and $\mathrm{RMSE}=0.168$ statistics from fitting the model to data from all 197 glasses. The average $\mathrm{R}_{\mathrm{V}}^{2}=0.982$ and $\mathrm{RMSE}_{\mathrm{V}}=0.186$ across the five validation subsets are slightly better than the average $\mathrm{R}_{\mathrm{V}}^{2}=0.980$ and $\mathrm{RMSE}_{\mathrm{V}}=0.193$ obtained using the 44-term model for the same five subsets. Hence, the 27-term viscosity model appears to predict as well as the 44-term viscosity model, even though it has many fewer terms.

From entries in Table 8.6, the quantity $\hat{\sigma}_{\text {Total }}=\sqrt{\hat{\sigma}_{G}^{2}+\hat{\sigma}_{T}^{2}}=\sqrt{(0.1530)^{2}+(0.0773)^{2}}=$ 0.1714 was calculated. It is an estimate of the total uncertainty in a viscosity determination for a given glass and temperature, under the assumption that the 27-term model does not have a significant LOF. A significant model LOF would inflate this quantity and it would over-estimate the true total uncertainty in a viscosity determination. For the 27 -term model, $\hat{\sigma}_{\text {Total }}=0.1714$ is only slightly larger than $\hat{\sigma}_{\text {Total }}=0.1658$ for the 44 -term model. However, it is about $56 \%$ larger than the compromise overall pooled estimate of uncertainty $\mathrm{SD}=0.113$ calculated from replicate data that is not impacted by model LOF (see Section 8.1.1). Hence, the 27-term viscosity model may have some LOF, but it does not appear to be highly significant given the uncertainty inherent in the data. Together, these results indicate there is little consequence to reducing the viscosity model from 44 terms to 27 terms.

The predicted versus measured plot and the standardized residual plot for the 27-term truncated T2-LM model for viscosity are given in Figures 8.9 and 8.10, respectively. Figure 8.9 shows tight scatter about the $45^{\circ}$ line representing perfect prediction, with no significantly outlying data. Figure 8.9 does not show any tendency to over- or under-predict viscosity within the range of values available. In general, Figures 8.9 and 8.10 are very similar to the ones for the 44-term model in Figures 8.4 and 8.5. 
Figure 8.11 shows the predicted versus measured plot when the 27-term viscosity model is applied to the five validation sets obtained using data-splitting (see Section 8.1.2). The scatter and bias of the validation predictions around the $45^{\circ}$ line in Figure 8.11 is only slightly worse than for the fitted predictions in Figure 8.8. It is also only slightly worse than the corresponding plot for the 44-term model in Figure 8.6. Figure 8.12 is similar to Figure 8.11, except that it also contains 95\% PIs representing the model prediction uncertainty of single viscosity determinations for each glass in the validation subsets at one temperature (see Sections C.6 and C.7 of Appendix C). If the $95 \%$ PI for a validation point overlaps the $45^{\circ}$ line, the predicted and measured $\ln (\eta)$ values are within model and measurement uncertainty of each other. Note that the $95 \%$ PIs include the estimated uncertainties $\hat{\sigma}_{G}$ and $\hat{\sigma}_{T}$ resulting from the structure of the viscosity data. The $95 \%$ PIs for the 27 -term model overlap the $45^{\circ}$ line (i.e., contain the measured values) for all but 22 of the 680 (=5 validation subsets, each with 34 glasses having viscosity measurements at four temperatures per glass) observations. Failure of 100(22/680) $=$ $3.2 \%$ of the $95 \%$ PIs to include the corresponding measured values is slightly lower than the $5 \%$ that would be expected by chance for a model with no LOF. Hence, it does not appear that the 27-term viscosity model has significant LOF based on the statistical performance on this datasplitting approach. As a result of this, the width of the $95 \%$ PIs should be due primarily to the experimental uncertainty in fabricating glasses and measuring viscosity (and model uncertainty that results).

To understand the effects of HLW glass components on viscosity at different temperatures, the 27-term viscosity model was used to produce a response trace plot (see Section C.5.1) at each of the four nominal temperatures at which viscosity was measured $(950,1050$, 1150 , and $1250^{\circ} \mathrm{C}$ ). These response trace plots are shown in Figures 8.13a to 8.13d. Note that the $\mathrm{y}$-axis [predicted $\ln ($ Viscosity, $\mathrm{P})$ ] does not have the same scale and tic marks on each of the four plots. Using the same scale would have greatly condensed the individual plots and made it more difficult to differentiate response traces of individual components. The response trace plots given in Figures $8.13 \mathrm{a}$ to $8.13 \mathrm{~d}$ are very similar to the ones for the 44-term model. The components $\mathrm{Na}_{2} \mathrm{O}$ and $\mathrm{Li}_{2} \mathrm{O}$ have decreasing effects on viscosity, while $\mathrm{SiO}_{2}, \mathrm{Al}_{2} \mathrm{O}_{3}$ and $\mathrm{ZrO}_{2}$ have the strongest increasing effects on viscosity. Figures $8.13 \mathrm{a}$ to $8.13 \mathrm{~d}$ also show that temperature changes have very little effect on (i) which components are important or (ii) the magnitudes of the effects that model components have on viscosity.

\subsection{Investigation of Adding Quadratic Terms to, and Eliminating Composition- Temperature Terms from, the 27-Term Truncated T2-Linear Mixture Model}

Several different quadratic (squared and crossproduct) terms were considered for inclusion into the 27-term viscosity model (Model 2). First, $\mathrm{Na}_{2} \mathrm{O} \times \mathrm{Li}_{2} \mathrm{O}, \mathrm{CaO} \times \mathrm{Li}_{2} \mathrm{O}$, and $\mathrm{CaO} \times \mathrm{Na}_{2} \mathrm{O}$ terms were considered (because they were also considered during EC modeling) but none were found to be statistically significant nor to impact other measures of goodness-of-fit in any significant way. Then, all quadratic (squared and two-component crossproduct) terms involving the 15 components in the model were considered for inclusion into the model. After this process, only five terms $\mathrm{Al}_{2} \mathrm{O}_{3} \times \mathrm{SiO}_{2}, \mathrm{~B}_{2} \mathrm{O}_{3} \times \mathrm{Na}_{2} \mathrm{O}, \mathrm{Li}_{2} \mathrm{O} \times \mathrm{ZnO}, \mathrm{Na}_{2} \mathrm{O} \times \mathrm{ThO}_{2}$, and $\left(\mathrm{Li}_{2} \mathrm{O}\right)^{2}$ were found to be statistically significant and to improve measures of goodness-of-fit. 
Incorporating these five quadratic terms into the 27-term Model 2 resulted in a new 32-term model (denoted as Model 3).

Even though the 27-term Model 2 and the 32-term Model 3 had only statistically significant composition-temperature terms, it was considered possible that some of those terms might not be practically significant and therefore could be eliminated without affecting the predictive properties of the models.

Starting with each of the 27-term Model 2 and the 32-term Model 3, the terms $\mathrm{ZnO} /(T / 1000)^{2}$, Others $/(T / 1000)^{2}$ and $\mathrm{MnO} /(T / 1000)^{2}$ were successively deleted based on significance tests of the model terms. At that point, more $x_{i} /(T / 1000)^{2}$ terms were investigated for elimination from each of these two models. However, the SSE and other goodness-of-fit statistics worsened with every newly eliminated composition-temperature term. Hence, it was decided to stop model modification after removing the three additional composition-temperature terms. Eliminating the three terms from the 27-term Model 2 and the 32-term Model 3 results in, respectively, a 24-term model (Model 4) and a 29-term model (Model 5). The 24-term Model 4 has no quadratic composition terms while the 29-term Model 5 includes the five statistically significant quadratic terms $\mathrm{Al}_{2} \mathrm{O}_{3} \times \mathrm{SiO}_{2}, \mathrm{~B}_{2} \mathrm{O}_{3} \times \mathrm{Na}_{2} \mathrm{O}, \mathrm{Li}_{2} \mathrm{O} \times \mathrm{ZnO}, \mathrm{Na}_{2} \mathrm{O} \times \mathrm{ThO}_{2}$, and $\left(\mathrm{Li}_{2} \mathrm{O}\right)^{2}$. Model coefficient estimates, coefficient standard deviations and goodness-of-fit statistics for the 24-term Model 4 are given in Table 8.7. Table 8.8 shows similar results and statistics for the 29term Model 5.

Table 8.9 summarizes key results for Models 1 to 5 (Model 1 is the 44-term model in Table 8.5 and Model 2 is the 27-term model in Table 8.6). Summarized are the results from fitting the models to the viscosity data from all 197 glasses. Table 8.9 also shows goodness-of-fit statistics averaged across the five modeling subsets and the five validation subsets resulting from data-splitting.

Based on the results from this section, Model 5 is recommended for viscosity prediction, with Model 4 recommended as a possible second-choice model. The recommendation of Model 5 for viscosity prediction is based both on its relatively small size (29 total terms) and its level of performance. Model 5 has close to the best goodness-of-fit statistic values among all models explored and maintains its level of performance when applied to the five data-splitting subsets created for validation purposes. Because there is a possibility that the quadratic terms may be over-fitting the data, Model 4 (which has none of these terms and is also the smallest among the models considered) is suggested as a second-choice model.

\subsection{Results for the Recommended 29-Term Viscosity Model}

Section 8.5.1 presents the results for the recommended 29-term viscosity model fitted to the 197-glass modeling dataset. Section 8.5.2 presents the validation results for that model. 


\subsubsection{Results for the Recommended 29-Term Viscosity Model Fitted to the 197- Glass Modeling Dataset}

The 29-term Model 5 of the form in Equation (8.2) was fitted to the viscosity data for the 197 glasses in the modeling dataset. The PROC MIXED procedure in SAS (2005) was used to perform the GLS regression required for the viscosity data structure. Table 8.8 lists the fitted model coefficients, the coefficient standard deviations, and estimates of the $\sigma_{G}$ and $\sigma_{T}$ error standard deviations (see Section 8.2.2).

The statistics from fitting the 29-term truncated T2-PQM Model 5 to the viscosity data from 197 glasses are given in the upper right corner of Table 8.8. The $\mathrm{R}^{2}=0.988$ and $\mathrm{RMSE}=$ 0.151 statistics are second only to those for Model 3. The $\mathrm{R}^{2}$ value indicates that nearly $99 \%$ of the variation in $\ln (\eta)$ values is accounted for by the model.

Performance statistics for the 29-term IHLW viscosity model when applied to the five modeling/validation splits formed from the 197-glass modeling dataset are given in the bottom part of Table 8.8. The columns are labeled DS1, DS2, DS3, DS4, and DS5 to denote the five modeling/validation splits of the data as described in Section 8.1.2. The last column of this part of Table 8.8 presents averages of the modeling $\left(\mathrm{R}^{2}, \mathrm{SSE}\right.$, and RMSE) and validation $\left(\mathrm{R}_{\mathrm{V}}^{2}\right.$ and $\mathrm{RMSE}_{\mathrm{V}}$ ) statistics over the five data-splits. The average modeling statistics $\mathrm{R}^{2}=0.989$ and $\mathrm{RMSE}=0.150$ are nearly identical to their values from the 197-glass viscosity modeling dataset.

From entries in Table 8.8, the quantity $\hat{\sigma}_{\text {Total }}=\sqrt{\hat{\sigma}_{G}^{2}+\hat{\sigma}_{T}^{2}}=\sqrt{(0.1283)^{2}+(0.0869)^{2}}=$ 0.1550 was calculated. This is an estimate of the total uncertainty in a viscosity determination for a given glass and temperature, under the assumption that the 29-term model does not have a significant LOF. A significant model LOF would inflate this quantity and it would over-estimate the true total uncertainty in a viscosity determination. For the 29-term model, $\hat{\sigma}_{\text {Total }}=0.1550$ is about $40 \%$ larger than the compromise overall pooled estimate of uncertainty SD $=0.113$ (see Section 8.1.1) calculated from replicate data that is not impacted by model LOF. Hence, the 29term model may have some LOF, but it does not appear to be highly significant given the uncertainty inherent in the data.

A histogram and normal probability plot of the standardized residuals for the fit of the 29-term model in Table 8.8 to the 197-glass viscosity modeling dataset for HLW glasses were generated, although they are not shown in this report. These two plots do not show any significant departure from normality, which is required to utilize the statistical interval formulas for model prediction uncertainties that are discussed subsequently.

The predicted versus measured plot and the standardized residual plot for the 29-term $\ln (\eta)$ model are given in Figures 8.14 and 8.15, respectively. Figure 8.14 shows that there is very tight scatter about the $45^{\circ}$ line representing perfect prediction, with no significantly outlying data for the predictions made with Model 5. Figure 8.14 does not show any tendency to over- or under-predict viscosity within any range of values. Figure 8.15 shows no significant problems with the residuals obtained using this model or with the modeling assumption of constant variance (see Section C.3.1 of Appendix C). 
To understand the effects of HLW glass components on viscosity at different temperatures, the 29-term viscosity model was used to produce a response trace plot (see Section C.5.1) at each of the four nominal temperatures at which viscosity was measured $(950,1050$, 1150 , and $1250^{\circ} \mathrm{C}$ ). These response trace plots are shown in Figures 8.16a to 8.16d. Note that the $y$-axis [predicted $\ln (\eta, P)$ ] does not have the same scale and tic marks on each of the four plots. Using the same scale would have greatly condensed the individual plots and made it even more difficult to differentiate response traces of individual components. The response trace plots show that $\mathrm{Li}_{2} \mathrm{O}$ and $\mathrm{Na}_{2} \mathrm{O}$ have dominant decreasing effects on viscosity, while $\mathrm{SiO}_{2}, \mathrm{Al}_{2} \mathrm{O}_{3}$ and $\mathrm{ZrO}_{2}$ have the strongest increasing effects on viscosity. Figures $8.16 \mathrm{a}$ to $8.16 \mathrm{~d}$ also show that the individual response traces change little with changes in temperature.

\subsubsection{Validation Results for the Recommended 29-Term Viscosity Model}

The statistics from using the 29-term model to predict viscosity values for the five validation subsets that result from the data-splitting procedure described in Section 8.1.2 are given in the bottom part of Table 8.8. The average validation statistics $R_{V}^{2}=0.985$ and $\mathrm{RMSE}_{\mathrm{V}}$ $=0.169$ across the five validation subsets are slightly worse (i.e., smaller and larger, respectively) than $\mathrm{R}^{2}=0.989$ and $\mathrm{RMSE}=0.151$ when fitting the viscosity data from all 197 glasses in the modeling set. The average validation statistics $\mathrm{R}_{\mathrm{V}}^{2}=0.985$ and $\mathrm{RMSE}_{\mathrm{V}}=0.169$ using the 29-term model are slightly better than the average statistics $\mathrm{R}_{\mathrm{V}}^{2}=0.982$ and $\mathrm{RMSE}_{\mathrm{V}}=$ 0.186 obtained using the 27-term model for the same five validation subsets. Hence, the recommended 29 -term viscosity model validates slightly better than the 27 -term viscosity model for the five validation subsets.

Figure 8.17 shows the predicted versus measured plot when the recommended 29-term viscosity model is applied to the five validation datasets that result from data-splitting. The 29term model predicts viscosity fairly accurately for nearly all of the glasses. Figure 8.17 shows that there is very tight scattering around the $45^{\circ}$ line representing perfect prediction. In fact, the scatter for the five validation subsets in Figure 8.17 is not much larger than that found when the entire 197-glass dataset is used, which is an indication of the good predictive properties of this model.

Figure 8.18 shows 95\% PIs representing the model prediction uncertainty of single viscosity determinations for each glass in the validation subsets at one temperature (see Sections C.6 and C.7 of Appendix C). If the 95\% PI for a validation point overlaps the $45^{\circ}$ line, the predicted and measured $\ln (\eta)$ values are within model and measurement uncertainty of each other. Note that the $95 \%$ PIs include the estimated uncertainties $\hat{\sigma}_{G}$ and $\hat{\sigma}_{T}$ resulting from the structure of the viscosity data. The $95 \%$ PIs for the 29 -term model overlap the $45^{\circ}$ line (i.e., contain the measured values) for all but 18 of the 680 (= $=5$ datasets, each with 34 glasses with viscosity measurements at four temperatures per glass) observations in the validation subsets. Failure of $100(18 / 680)=2.6 \%$ of the $95 \%$ PIs to include the corresponding measured values is lower than the 5\% that would be expected by chance for a model with no LOF. Hence, it does not appear that the 29-term model has significant LOF based on the statistical performance on this data-splitting approach. As a result of this, the width of the 95\% PIs should be due primarily 
to the experimental uncertainty in fabricating glasses and measuring viscosity (and model uncertainty that results). Separate work to assess the consequences of LOF (if any) and prediction uncertainty for this recommended viscosity model is discussed further in Section 8.7.

\subsection{Example Illustrating Viscosity Model Predictions and Statistical Intervals}

This section contains examples to illustrate using the recommended 29-term truncated T2-LM model with five quadratic terms and the second-choice 24-term truncated T2-LM model to obtain predicted viscosity values and corresponding $90 \%$ lower confidence intervals (LCIs), 90\% upper confidence intervals (UCIs), and two-sided $90 \%$ confidence intervals (CIs) as described in Section C.7 of Appendix C. The 29-term model is the one recommended in Section 8.4 and discussed in detail in Section 8.5. For comparison purposes, calculations are also performed in this section for the second-choice 24-term model discussed in Section 8.4. The 90\% confidence levels associated with LCIs, UCIs, and CIs were chosen for illustration purposes only. The WTP project can use an appropriate confidence level depending on the use of the viscosity-composition-temperature model and the type of statistical uncertainty expression desired.

The glass composition used in this example is HLW03-06, which was used previously for PCT, spinel $\mathrm{T}_{1 \%}$, and EC examples in Sections 5.7, 6.7, and 7.6. The 22-component composition of HLW03-06 for viscosity modeling is given in Table 8.1 in mass fraction format. To apply the 29-term and 24-term viscosity models to this composition, the mass fractions of the 22 components must be converted to mass fractions (that sum to 1.0) of the 15 HLW glass components contained in both models. Table 8.10 contains the composition of HLW03-06 prepared for use in the two IHLW viscosity models.

For each of the viscosity models, predicted $\ln (\eta, \mathrm{P})$ values are obtained by multiplying the composition in the format needed for that model by the coefficients for that model, then summing the results. That is, the predicted values are calculated by

$$
\hat{y}(\boldsymbol{a})=\boldsymbol{a}^{\mathrm{T}} \boldsymbol{b}
$$

where $\boldsymbol{a}$ is a vector with entries corresponding to terms in a given model based on the HLW0306 composition and a specific temperature value (in Kelvin), the superscript $\mathrm{T}$ represents a matrix transpose (or vector transpose in this case), and $\boldsymbol{b}$ is the vector of coefficients for a given model. The predicted $\ln (\eta)$ values for HLW03-06 at $1146^{\circ} \mathrm{C}^{16}$ using each of the IHLW viscosity models are listed in the second column of Table 8.11. The predicted $\ln (\eta)$ values in $\ln (\mathrm{P})$ units are easily converted to viscosity values $(\mathrm{P})$ by exponentiation. The third column of Table 8.11 contains the predicted viscosity values (P). However, as discussed in Section C.7 of Appendix C, these back-transformed viscosity predictions (P) should be considered estimates of the true median (not the true mean) of the distribution of viscosity values that would result if viscosity

\footnotetext{
16 The temperature of $1146^{\circ} \mathrm{C}$ was chosen because it was one of the temperatures at which the viscosity of HLW0306 was measured. This facilitates comparison of the predicted and measured values.
} 
measurements at the specific temperature were repeated multiple times on separately batched and melted samples of the HLW03-06 glass composition.

The predicted viscosity values for HLW03-06 at $1146^{\circ} \mathrm{C}$ in Table 8.11 are $124.931 \mathrm{P}$ for the second-choice 24-term viscosity model and $111.367 \mathrm{P}$ for the recommended 29-term model. The predicted value using the recommended 29-term model is closest to the measured value of 93.53 $\mathrm{P}$ for $\mathrm{HLW} 03-06$ at $1146^{\circ} \mathrm{C}$.

Equations (C.31c), (C.32c), and (C.33c) from Sections C.7.1 and C.7.2 of Appendix C can be used to calculate, respectively, a CL\% upper confidence interval (CL\% UCI), a CL\% lower confidence interval (CL\% LCI), or a two-sided CLI\% confidence interval (CL\% CI) for the true mean of $\ln (\eta)$ values for the HLW03-06 glass composition at a specific temperature with each of the IHLW viscosity models. For the illustrations to follow, we use CL\% $=90 \%$. In the notation of these equations:

- $\mathrm{CL} \%=100(1-\alpha) \%=90 \%$, so that $\alpha=0.10$ for a $90 \% \mathrm{UCI}$, a $90 \% \mathrm{LCI}$, and a $90 \% \mathrm{CI}$ in Equations (C.31c), (C.32c), and (C.33c), respectively.

- The vector $\boldsymbol{a}$ contains entries corresponding to the terms in a given viscosity model, which are calculated using the composition of HLW03-06 in Table 8.10 and a specific temperature value.

- Matrix $\boldsymbol{A}$ is formed from the data matrix used in the regression that generated a given viscosity model. Matrix $\boldsymbol{A}$ has the number of rows in the viscosity modeling dataset (788 $=197 \times 4$ temperatures each) and the number of columns corresponding to the number of terms in a given viscosity model. Each column is calculated according to the corresponding term in the model using the HLW glass compositions and the actual (not nominal or intended) temperatures in the viscosity modeling dataset.

- Matrix $\hat{V}$ is the estimated variance-covariance matrix for the vector of viscosity-attemperature data used to fit a viscosity model. This matrix accounts for the two sources of uncertainty, as discussed in Section C.3.3 of Appendix C.

To calculate a $90 \%$ UCI or LCI in $\ln (\eta)$ units of $\ln (\mathrm{P})$, the quantity $t_{1-\alpha, n-p} \sqrt{\boldsymbol{a}^{T}\left(\boldsymbol{A}^{T} \hat{\boldsymbol{V}}^{-1} \boldsymbol{A}\right)^{-1} \boldsymbol{a}}$ is added to (UCI) or subtracted from (LCI) the predicted $\ln (\eta)$ [denoted $\hat{y}(\boldsymbol{a})$ ] described above. The calculations are given by Equation (C.31c) for an UCI and Equation (C.32c) for a LCI. To calculate a $90 \%$ two-sided CI, the quantity $t_{1-\alpha / 2, n-p} \sqrt{\boldsymbol{a}^{T}\left(\boldsymbol{A}^{T} \hat{\boldsymbol{V}}^{-1} \boldsymbol{A}\right)^{-1} \boldsymbol{a}}$ is subtracted from and added to the predicted $\ln (\eta)$ [denoted $\hat{y}(\boldsymbol{a})$ ], as indicated by Equation (C.33c). The $\left(\boldsymbol{A}^{T} \hat{\boldsymbol{V}}^{-1} \boldsymbol{A}\right)^{-1}$ portion of these expressions is an approximate estimate of variance-covariance matrix for the estimated model coefficients, as discussed near the end of Section C.7 of Appendix C. The variance-covariance matrices for the second-choice 24-term and the recommended 29-term viscosity models are respectively listed in 
Tables D.15 and D.16 of Appendix D. The quantity $\sqrt{\boldsymbol{a}^{T}\left(\boldsymbol{A}^{T} \hat{\boldsymbol{V}}^{-1} \boldsymbol{A}\right)^{-1} \boldsymbol{a}}$ is the standard deviation of a model prediction; the value for each model is given in the fourth column of Table 8.11.

The $90 \%$ LCI, 90\% UCI, and 90\% CI values for the true mean $\ln (\eta)$ in units of $\ln (\mathrm{P})$ for the HLW03-06 composition at a temperature of $1146^{\circ} \mathrm{C}$ based on the recommended and secondchoice IHLW viscosity models are given in the fifth, seventh, and ninth columns of Table 8.11. Exponentiating the resulting $90 \%$ UCIs, LCIs, and CIs for the mean viscosity values in $\ln (\mathrm{P})$ units yields $90 \%$ LCIs, UCIs, and CIs for the median viscosity $(\mathrm{P})$. These values are in the sixth, eighth, and tenth columns of Table 8.11. For example, the recommended 29-term viscosity model has $(4.617,4.809) \ln (\mathrm{P})$ as the two-sided $90 \%$ CI on the true mean $\ln (\eta)$ for HLW03-06 at $1146^{\circ} \mathrm{C}$. Then $\left(\mathrm{e}^{4.617}, \mathrm{e}^{4.809}\right)=(101.190,122.567) \mathrm{P}$ is the two-sided $90 \% \mathrm{CI}$ on the true median viscosity for $\mathrm{HLW} 03-06$ at $1146^{\circ} \mathrm{C}$. The second-choice 24 -term model has $(4.814,4.842)$ $\ln$ (Poise) as the two-sided $90 \% \mathrm{CI}$ on the true mean $\ln$ (Viscosity) for HLW03-06 at $1146^{\circ} \mathrm{C}$. Then $\left(\mathrm{e}^{4.814}, \mathrm{e}^{.4 .842}\right)=(123.181,126.706)$ Poise is the two-sided $90 \%$ CI on the true median viscosity for HLW03-06 at $1146^{\circ} \mathrm{C}$. Rounding accounts for the differences between the values in $\ln (\mathrm{P})$ units and the corresponding viscosity values expressed in Poise units.

Note that neither of the $90 \%$ CIs (in the last column of Table 8.11 ) based on the recommended and second-choice models contains the measured value of $93.53 \mathrm{P}$ for viscosity at $1146^{\circ} \mathrm{C}$. However, this is not a fault of the $90 \% \mathrm{CIs}$, which are statistical confidence statements about the true mean $[\ln (\mathrm{P})]$ or median $(\mathrm{P})$ value of viscosity at $1146^{\circ} \mathrm{C}$. The appropriate type of statistical interval to compare to a single measured viscosity determination is a prediction interval (PI). The formula for calculating a two-sided PI on an individual viscosity value for a given HLW glass composition and temperature is given in Equation (C.34c) of Section C.7.3 of Appendix C. The calculation of a two-sided 90\% PI is not illustrated in Table 8.11 because PIs are not the appropriate type of statistical interval for verifying that viscosity constraints are satisfied during WTP HLW vitrification operations.

\subsection{Suitability of the Recommended Viscosity Model for Application by the WTP Project}

The 29-term model for viscosity discussed in Section 8.5 is recommended for use by the WTP project as the best model currently available for predicting viscosity of HLW glasses. This model appears to yield unbiased predictions of viscosity over the full range of measured viscosity values in the modeling dataset, with relatively tight scatter for the data points around the fitted model (see Figure 8.14). The recommended viscosity model does not seem to have statistically significant LOF, so that viscosity predictions can be expected to be within the uncertainty of what would be obtained by batching and melting glasses and measuring the viscosity.

The magnitudes of uncertainties in viscosity predictions using the recommended 29-term model should be small enough that they will not overly restrict the formulation and processing of HLW glasses in the WTP facility. Figure 8.19 displays the $\ln (\eta)$ prediction standard deviations versus predicted values [both in $\ln$ (poise) units] for the HLW glass compositions in the viscosity 
modeling dataset at temperatures of $950,1050,1150$, and $1250^{\circ} \mathrm{C}$. The $\ln (\eta)$ prediction standard deviations for viscosity modeling dataset glasses at these temperatures range from approximately 0.02 to $0.09 \ln$ (poise) for the recommended viscosity model. Note that these are standard deviations of model predictions considered as the mean viscosity value for a given glass. Standard deviations of predictions considered as individual determinations of viscosity are larger, ranging from approximately 0.12 to $0.15 \ln$ (Poise) for the recommended viscosity model. Note also that prediction standard deviations will be larger for HLW glass compositions as their distance from glasses in the viscosity modeling dataset increases. Finally, the total uncertainty in predictions with the recommended viscosity model will depend on the type of statistical interval used (see Section C.7 of Appendix C).

Work to assess the impact of HLW glass composition and model uncertainties for the recommended viscosity $\ln (\eta)$ model (Section 8.5) on satisfying WTP IHLW processing requirements is planned to be addressed as part of the Technical Scoping Statement (TSS) B6270 work scope of the River Protection Project-Waste Treatment Plant Support Program at PNNL. The impacts of these uncertainties on glass formulation and processability are also planned to be addressed as part of the second iteration of the HLW glass formulation algorithm development work planned by WTP project staff. The first iteration of that work (Vienna and Kim 2007) utilized a preliminary viscosity model (Gan et al. 2004). 


\section{SECTION 9 REGIONS OF VALIDITY FOR HLW GLASS PROPERTY MODELS}

There are five properties of HLW glasses for which property-composition or propertycomposition-temperature models are envisioned as necessary by the Waste Treatment and Immobilization Plant (WTP) project. These include the four properties discussed in this report: Product Consistency Test (PCT), spinel $\mathrm{T}_{1 \%}$, electrical conductivity (EC), and viscosity. The fifth property is $\mathrm{Cd}$ release $(\mathrm{mg} / \mathrm{L})$ from the Toxicity Characteristic Leaching Procedure (TCLP). TCLP-Cd release models were addressed by Kot et al. (2004). The composition or compositiontemperature regions over which the recommended property model for each property may be validly applied are presented in this section.

The PCT, spinel $\mathrm{T}_{1 \%}$, EC, and viscosity models for HLW glasses recommended in Sections 5 to 8 were fit to experimental data using regression methods. Similarly, the TCLP-Cd model recommended by Kot et al. (2004) was fit to experimental data ${ }^{17}$ using regression methods. These methods yield the optimal estimates of the model coefficients based on the modeling data used, provided the assumptions of the regression method are satisfied. In general, models obtained in this way should only be applied within appropriate composition regions of validity (or composition-temperature regions of validity in the case of EC and viscosity). Such regions are referred to as model validity regions. The starting point for a model validity region is often the experimental region covered by the data used to develop the model. However, if a model yields biased predictions over some subregions, those subregions may be excluded from the model validity region (unless addressed by bias-corrections, as was done for the PCT models). Extrapolations of models to compositions (or composition-temperature combinations) slightly outside the experimental composition (or composition-temperature) region are sometimes acceptable. However, such extrapolative uses of regression models should be validated before being applied.

The model validity regions for (i) the PCT, spinel $\mathrm{T}_{1 \%}$, melt $\mathrm{EC}$, and melt viscosity models on HLW glasses recommended in Sections 5 to 8 , and (ii) the TCLP-Cd model recommended by Kot et al. (2004) were developed as follows. It was decided in consultation with the WTP Project to (i) specify the model validity regions as the regions covered by the modeling datasets, but (ii) exclude any subregions in which models may yield unacceptably biased predictions. The modeling datasets for the various properties each had a different number of glasses used to develop models: 266 glass for PCT-B, 250 glasses for PCT-Li, 268 glasses for PCT-Na, 168 glasses for spinel $\mathrm{T}_{1 \%}, 208$ glasses for EC, 197 glasses for viscosity, and 100 glasses for TCLP-Cd. Mathematically, the convex hull of the compositions ${ }^{18}$ comprising a

\footnotetext{
17 The 102 glasses in the HLW02 and HLW03 test matrices had TCLP-Cd release data to support model development. However, the data for HLW03-01 and HLW03-08 were found to be significant outliers, and were removed from the TCLP-Cd modeling dataset. Hence, data for $100 \mathrm{HLW}$ glasses were used to develop TCLP-Cd models. See Kot et al. (2004) for additional information.

${ }^{18}$ A convex hull of the HLW glass compositions in the modeling set would be the smallest convex polyhedral region enclosing all of the compositions.
} 
modeling dataset could be the starting point for defining the model validity region for that property. However, we are unaware of any algorithm or software to identify all of the mathematical constraints that would specify the convex hull in high-dimensional HLW glass composition space.

The model validity regions for the recommended HLW glass property models are specified using (i) single-component constraints on HLW glass composition, (ii) single-variable constraints on HLW glass melt temperature (for EC and viscosity models), (iii) multiplecomponent constraints for PCT, spinel $\mathrm{T}_{1 \%}$, and TCLP-Cd properties, and (iv) multiple-variable constraints involving HLW glass composition and melt temperature for EC and viscosity. The single-component (composition) constraints and single-variable (temperature) constraints are discussed in Section 9.1. The multiple-component constraints for PCT, spinel $\mathrm{T}_{1 \%}$, and TCLP$\mathrm{Cd}$, as well as the multiple-variable (composition and temperature) constraints for EC and viscosity, are discussed in Section 9.2. Section 9.3 summarizes and discusses the model validity regions.

\subsection{Single-Component Composition and Temperature Constraints}

The ranges (minimum and maximum values) of HLW glass components in the modeling dataset for each of the five properties of interest to the WTP project were determined and are listed in Tables 9.1 and 9.2. Table 9.1 lists minimum and maximum values for the 25 components that had sufficient support for initial property modeling work ${ }^{19}$, with one of those components being "Others". The minimums and maximums for the specific components making up the Others component are listed in Table 9.2. The minimum and maximum component values are similar for some properties, but differ for others. The biggest differences occur for TCLP-Cd and spinel $\mathrm{T}_{1 \%}$ because of the smaller datasets used for modeling those properties.

The first step in specifying composition regions of validity for the PCT $(\mathrm{B}, \mathrm{Li}$, and $\mathrm{Na}$ releases), spinel $\mathrm{T}_{1 \%}$, EC, viscosity, and TCLP-Cd models is to list the lower and upper bounds on HLW glass components in the modeling dataset for each property. The minimum and maximum columns in Tables 9.1 and 9.2 are a starting place, but rounded values are preferred for practical use. Also, it is important to assess whether any of the PCT, spinel $\mathrm{T}_{1 \%}$, EC, and viscosity models recommended in this report, or the TCLP-Cd model recommended in Kot et al. (2004) make biased predictions at extremes of component ranges. If so, the lower and upper bounds for those components should be reduced from their minimums and maximums in the modeling datasets. Tendencies of recommended models for PCT, spinel $\mathrm{T}_{1 \%}, \mathrm{EC}$, and viscosity (discussed in Sections 5 to 8) and for TCLP-Cd (discussed in Kot et al. 2004) to yield biased predictions were not observed relating to low and high values of specific components. Because such tendencies for biased model predictions are likely to be a multiple-component phenomenon

19 The initial modeling datasets for PCT and spinel $\mathrm{T}_{1 \%}$ had 25 components including Others, while the initial modeling datasets for EC and viscosity had 22 components including Others. The initial modeling dataset for TCLP$\mathrm{Cd}$ had 22 components, some of which were grouped components. The 25 components initially used for PCT and spinel $\mathrm{T}_{1 \%}$ modeling were used as the basis for the partition of HLW glass components shown in Tables 9.1 and 9.2. 
and not a single-component phenomenon, the HLW glass component ranges in Table 9.1 and Table 9.2 were not reduced to form the model validity lower and upper bounds.

Table 9.3 lists rounded values of the minimums and maximums of the HLW glass components for each of the five properties in Tables 9.1 and 9.2. Minimum mass fraction values were rounded down to the nearest third decimal place (nearest $0.1 \mathrm{wt} \%$ ). Maximum mass fraction values were rounded up to the nearest third decimal place (nearest $0.1 \mathrm{wt} \%$ ). Rounding in this way provides for all of the HLW glass compositions in each property modeling dataset to satisfy the single-component constraints. ${ }^{20}$ Choosing the lower and upper HLW glass component bounds in this way is not intended to limit other choices the WTP project might decide to make in specifying single-component model validity constraints. The WTP could decide to allow extrapolative use of HLW glass property models outside these lower and upper bounds. As an example, the decision could be made to expand the lower and upper bounds by $10 \%$ relative. Rather than making such decisions in this report, it was decided to merely list in Table 9.3 the rounded minimums and maximums as the component lower and upper bounds of the model validity region for each property.

Because EC and viscosity models depend on melt temperature as well as HLW glass composition, the validity regions for EC and viscosity models must specify constraints on temperature as well as HLW glass composition. Viscosity and EC data were generally measured in the vicinity of four nominal temperatures: $950,1050,1150$, and $1250^{\circ} \mathrm{C}$. However, for a few glasses, viscosity measurements were made at nominal temperatures closer to $1000^{\circ} \mathrm{C}$. For $\mathrm{EC}$, only about one-quarter of the measurements were made at temperatures close to their nominal values, the rest show significant scatter around the nominal temperature values. Actual temperature values at which EC was measured ranged from 908 to $1277^{\circ} \mathrm{C}$. Actual temperature values at which viscosity was measured ranged from 931 to $1281^{\circ} \mathrm{C}$. These ranges are from the property measurements for the 208 HLW glasses in the EC modeling dataset and 197 HLW glasses in the viscosity modeling dataset. These temperature ranges and the rounded values of these ranges chosen as single-variable lower and upper bounds on temperature are summarized in Table 9.4.

\subsection{Multiple-Component Composition and Temperature Constraints}

The lower and upper bounds on the HLW glass components in Table 9.3 are necessary but not sufficient to specify the composition region of validity for each of the HLW glass property models. The lower and upper bounds in Table 9.3 allow HLW glass compositions with (i) combinations of components that are far from the compositions in a given HLW glass property modeling dataset, and/or (ii) property values that may be far outside of acceptable limits. Hence, it is necessary to develop multiple-component constraints that mathematically specify the allowable combinations of glass components in the composition region of validity for HLW glass property models.

\footnotetext{
${ }^{20}$ Note, however, that the HLW glasses identified as outliers and excluded from each property-composition modeling dataset will be outside the lower and upper bounds selected.
} 
It is difficult to directly develop multiple-component composition constraints. Instead, multiple-component constraints on HLW glass composition were specified indirectly via lower and upper bounds on properties of HLW glasses. The development of these constraints is discussed in Section 9.2.1. The reasons why multiple-component constraints based on pairs of correlated HLW glass components were considered unnecessary, and therefore were not developed, are discussed in Section 9.2.2. Finally, Section 9.2.3 discusses the results of investigating multi-component constraints that were imposed in defining several test matrices that generated data used in modeling HLW glass properties.

\subsubsection{Multiple-Component Constraints on Primary HLW Glass Properties}

The primary approach for developing multiple-component constraints was to specify lower and upper bounds on the five modeled properties of HLW glasses (PCT, spinel $\mathrm{T}_{1 \%}, \mathrm{EC}$, viscosity, and TCLP-Cd). These lower and upper bounds can be implemented using the recommended or second-choice model for each property (see Sections 5 to 8 for the first four properties, and Kot et al. 2004 for TCLP-Cd). Because the models are functions of (i) HLW glass composition (for PCT-B, PCT-Li, PCT-Na, spinel $\mathrm{T}_{1 \%}$, and TCLP-Cd), and (ii) HLW glass composition and melt temperature (for EC and viscosity), the lower and upper bounds on properties indirectly constrain the HLW glass composition region and the glass compositiontemperature region.

Table 9.5 lists the minimum and maximum measured values of HLW glass properties over the modeling dataset for each property. Because the minimum values of PCT-B, PCT-Li, PCT-Na, and TCLP-Cd in Table 9.5 are relatively small, it was decided that no lower limits were needed on these properties for the model validity region. This is shown in Table 9.6 by listing "None" under the lower bound column for these four properties.

\section{Model Validity Upper Bounds for PCT Releases}

As discussed in Section 5.7, the first- and second-choice models for PCT-B, PCT-Li, and PCT-Na tended to underpredict those releases above values of $0.5 \ln (\mathrm{g} / \mathrm{L}), 0.5 \ln (\mathrm{g} / \mathrm{L})$, and 1.0 $\ln (\mathrm{g} / \mathrm{L})$, respectively. These correspond to PCT-B, PCT-Li, and PCT-Na releases of 1.65, 1.65, and $2.72 \mathrm{~g} / \mathrm{L}$, respectively. In conjunction with the WTP project, it was decided to apply biascorrections to the first- and second-choice PCT models to rectify the areas of under-prediction. Using bias-corrected models also allows selecting larger PCT-B, PCT-Li, and PCT-Na release values as model validity upper bounds compared to the $1.65,1.65$, and $2.72 \mathrm{~g} / \mathrm{L}$ values that would have been chosen for versions of the PCT-B, PCT-Li, and PCT-Na models without bias correction.

For the bias-corrected versions of the recommended and second-choice PCT models (see Section 5.7), the main limitation on model validity derives from the fact that bias-corrected models for PCT-B, PCT-Li, and PCT-Na still under-predict the measured releases for HLWALG-03. This is the only glass in the PCT modeling dataset that had measured PCT-B and PCTLi releases above the corresponding DWPF-EA glass limits, and PCT-Na release close to the corresponding DWPF-EA limit (see Section 5.1.1). Hence, model validity upper bounds on PCT- 
B, PCT-Li, and PCT-Na releases were determined by the bias-corrected predictions of these releases for the HLW-ALG-03 glass. The concept is illustrated in Figure 9.1 for the recommended PCT-B model. The predicted PCT-B, PCT-Li, and PCT-Na release values for HLW-ALG-03 using the bias-corrected recommended and second-choice models are shown in the following chart.

\begin{tabular}{|l|c|c|c|c|c|c|}
\hline \multirow{2}{*}{$\begin{array}{l}\text { PCT } \\
\text { Release }\end{array}$} & \multicolumn{2}{|c|}{$\begin{array}{c}\text { Recommended } \\
\text { Model }\end{array}$} & \multicolumn{2}{c|}{$\begin{array}{c}\text { Second-Choice } \\
\text { Model }\end{array}$} & \multicolumn{2}{c|}{$\begin{array}{c}\text { Model Validity } \\
\text { Upper Bound }\end{array}$} \\
\cline { 2 - 7 } & $\ln (\mathrm{g} / \mathrm{L})$ & $\mathrm{g} / \mathrm{L}$ & $\ln (\mathrm{g} / \mathrm{L})$ & $\mathrm{g} / \mathrm{L}$ & $\ln (\mathrm{g} / \mathrm{L})$ & $\mathrm{g} / \mathrm{L}$ \\
\hline PCT-B & 1.889 & 6.61 & 2.064 & 7.88 & 1.889 & 6.61 \\
\hline PCT-Li & 1.472 & 4.36 & 1.452 & 4.27 & 1.452 & 4.27 \\
\hline PCT-Na & 1.711 & 5.53 & 1.748 & 5.75 & 1.711 & 5.53 \\
\hline
\end{tabular}

These predicted values for the recommended and second-choice models of each PCT release are relatively close. However, to be conservative with respect to both models for a given PCT release, the smaller value of the two was chosen as the model validity upper bound for that PCT release, as shown in the chart. The upper bounds on PCT-B, PCT-Li, and PCT-Na for the model validity region of each property are listed in Table 9.6 in units of $\mathrm{g} / \mathrm{L}$. The model validity upper bounds in Table 9.6 restrict the PCT models from being used on glasses that may have PCT-B, PCT-Li, or PCT-Na releases above the corresponding DWPF-EA glass limits but are predicted to have releases as low as the model validity upper bounds (which are smaller than the DWPF-EA glass limits).

\section{Model Validity Lower and Upper Bounds for Spinel $\mathrm{T}_{1 \%}$}

Because the recommended model for spinel $\mathrm{T}_{1 \%}$ yields relatively unbiased predictions, it was decided to set lower and upper bounds for application of that model to rounded values of the minimum and maximum spinel $\mathrm{T}_{1 \%}$ values from Table 9.5. The rounded lower and upper bounds on spinel $\mathrm{T}_{1 \%}$ are listed in Table 9.6.

\section{Model Validity Lower and Upper Bounds for Electrical Conductivity and Viscosity}

The lower and upper bounds on EC and viscosity for the model validity region of each property are listed in Table 9.6, and were obtained as follows. The recommended model for each property was used to predict property values for each HLW glass at the temperatures for which that property was measured. Then, bounding lines were determined to specify the lower and upper bounds for EC and viscosity as a function of temperature. Specifically, the lower and upper bound lines for EC and viscosity are of the form

$$
\ln (\text { property })=\text { intercept }+ \text { slope }(1 / T)
$$

where $T$ is temperature in ${ }^{\circ} \mathrm{C}^{21}$. The lower and upper bound lines for EC and viscosity are listed in Table 9.6 and displayed in Figures 9.2 and 9.3, respectively.

21 Note that this constraint was developed using temperature in ${ }^{\circ} \mathrm{C}$ rather than $\mathrm{K}$ (which was used for electrical conductivity and viscosity models). 
Model Validity Upper Bound for TCLP-Cd Release

As noted previously, the development of a recommended model for TCLP-Cd was discussed by Kot et al. (2004). However, the topic of a model validity region was not discussed in that report, so it is included here. The recommended model includes 10 terms and was presented in Table 6.16 of Kot et al. (2004). The predicted versus measured plot for the recommended model fitted to the modeling dataset for $100 \mathrm{HLW}$ glasses is given in Figure 6.20 of Kot et al. (2004). That figure shows that the recommended TCLP-Cd model predicts without noticeable bias up to approximately $0.80 \mathrm{mg} / \mathrm{L}$, which is beyond the TCLP-Cd delisting limit of $0.48 \mathrm{mg} / \mathrm{L}$. However, the recommended model had a tendency to under-predict TCLP-Cd release above $0.25 \mathrm{mg} / \mathrm{L}$ for two sets of validation data. For the larger validation set (see Figure 6.24 of Kot et al. 2004), all but one of the glasses for which the recommended TCLP-Cd model underpredicts are outside the composition region for the data used to develop the model. For the smaller validation dataset (which removed extrapolative compositions), only HLW98-42 had TCLP-Cd release beyond $0.25 \mathrm{mg} / \mathrm{L}$. Its measured value was $0.484 \mathrm{mg} / \mathrm{L}$, but the recommended model noticeably under-predicts (see Figure 6.25 of Kot et al. 2004). Ultimately, $0.80 \mathrm{mg} / \mathrm{L}$ was chosen as the model validity limit for the recommended TCLP-Cd model, although with the suggestion that any future work confirm that the model makes unbiased predictions from 0.25 to $0.80 \mathrm{mg} / \mathrm{L}$ (see Section 11.4).

\subsubsection{Constraints on Pairs of Correlated HLW Glass Components}

It was noted in Sections 5.1.1, 6.1.1, 7.1.1, and 8.1.1 for each of the HLW glass property modeling datasets that several pairs of HLW glass components have strong correlation coefficients (i.e., above 0.60 in absolute value). However, because none of the pairs with high correlation coefficients involve two components in the recommended property models, it is not expected that highly-correlated pairs of components will impact predictions of HLW glass properties. Hence, it was deemed unnecessary to further constrain the model validity regions using constraints on pairs of components, as was done for ILAW property models (see Section 9.2.2 of Piepel et al. 2007).

\subsubsection{Constraints on Other HLW Glass Properties and Composition Expressions}

In developing the HLW02, HLW03, HLW05, HLW06, and HLW07 test matrices, various multiple-component constraints were used to partially define the composition regions to be explored with those test matrices. Those multiple-component constraints are summarized in Table 2.6. Several of those constraints involved PCT releases (B, Li, and Na), spinel $\mathrm{T}_{1 \%}$, viscosity, and EC. Constraints partially defining model validity regions for these properties are discussed in Section 9.2.1. However, Table 2.6 contains constraints on four other HLW glass properties

- $\quad$ TCLP B = Toxicity Characteristic Leaching Procedure (TCLP) boron release (g/L) 
- $\mathrm{T}_{\mathrm{LS}}=$ liquidus temperature of $\mathrm{Cr}$-bearing spinel $\left({ }^{\circ} \mathrm{C}\right)$

- $\mathrm{T}_{\mathrm{LZ}}=$ liquidus temperature of zircon $\left({ }^{\circ} \mathrm{C}\right)$

- $\mathrm{T}_{\mathrm{LzO}}=$ liquidus temperature of zirconia $\left({ }^{\circ} \mathrm{C}\right)$

and on four multiple-component composition expressions

- $\mathrm{AlFeZr}=\mathrm{Al}_{2} \mathrm{O}_{3}+\mathrm{Fe}_{2} \mathrm{O}_{3}+\mathrm{ZrO}_{2}(\mathrm{wt} \%)$

- $\mathrm{AlFeZrTh}=\mathrm{Al}_{2} \mathrm{O}_{3}+\mathrm{Fe}_{2} \mathrm{O}_{3}+\mathrm{ZrO}_{2}+3 \mathrm{ThO}_{2}(\mathrm{wt} \%)$

- $\mathrm{LiNaTh}=2 \mathrm{Li}_{2} \mathrm{O}+\mathrm{Na}_{2} \mathrm{O}-3.75 \mathrm{ThO}_{2}$ (wt\%) to limit thorium crystallization

- $\mathrm{LiNa}=\mathrm{Na}_{2} \mathrm{O}+2 \mathrm{Li}_{2} \mathrm{O}(\mathrm{wt} \%)$.

It was decided to calculate for all $302 \mathrm{HLW}$ glasses (with data for at least one of the four modeled properties, see Table 4.1) the values of the four properties using the propertycomposition models used to implement the constraints. The models for TCLP B and $T_{L S}$ were based on Table 7 from Cooley et al. (2003). The model used to implement the $T_{L Z}$ constraint is from the "TRU + CVS" column of Table 4 in Rao et al. (1997). The model used to implement the $T_{\text {LzO }}$ constraint is from the baddeleyite ( $Z$ ) column of Table II in Plaisted et al. (2000). Similarly, the values of the four multiple-component composition expressions were calculated for all $302 \mathrm{HLW}$ glasses. The minimum and maximum values of these eight quantities are listed in Table 9.7 for each HLW glass group and over the combined set of 302 HLW glasses.

The calculated minimum and maximum values in Table 9.7 were compared to the respective lower and upper limits that were set in designing the tests matrices, as shown in Table 2.6 (note that different limits may be set for different test matrices, including the omission of some limits for selected matrices). Table 9.7 shows that the calculated values are outside the lower or upper limits for many of the properties and multi-component expressions, in some cases by considerable margins. Many of the calculated minimum and maximum values were found for glasses in the later test matrices (e.g., HLW06 and HLW07), a reflection of the continual expansion of compositional regions as this work progressed. This suggests that some additional multi-component constraints (direct or indirect through property models) on the validity regions for PCT, spinel $\mathrm{T}_{1 \%}, \mathrm{EC}$, viscosity, and TCLP-Cd models may be needed. However, the consequences of exceeding some of the multi-component constraints imposed in certain studies is unclear, Hence, it was decided not to impose at this time any additional multi-component constraints to define the validity regions for IHLW property models.

\subsection{Summary and Discussion of HLW Glass Property Model Validity Regions}

Table 9.8 summarizes the constraints defining the model validity region for each HLW glass property. The multiple-component and multiple-variable constraints implemented via lower and upper bounds on HLW glass properties eliminate HLW glass compositions (component combinations) that would otherwise be allowed by the single-component constraints. The resulting model validity region for each HLW glass property thus represents the HLW glass 
composition region and property data used to develop models for each property. The recommended and second-choice PCT-B, PCT-Li, PCT-Na, and spinel $\mathrm{T}_{1 \%}$ models developed in this report, and the recommended TCLP-Cd model developed in Kot et al. (2004), should only be used to predict property values and their uncertainties for HLW glass compositions within the model validity region summarized in Table 9.8. Similarly, the EC and viscosity models should only be used to predict property values and their uncertainties for combinations of HLW glass compositions and melt temperatures within the model validity region summarized in Table 9.8. 


\section{SECTION 10 \\ SUMMARY AND CONCLUSIONS FOR HLW GLASS PROPERTY-COMPOSITION MODELS}

This report documents for HLW glasses in the composition region relevant to the Waste Treatment and Immobilization Plant (WTP) the (i) development of property data, (ii) development and validation of property models, (iii) development of uncertainty expressions for model predictions, and (iv) development of composition or composition-temperature regions over which models may be validly applied. Data and models have been developed to relate

- PCT responses for boron, lithium, and sodium to the composition of WTP HLW glasses.

- $\quad$ Spinel $\mathrm{T}_{1 \%}$ response to the composition of WTP HLW glasses.

- Viscosity and electrical conductivity (EC) to the melt temperature and composition of WTP HLW glasses

as discussed in this report. Models and uncertainty expressions were developed by least squares regression methods to fit empirical and semi-empirical model forms to the collected data. This work constitutes what has been denoted Phase 2 of the IHLW model development effort. The worked denoted as Phase 1 was documented by Kot et al. (2004, 2005a) and Gan et al. (2004). The Phase 1 work included developing models relating cadmium release from the Toxicity Characteristic Leaching Procedure (TCLP-Cd) to HLW glass composition, as discussed by Kot et al. (2004).

The IHLW property models and formulas for uncertainties in model predictions resulting from the modeling work can be used for numerous purposes, including (i) formulating HLW glasses for specific HLW waste compositions, (ii) developing HLW glass formulation algorithms to make process decisions during operation of the HLW vitrification facility, (iii) assessing whether proposed HLW glass compositions or HLW glass compositions calculated by process simulation codes will satisfy property specifications (PCT, spinel $\mathrm{T}_{1 \%}$, and TCLP-Cd) and processing requirements (viscosity and EC), and (iv) as the basis for any future IHLW model development work, if needed.

The datasets available for developing IHLW PCT, spinel $\mathrm{T}_{1 \%}, \mathrm{EC}$, and viscosity models are comprised of data from different HLW glass studies conducted over several years. The number of data points available for modeling varied by property because not every property was measured on every glass. The different studies from which data were drawn for IHLW property modeling are discussed in Section 2.1, while separate data available for model validation are discussed in Section 2.2. Some of these studies used statistical experimental design methods to select some or all of the test matrix glasses. Glasses in parts or all of some studies were "actively designed" using glass science knowledge and experience to achieve the desired purpose for the study or individual glasses in the study. The various samples encompass the effects of testing scale (from crucible melts of a few hundred grams to actual waste glass samples prepared in tens of grams), post-melt treatment such as canister cooling, and the use of actual radioactive waste as 
well as waste simulants. The datasets available for modeling HLW glass properties were assessed to remove outlying compositions from the modeling datasets. The HLW glass compositions and their property values in the available dataset and modeling dataset for each property are presented in tables in this report.

The data in the modeling dataset for a given property were used to develop models for that property. Model validation was accomplished by data-splitting, data-partitioning, and by applying the models to calculate the properties of separate validation glasses where available. Separate validation glasses were available for PCT and spinel $\mathrm{T}_{1 \%}$, but not $\mathrm{EC}$ and viscosity. In the data-splitting approach, the modeling dataset was split into five sets of modeling and validation subsets, using roughly $80 \%$ of the data for modeling and $20 \%$ for validation in each split of the dataset. In the data partition approach, the modeling dataset for a given property was partitioned into a modeling dataset (comprised of the HLW02, HLW03, HLW07, and other selected glasses) and a validation subset (comprised of all remaining glasses). Note that the HLW02, HLW03, and HLW07 series of glasses were statistically designed, whereas most or all of the glasses that remained in the data-partition validation subset were actively designed. Based on the performance of the models that were investigated, recommended models were selected.

Sections 10.1 to 10.4 summarize the model development data and work for PCT, spinel $\mathrm{T}_{1 \%}$, EC, and viscosity of HLW glasses. For each property, the recommended and second-choice models are mentioned and any limitations of the model noted. Section 10.5 summarizes the model validity region for each of the four HLW glass properties modeled. Section 10.6 discusses the suitability of the recommended models for WTP applications. Section 10.7 makes recommendations for any future property-composition modeling work that may occur for HLW glasses.

\subsection{Summary of IHLW PCT Modeling}

Data on PCT boron (PCT-B) and sodium (PCT-Na) releases were available for 268 HLW glasses, while data on PCT lithium (PCT-Li) releases were available for 253 HLW glasses. These glasses came from all nine of the data groups discussed in Sections 2.1.1 to 2.1.9. As discussed in Section 5.1, two glasses (HLW98-96A and HLW98-96B) with outlying compositions were removed from the PCT-B, PCT-Li, and PCT-Na modeling datasets. Additionally, two glasses (HLW03-13 and HLW-ALG-26) were removed from the PCT-B modeling dataset and one glass (HLW98-94) from the PCT-Li modeling dataset because of having very low releases. The final modeling datasets contained 264 glasses for PCT-B, 250 glasses for PCT-Li, and 266 glasses for PCT-Na. The PCT results in these final modeling datasets vary from 0.104 to $21.903 \mathrm{~g} / \mathrm{L}$ for PCT-B release, 0.141 to $10.675 \mathrm{~g} / \mathrm{L}$ for PCT-Li release, and 0.050 to $11.818 \mathrm{~g} / \mathrm{L}$ for PCT-Na release.

Assessment of the ranges and distributions of the component values over the HLW glasses with PCT data led to identifying 25 components as having sufficient support for separate model terms in initial PCT property-composition modeling. These 25 components are $\mathrm{Al}_{2} \mathrm{O}_{3}$, $\mathrm{B}_{2} \mathrm{O}_{3}, \mathrm{CaO}, \mathrm{CdO}, \mathrm{Cr}_{2} \mathrm{O}_{3}, \mathrm{Fe}_{2} \mathrm{O}_{3}, \mathrm{~K}_{2} \mathrm{O}, \mathrm{La}_{2} \mathrm{O}_{3} . \mathrm{Li}_{2} \mathrm{O}, \mathrm{MgO}, \mathrm{MnO}, \mathrm{Na}_{2} \mathrm{O}, \mathrm{NiO}, \mathrm{PbO}, \mathrm{Sb}_{2} \mathrm{O}_{3}, \mathrm{SeO}_{2}$, $\mathrm{SiO}_{2}, \mathrm{SrO}, \mathrm{ThO}_{2}, \mathrm{TiO}_{2}, \mathrm{Tl}_{2} \mathrm{O}, \mathrm{UO}_{3}, \mathrm{ZnO}, \mathrm{ZrO}_{2}$, and Others (the sum of all remaining 
components). The 25-component HLW mass fraction compositions and PCT releases of the HLW glasses in the PCT-B, PCT-Li, and PCT-Na modeling datasets are listed in Tables 5.2 and 5.3 , respectively.

Several model forms were investigated for PCT-B, PCT-Li, and PCT-Na releases as functions of HLW glass composition.

- An 25-component linear mixture (LM) model using the 25 components listed in the previous paragraph.

- A 13-component reduced LM model involving $\mathrm{Al}_{2} \mathrm{O}_{3}, \mathrm{~B}_{2} \mathrm{O}_{3}, \mathrm{Fe}_{2} \mathrm{O}_{3}, \mathrm{Li}_{2} \mathrm{O}, \mathrm{MnO}, \mathrm{Na}_{2} \mathrm{O}$, $\mathrm{SiO}_{2}, \mathrm{SrO}, \mathrm{ThO}_{2}, \mathrm{UO}_{3}, \mathrm{ZnO}, \mathrm{ZrO}_{2}$, and the new Others. For PCT-B, PCT-Li, and PCT$\mathrm{Na}$ releases, these models had similar performances as the 25-component LM models.

- A series of a partial quadratic mixture (PQM) models, in which the 13-component reduced LM model was augmented with between two and nine quadratic (squared and/or crossproduct) terms, leading to PQM models having 15 to 22 terms. Some of the PQM models were limited to having the same quadratic terms in each of the PCT-B, PCT-Li, and PCT-Na models.

- A series of partial cubic mixture (PCM) models, in which the 13-component reduced LM model was augmented with up to five quadratic $\left(x_{i}^{2}\right.$ or $\left.x_{i} x_{j}\right)$ and/or cubic $\left(x_{i}^{3}, x_{i}{ }^{2} x_{j}\right.$, or $x_{i} x_{j} x_{k}$ ) terms, leading to PCM models having 15 to 22 terms.

Based on model fitting and validation results, the 18-term PQM models were preferred, with 15-term PQM models suggested as alternatives. However, the PCT-B, PCT-Li, and PCT-Na models tended to under-predict moderate-to-larger releases. Various solutions were considered, but ultimately adding a bias-correction term to each model was the solution chosen (see Section 5.7).

Models containing 19 terms (13 linear, 5 quadratic, 1 bias-correction) are recommended for predicting PCT-B, PCT-Li, and PCT-Na releases from HLW glasses. The 13 linear terms involve the same components $\left(\mathrm{Al}_{2} \mathrm{O}_{3}, \mathrm{~B}_{2} \mathrm{O}_{3}, \mathrm{Fe}_{2} \mathrm{O}_{3}, \mathrm{Li}_{2} \mathrm{O}, \mathrm{MnO}, \mathrm{Na}_{2} \mathrm{O}, \mathrm{SiO}_{2}, \mathrm{SrO}, \mathrm{ThO}_{2}, \mathrm{UO}_{3}\right.$, $\mathrm{ZnO}, \mathrm{ZrO}_{2}$, and Others) in each of the PCT-B, PCT-Li, and PCT-Na PQM models. However, the coefficients of the terms are different for each of the PCT-B, PCT-Li, and PCT-Na models. Similarly, the bias-correction coefficient is different for each of the models. The five quadratic terms in the PCT-B model are $\left(\mathrm{Al}_{2} \mathrm{O}_{3}\right)^{2}, \mathrm{UO}_{3} \times \mathrm{ZnO},\left(\mathrm{MnO}_{2}\right)^{2}, \mathrm{Fe}_{2} \mathrm{O}_{3} \times \mathrm{ZnO}$, and $\mathrm{Al}_{2} \mathrm{O}_{3} \times \mathrm{ZrO}_{2}$. Results for the 19-term PCT-B model are given in Table 5.19 and discussed in Section 5.7. The five quadratic terms in the PCT-Li model are $\left(\mathrm{Al}_{2} \mathrm{O}_{3}\right)^{2}, \mathrm{UO}_{3} \times \mathrm{ZnO}, \mathrm{Fe}_{2} \mathrm{O}_{3} \times \mathrm{LiO}_{2}, \mathrm{SrO} \times \mathrm{ZrO}_{2}$ and $\mathrm{Al}_{2} \mathrm{O}_{3} \times \mathrm{ZrO}_{2}$. Results for the 19-term PCT-Li model are given in Table 5.21 and discussed in Section 5.7. The five quadratic terms in the PCT-Na model are $\left(\mathrm{Al}_{2} \mathrm{O}_{3}\right)^{2}, \mathrm{Al}_{2} \mathrm{O}_{3} \times \mathrm{ZrO}_{2}$, $\mathrm{Fe}_{2} \mathrm{O}_{3} \times \mathrm{LiO}_{2}, \mathrm{SiO}_{2} \times \mathrm{ZnO}$, and $\mathrm{SiO}_{2} \times \mathrm{UO}_{3}$. Results for the 19-term PCT-Na model are given in Table 5.23 and discussed in Section 5.7. The underlying 18-term PQM models without the biascorrection terms are discussed in Sections 5.3.3 (PCT-B), 5.4.3 (PCT-Li), and 5.5.3 (PCT-Na).

Models containing 16 terms, consisting of the 13 linear terms, the same two quadratic terms $\left[\left(\mathrm{Al}_{2} \mathrm{O}_{3}\right)^{2}\right.$ and $\left.\mathrm{Al}_{2} \mathrm{O}_{3} \times \mathrm{ZrO}_{2}\right]$, and a bias-correction term were suggested as second-choice 
models for each of PCT-B, PCT-Li, and PCT-Na. The two quadratic terms were the only ones appearing in all three of the 19-term recommended models for PCT-B, PCT-Li, and PCT-Na. This may provide some protection against the 19-term models over-fitting the modeling data, at a possible cost of not predicting PCT releases as well.

The 13-component reduced LM models for PCT-B, PCT-Li, and PCT-Na tend to underpredict releases worse than did the 18-term and 15-term PQM models without bias-correction. Hence, the effort to bias-correct these models was not made and the LM models are not recommended for use.

Including bias-correction terms in the recommended and second-choice PCT-B, PCT-Li, and PCT-Na models substantially addressed the tendency to under-predict moderate PCT releases. However, the bias-corrected models may still under-predict larger PCT releases. Hence, constraints were included in the model validity region to restrict the use of the recommended PCT-B, PCT-Li, and PCT-Na models to glasses with predicted releases below 6.61, 4.27, and $5.53 \mathrm{~g} / \mathrm{L}$, respectively, as discussed in Section 9.2.1. These model validity upper bounds should not be overly limiting for WTP HLW glass formulation, product control, and product compliance during WTP HLW vitrification operations.

Because of the magnitudes of uncertainties in the PCT data (i.e., from making simulated and actual HLW glasses, PCT testing, and chemical analysis of leachates), as well as significant lack-of-fit (LOF) of the recommended PCT-B, PCT-Li, and PCT-Na models, prediction uncertainties for the models are relatively large (see Section 5.9). Unless different glass compositions (e.g., with higher waste loadings) are pursued, it is relatively easy to formulate HLW glasses with PCT-B, PCT-Li, and PCT-Na releases substantially below the WTP contract limits associated with the DWPF-EA glass. Hence, the relatively large prediction uncertainties may not overly restrict WTP HLW vitrification operations. Separate work that will be performed to assess the impact of HLW glass composition uncertainties, model uncertainties, and model under-predictions (for larger PCT releases) for the recommended PCT-B, PCT-Li, and PCT-Na models (with bias correction) is discussed in Section 5.9.

\subsection{Summary of IHLW Spinel $\mathbf{T}_{1 \%}$ Modeling}

To support the development of $\mathrm{T}_{1 \%}$-composition models, isothermal heat-treatment data (volume percent crystallinity at specified temperatures) were available for 247 HLW glasses from six of the eight data groups (HLW02, HLW03, HLW05, HLW06, HLW07, and HLW-ALG) discussed in Sections 2.1.1 to 2.1.8. There were no (temperature, vol\% crystallinity) data on any of the HLW glasses made from actual waste, which are discussed in Section 2.1.9. In cases where there were sufficient (temperature, vol\% crystallinity) data, they were regressed for each glass to estimate the $\mathrm{T}_{1 \%}$ value and its standard deviation.

Of the 247 glasses, 169 were identified as having spinel as the primary crystalline phase and a sufficient basis for estimating $\mathrm{T}_{1 \%}$. Assessment of the ranges and distributions of the component mass fractions over the $169 \mathrm{HLW}$ glasses with spinel $\mathrm{T}_{1 \%}$ data led to designating one glass (HLW06-31) as an outlier. Removing the outlier resulted in a modeling dataset consisting 
of $168 \mathrm{HLW}$ glasses with spinel $\mathrm{T}_{1 \%}$ values. These data are listed in Tables 6.2 and 6.3. Over these $168 \mathrm{HLW}$ glasses, the component ranges and distributions of 25 components $\left(\mathrm{Al}_{2} \mathrm{O}_{3}, \mathrm{~B}_{2} \mathrm{O}_{3}\right.$, $\mathrm{CaO}, \mathrm{CdO}, \mathrm{Cr}_{2} \mathrm{O}_{3}, \mathrm{Fe}_{2} \mathrm{O}_{3}, \mathrm{~K}_{2} \mathrm{O}, \mathrm{La}_{2} \mathrm{O}_{3}, \mathrm{Li}_{2} \mathrm{O}, \mathrm{MgO}, \mathrm{MnO}, \mathrm{Na}_{2} \mathrm{O}, \mathrm{NiO}, \mathrm{PbO}, \mathrm{Sb}_{2} \mathrm{O}_{3}, \mathrm{SeO}_{2}, \mathrm{SiO}_{2}$, $\mathrm{SrO}, \mathrm{ThO}_{2}, \mathrm{TiO}_{2}, \mathrm{Tl}_{2} \mathrm{O}, \mathrm{UO}_{3}, \mathrm{ZnO}, \mathrm{ZrO}_{2}$, and Others) were sufficient to support separate model terms if needed. These were the same 25 components selected for initial PCT modeling.

The 168 HLW glasses in the modeling dataset had spinel $\mathrm{T}_{1 \%}$ ranging from 635.7 to $1230.7^{\circ} \mathrm{C}$, with the values roughly symmetrically distributed around the WTP process requirement of $\mathrm{T}_{1 \%} \leq 950^{\circ} \mathrm{C}$ (see Figure 4.12). This indicates a good distribution of data for modeling spinel $\mathrm{T}_{1 \%}$ and being able to predict well at $950^{\circ} \mathrm{C}$. Gross compositional trends of the estimated spinel $\mathrm{T}_{1 \%}$ values were less apparent than for the PCT data and no simple correlations between HLW glass compositions and spinel $\mathrm{T}_{1 \%}$ could be identified.

Several model forms were investigated for modeling spinel $\mathrm{T}_{1 \%}$ as a function of HLW glass composition.

- An 25-component LM model using the 25 components listed previously.

- A reduced 15-component LM model involving $\mathrm{Al}_{2} \mathrm{O}_{3}, \mathrm{~B}_{2} \mathrm{O}_{3}, \mathrm{Cr}_{2} \mathrm{O}_{3}, \mathrm{Fe}_{2} \mathrm{O}_{3}, \mathrm{Li}_{2} \mathrm{O}, \mathrm{MnO}$, $\mathrm{Na}_{2} \mathrm{O}, \mathrm{NiO}, \mathrm{SiO}_{2}, \mathrm{SrO}, \mathrm{ThO}_{2}, \mathrm{UO}_{3}, \mathrm{ZnO}, \mathrm{ZrO}_{2}$, and Others. This model had similar performance as the 25-component LM model.

- A series of PQM models, in which the reduced 15-component LM model was augmented using statistical variable selection methods with between two and nine quadratic (squared and/or crossproduct) terms. Two 20-term PQM models were selected for presentation and other PQM models were discussed.

More information and results for the LM models are contained in Section 6.3, while results for PQM models are contained in Section 6.4. The LM and PQM model forms were also fitted to a subset of 144 HLW glasses containing only spinel as the primary crystalline phase, excluding 24 glasses with containing secondary crystalline phases in addition to the spinel primary phase.

Based on an extensive comparison of model fitting, validation, and other results in Sections 6.5 and 6.6, a 20-term PQM model (denoted PQM1a) consisting of 15 linear terms $\left(\mathrm{Al}_{2} \mathrm{O}_{3}, \mathrm{~B}_{2} \mathrm{O}_{3}, \mathrm{Cr}_{2} \mathrm{O}_{3}, \mathrm{Fe}_{2} \mathrm{O}_{3}, \mathrm{Li}_{2} \mathrm{O}, \mathrm{MnO}, \mathrm{Na}_{2} \mathrm{O}, \mathrm{NiO}, \mathrm{SiO}_{2}, \mathrm{SrO}, \mathrm{ThO}_{2}, \mathrm{UO}_{3}, \mathrm{ZnO}, \mathrm{ZrO}_{2}\right.$, and Others) and 5 quadratic terms $\left[\left(\mathrm{ZrO}_{2}\right)^{2}, \mathrm{MnO} \times \mathrm{Na}_{2} \mathrm{O}, \mathrm{Li}_{2} \mathrm{O} \times \mathrm{MnO}, \mathrm{MnO} \times \mathrm{NiO}\right.$, and $\left.\left(\mathrm{SiO}_{2}\right)^{2}\right]$ was recommended for predicting the spinel $\mathrm{T}_{1 \%}$ of HLW glasses. Results for this 20-term PQM model are given in Table 6.10 and discussed in Section 6.4.1. A different 20-term PQM model was chosen as the second-choice model, with the main difference being that quadratic terms involving $\mathrm{ZrO}_{2}$ and $\mathrm{ThO}_{2}$ were not allowed. ${ }^{22}$ That 20-term PQM model (denoted PQM1b) consists of the same 15 linear terms and 5 quadratic terms $\left(\mathrm{Cr}_{2} \mathrm{O}_{3} \times \mathrm{SiO}_{2}, \mathrm{Al}_{2} \mathrm{O}_{3} \times \mathrm{MnO}\right.$, $\mathrm{MnO} \times \mathrm{Na}_{2} \mathrm{O}, \mathrm{Li}_{2} \mathrm{O} \times \mathrm{MnO}$, and $\mathrm{Na}_{2} \mathrm{O} \times \mathrm{SiO}_{2}$ ). Results for this 20 -term PQM model are given in Table 6.11 and discussed in Section 6.4.2. These two PQM models performed better than the 25-

\footnotetext{
${ }^{22}$ In modeling work, quadratic terms involving $\mathrm{ZrO}_{2}$ or $\mathrm{ThO}_{2}$ were sometimes selected, which could have been due to several of the $168 \mathrm{HLW}$ glasses in the spinel $\mathrm{T}_{1 \%}$ modeling dataset having secondary crystalline phases involving $\mathrm{Zr}$ and Th (see Table 6.3).
} 
component and 15-component LM models for the 168-glass modeling dataset, data-splitting validation, and data-partitioning validation. The 15-component reduced LM model had the best performance on the 38-glass separate validation set, but owing to the limited nature of that data, the advantages of the 20-term PQM models out-weighed this advantage of the 15-component reduced LM model.

The recommended 20-term PQM model (PQM1a) for spinel $\mathrm{T}_{1 \%}$ appears to yield unbiased predictions over the full range of measured spinel $\mathrm{T}_{1 \%}$ values in the modeling dataset. However, the model does have moderately large scatter in data points about the fitted model (see Figure 6.16). This scatter is a result of (i) relatively large uncertainties in the estimated spinel $\mathrm{T}_{1 \%}$ values (see Table 6.4), and (ii) significant LOF of the recommended PQM1a model. Because of these reasons, prediction uncertainties for the model are relatively large (see Section 6.8). It is unclear whether the magnitudes of uncertainties in spinel $\mathrm{T}_{1 \%}$ model predictions are small enough that they will not overly restrict the formulation and processing of HLW glasses in the WTP facility. However, separate work to confirm this is planned, as discussed in Section 6.8.

Modeling of $\mathrm{T}_{1 \%}$ for the 59 simulated glasses with non-spinel primary crystalline phases was not attempted because there were an insufficient number of glasses with any given primary crystalline phase. Also, the tank waste anticipated to generate HLW glasses with primary phases high in $\mathrm{Th}$ and $\mathrm{Zr}$ (C-104) will be blended to significantly change its composition (Kirkbride et al. 2007).

\subsection{Summary of IHLW Electrical Conductivity Modeling}

Data on EC were available for $210 \mathrm{HLW}$ glasses from the eight data groups discussed in Sections 2.1.1 to 2.1.8. There were no EC data on any of the five HLW glasses made from actual waste, which are discussed in Section 2.1.9. Electrical conductivity was measured for each HLW glass at four temperatures, generally in the vicinity of $950,1050,1150$, and $1250^{\circ} \mathrm{C}$. Actual temperatures at which EC was measured ranged from 909 to $1277^{\circ} \mathrm{C}$. The $\mathrm{EC}$ results vary from 0.034 to $1.376 \mathrm{~S} / \mathrm{cm}$, with smaller values occurring at lower temperatures and larger values occurring at higher temperatures.

Assessing the ranges and distributions of the component values over the 210 HLW glasses with EC data led to designating two glasses (HLW98-96A and HLW98-96B) as having outlying compositions. Hence, the EC modeling dataset consisted of EC values at four temperatures for each of 208 HLW glasses. The HLW glass compositions and EC data are listed in Tables 7.2 and 7.3, respectively. Over these 208 HLW glasses, the component ranges and distributions of 22 components were sufficient to support separate model terms if needed. These 22 components are $\mathrm{Al}_{2} \mathrm{O}_{3}, \mathrm{~B}_{2} \mathrm{O}_{3}, \mathrm{CaO}, \mathrm{CdO}, \mathrm{Cr}_{2} \mathrm{O}_{3}, \mathrm{Fe}_{2} \mathrm{O}_{3}, \mathrm{Li}_{2} \mathrm{O}, \mathrm{MgO}, \mathrm{MnO} \mathrm{Na} \mathrm{N}_{2} \mathrm{O} \mathrm{NiO}, \mathrm{PbO}$, $\mathrm{Sb}_{2} \mathrm{O}_{3}, \mathrm{SeO}_{2}, \mathrm{SiO}_{2}, \mathrm{SrO}, \mathrm{ThO}_{2}, \mathrm{Tl}_{2} \mathrm{O}, \mathrm{UO}_{3}, \mathrm{ZnO}, \mathrm{ZrO}_{2}$, and Others (the sum of all remaining components).

Investigation of three equations (Arrhenius, truncated T2, and T2; see Section C.2.1) for the temperature dependence of EC showed that the truncated-T2 equation was sufficient for the vast majority of the $208 \mathrm{HLW}$ glasses in the EC modeling dataset. Several property-composition- 
temperature model forms for EC were developed by expanding the two parameters of the truncated-T2 equation as linear or partial quadratic mixture experiment models.

- A 44-term truncated T2-LM model involving $22 x_{i}$ terms and $22 x_{i} /(T / 1000)^{2}$ terms based on the 22 components listed previously.

- A reduced 27-term truncated T2-LM model involving $14 x_{i}$ terms $\left(\mathrm{Al}_{2} \mathrm{O}_{3}, \mathrm{~B}_{2} \mathrm{O}_{3}, \mathrm{Fe}_{2} \mathrm{O}_{3}\right.$, $\mathrm{Li}_{2} \mathrm{O}, \mathrm{MgO}, \mathrm{MnO}, \mathrm{Na}_{2} \mathrm{O}, \mathrm{SiO}_{2}, \mathrm{SrO}, \mathrm{ThO}_{2}, \mathrm{UO}_{3}, \mathrm{ZnO}, \mathrm{ZrO}_{2}$, and Others) and 13 corresponding $x_{i} /(T / 1000)^{2}$ terms, with only the $\mathrm{MgO} /(T / 1000)^{2}$ term eliminated. This model had similar performance as the 44-term truncated T2-LM model.

- A series of models adding crossproduct terms $\left(x_{i} x_{j}\right)$ to the "composition only" portion, and removing additional $x_{i} /(T / 1000)^{2}$ terms from the "composition-temperature" portion of the 27-term truncated T2-LM model discussed in the previous bullet. The number of terms in these models ranged up to 28 and down to 22 .

Based on model fitting and validation results, a 22-term truncated T2-LM model was selected as the recommended model for EC of HLW glasses. This model has 14 linear composition terms of the form $x_{i}$ (involving $\mathrm{Al}_{2} \mathrm{O}_{3}, \mathrm{~B}_{2} \mathrm{O}_{3}, \mathrm{Fe}_{2} \mathrm{O}_{3}, \mathrm{Li}_{2} \mathrm{O}, \mathrm{MgO}, \mathrm{MnO}, \mathrm{Na}_{2} \mathrm{O}, \mathrm{SiO}_{2}$, $\mathrm{SrO}, \mathrm{ThO}_{2}, \mathrm{UO}_{3}, \mathrm{ZnO}, \mathrm{ZrO}_{2}$, and Others), the $\mathrm{Li}_{2} \mathrm{O} \times \mathrm{Na}_{2} \mathrm{O}$ quadratic term, and 7 compositiontemperature terms of the form $x_{i} /(T / 1000)^{2}$ with $x_{i}=\mathrm{B}_{2} \mathrm{O}_{3}, \mathrm{MnO}, \mathrm{SiO}_{2}, \mathrm{SrO}, \mathrm{UO}_{3}, \mathrm{ZnO}$, and $\mathrm{ZrO}_{2}$. The temperature ( $T$, Kelvin) is scaled by 1000 so that the model coefficients for those terms are of comparable magnitudes to those of the linear composition terms. Results for the recommended 22-term EC model are given in Table 7.9 and discussed in Section 7.5. Methods for making EC predictions and quantifying the uncertainties in the predictions are discussed and illustrated in Section 7.6.

The recommended EC model for HLW glasses provides unbiased predictions over the full range of measured EC values in the modeling dataset. The predicted versus measured plot has relatively tight scatter for most data points, moderate scatter for some data points, and outlying data for glasses HLW07-28 and HLW07-40 (see Figure 7.12). The recommended EC model does not have a significant LOF, so that EC predictions can be expected to be within the uncertainty of what would be obtained by batching and melting HLW glasses and measuring the EC. The magnitudes of uncertainties in EC model predictions should be small enough that they will not overly restrict the formulation and processing of HLW glasses in the WTP facility. However, separate work to confirm this is planned, as discussed in Section 7.7.

\subsection{Summary of IHLW Viscosity Modeling}

Data on viscosity were available for 210 HLW glasses from the eight data groups discussed in Sections 2.1.1 to 2.1.8. There were no viscosity data on any of the five HLW glasses made from actual waste, which are discussed in Section 2.1.9. Viscosity was measured for each HLW glass at four temperatures (with a few exceptions), generally in the vicinity of 950, 1050, 1150 , and $1250^{\circ} \mathrm{C}$. Actual temperatures at which viscosity was measured ranged from 931 to $1281^{\circ} \mathrm{C}$. The viscosity results vary from 3.60 to 3165.51 poise, with smaller values occurring at higher temperatures and larger values occurring at lower temperatures. 
Assessment of the ranges and distributions of the component values over the 210 HLW glasses with viscosity data led to designating two glasses (HLW98-96A and HLW98-96B) as having outlying compositions. Glasses HLW03-01, HLW03-10, HLW03-13, HLW03-32, HLW06-04, HLW-ALG-13 and HLW-ALG-38 were excluded from the modeling dataset because of not having viscosity data at four temperatures. Initial modeling efforts with the remaining 201 glasses identified four more glasses (HLW02-06, HLW02-14, HLW07-28, and HLW07-40) as significant outliers. The composition and viscosity data for the remaining 197 HLW glasses are listed in Tables 8.1 and 8.2, respectively. Hence, the viscosity modeling dataset consisted of viscosity values at four temperatures for each of 197 HLW glasses. Over these 197 HLW glasses, the component ranges and distributions of 22 components were sufficient to support separate model terms if needed. These 22 components are $\mathrm{Al}_{2} \mathrm{O}_{3}, \mathrm{~B}_{2} \mathrm{O}_{3}, \mathrm{CaO}, \mathrm{CdO}$, $\mathrm{Cr}_{2} \mathrm{O}_{3}, \mathrm{Fe}_{2} \mathrm{O}_{3}, \mathrm{Li}_{2} \mathrm{O}, \mathrm{MgO}, \mathrm{MnO} \mathrm{Na}_{2} \mathrm{O}, \mathrm{NiO}, \mathrm{PbO}, \mathrm{Sb}_{2} \mathrm{O}_{3}, \mathrm{SeO}_{2}, \mathrm{SiO}_{2}, \mathrm{SrO}, \mathrm{ThO}_{2}, \mathrm{Tl}_{2} \mathrm{O}, \mathrm{UO}_{3}$, $\mathrm{ZnO}, \mathrm{ZrO}_{2}$, and Others (the sum of all remaining components). These were the same 22 components selected for initial EC modeling.

Investigation of three equations (Arrhenius, truncated T2, and T2; see Section C.2.1) for the temperature dependence of viscosity showed that the truncated-T2 equation was sufficient for the vast majority of the 197 HLW glasses in the viscosity modeling dataset. Several propertycomposition-temperature model forms for viscosity were developed by expanding the two parameters of the truncated-T2 equation as linear or partial quadratic mixture experiment models.

- A 44-term truncated T2-LM model involving $22 x_{i}$ terms and $22 x_{i} /(T / 1000)^{2}$ terms based on the 22 components listed previously.

- A reduced 27-term truncated T2-LM model involving $15 x_{i}$ terms $\left(\mathrm{Al}_{2} \mathrm{O}_{3}, \mathrm{~B}_{2} \mathrm{O}_{3}, \mathrm{CaO}\right.$, $\mathrm{Fe}_{2} \mathrm{O}_{3}, \mathrm{Li}_{2} \mathrm{O}, \mathrm{MgO}, \mathrm{MnO}, \mathrm{Na}_{2} \mathrm{O}, \mathrm{SiO}_{2}, \mathrm{SrO}, \mathrm{ThO}_{2}, \mathrm{UO}_{3}, \mathrm{ZnO}, \mathrm{ZrO}_{2}$, and Others) and 12 of the corresponding $x_{i} /(T / 1000)^{2}$ terms (with the terms for $x_{i}=\mathrm{B}_{2} \mathrm{O}_{3}, \mathrm{CaO}$, and $\mathrm{MgO}$ eliminated). This model had similar performance as the 44-term truncated T2-LM model.

- A series of models adding crossproduct terms $\left(x_{i} x_{j}\right)$ to the "composition only" portion, and removing additional $x_{i} /(T / 1000)^{2}$ terms from the "composition-temperature" portion of the 27-term truncated T2-LM model discussed in the previous bullet. The number of terms in these models ranged up to 32 and down to 24 .

Based on model fitting and validation results, a 29-term truncated T2-LM model with five additional quadratic terms is the recommended model for viscosity of HLW glasses. This model has 15 linear composition terms of the form $x_{i}$ (involving $\mathrm{Al}_{2} \mathrm{O}_{3}, \mathrm{~B}_{2} \mathrm{O}_{3}, \mathrm{CaO}, \mathrm{Fe}_{2} \mathrm{O}_{3}, \mathrm{Li}_{2} \mathrm{O}$, $\mathrm{MgO}, \mathrm{MnO}, \mathrm{Na}_{2} \mathrm{O}, \mathrm{SiO}_{2}, \mathrm{SrO}, \mathrm{ThO}_{2}, \mathrm{UO}_{3}, \mathrm{ZnO}, \mathrm{ZrO}_{2}$, and Others), five quadratic terms of the form $x_{i} x_{j}$ or $x_{i}^{2}\left[\mathrm{Al}_{2} \mathrm{O}_{3} \times \mathrm{SiO}_{2}, \mathrm{~B}_{2} \mathrm{O}_{3} \times \mathrm{Na}_{2} \mathrm{O}, \mathrm{Li}_{2} \mathrm{O} \times \mathrm{ZnO}, \mathrm{Na}_{2} \mathrm{O} \times \mathrm{ThO}_{2}\right.$, and $\left.\left(\mathrm{Li}_{2} \mathrm{O}\right)^{2}\right]$, and 9 composition-temperature terms of the form $x_{i} /(T / 1000)^{2}$ involving $\mathrm{Al}_{2} \mathrm{O}_{3}, \mathrm{Fe}_{2} \mathrm{O}_{3}, \mathrm{Li}_{2} \mathrm{O}, \mathrm{Na}_{2} \mathrm{O}$, $\mathrm{SiO}_{2}, \mathrm{SrO}, \mathrm{ThO}_{2}, \mathrm{UO}_{3}$, and $\mathrm{ZrO}_{2}$. The temperature (T, Kelvin) is scaled by 1000 so that the model coefficients for those terms are of comparable magnitudes to those of the linear-composition terms. Results for the recommended 29-term viscosity model are given in Table 8.8 and discussed in Section 8.5. Methods for making viscosity predictions and quantifying the uncertainties in the predictions are discussed and illustrated in Section 8.6. 
The recommended viscosity model for HLW glasses provides unbiased predictions over the full range of measured viscosity values in the modeling dataset. The predicted versus measured plot has relatively tight scatter for all viscosity data on the 197 glasses in the modeling dataset (see Figure 8.12). The recommended viscosity model does not have a significant LOF, so that viscosity predictions can be expected to be within the uncertainty of what would be obtained by batching and melting HLW glasses and measuring the viscosity. The magnitudes of uncertainties in viscosity model predictions should be small enough that they will not overly restrict the formulation and processing of HLW glasses in the WTP facility. However, separate work to confirm this is planned, as discussed in Section 8.7.

\subsection{Summary of Model Validity Regions for Recommended HLW Glass Property Models}

The PCT, spinel $\mathrm{T}_{1 \%}, \mathrm{EC}$, and viscosity models for HLW glasses recommended in this report, and the TCLP-Cd model recommended in Kot et al. (2004), were obtained by estimating coefficients of models using least squares regression methods. PCT, spinel $\mathrm{T}_{1 \%}$, and TCLP-Cd models developed in this way should only be applied to HLW glass compositions inside the composition region over which the models were developed and demonstrated to yield unbiased predictions. Similarly, EC and viscosity models developed in this way should only be applied to HLW glass compositions at melt temperatures inside the composition-temperature region over which the models were developed and demonstrated to yield unbiased predictions. Such regions are referred to as model validity regions, which are defined using single- and multiplecomponent constraints on HLW glass components. Some single- and multiple-component constraints are specified directly on HLW glass compositions. Other multiple-component constraints involve limits on HLW glass and melt properties, and are implemented using the recommended or second-choice property models. Such multiple-component constraints are indirectly constraints on HLW glass compositions. Because EC and viscosity also depend on melt temperature, there is a temperature aspect of the model validity region for those properties. In general, each property (i.e., PCT-B, PCT-Li, and PCT-Na, spinel $\mathrm{T}_{1 \%}$, EC, viscosity, and TCLP-Cd) has its own model validity region. For a given property, the model validity regions for the recommended and second-choice models are the same. The model validity regions are discussed in Section 9, and the constraints defining them are summarized in Table 9.8.

\subsection{Suitability of Recommended HLW Glass Property Models for Use by the WTP Project}

The test objectives for this work (see Section 1.1) were achieved by developing, validating, and quantifying uncertainty in property-composition models for HLW glasses. Recommended models are presented in this report for PCT responses ( $\mathrm{B}, \mathrm{Li}$, and $\mathrm{Na}$ releases), spinel $\mathrm{T}_{1 \%}$, EC, and viscosity. Kot et al. (2004) previously recommended a model for TCLP-Cd. The recommended models for each property, being the best of the models considered in the development and validation process, are suitable for predicting properties of HLW glasses within the constraints of the model validity region for each property as discussed in Section 9. 
The recommended and second-choice PCT-B, PCT-Li, and PCT-Na models (before the addition of bias-correction terms) tended to under-predict normalized PCT releases above 1.65, 1.65 , and $2.72 \mathrm{~g} / \mathrm{L}$, respectively. These model limitations are attributed to what are apparently more complicated relationships between PCT-B, PCT-Li, and PCT-Na releases over the relatively large HLW glass composition region of interest than can be approximated by quadratic or cubic polynomial-type models. Bias-correction terms were added to substantially correct the under-prediction problems, but the models may still under-predict for larger PCT releases. Hence, the PCT-B, PCT-Li, and PCT-Na models are limited to use for predicted releases below $6.61,4.27$, and $5.53 \mathrm{~g} / \mathrm{L}$, respectively. Because it is relatively easy to formulate HLW glasses with lower PCT releases, these model validity constraints may not overly limit WTP operations in the HLW vitrification facility. If the WTP project determines that (i) these constraints on the PCT-B, PCT-Li, and PCT-Na models may be overly restrictive or (ii) models are preferred that yield unbiased predictions without the use of bias-correction terms, additional work might be needed in the future to address the issue by developing better models (see Section 11.1).

The recommended spinel $\mathrm{T}_{1 \%}$ model as a function of HLW glass composition yields unbiased predictions over the full range of the modeling dataset. However, the recommended spinel $\mathrm{T}_{1 \%}$ model is subject to moderately large prediction uncertainties because of (i) the magnitude of uncertainty in spinel $\mathrm{T}_{1 \%}$ data and (ii) significant model LOF. Planned future work to assess the suitability of the recommended models in this report (discussed subsequently in this section) will have to determine whether the relatively large uncertainties in spinel $\mathrm{T}_{1 \%}$ predictions are sufficient to restrict operations of the HLW vitrification facility. If the WTP project determines that the limitations of the recommended spinel $\mathrm{T}_{1 \%}$ model are restrictive, additional future work would then be necessary to address the issue (see Section 11.2).

Electrical conductivity and viscosity models as functions of HLW glass composition and melt temperature fit their respective modeling datasets very well without bias or statistically significant LOF within the composition-temperature region represented by the modeling dataset. The only limitations of these models are the lack of data outside the processing ranges of their respective properties (see Section 11.3). Because EC and viscosity models can often tolerate small to moderate extrapolation reasonably well, the lack of data outside the property processing ranges is not likely to be a major issue for the WTP project. However, if the WTP project decides this issue must be addressed, work would be needed to (i) validate the extrapolative performance of the recommended electrical conductivity and viscosity models, or (ii) expand the modeling dataset and update models to cover a larger desired region of applicability. In summary, the electrical conductivity and viscosity models for HLW glasses are well-suited for application by the WTP project as long as they are limited to application within the range of the modeling dataset.

It is outside the scope of work in this report to completely assess the suitability of the recommended HLW glass property models. Ultimately, the WTP project needs to assess whether the recommended models, along with their corresponding uncertainties (and regions of biased prediction, in the case of PCT models), are suitable for their various intended uses (e.g., glass formulation, addition of glass-forming chemicals to waste during HLW vitrification operations, and compliance with WTP contract specifications and processing constraints). Such assessments 
are within the scopes for algorithm development and verification (work being conducted by WTP project staff) and statistical compliance methodology development and demonstration (work under separate PNNL scope). Using earlier versions of property-composition models for HLW glasses (Kot et al. 2005a), initial work has been previously conducted on algorithm development and verification (Vienna and Kim 2007) and on statistical compliance methodology development and demonstration (Piepel et al. 2005). The WTP project has future work planned to update the algorithm work (within the WTP project) and statistical compliance work (at PNNL). 


\section{SECTION 11 \\ RECOMMENDATIONS FOR ANY FUTURE IHLW PROPERTY-COMPOSITION DATA COLLECTION, MODEL DEVELOPMENT, OR MODEL VALIDATION WORK}

The work in this report to develop, validate, and quantify the uncertainty in models for PCT releases (PCT-B, PCT-Li, PCT-Na), spinel $\mathrm{T}_{1 \%}$, electrical conductivity (EC), and viscosity of HLW glasses is the last iteration of such work that is currently scheduled. Work to develop a property-composition model for for $\mathrm{Cd}$ release from the Toxicity Characteristic Leaching Procedure (TCLP) was previously discussed by Kot et al. (2004). There are many years between now and when the WTP HLW vitrification facility is scheduled to become operational. In that time, knowledge of tank waste compositions, blending scenarios, pretreatment outcomes, glass formulations, and desired waste loadings may improve. Improved knowledge could lead to a need to revise the HLW glass composition region of interest, and thus to additional glass property-composition data collection and model development and/or validation work. That situation already exists for TCLP-Cd release, as discussed subsequently in this section. Further, the PCT, spinel $\mathrm{T}_{1 \%}, \mathrm{EC}$, and viscosity models recommended in this report have some limitations as discussed in Sections 10.1 to 10.4 and 10.6. The WTP project may decide to address these limitations by collecting additional property-composition data and performing additional model development and/or validation work. It is in this context that the following discussion, suggestions, and recommendations are made.

An issue common to four of the five properties for which models are needed is limited data outside contract or processing limits on the properties. This issue applies to PCT, EC, viscosity, and TCLP-Cd. One of the primary requirements for the IHLW property-composition models is that they be able to accurately predict, with acceptable uncertainty ${ }^{23}$, when an HLW glass would have property values outside WTP contract or processing limits. To achieve this goal, there must be sufficient HLW glasses with property values near and somewhat beyond the contract and processing limits.

Several recommendations are made in Sections 11.1 to 11.5 for any additional IHLW property-composition data collection and modeling work that may be performed in the future. A recommendation is made in each of Sections $11.1,11.3,11.4$, and 11.5 to address the common issue discussed in the preceding paragraph. Sections 11.1 and 11.2 also make other recommendations for any future PCT and spinel $\mathrm{T}_{1 \%}$ property-composition data development, model development, or model validation work. Section 11.4 discusses recommendations associated with TCLP-Cd release datasets and models. Section 11.5 discusses some general recommendations.

\footnotetext{
23 Here "acceptable uncertainty" refers to the uncertainty that will allow compliance and processing constraints to
} be met without overly restricting glass compositions or processing properties. 


\subsection{Recommendations for IHLW PCT}

The recommended and second-choice models for PCT-B, PCT-Li, and PCT-Na releases of HLW glasses have two limitations, as summarized in Section 10.1. The first limitation is that the models prior to bias-correction tend to under-predict (i) PCT-B and PCT-Li releases above $1.65 \mathrm{~g} / \mathrm{L}$, and (ii) PCT-Na releases above $2.72 \mathrm{~g} / \mathrm{L}$. Data-based bias-correction terms were added to the recommended and second-choice PCT-B, PCT-Li, and PCT-Na models to substantially correct for these under-predictions (see Section 5.7). However, the bias-corrected models may still under-predict for larger PCT-B, PCT-Li, and PCT-Na releases, resulting in model validity upper bounds of 6.61, 4.27, and $5.53 \mathrm{~g} / \mathrm{L}$, respectively, being set (see Sections 5.9 and 9.2.1). These model validity constraints are far less restrictive than they would have been for the recommended and second-choice models before adding the bias-correction terms. The bias corrections made to the PCT models are limited because they were developed using the same data used to develop the models. Also, it is less desirable to use models with bias-correction terms added than to develop models that yield unbiased predictions over the whole HLW glass composition region of interest.

The second limitation of the recommended and second-choice PCT-B, PCT-Li, and PCT$\mathrm{Na}$ models (with bias corrections) is that they are subject to relatively large prediction uncertainties, resulting from uncertainty in the modeling data (larger for PCT-B than PCT-Li and PCT-Na) and from highly statistically significant model LOF. The magnitudes of the PCT model prediction uncertainties are discussed in Section 5.9.

If the future work summarized in Section 10.6 concludes that the two preceding limitations of PCT models are not overly restrictive to operation of the WTP HLW vitrification facility, then no additional property-composition data and model development work will be needed. However, if the WTP project decides that such additional work is needed, the following recommendations are offered.

Collect Additional Data for HLW Glasses with Higher PCT Releases: The PCT modeling dataset contains relatively few HLW glasses with larger PCT-B, PCT-Li, and PCT-Na releases. The following chart gives the numbers of HLW glasses with PCT-B, PCT-Li, and PCT-Na releases above the DWPF-EA glass limits and other values.

The numbers of HLW glasses shown in the chart provide insufficient data to accurately predict (and validate such predictions) for PCT-B, PCT-Li, and PCT-Na releases above $4 \mathrm{~g} / \mathrm{L}$. The 17 glasses with PCT-Na releases above the model bias-cutoff value of $2.72 \mathrm{~g} / \mathrm{L}$ also are insufficient for developing and validating models above this value. The 28 glasses with PCT-Li releases above the model bias-cutoff value of $1.65 \mathrm{~g} / \mathrm{L}$ are borderline for model development above the model validity constraint. Either there were not enough data above that point, or the relationship between PCT-Li release and compositions of HLW glasses is more complicated than can be approximated by quadratic or cubic polynomial-type models. Similarly, 43 glasses with PCT-B releases above the model validity bias-cutoff value of $1.65 \mathrm{~g} / \mathrm{L}$ would seem to be sufficient, 
Number of HLW Glasses with PCT Releases Above Specified Values

\begin{tabular}{|c|c|c|c|}
\hline & PCT-B & PCT-Li & PCT-Na \\
\hline Number of HLW Glasses in Modeling Datasets & 264 & 250 & 266 \\
\hline \multicolumn{4}{|c|}{ Number of HLW Glasses with Releases Greater than Specified Values } \\
\hline DWPF-EA glass limits ${ }^{(a)}$ & 1 & 1 & 0 \\
\hline $4 \mathrm{~g} / \mathrm{L}^{(\mathrm{b})}$ & 15 & 9 & 10 \\
\hline Model bias-cutoff values ${ }^{(c)}$ & 43 & 28 & 17 \\
\hline
\end{tabular}

(a) The WTP contract limits corresponding to releases of PCT-B, PCT-Li, and PCT-Na from the DWPF-EA glass are 16.695, 9.565, and $13.346 \mathrm{~g} / \mathrm{L}$, respectively (Jantzen et al. 1993).

(b) Arbitrarily selected, although $4 \mathrm{~g} / \mathrm{L}$ is the WTP contract limit for PCT-B, PCT-Na, and PCT-Si releases from LAW glasses.

(c) The values above which recommended PCT models (before bias correction) tend to under-predict PCT releases are normalized releases of $1.65 \mathrm{~g} / \mathrm{L}$ for PCT-B and PCT-Li, and $2.72 \mathrm{~g} / \mathrm{L}$ for PCT-Na.

indicating that the model relationship between PCT-B release and HLW glass compositions is more complicated. Also, the uncertainty standard deviation in PCT-B values estimated from replicates was twice as large as for PCT-Li and PCT-Na (see Table 5.4), which contributes to difficulty in modeling PCT-B releases. In summary, if judged necessary by the WTP project, it is recommended that additional data be collected on HLW glasses with higher PCT releases. Such data may support development of new PCT-B, PCT-Li, and PCT-Na models with unbiased predictive performance above the model validity constraints imposed for the models recommended in this report. After such an outcome, the ad-hoc bias-correction of PCT-B, PCT-Li, and PCT-Na models performed in this report would no longer be needed.

Investigate Other Model Development Approaches: The uncertainty in measured PCT-B releases based on replicates is relatively large at $0.2515 \ln (\mathrm{g} / \mathrm{L})$. Uncertainties in measured PCT-Li, and PCT-Na releases $[0.1317 \ln (\mathrm{g} / \mathrm{L})$ and $0.1318 \ln (\mathrm{g} / \mathrm{L})$, respectively] are considerably smaller, but still substantive. Despite these uncertainties in measured PCT releases, the recommended PCT-B, PCT-Li, and PCT-Na models have highly statistically significant (as well as practically significant) lack-of-fits (LOF). This means that the model prediction uncertainties are larger than can be accounted for by the uncertainties in PCT-B, PCT-Li, and PCT-Na data. The significant model LOFs are presumably because of more complicated non-linear blending effects of HLW glass components on PCT releases over the HLW glass composition region of interest than can be captured by a single quadratic or cubic polynomial-type model. There are two categories of solutions to this situation. The first is to adopt other modeling approaches that provide for better capturing local dependence of PCT releases on HLW glass composition over the full glass composition region of interest. This option is discussed further in Sections 11.5.3 and 11.5.4. The second is to develop models of the forms 
considered so far, but over smaller HLW glass composition regions where they are likely to fit and predict better. Hence, there would be multiple models covering different HLW glass composition regions. The smaller glass composition regions might correspond to glasses made from specific HLW wastes or groups of similar HLW wastes, for example.

It is relatively easy to formulate HLW glasses with PCT releases significantly below the DWPF-EA glass limits. In fact, only one glass in the PCT modeling dataset had PCT-B and PCT-Li releases larger than the DWPF-EA glass limits. No glasses had PCT-Na releases above the DWPF-EA glass limit. Thus, the recommendations for improving PCT-composition databases and models to meet glass formulation and product compliance needs must be judged in light of the relative ease of meeting DWPF-EA limits for PCT releases from HLW glasses.

\subsection{Recommendations for IHLW $\mathbf{T}_{1 \%}$}

The recommended and second-choice models for spinel $\mathrm{T}_{1 \%}$ of HLW glasses have an issue of moderate concern. This issue is briefly summarized and associated recommendations are given subsequently. Another issue is that the data for primary crystalline phases other than spinel are insufficient to develop $\mathrm{T}_{1 \%}$-composition models for those phases. Recommendations for this issue are discussed.

The issue of moderate concern is that predictions of spinel $\mathrm{T}_{1 \%}$ using the recommended and second-choice models are subject to moderately large prediction uncertainties, resulting from uncertainty in the estimated spinel $\mathrm{T}_{1 \%}$ values in the modeling dataset and from significant model LOF. This topic was discussed in Sections 6.8 and 10.2. If the future work summarized in Section 10.6 concludes that the uncertainties in spinel $\mathrm{T}_{1 \%}$ model predictions are not overly restrictive to operation of the WTP HLW vitrification facility, then no additional spinel $\mathrm{T}_{1 \% \text { - }}$ composition data and model development work will be needed. However, if the WTP project decides that such additional work is needed, the following recommendations are offered.

Improve the Data Used to Estimate Spinel $\mathrm{T}_{1 \%}$ : For a given HLW glass, the $\mathrm{T}_{1 \%}$ value is currently estimated by regressing a line to (temperature, vol\% crystallinity) data points, as discussed and illustrated in Appendix E. In practice, the number of data points may be as small as 3 or 4 , and the vol\% values may not be evenly distributed below and above $1 \%$. Some times, data points have vol\% crystallinity values significantly larger than $1 \%$, so that the relationship between vol\% crystallinity and temperature is no longer linear. The biggest issue is that there is considerable uncertainty in determining vol\% crystallinity, so that even with a sufficient number of (temperature, vol\% crystallinity) points for a given glass, there can be considerable scatter about the regression line. Hence, a way to improve spinel $\mathrm{T}_{1 \%}$-composition models is to improve the data and process used for estimating $\mathrm{T}_{1 \%}$ values. Although methods for heat-treating glass samples and determining vol\% crystallinity that yield better precision could be employed, they would require correspondingly significant increases in time and cost. Therefore, fom a practical perspective, the biggest improvement in data would likely come from collecting more data points using the current methods to improve the distribution of vol $\%$ values below and above $1 \%$. There should be at least three data points with vol\% crystallinity 
values both below and at least three with values above $1 \%$, but not too far above. The vol\% values should be well-distributed over their range within the area of linear dependence on temperature. This would provide a data set of at least six well-distributed points for regression and interpolating the $\mathrm{T}_{1 \%}$ value for each glass. It is recognized that this recommendation may require more heat-treatments spaced within a relatively narrow temperature range, and may involve collecting more than the minimum number of six (temperature, vol\% crystallinity) points if some have vol\% values too large or multiple points at essentially $0 \%$. Using a quadratic rather than a linear equation for the regression is also an option if clearly needed, although it could be counter-productive if it led to better fits for larger vol\% values and thus poorer estimation of $\mathrm{T}_{1 \%}$.

Investigate Other Model Development Approaches: The spinel $\mathrm{T}_{1 \%}$ data have relatively large uncertainties (approximate $\mathrm{SD}=27^{\circ} \mathrm{C}$ ), but the recommended model still has a statistically significant LOF (meaning that the model prediction uncertainty is larger than can be accounted for by the uncertainty in spinel $\mathrm{T}_{1 \%}$ data). This is presumably due to more complicated non-linear blending effects of HLW glass components on spinel $\mathrm{T}_{1 \%}$ over the WTP HLW glass composition region than can be represented by a single quadratic or cubic polynomial-type model. There are two categories of solutions to this situation. The first is to adopt other modeling approaches that provide for better capturing local dependence of spinel $\mathrm{T}_{1 \%}$ on HLW glass composition over the full composition region of interest. This option is discussed further in Sections 11.5.3 and 11.5.4. The second is to develop models of the forms considered so far, but over smaller HLW glass composition regions where they are likely to fit and predict better. Hence, there would be multiple models covering different HLW glass composition regions. The smaller glass composition regions might correspond to specific HLW wastes or groups of similar HLW wastes, for example.

The second issue raised at the start of this section is that currently there are sufficient data only to have developed $\mathrm{T}_{1 \%}$-composition models for spinel as the primary crystalline phase. Past experience has shown that separate models are required for each type of primary crystalline phase, because of different mechanisms leading to different component effects. The WTP project will need to assess the extent to which primary phases other than spinel may occur at 1 vol\% crystallinity levels. If other primary phases can occur for glass composition subregions corresponding to some HLW wastes, the WTP project will have to decide whether to generate additional data and develop $\mathrm{T}_{1 \%}$-composition models for those primary phases, or whether there is a non-model based approach to avoid violating the $\mathrm{T}_{1 \%} \leq 950^{\circ} \mathrm{C}$ processing limit.

\subsection{Recommendations for IHLW Electrical Conductivity and Viscosity}

The recommended models for electrical conductivity (EC) and viscosity of HLW glasses perform very well within the composition and temperature region represented by the modeling datasets for these properties. However, there are limited data outside of the processing ranges for these properties. 
- The current WTP limits for glass melt electrical conductivity are 0.1 to $0.7 \mathrm{~S} / \mathrm{cm}$ in the temperature range of 1100 to $1200^{\circ} \mathrm{C}$ (Casassa 2005). Only 21 of the 208 glasses included in the modeling had calculated ECs outside of these limits within this temperature range: 4 below $0.1 \mathrm{~S} / \mathrm{cm}$ at $1100^{\circ} \mathrm{C}$ and 17 above $0.7 \mathrm{~S} / \mathrm{cm}$ at $1200^{\circ} \mathrm{C}$.

- The current WTP limits for melt viscosity are 10 to 150 poise at $1100^{\circ} \mathrm{C}$ (Casassa 2005). Of the 197 glasses included in model development, 47 had calculated viscosities outside of this range at this temperature. The calculated viscosities of these 47 glasses were all higher than 150 poise at $1100^{\circ} \mathrm{C}$. There were no glasses with calculated viscosities beneath the lower limit of 10 poise.

The limited support for applying the EC and viscosity models outside of their processing ranges could be improved with additional data. The WTP project will have to decide how likely it is that EC and viscosity may go outside their processing ranges, what the risks of such excursions would be, and the extent to which the risks could be acceptably addressed by extrapolative use of the recommended models. If the WTP project judges the risks are sufficient to need addressing, then additional data should be collected for HLW glasses with EC and viscosity outside the processing limits. Such data could first be used to validate the models recommended in this report, and if necessary to develop new models with improved predictive performance for EC and viscosity outside their processing ranges.

\subsection{Recommendations for IHLW TCLP-Cd Release}

Property-composition data and models for TCLP-Cd release were previously discussed by Kot et al. (2004). At that time, the data used for developing TCLP models and selecting a recommended model consisted of 100 out of the 102 HLW glasses in the HLW02 and HLW03 series. As seen in Table 9.3, the single-component constraints for the TCLP-Cd release model validity region are narrower for several HLW glass components than for the other properties modeled in this report (PCT, spinel $\mathrm{T}_{1 \%}, \mathrm{EC}$, and viscosity). If the WTP project needs the TCLP$\mathrm{Cd}$ release model to apply over larger HLW glass composition regions similar to those for the other four properties, additional property-composition data would need to be collected and the TCLP-Cd modeling work updated.

The TCLP-Cd model validity constraint of $0.80 \mathrm{mg} / \mathrm{L}$ was selected because the recommended model accurately predicts TCLP-Cd releases for the modeling dataset up to that value. However, as discussed in Section 9.2.1, the recommended model under-predicted TCLP$\mathrm{Cd}$ releases for many glasses with releases above $0.25 \mathrm{mg} / \mathrm{L}$. However, all but one of those validation glasses were outside the composition region covered by the TCLP-Cd modeling dataset. The one glass with a larger TCLP release that was inside the modeling composition region (HLW98-42) had a TCLP-Cd release of 0.484, slightly above the delisting limit. The recommended TCLP-Cd model significantly under-predicts this release. These model validation results raise the question whether the recommended TCLP-Cd model yields accurate predictions above $0.25 \mathrm{mg} / \mathrm{L}$ up to $0.80 \mathrm{mg} / \mathrm{L}$. Hence, it is recommended that the WTP project collect additional data on HLW glasses with TCLP-Cd releases somewhat below and above the 0.48 $\mathrm{mg} / \mathrm{L}$ delisting limit. 


\subsection{General Recommendations}

Sections 11.5.1 to 11.5.4 present general recommendations not specific to a given HLW glass property. Whether each recommendation is considered necessary or optional is discussed.

\subsubsection{Recommendation for Additional Work to Assess Suitability of the Recommended HLW Glass Property Models}

Sections 5.9, 6.8, 7.7, and 8.7 discussed separate work that is planned to assess the impact on WTP operations and compliance of HLW glass composition and model uncertainties using the HLW glass property models recommended in this report. This separate work should also include assessment of the TCLP-Cd release model recommended in Kot et al. (2004). This separate work includes the second iterations of glass formulation algorithm development and verification work (planned to be performed by WTP project staff) and compliance methodology and verification work (planned to be conducted by PNNL). It is recommended that these planned future work scopes be completed as a necessary step in either (i) verifying the recommended HLW glass property models are sufficient for WTP needs, or (ii) deciding that additional property-composition data collection and model development and/or validation work is needed.

\subsubsection{Recommendations for Replication}

In any future property-composition data and model development efforts, it is recommended that consideration be given to including the same glasses as replicates in each new study. At least one and up to five such replicate glasses should be included in each new study, depending on the number of glasses in the study. Including such replicate glasses would provide a better basis for directly assessing whether the new data are biased (i.e., impacted by systematic effects). As an illustration, Figure 8.13 shows that the recommended viscosity model appears to under-predict viscosity for the HLW05 group of glasses discussed in Section 2.1.4. It is not clear whether this is due to model inadequacy or a bias in the data for the HLW05 group. Including replicates of the same three to five glasses in each new study would provide a direct basis for assessing and possibly correcting for any biases in data. However, the relative benefit of spending this effort (glass fabrication and testing) on replicates rather than new glass compositions should be assessed before proceeding. This recommendation to include in new studies replicates from past studies should be considered as advisable for any future work to generate property-composition data for developing and/or validating HLW glass propertycomposition models.

Because of the restriction on randomization that occurs in measuring $\mathrm{EC}$ and viscosity data (see Sections C.3.2 and C.3.3 of Appendix C), it would be useful to collect replicate measurements of these properties at some temperature(s) for each glass. Currently, these properties are measured at four temperatures for each glass, without replication because the benefits of such replication have been judged to not justify the additional cost. Replication of 
viscosity and EC measurements at one or more temperature values would provide a basis for directly estimating the standard deviation of the uncertainty associated with measuring these properties. Currently, this can only be estimated indirectly, and is inflated by any LOF of the composition-temperature portion of the viscosity or EC model. Replication of viscosity and EC measurements at one or more temperatures would also provide for assessing the LOF of the portions of EC and viscosity models involving composition-temperature terms. This recommendation would improve the ability to quantify viscosity and EC measurement uncertainty and to develop and future EC and viscosity models, but it is not considered necessary.

\subsubsection{Recommendation to Investigate Local As Well As Global Modeling Approaches}

The approach of using a single "global" model to predict PCT releases $(\mathrm{B}, \mathrm{Li}$, and $\mathrm{Na})$, spinel $\mathrm{T}_{1 \%}$, and TCLP-Cd release as functions of HLW glass composition may need to be revisited in the future under certain situations. One such situation would be collecting additional data with higher PCT and TCLP-Cd releases, as discussed in Sections 11.1 and 11.4, respectively. Another situation would be collecting additional property-composition data over a wider region of HLW glass compositions corresponding to a wider region of HLW compositions. Under such situations, a single global model may not be able to adequately approximate the changing relationship between a given property and HLW glass composition over a wider composition region. It may be necessary to investigate in any future modeling work the use of "local" rather than "global" modeling approaches to obtain models having more accurate predictions of IHLW properties with smaller prediction uncertainties. One type of local modeling approach would be to develop multiple models over smaller, local regions of HLW glass composition space. Past experience has shown that linear mixture models or partial quadratic mixture models can be sufficiently accurate with lower uncertainties over less expansive glass compositions regions. Another type of local modeling approach would be to use non-parametric regression methods such as local linear (or polynomial) regression, neural networks, or others. Such modeling methods are not restricted by requiring the same global model form to apply over all subregions of the glass composition region of interest. The non-parametric regression methods have the disadvantage of requiring larger datasets with more evenly distributed data than does the global, parametric modeling approach. However, this issue could be addressed by collecting additional data as described subsequently in Section 11.5.4, and combining such data with data collected so far. This recommendation should be considered advisory rather than necessary at this point, pending the completion of work to assess the suitability of the PCT and spinel $\mathrm{T}_{1 \%}$ models recommended in this report, and the TCLP-Cd release model recommended in Kot et al. (2004), given their limitations (as discussed in Sections 5.9, 6.8, and 11.4).

\subsubsection{Recommendation for Space-Filling Experimental Design}

For the work in this report, glass compositions used to develop property-composition models were a combination of 
- $\quad$ statistically designed test matrices developed using a layered design approach (Piepel et al. 1993, Piepel et al. 2002), which includes extreme compositions on the outer layer of a composition region, as well as more reasonable compositions on inner layers of a composition region

- actively designed glasses developed using glass science methods for specific waste compositions or to achieve other specific goals.

This combined approach has worked well for the forms of models considered in this report. However, the limited data and associated restrictions on PCT models for predicting normalized releases near and above their contract limits could be determined by the WTP Project to be too restrictive for WTP HLW vitrification operations. Hence, it may be necessary to consider other model forms for PCT releases. Similarly, although the recommended spinel $\mathrm{T}_{1 \%}$ model yields unbiased predictions over the range of modeling data, prediction uncertainty is relatively high. This might be improved by use of different model forms.

The TCLP-Cd release model recommended in Kot et al. (2004) was based only on two statistically designed test matrices (HLW02 and HLW03). Later series of tests that collected data for the four properties modeled in this report covered wider compositional regions, as discussed in Section 11.4.

In the future, glass composition regions may need to be expanded by adding additional components or expanding the ranges of components (e.g., in the TCLP-Cd situation). In such cases, it may be necessary to consider more advanced property-composition modeling approaches (e.g., local or nonparametric modeling approaches as discussed in Section 11.4.3). A more even coverage of the HLW glass composition region would provide better support for such modeling approaches, which can better capture higher-order and/or local nonlinear composition effects. These types of more advanced modeling approaches may be necessary to more accurately predict HLW glass properties over larger composition regions.

Space-filling designs have as a goal the uniform coverage of the region of interest. Such designs should be considered for any future IHLW property-composition data collection and modeling work where advanced nonparametric or local regression methods may be investigated. This recommendation should be considered advisory rather than necessary at this point, pending the completion of work to assess the suitability of the PCT and spinel $\mathrm{T}_{1 \%}$ models recommended in this report, and the TCLP-Cd release model recommended by Kot et al. (2004), given the limitations of these models (as discussed in Sections 5.8, 6.8, and 11.4). 


\section{SECTION 12 QUALITY ASSURANCE}

The QA requirements for the work in this report are described in the approved Test Plans for components of the work that were performed at the Vitreous State Laboratory (VSL) of the Catholic University of American (Gan and Pegg 2002) and at the Pacific Northwest National Laboratory (PNNL) (Piepel and Cooley 2003). The VSL and PNNL are separate and independent sub-contractors to Bechtel National, Inc. (BNI) for WTP support work (VSL's subcontract is through Duratek, Inc.) with separate and independent responsibilities to BNI for QA compliance. Accordingly, neither VSL nor PNNL make any representations or claims as to the adequacy or appropriateness of each other's QA program for any of the work presented in this report. Similarly, Duratek's responsibility is limited solely to the Duratek and VSL QA programs.

The portions of this work performed at VSL were conducted under a quality assurance program compliant with NQA-1 (1989), NQA-2a (1990) Part 2.7, and the Quality Assurance Requirements and Description (QARD) document (U. S. DOE-RW 2000 and 2004). This program is supplemented by a Quality Assurance Project Plan for WTP work (VSL 2003) that is performed at VSL. Test and procedure requirements by which the testing activities are planned and controlled are also defined in that plan. The program is supported by VSL standard operating procedures that were used for this work (VSL 2006).

All simulated HLW glasses were prepared and characterized at VSL as part of the contract work under Bechtel National, Inc. The QA program as described above was in place during all of this work. Five actual waste glasses were prepared and characterized at PNNL and SRNL. The following QA programs were implemented for the preparation and testing of the actual waste glasses, which have been reported previously:

- AZ-101 glass at PNNL (Hrma et al. 2004): This work was performed to the quality requirements of NQA-1 (1989), NQA-2a (1990) Part 2.7, and QARD (2004). A matrix that cross-references the NQA-1, 2a and QARD requirements with the procedures at PNNL was given by Hrma et al. (2004), including justification for those requirements that were not implemented.

- AZ-102 glass and C-104 glass at PNNL (Smith et al. 2001): Feed preparation and glass fabrication work was conducted under the quality requirements of the Standards-Based Management System as described in the document BNFL Phase B-1 Support Quality Assurance Planning Document. The work elements relating to glass product testing were conducted to meet the requirements of QARD and the Nuclear Quality Assurance Requirements and Description Manual.

- C-106 glass at SRNL (Schumacher et al. 2002): The QA program for this work was in compliance with the applicable elements of QARD for areas affecting IHLW development, qualification, characterization, and certification. 
- AY-102/C-106 glass at SRNL (Crawford et al. 2005): This work was conducted in accordance with the SRNL QA program which complied with NQA-1 (1989), NQA-2a (1990) Part 2.7, and QARD (2004). The Task Technical and Quality Assurance Plan (Crawford 2003) provided the specific quality requirements.

PNNL's Quality Assurance Program is based on requirements defined in the United States Department of Energy (DOE) Order 414.1C, Quality Assurance and 10 CFR 830, Energy/Nuclear Safety Management, Subpart A -- Quality Assurance Requirements (a.k.a. the Quality Rule). PNNL has chosen to implement the requirements of DOE Order 414.1C and 10 CFR 830, Subpart A by integrating them into the Laboratory's management systems and daily operating processes. The procedures necessary to implement the requirements are documented through PNNL's Standards-Based Management System.

The QA requirements for PNNL work in this report were met through the Quality Assurance Plan (PNNL 2007a) for the River Protection Project-Waste Treatment Plant Support Program (RPP-WTP Support Program). The RPP-WTP Support Program implementing procedures (PNNL 2007b) comply with the requirements of NQA-1 (1989), NQA-2a (1990) subpart 2.7, and QARD (U. S. DOE-RW 2000 and 2004).

The following specific areas of this work are subject to the QARD: glass preparation, glass compositional analysis, PCT testing, and PCT model development. All work in these areas was performed according to VSL and PNNL QA programs and implementing procedures that are compliant with QARD.

Although not directly relevant to the applications described in this report, it is noted that the glass preparation in this work also was subject to the requirements in Blumenkranz (2001). Under this document appropriate applications are defined of the additional documents EPA (1993) and EPA (2001). 


\section{SECTION 13 REFERENCES}

Abel, K. (2007), “Test Exception to Test Specifications - 24590-HLW-TSP-RT-01-006, Rev 1, HLW Glass Property Composition Modeling \& 24590-WTP-TSP-RT-02-001, Rev 0, Statistics for HLW \& LAW Glass Property-Composition Modeling. Test Plan - VSL-02T7800-1, Rev 1, HLW Glass Property Composition Modeling," 24590-WTP-TEF-RT-07-00017, River Protection Project, Waste Treatment Plant, Richland, WA, December 5, 2007.

Atkinson, A. C. and A. N. Donev (1992), Optimal Experimental Design, Oxford University Press, New York, 1992.

ASTM (2002), Standard Test Methods for Determining Chemical Durability of Nuclear, Hazardous, and Mixed Waste Glasses: The Product Consistency Test, ASTM C1285-02, American Society for Testing and Materials, West Conshohocken, PA, 2002.

Barnes, S. M. (1995), West Valley Demonstration Project Waste Form Qualification Report Waste Form Specifications, WVDP-186, Section 1.3, Rev. 1, West Valley Nuclear Services Company Inc., West Valley, NY, 1995.

Blumenkranz, D.B. (2001), Quality Assurance Project Plan for Testing Programs Generating Environmental Regulatory Data, PL-24590-QA00001, Rev. 0, River Protection Project, Waste Treatment Plant, Richland, WA, June 7, 2001.

Casassa, R. P. (2005), River Protection Project-Waste Treatment Plant Engineering Specification for High Level Waste Melters, 24590-HLW-3PS-AE00-TP-001, Rev. 0, River Protection Project, Waste Treatment Plant, Richland, WA, January 31, 2005.

CH2M Hill (2000), Tank Farm Contractor Operations and Utilization Plan, HNF-SD-WM-SP012, Rev. 2, CH2M Hill Hanford Group, Richland WA, April 2000.

CH2M Hill (2001), Tank Farm Contractor Operations and Utilization Plan, HNF-SD-WM-SP012, Rev. 3A, CH2M Hill Hanford Group, Richland WA, December 2001.

Cooley, S. K., G. F. Piepel, H. Gan, W. K. Kot, and I. L. Pegg (2003), Augmentation Test Matrix to Support TCLP Model Development for RPP-WTP HLW Glasses, VSL-03S3780-1, Rev. 1, Vitreous State Laboratory, The Catholic University of America, Washington, DC, October 22, 2003.

Cornell, J. A. (2002), Experiments with Mixtures, Third Edition, John Wiley and Sons, NY, 2002. 
Crawford, C. L. (2003), Task Technical and Quality Assurance Plan for AY-102/C-106 HLW (Env. D) Rheology, Vitrification and Product Testing (U), WSRC-TR-2003-00165, Rev. 0 \& SRT-RPP-2003-00072, Rev. 0, Westinghouse Savannah River Company, Aiken, SC, August 21, 2003.

Crawford, C. L., E. K. Hansen, R. F. Schumacher, and N. E. Bibler (2005), Vitrification and Product Testing of AY-102/C-106 HLW (Env. D) (U), WSRC-TR-2005-00410 (SRNL-RPP2005-00047), Savannah River National Laboratory, Aiken, SC, November 2005.

Deng, Y. (2004), Dynamic (G2) Model Design Document, 24590-WTP-MDD-PR-01-002 Rev. 7, River Protection Project, Waste Treatment Plant, Richland, WA, October 25, 2004.

Design-Expert (2000), Design-Expert - Software for Design of Experiments, Version 6.0.10, Stat-Ease, Inc., Minneapolis, MN, 2000.

DOE-EM (1996), Waste Acceptance Product Specifications for Vitrified High-Level Waste Forms, EM-WAPS, Revision 2, U. S. Department of Energy, Office of Environmental Management, Washington, DC, December 1996.

DOE-ORP (2000), Design, Construction, and Commissioning of the Hanford Tank Waste Treatment and Immobilization Plant, Contract Number: DE-AC27-01RV14136, U. S. Department of Energy, Office of River Protection, Richland, WA, 2000.

DOE-RW (2000), Quality Assurance Requirements and Description, DOE/RW-0333P, Revision 10, U. S. Department of Energy, Office of Civilian Radioactive Waste Management, Washington, DC, April, 2000.

DOE-RW (2004), Quality Assurance Requirements and Description, DOE/RW-0333P, Revision 13, U. S. Department of Energy, Office of Civilian Radioactive Waste Management, Washington, DC, August 23, 2004.

DOE-RW (2002), Waste Acceptance System Requirements Document, DOE/RW-0351, Revision 4, U. S. Department of Energy, Office of Civilian Radioactive Waste Management, Washington, DC, January 2002.

Doremus, R. H. (1979), "Chemical Durability of Glass," in Treatise on Material Science and Technology, Vol. 17, 41-69 Tomazawa, M. and Dormeus, R. H., (Eds), Academic Press, New York, 1979.

Draper, N. R. and H. Smith (1998), Applied Regression Analysis, Third Edition, John Wiley and Sons, Inc., New York, NY, 1998.

EPA (1993), Test Methods for Evaluating Solid Wastes-Physical/Chemical Methods, SW-846, $3^{\text {rd }}$ edition, as amended by Updates I (July 1992), II and IIA (August 1993), IIB, III and IIIA, U. S. Environmental Protection Agency, Washington, DC, 1993. 
EPA (2001), EPA Requirements for Quality Assurance Project Plans for Environmental Data Operations, EPA QA/R-5, U. S. Environmental Protection Agency, Washington, DC, March 2001.

Excel (2003), Microsoft Office Excel 2003, SP2 (11.8146.8132), Microsoft Corporation, Redmond, WA, 2003.

Feng, Z, F. Perez-Cardenas, H. Gan, and I. L. Pegg (2004), Summary and Recommendations on Viscosity and Electrical Conductivity Model Forms to Support LAW Vitrification, VSL03L4480-2, Letter Report, Rev. 1, Vitreous State Laboratory, The Catholic University of America, Washington, DC, October 22, 2004.

Freund, R. J. and R. C. Littell (1995), SAS System for Regression, Second Edition, SAS Institute, Inc., Cary, NC, 1995.

Fu, S. S. and I. L. Pegg (1998), Glass Formulation and Testing with TWRS HLW Simulants, Final Report, Vitreous State Laboratory, The Catholic University of America, Washington, DC, January 18, 1998.

Gan, H., Z. Feng, and I. L. Pegg (2004), Summary and Recommendations on Viscosity and Electrical Conductivity Model Forms to Support HLW Vitrification, VSL-04L4780-1, Letter Report, Rev. 0, Vitreous State Laboratory, The Catholic University of America, Washington, DC, October 22, 2004.

Gan, H. and I. L. Pegg (2001), Development of Property-Composition Models for RPP-WTP HLW Glasses, VSL-01R3600-1, Final Report, Rev. 0, Vitreous State Laboratory, The Catholic University of America, Washington, DC, July 30, 2001.

Gan, H. and I. L. Pegg (2002), HLW Glass Property Composition Modeling, Test Plan, VSL-02T7800-1, Rev. 1, Vitreous State Laboratory, The Catholic University of America, Washington, DC, April 16, 2002.

Hahn, G. J. and S. S. Shapiro (1967), Statistical Models in Engineering, John Wiley and Sons, New York, 1967.

Hench, L. L. and D. E. Clark (1978), "Physical Chemistry of Glass Surfaces," J. Non-Crystalline Solids, 28, 83-105, 1978.

Hrma, P., G. F. Piepel, M. J. Schweiger, D. E. Smith, D.-S. Kim, P. E. Regate, J. D. Vienna, C. A. LoPresti, D. B. Simpson, D. K. Peeler, and M. H. Langowski (1994), Property/Composition Relationships for Hanford High-Level Waste Glass Melting at $1150^{\circ} \mathrm{C}$, PNL-10359, Vol. 1 and 2, Pacific Northwest Laboratory, Richland, WA, December 1994.

Hrma, P, D. J. Bates, P. R. Bredt, J. V. Crum, L. R. Greenwood, and H. D. Smith (2004). Vitrification and Product Testing of AZ-101 Pretreated High-Level Waste Envelope D Glass, WTP-RPT-116, Rev. 0, Battelle-Pacific Northwest Division, Richland, WA, September 2004. 
Ihaka, R. and R. Gentleman (1996), "R: A Language for Data Analysis and Graphics", Journal of Computational and Graphical Statistics, 5, 299-314, 1996.

Jantzen, C. M., N. E. Bibler, D. C. Beam, C. L. Crawford, and M. A. Pickett (1993), Characterization of the Defense Waste Processing Facility (DWPF) Environmental Assessment (EA) Glass Standard Reference Material, WSRC-TR-92-346, Westinghouse Savannah River Company, Aiken, SC, June, 1993.

Jantzen, C. M., J. B. Pickett, K. G. Brown, T. B. Edwards, and D. C. Beam (1998), Process/Product Models for the Defense Waste Processing Facility (DWPF): Part I. Predicting Glass Durability from Composition Using a Thermodynamic Hydration Energy Reaction Model (THERMO), WSRC-TR-93-0672, Westinghouse Savannah River Company, Aiken, SC, 1998.

Kelly, S. (2002), “Test Exception for VSL-02T7800-1,” Rev. 1, 24590-WTP-TEF-RT-02-07, River Protection Project, Waste Treatment Plant, Richland, WA, October 16, 2002.

Kinoshita, M., M. Harada, Y. Sato, and Y. Hariguchi (1991), "Percolation Phenomenon for Dissolution of Sodium Borosilicate Glass in Aqueous Solution," Journal of the American Ceramic Society, 74, 783-787, 1991.

Kirkbride, R. A., G. K. Allen, P. J. Certa, T. W. Crawford, and P. G. Haigh (2007), Tank Farm Contractor Operation and Utilization Plan, HNF-SD-WM-SP-012, Rev. 6, CH2M Hill Hanford Group, Inc., Richland, WA, January 16, 2007.

Kot, W. K., H. Gan, Z. Feng, F. Perez-Cardenas, I. L. Pegg, S. K. Cooley, and G. F. Piepel (2005a), Development of Phase 1 IHLW Models for PCT Response and One-Percent Crystal Fraction Temperature (T $\left.T_{1 \%}\right)$, VSL-05R5780-1, Rev. 0, Vitreous State Laboratory, The Catholic University of America, Washington, DC, April 12, 2005.

Kot, W. K., H. Gan, and I. L. Pegg (2005b), Preparation and Testing (T $T_{1 \%}$ and PCT) of HLW Matrix Glasses to Support WTP Property-Composition Model Development, VSL-05R5780-2, Rev. 0, Vitreous State Laboratory, The Catholic University of America, Washington, DC, October 12, 2005.

Kot, W. K., H. Gan, and I. L. Pegg (2006a), Preparation and Testing of HLW Glasses to Support Development of WTP IHLW Formulation Algorithm, Final Report, VSL-06R1240-1, Rev. 0, Vitreous State Laboratory, The Catholic University of America, Washington, DC, December 15, 2006.

Kot, W. K., H. Gan, and I. L. Pegg (2006b), Preparation and Testing of HLW Matrix Glasses to Support Development of WTP Phase 2 Property-Composition Models, Final Report, VSL06R6780-2, Rev. 0, Vitreous State Laboratory, The Catholic University of America, Washington, DC, November 7, 2006. 
Kot, W. K., I. Joseph, and I. L. Pegg (2005c), Comparison of HLW Simulants, Actual Waste, and Melter Glasses, VSL-05R5760-1, Rev. 0, Vitreous State Laboratory, The Catholic University of America, Washington, DC, December 2, 2005.

Kot, W. K., K. Klatt, H. Gan, I. L. Pegg, S. K. Cooley, G. F. Piepel, and D. J. Bates (2004), Regulatory Testing of RPP-WTP HLW Glass to Support Delisting Compliance, Final Report, VSL-04R4780-1, Rev. 0, Vitreous State Laboratory, The Catholic University of America, Washington, DC, September 30, 2004.

Kot, W. K., K. Klatt, I. S. Muller, C. N. Wilson, I. L. Pegg, D. J. Bates, G. F. Piepel, and D. R. Weier (2003a), Regulatory Spike Testing of RPP-WTP LAW and HLW Glasses for Compliance with Land Disposal Restriction, VSL-03R3760-1, Rev. 1, Vitreous State Laboratory, The Catholic University of America, Washington, DC, August 1, 2003.

Kot, W. K., K. Klatt, and I. L. Pegg (2003b), Glass Formulation to Support Melter Runs with HLW Simulants, Final Report, VSL-03R3760-2, Rev. 0, Vitreous State laboratory, The Catholic University of America, Washington, DC, September 30, 2003.

Kot, W. K. and I. L. Pegg (2001), Glass Formulation and Testing with RPP-WTP HLW Simulants, VSL-01R2540-2, Rev. 0, Vitreous State Laboratory, The Catholic University of America, Washington, DC, February 16, 2001.

Kot, W. K. and I. L. Pegg (2003), HLW Glass Formulation to Support AZ-101 Actual Waste Testing, VSL-02R3770-1, Rev. 0, Vitreous State Laboratory, The Catholic University of America, Washington, DC, March 21, 2003.

Kot, W. K. and I. L. Pegg (2004), HLW Glass Formulation to Support C-106/AY-102 Actual Waste Testing, Final Report, VSL-04R4770-1, Rev. 0, Vitreous State Laboratory, The Catholic University of America, Washington, DC, August 12, 2004.

Matlab (2006), Version 7.3.0.267 (R2006b), The Mathworks, Inc. Natick, Massachusetts, 2006.

Mika, M., M. J. Schweiger, J. D. Vienna, and P. Hrma (1997), “Liquidus Temperature of Spinel Precipitating High-Level Glass,” Materials Research Society Proceedings, 465, 71-78 (1997).

Montgomery, D. C., E. A. Peck, and G. G. Vining (2001), Introduction to Linear Regression Analysis, Third Edition, John Wiley and Sons, New York, NY, 2001.

Muller, I. S., A. C. Buechele, and I. L. Pegg (2001), Glass Formulation and Testing with RPPWTP LAW Simulants, VSL-01R3560-2, Vitreous State Laboratory, The Catholic University of America, Washington, DC, February 23, 2001.

Musick, C. A. (2002), "Guidance for Development of IHLW Augmentation Matrix," CCN043619, C. A. Musick Memo to I. L. Pegg and G. F. Piepel, River Protection Project, Waste Treatment Plant, Richland, WA, November 11, 2002. 
Musick, C. A. (2004), "Guidance for Conducting Scoping Studies on Non-Spinel Crystallization from Simulated HLW Glass Melts," CCN 085763, C. A. Musick Memo to I. L. Pegg, River Protection Project, Waste Treatment Plant, Richland, WA, November 1, 2004.

Musick, C. A. (2005), "Guidance for Extending Database of Spinel Crystallization and PCT in Simulated HLW Glass Melts," CCN 085766, C. A. Musick Memo to I. L. Pegg, River Protection Project, Waste Treatment Plant, Richland, WA, January 19, 2005.

Myers, R. H. and D. C. Montgomery (1995), Response Surface Methodology: Process and Product Optimization Using Designed Experiments, John Wiley and Sons, New York, NY, 1995.

Myers, R. H., D. C. Montgomery, and G. G. Vining (2002), Generalized Linear Models: With Applications in Engineering and the Sciences, John Wiley and Sons, New York, NY, 2002.

Olson, K. M. (1993), Fabrication and Leaching of West Valley Demonstration Project Glasses: Ten Quarter 2 and Ten Quarter 3 Glasses, Letter Report, Pacific Northwest National Laboratory, Richland, WA, 1993.

Olson, K. M., G. F. Piepel, S. C. Marschman, and G. K. Whiting (1994), Product Consistency Testing of West Valley Compositional Variation Glasses, PNL-10901, Pacific Northwest Laboratory, Richland, WA, 1994.

Pegg, I. L. (2002), "Comments on Guidance for Development of IHLW Augmentation Matrix," I. L. Pegg Memo to C. A. Musick, Vitreous State Laboratory, The Catholic University of America, Washington, DC, November 13, 2002.

Perez, J. M. (2002), Integrated DM1200 Testing of HLW Compositions Using Bubblers, RPPWTP Test Specification, 24590-HLW-TSP-RT-02-005, Rev 0, Bechtel National Inc., Richland, WA, April 1, 2002.

Perez-Cardenas, F., H. Gan, and I. L. Pegg (2003), Summary and Recommendations on PCT Model Form to Support HLW Vitrification, VSL-03L4780-1, Rev. 0, Vitreous State Laboratory, The Catholic University of America, Washington, D. C., December 15, 2003.

Petkus, L. (2003) “Canister Centerline Cooling Data, Revision 1,” RPP-WTP Memorandum, L. Petkus to C. Musick, CCN 074851, October 29, 2003.

Piepel, G. F. (2003), MIXSOFT-Software for the Design and Analysis of Mixture and Other Constrained Region Experiments, User's Guide Version 2.4.1, MIXSOFT Mixture Experiment Software, Richland, WA, January 2003.

Piepel, G. F. (2006a), MIXSOFT-Software for the Design and Analysis of Mixture and Other Constrained Region Experiments, Version 2.5, MIXSOFT Mixture Experiment Software, Richland, WA, March 2006. 
Piepel, G.F. (2006b), "A Note Comparing Component-Slope, Scheffé, and Cox Parameterizations of the Linear Mixture Experiment Model," Journal of Applied Statistics, 33, 397-403.

Piepel, G.F. (2007), “A Component Slope Linear Model for Mixture Experiments,” Quality Technology and Quantitative Management, 4, 331-343.

Piepel G. F., B. G. Amidan, A. Heredia-Langner, D. R. Weier, and S. K. Cooley (2005), Statistical Methods and Results for WTP IHLW and ILAW Compliance, PNWD-3568 (WTPRPT-072), Rev. 0, Battelle-Pacific Northwest Division, Richland, WA, April 2005.

Piepel, G. F., C. M. Anderson, and P. E. Redgate (1993), "Response Surface Designs for Irregularly-Shaped Regions" (Parts 1, 2, and 3), 1993 Proceedings of the Section on Physical and Engineering Sciences, 205-227, American Statistical Association, Alexandria, VA, 1993.

Piepel, G. F. and S. K. Cooley (2003), "Statistics for IHLW and ILAW Property-Composition Modeling," Test Plan, TP-RPP-WTP-179, Rev. 1, Battelle, Pacific Northwest Division, Richland, WA, July 8, 2003.

Piepel, G. F. and S. K. Cooley (2006), “Automated Method for Reducing Scheffé Linear Mixture Experiment Models”, PNWD-SA-7469, Rev. 0, Battelle-Pacific Northwest Division, Richland, WA. (To appear in a special Response Surface Methodology issue of Quality Technology and Quantitative Management, December 2007).

Piepel, G. F., S. K. Cooley, H. Gan, W. K. Kot, and I. L. Pegg (2002a), Test Matrix to Support TCLP Model Development for RPP-WTP HLW Glasses, Summary Report, VSL-02S7800-1, Rev. 0, Vitreous State Laboratory, The Catholic University of America, Washington, DC, November 14, 2002.

Piepel, G. F., S. K. Cooley, D. K. Peeler, J. D. Vienna, and T. B. Edwards (2002b), “Augmenting a Waste Glass Mixture Experiment Study with Additional Glass Components and Experimental Runs," Quality Engineering, 15, 91-111, 2002.

Piepel, G. F., S. K. Cooley, I. Muller, H. Gan, I. Joseph, and I. L. Pegg (2007), ILAW PCT, VHT, Viscosity, and Electrical Conductivity Model Development, VSL-07R1230-1, Rev. 0, Vitreous State Laboratory, The Catholic University of America, Washington, D. C., June 28, 2007.

Piepel, G. and T. Redgate (1997), "Mixture Experiment Techniques for Reducing the Number of Components Applied for Modeling Waste Glass Sodium Release," Journal of the American Ceramic Society, 80, 3038-3044, 1997.

Piepel, G. F., J. M. Szychowski, and J. L. Loeppky (2002c), "Augmenting Scheffé Linear Mixture Models with Squared and/or Crossproduct Terms," Journal of Quality Technology, 34, 297-314, 2002. 
Plaisted, T., P. Hrma, J. Vienna, and A. Jiricka (2000), "Liquidus Temperature and Primary Crystalline Phases in High-Zirconia High-Level Waste Borosilicate Glasses," Materials Research Society Symposium Proceedings, 608, 709-714.

PNNL (2007a), River Protection Project - Waste Treatment Plant Support Program Quality Assurance Plan (QAP), RPP-WTP-QA-001, Rev. 0, Pacific Northwest National Laboratory, Richland, WA, February, 2007.

PNNL (2007b), River Projection Project - Waste Treatment Plant Support Program Quality Assurance Manual (QAM), RPP-WTP-QA-003, Rev. 0, Pacific Northwest National Laboratory, Richland, WA, February 2007.

Pye, L. D., V. D. Frecheet and N. J. Kreidl (1978), Editors, Borate Glasses, Structure, Properties, Applications, Plenum Press, New York, NY, 1978.

R Development Core Team (2006), R: A Language and Environment for Statistical Computing, $\mathrm{R}$ Foundation for Statistical Computing, Vienna, Austria. ISBN 3-900051-07-0, URL http://www.R-project.org.

Rao, Q., G. F. Piepel, P. Hrma, and J. V. Crum (1997), "Liquidus Temperatures of HLW Glasses with Zirconium-Containing Primary Crystalline Phases," Journal of Non-Crystalline Solids, 220, 17-29.

Schumacher, R. F., C. L. Crawford, D. M. Ferrara, and N. E. Bibler (2002), Final Report for Crucible Scale Vitrification of Pretreated C-106 Sludge Mixed with Secondary Waste, WSRCTR-2001-00252 (SRT-RPP-2001-00068) Rev. 0, Savannah River Site, Aiken, SC, July 18, 2002.

SAS (2005), SAS Release 9.1.3, SAS Institute, Inc., Cary, NC, 2005.

Shukla, G. K. (1972), “On the Problem of Calibration,” Technometrics, 14, 547-553, 1972.

Smith, G. L., D. R. Bates, R. W. Goles, L. R. Greenwood, R. C. Lettau, G. F. Piepel, M. J. Schweiger, H. D. Smith, M. W. Urie, and J. J. Wagner (2001), Vitrification and Product Testing of C-104 and AZ-102 Pretreated Sludge Mixed with Flowsheet Quantities of Secondary Wastes, PNNL-13452 (WTP-RPT-006), Rev. 0, Pacific Northwest National Laboratory, Richland, WA, February 2001.

Swanberg, D. J. (2001), HLW Glass Property Composition Modeling, BNI Test Specification, 24590-HLW-TSP-RT-01-006, Rev. 1, River Protection Project, Waste Treatment Plant, Richland, WA, November 27, 2001.

Swanberg, D. J. (2002), Statistics for HLW \& LAW Glass Property-Composition Modeling, BNI Test Specification, 24590-WTP-TSP-RT-02-001, Rev. 0, River Protection Project, Waste Treatment Plant, Richland, WA, May 20, 2002. 
Vienna, J. D., S. K. Cooley, J. V. Crum, T. B. Edwards, J. Matyas, D. K. Peeler, G. F. Piepel, and D. E. Smith (2003), Liquidus Temperature Testing and Model Evaluation Results, PNWD3369 (WTP-RPT-085), Rev. 0, Battelle-Pacific Northwest Division, Richland, WA, December 2003.

Vienna, J. D., D.-S. Kim, and P. Hrma (2002), Database and Interim Glass Property Models for Hanford HLW and LAW Glass, PNNL-14060, Pacific Northwest Laboratory, Richland, WA, September 2002.

Vienna, J. D. and D.-S. Kim (2007), Preliminary IHLW Formulation Algorithm Description, 24590-HLW-RPT-RT-05-001, Draft, Rev. C, River Protection Program, Waste Treatment and Immobilization Plant, Richland, WA, 2007.

Vora, V. (2004), Dynamic (G2) Model Version 3.1 Verification and Validation Report, 24590WTP-VV-PO-04-0004 Rev. 0, River Protection Project, Waste Treatment Plant, Richland, WA, September 2, 2004.

VSL (2002), "Crucible Melts," Technical Procedure TPC-CM, Rev. 1, Vitreous State Laboratory, The Catholic University of America, DC, July 10, 2002.

VSL (2003), Quality Assurance Project Plan for RPP-WTP Support Activities Conducted by VSL, QAPP, Rev. 6, Vitreous State Laboratory, The Catholic University of America, Washington, DC, November 12, 2003.

VSL (2006), Master List of Controlled VSL Manuals and Standard Operating Procedures in Use, QA-MLCP, Rev. 19, Vitreous State Laboratory, The Catholic University of America, Washington, DC, September 20, 2006.

Weier, D. R. and G. F. Piepel (2003), Methodology for Adjusting and Normalizing Analyzed Glass Compositions, PNWD-3260 (WTP-RPT-049), Battelle-Pacific Northwest Division, Richland, WA, March 2003.

Welch, W. J. (1987), ACED, Algorithms for the Construction of Experimental Designs, Users Guide Version 1.6.1, University of Waterloo, Waterloo, Ontario, Canada, 1987.

Westsik, Jr., J. H. (2003a), “Test Exception to Test Specification 24590-WTP-TSP-RT-02-001 Rev. 0 and Test Plan TP-RPP-WTP-179," 24590-WTP-TEF-RT-03-040, River Protection Project, Waste Treatment Plant, Richland, WA, August 7, 2003.

Westsik, Jr., J. H. (2003b), “Test Exception to Test Specification 24590-HLW-TSP-RT-01-006 HLW Glass Property Composition Modeling and Test Plan VSL-02T7800-1 HLW Glass Property Composition Modeling," 24590-WTP-TEF-RT-03-078, River Protection Project, Waste Treatment Plant, Richland, WA, December 10, 2003. 
Table 2.1. Components with Lower and Upper Limits (wt\%) for Groups of HLW Glasses.

\begin{tabular}{|c|c|c|c|c|c|c|c|c|c|c|c|c|c|c|c|c|c|c|c|c|}
\hline \multirow{3}{*}{ 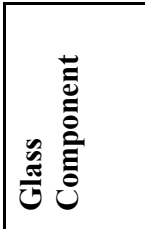 } & \multicolumn{4}{|c|}{ HLW02 } & \multicolumn{4}{|c|}{ HLW03 } & \multicolumn{4}{|c|}{ HLW05 } & \multicolumn{4}{|c|}{ HLW06 } & \multicolumn{4}{|c|}{ HLW07 } \\
\hline & \multicolumn{2}{|c|}{ Outer Layer } & \multicolumn{2}{|c|}{ Inner Layer } & \multicolumn{2}{|c|}{ Outer Layer } & \multicolumn{2}{|c|}{ Inner Layer } & \multicolumn{2}{|c|}{ Outer Layer } & \multicolumn{2}{|c|}{ Inner Layer } & \multicolumn{2}{|c|}{ Outer Layer } & \multicolumn{2}{|c|}{ Inner Layer } & \multicolumn{2}{|c|}{ Outer Layer } & \multicolumn{2}{|c|}{ Inner Layer } \\
\hline & 离 & 离: & 离苔 & 㐫: & 离 & 㐫. & 离葛 & & 离 & 离: & 离 & 这: & لِّ. & 离. & 离葛 & 离: & 离莧 & 离泀 & 离 & 离: \\
\hline $\mathrm{Al}_{2} \mathrm{O}_{3}$ & 4 & 8.5 & 5.5 & 7.5 & 2 & 8.5 & 3 & 5 & 2 & 13 & 6 & 10 & 1.88 & 13 & 8 & 11 & 3 & 11.5 & 5 & 10 \\
\hline $\mathrm{B}_{2} \mathrm{O}_{3}$ & 5 & 14 & 8 & 13 & 5 & 14 & 7 & 12 & 4.5 & 14 & 7 & 12 & 4.3 & 15 & 6.5 & 11 & 6 & 13 & 8 & 11 \\
\hline $\mathrm{CdO}$ & 0.05 & 1.5 & 0.5 & 1.0 & 0.05 & 1.6 & 0.1 & 0.3 & (a) & (a) & (a) & (a) & (a) & (a) & (a) & (a) & (b) & (b) & (b) & (b) \\
\hline $\mathrm{Cr}_{2} \mathrm{O}_{3}$ & (c) & (c) & (c) & (c) & 0.02 & 0.5 & 0.08 & 0.2 & 0.05 & 0.25 & 0.1 & 0.2 & 0 & 0.6 & 0.25 & 0.5 & 0.05 & 0.6 & 0.15 & 0.4 \\
\hline $\mathrm{Fe}_{2} \mathrm{O}_{3}$ & 8 & 14 & 10 & 12 & 2 & 14 & 5 & 10 & 1.5 & 12 & 5 & 8 & 1.4 & 15 & 7 & 14 & 4 & 14 & 6 & 11 \\
\hline $\mathrm{Li}_{2} \mathrm{O}$ & 2 & 6 & 2.5 & 5 & 2 & 6 & 2.5 & 5 & 0 & 6 & 3 & 5 & 0 & 6 & 0.25 & 3 & 0 & 4.5 & 1 & 3.5 \\
\hline $\mathrm{MnO}$ & 0 & 5 & 1.5 & 3.5 & 0 & 7 & 1.5 & 4.5 & (a) & (a) & (a) & (a) & 0 & 8 & 1 & 4 & 0.5 & 6 & 2.5 & 4 \\
\hline $\mathrm{Na}_{2} \mathrm{O}$ & 4 & 15 & 9 & 15 & 4 & 15 & 7 & 12 & 6.5 & 20 & 8 & 16 & 3.7 & 20 & 14 & 20 & 6 & 18 & 10 & 14 \\
\hline $\mathrm{NiO}$ & 0.1 & 1.0 & 0.3 & 0.8 & 0.1 & 1.0 & 0.3 & 0.5 & (a) & (a) & (a) & (a) & 0 & 1.2 & 0.6 & 1 & 0 & 1 & 0.2 & 0.65 \\
\hline $\mathrm{Sb}_{2} \mathrm{O}_{3}$ & 0.02 & 0.2 & 0.05 & 0.15 & 0.02 & 0.3 & 0.05 & 0.15 & - & - & - & - & - & - & - & - & (e) & (e) & (e) & (e) \\
\hline \begin{tabular}{|l|}
$\mathrm{SeO}_{2}$ \\
\end{tabular} & 0.02 & 0.2 & 0.05 & 0.15 & 0.02 & 0.2 & 0.05 & 0.15 & - & - & - & - & - & - & - & - & - & - & - & - \\
\hline $\mathrm{SiO}_{2}$ & 38 & 53 & 41 & 49 & 36 & 53 & 41 & 49 & 34 & 49 & 38 & 44 & 33 & 53.1 & 35 & 40 & 35 & 51 & 40 & 47 \\
\hline \begin{tabular}{|l|}
$\mathrm{SrO}$ \\
\end{tabular} & 0 & 5 & 1.5 & 3.5 & 0 & 10 & 1.5 & 4.5 & $1.2^{(\mathrm{e})}$ & $1.2^{(\mathrm{e})}$ & $1.2^{(\mathrm{e})}$ & \begin{tabular}{|l}
$1.2^{(\mathrm{e})}$ \\
\end{tabular} & (a) & (a) & (a) & (a) & 0 & 10 & 2.5 & 7 \\
\hline \begin{tabular}{|l}
$\mathrm{ThO}_{2}$ \\
\end{tabular} & - $^{(\mathrm{d})}$ & - & - & - & 0 & 6 & 3 & 4.5 & 1.5 & 6 & 3 & 4.5 & 0 & 5.94 & 0.25 & 1.5 & 0 & 4.4 & 1 & 3.5 \\
\hline $\mathrm{Tl}_{2} \mathrm{O}^{(\mathrm{f})}$ & 0.02 & 0.2 & 0.05 & 0.15 & 0.02 & 0.33 & 0.05 & 0.15 & $0.05^{(\mathrm{e})}$ & $0.05^{(\mathrm{e})}$ & $0.05^{(\mathrm{e})}$ & \begin{tabular}{|l}
$0.05^{(\mathrm{e})}$ \\
\end{tabular} & - & - & - & - & - & - & - & - \\
\hline $\mathrm{UO}_{3}{ }^{(\mathrm{g})}$ & - & - & - & - & 0 & 6 & 2 & 4 & 1 & 6.5 & 2.5 & \begin{tabular}{|l}
4.5 \\
\end{tabular} & 0 & 6.5 & 0.75 & 4 & 0 & 4.1 & 1.5 & 3 \\
\hline $\mathrm{ZnO}$ & $2^{(\mathrm{e})}$ & $2^{(\mathrm{e})}$ & $2^{(\mathrm{e})}$ & $2^{(\mathrm{e})}$ & 0 & 4 & 1 & 3 & $1.2^{(\mathrm{e})}$ & $1.2^{(\mathrm{e})}$ & $1.2^{(\mathrm{e})}$ & $1.2^{(\mathrm{e})}$ & 0 & 4 & 1.5 & 2.5 & 0 & 2.5 & 0.5 & 1.5 \\
\hline $\mathrm{ZrO}_{2}$ & 0 & 6 & 1.5 & 4.5 & 0 & 10 & 6 & 9 & 2.5 & 11.5 & 5 & 10.5 & 0 & 11.5 & 1.5 & 4 & 1 & 9.6 & 2.5 & 6.5 \\
\hline Spike $^{(\mathrm{h})}$ & 0.15 & 1.5 & 0.3 & 1 & 0.13 & 1.3 & 0.26 & 0.87 & - & - & - & - & - & - & - & - & - & - & - & - \\
\hline 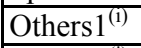 & - & - & - & - & - & - & - & - & 0.2 & 2 & 0.5 & 1 & 0 & 14 & 2 & 6 & 0 & 1.36 & 0 & 1.36 \\
\hline Others $2^{(i)}$ & - & - & - & - & - & - & - & - & - & - & - & - & 0 & 6.02 & 1 & 6.02 & 0 & 2.48 & 0 & 1.24 \\
\hline Constant $^{(\mathrm{j})}$ & 2.2 & 2.2 & 2.2 & 2.2 & 2.2 & 2.2 & 2.2 & 2.2 & 5.5 & 5.5 & 5.5 & 5.5 & 2.09 & 2.09 & 2.09 & 2.09 & 3.48 & 3.48 & 1.74 & 1.74 \\
\hline
\end{tabular}

(a) Included in Others1.

(b) Included in Others2.

(c) $\mathrm{Cr}_{2} \mathrm{O}_{3}$ was included in the Spike component in HLW02 (see Table 2.2).

(d) A "- " indicates the component was not included (i.e., was zero) in this study phase.

(e) Included in Constant.

(f)The HLW02 and HLW03 outer- and inner-layer limits are for $\mathrm{Tl}_{2} \mathrm{O}_{3}$ rather than $\mathrm{Tl}_{2} \mathrm{O}$.

(g) The HLW03 outer- and inner-layer limits are for $\mathrm{UO}_{2}$ rather than $\mathrm{UO}_{3}$.

(h) The Spike component used in HLW03 glasses is defined in Table 2.2. In $\mathrm{HLW} 02, \mathrm{Cr}_{2} \mathrm{O}_{3}$ was also included in the Spike component.

(i) For the applicable studies, Others1 and Others 2 are defined in Table 2.3.

(j) The Constant component is defined for each study in Table 2.4. 
Table 2.2. Composition of "Spike" Components for IHLW Initial Matrix (HLW02) and Augmentation Test Matrix (HLW03).

\begin{tabular}{|c||c|c|c|c|}
\hline \multirow{2}{*}{\multicolumn{1}{|c||}{ Components }} & \multicolumn{2}{c|}{ Initial Matrix (HLW02) } & \multicolumn{2}{c|}{ Augmentation Matrix (HLW03) } \\
\cline { 2 - 5 } & Relative \% & $\begin{array}{c}\text { Wt\% Range in } \\
\text { Glass }\end{array}$ & Relative \% & $\begin{array}{c}\text { Wt\% Range in } \\
\text { Glass }\end{array}$ \\
\hline $\mathrm{Ag}_{2} \mathrm{O}$ & 13.333 & $0.02-0.20$ & 15.385 & $0.02-0.20$ \\
\hline $\mathrm{As}_{2} \mathrm{O}_{3}$ & 13.333 & $0.02-0.20$ & 15.385 & $0.02-0.20$ \\
\hline $\mathrm{BaO}$ & 20.000 & $0.03-0.30$ & 23.077 & $0.03-0.30$ \\
\hline $\mathrm{Cr}_{2} \mathrm{O}_{3}$ & 13.333 & $0.02-0.20$ & Not included in “Spike” (see Table 2.1) \\
\hline $\mathrm{CuO}$ & 6.667 & $0.01-0.10$ & 7.692 & $0.01-0.10$ \\
\hline $\mathrm{PbO}$ & 26.667 & $0.04-0.40$ & 30.769 & $0.04-0.40$ \\
\hline $\mathrm{V}_{2} \mathrm{O}_{5}$ & 6.667 & $0.01-0.10$ & 7.692 & $0.01-0.10$ \\
\hline \hline $\mathrm{Subtotal}$ & 100.000 & $0.15-1.50$ & 100.000 & $0.13-1.30$ \\
\hline
\end{tabular}


Table 2.3. Composition of Others1 and Others2 Components for HLW Study Glasses.

\begin{tabular}{|c|c|c|c|c|c|c|c|c|c|c|}
\hline \multirow[b]{2}{*}{ Components } & \multicolumn{2}{|c|}{ HLW05 Others1 } & \multicolumn{2}{|c|}{ HLW06 Others1 } & \multicolumn{2}{|c|}{ HLW06 Others2 } & \multicolumn{2}{|c|}{ HLW07 Others1 } & \multicolumn{2}{|c|}{ HLW07 Others2 } \\
\hline & $\begin{array}{c}\text { Relative } \\
\%\end{array}$ & $\begin{array}{c}\text { Wt\% Range } \\
\text { in Glass }\end{array}$ & \begin{tabular}{|c|} 
Relative \\
$\%$
\end{tabular} & $\begin{array}{c}\text { Wt\% Range } \\
\text { in Glass }\end{array}$ & \begin{tabular}{|c|} 
Relative \\
$\%$
\end{tabular} & $\begin{array}{c}\text { Wt\% Range } \\
\text { in Glass }\end{array}$ & $\begin{array}{c}\text { Relative } \\
\%\end{array}$ & $\begin{array}{c}\text { Wt\% Range } \\
\text { in Glass }\end{array}$ & $\begin{array}{c}\text { Relative } \\
\%\end{array}$ & $\begin{array}{c}\text { Wt\% Range } \\
\text { in Glass }\end{array}$ \\
\hline $\mathrm{BaO}$ & $-^{\text {(a) }}$ & - & - & - & 4.98 & $0-0.30$ & - & - & - & - \\
\hline $\mathrm{CaO}$ & - & - & - & - & 16.61 & $0-1.00$ & - & - & - & - \\
\hline $\mathrm{CdO}$ & 25 & $0.05-0.50$ & 11.76 & $0-1.65$ & - & - & - & - & 40.32 & $0-1.00$ \\
\hline $\mathrm{CoO}$ & - & - & - & - & - & - & - & - & 9.27 & $0-0.23$ \\
\hline $\mathrm{CuO}$ & - & - & - & - & - & - & - & - & 9.68 & $0-0.24$ \\
\hline $\mathrm{K}_{2} \mathrm{O}$ & - & - & - & - & 27.24 & $0-1.64$ & - & - & - & - \\
\hline $\mathrm{La}_{2} \mathrm{O}_{3}$ & - & - & 8.82 & $0-1.23$ & - & - & - & - & - & - \\
\hline $\mathrm{Nd}_{2} \mathrm{O}_{3}$ & - & - & 3.94 & $0-0.55$ & - & - & - & - & - & - \\
\hline $\mathrm{MgO}$ & - & - & - & - & 19.44 & $0-1.17$ & - & - & - & - \\
\hline $\mathrm{MnO}$ & 50 & $0.10-1.00$ & - & - & - & - & - & - & - & - \\
\hline $\mathrm{MoO}_{3}$ & - & - & - & - & - & - & 28.68 & $0-0.39$ & - & - \\
\hline $\mathrm{NiO}$ & 25 & $0.05-0.50$ & - & - & - & - & - & - & - & - \\
\hline $\mathrm{P}_{2} \mathrm{O}_{5}$ & - & - & - & - & - & - & 47.06 & $0-0.64$ & - & - \\
\hline $\mathrm{PbO}$ & - & - & - & - & 15.12 & $0-0.91$ & - & - & 40.73 & $0-1.01$ \\
\hline $\mathrm{SO}_{3}$ & - & - & 2.00 & $0-0.28$ & - & - & 24.26 & $0-0.33$ & - & - \\
\hline $\mathrm{SrO}$ & - & - & 73.48 & $0-10.29$ & - & - & - & - & - & - \\
\hline $\mathrm{TiO}_{2}$ & - & - & - & - & 16.61 & $0-1.00$ & - & - & - & - \\
\hline Sum & 100 & $0.2-2.0$ & 100.00 & $0-14.00$ & 100.00 & $0-6.02$ & 100.00 & $0-1.36$ & 100.00 & $0-2.48$ \\
\hline
\end{tabular}

(a) A " - " indicates the component was not present (i.e., was zero) in the grouped Others1 or Others 2 component. 
Table 2.4. Composition of "Constant" Component for IHLW Study Glasses.

\begin{tabular}{|c|c|c|c|c|c|c|c|c|c|c|c|}
\hline \multirow[b]{2}{*}{ Components } & \multicolumn{2}{|c|}{ HLW02 } & \multicolumn{2}{|c|}{ HLW03 } & \multicolumn{2}{|c|}{ HLW05 } & \multicolumn{2}{|c|}{ HLW06 } & \multicolumn{3}{|c|}{ HLW07 } \\
\hline & $\begin{array}{c}\text { Relative } \\
\%\end{array}$ & $\begin{array}{c}\text { Wt\% in } \\
\text { Glass }\end{array}$ & $\begin{array}{c}\text { Relative } \\
\%\end{array}$ & $\begin{array}{c}\text { Wt\% in } \\
\text { Glass }\end{array}$ & $\begin{array}{c}\text { Relative } \\
\%\end{array}$ & $\begin{array}{c}\text { Wt\% in } \\
\text { Glass }\end{array}$ & $\begin{array}{c}\text { Relative } \\
\%\end{array}$ & $\begin{array}{c}\text { Wt\% in } \\
\text { Glass }\end{array}$ & $\begin{array}{c}\text { Relative } \\
\%\end{array}$ & $\begin{array}{c}\text { Inner Wt\% } \\
\text { in Glass }\end{array}$ & $\begin{array}{c}\text { Outer Wt\% } \\
\text { in Glass }\end{array}$ \\
\hline $\mathrm{Ag}_{2} \mathrm{O}$ & - ${ }^{\text {(a) }}$ & - & - & - & 1.818 & 0.10 & 4.785 & 0.10 & - & - & - \\
\hline $\mathrm{BaO}$ & - & - & - & - & 9.091 & 0.50 & - & - & - & - & - \\
\hline $\mathrm{Bi}_{2} \mathrm{O}_{3}$ & 0.24 & 0.01 & 0.455 & 0.01 & 3.636 & 0.20 & 14.354 & 0.30 & - & - & - \\
\hline $\mathrm{CaO}$ & 11.90 & 0.50 & 22.727 & 0.50 & 13.636 & 0.75 & - & - & 8.62 & 0.15 & 0.30 \\
\hline $\mathrm{Ce}_{2} \mathrm{O}_{3}{ }^{(\mathrm{b})}$ & 1.19 & 0.05 & 2.273 & 0.05 & - & - & - & - & 10.92 & 0.19 & 0.38 \\
\hline $\mathrm{Cl}$ & 4.76 & 0.20 & 9.091 & 0.20 & - & - & 9.569 & 0.20 & 9.77 & 0.17 & 0.34 \\
\hline $\mathrm{CoO}$ & 0.24 & 0.01 & 0.455 & 0.01 & - & - & - & - & - & - & - \\
\hline $\mathrm{Cs}_{2} \mathrm{O}$ & 0.24 & 0.01 & 0.455 & 0.01 & - & - & - & - & 7.18 & 0.125 & 0.25 \\
\hline $\mathrm{F}$ & 1.19 & 0.05 & 2.273 & 0.05 & 0.909 & 0.05 & 21.053 & 0.44 & 3.45 & 0.06 & 0.12 \\
\hline $\mathrm{K}_{2} \mathrm{O}$ & 1.43 & 0.06 & 2.727 & 0.06 & 3.636 & 0.20 & - & - & 16.67 & 0.29 & 0.58 \\
\hline $\mathrm{La}_{2} \mathrm{O}_{3}$ & 7.14 & 0.30 & 13.636 & 0.30 & 9.091 & 0.50 & - & - & 7.18 & 0.125 & 0.25 \\
\hline $\mathrm{Nd}_{2} \mathrm{O}_{3}$ & - & - & - & - & - & - & 11.962 & 0.25 & - & - & - \\
\hline $\mathrm{MgO}$ & 2.86 & 0.12 & 5.454 & 0.12 & 1.818 & 0.10 & - & - & - & - & - \\
\hline $\mathrm{P}_{2} \mathrm{O}_{5}$ & 11.90 & 0.50 & 22.727 & 0.50 & 5.454 & 0.30 & 23.923 & 0.50 & - & - & - \\
\hline $\mathrm{PbO}$ & - & - & - & - & 2.727 & 0.15 & - & - & - & - & - \\
\hline $\mathrm{PdO}$ & 2.86 & 0.12 & 5.454 & 0.12 & 0.364 & 0.02 & 5.742 & 0.12 & - & - & - \\
\hline $\mathrm{Pr}_{2} \mathrm{O}_{3}$ & - & - & - & - & - & - & - & - & 4.60 & 0.08 & 0.16 \\
\hline $\mathrm{Rb}_{2} \mathrm{O}$ & - & - & - & - & - & - & - & - & 2.30 & 0.04 & 0.08 \\
\hline $\mathrm{Rh}_{2} \mathrm{O}_{3}$ & 1.19 & 0.05 & 2.273 & 0.05 & 0.727 & 0.04 & 2.392 & 0.05 & 2.30 & 0.04 & 0.08 \\
\hline $\mathrm{RuO}_{2}$ & 1.90 & 0.08 & 3.636 & 0.08 & 0.364 & 0.02 & 6.220 & 0.13 & 2.87 & 0.05 & 0.10 \\
\hline $\mathrm{SO}_{3}$ & 2.38 & 0.10 & 4.545 & 0.10 & 1.818 & 0.10 & - & - & - & - & - \\
\hline $\mathrm{Sb}_{2} \mathrm{O}_{3}$ & - & - & - & - & - & - & - & - & 11.49 & 0.20 & 0.40 \\
\hline $\mathrm{SnO}_{2}$ & - & - & - & - & - & - & - & - & 6.61 & 0.115 & 0.23 \\
\hline $\mathrm{SrO}$ & - & - & - & - & 21.818 & 1.20 & - & - & - & - & - \\
\hline $\mathrm{Ta}_{2} \mathrm{O}_{5}$ & - & - & - & - & - & - & - & - & 0.29 & 0.005 & 0.01 \\
\hline $\mathrm{TeO}_{2}$ & 0.24 & 0.01 & 0.455 & 0.01 & - & - & - & - & - & - & - \\
\hline $\mathrm{TiO}_{2}$ & 0.72 & 0.03 & 1.364 & 0.03 & 0.364 & 0.02 & - & - & - & - & - \\
\hline $\mathrm{Tl}_{2} \mathrm{O}$ & - & - & - & - & 0.909 & 0.05 & - & - & - & - & - \\
\hline $\mathrm{WO}_{3}$ & - & - & - & - & - & - & - & - & 3.45 & 0.06 & 0.12 \\
\hline $\mathrm{Y}_{2} \mathrm{O}_{3}$ & - & - & - & - & - & - & - & - & 2.30 & 0.04 & 0.08 \\
\hline $\mathrm{ZnO}$ & 47.62 & 2.00 & - & - & 21.820 & 1.20 & - & - & - & - & - \\
\hline Sum & 100.00 & 4.20 & 100.000 & 2.20 & 100.000 & 5.50 & 100.000 & 2.09 & 100.00 & 1.74 & 3.48 \\
\hline
\end{tabular}

(a) A " - " indicates the component was not present (i.e., was zero) in the grouped Constant component.

(b) The HLW02 and HLW03 outer- and inner-layer limits are for $\mathrm{CeO}_{2}$ rather than $\mathrm{Ce}_{2} \mathrm{O}_{3}$. 
Table 2.5. Least-Restrictive Component Lower and Upper Limits (wt\%) for IHLW Test Matrices HLW02, HLW03, HLW05, HLW06, and HLW07.

\begin{tabular}{|c|c|c|c|c|c|c|c|c|}
\hline \multicolumn{3}{|c|}{ Varied Individually $^{(\mathrm{a})}$} & \multicolumn{6}{|c|}{ Varied Via Grouped Components ${ }^{\left({ }^{(b)}\right.}$} \\
\hline 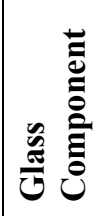 & 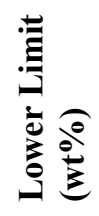 & 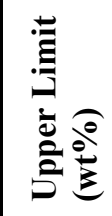 & 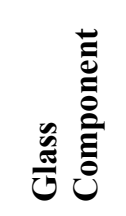 & 兽 & 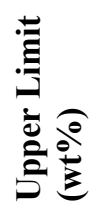 & 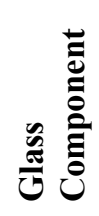 & ڤ气 & 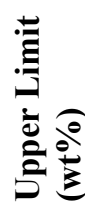 \\
\hline $\mathrm{Al}_{2} \mathrm{O}_{3}$ & 1.88 & 13 & $\mathrm{Ag}_{2} \mathrm{O}$ & 0.02 & 0.20 & $\mathrm{PbO}$ & 0 & 1.01 \\
\hline $\mathrm{B}_{2} \mathrm{O}_{3}$ & 4.3 & 15 & $\mathrm{As}_{2} \mathrm{O}_{3}$ & 0.02 & 0.20 & $\mathrm{PdO}$ & 0.02 & 0.12 \\
\hline $\mathrm{CdO}$ & $0^{(\mathrm{c})}$ & $1.65^{(\mathrm{c})}$ & $\mathrm{BaO}$ & 0 & 0.50 & $\mathrm{Pr}_{2} \mathrm{O}_{3}$ & 0.08 & 0.16 \\
\hline $\mathrm{Cr}_{2} \mathrm{O}_{3}$ & 0 & 0.6 & $\overline{\mathrm{Bi}_{2} \mathrm{O}_{3}}$ & 0.01 & 0.30 & $\mathrm{PdO}$ & 0.02 & 0.12 \\
\hline $\mathrm{Fe}_{2} \mathrm{O}_{3}$ & 1.4 & 15 & $\mathrm{CaO}$ & 0 & 1.00 & $\mathrm{Pr}_{2} \mathrm{O}_{3}$ & 0.08 & 0.16 \\
\hline $\mathrm{Li}_{2} \mathrm{O}$ & 0 & 6 & $\mathrm{Ce}_{2} \mathrm{O}_{3}{ }^{(\mathrm{(h)}}$ & 0.05 & 0.38 & $\mathrm{Rb}_{2} \mathrm{O}$ & 0.04 & 0.08 \\
\hline $\mathrm{MnO}$ & 0 & 8 & $\mathrm{Cl}$ & 0.17 & 0.34 & $\mathrm{Rh}_{2} \mathrm{O}_{3}$ & 0.04 & 0.08 \\
\hline $\mathrm{Na}_{2} \mathrm{O}$ & 3.7 & 20 & $\mathrm{CoO}$ & 0 & 0.23 & $\mathrm{RuO}_{2}$ & 0.02 & 0.13 \\
\hline $\mathrm{NiO}$ & 0 & 1.2 & $\mathrm{Cs}_{2} \mathrm{O}$ & 0.01 & 0.25 & $\mathrm{SO}_{3}$ & 0 & 0.33 \\
\hline $\mathrm{Sb}_{2} \mathrm{O}_{3}$ & 0.02 & $0.4^{(\mathrm{d})}$ & $\mathrm{CuO}$ & 0 & 0.24 & $\mathrm{SnO}_{2}$ & 0.115 & 0.23 \\
\hline $\mathrm{SeO}_{2}$ & 0.02 & 0.2 & $F$ & 0.05 & 0.44 & $\mathrm{Ta}_{2} \mathrm{O}_{5}$ & 0.005 & 0.01 \\
\hline $\mathrm{SiO}_{2}$ & 33 & 53.1 & $\mathrm{~K}_{2} \mathrm{O}$ & 0 & 1.64 & $\mathrm{TeO}_{2}$ & 0.01 & 0.01 \\
\hline \begin{tabular}{|l}
$\mathrm{SrO}$ \\
\end{tabular} & 0 & $10.26^{(\mathrm{e})}$ & $\mathrm{La}_{2} \mathrm{O}_{3}$ & 0 & 1.23 & $\mathrm{TiO}_{2}$ & 0 & 1.00 \\
\hline $\mathrm{ThO}_{2}$ & 0 & 6 & $\mathrm{Nd}_{2} \mathrm{O}_{3}$ & 0 & 0.55 & $\mathrm{~V}_{2} \mathrm{O}_{5}$ & 0.01 & 0.10 \\
\hline $\mathrm{Tl}_{2} \mathrm{O}^{(\mathrm{f})}$ & 0 & 0.33 & $\mathrm{MgO}$ & 0 & 1.17 & $\mathrm{WO}_{3}$ & 0.06 & 0.12 \\
\hline $\mathrm{UO}_{3}{ }^{(\mathrm{g})}$ & 0 & 6.5 & $\mathrm{MoO}_{3}$ & 0 & 0.39 & $\mathrm{Y}_{2} \mathrm{O}_{3}$ & 0.04 & 0.08 \\
\hline $\mathrm{ZnO}$ & 0 & 4 & $\mathrm{P}_{2} \mathrm{O}_{5}$ & 0 & 0.64 & & & \\
\hline $\mathrm{ZrO}_{2}$ & 0 & 11.5 & & & & & & \\
\hline
\end{tabular}

(a) These components were varied individually in at least one of the WTP HLW glass studies (HLW02, HLW03, HLW05, HLW06, or HLW07). Note that all of these ranges were achieved over HLW02, HLW03, HLW05, and HLW06, except for the upper limit of $\mathrm{Sb}_{2} \mathrm{O}_{3}$ achieved in HLW07 as explained in footnote $(\mathrm{d})$.

(b) These components were varied as parts of the "Spike", "Others1", "Others2", or "Constant" groups of components. The ranges given are over all of the WTP HLW glass studies (HLW02, HLW03, HLW05, HLW06, or HLW07).

(c) $\mathrm{CdO}$ varied from 0.05 to $1.6 \mathrm{wt} \%$ in HLW03. It got down to $0 \mathrm{wt} \%$ as part of Others 1 in HLW06 and Others2 in HLW07, and got up to $1.65 \mathrm{wt} \%$ as part of Others1 in HLW06.

(d) $\mathrm{Sb}_{2} \mathrm{O}_{3}$ varied from 0.02 to $0.3 \mathrm{wt} \%$ in HLW03. It got up to $0.4 \mathrm{wt} \%$ as part of the Constant component in HLW07.

(e) SrO varied from 0 to $10 \mathrm{wt} \%$ in HLW03 and HLW07. It got up to $10.26 \mathrm{wt} \%$ as part of Others 1 in HLW06.

(f) The HLW02 and HLW03 outer-layer limits used to determine the range are for $\mathrm{Tl}_{2} \mathrm{O}_{3}$ rather than $\mathrm{Tl}_{2} \mathrm{O}$.

(g) The HLW03 outer-layer limits used to determine the range are for $\mathrm{UO}_{2}$ rather than $\mathrm{UO}_{3}$.

(h) The HLW02 and HLW03 outer-layer limits used to determine the range are for $\mathrm{CeO}_{2}$ rather than $\mathrm{Ce}_{2} \mathrm{O}_{3}$. 
Table 2.6. Multi-Component Constraints for WTP IHLW Test Matrices HLW02, HLW03, HLW05, HLW06, and HLW07 ${ }^{(a)}$

\begin{tabular}{|c|c|c|c|c|c|c|c|c|c|c|c|c|c|c|c|c|c|c|c|c|}
\hline \multirow{3}{*}{ 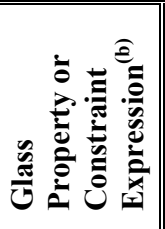 } & \multicolumn{4}{|c|}{ HLW02 } & \multicolumn{4}{|c|}{ HLW03 } & \multicolumn{4}{|c|}{ HLW05 } & \multicolumn{4}{|c|}{ HLW06 } & \multicolumn{4}{|c|}{ HLW07 } \\
\hline & \multicolumn{2}{|c|}{ Outer Layer } & \multicolumn{2}{|c|}{ Inner Layer } & \multicolumn{2}{|c|}{ Outer Layer } & \multicolumn{2}{|c|}{ Inner Layer } & \multicolumn{2}{|c|}{ Outer Layer } & \multicolumn{2}{|c|}{ Inner Layer } & \multicolumn{2}{|c|}{ Outer Layer } & \multicolumn{2}{|c|}{ Inner Layer } & \multicolumn{2}{|c|}{ Outer Layer } & \multicolumn{2}{|c|}{ Inner Layer } \\
\hline & 莺节 & 离总 & 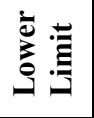 & 离: & 离 & 产: & 离泀 & 言离. & 总 & 离苛 & 氙苛 & 离: & 氙离 & 高竞: & 莺茴 & 言苛. & 总节 & 离: & 总 & 高:苜 \\
\hline PCT B & - $^{(\mathrm{c})}$ & 16.695 & - & 16.695 & - & 16.695 & - & 16.695 & - & 16.695 & - & 16.695 & - & - & - & - & - & - & - & - \\
\hline PCT Na & - & 13.346 & - & 13.346 & - & 13.346 & - & 13.346 & - & - & - & - & - & - & - & - & - & - & - & - \\
\hline \begin{tabular}{|l|} 
PCT Li \\
\end{tabular} & - & 9.565 & - & \begin{tabular}{|l|}
9.565 \\
\end{tabular} & - & 9.565 & - & \begin{tabular}{|l|}
9.565 \\
\end{tabular} & - & - & - & - & - & - & - & - & - & - & - & - \\
\hline TCLP B & - & 0.3 & - & 0.3 & - & 0.3 & - & 0.3 & - & 0.3 & - & 0.3 & - & - & - & - & - & - & - & - \\
\hline Spinel $\mathrm{T}_{1 \%}$ & - & - & - & - & - & - & - & - & - & 850 & - & 850 & 650 & 1200 & 650 & 1200 & - & 1000 & - & 1000 \\
\hline $\mathrm{T}_{\mathrm{LS}}$ & - & 1050 & - & 1050 & - & 1150 & - & 1150 & - & - & - & - & - & - & - & - & - & - & - & - \\
\hline $\mathrm{T}_{\mathrm{LZ}}$ & - & - & - & - & - & 1150 & - & 1150 & - & - & - & - & - & - & - & - & - & - & - & - \\
\hline $\mathrm{T}_{\text {LZO }}$ & - & - & - & - & - & - & - & - & 800 & 1200 & 850 & 1150 & - & 1420 & - & - & - & - & - & - \\
\hline$\eta_{1150}$ & 10 & 100 & 10 & 100 & 10 & 100 & 10 & 100 & 10 & 100 & 10 & 100 & 10 & 100 & 10 & 100 & 10 & 100 & 10 & 100 \\
\hline $\mathrm{EC}_{1150}$ & 0.2 & 0.7 & 0.2 & 0.6 & 0.2 & 0.7 & 0.2 & 0.6 & 0.2 & 0.6 & 0.2 & 0.6 & 0.2 & 0.7 & 0.2 & 0.7 & 0.2 & 0.7 & 0.2 & 0.7 \\
\hline $\mathrm{AlFeZr}$ & 18 & 22.5 & 18 & 22.5 & - & 26 & - & 26 & 18 & 27 & 18 & 27 & - & - & - & - & 18 & - & 18 & - \\
\hline AlFeZrTh & - & - & - & - & 19 & 34 & 19 & 34 & - & - & - & - & - & - & - & - & - & - & - & - \\
\hline \begin{tabular}{|l}
$\mathrm{LiNaTh}$ \\
\end{tabular} & - & - & - & - & 0 & - & 0 & - & - & - & - & - & - & - & - & - & - & - & - & - \\
\hline $\mathrm{LiNa}$ & - & - & - & - & - & - & - & - & - & 24 & - & 22.5 & - & - & - & - & - & - & - & - \\
\hline
\end{tabular}

(a) The limiting values of the constraints in this table were not able to be achieved in some cases (see Tables 9.5 and 9.6).

(b) PCT B = normalized boron release from the 7-day PCT $(\mathrm{g} / \mathrm{L})$, PCT Na = normalized sodium release from the 7-day PCT $(\mathrm{g} / \mathrm{L})$, PCT Li $=$ normalized lithium release from the 7-day PCT $(\mathrm{g} / \mathrm{L})$, TCLP B = normalized boron release from the TCLP $(\mathrm{g} / \mathrm{L})$, Spinel $\mathrm{T}_{1 \%}=$ temperature at which spinel makes up $1 \mathrm{vol} \%$ of a glass melt $\left({ }^{\circ} \mathrm{C}\right), \mathrm{T}_{\mathrm{LS}}=$ liquidus temperature of $\mathrm{Cr}$-bearing spinel $\left({ }^{\circ} \mathrm{C}\right), \mathrm{T}_{\mathrm{LZ}}=$ liquidus temperature of zircon $\left({ }^{\circ} \mathrm{C}\right), \mathrm{T}_{\mathrm{LzO}}=$ liquidus temperature of zirconia $\left({ }^{\circ} \mathrm{C}\right)$, $\eta_{1150}=$ viscosity at $1150^{\circ} \mathrm{C}$ (poise), $\mathrm{EC}_{1150}=$ electrical conductivity at $1150^{\circ} \mathrm{C}(\mathrm{S} / \mathrm{cm}), \mathrm{AlFeZr}=\mathrm{Al}_{2} \mathrm{O}_{3}+\mathrm{Fe}_{2} \mathrm{O}_{3}+\mathrm{ZrO}_{2}(\mathrm{wt} \%), \mathrm{AlFeZrTh}^{\circ}=$

$\mathrm{Al}_{2} \mathrm{O}_{3}+\mathrm{Fe}_{2} \mathrm{O}_{3}+\mathrm{ZrO}_{2}+3 \mathrm{ThO}_{2}(\mathrm{wt} \%), \mathrm{LiNaTh}=2 \mathrm{Li}_{2} \mathrm{O}+\mathrm{Na}_{2} \mathrm{O}-3.75 \mathrm{ThO}_{2}(\mathrm{wt} \%)$ to limit thorium crystallization, $\mathrm{LiNa}=\mathrm{Na}_{2} \mathrm{O}+2 \mathrm{Li}{ }_{2} \mathrm{O}(\mathrm{wt} \%)$

(c) A "_" indicates there was no limit on the property or expression for that WTP HLW study. 


\section{Table 2.7. Model-Based ${ }^{(a, b)}$ Glass Property Constraints for the IHLW Initial (HLW02) and Augmentation (HLW03) Matrices.}

\begin{tabular}{|c|c|c|c|c|c|c|c|c|}
\hline Property & $\eta_{1150}$ & $\sigma_{1150}$ & $r_{B}^{P C T}$ & $r_{N a}^{P C T}$ & $r_{L i}^{P C T}$ & TCLP B & Spinel $T_{L S}$ & Zircon $T_{L Z}$ \\
\hline $\begin{array}{l}\text { Modeled } \\
\text { Response }\end{array}$ & $\ln \left(\eta_{1150}\right)$ & $\ln \left(\sigma_{1150}\right)$ & $\ln \left(r_{B}^{P C T}\right)$ & $\ln \left(r_{N a}^{P C T}\right)$ & $\ln \left(r_{L i}^{P C T}\right)$ & $\ln (\mathrm{TCLP} B)$ & $1000 / T_{L S}$ & $1000 / T_{L S}$ \\
\hline Unit & $\ln ($ poise $)$ & $\ln (\mathrm{S} / \mathrm{cm})$ & $\ln (\mathrm{g} / \mathrm{l})$ & $\ln (\mathrm{g} / \mathrm{l})$ & $\ln (g / 1)$ & $\ln (\mathrm{g} / \mathrm{l})$ & $1000 / \mathrm{K}$ & ${ }^{\circ} \mathrm{C}$ \\
\hline Component & \multicolumn{8}{|c|}{ Constraint Model Coefficients and Constraint Lower \& Upper Limits } \\
\hline $\mathbf{A l}_{2} \mathbf{O}_{3}$ & 0.18657 & -0.01728 & -0.05722 & -0.06358 & -0.05649 & 0.177471 & $\begin{array}{c}-0.008872(\mathrm{I}) \\
-0.010035(\mathrm{~A})\end{array}$ & 19.33(A) \\
\hline $\mathbf{B}_{2} \mathbf{O}_{3}$ & -0.02217 & 0.023548 & 0.12314 & 0.07598 & 0.10705 & 0.020751 & $\begin{array}{c}0.004608(\mathrm{I}) \\
0.003834(\mathrm{~A})\end{array}$ & $6.02(\mathrm{~A})$ \\
\hline $\mathrm{Fe}_{2} \mathrm{O}_{3}$ & 0.0390715 & -0.01971 & -0.0049 & -0.01541 & -0.02529 & -0.142703 & $\begin{array}{c}-0.008202(\mathrm{I}) \\
-0.009954(\mathrm{~A}) \\
\end{array}$ & $22.54(\mathrm{~A})$ \\
\hline $\mathbf{L i}_{2} \mathbf{O}$ & -0.290011 & 0.206174 & 0.2443 & 0.18435 & 0.29065 & 0.154931 & $\begin{array}{c}0.154931(\mathrm{I}) \\
0.014920(\mathrm{~A})\end{array}$ & $-16.20(\mathrm{~A})$ \\
\hline MnO & $-^{(\mathrm{c})}$ & - & 0.11568 & 0.08245 & 0.14456 & - & $\begin{array}{c}-0.003258(\mathrm{I}) \\
0.001536(\mathrm{~A})\end{array}$ & 16.31(A) \\
\hline $\mathrm{Na}_{2} \mathrm{O}$ & -0.044155 & 0.114266 & 0.23097 & 0.22255 & 0.21421 & 0.105911 & $\begin{array}{c}0.012308(\mathrm{I}) \\
0.011639(\mathrm{~A})\end{array}$ & $-28.45(\mathrm{~A})$ \\
\hline $\mathrm{SiO}_{2}$ & 0.1485 & -0.01638 & -0.00802 & -0.01545 & 0.01268 & -0.136931 & $\begin{array}{c}0.000257(\mathrm{I}) \\
-0.001100(\mathrm{~A})\end{array}$ & 9.99(A) \\
\hline SrO & - & - & - & - & - & -0.023195 & - & $16.31(\mathrm{~A})$ \\
\hline $\mathrm{ThO}_{2}$ & - & - & - & & - & $-0.09344(\mathrm{~A})$ & - & $16.31(\mathrm{~A})$ \\
\hline $\mathbf{U O}_{2}$ & - & - & $0.07011(\mathrm{~A})$ & $0.06703(\mathrm{~A})$ & $0.13294(\mathrm{~A})$ & $-0.07421(\mathrm{~A})$ & $-0.002953(\mathrm{~A})$ & 16.31(A) \\
\hline $\mathrm{ZrO}_{2}$ & 0.09522 & -0.07185 & -0.01614 & -0.0411 & -0.06408 & -0.15205 & $\begin{array}{c}-0.006011(\mathrm{I}) \\
-0.006041(\mathrm{~A}) \\
\end{array}$ & $54.68(\mathrm{~A})$ \\
\hline $\mathrm{ZnO}$ & $0.05186(\mathrm{~A})$ & $-0.01459(\mathrm{~A})$ & - & - & - & - & $-0.046261(\mathrm{~A})$ & $16.31(\mathrm{~A})$ \\
\hline $\mathrm{Cr}_{2} \mathrm{O}_{3}$ & - & - & - & - & - & - & $-0.111396(\mathrm{~A})$ & $16.31(\mathrm{~A})$ \\
\hline $\mathrm{NiO}$ & - & - & 0.1300 & 0.157237 & 0.031708 & - & $\begin{array}{c}-0.038605(\mathrm{I}) \\
-0.047065(\mathrm{~A}) \\
\end{array}$ & $16.31(\mathrm{~A})$ \\
\hline Spike & - & - & - & - & - & - & $-0.0119967(\mathrm{I})$ & - \\
\hline $\begin{array}{c}\mathrm{CdO}, \mathrm{Sb}_{2} \mathrm{O}_{3}, \\
\mathrm{SeO}_{2}, \mathrm{Tl}_{2} \mathrm{O}_{3}\end{array}$ & - & - & - & - & - & - & - & - \\
\hline $\begin{array}{l}\text { Lower } \\
\text { Limit }\end{array}$ & $\begin{array}{c}5.498(\mathrm{I})^{(\mathrm{e})} \\
5.60181(\mathrm{~A})\end{array}$ & $\begin{array}{c}0.157185(\mathrm{I})^{(\mathrm{e})} \\
0.128005(\mathrm{~A})\end{array}$ & (d) & (d) & (d) & (d) & $\begin{array}{c}0.03355(\mathrm{I}) \\
-0.234627(\mathrm{~A})\end{array}$ & (d) \\
\hline $\begin{array}{l}\text { Upper } \\
\text { Limit }\end{array}$ & $\begin{array}{c}7.80045(\mathrm{I}) \\
7.904176(\mathrm{~A})\end{array}$ & $\begin{array}{c}1.25578(\mathrm{I}, \mathrm{IL}) \\
1.4099(\mathrm{I}, \mathrm{OL}) \\
1.22657(\mathrm{~A}, \mathrm{IL}) \\
1.38073(\mathrm{~A}, \mathrm{OL}) \\
\end{array}$ & $\begin{array}{c}6.94232(\mathrm{I})^{(\mathrm{f})} \\
7.032582(\mathrm{~A})^{(\mathrm{f})}\end{array}$ & $\begin{array}{c}\text { 7.77179(I) }{ }^{(\mathrm{f})} \\
5.881264(\mathrm{~A})^{(\mathrm{f})}\end{array}$ & $\begin{array}{l}6.95212(\mathrm{I})^{(\mathrm{f})} \\
7.02258(\mathrm{~A})^{(\mathrm{e})}\end{array}$ & $\begin{array}{c}-5.25536(\mathrm{I})^{(\mathrm{f})} \\
-5.255706(\mathrm{~A})^{(\mathrm{e})}\end{array}$ & (d) & 1079.06(A) \\
\hline
\end{tabular}

(a) Property-composition model intercepts and the part due to "Constant" are incorporated into the lower and/or upper limits.

(b) All values are used for both Initial and Augmentation Matrices, unless otherwise stated: (I)=for Initial Matrix only, (A)=for Augmentation Matrix only, (IL) $=$ Inner Layer, $(\mathrm{OL})=$ Outer Layer. Values are listed as used in constraints development and without rounding.

(c) A "_" indicates the component is expected to have a minor effect on the property and is not included in the model used to form the constraint.

(d) No limits were imposed for these properties.

(e) Constraints unnecessary (i.e., not triggered) for the inner layer.

(f) Constraints unnecessary (i.e., not triggered) for both the inner and outer layers. 
Table 2.8. Target Glass Compositions (wt\%) for the IHLW Initial (HLW02) and Augmentation (HLW03) Test Matrices Expressed in the Original Oxide Forms.

\begin{tabular}{|c|c|c|c|c|c|c|c|c|c|c|c|c|c|c|c|c|c|c|c|c|c|c|}
\hline Glass ID $^{(a)}$ & Point Type (b) $^{(\mathbf{b})}$ & $\begin{array}{c}\text { Melt } \\
\text { Order }\end{array}$ & ${ }_{2} \mathbf{O}_{3}$ & $\mathbf{B}_{2} \mathbf{O}_{3}$ & $\mathrm{O}_{3}$ & $\mathbf{i}_{2} \mathbf{O}$ & $\mathbf{O}$ & $\mathrm{Na}_{2} \mathrm{O}$ & S & SrO & $O_{2}$ & $\mathbf{U O}_{2}$ & $\mathbf{O}_{2}$ & 3 & o & $\mathbf{0}$ & 0 & $O_{3}$ & $\mathrm{O}_{3}$ & $\mathrm{O}_{2}$ & Spike & Constant \\
\hline HLW & Center & I-29 & 172 & 9.928 & 899 & .996 & 2.385 & 10.958 & 3.616 & 2.444 & 000 & 000 & 974 & 108 & 518 & 000 & .771 & 110 & .110 & .110 & .702 & 2.200 \\
\hline HLI & $\mathrm{r} 01$ & $\mathrm{I}-25$ & 4.000 & 14.000 & 4.000 & 6.000 & 0.000 & 4.000 & 50.460 & 0.000 & 000 & 000 & 0.000 & & 0.100 & 2.000 & 1.500 & 0.020 & 200 & .020 & & \\
\hline HLW02-03 & Outer02 & $\mathrm{I}-12$ & 000 & 14.000 & 3.000 & .000 & \begin{tabular}{|l|}
0.000 \\
\end{tabular} & 15.000 & 38.000 & 4.380 & .000 & 0.000 & 6.000 & 200 & 1.000 & 2.000 & 1.500 & .200 & .020 & .200 & 1.301 & 200 \\
\hline HLW02-04 & $\mathrm{r} 03$ & $\mathrm{I}-46$ & 4.000 & 5.000 & 14.000 & 000 & 518 & .000 & 2.932 & 000 & 000 & 000 & 0.000 & 020 & 0.100 & 2.000 & .500 & 200 & 200 & 200 & 130 & 200 \\
\hline HLW & er04 & $\mathrm{I}-53$ & 4.000 & 5.000 & 8.000 & .000 & 0.000 & 3.788 & 52.653 & 0.000 & .000 & 000 & 6.000 & 020 & 0.100 & 2.000 & 0.050 & 0.020 & .020 & 020 & 130 & 200 \\
\hline HLW & & $\mathrm{I}-45$ & 8.500 & 5.000 & 8.000 & 4.739 & 5.000 & 15.000 & 40.491 & 0.000 & .000 & .000 & 6.000 & 0.020 & 1.000 & 2.000 & 1.500 & 0.200 & .020 & .200 & .130 & 2.200 \\
\hline HLW02-07 & r06 & I-43 & 8.500 & 5.000 & 8.000 & 6.000 & 0.000 & 11.705 & 53.000 & 0.000 & 0.000 & 0.000 & 1.525 & \begin{tabular}{|l|}
0.200 \\
\end{tabular} & 0.100 & 2.000 & 0.050 & 0.200 & 0.200 & 0.020 & 1.301 & 2.200 \\
\hline HLW02-08 & a.Outer07 & I-56 & 4.000 & 14.000 & 9.205 & 3.310 & \begin{tabular}{|l|}
5.000 \\
\end{tabular} & 15.000 & 38.745 & 0.000 & 0.000 & 0.000 & 6.000 & \begin{tabular}{|l|}
0.020 \\
\end{tabular} & 0.100 & 2.000 & 0.050 & 0.020 & 0.200 & 0.020 & 0.130 & 2.200 \\
\hline $\begin{array}{l}\text { HLW02-09 } \\
\end{array}$ & Outer08 & $\mathrm{I}-21$ & 8.500 & 11.589 & 14.000 & 2.271 & \begin{tabular}{|l|}
0.000 \\
\end{tabular} & 15.000 & 38.000 & 5.000 & 0.000 & 0.000 & 0.000 & 0.020 & 1.000 & 2.000 & \begin{tabular}{|l|}
0.050 \\
\end{tabular} & 0.020 & \begin{tabular}{|l|}
0.200 \\
\end{tabular} & 0.020 & 0.130 & 2.200 \\
\hline $\mathrm{HI}$ & & $\mathrm{I}-42$ & 8.500 & 14.000 & 8.000 & 6.000 & 0.000 & 10.513 & 38.000 & 2.797 & 0.000 & 0.000 & 6.000 & & 0.100 & 2.000 & 1.500 & 0.020 & .020 & .200 & 30 & 200 \\
\hline & & $\mathrm{I}-32$ & 4.000 & 14.000 & 8.000 & 6.000 & 0.000 & 10.857 & 45.144 & 0.000 & 0.000 & 0.000 & 6.000 & 0.020 & 1.000 & 2.000 & 0.050 & 0.200 & 200 & 0.200 & 0.130 & 00 \\
\hline $\mathrm{HI}$ & & $\mathrm{I}-44$ & 4.000 & 5.000 & 11.386 & 6.000 & \begin{tabular}{|l|}
5.000 \\
\end{tabular} & 12.761 & 41.414 & 0.000 & .000 & 0.000 & 6.000 & \begin{tabular}{|l|}
0.200 \\
\end{tabular} & 1.000 & 2.000 & 1.500 & 0.020 & .020 & .200 & .301 & 00 \\
\hline & & I-39 & 4.000 & 5.000 & 14.000 & 6.000 & 5.000 & 10.427 & 43.121 & 5.000 & .000 & 0.000 & 1.182 & 0.200 & 0.100 & 2.000 & \begin{tabular}{|l|}
0.050 \\
\end{tabular} & 0.200 & .020 & .200 & 1.301 & 00 \\
\hline $\mathrm{HI}$ & & $\mathrm{I}-41$ & 4.000 & 5.000 & 8.000 & 6.000 & 2.490 & 4.140 & 53.000 & 5.000 & .000 & 000 & 6.000 & 0.020 & .100 & 2.000 & .500 & 0.200 & .200 & .020 & .130 & 00 \\
\hline HLW02-15 & 1a.Outer14 & $\mathrm{I}-18$ & 8.500 & 14.000 & 14.000 & 2.000 & \begin{tabular}{|l|}
4.689 \\
\end{tabular} & 12.541 & 38.000 & 0.000 & 0.000 & 0.000 & 0.000 & 0.200 & 0.100 & 2.000 & 0.050 & 0.200 & \begin{tabular}{|l|}
0.020 \\
\end{tabular} & 0.200 & 1.301 & 2.200 \\
\hline HLW02-16 & Outer15 & I-51 & 8.500 & 5.000 & 8.000 & 6.000 & 5.000 & 9.654 & 39.126 & 5.000 & 0.000 & 0.000 & 6.000 & \begin{tabular}{|l|}
0.200 \\
\end{tabular} & 0.100 & 2.000 & 1.500 & 0.020 & 0.200 & 0.200 & 1.301 & 2.200 \\
\hline HLW02-17 & & I-19 & 8.500 & 5.000 & 13.843 & 6.000 & \begin{tabular}{|l|}
0.000 \\
\end{tabular} & 7.690 & 52.958 & 0.000 & 0.000 & 0.000 & 0.000 & \begin{tabular}{|l|}
0.020 \\
\end{tabular} & 0.100 & 2.000 & 1.500 & 0.020 & 0.020 & .020 & 0.130 & 200 \\
\hline & & I-8 & 4.000 & 5.000 & 11.130 & 2.014 & \begin{tabular}{|l|}
0.000 \\
\end{tabular} & 15.000 & & 0.000 & 0.000 & 00 & 6.000 & & 1.000 & 2.000 & 0.050 & 020 & 200 & .020 & 1.301 & 200 \\
\hline & & I-57 & 4.000 & 14.000 & 0.781 & 2.000 & 5.000 & 8.849 & 38.000 & 5.000 & 0.000 & 0.000 & 6.000 & 0.020 & 0.100 & 2.000 & 1.500 & 0.020 & 0.200 & 0.200 & 0.130 & 00 \\
\hline $\mathrm{HL}$ & & I-30 & 4.000 & 14.000 & 14.000 & 2.000 & \begin{tabular}{|l|}
0.000 \\
\end{tabular} & 53 & \begin{tabular}{|l|}
51.734 \\
\end{tabular} & 3.253 & 0.000 & 0.000 & 0.000 & \begin{tabular}{|l|}
0.020 \\
\end{tabular} & 0.100 & 2.000 & 0.050 & 0.020 & 0.020 & 0.020 & 0.130 & 200 \\
\hline HLV & & $\mathrm{I}-24$ & 8.500 & 14.000 & 8.000 & 2.000 & \begin{tabular}{|l|}
0.000 \\
\end{tabular} & 15.000 & 46.440 & 0.000 & 0.000 & 0.000 & 1.500 & \begin{tabular}{|l|}
0.020 \\
\end{tabular} & 0.100 & 2.000 & 0.050 & 0.020 & 0.020 & 0.020 & 0.130 & 200 \\
\hline HLW & & I-36 & 8.500 & 14.000 & 9.500 & 6.000 & 0.000 & 4.000 & 53.000 & 0.080 & .000 & 0.000 & 0.000 & 0.020 & 0.100 & 2.000 & \begin{tabular}{|l|}
0.050 \\
\end{tabular} & 0.020 & 0.200 & 0.200 & 0.130 & 200 \\
\hline HLW02-23 & 1a.Outer22 & $\mathrm{I}-15$ & 8.500 & 14.000 & 8.000 & 6.000 & 5.000 & 5.590 & 39.320 & 5.000 & 0.000 & 0.000 & 1.500 & 0.020 & 1.000 & 2.000 & 1.500 & 0.200 & \begin{tabular}{|l|}
0.020 \\
\end{tabular} & 0.020 & 0.130 & 2.200 \\
\hline HLW02-24 & 1a.Outer23 & I-31 & 8.500 & 5.000 & 8.000 & 2.000 & 5.000 & 12.198 & 47.062 & 5.000 & 0.000 & 0.000 & 1.500 & \begin{tabular}{|l|}
0.153 \\
\end{tabular} & 0.100 & 2.000 & 0.050 & 0.020 & 0.020 & 0.200 & 0.998 & 2.200 \\
\hline HLW02-25 & 1a.Outer24 & I-34 & 8.500 & 14.000 & 9.500 & 2.000 & 0.355 & 6.883 & 47.392 & 5.000 & 0.000 & 0.000 & 0.000 & \begin{tabular}{|l|}
0.020 \\
\end{tabular} & 0.100 & 2.000 & 1.500 & 0.200 & 0.200 & 0.020 & 0.130 & 2.200 \\
\hline HLW02-26 & 1a.Outer25 & $\mathrm{I}-5$ & 4.000 & 5.000 & 12.500 & 2.000 & 4.960 & 15.000 & 38.000 & 5.000 & 0.000 & 0.000 & 6.000 & 0.200 & 0.100 & 2.000 & 1.500 & 0.200 & \begin{tabular}{|l|}
0.020 \\
\end{tabular} & 0.020 & 1.301 & 2.200 \\
\hline $\begin{array}{l}\text { HLW02-27 } \\
\end{array}$ & Outer26 & $\mathrm{I}-23$ & 4.000 & 14.000 & 12.500 & 6.000 & \begin{tabular}{|l|}
3.365 \\
\end{tabular} & 4.274 & 39.941 & 5.000 & 0.000 & 0.000 & 6.000 & 0.020 & 0.100 & 2.000 & 0.050 & 0.200 & \begin{tabular}{|l|}
0.020 \\
\end{tabular} & 0.200 & 0.130 & 200 \\
\hline HLW02-28 & er01 & I-49 & 7.500 & 8.000 & 10.450 & 2.500 & \begin{tabular}{|l|}
1.500 \\
\end{tabular} & 15.000 & 41.000 & 3.500 & 0.000 & 0.000 & 4.500 & 0.040 & 0.300 & 2.000 & 1.000 & 0.150 & 0.050 & 0.050 & 0.260 & 200 \\
\hline $2-29$ & & I-6 & 7.500 & 13.000 & 10.000 & 3.750 & 1.500 & 9.000 & 41.000 & 3.500 & 0.000 & 0.000 & 4.500 & 0.133 & 0.300 & 2.000 & 0.500 & 0.050 & 0.050 & 0.150 & 0.867 & 200 \\
\hline & & $\mathrm{I}-22$ & 5.500 & & 10.000 & 5.000 & 3.500 & 11.229 & & 3.500 & 0.000 & 0.000 & 4.500 & 0.040 & 0.300 & 2.000 & \begin{tabular}{|l|}
1.000 \\
\end{tabular} & 0.050 & .150 & 0.050 & 0.260 & 2.200 \\
\hline HLW02-31 & 1a.Inner04 & $\mathrm{I}-20$ & 5.500 & 13.000 & 10.000 & 2.500 & 1.500 & 14.981 & 41.000 & 1.500 & 0.000 & 0.000 & 4.369 & 0.040 & 0.300 & 2.000 & \begin{tabular}{|l|l|}
0.500 \\
\end{tabular} & 0.150 & 0.050 & 0.150 & 0.260 & 2.200 \\
\hline
\end{tabular}

(a) Glass IDs HLW02-01 to HLW02-57 identify the initial test matrix of HLW glasses, while Glass IDs HLW03-01 to HLW03-45 identify the augmentation test matrix of HLW glasses.

(b) The "Point Type" notation generally begins with either 1a [denoting the initial (Phase 1a) test matrix] or 1b [denoting the augmentation (Phase 1b) test matrix]. After a separating dot, the notation continues with "Center", "Outer", or "Inner", denoting whether the glass was a center point, outer-layer point, or inner-layer point. The "Center", "Outer", or "Inner" designation is with respect to Phase 1a or Phase 1b. The "XX" following "Outer" and "Inner" denotes the number of each outer-layer or inner-layer point with respect to Phase 1a or Phase 1b. Replicate points are denoted by "RepHLW02-xx" and "RepHLW03-xx", where the "xx" represents a specific Glass ID number for a replicated glass. 
Table 2.8. Target Glass Compositions (wt\%) for the IHLW Initial (HLW02) and Augmentation (HLW03) Test Matrices Expressed in the Original Oxide Forms (continued).

\begin{tabular}{|c|c|c|c|c|c|c|c|c|c|c|c|c|c|c|c|c|c|c|c|c|c|c|}
\hline Glass ID ${ }^{(a)}$ & Point Type ${ }^{(\mathbf{b})}$ & $\begin{array}{c}\text { Melt } \\
\text { Order }\end{array}$ & $\mathbf{A l}_{2} \mathbf{O}_{3}$ & $\mathbf{B}_{2} \mathbf{O}_{3}$ & $\mathrm{Fe}_{2} \mathrm{O}_{3}$ & $\mathbf{L i}_{2} \mathbf{O}$ & MnO & $\mathrm{Na}_{2} \mathrm{O}$ & $\mathrm{SiO}_{2}$ & SrO & $\mathrm{ThO}_{2}$ & $\mathbf{U O}_{2}$ & $\mathrm{ZrO}_{2}$ & $\mathrm{Cr}_{2} \mathrm{O}_{3}$ & $\mathrm{NiO}$ & $\mathrm{ZnO}$ & CdO & $\mathbf{T l}_{2} \mathbf{O}_{3}$ & $\mathbf{S b}_{2} \mathbf{O}_{3}$ & $\mathrm{SeO}_{2}$ & Spike & Constant \\
\hline HLW02-32 & 1a.Inner05 & I-9 & 7.500 & 8.000 & 10.000 & 000 & 1.500 & 10.733 & 6.118 & 3.500 & 000 & .000 & 500 & .040 & .300 & 2.000 & 1.000 & .050 & .150 & .150 & 0.260 & 2.200 \\
\hline HLW02-33 & Inner06 & I-17 & 6.341 & 8.000 & 12.000 & 2.500 & 3.500 & 15.000 & 41.000 & 3.500 & .000 & 0.000 & 2.009 & \begin{tabular}{|l|}
0.040 \\
\end{tabular} & 0.800 & 2.000 & 0.500 & \begin{tabular}{|l|}
0.050 \\
\end{tabular} & 0.150 & 0.150 & 0.260 & 2.200 \\
\hline HLW02-34 & Inner07 & I-26 & 5.500 & 13.000 & 12.000 & 3.957 & 1.500 & 10.893 & 41.000 & 3.500 & 0.000 & 0.000 & 1.500 & \begin{tabular}{|l|}
0.133 \\
\end{tabular} & 0.800 & 2.000 & 1.000 & \begin{tabular}{|l|}
0.050 \\
\end{tabular} & 0.050 & 0.050 & 0.867 & 2.200 \\
\hline HLW02-35 & a.Inner08 & I-35 & 6.489 & 13.000 & 12.000 & 5.000 & 3.500 & 9.161 & 41.000 & 1.500 & 0.000 & 0.000 & 1.500 & 0.133 & 0.800 & 2.000 & 0.500 & \begin{tabular}{|l|}
0.150 \\
\end{tabular} & 0.150 & 0.050 & 0.867 & 2.200 \\
\hline HLW02-36 & rno & I-48 & 5.500 & 8.669 & 12.000 & 2.500 & 1.500 & 15.000 & 45.082 & 1.500 & 0.000 & 0.000 & 1.500 & 0.133 & 0.300 & 2.000 & 1.000 & 0.050 & 0.050 & .150 & 0.867 & 2.200 \\
\hline HLW02-37 & & $\mathrm{I}-3$ & 6.762 & 13.000 & 10.000 & 2.500 & 3.500 & 11.188 & 41.000 & 1.500 & 0.000 & 0.000 & 4.500 & 0.040 & 0.800 & 2.000 & 0.500 & 0.050 & 0.150 & 0.050 & 0.260 & 200 \\
\hline HLW02-38 & er11 & I-4 & 6.894 & 13.000 & 12.000 & 4.256 & 1.500 & 9.000 & 41.000 & 3.500 & 0.000 & 0.000 & 1.500 & 0.133 & 0.800 & 2.000 & 1.000 & 0.050 & 150 & .150 & 0.867 & 2.200 \\
\hline HLW02-39 & & $\mathrm{I}-40$ & 7.500 & 8.992 & 10.000 & 2.500 & 1.500 & 11.059 & 49.000 & 1.500 & 0.000 & 0.000 & 1.500 & 0.040 & 0.800 & 2.000 & 1.000 & 0.050 & .050 & .050 & 0.260 & 2.200 \\
\hline $\mathrm{HLV}$ & & I-33 & 7.500 & 9.834 & 10.000 & 2.632 & 1.500 & 9.684 & 49. & 1.500 & 0.000 & 0.000 & 1.500 & 0.133 & 0.300 & 2.000 & 1.000 & 0.150 & .150 & .050 & 0.867 & 2.200 \\
\hline HLW02-41 & 14 & $\mathrm{I}-14$ & 6.500 & 13.000 & 10.000 & 2.500 & 1.500 & 9.000 & 48.950 & 1.500 & 0.000 & 0.000 & 1.500 & 0.040 & 0.300 & 2.000 & 0.500 & 0.150 & 0.050 & 0.050 & 0.260 & 2.200 \\
\hline HLW02-42 & 1a.Inner15 & $\mathrm{I}-55$ & 5.500 & 13.000 & 10.000 & 5.000 & 1.500 & 9.000 & 44.450 & 3.500 & 0.000 & 0.000 & 2.500 & \begin{tabular}{|l|}
0.040 \\
\end{tabular} & 0.300 & 2.000 & 0.500 & 0.150 & 0.050 & 0.050 & 0.260 & 2.200 \\
\hline HLW02-43 & 1a.Inner16 & I-38 & 6.500 & 13.000 & 10.000 & 2.500 & 3.500 & 12.450 & 41.000 & 3.500 & 0.000 & 0.000 & 1.500 & \begin{tabular}{|l|}
0.040 \\
\end{tabular} & 0.300 & 2.000 & 1.000 & 0.050 & 0.150 & 0.050 & 0.260 & 2.200 \\
\hline HLW02-44 & & $\mathrm{I}-2$ & 5.500 & 9.071 & 10.000 & 2.500 & 3.500 & 15.000 & 43.680 & 1.500 & 0.000 & 0.000 & 2.500 & 0.133 & 0.300 & 2.000 & 1.000 & 0.050 & 0.150 & 0.050 & 0.867 & 2.200 \\
\hline $\mathrm{HL}$ & & $\mathrm{I}-11$ & 5.500 & 8.000 & 11.000 & 2.500 & 3.500 & 9.619 & 48.831 & 3.500 & 0.000 & 0.000 & 1.500 & \begin{tabular}{|l|}
0.040 \\
\end{tabular} & 0.300 & 2.000 & 1.000 & \begin{tabular}{|l|}
0.050 \\
\end{tabular} & 0.050 & 0.150 & 0.260 & 200 \\
\hline HLW02-46 & & $\mathrm{I}-13$ & 5.500 & 9.149 & 10.000 & 3.701 & 3.500 & 9.000 & 49.000 & 1.500 & 0.000 & 0.000 & 2.500 & \begin{tabular}{|l|}
0.040 \\
\end{tabular} & 0.800 & 2.000 & 0.500 & \begin{tabular}{|l|}
0.150 \\
\end{tabular} & 0.050 & 0.150 & 0.260 & 2.200 \\
\hline HLV & 20 & $\mathrm{I}-27$ & 5.500 & 9.807 & 10.000 & 2.500 & 3.500 & 9.444 & 49.000 & 1.500 & 0.000 & 0.000 & 2.500 & 0.133 & 0.300 & 2.000 & 0.500 & 0.150 & 0.050 & 0.050 & 0.867 & 2.200 \\
\hline HLI & & $\mathrm{I}-10$ & 6.000 & 8.000 & 12.000 & 3.340 & 1.500 & 15.000 & 41.000 & 1.711 & .000 & 0.000 & 4.500 & 33 & 0.800 & 2.000 & 0.500 & 0.150 & .150 & .150 & 0.867 & 00 \\
\hline HLW02-49 & 1a.Inner22 & $\mathrm{I}-54$ & 7.500 & 8.740 & 12.000 & 5.000 & 3.500 & 9.000 & 44.211 & 1.500 & 0.000 & 0.000 & 3.000 & \begin{tabular}{|l|}
0.040 \\
\end{tabular} & 0.300 & 2.000 & 0.500 & \begin{tabular}{|l|}
0.150 \\
\end{tabular} & 0.050 & 0.050 & 0.260 & 2.200 \\
\hline HLW02-50 & 1a.Inner23 & $\mathrm{I}-28$ & 6.000 & 13.000 & 12.000 & 2.500 & 1.500 & 9.820 & 43.530 & 1.500 & 0.000 & 0.000 & 4.500 & 0.040 & 0.300 & 2.000 & 0.500 & 0.150 & 0.150 & 0.050 & 0.260 & 2.200 \\
\hline HLW02-51 & 1a.Inner24 & I-7 & 7.500 & 8.000 & 10.500 & 4.589 & 1.500 & 9.000 & 45.162 & 3.500 & 0.000 & 0.000 & 4.500 & 0.040 & 0.300 & 2.000 & 0.500 & 0.150 & 0.150 & 0.150 & 0.260 & 2.200 \\
\hline HLW02-52 & RepHLW02-01 & $\mathrm{I}-50$ & 6.172 & 9.928 & 10.899 & 3.996 & 2.385 & 10.958 & 43.616 & 2.444 & 0.000 & 0.000 & 2.974 & 0.108 & 0.518 & 2.000 & 0.771 & 0.110 & 0.110 & 0.110 & 0.702 & 2.200 \\
\hline HLW02-53 & \begin{tabular}{|l|} 
RepHLW02-17 \\
\end{tabular} & I-52 & 8.500 & 5.000 & 13.843 & 6.000 & 0.000 & 7.690 & 52.958 & 0.000 & 0.000 & 0.000 & 0.000 & 0.020 & 0.100 & 2.000 & 1.500 & 0.020 & 0.020 & 0.020 & 0.130 & 2.200 \\
\hline HLW02-54 & V02-4 & $\mathrm{I}-1$ & 4.000 & 5.000 & 14.000 & 2.000 & 0.518 & 15.000 & 52.932 & 0.000 & 0.000 & 0.000 & 0.000 & 0.020 & 0.100 & 2.000 & 1.500 & 0.200 & 0.200 & 0.200 & 0.130 & 200 \\
\hline HLW02-55 & $02-42$ & 16 & 5.500 & 3.000 & 10000 & 5.000 & 1.500 & 9.000 & 44.450 & 3.500 & 0.000 & 0.000 & 2.500 & \begin{tabular}{|l|}
0.040 \\
\end{tabular} & 0.300 & 2.000 & 0.500 & \begin{tabular}{|l|}
0.150 \\
\end{tabular} & 0.050 & 0.050 & 0.260 & 200 \\
\hline HLV & & I-37 & 5.500 & 9.071 & 10.000 & 2.500 & 3.500 & 15.000 & 43.680 & 1.500 & 0.000 & 0.000 & 2.500 & 0.133 & 0.300 & 2.000 & 1.000 & 0.050 & 0.150 & 0.050 & 0.867 & 2.200 \\
\hline HLW02-57 & $22-8$ & I-47 & 4.000 & 4.000 & 9.205 & 3.310 & 5.000 & 15.000 & 38.745 & 0.000 & 0.000 & 0.000 & 6.000 & 0.020 & 0.100 & 2.000 & 0.050 & 0.020 & 00 & 0.020 & 0.130 & \\
\hline HLW03-01 & 1b.Outer01 & A-4 & 8.335 & 13.728 & 13.728 & 5.883 & 6.078 & 3.922 & 35.301 & 0.000 & 2.764 & 0.000 & 2.983 & \begin{tabular}{|l|}
0.020 \\
\end{tabular} & 0.098 & 3.059 & 0.050 & \begin{tabular}{|l|}
0.330 \\
\end{tabular} & 0.020 & 0.200 & 1.300 & 2.200 \\
\hline HLW03-02 & 1b.Outer02 & A-28 & 1.951 & 13.659 & 13.659 & 2.472 & 6.830 & 11.175 & 35.124 & 0.000 & 0.000 & 0.000 & 9.086 & 0.488 & 0.976 & 0.000 & 1.600 & 0.330 & 0.300 & 0.020 & 0.130 & 2.200 \\
\hline HLW03-03 & 1b.Outer03 & A-26 & 1.953 & 4.883 & 13.674 & 2.677 & 6.837 & 10.753 & 35.161 & 9.767 & 0.000 & 0.000 & 6.403 & \begin{tabular}{|l|}
0.488 \\
\end{tabular} & 0.977 & 1.946 & 1.600 & \begin{tabular}{|l|}
0.330 \\
\end{tabular} & 0.020 & 0.200 & 0.130 & 2.200 \\
\hline HLW03-04 & 1b.Outer04 & A-9 & 1.961 & 4.903 & 13.728 & 5.883 & 3.172 & 4.458 & 42.575 & 9.806 & 0.000 & 5.883 & 2.942 & \begin{tabular}{|l|}
0.490 \\
\end{tabular} & 0.098 & 0.000 & 0.050 & 0.330 & 0.020 & 0.200 & 1.300 & 2.200 \\
\hline HLW03-05 & 1b.Outer05 & A-2 & 8.176 & 4.809 & 1.924 & 1.924 & 6.733 & 14.428 & 47.840 & 0.000 & 3.812 & 0.000 & 0.000 & 0.481 & 0.096 & 3.847 & 1.600 & 0.330 & 0.300 & 0.200 & 1.300 & 2.200 \\
\hline HLW03-06 & 1b.Outer06 & A-35 & 8.344 & 4.908 & 1.963 & 5.890 & 6.872 & 3.927 & 52.030 & 5.091 & 1.416 & 0.000 & 4.095 & \begin{tabular}{|l|}
0.491 \\
\end{tabular} & 0.982 & 0.000 & 1.600 & 0.020 & 0.020 & 0.020 & 0.130 & 2.200 \\
\hline
\end{tabular}

(a) Glass IDs HLW02-01 to HLW02-57 identify the initial test matrix of HLW glasses, while Glass IDs HLW03-01 to HLW03-45 identify the augmentation test matrix of HLW glasses.

(b) The "Point Type" notation generally begins with either 1a [denoting the initial (Phase 1a) test matrix] or 1b [denoting the augmentation (Phase 1b) test matrix]. After a separating dot, the notation continues with "Center", "Outer", or "Inner", denoting whether the glass was a center point, outer-layer point, or inner-layer point. The "Center", "Outer", or "Inner" designation is with respect to Phase 1a or Phase 1b. The "XX" following "Outer" and "Inner" denotes the number of each outer-layer or inner-layer point with respect to Phase 1a or Phase 1b. Replicate points are denoted by "RepHLW02-xx" and "RepHLW03-xx", where the "xx" represents a specific Glass ID number for a replicated glass. 
Table 2.8. Target Glass Compositions (wt\%) for the IHLW Initial (HLW02) and Augmentation (HLW03) Test Matrices Expressed in the Original Oxide Forms (continued).

\begin{tabular}{|c|c|c|c|c|c|c|c|c|c|c|c|c|c|c|c|c|c|c|c|c|c|c|}
\hline Glass ID $^{(a)}$ & Point Type $^{(\mathbf{b})}$ & $\begin{array}{c}\text { Melt } \\
\text { Order }\end{array}$ & $\mathbf{A l}_{2} \mathbf{O}_{3}$ & $\mathbf{B}_{2} \mathbf{O}_{3}$ & $\mathrm{Fe}_{2} \mathrm{O}_{3}$ & $\mathbf{L i}_{2} \mathbf{O}$ & MnO & $\mathrm{Na}_{2} \mathrm{O}$ & $\mathrm{SiO}_{2}$ & SrO & $\mathrm{ThO}_{2}$ & $\mathbf{U O}_{2}$ & $\mathrm{ZrO}_{2}$ & $\mathrm{Cr}_{2} \mathrm{O}_{3}$ & $\mathrm{NiO}$ & $\mathrm{ZnO}$ & CdO & $\mathrm{Tl}_{2} \mathrm{O}_{3}$ & $\mathbf{S b}_{2} \mathbf{O}_{3}$ & $\mathrm{SeO}_{2}$ & Spike & Constant \\
\hline HLW03-07 & 1b.Outer07 & A-25 & 4.979 & 4.979 & 13.940 & 4.767 & 970 & .735 & 39.967 & 0.000 & 0.000 & 974 & 0.000 & .470 & .100 & 3.473 & .050 & .020 & .020 & .200 & 0.130 & 2.200 \\
\hline HLW03-08 & 1b.Outer08 & A-31 & 8.033 & 4.834 & 1.934 & 5.152 & 6.768 & 14.503 & 34.807 & 0.000 & 4.413 & 0.000 & 9.669 & 0.483 & 0.097 & 3.867 & \begin{tabular}{|l|}
1.600 \\
\end{tabular} & 0.020 & 0.300 & 0.020 & 1.300 & 2.200 \\
\hline HLW03-09 & b.Outer09 & A-11 & 7.666 & 13.692 & 3.485 & 1.979 & 0.000 & 14.845 & 52.453 & 0.000 & 2.551 & 0.000 & 0.000 & 0.020 & 0.099 & 0.000 & \begin{tabular}{|l|}
0.050 \\
\end{tabular} & 0.330 & 0.300 & 0.200 & 0.130 & 2.200 \\
\hline HLW03-10 & 1b.Outer10 & A-45 & 8.377 & 4.928 & 9.991 & 5.913 & 6.899 & 12.863 & 35.481 & 0.000 & 2.628 & 1.047 & 7.257 & 0.020 & 0.986 & 0.000 & \begin{tabular}{|l|}
0.050 \\
\end{tabular} & 0.020 & 0.020 & 0.020 & 1.300 & 2.200 \\
\hline HLW03-11 & 1b.Outer11 & 38 & 1.991 & 4.979 & 9.572 & 1.991 & 0.000 & 14.936 & \begin{tabular}{|l|}
52.772 \\
\end{tabular} & 0.000 & 5.045 & 5.974 & 0.000 & 0.020 & 0.100 & 0.000 & \begin{tabular}{|l|}
0.050 \\
\end{tabular} & 0.020 & .020 & 0.200 & 0.130 & 2.200 \\
\hline HLW03-12 & er12 & 34 & 1.989 & 4.973 & 1.989 & 5.026 & 6.963 & 3.979 & 44.433 & 9.947 & 3.742 & 5.968 & 3.695 & 0.497 & 0.099 & 3.979 & 0.050 & 0.020 & 0.300 & 0.020 & .130 & .200 \\
\hline HLW03-13 & Outer13 & 13 & 8.463 & 4.979 & 8.664 & 5.227 & 6.970 & 3.983 & 35.845 & 9.957 & 3.850 & 5.974 & 0.849 & 498 & 0.996 & 1.125 & \begin{tabular}{|l|}
0.050 \\
\end{tabular} & 0.020 & 0.020 & 0.200 & 130 & 200 \\
\hline HLW03-14 & er14 & 27 & 1.989 & 4972 & 9.045 & 2.503 & 6.961 & 10.423 & 35.798 & 9.944 & 4.114 & 0.000 & 6.510 & 0.020 & 0.994 & 3.978 & 0.050 & 0.330 & 0.020 & .020 & 130 & .200 \\
\hline HLW & & & 1.951 & 13.659 & 13.659 & 1.951 & 1.348 & 5.247 & \begin{tabular}{|l|l|}
51.710 \\
\end{tabular} & 0.000 & 2.440 & .000 & 0.000 & 0.020 & 0.098 & 3.336 & $\mid 1.600$ & 0.330 & .300 & .020 & & 200 \\
\hline HLW03-16 & & & 1.962 & 4.904 & 7.935 & 2.873 & 6.866 & 3.924 & \begin{tabular}{|l|}
44.407 \\
\end{tabular} & 9.809 & 2.578 & 5.885 & 1.005 & 0.020 & 0.981 & 2.782 & \begin{tabular}{|l|}
0.050 \\
\end{tabular} & 0.020 & 0.300 & .200 & 1.300 & 200 \\
\hline HLW03-17 & 1b.Outer17 & A-29 & 8.377 & 13.798 & 1.971 & 1.971 & 6.899 & 4.474 & 46.224 & 0.000 & 2.244 & 4.530 & 1.644 & 0.020 & 0.294 & 3.942 & \begin{tabular}{|l|}
0.050 \\
\end{tabular} & 0.020 & 0.020 & 0.020 & 1.300 & 2.200 \\
\hline HLW03-18 & 1b.Outer18 & A-14 & 1.989 & 4.972 & 13.921 & 5.921 & 0.000 & 10.531 & 52.472 & 0.000 & 5.966 & 0.000 & 0.000 & \begin{tabular}{|l|}
0.497 \\
\end{tabular} & 0.980 & 0.000 & \begin{tabular}{|l|}
0.050 \\
\end{tabular} & 0.330 & 0.020 & 0.020 & 0.130 & 2.200 \\
\hline HLW03-19 & & & 1.963 & 4.908 & 9.634 & 5.890 & 0.197 & 10.142 & 52.030 & 0.000 & 5.846 & 0.000 & 0.000 & 0.491 & 0.982 & 3.927 & 1.600 & 0.020 & 0.020 & .020 & 0.130 & 200 \\
\hline HLV & & & 1.924 & 4.809 & 13.466 & 5.771 & 0.000 & 10.100 & \begin{tabular}{|l|}
50.697 \\
\end{tabular} & 0.145 & 5.771 & 0.406 & 0.000 & \begin{tabular}{|l|}
0.019 \\
\end{tabular} & 0.962 & 0.000 & \begin{tabular}{|l|}
1.600 \\
\end{tabular} & 0.330 & 0.300 & 0.200 & 0 & 00 \\
\hline HLW03-21 & & $\overline{44}$ & 4.964 & 6.949 & 4.964 & 2.482 & 4.467 & 10.841 & \begin{tabular}{|l|}
48.644 \\
\end{tabular} & 1.489 & 2.978 & 1.985 & 5.956 & 0.079 & 0.298 & 0.993 & \begin{tabular}{|l|}
0.300 \\
\end{tabular} & 0.050 & 0.050 & 0.050 & 0.260 & 200 \\
\hline HLW & 02 & 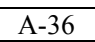 & 4.927 & 6.898 & 9.776 & 2.464 & 1.478 & 11.826 & 40.405 & 4.435 & 2.956 & 3.942 & 5.913 & 0.079 & 0.296 & 0.985 & 0.300 & 0.050 & 0.050 & 0.150 & 0.870 & 200 \\
\hline HLV & & & 4.969 & 11.925 & 7.751 & 2.484 & 1.491 & 11.925 & 40.744 & 1.491 & 2.981 & 3.975 & 5.963 & 0.199 & 0.298 & 0.994 & \begin{tabular}{|l|}
0.100 \\
\end{tabular} & 0.050 & .050 & .150 & 60 & 200 \\
\hline HLW03-24 & Inner04 & & 2.978 & 6.949 & 4.964 & 4.964 & 4.467 & 8.160 & \begin{tabular}{|l|}
48.644 \\
\end{tabular} & 1.489 & 2.978 & 1.985 & 5.956 & \begin{tabular}{|l|}
0.079 \\
\end{tabular} & 0.496 & 2.978 & \begin{tabular}{|l|}
0.300 \\
\end{tabular} & 0.050 & .050 & .050 & 0.260 & 2.200 \\
\hline HLW03-25 & 1b.Inner05 & A-39 & 2.960 & 11.838 & 4.933 & 2.466 & 1.480 & 11.838 & 42.143 & 4.439 & 2.960 & 1.973 & 5.919 & 0.079 & 0.493 & 2.960 & \begin{tabular}{|l|}
0.100 \\
\end{tabular} & 0.150 & 0.050 & 0.150 & 0.870 & 2.200 \\
\hline HLW03-26 & 1b.Inner06 & A-17 & 4.933 & 6.906 & 4.933 & 4.933 & 1.480 & 10.457 & \begin{tabular}{|l|}
40.447 \\
\end{tabular} & 4.439 & 4.439 & 3.946 & 5.919 & \begin{tabular}{|l|}
0.197 \\
\end{tabular} & 0.493 & 2.960 & \begin{tabular}{|l|}
0.100 \\
\end{tabular} & 0.050 & 0.150 & 0.150 & 0.870 & 2.200 \\
\hline HLW03-27 & 1b.Inner07 & A-24 & 4.933 & 6.906 & 9.372 & 4.045 & 1.480 & 11.838 & \begin{tabular}{|l|}
40.447 \\
\end{tabular} & 1.480 & 4.439 & 1.973 & 5.919 & 0.197 & 0.493 & 2.960 & \begin{tabular}{|l|}
0.100 \\
\end{tabular} & 0.050 & 0.150 & 0.150 & 0.870 & 2.200 \\
\hline HLW03-28 & & & 3.633 & 11.925 & 9.938 & 4.969 & 1.491 & 10.499 & 40.744 & 1.491 & 2.981 & 1.988 & 5.963 & 0.080 & 0.497 & 0.994 & \begin{tabular}{|l|}
0.100 \\
\end{tabular} & 0.050 & 0.150 & 0.050 & 0.260 & 2.200 \\
\hline HLW03-29 & & & 2.978 & 6.949 & 4.964 & 4.964 & 3.526 & 11.913 & \begin{tabular}{|l|}
40.702 \\
\end{tabular} & 1.489 & 4.467 & 3.971 & 7.692 & 0.199 & 0.298 & 2.978 & 0.300 & 0.050 & 0.050 & 0.050 & 0.260 & 200 \\
\hline HLW03-30 & & & 2.975 & 1.901 & 4.959 & 4.959 & 463 & 6.942 & 43252 & 1.488 & 4.463 & 1.983 & 8.238 & 0.079 & 0.298 & 0.992 & \begin{tabular}{|l|}
0.100 \\
\end{tabular} & 0.150 & 0.150 & 0.150 & 0.260 & 200 \\
\hline HLV & & & 4.959 & 6.942 & 59 & 4.959 & 4.463 & 543 & 45.109 & 1.488 & 2.975 & 1.983 & 8.925 & 0.198 & 0.496 & 0.992 & \begin{tabular}{|l|}
0.100 \\
\end{tabular} & 0.150 & 0.150 & 0.150 & 0.260 & 200 \\
\hline HLV & & & 4.933 & 6.90 & & 4.933 & 2.932 & 9.123 & 40.447 & 1.480 & 4.439 & 3.946 & 8.879 & 0.079 & 0.493 & 2.960 & \begin{tabular}{|l|}
0.100 \\
\end{tabular} & 0.150 & 150 & .050 & & \\
\hline HLW03-33 & 1b.Inner13 & & 4.969 & 11.925 & 9.938 & 3.905 & 1.491 & 6.956 & 40.744 & 1.491 & 2.981 & 3.195 & 5.963 & \begin{tabular}{|l|}
0.199 \\
\end{tabular} & 0.452 & 2.981 & \begin{tabular}{|l|}
0.100 \\
\end{tabular} & 0.050 & 0.150 & 0.050 & 0.260 & 2.200 \\
\hline HLW03-34 & 1b.Inner14 & A-23 & 2.960 & 6.906 & 9.865 & 2.466 & 1.480 & 9.553 & 48.339 & 1.480 & 3.863 & 1.973 & 5.919 & 0.197 & 0.493 & 0.987 & 0.100 & 0.150 & 0.050 & 0.150 & 0.870 & 2.200 \\
\hline HLW03-35 & 1b.Inner15 & A-20 & 4.969 & 10.409 & 4.969 & 2.484 & 4.472 & 6.956 & 48.694 & 1.491 & 3.180 & 1.988 & 5.963 & 0.080 & 0.497 & 1.040 & 0.100 & 0.150 & 0.050 & 0.050 & 0.260 & 2.200 \\
\hline HLW03-36 & 1b.Inner16 & A-8 & 4.927 & 6.898 & 9.520 & 2.696 & 1.478 & 7.971 & \begin{tabular}{|l|}
48.289 \\
\end{tabular} & 1.478 & 3.563 & 1.971 & 5.913 & \begin{tabular}{|l|}
0.197 \\
\end{tabular} & 0.493 & 0.985 & $\mid 0.300$ & 0.050 & 0.150 & 0.050 & 0.870 & 2.200 \\
\hline HLW03-37 & 1b.Inner17 & A-21 & 2.960 & 11.838 & 7.240 & 4.871 & 1.480 & 6.906 & 40.447 & 1.480 & 4.439 & 3.946 & 7.343 & 0.079 & 0.493 & 2.960 & \begin{tabular}{|l|}
0.100 \\
\end{tabular} & 0.150 & 0.050 & 0.150 & 0.870 & 2.200 \\
\hline HLW03-38 & 1b.Inner18 & A-12 & 4.927 & 6.898 & 9.855 & 2.464 & 1.478 & 9.642 & 43.263 & 1.478 & 3.885 & 3.942 & 7.069 & 0.197 & 0.296 & 0.985 & \begin{tabular}{|l|}
0.300 \\
\end{tabular} & 0.050 & 0.050 & 0.150 & 0.870 & 2.200 \\
\hline
\end{tabular}

(a) Glass IDs HLW02-01 to HLW02-57 identify the initial test matrix of HLW glasses, while Glass IDs HLW03-01 to HLW03-45 identify the augmentation test matrix of HLW glasses.

(b) The "Point Type" notation generally begins with either 1a [denoting the initial (Phase 1a) test matrix] or 1b [denoting the augmentation (Phase 1b) test matrix]. After a separating dot, the notation continues with "Center", "Outer", or "Inner", denoting whether the glass was a center point, outer-layer point, or inner-layer point. The "Center", "Outer", or "Inner" designation is with respect to Phase 1a or Phase 1b. The "XX" following "Outer" and "Inner" denotes the number of each outer-layer or inner-layer point with respect to Phase 1a or Phase 1b. Replicate points are denoted by "RepHLW02-xx" and "RepHLW03-xx", where the "xx" represents a specific Glass ID number for a replicated glass. 
Table 2.8. Target Glass Compositions (wt\%) for the IHLW Initial (HLW02) and Augmentation (HLW03) Test Matrices Expressed in the Original Oxide Forms (continued).

\begin{tabular}{|c|c|c|c|c|c|c|c|c|c|c|c|c|c|c|c|c|c|c|c|c|c|c|}
\hline Glass ID $^{(a)}$ & Point Type $^{(\mathbf{b})}$ & $\begin{array}{c}\text { Melt } \\
\text { Order }\end{array}$ & $\mathbf{A l}_{2} \mathbf{O}_{3}$ & $\mathbf{B}_{2} \mathbf{O}_{3}$ & $\mathrm{Fe}_{2} \mathrm{O}_{3}$ & $\mathbf{L i}_{2} \mathbf{O}$ & MnO & $\mathrm{Na}_{2} \mathrm{O}$ & $\mathrm{SiO}_{2}$ & SrO & $\mathrm{ThO}_{2}$ & $\mathbf{U O}_{2}$ & $\mathrm{ZrO}_{2}$ & $\mathrm{Cr}_{2} \mathrm{O}_{3}$ & $\mathrm{NiO}$ & $\mathrm{ZnO}$ & CdO & $\mathbf{T l}_{2} \mathbf{O}_{3}$ & $\mathrm{Sb}_{2} \mathrm{O}_{3}$ & $\mathrm{SeO}_{2}$ & Spike & Constant \\
\hline HLW & Inner19 & -16 & 2.950 & 6.884 & .513 & 4.856 & 1.475 & 884 & 8.188 & 1.475 & 425 & \begin{tabular}{|l|}
1.967 \\
\end{tabular} & 7.087 & 0.197 & 0.295 & 0.983 & 0.300 & 0.150 & 150 & 0.150 & 0.870 & 2.200 \\
\hline HLW03-40 & 1b.Inner20 & A-7 & 4.953 & 6.935 & 9.412 & 4.892 & 1.486 & 6.935 & 43.060 & 3.287 & 4.458 & 3.963 & 5.944 & 0.079 & 0.495 & 0.991 & 0.300 & 0.050 & 0.150 & 0.150 & 0.260 & 2.200 \\
\hline $\mathrm{HL}$ & $1 \mathrm{~b} . \mathrm{C}$ & A-18 & 3.895 & 8.747 & 6.951 & 3.716 & 2.703 & 9.109 & 43.134 & 2.710 & 3.664 & 2.867 & 6.779 & \begin{tabular}{|l|}
0.140 \\
\end{tabular} & 0.396 & 1.923 & 0.200 & 0.100 & 0.100 & 0.100 & 0.565 & 2.200 \\
\hline $\mathrm{HL}$ & -46 & 19 & 5.500 & 9.149 & 10.000 & 3.701 & 3.500 & 9.000 & 49.000 & 1.500 & 0.000 & 0.000 & 2.500 & 0.040 & 0.800 & 1.999 & 0.500 & 0.150 & 0.050 & .150 & 0.260 & 200 \\
\hline HLW03-43 & $3-06$ & A-42 & 8.344 & 4.908 & 1.963 & 5.890 & 6.872 & 3.927 & 52.030 & 5.091 & 1.416 & 0.000 & 4.095 & 0.491 & 0.982 & 0.000 & 1.600 & 0.020 & 020 & .020 & 30 & 2.200 \\
\hline$\overline{\mathrm{HL}}$ & & $\mathrm{A}$ & 991 & 4.979 & 72 & 1.991 & 0.000 & 14.936 & 2.772 & 0.000 & 5.045 & 5.974 & 0.000 & 20 & 0.100 & 0.000 & 0.050 & 0.020 & 020 & 200 & 30 & 2.200 \\
\hline HLW03-45 & \begin{tabular}{|l|} 
RepHLW03-26 \\
\end{tabular} & A-32 & 4.933 & 6.906 & 4.933 & 4.933 & 1.480 & 10.457 & 40.447 & 4.439 & 4.439 & 3.946 & 5.919 & \begin{tabular}{|l|}
0.197 \\
\end{tabular} & 0.493 & 2.960 & 0.100 & 0.050 & 0.150 & 0.150 & 0.870 & 2.200 \\
\hline
\end{tabular}

(a) Glass IDs HLW02-01 to HLW02-57 identify the initial test matrix of HLW glasses, while Glass IDs HLW03-01 to HLW03-45 identify the augmentation test matrix of HLW glasses.

(b) The "Point Type" notation generally begins with either 1a [denoting the initial (Phase 1a) test matrix] or 1b [denoting the augmentation (Phase 1b) test matrix]. After a separating dot, the notation continues with "Center", "Outer", or "Inner", denoting whether the glass was a center point, outer-layer point, or inner-layer point. The "Center", "Outer", or "Inner" designation is with respect to Phase 1a or Phase 1b. The "XX" following "Outer" and "Inner" denotes the number of each outer-layer or inner-layer point with respect to Phase 1a or Phase 1b. Replicate points are denoted by "RepHLW02-xx" and "RepHLW03-xx", where the "xx" represents a specific Glass ID number for a replicated glass. 
Table 2.9. Composition Expansions of the Spike and Constant Components for the IHLW Initial (HLW02) and Augmentation (HLW03) Test Matrices Expressed in the Original Oxide Forms.

\begin{tabular}{|c|c|c|c|c|c|c|c|c|c|c|c|c|c|c|c|c|c|c|c|c|c|c|c|}
\hline \multirow{2}{*}{ Glass ID $^{(a)}$} & \multicolumn{6}{|c|}{ Spike Components (wt\%) ${ }^{(b)}$} & \multicolumn{17}{|c|}{ Constant Components (wt\%) ${ }^{(c)}$} \\
\hline & $\mathbf{A g}_{2} \mathbf{O}$ & b & $\mathbf{V}_{2} \mathbf{O}_{5}$ & $\mathrm{As}_{2} \mathrm{O}_{3}$ & ) & D & 3 & o & $\mathrm{O}_{2}$ & Cl & o & $\mathbf{C}$ & $\mathbf{F}$ & $\mathbf{K}_{2} \mathbf{O}$ & $a_{2} \mathbf{O}_{3}$ & 0 & $\mathbf{P}_{2} \mathbf{O}_{5}$ & $\mathbf{O}$ & $\mathbf{R h}_{2} \mathbf{O}_{3}$ & $\mathrm{RuO}_{2}$ & $\mathrm{SO}_{3}$ & $\mathrm{TeO}_{2}$ & $\mathrm{TiO}_{2}$ \\
\hline $\mathrm{HLW}$ & 108 & 216 & 054 & \begin{tabular}{|l|}
0.108 \\
\end{tabular} & 0.162 & 054 & 0.01 & 0.50 & 0.05 & 0.20 & 0.01 & 0.01 & 0.05 & 0.06 & 0.30 & 0.12 & 0.50 & 0.12 & 0.05 & 0.08 & 0.1 & 0.01 & 0.03 \\
\hline HLW02-02 & 200 & 400 & 100 & 200 & 0.300 & 100 & 01 & 0.50 & 0.05 & 0.20 & 0.01 & 0.01 & 0.05 & 0.06 & 0.30 & 0.12 & & 0.12 & 0.05 & 0.08 & 0.1 & & 0.03 \\
\hline HLW02-03 & 200 & 0.400 & 0.100 & 200 & 0.300 & 0.100 & 0.01 & 0.50 & 0.05 & 0.20 & 0.01 & 0.01 & 0.05 & 0.06 & 0.30 & 0.12 & 0.50 & 0.12 & 0.05 & 0.08 & 0.1 & 0.01 & 0.03 \\
\hline HLW02-04 & 0.020 & 0.040 & 0.010 & \begin{tabular}{|l|}
0.020 \\
\end{tabular} & 0.030 & 0.010 & 0.01 & 0.50 & 0.05 & 0.20 & 0.01 & 0.01 & 0.05 & 0.06 & 0.30 & 0.12 & 0.50 & 0.12 & 0.05 & 0.08 & 0.1 & 0.01 & 0.03 \\
\hline HLW02-05 & 0.020 & 0.040 & 0.010 & 0.020 & 0.030 & 0.010 & 0.01 & 0.50 & 0.05 & 0.20 & 0.01 & 0.01 & 0.05 & 0.06 & & & 50 & 0.12 & 0.05 & 0.08 & 0.1 & 0.01 & 0.03 \\
\hline HLW02-06 & 0.020 & 0.040 & 010 & 0.020 & 0.030 & 0.010 & 0.0 & 0.50 & 0.05 & 0 . & 0.01 & & & & & & & & 0.05 & 08 & 0.1 & 0.01 & 0.03 \\
\hline HLW02-07 & 0.200 & 0 . & 0 & 0.200 & 0.300 & 0.100 & $\overline{0.0}$ & 0.50 & 5 & 0 . & 0.0 & 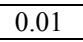 & 0.1 & 0.06 & 30 & & 0 & 2 & .05 & 08 & 0.1 & 1 & 0.03 \\
\hline HLW02-08 & 0.020 & 0.040 & 010 & 0.020 & 0.030 & 0.010 & 0.01 & 0.50 & 05 & 0. & 0.0 & 0.01 & 0.0 & 0.0 & 30 & 0.1 & 0 & 2 & .05 & 0.08 & 0.1 & .01 & 0.03 \\
\hline HLW02-09 & 0.020 & 0.040 & 010 & 0.020 & 0.030 & 0.010 & 0.01 & 0.5 & 05 & 0. & 0.0 & 0.0 & 0.0 & 0.0 & 50 & 0. & . & 2 & .05 & 0.08 & 0.1 & 0.01 & 0.03 \\
\hline HLV & 0.020 & 0.040 & & \begin{tabular}{|l|}
0.020 \\
\end{tabular} & 0.030 & 010 & & 0. & & 0.2 & 0.0 & 0 & 00 & 00 & & & 0 & 2 & .05 & .08 & 0.1 & 1 & 0.03 \\
\hline HLW02-11 & 0.020 & 0.040 & 0.010 & \begin{tabular}{|l|}
0.020 \\
\end{tabular} & 0.030 & 0.010 & 0.01 & 0.50 & 0.05 & 0.20 & 0.0 & 001 & 0.0 & 0.06 & 0.30 & 0.1 & 0.50 & 0.12 & 0.05 & 0.08 & 0.1 & 0.01 & 0.03 \\
\hline HLW02-12 & 0.200 & 0.400 & 0.100 & 0.200 & 0.300 & 0.100 & 0.01 & 0.50 & 0.05 & 0.20 & 0.01 & 0.01 & 0.0 & 0.06 & 0.30 & 0.1 & 0.50 & 0.12 & 0.05 & 0.08 & 0.1 & 0.01 & 0.03 \\
\hline HLW02-13 & 0.200 & 0.400 & 0.100 & \begin{tabular}{|l|}
0.200 \\
\end{tabular} & 0.300 & 0.100 & 0.01 & 0.50 & 0.05 & 0.20 & 0.01 & 0.01 & 0.0 & 0.06 & 0.30 & & 0.50 & 12 & 0.05 & 0.08 & 0.1 & 0.01 & 0.03 \\
\hline HLW02-14 & 0.020 & 0.040 & 0.010 & \begin{tabular}{|l|}
0.020 \\
\end{tabular} & 0.030 & 0.010 & & 0.50 & 0.05 & 0.20 & 001 & & & 0.06 & & & 0.50 & 0.12 & 0.05 & 0.08 & 0.1 & 0.01 & 0.03 \\
\hline HLW02-15 & 0.200 & 0. & 0. & \begin{tabular}{|l|}
0.200 \\
\end{tabular} & 0.300 & 0.100 & & 0.50 & & & 0.0 & 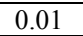 & & & & & 0.5 & 2 & .05 & 8 & 0.1 & 1 & 0.03 \\
\hline HLV & 0.200 & 0.400 & 0 & 0.200 & 0.300 & 0.100 & 0.0 & 0.50 & 55 & 0 & 00 & 00 & 0.0 & 0. & 0.30 & & 0.5 & 0.12 & 0.05 & 0.08 & 0.1 & 1 & 0.03 \\
\hline HLW02-17 & 0.020 & 0. & $\Omega$ & \begin{tabular}{|l|}
0.020 \\
\end{tabular} & 0.030 & 0.010 & 00 & 0.50 & 0.05 & 0 & 00 & 00 & 0.0 & 00 & 0.30 & & 0.5 & 0.12 & 0.05 & 0.08 & 0.1 & 0.01 & 0.03 \\
\hline HLW & 0.200 & 0.400 & 0.100 & \begin{tabular}{|l|}
0.200 \\
\end{tabular} & 0.300 & 0.100 & 0.0 & 0.50 & 0.05 & 0.2 & $\overline{00}$ & 0.0 & 0.1 & 0 . & & & 0.50 & 0.12 & 0.05 & 0.08 & 0.1 & 0.01 & 0.03 \\
\hline HLW02-19 & 0.020 & 0.040 & 0.010 & \begin{tabular}{|l|}
0.020 \\
\end{tabular} & 0.030 & 0.010 & 0.0 & 0.50 & 0.05 & 0.20 & 0.0 & & & 0. & & & 0.50 & 0.12 & .05 & 0.08 & 0.1 & 0.01 & 0.03 \\
\hline HLW02-20 & 0.020 & 0.040 & 0.010 & \begin{tabular}{|l|}
0.020 \\
\end{tabular} & 0.030 & 0.010 & 0.0 & 0.50 & 0.05 & 0.20 & 0.01 & 0.0 & 0.0 & 0.06 & 0.30 & 0.1 & 0.50 & 0.12 & 0.05 & 0.08 & 0.1 & 0.01 & 0.03 \\
\hline HLW02-21 & 0.020 & 0.040 & 0.010 & \begin{tabular}{|l|}
0.020 \\
\end{tabular} & 0.030 & 0.010 & 0.01 & 0.50 & 0.05 & 0.20 & 0.01 & 0.01 & 0.05 & 0.06 & 0.30 & 0.12 & 0.50 & 0.12 & 0.05 & 0.08 & 0.1 & 0.01 & 0.03 \\
\hline HLW02-22 & 0.020 & 0.040 & 0.010 & \begin{tabular}{|l|}
0.020 \\
\end{tabular} & 0.030 & 0.010 & 0.01 & 0.50 & 0.05 & 0.20 & 0.01 & 0.01 & 0.05 & 0.06 & 0.30 & 0.12 & 0.50 & 0.12 & 0.05 & 0.08 & 0.1 & 0.01 & 0.03 \\
\hline HLW02-23 & 0.020 & 0.040 & 0.010 & \begin{tabular}{|l|}
0.020 \\
\end{tabular} & 0.030 & 0.010 & 0.01 & 0.50 & 0.05 & 0.20 & 0.01 & 0.01 & 0.05 & 0.06 & 0.30 & & 0.50 & 0.12 & 0.05 & 0.08 & 0.1 & 0.01 & 0.03 \\
\hline HLW02-24 & 0.154 & 0.307 & 0.077 & \begin{tabular}{|l|}
0.154 \\
\end{tabular} & 0.230 & 0.077 & 0.01 & 0.50 & 0.05 & 0.2 & 0.01 & 0.0 & 0.0 & 0.06 & 0.30 & 0. & 0.50 & 0.12 & 0.05 & 0.08 & 0.1 & 0.01 & 0.03 \\
\hline HLW02-25 & 0.020 & 0.040 & 0.010 & \begin{tabular}{|l|}
0.020 \\
\end{tabular} & 0.030 & 0.010 & 0.0 & 0.50 & 0.05 & 0.20 & 0.0 & 0.0 & 0.0 & 0.06 & 0.30 & & 0.50 & 0.12 & 0.05 & 0.08 & 0.1 & 0.01 & 0.03 \\
\hline $2-26$ & 0.200 & 0.400 & 0.100 & \begin{tabular}{|l|}
0.200 \\
\end{tabular} & 0.300 & 0.100 & 0.0 & 0.50 & 0.05 & 0.20 & 0.0 & 0.0 & 0.0 & 0.06 & 30 & & 0.50 & 0.12 & 0.05 & 0.08 & 0.1 & 0.01 & 0.03 \\
\hline HLW02-27 & 0.020 & 0.040 & 0.010 & \begin{tabular}{|l|l|}
0.020 \\
\end{tabular} & 0.030 & 0.010 & 0.01 & 0.50 & 0.05 & 0.20 & 0.01 & 0.0 & 0.0 & 0.06 & 030 & & 0.50 & 0.12 & 0.05 & 0.08 & 0.1 & 0.01 & 0.03 \\
\hline HLW02-28 & 0.040 & 0.080 & & \begin{tabular}{|l|}
0.040 \\
\end{tabular} & 0.060 & 0.020 & 0.01 & 0.50 & 0.05 & 0.20 & 0.01 & 0.01 & 0.05 & 0.06 & 0.30 & & 0.50 & 0.12 & 0.05 & 0.08 & 0.1 & 0.01 & 0.03 \\
\hline HLW02-29 & 0.133 & 0.267 & 0.067 & \begin{tabular}{|l|}
0.133 \\
\end{tabular} & 0.200 & 0.067 & 0.01 & 0.50 & 0.05 & 0.20 & 0.0 & 0.01 & 0.0 & 0.06 & 0.30 & 0. & 0.50 & 0.12 & 0.05 & 0.08 & 0.1 & 0.01 & 0.03 \\
\hline HLW02-30 & 0.040 & 0.080 & 0.020 & \begin{tabular}{|l|}
0.040 \\
\end{tabular} & 0.060 & 0.020 & 0.01 & 0.50 & 0.05 & 0.20 & 0.01 & 0.01 & 0.05 & 0.06 & 0.30 & 0.12 & 0.50 & 0.12 & 0.05 & 0.08 & 0.1 & 0.01 & 0.03 \\
\hline
\end{tabular}

(a) Glass IDs HLW02-01 to HLW02-57 identify the initial test matrix of HLW glasses. Glass IDs HLW03-01 to HLW03-45 identify the augmentation matrix of HLW glasses.

(b) Spike component wt\% values are rounded to 3 decimal places for each glass and may not equal the wt $\%$ value listed in the Spike column of Table 2.8 .

(c) The sum of the Constant component wt $\%$ values sum to $2.20 \mathrm{wt} \%$ for each glass, as shown in Table 2.8 . 
Table 2.9. Composition Expansions of the Spike and Constant Components for the IHLW Initial (HLW02) and Augmentation (HLW03) Test Matrices Expressed in the Original Oxide Forms (continued).

\begin{tabular}{|c|c|c|c|c|c|c|c|c|c|c|c|c|c|c|c|c|c|c|c|c|c|c|c|}
\hline \multirow{2}{*}{ Glass ID $^{(a)}$} & \multicolumn{6}{|c|}{ Spike Components $(w t \%)^{(b)}$} & \multicolumn{17}{|c|}{ Constant Components (wt\%) } \\
\hline & $\mathrm{Ag}_{2} \mathrm{O}$ & PbO & $\mathbf{V}_{2} \mathbf{O}_{5}$ & $\mathbf{S}_{2} \mathbf{O}_{3}$ & 10 & $\mathbf{O}$ & $\mathrm{O}_{3}$ & $\mathrm{aO}$ & $\mathrm{CeO}_{2}$ & $\mathbf{C l}$ & $\mathrm{CoO}$ & $\mathbf{O}$ & $\mathbf{F}$ & $\mathbf{K}_{2} \mathbf{O}$ & $\mathbf{L a}_{2} \mathbf{O}_{3}$ & $\mathbf{O}$ & $\mathbf{P}_{2} \mathbf{O}_{5}$ & PdO & $\mathbf{R h}_{2} \mathbf{O}_{3}$ & $\mathrm{RuO}_{2}$ & $\mathrm{SO}_{3}$ & $\mathrm{TeO}_{2}$ & $\mathrm{TiO}_{2}$ \\
\hline HLW02-31 & 0.040 & 080 & 0.020 & 0.040 & 0.060 & .020 & 0.01 & 0.50 & 0.05 & 0.20 & 0.01 & 0.01 & 0.05 & 0.06 & 0.30 & 0.12 & 0.50 & 0.12 & 0.05 & 0.08 & 0.1 & 0.01 & 0.03 \\
\hline \begin{tabular}{|l|} 
HLW02-32 \\
\end{tabular} & .040 & .080 & .020 & 0.040 & 0.060 & 0.020 & 0.01 & 0.50 & 0.05 & 0.20 & 0.01 & 0.01 & 0.05 & 0.06 & 0.30 & 0.12 & 0.50 & 0.12 & 0.05 & 0.08 & 0.1 & 0.01 & 0.03 \\
\hline HLW02-33 & .040 & .080 & 0.020 & 0.040 & 0.060 & 0.020 & 0.01 & 0.50 & 0.05 & 0.20 & 0.01 & 0.01 & 0.0 & 0.06 & 0.30 & 0.12 & 0.50 & 0.12 & 0.05 & 0.08 & 0.1 & 0.01 & 0.03 \\
\hline \begin{tabular}{|l|} 
HLW02-34 \\
\end{tabular} & .133 & 0.267 & 0.067 & 0.133 & 0.200 & 0.067 & 0.01 & 0.50 & 0.05 & 0.20 & 0.01 & 0.01 & 0.05 & 0.06 & 0.30 & 0.12 & 0.50 & 0.12 & 0.05 & 0.08 & 0.1 & 0.01 & 0.03 \\
\hline \begin{tabular}{|l|} 
HLW02-35 \\
\end{tabular} & .133 & 0.267 & 0.067 & 0.133 & 0.200 & 0.067 & 0.01 & 0.50 & 0.05 & 0.20 & 0.01 & 0.01 & 0.0 & 0.06 & 0.30 & 0.12 & 0.50 & 0.12 & 0.05 & 0.08 & 0.1 & 0.01 & 0.03 \\
\hline \begin{tabular}{|l|} 
HLW02-36 \\
\end{tabular} & .133 & .267 & \begin{tabular}{|l|l|}
0.067 \\
\end{tabular} & 0.133 & 0.200 & 0.067 & 0.0 & 0.50 & 0.05 & 0.20 & 0.01 & 0.01 & 0.1 & 0.06 & 30 & 2 & 0.50 & 0.12 & 0.05 & 0.08 & 0.1 & 0.01 & 0.03 \\
\hline \begin{tabular}{|l|} 
HLW02-37 \\
\end{tabular} & .040 & .080 & 0.020 & 0.040 & 0.060 & 0.020 & $0 .($ & .50 & 0.0 & 0 & 0.01 & 0.01 & 0 & 0.06 & .30 & 2 & 0.50 & 12 & 05 & 0.08 & 1 & .01 & 0.03 \\
\hline \begin{tabular}{|l|} 
HLW02-38 \\
\end{tabular} & 133 & .267 & 0.067 & 0.133 & 0.200 & 0.067 & 0.0 & .50 & 0.0 & 0.2 & 0.0 & 0.01 & 0. & 0.06 & 0.30 & 2 & 0.50 & 0.12 & 0.05 & 0.08 & 4 & 0.01 & 0.03 \\
\hline HLW02-39 & .040 & .080 & 0.020 & 0.040 & 0.060 & 0.020 & 0.0 & 0.50 & 0.0 & 0 & 0.0 & 0.01 & 0. & 0.06 & 0.30 & 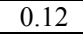 & 0.50 & 0.12 & 0.05 & 0.08 & 0.1 & 0.01 & 0.03 \\
\hline HLW & 133 & 267 & 0.067 & 0.133 & 0.200 & 0.067 & 0.1 & 0.50 & 0.0 & 0.20 & 0.01 & 0.01 & 0.0 & 0.06 & 0 & 12 & 0.50 & 0.12 & 0.05 & 0.08 & 0.1 & .01 & 0.03 \\
\hline \begin{tabular}{|l|} 
HLW02-41 \\
\end{tabular} & 0.040 & 0.080 & 0.020 & 0.040 & 0.060 & 0.020 & 0.01 & 0.50 & 0.05 & 0.20 & 0.01 & 0.01 & 0.0 & 0.06 & 0.30 & 0.12 & 0.50 & 0.12 & 0.05 & 0.08 & 0.1 & 0.01 & 0.03 \\
\hline HLW02-42 & 0.040 & 0.080 & 0.020 & 0.040 & 0.060 & 0.020 & 0.01 & 0.50 & 0.05 & 0.20 & 0.01 & 0.01 & 0.0 & 0.06 & 0.30 & 0.12 & 0.50 & 0.12 & 0.05 & 0.08 & 0.1 & 0.01 & 0.03 \\
\hline \begin{tabular}{|l|} 
HLW $02-43$ \\
\end{tabular} & 0.040 & 0.080 & 0.020 & \begin{tabular}{|l|}
0.040 \\
\end{tabular} & 0.060 & 0.020 & 0.01 & 0.50 & 0.05 & 0.20 & 0.01 & 0.01 & 0.0 & 0.06 & 0.30 & 0.12 & 0.50 & 0.12 & 0.05 & 0.08 & 0.10 & 0.01 & 0.03 \\
\hline \begin{tabular}{|l|} 
HLW02-44 \\
\end{tabular} & 0.133 & 0.267 & 0.067 & 0.133 & 0.200 & 0.067 & 0.01 & 0.50 & 0.05 & 0.20 & & 0.01 & & 0.06 & .30 & .12 & 0.50 & 0.12 & 0.05 & 0.08 & 0.10 & \begin{tabular}{|l|}
0.01 \\
\end{tabular} & 0.03 \\
\hline \begin{tabular}{|l|} 
HLW02-45 \\
\end{tabular} & 0.040 & 0.080 & 0.020 & 0.040 & 0.060 & 0.020 & 0 & 0.50 & 0. & 0 & 0 & & & 0.06 & 0 & 2 & 0.50 & 0.12 & 0.05 & 0.08 & 0.10 & 0.01 & 0.03 \\
\hline \begin{tabular}{|l|} 
HLW02-46 \\
\end{tabular} & 0.040 & 0.080 & 0.020 & 0.040 & 0.060 & 0.0 & 00 & 0.50 & 08 & 0.2 & 0. & 0.01 & 0 . & 0.06 & 0 & 2 & 0.50 & 0.12 & 0.05 & 0.08 & 0.10 & 0.01 & 0.03 \\
\hline \begin{tabular}{|l|} 
HLW02-47 \\
\end{tabular} & 133 & 0.267 & 0.067 & 0.133 & 0.200 & 0.06 & 08 & 0.50 & 0 & 0. & 0. & 0.01 & 0. & 0.06 & 0 & 0 & 0.50 & 0.12 & 0.05 & 0.08 & 0.10 & 0.01 & 0.03 \\
\hline \begin{tabular}{|l|} 
HLW02-48 \\
\end{tabular} & 0.133 & 0.267 & 0.067 & 0.133 & 0.200 & 0.067 & 0.0 & 0.50 & 0.0 & 0.2 & 0.01 & 0.01 & 0. & 0.06 & 0.30 & 0.12 & 0.50 & 0.12 & 0.05 & 0.08 & 0.10 & 0.01 & 0.03 \\
\hline \begin{tabular}{|l|} 
HLW02-49 \\
\end{tabular} & 0.040 & 0.080 & 0.020 & 0.040 & 0.060 & 0.020 & 0.0 & 0.50 & 0.05 & 0.20 & 0.01 & 0.01 & 0.1 & 0.06 & 0.30 & 0.12 & 0.50 & 0.12 & 0.05 & 0.08 & 0.10 & 0.01 & 0.03 \\
\hline \begin{tabular}{|l|} 
HLW02-50 \\
\end{tabular} & 0.040 & 0.080 & 0.020 & 0.040 & 0.060 & 0.020 & 0.01 & 0.50 & 0.05 & 0.20 & 0.01 & 0.01 & 0.0 & 0.06 & 0.30 & 0.12 & 0.50 & 0.12 & 0.05 & 0.08 & 0.10 & \begin{tabular}{|l|}
0.01 \\
\end{tabular} & 0.03 \\
\hline HLW02-51 & 0.040 & 0.080 & 0.020 & 0.040 & 0.060 & 0.020 & 0.01 & 0.50 & 0.05 & 0.20 & 0.01 & 0.01 & 0.05 & 0.06 & 0.30 & 0.12 & 0.50 & 0.12 & 0.05 & 0.08 & 0.10 & \begin{tabular}{|l|}
0.01 \\
\end{tabular} & 0.03 \\
\hline \begin{tabular}{|l|} 
HLW02-52 \\
\end{tabular} & 0.108 & 0.216 & 0.054 & \begin{tabular}{|l|l|}
0.108 \\
\end{tabular} & 0.162 & 0.054 & 0.01 & 0.50 & 0.05 & 0.20 & 0.01 & 0.01 & 0.05 & 0.06 & 0.30 & 0.12 & 0.50 & 0.12 & 0.05 & 0.08 & 0.10 & \begin{tabular}{|l|}
0.01 \\
\end{tabular} & 0.03 \\
\hline \begin{tabular}{|l|} 
HLW $02-53$ \\
\end{tabular} & 0.020 & 0.040 & 0.010 & 0.020 & 0.030 & 0.010 & 0.01 & 0.50 & 0.05 & 0.20 & 0.01 & 0.01 & 0.05 & 0.06 & 0.30 & 0.12 & 0.50 & 0.12 & 0.05 & 0.08 & 0.10 & \begin{tabular}{|l|}
0.01 \\
\end{tabular} & 0.03 \\
\hline \begin{tabular}{|l|} 
HLW02-54 \\
\end{tabular} & 0.020 & 0.040 & 0.010 & 0.020 & 0.030 & 0.010 & 0.01 & 0.50 & 0.05 & 0.20 & 0.01 & 0.01 & 0.1 & 0.06 & 0.30 & 0.12 & 0.50 & 0.12 & 0.05 & 0.08 & 0.10 & \begin{tabular}{|l|}
0.01 \\
\end{tabular} & 0.03 \\
\hline HLW02-55 & 0.040 & 0.080 & 0.020 & 0.040 & 0.060 & 0.020 & 0.0 & 0.50 & 0.05 & 0.20 & 0.0 & 0.01 & 0.1 & 0.06 & 0.30 & 0.12 & 0.50 & 0.12 & 0.05 & 0.08 & 0.10 & 0.01 & 0.03 \\
\hline \begin{tabular}{|l|l} 
HLW \\
\end{tabular} & 0.133 & 0.267 & 0.067 & \begin{tabular}{|l|}
0.133 \\
\end{tabular} & 0.200 & 0.067 & 0.0 & 0.50 & 0.05 & 0.20 & 0.01 & 0.01 & 0.0 & 0.06 & 0.30 & 0.12 & 0.50 & 0.12 & 0.05 & 0.08 & 0.10 & 0.01 & 0.03 \\
\hline \begin{tabular}{|l|} 
HLW02-57 \\
\end{tabular} & 0.020 & 0.040 & 0.010 & 0.020 & 0.030 & 0.010 & 0.0 & 0.50 & 0.0 & 0.20 & 0.01 & 0.01 & 0.0 & 0.06 & 0.30 & 0.12 & 0.50 & 0.12 & 0.05 & 0.08 & 0.10 & \begin{tabular}{|l|}
0.01 \\
\end{tabular} & 0.03 \\
\hline \begin{tabular}{|l|} 
HLW03-01 \\
\end{tabular} & 0.200 & 0.400 & 0.100 & 0.200 & 0.300 & 0.100 & 0.01 & 0.50 & 0.05 & 0.20 & 0.01 & 0.01 & 0.1 & 0.06 & 0.30 & 0.12 & 0.50 & 0.12 & 0.05 & 0.08 & 0.10 & 0.01 & 0.03 \\
\hline \begin{tabular}{|l|} 
HLW-02 \\
\end{tabular} & 0.020 & 0.040 & 0.010 & 0.020 & 0.030 & 0.010 & 0.01 & 0.50 & 0.05 & 0.20 & 0.01 & 0.01 & 0.05 & 0.06 & 0.30 & 0.12 & 0.50 & 0.12 & 0.05 & 0.08 & 0.10 & \begin{tabular}{|l|}
0.01 \\
\end{tabular} & 0.03 \\
\hline \begin{tabular}{|l|l|} 
HLW-03 \\
\end{tabular} & 0.020 & 0.040 & 0.010 & 0.020 & 0.030 & 0.010 & 0.01 & 0.50 & 0.05 & 0.20 & 0.01 & 0.01 & 0.05 & 0.06 & 0.30 & 0.12 & 0.50 & 0.12 & 0.05 & 0.08 & 0.10 & \begin{tabular}{|l|}
0.01 \\
\end{tabular} & 0.03 \\
\hline
\end{tabular}

(a) Glass IDs HLW02-01 to HLW02-57 identify the initial test matrix of HLW glasses. Glass IDs HLW03-01 to HLW03-45 identify the augmentation matrix of HLW glasses.

(b) Spike component wt\% values are rounded to 3 decimal places for each glass and may not equal the wt $\%$ value listed in the Spike column of Table 2.8 .

(c) The sum of the Constant component wt $\%$ values sum to $2.20 \mathrm{wt} \%$ for each glass, as shown in Table 2.8 . 
Table 2.9. Composition Expansions of the Spike and Constant Components for the IHLW Initial (HLW02) and Augmentation (HLW03) Test Matrices Expressed in the Original Oxide Forms (continued).

\begin{tabular}{|c|c|c|c|c|c|c|c|c|c|c|c|c|c|c|c|c|c|c|c|c|c|c|c|}
\hline \multirow{2}{*}{ Glass ID (a) $^{\text {a }}$} & \multicolumn{6}{|c|}{ Spike Components $(w t \%)^{(b)}$} & \multicolumn{17}{|c|}{ Constant Components (wt\%) } \\
\hline & $\mathrm{Ag}_{2} \mathrm{O}$ & PbO & $\mathbf{V}_{2} \mathbf{O}_{5}$ & $\mathbf{S}_{2} \mathbf{O}_{3}$ & 10 & $\mathbf{O}$ & $\mathrm{O}_{3}$ & $\mathrm{aO}$ & $\mathrm{CeO}_{2}$ & $\mathbf{C l}$ & $\mathrm{CoO}$ & $\mathbf{O}$ & $\mathbf{F}$ & $\mathbf{K}_{2} \mathbf{O}$ & $\mathbf{L a}_{2} \mathbf{O}_{3}$ & $\mathbf{O}$ & $\mathbf{P}_{2} \mathbf{O}_{5}$ & PdO & $\mathbf{R h}_{2} \mathbf{O}_{3}$ & $\mathrm{RuO}_{2}$ & $\mathrm{SO}_{3}$ & $\mathrm{TeO}_{2}$ & $\mathrm{TiO}_{2}$ \\
\hline HLW03-04 & 200 & 400 & 100 & 0.200 & 0.300 & 100 & 0.01 & 0.50 & 0.05 & 0.20 & 0.01 & 0.01 & 0.05 & 0.06 & 0.30 & 0.12 & 0.50 & 0.12 & 0.05 & 0.08 & 0.10 & 0.01 & 0.03 \\
\hline \begin{tabular}{|l|} 
HLW03-05 \\
\end{tabular} & 200 & 400 & 100 & 0.200 & 0.300 & 0.100 & 0.01 & 0.50 & 0.05 & 0.20 & 0.01 & 0.01 & 0.05 & 0.06 & 0.30 & 0.12 & 0.50 & 0.12 & 0.05 & 0.08 & 0.10 & 0.01 & 0.03 \\
\hline HLW03-06 & .020 & .040 & 0.010 & 0.020 & 0.030 & 0.010 & 0.01 & 0.50 & 0.05 & 0.20 & 0.01 & 0.01 & 0.0 & 0.06 & 0.30 & 0.12 & 0.50 & 0.12 & 0.05 & 0.08 & 0.10 & 0.01 & 0.03 \\
\hline \begin{tabular}{|l|} 
HLW-03-07 \\
\end{tabular} & .020 & 0.040 & 0.010 & 0.020 & 0.030 & 0.010 & 0.01 & 0.50 & 0.05 & 0.20 & 0.01 & 0.01 & 0.0 & 0.06 & 0.30 & 0.12 & 0.50 & 0.12 & 0.05 & 0.08 & 0.10 & 0.01 & 0.03 \\
\hline \begin{tabular}{|l|} 
HLW03-08 \\
\end{tabular} & .200 & 0.400 & 0.100 & 0.200 & 0.300 & 0.100 & 0.01 & 0.50 & 0.05 & 0.20 & 0.01 & 0.01 & 0.0 & 0.06 & 0.30 & 0.12 & 0.50 & 0.12 & 0.05 & 0.08 & 0.10 & 0.01 & 0.03 \\
\hline \begin{tabular}{|l|} 
HLW03-09 \\
\end{tabular} & .020 & 0.040 & 0.010 & 0.020 & 0.030 & 0.010 & 0.01 & 0.50 & 0.05 & 0.20 & 0.01 & 0.01 & 0.0 & 0.06 & 30 & 12 & 0.50 & 0.12 & 0.05 & 0.08 & 0.10 & 0.01 & 0.03 \\
\hline \begin{tabular}{|l|} 
HLW03-10 \\
\end{tabular} & 200 & .400 & 0.100 & 0.200 & 0.300 & 0.100 & 0.0 & 50 & 0.0 & 0 & 0. & 0.01 & 0 & 0.06 & 0 & 2 & 0.50 & .12 & 0.05 & 0.08 & 10 & .01 & 0.03 \\
\hline \begin{tabular}{|l|} 
HLW03-11 \\
\end{tabular} & 020 & .040 & 0.010 & 0.020 & 0.030 & 0.010 & 0.0 & .50 & 0.0 & 0 & 0.0 & 0.01 & 0. & 0.06 & .30 & 2 & 0.50 & 0.12 & 0.05 & 0.08 & 0.10 & 0.01 & 0.03 \\
\hline HLW03-12 & .020 & .040 & 0.010 & 0.020 & 0.030 & 0.010 & 0.0 & 0.50 & 0.0 & 0 & 0.0 & 0.01 & 0. & 0.06 & .30 & 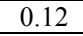 & 0.50 & 0.12 & 0.05 & 0.08 & 0.10 & 0.01 & 0.03 \\
\hline HLW & 020 & .040 & 0.010 & 0.020 & 0.030 & 0.010 & 0.1 & 0.50 & 0.0 & 0.20 & 0.01 & 0.01 & 0.0 & 0.06 & 0 & 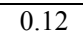 & 0.50 & 0.12 & 0.05 & 0.08 & 0.10 & .01 & 0.03 \\
\hline \begin{tabular}{|l|} 
HLW03-14 \\
\end{tabular} & 0.020 & 0.040 & 0.010 & 0.020 & 0.030 & 0.010 & 0.0 & 0.50 & 0.05 & 0.20 & 0.01 & 0.01 & 0.0 & 0.06 & 0.30 & 0.12 & 0.50 & 0.12 & 0.05 & 0.08 & 0.10 & 0.01 & 0.03 \\
\hline HLW03-15 & 0.020 & 0.040 & 0.010 & 0.020 & 0.030 & 0.010 & 0.01 & 0.50 & 0.05 & 0.20 & 0.01 & 0.01 & 0.0 & 0.06 & 0.30 & 0.12 & 0.50 & 0.12 & 0.05 & 0.08 & 0.10 & 0.01 & 0.03 \\
\hline HLW03-16 & 0.200 & 0.400 & 0.100 & \begin{tabular}{|l|}
0.200 \\
\end{tabular} & 0.300 & 0.100 & 0.01 & 0.50 & 0.05 & 0.20 & 0.01 & 0.01 & 0.0 & 0.06 & 0.30 & 0.12 & 0.50 & 0.12 & 0.05 & 0.08 & 0.10 & 0.01 & 0.03 \\
\hline HLW03-17 & 0.200 & 0.400 & 0.100 & 0.200 & 0.300 & 0.100 & 0.01 & 0.50 & 0.05 & 0.20 & & 0.01 & & 0.06 & .30 & .12 & 0.50 & 0.12 & 0.05 & 0.08 & 0.10 & \begin{tabular}{|l|}
0.01 \\
\end{tabular} & 0.03 \\
\hline \begin{tabular}{|l|} 
HLW03-18 \\
\end{tabular} & 020 & 0.040 & 0.010 & 0.020 & 0.030 & 0.010 & 0 & 0.50 & 0 & 0 & & & & 0.06 & 0 & 2 & 0.50 & 0.12 & 0.05 & 0.08 & 0.10 & 0.01 & 0.03 \\
\hline HLW03-19 & 0.020 & 0.040 & 0.010 & 0.020 & 0.030 & 0.010 & 0 & 0.50 & 0.05 & 0 & 0. & 0.01 & 0 & 0.06 & 0 & 0 & 0.50 & .12 & 05 & 0.08 & 0.10 & 0.01 & 0.03 \\
\hline HLW03-20 & 200 & 0.400 & 0.100 & 0.200 & 0.300 & 0.1 & 08 & 0.50 & 0 & 0 & 0. & 0.01 & 0. & 0.06 & 0 & 0 & 0.50 & 0.12 & 0.05 & 0.08 & 0.10 & 0.01 & 0.03 \\
\hline \begin{tabular}{|l|} 
HLW03-21 \\
\end{tabular} & 0.040 & 0.080 & 0.020 & 0.040 & 0.060 & 0.020 & $\overline{0.0}$ & 0.50 & 0.0 & 0.2 & 0.01 & 0.01 & 0. & 0.06 & 0.30 & 0.12 & 0.50 & 0.12 & 0.05 & 0.08 & 0.10 & 0.01 & 0.03 \\
\hline \begin{tabular}{|l|} 
HLW03-22 \\
\end{tabular} & 0.134 & 0.268 & 0.067 & 0.134 & 0.201 & 0.067 & 0.0 & 0.50 & 0.05 & 0.20 & 0.0 & 0.01 & 0.1 & 0.06 & 0.30 & 2 & 0.50 & 0.12 & 0.05 & 0.08 & 0.10 & 0.01 & 0.03 \\
\hline \begin{tabular}{|l|} 
HLW $03-23$ \\
\end{tabular} & 0.040 & 0.080 & 0.020 & 0.040 & 0.060 & 0.020 & 0.01 & 0.50 & 0.05 & 0.20 & 0.01 & 0.01 & 0.0 & 0.06 & 0.30 & 0.12 & 0.50 & 0.12 & 0.05 & 0.08 & 0.10 & \begin{tabular}{|l|}
0.01 \\
\end{tabular} & 0.03 \\
\hline HLW03-24 & 0.040 & 0.080 & 0.020 & 0.040 & 0.060 & 0.020 & 0.01 & 0.50 & 0.05 & 0.20 & 0.01 & 0.01 & 0.05 & 0.06 & 0.30 & 0.12 & 0.50 & 0.12 & 0.05 & 0.08 & 0.10 & \begin{tabular}{|l|}
0.01 \\
\end{tabular} & 0.03 \\
\hline HLW03-25 & 0.134 & 0.268 & 0.067 & \begin{tabular}{|l|}
0.134 \\
\end{tabular} & 0.201 & 0.067 & 0.01 & 0.50 & 0.05 & 0.20 & 0.01 & 0.01 & 0.05 & 0.06 & 0.30 & 0.12 & 0.50 & 0.12 & 0.05 & 0.08 & 0.10 & \begin{tabular}{|l|}
0.01 \\
\end{tabular} & 0.03 \\
\hline HLW03-26 & 0.134 & 0.268 & 0.067 & 0.134 & 0.201 & 0.067 & 0.01 & 0.50 & 0.05 & 0.20 & 0.01 & 0.01 & 0.05 & 0.06 & 0.30 & 0.12 & 0.50 & 0.12 & 0.05 & 0.08 & 0.10 & \begin{tabular}{|l|}
0.01 \\
\end{tabular} & 0.03 \\
\hline \begin{tabular}{|l|} 
HLW03-27 \\
\end{tabular} & 0.134 & 0.268 & 0.067 & 0.134 & 0.201 & 0.067 & 0.01 & 0.50 & 0.05 & 0.20 & 0.01 & 0.01 & 0.1 & 0.06 & 0.30 & 0.12 & 0.50 & 0.12 & 0.05 & 0.08 & 0.10 & \begin{tabular}{|l|}
0.01 \\
\end{tabular} & 0.03 \\
\hline HLW03-28 & 0.040 & 0.080 & 0.020 & 0.040 & 0.060 & 0.020 & 0.0 & 0.50 & 0.0 & 0.20 & 0.1 & 0.01 & 0. & 0.06 & 0.30 & 0.12 & 0.50 & 0.12 & 0.05 & 0.08 & 0.10 & 0.01 & 0.03 \\
\hline \begin{tabular}{|l|l|} 
HLW-29 \\
\end{tabular} & 0.040 & 0.080 & 0.020 & \begin{tabular}{|l|}
0.040 \\
\end{tabular} & 0.060 & 0.020 & 0.0 & 0.50 & 0.05 & 0.20 & 0.01 & 0.01 & 0.0 & 0.06 & 0.30 & 0.12 & 0.50 & 0.12 & 0.05 & 0.08 & 0.10 & 0.01 & 0.03 \\
\hline \begin{tabular}{|l|} 
HLW03-30 \\
\end{tabular} & 0.040 & 0.080 & 0.020 & 0.040 & 0.060 & 0.020 & 0.0 & 0.50 & 0.05 & 0.20 & 0.01 & 0.01 & 0.0 & 0.06 & 0.30 & 0.12 & 0.50 & 0.12 & 0.05 & 0.08 & 0.10 & \begin{tabular}{|l|}
0.01 \\
\end{tabular} & 0.03 \\
\hline \begin{tabular}{|l|} 
HLW03-31 \\
\end{tabular} & 0.040 & 0.080 & 0.020 & 0.040 & 0.060 & 0.020 & 0.01 & 0.50 & 0.05 & 0.20 & 0.01 & 0.01 & 0.1 & 0.06 & 0.30 & 0.12 & 0.50 & 0.12 & 0.05 & 0.08 & 0.10 & 0.01 & 0.03 \\
\hline HLW03-32 & 0.134 & 0.268 & 0.067 & \begin{tabular}{|l|}
0.134 \\
\end{tabular} & 0.201 & 0.067 & 0.01 & 0.50 & 0.05 & 0.20 & 0.01 & 0.01 & 0.05 & 0.06 & 0.30 & 0.12 & 0.50 & 0.12 & 0.05 & 0.08 & 0.10 & \begin{tabular}{|l|}
0.01 \\
\end{tabular} & 0.03 \\
\hline \begin{tabular}{|l|l|} 
HLW-33 \\
\end{tabular} & 0.040 & 0.080 & 0.020 & 0.040 & 0.060 & 0.020 & 0.01 & 0.50 & 0.05 & 0.20 & 0.01 & 0.01 & 0.05 & 0.06 & 0.30 & 0.12 & 0.50 & 0.12 & 0.05 & 0.08 & 0.10 & \begin{tabular}{|l|}
0.01 \\
\end{tabular} & 0.03 \\
\hline
\end{tabular}

(a) Glass IDs HLW02-01 to HLW02-57 identify the initial test matrix of HLW glasses. Glass IDs HLW03-01 to HLW03-45 identify the augmentation matrix of HLW glasses.

(b) Spike component wt\% values are rounded to 3 decimal places for each glass and may not equal the wt $\%$ value listed in the Spike column of Table 2.8 .

(c) The sum of the Constant component wt $\%$ values sum to $2.20 \mathrm{wt} \%$ for each glass, as shown in Table 2.8 . 
Table 2.9. Composition Expansions of the Spike and Constant Components for the IHLW Initial (HLW02) and Augmentation (HLW03) Test Matrices Expressed in the Original Oxide Forms (continued).

\begin{tabular}{|c|c|c|c|c|c|c|c|c|c|c|c|c|c|c|c|c|c|c|c|c|c|c|c|}
\hline \multirow{2}{*}{ Glass ID $^{(a)}$} & \multicolumn{6}{|c|}{ Spike Components $(w t \%)^{(b)}$} & \multicolumn{17}{|c|}{ Constant Components $(w t \%){ }^{(c)}$} \\
\hline & $\mathbf{A g}_{2} \mathbf{O}$ & PbO & $\mathbf{V}_{2} \mathbf{O}_{5}$ & $\mathbf{A s}_{2} \mathbf{O}_{3}$ & $\mathrm{BaO}$ & $\mathrm{CuO}$ & $\mathrm{Bi}_{2} \mathbf{O}_{3}$ & $\mathrm{CaO}$ & $\mathrm{CeO}_{2}$ & $\mathrm{Cl}$ & $\mathrm{CoO}$ & $\mathrm{Cs}_{2} \mathrm{O}$ & $\mathbf{F}$ & $\mathbf{K}_{2} \mathbf{O}$ & $\mathrm{La}_{2} \mathbf{O}_{3}$ & MgO & $\mathbf{P}_{2} \mathbf{O}_{5}$ & PdO & $\mathbf{R} \mathbf{h}_{2} \mathbf{O}_{3}$ & $\mathrm{RuO}_{2}$ & $\mathrm{SO}_{3}$ & $\mathrm{TeO}_{2}$ & $\mathrm{TiO}_{2}$ \\
\hline HLW03-34 & 0.134 & 0.268 & 0.067 & 0.134 & 0.201 & 0.067 & 0.01 & 0.50 & 0.05 & 0.20 & 0.01 & 0.01 & 0.05 & 0.06 & 0.30 & 0.12 & 0.50 & 0.12 & 0.05 & 0.08 & 0.10 & 0.01 & 0.03 \\
\hline \begin{tabular}{|l|} 
HLW03-35 \\
\end{tabular} & 0.040 & 0.080 & 0.020 & 0.040 & 0.060 & 0.020 & 0.01 & 0.50 & 0.05 & 0.20 & 0.01 & 0.01 & 0.05 & 0.06 & 0.30 & 0.12 & 0.50 & 0.12 & 0.05 & 0.08 & 0.10 & 0.01 & 0.03 \\
\hline HLW03-36 & 0.134 & 0.268 & 0.067 & 0.134 & 0.201 & 0.067 & 0.01 & 0.50 & 0.05 & 0.20 & 0.01 & 0.01 & 0.05 & 0.06 & 0.30 & 0.12 & 0.50 & 0.12 & 0.05 & 0.08 & 0.10 & 0.01 & 0.03 \\
\hline \begin{tabular}{|l|l} 
HLW $03-37$ \\
\end{tabular} & 0.134 & 0.268 & 0.067 & 0.134 & 0.201 & 0.067 & 0.01 & 0.50 & 0.05 & 0.20 & 0.01 & 0.01 & 0.05 & 0.06 & 0.30 & 0.12 & 0.50 & 0.12 & 0.05 & 0.08 & 0.10 & 0.01 & 0.03 \\
\hline \begin{tabular}{|l|} 
HLW03-38 \\
\end{tabular} & 0.134 & 0.268 & 0.067 & 0.134 & 0.201 & 0.067 & 0.01 & 0.50 & 0.05 & 0.20 & 0.01 & 0.01 & 0.05 & 0.06 & 0.30 & 0.12 & 0.50 & 0.12 & 0.05 & 0.08 & 0.10 & 0.01 & 0.03 \\
\hline HLW & 0.134 & 0.268 & 0.067 & 0.134 & 0.201 & 0.067 & 0.01 & 0.50 & 0.05 & 0.20 & 0.01 & 0 & 0. & 0.06 & 0.30 & 01 & 0.50 & 0.12 & 0.05 & 0.08 & 0.10 & 01 & 0.03 \\
\hline HLW03-40 & 0.040 & 0.080 & 0.020 & 0.040 & 0.060 & 0.020 & 0 & 0.50 & 0.05 & 0.20 & 0.01 & 0 & 0.0 & 0.06 & 0.30 & 0.12 & 0.50 & 0.12 & 0.05 & 0.08 & 0.10 & 0.01 & 0.03 \\
\hline HLW03-41 & 0.087 & 0.174 & 0.044 & 0.087 & 0.130 & 0.044 & 0.01 & 0.50 & 0.05 & 0.20 & 0.01 & 0.01 & 0.0 & 0.06 & 0.30 & 0.12 & 0.50 & 0.12 & 0.05 & 0.08 & 0.10 & 0.01 & 0.03 \\
\hline \begin{tabular}{|l|} 
HLW03-42 \\
\end{tabular} & 0.040 & 0.080 & 0.020 & 0.040 & 0.060 & 0.020 & 0.01 & 0.50 & 0.05 & 0.20 & 0.01 & 0.01 & 0.05 & 0.06 & 0.30 & 0.12 & 0.50 & 0.12 & 0.05 & 0.08 & 0.10 & 0.01 & 0.03 \\
\hline \begin{tabular}{|l|} 
HLW03-43 \\
\end{tabular} & 0.020 & 0.040 & 0.010 & 0.020 & 0.030 & 0.010 & 0.01 & 0.50 & 0.05 & 0.20 & 0.01 & 0.01 & 0.05 & 0.06 & 0.30 & 0.12 & 0.50 & 0.12 & 0.05 & 0.08 & 0.10 & 0.01 & 0.03 \\
\hline HLW03-44 & 0.020 & 0.040 & 0.010 & 0.020 & 0.030 & 0.010 & 0.01 & 0.50 & 0.05 & 0.20 & 0.01 & 0.01 & 0.05 & 0.06 & 0.30 & 0.12 & 0.50 & 0.12 & 0.05 & 0.08 & 0.10 & 0.01 & 0.03 \\
\hline \begin{tabular}{|l|l} 
HLW $03-45$ \\
\end{tabular} & 0.134 & 0.268 & 0.067 & 0.134 & 0.201 & 0.067 & 0.01 & 0.50 & 0.05 & 0.20 & 0.01 & 0.01 & 0.05 & 0.06 & 0.30 & 0.12 & 0.50 & 0.12 & 0.05 & 0.08 & 0.10 & 0.01 & 0.03 \\
\hline
\end{tabular}

(a) Glass IDs HLW02-01 to HLW02-57 identify the initial test matrix of HLW glasses. Glass IDs HLW03-01 to HLW03-45 identify the augmentation matrix of HLW glasses.

(b) Spike component wt\% values are rounded to 3 decimal places for each glass and may not equal the wt $\%$ value listed in the Spike column of Table 2.8 .

(c) The sum of the Constant component wt $\%$ values sum to $2.20 \mathrm{wt} \%$ for each glass, as shown in Table 2.8 . 
Table 2.10. Original and Revised Oxide Forms for IHLW Glass Compositions.

\begin{tabular}{|c|c|c|}
\hline \multicolumn{3}{|c|}{ Original Oxide Forms } \\
\hline Main & Spike & Constant \\
\hline $\mathrm{Al}_{2} \mathrm{O}_{3}$ & $\mathrm{Ag}_{2} \mathrm{O}$ & $\mathrm{Bi}_{2} \mathrm{O}_{3}$ \\
$\mathrm{~B}_{2} \mathrm{O}_{3}$ & $\mathrm{PbO}$ & $\mathrm{CaO}$ \\
$\mathrm{Fe}_{2} \mathrm{O}_{3}$ & $\mathrm{~V}_{2} \mathrm{O}_{5}$ & $\mathbf{C e O}_{2}$ \\
$\mathrm{Li}_{2} \mathrm{O}$ & $\mathbf{A s}_{2} \mathrm{O}_{3}$ & $\mathrm{Cl}$ \\
$\mathrm{MnO}$ & $\mathrm{BaO}$ & $\mathrm{CoO}$ \\
$\mathrm{Na}_{2} \mathrm{O}$ & $\mathrm{CuO}$ & $\mathrm{Cs}_{2} \mathrm{O}$ \\
$\mathrm{SiO}_{2}$ & & $\mathrm{~F}$ \\
$\mathrm{SrO} \mathrm{O}$ & & $\mathrm{K}_{2} \mathrm{O}$ \\
$\mathrm{ThO}_{2}$ & & $\mathrm{La}_{2} \mathrm{O}_{3}$ \\
$\mathbf{U O}_{2}$ & & $\mathrm{MgO}$ \\
$\mathrm{ZrO}_{2}$ & & $\mathrm{P}_{2} \mathrm{O}_{5}$ \\
$\mathrm{Cr}_{2} \mathrm{O}_{3}$ & & $\mathrm{PdO}$ \\
$\mathrm{NiO}$ & & $\mathrm{Rh}_{2} \mathrm{O}_{3}$ \\
$\mathrm{ZnO}$ & & $\mathrm{RuO}_{2}$ \\
$\mathrm{CdO}^{\mathbf{T l} \mathbf{O}_{3}}$ & & $\mathrm{SO}_{3}$ \\
$\mathrm{Sb}_{2} \mathrm{O}_{3}$ & & $\mathrm{TeO}_{2}$ \\
$\mathrm{SeO}_{2}$ & & $\mathrm{TiO}_{2}$ \\
\hline
\end{tabular}

\begin{tabular}{|c|c|c|}
\hline \multicolumn{3}{|c|}{ Revised Oxide Forms } \\
\hline Main & Spike & Constant \\
\hline $\mathrm{Al}_{2} \mathrm{O}_{3}$ & $\mathrm{Ag}_{2} \mathrm{O}$ & $\mathrm{Bi}_{2} \mathrm{O}_{3}$ \\
$\mathrm{~B}_{2} \mathrm{O}_{3}$ & $\mathrm{PbO}$ & $\mathrm{CaO}$ \\
$\mathrm{Fe}_{2} \mathrm{O}_{3}$ & $\mathrm{~V}_{2} \mathrm{O}_{5}$ & $\mathbf{C e}_{2} \mathrm{O}_{3}$ \\
$\mathrm{Li}_{2} \mathrm{O}$ & $\mathbf{A s}_{2} \mathrm{O}_{5}$ & $\mathrm{Cl}$ \\
$\mathrm{MnO}$ & $\mathrm{BaO}$ & $\mathrm{CoO}$ \\
$\mathrm{Na}_{2} \mathrm{O}$ & $\mathrm{CuO}$ & $\mathrm{Cs}_{2} \mathrm{O}$ \\
$\mathrm{SiO}_{2}$ & & $\mathrm{~F}$ \\
$\mathrm{SrO}$ & & $\mathrm{K}_{2} \mathrm{O}$ \\
$\mathrm{ThO}_{2}$ & & $\mathrm{La}_{2} \mathrm{O}_{3}$ \\
$\mathbf{U O}_{3}$ & & $\mathrm{MgO}$ \\
$\mathrm{ZrO}_{2}$ & & $\mathrm{P}_{2} \mathrm{O}_{5}$ \\
$\mathrm{Cr}_{2} \mathrm{O}_{3}$ & & $\mathrm{PdO}$ \\
$\mathrm{NiO}$ & & $\mathrm{Rh}_{2} \mathrm{O}_{3}$ \\
$\mathrm{ZnO}$ & & $\mathrm{RuO}_{2}$ \\
$\mathrm{CdO}$ & & $\mathrm{SO}_{3}$ \\
$\mathbf{T l}_{\mathbf{2}} \mathbf{O}$ & & $\mathrm{TeO}_{2}$ \\
$\mathrm{Sb}_{2} \mathrm{O}_{3}$ & & $\mathrm{TiO}_{2}$ \\
$\mathrm{SeO}_{2}$ & & \\
\hline
\end{tabular}


Table 2.11. Target Glass Compositions Expressed in Revised Oxides (wt\%) for the Initial (HLW02) and Augmentation (HLW03) Test Matrices.

\begin{tabular}{|c|c|c|c|c|c|c|c|c|c|c|c|c|c|c|c|c|c|c|c|c|c|c|}
\hline Glass ID $^{(a)}$ & $\begin{array}{c}\text { Point } \\
\text { Type }^{(b)}\end{array}$ & $\begin{array}{c}\text { Melt } \\
\text { Order }\end{array}$ & $\mathbf{A l}_{2} \mathbf{O}_{3}$ & $\mathbf{B}_{2} \mathbf{O}_{3}$ & $\mathrm{Fe}_{2} \mathrm{O}_{3}$ & $\mathbf{L i}_{2} \mathbf{O}$ & InO & $\mathrm{Na}_{2} \mathrm{O}$ & $\mathrm{SiO}_{2}$ & SrO & $\mathrm{ThO}_{2}$ & $\mathbf{U O}_{3}$ & $\mathrm{ZrO}_{2}$ & $\mathrm{Cr}_{2} \mathrm{O}_{3}$ & GiO & $\mathrm{EnO}$ & dO & $\mathrm{Tl}_{2} \mathrm{O}$ & $\mathrm{Sb}_{2} \mathrm{O}_{3}$ & $\mathrm{SeO}_{2}$ & pike & Constant $^{(\mathrm{c})}$ \\
\hline HLW02-01 & 1a.Center & I-29 & 6.171 & 9.927 & 10.898 & 3.996 & 2.385 & 10.957 & 3.612 & .444 & 0.000 & .000 & 2.974 & 0.108 & 0.518 & 2.000 & 0.771 & 0.102 & 0.110 & \begin{tabular}{|l|}
0.110 \\
\end{tabular} & 0.721 & 2.197 \\
\hline HLW02-02 & 1a.Outer01 & $\mathrm{I}-25$ & 3.999 & 13.996 & 13.996 & 5.998 & 0.000 & 3.999 & 50.445 & 0.000 & 0.000 & 0.000 & 0.000 & 0.200 & 0.100 & 1.999 & 1.500 & 0.019 & 0.200 & 0.020 & 1.333 & 2.197 \\
\hline HLW02-03 & 1a.Outer02 & $\mathrm{I}-12$ & 3.999 & 13.998 & 7.999 & 2.000 & 0.000 & 14.997 & 37.993 & 4.379 & 0.000 & 0.000 & 5.999 & 0.200 & 1.000 & 2.000 & 1.500 & 0.186 & 0.020 & 0.200 & 1.333 & 2.197 \\
\hline HLW02-04 & 1a.Outer03 & I-46 & 4.001 & 5.001 & 14.002 & 2.000 & 0.518 & 15.002 & 52.939 & 0.000 & 0.000 & 0.000 & 0.000 & 0.020 & 0.100 & 2.000 & 1.500 & 0.186 & 0.200 & 0.200 & .133 & .198 \\
\hline HLW02-05 & 1a.Outer04 & $\mathrm{I}-53$ & .000 & 5.000 & 8.000 & 6.000 & 0.000 & 13.788 & 52.653 & .000 & 0.000 & 0.000 & 6.000 & 0.020 & 0.100 & 2.000 & 0.050 & 0.019 & 0.020 & 0.020 & 133 & 198 \\
\hline HLW02-06 & 1a.Outer05 & $\mathrm{I}-45$ & .501 & 5.001 & 8.001 & 4.740 & 5.001 & 15.002 & 40.496 & 0.000 & 0.000 & 0.000 & 6.001 & 0.020 & 1.000 & 2.000 & $\begin{array}{ll}1.500 \\
\end{array}$ & 0.186 & 0.020 & 0.200 & 133 & 198 \\
\hline HLW02-07 & 1a.Outer06 & $\mathrm{I}-43$ & .499 & 4.999 & 7.999 & 5.999 & 0.000 & 11.703 & 52.991 & 0.000 & 0.000 & 0.000 & 1.525 & 0.200 & 0.100 & 2.000 & 0.050 & 0.186 & 0.200 & 0.020 & 1.333 & 197 \\
\hline $2-08$ & $1 \mathrm{a} . \mathrm{O}$ & I-56 & 4.000 & \begin{tabular}{|l|}
14.000 \\
\end{tabular} & 9.205 & 3.310 & 5.000 & 15.000 & 38.745 & .000 & 0.000 & .000 & 6.000 & 0.020 & .100 & 2.000 & 0.050 & 0.019 & 0.200 & 0.020 & .133 & 98 \\
\hline HLW02-09 & 1a.Out & $\mathrm{I}-21$ & 8.500 & 11.589 & 14.000 & 2.271 & 0.000 & 15.000 & 38.000 & 5.000 & 0.000 & 0.000 & 0.000 & 0.020 & 1.000 & 2.000 & 0.050 & 0.019 & 0.200 & 0.020 & 0.133 & 198 \\
\hline HLW02-10 & 1a.Outer09 & $\mathrm{I}-42$ & 8.500 & 14.000 & 8.000 & 6.000 & 0.000 & 10.513 & 38.000 & 2.797 & 0.000 & 0.000 & 6.000 & 0.020 & 0.100 & 2.000 & 1.500 & 0.019 & 0.020 & 0.200 & 0.133 & 2.198 \\
\hline HLW02-11 & 1a.Outer10 & $\mathrm{I}-32$ & 4.000 & 14.002 & 8.001 & 6.001 & 0.000 & 10.858 & 45.149 & 0.000 & 0.000 & 0.000 & 6.001 & 0.020 & 1.000 & 2.000 & 0.050 & 0.186 & 0.200 & \begin{tabular}{|l|}
0.200 \\
\end{tabular} & 0.133 & 2.198 \\
\hline HLW02-12 & 1a.Outer11 & I-44 & 3.999 & 4.998 & \begin{tabular}{|l|}
11.382 \\
\end{tabular} & 5.998 & 4.998 & 12.757 & 41.401 & 0.000 & 0.000 & 0.000 & 5.998 & 0.200 & 1.000 & 1.999 & 1.500 & 0.019 & 0.020 & 0.200 & 1.333 & 197 \\
\hline $\mathrm{HL}$ & 1 & I-39 & 3.999 & 4.999 & 13.998 & 5.999 & 4.999 & 10.425 & 43.114 & 4.999 & 0.000 & 0.000 & 1.182 & 0.200 & 0.100 & 2.000 & 0.050 & 0.186 & 0.020 & 0.200 & 1.333 & 97 \\
\hline $2-14$ & 190 & I-41 & .001 & 5.001 & 8.001 & 6.001 & 2.490 & 4.141 & 3.007 & 5.001 & 0.000 & 0.000 & 6.001 & 0.020 & .100 & 2.000 & 1.500 & 0.186 & 0.200 & 0.020 & 33 & 98 \\
\hline HLW02-15 & $1 \mathrm{a} . \mathrm{O}$ & $\mathrm{I}-18$ & 8.499 & 13.998 & 13.998 & 2.000 & 4.688 & 12.539 & 37.993 & 0.000 & 0.000 & 0.000 & 0.000 & 0.200 & 0.100 & 2.000 & 0.050 & 0.186 & 0.020 & 0.200 & 1.333 & 197 \\
\hline HLW02-16 & 1a.C & I-51 & 8.497 & 4.999 & 7.998 & 5.998 & 4.999 & 9.651 & 39.114 & .999 & 0.000 & 0.000 & 5.998 & 0.200 & .100 & 1.999 & 1.500 & 0.019 & 0.200 & 0.200 & 1.333 & .197 \\
\hline HLW02-17 & 1a.Outer16 & I-19 & 8.500 & 5.000 & 13.843 & 6.000 & 0.000 & 7.690 & 52.958 & 0.000 & 0.000 & .000 & 0.000 & .020 & .100 & 2.000 & 1.500 & 0.019 & 0.020 & 0.020 & 0.133 & .198 \\
\hline HLW02-18 & 1a.Outer17 & I-8 & 3.999 & 4.998 & \begin{tabular}{|l|}
11.127 \\
\end{tabular} & 2.013 & 0.000 & 14.995 & 49.852 & 0.000 & 0.000 & 0.000 & 5.998 & 0.200 & 1.000 & $\begin{array}{l}1.999 \\
\end{array}$ & $\begin{array}{ll}0.050 \\
\end{array}$ & 0.019 & 0.200 & 0.020 & 1.333 & 2.197 \\
\hline HLW02-19 & 1a.Outer18 & I-57 & 4.000 & 14.000 & 10.781 & 2.000 & 5.000 & 8.849 & 38.000 & 5.000 & 0.000 & 0.000 & 6.000 & 0.020 & 0.100 & 2.000 & 1.500 & 0.019 & 0.200 & \begin{tabular}{|l|}
0.200 \\
\end{tabular} & 0.133 & 2.198 \\
\hline HLW02-20 & 1a.Outer19 & $\mathrm{I}-30$ & 4.000 & 14.000 & 14.000 & 2.000 & 0.000 & 6.453 & 51.734 & 3.253 & 0.000 & 0.000 & 0.000 & 0.020 & 0.100 & 2.000 & 0.050 & 0.019 & 0.020 & \begin{tabular}{|l|}
0.020 \\
\end{tabular} & 0.133 & 2.198 \\
\hline HLW02-21 & 1a.Outer20 & $\mathrm{I}-24$ & 8.500 & 14.000 & 8.000 & 2.000 & 0.000 & 15.000 & 46.440 & 0.000 & 0.000 & 0.000 & 1.500 & 0.020 & 0.100 & 2.000 & 0.050 & 0.019 & 0.020 & 0.020 & 0.133 & .198 \\
\hline & & I-36 & 8.500 & 14.000 & 9.500 & 6.000 & 0.000 & 4.000 & 53.000 & 0.080 & 0.000 & 0.000 & 0.000 & 0.020 & 0.100 & 2.000 & 0.050 & 0.019 & 0.200 & 0.200 & 0.133 & 198 \\
\hline $2-23$ & & $\mathrm{I}-15$ & 8.501 & 14.002 & 8.001 & 6.001 & 5.001 & 5.591 & 9.325 & 5.001 & 0.000 & 0.000 & 1.500 & 0.020 & 1.000 & 2.000 & 1.500 & 0.186 & 0.020 & \begin{tabular}{|l|}
0.020 \\
\end{tabular} & 0.133 & 198 \\
\hline & 23 & $\mathrm{I}-31$ & 3.498 & 4.999 & 7.998 & 2.000 & 4.999 & 12.195 & 47.052 & 4.999 & 0.000 & 0.000 & 1.500 & 0.153 & 0.100 & 2.000 & 0.050 & 0.019 & 0.020 & \begin{tabular}{|l|}
0.200 \\
\end{tabular} & 1.023 & 197 \\
\hline $2-25$ & 24 & I-34 & 8.501 & 14.002 & 9.501 & 2.000 & 0.355 & 6.884 & 47.398 & 001 & 0.000 & 0.000 & 0.000 & 0.020 & .100 & 2.000 & 1.500 & 0.186 & 0.200 & 0.020 & 0.133 & .198 \\
\hline HLW02-26 & 1a.Outer25 & $\mathrm{I}-5$ & 3.999 & 4.999 & 12.498 & 2.000 & 4.959 & 14.997 & 37.993 & 4.999 & 0.000 & 0.000 & 5.999 & 0.200 & 0.100 & 2.000 & $\begin{array}{ll}1.500 \\
\end{array}$ & 0.186 & 0.020 & 0.020 & 1.333 & 2.197 \\
\hline HLW02-27 & 1a.Outer26 & $\mathrm{I}-23$ & 4.001 & 14.002 & 12.502 & 6.001 & 3.365 & 4.275 & 39.946 & 5.001 & 0.000 & 0.000 & 6.001 & 0.020 & 0.100 & 2.000 & 0.050 & 0.186 & 0.020 & 0.200 & 0.133 & 2.198 \\
\hline HLW02-28 & 1a.Inner01 & I-49 & 7.500 & 8.001 & 10.451 & 2.500 & 1.500 & 15.001 & 41.003 & 3.500 & 0.000 & 0.000 & 4.500 & 0.040 & 0.300 & 2.000 & 1.000 & 0.140 & 0.050 & \begin{tabular}{|l|}
0.050 \\
\end{tabular} & 0.266 & 2.198 \\
\hline
\end{tabular}

(a) Glass IDs HLW02-01 to HLW02-57 identify the initial test matrix of HLW glasses, while Glass IDs HLW03-01 to HLW03-45 identify the augmentation test matrix of HLW glasses.

(b) The "Point Type" notation generally begins with either 1a [denoting the initial (Phase 1a) test matrix] or 1b [denoting the augmentation (Phase 1b) test matrix]. After a separating dot, the notation continues with "Center", "Outer", or "Inner", denoting whether the glass was a center point, outer-layer point, or inner-layer point. The "Center", "Outer", or "Inner" designation is with respect to Phase 1a or Phase 1b. The "XX" following "Outer" and "Inner" denotes the number of each outer-layer or inner-layer point with respect to Phase 1a or Phase 1b. Replicate points are denoted by "RepHLW02-xx" and "RepHLW03-xx", where the "xx" represents a specific Glass ID number for a replicated glass.

(c) Note that the values in the Constant column are no longer exactly constant because of the change in oxides forms used to express glass composition. 
Table 2.11. Target Glass Compositions Expressed in Revised Oxides (wt\%) for the Initial (HLW02) and Augmentation (HLW03) Test Matrices (continued).

\begin{tabular}{|c|c|c|c|c|c|c|c|c|c|c|c|c|c|c|c|c|c|c|c|c|c|c|}
\hline Glass ID Ia) $^{(a)}$ & Point Type $^{(\mathbf{b})}$ & $\begin{array}{c}\text { Melt } \\
\text { Order }\end{array}$ & $\mathbf{A l}_{2} \mathbf{O}_{3}$ & $\mathbf{B}_{2} \mathbf{O}_{3}$ & $\mathrm{Fe}_{2} \mathrm{O}_{3}$ & $\mathbf{L i}_{2} \mathbf{O}$ & MnO & $\mathrm{Na}_{2} \mathrm{O}$ & $\mathrm{SiO}_{2}$ & SrO & $\mathrm{ThO}_{2}$ & $\mathbf{U O}_{3}$ & $\mathrm{ZrO}_{2}$ & $\mathrm{Cr}_{2} \mathrm{O}_{3}$ & NiO & $\mathrm{ZnO}$ & CdO & $\mathbf{T l}_{2} \mathbf{O}$ & $\mathbf{S b}_{2} \mathbf{O}_{3}$ & $\mathrm{SeO}_{2}$ & Spike & 0 \\
\hline 702-29 & 102 & I-6 & 499 & 2.998 & 770 & 749 & 500 & 999 & 40.994 & ק & 000 & .000 & 4.499 & 133 & .300 & .000 & .500 & .046 & .050 & .150 & .007 & 2.197 \\
\hline $\mathrm{HLI}$ & & $\mathrm{I}-22$ & 5.500 & 9.722 & 10.000 & 5.000 & 500 & 11.229 & 40.999 & 3.500 & 000 & .000 & 4.500 & .040 & 0.300 & 2.000 & 1.000 & 0.046 & .150 & 0.050 & .266 & 98 \\
\hline HLW02-32 & 205 & I-9 & 7.500 & 8.000 & 10.000 & 5.000 & 1.500 & 10.733 & 46.117 & 3.500 & 0.000 & 0.000 & 1.500 & 0.040 & 0.300 & 2.000 & 1.000 & 0.046 & 0.150 & \begin{tabular}{|l|}
0.150 \\
\end{tabular} & 0.266 & 2.198 \\
\hline HLW02-33 & 1 Innor & $\mathrm{I}-17$ & 6.341 & 8.000 & 12.000 & 2.500 & 3.500 & 15.000 & 41.000 & 3.500 & 0.000 & 0.000 & 2.009 & 0.040 & 0.800 & 2.000 & 0.500 & \begin{tabular}{|l|l|}
0.046 \\
\end{tabular} & 0.150 & \begin{tabular}{|l|}
0.150 \\
\end{tabular} & 0.266 & 2.198 \\
\hline \begin{tabular}{|l|} 
HLW02-34 \\
\end{tabular} & & $I-26$ & 5.499 & 12.998 & 11.998 & 3.956 & 1.500 & 10.891 & 40.994 & 3.499 & 0.000 & 0.000 & 1.500 & 0.133 & 0.800 & 2.000 & 1.000 & \begin{tabular}{|l|}
0.046 \\
\end{tabular} & .050 & .050 & 8.889 & 197 \\
\hline & & & 6.488 & 2.999 & 11.999 & .000 & 3.500 & 9.160 & 40.996 & 1.500 & 0.000 & 0.000 & 1.500 & 133 & 0.800 & 2.000 & 0.500 & \begin{tabular}{|l|l|}
0.139 \\
\end{tabular} & .150 & 050 & 889 & \\
\hline & & 48 & 499 & .668 & 11.998 & 2.500 & .500 & 14.997 & 45.074 & 1.500 & 0.000 & .000 & 1.500 & 133 & 0.300 & 2.000 & 1.000 & 0.046 & .050 & .150 & 889 & \\
\hline & & & 762 & .000 & 10.000 & .500 & .500 & 11.188 & 41.000 & 1.500 & .000 & .000 & 4.500 & .040 & 0.800 & 2.000 & 0.500 & 0.046 & .150 & .050 & .266 & \\
\hline & & & 893 & 2.998 & 11.998 & 255 & .500 & 8.999 & 40.994 & 3.499 & 000 & .000 & 1.500 & 133 & .800 & 2.000 & 1.000 & \begin{tabular}{|l|l|}
0.046 \\
\end{tabular} & .150 & .150 & .889 & \\
\hline HLV & & 40 & 7.500 & 8.992 & 10.000 & 2.500 & 1.500 & 11.059 & 48.999 & 1.500 & 000 & 00 & 1.500 & 0.040 & 800 & 2.000 & 1.000 & 0.046 & .050 & 0.050 & .266 & \\
\hline HLW02-40 & & & 7.499 & 9.833 & 9.999 & 2.632 & 1.500 & 9.683 & 48.996 & 1.500 & 0.000 & 0.000 & 1.500 & 0.133 & 0.300 & 2.000 & 1.000 & 0.139 & 0.150 & 0.050 & 0.889 & 97 \\
\hline \begin{tabular}{|l|} 
HLW $02-41$ \\
\end{tabular} & & & 6.500 & 13.001 & 10.001 & 2.500 & 1.500 & 9.001 & 48.953 & 1.500 & 0.000 & 0.000 & 1.500 & 0.040 & 0.300 & 2.000 & 0.500 & 0.140 & 0.050 & 0.050 & 0.266 & .198 \\
\hline HLV & & & 5.500 & 3.001 & $\mid 10.001$ & 5.000 & 1.500 & 9.001 & 44.453 & 3.500 & 0.000 & 0.000 & 2.500 & 0.040 & 0.300 & 2.000 & 0.500 & \begin{tabular}{|l|l|}
0.140 \\
\end{tabular} & .050 & \begin{tabular}{|l|}
0.050 \\
\end{tabular} & .266 & 98 \\
\hline & & & 00 & & 10.000 & 0 & 3.500 & 12.450 & 000 & 00 & 00 & $\overline{00}$ & 1.500 & & 0.300 & 2.000 & 1.000 & \begin{tabular}{|l|l|}
0.046 \\
\end{tabular} & 150 & \begin{tabular}{|l|}
0.050 \\
\end{tabular} & 266 & \\
\hline & & & 5.499 & 9.069 & 9.998 & 2.500 & 3.499 & 14.997 & 43.673 & 1.500 & 0.000 & 0.000 & 2.500 & 133 & 0.300 & 2.000 & 1.000 & 0.046 & .150 & \begin{tabular}{|l|}
0.050 \\
\end{tabular} & 889 & \\
\hline-45 & & & 500 & 000 & 11.000 & .500 & 3.500 & 9.619 & 48.831 & 0 & ( & 00 & 1.500 & .040 & 0.300 & 2.000 & 1.000 & 0.046 & .050 & 0.150 & .266 & \\
\hline & & & 500 & 0 & 10.001 & 01 & $n^{2}$ & 1 & 03 & 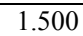 & $\overline{00}$ & $\overline{00}$ & 2.500 & 40 & $\overline{00}$ & 2.000 & 0.500 & .140 & 050 & \begin{tabular}{|l|}
0.150 \\
\end{tabular} & 66 & \\
\hline HLV & & & 5.499 & 9.806 & 9.999 & 2.500 & 3.500 & 9.443 & 48.995 & 1.500 & 0.000 & 0.000 & 2.500 & 0.133 & 0.300 & 2.000 & 0.500 & 0.139 & 0.050 & 0.050 & 0.889 & .197 \\
\hline HLW02-48 & 21 & & 5.999 & 7.999 & 11.999 & 3.340 & 1.500 & 14.999 & 40.996 & 1.711 & 0.000 & 0.000 & 4.500 & 0.133 & 0.800 & 2.000 & 0.500 & \begin{tabular}{|l|l|}
0.139 \\
\end{tabular} & 0.150 & \begin{tabular}{|l|}
0.150 \\
\end{tabular} & 0.889 & 2.197 \\
\hline HLW02-49 & er22 & $\mathrm{I}-54$ & 7.500 & 8.740 & 12.001 & 5.000 & 3.500 & 9.000 & 44.213 & 1.500 & 0.000 & 0.000 & 3.000 & 0.040 & 0.300 & 2.000 & 0.500 & \begin{tabular}{|l|l|}
0.139 \\
\end{tabular} & 0.050 & \begin{tabular}{|l|l|}
0.050 \\
\end{tabular} & 0.266 & .198 \\
\hline \begin{tabular}{|l} 
HLW02-50 \\
\end{tabular} & & & 6.000 & 13.001 & 12.001 & 2.500 & 1.500 & 9.821 & 43.533 & 1.500 & 0.000 & 0.000 & 4.500 & 0.040 & 0.300 & 2.000 & 0.500 & \begin{tabular}{|l|}
0.140 \\
\end{tabular} & 0.150 & \begin{tabular}{|l|}
0.050 \\
\end{tabular} & 0.266 & .198 \\
\hline & & & 7.500 & .000 & 10.501 & 4.589 & 1.500 & 9.000 & 45.164 & 3.500 & 0.000 & 0.000 & 4.500 & 0.040 & 0.300 & 2.000 & 0.500 & \begin{tabular}{|l|l|}
0.139 \\
\end{tabular} & .150 & \begin{tabular}{|l|}
0.150 \\
\end{tabular} & 266 & \\
\hline & & & 6.171 & 9.927 & 10.898 & 3.996 & 2.385 & 10.957 & 43.612 & 2.444 & 0.000 & 0.000 & 2.974 & .108 & 0.518 & 2.000 & 0.771 & 0.102 & .110 & \begin{tabular}{|l|}
0.110 \\
\end{tabular} & .719 & 97 \\
\hline & & & 20 & .000 & 13.843 & 5.000 & 0.000 & 7.690 & 52.958 & 0.000 & 0.000 & 0.000 & 0.000 & 020 & 0.100 & 2.000 & 1.500 & .019 & .020 & 0.020 & .133 & \\
\hline & & & 001 & 1 & 14.002 & 00 & 518 & 15. & 39 & 00 & 00 & 00 & 0.000 & 20 & 00 & 2.000 & 1.500 & 0.186 & 200 & 0.200 & 133 & 98 \\
\hline & & & 5.500 & 3.001 & 10.001 & 5.000 & .500 & 9.001 & 44.453 & 00 & 00 & 00 & 2.500 & 40 & $\overline{00}$ & 2.000 & 0.500 & \begin{tabular}{|l|l|}
0.140 \\
\end{tabular} & .050 & \begin{tabular}{|l|}
0.050 \\
\end{tabular} & 0.266 & 98 \\
\hline HLW & $2-44$ & & 5.499 & 9.069 & 9.998 & 2.500 & 3.499 & 14.997 & 43.673 & 1.500 & 0.000 & 0.000 & 2.500 & 0.133 & 0.300 & 2.000 & 1.000 & 0.046 & .150 & \begin{tabular}{|l|}
0.050 \\
\end{tabular} & 0.889 & 2.197 \\
\hline HLW02-57 & RepHLW02-8 & $\mathrm{I}-47$ & 4.000 & 4.000 & 9.205 & 3.310 & 5.000 & 15.000 & 38.745 & 0.000 & 0.000 & 0.000 & 6.000 & 0.020 & 0.100 & 2.000 & 0.050 & 0.019 & 0.200 & \begin{tabular}{|l|}
0.020 \\
\end{tabular} & 0.133 & 2.198 \\
\hline \begin{tabular}{|l} 
HLW03-01 \\
\end{tabular} & 1b.Outer01 & A-4 & 8.335 & 3.727 & 13.727 & 5.883 & 6.078 & 3.922 & 35.299 & 0.000 & 2.764 & 0.000 & 2.983 & 0.020 & 0.098 & 3.059 & 0.050 & \begin{tabular}{|l|l|}
0.307 \\
\end{tabular} & 0.020 & \begin{tabular}{|l|}
0.200 \\
\end{tabular} & 1.332 & 2.198 \\
\hline \begin{tabular}{|l|} 
HLW03-02 \\
\end{tabular} & 1b.Outer02 & A-28 & 1.951 & 13.662 & 13.662 & 2.473 & 6.832 & 11.177 & 35.132 & 0.000 & 0.000 & 0.000 & 9.088 & 0.488 & 0.976 & 0.000 & 1.600 & \begin{tabular}{|l|l|}
0.307 \\
\end{tabular} & 0.300 & \begin{tabular}{|l|}
0.020 \\
\end{tabular} & 0.133 & 198 \\
\hline HLW03-03 & 1b.Outer03 & A-26 & 1.953 & 4.884 & 13.677 & 2.678 & 6.839 & 10.755 & 35.169 & 9.769 & 0.000 & 0.000 & 6.404 & 0.488 & 0.977 & 1.946 & 1.600 & \begin{tabular}{|l|l|}
0.307 \\
\end{tabular} & 0.020 & 0.200 & 0.133 & 2.198 \\
\hline
\end{tabular}

(a) Glass IDs HLW02-01 to HLW02-57 identify the initial test matrix of HLW glasses, while Glass IDs HLW03-01 to HLW03-45 identify the augmentation test matrix of HLW glasses.

(b) The "Point Type" notation generally begins with either 1a [denoting the initial (Phase 1a) test matrix] or 1b [denoting the augmentation (Phase 1b) test matrix]. After a separating dot, the notation continues with "Center", "Outer", or "Inner", denoting whether the glass was a center point, outer-layer point, or inner-layer point. The "Center", "Outer", or "Inner" designation is with respect to Phase 1a or Phase 1b. The "XX" following "Outer" and "Inner" denotes the number of each outer-layer or inner-layer point with respect to Phase 1a or Phase 1b. Replicate points are denoted by "RepHLW02-xx" and "RepHLW03-xx", where the "xx" represents a specific Glass ID number for a replicated glass.

(c) Note that the values in the Constant column are no longer exactly constant because of the change in oxides forms used to express glass composition. 
Table 2.11. Target Glass Compositions Expressed in Revised Oxides (wt\%) for the Initial (HLW02) and Augmentation (HLW03) Test Matrices (continued).

\begin{tabular}{|c|c|c|c|c|c|c|c|c|c|c|c|c|c|c|c|c|c|c|c|c|c|c|}
\hline Glass ID $^{(a)}$ & Point Type $^{(\mathbf{b})}$ & $\begin{array}{l}\text { Melt } \\
\text { Order }\end{array}$ & $\mathbf{A l}_{2} \mathbf{O}_{3}$ & $\mathbf{B}_{2} \mathbf{O}_{3}$ & $\mathrm{Fe}_{2} \mathrm{O}_{3}$ & $\mathbf{L i}_{2} \mathbf{O}$ & MnO & $\mathrm{Na}_{2} \mathbf{O}$ & $\mathrm{SiO}_{2}$ & SrO & $\mathrm{hO}_{2}$ & $\mathbf{U O}_{3}$ & $\mathrm{ZrO}_{2}$ & $\mathrm{Cr}_{2} \mathrm{O}_{3}$ & $\mathbf{N i O}$ & ZnO & CdO & $\mathbf{T l}_{2} \mathbf{O}$ & $\mathbf{S b}_{2} \mathbf{O}_{3}$ & $\mathrm{SeO}_{2}$ & Spike & $\mathbf{0}$ \\
\hline HLW03-04 & 1b.Outer04 & A-9 & 1.954 & 4.886 & 13.680 & 5.862 & 3.161 & 4.442 & 42.425 & 9.771 & 0.000 & 210 & 2.932 & 0.488 & 0.098 & 0.000 & \begin{tabular}{|l|}
0.050 \\
\end{tabular} & 0.306 & 0.020 & 0.199 & 1.328 & 2.190 \\
\hline HLW03-05 & 1b.Outer05 & A-2 & 8.175 & 4.809 & 1.924 & 1.924 & 6.733 & 14.427 & 47.837 & 0.000 & 3.812 & 0.000 & 0.000 & 0.481 & 0.096 & 3.847 & 1.600 & 0.307 & \begin{tabular}{|l|}
0.300 \\
\end{tabular} & 0.200 & 1.332 & .198 \\
\hline \begin{tabular}{|l} 
HLW03-06 \\
\end{tabular} & 1b.Outer06 & A-35 & 8.344 & 4.908 & 1.963 & 5.890 & 6.872 & 3.927 & 52.031 & 5.091 & 1.416 & 0.000 & 4.095 & \begin{tabular}{|l|l}
0.491 \\
\end{tabular} & 0.982 & 0.000 & 1.600 & \begin{tabular}{|l|}
0.019 \\
\end{tabular} & 0.020 & 0.020 & 0.133 & 2.198 \\
\hline HLW03-07 & 1b.Outer07 & A-25 & 961 & 4.961 & 13.891 & 4.750 & 6.945 & 11.693 & 39.825 & 0.000 & 0.000 & 6.306 & 0.000 & \begin{tabular}{|l|l|}
0.496 \\
\end{tabular} & 0.100 & 3.461 & 0.050 & 0.019 & 0.020 & 0.199 & 0.133 & 90 \\
\hline \begin{tabular}{|l|} 
HLW03-08 \\
\end{tabular} & 8 & A-31 & .031 & 4.833 & 1.933 & 5.151 & 6.766 & 14.499 & 34.797 & 0.000 & 4.412 & 0.000 & 9.666 & 0.483 & 0.097 & 3.866 & 1.600 & 0.019 & 0.300 & 0.020 & 1.332 & 97 \\
\hline HLW03-09 & 09 & -11 & 668 & 13.695 & 3.486 & 1.979 & 0.000 & 14.848 & 52.465 & 0.000 & 2.552 & 0.000 & 0.000 & 0.020 & 0.099 & 0.000 & 0.050 & 0.307 & 0.300 & 0.200 & 133 & 98 \\
\hline HLV & r10 & A-45 & 369 & 4.924 & 9.982 & 5.908 & .893 & 12.851 & 35.449 & 0.000 & 2.626 & .108 & 7.250 & 0.020 & 0.985 & 0.000 & 0.050 & 0.019 & .020 & 0.020 & .331 & 96 \\
\hline HLV & & A-38 & 984 & 961 & .538 & 1.984 & 0.000 & 14.883 & 2.586 & 0.000 & 5.027 & .306 & 0.000 & .020 & 0.100 & 0.000 & 0.050 & 0.019 & .020 & 0.199 & 133 & \\
\hline HLW03-12 & 12 & A-34 & 1.982 & 4.956 & 1.982 & 5.008 & 6.939 & 3.965 & 44.277 & 9.912 & 3.729 & 6.299 & 3.682 & 0.495 & 0.099 & 3.965 & 0.050 & 0.019 & \begin{tabular}{|l|}
0.299 \\
\end{tabular} & 0.020 & 0.133 & 90 \\
\hline HLW03-13 & 1b.Outer13 & A-13 & 8.433 & 4.961 & 8.633 & 5.209 & 6.945 & 3.969 & 35.719 & 9.922 & 3.836 & 6.306 & 0.846 & 0.496 & 0.992 & 1.121 & 0.050 & 0.019 & 0.020 & 0.199 & 0.133 & 190 \\
\hline HLW03-14 & 1b.Outer14 & A-27 & 1.989 & 4.973 & 9.047 & 2.504 & 6.962 & 10.425 & 35.806 & 9.946 & 4.115 & 0.000 & 6.511 & 0.020 & \begin{tabular}{|l|}
0.994 \\
\end{tabular} & \begin{tabular}{|l|}
3.979 \\
\end{tabular} & \begin{tabular}{|l|}
0.050 \\
\end{tabular} & 0.307 & \begin{tabular}{|l|}
0.020 \\
\end{tabular} & 0.020 & 0.133 & .198 \\
\hline HLW03-15 & & A-1 & 1.951 & 13.662 & 13.662 & 1.951 & 1.348 & 5.248 & 51.722 & 0.000 & 2.441 & 0.000 & 0.000 & 0.020 & 0.098 & 3.337 & 1.600 & $\mid 0.307$ & 0.300 & 0.020 & 0.133 & 198 \\
\hline-16 & & A-30 & 955 & 4.886 & 7.905 & 2.862 & 6.840 & 3.909 & 44.240 & 9.772 & 2.568 & 6.210 & 1.001 & 0.020 & 0.977 & 2.772 & 0.050 & 0.019 & 0.299 & 0.199 & 1.327 & 89 \\
\hline $\mathrm{HL}$ & & A-29 & 352 & 13.757 & 1.965 & 1.965 & 6.879 & 4.461 & 46.088 & 0.000 & 2.237 & 4.784 & 1.639 & 0.020 & 0.293 & 3.930 & 0.050 & 0.019 & 0.020 & 0.020 & 1.328 & 91 \\
\hline $3-18$ & 18 & A-14 & .989 & 4.973 & 13.924 & 5.922 & 0.000 & 10.533 & 52.484 & 0.000 & 5.967 & 0.000 & 0.000 & 0.497 & 0.980 & 0.000 & 0.050 & 0.307 & 0.020 & 0.020 & .133 & 198 \\
\hline-19 & 19 & A-37 & 963 & 4.908 & 9.634 & 5.890 & 0.197 & 10.142 & 2.030 & 0.000 & 5.846 & .000 & 0.000 & 0.491 & 0.982 & 3.927 & 1.600 & 0.019 & .020 & 0.020 & .133 & 198 \\
\hline HLV & 20 & A-22 & .923 & 4.808 & 13.462 & 5.769 & 0.000 & 10.097 & 50.681 & 0.145 & 5.769 & .430 & 0.000 & .019 & 0.962 & 0.000 & 1.600 & 0.307 & .300 & 0.200 & 1.332 & 197 \\
\hline HLW03-21 & 1b.Inner01 & A-44 & 4.958 & 6.941 & 4.958 & 2.479 & 4.462 & 10.828 & 48.587 & 1.487 & 2.975 & 2.100 & 5.949 & 0.079 & 0.298 & 0.992 & 0.300 & 0.046 & 0.050 & 0.050 & 0.266 & 2.195 \\
\hline HLW03-22 & 1b.Inner02 & A-36 & 4.915 & 6.881 & 9.752 & 2.458 & 1.474 & 11.797 & 40.305 & 4.424 & 2.949 & 4.165 & 5.898 & 0.079 & 0.295 & \begin{tabular}{|l|}
0.983 \\
\end{tabular} & \begin{tabular}{|l|}
0.299 \\
\end{tabular} & 0.046 & \begin{tabular}{|l|}
0.050 \\
\end{tabular} & 0.150 & 0.889 & 2.192 \\
\hline HLW03-23 & 1b.Inner03 & A-10 & 4.957 & 11.897 & 7.733 & 2.478 & 1.487 & 11.897 & 40.648 & 1.487 & 2.974 & 4.201 & 5.949 & \begin{tabular}{|l|l|}
0.199 \\
\end{tabular} & 0.297 & 0.992 & 0.100 & 0.046 & \begin{tabular}{|l|}
0.050 \\
\end{tabular} & 0.150 & 0.266 & 2.193 \\
\hline HLW03-24 & & A-3 & 2.975 & 6.941 & 4.958 & 4.958 & 4.462 & 8.151 & 48.588 & 1.487 & 2.975 & 2.100 & 5.949 & \begin{tabular}{|l|l|}
0.079 \\
\end{tabular} & 0.495 & 2.975 & 0.300 & 0.046 & \begin{tabular}{|l|}
0.050 \\
\end{tabular} & 0.050 & 0.266 & .195 \\
\hline & & -39 & .956 & 11.823 & 4.927 & 2.463 & 1.478 & 11.823 & 42.090 & 4.433 & 2.956 & 2.087 & 5.912 & 0.079 & 0.492 & 2.956 & \begin{tabular}{|l|}
0.100 \\
\end{tabular} & \begin{tabular}{|l|}
0.139 \\
\end{tabular} & 0.050 & 0.150 & 0.890 & 95 \\
\hline & & A-17 & .921 & 6.889 & 4.921 & 4.921 & 1.476 & 10.431 & 40.346 & 4.428 & 4.428 & 4.169 & 5.904 & 0.197 & 0.492 & 2.953 & 0.100 & \begin{tabular}{|l|}
0.046 \\
\end{tabular} & 0.150 & 0.150 & 0.889 & 92 \\
\hline & & -24 & 926 & 6.897 & 9.359 & 4.040 & 1.478 & 11.822 & 40.393 & 1.478 & 4.433 & 2.087 & 5.911 & 0.197 & 0.492 & 2.956 & \begin{tabular}{|l|}
0.100 \\
\end{tabular} & 0.046 & 0.150 & 0.150 & 0.890 & 195 \\
\hline-28 & & A-5 & 629 & 11.911 & 9.926 & 4.963 & 1.489 & 10.486 & 40.695 & 1.489 & 2.977 & 2.103 & 5.956 & 0.080 & 0.496 & 0.993 & 0.100 & 0.046 & 0.150 & 0.050 & .266 & 195 \\
\hline HLW03-29 & 99 & A-41 & 971 & 6.933 & 4.952 & 4.952 & 3.518 & 11.885 & 40.606 & 1.485 & 4.456 & 4.196 & 7.674 & 0.199 & 0.297 & 2.971 & \begin{tabular}{|l|}
0.299 \\
\end{tabular} & 0.046 & .050 & 0.050 & 0.266 & .193 \\
\hline HLW03-30 & 0 & A-6 & .972 & 11.888 & 4.953 & 4.953 & 4.458 & 6.934 & 43.203 & 1.486 & 4.458 & 2.098 & 8.229 & \begin{tabular}{|l|l|}
0.079 \\
\end{tabular} & 0.298 & 0.991 & 0.100 & 0.139 & \begin{tabular}{|l|}
0.150 \\
\end{tabular} & 0.150 & 0.266 & 195 \\
\hline HLW03-31 & 1b.Inner11 & A-43 & 4.953 & 6.934 & 4.953 & 4.953 & 4.458 & 8.533 & 45.058 & 1.486 & 2.972 & 2.098 & 8.915 & 0.198 & 0.495 & 0.991 & \begin{tabular}{|l|}
0.100 \\
\end{tabular} & 0.139 & 0.150 & 0.150 & 0.266 & 2.195 \\
\hline HLW03-32 & 1b.Inner12 & A-40 & 4.921 & 6.889 & 4.921 & 4.921 & 2.925 & 9.101 & 40.348 & 1.476 & 4.428 & 4.170 & 8.857 & 0.079 & 0.492 & 2.953 & 0.100 & 0.139 & \begin{tabular}{|l|}
0.150 \\
\end{tabular} & 0.050 & 0.889 & 2.192 \\
\hline HLW03-33 & 1b.Inner13 & A-15 & 4.960 & 11.902 & 9.919 & 3.898 & 1.488 & 6.943 & 40.667 & 1.488 & 2.975 & 3.378 & 5.952 & \begin{tabular}{|l|l|}
0.199 \\
\end{tabular} & 0.451 & 2.975 & 0.100 & 0.046 & \begin{tabular}{|l|}
0.150 \\
\end{tabular} & 0.050 & 0.266 & 2.194 \\
\hline
\end{tabular}

(a) Glass IDs HLW02-01 to HLW02-57 identify the initial test matrix of HLW glasses, while Glass IDs HLW03-01 to HLW03-45 identify the augmentation test matrix of HLW glasses.

(b) The "Point Type" notation generally begins with either 1a [denoting the initial (Phase 1a) test matrix] or 1b [denoting the augmentation (Phase 1b) test matrix]. After a separating dot, the notation continues with "Center", "Outer", or "Inner", denoting whether the glass was a center point, outer-layer point, or inner-layer point. The "Center", "Outer", or "Inner" designation is with respect to Phase 1a or Phase 1b. The "XX" following "Outer" and "Inner" denotes the number of each outer-layer or inner-layer point with respect to Phase 1a or Phase 1b. Replicate points are denoted by "RepHLW02-xx" and "RepHLW03-xx", where the "xx" represents a specific Glass ID number for a replicated glass.

(c) Note that the values in the Constant column are no longer exactly constant because of the change in oxides forms used to express glass composition. 
Table 2.11. Target Glass Compositions Expressed in Revised Oxides (wt\%) for the Initial (HLW02) and Augmentation (HLW03) Test Matrices (continued).

\begin{tabular}{|c|c|c|c|c|c|c|c|c|c|c|c|c|c|c|c|c|c|c|c|c|c|c|}
\hline G & Point Type $^{(\mathbf{b})}$ & $\begin{array}{c}\text { Melt } \\
\text { Order }\end{array}$ & 3 & ${ }_{2} \mathrm{O}_{3}$ & $\mathrm{Fe}_{2} \mathrm{O}_{3}$ & $\mathbf{i}_{2} \mathbf{O}$ & MnO & $\mathrm{Na}_{2} \mathrm{O}$ & $\mathrm{O}_{2}$ & $\mathbf{O}$ & $\mathrm{ThO}_{2}$ & $\mathrm{O}_{3}$ & $\mathrm{ZrO}_{2}$ & $\mathrm{Cr}_{2} \mathrm{O}_{3}$ & $\mathrm{NiO}$ & ZnO & 0 & $\mathbf{l}_{2} \mathrm{O}$ & $\mathbf{S b}_{2} \mathbf{O}_{3}$ & $\mathrm{SeO}_{2}$ & e & Constant ${ }^{(\mathrm{c})}$ \\
\hline & & & & & & 2462 & & 1 & 48.278 & 0 & 2858 & 87 & 12 & 77 & 92 & & 00 & 37 & 50 & 150 & & 2.195 \\
\hline & & & & 10.397 & & & & & & & & & & & & & \begin{tabular}{|l|}
0.100 \\
\end{tabular} & 0.139 & 0.050 & & & \\
\hline & & & & & & & & & & & & & & & & & & & & & & \\
\hline & & & & .8 & & & & & & & & & & & 0.492 & & & & & & & \\
\hline & & & & & & & & & & & & 55 & 7.0 & & 0.295 & & 299 & 0 & 50 & & & \\
\hline & & & ${ }_{0}$ & 5 & 502 & & 4 & 875 & 28 & 3 & 420 & 2.081 & 7.078 & 197 & 0.295 & 0.982 & 0.300 & 0.139 & 150 & 150 & & \\
\hline & & & 941 & 9 & 0 & & & 919 & 959 & 279 & 448 & 4.188 & 5.930 & 079 & 0.494 & 0.989 & 299 & $\mid 0.046$ & & 150 & & \\
\hline HLV & 11 & 10 & 3.888 & 8.732 & 6.939 & 3.710 & 2.698 & 9.093 & \begin{tabular}{|l|}
43.059 \\
\end{tabular} & 2.705 & 3.658 & 3.032 & \begin{tabular}{|l|}
6.767 \\
\end{tabular} & 0.140 & 0.395 & 1.920 & 0.200 & 0.093 & 0.100 & 0.100 & .578 & 2.194 \\
\hline HLW & pHLW02-46 & 19 & 500 & .150 & .001 & 3.701 & 3.500 & 9.001 & 49.004 & 1.500 & 0.000 & 0.000 & 2.500 & 0.040 & 0.800 & 1.999 & 0.500 & 0.140 & 0.050 & 0.150 & 266 & 2.198 \\
\hline $\mathrm{HL}$ & $3-06$ & 42 & 8.344 & 4.908 & 1.963 & 5.890 & 6.872 & 3.927 & 52.031 & 5.091 & 1.416 & 0.000 & 4.095 & 0.491 & 0.982 & 0.000 & 1.600 & 0.019 & 0.020 & 0.020 & 33 & 2.198 \\
\hline & 11 & 27 & 984 & 961 & & 984 & 0.000 & 4.883 & & .000 & \begin{tabular}{|l|}
5.027 \\
\end{tabular} & 6.306 & 0.000 & 020 & 0.100 & 0.000 & 0.050 & 0.019 & 0.020 & \begin{tabular}{|l|}
0.199 \\
\end{tabular} & 33 & 90 \\
\hline ILW03-45 & epHLW03-26 & A-32 & 4.921 & 6.889 & 4.921 & 4.921 & 1.476 & 0.431 & 40.346 & 4.428 & 4.428 & 4.169 & 5.904 & 0.197 & 0.492 & 2.953 & \begin{tabular}{|l|}
0.100 \\
\end{tabular} & 0.046 & 0.150 & 0.150 & 0.889 & 2.192 \\
\hline
\end{tabular}

(a) Glass IDs HLW02-01 to HLW02-57 identify the initial test matrix of HLW glasses, while Glass IDs HLW03-01 to HLW03-45 identify the augmentation test matrix of HLW glasses.

(b) The "Point Type" notation generally begins with either 1a [denoting the initial (Phase 1a) test matrix] or 1b [denoting the augmentation (Phase 1b) test matrix]. After a separating dot, the notation continues with "Center", "Outer", or "Inner", denoting whether the glass was a center point, outer-layer point, or inner-layer point. The "Center", "Outer", or "Inner" designation is with respect to Phase 1a or Phase 1b. The "XX" following "Outer" and "Inner" denotes the number of each outer-layer or inner-layer point with respect to Phase 1a or Phase 1b. Replicate points are denoted by "RepHLW02-xx" and "RepHLW03-xx", where the "xx" represents a specific Glass ID number for a replicated glass.

(c) Note that the values in the Constant column are no longer exactly constant because of the change in oxides forms used to express glass composition. 
Table 2.12. Expanded Compositions in Revised Oxides of Spike and Constant Components for the Initial (HLW02) and Augmentation (HLW03) Test Matrices.

\begin{tabular}{|c|c|c|c|c|c|c|c|c|c|c|c|c|c|c|c|c|c|c|c|c|c|c|c|}
\hline \multirow{2}{*}{ Glass ID $^{(a)}$} & \multicolumn{6}{|c|}{ Spike Components (wt\%) ${ }^{(b)}$} & \multicolumn{17}{|c|}{ Constant Components (wt\%) ${ }^{(c)}$} \\
\hline & $\mathrm{Ag}_{2} \mathrm{O}$ & PbO & $\mathbf{V}_{2} \mathrm{O}_{5}$ & $\mathbf{A s}_{2} \mathbf{O}_{5}$ & $\mathrm{BaO}$ & $\mathrm{CuO}$ & $\mathrm{Bi}_{2} \mathrm{O}_{3}$ & $\mathrm{CaO}$ & $\mathrm{Ce}_{2} \mathrm{O}_{3}$ & $\mathbf{C l}$ & $\mathrm{CoO}$ & $\mathrm{Cs}_{2} \mathrm{O}$ & $\mathbf{F}$ & $\mathbf{K}_{2} \mathbf{O}$ & $\mathbf{L a}_{2} \mathrm{O}_{3}$ & MgO & $\mathbf{P}_{2} \mathbf{O}_{5}$ & PdO & $\mathbf{R h}_{2} \mathbf{O}_{3}$ & $\mathrm{RuO}_{2}$ & $\mathrm{SO}_{3}$ & $\mathrm{TeO}_{2}$ & $\mathrm{TiO}_{2}$ \\
\hline 01 & 110 & 6 & 4 & 125 & 62 & 4 & 10 & 500 & 048 & 200 & 010 & .010 & 0.050 & .060 & 300 & 120 & 500 & 120 & 0.050 & 080 & .100 & .010 & $\overline{30}$ \\
\hline HLWC & 200 & 400 & $\overline{0}$ & 233 & 00 & & 10 & 500 & 048 & 200 & 10 & 10 & 50 & 060 & 300 & 20 & 500 & 20 & 050 & 080 & 100 & 10 & 030 \\
\hline HLW02-03 & 200 & 0 & & 32 & & & & 500 & & 0.200 & 0.010 & & & & & 120 & 500 & & & & & & \\
\hline HLW & .020 & 040 & 0 & 23 & 030 & 010 & 010 & 0.500 & \begin{tabular}{|l|}
0.048 \\
\end{tabular} & 0.200 & 0.010 & 0.010 & 050 & 0.060 & 300 & 120 & 500 & .120 & 0.050 & .080 & 0.100 & 10 & 030 \\
\hline HLW02-05 & 0.020 & 0.040 & 0.010 & . .025 & 0.030 & 0.010 & 010 & 0.500 & \begin{tabular}{|l|}
0.048 \\
\end{tabular} & 0.200 & 0.010 & 0.010 & 0.050 & 0.060 & 300 & 120 & .500 & 0.120 & 0.050 & 0.080 & 0.100 & & 030 \\
\hline HLW02-06 & 0.020 & 0.040 & 0.010 & 0.023 & 0.030 & 0.010 & 0.010 & 0.500 & 0.048 & 0.200 & 0.010 & 0.010 & 0.050 & 0.060 & \begin{tabular}{|l|}
0.300 \\
\end{tabular} & 0.120 & 0.500 & 0.120 & 0.050 & 0.080 & 0.100 & 0.010 & 0.030 \\
\hline HLW02-07 & 0.200 & 0.400 & 0.100 & 0233 & 0.300 & 0.100 & 0.010 & 0.500 & \begin{tabular}{|l|}
0.048 \\
\end{tabular} & 0.200 & 0.010 & 0.010 & 0.050 & 0.060 & \begin{tabular}{|l|}
0.300 \\
\end{tabular} & 0.120 & 0.500 & 0.120 & 0.050 & 0.080 & 0.100 & .010 & 0.030 \\
\hline HLW & 0.020 & 0.040 & & & & 0010 & & 0.500 & & \begin{tabular}{|l|}
0.200 \\
\end{tabular} & & & 0.050 & & & & & & \begin{tabular}{|l|}
0.050 \\
\end{tabular} & 0.080 & 0.100 & & 030 \\
\hline & 0.020 & & & & & & & 00 & & 0.200 & & & 0.050 & & & & & & & & & & 030 \\
\hline $\mathrm{HL}$ & 0.020 & 0 & 0.0 & & & 0010 & 10 & 0.500 & \begin{tabular}{|l|}
0.048 \\
\end{tabular} & 0.200 & 0.010 & 0.010 & 0.050 & 0.060 & 0 & & 00 & & 50 & 80 & 100 & & 030 \\
\hline $\mathrm{HLI}$ & 0.020 & 0.040 & .0 & 0.02 & 30 & 010 & 0 & 0.500 & 0.04 & 0.200 & 0.010 & 0.010 & 0.050 & 0.060 & 300 & 20 & .500 & .120 & 0.050 & .080 & .100 & 10 & 0.030 \\
\hline $\mathrm{HL}$ & .200 & 400 & 0.100 & 0 & 300 & 100 & 010 & 0.500 & 0.048 & 0.200 & 0.010 & 0.010 & 0.050 & 0.060 & 300 & 120 & .500 & .120 & 0.050 & .080 & 100 & 10 & .030 \\
\hline & 200 & 400 & & & 300 & 100 & 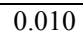 & 0.500 & 0.048 & 0.200 & 0.010 & 0.010 & 050 & .060 & 300 & 120 & .500 & .120 & 0.050 & 0.080 & .100 & 10 & .030 \\
\hline HLW02-14 & 0.020 & 0.040 & 0.010 & 0.023 & 0.030 & 0.010 & 010 & 0.500 & \begin{tabular}{|l|}
0.048 \\
\end{tabular} & 0.200 & 0.010 & 0.010 & 0.050 & 0.060 & 300 & .120 & 0.500 & 0.120 & 0.050 & 0.080 & 0.100 & .010 & 0.030 \\
\hline HLW02-15 & 0.200 & 0.400 & 0.100 & 0.233 & 0.300 & 0.100 & 0.010 & 0.500 & \begin{tabular}{|l|}
0.048 \\
\end{tabular} & 0.200 & 0.010 & 0.010 & 0.050 & 0.060 & \begin{tabular}{|l|}
0.300 \\
\end{tabular} & 0.120 & 0.500 & 0.120 & 0.050 & 0.080 & 0.100 & 0.010 & 0.030 \\
\hline HLW02-16 & 0.200 & 0.400 & 0.100 & & 0.300 & 0.100 & 0.010 & 0.500 & 0.048 & 0.200 & 0.010 & 0.010 & 0.050 & 0.060 & 300 & .120 & 0.500 & 0.120 & 0.050 & 0.080 & 100 & 010 & 0.030 \\
\hline & 0.020 & & & & & & & 0.500 & \begin{tabular}{|l|}
0.048 \\
\end{tabular} & 0.200 & & 0.010 & 0.050 & 0.060 & 300 & .120 & 0.500 & & 0.050 & 0.080 & 0.100 & & .030 \\
\hline & 0.200 & & & & & & & 0.500 & & 0.2 & & & & & & & & & & & & & \\
\hline & 0.020 & 0.040 & & & 0 & 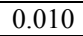 & j & 0.500 & 04048 & 0.200 & 0.010 & 0.010 & 00 & 0.060 & 300 & 20 & 0.500 & 0.120 & 50 & 0.080 & 100 & & 0.030 \\
\hline HLV & 0.020 & 0.040 & 0 & 0.023 & 330 & 0.010 & 010 & 0.500 & \begin{tabular}{|l|}
0.048 \\
\end{tabular} & 0.200 & 0.010 & 0.010 & 0.050 & 0.060 & 300 & .120 & 0.500 & 0.120 & \begin{tabular}{|l}
0.050 \\
\end{tabular} & 0.080 & .100 & .010 & 0.030 \\
\hline & 0.020 & 0.040 & & & 0.030 & 0.010 & 010 & 0.500 & \begin{tabular}{|l|}
0.048 \\
\end{tabular} & 0.200 & 0.010 & 0.010 & 0.050 & 0.060 & .300 & .120 & .500 & 0.120 & 0.050 & 0.080 & .100 & .010 & 0.030 \\
\hline HLW02-22 & 0.020 & 0.040 & 0. & 0.023 & 0.030 & 0.010 & 010 & 0.500 & \begin{tabular}{|l|}
0.048 \\
\end{tabular} & 0.200 & 0.010 & 0.010 & 0.050 & 0.060 & 300 & .120 & 0.500 & 0.120 & 0.050 & 0.080 & 0.100 & .010 & 0.030 \\
\hline HLW02-23 & 0.020 & 0.040 & 0.010 & 0.023 & 0.030 & 0.010 & 0.010 & 0.500 & \begin{tabular}{|l|}
0.048 \\
\end{tabular} & 0.200 & 0.010 & 0.010 & 0.050 & 0.060 & \begin{tabular}{|l|}
0.300 \\
\end{tabular} & 0.120 & 0.500 & 0.120 & 0.050 & 0.080 & 0.100 & 0.010 & 0.030 \\
\hline HLW02-24 & 0.153 & 0.307 & 0.077 & 0.178 & 0.230 & 0.077 & 0.010 & 0.500 & 0.048 & 0.200 & 0.010 & 0.010 & 0.050 & 0.060 & \begin{tabular}{|l|}
0.300 \\
\end{tabular} & 0.120 & 0.500 & 0.120 & 0.050 & 0.080 & 0.100 & 0.010 & 0.030 \\
\hline HLW02-25 & 0.020 & 0.040 & 0.010 & & 0.030 & 0.010 & 0.010 & 0.500 & 0.048 & 0.200 & 0.010 & 0.010 & 0.050 & 0.060 & \begin{tabular}{|l|}
0.300 \\
\end{tabular} & 0.120 & 0.500 & 0.120 & 0.050 & 0.080 & 0.100 & .010 & 0.030 \\
\hline & 0.200 & 0.400 & 0.100 & 0.233 & 0.300 & 0.100 & 0.010 & 0.500 & \begin{tabular}{|l|}
0.048 \\
\end{tabular} & \begin{tabular}{|l|}
0.200 \\
\end{tabular} & 0.010 & 0.010 & 0.050 & 0.060 & \begin{tabular}{|l|}
0.300 \\
\end{tabular} & 0.120 & 0.500 & 0.120 & 0.050 & 0.080 & 0.100 & 010 & 0.030 \\
\hline$\overline{\mathrm{HL}}$ & 0.020 & 0.040 & 0.010 & 0.023 & 0.030 & 0.010 & 0.010 & 0.500 & \begin{tabular}{|l|}
0.048 \\
\end{tabular} & 0.200 & 0.010 & 0.010 & 0.050 & 0.060 & \begin{tabular}{|l|}
0.300 \\
\end{tabular} & 0.120 & 0.500 & 0.120 & 0.050 & 0.080 & .100 & 0.010 & 0.030 \\
\hline-28 & 0.040 & 0.080 & 0.020 & 0.046 & 0.060 & 0.020 & 010 & 0.500 & \begin{tabular}{|l|}
0.048 \\
\end{tabular} & 0.200 & 0.010 & 0.010 & 0.050 & 0.060 & \begin{tabular}{|l|}
0.300 \\
\end{tabular} & 0.120 & 0.500 & 0.120 & 0.050 & 0.080 & .100 & .010 & 0.030 \\
\hline & 0.133 & 0.267 & 0.067 & \begin{tabular}{|l|l|}
0.155 \\
\end{tabular} & 0.200 & 0.067 & 0.010 & 0.500 & 0.048 & 0.200 & 0.010 & 0.010 & 0.050 & 0.060 & 0.300 & 0.120 & 0.500 & 0.120 & 0.050 & 0.080 & .100 & .010 & 0.030 \\
\hline HLW02-30 & 0.040 & 0.080 & \begin{tabular}{|l|l}
0.020 \\
\end{tabular} & 0.046 & 0.060 & 0.020 & 0.010 & 0.500 & 0.048 & \begin{tabular}{|l|}
0.200 \\
\end{tabular} & 0.010 & 0.010 & 0.050 & 0.060 & 0.300 & 0.120 & .500 & 0.120 & 0.050 & 0.080 & 0.100 & .010 & 0.030 \\
\hline
\end{tabular}

(a) Glass IDs HLW02-01 to HLW02-57 identify the initial test matrix of HLW glasses. Glass IDs HLW03-01 to HLW03-45 identify the augmentation matrix of HLW glasses.

(b) Spike component wt $\%$ values are rounded to 3 decimal places for each glass and may not equal the wt $\%$ value listed in the Spike column of Table 2.10

(c) The sum of the Constant component wt $\%$ values for each glass equals the $\mathrm{wt} \%$ value listed in the Constant column shown in Table 2.10 . Note that the values are no longer exactly constant due to the revision in oxide forms. 
Table 2.12. Expanded Compositions in Revised Oxides of Spike and Constant Components for the Initial (HLW02) and Augmentation (HLW03) Test Matrices (continued).

\begin{tabular}{|c|c|c|c|c|c|c|c|c|c|c|c|c|c|c|c|c|c|c|c|c|c|c|c|}
\hline \multirow{2}{*}{ Glass ID $^{(a)}$} & \multicolumn{6}{|c|}{ Spike Components (wt\%) ${ }^{(b)}$} & \multicolumn{17}{|c|}{ Constant Components (wt\%) ${ }^{(c)}$} \\
\hline & $\mathrm{Ag}_{2} \mathrm{O}$ & PbO & $\mathbf{V}_{2} \mathrm{O}_{5}$ & $\mathbf{A s}_{2} \mathbf{O}_{5}$ & $\mathrm{BaO}$ & $\mathrm{CuO}$ & $\mathrm{Bi}_{2} \mathrm{O}_{3}$ & $\mathrm{CaO}$ & $\mathrm{Ce}_{2} \mathrm{O}_{3}$ & $\mathbf{C l}$ & $\mathrm{CoO}$ & $\mathrm{Cs}_{2} \mathrm{O}$ & $\mathbf{F}$ & $\mathbf{K}_{2} \mathbf{O}$ & $\mathbf{L a}_{2} \mathrm{O}_{3}$ & MgO & $\mathbf{P}_{2} \mathbf{O}_{5}$ & PdO & $\mathbf{R h}_{2} \mathbf{O}_{3}$ & $\mathrm{RuO}_{2}$ & $\mathrm{SO}_{3}$ & $\mathrm{TeO}_{2}$ & $\mathrm{TiO}_{2}$ \\
\hline 31 & .040 & 0.080 & 0 & $\overline{046}$ & 60 & 0 & 10 & 500 & 048 & 200 & 010 & .010 & $\overline{0.050}$ & .060 & 300 & 120 & 500 & 120 & 0.050 & 080 & .100 & .010 & $\overline{30}$ \\
\hline HLW & 040 & $\overline{0}$ & 20 & 46 & 60 & & 10 & 500 & 048 & 200 & 10 & 10 & 50 & 060 & 300 & 20 & 500 & & 550 & 080 & 100 & 10 & 030 \\
\hline HLW02-33 & .040 & & & 46 & & 20 & & 500 & & 0.200 & 0.010 & & & & & 120 & 500 & & & & & & \\
\hline HLW & 133 & 267 & 7 & 55 & 200 & 067 & 010 & 0.500 & \begin{tabular}{|l|}
0.048 \\
\end{tabular} & 0.200 & 0.010 & 0.010 & 050 & 0.060 & 300 & 120 & 500 & .120 & 0.050 & .080 & 0.100 & 10 & 030 \\
\hline HLW02-35 & 0.133 & 0.267 & \begin{tabular}{|l|l|}
0.067 \\
\end{tabular} & \begin{tabular}{|l|}
0.155 \\
\end{tabular} & 0.200 & 0.067 & 010 & 0.500 & \begin{tabular}{|l|}
0.048 \\
\end{tabular} & 0.200 & 0.010 & 0.010 & 0.050 & 0.060 & 300 & 120 & .500 & 0.120 & 0.050 & 0.080 & 0.100 & & 030 \\
\hline HLW02-36 & 0.133 & 0.267 & \begin{tabular}{|l|l|}
0.067 \\
\end{tabular} & 0.155 & 0.200 & 0.067 & 0.010 & 0.500 & 0.048 & 0.200 & 0.010 & 0.010 & 0.050 & 0.060 & \begin{tabular}{|l|}
0.300 \\
\end{tabular} & 0.120 & 0.500 & 0.120 & 0.050 & 0.080 & 0.100 & 0.010 & 0.030 \\
\hline HLW02-37 & 0.040 & 0.080 & 0.020 & 0.046 & 0.060 & 0.020 & 0.010 & 0.500 & \begin{tabular}{|l|}
0.048 \\
\end{tabular} & 0.200 & 0.010 & 0.010 & 0.050 & 0.060 & 300 & 0.120 & 0.500 & 0.120 & 0.050 & 0.080 & 0.100 & .010 & 0.030 \\
\hline HLW & 0.133 & 0.267 & & & & & & 0.500 & & 0.200 & & & 0.050 & & & & & & \begin{tabular}{|l|}
0.050 \\
\end{tabular} & 0.080 & 0.100 & & 030 \\
\hline & 0.040 & & & & & & & 00 & & 0.200 & 0.010 & & 0.050 & & & & & & & & & & 030 \\
\hline $\mathrm{HL}$ & 0.133 & 02 & 0.0 & 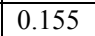 & 0 & 0.067 & 10 & 0.500 & \begin{tabular}{|l|}
0.048 \\
\end{tabular} & 0.200 & 0.010 & 0.010 & 0.050 & 0.060 & 0 & & 00 & & 50 & 80 & 100 & & 030 \\
\hline $\mathrm{HLI}$ & 0.040 & 0.080 & 0.02 & 0.046 & 0.060 & 0.020 & 0 & 0.500 & 0.04 & 0.200 & 0.010 & 0.010 & 0.050 & 0.060 & 300 & 20 & .500 & .120 & 0.050 & .080 & .100 & 10 & 0.030 \\
\hline $\mathrm{HL}$ & 0.040 & 080 & 0.020 & 046 & 060 & 020 & 010 & 0.500 & 0.048 & 0.200 & 0.010 & 0.010 & 0.050 & .060 & 300 & 120 & .500 & .120 & 0.050 & .080 & 100 & 10 & .030 \\
\hline & 0.040 & $.0 \zeta^{-1}$ & & 0.046 & 060 & 020 & 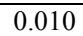 & 0.500 & 0.048 & 0.200 & 0.010 & 0.010 & 050 & .060 & 300 & 120 & .500 & .120 & 0.050 & 0.080 & 100 & 10 & .030 \\
\hline HLW02-44 & 0.133 & 0.267 & \begin{tabular}{|l|l|}
0.067 \\
\end{tabular} & 0.155 & 0.200 & 0.067 & 010 & 0.500 & \begin{tabular}{|l|}
0.048 \\
\end{tabular} & 0.200 & 0.010 & 0.010 & 0.050 & 0.060 & 300 & 0.120 & 0.500 & 0.120 & 0.050 & 0.080 & 0.100 & .010 & 0.030 \\
\hline HLW02-45 & 0.040 & 0.080 & 0.020 & 0.046 & 0.060 & 0.020 & 0.010 & 0.500 & \begin{tabular}{|l|}
0.048 \\
\end{tabular} & 0.200 & 0.010 & 0.010 & 0.050 & 0.060 & \begin{tabular}{|l|}
0.300 \\
\end{tabular} & 0.120 & 0.500 & 0.120 & 0.050 & 0.080 & 0.100 & 0.010 & 0.030 \\
\hline HLW02-46 & 0.040 & 0.080 & 0.020 & 0.046 & 0.060 & 0.020 & 0.010 & 0.500 & 0.048 & 0.200 & 0.010 & 0.010 & 0.050 & 0.060 & 300 & .120 & 0.500 & 0.120 & 0.050 & 0.080 & 100 & 010 & 0.030 \\
\hline & 0.133 & 0.267 & & & & & & 0.500 & \begin{tabular}{|l|}
0.048 \\
\end{tabular} & 0.200 & & 0.010 & 0.050 & 0.060 & 300 & 20 & 0.500 & & 0.050 & 0.080 & 0.100 & & .030 \\
\hline & & & & & & & & 0.500 & & 0.2 & & & & & & & & & & & & & \\
\hline & 0.040 & 0.080 & & 00 & 0 & 0 & j & 0.500 & 04048 & 0.200 & 0.010 & 0.010 & 00 & 0.060 & 300 & 20 & 0.500 & 0.120 & 50 & 0.080 & 100 & & 0.030 \\
\hline HLV & 0.040 & 0.080 & 20 & 0.046 & 0.060 & 0.020 & 10 & 0.500 & \begin{tabular}{|l|}
0.048 \\
\end{tabular} & 0.200 & 0.010 & 0.010 & 0.050 & 0.060 & 300 & .120 & .500 & 0.120 & \begin{tabular}{|l}
0.050 \\
\end{tabular} & 0.080 & .100 & 10 & 0.030 \\
\hline & 0.040 & 0.080 & & 0046 & 0.060 & 0.020 & 010 & 0.500 & \begin{tabular}{|l|}
0.048 \\
\end{tabular} & 0.200 & 0.010 & 0.010 & 0.050 & 0.060 & .300 & .120 & .500 & 0.120 & 0.050 & 0.080 & .100 & .010 & 0.030 \\
\hline HLW02-52 & 0.108 & 0.216 & \begin{tabular}{|l|l|}
0.054 \\
\end{tabular} & 0.125 & 0.162 & 0.054 & 010 & 0.500 & \begin{tabular}{|l|}
0.048 \\
\end{tabular} & 0.200 & 0.010 & 0.010 & 0.050 & 0.060 & 300 & .120 & 0.500 & 0.120 & 0.050 & 0.080 & 0.100 & .010 & 0.030 \\
\hline HLW02-53 & 0.020 & 0.040 & 0.010 & 0.023 & 0.030 & 0.010 & 0.010 & 0.500 & \begin{tabular}{|l|}
0.048 \\
\end{tabular} & 0.200 & 0.010 & 0.010 & 0.050 & 0.060 & \begin{tabular}{|l|}
0.300 \\
\end{tabular} & 0.120 & 0.500 & 0.120 & 0.050 & 0.080 & 0.100 & 0.010 & 0.030 \\
\hline HLW02-54 & 0.020 & 0.040 & 0.010 & 0.023 & 0.030 & 0.010 & 0.010 & 0.500 & 0.048 & 0.200 & 0.010 & 0.010 & 0.050 & 0.060 & \begin{tabular}{|l|}
0.300 \\
\end{tabular} & 0.120 & 0.500 & 0.120 & 0.050 & 0.080 & 0.100 & 0.010 & 0.030 \\
\hline HLW02-55 & 0.040 & 0.080 & 0.020 & 0.046 & 0.060 & 0.020 & 0.010 & 0.500 & 0.048 & 0.200 & 0.010 & 0.010 & 0.050 & 0.060 & \begin{tabular}{|l|}
0.300 \\
\end{tabular} & 0.120 & 0.500 & 0.120 & 0.050 & 0.080 & 0.100 & .010 & 0.030 \\
\hline & 0.133 & 0.267 & \begin{tabular}{|l|l|}
0.067 \\
\end{tabular} & \begin{tabular}{|l|}
0.155 \\
\end{tabular} & 0.200 & 0.067 & 0.010 & 0.500 & \begin{tabular}{|l|}
0.048 \\
\end{tabular} & 0.200 & 0.010 & 0.010 & 0.050 & 0.060 & \begin{tabular}{|l|}
0.300 \\
\end{tabular} & 0.120 & 0.500 & 0.120 & 0.050 & 0.080 & 0.100 & 010 & 0.030 \\
\hline $2-57$ & 0.020 & 0.040 & 0.010 & 0.023 & 0.030 & 0.010 & 0.010 & 0.500 & \begin{tabular}{|l|}
0.048 \\
\end{tabular} & 0.200 & 0.010 & 0.010 & 0.050 & 0.060 & \begin{tabular}{|l|}
0.300 \\
\end{tabular} & 0.120 & 0.500 & 0.120 & 0.050 & 0.080 & .100 & .010 & 0.030 \\
\hline-01 & 0.200 & 0.400 & 0.100 & 0.232 & 0.300 & 0.100 & 010 & 0.500 & \begin{tabular}{|l|}
0.048 \\
\end{tabular} & 0.200 & 0.010 & 0.010 & 0.050 & 0.060 & \begin{tabular}{|l|}
0.300 \\
\end{tabular} & 0.120 & 0.500 & 0.120 & 0.050 & 0.080 & .100 & .010 & 0.030 \\
\hline & 0.020 & 0.040 & \begin{tabular}{|l|l}
0.010 \\
\end{tabular} & 0.023 & 0.030 & 0.010 & 010 & 0.500 & 0.048 & 0.200 & 0.010 & 0.010 & 0.050 & 0.060 & 0.300 & 0.120 & 0.500 & 120 & 0.050 & 0.080 & .100 & .010 & 0.030 \\
\hline HLW03-03 & 0.020 & 0.040 & \begin{tabular}{|l|l}
0.010 \\
\end{tabular} & 0.023 & 0.030 & 0.010 & 0.010 & 0.500 & 0.048 & 0.200 & 0.010 & 0.010 & 0.050 & 0.060 & 0.300 & 0.120 & .500 & 0.120 & 0.050 & 0.080 & 0.100 & 0.010 & 0.030 \\
\hline
\end{tabular}

(a) Glass IDs HLW02-01 to HLW02-57 identify the initial test matrix of HLW glasses. Glass IDs HLW03-01 to HLW03-45 identify the augmentation matrix of HLW glasses.

(b) Spike component wt $\%$ values are rounded to 3 decimal places for each glass and may not equal the wt $\%$ value listed in the Spike column of Table 2.10

(c) The sum of the Constant component wt $\%$ values for each glass equals the $\mathrm{wt} \%$ value listed in the Constant column shown in Table 2.10 . Note that the values are no longer exactly constant due to the revision in oxide forms. 
Table 2.12. Expanded Compositions in Revised Oxides of Spike and Constant Components for the Initial (HLW02) and Augmentation (HLW03) Test Matrices (continued).

\begin{tabular}{|c|c|c|c|c|c|c|c|c|c|c|c|c|c|c|c|c|c|c|c|c|c|c|c|}
\hline \multirow{2}{*}{ Glass ID $^{(a)}$} & \multicolumn{6}{|c|}{ Spike Components (wt\%) ${ }^{(b)}$} & \multicolumn{17}{|c|}{ Constant Components (wt\%) ${ }^{(c)}$} \\
\hline & $\mathrm{Ag}_{2} \mathrm{O}$ & PbO & $\mathbf{V}_{2} \mathrm{O}_{5}$ & $\mathbf{A s}_{2} \mathbf{O}_{5}$ & $\mathrm{BaO}$ & $\mathrm{CuO}$ & $\mathrm{Bi}_{2} \mathrm{O}_{3}$ & $\mathrm{CaO}$ & $\mathrm{Ce}_{2} \mathrm{O}_{3}$ & $\mathbf{C l}$ & $\mathrm{CoO}$ & $\mathrm{Cs}_{2} \mathrm{O}$ & $\mathbf{F}$ & $\mathbf{K}_{2} \mathbf{O}$ & $\mathbf{L a}_{2} \mathrm{O}_{3}$ & MgO & $\mathbf{P}_{2} \mathbf{O}_{5}$ & PdO & $\mathbf{R h}_{2} \mathbf{O}_{3}$ & $\mathrm{RuO}_{2}$ & $\mathrm{SO}_{3}$ & $\mathrm{TeO}_{2}$ & $\mathrm{TiO}_{2}$ \\
\hline-04 & 199 & 0.399 & 0 & 232 & 99 & 100 & 10 & 498 & 048 & 199 & 010 & .010 & $\overline{0.050}$ & .060 & 299 & 120 & 498 & 120 & 0.050 & 080 & .100 & .010 & 30 \\
\hline \begin{tabular}{|l|} 
HLW03-05 \\
\end{tabular} & 200 & 400 & 00 & 32 & & & 10 & 500 & 048 & 200 & 10 & 10 & 50 & 060 & 300 & 20 & 500 & & 550 & 080 & 100 & 10 & 030 \\
\hline HLW03-06 & .020 & 0 & 10 & & & 010 & & 500 & & 0.200 & 0.010 & & & & & & 500 & & & & & & \\
\hline \begin{tabular}{|l|} 
HLW \\
\end{tabular} & .020 & 040 & 10 & 0.023 & 030 & 010 & 010 & .498 & 0.048 & 0.199 & 0.010 & 0.010 & 050 & 0.060 & 299 & 120 & 498 & .120 & 0.050 & .080 & .100 & 10 & 030 \\
\hline \begin{tabular}{|l|} 
HLW03-08 \\
\end{tabular} & 0.200 & 0.400 & 0.100 & 0.232 & 0.300 & 0.100 & 010 & 0.500 & 0.048 & 0.200 & 0.010 & 0.010 & 0.050 & 0.060 & 300 & 120 & .500 & 0.120 & 0.050 & 0.080 & 0.100 & & 030 \\
\hline \begin{tabular}{|l|} 
HLW03-09 \\
\end{tabular} & 0.020 & 0.040 & 0.010 & 2023 & 0.030 & 0.010 & 0.010 & 0.500 & 0.048 & 0.200 & 0.010 & 0.010 & 0.050 & 0.060 & \begin{tabular}{|l|}
0.300 \\
\end{tabular} & 0.120 & 0.500 & 0.120 & 0.050 & 0.080 & 0.100 & 0.010 & 0.030 \\
\hline HLW03-10 & 0.200 & 0.400 & 0.100 & 0232 & 0.300 & 0.100 & 0.010 & 0.500 & 0.048 & 0.200 & 0.010 & 0.010 & 0.050 & 0.060 & 300 & 0.120 & 0.500 & 0.120 & 0.050 & 0.080 & 0.100 & .010 & 0.030 \\
\hline \begin{tabular}{|l} 
HLW03-11 \\
\end{tabular} & 0.020 & 0.040 & & & & 0.010 & & 0.498 & & 0.199 & & & 0.050 & & & & .498 & & \begin{tabular}{|l|}
0.050 \\
\end{tabular} & 0.080 & 0.100 & & 030 \\
\hline & 0.020 & & & & & & & 0.498 & & 0.199 & & & 0.050 & & & & & & & & & & 030 \\
\hline $\mathrm{HL}$ & 0.020 & 0 & 0.0 & & & 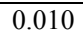 & 10 & 0.498 & 0.048 & 0.199 & 0.010 & 0.010 & 0.050 & 0.060 & 299 & & 98 & & 50 & 80 & 100 & & 030 \\
\hline HLI & 0.020 & 0.040 & 0.0 & 0.023 & a & 010 & 0 & 0.500 & 0.0 & 0.200 & 0.010 & 0.010 & 0.050 & 0.060 & 300 & 20 & .500 & .120 & 0.050 & .080 & .100 & 10 & 0.030 \\
\hline $\mathrm{HL}$ & .020 & 040 & 0.010 & 0 . & 330 & 010 & 010 & 0.500 & 0.0 & 0.200 & 0.010 & 0.010 & 0.050 & 0.060 & 300 & 20 & .500 & .120 & 0.050 & .080 & 100 & 10 & .030 \\
\hline & .199 & 398 & & & 299 & 100 & $T_{1}$ & 0.498 & \begin{tabular}{|l|}
0.047 \\
\end{tabular} & 0.199 & 0.010 & 0.010 & 050 & .060 & 299 & 120 & .498 & .120 & 0.050 & 0.080 & 100 & 10 & .030 \\
\hline \begin{tabular}{|l|} 
HLW03-17 \\
\end{tabular} & 0.199 & 0.399 & 0.100 & 0.232 & 0.299 & 0.100 & 010 & 0.499 & 0.048 & 0.199 & 0.010 & 0.010 & 0.050 & 0.060 & \begin{tabular}{|l|}
0.299 \\
\end{tabular} & 0.120 & 0.499 & 0.120 & 0.050 & 0.080 & 0.100 & .010 & 0.030 \\
\hline HLW03-18 & 0.020 & 0.040 & 0.010 & 0.023 & 0.030 & 0.010 & 0.010 & 0.500 & 0.048 & 0.200 & 0.010 & 0.010 & 0.050 & 0.060 & \begin{tabular}{|l|}
0.300 \\
\end{tabular} & 0.120 & 0.500 & 0.120 & 0.050 & 0.080 & 0.100 & 0.010 & 0.030 \\
\hline HLW03-19 & 0.020 & 0.040 & 0.010 & & 0.030 & 0.010 & 0.010 & 0.500 & 0.048 & 0.200 & 0.010 & 0.010 & 0.050 & 0.060 & 300 & .120 & 0.500 & 0.120 & 0.050 & 0.080 & 100 & 010 & 0.030 \\
\hline & 0.200 & & & & & & & 0.500 & 0.048 & 0.200 & & 0.010 & 0.050 & 60 & 300 & .120 & 0.500 & & 0.050 & 0.080 & 0.100 & & .030 \\
\hline & 0.040 & & & & & & & 0.499 & & 0.200 & & & & & & & & & & & & & \\
\hline & 0.133 & 0.267 & & & 0 & 0.067 & j & 0.499 & 0.048 & 0.200 & 0.010 & 0.010 & 00 & 0.060 & 299 & 20 & 0.499 & 0.120 & 50 & 0.080 & 100 & & 0.030 \\
\hline \begin{tabular}{|l|} 
HLV \\
\end{tabular} & 0.040 & 0.080 & 20 & 0 & 0.060 & 0.020 & 010 & 0.499 & 0.048 & 0.200 & 0.010 & 0.010 & 0.050 & 0.060 & 299 & .120 & 0.499 & 0.120 & \begin{tabular}{|l}
0.050 \\
\end{tabular} & 0.080 & .100 & .010 & 0.030 \\
\hline HLV & 0.040 & 0.080 & 0 & 0046 & 0.060 & 0.020 & 010 & 0.499 & 0.048 & 0.200 & 0.010 & 0.010 & 0.050 & 0.060 & 300 & .120 & .499 & .120 & 0.050 & 0.080 & .100 & .010 & 0.030 \\
\hline HLW03-25 & 0.134 & 0.267 & \begin{tabular}{|l|l|}
0.067 \\
\end{tabular} & & 0.201 & 0.067 & 010 & 0.499 & 0.048 & 0.200 & 0.010 & 0.010 & 0.050 & 0.060 & 300 & .120 & 0.499 & 0.120 & 0.050 & 0.080 & 0.100 & .010 & 0.030 \\
\hline \begin{tabular}{|l|} 
HLW03-26 \\
\end{tabular} & 0.133 & 0.267 & \begin{tabular}{|l|l|}
0.067 \\
\end{tabular} & 0.155 & 0.200 & 0.067 & 0.010 & 0.499 & 0.048 & 0.199 & 0.010 & 0.010 & 0.050 & 0.060 & \begin{tabular}{|l|}
0.299 \\
\end{tabular} & 0.120 & 0.499 & 0.120 & 0.050 & 0.080 & 0.100 & 0.010 & 0.030 \\
\hline HLW03-27 & 0.134 & 0.267 & 0.067 & 0.155 & 0.201 & 0.067 & 0.010 & 0.499 & 0.048 & 0.200 & 0.010 & 0.010 & 0.050 & 0.060 & \begin{tabular}{|l|}
0.300 \\
\end{tabular} & 0.120 & 0.499 & 0.120 & 0.050 & 0.080 & 0.100 & 0.010 & 0.030 \\
\hline HLW03-28 & 0.040 & 0.080 & 0.020 & 0.046 & 0.060 & 0.020 & 0.010 & 0.499 & 0.048 & 0.200 & 0.010 & 0.010 & 0.050 & 0.060 & \begin{tabular}{|l|}
0.300 \\
\end{tabular} & 0.120 & 0.499 & 0.120 & 0.050 & 0.080 & 0.100 & .010 & 0.030 \\
\hline \begin{tabular}{|l|} 
HLW03-29 \\
\end{tabular} & 0.040 & 0.080 & \begin{tabular}{|l|l}
0.020 \\
\end{tabular} & 0.046 & 0.060 & 0.020 & 0.010 & 0.499 & 0.048 & 0.200 & 0.010 & 0.010 & 0.050 & 0.060 & \begin{tabular}{|l|}
0.299 \\
\end{tabular} & 0.120 & 0.499 & 0.120 & 0.050 & 0.080 & 0.100 & 010 & 0.030 \\
\hline \begin{tabular}{|l|} 
HLW03-30 \\
\end{tabular} & 0.040 & 0.080 & 0.020 & 0.046 & 0.060 & 0.020 & 0.010 & 0.499 & 0.048 & 0.200 & 0.010 & 0.010 & 0.050 & 0.060 & \begin{tabular}{|l|}
0.300 \\
\end{tabular} & 0.120 & 0.499 & 0.120 & 0.050 & 0.080 & .100 & .010 & 0.030 \\
\hline-31 & 0.040 & 0.080 & 0.020 & 0.046 & 0.060 & 0.020 & 010 & 0.499 & 0.048 & 0.200 & 0.010 & 0.010 & 0.050 & 0.060 & \begin{tabular}{|l|}
0.300 \\
\end{tabular} & 0.120 & 0.499 & 0.120 & 0.050 & 0.080 & .100 & .010 & 0.030 \\
\hline & 0.133 & 0.267 & \begin{tabular}{|l|l|}
0.067 \\
\end{tabular} & 0.155 & 0.200 & 0.067 & 010 & 0.499 & 0.048 & 0.200 & 0.010 & 0.010 & 0.050 & 0.060 & 0.299 & 0.120 & 0.499 & 120 & 0.050 & 0.080 & 0.100 & .010 & 0.030 \\
\hline \begin{tabular}{|l|} 
HLW03-33 \\
\end{tabular} & 0.040 & 0.080 & \begin{tabular}{|l|l}
0.020 \\
\end{tabular} & 0.046 & 0.060 & 0.020 & 0.010 & 0.499 & 0.048 & 0.200 & 0.010 & 0.010 & 0.050 & 0.060 & 0.299 & 0.120 & .499 & 0.120 & 0.050 & 0.080 & 0.100 & .010 & 0.030 \\
\hline
\end{tabular}

(a) Glass IDs HLW02-01 to HLW02-57 identify the initial test matrix of HLW glasses. Glass IDs HLW03-01 to HLW03-45 identify the augmentation matrix of HLW glasses.

(b) Spike component wt $\%$ values are rounded to 3 decimal places for each glass and may not equal the wt $\%$ value listed in the Spike column of Table 2.10

(c) The sum of the Constant component wt $\%$ values for each glass equals the $\mathrm{wt} \%$ value listed in the Constant column shown in Table 2.10 . Note that the values are no longer exactly constant due to the revision in oxide forms. 
Table 2.12. Expanded Compositions in Revised Oxides of Spike and Constant Components for the Initial (HLW02) and Augmentation (HLW03) Test Matrices (continued).

\begin{tabular}{|c|c|c|c|c|c|c|c|c|c|c|c|c|c|c|c|c|c|c|c|c|c|c|c|}
\hline \multirow{2}{*}{ Glass ID ${ }^{(a)}$} & \multicolumn{6}{|c|}{ Spike Components (wt\%) ${ }^{(b)}$} & \multicolumn{17}{|c|}{ Constant Components (wt\%) ${ }^{(c)}$} \\
\hline & $\mathbf{A g}_{2} \mathbf{O}$ & PbO & $\mathbf{V}_{2} \mathbf{O}_{5}$ & $\mathbf{A s}_{2} \mathbf{O}_{5}$ & $\mathrm{BaO}$ & $\mathrm{CuO}$ & $\mathbf{B i}_{2} \mathbf{O}_{3}$ & $\mathrm{CaO}$ & $\mathrm{Ce}_{2} \mathrm{O}_{3}$ & $\mathrm{Cl}$ & $\mathrm{CoO}$ & $\mathrm{Cs}_{2} \mathrm{O}$ & $\mathbf{F}$ & $\mathbf{K}_{2} \mathbf{O}$ & $\mathbf{L a}_{2} \mathbf{O}_{3}$ & MgO & $\mathbf{P}_{2} \mathbf{O}_{5}$ & PdO & $\mathbf{R h}_{2} \mathbf{O}_{3}$ & $\mathrm{RuO}_{2}$ & $\mathrm{SO}_{3}$ & $\mathrm{TeO}_{2}$ & $\mathrm{TiO}_{2}$ \\
\hline HLW03-34 & 134 & 267 & 067 & 155 & 01 & 67 & 0.010 & 0.499 & 048 & 200 & 010 & 0.010 & 0.050 & .060 & 300 & 120 & 499 & 120 & .050 & 080 & 0.100 & .010 & .030 \\
\hline HLW03-35 & 0.040 & 0.080 & 0.020 & 0.046 & 0.060 & 0.020 & 0.010 & 0.499 & 0.048 & 0.200 & 0.010 & 0.010 & 0.050 & 0.060 & 0.300 & 0.120 & 0.499 & 0.120 & \begin{tabular}{|l|}
0.050 \\
\end{tabular} & 0.080 & 0.100 & 0.010 & .030 \\
\hline HLW03-36 & 0.134 & 0.267 & 0.067 & 0.155 & 0.201 & 0.067 & 0.010 & 0.499 & 0.048 & 0.200 & 0.010 & 0.010 & 0.050 & 0.060 & 0.300 & 0.120 & 0.499 & 0.120 & \begin{tabular}{|l|}
0.050 \\
\end{tabular} & 0.080 & 0.100 & 0.010 & 0.030 \\
\hline HLW03-37 & 0.133 & 0.267 & 0.067 & 0.155 & 0.200 & 0.067 & 0.010 & 0.499 & 0.048 & 0.200 & 0.010 & 0.010 & 0.050 & 0.060 & 0.299 & 0.120 & 0.499 & 0.120 & \begin{tabular}{|l|}
0.050 \\
\end{tabular} & 0.080 & 0.100 & 0.010 & 0.030 \\
\hline HLW03-38 & 0.133 & 0.267 & 0.067 & 0.155 & 0.200 & 0.067 & 0.010 & 0.499 & 0.048 & 0.200 & 0.010 & 0.010 & 0.050 & 0.060 & 0.299 & 0.120 & 0.499 & 0.120 & 0.050 & 0.080 & 0.100 & 0.010 & 0.030 \\
\hline HLW03-39 & 0.134 & 0.267 & 0.067 & 0.155 & 0.201 & 0.067 & 0.010 & 0.499 & 0.048 & 0.200 & 0.010 & 0.010 & 0.050 & 0.060 & 0.300 & 0.120 & 0.499 & 0.120 & \begin{tabular}{|l|}
0.050 \\
\end{tabular} & 0.080 & 0.100 & 0.010 & 0.030 \\
\hline HLW03-40 & 0.040 & 0.080 & 0.020 & 0.046 & 0.060 & 0.020 & 0.010 & 0.499 & 0.048 & 0.200 & 0.010 & 0.010 & 0.050 & 0.060 & 0.299 & 0.120 & 0.499 & 0.120 & \begin{tabular}{|l|}
0.050 \\
\end{tabular} & 0.080 & 0.100 & 0.010 & 0.030 \\
\hline HLW03-41 & 0.087 & 0.173 & 0.043 & 0.101 & 0.130 & 0.043 & 0.010 & 0.499 & 0.048 & 0.200 & 0.010 & 0.010 & 0.050 & 0.060 & 0.299 & 0.120 & 0.499 & 0.120 & \begin{tabular}{|l|}
0.050 \\
\end{tabular} & 0.080 & 0.100 & 0.010 & 0.030 \\
\hline HLW03-42 & 0.040 & 0.080 & 0.020 & 0.046 & 0.060 & 0.020 & 0.010 & 0.500 & 0.048 & 0.200 & 0.010 & 0.010 & 0.050 & 0.060 & 0.300 & 0.120 & 0.500 & 0.120 & \begin{tabular}{|l|}
0.050 \\
\end{tabular} & 0.080 & 0.100 & 0.010 & 0.030 \\
\hline $3-43$ & 0.020 & 0.040 & 0.010 & 0.023 & 0.030 & 0.010 & 0.010 & 0.500 & 0.048 & 0.200 & 0.010 & 0.010 & 0.050 & 0.060 & 0.300 & 0.120 & 0.500 & 0.120 & \begin{tabular}{|l|}
0.050 \\
\end{tabular} & 0.080 & 0.100 & 0.010 & 0.030 \\
\hline HLW03-44 & 0.020 & 0.040 & 0.010 & 0.023 & 0.030 & 0.010 & 0.010 & 0.498 & 0.048 & 0.199 & 0.010 & 0.010 & 0.050 & 0.060 & 0.299 & 0.120 & 0.498 & 0.120 & \begin{tabular}{|l|}
0.050 \\
\end{tabular} & 0.080 & 0.100 & 0.010 & 0.030 \\
\hline HLW03-45 & 0.133 & 0.267 & 0.067 & 0.155 & 0.200 & 0.067 & 0.010 & 0.499 & 0.048 & 0.199 & 0.010 & 0.010 & 0.050 & 0.060 & 0.299 & 0.120 & 0.499 & 0.120 & \begin{tabular}{|l|}
0.050 \\
\end{tabular} & 0.080 & 0.100 & 0.010 & 0.030 \\
\hline
\end{tabular}

(a) Glass IDs HLW02-01 to HLW02-57 identify the initial test matrix of HLW glasses. Glass IDs HLW03-01 to HLW03-45 identify the augmentation matrix of HLW glasses.

(b) Spike component wt $\%$ values are rounded to 3 decimal places for each glass and may not equal the wt $\%$ value listed in the Spike column of Table 2.10 .

(c) The sum of the Constant component wt $\%$ values for each glass equals the wt $\%$ value listed in the Constant column shown in Table 2.10 . Note that the values are no longer exactly constant due to the revision in oxide forms. 
Table 2.13. Target Glass Compositions (wt\%) Expressed in Revised Oxides for the HLW04 Glasses.

\begin{tabular}{|c|c|c|c|c|c|c|c|c|c|c|c|c|c|c|c|c|c|c|c|}
\hline Glass ID & $\mathrm{Ag}_{2} \mathrm{O}$ & $\mathbf{A l}_{2} \mathbf{O}_{3}$ & $\mathbf{B}_{2} \mathbf{O}_{3}$ & $\mathrm{BaO}$ & $\mathrm{CaO}$ & CdO & $\mathrm{Ce}_{2} \mathrm{O}_{3}$ & $\mathrm{CoO}$ & $\mathrm{Cr}_{2} \mathrm{O}_{3}$ & $\mathrm{Cs}_{2} \mathrm{O}$ & $\mathrm{CuO}$ & $\mathrm{Fe}_{2} \mathrm{O}_{3}$ & $\mathbf{G d}_{2} \mathbf{O}_{3}$ & $\mathbf{K}_{2} \mathrm{O}$ & $\mathbf{L a}_{2} \mathbf{O}_{3}$ & $\mathbf{L i}_{2} \mathbf{O}$ & MgO & MnO & $\mathrm{MoO}_{3}$ \\
\hline HLW04-01 & 0.070 & 4.781 & 11.258 & 0.050 & 0.363 & 0.011 & 0.128 & 0.007 & 0.212 & 0.000 & 0.032 & 13.088 & 0.000 & 0.000 & 0.064 & 2.808 & 0.113 & 2.054 & 0.046 \\
\hline HLW04-02 & 0.070 & 4.781 & 12.508 & 0.050 & 0.363 & 0.011 & 0.128 & 0.007 & 0.212 & 0.000 & 0.032 & 13.088 & 0.000 & 0.000 & 0.064 & 2.808 & 0.113 & 2.054 & 0.046 \\
\hline HLW04-03 & 0.072 & 4.917 & 11.088 & 0.051 & 0.373 & 0.011 & 0.132 & 0.007 & 0.218 & 0.000 & 0.033 & 13.460 & 0.000 & 0.000 & 0.065 & 2.770 & 0.116 & 2.112 & 0.047 \\
\hline HLW04-04 & 0.068 & 4.584 & 10.757 & 0.048 & 0.348 & 0.010 & 0.123 & 0.007 & 0.203 & 0.000 & 0.031 & 12.548 & 0.000 & 0.000 & 0.061 & 2.805 & 0.108 & 1.969 & 0.044 \\
\hline HLW04-05 & 0.069 & 4.652 & 11.368 & 0.048 & 0.353 & 0.010 & 0.125 & 0.007 & 0.206 & 0.000 & 0.031 & 12.735 & 0.000 & 0.000 & 0.062 & 2.837 & 0.110 & 1.998 & 0.045 \\
\hline HLW04-06 & 0.072 & 4.917 & 10.358 & 0.051 & 0.373 & 0.011 & 0.132 & 0.007 & 0.218 & 0.000 & 0.033 & 13.460 & 0.000 & 0.000 & 0.065 & 2.620 & 0.116 & 2.112 & 0.047 \\
\hline HLW04-07 & 0.185 & 4.882 & 10.368 & 0.075 & 0.456 & 0.011 & 0.101 & 0.000 & 0.223 & 0.000 & 0.034 & 14.005 & 0.000 & 0.011 & 0.074 & 2.643 & 0.145 & 2.821 & 0.033 \\
\hline $\begin{array}{l}\text { HLW04- } \\
\text { 07NRE9 }\end{array}$ & 0.052 & 4.885 & 10.374 & 0.075 & 0.456 & 0.011 & 0.101 & 0.000 & 0.223 & 0.000 & 0.034 & 14.013 & 0.000 & 0.011 & 0.074 & 2.644 & 0.145 & 2.823 & 0.033 \\
\hline $\begin{array}{c}\text { HLW04- } \\
\text { 07NRE9CCC }\end{array}$ & 0.052 & 4.885 & 10.374 & 0.075 & 0.456 & 0.011 & 0.101 & 0.000 & 0.223 & 0.000 & 0.034 & 14.013 & 0.000 & 0.011 & 0.074 & 2.644 & 0.145 & 2.823 & 0.033 \\
\hline $\begin{array}{l}\text { HLW04- } \\
\text { 07RE39 }\end{array}$ & 0.185 & 4.882 & 10.368 & 0.075 & 0.456 & 0.011 & 0.101 & 0.000 & 0.223 & 0.000 & 0.034 & 14.005 & 0.000 & 0.011 & 0.074 & 2.643 & 0.145 & 2.821 & 0.033 \\
\hline $\begin{array}{c}\text { HLW04- } \\
\text { 07RE39CCC }\end{array}$ & 0.185 & 4.882 & 10.368 & 0.075 & 0.456 & 0.011 & 0.101 & 0.000 & 0.223 & 0.000 & 0.034 & 14.005 & 0.000 & 0.011 & 0.074 & 2.643 & 0.145 & 2.821 & 0.033 \\
\hline HLW04-08 & 0.181 & 4.778 & 10.362 & 0.073 & 0.446 & 0.011 & 0.099 & 0.000 & 0.218 & 0.000 & 0.033 & 13.707 & 0.000 & 0.011 & 0.073 & 2.642 & 0.141 & 2.761 & 0.033 \\
\hline HLW04-09 & 0.186 & 4.884 & 10.270 & 0.074 & 0.456 & 0.011 & 0.100 & 0.000 & 0.223 & 0.000 & 0.033 & 14.006 & 0.007 & 0.011 & 0.074 & 2.644 & 0.145 & 2.821 & 0.033 \\
\hline
\end{tabular}


Table 2.13. Target Glass Compositions (wt\%) Expressed in Revised Oxides for the HLW04 Glasses (continued).

\begin{tabular}{|c|c|c|c|c|c|c|c|c|c|c|c|c|c|c|c|c|c|c|}
\hline Glass ID & $\mathrm{Na}_{2} \mathrm{O}$ & $\mathrm{NiO}$ & $\mathbf{P}_{2} \mathbf{O}_{5}$ & PbO & PdO & $\mathbf{R h}_{2} \mathbf{O}_{3}$ & $\mathrm{RuO}_{2}$ & $\mathrm{SO}_{3}$ & $\mathrm{Sb}_{2} \mathrm{O}_{3}$ & $\mathrm{SeO}_{2}$ & $\mathrm{SiO}_{2}$ & $\mathrm{SnO}_{2}$ & SrO & $\mathrm{TiO}_{2}$ & $\mathbf{U O}_{3}$ & $\mathbf{V}_{2} \mathbf{O}_{5}$ & $\mathrm{ZnO}$ & $\mathrm{ZrO}_{2}$ \\
\hline HLW04-01 & 12.251 & 0.384 & 0.419 & 0.465 & 0.000 & 0.000 & 0.000 & 0.000 & 0.000 & 0.000 & 48.507 & 0.666 & 0.201 & 0.028 & 0.000 & 0.018 & 1.978 & 0.000 \\
\hline HLW04-02 & 12.251 & 0.384 & 0.419 & 0.465 & 0.000 & 0.000 & 0.000 & 0.000 & 0.000 & 0.000 & 47.257 & 0.666 & 0.201 & 0.028 & 0.000 & 0.018 & 1.978 & 0.000 \\
\hline HLW04-03 & 12.307 & 0.395 & 0.431 & 0.478 & 0.000 & 0.000 & 0.000 & 0.000 & 0.000 & 0.000 & 48.028 & 0.685 & 0.207 & 0.029 & 0.000 & 0.018 & 1.949 & 0.000 \\
\hline HLW04-04 & 12.523 & 0.368 & 0.402 & 0.446 & 0.000 & 0.000 & 0.000 & 0.000 & 0.000 & 0.000 & 49.256 & 0.638 & 0.193 & 0.027 & 0.420 & 0.017 & 1.997 & 0.000 \\
\hline HLW04-05 & 12.452 & 0.374 & 0.408 & 0.452 & 0.000 & 0.000 & 0.000 & 0.000 & 0.000 & 0.000 & 48.775 & 0.648 & 0.195 & 0.027 & 0.000 & 0.017 & 1.997 & 0.000 \\
\hline HLW04-06 & 12.287 & 0.395 & 0.431 & 0.478 & 0.000 & 0.000 & 0.000 & 0.000 & 0.000 & 0.000 & 48.928 & 0.685 & 0.207 & 0.029 & 0.000 & 0.018 & 1.949 & 0.000 \\
\hline HLW04-07 & 12.527 & 0.412 & 0.560 & 0.541 & 0.000 & 0.000 & 0.000 & 0.189 & 0.037 & 0.000 & 47.445 & 0.061 & 0.171 & 0.033 & 0.000 & 0.015 & 1.480 & 0.463 \\
\hline $\begin{array}{l}\text { HLW04- } \\
\text { 07NRE9 }\end{array}$ & 12.534 & 0.412 & 0.560 & 0.542 & 0.002 & 0.004 & 0.070 & 0.189 & 0.037 & 0.000 & 47.472 & 0.061 & 0.171 & 0.033 & 0.000 & 0.015 & 1.481 & 0.464 \\
\hline $\begin{array}{c}\text { HLW04- } \\
\text { 07NRE9CCC }\end{array}$ & 12.534 & 0.412 & 0.560 & 0.542 & 0.002 & 0.004 & 0.070 & 0.189 & 0.037 & 0.000 & 47.472 & 0.061 & 0.171 & 0.033 & 0.000 & 0.015 & 1.481 & 0.464 \\
\hline $\begin{array}{l}\text { HLW04- } \\
\text { 07RE39 }\end{array}$ & 12.527 & 0.412 & 0.560 & 0.541 & 0.000 & 0.000 & 0.000 & 0.189 & 0.037 & 0.000 & 47.445 & 0.061 & 0.171 & 0.033 & 0.000 & 0.015 & 1.480 & 0.463 \\
\hline $\begin{array}{c}\text { HLW04- } \\
\text { 07RE39CCC }\end{array}$ & 12.527 & 0.412 & 0.560 & 0.541 & 0.000 & 0.000 & 0.000 & 0.189 & 0.037 & 0.000 & 47.445 & 0.061 & 0.171 & 0.033 & 0.000 & 0.015 & 1.480 & 0.463 \\
\hline HLW04-08 & 12.412 & 0.403 & 0.548 & 0.530 & 0.000 & 0.000 & 0.000 & 0.185 & 0.040 & 0.000 & 48.106 & 0.060 & 0.167 & 0.033 & 0.000 & 0.015 & 1.479 & 0.454 \\
\hline HLW04-09 & 12.531 & 0.412 & 0.560 & 0.542 & 0.000 & 0.000 & 0.000 & 0.189 & 0.037 & 0.000 & 47.744 & 0.063 & 0.171 & 0.033 & 0.529 & 0.015 & 0.730 & 0.464 \\
\hline
\end{tabular}


Table 2.14. Target Glass Compositions Expressed in Revised Oxides (wt\%) for the Non-Spinel (HLW05) Test Matrix ${ }^{(a)}$.

\begin{tabular}{|c|c|c|c|c|c|c|c|c|c|c|c|c|c|c|}
\hline Glass ID & Point Type $^{(\mathbf{b})}$ & $\begin{array}{c}\text { Melt } \\
\text { Order }\end{array}$ & $\mathrm{Al}_{2} \mathbf{O}_{3}$ & $\mathbf{B}_{2} \mathbf{O}_{3}$ & $\mathrm{Cr}_{2} \mathrm{O}_{3}$ & $\mathrm{Fe}_{2} \mathrm{O}_{3}$ & $\mathbf{L i}_{\mathbf{2}} \mathbf{O}$ & $\mathrm{Na}_{2} \mathrm{O}$ & $\mathrm{SiO}_{2}$ & $\mathrm{ThO}_{2}$ & $\mathbf{U O}_{3}$ & $\mathrm{ZrO}_{2}$ & Others & Constant \\
\hline HLW05-01 & $\mathrm{I}$ & 7 & 6.000 & 12.000 & 0.100 & 6.060 & 3.000 & 8.000 & 43.770 & 4.500 & 4.500 & 6.080 & 0.500 & 5.500 \\
\hline HLW05-02 & $\mathrm{I}$ & 29 & 10.000 & 12.000 & 0.200 & 5.000 & 3.000 & 11.680 & 41.120 & 3.000 & 2.500 & 5.000 & 1.000 & 5.500 \\
\hline HLW05-03 & $\mathrm{I}$ & 11 & 6.000 & 11.300 & 0.200 & 5.000 & 3.000 & 16.000 & 38.000 & 3.000 & 4.500 & 7.000 & 0.500 & 5.500 \\
\hline HLW05-04 & $\mathrm{I}$ & 28 & 6.000 & 7.000 & 0.100 & 5.000 & 5.000 & 10.750 & 44.000 & 3.000 & 4.500 & 8.150 & 1.000 & 5.500 \\
\hline HLW05-05 & $\mathrm{I}$ & 27 & 6.000 & 7.000 & 0.100 & 7.000 & 3.250 & 16.000 & 44.000 & 3.000 & 2.650 & 5.000 & 0.500 & 5.500 \\
\hline HLW05-06 & $\mathrm{I}$ & 2 & 6.000 & 7.060 & 0.200 & 8.000 & 3.000 & 16.000 & 38.000 & 4.500 & 2.500 & 8.240 & 1.000 & 5.500 \\
\hline HLW05-07 & RepHLW05-02 & 1 & 10.000 & 12.000 & 0.200 & 5.000 & 3.000 & 11.680 & 41.120 & 3.000 & 2.500 & 5.000 & 1.000 & 5.500 \\
\hline HLW05-08 & $\mathrm{I}$ & 30 & 6.000 & 12.000 & 0.100 & 5.000 & 5.000 & 11.900 & 38.000 & 3.000 & 2.500 & 10.500 & 0.500 & 5.500 \\
\hline HLW05-09 & $\mathrm{I}$ & 26 & 6.000 & 12.000 & 0.100 & 7.670 & 5.000 & 12.500 & 38.230 & 4.500 & 2.500 & 5.000 & 1.000 & 5.500 \\
\hline HLW05-10 & $\mathrm{I}$ & 18 & 10.000 & 7.000 & 0.200 & 5.000 & 5.000 & 12.500 & 42.300 & 4.500 & 2.500 & 5.000 & 0.500 & 5.500 \\
\hline HLW05-11 & $\mathrm{I}$ & 5 & 6.000 & 12.000 & 0.200 & 8.000 & 5.000 & 8.300 & 44.000 & 3.000 & 2.500 & 5.000 & 0.500 & 5.500 \\
\hline HLW05-12 & RepHLW05-06 & 23 & 6.000 & 7.060 & 0.200 & 8.000 & 3.000 & 16.000 & 38.000 & 4.500 & 2.500 & 8.240 & 1.000 & 5.500 \\
\hline HLW05-13 & $\mathrm{I}$ & 13 & 9.770 & 7.000 & 0.100 & 7.630 & 3.000 & 16.000 & 38.000 & 3.000 & 4.500 & 5.000 & 0.500 & 5.500 \\
\hline HLW05-14 & $\mathrm{I}$ & 15 & 6.000 & 11.300 & 0.200 & 8.000 & 5.000 & 12.500 & 38.000 & 3.000 & 4.500 & 5.000 & 1.000 & 5.500 \\
\hline HLW05-15 & $\mathrm{O}$ & 8 & 2.000 & 4.500 & 0.250 & 12.000 & 0.000 & 16.670 & 49.000 & 1.500 & 4.380 & 4.000 & 0.200 & 5.500 \\
\hline HLW05-16 & $\mathrm{O}$ & 9 & 5.110 & 14.000 & 0.250 & 1.500 & 6.000 & 7.420 & 36.130 & 6.000 & 6.500 & 11.390 & 0.200 & 5.500 \\
\hline HLW05-17 & $\mathrm{O}$ & 22 & 11.870 & 14.000 & 0.050 & 7.180 & 6.000 & 10.750 & 34.000 & 1.500 & 1.000 & 7.950 & 0.200 & 5.500 \\
\hline HLW05-18 & $\mathrm{O}$ & 25 & 2.000 & 14.000 & 0.050 & 6.460 & 0.000 & 11.420 & 42.030 & 6.000 & 1.000 & 9.540 & 2.000 & 5.500 \\
\hline HLW05-19 & $\mathrm{O}$ & 20 & 13.000 & 4.500 & 0.050 & 5.920 & 1.450 & 20.000 & 34.380 & 6.000 & 6.500 & 2.500 & 0.200 & 5.500 \\
\hline HLW05-20 & $\mathrm{O}$ & 24 & 13.000 & 14.000 & 0.250 & 1.500 & 0.000 & 20.000 & 37.750 & 1.500 & 1.000 & 3.500 & 2.000 & 5.500 \\
\hline HLW05-21 & $\mathrm{O}$ & 14 & 2.000 & 14.000 & 0.250 & 12.000 & 0.000 & 19.710 & 34.000 & 6.000 & 1.000 & 5.340 & 0.200 & 5.500 \\
\hline HLW05-22 & $\mathrm{O}$ & 16 & 13.000 & 14.000 & 0.050 & 2.500 & 3.700 & 6.500 & 44.050 & 1.500 & 6.500 & 2.500 & 0.200 & 5.500 \\
\hline HLW05-23 & $\mathrm{O}$ & 3 & 12.730 & 4.500 & 0.250 & 1.500 & 6.000 & 10.000 & 46.750 & 6.000 & 1.000 & 3.770 & 2.000 & 5.500 \\
\hline HLW05-24 & $\mathrm{O}$ & 4 & 2.170 & 4.500 & 0.250 & 8.940 & 1.490 & 20.000 & 35.640 & 1.500 & 6.500 & 11.500 & 2.000 & 5.500 \\
\hline HLW05-25 & $\mathrm{O}$ & 17 & 2.000 & 7.430 & 0.250 & 9.120 & 6.000 & 6.500 & 49.000 & 1.500 & 1.000 & 11.500 & 0.200 & 5.500 \\
\hline HLW05-26 & $\mathrm{O}$ & 6 & 5.000 & 4.500 & 0.050 & 1.500 & 1.780 & 20.000 & 47.470 & 1.500 & 1.000 & 11.500 & 0.200 & 5.500 \\
\hline HLW05-27 & $\mathrm{O}$ & 21 & 2.000 & 4.500 & 0.050 & 12.000 & 5.950 & 10.390 & 45.610 & 1.500 & 6.500 & 4.000 & 2.000 & 5.500 \\
\hline HLW05-28 & RepHLW05-18 & 10 & 2.000 & 14.000 & 0.050 & 6.460 & 0.000 & 11.420 & 42.030 & 6.000 & 1.000 & 9.540 & 2.000 & 5.500 \\
\hline HLW05-29 & RepHLW05-26 & 12 & 5.000 & 4.500 & 0.050 & 1.500 & 1.780 & 20.000 & 47.470 & 1.500 & 1.000 & 11.500 & 0.200 & 5.500 \\
\hline HLW05-30 & $\mathrm{C}$ & 19 & 6.610 & 9.860 & 0.140 & 6.250 & 2.780 & 14.710 & 40.960 & 3.200 & 3.000 & 6.000 & 0.980 & 5.500 \\
\hline
\end{tabular}

(a) The thirteen (13) HLW05 glasses that have spinel $\mathrm{T}_{1 \%}$, electrical conductivity, or viscosity data are not shaded.

(b) "Point Type" notation: I = Inner layer, O = Outer layer, C = Center point. Replicate points are denoted by "RepHLW05-xx", where the "xx" represents a specific Glass ID number for a replicated glass. 
Table 2.15. Expanded Compositions in Revised Oxides (wt\%) of "Others" and Constant Components for the Non-Spinel (HLW05) Matrix. ${ }^{(a)}$

\begin{tabular}{|c|c|c|c|c|c|c|c|c|c|c|c|c|c|c|c|c|c|c|c|c|c|}
\hline \multirow{2}{*}{ Glass ID } & \multicolumn{3}{|c|}{ "Others" Components } & \multicolumn{18}{|c|}{ Constant Components } \\
\hline & CdO & MnO & $\mathrm{NiO}$ & $\mathbf{A g}_{2} \mathbf{O}$ & $\mathrm{BaO}$ & ${ }_{2} \mathbf{O}_{3}$ & $\mathrm{CaO}$ & $\mathbf{F}$ & $\mathbf{K}_{2} \mathbf{O}$ & $\mathrm{La}_{2} \mathrm{O}_{3}$ & $\mathrm{MgO}$ & $\mathbf{P}_{2} \mathbf{O}_{5}$ & PbO & PdO & $\mathbf{R h}_{2} \mathbf{O}_{3}$ & $\mathrm{RuO}_{2}$ & $\mathrm{SO}_{3}$ & SrO & $\mathrm{TiO}_{2}$ & $\mathrm{Tl}_{2} \mathrm{O}$ & ZnO \\
\hline HLW05-01 & 0.125 & 0.250 & 0.125 & 0.100 & 0.500 & 0.200 & 0.750 & 0.050 & 0.200 & 0.500 & 0.100 & 0.300 & 0.150 & 0.020 & 0.040 & 0.020 & 0.100 & 1.200 & 0.020 & 0.050 & 1.200 \\
\hline HLW05-02 & 0.250 & 0.500 & 0.250 & 0.100 & 0.500 & 0.200 & 0.750 & 0.050 & 0.200 & 0.500 & 0.100 & 0.300 & 0.150 & 0.020 & 0.040 & 0.020 & 0.100 & 1.200 & 0.020 & 0.050 & 1.200 \\
\hline HLW05-03 & 0.125 & 0.250 & 0.125 & 0.100 & 0.500 & 0.200 & 0.750 & 0.050 & 0.200 & 0.500 & 0.100 & 0.300 & 0.150 & 0.020 & 0.040 & 0.020 & 0.100 & 1.200 & 0.020 & 0.050 & 1.200 \\
\hline HLW05-04 & 0.250 & 0.500 & 0.250 & 0.100 & 0.500 & 0.200 & 0.750 & 0.050 & 0.200 & 0.500 & 0.100 & 0.300 & 0.150 & 0.020 & 0.040 & 0.020 & 0.100 & 1.200 & 0.020 & 0.050 & 1.200 \\
\hline HLW05-05 & 0.125 & 0.250 & 0.125 & 0.100 & 0.500 & 0.200 & 0.750 & 0.050 & 0.200 & 0.500 & 0.100 & 0.300 & 0.150 & 0.020 & 0.040 & 0.020 & 0.100 & 1.200 & 0.020 & 0.050 & 1.200 \\
\hline HLW05-06 & 0.250 & 0.500 & 0.250 & 0.100 & 0.500 & 0.200 & 0.750 & 0.050 & 0.200 & 0.500 & 0.100 & 0.300 & 0.150 & 0.020 & 0.040 & 0.020 & 0.100 & 1.200 & 0.020 & 0.050 & 1.200 \\
\hline HLW05-07 & 0.250 & 0.500 & 0.250 & 0.100 & 0.500 & 0.200 & 0.750 & 0.050 & 0.200 & 0.500 & 0.100 & 0.300 & 0.150 & 0.020 & 0.040 & 0.020 & 0.100 & 1.200 & 0.020 & 0.050 & 1.200 \\
\hline HLW05-08 & 0.125 & 0.250 & 0.125 & 0.100 & 0.500 & 0.200 & 0.750 & 0.050 & 0.200 & 0.500 & 0.100 & 0.300 & 0.150 & 0.020 & 0.040 & 0.020 & 0.100 & 1.200 & 0.020 & 0.050 & 1.200 \\
\hline HLW05-09 & 0.250 & 0.500 & 0.250 & 0.100 & 0.500 & 0.200 & 0.750 & 0.050 & 0.200 & 0.500 & 0.100 & 0.300 & 0.150 & 0.020 & 0.040 & 0.020 & 0.100 & 1.200 & 0.020 & 0.050 & 1.200 \\
\hline HLW05-10 & 0.125 & 0.250 & 0.125 & 0.100 & 0.500 & 0.200 & 0.750 & 0.050 & 0.200 & 0.500 & 0.100 & 0.300 & 0.150 & 0.020 & 0.040 & 0.020 & 0.100 & 1.200 & 0.020 & 0.050 & 1.200 \\
\hline HLW05-11 & 0.125 & 0.250 & 0.125 & 0.100 & 0.500 & 0.200 & 0.750 & 0.050 & 0.200 & 0.500 & 0.100 & 0.300 & 0.150 & 0.020 & 0.040 & 0.020 & 0.100 & 1.200 & 0.020 & 0.050 & 1.200 \\
\hline HLW05-12 & 0.250 & 0.500 & 0.250 & 0.100 & 0.500 & 0.200 & 0.750 & 0.050 & 0.200 & 0.500 & 0.100 & 0.300 & 0.150 & 0.020 & 0.040 & 0.020 & 0.100 & 1.200 & 0.020 & 0.050 & 1.200 \\
\hline HLW05-13 & 0.125 & 0.250 & 0.125 & 0.100 & 0.500 & 0.200 & 0.750 & 0.050 & 0.200 & 0.500 & 0.100 & 0.300 & 0.150 & 0.020 & 0.040 & 0.020 & 0.100 & 1.200 & 0.020 & 0.050 & 1.200 \\
\hline HLW05-14 & 0.250 & 0.500 & 0.250 & 0.100 & 0.500 & 0.200 & 0.750 & 0.050 & 0.200 & 0.500 & 0.100 & 0.300 & 0.150 & 0.020 & 0.040 & 0.020 & 0.100 & 1.200 & 0.020 & 0.050 & 1.200 \\
\hline HLW05-15 & 0.050 & 0.100 & 0.050 & 0.100 & 0.500 & 0.200 & 0.750 & 0.050 & 0.200 & 0.500 & 0.100 & 0.300 & 0.150 & 0.020 & 0.040 & 0.020 & 0.100 & 1.200 & 0.020 & 0.050 & 1.200 \\
\hline HLW05-16 & 0.050 & 0.100 & 0.050 & 0.100 & 0.500 & 0.200 & 0.750 & 0.050 & 0.200 & 0.500 & 0.100 & 0.300 & 0.150 & 0.020 & 0.040 & 0.020 & 0.100 & 1.200 & 0.020 & 0.050 & 1.200 \\
\hline HLW05-17 & 0.050 & 0.100 & 0.050 & 0.100 & 0.500 & 0.200 & 0.750 & 0.050 & 0.200 & 0.500 & 0.100 & 0.300 & 0.150 & 0.020 & 0.040 & 0.020 & 0.100 & 1.200 & 0.020 & 0.050 & 1.200 \\
\hline HLW05-18 & 0.500 & 1.000 & 0.500 & 0.100 & 0.500 & 0.200 & 0.750 & 0.050 & 0.200 & 0.500 & 0.100 & 0.300 & 0.150 & 0.020 & 0.040 & 0.020 & 0.100 & 1.200 & 0.020 & 0.050 & 1.200 \\
\hline HLW05-19 & 0.050 & 0.100 & 0.050 & 0.100 & 0.500 & 0.200 & 0.750 & 0.050 & 0.200 & 0.500 & 0.100 & 0.300 & 0.150 & 0.020 & 0.040 & 0.020 & 0.100 & 1.200 & 0.020 & 0.050 & 1.200 \\
\hline HLW05-20 & 0.500 & 1.000 & 0.500 & 0.100 & 0.500 & 0.200 & 0.750 & 0.050 & 0.200 & 0.500 & 0.100 & 0.300 & 0.150 & 0.020 & 0.040 & 0.020 & 0.100 & 1.200 & 0.020 & 0.050 & 1.200 \\
\hline HLW05-21 & 0.050 & 0.100 & 0.050 & 0.100 & 0.500 & 0.200 & 0.750 & 0.050 & 0.200 & 0.500 & 0.100 & 0.300 & 0.150 & 0.020 & 0.040 & 0.020 & 0.100 & 1.200 & 0.020 & 0.050 & 1.200 \\
\hline HLW05-22 & 0.050 & 0.100 & 0.050 & 0.100 & 0.500 & 0.200 & 0.750 & 0.050 & 0.200 & 0.500 & 0.100 & 0.300 & 0.150 & 0.020 & 0.040 & 0.020 & 0.100 & 1.200 & 0.020 & 0.050 & 1.200 \\
\hline HLW05-23 & 0.500 & 1.000 & 0.500 & 0.100 & 0.500 & 0.200 & 0.750 & 0.050 & 0.200 & 0.500 & 0.100 & 0.300 & 0.150 & 0.020 & 0.040 & 0.020 & 0.100 & 1.200 & 0.020 & 0.050 & 1.200 \\
\hline HLW05-24 & 0.500 & 1.000 & 0.500 & 0.100 & 0.500 & 0.200 & 0.750 & 0.050 & 0.200 & 0.500 & 0.100 & 0.300 & 0.150 & 0.020 & 0.040 & 0.020 & 0.100 & 1.200 & 0.020 & 0.050 & 1.200 \\
\hline HLW05-25 & 0.050 & 0.100 & 0.050 & 0.100 & 0.500 & 0.200 & 0.750 & 0.050 & 0.200 & 0.500 & 0.100 & 0.300 & 0.150 & 0.020 & 0.040 & 0.020 & 0.100 & 1.200 & 0.020 & 0.050 & 1.200 \\
\hline HLW05-26 & 0.050 & 0.100 & 0.050 & 0.100 & 0.500 & 0.200 & 0.750 & 0.050 & 0.200 & 0.500 & 0.100 & 0.300 & 0.150 & 0.020 & 0.040 & 0.020 & 0.100 & 1.200 & 0.020 & 0.050 & 1.200 \\
\hline HLW05-27 & 0.500 & 1.000 & 0.500 & 0.100 & 0.500 & 0.200 & 0.750 & 0.050 & 0.200 & 0.500 & 0.100 & 0.300 & 0.150 & 0.020 & 0.040 & 0.020 & 0.100 & 1.200 & 0.020 & 0.050 & 1.200 \\
\hline HLW05-28 & 0.500 & 1.000 & 0.500 & 0.100 & 0.500 & 0.200 & 0.750 & 0.050 & 0.200 & 0.500 & 0.100 & 0.300 & 0.150 & 0.020 & 0.040 & 0.020 & 0.100 & 1.200 & 0.020 & 0.050 & 1.200 \\
\hline HLW05-29 & 0.050 & 0.100 & 0.050 & 0.100 & 0.500 & 0.200 & 0.750 & 0.050 & 0.200 & 0.500 & 0.100 & 0.300 & 0.150 & 0.020 & 0.040 & 0.020 & 0.100 & 1.200 & 0.020 & 0.050 & 1.200 \\
\hline HLW05-30 & 0.245 & 0.490 & 0.245 & 0.100 & 0.500 & 0.200 & 0.750 & 0.050 & 0.200 & 0.500 & 0.100 & 0.300 & 0.150 & 0.020 & 0.040 & 0.020 & 0.100 & 1.200 & 0.020 & 0.050 & 1.200 \\
\hline
\end{tabular}

(a) The thirteen (13) HLW05 glasses that have spinel $\mathrm{T}_{1 \%}$, electrical conductivity, or viscosity data are not shaded. 
Table 2.16. Target Glass Compositions Expressed in Revised Oxides (wt\%) for the Spinel (HLW06) Test Matrix.

\begin{tabular}{|c|c|c|c|c|c|c|c|c|c|c|c|c|c|c|c|c|c|c|}
\hline Glass ID & Point Type $^{(\mathrm{a})}$ & $\begin{array}{c}\text { Melt } \\
\text { Order }\end{array}$ & $\mathbf{A l}_{2} \mathbf{O}_{3}$ & $\mathbf{B}_{2} \mathbf{O}_{3}$ & $\mathrm{Cr}_{2} \mathrm{O}_{3}$ & $\mathrm{Fe}_{2} \mathrm{O}_{3}$ & $\mathbf{L i}_{2} \mathbf{O}$ & MnO & $\mathrm{Na}_{2} \mathrm{O}$ & $\mathrm{NiO}$ & $\mathrm{SiO}_{2}$ & $\mathrm{ThO}_{2}$ & $\mathrm{UO}_{3}$ & $\mathrm{ZnO}$ & $\mathrm{ZrO}_{2}$ & Others1 & Others2 & Constant \\
\hline HLW06-01 & I & 1 & 11.000 & 6.500 & 0.500 & 7.000 & 3.000 & 1.000 & 14.000 & 1.000 & 40.000 & 1.500 & 0.750 & 2.140 & 1.500 & 2.000 & 6.020 & 2.090 \\
\hline HLW06-02 & I & 23 & 10.390 & 11.000 & 0.250 & 7.000 & 0.250 & 1.000 & 20.000 & 1.000 & 35.000 & 0.250 & 0.750 & 1.500 & 1.500 & 2.000 & 6.020 & 2.090 \\
\hline HLW06-03 & I & 12 & 11.000 & 6.500 & 0.250 & 14.000 & 0.250 & 1.000 & 14.000 & 0.600 & 35.000 & 0.250 & 0.750 & 1.500 & 4.000 & 6.000 & 2.810 & 2.090 \\
\hline HLW06-04 & I & 31 & 8.000 & 6.500 & 0.250 & 7.000 & 0.250 & 1.000 & 20.000 & 0.600 & 35.000 & 1.500 & 0.750 & 2.500 & 4.000 & 6.000 & 4.560 & 2.090 \\
\hline HLW06-05 & I & 25 & 8.000 & 6.500 & 0.250 & 7.000 & 0.250 & 4.000 & 20.000 & 0.600 & 40.000 & 1.500 & 0.750 & 1.500 & 1.500 & 2.000 & 4.060 & 2.090 \\
\hline HLW06-06 & I & 20 & 11.000 & 6.500 & 0.500 & 7.000 & 0.250 & 4.000 & 14.000 & 1.000 & 35.000 & 1.500 & 4.000 & 1.500 & 4.000 & 2.000 & 5.660 & 2.090 \\
\hline HLW06-07 & I & 14 & 8.000 & 6.500 & 0.250 & 14.000 & 0.250 & 4.000 & 15.890 & 1.000 & 35.000 & 0.250 & 0.750 & 2.500 & 1.500 & 2.000 & 6.020 & 2.090 \\
\hline HLW06-08 & $\mathrm{I}$ & 34 & 8.000 & 6.500 & 0.250 & 7.000 & 0.250 & 4.000 & 14.000 & 1.000 & 40.000 & 0.250 & 4.000 & 1.500 & 1.500 & 6.000 & 3.660 & 2.090 \\
\hline HLW06-09 & I & 32 & 8.000 & 6.500 & 0.250 & 14.000 & 3.000 & 2.410 & 14.000 & 1.000 & 35.000 & 0.250 & 4.000 & 2.500 & 4.000 & 2.000 & 1.000 & 2.090 \\
\hline HLW06-10 & I & 30 & 8.000 & 11.000 & 0.500 & 7.000 & 0.250 & 1.000 & 14.000 & 0.600 & 40.000 & 0.250 & 4.000 & 2.500 & 4.000 & 2.000 & 2.810 & 2.090 \\
\hline HLW06-11 & $\mathrm{I}$ & 11 & 8.000 & 11.000 & 0.250 & 14.000 & 0.250 & 1.000 & 14.000 & 0.600 & 35.000 & 1.500 & 4.000 & 1.500 & 1.500 & 2.000 & 3.310 & 2.090 \\
\hline HLW06-12 & I & 33 & 9.410 & 11.000 & 0.250 & 7.000 & 3.000 & 4.000 & 14.000 & 1.000 & 35.000 & 1.500 & 0.750 & 2.500 & 1.500 & 6.000 & 1.000 & 2.090 \\
\hline HLW06-13 & RepHLW06-06 & 29 & 11.000 & 6.500 & 0.500 & 7.000 & 0.250 & 4.000 & 14.000 & 1.000 & 35.000 & 1.500 & 4.000 & 1.500 & 4.000 & 2.000 & 5.660 & 2.090 \\
\hline HLW06-14 & I & 21 & 8.000 & 11.000 & 0.250 & 7.000 & 3.000 & 4.000 & 14.000 & 0.600 & 35.000 & 1.500 & 0.750 & 1.500 & 3.290 & 2.000 & 6.020 & 2.090 \\
\hline HLW06-15 & I & 13 & 8.000 & 11.000 & 0.500 & 7.000 & 3.000 & 2.910 & 20.000 & 1.000 & 35.000 & 0.250 & 0.750 & 1.500 & 4.000 & 2.000 & 1.000 & 2.090 \\
\hline HLW06-16 & I & 4 & 10.000 & 6.500 & 0.250 & 7.000 & 3.000 & 1.750 & 20.000 & 1.000 & 35.000 & 1.500 & 4.000 & 2.500 & 1.500 & 2.000 & 1.910 & 2.090 \\
\hline HLW06-17 & RepHLW06-01 & 6 & 11.000 & 6.500 & 0.500 & 7.000 & 3.000 & 1.000 & 14.000 & 1.000 & 40.000 & 1.500 & 0.750 & 2.140 & 1.500 & 2.000 & 6.020 & 2.090 \\
\hline HLW06-18 & I & 16 & 11.000 & 11.000 & 0.250 & 7.000 & 0.250 & 1.000 & 14.000 & 1.000 & 40.000 & 1.500 & 0.750 & 2.500 & 4.000 & 2.000 & 1.660 & 2.090 \\
\hline HLW06-19 & I & 8 & 11.000 & 6.500 & 0.500 & 12.060 & 0.250 & 4.000 & 20.000 & 0.600 & 35.000 & 0.250 & 0.750 & 2.500 & 1.500 & 2.000 & 1.000 & 2.090 \\
\hline HLW06-20 & I & 9 & 11.000 & 6.500 & 0.250 & 7.290 & 3.000 & 4.000 & 14.000 & 0.600 & 35.000 & 0.250 & 4.000 & 2.500 & 1.500 & 2.000 & 6.020 & 2.090 \\
\hline HLW06-21 & $\mathrm{O}$ & 35 & 13.000 & 4.300 & 0.000 & 1.400 & 0.000 & 8.000 & 20.000 & 0.000 & 38.770 & 5.940 & 6.500 & 0.000 & 0.000 & 0.000 & 0.000 & 2.090 \\
\hline HLW06-22 & $\mathrm{O}$ & 18 & 13.000 & 15.000 & 0.600 & 1.400 & 6.010 & 0.000 & 6.840 & 0.000 & 34.560 & 0.000 & 6.500 & 0.000 & 0.000 & 14.000 & 0.000 & 2.090 \\
\hline HLW06-23 & $\mathrm{O}$ & 7 & 1.880 & 4.300 & 0.600 & 15.000 & 0.000 & 0.000 & 20.000 & 0.000 & 34.690 & 5.940 & 0.000 & 4.000 & 11.500 & 0.000 & 0.000 & 2.090 \\
\hline HLW06-24 & $\mathrm{O}$ & 2 & 13.000 & 4.300 & 0.000 & 1.400 & 0.000 & 0.000 & 16.250 & 0.000 & 33.000 & 5.940 & 0.000 & 4.000 & 0.000 & 14.000 & 6.020 & 2.090 \\
\hline HLW06-25 & $\mathrm{O}$ & 3 & 13.000 & 15.000 & 0.600 & 1.400 & 6.010 & 0.000 & 3.700 & 0.000 & 42.240 & 5.940 & 0.000 & 4.000 & 0.000 & 0.000 & 6.020 & 2.090 \\
\hline HLW06-26 & $\mathrm{O}$ & 17 & 1.880 & 4.300 & 0.600 & 1.400 & 0.000 & 0.730 & 20.000 & 0.000 & 33.000 & 0.000 & 6.500 & 4.000 & 11.500 & 14.000 & 0.000 & 2.090 \\
\hline HLW06-27 & $\mathrm{O}$ & 22 & 1.880 & 9.820 & 0.000 & 1.400 & 6.010 & 0.000 & 3.700 & 0.000 & 53.100 & 0.000 & 6.500 & 4.000 & 11.500 & 0.000 & 0.000 & 2.090 \\
\hline HLW06-28 & $\mathrm{O}$ & 24 & 1.880 & 15.000 & 0.600 & 11.480 & 6.010 & 0.000 & 3.700 & 0.000 & 42.720 & 0.000 & 6.500 & 4.000 & 0.000 & 0.000 & 6.020 & 2.090 \\
\hline HLW06-29 & $\mathrm{O}$ & 26 & 1.880 & 4.300 & 0.000 & 15.000 & 6.010 & 0.000 & 3.700 & 0.000 & 43.560 & 5.940 & 0.000 & 0.000 & 11.500 & 0.000 & 6.020 & 2.090 \\
\hline HLW06-30 & $\mathrm{O}$ & 27 & 13.000 & 4.300 & 0.000 & 15.000 & 0.000 & 0.000 & 20.000 & 0.000 & 35.110 & 0.000 & 6.500 & 4.000 & 0.000 & 0.000 & 0.000 & 2.090 \\
\hline HLW06-31 & $\mathrm{O}$ & 10 & 13.000 & 4.300 & 0.600 & 15.000 & 5.490 & 0.000 & 3.700 & 0.000 & 35.880 & 5.940 & 0.000 & 0.000 & 0.000 & 14.000 & 0.000 & 2.090 \\
\hline HLW06-32 & $\mathrm{O}$ & 28 & 1.880 & 15.000 & 0.600 & 15.000 & 0.000 & 8.000 & 20.000 & 0.000 & 37.430 & 0.000 & 0.000 & 0.000 & 0.000 & 0.000 & 0.000 & 2.090 \\
\hline HLW06-33 & $\mathrm{O}$ & 19 & 1.880 & 4.300 & 0.000 & 15.000 & 4.730 & 0.000 & 3.700 & 0.000 & 33.000 & 0.000 & 6.500 & 0.000 & 8.780 & 14.000 & 6.020 & 2.090 \\
\hline HLW06-34 & $\mathrm{O}$ & 15 & 1.880 & 15.000 & 0.600 & 1.400 & 0.000 & 8.000 & 20.000 & 0.000 & 33.030 & 0.000 & 6.500 & 0.000 & 11.500 & 0.000 & 0.000 & 2.090 \\
\hline HLW06-35 & $\mathrm{C}$ & 5 & 7.470 & 10.190 & 0.300 & 10.630 & 3.280 & 0.290 & 11.910 & 0.000 & 39.430 & 3.250 & 3.290 & 0.310 & 4.810 & 1.810 & 0.940 & 2.090 \\
\hline
\end{tabular}

(a) "Point Type" notation: $\mathrm{I}=$ Inner layer, $\mathrm{O}=$ Outer layer, $\mathrm{C}=$ Center point. Replicate points are denoted by "RepHLW06-xx", where the "xx" represents a specific Glass ID number for a replicated glass. 
Table 2.17. Expanded Compositions in Revised Oxides (wt\%) of "Others1," "Others2," and Constant Components for the Spinel (HLW06) Matrix.

\begin{tabular}{|c|c|c|c|c|c|c|c|c|c|c|c|c|c|c|c|c|c|c|c|}
\hline \multirow{2}{*}{ Glass ID } & \multicolumn{5}{|c|}{ “Others1" Components } & \multicolumn{6}{|c|}{ “Others2" Components } & \multicolumn{8}{|c|}{ Constant Components } \\
\hline & $\mathrm{CdO}$ & $\mathrm{La}_{2} \mathrm{O}_{3}$ & $\mathrm{Nd}_{2} \mathrm{O}_{3}{ }^{\text {(a) }}$ & $\mathrm{SO}_{3}$ & SrO & $\mathrm{BaO}$ & $\mathrm{CaO}$ & $\mathrm{K}_{2} \mathrm{O}$ & MgO & PbO & $\mathrm{TiO}_{2}$ & $\mathbf{A g}_{2} \mathrm{O}$ & $\mathbf{B i}_{2} \mathbf{O}_{3}$ & $\mathbf{C l}$ & $\mathbf{F}$ & $\mathbf{P}_{2} \mathbf{O}_{5}$ & PdO & $\mathrm{Rh}_{2} \mathrm{O}_{3}$ & $\mathrm{RuO}_{2}$ \\
\hline HLW06-01 & 0.235 & 0.176 & 0.329 & 0.040 & 1.470 & 0.300 & 1.000 & 1.640 & 1.170 & 0.910 & 1.000 & 0.100 & 0.300 & 0.200 & 0.440 & 0.500 & 0.120 & 0.050 & 0.130 \\
\hline HLW06-02 & 0.235 & 0.176 & 0.329 & 0.040 & 1.470 & 0.300 & 1.000 & 1.640 & 1.170 & 0.910 & 1.000 & 0.100 & 0.300 & 0.200 & 0.440 & .500 & 0.120 & 0.050 & 0.130 \\
\hline HLW06-03 & 706 & 0.529 & 487 & 0.120 & 4.409 & 0.140 & 0.467 & 0.766 & 0.546 & 0.425 & 0.467 & 0.100 & 0.300 & 0.200 & 0.440 & .500 & 0.120 & .050 & 0.130 \\
\hline HLW06-04 & 706 & 0.529 & 487 & 0.120 & 4.409 & 0.227 & 0.757 & 1.242 & 0.886 & 0.689 & 0.757 & 0.100 & 0.300 & 0.200 & 0.440 & .500 & 0.120 & .050 & 0.130 \\
\hline HLW06-05 & 35 & & & & & & 0.674 & & & & & & & 0.200 & 0.440 & & & & \\
\hline HLW06-06 & & & & & & & & & & & & & & & & & & & \\
\hline HLW06-07 & & & & & 0 & & 1.00 & & & & 1.000 & & & 0.200 & & & & 050 & \\
\hline HLW06-08 & 706 & 29 & & 20 & 409 & 32 & 0.608 & 997 & 11 & 53 & 0.608 & 00 & 300 & 0.200 & 440 & 500 & 20 & 050 & 130 \\
\hline HLW06-09 & 235 & 76 & & 040 & 470 & 050 & 0.166 & 272 & 94 & 151 & 0.166 & 100 & 300 & 0.200 & 440 & 500 & & .050 & 130 \\
\hline HLW06-10 & 235 & 76 & & .040 & 1.470 & 140 & 0.467 & 766 & 546 & 425 & 0.467 & 100 & 0.300 & 0.200 & .440 & .500 & & .050 & .130 \\
\hline HLW06-11 & 35 & 76 & & 0.040 & 1.470 & 0.165 & 0.550 & 0.902 & 43 & 0.500 & 0.550 & 100 & 300 & 0.200 & .440 & .500 & & .050 & 0.130 \\
\hline HLW06-12 & 0.706 & 529 & & 0.120 & 4.409 & 0.050 & 0.166 & 0.272 & 0.194 & 0.151 & 0.166 & 0.100 & 0.300 & 0.200 & 0.440 & .500 & & .050 & 0.130 \\
\hline HLW06-13 & 235 & 76 & & 0.040 & 1.470 & 0.282 & 0.940 & 1.542 & & & 0.940 & 0.100 & 00 & 0.200 & 0.440 & & & .050 & 0.130 \\
\hline HLW06-14 & 25 & 176 & & 0.040 & 1.470 & 0.300 & 1.000 & 1.640 & 1.170 & & 1.000 & 0.100 & & 0.200 & 0.440 & & & .050 & 0.130 \\
\hline HLW06-15 & & & & & & & & & & & & & & 0.200 & & & & 50 & 0.130 \\
\hline & & & & & & & & & & & & & & & & & & & \\
\hline HLW06-17 & & & & & & & & & & & & & & & & & & 050 & 130 \\
\hline HLW06-18 & & 76 & & .040 & & 083 & 0.276 & & & 1 & 0.276 & 00 & 0 & 0.200 & 40 & .500 & & .050 & 0.130 \\
\hline HLW06-19 & & 76 & & .040 & 1.470 & .050 & 0.166 & 0.272 & & $\pi$ & 0.166 & & 300 & 0.200 & .440 & .500 & & .050 & 0.130 \\
\hline HLW06-20 & 235 & 176 & 0.329 & .040 & 1.470 & 300 & 1.000 & 1.640 & 70 & 910 & 1.000 & 100 & 0.300 & 0.200 & 0.440 & .500 & 20 & .050 & 0.130 \\
\hline HLW06-21 & 0.000 & 000 & & 0.000 & 0.000 & 0.000 & 0.000 & 0.000 & 0.000 & 0.000 & 0.000 & 0.100 & 0 & 0.200 & 0.440 & 0 & & .050 & 0.130 \\
\hline HLW06-22 & 1.646 & 1.234 & & 0.280 & 10.287 & 0.000 & 0.000 & 0 & 0.000 & 0.000 & 0.000 & 0.100 & 0.300 & 0.200 & 0.440 & .500 & 20 & .050 & 0.130 \\
\hline HLW06-23 & 0.000 & 0.000 & & 0.000 & 0.000 & 0.000 & 0.00 & 0.000 & 0.000 & 0.000 & 0.000 & 0.100 & 0.300 & 0.200 & 0.440 & .500 & & .050 & 0.130 \\
\hline HLW06-24 & 1.646 & 1.234 & & 0.280 & 10.287 & 0.300 & 1.00 & 1.640 & & & 1.000 & & & 0.200 & 0.440 & .500 & & .050 & 0.130 \\
\hline HLW06-25 & & & & & & & & & & & & & & & & & & 50 & 0.130 \\
\hline HLW06-26 & & & & & & & & & & & & & & & & & & & 30 \\
\hline HLW06-27 & & & & .000 & 0.000 & 0.000 & 0.000 & 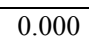 & 0.000 & .000 & 0.000 & 0 & 0 & 0.200 & 0 & 0 & & .050 & 0.130 \\
\hline HLW06-28 & 0.000 & 000 & 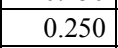 & 0.000 & 0.000 & 0.300 & 1.000 & 1.640 & 1.170 & 910 & 1.000 & .100 & 0 & 0.200 & 0.440 & .500 & 20 & .050 & 0.130 \\
\hline HLW06-29 & 0.000 & 000 & 0.250 & 0.000 & 0.000 & 0.300 & 1.000 & 1.640 & 1.170 & 0.910 & 1.000 & 0.100 & 0.300 & 0.200 & 0.440 & .500 & .120 & .050 & 0.130 \\
\hline HLW06-30 & 0.000 & 0.000 & 0.250 & 0.000 & 0.000 & 0.000 & 0.000 & 0.000 & 0.000 & 0.000 & 0.000 & 0.100 & 0.300 & 0.200 & 0.440 & .500 & .120 & .050 & 0.130 \\
\hline HLW06-31 & 1.646 & 1.234 & 0.802 & 0.280 & 10.287 & 0.000 & 0.000 & 0.000 & 0.000 & 0.000 & 0.000 & 0.100 & 0.300 & 0.200 & 0.440 & 0.500 & 0.120 & 0.050 & 0.130 \\
\hline HLW06-32 & 0.000 & 0.000 & & 0.000 & 0.000 & 0.000 & 0.000 & 0.000 & 0.000 & 0.000 & 0.000 & 0.100 & 0.300 & 0.200 & 0.440 & 0.500 & 0.120 & 0.050 & 0.130 \\
\hline HLW06-33 & 1.646 & 1.234 & & 0.280 & 10.287 & 0.300 & 1.000 & 1.640 & 1.170 & 0.910 & 1.000 & 0.100 & & 0.200 & 0.440 & 0.500 & 0.120 & 0.050 & 0.130 \\
\hline & & & & & & & & & & & & & & 0.200 & & & & 0.050 & 0.130 \\
\hline HLW06-35 & 0.213 & 0.160 & 0.321 & 0.036 & 1.330 & 0.047 & 0.156 & 0.256 & 0.183 & 0.142 & 0.156 & 0.100 & 0.300 & 0.200 & 0.440 & 0.500 & 0.120 & 0.050 & 0.130 \\
\hline
\end{tabular}

(a) Total concentrations of $\mathrm{Nd}_{2} \mathrm{O}_{3}$ are listed and include contributions from two groups: "Others1" and Constant $(0.250 \mathrm{wt} \%)$. 
Table 2.18. Target Glass Compositions Expressed in Revised Oxides (wt\%) for the HLW07 Test Matrix.

\begin{tabular}{|c|c|c|c|c|c|c|c|c|c|c|c|c|c|c|c|c|c|c|c|c|}
\hline Glass ID & oint Type ${ }^{(a)}$ & $\begin{array}{c}\text { Melt } \\
\text { Order }\end{array}$ & $\mathbf{A l}_{2} \mathrm{O}_{3}$ & $\mathbf{B}_{2} \mathbf{O}_{3}$ & $\mathrm{Cr}_{2} \mathrm{O}_{3}$ & $\mathrm{Fe}_{2} \mathrm{O}_{3}$ & $\mathbf{L i}_{2} \mathbf{O}$ & MnO & $\mathrm{Na}_{2} \mathrm{O}$ & $\mathrm{NiO}$ & $\mathrm{SiO}_{2}$ & SrO & $\mathrm{ThO}_{2}$ & $\mathbf{U O}_{3}$ & $\mathrm{ZnO}$ & $\mathrm{ZrO}_{2}$ & Others1 & Others2 & Constant & $\begin{array}{c}\text { Remain- } \\
\text { ing }\end{array}$ \\
\hline HLW07-01 & $\mathrm{C}$ & 20 & .161 & 9.206 & 277 & 7.993 & 1.802 & 3.171 & 1.287 & 0.422 & 41.825 & 4.260 & 2.138 & 2.206 & 0.983 & 4.300 & 0.644 & 0.588 & 1.735 & 0.000 \\
\hline HLW07-02 & pHLW02-46 & 6 & 5.500 & 9.149 & 0.040 & 10.001 & 3.701 & 3.500 & 9.001 & 0.800 & 49.003 & 1.500 & 0.000 & 0.000 & 2.000 & 2.500 & 0.600 & 0.610 & 1.348 & 0.746 \\
\hline HLW07-03 & epHLW03-41 & 26 & 3.888 & 8.732 & 0.140 & 6.939 & 3.710 & 2.698 & 9.093 & 0.395 & 43.059 & 2.705 & 3.658 & 3.032 & 1.920 & 6.767 & 0.599 & 0.427 & 1.395 & 0.843 \\
\hline HLW07-04 & RepHLW02-22 & 34 & 8.500 & 14.000 & 0.020 & 9.500 & 6.000 & 0.000 & 4.000 & 0.100 & 53.000 & 0.080 & 0.000 & 0.000 & 2.000 & 0.000 & 0.600 & 0.110 & 1.498 & 0.592 \\
\hline HLW07-05 & RepHLW03-07 & 33 & 4.961 & 4.961 & 0.496 & 13.891 & 4.750 & 6.945 & 11.693 & 0.100 & 39.825 & 0.000 & 0.000 & 6.306 & 3.461 & 0.000 & 0.598 & 0.110 & 1.313 & 0.590 \\
\hline HLW07-06 & $\mathrm{O}$ & 37 & 11.501 & 6.001 & 0.600 & 4.000 & 0.000 & 6.001 & 12.530 & 0.000 & 35.004 & 10.001 & 0.000 & 4.100 & 0.000 & 2.951 & 1.360 & 2.480 & 3.470 & 0.000 \\
\hline HLW07-07 & $\mathrm{O}$ & 1 & 3.000 & 6.001 & 0.050 & 14.001 & 0.000 & 0.500 & 17.977 & 1.000 & 35.059 & 10.001 & 0.000 & 4.100 & 0.000 & 1.000 & 1.360 & 2.480 & 3.470 & 0.000 \\
\hline HLW07-08 & $\mathrm{O}$ & 21 & 1.501 & 6.001 & 0.050 & 5.667 & 0.000 & 6.001 & 18.002 & 0.000 & 35.307 & 0.000 & 4.400 & 0.000 & 0.000 & 9.601 & 0.000 & 0.000 & 3.470 & 0.000 \\
\hline HLW07-09 & 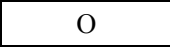 & 52 & 3.000 & 6.001 & 0.600 & 0.459 & 4.500 & 0.500 & 8.603 & 0.000 & 35.004 & 10.001 & 4.400 & 0.000 & 2.500 & 9.601 & 1.360 & 0.000 & 3.470 & 0.000 \\
\hline $\mathrm{HLV}$ & $\mathrm{O}$ & 7 & 000 & 11.867 & 0.600 & .001 & 000 & .500 & 461 & 14 & 35.004 & 10.001 & 4.400 & 4.100 & 0.000 & 1.000 & 000 & 80 & .470 & 000 \\
\hline HLW07-11 & $\mathrm{C}$ & 1 & 1 & 6 & 00 & 10.4 & 4.500 & .500 & 17.016 & 1.000 & 35 & 32 & 0.000 & 4.100 & 0.000 & .000 & .000 & 80 & 470 & .000 \\
\hline HLW07-12 & $\mathrm{O}$ & 4 & 11.501 & 6.001 & 0.116 & 13.191 & 4.413 & 0.500 & 17.903 & 0.000 & 35.004 & 0.000 & 4.400 & 0.000 & 2.500 & 1.000 & 0.000 & 0.000 & 3.470 & 0.000 \\
\hline HLW07-13 & $\mathrm{O}$ & 3 & 11.501 & 6.001 & 0.600 & 4.000 & 0.790 & 0.500 & 18.002 & 0.000 & 36.494 & 0.000 & 0.000 & 4.100 & 2.500 & 9.601 & 1.360 & 1.080 & 3.470 & 0.000 \\
\hline HLW07-14 & $\mathrm{O}$ & 8 & 11.501 & 6.001 & 0.050 & 4.647 & 4.284 & 0.500 & 6.001 & 1.000 & 35.004 & 10.001 & 0.000 & 4.100 & 0.000 & 9.601 & 1.360 & 2.480 & 3.470 & 0.000 \\
\hline HLW07-15 & $\mathrm{O}$ & 9 & 4.400 & 6.001 & 0.050 & 4.000 & 0.000 & 6.001 & 18.002 & 1.000 & 35.004 & 10.001 & 0.000 & 2.470 & 0.000 & 9.601 & 0.000 & 0.000 & 3.470 & 0.000 \\
\hline HLW07-16 & $\mathrm{O}$ & 2 & 4.400 & 11.569 & 0.600 & 4.000 & 3.853 & 6.001 & 18.002 & 1.000 & 35.004 & 0.000 & 0.000 & 0.000 & 2.500 & 9.601 & 0.000 & 0.000 & 3.470 & 0.000 \\
\hline HLW07-17 & $\mathrm{O}$ & 12 & 11.501 & 13.001 & 0.050 & 4.000 & 4.253 & 6.001 & 18.002 & 0.000 & 35.861 & 0.000 & 0.000 & 0.000 & 0.000 & 2.500 & 1.360 & 0.000 & 3.470 & 0.000 \\
\hline HLW07-18 & $\mathrm{O}$ & 15 & 9.077 & 13.001 & 0.600 & 7.925 & 4.500 & 0.500 & 18.002 & 0.000 & 37.524 & 0.000 & 4.400 & 0.000 & 0.000 & 1.000 & 0.000 & 0.000 & 3.470 & 0.000 \\
\hline HLW07-19 & $\mathrm{C}$ & 25 & 3.000 & 6.572 & 0.600 & 5.401 & 4.210 & 0.500 & 15.061 & 0.000 & 35.004 & 10.001 & 0.000 & 4.100 & 0.000 & 9.601 & 0.000 & 2.480 & 3.470 & 0.000 \\
\hline HLW07-20 & 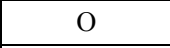 & 10 & 11.501 & 13.001 & 0.600 & 5.501 & 4.500 & 6.001 & 6.001 & 0.000 & 46.179 & 0.000 & 2.246 & 0.000 & 0.000 & 1.000 & 0.000 & 0.000 & 3.470 & 0.000 \\
\hline HLW07-21 & $\mathrm{O}$ & 19 & 3.000 & 6.001 & 0.050 & 5.401 & 0.000 & 0.500 & 11.335 & 0.000 & 42.700 & 10.001 & 0.000 & 4.100 & 0.000 & 9.601 & 1.360 & 2.480 & 3.470 & 0.000 \\
\hline HLW07-22 & $\mathrm{O}$ & 17 & 11.501 & 6.073 & 0.050 & 4.000 & 0.000 & 0.500 & 12.419 & 1.000 & 35.004 & 10.001 & 4.400 & 4.100 & 2.500 & 2.500 & 0.000 & 480 & 3.470 & .000 \\
\hline HLW07-23 & $\mathrm{O}$ & 35 & 4.400 & 13.001 & 0.600 & 4.000 & 1.822 & 0.500 & 6.620 & 1.000 & 41.883 & 6.501 & 0.000 & 4.100 & 2.500 & 9.601 & 0.000 & .000 & 3.470 & .000 \\
\hline HLW07-24 & $\mathrm{O}$ & 23 & 11.501 & 13.001 & 0.600 & 5.501 & 0.000 & 0.500 & 16.120 & 1.000 & 37.445 & 0.000 & 4.400 & 4.100 & 0.000 & 1.000 & 1.360 & .000 & 3.470 & 0.000 \\
\hline HLW07-25 & $\mathrm{O}$ & 22 & 11.501 & 6.001 & 0.050 & 5.501 & 0.997 & 6.001 & 11.453 & 0.000 & 42.662 & 0.000 & 4.400 & 4.100 & 0.384 & 1.000 & 0.000 & 2.480 & 3.470 & 0.000 \\
\hline
\end{tabular}

(a) "Point Type" notation: I = Inner layer, $\mathrm{O}$ = Outer layer, $\mathrm{C}=$ Center point. Replicate points are denoted by "RepHLWxx-xx", where the "xx-xx" represents a specific Glass ID number for a replicated glass. 
Table 2.18. Target Glass Compositions Expressed in Revised Oxides (wt\%) for the HLW07 Test Matrix (continued).

\begin{tabular}{|c|c|c|c|c|c|c|c|c|c|c|c|c|c|c|c|c|c|c|c|c|}
\hline Glass ID & $\begin{array}{l}\text { Point } \\
\text { Type }^{(a)}\end{array}$ & $\begin{array}{c}\text { Melt } \\
\text { Order }\end{array}$ & $\mathbf{l}_{2} \mathrm{O}_{3}$ & $\mathbf{B}_{2} \mathbf{O}_{3}$ & $\mathrm{Cr}_{2} \mathrm{O}_{3}$ & $\mathrm{Fe}_{2} \mathrm{O}_{3}$ & $\mathbf{L i}_{2} \mathbf{O}$ & MnO & $\mathrm{Na}_{2} \mathrm{O}$ & $\mathrm{NiO}$ & $\mathrm{SiO}_{2}$ & SrO & $\mathrm{ThO}_{2}$ & $\mathbf{U O}_{3}$ & $\mathrm{ZnO}$ & $\mathrm{ZrO}_{2}$ & Others1 & Others2 & Constant & $\begin{array}{c}\text { Remain } \\
\text { ing }\end{array}$ \\
\hline HLW07-26 & I & 1 & .001 & 8.000 & 150 & 6.000 & .460 & 2.500 & .001 & 0.650 & 7.002 & 2.500 & 3.500 & 1.500 & 0.500 & 2.500 & 0.000 & 0.000 & 1.735 & 0.000 \\
\hline HLW07-27 & I & 39 & 10.001 & 11.001 & 0.400 & 6.000 & 3.500 & 2.500 & 10.001 & 0.200 & 40.002 & 7.000 & 1.000 & 3.000 & 0.500 & 2.500 & 0.660 & 0.000 & 1.735 & 0.000 \\
\hline HLW07-28 & I & 30 & 10.001 & 8.000 & 0.150 & 6.000 & 3.500 & 2.500 & 14.001 & 0.650 & 40.002 & 3.100 & 3.500 & 1.500 & 1.500 & 2.500 & 1.360 & 0.000 & 1.735 & 0.000 \\
\hline HLW07-29 & I & 40 & 5.000 & 11.001 & 0.150 & 11.001 & 1.000 & 4.000 & 10.782 & 0.650 & 40.002 & 5.179 & 3.500 & 3.000 & 0.500 & 2.500 & 0.000 & 0.000 & 1.735 & 0.000 \\
\hline HLW07-30 & I & 11 & 5.000 & 8.000 & 0.400 & 11.001 & 1.000 & 3.687 & 12.614 & 0.200 & 47.002 & 2.500 & 1.000 & 1.500 & 0.500 & 2.500 & 1.360 & 0.000 & 1.735 & 0.000 \\
\hline HLW07-31 & I & 36 & 10.001 & 11.001 & 0.400 & 6.000 & 1.357 & 2.500 & 10.001 & 0.403 & 40.002 & 7.000 & 1.000 & 3.000 & 0.500 & 2.500 & 1.360 & 1.240 & 1.735 & 0.000 \\
\hline HLW07-32 & I & 5 & 5.000 & 8.000 & 0.150 & 11.001 & 1.000 & 2.500 & 14.001 & 0.650 & 40.002 & 3.264 & 1.000 & 1.500 & 1.096 & 6.500 & 1.360 & 1.240 & 1.735 & 0.000 \\
\hline HLW07-33 & I & 27 & 10.001 & 8.000 & 0.400 & 6.297 & 1.000 & 4.000 & 12.268 & 0.650 & 42.207 & 6.940 & 1.000 & 1.500 & 1.500 & 2.500 & 0.000 & 0.000 & 1.735 & 0.000 \\
\hline HLW07-34 & 1 & 31 & 10.001 & 11.001 & 0.150 & 6.000 & 2.063 & 4.000 & 10.001 & 0.650 & 41.514 & 2.905 & 1.000 & 1.981 & 0.500 & 6.500 & 0.000 & 0.000 & 1.735 & 0.000 \\
\hline HLW07-35 & 1 & 38 & 10.001 & 9.587 & 0.400 & 6.000 & 1.347 & 2.500 & 10.001 & 0.200 & 40.002 & 7.000 & 3.500 & 1.500 & 1.500 & 4.727 & 0.000 & 0.000 & 1.735 & 0.000 \\
\hline HLW07-36 & I & 24 & 9.500 & 11.001 & 0.150 & 6.000 & 1.000 & 2.500 & 14.001 & 0.200 & 40.002 & 6.910 & 1.000 & 3.000 & 0.500 & 2.500 & 0.000 & 0.000 & 1.735 & 0.000 \\
\hline HLW07-37 & I & 13 & 5.000 & 8.000 & 0.150 & 10.501 & 3.500 & 4.000 & 13.811 & 0.200 & 40.002 & 2.500 & 3.500 & 1.500 & 0.500 & 2.500 & 1.360 & 1.240 & 1.735 & 0.000 \\
\hline HLW07-38 & I & 28 & 5.000 & 11.001 & 0.400 & 6.500 & 1.000 & 4.000 & 10.393 & 0.200 & 41.670 & 2.500 & 3.500 & 1.500 & 1.500 & 6.500 & 1.360 & 1.240 & 1.735 & 0.000 \\
\hline HLW07-39 & I & 16 & 5.500 & 11.001 & 0.400 & 6.000 & 1.000 & 2.500 & 13.629 & 0.200 & 44.794 & 2.500 & 1.000 & 1.500 & 0.500 & 6.500 & 0.000 & 1.240 & 1.735 & 0.000 \\
\hline HLW07-40 & I & 29 & 5.000 & 8.000 & 0.400 & 10.384 & 1.000 & 2.500 & 10.001 & 0.200 & 42.803 & 7.000 & 3.500 & 2.119 & 1.500 & 2.617 & 0.000 & 1.240 & 1.735 & 0.000 \\
\hline
\end{tabular}

(a) "Point Type" notation: I = Inner layer, O = Outer layer, C = Center point. Replicate points are denoted by "RepHLWxx-xx", where the "xx-xx" represents a specific Glass ID number for a replicated glass. 


\section{Table 2.19. Expanded Compositions in Revised Oxides (wt\%) of "Others1," "Others2," and Constant Components for the HLW07 Test Matrix.}

\begin{tabular}{|c|c|c|c|c|c|c|c|c|c|c|c|c|c|c|c|c|c|c|c|c|c|c|c|}
\hline \multirow{2}{*}{ Glass ID } & \multicolumn{3}{|c|}{ Others1 Components } & \multicolumn{4}{|c|}{ Others2 Components } & \multicolumn{16}{|c|}{ Constant Components } \\
\hline & $\mathrm{MoO}_{3}$ & ${ }_{2} \mathrm{O}_{5}$ & $\mathrm{SO}_{3}$ & $\mathrm{dO}$ & $\mathrm{CoO}$ & $\mathrm{CuO}$ & $\mathbf{O}$ & D & 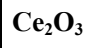 & $\mathrm{Cl}$ & o & $\mathbf{F}$ & ${ }_{2} \mathbf{O}$ & )$_{3}$ & )$_{3}$ & $\mathbf{O}$ & $\mathbf{h}_{2} \mathbf{O}_{3}$ & $\mathrm{O}_{2}$ & $\mathbf{b}_{2} \mathbf{O}_{3}$ & $\mathrm{OO}_{2}$ & $\mathrm{O}_{5}$ & $\mathrm{VO}_{3}$ & $\gamma_{2} \mathbf{O}_{3}$ \\
\hline HLW07-01 & 0.185 & 0.303 & 156 & .237 & .055 & .057 & 240 & 150 & .190 & 170 & 125 & .060 & 290 & 125 & 080 & .040 & .040 & .050 & .200 & .115 & .000 & .060 & 0.040 \\
\hline HLW07-02 & .000 & 0.500 & .100 & .500 & 010 & 020 & .080 & 500 & 048 & 200 & 010 & .050 & 0.060 & 0.300 & 000 & .000 & .050 & .080 & .050 & .000 & .000 & .000 & 0.000 \\
\hline HLW07-03 & 0.000 & 0.499 & 0.100 & 0.200 & 0.010 & 0.043 & 0.174 & 499 & .048 & 200 & .010 & 0.050 & 0.060 & \begin{tabular}{|l|}
0.299 \\
\end{tabular} & 0.000 & 0.000 & 0.050 & 0.080 & 0.100 & .000 & .000 & 0.000 & 0.000 \\
\hline HLW07-04 & 000 & 0.500 & .100 & 0.050 & 0.010 & 0.010 & 0.040 & 500 & 048 & .200 & 010 & .050 & 0.060 & 0.300 & 000 & 0.000 & .050 & 080 & 200 & 000 & 00 & .000 & 0.000 \\
\hline HLW07-05 & 0.000 & 498 & 100 & 0.050 & 0.010 & 0.010 & 0.040 & 498 & 48 & 19 & 010 & .0 & 0.060 & 99 & 000 & .000 & 050 & 080 & .020 & .000 & 00 & .000 & 0.000 \\
\hline HLW07-06 & 390 & 040 & 550 & 000 & 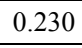 & 0 & 1.010 & 0.300 & 0.300 & טרד. & 0 & 0.120 & 0 & 0.250 & . & ov & ov & 0.100 & 西 & 30 & 00 & 20 & .080 \\
\hline HLW07-07 & 390 & 0.640 & טJנ. & 1.000 & 0.230 & .240 & . 010 & 80 & 500 & D & 250 & 120 & 0.000 & 80 & 100 & .000 & .000 & .100 & .400 & 230 & 000 & .120 & 0.080 \\
\hline HLW07-08 & 00 & 000 & 00 & 000 & 00 & 0 & 00 & & & & 50 & 20 & 00 & Jo & 60 & 80 & 080 & 100 & 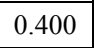 & 230 & 000 & 120 & .080 \\
\hline $\mathrm{H}$ & 390 & 0.640 & 0.330 & 000 & 0 & 0 & 0 & 0.300 & 0380 & 0.340 & .250 & 0 & 0.580 & 0.250 & 0.160 & 80 & 0 & 0.100 & 0.400 & 0 & 0 & 0.120 & 80 \\
\hline HLW & 0.000 & 0.000 & 0.000 & 1.000 & 0.230 & 0 & 1.010 & 300 & 380 & 34 & 250 & .120 & 0.580 & 0.250 & 0.160 & 0.080 & .080 & .100 & 400 & .230 & 000 & 20 & 0.080 \\
\hline HLW07-11 & 0.000 & 0.000 & 0.000 & 1.000 & 0.230 & 0.240 & 1.010 & 0.300 & 0.380 & 0.340 & 0.250 & 0.120 & 0.580 & 0.250 & 0.160 & 0.080 & 0.080 & 0.100 & 0.400 & 0.230 & 0.000 & 0.120 & 0.080 \\
\hline HLW07-12 & 0.000 & 0.000 & 0.000 & 0.000 & 0.000 & 0.000 & 0.000 & 0.300 & 0.380 & 0.340 & 0.250 & 0.120 & 0.580 & 0.250 & 0.160 & 0.080 & 0.080 & 0.100 & 0.400 & 0.230 & 0.000 & 0.120 & 0.080 \\
\hline HLW07-13 & 0.390 & 0.640 & 0.330 & 0.435 & 0.100 & 0.105 & 0.440 & 0.300 & 0.380 & 0.340 & 0.250 & 0.120 & 0.580 & 0.250 & 0.160 & 0.080 & 0.080 & 0.100 & 0.400 & 0.230 & 0.000 & 0.120 & 0.080 \\
\hline HLW07-14 & 0.390 & 0.640 & 0.330 & 1.000 & 0.230 & 0.240 & 1.010 & 0.300 & 0.380 & 0.340 & 0.250 & 0.120 & 0.580 & 0.250 & 0.160 & 0.080 & 0.080 & 0.100 & 0.400 & 0.230 & 0.000 & 0.120 & 0.080 \\
\hline HLW07-15 & 0.000 & 0.000 & 0.000 & 0.000 & 0.000 & 0.000 & 0.000 & 300 & 0.380 & 340 & 250 & .120 & 0.580 & 0.250 & 0.160 & .080 & .080 & 0.100 & 0.400 & .230 & 000 & .120 & 0.080 \\
\hline HLW07-16 & 0 & 0 & 0.000 & jo & 0 & 0 & 0 & 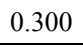 & 0.380 & .340 & J & 20 & 0 & 0 & 0 & 50 & 0.080 & 00 & 0 & 30 & 00 & 20 & 80 \\
\hline HLW07-1 & 0 & 0 & 0 & 00 & 00 & 0 & 0 & & & & & & & 50 & 60 & 80 & 80 & 100 & 00 & 230 & 00 & 20 & .080 \\
\hline HLW07-18 & 0.000 & 0.000 & 0.000 & 0.000 & 0.000 & 0.000 & 0.000 & 300 & 0.000 & .04 & .250 & .120 & 0.580 & 0.250 & .160 & .080 & .080 & 0.100 & .400 & 230 & .000 & .120 & 0.080 \\
\hline HLW07-19 & 0.000 & 0.000 & 0.000 & .000 & 0.230 & 0.240 & 1.010 & 0.300 & 0.380 & 0.340 & 250 & 0.120 & 0.580 & 50 & 160 & .080 & 080 & .100 & 400 & 230 & 00 & 120 & 0.080 \\
\hline HLW07-20 & 0.000 & 0.000 & 0.000 & 0.000 & 0.000 & 0.000 & 0.000 & 0.300 & 0.380 & 0.340 & 0.250 & 0.120 & 0.580 & 0.250 & 0.160 & 0.080 & 0.080 & 0.100 & 0.400 & .230 & .000 & .120 & 0.080 \\
\hline HLW07-21 & 0.390 & 0.640 & 0.330 & 1.000 & 0.230 & 0.240 & 1.010 & 0.300 & 0.380 & 0.340 & 0.250 & 0.120 & 0.580 & 0.250 & 0.160 & 0.080 & 0.080 & 0.100 & 0.400 & 0.230 & .000 & 0.120 & 0.080 \\
\hline HLW07-22 & 0.000 & 0.000 & 0.000 & 1.000 & 0.230 & 0.240 & 1.010 & 0.300 & 0.380 & .340 & .250 & 0.120 & 0.580 & \begin{tabular}{|l|}
0.250 \\
\end{tabular} & 0.160 & 0.080 & 0.080 & 0.100 & 0.400 & 0.230 & .000 & 0.120 & 0.080 \\
\hline HLW07-23 & 0.000 & 0.000 & 0.000 & 0.000 & 0.000 & 0.000 & 0.000 & 0.300 & 0.380 & 0.340 & 0.250 & 0.120 & 0.580 & 0.250 & 0.160 & 0.080 & \begin{tabular}{|l|}
0.080 \\
\end{tabular} & 0.100 & 0.400 & 0.230 & 0.000 & 0.120 & 0.080 \\
\hline HLW07-24 & 0.390 & 0.640 & 0.330 & 0.000 & 0.000 & 0.000 & 0.000 & 0.300 & 0.380 & 0.340 & 0.250 & 0.120 & 0.580 & \begin{tabular}{|l|}
0.250 \\
\end{tabular} & 0.160 & 0.080 & 0.080 & 0.100 & 0.400 & 0.230 & 0.000 & 0.120 & 0.080 \\
\hline HLW07-25 & 0.000 & 0.000 & 0.000 & 1.000 & 0.230 & 0.240 & 1.010 & 0.300 & 0.380 & 0.340 & 0.250 & 0.120 & 0.580 & 0.250 & 0.160 & 0.080 & 0.080 & 0.100 & 0.400 & 0.230 & 0.000 & 0.120 & 0.080 \\
\hline
\end{tabular}


Table 2.19. Expanded Compositions in Revised Oxides (wt\%) of "Others1," "Others2," and Constant Components for the HLW07 Test Matrix (continued).

\begin{tabular}{|c|c|c|c|c|c|c|c|c|c|c|c|c|c|c|c|c|c|c|c|c|c|c|c|}
\hline \multirow{2}{*}{ Glass ID } & \multicolumn{3}{|c|}{ Others1 Components } & \multicolumn{4}{|c|}{ Others2 Components } & \multicolumn{16}{|c|}{ Constant Components } \\
\hline & $\mathrm{MoO}_{3}$ & $\mathbf{P}_{2} \mathbf{O}_{5}$ & $\mathrm{SO}_{3}$ & CdO & $\mathrm{CoO}$ & $\mathrm{CuO}$ & PbO & $\mathrm{CaO}$ & $\mathrm{Ce}_{2} \mathrm{O}_{3}$ & $\mathrm{Cl}$ & $\mathrm{Cs}_{2} \mathrm{O}$ & $\mathbf{F}$ & $\mathbf{K}_{2} \mathbf{O}$ & $\mathbf{L a}_{2} \mathbf{O}_{3}$ & $\mathrm{Pr}_{2} \mathrm{O}_{3}$ & $\mathbf{R} \mathbf{b}_{2} \mathbf{O}$ & $\mathbf{R h}_{2} \mathbf{O}_{3}$ & $\mathrm{RuO}_{2}$ & $\mathbf{S b}_{2} \mathbf{O}_{3}$ & $\mathrm{SnO}_{2}$ & $\mathrm{Ta}_{2} \mathrm{O}_{5}$ & $\mathrm{WO}_{3}$ & $\mathbf{Y}_{2} \mathbf{O}_{3}$ \\
\hline HLW07-26 & 0.000 & 0.000 & .000 & 000 & 0.000 & 0.000 & 0.000 & 150 & 0.190 & 170 & 125 & 0.060 & 0.290 & 125 & 0.080 & .040 & .040 & 0.050 & 0.200 & 115 & 0.000 & 0.060 & 0.040 \\
\hline HLW07-27 & 0.189 & 0.311 & 0.160 & 0.000 & 0.000 & 0.000 & 0.000 & 150 & 190 & 170 & .125 & 0.060 & 0.290 & 0.125 & 0.080 & .040 & .040 & 0.050 & .200 & .115 & 0.000 & 0.060 & 0.040 \\
\hline HLW07-28 & 0.390 & 0.640 & 0.330 & 0.000 & 0.000 & 0.000 & 0.000 & 150 & .190 & 170 & .125 & 0.060 & 0.290 & 0.125 & 0.080 & 0.040 & 0.040 & 0.050 & 0.200 & 0.115 & 0.000 & 0.060 & 0.040 \\
\hline HLW07-29 & 0.000 & 0.000 & 0.000 & 0.000 & 0.000 & 0.000 & 0.000 & 0.150 & 0.190 & 0.170 & 0.125 & 0.060 & 0.290 & 0.125 & 0.080 & 0.040 & 0.040 & 0.050 & 0.200 & 0.115 & 0.000 & 0.060 & 0.040 \\
\hline HLW07-30 & 0.390 & 0.640 & 0.330 & 0.000 & 0.000 & 0.000 & 0.000 & 150 & 0.190 & 0.170 & 0.125 & 0.060 & 0.290 & 0.125 & 0.080 & 0.040 & 0.040 & 0.050 & 0.200 & 0.115 & 0.000 & 0.060 & 0.040 \\
\hline HLW07-31 & 0.390 & 0.640 & 330 & 500 & 5 & 0 & 0 & 0 & 190 & 70 & 25 & 60 & 290 & 25 & 80 & 040 & 040 & 050 & 200 & 115 & 000 & 060 & .040 \\
\hline HLV & 0.390 & 0.640 & 5 & 0 & 0.115 & 0. & 0 & 0 & 90 & 70 & 5 & 50 & 0.290 & 125 & 80 & 040 & 40 & 950 & 200 & 15 & 000 & 060 & .040 \\
\hline HLW07-33 & 0.000 & 0.000 & 0.000 & 0.000 & 0.000 & 0.000 & 0.000 & 0.150 & 0.190 & 0.170 & 0.125 & 0.060 & 0.290 & 0.125 & 0.080 & 0.040 & 0.040 & 0.050 & 0.200 & 0.115 & 0.000 & 0.060 & 0.040 \\
\hline HLW07-34 & 0.000 & 0.000 & 0.000 & 0.000 & 0.000 & 0.000 & 0.000 & 0.150 & 0.190 & 0.170 & 0.125 & 0.060 & 0.290 & 0.125 & 0.080 & 0.040 & 0.040 & 0.050 & 0.200 & 0.115 & 0.000 & 0.060 & 0.040 \\
\hline HLW07-35 & 0.000 & 0.000 & 0.000 & 0.000 & 0.000 & 0.000 & 0.000 & 0.150 & 0.190 & 0.170 & 0.125 & 0.060 & 0.290 & 0.125 & 0.080 & 0.040 & 0.040 & 0.050 & 0.200 & 0.115 & 0.000 & 0.060 & 0.040 \\
\hline HLW07-36 & 0.000 & 0.000 & 0.000 & 0.000 & 0.000 & 0.000 & 0.000 & 0.150 & 0.190 & 0.170 & 0.125 & 0.060 & 0.290 & 0.125 & 0.080 & 0.040 & 0.040 & 0.050 & 0.200 & 0.115 & 0.000 & 0.060 & 0.040 \\
\hline HLW07-37 & 0.390 & 0.640 & 0.330 & 0.500 & 0.115 & 0.120 & 0.505 & 0.150 & 0.190 & 0.170 & 0.125 & 0.060 & 0.290 & 0.125 & 0.080 & 0.040 & 0.040 & 0.050 & 0.200 & 0.115 & 0.000 & 0.060 & 0.040 \\
\hline HLW07-38 & 0.390 & 0.640 & 0.330 & 0.500 & 0.115 & 0.120 & 0.505 & 0.150 & 0.190 & 0.170 & 0.125 & 0.060 & 0.290 & 0.125 & 0.080 & 0.040 & 0.040 & 0.050 & 0.200 & 0.115 & 0.000 & 0.060 & 0.040 \\
\hline HLW07-39 & 0.000 & 0.000 & 0.000 & 0.500 & 0.115 & 0.120 & 0.505 & 0.150 & 0.190 & 0.170 & 0.125 & 0.060 & 0.290 & 0.125 & 0.080 & 0.040 & 0.040 & 0.050 & 0.200 & 0.115 & 0.000 & 0.060 & 0.040 \\
\hline HLW07-40 & 0.000 & 0.000 & 0.000 & 0.500 & 0.115 & 0.120 & 0.505 & 0.150 & 0.190 & 0.170 & 0.125 & 0.060 & 0.290 & 0.125 & 0.080 & 0.040 & \begin{tabular}{|l|}
0.040 \\
\end{tabular} & 0.050 & 0.200 & 0.115 & 0.000 & 0.060 & 0.040 \\
\hline
\end{tabular}


Table 2.20. Expanded Compositions in Revised Oxides (wt\%) of "Remaining" Components for the HLW07 Test Matrix.

\begin{tabular}{|c|c|c|c|c|c|c|c|c|c|c|c|c|}
\hline \multirow{2}{*}{ Glass ID } & \multicolumn{12}{|c|}{ Remaining Components $(w t \%)^{(\mathrm{a}, \mathrm{b})}$} \\
\hline & $\mathrm{Ag}_{2} \mathrm{O}$ & $\mathrm{As}_{2} \mathrm{O}_{5}$ & $\mathrm{BaO}$ & $\mathrm{Bi}_{2} \mathrm{O}_{3}$ & MgO & $\mathrm{Nd}_{2} \mathrm{O}_{3}$ & PdO & $\mathrm{SeO}_{2}$ & $\mathrm{TeO}_{2}$ & $\mathrm{TiO}_{2}$ & $\mathrm{Tl}_{2} \mathrm{O}$ & $\mathrm{V}_{2} \mathrm{O}_{5}$ \\
\hline HLW07-01 & 0.000 & 0.000 & 0.000 & 0.000 & 0.000 & 0.000 & 0.000 & 0.000 & 0.000 & 0.000 & 0.000 & 0.000 \\
\hline HLW07-02 & 0.040 & 0.046 & 0.060 & 0.010 & 0.120 & 0.000 & 0.120 & 0.150 & 0.010 & 0.030 & 0.140 & 0.020 \\
\hline HLW07-03 & 0.087 & 0.101 & 0.130 & 0.010 & 0.120 & 0.000 & 0.120 & 0.100 & 0.010 & 0.030 & 0.093 & 0.043 \\
\hline HLW07-04 & 0.020 & 0.023 & 0.030 & 0.010 & 0.120 & 0.000 & 0.120 & 0.200 & 0.010 & 0.030 & 0.019 & 0.010 \\
\hline HLW07-05 & 0.020 & 0.023 & 0.030 & 0.010 & 0.120 & 0.000 & 0.120 & 0.199 & 0.010 & 0.030 & 0.019 & 0.010 \\
\hline HLW07-06 & 0.000 & 0.000 & 0.000 & 0.000 & 0.000 & 0.000 & 0.000 & 0.000 & 0.000 & 0.000 & 0.000 & 0.000 \\
\hline HLW07-07 & 0.000 & 0.000 & 0.000 & 0.000 & 0.000 & 0.000 & 0.000 & 0.000 & 0.000 & 0.000 & 0.000 & 0.000 \\
\hline HLW07-08 & 0.000 & 0.000 & 0.000 & 0.000 & 0.000 & 0.000 & 0.000 & 0.000 & 0.000 & 0.000 & 0.000 & 0.000 \\
\hline HLW07-09 & 0.000 & 0.000 & 0.000 & 0.000 & 0.000 & 0.000 & 0.000 & 0.000 & 0.000 & 0.000 & 0.000 & 0.000 \\
\hline HLW07-10 & 0.000 & 0.000 & 0.000 & 0.000 & 0.000 & 0.000 & 0.000 & 0.000 & 0.000 & 0.000 & 0.000 & 0.000 \\
\hline HLW07-11 & 0.000 & 0.000 & 0.000 & 0.000 & 0.000 & 0.000 & 0.000 & 0.000 & 0.000 & 0.000 & 0.000 & 0.000 \\
\hline HLW07-12 & 0.000 & 0.000 & 0.000 & 0.000 & 0.000 & 0.000 & 0.000 & 0.000 & 0.000 & 0.000 & 0.000 & 0.000 \\
\hline HLW07-13 & 0.000 & 0.000 & 0.000 & 0.000 & 0.000 & 0.000 & 0.000 & 0.000 & 0.000 & 0.000 & 0.000 & 0.000 \\
\hline HLW07-14 & 0.000 & 0.000 & 0.000 & 0.000 & 0.000 & 0.000 & 0.000 & 0.000 & 0.000 & 0.000 & 0.000 & 0.000 \\
\hline HLW07-15 & 0.000 & 0.000 & 0.000 & 0.000 & 0.000 & 0.000 & 0.000 & 0.000 & 0.000 & 0.000 & 0.000 & 0.000 \\
\hline HLW07-16 & 0.000 & 0.000 & 0.000 & 0.000 & 0.000 & 0.000 & 0.000 & 0.000 & 0.000 & 0.000 & 0.000 & 0.000 \\
\hline HLW07-17 & 0.000 & 0.000 & 0.000 & 0.000 & 0.000 & 0.000 & 0.000 & 0.000 & 0.000 & 0.000 & 0.000 & 0.000 \\
\hline HLW07-18 & 0.000 & 0.000 & 0.000 & 0.000 & 0.000 & 0.000 & 0.000 & 0.000 & 0.000 & 0.000 & 0.000 & 0.000 \\
\hline HLW07-19 & 0.000 & 0.000 & 0.000 & 0.000 & 0.000 & 0.000 & 0.000 & 0.000 & 0.000 & 0.000 & 0.000 & 0.000 \\
\hline HLW07-20 & 0.000 & 0.000 & 0.000 & 0.000 & 0.000 & 0.000 & 0.000 & 0.000 & 0.000 & 0.000 & 0.000 & 0.000 \\
\hline HLW07-21 & 0.000 & 0.000 & 0.000 & 0.000 & 0.000 & 0.000 & 0.000 & 0.000 & 0.000 & 0.000 & 0.000 & 0.000 \\
\hline HLW07-22 & 0.000 & 0.000 & 0.000 & 0.000 & 0.000 & 0.000 & 0.000 & 0.000 & 0.000 & 0.000 & 0.000 & 0.000 \\
\hline HLW07-23 & 0.000 & 0.000 & 0.000 & 0.000 & 0.000 & 0.000 & 0.000 & 0.000 & 0.000 & 0.000 & 0.000 & 0.000 \\
\hline HLW07-24 & 0.000 & 0.000 & 0.000 & 0.000 & 0.000 & 0.000 & 0.000 & 0.000 & 0.000 & 0.000 & 0.000 & 0.000 \\
\hline HLW07-25 & 0.000 & 0.000 & 0.000 & 0.000 & 0.000 & 0.000 & 0.000 & 0.000 & 0.000 & 0.000 & 0.000 & 0.000 \\
\hline
\end{tabular}

(a) For each glass, the sum of the wt\% values for the components comprising "Remaining" equals the $w t \%$ value listed in the Remaining column of Table 2.18 , except for any differences resulting from rounding $\mathrm{wt} \%$ values to three decimal places.

(b) These components are present only in glasses replicated from Phase 1 Initial and Augmentation matrices (i.e., HLW07-02 through -05). They are not part of the design for the new HLW07 glasses (i.e., HLW07-06 through -40) and are not present in those glasses. Full composition expansions are given for all glasses for the purpose of completeness and consistency with earlier modeling reports. 
Table 2.21. Target Glass Compositions (wt\%) Expressed in Revised Oxides for the HLW-ALG Series.

\begin{tabular}{|c|c|c|c|c|c|c|c|c|c|c|c|c|c|c|c|c|c|c|c|}
\hline Glass ID & $\mathbf{A g}_{2} \mathrm{O}$ & $\mathrm{Al}_{2} \mathbf{O}_{3}$ & $\mathbf{B}_{2} \mathbf{O}_{3}$ & $\mathrm{BaO}$ & $\mathbf{B i}_{2} \mathbf{O}_{3}$ & $\mathrm{CaO}$ & CdO & $\mathrm{Ce}_{2} \mathrm{O}_{3}$ & $\mathrm{Cl}$ & $\mathrm{Cr}_{2} \mathrm{O}_{3}$ & $\mathrm{Cs}_{2} \mathrm{O}$ & $\mathrm{CuO}$ & $\mathbf{F}$ & $\mathrm{Fe}_{2} \mathrm{O}_{3}$ & $\mathbf{K}_{2} \mathbf{O}$ & $\mathrm{La}_{2} \mathrm{O}_{3}$ & $\mathbf{L i}_{2} \mathbf{O}$ & MgO & MnO \\
\hline HLW-ALG-01 & .046 & 1.086 & 0.560 & 0.035 & 0.000 & 0.331 & 0.000 & 0.050 & .000 & 0.501 & 0.000 & 0.000 & 0.032 & 9.619 & 0.124 & .101 & 3.329 & 0.096 & 0.000 \\
\hline HLW & 048 & 001 & .088 & 0.037 & 000 & $250 \quad 1$ & 000 & 053 & .000 & 278 & 0.000 & 0.000 & .033 & 7.145 & 0.132 & .107 & .550 & 0.101 & 0.000 \\
\hline HLW-ALG-03 & 047 & .926 & 8.621 & 0.036 & 0.000 & 0.339 & 0.000 & 0.051 & .000 & 0.501 & 0.000 & 0.000 & 0.032 & 12.650 & 0.127 & 0.103 & 3.057 & 0.098 & 2.095 \\
\hline LG-04 & 030 & 926 & .134 & 0.000 & 000 & 224 & 0.000 & 0.033 & 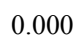 & 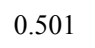 & 0.000 & 0.000 & 0.000 & 12.639 & 0.083 & 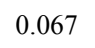 & .876 & .066 & 0.000 \\
\hline HLW & 072 & 927 & 810 & 0.056 & 00 & .521 & 1.198 & 079 & .000 & .4 & 0.000 & 0.000 & 0.050 & 12.536 & 0.197 & 0.160 & .286 & 0.149 & 6.906 \\
\hline HLW-ALG-06 & 0.080 & 9.670 & 807 & 0.062 & 0.000 & 0.579 & 1.322 & 0 & 0.000 & 201 & 0.025 & 25 & .056 & 10.620 & 0.219 & 78 & .530 & 0.164 & 4.007 \\
\hline HLW-ALG-07 & 0.054 & .194 & 10.704 & 0.042 & 0.000 & 0.390 & 0.000 & 0.059 & 0.000 & 0.000 & 0.000 & 0.000 & 0.037 & 1.928 & 0.147 & 0.119 & 3.258 & 0.114 & 2.339 \\
\hline HLW-ALG-08 & 0.082 & .926 & 4.807 & 0.064 & 0.000 & 0.591 & 1.349 & 0.090 & 0.000 & 0.471 & 0.026 & 0.026 & 0.057 & 7.318 & 0.224 & 0.182 & 2.081 & 0.167 & 3.560 \\
\hline HLW-ALG-09 & 053 & 5.480 & 4 ene & 0.080 & 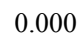 & 0560 & 0.084 & 0124 & 0.050 & 211 & 0000 & 0.000 & 0.076 & 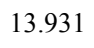 & .354 & .387 & 1.987 & .492 & 3.916 \\
\hline HLW-ALG-10 & 0.046 & 926 & 9.448 & 0.035 & 0.000 & 0.332 & 0.854 & 0.050 & 0.000 & 0.501 & 0.000 & 0.000 & 0.032 & 10.984 & 0.125 & 0.101 & 2.020 & 0.096 & 7.010 \\
\hline HLW-ALG-11 & 0.078 & 11.886 & 12.188 & 0.061 & 0.000 & 0.565 & 0.000 & 0.086 & 0.000 & 0.000 & 0.000 & 0.000 & 0.054 & 1.928 & 0.214 & 0.174 & 6.013 & 0.163 & 3.408 \\
\hline HLW-ALG-12 & 0.081 & 938 & 807 & 0.063 & (2) & .586 & 0.406 & 0.00 & c & 20 & 0.025 & 0.026 & 56 & 12.540 & 0.222 & 80 & .750 & 166 & 2.029 \\
\hline HLW-ALG-13 & 0.123 & 166 & 4.808 & 0.095 & 0.033 & 0.882 & 0.061 & 0.135 & 0.028 & 0.000 & 0.038 & 0.039 & 0.085 & 7.216 & 0.335 & 0.272 & 3.354 & 0.247 & 3.063 \\
\hline HLW-ALG-14 & 0.070 & 3.543 & 4.809 & 0.054 & 0.000 & 0.507 & 1.486 & 0.077 & 0.000 & 0.000 & 0.000 & 0.000 & 0.048 & 12.562 & 0.191 & 0.155 & 6.012 & 0.146 & 6.715 \\
\hline HLW-ALG-15 & 0.059 & 9.731 & 14.029 & 0.046 & 0.000 & 0.424 & 0.000 & 0.065 & 0.000 & .338 & 0.000 & 0.000 & 0.041 & 9.780 & 0.161 & 0.130 & 1.928 & 0.121 & 0.000 \\
\hline HLW-ALG-16 & 0.050 & 10.329 & 13.850 & 0.039 & 0.000 & 0.363 & 0.025 & 0.055 & 0.000 & 0.501 & 0.000 & 0.000 & 0.035 & 4.396 & 0.137 & 0.111 & 2.021 & 0.104 & 0.000 \\
\hline HLW-ALG-17 & 0.045 & 1.926 & 10.338 & 0.035 & 0.000 & 0.331 & 0.000 & 0.050 & 0.000 & 0.501 & 0.000 & 0.000 & 0.031 & 12.515 & 0.124 & 0.101 & 2.020 & 0.095 & 6.912 \\
\hline HLW-ALG-18 & 0.047 & 11.360 & 11.109 & 0.036 & 0.000 & 0.339 & 0.000 & 0.051 & 0.000 & 0.000 & 0.000 & 0.000 & 0.032 & 10.369 & 0.128 & 0.103 & 3.437 & 0.098 & 0.000 \\
\hline HLW-ALG-19 & 0.047 & 1.926 & 9.652 & 0.036 & 0.000 & 0.340 & 0.000 & 0.051 & 0.000 & 0.501 & 0.000 & 0.000 & 0.032 & 12.652 & 0.127 & 0.103 & 2.659 & 0.098 & 2.096 \\
\hline HLW-ALG-20 & 0.047 & 1.926 & 7.754 & 0.036 & 0.000 & 0.340 & 0.000 & 0.051 & 0.000 & 0.501 & 0.000 & 0.000 & 0.032 & 12.651 & 0.127 & 0.103 & 2.926 & 0.098 & 2.095 \\
\hline
\end{tabular}


Table 2.21. Target Glass Compositions (wt\%) Expressed in Revised Oxides for the HLW-ALG Series (continued).

\begin{tabular}{|c|c|c|c|c|c|c|c|c|c|c|c|c|c|c|c|c|c|c|c|}
\hline Glass ID & $\mathrm{Na}_{2} \mathrm{O}$ & $\mathrm{Nd}_{2} \mathrm{O}_{3}$ & $\mathrm{NiO}$ & $\mathbf{P}_{2} \mathbf{O}_{5}$ & PbO & PdO & $\operatorname{Pr}_{2} \mathrm{O}_{3}$ & $\mathbf{R b}_{2} \mathbf{O}$ & $\mathbf{R h}_{2} \mathbf{O}_{3}$ & $\mathrm{RuO}_{2}$ & $\mathrm{SO}_{3}$ & $\mathrm{SiO}_{2}$ & SrO & $\mathrm{ThO}_{2}$ & $\mathrm{TiO}_{2}$ & $\mathbf{U O}_{3}$ & $\mathrm{WO}_{3}$ & $\mathrm{ZnO}$ & $\mathrm{ZrO}_{2}$ \\
\hline HLW-ALG-01 & 17.280 & 0.085 & 0.000 & 0.096 & 0.202 & 0.000 & 0.000 & 0.000 & 0.000 & 0.028 & 0.052 & 45.286 & 0.000 & 0.000 & 0.000 & 0.000 & 0.000 & 1.062 & 0.000 \\
\hline HLW-ALG-02 & 15.318 & 0.090 & 0.522 & 0.101 & 0.214 & 0.000 & 0.000 & 0.000 & 0.000 & 0.030 & 0.055 & 44.674 & 0.000 & 0.000 & 0.000 & 0.000 & 0.000 & 1.577 & 6.495 \\
\hline HLW-ALG-03 & 18.966 & 0.087 & 1.001 & 0.098 & 0.207 & 0.000 & 0.000 & 0.000 & 0.000 & 0.029 & 0.054 & 44.365 & 0.000 & 0.000 & 0.043 & 0.000 & 0.000 & 0.032 & 5.433 \\
\hline HLW-ALG-04 & 15.980 & 0.057 & 1.001 & 0.064 & 0.135 & 0.000 & 0.000 & 0.000 & 0.000 & 0.000 & 0.036 & 51.881 & 0.000 & 0.000 & 0.039 & 0.000 & 0.000 & 1.226 & 0.000 \\
\hline HLW-ALG-05 & 8.937 & 0.134 & 0.781 & 0.151 & 0.320 & 0.000 & 0.027 & 0.000 & 0.000 & 0.045 & 0.080 & 46.197 & 9.891 & 0.000 & 0.026 & 0.000 & 0.000 & 0.050 & 0.000 \\
\hline HLW-ALG-06 & 15.635 & 0.149 & 0.481 & 0.169 & 0.357 & 0.000 & 0.030 & 0.000 & 0.000 & 0.050 & 0.088 & 37.279 & 8.015 & 1.603 & 0.025 & 0.601 & 0.026 & 0.055 & 0.801 \\
\hline HLW-ALG-07 & 11.777 & 0.100 & 0.000 & 0.118 & 0.239 & 0.000 & 0.000 & 0.000 & 0.000 & 0.034 & 0.061 & 44.110 & 4.113 & 4.126 & 0.000 & 0.000 & 0.000 & 1.675 & 6.262 \\
\hline HLW-ALG-08 & 13.943 & 0.152 & 0.887 & 0.172 & 0.364 & 0.000 & 0.031 & 0.000 & 0.000 & 0.051 & 0.089 & 36.699 & 6.267 & 4.006 & 0.052 & 4.644 & 0.026 & 0.056 & 9.541 \\
\hline HLW-ALG-09 & 15.116 & 0.299 & 0.189 & 0.204 & 0.410 & 0.000 & 0.028 & 0.000 & 0.000 & 0.000 & 0.229 & 38.868 & 7.479 & 0.603 & 0.000 & 1.360 & 0.000 & 0.059 & 2.565 \\
\hline HLW-ALG-10 & 17.410 & 0.085 & 1.001 & 0.096 & 0.203 & 0.000 & 0.000 & 0.000 & 0.000 & 0.028 & 0.051 & 47.112 & 0.000 & 0.228 & 0.036 & 0.000 & 0.000 & 0.031 & 0.159 \\
\hline HLW-ALG-11 & 6.065 & 0.146 & 0.000 & 0.170 & 0.348 & 0.000 & 0.029 & 0.000 & 0.000 & 0.049 & 0.088 & 35.076 & 5.994 & 6.013 & 0.000 & 0.000 & 0.025 & 0.054 & 9.125 \\
\hline HLW-ALG-12 & 15.899 & 0.151 & 0.812 & 0.171 & 0.361 & 0.000 & 0.031 & 0.000 & 0.000 & 0.051 & 0.089 & 40.350 & 6.087 & 1.623 & 0.026 & 1.623 & 0.026 & 0.056 & 2.394 \\
\hline HLW-ALG-13 & 9.504 & 0.228 & 0.061 & 0.258 & 0.545 & 0.000 & 0.046 & 0.000 & 0.000 & 0.077 & 0.130 & 35.058 & 6.125 & 5.513 & 0.036 & 6.125 & 0.040 & 0.084 & 9.188 \\
\hline HLW-ALG-14 & 4.804 & 0.130 & 0.759 & 0.147 & 0.311 & 0.000 & 0.026 & 0.000 & 0.000 & 0.044 & 0.078 & 47.605 & 9.618 & 0.000 & 0.052 & 0.000 & 0.000 & 0.048 & 0.000 \\
\hline HLW-ALG-15 & 17.583 & 0.109 & 0.636 & 0.124 & 0.261 & 0.000 & 0.000 & 0.000 & 0.000 & 0.037 & 0.065 & 37.449 & 0.000 & 0.000 & 0.000 & 0.000 & 0.000 & 0.040 & 6.845 \\
\hline HLW-ALG-16 & 17.406 & 0.093 & 0.751 & 0.106 & 0.223 & 0.000 & 0.000 & 0.000 & 0.000 & 0.031 & 0.056 & 43.773 & 0.000 & 0.000 & 0.000 & 0.000 & 0.000 & 1.786 & 3.757 \\
\hline HLW-ALG-17 & 17.414 & 0.085 & 0.997 & 0.095 & 0.202 & 0.000 & 0.000 & 0.000 & 0.000 & 0.028 & 0.051 & 45.869 & 0.000 & 0.000 & 0.043 & 0.000 & 0.000 & 0.031 & 0.159 \\
\hline HLW-ALG-18 & 14.807 & 0.087 & 0.000 & 0.098 & 0.207 & 0.000 & 0.000 & 0.000 & 0.000 & 0.029 & 0.053 & 45.993 & 0.000 & 0.000 & 0.000 & 0.000 & 0.000 & 1.616 & 0.000 \\
\hline HLW-ALG-19 & 16.131 & 0.087 & 1.001 & 0.098 & 0.207 & 0.000 & 0.000 & 0.000 & 0.000 & 0.029 & 0.053 & 46.563 & 0.000 & 0.000 & 0.043 & 0.000 & 0.000 & 0.032 & 5.434 \\
\hline HLW-ALG-20 & 17.400 & 0.087 & 1.001 & 0.098 & 0.207 & 0.000 & 0.000 & 0.000 & 0.000 & 0.029 & 0.053 & 46.929 & 0.000 & 0.000 & 0.043 & 0.000 & 0.000 & 0.032 & 5.434 \\
\hline
\end{tabular}


Table 2.21. Target Glass Compositions (wt\%) Expressed in Revised Oxides for the HLW-ALG Series (continued).

\begin{tabular}{|c|c|c|c|c|c|c|c|c|c|c|c|c|c|c|c|c|c|c|c|}
\hline Glass ID & $\mathrm{Ag}_{2} \mathrm{O}$ & $\mathbf{A l}_{2} \mathbf{O}_{3}$ & $\mathbf{B}_{2} \mathbf{O}_{3}$ & $\mathrm{BaO}$ & $\mathbf{B i}_{2} \mathbf{O}_{3}$ & $\mathrm{CaO}$ & $\mathrm{CdO}$ & $\mathrm{Ce}_{2} \mathrm{O}_{3}$ & $\mathbf{C l}$ & $\mathrm{Cr}_{2} \mathrm{O}_{3}$ & $\mathrm{Cs}_{2} \mathrm{O}$ & $\mathrm{CuO}$ & $\mathbf{F}$ & $\mathrm{Fe}_{2} \mathrm{O}_{3}$ & $\mathbf{K}_{2} \mathbf{O}$ & $\mathbf{L a}_{2} \mathrm{O}_{3}$ & $\mathbf{L i}_{2} \mathbf{O}$ & MgO & MnO \\
\hline HLW-ALG-21 & 0.140 & 2.619 & 4.810 & 0.048 & 0.000 & 0.642 & 0.131 & 0.049 & 0.000 & 0.493 & 0.000 & 0.034 & 0.039 & 9.663 & 0.174 & 0.136 & 2.475 & 0.112 & 1.186 \\
\hline HLW-ALG-22 & 0.138 & 2.588 & 6.599 & 0.048 & 0.000 & 0.635 & 0.129 & 0.049 & 0.000 & 0.487 & 0.000 & 0.033 & 0.038 & 9.548 & 0.172 & 0.135 & 2.407 & 0.111 & 1.172 \\
\hline HLW-ALG-23 & 0.133 & 2.492 & 4.809 & 0.046 & 0.000 & 0.611 & 0.124 & 0.047 & 0.000 & 0.469 & 0.000 & 0.032 & 0.037 & 9.180 & 0.165 & 0.130 & 2.069 & 0.107 & 1.127 \\
\hline HLW-ALG-24 & 0.126 & 12.589 & 4.808 & 0.097 & 0.034 & 0.902 & 0.063 & 0.138 & 0.029 & 0.000 & 0.039 & 0.040 & 0.087 & 1.927 & 0.343 & 0.278 & 4.265 & 0.255 & 3.134 \\
\hline HLW-ALG-25 & 0.046 & 1.926 & 10.096 & 0.035 & 0.000 & 0.332 & 0.000 & 0.050 & 0.000 & 0.501 & 0.000 & 0.000 & 0.032 & 11.817 & 0.125 & 0.101 & 2.020 & 0.096 & 7.012 \\
\hline HLW-ALG-26 & 0.092 & 4.632 & 7.474 & 0.071 & 0.000 & 0.661 & 0.046 & 0.101 & 0.000 & 0.000 & 0.029 & 0.029 & 0.063 & 5.397 & 0.251 & 0.203 & 3.024 & 0.187 & 2.289 \\
\hline HLW-ALG-27 & 0.054 & 13.025 & 14.027 & 0.042 & 0.000 & 0.387 & 0.000 & 0.059 & 0.000 & 0.000 & 0.000 & 0.000 & 0.037 & 11.905 & 0.146 & 0.119 & 1.928 & 0.111 & 0.000 \\
\hline HLW-ALG-28 & 0.054 & 8.839 & 14.027 & 0.042 & 0.000 & 0.388 & 0.000 & 0.059 & 0.000 & 0.322 & 0.000 & 0.000 & 0.037 & 12.884 & 0.147 & 0.119 & 1.928 & 0.111 & 2.330 \\
\hline HLW-ALG-29 & 0.060 & 9.926 & 14.030 & 0.047 & 0.000 & 0.433 & 0.000 & 0.066 & 0.000 & 0.345 & 0.000 & 0.000 & 0.041 & 8.882 & 0.164 & 0.133 & 1.928 & 0.123 & 0.000 \\
\hline HLW-ALG-30 & 0.037 & 7.250 & 9.597 & 0.065 & 0.000 & 0.422 & 0.631 & 0.233 & 0.058 & 0.141 & 0.000 & 0.029 & 0.000 & 11.020 & 0.133 & 0.259 & 3.099 & 0.102 & 0.323 \\
\hline HLW-ALG-31 & 0.047 & 1.926 & 10.888 & 0.036 & 0.000 & 0.340 & 0.000 & 0.051 & 0.000 & 0.501 & 0.000 & 0.000 & 0.032 & 12.650 & 0.127 & 0.103 & 3.078 & 0.098 & 2.095 \\
\hline HLW-ALG-32 & 0.073 & 6.000 & 4.810 & 0.057 & 0.000 & 0.529 & 1.213 & 0.080 & 0.000 & 0.420 & 0.000 & 0.000 & 0.051 & 12.753 & 0.200 & 0.162 & 3.972 & 0.151 & 6.996 \\
\hline HLW-ALG-33 & 0.069 & 11.389 & 8.006 & 0.053 & 0.000 & 0.497 & 0.000 & 0.076 & 0.000 & 0.396 & 0.000 & 0.000 & 0.048 & 11.456 & 0.188 & 0.153 & 3.783 & 0.141 & 0.000 \\
\hline HLW-ALG-34 & 0.046 & 1.926 & 8.223 & 0.035 & 0.000 & 0.331 & 0.000 & 0.050 & 0.000 & 0.501 & 0.000 & 0.000 & 0.031 & 12.515 & 0.124 & 0.101 & 2.020 & 0.096 & 6.912 \\
\hline HLW-ALG-35 & 0.053 & 5.519 & 4.808 & 0.080 & 0.000 & 0.564 & 0.085 & 0.125 & 0.049 & 0.212 & 0.000 & 0.000 & 0.076 & 14.024 & 0.356 & 0.390 & 2.801 & 0.495 & 3.942 \\
\hline HLW-ALG-36 & 0.090 & 6.536 & 6.511 & 0.070 & 0.000 & 0.645 & 0.447 & 0.099 & 0.000 & 0.314 & 0.028 & 0.028 & 0.062 & 13.819 & 0.245 & 0.199 & 2.903 & 0.182 & 2.236 \\
\hline HLW-ALG-37 & 0.123 & 6.186 & 4.808 & 0.096 & 0.033 & 0.884 & 0.062 & 0.135 & 0.028 & 0.000 & 0.039 & 0.039 & 0.085 & 7.240 & 0.336 & 0.273 & 2.580 & 0.248 & 3.072 \\
\hline HLW-ALG-38 & 0.142 & 2.661 & 7.901 & 0.049 & 0.000 & 0.652 & 0.133 & 0.050 & 0.000 & 0.501 & 0.000 & 0.034 & 0.039 & 9.809 & 0.176 & 0.139 & 2.880 & 0.114 & 1.204 \\
\hline HLW-ALG-39 & 0.102 & 1.927 & 10.207 & 0.035 & 0.000 & 0.468 & 0.095 & 0.036 & 0.000 & 0.358 & 0.000 & 0.000 & 0.028 & 7.012 & 0.126 & 0.099 & 3.110 & 0.084 & 0.860 \\
\hline HLW-ALG-40 & 0.047 & 9.195 & 8.436 & 0.082 & 0.000 & 0.535 & 0.802 & 0.297 & 0.073 & 0.179 & 0.000 & 0.037 & 0.000 & 14.008 & 0.170 & 0.329 & 3.054 & 0.128 & 0.411 \\
\hline
\end{tabular}


Table 2.21. Target Glass Compositions (wt\%) Expressed in Revised Oxides for the HLW-ALG Series (continued).

\begin{tabular}{|c|c|c|c|c|c|c|c|c|c|c|c|c|c|c|c|c|c|c|c|}
\hline Glass ID & $\mathrm{Na}_{2} \mathrm{O}$ & $\mathrm{Nd}_{2} \mathrm{O}_{3}$ & $\mathrm{NiO}$ & $\mathbf{P}_{2} \mathbf{O}_{5}$ & PbO & PdO & $\mathrm{Pr}_{2} \mathrm{O}_{3}$ & $\mathbf{R} \mathbf{b}_{2} \mathbf{O}$ & $\mathbf{R h}_{2} \mathbf{O}_{3}$ & $\mathrm{RuO}_{2}$ & $\mathrm{SO}_{3}$ & $\mathrm{SiO}_{2}$ & SrO & $\mathrm{ThO}_{2}$ & $\mathrm{TiO}_{2}$ & $\mathbf{U O}_{3}$ & $\mathrm{WO}_{3}$ & $\mathrm{ZnO}$ & $\mathrm{ZrO}_{2}$ \\
\hline HLW-ALG-21 & 17.623 & 0.103 & 0.542 & 0.118 & 0.180 & 0.000 & 0.000 & 0.030 & 0.000 & 0.000 & 0.121 & 38.986 & 0.000 & 5.894 & 0.027 & 4.502 & 0.123 & 0.084 & 8.915 \\
\hline HLW-ALG-22 & 16.615 & 0.101 & 0.535 & 0.117 & 0.178 & 0.000 & 0.000 & 0.029 & 0.000 & 0.000 & 0.120 & 38.701 & 0.000 & 5.824 & 0.027 & 4.449 & 0.121 & 0.083 & 8.809 \\
\hline HLW-ALG-23 & 19.298 & 0.097 & 0.515 & 0.112 & 0.171 & 0.000 & 0.000 & 0.028 & 0.000 & 0.000 & 0.116 & 39.517 & 0.000 & 5.599 & 0.026 & 4.278 & 0.116 & 0.079 & 8.469 \\
\hline HLW-ALG-24 & 9.813 & 0.234 & 0.063 & 0.269 & 0.558 & 0.000 & 0.047 & 0.000 & 0.000 & 0.078 & 0.135 & 35.060 & 4.071 & 5.637 & 0.036 & 5.637 & 0.040 & 0.086 & 9.082 \\
\hline HLW-ALG-25 & 17.414 & 0.085 & 1.002 & 0.096 & 0.203 & 0.000 & 0.000 & 0.000 & 0.000 & 0.029 & 0.051 & 46.478 & 0.000 & 0.228 & 0.036 & 0.000 & 0.000 & 0.031 & 0.159 \\
\hline HLW-ALG-26 & 9.610 & 0.171 & 0.046 & 0.193 & 0.408 & 0.000 & 0.035 & 0.000 & 0.000 & 0.057 & 0.098 & 43.210 & 4.578 & 4.120 & 0.029 & 4.578 & 0.030 & 1.427 & 6.866 \\
\hline HLW-ALG-27 & 17.589 & 0.100 & 0.000 & 0.113 & 0.238 & 0.000 & 0.000 & 0.000 & 0.000 & 0.033 & 0.059 & 37.713 & 0.000 & 0.000 & 0.000 & 0.000 & 0.000 & 2.316 & 0.000 \\
\hline HLW-ALG-28 & 17.589 & 0.100 & 0.589 & 0.113 & 0.238 & 0.000 & 0.000 & 0.000 & 0.000 & 0.034 & 0.059 & 39.956 & 0.000 & 0.000 & 0.000 & 0.000 & 0.000 & 0.037 & 0.000 \\
\hline HLW-ALG-29 & 17.581 & 0.112 & 0.649 & 0.126 & 0.266 & 0.000 & 0.000 & 0.000 & 0.000 & 0.037 & 0.066 & 36.865 & 0.000 & 0.000 & 0.000 & 0.000 & 0.000 & 0.041 & 8.079 \\
\hline HLW-ALG-30 & 15.321 & 0.190 & 0.485 & 0.393 & 0.073 & 0.101 & 0.000 & 0.000 & 0.000 & 0.075 & 0.000 & 44.901 & 0.153 & 0.000 & 0.000 & 0.911 & 0.000 & 0.654 & 3.343 \\
\hline HLW-ALG-31 & 11.711 & 0.087 & 1.001 & 0.098 & 0.207 & 0.000 & 0.000 & 0.000 & 0.000 & 0.029 & 0.052 & 47.666 & 0.000 & 0.000 & 0.043 & 0.000 & 0.000 & 1.699 & 5.433 \\
\hline HLW-ALG-32 & 9.317 & 0.136 & 0.791 & 0.153 & 0.324 & 0.000 & 0.027 & 0.000 & 0.000 & 0.046 & 0.080 & 41.153 & 10.020 & 0.000 & 0.082 & 0.000 & 0.000 & 0.404 & 0.000 \\
\hline HLW-ALG-33 & 17.656 & 0.128 & 0.746 & 0.145 & 0.306 & 0.000 & 0.026 & 0.000 & 0.000 & 0.043 & 0.077 & 36.552 & 0.000 & 0.000 & 0.000 & 0.000 & 0.000 & 0.047 & 8.019 \\
\hline HLW-ALG-34 & 19.002 & 0.085 & 0.997 & 0.095 & 0.202 & 0.000 & 0.000 & 0.000 & 0.000 & 0.028 & 0.051 & 46.396 & 0.000 & 0.000 & 0.043 & 0.000 & 0.000 & 0.031 & 0.159 \\
\hline HLW-ALG-35 & 10.818 & 0.301 & 0.190 & 0.205 & 0.413 & 0.000 & 0.028 & 0.000 & 0.000 & 0.000 & 0.230 & 40.921 & 7.529 & 0.607 & 0.000 & 1.369 & 0.000 & 1.228 & 2.582 \\
\hline HLW-ALG-36 & 12.535 & 0.167 & 0.894 & 0.188 & 0.398 & 0.000 & 0.034 & 0.000 & 0.000 & 0.056 & 0.097 & 38.173 & 6.709 & 1.789 & 0.028 & 1.789 & 0.029 & 0.062 & 2.639 \\
\hline HLW-ALG-37 & 9.358 & 0.229 & 0.061 & 0.259 & 0.547 & 0.000 & 0.046 & 0.000 & 0.000 & 0.077 & 0.130 & 35.059 & 6.145 & 5.530 & 0.036 & 6.145 & 0.040 & 0.853 & 9.217 \\
\hline HLW-ALG-38 & 10.641 & 0.104 & 0.550 & 0.120 & 0.183 & 0.000 & 0.000 & 0.030 & 0.000 & 0.000 & 0.122 & 41.588 & 0.000 & 5.983 & 0.028 & 4.570 & 0.124 & 0.420 & 9.050 \\
\hline HLW-ALG-39 & 11.054 & 0.074 & 0.393 & 0.086 & 0.131 & 0.000 & 0.000 & 0.000 & 0.000 & 0.000 & 0.088 & 47.962 & 0.000 & 4.274 & 0.000 & 3.265 & 0.089 & 1.572 & 6.465 \\
\hline HLW-ALG-40 & 14.348 & 0.242 & 0.616 & 0.499 & 0.092 & 0.128 & 0.000 & 0.000 & 0.031 & 0.096 & 0.000 & 40.399 & 0.195 & 0.000 & 0.000 & 1.158 & 0.000 & 0.162 & 4.250 \\
\hline
\end{tabular}


Table 2.22. Target Glass Compositions (wt\%) Expressed in Revised Oxides for the 40 HLW98 Glasses Having PCT, T $1 \%$, Electrical Conductivity, or Viscosity Data.

\begin{tabular}{|c|c|c|c|c|c|c|c|c|c|c|c|c|c|c|c|c|}
\hline Glass ID & $\mathbf{A g}_{2} \mathrm{O}$ & $\mathbf{A l}_{2} \mathbf{O}_{3}$ & $\mathrm{As}_{2} \mathrm{O}_{5}$ & $\mathbf{B}_{2} \mathbf{O}_{3}$ & $\mathrm{BaO}$ & $\mathrm{CaO}$ & CdO & $\mathrm{Ce}_{2} \mathrm{O}_{3}$ & $\mathbf{C l}$ & $\mathrm{CoO}$ & $\mathrm{Cr}_{2} \mathrm{O}_{3}$ & $\mathrm{Cs}_{2} \mathrm{O}$ & $\mathrm{CuO}$ & $\mathbf{F}$ & $\mathrm{Fe}_{2} \mathrm{O}_{3}$ & $\mathrm{HfO}_{2}$ \\
\hline HLW98-34CG & 0.236 & 10.775 & 0.000 & 7.000 & 0.066 & 0.715 & 0.044 & 0.030 & 0.024 & 0.000 & 0.163 & 0.102 & 0.000 & 0.024 & 11.726 & 0.000 \\
\hline HLW98-51AW & 0.045 & 2.648 & 0.000 & 9.227 & 0.024 & 0.675 & 0.056 & 0.076 & 0.000 & 0.002 & 0.145 & 0.000 & 0.030 & 0.000 & 4.551 & 0.000 \\
\hline HLW98-51AWCG & 0.045 & 2.648 & 0.000 & 9.227 & 0.024 & 0.675 & 0.056 & 0.076 & 0.000 & 0.002 & 0.145 & 0.000 & 0.030 & 0.000 & 4.551 & 0.000 \\
\hline HLW98-61 & 0.020 & 7.693 & 0.000 & 3.996 & 0.040 & 0.490 & 1.389 & 0.057 & 0.030 & 0.010 & 0.110 & 0.000 & 0.030 & 0.010 & 12.229 & 0.000 \\
\hline HLW98-61CG1 & 0.020 & 7.693 & 0.000 & 3.996 & 0.040 & 0.490 & 1.389 & 0.057 & 0.030 & 0.010 & 0.110 & 0.000 & 0.030 & 0.010 & 12.229 & 0.000 \\
\hline HLW98-72 & 0.023 & 5.192 & 0.000 & 8.185 & 0.000 & 0.278 & 0.064 & 0.000 & 0.000 & 0.000 & 0.000 & 0.008 & 0.036 & 0.036 & 12.189 & 0.000 \\
\hline HLW98-74 & 0.024 & 5.495 & 0.000 & 8.193 & 0.000 & 0.295 & 0.068 & 0.000 & 0.000 & 0.000 & 0.000 & 0.008 & 0.038 & 0.038 & 12.902 & 0.000 \\
\hline HLW98-75 & 0.024 & 5.495 & 0.000 & 6.691 & 0.000 & 0.295 & 0.068 & 0.000 & 0.000 & 0.000 & 0.000 & 0.008 & 0.038 & 0.038 & 12.902 & 0.000 \\
\hline HLW98-77 & 0.022 & 5.196 & 0.000 & 11.908 & 0.000 & 0.280 & 0.064 & 0.000 & 0.000 & 0.000 & 0.000 & 0.000 & 0.030 & 0.037 & 12.221 & 0.000 \\
\hline HLW98-77CG & 0.022 & 5.196 & 0.000 & 11.908 & 0.000 & 0.280 & 0.064 & 0.000 & 0.000 & 0.000 & 0.000 & 0.000 & 0.030 & 0.037 & 12.221 & 0.000 \\
\hline HLW98-80 & 0.034 & 5.590 & 0.000 & 12.529 & 0.000 & 0.233 & 0.114 & 0.000 & 0.000 & 0.000 & 0.000 & 0.000 & 0.000 & 0.000 & 12.530 & 0.000 \\
\hline HLW98-80CG & 0.034 & 5.590 & 0.000 & 12.529 & 0.000 & 0.233 & 0.114 & 0.000 & 0.000 & 0.000 & 0.000 & 0.000 & 0.000 & 0.000 & 12.530 & 0.000 \\
\hline HLW98-83 & 0.153 & 1.428 & 0.200 & 11.914 & 0.000 & 0.668 & 0.000 & 0.000 & 0.139 & 0.000 & 0.045 & 0.000 & 0.047 & 0.000 & 12.746 & 0.000 \\
\hline HLW98-84 & 0.153 & 5.182 & 0.200 & 11.163 & 0.000 & 0.668 & 0.000 & 0.000 & 0.139 & 0.000 & 0.045 & 0.000 & 0.047 & 0.000 & 12.746 & 0.000 \\
\hline HLW98-84CG & 0.153 & 5.182 & 0.200 & 11.163 & 0.000 & 0.668 & 0.000 & 0.000 & 0.139 & 0.000 & 0.045 & 0.000 & 0.047 & 0.000 & 12.746 & 0.000 \\
\hline HLW98-86 & 0.147 & 5.289 & 0.192 & 9.393 & 0.000 & 0.300 & 0.000 & 0.000 & 0.108 & 0.000 & 0.078 & 0.000 & 0.044 & 0.000 & 12.563 & 0.000 \\
\hline HLW98-86AG & 0.000 & 5.297 & 0.192 & 9.407 & 0.000 & 0.300 & 0.000 & 0.000 & 0.108 & 0.000 & 0.078 & 0.000 & 0.044 & 0.000 & 12.582 & 0.000 \\
\hline HLW98-86CG & 0.147 & 5.289 & 0.192 & 9.393 & 0.000 & 0.300 & 0.000 & 0.000 & 0.108 & 0.000 & 0.078 & 0.000 & 0.044 & 0.000 & 12.563 & 0.000 \\
\hline HLW98-87 & 0.039 & 7.680 & 0.000 & 10.102 & 0.069 & 0.442 & 0.674 & 0.249 & 0.029 & 0.000 & 0.143 & 0.000 & 0.043 & 0.000 & 11.759 & 0.000 \\
\hline HLW98-88 & 0.038 & 7.454 & 0.000 & 10.599 & 0.067 & 0.429 & 0.654 & 0.242 & 0.028 & 0.000 & 0.139 & 0.000 & 0.042 & 0.000 & 11.413 & 0.000 \\
\hline
\end{tabular}


Table 2.22. Target Glass Compositions (wt\%) Expressed in Revised Oxides for the 40 HLW98 Glasses Having PCT, T $1 \%$, Electrical Conductivity, or Viscosity Data (continued).

\begin{tabular}{|c|c|c|c|c|c|c|c|c|c|c|c|c|c|c|c|c|}
\hline Glass ID & $\mathbf{K}_{2} \mathbf{O}$ & $\mathbf{L a}_{2} \mathbf{O}_{3}$ & $\mathbf{L i}_{2} \mathbf{O}$ & MgO & MnO & $\mathrm{MoO}_{3}$ & $\mathrm{Na}_{2} \mathrm{O}$ & $\mathrm{Nd}_{2} \mathrm{O}_{3}$ & $\mathrm{NiO}$ & $\mathbf{P}_{2} \mathbf{O}_{5}$ & PbO & PdO & $\mathrm{Pr}_{2} \mathrm{O}_{3}$ & $\mathbf{R h}_{2} \mathbf{O}_{3}$ & $\mathrm{RuO}_{2}$ & $\mathrm{SO}_{3}$ \\
\hline HLW98-34CG & 0.027 & 0.111 & 4.000 & 0.220 & 4.435 & 0.000 & 9.364 & 0.000 & 0.154 & 0.151 & 0.215 & 0.000 & 0.000 & 0.000 & 0.000 & 0.024 \\
\hline HLW98-51AW & 0.060 & 0.019 & 5.662 & 0.059 & 2.449 & 0.002 & 9.084 & 0.044 & 0.239 & 0.369 & 0.200 & 0.011 & 0.000 & 0.032 & 0.016 & 0.000 \\
\hline HLW98-51AWCG & 0.060 & 0.019 & 5.662 & 0.059 & 2.449 & 0.002 & 9.084 & 0.044 & 0.239 & 0.369 & 0.200 & 0.011 & 0.000 & 0.032 & 0.016 & 0.000 \\
\hline HLW98-61 & 0.030 & 0.300 & 4.995 & 0.120 & 1.029 & 0.000 & 13.897 & 0.220 & 0.759 & 0.460 & 0.110 & 0.010 & 0.000 & 0.000 & 0.000 & 0.020 \\
\hline HLW98-61CG1 & 0.030 & 0.300 & 4.995 & 0.120 & 1.029 & 0.000 & 13.897 & 0.220 & 0.759 & 0.460 & 0.110 & 0.010 & 0.000 & 0.000 & 0.000 & 0.020 \\
\hline HLW98-72 & 0.061 & 0.406 & 5.028 & 0.107 & 0.169 & 0.000 & 13.447 & 0.250 & 0.618 & 0.000 & 0.036 & 0.000 & 0.000 & 0.000 & 0.000 & 0.074 \\
\hline HLW98-74 & 0.065 & 0.430 & 5.027 & 0.114 & 0.178 & 0.000 & 13.528 & 0.265 & 0.654 & 0.000 & 0.038 & 0.000 & 0.000 & 0.000 & 0.000 & 0.078 \\
\hline HLW98-75 & 0.065 & 0.430 & 5.027 & 0.114 & 0.178 & 0.000 & 13.528 & 0.265 & 0.654 & 0.000 & 0.038 & 0.000 & 0.000 & 0.000 & 0.000 & 0.078 \\
\hline HLW98-77 & 0.033 & 0.407 & 3.525 & 0.106 & 0.170 & 0.000 & 11.659 & 0.309 & 0.615 & 0.000 & 0.034 & 0.000 & 0.000 & 0.000 & 0.000 & 0.075 \\
\hline HLW98-77CG & 0.033 & 0.407 & 3.525 & 0.106 & 0.170 & 0.000 & 11.659 & 0.309 & 0.615 & 0.000 & 0.034 & 0.000 & 0.000 & 0.000 & 0.000 & 0.075 \\
\hline HLW98-80 & 0.032 & 0.376 & 3.260 & 0.073 & 0.357 & 0.000 & 12.033 & 0.165 & 0.447 & 0.024 & 0.070 & 0.000 & 0.000 & 0.000 & 0.000 & 0.041 \\
\hline HLW98-80CG & 0.032 & 0.376 & 3.260 & 0.073 & 0.357 & 0.000 & 12.033 & 0.165 & 0.447 & 0.024 & 0.070 & 0.000 & 0.000 & 0.000 & 0.000 & 0.041 \\
\hline HLW98-83 & 0.000 & 0.249 & 2.755 & 0.565 & 3.040 & 0.000 & 11.738 & 0.158 & 0.374 & 0.099 & 0.252 & 0.000 & 0.000 & 0.000 & 0.000 & 0.000 \\
\hline HLW98-84 & 0.000 & 0.249 & 2.755 & 0.565 & 3.040 & 0.000 & 11.988 & 0.158 & 0.374 & 0.099 & 0.252 & 0.000 & 0.000 & 0.000 & 0.000 & 0.000 \\
\hline HLW98-84CG & 0.000 & 0.249 & 2.755 & 0.565 & 3.040 & 0.000 & 11.988 & 0.158 & 0.374 & 0.099 & 0.252 & 0.000 & 0.000 & 0.000 & 0.000 & 0.000 \\
\hline HLW98-86 & 0.000 & 0.242 & 3.008 & 1.166 & 3.991 & 0.000 & 11.841 & 0.150 & 0.172 & 0.094 & 0.144 & 0.000 & 0.000 & 0.000 & 0.000 & 0.000 \\
\hline HLW98-86AG & 0.000 & 0.242 & 3.012 & 1.168 & 3.996 & 0.000 & 11.859 & 0.150 & 0.172 & 0.095 & 0.145 & 0.000 & 0.000 & 0.000 & 0.000 & 0.000 \\
\hline HLW98-86CG & 0.000 & 0.242 & 3.008 & 1.166 & 3.991 & 0.000 & 11.841 & 0.150 & 0.172 & 0.094 & 0.144 & 0.000 & 0.000 & 0.000 & 0.000 & 0.000 \\
\hline HLW98-87 & 0.717 & 0.277 & 3.509 & 0.104 & 0.345 & 0.000 & 11.076 & 0.203 & 0.517 & 0.419 & 0.078 & 0.108 & 0.000 & 0.026 & 0.086 & 0.083 \\
\hline HLW98-88 & 0.696 & 0.269 & 3.759 & 0.101 & 0.335 & 0.000 & 11.713 & 0.197 & 0.502 & 0.407 & 0.075 & 0.104 & 0.000 & 0.025 & 0.083 & 0.080 \\
\hline
\end{tabular}


Table 2.22. Target Glass Compositions (wt \%) Expressed in Revised Oxides for the 40 HLW98 Glasses Having PCT, T $1 \%$, Electrical Conductivity, or Viscosity Data (continued).

\begin{tabular}{|c|c|c|c|c|c|c|c|c|c|c|c|c|c|}
\hline Glass ID & $\mathrm{Sb}_{2} \mathbf{O}_{3}$ & $\mathrm{SeO}_{2}$ & $\mathrm{SiO}_{2}$ & $\mathrm{SnO}_{2}$ & SrO & $\mathrm{ThO}_{2}$ & $\mathrm{TiO}_{2}$ & $\mathbf{U O}_{3}$ & $\mathbf{V}_{2} \mathbf{O}_{5}$ & $\mathrm{WO}_{3}$ & $\mathbf{Y}_{2} \mathbf{O}_{3}$ & $\mathrm{ZnO}$ & $\mathrm{ZrO}_{2}$ \\
\hline HLW98-34CG & 0.000 & 0.000 & 40.889 & 0.000 & 7.348 & 0.000 & 0.039 & 0.000 & 0.000 & 0.000 & 0.000 & 2.000 & 0.116 \\
\hline HLW98-51AW & 0.000 & 0.000 & 47.095 & 0.068 & 2.934 & 3.800 & 0.030 & 4.101 & 0.005 & 0.000 & 0.003 & 1.986 & 4.252 \\
\hline HLW98-51AWCG & 0.000 & 0.000 & 47.095 & 0.068 & 2.934 & 3.800 & 0.030 & 4.101 & 0.005 & 0.000 & 0.003 & 1.986 & 4.252 \\
\hline HLW98-61 & 0.000 & 0.000 & 47.036 & 0.160 & 1.499 & 0.010 & 0.010 & 1.714 & 0.000 & 0.000 & 0.010 & 0.040 & 1.469 \\
\hline HLW98-61CG1 & 0.000 & 0.000 & 47.036 & 0.160 & 1.499 & 0.010 & 0.010 & 1.714 & 0.000 & 0.000 & 0.010 & 0.040 & 1.469 \\
\hline HLW98-72 & 0.000 & 0.000 & 47.982 & 0.000 & 0.000 & 0.000 & 0.000 & 0.000 & 0.000 & 0.000 & 0.000 & 2.018 & 3.795 \\
\hline HLW98-74 & 0.000 & 0.000 & 46.491 & 0.000 & 0.035 & 0.000 & 0.000 & 0.000 & 0.000 & 0.000 & 0.000 & 2.019 & 4.017 \\
\hline HLW98-75 & 0.000 & 0.000 & 47.993 & 0.000 & 0.035 & 0.000 & 0.000 & 0.000 & 0.000 & 0.000 & 0.000 & 2.019 & 4.017 \\
\hline HLW98-77 & 0.000 & 0.000 & 47.453 & 0.000 & 0.032 & 0.000 & 0.000 & 0.000 & 0.000 & 0.000 & 0.000 & 2.016 & 3.806 \\
\hline HLW98-77CG & 0.000 & 0.000 & 47.453 & 0.000 & 0.032 & 0.000 & 0.000 & 0.000 & 0.000 & 0.000 & 0.000 & 2.016 & 3.806 \\
\hline HLW98-80 & 0.000 & 0.000 & 48.308 & 0.000 & 0.000 & 0.000 & 0.000 & 0.000 & 0.000 & 0.000 & 0.000 & 2.012 & 1.772 \\
\hline HLW98-80CG & 0.000 & 0.000 & 48.308 & 0.000 & 0.000 & 0.000 & 0.000 & 0.000 & 0.000 & 0.000 & 0.000 & 2.012 & 1.772 \\
\hline HLW98-83 & 0.108 & 0.212 & 50.938 & 0.000 & 0.000 & 0.000 & 0.028 & 0.000 & 0.000 & 0.000 & 0.000 & 2.019 & 0.127 \\
\hline HLW98-84 & 0.108 & 0.212 & 47.684 & 0.000 & 0.000 & 0.000 & 0.028 & 0.000 & 0.000 & 0.000 & 0.000 & 2.019 & 0.127 \\
\hline HLW98-84CG & 0.108 & 0.212 & 47.684 & 0.000 & 0.000 & 0.000 & 0.028 & 0.000 & 0.000 & 0.000 & 0.000 & 2.019 & 0.127 \\
\hline HLW98-86 & 0.255 & 0.369 & 47.068 & 0.000 & 0.916 & 0.000 & 0.139 & 0.000 & 0.000 & 0.000 & 0.000 & 2.071 & 0.258 \\
\hline HLW98-86AG & 0.256 & 0.370 & 47.137 & 0.000 & 0.918 & 0.000 & 0.139 & 0.000 & 0.000 & 0.000 & 0.000 & 2.074 & 0.259 \\
\hline HLW98-86CG & 0.255 & 0.369 & 47.068 & 0.000 & 0.916 & 0.000 & 0.139 & 0.000 & 0.000 & 0.000 & 0.000 & 2.071 & 0.258 \\
\hline HLW98-87 & 0.000 & 0.000 & 44.503 & 0.000 & 0.164 & 0.000 & 0.000 & 0.973 & 0.000 & 0.000 & 0.000 & 2.014 & 3.570 \\
\hline HLW98-88 & 0.000 & 0.000 & 43.966 & 0.000 & 0.159 & 0.000 & 0.000 & 0.944 & 0.000 & 0.000 & 0.000 & 2.013 & 3.465 \\
\hline
\end{tabular}


Table 2.22. Target Glass Compositions (wt\%) Expressed in Revised Oxides for the 40 HLW98 Glasses Having PCT, T $1 \%$, Electrical Conductivity, or Viscosity Data (continued).

\begin{tabular}{|c|c|c|c|c|c|c|c|c|c|c|c|c|c|c|c|c|}
\hline Glass ID & $\mathbf{A g}_{2} \mathrm{O}$ & $\mathrm{Al}_{2} \mathrm{O}_{3}$ & $\mathbf{A s}_{2} \mathbf{O}_{5}$ & $\mathbf{B}_{2} \mathbf{O}_{3}$ & $\mathrm{BaO}$ & $\mathrm{CaO}$ & CdO & $\mathrm{Ce}_{2} \mathrm{O}_{3}$ & Cl & $\mathrm{CoO}$ & $\mathrm{Cr}_{2} \mathrm{O}_{3}$ & $\mathrm{Cs}_{2} \mathrm{O}$ & $\mathrm{CuO}$ & $\mathbf{F}$ & $\mathrm{Fe}_{2} \mathrm{O}_{3}$ & $\mathrm{HfO}_{2}$ \\
\hline HLW98-89 & 0.028 & 3.360 & 0.000 & 9.096 & 0.000 & 0.452 & 0.000 & 0.000 & 0.000 & 0.000 & 0.059 & 0.000 & 0.028 & 0.111 & 8.947 & 0.000 \\
\hline HLW98-94 & 0.000 & 9.376 & 0.000 & 11.514 & 0.065 & 0.242 & 0.653 & 0.389 & 0.000 & 0.000 & 0.026 & 0.062 & 0.097 & 0.036 & 10.523 & 0.000 \\
\hline HLW98-95 & 0.038 & 7.317 & 0.000 & 10.632 & 0.066 & 0.425 & 0.642 & 0.238 & 0.056 & 0.000 & 0.143 & 0.000 & 0.029 & 0.016 & 11.206 & 0.000 \\
\hline HLW98-95CG-1 & 0.038 & 7.317 & 0.000 & 10.632 & 0.066 & 0.425 & 0.642 & 0.238 & 0.056 & 0.000 & 0.143 & 0.000 & 0.029 & 0.016 & 11.206 & 0.000 \\
\hline HLW98-96 & 0.028 & 3.360 & 0.000 & 10.096 & 0.000 & 0.452 & 0.000 & 0.000 & 0.000 & 0.000 & 0.059 & 0.000 & 0.028 & 0.111 & 8.947 & 0.000 \\
\hline HLW98-96A & 0.029 & 3.449 & 0.000 & 10.364 & 0.000 & 0.464 & 0.000 & 2.585 & 0.000 & 0.000 & 0.061 & 0.000 & 0.029 & 0.114 & 9.185 & 0.000 \\
\hline HLW98-96B & 0.028 & 3.424 & 0.000 & 10.289 & 0.000 & 0.460 & 0.000 & 0.000 & 0.000 & 0.000 & 0.060 & 0.000 & 0.028 & 0.113 & 9.118 & 3.292 \\
\hline HLW98-96CG & 0.028 & 3.360 & 0.000 & 10.096 & 0.000 & 0.452 & 0.000 & 0.000 & 0.000 & 0.000 & 0.059 & 0.000 & 0.028 & 0.111 & 8.947 & 0.000 \\
\hline HLW98-96D & 0.030 & 3.598 & 0.000 & 10.812 & 0.000 & 0.484 & 0.000 & 0.000 & 0.000 & 0.000 & 0.063 & 0.000 & 0.030 & 0.119 & 9.581 & 0.000 \\
\hline HLW98-96NRE4 & 0.128 & 3.356 & 0.000 & 10.083 & 0.000 & 0.451 & 0.000 & 0.000 & 0.000 & 0.000 & 0.059 & 0.000 & 0.028 & 0.111 & 8.936 & 0.000 \\
\hline $\begin{array}{c}\text { HLW98- } \\
\text { 96NRE4CCC }\end{array}$ & 0.128 & 3.356 & 0.000 & 10.083 & 0.000 & 0.451 & 0.000 & 0.000 & 0.000 & 0.000 & 0.059 & 0.000 & 0.028 & 0.111 & 8.936 & 0.000 \\
\hline HLW98-96RE7 & 0.028 & 3.360 & 0.000 & 10.096 & 0.000 & 0.452 & 0.000 & 0.000 & 0.000 & 0.000 & 0.059 & 0.000 & 0.028 & 0.111 & 8.947 & 0.000 \\
\hline $\begin{array}{c}\text { HLW98- } \\
\text { 96RE7CCC }\end{array}$ & 0.028 & 3.360 & 0.000 & 10.096 & 0.000 & 0.452 & 0.000 & 0.000 & 0.000 & 0.000 & 0.059 & 0.000 & 0.028 & 0.111 & 8.947 & 0.000 \\
\hline HLW98-97 & 0.000 & 9.754 & 0.000 & 11.050 & 0.068 & 0.252 & 0.679 & 0.405 & 0.000 & 0.000 & 0.028 & 0.064 & 0.100 & 0.037 & 10.947 & 0.000 \\
\hline HLW98-T05 & 0.093 & 5.386 & 0.100 & 11.846 & 0.000 & 0.451 & 0.057 & 0.000 & 0.069 & 0.000 & 0.022 & 0.000 & 0.024 & 0.000 & 12.638 & 0.000 \\
\hline HLW98-V01 & 0.026 & 6.110 & 0.000 & 11.237 & 0.000 & 0.329 & 0.075 & 0.000 & 0.000 & 0.000 & 0.000 & 0.000 & 0.036 & 0.043 & 14.372 & 0.000 \\
\hline HLW98-V07 & 0.040 & 6.589 & 0.000 & 11.936 & 0.000 & 0.275 & 0.134 & 0.000 & 0.000 & 0.000 & 0.000 & 0.000 & 0.000 & 0.000 & 14.770 & 0.000 \\
\hline HLW98-V13 & 0.181 & 5.233 & 0.236 & 10.581 & 0.000 & 0.789 & 0.000 & 0.000 & 0.164 & 0.000 & 0.053 & 0.000 & 0.056 & 0.000 & 15.052 & 0.000 \\
\hline HLW98-V19 & 0.172 & 5.774 & 0.224 & 8.816 & 0.000 & 0.351 & 0.000 & 0.000 & 0.127 & 0.000 & 0.091 & 0.000 & 0.052 & 0.000 & 14.687 & 0.000 \\
\hline HLW98-V24 & 0.119 & 4.732 & 0.154 & 10.055 & 0.000 & 0.242 & 0.000 & 0.000 & 0.087 & 0.000 & 0.063 & 0.000 & 0.036 & 0.000 & 10.123 & 0.000 \\
\hline
\end{tabular}


Table 2.22. Target Glass Compositions (wt\%) Expressed in Revised Oxides for the 40 HLW98 Glasses Having PCT, T $1 \%$, Electrical Conductivity, or Viscosity Data (continued).

\begin{tabular}{|c|c|c|c|c|c|c|c|c|c|c|c|c|c|c|c|c|}
\hline Glass ID & $\mathrm{K}_{2} \mathrm{O}$ & $\mathrm{La}_{2} \mathrm{O}_{3}$ & $\mathbf{L i}_{2} \mathbf{O}$ & MgO & MnO & $\mathrm{MoO}_{3}$ & $\mathrm{Na}_{2} \mathrm{O}$ & $\mathrm{Nd}_{2} \mathrm{O}_{3}$ & $\mathrm{NiO}$ & $\mathbf{P}_{2} \mathbf{O}_{5}$ & PbO & PdO & $\mathrm{Pr}_{2} \mathrm{O}_{3}$ & $\mathbf{R h}_{2} \mathbf{O}_{3}$ & $\mathrm{RuO}_{2}$ & $\mathrm{SO}_{3}$ \\
\hline HLW98-89 & 0.000 & 0.149 & 2.843 & 0.000 & 1.425 & 0.000 & 10.736 & 0.101 & 0.438 & 0.038 & 0.115 & 0.000 & 0.000 & 0.000 & 0.000 & 0.000 \\
\hline HLW98-94 & 0.412 & 0.345 & 3.872 & 0.090 & 0.122 & 0.000 & 11.853 & 0.211 & 0.598 & 0.000 & 0.060 & 0.000 & 0.050 & 0.000 & 0.000 & 0.130 \\
\hline HLW98-95 & 0.136 & 0.264 & 3.758 & 0.099 & 0.329 & 0.000 & 11.925 & 0.194 & 0.493 & 0.400 & 0.074 & 0.102 & 0.000 & 0.024 & 0.082 & 0.119 \\
\hline HLW98-95CG-1 & 0.136 & 0.264 & 3.758 & 0.099 & 0.329 & 0.000 & 11.925 & 0.194 & 0.493 & 0.400 & 0.074 & 0.102 & 0.000 & 0.024 & 0.082 & 0.119 \\
\hline HLW98-96 & 0.000 & 0.149 & 3.093 & 0.000 & 1.425 & 0.000 & 10.736 & 0.101 & 0.438 & 0.038 & 0.115 & 0.000 & 0.000 & 0.000 & 0.000 & 0.000 \\
\hline HLW98-96A & 0.000 & 0.153 & 3.176 & 0.000 & 1.462 & 0.000 & 11.021 & 1.657 & 0.449 & 0.039 & 0.118 & 0.000 & 0.000 & 0.000 & 0.000 & 0.000 \\
\hline HLW98-96B & 0.000 & 0.152 & 3.153 & 0.000 & 1.452 & 0.000 & 10.941 & 1.645 & 0.446 & 0.039 & 0.117 & 0.000 & 0.000 & 0.000 & 0.000 & 0.000 \\
\hline HLW98-96CG & 0.000 & 0.149 & 3.093 & 0.000 & 1.425 & 0.000 & 10.736 & 0.101 & 0.438 & 0.038 & 0.115 & 0.000 & 0.000 & 0.000 & 0.000 & 0.000 \\
\hline HLW98-96D & 0.000 & 0.160 & 3.313 & 0.000 & 1.526 & 0.000 & 11.497 & 0.108 & 0.469 & 0.041 & 0.123 & 0.000 & 0.000 & 0.000 & 0.000 & 0.000 \\
\hline HLW98-96NRE4 & 0.000 & 0.149 & 3.090 & 0.000 & 1.423 & 0.000 & 10.722 & 0.101 & 0.437 & 0.038 & 0.115 & 0.000 & 0.000 & 0.017 & 0.006 & 0.000 \\
\hline $\begin{array}{c}\text { HLW98- } \\
\text { 96NRE4CCC }\end{array}$ & 0.000 & 0.149 & 3.090 & 0.000 & 1.423 & 0.000 & 10.722 & 0.101 & 0.437 & 0.038 & 0.115 & 0.000 & 0.000 & 0.017 & 0.006 & 0.000 \\
\hline HLW98-96RE7 & 0.000 & 0.149 & 3.093 & 0.000 & 1.425 & 0.000 & 10.736 & 0.101 & 0.438 & 0.038 & 0.115 & 0.000 & 0.000 & 0.000 & 0.000 & 0.000 \\
\hline $\begin{array}{c}\text { HLW98- } \\
\text { 96RE7CCC }\end{array}$ & 0.000 & 0.149 & 3.093 & 0.000 & 1.425 & 0.000 & 10.736 & 0.101 & 0.438 & 0.038 & 0.115 & 0.000 & 0.000 & 0.000 & 0.000 & 0.000 \\
\hline HLW98-97 & 0.429 & 0.359 & 3.877 & 0.094 & 0.126 & 0.000 & 12.180 & 0.220 & 0.622 & 0.000 & 0.063 & 0.000 & 0.052 & 0.000 & 0.000 & 0.135 \\
\hline HLW98-T05 & 0.016 & 0.313 & 3.008 & 0.319 & 1.698 & 0.000 & 12.010 & 0.161 & 0.410 & 0.062 & 0.161 & 0.000 & 0.000 & 0.000 & 0.000 & 0.021 \\
\hline HLW98-V01 & 0.039 & 0.479 & 3.321 & 0.125 & 0.200 & 0.000 & 11.239 & 0.364 & 0.723 & 0.000 & 0.040 & 0.000 & 0.000 & 0.000 & 0.000 & 0.088 \\
\hline HLW98-V07 & 0.037 & 0.443 & 3.076 & 0.086 & 0.421 & 0.000 & 11.529 & 0.195 & 0.526 & 0.029 & 0.083 & 0.000 & 0.000 & 0.000 & 0.000 & 0.049 \\
\hline HLW98-V13 & 0.000 & 0.294 & 2.604 & 0.667 & 3.589 & 0.000 & 11.437 & 0.186 & 0.442 & 0.117 & 0.297 & 0.000 & 0.000 & 0.000 & 0.000 & 0.000 \\
\hline HLW98-V19 & 0.000 & 0.282 & 2.814 & 1.364 & 4.665 & 0.000 & 11.211 & 0.175 & 0.201 & 0.110 & 0.169 & 0.000 & 0.000 & 0.000 & 0.000 & 0.000 \\
\hline HLW98-V24 & 0.000 & 0.195 & 3.230 & 0.940 & 3.216 & 0.000 & 12.566 & 0.121 & 0.139 & 0.076 & 0.116 & 0.000 & 0.000 & 0.000 & 0.000 & 0.000 \\
\hline
\end{tabular}


Table 2.22. Target Glass Compositions (wt \%) Expressed in Revised Oxides for the 40 HLW98 Glasses Having PCT, T $1 \%$, Electrical Conductivity, or Viscosity Data (continued).

\begin{tabular}{|c|c|c|c|c|c|c|c|c|c|c|c|c|c|}
\hline Glass ID & $\mathrm{Sb}_{2} \mathbf{O}_{3}$ & $\mathrm{SeO}_{2}$ & $\mathrm{SiO}_{2}$ & $\mathrm{SnO}_{2}$ & SrO & $\mathrm{ThO}_{2}$ & $\mathrm{TiO}_{2}$ & $\mathbf{U O}_{3}$ & $\mathbf{V}_{2} \mathbf{O}_{5}$ & $\mathrm{WO}_{3}$ & $\mathbf{Y}_{2} \mathbf{O}_{3}$ & $\mathrm{ZnO}$ & $\mathrm{ZrO}_{2}$ \\
\hline HLW98-89 & 0.000 & 0.000 & 44.571 & 0.000 & 0.000 & 4.051 & 0.021 & 2.573 & 0.000 & 0.000 & 0.000 & 2.017 & 8.843 \\
\hline HLW98-94 & 0.000 & 0.000 & 43.952 & 0.000 & 0.028 & 0.000 & 0.000 & 0.000 & 0.000 & 0.000 & 0.000 & 2.060 & 3.235 \\
\hline HLW98-95 & 0.000 & 0.000 & 44.687 & 0.000 & 0.156 & 0.000 & 0.011 & 0.927 & 0.000 & 0.000 & 0.000 & 2.012 & 3.402 \\
\hline HLW98-95CG-1 & 0.000 & 0.000 & 44.687 & 0.000 & 0.156 & 0.000 & 0.011 & 0.927 & 0.000 & 0.000 & 0.000 & 2.012 & 3.402 \\
\hline HLW98-96 & 0.000 & 0.000 & 43.322 & 0.000 & 0.000 & 4.051 & 0.021 & 2.573 & 0.000 & 0.000 & 0.000 & 2.017 & 8.843 \\
\hline HLW98-96A & 0.000 & 0.000 & 44.475 & 0.000 & 0.000 & 0.000 & 0.021 & 0.000 & 0.000 & 0.000 & 0.000 & 2.071 & 9.078 \\
\hline HLW98-96B & 0.000 & 0.000 & 44.152 & 0.000 & 0.000 & 0.000 & 0.021 & 0.000 & 0.000 & 0.000 & 0.000 & 2.056 & 9.012 \\
\hline HLW98-96CG & 0.000 & 0.000 & 43.322 & 0.000 & 0.000 & 4.051 & 0.021 & 2.573 & 0.000 & 0.000 & 0.000 & 2.017 & 8.843 \\
\hline HLW98-96D & 0.000 & 0.000 & 46.395 & 0.000 & 0.000 & 0.000 & 0.022 & 0.000 & 0.000 & 0.000 & 0.000 & 2.160 & 9.470 \\
\hline HLW98-96NRE4 & 0.000 & 0.000 & 43.268 & 0.000 & 0.000 & 4.046 & 0.021 & 2.569 & 0.000 & 0.000 & 0.000 & 2.015 & 8.832 \\
\hline $\begin{array}{c}\text { HLW98- } \\
\text { 96NRE4CCC }\end{array}$ & 0.000 & 0.000 & 43.268 & 0.000 & 0.000 & 4.046 & 0.021 & 2.569 & 0.000 & 0.000 & 0.000 & 2.015 & 8.832 \\
\hline HLW98-96RE7 & 0.000 & 0.000 & 43.322 & 0.000 & 0.000 & 4.051 & 0.021 & 2.573 & 0.000 & 0.000 & 0.000 & 2.017 & 8.843 \\
\hline $\begin{array}{c}\text { HLW98- } \\
\text { 96RE7CCC }\end{array}$ & 0.000 & 0.000 & 43.322 & 0.000 & 0.000 & 4.051 & 0.021 & 2.573 & 0.000 & 0.000 & 0.000 & 2.017 & 8.843 \\
\hline HLW98-97 & 0.000 & 0.000 & 43.002 & 0.000 & 0.029 & 0.000 & 0.000 & 0.000 & 0.000 & 0.000 & 0.000 & 2.063 & 3.366 \\
\hline HLW98-T05 & 0.054 & 0.106 & 47.996 & 0.000 & 0.000 & 0.000 & 0.014 & 0.000 & 0.000 & 0.000 & 0.000 & 2.015 & 0.950 \\
\hline HLW98-V01 & 0.000 & 0.000 & 44.738 & 0.000 & 0.038 & 0.000 & 0.000 & 0.000 & 0.000 & 0.000 & 0.000 & 1.900 & 4.476 \\
\hline HLW98-V07 & 0.000 & 0.000 & 45.793 & 0.000 & 0.000 & 0.000 & 0.000 & 0.000 & 0.000 & 0.000 & 0.000 & 1.899 & 2.089 \\
\hline HLW98-V13 & 0.128 & 0.250 & 45.551 & 0.000 & 0.000 & 0.000 & 0.033 & 0.000 & 0.000 & 0.000 & 0.000 & 1.911 & 0.150 \\
\hline HLW98-V19 & 0.299 & 0.432 & 44.496 & 0.000 & 1.071 & 0.000 & 0.162 & 0.000 & 0.000 & 0.000 & 0.000 & 1.953 & 0.302 \\
\hline HLW98-V24 & 0.206 & 0.298 & 50.023 & 0.000 & 0.738 & 0.000 & 0.112 & 0.000 & 0.000 & 0.000 & 0.000 & 2.206 & 0.208 \\
\hline
\end{tabular}


Table 2.23. Target Glass Compositions (wt\%) Expressed in Revised Oxides for the Actual HLW Glasses.

\begin{tabular}{|c|c|c|c|c|c|c|c|c|c|c|c|c|c|c|c|}
\hline Waste Group & $\mathrm{Ag}_{2} \mathbf{O}$ & $\mathrm{Al}_{2} \mathbf{O}_{3}$ & $\mathbf{B}_{2} \mathbf{O}_{3}$ & $\mathbf{B a O}$ & $\mathbf{B e O}$ & $\mathbf{B i}_{2} \mathbf{O}_{3}$ & $\mathbf{C a O}$ & $\mathbf{C d O}$ & $\mathrm{Ce}_{2} \mathbf{O}_{3}$ & $\mathbf{C l}$ & $\mathrm{CoO}_{\mathbf{O}}$ & $\mathrm{Cr}_{2} \mathbf{O}_{3}$ & $\mathrm{Cs}_{2} \mathbf{O}$ & $\mathrm{CuO}$ & $\mathbf{D y}_{2} \mathbf{O}_{3}$ \\
\hline $\mathrm{AZ101}$ & 0.010 & 8.230 & 10.080 & 0.060 & 0.000 & 0.020 & 0.470 & 0.680 & 0.060 & 0.030 & 0.010 & 0.130 & 0.000 & 0.020 & 0.000 \\
\hline $\mathrm{AZ}-102$ & 0.027 & 7.813 & 3.785 & 0.048 & 0.000 & 0.000 & 0.339 & 1.288 & 0.056 & 0.000 & 0.037 & 0.111 & 0.000 & 0.049 & 0.030 \\
\hline $\mathrm{C}-104$ & 0.045 & 2.648 & 9.228 & 0.024 & 0.005 & 0.000 & 0.675 & 0.056 & 0.076 & 0.000 & 0.002 & 0.145 & 0.000 & 0.030 & 0.000 \\
\hline $\mathrm{C}-106$ & 0.022 & 7.214 & 4.401 & 0.052 & 0.000 & 0.000 & 0.717 & 0.021 & 0.000 & 0.000 & 0.124 & 0.287 & 0.000 & 0.230 & 0.000 \\
\hline $\mathrm{AY}-102 / \mathrm{C}-106$ & 0.116 & 5.188 & 14.624 & 0.010 & 0.000 & 0.000 & 0.469 & 0.003 & 0.212 & 0.000 & 0.000 & 0.187 & 0.000 & 0.121 & 0.000 \\
\hline
\end{tabular}

\begin{tabular}{|c|c|c|c|c|c|c|c|c|c|c|c|c|c|c|c|}
\hline Waste Group & $\mathbf{E u}_{2} \mathbf{O}_{3}$ & $\mathbf{F}$ & $\mathrm{Fe}_{2} \mathrm{O}_{3}$ & $\mathbf{G d}_{2} \mathbf{O}_{3}$ & $\mathbf{K}_{2} \mathbf{O}$ & $\mathrm{La}_{2} \mathrm{O}_{3}$ & $\mathbf{L i}_{2} \mathbf{O}$ & MgO & MnO & $\mathrm{MoO}_{3}$ & $\mathrm{Na}_{2} \mathrm{O}$ & $\mathbf{N d}_{2} \mathrm{O}_{3}$ & $\mathrm{NiO}$ & $\mathbf{P}_{2} \mathbf{O}_{5}$ & $\mathrm{PbO}$ \\
\hline AZ101 & 0.000 & 0.020 & 12.000 & 0.000 & 0.020 & 0.470 & 3.730 & 0.110 & 0.300 & 0.000 & 10.580 & 0.170 & 0.540 & 0.450 & 0.040 \\
\hline AZ-102 & 0.009 & 0.000 & 12.415 & 0.000 & 0.026 & 0.302 & 5.191 & 0.178 & 0.910 & 0.000 & 13.713 & 0.303 & 0.788 & 0.573 & 0.151 \\
\hline C-104 & 0.000 & 0.000 & 4.551 & 0.000 & 0.060 & 0.019 & 5.663 & 0.059 & 2.450 & 0.002 & 9.085 & 0.044 & 0.239 & 0.369 & 0.200 \\
\hline C-106 & 0.000 & 0.000 & 12.859 & 0.000 & 0.321 & 0.018 & 4.136 & 0.151 & 3.422 & 0.005 & 12.786 & 0.000 & 0.297 & 0.614 & 0.343 \\
\hline AY-102/C-106 & 0.000 & 0.000 & 13.998 & 0.010 & 0.220 & 0.020 & 2.695 & 0.126 & 2.851 & 0.078 & 7.852 & 0.000 & 0.404 & 0.371 & 0.452 \\
\hline
\end{tabular}

\begin{tabular}{|c|c|c|c|c|c|c|c|c|c|c|c|c|c|c|c|}
\hline Waste Group & PdO & $\mathbf{R h}_{2} \mathbf{O}_{3}$ & $\mathrm{RuO}_{2}$ & $\mathrm{SO}_{3}$ & $\mathrm{Sb}_{2} \mathrm{O}_{3}$ & $\mathrm{SiO}_{2}$ & $\mathrm{SnO}_{2}$ & SrO & $\mathrm{ThO}_{2}$ & $\mathrm{TiO}_{2}$ & $\mathbf{U O}_{3}$ & $\mathbf{V}_{2} \mathrm{O}_{5}$ & $\mathbf{Y}_{2} \mathbf{O}_{3}$ & $\mathrm{ZnO}$ & $\mathrm{ZrO}_{2}$ \\
\hline AZ101 & 0.100 & 0.080 & 0.080 & 0.110 & 0.000 & 44.300 & 0.230 & 0.200 & 0.000 & 0.020 & 0.900 & 0.000 & 0.020 & 1.990 & 3.740 \\
\hline AZ-102 & 0.000 & 0.000 & 0.000 & 0.000 & 0.021 & 46.876 & 0.165 & 1.239 & 0.000 & 0.011 & 1.735 & 0.004 & 0.015 & 0.041 & 1.752 \\
\hline C-104 & 0.011 & 0.032 & 0.016 & 0.000 & 0.000 & 47.097 & 0.068 & 2.934 & 3.800 & 0.030 & 4.101 & 0.000 & 0.000 & 1.987 & 4.252 \\
\hline C-106 & 0.000 & 0.000 & 0.000 & 0.000 & 0.000 & 44.728 & 0.034 & 6.220 & 0.000 & 0.175 & 0.000 & 0.021 & 0.000 & 0.292 & 0.510 \\
\hline AY-102/C-106 & 0.000 & 0.000 & 0.000 & 0.058 & 0.063 & 47.646 & 0.267 & 0.202 & 0.000 & 0.010 & 0.504 & 0.078 & 0.000 & 0.732 & 0.434 \\
\hline
\end{tabular}


Table 2.24. Groups and Numbers of HLW Glasses.

\begin{tabular}{|l|c|c|c|c|}
\hline \multicolumn{1}{|c|}{ Group of HLW Glasses } & Group & $\begin{array}{c}\text { Number of } \\
\text { Glasses }\end{array}$ & $\begin{array}{c}\text { Number of } \\
\text { Glasses with } \\
\text { Data for One or } \\
\text { More Property }\end{array}$ & $\begin{array}{c}\text { Statistically or } \\
\text { Actively Designed }\end{array}$ \\
\hline Phase 1 Initial Matrix & HLW02 & 57 & 57 & Statistically \\
\hline Phase 1 Augmentation Matrix & HLW03 & 45 & 45 & Statistically \\
\hline AY-102/C-106 Waste & HLW04 & 13 & 10 & Actively \\
\hline Non-Spinel Matrix & HLW05 & 30 & 13 & Statistically \\
\hline Spinel Matrix & HLW06 & 35 & 35 & Statistically \\
\hline HLW07 Test Matrix & HLW07 & 40 & 40 & Statistically \\
\hline IHLW Formulation Algorithm & HLWALG & 40 & 40 & Calculated \\
\hline Melter and Actual Waste Testing Support & HLW98 & 40 & 40 & Actively \\
\hline Actual Waste & Actual & 5 & 5 & Actively \\
\hline Total & & $\mathbf{3 0 5}$ & $\mathbf{2 8 5}$ & \\
\hline
\end{tabular}


Table 2.25. Summary of Data Sets for Validating PCT Models on HLW Glasses.

\begin{tabular}{|c|c|c|c|}
\hline Study & Description & $\begin{array}{c}\text { Number } \\
\text { of Glasses }\end{array}$ & References \\
\hline $\begin{array}{l}\text { TWRS Part A and WTP } \\
\text { Part B1 HLW Glass } \\
\text { Formulations at VSL }\end{array}$ & $\begin{array}{c}\text { TWRS Part A (based on contract Envelope } \\
\text { D waste specification) and WTP Part B1 } \\
\text { (based on inventory and actual waste data) } \\
\text { studies }\end{array}$ & $55^{(\mathrm{a})}$ & $\frac{\frac{\text { Kot and Pegg }}{(2001), \text { Fu and }}}{\underline{\text { Pegg (1998) }}}$ \\
\hline $\begin{array}{c}\text { HWVP CVS } 1 \text { and } 2 \text { at } \\
\text { PNNL }\end{array}$ & $\begin{array}{c}\text { Five statistically designed experimental } \\
\text { phases in the Hanford Waste Vitrification } \\
\text { Project (HWVP) Composition Variation } \\
\text { Study (CVS). Compositions based on } \\
\text { glasses to be made from NCAW and } \\
\text { processed by HWVP. }\end{array}$ & 146 & Hrma et al. (1994) \\
\hline $\begin{array}{l}\text { DWPF PCT Modeling } \\
\text { at SRTC }\end{array}$ & Data used to develop THERMO & 177 & Jantzen et al. (1998) \\
\hline $\begin{array}{l}\text { WVDP Support at } \\
\text { PNNL }\end{array}$ & $\begin{array}{l}\text { Support development of glass-composition } \\
\text { control strategy at VWNS }\end{array}$ & 20 & Olson (1993) \\
\hline WVDP CVS at PNNL & Glasses fabricated as sets of CVS glasses & 44 & Olson et al. (1994) \\
\hline WVDP WQR at WVNS & $\begin{array}{c}\text { Glasses and data support development of } \\
\text { PCT release models. Compositions based } \\
\text { on WVDP target glass, with boundary equal } \\
\text { to three times the expected process } \\
\text { variation. }\end{array}$ & 46 & Barnes (1995) \\
\hline $\begin{array}{l}\text { WTP LAW Glass } \\
\text { Formulations at VSL }\end{array}$ & Glasses and data developed for LAW & 66 & Muller et al. (2001) \\
\hline \multicolumn{2}{|c|}{ Total Number of Historical Glasses for Validating PCT Models ${ }^{(b)}$} & 554 & \\
\hline
\end{tabular}

(a) This number excludes 20 HLW98 glasses that were included in the PCT modeling dataset.

(b) See Appendix B for additional discussion. 
Table 2.26. Compositions of HLW Glasses Expressed in Revised Oxides (wt\%) for Validating Spinel $\mathbf{T}_{1 \%}$ Models.

\begin{tabular}{|c|c|c|c|c|c|c|c|c|c|c|c|c|c|c|c|c|c|c|c|c|c|c|c|c|}
\hline Glass ID $^{(a)}$ & $\mathrm{Al}_{2} \mathrm{O}_{3}$ & $\mathbf{B}_{2} \mathbf{O}_{3}$ & $\mathrm{CaO}$ & $\mathrm{CdO}$ & $\mathrm{Cr}_{2} \mathrm{O}_{3}$ & $\mathrm{Fe}_{2} \mathrm{O}_{3}$ & $\mathrm{~K}_{2} \mathrm{O}$ & $\mathrm{La}_{2} \mathrm{O}_{3}$ & $\mathbf{L i}_{2} \mathbf{O}$ & MgO & MnO & $\mathrm{Na}_{2} \mathrm{O}$ & $\mathrm{NiO}$ & PbO & $\mathrm{Sb}_{2} \mathrm{O}_{3}$ & $\mathrm{SeO}_{2}$ & $\mathrm{SiO}_{2}$ & SrO & $\mathrm{ThO}_{2}$ & $\mathrm{TiO}_{2}$ & $\mathrm{Tl}_{2} \mathrm{O}$ & $\mathrm{UO}_{3}$ & $\mathrm{ZnO}$ & $\mathrm{ZrO}_{2}$ \\
\hline MS-7a & 8.00 & 7.00 & 0.00 & 0.00 & 0.30 & 11.50 & 0.00 & 0.00 & 4.54 & 0.60 & 0.50 & 15.30 & 0.95 & 0.00 & 0.00 & 0.00 & 45.31 & 0.00 & 0.00 & 0.00 & 0.00 & 0.00 & 0.00 & 6.00 \\
\hline MS-7d & 00 & 7.00 & 0.00 & 0.00 & 30 & .50 & 00 & 00 & 4.54 & 0.60 & 50 & 15.30 & 0.95 & 0.00 & 0.00 & .00 & 45.31 & 0.00 & 0.00 & 0.00 & 0.00 & 0.00 & 0.00 & 6.00 \\
\hline MS-7e & 8.00 & 7.00 & 0.00 & 0.00 & 30 & .50 & 00 & 0.00 & 4.54 & 0.60 & 50 & 15.30 & 0.95 & 0.00 & 0.00 & .00 & 45.31 & 0.00 & 0.00 & 0.00 & 0.00 & 0.00 & 0.00 & 6.00 \\
\hline MS7-H-Al & 11.00 & 6.77 & 0.00 & 0.00 & 0.29 & 1.13 & 0.00 & 0.00 & 4.39 & 0.58 & 48 & 14.80 & 0.92 & 0.00 & 0.00 & 0.00 & 43.83 & 0.00 & 0.00 & 0.00 & 0.00 & 0.00 & 0.00 & 5.80 \\
\hline MS7-L-Al & 5.00 & 7.23 & 0.00 & 0.00 & 0.31 & 1.81 & 0.00 & 0.00 & 4.69 & 0.62 & 52 & 15.81 & 0.98 & 0.00 & 0.00 & 0.00 & 46.82 & 0.00 & 0.00 & 0.00 & 0.00 & 0.00 & 0.00 & 6.20 \\
\hline MS7-H-Cr & 7.90 & 7.00 & 0.00 & 0.00 & 0.50 & 11.49 & 0.00 & 0.00 & 4.53 & 0.60 & .50 & 15.28 & 0.95 & 0.00 & 0.00 & 0.00 & 45.26 & 0.00 & 0.00 & 0.00 & 0.00 & 0.00 & 0.00 & 5.99 \\
\hline MS7-L-Cr & 8.02 & 7.01 & 0.00 & 0.00 & 0.10 & .52 & 0.00 & 0.00 & 4.55 & 0.60 & .50 & 15.33 & 0.95 & 0.00 & 0.00 & 0.00 & 45.40 & 0.00 & 0.00 & 0.00 & 0.00 & 0.00 & 0.00 & 6.01 \\
\hline MS7-L-Fe & 8.32 & 7.28 & 0.00 & 0.00 & 31 & 00 & 0.00 & 0.00 & 4.72 & 0.62 & .52 & 15.91 & 0.99 & 0.00 & 0.00 & 0.00 & 47.10 & 0.00 & 0.00 & 0.00 & 0.00 & 0.00 & 0.00 & 6.24 \\
\hline MS7-H-Li & 7.88 & 6.89 & 0.00 & 0.00 & 0.30 & .32 & 00 & 0.00 & 6.00 & 0.59 & 49 & 15.07 & 0.94 & 0.00 & 0.00 & 0.00 & 44.62 & 0.00 & 0.00 & 0.00 & 0.00 & 0.00 & 0.00 & 5.91 \\
\hline MS7-L-Li & 8.13 & 7.11 & 0.00 & 0.00 & 0.30 & .69 & 0.00 & 0.00 & 3.00 & 0.61 & 51 & 15.55 & 0.97 & 0.00 & 0.00 & 0.00 & 46.04 & 0.00 & 0.00 & 0.00 & 0.00 & 0.00 & 0.00 & 6.10 \\
\hline MS7-H-Mg & 7.81 & 6.83 & 0.00 & 0.00 & 0.29 & 22 & 0.00 & 0.00 & 4.43 & 3.00 & 49 & 14.93 & 0.93 & 0.00 & 0.00 & 0.00 & 44.22 & 0.00 & 0.00 & 0.00 & 0.00 & 0.00 & 0.00 & 5.86 \\
\hline MS7-L-Mg & 8.05 & 7.04 & 0.00 & 0.00 & 0.30 & .57 & 0.00 & 0.00 & 4.57 & 0.00 & .50 & 15.39 & 0.96 & 0.00 & 0.00 & 0.00 & 45.58 & 0.00 & 0.00 & 0.00 & 0.00 & 0.00 & 0.00 & 6.04 \\
\hline MS7-H-Na & 7.74 & 6.78 & 0.00 & 0.00 & 0.29 & 13 & 0.00 & 0.00 & 4.40 & 0.58 & 48 & 18.00 & 0.92 & 0.00 & 0.00 & 0.00 & 43.87 & 0.00 & 0.00 & 0.00 & 0.00 & 0.00 & 0.00 & 5.81 \\
\hline MS7-L-Na & 8.31 & 7.27 & 0.00 & 0.00 & 0.31 & .95 & 0.00 & 0.00 & 4.72 & 0.62 & .52 & 12.00 & 0.99 & 0.00 & 0.00 & 0.00 & 47.08 & 0.00 & 0.00 & 0.00 & 0.00 & 0.00 & 0.00 & 6.23 \\
\hline MS7-H-Ni & 7.93 & 6.94 & 0.00 & 0.00 & 0.30 & .40 & 0.00 & 0.00 & 4.50 & 0.59 & .50 & 15.17 & 1.80 & 0.00 & 0.00 & 0.00 & 44.92 & 0.00 & 0.00 & 0.00 & 0.00 & 0.00 & 0.00 & 5.95 \\
\hline MS7-L-Ni & 8.05 & 7.05 & 0.00 & 0.00 & 0.30 & .58 & 0.00 & 0.00 & 4.57 & 0.60 & 0.50 & 15.40 & 0.30 & 0.00 & 0.00 & 0.00 & 45.61 & 0.00 & 0.00 & 0.00 & 0.00 & 0.00 & 0.00 & 6.04 \\
\hline SP-Al-1 & 4.00 & 7.30 & 1.04 & 0.72 & 0.23 & .04 & 0.29 & 0.28 & 3.13 & 0.63 & 0.38 & 16.41 & 0.54 & 0.18 & 0.07 & 0.09 & 48.00 & 0.03 & 0.00 & 0.03 & 0.00 & 0.00 & 0.04 & 1.91 \\
\hline SP-Cr-1-o & 8.02 & 7.02 & 1.00 & 0.69 & 0.00 & 12.53 & 0.28 & 0.27 & 3.01 & 0.60 & 0.36 & 15.76 & 0.52 & 0.17 & 0.07 & 0.09 & 46.10 & 0.03 & 0.00 & 0.03 & 0.00 & 0.00 & 0.04 & 1.83 \\
\hline SP-Cr-1-r & 8.02 & 7.02 & 1.00 & 0.69 & 0.00 & 12.53 & 0.28 & 0.27 & 3.01 & 0.60 & 0.36 & 15.76 & 0.52 & 0.17 & 0.07 & 0.09 & 46.10 & 0.03 & 0.00 & 0.03 & 0.00 & 0.00 & $\begin{array}{l}0.04 \\
\end{array}$ & 1.83 \\
\hline SP-Li-3-o & 8.00 & 7.00 & 1.00 & 0.69 & 0.2 & 12.50 & 0.28 & 0.27 & 3.00 & 0.60 & 0.36 & 15.73 & 0.52 & 0.17 & 0.07 & 0.09 & 46.00 & 0.03 & 0.00 & 0.03 & 0.00 & 0.00 & 0.04 & 1.83 \\
\hline SP-Li-3-r & 8.00 & 7.00 & 1.00 & 0.69 & 0.2 & 12.50 & 0.28 & 0.27 & 3.00 & 0.60 & 0.36 & 15.73 & 0.52 & 0.17 & 0.07 & 0.09 & 46.00 & 0.03 & 0.00 & 0.03 & 0.00 & 0.00 & 0.04 & 1.83 \\
\hline SP-Mg-1 & 7.97 & 6.97 & 1.00 & 0.69 & 0.2 & 12.45 & 0.28 & 0.27 & 2.99 & 1.00 & 0.36 & 15.67 & 0.52 & 0.17 & 0.07 & 0.09 & 45.81 & 0.03 & 0.00 & 0.03 & 0.00 & 0.00 & $\begin{array}{l}0.04 \\
\end{array}$ & 1.82 \\
\hline SP-Mn-1 & 8.03 & 7.03 & 1.00 & 0.69 & 0.2 & 12.54 & 0.28 & 0.27 & 3.01 & 0.60 & 0.00 & 15.79 & 0.52 & 0.17 & 0.07 & 0.09 & 46.16 & 0.03 & 0.00 & 0.03 & 0.00 & 0.00 & 0.04 & 1.84 \\
\hline SP-Mn-3 & 7.71 & 6.74 & 0.96 & 0.66 & 0.2 & 12.04 & 0.27 & 0.26 & 2.89 & 0.58 & 4.00 & 15.15 & 0.50 & 0.16 & 0.07 & 0.09 & 44.32 & 0.03 & 0.00 & 0.03 & 0.00 & 0.00 & 0.04 & 1.76 \\
\hline SP-Na-1 & 8.73 & 7.64 & 1.09 & 0.75 & 0.2 & 13.65 & 0.31 & 0.29 & 3.28 & 0.66 & 0.39 & 8.00 & 0.57 & 0.19 & 0.08 & 0.10 & 50.22 & 0.03 & 0.00 & 0.03 & 0.00 & 0.00 & 0.04 & 2.00 \\
\hline SP-Na-3 & 7.59 & 6.65 & 0.95 & 0.66 & 0.2 & 11.87 & 0.27 & 0.26 & 2.85 & 0.57 & 0.34 & 20.00 & 0.49 & 0.16 & 0.07 & 0.09 & 43.67 & 0.03 & 0.00 & 0.03 & 0.00 & 0.00 & 0.04 & 1.74 \\
\hline SPA-18 & 6.00 & 8.18 & 2.00 & 0.00 & 0.3 & 14.00 & 3.89 & 0.26 & 3.79 & 0.00 & 1.00 & 15.89 & 0.50 & 0.29 & 0.03 & 0.06 & 35.54 & 1.42 & 0.00 & 0.00 & 0.00 & 0.00 & 0.99 & 3.00 \\
\hline SPA-38 & 8.00 & 7.00 & 1.00 & 0.70 & 0.22 & 12.50 & 0.28 & 0.27 & 3.00 & 0.60 & 0.36 & 15.73 & 0.52 & 0.17 & 0.08 & 0.09 & 46.01 & 0.03 & 0.00 & 0.03 & 0.00 & 0.00 & 0.04 & 1.85 \\
\hline WTP-TL-16 & 11.00 & 15.00 & 0.38 & 1.00 & 0.50 & 13.00 & 0.02 & 0.28 & 6.00 & 0.38 & 5.00 & 4.00 & 0.00 & 0.12 & 0.07 & 0.12 & 40.06 & 0.00 & 0.00 & 0.04 & 0.00 & 0.00 & 2.50 & 0.00 \\
\hline WTP-TL-17 & 11.00 & 15.00 & 0.38 & 0.00 & 0.50 & 6.56 & 0.02 & 0.28 & 0.00 & 0.38 & 0.00 & 15.00 & 1.00 & 0.12 & 0.07 & 0.12 & 38.00 & 8.50 & 0.00 & 0.04 & 0.00 & 0.00 & 2.50 & 0.00 \\
\hline WTP-TL-19 & 2.00 & 15.00 & 0.38 & 1.00 & 0.50 & 3.00 & 0.02 & 0.28 & 0.00 & 0.38 & 5.00 & 15.00 & 1.00 & 0.12 & 0.07 & 0.12 & 49.56 & 0.00 & 0.00 & 0.04 & 0.00 & 0.00 & 0.00 & 6.00 \\
\hline WTP-TL-20 & 2.00 & 4.00 & 0.38 & 1.00 & 0.50 & 13.00 & 0.02 & 0.28 & 6.00 & 0.38 & 0.00 & 4.00 & 1.00 & 0.12 & 0.07 & 0.12 & 49.56 & 8.50 & 0.00 & 0.04 & 0.00 & 0.00 & 2.50 & 6.00 \\
\hline WTP-TL-21 & 2.00 & 4.00 & 0.38 & 1.00 & 0.50 & 13.00 & 0.02 & 0.28 & 0.02 & 0.38 & 5.00 & 15.00 & 0.00 & 0.12 & 0.07 & 0.12 & 52.99 & 2.04 & 0.00 & 0.04 & 0.00 & 0.00 & 2.50 & 0.00 \\
\hline WTP-TL-23 & 8.75 & 6.75 & 0.38 & 0.75 & 0.38 & 7.93 & 0.02 & 0.28 & 4.50 & 0.38 & 3.75 & 6.75 & 0.75 & 0.12 & 0.07 & 0.12 & 49.25 & 6.38 & 0.00 & 0.04 & 0.00 & 0.00 & 0.62 & 1.50 \\
\hline WTP-TL-24 & 4.25 & 6.75 & 0.38 & 0.25 & 0.12 & 10.50 & 0.02 & 0.28 & 1.50 & 0.38 & 3.75 & 11.18 & 0.75 & 0.12 & 0.07 & 0.12 & 49.25 & 6.38 & 0.00 & 0.04 & 0.00 & 0.00 & 1.88 & 1.50 \\
\hline WTP-TL-27 & 8.75 & 12.25 & 0.38 & 0.25 & 0.12 & 10.50 & 0.02 & 0.28 & 4.50 & 0.38 & 3.75 & 6.75 & 0.25 & 0.12 & 0.07 & 0.12 & 42.44 & 2.12 & 0.00 & 0.04 & 0.00 & 0.00 & 1.88 & 4.50 \\
\hline WTP-TL-28 & 4.25 & 6.75 & 0.38 & 0.25 & 0.12 & 10.50 & 0.02 & 0.28 & 4.50 & 0.38 & 3.75 & 6.75 & 0.25 & 0.12 & 0.07 & 0.12 & 48.18 & 6.38 & 0.00 & 0.04 & 0.00 & 0.00 & 1.88 & 4.50 \\
\hline WTP-TL-29 & 4.25 & 12.25 & 0.38 & 0.75 & 0.38 & 10.50 & 0.02 & 0.28 & 1.50 & 0.38 & 3.75 & 6.75 & 0.25 & 0.12 & 0.07 & 0.12 & 49.25 & 5.20 & 0.00 & 0.04 & 0.00 & 0.00 & 0.62 & 2.61 \\
\hline WTP-TL-30 & 8.75 & 12.25 & 0.38 & 0.25 & 0.38 & 5.50 & 0.02 & 0.28 & 4.50 & 0.38 & 1.58 & 6.75 & 0.75 & 0.12 & 0.07 & 0.12 & 48.85 & 2.12 & 0.00 & 0.04 & 0.00 & 0.00 & 1.88 & 4.50 \\
\hline
\end{tabular}

(a) The compositions of the SP series of glasses were recalculated in June 2007 by Dong Kim to correct minor errors. 
Table 2.26. Compositions of HLW Glasses Expressed in Revised Oxides (wt\%) for Validating Spinel $\mathbf{T}_{\mathbf{1} \%}$ Models (continued).

\begin{tabular}{|c|c|c|c|c|c|c|c|c|c|c|c|c|c|}
\hline Glass ID $^{(a)}$ & $\mathrm{Ag}_{2} \mathrm{O}$ & $\mathbf{A s}_{2} \mathbf{O}_{5}$ & $\mathrm{BaO}$ & $\mathrm{Bi}_{2} \mathrm{O}_{3}$ & $\mathrm{Ce}_{2} \mathrm{O}_{3}$ & $\mathrm{Cl}$ & $\mathrm{CoO}$ & $\mathrm{Cs}_{2} \mathrm{O}$ & $\mathrm{CuO}$ & $\mathbf{F}$ & $\mathrm{MoO}_{3}$ & $\mathrm{Nd}_{2} \mathrm{O}_{3}$ & $\mathrm{P}_{2} \mathrm{O}_{5}$ \\
\hline MS-7a & 0.00 & 0.00 & 0.00 & 0.00 & 0.00 & 0.00 & 0.00 & 0.00 & 0.00 & 0.00 & 0.00 & 0.00 & 0.00 \\
\hline MS-7d & 0.00 & 0.00 & 0.00 & 0.00 & 0.00 & 0.00 & 0.00 & 0.00 & 0.00 & 0.00 & 0.00 & 0.00 & 0.00 \\
\hline MS-7e & 0.00 & 0.00 & 0.00 & 0.00 & 0.00 & 0.00 & 0.00 & 0.00 & 0.00 & 0.00 & 0.00 & 0.00 & 0.00 \\
\hline MS7-H-Al & 0.00 & 0.00 & 0.00 & 0.00 & 0.00 & 0.00 & 0.00 & 0.00 & 0.00 & 0.00 & 0.00 & 0.00 & 0.00 \\
\hline MS7-L-Al & 0.00 & 0.00 & 0.00 & 0.00 & 0.00 & 0.00 & 0.00 & 0.00 & 0.00 & 0.00 & 0.00 & 0.00 & 0.00 \\
\hline MS7-H-Cr & 0.00 & 0.00 & 0.00 & 0.00 & 0.00 & 0.00 & 0.00 & 0.00 & 0.00 & 0.00 & 0.00 & 0.00 & 0.00 \\
\hline MS7-L-Cr & 0.00 & 0.00 & 0.00 & 0.00 & 0.00 & 0.00 & 0.00 & 0.00 & 0.00 & 0.00 & 0.00 & 0.00 & 0.00 \\
\hline MS7-L-Fe & 0.00 & 0.00 & 0.00 & 0.00 & 0.00 & 0.00 & 0.00 & 0.00 & 0.00 & 0.00 & 0.00 & 0.00 & 0.00 \\
\hline MS7-H-Li & 0.00 & 0.00 & 0.00 & 0.00 & 0.00 & 0.00 & 0.00 & 0.00 & 0.00 & 0.00 & 0.00 & 0.00 & 0.00 \\
\hline MS7-L-Li & 0.00 & 0.00 & 0.00 & 0.00 & 0.00 & 0.00 & 0.00 & 0.00 & 0.00 & 0.00 & 0.00 & 0.00 & 0.00 \\
\hline MS7-H-Mg & 0.00 & 0.00 & 0.00 & 0.00 & 0.00 & 0.00 & 0.00 & 0.00 & 0.00 & 0.00 & 0.00 & 0.00 & 0.00 \\
\hline MS7-L-Mg & 0.00 & 0.00 & 0.00 & 0.00 & 0.00 & 0.00 & 0.00 & 0.00 & 0.00 & 0.00 & 0.00 & 0.00 & 0.00 \\
\hline MS7-H-Na & 0.00 & 0.00 & 0.00 & 0.00 & 0.00 & 0.00 & 0.00 & 0.00 & 0.00 & 0.00 & 0.00 & 0.00 & 0.00 \\
\hline MS7-L-Na & 0.00 & 0.00 & 0.00 & 0.00 & 0.00 & 0.00 & 0.00 & 0.00 & 0.00 & 0.00 & 0.00 & 0.00 & 0.00 \\
\hline MS7-H-Ni & 0.00 & 0.00 & 0.00 & 0.00 & 0.00 & 0.00 & 0.00 & 0.00 & 0.00 & 0.00 & 0.00 & 0.00 & 0.00 \\
\hline MS7-L-Ni & 0.00 & 0.00 & 0.00 & 0.00 & 0.00 & 0.00 & 0.00 & 0.00 & 0.00 & 0.00 & 0.00 & 0.00 & 0.00 \\
\hline SP-Al-1 & 0.07 & 0.05 & 0.31 & 0.00 & 0.07 & 0.01 & 0.09 & 0.00 & 0.03 & 0.06 & 0.01 & 0.19 & 0.48 \\
\hline SP-Cr-1-o & 0.07 & 0.05 & 0.30 & 0.00 & 0.07 & 0.01 & 0.09 & 0.00 & 0.03 & 0.06 & 0.01 & 0.18 & 0.46 \\
\hline SP-Cr-1-r & 0.07 & 0.05 & 0.30 & 0.00 & 0.07 & 0.01 & 0.09 & 0.00 & 0.03 & 0.06 & 0.01 & 0.18 & 0.46 \\
\hline SP-Li-3-o & 0.07 & 0.05 & 0.30 & 0.00 & 0.07 & 0.01 & 0.09 & 0.00 & 0.03 & 0.06 & 0.01 & 0.18 & 0.46 \\
\hline SP-Li-3-r & 0.07 & 0.05 & 0.30 & 0.00 & 0.07 & 0.01 & 0.09 & 0.00 & 0.03 & 0.06 & 0.01 & 0.18 & 0.46 \\
\hline SP-Mg-1 & 0.07 & 0.05 & 0.30 & 0.00 & 0.07 & 0.01 & 0.09 & 0.00 & 0.03 & 0.06 & 0.01 & 0.18 & 0.46 \\
\hline SP-Mn-1 & 0.07 & 0.05 & 0.30 & 0.00 & 0.07 & 0.01 & 0.09 & 0.00 & 0.03 & 0.06 & 0.01 & 0.18 & 0.46 \\
\hline SP-Mn-3 & 0.07 & 0.04 & 0.29 & 0.00 & 0.06 & 0.01 & 0.09 & 0.00 & 0.03 & 0.06 & 0.01 & 0.17 & 0.44 \\
\hline SP-Na-1 & 0.08 & 0.05 & 0.33 & 0.00 & 0.07 & 0.01 & 0.10 & 0.00 & 0.03 & 0.07 & 0.01 & 0.20 & 0.50 \\
\hline SP-Na-3 & 0.07 & 0.04 & 0.28 & 0.00 & 0.06 & 0.01 & 0.09 & 0.00 & 0.03 & 0.06 & 0.01 & 0.17 & 0.44 \\
\hline SPA-18 & 0.04 & 0.06 & 0.07 & 0.00 & 0.44 & 0.01 & 0.01 & 0.00 & 0.02 & 1.50 & 0.01 & 0.08 & 0.50 \\
\hline SPA-38 & 0.07 & 0.00 & 0.30 & 0.00 & 0.07 & 0.01 & 0.08 & 0.00 & 0.03 & 0.06 & 0.01 & 0.18 & 0.46 \\
\hline WTP-TL-16 & 0.08 & 0.08 & 0.01 & 0.00 & 0.00 & 0.05 & 0.00 & 0.00 & 0.03 & 0.03 & 0.01 & 0.15 & 0.05 \\
\hline WTP-TL-17 & 0.08 & 0.08 & 0.01 & 0.00 & 0.00 & 0.05 & 0.00 & 0.00 & 0.03 & 0.03 & 0.01 & 0.15 & 0.05 \\
\hline WTP-TL-19 & 0.08 & 0.08 & 0.01 & 0.00 & 0.00 & 0.05 & 0.00 & 0.00 & 0.03 & 0.03 & 0.01 & 0.15 & 0.05 \\
\hline WTP-TL-20 & 0.08 & 0.08 & 0.01 & 0.00 & 0.00 & 0.05 & 0.00 & 0.00 & 0.03 & 0.03 & 0.01 & 0.15 & 0.05 \\
\hline WTP-TL-21 & 0.08 & 0.08 & 0.01 & 0.00 & 0.00 & 0.05 & 0.00 & 0.00 & 0.03 & 0.03 & 0.01 & 0.15 & 0.05 \\
\hline WTP-TL-23 & 0.08 & 0.08 & 0.01 & 0.00 & 0.00 & 0.05 & 0.00 & 0.00 & 0.03 & 0.03 & 0.01 & 0.15 & 0.05 \\
\hline WTP-TL-24 & 0.08 & 0.08 & 0.01 & 0.00 & 0.00 & 0.05 & 0.00 & 0.00 & 0.03 & 0.03 & 0.01 & 0.15 & 0.05 \\
\hline WTP-TL-27 & 0.08 & 0.08 & 0.01 & 0.00 & 0.00 & 0.05 & 0.00 & 0.00 & 0.03 & 0.03 & 0.01 & 0.15 & 0.05 \\
\hline WTP-TL-28 & 0.08 & 0.08 & 0.01 & 0.00 & 0.00 & 0.05 & 0.00 & 0.00 & 0.03 & 0.03 & 0.01 & 0.15 & 0.05 \\
\hline WTP-TL-29 & 0.08 & 0.08 & 0.01 & 0.00 & 0.00 & 0.05 & 0.00 & 0.00 & 0.03 & 0.03 & 0.01 & 0.15 & 0.05 \\
\hline WTP-TL-30 & 0.08 & 0.08 & 0.01 & 0.00 & 0.00 & 0.05 & 0.00 & 0.00 & 0.03 & 0.03 & 0.01 & 0.15 & 0.05 \\
\hline
\end{tabular}

(a) The compositions of the SP series of glasses were recalculated in June 2007 by Dong Kim to correct minor errors. 
Table 2.26. Compositions of HLW Glasses Expressed in Revised Oxides (wt\%) for Validating Spinel $\mathbf{T}_{1 \%}$ Models (continued).

\begin{tabular}{|c|c|c|c|c|c|c|c|c|c|c|c|c|}
\hline Glass ID $^{(a)}$ & PdO & $\mathrm{Pr}_{2} \mathrm{O}_{3}$ & $\mathbf{R} \mathbf{b}_{2} \mathbf{O}$ & $\mathbf{R h}_{2} \mathbf{O}_{3}$ & $\mathrm{RuO}_{2}$ & $\mathrm{Sm}_{2} \mathrm{O}_{3}$ & $\mathrm{SO}_{3}$ & $\mathrm{TeO}_{2}$ & $\mathrm{~V}_{2} \mathrm{O}_{5}$ & $\mathrm{WO}_{3}$ & $\mathbf{Y}_{2} \mathbf{O}_{3}$ & Total \\
\hline MS-7a & 0.00 & 0.00 & 0.00 & 0.00 & 0.00 & 0.00 & 0.00 & 0.00 & 0.00 & 0.00 & 0.00 & 100.00 \\
\hline MS-7d & 0.00 & 0.00 & 0.00 & 0.00 & 0.00 & 0.00 & 0.00 & 0.00 & 0.00 & 0.00 & 0.00 & 100.00 \\
\hline MS-7e & 0.00 & 0.00 & 0.00 & 0.00 & 0.00 & 0.00 & 0.00 & 0.00 & 0.00 & 0.00 & 0.00 & 100.00 \\
\hline MS7-H-Al & 0.00 & 0.00 & 0.00 & 0.00 & 0.00 & 0.00 & 0.00 & 0.00 & 0.00 & 0.00 & 0.00 & 100.00 \\
\hline MS7-L-Al & 0.00 & 0.00 & 0.00 & 0.00 & 0.00 & 0.00 & 0.00 & 0.00 & 0.00 & 0.00 & 0.00 & 100.00 \\
\hline MS7-H-Cr & 0.00 & 0.00 & 0.00 & 0.00 & 0.00 & 0.00 & 0.00 & 0.00 & 0.00 & 0.00 & 0.00 & 100.00 \\
\hline MS7-L-Cr & 0.00 & 0.00 & 0.00 & 0.00 & 0.00 & 0.00 & 0.00 & 0.00 & 0.00 & 0.00 & 0.00 & 100.00 \\
\hline MS7-L-Fe & 0.00 & 0.00 & 0.00 & 0.00 & 0.00 & 0.00 & 0.00 & 0.00 & 0.00 & 0.00 & 0.00 & 100.00 \\
\hline MS7-H-Li & 0.00 & 0.00 & 0.00 & 0.00 & 0.00 & 0.00 & 0.00 & 0.00 & 0.00 & 0.00 & 0.00 & 100.00 \\
\hline MS7-L-Li & 0.00 & 0.00 & 0.00 & 0.00 & 0.00 & 0.00 & 0.00 & 0.00 & 0.00 & 0.00 & 0.00 & 100.00 \\
\hline MS7-H-Mg & 0.00 & 0.00 & 0.00 & 0.00 & 0.00 & 0.00 & 0.00 & 0.00 & 0.00 & 0.00 & 0.00 & 100.00 \\
\hline MS7-L-Mg & 0.00 & 0.00 & 0.00 & 0.00 & 0.00 & 0.00 & 0.00 & 0.00 & 0.00 & 0.00 & 0.00 & 100.00 \\
\hline MS7-H-Na & 0.00 & 0.00 & 0.00 & 0.00 & 0.00 & 0.00 & 0.00 & 0.00 & 0.00 & 0.00 & 0.00 & 100.00 \\
\hline MS7-L-Na & 0.00 & 0.00 & 0.00 & 0.00 & 0.00 & 0.00 & 0.00 & 0.00 & 0.00 & 0.00 & 0.00 & 100.00 \\
\hline MS7-H-Ni & 0.00 & 0.00 & 0.00 & 0.00 & 0.00 & 0.00 & 0.00 & 0.00 & 0.00 & 0.00 & 0.00 & 100.00 \\
\hline MS7-L-Ni & 0.00 & 0.00 & 0.00 & 0.00 & 0.00 & 0.00 & 0.00 & 0.00 & 0.00 & 0.00 & 0.00 & 100.00 \\
\hline SP-Al-1 & 0.00 & 0.00 & 0.00 & 0.03 & 0.03 & 0.00 & 0.20 & 0.00 & 0.00 & 0.00 & 0.00 & 100.00 \\
\hline SP-Cr-1-o & 0.00 & 0.00 & 0.00 & 0.03 & 0.03 & 0.00 & 0.19 & 0.00 & 0.00 & 0.00 & 0.00 & 100.00 \\
\hline SP-Cr-1-r & 0.00 & 0.00 & 0.00 & 0.03 & 0.03 & 0.00 & 0.19 & 0.00 & 0.00 & 0.00 & 0.00 & 100.00 \\
\hline SP-Li-3-o & 0.00 & 0.00 & 0.00 & 0.03 & 0.03 & 0.00 & 0.19 & 0.00 & 0.00 & 0.00 & 0.00 & 100.00 \\
\hline SP-Li-3-r & 0.00 & 0.00 & 0.00 & 0.03 & 0.03 & 0.00 & 0.19 & 0.00 & 0.00 & 0.00 & 0.00 & 100.00 \\
\hline SP-Mg-1 & 0.00 & 0.00 & 0.00 & 0.03 & 0.03 & 0.00 & 0.19 & 0.00 & 0.00 & 0.00 & 0.00 & 100.00 \\
\hline SP-Mn-1 & 0.00 & 0.00 & 0.00 & 0.03 & 0.03 & 0.00 & 0.19 & 0.00 & 0.00 & 0.00 & 0.00 & 100.00 \\
\hline SP-Mn-3 & 0.00 & 0.00 & 0.00 & 0.03 & 0.03 & 0.00 & 0.18 & 0.00 & 0.00 & 0.00 & 0.00 & 100.00 \\
\hline SP-Na-1 & 0.00 & 0.00 & 0.00 & 0.03 & 0.03 & 0.00 & 0.21 & 0.00 & 0.00 & 0.00 & 0.00 & 100.00 \\
\hline SP-Na-3 & 0.00 & 0.00 & 0.00 & 0.03 & 0.03 & 0.00 & 0.18 & 0.00 & 0.00 & 0.00 & 0.00 & 100.00 \\
\hline SPA-18 & 0.00 & 0.00 & 0.00 & 0.00 & 0.00 & 0.00 & 0.09 & 0.01 & 0.03 & 0.00 & 0.00 & 100.00 \\
\hline SPA-38 & 0.00 & 0.00 & 0.00 & 0.03 & 0.03 & 0.00 & 0.19 & 0.00 & 0.00 & 0.00 & 0.00 & 100.00 \\
\hline WTP-TL-16 & 0.00 & 0.01 & 0.01 & 0.00 & 0.00 & 0.00 & 0.03 & 0.00 & 0.00 & 0.00 & 0.00 & 100.00 \\
\hline WTP-TL-17 & 0.00 & 0.01 & 0.01 & 0.00 & 0.00 & 0.00 & 0.03 & 0.00 & 0.00 & 0.00 & 0.00 & 100.00 \\
\hline WTP-TL-19 & 0.00 & 0.01 & 0.01 & 0.00 & 0.00 & 0.00 & 0.03 & 0.00 & 0.00 & 0.00 & 0.00 & 100.00 \\
\hline WTP-TL-20 & 0.00 & 0.01 & 0.01 & 0.00 & 0.00 & 0.00 & 0.03 & 0.00 & 0.00 & 0.00 & 0.00 & 100.00 \\
\hline WTP-TL-21 & 0.00 & 0.01 & 0.01 & 0.00 & 0.00 & 0.00 & 0.03 & 0.00 & 0.00 & 0.00 & 0.00 & 100.00 \\
\hline WTP-TL-23 & 0.00 & 0.01 & 0.01 & 0.00 & 0.00 & 0.00 & 0.03 & 0.00 & 0.00 & 0.00 & 0.00 & 100.00 \\
\hline WTP-TL-24 & 0.00 & 0.01 & 0.01 & 0.00 & 0.00 & 0.00 & 0.03 & 0.00 & 0.00 & 0.00 & 0.00 & 100.00 \\
\hline WTP-TL-27 & 0.00 & 0.01 & 0.01 & 0.00 & 0.00 & 0.00 & 0.03 & 0.00 & 0.00 & 0.00 & 0.00 & 100.00 \\
\hline WTP-TL-28 & 0.00 & 0.01 & 0.01 & 0.00 & 0.00 & 0.00 & 0.03 & 0.00 & 0.00 & 0.00 & 0.00 & 100.00 \\
\hline WTP-TL-29 & 0.00 & 0.01 & 0.01 & 0.00 & 0.00 & 0.00 & 0.03 & 0.00 & 0.00 & 0.00 & 0.00 & 100.00 \\
\hline WTP-TL-30 & 0.00 & 0.01 & 0.01 & 0.00 & 0.00 & 0.00 & 0.03 & 0.00 & 0.00 & 0.00 & 0.00 & 100.00 \\
\hline
\end{tabular}

(a) The compositions of the SP series of glasses were recalculated in June 2007 by Dong Kim to correct minor errors. 
The Catholic University of America Vitreous State Laboratory
IHLW PCT, Spinel $T_{1 \%}$ Electrical Conductivity, and Viscosity Model Development Final Report, VSL-07R1240-4, Rev. 0

Table 3.1. HLW Canister Centerline Cooling (CCC) Temperature Profile.

\begin{tabular}{|c|c|c|c|}
\hline Segment & $\begin{array}{c}\text { Time } \\
(\mathbf{m i n})\end{array}$ & $\begin{array}{c}\text { Start } \\
\text { Temperature } \\
\left({ }^{\circ} \mathbf{C}\right)\end{array}$ & $\begin{array}{c}\text { Rate } \\
\left({ }^{\circ} \mathbf{C} / \mathbf{m i n}\right)\end{array}$ \\
\hline 1 & $0-45$ & 1050 & -1.556 \\
\hline 2 & $45-107$ & 980 & -0.806 \\
\hline 3 & $107-200$ & 930 & -0.591 \\
\hline 4 & $200-329$ & 875 & -0.388 \\
\hline 5 & $329-527$ & 825 & -0.253 \\
\hline 6 & $527-707$ & 775 & -0.278 \\
\hline 7 & $707-1776$ & 725 & -0.304 \\
\hline
\end{tabular}


Table 4.1. HLW Glasses Having Data for PCT, Spinel $T_{1 \%}$, Viscosity, and Electrical Conductivity.

\begin{tabular}{|c|c|c|c|c|c|c|c|c|c|c|c|}
\hline Glass ID & 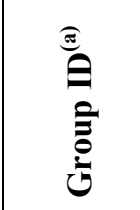 & $\stackrel{\widehat{\varrho}}{\underline{\omega}}$ & 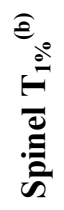 & 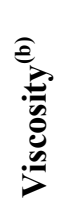 & 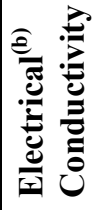 & Glass ID & 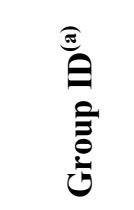 & 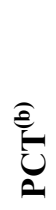 & 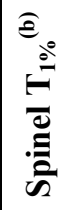 & 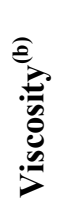 & 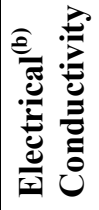 \\
\hline HLW02-01 & HLW02 & 1 & 1 & 1 & 1 & HLW02-37 & HLW02 & 1 & 1 & 1 & 1 \\
\hline HLW02-02 & HLW02 & 1 & 1 & 1 & 1 & HLW02-38 & HLW02 & 1 & 1 & 1 & 1 \\
\hline HLW02-03 & HLW02 & 1 & 1 & 1 & 1 & HLW02-39 & HLW02 & 1 & 1 & 1 & 1 \\
\hline HLW02-04 & HLW02 & 1 & 1 & 1 & 1 & HLW02-40 & HLW02 & 1 & 1 & 1 & 1 \\
\hline HLW02-05 & HLW02 & 1 & $0^{(\mathrm{c})}$ & 1 & 1 & HLW02-41 & HLW02 & 1 & 1 & 1 & 1 \\
\hline HLW02-06 & HLW02 & 1 & 1 & 1 & 1 & HLW02-42 & HLW02 & 1 & 1 & 1 & 1 \\
\hline HLW02-07 & HLW02 & 1 & 1 & 1 & 1 & HLW02-43 & HLW02 & 1 & 1 & 1 & 1 \\
\hline HLW02-08 & HLW02 & 1 & 1 & 1 & 1 & \begin{tabular}{|l|} 
HLW02-44 \\
\end{tabular} & HLW02 & 1 & 1 & 1 & 1 \\
\hline HLW02-09 & HLW02 & 1 & 1 & 1 & 1 & HLW02-45 & HLW02 & 1 & 1 & 1 & 1 \\
\hline HLW02-10 & HLW02 & 1 & 1 & 1 & 1 & HLW02-46 & HLW02 & 1 & 1 & 1 & 1 \\
\hline HLW02-11 & HLW02 & 1 & 1 & 1 & 1 & HLW02-47 & HLW02 & 1 & 1 & 1 & 1 \\
\hline HLW02-12 & HLW02 & 1 & 1 & 1 & 1 & HLW02-48 & HLW02 & 1 & 1 & 1 & 1 \\
\hline HLW02-13 & HLW02 & 1 & 1 & 1 & 1 & HLW02-49 & HLW02 & 1 & 1 & 1 & 1 \\
\hline HLW02-14 & HLW02 & 1 & $0^{(\mathrm{d})}$ & 1 & 1 & \begin{tabular}{|l|} 
HLW02-50 \\
\end{tabular} & HLW02 & 1 & 1 & 1 & 1 \\
\hline HLW02-15 & HLW02 & 1 & 1 & 1 & 1 & HLW02-51 & HLW02 & 1 & 1 & 1 & 1 \\
\hline HLW02-16 & HLW02 & 1 & 1 & 1 & 1 & HLW02-52 & HLW02 & 1 & 1 & 1 & 1 \\
\hline HLW02-17 & HLW02 & 1 & 1 & 1 & 1 & \begin{tabular}{|l|} 
HLW02-53 \\
\end{tabular} & HLW02 & 1 & 1 & 1 & 1 \\
\hline HLW02-18 & HLW02 & 1 & 1 & 1 & 1 & \begin{tabular}{|l|} 
HLW02-54 \\
\end{tabular} & HLW02 & 1 & 1 & 1 & 1 \\
\hline HLW02-19 & HLW02 & 1 & 1 & 1 & 1 & HLW02-55 & HLW02 & 1 & 1 & 1 & 1 \\
\hline HLW02-20 & HLW02 & 1 & 1 & 1 & 1 & \begin{tabular}{|l|} 
HLW02-56 \\
\end{tabular} & HLW02 & 1 & 1 & 1 & 1 \\
\hline HLW02-21 & HLW02 & 1 & $0^{(\mathrm{e})}$ & 1 & 1 & \begin{tabular}{|l|} 
HLW02-57 \\
\end{tabular} & HLW02 & 1 & 1 & 1 & 1 \\
\hline HLW02-22 & HLW02 & 1 & 1 & 1 & 1 & HLW03-01 & HLW03 & 1 & 1 & 1 & 1 \\
\hline HLW02-23 & HLW02 & 1 & 1 & 1 & 1 & \begin{tabular}{|l|} 
HLW03-02 \\
\end{tabular} & HLW03 & 1 & 1 & 1 & 1 \\
\hline HLW02-24 & HLW02 & 1 & 1 & 1 & 1 & \begin{tabular}{|l|} 
HLW03-03 \\
\end{tabular} & HLW03 & 1 & 1 & 1 & 1 \\
\hline HLW02-25 & HLW02 & 1 & 1 & 1 & 1 & HLW03-04 & HLW03 & 1 & 1 & 1 & 1 \\
\hline HLW02-26 & HLW02 & 1 & 1 & 1 & 1 & HLW03-05 & HLW03 & 1 & 1 & 1 & 1 \\
\hline HLW02-27 & HLW02 & 1 & 1 & 1 & 1 & HLW03-06 & HLW03 & 1 & 1 & 1 & 1 \\
\hline HLW02-28 & HLW02 & 1 & 1 & 1 & 1 & HLW03-07 & HLW03 & 1 & 1 & 1 & 1 \\
\hline HLW02-29 & HLW02 & 1 & 1 & 1 & 1 & HLW03-08 & HLW03 & 1 & $0^{(\mathrm{d})}$ & 0 & 1 \\
\hline HLW02-30 & HLW02 & 1 & 1 & 1 & 1 & HLW03-09 & HLW03 & 1 & $0^{(\mathrm{c})}$ & 1 & 1 \\
\hline HLW02-31 & HLW02 & 1 & 1 & 1 & 1 & HLW03-10 & HLW03 & 1 & 1 & 1 & 1 \\
\hline HLW02-32 & HLW02 & 1 & 1 & 1 & 1 & HLW03-11 & HLW03 & 1 & $0^{(\mathrm{c})}$ & 1 & 1 \\
\hline HLW02-33 & HLW02 & 1 & 1 & 1 & 1 & \begin{tabular}{|l|} 
HLW $03-12$ \\
\end{tabular} & HLW03 & 1 & 1 & 1 & 1 \\
\hline HLW02-34 & HLW02 & 1 & 1 & 1 & 1 & HLW03-13 & HLW03 & 1 & 1 & 1 & 1 \\
\hline HLW02-35 & HLW02 & 1 & 1 & 1 & 1 & HLW03-14 & HLW03 & 1 & 1 & 1 & 1 \\
\hline HLW02-36 & HLW02 & 1 & 1 & 1 & 1 & HLW03-15 & HLW03 & 1 & 1 & 1 & 1 \\
\hline
\end{tabular}

(a) HLW02 denotes the Initial Matrix glasses (see Section 2.1.1), while HLW03 denotes the Augmentation Matrix glasses that were selected to augment the Initial Matrix (HLW02) glasses (see Section 2.1.2).

(b) An entry of 1 indicates data is available for that property on that glass, while an entry of 0 indicates no data is available for that property on that glass.

(c) Insufficient data to estimate $\mathrm{T}_{1 \%}$ for a non-spinel primary crystalline phase.

(d) $\mathrm{T}_{1 \%}$ estimated, but for a non-spinel primary crystalline phase.

(e) Insufficient data to estimate spinel $T_{1 \%}$. 
Table 4.1. HLW Glasses Having Data for PCT, Spinel $T_{1 \%}$, Viscosity, and Electrical Conductivity (continued).

\begin{tabular}{|c|c|c|c|c|c|}
\hline Glass ID & 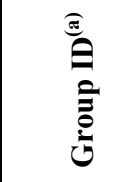 & $\widehat{\widehat{a}}$ & 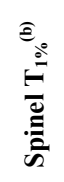 & 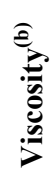 & 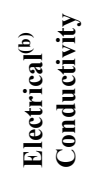 \\
\hline HLW03-16 & HLW03 & 1 & 1 & 1 & 1 \\
\hline HLW03-17 & HLW03 & 1 & 1 & 1 & 1 \\
\hline HLW03-18 & HLW03 & 1 & 1 & 1 & 1 \\
\hline HLW03-19 & HLW03 & 1 & 1 & 1 & 1 \\
\hline HLW03-20 & HLW03 & 1 & 1 & 1 & 1 \\
\hline HLW03-21 & HLW03 & 1 & 1 & 1 & 1 \\
\hline HLW03-22 & HLW03 & 1 & 1 & 1 & 1 \\
\hline HLW03-23 & HLW03 & 1 & 1 & 1 & 1 \\
\hline HLW03-24 & HLW03 & 1 & 1 & 1 & 1 \\
\hline HLW03-25 & HLW03 & 1 & 1 & 1 & 1 \\
\hline HLW03-26 & HLW03 & 1 & 1 & 1 & 1 \\
\hline HLW03-27 & HLW03 & 1 & 1 & 1 & 1 \\
\hline HLW03-28 & HLW03 & 1 & 1 & 1 & 1 \\
\hline HLW03-29 & HLW03 & 1 & 1 & 1 & 1 \\
\hline HLW03-30 & HLW03 & 1 & 1 & 1 & 1 \\
\hline HLW03-31 & HLW03 & 1 & 1 & 1 & 1 \\
\hline \begin{tabular}{|l|} 
HLW03-32 \\
\end{tabular} & HLW03 & 1 & 1 & $1^{(\mathrm{f})}$ & 1 \\
\hline HLW03-33 & HLW03 & 1 & $0^{(\mathrm{d})}$ & 1 & 1 \\
\hline HLW03-34 & HLW03 & 1 & $0^{(\mathrm{d})}$ & 1 & 1 \\
\hline HLW03-35 & HLW03 & 1 & $0^{(\mathrm{d})}$ & 1 & 1 \\
\hline HLW03-36 & HLW03 & 1 & $0^{(\mathrm{d})}$ & 1 & 1 \\
\hline HLW03-37 & HLW03 & 1 & 1 & 1 & 1 \\
\hline HLW03-38 & HLW03 & 1 & 1 & 1 & 1 \\
\hline HLW03-39 & HLW03 & 1 & 1 & 1 & 1 \\
\hline HLW03-40 & HLW03 & 1 & 1 & 1 & 1 \\
\hline HLW03-41 & HLW03 & 1 & 1 & 1 & 1 \\
\hline HLW03-42 & HLW03 & 1 & 1 & 1 & 1 \\
\hline HLW03-43 & HLW03 & 1 & 1 & 1 & 1 \\
\hline HLW03-44 & HLW03 & 1 & $0^{(\mathrm{c})}$ & 1 & 1 \\
\hline HLW03-45 & HLW03 & 1 & 1 & 1 & 1 \\
\hline HLW04-01 & HLW04 & 0 & $0^{(\mathrm{g})}$ & 1 & 1 \\
\hline HLW04-02 & HLW04 & 0 & $0^{(\mathrm{g})}$ & 0 & 0 \\
\hline
\end{tabular}

\begin{tabular}{|c|c|c|c|c|c|}
\hline Glass ID & 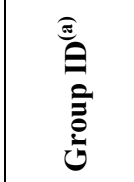 & $\stackrel{\widehat{\varrho}}{\underline{E}}$ & 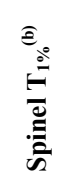 & 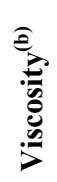 & 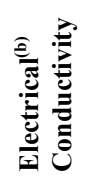 \\
\hline HLW04-03 & HLW04 & 1 & $0^{(\mathrm{g})}$ & 1 & 0 \\
\hline HLW04-04 & HLW04 & 0 & $0^{(\mathrm{g})}$ & 0 & 0 \\
\hline HLW04-05 & HLW04 & 0 & $0^{(\mathrm{g})}$ & 0 & 0 \\
\hline HLW04-06 & HLW04 & 0 & $0^{(\mathrm{g})}$ & 1 & 0 \\
\hline HLW04-07 & HLW04 & 1 & $0^{(\mathrm{g})}$ & 1 & 0 \\
\hline HLW04-07NRE9 & HLW04 & 1 & $0^{(\mathrm{g})}$ & 0 & 0 \\
\hline HLW04-07NRE9CCC & HLW04 & 1 & $0^{(\mathrm{g})}$ & 0 & 0 \\
\hline HLW04-07RE39 & HLW04 & 1 & $0^{(\mathrm{g})}$ & 0 & 0 \\
\hline HLW04-07RE39CCC & HLW04 & 1 & $0^{(\mathrm{g})}$ & 0 & 0 \\
\hline HLW04-08 & HLW04 & 1 & $0^{(\mathrm{g})}$ & 0 & 0 \\
\hline HLW04-09 & HLW04 & 1 & $0^{(\mathrm{g})}$ & 0 & 0 \\
\hline HLW05-01 & HLW05 & 0 & $0^{(\mathrm{d})}$ & 0 & 0 \\
\hline HLW05-02 & HLW05 & 0 & 1 & 0 & 0 \\
\hline HLW05-03 & HLW05 & 0 & 1 & 0 & 0 \\
\hline HLW05-04 & HLW05 & 0 & 1 & 0 & 0 \\
\hline HLW05-05 & HLW05 & 0 & $0^{(\mathrm{e})}$ & 0 & 0 \\
\hline HLW05-06 & HLW05 & 0 & $0^{(\mathrm{d})}$ & 0 & 0 \\
\hline HLW05-07 & HLW05 & 0 & 1 & 0 & 0 \\
\hline HLW05-08 & HLW05 & 0 & $0^{(\mathrm{d})}$ & 0 & 0 \\
\hline HLW05-09 & HLW05 & 0 & 1 & 0 & 0 \\
\hline HLW05-10 & HLW05 & 0 & $0^{(\mathrm{d})}$ & 0 & 0 \\
\hline HLW05-11 & HLW05 & 0 & 1 & 0 & 0 \\
\hline HLW05-12 & HLW05 & 0 & $0^{(\mathrm{d})}$ & 0 & 0 \\
\hline HLW05-13 & HLW05 & 0 & 1 & 0 & 0 \\
\hline HLW05-14 & HLW05 & 0 & 1 & 0 & 0 \\
\hline HLW05-15 & HLW05 & 0 & 0 & 1 & 1 \\
\hline HLW05-16 & HLW05 & 0 & $0^{(\mathrm{d})}$ & 0 & 0 \\
\hline HLW05-17 & HLW05 & 0 & $0^{(\mathrm{d})}$ & 0 & 0 \\
\hline HLW05-18 & HLW05 & 0 & $0^{(\mathrm{d})}$ & 0 & 0 \\
\hline HLW05-19 & HLW05 & 0 & $0^{(\mathrm{d})}$ & 0 & 0 \\
\hline HLW05-20 & HLW05 & 0 & $0^{(\mathrm{d})}$ & 1 & 1 \\
\hline HLW05-21 & HLW05 & 0 & $0^{(\mathrm{c})}$ & 1 & 1 \\
\hline
\end{tabular}

(a) HLW03 denotes the Augmentation Matrix glasses that were selected to augment the Initial Matrix (HLW02) glasses (see Section 2.1.2). HLW04 denotes the glasses formulated to support actual AY-102/C-106 waste testing (see Section 2.1.3). HLW05 denotes the Non-Spinel Matrix glasses (see Section 2.1.4).

(b) An entry of 1 indicates data is available for that property on that glass, while an entry of 0 indicates no data is available for that property on that glass.

(c) Insufficient data to estimate $T_{1 \%}$ for a non-spinel primary crystalline phase.

(d) $\mathrm{T}_{1 \%}$ estimated, but for a non-spinel primary crystalline phase.

(e) Insufficient data to estimate spinel $\mathrm{T}_{1 \%}$.

(f) Viscosity was only measured at one temperature $\left(1247^{\circ} \mathrm{C}\right)$ for HLW03-32.

(g) Crystallinity data were not measured for HLW04 glasses. 
Table 4.1. HLW Glasses Having Data for PCT, Spinel $T_{1 \%}$, Viscosity, and Electrical Conductivity (continued).

\begin{tabular}{|c|c|c|c|c|c|c|c|c|c|c|c|}
\hline Glass ID & 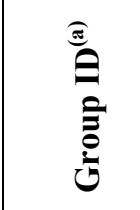 & 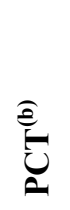 & 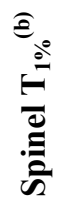 & 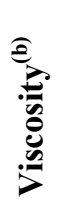 & 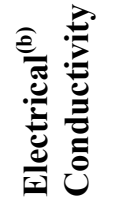 & Glass ID & 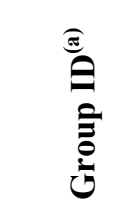 & 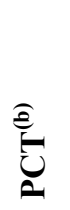 & 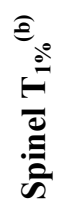 & 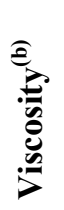 & 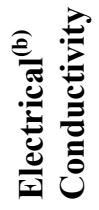 \\
\hline HLW05-22 & HLW05 & 0 & 0 & 1 & 1 & HLW06-24 & HLW06 & $1^{(\mathrm{f})}$ & $0^{(\mathrm{d})}$ & 0 & 0 \\
\hline HLW05-23 & HLW05 & 0 & $0^{(\mathrm{d})}$ & 0 & 0 & HLW06-25 & HLW06 & 1 & 1 & 0 & 0 \\
\hline HLW05-24 & HLW05 & 0 & $0^{\text {(d) }}$ & 0 & 0 & \begin{tabular}{|l|} 
HLW06-26 \\
\end{tabular} & HLW06 & $1^{(\mathrm{f})}$ & $0^{(\mathrm{d})}$ & 0 & 0 \\
\hline HLW05-25 & HLW05 & 0 & $0^{(\mathrm{d})}$ & 0 & 0 & HLW06-27 & HLW06 & 1 & $0^{(\mathrm{d})}$ & 0 & 0 \\
\hline HLW05-26 & HLW05 & 0 & $0^{\text {(d) }}$ & 0 & 0 & \begin{tabular}{|l|} 
HLW06-28 \\
\end{tabular} & HLW06 & 1 & 1 & 0 & 0 \\
\hline HLW05-27 & HLW05 & 0 & 1 & 1 & 1 & \begin{tabular}{|l|} 
HLW06-29 \\
\end{tabular} & HLW06 & 1 & $0^{(\mathrm{d})}$ & 0 & 0 \\
\hline HLW05-28 & HLW05 & 0 & $0^{(\mathrm{d})}$ & 0 & 0 & HLW06-30 & HLW06 & $1^{(\mathrm{f})}$ & 1 & 0 & 0 \\
\hline \begin{tabular}{|l|} 
HLW05-29 \\
\end{tabular} & HLW05 & 0 & $0^{(\mathrm{d})}$ & 0 & 0 & \begin{tabular}{|l|} 
HLW06-31 \\
\end{tabular} & HLW06 & 1 & 1 & 0 & 0 \\
\hline HLW05-30 & HLW05 & 0 & $0^{(\mathrm{e})}$ & 0 & 0 & \begin{tabular}{|l} 
HLW06-32 \\
\end{tabular} & HLW06 & $1^{(\mathrm{f})}$ & 1 & 1 & 1 \\
\hline HLW06-01 & HLW06 & 1 & 1 & 0 & 0 & HLW06-33 & HLW06 & 1 & $0^{(\mathrm{d})}$ & 0 & 0 \\
\hline \begin{tabular}{|l|} 
HLW06-02 \\
\end{tabular} & HLW06 & 1 & 1 & 1 & 1 & \begin{tabular}{|l|} 
HLW06-34 \\
\end{tabular} & HLW06 & $1^{(\mathrm{f})}$ & $0^{(\mathrm{d})}$ & 1 & 1 \\
\hline HLW06-03 & HLW06 & 1 & 1 & 0 & 0 & HLW06-35 & HLW06 & 1 & $0^{(\mathrm{d})}$ & 0 & 0 \\
\hline HLW06-04 & HLW06 & 1 & 1 & 1 & 1 & HLW07-01 & HLW07 & 1 & 1 & 1 & 1 \\
\hline HLW06-05 & HLW06 & 1 & 1 & 0 & 0 & HLW07-02 & HLW07 & 1 & 1 & 1 & 1 \\
\hline HLW06-06 & HLW06 & 1 & 1 & 0 & 0 & HLW07-03 & HLW07 & 1 & 1 & 1 & 1 \\
\hline HLW06-07 & HLW06 & 1 & 1 & 0 & 0 & HLW07-04 & HLW07 & 1 & 1 & 1 & 1 \\
\hline \begin{tabular}{|l|} 
HLW06-08 \\
\end{tabular} & HLW06 & 1 & 1 & 0 & 0 & \begin{tabular}{|l|} 
HLW07-05 \\
\end{tabular} & HLW07 & 1 & 1 & 1 & 1 \\
\hline \begin{tabular}{|l|} 
HLW06-09 \\
\end{tabular} & HLW06 & 1 & 1 & 0 & 0 & \begin{tabular}{|l|} 
HLW07-06 \\
\end{tabular} & HLW07 & $1^{(\mathrm{f})}$ & 1 & 1 & 1 \\
\hline HLW06-10 & HLW06 & 1 & 1 & 0 & 0 & HLW07-07 & HLW07 & $1^{(\mathrm{f})}$ & 1 & 1 & 1 \\
\hline HLW06-11 & HLW06 & 1 & 1 & 0 & 0 & \begin{tabular}{|l|} 
HLW07-08 \\
\end{tabular} & HLW07 & $1^{(\mathrm{f})}$ & $0^{(\mathrm{d})}$ & 0 & 1 \\
\hline HLW06-12 & HLW06 & 1 & 1 & 0 & 0 & \begin{tabular}{|l|} 
HLW07-09 \\
\end{tabular} & HLW07 & 1 & $0^{(\mathrm{d})}$ & 1 & 1 \\
\hline HLW06-13 & HLW06 & 1 & 1 & 0 & 0 & HLW07-10 & HLW07 & $1^{(\mathrm{f})}$ & $0^{(\mathrm{d})}$ & 1 & 1 \\
\hline HLW06-14 & HLW06 & 1 & 1 & 0 & 0 & HLW07-11 & HLW07 & 1 & 1 & 1 & 1 \\
\hline HLW06-15 & HLW06 & 1 & 1 & 0 & 0 & HLW07-12 & HLW07 & 1 & $0^{(\mathrm{d})}$ & 1 & 1 \\
\hline HLW06-16 & HLW06 & 1 & 1 & 0 & 0 & HLW07-13 & HLW07 & 1 & $0^{(\mathrm{d})}$ & 1 & 1 \\
\hline HLW06-17 & HLW06 & 1 & 1 & 0 & 0 & HLW07-14 & HLW07 & 1 & $0^{(\mathrm{d})}$ & 0 & 1 \\
\hline HLW06-18 & HLW06 & 1 & 1 & 0 & 0 & HLW07-15 & HLW07 & $1^{(\mathrm{f})}$ & $0^{(\mathrm{d})}$ & 1 & 1 \\
\hline HLW06-19 & HLW06 & 1 & 1 & 0 & 0 & HLW07-16 & HLW07 & 1 & 1 & 1 & 1 \\
\hline HLW06-20 & HLW06 & 1 & 1 & 0 & 0 & HLW07-17 & HLW07 & 1 & 1 & 1 & 1 \\
\hline HLW06-21 & HLW06 & $1^{(f)}$ & $0^{(\mathrm{d})}$ & 0 & 0 & \begin{tabular}{|l|} 
HLW07-18 \\
\end{tabular} & HLW07 & 1 & $0^{(\mathrm{d})}$ & 1 & 1 \\
\hline HLW06-22 & HLW06 & 1 & $0^{(\mathrm{d})}$ & 1 & 1 & HLW07-19 & HLW07 & 1 & $0^{(\mathrm{d})}$ & 1 & 1 \\
\hline HLW06-23 & HLW06 & $1^{(\mathrm{f})}$ & $0^{(\mathrm{d})}$ & 0 & 0 & HLW07-20 & HLW07 & 1 & 1 & 1 & 1 \\
\hline
\end{tabular}

(a) HLW05 denotes the Non-Spinel Matrix glasses (see Section 2.1.4). HLW06 denotes the Spinel Matrix glasses (see Section 2.1.5). HLW07 denotes a test matrix of glasses selected to better cover the HLW glass composition region of interest (see Section 2.1.6).

(b) An entry of 1 indicates data is available for that property on that glass, while an entry of 0 indicates no data is available for that property on that glass.

(c) Insufficient data to estimate $\mathrm{T}_{1 \%}$ for a non-spinel primary crystalline phase.

(d) $\mathrm{T}_{1 \%}$ estimated, but for a non-spinel primary crystalline phase.

(e) Insufficient data to estimate spinel $\mathrm{T}_{1 \%}$.

(f) This glass had $\mathrm{Li}_{2} \mathrm{O}=0 \mathrm{wt} \%$, so that the PCT-Li release is zero. 
Table 4.1. HLW Glasses Having Data for PCT, Spinel T1\%, Viscosity, and Electrical Conductivity (continued).

\begin{tabular}{|c|c|c|c|c|c|}
\hline Glass ID & 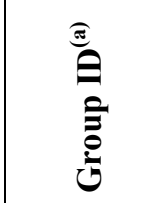 & $\stackrel{\hat{a}}{\underline{\omega}}$ & 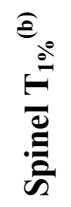 & 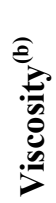 & 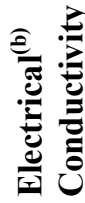 \\
\hline HLW07-21 & HLW07 & $1^{(\mathrm{f})}$ & $0^{(\mathrm{d})}$ & 1 & 1 \\
\hline HLW07-22 & HLW07 & $1^{(\mathrm{f})}$ & $0^{(\mathrm{d})}$ & 1 & 1 \\
\hline HLW07-23 & HLW07 & 1 & $0^{(d)}$ & 1 & 1 \\
\hline HLW07-24 & HLW07 & $1^{(\mathrm{f})}$ & 1 & 1 & 1 \\
\hline HLW07-25 & HLW07 & 1 & $0^{(\mathrm{d})}$ & 1 & 1 \\
\hline HLW07-26 & HLW07 & 1 & 1 & 1 & 1 \\
\hline HLW07-27 & HLW07 & 1 & 1 & 1 & 1 \\
\hline HLW07-28 & HLW07 & 1 & 1 & 1 & 1 \\
\hline HLW07-29 & HLW07 & 1 & 1 & 1 & 1 \\
\hline HLW07-30 & HLW07 & 1 & 1 & 1 & 1 \\
\hline HLW07-31 & HLW07 & 1 & 1 & 1 & 1 \\
\hline HLW07-32 & HLW07 & 1 & 1 & 1 & 1 \\
\hline HLW07-33 & HLW07 & 1 & 1 & 1 & 1 \\
\hline HLW07-34 & HLW07 & 1 & $0^{(\mathrm{d})}$ & 1 & 1 \\
\hline HLW07-35 & HLW07 & 1 & 1 & 1 & 1 \\
\hline HLW07-36 & HLW07 & 1 & $0^{(\mathrm{e})}$ & 1 & 1 \\
\hline HLW07-37 & HLW07 & 1 & 1 & 1 & 1 \\
\hline HLW07-38 & HLW07 & 1 & 1 & 1 & 1 \\
\hline HLW07-39 & HLW07 & 1 & 1 & 1 & 1 \\
\hline HLW07-40 & HLW07 & 1 & 1 & 1 & 1 \\
\hline HLW-ALG-01 & HLWALG & 1 & $0^{(\mathrm{e})}$ & 1 & 1 \\
\hline HLW-ALG-02 & HLWALG & 1 & $0^{(\mathrm{e})}$ & 1 & 1 \\
\hline HLW-ALG-03 & HLWALG & 1 & 1 & 1 & 1 \\
\hline HLW-ALG-04 & HLWALG & 1 & $0^{(\mathrm{e})}$ & 1 & 1 \\
\hline HLW-ALG-05 & HLWALG & 1 & 1 & 1 & 1 \\
\hline HLW-ALG-06 & HLWALG & 1 & 1 & 1 & 1 \\
\hline HLW-ALG-07 & HLWALG & 1 & $0^{(\mathrm{c})}$ & 1 & 1 \\
\hline HLW-ALG-08 & HLWALG & 1 & $0^{(\mathrm{d})}$ & 1 & 1 \\
\hline HLW-ALG-09 & HLWALG & 1 & 1 & 1 & 1 \\
\hline HLW-ALG-10 & HLWALG & 1 & 1 & 1 & 1 \\
\hline HLW-ALG-11 & HLWALG & 1 & $0^{(\mathrm{d})}$ & 1 & 1 \\
\hline HLW-ALG-12 & HLWALG & 1 & 1 & 1 & 1 \\
\hline
\end{tabular}

\begin{tabular}{|c|c|c|c|c|c|}
\hline Glass ID & 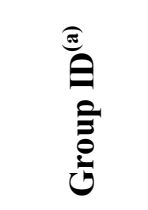 & 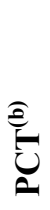 & 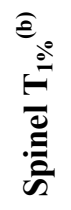 & 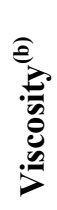 & 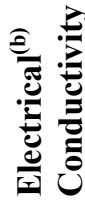 \\
\hline HLW-ALG-13 & HLWALG & 1 & $0^{(\mathrm{d})}$ & $1^{(\mathrm{g})}$ & 1 \\
\hline HLW-ALG-14 & HLWALG & 1 & 1 & 1 & 1 \\
\hline HLW-ALG-15 & HLWALG & 1 & 1 & 1 & 1 \\
\hline HLW-ALG-16 & HLWALG & 1 & $0^{(\mathrm{c})}$ & 1 & 1 \\
\hline HLW-ALG-17 & HLWALG & 1 & 1 & 1 & 1 \\
\hline HLW-ALG-18 & HLWALG & 1 & 1 & 1 & 1 \\
\hline HLW-ALG-19 & HLWALG & 1 & 1 & 1 & 1 \\
\hline HLW-ALG-20 & HLWALG & 1 & 1 & 1 & 1 \\
\hline HLW-ALG-21 & HLWALG & 1 & $0^{(\mathrm{d})}$ & 1 & 1 \\
\hline HLW-ALG-22 & HLWALG & 1 & $0^{\text {(d) }}$ & 1 & 1 \\
\hline HLW-ALG-23 & HLWALG & 1 & $0^{\text {(d) }}$ & 1 & 1 \\
\hline HLW-ALG-24 & HLWALG & 1 & $0^{(\mathrm{d})}$ & 0 & 1 \\
\hline HLW-ALG-25 & HLWALG & 1 & 1 & 1 & 1 \\
\hline HLW-ALG-26 & HLWALG & 1 & $0^{(\mathrm{c})}$ & 1 & 1 \\
\hline HLW-ALG-27 & HLWALG & 1 & 1 & 1 & 1 \\
\hline HLW-ALG-28 & HLWALG & 1 & 1 & 1 & 1 \\
\hline HLW-ALG-29 & HLWALG & 1 & $0^{(\mathrm{e})}$ & 1 & 1 \\
\hline HLW-ALG-30 & HLWALG & 1 & 1 & 1 & 1 \\
\hline HLW-ALG-31 & HLWALG & 1 & 1 & 1 & 1 \\
\hline HLW-ALG-32 & HLWALG & 1 & 1 & 1 & 1 \\
\hline HLW-ALG-33 & HLWALG & 1 & $0^{(\mathrm{d})}$ & 1 & 1 \\
\hline HLW-ALG-34 & HLWALG & 1 & 1 & 1 & 1 \\
\hline HLW-ALG-35 & HLWALG & 1 & 1 & 1 & 1 \\
\hline HLW-ALG-36 & HLWALG & 1 & 1 & 1 & 1 \\
\hline HLW-ALG-37 & HLWALG & 1 & $0^{\text {(d) }}$ & 1 & 1 \\
\hline HLW-ALG-38 & HLWALG & 1 & $0^{(\mathrm{d})}$ & 1 & 1 \\
\hline HLW-ALG-39 & HLWALG & 1 & $0^{(\mathrm{e})}$ & 1 & 1 \\
\hline HLW-ALG-40 & HLWALG & 1 & 1 & 1 & 1 \\
\hline HLW98-34CG & HLW98 & 1 & $0^{(\mathrm{h})}$ & 0 & 0 \\
\hline HLW98-51AW & HLW98 & 1 & $0^{(\mathrm{h})}$ & 0 & 0 \\
\hline HLW98-51AWCG & HLW98 & 1 & $0^{(\mathrm{h})}$ & 0 & 0 \\
\hline HLW98-61 & HLW98 & 1 & $0^{(\mathrm{h})}$ & 0 & 0 \\
\hline
\end{tabular}

(a) HLW07 denotes a test matrix of glasses selected to better cover the HLW glass composition region of interest (see Section 2.1.6). HLW-ALG denotes glasses designed to assess the performance of the HLW glass formulation algorithm (see Section 2.1.7). HLW98 denotes simulated glasses actively designed to support melter and other tests (see Section 2.1.8).

(b) An entry of 1 indicates data is available for that property on that glass, while an entry of 0 indicates no data is available for that property on that glass.

(c) Insufficient data to estimate $T_{1 \%}$ for a non-spinel primary crystalline phase.

(d) $\mathrm{T}_{1 \%}$ estimated, but for a non-spinel primary crystalline phase.

(e) Insufficient data to estimate spinel $\mathrm{T}_{1 \%}$.

(f) This glass had $\mathrm{Li}_{2} \mathrm{O}=0 \mathrm{wt} \%$, so that the PCT-Li release is zero.

(g) Viscosity was only measured at two temperatures $\left(1154\right.$ and $\left.1249^{\circ} \mathrm{C}\right)$ for HLW-ALG-13.

(h) Spienl $\mathrm{T}_{1 \%}$ values were not estimated for HLW98 glasses. 
Table 4.1. HLW Glasses Having Data for PCT, Spinel T1\%, Viscosity, and Electrical Conductivity (continued).

\begin{tabular}{|c|c|c|c|c|c|}
\hline Glass ID & 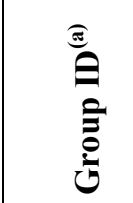 & $\begin{array}{l}\hat{\mathrm{a}} \\
\hat{\mathrm{E}}\end{array}$ & 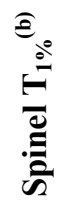 & 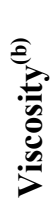 & 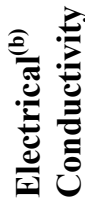 \\
\hline HLW98-61CG1 & HLW98 & 1 & $0^{(\mathrm{c})}$ & 0 & 0 \\
\hline HLW98-72 & HLW98 & 0 & $0^{(\mathrm{c})}$ & 1 & 1 \\
\hline HLW98-74 & HLW98 & 1 & $0^{(\mathrm{c})}$ & 0 & 0 \\
\hline HLW98-75 & HLW98 & 1 & $0^{(\mathrm{c})}$ & 0 & 0 \\
\hline HLW98-77 & HLW98 & 1 & $0^{(\mathrm{c})}$ & 1 & 1 \\
\hline HLW98-77CG & HLW98 & 1 & $0^{(\mathrm{c})}$ & 0 & 0 \\
\hline HLW98-80 & HLW98 & 1 & $0^{(\mathrm{c})}$ & 1 & 1 \\
\hline HLW98-80CG & HLW98 & 1 & $0^{(\mathrm{c})}$ & 0 & 0 \\
\hline HLW98-83 & HLW98 & 1 & $0^{(\mathrm{c})}$ & 1 & 1 \\
\hline HLW98-84 & HLW98 & 1 & $0^{(\mathrm{c})}$ & 1 & 1 \\
\hline HLW98-84CG & HLW98 & 1 & $0^{(\mathrm{c})}$ & 0 & 0 \\
\hline HLW98-86 & HLW98 & 1 & $0^{(\mathrm{c})}$ & 0 & 0 \\
\hline HLW98-86AG & HLW98 & 0 & $0^{(\mathrm{c})}$ & 1 & 1 \\
\hline HLW98-86CG & HLW98 & 1 & $0^{(\mathrm{c})}$ & 0 & 0 \\
\hline HLW98-87 & HLW98 & 1 & $0^{(\mathrm{c})}$ & 1 & 0 \\
\hline HLW98-88 & HLW98 & 1 & $0^{(\mathrm{c})}$ & 1 & 1 \\
\hline HLW98-89 & HLW98 & 1 & $0^{(\mathrm{c})}$ & 1 & 1 \\
\hline HLW98-94 & HLW98 & 1 & $0^{(\mathrm{c})}$ & 0 & 0 \\
\hline HLW98-95 & HLW98 & 1 & $0^{(\mathrm{c})}$ & 1 & 1 \\
\hline HLW98-95CG-1 & HLW98 & 1 & $0^{(\mathrm{c})}$ & 0 & 0 \\
\hline HLW98-96 & HLW98 & 1 & $0^{(\mathrm{c})}$ & 1 & 1 \\
\hline
\end{tabular}

\begin{tabular}{|c|c|c|c|c|c|}
\hline Glass ID & 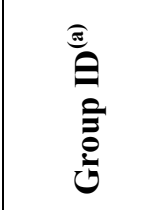 & $\begin{array}{l}\hat{\theta} \\
\bar{U} \\
\hat{U}\end{array}$ & 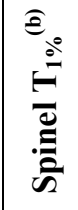 & 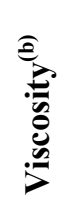 & 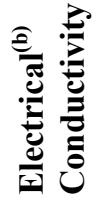 \\
\hline HLW98-96A & HLW98 & 1 & $0^{\text {(c) }}$ & 1 & 1 \\
\hline HLW98-96B & HLW98 & 1 & $0^{(\mathrm{c})}$ & 1 & 1 \\
\hline HLW98-96CG & HLW98 & 1 & $0^{(\mathrm{c})}$ & 0 & 0 \\
\hline HLW98-96D & HLW98 & 1 & $0^{\text {(c) }}$ & 1 & 1 \\
\hline HLW98-96NRE4 & HLW98 & 1 & $0^{(\mathrm{c})}$ & 0 & 0 \\
\hline HLW98-96NRE4CCC & HLW98 & 1 & $0^{\text {(c) }}$ & 0 & 0 \\
\hline HLW98-96RE7 & HLW98 & 1 & $0^{\text {(c) }}$ & 0 & 0 \\
\hline HLW98-96RE7CCC & HLW98 & 1 & $0^{(\mathrm{c})}$ & 0 & 0 \\
\hline HLW98-97 & HLW98 & 1 & $0^{(\mathrm{c})}$ & 1 & 1 \\
\hline HLW98-T05 & HLW98 & 1 & $0^{(\mathrm{c})}$ & 1 & 1 \\
\hline HLW98-V01 & HLW98 & 1 & $0^{(\mathrm{c})}$ & 0 & 0 \\
\hline HLW98-V07 & HLW98 & 1 & $0^{\text {(c) }}$ & 0 & 0 \\
\hline HLW98-V13 & HLW98 & 1 & $0^{\text {(c) }}$ & 0 & 0 \\
\hline HLW98-V19 & HLW98 & 1 & $0^{(\mathrm{c})}$ & 1 & 1 \\
\hline HLW98-V24 & HLW98 & 1 & $0^{\text {(c) }}$ & 1 & 1 \\
\hline AZ-101 Actual & Actual & 1 & $0^{(\mathrm{d})}$ & 0 & 0 \\
\hline AZ-102 Actual & Actual & 1 & $0^{(\mathrm{d})}$ & $0^{(\mathrm{d})}$ & $0^{(\mathrm{d})}$ \\
\hline AY-102/C-106 Actual & Actual & 1 & $0^{(\mathrm{d})}$ & $0^{(\mathrm{d})}$ & $0^{(\mathrm{d})}$ \\
\hline C-106 Actual & Actual & 1 & $0^{(\mathrm{d})}$ & $0^{(\mathrm{d})}$ & $0^{(\mathrm{d})}$ \\
\hline C-104 Actual & Actual & 1 & $0^{(\mathrm{d})}$ & $0^{(\mathrm{d})}$ & $0^{(\mathrm{d})}$ \\
\hline Totals & \# Glasses $=305^{(\mathrm{e})}$ & 268 & 172 & 210 & 210 \\
\hline
\end{tabular}

(a) HLW98 denotes simulated glasses actively designed to support melter and other tests (see Section 2.1.8). Actual denotes glasses made from actual HLW samples (see Section 2.1.9).

(b) An entry of 1 indicates data is available for that property on that glass, while an entry of 0 indicates no data is available for that property on that glass.

(c) Spienl $\mathrm{T}_{1 \%}$ values were not estimated for HLW98 glasses.

(d) Crystallinity, viscosity, and electrical conductivity data were not measured for Actual HLW glasses.

(e) Of the 305 total glasses listed in this table, only 285 have PCT, spinel $\mathrm{T}_{1 \%}$, viscosity, or electrical conductivity data. An additional 17 glasses have crystallinity data. The remaining three glasses (HLW04-02, HLW04-04, and HLW04-05) do not have PCT, crystallinity, viscosity, or electrical conductivity data. Hence, only 302 of the 305 glasses listed have data for at least one property. 
Table 4.2. PCT Results ${ }^{(a)}$ for 268 Simulated and Actual HLW Glasses.

\begin{tabular}{|c|c|c|c|c|c|c|c|c|c|c|c|}
\hline \multirow[b]{2}{*}{ Glass ID } & \multirow[b]{2}{*}{ Group ID (b) $^{(b)}$} & \multicolumn{3}{|c|}{$\begin{array}{c}\text { Concentration } \\
(\mathbf{p p m})\end{array}$} & \multicolumn{3}{|c|}{$\begin{array}{c}\text { Normalized Concentration } \\
(\mathrm{g} / \mathrm{L})\end{array}$} & \multicolumn{3}{|c|}{$\begin{array}{c}\text { Normalized Mass Loss } \\
\left(\mathrm{g} / \mathrm{m}^{2}\right)\end{array}$} & \multirow{2}{*}{$\begin{array}{c}\text { Leachate } \\
\text { pH }\end{array}$} \\
\hline & & PCT-B & PCT-Li & PCT-Na & PCT-B & PCT-Li & PCT-Na & PCT-B & PCT-Li & PCT-Na & \\
\hline HLW02-01 & HLW02 & 21.580 & 12.720 & 51.060 & 0.700 & 0.685 & 0.628 & 0.350 & 0.343 & 0.314 & 10.64 \\
\hline HLW02-02 & HLW02 & 39.350 & 22.260 & 11.810 & 0.905 & 0.799 & 0.398 & 0.453 & 0.399 & 0.199 & 9.86 \\
\hline HLW02-03 & HLW02 & 123.300 & 19.880 & 224.200 & 2.837 & 2.140 & 2.015 & 1.418 & 1.070 & 1.007 & 10.68 \\
\hline HLW02-04 & HLW02 & 8.913 & 6.730 & 97.650 & 0.574 & 0.724 & 0.877 & 0.287 & 0.362 & 0.439 & 10.84 \\
\hline HLW02-05 & HLW02 & 11.340 & 23.700 & 103.800 & 0.730 & 0.850 & 1.015 & 0.365 & 0.425 & 0.507 & 11.46 \\
\hline HLW02-06 & HLW02 & 6.167 & 15.440 & 110.800 & 0.397 & 0.701 & 0.996 & 0.199 & 0.351 & 0.498 & 11.54 \\
\hline HLW02-07 & HLW02 & 7.795 & 18.710 & 54.280 & 0.502 & 0.671 & 0.625 & 0.251 & 0.336 & 0.313 & 11.18 \\
\hline HLW02-08 & HLW02 & 153.500 & 41.200 & 251.700 & 3.531 & 2.679 & 2.262 & 1.766 & 1.340 & 1.131 & 10.97 \\
\hline HLW02-09 & HLW02 & 23.260 & 6.140 & 80.670 & 0.646 & 0.582 & 0.725 & 0.323 & 0.291 & 0.362 & 10.74 \\
\hline HLW02-10 & HLW02 & 40.640 & 23.210 & 57.820 & 0.935 & 0.833 & 0.741 & 0.467 & 0.416 & 0.371 & 10.82 \\
\hline HLW02-11 & HLW02 & 99.010 & 47.040 & 103.700 & 2.277 & 1.688 & 1.287 & 1.139 & 0.844 & 0.644 & 10.64 \\
\hline HLW02-12 & HLW02 & 50.760 & 64.600 & 210.700 & 3.270 & 2.319 & 2.226 & 1.635 & 1.159 & 1.113 & 11.84 \\
\hline HLW02-13 & HLW02 & 54.240 & 69.930 & 205.400 & 3.494 & 2.510 & 2.656 & 1.747 & 1.255 & 1.328 & 11.85 \\
\hline HLW02-14 & HLW02 & 1.620 & 10.670 & 5.787 & 0.104 & 0.383 & 0.188 & 0.052 & 0.191 & 0.094 & 10.51 \\
\hline HLW02-15 & HLW02 & 55.180 & 9.717 & 85.220 & 1.270 & 1.046 & 0.916 & 0.635 & 0.523 & 0.458 & 9.95 \\
\hline HLW02-16 & HLW02 & 11.470 & 20.810 & 49.660 & 0.739 & 0.747 & 0.694 & 0.370 & 0.373 & 0.347 & 11.23 \\
\hline HLW02-17 & HLW02 & 8.470 & 20.240 & 19.400 & 0.546 & 0.726 & 0.340 & 0.273 & 0.363 & 0.170 & 10.66 \\
\hline HLW02-18 & HLW02 & 9.360 & 5.303 & 80.290 & 0.603 & 0.567 & 0.722 & 0.302 & 0.284 & 0.361 & 10.86 \\
\hline HLW02-19 & HLW02 & 27.610 & 5.480 & 33.770 & 0.635 & 0.590 & 0.514 & 0.318 & 0.295 & 0.257 & 9.84 \\
\hline HLW02-20 & HLW02 & 21.530 & 5.717 & 14.670 & 0.495 & 0.615 & 0.306 & 0.248 & 0.308 & 0.153 & 9.38 \\
\hline HLW02-21 & HLW02 & 63.100 & 10.460 & 102.800 & 1.452 & 1.126 & 0.924 & 0.726 & 0.563 & 0.462 & 10.33 \\
\hline HLW02-22 & HLW02 & 23.890 & 17.270 & 2.257 & 0.550 & 0.620 & 0.076 & 0.275 & 0.310 & 0.038 & 9.84 \\
\hline HLW02-23 & HLW02 & 29.920 & 18.730 & 24.990 & 0.688 & 0.672 & 0.602 & 0.344 & 0.336 & 0.301 & 10.38 \\
\hline HLW02-24 & HLW02 & 4.900 & 4.027 & 46.970 & 0.316 & 0.434 & 0.519 & 0.158 & 0.217 & 0.260 & 10.84 \\
\hline HLW02-25 & HLW02 & 13.770 & 3.543 & 7.317 & 0.317 & 0.381 & 0.143 & 0.158 & 0.191 & 0.072 & 9.43 \\
\hline HLW02-26 & HLW02 & 19.250 & 8.577 & 121.700 & 1.240 & 0.923 & 1.094 & 0.620 & 0.462 & 0.547 & 11.43 \\
\hline HLW02-27 & HLW02 & 25.920 & 15.460 & 13.330 & 0.596 & 0.555 & 0.420 & 0.298 & 0.277 & 0.210 & 10.14 \\
\hline HLW02-28 & HLW02 & 14.910 & 5.413 & 66.330 & 0.600 & 0.466 & 0.596 & 0.300 & 0.233 & 0.298 & 11.06 \\
\hline
\end{tabular}

(a) 7-Day PCT, stainless steel vessel with $\mathrm{S} / \mathrm{V}=2000 \mathrm{~m}^{-1}$. The PCT concentrations (ppm) are as measured. Normalized concentrations (g/L) and normalized mass losses $\left(\mathrm{g} / \mathrm{m}^{2}\right)$ are calculated as discussed in Section 3.3.

(b) The Group IDs are described in Sections 2.1.1 to 2.1.9. 
Table 4.2. PCT Results ${ }^{(a)}$ for 268 Simulated and Actual HLW Glasses (continued).

\begin{tabular}{|c|c|c|c|c|c|c|c|c|c|c|c|}
\hline \multirow[b]{2}{*}{ Glass ID } & \multirow[b]{2}{*}{ Group ID (b) $^{(b)}$} & \multicolumn{3}{|c|}{$\begin{array}{l}\text { Concentration } \\
(\text { ppm) }\end{array}$} & \multicolumn{3}{|c|}{$\begin{array}{c}\text { Normalized Concentration } \\
(\mathrm{g} / \mathrm{L})\end{array}$} & \multicolumn{3}{|c|}{$\begin{array}{c}\text { Normalized Mass Loss } \\
\left(\mathrm{g} / \mathrm{m}^{2}\right)\end{array}$} & \multirow{2}{*}{$\begin{array}{c}\text { Leachate } \\
\text { pH }\end{array}$} \\
\hline & & PCT-B & PCT-Li & PCT-Na & PCT-B & PCT-Li & PCT-Na & PCT-B & PCT-Li & PCT-Na & \\
\hline HLW02-29 & HLW02 & 33.080 & 10.450 & 37.970 & 0.820 & 0.600 & 0.569 & 0.410 & 0.300 & 0.284 & 9.85 \\
\hline HLW02-30 & HLW02 & 66.440 & 41.240 & 134.100 & 2.201 & 1.776 & 1.610 & 1.101 & 0.888 & 0.805 & 11.31 \\
\hline HLW02-31 & HLW02 & 53.250 & 12.510 & 58.850 & 1.319 & 1.077 & 0.529 & 0.660 & 0.539 & 0.265 & 10.53 \\
\hline HLW02-32 & HLW02 & 14.060 & 15.420 & 48.390 & 0.566 & 0.664 & 0.608 & 0.283 & 0.332 & 0.304 & 10.88 \\
\hline HLW02-33 & HLW02 & 24.940 & 8.553 & 95.340 & 1.004 & 0.737 & 0.857 & 0.502 & 0.368 & 0.428 & 11.16 \\
\hline HLW02-34 & HLW02 & 47.390 & 17.270 & 70.940 & 1.174 & 0.940 & 0.878 & 0.587 & 0.470 & 0.439 & 10.46 \\
\hline HLW02-35 & HLW02 & 49.600 & 23.910 & 62.290 & 1.229 & 1.030 & 0.917 & 0.614 & 0.515 & 0.458 & 10.47 \\
\hline HLW02-36 & HLW02 & 15.970 & 7.027 & 85.590 & 0.593 & 0.605 & 0.769 & 0.297 & 0.303 & 0.385 & 10.77 \\
\hline HLW02-37 & HLW02 & 22.020 & 5.990 & 36.900 & 0.546 & 0.516 & 0.445 & 0.273 & 0.258 & 0.222 & 9.97 \\
\hline HLW02-38 & HLW02 & 25.640 & 13.620 & 38.030 & 0.635 & 0.689 & 0.570 & 0.318 & 0.345 & 0.285 & 10.14 \\
\hline HLW02-39 & HLW02 & 7.930 & 6.183 & 31.910 & 0.284 & 0.532 & 0.389 & 0.142 & 0.266 & 0.194 & 10.14 \\
\hline HLW02-40 & HLW02 & 8.447 & 6.797 & 23.200 & 0.277 & 0.556 & 0.323 & 0.138 & 0.278 & 0.161 & 9.96 \\
\hline HLW02-41 & HLW02 & 19.340 & 7.677 & 23.620 & 0.479 & 0.661 & 0.354 & 0.240 & 0.331 & 0.177 & 9.84 \\
\hline HLW02-42 & HLW02 & 43.600 & 22.060 & 54.970 & 1.080 & 0.950 & 0.823 & 0.540 & 0.475 & 0.412 & 10.33 \\
\hline HLW02-43 & HLW02 & 42.650 & 9.747 & 77.980 & 1.057 & 0.839 & 0.844 & 0.528 & 0.420 & 0.422 & 10.42 \\
\hline HLW02-44 & HLW02 & 22.780 & 8.683 & 94.940 & 0.809 & 0.748 & 0.853 & 0.404 & 0.374 & 0.427 & 10.84 \\
\hline HLW02-45 & HLW02 & 15.790 & 7.353 & 35.330 & 0.636 & 0.633 & 0.495 & 0.318 & 0.317 & 0.248 & 10.25 \\
\hline HLW02-46 & HLW02 & 15.240 & 10.860 & 30.170 & 0.536 & 0.632 & 0.452 & 0.268 & 0.316 & 0.226 & 10.14 \\
\hline HLW02-47 & HLW02 & 14.790 & 6.377 & 23.700 & 0.486 & 0.549 & 0.338 & 0.243 & 0.275 & 0.169 & 9.93 \\
\hline HLW02-48 & HLW02 & 21.540 & 13.250 & 111.400 & 0.867 & 0.854 & 1.001 & 0.434 & 0.427 & 0.501 & 11.26 \\
\hline HLW02-49 & HLW02 & 16.040 & 15.850 & 38.640 & 0.591 & 0.682 & 0.579 & 0.296 & 0.341 & 0.289 & 10.66 \\
\hline HLW02-50 & HLW02 & 21.540 & 7.873 & 30.430 & 0.534 & 0.678 & 0.418 & 0.267 & 0.339 & 0.209 & 9.95 \\
\hline HLW02-51 & HLW02 & 6.473 & 12.110 & 26.770 & 0.261 & 0.568 & 0.401 & 0.130 & 0.284 & 0.200 & 10.48 \\
\hline HLW02-52 & HLW02 & 18.140 & 12.510 & 51.790 & 0.588 & 0.674 & 0.637 & 0.294 & 0.337 & 0.319 & 10.57 \\
\hline HLW02-53 & HLW02 & 5.337 & 21.730 & 21.470 & 0.344 & 0.780 & 0.376 & 0.172 & 0.390 & 0.188 & 10.64 \\
\hline HLW02-54 & HLW02 & 25.950 & 6.553 & 104.400 & 1.671 & 0.705 & 0.938 & 0.836 & 0.353 & 0.469 & 10.64 \\
\hline HLW02-55 & HLW02 & 33.480 & 20.070 & 47.770 & 0.829 & 0.864 & 0.715 & 0.415 & 0.432 & 0.358 & 10.35 \\
\hline HLW02-56 & HLW02 & 21.000 & 6.720 & 81.370 & 0.746 & 0.579 & 0.731 & 0.373 & 0.289 & 0.366 & 10.93 \\
\hline
\end{tabular}

(a) 7-Day PCT, stainless steel vessel with $\mathrm{S} / \mathrm{V}=2000 \mathrm{~m}^{-1}$. The PCT concentrations (ppm) are as measured. Normalized concentrations (g/L) and normalized mass losses $\left(\mathrm{g} / \mathrm{m}^{2}\right)$ are calculated as discussed in Section 3.3

(b) The Group IDs are described in Sections 2.1.1 to 2.1.9. 
Table 4.2. PCT Results ${ }^{(a)}$ for 268 Simulated and Actual HLW Glasses (continued).

\begin{tabular}{|c|c|c|c|c|c|c|c|c|c|c|c|}
\hline \multirow[b]{2}{*}{ Glass ID } & \multirow[b]{2}{*}{ Group ID (b) $^{(\mathbf{b}}$} & \multicolumn{3}{|c|}{$\begin{array}{c}\text { Concentration } \\
(\text { ppm) }\end{array}$} & \multicolumn{3}{|c|}{$\begin{array}{l}\text { Normalized Concentration } \\
(\mathrm{g} / \mathrm{L})\end{array}$} & \multicolumn{3}{|c|}{$\begin{array}{c}\text { Normalized Mass Loss } \\
\left(\mathrm{g} / \mathrm{m}^{2}\right)\end{array}$} & \multirow{2}{*}{$\begin{array}{l}\text { Leachate } \\
\text { pH }\end{array}$} \\
\hline & & PCT-B & PCT-Li & PCT-Na & PCT-B & PCT-Li & PCT-Na & PCT-B & PCT-Li & PCT-Na & \\
\hline HLW02-57 & HLW02 & 192.100 & 50.000 & 285.500 & 4.419 & 3.252 & 2.565 & 2.210 & 1.626 & 1.283 & 11.07 \\
\hline HLW03-01 & HLW03 & 41.110 & 20.230 & 16.780 & 0.965 & 0.740 & 0.577 & 0.482 & 0.370 & 0.288 & 9.93 \\
\hline HLW03-02 & HLW03 & 53.890 & 10.870 & 71.470 & 1.270 & 0.946 & 0.862 & 0.635 & 0.473 & 0.431 & 10.05 \\
\hline HLW03-03 & HLW03 & 20.560 & 17.330 & 119.600 & 1.356 & 1.393 & 1.499 & 0.678 & 0.697 & 0.749 & 11.54 \\
\hline HLW03-04 & HLW03 & 8.377 & 26.900 & 26.600 & 0.552 & 0.988 & 0.807 & 0.276 & 0.494 & 0.404 & 11.17 \\
\hline HLW03-05 & HLW03 & 8.290 & 4.237 & 70.160 & 0.555 & 0.474 & 0.655 & 0.278 & 0.237 & 0.328 & 10.78 \\
\hline HLW03-06 & HLW03 & 4.590 & 10.350 & 4.777 & 0.301 & 0.378 & 0.164 & 0.151 & 0.189 & 0.082 & 10.43 \\
\hline HLW03-07 & HLW03 & 44.710 & 41.510 & 181.800 & 2.902 & 1.881 & 2.096 & 1.451 & 0.941 & 1.048 & 11.48 \\
\hline HLW03-08 & HLW03 & 19.320 & 24.920 & 162.500 & 1.288 & 1.042 & 1.511 & 0.644 & 0.521 & 0.755 & 11.75 \\
\hline HLW03-09 & HLW03 & 106.600 & 16.610 & 161.100 & 2.507 & 1.807 & 1.462 & 1.253 & 0.903 & 0.731 & 10.16 \\
\hline HLW03-10 & HLW03 & 13.550 & 27.990 & 112.500 & 0.886 & 1.020 & 1.180 & 0.443 & 0.510 & 0.590 & 11.57 \\
\hline HLW03-11 & HLW03 & 21.750 & 8.963 & 133.200 & 1.412 & 0.973 & 1.206 & 0.706 & 0.486 & 0.603 & 10.65 \\
\hline HLW03-12 & HLW03 & 12.860 & 17.790 & 21.740 & 0.836 & 0.765 & 0.739 & 0.418 & 0.382 & 0.370 & 10.67 \\
\hline HLW03-13 & HLW03 & 0.310 & 14.390 & 13.510 & 0.020 & 0.595 & 0.459 & 0.010 & 0.297 & 0.229 & 10.97 \\
\hline HLW03-14 & HLW03 & 23.480 & 15.670 & 101.400 & 1.521 & 1.348 & 1.311 & 0.760 & 0.674 & 0.656 & 11.36 \\
\hline HLW03-15 & HLW03 & 23.860 & 5.630 & 13.740 & 0.562 & 0.621 & 0.353 & 0.281 & 0.311 & 0.176 & 9.33 \\
\hline HLW03-16 & HLW03 & 10.100 & 10.510 & 22.470 & 0.666 & 0.791 & 0.775 & 0.333 & 0.395 & 0.387 & 10.16 \\
\hline HLW03-17 & HLW03 & 17.780 & 6.370 & 3.200 & 0.416 & 0.698 & 0.097 & 0.208 & 0.349 & 0.048 & 9.17 \\
\hline HLW03-18 & HLW03 & 53.920 & 73.430 & 197.900 & 3.492 & 2.669 & 2.532 & 1.746 & 1.335 & 1.266 & 11.25 \\
\hline HLW03-19 & HLW03 & 43.670 & 58.220 & 172.400 & 2.866 & 2.128 & 2.291 & 1.433 & 1.064 & 1.146 & 11.35 \\
\hline HLW03-20 & HLW03 & 59.420 & 77.210 & 209.900 & 3.981 & 2.881 & 2.802 & 1.990 & 1.441 & 1.401 & 11.35 \\
\hline HLW03-21 & HLW03 & 8.693 & 5.370 & 27.900 & 0.403 & 0.466 & 0.347 & 0.202 & 0.233 & 0.174 & 10.23 \\
\hline HLW03-22 & HLW03 & 12.880 & 7.650 & 58.510 & 0.603 & 0.670 & 0.669 & 0.301 & 0.335 & 0.334 & 10.84 \\
\hline HLW03-23 & HLW03 & 30.730 & 8.475 & 52.510 & 0.832 & 0.736 & 0.595 & 0.416 & 0.368 & 0.297 & 10.18 \\
\hline HLW03-24 & HLW03 & 15.260 & 15.550 & 31.770 & 0.708 & 0.675 & 0.525 & 0.354 & 0.338 & 0.263 & 10.45 \\
\hline HLW03-25 & HLW03 & 72.950 & 17.090 & 129.300 & 1.987 & 1.494 & 1.474 & 0.994 & 0.747 & 0.737 & 10.32 \\
\hline HLW03-26 & HLW03 & 28.100 & 18.980 & 63.470 & 1.314 & 0.830 & 0.820 & 0.657 & 0.415 & 0.410 & 11.16 \\
\hline HLW03-27 & HLW03 & 22.620 & 15.790 & 75.600 & 1.056 & 0.842 & 0.862 & 0.528 & 0.421 & 0.431 & 11.12 \\
\hline
\end{tabular}

(a) 7-Day PCT, stainless steel vessel with $\mathrm{S} / \mathrm{V}=2000 \mathrm{~m}^{-1}$. The PCT concentrations (ppm) are as measured. Normalized concentrations (g/L) and normalized mass losses $\left(\mathrm{g} / \mathrm{m}^{2}\right)$ are calculated as discussed in Section 3.3.

(b) The Group IDs are described in Sections 2.1.1 to 2.1.9. 
Table 4.2. PCT Results ${ }^{(a)}$ for 268 Simulated and Actual HLW Glasses (continued).

\begin{tabular}{|c|c|c|c|c|c|c|c|c|c|c|c|}
\hline \multirow[b]{2}{*}{ Glass ID } & \multirow[b]{2}{*}{ Group ID (b) $^{(b)}$} & \multicolumn{3}{|c|}{$\begin{array}{c}\text { Concentration } \\
\text { (ppm) }\end{array}$} & \multicolumn{3}{|c|}{$\begin{array}{c}\text { Normalized Concentration } \\
(\mathrm{g} / \mathrm{L})\end{array}$} & \multicolumn{3}{|c|}{$\begin{array}{c}\text { Normalized Mass Loss } \\
\left(\mathrm{g} / \mathbf{m}^{2}\right)\end{array}$} & \multirow{2}{*}{$\begin{array}{c}\text { Leachate } \\
\text { pH }\end{array}$} \\
\hline & & PCT-B & PCT-Li & PCT-Na & PCT-B & PCT-Li & PCT-Na & PCT-B & PCT-Li & PCT-Na & \\
\hline HLW03-28 & HLW03 & 60.520 & 29.310 & 87.180 & 1.636 & 1.271 & 1.121 & 0.818 & 0.636 & 0.560 & 10.76 \\
\hline HLW03-29 & HLW03 & 23.600 & 21.470 & 85.440 & 1.096 & 0.933 & 0.969 & 0.548 & 0.467 & 0.484 & 11.23 \\
\hline HLW03-30 & HLW03 & 33.960 & 16.860 & 25.230 & 0.920 & 0.733 & 0.490 & 0.460 & 0.366 & 0.245 & 10.16 \\
\hline HLW03-31 & HLW03 & 23.740 & 14.060 & 26.310 & 1.103 & 0.611 & 0.416 & 0.551 & 0.306 & 0.208 & 10.66 \\
\hline HLW03-32 & HLW03 & 10.710 & 15.110 & 37.190 & 0.501 & 0.661 & 0.551 & 0.250 & 0.331 & 0.275 & 11.14 \\
\hline HLW03-33 & HLW03 & 20.740 & 10.690 & 17.830 & 0.561 & 0.590 & 0.346 & 0.281 & 0.295 & 0.173 & 9.89 \\
\hline HLW03-34 & HLW03 & 14.200 & 8.927 & 33.490 & 0.663 & 0.780 & 0.473 & 0.332 & 0.390 & 0.237 & 10.24 \\
\hline HLW03-35 & HLW03 & 12.630 & 7.173 & 11.680 & 0.391 & 0.622 & 0.227 & 0.196 & 0.311 & 0.113 & 9.64 \\
\hline HLW03-36 & HLW03 & 27.000 & 8.313 & 14.200 & 1.262 & 0.665 & 0.240 & 0.631 & 0.332 & 0.120 & 10.04 \\
\hline HLW03-37 & HLW03 & 63.260 & 42.450 & 48.840 & 1.725 & 1.881 & 0.956 & 0.863 & 0.940 & 0.478 & 10.58 \\
\hline HLW03-38 & HLW03 & 11.890 & 7.633 & 28.270 & 0.557 & 0.669 & 0.396 & 0.278 & 0.334 & 0.198 & 10.38 \\
\hline HLW03-39 & HLW03 & 9.740 & 14.660 & 15.140 & 0.456 & 0.651 & 0.297 & 0.228 & 0.325 & 0.148 & 10.35 \\
\hline HLW03-40 & HLW03 & 8.530 & 13.380 & 19.040 & 0.397 & 0.590 & 0.371 & 0.199 & 0.295 & 0.185 & 10.48 \\
\hline HLW03-41 & HLW03 & 13.510 & 9.680 & 31.340 & 0.498 & 0.562 & 0.465 & 0.249 & 0.281 & 0.232 & 10.34 \\
\hline HLW03-42 & HLW03 & 10.630 & 8.100 & 22.810 & 0.374 & 0.471 & 0.342 & 0.187 & 0.236 & 0.171 & 10.14 \\
\hline HLW03-43 & HLW03 & 20.230 & 10.430 & 4.413 & 1.327 & 0.381 & 0.151 & 0.664 & 0.191 & 0.076 & 10.42 \\
\hline HLW03-44 & HLW03 & 12.320 & 8.910 & 125.600 & 0.800 & 0.967 & 1.137 & 0.400 & 0.483 & 0.569 & 10.75 \\
\hline HLW03-45 & HLW03 & 14.530 & 17.240 & 60.120 & 0.679 & 0.754 & 0.777 & 0.340 & 0.377 & 0.388 & 11.34 \\
\hline HLW04-03 & HLW04 & 121.20 & 10.77 & 138.40 & 3.520 & 0.837 & 1.516 & 1.760 & 0.419 & 0.758 & 10.52 \\
\hline HLW04-07 & HLW04 & 22.06 & 9.75 & 68.48 & 0.685 & 0.794 & 0.737 & 0.343 & 0.397 & 0.368 & 10.23 \\
\hline HLW04-07NRE9 & HLW04 & 11.42 & 6.46 & 37.62 & 0.355 & 0.526 & 0.405 & 0.177 & 0.263 & 0.202 & 10.23 \\
\hline HLW04-07NRE9CCC & HLW04 & 12.24 & 6.19 & 35.40 & 0.380 & 0.504 & 0.381 & 0.190 & 0.252 & 0.190 & 10.21 \\
\hline HLW04-07RE39 & HLW04 & 18.63 & 8.49 & 57.89 & 0.579 & 0.692 & 0.623 & 0.289 & 0.346 & 0.311 & 10.28 \\
\hline HLW04-07RE39CCC & HLW04 & 14.84 & 6.94 & 47.36 & 0.461 & 0.566 & 0.510 & 0.230 & 0.283 & 0.255 & 10.22 \\
\hline HLW04-08 & HLW04 & 27.00 & 9.85 & 66.56 & 0.839 & 0.803 & 0.723 & 0.420 & 0.401 & 0.361 & 10.16 \\
\hline HLW04-09 & HLW04 & 17.49 & 7.46 & 51.43 & 0.548 & 0.607 & 0.553 & 0.274 & 0.304 & 0.277 & 10.33 \\
\hline HLW06-01 & HLW06 & 12.72 & 7.07 & 68.50 & 0.630 & 0.507 & 0.660 & 0.315 & 0.254 & 0.330 & 11.04 \\
\hline HLW06-02 & HLW06 & 67.47 & 1.12 & 211.80 & 1.975 & 0.967 & 1.427 & 0.988 & 0.484 & 0.714 & 11.18 \\
\hline
\end{tabular}

(a) 7-Day PCT, stainless steel vessel with $\mathrm{S} / \mathrm{V}=2000 \mathrm{~m}^{-1}$. The PCT concentrations (ppm) are as measured. Normalized concentrations (g/L) and normalized mass losses $\left(\mathrm{g} / \mathrm{m}^{2}\right)$ are calculated as discussed in Section 3.3.

(b) The Group IDs are described in Sections 2.1.1 to 2.1.9. 
Table 4.2. PCT Results ${ }^{(a)}$ for 268 Simulated and Actual HLW Glasses (continued).

\begin{tabular}{|c|c|c|c|c|c|c|c|c|c|c|c|}
\hline \multirow[b]{2}{*}{ Glass ID } & \multirow[b]{2}{*}{ Group ID (b) $^{(\mathbf{b}}$} & \multicolumn{3}{|c|}{$\begin{array}{c}\text { Concentration } \\
(\mathbf{p p m})\end{array}$} & \multicolumn{3}{|c|}{$\begin{array}{l}\text { Normalized Concentration } \\
(\mathrm{g} / \mathrm{L})\end{array}$} & \multicolumn{3}{|c|}{$\begin{array}{c}\text { Normalized Mass Loss } \\
\qquad\left(\mathrm{g} / \mathrm{m}^{2}\right)\end{array}$} & \multirow{2}{*}{$\begin{array}{c}\text { Leachate } \\
\text { pH }\end{array}$} \\
\hline & & PCT-B & PCT-Li & PCT-Na & PCT-B & PCT-Li & PCT-Na & PCT-B & PCT-Li & PCT-Na & \\
\hline HLW06-03 & HLW06 & 6.47 & 0.23 & 51.27 & 0.321 & 0.195 & 0.494 & 0.160 & 0.098 & 0.247 & 10.54 \\
\hline HLW06-04 & HLW06 & 38.80 & 0.92 & 348.10 & 1.922 & 0.795 & 2.346 & 0.961 & 0.397 & 1.173 & 11.72 \\
\hline HLW06-05 & HLW06 & 15.60 & 0.62 & 154.20 & 0.773 & 0.536 & 1.039 & 0.386 & 0.268 & 0.520 & 11.33 \\
\hline HLW06-06 & HLW06 & 6.53 & 0.47 & 48.76 & 0.324 & 0.407 & 0.469 & 0.162 & 0.204 & 0.235 & 10.52 \\
\hline HLW06-07 & HLW06 & 11.83 & 0.48 & 117.40 & 0.586 & 0.416 & 0.996 & 0.293 & 0.208 & 0.498 & 11.11 \\
\hline HLW06-08 & HLW06 & 14.12 & 0.62 & 93.66 & 0.700 & 0.536 & 0.902 & 0.350 & 0.268 & 0.451 & 10.71 \\
\hline HLW06-09 & HLW06 & 30.86 & 19.65 & 184.50 & 1.529 & 1.410 & 1.776 & 0.765 & 0.705 & 0.888 & 11.32 \\
\hline HLW06-10 & HLW06 & 13.68 & 0.37 & 46.41 & 0.401 & 0.316 & 0.447 & 0.200 & 0.158 & 0.223 & 9.95 \\
\hline HLW06-11 & HLW06 & 15.35 & 0.43 & 54.60 & 0.449 & 0.373 & 0.526 & 0.225 & 0.186 & 0.263 & 10.12 \\
\hline HLW06-12 & HLW06 & 59.49 & 17.00 & 150.40 & 1.742 & 1.220 & 1.448 & 0.871 & 0.610 & 0.724 & 10.94 \\
\hline HLW06-13 & HLW06 & 6.55 & 0.32 & 55.27 & 0.325 & 0.278 & 0.532 & 0.162 & 0.139 & 0.266 & 10.51 \\
\hline HLW06-14 & HLW06 & 48.44 & 16.40 & 115.20 & 1.418 & 1.177 & 1.109 & 0.709 & 0.588 & 0.555 & 11.02 \\
\hline HLW06-15 & HLW06 & 111.80 & 27.61 & 342.20 & 3.273 & 1.981 & 2.306 & 1.637 & 0.991 & 1.153 & 11.72 \\
\hline HLW06-16 & HLW06 & 24.23 & 10.59 & 244.20 & 1.201 & 0.760 & 1.646 & 0.600 & 0.380 & 0.823 & 11.75 \\
\hline HLW06-17 & HLW06 & 9.38 & 7.39 & 72.96 & 0.465 & 0.530 & 0.702 & 0.232 & 0.265 & 0.351 & 11.22 \\
\hline HLW06-18 & HLW06 & 11.14 & 0.37 & 37.13 & 0.326 & 0.321 & 0.357 & 0.163 & 0.161 & 0.179 & 9.81 \\
\hline HLW06-19 & HLW06 & 14.40 & 0.26 & 152.40 & 0.713 & 0.226 & 1.027 & 0.357 & 0.113 & 0.514 & 11.46 \\
\hline HLW06-20 & HLW06 & 13.47 & 9.19 & 88.71 & 0.667 & 0.659 & 0.854 & 0.334 & 0.330 & 0.427 & 11.33 \\
\hline HLW06-21 & HLW06 & 17.83 & 0.18 & 227.40 & 1.335 & (c) $^{(\mathrm{c})}$ & 1.533 & 0.668 & - & 0.766 & 10.36 \\
\hline HLW06-22 & HLW06 & 12.45 & 9.78 & 13.42 & 0.267 & 0.350 & 0.264 & 0.134 & 0.175 & 0.132 & 10.22 \\
\hline HLW06-23 & HLW06 & 29.81 & 0.15 & 273.30 & 2.233 & - & 1.842 & 1.116 & - & 0.921 & 11.91 \\
\hline HLW06-24 & HLW06 & 3.31 & 0.00 & 128.80 & 0.248 & - & 1.068 & 0.124 & - & 0.534 & 11.43 \\
\hline HLW06-25 & HLW06 & 21.45 & 13.13 & 5.19 & 0.461 & 0.470 & 0.189 & 0.230 & 0.235 & 0.094 & 9.81 \\
\hline HLW06-26 & HLW06 & 20.09 & 0.07 & 429.10 & 1.505 & - & 2.892 & 0.752 & - & 1.446 & 11.79 \\
\hline HLW06-27 & HLW06 & 13.31 & 15.27 & 1.37 & 0.437 & 0.547 & 0.050 & 0.218 & 0.273 & 0.025 & 9.95 \\
\hline HLW06-28 & HLW06 & 209.30 & 101.30 & 83.88 & 4.494 & 3.629 & 3.056 & 2.247 & 1.814 & 1.528 & 9.83 \\
\hline HLW06-29 & HLW06 & 3.59 & 17.85 & 12.70 & 0.269 & 0.639 & 0.463 & 0.134 & 0.320 & 0.231 & 10.81 \\
\hline HLW06-30 & HLW06 & 14.35 & 0.04 & 177.20 & 1.075 & - & 1.194 & 0.537 & - & 0.597 & 11.38 \\
\hline
\end{tabular}

(a) 7-Day PCT, stainless steel vessel with $\mathrm{S} / \mathrm{V}=2000 \mathrm{~m}^{-1}$. The PCT concentrations (ppm) are as measured. Normalized concentrations (g/L) and normalized mass losses $\left(\mathrm{g} / \mathrm{m}^{2}\right)$ are calculated as discussed in Section 3.3.

(b) The Group IDs are described in Sections 2.1.1 to 2.1.9.

(c) A dash (-) denotes that the corresponding HLW glass did not contain $\mathrm{Li}_{2} \mathrm{O}$ and hence did not have PCT-Li releases. 
Table 4.2. PCT Results ${ }^{(a)}$ for 268 Simulated and Actual HLW Glasses (continued).

\begin{tabular}{|c|c|c|c|c|c|c|c|c|c|c|c|}
\hline \multirow[b]{2}{*}{ Glass ID } & \multirow[b]{2}{*}{ Group ID Ib) $^{(b)}$} & \multicolumn{3}{|c|}{$\begin{array}{c}\text { Concentration } \\
\text { (ppm) }\end{array}$} & \multicolumn{3}{|c|}{$\begin{array}{c}\text { Normalized Concentration } \\
(\mathrm{g} / \mathrm{L})\end{array}$} & \multicolumn{3}{|c|}{$\begin{array}{c}\text { Normalized Mass Loss } \\
\left(\mathrm{g} / \mathrm{m}^{2}\right)\end{array}$} & \multirow{2}{*}{$\begin{array}{c}\text { Leachate } \\
\text { pH }\end{array}$} \\
\hline & & PCT-B & PCT-Li & PCT-Na & PCT-B & PCT-Li & PCT-Na & PCT-B & PCT-Li & PCT-Na & \\
\hline HLW06-31 & HLW06 & 2.49 & 8.50 & 5.45 & 0.187 & 0.333 & 0.198 & 0.093 & 0.167 & 0.099 & 10.67 \\
\hline HLW06-32 & HLW06 & 551.20 & 0.20 & 1073.00 & 11.835 & - & 7.231 & 5.917 & - & 3.616 & 10.45 \\
\hline HLW06-33 & HLW06 & 1.69 & 7.11 & 5.74 & 0.126 & 0.323 & 0.209 & 0.063 & 0.162 & 0.105 & 10.68 \\
\hline HLW06-34 & HLW06 & 578.80 & 0.92 & 977.30 & 12.427 & - & 6.586 & 6.214 & - & 3.293 & 10.18 \\
\hline HLW06-35 & HLW06 & 15.44 & 8.75 & 38.85 & 0.488 & 0.574 & 0.440 & 0.244 & 0.287 & 0.220 & 10.54 \\
\hline HLW07-01 & HLW07 & 10.43 & 3.98 & 35.48 & 0.365 & 0.475 & 0.424 & 0.182 & 0.238 & 0.212 & 10.21 \\
\hline HLW07-02 & HLW07 & 14.29 & 10.73 & 27.78 & 0.503 & 0.624 & 0.416 & 0.252 & 0.312 & 0.208 & 10.11 \\
\hline HLW07-03 & HLW07 & 14.91 & 10.74 & 31.02 & 0.550 & 0.623 & 0.460 & 0.275 & 0.312 & 0.230 & 10.35 \\
\hline HLW07-04 & HLW07 & 27.13 & 20.58 & 2.10 & 0.624 & 0.738 & 0.071 & 0.312 & 0.369 & 0.035 & 9.61 \\
\hline HLW07-05 & HLW07 & 32.39 & 31.35 & 124.50 & 2.103 & 1.421 & 1.435 & 1.051 & 0.710 & 0.718 & 11.14 \\
\hline HLW07-06 & HLW07 & 4.64 & 0.00 & 38.67 & 0.249 & - & 0.416 & 0.124 & - & 0.208 & 10.38 \\
\hline HLW07-07 & HLW07 & 113.00 & 0.00 & 635.90 & 6.065 & - & 4.768 & 3.032 & - & 2.384 & 11.92 \\
\hline HLW07-08 & HLW07 & 11.98 & 0.20 & 122.00 & 0.643 & - & 0.913 & 0.321 & - & 0.457 & 11.20 \\
\hline HLW07-09 & HLW07 & 6.79 & 14.83 & 44.39 & 0.365 & 0.709 & 0.695 & 0.182 & 0.355 & 0.348 & 11.08 \\
\hline HLW07-10 & HLW07 & 29.43 & 0.17 & 61.32 & 0.799 & - & 0.874 & 0.399 & - & 0.437 & 9.81 \\
\hline HLW07-11 & HLW07 & 18.19 & 18.95 & 187.00 & 0.976 & 0.906 & 1.481 & 0.488 & 0.453 & 0.741 & 11.53 \\
\hline HLW07-12 & HLW07 & 23.69 & 20.67 & 214.80 & 1.271 & 1.008 & 1.617 & 0.636 & 0.504 & 0.809 & 11.65 \\
\hline HLW07-13 & HLW07 & 11.73 & 1.33 & 119.30 & 0.630 & 0.363 & 0.893 & 0.315 & 0.182 & 0.447 & 11.32 \\
\hline HLW07-14 & HLW07 & 3.58 & 8.69 & 14.74 & 0.192 & 0.437 & 0.331 & 0.096 & 0.218 & 0.166 & 10.54 \\
\hline HLW07-15 & HLW07 & 22.27 & 0.25 & 208.00 & 1.195 & - & 1.557 & 0.598 & - & 0.779 & 11.53 \\
\hline HLW07-16 & HLW07 & 141.50 & 50.34 & 324.40 & 3.939 & 2.813 & 2.429 & 1.970 & 1.406 & 1.214 & 11.67 \\
\hline HLW07-17 & HLW07 & 234.90 & 90.10 & 457.60 & 5.819 & 4.561 & 3.426 & 2.909 & 2.281 & 1.713 & 11.67 \\
\hline HLW07-18 & HLW07 & 207.20 & 85.70 & 429.50 & 5.133 & 4.100 & 3.216 & 2.566 & 2.050 & 1.608 & 11.75 \\
\hline HLW07-19 & HLW07 & 29.90 & 31.54 & 233.50 & 1.465 & 1.613 & 2.090 & 0.733 & 0.807 & 1.045 & 11.81 \\
\hline HLW07-20 & HLW07 & 17.55 & 12.10 & 6.86 & 0.435 & 0.579 & 0.154 & 0.217 & 0.289 & 0.077 & 9.65 \\
\hline HLW07-21 & HLW07 & 5.11 & 0.27 & 36.01 & 0.274 & - & 0.428 & 0.137 & - & 0.214 & 10.39 \\
\hline HLW07-22 & HLW07 & 4.81 & 0.32 & 41.33 & 0.255 & - & 0.449 & 0.128 & - & 0.224 & 10.61 \\
\hline HLW07-23 & HLW07 & 17.58 & 4.49 & 18.88 & 0.435 & 0.531 & 0.384 & 0.218 & 0.265 & 0.192 & 9.53 \\
\hline
\end{tabular}

(a) 7-Day PCT, stainless steel vessel with $\mathrm{S} / \mathrm{V}=2000 \mathrm{~m}^{-1}$. The PCT concentrations (ppm) are as measured. Normalized concentrations (g/L) and normalized mass losses $\left(\mathrm{g} / \mathrm{m}^{2}\right)$ are calculated as discussed in Section 3.3.

(b) The Group IDs are described in Sections 2.1.1 to 2.1.9.

(c) A dash (-) denotes that the corresponding HLW glass did not contain $\mathrm{Li}_{2} \mathrm{O}$ and hence did not have PCT-Li releases. 
Table 4.2. PCT Results ${ }^{(a)}$ for 268 Simulated and Actual HLW Glasses (continued).

\begin{tabular}{|c|c|c|c|c|c|c|c|c|c|c|c|}
\hline \multirow[b]{2}{*}{ Glass ID } & \multirow[b]{2}{*}{ Group ID ${ }^{(b)}$} & \multicolumn{3}{|c|}{$\begin{array}{c}\text { Concentration } \\
\text { (ppm) }\end{array}$} & \multicolumn{3}{|c|}{$\begin{array}{l}\text { Normalized Concentration } \\
(\mathrm{g} / \mathrm{L})\end{array}$} & \multicolumn{3}{|c|}{$\begin{array}{c}\text { Normalized Mass Loss } \\
\left(\mathrm{g} / \mathrm{m}^{2}\right)\end{array}$} & \multirow{2}{*}{$\begin{array}{c}\text { Leachate } \\
\text { pH }\end{array}$} \\
\hline & & PCT-B & PCT-Li & PCT-Na & PCT-B & PCT-Li & PCT-Na & PCT-B & PCT-Li & PCT-Na & \\
\hline HLW07-24 & HLW07 & 46.36 & 0.20 & 89.35 & 1.148 & - & 0.747 & 0.574 & - & 0.374 & 9.82 \\
\hline HLW07-25 & HLW07 & 6.84 & 2.49 & 36.03 & 0.367 & 0.537 & 0.424 & 0.183 & 0.269 & 0.212 & 10.14 \\
\hline HLW07-26 & HLW07 & 7.39 & 8.47 & 23.47 & 0.298 & 0.527 & 0.316 & 0.149 & 0.263 & 0.158 & 10.28 \\
\hline HLW07-27 & HLW07 & 12.91 & 7.67 & 28.62 & 0.378 & 0.472 & 0.386 & 0.189 & 0.236 & 0.193 & 10.25 \\
\hline HLW07-28 & HLW07 & 11.50 & 7.51 & 61.25 & 0.463 & 0.462 & 0.590 & 0.231 & 0.231 & 0.295 & 10.74 \\
\hline HLW07-29 & HLW07 & 22.13 & 3.10 & 44.50 & 0.648 & 0.667 & 0.556 & 0.324 & 0.333 & 0.278 & 9.93 \\
\hline HLW07-30 & HLW07 & 11.44 & 2.53 & 47.82 & 0.461 & 0.545 & 0.511 & 0.230 & 0.272 & 0.256 & 10.16 \\
\hline HLW07-31 & HLW07 & 10.51 & 2.44 & 23.44 & 0.308 & 0.387 & 0.316 & 0.154 & 0.194 & 0.158 & 9.75 \\
\hline HLW07-32 & HLW07 & 13.38 & 2.36 & 61.44 & 0.539 & 0.508 & 0.592 & 0.269 & 0.254 & 0.296 & 10.46 \\
\hline HLW07-33 & HLW07 & 6.21 & 1.49 & 34.67 & 0.250 & 0.321 & 0.381 & 0.125 & 0.161 & 0.190 & 10.24 \\
\hline HLW07-34 & HLW07 & 10.71 & 4.46 & 20.37 & 0.314 & 0.465 & 0.275 & 0.157 & 0.233 & 0.137 & 9.77 \\
\hline HLW07-35 & HLW07 & 8.69 & 2.49 & 25.00 & 0.292 & 0.398 & 0.337 & 0.146 & 0.199 & 0.168 & 9.95 \\
\hline HLW07-36 & HLW07 & 15.59 & 1.92 & 52.89 & 0.456 & 0.413 & 0.509 & 0.228 & 0.206 & 0.255 & 10.37 \\
\hline HLW07-37 & HLW07 & 35.00 & 19.68 & 116.50 & 1.409 & 1.210 & 1.137 & 0.704 & 0.605 & 0.569 & 11.15 \\
\hline HLW07-38 & HLW07 & 11.90 & 1.71 & 25.52 & 0.348 & 0.367 & 0.331 & 0.174 & 0.184 & 0.165 & 9.67 \\
\hline HLW07-39 & HLW07 & 13.23 & 2.25 & 45.05 & 0.387 & 0.485 & 0.446 & 0.194 & 0.243 & 0.223 & 10.16 \\
\hline HLW07-40 & HLW07 & 8.90 & 1.78 & 29.71 & 0.358 & 0.384 & 0.400 & 0.179 & 0.192 & 0.200 & 9.99 \\
\hline HLW-ALG-01 & HLWALG & 40.76 & 11.37 & 115.30 & 1.243 & 0.735 & 0.899 & 0.622 & 0.368 & 0.450 & 11.08 \\
\hline HLW-ALG-02 & HLWALG & 24.75 & 9.54 & 70.73 & 0.719 & 0.578 & 0.622 & 0.359 & 0.289 & 0.311 & 10.78 \\
\hline HLW-ALG-03 & HLWALG & 586.30 & 151.60 & 1663.00 & 21.903 & 10.675 & 11.819 & 10.952 & 5.338 & 5.909 & 12.18 \\
\hline HLW-ALG-04 & HLWALG & 305.60 & 82.35 & 678.80 & 8.839 & 6.164 & 5.726 & 4.420 & 3.082 & 2.863 & 10.87 \\
\hline HLW-ALG-05 & HLWALG & 52.34 & 65.41 & 212.30 & 3.505 & 3.285 & 3.202 & 1.752 & 1.643 & 1.601 & 11.62 \\
\hline HLW-ALG-06 & HLWALG & 15.44 & 11.73 & 144.80 & 1.034 & 0.998 & 1.248 & 0.517 & 0.499 & 0.624 & 11.55 \\
\hline HLW-ALG-07 & HLWALG & 11.50 & 5.80 & 32.58 & 0.346 & 0.383 & 0.373 & 0.173 & 0.192 & 0.186 & 10.66 \\
\hline HLW-ALG-08 & HLWALG & 13.86 & 7.93 & 99.08 & 0.929 & 0.820 & 0.958 & 0.464 & 0.410 & 0.479 & 11.33 \\
\hline HLW-ALG-09 & HLWALG & 22.25 & 11.25 & 149.90 & 1.490 & 1.219 & 1.337 & 0.745 & 0.609 & 0.668 & 11.45 \\
\hline HLW-ALG-10 & HLWALG & 365.10 & 62.06 & 1006.00 & 12.445 & 6.615 & 7.788 & 6.222 & 3.308 & 3.894 & 11.53 \\
\hline HLW-ALG-11 & HLWALG & 14.66 & 13.44 & 17.56 & 0.387 & 0.481 & 0.390 & 0.194 & 0.241 & 0.195 & 10.55 \\
\hline
\end{tabular}

(a) 7-Day PCT, stainless steel vessel with $\mathrm{S} / \mathrm{V}=2000 \mathrm{~m}^{-1}$. The PCT concentrations (ppm) are as measured. Normalized concentrations (g/L) and normalized mass losses $\left(\mathrm{g} / \mathrm{m}^{2}\right)$ are calculated as discussed in Section 3.3.

(b) The Group IDs are described in Sections 2.1.1 to 2.1.9.

(c) A dash (-) denotes that the corresponding HLW glass did not contain $\mathrm{Li}_{2} \mathrm{O}$ and hence did not have PCT-Li releases. 
Table 4.2. PCT Results ${ }^{(a)}$ for 268 Simulated and Actual HLW Glasses (continued).

\begin{tabular}{|c|c|c|c|c|c|c|c|c|c|c|c|}
\hline \multirow[b]{2}{*}{ Glass ID } & \multirow[b]{2}{*}{ Group ID $^{(\mathbf{b})}$} & \multicolumn{3}{|c|}{$\begin{array}{c}\text { Concentration } \\
(\mathrm{ppm})\end{array}$} & \multicolumn{3}{|c|}{$\begin{array}{c}\text { Normalized Concentration } \\
(\mathrm{g} / \mathrm{L})\end{array}$} & \multicolumn{3}{|c|}{$\begin{array}{c}\text { Normalized Mass Loss } \\
\left(\mathrm{g} / \mathrm{m}^{2}\right)\end{array}$} & \multirow{2}{*}{$\begin{array}{c}\text { Leachate } \\
\text { pH }\end{array}$} \\
\hline & & PCT-B & PCT-Li & PCT-Na & PCT-B & PCT-Li & PCT-Na & PCT-B & PCT-Li & PCT-Na & \\
\hline HLW-ALG-12 & HLWALG & 15.23 & 10.18 & 124.90 & 1.020 & 0.797 & 1.059 & 0.510 & 0.399 & 0.529 & 11.45 \\
\hline HLW-ALG-13 & HLWALG & 1.78 & 9.53 & 45.65 & 0.119 & 0.612 & 0.647 & 0.060 & 0.306 & 0.324 & 11.06 \\
\hline HLW-ALG-14 & HLWALG & 5.73 & 24.60 & 28.71 & 0.384 & 0.881 & 0.806 & 0.192 & 0.440 & 0.403 & 10.97 \\
\hline HLW-ALG-15 & HLWALG & 63.32 & 7.71 & 144.80 & 1.454 & 0.861 & 1.110 & 0.727 & 0.430 & 0.555 & 10.54 \\
\hline HLW-ALG-16 & HLWALG & 97.74 & 13.02 & 196.60 & 2.273 & 1.387 & 1.522 & 1.136 & 0.693 & 0.761 & 10.55 \\
\hline HLW-ALG-17 & HLWALG & 412.90 & 60.28 & 1155.00 & 12.863 & 6.424 & 8.940 & 6.431 & 3.212 & 4.470 & 11.43 \\
\hline HLW-ALG-18 & HLWALG & 22.12 & 8.98 & 62.78 & 0.641 & 0.563 & 0.571 & 0.321 & 0.281 & 0.286 & 10.53 \\
\hline HLW-ALG-19 & HLWALG & 86.26 & 24.40 & 217.20 & 2.878 & 1.976 & 1.815 & 1.439 & 0.988 & 0.907 & 11.02 \\
\hline HLW-ALG-20 & HLWALG & 133.90 & 47.36 & 416.70 & 5.562 & 3.485 & 3.228 & 2.781 & 1.742 & 1.614 & 11.61 \\
\hline HLW-ALG-21 & HLWALG & 12.20 & 6.75 & 157.20 & 0.817 & 0.587 & 1.202 & 0.408 & 0.294 & 0.601 & 11.54 \\
\hline HLW-ALG-22 & HLWALG & 18.60 & 6.84 & 126.80 & 0.908 & 0.612 & 1.029 & 0.454 & 0.306 & 0.514 & 11.43 \\
\hline HLW-ALG-23 & HLWALG & 15.59 & 5.50 & 193.70 & 1.044 & 0.573 & 1.353 & 0.522 & 0.286 & 0.676 & 11.65 \\
\hline HLW-ALG-24 & HLWALG & 5.02 & 11.19 & 42.03 & 0.336 & 0.565 & 0.577 & 0.168 & 0.282 & 0.289 & 10.98 \\
\hline HLW-ALG-25 & HLWALG & 373.10 & 63.36 & 967.40 & 11.902 & 6.752 & 7.488 & 5.951 & 3.376 & 3.744 & 11.41 \\
\hline HLW-ALG-26 & HLWALG & 0.17 & 6.02 & 28.03 & 0.007 & 0.429 & 0.393 & 0.004 & 0.214 & 0.197 & 10.53 \\
\hline HLW-ALG-27 & HLWALG & 84.16 & 11.78 & 141.40 & 1.932 & 1.316 & 1.084 & 0.966 & 0.658 & 0.542 & 10.47 \\
\hline HLW-ALG-28 & HLWALG & 101.50 & 14.36 & 177.50 & 2.331 & 1.604 & 1.360 & 1.165 & 0.802 & 0.680 & 10.67 \\
\hline HLW-ALG-29 & HLWALG & 46.97 & 5.68 & 99.16 & 1.078 & 0.634 & 0.760 & 0.539 & 0.317 & 0.380 & 10.48 \\
\hline HLW-ALG-30 & HLWALG & 9.78 & 6.14 & 61.71 & 0.328 & 0.427 & 0.543 & 0.164 & 0.213 & 0.271 & 10.67 \\
\hline HLW-ALG-31 & HLWALG & 53.31 & 17.82 & 91.65 & 1.577 & 1.246 & 1.055 & 0.788 & 0.623 & 0.527 & 10.18 \\
\hline HLW-ALG-32 & HLWALG & 6.57 & 11.55 & 43.68 & 0.440 & 0.626 & 0.632 & 0.220 & 0.313 & 0.316 & 11.01 \\
\hline HLW-ALG-33 & HLWALG & 15.75 & 8.59 & 113.60 & 0.634 & 0.489 & 0.867 & 0.317 & 0.244 & 0.434 & 11.27 \\
\hline HLW-ALG-34 & HLWALG & 361.20 & 65.55 & 1208.00 & 14.147 & 6.986 & 8.569 & 7.073 & 3.493 & 4.285 & 11.59 \\
\hline HLW-ALG-35 & HLWALG & 5.81 & 9.26 & 61.32 & 0.389 & 0.712 & 0.764 & 0.195 & 0.356 & 0.382 & 11.02 \\
\hline HLW-ALG-36 & HLWALG & 18.93 & 14.54 & 107.20 & 0.936 & 1.078 & 1.153 & 0.468 & 0.539 & 0.576 & 11.30 \\
\hline HLW-ALG-37 & HLWALG & 2.68 & 6.50 & 36.41 & 0.180 & 0.542 & 0.524 & 0.090 & 0.271 & 0.262 & 10.88 \\
\hline HLW-ALG-38 & HLWALG & 9.50 & 1.89 & 26.19 & 0.387 & 0.141 & 0.332 & 0.194 & 0.070 & 0.166 & 9.79 \\
\hline HLW-ALG-39 & HLWALG & 22.19 & 10.88 & 43.68 & 0.700 & 0.753 & 0.533 & 0.350 & 0.377 & 0.266 & 10.18 \\
\hline
\end{tabular}

(a) 7-Day PCT, stainless steel vessel with $\mathrm{S} / \mathrm{V}=2000 \mathrm{~m}^{-1}$. The PCT concentrations (ppm) are as measured. Normalized concentrations (g/L) and normalized mass losses $\left(\mathrm{g} / \mathrm{m}^{2}\right)$ are calculated as discussed in Section 3.3 .

(b) The Group IDs are described in Sections 2.1.1 to 2.1.9. 
Table 4.2. PCT Results ${ }^{(a)}$ for 268 Simulated and Actual HLW Glasses (continued).

\begin{tabular}{|c|c|c|c|c|c|c|c|c|c|c|c|}
\hline \multirow[b]{2}{*}{ Glass ID } & \multirow[b]{2}{*}{ Group ID (b) $^{(b)}$} & \multicolumn{3}{|c|}{$\begin{array}{c}\text { Concentration } \\
(\mathrm{ppm})\end{array}$} & \multicolumn{3}{|c|}{$\begin{array}{c}\text { Normalized Concentration } \\
(\mathrm{g} / \mathrm{L})\end{array}$} & \multicolumn{3}{|c|}{$\begin{array}{c}\text { Normalized Mass Loss } \\
\left(\mathrm{g} / \mathrm{m}^{2}\right)\end{array}$} & \multirow{2}{*}{$\begin{array}{c}\text { Leachate } \\
\text { pH }\end{array}$} \\
\hline & & PCT-B & PCT-Li & PCT-Na & PCT-B & PCT-Li & PCT-Na & PCT-B & PCT-Li & PCT-Na & \\
\hline HLW-ALG-40 & HLWALG & 9.54 & 8.18 & 66.10 & 0.364 & 0.577 & 0.621 & 0.182 & 0.288 & 0.310 & 10.85 \\
\hline HLW98-34CG & HLW98 & 6.04 & 6.70 & 23.75 & 0.278 & 0.360 & 0.342 & 0.139 & 0.180 & 0.171 & 10.68 \\
\hline HLW98-51AW & HLW98 & 49.73 & 37.46 & 86.61 & 1.736 & 1.424 & 1.285 & 0.868 & 0.712 & 0.643 & 10.77 \\
\hline HLW98-51AWCG & HLW98 & 39.96 & 31.91 & 74.92 & 1.395 & 1.213 & 1.112 & 0.697 & 0.607 & 0.556 & 10.61 \\
\hline HLW98-61 & HLW98 & 8.21 & 17.38 & 95.22 & 0.662 & 0.749 & 0.924 & 0.331 & 0.375 & 0.462 & 11.12 \\
\hline HLW98-61CG1 & HLW98 & 7.09 & 16.67 & 81.16 & 0.571 & 0.718 & 0.787 & 0.286 & 0.359 & 0.394 & 11.06 \\
\hline HLW98-74 & HLW98 & 20.94 & 17.86 & 80.66 & 0.823 & 0.765 & 0.804 & 0.412 & 0.382 & 0.402 & 10.94 \\
\hline HLW98-75 & HLW98 & 15.26 & 16.82 & 76.33 & 0.734 & 0.720 & 0.761 & 0.367 & 0.360 & 0.380 & 10.95 \\
\hline HLW98-77 & HLW98 & 19.68 & 9.58 & 36.64 & 0.532 & 0.585 & 0.424 & 0.266 & 0.293 & 0.212 & 10.18 \\
\hline HLW98-77CG & HLW98 & 26.08 & 11.92 & 47.36 & 0.705 & 0.728 & 0.548 & 0.353 & 0.364 & 0.274 & 10.27 \\
\hline HLW98-80 & HLW98 & 26.13 & 10.75 & 46.19 & 0.672 & 0.710 & 0.517 & 0.336 & 0.355 & 0.259 & 10.12 \\
\hline HLW98-80CG & HLW98 & 26.95 & 8.97 & 41.34 & 0.693 & 0.592 & 0.463 & 0.346 & 0.296 & 0.232 & 10.16 \\
\hline HLW98-83 & HLW98 & 237.10 & 60.85 & 362.30 & 6.410 & 4.754 & 4.160 & 3.205 & 2.377 & 2.080 & 10.17 \\
\hline HLW98-84 & HLW98 & 25.64 & 8.18 & 51.21 & 0.740 & 0.639 & 0.576 & 0.370 & 0.320 & 0.288 & 10.21 \\
\hline HLW98-84CG & HLW98 & 31.42 & 9.06 & 58.81 & 0.907 & 0.708 & 0.661 & 0.453 & 0.354 & 0.331 & 10.13 \\
\hline HLW98-86 & HLW98 & 23.52 & 9.24 & 56.67 & 0.806 & 0.661 & 0.645 & 0.403 & 0.331 & 0.323 & 10.34 \\
\hline HLW98-86CG & HLW98 & 24.23 & 9.53 & 59.93 & 0.831 & 0.682 & 0.682 & 0.415 & 0.341 & 0.341 & 10.24 \\
\hline HLW98-87 & HLW98 & 16.37 & 9.28 & 32.37 & 0.522 & 0.569 & 0.394 & 0.261 & 0.285 & 0.197 & 10.35 \\
\hline HLW98-88 & HLW98 & 17.02 & 9.99 & 38.92 & 0.517 & 0.572 & 0.448 & 0.259 & 0.286 & 0.224 & 10.45 \\
\hline HLW98-89 & HLW98 & 9.40 & 7.96 & 30.54 & 0.333 & 0.602 & 0.383 & 0.166 & 0.301 & 0.192 & 10.34 \\
\hline HLW98-94 & HLW98 & 30.40 & 0.11 & 156.00 & 0.850 & 0.006 & 1.774 & 0.425 & 0.003 & 0.887 & 11.05 \\
\hline HLW98-95 & HLW98 & 18.29 & 10.21 & 40.77 & 0.740 & 0.639 & 0.576 & 0.277 & 0.292 & 0.230 & 10.34 \\
\hline HLW98-95CG-1 & HLW98 & 17.29 & 9.65 & 40.78 & 0.524 & 0.553 & 0.461 & 0.262 & 0.277 & 0.230 & 10.27 \\
\hline HLW98-96 & HLW98 & 15.22 & 8.45 & 31.86 & 0.486 & 0.588 & 0.400 & 0.243 & 0.294 & 0.200 & 10.33 \\
\hline HLW98-96A & HLW98 & 18.33 & 8.78 & 38.07 & 0.570 & 0.595 & 0.466 & 0.285 & 0.298 & 0.233 & 10.25 \\
\hline HLW98-96B & HLW98 & 17.25 & 8.80 & 35.35 & 0.540 & 0.601 & 0.435 & 0.270 & 0.301 & 0.218 & 10.25 \\
\hline HLW98-96CG & HLW98 & 10.87 & 7.63 & 31.67 & 0.347 & 0.531 & 0.398 & 0.173 & 0.266 & 0.199 & 10.42 \\
\hline
\end{tabular}

(a) 7-Day PCT, stainless steel vessel with $\mathrm{S} / \mathrm{V}=2000 \mathrm{~m}^{-1}$. The PCT concentrations (ppm) are as measured. Normalized concentrations (g/L) and normalized mass losses $\left(\mathrm{g} / \mathrm{m}^{2}\right)$ are calculated as discussed in Section 3.3

(b) The Group IDs are described in Sections 2.1.1 to 2.1.9. 
Table 4.2. PCT Results ${ }^{(a)}$ for 268 Simulated and Actual HLW Glasses (continued).

\begin{tabular}{|c|c|c|c|c|c|c|c|c|c|c|c|}
\hline \multirow[b]{2}{*}{ Glass ID } & \multirow[b]{2}{*}{ Group ID (b) $^{(b)}$} & \multicolumn{3}{|c|}{$\begin{array}{c}\text { Concentration } \\
(\mathbf{p p m})\end{array}$} & \multicolumn{3}{|c|}{$\begin{array}{l}\text { Normalized Concentration } \\
(\mathrm{g} / \mathrm{L})\end{array}$} & \multicolumn{3}{|c|}{$\begin{array}{c}\text { Normalized Mass Loss } \\
\left(\mathrm{g} / \mathrm{m}^{2}\right)\end{array}$} & \multirow{2}{*}{$\begin{array}{c}\text { Leachate } \\
\text { pH }\end{array}$} \\
\hline & & PCT-B & PCT-Li & PCT-Na & PCT-B & PCT-Li & PCT-Na & PCT-B & PCT-Li & PCT-Na & \\
\hline HLW98-96D & HLW98 & 21.92 & 11.07 & 40.46 & 0.653 & 0.719 & 0.474 & 0.326 & 0.360 & 0.237 & 10.33 \\
\hline HLW98-96NRE4 & HLW98 & 20.39 & 10.12 & 40.28 & 0.651 & 0.705 & 0.506 & 0.326 & 0.353 & 0.253 & 10.42 \\
\hline HLW98-96NRE4CCC & HLW98 & 15.36 & 7.87 & 30.79 & 0.491 & 0.548 & 0.387 & 0.245 & 0.274 & 0.194 & 10.25 \\
\hline HLW98-96RE7 & HLW98 & 17.67 & 9.78 & 37.17 & 0.564 & 0.680 & 0.467 & 0.282 & 0.340 & 0.233 & 10.41 \\
\hline HLW98-96RE7CCC & HLW98 & 12.72 & 7.64 & 29.32 & 0.406 & 0.532 & 0.368 & 0.203 & 0.266 & 0.184 & 10.24 \\
\hline HLW98-97 & HLW98 & 22.10 & 10.59 & 45.22 & 0.644 & 0.588 & 0.500 & 0.322 & 0.294 & 0.250 & 10.65 \\
\hline HLW98-T05 & HLW98 & 25.15 & 8.97 & 49.44 & 0.684 & 0.642 & 0.555 & 0.342 & 0.321 & 0.277 & 10.14 \\
\hline HLW98-V01 & HLW98 & 19.69 & 8.98 & 32.47 & 0.564 & 0.582 & 0.389 & 0.282 & 0.291 & 0.195 & 10.24 \\
\hline HLW98-V07 & HLW98 & 21.18 & 8.59 & 35.84 & 0.571 & 0.601 & 0.419 & 0.286 & 0.300 & 0.210 & 10.84 \\
\hline HLW98-V13 & HLW98 & 28.47 & 8.88 & 56.13 & 0.867 & 0.735 & 0.661 & 0.433 & 0.367 & 0.331 & 10.35 \\
\hline HLW98-V19 & HLW98 & 21.55 & 9.88 & 61.18 & 0.787 & 0.756 & 0.736 & 0.394 & 0.378 & 0.368 & 10.24 \\
\hline HLW98-V24 & HLW98 & 29.90 & 14.18 & 85.27 & 0.958 & 0.945 & 0.915 & 0.479 & 0.473 & 0.457 & 10.32 \\
\hline AZ-101 Actual & Actual & 16.3 & 11.6 & 40.6 & 0.520 & 0.666 & 0.512 & 0.260 & 0.333 & 0.256 & 9.41 \\
\hline AZ-102 Actual & Actual & $6.2^{(\mathrm{d})}$ & $18.1^{(\mathrm{d})}$ & $80.6^{(\mathrm{d})}$ & 0.528 & 0.750 & 0.792 & 0.264 & 0.375 & 0.396 & $9.72^{(\mathrm{c})}$ \\
\hline AY-102/C-106 Actual & Actual & 15.5 & 7.3 & 44.3 & 0.480 & 0.580 & 0.480 & 0.240 & 0.290 & 0.240 & 9.90 \\
\hline C-106 Actual & Actual & 13.3 & 16.9 & 84.4 & 0.960 & 0.880 & 0.900 & 0.480 & 0.440 & 0.450 & 10.70 \\
\hline C-104 Actual & Actual & $25.0^{(\mathrm{d})}$ & $23.8^{(\mathrm{d})}$ & $49.3^{(\mathrm{d})}$ & 0.872 & 0.906 & 0.732 & 0.436 & 0.453 & 0.366 & $8.96^{(\mathrm{c})}$ \\
\hline
\end{tabular}

(a) 7-Day PCT, stainless steel vessel with $\mathrm{S} / \mathrm{V}=2000 \mathrm{~m}^{-1}$. The PCT concentrations (ppm) are as measured. Normalized concentrations (g/L) and normalized mass losses $\left(\mathrm{g} / \mathrm{m}^{2}\right)$ are calculated as discussed in Section 3.3.

(b) The Group IDs are described in Sections 2.1.1 to 2.1.9.

(c) Median of the measured $\mathrm{pH}$ range is given.

(d) These PCT concentrations were not originally reported, and so were back-calculated from the normalized concentration values and glass compositions. 
Table 4.3. Temperature and Volume \%-Crystallinity Data for 247 Simulated HLW Glasses.

\begin{tabular}{|c|c|c|c|c|c|c|c|c|c|c|c|c|c|c|c|c|c|c|c|}
\hline \multirow[b]{2}{*}{ Glass ID } & \multirow[b]{2}{*}{$\underset{\text { ID }^{(a)}}{\text { Group }}$} & \multicolumn{18}{|c|}{ Temperature in ${ }^{\circ} \mathrm{C}$} \\
\hline & & 650 & 700 & 750 & 800 & $\begin{array}{c}\mathbf{8 5 0} \\
\text { (Set 1) }\end{array}$ & $\begin{array}{c}850 \\
\text { (Set 2) }\end{array}$ & 875 & $\begin{array}{c}900 \\
\text { (Set 1) }\end{array}$ & $\begin{array}{c}900 \\
(\text { Set 2) }\end{array}$ & $\begin{array}{c}950 \\
(\text { Set } 1)\end{array}$ & $\begin{array}{c}950 \\
\text { (Set 2) }\end{array}$ & $\begin{array}{c}950 \\
(\text { Set 3) }\end{array}$ & $\begin{array}{c}1000 \\
\text { (Set 1) }\end{array}$ & $\begin{array}{c}1000 \\
\text { (Set 2) }\end{array}$ & 1050 & 1100 & 1150 & 1200 \\
\hline HLW02-01 & HLW02 & - (b) $^{\text {(b) }}$ & - & 3.0 & - & - & 1.88 & - & - & - & 0.27 & - & 0.5 & - & - & - & - & - & - \\
\hline HLW02-02 & HLW02 & - & - & - & - & - & 1.1 & - & - & 1.1 & - & - & 0.5 & - & - & - & - & - & - \\
\hline HLW02-04 & HLW02 & - & - & 23.4 & 14.2 & 0.1 & 0.7 & - & - & - & - & - & - & - & - & - & - & - & - \\
\hline HLW02-05 & HLW02 & - & - & $0.1^{(\mathrm{c})}$ & - & - & 0.1 & - & 0.1 & - & - & - & 0.1 & - & - & - & - & - & - \\
\hline HLW02-06 & HLW02 & - & - & - & - & - & 5.1 & - & 3.2 & - & 2.8 & - & 2.4 & - & - & 0.8 & - & - & - \\
\hline HLW02-07 & HLW02 & - & - & 1 & - & - & 0.8 & - & 0.5 & - & - & - & 0.4 & - & - & - & - & - & - \\
\hline HLW02-08 & HLW02 & - & - & 1.2 & - & - & 0.6 & - & - & - & - & - & 0.1 & - & - & - & - & - & - \\
\hline HLW02-09 & HLW02 & - & - & - & - & - & 2.9 & - & 4.4 & 3.5 & - & - & 1.2 & 0.2 & - & - & - & - & - \\
\hline HLW02-10 & HLW02 & - & 0.4 & 0.6 & - & - & 0.1 & - & 0.1 & - & - & - & 0.1 & - & - & - & - & - & - \\
\hline HLW02-11 & HLW02 & - & 1.8 & 1.2 & - & - & 1.0 & - & - & - & - & - & 0.1 & - & - & - & - & - & - \\
\hline HLW02-12 & HLW02 & - & - & - & - & - & 4.4 & - & 3.3 & - & - & - & - & - & - & 1.0 & - & - & - \\
\hline HLW02-13 & HLW02 & - & - & - & - & - & 5.6 & 4.3 & 0.2 & - & - & - & - & 1.0 & - & 0.3 & - & - & - \\
\hline HLW02-14 & HLW02 & - & - & - & - & - & 1.7 & - & - & - & 1.4 & - & 1.1 & 0.2 & - & - & - & - & - \\
\hline HLW02-15 & HLW02 & - & - & - & - & - & 3.7 & - & 3.1 & - & - & - & 2.7 & - & - & 0.9 & - & - & - \\
\hline HLW02-16 & HLW02 & - & - & - & - & - & 4.0 & - & 3.6 & - & 3.1 & - & 1.3 & 0.7 & - & - & - & - & - \\
\hline HLW02-17 & HLW02 & - & - & - & - & - & - & - & 2.07 & - & 0.9 & - & 1.2 & 0.2 & - & 0.4 & - & - & - \\
\hline HLW02-18 & HLW02 & - & - & 2.2 & - & - & 1.8 & - & - & - & - & - & 1.0 & - & - & - & - & - & - \\
\hline HLW02-21 & HLW02 & - & - & 0.2 & 0.2 & - & - & - & 0.2 & - & - & - & - & - & - & - & - & - & - \\
\hline HLW02-22 & HLW02 & - & - & - & - & - & 1.6 & - & - & 0.7 & - & - & 1.5 & - & - & 0.2 & - & - & - \\
\hline HLW02-23 & HLW02 & - & - & - & - & - & 2.4 & - & 1.7 & - & 1.1 & - & 0.8 & - & - & - & - & - & - \\
\hline HLW02-24 & HLW02 & - & - & - & - & - & 2.3 & - & 1.24 & - & 0.61 & - & - & - & - & - & - & - & - \\
\hline HLW02-25 & HLW02 & - & - & - & - & - & 2.0 & - & 0.5 & - & 1.0 & - & - & - & - & - & - & - & - \\
\hline HLW02-26 & HLW02 & - & - & - & - & - & 3.9 & - & 2.47 & - & - & 0.9 & 1.6 & 0.8 & - & - & - & - & - \\
\hline HLW02-27 & HLW02 & - & - & - & - & - & 2.5 & - & 1.28 & - & - & - & 1.5 & 0.5 & - & 0.2 & - & - & - \\
\hline HLW02-28 & HLW02 & - & - & - & - & - & 1.9 & - & - & 1.1 & - & - & 0.9 & 0.1 & - & - & - & - & - \\
\hline HLW02-29 & HLW02 & - & - & - & - & - & 3.5 & - & 1.86 & - & 0.7 & 0.6 & 0.8 & - & - & 0.2 & - & - & - \\
\hline HLW02-30 & HLW02 & - & - & 2.3 & - & - & 1.1 & - & - & - & - & - & 0.8 & - & - & - & - & - & - \\
\hline HLW02-31 & HLW02 & - & 1.2 & 1.3 & - & - & 0.99 & - & - & - & - & - & 0.2 & - & - & - & - & - & - \\
\hline HLW02-32 & HLW02 & - & 1.1 & - & 1.4 & - & \begin{tabular}{|l|}
0.267 \\
\end{tabular} & - & 0.4 & - & - & - & 0.4 & - & - & - & - & - & - \\
\hline HLW02-33 & HLW02 & - & - & - & - & - & 5.8 & - & 2.74 & - & 0.14 & 1.5 & 1.7 & - & - & - & - & - & - \\
\hline HLW02-34 & HLW02 & - & - & - & - & - & 6.2 & - & 2.46 & - & 0.11 & 0.6 & 1.5 & - & - & - & - & - & - \\
\hline HLW02-35 & HLW02 & - & - & - & - & - & 7.2 & - & - & - & 1.7 & - & 2.3 & 0.8 & - & - & - & - & - \\
\hline HLW02-36 & HLW02 & - & - & 1.9 & - & - & 1.4 & - & 0.3 & 0.6 & - & - & 0.8 & - & - & - & - & - & - \\
\hline
\end{tabular}

(a) The Group IDs are described in Sections 2.1.1 to 2.1.9.

(b) A dash (-) indicates that no data were collected for the specified temperatures.

(c) Table entries that were excluded from calculations to determine the $T_{1 \%}$ value for a glass are shaded gray. 
Table 4.3. Temperature and Volume \%-Crystallinity Data for 247 Simulated HLW Glasses (continued).

\begin{tabular}{|c|c|c|c|c|c|c|c|c|c|c|c|c|c|c|c|c|c|c|c|}
\hline \multirow[b]{2}{*}{ Glass ID } & \multirow{2}{*}{$\begin{array}{c}\text { Group } \\
\text { ID }\end{array}$} & \multicolumn{18}{|c|}{ Temperature in ${ }^{\circ} \mathrm{C}$} \\
\hline & & 650 & 700 & 750 & 800 & $\begin{array}{c}850 \\
(\text { Set 1) }\end{array}$ & $\begin{array}{c}850 \\
(\text { Set 2) }\end{array}$ & 875 & $\begin{array}{c}900 \\
(\text { Set } 1)\end{array}$ & $\begin{array}{c}900 \\
(\text { Set 2) }\end{array}$ & $\begin{array}{c}950 \\
(\text { Set } 1)\end{array}$ & $\begin{array}{c}950 \\
(\text { Set 2) }\end{array}$ & $\begin{array}{c}950 \\
(\text { Set 3) }\end{array}$ & $\begin{array}{c}1000 \\
\text { (Set 1) }\end{array}$ & $\begin{array}{c}1000 \\
\text { (Set 2) }\end{array}$ & 1050 & 1100 & 1150 & 1200 \\
\hline HLW02-37 & HLW02 & - & - & - & - & - & 2.9 & - & 2.1 & - & 0.8 & - & - & - & - & 0.6 & - & $\overline{-}$ & - \\
\hline HLW02-38 & HLW02 & - & - & - & - & - & 2.7 & - & 1.25 & - & 1.61 & - & 1.5 & - & - & 0.2 & - & - & - \\
\hline HLW02-39 & HLW02 & - & - & - & - & - & 2.5 & - & 1.79 & - & 1.95 & - & 1.6 & - & - & 0.2 & - & - & - \\
\hline HLW02-40 & HLW02 & - & - & 4.0 & - & - & 1.95 & - & - & - & - & - & 1.6 & 0.4 & - & - & - & - & - \\
\hline HLW02-41 & HLW02 & - & - & - & - & - & 2.4 & - & 1.04 & - & 0.6 & - & 0.6 & - & - & 0.1 & - & - & - \\
\hline HLW02-42 & HLW02 & - & 2.1 & 1.1 & - & - & 0.66 & - & 0.3 & - & - & - & 0.5 & - & - & - & - & - & - \\
\hline HLW02-43 & HLW02 & - & - & - & - & - & 2.6 & - & 0.58 & - & 0.31 & - & 0.9 & - & - & - & - & - & - \\
\hline HLW02-44 & HLW02 & - & - & 1.3 & 1.1 & 0.8 & - & - & 0.57 & - & - & - & - & - & - & - & - & - & - \\
\hline HLW02-45 & HLW02 & - & - & - & - & - & 2.4 & - & 0.95 & - & - & - & 0.8 & - & - & - & - & - & - \\
\hline HLW02-46 & HLW02 & - & - & - & - & - & 2.9 & - & 1.6 & - & 1.07 & - & 0.9 & - & - & 0.2 & - & - & - \\
\hline HLW02-47 & HLW02 & 4.5 & 4.9 & - & 2.4 & - & 0.8 & - & - & - & - & - & - & - & - & - & - & - & - \\
\hline HLW02-48 & HLW02 & - & - & 2.7 & - & - & 1.5 & - & - & - & - & - & 1.4 & 0.7 & - & - & - & - & - \\
\hline HLW02-49 & HLW02 & - & - & - & - & - & 3.68 & - & 1.73 & - & 2.1 & 0.9 & 2.4 & - & - & 0.8 & - & - & - \\
\hline HLW02-50 & HLW02 & - & - & - & - & - & 5.3 & - & 1.96 & - & 1.52 & - & 0.8 & - & - & 0.9 & - & - & - \\
\hline HLW02-51 & HLW02 & - & - & - & - & - & 2.0 & 1.2 & 0.8 & - & - & 0.8 & - & - & - & - & - & - & - \\
\hline HLW02-52 & HLW02 & - & - & 2.5 & - & 1.3 & - & - & 2.1 & - & 1.2 & - & - & - & - & 0.4 & - & - & - \\
\hline HLW02-53 & HLW02 & - & - & - & - & 2.1 & - & - & 1.4 & 1.4 & 1.0 & - & 0.8 & 0.4 & 0.9 & - & - & - & - \\
\hline HLW02-54 & HLW02 & - & - & - & - & - & 2.6 & - & 1.1 & - & - & - & 0.1 & - & - & - & - & - & - \\
\hline HLW02-55 & HLW02 & - & 1.9 & 1.1 & - & - & 1.4 & - & - & - & - & - & 0.2 & - & - & - & - & - & - \\
\hline HLW02-56 & HLW02 & - & 1.4 & 0.9 & - & - & 1.0 & - & 0.4 & - & - & - & 0.5 & - & - & - & - & - & - \\
\hline HLW02-57 & HLW02 & - & 1.3 & 0.9 & - & 0.3 & - & - & - & - & - & - & - & - & - & - & - & - & - \\
\hline HLW03-01 & HLW03 & - & - & 13 & - & - & 10 & - & - & - & - & - & 1.4 & - & - & 2.2 & 1.1 & 0.7 & - \\
\hline HLW03-02 & HLW03 & - & - & - & - & - & 7.3 & - & - & - & 4.6 & - & 2.9 & - & - & 2.0 & 3.3 & 3.3 & 4.0 \\
\hline HLW03-03 & HLW03 & - & - & - & - & - & - & - & - & - & 2.6 & - & 2.8 & - & - & 2.5 & - & 2.0 & $0.1^{(\mathrm{d})}$ \\
\hline HLW03-04 & HLW03 & - & - & - & 8.3 & 2.4 & 2.8 & - & - & - & - & - & 0.6 & - & - & 0.4 & - & - & - \\
\hline HLW03-05 & HLW03 & - & - & - & - & - & 2.1 & - & 1.2 & - & - & - & 0.5 & - & - & - & - & - & - \\
\hline HLW03-06 & HLW03 & - & - & - & - & - & - & - & 2.0 & 1.9 & - & 1.0 & 0.9 & 0.9 & - & - & - & - & - \\
\hline HLW03-07 & HLW03 & - & - & 9.9 & - & - & 6.2 & - & - & - & - & - & 6.0 & - & - & 4.2 & - & 2.9 & 1.0 \\
\hline HLW03-08 & HLW03 & - & - & - & - & - & - & - & - & - & - & - & 12.2 & - & - & 6.6 & 7.3 & 9.8 & 4.2 \\
\hline HLW03-09 & HLW03 & 0.2 & - & 0.1 & - & - & 0.2 & - & - & - & - & - & 0.1 & - & - & - & - & - & - \\
\hline HLW03-10 & HLW03 & - & - & 10.3 & - & - & 12.5 & - & - & - & - & - & 8.7 & - & - & 3.7 & 2.9 & 3.5 & 1.4 \\
\hline HLW03-11 & HLW03 & 0.4 & - & 0.4 & - & - & 0.3 & - & - & - & - & - & 0.2 & - & - & - & - & - & - \\
\hline HLW03-12 & HLW03 & - & - & 1.2 & - & - & 0.7 & - & 0.8 & - & - & - & 0.6 & - & - & - & - & - & - \\
\hline HLW03-13 & HLW03 & - & - & - & - & - & 7.9 & - & - & - & - & - & 5.3 & - & - & 5.0 & - & 3.5 & 0.6 \\
\hline HLW03-14 & HLW03 & - & - & - & - & - & 4.6 & - & - & - & - & 3.5 & 2.9 & 1.5 & - & 2.2 & 0.5 & - & - \\
\hline HLW03-15 & HLW03 & - & - & - & - & - & - & - & - & - & - & - & 2.7 & - & - & 0.9 & 0.3 & - & - \\
\hline
\end{tabular}

(a) The Group IDs are described in Sections 2.1.1 to 2.1.9

(b) A dash (-) indicates that no data were collected for the specified temperatures.

(c) Table entries that were excluded from calculations to determine the $\mathrm{T}_{1 \%}$ value for a glass are shaded gray.

(d) This value was originally reported as $<0.10 \mathrm{vol} \%$, but was assigned the value of $0.1 \mathrm{vol} \%$ for purposes of calculating $\mathrm{T}_{1 \%}$ values. 
Table 4.3. Temperature and Volume \%-Crystallinity Data for 247 Simulated HLW Glasses (continued).

\begin{tabular}{|c|c|c|c|c|c|c|c|c|c|c|c|c|c|c|c|c|c|c|c|}
\hline \multirow[b]{2}{*}{ Glass ID } & \multirow[b]{2}{*}{$\begin{array}{c}\text { Group } \\
\text { ID }\end{array}$} & \multicolumn{18}{|c|}{ Temperature in ${ }^{\circ} \mathrm{C}$} \\
\hline & & 650 & 700 & 750 & 800 & $\begin{array}{c}\mathbf{8 5 0} \\
\text { (Set 1) }\end{array}$ & $\begin{array}{c}\mathbf{8 5 0} \\
\text { (Set 2) }\end{array}$ & 875 & $\begin{array}{c}900 \\
\text { (Set 1) }\end{array}$ & $\begin{array}{c}900 \\
(\text { Set 2) }\end{array}$ & $\begin{array}{c}950 \\
(\text { Set 1) }\end{array}$ & $\begin{array}{c}950 \\
\text { (Set 2) }\end{array}$ & $\begin{array}{c}950 \\
\text { (Set 3) }\end{array}$ & $\begin{array}{c}1000 \\
\text { (Set 1) }\end{array}$ & $\begin{array}{c}1000 \\
\text { (Set 2) }\end{array}$ & 1050 & 1100 & 1150 & 1200 \\
\hline HLW03-16 & HLW03 & - & - & 4.6 & - & 2.8 & 2.8 & - & - & - & - & - & 1.9 & - & - & 0.9 & - & - & - \\
\hline HLW03-17 & HLW03 & - & - & - & - & - & 5.7 & - & - & - & - & 2.4 & 1.7 & - & - & 0.5 & - & - & - \\
\hline HLW03-18 & HLW03 & - & - & - & - & - & 2.4 & - & - & - & - & 0.5 & 0.7 & - & - & 0.5 & - & - & - \\
\hline HLW03-19 & HLW03 & - & - & - & - & - & 1.5 & - & - & - & - & - & 0.8 & - & - & 0.6 & - & - & - \\
\hline HLW03-20 & HLW03 & - & - & - & - & - & 1.0 & - & 1.0 & - & - & - & 0.3 & - & - & - & - & - & - \\
\hline HLW03-21 & HLW03 & - & - & - & 2 & - & 1.0 & - & 0.3 & - & - & - & 0.2 & - & - & - & - & - & - \\
\hline HLW03-22 & HLW03 & - & - & 4.4 & - & - & 2.3 & - & 0.6 & - & - & - & 0.5 & - & - & - & - & - & - \\
\hline HLW03-23 & HLW03 & - & - & 1.5 & 1.3 & 0.9 & 0.6 & - & - & - & - & - & 0.4 & - & - & - & - & - & - \\
\hline HLW03-24 & HLW03 & - & - & 2.3 & 1.6 & 0.6 & 0.4 & - & - & - & - & - & - & - & - & - & - & - & - \\
\hline HLW03-25 & HLW03 & - & - & 1.6 & 0.2 & - & 0.2 & - & - & - & - & - & 0.1 & - & - & - & - & - & - \\
\hline HLW03-26 & HLW03 & - & - & 1.2 & 1.0 & - & 0.8 & - & - & 0.4 & - & - & 0.3 & - & - & - & - & - & - \\
\hline HLW03-27 & HLW03 & - & - & - & - & - & 1.7 & - & - & - & - & - & 1.6 & - & - & 0.6 & - & - & - \\
\hline HLW03-28 & HLW03 & - & - & 1.4 & 1.3 & 1.0 & 0.5 & - & - & - & - & - & 0.2 & - & - & - & - & - & - \\
\hline HLW03-29 & HLW03 & - & - & 1.4 & 1.7 & - & 0.7 & - & - & - & - & - & 0.4 & - & - & - & - & - & - \\
\hline HLW03-30 & HLW03 & - & - & 1.0 & 0.9 & - & 0.6 & - & - & - & - & - & 0.2 & - & - & - & - & - & - \\
\hline HLW03-31 & HLW03 & - & - & 2.6 & - & - & 2.4 & - & - & - & - & - & 1.6 & 1.8 & - & $\begin{array}{ll}0.7 \\
\end{array}$ & - & 0.9 & - \\
\hline HLW03-32 & HLW03 & - & - & 5.0 & - & - & 4.6 & - & 3.6 & - & - & - & 1.6 & - & - & 2.0 & 1.5 & - & - \\
\hline HLW03-33 & HLW03 & - & - & 5.5 & - & - & 2.7 & - & - & - & - & - & 3.9 & - & - & 1.8 & - & 1.1 & - \\
\hline HLW03-34 & HLW03 & - & - & - & 3.0 & - & 1.7 & - & - & - & - & - & 1.0 & - & - & 0.3 & - & - & - \\
\hline HLW03-35 & HLW03 & - & - & - & - & - & - & - & - & - & - & - & 6.2 & - & - & 3.0 & 2.4 & 0.4 & - \\
\hline HLW03-36 & HLW03 & - & - & - & - & - & 10 & - & - & - & - & - & 6.1 & - & - & 3.4 & - & 3.5 & 0.1 \\
\hline HLW03-37 & HLW03 & - & - & - & - & - & 1.9 & - & 0.9 & - & - & - & 0.3 & - & - & - & - & - & - \\
\hline HLW03-38 & HLW03 & - & - & 6.5 & - & - & 3.8 & - & - & - & - & - & 2.5 & - & - & 1.4 & 2.0 & - & - \\
\hline HLW03-39 & HLW03 & - & - & 2.8 & - & - & 1.8 & - & - & - & - & - & 0.4 & - & - & - & - & - & - \\
\hline HLW03-40 & HLW03 & - & - & 5.6 & - & - & 2.5 & - & - & - & - & - & 1.3 & - & - & 0.4 & - & - & - \\
\hline HLW03-41 & HLW03 & - & - & - & 1.5 & - & 0.8 & - & - & - & - & - & 0.4 & - & - & - & - & - & - \\
\hline HLW03-42 & HLW03 & - & - & - & - & - & 3.0 & - & - & - & 1.2 & - & 1.1 & - & - & 0.3 & - & - & - \\
\hline HLW03-43 & HLW03 & - & - & - & - & - & 1.8 & - & - & 1.6 & - & - & 0.6 & - & 0.9 & - & - & - & - \\
\hline HLW03-44 & HLW03 & 0.3 & - & - & - & - & 0.1 & - & - & - & - & - & 0.1 & - & - & - & - & - & - \\
\hline HLW03-45 & HLW03 & - & - & - & 1.3 & - & 1.3 & - & - & 0.3 & - & - & - & - & - & - & - & - & - \\
\hline HLW05-01 & HLW05 & - & - & 0.7 & 1.0 & 0.9 & - & - & - & - & 0.8 & - & - & - & - & 0.4 & - & - & - \\
\hline HLW05-02 & HLW05 & - & 0.9 & 1.1 & 0.7 & 0.6 & - & - & - & - & 0.3 & - & - & - & - & - & - & - & - \\
\hline HLW05-03 & HLW05 & - & 0.1 & 0.8 & 0.2 & 0.1 & - & - & - & - & 0.1 & - & - & - & - & - & - & - & - \\
\hline HLW05-04 & HLW05 & - & 0.4 & 0.3 & 0.7 & 0.4 & - & - & - & - & 0.2 & - & - & - & - & - & - & - & - \\
\hline HLW05-05 & HLW05 & - & 0.1 & 0.2 & - & 0.1 & - & - & - & - & 0.1 & - & - & - & - & - & - & - & - \\
\hline HLW05-06 & HLW05 & - & - & - & - & 3.0 & - & - & - & - & 2.1 & - & - & - & - & 0.9 & 1.0 & 0.1 & - \\
\hline
\end{tabular}

(a) The Group IDs are described in Sections 2.1.1 to 2.1.9.

(b) A dash (-) indicates that no data were collected for the specified temperatures

(c) Table entries that were excluded from calculations to determine the $T_{1 \%}$ value for a glass are shaded gray. 
Table 4.3. Temperature and Volume \%-Crystallinity Data for 247 Simulated HLW Glasses (continued).

\begin{tabular}{|c|c|c|c|c|c|c|c|c|c|c|c|c|c|c|c|c|c|c|c|}
\hline \multirow[b]{2}{*}{ Glass ID } & \multirow{2}{*}{$\begin{array}{c}\text { Group } \\
\text { ID }\end{array}$} & \multicolumn{18}{|c|}{ Temperature in ${ }^{\circ} \mathrm{C}$} \\
\hline & & 650 & 700 & 750 & 800 & $\begin{array}{c}850 \\
\text { (Set 1) }\end{array}$ & $\begin{array}{c}850 \\
\text { (Set 2) }\end{array}$ & 875 & $\begin{array}{c}900 \\
\text { (Set 1) }\end{array}$ & $\begin{array}{c}900 \\
\text { (Set 2) }\end{array}$ & $\begin{array}{c}950 \\
\text { (Set 1) }\end{array}$ & $\begin{array}{c}950 \\
(\text { Set 2) }\end{array}$ & $\begin{array}{c}950 \\
(\text { Set 3) }\end{array}$ & $\begin{array}{c}1000 \\
\text { (Set 1) }\end{array}$ & $\begin{array}{c}1000 \\
\text { (Set 2) }\end{array}$ & 1050 & 1100 & 1150 & 1200 \\
\hline HLW05-07 & HLW05 & - & 0.6 & 1.0 & 0.6 & 0.5 & - & - & - & - & 0.2 & - & - & - & - & - & - & - & - \\
\hline HLW05-08 & HLW05 & - & - & 0.7 & 0.9 & 1.7 & - & - & - & - & 1.6 & - & - & - & - & 1.0 & 0.7 & 0.9 & - \\
\hline HLW05-09 & HLW05 & - & 0.9 & 0.9 & - & 0.2 & - & - & - & - & 0.1 & - & - & - & - & 0.1 & - & - & - \\
\hline HLW05-10 & HLW05 & - & - & 0.4 & 0.9 & 1.1 & - & - & - & - & 1.0 & - & - & - & - & 0.4 & 0.3 & 0.1 & - \\
\hline HLW05-11 & HLW05 & - & 1.0 & 0.3 & 0.4 & 0.4 & - & - & - & - & 0.2 & - & - & - & - & - & - & - & - \\
\hline HLW05-12 & HLW05 & - & - & 0.7 & - & 2.7 & - & - & - & - & 1.6 & - & - & - & - & 0.9 & 1.1 & 0.5 & - \\
\hline HLW05-13 & HLW05 & - & - & 7.7 & 0.8 & 0.7 & - & - & - & - & 0.7 & - & - & - & - & 0.2 & - & - & - \\
\hline HLW05-14 & HLW05 & - & 1.0 & 0.7 & - & 0.3 & - & - & - & - & 0.1 & - & - & - & - & - & - & - & - \\
\hline HLW05-15 & HLW05 & - & 0.1 & 0.1 & 0.1 & 0.3 & - & - & - & - & 0.1 & - & - & - & - & - & - & - & - \\
\hline HLW05-16 & HLW05 & - & - & - & - & 3.2 & - & - & - & - & 2.9 & - & - & - & - & 2.1 & 1.7 & 1.9 & 1.9 \\
\hline HLW05-17 & HLW05 & - & - & 2.5 & - & 2.7 & - & - & - & - & 1.6 & - & - & - & - & 1.2 & 0.9 & 0.7 & - \\
\hline HLW05-18 & HLW05 & - & - & - & - & 3.5 & - & - & - & - & 4.8 & - & - & - & - & 8.9 & 2.3 & 2.2 & 2.6 \\
\hline HLW05-19 & HLW05 & - & - & - & - & 29.9 & - & - & - & - & 17.1 & - & - & - & - & 2.1 & - & 0.9 & - \\
\hline HLW05-20 & HLW05 & - & 3.1 & 0.2 & 0.2 & 0.1 & - & - & - & - & 0.1 & - & - & - & - & 0.1 & - & - & 0.1 \\
\hline HLW05-21 & HLW05 & - & 0.1 & 0.1 & - & 0.1 & - & - & - & - & 0.1 & - & - & - & - & - & - & - & - \\
\hline HLW05-22 & HLW05 & - & 1.0 & - & 0.5 & 0.5 & - & - & - & - & 0.1 & - & - & - & - & - & - & - & - \\
\hline HLW05-23 & HLW05 & - & - & - & - & 1.5 & - & - & - & - & 1.1 & - & - & - & - & 0.8 & 0.9 & 0.8 & 0.7 \\
\hline HLW05-24 & HLW05 & - & - & - & - & 17.5 & - & - & - & - & 10.8 & - & - & - & - & 8.9 & - & 5.9 & 2.4 \\
\hline HLW05-25 & HLW05 & - & - & - & - & 8.4 & - & - & - & - & 6.0 & - & - & - & - & 4.2 & 3.9 & 2.6 & 2.0 \\
\hline HLW05-26 & HLW05 & - & - & - & - & 18.9 & - & - & - & - & 16.3 & - & - & - & - & 10.5 & - & 3.7 & 0.1 \\
\hline HLW05-27 & HLW05 & - & 9.7 & - & 1.4 & 0.7 & - & - & - & - & 0.6 & - & - & - & - & - & - & - & - \\
\hline HLW05-28 & HLW05 & - & - & - & - & 3.4 & - & - & - & - & 6.3 & - & - & - & - & 3.5 & 2.3 & 2.3 & 2.2 \\
\hline HLW05-29 & HLW05 & - & - & - & - & 19.8 & - & - & - & - & 15.9 & - & - & - & - & 10.9 & - & 4.6 & 0.1 \\
\hline HLW05-30 & HLW05 & - & 0.4 & - & 0.3 & 0.2 & - & - & - & - & 0.1 & - & - & - & - & - & - & - & - \\
\hline HLW06-01 & HLW06 & - & 4.4 & - & 2.7 & - & - & - & - & - & 2.0 & - & - & 1.0 & - & 1.0 & - & - & - \\
\hline HLW06-02 & HLW06 & - & - & 2.4 & 1.9 & 1.5 & - & - & - & - & 1.1 & - & - & 0.3 & - & 0.3 & - & - & - \\
\hline HLW06-03 & HLW06 & - & - & - & - & 5.6 & - & - & - & - & 4.7 & - & - & - & - & 2.7 & 2.0 & 2.9 & 1.2 \\
\hline HLW06-04 & HLW06 & - & - & 10.3 & - & 1.0 & - & - & 0.6 & - & 0.6 & - & - & 0.2 & - & 0.1 & - & - & - \\
\hline HLW06-05 & HLW06 & - & - & 1.7 & 1.3 & 1.8 & - & - & 0.9 & - & 0.9 & - & - & 0.3 & - & - & - & - & - \\
\hline HLW06-06 & HLW06 & - & - & - & - & 3.7 & - & - & - & - & 4.1 & - & - & 3.9 & - & 3.1 & 2.2 & 2.5 & 1.3 \\
\hline HLW06-07 & HLW06 & - & - & - & - & 8.5 & - & - & - & - & 5.5 & - & - & - & - & 2.5 & 3.1 & 2.6 & 1.5 \\
\hline HLW06-08 & HLW06 & - & - & - & - & 2.2 & - & - & 1.7 & - & 1.6 & - & - & - & - & 0.9 & 0.9 & 0.3 & - \\
\hline HLW06-09 & HLW06 & - & - & - & - & 3.7 & - & - & - & - & 4.6 & - & - & 3.3 & - & 2.3 & 3.0 & 1.8 & 1.1 \\
\hline HLW06-10 & HLW06 & - & - & - & - & 1.4 & - & - & 1.5 & - & 1.0 & - & - & 1.3 & - & 1.0 & 0.6 & 0.5 & 0.3 \\
\hline HLW06-11 & HLW06 & - & - & - & - & 4.0 & - & - & - & - & 2.9 & - & - & - & - & 1.3 & 1.0 & 1.3 & 0.4 \\
\hline HLW06-12 & HLW06 & - & - & - & 2.8 & 2.7 & - & - & 2.3 & - & 1.0 & - & - & 1.4 & - & 1.1 & 0.1 & - & - \\
\hline
\end{tabular}

(a) The Group IDs are described in Sections 2.1.1 to 2.1.9.

(b) A dash (-) indicates that no data were collected for the specified temperatures

(c) Table entries that were excluded from calculations to determine the $T_{1 \%}$ value for a glass are shaded gray. 
Table 4.3. Temperature and Volume \%-Crystallinity Data for 247 Simulated HLW Glasses (continued).

\begin{tabular}{|c|c|c|c|c|c|c|c|c|c|c|c|c|c|c|c|c|c|c|c|}
\hline \multirow[b]{2}{*}{ Glass ID } & \multirow[b]{2}{*}{$\begin{array}{c}\text { Group } \\
\text { ID }\end{array}$} & \multicolumn{18}{|c|}{ Temperature in ${ }^{\circ} \mathrm{C}$} \\
\hline & & 650 & 700 & 750 & 800 & $\begin{array}{c}850 \\
\text { (Set 1) }\end{array}$ & $\begin{array}{c}\mathbf{8 5 0} \\
(\text { Set 2) }\end{array}$ & 875 & $\begin{array}{c}900 \\
\text { (Set 1) }\end{array}$ & $\begin{array}{c}900 \\
(\text { Set 2) }\end{array}$ & $\begin{array}{c}950 \\
(\text { Set 1) }\end{array}$ & $\begin{array}{c}950 \\
\text { (Set 2) }\end{array}$ & $\begin{array}{c}950 \\
(\text { Set 3) }\end{array}$ & $\begin{array}{c}1000 \\
\text { (Set 1) }\end{array}$ & $\begin{array}{c}1000 \\
\text { (Set 2) }\end{array}$ & 1050 & 1100 & 1150 & 1200 \\
\hline HLW06-13 & HLW06 & - & - & - & - & 3.6 & - & - & - & - & 2.4 & - & - & 3.7 & - & 3.2 & 2.2 & 1.6 & 0.5 \\
\hline HLW06-14 & HLW06 & - & - & 2.8 & - & 2.1 & - & - & 1.4 & - & 1.3 & - & - & 0.7 & - & 0.4 & - & - & - \\
\hline HLW06-15 & HLW06 & - & - & 2.4 & - & 2.4 & - & - & 1.5 & - & 0.6 & - & - & 0.1 & - & - & - & - & - \\
\hline HLW06-16 & HLW06 & - & 13.1 & 11.5 & 3.2 & - & - & - & 2.1 & - & 1.0 & - & - & 0.5 & - & - & - & - & - \\
\hline HLW06-17 & HLW06 & - & 6.0 & - & - & - & - & - & 2.2 & - & 1.8 & - & - & 1.1 & - & 1.0 & 0.4 & - & - \\
\hline HLW06-18 & HLW06 & - & - & - & - & 2.9 & - & - & - & - & 2.0 & - & - & 1.2 & - & 1.1 & 0.6 & 0.9 & - \\
\hline HLW06-19 & HLW06 & - & - & - & - & - & - & - & - & - & 5.2 & - & - & - & - & 2.7 & 1.5 & 2.1 & 1.1 \\
\hline HLW06-20 & HLW06 & - & - & 19.6 & - & - & - & - & - & - & 2.2 & - & - & 2.1 & - & 1.9 & 1.2 & 0.9 & - \\
\hline HLW06-21 & HLW06 & - & - & 21.9 & - & 2.0 & - & - & 1.6 & - & 4.7 & - & - & 1.2 & - & 1.4 & - & 1.1 & - \\
\hline HLW06-22 & HLW06 & - & - & 0.3 & 0.2 & 0.4 & - & - & 0.4 & - & 0.2 & - & - & - & - & - & - & - & - \\
\hline HLW06-23 & HLW06 & - & - & - & - & - & - & - & - & - & 23.2 & - & - & - & - & 13.4 & 8.5 & 6.0 & 3.3 \\
\hline HLW06-24 & HLW06 & - & - & 49.9 & 41.5 & - & - & - & - & - & 28.6 & - & - & 1.9 & - & 2.3 & - & 1.5 & 1.3 \\
\hline HLW06-25 & HLW06 & - & - & - & 3.0 & - & - & - & - & - & 1.6 & - & - & 1.5 & - & 0.8 & 0.8 & - & - \\
\hline HLW06-26 & HLW06 & - & - & 22.8 & - & 12.3 & - & - & - & - & 3.3 & - & - & 5.6 & - & 5.5 & 4.5 & 4.7 & - \\
\hline HLW06-27 & HLW06 & - & - & 12.2 & - & 11.0 & - & - & - & - & 7.5 & - & - & - & - & 7.0 & - & 5.6 & 4.6 \\
\hline HLW06-28 & HLW06 & - & - & - & 5.8 & 0.8 & - & - & 1.3 & - & 1.3 & - & - & 0.5 & - & 0.6 & - & - & - \\
\hline HLW06-29 & HLW06 & - & - & - & - & 17.7 & - & - & - & - & 10.9 & - & - & - & - & 5.4 & 7.5 & 5.8 & 3.2 \\
\hline HLW06-30 & HLW06 & - & - & - & - & 23.3 & - & - & - & - & 14.3 & - & - & - & - & 1.7 & 0.8 & 0.7 & 0.1 \\
\hline HLW06-31 & HLW06 & - & - & - & - & 7.4 & - & - & - & - & 7.6 & - & - & - & - & 6.6 & - & 3.4 & 2.9 \\
\hline HLW06-32 & HLW06 & - & - & 2.5 & 2.3 & 0.9 & - & - & 1.1 & - & 0.5 & - & - & 0.4 & - & - & - & - & - \\
\hline HLW06-33 & HLW06 & - & - & 19.1 & - & 3.7 & - & - & - & - & 3.4 & - & - & 3.0 & - & 3.3 & 2.1 & 2.0 & - \\
\hline HLW06-34 & HLW06 & - & - & 2.8 & - & 13.7 & - & - & 5.6 & - & 0.2 & - & - & 0.1 & - & - & - & - & - \\
\hline HLW06-35 & HLW06 & - & - & 2.7 & 2.1 & - & - & - & 0.6 & - & 0.5 & - & - & 0.5 & - & - & - & - & - \\
\hline HLW07-01 & HLW07 & - & - & - & 1.9 & 1.4 & - & - & 1.0 & - & 0.9 & - & - & 0.5 & - & - & - & - & - \\
\hline HLW07-02 & HLW07 & - & - & - & 2.3 & 1.7 & - & - & 1.6 & - & 0.9 & - & - & 0.7 & - & - & - & - & - \\
\hline HLW07-03 & HLW07 & - & 0.8 & 1.2 & 1.2 & 1.0 & - & - & 0.6 & - & 0.4 & - & - & - & - & - & - & - & - \\
\hline HLW07-04 & HLW07 & - & - & 25.0 & 1.9 & 0.6 & - & - & 0.4 & - & 0.3 & - & - & - & - & - & - & - & - \\
\hline HLW07-05 & HLW07 & - & - & - & - & - & - & - & - & - & - & - & - & 3.5 & - & 3.1 & 3.3 & 2.0 & 0.5 \\
\hline HLW07-06 & HLW07 & - & - & - & - & - & - & - & 5.8 & - & 3.1 & - & - & 3.4 & - & 0.8 & 0.5 & - & - \\
\hline HLW07-07 & HLW07 & - & 15.7 & 4.4 & 1.0 & 0.2 & - & - & 0.3 & - & - & - & - & - & - & - & - & - & - \\
\hline HLW07-08 & HLW07 & - & - & - & - & 9.3 & - & - & - & - & - & - & - & - & - & 9.4 & 4.9 & 4.2 & 4.2 \\
\hline HLW07-09 & HLW07 & - & - & - & - & 5.1 & - & - & - & - & - & - & - & 4.9 & - & 3.2 & 1.2 & 1.7 & 1.1 \\
\hline HLW07-10 & HLW07 & - & - & - & 2.7 & 2.1 & - & - & 1.2 & - & 1.0 & - & - & - & - & 0.5 & - & - & - \\
\hline HLW07-11 & HLW07 & - & - & - & 13.8 & - & - & - & 2.2 & - & 1.4 & - & - & 1.2 & - & 0.7 & 0.3 & - & - \\
\hline HLW07-12 & HLW07 & - & - & - & 24.9 & - & - & - & - & - & 1.5 & - & - & 1.6 & - & 1.4 & 1.6 & 1.1 & 1.0 \\
\hline HLW07-13 & HLW07 & - & - & - & 21.1 & - & - & - & - & - & - & - & - & 3.2 & - & 3.6 & 3.1 & 2.1 & 3.1 \\
\hline
\end{tabular}

(a) The Group IDs are described in Sections 2.1.1 to 2.1.9.

(b) A dash ( - ) indicates that no data were collected for the specified temperatures.

(c) Table entries that were excluded from calculations to determine the $T_{1 \%}$ value for a glass are shaded gray. 
Table 4.3. Temperature and Volume \%-Crystallinity Data for 247 Simulated HLW Glasses (continued).

\begin{tabular}{|c|c|c|c|c|c|c|c|c|c|c|c|c|c|c|c|c|c|c|c|}
\hline \multirow[b]{2}{*}{ Glass ID } & \multirow{2}{*}{$\begin{array}{l}\text { Group } \\
\text { ID }\end{array}$} & \multicolumn{18}{|c|}{ Temperature in ${ }^{\circ} \mathrm{C}$} \\
\hline & & 650 & 700 & 750 & 800 & $\begin{array}{c}850 \\
(\text { Set 1) }\end{array}$ & $\begin{array}{c}850 \\
\text { (Set 2) }\end{array}$ & 875 & $\begin{array}{c}900 \\
(\text { Set 1) }\end{array}$ & $\begin{array}{c}900 \\
\text { (Set 2) }\end{array}$ & $\begin{array}{c}950 \\
(\text { Set 1) }\end{array}$ & $\begin{array}{c}950 \\
(\text { Set 2) }\end{array}$ & $\begin{array}{c}950 \\
\text { (Set 3) }\end{array}$ & $\begin{array}{c}1000 \\
(\text { Set } 1)\end{array}$ & $\begin{array}{c}1000 \\
\text { (Set 2) }\end{array}$ & 1050 & 1100 & 1150 & 1200 \\
\hline HLW07-14 & \begin{tabular}{|l|} 
HLW07 \\
\end{tabular} & - & - & - & 6.9 & - & - & - & - & - & - & - & - & 4.4 & - & 2.6 & 3.5 & 4.1 & 2.8 \\
\hline HLW07-15 & \begin{tabular}{|l|} 
HLW07 \\
\end{tabular} & - & - & - & 22.2 & - & - & - & - & - & - & - & - & 14.3 & - & 7.5 & 4.7 & 0.6 & 0.9 \\
\hline HLW07-16 & HLW07 & - & - & - & - & 4.8 & - & - & 2.0 & - & 1.0 & - & - & 1.1 & - & 0.5 & 0.7 & - & - \\
\hline HLW07-17 & HLW07 & - & 5.8 & 4.3 & - & 0.7 & - & - & 0.3 & - & - & - & - & - & - & - & - & - & - \\
\hline HLW07-18 & \begin{tabular}{|l|} 
HLW07 \\
\end{tabular} & - & 0.6 & 1.4 & 0.6 & 0.5 & - & - & 0.4 & - & - & - & - & - & - & - & - & - & - \\
\hline HLW07-19 & HLW07 & - & - & - & 13.1 & 11.8 & - & - & - & - & 2.5 & - & - & 2.5 & - & 0.7 & 0.4 & 0.5 & - \\
\hline HLW07-20 & HLW07 & - & - & - & 2.6 & 2.0 & - & - & 1.3 & - & 1.2 & - & - & 0.8 & - & 0.7 & - & - & - \\
\hline HLW07-21 & \begin{tabular}{|l|} 
HLW07 \\
\end{tabular} & - & - & 0.2 & 0.8 & 0.7 & - & - & 0.1 & - & 0.2 & - & - & - & - & - & - & - & - \\
\hline HLW07-22 & \begin{tabular}{|l|} 
HLW07 \\
\end{tabular} & - & - & - & 13.0 & - & - & - & - & - & - & - & - & 2.7 & - & 1.7 & 1.7 & 1.4 & 0.9 \\
\hline HLW07-23 & HLW07 & - & - & - & - & 5.6 & - & - & - & - & - & - & - & 5.4 & - & 4.9 & 3.0 & 3.8 & 2.4 \\
\hline HLW07-24 & HLW07 & - & - & - & 2.0 & - & - & - & 1.6 & - & 1.4 & - & - & 1.4 & - & 0.9 & - & - & - \\
\hline HLW07-25 & HLW07 & - & - & - & 4.3 & 4.0 & - & - & - & - & - & - & - & 2.7 & - & 3.3 & 1.6 & 1.2 & - \\
\hline HLW07-26 & \begin{tabular}{|l|} 
HLW07 \\
\end{tabular} & - & - & 1.4 & 0.9 & 1.2 & - & - & 1.0 & - & 0.8 & - & - & 0.8 & - & - & - & - & - \\
\hline HLW07-27 & \begin{tabular}{|l|} 
HLW07 \\
\end{tabular} & - & 1.1 & 1.2 & 1.1 & 0.9 & - & - & 0.5 & - & 0.4 & - & - & - & - & - & - & - & - \\
\hline HLW07-28 & HLW07 & - & - & 1.5 & 1.5 & 1.2 & - & - & 1.0 & - & 0.8 & - & - & - & - & - & - & - & - \\
\hline HLW07-29 & HLW07 & - & - & 3.2 & 2.6 & 2.3 & - & - & 1.8 & - & 1.2 & - & - & 0.8 & - & - & - & - & - \\
\hline HLW07-30 & \begin{tabular}{|l|} 
HLW07 \\
\end{tabular} & - & - & - & 1.5 & 1.4 & - & - & 0.9 & - & 0.6 & - & - & 0.5 & - & - & - & - & - \\
\hline HLW07-31 & \begin{tabular}{|l|} 
HLW07 \\
\end{tabular} & - & - & - & 1.5 & 1.2 & - & - & 1.0 & - & 0.8 & - & - & 0.6 & - & - & - & - & - \\
\hline HLW07-32 & HLW07 & - & - & - & 2.1 & 1.7 & - & - & 1.6 & - & 1.1 & - & - & 0.7 & - & - & - & - & - \\
\hline HLW07-33 & HLW07 & - & - & - & 2.3 & 2.0 & - & - & 1.7 & - & 1.3 & - & - & 1.0 & - & - & - & - & - \\
\hline HLW07-34 & \begin{tabular}{|l|} 
HLW07 \\
\end{tabular} & - & - & - & 2.8 & 2.5 & - & - & 2.5 & - & 2.3 & - & - & 2.2 & - & 1.5 & 1.1 & - & - \\
\hline HLW07-35 & \begin{tabular}{|l|} 
HLW07 \\
\end{tabular} & - & - & - & 1.8 & 1.9 & - & - & 1.8 & - & 1.7 & - & - & 1.2 & - & 0.8 & 0.4 & - & - \\
\hline HLW07-36 & HLW07 & - & - & 0.2 & 0.3 & 0.2 & - & - & - & - & 0.2 & - & - & - & - & - & - & - & - \\
\hline HLW07-37 & HLW07 & - & - & 2.1 & 1.5 & 1.0 & - & - & 0.5 & - & 0.3 & - & - & - & - & - & - & - & - \\
\hline HLW07-38 & HLW07 & - & - & 2.1 & - & 1.5 & - & - & 1.7 & - & 1.9 & - & - & 1.1 & - & - & 0.3 & - & - \\
\hline HLW07-39 & \begin{tabular}{|l|} 
HLW07 \\
\end{tabular} & - & 0.4 & 0.5 & 0.8 & 0.5 & - & - & 0.5 & - & - & - & - & - & - & - & - & - & - \\
\hline HLW07-40 & HLW07 & - & - & 2.0 & 2.0 & 1.5 & - & - & 1.3 & - & 1.0 & - & - & 0.7 & - & - & - & - & - \\
\hline HLW-ALG-01 & HLWALG & 0.1 & 0.1 & 0.1 & 0.1 & 0.2 & - & - & - & - & 0.1 & - & - & - & - & 0.0 & - & - & - \\
\hline HLW-ALG-02 & HLWALG & - & 0.1 & 0.2 & 0.3 & 0.3 & - & - & - & - & 0.1 & - & - & - & - & 0.1 & - & - & - \\
\hline HLW-ALG-03 & HLWALG & - & - & 0.2 & 0.7 & 0.5 & - & - & 0.1 & - & 0.0 & - & - & - & - & 0.0 & - & - & - \\
\hline HLW-ALG-04 & HLWALG & - & 0.5 & 0.1 & 0.2 & 0.1 & - & - & - & - & 0.0 & - & - & - & - & - & - & - & - \\
\hline HLW-ALG-05 & HLWALG & - & 2.3 & 2.7 & 1.9 & 2.5 & - & - & - & - & 1.2 & - & - & 0.5 & - & 0.3 & - & - & - \\
\hline HLW-ALG-06 & HLWALG & - & 25.6 & 24.6 & 21.0 & 2.6 & - & - & 1.5 & - & 0.7 & - & - & 1.0 & - & - & - & - & - \\
\hline HLW-ALG-07 & HLWALG & - & 0.1 & 0.1 & 0.1 & 0.1 & - & - & 0.1 & - & 0.1 & - & - & - & - & - & - & - & - \\
\hline HLW-ALG-08 & HLWALG & - & - & - & - & - & - & - & 13.6 & - & 9.2 & - & - & 4.8 & - & 1.9 & 1.6 & 1.1 & 0.8 \\
\hline HLW-ALG-09 & HLWALG & - & 1.1 & 1.0 & 1.1 & - & - & - & 1.0 & - & 0.5 & - & - & 0.3 & - & - & - & - & - \\
\hline
\end{tabular}

(a) The Group IDs are described in Sections 2.1.1 to 2.1.9.

(b) A dash ( - ) indicates that no data were collected for the specified temperatures.

(c) Table entries that were excluded from calculations to determine the $T_{1 \%}$ value for a glass are shaded gray. 
Table 4.3. Temperature and Volume \%-Crystallinity Data for 247 Simulated HLW Glasses (continued).

\begin{tabular}{|c|c|c|c|c|c|c|c|c|c|c|c|c|c|c|c|c|c|c|c|}
\hline \multirow[b]{2}{*}{ Glass ID } & \multirow{2}{*}{$\begin{array}{c}\text { Group } \\
\text { ID }\end{array}$} & \multicolumn{18}{|c|}{ Temperature in ${ }^{\circ} \mathrm{C}$} \\
\hline & & 650 & 700 & 750 & 800 & $\begin{array}{c}850 \\
\text { (Set 1) }\end{array}$ & $\begin{array}{c}\mathbf{8 5 0} \\
\text { (Set 2) }\end{array}$ & 875 & $\begin{array}{c}900 \\
\text { (Set 1) }\end{array}$ & $\begin{array}{c}900 \\
\text { (Set 2) }\end{array}$ & $\begin{array}{c}950 \\
\text { (Set 1) }\end{array}$ & $\begin{array}{c}950 \\
\text { (Set 2) }\end{array}$ & $\begin{array}{c}950 \\
\text { (Set 3) }\end{array}$ & $\begin{array}{c}1000 \\
\text { (Set 1) }\end{array}$ & $\begin{array}{c}1000 \\
\text { (Set 2) }\end{array}$ & 1050 & 1100 & 1150 & 1200 \\
\hline HLW-ALG-10 & HLWALG & - & 3.5 & 0.5 & 0.8 & 0.6 & - & - & 0.2 & - & - & - & - & - & - & - & - & - & - \\
\hline HLW-ALG-11 & HLWALG & 0.7 & - & 1.2 & 1.7 & 3.9 & - & - & 4.6 & - & 3.8 & - & - & 2.1 & - & 2.7 & 2.6 & - & 1.1 \\
\hline \begin{tabular}{|l|} 
HLW-ALG-12 \\
\end{tabular} & \begin{tabular}{|l|} 
HLWALG \\
\end{tabular} & - & - & 0.4 & 1.5 & 0.6 & - & - & 1.3 & - & 0.4 & - & - & 0.3 & - & 0.1 & - & - & - \\
\hline HLW-ALG-13 & HLWALG & - & - & - & 11.3 & 9.5 & - & - & 5.6 & - & 3.9 & - & - & - & - & 3.0 & 2.9 & 3.4 & 2.9 \\
\hline HLW-ALG-14 & HLWALG & - & - & - & 3.3 & 2.6 & - & - & 2.8 & - & 1.9 & - & - & 0.7 & - & 0.1 & - & - & - \\
\hline HLW-ALG-15 & HLWALG & - & 0.2 & 0.5 & 1.0 & 0.7 & - & - & 0.5 & - & 0.8 & - & - & - & - & - & - & - & - \\
\hline HLW-ALG-16 & HLWALG & 0.1 & 0.1 & 0.1 & 0.1 & 0.1 & - & - & - & - & - & - & - & - & - & - & - & - & - \\
\hline HLW-ALG-17 & HLWALG & - & 1.5 & 0.3 & 0.7 & 0.3 & - & - & 0.5 & - & - & - & - & - & - & - & - & - & - \\
\hline HLW-ALG-18 & HLWALG & 0.8 & 0.1 & 0.1 & 0.1 & 0.0 & - & - & - & - & - & - & - & - & - & - & - & - & - \\
\hline HLW-ALG-19 & HLWALG & - & 0.3 & 0.1 & 0.4 & 0.7 & - & - & 0.5 & - & 0.4 & - & - & - & - & - & - & - & - \\
\hline HLW-ALG-20 & HLWALG & - & 0.4 & 0.6 & 0.5 & 0.6 & - & - & 0.3 & - & 0.2 & - & - & - & - & - & - & - & - \\
\hline HLW-ALG-21 & HLWALG & - & 0.4 & 0.8 & 3.4 & 7.5 & - & - & 10.4 & - & 7.8 & - & - & 3.0 & - & 1.2 & 1.3 & 1.6 & 0.2 \\
\hline HLW-ALG-22 & HLWALG & - & 0.1 & 0.1 & 0.1 & 0.8 & - & - & 3.1 & - & 5.5 & - & - & 0.6 & - & - & - & - & - \\
\hline HLW-ALG-23 & \begin{tabular}{|l|} 
HLWALG \\
\end{tabular} & 0.1 & - & - & 1.9 & 3.4 & - & - & 9.3 & - & 5.9 & - & - & 2.6 & - & - & - & - & - \\
\hline \begin{tabular}{|l|} 
HLW-ALG-24 \\
\end{tabular} & \begin{tabular}{|l|} 
HLWALG \\
\end{tabular} & - & - & - & - & 11.5 & - & - & 6.7 & - & 0.7 & - & - & - & - & 5.2 & 5.7 & 4.3 & 4.5 \\
\hline HLW-ALG-25 & HLWALG & - & 2.9 & 1.0 & 1.0 & 0.6 & - & - & 0.5 & - & - & - & - & - & - & - & - & - & - \\
\hline HLW-ALG-26 & HLWALG & 0.1 & 0.1 & 0.1 & 0.1 & 0.1 & - & - & - & - & 0.1 & - & - & - & - & - & - & - & - \\
\hline HLW-ALG-27 & HLWALG & - & 16.9 & 14.0 & 0.4 & 0.1 & - & - & 0.1 & - & - & - & - & - & - & - & - & - & - \\
\hline HLW-ALG-28 & \begin{tabular}{|l|} 
HLWALG \\
\end{tabular} & - & 0.5 & 0.4 & 2.0 & 1.0 & - & - & 0.3 & - & - & - & - & - & - & - & - & - & - \\
\hline HLW-ALG-29 & HLWALG & 0.1 & 0.1 & 0.4 & 0.8 & 0.9 & - & - & - & - & - & - & - & - & - & - & - & - & - \\
\hline HLW-ALG-30 & HLWALG & - & 1.1 & - & 0.7 & 0.6 & - & - & - & - & 0.1 & - & - & - & - & - & - & - & - \\
\hline HLW-ALG-31 & HLWALG & - & - & - & - & 2.2 & - & - & - & - & 1.7 & - & - & 1.0 & - & 0.5 & 0.2 & - & - \\
\hline HLW-ALG-32 & HLWALG & - & - & - & - & 6.3 & - & - & - & - & 3.4 & - & - & 2.8 & - & 1.9 & 2.4 & 0.4 & 0.1 \\
\hline HLW-ALG-33 & HLWALG & - & - & 29.8 & - & 5.1 & - & - & - & - & 1.9 & - & - & 2.2 & - & 1.4 & 1.5 & 1.0 & 0.5 \\
\hline HLW-ALG-34 & HLWALG & - & - & - & 1.1 & 0.9 & - & - & 0.5 & - & 0.1 & - & - & 0.1 & - & - & - & - & - \\
\hline HLW-ALG-35 & HLWALG & - & - & - & - & 3.8 & - & - & 1.8 & - & 1.1 & - & - & 1.5 & - & 1.1 & 0.1 & - & - \\
\hline HLW-ALG-36 & \begin{tabular}{|l|} 
HLWALG \\
\end{tabular} & - & - & - & - & 3.3 & - & - & 1.7 & - & 1.7 & - & - & 2.6 & - & 1.0 & 0.4 & - & - \\
\hline HLW-ALG-37 & HLWALG & - & - & - & - & - & - & - & 3.5 & - & 2.9 & - & - & 4.1 & - & 3.6 & 3.2 & - & 3.1 \\
\hline HLW-ALG-38 & \begin{tabular}{|l|} 
HLWALG \\
\end{tabular} & - & - & - & 3.8 & 3.9 & - & - & 2.8 & - & 2.8 & - & - & 2.4 & - & 1.9 & 1.3 & - & - \\
\hline HLW-ALG-39 & HLWALG & - & - & - & 0.1 & 0.2 & - & - & 0.1 & - & 0.2 & - & - & 0.1 & - & - & - & - & - \\
\hline HLW-ALG-40 & HLWALG & - & - & - & - & 2.1 & - & - & 1.8 & - & 1.5 & - & - & 1.0 & - & 0.9 & 0.3 & - & - \\
\hline
\end{tabular}

(a) The Group IDs are described in Sections 2.1.1 to 2.1.9.

(b) A dash (-) indicates that no data were collected for the specified temperatures.

(c) Table entries that were excluded from calculations to determine the $T_{1 \%}$ value for a glass are shaded gray. 
Table 4.4. Primary Crystalline Phase, Estimated One-Percent Crystal Fraction Temperature $\left(T_{1 \%}\right)$, and Estimated Standard Deviation of $T_{1 \%}$ for 247 Simulated HLW Glasses.

\begin{tabular}{|c|c|c|c|c|c|c|c|}
\hline \multirow[b]{3}{*}{ Glass ID } & \multirow[b]{3}{*}{$\begin{array}{l}\text { Group } \\
\text { ID }\end{array}$} & \multirow[b]{3}{*}{$\begin{array}{c}\text { Primary Crystalline } \\
\text { Phase at } \mathbf{T}_{1 \%}\end{array}$} & \multicolumn{3}{|c|}{ Inverse Regression } & \multirow[b]{3}{*}{$\begin{array}{l}\mathrm{T}_{1 \%} \% \\
\left({ }^{\circ} \mathrm{C}\right)\end{array}$} & \multirow[b]{3}{*}{$\begin{array}{c}\operatorname{SD}\left(\mathrm{T}_{1 \%}\right) \\
\left({ }^{\circ} \mathrm{C}\right)\end{array}$} \\
\hline & & & \multirow[b]{2}{*}{ \# Points } & \multicolumn{2}{|c|}{ Coefficients } & & \\
\hline & & & & $\begin{array}{c}\text { Intercept } \\
\mathbf{a}_{0}\end{array}$ & $\begin{array}{c}\text { Slope } \\
a_{1}\end{array}$ & & \\
\hline HLW02-01 & HLW02 & Spinel & 4 & 980.50 & -74.69 & 905.8 & 6.46 \\
\hline HLW02-02 & \begin{tabular}{|l|} 
HLW02 \\
\end{tabular} & Spinel & 3 & 1012.50 & -125.00 & 887.5 & 21.65 \\
\hline HLW02-03 & HLW02 & Spinel & 3 & 957.46 & -119.40 & 838.1 & 17.47 \\
\hline HLW02-04 & \begin{tabular}{|l|} 
HLW02 \\
\end{tabular} & Spinel & 4 & 853.06 & -4.23 & 848.8 & 4.02 \\
\hline HLW02-05 & HLW02 & Noble metal & $\mathrm{NA}^{(\mathrm{a})}$ & $\mathrm{NA}^{(\mathrm{a})}$ & $\mathrm{NA}^{(\mathrm{a})}$ & $\mathrm{NA}^{(\mathrm{a})}$ & $\mathrm{NA}^{(\mathrm{a})}$ \\
\hline HLW02-06 & HLW02 & Spinel & 5 & 1073.28 & -46.60 & 1026.7 & 14.78 \\
\hline HLW02-07 & HLW02 & Spinel & 4 & 1066.48 & -302.20 & 764.3 & 19.81 \\
\hline HLW02-08 & HLW02 & Spinel & 3 & 964.84 & -181.32 & 783.5 & 5.52 \\
\hline HLW02-09 & HLW02 & Spinel & 5 & 984.27 & -26.34 & 957.9 & 24.71 \\
\hline HLW02-10 & HLW02 & Spinel & 5 & 926.89 & -372.64 & 554.2 & 112.16 \\
\hline HLW02-11 & HLW02 & Spinel & 4 & 968.40 & -152.10 & 816.3 & 17.56 \\
\hline HLW02-12 & HLW02 & Spinel & 3 & 1106.76 & -59.80 & 1047.0 & 11.36 \\
\hline HLW02-13 & HLW02 & Spinel & 5 & 993.53 & -25.67 & 967.9 & 33.96 \\
\hline HLW02-14 & HLW02 & $\mathrm{ZrSiO}_{4}+$ Spinel & 4 & 1029.17 & -83.33 & 945.8 & 20.08 \\
\hline HLW02-15 & HLW02 & Spinel & 4 & 1119.38 & -69.95 & 1049.4 & 15.02 \\
\hline HLW02-16 & HLW02 & Spinel $+\mathrm{ZrO}_{2}$ & 5 & 1017.04 & -34.27 & 982.8 & 21.99 \\
\hline HLW02-17 & HLW02 & Spinel & 5 & 1035.03 & -68.17 & 966.9 & 13.82 \\
\hline HLW02-18 & HLW02 & Spinel & 3 & 1117.86 & -160.71 & 957.1 & 25.75 \\
\hline HLW02-19 & HLW02 & Spinel & 5 & 983.79 & -63.48 & 920.3 & 12.07 \\
\hline HLW02-20 & HLW02 & Spinel & 4 & 958.02 & -16.63 & 941.4 & 18.63 \\
\hline HLW02-21 & HLW02 & Spinel & $\mathrm{NA}^{(\mathrm{a})}$ & $\mathrm{NA}^{(\mathrm{a})}$ & $\mathrm{NA}^{(\mathrm{a})}$ & $\mathrm{NA}^{(\mathrm{a})}$ & $\mathrm{NA}^{(\mathrm{a})}$ \\
\hline HLW02-22 & HLW02 & Spinel & 4 & 1030.78 & -93.28 & 937.5 & 35.73 \\
\hline HLW02-23 & HLW02 & Spinel & 4 & 1012.50 & -66.67 & 945.8 & 6.59 \\
\hline HLW02-24 & HLW02 & Spinel & 3 & 980.12 & -57.92 & 922.2 & 6.77 \\
\hline HLW02-25 & HLW02 & Spinel & 2 & 1050.00 & -100.00 & 950.0 & $\mathrm{NA}^{(\mathrm{b})}$ \\
\hline HLW02-26 & HLW02 & Spinel & 5 & 1011.84 & -42.32 & 969.5 & 11.26 \\
\hline HLW02-27 & HLW02 & Spinel $+\mathrm{ZrSiO}_{4}$ & 5 & 1048.20 & -82.10 & 966.1 & 14.34 \\
\hline HLW02-28 & HLW02 & Spinel & 4 & 1010.37 & -85.37 & 925.0 & 8.28 \\
\hline HLW02-29 & HLW02 & Spinel & 6 & 1003.13 & -48.14 & 955.0 & 14.56 \\
\hline HLW02-30 & HLW02 & Spinel & 3 & 1016.67 & -119.05 & 897.6 & 31.41 \\
\hline HLW02-31 & HLW02 & Spinel & 4 & 999.98 & -203.23 & 796.7 & 27.96 \\
\hline HLW02-32 & HLW02 & Spinel & 5 & 937.78 & -137.06 & 800.7 & 40.94 \\
\hline HLW02-33 & HLW02 & Spinel & 5 & 967.39 & -19.94 & 947.4 & 9.06 \\
\hline HLW02-34 & HLW02 & Spinel & 5 & 958.60 & -17.75 & 940.8 & 7.18 \\
\hline HLW02-35 & HLW02 & Spinel & 4 & 1001.98 & -21.49 & 980.5 & 9.99 \\
\hline HLW02-36 & HLW02 & Spinel & 5 & 969.40 & -99.40 & 870.0 & 20.98 \\
\hline HLW02-37 & HLW02 & Spinel & 4 & 1051.47 & -71.23 & 980.2 & 25.51 \\
\hline HLW02-38 & HLW02 & Spinel & 5 & 1049.09 & -75.13 & 974.0 & 18.70 \\
\hline HLW02-39 & HLW02 & Spinel & 5 & 1071.30 & -81.65 & 989.6 & 16.41 \\
\hline HLW02-40 & HLW02 & Spinel & 4 & 1028.87 & -71.13 & 957.7 & 23.79 \\
\hline
\end{tabular}

(a) $\mathrm{NA}=$ Not Available ( $\mathrm{T}_{1 \%}$ could not be estimated).

(b) Not enough points available to compute this parameter. 
Table 4.4. Primary Crystalline Phase, Estimated One-Percent Crystal Fraction Temperature $\left(T_{1 \%}\right)$, and Estimated Standard Deviation of $T_{1 \%}$ for 247 Simulated HLW Glasses (continued).

\begin{tabular}{|c|c|c|c|c|c|c|c|}
\hline \multirow[b]{3}{*}{ Glass ID } & \multirow[b]{3}{*}{$\begin{array}{c}\text { Group } \\
\text { ID }\end{array}$} & \multirow[b]{3}{*}{$\begin{array}{c}\text { Primary Crystalline } \\
\text { Phase at } \mathbf{T}_{1 \%}\end{array}$} & \multicolumn{3}{|c|}{ Inverse Regression } & \multirow[b]{3}{*}{$\begin{array}{l}\mathrm{T}_{1 \%} \\
\left({ }^{\circ} \mathrm{C}\right)\end{array}$} & \multirow[b]{3}{*}{$\begin{array}{c}\operatorname{SD}\left(\mathrm{T}_{1 \%}\right) \\
\left({ }^{\circ} \mathrm{C}\right)\end{array}$} \\
\hline & & & \multirow[b]{2}{*}{ \# Points } & \multicolumn{2}{|c|}{ Coefficients } & & \\
\hline & & & & $\begin{array}{c}\text { Intercept } \\
\mathbf{a}_{0}\end{array}$ & $\begin{array}{c}\text { Slope } \\
a_{1}\end{array}$ & & \\
\hline HLW02-41 & HLW02 & Spinel & 5 & 1012.25 & -76.22 & 936.0 & 16.61 \\
\hline HLW02-42 & \begin{tabular}{|l|} 
HLW02 \\
\end{tabular} & Spinel & 5 & 951.15 & -129.99 & 821.2 & 23.68 \\
\hline HLW02-43 & HLW02 & Spinel & 4 & 955.36 & -39.06 & 916.3 & 15.97 \\
\hline HLW02-44 & HLW02 & Spinel & 4 & 1013.24 & -199.73 & 813.5 & 2.95 \\
\hline HLW02-45 & HLW02 & Spinel & 3 & 970.86 & -51.23 & 919.6 & 19.63 \\
\hline HLW02-46 & HLW02 & Spinel & 5 & 1032.92 & -69.66 & 963.3 & 13.11 \\
\hline HLW02-47 & HLW02 & Spinel & 4 & 892.14 & -45.12 & 847.0 & 29.90 \\
\hline HLW02-48 & HLW02 & Spinel & 4 & 1086.52 & -126.36 & 960.2 & 28.14 \\
\hline HLW02-49 & HLW02 & Spinel & 6 & 1036.12 & -48.81 & 987.3 & 26.13 \\
\hline HLW02-50 & HLW02 & Spinel & 5 & 1006.15 & -31.56 & 974.6 & 28.25 \\
\hline HLW02-51 & HLW02 & Spinel & 3 & 1025.00 & -125.00 & 900.0 & 21.65 \\
\hline HLW02-52 & HLW02 & Spinel & 5 & 1077.78 & -118.52 & 959.3 & 34.32 \\
\hline HLW02-53 & HLW02 & Spinel & 7 & 1044.28 & -94.99 & 949.3 & 8.52 \\
\hline HLW02-54 & HLW02 & Spinel & 3 & 950.00 & -39.47 & 910.5 & 4.84 \\
\hline HLW02-55 & HLW02 & Spinel & 4 & 964.71 & -132.35 & 832.4 & 36.51 \\
\hline HLW02-56 & HLW02 & Spinel & 5 & 1018.10 & -223.93 & 794.2 & 28.67 \\
\hline HLW02-57 & HLW02 & Spinel & 3 & 892.76 & -151.32 & 741.4 & 5.05 \\
\hline HLW03-01 & HLW03 & Spinel & 4 & 1154.55 & -68.18 & 1086.4 & 53.42 \\
\hline HLW03-02 & HLW03 & Spinel $+\mathrm{ZrO}_{2}$ & 7 & 1198.60 & -41.61 & 1157.0 & 89.51 \\
\hline HLW03-03 & HLW03 & Spinel & 5 & 1234.90 & -87.45 & 1147.4 & 44.79 \\
\hline HLW03-04 & HLW03 & Spinel & 5 & 970.80 & -24.41 & 946.4 & 38.69 \\
\hline HLW03-05 & HLW03 & Spinel & 3 & 978.76 & -62.18 & 916.6 & 3.17 \\
\hline HLW03-06 & HLW03 & Spinel & 3 & 1200.00 & -250.00 & 950.0 & 35.36 \\
\hline HLW03-07 & HLW03 & Spinel & 6 & 1268.10 & -54.92 & 1213.2 & 33.53 \\
\hline HLW03-08 & HLW03 & $\mathrm{ZrO} 2$ & 5 & 1270.28 & -22.48 & 1247.8 & 94.80 \\
\hline HLW03-09 & HLW03 & Noble Metal & $\mathrm{NA}^{(\mathrm{a})}$ & $\mathrm{NA}^{(\mathrm{a})}$ & $\mathrm{NA}^{(\mathrm{a})}$ & $\mathrm{NA}^{(\mathrm{a})}$ & $\mathrm{NA}^{(\mathrm{a})}$ \\
\hline HLW03-10 & HLW03 & Spinel $+\mathrm{ZrO}_{2}\left(\mathrm{ThO}_{2}\right)$ & 7 & 1225.22 & -35.50 & 1189.7 & 42.20 \\
\hline HLW03-11 & HLW03 & $\mathrm{ThO}_{2}+$ Noble metal & $\mathrm{NA}^{\text {(a) }}$ & $\mathrm{NA}^{(\mathrm{a})}$ & $\mathrm{NA}^{(\mathrm{a})}$ & $\mathrm{NA}^{(\mathrm{a})}$ & $\mathrm{NA}^{(\mathrm{a})}$ \\
\hline HLW03-12 & HLW03 & Spinel & 4 & 1106.02 & -295.18 & 810.8 & 27.47 \\
\hline HLW03-13 & HLW03 & Spinel $+\mathrm{ThO}_{2}\left(\mathrm{UO}_{2}\right)$ & 5 & 1265.24 & -50.50 & 1214.7 & 42.87 \\
\hline HLW03-14 & HLW03 & Spinel $+\mathrm{ZrO}_{2}$ & 6 & 1125.22 & -56.01 & 1069.2 & 21.82 \\
\hline HLW03-15 & HLW03 & Spinel $+\mathrm{ThO}_{2}$ & 3 & 1112.50 & -60.90 & 1051.6 & 5.90 \\
\hline HLW03-16 & HLW03 & Spinel & 5 & 1102.60 & -81.77 & 1020.8 & 19.59 \\
\hline HLW03-17 & HLW03 & Spinel & 4 & 1040.06 & -34.98 & 1005.1 & 19.44 \\
\hline HLW03-18 & HLW03 & Spinel & 4 & 1026.45 & -74.58 & 951.9 & 27.01 \\
\hline HLW03-19 & HLW03 & Spinel & 3 & 1144.78 & -201.49 & 943.3 & 25.03 \\
\hline HLW03-20 & HLW03 & Spinel & 3 & 982.14 & -107.14 & 875.0 & 25.00 \\
\hline HLW03-21 & HLW03 & Spinel & 4 & 939.54 & -73.76 & 865.8 & 12.70 \\
\hline HLW03-22 & HLW03 & Spinel & 4 & 951.27 & -45.52 & 905.7 & 13.35 \\
\hline HLW03-23 & \begin{tabular}{|l|} 
HLW03 \\
\end{tabular} & Spinel & 5 & 981.22 & -150.23 & 831.0 & 13.73 \\
\hline
\end{tabular}

(a) $\mathrm{NA}=$ Not Available ( $\mathrm{T}_{1 \%}$ could not be estimated).

(b) Not enough points available to compute this parameter. 


\section{Table 4.4. Primary Crystalline Phase, Estimated One-Percent Crystal Fraction Temperature ( $\left.T_{1 \%}\right)$, and Estimated Standard Deviation of $T_{1 \%}$ for 247 Simulated HLW Glasses (continued).}

\begin{tabular}{|c|c|c|c|c|c|c|c|}
\hline \multirow[b]{3}{*}{ Glass ID } & \multirow[b]{3}{*}{$\begin{array}{c}\text { Group } \\
\text { ID }\end{array}$} & \multirow[b]{3}{*}{$\begin{array}{c}\text { Primary Crystalline } \\
\text { Phase at } \mathbf{T}_{1 \%}\end{array}$} & \multicolumn{3}{|c|}{ Inverse Regression } & \multirow[b]{3}{*}{$\begin{array}{l}\mathrm{T}_{1 \%} \% \\
\left({ }^{\circ} \mathrm{C}\right)\end{array}$} & \multirow[b]{3}{*}{$\begin{array}{c}\operatorname{SD}\left(\mathrm{T}_{1 \%}\right) \\
\left({ }^{\circ} \mathrm{C}\right)\end{array}$} \\
\hline & & & \multirow[b]{2}{*}{ \# Points } & \multicolumn{2}{|c|}{ Coefficients } & & \\
\hline & & & & $\begin{array}{c}\text { Intercept } \\
\mathbf{a}_{0}\end{array}$ & $\begin{array}{c}\text { Slope } \\
\mathbf{a}_{1}\end{array}$ & & \\
\hline HLW03-24 & HLW03 & Spinel & 4 & 877.82 & -53.33 & 824.5 & 4.40 \\
\hline HLW03-25 & HLW03 & Spinel & 4 & 882.88 & -86.43 & 796.4 & 45.18 \\
\hline HLW03-26 & HLW03 & Spinel $+\mathrm{ThO}_{2}$ & 5 & 1000.00 & -202.70 & 797.3 & 8.41 \\
\hline HLW03-27 & HLW03 & Spinel $+\mathrm{ThO}_{2}$ & 3 & 1143.24 & -148.65 & 994.6 & 40.74 \\
\hline HLW03-28 & HLW03 & Spinel & 5 & 956.18 & -132.02 & 824.2 & 15.52 \\
\hline HLW03-29 & HLW03 & Spinel & 4 & 965.14 & -121.56 & 843.6 & 26.98 \\
\hline HLW03-30 & HLW03 & Spinel & 4 & 996.45 & -235.48 & 761.0 & 10.06 \\
\hline HLW03-31 & HLW03 & Spinel $+\mathrm{ZrO}_{2}$ & 6 & 1242.38 & -170.43 & 1072.0 & 35.95 \\
\hline HLW03-32 & HLW03 & Spinel $+\mathrm{ZrO}_{2}$ & 6 & 1162.43 & -75.11 & 1087.3 & 43.85 \\
\hline HLW03-33 & HLW03 & $\mathrm{ZrSiO}_{4}+\mathrm{ThO}_{2}+$ Spinel & 5 & 1188.52 & -79.51 & 1109.0 & 63.45 \\
\hline HLW03-34 & HLW03 & ThO2 + Spinel & 4 & 1050.06 & -91.71 & 958.4 & 23.07 \\
\hline HLW03-35 & HLW03 & $\mathrm{ZrSiO}_{4}+\mathrm{ThO}_{2}+\mathrm{ZrO}_{2}$ & 4 & 1167.91 & -35.14 & 1132.8 & 10.29 \\
\hline HLW03-36 & HLW03 & $\mathrm{ZrSiO}_{4}(\mathrm{ThO} 2)+$ Spinel & 5 & 1211.33 & -37.08 & 1174.2 & 32.79 \\
\hline HLW03-37 & HLW03 & Spinel & 3 & 963.27 & -61.22 & 902.0 & 5.84 \\
\hline HLW03-38 & HLW03 & Spinel $+\mathrm{ZrO}_{2}$ & 5 & 1152.82 & -65.68 & 1087.1 & 43.44 \\
\hline HLW03-39 & HLW03 & Spinel & 3 & 987.61 & -82.57 & 905.0 & 9.45 \\
\hline HLW03-40 & HLW03 & Spinel $+\mathrm{ThO}_{2}$ & 4 & 1033.20 & -54.37 & 978.8 & 28.91 \\
\hline HLW03-41 & HLW03 & Spinel & 3 & 982.80 & -129.03 & 853.8 & 21.67 \\
\hline HLW03-42 & HLW03 & Spinel & 4 & 1046.92 & -69.23 & 977.7 & 13.79 \\
\hline HLW03-43 & HLW03 & Spinel & 4 & 1042.12 & -95.61 & 946.5 & 23.51 \\
\hline HLW03-44 & HLW03 & Noble Metal & $\mathrm{NA}^{(\mathrm{a})}$ & $\mathrm{NA}^{(\mathrm{a})}$ & $\mathrm{NA}^{(\mathrm{a})}$ & $\mathrm{NA}^{(\mathrm{a})}$ & $\mathrm{NA}^{(\mathrm{a})}$ \\
\hline HLW03-45 & HLW03 & Spinel $+\mathrm{ThO}_{2}$ & 3 & 922.50 & -75.00 & 847.5 & 20.46 \\
\hline HLW05-01 & HLW05 & $\mathrm{ThO}_{2}+$ Spinel & 4 & 1225.30 & -403.61 & 821.7 & 27.55 \\
\hline HLW05-02 & HLW05 & Spinel & 4 & 1004.96 & -248.09 & 756.9 & 22.17 \\
\hline HLW05-03 & HLW05 & Spinel & 3 & 844.77 & -122.09 & 722.7 & 35.48 \\
\hline HLW05-04 & HLW05 & Spinel & 3 & 992.11 & -289.47 & 702.6 & 54.95 \\
\hline HLW05-05 & HLW05 & Spinel & $\mathrm{NA}^{(\mathrm{a})}$ & $\mathrm{NA}^{(\mathrm{a})}$ & $\mathrm{NA}^{(\mathrm{a})}$ & $\mathrm{NA}^{(\mathrm{a})}$ & $\mathrm{NA}^{(\mathrm{a})}$ \\
\hline HLW05-06 & HLW05 & $\mathrm{ZrO}_{2}+\mathrm{ThO}_{2}$ & 5 & 1168.12 & -104.31 & 1063.8 & 12.45 \\
\hline HLW05-07 & HLW05 & Spinel & 4 & 980.15 & -248.09 & 732.1 & 26.24 \\
\hline HLW05-08 & HLW05 & $\mathrm{ZrO}_{2}$ & 5 & 1316.50 & -251.27 & 1065.2 & 25.75 \\
\hline HLW05-09 & HLW05 & Spinel & 4 & 938.55 & -240.09 & 698.5 & 36.71 \\
\hline HLW05-10 & HLW05 & $\mathrm{ThO}_{2}+$ Spinel & 5 & 1173.10 & -263.96 & 909.1 & 20.92 \\
\hline HLW05-11 & HLW05 & Spinel & 4 & 963.89 & -277.78 & 686.1 & 47.22 \\
\hline HLW05-12 & HLW05 & $\mathrm{ZrO}_{2}+\mathrm{ThO}_{2}$ & 5 & 1205.15 & -136.14 & 1069.0 & 19.74 \\
\hline HLW05-13 & HLW05 & Spinel $+\mathrm{ThO}_{2}$ & 4 & 1130.68 & -363.64 & 767.0 & 61.67 \\
\hline HLW05-14 & HLV & $\begin{array}{c}\text { Spinel + Sodium/Uranium/ } \\
\text { Strontium Oxide }\end{array}$ & 4 & 953.85 & .23 & 684.6 & 3.42 \\
\hline HLW05-15 & HLW05 & Spinel + Noble Metal & $\mathrm{NA}^{(\mathrm{a})}$ & $\mathrm{NA}^{(\mathrm{a})}$ & $\mathrm{NA}^{(\mathrm{a})}$ & $\mathrm{NA}^{(\mathrm{a})}$ & $\mathrm{NA}^{(\mathrm{a})}$ \\
\hline HLW05-16 & HLW05 & $\mathrm{ZrO}_{2}$ & 6 & 1497.40 & -195.94 & 1301.5 & 56.98 \\
\hline HLW05-17 & HLW05 & $\mathrm{ZrO}_{2}$ & 5 & 1230.62 & -148.33 & 1082.3 & 15.95 \\
\hline HLW05-18 & HLW05 & $\mathrm{ZrSiO}_{4}$ & 4 & 1184.19 & -14.80 & 1169.4 & 38.09 \\
\hline
\end{tabular}

(a) $\mathrm{NA}=$ Not Available ( $\mathrm{T}_{1 \%}$ could not be estimated).

(b) Not enough points available to compute this parameter. 


\section{Table 4.4. Primary Crystalline Phase, Estimated One-Percent Crystal Fraction Temperature $\left(T_{1 \%}\right)$, and Estimated Standard Deviation of $T_{1 \%}$ for 247 Simulated HLW Glasses (continued).}

\begin{tabular}{|c|c|c|c|c|c|c|c|}
\hline \multirow[b]{3}{*}{ Glass ID } & \multirow[b]{3}{*}{$\begin{array}{l}\text { Group } \\
\text { ID }\end{array}$} & \multirow[b]{3}{*}{$\begin{array}{c}\text { Primary Crystalline } \\
\text { Phase at } \mathbf{T}_{1 \%}\end{array}$} & \multicolumn{3}{|c|}{ Inverse Regression } & \multirow[b]{3}{*}{$\begin{array}{l}\mathrm{T}_{1 \%} \% \\
\left({ }^{\circ} \mathrm{C}\right)\end{array}$} & \multirow[b]{3}{*}{$\begin{array}{c}\operatorname{SD}\left(\mathrm{T}_{1 \%}\right) \\
\left({ }^{\circ} \mathrm{C}\right)\end{array}$} \\
\hline & & & \multirow[b]{2}{*}{ \# Points } & \multicolumn{2}{|c|}{ Coefficients } & & \\
\hline & & & & $\begin{array}{c}\text { Intercept } \\
\mathbf{a}_{0}\end{array}$ & $\begin{array}{c}\text { Slope } \\
a_{1}\end{array}$ & & \\
\hline HLW05-19 & HLW05 & $\mathrm{ThO}_{2}$ & 2 & 1225.00 & -83.33 & 1141.7 & $\mathrm{NA}^{(\mathrm{b})}$ \\
\hline HLW05-20 & HLW05 & Sodium Al Silicate & 3 & 780.17 & -25.86 & 754.3 & 20.56 \\
\hline HLW05-21 & HLW05 & Spinel + Noble Metal & $\mathrm{NA}^{(\mathrm{a})}$ & $\mathrm{NA}^{(\mathrm{a})}$ & $\mathrm{NA}^{(\mathrm{a})}$ & $\mathrm{NA}^{(\mathrm{a})}$ & $\mathrm{NA}^{(\mathrm{a})}$ \\
\hline HLW05-22 & HLW05 & Uranium Oxide & 4 & 969.94 & -276.07 & 693.9 & 24.07 \\
\hline HLW05-23 & HLW05 & $\mathrm{ThO}_{2}$ & 6 & 1451.54 & -415.38 & 1036.2 & 20.80 \\
\hline HLW05-24 & HLW05 & $\mathrm{ZrO}_{2}+\mathrm{Na}_{2} \mathrm{ZrSi}_{2} \mathrm{O}_{7}$ & 5 & 1264.63 & -24.69 & 1239.9 & 29.29 \\
\hline HLW05-25 & HLW05 & $\mathrm{ZrSiO}_{4}$ & 6 & 1298.05 & -54.92 & 1243.1 & 13.82 \\
\hline HLW05-26 & HLW05 & $\mathrm{Na}_{2} \mathrm{ZrSi}_{2} \mathrm{O}_{7}$ & 5 & 1214.64 & -17.64 & 1197.0 & 18.82 \\
\hline HLW05-27 & HLW05 & Spinel & 3 & 996.93 & -144.74 & 852.2 & 36.51 \\
\hline HLW05-28 & HLW05 & $\mathrm{ZrSiO}_{4}$ & 5 & 1257.79 & -50.54 & 1207.3 & 34.91 \\
\hline HLW05-29 & HLW05 & $\mathrm{Na}_{2} \mathrm{ZrSi}_{2} \mathrm{O}_{7}$ & 5 & 1221.07 & -17.65 & 1203.4 & 16.24 \\
\hline HLW05-30 & HLW05 & Spinel & $\mathrm{NA}^{(\mathrm{a})}$ & $\mathrm{NA}^{(\mathrm{a})}$ & $\mathrm{NA}^{(\mathrm{a})}$ & $\mathrm{NA}^{(\mathrm{a})}$ & $\mathrm{NA}^{(\mathrm{a})}$ \\
\hline HLW06-01 & HLW06 & Spinel & 5 & 1121.78 & -99.90 & 1021.9 & 25.56 \\
\hline HLW06-02 & HLW06 & Spinel & 6 & 1070.22 & -136.18 & 934.0 & 10.92 \\
\hline HLW06-03 & HLW06 & Spinel $+\mathrm{ZrO}_{2}$ & 6 & 1285.49 & -73.98 & 1211.5 & 34.97 \\
\hline HLW06-04 & HLW06 & Spinel & 5 & 1055.77 & -211.54 & 844.2 & 19.82 \\
\hline HLW06-05 & HLW06 & Spinel & 6 & 1039.03 & -142.63 & 896.4 & 22.60 \\
\hline HLW06-06 & HLW06 & Spinel $+\mathrm{ZrO}_{2}$ & 6 & 1314.80 & -84.14 & 1230.7 & 26.22 \\
\hline HLW06-07 & HLW06 & Spinel & 5 & 1266.70 & -58.12 & 1208.6 & 39.14 \\
\hline HLW06-08 & HLW06 & Spinel & 6 & 1213.48 & -168.54 & 1044.9 & 11.27 \\
\hline HLW06-09 & HLW06 & Spinel & 5 & 1277.20 & -77.04 & 1200.2 & 38.64 \\
\hline HLW06-10 & HLW06 & Spinel & 8 & 1269.38 & -257.25 & 1012.1 & 17.00 \\
\hline HLW06-11 & HLW06 & Spinel & 6 & 1218.79 & $\begin{array}{l}-92.91 \\
\end{array}$ & 1125.9 & 18.99 \\
\hline HLW06-12 & HLW06 & Spinel & 7 & 1114.63 & -101.09 & 1013.5 & 18.64 \\
\hline HLW06-13 & HLW06 & Spinel & 5 & 1238.02 & -61.61 & 1176.4 & 7.18 \\
\hline HLW06-14 & HLW06 & Spinel & 6 & 1091.70 & -120.71 & 971.0 & 7.37 \\
\hline HLW06-15 & HLW06 & Spinel & 4 & 997.57 & -63.11 & 934.5 & 5.00 \\
\hline HLW06-16 & HLW06 & Spinel & 4 & 1031.97 & -70.28 & 961.7 & 8.94 \\
\hline HLW06-17 & HLW06 & Spinel & 5 & 1143.00 & -110.00 & 1033.0 & 8.08 \\
\hline HLW06-18 & HLW06 & Spinel & 6 & 1189.14 & -118.95 & 1070.2 & 20.00 \\
\hline HLW06-19 & HLW06 & Spinel & 4 & 1257.14 & -71.43 & 1185.7 & 43.06 \\
\hline HLW06-20 & HLW06 & Spinel & 5 & 1268.09 & -131.38 & 1136.7 & 18.78 \\
\hline HLW06-21 & HLW06 & $\mathrm{ThO}_{2}$ & 5 & 1423.44 & -296.88 & 1126.6 & 49.27 \\
\hline HLW06-22 & HLW06 & Unidentified Cr-Fe Oxide & 3 & 1025.00 & -375.00 & 650.0 & 145.77 \\
\hline HLW06-23 & HLW06 & $\mathrm{ZrO}_{2}$ & 4 & 1240.58 & -14.82 & 1225.8 & 13.78 \\
\hline HLW06-24 & HLW06 & $\mathrm{ThO}_{2}$ & 4 & 1396.61 & -169.49 & 1227.1 & 69.60 \\
\hline HLW06-25 & HLW06 & Spinel $+\mathrm{ThO}_{2}$ & 5 & 1173.45 & -125.62 & 1047.8 & 13.91 \\
\hline HLW06-26 & HLW06 & $\mathrm{Na}_{2} \mathrm{ZrSi}_{2} \mathrm{O}_{7}+\mathrm{ZrO}_{2}$ & 4 & 1581.13 & -99.73 & 1481.4 & 172.41 \\
\hline HLW06-27 & HLW06 & $\mathrm{ZrSiO}_{4}$ & 6 & 1444.77 & -56.76 & 1388.0 & 44.84 \\
\hline HLW06-28 & HLW06 & $\begin{array}{c}\text { Spinel + Unidentified } \\
\text { Na-Ca-U and Cr-Fe oxides }\end{array}$ & 4 & 1093.17 & -127.75 & 965.4 & 20.51 \\
\hline
\end{tabular}

(a) $\mathrm{NA}=$ Not Available ( $\mathrm{T}_{1 \%}$ could not be estimated).

(b) Not enough points available to compute this parameter. 


\section{Table 4.4. Primary Crystalline Phase, Estimated One-Percent Crystal Fraction Temperature $\left(T_{1 \%}\right)$, and Estimated Standard Deviation of $T_{1 \%}$ for 247 Simulated HLW Glasses (continued).}

\begin{tabular}{|c|c|c|c|c|c|c|c|}
\hline \multirow[b]{3}{*}{ Glass ID } & \multirow[b]{3}{*}{$\begin{array}{c}\text { Group } \\
\text { ID }\end{array}$} & \multirow[b]{3}{*}{$\begin{array}{c}\text { Primary Crystalline } \\
\text { Phase at } \mathbf{T}_{1 \%}\end{array}$} & \multicolumn{3}{|c|}{ Inverse Regression } & \multirow[b]{3}{*}{$\begin{array}{l}\mathrm{T}_{1 \%} \% \\
\left({ }^{\circ} \mathrm{C}\right)\end{array}$} & \multirow[b]{3}{*}{$\begin{array}{c}\operatorname{SD}\left(\mathrm{T}_{1 \%}\right) \\
\left({ }^{\circ} \mathrm{C}\right)\end{array}$} \\
\hline & & & \multirow[b]{2}{*}{ \# Points } & \multicolumn{2}{|c|}{ Coefficients } & & \\
\hline & & & & $\begin{array}{c}\text { Intercept } \\
\mathbf{a}_{0}\end{array}$ & $\begin{array}{c}\text { Slope } \\
\mathbf{a}_{1}\end{array}$ & & \\
\hline HLW06-29 & HLW06 & $\mathrm{ZrSiO}_{4}+\mathrm{ZrO}_{2}$ & 5 & 1282.62 & -29.36 & 1253.3 & 57.15 \\
\hline \begin{tabular}{|l|} 
HLW06-30 \\
\end{tabular} & HLW06 & Spinel & 4 & 1202.29 & -93.69 & 1108.6 & 11.83 \\
\hline HLW06-31 & HLW06 & Spinel $+\mathrm{ThO}_{2}$ & 4 & 1325.55 & -46.45 & 1279.1 & 34.79 \\
\hline HLW06-32 & HLW06 & Spinel & 6 & 998.21 & -96.00 & 902.2 & 16.81 \\
\hline HLW06-33 & HLW06 & $\mathrm{ZrO}_{2}$ & 6 & 1413.95 & -136.21 & 1277.7 & 69.35 \\
\hline HLW06-34 & HLW06 & $\mathrm{Na}_{2} \mathrm{ZrSi}_{2} \mathrm{O}_{7}+$ Spinel & 3 & 947.51 & -7.31 & 940.2 & 6.59 \\
\hline HLW06-35 & HLW06 & $\begin{array}{c}\text { Unidentified Cr-Fe Oxide } \\
+\mathrm{ThO}_{2}\end{array}$ & 5 & 1000.73 & -94.32 & 906.4 & 17.34 \\
\hline HLW07-01 & HLW07 & Spinel & 5 & 1066.17 & -145.76 & 920.4 & 8.29 \\
\hline HLW07-02 & HLW07 & Spinel & 5 & 1072.25 & -119.62 & 952.6 & 10.65 \\
\hline HLW07-03 & HLW07 & Spinel & 4 & 1015.00 & -175.00 & 840.0 & 6.61 \\
\hline HLW07-04 & HLW07 & Spinel & 4 & 935.24 & -75.30 & 859.9 & 20.57 \\
\hline HLW07-05 & HLW07 & Spinel & 5 & 1240.91 & -56.82 & 1184.1 & 29.77 \\
\hline HLW07-06 & HLW07 & Spinel & 5 & 1093.78 & -34.48 & 1059.3 & 18.16 \\
\hline HLW07-07 & HLW07 & Spinel+ $\mathrm{Na}(\mathrm{Al}, \mathrm{Fe})$ Silicate & 3 & 793.64 & -6.21 & 787.4 & 16.77 \\
\hline HLW07-08 & HLW07 & $\mathrm{ThO}_{2}+\mathrm{ZrO}_{2}$ & 4 & 1247.83 & -21.64 & 1226.2 & 50.95 \\
\hline HLW07-09 & HLW07 & $\mathrm{ZrO}_{2}$ & 5 & 1204.79 & -43.30 & 1161.5 & 26.31 \\
\hline HLW07-10 & HLW07 & $\mathrm{ThO}_{2}+\mathrm{Cr} / \mathrm{Fe}$ oxide & 5 & 1065.25 & -103.50 & 961.8 & 17.70 \\
\hline HLW07-11 & HLW07 & Spinel & 5 & 1124.76 & -107.55 & 1017.2 & 7.53 \\
\hline HLW07-12 & HLW07 & $\mathrm{ThO}_{2}$ & 6 & 1464.50 & -285.00 & 1179.5 & 48.75 \\
\hline HLW07-13 & HLW07 & $\mathrm{ZrO}_{2}$ & 5 & 1309.04 & -69.22 & 1239.8 & 149.83 \\
\hline HLW07-14 & HLW07 & $\mathrm{ZrO}_{2}$ & 6 & 1361.67 & -76.95 & 1284.7 & 80.12 \\
\hline HLW07-15 & HLW07 & $\mathrm{ZrO}_{2}$ & 6 & 1186.81 & -16.35 & 1170.5 & 19.11 \\
\hline HLW07-16 & HLW07 & Spinel $+\mathrm{ZrO}_{2}$ & 5 & 1123.35 & -116.37 & 1007.0 & 21.69 \\
\hline HLW07-17 & HLW07 & Spinel & 4 & 892.47 & -33.32 & 859.1 & 11.53 \\
\hline HLW07-18 & HLW07 & $\mathrm{ThO}_{2}$ & 3 & 877.05 & -92.47 & 784.6 & 18.10 \\
\hline HLW07-19 & HLW07 & $\mathrm{ZrO}_{2}$ & 5 & 1034.77 & -17.12 & 1017.7 & 19.71 \\
\hline HLW07-20 & HLW07 & Spinel & 6 & 1100.62 & -122.52 & 978.1 & 14.00 \\
\hline HLW07-21 & HLW07 & Strontium phosphate & 4 & 947.97 & -162.16 & 785.8 & 38.45 \\
\hline HLW07-22 & HLW07 & $\mathrm{ThO}_{2}$ & 5 & 1289.58 & -112.85 & 1176.7 & 21.61 \\
\hline HLW07-23 & HLW07 & Zircon & 6 & 1398.22 & -81.25 & 1317.0 & 80.38 \\
\hline HLW07-24 & HLW07 & Spinel $+\mathrm{ThO}_{2}$ & 5 & 1279.59 & -232.59 & 1047.0 & 22.38 \\
\hline HLW07-25 & HLW07 & $\mathrm{ThO}_{2}$ & 6 & 1283.49 & -102.39 & 1181.1 & 45.57 \\
\hline HLW07-26 & HLW07 & Spinel & 5 & 1264.71 & -360.29 & 904.4 & 10.77 \\
\hline HLW07-27 & HLW07 & Spinel & 6 & 1044.19 & -252.91 & 791.3 & 18.70 \\
\hline HLW07-28 & HLW07 & Spinel & 5 & 1150.00 & -250.00 & 900.0 & 11.28 \\
\hline HLW07-29 & HLW07 & Spinel & 6 & 1081.58 & -104.16 & 977.4 & 5.19 \\
\hline HLW07-30 & HLW07 & Spinel & 5 & 1065.70 & -169.08 & 896.6 & 9.42 \\
\hline HLW07-31 & HLW07 & Spinel & 5 & 1129.92 & -225.41 & 904.5 & 3.70 \\
\hline HLW07-32 & HLW07 & Spinel & 5 & 1105.37 & -142.62 & 962.8 & 9.55 \\
\hline HLW07-33 & HLW07 & Spinel & 5 & 1150.82 & -151.10 & 999.7 & 3.70 \\
\hline
\end{tabular}

(a) $\mathrm{NA}=$ Not Available ( $\mathrm{T}_{1 \%}$ could not be estimated).

(b) Not enough points available to compute this parameter. 
Table 4.4. Primary Crystalline Phase, Estimated One-Percent Crystal Fraction Temperature ( $\left.T_{1 \%}\right)$, and Estimated Standard Deviation of $T_{1 \%}$ for 247 Simulated HLW Glasses (continued).

\begin{tabular}{|c|c|c|c|c|c|c|c|}
\hline \multirow[b]{3}{*}{ Glass ID } & \multirow[b]{3}{*}{$\begin{array}{c}\text { Group } \\
\text { ID }\end{array}$} & \multirow[b]{3}{*}{$\begin{array}{c}\text { Primary Crystalline } \\
\text { Phase at } T_{1 \%}\end{array}$} & \multicolumn{3}{|c|}{ Inverse Regression } & \multirow[b]{3}{*}{$\begin{array}{l}\mathrm{T}_{1 \%} \\
\left({ }^{\circ} \mathrm{C}\right)\end{array}$} & \multirow[b]{3}{*}{$\begin{array}{c}\operatorname{SD}\left(\mathrm{T}_{1 \%}\right) \\
\left({ }^{\circ} \mathrm{C}\right)\end{array}$} \\
\hline & & & \multirow[b]{2}{*}{ \# Points } & \multicolumn{2}{|c|}{ Coefficients } & & \\
\hline & & & & $\begin{array}{c}\text { Intercept } \\
\mathbf{a}_{0}\end{array}$ & $\begin{array}{c}\text { Slope } \\
\mathbf{a}_{1}\end{array}$ & & \\
\hline HLW07-34 & HLW07 & $\mathrm{ZrO}_{2}+$ Spinel & 7 & 1305.68 & -167.10 & 1138.6 & 34.26 \\
\hline HLW07-35 & HLW07 & Spinel $+\mathrm{ZrO}_{2}+\mathrm{ThO}_{2}$ & 6 & 1169.29 & -149.46 & 1019.8 & 11.95 \\
\hline HLW07-36 & HLW07 & Spinel & $\mathrm{NA}^{(\mathrm{a})}$ & $\mathrm{NA}^{\text {(a) }}$ & $\mathrm{NA}^{(\mathrm{a})}$ & $\mathrm{NA}^{(\mathrm{a})}$ & $\mathrm{NA}^{(\mathrm{a})}$ \\
\hline HLW07-37 & HLW07 & Spinel & 5 & 964.58 & -106.09 & 858.5 & 6.37 \\
\hline HLW07-38 & HLW07 & Spinel & 6 & 1153.44 & -159.38 & 994.1 & 35.29 \\
\hline HLW07-39 & HLW07 & Spinel & 3 & 1000.00 & -250.00 & 750.0 & 61.24 \\
\hline HLW07-40 & HLW07 & Spinel & 6 & 1122.45 & -174.67 & 947.8 & 10.08 \\
\hline HLW-ALG-01 & HLWALG & Spinel $+\mathrm{RuO}_{2}$ & $\mathrm{NA}^{\text {(a) }}$ & $\mathrm{NA}^{\text {(a) }}$ & $\mathrm{NA}^{\text {(a) }}$ & $\mathrm{NA}^{(\mathrm{a})}$ & $\mathrm{NA}^{(\mathrm{a})}$ \\
\hline HLW-ALG-02 & HLWALG & Spinel + $\mathrm{RuO}_{2}$ & $\mathrm{NA}^{\text {(a) }}$ & $\mathrm{NA}^{(\mathrm{a})}$ & $\mathrm{NA}^{(\mathrm{a})}$ & $\mathrm{NA}^{(\mathrm{a})}$ & $\mathrm{NA}^{(\mathrm{a})}$ \\
\hline HLW-ALG-03 & $\begin{array}{l}\text { HLWALG } \\
\text { HLWA }\end{array}$ & Spinel & 3 & 919.64 & -160.71 & 758.9 & 19.15 \\
\hline HLW-ALG-04 & HLWALG & Spinel & $\mathrm{NA}^{(\mathrm{a})}$ & $\mathrm{NA}^{\text {(a) }}$ & $\mathrm{NA}^{\text {(a) }}$ & $\mathrm{NA}^{(\mathrm{a})}$ & $\mathrm{NA}^{(\mathrm{a})}$ \\
\hline HLW-ALG-05 & HLWALG & Spinel & 7 & 1072.84 & -123.67 & 949.2 & 27.52 \\
\hline HLW-ALG-06 & \begin{tabular}{|l} 
HLWALG \\
\end{tabular} & Spinel & 4 & 1022.13 & $\begin{array}{l}-66.99 \\
\end{array}$ & 955.1 & 23.27 \\
\hline HLW-ALG-07 & HLWALG & $\mathrm{RuO}_{2}$ & $\mathrm{NA}^{\text {(a) }}$ & $\mathrm{NA}^{(\mathrm{a})}$ & $\mathrm{NA}^{(\mathrm{a})}$ & $\mathrm{NA}^{(\mathrm{a})}$ & $\mathrm{NA}^{(\mathrm{a})}$ \\
\hline HLW-ALG-08 & HLWALG & $\mathrm{ZrO}_{2}$ & 4 & 1300.68 & -130.14 & 1170.5 & 5.35 \\
\hline HLW-ALG-09 & \begin{tabular}{|l} 
HLWALG \\
\end{tabular} & Spinel & 6 & 1095.79 & $\begin{array}{l}-294.94 \\
\end{array}$ & 800.8 & 31.32 \\
\hline HLW-ALG-10 & \begin{tabular}{|l} 
HLWALG \\
\end{tabular} & Spinel & 3 & 935.71 & -160.71 & 775.0 & 16.37 \\
\hline HLW-ALG-11 & HLWALG & $\mathrm{ZrO}_{2}+\mathrm{ThO}_{2}$ & 7 & 1270.42 & -88.60 & 1181.8 & 47.44 \\
\hline HLW-ALG-12 & HLWALG & Spinel & 5 & 989.73 & -109.43 & 880.3 & 28.57 \\
\hline HLW-ALG-13 & HLWALG & $\mathrm{ZrO}_{2}+\mathrm{ThO}_{2}$ & 6 & 1382.96 & -89.76 & 1293.2 & 90.37 \\
\hline HLW-ALG-14 & HLWALG & Spinel & 5 & 1064.54 & -72.80 & 991.7 & 26.36 \\
\hline HLW-ALG-15 & HLWALG & Spinel & 3 & 994.74 & $\begin{array}{l}-197.37 \\
\end{array}$ & 797.4 & 7.67 \\
\hline HLW-ALG-16 & HLWALG & Spinel $+\mathrm{RuO}_{2}$ & $\mathrm{NA}^{(\mathrm{a})}$ & $\mathrm{NA}^{\text {(a) }}$ & $\mathrm{NA}^{(\mathrm{a})}$ & $\mathrm{NA}^{(\mathrm{a})}$ & $\mathrm{NA}^{(\mathrm{a})}$ \\
\hline HLW-ALG-17 & HLWALG & $\begin{array}{c}\text { Spinel + } \mathrm{Na}(\mathrm{Mn}, \mathrm{Fe}, \mathrm{Ni}) \\
\text { Silicate }\end{array}$ & 3 & 832.40 & -12.67 & 819.7 & 20.21 \\
\hline HLW-ALG-18 & HLWALG & Spinel & 2 & 707.14 & -71.43 & 635.7 & NA \\
\hline HLW-ALG-19 & HLWALG & Spinel & 3 & 1071.43 & -321.43 & 750.0 & 29.88 \\
\hline HLW-ALG-20 & HLWALG & Spinel & 5 & 1016.67 & -378.79 & 637.9 & 72.14 \\
\hline HLW-ALG-21 & HLWALG & $\mathrm{ZrO}_{2}+\mathrm{ThO}_{2}$ & 4 & 1190.52 & -60.95 & 1129.6 & 32.70 \\
\hline HLW-ALG-22 & HLWALG & $\mathrm{ZrO}_{2}+\mathrm{ThO}_{2}$ & 2 & 1006.12 & -10.20 & 995.9 & $\mathrm{NA}^{(\mathrm{b})}$ \\
\hline HLW-ALG-23 & HLWALG & $\mathrm{Na}_{2} \mathrm{ZrSi}_{2} \mathrm{O}_{7}+\mathrm{ZrO}_{2}$ & 3 & 1038.55 & -14.92 & 1023.6 & 0.73 \\
\hline HLW-ALG-24 & HLWALG & $\mathrm{ZrO}_{2}+\mathrm{ThO}_{2}$ & 6 & 1322.20 & -44.41 & 1277.8 & 78.75 \\
\hline HLW-ALG-25 & HLWALG & Spinel & 4 & 1002.41 & -228.92 & 773.5 & 20.04 \\
\hline HLW-ALG-26 & HLWALG & $\mathrm{ThO}_{2}+\mathrm{RuO}_{2}$ & $\mathrm{NA}^{(\mathrm{a})}$ & $\mathrm{NA}^{(\mathrm{a})}$ & $\mathrm{NA}^{(\mathrm{a})}$ & $\mathrm{NA}^{(\mathrm{a})}$ & $\mathrm{NA}^{(\mathrm{a})}$ \\
\hline HLW-ALG-27 & HLWALG & Spinel + NaAlFe silicate & 3 & 805.46 & -5.32 & 800.1 & 23.61 \\
\hline HLW-ALG-28 & HLWALG & Spinel & 3 & 914.04 & -58.22 & 855.8 & 4.18 \\
\hline HLW-ALG-29 & HLWALG & Spinel & $\mathrm{NA}^{(\mathrm{a})}$ & $\mathrm{NA}^{(\mathrm{a})}$ & $\mathrm{NA}^{(\mathrm{a})}$ & $\mathrm{NA}^{(\mathrm{a})}$ & $\mathrm{NA}^{(\mathrm{a})}$ \\
\hline HLW-ALG-30 & HLWALG & Spinel & 4 & 982.02 & -251.23 & 730.8 & 11.11 \\
\hline HLW-ALG-31 & HLWALG & Spinel & 5 & 1117.98 & -114.26 & 1003.7 & 8.76 \\
\hline HLW-ALG-32 & HLWALG & Spinel & 7 & 1180.54 & -55.71 & 1124.8 & 17.61 \\
\hline HLW-ALG-33 & HLWALG & $\mathrm{ZrO}_{2}+$ Spinel & 6 & 1274.04 & -140.50 & 1133.5 & 21.11 \\
\hline
\end{tabular}

(a) $\mathrm{NA}=$ Not Available ( $\mathrm{T}_{1 \%}$ could not be estimated).

(b) Not enough points available to compute this parameter. 
Table 4.4. Primary Crystalline Phase, Estimated One-Percent Crystal Fraction Temperature $\left(T_{1 \%}\right)$, and Estimated Standard Deviation of $T_{1 \%}$ for 247 Simulated HLW Glasses (continued).

\begin{tabular}{|c|c|c|c|c|c|c|c|}
\hline \multirow[b]{3}{*}{ Glass ID } & \multirow[b]{3}{*}{$\begin{array}{c}\text { Group } \\
\text { ID }\end{array}$} & \multirow[b]{3}{*}{$\begin{array}{c}\text { Primary Crystalline } \\
\text { Phase at } \mathbf{T}_{1 \%}\end{array}$} & \multicolumn{3}{|c|}{ Inverse Regression } & \multirow[b]{3}{*}{$\begin{array}{l}\mathbf{T}_{1 \%} \% \\
\left({ }^{\circ} \mathrm{C}\right)\end{array}$} & \multirow[b]{3}{*}{$\begin{array}{l}\operatorname{SD}\left(\mathbf{T}_{1 \%}\right) \\
\left({ }^{\circ} \mathbf{C}\right)\end{array}$} \\
\hline & & & \multirow[b]{2}{*}{ \# Points } & \multicolumn{2}{|c|}{ Coefficients } & & \\
\hline & & & & $\begin{array}{c}\text { Intercept } \\
\mathbf{a}_{0}\end{array}$ & $\begin{array}{c}\text { Slope } \\
\mathbf{a}_{1}\end{array}$ & & \\
\hline HLW-ALG-34 & HLWALG & Spinel & 4 & 968.64 & -144.07 & 824.6 & 7.63 \\
\hline HLW-ALG-35 & \begin{tabular}{|l|} 
HLWALG \\
\end{tabular} & Spinel & 4 & 1143.17 & -122.30 & 1020.9 & 48.89 \\
\hline HLW-ALG-36 & HLWALG & Spinel & 6 & 1102.07 & -71.26 & 1030.8 & 33.12 \\
\hline HLW-ALG-37 & \begin{tabular}{|l|} 
HLWALG \\
\end{tabular} & $\mathrm{ZrO}_{2}+\mathrm{ThO}_{2}$ & 4 & 1680.24 & -169.35 & 1510.9 & 145.40 \\
\hline HLW-ALG-38 & \begin{tabular}{|l|} 
HLWALG \\
\end{tabular} & $\mathrm{ZrO}_{2}+\mathrm{ThO}_{2}+$ Spinel & 7 & 1249.72 & -111.01 & 1138.7 & 23.21 \\
\hline HLW-ALG-39 & HLWALG & Spinel & $\mathrm{NA}^{(\mathrm{a})}$ & $\mathrm{NA}^{(\mathrm{a})}$ & $\mathrm{NA}^{(\mathrm{a})}$ & $\mathrm{NA}^{(\mathrm{a})}$ & $\mathrm{NA}^{(\mathrm{a})}$ \\
\hline HLW-ALG-40 & HLWALG & Spinel & 6 & 1152.76 & -140.34 & 1012.4 & 6.87 \\
\hline
\end{tabular}

(a) $\mathrm{NA}=$ Not Available $\left(\mathrm{T}_{1 \%}\right.$ could not be estimated $)$.

(b) Not enough points available to compute this parameter. 
Table 4.5. Melt Electrical Conductivity Data for 210 Simulated HLW Glasses.

\begin{tabular}{|c|c|c|c|c|c|c|c|c|c|}
\hline Glass ID & $\begin{array}{l}\text { Group } \\
\text { ID }^{(\mathbf{a})}\end{array}$ & $\begin{array}{c}\text { Temp1 } \\
\left({ }^{\circ} \mathrm{C}\right)\end{array}$ & $\begin{array}{c}\text { EC1 } \\
(\mathrm{S} / \mathrm{cm})\end{array}$ & $\begin{array}{c}\text { Temp2 } \\
\left({ }^{\circ} \mathrm{C}\right)\end{array}$ & $\begin{array}{c}\text { EC2 } \\
(\mathrm{S} / \mathrm{cm})\end{array}$ & $\begin{array}{c}\text { Temp3 } \\
\left({ }^{\circ} \mathrm{C}\right)\end{array}$ & $\begin{array}{c}\text { EC3 } \\
(\mathrm{S} / \mathbf{c m})\end{array}$ & $\begin{array}{c}\text { Temp4 } \\
\left({ }^{\circ} \mathrm{C}\right)\end{array}$ & $\begin{array}{c}\text { EC4 } \\
(\mathrm{S} / \mathrm{cm})\end{array}$ \\
\hline HLW02-01 & HLW02 & 1260 & 0.480 & 1166 & 0.356 & 1071 & 0.252 & 978 & 0.157 \\
\hline HLW02-02 & HLW02 & 1251 & 0.326 & 1155 & 0.240 & 1054 & 0.167 & 957 & 0.104 \\
\hline HLW02-03 & HLW02 & 1257 & 0.532 & 1165 & 0.402 & 1070 & 0.276 & 977 & 0.173 \\
\hline HLW02-04 & HLW02 & 1236 & 0.420 & 1145 & 0.321 & 1051 & 0.242 & 958 & 0.159 \\
\hline HLW02-05 & HLW02 & 1245 & 0.618 & 1151 & 0.482 & 1056 & 0.367 & 962 & 0.241 \\
\hline HLW02-06 & HLW02 & 1250 & 0.624 & 1154 & 0.468 & 1057 & 0.333 & 960 & 0.220 \\
\hline HLW02-07 & HLW02 & 1245 & 0.628 & 1150 & 0.441 & 1054 & 0.309 & 959 & 0.205 \\
\hline HLW02-08 & HLW02 & 1245 & 0.525 & 1152 & 0.412 & 1057 & 0.295 & 963 & 0.187 \\
\hline HLW02-09 & HLW02 & 1251 & 0.414 & 1151 & 0.350 & 1055 & 0.219 & 959 & 0.139 \\
\hline HLW02-10 & HLW02 & 1237 & 0.513 & 1143 & 0.370 & 1048 & 0.269 & 953 & 0.180 \\
\hline HLW02-11 & HLW02 & 1244 & 0.514 & 1149 & 0.405 & 1053 & 0.284 & 957 & 0.182 \\
\hline HLW02-12 & HLW02 & 1247 & 0.744 & 1152 & 0.567 & 1059 & 0.384 & 963 & 0.243 \\
\hline HLW02-13 & HLW02 & 1242 & 0.586 & 1148 & 0.454 & 1055 & 0.330 & 960 & 0.211 \\
\hline HLW02-14 & HLW02 & 1247 & 0.575 & 1151 & 0.426 & 1055 & 0.309 & 959 & 0.196 \\
\hline HLW02-15 & HLW02 & 1249 & 0.350 & 1155 & 0.262 & 1060 & 0.183 & 964 & 0.113 \\
\hline HLW02-16 & HLW02 & 1245 & 0.541 & 1154 & 0.402 & 1059 & 0.282 & 964 & 0.175 \\
\hline HLW02-17 & HLW02 & 1246 & 0.426 & 1151 & 0.311 & 1055 & 0.224 & 959 & 0.150 \\
\hline HLW02-18 & HLW02 & 1249 & 0.368 & 1153 & 0.290 & 1052 & 0.195 & 956 & 0.123 \\
\hline HLW02-19 & HLW02 & 1250 & 0.221 & 1155 & 0.148 & 1060 & 0.095 & 964 & 0.052 \\
\hline HLW02-20 & HLW02 & 1245 & 0.118 & 1150 & 0.086 & 1054 & 0.057 & 957 & 0.034 \\
\hline HLW02-21 & HLW02 & 1247 & 0.370 & 1154 & 0.279 & 1059 & 0.198 & 963 & 0.130 \\
\hline HLW02-22 & HLW02 & 1246 & 0.287 & 1150 & 0.225 & 1054 & 0.164 & 958 & 0.101 \\
\hline HLW02-23 & HLW02 & 1249 & 0.419 & 1154 & 0.314 & 1060 & 0.227 & 964 & 0.130 \\
\hline HLW02-24 & HLW02 & 1247 & 0.240 & 1151 & 0.174 & 1055 & 0.117 & 958 & 0.071 \\
\hline HLW02-25 & HLW02 & 1247 & 0.245 & 1152 & 0.174 & 1056 & 0.116 & 959 & 0.072 \\
\hline HLW02-26 & HLW02 & 1250 & 0.423 & 1154 & 0.289 & 1059 & 0.199 & 963 & 0.121 \\
\hline HLW02-27 & HLW02 & 1247 & 0.533 & 1154 & 0.347 & 1058 & 0.251 & 963 & 0.151 \\
\hline HLW02-28 & HLW02 & 1246 & 0.568 & 1152 & 0.417 & 1045 & 0.277 & 958 & 0.184 \\
\hline HLW02-29 & HLW02 & 1250 & 0.491 & 1155 & 0.364 & 1059 & 0.240 & 963 & 0.146 \\
\hline HLW02-30 & HLW02 & 1247 & 0.572 & 1158 & 0.425 & 1054 & 0.291 & 958 & 0.181 \\
\hline HLW02-31 & HLW02 & 1249 & 0.532 & 1152 & 0.388 & 1057 & 0.279 & 962 & 0.167 \\
\hline HLW02-32 & HLW02 & 1229 & 0.434 & 1141 & 0.337 & 1047 & 0.271 & 954 & 0.149 \\
\hline HLW02-33 & HLW02 & 1251 & 0.443 & 1150 & 0.322 & 1055 & 0.232 & 958 & 0.144 \\
\hline HLW02-34 & HLW02 & 1246 & 0.373 & 1150 & 0.282 & 1054 & 0.196 & 958 & 0.121 \\
\hline HLW02-35 & HLW02 & 1250 & 0.463 & 1151 & 0.403 & 1055 & 0.269 & 958 & 0.171 \\
\hline HLW02-36 & HLW02 & 1248 & 0.353 & 1151 & 0.263 & 1055 & 0.188 & 958 & 0.122 \\
\hline HLW02-37 & HLW02 & 1243 & 0.422 & 1149 & 0.316 & 1054 & 0.208 & 960 & 0.125 \\
\hline HLW02-38 & HLW02 & 1243 & 0.370 & 1147 & 0.273 & 1052 & 0.185 & 956 & 0.117 \\
\hline HLW02-39 & HLW02 & 1251 & 0.246 & 1154 & 0.195 & 1057 & 0.132 & 960 & 0.077 \\
\hline HLW02-40 & HLW02 & 1252 & 0.202 & 1155 & 0.168 & 1059 & 0.114 & 957 & 0.066 \\
\hline HLW02-41 & HLW02 & 1249 & 0.216 & 1154 & 0.174 & 1058 & 0.105 & 963 & 0.080 \\
\hline HLW02-42 & HLW02 & 1245 & 0.479 & 1151 & 0.370 & 1057 & 0.245 & 962 & 0.143 \\
\hline HLW02-43 & HLW02 & 1242 & 0.265 & 1147 & 0.181 & 1053 & 0.125 & 957 & 0.068 \\
\hline HLW02-44 & HLW02 & 1242 & 0.616 & 1148 & 0.449 & 1054 & 0.324 & 960 & 0.194 \\
\hline HLW02-45 & HLW02 & 1249 & 0.243 & 1153 & 0.173 & 1057 & 0.130 & 961 & 0.078 \\
\hline
\end{tabular}

(a) The Group IDs are described in Sections 2.1.1 to 2.1.9. 
Table 4.5. Melt Electrical Conductivity Data for 210 Simulated HLW Glasses (continued).

\begin{tabular}{|c|c|c|c|c|c|c|c|c|c|}
\hline Glass ID & $\begin{array}{l}\text { Group } \\
\text { ID }^{\text {(a) }}\end{array}$ & $\begin{array}{c}\text { Temp1 } \\
\left({ }^{\circ} \mathrm{C}\right)\end{array}$ & $\begin{array}{c}\text { EC1 } \\
(\mathrm{S} / \mathrm{cm})\end{array}$ & $\begin{array}{c}\text { Temp2 } \\
\left({ }^{\circ} \mathrm{C}\right)\end{array}$ & $\begin{array}{c}\text { EC2 } \\
(\mathrm{S} / \mathrm{cm})\end{array}$ & $\begin{array}{c}\text { Temp3 } \\
\left({ }^{\circ} \mathrm{C}\right)\end{array}$ & $\begin{array}{c}\text { EC3 } \\
(\mathbf{S} / \mathbf{c m})\end{array}$ & $\begin{array}{c}\text { Temp4 } \\
\left({ }^{\circ} \mathrm{C}\right)\end{array}$ & $\begin{array}{c}\text { EC4 } \\
(\mathrm{S} / \mathrm{cm})\end{array}$ \\
\hline HLW02-46 & HLW02 & 1249 & 0.324 & 1148 & 0.242 & 1053 & 0.146 & 957 & 0.090 \\
\hline HLW02-47 & HLW02 & 1248 & 0.230 & 1153 & 0.168 & 1058 & 0.112 & 962 & 0.068 \\
\hline HLW02-48 & HLW02 & 1250 & 0.509 & 1154 & 0.408 & 1059 & 0.288 & 963 & 0.183 \\
\hline HLW02-49 & HLW02 & 1256 & 0.421 & 1160 & 0.308 & 1064 & 0.215 & 968 & 0.135 \\
\hline HLW02-50 & HLW02 & 1252 & 0.256 & 1156 & 0.187 & 1060 & 0.123 & 965 & 0.075 \\
\hline HLW02-51 & HLW02 & 1248 & 0.342 & 1153 & 0.246 & 1058 & 0.169 & 964 & 0.102 \\
\hline HLW02-52 & HLW02 & 1250 & 0.382 & 1153 & 0.288 & 1052 & 0.190 & 955 & 0.119 \\
\hline HLW02-53 & HLW02 & 1251 & 0.475 & 1156 & 0.369 & 1061 & 0.255 & 965 & 0.170 \\
\hline HLW02-54 & HLW02 & 1246 & 0.416 & 1152 & 0.342 & 1057 & 0.220 & 962 & 0.145 \\
\hline HLW02-55 & HLW02 & 1250 & 0.388 & 1150 & 0.271 & 1054 & 0.194 & 958 & 0.119 \\
\hline HLW02-56 & HLW02 & 1246 & 0.428 & 1151 & 0.325 & 1053 & 0.219 & 957 & 0.142 \\
\hline HLW02-57 & HLW02 & 1249 & 0.422 & 1153 & 0.332 & 1056 & 0.230 & 959 & 0.156 \\
\hline HLW03-01 & HLW03 & 1212 & 0.589 & 1124 & 0.377 & 1027 & 0.255 & 921 & 0.158 \\
\hline HLW03-02 & HLW03 & 1241 & 0.295 & 1146 & 0.215 & 1039 & 0.147 & 954 & 0.098 \\
\hline HLW03-03 & HLW03 & 1250 & 0.365 & 1153 & 0.246 & 1056 & 0.166 & 959 & 0.104 \\
\hline HLW03-04 & HLW03 & 1209 & 0.492 & 1130 & 0.353 & 1036 & 0.232 & 940 & 0.141 \\
\hline HLW03-05 & HLW03 & 1230 & 0.517 & 1139 & 0.354 & 1044 & 0.240 & 945 & 0.158 \\
\hline HLW03-06 & HLW03 & 1233 & 0.386 & 1140 & 0.302 & 1045 & 0.192 & 950 & 0.119 \\
\hline HLW03-07 & HLW03 & 1230 & 0.835 & 1128 & 0.648 & 1041 & 0.466 & 944 & 0.285 \\
\hline HLW03-08 & HLW03 & 1230 & 0.918 & 1137 & 0.786 & 1042 & 0.532 & 948 & 0.352 \\
\hline HLW03-09 & HLW03 & 1225 & 0.438 & 1131 & 0.317 & 1034 & 0.220 & 935 & 0.141 \\
\hline HLW03-10 & HLW03 & 1221 & 0.893 & 1128 & 0.725 & 1032 & 0.464 & 938 & 0.329 \\
\hline HLW03-11 & HLW03 & 1228 & 0.443 & 1133 & 0.384 & 1038 & 0.261 & 943 & 0.190 \\
\hline HLW03-12 & HLW03 & 1219 & 0.418 & 1129 & 0.293 & 1035 & 0.174 & 939 & 0.090 \\
\hline HLW03-13 & HLW03 & 1213 & 0.400 & 1121 & 0.304 & 1022 & 0.177 & 923 & 0.103 \\
\hline HLW03-14 & HLW03 & 1224 & 0.454 & 1132 & 0.302 & 1037 & 0.171 & 943 & 0.090 \\
\hline HLW03-15 & HLW03 & 1233 & 0.179 & 1141 & 0.121 & 1045 & 0.077 & 951 & 0.047 \\
\hline HLW03-16 & HLW03 & 1217 & 0.193 & 1123 & 0.130 & 1029 & 0.074 & 932 & 0.037 \\
\hline HLW03-17 & HLW03 & 1230 & 0.178 & 1139 & 0.135 & 1043 & 0.074 & 947 & 0.042 \\
\hline HLW03-18 & HLW03 & 1214 & 0.623 & 1118 & 0.490 & 1014 & 0.318 & 908 & 0.180 \\
\hline HLW03-19 & HLW03 & 1212 & 0.653 & 1120 & 0.463 & 1024 & 0.335 & 920 & 0.195 \\
\hline HLW03-20 & HLW03 & 1218 & 0.648 & 1127 & 0.530 & 1032 & 0.342 & 933 & 0.214 \\
\hline HLW03-21 & HLW03 & 1230 & 0.313 & 1136 & 0.254 & 1041 & 0.155 & 944 & 0.093 \\
\hline HLW03-22 & HLW03 & 1217 & 0.444 & 1125 & 0.307 & 1029 & 0.199 & 935 & 0.110 \\
\hline HLW03-23 & HLW03 & 1224 & 0.432 & 1129 & 0.296 & 1034 & 0.212 & 937 & 0.122 \\
\hline HLW03-24 & HLW03 & 1227 & 0.471 & 1132 & 0.352 & 1036 & 0.222 & 937 & 0.130 \\
\hline HLW03-25 & HLW03 & 1222 & 0.428 & 1131 & 0.329 & 1034 & 0.205 & 928 & 0.107 \\
\hline HLW03-26 & HLW03 & 1212 & 0.622 & 1129 & 0.425 & 1034 & 0.298 & 937 & 0.162 \\
\hline HLW03-27 & HLW03 & 1219 & 0.582 & 1125 & 0.394 & 1029 & 0.253 & 930 & 0.159 \\
\hline HLW03-28 & HLW03 & 1229 & 0.718 & 1130 & 0.444 & 1033 & 0.295 & 936 & 0.188 \\
\hline HLW03-29 & HLW03 & 1227 & 0.690 & 1134 & 0.552 & 1037 & 0.368 & 941 & 0.220 \\
\hline HLW03-30 & HLW03 & 1227 & 0.406 & 1127 & 0.316 & 1024 & 0.213 & 919 & 0.105 \\
\hline HLW03-31 & HLW03 & 1212 & 0.425 & 1121 & 0.327 & 1022 & 0.194 & 923 & 0.099 \\
\hline HLW03-32 & HLW03 & 1211 & 0.523 & 1121 & 0.394 & 1022 & 0.248 & 920 & 0.133 \\
\hline HLW03-33 & HLW03 & 1215 & 0.339 & 1125 & 0.247 & 1033 & 0.170 & 941 & 0.096 \\
\hline
\end{tabular}

(a) The Group IDs are described in Sections 2.1.1 to 2.1.9. 
Table 4.5. Melt Electrical Conductivity Data for 210 Simulated HLW Glasses (continued).

\begin{tabular}{|c|c|c|c|c|c|c|c|c|c|}
\hline Glass ID & $\begin{array}{l}\text { Group } \\
\text { ID }^{(\mathbf{a})}\end{array}$ & $\begin{array}{c}\text { Temp1 } \\
\left({ }^{\circ} \mathbf{C}\right)\end{array}$ & $\begin{array}{c}\text { EC1 } \\
(\mathrm{S} / \mathbf{c m})\end{array}$ & $\begin{array}{c}\text { Temp2 } \\
\left({ }^{\circ} \mathrm{C}\right)\end{array}$ & $\begin{array}{c}\text { EC2 } \\
(\mathrm{S} / \mathbf{c m})\end{array}$ & $\begin{array}{c}\text { Temp3 } \\
\left({ }^{\circ} \mathrm{C}\right)\end{array}$ & $\begin{array}{c}\text { EC3 } \\
(\mathbf{S} / \mathbf{c m})\end{array}$ & $\begin{array}{c}\text { Temp4 } \\
\left({ }^{\circ} \mathrm{C}\right)\end{array}$ & $\begin{array}{c}\text { EC4 } \\
\text { (S/cm) }\end{array}$ \\
\hline HLW03-34 & HLW03 & 1224 & 0.273 & 1129 & 0.199 & 1039 & 0.128 & 940 & 0.080 \\
\hline HLW03-35 & HLW03 & 1217 & 0.189 & 1133 & 0.136 & 1039 & 0.088 & 942 & 0.049 \\
\hline HLW03-36 & HLW03 & 1224 & 0.231 & 1132 & 0.179 & 1034 & 0.111 & 938 & 0.071 \\
\hline HLW03-37 & HLW03 & 1217 & 0.443 & 1122 & 0.327 & 1026 & 0.207 & 927 & 0.122 \\
\hline HLW03-38 & HLW03 & 1214 & 0.368 & 1128 & 0.288 & 1032 & 0.195 & 935 & 0.107 \\
\hline HLW03-39 & HLW03 & 1226 & 0.302 & 1131 & 0.223 & 1036 & 0.124 & 934 & 0.079 \\
\hline HLW03-40 & HLW03 & 1226 & 0.405 & 1132 & 0.310 & 1031 & 0.198 & 937 & 0.116 \\
\hline HLW03-41 & HLW03 & 1200 & 0.344 & 1120 & 0.278 & 1019 & 0.181 & 921 & 0.111 \\
\hline HLW03-42 & HLW03 & 1251 & 0.261 & 1152 & 0.182 & 1050 & 0.120 & 953 & 0.073 \\
\hline HLW03-43 & HLW03 & 1223 & 0.407 & 1132 & 0.283 & 1038 & 0.185 & 943 & 0.119 \\
\hline HLW03-44 & HLW03 & 1226 & 0.465 & 1133 & 0.413 & 1038 & 0.281 & 941 & 0.170 \\
\hline HLW03-45 & HLW03 & 1224 & 0.594 & 1137 & 0.474 & 1043 & 0.335 & 945 & 0.191 \\
\hline HLW04-01 & HLW04 & 1245 & 0.480 & 1146 & 0.360 & 1047 & 0.261 & 949 & 0.148 \\
\hline HLW05-15 & HLW05 & 1236 & 0.419 & 1139 & 0.338 & 1042 & 0.243 & 942 & 0.158 \\
\hline HLW05-20 & HLW05 & 1225 & 0.504 & 1132 & 0.463 & 1029 & 0.285 & 928 & 0.174 \\
\hline HLW05-21 & HLW05 & 1231 & 0.638 & 1137 & 0.533 & 1041 & 0.369 & 943 & 0.225 \\
\hline HLW05-22 & HLW05 & 1225 & 0.261 & 1133 & 0.186 & 1037 & 0.134 & 938 & 0.080 \\
\hline HLW05-27 & HLW05 & 1221 & 0.712 & 1128 & 0.478 & 1032 & 0.364 & 933 & 0.228 \\
\hline HLW06-02 & HLW06 & 1231 & 0.697 & 1136 & 0.499 & 1040 & 0.363 & 939 & 0.244 \\
\hline HLW06-04 & HLW06 & 1228 & 0.687 & 1132 & 0.491 & 1033 & 0.385 & 932 & 0.268 \\
\hline HLW06-22 & HLW06 & 1226 & 0.592 & 1131 & 0.379 & 1033 & 0.259 & 933 & 0.163 \\
\hline HLW06-32 & HLW06 & 1223 & 0.699 & 1133 & 0.557 & 1043 & 0.398 & 954 & 0.277 \\
\hline HLW06-34 & HLW06 & 1220 & 0.650 & 1130 & 0.475 & 1033 & 0.333 & 932 & 0.214 \\
\hline HLW07-01 & HLW07 & 1231 & 0.276 & 1132 & 0.200 & 1035 & 0.150 & 933 & 0.079 \\
\hline HLW07-02 & HLW07 & 1274 & 0.360 & 1177 & 0.264 & 1080 & 0.186 & 983 & 0.113 \\
\hline HLW07-03 & HLW07 & 1239 & 0.442 & 1145 & 0.331 & 1048 & 0.227 & 950 & 0.133 \\
\hline HLW07-04 & HLW07 & 1269 & 0.402 & 1170 & 0.310 & 1072 & 0.223 & 973 & 0.149 \\
\hline HLW07-05 & HLW07 & 1253 & 0.894 & 1160 & 0.703 & 1062 & 0.496 & 965 & 0.308 \\
\hline HLW07-06 & HLW07 & 1249 & 0.269 & 1154 & 0.192 & 1057 & 0.126 & 960 & 0.070 \\
\hline HLW07-07 & HLW07 & 1249 & 0.552 & 1155 & 0.419 & 1058 & 0.285 & 962 & 0.178 \\
\hline HLW07-08 & HLW07 & 1239 & 0.384 & 1144 & 0.341 & 1049 & 0.245 & 951 & 0.157 \\
\hline HLW07-09 & HLW07 & 1252 & 0.645 & 1153 & 0.446 & 1058 & 0.294 & 960 & 0.167 \\
\hline HLW07-10 & HLW07 & 1243 & 0.191 & 1149 & 0.122 & 1053 & 0.072 & 956 & 0.039 \\
\hline HLW07-11 & HLW07 & 1240 & 0.683 & 1145 & 0.609 & 1048 & 0.432 & 950 & 0.289 \\
\hline HLW07-12 & HLW07 & 1249 & 0.901 & 1154 & 0.671 & 1057 & 0.523 & 960 & 0.324 \\
\hline HLW07-13 & HLW07 & 1245 & 0.550 & 1150 & 0.423 & 1055 & 0.273 & 958 & 0.181 \\
\hline HLW07-14 & HLW07 & 1219 & 0.295 & 1128 & 0.182 & 1033 & 0.133 & 937 & 0.072 \\
\hline HLW07-15 & HLW07 & 1233 & 0.612 & 1141 & 0.469 & 1045 & 0.305 & 948 & 0.175 \\
\hline HLW07-16 & HLW07 & 1270 & 1.376 & 1173 & 1.023 & 1076 & 0.780 & 981 & 0.524 \\
\hline HLW07-17 & HLW07 & 1277 & 1.035 & 1177 & 0.816 & 1078 & 0.618 & 979 & 0.424 \\
\hline HLW07-18 & HLW07 & 1245 & 0.867 & 1149 & 0.634 & 1052 & 0.492 & 954 & 0.335 \\
\hline HLW07-19 & HLW07 & 1251 & 1.046 & 1154 & 0.772 & 1059 & 0.549 & 964 & 0.347 \\
\hline HLW07-20 & HLW07 & 1237 & 0.312 & 1142 & 0.211 & 1046 & 0.141 & 946 & 0.082 \\
\hline HLW07-21 & HLW07 & 1239 & 0.167 & 1141 & 0.107 & 1043 & 0.064 & 943 & 0.034 \\
\hline HLW07-22 & HLW07 & 1232 & 0.187 & 1135 & 0.116 & 1039 & 0.078 & 941 & 0.038 \\
\hline
\end{tabular}

(a) The Group IDs are described in Sections 2.1.1 to 2.1.9. 
Table 4.5. Melt Electrical Conductivity Data for 210 Simulated HLW Glasses (continued).

\begin{tabular}{|c|c|c|c|c|c|c|c|c|c|}
\hline Glass ID & $\begin{array}{l}\text { Group } \\
\text { ID }^{(\mathbf{a})}\end{array}$ & $\begin{array}{c}\text { Temp1 } \\
\left({ }^{\circ} \mathrm{C}\right)\end{array}$ & $\begin{array}{c}\text { EC1 } \\
(\mathrm{S} / \mathrm{cm})\end{array}$ & $\begin{array}{c}\text { Temp2 } \\
\left({ }^{\circ} \mathrm{C}\right)\end{array}$ & $\begin{array}{c}\text { EC2 } \\
(\mathrm{S} / \mathrm{cm})\end{array}$ & $\begin{array}{c}\text { Temp3 } \\
\left({ }^{\circ} \mathrm{C}\right)\end{array}$ & $\begin{array}{c}\text { EC3 } \\
(\mathrm{S} / \mathbf{c m})\end{array}$ & $\begin{array}{c}\text { Temp4 } \\
\left({ }^{\circ} \mathrm{C}\right)\end{array}$ & $\begin{array}{c}\text { EC4 } \\
(\mathrm{S} / \mathrm{cm})\end{array}$ \\
\hline HLW07-23 & HLW07 & 1250 & 0.191 & 1155 & 0.132 & 1058 & 0.076 & 961 & 0.044 \\
\hline HLW07-24 & HLW07 & 1197 & 0.418 & 1105 & 0.323 & 1010 & 0.225 & 911 & 0.140 \\
\hline HLW07-25 & HLW07 & 1259 & 0.239 & 1160 & 0.167 & 1063 & 0.112 & 965 & 0.074 \\
\hline HLW07-26 & HLW07 & 1256 & 0.330 & 1160 & 0.231 & 1061 & 0.155 & 962 & 0.095 \\
\hline HLW07-27 & HLW07 & 1210 & 0.425 & 1115 & 0.321 & 1020 & 0.185 & 923 & 0.121 \\
\hline HLW07-28 & HLW07 & 1248 & 0.254 & 1154 & 0.193 & 1058 & 0.115 & 959 & 0.062 \\
\hline HLW07-29 & HLW07 & 1247 & 0.274 & 1153 & 0.206 & 1057 & 0.129 & 960 & 0.086 \\
\hline HLW07-30 & HLW07 & 1235 & 0.274 & 1140 & 0.202 & 1046 & 0.141 & 946 & 0.076 \\
\hline HLW07-31 & HLW07 & 1218 & 0.227 & 1126 & 0.169 & 1031 & 0.109 & 935 & 0.062 \\
\hline HLW07-32 & HLW07 & 1252 & 0.293 & 1154 & 0.236 & 1058 & 0.156 & 961 & 0.093 \\
\hline HLW07-33 & HLW07 & 1246 & 0.339 & 1150 & 0.239 & 1054 & 0.156 & 958 & 0.094 \\
\hline HLW07-34 & HLW07 & 1223 & 0.337 & 1118 & 0.208 & 1031 & 0.135 & 933 & 0.079 \\
\hline HLW07-35 & HLW07 & 1249 & 0.238 & 1152 & 0.159 & 1055 & 0.113 & 958 & 0.061 \\
\hline HLW07-36 & HLW07 & 1252 & 0.437 & 1152 & 0.315 & 1057 & 0.219 & 959 & 0.128 \\
\hline HLW07-37 & HLW07 & 1244 & 0.579 & 1150 & 0.438 & 1052 & 0.288 & 954 & 0.185 \\
\hline HLW07-38 & HLW07 & 1245 & 0.289 & 1150 & 0.205 & 1055 & 0.134 & 957 & 0.075 \\
\hline HLW07-39 & HLW07 & 1242 & 0.284 & 1144 & 0.216 & 1046 & 0.147 & 946 & 0.090 \\
\hline HLW07-40 & HLW07 & 1240 & 0.626 & 1147 & 0.527 & 1051 & 0.370 & 953 & 0.221 \\
\hline HLW-ALG-01 & HLWALG & 1261 & 0.756 & 1162 & 0.587 & 1069 & 0.444 & 975 & 0.317 \\
\hline HLW-ALG-02 & HLWALG & 1254 & 0.584 & 1154 & 0.463 & 1062 & 0.349 & 969 & 0.236 \\
\hline HLW-ALG-03 & HLWALG & 1248 & 0.841 & 1155 & 0.694 & 1062 & 0.491 & 970 & 0.344 \\
\hline HLW-ALG-04 & HLWALG & 1248 & 0.568 & 1150 & 0.501 & 1059 & 0.345 & 967 & 0.229 \\
\hline HLW-ALG-05 & HLWALG & 1270 & 0.494 & 1174 & 0.374 & 1080 & 0.250 & 983 & 0.153 \\
\hline HLW-ALG-06 & HLWALG & 1229 & 0.555 & 1132 & 0.436 & 1036 & 0.298 & 937 & 0.189 \\
\hline HLW-ALG-07 & HLWALG & 1223 & 0.394 & 1128 & 0.288 & 1031 & 0.195 & 927 & 0.113 \\
\hline HLW-ALG-08 & HLWALG & 1236 & 0.501 & 1139 & 0.371 & 1041 & 0.243 & 943 & 0.141 \\
\hline HLW-ALG-09 & HLWALG & 1231 & 0.657 & 1137 & 0.439 & 1042 & 0.294 & 946 & 0.187 \\
\hline HLW-ALG-10 & HLWALG & 1230 & 0.791 & 1142 & 0.627 & 1043 & 0.395 & 946 & 0.273 \\
\hline HLW-ALG-11 & HLWALG & 1239 & 0.547 & 1143 & 0.394 & 1047 & 0.317 & 950 & 0.180 \\
\hline HLW-ALG-12 & HLWALG & 1224 & 0.617 & 1130 & 0.518 & 1034 & 0.359 & 937 & 0.227 \\
\hline HLW-ALG-13 & HLWALG & 1231 & 0.484 & 1138 & 0.350 & 1042 & 0.229 & 944 & 0.134 \\
\hline HLW-ALG-14 & HLWALG & 1209 & 0.531 & 1120 & 0.382 & 1031 & 0.252 & 941 & 0.151 \\
\hline HLW-ALG-15 & HLWALG & 1213 & 0.632 & 1123 & 0.495 & 1034 & 0.351 & 943 & 0.226 \\
\hline HLW-ALG-16 & HLWALG & 1221 & 0.765 & 1129 & 0.494 & 1038 & 0.377 & 947 & 0.249 \\
\hline HLW-ALG-17 & HLWALG & 1214 & 0.571 & 1122 & 0.414 & 1031 & 0.307 & 940 & 0.202 \\
\hline HLW-ALG-18 & HLWALG & 1217 & 0.538 & 1125 & 0.403 & 1034 & 0.291 & 943 & 0.189 \\
\hline HLW-ALG-19 & HLWALG & 1215 & 0.582 & 1127 & 0.446 & 1040 & 0.329 & 952 & 0.217 \\
\hline HLW-ALG-20 & HLWALG & 1226 & 0.787 & 1136 & 0.602 & 1048 & 0.437 & 959 & 0.291 \\
\hline HLW-ALG-21 & HLWALG & 1217 & 0.610 & 1125 & 0.548 & 1030 & 0.366 & 933 & 0.233 \\
\hline HLW-ALG-22 & HLWALG & 1223 & 0.780 & 1127 & 0.612 & 1030 & 0.404 & 941 & 0.251 \\
\hline HLW-ALG-23 & HLWALG & 1235 & 0.951 & 1139 & 0.879 & 1042 & 0.579 & 942 & 0.380 \\
\hline HLW-ALG-24 & HLWALG & 1232 & 0.452 & 1134 & 0.360 & 1039 & 0.313 & 941 & 0.145 \\
\hline HLW-ALG-25 & HLWALG & 1231 & 0.623 & 1135 & 0.482 & 1039 & 0.388 & 941 & 0.213 \\
\hline HLW-ALG-26 & HLWALG & 1244 & 0.443 & 1148 & 0.300 & 1051 & 0.202 & 952 & 0.122 \\
\hline HLW-ALG-27 & HLWALG & 1247 & 0.752 & 1155 & 0.576 & 1066 & 0.442 & 973 & 0.288 \\
\hline
\end{tabular}

(a) The Group IDs are described in Sections 2.1.1 to 2.1.9. 
Table 4.5. Melt Electrical Conductivity Data for 210 Simulated HLW Glasses (continued).

\begin{tabular}{|c|c|c|c|c|c|c|c|c|c|}
\hline Glass ID & $\begin{array}{l}\text { Group } \\
\text { ID }^{(\text {a) }}\end{array}$ & $\begin{array}{c}\text { Temp1 } \\
\left({ }^{\circ} \mathbf{C}\right)\end{array}$ & $\begin{array}{c}\text { EC1 } \\
(\mathbf{S} / \mathbf{c m})\end{array}$ & $\begin{array}{c}\text { Temp2 } \\
\left({ }^{\circ} \mathrm{C}\right)\end{array}$ & $\begin{array}{c}\text { EC2 } \\
\text { (S/cm) }\end{array}$ & $\begin{array}{c}\text { Temp3 } \\
\left({ }^{\circ} \mathbf{C}\right)\end{array}$ & $\begin{array}{c}\text { EC3 } \\
(\mathbf{S} / \mathbf{c m})\end{array}$ & $\begin{array}{c}\text { Temp4 } \\
\left({ }^{\circ} \mathrm{C}\right)\end{array}$ & $\begin{array}{c}\text { EC4 } \\
\text { (S/cm) }\end{array}$ \\
\hline HLW-ALG-28 & HLWALG & 1214 & 0.621 & 1129 & 0.490 & 1041 & 0.365 & 952 & 0.243 \\
\hline HLW-ALG-29 & HLWALG & 1237 & 0.688 & 1136 & 0.504 & 1055 & 0.364 & 963 & 0.222 \\
\hline HLW-ALG-30 & HLWALG & 1222 & 0.636 & 1128 & 0.514 & 1032 & 0.353 & 924 & 0.226 \\
\hline HLW-ALG-31 & HLWALG & 1270 & 0.498 & 1173 & 0.329 & 1073 & 0.220 & 975 & 0.144 \\
\hline HLW-ALG-32 & HLWALG & 1243 & 0.572 & 1145 & 0.408 & 1048 & 0.254 & 950 & 0.152 \\
\hline HLW-ALG-33 & HLWALG & 1251 & 0.828 & 1154 & 0.637 & 1056 & 0.478 & 958 & 0.317 \\
\hline HLW-ALG-34 & HLWALG & 1225 & 0.787 & 1127 & 0.555 & 1028 & 0.404 & 930 & 0.265 \\
\hline HLW-ALG-35 & HLWALG & 1239 & 0.446 & 1144 & 0.323 & 1048 & 0.206 & 951 & 0.115 \\
\hline HLW-ALG-36 & HLWALG & 1248 & 0.667 & 1151 & 0.480 & 1055 & 0.320 & 956 & 0.177 \\
\hline HLW-ALG-37 & HLWALG & 1212 & 0.374 & 1120 & 0.279 & 1026 & 0.177 & 929 & 0.096 \\
\hline HLW-ALG-38 & HLWALG & 1243 & 0.332 & 1148 & 0.268 & 1052 & 0.155 & 955 & 0.101 \\
\hline HLW-ALG-39 & HLWALG & 1230 & 0.427 & 1135 & 0.318 & 1038 & 0.213 & 940 & 0.128 \\
\hline HLW-ALG-40 & HLWALG & 1231 & 0.626 & 1141 & 0.527 & 1046 & 0.370 & 949 & 0.221 \\
\hline HLW98-72 & HLW98 & 1243 & 0.827 & 1142 & 0.582 & 1046 & 0.467 & 950 & 0.270 \\
\hline HLW98-77 & HLW98 & 1226 & 0.454 & 1131 & 0.351 & 1036 & 0.219 & 942 & 0.141 \\
\hline HLW98-80 & HLW98 & 1249 & 0.491 & 1151 & 0.370 & 1054 & 0.242 & 958 & 0.146 \\
\hline HLW98-83 & HLW98 & 1228 & 0.425 & 1135 & 0.323 & 1041 & 0.223 & 947 & 0.138 \\
\hline HLW98-84 & HLW98 & 1211 & 0.479 & 1118 & 0.348 & 1026 & 0.238 & 933 & 0.149 \\
\hline HLW98-86AG & HLW98 & 1228 & 0.462 & 1134 & 0.348 & 1040 & 0.239 & 952 & 0.158 \\
\hline HLW98-88 & HLW98 & 1228 & 0.441 & 1135 & 0.329 & 1037 & 0.223 & 943 & 0.138 \\
\hline HLW98-89 & HLW98 & 1224 & 0.451 & 1129 & 0.332 & 1037 & 0.224 & 942 & 0.138 \\
\hline HLW98-95 & HLW98 & 1234 & 0.472 & 1137 & 0.350 & 1043 & 0.247 & 948 & 0.156 \\
\hline HLW98-96 & HLW98 & 1233 & 0.353 & 1138 & 0.266 & 1044 & 0.190 & 950 & 0.109 \\
\hline HLW98-96A & HLW98 & 1247 & 0.500 & 1153 & 0.312 & 1059 & 0.237 & 964 & 0.145 \\
\hline HLW98-96B & HLW98 & 1245 & 0.527 & 1152 & 0.400 & 1057 & 0.262 & 963 & 0.152 \\
\hline HLW98-96D & HLW98 & 1247 & 0.640 & 1154 & 0.479 & 1058 & 0.316 & 964 & 0.189 \\
\hline HLW98-97 & HLW98 & 1241 & 0.502 & 1147 & 0.365 & 1052 & 0.257 & 958 & 0.159 \\
\hline HLW98-T05 & HLW98 & 1240 & 0.464 & 1148 & 0.368 & 1054 & 0.237 & 961 & 0.156 \\
\hline HLW98-V19 & HLW98 & 1245 & 0.448 & 1153 & 0.354 & 1059 & 0.241 & 966 & 0.145 \\
\hline HLW98-V24 & HLW98 & 1240 & 0.508 & 1148 & 0.378 & 1054 & 0.273 & 962 & 0.169 \\
\hline
\end{tabular}

(a) The Group IDs are described in Sections 2.1.1 to 2.1.9. 
Table 4.6. Melt Viscosity Data for Simulated HLW Glasses.

\begin{tabular}{|c|c|c|c|c|c|c|c|c|c|}
\hline Glass ID & $\begin{array}{l}\text { Group } \\
\text { ID }^{(\mathbf{a})}\end{array}$ & $\begin{array}{c}\text { Temp1 } \\
\left({ }^{\circ} \mathrm{C}\right)\end{array}$ & $\begin{array}{c}\text { Vis1 } \\
\text { (P) }\end{array}$ & $\begin{array}{c}\text { Temp2 } \\
\left({ }^{\circ} \mathrm{C}\right)\end{array}$ & $\begin{array}{c}\text { Vis2 } \\
\text { (P) }\end{array}$ & $\begin{array}{c}\text { Temp3 } \\
\left({ }^{\circ} \mathrm{C}\right) \\
\end{array}$ & $\begin{array}{l}\text { Vis3 } \\
\text { (P) }\end{array}$ & $\begin{array}{c}\text { Temp4 } \\
\left({ }^{\circ} \mathrm{C}\right)\end{array}$ & $\begin{array}{c}\text { Vis4 } \\
\text { (P) }\end{array}$ \\
\hline HLW02-01 & HLW02 & 1245 & 15.13 & 1148 & 31.72 & 1050 & 75.25 & 952 & 235.47 \\
\hline HLW02-02 & HLW02 & 1247 & 20.39 & 1146 & 40.63 & 1047 & 96.00 & 946 & 289.21 \\
\hline HLW02-03 & HLW02 & 1245 & 8.54 & 1148 & 19.03 & 1050 & 47.37 & 953 & 158.90 \\
\hline HLW02-04 & HLW02 & 1250 & 51.32 & 1151 & 114.25 & 1052 & 296.76 & 952 & 971.22 \\
\hline HLW02-05 & HLW02 & 1251 & 26.99 & 1152 & 51.58 & 1053 & 135.84 & 953 & 451.69 \\
\hline HLW02-06 & HLW02 & 1236 & 40.01 & 1139 & 99.40 & 1043 & 303.36 & 946 & 1240.98 \\
\hline HLW02-07 & HLW02 & 1221 & 42.99 & 1125 & 84.95 & 1030 & 210.73 & 934 & 646.25 \\
\hline HLW02-08 & HLW02 & 1247 & 5.62 & 1149 & 11.58 & 1051 & 27.12 & 952 & 80.66 \\
\hline HLW02-09 & HLW02 & 1234 & 9.70 & 1137 & 18.79 & 1040 & 40.70 & 943 & 114.33 \\
\hline HLW02-10 & HLW02 & 1251 & 7.05 & 1152 & 13.40 & 1054 & 29.16 & 955 & 81.10 \\
\hline HLW02-11 & HLW02 & 1228 & 9.35 & 1132 & 18.21 & 1030 & 40.91 & 940 & 125.47 \\
\hline HLW02-12 & HLW02 & 1254 & 7.15 & 1155 & 13.51 & 1057 & 29.31 & 958 & 86.51 \\
\hline HLW02-13 & HLW02 & 1246 & 7.31 & 1149 & 12.94 & 1053 & 26.58 & 956 & 69.77 \\
\hline HLW02-14 & HLW02 & 1241 & 12.50 & 1142 & 26.84 & 1043 & 64.49 & 944 & 258.81 \\
\hline HLW02-15 & HLW02 & 1253 & 11.34 & 1154 & 23.10 & 1055 & 54.80 & 956 & 170.21 \\
\hline HLW02-16 & HLW02 & 1252 & 11.66 & 1152 & 20.94 & 1053 & 49.58 & 953 & 170.26 \\
\hline HLW02-17 & HLW02 & 1227 & 45.80 & 1130 & 102.04 & 1034 & 257.92 & 936 & 822.82 \\
\hline HLW02-18 & HLW02 & 1240 & 48.68 & 1142 & 123.06 & 1045 & 376.83 & 946 & 1573.09 \\
\hline HLW02-19 & HLW02 & 1250 & 10.29 & 1152 & 22.77 & 1053 & 61.62 & 957 & 229.73 \\
\hline HLW02-20 & HLW02 & 1239 & 73.19 & 1143 & 172.70 & 1047 & 492.51 & 950 & 1799.91 \\
\hline HLW02-21 & HLW02 & 1249 & 27.95 & 1151 & 58.10 & 1053 & 147.29 & 955 & 506.85 \\
\hline HLW02-22 & HLW02 & 1247 & 48.95 & 1147 & 106.91 & 1048 & 267.10 & 947 & 919.37 \\
\hline HLW02-23 & HLW02 & 1254 & 8.47 & 1154 & 14.46 & 1055 & 29.26 & 955 & 78.63 \\
\hline HLW02-24 & HLW02 & 1244 & 48.74 & 1144 & 118.54 & 1044 & 353.91 & 943 & 1373.72 \\
\hline HLW02-25 & HLW02 & 1235 & 68.92 & 1138 & 164.70 & 1041 & 512.65 & 944 & 1726.81 \\
\hline HLW02-26 & HLW02 & 1241 & 8.98 & 1141 & 20.26 & 1042 & 54.57 & 942 & 205.34 \\
\hline HLW02-27 & HLW02 & 1246 & 6.31 & 1149 & 13.75 & 1052 & 33.17 & 956 & 104.05 \\
\hline HLW02-28 & HLW02 & 1230 & 19.48 & 1135 & 42.53 & 1040 & 115.74 & 944 & 379.76 \\
\hline HLW02-29 & HLW02 & 1251 & 14.38 & 1151 & 31.02 & 1051 & 81.43 & 951 & 279.67 \\
\hline HLW02-30 & HLW02 & 1235 & 7.63 & 1138 & 15.11 & 1041 & 34.99 & 944 & 104.76 \\
\hline HLW02-31 & HLW02 & 1253 & 11.74 & 1154 & 24.58 & 1054 & 62.29 & 955 & 195.38 \\
\hline HLW02-32 & HLW02 & 1230 & 20.75 & 1135 & 41.77 & 1040 & 100.67 & 945 & 293.48 \\
\hline HLW02-33 & HLW02 & 1238 & 11.69 & 1141 & 23.91 & 1044 & 57.54 & 947 & 176.67 \\
\hline HLW02-34 & HLW02 & 1229 & 9.22 & 1136 & 17.24 & 1044 & 38.12 & 951 & 108.00 \\
\hline HLW02-35 & HLW02 & 1226 & 10.62 & 1133 & 19.05 & 1041 & 39.89 & 948 & 122.16 \\
\hline
\end{tabular}

(a) The Group IDs are described in Sections 2.1.1 to 2.1.9. 
Table 4.6. Melt Viscosity Data for Simulated HLW Glasses (continued).

\begin{tabular}{|c|c|c|c|c|c|c|c|c|c|}
\hline Glass ID & $\begin{array}{l}\text { Group } \\
\text { ID }^{(\mathbf{a})}\end{array}$ & $\begin{array}{c}\text { Temp1 } \\
\left({ }^{\circ} \mathrm{C}\right)\end{array}$ & $\begin{array}{l}\text { Vis1 } \\
\text { (P) }\end{array}$ & $\begin{array}{c}\text { Temp2 } \\
\left({ }^{\circ} \mathbf{C}\right)\end{array}$ & $\begin{array}{c}\text { Vis2 } \\
\text { (P) }\end{array}$ & $\begin{array}{c}\text { Temp3 } \\
\left({ }^{\circ} \mathrm{C}\right)\end{array}$ & $\begin{array}{c}\text { Vis3 } \\
\text { (P) }\end{array}$ & $\begin{array}{c}\text { Temp4 } \\
\left({ }^{\circ} \mathrm{C}\right)\end{array}$ & $\begin{array}{c}\text { Vis4 } \\
\text { (P) }\end{array}$ \\
\hline HLW02-36 & HLW02 & 1235 & 18.69 & 1138 & 39.39 & 1041 & 99.31 & 943 & 309.38 \\
\hline HLW02-37 & HLW02 & 1245 & 15.68 & 1143 & 36.74 & 1040 & 99.52 & 938 & 367.45 \\
\hline HLW02-38 & HLW02 & 1244 & 10.13 & 1143 & 20.30 & 1042 & 47.59 & 941 & 147.90 \\
\hline HLW02-39 & HLW02 & 1253 & 51.96 & 1152 & 122.69 & 1051 & 340.15 & 950 & 1221.48 \\
\hline HLW02-40 & HLW02 & 1239 & 72.24 & 1142 & 171.24 & 1045 & 482.91 & 948 & 1830.58 \\
\hline HLW02-41 & HLW02 & 1241 & 38.16 & 1141 & 85.81 & 1042 & 230.44 & 942 & 796.60 \\
\hline HLW02-42 & HLW02 & 1246 & 10.82 & 1148 & 21.57 & 1050 & 50.09 & 951 & 148.44 \\
\hline HLW02-43 & HLW02 & 1236 & 10.73 & 1139 & 20.96 & 1042 & 48.17 & 945 & 145.30 \\
\hline HLW02-44 & HLW02 & 1238 & 16.53 & 1137 & 37.07 & 1035 & 95.53 & 934 & 321.40 \\
\hline HLW02-45 & HLW02 & 1233 & 35.18 & 1135 & 80.79 & 1038 & 222.26 & 941 & 783.14 \\
\hline HLW02-46 & HLW02 & 1244 & 25.35 & 1144 & 55.19 & 1044 & 143.78 & 944 & 491.02 \\
\hline HLW02-47 & HLW02 & 1237 & 40.58 & 1138 & 92.22 & 1040 & 284.16 & 941 & 1046.42 \\
\hline HLW02-48 & HLW02 & 1236 & 10.54 & 1137 & 22.60 & 1038 & 56.18 & 940 & 178.91 \\
\hline HLW02-49 & HLW02 & 1247 & 16.26 & 1148 & 33.21 & 1049 & 81.95 & 949 & 260.62 \\
\hline HLW02-50 & HLW02 & 1241 & 24.43 & 1141 & 55.09 & 1042 & 153.69 & 943 & 514.45 \\
\hline HLW02-51 & HLW02 & 1243 & 23.43 & 1145 & 49.28 & 1047 & 134.39 & 948 & 470.53 \\
\hline HLW02-52 & HLW02 & 1255 & 14.43 & 1155 & 29.91 & 1055 & 73.74 & 955 & 238.39 \\
\hline HLW02-53 & HLW02 & 1244 & 47.79 & 1145 & 106.56 & 1046 & 275.47 & 947 & 875.67 \\
\hline HLW02-54 & HLW02 & 1242 & 50.75 & 1138 & 114.86 & 1035 & 306.81 & 931 & 1065.15 \\
\hline HLW02-55 & HLW02 & 1239 & 9.66 & 1140 & 19.25 & 1042 & 44.07 & 943 & 130.06 \\
\hline HLW02-56 & HLW02 & 1235 & 15.31 & 1138 & 32.29 & 1041 & 79.94 & 943 & 260.34 \\
\hline HLW02-57 & HLW02 & 1231 & 7.56 & 1135 & 13.91 & 1039 & 30.45 & 943 & 92.93 \\
\hline HLW03-01 & HLW03 & 1245 & 6.16 & 1149 & 11.73 & 1053 & 35.92 & (b) & (b) \\
\hline HLW03-02 & HLW03 & 1253 & 5.95 & 1154 & 13.40 & 1056 & 37.57 & 957 & 159.81 \\
\hline HLW03-03 & HLW03 & 1257 & 4.81 & 1157 & 10.64 & 1057 & 30.91 & 957 & 125.46 \\
\hline HLW03-04 & HLW03 & 1261 & 6.18 & 1163 & 11.31 & 1064 & 28.46 & 965 & 90.61 \\
\hline HLW03-05 & HLW03 & 1251 & 30.18 & 1155 & 64.07 & 1058 & 164.75 & 960 & 476.54 \\
\hline HLW03-06 & HLW03 & 1245 & 39.29 & 1146 & 93.53 & 1049 & 267.56 & 951 & 977.37 \\
\hline HLW03-07 & HLW03 & 1281 & 5.08 & 1192 & 9.29 & 1104 & 21.11 & 1016 & 62.80 \\
\hline HLW03-09 & HLW03 & 1278 & 35.95 & 1175 & 72.51 & 1073 & 175.89 & 970 & 561.84 \\
\hline HLW03-10 & HLW03 & 1252 & 5.69 & 1153 & 12.04 & 1055 & 43.26 & (b) & (b) \\
\hline HLW03-11 & HLW03 & 1261 & 44.28 & 1165 & 95.82 & 1069 & 252.03 & 972 & 788.90 \\
\hline HLW03-12 & HLW03 & 1256 & 11.94 & 1157 & 26.08 & 1057 & 71.77 & 958 & 273.50 \\
\hline HLW03-13 & HLW03 & 1253 & 9.67 & 1153 & 20.42 & (b) & (b) & (b) & (b) \\
\hline HLW03-14 & HLW03 & 1245 & 5.91 & 1148 & 13.12 & 1051 & 37.61 & 953 & 167.78 \\
\hline
\end{tabular}

(a) The Group IDs are described in Sections 2.1.1 to 2.1.9.

(b) Viscosity was not measured at four temperatures for this glass. 
Table 4.6. Melt Viscosity Data for Simulated HLW Glasses (continued).

\begin{tabular}{|c|c|c|c|c|c|c|c|c|c|}
\hline Glass ID & $\begin{array}{l}\text { Group } \\
\text { ID }^{(\mathbf{a})}\end{array}$ & $\begin{array}{c}\text { Temp1 } \\
\left({ }^{\circ} \mathrm{C}\right)\end{array}$ & $\begin{array}{c}\text { Vis1 } \\
\text { (P) }\end{array}$ & $\begin{array}{c}\text { Temp2 } \\
\left({ }^{\circ} \mathrm{C}\right)\end{array}$ & $\begin{array}{c}\text { Vis2 } \\
\text { (P) }\end{array}$ & $\begin{array}{c}\text { Temp3 } \\
\left({ }^{\circ} \mathrm{C}\right)\end{array}$ & $\begin{array}{c}\text { Vis3 } \\
\text { (P) } \\
\end{array}$ & $\begin{array}{c}\text { Temp4 } \\
\left({ }^{\circ} \mathrm{C}\right)\end{array}$ & $\begin{array}{c}\text { Vis4 } \\
\text { (P) }\end{array}$ \\
\hline HLW03-15 & HLW03 & 1260 & 53.15 & 1166 & 120.97 & 1072 & 318.75 & 979 & 1198.38 \\
\hline HLW03-16 & HLW03 & 1248 & 17.92 & 1155 & 39.81 & 1062 & 115.98 & 969 & 461.19 \\
\hline HLW03-17 & HLW03 & 1254 & 71.47 & 1154 & 175.51 & 1055 & 555.02 & 955 & 2259.05 \\
\hline HLW03-18 & HLW03 & 1250 & 17.41 & 1153 & 31.32 & 1056 & 72.41 & 959 & 213.16 \\
\hline HLW03-19 & HLW03 & 1252 & 15.83 & 1153 & 31.44 & 1055 & 74.70 & 956 & 232.06 \\
\hline HLW03-20 & HLW03 & 1252 & 18.75 & 1152 & 31.44 & 1052 & 73.10 & 952 & 213.30 \\
\hline HLW03-21 & HLW03 & 1251 & 52.94 & 1152 & 127.49 & 1054 & 400.00 & 955 & 1725.10 \\
\hline HLW03-22 & HLW03 & 1255 & 18.97 & 1155 & 45.70 & 1055 & 136.42 & 955 & 570.39 \\
\hline HLW03-23 & HLW03 & 1250 & 18.78 & 1150 & 42.33 & 1052 & 117.18 & 953 & 444.89 \\
\hline HLW03-24 & HLW03 & 1254 & 19.96 & 1156 & 45.11 & 1060 & 124.37 & 963 & 437.95 \\
\hline HLW03-25 & HLW03 & 1252 & 12.48 & 1155 & 27.54 & 1059 & 75.02 & 964 & 279.19 \\
\hline HLW03-26 & HLW03 & 1259 & 9.67 & 1162 & 18.33 & 1066 & 49.49 & 971 & 167.66 \\
\hline HLW03-27 & HLW03 & 1252 & 11.30 & 1155 & 23.43 & 1059 & 59.15 & 964 & 200.77 \\
\hline HLW03-28 & HLW03 & 1239 & 6.51 & 1142 & 13.10 & 1046 & 30.38 & 951 & 90.34 \\
\hline HLW03-29 & HLW03 & 1247 & 8.74 & 1150 & 19.18 & 1054 & 51.62 & 958 & 187.70 \\
\hline HLW03-30 & HLW03 & 1249 & 12.54 & 1155 & 26.72 & 1062 & 72.04 & 969 & 243.50 \\
\hline HLW03-31 & HLW03 & 1244 & 24.22 & 1147 & 53.82 & 1051 & 158.48 & 954 & 635.13 \\
\hline HLW03-32 & HLW03 & 1247 & 15.96 & (b) & (b) & (b) & (b) & (b) & (b) \\
\hline HLW03-33 & HLW03 & 1250 & 14.39 & 1153 & 31.97 & 1056 & 90.15 & 960 & 329.48 \\
\hline HLW03-34 & HLW03 & 1249 & 46.31 & 1151 & 112.97 & 1054 & 353.32 & 957 & 1436.25 \\
\hline HLW03-35 & HLW03 & 1243 & 69.54 & 1146 & 177.42 & 1049 & 567.22 & 952 & 2645.67 \\
\hline HLW03-36 & HLW03 & 1246 & 68.84 & 1148 & 184.37 & 1049 & 636.30 & 951 & 3165.51 \\
\hline HLW03-37 & HLW03 & 1246 & 10.94 & 1147 & 22.71 & 1049 & 60.63 & 950 & 201.62 \\
\hline HLW03-38 & HLW03 & 1248 & 42.04 & 1151 & 104.95 & 1053 & 352.03 & 956 & 1741.64 \\
\hline HLW03-39 & HLW03 & 1250 & 28.09 & 1153 & 64.55 & 1056 & 184.89 & 959 & 728.10 \\
\hline HLW03-40 & HLW03 & 1255 & 17.42 & 1156 & 37.28 & 1058 & 106.40 & 959 & 408.01 \\
\hline HLW03-41 & HLW03 & 1244 & 17.13 & 1147 & 39.20 & 1049 & 110.91 & 952 & 442.89 \\
\hline HLW03-42 & HLW03 & 1244 & 29.97 & 1148 & 66.99 & 1052 & 172.22 & 956 & 594.67 \\
\hline HLW03-43 & HLW03 & 1257 & 40.72 & 1161 & 94.67 & 1066 & 285.60 & 971 & 1081.87 \\
\hline HLW03-44 & HLW03 & 1259 & 48.85 & 1161 & 104.35 & 1063 & 257.33 & 965 & 877.42 \\
\hline HLW03-45 & HLW03 & 1257 & 9.30 & 1155 & 18.70 & 1054 & 48.24 & 952 & 201.02 \\
\hline HLW04-01 & HLW04 & 1239 & 21.57 & 1139 & 41.59 & 1041 & 100.90 & 941 & 307.76 \\
\hline HLW04-03 & HLW04 & 1242 & 28.00 & 1144 & 58.74 & 1046 & 152.10 & 948 & 529.86 \\
\hline HLW04-06 & HLW04 & 1240 & 28.47 & 1142 & 59.27 & 1045 & 145.48 & 947 & 420.54 \\
\hline HLW04-07 & HLW04 & 1248 & 22.26 & 1149 & 44.24 & 1050 & 109.91 & 952 & 322.41 \\
\hline
\end{tabular}

(a) The Group IDs are described in Sections 2.1.1 to 2.1.9.

(b) Viscosity was not measured at four temperatures for this glass. 
Table 4.6. Melt Viscosity Data for Simulated HLW Glasses (continued).

\begin{tabular}{|c|c|c|c|c|c|c|c|c|c|}
\hline Glass ID & $\begin{array}{l}\text { Group } \\
\text { ID }^{(a)}\end{array}$ & $\begin{array}{c}\text { Temp1 } \\
\left({ }^{\circ} \mathrm{C}\right)\end{array}$ & $\begin{array}{c}\text { Vis1 } \\
\text { (P) }\end{array}$ & $\begin{array}{c}\text { Temp2 } \\
\left({ }^{\circ} \mathrm{C}\right)\end{array}$ & $\begin{array}{c}\text { Vis2 } \\
\text { (P) }\end{array}$ & $\begin{array}{c}\text { Temp3 } \\
\left({ }^{\circ} \mathrm{C}\right)\end{array}$ & $\begin{array}{l}\text { Vis3 } \\
\text { (P) }\end{array}$ & $\begin{array}{c}\text { Temp4 } \\
\left({ }^{\circ} \mathrm{C}\right)\end{array}$ & $\begin{array}{l}\text { Vis4 } \\
(\mathrm{P})\end{array}$ \\
\hline HLW05-15 & HLW05 & 1269 & 69.68 & 1170 & 185.68 & 1072 & 607.76 & 973 & 2992.31 \\
\hline HLW05-20 & HLW05 & 1259 & 33.35 & 1162 & 72.86 & 1061 & 196.96 & 965 & 732.91 \\
\hline HLW05-21 & HLW05 & 1265 & 6.14 & 1166 & 12.57 & 1067 & 30.90 & 967 & 104.40 \\
\hline HLW05-22 & HLW05 & 1260 & 67.15 & 1163 & 155.59 & 1066 & 434.28 & 968 & 1616.10 \\
\hline HLW05-27 & HLW05 & 1260 & 11.60 & 1162 & 23.57 & 1064 & 56.64 & 965 & 164.21 \\
\hline HLW06-02 & HLW06 & 1262 & 12.61 & 1163 & 25.72 & 1066 & 65.65 & 967 & 202.89 \\
\hline HLW06-04 & HLW06 & 1268 & 13.82 & 1166 & 30.79 & (b) & (b) & (b) & (b) \\
\hline HLW06-22 & HLW06 & 1264 & 7.85 & 1159 & 14.30 & 1060 & 31.33 & 962 & 87.41 \\
\hline HLW06-32 & HLW06 & 1246 & 3.85 & 1151 & 7.27 & 1056 & 15.66 & 960 & 41.34 \\
\hline HLW06-34 & HLW06 & 1256 & 5.69 & 1158 & 12.49 & 1059 & 35.47 & 961 & 143.12 \\
\hline HLW07-01 & HLW07 & 1262 & 31.50 & 1166 & 67.03 & 1071 & 199.52 & 975 & 789.61 \\
\hline HLW07-02 & HLW07 & 1274 & 29.67 & 1173 & 62.41 & 1074 & 150.59 & 974 & 439.11 \\
\hline HLW07-03 & HLW07 & 1260 & 16.94 & 1158 & 37.50 & 1056 & 80.62 & 956 & 359.53 \\
\hline HLW07-04 & HLW07 & 1253 & 52.33 & 1151 & 109.69 & 1049 & 281.79 & 948 & 888.65 \\
\hline HLW07-05 & HLW07 & 1247 & 7.51 & 1157 & 12.18 & 1067 & 31.76 & 979 & 92.23 \\
\hline HLW07-06 & HLW07 & 1245 & 35.88 & 1155 & 96.44 & 1065 & 336.71 & 977 & 1679.68 \\
\hline HLW07-07 & HLW07 & 1255 & 9.19 & 1160 & 16.69 & 1066 & 36.07 & 971 & 107.57 \\
\hline HLW07-09 & HLW07 & 1252 & 6.56 & 1158 & 13.48 & 1064 & 35.05 & 972 & 121.42 \\
\hline HLW07-10 & HLW07 & 1257 & 12.42 & 1162 & 25.67 & 1067 & 73.75 & 974 & 285.30 \\
\hline HLW07-11 & HLW07 & 1256 & 8.84 & 1156 & 17.02 & 1056 & 37.73 & 956 & 119.30 \\
\hline HLW07-12 & HLW07 & 1255 & 9.67 & 1161 & 19.44 & 1067 & 56.58 & 975 & 162.44 \\
\hline HLW07-13 & HLW07 & 1259 & 66.85 & 1160 & 170.87 & 1062 & 531.96 & 1014 & 1063.25 \\
\hline HLW07-15 & HLW07 & 1258 & 10.27 & 1162 & 24.35 & 1066 & 79.23 & 972 & 351.34 \\
\hline HLW07-16 & HLW07 & 1263 & 3.60 & 1160 & 7.49 & 1056 & 17.99 & 951 & 55.89 \\
\hline HLW07-17 & HLW07 & 1264 & 5.65 & 1170 & 10.45 & 1074 & 20.32 & 983 & 45.10 \\
\hline HLW07-18 & HLW07 & 1247 & 5.74 & 1153 & 9.77 & 1059 & 22.06 & 965 & 47.64 \\
\hline HLW07-19 & HLW07 & 1251 & 4.41 & 1159 & 8.19 & 1068 & 19.61 & 979 & 57.90 \\
\hline HLW07-20 & HLW07 & 1254 & 39.36 & 1158 & 80.72 & 1062 & 195.47 & 966 & 685.48 \\
\hline HLW07-21 & HLW07 & 1265 & 48.00 & 1165 & 224.06 & 1065 & 1051.18 & 1016 & 2575.48 \\
\hline HLW07-22 & HLW07 & 1256 & 50.16 & 1155 & 142.90 & 1053 & 517.46 & 951 & 2718.95 \\
\hline HLW07-23 & HLW07 & 1258 & 39.65 & 1160 & 85.00 & 1062 & 261.17 & 966 & 1012.38 \\
\hline HLW07-24 & HLW07 & 1261 & 45.25 & 1164 & 101.86 & 1067 & 308.82 & 972 & 1252.75 \\
\hline HLW07-25 & HLW07 & 1263 & 93.67 & 1165 & 229.41 & 1067 & 669.47 & 1020 & 1454.75 \\
\hline HLW07-26 & HLW07 & 1255 & 48.76 & 1157 & 106.99 & 1059 & 274.78 & 961 & 1004.53 \\
\hline HLW07-27 & HLW07 & 1248 & 17.96 & 1158 & 35.69 & 1068 & 95.47 & 980 & 282.33 \\
\hline
\end{tabular}

(a) The Group IDs are described in Sections 2.1.1 to 2.1.9.

(b) Viscosity was not measured at four temperatures for this glass. 
Table 4.6. Melt Viscosity Data for Simulated HLW Glasses (continued).

\begin{tabular}{|c|c|c|c|c|c|c|c|c|c|}
\hline Glass ID & $\begin{array}{l}\text { Group } \\
\text { ID }^{\text {(a) }}\end{array}$ & $\begin{array}{c}\text { Temp1 } \\
\left({ }^{\circ} \mathrm{C}\right)\end{array}$ & $\begin{array}{l}\text { Vis1 } \\
\text { (P) }\end{array}$ & $\begin{array}{c}\text { Temp2 } \\
\left({ }^{\circ} \mathbf{C}\right)\end{array}$ & $\begin{array}{c}\text { Vis2 } \\
\text { (P) }\end{array}$ & $\begin{array}{c}\text { Temp3 } \\
\left({ }^{\circ} \mathrm{C}\right)\end{array}$ & $\begin{array}{c}\text { Vis3 } \\
\text { (P) } \\
\end{array}$ & $\begin{array}{c}\text { Temp4 } \\
\left({ }^{\circ} \mathrm{C}\right)\end{array}$ & $\begin{array}{c}\text { Vis4 } \\
\text { (P) }\end{array}$ \\
\hline HLW07-28 & HLW07 & 1249 & 34.29 & 1156 & 77.29 & 1063 & 250.59 & 972 & 1060.19 \\
\hline HLW07-29 & HLW07 & 1257 & 19.02 & 1159 & 38.29 & 1061 & 106.47 & 965 & 396.92 \\
\hline HLW07-30 & HLW07 & 1251 & 48.47 & 1156 & 109.12 & 1061 & 327.15 & 966 & 1247.92 \\
\hline HLW07-31 & HLW07 & 1252 & 41.41 & 1159 & 99.38 & 1066 & 292.47 & 975 & 1295.89 \\
\hline HLW07-32 & HLW07 & 1258 & 21.82 & 1156 & 51.14 & 1054 & 162.34 & 952 & 683.02 \\
\hline HLW07-33 & HLW07 & 1242 & 42.40 & 1152 & 98.44 & 1062 & 284.76 & 974 & 1187.56 \\
\hline HLW07-34 & HLW07 & 1248 & 42.20 & 1158 & 101.75 & 1068 & 322.18 & 980 & 1604.68 \\
\hline HLW07-35 & HLW07 & 1249 & 43.44 & 1156 & 98.02 & 1063 & 303.68 & 972 & 1396.56 \\
\hline HLW07-36 & HLW07 & 1253 & 25.02 & 1156 & 51.80 & 1059 & 135.80 & 964 & 476.70 \\
\hline HLW07-37 & HLW07 & 1256 & 9.26 & 1160 & 17.51 & 1066 & 37.93 & 970 & 104.93 \\
\hline HLW07-38 & HLW07 & 1252 & 29.54 & 1157 & 81.89 & 1062 & 262.90 & 969 & 1151.04 \\
\hline HLW07-39 & HLW07 & 1257 & 37.01 & 1163 & 86.34 & 1070 & 277.84 & 976 & 1502.00 \\
\hline HLW07-40 & HLW07 & 1248 & 16.83 & 1157 & 33.92 & 1066 & 76.59 & 977 & 256.23 \\
\hline HLW-ALG-01 & HLWALG & 1253 & 15.18 & 1156 & 28.96 & 1057 & 60.84 & 959 & 167.81 \\
\hline HLW-ALG-02 & HLWALG & 1259 & 16.77 & 1160 & 34.87 & 1059 & 88.47 & 959 & 289.17 \\
\hline HLW-ALG-03 & HLWALG & 1261 & 8.18 & 1161 & 16.08 & 1061 & 36.31 & 960 & 108.34 \\
\hline HLW-ALG-04 & HLWALG & 1262 & 14.78 & 1161 & 27.49 & 1060 & 59.35 & 958 & 170.17 \\
\hline HLW-ALG-05 & HLWALG & 1258 & 7.82 & 1159 & 14.95 & 1058 & 33.06 & 958 & 97.28 \\
\hline HLW-ALG-06 & HLWALG & 1273 & 12.71 & 1170 & 26.24 & 1067 & 62.52 & 964 & 198.59 \\
\hline HLW-ALG-07 & HLWALG & 1255 & 26.85 & 1156 & 58.72 & 1058 & 172.10 & 959 & 639.26 \\
\hline HLW-ALG-08 & HLWALG & 1254 & 8.86 & 1159 & 21.24 & 1065 & 64.77 & 970 & 273.63 \\
\hline HLW-ALG-09 & HLWALG & 1249 & 9.94 & 1153 & 20.60 & 1057 & 46.56 & 963 & 157.46 \\
\hline HLW-ALG-10 & HLWALG & 1267 & 9.19 & 1168 & 17.00 & 1070 & 36.23 & 971 & 95.80 \\
\hline HLW-ALG-11 & HLWALG & 1272 & 10.60 & 1172 & 21.96 & 1073 & 59.33 & 973 & 212.31 \\
\hline HLW-ALG-12 & HLWALG & 1249 & 11.84 & 1160 & 22.81 & 1071 & 52.12 & 984 & 172.35 \\
\hline HLW-ALG-13 & HLWALG & 1249 & 18.47 & 1154 & 42.40 & (b) & (b) & (b) & (b) \\
\hline HLW-ALG-14 & HLWALG & 1261 & 8.88 & 1158 & 17.78 & 1055 & 40.99 & 952 & 121.57 \\
\hline HLW-ALG-15 & HLWALG & 1251 & 15.15 & 1153 & 32.97 & 1054 & 86.45 & 955 & 293.00 \\
\hline HLW-ALG-16 & HLWALG & 1248 & 20.05 & 1151 & 43.02 & 1053 & 110.76 & 956 & 366.30 \\
\hline HLW-ALG-17 & HLWALG & 1264 & 10.02 & 1163 & 17.57 & 1063 & 35.68 & 963 & 95.36 \\
\hline HLW-ALG-18 & HLWALG & 1263 & 28.57 & 1161 & 57.01 & 1060 & 131.16 & 959 & 368.15 \\
\hline HLW-ALG-19 & HLWALG & 1265 & 13.67 & 1164 & 29.04 & 1061 & 73.46 & 959 & 244.87 \\
\hline HLW-ALG-20 & HLWALG & 1262 & 11.83 & 1160 & 24.48 & 1058 & 59.48 & 956 & 192.43 \\
\hline HLW-ALG-21 & HLWALG & 1246 & 14.63 & 1156 & 34.93 & 1066 & 109.65 & 978 & 508.70 \\
\hline HLW-ALG-22 & HLWALG & 1264 & 12.29 & 1169 & 25.65 & 1074 & 77.13 & 981 & 251.52 \\
\hline
\end{tabular}

(a) The Group IDs are described in Sections 2.1.1 to 2.1.9.

(b) Viscosity was not measured at four temperatures for this glass. 
Table 4.6. Melt Viscosity Data for Simulated HLW Glasses (continued).

\begin{tabular}{|c|c|c|c|c|c|c|c|c|c|}
\hline Glass ID & $\begin{array}{l}\text { Group } \\
\text { ID }^{\text {(a) }}\end{array}$ & $\begin{array}{c}\text { Temp1 } \\
\left({ }^{\circ} \mathbf{C}\right)\end{array}$ & $\begin{array}{c}\text { Vis1 } \\
\text { (P) }\end{array}$ & $\begin{array}{c}\text { Temp2 } \\
\left({ }^{\circ} \mathrm{C}\right)\end{array}$ & $\begin{array}{c}\text { Vis2 } \\
\text { (P) }\end{array}$ & $\begin{array}{c}\text { Temp3 } \\
\left({ }^{\circ} \mathrm{C}\right)\end{array}$ & $\begin{array}{c}\text { Vis3 } \\
\text { (P) }\end{array}$ & $\begin{array}{c}\text { Temp4 } \\
\left({ }^{\circ} \mathrm{C}\right)\end{array}$ & $\begin{array}{c}\text { Vis4 } \\
\text { (P) }\end{array}$ \\
\hline HLW-ALG-23 & HLWALG & 1273 & 11.58 & 1173 & 27.14 & 1073 & 78.53 & 973 & 316.45 \\
\hline HLW-ALG-25 & HLWALG & 1271 & 8.27 & 1171 & 15.24 & 1072 & 32.69 & 972 & 85.72 \\
\hline HLW-ALG-26 & HLWALG & 1252 & 26.97 & 1155 & 58.10 & 1057 & 185.41 & 963 & 741.02 \\
\hline HLW-ALG-27 & HLWALG & 1264 & 15.05 & 1163 & 30.56 & 1060 & 69.76 & 958 & 193.88 \\
\hline HLW-ALG-28 & HLWALG & 1263 & 10.63 & 1163 & 20.77 & 1061 & 45.60 & 960 & 125.21 \\
\hline HLW-ALG-29 & HLWALG & 1262 & 15.59 & 1161 & 35.07 & 1059 & 96.19 & 957 & 346.36 \\
\hline HLW-ALG-30 & HLWALG & 1243 & 20.63 & 1148 & 40.42 & 1053 & 98.39 & 960 & 293.76 \\
\hline HLW-ALG-31 & HLWALG & 1260 & 16.93 & 1159 & 37.08 & 1060 & 98.75 & 960 & 350.08 \\
\hline HLW-ALG-32 & HLWALG & 1243 & 8.10 & 1144 & 16.62 & 1046 & 40.33 & 948 & 127.33 \\
\hline HLW-ALG-33 & HLWALG & 1249 & 15.69 & 1149 & 33.05 & 1050 & 83.43 & 951 & 273.94 \\
\hline HLW-ALG-34 & HLWALG & 1236 & 8.54 & 1141 & 16.30 & 1046 & 34.55 & 952 & 88.98 \\
\hline HLW-ALG-35 & HLWALG & 1264 & 13.23 & 1166 & 27.74 & 1068 & 70.12 & 972 & 234.45 \\
\hline HLW-ALG-36 & HLWALG & 1261 & 10.01 & 1163 & 20.33 & 1065 & 51.03 & 969 & 167.31 \\
\hline HLW-ALG-37 & HLWALG & 1255 & 23.55 & 1161 & 56.29 & 1067 & 200.99 & 975 & 760.01 \\
\hline HLW-ALG-38 & HLWALG & 1249 & 21.62 & 1154 & 50.28 & 1059 & 160.64 & (b) & (b) \\
\hline HLW-ALG-39 & HLWALG & 1260 & 27.26 & 1162 & 59.39 & 1064 & 159.64 & 968 & 632.48 \\
\hline HLW-ALG-40 & HLWALG & 1258 & 20.38 & 1155 & 38.86 & 1052 & 107.47 & 951 & 369.89 \\
\hline HLW98-72 & HLW98 & 1277 & 12.06 & 1157 & 27.41 & 1057 & 64.22 & 957 & 176.20 \\
\hline HLW98-77 & HLW98 & 1259 & 22.08 & 1159 & 45.50 & 1059 & 119.42 & 959 & 380.59 \\
\hline HLW98-80 & HLW98 & 1261 & 22.78 & 1160 & 46.80 & 1060 & 114.71 & 967 & 336.45 \\
\hline HLW98-83 & HLW98 & 1264 & 16.82 & 1164 & 33.42 & 1064 & 80.29 & 964 & 238.93 \\
\hline HLW98-84 & HLW98 & 1261 & 22.32 & 1161 & 44.56 & 1060 & 112.24 & 959 & 337.23 \\
\hline HLW98-86AG & HLW98 & 1264 & 18.62 & 1164 & 38.61 & 1063 & 96.93 & 963 & 292.35 \\
\hline HLW98-87 & HLW98 & 1268 & 25.34 & 1166 & 57.51 & 1063 & 159.92 & 960 & 562.36 \\
\hline HLW98-88 & HLW98 & 1266 & 18.50 & 1164 & 40.90 & 1061 & 110.42 & 958 & 361.83 \\
\hline HLW98-89 & HLW98 & 1265 & 24.10 & 1162 & 61.74 & 1059 & 204.75 & 956 & 888.92 \\
\hline HLW98-95 & HLW98 & 1261 & 22.51 & 1161 & 48.55 & 1061 & 129.76 & 961 & 417.86 \\
\hline HLW98-96 & HLW98 & 1250 & 23.06 & 1152 & 55.11 & 1055 & 167.00 & 958 & 675.78 \\
\hline HLW98-96A & HLW98 & 1236 & 21.04 & 1136 & 52.24 & 1036 & 157.05 & 936 & 626.23 \\
\hline HLW98-96B & HLW98 & 1235 & 26.05 & 1135 & 70.36 & 1035 & 228.03 & 935 & 976.11 \\
\hline HLW98-96D & HLW98 & 1255 & 25.90 & 1149 & 58.70 & 1043 & 214.42 & 938 & 777.60 \\
\hline HLW98-97 & HLW98 & 1253 & 19.42 & 1154 & 41.58 & 1054 & 108.18 & 955 & 336.04 \\
\hline HLW98-T05 & HLW98 & 1245 & 22.92 & 1141 & 49.77 & 1036 & 125.61 & 932 & 408.10 \\
\hline HLW98-V19 & HLW98 & 1255 & 15.71 & 1152 & 34.18 & 1050 & 89.24 & 946 & 294.34 \\
\hline HLW98-V24 & HLW98 & 1256 & 22.28 & 1153 & 42.75 & 1048 & 107.38 & 945 & 325.76 \\
\hline
\end{tabular}

(a) The Group IDs are described in Sections 2.1.1 to 2.1.9.

(b) Viscosity was not measured at four temperatures for this glass. 
Table 5.1. List of HLW Glass Compositions with PCT Data Having Outlying Values for One or More Components.

\begin{tabular}{|c|l|c|}
\hline Glass ID & Mass Fractions of Outlying Component Values & $\begin{array}{c}\text { Remove from PCT } \\
\text { Modeling Dataset? }\end{array}$ \\
\hline HLW98-96A & $\begin{array}{l}\mathrm{Ce}_{2} \mathrm{O}_{3}=0.02585 \text { (most below 0.004) } \\
\mathrm{Nd}_{2} \mathrm{O}_{3}=0.01657 \text { (most below 0.003) }\end{array}$ & $\mathrm{Yes}$ \\
\hline $\mathrm{HLW} 98-96 \mathrm{~B}$ & $\begin{array}{l}\mathrm{HfO}_{2}=0.03292 \text { (all others are zero) } \\
\mathrm{Nd}_{2} \mathrm{O}_{3}=1.645 \text { (most below 0.003) }\end{array}$ & $\mathrm{No}^{(\mathrm{a})}$ \\
\hline $\begin{array}{c}\mathrm{HLW} 98-86 \\
\text { HLW98-86CG }\end{array}$ & $\mathrm{SeO}_{2}=0.00369$ (most below 0.002) & $\mathrm{No}^{(\mathrm{a})}$ \\
\hline HLW98-V19 & $\mathrm{SeO}_{2}=0.00432$ (most below 0.002) & $\mathrm{No}^{(\mathrm{a})}$ \\
\hline HLW04-03 & $\mathrm{SnO}_{2}=0.00685$ (others below 0.0025) & $\mathrm{No}^{(\mathrm{a})}$ \\
\hline HLW04-09 & $\mathrm{Gd}_{2} \mathrm{O}_{3}=0.00007$ wt $\%$ is a single non-zero value \\
\hline
\end{tabular}

(a) The outlying values of the specific components are not expected to have a significant impact on PCTcomposition modeling, and so the corresponding HLW glasses were not identified for removal from the modeling dataset. 
Table 5.2. Normalized 25-Component Compositions (mass fractions) of 266 HLW Glasses Used for PCT Model Development.

\begin{tabular}{|c|c|c|c|c|c|c|c|c|c|c|c|c|c|c|c|c|}
\hline Glass ID & $\underset{\text { ID }^{(a)}}{\text { Group }}$ & $\mathbf{A l}_{2} \mathbf{O}_{3}$ & $\mathbf{B}_{2} \mathbf{O}_{3}$ & $\mathrm{CaO}$ & CdO & $\mathrm{Cr}_{2} \mathrm{O}_{3}$ & $\mathrm{Fe}_{2} \mathrm{O}_{3}$ & $\mathrm{~K}_{2} \mathrm{O}$ & $\mathbf{L a}_{2} \mathbf{O}_{3}$ & $\mathbf{L i}_{2} \mathbf{O}$ & MgO & MnO & $\mathrm{Na}_{2} \mathrm{O}$ & $\mathrm{NiO}$ & PbO & $\mathrm{Sb}_{2} \mathrm{O}_{3}$ \\
\hline HLW02-01 & LW02 & 171 & .09927 & 500 & 0771 & 108 & .10899 & .00060 & .00300 & .03996 & .00120 & 2385 & .10957 & .00518 & 0216 & 10 \\
\hline HLW02-02 & LW02 & \begin{tabular}{|l|}
.03999 \\
\end{tabular} & .13996 & .00500 & .01500 & .00199 & .13996 & .00060 & .00300 & .05998 & .00120 & 0000 & .03999 & .00100 & 0400 & 200 \\
\hline HLW02-03 & HLW02 & \begin{tabular}{|l|}
.03999 \\
\end{tabular} & .13998 & .00500 & .01500 & .00199 & .07999 & .00060 & .00300 & .02000 & .00120 & .00000 & .14998 & .01000 & .00400 & .00020 \\
\hline HLW02-04 & HLW02 & \begin{tabular}{|l|}
.04001 \\
\end{tabular} & .05001 & .00500 & .01500 & .00020 & .14002 & .00060 & .00300 & .02000 & .00120 & .00518 & .15002 & .00100 & .00040 & .00200 \\
\hline HLW02-05 & HLW02 & .04000 & .05000 & .00500 & .00050 & .00020 & .08000 & .00060 & .00300 & .06000 & .00120 & .00000 & .13788 & .00100 & .00040 & .00020 \\
\hline HLW02-06 & LW02 & .08501 & .05001 & .00500 & .01500 & .00020 & .08001 & .00060 & .00300 & .04740 & .00120 & .05001 & .15002 & .01000 & .00040 & 020 \\
\hline HLW0 & 02 & .08499 & .04999 & .00500 & .00050 & .00199 & .07999 & .00060 & .00300 & .05999 & .00120 & .00000 & .11703 & .00100 & .00400 & .00200 \\
\hline HLW02-08 & HLW02 & .04000 & .14000 & .00500 & .00050 & .00020 & .09205 & .00060 & .00300 & .03310 & .00120 & .05000 & .15000 & .00100 & .00040 & .00200 \\
\hline HLW02-09 & HLW02 & .08500 & .11589 & .00500 & .00050 & .00020 & .14000 & .00060 & .00300 & .02271 & .00120 & .00000 & .15000 & .01000 & .00040 & .00200 \\
\hline HLW & 02 & .08500 & .14000 & .00500 & .01500 & .00020 & .08000 & .00060 & .00300 & .06000 & .00120 & .00000 & .10513 & .00100 & .00040 & .00020 \\
\hline HLW & & .04001 & .14002 & .00500 & .00050 & .00020 & .08001 & .00060 & .00300 & .06001 & .00120 & .00000 & .10858 & .01000 & .00040 & .00200 \\
\hline HLW02-12 & HL & .03999 & .04999 & .00500 & .01500 & .00199 & .11382 & .00060 & .00300 & .05998 & .00120 & .04999 & .12757 & .01000 & .00400 & 020 \\
\hline HLWC & HLW02 & \begin{tabular}{|l|}
.03999 \\
\end{tabular} & .04999 & .00500 & .00050 & .00199 & .13998 & .00060 & .00300 & .05999 & .00120 & .04999 & .10425 & .00100 & .00400 & .00020 \\
\hline HLW02-14 & HLW02 & .04001 & .05001 & .00500 & .01500 & .00020 & .08001 & .00060 & .00300 & .06001 & .00120 & .02490 & .04141 & .00100 & .00040 & .00200 \\
\hline HLV & & .08499 & .13998 & .00500 & .00050 & .00199 & .13998 & .00060 & .00300 & .02000 & 20 & .04688 & .12539 & .00100 & .00400 & 020 \\
\hline HLW & 02 & .08498 & .04999 & .00500 & .01500 & .00199 & .07998 & .00060 & .00300 & .05998 & .00120 & .04999 & .09651 & .00100 & .00400 & .00200 \\
\hline HLW0 & HLW02 & .08500 & .05000 & .00500 & .01500 & .00020 & .13843 & .00060 & .00300 & .06000 & .00120 & .00000 & .07690 & .00100 & .00040 & .00020 \\
\hline HLW0 & HLW02 & \begin{tabular}{|l|}
.03999 \\
\end{tabular} & .04999 & .00500 & .00050 & .00199 & .11126 & .00060 & .00300 & .02013 & .00120 & .00000 & .14996 & .01000 & .00400 & .00200 \\
\hline HLW & & .04000 & .14000 & .00500 & .01500 & .00020 & .10781 & .00060 & .00300 & .02000 & .00120 & .05000 & .08849 & .00100 & .00040 & .00200 \\
\hline HLW & & .04000 & .14000 & .00500 & .00050 & .00020 & .14000 & .00060 & .00300 & .02000 & .00120 & .00000 & .06453 & .00100 & .00040 & .00020 \\
\hline HLW02-21 & HLW02 & .08500 & .14000 & .00500 & .00050 & .00020 & .08000 & .00060 & .00300 & .02000 & .00120 & .00000 & .15000 & .00100 & .00040 & .00020 \\
\hline HLW02-22 & HLW02 & .08500 & .14000 & .00500 & .00050 & .00020 & .09500 & .00060 & .00300 & .06000 & .00120 & .00000 & .04000 & .00100 & .00040 & .00200 \\
\hline HLW02-23 & HLW02 & .08501 & .14002 & .00500 & .01500 & .00020 & .08001 & .00060 & .00300 & .06001 & .00120 & .05001 & .05591 & .01000 & .00040 & .00020 \\
\hline HLW & ILW02 & & .04999 & .00500 & .00050 & .00153 & .07998 & .00060 & .00300 & .02000 & .00120 & .04999 & .12195 & .00100 & .00307 & .00020 \\
\hline HLW02-25 & \begin{tabular}{|l|} 
HLW02 \\
\end{tabular} & .08501 & .14002 & .00500 & .01500 & .00020 & .09501 & .00060 & .00300 & .02000 & .00120 & .00355 & .06884 & .00100 & .00040 & .00200 \\
\hline HLW02-26 & $\begin{array}{l}\text { HLW02 } \\
\end{array}$ & \begin{tabular}{|l|}
.03999 \\
\end{tabular} & .04999 & .00500 & .01500 & .00199 & .12498 & .00060 & .00300 & .02000 & .00120 & .04959 & .14998 & .00100 & .00400 & .00020 \\
\hline HLW02-27 & HLW02 & .04001 & .14002 & .00500 & .00050 & .00020 & .12502 & .00060 & .00300 & .06001 & .00120 & .03366 & .04275 & .00100 & .00040 & .00020 \\
\hline HLW & HLW02 & .07500 & .08000 & .00500 & .01000 & .00040 & .10451 & .00060 & .00300 & .02500 & .00120 & .01500 & .15001 & .00300 & .00080 & .00050 \\
\hline & \begin{tabular}{|l|} 
HLW02 \\
\end{tabular} & .07499 & .12998 & .00500 & .00500 & .00133 & .09998 & .00060 & .00300 & .03749 & .00120 & .01500 & .08999 & .00300 & .00267 & .00050 \\
\hline HLW02-30 & HLW02 & .05500 & .09721 & .00500 & .01000 & .00040 & .10000 & .00060 & .00300 & .05000 & .00120 & .03500 & .11228 & .00300 & .00080 & .00150 \\
\hline
\end{tabular}

(a) The Group IDs are described in Sections 2.1.1 to 2.1.9. 
Table 5.2. Normalized 25-Component Compositions (mass fractions) of 266 HLW Glasses Used for PCT Model Development (continued).

\begin{tabular}{|c|c|c|c|c|c|c|c|c|c|c|c|c|}
\hline Gla & $\underset{\text { ID }^{(a)}}{\text { Group }}$ & $\mathrm{SeO}_{2}$ & $\mathrm{SiO}_{2}$ & SrO & $\mathrm{ThO}_{2}$ & $\mathrm{TiO}_{2}$ & $\mathbf{T l}_{2} \mathbf{O}$ & $\mathbf{U O}_{3}$ & $\mathrm{ZnO}$ & $\mathrm{ZrO}_{2}$ & Others & Sum $^{(b)}$ \\
\hline HLW02-01 & LW02 & 0110 & .43612 & 2444 & .00000 & .00030 & .00102 & .00000 & .02000 & .02974 & .01690 & 1.00000 \\
\hline HLW02-02 & LW02 & .00020 & .50445 & .00000 & .00000 & .00030 & .00019 & .00000 & .01999 & .00000 & .02119 & 1.00000 \\
\hline HLW02-03 & ILW02 & .00200 & .37994 & .04379 & .00000 & .00030 & .00186 & .00000 & .02000 & .05999 & .02120 & 1.00000 \\
\hline HLW02-04 & LW02 & .00200 & .52939 & .00000 & .00000 & .00030 & .00186 & .00000 & .02000 & .00000 & .01281 & 1.00000 \\
\hline HLW02-05 & ILW02 & .00020 & .52652 & .00000 & .00000 & .00030 & .00019 & .00000 & .02000 & .06000 & .01281 & 1.00000 \\
\hline HLW02-06 & HLW02 & .00200 & .40496 & .00000 & .00000 & .00030 & .00186 & .00000 & .02000 & .06001 & .01281 & 1.00000 \\
\hline \begin{tabular}{|l|} 
HLW2-07 \\
\end{tabular} & ILW02 & .00020 & .52992 & .00000 & .00000 & .00030 & .00186 & .00000 & .02000 & .01525 & .02120 & 1.00000 \\
\hline \begin{tabular}{|l|} 
HLWO \\
\end{tabular} & LW02 & .00020 & .38744 & .00000 & .00000 & .00030 & .00019 & .00000 & .02000 & .06000 & .01281 & 1.00000 \\
\hline HLW0 & & .00020 & .38000 & .05000 & .00000 & .00030 & .00019 & .00000 & .02000 & .00000 & .01281 & 1.00000 \\
\hline HLW02-10 & HLW02 & .00200 & .38000 & .02797 & .00000 & .00030 & .00019 & .00000 & .02000 & .06000 & .01281 & 1.00000 \\
\hline HLW02-11 & HLW02 & .00200 & .45149 & .00000 & .00000 & .00030 & .00186 & .00000 & .02000 & .06001 & .01281 & 1.00000 \\
\hline HLW0 & LW02 & .00200 & .41402 & .00000 & .00000 & .00030 & .00019 & .00000 & .01999 & .05998 & .02119 & 1.00000 \\
\hline HLV & & .00200 & .43114 & .04999 & .00000 & .00030 & .00186 & .00000 & .02000 & .01182 & .02120 & 000 \\
\hline HLV & HLW02 & .00020 & .53007 & .05001 & .00000 & .00030 & .00186 & .00000 & .02000 & .06001 & .01281 & 1.00000 \\
\hline HLW02-15 & HLW02 & .00200 & .37994 & .00000 & .00000 & .00030 & .00186 & .00000 & .02000 & .00000 & .02120 & 1.00000 \\
\hline HLW02-16 & HLW02 & .00200 & .39115 & .04999 & .00000 & .00030 & .00019 & .00000 & .01999 & .05998 & .02119 & 1.00000 \\
\hline HLW & LW02 & .00020 & .52958 & .00000 & .00000 & .00030 & .00019 & .00000 & .02000 & .00000 & .01281 & 1.00000 \\
\hline HLW & LW02 & .00020 & .49852 & .00000 & .00000 & .00030 & .00019 & .00000 & .01999 & .05998 & .02119 & 1.00000 \\
\hline HLWC & HLW02 & .00200 & .38000 & .05000 & .00000 & .00030 & .00019 & .00000 & .02000 & .06000 & .01281 & 1.00000 \\
\hline HLW02-20 & HLW02 & .00020 & .51734 & .03253 & .00000 & .00030 & .00019 & .00000 & .02000 & .00000 & .01281 & 1.00000 \\
\hline HLW02-21 & HLW02 & .00020 & .46440 & .00000 & .00000 & .00030 & .00019 & .00000 & .02000 & .01500 & .01281 & 1.00000 \\
\hline HLW & HLW02 & .00200 & .53000 & .00080 & .00000 & .00030 & .00019 & .00000 & .02000 & .00000 & .01281 & 1.00000 \\
\hline HLW02-23 & \begin{tabular}{|l|} 
HLW02 \\
\end{tabular} & .00020 & .39325 & .05001 & .00000 & .00030 & .00186 & .00000 & .02000 & .01500 & .01281 & 1.00000 \\
\hline HLW02-24 & HLW02 & .00200 & .47052 & .04999 & .00000 & .00030 & .00019 & .00000 & .02000 & .01500 & .01903 & 1.00000 \\
\hline HLW02-25 & HLW02 & .00020 & .47398 & .05001 & .00000 & .00030 & .00186 & .00000 & .02000 & .00000 & .01281 & 1.00000 \\
\hline HLW02-26 & HLW02 & .00020 & .37994 & .04999 & .00000 & .00030 & .00186 & .00000 & .02000 & .05999 & .02120 & 1.00000 \\
\hline HLW & & & .39946 & .05001 & .00000 & .00030 & .00186 & .00000 & .02000 & .06001 & .01281 & 1.00000 \\
\hline HLW02-28 & \begin{tabular}{|l|} 
HLW02 \\
\end{tabular} & .00050 & .41003 & .03500 & .00000 & .00030 & .00140 & .00000 & .02000 & .04500 & .01374 & 1.00000 \\
\hline HLW02-29 & HLW02 & .00150 & .40994 & .03499 & .00000 & .00030 & .00046 & .00000 & .02000 & .04499 & .01809 & 1.00000 \\
\hline HLW02-30 & HLW02 & .00050 & .41000 & .03500 & .00000 & .00030 & .00047 & .00000 & .02000 & .04500 & .01374 & 1.00000 \\
\hline
\end{tabular}

(a) The Group IDs are described in Sections 2.1.1 to 2.1.9.

(b) The component mass fractions are normalized to sum to one over the 25 components listed in this table. The normalized component mass fractions listed in this table were rounded to five decimals, and may not sum exactly to 1.00000 as listed. However, complete compositions listed to more decimal places and summing to 1.0000 were used for property-composition modeling. 
Table 5.2. Normalized 25-Component Compositions (mass fractions) of 266 HLW Glasses Used for PCT Model Development (continued).

\begin{tabular}{|c|c|c|c|c|c|c|c|c|c|c|c|c|c|c|c|c|}
\hline ID & $\underset{\text { ID }^{(a)}}{\text { Group }}$ & $\mathbf{A l}_{2} \mathbf{O}_{3}$ & $\mathbf{B}_{2} \mathbf{O}_{3}$ & $\mathrm{CaO}$ & $\mathrm{CdO}$ & $\mathrm{Cr}_{2} \mathrm{O}_{3}$ & $\mathrm{Fe}_{2} \mathrm{O}_{3}$ & $\mathbf{K}_{2} \mathbf{O}$ & $\mathbf{L a}_{2} \mathbf{O}_{3}$ & $\mathbf{L i}_{2} \mathbf{O}$ & MgO & MnO & $\mathrm{Na}_{2} \mathrm{O}$ & $\mathrm{NiO}$ & PbO & $\mathrm{Sb}_{2} \mathrm{O}_{3}$ \\
\hline HLW02-31 & LW02 & 5500 & 3001 & 0500 & 0500 & .00040 & .10001 & 0060 & 0300 & .02500 & .00120 & .01500 & .14982 & .00300 & .00080 & .00050 \\
\hline HLW0 & W02 & \begin{tabular}{|l|}
.07500 \\
\end{tabular} & 8000 & 0500 & 1000 & .00040 & .10000 & .00060 & 0300 & .05000 & .00120 & .01500 & .10733 & .00300 & 80 & 150 \\
\hline HLW02-33 & $\mathrm{CW} 02$ & .06341 & .08000 & .00500 & .00500 & .00040 & .12000 & .00060 & .00300 & .02500 & .00120 & .03500 & .15000 & .00800 & .00080 & 0150 \\
\hline HLW02-34 & W02 & \begin{tabular}{|l|}
.05499 \\
\end{tabular} & .12998 & .00500 & .01000 & .00133 & .11998 & .00060 & .00300 & .03957 & .00120 & .01500 & 0891 & .00800 & .00267 & 050 \\
\hline HLW02-35 & LW02 & .06488 & .12999 & .00500 & .00500 & .00133 & .11999 & .00060 & .00300 & .05000 & .00120 & .03500 & .09160 & .00800 & .00267 & .00150 \\
\hline HLW02-36 & LW02 & \begin{tabular}{|l|}
.05499 \\
\end{tabular} & .08667 & .00500 & .01000 & .00133 & .11998 & .00060 & .00300 & .02500 & .00120 & .01500 & .14998 & .00300 & .00267 & .00050 \\
\hline HLW02-37 & & .06762 & .13000 & .00500 & .00500 & .00040 & .10000 & .00060 & .00300 & .02500 & .00120 & .03500 & .11188 & .00800 & .00080 & 150 \\
\hline HLW & W02 & .06893 & .12998 & .00500 & .01000 & .00133 & .11998 & .00060 & .00300 & .04255 & .00120 & .01500 & .08999 & .00800 & .00267 & 150 \\
\hline HLV & & \begin{tabular}{|l|}
.07500 \\
\end{tabular} & .08991 & .00500 & .01000 & .00040 & .10000 & .00060 & .00300 & .02500 & .00120 & .01500 & .11058 & .00800 & .00080 & 050 \\
\hline HLW02-40 & LW02 & \begin{tabular}{|c|}
.07499 \\
\end{tabular} & .09833 & .00500 & .01000 & .00133 & .09999 & .00060 & .00300 & .02632 & .00120 & .01500 & .09683 & .00300 & .00267 & .00150 \\
\hline HLW02-41 & LW02 & .06500 & .13001 & .00500 & .00500 & .00040 & .10001 & .00060 & .00300 & .02500 & .00120 & .01500 & .09001 & .00300 & .00080 & .00050 \\
\hline HLW & W02 & .05500 & .13001 & .00500 & .00500 & .00040 & .10001 & .00060 & .00300 & .05000 & .00120 & .01500 & .09001 & .00300 & .00080 & 050 \\
\hline HLV & W02 & .06500 & .13000 & .00500 & .01000 & .00040 & .10000 & .00060 & .00300 & .02500 & .00120 & .03500 & .12450 & .00300 & .00080 & 150 \\
\hline HLV & 02 & \begin{tabular}{|l|}
.05499 \\
\end{tabular} & .09069 & .00500 & .01000 & .00133 & .09998 & .00060 & .00300 & .02500 & .00120 & .03499 & .14998 & .00300 & .00267 & 150 \\
\hline HLW & LW02 & .05500 & .08000 & .00500 & .01000 & .00040 & .11000 & .00060 & .00300 & .02500 & .00120 & .03500 & .09619 & .00300 & .00080 & .00050 \\
\hline HLW02-46 & LW02 & .05500 & .09149 & .00500 & .00500 & .00040 & .10001 & .00060 & .00300 & .03701 & .00120 & .03500 & .09001 & .00800 & .00080 & .00050 \\
\hline$\overline{\mathrm{HLV}}$ & & \begin{tabular}{|l|}
.05499 \\
\end{tabular} & .09806 & .00500 & .00500 & & .09999 & .00060 & .00300 & .02500 & .00120 & .03500 & .09443 & .00300 & .00267 & 050 \\
\hline HLW & $\mathrm{LW} 02$ & .05999 & .07999 & .00500 & .00500 & .00133 & .11999 & .00060 & .00300 & .03339 & .00120 & .01500 & .14999 & .00800 & .00267 & .00150 \\
\hline HLW02-49 & LW02 & .07500 & .08740 & .00500 & .00500 & .00040 & .12001 & .00060 & .00300 & .05000 & .00120 & .03500 & .09001 & .00300 & .00080 & .00050 \\
\hline HLW02-50 & LW02 & .06000 & .13001 & .00500 & .00500 & .00040 & .12001 & .00060 & .00300 & .02500 & .00120 & .01500 & .09821 & .00300 & .00080 & .00150 \\
\hline HLW02-51 & & \begin{tabular}{|l|}
.07500 \\
\end{tabular} & .08000 & .00500 & .00500 & & .10501 & & .00300 & .04589 & .00120 & .01500 & .09001 & .00300 & .00080 & .00150 \\
\hline HLW & LW02 & \begin{tabular}{|l|}
.06171 \\
\end{tabular} & .09927 & .00500 & .00771 & .00108 & .10899 & .00060 & .00300 & .03996 & .00120 & .02385 & .10957 & .00518 & .00216 & 110 \\
\hline HLW02-53 & HLW02 & .08500 & .05000 & .00500 & .01500 & .00020 & .13843 & .00060 & .00300 & .06000 & .00120 & .00000 & .07690 & .00100 & .00040 & .00020 \\
\hline HLW02-54 & HLW02 & .04001 & .05001 & .00500 & .01500 & .00020 & .14002 & .00060 & .00300 & .02000 & .00120 & .00518 & .15002 & .00100 & .00040 & .00200 \\
\hline HLW02-55 & LW02 & .05500 & .13001 & .00500 & .00500 & .00040 & .10001 & .00060 & .00300 & .05000 & .00120 & .01500 & .09001 & .00300 & .00080 & .00050 \\
\hline HLW02-56 & LW02 & \begin{tabular}{|l|}
.05499 \\
\end{tabular} & .09069 & .00500 & .01000 & & .09998 & .00060 & .00300 & .02500 & .00120 & .03499 & .14998 & .00300 & .00267 & .00150 \\
\hline HLW02-57 & W02 & $\begin{array}{l}.04000 \\
\end{array}$ & .14000 & .00500 & .00050 & .00020 & .09205 & .00060 & .00300 & .03310 & .00120 & .05000 & .15000 & .00100 & .00040 & .00200 \\
\hline HLW03-01 & \begin{tabular}{|l|} 
HLW03 \\
\end{tabular} & .08335 & .13727 & .00500 & .00050 & .00020 & .13727 & .00060 & .00300 & .05883 & .00120 & .06078 & .03922 & .00098 & .00400 & .00020 \\
\hline HLW03-02 & HLW03 & .01951 & .13662 & .00500 & .01600 & .00488 & .13662 & .00060 & .00300 & .02473 & .00120 & .06832 & .11177 & .00976 & .00040 & .00300 \\
\hline HLW03-03 & HLW03 & .01953 & .04884 & .00500 & .01600 & .00488 & .13677 & .00060 & .00300 & .02678 & .00120 & .06839 & .10755 & .00977 & .00040 & .00020 \\
\hline
\end{tabular}

(a) The Group IDs are described in Sections 2.1.1 to 2.1.9. 
Table 5.2. Normalized 25-Component Compositions (mass fractions) of 266 HLW Glasses Used for PCT Model Development (continued).

\begin{tabular}{|c|c|c|c|c|c|c|c|c|c|c|c|c|}
\hline Gla & $\underset{\text { ID }^{(a)}}{\text { Group }}$ & $\mathrm{SeO}_{2}$ & $\mathrm{SiO}_{2}$ & SrO & $\mathrm{ThO}_{2}$ & $\mathrm{TiO}_{2}$ & $\mathbf{T l}_{2} \mathbf{O}$ & $\mathbf{U O}_{3}$ & $\mathrm{ZnO}$ & $\mathrm{ZrO}_{2}$ & Others & Sum $^{(b)}$ \\
\hline HLW02-31 & LW02 & 0150 & 1003 & 1500 & 0000 & .00030 & .00140 & .00000 & .02000 & 04369 & .01374 & 1.00000 \\
\hline HLW02-32 & LW02 & .00150 & .46117 & .03500 & .00000 & .00030 & .00047 & .00000 & .02000 & .01500 & .01374 & 1.00000 \\
\hline HLW02-33 & ILW02 & .00150 & .41000 & .03500 & .00000 & .00030 & .00047 & .00000 & .02000 & .02009 & .01374 & 1.00000 \\
\hline HLW02-34 & LW02 & .00050 & .40994 & .03499 & .00000 & .00030 & .00046 & .00000 & .02000 & .01500 & .01809 & 1.00000 \\
\hline HLW02-35 & ILW02 & .00050 & .40996 & .01500 & .00000 & .00030 & .00140 & .00000 & .02000 & .01500 & .01809 & 1.00000 \\
\hline HLW02-36 & HLW02 & .00150 & .45074 & .01500 & .00000 & .00030 & .00046 & .00000 & .02000 & .01500 & .01809 & 1.00000 \\
\hline \begin{tabular}{|l|} 
HLW -37 \\
\end{tabular} & ILW02 & .00050 & .41000 & .01500 & .00000 & .00030 & .00047 & .00000 & .02000 & .04500 & \begin{tabular}{|l|l|}
.01374 \\
\end{tabular} & 1.00000 \\
\hline HLW & LW02 & .00150 & .40994 & .03499 & .00000 & .00030 & .00046 & .00000 & .02000 & .01500 & .01809 & 1.00000 \\
\hline HLWC & & .00050 & .49000 & .01500 & .00000 & .00030 & .00047 & .00000 & .02000 & .01500 & .01374 & 1.00000 \\
\hline HLW02-40 & HLW02 & .00050 & .48996 & .01500 & .00000 & .00030 & .00140 & .00000 & .02000 & .01500 & .01809 & 1.00000 \\
\hline HLW02-41 & HLW02 & .00050 & .48953 & .01500 & .00000 & .00030 & .00140 & .00000 & .02000 & .01500 & .01374 & 1.00000 \\
\hline HLW02-42 & LW02 & .00050 & .44453 & .03500 & .00000 & .00030 & .00140 & .00000 & .02000 & .02500 & .01374 & 1.00000 \\
\hline HLV & LW02 & .00050 & .41000 & .03500 & .00000 & .00030 & .00047 & .00000 & .02000 & .01500 & .01374 & 000 \\
\hline HLV & HLW02 & .00050 & .43673 & .01500 & .00000 & .00030 & .00046 & .00000 & .02000 & .02500 & .01809 & 1.00000 \\
\hline HLW02-45 & HLW02 & .00150 & .48831 & .03500 & .00000 & .00030 & .00047 & .00000 & .02000 & .01500 & .01374 & 1.00000 \\
\hline HLW02-46 & HLW02 & .00150 & .49003 & .01500 & .00000 & .00030 & .00140 & .00000 & .02000 & .02500 & .01374 & 1.00000 \\
\hline HLW & LW02 & .00050 & .48996 & .01500 & .00000 & .00030 & .00140 & .00000 & .02000 & .02500 & .01809 & 1.00000 \\
\hline HLW & LW02 & .00150 & .40996 & .01710 & .00000 & .00030 & .00140 & .00000 & .02000 & .04500 & .01809 & 1.00000 \\
\hline HLW02-49 & HLW02 & .00050 & .44213 & .01500 & .00000 & .00030 & .00140 & .00000 & .02000 & .03000 & .01374 & 1.00000 \\
\hline \begin{tabular}{|l|} 
HLW02-50 \\
\end{tabular} & HLW02 & .00050 & .43532 & .01500 & .00000 & .00030 & .00140 & .00000 & .02000 & .04500 & \begin{tabular}{|l|}
.01374 \\
\end{tabular} & 1.00000 \\
\hline HLW02-51 & HLW02 & .00150 & .45164 & .03500 & .00000 & .00030 & .00140 & .00000 & .02000 & .04500 & .01374 & 1.00000 \\
\hline HLW02-52 & HLW02 & .00110 & .43612 & .02444 & .00000 & .00030 & .00102 & .00000 & .02000 & .02974 & .01690 & 1.00000 \\
\hline HLW02-53 & \begin{tabular}{|l|} 
HLW02 \\
\end{tabular} & .00020 & .52958 & .00000 & .00000 & .00030 & .00019 & .00000 & .02000 & .00000 & .01281 & 1.00000 \\
\hline HLW02-54 & HLW02 & .00200 & .52939 & .00000 & .00000 & .00030 & .00186 & .00000 & .02000 & .00000 & .01281 & 1.00000 \\
\hline HLW02-55 & HLW02 & .00050 & .44453 & .03500 & .00000 & .00030 & .00140 & .00000 & .02000 & .02500 & .01374 & 1.00000 \\
\hline HLW02-56 & HLW02 & .00050 & .43673 & .01500 & .00000 & .00030 & .00046 & .00000 & .02000 & .02500 & .01809 & 1.00000 \\
\hline HLW & & & .38744 & .00000 & .00000 & .00030 & .00019 & .00000 & .02000 & .06000 & .01281 & 1.00000 \\
\hline HLW03-01 & \begin{tabular}{|l|} 
HLW03 \\
\end{tabular} & .00200 & .35299 & .00000 & .02764 & .00030 & .00307 & .00000 & .03059 & .02983 & .02120 & 1.00000 \\
\hline HLW03-02 & HLW03 & .00020 & .35132 & .00000 & .00000 & .00030 & .00307 & .00000 & .00000 & .09088 & .01281 & 1.00000 \\
\hline HLW03-03 & HLW03 & .00200 & .35169 & .09769 & .00000 & .00030 & .00307 & .00000 & .01946 & .06404 & .01281 & 1.00000 \\
\hline
\end{tabular}

(a) The Group IDs are described in Sections 2.1.1 to 2.1.9.

(b) The component mass fractions are normalized to sum to one over the 25 components listed in this table. The normalized component mass fractions listed in this table were rounded to five decimals, and may not sum exactly to 1.00000 as listed. However, complete compositions listed to more decimal places and summing to 1.0000 were used for property-composition modeling. 
Table 5.2. Normalized 25-Component Compositions (mass fractions) of 266 HLW Glasses Used for PCT Model Development (continued).

\begin{tabular}{|c|c|c|c|c|c|c|c|c|c|c|c|c|c|c|c|c|}
\hline Gla & $\underset{\text { ID }^{(a)}}{\text { Group }}$ & $\mathbf{A l}_{2} \mathbf{O}_{3}$ & $\mathbf{B}_{2} \mathbf{O}_{3}$ & $\mathrm{CaO}$ & CdO & $\mathrm{Cr}_{2} \mathrm{O}_{3}$ & $\mathrm{Fe}_{2} \mathrm{O}_{3}$ & $\mathrm{~K}_{2} \mathrm{O}$ & $\mathbf{L a}_{2} \mathbf{O}_{3}$ & $\mathbf{L i}_{2} \mathbf{O}$ & MgO & MnO & $\mathrm{Na}_{2} \mathrm{O}$ & $\mathrm{NiO}$ & PbO & $\mathrm{Sb}_{2} \mathrm{O}_{3}$ \\
\hline HLW03-04 & LW03 & 1954 & 4886 & 0498 & 0050 & 0488 & 3680 & 0060 & 0299 & 5862 & 0120 & 3161 & 4442 & 0098 & 0399 & .00020 \\
\hline HLW0 & LW03 & 8175 & .04809 & .00500 & .01600 & .00481 & .01924 & .00060 & .00300 & .01924 & .00120 & .06733 & .14427 & .00096 & .00400 & 300 \\
\hline HLW03-06 & LW03 & .08344 & .04908 & .00500 & .01600 & .00491 & .01963 & .00060 & .00300 & .05890 & .00120 & .06872 & .03927 & 00982 & .00040 & .00020 \\
\hline HLW03-07 & HLW03 & .04961 & .04961 & .00498 & .00050 & .00496 & .13891 & .00060 & .00299 & .04750 & .00120 & .06945 & .11693 & .00100 & .00040 & .00020 \\
\hline HLW03-08 & HLW03 & .08031 & .04833 & .00500 & .01600 & .00483 & .01933 & .00060 & .00300 & .05151 & .00120 & .06766 & .14499 & .00097 & .00400 & .00300 \\
\hline HLW03-09 & HLW03 & .07668 & .13695 & .00500 & .00050 & .00020 & .03486 & .00060 & .00300 & .01979 & .00120 & .00000 & .14848 & .00099 & .00040 & .00300 \\
\hline HLW03-10 & \begin{tabular}{|l|} 
HLW03 \\
\end{tabular} & .08369 & .04924 & .00500 & .00050 & .00020 & .09982 & .00060 & .00300 & .05908 & .00120 & .06893 & .12851 & .00985 & .00400 & .00020 \\
\hline HLW0 & HLW03 & .01984 & .04961 & .00498 & .00050 & .00020 & .09538 & .00060 & .00299 & .01984 & .00120 & .00000 & .14883 & .00100 & .00040 & .00020 \\
\hline HLW03-12 & HLW03 & .01982 & .04956 & .00498 & .00050 & .00495 & .01982 & .00060 & .00299 & .05008 & .00120 & .06939 & .03965 & .00099 & .00040 & .00299 \\
\hline HLW03-13 & HLW03 & .08433 & .04961 & .00498 & .00050 & .00496 & .08633 & .00060 & .00299 & .05209 & .00120 & .06945 & .03969 & .00992 & .00040 & .00020 \\
\hline HLV & 03 & .01989 & .04973 & .00500 & .00050 & .00020 & .09047 & .00060 & .00300 & .02504 & .00120 & .06962 & .10425 & .00994 & .00040 & 020 \\
\hline HLW & 03 & .01951 & .13662 & .00500 & .01600 & .00020 & .13662 & .00060 & .00300 & .01951 & .00120 & .01348 & .05248 & .00098 & .00040 & 300 \\
\hline HLW & HLW03 & .01955 & .04886 & .00498 & .00050 & .00020 & .07905 & .00060 & .00299 & .02862 & .00120 & .06840 & .03909 & .00977 & .00398 & .00299 \\
\hline HLW & HLW03 & .08352 & .13757 & .00499 & .00050 & .00020 & .01965 & .00060 & .00299 & .01965 & .00120 & .06879 & .04461 & .00293 & .00399 & .00020 \\
\hline HLW03-18 & HLW03 & .01989 & .04973 & .00500 & .00050 & .00497 & .13924 & .00060 & .00300 & .05922 & .00120 & .00000 & .10533 & .00980 & .00040 & .00020 \\
\hline HLW & HLW03 & .01963 & .04908 & .00500 & .01600 & .00491 & .09634 & .00060 & .00300 & .05890 & .00120 & .00197 & .10142 & .00982 & .00040 & .00020 \\
\hline HLV & \begin{tabular}{|l|} 
HLW03 \\
\end{tabular} & .01923 & .04808 & .00500 & .01600 & .00019 & .13462 & .00060 & .00300 & .05769 & .00120 & .00000 & .10097 & .00962 & .00400 & 0300 \\
\hline HLW03-21 & HLW03 & .04958 & .06941 & .00499 & .00300 & .00079 & .04958 & .00060 & .00300 & .02479 & .00120 & .04462 & .10828 & .00298 & .00080 & .00050 \\
\hline HLW03-22 & HLW03 & .04915 & .06881 & .00499 & .00299 & .00079 & .09752 & .00060 & .00299 & .02458 & .00120 & .01474 & .11797 & .00295 & .00267 & .00050 \\
\hline HLW03-23 & HLW03 & .04957 & .11897 & .00499 & .00100 & .00199 & .07733 & & .00299 & .02478 & .00120 & .01487 & .11897 & .00297 & .00080 & .00050 \\
\hline HLW & \begin{tabular}{|l|} 
HLW03 \\
\end{tabular} & .02975 & .06941 & .00499 & .00300 & .00079 & .04958 & & & .04958 & & .04462 & & .00495 & & .00050 \\
\hline HLW03-25 & HLW03 & .02956 & .11823 & .00499 & .00100 & .00079 & .04927 & .00060 & .00300 & .02463 & .00120 & .01478 & .11823 & .00492 & .00267 & .00050 \\
\hline HLW03-26 & HLW03 & .04921 & .06889 & .00499 & .00100 & .00197 & .04921 & .00060 & .00299 & .04921 & .00120 & .01476 & .10431 & .00492 & .00267 & .00150 \\
\hline HLW03-27 & HLW03 & .04926 & .06897 & .00499 & .00100 & .00197 & .09359 & .00060 & .00300 & .04040 & .00120 & .01478 & .11822 & .00492 & .00267 & .00150 \\
\hline HLW03-28 & & & & .00499 & .00100 & & .09926 & & .00300 & .04963 & .00120 & .01489 & .10486 & .00496 & .00080 & .00150 \\
\hline HLW03-29 & HLW03 & .02971 & .06933 & .00499 & .00299 & .00199 & .04952 & .00060 & .00299 & .04952 & .00120 & .03518 & .11885 & .00297 & .00080 & .00050 \\
\hline HLW03-30 & HLW03 & .02972 & .11888 & .00499 & .00100 & .00079 & .04953 & .00060 & .00300 & .04953 & .00120 & .04458 & .06934 & .00298 & .00080 & .00150 \\
\hline HLW03-31 & HLW03 & .04953 & .06934 & .00499 & .00100 & .00198 & .04953 & .00060 & .00300 & .04953 & .00120 & .04458 & .08533 & .00495 & .00080 & .00150 \\
\hline HLW03-32 & HLW03 & .04921 & .06889 & .00499 & .00100 & .00079 & .04921 & .00060 & .00299 & .04921 & .00120 & .02925 & .09101 & .00492 & .00267 & .00150 \\
\hline HLW03-33 & HLW03 & .04960 & .11902 & .00499 & .00100 & .00199 & .09919 & .00060 & .00299 & .03898 & .00120 & .01488 & .06943 & .00451 & .00080 & .00150 \\
\hline
\end{tabular}

(a) The Group IDs are described in Sections 2.1.1 to 2.1.9. 
Table 5.2. Normalized 25-Component Compositions (mass fractions) of 266 HLW Glasses Used for PCT Model Development (continued).

\begin{tabular}{|c|c|c|c|c|c|c|c|c|c|c|c|c|}
\hline Gla & $\underset{\text { ID }^{(a)}}{\text { Group }}$ & $\mathrm{SeO}_{2}$ & $\mathrm{SiO}_{2}$ & SrO & $\mathrm{ThO}_{2}$ & $\mathrm{TiO}_{2}$ & $\mathbf{T l}_{2} \mathbf{O}$ & $\mathbf{U O}_{3}$ & $\mathrm{ZnO}$ & $\mathrm{ZrO}_{2}$ & Others & Sum $^{(b)}$ \\
\hline HLW03-04 & LW03 & 0199 & .42425 & 99771 & 0000 & .00030 & .00306 & .06210 & .00000 & 02932 & 02113 & 1.00000 \\
\hline HLW03-05 & LW03 & .00200 & .47837 & .00000 & .03812 & .00030 & .00307 & .00000 & .03847 & .00000 & .02120 & 1.00000 \\
\hline HLW03-06 & ILW03 & .00020 & .52031 & .05091 & .01416 & .00030 & .00019 & .00000 & .00000 & .04095 & .01281 & 1.00000 \\
\hline HLW03-07 & LW03 & .00199 & .39825 & .00000 & .00000 & .00030 & .00019 & .06306 & .03461 & .00000 & .01276 & 1.00000 \\
\hline HLW03-08 & ILW03 & .00020 & .34797 & .00000 & .04412 & .00030 & .00019 & .00000 & .03866 & .09666 & .02119 & 1.00000 \\
\hline HLW03-09 & HLW03 & .00200 & .52465 & .00000 & .02552 & .00030 & .00307 & .00000 & .00000 & .00000 & .01281 & 1.00000 \\
\hline HLW03-10 & ILW03 & .00020 & .35449 & .00000 & .02626 & .00030 & .00019 & .01108 & .00000 & .07250 & .02118 & 1.00000 \\
\hline HLW03-11 & LW03 & .00199 & .52586 & .00000 & .05027 & .00030 & .00019 & .06306 & .00000 & .00000 & .01276 & 1.00000 \\
\hline HLW03-12 & & .00020 & .44277 & .09912 & .03729 & .00030 & .00019 & .06299 & .03965 & .03682 & .01276 & 1.00000 \\
\hline HLW03-13 & HLW03 & .00199 & .35719 & .09922 & .03836 & .00030 & .00019 & .06306 & .01121 & .00846 & .01276 & 1.00000 \\
\hline HLW03-14 & HLW03 & .00020 & .35806 & .09946 & .04115 & .00030 & .00307 & .00000 & .03979 & .06511 & .01281 & 1.00000 \\
\hline HLW03-15 & LW03 & .00020 & .51722 & .00000 & .02441 & .00030 & .00307 & .00000 & .03337 & .00000 & .01281 & 1.00000 \\
\hline \begin{tabular}{|l|} 
HLI \\
\end{tabular} & & .00199 & .44240 & .09772 & .02568 & .00030 & .00019 & .06210 & .02772 & .01001 & .02112 & 000 \\
\hline HLV & 03 & .00020 & .46088 & .00000 & .02237 & .00030 & .00019 & .04784 & .03930 & .01639 & .02114 & 1.00000 \\
\hline HLW03-18 & HLW03 & .00020 & .52484 & .00000 & .05967 & .00030 & .00307 & .00000 & .00000 & .00000 & .01281 & 1.00000 \\
\hline HLW03-19 & HLW03 & .00020 & .52030 & .00000 & .05846 & .00030 & .00019 & .00000 & .03927 & .00000 & .01281 & 1.00000 \\
\hline HLW & LW03 & .00200 & .50681 & .00145 & .05769 & .00030 & .00307 & .00430 & .00000 & .00000 & .02119 & 1.00000 \\
\hline HLW & LW03 & .00050 & .48587 & .01487 & .02975 & .00030 & .00046 & .02100 & .00992 & .05949 & .01373 & 1.00000 \\
\hline HLW0 & HLW03 & .00150 & .40304 & .04424 & .02949 & .00030 & .00046 & .04165 & .00983 & .05898 & .01807 & 1.00000 \\
\hline HLW03-23 & HLW03 & .00150 & .40648 & .01487 & .02974 & .00030 & .00046 & .04201 & .00992 & .05949 & .01371 & 1.00000 \\
\hline HLW03-24 & HLW03 & .00050 & .48588 & .01487 & .02975 & .00030 & .00046 & .02100 & .02975 & .05949 & .01373 & 1.00000 \\
\hline HLW & HLW03 & .00150 & .42090 & .04433 & .02956 & .00030 & .00139 & .02087 & .02956 & .05912 & .01809 & 1.00000 \\
\hline HLW03-26 & HLW03 & .00150 & .40345 & .04428 & .04428 & .00030 & .00046 & .04169 & .02953 & .05904 & .01807 & 1.00000 \\
\hline HLW03-27 & HLW03 & .00150 & .40393 & .01478 & .04433 & .00030 & .00046 & .02087 & .02956 & .05911 & .01809 & 1.00000 \\
\hline HLW03-28 & HLW03 & .00050 & .40695 & .01489 & .02977 & .00030 & .00046 & .02103 & .00993 & .05956 & .01372 & 1.00000 \\
\hline HLW03-29 & HLW03 & .00050 & .40606 & .01485 & .04456 & .00030 & .00046 & .04196 & .02971 & .07674 & .01371 & 1.00000 \\
\hline HLW & & & .43203 & .01486 & .04458 & .00030 & .00139 & .02098 & .00991 & .08229 & .01373 & 1.00000 \\
\hline HLW03-31 & \begin{tabular}{|l|} 
HLW03 \\
\end{tabular} & .00150 & .45058 & .01486 & .02972 & .00030 & .00139 & .02098 & .00991 & .08915 & .01373 & 1.00000 \\
\hline HLW03-32 & HLW03 & .00050 & .40348 & .01476 & .04428 & .00030 & .00139 & .04170 & .02953 & .08857 & .01807 & 1.00000 \\
\hline HLW03-33 & HLW03 & .00050 & .40667 & .01488 & .02975 & .00030 & .00046 & .03378 & .02975 & .05952 & .01372 & 1.00000 \\
\hline
\end{tabular}

(a) The Group IDs are described in Sections 2.1.1 to 2.1.9.

(b) The component mass fractions are normalized to sum to one over the 25 components listed in this table. The normalized component mass fractions listed in this table were rounded to five decimals, and may not sum exactly to 1.00000 as listed. However, complete compositions listed to more decimal places and summing to 1.0000 were used for property-composition modeling. 
Table 5.2. Normalized 25-Component Compositions (mass fractions) of 266 HLW Glasses Used for PCT Model Development (continued).

\begin{tabular}{|c|c|c|c|c|c|c|c|c|c|c|c|c|c|c|c|c|}
\hline Glass ID & $\underset{\text { ID }^{(\mathbf{a})}}{\operatorname{Group}}$ & $\mathbf{A l}_{2} \mathbf{O}_{3}$ & $\mathbf{B}_{2} \mathbf{O}_{3}$ & $\mathrm{CaO}$ & $\mathrm{CdO}$ & $\mathrm{Cr}_{2} \mathrm{O}_{3}$ & $\mathrm{Fe}_{2} \mathrm{O}_{3}$ & $\mathbf{K}_{2} \mathbf{O}$ & $\mathbf{L a}_{2} \mathbf{O}_{3}$ & $\mathbf{L i}_{2} \mathbf{O}$ & MgO & MnO & $\mathrm{Na}_{2} \mathrm{O}$ & $\mathrm{NiO}$ & PbO & $\mathrm{Sb}_{2} \mathrm{O}_{3}$ \\
\hline 34 & & 956 & 897 & 499 & .00100 & & 9853 & 060 & & .02463 & 0120 & 478 & 9541 & & & Uju \\
\hline & & & 0397 & 0499 & .00100 & & .04963 & 0060 & 0300 & .02481 & .00120 & 4467 & .06948 & .00496 & & \\
\hline HLW03-36 & 3 & 4921 & 6889 & 0499 & .00300 & .00197 & .09507 & .00060 & 0300 & .02692 & .00120 & 1476 & .07961 & .00492 & .00267 & \\
\hline HLW03-37 & LW03 & .02953 & 1809 & 0499 & .00100 & .00079 & .07222 & .00060 & .00299 & .04859 & .00120 & .01476 & .06889 & .00492 & .00267 & .00050 \\
\hline HLW03-38 & LW03 & .04915 & .06881 & .00499 & .00299 & .00197 & .09831 & .00060 & .00299 & .02458 & .00120 & .01474 & .09618 & .00295 & .00267 & .00050 \\
\hline HLW & & .02946 & .06875 & & .00300 & & & .00060 & & .04850 & .00120 & 73 & 75 & 295 & .00267 & \\
\hline & & 4941 & .06919 & .00499 & .00299 & & .09390 & .00060 & & .04881 & .00120 & & & .00494 & & \\
\hline $\mathrm{HL}$ & & & 8732 & .00499 & .00200 & & & & & .03710 & .00120 & & & & 174 & \\
\hline HLV & & .05500 & .09150 & .00500 & .00500 & .00040 & .10001 & .00060 & & .03701 & .00120 & .03500 & .09001 & .00800 & .00080 & 050 \\
\hline HLW & 4 & .08344 & 4908 & .00500 & .01600 & .00491 & .01963 & .00060 & .00300 & .05890 & .00120 & .06872 & .03927 & .00982 & .00040 & .00020 \\
\hline $\mathrm{HLV}$ & & 4 & 4961 & & .00050 & & & & & & .00120 & 00 & .14883 & 00 & 40 & \\
\hline HLV & & .04921 & 6889 & .00499 & .00100 & .00 & .04921 & .00060 & .00299 & .04921 & .00120 & .01476 & .10431 & .00492 & .00267 & \\
\hline HLW & & .04917 & .11088 & .00373 & .00011 & .00218 & .13460 & .00000 & .00065 & .02770 & .00116 & .02112 & .12307 & .00395 & .00478 & 000 \\
\hline HLV & & .04882 & .10368 & .00456 & .00011 & .00223 & .14005 & .00011 & .00074 & .02643 & .00145 & .02821 & .12527 & .00412 & .00541 & 037 \\
\hline HLW & & .04885 & .10374 & & .00011 & .00 & .14013 & .00011 & & & .00145 & & & & & \\
\hline HLV & & .04885 & .10374 & & .00011 & & & & & & & & .12534 & & .00542 & \\
\hline HLW0 & 4 & .04882 & .10368 & .00456 & .00011 & .00223 & .14005 & .00011 & .00074 & .02643 & .00145 & .02821 & .12527 & .00412 & .00541 & .00037 \\
\hline HLW & W04 & .04882 & .10368 & .00456 & .00011 & .00223 & .14005 & .00011 & .00074 & .02643 & .00145 & .02821 & .12527 & .00412 & .00541 & .00037 \\
\hline HLW04-08 & & .04778 & .10362 & .00446 & .00011 & .00218 & .13707 & .00011 & .00073 & .02642 & .00141 & .02761 & .12412 & .00403 & .00530 & .00040 \\
\hline & & .04884 & .10270 & & & & & & & & & & .12531 & & & \\
\hline & & & & & & & & & & & & & & & & \\
\hline 02 & 06 & .10390 & .11000 & .01000 & .00235 & .00250 & .07000 & .00766 & .00176 & .00250 & .01170 & .01000 & .20000 & .01000 & .00910 & .00000 \\
\hline HLW06-03 & LW06 & .11000 & .06500 & .00467 & .00706 & .00250 & .14000 & .00060 & .00529 & .00250 & .00546 & .01000 & .14000 & .00600 & .00425 & .00000 \\
\hline HLW06-04 & W06 & .08000 & .06500 & .00757 & .00706 & .00250 & .07000 & .00060 & .00529 & .00250 & .00886 & .01000 & .20000 & .00600 & .00689 & .00000 \\
\hline & & & & & & & & & & & & & 20000 & & & \\
\hline HLW & W06 & .11000 & .06500 & .00940 & .00235 & .00500 & .07000 & .00060 & .00176 & .00250 & .01100 & .04000 & .14000 & .01000 & .00856 & .00000 \\
\hline HLW06-07 & W06 & .08000 & .06500 & .01000 & .00235 & .00250 & .14000 & .00060 & .00176 & .00250 & .01170 & .04000 & .15890 & .01000 & .00910 & .00000 \\
\hline HLW06-08 & LW06 & .08000 & .06500 & .00608 & .00706 & .00250 & .07000 & .00060 & .00529 & .00250 & .00711 & .04000 & .14000 & .01000 & .00553 & .00000 \\
\hline HLV & & .08000 & .06500 & .00166 & .00235 & .00250 & .14000 & & & & .00194 & .02410 & .14000 & .01000 & & .00000 \\
\hline HLW06-10 & HLW06 & .08000 & .11000 & .00467 & .00235 & .00500 & .07000 & .00060 & .00176 & .00250 & .00546 & .01000 & .14000 & .00600 & .00425 & .00000 \\
\hline
\end{tabular}

(a) The Group IDs are described in Sections 2.1.1 to 2.1.9. 
Table 5.2. Normalized 25-Component Compositions (mass fractions) of 266 HLW Glasses Used for PCT Model Development (continued).

\begin{tabular}{|c|c|c|c|c|c|c|c|c|c|c|c|c|}
\hline D & $\underset{\text { ID }^{(a)}}{\text { Group }}$ & $\mathrm{SeO}_{2}$ & $\mathrm{SiO}_{2}$ & SrO & $\mathrm{ThO}_{2}$ & $\mathrm{TiO}_{2}$ & $\mathbf{T l}_{2} \mathbf{O}$ & $\mathbf{U O}_{3}$ & ZnO & $\mathrm{ZrO}_{2}$ & rs & \\
\hline HLW03-34 & 3 & 0 & 48278 & 478 & 858 & .00030 & 8 & .02087 & 00986 & 55912 & 1809 & .00000 \\
\hline HLW03-35 & W03 & 0050 & .48639 & 01489 & 3176 & .00030 & .00139 & .02103 & .01039 & .05956 & .01373 & 1.00000 \\
\hline HLW03-36 & & 0050 & .48226 & $\overline{01476}$ & .03558 & .00030 & .00046 & .02085 & .00984 & .05905 & .01809 & \\
\hline HLW03-37 & W03 & 0150 & .40348 & .01476 & .04428 & .00030 & .00139 & .04170 & .02953 & .07325 & .01807 & .00000 \\
\hline HLW03-38 & & & .43156 & .01474 & .03875 & .00030 & & .04165 & .00983 & .07051 & .01807 & 1.00000 \\
\hline HLW03-39 & LW03 & .00150 & .48128 & .01473 & .04420 & .00030 & .00139 & .02081 & .00982 & .07078 & .01809 & 1.00000 \\
\hline HLW03-40 & & .00150 & .42959 & .03279 & .04448 & .00030 & .00046 & & .00989 & 30 & 71 & \\
\hline $\mathrm{HL}$ & & 0100 & .43059 & .02705 & .03658 & .00030 & .00093 & .03032 & .01920 & 767 & 590 & \\
\hline & & & .49004 & & & .00030 & & & 999 & & 374 & \\
\hline HL & & .00 & .52031 & .05091 & .01416 & .00030 & .00019 & .00000 & .00000 & .04095 & 281 & 0000 \\
\hline HLW & & .00199 & .52586 & .00000 & .05027 & .00030 & .00019 & .06306 & .00000 & & .01276 & 1.00000 \\
\hline HLV & & .00150 & .40345 & .04428 & .04428 & .00030 & .00046 & .04169 & .02953 & .05904 & 807 & 000 \\
\hline & & & .48028 & .00207 & .00000 & & & & 49 & & & \\
\hline $\mathrm{HL}$ & & .00000 & .47445 & .00171 & .00000 & .00033 & .00000 & .00000 & .01480 & .00463 & 253 & 000 \\
\hline HLW & & .00000 & .47472 & .00171 & .00000 & .00033 & & .00000 & .01481 & .00464 & 197 & 1.00000 \\
\hline HLW04-07NF & LW04 & .00000 & .47472 & .00171 & .00000 & .00033 & .00000 & .00000 & .01481 & .00464 & .01197 & 0000 \\
\hline$\overline{\mathrm{HLV}}$ & & & .47445 & .00171 & .00000 & .00033 & .00000 & .00000 & .01480 & 463 & 253 & \\
\hline $\mathrm{HL}$ & & & .47445 & .00171 & .00 & & .00000 & .00000 & .01480 & & & \\
\hline$\overline{\mathrm{HL}}$ & 4 & .00000 & .48106 & .00167 & .00000 & .00033 & .00000 & .00000 & .01479 & .00454 & .01227 & 1.00000 \\
\hline HLW & LW04 & .00000 & .47744 & .00171 & .00000 & .00033 & .00000 & .00529 & .00730 & .00464 & .01262 & 1.00000 \\
\hline & & & .40000 & .01470 & .01500 & & & .00750 & .02140 & .01500 & .02509 & 1.00000 \\
\hline & & & .35000 & & .00 & .01000 & .00000 & & .01500 & .01500 & 509 & 000 \\
\hline $\mathrm{HL}$ & 6 & .00000 & .35000 & .04409 & .00250 & .00467 & .00000 & .00750 & .01500 & .04000 & .02587 & 1.00000 \\
\hline HLW & HLW06 & .00000 & .35000 & .04409 & .01500 & .00757 & .00000 & .00750 & .02500 & .04000 & .02674 & 1.00000 \\
\hline HLW06-05 & HLW06 & .00000 & .40000 & .01470 & .01500 & .00674 & .00000 & .00750 & .01500 & .01500 & .02411 & 1.00000 \\
\hline $6-06$ & & .00000 & .35000 & .01470 & .01500 & .00940 & .00000 & .04000 & .01500 & .04000 & .02491 & 1.00000 \\
\hline & & & & & & & & & .02500 & & .02509 & 000 \\
\hline HLW06-08 & \begin{tabular}{|l} 
HLW06 \\
\end{tabular} & .00000 & .40000 & .04409 & .00250 & .00608 & .00000 & .04000 & .01500 & .01500 & .02629 & 1.00000 \\
\hline HLW06-09 & HLW06 & .00000 & .35000 & .01470 & .00250 & .00166 & .00000 & .04000 & .02500 & .04000 & .02259 & 1.00000 \\
\hline HLW06-10 & HLW06 & .00000 & .40000 & .01470 & .00250 & .00467 & .00000 & .04000 & .02500 & .04000 & .02349 & 1.00000 \\
\hline
\end{tabular}

(a) The Group IDs are described in Sections 2.1.1 to 2.1.9.

(b) The component mass fractions are normalized to sum to one over the 25 components listed in this table. The normalized component mass fractions listed in this table were rounded to five decimals, and may not sum exactly to 1.00000 as listed. However, complete compositions listed to more decimal places and summing to 1.0000 were used for property-composition modeling. 
Table 5.2. Normalized 25-Component Compositions (mass fractions) of 266 HLW Glasses Used for PCT Model Development (continued).

\begin{tabular}{|c|c|c|c|c|c|c|c|c|c|c|c|c|c|c|c|c|}
\hline Glass ID & $\underset{\text { ID }^{(\mathbf{a})}}{\operatorname{Group}}$ & $\mathbf{A l}_{\mathbf{2}} \mathbf{O}_{3}$ & $\mathbf{B}_{2} \mathbf{O}_{3}$ & $\mathrm{CaO}$ & CdO & $\mathrm{Cr}_{2} \mathrm{O}_{3}$ & $\mathrm{Fe}_{2} \mathrm{O}_{3}$ & $\mathbf{K}_{2} \mathbf{O}$ & $\mathbf{L a}_{2} \mathbf{O}_{3}$ & $\mathbf{L i}_{2} \mathbf{O}$ & MgO & MnO & $\mathrm{Na}_{2} \mathrm{O}$ & $\mathrm{NiO}$ & PbO & $\mathrm{Sb}_{2} \mathrm{O}_{3}$ \\
\hline HLW06-11 & LW06 & 8000 & .11000 & 0550 & .00235 & .00250 & .14000 & .00902 & .00176 & .00250 & .00643 & 1000 & .14000 & .00600 & .00500 & .00000 \\
\hline HLW06-12 & & .09410 & .11000 & .00166 & .00706 & .00250 & .07000 & .00272 & .00529 & .03000 & .00194 & .04000 & .14000 & .01000 & .00151 & .00000 \\
\hline HLW06-13 & W06 & .11000 & 6500 & .00940 & .00235 & .00500 & .07000 & .01542 & .00176 & .00250 & .01100 & .04000 & .14000 & .01000 & .00856 & .00000 \\
\hline HLW06-14 & LW06 & .08000 & .11000 & .01000 & .00235 & .00250 & .07000 & .01640 & .00176 & .03000 & .01170 & .04000 & .14000 & .00600 & .00910 & .00000 \\
\hline HLW06-15 & LW06 & .08000 & .11000 & .00166 & .00235 & .00500 & .07000 & .00272 & .00176 & .03000 & .00194 & .02910 & .20000 & .01000 & .00151 & .00000 \\
\hline HLW06-16 & LW06 & .10000 & .06500 & .00317 & .00235 & .00250 & .07000 & .00520 & & .03000 & .00371 & .01750 & .20000 & .01000 & .00289 & \\
\hline HLW06-17 & W06 & .11000 & .06500 & .01000 & .00235 & .00500 & .07000 & .01640 & .00176 & .03000 & .01170 & .01000 & .14000 & .01000 & .00910 & .00000 \\
\hline HLW06-18 & W06 & .11000 & .11000 & .00276 & .00235 & .00250 & .07000 & .00452 & .00176 & .00250 & .00323 & .01000 & .14000 & .01000 & .00251 & 000 \\
\hline HLW06-19 & LW06 & .11000 & .06500 & .00166 & .00235 & .00500 & .12060 & .00272 & .00176 & .00250 & .00194 & .04000 & .20000 & .00600 & .00151 & .00000 \\
\hline HLW06-20 & LW06 & .11000 & .06500 & .01000 & .00235 & .00250 & .07290 & .01640 & .00176 & .03000 & .01170 & .04000 & .14000 & .00600 & .00910 & .00000 \\
\hline HLW & 06 & .13000 & .04300 & .00000 & .00000 & .00000 & .01400 & .00000 & .00000 & .00000 & .00000 & .08000 & .20000 & .00000 & .00000 & 00 \\
\hline HLW06-22 & N06 & .13000 & .15000 & .00000 & .01646 & .00600 & .01400 & .00000 & .01234 & .06010 & .00000 & .00000 & .06840 & .00000 & .00000 & .00000 \\
\hline HLW06-23 & LW06 & .01880 & .04300 & .00000 & .00000 & .00600 & .15000 & .00000 & .00000 & .00000 & .00000 & .00000 & 20000 & .00000 & .00000 & .00000 \\
\hline HLW06-24 & LW06 & .13000 & .04300 & .01000 & .01646 & .00000 & .01400 & .01640 & .01234 & .00000 & .01170 & .00000 & .16250 & .00000 & .00910 & .00000 \\
\hline HLW06-25 & & .13000 & .15000 & .01000 & .00000 & .00600 & .01400 & .01640 & .00000 & .06010 & .01170 & .00000 & .03700 & .00000 & .00910 & .00000 \\
\hline HLW06-26 & & .01880 & .04300 & .00000 & .01646 & .00600 & .01400 & .00000 & & .00000 & .00000 & .00730 & .20000 & .00000 & .00000 & \\
\hline HLW06-27 & HLW06 & .01880 & .09820 & .00000 & .00000 & .00000 & .01400 & .00000 & .00000 & .06010 & .00000 & .00000 & .03700 & .00000 & .00000 & .00000 \\
\hline HLW06-28 & HLW06 & .01880 & .15000 & .01000 & .00000 & .00600 & .11480 & .01640 & .00000 & .06010 & .01170 & .00000 & .03700 & .00000 & .00910 & .00000 \\
\hline HLW06-29 & LW06 & .01880 & .04300 & .01000 & .00000 & .00000 & .15000 & .01640 & .00000 & .06010 & .01170 & .00000 & .03700 & .00000 & .00910 & .00000 \\
\hline HLW06-30 & & .13000 & .04300 & .00000 & .00000 & .00000 & .15000 & & .00000 & .00000 & .00000 & .00000 & .20000 & .00000 & .00000 & .00000 \\
\hline & & & & .00000 & .01646 & .00600 & .15000 & & & & .00000 & .00000 & .03700 & .00000 & .00000 & .00000 \\
\hline HLW06-32 & HLW06 & .01880 & .15000 & .00000 & .00000 & .00600 & .15000 & .00000 & .00000 & .00000 & .00000 & .08000 & .20000 & .00000 & .00000 & .00000 \\
\hline HLW06-33 & HLW06 & .01880 & .04300 & .01000 & .01646 & .00000 & .15000 & .01640 & .01234 & .04730 & .01170 & .00000 & .03700 & .00000 & .00910 & .00000 \\
\hline HLW06-34 & LW06 & .01880 & .15000 & .00000 & .00000 & .00600 & .01400 & .00000 & .00000 & .00000 & .00000 & .08000 & .20000 & .00000 & .00000 & .00000 \\
\hline HLV & & & & & & & & & & & & .00290 & & & .00142 & \\
\hline HLW07-01 & HLW07 & .07161 & .09206 & .00150 & .00237 & .00277 & .07993 & .00290 & .00125 & .01802 & .00000 & .03171 & .11287 & .00422 & .00240 & .00200 \\
\hline HLW07-02 & HLW07 & .05500 & .09149 & .00500 & .00500 & .00040 & .10001 & .00060 & .00300 & .03701 & .00120 & .03500 & .09001 & .00800 & .00080 & .00050 \\
\hline HLW07-03 & HLW07 & .03888 & .08732 & .00499 & .00200 & .00140 & .06939 & .00060 & .00299 & .03710 & .00120 & .02698 & .09093 & .00395 & .00174 & .00100 \\
\hline HLW07-04 & LW07 & .08500 & .14000 & .00500 & .00050 & .00020 & .09500 & .00060 & .00300 & .06000 & .00120 & .00000 & .04000 & .00100 & .00040 & .00200 \\
\hline HLW07-05 & HLW07 & .04961 & .04961 & .00498 & .00050 & .00496 & .13891 & .00060 & .00299 & .04750 & .00120 & .06945 & .11693 & .00100 & .00040 & .00020 \\
\hline
\end{tabular}

(a) The Group IDs are described in Sections 2.1.1 to 2.1.9. 
Table 5.2. Normalized 25-Component Compositions (mass fractions) of 266 HLW Glasses Used for PCT Model Development (continued).

\begin{tabular}{|c|c|c|c|c|c|c|c|c|c|c|c|c|}
\hline Gla & $\underset{\text { ID }^{(\mathbf{a})}}{\text { Group }}$ & $\mathrm{SeO}_{2}$ & $\mathrm{SiO}_{2}$ & SrO & $\mathrm{ThO}_{2}$ & $\mathrm{TiO}_{2}$ & $\mathbf{T l}_{2} \mathbf{O}$ & $\mathbf{U O}_{3}$ & $\mathrm{ZnO}$ & $\mathrm{ZrO}_{2}$ & Others & $\operatorname{Sum}^{(\mathbf{b})}$ \\
\hline HLW06-11 & V06 & 0000 & 5000 & .01470 & 1500 & 0550 & .00000 & .04000 & .01500 & .01500 & .02374 & 1.00000 \\
\hline HLW06-12 & LW06 & .00000 & .35000 & .04409 & .01500 & .00166 & .00000 & .00750 & .02500 & .01500 & .02496 & 1.00000 \\
\hline HLW06-13 & HLW06 & .00000 & .35000 & .01470 & .01500 & .00940 & .00000 & .04000 & .01500 & .04000 & .02491 & 1.00000 \\
\hline HLW06-14 & HLW06 & .00000 & .35000 & .01470 & .01500 & .01000 & .00000 & .00750 & .01500 & .03290 & .02509 & 1.00000 \\
\hline HLW06-15 & HLW06 & .00000 & .35000 & .01470 & .00250 & .00166 & .00000 & .00750 & .01500 & .04000 & .02259 & 1.00000 \\
\hline HLW06-16 & HLW06 & .00000 & .35000 & .01470 & .01500 & .00317 & .00000 & .04000 & .02500 & .01500 & .02304 & 1.00000 \\
\hline HLW06-17 & HLW06 & .00000 & .40000 & .01470 & .01500 & .01000 & .00000 & .00750 & .02140 & .01500 & .02509 & 1.00000 \\
\hline HLW06-18 & HLW06 & .00000 & .40000 & .01470 & .01500 & .00276 & .00000 & .00750 & .02500 & .04000 & .02292 & 1.00000 \\
\hline HLW06-19 & HLW06 & .00000 & .35000 & .01470 & .00250 & .00166 & .00000 & .00750 & .02500 & .01500 & .02259 & 1.00000 \\
\hline HLW06-20 & HLW06 & .00000 & .35000 & .01470 & .00250 & .01000 & .00000 & .04000 & .02500 & .01500 & .02509 & 1.00000 \\
\hline HLW06-21 & HLW06 & .00000 & .38770 & .00000 & .05940 & .00000 & .00000 & .06500 & .00000 & .00000 & .02090 & 1.00000 \\
\hline HLW06-22 & HLW06 & .00000 & .34560 & .10287 & .00000 & .00000 & .00000 & .06500 & .00000 & .00000 & .02922 & 1.00000 \\
\hline HLV & V06 & .00000 & .34690 & .00000 & .05940 & .00000 & .00000 & .00000 & .04000 & .11500 & .02090 & 000 \\
\hline $\mathrm{HLV}$ & V06 & .00000 & .33000 & .10287 & .05940 & .01000 & .00000 & .00000 & .04000 & .00000 & .03222 & 1.00000 \\
\hline HLW06-25 & HLW06 & .00000 & .42240 & .00000 & .05940 & .01000 & .00000 & .00000 & .04000 & .00000 & .02390 & 1.00000 \\
\hline HLW06-26 & HLW06 & .00000 & .33000 & .10287 & .00000 & .00000 & .00000 & .06500 & .04000 & .11500 & .02922 & 1.00000 \\
\hline HLW & HLW06 & .00000 & .53100 & .00000 & .00000 & .00000 & .00000 & .06500 & .04000 & .11500 & .02090 & 1.00000 \\
\hline $\mathrm{HLV}$ & HLW06 & .00000 & .42720 & .00000 & .00000 & .01000 & .00000 & .06500 & .04000 & .00000 & .02390 & 1.00000 \\
\hline HLV & HLW06 & .00000 & .43560 & .00000 & .05940 & .01000 & .00000 & .00000 & .00000 & .11500 & .02390 & 1.00000 \\
\hline HLW06-30 & HLW06 & .00000 & .35110 & .00000 & .00000 & .00000 & .00000 & .06500 & .04000 & .00000 & .02090 & 1.00000 \\
\hline HLW06-31 & HLW06 & .00000 & .35880 & .10287 & .05940 & .00000 & .00000 & .00000 & .00000 & .00000 & .02922 & 1.00000 \\
\hline HLW & HLW06 & .00000 & .37430 & .00000 & .00000 & .00000 & .00000 & .00000 & .00000 & .00000 & .02090 & 1.00000 \\
\hline HLW06-33 & HLW06 & .00000 & .33000 & .10287 & .00000 & .01000 & .00000 & .06500 & .00000 & .08780 & .03222 & 1.00000 \\
\hline HLW06-34 & HLW06 & .00000 & .33030 & .00000 & .00000 & .00000 & .00000 & .06500 & .00000 & .11500 & .02090 & 1.00000 \\
\hline HLW06-35 & HLW06 & .00000 & .39430 & .01330 & .03250 & .00156 & .00000 & .03290 & .00310 & .04810 & .02244 & 1.00000 \\
\hline HLW07-01 & HLW07 & .00000 & .41825 & .04260 & .02138 & .00000 & .00000 & .02206 & .00983 & .04300 & .01725 & 1.00000 \\
\hline HLW07-02 & HLW07 & .00150 & .49003 & .01500 & .00000 & .00030 & .00140 & .00000 & .02000 & .02500 & .01374 & 1.00000 \\
\hline HLW07-03 & HLW07 & .00100 & .43059 & .02705 & .03658 & .00030 & .00093 & .03032 & .01920 & .06767 & .01590 & 1.00000 \\
\hline HLW07-04 & HLW07 & .00200 & .53000 & .00080 & .00000 & .00030 & .00019 & .00000 & .02000 & .00000 & .01281 & 1.00000 \\
\hline HLW07-05 & HLW07 & .00199 & .39825 & .00000 & .00000 & .00030 & .00019 & .06306 & .03461 & .00000 & .01276 & 1.00000 \\
\hline
\end{tabular}

(a) The Group IDs are described in Sections 2.1.1 to 2.1.9.

(b) The component mass fractions are normalized to sum to one over the 25 components listed in this table. The normalized component mass fractions listed in this table were rounded to five decimals, and may not sum exactly to 1.00000 as listed. However, complete compositions listed to more decimal places and summing to 1.0000 were used for property-composition modeling. 
Table 5.2. Normalized 25-Component Compositions (mass fractions) of 266 HLW Glasses Used for PCT Model Development (continued).

\begin{tabular}{|c|c|c|c|c|c|c|c|c|c|c|c|c|c|c|c|c|}
\hline Glass ID & $\underset{\text { ID }^{(\mathbf{a})}}{\text { Group }}$ & $\mathbf{A l}_{2} \mathbf{O}_{3}$ & $\mathbf{B}_{2} \mathbf{O}_{3}$ & $\mathrm{CaO}$ & CdO & $\mathrm{Cr}_{2} \mathrm{O}_{3}$ & $\mathrm{Fe}_{2} \mathrm{O}_{3}$ & $\mathbf{K}_{2} \mathbf{O}$ & $\mathbf{L a}_{2} \mathbf{O}_{3}$ & $\mathbf{L i}_{2} \mathbf{O}$ & MgO & MnO & $\mathrm{Na}_{2} \mathrm{O}$ & $\mathrm{NiO}$ & PbO & $\mathrm{Sb}_{2} \mathrm{O}_{3}$ \\
\hline HLW07-06 & LW07 & 1501 & 6001 & 0300 & .01000 & .00600 & .04000 & .00580 & .00250 & .00000 & .00000 & 6001 & .12530 & .00000 & .01010 & .00400 \\
\hline HLW07-07 & & .03000 & .06001 & 0300 & .01000 & .00050 & .14001 & .00580 & & .00000 & .00000 & .00500 & .17977 & .01000 & .01010 & .00400 \\
\hline HLW07-08 & W07 & .11501 & .06001 & .00300 & .00000 & .00050 & .05667 & .00580 & .00250 & .00000 & .00000 & .06001 & .18002 & .00000 & .00000 & .00400 \\
\hline HLW07-09 & LW07 & .03000 & .06001 & .00300 & .00000 & .00600 & .10459 & .00580 & .00250 & .04500 & .00000 & .00500 & .08603 & .00000 & .00000 & .00400 \\
\hline HLW07-10 & LW07 & .03000 & .11867 & .00300 & .01000 & .00600 & .14001 & .00580 & .00250 & .00000 & .00000 & .00500 & .09461 & .00114 & .01010 & .00400 \\
\hline HLW07-11 & & .11501 & .06001 & .00300 & .01000 & .00600 & .10495 & .00580 & .00250 & .04500 & .00000 & .00500 & .17016 & .01000 & .01010 & \\
\hline HLW07-12 & W07 & .11501 & .06001 & .00300 & .00000 & .00116 & .13191 & .00580 & .00250 & .04413 & .00000 & .00500 & .17903 & .00000 & .00000 & .00400 \\
\hline HLW07-13 & W07 & .11501 & .06001 & .00300 & .00435 & .00600 & .04000 & .00580 & .00250 & .00790 & .00000 & .00500 & .18002 & .00000 & .00440 & .00400 \\
\hline HLW07-14 & LW07 & .11501 & .06001 & .00300 & .01000 & .00050 & .04647 & .00580 & .00250 & .04284 & .00000 & .00500 & .06001 & .01000 & .01010 & .00400 \\
\hline HLW07-15 & LW07 & .04400 & .06001 & .00300 & .00000 & .00050 & .04000 & .00580 & .00250 & .00000 & .00000 & .06001 & .18002 & .01000 & .00000 & .00400 \\
\hline HLW & 77 & .04400 & .11569 & .00300 & .00000 & .00600 & .04000 & .00580 & & .03853 & .00000 & .06001 & .18002 & .01000 & .00000 & 00 \\
\hline HLW07-17 & W07 & .11501 & .13001 & .00300 & .00000 & .00050 & .04000 & .00580 & .00250 & .04253 & .00000 & .06001 & .18002 & .00000 & .00000 & .00400 \\
\hline HLW07-18 & N07 & .09077 & .13001 & .00300 & .00000 & .00600 & .07925 & .00580 & .00250 & .04500 & .00000 & .00500 & .18002 & .00000 & .00000 & .00400 \\
\hline HLW07-19 & LW07 & .03000 & .06572 & .00300 & .01000 & .00600 & \begin{tabular}{|l|}
.05401 \\
\end{tabular} & .00580 & .00250 & .04210 & .00000 & .00500 & .15061 & .00000 & .01010 & .00400 \\
\hline HLW07-20 & & .11501 & .13001 & .00300 & .00000 & .00600 & .05501 & .00580 & .00250 & .04500 & .00000 & .06001 & .06001 & .00000 & .00000 & .00400 \\
\hline HLW07-21 & & .03000 & .06001 & .00300 & .01000 & .00050 & .05401 & .00580 & & .00000 & .00000 & .00500 & .11335 & .00000 & .01010 & .00400 \\
\hline HLW07-22 & \begin{tabular}{ll|} 
HLW07 \\
\end{tabular} & .11501 & .06073 & .00300 & .01000 & .00050 & .04000 & .00580 & .00250 & .00000 & .00000 & .00500 & .12419 & .01000 & .01010 & .00400 \\
\hline HLW07-23 & HLW07 & .04400 & .13001 & .00300 & .00000 & .00600 & .04000 & .00580 & .00250 & .01822 & .00000 & .00500 & .06620 & .01000 & .00000 & .00400 \\
\hline HLW07-24 & LW07 & .11501 & .13001 & .00300 & .00000 & .00600 & .05501 & .00580 & .00250 & .00000 & .00000 & .00500 & .16120 & .01000 & .00000 & .00400 \\
\hline HLW07-25 & & .11501 & .06001 & .00300 & .01000 & .00050 & .05501 & .00580 & .00250 & .00997 & .00000 & .06001 & .11453 & .00000 & .01010 & .00400 \\
\hline & & .10001 & .08000 & & .00000 & & .06000 & & & & .00000 & & .10001 & .00650 & .00000 & .00200 \\
\hline $7-27$ & HLW07 & .10001 & .11001 & .00150 & .00000 & .00400 & .06000 & .00290 & .00125 & .03500 & .00000 & .02500 & .10001 & .00200 & .00000 & .00200 \\
\hline HLW07-28 & HLW07 & .10001 & .08000 & .00150 & .00000 & .00150 & .06000 & .00290 & .00125 & .03500 & .00000 & .02500 & .14001 & .00650 & .00000 & .00200 \\
\hline HLW07-29 & LW07 & .05000 & .11001 & .00150 & .00000 & .00150 & .11001 & .00290 & .00125 & .01000 & .00000 & .04000 & .10782 & .00650 & .00000 & .00200 \\
\hline HLV & & & & & & & & & & & & & .12614 & & & \\
\hline HLW07-31 & HLW07 & .10001 & .11001 & .00150 & .00500 & .00400 & .06000 & .00290 & .00125 & .01357 & .00000 & .02500 & .10001 & .00403 & .00505 & .00200 \\
\hline HLW07-32 & HLW07 & .05000 & .08000 & .00150 & .00500 & .00150 & .11001 & .00290 & .00125 & .01000 & .00000 & .02500 & .14001 & .00650 & .00505 & .00200 \\
\hline HLW07-33 & HLW07 & .10001 & .08000 & .00150 & .00000 & .00400 & .06297 & .00290 & .00125 & .01000 & .00000 & .04000 & .12268 & .00650 & .00000 & .00200 \\
\hline HLW07-34 & LW07 & .10001 & .11001 & .00150 & .00000 & .00150 & .06000 & .00290 & .00125 & .02063 & .00000 & .04000 & .10001 & .00650 & .00000 & .00200 \\
\hline HLW07-35 & HLW07 & .10001 & .09587 & .00150 & .00000 & .00400 & .06000 & .00290 & .00125 & .01347 & .00000 & .02500 & .10001 & .00200 & .00000 & .00200 \\
\hline
\end{tabular}

(a) The Group IDs are described in Sections 2.1.1 to 2.1.9. 
Table 5.2. Normalized 25-Component Compositions (mass fractions) of 266 HLW Glasses Used for PCT Model Development (continued).

\begin{tabular}{|c|c|c|c|c|c|c|c|c|c|c|c|c|}
\hline Gla & $\begin{array}{c}\text { Group } \\
\text { ID }^{(\text {a) }}\end{array}$ & $\mathrm{SeO}_{2}$ & $\mathrm{SiO}_{2}$ & SrO & $\mathrm{ThO}_{2}$ & $\mathrm{TiO}_{2}$ & $\mathbf{T l}_{2} \mathbf{O}$ & $\mathbf{U O}_{3}$ & $\mathrm{ZnO}$ & $\mathrm{ZrO}_{2}$ & Others & $\operatorname{Sum}^{(\mathbf{b})}$ \\
\hline HLW07-06 & LW07 & 0000 & .35004 & 0001 & 00000 & .00000 & 0000 & .04100 & .00000 & .02951 & .03770 & 1.00000 \\
\hline HLW07-07 & LW07 & .00000 & .35059 & .10001 & .00000 & .00000 & .00000 & .04100 & .00000 & .01000 & .03770 & 1.00000 \\
\hline HLW07-08 & ILW07 & .00000 & .35307 & .00000 & .04400 & .00000 & .00000 & .00000 & .00000 & .09601 & .01940 & 1.00000 \\
\hline HLW07-09 & LW07 & .00000 & .35004 & .10001 & .04400 & .00000 & .00000 & .00000 & .02500 & .09601 & .03300 & 1.00000 \\
\hline HLW07-10 & HLW07 & .00000 & .35004 & .10001 & .04400 & .00000 & .00000 & .04100 & .00000 & .01000 & .02410 & 1.00000 \\
\hline HLW07-11 & HLW07 & .00000 & .35004 & .02332 & .00000 & .00000 & .00000 & .04100 & .00000 & .01000 & .02410 & 1.00000 \\
\hline HLW07-12 & ILW07 & .00000 & .35004 & .00000 & .04400 & .00000 & .00000 & .00000 & .02500 & .01000 & .01940 & 1.00000 \\
\hline HLW07-13 & LW07 & .00000 & .36494 & .00000 & .00000 & .00000 & .00000 & .04100 & .02500 & .09601 & .03505 & 000 \\
\hline HLW07-14 & LW07 & .00000 & .35004 & .10001 & .00000 & .00000 & .00000 & .04100 & .00000 & .09601 & .03770 & $\overline{000}$ \\
\hline HLW07-15 & HLW07 & .00000 & .35004 & .10001 & .00000 & .00000 & .00000 & .02470 & .00000 & .09601 & .01940 & 1.00000 \\
\hline HLW07-16 & HLW07 & .00000 & .35004 & .00000 & .00000 & .00000 & .00000 & .00000 & .02500 & .09601 & .01940 & 1.00000 \\
\hline HLW07-17 & LW07 & .00000 & .35861 & .00000 & .00000 & .00000 & .00000 & .00000 & .00000 & .02500 & .03300 & 000 \\
\hline \begin{tabular}{|l|} 
HLI \\
\end{tabular} & 07 & .00000 & .37524 & .00000 & .04400 & .00000 & .00000 & .00000 & .00000 & .01000 & .01940 & 000 \\
\hline HLV & HLW07 & .00000 & .35004 & .10001 & .00000 & .00000 & .00000 & .04100 & .00000 & .09601 & .02410 & 0000 \\
\hline HLW07-20 & HLW07 & .00000 & .46179 & .00000 & .02246 & .00000 & .00000 & .00000 & .00000 & .01000 & .01940 & 1.00000 \\
\hline HLW07-21 & HLW07 & .00000 & .42700 & .10001 & .00000 & .00000 & .00000 & .04100 & .00000 & .09601 & .03770 & 1.00000 \\
\hline HLV & LW07 & .00000 & .35004 & .10001 & .04400 & .00000 & .00000 & .04100 & .02500 & .02500 & .02410 & 1.00000 \\
\hline HLV & LW07 & .00000 & .41883 & .06501 & .00000 & .00000 & .00000 & .04100 & .02500 & .09601 & .01940 & 1.0 \\
\hline HLV & \begin{tabular}{|l|} 
HLW07 \\
\end{tabular} & .00000 & .37445 & .00000 & .04400 & .00000 & .00000 & .04100 & .00000 & .01000 & .03300 & 1.00000 \\
\hline HLW07-25 & HLW07 & .00000 & .42662 & .00000 & .04400 & .00000 & .00000 & .04100 & .00384 & .01000 & .02410 & 1.00000 \\
\hline HLW07-26 & HLW07 & .00000 & .47002 & .02500 & .03500 & .00000 & .00000 & .01500 & .00500 & .02500 & .00970 & 1.00000 \\
\hline HLW07-27 & HLW07 & .00000 & .40002 & .07000 & .01000 & .00000 & .00000 & .03000 & .00500 & .02500 & .01630 & 1.00000 \\
\hline HLW07-28 & \begin{tabular}{|l|} 
HLW07 \\
\end{tabular} & .00000 & .40002 & .03100 & .03500 & .00000 & .00000 & .01500 & .01500 & .02500 & .02330 & 1.00000 \\
\hline HLW07-29 & \begin{tabular}{|l|} 
HLW07 \\
\end{tabular} & .00000 & .40002 & .05179 & .03500 & .00000 & .00000 & .03000 & .00500 & .02500 & .00970 & 1.00000 \\
\hline HLW07-30 & HLW07 & .00000 & .47002 & .02500 & .01000 & .00000 & .00000 & .01500 & .00500 & .02500 & .02330 & 1.00000 \\
\hline HLW07-31 & HLW07 & .00000 & .40002 & .07000 & .01000 & .00000 & .00000 & .03000 & .00500 & .02500 & .02565 & 1.00000 \\
\hline HLW07-32 & & .00000 & .40002 & .03264 & .01000 & .00000 & .00000 & .01500 & .01096 & .06500 & .02565 & 1.00000 \\
\hline HLW07-33 & \begin{tabular}{|l|} 
HLW07 \\
\end{tabular} & .00000 & .42207 & .06940 & .01000 & .00000 & .00000 & .01500 & .01500 & .02500 & .00970 & 1.00000 \\
\hline HLW07-34 & HLW07 & .00000 & .41514 & .02905 & .01000 & .00000 & .00000 & .01981 & .00500 & .06500 & .00970 & 1.00000 \\
\hline HLW07-35 & HLW07 & .00000 & .40002 & .07000 & .03500 & .00000 & .00000 & .01500 & .01500 & .04727 & .00970 & 1.00000 \\
\hline
\end{tabular}

(a) The Group IDs are described in Sections 2.1.1 to 2.1.9.

(b) The component mass fractions are normalized to sum to one over the 25 components listed in this table. The normalized component mass fractions listed in this table were rounded to five decimals, and may not sum exactly to 1.00000 as listed. However, complete compositions listed to more decimal places and summing to 1.0000 were used for property-composition modeling. 
Table 5.2. Normalized 25-Component Compositions (mass fractions) of 266 HLW Glasses Used for PCT Model Development (continued).

\begin{tabular}{|c|c|c|c|c|c|c|c|c|c|c|c|c|c|c|c|c|}
\hline Glass ID & $\begin{array}{c}\text { Group } \\
\text { ID }^{(\text {a) }}\end{array}$ & $\mathbf{A l}_{2} \mathbf{O}_{3}$ & $\mathbf{B}_{2} \mathbf{O}_{3}$ & $\mathrm{CaO}$ & $\mathrm{CdO}$ & $\mathrm{Cr}_{2} \mathrm{O}_{3}$ & $\mathrm{Fe}_{2} \mathrm{O}_{3}$ & $\mathrm{~K}_{2} \mathrm{O}$ & $\mathrm{La}_{2} \mathrm{O}_{3}$ & $\mathbf{L i}_{2} \mathbf{O}$ & MgO & MnO & $\mathrm{Na}_{2} \mathrm{O}$ & $\mathrm{NiO}$ & PbO & $\mathrm{Sb}_{2} \mathrm{O}_{3}$ \\
\hline HLW07-36 & LW07 & .09500 & .11001 & .00150 & .00000 & .00150 & .06000 & .00290 & .00125 & .01000 & .00000 & .02500 & .14001 & 0200 & 0000 & 0200 \\
\hline HLW07-37 & LW07 & .05000 & .08000 & .00150 & .00500 & .00150 & .10501 & .00290 & .00125 & .03500 & .00000 & .04000 & .13811 & .00200 & .00505 & .00200 \\
\hline HLW07-38 & LW07 & .05000 & .11001 & .00150 & .00500 & .00400 & .06500 & .00290 & .00125 & .01000 & .00000 & .04000 & .10393 & .00200 & .00505 & .00200 \\
\hline HLW07-39 & LW07 & .05500 & .11001 & .00150 & .00500 & .00400 & .06000 & .00290 & .00125 & .01000 & .00000 & .02500 & .13629 & .00200 & .00505 & .00200 \\
\hline HLW07-40 & LW07 & .05000 & .08000 & .00150 & .00500 & .00400 & .10384 & .00290 & .00125 & .01000 & .00000 & .02500 & .10001 & .00200 & .00505 & .00200 \\
\hline HLW-ALG-01 & LWALG & .11086 & .10560 & .00331 & .00000 & .00501 & .09619 & .00124 & .00101 & .03329 & .00096 & .00000 & .17280 & .00000 & .00202 & .00000 \\
\hline HLW-ALG-02 & ILWALG & .08001 & .11088 & .00350 & .00000 & .00278 & .07145 & .00132 & .00107 & .03550 & .00101 & .00000 & .15318 & .00522 & .00214 & .00000 \\
\hline HLW-ALG-03 & LWALG & .01926 & .08621 & .00339 & .00000 & .00501 & .12650 & .00127 & .00103 & .03057 & .00098 & .02095 & .18966 & .01001 & .00207 & .00000 \\
\hline HLW-ALG-04 & LWALG & .01926 & .11134 & .00224 & .00000 & .00501 & .12639 & .00083 & .00067 & .02876 & .00066 & .00000 & .15980 & .01001 & .00135 & .00000 \\
\hline HLW-ALG-05 & LWALG & .01927 & .04810 & .00521 & .01198 & .00415 & .12536 & .00197 & .00160 & .04286 & .00149 & .06906 & .08937 & .00781 & .00320 & .00000 \\
\hline HLW-ALG-06 & HLWALG & .09670 & .04807 & .00579 & .01322 & .00201 & .10620 & .00219 & .00178 & .02530 & .00164 & .04007 & .15635 & .00481 & .00357 & .00000 \\
\hline HLW-ALG-07 & ILWALG & .08194 & .10704 & .00390 & .00000 & .00000 & .01928 & .00147 & .00119 & .03258 & .00114 & .02339 & .11777 & .00000 & .00239 & .00000 \\
\hline HLW-ALG-08 & LWALG & .01926 & .04807 & .00591 & .01349 & .00471 & .07318 & .00224 & .00182 & .02081 & .00167 & .03560 & .13943 & .00887 & .00364 & .00000 \\
\hline HLW-ALG-09 & LWALG & .05480 & .04808 & .00560 & .00084 & .00211 & .13931 & .00354 & .00387 & .01987 & .00492 & .03916 & .15116 & .00189 & .00410 & .00000 \\
\hline HLW-ALG-10 & LWALG & .01926 & .09448 & .00332 & .00854 & .00501 & .10984 & .00125 & .00101 & .03329 & .00096 & .00000 & .17280 & .00000 & .00202 & .00000 \\
\hline HLW-ALG-11 & HLWALG & .11886 & .12188 & .00565 & .00000 & .00000 & .01928 & .00214 & .00174 & .06013 & .00163 & .03408 & .06065 & .00000 & .00348 & .00000 \\
\hline HLW-ALG-12 & HLWALG & .05938 & .04807 & .00586 & .00406 & .00285 & .12540 & .00222 & .00180 & .02750 & .00166 & .02029 & .15899 & .00812 & .00361 & .00000 \\
\hline HLW-ALG-13 & LWALG & .06166 & .04808 & .00882 & .00061 & .00000 & .07216 & .00335 & .00272 & .03354 & .00247 & .03063 & .09504 & .00061 & .00545 & .00000 \\
\hline HLW-ALG-14 & LWALG & .03543 & .04809 & .00507 & .01486 & .00000 & .12562 & .00191 & .00155 & .06012 & .00146 & .06715 & .04804 & .00759 & .00311 & .00000 \\
\hline HLW-ALG-15 & LWALG & .09731 & .14029 & .00424 & .00000 & .00338 & .09780 & .00161 & .00130 & .01928 & .00121 & .00000 & .17583 & .00636 & .00261 & .00000 \\
\hline HLW-ALG-16 & HLWALG & .10329 & .13850 & .00363 & .00025 & .00501 & .04396 & .00137 & .00111 & .02021 & .00104 & .00000 & .17406 & .00751 & .00223 & .00000 \\
\hline HLW-ALG-17 & HLWALG & .01926 & .10338 & .00331 & .00000 & .00501 & .12515 & .00124 & .00101 & .02020 & .00095 & .06912 & .17414 & .00997 & .00202 & .00000 \\
\hline HLW-ALG-18 & LWALG & .11360 & .11109 & .00339 & .00000 & .00000 & .10369 & .00128 & .00103 & .03437 & .00098 & .00000 & .14807 & .00000 & .00207 & .00000 \\
\hline HLW-ALG-19 & HLWALG & .01926 & .09652 & .00340 & .00000 & .00501 & .12652 & .00127 & .00103 & .02659 & .00098 & .02096 & .16131 & .01001 & .00207 & .00000 \\
\hline HLW-ALG-20 & HLWALG & .01926 & .07754 & .00340 & .00000 & .00501 & .12651 & .00127 & .00103 & .02926 & .00098 & .02095 & .17400 & .01001 & .00207 & .00000 \\
\hline HLW-ALG-21 & HLWALG & .02619 & .04810 & .00642 & .00131 & .00493 & .09663 & .00174 & .00136 & .02475 & .00112 & .01186 & .17623 & .00542 & .00180 & .00000 \\
\hline HLW-ALG-22 & HLWALG & .02588 & .06599 & .00635 & .00129 & .00487 & .09548 & .00172 & .00135 & .02407 & .00111 & .01172 & .16615 & .00535 & .00178 & .00000 \\
\hline HLW-ALG-23 & HLWALG & .02492 & .04809 & .00611 & .00124 & .00469 & .09180 & .00165 & .00130 & .02069 & .00107 & .01127 & .19298 & .00515 & .00171 & .00000 \\
\hline HLW-ALG-24 & HLWALG & .12589 & .04808 & .00902 & .00063 & .00000 & .01927 & .00343 & .00278 & .04265 & .00255 & .03134 & .09813 & .00063 & .00558 & .00000 \\
\hline HLW-ALG-25 & HLWALG & .01926 & .10096 & .00332 & .00000 & .00501 & .11817 & .00125 & .00101 & .02020 & .00096 & .07012 & .17414 & .01002 & .00203 & .00000 \\
\hline
\end{tabular}

(a) The Group IDs are described in Sections 2.1.1 to 2.1.9. 
Table 5.2. Normalized 25-Component Compositions (mass fractions) of 266 HLW Glasses Used for PCT Model Development (continued).

\begin{tabular}{|c|c|c|c|c|c|c|c|c|c|c|c|c|}
\hline Gl & $\underset{\text { ID }^{(\mathbf{a})}}{\text { Group }}$ & $\mathrm{SeO}_{2}$ & $\mathrm{SiO}_{2}$ & SrO & $\mathrm{ThO}_{2}$ & $\mathrm{TiO}_{2}$ & $\mathrm{Tl}_{2} \mathrm{O}$ & $\mathbf{U O}_{3}$ & $\mathrm{ZnO}$ & $\mathrm{ZrO}_{2}$ & C & $\mathbf{S}$ \\
\hline HLW07-36 & 1 & 000 & 0002 & 6910 & 1000 & .00000 & 00000 & .03000 & 00500 & 02500 & 0970 & 1.00000 \\
\hline HLW07-37 & & 0000 & .40002 & .02500 & 03500 & .00000 & .00000 & .01500 & .00500 & .02500 & .02565 & 1.00000 \\
\hline & ILW07 & .00000 & .41670 & .02500 & .03500 & .00000 & .00000 & .01500 & .01500 & .06500 & 02565 & \\
\hline HLW07-39 & LW07 & 00000 & .44794 & .02500 & 1000 & .00000 & .00000 & .01500 & .00500 & .06500 & 1205 & \\
\hline HLW07-40 & ILW07 & .00000 & .42803 & .07000 & .03500 & .00000 & .00000 & .02119 & .01500 & .02617 & .01205 & 1.00000 \\
\hline HLW-ALG-01 & ILWALG & .00000 & .45286 & .00000 & .00000 & .00000 & .00000 & .00000 & .01062 & .00000 & .00424 & 1.00000 \\
\hline \begin{tabular}{|l|} 
HLW-ALG-02 \\
\end{tabular} & I & .00000 & .44674 & .00000 & .00000 & .00000 & .00000 & .00000 & & & & \\
\hline G-03 & ALG & .00000 & .44365 & .00000 & .00000 & .00043 & .00000 & .00000 & .00032 & .05433 & 434 & \\
\hline G-04 & $\overline{\mathrm{ALG}}$ & .00000 & .51881 & .00000 & & .00039 & .00000 & .00000 & .01226 & 000 & 220 & \\
\hline G-05 & $\overline{\mathrm{ALG}}$ & .00000 & .46197 & .09891 & .00000 & .00026 & .00000 & .00000 & & .00000 & .00695 & 000 \\
\hline HLW-ALG-06 & LWALG & .00000 & .37279 & .08015 & .01603 & .00025 & .00000 & .00601 & .00055 & & .00850 & 1.00000 \\
\hline HLV & $\mathrm{LG}$ & .00000 & .44110 & .04113 & .04126 & .00000 & .00000 & .00000 & 575 & .06262 & 505 & 00 \\
\hline $\mathrm{HL}$ & $\mathrm{G}$ & .00000 & .36699 & .06267 & 4006 & .00052 & .00000 & .04644 & & & & \\
\hline $\mathrm{G}-09$ & $\overline{\mathrm{ALG}}$ & .00000 & .38868 & .07479 & .00603 & .00000 & .00000 & .01360 & 059 & .02565 & 42 & 000 \\
\hline G-10 & LLG & .00000 & .47112 & .00000 & .00228 & .00036 & .00000 & .00000 & .00031 & & .00423 & 1.00000 \\
\hline G-11 & ILWALG & .00000 & .35076 & .05994 & .06013 & .00000 & .00000 & .00000 & .00054 & .09125 & .00787 & 0000 \\
\hline $\mathrm{HL}$ & & .00000 & .40350 & .06087 & & .00026 & .00000 & .01623 & .00056 & .02394 & .00860 & \\
\hline & $\mathrm{LG}$ & .00000 & .35058 & .06125 & & .00036 & .00000 & .06125 & & .09188 & .01356 & \\
\hline $\mathrm{G}-14$ & LG & .00000 & .47605 & .09618 & .00000 & .00052 & .00000 & .00000 & .00048 & .00000 & .00676 & 1.00000 \\
\hline HLW-ALG-15 & ILWALG & .00000 & .37449 & .00000 & .00000 & .00000 & .00000 & .00000 & .00040 & .06845 & .00544 & 1.00000 \\
\hline HLW-ALG-16 & HLWALG & .00000 & .43773 & .00000 & & .00000 & & .00000 & .01786 & .03757 & .00465 & 1.00000 \\
\hline HLI & LG & .00000 & .45869 & .00000 & .00000 & .00043 & .00000 & .00000 & .00031 & .00159 & .00421 & 000 \\
\hline G-18 & ALG & .00000 & .45993 & .00000 & .00000 & .00000 & .00000 & .00000 & .01616 & .00000 & .00434 & 000 \\
\hline HLW-ALG-19 & HLWALG & .00000 & .46563 & .00000 & .00000 & .00043 & .00000 & .00000 & .00032 & .05434 & .00433 & 1.00000 \\
\hline HLW-ALG-20 & HLWALG & .00000 & .46929 & .00000 & .00000 & .00043 & .00000 & .00000 & .00032 & .05434 & .00434 & 1.00000 \\
\hline HLW-ALG-21 & ILWALG & .00000 & .38986 & .00000 & .05894 & .00027 & .00000 & .04502 & .00084 & .08915 & .00804 & 1.00000 \\
\hline & HLV & .00000 & & & & .00027 & .00000 & .04449 & .00083 & .08809 & .00795 & 000 \\
\hline HLW-ALG-23 & HLWALG & .00000 & .39517 & .00000 & .05599 & .00026 & .00000 & .04278 & .00079 & .08469 & .00764 & 1.00000 \\
\hline HLW-ALG-24 & HLWALG & .00000 & .35060 & .04071 & .05637 & .00036 & .00000 & .05637 & .00086 & .09082 & .01393 & 1.00000 \\
\hline HLW-ALG-25 & HLWALG & .00000 & .46478 & .00000 & .00228 & .00036 & .00000 & .00000 & .00031 & .00159 & .00423 & 1.00000 \\
\hline
\end{tabular}

(a) The Group IDs are described in Sections 2.1.1 to 2.1.9.

(b) The component mass fractions are normalized to sum to one over the 25 components listed in this table. The normalized component mass fractions listed in this table were rounded to five decimals, and may not sum exactly to 1.00000 as listed. However, complete compositions listed to more decimal places and summing to 1.0000 were used for property-composition modeling. 
Table 5.2. Normalized 25-Component Compositions (mass fractions) of 266 HLW Glasses Used for PCT Model Development (continued).

\begin{tabular}{|c|c|c|c|c|c|c|c|c|c|c|c|c|c|c|c|c|}
\hline Glass ID & $\underset{\text { ID }^{(\text {a) }}}{\text { Group }}$ & $\mathbf{l}_{2} \mathrm{O}_{3}$ & $\mathbf{B}_{2} \mathbf{O}_{3}$ & $\mathrm{CaO}$ & $\mathrm{CdO}$ & $\mathrm{Cr}_{2} \mathrm{O}_{3}$ & $\mathrm{Fe}_{2} \mathrm{O}_{3}$ & $\mathbf{K}_{2} \mathbf{O}$ & $\mathbf{L a}_{2} \mathbf{O}_{3}$ & $\mathbf{L i}_{2} \mathbf{O}$ & MgO & MnO & $\mathrm{Na}_{2} \mathrm{O}$ & $\mathrm{NiO}$ & PbO & $\mathrm{Sb}_{2} \mathrm{O}_{3}$ \\
\hline 26 & & 632 & 474 & 661 & 046 & 00 & 397 & 51 & & 3024 & 0187 & 289 & .09610 & & & 000 \\
\hline & & & 4027 & 0387 & .00000 & & & & & & & & & & & \\
\hline HLW-ALG-28 & & 839 & 4027 & 0388 & .00000 & 0322 & .12884 & 47 & 19 & .01928 & 111 & 330 & .17589 & .00589 & 238 & \\
\hline HLW-ALG-29 & WALG & .09926 & 4030 & 0433 & .00000 & .00345 & .08882 & .00164 & .00133 & .01928 & .00123 & .00000 & .17581 & .00649 & .00266 & .00000 \\
\hline HLW-ALG-30 & WALG & .07250 & .09597 & .00422 & .00631 & .00141 & .11020 & .00133 & .00259 & .03099 & .00102 & .00323 & .15321 & .00485 & .00073 & .00000 \\
\hline HLW & & & .10888 & & .00000 & & & & & & & 095 & 11 & 01 & & \\
\hline & & 6000 & .04810 & .00529 & .01213 & .00420 & & & & .03972 & & & & 91 & & \\
\hline $\mathrm{HL}$ & & .11389 & .08006 & .00497 & .00000 & .00396 & & & & .03783 & & .00000 & .17656 & .00746 & & \\
\hline HLV & & .01926 & .08223 & .00331 & .00000 & .00501 & .12515 & .00124 & & .02020 & .00096 & .06912 & .19002 & .00997 & .00202 & 000 \\
\hline $\mathrm{HLV}$ & & .05519 & 4808 & .00564 & .00085 & .00212 & .14024 & .00356 & .00390 & .02801 & .00495 & .03942 & & .00190 & & 000 \\
\hline$\overline{\mathrm{HLI}}$ & & .065 & 6511 & 0645 & .00447 & & & & & & & 36 & 35 & 94 & & \\
\hline HLI & & .06186 & .04808 & .00884 & .00062 & .00000 & & & & .02580 & .00248 & .03072 & .09358 & .00061 & 47 & \\
\hline HLI & & .02661 & .07901 & .00652 & .00133 & & & & & .02880 & & .01204 & .10641 & .00550 & 83 & 000 \\
\hline HLV & & .01927 & .10207 & .00468 & .00095 & .00358 & .07012 & .00126 & & .03110 & .00084 & .00860 & & .00393 & & 000 \\
\hline$\overline{\text { HLW }}$ & & .09195 & .08436 & .00535 & .00802 & .00179 & .14008 & & & & .00128 & & & & & \\
\hline & & & & & .00044 & & & & & & & & .09364 & & & \\
\hline $\mathrm{AW}$ & & .02648 & .09227 & .00675 & .00056 & .00145 & .04551 & .00060 & .00019 & .05662 & .00059 & .02449 & .09084 & .00239 & .00200 & .00000 \\
\hline$\overline{\mathrm{AWC}}$ & & .02648 & .09227 & .00675 & .00056 & .00145 & .04551 & .00060 & & .05662 & .00059 & .02449 & .09084 & .00239 & .00200 & 000 \\
\hline HLW9 & & $\begin{array}{l}.07693 \\
\end{array}$ & .03996 & $\begin{array}{l}.00490 \\
\end{array}$ & .01389 & .00110 & .12229 & .00030 & .00300 & .04995 & .00120 & .01029 & .13897 & .00759 & .00110 & .00000 \\
\hline HLI & & & & & & & & & & & & & & & & \\
\hline & & & & & & & & & & & & & & & & \\
\hline HL & 8 & .05495 & .06691 & .00295 & .00068 & .00000 & .12902 & .00065 & .00430 & .05027 & .00114 & .00178 & .13528 & .00654 & .00038 & .00000 \\
\hline HLV & & .05196 & .11908 & .00280 & .00064 & .00000 & .12221 & .00033 & .00407 & .03525 & .00106 & .00170 & .11659 & .00615 & .00034 & .00000 \\
\hline HLV & & .05196 & .11908 & .00280 & .00064 & .00000 & .12221 & .00033 & & .03525 & .00106 & .00170 & .11659 & .00615 & .00034 & .00000 \\
\hline & & & & & & & & & & & & & & & & \\
\hline HLW & & & .12529 & .00233 & .00114 & .00000 & & & & .03260 & .00073 & .00357 & .12033 & .00447 & .00070 & .00000 \\
\hline HLW & 98 & .01428 & .11914 & .00668 & .00000 & .00045 & .12746 & .00000 & .00249 & .02755 & .00565 & .03040 & .11738 & .00374 & .00252 & .00108 \\
\hline HLV & 98 & .05182 & .11163 & .00668 & .00000 & .00045 & .12746 & .00000 & .00249 & .02755 & .00565 & .03040 & .11988 & .00374 & .00252 & .00108 \\
\hline HLV & & & .11163 & .00668 & .00000 & .00045 & & .00000 & & & & & .11988 & & & \\
\hline HLW98-86 & HLW98 & .05289 & .09393 & .00300 & .00000 & .00078 & .12563 & .00000 & .00242 & .03008 & .01166 & .03991 & .11841 & .00172 & .00144 & .00255 \\
\hline
\end{tabular}

(a) The Group IDs are described in Sections 2.1.1 to 2.1.9. 
Table 5.2. Normalized 25-Component Compositions (mass fractions) of 266 HLW Glasses Used for PCT Model Development (continued).

\begin{tabular}{|c|c|c|c|c|c|c|c|c|c|c|c|c|}
\hline D & $\underset{\text { ID }^{(a)}}{\text { Group }}$ & $\mathrm{SeO}_{2}$ & $\mathrm{SiO}_{2}$ & $\mathbf{O}$ & $\mathrm{ThO}_{2}$ & $\mathrm{TiO}_{2}$ & $\mathrm{Tl}_{2} \mathrm{O}$ & $\mathbf{U O}_{3}$ & $\mathrm{ZnO}$ & $\mathrm{ZrO}_{2}$ & 0 & $\mathbf{S}$ \\
\hline HLW-ALG-26 & $G$ & 000 & 3210 & 4578 & 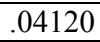 & 00029 & 000 & 4578 & 01427 & 06866 & & .00000 \\
\hline HLW-ALG-27 & & 0000 & .37713 & .00000 & 00000 & .00000 & .00000 & .00000 & .02316 & .00000 & & \\
\hline HLW-ALG-28 & & 0000 & .39956 & .00000 & 00000 & .00000 & .00000 & .00000 & .00037 & & & \\
\hline HLW-ALG-29 & LG & 00000 & .36865 & .00000 & .00000 & .00000 & .00000 & .00000 & .00041 & & & \\
\hline HLW-ALG-30 & LWALG & .00000 & .44901 & .00153 & & .00000 & .00000 & & .00654 & & & \\
\hline HLW-ALG-31 & LWALG & .00000 & .47666 & .00000 & .00000 & .00043 & .00000 & .00000 & .01699 & .05433 & .00433 & 1.00000 \\
\hline HLW & & .00000 & & .10020 & & & & & .00404 & & & \\
\hline $\mathrm{HL}$ & & .00000 & .36552 & .00000 & .00000 & .00000 & .00000 & .00000 & .00047 & & & \\
\hline & & & & .00000 & & .00043 & .00000 & & & & & \\
\hline $\mathrm{s}-35$ & LWALG & .00000 & .40921 & .07529 & .00607 & .00000 & .00000 & .01369 & .01228 & & & 000 \\
\hline HLV & LWALG & .00000 & & .06709 & .01789 & .00028 & .00000 & .01789 & .00062 & & & \\
\hline \begin{tabular}{|l}
$\mathrm{HL}$ \\
\end{tabular} & & .00000 & .35059 & .06145 & .05530 & .00036 & .00000 & .06145 & .00853 & 17 & 59 & \\
\hline & & & & .00000 & & .00 & .00 & & & & & \\
\hline & & .00000 & .47 & .00000 & & .00000 & .00000 & .03265 & 572 & 465 & & 000 \\
\hline & & .00000 & .40399 & & & .00000 & .00000 & & & & & 1.00000 \\
\hline \begin{tabular}{|l} 
HLI \\
\end{tabular} & TUOO & .00000 & .40889 & .07348 & .00000 & .00039 & .00000 & .00000 & .02000 & & & \\
\hline & & & & .02934 & & .00030 & .000 & .04 & .0 & 52 & & \\
\hline $\mathrm{HL}$ & & & & & & & .00000 & .04 & & & & \\
\hline & 8 & .00000 & .47036 & .01 & .00010 & .00010 & .00000 & .01714 & .00040 & .01469 & 76 & 1.00000 \\
\hline ICG1 & & .00000 & .47036 & .01499 & .00010 & .00010 & .00000 & .01714 & .00040 & .01469 & & 1.00000 \\
\hline & & & .46491 & & & & & .00000 & .02019 & & & \\
\hline & & .00000 & & & & .00000 & & .00000 & & & & \\
\hline & & .00000 & .47453 & .00032 & .00000 & .00000 & .00000 & .00000 & .02016 & .03806 & .00474 & 000 \\
\hline $77 \mathrm{CG}$ & 98 & .00000 & .47453 & .00032 & .00000 & .00000 & .00000 & .00000 & .02016 & .03806 & .00474 & 1.00000 \\
\hline HLV & LW98 & .00000 & .48308 & .00000 & .00000 & .00000 & .00000 & .00000 & .02012 & .01772 & .00265 & 1.00000 \\
\hline HL & & .00000 & & & & .00000 & & .00000 & .02012 & .01772 & .00265 & \\
\hline & & .002 & .50938 & .00000 & & & & & & & & \\
\hline \begin{tabular}{|l|} 
HLWS \\
\end{tabular} & HLW98 & .00212 & .47684 & .00000 & .00000 & .00028 & .00000 & .00000 & .02019 & .00127 & .00795 & 1.00000 \\
\hline HLW98-84CG & IUTUR & & .47684 & .00000 & .00000 & .00028 & .00000 & .00000 & .02019 & .00127 & .00795 & 1.00000 \\
\hline HLW98-86 & HLW98 & .00369 & .47068 & .00916 & .00000 & .00139 & .00000 & .00000 & .02071 & .00258 & .00736 & 1.00000 \\
\hline
\end{tabular}

(a) The Group IDs are described in Sections 2.1.1 to 2.1.9.

(b) The component mass fractions are normalized to sum to one over the 25 components listed in this table. The normalized component mass fractions listed in this table were rounded to five decimals, and may not sum exactly to 1.00000 as listed. However, complete compositions listed to more decimal places and summing to 1.0000 were used for property-composition modeling. 
Table 5.2. Normalized 25-Component Compositions (mass fractions) of 266 HLW Glasses Used for PCT Model Development (continued).

\begin{tabular}{|c|c|c|c|c|c|c|c|c|c|c|c|c|c|c|c|c|}
\hline Glass ID & $\underset{\text { ID }^{(\mathbf{a})}}{\text { Group }}$ & $\mathbf{A l}_{2} \mathbf{O}_{3}$ & $\mathbf{B}_{2} \mathbf{O}_{3}$ & $\mathrm{CaO}$ & CdO & $\mathrm{Cr}_{2} \mathrm{O}_{3}$ & $\mathrm{Fe}_{2} \mathrm{O}_{3}$ & $\mathbf{K}_{2} \mathbf{O}$ & $\mathrm{La}_{2} \mathrm{O}_{3}$ & $\mathbf{L i}_{\mathbf{2}} \mathbf{O}$ & MgO & MnO & $\mathrm{Na}_{2} \mathrm{O}$ & $\mathrm{NiO}$ & PbO & $\mathrm{Sb}_{2} \mathrm{O}_{3}$ \\
\hline $\mathrm{HL}$ & & 209 & 393 & 0 & & 78 & 563 & 0 & & 50 & & 91 & 41 & 72 & & 255 \\
\hline HLWC & & 7680 & 0102 & 0442 & 0674 & & 1759 & & & .03509 & & 0345 & & & 78 & 000 \\
\hline HLW98-88 & & 7454 & 0599 & 0429 & 0654 & .00139 & .11413 & $\overline{96}$ & 69 & .03759 & 101 & 0335 & 713 & 502 & 075 & 000 \\
\hline HLW98-89 & W98 & .03360 & .09096 & .00452 & .00000 & .00059 & .08947 & .00000 & .00149 & .02843 & .00000 & .01425 & .10736 & .00438 & .00115 & .00000 \\
\hline HLW98-94 & LW98 & .09376 & .11514 & .00242 & .00653 & .00026 & .10523 & .00412 & .00345 & .03872 & .00090 & .00122 & & .00598 & .00060 & .00000 \\
\hline HLWS & & .07317 & .10632 & .00425 & .00642 & .00143 & .11206 & .00136 & 64 & .03758 & .00099 & .00329 & .11925 & .00493 & .00074 & .00000 \\
\hline HLV & & & .10632 & .00425 & .00642 & & .11206 & & & & & 29 & & & & 000 \\
\hline HLV & & 360 & .10096 & .00452 & .00000 & .00059 & .08947 & .00000 & & .03093 & 000 & 425 & 736 & & & 000 \\
\hline HLV & & .03360 & .10096 & .00452 & .00000 & .00059 & .08947 & .00000 & & .03093 & .00000 & .01425 & .10736 & .00438 & .00115 & .00000 \\
\hline HLW & 98 & .03598 & .10812 & .00484 & .00000 & .00063 & .09581 & .00000 & .00160 & .03313 & .00000 & .01526 & .11497 & .00469 & & .00000 \\
\hline HLI & & & & .00451 & .00000 & & .08936 & .00000 & & .03090 & & 423 & .10722 & .00 & & 000 \\
\hline HLV & & & .10083 & .00451 & .00000 & & .08936 & .00000 & & .03090 & & .01423 & .10722 & .00437 & 15 & 000 \\
\hline HLV & & .03360 & .10096 & .00452 & .00000 & .00059 & .08947 & .00000 & & .03093 & .00000 & .01425 & .10736 & .00438 & 115 & .00000 \\
\hline HLW & & .03360 & .10096 & .00452 & .00000 & .00059 & .08947 & .00000 & .00149 & .03093 & .00000 & .01425 & .10736 & .00438 & & .00000 \\
\hline HLW & & .09754 & .11050 & .00252 & .00679 & & .10947 & .00429 & & & & .00126 & & & & .00000 \\
\hline HLI & & .05386 & .11846 & & & & .12638 & & & .03008 & & & .12010 & .00 & & 054 \\
\hline HLV & & .06110 & .11237 & .00329 & .00075 & .00000 & .14372 & .00039 & 79 & .03321 & .00125 & .00200 & .11239 & .00723 & .00040 & .00000 \\
\hline HLWS & 198 & .06589 & .11936 & .00275 & .00134 & .00000 & .14770 & .00037 & .00443 & .03076 & .00086 & .00421 & .11529 & .00526 & .00083 & .00000 \\
\hline HLW98-V13 & LW98 & .05233 & .10581 & .00789 & .00000 & .00053 & .15052 & .00000 & .00294 & .02604 & .00667 & .03589 & .11437 & .00442 & .00297 & .00128 \\
\hline HLW & & .05774 & .08816 & .00351 & .00000 & & .14687 & .00000 & & .02814 & & .04665 & .11211 & .00201 & .00169 & .00299 \\
\hline HLV & & .04732 & & .00242 & .00000 & .00063 & .10123 & .00000 & & & & .03216 & .12566 & & & 206 \\
\hline AZ-1 & ual & .08230 & .10080 & .00470 & .00680 & .00130 & .12000 & .00020 & .00470 & .03730 & .00110 & .00300 & .10580 & .00540 & .00040 & .00000 \\
\hline AZ-11 & ctual & .07813 & .03785 & .00339 & .01288 & .00111 & .12415 & .00026 & .00302 & .05191 & .00178 & .00910 & .13713 & .00788 & .00151 & .00021 \\
\hline AY-10 & 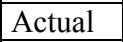 & .05754 & .10657 & .00510 & .00010 & .00193 & .13200 & .00188 & .00079 & .02573 & .00143 & .02508 & .11676 & .00386 & .00495 & .00049 \\
\hline C-106 & & & & & & & & & & & & & & & & .00000 \\
\hline C-104 Actual & ctual & .02648 & .09228 & .00675 & .00056 & .00145 & .04551 & .00060 & .00019 & .05663 & .00059 & .02450 & .09085 & .00239 & .00200 & .00000 \\
\hline
\end{tabular}

(a) The Group IDs are described in Sections 2.1.1 to 2.1.9. 
Table 5.2. Normalized 25-Component Compositions (mass fractions) of 266 HLW Glasses Used for PCT Model Development (continued).

\begin{tabular}{|c|c|c|c|c|c|c|c|c|c|c|c|c|}
\hline Gl & $\underset{\text { ID }^{(a)}}{\text { Group }}$ & $\mathrm{SeO}_{2}$ & $\mathrm{SiO}_{2}$ & SrO & $\mathrm{ThO}_{2}$ & $\mathrm{TiO}_{2}$ & $\mathbf{T l}_{2} \mathbf{O}$ & $\mathbf{U O}_{3}$ & ZnO & $\mathrm{ZrO}_{2}$ & Ot & Sum $^{(b)}$ \\
\hline HLW & & 0 & 068 & 16 & 00 & 39 & 0 & 0000 & 71 & 0258 & 9736 & .00000 \\
\hline HLW98-87 & LW98 & 0000 & .44503 & .00164 & 00000 & .00000 & .00000 & .00973 & .02014 & .03570 & .01355 & 1.00000 \\
\hline HLW98-88 & & .00000 & .43966 & .00159 & .00000 & .00000 & & .00944 & & & & \\
\hline HLWS & & .00000 & .44571 & .00000 & .04051 & .00021 & .00000 & .02573 & .02017 & .08843 & 306 & \\
\hline \begin{tabular}{|l} 
HLW \\
\end{tabular} & & 0000 & .43952 & .00028 & 000 & .00000 & 00000 & .00000 & & 235 & 039 & \\
\hline HLW98-95 & & .00000 & .44687 & .00156 & .00000 & .00011 & .00000 & .00927 & .02012 & .03402 & .01363 & 1.00000 \\
\hline HLW98-95C & LW98 & .00000 & .44687 & .00156 & .00000 & .00011 & .00000 & .00927 & .02012 & .03402 & .01363 & 1.00000 \\
\hline HLW & & .00000 & .43322 & .00000 & .04051 & .00021 & .00 & .02573 & 017 & 43 & 06 & 000 \\
\hline $\mathrm{HL}$ & & 0 & .43322 & .00000 & & .00 & & & & & & \\
\hline HL & & .00000 & .46395 & .00000 & .00000 & .00022 & & .00000 & 160 & 470 & 327 & 000 \\
\hline HLW & & .00000 & .43268 & .00000 & .04046 & .00021 & .00000 & .02569 & .02015 & & 428 & 1.00000 \\
\hline HLW98-96NRE4C & 98 & .00000 & .43268 & .00000 & .04046 & .00021 & .00000 & .02569 & .02015 & .08832 & .00428 & 1.00000 \\
\hline$\overline{\mathrm{HL}}$ & & .000 & .43322 & .000 & .04051 & .00 & & .02573 & 17 & & 06 & \\
\hline $\mathrm{HL}$ & & .00000 & .43322 & .00000 & .04051 & .00021 & & 73 & .02017 & .08843 & 306 & \\
\hline $\mathrm{HL}$ & & .00000 & .43002 & .00029 & .00000 & .00000 & .00000 & .00000 & .02063 & .03366 & .01081 & 1.00000 \\
\hline T05 & 98 & .00106 & .47996 & .00000 & .00000 & .00014 & .00000 & .00000 & .02015 & .00950 & .00530 & 1.00000 \\
\hline & & .00000 & .44738 & .00038 & & & & .00000 & & .04476 & & 1.00000 \\
\hline -V07 & & & & & .00 & .00000 & & .00000 & & 89 & & $\overline{000}$ \\
\hline $3-\mathrm{V} 13$ & 98 & .00250 & .45551 & .00000 & .00000 & .00033 & .00000 & .00000 & .01911 & 50 & .00939 & 1.00000 \\
\hline \begin{tabular}{|l} 
HLW98-V19 \\
\end{tabular} & LW98 & .00432 & .44496 & .01071 & .00000 & .00162 & .00000 & .00000 & .01953 & .00302 & .00860 & 1.00000 \\
\hline HLW98-V24 & LW98 & .00298 & .50023 & .00738 & .00000 & .00112 & .00000 & .00000 & .02206 & .00208 & .00593 & 1.00000 \\
\hline AZ-101 Actua & & .00000 & .44300 & .00200 & .00000 & .00020 & .00000 & .00900 & .01990 & .03740 & .01470 & 1.00000 \\
\hline Actual & & & & & & & & & .00041 & & & 000 \\
\hline AY-102/C-106 & $\mathrm{Ac}$ & .00000 & .48949 & .00143 & .00000 & .00040 & .00000 & .00232 & .00703 & .00386 & .01126 & 1.00000 \\
\hline C-106 Actual & Actual & .00000 & .44728 & .06220 & .00000 & .00175 & .00000 & .00000 & .00292 & .00510 & .01102 & 1.00000 \\
\hline C-104 Actual & Actual & .00000 & .47097 & .02934 & .03800 & .00030 & .00000 & .04101 & .01987 & .04252 & .00725 & 1.00000 \\
\hline
\end{tabular}

(a) The Group IDs are described in Sections 2.1.1 to 2.1.9.

(b) The component mass fractions are normalized to sum to one over the 25 components listed in this table. The normalized component mass fractions listed in this table were rounded to five decimals, and may not sum exactly to 1.00000 as listed. However, complete compositions listed to more decimal places and summing to 1.0000 were used for property-composition modeling. 
Table 5.3. PCT Releases and Data Splitting Validation Sets of HLW Glasses Used for PCT Model Development.

\begin{tabular}{|c|c|c|c|c|c|c|c|c|c|}
\hline \multirow[t]{2}{*}{ Glass ID } & \multicolumn{3}{|c|}{$\begin{array}{c}\text { Used for } \\
\text { PCT Model } \\
\text { Development }\end{array}$} & \multirow{2}{*}{$\begin{array}{l}\text { PCT- } \\
\text { B } \\
(\mathrm{g} / \mathrm{L})\end{array}$} & \multirow{2}{*}{$\begin{array}{c}\text { PCT- } \\
\text { Li } \\
(\mathrm{g} / \mathrm{L})\end{array}$} & \multirow{2}{*}{$\begin{array}{l}\text { PCT- } \\
\mathrm{Na} \\
(\mathrm{g} / \mathrm{L})\end{array}$} & \multirow{2}{*}{$\begin{array}{c}\text { PCT-B Data } \\
\text { Splitting } \\
\text { Validation Set }\end{array}$} & \multirow{2}{*}{$\begin{array}{c}\text { PCT-Li Data } \\
\text { Splitting } \\
\text { Validation Set }\end{array}$} & \multirow{2}{*}{$\begin{array}{c}\text { PCT-Na } \\
\text { Data } \\
\text { Splitting } \\
\text { Validation }\end{array}$} \\
\hline & PCT-B & PCT-Li & PCT-Na & & & & & & \\
\hline HLW02-01 & Yes & Yes & Yes & 0.700 & 0.685 & 0.628 & NA-Rep $^{(a)}$ & NA-Rep & NA-Rep \\
\hline HLW02-02 & Yes & Yes & Yes & 0.905 & 0.799 & 0.398 & 1 & 2 & 2 \\
\hline HLW02-03 & Yes & Yes & Yes & 2.837 & 2.140 & 2.015 & 4 & 2 & 5 \\
\hline HLW02-04 & Yes & Yes & Yes & 0.574 & 0.724 & 0.877 & NA-Rep & NA-Rep & NA-Rep \\
\hline HLW02-05 & Yes & Yes & Yes & 0.730 & 0.850 & 1.015 & 5 & 4 & 4 \\
\hline HLW02-06 & Yes & Yes & Yes & 0.397 & 0.701 & 0.996 & 5 & 5 & 1 \\
\hline HLW02-07 & Yes & Yes & Yes & 0.502 & 0.671 & 0.625 & 5 & 3 & 2 \\
\hline HLW02-08 & Yes & Yes & Yes & 3.531 & 2.679 & 2.262 & NA-Rep & NA-Rep & NA-Rep \\
\hline HLW02-09 & Yes & Yes & Yes & 0.646 & 0.582 & 0.725 & 2 & 4 & 2 \\
\hline HLW02-10 & Yes & Yes & Yes & 0.935 & 0.833 & 0.741 & 5 & 5 & 5 \\
\hline HLW02-11 & Yes & Yes & Yes & 2.277 & 1.688 & 1.287 & 1 & 5 & 2 \\
\hline HLW02-12 & Yes & Yes & Yes & 3.270 & 2.319 & 2.226 & 2 & 3 & 2 \\
\hline HLW02-13 & Yes & Yes & Yes & 3.494 & 2.510 & 2.656 & 5 & 4 & 3 \\
\hline HLW02-14 & Yes & Yes & Yes & 0.104 & 0.383 & 0.188 & 2 & 1 & 1 \\
\hline HLW02-15 & Yes & Yes & Yes & 1.270 & 1.046 & 0.916 & 4 & 2 & 5 \\
\hline HLW02-16 & Yes & Yes & Yes & 0.739 & 0.747 & 0.694 & 2 & 1 & 3 \\
\hline HLW02-17 & Yes & Yes & Yes & 0.546 & 0.726 & 0.340 & NA-Rep & NA-Rep & NA-Rep \\
\hline HLW02-18 & Yes & Yes & Yes & 0.603 & 0.567 & 0.722 & 3 & 4 & 5 \\
\hline HLW02-19 & Yes & Yes & Yes & 0.635 & 0.590 & 0.514 & 1 & 3 & 1 \\
\hline HLW02-20 & Yes & Yes & Yes & 0.495 & 0.615 & 0.306 & 3 & 5 & 5 \\
\hline HLW02-21 & Yes & Yes & Yes & 1.452 & 1.126 & 0.924 & 3 & 5 & 2 \\
\hline HLW02-22 & Yes & Yes & Yes & 0.550 & 0.620 & 0.076 & NA-Rep & NA-Rep & NA-Rep \\
\hline HLW02-23 & Yes & Yes & Yes & 0.688 & 0.672 & 0.602 & 4 & 4 & 3 \\
\hline HLW02-24 & Yes & Yes & Yes & 0.316 & 0.434 & 0.519 & 3 & 5 & 2 \\
\hline HLW02-25 & Yes & Yes & Yes & 0.317 & 0.381 & 0.143 & 4 & 5 & 4 \\
\hline
\end{tabular}

(a) NA-Rep indicates glasses that were not included in any of the validation splits because they were replicates.

(b) NA-Outlier indicates glasses that were not included in any of the validation splits because they were identified as outliers and removed from the PCT modeling dataset.

(c) A dash (-) or NA-No Data indicates glasses that did not contain $\mathrm{Li}_{2} \mathrm{O}$ and hence did not have PCT-Li releases. 
Table 5.3. PCT Releases and Data Splitting Validation Sets of HLW Glasses Used for PCT Model Development (continued).

\begin{tabular}{|c|c|c|c|c|c|c|c|c|c|}
\hline \multirow[t]{2}{*}{ Glass ID } & \multicolumn{3}{|c|}{$\begin{array}{c}\text { Used for } \\
\text { PCT Model } \\
\text { Development } \\
\end{array}$} & \multirow[t]{2}{*}{$\begin{array}{c}\text { PCT- } \\
\text { B } \\
(\mathrm{g} / \mathrm{L})\end{array}$} & \multirow[t]{2}{*}{$\begin{array}{l}\text { PCT- } \\
\mathbf{L i} \\
(\mathrm{g} / \mathrm{L})\end{array}$} & \multirow[t]{2}{*}{$\begin{array}{l}\text { PCT- } \\
\text { Na } \\
(\mathrm{g} / \mathrm{L})\end{array}$} & \multirow[t]{2}{*}{$\begin{array}{c}\text { PCT-B Data } \\
\text { Splitting } \\
\text { Validation Set }\end{array}$} & \multirow[t]{2}{*}{$\begin{array}{c}\text { PCT-Li Data } \\
\text { Splitting } \\
\text { Validation Set }\end{array}$} & \multirow{2}{*}{$\begin{array}{c}\text { PCT-Na } \\
\text { Data } \\
\text { Splitting } \\
\text { Validation }\end{array}$} \\
\hline & PCT-B & PCT-Li & \begin{tabular}{|l|} 
PCT-Na \\
\end{tabular} & & & & & & \\
\hline HLW02-26 & Yes & Yes & Yes & 1.240 & 0.923 & 1.094 & 1 & 5 & 2 \\
\hline HLW02-27 & Yes & Yes & Yes & 0.596 & 0.555 & 0.420 & 5 & 5 & 4 \\
\hline HLW02-28 & Yes & Yes & Yes & 0.600 & 0.466 & 0.596 & 1 & 4 & 2 \\
\hline HLW02-29 & Yes & Yes & Yes & 0.820 & 0.600 & 0.569 & 2 & 2 & 3 \\
\hline HLW02-30 & Yes & Yes & Yes & 2.201 & 1.776 & 1.610 & 3 & 1 & 3 \\
\hline HLW02-31 & Yes & Yes & Yes & 1.319 & 1.077 & 0.529 & 3 & 3 & 1 \\
\hline HLW02-32 & Yes & Yes & Yes & 0.566 & 0.664 & 0.608 & 5 & 2 & 4 \\
\hline HLW02-33 & Yes & Yes & Yes & 1.004 & 0.737 & 0.857 & 1 & 4 & 3 \\
\hline HLW02-34 & Yes & Yes & Yes & 1.174 & 0.940 & 0.878 & 2 & 2 & 3 \\
\hline HLW02-35 & Yes & Yes & Yes & 1.229 & 1.030 & 0.917 & 5 & 5 & 1 \\
\hline HLW02-36 & Yes & Yes & Yes & 0.593 & 0.605 & 0.769 & 4 & 5 & 5 \\
\hline HLW02-37 & Yes & Yes & Yes & 0.546 & 0.516 & 0.445 & 2 & 4 & 4 \\
\hline HLW02-38 & Yes & Yes & Yes & 0.635 & 0.689 & 0.570 & 2 & 3 & 4 \\
\hline HLW02-39 & Yes & Yes & Yes & 0.284 & 0.532 & 0.389 & 3 & 2 & 1 \\
\hline HLW02-40 & Yes & Yes & Yes & 0.277 & 0.556 & 0.323 & 1 & 1 & 3 \\
\hline HLW02-41 & Yes & Yes & Yes & 0.479 & 0.661 & 0.354 & 4 & 1 & 3 \\
\hline HLW02-42 & Yes & Yes & Yes & 1.080 & 0.950 & 0.823 & NA-Rep & NA-Rep & NA-Rep \\
\hline HLW02-43 & Yes & Yes & Yes & 1.057 & 0.839 & 0.844 & 1 & 2 & 1 \\
\hline HLW02-44 & Yes & Yes & Yes & 0.809 & 0.748 & 0.853 & NA-Rep & NA-Rep & NA-Rep \\
\hline HLW02-45 & Yes & Yes & Yes & 0.636 & 0.633 & 0.495 & 3 & 4 & 1 \\
\hline HLW02-46 & Yes & Yes & Yes & 0.536 & 0.632 & 0.452 & NA-Rep & NA-Rep & NA-Rep \\
\hline HLW02-47 & Yes & Yes & Yes & 0.486 & 0.549 & 0.338 & 1 & 4 & 3 \\
\hline HLW02-48 & Yes & Yes & Yes & 0.867 & 0.854 & 1.001 & 4 & 5 & 3 \\
\hline HLW02-49 & Yes & Yes & Yes & 0.591 & 0.682 & 0.579 & 3 & 2 & 3 \\
\hline HLW02-50 & Yes & Yes & Yes & 0.534 & 0.678 & 0.418 & 5 & 1 & 2 \\
\hline
\end{tabular}

(a) NA-Rep indicates glasses that were not included in any of the validation splits because they were replicates.

(b) NA-Outlier indicates glasses that were not included in any of the validation splits because they were identified as outliers and removed from the PCT modeling dataset.

(c) A dash (-) or NA-No Data indicates glasses that did not contain $\mathrm{Li}_{2} \mathrm{O}$ and hence did not have PCT-Li releases. 
Table 5.3. PCT Releases and Data Splitting Validation Sets of HLW Glasses Used for PCT Model Development (continued).

\begin{tabular}{|c|c|c|c|c|c|c|c|c|c|}
\hline \multirow[t]{2}{*}{ Glass ID } & \multicolumn{3}{|c|}{$\begin{array}{c}\text { Used for } \\
\text { PCT Model } \\
\text { Development }\end{array}$} & \multirow{2}{*}{$\begin{array}{c}\text { PCT- } \\
\text { B } \\
(\mathrm{g} / \mathrm{L})\end{array}$} & \multirow{2}{*}{$\begin{array}{l}\text { PCT- } \\
\mathbf{L i} \\
(\mathrm{g} / \mathrm{L})\end{array}$} & \multirow{2}{*}{$\begin{array}{l}\text { PCT- } \\
\text { Na } \\
(g / L)\end{array}$} & \multirow[t]{2}{*}{$\begin{array}{c}\text { PCT-B Data } \\
\text { Splitting } \\
\text { Validation Set }\end{array}$} & \multirow[t]{2}{*}{$\begin{array}{c}\text { PCT-Li Data } \\
\text { Splitting } \\
\text { Validation Set }\end{array}$} & \multirow{2}{*}{$\begin{array}{c}\text { PCT-Na } \\
\text { Data } \\
\text { Splitting } \\
\text { Validation }\end{array}$} \\
\hline & PCT-B & PCT-Li & PCT-Na & & & & & & \\
\hline HLW02-51 & Yes & Yes & Yes & 0.261 & 0.568 & 0.401 & 2 & 5 & 4 \\
\hline HLW02-52 & Yes & Yes & Yes & 0.588 & 0.674 & 0.637 & NA-Rep & NA-Rep & NA-Rep \\
\hline HLW02-53 & Yes & Yes & Yes & 0.344 & 0.780 & 0.376 & NA-Rep & NA-Rep & NA-Rep \\
\hline HLW02-54 & Yes & Yes & Yes & 1.671 & 0.705 & 0.938 & NA-Rep & NA-Rep & NA-Rep \\
\hline HLW02-55 & Yes & Yes & Yes & 0.829 & 0.864 & 0.715 & NA-Rep & NA-Rep & NA-Rep \\
\hline HLW02-56 & Yes & Yes & Yes & 0.746 & 0.579 & 0.731 & NA-Rep & NA-Rep & NA-Rep \\
\hline HLW02-57 & Yes & Yes & Yes & 4.419 & 3.252 & 2.565 & NA-Rep & NA-Rep & NA-Rep \\
\hline HLW03-01 & Yes & Yes & Yes & 0.965 & 0.740 & 0.577 & 4 & 5 & 1 \\
\hline HLW03-02 & Yes & Yes & Yes & 1.270 & 0.946 & 0.862 & 5 & 4 & 4 \\
\hline HLW03-03 & Yes & Yes & Yes & 1.356 & 1.393 & 1.499 & 5 & 5 & 2 \\
\hline HLW03-04 & Yes & Yes & Yes & 0.552 & 0.988 & 0.807 & 4 & 1 & 5 \\
\hline HLW03-05 & Yes & Yes & Yes & 0.555 & 0.474 & 0.655 & 5 & 3 & 5 \\
\hline HLW03-06 & Yes & Yes & Yes & 0.301 & 0.378 & 0.164 & NA-Rep & NA-Rep & NA-Rep \\
\hline HLW03-07 & Yes & Yes & Yes & 2.902 & 1.881 & 2.096 & NA-Rep & NA-Rep & NA-Rep \\
\hline HLW03-08 & Yes & Yes & Yes & 1.288 & 1.042 & 1.511 & 2 & 1 & 3 \\
\hline HLW03-09 & Yes & Yes & Yes & 2.507 & 1.807 & 1.462 & 3 & 2 & 4 \\
\hline HLW03-10 & Yes & Yes & Yes & 0.886 & 1.020 & 1.180 & 5 & 4 & 3 \\
\hline HLW03-11 & Yes & Yes & Yes & 1.412 & 0.973 & 1.206 & NA-Rep & NA-Rep & NA-Rep \\
\hline HLW03-12 & Yes & Yes & Yes & 0.836 & 0.765 & 0.739 & 5 & 1 & 4 \\
\hline HLW03-13 & Yes & Yes & Yes & 0.020 & 0.595 & 0.459 & NA-Outlier ${ }^{(b)}$ & 1 & 4 \\
\hline HLW03-14 & Yes & Yes & Yes & 1.521 & 1.348 & 1.311 & 3 & 3 & 3 \\
\hline HLW03-15 & Yes & Yes & Yes & 0.562 & 0.621 & 0.353 & 3 & 1 & 2 \\
\hline HLW03-16 & Yes & Yes & Yes & 0.666 & 0.791 & 0.775 & 1 & 4 & 1 \\
\hline HLW03-17 & Yes & Yes & Yes & 0.416 & 0.698 & 0.097 & 3 & 4 & 3 \\
\hline HLW03-18 & Yes & Yes & Yes & 3.492 & 2.669 & 2.532 & 4 & 5 & 2 \\
\hline
\end{tabular}

(a) NA-Rep indicates glasses that were not included in any of the validation splits because they were replicates.

(b) NA-Outlier indicates glasses that were not included in any of the validation splits because they were identified as outliers and removed from the PCT modeling dataset.

(c) A dash (-) or NA-No Data indicates glasses that did not contain $\mathrm{Li}_{2} \mathrm{O}$ and hence did not have PCT-Li releases. 
Table 5.3. PCT Releases and Data Splitting Validation Sets of HLW Glasses Used for PCT Model Development (continued).

\begin{tabular}{|c|c|c|c|c|c|c|c|c|c|}
\hline \multirow[t]{2}{*}{ Glass ID } & \multicolumn{3}{|c|}{$\begin{array}{c}\text { Used for } \\
\text { PCT Model } \\
\text { Development } \\
\end{array}$} & \multirow[t]{2}{*}{$\begin{array}{c}\text { PCT- } \\
\text { B } \\
(\mathrm{g} / \mathrm{L})\end{array}$} & \multirow[t]{2}{*}{$\begin{array}{l}\text { PCT- } \\
\mathbf{L i} \\
(\mathrm{g} / \mathrm{L})\end{array}$} & \multirow[t]{2}{*}{$\begin{array}{c}\text { PCT- } \\
\text { Na } \\
(\mathbf{g} / \mathbf{L})\end{array}$} & \multirow[t]{2}{*}{$\begin{array}{c}\text { PCT-B Data } \\
\text { Splitting } \\
\text { Validation Set }\end{array}$} & \multirow[t]{2}{*}{$\begin{array}{c}\text { PCT-Li Data } \\
\text { Splitting } \\
\text { Validation Set }\end{array}$} & \multirow{2}{*}{$\begin{array}{c}\text { PCT-Na } \\
\text { Data } \\
\text { Splitting } \\
\text { Validation }\end{array}$} \\
\hline & PCT-B & PCT-Li & \begin{tabular}{|l|} 
PCT-Na \\
\end{tabular} & & & & & & \\
\hline HLW03-19 & Yes & Yes & Yes & 2.866 & 2.128 & 2.291 & 5 & 1 & 3 \\
\hline HLW03-20 & Yes & Yes & Yes & 3.981 & 2.881 & 2.802 & 4 & 2 & 4 \\
\hline HLW03-21 & Yes & Yes & Yes & 0.403 & 0.466 & 0.347 & 2 & 5 & 1 \\
\hline HLW03-22 & Yes & Yes & Yes & 0.603 & 0.670 & 0.669 & 2 & 2 & 2 \\
\hline HLW03-23 & Yes & Yes & Yes & 0.832 & 0.736 & 0.595 & 4 & 3 & 1 \\
\hline HLW03-24 & Yes & Yes & Yes & 0.708 & 0.675 & 0.525 & 2 & 5 & 4 \\
\hline HLW03-25 & Yes & Yes & Yes & 1.987 & 1.494 & 1.474 & 2 & 2 & 5 \\
\hline HLW03-26 & Yes & Yes & Yes & 1.314 & 0.830 & 0.820 & NA-Rep & NA-Rep & NA-Rep \\
\hline HLW03-27 & Yes & Yes & Yes & 1.056 & 0.842 & 0.862 & 5 & 3 & 5 \\
\hline HLW03-28 & Yes & Yes & Yes & 1.636 & 1.271 & 1.121 & 1 & 1 & 5 \\
\hline HLW03-29 & Yes & Yes & Yes & 1.096 & 0.933 & 0.969 & 4 & 1 & 5 \\
\hline HLW03-30 & Yes & Yes & Yes & 0.920 & 0.733 & 0.490 & 3 & 5 & 4 \\
\hline HLW03-31 & Yes & Yes & Yes & 1.103 & 0.611 & 0.416 & 5 & 2 & 5 \\
\hline HLW03-32 & Yes & Yes & Yes & 0.501 & 0.661 & 0.551 & 4 & 5 & 4 \\
\hline HLW03-33 & Yes & Yes & Yes & 0.561 & 0.590 & 0.346 & 2 & 5 & 5 \\
\hline HLW03-34 & Yes & Yes & Yes & 0.663 & 0.780 & 0.473 & 5 & 3 & 1 \\
\hline HLW03-35 & Yes & Yes & Yes & 0.391 & 0.622 & 0.227 & 3 & 2 & 5 \\
\hline HLW03-36 & Yes & Yes & Yes & 1.262 & 0.665 & 0.240 & 3 & 3 & 1 \\
\hline HLW03-37 & Yes & Yes & Yes & 1.725 & 1.881 & 0.956 & 2 & 3 & 3 \\
\hline HLW03-38 & Yes & Yes & Yes & 0.557 & 0.669 & 0.396 & 1 & 1 & 1 \\
\hline HLW03-39 & Yes & Yes & Yes & 0.456 & 0.651 & 0.297 & 4 & 3 & 4 \\
\hline HLW03-40 & Yes & Yes & Yes & 0.397 & 0.590 & 0.371 & 4 & 4 & 5 \\
\hline HLW03-41 & Yes & Yes & Yes & 0.498 & 0.562 & 0.465 & NA-Rep & NA-Rep & NA-Rep \\
\hline HLW03-42 & Yes & Yes & Yes & 0.374 & 0.471 & 0.342 & NA-Rep & NA-Rep & NA-Rep \\
\hline HLW03-43 & Yes & Yes & Yes & 1.327 & 0.381 & 0.151 & NA-Rep & NA-Rep & NA-Rep \\
\hline
\end{tabular}

(a) NA-Rep indicates glasses that were not included in any of the validation splits because they were replicates.

(b) NA-Outlier indicates glasses that were not included in any of the validation splits because they were identified as outliers and removed from the PCT modeling dataset.

(c) A dash (-) or NA-No Data indicates glasses that did not contain $\mathrm{Li}_{2} \mathrm{O}$ and hence did not have PCT-Li releases. 
Table 5.3. PCT Releases and Data Splitting Validation Sets of HLW Glasses Used for PCT Model Development (continued).

\begin{tabular}{|c|c|c|c|c|c|c|c|c|c|}
\hline \multirow[t]{2}{*}{ Glass ID } & \multicolumn{3}{|c|}{$\begin{array}{c}\text { Used for } \\
\text { PCT Model } \\
\text { Development } \\
\end{array}$} & \multirow[t]{2}{*}{$\begin{array}{c}\text { PCT- } \\
\text { B } \\
(\mathrm{g} / \mathrm{L})\end{array}$} & \multirow[t]{2}{*}{$\begin{array}{l}\text { PCT- } \\
\mathbf{L i} \\
(\mathrm{g} / \mathrm{L})\end{array}$} & \multirow[t]{2}{*}{$\begin{array}{c}\text { PCT- } \\
\mathrm{Na} \\
(\mathrm{g} / \mathrm{L})\end{array}$} & \multirow[t]{2}{*}{$\begin{array}{c}\text { PCT-B Data } \\
\text { Splitting } \\
\text { Validation Set }\end{array}$} & \multirow[t]{2}{*}{$\begin{array}{c}\text { PCT-Li Data } \\
\text { Splitting } \\
\text { Validation Set }\end{array}$} & \multirow{2}{*}{$\begin{array}{c}\text { PCT-Na } \\
\text { Data } \\
\text { Splitting } \\
\text { Validation }\end{array}$} \\
\hline & PCT-B & \begin{tabular}{|l|} 
PCT-Li \\
\end{tabular} & \begin{tabular}{|l|} 
PCT-Na \\
\end{tabular} & & & & & & \\
\hline HLW03-44 & Yes & Yes & Yes & 0.800 & 0.967 & 1.137 & NA-Rep & NA-Rep & NA-Rep \\
\hline HLW03-45 & Yes & Yes & Yes & 0.679 & 0.754 & 0.777 & NA-Rep & NA-Rep & NA-Rep \\
\hline HLW04-03 & Yes & Yes & Yes & 3.520 & 0.837 & 1.516 & 2 & 1 & 4 \\
\hline HLW04-07 & Yes & Yes & Yes & 0.685 & 0.794 & 0.737 & NA-Rep & NA-Rep & NA-Rep \\
\hline HLW04-07NRE9 & Yes & Yes & Yes & 0.355 & 0.526 & 0.405 & NA-Rep & NA-Rep & NA-Rep \\
\hline HLW04-07NRE9CCC & Yes & Yes & Yes & 0.380 & 0.504 & 0.381 & NA-Rep & NA-Rep & NA-Rep \\
\hline HLW04-07RE39 & Yes & Yes & Yes & 0.579 & 0.692 & 0.623 & NA-Rep & NA-Rep & NA-Rep \\
\hline HLW04-07RE39CCC & Yes & Yes & Yes & 0.461 & 0.566 & 0.510 & NA-Rep & NA-Rep & NA-Rep \\
\hline HLW04-08 & Yes & Yes & Yes & 0.839 & 0.803 & 0.723 & 1 & 3 & 1 \\
\hline HLW04-09 & Yes & Yes & Yes & 0.548 & 0.607 & 0.553 & 3 & 1 & 5 \\
\hline HLW06-01 & Yes & Yes & Yes & 0.630 & 0.507 & 0.660 & NA-Rep & NA-Rep & NA-Rep \\
\hline HLW06-02 & Yes & Yes & Yes & 1.975 & 0.967 & 1.427 & 1 & 5 & 2 \\
\hline HLW06-03 & Yes & Yes & Yes & 0.321 & 0.195 & 0.494 & 5 & 3 & 5 \\
\hline HLW06-04 & Yes & Yes & Yes & 1.922 & 0.795 & 2.346 & 4 & 5 & 5 \\
\hline HLW06-05 & Yes & Yes & Yes & 0.773 & 0.536 & 1.039 & 3 & 3 & 2 \\
\hline HLW06-06 & Yes & Yes & Yes & 0.324 & 0.407 & 0.469 & NA-Rep & NA-Rep & NA-Rep \\
\hline HLW06-07 & Yes & Yes & Yes & 0.586 & 0.416 & 0.996 & 2 & 2 & 2 \\
\hline HLW06-08 & Yes & Yes & Yes & 0.700 & 0.536 & 0.902 & 5 & 4 & 2 \\
\hline HLW06-09 & Yes & Yes & Yes & 1.529 & 1.410 & 1.776 & 4 & 1 & 2 \\
\hline HLW06-10 & Yes & Yes & Yes & 0.401 & 0.316 & 0.447 & 1 & 5 & 1 \\
\hline HLW06-11 & Yes & Yes & Yes & 0.449 & 0.373 & 0.526 & 3 & 4 & 5 \\
\hline HLW06-12 & Yes & Yes & Yes & 1.742 & 1.220 & 1.448 & 3 & 4 & 3 \\
\hline HLW06-13 & Yes & Yes & Yes & 0.325 & 0.278 & 0.532 & NA-Rep & NA-Rep & NA-Rep \\
\hline HLW06-14 & Yes & Yes & Yes & 1.418 & 1.177 & 1.109 & 2 & 1 & 3 \\
\hline HLW06-15 & Yes & Yes & Yes & 3.273 & 1.981 & 2.306 & 3 & 5 & 4 \\
\hline
\end{tabular}

(a) NA-Rep indicates glasses that were not included in any of the validation splits because they were replicates.

(b) NA-Outlier indicates glasses that were not included in any of the validation splits because they were identified as outliers and removed from the PCT modeling dataset.

(c) A dash (-) or NA-No Data indicates glasses that did not contain $\mathrm{Li}_{2} \mathrm{O}$ and hence did not have PCT-Li releases. 
Table 5.3. PCT Releases and Data Splitting Validation Sets of HLW Glasses Used for PCT Model Development (continued).

\begin{tabular}{|c|c|c|c|c|c|c|c|c|c|}
\hline \multirow[t]{2}{*}{ Glass ID } & \multicolumn{3}{|c|}{$\begin{array}{c}\text { Used for } \\
\text { PCT Model } \\
\text { Development } \\
\end{array}$} & \multirow[t]{2}{*}{$\begin{array}{c}\text { PCT- } \\
\text { B } \\
(\mathrm{g} / \mathrm{L})\end{array}$} & \multirow[t]{2}{*}{$\begin{array}{l}\text { PCT- } \\
\mathbf{L i} \\
(\mathrm{g} / \mathrm{L})\end{array}$} & \multirow[t]{2}{*}{$\begin{array}{c}\text { PCT- } \\
\text { Na } \\
(\mathbf{g} / \mathbf{L})\end{array}$} & \multirow[t]{2}{*}{$\begin{array}{c}\text { PCT-B Data } \\
\text { Splitting } \\
\text { Validation Set }\end{array}$} & \multirow[t]{2}{*}{$\begin{array}{c}\text { PCT-Li Data } \\
\text { Splitting } \\
\text { Validation Set }\end{array}$} & \multirow{2}{*}{$\begin{array}{c}\text { PCT-Na } \\
\text { Data } \\
\text { Splitting } \\
\text { Validation }\end{array}$} \\
\hline & PCT-B & PCT-Li & \begin{tabular}{|l|} 
PCT-Na \\
\end{tabular} & & & & & & \\
\hline HLW06-16 & Yes & Yes & Yes & 1.201 & 0.760 & 1.646 & 4 & 5 & 5 \\
\hline HLW06-17 & Yes & Yes & Yes & 0.465 & 0.530 & 0.702 & NA-Rep & NA-Rep & NA-Rep \\
\hline HLW06-18 & Yes & Yes & Yes & 0.326 & 0.321 & 0.357 & 1 & 1 & 4 \\
\hline HLW06-19 & Yes & Yes & Yes & 0.713 & 0.226 & 1.027 & 3 & 4 & 5 \\
\hline HLW06-20 & Yes & Yes & Yes & 0.667 & 0.659 & 0.854 & 2 & 4 & 2 \\
\hline HLW06-21 & Yes & No & Yes & 1.335 & - $^{\text {(c) }}$ & 1.533 & 4 & NA-No Data ${ }^{(\mathrm{c})}$ & 1 \\
\hline HLW06-22 & Yes & Yes & Yes & 0.267 & 0.350 & 0.264 & 3 & 5 & 2 \\
\hline HLW06-23 & Yes & $\mathrm{No}$ & Yes & 2.233 & - & 1.842 & 4 & NA-No Data & 4 \\
\hline HLW06-24 & Yes & No & Yes & 0.248 & - & 1.068 & 3 & NA-No Data & 5 \\
\hline HLW06-25 & Yes & Yes & Yes & 0.461 & 0.470 & 0.189 & 2 & 1 & 2 \\
\hline HLW06-26 & Yes & No & Yes & 1.505 & - & 2.892 & 2 & NA-No Data & 5 \\
\hline HLW06-27 & Yes & Yes & Yes & 0.437 & 0.547 & 0.050 & 1 & 3 & 2 \\
\hline HLW06-28 & Yes & Yes & Yes & 4.494 & 3.629 & 3.056 & 5 & 5 & 1 \\
\hline HLW06-29 & Yes & Yes & Yes & 0.269 & 0.639 & 0.463 & 4 & 1 & 5 \\
\hline HLW06-30 & Yes & No & Yes & 1.075 & - & 1.194 & 2 & NA-No Data & 4 \\
\hline HLW06-31 & Yes & Yes & Yes & 0.187 & 0.333 & 0.198 & 1 & 4 & 3 \\
\hline HLW06-32 & Yes & No & Yes & 11.835 & - & 7.231 & 2 & NA-No Data & 5 \\
\hline HLW06-33 & Yes & Yes & Yes & 0.126 & 0.323 & 0.209 & 4 & 3 & 4 \\
\hline HLW06-34 & Yes & No & Yes & 12.427 & - & 6.586 & 4 & NA-No Data & 4 \\
\hline HLW06-35 & Yes & Yes & Yes & 0.488 & 0.574 & 0.440 & 2 & 4 & 3 \\
\hline HLW07-01 & Yes & Yes & Yes & 0.365 & 0.475 & 0.424 & 5 & 4 & 5 \\
\hline HLW07-02 & Yes & Yes & Yes & 0.503 & 0.624 & 0.416 & NA-Rep & NA-Rep & NA-Rep \\
\hline HLW07-03 & Yes & Yes & Yes & 0.550 & 0.623 & 0.460 & NA-Rep & NA-Rep & NA-Rep \\
\hline HLW07-04 & Yes & Yes & Yes & 0.624 & 0.738 & 0.071 & NA-Rep & NA-Rep & NA-Rep \\
\hline HLW07-05 & Yes & Yes & Yes & 2.103 & 1.421 & 1.435 & NA-Rep & NA-Rep & NA-Rep \\
\hline
\end{tabular}

(a) NA-Rep indicates glasses that were not included in any of the validation splits because they were replicates.

(b) NA-Outlier indicates glasses that were not included in any of the validation splits because they were identified as outliers that should be removed from the PCT modeling dataset.

(c) A dash (-) or NA-No Data indicates glasses that did not contain $\mathrm{Li}_{2} \mathrm{O}$ and hence did not have PCT-Li releases. 
Table 5.3. PCT Releases and Data Splitting Validation Sets of HLW Glasses Used for PCT Model Development (continued).

\begin{tabular}{|c|c|c|c|c|c|c|c|c|c|}
\hline \multirow[t]{2}{*}{ Glass ID } & \multicolumn{3}{|c|}{$\begin{array}{c}\text { Used for } \\
\text { PCT Model } \\
\text { Development }\end{array}$} & \multirow{2}{*}{$\begin{array}{c}\text { PCT- } \\
\text { B } \\
(\mathrm{g} / \mathrm{L})\end{array}$} & \multirow{2}{*}{$\begin{array}{c}\text { PCT- } \\
\mathbf{L i} \\
(\mathrm{g} / \mathrm{L})\end{array}$} & \multirow{2}{*}{$\begin{array}{l}\text { PCT- } \\
\mathrm{Na} \\
(\mathrm{g} / \mathrm{L})\end{array}$} & \multirow{2}{*}{$\begin{array}{c}\text { PCT-B Data } \\
\text { Splitting } \\
\text { Validation Set }\end{array}$} & \multirow[t]{2}{*}{$\begin{array}{l}\text { PCT-Li Data } \\
\text { Splitting } \\
\text { Validation Set }\end{array}$} & \multirow{2}{*}{$\begin{array}{l}\text { PCT-Na } \\
\text { Data } \\
\text { Splitting } \\
\text { Validation }\end{array}$} \\
\hline & PCT-B & PCT-Li & PCT-Na & & & & & & \\
\hline HLW07-06 & Yes & No & Yes & 0.249 & - $^{\text {(c) }}$ & 0.416 & 4 & NA-No Data ${ }^{(\mathrm{c})}$ & 1 \\
\hline HLW07-07 & Yes & No & Yes & 6.065 & - & 4.768 & 4 & NA-No Data & 2 \\
\hline HLW07-08 & Yes & No & Yes & 0.643 & - & 0.913 & 5 & NA-No Data & 3 \\
\hline HLW07-09 & Yes & Yes & Yes & 0.365 & 0.709 & 0.695 & 4 & 1 & 4 \\
\hline HLW07-10 & Yes & No & Yes & 0.799 & - & 0.874 & 5 & NA-No Data & 2 \\
\hline HLW07-11 & Yes & Yes & Yes & 0.976 & 0.906 & 1.481 & 5 & 4 & 1 \\
\hline HLW07-12 & Yes & Yes & Yes & 1.271 & 1.008 & 1.617 & 1 & 3 & 4 \\
\hline HLW07-13 & Yes & Yes & Yes & 0.630 & 0.363 & 0.893 & 4 & 2 & 4 \\
\hline HLW07-14 & Yes & Yes & Yes & 0.192 & 0.437 & 0.331 & 2 & 1 & 5 \\
\hline HLW07-15 & Yes & No & Yes & 1.195 & - & 1.557 & 3 & NA-No Data & 2 \\
\hline HLW07-16 & Yes & Yes & Yes & 3.939 & 2.813 & 2.429 & 3 & 1 & 1 \\
\hline HLW07-17 & Yes & Yes & Yes & 5.819 & 4.561 & 3.426 & 3 & 2 & 5 \\
\hline HLW07-18 & Yes & Yes & Yes & 5.133 & 4.100 & 3.216 & 1 & 1 & 3 \\
\hline HLW07-19 & Yes & Yes & Yes & 1.465 & 1.613 & 2.090 & 5 & 4 & 1 \\
\hline HLW07-20 & Yes & Yes & Yes & 0.435 & 0.579 & 0.154 & 4 & 2 & 5 \\
\hline HLW07-21 & Yes & No & Yes & 0.274 & - & 0.428 & 5 & NA-No Data & 2 \\
\hline HLW07-22 & Yes & No & Yes & 0.255 & - & 0.449 & 1 & NA-No Data & 3 \\
\hline HLW07-23 & Yes & Yes & Yes & 0.435 & 0.531 & 0.384 & 5 & 1 & 4 \\
\hline HLW07-24 & Yes & No & Yes & 1.148 & - & 0.747 & 1 & NA-No Data & 1 \\
\hline HLW07-25 & Yes & Yes & Yes & 0.367 & 0.537 & 0.424 & 1 & 5 & 1 \\
\hline HLW07-26 & Yes & Yes & Yes & 0.298 & 0.527 & 0.316 & 5 & 5 & 2 \\
\hline HLW07-27 & Yes & Yes & Yes & 0.378 & 0.472 & 0.386 & 2 & 2 & 5 \\
\hline HLW07-28 & Yes & Yes & Yes & 0.463 & 0.462 & 0.590 & 3 & 2 & 4 \\
\hline HLW07-29 & Yes & Yes & Yes & 0.648 & 0.667 & 0.556 & 3 & 5 & 2 \\
\hline HLW07-30 & Yes & Yes & Yes & 0.461 & 0.545 & 0.511 & 1 & 2 & 4 \\
\hline
\end{tabular}

(a) NA-Rep indicates glasses that were not included in any of the validation splits because they were replicates.

(b) NA-Outlier indicates glasses that were not included in any of the validation splits because they were identified as outliers and removed from the PCT modeling dataset.

(c) A dash (-) or NA-No Data indicates glasses that did not contain $\mathrm{Li}_{2} \mathrm{O}$ and hence did not have PCT-Li releases. 
Table 5.3. PCT Releases and Data Splitting Validation Sets of HLW Glasses Used for PCT Model Development (continued).

\begin{tabular}{|c|c|c|c|c|c|c|c|c|c|}
\hline \multirow[t]{2}{*}{ Glass ID } & \multicolumn{3}{|c|}{$\begin{array}{c}\text { Used for } \\
\text { PCT Model } \\
\text { Development }\end{array}$} & \multirow{2}{*}{$\begin{array}{c}\text { PCT- } \\
\text { B } \\
(\mathrm{g} / \mathrm{L})\end{array}$} & \multirow{2}{*}{$\begin{array}{c}\text { PCT- } \\
\text { Li } \\
(\mathrm{g} / \mathrm{L})\end{array}$} & \multirow{2}{*}{$\begin{array}{c}\text { PCT- } \\
\text { Na } \\
(\mathbf{g} / \mathbf{L})\end{array}$} & \multirow{2}{*}{$\begin{array}{c}\text { PCT-B Data } \\
\text { Splitting } \\
\text { Validation Set }\end{array}$} & \multirow{2}{*}{$\begin{array}{c}\text { PCT-Li Data } \\
\text { Splitting } \\
\text { Validation Set }\end{array}$} & \multirow{2}{*}{$\begin{array}{l}\text { PCT-Na } \\
\text { Data } \\
\text { Splitting } \\
\text { Validation }\end{array}$} \\
\hline & PCT-B & PCT-Li & PCT-Na & & & & & & \\
\hline HLW07-31 & Yes & Yes & Yes & 0.308 & 0.387 & 0.316 & 1 & 4 & 1 \\
\hline HLW07-32 & Yes & Yes & Yes & 0.539 & 0.508 & 0.592 & 1 & 3 & 5 \\
\hline HLW07-33 & Yes & Yes & Yes & 0.250 & 0.321 & 0.381 & 5 & 2 & 2 \\
\hline HLW07-34 & Yes & Yes & Yes & 0.314 & 0.465 & 0.275 & 2 & 3 & 3 \\
\hline HLW07-35 & Yes & Yes & Yes & 0.292 & 0.398 & 0.337 & 4 & 5 & 2 \\
\hline HLW07-36 & Yes & Yes & Yes & 0.456 & 0.413 & 0.509 & 5 & 1 & 3 \\
\hline HLW07-37 & Yes & Yes & Yes & 1.409 & 1.210 & 1.137 & 1 & 2 & 1 \\
\hline HLW07-38 & Yes & Yes & Yes & 0.348 & 0.367 & 0.331 & 1 & 3 & 4 \\
\hline HLW07-39 & Yes & Yes & Yes & 0.387 & 0.485 & 0.446 & 5 & 1 & 5 \\
\hline HLW07-40 & Yes & Yes & Yes & 0.358 & 0.384 & 0.400 & 2 & 3 & 3 \\
\hline HLW-ALG-01 & Yes & Yes & Yes & 1.243 & 0.735 & 0.899 & 2 & 2 & 5 \\
\hline HLW-ALG-02 & Yes & Yes & Yes & 0.719 & 0.578 & 0.622 & 4 & 1 & 1 \\
\hline HLW-ALG-03 & Yes & Yes & Yes & 21.903 & 10.675 & 11.819 & 3 & 4 & 5 \\
\hline HLW-ALG-04 & Yes & Yes & Yes & 8.839 & 6.164 & 5.726 & 1 & 4 & 3 \\
\hline HLW-ALG-05 & Yes & Yes & Yes & 3.505 & 3.285 & 3.202 & 1 & 3 & 2 \\
\hline HLW-ALG-06 & Yes & Yes & Yes & 1.034 & 0.998 & 1.248 & 3 & 2 & 1 \\
\hline HLW-ALG-07 & Yes & Yes & Yes & 0.346 & 0.383 & 0.373 & 5 & 2 & 1 \\
\hline HLW-ALG-08 & Yes & Yes & Yes & 0.929 & 0.820 & 0.958 & 4 & 4 & 4 \\
\hline HLW-ALG-09 & Yes & Yes & Yes & 1.490 & 1.219 & 1.337 & 1 & 3 & 4 \\
\hline HLW-ALG-10 & Yes & Yes & Yes & 12.445 & 6.615 & 7.788 & 5 & 1 & 2 \\
\hline HLW-ALG-11 & Yes & Yes & Yes & 0.387 & 0.481 & 0.390 & 1 & 5 & 3 \\
\hline HLW-ALG-12 & Yes & Yes & Yes & 1.020 & 0.797 & 1.059 & 2 & 1 & 4 \\
\hline HLW-ALG-13 & Yes & Yes & Yes & 0.119 & 0.612 & 0.647 & 3 & 3 & 4 \\
\hline HLW-ALG-14 & Yes & Yes & Yes & 0.384 & 0.881 & 0.806 & 3 & 3 & 4 \\
\hline HLW-ALG-15 & Yes & Yes & Yes & 1.454 & 0.861 & 1.110 & 4 & 1 & 4 \\
\hline
\end{tabular}

(a) NA-Rep indicates glasses that were not included in any of the validation splits because they were replicates.

(b) NA-Outlier indicates glasses that were not included in any of the validation splits because they were identified as outliers and removed from the PCT modeling dataset.

(c) A dash (-) or NA-No Data indicates glasses that did not contain $\mathrm{Li}_{2} \mathrm{O}$ and hence did not have PCT-Li releases. 
Table 5.3. PCT Releases and Data Splitting Validation Sets of HLW Glasses Used for PCT Model Development (continued).

\begin{tabular}{|c|c|c|c|c|c|c|c|c|c|}
\hline \multirow[t]{2}{*}{ Glass ID } & \multicolumn{3}{|c|}{$\begin{array}{c}\text { Used for } \\
\text { PCT Model } \\
\text { Development }\end{array}$} & \multirow{2}{*}{$\begin{array}{c}\text { PCT- } \\
\text { B } \\
(g / L)\end{array}$} & \multirow{2}{*}{$\begin{array}{c}\text { PCT- } \\
\mathbf{L i} \\
(\mathrm{g} / \mathrm{L})\end{array}$} & \multirow{2}{*}{$\begin{array}{c}\text { PCT- } \\
\text { Na } \\
(\mathbf{g} / \mathbf{L})\end{array}$} & \multirow{2}{*}{$\begin{array}{c}\text { PCT-B Data } \\
\text { Splitting } \\
\text { Validation Set }\end{array}$} & \multirow[t]{2}{*}{$\begin{array}{c}\text { PCT-Li Data } \\
\text { Splitting } \\
\text { Validation Set }\end{array}$} & \multirow{2}{*}{$\begin{array}{l}\text { PCT-Na } \\
\text { Data } \\
\text { Splitting } \\
\text { Validation }\end{array}$} \\
\hline & PCT-B & PCT-Li & PCT-Na & & & & & & \\
\hline HLW-ALG-16 & Yes & Yes & Yes & 2.273 & 1.387 & 1.522 & 5 & 4 & 5 \\
\hline HLW-ALG-17 & Yes & Yes & Yes & 12.863 & 6.424 & 8.940 & 1 & 5 & 4 \\
\hline HLW-ALG-18 & Yes & Yes & Yes & 0.641 & 0.563 & 0.571 & 4 & 2 & 5 \\
\hline HLW-ALG-19 & Yes & Yes & Yes & 2.878 & 1.976 & 1.815 & 1 & 4 & 3 \\
\hline HLW-ALG-20 & Yes & Yes & Yes & 5.562 & 3.485 & 3.228 & 2 & 4 & 4 \\
\hline HLW-ALG-21 & Yes & Yes & Yes & 0.817 & 0.587 & 1.202 & 1 & 1 & 5 \\
\hline HLW-ALG-22 & Yes & Yes & Yes & 0.908 & 0.612 & 1.029 & 2 & 4 & 1 \\
\hline HLW-ALG-23 & Yes & Yes & Yes & 1.044 & 0.573 & 1.353 & 4 & 3 & 5 \\
\hline HLW-ALG-24 & Yes & Yes & Yes & 0.336 & 0.565 & 0.577 & 4 & 3 & 2 \\
\hline HLW-ALG-25 & Yes & Yes & Yes & 11.902 & 6.752 & 7.488 & 3 & 2 & 1 \\
\hline HLW-ALG-26 & No & Yes & Yes & 0.007 & 0.429 & 0.393 & NA-Outlier ${ }^{(b)}$ & 4 & 4 \\
\hline HLW-ALG-27 & Yes & Yes & Yes & 1.932 & 1.316 & 1.084 & 5 & 2 & 1 \\
\hline HLW-ALG-28 & Yes & Yes & Yes & 2.331 & 1.604 & 1.360 & 2 & 3 & 1 \\
\hline HLW-ALG-29 & Yes & Yes & Yes & 1.078 & 0.634 & 0.760 & 3 & 5 & 2 \\
\hline HLW-ALG-30 & Yes & Yes & Yes & 0.328 & 0.427 & 0.543 & 2 & 3 & 3 \\
\hline HLW-ALG-31 & Yes & Yes & Yes & 1.577 & 1.246 & 1.055 & 5 & 5 & 3 \\
\hline HLW-ALG-32 & Yes & Yes & Yes & 0.440 & 0.626 & 0.632 & 2 & 3 & 3 \\
\hline HLW-ALG-33 & Yes & Yes & Yes & 0.634 & 0.489 & 0.867 & 5 & 2 & 1 \\
\hline HLW-ALG-34 & Yes & Yes & Yes & 14.147 & 6.986 & 8.569 & 2 & 3 & 3 \\
\hline HLW-ALG-35 & Yes & Yes & Yes & 0.389 & 0.712 & 0.764 & 2 & 2 & 4 \\
\hline HLW-ALG-36 & Yes & Yes & Yes & 0.936 & 1.078 & 1.153 & 1 & 4 & 2 \\
\hline HLW-ALG-37 & Yes & Yes & Yes & 0.180 & 0.542 & 0.524 & 5 & 1 & 3 \\
\hline HLW-ALG-38 & Yes & Yes & Yes & 0.387 & 0.141 & 0.332 & 4 & 2 & 1 \\
\hline HLW-ALG-39 & Yes & Yes & Yes & 0.700 & 0.753 & 0.533 & 1 & 3 & 2 \\
\hline HLW-ALG-40 & Yes & Yes & Yes & 0.364 & 0.577 & 0.621 & 3 & 5 & 5 \\
\hline
\end{tabular}

(a) NA-Rep indicates glasses that were not included in any of the validation splits because they were replicates.

(b) NA-Outlier indicates glasses that were not included in any of the validation splits because they were identified as outliers and removed from the PCT modeling dataset.

(c) A dash (-) or NA-No Data indicates glasses that did not contain $\mathrm{Li}_{2} \mathrm{O}$ and hence did not have PCT-Li releases. 
Table 5.3. PCT Releases and Data Splitting Validation Sets of HLW Glasses Used for PCT Model Development (continued) •

\begin{tabular}{|c|c|c|c|c|c|c|c|c|c|}
\hline \multirow[t]{2}{*}{ Glass ID } & \multicolumn{3}{|c|}{$\begin{array}{c}\text { Used for } \\
\text { PCT Model } \\
\text { Development } \\
\end{array}$} & \multirow[t]{2}{*}{$\begin{array}{c}\text { PCT- } \\
\text { B } \\
(\mathrm{g} / \mathrm{L})\end{array}$} & \multirow[t]{2}{*}{$\begin{array}{l}\text { PCT- } \\
\mathbf{L i} \\
(\mathrm{g} / \mathrm{L})\end{array}$} & \multirow[t]{2}{*}{$\begin{array}{l}\text { PCT- } \\
\text { Na } \\
(\mathrm{g} / \mathrm{L})\end{array}$} & \multirow[t]{2}{*}{$\begin{array}{c}\text { PCT-B Data } \\
\text { Splitting } \\
\text { Validation Set }\end{array}$} & \multirow[t]{2}{*}{$\begin{array}{c}\text { PCT-Li Data } \\
\text { Splitting } \\
\text { Validation Set }\end{array}$} & \multirow{2}{*}{$\begin{array}{c}\text { PCT-Na } \\
\text { Data } \\
\text { Splitting } \\
\text { Validation }\end{array}$} \\
\hline & PCT-B & PCT-Li & \begin{tabular}{|l|} 
PCT-Na \\
\end{tabular} & & & & & & \\
\hline HLW98-34CG & Yes & Yes & Yes & 0.278 & 0.360 & 0.342 & 2 & 1 & 4 \\
\hline HLW98-51AW & Yes & Yes & Yes & 1.736 & 1.424 & 1.285 & NA-Rep & NA-Rep & NA-Rep \\
\hline HLW98-51AWCG & Yes & Yes & Yes & 1.395 & 1.213 & 1.112 & NA-Rep & NA-Rep & NA-Rep \\
\hline HLW98-61 & Yes & Yes & Yes & 0.662 & 0.749 & 0.924 & NA-Rep & NA-Rep & NA-Rep \\
\hline HLW98-61CG1 & Yes & Yes & Yes & 0.571 & 0.718 & 0.787 & NA-Rep & NA-Rep & NA-Rep \\
\hline HLW98-74 & Yes & Yes & Yes & 0.823 & 0.765 & 0.804 & 3 & 2 & 3 \\
\hline HLW98-75 & Yes & Yes & Yes & 0.734 & 0.720 & 0.761 & 1 & 4 & 3 \\
\hline HLW98-77 & Yes & Yes & Yes & 0.532 & 0.585 & 0.424 & NA-Rep & NA-Rep & NA-Rep \\
\hline HLW98-77CG & Yes & Yes & Yes & 0.705 & 0.728 & 0.548 & NA-Rep & NA-Rep & NA-Rep \\
\hline HLW98-80 & Yes & Yes & Yes & 0.672 & 0.710 & 0.517 & NA-Rep & NA-Rep & NA-Rep \\
\hline HLW98-80CG & Yes & Yes & Yes & 0.693 & 0.592 & 0.463 & NA-Rep & NA-Rep & NA-Rep \\
\hline \begin{tabular}{|l|} 
HLW98-83 \\
\end{tabular} & Yes & Yes & Yes & 6.410 & 4.754 & 4.160 & 5 & 3 & 1 \\
\hline HLW98-84 & Yes & Yes & Yes & 0.740 & 0.639 & 0.576 & NA-Rep & NA-Rep & NA-Rep \\
\hline HLW98-84CG & Yes & Yes & Yes & 0.907 & 0.708 & 0.661 & NA-Rep & NA-Rep & NA-Rep \\
\hline \begin{tabular}{|l|} 
HLW98-86 \\
\end{tabular} & Yes & Yes & Yes & 0.806 & 0.661 & 0.645 & NA-Rep & NA-Rep & NA-Rep \\
\hline HLW98-86CG & Yes & Yes & Yes & 0.831 & 0.682 & 0.682 & NA-Rep & NA-Rep & NA-Rep \\
\hline HLW98-87 & Yes & Yes & Yes & 0.522 & 0.569 & 0.394 & 3 & 1 & 5 \\
\hline HLW98-88 & Yes & Yes & Yes & 0.517 & 0.572 & 0.448 & 1 & 2 & 2 \\
\hline HLW98-89 & Yes & Yes & Yes & 0.333 & 0.602 & 0.383 & 3 & 4 & 3 \\
\hline HLW98-94 & Yes & No & Yes & 0.850 & 0.006 & 1.774 & 2 & NA-Outlier ${ }^{(b)}$ & 1 \\
\hline HLW98-95 & Yes & Yes & Yes & 0.554 & 0.585 & 0.461 & NA-Rep & NA-Rep & NA-Rep \\
\hline HLW98-95CG-1 & Yes & Yes & Yes & 0.524 & 0.553 & 0.461 & NA-Rep & NA-Rep & NA-Rep \\
\hline HLW98-96 & Yes & Yes & Yes & 0.486 & 0.588 & 0.400 & NA-Rep & NA-Rep & NA-Rep \\
\hline HLW98-96CG & Yes & Yes & Yes & 0.347 & 0.531 & 0.398 & NA-Rep & NA-Rep & NA-Rep \\
\hline HLW98-96D & Yes & Yes & Yes & 0.653 & 0.719 & 0.474 & 4 & 3 & 2 \\
\hline
\end{tabular}

(a) NA-Rep indicates glasses that were not included in any of the validation splits because they were replicates.

(b) NA-Outlier indicates glasses that were not included in any of the validation splits because they were identified as outliers and removed from the PCT modeling dataset.

(c) A dash (-) or NA-No Data indicates glasses that did not contain $\mathrm{Li}_{2} \mathrm{O}$ and hence did not have PCT-Li releases. 
Table 5.3. PCT Releases and Data Splitting Validation Sets of HLW Glasses Used for PCT Model Development (continued).

\begin{tabular}{|c|c|c|c|c|c|c|c|c|c|}
\hline \multirow[t]{2}{*}{ Glass ID } & \multicolumn{3}{|c|}{$\begin{array}{c}\text { Used for } \\
\text { PCT Model } \\
\text { Development }\end{array}$} & \multirow[t]{2}{*}{$\begin{array}{c}\text { PCT- } \\
\text { B } \\
(\mathrm{g} / \mathrm{L})\end{array}$} & \multirow[t]{2}{*}{$\begin{array}{l}\text { PCT- } \\
\mathbf{L i} \\
(\mathrm{g} / \mathrm{L})\end{array}$} & \multirow[t]{2}{*}{$\begin{array}{l}\text { PCT- } \\
\text { Na } \\
(\mathrm{g} / \mathrm{L})\end{array}$} & \multirow[t]{2}{*}{$\begin{array}{c}\text { PCT-B Data } \\
\text { Splitting } \\
\text { Validation Set }\end{array}$} & \multirow[t]{2}{*}{$\begin{array}{c}\text { PCT-Li Data } \\
\text { Splitting } \\
\text { Validation Set }\end{array}$} & \multirow{2}{*}{$\begin{array}{c}\text { PCT-Na } \\
\text { Data } \\
\text { Splitting } \\
\text { Validation }\end{array}$} \\
\hline & PCT-B & PCT-Li & PCT-Na & & & & & & \\
\hline HLW98-96NRE4 & Yes & Yes & Yes & 0.651 & 0.705 & 0.506 & NA-Rep & NA-Rep & NA-Rep \\
\hline HLW98-96NRE4CCC & Yes & Yes & Yes & 0.491 & 0.548 & 0.387 & NA-Rep & NA-Rep & NA-Rep \\
\hline HLW98-96RE7 & Yes & Yes & Yes & 0.564 & 0.680 & 0.467 & NA-Rep & NA-Rep & NA-Rep \\
\hline HLW98-96RE7CCC & Yes & Yes & Yes & 0.406 & 0.532 & 0.368 & NA-Rep & NA-Rep & NA-Rep \\
\hline HLW98-97 & Yes & Yes & Yes & 0.644 & 0.588 & 0.500 & 1 & 2 & 2 \\
\hline HLW98-T05 & Yes & Yes & Yes & 0.684 & 0.642 & 0.555 & 3 & 2 & 1 \\
\hline HLW98-V01 & Yes & Yes & Yes & 0.564 & 0.582 & 0.389 & 4 & 5 & 2 \\
\hline HLW98-V07 & Yes & Yes & Yes & 0.571 & 0.601 & 0.419 & 1 & 3 & 3 \\
\hline HLW98-V13 & Yes & Yes & Yes & 0.867 & 0.735 & 0.661 & 3 & 1 & 1 \\
\hline HLW98-V19 & Yes & Yes & Yes & 0.787 & 0.756 & 0.736 & 4 & 4 & 3 \\
\hline HLW98-V24 & Yes & Yes & Yes & 0.958 & 0.945 & 0.915 & 2 & 3 & 4 \\
\hline AZ-101 Actual & Yes & Yes & Yes & 0.520 & 0.666 & 0.512 & 2 & 4 & 5 \\
\hline AZ-102 Actual & Yes & Yes & Yes & 0.528 & 0.750 & 0.792 & 4 & 2 & 2 \\
\hline AY-102/C-106 Actual & Yes & Yes & Yes & 0.480 & 0.580 & 0.480 & 5 & 3 & 3 \\
\hline C-106 Actual & Yes & Yes & Yes & 0.960 & 0.880 & 0.900 & 3 & 2 & 1 \\
\hline C-104 Actual & Yes & Yes & Yes & 0.872 & 0.906 & 0.732 & NA-Rep & NA-Rep & NA-Rep \\
\hline
\end{tabular}

(a) NA-Rep indicates glasses that were not included in any of the validation splits because they were replicates.

(b) NA-Outlier indicates glasses that were not included in any of the validation splits because they were identified as outliers and removed from the PCT modeling dataset.

(c) A dash (-) or NA-No Data indicates glasses that did not contain $\mathrm{Li}_{2} \mathrm{O}$ and hence did not have PCT-Li releases. 
Table 5.4. PCT Release Data, \%RSDs, and Standard Deviations for Replicate Sets of HLW Glasses.

\begin{tabular}{|c|c|c|c|c|c|c|}
\hline \multirow{2}{*}{ Glass IDs of Replicate Sets ${ }^{(a)}$} & \multicolumn{2}{|c|}{ PCT-B } & \multicolumn{2}{|c|}{ PCT-Li } & \multicolumn{2}{|c|}{ PCT-Na } \\
\hline & $g / L$ & $\ln (g / L)$ & $g / L$ & $\ln (g / L)$ & $\mathrm{g} / \mathbf{L}$ & $\ln (g / L)$ \\
\hline HLW02-01 & 0.700 & -0.357 & 0.685 & -0.378 & 0.628 & -0.465 \\
\hline \multirow[t]{2}{*}{ HLW02-52 } & 0.588 & -0.530 & 0.674 & -0.395 & 0.637 & -0.451 \\
\hline & $\%$ RSD $=12.25$ & SD $=0.1228$ & $\%$ RSD $=1.18$ & SD $=0.0118$ & $\%$ RSD $=1.00$ & SD $=\mathbf{0 . 0 1 0 0}$ \\
\hline HLW02-04 & 0.574 & -0.555 & 0.724 & -0.322 & 0.877 & -0.131 \\
\hline \multirow[t]{2}{*}{ HLW02-54 } & 1.671 & 0.514 & 0.705 & -0.349 & 0.938 & -0.064 \\
\hline & $\%$ RSD $=69.11$ & SD $=0.7557$ & $\%$ RSD =1.88 & SD $=\mathbf{0 . 0 1 8 8}$ & $\%$ RSD $=4.72$ & SD $=\mathbf{0 . 0 4 7 3}$ \\
\hline HLW02-08 & 3.531 & 1.262 & 2.679 & 0.986 & 2.262 & 0.816 \\
\hline \multirow{2}{*}{ HLW02-57 } & 4.419 & 1.486 & 3.252 & 1.179 & 2.565 & 0.942 \\
\hline & $\%$ RSD $=15.80$ & SD $=0.1586$ & $\%$ RSD $=13.65$ & SD $=\mathbf{0 . 1 3 6 9}$ & \%RSD=8.90 & $\mathrm{SD}=\mathbf{0 . 0 8 9 1}$ \\
\hline HLW02-17 & 0.546 & -0.606 & 0.726 & -0.320 & 0.340 & -1.079 \\
\hline \multirow[t]{2}{*}{ HLW02-53 } & 0.344 & -1.068 & 0.780 & -0.249 & 0.376 & -0.977 \\
\hline & \%RSD=32.09 & SD $=0.3266$ & \%RSD=5.02 & SD $=\mathbf{0 . 0 5 0 2}$ & \begin{tabular}{|l|} 
\%RSD=7.16 \\
\end{tabular} & SD $=\mathbf{0 . 0 7 1 7}$ \\
\hline HLW02-22 & 0.550 & -0.599 & 0.620 & -0.479 & 0.076 & -2.576 \\
\hline \multirow{2}{*}{ HLW07-04 } & 0.624 & -0.471 & 0.738 & -0.303 & 0.071 & -2.647 \\
\hline & \%RSD=8.98 & SD $=0.0899$ & \%RSD=12.37 & SD $=\mathbf{0 . 1 2 4 0}$ & \begin{tabular}{|l|} 
\%RSD $=5.00$ \\
\end{tabular} & SD $=\mathbf{0 . 0 5 0 0}$ \\
\hline HLW02-42 & 1.080 & 0.077 & 0.950 & -0.052 & 0.823 & -0.195 \\
\hline \multirow{2}{*}{ HLW02-55 } & 0.829 & -0.187 & 0.864 & -0.146 & 0.715 & -0.335 \\
\hline & \%RSD $=18.57$ & SD $=0.1868$ & $\%$ RSD=6.68 & SD $=0.0668$ & \begin{tabular}{|l|} 
\%RSD=9.91 \\
\end{tabular} & SD $=\mathbf{0 . 0 9 9 3}$ \\
\hline HLW02-44 & 0.809 & -0.212 & 0.748 & -0.291 & 0.853 & -0.159 \\
\hline \multirow{2}{*}{ HLW02-56 } & 0.746 & -0.293 & 0.579 & -0.547 & 0.731 & -0.313 \\
\hline & $\%$ RSD $=5.75$ & SD $=0.0575$ & \%RSD=18.02 & SD $=\mathbf{0 . 1 8 1 2}$ & \%RSD $=\mathbf{1 0 . 8 8}$ & SD $=0.1091$ \\
\hline HLW02-46 & 0.536 & -0.623 & 0.632 & -0.459 & 0.452 & -0.794 \\
\hline HLW & 0.374 & -0.983 & 0.471 & -0.753 & 0.342 & -1.074 \\
\hline \multirow{2}{*}{ HLW07-02 } & 0.503 & -0.687 & 0.624 & -0.471 & 0.416 & -0.877 \\
\hline & $\%$ RSD $=18.19$ & SD $=0.1921$ & $\%$ RSD $=15.73$ & SD $=0.1659$ & $\%$ RSD $=13.95$ & SD $=\mathbf{0 . 1 4 3 7}$ \\
\hline HLW03-06 & $0.301^{(\mathrm{b})}$ & -1.200 & 0.378 & -0.972 & 0.164 & -1.808 \\
\hline \multirow[t]{2}{*}{ HLW03-43 } & $1.327^{(\mathrm{b})}$ & 0.283 & 0.381 & -0.964 & 0.151 & -1.887 \\
\hline & $\%$ RSD $=89.11$ & SD $=1.0488$ & $\%$ RSD $=0.54$ & SD $=0.0054$ & $\%$ RSD $=5.60$ & SD $=\mathbf{0 . 0 5 6 0}$ \\
\hline HLW03-07 & 2.902 & 1.066 & 1.881 & 0.632 & 2.096 & 0.740 \\
\hline \multirow{2}{*}{ HLW07-05 } & 2.103 & 0.743 & 1.421 & 0.351 & 1.435 & 0.361 \\
\hline & $\%$ RSD $=22.60$ & SD $=0.2279$ & $\%$ RSD $=19.72$ & SD $=\mathbf{0 . 1 9 8 5}$ & $\%$ RSD $=26.46$ & SD $=\mathbf{0 . 2 6 7 7}$ \\
\hline HLW03-11 & 1.412 & 0.345 & 0.973 & -0.027 & 1.206 & 0.188 \\
\hline \multirow[t]{2}{*}{ HLW03-44 } & 0.800 & -0.223 & 0.967 & -0.034 & 1.137 & 0.129 \\
\hline & $\%$ RSD $=39.14$ & SD $=0.4019$ & $\%$ RSD $=0.42$ & SD $=0.0042$ & $\%$ RSD $=4.15$ & SD $=\mathbf{0 . 0 4 1 5}$ \\
\hline HLW03-26 & 1.314 & 0.273 & 0.830 & -0.186 & 0.820 & -0.198 \\
\hline \multirow[t]{2}{*}{ HLW03-45 } & 0.679 & -0.387 & 0.754 & -0.282 & 0.777 & -0.252 \\
\hline & $\%$ RSD $=45.02$ & SD $=0.4664$ & \%RSD=6.79 & SD $=\mathbf{0 . 0 6 8 0}$ & \%RSD=3.83 & SD $=\mathbf{0 . 0 3 8 3}$ \\
\hline HLW03-41 & 0.498 & -0.697 & 0.562 & -0.577 & 0.465 & -0.767 \\
\hline \multirow{2}{*}{ HLW07-03 } & 0.550 & -0.598 & 0.623 & -0.473 & 0.460 & -0.777 \\
\hline & \%RSD=6.97 & SD $=0.0697$ & \%RSD=7.34 & SD $=\mathbf{0 . 0 7 3 5}$ & \begin{tabular}{|l|}
$\%$ RSD $=0.73$ \\
\end{tabular} & SD $=\mathbf{0 . 0 0 7 3}$ \\
\hline HLW04-07 & 0.685 & -0.378 & 0.794 & -0.231 & 0.737 & -0.305 \\
\hline HLW04-07RE39 & 0.579 & -0.547 & 0.692 & -0.369 & 0.623 & -0.473 \\
\hline \multirow[t]{2}{*}{ HLW04-07RE39CCC } & 0.461 & -0.774 & 0.566 & -0.570 & 0.510 & -0.674 \\
\hline & \%RSD $=19.51$ & SD $=0.1989$ & $\%$ RSD $=16.73$ & SD $=0.1706$ & \%RSD=18.24 & SD $=\mathbf{0 . 1 8 4 6}$ \\
\hline
\end{tabular}

(a) Some replicate sets involve canister centerline cooling (CCC) or redox treatments of a base glass. The PCT results do not seem to be affected by these treatments, as thus were included as replicate sets.

(b) These values were checked and no reason could be found for the relatively large difference. 
Table 5.4. PCT Release Data, \%RSDs, and Standard Deviations for Replicate Sets of HLW Glasses (continued).

\begin{tabular}{|c|c|c|c|c|c|c|}
\hline \multirow[b]{2}{*}{ Glass IDs of Replicate Sets ${ }^{(a)}$} & \multicolumn{2}{|c|}{ PCT-B } & \multicolumn{2}{|c|}{ PCT-Li } & \multicolumn{2}{|c|}{ PCT-Na } \\
\hline & $\mathrm{g} / \mathrm{L}$ & $\ln (g / L)$ & $\mathrm{g} / \mathrm{L}$ & $\ln (g / L)$ & $\mathrm{g} / \mathbf{L}$ & $\ln (g / L)$ \\
\hline HLW04-07NRE9 & 0.355 & -1.037 & 0.526 & -0.643 & 0.405 & -0.905 \\
\hline \multirow{2}{*}{ HLW04-07NRE9CCC } & 0.380 & -0.968 & 0.504 & -0.685 & 0.381 & -0.966 \\
\hline & $\%$ RSD $=4.90$ & SD $=\mathbf{0 . 0 4 9 0}$ & $\%$ RSD $=2.95$ & $\mathrm{SD}=\mathbf{0 . 0 2 9 5}$ & $\%$ RSD $=4.30$ & SD $=0.0430$ \\
\hline HLW06-01 & 0.630 & -0.462 & 0.507 & -0.679 & 0.660 & -0.416 \\
\hline \multirow{2}{*}{ HLW06-17 } & 0.465 & -0.766 & 0.530 & -0.634 & 0.702 & -0.353 \\
\hline & $\%$ RSD $=21.35$ & SD $=0.2152$ & \%RSD $=3.13$ & SD $=0.0313$ & $\%$ RSD $=4.46$ & SD $=0.0446$ \\
\hline HLW06-06 & 0.324 & -1.128 & 0.407 & -0.898 & 0.469 & -0.756 \\
\hline \multirow{2}{*}{ HLW06-13 } & 0.325 & -1.125 & 0.278 & -1.280 & 0.532 & -0.631 \\
\hline & $\%$ RSD $=0.25$ & SD $=\mathbf{0 . 0 0 2 5}$ & $\%$ RSD $=26.65$ & $\mathrm{SD}=\mathbf{0 . 2 6 9 7}$ & \%RSD=8.85 & SD $=\mathbf{0 . 0 8 8 6}$ \\
\hline HLW98-51AW & 1.736 & 0.551 & 1.424 & 0.354 & 1.285 & 0.251 \\
\hline HLW98-5 & 1.395 & 0.333 & 1.213 & 0.193 & 1.112 & 0.106 \\
\hline \multirow{2}{*}{\begin{tabular}{|l|} 
C-104 Actual \\
\end{tabular}} & 0.872 & -0.137 & 0.906 & -0.099 & 0.732 & -0.312 \\
\hline & $\%$ RSD=32.61 & SD $=\mathbf{0 . 3 5 1 7}$ & $\%$ RSD $=22.06$ & $\mathrm{SD}=\mathbf{0 . 2 2 9 3}$ & $\%$ RSD $=27.12$ & SD $=0.2922$ \\
\hline HLW98-61 & 0.662 & -0.413 & 0.749 & -0.289 & 0.924 & -0.080 \\
\hline \multirow[t]{2}{*}{ HLW98-61CG1 } & 0.571 & -0.560 & 0.718 & -0.331 & 0.787 & -0.239 \\
\hline & $\%$ RSD $=10.38$ & SD $=\mathbf{0 . 1 0 4 0}$ & $\%$ RSD=2.95 & SD $=\mathbf{0 . 0 2 9 5}$ & $\%$ RSD $=11.27$ & SD $=0.1130$ \\
\hline HLW98-77 & 0.532 & -0.631 & 0.585 & -0.536 & 0.424 & -0.859 \\
\hline \multirow[t]{2}{*}{ HLW98-77CG } & 0.705 & -0.349 & 0.728 & -0.317 & 0.548 & -0.602 \\
\hline & $\%$ RSD $=19.78$ & SD $=\mathbf{0 . 1 9 9 1}$ & \%RSD $=15.37$ & $\mathrm{SD}=\mathbf{0 . 1 5 4 3}$ & $\%$ RSD $=18.05$ & SD $=0.1815$ \\
\hline HLW98-80 & 0.672 & -0.398 & 0.710 & -0.343 & 0.517 & -0.659 \\
\hline \multirow[t]{2}{*}{ HLW98-80CG } & 0.693 & -0.367 & 0.592 & -0.523 & 0.463 & -0.770 \\
\hline & $\%$ RSD $=2.18$ & SD $=\mathbf{0 . 0 2 1 8}$ & \%RSD $=12.74$ & $\mathrm{SD}=\mathbf{0 . 1 2 7 8}$ & $\%$ RSD=7.84 & $\mathrm{SD}=\mathbf{0 . 0 7 8 4}$ \\
\hline HLW98-84 & 0.740 & -0.301 & 0.639 & -0.448 & 0.576 & -0.552 \\
\hline \multirow[t]{2}{*}{ HLW98-84CG } & 0.907 & -0.098 & 0.708 & -0.345 & 0.661 & -0.414 \\
\hline & $\%$ RSD $=14.33$ & SD $=\mathbf{0 . 1 4 3 7}$ & $\%$ RSD=7.24 & $\mathrm{SD}=\mathbf{0 . 0 7 2 5}$ & $\%$ RSD $=9.77$ & $\mathrm{SD}=\mathbf{0 . 0 9 7 8}$ \\
\hline HLW98-86 & 0.806 & -0.215 & 0.661 & -0.413 & 0.645 & -0.438 \\
\hline \multirow{2}{*}{ HLW98-86CG } & 0.831 & -0.185 & 0.682 & -0.383 & 0.682 & -0.382 \\
\hline & $\%$ RSD $=2.10$ & SD $=\mathbf{0 . 0 2 1 0}$ & $\%$ RSD $=2.18$ & SD $=0.0219$ & $\%$ RSD $=3.95$ & $\mathrm{SD}=0.0396$ \\
\hline HLW98-95 & 0.554 & -0.591 & 0.585 & -0.536 & 0.461 & -0.775 \\
\hline \multirow{2}{*}{ HLW98-95CG-1 } & 0.524 & -0.647 & 0.553 & -0.592 & 0.461 & -0.774 \\
\hline & \%RSD=3.97 & SD $=\mathbf{0 . 0 3 9 8}$ & \%RSD=3.97 & SD $=\mathbf{0 . 0 3 9 7}$ & \%RSD $=0.02$ & $\mathrm{SD}=\mathbf{0 . 0 0 0 2}$ \\
\hline HLW9 & 0.486 & -0.723 & 0.588 & -0.531 & 0.400 & -0.916 \\
\hline HLWS & 0.347 & -1.059 & 0.531 & -0.633 & 0.398 & -0.922 \\
\hline HLW98-96RE7 & 0.564 & -0.573 & 0.680 & -0.385 & 0.467 & -0.762 \\
\hline \multirow[t]{2}{*}{ HLW98-96RE7CCC } & 0.406 & -0.902 & 0.532 & -0.632 & 0.368 & -0.999 \\
\hline & $\%$ RSD $=20.98$ & $\mathrm{SD}=\mathbf{0 . 2 1 1 5}$ & $\%$ RSD $=12.05$ & SD $=0.1168$ & \%RSD=10.21 & SD $=0.0994$ \\
\hline HLW98-96NRE4 & 0.651 & -0.429 & 0.705 & -0.349 & 0.506 & -0.681 \\
\hline \multirow[t]{2}{*}{ HLW98-96NRE4CCC } & 0.491 & -0.712 & 0.548 & -0.601 & 0.387 & -0.949 \\
\hline & $\%$ RSD $=19.90$ & SD $=0.2003$ & $\%$ RSD $=17.71$ & $\mathrm{SD}=\mathbf{0 . 1 7 8 1}$ & $\%$ RSD $=18.88$ & SD $=0.1900$ \\
\hline $\begin{array}{l}\text { Pooled Over All } 26 \\
\text { Replicate Sets } \\
\end{array}$ & $\%$ RSD=28.51 & SD $=0.3109$ & $\%$ RSD $=12.97$ & $\mathrm{SD}=\mathbf{0 . 1 3 1 7}$ & $\%$ RSD $=12.82$ & $\mathrm{SD}=\mathbf{0 . 1 3 1 8}$ \\
\hline $\begin{array}{l}\text { Pooled w/o HLW03-06 \& } \\
\text { HLW03-43 Replicate Set }\end{array}$ & $\%$ RSD $=23.98$ & $\mathrm{SD}=\mathbf{0 . 2 5 1 5}$ & $\mathbf{N} \mathbf{A}^{(\mathbf{b})}$ & $\mathbf{N} \mathbf{A}^{(\mathbf{b})}$ & $\mathbf{N} \mathbf{A}^{(\mathbf{b})}$ & $\mathbf{N} \mathbf{A}^{(\mathbf{b})}$ \\
\hline
\end{tabular}

(a) Some replicate sets involve canister centerline cooling (CCC) or redox treatments of a base glass. The PCT results do not seem to be affected by these treatments, as thus were included as replicate sets.

(b) $\mathrm{NA}=$ not applicable. 
Table 5.5. Coefficients and Performance Summary for the 25-Component Full Linear Mixture Model on the Natural Logarithm of PCT-B for HLW Glasses. ${ }^{\text {(a) }}$

\begin{tabular}{|c|c|c|c|c|c|c|c|c|}
\hline $\begin{array}{l}\text { In(PCT-B) } \\
\text { Model Term }\end{array}$ & $\begin{array}{c}\text { Coefficient } \\
\text { Estimate }\end{array}$ & $\begin{array}{l}\text { Coefficient } \\
\text { Standard } \\
\text { Deviation }\end{array}$ & $\begin{array}{l}\text { t-value }= \\
\text { Coeff/SD }\end{array}$ & p-value & \multicolumn{3}{|c|}{$\begin{array}{l}\text { Modeling Data Statistic, } \\
264 \text { Glasses }^{(b)}\end{array}$} & Value \\
\hline $\mathrm{Al}_{2} \mathrm{O}_{3}$ & -18.6460 & 1.2493 & $\mathrm{NA}^{(\mathrm{c})}$ & NA & \multicolumn{3}{|c|}{$\mathrm{R}^{2}$} & 0.727 \\
\hline $\mathrm{B}_{2} \mathrm{O}_{3}$ & 6.9499 & 1.0320 & NA & NA & \multicolumn{3}{|c|}{$\mathrm{R}^{2}$ Adjusted $\left(\mathrm{R}_{\mathrm{A}}^{2}\right)$} & 0.700 \\
\hline $\mathrm{CaO}$ & -28.5754 & 25.5721 & NA & NA & \multicolumn{3}{|c|}{$\mathrm{R}^{2}$ Predicted $\left(\mathrm{R}_{\mathrm{P}}^{2}\right)$} & 0.659 \\
\hline $\mathrm{CdO}$ & -5.4477 & 7.5074 & NA & NA & \multicolumn{3}{|c|}{ RMSE } & 0.486 \\
\hline $\mathrm{Cr}_{2} \mathrm{O}_{3}$ & 44.5129 & 18.5945 & NA & NA & \multicolumn{3}{|c|}{ Model LOF p-value } & 0.001 \\
\hline $\mathrm{Fe}_{2} \mathrm{O}_{3}$ & -4.1219 & 1.0248 & NA & NA & & \\
\hline $\mathrm{K}_{2} \mathrm{O}$ & 48.1341 & \multirow{2}{*}{$\begin{array}{l}29.0474 \\
23.8120\end{array}$} & NA & NA & \multirow{2}{*}{\multicolumn{3}{|c|}{$\begin{array}{l}\text { Separate (Extrapolative) Validation } \\
\text { Statistic, } 556 \text { Outlying Glasses }^{(\mathbf{b}, \mathbf{d})} \\
\end{array}$}} & \\
\hline $\mathrm{La}_{2} \mathrm{O}_{3}$ & -13.7983 & & NA & NA & & & & Value \\
\hline $\mathrm{Li}_{2} \mathrm{O}$ & 22.8898 & 2.3935 & NA & NA & \multicolumn{3}{|c|}{\begin{tabular}{|c|} 
Statistic, 556 Outlying Glasses \\
\\
$\mathrm{R}^{2}$ Validation $\left(\mathrm{R}^{2} \mathrm{~d}\right)$
\end{tabular}} & $<0$ \\
\hline $\mathrm{MgO}$ & -19.1693 & 31.1366 & NA & NA & & Validati & $\left(\mathrm{SE}_{\mathrm{V}}\right)$ & 1.599 \\
\hline $\mathrm{MnO}$ & 5.5864 & 1.5455 & NA & NA & & & & \\
\hline $\mathrm{Na}_{2} \mathrm{O}$ & 15.1215 & 0.9700 & NA & NA & Dat & ition Sta & & \\
\hline $\mathrm{NiO}$ & 17.8172 & 9.7668 & NA & NA & 162 & ling \& 1 & idation $^{(\mathbf{b}, \mathrm{e})}$ & Value \\
\hline $\mathrm{PbO}$ & -4.3327 & 18.6487 & NA & NA & & & & 0.794 \\
\hline $\mathrm{Sb}_{2} \mathrm{O}_{3}$ & -47.0236 & 39.2774 & NA & NA & & isted $\left(\mathrm{R}^{2}\right.$ & & 0.757 \\
\hline $\mathrm{SeO}_{2}$ & 102.8333 & 59.8387 & NA & NA & & icted $(\mathrm{R}$ & & $<0$ \\
\hline $\mathrm{SiO}_{2}$ & -3.7600 & 0.4607 & NA & NA & & & & 0.464 \\
\hline $\mathrm{SrO}$ & -2.4606 & 1.3024 & NA & NA & & dation (I & & $<0$ \\
\hline $\mathrm{ThO}_{2}$ & 0.9572 & 1.8658 & NA & NA & & Validati & $\left.\mathrm{ISE}_{\mathrm{V}}\right)$ & 2.015 \\
\hline $\mathrm{TiO}_{2}$ & -47.5036 & 61.1711 & NA & NA & & & & \\
\hline $\mathrm{Tl}_{2} \mathrm{O}$ & 36.8632 & 53.8058 & NA & NA & & & & \\
\hline $\mathrm{UO}_{3}$ & -2.6171 & 1.9728 & NA & NA & & & & \\
\hline $\mathrm{ZnO}$ & -2.0762 & 3.1550 & NA & NA & & & & \\
\hline $\mathrm{ZrO}_{2}$ & -11.1906 & 1.1508 & NA & NA & & & & \\
\hline Others $^{(\mathrm{g})}$ & 9.8867 & 7.2410 & NA & NA & & & & \\
\hline Data Splitting & tistic $^{(b, f)}$ & DS & & $\overline{D S 2}$ & DS3 & DS4 & DS5 & Average \\
\hline $\mathrm{R}^{2}$ & & 0.7 & & .714 & 0.736 & 0.729 & 0.739 & 0.726 \\
\hline $\mathrm{R}^{2}$ Adjusted (I & & 0.6 & & .679 & 0.704 & 0.696 & 0.707 & 0.692 \\
\hline $\mathrm{R}^{2}$ Predicted ( & & 0.6 & & .620 & 0.653 & 0.640 & 0.661 & 0.639 \\
\hline RMSE & & 0.5 & & .490 & 0.467 & 0.487 & 0.479 & 0.485 \\
\hline $\mathrm{R}^{2}$ Validation & & 0.7 & & .751 & 0.655 & 0.681 & 0.599 & 0.693 \\
\hline RMSE Valida & $\left(\mathrm{RMSE}_{\mathrm{V}}\right)$ & 0.4 & & .496 & 0.598 & 0.511 & 0.567 & 0.521 \\
\hline
\end{tabular}

(a) Model results and summary statistics were generated using PCT-B normalized releases calculated to many decimal places. Rounded versions of these PCT-B values are given in Table 5.3. Conducting modeling with the rounded versions of the PCT-B normalized releases may result in slightly different model results and summary statistics.

(b) The model evaluation statistics are defined in Section C.3 of Appendix C. Model validation statistics are defined in Section C.5 of Appendix C. A negative value for $\mathrm{R}_{\mathrm{V}}^{2}$ means that the sum of squares of model prediction errors is larger than if the mean response value over the validation data set were used as the predicted value for each glass. In other words, the model predicts worse for the validation data than the mean response value does.

(c) NA denotes that it is not applicable to perform a statistical t-test on linear terms in a mixture model (see Section C.5.1).

(d) The 556 separate HLW glass compositions with PCT-B data for validation (mostly extrapolative) of PCT-B models are discussed in Section 5.1.4.

(e) The partition of the PCT-B modeling dataset into modeling and validation subsets is described in Section 5.1.3.

(f) The evaluation and validation statistics calculated for data-splits are defined the same as for separate modeling and validation sets. Section 5.1.2 describes how the data-splitting was accomplished.

(g) For the 25-component full linear mixture model, the "Others" component includes $\mathrm{Ag}_{2} \mathrm{O}, \mathrm{As}_{2} \mathrm{O}_{5}, \mathrm{BaO}, \mathrm{BeO}_{2} \mathrm{Bi}_{2} \mathrm{O}_{3}, \mathrm{Ce}_{2} \mathrm{O}_{3}$, $\mathrm{Cl}, \mathrm{CoO}, \mathrm{Cs}_{2} \mathrm{O}, \mathrm{CuO}, \mathrm{Dy}_{2} \mathrm{O}, \mathrm{Eu}_{2} \mathrm{O}, \mathrm{F}, \mathrm{Gd}_{2} \mathrm{O}_{3}, \mathrm{HfO}_{2}, \mathrm{HgO}, \mathrm{MoO}_{3}, \mathrm{Nd}_{2} \mathrm{O}_{3}, \mathrm{P}_{2} \mathrm{O}_{5}, \mathrm{PdO}, \mathrm{Pr}_{2} \mathrm{O}_{3}, \mathrm{Rb}_{2} \mathrm{O}, \mathrm{Re}_{2} \mathrm{O}_{7}, \mathrm{Rh}_{2} \mathrm{O}_{3}, \mathrm{RuO}_{2}$, $\mathrm{SO}_{3}, \mathrm{Sm}_{2} \mathrm{O}_{3}, \mathrm{SnO}_{2}, \mathrm{Tc}_{2} \mathrm{O}_{7}, \mathrm{TeO}_{2}, \mathrm{~V}_{2} \mathrm{O}_{5}, \mathrm{WO}_{3}$, and $\mathrm{Y}_{2} \mathrm{O}_{3}$. 


\section{Table 5.6. Coefficients and Performance Summary for the 13-Component Reduced Linear Mixture Model on the Natural Logarithm of PCT-B for HLW Glasses. $^{\text {(a) }}$}

\begin{tabular}{|c|c|c|c|c|c|c|c|c|}
\hline $\begin{array}{l}\text { In(PCT-B) } \\
\text { Model Term }\end{array}$ & $\begin{array}{c}\text { Coefficient } \\
\text { Estimate }\end{array}$ & $\begin{array}{l}\text { Coefficient } \\
\text { Standard } \\
\text { Deviation } \\
\end{array}$ & $\begin{array}{l}\text { t-value }= \\
\text { Coeff } / \text { SD }\end{array}$ & p-value & \multicolumn{3}{|c|}{$\begin{array}{l}\text { Modeling Data Statistic, } \\
264 \text { Glasses }^{(b)}\end{array}$} & Value \\
\hline $\mathrm{Al}_{2} \mathrm{O}_{3}$ & -18.8858 & 1.1430 & $\mathrm{NA}^{(\mathrm{c})}$ & NA & \multicolumn{3}{|c|}{$\mathrm{R}^{2}$} & 0.700 \\
\hline $\mathrm{B}_{2} \mathrm{O}_{3}$ & 7.6325 & 1.0076 & NA & NA & \multicolumn{3}{|c|}{$\mathrm{R}^{2}$ Adjusted $\left(\mathrm{R}_{\mathrm{A}}^{2}\right)$} & 0.685 \\
\hline $\mathrm{Fe}_{2} \mathrm{O}_{3}$ & -4.3499 & 0.9987 & NA & NA & \multicolumn{3}{|c|}{$\mathrm{R}^{2}$ Predicted $\left(\mathrm{R}_{\mathrm{P}}^{2}\right)$} & 0.659 \\
\hline $\mathrm{Li}_{2} \mathrm{O}$ & 23.1195 & 2.2738 & NA & NA & \multicolumn{3}{|c|}{ RMSE } & 0.497 \\
\hline $\mathrm{MnO}$ & 6.4828 & 1.4474 & NA & NA & \multicolumn{3}{|c|}{ Model LOF p-value } & 0.001 \\
\hline $\mathrm{Na}_{2} \mathrm{O}$ & 16.3204 & 0.9136 & NA & NA & & \\
\hline $\mathrm{SiO}_{2}$ & -4.0515 & \multirow{2}{*}{$\begin{array}{l}0.4387 \\
1.1670\end{array}$} & NA & NA & \multirow{2}{*}{\multicolumn{3}{|c|}{$\begin{array}{l}\text { Separate (Extrapolative) Validation } \\
\text { Statistic, } 556 \text { Outlying Glasses }{ }^{(b, d)}\end{array}$}} & \\
\hline $\mathrm{SrO}$ & -2.3181 & & NA & NA & & & & Value \\
\hline $\mathrm{ThO}_{2}$ & 0.9236 & 1.8077 & NA & NA & \multicolumn{3}{|c|}{$\mathrm{R}^{2}$ Validation $\left(\mathrm{R}_{\mathrm{V}}^{2}\right)$} & 0.524 \\
\hline $\mathrm{UO}_{3}$ & -1.2580 & \multirow{2}{*}{$\frac{1.7970}{2.9480}$} & NA & NA & \multicolumn{3}{|c|}{ RMSE Validation $\left(\mathrm{RMSE}_{\mathrm{V}}\right)$} & 0.935 \\
\hline $\mathrm{ZnO}$ & -3.9785 & & NA & NA & & & & \\
\hline $\mathrm{ZrO}_{2}$ & -11.1356 & 1.1224 & NA & NA & Dat & ition $\mathrm{St}$ & & \\
\hline Others $^{(\mathrm{g})}$ & 2.7124 & 1.7565 & NA & NA & 162 & $\operatorname{ling} \&$ & idation $^{(b, e)}$ & Value \\
\hline & & & & & & & & 0.759 \\
\hline & & & & & & usted $(\mathrm{R}$ & & 0.739 \\
\hline & & & & & & licted $(\mathrm{R}$ & & 0.710 \\
\hline & & & & & & & & 0.481 \\
\hline & & & & & & dation ( & & 0.473 \\
\hline & & & & & & Validat & $\left(\mathrm{SE}_{\mathrm{V}}\right)$ & 0.552 \\
\hline Data Splitting & tistic $^{(\mathrm{b}, \mathrm{f})}$ & $\overline{D S}$ & & $\overline{\text { DS2 }}$ & $\mathbf{S 3}$ & DS4 & DS5 & Average \\
\hline $\mathrm{R}^{2}$ & & 0.6 & & .688 & 703 & 0.698 & 0.703 & 0.694 \\
\hline $\mathrm{R}^{2}$ Adjusted (I & & 0.6 & & .670 & 686 & 0.681 & 0.686 & 0.676 \\
\hline $\mathrm{R}^{2}$ Predicted ( & & 0.6 & & .635 & 653 & 0.649 & 0.654 & 0.643 \\
\hline RMSE & & 0.5 & & .497 & 481 & 0.499 & 0.496 & 0.497 \\
\hline $\mathrm{R}^{2}$ Validation & & 0.7 & & .737 & 667 & 0.691 & 0.654 & 0.710 \\
\hline RMSE Valida & $\left(\mathrm{RMSE}_{\mathrm{V}}\right)$ & 0.4 & & .510 & 588 & 0.503 & 0.527 & 0.508 \\
\hline
\end{tabular}

(a) Model results and summary statistics were generated using PCT-B normalized releases calculated to many decimal places. Rounded versions of these PCT-B values are given in Table 5.3. Conducting modeling with the rounded versions of the PCT-B normalized releases may result in slightly different model results and summary statistics.

(b) The model evaluation statistics are defined in Section C.3 of Appendix C. Model validation statistics are defined in Section C.5 of Appendix C. A negative value for $\mathrm{R}_{\mathrm{V}}^{2}$ means that the sum of squares of model prediction errors is larger than if the mean response value over the validation data set were used as the predicted value for each glass. In other words, the model predicts worse for the validation data than the mean response value does.

(c) NA denotes that it is not applicable to perform a statistical t-test on linear terms in a mixture model (see Section C.5.1).

(d) The 566 separate HLW glass compositions with PCT-B data for validation (mostly extrapolative) of PCT-B models are discussed in Section 5.1.4.

(e) The partition of the PCT-B modeling dataset into modeling and validation subsets is described in Section 5.1.3.

(f) The evaluation and validation statistics calculated for data-splits are defined the same as for separate modeling and validation sets. Section 5.1.2 describes how the data-splitting was accomplished.

(g) For the 13-component reduced linear mixture model, the "Others" component includes $\mathrm{Ag}_{2} \mathrm{O}, \mathrm{As}_{2} \mathrm{O}_{5}, \mathrm{BaO}, \mathrm{BeO}, \mathrm{Bi}_{2} \mathrm{O}_{3}$, $\mathrm{Ce}_{2} \mathrm{O}_{3}, \mathrm{Cl}, \mathrm{CoO}, \mathrm{Cs}_{2} \mathrm{O}, \mathrm{CuO}, \mathrm{Dy}_{2} \mathrm{O}, \mathrm{Eu}_{2} \mathrm{O}, \mathrm{F}, \mathrm{Gd}_{2} \mathrm{O}_{3}, \mathrm{HfO}_{2}, \mathrm{HgO}, \mathrm{MoO}_{3}, \mathrm{Nd}_{2} \mathrm{O}_{3}, \mathrm{P}_{2} \mathrm{O}_{5}, \mathrm{PdO}, \mathrm{Pr}_{2} \mathrm{O}_{3}, \mathrm{Rb}_{2} \mathrm{O}, \mathrm{Re}_{2} \mathrm{O}_{7}, \mathrm{Rh}_{2} \mathrm{O}_{3}$, $\mathrm{RuO}_{2}, \mathrm{SO}_{3}, \mathrm{Sm}_{2} \mathrm{O}_{3}, \mathrm{SnO}_{2}, \mathrm{Tc}_{2} \mathrm{O}_{7}, \mathrm{TeO}_{2}, \mathrm{~V}_{2} \mathrm{O}_{5}, \mathrm{WO}_{3}, \mathrm{Y}_{2} \mathrm{O}_{3}, \mathrm{CaO}, \mathrm{CdO}, \mathrm{Cr}_{2} \mathrm{O}_{3}, \mathrm{~K}_{2} \mathrm{O}, \mathrm{La}_{2} \mathrm{O}_{3}, \mathrm{MgO}, \mathrm{NiO}, \mathrm{PbO}, \mathrm{Sb}_{2} \mathrm{O}_{3}, \mathrm{SeO}_{2}$, $\mathrm{TiO}_{2}$, and $\mathrm{Tl}_{2} \mathrm{O}$. 
Table 5.7. Coefficients and Performance Summary for the 18-Term Partial Quadratic Mixture Model on the Natural Logarithm of PCT-B for HLW Glasses. ${ }^{\text {(a) }}$

\begin{tabular}{|c|c|c|c|c|c|c|c|c|}
\hline $\begin{array}{l}\ln (\text { PCT-B }) \\
\text { Model Term }\end{array}$ & $\begin{array}{l}\text { Coefficient } \\
\text { Estimate }\end{array}$ & $\begin{array}{l}\text { Coefficient } \\
\text { Standard } \\
\text { Deviation }\end{array}$ & $\begin{array}{l}\text { t-value }= \\
\text { Coeff } / \text { SD }\end{array}$ & p-value & \multicolumn{3}{|c|}{$\begin{array}{l}\text { Modeling Data Statistic, } \\
264 \text { Glasses }^{(\mathbf{b})}\end{array}$} & Value \\
\hline $\mathrm{Al}_{2} \mathrm{O}_{3}$ & -43.7679 & 4.6452 & $\mathrm{NA}^{(\mathrm{c})}$ & NA & \multicolumn{3}{|c|}{$\overline{\mathrm{R}^{2}}$} & 0.788 \\
\hline $\mathrm{B}_{2} \mathrm{O}_{3}$ & 8.9421 & 0.8678 & NA & $\mathrm{NA}$ & \multicolumn{3}{|c|}{$\mathrm{R}^{2}$ Adjusted $\left(\mathrm{R}_{\mathrm{A}}^{2}\right)$} & 0.774 \\
\hline $\mathrm{Fe}_{2} \mathrm{O}_{3}$ & -5.6911 & 1.2828 & NA & NA & \multicolumn{3}{|c|}{$\mathrm{R}^{2}$ Predicted $\left(\mathrm{R}_{\mathrm{P}}^{2}\right)$} & 0.751 \\
\hline $\mathrm{Li}_{2} \mathrm{O}$ & 22.5985 & 1.9611 & NA & NA & \multicolumn{3}{|c|}{ RMSE } & 0.422 \\
\hline $\mathrm{MnO}$ & -7.7193 & \multirow{2}{*}{$\begin{array}{l}4.1556 \\
0.8067\end{array}$} & NA & NA & \multicolumn{3}{|c|}{ Model LOF p-value } & 0.014 \\
\hline $\mathrm{Na}_{2} \mathrm{O}$ & 17.0391 & & NA & $\mathrm{NA}$ & \multicolumn{3}{|c|}{$r$} & \\
\hline $\mathrm{SiO}_{2}$ & -2.4959 & 0.4182 & NA & NA & \multirow{2}{*}{\multicolumn{3}{|c|}{$\begin{array}{l}\text { Separate (Extrapolative) Validation } \\
\text { Statistic, 556 Outlying Glasses }{ }^{(\mathbf{b})} \\
\end{array}$}} & \\
\hline $\mathrm{SrO}$ & -0.0577 & 1.0318 & NA & $\mathrm{NA}$ & & & & Value \\
\hline $\mathrm{ThO}_{2}$ & 2.4230 & 1.6631 & NA & NA & \multicolumn{3}{|c|}{$\mathrm{R}^{2}$ Validation $\left(\mathrm{R}_{\mathrm{V}}^{2}\right)$} & 0.623 \\
\hline $\mathrm{UO}_{3}$ & -11.3780 & \multirow{2}{*}{$\begin{array}{l}2.4500 \\
6.6929\end{array}$} & NA & NA & \multicolumn{3}{|c|}{ RMSE Validation $\left(\mathrm{RMSE}_{\mathrm{V}}\right)$} & 0.832 \\
\hline $\mathrm{ZnO}$ & -28.0347 & & NA & NA & & & & \\
\hline $\mathrm{ZrO}_{2}$ & -13.2496 & 1.6845 & NA & NA & Data & rtition Stati & & \\
\hline Others $^{(\mathrm{g})}$ & 5.0368 & 1.5768 & NA & NA & $162 \mathrm{I}$ & ling \& 10 & dation $^{(\mathbf{b}, \mathbf{e})}$ & Value \\
\hline$\left(\mathrm{Al}_{2} \mathrm{O}_{3}\right)^{2}$ & 169.7017 & 33.1963 & 5.11 & $<0.0001$ & $\mathrm{R}$ & & & 0.826 \\
\hline $\mathrm{UO}_{3} \times \mathrm{ZnO}$ & 511.2763 & 105.4536 & 4.85 & $<0.0001$ & & djusted $\left(\mathrm{R}_{\mathrm{A}}^{2}\right.$ & & 0.806 \\
\hline$(\mathrm{MnO})^{2}$ & 214.6560 & 60.5468 & 3.55 & 0.0005 & & edicted $\left(\mathrm{R}_{\mathrm{P}}^{2}\right.$ & & 0.772 \\
\hline $\mathrm{Fe}_{2} \mathrm{O}_{3} \times \mathrm{ZnO}$ & 193.2526 & 58.9749 & 3.28 & 0.0012 & & & & 0.415 \\
\hline $\mathrm{Al}_{2} \mathrm{O}_{3} \times \mathrm{ZrO}_{2}$ & 79.4113 & 25.9429 & 3.06 & 0.0025 & & alidation $\left(\mathrm{R}^{2}\right.$ & & 0.618 \\
\hline & & & & & & E Validation & $\left.\mathrm{MSE}_{\mathrm{V}}\right)$ & 0.470 \\
\hline Data Splittin & tistic $^{(\mathbf{b}, \mathbf{f})}$ & DS & & DS2 & DS3 & DS4 & DS5 & Average \\
\hline $\mathrm{R}^{2}$ & & 0.7 & & 0.782 & 0.806 & 0.787 & 0.785 & 0.786 \\
\hline $\mathrm{R}^{2}$ Adjusted (l & & 0.7 & & 9.764 & 0.790 & 0.770 & 0.768 & 0.768 \\
\hline $\mathrm{R}^{2}$ Predicted & & 0.7 & & 0.732 & 0.765 & 0.743 & 0.737 & 0.739 \\
\hline RMSE & & 0.4 & & 0.420 & 0.393 & 0.424 & 0.427 & 0.421 \\
\hline $\mathrm{R}^{2}$ Validation & & $0.8^{\prime}$ & & .800 & 0.694 & 0.758 & 0.779 & 0.782 \\
\hline RMSE Valida & $\left(\mathrm{RMSE}_{\mathrm{V}}\right)$ & 0.32 & & 0.445 & 0.564 & 0.445 & 0.421 & 0.439 \\
\hline
\end{tabular}

(a) Model results and summary statistics were generated using PCT-B normalized releases calculated to many decimal places. Rounded versions of these PCT-B values are given in Table 5.3. Conducting modeling with the rounded versions of the PCT-B normalized releases may result in slightly different model results and summary statistics.

(b) The model evaluation statistics are defined in Section C.3 of Appendix C. Model validation statistics are defined in Section C.5 of Appendix C. A negative value for $\mathrm{R}_{\mathrm{V}}^{2}$ means that the sum of squares of model prediction errors is larger than if the mean response value over the validation data set were used as the predicted value for each glass. In other words, the model predicts worse for the validation data than the mean response value does.

(c) NA denotes that it is not applicable to perform a statistical t-test on linear terms in a mixture model (see Section C.5.1).

(d) The 566 separate HLW glass compositions with PCT-B data for validation (mostly extrapolative) of PCT-B models are discussed in Section 5.1.4.

(e) The partition of the PCT-B modeling dataset into modeling and validation subsets is described in Section 5.1.3.

(f) The evaluation and validation statistics calculated for data-splits are defined the same as for separate modeling and validation sets. Section 5.1.2 describes how the data-splitting was accomplished.

(g) For the 18-term partial quadratic mixture model, the "Others" component includes $\mathrm{Ag}_{2} \mathrm{O}, \mathrm{As}_{2} \mathrm{O}_{5}, \mathrm{BaO}, \mathrm{BeO}, \mathrm{Bi}_{2} \mathrm{O}_{3}, \mathrm{Ce}_{2} \mathrm{O}_{3}$, $\mathrm{Cl}, \mathrm{CoO}, \mathrm{Cs}_{2} \mathrm{O}, \mathrm{CuO}, \mathrm{Dy}_{2} \mathrm{O}, \mathrm{Eu}_{2} \mathrm{O}, \mathrm{F}, \mathrm{Gd}_{2} \mathrm{O}_{3}, \mathrm{HfO}_{2}, \mathrm{HgO}, \mathrm{MoO}_{3}, \mathrm{Nd}_{2} \mathrm{O}_{3}, \mathrm{P}_{2} \mathrm{O}_{5}, \mathrm{PdO}, \mathrm{Pr}_{2} \mathrm{O}_{3}, \mathrm{Rb}_{2} \mathrm{O}, \mathrm{Re}_{2} \mathrm{O}_{7}, \mathrm{Rh}_{2} \mathrm{O}_{3}, \mathrm{RuO}_{2}$, $\mathrm{SO}_{3}, \mathrm{Sm}_{2} \mathrm{O}_{3}, \mathrm{SnO}_{2}, \mathrm{Tc}_{2} \mathrm{O}_{7}, \mathrm{TeO}_{2}, \mathrm{~V}_{2} \mathrm{O}_{5}, \mathrm{WO}_{3}, \mathrm{Y}_{2} \mathrm{O}_{3}, \mathrm{CaO}, \mathrm{CdO}, \mathrm{Cr}_{2} \mathrm{O}_{3}, \mathrm{~K} 2 \mathrm{O}, \mathrm{La}_{2} \mathrm{O}_{3}, \mathrm{MgO}, \mathrm{NiO}, \mathrm{PbO}, \mathrm{Sb}_{2} \mathrm{O}_{3}, \mathrm{SeO}_{2}, \mathrm{TiO}_{2}$, and $\mathrm{Tl}_{2} \mathrm{O}$. 
Table 5.8. Coefficients and Performance Summary for the 15-Term Partial Quadratic Mixture Model on the Natural Logarithm of PCT-B for HLW Glasses. ${ }^{\text {(a) }}$

\begin{tabular}{|c|c|c|c|c|c|c|c|c|}
\hline $\begin{array}{l}\text { In(PCT-B) } \\
\text { Model Term }\end{array}$ & $\begin{array}{c}\text { Coefficient } \\
\text { Estimate }\end{array}$ & $\begin{array}{l}\text { Coefficient } \\
\text { Standard } \\
\text { Deviation }\end{array}$ & $\begin{array}{l}\text { t-value }= \\
\text { Coeff } / \text { SD }\end{array}$ & p-value & \multicolumn{3}{|c|}{$\begin{array}{l}\text { Modeling Data Statistic, } \\
264 \text { Glasses }^{(b)}\end{array}$} & Value \\
\hline $\mathrm{Al}_{2} \mathrm{O}_{3}$ & $\begin{array}{l}-51.6810 \\
\end{array}$ & 4.6104 & $\mathrm{NA}^{(\mathrm{c})}$ & NA & \multicolumn{3}{|c|}{$\overline{\mathrm{R}^{2}}$} & 0.753 \\
\hline $\mathrm{B}_{2} \mathrm{O}_{3}$ & 8.4922 & 0.9270 & NA & NA & \multicolumn{3}{|c|}{$\mathrm{R}^{2}$ Adjusted $\left(\mathrm{R}_{\mathrm{A}}^{2}\right)$} & 0.739 \\
\hline $\mathrm{Fe}_{2} \mathrm{O}_{3}$ & -2.8518 & \multirow{2}{*}{$\frac{0.9317}{2.0714}$} & $\mathrm{NA}$ & NA & \multicolumn{3}{|c|}{$\mathrm{R}^{2}$ Predicted $\left(\mathrm{R}_{\mathrm{P}}^{2}\right)$} & 0.715 \\
\hline $\mathrm{Li}_{2} \mathrm{O}$ & 23.3308 & & $\mathrm{NA}$ & NA & \multicolumn{3}{|c|}{ RMSE } & 0.453 \\
\hline $\mathrm{MnO}$ & 7.3087 & 1.3305 & \multirow{2}{*}{$\frac{\mathrm{NA}}{\mathrm{NA}}$} & NA & & 0.004 \\
\hline $\mathrm{Na}_{2} \mathrm{O}$ & 16.5878 & 0.8403 & & NA & & & Model LOF p-value & \\
\hline $\mathrm{SiO}_{2}$ & -2.8000 & 0.4357 & NA & NA & \multirow{2}{*}{\multicolumn{3}{|c|}{$\begin{array}{l}\text { Separate (Extrapolative) Validation } \\
\text { Statistic, } 556 \text { Outlying Glasses }{ }^{\text {b.d) }}\end{array}$}} & \\
\hline $\mathrm{SrO}$ & -1.4447 & 1.0726 & NA & NA & & & & Value \\
\hline $\mathrm{ThO}_{2}$ & -0.9257 & 1.6896 & NA & NA & \multirow{2}{*}{\multicolumn{3}{|c|}{$\frac{R^{2} \text { Validation }\left(R_{V}^{2}\right)}{R^{2} \text { MSE Validation }\left(R_{M S F_{V}}\right.}$}} & 0.597 \\
\hline $\mathrm{UO}_{3}$ & $\begin{array}{l}-1.7878 \\
\end{array}$ & 1.6535 & $\mathrm{NA}$ & NA & & & & 0.860 \\
\hline $\mathrm{ZnO}$ & 0.4193 & 2.7695 & NA & NA & & & & \\
\hline $\mathrm{ZrO}_{2}$ & -14.2673 & 1.7981 & NA & NA & Data & artition Sta & & \\
\hline Others $^{(g)}$ & 2.6687 & 1.6013 & NA & NA & 162 & deling \& 1 & $\operatorname{ation}^{(b, e)}$ & Value \\
\hline$\left(\mathrm{Al}_{2} \mathrm{O}_{3}\right)^{2}$ & 228.6864 & 32.8368 & 6.96 & $<0.0001$ & $\mathrm{R}$ & & & 0.799 \\
\hline $\mathrm{Al}_{2} \mathrm{O}_{3} \times \mathrm{ZrO}_{2}$ & 92.1624 & 27.6780 & 3.33 & 0.0010 & & djusted $\left(\mathrm{R}^{2}\right.$ & & 0.780 \\
\hline & & & & & & redicted $\left(\mathrm{R}^{2}\right.$ & & 0.752 \\
\hline & & & & & & & & 0.442 \\
\hline & & & & & & alidation $(\mathrm{R}$ & & 0.565 \\
\hline & & & & & & SE Validatic & $\overline{\left.4 S E_{V}\right)}$ & 0.502 \\
\hline Data Splittin & tistic $^{(b, f)}$ & DS & & DS2 & DS3 & DS4 & DS5 & Average \\
\hline $\mathrm{R}^{2}$ & & 0.72 & & 0.735 & 0.771 & 0.752 & 0.743 & 0.746 \\
\hline $\mathrm{R}^{2}$ Adjusted $(\mathrm{l}$ & & 0.7 & & 0.717 & 0.756 & 0.735 & 0.726 & 0.729 \\
\hline $\mathrm{R}^{2}$ Predicted ( & & 0.6 & & 0.681 & 0.729 & 0.705 & 0.692 & 0.697 \\
\hline RMSE & & 0.4 & & 0.460 & 0.424 & 0.455 & 0.463 & 0.455 \\
\hline $\mathrm{R}^{2}$ Validation & & 0.86 & & 0.817 & 0.662 & 0.739 & 0.784 & 0.774 \\
\hline RMSE Valida & $\left(\mathrm{RMSE}_{\mathrm{V}}\right)$ & 0.3 . & & 0.426 & 0.592 & 0.462 & 0.417 & 0.446 \\
\hline
\end{tabular}

(a) Model results and summary statistics were generated using PCT-B normalized releases calculated to many decimal places. Rounded versions of these PCT-B values are given in Table 5.3. Conducting modeling with the rounded versions of the PCT-B normalized releases may result in slightly different model results and summary statistics.

(b) The model evaluation statistics are defined in Section C.3 of Appendix C. Model validation statistics are defined in Section C.5 of Appendix C. A negative value for $\mathrm{R}_{\mathrm{V}}^{2}$ means that the sum of squares of model prediction errors is larger than if the mean response value over the validation data set were used as the predicted value for each glass. In other words, the model predicts worse for the validation data than the mean response value does.

(c) NA denotes that it is not applicable to perform a statistical t-test on linear terms in a mixture model (see Section C.5.1).

(d) The 566 separate HLW glass compositions with PCT-B data for validation (mostly extrapolative) of PCT-B models are discussed in Section 5.1.4.

(e) The partition of the PCT-B modeling dataset into modeling and validation subsets is described in Section 5.1.3.

(f) The evaluation and validation statistics calculated for data-splits are defined the same as for separate modeling and validation sets. Section 5.1.2 describes how the data-splitting was accomplished.

(g) For the 15-term partial quadratic mixture model, the "Others" component includes $\mathrm{Ag}_{2} \mathrm{O}, \mathrm{As}_{2} \mathrm{O}_{5}, \mathrm{BaO}, \mathrm{BeO} \mathrm{Bi}_{2} \mathrm{O}_{3}, \mathrm{Ce}_{2} \mathrm{O}_{3}$, $\mathrm{Cl}, \mathrm{CoO}, \mathrm{Cs}_{2} \mathrm{O}, \mathrm{CuO}, \mathrm{Dy}_{2} \mathrm{O}, \mathrm{Eu}_{2} \mathrm{O}, \mathrm{F}, \mathrm{Gd}_{2} \mathrm{O}_{3}, \mathrm{HfO}_{2}, \mathrm{HgO}, \mathrm{MoO}_{3}, \mathrm{Nd}_{2} \mathrm{O}_{3}, \mathrm{P}_{2} \mathrm{O}_{5}, \mathrm{PdO}, \mathrm{Pr}_{2} \mathrm{O}_{3}, \mathrm{Rb}_{2} \mathrm{O}, \mathrm{Re}_{2} \mathrm{O}_{7}, \mathrm{Rh}_{2} \mathrm{O}_{3}, \mathrm{RuO}_{2}$, $\mathrm{SO}_{3}, \mathrm{Sm}_{2} \mathrm{O}_{3}, \mathrm{SnO}_{2}, \mathrm{Tc}_{2} \mathrm{O}_{7}, \mathrm{TeO}_{2}, \mathrm{~V}_{2} \mathrm{O}_{5}, \mathrm{WO}_{3}, \mathrm{Y}_{2} \mathrm{O}_{3}, \mathrm{CaO}, \mathrm{CdO}, \mathrm{Cr}_{2} \mathrm{O}_{3}, \mathrm{~K} 2 \mathrm{O}, \mathrm{La}_{2} \mathrm{O}_{3}, \mathrm{MgO}, \mathrm{NiO}, \mathrm{PbO}, \mathrm{Sb}_{2} \mathrm{O}_{3}, \mathrm{SeO}_{2}, \mathrm{TiO}_{2}$, and $\mathrm{Tl}_{2} \mathrm{O}$. 
Table 5.9. Coefficients and Performance Summary for the 25-Component Full Linear Mixture Model on the Natural Logarithm of PCT-Li for HLW Glasses. ${ }^{\text {(a) }}$

\begin{tabular}{|c|c|c|c|c|c|c|c|c|}
\hline $\begin{array}{l}\text { In(PCT-Li) } \\
\text { Model Term }\end{array}$ & $\begin{array}{c}\text { Coefficient } \\
\text { Estimate }\end{array}$ & $\begin{array}{l}\text { Coefficient } \\
\text { Standard } \\
\text { Deviation }\end{array}$ & $\begin{array}{l}\text { t-value }= \\
\text { Coeff/SD }\end{array}$ & p-value & \multicolumn{3}{|c|}{$\begin{array}{l}\text { Modeling Data Statistic, } \\
250 \text { Glasses }^{(b)}\end{array}$} & Value \\
\hline $\mathrm{Al}_{2} \mathrm{O}_{3}$ & -15.5611 & 1.0979 & $\mathrm{NA}^{(\mathrm{c})}$ & NA & \multicolumn{3}{|c|}{$\mathrm{R}^{2}$} & 0.670 \\
\hline $\mathrm{B}_{2} \mathrm{O}_{3}$ & 4.8344 & 0.8825 & NA & NA & \multicolumn{3}{|c|}{$\mathrm{R}^{2}$ Adjusted $\left(\mathrm{R}_{\mathrm{A}}^{2}\right)$} & 0.635 \\
\hline $\mathrm{CaO}$ & -3.5452 & 21.5811 & NA & NA & \multicolumn{3}{|c|}{$\mathrm{R}^{2}$ Predicted $\left(\mathrm{R}_{\mathrm{P}}^{2}\right)$} & 0.578 \\
\hline $\mathrm{CdO}$ & -9.4762 & 6.0854 & NA & NA & \multicolumn{3}{|c|}{ RMSE } & 0.386 \\
\hline $\mathrm{Cr}_{2} \mathrm{O}_{3}$ & 6.6555 & 16.3528 & NA & NA & \multicolumn{3}{|c|}{ Model LOF p-value } & $<0.0001$ \\
\hline $\mathrm{Fe}_{2} \mathrm{O}_{3}$ & -3.2526 & 0.9011 & NA & NA & & \\
\hline $\mathrm{K}_{2} \mathrm{O}$ & 75.6899 & \multirow{2}{*}{$\begin{array}{l}24.2445 \\
22.5346 \\
\end{array}$} & NA & NA & \multirow{2}{*}{\multicolumn{3}{|c|}{$\begin{array}{l}\text { Separate (Extrapolative) Validation } \\
\text { Statistic, } 480 \text { Outlying Glasses }{ }^{(\mathbf{b}, \mathbf{d})} \\
\end{array}$}} & \\
\hline $\mathrm{La}_{2} \mathrm{O}_{3}$ & 13.5098 & & NA & NA & & & & Value \\
\hline $\mathrm{Li}_{2} \mathrm{O}$ & 22.3393 & 1.9849 & NA & NA & \multicolumn{3}{|c|}{$\mathrm{R}^{2}$ Validation $\left(\mathrm{R}_{\mathrm{V}}^{2}\right)$} & $<0$ \\
\hline $\mathrm{MgO}$ & -18.2130 & 24.9683 & NA & NA & & Validati & $\left.\mathrm{ISE}_{\mathrm{V}}\right)$ & 1.757 \\
\hline $\mathrm{MnO}$ & 4.8885 & 1.3422 & NA & NA & & & & \\
\hline $\mathrm{Na}_{2} \mathrm{O}$ & 9.1701 & 0.8281 & NA & NA & Dat & ition Sta & & \\
\hline $\mathrm{NiO}$ & 14.1714 & 8.5910 & NA & NA & 154 & ling \& 9 & $\operatorname{dation}^{(\mathbf{b}, \mathrm{e})}$ & Value \\
\hline $\mathrm{PbO}$ & 14.5906 & 16.8598 & NA & NA & & & & 0.751 \\
\hline $\mathrm{Sb}_{2} \mathrm{O}_{3}$ & -15.7536 & 32.8278 & NA & NA & & isted $\left(\mathrm{R}^{2}\right.$ & & 0.705 \\
\hline $\mathrm{SeO}_{2}$ & 50.6129 & 47.4895 & NA & NA & & icted $(\mathrm{R}$ & & $<0$ \\
\hline $\mathrm{SiO}_{2}$ & -2.4204 & 0.3756 & NA & NA & & & & 0.368 \\
\hline $\mathrm{SrO}$ & -1.2219 & 1.0911 & NA & NA & & dation (I & & $<0$ \\
\hline $\mathrm{ThO}_{2}$ & -0.6452 & 1.6503 & NA & NA & & Validati & $\left.\mathrm{ISE}_{\mathrm{V}}\right)$ & 1.359 \\
\hline $\mathrm{TiO}_{2}$ & -92.6624 & 50.0947 & NA & NA & & & & \\
\hline $\mathrm{Tl}_{2} \mathrm{O}$ & 45.2989 & 43.2338 & NA & NA & & & & \\
\hline $\mathrm{UO}_{3}$ & -2.6951 & 1.7419 & NA & NA & & & & \\
\hline $\mathrm{ZnO}$ & -6.2313 & 2.8144 & NA & NA & & & & \\
\hline $\mathrm{ZrO}_{2}$ & -8.8477 & 0.9984 & NA & NA & & & & \\
\hline Others $^{(g)}$ & 0.2416 & 6.3583 & NA & NA & & & & \\
\hline Data Splitting & tistic $^{(b, f)}$ & DS & & $\overline{D S 2}$ & DS3 & DS4 & DS5 & Average \\
\hline $\mathrm{R}^{2}$ & & 0.6 & & .682 & 0.683 & 0.682 & 0.663 & 0.676 \\
\hline $\mathrm{R}^{2}$ Adjusted (I & & 0.6 & & .641 & 0.643 & 0.641 & 0.619 & 0.634 \\
\hline $\mathrm{R}^{2}$ Predicted ( & & 0.5 & & .579 & 0.565 & 0.580 & 0.556 & 0.564 \\
\hline RMSE & & 0.3 & & .375 & 0.374 & 0.368 & 0.395 & 0.381 \\
\hline $\mathrm{R}^{2}$ Validation & & 0.6 & & .546 & 0.557 & 0.538 & 0.639 & 0.582 \\
\hline RMSE Valida & $\left(\mathrm{RMSE}_{\mathrm{V}}\right)$ & 0.3 & & .473 & 0.465 & 0.510 & 0.377 & 0.443 \\
\hline
\end{tabular}

(a) Model results and summary statistics were generated using PCT-Li normalized releases calculated to many decimal places. Rounded versions of these PCT-Li values are given in Table 5.3. Conducting modeling with the rounded versions of the PCT-Li normalized releases may result in slightly different model results and summary statistics.

(b) The model evaluation statistics are defined in Section C.3 of Appendix C. Model validation statistics are defined in Section C.5 of Appendix C. A negative value for $\mathrm{R}_{\mathrm{V}}^{2}$ means that the sum of squares of model prediction errors is larger than if the mean response value over the validation data set were used as the predicted value for each glass. In other words, the model predicts worse for the validation data than the mean response value does.

(c) NA denotes that it is not applicable to perform a statistical t-test on linear terms in a mixture model (see Section C.5.1).

(d) The 480 separate HLW glass compositions with PCT-Li data for validation (mostly extrapolative) of PCT-Li models are discussed in Section 5.1.4.

(e) The partition of the PCT-Li modeling dataset into modeling and validation subsets is described in Section 5.1.3.

(f) The evaluation and validation statistics calculated for data-splits are defined the same as for separate modeling and validation sets. Section 5.1.2 describes how the data-splitting was accomplished.

(g) For the 25-component full linear mixture model, the "Others" component includes $\mathrm{Ag}_{2} \mathrm{O}, \mathrm{As}_{2} \mathrm{O}_{5}, \mathrm{BaO}, \mathrm{BeO}_{2} \mathrm{Bi}_{2} \mathrm{O}_{3}, \mathrm{Ce}_{2} \mathrm{O}_{3}$, $\mathrm{Cl}, \mathrm{CoO}, \mathrm{Cs}_{2} \mathrm{O}, \mathrm{CuO}, \mathrm{Dy}_{2} \mathrm{O}, \mathrm{Eu}_{2} \mathrm{O}, \mathrm{F}, \mathrm{Gd}_{2} \mathrm{O}_{3}, \mathrm{HfO}_{2}, \mathrm{HgO}, \mathrm{MoO}_{3}, \mathrm{Nd}_{2} \mathrm{O}_{3}, \mathrm{P}_{2} \mathrm{O}_{5}, \mathrm{PdO}, \mathrm{Pr}_{2} \mathrm{O}_{3}, \mathrm{Rb}_{2} \mathrm{O}, \mathrm{Re}_{2} \mathrm{O}_{7}, \mathrm{Rh}_{2} \mathrm{O}_{3}, \mathrm{RuO}_{2}$, $\mathrm{SO}_{3}, \mathrm{Sm}_{2} \mathrm{O}_{3}, \mathrm{SnO}_{2}, \mathrm{Tc}_{2} \mathrm{O}_{7}, \mathrm{TeO}_{2}, \mathrm{~V}_{2} \mathrm{O}_{5}, \mathrm{WO}_{3}$, and $\mathrm{Y}_{2} \mathrm{O}_{3}$. 


\section{Table 5.10. Coefficients and Performance Summary for the 13-Component Reduced Linear Mixture Model on the Natural Logarithm of PCT-Li for HLW Glasses. ${ }^{\text {(a) }}$}

\begin{tabular}{|c|c|c|c|c|c|c|c|c|}
\hline $\begin{array}{l}\text { In(PCT-Li) } \\
\text { Model Term }\end{array}$ & $\begin{array}{c}\text { Coefficient } \\
\text { Estimate }\end{array}$ & $\begin{array}{l}\text { Coefficient } \\
\text { Standard } \\
\text { Deviation } \\
\end{array}$ & $\begin{array}{l}\text { t-value }= \\
\text { Coeff } / \text { SD }\end{array}$ & p-value & \multicolumn{3}{|c|}{$\begin{array}{l}\text { Modeling Data Statistic, } \\
250 \text { Glasses }^{(b)}\end{array}$} & Value \\
\hline $\mathrm{Al}_{2} \mathrm{O}_{3}$ & -15.0800 & 0.9951 & $\mathrm{NA}^{(\mathrm{c})}$ & NA & \multicolumn{3}{|c|}{$\mathrm{R}^{2}$} & 0.641 \\
\hline $\mathrm{B}_{2} \mathrm{O}_{3}$ & 5.4159 & 0.8591 & NA & NA & \multicolumn{3}{|c|}{$\mathrm{R}^{2}$ Adjusted $\left(\mathrm{R}_{\mathrm{A}}^{2}\right)$} & 0.623 \\
\hline $\mathrm{Fe}_{2} \mathrm{O}_{3}$ & -3.3206 & 0.8524 & NA & NA & \multicolumn{3}{|c|}{$\mathrm{R}^{2}$ Predicted $\left(\mathrm{R}_{\mathrm{P}}^{2}\right)$} & 0.590 \\
\hline $\mathrm{Li}_{2} \mathrm{O}$ & 22.1747 & 1.8877 & NA & NA & \multicolumn{3}{|c|}{ RMSE } & 0.392 \\
\hline $\mathrm{MnO}$ & 5.0066 & 1.2580 & NA & NA & \multicolumn{3}{|c|}{ Model LOF p-value } & $<0.0001$ \\
\hline $\mathrm{Na}_{2} \mathrm{O}$ & 9.9099 & 0.7627 & NA & NA & & \\
\hline $\mathrm{SiO}_{2}$ & -2.6184 & \multirow{2}{*}{$\begin{array}{ll}0.3572 \\
1.0327\end{array}$} & NA & NA & \multirow{2}{*}{\multicolumn{3}{|c|}{$\begin{array}{l}\text { Separate (Extrapolative) Validation } \\
\text { Statistic, } 480 \text { Outlying Glasses }{ }^{(b, d)}\end{array}$}} & \\
\hline $\mathrm{SrO}$ & -0.7933 & & NA & NA & & & & Value \\
\hline $\mathrm{ThO}_{2}$ & -0.1031 & 1.5906 & NA & NA & \multicolumn{3}{|c|}{$\mathrm{R}^{2}$ Validation $\left(\mathrm{R}_{\mathrm{V}}^{2}\right)$} & 0.507 \\
\hline $\mathrm{UO}_{3}$ & -1.7841 & \multirow{2}{*}{$\frac{1.5527}{2.6216}$} & NA & NA & \multicolumn{3}{|c|}{ RMSE Validation $\left(\mathrm{RMSE}_{\mathrm{V}}\right)$} & 0.866 \\
\hline $\mathrm{ZnO}$ & -8.4792 & & NA & NA & & & & \\
\hline $\mathrm{ZrO}_{2}$ & -8.2743 & 0.9537 & NA & NA & Dat & ition $\mathrm{St}$ & & \\
\hline Others $^{(\mathrm{g})}$ & 2.1956 & 1.4734 & NA & NA & 154 & $\operatorname{ling} \&$ & dation $^{(\mathbf{b}, \mathrm{e})}$ & Value \\
\hline & & & & & & & & 0.704 \\
\hline & & & & & & usted $(\mathrm{R}$ & & 0.679 \\
\hline & & & & & & licted $(\mathrm{R}$ & & 0.637 \\
\hline & & & & & & & & 0.384 \\
\hline & & & & & & dation ( & & 0.331 \\
\hline & & & & & & Validat & $\left(\mathrm{SE}_{\mathrm{V}}\right)$ & 0.435 \\
\hline Data Splitting & tistic $^{(\mathrm{b}, \mathrm{f})}$ & $\overline{D S}$ & & $\overline{\text { DS2 }}$ & $\mathbf{S 3}$ & DS4 & DS5 & Average \\
\hline $\mathrm{R}^{2}$ & & 0.6 & & .639 & 652 & 0.645 & 0.633 & 0.641 \\
\hline $\mathrm{R}^{2}$ Adjusted (I & & 0.6 & & .617 & 631 & 0.624 & 0.611 & 0.619 \\
\hline $\mathrm{R}^{2}$ Predicted ( & & 0.5 & & .578 & 589 & 0.581 & 0.576 & 0.579 \\
\hline RMSE & & 0.3 & & .387 & 381 & 0.377 & 0.399 & 0.388 \\
\hline $\mathrm{R}^{2}$ Validation & & 0.6 & & .626 & 577 & 0.598 & 0.652 & 0.619 \\
\hline RMSE Valida & $\left(\mathrm{RMSE}_{\mathrm{V}}\right)$ & 0.3 & & .429 & 455 & 0.476 & 0.369 & 0.423 \\
\hline
\end{tabular}

(a) Model results and summary statistics were generated using PCT-Li normalized releases calculated to many decimal places. Rounded versions of these PCT-Li values are given in Table 5.3. Conducting modeling with the rounded versions of the PCT-Li normalized releases may result in slightly different model results and summary statistics.

(b) The model evaluation statistics are defined in Section C.3 of Appendix C. Model validation statistics are defined in Section C.5 of Appendix C. A negative value for $\mathrm{R}_{\mathrm{V}}^{2}$ means that the sum of squares of model prediction errors is larger than if the mean response value over the validation data set were used as the predicted value for each glass. In other words, the model predicts worse for the validation data than the mean response value does.

(c) NA denotes that it is not applicable to perform a statistical t-test on linear terms in a mixture model (see Section C.5.1).

(d) The 480 separate HLW glass compositions with PCT-Li data for validation (mostly extrapolative) of PCT-Li models are discussed in Section 5.1.4.

(e) The partition of the PCT-Li modeling dataset into modeling and validation subsets is described in Section 5.1.3.

(f) The evaluation and validation statistics calculated for data-splits are defined the same as for separate modeling and validation sets. Section 5.1.2 describes how the data-splitting was accomplished.

(g) For the 13-component reduced linear mixture model, the "Others" component includes $\mathrm{Ag}_{2} \mathrm{O}, \mathrm{As}_{2} \mathrm{O}_{5}, \mathrm{BaO}, \mathrm{BeO}, \mathrm{Bi}_{2} \mathrm{O}_{3}$, $\mathrm{Ce}_{2} \mathrm{O}_{3}, \mathrm{Cl}, \mathrm{CoO}, \mathrm{Cs}_{2} \mathrm{O}, \mathrm{CuO}, \mathrm{Dy}_{2} \mathrm{O}, \mathrm{Eu}_{2} \mathrm{O}, \mathrm{F}, \mathrm{Gd}_{2} \mathrm{O}_{3}, \mathrm{HfO}_{2}, \mathrm{HgO}, \mathrm{MoO}_{3}, \mathrm{Nd}_{2} \mathrm{O}_{3}, \mathrm{P}_{2} \mathrm{O}_{5}, \mathrm{PdO}, \mathrm{Pr}_{2} \mathrm{O}_{3}, \mathrm{Rb}_{2} \mathrm{O}, \mathrm{Re}_{2} \mathrm{O}_{7}, \mathrm{Rh}_{2} \mathrm{O}_{3}$, $\mathrm{RuO}_{2}, \mathrm{SO}_{3}, \mathrm{Sm}_{2} \mathrm{O}_{3}, \mathrm{SnO}_{2}, \mathrm{Tc}_{2} \mathrm{O}_{7}, \mathrm{TeO}_{2}, \mathrm{~V}_{2} \mathrm{O}_{5}, \mathrm{WO}_{3}, \mathrm{Y}_{2} \mathrm{O}_{3}, \mathrm{CaO}, \mathrm{CdO}, \mathrm{Cr}_{2} \mathrm{O}_{3}, \mathrm{~K}_{2} \mathrm{O}, \mathrm{La}_{2} \mathrm{O}_{3}, \mathrm{MgO}, \mathrm{NiO}, \mathrm{PbO}, \mathrm{Sb}_{2} \mathrm{O}_{3}, \mathrm{SeO}_{2}$, $\mathrm{TiO}_{2}$, and $\mathrm{Tl}_{2} \mathrm{O}$. 


\section{Table 5.11. Coefficients and Performance Summary for the 18-Term Partial Quadratic Mixture Model on the Natural Logarithm of PCT-Li for HLW Glasses. ${ }^{(a)}$}

\begin{tabular}{|c|c|c|c|c|c|c|c|c|}
\hline $\begin{array}{l}\text { In(PCT-Li) } \\
\text { Model Term }\end{array}$ & $\begin{array}{c}\text { Coefficient } \\
\text { Estimate }\end{array}$ & $\begin{array}{c}\text { Coefficient } \\
\text { Standard } \\
\text { Deviation } \\
\end{array}$ & $\begin{array}{l}\text { t-value }= \\
\text { Coeff/SD }\end{array}$ & p-value & \multicolumn{3}{|c|}{$\begin{array}{l}\text { Modeling Data Statistic, } \\
250 \text { Glasses }^{(b)}\end{array}$} & Value \\
\hline $\mathrm{Al}_{2} \mathrm{O}_{3}$ & -36.7423 & 3.6001 & $\mathrm{NA}^{(\mathrm{c})}$ & NA & \multicolumn{3}{|c|}{$\mathrm{R}^{2}$} & 0.742 \\
\hline $\mathrm{B}_{2} \mathrm{O}_{3}$ & 6.6931 & 0.7720 & NA & NA & \multicolumn{3}{|c|}{$\mathrm{R}^{2}$ Adjusted $\left(\mathrm{R}_{\mathrm{A}}^{2}\right)$} & 0.723 \\
\hline $\mathrm{Fe}_{2} \mathrm{O}_{3}$ & -6.7440 & 1.4956 & NA & NA & \multicolumn{3}{|c|}{$\mathrm{R}^{2}$ Predicted $\left(\mathrm{R}_{\mathrm{P}}^{2}\right)$} & 0.694 \\
\hline $\mathrm{Li}_{2} \mathrm{O}$ & 8.2175 & 3.6817 & NA & NA & \multicolumn{3}{|c|}{ RMSE } & 0.336 \\
\hline $\mathrm{MnO}$ & 6.1378 & 1.1547 & NA & NA & \multicolumn{3}{|c|}{ Model LOF p-value } & $<0.0001$ \\
\hline $\mathrm{Na}_{2} \mathrm{O}$ & 11.1232 & 0.6796 & NA & NA & \multirow{3}{*}{\multicolumn{3}{|c|}{$\begin{array}{l}\text { Separate (Extrapolative) Validation } \\
\text { Statistic, } \mathbf{4 8 0} \text { Outlying Glasses }{ }^{(b, d)}\end{array}$}} & \\
\hline $\mathrm{SiO}_{2}$ & -1.1853 & 0.3585 & NA & NA & & & & \\
\hline $\mathrm{SrO}$ & -1.3780 & 1.2437 & NA & NA & & & & Value \\
\hline $\mathrm{ThO}_{2}$ & 0.9472 & 1.4250 & NA & NA & & dation ( & & 0.543 \\
\hline $\mathrm{UO}_{3}$ & -8.9335 & 2.1257 & NA & NA & & Validat & $\left.\mathrm{SE}_{\mathrm{V}}\right)$ & 0.834 \\
\hline $\mathrm{ZnO}$ & -12.4629 & 3.0251 & NA & NA & & & & \\
\hline $\mathrm{ZrO}_{2}$ & -11.7027 & 1.4941 & NA & NA & Dat & tion St & & \\
\hline Others $^{(\mathrm{g})}$ & 1.7236 & 1.2977 & NA & NA & 154 & ing \& & lation $^{(\mathbf{b}, \mathrm{e})}$ & Value \\
\hline$\left(\mathrm{Al}_{2} \mathrm{O}_{3}\right)^{2}$ & 159.2293 & 26.2788 & 6.06 & $<0.0001$ & & & & 0.800 \\
\hline $\mathrm{UO}_{3} \times \mathrm{ZnO}$ & 427.8549 & 93.8998 & 4.56 & $<0.0001$ & & isted (R & & 0.775 \\
\hline $\mathrm{Fe}_{2} \mathrm{O}_{3} \times \mathrm{Li}_{2} \mathrm{O}$ & 153.3909 & 38.3031 & 4.00 & 0.0001 & & icted ( & & 0.731 \\
\hline $\mathrm{SrO} \times \mathrm{ZrO}_{2}$ & 73.0947 & 22.6465 & 3.23 & 0.0014 & & & & 0.322 \\
\hline $\mathrm{Al}_{2} \mathrm{O}_{3} \times \mathrm{ZrO}_{2}$ & 72.7130 & 23.0100 & 3.16 & 0.0018 & & dation ( & & 0.467 \\
\hline & & & & & & Validat & $\left.\mathrm{SE}_{\mathrm{V}}\right)$ & 0.388 \\
\hline Data Splittin & tistic $^{(b, f)}$ & DS & & DS2 & DS3 & DS4 & DS5 & Average \\
\hline $\mathrm{R}^{2}$ & & 0.75 & & 0.747 & 0.751 & 0.736 & 0.731 & 0.745 \\
\hline $\mathrm{R}^{2}$ Adjusted & & 0.73 & & .725 & 0.729 & 0.713 & 0.708 & 0.722 \\
\hline $\mathrm{R}^{2}$ Predicted & & 0.70 & & .691 & 0.697 & 0.673 & 0.673 & 0.687 \\
\hline RMSE & & 0.32 & & 0.328 & 0.326 & 0.329 & 0.346 & 0.331 \\
\hline $\mathrm{R}^{2}$ Validation & & $0.5 \mathrm{C}$ & & .686 & 0.668 & 0.739 & 0.768 & 0.691 \\
\hline RMSE Valida & $\left(\mathrm{RMSE}_{\mathrm{V}}\right)$ & 0.40 & & .393 & 0.403 & 0.384 & 0.302 & 0.378 \\
\hline
\end{tabular}

(a) Model results and summary statistics were generated using PCT-Li normalized releases calculated to many decimal places. Rounded versions of these PCT-Li values are given in Table 5.3. Conducting modeling with the rounded versions of the PCT-Li normalized releases may result in slightly different model results and summary statistics.

(b) The model evaluation statistics are defined in Section C.3 of Appendix C. Model validation statistics are defined in Section C.5 of Appendix C. A negative value for $\mathrm{R}_{\mathrm{V}}^{2}$ means that the sum of squares of model prediction errors is larger than if the mean response value over the validation data set were used as the predicted value for each glass. In other words, the model predicts worse for the validation data than the mean response value does.

(c) NA denotes that it is not applicable to perform a statistical t-test on linear terms in a mixture model (see Section C.5.1).

(d) The 480 separate HLW glass compositions with PCT-Li data for validation (mostly extrapolative) of PCT-Li models are discussed in Section 5.1.4.

(e) The partition of the PCT-Li modeling dataset into modeling and validation subsets is described in Section 5.1.3.

(f) The evaluation and validation statistics calculated for data-splits are defined the same as for separate modeling and validation sets. Section 5.1.2 describes how the data-splitting was accomplished.

(g) For the 18-term partial quadratic mixture model, the "Others" component includes $\mathrm{Ag}_{2} \mathrm{O}, \mathrm{As}_{2} \mathrm{O}_{5}, \mathrm{BaO}, \mathrm{BeO}_{2} \mathrm{Bi}_{2} \mathrm{O}_{3}, \mathrm{Ce}_{2} \mathrm{O}_{3}$, $\mathrm{Cl}, \mathrm{CoO}, \mathrm{Cs}_{2} \mathrm{O}, \mathrm{CuO}, \mathrm{Dy}_{2} \mathrm{O}, \mathrm{Eu}_{2} \mathrm{O}, \mathrm{F}, \mathrm{Gd}_{2} \mathrm{O}_{3}, \mathrm{HfO}_{2}, \mathrm{HgO}, \mathrm{MoO}_{3}, \mathrm{Nd}_{2} \mathrm{O}_{3}, \mathrm{P}_{2} \mathrm{O}_{5}, \mathrm{PdO}, \mathrm{Pr}_{2} \mathrm{O}_{3}, \mathrm{Rb}_{2} \mathrm{O}, \mathrm{Re}_{2} \mathrm{O}_{7}, \mathrm{Rh}_{2} \mathrm{O}_{3}, \mathrm{RuO}_{2}$, $\mathrm{SO}_{3}, \mathrm{Sm}_{2} \mathrm{O}_{3}, \mathrm{SnO}_{2}, \mathrm{Tc}_{2} \mathrm{O}_{7}, \mathrm{TeO}_{2}, \mathrm{~V}_{2} \mathrm{O}_{5}, \mathrm{WO}_{3}, \mathrm{Y}_{2} \mathrm{O}_{3}, \mathrm{CaO}, \mathrm{CdO}, \mathrm{Cr}_{2} \mathrm{O}_{3}, \mathrm{~K}_{2} \mathrm{O}, \mathrm{La}_{2} \mathrm{O}_{3}, \mathrm{MgO}, \mathrm{NiO}, \mathrm{PbO}, \mathrm{Sb}_{2} \mathrm{O}_{3}, \mathrm{SeO}_{2}, \mathrm{TiO}_{2}$, and $\mathrm{Tl}_{2} \mathrm{O}$. 


\section{Table 5.12. Coefficients and Performance Summary for the 15-Term Partial Quadratic Mixture Model on the Natural Logarithm of PCT-Li for HLW Glasses. ${ }^{(a)}$}

\begin{tabular}{|c|c|c|c|c|c|c|c|c|}
\hline $\begin{array}{l}\text { In(PCT-Li) } \\
\text { Model Term }\end{array}$ & $\begin{array}{c}\text { Coefficient } \\
\text { Estimate }\end{array}$ & $\begin{array}{l}\text { Coefficient } \\
\text { Standard } \\
\text { Deviation } \\
\end{array}$ & $\begin{array}{l}\text { t-value }= \\
\text { Coeff/SD }\end{array}$ & p-value & \multicolumn{3}{|c|}{$\begin{array}{l}\text { Modeling Data Statistic, } \\
250 \text { Glasses }^{(b)}\end{array}$} & Value \\
\hline $\mathrm{Al}_{2} \mathrm{O}_{3}$ & -38.0163 & 3.8317 & $\mathrm{NA}^{(\mathrm{c})}$ & NA & \multicolumn{3}{|c|}{$\mathrm{R}^{2}$} & 0.695 \\
\hline $\mathrm{B}_{2} \mathrm{O}_{3}$ & 5.9631 & 0.8037 & NA & NA & \multicolumn{3}{|c|}{$\mathrm{R}^{2}$ Adjusted $\left(\mathrm{R}_{\mathrm{A}}^{2}\right)$} & 0.677 \\
\hline $\mathrm{Fe}_{2} \mathrm{O}_{3}$ & -1.9839 & 0.8152 & NA & NA & \multicolumn{3}{|c|}{$\mathrm{R}^{2}$ Predicted $\left(\mathrm{R}_{\mathrm{P}}^{2}\right)$} & 0.643 \\
\hline $\mathrm{Li}_{2} \mathrm{O}$ & 21.9008 & 1.7551 & NA & NA & \multicolumn{3}{|c|}{ RMSE } & 0.363 \\
\hline $\mathrm{MnO}$ & 5.7451 & 1.1795 & NA & NA & \multicolumn{3}{|c|}{ Model LOF p-value } & $<0.0001$ \\
\hline $\mathrm{Na}_{2} \mathrm{O}$ & 10.2496 & 0.7080 & NA & NA & \multirow{3}{*}{\multicolumn{3}{|c|}{\begin{tabular}{|l|} 
\\
Separate (Extrapolative) Validation \\
Statistic, 480 Outlying Glasses $^{(b, d)}$ \\
\end{tabular}}} & \\
\hline $\mathrm{SiO}_{2}$ & -1.8115 & 0.3577 & NA & NA & & & & \\
\hline $\mathrm{SrO}$ & -0.0293 & 0.9633 & NA & NA & & & & Value \\
\hline $\mathrm{ThO}_{2}$ & -0.6263 & 1.5081 & NA & NA & \multicolumn{3}{|c|}{$\mathrm{R}^{2}$ Validation $\left(\mathrm{R}_{\mathrm{V}}^{2}\right)$} & 0.557 \\
\hline $\mathrm{UO}_{3}$ & -1.8175 & 1.4379 & NA & NA & \multicolumn{3}{|c|}{ RMSE Validation $\left(\mathrm{RMSE}_{\mathrm{V}}\right)$} & 0.821 \\
\hline $\mathrm{ZnO}$ & -4.3848 & 2.5067 & NA & NA & & & & \\
\hline $\mathrm{ZrO}_{2}$ & -11.9532 & 1.5885 & NA & NA & Dat & ition St & & \\
\hline Others $^{(\mathrm{g})}$ & 1.9026 & 1.3741 & NA & NA & 154 & ling \& 9 & lation $^{(\mathbf{b}, \mathrm{e})}$ & Value \\
\hline$\left(\mathrm{Al}_{2} \mathrm{O}_{3}\right)^{2}$ & 156.5080 & 28.0674 & 5.58 & $<0.0001$ & & & & 0.764 \\
\hline $\mathrm{Al}_{2} \mathrm{O}_{3} \times \mathrm{ZrO}_{2}$ & 90.1825 & 24.3619 & 3.70 & 0.0003 & & isted $(\mathrm{R}$ & & 0.741 \\
\hline & & & & & & icted $(\mathrm{R}$ & & 0.700 \\
\hline & & & & & & & & 0.345 \\
\hline & & & & & & dation ( & & 0.357 \\
\hline & & & & & & Validati & $\left.\mathrm{SE}_{\mathrm{V}}\right)$ & 0.426 \\
\hline Data Splittin & tistic $^{(\mathbf{b}, \mathbf{f})}$ & DS & & DS2 & DS3 & DS4 & DS5 & Average \\
\hline $\mathrm{R}^{2}$ & & 0.70 & & 0.698 & 0.688 & 0.695 & 0.692 & 0.695 \\
\hline $\mathrm{R}^{2}$ Adjusted ( & & 0.68 & & 0.676 & 0.666 & 0.674 & 0.670 & 0.673 \\
\hline $\mathrm{R}^{2}$ Predicted & & 0.63 & & .635 & 0.619 & 0.629 & 0.635 & 0.631 \\
\hline RMSE & & 0.36 & & 0.356 & 0.362 & 0.351 & 0.368 & 0.360 \\
\hline $\mathrm{R}^{2}$ Validation & & 0.61 & & .651 & 0.708 & 0.673 & 0.663 & 0.662 \\
\hline RMSE Valida & $\left(\mathrm{RMSE}_{\mathrm{V}}\right)$ & 0.39 & & .415 & 0.378 & 0.430 & 0.364 & 0.397 \\
\hline
\end{tabular}

(a) Model results and summary statistics were generated using PCT-Li normalized releases calculated to many decimal places. Rounded versions of these PCT-Li values are given in Table 5.3. Conducting modeling with the rounded versions of the PCT-Li normalized releases may result in slightly different model results and summary statistics.

(b) The model evaluation statistics are defined in Section C.3 of Appendix C. Model validation statistics are defined in Section C.5 of Appendix C. A negative value for $\mathrm{R}_{\mathrm{V}}^{2}$ means that the sum of squares of model prediction errors is larger than if the mean response value over the validation data set were used as the predicted value for each glass. In other words, the model predicts worse for the validation data than the mean response value does.

(c) NA denotes that it is not applicable to perform a statistical t-test on linear terms in a mixture model (see Section C.5.1).

(d) The 480 separate HLW glass compositions with PCT-Li data for validation (mostly extrapolative) of PCT-Li models are discussed in Section 5.1.4.

(e) The partition of the PCT-Li modeling dataset into modeling and validation subsets is described in Section 5.1.3.

(f) The evaluation and validation statistics calculated for data-splits are defined the same as for separate modeling and validation sets. Section 5.1.2 describes how the data-splitting was accomplished.

(g) For the 15-term partial quadratic mixture model, the "Others" component includes $\mathrm{Ag}_{2} \mathrm{O}, \mathrm{As}_{2} \mathrm{O}_{5}, \mathrm{BaO}, \mathrm{BeO}_{2} \mathrm{Bi}_{2} \mathrm{O}_{3}, \mathrm{Ce}_{2} \mathrm{O}_{3}$, $\mathrm{Cl}, \mathrm{CoO}, \mathrm{Cs}_{2} \mathrm{O}, \mathrm{CuO}, \mathrm{Dy}_{2} \mathrm{O}, \mathrm{Eu}_{2} \mathrm{O}, \mathrm{F}, \mathrm{Gd}_{2} \mathrm{O}_{3}, \mathrm{HfO}_{2}, \mathrm{HgO}, \mathrm{MoO}_{3}, \mathrm{Nd}_{2} \mathrm{O}_{3}, \mathrm{P}_{2} \mathrm{O}_{5}, \mathrm{PdO}, \mathrm{Pr}_{2} \mathrm{O}_{3}, \mathrm{Rb}_{2} \mathrm{O}, \mathrm{Re}_{2} \mathrm{O}_{7}, \mathrm{Rh}_{2} \mathrm{O}_{3}, \mathrm{RuO}_{2}$, $\mathrm{SO}_{3}, \mathrm{Sm}_{2} \mathrm{O}_{3}, \mathrm{SnO}_{2}, \mathrm{Tc}_{2} \mathrm{O}_{7}, \mathrm{TeO}_{2}, \mathrm{~V}_{2} \mathrm{O}_{5}, \mathrm{WO}_{3}, \mathrm{Y}_{2} \mathrm{O}_{3}, \mathrm{CaO}, \mathrm{CdO}, \mathrm{Cr}_{2} \mathrm{O}_{3}, \mathrm{~K}_{2} \mathrm{O}, \mathrm{La}_{2} \mathrm{O}_{3}, \mathrm{MgO}, \mathrm{NiO}, \mathrm{PbO}, \mathrm{Sb}_{2} \mathrm{O}_{3}, \mathrm{SeO}_{2}, \mathrm{TiO}_{2}$, and $\mathrm{Tl}_{2} \mathrm{O}$. 
Table 5.13. Coefficients and Performance Summary for the 25-Component Full Linear Mixture Model on the Natural Logarithm of PCT-Na for HLW Glasses. ${ }^{\text {(a) }}$

\begin{tabular}{|c|c|c|c|c|c|c|c|c|}
\hline $\begin{array}{l}\text { In(PCT-Na) } \\
\text { Model Term }\end{array}$ & $\begin{array}{c}\text { Coefficient } \\
\text { Estimate }\end{array}$ & $\begin{array}{l}\text { Coefficient } \\
\text { Standard } \\
\text { Deviation }\end{array}$ & $\begin{array}{l}\text { t-value }= \\
\text { Coeff/SD }\end{array}$ & p-value & \multicolumn{3}{|c|}{$\begin{array}{l}\text { Modeling Data Statistic, } \\
266 \text { Glasses }^{(b)}\end{array}$} & Value \\
\hline $\mathrm{Al}_{2} \mathrm{O}_{3}$ & -16.0524 & 0.9630 & $\mathrm{NA}^{(\mathrm{c})}$ & NA & \multicolumn{3}{|c|}{$\mathrm{R}^{2}$} & 0.804 \\
\hline $\mathrm{B}_{2} \mathrm{O}_{3}$ & 1.6437 & 0.8027 & NA & NA & \multicolumn{3}{|c|}{$\mathrm{R}^{2}$ Adjusted $\left(\mathrm{R}_{\mathrm{A}}^{2}\right)$} & 0.784 \\
\hline $\mathrm{CaO}$ & -15.5955 & 19.8640 & NA & NA & \multicolumn{3}{|c|}{$\mathrm{R}^{2}$ Predicted $\left(\mathrm{R}_{\mathrm{P}}^{2}\right)$} & 0.746 \\
\hline $\mathrm{CdO}$ & -1.6969 & 5.8283 & NA & NA & \multicolumn{3}{|c|}{ RMSE } & 0.378 \\
\hline $\mathrm{Cr}_{2} \mathrm{O}_{3}$ & 10.4021 & 14.3666 & NA & NA & \multicolumn{3}{|c|}{ Model LOF p-value } & $<0.0001$ \\
\hline $\mathrm{Fe}_{2} \mathrm{O}_{3}$ & -1.8851 & 0.7932 & NA & NA & \multirow{2}{*}{\multicolumn{3}{|c|}{ Separate (Extrapolative) Validation }} & \\
\hline $\mathrm{K}_{2} \mathrm{O}$ & 65.5626 & 22.5500 & NA & NA & & & & \\
\hline $\mathrm{La}_{2} \mathrm{O}_{3}$ & -2.4057 & 18.5246 & NA & NA & \multicolumn{3}{|c|}{ Statistic, 554 Outlying Glasses ${ }^{(b, d)}$} & Value \\
\hline $\mathrm{Li}_{2} \mathrm{O}$ & 20.9735 & 1.8615 & NA & NA & \multicolumn{3}{|c|}{$\mathrm{R}^{2}$ Validation $\left(\mathrm{R}_{\mathrm{V}}^{2}\right)$} & $<0$ \\
\hline $\mathrm{MgO}$ & 14.1267 & 24.0746 & NA & NA & & Validati & $\left.\mathrm{ISE}_{\mathrm{V}}\right)$ & 1.561 \\
\hline $\mathrm{MnO}$ & 4.4277 & 1.1994 & NA & NA & & & & \\
\hline $\mathrm{Na}_{2} \mathrm{O}$ & 17.7618 & 0.7506 & NA & NA & Dat & ition Sta & & \\
\hline $\mathrm{NiO}$ & 10.8725 & 7.5218 & NA & NA & 163 & ling \& 1 & idation $^{(b, e)}$ & Value \\
\hline $\mathrm{PbO}$ & 14.6358 & 14.4785 & NA & NA & & & & 0.874 \\
\hline $\mathrm{Sb}_{2} \mathrm{O}_{3}$ & -39.3900 & 30.4757 & NA & NA & & isted $\left(\mathrm{R}^{2}\right.$ & & 0.852 \\
\hline $\mathrm{SeO}_{2}$ & 20.9179 & 45.9593 & NA & NA & & icted $(\mathrm{R}$ & & $<0$ \\
\hline $\mathrm{SiO}_{2}$ & -4.6955 & 0.3573 & NA & NA & & & & 0.341 \\
\hline $\mathrm{SrO}$ & 1.3013 & 1.0069 & NA & NA & & dation (I & & $<0$ \\
\hline $\mathrm{ThO}_{2}$ & 1.7221 & 1.4493 & NA & NA & & Validati & $\left.\mathrm{ISE}_{\mathrm{V}}\right)$ & 1.515 \\
\hline $\mathrm{TiO}_{2}$ & -100.5428 & 47.2829 & NA & NA & & & & \\
\hline $\mathrm{Tl}_{2} \mathrm{O}$ & 88.0476 & 41.7479 & NA & NA & & & & \\
\hline $\mathrm{UO}_{3}$ & -0.9815 & 1.5239 & NA & NA & & & & \\
\hline $\mathrm{ZnO}$ & -0.4681 & 2.4540 & NA & NA & & & & \\
\hline $\mathrm{ZrO}_{2}$ & -9.6515 & 0.8938 & NA & NA & & & & \\
\hline Others $^{(g)}$ & 1.2983 & 5.6266 & NA & NA & & & & \\
\hline Data Splitting & tistic $^{(b, f)}$ & DS & & DS2 & DS3 & DS4 & DS5 & Average \\
\hline $\mathrm{R}^{2}$ & & 0.8 & & .804 & 0.795 & 0.808 & 0.811 & 0.811 \\
\hline $\mathrm{R}^{2}$ Adjusted (I & & 0.8 & & .780 & 0.771 & 0.785 & 0.789 & 0.788 \\
\hline $\mathrm{R}^{2}$ Predicted ( & & 0.7 & & .731 & 0.718 & 0.741 & 0.743 & 0.742 \\
\hline RMSE & & 0.3 & & .376 & 0.386 & 0.375 & 0.369 & 0.372 \\
\hline $\mathrm{R}^{2}$ Validation & & 0.5 & & .770 & 0.823 & 0.716 & 0.714 & 0.713 \\
\hline RMSE Valida & $\left(\mathrm{RMSE}_{\mathrm{V}}\right)$ & 0.5 & & .419 & 0.357 & 0.444 & 0.458 & 0.439 \\
\hline
\end{tabular}

(a) Model results and summary statistics were generated using PCT-Na normalized releases calculated to many decimal places. Rounded versions of these PCT-Na values are given in Table 5.3. Conducting modeling with the rounded versions of the PCT-Na normalized releases may result in slightly different model results and summary statistics.

(b) The model evaluation statistics are defined in Section C.3 of Appendix C. Model validation statistics are defined in Section C.5 of Appendix C. A negative value for $\mathrm{R}_{\mathrm{V}}^{2}$ means that the sum of squares of model prediction errors is larger than if the mean response value over the validation data set were used as the predicted value for each glass. In other words, the model predicts worse for the validation data than the mean response value does.

(c) NA denotes that it is not applicable to perform a statistical t-test on linear terms in a mixture model (see Section C.5.1).

(d) The 554 separate HLW glass compositions with PCT-Na data for validation (mostly extrapolative) of PCT-Na models are discussed in Section 5.1.4.

(e) The partition of the PCT-Na modeling dataset into modeling and validation subsets is described in Section 5.1.3.

(f) The evaluation and validation statistics calculated for data-splits are defined the same as for separate modeling and validation sets. Section 5.1.2 describes how the data-splitting was accomplished.

(g) For the 25-component full linear mixture model, the "Others" component includes $\mathrm{Ag}_{2} \mathrm{O}, \mathrm{As}_{2} \mathrm{O}_{5}, \mathrm{BaO}, \mathrm{BeO}_{2} \mathrm{Bi}_{2} \mathrm{O}_{3}, \mathrm{Ce}_{2} \mathrm{O}_{3}$, $\mathrm{Cl}, \mathrm{CoO}, \mathrm{Cs}_{2} \mathrm{O}, \mathrm{CuO}, \mathrm{Dy}_{2} \mathrm{O}, \mathrm{Eu}_{2} \mathrm{O}, \mathrm{F}, \mathrm{Gd}_{2} \mathrm{O}_{3}, \mathrm{HfO}_{2}, \mathrm{HgO}, \mathrm{MoO}_{3}, \mathrm{Nd}_{2} \mathrm{O}_{3}, \mathrm{P}_{2} \mathrm{O}_{5}, \mathrm{PdO}, \mathrm{Pr}_{2} \mathrm{O}_{3}, \mathrm{Rb}_{2} \mathrm{O}, \mathrm{Re}_{2} \mathrm{O}_{7}, \mathrm{Rh}_{2} \mathrm{O}_{3}, \mathrm{RuO}_{2}$, $\mathrm{SO}_{3}, \mathrm{Sm}_{2} \mathrm{O}_{3}, \mathrm{SnO}_{2}, \mathrm{Tc}_{2} \mathrm{O}_{7}, \mathrm{TeO}_{2}, \mathrm{~V}_{2} \mathrm{O}_{5}, \mathrm{WO}_{3}$, and $\mathrm{Y}_{2} \mathrm{O}_{3}$. 


\section{Table 5.14. Coefficients and Performance Summary for the 13-Component Reduced Linear Mixture Model on the Natural Logarithm of PCT-Na for HLW Glasses. ${ }^{\text {(a) }}$}

\begin{tabular}{|c|c|c|c|c|c|c|c|c|}
\hline $\begin{array}{l}\text { In(PCT-Na) } \\
\text { Model Term }\end{array}$ & $\begin{array}{c}\text { Coefficient } \\
\text { Estimate }\end{array}$ & $\begin{array}{l}\text { Coefficient } \\
\text { Standard } \\
\text { Deviation } \\
\end{array}$ & $\begin{array}{l}\text { t-value }= \\
\text { Coeff } / \text { SD }\end{array}$ & p-value & \multicolumn{3}{|c|}{$\begin{array}{l}\text { Modeling Data Statistic, } \\
266 \text { Glasses }^{(b)}\end{array}$} & Value \\
\hline $\mathrm{Al}_{2} \mathrm{O}_{3}$ & -15.8303 & 0.8718 & $\mathrm{NA}^{(\mathrm{c})}$ & NA & \multicolumn{3}{|c|}{$\mathrm{R}^{2}$} & 0.791 \\
\hline $\mathrm{B}_{2} \mathrm{O}_{3}$ & 1.9654 & 0.7710 & NA & NA & \multicolumn{3}{|c|}{$\mathrm{R}^{2}$ Adjusted $\left(\mathrm{R}_{\mathrm{A}}^{2}\right)$} & 0.781 \\
\hline $\mathrm{Fe}_{2} \mathrm{O}_{3}$ & -1.7325 & 0.7613 & NA & NA & \multicolumn{3}{|c|}{$\mathrm{R}^{2}$ Predicted $\left(\mathrm{R}_{\mathrm{P}}^{2}\right)$} & 0.761 \\
\hline $\mathrm{Li}_{2} \mathrm{O}$ & 20.4665 & 1.7352 & NA & NA & \multicolumn{3}{|c|}{ RMSE } & 0.381 \\
\hline $\mathrm{MnO}$ & 4.4780 & \multirow{2}{*}{1.0988} & NA & NA & \multicolumn{3}{|c|}{ Model LOF p-value } & $<0.0001$ \\
\hline $\mathrm{Na}_{2} \mathrm{O}$ & 18.0825 & & NA & NA & & \\
\hline $\mathrm{SiO}_{2}$ & -4.8494 & $\begin{array}{ll}0.6982 \\
0.3343\end{array}$ & NA & NA & \multirow{2}{*}{\multicolumn{3}{|c|}{$\begin{array}{l}\text { Separate (Extrapolative) Validation } \\
\text { Statistic, } 554 \text { Outlying Glasses }{ }^{(b, d)}\end{array}$}} & \\
\hline $\mathrm{SrO}$ & 1.5924 & 0.8889 & \multirow{2}{*}{$\frac{\text { NA }}{\text { NA }}$} & NA & & & & Value \\
\hline $\mathrm{ThO}_{2}$ & 2.0091 & 1.3808 & & NA & \multirow{2}{*}{\multicolumn{3}{|c|}{$\begin{array}{l}\mathrm{R}^{2} \text { Validation }\left(\mathrm{R}_{\mathrm{V}}^{2}\right) \\
\text { RMSE Validation }\left(\mathrm{RMSE}_{\mathrm{V}}\right)\end{array}$}} & 0.367 \\
\hline $\mathrm{UO}_{3}$ & -1.0234 & 1.3592 & NA & NA & & & & 0.996 \\
\hline $\mathrm{ZnO}$ & -2.9617 & 2.2559 & NA & NA & & & & \\
\hline $\mathrm{ZrO}_{2}$ & -9.3636 & 0.8560 & NA & NA & Dat & ition $\mathrm{St}$ & & \\
\hline Others $^{(\mathrm{g})}$ & 3.5188 & 1.3376 & NA & NA & 163 & $\operatorname{ling} \&$ & idation $^{(b, e)}$ & Value \\
\hline & & & & & & & & 0.848 \\
\hline & & & & & & usted $(\mathrm{R}$ & & 0.836 \\
\hline & & & & & & licted $(\mathrm{R}$ & & 0.817 \\
\hline & & & & & & & & 0.358 \\
\hline & & & & & & dation ( & & 0.616 \\
\hline & & & & & & Validat & $\left(\mathrm{SE}_{\mathrm{V}}\right)$ & 0.423 \\
\hline Data Splitting & tistic $^{(\mathrm{b}, \mathrm{f})}$ & $\overline{D S}$ & & DS2 & $\mathbf{S 3}$ & DS4 & DS5 & Average \\
\hline $\mathrm{R}^{2}$ & & 0.8 & & 0.788 & 781 & 0.795 & 0.791 & 0.795 \\
\hline $\mathrm{R}^{2}$ Adjusted (I & & 0.8 & & 0.776 & 768 & 0.783 & 0.779 & 0.784 \\
\hline $\mathrm{R}^{2}$ Predicted ( & & 0.7 & & 0.751 & 741 & 0.761 & 0.756 & 0.760 \\
\hline RMSE & & 0.3 & & 0.379 & 388 & 0.376 & 0.377 & 0.375 \\
\hline $\mathrm{R}^{2}$ Validation & & 0.5 & & 0.783 & 829 & 0.737 & 0.762 & 0.731 \\
\hline RMSE Valida & $\left(\mathrm{RMSE}_{\mathrm{V}}\right)$ & 0.5 & & 0.407 & 350 & 0.427 & 0.418 & 0.424 \\
\hline
\end{tabular}

(a) Model results and summary statistics were generated using PCT-Na normalized releases calculated to many decimal places. Rounded versions of these PCT-Na values are given in Table 5.3. Conducting modeling with the rounded versions of the PCT-Na normalized releases may result in slightly different model results and summary statistics.

(b) The model evaluation statistics are defined in Section C.3 of Appendix C. Model validation statistics are defined in Section C.5 of Appendix C. A negative value for $\mathrm{R}_{\mathrm{V}}^{2}$ means that the sum of squares of model prediction errors is larger than if the mean response value over the validation data set were used as the predicted value for each glass. In other words, the model predicts worse for the validation data than the mean response value does.

(c) NA denotes that it is not applicable to perform a statistical t-test on linear terms in a mixture model (see Section C.5.1).

(d) The 554 separate HLW glass compositions with PCT-Na data for validation (mostly extrapolative) of PCT-Na models are discussed in Section 5.1.4.

(e) The partition of the PCT-Na modeling dataset into modeling and validation subsets is described in Section 5.1.3.

(f) The evaluation and validation statistics calculated for data-splits are defined the same as for separate modeling and validation sets. Section 5.1.2 describes how the data-splitting was accomplished.

(g) For the 13-component reduced linear mixture model, the "Others" component includes $\mathrm{Ag}_{2} \mathrm{O}, \mathrm{As}_{2} \mathrm{O}_{5}, \mathrm{BaO}, \mathrm{BeO}, \mathrm{Bi}_{2} \mathrm{O}_{3}$, $\mathrm{Ce}_{2} \mathrm{O}_{3}, \mathrm{Cl}, \mathrm{CoO}, \mathrm{Cs}_{2} \mathrm{O}, \mathrm{CuO}, \mathrm{Dy}_{2} \mathrm{O}, \mathrm{Eu}_{2} \mathrm{O}, \mathrm{F}, \mathrm{Gd}_{2} \mathrm{O}_{3}, \mathrm{HfO}_{2}, \mathrm{HgO}, \mathrm{MoO}_{3}, \mathrm{Nd}_{2} \mathrm{O}_{3}, \mathrm{P}_{2} \mathrm{O}_{5}, \mathrm{PdO}, \mathrm{Pr}_{2} \mathrm{O}_{3}, \mathrm{Rb}_{2} \mathrm{O}, \mathrm{Re}_{2} \mathrm{O}_{7}, \mathrm{Rh}_{2} \mathrm{O}_{3}$, $\mathrm{RuO}_{2}, \mathrm{SO}_{3}, \mathrm{Sm}_{2} \mathrm{O}_{3}, \mathrm{SnO}_{2}, \mathrm{Tc}_{2} \mathrm{O}_{7}, \mathrm{TeO}_{2}, \mathrm{~V}_{2} \mathrm{O}_{5}, \mathrm{WO}_{3}, \mathrm{Y}_{2} \mathrm{O}_{3}, \mathrm{CaO}, \mathrm{CdO}, \mathrm{Cr}_{2} \mathrm{O}_{3}, \mathrm{~K}_{2} \mathrm{O}, \mathrm{La}_{2} \mathrm{O}_{3}, \mathrm{MgO}, \mathrm{NiO}, \mathrm{PbO}, \mathrm{Sb}_{2} \mathrm{O}_{3}, \mathrm{SeO}_{2}$, $\mathrm{TiO}_{2}$, and $\mathrm{Tl}_{2} \mathrm{O}$. 
Table 5.15. Coefficients and Performance Summary for the 18-Term Partial Quadratic Mixture Model on the Natural Logarithm of PCT-Na for HLW Glasses. ${ }^{\text {(a) }}$

\begin{tabular}{|c|c|c|c|c|c|c|c|c|}
\hline $\begin{array}{l}\text { In(PCT-Na) } \\
\text { Model Term } \\
\end{array}$ & $\begin{array}{c}\text { Coefficient } \\
\text { Estimate }\end{array}$ & $\begin{array}{l}\text { Coefficient } \\
\text { Standard } \\
\text { Deviation } \\
\end{array}$ & $\begin{array}{l}\text { t-value }= \\
\text { Coeff/SD }\end{array}$ & p-value & \multicolumn{3}{|c|}{$\begin{array}{l}\text { Modeling Data Statistic, } 66 \text { Glasses }^{(b)}\end{array}$} & Value \\
\hline $\mathrm{Al}_{2} \mathrm{O}_{3}$ & -46.8613 & 3.0497 & $\mathrm{NA}^{(\mathrm{c})}$ & NA & \multicolumn{3}{|c|}{$\mathrm{R}^{2}$} & 0.873 \\
\hline $\mathrm{B}_{2} \mathrm{O}_{3}$ & 3.1358 & 0.6464 & NA & NA & \multicolumn{3}{|c|}{$\mathrm{R}^{2}$ Adjusted $\left(\mathrm{R}_{\mathrm{A}}^{2}\right)$} & 0.864 \\
\hline $\mathrm{Fe}_{2} \mathrm{O}_{3}$ & -4.4268 & 0.9741 & NA & NA & \multicolumn{3}{|c|}{$\mathrm{R}^{2}$ Predicted $\left(\mathrm{R}_{\mathrm{P}}^{2}\right)$} & 0.848 \\
\hline $\mathrm{Li}_{2} \mathrm{O}$ & 11.2111 & 2.5782 & NA & NA & \multicolumn{3}{|c|}{ RMSE } & 0.300 \\
\hline $\mathrm{MnO}$ & 4.4626 & 0.9152 & NA & NA & \multicolumn{3}{|c|}{ Model LOF p-value } & $<0.0001$ \\
\hline $\mathrm{Na}_{2} \mathrm{O}$ & 17.7654 & \multirow{2}{*}{$\begin{array}{l}0.6496 \\
0.4341 \\
\end{array}$} & NA & NA & \multirow{3}{*}{\multicolumn{3}{|c|}{\begin{tabular}{|l|} 
\\
Separate (Extrapolative) Validation \\
Statistic, 554 Outlying Glasses \\
${ }^{(b, d)}$
\end{tabular}}} & \\
\hline $\mathrm{SiO}_{2}$ & -2.2193 & & NA & NA & & & & \\
\hline $\mathrm{SrO}$ & 2.0646 & 0.7611 & NA & NA & & & & Value \\
\hline $\mathrm{ThO}_{2}$ & 0.9885 & 1.1863 & NA & NA & \multicolumn{3}{|c|}{$\mathrm{R}^{2}$ Validation $\left(\mathrm{R}_{\mathrm{V}}^{2}\right)$} & 0.516 \\
\hline $\mathrm{UO}_{3}$ & 20.9346 & \multirow{2}{*}{$\begin{array}{r}6.9809 \\
127840\end{array}$} & NA & NA & \multicolumn{3}{|c|}{ RMSE Validation $\left(\mathrm{RMSE}_{\mathrm{V}}\right)$} & 0.870 \\
\hline $\mathrm{ZnO}$ & 44.6454 & & NA & NA & & & & \\
\hline $\mathrm{ZrO}_{2}$ & -17.1359 & 1.2146 & NA & NA & Dat & ition $\mathrm{St}$ & & \\
\hline Others $^{(\mathrm{g})}$ & 2.1508 & 1.0981 & NA & NA & 163 & ling \& 1 & idation $^{(\mathbf{b}, \mathbf{e})}$ & Value \\
\hline$\left(\mathrm{Al}_{2} \mathrm{O}_{3}\right)^{2}$ & 190.5345 & 21.6255 & 8.81 & $<0.0001$ & & & & 0.918 \\
\hline $\mathrm{Al}_{2} \mathrm{O}_{3} * \mathrm{ZrO}_{2}$ & 163.4298 & 18.4861 & 8.84 & $<0.0001$ & & usted $(\mathrm{R}$ & & 0.908 \\
\hline $\mathrm{Fe}_{2} \mathrm{O}_{3} * \mathrm{Li}_{2} \mathrm{O}$ & 108.0349 & 26.4100 & 4.09 & 0.0001 & & dicted $(\mathrm{R}$ & & 0.896 \\
\hline $\mathrm{SiO}_{2} * \mathrm{ZnO}$ & -102.2282 & 31.2527 & -3.27 & 0.0012 & & & & 0.268 \\
\hline $\mathrm{SiO}_{2} * \mathrm{UO}_{3}$ & -53.6409 & 17.2447 & -3.11 & 0.0021 & & idation ( & & 0.729 \\
\hline & & & & & & Validati & $\left.\mathrm{ISE}_{\mathrm{V}}\right)$ & 0.356 \\
\hline Data Splitting & tistic $^{(b, f)}$ & DS & & DS2 & $\mathbf{S 3}$ & DS4 & DS5 & Average \\
\hline $\mathrm{R}^{2}$ & & 0.8 & & .868 & 861 & 0.877 & 0.876 & 0.874 \\
\hline $\mathrm{R}^{2}$ Adjusted ( $\mathrm{R}$ & & 0.8 & & .857 & 849 & 0.867 & 0.866 & 0.864 \\
\hline $\mathrm{R}^{2}$ Predicted ( & & 0.8 & & .837 & 826 & 0.852 & 0.848 & 0.845 \\
\hline RMSE & & 0.2 & & .303 & 313 & 0.294 & 0.294 & 0.298 \\
\hline $\mathrm{R}^{2}$ Validation & & 0.7 & & .875 & 925 & 0.819 & 0.831 & 0.838 \\
\hline RMSE Validat & $\left(\mathrm{RMSE}_{\mathrm{V}}\right)$ & 0.3 & & .309 & 231 & 0.354 & 0.352 & 0.328 \\
\hline
\end{tabular}

(a) Model results and summary statistics were generated using PCT-Na normalized releases calculated to many decimal places. Rounded versions of these PCT-Na values are given in Table 5.3. Conducting modeling with the rounded versions of the PCT-Na normalized releases may result in slightly different model results and summary statistics.

(b) The model evaluation statistics are defined in Section C.3 of Appendix C. Model validation statistics are defined in Section C.5 of Appendix C. A negative value for $\mathrm{R}^{2}$ means that the sum of squares of model prediction errors is larger than if the mean response value over the validation data set were used as the predicted value for each glass. In other words, the model predicts worse for the validation data than the mean response value does.

(c) NA denotes that it is not applicable to perform a statistical t-test on linear terms in a mixture model (see Section C.5.1).

(d) The 554 separate HLW glass compositions with PCT-Na data for validation (mostly extrapolative) of PCT-Na models are discussed in Section 5.1.4.

(e) The partition of the PCT-Na modeling dataset into modeling and validation subsets is described in Section 5.1.3.

(f) The evaluation and validation statistics calculated for data-splits are defined the same as for separate modeling and validation sets. Section 5.1.2 describes how the data-splitting was accomplished.

(g) For the 18-term partial quadratic mixture model, the "Others" component includes $\mathrm{Ag}_{2} \mathrm{O}, \mathrm{As}_{2} \mathrm{O}_{5}, \mathrm{BaO}, \mathrm{BeO}, \mathrm{Bi}_{2} \mathrm{O}_{3}, \mathrm{Ce}_{2} \mathrm{O}_{3}$, $\mathrm{Cl}, \mathrm{CoO}, \mathrm{Cs}_{2} \mathrm{O}, \mathrm{CuO}, \mathrm{Dy}_{2} \mathrm{O}, \mathrm{Eu}_{2} \mathrm{O}, \mathrm{F}, \mathrm{Gd}_{2} \mathrm{O}_{3}, \mathrm{HfO} 2, \mathrm{HgO}, \mathrm{MoO}_{3}, \mathrm{Nd}_{2} \mathrm{O}_{3}, \mathrm{P}_{2} \mathrm{O}_{5}, \mathrm{PdO}, \mathrm{Pr}_{2} \mathrm{O}_{3}, \mathrm{Rb}_{2} \mathrm{O}, \mathrm{Re}_{2} \mathrm{O}_{7}, \mathrm{Rh}_{2} \mathrm{O}_{3}, \mathrm{RuO}_{2}$, $\mathrm{SO}_{3}, \mathrm{Sm}_{2} \mathrm{O}_{3}, \mathrm{SnO}_{2}, \mathrm{Tc}_{2} \mathrm{O}_{7}, \mathrm{TeO}_{2}, \mathrm{~V}_{2} \mathrm{O}_{5}, \mathrm{WO}_{3}, \mathrm{Y}_{2} \mathrm{O}_{3}, \mathrm{CaO}, \mathrm{CdO}, \mathrm{Cr}_{2} \mathrm{O}_{3}, \mathrm{~K} 2 \mathrm{O}, \mathrm{La}_{2} \mathrm{O}_{3}, \mathrm{MgO}, \mathrm{NiO}, \mathrm{PbO}, \mathrm{Sb}_{2} \mathrm{O}_{3}, \mathrm{SeO}_{2}, \mathrm{TiO}_{2}$, and $\mathrm{Tl}_{2} \mathrm{O}$. 
Table 5.16. Coefficients and Performance Summary for the 15-Term Partial Quadratic Mixture Model on the Natural Logarithm of PCT-Na for HLW Glasses. ${ }^{\text {(a) }}$

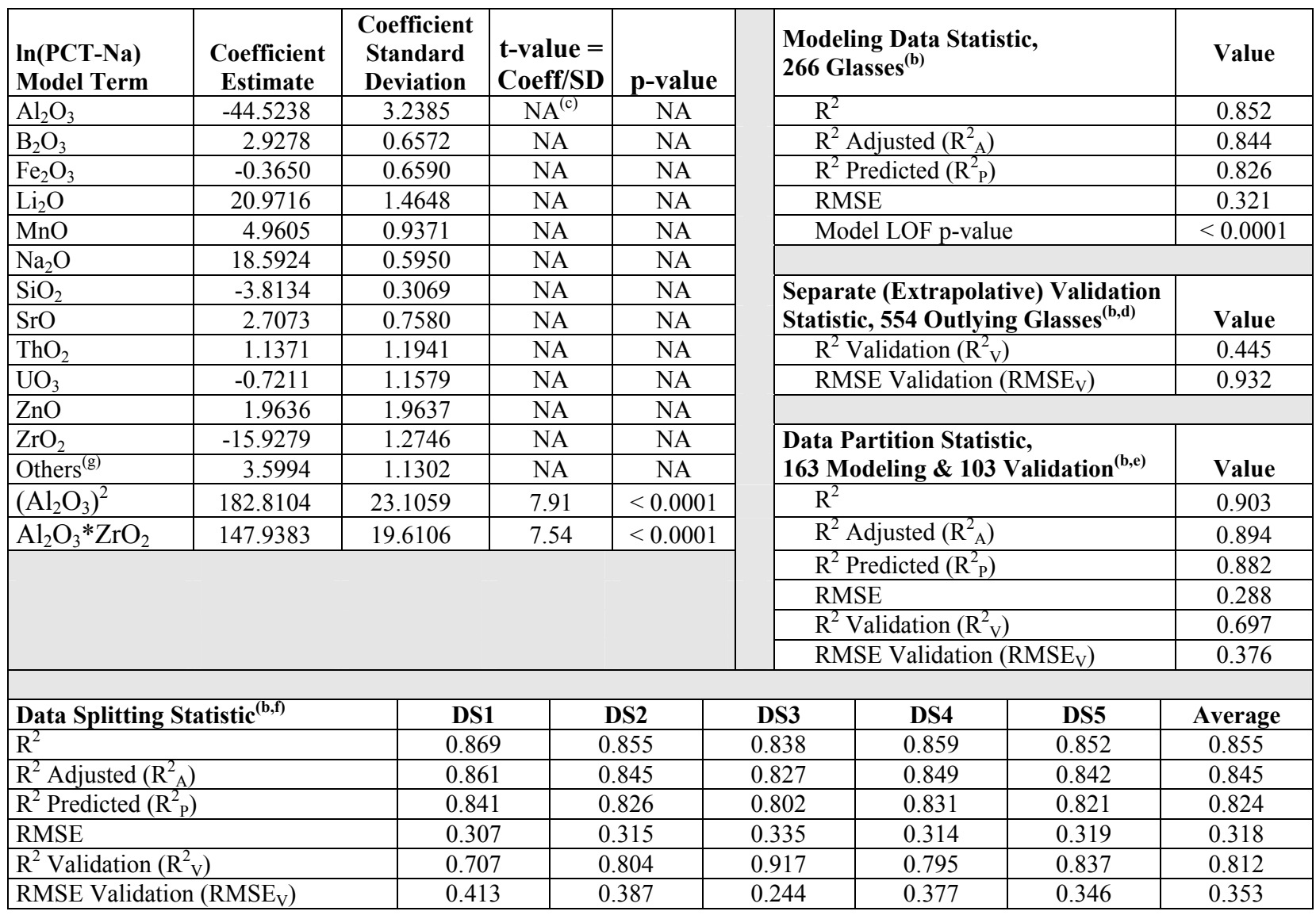

(a) Model results and summary statistics were generated using PCT-Na normalized releases calculated to many decimal places. Rounded versions of these PCT-Na values are given in Table 5.3. Conducting modeling with the rounded versions of the PCT-Na normalized releases may result in slightly different model results and summary statistics.

(b) The model evaluation statistics are defined in Section C.3 of Appendix C. Model validation statistics are defined in Section C.5 of Appendix C. A negative value for $\mathrm{R}_{\mathrm{V}}^{2}$ means that the sum of squares of model prediction errors is larger than if the mean response value over the validation data set were used as the predicted value for each glass. In other words, the model predicts worse for the validation data than the mean response value does.

(c) NA denotes that it is not applicable to perform a statistical t-test on linear terms in a mixture model (see Section C.5.1).

(d) The 554 separate HLW glass compositions with PCT-Na data for validation (mostly extrapolative) of PCT-Na models are discussed in Section 5.1.4.

(e) The partition of the PCT-Na modeling dataset into modeling and validation subsets is described in Section 5.1.3.

(f) The evaluation and validation statistics calculated for data-splits are defined the same as for separate modeling and validation sets. Section 5.1.2 describes how the data-splitting was accomplished.

(g) For the 15-term partial quadratic mixture model, the "Others" component includes $\mathrm{Ag}_{2} \mathrm{O}, \mathrm{As}_{2} \mathrm{O}_{5}, \mathrm{BaO}_{2} \mathrm{BeO}_{2} \mathrm{Bi}_{2} \mathrm{O}_{3}, \mathrm{Ce}_{2} \mathrm{O}_{3}$, $\mathrm{Cl}, \mathrm{CoO}, \mathrm{Cs}_{2} \mathrm{O}, \mathrm{CuO}, \mathrm{Dy}_{2} \mathrm{O}, \mathrm{Eu}_{2} \mathrm{O}, \mathrm{F}, \mathrm{Gd}_{2} \mathrm{O}_{3}, \mathrm{HfO}_{2}, \mathrm{HgO}, \mathrm{MoO}_{3}, \mathrm{Nd}_{2} \mathrm{O}_{3}, \mathrm{P}_{2} \mathrm{O}_{5}, \mathrm{PdO}, \mathrm{Pr}_{2} \mathrm{O}_{3}, \mathrm{Rb}_{2} \mathrm{O}, \mathrm{Re}_{2} \mathrm{O}_{7}, \mathrm{Rh}_{2} \mathrm{O}_{3}, \mathrm{RuO}_{2}$, $\mathrm{SO}_{3}, \mathrm{Sm}_{2} \mathrm{O}_{3}, \mathrm{SnO}_{2}, \mathrm{Tc}_{2} \mathrm{O}_{7}, \mathrm{TeO}_{2}, \mathrm{~V}_{2} \mathrm{O}_{5}, \mathrm{WO}_{3}, \mathrm{Y}_{2} \mathrm{O}_{3}, \mathrm{CaO}, \mathrm{CdO}, \mathrm{Cr}_{2} \mathrm{O}_{3}, \mathrm{~K}_{2} \mathrm{O}, \mathrm{La}_{2} \mathrm{O}_{3}, \mathrm{MgO}, \mathrm{NiO}, \mathrm{PbO}, \mathrm{Sb}_{2} \mathrm{O}_{3}, \mathrm{SeO}_{2}, \mathrm{TiO}_{2}$, and $\mathrm{Tl}_{2} \mathrm{O}$. 
Table 5.17. Terms in Selected Models for PCT-B, PCT-Li, and PCT-Na Releases from HLW Glasses.

\begin{tabular}{|c|c|c|c|c|c|}
\hline \multicolumn{6}{|c|}{ PCT-B } \\
\hline \multicolumn{6}{|c|}{ Model Type and Number of Terms } \\
\hline $\mathbf{L M}$ & $\mathbf{L M}$ & PQM & PCM & PQM & PQM \\
\hline 25 & 13 & 18 & 18 & 16 & 15 \\
\hline \multicolumn{6}{|c|}{ Linear Terms } \\
\hline (a) & \multicolumn{5}{|c|}{$\begin{array}{l}\mathrm{Al}_{2} \mathrm{O}_{3}, \mathrm{~B}_{2} \mathrm{O}_{3}, \mathrm{Fe}_{2} \mathrm{O}_{3}, \mathrm{Li}_{2} \mathrm{O}, \mathrm{MnO}, \mathrm{Na}_{2} \mathrm{O}, \mathrm{SiO}_{2}, \mathrm{SrO}, \mathrm{ThO}_{2}, \mathrm{UO}_{3} \text {, } \\
\mathrm{ZnO}, \mathrm{ZrO}_{2}, \text { Others. }\end{array}$} \\
\hline \multicolumn{6}{|c|}{ Quadratic and/or Cubic Terms } \\
\hline & & $\left(\mathrm{Al}_{2} \mathrm{O}_{3}\right)^{2}$ & $\left(\mathrm{Al}_{2} \mathrm{O}_{3}\right)^{2}$ & $\left(\mathrm{Al}_{2} \mathrm{O}_{3}\right)^{2}$ & $\left(\mathrm{Al}_{2} \mathrm{O}_{3}\right)^{2}$ \\
\hline & & $\mathrm{UO}_{3} \times \mathrm{ZnO}$ & $\mathrm{Fe}_{2} \mathrm{O}_{3} \times \mathrm{Na}_{2} \mathrm{O} \times \mathrm{SrO}$ & $\mathrm{Al}_{2} \mathrm{O}_{3} \times \mathrm{ZrO}_{2}$ & \multirow{4}{*}{$\mathrm{Al}_{2} \mathrm{O}_{3} \times \mathrm{ZrO}_{2}$} \\
\hline & & $(\mathrm{MnO})^{2}$ & $\mathrm{UO}_{3} \times \mathrm{ZnO}$ & $\mathrm{UO}_{3} \times \mathrm{ZnO}$ & \\
\hline & & $\mathrm{Fe}_{2} \mathrm{O}_{3} \times \mathrm{ZnO}$ & $\mathrm{Fe}_{2} \mathrm{O}_{3} \times(\mathrm{ZnO})^{2}$ & & \\
\hline & & $\mathrm{Al}_{2} \mathrm{O}_{3} \times \mathrm{ZrO}_{2}$ & $\mathrm{~B}_{2} \mathrm{O}_{3} \times\left(\mathrm{Na}_{2} \mathrm{O}\right)^{2}$ & & \\
\hline \multicolumn{6}{|c|}{ PCT-Li } \\
\hline \multicolumn{6}{|c|}{ Model Type and Number of Terms } \\
\hline $\mathbf{L M}$ & $\mathbf{L M}$ & PQM & PCM & PQM & PQM \\
\hline 25 & 13 & 18 & 18 & 16 & 15 \\
\hline \multicolumn{6}{|c|}{ Linear Terms } \\
\hline (a) & \multirow{2}{*}{\multicolumn{5}{|c|}{$\begin{array}{l}\begin{array}{l}\mathrm{Al}_{2} \mathrm{O}_{3}, \mathrm{~B}_{2} \mathrm{O}_{3}, \mathrm{Fe}_{2} \mathrm{O}_{3}, \mathrm{Li}_{2} \mathrm{O}, \mathrm{MnO}, \mathrm{Na}_{2} \mathrm{O}, \mathrm{SiO}_{2}, \mathrm{SrO}, \mathrm{ThO}_{2}, \mathrm{UO}_{3}, \\
\mathrm{ZnO}, \mathrm{ZrO}_{2}, \text { Others. }\end{array} \\
\text { Ouadratic and/or Cubic Terms }\end{array}$}} \\
\hline Quadratic and/or Cubic Terms & & & & & \\
\hline & & $\left(\mathrm{Al}_{2} \mathrm{O}_{3}\right)^{2}$ & $\left(\mathrm{Al}_{2} \mathrm{O}_{3}\right)^{2}$ & $\left(\mathrm{Al}_{2} \mathrm{O}_{3}\right)^{2}$ & $\left(\mathrm{Al}_{2} \mathrm{O}_{3}\right)^{2}$ \\
\hline & & $\mathrm{UO}_{3} \times \mathrm{ZnO}$ & $\mathrm{B}_{2} \mathrm{O}_{3} \times \mathrm{Li}_{2} \mathrm{O} \times \mathrm{SrO}$ & $\mathrm{Al}_{2} \mathrm{O}_{3} \times \mathrm{ZrO}_{2}$ & \multirow{4}{*}{$\mathrm{Al}_{2} \mathrm{O}_{3} \times \mathrm{ZrO}_{2}$} \\
\hline & & $\mathrm{Fe}_{2} \mathrm{O}_{3} \times \mathrm{Li}_{2} \mathrm{O}$ & $\mathrm{Al}_{2} \mathrm{O}_{3} \times \mathrm{SiO}_{2} \times \mathrm{UO}_{3}$ & $\mathrm{UO}_{3} \times \mathrm{ZnO}$ & \\
\hline & & $\mathrm{SrO} \times \mathrm{ZrO}_{2}$ & $\mathrm{Fe}_{2} \mathrm{O}_{3} \times \mathrm{UO}_{3} \times \mathrm{ZnO}$ & & \\
\hline & & $\mathrm{Al}_{2} \mathrm{O}_{3} \times \mathrm{ZrO}_{2}$ & $\mathrm{~B}_{2} \mathrm{O}_{3} \times \mathrm{Na}_{2} \mathrm{O} \times \mathrm{UO}_{3}$ & & \\
\hline \multicolumn{6}{|c|}{ PCT-Na } \\
\hline \multicolumn{6}{|c|}{ Model Type and Number of Terms } \\
\hline $\mathbf{L M}$ & $\mathbf{L M}$ & PQM & PCM & PQM & PQM \\
\hline 25 & 13 & 18 & 18 & 16 & 15 \\
\hline \multicolumn{6}{|c|}{ Linear Terms } \\
\hline (a) & $\begin{array}{l}\mathrm{Al}_{2} \mathrm{O} \\
\mathrm{ZnO}\end{array}$ & $\begin{array}{l}\mathrm{O}_{3}, \mathrm{~B}_{2} \mathrm{O}_{3}, \mathrm{Fe}_{2} \mathrm{O} \\
\mathrm{ZrO}_{2}, \text { Others }\end{array}$ & 3, $\mathrm{Li}_{2} \mathrm{O}, \mathrm{MnO}, \mathrm{Na}_{2} \mathrm{O}$ & $, \mathrm{SiO}_{2}, \mathrm{SrO}, \mathrm{T}$ & $\mathrm{ThO}_{2}, \mathrm{UO}_{3}$ \\
\hline \multicolumn{6}{|c|}{ Quadratic and/or Cubic Terms } \\
\hline & & $\left(\mathrm{Al}_{2} \mathrm{O}_{3}\right)^{2}$ & $\left(\mathrm{Al}_{2} \mathrm{O}_{3}\right)^{2}$ & $\left(\mathrm{Al}_{2} \mathrm{O}_{3}\right)^{2}$ & $\left(\mathrm{Al}_{2} \mathrm{O}_{3}\right)^{2}$ \\
\hline & & $\mathrm{Al}_{2} \mathrm{O}_{3} \times \mathrm{ZrO}_{2}$ & $\mathrm{Al}_{2} \mathrm{O}_{3} \times \mathrm{SiO}_{2} \times \mathrm{ZrO}_{2}$ & $\mathrm{Al}_{2} \mathrm{O}_{3} \times \mathrm{ZrO}_{2}$ & $\mathrm{Al}_{2} \mathrm{O}_{3} \times \mathrm{ZrO}_{2}$ \\
\hline & & $\mathrm{Fe}_{2} \mathrm{O}_{3} \times \mathrm{Li}_{2} \mathrm{O}$ & $\mathrm{Na}_{2} \mathrm{O} \times \mathrm{SiO}_{2} \times \mathrm{ThO}_{2}$ & $\mathrm{UO}_{3} \times \mathrm{ZnO}$ & \\
\hline & & $\mathrm{SiO}_{2} \times \mathrm{ZnO}$ & $\mathrm{Fe}_{2} \mathrm{O}_{3} \times(\mathrm{ZnO})^{2}$ & & \\
\hline & & $\mathrm{SiO}_{2} \times \mathrm{UO}_{3}$ & $\mathrm{Fe}_{2} \mathrm{O}_{3} \times \mathrm{Li}_{2} \mathrm{O}$ & & \\
\hline
\end{tabular}

(a) $\mathrm{Al}_{2} \mathrm{O}_{3}, \mathrm{~B}_{2} \mathrm{O}_{3}, \mathrm{CaO}, \mathrm{CdO}, \mathrm{Cr}_{2} \mathrm{O}_{3}, \mathrm{Fe}_{2} \mathrm{O}_{3}, \mathrm{~K}_{2} \mathrm{O}, \mathrm{La}_{2} \mathrm{O}_{3}, \mathrm{Li}_{2} \mathrm{O}, \mathrm{MgO}, \mathrm{MnO}, \mathrm{Na} 2 \mathrm{O}, \mathrm{NiO}, \mathrm{PbO}$, $\mathrm{Sb}_{2} \mathrm{O}_{3}, \mathrm{SeO}_{2}, \mathrm{SiO}_{2}, \mathrm{SrO}, \mathrm{ThO}_{2}, \mathrm{TiO}_{2}, \mathrm{Tl}_{2} \mathrm{O}, \mathrm{UO}_{3}, \mathrm{ZnO}, \mathrm{ZrO}_{2}$, and Others. 
Table 5.18. Fit and Validation Statistics for Selected PCT-B, PCT-Li, and PCT-Na Models for HLW Glasses.

\begin{tabular}{|c|c|c|c|c|c|c|c|c|c|c|c|c|c|c|c|c|c|c|}
\hline & \multicolumn{6}{|c|}{ PCT-B } & \multicolumn{6}{|c|}{ PCT-Li } & \multicolumn{6}{|c|}{ PCT-Na } \\
\hline Model & LM & LM & PQM & PCM & PQM & PQM & LM & $\mathbf{L M}$ & PQM & PCM & PQM & PQM & $\mathbf{L M}$ & $\mathbf{L M}$ & PQM & PCM & PQM & PQM \\
\hline \# Terms & 25 & 13 & 18 & 18 & 16 & 15 & 25 & 13 & 18 & 18 & 16 & 15 & 25 & 13 & 18 & 18 & 16 & 15 \\
\hline \multicolumn{19}{|c|}{ Modeling Results } \\
\hline \# Glasses & \multicolumn{6}{|c|}{264 Glasses } & \multicolumn{6}{|c|}{250 Glasses } & \multicolumn{6}{|c|}{266 Glasses } \\
\hline $\mathrm{R}^{2}$ & 0.727 & 0.700 & 0.788 & 0.802 & 0.769 & 0.753 & 0.670 & 0.641 & 0.742 & 0.770 & 0.714 & 0.695 & 0.804 & 0.791 & 0.873 & 0.879 & 0.854 & 0.852 \\
\hline $\mathrm{R}_{\mathrm{A}}^{2}$ & 0.700 & 0.685 & 0.774 & 0.788 & 0.755 & 0.739 & 0.635 & 0.623 & 0.723 & 0.753 & 0.695 & 0.677 & 0.784 & 0.781 & 0.864 & 0.870 & 0.845 & 0.844 \\
\hline $\mathrm{R}_{\mathrm{P}}^{2}$ & 0.659 & 0.659 & 0.751 & 0.769 & 0.731 & 0.715 & 0.578 & 0.590 & 0.694 & 0.726 & 0.663 & 0.643 & 0.746 & 0.761 & 0.848 & 0.857 & 0.825 & 0.826 \\
\hline RMSE & 0.486 & 0.497 & 0.422 & 0.408 & \begin{tabular}{|l|}
0.439 \\
\end{tabular} & 0.453 & 0.386 & 0.392 & 0.336 & 0.317 & 0.352 & 0.363 & 0.378 & 0.381 & 0.300 & 0.293 & 0.320 & 0.321 \\
\hline LOF $p$ & 0.001 & 0.001 & 0.014 & 0.024 & 0.007 & 0.004 & $<.0001$ & $<.0001$ & $<.0001$ & $<.0001$ & $<.0001$ & $<.0001$ & $<.0001$ & $<.0001$ & $<.0001$ & $<.0001$ & $<.0001$ & $<.0001$ \\
\hline \multicolumn{19}{|c|}{ Data-Splitting Averages over Five Splits } \\
\hline \# Glasses & \multicolumn{6}{|c|}{$\begin{array}{l}2 \text { Splits }=222 \text { modeling, } 42 \text { validation } \\
3 \text { Splits }=223 \text { modeling, } 41 \text { validation }\end{array}$} & \multicolumn{6}{|c|}{$\begin{array}{l}2 \text { Splits }=212 \text { modeling, } 38 \text { validation } \\
2 \text { Splits }=211 \text { modeling, } 39 \text { validation }\end{array}$} & \multicolumn{6}{|c|}{$\begin{array}{l}4 \text { Splits }=224 \text { modeling, } 42 \text { validation } \\
1 \text { Split }=225 \text { modeling, } 41 \text { validation }\end{array}$} \\
\hline $\mathrm{R}^{2}$ & 0.726 & 0.694 & 0.786 & 0.800 & 0.763 & 0.746 & 0.676 & 0.641 & 0.745 & 0.768 & 0.714 & 0.695 & 0.811 & 0.795 & 0.874 & 0.880 & 0.856 & 0.855 \\
\hline $\mathrm{R}_{\mathrm{A}}^{2}$ & 0.692 & 0.676 & 0.768 & 0.783 & 0.745 & 0.729 & 0.634 & 0.619 & 0.722 & 0.748 & 0.692 & 0.673 & 0.788 & 0.784 & 0.864 & 0.871 & 0.846 & 0.845 \\
\hline $\mathrm{R}_{\mathrm{P}}^{2}$ & 0.639 & 0.643 & 0.739 & 0.759 & 0.715 & 0.697 & 0.564 & 0.579 & 0.687 & 0.716 & 0.652 & 0.631 & 0.742 & 0.760 & 0.845 & 0.855 & 0.822 & 0.824 \\
\hline RMSE & 0.485 & 0.497 & 0.421 & 0.407 & 0.441 & 0.455 & 0.381 & 0.388 & 0.331 & 0.316 & 0.349 & 0.360 & 0.372 & 0.375 & 0.298 & 0.290 & 0.317 & 0.318 \\
\hline $\mathrm{R}_{\mathrm{V}}^{2}$ & 0.693 & 0.710 & 0.782 & 0.796 & 0.778 & 0.774 & 0.582 & 0.619 & 0.691 & 0.754 & 0.672 & 0.662 & 0.713 & 0.731 & 0.838 & 0.845 & 0.813 & 0.812 \\
\hline $\mathrm{RMSE}_{\mathrm{V}}$ & 0.521 & 0.508 & 0.439 & 0.425 & \begin{tabular}{|l|}
0.439 \\
\end{tabular} & 0.439 & 0.443 & 0.423 & 0.378 & 0.339 & 0.391 & 0.397 & 0.439 & 0.424 & 0.328 & 0.324 & 0.353 & 0.353 \\
\hline \multicolumn{19}{|c|}{ Data-Partitioning Validation } \\
\hline \# Glasses & \multicolumn{6}{|c|}{162 modeling, 102 validation } & \multicolumn{6}{|c|}{154 modeling, 96 validation } & \multicolumn{6}{|c|}{163 modeling, 103 validation } \\
\hline $\mathrm{R}^{2}$ & 0.794 & 0.759 & 0.826 & 0.830 & 0.819 & 0.799 & 0.751 & 0.704 & 0.800 & 0.818 & 0.776 & 0.764 & 0.874 & 0.848 & 0.918 & 0.918 & 0.906 & 0.903 \\
\hline $\mathrm{R}_{\mathrm{A}}^{2}$ & 0.757 & 0.739 & 0.806 & 0.810 & 0.801 & 0.780 & 0.705 & 0.679 & 0.775 & 0.795 & 0.752 & 0.741 & 0.852 & 0.836 & 0.908 & 0.909 & 0.897 & 0.894 \\
\hline $\mathrm{R}_{\mathrm{P}}^{2}$ & $<0^{(\mathrm{a})}$ & 0.710 & 0.772 & 0.776 & 0.772 & 0.752 & $<0^{(\mathrm{a})}$ & 0.637 & 0.731 & 0.763 & 0.704 & 0.700 & $<0^{(\mathrm{a})}$ & 0.817 & 0.896 & 0.896 & 0.883 & 0.882 \\
\hline RMSE & 0.464 & 0.481 & 0.415 & 0.411 & \begin{tabular}{|l|}
0.421 \\
\end{tabular} & 0.442 & 0.368 & 0.384 & 0.322 & 0.307 & 0.338 & 0.345 & 0.341 & 0.358 & 0.268 & 0.267 & 0.284 & 0.288 \\
\hline $\mathrm{R}_{\mathrm{V}}^{2}$ & $<0^{(\mathrm{a})}$ & 0.473 & 0.618 & 0.628 & 0.546 & 0.565 & $<0^{(\mathrm{a})}$ & 0.331 & 0.467 & 0.513 & 0.380 & 0.357 & $<0^{\text {(a) }}$ & 0.616 & 0.729 & 0.717 & 0.688 & 0.697 \\
\hline $\mathrm{RMSE}_{\mathrm{V}}$ & 2.015 & 0.552 & 0.470 & 0.464 & 0.512 & 0.502 & 1.359 & 0.435 & 0.388 & 0.371 & 0.418 & 0.426 & 1.515 & 0.423 & 0.356 & 0.363 & 0.381 & 0.376 \\
\hline \multicolumn{19}{|c|}{ Separate Validation Set, Mostly Extrapolations } \\
\hline \# Glasses & \multicolumn{6}{|c|}{556 Glasses } & \multicolumn{6}{|c|}{480 Glasses } & \multicolumn{6}{|c|}{554 Glasses } \\
\hline $\mathrm{R}_{\mathrm{V}}^{2}$ & $<0^{(\mathrm{a})}$ & 0.524 & 0.623 & 0.571 & 0.628 & 0.597 & $<0^{\text {(a) }}$ & 0.507 & 0.543 & 0.591 & 0.579 & 0.557 & $<0^{(\mathrm{a})}$ & 0.367 & 0.516 & 0.452 & 0.474 & 0.445 \\
\hline $\mathrm{RMSE}_{\mathrm{V}}$ & 1.599 & 0.935 & 0.832 & 0.888 & 0.826 & 0.860 & 1.757 & 0.866 & 0.834 & 0.789 & 0.801 & 0.821 & 1.561 & 0.996 & 0.870 & 0.926 & 0.907 & 0.932 \\
\hline
\end{tabular}

(a) The $\mathrm{R}_{\mathrm{P}}^{2}$ and $\mathrm{R}_{\mathrm{V}}^{2}$ statistics for the full 25-component linear mixture model are less than zero because of the sensitivity of non-significant models terms to data. This is a result of the modeling datasets having minimal support for some components in the 25-component LM models. 
Table 5.19. Coefficients and Performance Summary for the Recommended 19-Term Model (18-Term Partial Quadratic Mixture Model with Bias Correction) for the Natural Logarithm of PCT-B for HLW Glasses. ${ }^{(a)}$

\begin{tabular}{|c|c|c|c|c|c|c|}
\hline $\begin{array}{l}\text { In(PCT-B) } \\
\text { Model Term }\end{array}$ & $\begin{array}{c}\text { Coefficient } \\
\text { Estimate }\end{array}$ & $\begin{array}{l}\text { Coefficient } \\
\text { Standard } \\
\text { Deviation }\end{array}$ & $\begin{array}{l}\text { t-value }= \\
\text { Coeff } / \mathbf{S D}\end{array}$ & p-value & $\begin{array}{l}\text { Modeling Data Statistic, } \\
264 \text { Glasses }^{(\mathbf{b})}\end{array}$ & Value \\
\hline $\mathrm{Al}_{2} \mathrm{O}_{3}$ & -43.7679 & 4.6452 & $\mathrm{NA}^{(\mathrm{c})}$ & NA & $\mathrm{R}^{2}$ & 0.791 \\
\hline $\mathrm{B}_{2} \mathrm{O}_{3}$ & 8.9421 & 0.8678 & NA & $\mathrm{NA}$ & RMSE & 0.420 \\
\hline $\mathrm{Fe}_{2} \mathrm{O}_{3}$ & -5.6911 & 1.2828 & NA & NA & Model LOF p-value & 0.014 \\
\hline $\mathrm{Li}_{2} \mathrm{O}$ & 22.5985 & 1.9611 & NA & NA & & \\
\hline $\mathrm{MnO}$ & -7.7193 & 4.1556 & NA & NA & & \\
\hline $\mathrm{Na}_{2} \mathrm{O}$ & 17.0391 & 0.8067 & NA & NA & & \\
\hline $\mathrm{SiO}_{2}$ & -2.4959 & 0.4182 & NA & NA & \begin{tabular}{|l|} 
Separate (Extrapolative) Validation \\
\end{tabular} & \\
\hline $\mathrm{SrO}$ & -0.0577 & 1.0318 & NA & NA & Statistic, 556 Outlying Glasses ${ }^{(\mathrm{b}, \mathrm{d})}$ & Value \\
\hline $\mathrm{ThO}_{2}$ & 2.4230 & 1.6631 & NA & NA & $\mathrm{R}^{2}$ Validation $\left(\mathrm{R}_{\mathrm{v}}^{2}\right)$ & 0.624 \\
\hline $\mathrm{UO}_{3}$ & -11.3780 & 2.4566 & NA & NA & RMSE Validation $\left(\mathrm{RMSE}_{\mathrm{V}}\right)$ & 0.831 \\
\hline $\mathrm{ZnO}$ & -28.0347 & 6.6929 & NA & NA & & \\
\hline $\mathrm{ZrO}_{2}$ & -13.2496 & 1.6845 & NA & NA & & \\
\hline Others $^{(e)}$ & 5.0368 & 1.5768 & NA & $\mathrm{NA}$ & & \\
\hline$\left(\mathrm{Al}_{2} \mathrm{O}_{3}\right)^{2}$ & 169.7017 & 33.1963 & 5.11 & $<0.0001$ & & \\
\hline $\mathrm{UO}_{3} \times \mathrm{ZnO}$ & 511.2763 & 105.4536 & 4.85 & $<0.0001$ & & \\
\hline$(\mathrm{MnO})^{2}$ & 214.6560 & 60.5468 & 3.55 & 0.0005 & & \\
\hline $\mathrm{Fe}_{2} \mathrm{O}_{3} \times \mathrm{ZnO}$ & 193.2526 & 58.9749 & 3.28 & 0.0012 & & \\
\hline $\mathrm{Al}_{2} \mathrm{O}_{3} \times \mathrm{ZrO}_{2}$ & 79.4113 & 25.9429 & 3.06 & 0.0025 & & \\
\hline Bias Correction $^{(\mathrm{f})}$ & 0.3644 & 0.0595 & 6.13 & $<0.0001$ & & \\
\hline
\end{tabular}

(a) Model results and summary statistics were generated using PCT-B normalized releases calculated to many decimal places. Rounded versions of these PCT-B values are given in Table 5.3. Conducting modeling with the rounded versions of the PCT-B normalized releases may result in slightly different model results and summary statistics.

(b) The model evaluation statistics are defined in Section C.3 of Appendix C. Model validation statistics are defined in Section C.5 of Appendix C.

(c) NA denotes that it is not applicable to perform a statistical t-test on linear terms in a mixture model (see Section C.5.1).

(d) The 566 separate HLW glass compositions with PCT-B data for validation (mostly extrapolative) of PCT-B models are discussed in Section 5.1.4.

(e) For the 18-term partial quadratic mixture model, the "Others" component includes $\mathrm{Ag}_{2} \mathrm{O}, \mathrm{As}_{2} \mathrm{O}_{5}, \mathrm{BaO}, \mathrm{BeO}, \mathrm{Bi}_{2} \mathrm{O}_{3}, \mathrm{Ce}_{2} \mathrm{O}_{3}$, $\mathrm{Cl}, \mathrm{CoO}, \mathrm{Cs}_{2} \mathrm{O}, \mathrm{CuO}, \mathrm{Dy}_{2} \mathrm{O}, \mathrm{Eu}_{2} \mathrm{O}, \mathrm{F}, \mathrm{Gd}_{2} \mathrm{O}_{3}, \mathrm{HfO}_{2}, \mathrm{HgO}, \mathrm{MoO}_{3}, \mathrm{Nd}_{2} \mathrm{O}_{3}, \mathrm{P}_{2} \mathrm{O}_{5}, \mathrm{PdO}, \mathrm{Pr}_{2} \mathrm{O}_{3}, \mathrm{Rb}_{2} \mathrm{O}, \mathrm{Re}_{2} \mathrm{O}_{7}, \mathrm{Rh}_{2} \mathrm{O}_{3}, \mathrm{RuO}_{2}$, $\mathrm{SO}_{3}, \mathrm{Sm}_{2} \mathrm{O}_{3}, \mathrm{SnO}_{2}, \mathrm{Tc}_{2} \mathrm{O}_{7}, \mathrm{TeO}_{2}, \mathrm{~V}_{2} \mathrm{O}_{5}, \mathrm{WO}_{3}, \mathrm{Y}_{2} \mathrm{O}_{3}, \mathrm{CaO}, \mathrm{CdO}, \mathrm{Cr}_{2} \mathrm{O}_{3}, \mathrm{~K} 2 \mathrm{O}, \mathrm{La}_{2} \mathrm{O}_{3}, \mathrm{MgO}, \mathrm{NiO}, \mathrm{PbO}, \mathrm{Sb}_{2} \mathrm{O}_{3}, \mathrm{SeO}_{2}, \mathrm{TiO}_{2}$, and $\mathrm{Tl}_{2} \mathrm{O}$.

(f) The bias correction is a constant adjustment applied to glasses with predicted PCT-B releases $>0.5 \ln (\mathrm{g} / \mathrm{L})$. See Equation (5.9) in Section 5.7. 
Table 5.20. Coefficients and Performance Summary for the Second-Choice 16-Term Model (15-Term Partial Quadratic Mixture Model with Bias Correction) for the Natural Logarithm of PCT-B for HLW Glasses. ${ }^{\text {(a) }}$

\begin{tabular}{|c|c|c|c|c|c|c|}
\hline $\begin{array}{l}\ln (\text { PCT-B }) \\
\text { Model Term }\end{array}$ & $\begin{array}{c}\text { Coefficient } \\
\text { Estimate }\end{array}$ & $\begin{array}{l}\text { Coefficient } \\
\text { Standard } \\
\text { Deviation }\end{array}$ & $\begin{array}{l}\text { t-value }= \\
\text { Coeff/SD }\end{array}$ & p-value & $\begin{array}{l}\text { Modeling Data Statistic, } \\
264 \text { Glasses }^{(b)}\end{array}$ & Value \\
\hline $\mathrm{Al}_{2} \mathrm{O}_{3}$ & \begin{tabular}{|l|}
-51.6810 \\
\end{tabular} & 4.6104 & $\mathrm{NA}^{(\mathrm{c})}$ & NA & $\mathrm{R}^{2}$ & 0.749 \\
\hline $\mathrm{B}_{2} \mathrm{O}_{3}$ & 8.4922 & 0.9270 & NA & NA & RMSE & 0.457 \\
\hline $\mathrm{Fe}_{2} \mathrm{O}_{3}$ & -2.8518 & 0.9317 & NA & NA & Model LOF p-value & 0.003 \\
\hline $\mathrm{Li}_{2} \mathrm{O}$ & 23.3308 & 2.0714 & NA & NA & & \\
\hline $\mathrm{MnO}$ & 7.3087 & 1.3305 & NA & NA & & \\
\hline $\mathrm{Na}_{2} \mathrm{O}$ & 16.5878 & 0.8403 & NA & NA & & \\
\hline $\mathrm{SiO}_{2}$ & -2.8000 & 0.4357 & NA & NA & \multirow{2}{*}{$\begin{array}{l}\text { Separate (Extrapolative) Validation } \\
\text { Statistic, } 556 \text { Outlying Glasses }{ }^{(b, d)} \\
\end{array}$} & \multirow[b]{2}{*}{ Value } \\
\hline $\mathrm{SrO}$ & -1.4447 & 1.0726 & NA & NA & & \\
\hline $\mathrm{ThO}_{2}$ & -0.9257 & 1.6896 & NA & NA & $\mathrm{R}^{2}$ Validation $\left(\mathrm{R}_{\mathrm{V}}^{2}\right)$ & 0.636 \\
\hline $\mathrm{UO}_{3}$ & -1.7878 & 1.6535 & NA & NA & RMSE Validation $\left(\mathrm{RMSE}_{\mathrm{V}}\right)$ & 0.818 \\
\hline $\mathrm{ZnO}$ & 0.4193 & 2.7695 & NA & NA & & \\
\hline $\mathrm{ZrO}_{2}$ & -14.2673 & 1.7981 & NA & NA & & \\
\hline Others $^{(\mathrm{e})}$ & 2.6687 & 1.6013 & NA & NA & & \\
\hline$\left(\mathrm{Al}_{2} \mathrm{O}_{3}\right)^{2}$ & 228.6864 & 32.8368 & 6.96 & $<0.0001$ & & \\
\hline $\mathrm{Al}_{2} \mathrm{O}_{3} \times \mathrm{ZrO}_{2}$ & 92.1624 & 27.6780 & 3.33 & 0.0010 & & \\
\hline Bias Correction $^{(\mathrm{f})}$ & 0.4357 & 0.0527 & 8.27 & $<0.0001$ & & \\
\hline
\end{tabular}

(a) Model results and summary statistics were generated using PCT-B normalized releases calculated to many decimal places. Rounded versions of these PCT-B values are given in Table 5.3. Conducting modeling with the rounded versions of the PCT-B normalized releases may result in slightly different model results and summary statistics.

(b) The model evaluation statistics are defined in Section C.3 of Appendix C. Model validation statistics are defined in Section C.5 of Appendix C.

(c) NA denotes that it is not applicable to perform a statistical t-test on linear terms in a mixture model (see Section C.5.1).

(d) The 566 separate HLW glass compositions with PCT-B data for validation (mostly extrapolative) of PCT-B models are discussed in Section 5.1.4.

(e) For the 18-term partial quadratic mixture model, the "Others" component includes $\mathrm{Ag}_{2} \mathrm{O}, \mathrm{As}_{2} \mathrm{O}_{5}, \mathrm{BaO}_{2} \mathrm{BeO}_{2} \mathrm{Bi}_{2} \mathrm{O}_{3}, \mathrm{Ce}_{2} \mathrm{O}_{3}$, $\mathrm{Cl}, \mathrm{CoO}, \mathrm{Cs}_{2} \mathrm{O}, \mathrm{CuO}, \mathrm{Dy}_{2} \mathrm{O}, \mathrm{Eu}_{2} \mathrm{O}, \mathrm{F}, \mathrm{Gd}_{2} \mathrm{O}_{3}, \mathrm{HfO}_{2}, \mathrm{HgO}, \mathrm{MoO}_{3}, \mathrm{Nd}_{2} \mathrm{O}_{3}, \mathrm{P}_{2} \mathrm{O}_{5}, \mathrm{PdO}, \mathrm{Pr}_{2} \mathrm{O}_{3}, \mathrm{Rb}_{2} \mathrm{O}, \mathrm{Re}_{2} \mathrm{O}_{7}, \mathrm{Rh}_{2} \mathrm{O}_{3}, \mathrm{RuO}_{2}$, $\mathrm{SO}_{3}, \mathrm{Sm}_{2} \mathrm{O}_{3}, \mathrm{SnO}_{2}, \mathrm{Tc}_{2} \mathrm{O}_{7}, \mathrm{TeO}_{2}, \mathrm{~V}_{2} \mathrm{O}_{5}, \mathrm{WO}_{3}, \mathrm{Y}_{2} \mathrm{O}_{3}, \mathrm{CaO}, \mathrm{CdO}, \mathrm{Cr}_{2} \mathrm{O}_{3}, \mathrm{~K}_{2} \mathrm{O}, \mathrm{La}_{2} \mathrm{O}_{3}, \mathrm{MgO}, \mathrm{NiO}, \mathrm{PbO}, \mathrm{Sb}_{2} \mathrm{O}_{3}, \mathrm{SeO}_{2}, \mathrm{TiO}_{2}$, and $\mathrm{Tl}_{2} \mathrm{O}$.

(f) The bias correction is a constant adjustment applied to glasses with predicted PCT-B releases $>0.5 \ln (\mathrm{g} / \mathrm{L})$. See Equation (5.9) in Section 5.7. 
Table 5.21. Coefficients and Performance Summary for the Recommended 19-Term Model (18-Term Partial Quadratic Mixture Model with Bias Correction) for the Natural Logarithm of PCT-Li for HLW Glasses. ${ }^{(a)}$

\begin{tabular}{|c|c|c|c|c|c|c|}
\hline $\begin{array}{l}\ln (\text { PCT-Li) } \\
\text { Model Term }\end{array}$ & $\begin{array}{c}\text { Coefficient } \\
\text { Estimate }\end{array}$ & $\begin{array}{c}\text { Coefficient } \\
\text { Standard } \\
\text { Deviation }\end{array}$ & $\begin{array}{l}\text { t-value }= \\
\text { Coeff } / \text { SD }\end{array}$ & p-value & $\begin{array}{l}\text { Modeling Data Statistic, } \\
250 \text { Glasses }^{(b)}\end{array}$ & Value \\
\hline $\mathrm{Al}_{2} \mathrm{O}_{3}$ & -36.7423 & 3.6001 & $\mathrm{NA}^{(\mathrm{c})}$ & NA & $\mathrm{R}^{2}$ & 0.763 \\
\hline $\mathrm{B}_{2} \mathrm{O}_{3}$ & 6.6931 & 0.7720 & NA & NA & RMSE & 0.323 \\
\hline $\mathrm{Fe}_{2} \mathrm{O}_{3}$ & -6.7440 & 1.4956 & NA & NA & Model LOF p-value & $<0.0001$ \\
\hline $\mathrm{Li}_{2} \mathrm{O}$ & 8.2175 & 3.6817 & NA & NA & & \\
\hline $\mathrm{MnO}$ & 6.1378 & 1.1547 & NA & NA & & \\
\hline $\mathrm{Na}_{2} \mathrm{O}$ & 11.1232 & 0.6796 & NA & NA & & \\
\hline $\mathrm{SiO}_{2}$ & -1.1853 & 0.3585 & NA & NA & \multirow{2}{*}{$\begin{array}{l}\text { Separate (Extrapolative) Validation } \\
\text { Statistic, } 480 \text { Outlying Glasses }{ }^{(b, d)}\end{array}$} & \multirow[b]{2}{*}{ Value } \\
\hline $\mathrm{SrO}$ & -1.3780 & 1.2437 & NA & NA & & \\
\hline $\mathrm{ThO}_{2}$ & 0.9472 & 1.4250 & NA & NA & $\mathrm{R}^{2}$ Validation $\left(\mathrm{R}_{\mathrm{V}}^{2}\right)$ & 0.611 \\
\hline $\mathrm{UO}_{3}$ & -8.9335 & 2.1257 & NA & NA & RMSE Validation $\left(\mathrm{RMSE}_{\mathrm{V}}\right)$ & 0.769 \\
\hline $\mathrm{ZnO}$ & -12.4629 & 3.0251 & NA & NA & & \\
\hline $\mathrm{ZrO}_{2}$ & -11.7027 & 1.4941 & NA & NA & & \\
\hline Others $^{(\mathrm{e})}$ & 1.7236 & 1.2977 & NA & NA & & \\
\hline$\left(\mathrm{Al}_{2} \mathrm{O}_{3}\right)^{2}$ & 159.2293 & 26.2788 & 6.06 & $<0.0001$ & & \\
\hline $\mathrm{UO}_{3} \times \mathrm{ZnO}$ & 427.8549 & 93.8998 & 4.56 & $<0.0001$ & & \\
\hline $\mathrm{Fe}_{2} \mathrm{O}_{3} \times \mathrm{Li}_{2} \mathrm{O}$ & 153.3909 & 38.3031 & 4.00 & 0.0001 & & \\
\hline $\mathrm{SrO} \times \mathrm{ZrO}_{2}$ & 73.0947 & 22.6465 & 3.23 & 0.0014 & & \\
\hline $\mathrm{Al}_{2} \mathrm{O}_{3} \times \mathrm{ZrO}_{2}$ & 72.7130 & 23.0100 & 3.16 & 0.0018 & & \\
\hline Bias Correction $^{(\mathrm{f})}$ & 0.3539 & 0.0543 & 6.52 & $<0.0001$ & & \\
\hline
\end{tabular}

(a) Model results and summary statistics were generated using PCT-Li normalized releases calculated to many decimal places. Rounded versions of these PCT-Li values are given in Table 5.3. Conducting modeling with the rounded versions of the PCT-Li normalized releases may result in slightly different model results and summary statistics.

(b) The model evaluation statistics are defined in Section C.3 of Appendix C. Model validation statistics are defined in Section C.5 of Appendix C.

(c) NA denotes that it is not applicable to perform a statistical t-test on linear terms in a mixture model (see Section C.5.1).

(d) The 480 separate HLW glass compositions with PCT-Li data for validation (mostly extrapolative) of PCT-Li models are discussed in Section 5.1.4.

(e) For the 18-term partial quadratic mixture model, the "Others" component includes $\mathrm{Ag}_{2} \mathrm{O}, \mathrm{As}_{2} \mathrm{O}_{5}, \mathrm{BaO}, \mathrm{BeO}, \mathrm{Bi}_{2} \mathrm{O}_{3}, \mathrm{Ce}_{2} \mathrm{O}_{3}$, $\mathrm{Cl}, \mathrm{CoO}, \mathrm{Cs}_{2} \mathrm{O}, \mathrm{CuO}, \mathrm{Dy}_{2} \mathrm{O}, \mathrm{Eu}_{2} \mathrm{O}, \mathrm{F}, \mathrm{Gd}_{2} \mathrm{O}_{3}, \mathrm{HfO}_{2}, \mathrm{HgO}, \mathrm{MoO}_{3}, \mathrm{Nd}_{2} \mathrm{O}_{3}, \mathrm{P}_{2} \mathrm{O}_{5}, \mathrm{PdO}, \mathrm{Pr}_{2} \mathrm{O}_{3}, \mathrm{Rb}_{2} \mathrm{O}, \mathrm{Re}_{2} \mathrm{O}_{7}, \mathrm{Rh}_{2} \mathrm{O}_{3}, \mathrm{RuO}_{2}$, $\mathrm{SO}_{3}, \mathrm{Sm}_{2} \mathrm{O}_{3}, \mathrm{SnO}_{2}, \mathrm{Tc}_{2} \mathrm{O}_{7}, \mathrm{TeO}_{2}, \mathrm{~V}_{2} \mathrm{O}_{5}, \mathrm{WO}_{3}, \mathrm{Y}_{2} \mathrm{O}_{3}, \mathrm{CaO}, \mathrm{CdO}, \mathrm{Cr}_{2} \mathrm{O}_{3}, \mathrm{~K} 2 \mathrm{O}, \mathrm{La}_{2} \mathrm{O}_{3}, \mathrm{MgO}, \mathrm{NiO}, \mathrm{PbO}, \mathrm{Sb}_{2} \mathrm{O}_{3}, \mathrm{SeO}_{2}, \mathrm{TiO}_{2}$, and $\mathrm{Tl}_{2} \mathrm{O}$.

(f) The bias correction is a constant adjustment applied to glasses with predicted PCT-Li releases $>0.5 \ln (\mathrm{g} / \mathrm{L})$. See Equation (5.9) in Section 5.7. 
Table 5.22. Coefficients and Performance Summary for the Second-Choice 16-Term Model (15-Term Partial Quadratic Mixture Model with Bias Correction) for the Natural Logarithm of PCT-Li for HLW Glasses. ${ }^{\text {(a) }}$

\begin{tabular}{|c|c|c|c|c|c|c|}
\hline $\begin{array}{l}\ln (\text { PCT-Li) } \\
\text { Model Term }\end{array}$ & $\begin{array}{c}\text { Coefficient } \\
\text { Estimate }\end{array}$ & $\begin{array}{c}\text { Coefficient } \\
\text { Standard } \\
\text { Deviation } \\
\end{array}$ & $\begin{array}{l}\text { t-value }= \\
\text { Coeff } / \text { SD }\end{array}$ & p-value & $\begin{array}{l}\text { Modeling Data Statistic, } \\
250 \text { Glasses }^{(b)}\end{array}$ & Value \\
\hline $\mathrm{Al}_{2} \mathrm{O}_{3}$ & \begin{tabular}{|l|}
-38.0163 \\
\end{tabular} & 3.8317 & $\mathrm{NA}^{(\mathrm{c})}$ & NA & $\mathrm{R}^{2}$ & 0.730 \\
\hline $\mathrm{B}_{2} \mathrm{O}_{3}$ & 5.9631 & 0.8037 & NA & NA & RMSE & 0.342 \\
\hline $\mathrm{Fe}_{2} \mathrm{O}_{3}$ & -1.9839 & 0.8152 & NA & NA & Model LOF p-value & $<0.0001$ \\
\hline $\mathrm{Li}_{2} \mathrm{O}$ & 21.9008 & 1.7551 & NA & NA & & \\
\hline $\mathrm{MnO}$ & 5.7451 & 1.1795 & NA & NA & & \\
\hline $\mathrm{Na}_{2} \mathrm{O}$ & 10.2496 & 0.7080 & NA & NA & & \\
\hline $\mathrm{SiO}_{2}$ & -1.8115 & 0.3577 & NA & NA & \multirow{2}{*}{$\begin{array}{l}\text { Separate (Extrapolative) Validation } \\
\text { Statistic, } 480 \text { Outlying Glasses }{ }^{(\mathbf{b}, \mathbf{d})}\end{array}$} & \multirow[b]{2}{*}{ Value } \\
\hline $\mathrm{SrO}$ & -0.0293 & 0.9633 & NA & NA & & \\
\hline $\mathrm{ThO}_{2}$ & -0.6263 & 1.5081 & NA & NA & $\mathrm{R}^{2}$ Validation $\left(\mathrm{R}_{\mathrm{V}}^{2}\right)$ & 0.639 \\
\hline $\mathrm{UO}_{3}$ & -1.8175 & 1.4379 & NA & NA & RMSE Validation $\left(\mathrm{RMSE}_{\mathrm{V}}\right)$ & 0.742 \\
\hline $\mathrm{ZnO}$ & -4.3848 & 2.5067 & NA & NA & & \\
\hline $\mathrm{ZrO}_{2}$ & -11.9532 & 1.5885 & NA & NA & & \\
\hline Others $^{(\mathrm{e})}$ & 1.9026 & 1.3741 & NA & NA & & \\
\hline$\left(\mathrm{Al}_{2} \mathrm{O}_{3}\right)^{2}$ & 156.5080 & 28.0674 & 5.58 & $<0.0001$ & & \\
\hline $\mathrm{Al}_{2} \mathrm{O}_{3} \times \mathrm{ZrO}_{2}$ & 90.1825 & 24.3619 & 3.70 & 0.0003 & & \\
\hline Bias Correction $^{(\mathrm{f})}$ & 0.4351 & 0.0535 & 8.13 & $<0.0001$ & & \\
\hline
\end{tabular}

(a) Model results and summary statistics were generated using PCT-Li normalized releases calculated to many decimal places. Rounded versions of these PCT-Li values are given in Table 5.3. Conducting modeling with the rounded versions of the PCT-Li normalized releases may result in slightly different model results and summary statistics.

(b) The model evaluation statistics are defined in Section C.3 of Appendix C. Model validation statistics are defined in Section C.5 of Appendix C.

(c) NA denotes that it is not applicable to perform a statistical t-test on linear terms in a mixture model (see Section C.5.1).

(d) The 480 separate HLW glass compositions with PCT-Li data for validation (mostly extrapolative) of PCT-Li models are discussed in Section 5.1.4.

(e) For the 15-term partial quadratic mixture model, the "Others" component includes $\mathrm{Ag}_{2} \mathrm{O}, \mathrm{As}_{2} \mathrm{O}_{5}, \mathrm{BaO}_{2} \mathrm{BeO}_{2} \mathrm{Bi}_{2} \mathrm{O}_{3}, \mathrm{Ce}_{2} \mathrm{O}_{3}$, $\mathrm{Cl}, \mathrm{CoO}, \mathrm{Cs}_{2} \mathrm{O}, \mathrm{CuO}, \mathrm{Dy}_{2} \mathrm{O}, \mathrm{Eu}_{2} \mathrm{O}, \mathrm{F}, \mathrm{Gd}_{2} \mathrm{O}_{3}, \mathrm{HfO}_{2}, \mathrm{HgO}, \mathrm{MoO}_{3}, \mathrm{Nd}_{2} \mathrm{O}_{3}, \mathrm{P}_{2} \mathrm{O}_{5}, \mathrm{PdO}, \mathrm{Pr}_{2} \mathrm{O}_{3}, \mathrm{Rb}_{2} \mathrm{O}, \mathrm{Re}_{2} \mathrm{O}_{7}, \mathrm{Rh}_{2} \mathrm{O}_{3}, \mathrm{RuO}_{2}$, $\mathrm{SO}_{3}, \mathrm{Sm}_{2} \mathrm{O}_{3}, \mathrm{SnO}_{2}, \mathrm{Tc}_{2} \mathrm{O}_{7}, \mathrm{TeO}_{2}, \mathrm{~V}_{2} \mathrm{O}_{5}, \mathrm{WO}_{3}, \mathrm{Y}_{2} \mathrm{O}_{3}, \mathrm{CaO}, \mathrm{CdO}, \mathrm{Cr}_{2} \mathrm{O}_{3}, \mathrm{~K}_{2} \mathrm{O}, \mathrm{La}_{2} \mathrm{O}_{3}, \mathrm{MgO}, \mathrm{NiO}, \mathrm{PbO}, \mathrm{Sb}_{2} \mathrm{O}_{3}, \mathrm{SeO}_{2}, \mathrm{TiO}_{2}$, and $\mathrm{Tl}_{2} \mathrm{O}$.

(f) The bias correction is a constant adjustment applied to glasses with predicted PCT-Li releases $>0.5 \ln (\mathrm{g} / \mathrm{L})$. See Equation (5.9) in Section 5.7. 
Table 5.23. Coefficients and Performance Summary for the Recommended 19-Term Model (18-Term Partial Quadratic Mixture Model with Bias Correction) for the Natural Logarithm of PCT-Na for HLW Glasses. ${ }^{(a)}$

\begin{tabular}{|c|c|c|c|c|c|c|}
\hline $\begin{array}{l}\text { In(PCT-Na) } \\
\text { Model Term }\end{array}$ & $\begin{array}{c}\text { Coefficient } \\
\text { Estimate }\end{array}$ & $\begin{array}{c}\text { Coefficient } \\
\text { Standard } \\
\text { Deviation }\end{array}$ & $\begin{array}{l}\text { t-value }= \\
\text { Coeff } / \text { SD }\end{array}$ & p-value & $\begin{array}{l}\text { Modeling Data Statistic, }^{266 \text { Glasses }^{(\mathbf{b})}}\end{array}$ & Value \\
\hline $\mathrm{Al}_{2} \mathrm{O}_{3}$ & -46.8613 & 3.0497 & $\mathrm{NA}^{(\mathrm{c})}$ & NA & $\mathrm{R}^{2}$ & 0.872 \\
\hline $\mathrm{B}_{2} \mathrm{O}_{3}$ & 3.1358 & 0.6464 & NA & NA & RMSE & 0.301 \\
\hline $\mathrm{Fe}_{2} \mathrm{O}_{3}$ & -4.4268 & 0.9741 & NA & NA & Model LOF p-value & $<0.0001$ \\
\hline $\mathrm{Li}_{2} \mathrm{O}$ & 11.2111 & 2.5782 & NA & NA & & \\
\hline $\mathrm{MnO}$ & 4.4626 & 0.9152 & NA & NA & & \\
\hline $\mathrm{Na}_{2} \mathrm{O}$ & 17.7654 & 0.6496 & NA & NA & & \\
\hline $\mathrm{SiO}_{2}$ & -2.2193 & 0.4341 & NA & NA & \begin{tabular}{|l|} 
Separate (Extrapolative) Validation \\
\end{tabular} & \\
\hline $\mathrm{SrO}$ & 2.0646 & 0.7611 & NA & NA & Statistic, 554 Outlying Glasses ${ }^{(\mathrm{b}, \mathrm{d})}$ & Value \\
\hline $\mathrm{ThO}_{2}$ & 0.9885 & 1.1863 & NA & NA & $\mathrm{R}^{2}$ Validation $\left(\mathrm{R}_{\mathrm{v}}^{2}\right)$ & 0.540 \\
\hline $\mathrm{UO}_{3}$ & 20.9346 & 6.9809 & NA & NA & RMSE Validation $\left(\mathrm{RMSE}_{\mathrm{V}}\right)$ & 0.849 \\
\hline $\mathrm{ZnO}$ & 44.6454 & 12.7840 & NA & NA & & \\
\hline $\mathrm{ZrO}_{2}$ & -17.1359 & 1.2146 & NA & NA & & \\
\hline Others $^{(e)}$ & 2.1508 & 1.0981 & NA & NA & & \\
\hline$\left(\mathrm{Al}_{2} \mathrm{O}_{3}\right)^{2}$ & 190.5345 & 21.6255 & 8.81 & $<0.0001$ & & \\
\hline $\mathrm{Al}_{2} \mathrm{O}_{3} * \mathrm{ZrO}_{2}$ & 163.4298 & 18.4861 & 8.84 & $<0.0001$ & & \\
\hline $\mathrm{Fe}_{2} \mathrm{O}_{3} * \mathrm{Li}_{2} \mathrm{O}$ & 108.0349 & 26.4100 & 4.09 & 0.0001 & & \\
\hline $\mathrm{SiO}_{2} * \mathrm{ZnO}$ & -102.2282 & 31.2527 & -3.27 & 0.0012 & & \\
\hline $\mathrm{SiO}_{2} * \mathrm{UO}_{3}$ & \begin{tabular}{|l|}
-53.6409 \\
\end{tabular} & 17.2447 & -3.11 & 0.0021 & & \\
\hline Bias Correction $^{(t)}$ & 0.2922 & 0.0832 & 3.51 & 0.0029 & & \\
\hline
\end{tabular}

(a) Model results and summary statistics were generated using PCT-Na normalized releases calculated to many decimal places. Rounded versions of these PCT-Na values are given in Table 5.3. Conducting modeling with the rounded versions of the PCT-Na normalized releases may result in slightly different model results and summary statistics.

(b) The model evaluation statistics are defined in Section C.3 of Appendix C. Model validation statistics are defined in Section C.5 of Appendix C.

(c) NA denotes that it is not applicable to perform a statistical t-test on linear terms in a mixture model (see Section C.5.1).

(d) The 554 separate HLW glass compositions with PCT-Na data for validation (mostly extrapolative) of PCT-Na models are discussed in Section 5.1.4.

(e) For the 18-term partial quadratic mixture model, the "Others" component includes $\mathrm{Ag}_{2} \mathrm{O}, \mathrm{As}_{2} \mathrm{O}_{5}, \mathrm{BaO}, \mathrm{BeO}, \mathrm{Bi}_{2} \mathrm{O}_{3}, \mathrm{Ce}_{2} \mathrm{O}_{3}$, $\mathrm{Cl}, \mathrm{CoO}, \mathrm{Cs}_{2} \mathrm{O}, \mathrm{CuO}, \mathrm{Dy}_{2} \mathrm{O}, \mathrm{Eu}_{2} \mathrm{O}, \mathrm{F}, \mathrm{Gd}_{2} \mathrm{O}_{3}, \mathrm{HfO}_{2}, \mathrm{HgO}, \mathrm{MoO}_{3}, \mathrm{Nd}_{2} \mathrm{O}_{3}, \mathrm{P}_{2} \mathrm{O}_{5}, \mathrm{PdO}, \mathrm{Pr}_{2} \mathrm{O}_{3}, \mathrm{Rb}_{2} \mathrm{O}, \mathrm{Re}_{2} \mathrm{O}_{7}, \mathrm{Rh}_{2} \mathrm{O}_{3}, \mathrm{RuO}_{2}$, $\mathrm{SO}_{3}, \mathrm{Sm}_{2} \mathrm{O}_{3}, \mathrm{SnO}_{2}, \mathrm{Tc}_{2} \mathrm{O}_{7}, \mathrm{TeO}_{2}, \mathrm{~V}_{2} \mathrm{O}_{5}, \mathrm{WO}_{3}, \mathrm{Y}_{2} \mathrm{O}_{3}, \mathrm{CaO}, \mathrm{CdO}, \mathrm{Cr}_{2} \mathrm{O}_{3}, \mathrm{~K} 2 \mathrm{O}, \mathrm{La}_{2} \mathrm{O}_{3}, \mathrm{MgO}, \mathrm{NiO}, \mathrm{PbO}, \mathrm{Sb}_{2} \mathrm{O}_{3}, \mathrm{SeO}_{2}, \mathrm{TiO}_{2}$, and $\mathrm{Tl}_{2} \mathrm{O}$.

(f) The bias correction is a constant adjustment applied to glasses with predicted PCT-Na releases $>1.0 \ln (\mathrm{g} / \mathrm{L})$. See Equation (5.9) in Section 5.7. 
Table 5.24. Coefficients and Performance Summary for the Second-Choice 16-Term Model (15-Term Partial Quadratic Mixture Model with Bias Correction) for the Natural Logarithm of PCT-Na for HLW Glasses. ${ }^{\text {(a) }}$

\begin{tabular}{|c|c|c|c|c|c|c|}
\hline $\begin{array}{l}\ln (\mathrm{PCT}-\mathrm{Na}) \\
\text { Model Term }\end{array}$ & $\begin{array}{c}\text { Coefficient } \\
\text { Estimate }\end{array}$ & $\begin{array}{c}\text { Coefficient } \\
\text { Standard } \\
\text { Deviation }\end{array}$ & $\begin{array}{l}\text { t-value }= \\
\text { Coeff } / \text { SD }\end{array}$ & p-value & $\begin{array}{l}\text { Modeling Data Statistic, } \\
266 \text { Glasses }^{(b)}\end{array}$ & Value \\
\hline $\mathrm{Al}_{2} \mathrm{O}_{3}$ & -44.5238 & 3.2385 & $\mathrm{NA}^{(\mathrm{c})}$ & NA & $\mathrm{R}^{2}$ & 0.855 \\
\hline $\mathrm{B}_{2} \mathrm{O}_{3}$ & 2.9278 & 0.6572 & NA & NA & RMSE & 0.319 \\
\hline $\mathrm{Fe}_{2} \mathrm{O}_{3}$ & -0.3650 & 0.6590 & NA & NA & Model LOF p-value & $<0.0001$ \\
\hline $\mathrm{Li}_{2} \mathrm{O}$ & 20.9716 & 1.4648 & NA & NA & & \\
\hline $\mathrm{MnO}$ & 4.9605 & 0.9371 & NA & NA & & \\
\hline $\mathrm{Na}_{2} \mathrm{O}$ & 18.5924 & 0.5950 & NA & NA & & \\
\hline $\mathrm{SiO}_{2}$ & -3.8134 & 0.3069 & NA & NA & \multirow{2}{*}{$\begin{array}{l}\text { Separate (Extrapolative) Validation } \\
\text { Statistic, } 554 \text { Outlying Glasses }{ }^{(\mathbf{b}, \mathbf{d})}\end{array}$} & \multirow[b]{2}{*}{ Value } \\
\hline $\mathrm{SrO}$ & 2.7073 & 0.7580 & NA & NA & & \\
\hline $\mathrm{ThO}_{2}$ & 1.1371 & 1.1941 & NA & NA & $\mathrm{R}^{2}$ Validation $\left(\mathrm{R}_{\mathrm{V}}^{2}\right)$ & 0.464 \\
\hline $\mathrm{UO}_{3}$ & -0.7211 & 1.1579 & NA & NA & RMSE Validation $\left(\mathrm{RMSE}_{\mathrm{V}}\right)$ & 0.916 \\
\hline $\mathrm{ZnO}$ & 1.9636 & 1.9637 & NA & NA & & \\
\hline $\mathrm{ZrO}_{2}$ & -15.9279 & 1.2746 & NA & NA & & \\
\hline Others $^{(\mathrm{e})}$ & 3.5994 & 1.1302 & NA & NA & & \\
\hline$\left(\mathrm{Al}_{2} \mathrm{O}_{3}\right)^{2}$ & 182.8104 & 23.1059 & 7.91 & $<0.0001$ & & \\
\hline $\mathrm{Al}_{2} \mathrm{O}_{3} * \mathrm{ZrO}_{2}$ & 147.9383 & 19.6106 & 7.54 & $<0.0001$ & & \\
\hline Bias Correction $^{(\mathrm{f})}$ & 0.3596 & 0.0831 & 4.33 & 0.0005 & & \\
\hline
\end{tabular}

(a) Model results and summary statistics were generated using PCT-Na normalized releases calculated to many decimal places. Rounded versions of these PCT-Na values are given in Table 5.3. Conducting modeling with the rounded versions of the PCT-Na normalized releases may result in slightly different model results and summary statistics.

(b) The model evaluation statistics are defined in Section C.3 of Appendix C. Model validation statistics are defined in Section C.5 of Appendix C.

(c) NA denotes that it is not applicable to perform a statistical t-test on linear terms in a mixture model (see Section C.5.1).

(d) The 554 separate HLW glass compositions with PCT-Na data for validation (mostly extrapolative) of PCT-Na models are discussed in Section 5.1.4.

(e) For the 15-term partial quadratic mixture model, the "Others" component includes $\mathrm{Ag}_{2} \mathrm{O}, \mathrm{As}_{2} \mathrm{O}_{5}, \mathrm{BaO}, \mathrm{BeO}_{2} \mathrm{Bi}_{2} \mathrm{O}_{3}, \mathrm{Ce}_{2} \mathrm{O}_{3}$, $\mathrm{Cl}, \mathrm{CoO}, \mathrm{Cs}_{2} \mathrm{O}, \mathrm{CuO}, \mathrm{Dy}_{2} \mathrm{O}, \mathrm{Eu}_{2} \mathrm{O}, \mathrm{F}, \mathrm{Gd}_{2} \mathrm{O}_{3}, \mathrm{HfO}_{2}, \mathrm{HgO}, \mathrm{MoO}_{3}, \mathrm{Nd}_{2} \mathrm{O}_{3}, \mathrm{P}_{2} \mathrm{O}_{5}, \mathrm{PdO}, \mathrm{Pr}_{2} \mathrm{O}_{3}, \mathrm{Rb}_{2} \mathrm{O}, \mathrm{Re}_{2} \mathrm{O}_{7}, \mathrm{Rh}_{2} \mathrm{O}_{3}, \mathrm{RuO}_{2}$, $\mathrm{SO}_{3}, \mathrm{Sm}_{2} \mathrm{O}_{3}, \mathrm{SnO}_{2}, \mathrm{Tc}_{2} \mathrm{O}_{7}, \mathrm{TeO}_{2}, \mathrm{~V}_{2} \mathrm{O}_{5}, \mathrm{WO}_{3}, \mathrm{Y}_{2} \mathrm{O}_{3}, \mathrm{CaO}, \mathrm{CdO}, \mathrm{Cr}_{2} \mathrm{O}_{3}, \mathrm{~K} 2 \mathrm{O}, \mathrm{La}_{2} \mathrm{O}_{3}, \mathrm{MgO}, \mathrm{NiO}, \mathrm{PbO}, \mathrm{Sb}_{2} \mathrm{O}_{3}, \mathrm{SeO}_{2}, \mathrm{TiO}_{2}$, and $\mathrm{Tl}_{2} \mathrm{O}$.

(f) The bias correction is a constant adjustment applied to glasses with predicted PCT-Na releases $>1.0 \ln (\mathrm{g} / \mathrm{L})$. See Equation (5.9) in Section 5.7. 
Table 5.25. Fit and Validation Statistics for Recommended and Second-Choice Models Without and With Bias-Correction for PCT-B, PCT-Li, and PCT-Na Releases from HLW Glasses.

\begin{tabular}{|c|c|c|c|c|c|c|c|c|c|c|c|c|}
\hline \multirow[b]{2}{*}{ Model } & \multicolumn{4}{|c|}{ PCT-B } & \multicolumn{4}{|c|}{ PCT-Li } & \multicolumn{4}{|c|}{ PCT-Na } \\
\hline & PQM & $\begin{array}{l}\text { PQM } \\
+ \text { BC }\end{array}$ & PQM & $\begin{array}{l}\text { PQM } \\
+ \text { BC }\end{array}$ & PQM & $\begin{array}{l}\text { PQM } \\
+ \text { BC }\end{array}$ & PQM & $\begin{array}{l}\text { PQM } \\
+ \text { BC }\end{array}$ & PQM & $\begin{array}{l}\text { PQM } \\
+ \text { BC }\end{array}$ & PQM & $\begin{array}{l}\text { PQM } \\
+ \text { BC }\end{array}$ \\
\hline \# Terms & 18 & 19 & 15 & 16 & 18 & 19 & 15 & 16 & 18 & 19 & 15 & 16 \\
\hline \multicolumn{13}{|c|}{ Modeling Results } \\
\hline \# Glasses & \multicolumn{4}{|c|}{264 Glasses } & \multicolumn{4}{|c|}{250 Glasses } & \multicolumn{4}{|c|}{266 Glasses } \\
\hline $\mathrm{R}^{2}$ & 0.788 & 0.790 & 0.753 & 0.749 & 0.742 & 0.763 & 0.695 & 0.731 & 0.873 & 0.872 & 0.852 & 0.855 \\
\hline RMSE & 0.422 & 0.420 & 0.453 & 0.457 & 0.336 & 0.323 & 0.363 & 0.342 & 0.300 & 0.301 & 0.321 & 0.319 \\
\hline LOF $p$ & 0.014 & 0.014 & 0.004 & 0.003 & $<0.0001$ & $<0.0001$ & $<0.0001$ & $<0.0001$ & $<0.0001$ & $<0.0001$ & $<0.0001$ & $<0.0001$ \\
\hline \multicolumn{13}{|c|}{ Separate Validation Set, Mostly Extrapolations } \\
\hline \# Glasses & \multicolumn{4}{|c|}{556 Glasses } & \multicolumn{4}{|c|}{480 Glasses } & \multicolumn{4}{|c|}{554 Glasses } \\
\hline $\mathrm{R}_{\mathrm{V}}^{2}$ & 0.623 & 0.624 & 0.597 & 0.636 & 0.543 & 0.611 & 0.557 & 0.639 & 0.516 & 0.540 & 0.445 & 0.464 \\
\hline $\mathrm{RMSE}_{\mathrm{V}}$ & 0.832 & 0.831 & 0.860 & 0.818 & 0.834 & 0.769 & 0.821 & 0.742 & 0.870 & 0.849 & 0.932 & 0.916 \\
\hline
\end{tabular}


Table 5.26. HLW03-06 Composition in Formats Needed to Illustrate the Use of PCT Models for HLW Glasses.

\begin{tabular}{|c|c|c|c|c|c|c|}
\hline $\begin{array}{c}\text { Model } \\
\text { Term }\end{array}$ & $\begin{array}{c}\text { HLW03-06 } \\
\text { 25-Component } \\
\text { Composition }^{(a)} \\
\text { (mass fractions) }\end{array}$ & $\begin{array}{c}\text { HLW03-06 } \\
\text { 13-Component } \\
\text { Composition } \\
\text { (mass fractions) }\end{array}$ & $\begin{array}{c}\text { HLW03-06 } \\
\text { Composition } \\
\text { for 19-Term } \\
\text { PCT-B Model } \\
\text { (mass } \\
\text { fractions) } \\
\end{array}$ & $\begin{array}{c}\text { HLW03-06 } \\
\text { Composition } \\
\text { for 19-Term } \\
\text { PCT-Li Model } \\
\text { (mass } \\
\text { fractions) } \\
\end{array}$ & \begin{tabular}{|c|} 
HLW03-06 \\
Composition \\
for 19-Term \\
PCT-Na Model \\
(mass \\
fractions) \\
\end{tabular} & $\begin{array}{c}\text { HLW03-06 } \\
\text { Composition } \\
\text { for 16-Term } \\
\text { PCT Models } \\
\text { (mass } \\
\text { fractions) } \\
\end{array}$ \\
\hline $\mathrm{Al}_{2} \mathrm{O}_{3}$ & 0.08344 & 0.08344 & 0.08344 & 0.08344 & 0.08344 & 0.08344 \\
\hline $\mathrm{B}_{2} \mathrm{O}_{3}$ & 0.04908 & 0.04908 & 0.04908 & 0.04908 & 0.04908 & 0.04908 \\
\hline $\mathrm{CaO}$ & 0.00500 & NA & NA & NA & NA & NA \\
\hline $\mathrm{CdO}$ & 0.01600 & NA & NA & NA & NA & NA \\
\hline $\mathrm{Cr}_{2} \mathrm{O}_{3}$ & 0.00491 & NA & NA & NA & NA & NA \\
\hline $\mathrm{Fe}_{2} \mathrm{O}_{3}$ & 0.01963 & 0.01963 & 0.01963 & 0.01963 & 0.01963 & 0.01963 \\
\hline $\mathrm{K}_{2} \mathrm{O}$ & 0.00060 & NA & NA & NA & NA & NA \\
\hline $\mathrm{La}_{2} \mathrm{O}_{3}$ & 0.00300 & NA & NA & NA & NA & NA \\
\hline $\mathrm{Li}_{2} \mathrm{O}$ & 0.05890 & 0.05890 & 0.05890 & 0.05890 & 0.05890 & 0.05890 \\
\hline $\mathrm{MgO}$ & 0.00120 & NA & NA & NA & NA & NA \\
\hline $\mathrm{MnO}$ & 0.06872 & 0.06872 & 0.06872 & 0.06872 & 0.06872 & 0.06872 \\
\hline $\mathrm{Na}_{2} \mathrm{O}$ & 0.03927 & 0.03927 & 0.03927 & 0.03927 & 0.03927 & 0.03927 \\
\hline $\mathrm{NiO}$ & 0.00982 & NA & NA & NA & NA & NA \\
\hline $\mathrm{PbO}$ & 0.00040 & NA & NA & NA & NA & NA \\
\hline $\mathrm{Sb}_{2} \mathrm{O}_{3}$ & 0.00020 & NA & NA & NA & NA & NA \\
\hline $\mathrm{SeO}_{2}$ & 0.00020 & NA & NA & NA & NA & NA \\
\hline $\mathrm{SiO}_{2}$ & 0.52031 & 0.52031 & 0.52031 & 0.52031 & 0.52031 & 0.52031 \\
\hline $\mathrm{SrO}$ & 0.05091 & 0.05091 & 0.05091 & 0.05091 & 0.05091 & 0.05091 \\
\hline $\mathrm{ThO}_{2}$ & 0.01416 & 0.01416 & 0.01416 & 0.01416 & 0.01416 & 0.01416 \\
\hline $\mathrm{TiO}_{2}$ & 0.00030 & NA & NA & NA & NA & NA \\
\hline $\mathrm{Tl}_{2} \mathrm{O}$ & 0.00019 & NA & NA & NA & NA & NA \\
\hline $\mathrm{UO}_{3}$ & 0.00000 & 0.00000 & 0.00000 & 0.00000 & 0.00000 & 0.00000 \\
\hline $\mathrm{ZnO}$ & 0.00000 & 0.00000 & 0.00000 & 0.00000 & 0.00000 & 0.00000 \\
\hline $\mathrm{ZrO}_{2}$ & 0.04095 & 0.04095 & 0.04095 & 0.04095 & 0.04095 & 0.04095 \\
\hline Others & 0.01281 & 0.05463 & 0.05463 & 0.05463 & 0.05463 & 0.05463 \\
\hline$\left(\mathrm{Al}_{2} \mathrm{O}_{3}\right)^{2}$ & NA & NA & 0.0069622 & 0.0069622 & 0.0069622 & 0.0069622 \\
\hline $\mathrm{UO}_{3} \times \mathrm{ZnO}$ & NA & NA & 0.0000000 & 0.0000000 & NA & NA \\
\hline$(\mathrm{MnO})^{2}$ & NA & NA & 0.0047224 & NA & NA & NA \\
\hline $\mathrm{Fe}_{2} \mathrm{O}_{3} \times \mathrm{ZnO}$ & NA & NA & 0.0000000 & NA & NA & NA \\
\hline $\mathrm{Al}_{2} \mathrm{O}_{3} \times \mathrm{ZrO}_{2}$ & NA & NA & 0.0034169 & 0.0034169 & 0.0034169 & 0.0034169 \\
\hline $\mathrm{Fe}_{2} \mathrm{O}_{3} \times \mathrm{Li}_{2} \mathrm{O}$ & NA & NA & NA & 0.0011562 & 0.0011562 & NA \\
\hline $\mathrm{SrO} \times \mathrm{ZrO}_{2}$ & NA & NA & NA & 0.0020848 & NA & NA \\
\hline $\mathrm{SiO}_{2} \times \mathrm{ZnO}$ & NA & NA & NA & NA & 0.0000000 & NA \\
\hline $\mathrm{SiO}_{2} \times \mathrm{UO}_{3}$ & NA & NA & NA & NA & 0.0000000 & NA \\
\hline $\mathrm{BC}^{(\mathrm{c})}$ & (d) & (d) & (d) & (d) & (d) & (d) \\
\hline
\end{tabular}

(a) The composition in mass fractions is from Table 5.2.

(b) NA indicates that a term is not included in a specific PCT model.

(c) Bias-correction.

(d) The bias-correction term does not depend on glass composition. 
Table 5.27. HLW06-15 Composition in Formats Needed to Illustrate the Use of PCT Models for HLW Glasses.

\begin{tabular}{|c|c|c|c|c|c|c|}
\hline $\begin{array}{c}\text { Model } \\
\text { Term }\end{array}$ & $\begin{array}{c}\text { HLW06-15 } \\
\text { 25-Component } \\
\text { Composition }^{(a)} \\
\text { (mass fractions) }\end{array}$ & $\begin{array}{c}\text { HLW06-15 } \\
\text { 13-Component } \\
\text { Composition } \\
\text { (mass fractions) }\end{array}$ & $\begin{array}{c}\text { HLW06-15 } \\
\text { Composition } \\
\text { for 19-Term } \\
\text { PCT-B Model } \\
\text { (mass } \\
\text { fractions) }\end{array}$ & $\begin{array}{c}\text { HLW06-15 } \\
\text { Composition } \\
\text { for 19-Term } \\
\text { PCT-Li Model } \\
\text { (mass } \\
\text { fractions) } \\
\end{array}$ & \begin{tabular}{|c|} 
HLW06-15 \\
Composition \\
for 19-Term \\
PCT-Na Model \\
(mass \\
fractions) \\
\end{tabular} & $\begin{array}{c}\text { HLW06-15 } \\
\text { Composition } \\
\text { for 16-Term } \\
\text { PCT Models } \\
\text { (mass } \\
\text { fractions) }\end{array}$ \\
\hline $\mathrm{Al}_{2} \mathrm{O}_{3}$ & 0.08000 & 0.08000 & 0.08000 & 0.08000 & 0.08000 & 0.08000 \\
\hline $\mathrm{B}_{2} \mathrm{O}_{3}$ & 0.11000 & 0.11000 & 0.11000 & 0.11000 & 0.11000 & 0.11000 \\
\hline $\mathrm{CaO}$ & 0.00166 & NA & NA & NA & NA & NA \\
\hline $\mathrm{CdO}$ & 0.00235 & NA & NA & NA & NA & NA \\
\hline $\mathrm{Cr}_{2} \mathrm{O}_{3}$ & 0.00500 & NA & NA & NA & NA & NA \\
\hline $\mathrm{Fe}_{2} \mathrm{O}_{3}$ & 0.07000 & 0.07000 & 0.07000 & 0.07000 & 0.07000 & 0.07000 \\
\hline $\mathrm{K}_{2} \mathrm{O}$ & 0.00272 & NA & NA & NA & NA & NA \\
\hline $\mathrm{La}_{2} \mathrm{O}_{3}$ & 0.00176 & NA & NA & NA & NA & NA \\
\hline $\mathrm{Li}_{2} \mathrm{O}$ & 0.03000 & 0.03000 & 0.03000 & 0.03000 & 0.03000 & 0.03000 \\
\hline $\mathrm{MgO}$ & 0.00194 & NA & NA & NA & NA & NA \\
\hline $\mathrm{MnO}$ & 0.02910 & 0.02910 & 0.02910 & 0.02910 & 0.02910 & 0.02910 \\
\hline $\mathrm{Na}_{2} \mathrm{O}$ & 0.20000 & 0.20000 & 0.20000 & 0.20000 & 0.20000 & 0.20000 \\
\hline $\mathrm{NiO}$ & 0.01000 & NA & NA & NA & NA & NA \\
\hline $\mathrm{PbO}$ & 0.00151 & NA & NA & NA & NA & NA \\
\hline $\mathrm{Sb}_{2} \mathrm{O}_{3}$ & 0.00000 & NA & NA & NA & NA & NA \\
\hline $\mathrm{SeO}_{2}$ & 0.00000 & NA & NA & NA & NA & NA \\
\hline $\mathrm{SiO}_{2}$ & 0.35000 & 0.35000 & 0.35000 & 0.35000 & 0.35000 & 0.35000 \\
\hline $\mathrm{SrO}$ & 0.01470 & 0.01470 & 0.01470 & 0.01470 & 0.01470 & 0.01470 \\
\hline $\mathrm{ThO}_{2}$ & 0.00250 & 0.00250 & 0.00250 & 0.00250 & 0.00250 & 0.00250 \\
\hline $\mathrm{TiO}_{2}$ & 0.00166 & NA & NA & NA & NA & NA \\
\hline $\mathrm{Tl}_{2} \mathrm{O}$ & 0.00000 & NA & NA & NA & NA & NA \\
\hline $\mathrm{UO}_{3}$ & 0.00750 & 0.00750 & 0.00750 & 0.00750 & 0.00750 & 0.00750 \\
\hline $\mathrm{ZnO}$ & 0.01500 & 0.01500 & 0.01500 & 0.01500 & 0.01500 & 0.01500 \\
\hline $\mathrm{ZrO}_{2}$ & 0.04000 & 0.04000 & 0.04000 & 0.04000 & 0.04000 & 0.04000 \\
\hline Others & 0.02259 & 0.05120 & 0.05120 & 0.05120 & 0.05120 & 0.05120 \\
\hline$\left(\mathrm{Al}_{2} \mathrm{O}_{3}\right)^{2}$ & $\mathrm{NA}$ & NA & 0.0064000 & 0.0064000 & 0.0064000 & 0.0064000 \\
\hline $\mathrm{UO}_{3} \times \mathrm{ZnO}$ & NA & NA & 0.0001125 & 0.0001125 & NA & NA \\
\hline$(\mathrm{MnO})^{2}$ & $\mathrm{NA}$ & NA & 0.0008468 & NA & NA & NA \\
\hline $\mathrm{Fe}_{2} \mathrm{O}_{3} \times \mathrm{ZnO}$ & NA & NA & 0.0010500 & NA & NA & NA \\
\hline $\mathrm{Al}_{2} \mathrm{O}_{3} \times \mathrm{ZrO}_{2}$ & NA & NA & 0.0032000 & 0.0032000 & 0.0032000 & 0.0032000 \\
\hline $\mathrm{Fe}_{2} \mathrm{O}_{3} \times \mathrm{Li}_{2} \mathrm{O}$ & NA & NA & NA & 0.0021000 & 0.0021000 & NA \\
\hline $\mathrm{SrO} \times \mathrm{ZrO}_{2}$ & NA & NA & NA & 0.0005878 & NA & NA \\
\hline $\mathrm{SiO}_{2} \times \mathrm{ZnO}$ & NA & NA & NA & NA & 0.0052500 & NA \\
\hline $\mathrm{SiO}_{2} \times \mathrm{UO}_{3}$ & NA & NA & NA & NA & 0.0026250 & NA \\
\hline $\mathrm{BC}^{(\mathrm{c})}$ & (d) & (d) & (d) & (d) & (d) & (d) \\
\hline
\end{tabular}
(a) The composition in mass fractions is from Table 5.2.
(b) NA indicates that a term is not included in a specific PCT model.
(c) Bias-correction.
(d) The bias-correction term does not depend on glass composition. 
Table 5.28. Predicted PCT Releases and Corresponding 95\% UCIs and 95\% SUCIs for the HLW03-06 Composition Used in PCT Models for HLW Glasses.

\begin{tabular}{|c|c|c|c|c|c|c|c|c|}
\hline PCT Release & Model $^{(a)}$ & $\begin{array}{c}\text { Predicted } \\
\ln (\mathrm{PCT}) \\
{[\ln (\mathrm{g} / \mathrm{L})]} \\
\end{array}$ & $\begin{array}{c}\text { Predicted } \\
\text { PCT }^{(\mathbf{b})} \\
{[\mathrm{g} / \mathrm{L}]} \\
\end{array}$ & $\begin{array}{c}\text { SD of } \\
\text { Predicted } \\
\ln (\text { PCT })^{(\mathrm{c})} \\
{[\ln (\mathrm{g} / \mathrm{L})]} \\
\end{array}$ & $\begin{array}{c}90 \% \text { UCI } \\
\text { on Mean } \\
\ln (\mathrm{PCT}) \\
{[\ln (\mathrm{g} / \mathrm{L})]} \\
\end{array}$ & $\begin{array}{c}\text { 90\% UCI } \\
\text { on Median } \\
\text { PCT } \\
\text { [g/L] }\end{array}$ & $\begin{array}{c}90 \% \text { SUCI } \\
\text { on Mean } \\
\ln (\mathrm{PCT}) \\
{[\ln (\mathrm{g} / \mathrm{L})]} \\
\end{array}$ & $\begin{array}{c}\text { 90\% SUCI } \\
\text { on Median } \\
\text { PCT } \\
{[g / L]}\end{array}$ \\
\hline \multirow{3}{*}{ РCT-B } & $\begin{array}{l}\text { 13-Component Reduced } \\
\text { LM Model }\end{array}$ & $-1.3593^{(\mathrm{d})}$ & 0.257 & 0.1544 & -1.1609 & 0.313 & -0.7192 & 0.487 \\
\hline & $\begin{array}{l}\text { 18-Term PQM Model + } \\
\text { Bias-Correction Term }\end{array}$ & -0.9233 & 0.397 & 0.1653 & -0.7109 & 0.491 & -0.1294 & 0.879 \\
\hline & $\begin{array}{c}\text { 15-Term PQM Model + } \\
\text { Bias-Correction Term }\end{array}$ & -1.4985 & 0.223 & 0.1420 & -1.3161 & 0.268 & -0.8708 & 0.419 \\
\hline \multirow{3}{*}{ PCT-Li } & $\begin{array}{l}\text { 13-Component Reduced } \\
\text { LM Model }\end{array}$ & -0.6415 & 0.527 & 0.1332 & -0.4702 & 0.625 & -0.0889 & 0.915 \\
\hline & $\begin{array}{l}\text { 18-Term PQM Model + } \\
\text { Bias-Correction Term }\end{array}$ & -0.8988 & 0.407 & 0.1337 & -0.7270 & 0.483 & -0.2564 & 0.774 \\
\hline & $\begin{array}{l}\text { 15-Term PQM Model + } \\
\text { Bias-Correction Term }\end{array}$ & -0.7718 & 0.462 & 0.1250 & -0.6111 & 0.543 & -0.2188 & 0.804 \\
\hline \multirow{3}{*}{ PCT-Na } & $\begin{array}{l}\text { 13-Component Reduced } \\
\text { LM Model }\end{array}$ & -1.6400 & 0.194 & 0.1180 & -1.4884 & 0.226 & -1.1508 & 0.316 \\
\hline & $\begin{array}{l}\text { 18-Term PQM Model + } \\
\text { Bias-Correction Term }\end{array}$ & -1.7884 & 0.167 & 0.1274 & -1.6247 & 0.197 & -1.1764 & 0.308 \\
\hline & $\begin{array}{l}\text { 15-Term PQM Model + } \\
\text { Bias-Correction Term }\end{array}$ & -1.7799 & 0.169 & 0.1005 & -1.6508 & 0.192 & -1.3357 & 0.263 \\
\hline
\end{tabular}

(a) The three PCT-B models are given in Tables 5.6, 5.19, and 5.20. The three PCT-Li models are given in Tables 5.10, 5.21, and 5.22. The three PCT-Na models are given in Tables 5.14, 5.23, and 5.24. Note that $\mathrm{LM}=$ linear mixture and $\mathrm{PQM}=$ partial quadratic mixture. The bias-correction terms are not needed for HLW03-06.

(b) For comparison purposes, the measured releases (in g/L) for HLW03-06 are 0.301 for PCT-B, 0.378 for PCT-Li, and 0.164 for PCT-Na.

(c) The standard deviation is for the $\ln (\mathrm{PCT})$ prediction considered to be the mean of such values for the HLW03-06 glass.

(d) All calculations were performed using the HLW03-06 glass composition, model coefficients, and variance-covariance matrix values given in tables of this report. The calculated $\ln (\mathrm{g} / \mathrm{L})$ values were rounded to four decimal places in this table. The $\mathrm{g} / \mathrm{L}$ values were calculated by exponentiating the $\ln (\mathrm{g} / \mathrm{L})$ values before rounding, then rounding the resulting values to three decimal places in this table. 
Table 5.29. Predicted PCT Releases and Corresponding 95\% UCIs and 95\% SUCIs for the HLW06-15 Composition Used in PCT Models for HLW Glasses.

\begin{tabular}{|c|c|c|c|c|c|c|c|c|}
\hline PCT Release & Model $^{(\mathbf{a})}$ & $\begin{array}{c}\text { Predicted } \\
\ln (\mathrm{PCT}) \\
{[\ln (\mathrm{g} / \mathrm{L})]}\end{array}$ & $\begin{array}{c}\text { Predicted } \\
\text { PCT }^{(\mathbf{b})} \\
{[\mathrm{g} / \mathrm{L}]} \\
\end{array}$ & $\begin{array}{c}\text { SD of } \\
\text { Predicted } \\
\ln (\mathrm{PCT})^{(\mathrm{c})} \\
{[\ln (\mathrm{g} / \mathrm{L})]}\end{array}$ & $\begin{array}{l}90 \% \text { UCI } \\
\text { on Mean } \\
\ln (P C T) \\
{[\ln (g / L)]} \\
\end{array}$ & $\begin{array}{c}\text { 90\% UCI } \\
\text { on Median } \\
\text { PCT } \\
\text { [g/L] }\end{array}$ & $\begin{array}{c}90 \% \text { SUCI } \\
\text { on Mean } \\
\ln (\text { PCT }) \\
{[\ln (g / L)]} \\
\end{array}$ & $\begin{array}{c}\text { 90\% SUCI } \\
\text { on Median } \\
\text { PCT } \\
{[\mathrm{g} / \mathrm{L}]} \\
\end{array}$ \\
\hline \multirow{3}{*}{ PCT-B } & $\begin{array}{l}\text { 13-Component Reduced } \\
\text { LM Model }\end{array}$ & $1.3451^{(\mathrm{d})}$ & 3.838 & 0.0980 & 1.4710 & 4.354 & 1.7515 & 5.763 \\
\hline & $\begin{array}{l}\text { 18-Term PQM Model + } \\
\text { Bias-Correction Term }\end{array}$ & 1.4455 & 4.244 & 0.1115 & 1.5888 & 4.898 & 1.9944 & 7.348 \\
\hline & $\begin{array}{l}\text { 15-Term PQM Model + } \\
\text { Bias-Correction Term }\end{array}$ & 1.5797 & 4.854 & 0.1100 & 1.7210 & 5.590 & 2.0804 & 8.008 \\
\hline \multirow{3}{*}{ PCT-Li } & $\begin{array}{l}\text { 13-Component Reduced } \\
\text { LM Model }\end{array}$ & 0.6623 & 1.939 & 0.0819 & 0.7675 & 2.154 & 1.0018 & 2.723 \\
\hline & $\begin{array}{l}\text { 18-Term PQM Model + } \\
\text { Bias-Correction Term }\end{array}$ & 0.9269 & 2.527 & 0.0926 & 1.0459 & 2.846 & 1.3830 & 3.987 \\
\hline & $\begin{array}{l}\text { 15-Term PQM Model + } \\
\text { Bias-Correction Term }\end{array}$ & 0.9791 & 2.662 & 0.0966 & 1.1032 & 3.014 & 1.4189 & 4.133 \\
\hline \multirow{3}{*}{ PCT-Na } & $\begin{array}{l}\text { 13-Component Reduced } \\
\text { LM Model }\end{array}$ & 1.2740 & 3.575 & 0.0749 & 1.3702 & 3.936 & 1.5845 & 4.877 \\
\hline & $\begin{array}{l}\text { 18-Term PQM Model + } \\
\text { Bias-Correction Term }\end{array}$ & 1.3968 & 4.042 & 0.1057 & 1.5326 & 4.630 & 1.9171 & 6.801 \\
\hline & $\begin{array}{l}\text { 15-Term PQM Model + } \\
\text { Bias-Correction Term }\end{array}$ & 1.5088 & 4.521 & 0.1077 & 1.6471 & 5.192 & 1.9990 & 7.381 \\
\hline
\end{tabular}

(a) The three PCT-B models are given in Tables 5.6, 5.19, and 5.20. The three PCT-Li models are given in Tables 5.10, 5.21, and 5.22. The three PCT-Na models are given in Tables 5.14, 5.23, and 5.24. Note that LM = linear mixture and PQM = partial quadratic mixture. The bias-correction terms in the PQM models are needed for HLW06-15.

(b) For comparison purposes, the measured releases (in g/L) for HLW06-15 are 3.273 for PCT-B, 1.981 for PCT-Li, and 2.306 for PCT-Na.

(c) The standard deviation is for the $\ln (\mathrm{PCT})$ prediction considered to be the mean of such values for the HLW06-15 glass.

(d) All calculations were performed using the HLW06-15 glass composition, model coefficients, and variance-covariance matrix values given in tables of this report. The calculated $\ln (\mathrm{g} / \mathrm{L})$ values were rounded to four decimal places in this table. The $\mathrm{g} / \mathrm{L}$ values were calculated by exponentiating the $\ln (\mathrm{g} / \mathrm{L})$ values before rounding, then rounding the resulting values to three decimal places in this table. 
Table 6.1. Normalized 25-Component Compositions (mass fractions) of 168 HLW Glasses with Spinel as the Primary Crystalline Phase and Used in Spinel $\mathrm{T}_{1 \%}$ Modeling.

\begin{tabular}{|c|c|c|c|c|c|c|c|c|c|c|c|c|c|c|c|c|}
\hline Glass ID & $\underset{\text { ID }^{(\mathbf{a})}}{\text { Group }}$ & $\mathbf{A l}_{2} \mathbf{O}_{3}$ & $\mathrm{~B}_{2} \mathrm{O}_{3}$ & $\mathrm{CaO}$ & CdO & $\mathrm{Cr}_{2} \mathrm{O}_{3}$ & $\mathrm{Fe}_{2} \mathrm{O}_{3}$ & $\mathrm{~K}_{2} \mathrm{O}$ & $\mathbf{L a}_{2} \mathbf{O}_{3}$ & $\mathbf{L i}_{2} \mathbf{O}$ & MgO & MnO & $\mathrm{Na}_{2} \mathrm{O}$ & $\mathrm{NiO}$ & $\mathrm{PbO}$ & $\mathrm{Sb}_{2} \mathrm{O}_{3}$ \\
\hline HLW02-01 & ILW02 & .06171 & .09927 & .00500 & .00771 & .00108 & .10899 & .00060 & .00300 & .03996 & 0120 & 2385 & 10957 & 0518 & .00216 & 00110 \\
\hline HLW02-02 & ILW02 & \begin{tabular}{|l|}
.03999 \\
\end{tabular} & .13996 & .00500 & .01500 & .00199 & .13996 & .00060 & .00300 & .05998 & .00120 & .00000 & .03999 & .00100 & .00400 & .00200 \\
\hline HLW02-03 & ILW02 & .03999 & .13998 & .00500 & .01500 & .00199 & \begin{tabular}{|l|}
.07999 \\
\end{tabular} & .00060 & .00300 & .02000 & .00120 & .00000 & .14998 & .01000 & .00400 & .00020 \\
\hline HLW02-04 & ILW02 & \begin{tabular}{|l|}
.04001 \\
\end{tabular} & .05001 & .00500 & .01500 & .00020 & .14002 & \begin{tabular}{|l|}
.00060 \\
\end{tabular} & .00300 & .02000 & & \begin{tabular}{|l|l|}
.00518 \\
\end{tabular} & .15002 & .00100 & & \\
\hline HLW02-06 & LW02 & .08501 & .05001 & .00500 & .01500 & .00020 & .08001 & .00060 & .00300 & .04740 & .00120 & .05001 & .15002 & .01000 & .00040 & .00020 \\
\hline HLW02-07 & LW02 & .08499 & .04999 & .00500 & .00050 & .00199 & \begin{tabular}{|l|}
.07999 \\
\end{tabular} & .00060 & .00300 & .05999 & .00120 & .00000 & .11703 & .00100 & .00400 & .00200 \\
\hline HLW02-08 & HLW02 & .04000 & .14000 & .00500 & .00050 & .00020 & .09205 & .00060 & .00300 & .03310 & .00120 & .05000 & .15000 & .00100 & .00040 & .00200 \\
\hline HLW02-09 & ILW02 & \begin{tabular}{|l|}
.08500 \\
\end{tabular} & .11589 & .00500 & .00050 & .00020 & .14000 & .00060 & .00300 & .02271 & .00120 & .00000 & .15000 & .01000 & .00040 & .00200 \\
\hline HLWO & LW02 & \begin{tabular}{|l|}
.04001 \\
\end{tabular} & .14002 & .00500 & .00050 & .00020 & .08001 & .00060 & .00300 & .06001 & .00120 & .00000 & .10858 & .01000 & & 200 \\
\hline HLWC & 02 & \begin{tabular}{|l|}
.03999 \\
\end{tabular} & .04999 & .00500 & .01500 & .00199 & .11382 & .00060 & .00300 & .05998 & .00120 & \begin{tabular}{|l|}
.04999 \\
\end{tabular} & .12757 & .01000 & & 020 \\
\hline HLW0 & HLW02 & .03999 & .04999 & .00500 & .00050 & .00199 & .13998 & .00060 & .00300 & .05999 & .00120 & .04999 & .10425 & .00100 & .00400 & .00020 \\
\hline HLWO & HLW02 & .08499 & .13998 & .00500 & .00050 & .00199 & .13998 & .00060 & .00300 & .02000 & .00120 & .04688 & .12539 & .00100 & .00400 & .00020 \\
\hline HLW02-16 & ILW02 & .08498 & .04999 & .00500 & .01500 & .00199 & .07998 & .00060 & .00300 & .05998 & .00120 & .04999 & .09651 & .00100 & .00400 & .00200 \\
\hline \begin{tabular}{|l|} 
HLW \\
\end{tabular} & 02 & & & .00500 & .01500 & & \begin{tabular}{|l|}
.13843 \\
\end{tabular} & & & .06000 & & \begin{tabular}{|l}
.00000 \\
\end{tabular} & .07690 & & & 020 \\
\hline HLWO & 02 & & & .00500 & .00050 & .00199 & .11126 & .00060 & & .02013 & .00120 & .00000 & .14996 & .01000 & & .00200 \\
\hline HLW02-19 & HLW02 & .04000 & .14000 & .00500 & .01500 & .00020 & \begin{tabular}{|l|}
.10781 \\
\end{tabular} & .00060 & .00300 & .02000 & .00120 & \begin{tabular}{|l|l|}
.05000 \\
\end{tabular} & .08849 & .00100 & .00040 & .00200 \\
\hline HLWO & HLW02 & .04000 & .14000 & .00500 & .00050 & .00020 & .14000 & .00060 & .00300 & .02000 & .00120 & .00000 & .06453 & .00100 & .00040 & .00020 \\
\hline HLW02-22 & HLW02 & .08500 & .14000 & .00500 & .00050 & .00020 & \begin{tabular}{|l|}
.09500 \\
\end{tabular} & .00060 & .00300 & .06000 & .00120 & .00000 & .04000 & .00100 & & .00200 \\
\hline HLW & & & .14002 & .00500 & .01500 & .00020 & .08001 & & & .06001 & .00120 & .05001 & |.05591. & & & 520 \\
\hline HLW02-24 & HLW02 & \begin{tabular}{|l|}
.08498 \\
\end{tabular} & .04999 & .00500 & .00050 & .00153 & \begin{tabular}{|l|}
.07998 \\
\end{tabular} & .00060 & .00300 & .02000 & .00120 & \begin{tabular}{|l|}
.04999 \\
\end{tabular} & .12195 & .00100 & .00307 & .00020 \\
\hline HLW02-25 & HLW02 & \begin{tabular}{|l|}
.08501 \\
\end{tabular} & .14002 & .00500 & .01500 & .00020 & .09501 & .00060 & .00300 & .02000 & .00120 & .00355 & .06884 & .00100 & .00040 & .00200 \\
\hline HLW02-26 & HLW02 & \begin{tabular}{|l}
.03999 \\
\end{tabular} & \begin{tabular}{|l}
.04999 \\
\end{tabular} & .00500 & .01500 & .00199 & .12498 & .00060 & .00300 & .02000 & .00120 & \begin{tabular}{|l}
.04959 \\
\end{tabular} & .14998 & .00100 & .00400 & .00020 \\
\hline HLW02-27 & HLW02 & & .14002 & .00500 & .00050 & .00020 & .12502 & & .00300 & .06001 & .00120 & .03366 & .04275 & & & .00020 \\
\hline HLW & LW02 & $\begin{array}{l}.07500 \\
\end{array}$ & .08000 & .00500 & .01000 & .00040 & .10451 & .00060 & .00300 & .02500 & .00120 & .01500 & .15001 & .00300 & .00080 & .00050 \\
\hline HLW02-29 & HLW02 & .07499 & .12998 & .00500 & .00500 & .00133 & .09998 & .00060 & .00300 & .03749 & .00120 & .01500 & .08999 & .00300 & .00267 & .00050 \\
\hline HLW02-30 & HLW02 & .05500 & .09721 & .00500 & .01000 & .00040 & .10000 & .00060 & .00300 & .05000 & .00120 & .03500 & .11228 & .00300 & .00080 & .00150 \\
\hline HLW02-31 & HLW02 & .05500 & .13001 & .00500 & .00500 & .00040 & .10001 & .00060 & .00300 & .02500 & .00120 & .01500 & .14982 & .00300 & .00080 & .00050 \\
\hline HLW02-32 & & \begin{tabular}{|l|}
.07500 \\
\end{tabular} & .08000 & .00500 & .01000 & \begin{tabular}{|l|}
.00040 \\
\end{tabular} & \begin{tabular}{|l|}
.10000 \\
\end{tabular} & \begin{tabular}{|l|}
.00060 \\
\end{tabular} & .00300 & .05000 & .00120 & \begin{tabular}{|l|l|}
.01500 \\
\end{tabular} & .10733 & .00300 & .00080 & .00150 \\
\hline HLW02-33 & HLW02 & .06341 & .08000 & .00500 & .00500 & .00040 & .12000 & .00060 & .00300 & .02500 & .00120 & .03500 & .15000 & .00800 & .00080 & .00150 \\
\hline HLW02-34 & HLW02 & $\begin{array}{l}.05499 \\
\end{array}$ & .12998 & .00500 & .01000 & .00133 & .11998 & .00060 & .00300 & .03957 & .00120 & .01500 & .10891 & .00800 & \begin{tabular}{|l}
.00267 \\
\end{tabular} & .00050 \\
\hline
\end{tabular}

(a) The Group IDs are described in Sections 2.1.1 to 2.1.9. 
Table 6.1. Normalized 25-Component Compositions (mass fractions) of 168 HLW Glasses with Spinel as the Primary Crystalline Phase and Used in Spinel $\mathbf{T}_{1 \%}$ Modeling (continued).

\begin{tabular}{|c|c|c|c|c|c|c|c|c|c|c|c|c|}
\hline Glass ID & $\underset{\text { ID }^{(\text {a) }}}{\text { Group }}$ & $\mathrm{SeO}_{2}$ & $\mathrm{SiO}_{2}$ & SrO & $\mathrm{ThO}_{2}$ & $\mathrm{TiO}_{2}$ & $\mathbf{T l}_{2} \mathbf{O}$ & $\mathbf{U O}_{3}$ & ZnO & $\mathrm{ZrO}_{2}$ & Others & $\operatorname{Sum}^{(\mathbf{b})}$ \\
\hline HLW02-01 & LW02 & .00110 & 3612 & .02444 & .00000 & .00030 & .00102 & .00000 & .02000 & 22974 & .01690 & 1.00000 \\
\hline HLW02-02 & HLW02 & .00020 & .50445 & .00000 & .00000 & .00030 & .00019 & .00000 & .01999 & .00000 & .02119 & 1.00000 \\
\hline HLW02-03 & LW02 & .00200 & .37994 & .04379 & .00000 & .00030 & .00186 & .00000 & .02000 & .05999 & .02120 & 1.00000 \\
\hline HLW02-04 & & .00200 & .52939 & .00000 & .00000 & .00030 & .00186 & .00000 & .02000 & .00000 & .01281 & \\
\hline HLW02-06 & HLW02 & .00200 & .40496 & .00000 & .00000 & .00030 & .00186 & .00000 & .02000 & .06001 & .01281 & 1.00000 \\
\hline HLW02-07 & HLW02 & .00020 & .52992 & .00000 & .00000 & .00030 & .00186 & .00000 & .02000 & .01525 & .02120 & 1.00000 \\
\hline HLW02-08 & LW02 & .00020 & .38744 & .00000 & .00000 & .00030 & .00019 & .00000 & .02000 & .06000 & .01281 & 1.00000 \\
\hline HLW02-09 & LW02 & .00020 & .38000 & .05000 & .00000 & .00030 & .00019 & .00000 & .02000 & .00000 & & \\
\hline HLW02-1 & \begin{tabular}{|l|} 
HLW02 \\
\end{tabular} & .00200 & .45149 & .00000 & .00000 & .00030 & .00186 & .00000 & .02000 & .06001 & & 000 \\
\hline HLW02-12 & \begin{tabular}{|l|} 
HLW02 \\
\end{tabular} & .00200 & .41402 & .00000 & .00000 & .00030 & .00019 & .00000 & .01999 & .05998 & .02119 & 1.00000 \\
\hline HLW02-13 & HLW02 & .00200 & .43114 & .04999 & .00000 & .00030 & .00186 & .00000 & .02000 & .01182 & .02120 & 1.00000 \\
\hline HLW02-15 & LW02 & .00200 & .37994 & .00000 & .00000 & .00030 & .00186 & .00000 & .02000 & .00000 & .02120 & 1.00000 \\
\hline HLW02-16 & LW02 & .00200 & .39115 & .04999 & .00000 & .00030 & .00019 & .00000 & .01999 & .05998 & .02119 & 1.00000 \\
\hline HLW0 & & & .52958 & .00000 & & & & .00000 & .02000 & .00000 & & \\
\hline HLW02-18 & HLW02 & .00020 & .49852 & .00000 & .00000 & .00030 & .00019 & .00000 & .01999 & .05998 & .02119 & 1.00000 \\
\hline HLW02-19 & HLW02 & .00200 & .38000 & .05000 & .00000 & .00030 & .00019 & .00000 & .02000 & .06000 & .01281 & 1.00000 \\
\hline HLW02-20 & HLW02 & .00020 & .51734 & .03253 & .00000 & .00030 & .00019 & .00000 & .02000 & .00000 & .01281 & 1.00000 \\
\hline HLW02-22 & & & & & & & & & & .00000 & & \\
\hline HLW02-23 & HLW02 & .00020 & .39325 & .05001 & .00000 & & .00186 & .00000 & .02000 & .01500 & & 1.00000 \\
\hline HLW02-24 & \begin{tabular}{|l|} 
HLW02 \\
\end{tabular} & .00200 & .47052 & .04999 & .00000 & .00030 & .00019 & .00000 & .02000 & .01500 & .01903 & 1.00000 \\
\hline HLW02-25 & \begin{tabular}{|l|} 
HLW02 \\
\end{tabular} & .00020 & .47398 & .05001 & .00000 & .00030 & .00186 & .00000 & .02000 & .00000 & .01281 & 1.00000 \\
\hline HLW02-26 & HLW02 & .00020 & .37994 & .04999 & .00000 & .00030 & .00186 & .00000 & .02000 & .05999 & .02120 & 1.00000 \\
\hline HLW02-27 & HLW02 & .00200 & .39946 & .05001 & .00000 & .00030 & .00186 & .00000 & .02000 & .06001 & .01281 & 1.00000 \\
\hline HLW02-28 & \begin{tabular}{|l|} 
HLW02 \\
\end{tabular} & .00050 & .41003 & .03500 & .00000 & .00030 & .00140 & .00000 & .02000 & .04500 & .01374 & 1.00000 \\
\hline HLW02-29 & HLW02 & .00150 & .40994 & .03499 & .00000 & .00030 & .00046 & .00000 & .02000 & .04499 & .01809 & 1.00000 \\
\hline HLW02-30 & HLW02 & .00050 & .41000 & .03500 & .00000 & .00030 & .00047 & .00000 & .02000 & .04500 & .01374 & 1.00000 \\
\hline HLW02-3 & LW02 & .00150 & .41003 & .01500 & .00000 & .00030 & .00140 & .00000 & .02000 & .04369 & .01374 & 1.00000 \\
\hline HLW02-32 & \begin{tabular}{|l|} 
HLW02 \\
\end{tabular} & .00150 & .46117 & .03500 & .00000 & .00030 & .00047 & .00000 & .02000 & .01500 & .01374 & 1.00000 \\
\hline HLW02-33 & HLW02 & .00150 & .41000 & .03500 & .00000 & .00030 & .00047 & .00000 & .02000 & .02009 & .01374 & 1.00000 \\
\hline HLW02-34 & HLW02 & .00050 & .40994 & .03499 & .00000 & .00030 & .00046 & .00000 & .02000 & .01500 & .01809 & 1.00000 \\
\hline
\end{tabular}

(a) The Group IDs are described in Sections 2.1.1 to 2.1.9.

(b) The component mass fractions are normalized to sum to one over the 25 components listed in this table. The normalized component mass fractions listed in this table were rounded to five decimals, and may not sum exactly to 1.00000 as listed. However, complete compositions listed to more decimal places and summing to 1.0000 were used for property-composition modeling. 
Table 6.1. Normalized 25-Component Compositions (mass fractions) of 168 HLW Glasses with Spinel as the Primary Crystalline Phase and Used in Spinel $\mathbf{T}_{1 \%}$ Modeling (continued).

\begin{tabular}{|c|c|c|c|c|c|c|c|c|c|c|c|c|c|c|c|c|}
\hline Glass ID & $\underset{\text { ID }^{(\mathbf{a})}}{\text { Group }}$ & $\mathbf{A l}_{2} \mathbf{O}_{3}$ & $\mathrm{~B}_{2} \mathrm{O}_{3}$ & $\mathrm{CaO}$ & CdO & $\mathrm{Cr}_{2} \mathrm{O}_{3}$ & $\mathrm{Fe}_{2} \mathrm{O}_{3}$ & $\mathrm{~K}_{2} \mathrm{O}$ & $\mathbf{L a}_{2} \mathbf{O}_{3}$ & $\mathbf{L i}_{2} \mathbf{O}$ & MgO & MnO & $\mathrm{Na}_{2} \mathrm{O}$ & $\mathrm{NiO}$ & $\mathrm{PbO}$ & $\mathbf{S b}_{2} \mathbf{O}_{3}$ \\
\hline HLW02-35 & ILW02 & 488 & .12999 & .00500 & .00500 & .00133 & .11999 & .00060 & .00300 & .05000 & 0120 & 3500 & 9160 & 0800 & .00267 & .00150 \\
\hline HLW02-36 & ILW02 & .05499 & .08667 & .00500 & .01000 & .00133 & .11998 & .00060 & .00300 & .02500 & .00120 & .01500 & .14998 & .00300 & .00267 & .00050 \\
\hline HLW02-37 & ILW02 & .06762 & .13000 & .00500 & .00500 & .00040 & .10000 & .00060 & .00300 & .02500 & .00120 & .03500 & .11188 & .00800 & .00080 & .00150 \\
\hline HLW02-38 & ILW02 & \begin{tabular}{|l}
.06893 \\
\end{tabular} & .12998 & .00500 & \begin{tabular}{|l|}
.01000 \\
\end{tabular} & .00133 & .11998 & \begin{tabular}{|l|}
.00060 \\
\end{tabular} & .00300 & .04255 & & $\begin{array}{l}.01500 \\
\end{array}$ & \begin{tabular}{|l|}
.08999 \\
\end{tabular} & & & \\
\hline HLW02-39 & LW02 & .07500 & .08991 & .00500 & .01000 & .00040 & .10000 & .00060 & .00300 & .02500 & .00120 & .01500 & .11058 & .00800 & .00080 & \\
\hline HLW02-40 & LW02 & \begin{tabular}{|l}
.07499 \\
\end{tabular} & .09833 & .00500 & \begin{tabular}{|l|}
.01000 \\
\end{tabular} & 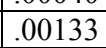 & \begin{tabular}{|l|}
.09999 \\
\end{tabular} & .00060 & .00300 & .02632 & .00120 & .01500 & .09683 & .00300 & .00267 & 150 \\
\hline HLW02-41 & HLW02 & .06500 & .13001 & .00500 & .00500 & .00040 & .10001 & .00060 & .00300 & .02500 & .00120 & .01500 & .09001 & .00300 & .00080 & .00050 \\
\hline HLW02-42 & ILW02 & .05500 & .13001 & .00500 & \begin{tabular}{|l|}
.00500 \\
\end{tabular} & .00040 & \begin{tabular}{|l|}
.10001 \\
\end{tabular} & .00060 & .00300 & .05000 & .00120 & .01500 & \begin{tabular}{|l|}
.09001 \\
\end{tabular} & .00300 & .00080 & .00050 \\
\hline HLW & ILW02 & .06500 & .13000 & .00500 & .01000 & .00040 & .10000 & .00060 & .00300 & .02500 & .00120 & .03500 & .12450 & .00300 & .00080 & 150 \\
\hline HLW & 02 & \begin{tabular}{|l|}
.05499 \\
\end{tabular} & .09069 & .00500 & \begin{tabular}{|l|}
.01000 \\
\end{tabular} & .00133 & \begin{tabular}{|l|}
.09998 \\
\end{tabular} & .00060 & .00300 & .02500 & .00120 & .03499 & .14998 & .00300 & .00267 & 150 \\
\hline HLW & 02 & .05500 & .08000 & .00500 & .01000 & .00040 & .11000 & .00060 & .00300 & .02500 & .00120 & .03500 & .09619 & .00300 & .00080 & 050 \\
\hline HLW0 & HLW02 & .05500 & \begin{tabular}{|l}
.09149 \\
\end{tabular} & 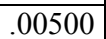 & \begin{tabular}{|l}
.00500 \\
\end{tabular} & .00040 & .10001 & .00060 & .00300 & \begin{tabular}{|l|}
.03701 \\
\end{tabular} & .00120 & .03500 & \begin{tabular}{|l|}
.09001 \\
\end{tabular} & .00800 & .00080 & .00050 \\
\hline HLW02-47 & ILW02 & .05499 & .09806 & .00500 & .00500 & .00133 & \begin{tabular}{|l|}
.09999 \\
\end{tabular} & .00060 & .00300 & .02500 & .00120 & .03500 & .09443 & .00300 & .00267 & .00050 \\
\hline \begin{tabular}{|l|} 
HLW \\
\end{tabular} & 02 & \begin{tabular}{|l}
.05999 \\
.059
\end{tabular} & \begin{tabular}{|l}
.07999 \\
\end{tabular} & .00500 & \begin{tabular}{|l|}
.00500 \\
\end{tabular} & & \begin{tabular}{|l|}
.11999 \\
\end{tabular} & \begin{tabular}{|l|}
.00060 \\
\end{tabular} & .00300 & .03339 & .00 & \begin{tabular}{|l}
.01500 \\
\end{tabular} & \begin{tabular}{|l|}
.14999 \\
\end{tabular} & .00800 & 67 & 50 \\
\hline HLW & & .07500 & .08740 & .00500 & .00500 & .00040 & .12001 & .00060 & .00300 & .05000 & .00120 & .03500 & .09001 & .00300 & .00080 & 050 \\
\hline HLW & HLW02 & \begin{tabular}{|l}
.06000 \\
\end{tabular} & .13001 & .00500 & \begin{tabular}{|l|}
.00500 \\
\end{tabular} & .00040 & \begin{tabular}{|l|}
.12001 \\
\end{tabular} & \begin{tabular}{|l|}
.00060 \\
\end{tabular} & .00300 & .02500 & .00120 & $\begin{array}{l}.01500 \\
\end{array}$ & \begin{tabular}{|l|}
.09821 \\
\end{tabular} & .00300 & .00080 & .00150 \\
\hline HLWC & HLW02 & .07500 & .08000 & .00500 & .00500 & .00040 & .10501 & .00060 & .00300 & .04589 & .00120 & .01500 & .09001 & .00300 & .00080 & .00150 \\
\hline HLW0 & HLW02 & .06171 & .09927 & .00500 & \begin{tabular}{|l|}
.00771 \\
\end{tabular} & .00108 & .10899 & .00060 & & .03996 & .00120 & .02385 & .10957 & .00518 & & .00110 \\
\hline HLW & & .08500 & .05000 & .00500 & .01500 & & .13843 & .00060 & & .06000 & & .00000 & .07690 & & & 020 \\
\hline HLW02-54 & HLW02 & \begin{tabular}{|l|}
.04001 \\
\end{tabular} & .05001 & .00500 & \begin{tabular}{|l|}
.01500 \\
\end{tabular} & .00020 & .14002 & .00060 & .00300 & .02000 & .00120 & .00518 & .15002 & .00100 & .00040 & .00200 \\
\hline HLW02-55 & HLW02 & \begin{tabular}{|l}
.05500 \\
.0500
\end{tabular} & .13001 & .00500 & .00500 & .00040 & .10001 & .00060 & .00300 & .05000 & .00120 & .01500 & \begin{tabular}{|l|}
.09001 \\
\end{tabular} & .00300 & .00080 & .00050 \\
\hline HLW02-56 & HLW02 & \begin{tabular}{|l}
.05499 \\
\end{tabular} & .09069 & .00500 & \begin{tabular}{|l|}
.01000 \\
\end{tabular} & .00133 & .09998 & .00060 & .00300 & .02500 & .00120 & .03499 & .14998 & .00300 & .00267 & .00150 \\
\hline HLW02-57 & & & .14000 & .00500 & & .00020 & .09205 & .00060 & .00300 & .03310 & .00120 & .05000 & .15000 & & .00040 & .00200 \\
\hline HLW03-01 & LW03 & .08335 & .13727 & .00500 & .00050 & .00020 & .13727 & .00060 & .00300 & .05883 & .00120 & .06078 & \begin{tabular}{|l|}
.03922 \\
\end{tabular} & .00098 & .00400 & .00020 \\
\hline HLW03-02 & HLW03 & .01951 & .13662 & .00500 & .01600 & .00488 & .13662 & .00060 & .00300 & .02473 & .00120 & .06832 & .11177 & .00976 & .00040 & .00300 \\
\hline HLW03-03 & HLW03 & .01953 & .04884 & .00500 & .01600 & .00488 & .13677 & .00060 & .00300 & .02678 & .00120 & .06839 & .10755 & .00977 & .00040 & .00020 \\
\hline HLW03-04 & HLW03 & .01954 & .04886 & .00498 & .00050 & .00488 & .13680 & .00060 & .00299 & .05862 & .00120 & .03161 & .04442 & .00098 & .00399 & .00020 \\
\hline HLW03-05 & & & .04809 & .00500 & \begin{tabular}{|l|}
.01600 \\
\end{tabular} & & \begin{tabular}{|l|}
.01924 \\
\end{tabular} & \begin{tabular}{|l|}
.00060 \\
\end{tabular} & .00300 & .01924 & .00120 & \begin{tabular}{|l|l|}
.06733 \\
\end{tabular} & \begin{tabular}{|l|}
.14427 \\
\end{tabular} & .00096 & .00400 & .00300 \\
\hline HLW03-06 & HLW03 & .08344 & .04908 & .00500 & .01600 & .00491 & .01963 & .00060 & .00300 & .05890 & .00120 & .06872 & .03927 & .00982 & .00040 & .00020 \\
\hline HLW03-07 & HLW03 & \begin{tabular}{|l}
.04961 \\
\end{tabular} & \begin{tabular}{|l|}
.04961 \\
\end{tabular} & .00498 & \begin{tabular}{|l|}
.00050 \\
\end{tabular} & \begin{tabular}{|l}
.00496 \\
\end{tabular} & \begin{tabular}{|l}
.13891 \\
\end{tabular} & .00060 & \begin{tabular}{|l}
.00299 \\
\end{tabular} & .04750 & .00120 & .06945 & \begin{tabular}{|l}
.11693 \\
\end{tabular} & .00100 & .00040 & .00020 \\
\hline
\end{tabular}

(a) The Group IDs are described in Sections 2.1.1 to 2.1.9. 
Table 6.1. Normalized 25-Component Compositions (mass fractions) of 168 HLW Glasses with Spinel as the Primary Crystalline Phase and Used in Spinel $\mathbf{T}_{1 \%}$ Modeling (continued).

\begin{tabular}{|c|c|c|c|c|c|c|c|c|c|c|c|c|}
\hline Glass ID & $\underset{\text { ID }^{(\text {a) }}}{\text { Group }}$ & $\mathrm{SeO}_{2}$ & $\mathrm{SiO}_{2}$ & SrO & $\mathrm{ThO}_{2}$ & $\mathrm{TiO}_{2}$ & $\mathbf{T l}_{2} \mathbf{O}$ & $\mathbf{U O}_{3}$ & $\mathrm{ZnO}$ & $\mathrm{ZrO}_{2}$ & Others & $\operatorname{Sum}^{(\mathbf{b})}$ \\
\hline HLW02-35 & W02 & .00050 & 0996 & 1500 & .00000 & 0030 & .00140 & .00000 & .02000 & 01500 & .01809 & 1.00000 \\
\hline HLW02-36 & LW02 & .00150 & .45074 & .01500 & .00000 & .00030 & .00046 & .00000 & .02000 & .01500 & .01809 & 1.00000 \\
\hline HLW02-37 & LW02 & .00050 & .41000 & .01500 & .00000 & .00030 & .00047 & .00000 & .02000 & .04500 & .01374 & 1.00000 \\
\hline HLW02-38 & & .00150 & .40994 & .03499 & .00000 & .00030 & .00046 & .00000 & .02000 & .01500 & & \\
\hline HLW02-39 & LW02 & .00050 & .49000 & .01500 & .00000 & .00030 & .00047 & .00000 & .02000 & .01500 & .01374 & 1.00000 \\
\hline HLW02-40 & HLW02 & .00050 & .48996 & .01500 & .00000 & .00030 & .00140 & .00000 & .02000 & .01500 & .01809 & 1.00000 \\
\hline HLW02-41 & LW02 & .00050 & .48953 & .01500 & .00000 & .00030 & .00140 & .00000 & .02000 & .01500 & .01374 & 1.00000 \\
\hline HLW02-42 & LW02 & .00050 & .44453 & .03500 & .00000 & .00030 & .00140 & .00000 & .02000 & .02500 & .01374 & \\
\hline HLW02-43 & \begin{tabular}{|l|} 
HLW02 \\
\end{tabular} & .00050 & .41000 & .03500 & .00000 & .00030 & .00047 & .00000 & .02000 & .01500 & 374 & 000 \\
\hline HLW02-44 & HLW02 & .00050 & .43673 & .01500 & .00000 & .00030 & .00046 & .00000 & .02000 & .02500 & .01809 & 1.00000 \\
\hline HLW02-45 & LW02 & .00150 & .48831 & .03500 & .00000 & .00030 & .00047 & .00000 & .02000 & .01500 & .01374 & 1.00000 \\
\hline HLW02-46 & HLW02 & .00150 & .49003 & .01500 & .00000 & .00030 & .00140 & .00000 & .02000 & .02500 & .01374 & 1.00000 \\
\hline HLW02-47 & 2 & .00050 & .48996 & .01500 & .00000 & .00030 & .00140 & .00000 & .02000 & .02500 & 809 & 1.00000 \\
\hline HLW02-48 & & & & .01710 & & & .00140 & & .02000 & .04500 & & \\
\hline HLW02-49 & HLW02 & .00050 & .44213 & .01500 & .00000 & .00030 & .00140 & .00000 & .02000 & .03000 & .01374 & 1.00000 \\
\hline HLW02-50 & HLW02 & .00050 & .43532 & .01500 & .00000 & .00030 & .00140 & .00000 & .02000 & .04500 & .01374 & 1.00000 \\
\hline HLW02-51 & HLW02 & .00150 & .45164 & .03500 & .00000 & .00030 & .00140 & .00000 & .02000 & .04500 & .01374 & 1.00000 \\
\hline HLW02-52 & & & & .02444 & & & & & & .02974 & & 000 \\
\hline HLW02-53 & HLW02 & .00020 & & .00000 & .00000 & .00030 & .00019 & .00000 & .02000 & .00000 & .01281 & 1.00000 \\
\hline HLW02-54 & HLW02 & .00200 & .52939 & .00000 & .00000 & .00030 & .00186 & .00000 & .02000 & .00000 & .01281 & 1.00000 \\
\hline HLW02-55 & \begin{tabular}{|l|} 
HLW02 \\
\end{tabular} & .00050 & .44453 & .03500 & .00000 & .00030 & .00140 & .00000 & .02000 & .02500 & .01374 & 1.00000 \\
\hline HLW02-56 & HLW02 & .00050 & .43673 & .01500 & .00000 & .00030 & .00046 & .00000 & .02000 & .02500 & .01809 & 1.00000 \\
\hline HLW02-57 & HLW02 & .00020 & .38744 & .00000 & .00000 & .00030 & .00019 & .00000 & .02000 & .06000 & .01281 & 1.00000 \\
\hline HLW03-01 & \begin{tabular}{|l|} 
HLW03 \\
\end{tabular} & .00200 & .35299 & .00000 & .02764 & .00030 & .00307 & .00000 & .03059 & .02983 & .02120 & 1.00000 \\
\hline HLW03-02 & HLW03 & .00020 & .35132 & .00000 & .00000 & .00030 & .00307 & .00000 & .00000 & .09088 & .01281 & 1.00000 \\
\hline HLW03-03 & HLW03 & .00200 & .35169 & .09769 & .00000 & .00030 & .00307 & .00000 & .01946 & .06404 & .01281 & 1.00000 \\
\hline HLW03-04 & LW03 & .00199 & .42425 & .09771 & .00000 & .00030 & .00306 & .06210 & .00000 & .02932 & .02113 & 1.00000 \\
\hline HLW03-05 & \begin{tabular}{|l|} 
HLW03 \\
\end{tabular} & .00200 & .47837 & .00000 & .03812 & .00030 & .00307 & .00000 & .03847 & .00000 & .02120 & 1.00000 \\
\hline HLW03-06 & HLW03 & .00020 & .52031 & .05091 & .01416 & .00030 & .00019 & .00000 & .00000 & .04095 & .01281 & 1.00000 \\
\hline HLW03-07 & HLW03 & .00199 & .39825 & .00000 & .00000 & .00030 & .00019 & .06306 & .03461 & .00000 & .01276 & 1.00000 \\
\hline
\end{tabular}

(a) The Group IDs are described in Sections 2.1.1 to 2.1.9.

(b) The component mass fractions are normalized to sum to one over the 25 components listed in this table. The normalized component mass fractions listed in this table were rounded to five decimals, and may not sum exactly to 1.00000 as listed. However, complete compositions listed to more decimal places and summing to 1.0000 were used for property-composition modeling. 
Table 6.1. Normalized 25-Component Compositions (mass fractions) of 168 HLW Glasses with Spinel as the Primary Crystalline Phase and Used in Spinel $\mathbf{T}_{1 \%}$ Modeling (continued).

\begin{tabular}{|c|c|c|c|c|c|c|c|c|c|c|c|c|c|c|c|c|}
\hline Glass ID & $\underset{\text { ID }^{(a)}}{\text { Group }}$ & $\mathbf{A l}_{2} \mathbf{O}_{3}$ & $\mathbf{B}_{2} \mathbf{O}_{3}$ & $\mathrm{CaO}$ & CdO & $\mathrm{Cr}_{2} \mathrm{O}_{3}$ & $\mathrm{Fe}_{2} \mathrm{O}_{3}$ & $\mathrm{~K}_{2} \mathrm{O}$ & $\mathbf{L a}_{2} \mathbf{O}_{3}$ & $\mathbf{L i}_{2} \mathbf{O}$ & MgO & MnO & $\mathrm{Na}_{2} \mathrm{O}$ & $\mathrm{NiO}$ & PbO & $\mathrm{Sb}_{2} \mathrm{O}_{3}$ \\
\hline HLW03-10 & 03 & 369 & 924 & 500 & 050 & 0020 & 9982 & 0060 & .00300 & .05908 & 0120 & 6893 & .12851 & 0985 & 0400 & 0020 \\
\hline HLW03-12 & LW03 & .01982 & .04956 & .00498 & .00050 & .00495 & .01982 & .00060 & .00299 & .05008 & .00120 & .06939 & .03965 & .00099 & .00040 & .00299 \\
\hline HLW03-13 & LW03 & .08433 & .04961 & .00498 & .00050 & .00496 & .08633 & .00060 & .00299 & .05209 & .00120 & .06945 & .03969 & .00992 & .00040 & .00020 \\
\hline HLW03-14 & & & .04973 & .00500 & .00050 & & & & & .02504 & & .06962 & .10425 & .00994 & .00040 & \\
\hline HLW03-15 & W03 & .01951 & .13662 & .00500 & .01600 & .00020 & .13662 & .00060 & .00300 & .01951 & .00120 & .01348 & .05248 & .00098 & .00040 & 0300 \\
\hline HLW03-16 & LW03 & .01955 & .04886 & .00498 & .00050 & .00020 & .07905 & .00060 & .00299 & .02862 & .00120 & .06840 & .03909 & .00977 & .00398 & 0299 \\
\hline HLW03-17 & LW03 & .08352 & .13757 & .00499 & .00050 & .00020 & .01965 & .00060 & .00299 & .01965 & .00120 & .06879 & .04461 & .00293 & .00399 & .00020 \\
\hline HLW03-18 & LW03 & .01989 & .04973 & .00500 & .00050 & .00497 & .13924 & .00060 & .00300 & .05922 & .00120 & .00000 & .10533 & .00980 & .00040 & .00020 \\
\hline HLW03-19 & 03 & .01963 & .04908 & .00500 & .01600 & .00491 & .09634 & .00060 & .00300 & .05890 & .00120 & .00197 & .10142 & .00982 & .00040 & .00020 \\
\hline HLV & W03 & .01923 & .04808 & .00500 & .01600 & .00019 & .13462 & .00060 & .00300 & .05769 & .00120 & .00000 & .10097 & .00962 & .00400 & .00300 \\
\hline HLW03-21 & 03 & .04958 & .06941 & .00499 & .00300 & .00079 & .04958 & .00060 & .00300 & .02479 & .00120 & .04462 & .10828 & .00298 & .00080 & .00050 \\
\hline HLW03-22 & LW03 & .04915 & .06881 & .00499 & .00299 & .00079 & .09752 & .00060 & .00299 & .02458 & .00120 & .01474 & .11797 & .00295 & .00267 & .00050 \\
\hline HLW & LW03 & .04957 & .11897 & .00499 & .00100 & .00199 & .07733 & .00060 & .00299 & .02478 & .00120 & .01487 & .11897 & .00297 & .00080 & .00050 \\
\hline HLW & & & .06941 & .00499 & .00300 & .00079 & .04958 & .00060 & .00300 & .04958 & .00120 & .04462 & .08151 & .00495 & .00080 & .00050 \\
\hline HLW & LW03 & .02956 & .11823 & .00499 & .00100 & .00079 & .04927 & .00060 & .00300 & .02463 & .00120 & .01478 & .11823 & .00492 & .00267 & .00050 \\
\hline HLW03-26 & LW03 & .04921 & .06889 & .00499 & .00100 & .00197 & .04921 & .00060 & .00299 & .04921 & .00120 & .01476 & .10431 & .00492 & .00267 & .00150 \\
\hline HLW03-27 & LW03 & .04926 & .06897 & .00499 & .00100 & .00197 & .09359 & .00060 & .00300 & .04040 & .00120 & .01478 & .11822 & .00492 & .00267 & .00150 \\
\hline HLWO & & & & .00499 & .00100 & & & .00060 & .00300 & .04963 & .00120 & & .10486 & .00496 & .00080 & .00150 \\
\hline HLW & CW03 & & .06933 & .00499 & .00299 & & .04952 & .00060 & .00299 & .04952 & .00120 & & .11885 & .00297 & .00080 & .00050 \\
\hline HLW & HLW03 & .02972 & .11888 & .00499 & .00100 & .00079 & .04953 & .00060 & .00300 & .04953 & .00120 & .04458 & .06934 & .00298 & .00080 & .00150 \\
\hline HLW03-31 & LW03 & .04953 & .06934 & .00499 & .00100 & .00198 & .04953 & .00060 & .00300 & .04953 & .00120 & .04458 & .08533 & .00495 & .00080 & .00150 \\
\hline HLW03-32 & LW03 & .04921 & .06889 & .00499 & .00100 & .00079 & .04921 & .00060 & .00299 & .04921 & .00120 & .02925 & .09101 & .00492 & .00267 & .00150 \\
\hline HLW & & & & .00499 & & & & & & .04859 & & .01476 & .06889 & .00492 & .00267 & .00050 \\
\hline HLW & \begin{tabular}{|l|} 
HLW03 \\
\end{tabular} & .04915 & .06881 & .00499 & .00299 & .00197 & .09831 & .00060 & .00299 & .02458 & .00120 & .01474 & .09618 & .00295 & .00267 & .00050 \\
\hline HLW03-39 & HLW03 & .02946 & .06875 & .00499 & .00300 & .00197 & .08502 & .00060 & .00300 & .04850 & .00120 & .01473 & .06875 & .00295 & .00267 & .00150 \\
\hline HLW03-40 & \begin{tabular}{|l|l|} 
HLW03 \\
\end{tabular} & .04941 & .06919 & .00499 & .00299 & .00079 & .09390 & .00060 & .00299 & .04881 & .00120 & .01483 & .06919 & .00494 & .00080 & .00150 \\
\hline HLW03-41 & LW03 & .03888 & .08732 & .00499 & .00200 & .00140 & .06939 & .00060 & .00299 & .03710 & .00120 & .02698 & .09093 & .00395 & .00174 & .00100 \\
\hline & & & & & & & & & .00300 & .03701 & .00120 & .03500 & .09001 & .00800 & .00080 & .00050 \\
\hline HLW03-43 & \begin{tabular}{|l|} 
HLW03 \\
\end{tabular} & .08344 & .04908 & .00500 & .01600 & .00491 & .01963 & .00060 & .00300 & .05890 & .00120 & .06872 & .03927 & .00982 & .00040 & .00020 \\
\hline HLW03-45 & HLW03 & .04921 & .06889 & .00499 & .00100 & .00197 & .04921 & .00060 & .00299 & .04921 & .00120 & .01476 & .10431 & .00492 & .00267 & .00150 \\
\hline
\end{tabular}

(a) The Group IDs are described in Sections 2.1.1 to 2.1.9. 
Table 6.1. Normalized 25-Component Compositions (mass fractions) of 168 HLW Glasses with Spinel as the Primary Crystalline Phase and Used in Spinel $\mathbf{T}_{1 \%}$ Modeling (continued).

\begin{tabular}{|c|c|c|c|c|c|c|c|c|c|c|c|c|}
\hline Glass ID & $\underset{\text { ID }^{(a)}}{\text { Group }}$ & $\mathrm{SeO}_{2}$ & $\mathrm{SiO}_{2}$ & SrO & $\mathrm{ThO}_{2}$ & $\mathrm{TiO}_{2}$ & $\mathbf{T l}_{2} \mathbf{O}$ & $\mathbf{U O}_{3}$ & $\mathrm{ZnO}$ & $\mathrm{ZrO}_{2}$ & Others & Sum $^{(b)}$ \\
\hline HLW03-10 & LW03 & 020 & 5449 & .00000 & .02626 & 0030 & .00019 & .01108 & .00000 & .07250 & .02118 & 1.00000 \\
\hline HLW03-12 & HLW03 & .00020 & .44277 & .09912 & .03729 & .00030 & .00019 & .06299 & .03965 & .03682 & .01276 & 1.00000 \\
\hline HLW03-13 & & .00199 & .35719 & .09922 & .03836 & .00030 & .00019 & .06306 & .01121 & .00846 & .01276 & \\
\hline HLW03-14 & HLW03 & .00020 & .35806 & .09946 & .04115 & .00030 & .00307 & .00000 & .03979 & .06511 & .01281 & 1.00000 \\
\hline HLW03-15 & HLW03 & .00020 & .51722 & .00000 & .02441 & .00030 & .00307 & .00000 & .03337 & .00000 & .01281 & 1.00000 \\
\hline HLW03-16 & HLW03 & .00199 & .44240 & .09772 & .02568 & .00030 & .00019 & .06210 & .02772 & .01001 & .02112 & 1.00000 \\
\hline HLW03-17 & HLW03 & .00020 & .46088 & .00000 & .02237 & .00030 & .00019 & .04784 & .03930 & .01639 & .02114 & 1.00000 \\
\hline HLW03-18 & \begin{tabular}{|l|} 
HLW03 \\
\end{tabular} & .00020 & .5248 & .00000 & .05967 & .00030 & .00307 & .00000 & .00000 & .00000 & 281 & 000 \\
\hline HLW03-19 & HLW03 & .00020 & .52030 & .00000 & .05846 & .00030 & .00019 & .00000 & .03927 & .00000 & 281 & 000 \\
\hline HLW03-20 & \begin{tabular}{|l|} 
HLW03 \\
\end{tabular} & .00200 & .50681 & .00145 & .05769 & .00030 & .00307 & .00430 & .00000 & .00000 & .02119 & 1.00000 \\
\hline HLW03-21 & HLW03 & .00050 & .48587 & .01487 & .02975 & .00030 & .00046 & .02100 & .00992 & .05949 & .01373 & 1.00000 \\
\hline HLW03-22 & HLW03 & .00150 & .40304 & .04424 & .02949 & .00030 & .00046 & .04165 & .00983 & .05898 & .01807 & 1.00000 \\
\hline HLW & LW03 & .00150 & .40648 & .01487 & .02974 & .00030 & .00046 & .04201 & .00992 & .05949 & 371 & 000 \\
\hline HLW03-24 & \begin{tabular}{|l|} 
HLW03 \\
\end{tabular} & .00050 & .48588 & .01487 & .02975 & .00030 & .00046 & .02100 & .02975 & .05949 & .01373 & 1.00000 \\
\hline HLW03-25 & HLW03 & .00150 & .42090 & .04433 & .02956 & .00030 & .00139 & .02087 & .02956 & .05912 & .01809 & 1.00000 \\
\hline HLW03-26 & HLW03 & .00150 & .40345 & .04428 & .04428 & .00030 & .00046 & .04169 & .02953 & .05904 & .01807 & 1.00000 \\
\hline HLW03-27 & HLW03 & .00150 & .40393 & .01478 & .04433 & .00030 & .00046 & .02087 & .02956 & .05911 & .01809 & 1.00000 \\
\hline HLW03-28 & \begin{tabular}{|l|} 
HLW03 \\
\end{tabular} & .00050 & .40695 & .01489 & .02977 & .00030 & .00046 & .02103 & .00993 & .05956 & .01372 & 1.00000 \\
\hline HLW03-29 & \begin{tabular}{|l|} 
HLW03 \\
\end{tabular} & .00050 & .40606 & .01485 & .04456 & .00030 & .00046 & .04196 & .02971 & .07674 & .01371 & 1.00000 \\
\hline HLW03-30 & \begin{tabular}{|l|} 
HLW03 \\
\end{tabular} & .00150 & .43203 & .01486 & .04458 & .00030 & .00139 & .02098 & .00991 & .08229 & .01373 & 1.00000 \\
\hline HLW03-31 & HLW03 & .00150 & .45058 & .01486 & .02972 & .00030 & .00139 & .02098 & .00991 & .08915 & .01373 & 1.00000 \\
\hline HLW03-32 & & & & .01476 & .04428 & & & .04170 & .02953 & .08857 & 307 & \\
\hline HLW03-37 & \begin{tabular}{|l|} 
HLW03 \\
\end{tabular} & .00150 & .40348 & .01476 & .04428 & .00030 & .00139 & .04170 & .02953 & .07325 & .01807 & 1.00000 \\
\hline HLW03-38 & HLW03 & .00150 & .43156 & .01474 & .03875 & .00030 & .00046 & .04165 & .00983 & .07051 & .01807 & 1.00000 \\
\hline HLW03-39 & HLW03 & .00150 & .48128 & .01473 & .04420 & .00030 & .00139 & .02081 & .00982 & .07078 & .01809 & 1.00000 \\
\hline HLW03-40 & HLW03 & .00150 & .42959 & .03279 & .04448 & .00030 & .00046 & .04188 & .00989 & .05930 & .01371 & 1.00000 \\
\hline HLW03-41 & HLW03 & .00100 & .43059 & .02705 & .03658 & .00030 & .00093 & .03032 & .01920 & .06767 & .01590 & 1.00000 \\
\hline HLW03-42 & HLW03 & .00150 & .49004 & .01500 & .00000 & .00030 & .00140 & .00000 & .01999 & .02500 & .01374 & 1.00000 \\
\hline HLW03-43 & HLW03 & .00020 & .52031 & .05091 & .01416 & .00030 & .00019 & .00000 & .00000 & .04095 & .01281 & 1.00000 \\
\hline HLW03-45 & HLW03 & .00150 & .40345 & .04428 & .04428 & .00030 & .00046 & .04169 & .02953 & .05904 & .01807 & 1.00000 \\
\hline
\end{tabular}

(a) The Group IDs are described in Sections 2.1.1 to 2.1.9.

(b) The component mass fractions are normalized to sum to one over the 25 components listed in this table. The normalized component mass fractions listed in this table were rounded to five decimals, and may not sum exactly to 1.00000 as listed. However, complete compositions listed to more decimal places and summing to 1.0000 were used for property-composition modeling. 
Table 6.1. Normalized 25-Component Compositions (mass fractions) of 168 HLW Glasses with Spinel as the Primary Crystalline Phase and Used in Spinel $\mathbf{T}_{1 \%}$ Modeling (continued).

\begin{tabular}{|c|c|c|c|c|c|c|c|c|c|c|c|c|c|c|c|c|}
\hline Glass ID & $\underset{\text { ID }^{(a)}}{\text { Group }}$ & $\mathbf{A l}_{2} \mathbf{O}_{3}$ & $\mathbf{B}_{2} \mathbf{O}_{3}$ & $\mathrm{CaO}$ & CdO & $\mathrm{Cr}_{2} \mathrm{O}_{3}$ & $\mathrm{Fe}_{2} \mathrm{O}_{3}$ & $\mathrm{~K}_{2} \mathrm{O}$ & $\mathbf{L a}_{2} \mathbf{O}_{3}$ & $\mathbf{L i}_{2} \mathbf{O}$ & MgO & MnO & $\mathrm{Na}_{2} \mathrm{O}$ & $\mathrm{NiO}$ & PbO & $\mathrm{Sb}_{2} \mathrm{O}_{3}$ \\
\hline HLW05-02 & W05 & .10000 & .12000 & .00750 & .00250 & .00200 & .05000 & .00200 & .00500 & .03000 & 0100 & 0500 & 1680 & 0250 & 0150 & .00000 \\
\hline HLW05-03 & LW05 & .06000 & .11300 & .00750 & .00125 & .00200 & .05000 & .00200 & .00500 & .03000 & .00100 & .00250 & .16000 & .00125 & .00150 & .00000 \\
\hline HLW05-04 & LW05 & .06000 & .07000 & .00750 & .00250 & .00100 & .05000 & .00200 & .00500 & .05000 & .00100 & .00500 & .10750 & .00250 & .00150 & .00000 \\
\hline HLW05-07 & LW05 & \begin{tabular}{|l|}
.10000 \\
\end{tabular} & .12000 & .00750 & .00250 & $\begin{array}{l}.00200 \\
\end{array}$ & .05000 & \begin{tabular}{|l|}
.00200 \\
\end{tabular} & .00500 & .03000 & .00100 & $\begin{array}{l}.00500 \\
\end{array}$ & .11680 & .00250 & & .00000 \\
\hline HLW05-09 & & .06000 & .12000 & .00750 & .00250 & .00100 & .07670 & .00200 & .00500 & .05000 & .00100 & .00500 & .12500 & .00250 & .00150 & .00000 \\
\hline HLW05-11 & W05 & .06000 & .12000 & .00750 & .00125 & .00200 & .08000 & .00200 & .00500 & .05000 & .00100 & .00250 & .08300 & .00125 & .00150 & .00000 \\
\hline HLW05-13 & HLW05 & \begin{tabular}{|l|}
.09770 \\
\end{tabular} & .07000 & .00750 & .00125 & .00100 & .07630 & .00200 & .00500 & .03000 & .00100 & .00250 & .16000 & .00125 & .00150 & .00000 \\
\hline HLW05-14 & LW05 & \begin{tabular}{|l|}
.06000 \\
\end{tabular} & .11300 & .00750 & .00250 & .00200 & .08000 & .00200 & .00500 & .05000 & .00100 & .00500 & .12500 & .00250 & .00150 & .00000 \\
\hline HLW05-27 & LW05 & .02000 & .04500 & .00750 & .00500 & .00050 & .12000 & .00200 & .00500 & .05950 & .00100 & .01000 & .10390 & .00500 & .00150 & .00000 \\
\hline HLW & & .11000 & .06500 & .01000 & .00235 & .00500 & .07000 & .00272 & .00176 & .03000 & .01170 & .01000 & .14000 & .01000 & 910 & .00000 \\
\hline HLWC & 106 & .10390 & .11000 & .01000 & .00235 & .00250 & .07000 & .00766 & .00176 & .00250 & .01170 & .01000 & .20000 & .01000 & .00910 & .00000 \\
\hline HLW06-03 & \begin{tabular}{|l|} 
HLW06 \\
\end{tabular} & \begin{tabular}{|l|}
.11000 \\
\end{tabular} & .06500 & \begin{tabular}{|l|}
.00467 \\
\end{tabular} & .00706 & \begin{tabular}{|l|}
.00250 \\
\end{tabular} & \begin{tabular}{|l|}
.14000 \\
\end{tabular} & .00060 & .00529 & .00250 & .00546 & .01000 & .14000 & .00600 & .00425 & .00000 \\
\hline HLW06-04 & LW06 & .08000 & .06500 & .00757 & .00706 & .00250 & .07000 & .00060 & .00529 & .00250 & .00886 & .01000 & .20000 & .00600 & .00689 & .00000 \\
\hline HLW & & \begin{tabular}{|l|}
.08000 \\
\end{tabular} & .06500 & .00674 & .00235 & \begin{tabular}{|l|l|}
.00250 \\
\end{tabular} & .07000 & .00 & .00176 & .00250 & .00 & \begin{tabular}{|l|l|}
.04000 \\
\end{tabular} & . 20000 & 00 & & .00000 \\
\hline HLV & & .11000 & .06500 & .00940 & .00235 & .00500 & .07000 & .00060 & .00176 & .00250 & .01100 & .04000 & .14000 & .01000 & 356 & .00000 \\
\hline HLW06-07 & N06 & \begin{tabular}{|l|}
.08000 \\
\end{tabular} & .06500 & .01000 & .00235 & $\begin{array}{l}.00250 \\
\end{array}$ & .14000 & \begin{tabular}{|l|}
.00060 \\
\end{tabular} & .00176 & .00250 & .01170 & \begin{tabular}{|l|l|}
.04000 \\
\end{tabular} & .15890 & .01000 & .00910 & .00000 \\
\hline HLW06-08 & LW06 & .08000 & .06500 & .00608 & .00706 & .00250 & .07000 & .00060 & .00529 & .00250 & .00711 & .04000 & .14000 & .01000 & .00553 & .00000 \\
\hline HLW06-09 & & \begin{tabular}{|l|}
.08000 \\
\end{tabular} & .06500 & .00166 & .00235 & .00250 & .14000 & .00060 & .00176 & .03000 & .00194 & .02410 & .14000 & .01000 & & .00000 \\
\hline HLW06 & & .08000 & .11000 & .00467 & & & .07000 & & & .00250 & & 000 & .14000 & 00 & & .00000 \\
\hline HLW06-11 & LW06 & \begin{tabular}{|l|}
.08000 \\
\end{tabular} & .11000 & .00550 & .00235 & .00250 & .14000 & .00902 & .00176 & .00250 & .00643 & .01000 & .14000 & .00600 & .00500 & .00000 \\
\hline HLW06-12 & HLW06 & .09410 & .11000 & .00166 & .00706 & .00250 & .07000 & .00272 & .00529 & .03000 & .00194 & .04000 & .14000 & .01000 & .00151 & .00000 \\
\hline HLW06-13 & \begin{tabular}{|l|} 
HLW06 \\
\end{tabular} & \begin{tabular}{|l|}
.11000 \\
\end{tabular} & .06500 & \begin{tabular}{|l|}
.00940 \\
\end{tabular} & .00235 & \begin{tabular}{|l|}
.00500 \\
\end{tabular} & \begin{tabular}{|l|}
.07000 \\
\end{tabular} & \begin{tabular}{|l|}
.01542 \\
\end{tabular} & \begin{tabular}{|l|}
.00176 \\
\end{tabular} & .00250 & .01100 & .04000 & .14000 & .01000 & .00856 & .00000 \\
\hline HLW06-14 & & & .11000 & .01000 & & .00250 & .07000 & .01640 & .00176 & .03000 & .01170 & .04000 & .14000 & & & .00000 \\
\hline HLW06-15 & LW06 & \begin{tabular}{|l|}
.08000 \\
\end{tabular} & .11000 & .00166 & .00235 & .00500 & .07000 & .00272 & .00176 & .03000 & .00194 & .02910 & .20000 & .01000 & .00151 & .00000 \\
\hline HLW06-16 & HLW06 & .10000 & .06500 & .00317 & .00235 & .00250 & .07000 & .00520 & .00176 & .03000 & .00371 & .01750 & .20000 & .01000 & .00289 & .00000 \\
\hline HLW06-17 & HLW06 & \begin{tabular}{|l|}
.11000 \\
\end{tabular} & .06500 & .01000 & .00235 & .00500 & .07000 & .01640 & .00176 & .03000 & .01170 & .01000 & .14000 & .01000 & .00910 & .00000 \\
\hline HLW06-18 & LW06 & .11000 & .11000 & .00276 & .00235 & .00250 & .07000 & .00452 & .00176 & .00250 & .00323 & .01000 & .14000 & .01000 & .00251 & .00000 \\
\hline HLW06-19 & & \begin{tabular}{|l|}
.11000 \\
\end{tabular} & .06500 & .00166 & .00235 & $\begin{array}{l}.00500 \\
\end{array}$ & .12060 & \begin{tabular}{|l|}
.00272 \\
\end{tabular} & .00176 & .00250 & .00194 & \begin{tabular}{|l|l|}
.04000 \\
\end{tabular} & .20000 & .00600 & .00151 & .00000 \\
\hline HLW06-20 & HLW06 & .11000 & .06500 & .01000 & .00235 & .00250 & .07290 & .01640 & .00176 & .03000 & .01170 & .04000 & .14000 & .00600 & .00910 & .00000 \\
\hline HLW06-25 & \begin{tabular}{|l} 
HLW06 \\
\end{tabular} & .13000 & .15000 & .01000 & .00000 & $\begin{array}{l}.00600 \\
\end{array}$ & .01400 & .01640 & .00000 & .06010 & .01170 & .00000 & .03700 & .00000 & .00910 & .00000 \\
\hline
\end{tabular}

(a) The Group IDs are described in Sections 2.1.1 to 2.1.9. 
Table 6.1. Normalized 25-Component Compositions (mass fractions) of 168 HLW Glasses with Spinel as the Primary Crystalline Phase and Used in Spinel $\mathbf{T}_{1 \%}$ Modeling (continued).

\begin{tabular}{|c|c|c|c|c|c|c|c|c|c|c|c|c|}
\hline Glass ID & $\underset{\text { ID }^{(a)}}{\text { Group }}$ & $\mathrm{SeO}_{2}$ & $\mathrm{SiO}_{2}$ & SrO & $\mathrm{ThO}_{2}$ & $\mathrm{TiO}_{2}$ & $\mathbf{T l}_{2} \mathbf{O}$ & $\mathbf{U O}_{3}$ & $\mathrm{ZnO}$ & $\mathrm{ZrO}_{2}$ & Others & $\operatorname{Sum}^{(\mathbf{b})}$ \\
\hline HLW05-02 & W05 & .00000 & 1120 & 1200 & .03000 & .00020 & .00050 & .02500 & .01200 & .05000 & .01330 & 1.00000 \\
\hline HLW05-03 & HLW05 & .00000 & .38000 & .01200 & .03000 & .00020 & .00050 & .04500 & .01200 & .07000 & .01330 & 1.00000 \\
\hline HLW05-04 & HLW05 & .00000 & .44000 & .01200 & .03000 & .00020 & .00050 & .04500 & .01200 & .08150 & .01330 & 1.00000 \\
\hline HLW05-07 & & .00000 & .41120 & .01200 & .03000 & .00020 & .00050 & .02500 & .01200 & .05000 & .01330 & \\
\hline HLW05-09 & HLW05 & .00000 & .38230 & .01200 & .04500 & .00020 & .00050 & .02500 & .01200 & .05000 & .01330 & 1.00000 \\
\hline HLW05-11 & HLW05 & .00000 & .44000 & .01200 & .03000 & .00020 & .00050 & .02500 & .01200 & .05000 & .01330 & 1.00000 \\
\hline HLW05-13 & HLW05 & .00000 & .38000 & .01200 & .03000 & .00020 & .00050 & .04500 & .01200 & .05000 & .01330 & 1.00000 \\
\hline HLW05-14 & HLW05 & .00000 & .38000 & .01200 & .03000 & .00020 & .00050 & .04500 & .01200 & .05000 & & \\
\hline HLW05-27 & \begin{tabular}{|l|} 
HLW05 \\
\end{tabular} & .00000 & .45610 & .01200 & .01500 & .00020 & .00050 & .06500 & .01200 & .04000 & 330 & 000 \\
\hline HLW06-01 & HLW06 & .00000 & .40000 & .01470 & .01500 & .01000 & .00000 & .00750 & .02140 & .01500 & .02509 & 1.00000 \\
\hline HLW06-02 & \begin{tabular}{|l|} 
HLW06 \\
\end{tabular} & .00000 & .35000 & .01470 & .00250 & .01000 & .00000 & .00750 & .01500 & .01500 & .02509 & 1.00000 \\
\hline HLW06-03 & HLW06 & .00000 & .35000 & .04409 & .00250 & .00467 & .00000 & .00750 & .01500 & .04000 & .02587 & 1.00000 \\
\hline HLW06-04 & HLW06 & .00000 & .35000 & .04409 & .01500 & .00757 & .00000 & .00750 & .02500 & .04000 & .02674 & 1.00000 \\
\hline HLW06-05 & & & .40000 & .01470 & & & & & .01500 & .01500 & & \\
\hline HLW06-06 & HLW06 & .00000 & .35000 & .01470 & .01500 & .00940 & .00000 & .04000 & .01500 & .04000 & .02491 & 1.00000 \\
\hline HLW06-07 & \begin{tabular}{|l|} 
HLW06 \\
\end{tabular} & .00000 & .35000 & .01470 & .00250 & .01000 & .00000 & .00750 & .02500 & .01500 & .02509 & 1.00000 \\
\hline HLW06-08 & HLW06 & .00000 & .40000 & .04409 & .00250 & .00608 & .00000 & .04000 & .01500 & .01500 & .02629 & 1.00000 \\
\hline HLW06-09 & & & & .01470 & & & & & .02500 & .04000 & .02259 & \\
\hline HLW06-10 & $\begin{array}{l}\text { HLW06 } \\
\end{array}$ & .00000 & .40000 & .01470 & & .00467 & .00000 & .04000 & .02500 & .04000 & .02349 & 1.00000 \\
\hline HLW06-11 & HLW06 & .00000 & .35000 & .01470 & .01500 & .00550 & .00000 & .04000 & .01500 & .01500 & .02374 & 1.00000 \\
\hline HLW06-12 & \begin{tabular}{|l|} 
HLW06 \\
\end{tabular} & .00000 & .35000 & .04409 & .01500 & .00166 & .00000 & .00750 & .02500 & .01500 & .02496 & 1.00000 \\
\hline HLW06-13 & HLW06 & .00000 & .35000 & .01470 & .01500 & .00940 & .00000 & .04000 & .01500 & .04000 & .02491 & 1.00000 \\
\hline HLW06-14 & HLW06 & .00000 & .35000 & .01470 & .01500 & .01000 & .00000 & .00750 & .01500 & .03290 & .02509 & 1.00000 \\
\hline HLW06-15 & HLW06 & .00000 & .35000 & .01470 & .00250 & .00166 & .00000 & .00750 & .01500 & .04000 & .02259 & 1.00000 \\
\hline HLW06-16 & HLW06 & .00000 & .35000 & .01470 & .01500 & .00317 & .00000 & .04000 & .02500 & .01500 & .02304 & 1.00000 \\
\hline HLW06-17 & \begin{tabular}{|l|} 
HLW06 \\
\end{tabular} & .00000 & .40000 & .01470 & .01500 & .01000 & .00000 & .00750 & .02140 & .01500 & .02509 & 1.00000 \\
\hline HLW06-18 & HLW06 & .00000 & .40000 & .01470 & .01500 & .00276 & .00000 & .00750 & .02500 & .04000 & .02292 & 1.00000 \\
\hline HLW06-19 & \begin{tabular}{|l} 
HLW06 \\
\end{tabular} & .00000 & .35000 & .01470 & .00250 & .00166 & .00000 & .00750 & .02500 & .01500 & .02259 & 1.00000 \\
\hline HLW06-20 & HLW06 & .00000 & .35000 & .01470 & .00250 & .01000 & .00000 & .04000 & .02500 & .01500 & .02509 & 1.00000 \\
\hline HLW06-25 & HLW06 & .00000 & .42240 & .00000 & .05940 & .01000 & .00000 & .00000 & .04000 & .00000 & .02390 & 1.00000 \\
\hline
\end{tabular}

(a) The Group IDs are described in Sections 2.1.1 to 2.1.9.

(b) The component mass fractions are normalized to sum to one over the 25 components listed in this table. The normalized component mass fractions listed in this table were rounded to five decimals, and may not sum exactly to 1.00000 as listed. However, complete compositions listed to more decimal places and summing to 1.0000 were used for property-composition modeling. 
Table 6.1. Normalized 25-Component Compositions (mass fractions) of 168 HLW Glasses with Spinel as the Primary Crystalline Phase and Used in Spinel $\mathbf{T}_{1 \%}$ Modeling (continued).

\begin{tabular}{|c|c|c|c|c|c|c|c|c|c|c|c|c|c|c|c|c|}
\hline Glass ID & $\underset{\text { ID }^{(\mathbf{a})}}{\text { Group }}$ & $\mathbf{A l}_{2} \mathbf{O}_{3}$ & $\mathbf{B}_{2} \mathbf{O}_{3}$ & $\mathrm{CaO}$ & CdO & $\mathrm{Cr}_{2} \mathrm{O}_{3}$ & $\mathrm{Fe}_{2} \mathrm{O}_{3}$ & $\mathrm{~K}_{2} \mathrm{O}$ & $\mathbf{L a}_{2} \mathbf{O}_{3}$ & $\mathbf{L i}_{2} \mathbf{O}$ & MgO & MnO & $\mathrm{Na}_{2} \mathrm{O}$ & $\mathrm{NiO}$ & $\mathrm{PbO}$ & $\mathbf{S b}_{2} \mathbf{O}_{3}$ \\
\hline HLW06-28 & HLW06 & .01880 & .15000 & .01000 & .00000 & .00600 & .11480 & .01640 & .00000 & .06010 & .01170 & .00000 & .03700 & .00000 & .00910 & .00000 \\
\hline HLW06-30 & HLW06 & .13000 & .04300 & .00000 & .00000 & .00000 & .15000 & .00000 & .00000 & .00000 & .00000 & .00000 & .20000 & .00000 & .00000 & .00000 \\
\hline HLW06-32 & ILW06 & .01880 & .15000 & .00000 & .00000 & .00600 & .15000 & .00000 & .00000 & .00000 & .00000 & .08000 & .20000 & .00000 & .00000 & .00000 \\
\hline HLW07-01 & ILW07 & \begin{tabular}{|l|}
.07161 \\
\end{tabular} & .09206 & .00150 & \begin{tabular}{|l}
.00237 \\
.0023
\end{tabular} & \begin{tabular}{|l}
.00277 \\
\end{tabular} & .07993 & \begin{tabular}{|l|}
.00290 \\
\end{tabular} & .00125 & .01802 & .00000 & \begin{tabular}{|l|l|}
.03171 \\
\end{tabular} & .11287 & .00422 & .00240 & .00200 \\
\hline HLW07-02 & HLW07 & .05500 & .09149 & .00500 & .00500 & .00040 & .10001 & .00060 & .00300 & .03701 & .00120 & .03500 & .09001 & .00800 & .00080 & .00050 \\
\hline HLW07-03 & HLW07 & .03888 & .08732 & .00499 & .00200 & .00140 & .06939 & .00060 & .00299 & .03710 & .00120 & .02698 & .09093 & .00395 & .00174 & .00100 \\
\hline HLW07-04 & HLW07 & .08500 & .14000 & .00500 & .00050 & .00020 & .09500 & .00060 & .00300 & .06000 & .00120 & .00000 & .04000 & .00100 & .00040 & .00200 \\
\hline HLW07-05 & HLW07 & \begin{tabular}{|l|}
.04961 \\
\end{tabular} & .04961 & .00498 & .00050 & .00496 & .13891 & .00060 & .00299 & .04750 & .00120 & .06945 & .11693 & .00100 & .00040 & .00020 \\
\hline HLW07-06 & HLW07 & .11501 & .06001 & .00300 & .01000 & .00600 & .04000 & .00580 & .00250 & .00000 & .00000 & .06001 & .12530 & .00000 & .01010 & .00400 \\
\hline HLW07-11 & HLW07 & .11501 & .06001 & .00300 & .01000 & .00600 & .10495 & .00580 & .00250 & .04500 & .00000 & .00500 & .17016 & .01000 & .01010 & .00400 \\
\hline HLW07-16 & HLW07 & .04400 & .11569 & .00300 & \begin{tabular}{|l|}
.00000 \\
\end{tabular} & .00600 & .04000 & .00580 & .00250 & .03853 & .00000 & .06001 & .18002 & .01000 & .00000 & .00400 \\
\hline HLW07-17 & HLW07 & .11501 & .13001 & .00300 & .00000 & .00050 & .04000 & .00580 & .00250 & .04253 & .00000 & .06001 & .18002 & .00000 & .00000 & .00400 \\
\hline HLW07-20 & HLW07 & .11501 & .13001 & .00300 & .00000 & .00600 & .05501 & .00580 & .00250 & .04500 & .00000 & .06001 & .06001 & .00000 & .00000 & .00400 \\
\hline HLW07-24 & HLW07 & \begin{tabular}{|l|}
.11501 \\
\end{tabular} & .13001 & .00300 & \begin{tabular}{|l|}
.00000 \\
\end{tabular} & .00600 & .05501 & \begin{tabular}{|l|}
.00580 \\
\end{tabular} & .00250 & .00000 & .00000 & \begin{tabular}{|l|l|}
.00500 \\
\end{tabular} & \begin{tabular}{|l|l|}
.16120 \\
\end{tabular} & .01000 & .00000 & .00400 \\
\hline HLW07-26 & HLW07 & .10001 & .08000 & .00150 & .00000 & .00150 & .06000 & .00290 & .00125 & .03460 & .00000 & .02500 & .10001 & .00650 & .00000 & .00200 \\
\hline HLW07-27 & HLW07 & .10001 & .11001 & .00150 & .00000 & .00400 & .06000 & .00290 & .00125 & .03500 & .00000 & .02500 & .10001 & .00200 & .00000 & .00200 \\
\hline HLW07-28 & HLW07 & .10001 & .08000 & .00150 & .00000 & .00150 & .06000 & .00290 & .00125 & .03500 & .00000 & .02500 & .14001 & .00650 & .00000 & .00200 \\
\hline HLW07-29 & HLW07 & \begin{tabular}{|l|}
.05000 \\
\end{tabular} & .11001 & .00150 & .00000 & .00150 & .11001 & .00290 & .00125 & .01000 & .00000 & .04000 & .10782 & .00650 & .00000 & .00200 \\
\hline HLW07-30 & HLW07 & .05000 & .08000 & .00150 & .00000 & .00400 & .11001 & .00290 & .00125 & .01000 & .00000 & .03687 & .12614 & .00200 & .00000 & .00200 \\
\hline HLW07-31 & HLW07 & \begin{tabular}{|l|}
.10001 \\
\end{tabular} & .11001 & .00150 & .00500 & .00400 & .06000 & .00290 & .00125 & .01357 & .00000 & .02500 & .10001 & .00403 & .00505 & .00200 \\
\hline HLW07-32 & HLW07 & .05000 & .08000 & .00150 & .00500 & .00150 & .11001 & .00290 & .00125 & .01000 & .00000 & .02500 & .14001 & .00650 & .00505 & .00200 \\
\hline HLW07-33 & HLW07 & .10001 & .08000 & .00150 & .00000 & .00400 & .06297 & .00290 & .00125 & .01000 & .00000 & .04000 & .12268 & .00650 & .00000 & .00200 \\
\hline HLW07-37 & & & .08000 & .00150 & & & .10501 & .00290 & .00125 & .03500 & .00000 & .04000 & .13811 & .00200 & .00505 & .00200 \\
\hline HLW07-38 & HLW07 & \begin{tabular}{|l|}
.05000 \\
\end{tabular} & .11001 & .00150 & .00500 & .00400 & .06500 & .00290 & .00125 & .01000 & .00000 & .04000 & .10393 & .00200 & .00505 & .00200 \\
\hline HLW07-39 & HLW07 & .05500 & .11001 & .00150 & .00500 & .00400 & .06000 & .00290 & .00125 & .01000 & .00000 & .02500 & .13629 & .00200 & .00505 & .00200 \\
\hline HLW07-40 & HLW07 & .05000 & .08000 & .00150 & .00500 & .00400 & .10384 & .00290 & .00125 & .01000 & .00000 & .02500 & .10001 & .00200 & .00505 & .00200 \\
\hline HLW-ALG-03 & HLWALG & .01926 & .08621 & .00339 & .00000 & .00501 & .12650 & .00127 & .00103 & .03057 & .00098 & .02095 & .18966 & .01001 & .00207 & .00000 \\
\hline HLW-ALG-05 & HLWALG & \begin{tabular}{|l|}
.01927 \\
\end{tabular} & .04810 & .00521 & \begin{tabular}{|l|}
.01198 \\
\end{tabular} & .00415 & .12536 & .00197 & .00160 & .04286 & .00149 & .06906 & .08937 & .00781 & .00320 & .00000 \\
\hline HLW-ALG-06 & HLWALG & .09670 & .04807 & .00579 & .01322 & .00201 & .10620 & .00219 & .00178 & .02530 & .00164 & .04007 & .15635 & .00481 & .00357 & .00000 \\
\hline
\end{tabular}

(a) The Group IDs are described in Sections 2.1.1 to 2.1.9. 
Table 6.1. Normalized 25-Component Compositions (mass fractions) of 168 HLW Glasses with Spinel as the Primary Crystalline Phase and Used in Spinel $\mathrm{T}_{1 \%}$ Modeling (continued).

\begin{tabular}{|c|c|c|c|c|c|c|c|c|c|c|c|c|}
\hline Glass ID & $\underset{\text { ID }^{(\text {a) }}}{\operatorname{Group}}$ & $\mathrm{SeO}_{2}$ & $\mathrm{SiO}_{2}$ & SrO & $\mathrm{ThO}_{2}$ & $\mathrm{TiO}_{2}$ & $\mathbf{T l}_{2} \mathbf{O}$ & $\mathbf{U O}_{3}$ & ZnO & $\mathrm{ZrO}_{2}$ & Others & Sum $^{(b)}$ \\
\hline HLW06-28 & 06 & .00000 & .42720 & .00000 & .00000 & .01000 & .00000 & 6500 & .04000 & .00000 & .02390 & 1.00000 \\
\hline HLW06-30 & LW06 & .00000 & .35110 & .00000 & .00000 & .00000 & .00000 & .06500 & .04000 & .00000 & .02090 & 1.00000 \\
\hline HLW06-32 & LW06 & .00000 & .37430 & .00000 & .00000 & .00000 & .00000 & .00000 & .00000 & .00000 & .02090 & 1.00000 \\
\hline HLW07-01 & LW07 & .00000 & .41825 & .04260 & .02138 & .00000 & .00000 & .02206 & .00983 & .04300 & .01725 & 1.00000 \\
\hline HLW07-02 & LW07 & .00150 & .49003 & .01500 & .00000 & .00030 & .00140 & .00000 & .02000 & .02500 & .01374 & 1.00000 \\
\hline HLW07-03 & 97 & .00100 & .43059 & .02705 & .03658 & .00030 & .00093 & .03032 & .01920 & .06767 & 590 & 000 \\
\hline HLW07-04 & & .00200 & .53000 & .00080 & .00000 & .00030 & .00019 & .00000 & .02000 & .00000 & 281 & 000 \\
\hline HLW07-05 & 07 & .00199 & .39825 & .00000 & .00000 & .00030 & .00019 & .06306 & .03461 & .00000 & .01276 & 1.00000 \\
\hline HLW07-06 & LW07 & .00000 & .35004 & .10001 & .00000 & .00000 & .00000 & .04100 & .00000 & .02951 & .03770 & 1.00000 \\
\hline HLW07-11 & 7 & .00000 & .35004 & .02332 & .00000 & .00000 & .00000 & .04100 & .00000 & .01000 & .02410 & 1.00000 \\
\hline HLW07-16 & & .00000 & .35004 & .00000 & .00000 & .00000 & .00000 & .00000 & .02500 & .09601 & 40 & 000 \\
\hline HLW07-17 & & .00000 & .35861 & .00000 & .00000 & .00000 & .00000 & .00000 & .00000 & .02500 & .03300 & 0000 \\
\hline HLW07-20 & & .00000 & .46179 & .00000 & .02246 & .00000 & .00000 & .00000 & .00000 & .01000 & .01940 & 1.00000 \\
\hline HLW07-24 & WOO7 & .00000 & .37445 & .00000 & .04400 & .00000 & .00000 & .04100 & .00000 & .01000 & .03300 & 1.00000 \\
\hline HLW07-26 & & .00000 & .47002 & .02500 & .03500 & .00000 & .00000 & .01500 & .00500 & .02500 & .00970 & 1.00000 \\
\hline & & & .40002 & & & & & & .00500 & & & \\
\hline HLW07-28 & 7 & .00000 & .40002 & .03100 & .03500 & .00000 & .00000 & .01500 & .01500 & .02500 & .02330 & 1.00000 \\
\hline HLW07-29 & & .00000 & .40002 & .05179 & .03500 & .00000 & .00000 & .03000 & .00500 & .02500 & .00970 & 1.00000 \\
\hline HLW07-30 & LW07 & .00000 & .47002 & .02500 & .01000 & .00000 & .00000 & .01500 & .00500 & .02500 & .02330 & 1.00000 \\
\hline & & & .40002 & & & & & & .00500 & .02500 & & \\
\hline HLW07-32 & & & .40002 & & & .00000 & .00000 & .01500 & .01096 & .06500 & & 1.00000 \\
\hline HLW07-33 & HLW07 & .00000 & .42207 & .06940 & .01000 & .00000 & .00000 & .01500 & .01500 & .02500 & .00970 & 1.00000 \\
\hline HLW07-37 & HLW07 & .00000 & .40002 & .02500 & .03500 & .00000 & .00000 & .01500 & .00500 & .02500 & .02565 & 1.00000 \\
\hline HLW07-38 & WOO7 & .00000 & .41670 & .02500 & .03500 & .00000 & .00000 & .01500 & .01500 & .06500 & .02565 & 1.00000 \\
\hline HLV & & & .44794 & .02500 & .01000 & .00000 & & .01500 & .00500 & .06500 & & \\
\hline HLW07-40 & HLW07 & .00000 & .42803 & .07000 & .03500 & .00000 & .00000 & .02119 & .01500 & .02617 & .01205 & 1.00000 \\
\hline HLW-ALG-03 & HLWALG & .00000 & .44365 & .00000 & .00000 & .00043 & .00000 & .00000 & .00032 & .05433 & .00434 & 1.00000 \\
\hline HLW-ALG-05 & HLWALG & .00000 & .46197 & .09891 & .00000 & .00026 & .00000 & .00000 & .00050 & .00000 & .00695 & 1.00000 \\
\hline HLW-ALG-06 & HLWALG & .00000 & .37279 & .08015 & .01603 & .00025 & .00000 & .00601 & .00055 & .00801 & .00850 & 1.00000 \\
\hline
\end{tabular}

(a) The Group IDs are described in Sections 2.1.1 to 2.1.9.

(b) The component mass fractions are normalized to sum to one over the 25 components listed in this table. The normalized component mass fractions listed in this table were rounded to five decimals, and may not sum exactly to 1.00000 as listed. However, complete compositions listed to more decimal places and summing to 1.0000 were used for property-composition modeling. 
Table 6.1. Normalized 25-Component Compositions (mass fractions) of 168 HLW Glasses with Spinel as the Primary Crystalline Phase and Used in Spinel $\mathbf{T}_{1 \%}$ Modeling (continued).

\begin{tabular}{|c|c|c|c|c|c|c|c|c|c|c|c|c|c|c|c|c|}
\hline Glass ID & $\underset{\text { ID }^{\text {(a) }}}{\text { Group }}$ & $\mathbf{A l}_{2} \mathbf{O}_{3}$ & $\mathrm{~B}_{2} \mathrm{O}_{3}$ & $\mathrm{CaO}$ & CdO & $\mathrm{Cr}_{2} \mathrm{O}_{3}$ & $\mathrm{Fe}_{2} \mathrm{O}_{3}$ & $\mathbf{K}_{2} \mathbf{O}$ & $\mathrm{La}_{2} \mathrm{O}_{3}$ & $\mathbf{L i}_{\mathbf{2}} \mathbf{O}$ & MgO & MnO & $\mathrm{Na}_{2} \mathbf{O}$ & $\mathrm{NiO}$ & PbO & $\mathrm{Sb}_{2} \mathbf{O}_{3}$ \\
\hline \begin{tabular}{|l|} 
HLW-ALG-09 \\
\end{tabular} & HLWALG & .05480 & .04808 & .00560 & .00084 & .00211 & .13931 & .00354 & .00387 & .01987 & .00492 & .03916 & .15116 & .00189 & .00410 & .00000 \\
\hline HLW-ALG-10 & HLWALG & .01926 & .09448 & .00332 & .00854 & .00501 & .10984 & .00125 & .00101 & .03329 & .00096 & .00000 & .17280 & .00000 & .00202 & .00000 \\
\hline \begin{tabular}{|l|} 
HLW-ALG-12 \\
\end{tabular} & HLWALG & .05938 & \begin{tabular}{|l|}
.04807 \\
\end{tabular} & .00586 & .00406 & .00285 & .12540 & .00222 & .00180 & .02750 & .00166 & .02029 & .15899 & .00812 & .00361 & .00000 \\
\hline HLW-ALG-14 & HLWALG & .03543 & \begin{tabular}{|l|}
.04809 \\
\end{tabular} & .00507 & .01486 & .00000 & .12562 & .00191 & .00155 & .06012 & .00146 & .06715 & .04804 & .00759 & .00311 & .00000 \\
\hline \begin{tabular}{|l|} 
HLW-ALG-15 \\
\end{tabular} & HLWALG & .09731 & .14029 & .00424 & .00000 & .00338 & .09780 & .00161 & .00130 & .01928 & .00121 & .00000 & .17583 & .00636 & .00261 & .00000 \\
\hline \begin{tabular}{|l} 
HLW-ALG-17 \\
\end{tabular} & HLWALG & .01926 & \begin{tabular}{|l|}
.10338 \\
\end{tabular} & .00331 & .00000 & .00501 & .12515 & .00124 & .00101 & .02020 & .00095 & .06912 & .17414 & .00997 & .00202 & .00000 \\
\hline \begin{tabular}{|l|} 
HLW-ALG-18 \\
\end{tabular} & HLWALG & .11360 & .11109 & .00339 & .00000 & .00000 & .10369 & .00128 & .00103 & .03437 & .00098 & .00000 & .14807 & .00000 & .00207 & .00000 \\
\hline \begin{tabular}{|l|} 
HLW-ALG-19 \\
\end{tabular} & HLWALG & .01926 & .09652 & .00340 & .00000 & .00501 & .12652 & .00127 & .00103 & .02659 & .00098 & .02096 & .16131 & .01001 & .00207 & .00000 \\
\hline \begin{tabular}{|l|} 
HLW-ALG-20 \\
\end{tabular} & HLWALG & .01926 & \begin{tabular}{|l|}
.07754 \\
\end{tabular} & .00340 & .00000 & .00501 & .12651 & .00127 & .00103 & .02926 & .00098 & .02095 & .17400 & .01001 & .00207 & .00000 \\
\hline \begin{tabular}{|l} 
HLW-ALG-25 \\
\end{tabular} & HLWALG & .01926 & \begin{tabular}{|l|}
.10096 \\
\end{tabular} & .00332 & .00000 & .00501 & .11817 & .00125 & .00101 & .02020 & .00096 & .07012 & .17414 & .01002 & .00203 & .00000 \\
\hline \begin{tabular}{|l} 
HLW-ALG-27 \\
\end{tabular} & HLWALG & .13025 & \begin{tabular}{|l|}
.14027 \\
\end{tabular} & .00387 & .00000 & .00000 & .11905 & .00146 & .00119 & .01928 & .00111 & .00000 & .17589 & .00000 & .00238 & .00000 \\
\hline \begin{tabular}{|l|} 
HLW-ALG-28 \\
\end{tabular} & HLWALG & .08839 & .14027 & .00388 & .00000 & .00322 & .12884 & .00147 & .00119 & .01928 & .00111 & .02330 & .17589 & .00589 & .00238 & .00000 \\
\hline HLW-ALG-30 & HLWALG & .07250 & \begin{tabular}{|l|}
.09597 \\
\end{tabular} & .00422 & .00631 & .00141 & .11020 & .00133 & .00259 & .03099 & .00102 & .00323 & .15321 & .00485 & .00073 & .00000 \\
\hline \begin{tabular}{|l|} 
HLW-ALG-31 \\
\end{tabular} & HLWALG & .01926 & .10888 & .00340 & .00000 & .00501 & .12650 & .00127 & .00103 & .03078 & .00098 & .02095 & .11711 & .01001 & .00207 & .00000 \\
\hline \begin{tabular}{|l|} 
HLW-ALG-32 \\
\end{tabular} & HLWALG & .06000 & \begin{tabular}{|l|}
.04810 \\
\end{tabular} & .00529 & .01213 & .00420 & .12753 & .00200 & .00162 & .03972 & .00151 & .06996 & .09317 & .00791 & .00324 & .00000 \\
\hline \begin{tabular}{|l} 
HLW-ALG-34 \\
\end{tabular} & HLWALG & .01926 & .08223 & .00331 & .00000 & .00501 & .12515 & .00124 & .00101 & .02020 & .00096 & .06912 & .19002 & .00997 & .00202 & .00000 \\
\hline \begin{tabular}{|l|} 
HLW-ALG-35 \\
\end{tabular} & HLWALG & .05519 & \begin{tabular}{|l|}
.04808 \\
\end{tabular} & .00564 & .00085 & .00212 & .14024 & .00356 & .00390 & \begin{tabular}{|l|}
.02801 \\
\end{tabular} & .00495 & .03942 & .10818 & .00190 & .00413 & .00000 \\
\hline HLW-ALG-36 & HLWALG & .06536 & \begin{tabular}{|l|}
.06511 \\
\end{tabular} & .00645 & .00447 & .00314 & .13819 & .00245 & .00199 & .02903 & .00182 & .02236 & .12535 & .00894 & .00398 & .00000 \\
\hline \begin{tabular}{|l|} 
HLW-ALG-40 \\
\end{tabular} & HLWALG & .09195 & \begin{tabular}{|l|}
.08436 \\
\end{tabular} & .00535 & .00802 & .00179 & .14008 & .00170 & .00329 & .03054 & .00128 & .00411 & \begin{tabular}{|l}
.14348 \\
\end{tabular} & .00616 & .00092 & .00000 \\
\hline
\end{tabular}

(a) The Group IDs are described in Sections 2.1.1 to 2.1.9. 
Table 6.1. Normalized 25-Component Compositions (mass fractions) of 168 HLW Glasses with Spinel as the Primary Crystalline Phase and Used in Spinel $\mathbf{T}_{1 \%}$ Modeling (continued).

\begin{tabular}{|c|c|c|c|c|c|c|c|c|c|c|c|c|}
\hline Glass ID & $\begin{array}{c}\text { Group } \\
\text { ID }^{(a)}\end{array}$ & $\mathrm{SeO}_{2}$ & $\mathrm{SiO}_{2}$ & SrO & $\mathrm{ThO}_{2}$ & $\mathrm{TiO}_{2}$ & $\mathrm{Tl}_{2} \mathrm{O}$ & $\mathbf{U O}_{3}$ & $\mathrm{ZnO}$ & $\mathrm{ZrO}_{2}$ & Others & $\operatorname{Sum}^{(\mathbf{b})}$ \\
\hline HLW-ALG-09 & HLWALG & .00000 & .38868 & .07479 & .00603 & .00000 & .00000 & .01360 & .00059 & .02565 & 01142 & 1.00000 \\
\hline HLW-ALG-10 & HLWALG & .00000 & .47112 & .00000 & .00228 & .00036 & - 00000 & .00000 & .00031 & - & .00423 & 1.00000 \\
\hline HLW-ALG-12 & LWALG & .00000 & .40350 & .06087 & .01623 & .00026 & .00000 & .01623 & .00056 & .02394 & .00860 & 1.00000 \\
\hline HLW-ALG-14 & HLWALG & .00000 & .47605 & .09618 & .00000 & .00052 & .00000 & .00000 & .00048 & .00000 & .00676 & 1.00000 \\
\hline HLW-ALG-15 & HLWALG & .00000 & .37449 & .00000 & .00000 & .00000 & .00000 & .00000 & .00040 & .06845 & .00544 & 1.00000 \\
\hline HLW-ALG-17 & HLWALG & .00000 & .45869 & .00000 & .00000 & .00043 & .00000 & .00000 & .00031 & .00159 & .00421 & 1.00000 \\
\hline HLW-ALG-18 & HLWALG & .00000 & .45993 & .00000 & .00000 & .00000 & .00000 & .00000 & .01616 & .00000 & .00434 & 1.00000 \\
\hline HLW-ALG-19 & HLWALG & .00000 & .46563 & .00000 & .00000 & .00043 & .00000 & .00000 & .00032 & .05434 & .00433 & 1.00000 \\
\hline HLW-ALG-20 & HLWALG & .00000 & .46929 & .00000 & .00000 & .00043 & .00000 & .00000 & .00032 & .05434 & .00434 & 1.00000 \\
\hline HLW-ALG-25 & HLWALG & .00000 & .46478 & .00000 & .00228 & .00036 & .00000 & .00000 & .00031 & .00159 & .00423 & 1.00000 \\
\hline HLW-ALG-27 & HLWALG & .00000 & .37713 & .00000 & .00000 & .00000 & .00000 & .00000 & .02316 & .00000 & .00496 & 1.00000 \\
\hline HLW-ALG-28 & HLWALG & .00000 & .39956 & .00000 & .00000 & .00000 & .00000 & .00000 & .00037 & .00000 & .00497 & 1.00000 \\
\hline HLW-ALG-30 & HLWALG & .00000 & .44901 & .00153 & .00000 & .00000 & .00000 & .00911 & .00654 & .03343 & .01181 & 1.00000 \\
\hline HLW-ALG-31 & HLWALG & .00000 & .47666 & .00000 & .00000 & .00043 & .00000 & .00000 & .01699 & .05433 & .00433 & 1.00000 \\
\hline HLW-ALG-32 & HLWALG & .00000 & .41153 & .10020 & .00000 & .00082 & .00000 & .00000 & .00404 & .00000 & .00703 & 1.00000 \\
\hline HLW-ALG-34 & HLWALG & .00000 & .46396 & .00000 & .00000 & .00043 & .00000 & .00000 & .00031 & .00159 & .00422 & 1.00000 \\
\hline HLW-ALG-35 & HLWALG & .00000 & .40921 & .07529 & .00607 & .00000 & .00000 & .01369 & .01228 & .02582 & .01148 & 1.00000 \\
\hline HLW-ALG-36 & HLWALG & .00000 & .38173 & .06709 & .01789 & .00028 & .00000 & .01789 & .00062 & .02639 & .00947 & 1.00000 \\
\hline HLW-ALG-40 & HLWALG & .00000 & .40399 & .00195 & .00000 & .00000 & .00000 & .01158 & .00162 & .04250 & .01531 & 1.00000 \\
\hline
\end{tabular}

(a) The Group IDs are described in Sections 2.1.1 to 2.1.9.

(b) The component mass fractions are normalized to sum to one over the 25 components listed in this table. The normalized component mass fractions listed in this table were rounded to five decimals, and may not sum exactly to 1.00000 as listed. However, complete compositions listed to more decimal places and summing to 1.0000 were used for property-composition modeling. 
Table 6.2. Temperature and Volume \%-Crystallinity Data for 168 HLW Glasses with Spinel as the Primary Crystalline Phase and Used in Spinel $\mathbf{T}_{1 \%}$ Modeling.

\begin{tabular}{|c|c|c|c|c|c|c|c|c|c|c|c|c|c|c|c|c|c|c|c|}
\hline \multirow[b]{2}{*}{ Glass ID } & \multirow[b]{2}{*}{$\begin{array}{c}\text { Group } \\
\text { ID }\end{array}$} & \multicolumn{18}{|c|}{ Temperature in ${ }^{\circ} \mathrm{C}$} \\
\hline & & 650 & 700 & 750 & 800 & $\begin{array}{c}850 \\
\text { (Set 1) }\end{array}$ & $\begin{array}{c}\mathbf{8 5 0} \\
(\text { Set 2) }\end{array}$ & 875 & $\begin{array}{c}900 \\
\text { (Set 1) }\end{array}$ & $\begin{array}{c}900 \\
(\text { Set 2) }\end{array}$ & $\begin{array}{c}950 \\
\text { (Set 1) }\end{array}$ & $\begin{array}{c}950 \\
(\text { Set 2) }\end{array}$ & $\begin{array}{c}950 \\
(\text { Set 3) }\end{array}$ & $\begin{array}{c}1000 \\
\text { (Set 1) }\end{array}$ & $\begin{array}{c}1000 \\
\text { (Set 2) }\end{array}$ & 1050 & 1100 & 1150 & 1200 \\
\hline HLW02-01 & HLW02 & - (a) & - & 3.0 & - & - & 1.88 & - & - & - & 0.27 & - & 0.5 & - & - & - & - & - & - \\
\hline HLW02-02 & HLW02 & - & - & - & - & - & 1.1 & - & - & 1.1 & - & - & 0.5 & - & - & - & - & - & - \\
\hline HLW02-03 & HLW02 & - & - & 1.8 & - & - & 0.7 & - & - & - & - & - & 0.2 & - & - & - & - & - & - \\
\hline HLW02-04 & HLW02 & - & - & 23.4 & 14.2 & 0.1 & 0.7 & - & - & - & - & - & - & - & - & - & - & - & - \\
\hline HLW02-06 & HLW02 & - & - & - & - & - & 5.1 & - & 3.2 & - & 2.8 & - & 2.4 & - & - & 0.8 & - & - & - \\
\hline HLW02-07 & HLW02 & - & - & 1 & - & - & 0.8 & - & 0.5 & - & - & - & 0.4 & - & - & - & - & - & - \\
\hline HLW02-08 & HLW02 & - & - & 1.2 & - & - & 0.6 & - & - & - & - & - & 0.1 & - & - & - & - & - & - \\
\hline HLW02-09 & HLW02 & - & - & - & - & - & 2.9 & - & 4.4 & 3.5 & - & - & 1.2 & 0.2 & - & - & - & - & - \\
\hline HLW02-11 & HLW02 & - & 1.8 & 1.2 & - & - & 1.0 & - & - & - & - & - & 0.1 & - & - & - & - & - & - \\
\hline HLW02-12 & HLW02 & - & - & - & - & - & 4.4 & - & 3.3 & - & - & - & - & - & - & 1.0 & - & - & - \\
\hline HLW02-13 & HLW02 & - & - & - & - & - & 5.6 & 4.3 & 0.2 & - & - & - & - & 1.0 & - & 0.3 & - & - & - \\
\hline HLW02-15 & HLW02 & - & - & - & - & - & 3.7 & - & 3.1 & - & - & - & 2.7 & - & - & 0.9 & - & - & - \\
\hline HLW02-16 & HLW02 & - & - & - & - & - & 4.0 & - & 3.6 & - & 3.1 & - & 1.3 & 0.7 & - & - & - & - & - \\
\hline HLW02-17 & HLW02 & - & - & - & - & - & - & - & 2.07 & - & 0.9 & - & 1.2 & 0.2 & - & 0.4 & - & - & - \\
\hline HLW02-18 & HLW02 & - & - & 2.2 & - & - & 1.8 & - & - & - & - & - & 1.0 & - & - & - & - & - & - \\
\hline HLW02-19 & HLW02 & - & - & - & - & 1.6 & 2.4 & - & 1.2 & - & 0.8 & - & 0.6 & - & - & - & - & - & - \\
\hline HLW02-20 & HLW02 & - & - & - & - & - & 6.4 & - & 1.65 & - & 0.8 & - & 2.1 & - & - & - & - & - & - \\
\hline HLW02-22 & HLW02 & - & - & - & - & - & 1.6 & - & - & 0.7 & - & - & 1.5 & - & - & 0.2 & - & - & - \\
\hline HLW02-23 & HLW02 & - & - & - & - & - & 2.4 & - & 1.7 & - & 1.1 & - & 0.8 & - & - & - & - & - & - \\
\hline HLW02-24 & HLW02 & - & - & - & - & - & 2.3 & - & 1.24 & - & 0.61 & - & - & - & - & - & - & - & - \\
\hline HLW02-25 & HLW02 & - & - & - & - & - & 2.0 & - & 0.5 & - & 1.0 & - & - & - & - & - & - & - & - \\
\hline HLW02-26 & HLW02 & - & - & - & - & - & 3.9 & - & 2.47 & - & - & 0.9 & 1.6 & 0.8 & - & - & - & - & - \\
\hline HLW02-27 & HLW02 & - & - & - & - & - & 2.5 & - & 1.28 & - & - & - & 1.5 & 0.5 & - & 0.2 & - & - & - \\
\hline HLW02-28 & HLW02 & - & - & - & - & - & 1.9 & - & - & 1.1 & - & - & 0.9 & 0.1 & - & - & - & - & - \\
\hline HLW02-29 & HLW02 & - & - & - & - & - & 3.5 & - & 1.86 & - & 0.7 & 0.6 & 0.8 & - & - & 0.2 & - & - & - \\
\hline HLW02-30 & HLW02 & - & - & 2.3 & - & - & 1.1 & - & - & - & - & - & 0.8 & - & - & - & - & - & - \\
\hline HLW02-31 & HLW02 & - & 1.2 & 1.3 & - & - & 0.99 & - & - & - & - & - & 0.2 & - & - & - & - & - & - \\
\hline HLW02-32 & HLW02 & - & 1.1 & - & 1.4 & - & 0.267 & - & 0.4 & - & - & - & 0.4 & - & - & - & - & - & - \\
\hline HLW02-33 & HLW02 & - & - & - & - & - & 5.8 & - & 2.74 & - & 0.14 & 1.5 & 1.7 & - & - & - & - & - & - \\
\hline HLW02-34 & HLW02 & - & - & - & - & - & 6.2 & - & 2.46 & - & 0.11 & 0.6 & 1.5 & - & - & - & - & - & - \\
\hline HLW02-35 & HLW02 & - & - & - & - & - & 7.2 & - & - & - & 1.7 & - & 2.3 & 0.8 & - & - & - & - & - \\
\hline HLW02-36 & HLW02 & - & - & 1.9 & - & - & 1.4 & - & 0.3 & 0.6 & - & - & 0.8 & - & - & - & - & - & - \\
\hline HLW02-37 & HLW02 & - & - & - & - & - & 2.9 & - & 2.1 & - & 0.8 & - & - & - & - & 0.6 & - & - & - \\
\hline HLW02-38 & HLW02 & - & - & - & - & - & 2.7 & - & 1.25 & - & 1.61 & - & 1.5 & - & - & 0.2 & - & - & - \\
\hline HLW02-39 & HLW02 & - & - & - & - & - & 2.5 & - & 1.79 & - & 1.95 & - & 1.6 & - & - & 0.2 & - & - & - \\
\hline
\end{tabular}

(a) The Group IDs are described in Sections 2.1.1 to 2.1.9.

(b) A dash ( - ) indicates that no data were collected for the specified temperatures.

(c) Table entries that were excluded from calculations to determine the $T_{1 \%}$ value for a glass are shaded gray. 
Table 6.2. Temperature and Volume \%-Crystallinity Data for 168 HLW Glasses with Spinel as the Primary Crystalline Phase and Used in Spinel $\mathbf{T}_{1 \%}$ Modeling (continued).

\begin{tabular}{|c|c|c|c|c|c|c|c|c|c|c|c|c|c|c|c|c|c|c|c|}
\hline \multirow[b]{2}{*}{ Glass ID } & \multirow{2}{*}{$\begin{array}{c}\text { Group } \\
\text { ID }\end{array}$} & \multicolumn{18}{|c|}{ Temperature in ${ }^{\circ} \mathrm{C}$} \\
\hline & & 650 & 700 & 750 & 800 & $\begin{array}{c}\mathbf{8 5 0} \\
(\text { Set 1) }\end{array}$ & $\begin{array}{c}850 \\
\text { (Set 2) }\end{array}$ & 875 & $\begin{array}{c}900 \\
\text { (Set 1) }\end{array}$ & $\begin{array}{c}900 \\
(\text { Set 2) }\end{array}$ & $\begin{array}{c}950 \\
\text { (Set 1) }\end{array}$ & $\begin{array}{c}950 \\
(\text { Set 2) }\end{array}$ & $\begin{array}{c}950 \\
\text { (Set 3) }\end{array}$ & $\begin{array}{c}1000 \\
\text { (Set 1) }\end{array}$ & $\begin{array}{c}1000 \\
\text { (Set 2) }\end{array}$ & 1050 & 1100 & 1150 & 1200 \\
\hline HLW02-40 & HLW02 & - & - & 4.0 & - & - & 1.95 & - & - & - & - & - & 1.6 & 0.4 & - & - & - & - & - \\
\hline HLW02-41 & \begin{tabular}{|l|} 
HLW02 \\
\end{tabular} & - & - & - & - & - & 2.4 & - & 1.04 & - & 0.6 & - & 0.6 & - & - & 0.1 & - & - & - \\
\hline HLW02-42 & $\begin{array}{l}\text { HLW02 } \\
\end{array}$ & - & 2.1 & 1.1 & - & - & 0.66 & - & 0.3 & - & - & - & 0.5 & - & - & - & - & - & - \\
\hline HLW02-43 & $\begin{array}{l}\text { HLW02 } \\
\end{array}$ & - & - & - & - & - & 2.6 & - & 0.58 & - & 0.31 & - & 0.9 & - & - & - & - & - & - \\
\hline HLW02-44 & \begin{tabular}{|l|} 
HLW02 \\
\end{tabular} & - & - & 1.3 & 1.1 & 0.8 & - & - & 0.57 & - & - & - & - & - & - & - & - & - & - \\
\hline HLW02-45 & \begin{tabular}{|l|} 
HLW02 \\
\end{tabular} & - & - & - & - & - & 2.4 & - & 0.95 & - & - & - & 0.8 & - & - & - & - & - & - \\
\hline HLW02-46 & \begin{tabular}{|l|} 
HLW02 \\
\end{tabular} & - & - & - & - & - & 2.9 & - & 1.6 & - & 1.07 & - & 0.9 & - & - & 0.2 & - & - & - \\
\hline HLW02-47 & HLW02 & 4.5 & 4.9 & - & 2.4 & - & 0.8 & - & - & - & - & - & - & - & - & - & - & - & - \\
\hline HLW02-48 & \begin{tabular}{|l|} 
HLW02 \\
\end{tabular} & - & - & 2.7 & - & - & 1.5 & - & - & - & - & - & 1.4 & 0.7 & - & - & - & - & - \\
\hline HLW02-49 & $\begin{array}{l}\text { HLW02 } \\
\end{array}$ & - & - & - & - & - & 3.68 & - & 1.73 & - & 2.1 & 0.9 & 2.4 & - & - & 0.8 & - & - & - \\
\hline HLW02-50 & \begin{tabular}{|l|} 
HLW02 \\
\end{tabular} & - & - & - & - & - & 5.3 & - & 1.96 & - & 1.52 & - & 0.8 & - & - & 0.9 & - & - & - \\
\hline HLW02-51 & \begin{tabular}{|l|} 
HLW02 \\
\end{tabular} & - & - & - & - & - & 2.0 & 1.2 & 0.8 & - & - & 0.8 & - & - & - & - & - & - & - \\
\hline HLW02-52 & $\begin{array}{l}\text { HLW02 } \\
\end{array}$ & - & - & 2.5 & - & 1.3 & - & - & 2.1 & - & 1.2 & - & - & - & - & 0.4 & - & - & - \\
\hline HLW02-53 & HLW02 & - & - & - & - & 2.1 & - & - & 1.4 & 1.4 & 1.0 & - & 0.8 & 0.4 & 0.9 & - & - & - & - \\
\hline HLW02-54 & \begin{tabular}{|l|} 
HLW02 \\
\end{tabular} & - & - & - & - & - & 2.6 & - & 1.1 & - & - & - & 0.1 & - & - & - & - & - & - \\
\hline HLW02-55 & $\begin{array}{l}\text { HLW02 } \\
\end{array}$ & - & 1.9 & 1.1 & - & - & 1.4 & - & - & - & - & - & 0.2 & - & - & - & - & - & - \\
\hline HLW02-56 & HLW02 & - & 1.4 & 0.9 & - & - & 1.0 & - & 0.4 & - & - & - & 0.5 & - & - & - & - & - & - \\
\hline HLW02-57 & \begin{tabular}{|l|} 
HLW02 \\
\end{tabular} & - & 1.3 & 0.9 & - & 0.3 & - & - & - & - & - & - & - & - & - & - & - & - & - \\
\hline HLW03-01 & \begin{tabular}{|l|} 
HLW03 \\
\end{tabular} & - & - & 13 & - & - & 10 & - & - & - & - & - & 1.4 & - & - & 2.2 & 1.1 & 0.7 & - \\
\hline HLW03-02 & \begin{tabular}{|l|} 
HLW03 \\
\end{tabular} & - & - & - & - & - & 7.3 & - & - & - & 4.6 & - & 2.9 & - & - & 2.0 & 3.3 & 3.3 & 4.0 \\
\hline HLW03-03 & \begin{tabular}{|l|} 
HLW03 \\
\end{tabular} & - & - & - & - & - & - & - & - & - & 2.6 & - & 2.8 & - & - & 2.5 & - & 2.0 & $0.1^{(\mathrm{d})}$ \\
\hline HLW03-04 & \begin{tabular}{|l|} 
HLW03 \\
\end{tabular} & - & - & - & 8.3 & 2.4 & 2.8 & - & - & - & - & - & 0.6 & - & - & 0.4 & - & - & - \\
\hline HLW03-05 & \begin{tabular}{|l|} 
HLW03 \\
\end{tabular} & - & - & - & - & - & 2.1 & - & 1.2 & - & - & - & 0.5 & - & - & - & - & - & - \\
\hline HLW03-06 & $\begin{array}{l}\text { HLW03 } \\
\end{array}$ & - & - & - & - & - & - & - & 2.0 & 1.9 & - & 1.0 & 0.9 & 0.9 & - & - & - & - & - \\
\hline HLW03-07 & HLW03 & - & - & 9.9 & - & - & 6.2 & - & - & - & - & - & 6.0 & - & - & 4.2 & - & 2.9 & 1.0 \\
\hline HLW03-10 & \begin{tabular}{|l|} 
HLW03 \\
\end{tabular} & - & - & 10.3 & - & - & 12.5 & - & - & - & - & - & 8.7 & - & - & 3.7 & 2.9 & 3.5 & 1.4 \\
\hline HLW03-12 & HLW03 & - & - & 1.2 & - & - & 0.7 & - & 0.8 & - & - & - & 0.6 & - & - & - & - & - & - \\
\hline HLW03-13 & \begin{tabular}{|l|} 
HLW03 \\
\end{tabular} & - & - & - & - & - & 7.9 & - & - & - & - & - & 5.3 & - & - & 5.0 & - & 3.5 & 0.6 \\
\hline HLW03-14 & \begin{tabular}{|l|} 
HLW03 \\
\end{tabular} & - & - & - & - & - & 4.6 & - & - & - & - & 3.5 & 2.9 & 1.5 & - & 2.2 & 0.5 & - & - \\
\hline HLW03-15 & \begin{tabular}{|l|} 
HLW03 \\
\end{tabular} & - & - & - & - & - & - & - & - & - & - & - & 2.7 & - & - & 0.9 & 0.3 & - & - \\
\hline HLW03-16 & \begin{tabular}{|l|} 
HLW03 \\
\end{tabular} & - & - & 4.6 & - & 2.8 & 2.8 & - & - & - & - & - & 1.9 & - & - & 0.9 & - & - & - \\
\hline HLW03-17 & $\begin{array}{l}\text { HLW03 } \\
\end{array}$ & - & - & - & - & - & 5.7 & - & - & - & - & 2.4 & 1.7 & - & - & 0.5 & - & - & - \\
\hline HLW03-18 & \begin{tabular}{|l|} 
HLW03 \\
\end{tabular} & - & - & - & - & - & 2.4 & - & - & - & - & 0.5 & 0.7 & - & - & 0.5 & - & - & - \\
\hline HLW03-19 & \begin{tabular}{|l|} 
HLW03 \\
\end{tabular} & - & - & - & - & - & 1.5 & - & - & - & - & - & 0.8 & - & - & 0.6 & - & - & - \\
\hline
\end{tabular}

(a) The Group IDs are described in Sections 2.1.1 to 2.1.9.

(b) A dash (-) indicates that no data were collected for the specified temperatures.

(c) Table entries that were excluded from calculations to determine the $\mathrm{T}_{1 \%}$ value for a glass are shaded gray.

(d) This value was originally reported as $<0.1 \mathrm{vol} \%$, but was assigned the value of $0.1 \mathrm{vol} \%$ for purposes of calculating $\mathrm{T}_{1 \%} \mathrm{values}$. 
Table 6.2. Temperature and Volume \%-Crystallinity Data for 168 HLW Glasses with Spinel as the Primary Crystalline Phase and Used in Spinel $\mathbf{T}_{1 \%}$ Modeling (continued).

\begin{tabular}{|c|c|c|c|c|c|c|c|c|c|c|c|c|c|c|c|c|c|c|c|}
\hline \multirow[b]{2}{*}{ Glass ID } & \multirow{2}{*}{$\begin{array}{c}\text { Group } \\
\text { ID }\end{array}$} & \multicolumn{18}{|c|}{ Temperature in ${ }^{\circ} \mathrm{C}$} \\
\hline & & 650 & 700 & 750 & 800 & $\begin{array}{c}850 \\
\text { (Set 1) } \\
\end{array}$ & $\begin{array}{c}\mathbf{8 5 0} \\
\text { (Set 2) }\end{array}$ & 875 & $\begin{array}{c}900 \\
\text { (Set 1) }\end{array}$ & $\begin{array}{c}900 \\
\text { (Set 2) }\end{array}$ & $\begin{array}{c}950 \\
\text { (Set 1) }\end{array}$ & $\begin{array}{c}950 \\
\text { (Set 2) }\end{array}$ & $\begin{array}{c}950 \\
\text { (Set 3) }\end{array}$ & $\begin{array}{c}1000 \\
\text { (Set 1) }\end{array}$ & $\begin{array}{c}1000 \\
(\text { Set 2) } \\
\end{array}$ & 1050 & 1100 & 1150 & 1200 \\
\hline HLW03-20 & HLW03 & - & - & - & - & - & 1.0 & - & 1.0 & - & - & - & 0.3 & - & - & - & - & - & - \\
\hline HLW03-21 & HLW03 & - & - & - & 2 & - & 1.0 & - & 0.3 & - & - & - & 0.2 & - & - & - & - & - & - \\
\hline HLW03-22 & HLW03 & - & - & 4.4 & - & - & 2.3 & - & 0.6 & - & - & - & 0.5 & - & - & - & - & - & - \\
\hline HLW03-23 & HLW03 & - & - & 1.5 & 1.3 & 0.9 & 0.6 & - & - & - & - & - & 0.4 & - & - & - & - & - & - \\
\hline HLW03-24 & HLW03 & - & - & 2.3 & 1.6 & 0.6 & 0.4 & - & - & - & - & - & - & - & - & - & - & - & - \\
\hline HLW03-25 & HLW03 & - & - & 1.6 & 0.2 & - & 0.2 & - & - & - & - & - & 0.1 & - & - & - & - & - & - \\
\hline HLW03-26 & HLW03 & - & - & 1.2 & 1.0 & - & 0.8 & - & - & 0.4 & - & - & 0.3 & - & - & - & - & - & - \\
\hline HLW03-27 & HLW03 & - & - & - & - & - & 1.7 & - & - & - & - & - & 1.6 & - & - & 0.6 & - & - & - \\
\hline HLW03-28 & HLW03 & - & - & 1.4 & 1.3 & 1.0 & 0.5 & - & - & - & - & - & 0.2 & - & - & - & - & - & - \\
\hline HLW03-29 & HLW03 & - & - & 1.4 & 1.7 & - & 0.7 & - & - & - & - & - & 0.4 & - & - & - & - & - & - \\
\hline HLW03-30 & HLW03 & - & - & 1.0 & 0.9 & - & 0.6 & - & - & - & - & - & 0.2 & - & - & - & - & - & - \\
\hline HLW03-31 & HLW03 & - & - & 2.6 & - & - & 2.4 & - & - & - & - & - & 1.6 & 1.8 & - & 0.7 & - & 0.9 & - \\
\hline HLW03-32 & HLW03 & - & - & 5.0 & - & - & 4.6 & - & 3.6 & - & - & - & 1.6 & - & - & 2.0 & 1.5 & - & - \\
\hline HLW03-37 & HLW03 & - & - & - & - & - & 1.9 & - & 0.9 & - & - & - & 0.3 & - & - & - & - & - & - \\
\hline HLW03-38 & HLW03 & - & - & 6.5 & - & - & 3.8 & - & - & - & - & - & 2.5 & - & - & 1.4 & 2.0 & - & - \\
\hline HLW03-39 & HLW03 & - & - & 2.8 & - & - & 1.8 & - & - & - & - & - & 0.4 & - & - & - & - & - & - \\
\hline HLW03-40 & HLW03 & - & - & 5.6 & - & - & 2.5 & - & - & - & - & - & 1.3 & - & - & 0.4 & - & - & - \\
\hline HLW03-41 & HLW03 & - & - & - & 1.5 & - & 0.8 & - & - & - & - & - & 0.4 & - & - & - & - & - & - \\
\hline HLW03-42 & HLW03 & - & - & - & - & - & 3.0 & - & - & - & 1.2 & - & 1.1 & - & - & 0.3 & - & - & - \\
\hline HLW03-43 & HLW03 & - & - & - & - & - & 1.8 & - & - & 1.6 & - & - & 0.6 & - & 0.9 & - & - & - & - \\
\hline HLW03-45 & HLW03 & - & - & - & 1.3 & - & 1.3 & - & - & 0.3 & - & - & - & - & - & - & - & - & - \\
\hline HLW05-02 & HLW05 & - & 0.9 & 1.1 & 0.7 & 0.6 & - & - & - & - & 0.3 & - & - & - & - & - & - & - & - \\
\hline HLW05-03 & HLW05 & - & 0.1 & 0.8 & 0.2 & 0.1 & - & - & - & - & 0.1 & - & - & - & - & - & - & - & - \\
\hline HLW05-04 & HLW05 & - & 0.4 & 0.3 & 0.7 & 0.4 & - & - & - & - & 0.2 & - & - & - & - & - & - & - & - \\
\hline HLW05-07 & HLW05 & - & 0.6 & 1.0 & 0.6 & 0.5 & - & - & - & - & 0.2 & - & - & - & - & - & - & - & - \\
\hline HLW05-09 & HLW05 & - & 0.9 & 0.9 & - & 0.2 & - & - & - & - & 0.1 & - & - & - & - & 0.1 & - & - & - \\
\hline HLW05-11 & HLW05 & - & 1.0 & 0.3 & 0.4 & 0.4 & - & - & - & - & 0.2 & - & - & - & - & - & - & - & - \\
\hline HLW05-13 & HLW05 & - & - & 7.7 & 0.8 & 0.7 & - & - & - & - & 0.7 & - & - & - & - & 0.2 & - & - & - \\
\hline HLW05-14 & HLW05 & - & 1.0 & 0.7 & - & 0.3 & - & - & - & - & 0.1 & - & - & - & - & - & - & - & - \\
\hline HLW05-27 & HLW05 & - & 9.7 & - & 1.4 & 0.7 & - & - & - & - & 0.6 & - & - & - & - & - & - & - & - \\
\hline HLW06-01 & HLW06 & - & 4.4 & - & 2.7 & - & - & - & - & - & 2.0 & - & - & 1.0 & - & 1.0 & - & - & - \\
\hline HLW06-02 & HLW06 & - & - & 2.4 & 1.9 & 1.5 & - & - & - & - & 1.1 & - & - & 0.3 & - & 0.3 & - & - & - \\
\hline HLW06-03 & HLW06 & - & - & - & - & 5.6 & - & - & - & - & 4.7 & - & - & - & - & 2.7 & 2.0 & 2.9 & 1.2 \\
\hline HLW06-04 & HLW06 & - & - & 10.3 & - & 1.0 & - & - & 0.6 & - & 0.6 & - & - & 0.2 & - & 0.1 & - & - & - \\
\hline HLW06-05 & HLW06 & - & - & 1.7 & 1.3 & 1.8 & - & - & 0.9 & - & 0.9 & - & - & 0.3 & - & - & - & - & - \\
\hline HLW06-06 & HLW06 & - & - & - & - & 3.7 & - & - & - & - & 4.1 & - & - & 3.9 & - & 3.1 & 2.2 & 2.5 & 1.3 \\
\hline
\end{tabular}

(a) The Group IDs are described in Sections 2.1.1 to 2.1.9.

(b) A dash (-) indicates that no data were collected for the specified temperatures.

(c) Table entries that were excluded from calculations to determine the $\mathrm{T}_{1 \%}$ value for a glass are shaded gray. 
Table 6.2. Temperature and Volume \%-Crystallinity Data for 168 HLW Glasses with Spinel as the Primary Crystalline Phase and Used in Spinel $\mathbf{T}_{1 \%}$ Modeling (continued).

\begin{tabular}{|c|c|c|c|c|c|c|c|c|c|c|c|c|c|c|c|c|c|c|c|}
\hline \multirow[b]{2}{*}{ Glass ID } & \multirow{2}{*}{$\begin{array}{c}\text { Group } \\
\text { ID }\end{array}$} & \multicolumn{18}{|c|}{ Temperature in ${ }^{\circ} \mathrm{C}$} \\
\hline & & 650 & 700 & 750 & 800 & $\begin{array}{c}\mathbf{8 5 0} \\
\text { (Set 1) }\end{array}$ & $\begin{array}{c}850 \\
\text { (Set 2) }\end{array}$ & 875 & $\begin{array}{c}900 \\
\text { (Set 1) }\end{array}$ & $\begin{array}{c}900 \\
\text { (Set 2) }\end{array}$ & $\begin{array}{c}950 \\
\text { (Set 1) }\end{array}$ & $\begin{array}{c}950 \\
\text { (Set 2) }\end{array}$ & $\begin{array}{c}950 \\
(\text { Set 3) }\end{array}$ & $\begin{array}{c}1000 \\
\text { (Set 1) }\end{array}$ & $\begin{array}{c}1000 \\
\text { (Set 2) }\end{array}$ & 1050 & 1100 & 1150 & 1200 \\
\hline HLW06-07 & HLW06 & - & - & - & - & 8.5 & - & - & - & - & 5.5 & - & - & - & - & 2.5 & 3.1 & 2.6 & 1.5 \\
\hline HLW06-08 & HLW06 & - & - & - & - & 2.2 & - & - & 1.7 & - & 1.6 & - & - & - & - & 0.9 & 0.9 & 0.3 & - \\
\hline HLW06-09 & HLW06 & - & - & - & - & 3.7 & - & - & - & - & 4.6 & - & - & 3.3 & - & 2.3 & 3.0 & 1.8 & 1.1 \\
\hline HLW06-10 & HLW06 & - & - & - & - & 1.4 & - & - & 1.5 & - & 1.0 & - & - & 1.3 & - & 1.0 & 0.6 & 0.5 & 0.3 \\
\hline HLW06-11 & HLW06 & - & - & - & - & 4.0 & - & - & - & - & 2.9 & - & - & - & - & 1.3 & 1.0 & 1.3 & 0.4 \\
\hline HLW06-12 & HLW06 & - & - & - & 2.8 & 2.7 & - & - & 2.3 & - & 1.0 & - & - & 1.4 & - & 1.1 & 0.1 & - & - \\
\hline HLW06-13 & HLW06 & - & - & - & - & 3.6 & - & - & - & - & 2.4 & - & - & 3.7 & - & 3.2 & 2.2 & 1.6 & 0.5 \\
\hline HLW06-14 & HLW06 & - & - & 2.8 & - & 2.1 & - & - & 1.4 & - & 1.3 & - & - & 0.7 & - & 0.4 & - & - & - \\
\hline HLW06-15 & HLW06 & - & - & 2.4 & - & 2.4 & - & - & 1.5 & - & 0.6 & - & - & 0.1 & - & - & - & - & - \\
\hline HLW06-16 & HLW06 & - & 13.1 & 11.5 & 3.2 & - & - & - & 2.1 & - & 1.0 & - & - & 0.5 & - & - & - & - & - \\
\hline HLW06-17 & HLW06 & - & 6.0 & - & - & - & - & - & 2.2 & - & 1.8 & - & - & 1.1 & - & 1.0 & 0.4 & - & - \\
\hline HLW06-18 & HLW06 & - & - & - & - & 2.9 & - & - & - & - & 2.0 & - & - & 1.2 & - & 1.1 & 0.6 & 0.9 & - \\
\hline HLW06-19 & HLW06 & - & - & - & - & - & - & - & - & - & 5.2 & - & - & - & - & 2.7 & 1.5 & 2.1 & 1.1 \\
\hline HLW06-20 & HLW06 & - & - & 19.6 & - & - & - & - & - & - & 2.2 & - & - & 2.1 & - & 1.9 & 1.2 & 0.9 & - \\
\hline HLW06-25 & HLW06 & - & - & - & 3.0 & - & - & - & - & - & 1.6 & - & - & 1.5 & - & 0.8 & 0.8 & - & - \\
\hline HLW06-28 & HLW06 & - & - & - & 5.8 & 0.8 & - & - & 1.3 & - & 1.3 & - & - & 0.5 & - & 0.6 & - & - & - \\
\hline HLW06-30 & HLW06 & - & - & - & - & 23.3 & - & - & - & - & 14.3 & - & - & - & - & 1.7 & 0.8 & 0.7 & 0.1 \\
\hline HLW06-32 & HLW06 & - & - & 2.5 & 2.3 & 0.9 & - & - & 1.1 & - & 0.5 & - & - & 0.4 & - & - & - & - & - \\
\hline HLW07-01 & HLW07 & - & - & - & 1.9 & 1.4 & - & - & 1.0 & - & 0.9 & - & - & 0.5 & - & - & - & - & - \\
\hline HLW07-02 & HLW07 & - & - & - & 2.3 & 1.7 & - & - & 1.6 & - & 0.9 & - & - & 0.7 & - & - & - & - & - \\
\hline HLW07-03 & HLW07 & - & 0.8 & 1.2 & 1.2 & 1.0 & - & - & 0.6 & - & 0.4 & - & - & - & - & - & - & - & - \\
\hline HLW07-04 & HLW07 & - & - & 25.0 & 1.9 & 0.6 & - & - & 0.4 & - & 0.3 & - & - & - & - & - & - & - & - \\
\hline HLW07-05 & HLW07 & - & - & - & - & - & - & - & - & - & - & - & - & 3.5 & - & 3.1 & 3.3 & 2.0 & 0.5 \\
\hline HLW07-06 & HLW07 & - & - & - & - & - & - & - & 5.8 & - & 3.1 & - & - & 3.4 & - & 0.8 & 0.5 & - & - \\
\hline HLW07-11 & HLW07 & - & - & - & 13.8 & - & - & - & 2.2 & - & 1.4 & - & - & 1.2 & - & 0.7 & 0.3 & - & - \\
\hline HLW07-16 & HLW07 & - & - & - & - & 4.8 & - & - & 2.0 & - & 1.0 & - & - & 1.1 & - & 0.5 & 0.7 & - & - \\
\hline HLW07-17 & HLW07 & - & 5.8 & 4.3 & - & 0.7 & - & - & 0.3 & - & - & - & - & - & - & - & - & - & - \\
\hline HLW07-20 & HLW07 & - & - & - & 2.6 & 2.0 & - & - & 1.3 & - & 1.2 & - & - & 0.8 & - & 0.7 & - & - & - \\
\hline HLW07-24 & HLW07 & - & - & - & 2.0 & - & - & - & 1.6 & - & 1.4 & - & - & 1.4 & - & 0.9 & - & - & - \\
\hline HLW07-26 & HLW07 & - & - & 1.4 & 0.9 & 1.2 & - & - & 1.0 & - & 0.8 & - & - & 0.8 & - & - & - & - & - \\
\hline HLW07-27 & HLW07 & - & 1.1 & 1.2 & 1.1 & 0.9 & - & - & 0.5 & - & 0.4 & - & - & - & - & - & - & - & - \\
\hline HLW07-28 & HLW07 & - & - & 1.5 & 1.5 & 1.2 & - & - & 1.0 & - & 0.8 & - & - & - & - & - & - & - & - \\
\hline HLW07-29 & HLW07 & - & - & 3.2 & 2.6 & 2.3 & - & - & 1.8 & - & 1.2 & - & - & 0.8 & - & - & - & - & - \\
\hline HLW07-30 & HLW07 & - & - & - & 1.5 & 1.4 & - & - & 0.9 & - & 0.6 & - & - & 0.5 & - & - & - & - & - \\
\hline
\end{tabular}

(a) The Group IDs are described in Sections 2.1.1 to 2.1.9.

(b) A dash (-) indicates that no data were collected for the specified temperatures.

(c) Table entries that were excluded from calculations to determine the $T_{1 \%}$ value for a glass are shaded gray. 
Table 6.2. Temperature and Volume \%-Crystallinity Data for 168 HLW Glasses with Spinel as the Primary Crystalline Phase and Used in Spinel $\mathbf{T}_{1 \%}$ Modeling (continued).

\begin{tabular}{|c|c|c|c|c|c|c|c|c|c|c|c|c|c|c|c|c|c|c|c|}
\hline \multirow[b]{2}{*}{ Glass ID } & \multirow[b]{2}{*}{$\begin{array}{c}\text { Group } \\
\text { ID }\end{array}$} & \multicolumn{18}{|c|}{ Temperature in ${ }^{\circ} \mathrm{C}$} \\
\hline & & 650 & 700 & $\mathbf{7 5 0}$ & 800 & $\begin{array}{c}850 \\
\text { (Set 1) }\end{array}$ & $\begin{array}{c}850 \\
\text { (Set 2) }\end{array}$ & 875 & $\begin{array}{c}900 \\
\text { (Set 1) }\end{array}$ & $\begin{array}{c}900 \\
\text { (Set 2) }\end{array}$ & $\begin{array}{c}950 \\
\text { (Set 1) }\end{array}$ & $\begin{array}{c}950 \\
(\text { Set 2) }\end{array}$ & $\begin{array}{c}950 \\
(\text { Set 3) }\end{array}$ & $\begin{array}{c}1000 \\
\text { (Set 1) }\end{array}$ & $\begin{array}{c}1000 \\
\text { (Set 2) }\end{array}$ & 1050 & 1100 & 1150 & 1200 \\
\hline HLW07-31 & HLW07 & - & - & - & 1.5 & 1.2 & - & - & 1.0 & - & 0.8 & - & - & 0.6 & - & - & - & - & - \\
\hline HLW07-32 & HLW07 & - & - & - & 2.1 & 1.7 & - & - & 1.6 & - & 1.1 & - & - & 0.7 & - & - & - & - & - \\
\hline HLW07-33 & HLW07 & - & - & - & 2.3 & 2.0 & - & - & 1.7 & - & 1.3 & - & - & 1.0 & - & - & - & - & - \\
\hline HLW07-37 & HLW07 & - & - & 2.1 & 1.5 & 1.0 & - & - & 0.5 & - & 0.3 & - & - & - & - & - & - & - & - \\
\hline HLW07-38 & HLW07 & - & - & 2.1 & - & 1.5 & - & - & 1.7 & - & 1.9 & - & - & 1.1 & - & - & 0.3 & - & - \\
\hline HLW07-39 & HLW07 & - & 0.4 & 0.5 & 0.8 & 0.5 & - & - & 0.5 & - & - & - & - & - & - & - & - & - & - \\
\hline HLW07-40 & HLW07 & - & - & 2.0 & 2.0 & 1.5 & - & - & 1.3 & - & 1.0 & - & - & 0.7 & - & - & - & - & - \\
\hline HLW-ALG-03 & HLWALG & - & - & 0.2 & 0.7 & 0.5 & - & - & 0.1 & - & 0.0 & - & - & - & - & 0.0 & - & - & - \\
\hline HLW-ALG-05 & HLWALG & - & 2.3 & 2.7 & 1.9 & 2.5 & - & - & - & - & 1.2 & - & - & 0.5 & - & 0.3 & - & - & - \\
\hline HLW-ALG-06 & HLWALG & - & 25.6 & 24.6 & 21.0 & 2.6 & - & - & 1.5 & - & 0.7 & - & - & 1.0 & - & - & - & - & - \\
\hline HLW-ALG-09 & HLWALG & - & 1.1 & 1.0 & 1.1 & - & - & - & 1.0 & - & 0.5 & - & - & 0.3 & - & - & - & - & - \\
\hline HLW-ALG-10 & HLWALG & - & 3.5 & 0.5 & 0.8 & 0.6 & - & - & 0.2 & - & - & - & - & - & - & - & - & - & - \\
\hline HLW-ALG-12 & HLWALG & - & - & 0.4 & 1.5 & 0.6 & - & - & 1.3 & - & 0.4 & - & - & 0.3 & - & 0.1 & - & - & - \\
\hline HLW-ALG-14 & HLWALG & - & - & - & 3.3 & 2.6 & - & - & 2.8 & - & 1.9 & - & - & 0.7 & - & 0.1 & - & - & - \\
\hline HLW-ALG-15 & HLWALG & - & 0.2 & 0.5 & 1.0 & 0.7 & - & - & 0.5 & - & 0.8 & - & - & - & - & - & - & - & - \\
\hline HLW-ALG-17 & HLWALG & - & 1.5 & 0.3 & 0.7 & 0.3 & - & - & 0.5 & - & - & - & - & - & - & - & - & - & - \\
\hline HLW-ALG-18 & HLWALG & 0.8 & 0.1 & 0.1 & 0.1 & 0.0 & - & - & - & - & - & - & - & - & - & - & - & - & - \\
\hline HLW-ALG-19 & HLWALG & - & 0.3 & 0.1 & 0.4 & 0.7 & - & - & 0.5 & - & 0.4 & - & - & - & - & - & - & - & - \\
\hline HLW-ALG-20 & HLWALG & - & $\begin{array}{ll}0.4 \\
\end{array}$ & 0.6 & 0.5 & 0.6 & - & - & 0.3 & - & 0.2 & - & - & - & - & - & - & - & - \\
\hline HLW-ALG-25 & HLWALG & - & 2.9 & 1.0 & 1.0 & 0.6 & - & - & 0.5 & - & - & - & - & - & - & - & - & - & - \\
\hline HLW-ALG-27 & HLWALG & - & 16.9 & 14.0 & 0.4 & 0.1 & - & - & 0.1 & - & - & - & - & - & - & - & - & - & - \\
\hline HLW-ALG-28 & HLWALG & - & 0.5 & 0.4 & 2.0 & 1.0 & - & - & 0.3 & - & - & - & - & - & - & - & - & - & - \\
\hline HLW-ALG-30 & HLWALG & - & 1.1 & - & 0.7 & 0.6 & - & - & - & - & 0.1 & - & - & - & - & - & - & - & - \\
\hline HLW-ALG-31 & HLWALG & - & - & - & - & 2.2 & - & - & - & - & 1.7 & - & - & 1.0 & - & 0.5 & 0.2 & - & - \\
\hline HLW-ALG-32 & HLWALG & - & - & - & - & 6.3 & - & - & - & - & 3.4 & - & - & 2.8 & - & 1.9 & 2.4 & 0.4 & 0.1 \\
\hline HLW-ALG-34 & HLWALG & - & - & - & 1.1 & 0.9 & - & - & 0.5 & - & 0.1 & - & - & 0.1 & - & - & - & - & - \\
\hline HLW-ALG-35 & HLWALG & - & - & - & - & 3.8 & - & - & 1.8 & - & 1.1 & - & - & 1.5 & - & 1.1 & 0.1 & - & - \\
\hline HLW-ALG-36 & HLWALG & - & - & - & - & 3.3 & - & - & 1.7 & - & 1.7 & - & - & 2.6 & - & 1.0 & 0.4 & - & - \\
\hline HLW-ALG-40 & HLWALG & - & - & - & - & 2.1 & - & - & 1.8 & - & 1.5 & - & - & 1.0 & - & 0.9 & 0.3 & - & - \\
\hline
\end{tabular}

(a) The Group IDs are described in Sections 2.1.1 to 2.1.9.

(b) A dash (-) indicates that no data were collected for the specified temperatures

(c) Table entries that were excluded from calculations to determine the $\mathrm{T}_{1 \%}$ value for a glass are shaded gray. 
Table 6.3. Number of Temperature vs. Vol\%-Crystallinity Points, Intercepts, Slopes, Estimated $T_{1 \%}$ Values, and Standard Deviations of $T_{1 \%}$ Values for $168 \mathrm{HLW}$ Glasses Having Spinel as the Primary Crystalline Phase and Used for Spinel T $1 \%$ Modeling.

\begin{tabular}{|c|c|c|c|c|c|c|c|}
\hline \multirow{2}{*}{ Glass ID } & \multirow{2}{*}{$\begin{array}{l}\text { Primary \& } \\
\text { Secondary } \\
\text { Crystalline } \\
\text { Phases }\end{array}$} & \multicolumn{3}{|c|}{$\begin{array}{c}\text { Inverse Regression Used to } \\
\text { Calculate } \mathbf{T}_{1 \%}\end{array}$} & \multirow{2}{*}{$\begin{array}{c}\text { Estimated } \\
\text { Spinel T T } \\
\quad\left({ }^{\circ} \mathbf{C}\right)\end{array}$} & \multirow{2}{*}{$\begin{array}{l}\operatorname{SD}\left(\mathrm{T}_{1 \%}\right) \\
\left({ }^{\circ} \mathrm{C}\right)\end{array}$} & \multirow{2}{*}{$\begin{array}{c}\text { Spinel } \mathbf{T}_{1 \%} \\
\text { Data } \\
\text { Splitting } \\
\text { Validation } \\
\text { Set }\end{array}$} \\
\hline & & $\begin{array}{l}\text { Number } \\
\text { of Points }\end{array}$ & Intercept $^{(a)}$ & Slope $^{(a)}$ & & & \\
\hline HLW02-01 & Spinel & 4 & $980.50^{(\mathrm{b})}$ & $-74.69^{(\mathrm{b})}$ & $905.8^{(\mathrm{b})}$ & $6.46^{(\mathrm{b})}$ & $\mathrm{NA}^{(\mathrm{c})}$ \\
\hline HLW02-02 & Spinel & 3 & 1012.50 & -125.00 & 887.5 & 21.65 & 4 \\
\hline HLW02-03 & Spinel & 3 & 957.46 & -119.40 & 838.1 & 17.47 & 2 \\
\hline HLW02-04 & Spinel & 4 & 853.06 & -4.23 & 848.8 & 4.02 & $\mathrm{NA}^{(\mathrm{c})}$ \\
\hline HLW02-06 & Spinel & 5 & 1073.28 & -46.60 & 1026.7 & 14.78 & 2 \\
\hline HLW02-07 & Spinel & 4 & 1066.48 & -302.20 & 764.3 & 19.81 & 4 \\
\hline HLW02-08 & Spinel & 3 & 964.84 & -181.32 & 783.5 & 5.52 & $\mathrm{NA}^{(\mathrm{c})}$ \\
\hline HLW02-09 & Spinel & 5 & 984.27 & -26.34 & 957.9 & 24.71 & 5 \\
\hline HLW02-11 & Spinel & 4 & 968.40 & -152.10 & 816.3 & 17.56 & 1 \\
\hline HLW02-12 & Spinel & 3 & 1106.76 & -59.80 & 1047.0 & 11.36 & 5 \\
\hline HLW02-13 & Spinel & 5 & 993.53 & -25.67 & 967.9 & 33.96 & 1 \\
\hline HLW02-15 & Spinel & 4 & 1119.38 & -69.95 & 1049.4 & 15.02 & 3 \\
\hline HLW02-16 & Spinel $+\mathrm{ZrO}_{2}$ & 5 & 1017.04 & -34.27 & 982.8 & 21.99 & 1 \\
\hline HLW02-17 & Spinel & 5 & 1035.03 & -68.17 & 966.9 & 13.82 & $\mathrm{NA}^{(\mathrm{c})}$ \\
\hline HLW02-18 & Spinel & 3 & 1117.86 & -160.71 & 957.1 & 25.75 & 3 \\
\hline HLW02-19 & Spinel & 5 & 983.79 & -63.48 & 920.3 & 12.07 & 4 \\
\hline HLW02-20 & Spinel & 4 & 958.02 & -16.63 & 941.4 & 18.63 & 2 \\
\hline HLW02-22 & Spinel & 4 & 1030.78 & -93.28 & 937.5 & 35.73 & $\mathrm{NA}^{(\mathrm{c})}$ \\
\hline HLW02-23 & Spinel & 4 & 1012.50 & -66.67 & 945.8 & 6.59 & 4 \\
\hline HLW02-24 & Spinel & 3 & 980.12 & -57.92 & 922.2 & 6.77 & 1 \\
\hline HLW02-25 & Spinel & 2 & 1050.00 & -100.00 & 950.0 & $\mathrm{NA}^{(\mathrm{d})}$ & 4 \\
\hline HLW02-26 & Spinel & 5 & 1011.84 & -42.32 & 969.5 & 11.26 & 2 \\
\hline HLW02-27 & Spinel $+\mathrm{ZrSiO}_{4}$ & 5 & 1048.20 & -82.10 & 966.1 & 14.34 & 5 \\
\hline HLW02-28 & Spinel & 4 & 1010.37 & -85.37 & 925.0 & 8.28 & 2 \\
\hline HLW02-29 & Spinel & 6 & 1003.13 & -48.14 & 955.0 & 14.56 & 1 \\
\hline HLW02-30 & Spinel & 3 & 1016.67 & -119.05 & 897.6 & 31.41 & 2 \\
\hline HLW02-31 & Spinel & 4 & 999.98 & -203.23 & 796.7 & 27.96 & 5 \\
\hline HLW02-32 & Spinel & 5 & 937.78 & -137.06 & 800.7 & 40.94 & 3 \\
\hline HLW02-33 & Spinel & 5 & 967.39 & -19.94 & 947.4 & 9.06 & 1 \\
\hline HLW02-34 & Spinel & 5 & 958.60 & -17.75 & 940.8 & 7.18 & 1 \\
\hline HLW02-35 & Spinel & 4 & 1001.98 & -21.49 & 980.5 & 9.99 & 5 \\
\hline HLW02-36 & Spinel & 5 & 969.40 & -99.40 & 870.0 & 20.98 & 1 \\
\hline HLW02-37 & Spinel & 4 & 1051.47 & -71.23 & 980.2 & 25.51 & 4 \\
\hline
\end{tabular}

(a) The intercept and slope are from fitting the inverse regression equation in Equation (E.1) of Appendix E to the temperature versus spinel percent crystallinity data for each glass given in Table 6.2.

(b) Estimated $\mathrm{T}_{1 \%}$ values in this table have been rounded to one decimal place; intercepts, slopes, and standard deviations have been rounded to two decimal places.

(c) NA = not applicable for glasses not included in data splitting validation sets because they were replicates. These glasses were included in the modeling splits rather than the validation splits.

(d) $\mathrm{NA}=$ The standard deviation of the estimated spinel $\mathrm{T} 1 \%$ value could not be calculated because only 2 data points were available. 
Table 6.3. Number of Temperature vs. Vol\%-Crystallinity Points, Intercepts, Slopes, Estimated $T_{1 \%}$ Values, and Standard Deviations of $T_{1 \%}$ Values for $168 \mathrm{HLW}$ Glasses Having Spinel as the Primary Crystalline Phase and Used for Spinel $\mathbf{T}_{1 \%}$ Modeling (continued).

\begin{tabular}{|c|c|c|c|c|c|c|c|}
\hline \multirow{2}{*}{ Glass ID } & \multirow{2}{*}{$\begin{array}{l}\text { Primary \& } \\
\text { Secondary } \\
\text { Crystalline } \\
\text { Phases }\end{array}$} & \multicolumn{3}{|c|}{$\begin{array}{c}\text { Inverse Regression Used to } \\
\text { Calculate } \mathbf{T}_{1 \%}\end{array}$} & \multirow{2}{*}{$\begin{array}{c}\text { Estimated } \\
\text { Spinel } \\
\mathbf{T}_{1 \%} \\
\left({ }^{\circ} \mathrm{C}\right)\end{array}$} & \multirow{2}{*}{$\begin{array}{l}\operatorname{SD}\left(\mathrm{T}_{1 \%}\right) \\
\quad\left({ }^{\circ} \mathrm{C}\right)\end{array}$} & \multirow{2}{*}{$\begin{array}{c}\text { Spinel } \mathbf{T}_{1 \%} \\
\text { Data } \\
\text { Splitting } \\
\text { Validation } \\
\text { Set }\end{array}$} \\
\hline & & $\begin{array}{l}\text { Number } \\
\text { of Points }\end{array}$ & Intercept $^{(a)}$ & Slope $^{(a)}$ & & & \\
\hline HLW02-38 & Spinel & 5 & 1049.09 & -75.13 & 974.0 & 18.70 & 4 \\
\hline HLW02-39 & Spinel & 5 & 1071.30 & -81.65 & 989.6 & 16.41 & 3 \\
\hline HLW02-40 & Spinel & 4 & 1028.87 & -71.13 & 957.7 & 23.79 & 4 \\
\hline HLW02-41 & Spinel & 5 & 1012.25 & -76.22 & 936.0 & 16.61 & 5 \\
\hline HLW02-42 & Spinel & 5 & 951.15 & -129.99 & 821.2 & 23.68 & $\mathrm{NA}^{(\mathrm{c})}$ \\
\hline HLW02-43 & Spinel & 4 & 955.36 & -39.06 & 916.3 & 15.97 & 1 \\
\hline HLW02-44 & Spinel & 4 & $1013.24^{(b)}$ & $-199.73^{(b)}$ & $813.5^{(\mathrm{b})}$ & $2.95^{(b)}$ & $\mathrm{NA}^{(\mathrm{c})}$ \\
\hline HLW02-45 & Spinel & 3 & 970.86 & -51.23 & 919.6 & 19.63 & 3 \\
\hline HLW02-46 & Spinel & 5 & 1032.92 & -69.66 & 963.3 & 13.11 & NA \\
\hline HLW02-47 & Spinel & 4 & 892.14 & -45.12 & 847.0 & 29.90 & 5 \\
\hline HLW02-48 & Spinel & 4 & 1086.52 & -126.36 & 960.2 & 28.14 & 1 \\
\hline HLW02-49 & Spinel & 6 & 1036.12 & -48.81 & 987.3 & 26.13 & 2 \\
\hline HLW02-50 & Spinel & 5 & 1006.15 & -31.56 & 974.6 & 28.25 & 5 \\
\hline HLW02-51 & Spinel & 3 & 1025.00 & -125.00 & 900.0 & 21.65 & 4 \\
\hline HLW02-52 & Spinel & 5 & 1077.78 & -118.52 & 959.3 & 34.32 & $\mathrm{NA}^{(\mathrm{c})}$ \\
\hline HLW02-53 & Spinel & 7 & 1044.28 & -94.99 & 949.3 & 8.52 & $\mathrm{NA}^{(\mathrm{c})}$ \\
\hline HLW02-54 & Spinel & 3 & 950.00 & -39.47 & 910.5 & 4.84 & $\mathrm{NA}^{(\mathrm{c})}$ \\
\hline HLW02-55 & Spinel & 4 & 964.71 & -132.35 & 832.4 & 36.51 & $\mathrm{NA}^{(\mathrm{c})}$ \\
\hline HLW02-56 & Spinel & 5 & 1018.10 & -223.93 & 794.2 & 28.67 & $\mathrm{NA}^{(\mathrm{c})}$ \\
\hline HLW02-57 & Spinel & 3 & 892.76 & -151.32 & 741.4 & 5.05 & $\mathrm{NA}^{(\mathrm{c})}$ \\
\hline HLW03-01 & Spinel & 4 & 1154.55 & -68.18 & 1086.4 & 53.42 & 4 \\
\hline HLW03-02 & Spinel $+\mathrm{ZrO}_{2}$ & 7 & 1198.60 & -41.61 & 1157.0 & 89.51 & 2 \\
\hline HLW03-03 & Spinel & 5 & 1234.90 & -87.45 & 1147.4 & 44.79 & 1 \\
\hline HLW03-04 & Spinel & 5 & 970.80 & -24.41 & 946.4 & 38.69 & 5 \\
\hline HLW03-05 & Spinel & 3 & 978.76 & -62.18 & 916.6 & 3.17 & 2 \\
\hline HLW03-06 & Spinel & 3 & 1200.00 & -250.00 & 950.0 & 35.36 & $\mathrm{NA}^{(\mathrm{c})}$ \\
\hline HLW03-07 & Spinel & 6 & 1268.10 & -54.92 & 1213.2 & 33.53 & $\mathrm{NA}^{(\mathrm{c})}$ \\
\hline HLW03-10 & Spinel $+\mathrm{ZrO}_{2}\left(\mathrm{ThO}_{2}\right)$ & 7 & 1225.22 & -35.50 & 1189.7 & 42.20 & 4 \\
\hline HLW03-12 & Spinel & 4 & 1106.02 & -295.18 & 810.8 & 27.47 & 5 \\
\hline HLW03-13 & Spinel $+\mathrm{ThO}_{2}\left(\mathrm{UO}_{2}\right)$ & 5 & 1265.24 & -50.50 & 1214.7 & 42.87 & 3 \\
\hline HLW03-14 & Spinel $+\mathrm{ZrO}_{2}$ & 6 & 1125.22 & -56.01 & 1069.2 & 21.82 & 1 \\
\hline HLW03-15 & Spinel $+\mathrm{ThO}_{2}$ & 3 & 1112.50 & -60.90 & 1051.6 & 5.90 & 4 \\
\hline HLW03-16 & Spinel & 5 & 1102.60 & -81.77 & 1020.8 & 19.59 & 5 \\
\hline
\end{tabular}

(a) The intercept and slope are from fitting the inverse regression equation in Equation (E.1) of Appendix E to the temperature versus spinel percent crystallinity data for each glass given in Table 6.2.

(b) Estimated $\mathrm{T}_{1 \%}$ values in this table have been rounded to one decimal place; intercepts, slopes, and standard deviations have been rounded to two decimal places.

(c) NA = not applicable for glasses not included in data splitting validation sets because they were replicates. These glasses were included in the modeling splits rather than the validation splits.

(d) NA $=$ The standard deviation of the estimated spinel T1\% value could not be calculated because only 2 data points were available. 
Table 6.3. Number of Temperature vs. Vol\%-Crystallinity Points, Intercepts, Slopes, Estimated $T_{1 \%}$ Values, and Standard Deviations of $T_{1 \%}$ Values for $168 \mathrm{HLW}$ Glasses Having Spinel as the Primary Crystalline Phase and Used for Spinel $\mathbf{T}_{1 \%}$ Modeling (continued).

\begin{tabular}{|c|c|c|c|c|c|c|c|}
\hline \multirow{2}{*}{ Glass ID } & \multirow{2}{*}{$\begin{array}{c}\text { Primary \& } \\
\text { Secondary } \\
\text { Crystalline } \\
\text { Phases }\end{array}$} & \multicolumn{3}{|c|}{$\begin{array}{c}\text { Inverse Regression Used to } \\
\text { Calculate } \mathrm{T}_{1 \%}\end{array}$} & \multirow{2}{*}{$\begin{array}{c}\text { Estimated } \\
\text { Spinel } \\
\mathbf{T}_{1 \%} \\
\left({ }^{\circ} \mathbf{C}\right)\end{array}$} & \multirow{2}{*}{$\begin{array}{l}\operatorname{SD}\left(\mathrm{T}_{1 \%}\right) \\
\quad\left({ }^{\circ} \mathrm{C}\right)\end{array}$} & \multirow{2}{*}{$\begin{array}{c}\text { Spinel } \\
\mathrm{T}_{1 \%} \text { Data } \\
\text { Splitting } \\
\text { Validation } \\
\text { Set }\end{array}$} \\
\hline & & $\begin{array}{l}\text { Number } \\
\text { of Points }\end{array}$ & Intercept $^{(a)}$ & Slope $^{(a)}$ & & & \\
\hline HLW03-17 & Spinel & 4 & 1040.06 & -34.98 & 1005.1 & 19.44 & 4 \\
\hline HLW03-18 & Spinel & 4 & 1026.45 & -74.58 & 951.9 & 27.01 & 5 \\
\hline HLW03-19 & Spinel & 3 & 1144.78 & -201.49 & 943.3 & 25.03 & 3 \\
\hline HLW03-20 & Spinel & 3 & 982.14 & -107.14 & 875.0 & 25.00 & 2 \\
\hline HLW03-21 & Spinel & 4 & 939.54 & -73.76 & 865.8 & 12.70 & 5 \\
\hline HLW03-22 & Spinel & 4 & 951.27 & -45.52 & 905.7 & 13.35 & 5 \\
\hline HLW03-23 & Spinel & 5 & 981.22 & -150.23 & 831.0 & 13.73 & 1 \\
\hline HLW03-24 & Spinel & 4 & 877.82 & -53.33 & 824.5 & 4.40 & 4 \\
\hline HLW03-25 & Spinel & 4 & 882.88 & -86.43 & 796.4 & 45.18 & 4 \\
\hline HLW03-26 & Spinel $+\mathrm{ThO}_{2}$ & 5 & 1000.00 & -202.70 & 797.3 & 8.41 & $\mathrm{NA}^{(\mathrm{c})}$ \\
\hline HLW03-27 & Spinel+ThO ${ }_{2}$ & 3 & 1143.24 & -148.65 & 994.6 & 40.74 & 1 \\
\hline HLW03-28 & Spinel & 5 & 956.18 & -132.02 & 824.2 & 15.52 & 3 \\
\hline HLW03-29 & Spinel & 4 & 965.14 & -121.56 & 843.6 & 26.98 & 3 \\
\hline HLW03-30 & Spinel & 4 & $996.45^{(b)}$ & $-235.48^{(\mathrm{b})}$ & $761.0^{(\mathrm{b})}$ & $10.06^{(b)}$ & 3 \\
\hline HLW03-31 & Spinel $+\mathrm{ZrO}_{2}$ & 6 & 1242.38 & -170.43 & 1072.0 & 35.95 & 3 \\
\hline HLW03-32 & Spinel $+\mathrm{ZrO}_{2}$ & 6 & 1162.43 & -75.11 & 1087.3 & 43.85 & 1 \\
\hline HLW03-37 & Spinel & 3 & 963.27 & -61.22 & 902.0 & 5.84 & 5 \\
\hline HLW03-38 & Spinel $+\mathrm{ZrO}_{2}$ & 5 & 1152.82 & -65.68 & 1087.1 & 43.44 & 5 \\
\hline HLW03-39 & Spinel & 3 & 987.61 & -82.57 & 905.0 & 9.45 & 4 \\
\hline HLW03-40 & Spinel+ $+\mathrm{ThO}_{2}$ & 4 & 1033.20 & -54.37 & 978.8 & 28.91 & 3 \\
\hline HLW03-41 & Spinel & 3 & 982.80 & -129.03 & 853.8 & 21.67 & $\mathrm{NA}^{(\mathrm{c})}$ \\
\hline HLW03-42 & Spinel & 4 & 1046.92 & -69.23 & 977.7 & 13.79 & NA \\
\hline HLW03-43 & Spinel & 4 & 1042.12 & -95.61 & 946.5 & 23.51 & NA \\
\hline HLW03-45 & Spinel+ $+\mathrm{ThO}_{2}$ & 3 & 922.50 & -75.00 & 847.5 & 20.46 & NA \\
\hline HLW05-02 & Spinel & 4 & 1004.96 & -248.09 & 756.9 & 22.17 & NA \\
\hline HLW05-03 & Spinel & 3 & 844.77 & -122.09 & 722.7 & 35.48 & 3 \\
\hline HLW05-04 & Spinel & 3 & 992.11 & -289.47 & 702.6 & 54.95 & 2 \\
\hline HLW05-07 & Spinel & 4 & 980.15 & -248.09 & 732.1 & 26.24 & NA \\
\hline HLW05-09 & Spinel & 4 & 938.55 & -240.09 & 698.5 & 36.71 & 1 \\
\hline HLW05-11 & Spinel & 4 & 963.89 & -277.78 & 686.1 & 47.22 & 5 \\
\hline HLW05-13 & Spinel+ $\mathrm{ThO}_{2}$ & 4 & 1130.68 & -363.64 & 767.0 & 61.67 & 5 \\
\hline HLW05-14 & $\begin{array}{l}\text { Spinel + } \\
\text { Sodium/Uranium// } \\
\text { Strontium Oxide }\end{array}$ & 4 & 953.85 & -269.23 & 684.6 & 23.42 & 4 \\
\hline
\end{tabular}

(a) The intercept and slope are from fitting the inverse regression equation in Equation (E.1) of Appendix E to the temperature versus spinel percent crystallinity data for each glass given in Table 6.2.

(b) Estimated $\mathrm{T}_{1 \%}$ values in this table have been rounded to one decimal place; intercepts, slopes, and standard deviations have been rounded to two decimal places.

(c) NA = not applicable for glasses not included in data splitting validation sets because they were replicates. These glasses were included in the modeling splits rather than the validation splits.

(d) NA $=$ The standard deviation of the estimated spinel T1\% value could not be calculated because only 2 data points were available. 
Table 6.3. Number of Temperature vs. Vol\%-Crystallinity Points, Intercepts, Slopes, Estimated $T_{1 \%}$ Values, and Standard Deviations of $T_{1 \%}$ Values for $168 \mathrm{HLW}$ Glasses Having Spinel as the Primary Crystalline Phase and Used for Spinel $\mathbf{T}_{\mathbf{1} \%}$ Modeling (continued).

\begin{tabular}{|c|c|c|c|c|c|c|c|}
\hline \multirow{2}{*}{ Glass ID } & \multirow{2}{*}{$\begin{array}{l}\text { Primary \& } \\
\text { Secondary } \\
\text { Crystalline } \\
\text { Phases }\end{array}$} & \multicolumn{3}{|c|}{$\begin{array}{c}\text { Inverse Regression Used to } \\
\text { Calculate } \mathbf{T}_{1 \%}\end{array}$} & \multirow{2}{*}{$\begin{array}{c}\text { Estimated } \\
\text { Spinel } \\
\mathbf{T}_{1 \%} \\
\left({ }^{\circ} \mathbf{C}\right)\end{array}$} & \multirow{2}{*}{$\begin{array}{l}\operatorname{SD}\left(\mathrm{T}_{1 \%}\right) \\
\quad\left({ }^{\circ} \mathrm{C}\right)\end{array}$} & \multirow{2}{*}{$\begin{array}{c}\text { Spinel } \mathbf{T}_{1 \%} \\
\text { Data } \\
\text { Splitting } \\
\text { Validation } \\
\text { Set }\end{array}$} \\
\hline & & $\begin{array}{l}\text { Number } \\
\text { of Points }\end{array}$ & Intercept $^{(a)}$ & Slope $^{(a)}$ & & & \\
\hline HLW05-27 & Spinel & 3 & 996.93 & -144.74 & 852.2 & 36.51 & 1 \\
\hline HLW06-01 & Spinel & 5 & 1121.78 & -99.90 & 1021.9 & 25.56 & NA \\
\hline HLW06-02 & Spinel & 6 & 1070.22 & -136.18 & 934.0 & 10.92 & 3 \\
\hline HLW06-03 & Spinel $+\mathrm{ZrO}_{2}$ & 6 & 1285.49 & -73.98 & 1211.5 & 34.97 & 2 \\
\hline HLW06-04 & Spinel & 5 & 1055.77 & -211.54 & 844.2 & 19.82 & 4 \\
\hline HLW06-05 & Spinel & 6 & 1039.03 & -142.63 & 896.4 & 22.60 & 5 \\
\hline HLW06-06 & Spinel $+\mathrm{ZrO}_{2}$ & 6 & 1314.80 & -84.14 & 1230.7 & 26.22 & NA \\
\hline HLW06-07 & Spinel & 5 & 1266.70 & -58.12 & 1208.6 & 39.14 & 1 \\
\hline HLW06-08 & Spinel & 6 & 1213.48 & -168.54 & 1044.9 & 11.27 & 4 \\
\hline HLW06-09 & Spinel & 5 & 1277.20 & -77.04 & 1200.2 & 38.64 & 5 \\
\hline HLW06-10 & Spinel & 8 & 1269.38 & -257.25 & 1012.1 & 17.00 & 1 \\
\hline HLW06-11 & Spinel & 6 & 1218.79 & -92.91 & 1125.9 & 18.99 & 4 \\
\hline HLW06-12 & Spinel & 7 & 1114.63 & -101.09 & 1013.5 & 18.64 & 3 \\
\hline HLW06-13 & Spinel & 5 & 1238.02 & -61.61 & 1176.4 & 7.18 & NA \\
\hline HLW06-14 & Spinel & 6 & 1091.70 & -120.71 & 971.0 & 7.37 & 3 \\
\hline HLW06-15 & Spinel & 4 & 997.57 & -63.11 & 934.5 & 5.00 & 4 \\
\hline HLW06-16 & Spinel & 4 & 1031.97 & -70.28 & 961.7 & 8.94 & 2 \\
\hline HLW06-17 & Spinel & 5 & 1143.00 & -110.00 & 1033.0 & 8.08 & NA \\
\hline HLW06-18 & Spinel & 6 & 1189.14 & -118.95 & 1070.2 & 20.00 & 2 \\
\hline HLW06-19 & Spinel & 4 & 1257.14 & -71.43 & 1185.7 & 43.06 & 3 \\
\hline HLW06-20 & Spinel & 5 & 1268.09 & -131.38 & 1136.7 & 18.78 & 5 \\
\hline HLW06-25 & Spinel $+\mathrm{ThO}_{2}$ & 5 & $1173.45^{(\mathrm{b})}$ & $-125.62^{(\mathrm{b})}$ & $1047.8^{(b)}$ & $13.91^{(\mathrm{b})}$ & 2 \\
\hline HLW06-28 & $\begin{array}{l}\text { Spinel }+ \\
\text { Unidentified } \\
\mathrm{Na}-\mathrm{Ca}-\mathrm{U} \text { oxide } \\
\text { and } \mathrm{Cr}-\mathrm{Fe} \\
\text { oxide } \\
\end{array}$ & 4 & 1093.17 & -127.75 & 965.4 & 20.51 & 4 \\
\hline HLW06-30 & Spinel & 4 & 1202.29 & -93.69 & 1108.6 & 11.83 & 2 \\
\hline HLW06-32 & Spinel & 6 & 998.21 & -96.00 & 902.2 & 16.81 & 1 \\
\hline HLW07-01 & Spinel & 5 & 1066.17 & -145.76 & 920.4 & 8.29 & 5 \\
\hline HLW07-02 & Spinel & 5 & 1072.25 & -119.62 & 952.6 & 10.65 & $\mathrm{NA}^{(\mathrm{c})}$ \\
\hline HLW07-03 & Spinel & 4 & 1015.00 & -175.00 & 840.0 & 6.61 & $\mathrm{NA}^{(\mathrm{c})}$ \\
\hline HLW07-04 & Spinel & 4 & 935.24 & -75.30 & 859.9 & 20.57 & $\mathrm{NA}^{(\mathrm{c})}$ \\
\hline HLW07-05 & Spinel & 5 & 1240.91 & -56.82 & 1184.1 & 29.77 & $\mathrm{NA}^{(\mathrm{c})}$ \\
\hline HLW07-06 & Spinel & 5 & 1093.78 & -34.48 & $\begin{array}{l}1059.3 \\
\end{array}$ & 18.16 & 5 \\
\hline
\end{tabular}

(a) The intercept and slope are from fitting the inverse regression equation in Equation (E.1) of Appendix E to the temperature versus spinel percent crystallinity data for each glass given in Table 6.2.

(b) Estimated $\mathrm{T}_{1 \%}$ values in this table have been rounded to one decimal place; intercepts, slopes, and standard deviations have been rounded to two decimal places.

(c) NA = not applicable for glasses not included in data splitting validation sets because they were replicates. These glasses were included in the modeling splits rather than the validation splits.

(d) NA = The standard deviation of the estimated spinel T1\% value could not be calculated because only 2 data points were available. 
Table 6.3. Number of Temperature vs. Vol\%-Crystallinity Points, Intercepts, Slopes, Estimated $T_{1 \%}$ Values, and Standard Deviations of $T_{1 \%}$ Values for $168 \mathrm{HLW}$ Glasses Having Spinel as the Primary Crystalline Phase and Used for Spinel $\mathbf{T}_{\mathbf{1} \%}$ Modeling (continued).

\begin{tabular}{|c|c|c|c|c|c|c|c|}
\hline \multirow[b]{2}{*}{ Glass ID } & \multirow{2}{*}{$\begin{array}{c}\text { Primary \& } \\
\text { Secondary } \\
\text { Crystalline } \\
\text { Phases }\end{array}$} & \multicolumn{3}{|c|}{$\begin{array}{c}\text { Inverse Regression Used to } \\
\text { Calculate } \mathrm{T}_{1 \%}\end{array}$} & \multirow{2}{*}{$\begin{array}{c}\text { Estimated } \\
\text { Spinel } \\
\mathbf{T}_{1 \%} \\
\left({ }^{\circ} \mathrm{C}\right)\end{array}$} & \multirow{2}{*}{$\begin{array}{l}\operatorname{SD}\left(\mathrm{T}_{1 \%}\right) \\
\quad\left({ }^{\circ} \mathrm{C}\right)\end{array}$} & \multirow{2}{*}{$\begin{array}{c}\text { Spinel }_{1 \%} \\
\text { Data } \\
\text { Splitting } \\
\text { Validation } \\
\text { Set }\end{array}$} \\
\hline & & $\begin{array}{l}\text { Number } \\
\text { of Points }\end{array}$ & Intercept $^{(a)}$ & Slope $^{(a)}$ & & & \\
\hline HLW07-11 & Spinel & 5 & 1124.76 & -107.55 & 1017.2 & 7.53 & 4 \\
\hline HLW07-16 & Spinel $+\mathrm{ZrO}_{2}$ & 5 & 1123.35 & -116.37 & 1007.0 & 21.69 & 5 \\
\hline HLW07-17 & Spinel & 4 & 892.47 & -33.32 & 859.1 & 11.53 & 4 \\
\hline HLW07-20 & Spinel & 6 & 1100.62 & -122.52 & 978.1 & 14.00 & 2 \\
\hline HLW07-24 & Spinel $+\mathrm{ThO}_{2}$ & 5 & 1279.59 & -232.59 & 1047.0 & 22.38 & 1 \\
\hline HLW07-26 & Spinel & 5 & 1264.71 & -360.29 & 904.4 & 10.77 & 2 \\
\hline HLW07-27 & Spinel & 6 & 1044.19 & -252.91 & 791.3 & 18.70 & 3 \\
\hline HLW07-28 & Spinel & 5 & 1150.00 & -250.00 & 900.0 & 11.28 & 3 \\
\hline HLW07-29 & Spinel & 6 & 1081.58 & -104.16 & 977.4 & 5.19 & 1 \\
\hline HLW07-30 & Spinel & 5 & 1065.70 & -169.08 & 896.6 & 9.42 & 1 \\
\hline HLW07-31 & Spinel & 5 & 1129.92 & -225.41 & 904.5 & 3.70 & 3 \\
\hline HLW07-32 & Spinel & 5 & 1105.37 & -142.62 & 962.8 & 9.55 & 3 \\
\hline HLW07-33 & Spinel & 5 & 1150.82 & -151.10 & 999.7 & 3.70 & 2 \\
\hline HLW07-37 & Spinel & 5 & 964.58 & -106.09 & 858.5 & 6.37 & 3 \\
\hline HLW07-38 & Spinel & 6 & 1153.44 & -159.38 & 994.1 & 35.29 & 5 \\
\hline HLW07-39 & Spinel & 3 & 1000.00 & -250.00 & 750.0 & 61.24 & 5 \\
\hline HLW07-40 & Spinel & 6 & 1122.45 & -174.67 & 947.8 & 10.08 & 2 \\
\hline HLW-ALG-03 & Spinel & 3 & 919.64 & -160.71 & 758.9 & 19.15 & 2 \\
\hline HLW-ALG-05 & Spinel & 7 & 1072.84 & -123.67 & 949.2 & 27.52 & 3 \\
\hline HLW-ALG-06 & Spinel & 4 & 1022.13 & -66.99 & 955.1 & 23.27 & 2 \\
\hline HLW-ALG-09 & Spinel & 6 & 1095.79 & -294.94 & 800.8 & 31.32 & 4 \\
\hline HLW-ALG-10 & Spinel & 3 & 935.71 & -160.71 & 775.0 & 16.37 & 2 \\
\hline HLW-ALG-12 & Spinel & 5 & 989.73 & -109.43 & 880.3 & 28.57 & 3 \\
\hline HLW-ALG-14 & Spinel & 5 & 1064.54 & -72.80 & 991.7 & 26.36 & 4 \\
\hline HLW-ALG-15 & Spinel & 3 & 994.74 & -197.37 & 797.4 & 7.67 & 1 \\
\hline HLW-ALG-17 & \begin{tabular}{|l|} 
Spinel + \\
Na(Mn.Fe.Ni) \\
Silicate
\end{tabular} & 3 & 832.40 & -12.67 & 819.7 & 20.21 & 2 \\
\hline HLW-ALG-18 & Spinel & 2 & 707.14 & -71.43 & 635.7 & $\mathrm{NA}^{(\mathrm{d})}$ & 2 \\
\hline HLW-ALG-19 & Spinel & 3 & 1071.43 & -321.43 & 750.0 & 29.88 & 1 \\
\hline HLW-ALG-20 & Spinel & 5 & 1016.67 & -378.79 & 637.9 & 72.14 & 3 \\
\hline HLW-ALG-25 & Spinel & 4 & $1002.41^{(\mathrm{b})}$ & $-228.92^{(\mathrm{b})}$ & $773.5^{(\mathrm{b})}$ & $20.04^{(b)}$ & 1 \\
\hline
\end{tabular}

(a) The intercept and slope are from fitting the inverse regression equation in Equation (E.1) of Appendix E to the temperature versus spinel percent crystallinity data for each glass given in Table 6.2.

(b) Estimated $\mathrm{T}_{1 \%}$ values in this table have been rounded to one decimal place; intercepts, slopes, and standard deviations have been rounded to two decimal places.

(c) NA = not applicable for glasses not included in data splitting validation sets because they were replicates. These glasses were included in the modeling splits rather than the validation splits.

(d) $\mathrm{NA}=$ The standard deviation of the estimated spinel $\mathrm{T} 1 \%$ value could not be calculated because only 2 data points were available. 
Table 6.3. Number of Temperature vs. Vol\%-Crystallinity Points, Intercepts, Slopes, Estimated $\mathbf{T}_{1 \%}$ Values, and Standard Deviations of $\mathrm{T}_{1 \%}$ Values for $168 \mathrm{HLW}$ Glasses Having Spinel as the Primary Crystalline Phase and Used for Spinel $\mathbf{T}_{1 \%}$ Modeling (continued).

\begin{tabular}{|c|c|c|c|c|c|c|c|}
\hline \multirow{2}{*}{ Glass ID } & \multirow{2}{*}{$\begin{array}{c}\text { Primary \& } \\
\text { Secondary } \\
\text { Crystalline } \\
\text { Phases }\end{array}$} & \multicolumn{3}{|c|}{$\begin{array}{c}\text { Inverse Regression Used to } \\
\text { Calculate } \mathrm{T}_{\mathbf{1} \%}\end{array}$} & \multirow{2}{*}{$\begin{array}{c}\text { Estimated } \\
\text { Spinel } \\
\mathbf{T}_{1 \%} \\
\left({ }^{\circ} \mathbf{C}\right)\end{array}$} & \multirow{2}{*}{$\begin{array}{l}\operatorname{SD}\left(\mathrm{T}_{1 \%}\right) \\
\quad\left({ }^{\circ} \mathrm{C}\right)\end{array}$} & \multirow{2}{*}{$\begin{array}{c}\text { Spinel } \mathbf{T}_{1 \%} \\
\text { Data } \\
\text { Splitting } \\
\text { Validation } \\
\text { Set }\end{array}$} \\
\hline & & $\begin{array}{l}\text { Number } \\
\text { of Points }\end{array}$ & Intercept $^{(a)}$ & Slope $^{(a)}$ & & & \\
\hline HLW-ALG-27 & $\begin{array}{l}\text { Spinel + } \\
\text { NaAlFe silicate }\end{array}$ & 3 & 805.46 & -5.32 & 800.1 & 23.61 & 2 \\
\hline HLW-ALG-28 & Spinel & 3 & 914.04 & -58.22 & 855.8 & 4.18 & 2 \\
\hline HLW-ALG-30 & Spinel & 4 & 982.02 & -251.23 & 730.8 & 11.11 & 4 \\
\hline HLW-ALG-31 & Spinel & 5 & 1117.98 & -114.26 & 1003.7 & 8.76 & 3 \\
\hline HLW-ALG-32 & Spinel & 7 & 1180.54 & -55.71 & 1124.8 & 17.61 & 3 \\
\hline HLW-ALG-34 & Spinel & 4 & 968.64 & -144.07 & 824.6 & 7.63 & 5 \\
\hline HLW-ALG-35 & Spinel & 4 & 1143.17 & -122.30 & 1020.9 & 48.89 & 1 \\
\hline HLW-ALG-36 & Spinel & 6 & 1102.07 & -71.26 & 1030.8 & 33.12 & 3 \\
\hline HLW-ALG-40 & Spinel & 6 & 1152.76 & -140.34 & 1012.4 & 6.87 & 2 \\
\hline
\end{tabular}

(a) The intercept and slope are from fitting the inverse regression equation in Equation (E.1) of Appendix E to the temperature versus spinel percent crystallinity data for each glass given in Table 6.2.

(b) Estimated $\mathrm{T}_{1 \%}$ values in this table have been rounded to one decimal place; intercepts, slopes, and standard deviations have been rounded to two decimal places.

(c) NA = not applicable for glasses not included in data splitting validation sets because they were replicates. These glasses were included in the modeling splits rather than the validation splits.

(d) $\mathrm{NA}=$ The standard deviation of the estimated spinel $\mathrm{T} 1 \%$ value could not be calculated because only 2 data points were available. 
Table 6.4. Spinel $T_{1 \%}$ Data and Standard Deviations for Replicates of HLW Glasses Used for Modeling.

\begin{tabular}{|c|c|c|}
\hline $\begin{array}{l}\text { Glass IDs of } \\
\text { Replicate Sets }\end{array}$ & $\begin{array}{c}\text { Estimated } \\
\text { Spinel } \\
\mathrm{T}_{1 \%} \text { Values } \\
\text { and SDs }\left({ }^{\circ} \mathrm{C}\right)\end{array}$ & $\begin{array}{l}\text { SDs from } \\
\text { Replicate } \\
\text { Spinel } T_{1 \%} \\
\text { Vales }\left({ }^{\circ} \mathrm{C}\right)\end{array}$ \\
\hline HLW02-01 & $905.8^{(\mathrm{a})}$ & \multirow{2}{*}{$37.79^{(a)}$} \\
\hline HLW02-52 & 959.3 & \\
\hline HLW02-17 & 966.9 & \multirow{2}{*}{12.43} \\
\hline HLW02-53 & 949.3 & \\
\hline HLW02-04 & 848.8 & \multirow{2}{*}{43.62} \\
\hline HLW02-54 & 910.5 & \\
\hline HLW02-42 & 821.2 & \multirow{2}{*}{7.91} \\
\hline HLW02-55 & 832.4 & \\
\hline HLW02-44 & 813.5 & \multirow{2}{*}{13.68} \\
\hline HLW02-56 & 794.2 & \\
\hline HLW02-08 & 783.5 & \multirow{2}{*}{29.75} \\
\hline HLW02-57 & 741.4 & \\
\hline HLW02-46 & 963.3 & \multirow{3}{*}{12.58} \\
\hline HLW03-42 & 977.7 & \\
\hline HLW07-02 & 952.6 & \\
\hline HLW03-06 & 950.0 & \multirow{2}{*}{2.47} \\
\hline HLW03-43 & 946.5 & \\
\hline HLW03-26 & 797.3 & \multirow{2}{*}{35.50} \\
\hline HLW03-45 & 847.5 & \\
\hline HLW05-02 & 756.9 & \multirow{2}{*}{17.54} \\
\hline HLW05-07 & 732.1 & \\
\hline HLW02-22 & 937.5 & \multirow{2}{*}{54.84} \\
\hline HLW07-04 & 859.9 & \\
\hline HLW03-07 & 1213.2 & \multirow{2}{*}{20.57} \\
\hline HLW07-05 & 1184.1 & \\
\hline HLW03-41 & 853.8 & \multirow{2}{*}{9.73} \\
\hline HLW07-03 & 840.0 & \\
\hline HLW06-06 & 1230.7 & \multirow{2}{*}{38.37} \\
\hline HLW06-13 & 1176.4 & \\
\hline HLW06-01 & 1021.9 & \multirow{2}{*}{7.86} \\
\hline HLW06-17 & 1033.0 & \\
\hline \multicolumn{2}{|c|}{$\begin{array}{l}\text { Pooled Over } 15 \text { Replicate Sets } \\
\text { Used in Spinel } \mathbf{T}_{1 \%} \text { Model } \\
\text { Development }\end{array}$} & $\mathrm{SD}=\mathbf{2 6 . 8 9}$ \\
\hline
\end{tabular}

(a) Estimated $T_{1 \%}$ values in this table have been rounded to one decimal place and standard deviations have been rounded to two decimal places. 
Table 6.5. Compositions of 39 HLW Glasses (Mass Fractions of 25 Normalized Components) for Validating Spinel $\mathrm{T}_{1 \%}$ Models.

\begin{tabular}{|c|c|c|c|c|c|c|c|c|c|c|c|c|c|c|}
\hline D & $\mathrm{I}_{2} \mathrm{O}_{3}$ & $\mathbf{B}_{2} \mathbf{O}_{3}$ & $\mathrm{CaO}$ & CdO & $\mathrm{Cr}_{2} \mathrm{O}_{3}$ & $\mathbf{e}_{2} \mathrm{O}_{3}$ & $\mathrm{~K}_{2} \mathrm{O}$ & $\mathrm{La}_{2} \mathrm{O}_{3}$ & $\mathbf{L i}_{2} \mathbf{O}$ & MgO & MnO & $\mathrm{Na}_{2} \mathrm{O}$ & $\mathrm{NiO}$ & PbO \\
\hline & & 0.07000 & 0.00000 & .00000 & 0.00300 & 0.11500 & 0.00000 & & 0.04540 & & & 0.15300 & & \\
\hline & & & & & & & & & & & & & & \\
\hline & & & & & & & & & & & & & & \\
\hline MS7-H-Al & & 71 & 00 & & 90 & & & & 90 & & & & & \\
\hline & & 31 & & & & & & & 690 & & & & & 000 \\
\hline & & & & & & & & & & & & & & \\
\hline 1S7-L-Cr & 21 & 0.07011 & 0.00000 & 000 & 00 & 521 & & & 0.04550 & & & 32 & 50 & \\
\hline $\mathrm{Fe}$ & & 79 & 00 & & 10 & 99 & & & 720 & & & & & \\
\hline & & & & & & & & & & & & & & \\
\hline L-Li & & 09 & 0.0 & & 00 & & & & 000 & & & & 70 & \\
\hline $\mathrm{H}-\mathrm{Mg}$ & & & & & & & & & 30 & & & & & \\
\hline & & & & & & & & & & & & & & \\
\hline $\mathrm{H}-\mathrm{Na}$ & & & 00 & & 290 & & & & 400 & & & & 20 & \\
\hline L-Na & & 70 & 00 & & & & & & 720 & & & & & \\
\hline & & & & & & & & & & & & & & \\
\hline -L-Ni & & & & & & & & & 70 & & & & & \\
\hline $1-1$ & & 04 & 43 & 20 & & 43 & & & 30 & & & & 43 & 177 \\
\hline $1-1-0$ & & & & & & & & & & & & & & \\
\hline Cr-1-r & & & & & & & & & 007 & & & & & \\
\hline SP-Li-3-o & & 0.0 & 0.0 & 0.0 & 220 & 500 & 280 & 70 & 000 & 600 & 360 & 729 & 520 & 170 \\
\hline SP-Li-3-r & & & & 0.00690 & & & & & 0.03000 & 00 & & 5729 & 520 & 70 \\
\hline SP-Mg-1 & 68 & 72 & 996 & 87 & 219 & 449 & 79 & 69 & 988 & & & 666 & & \\
\hline SP-Mn-1 & 029 & 0.07025 & 0.01004 & 0.00692 & 0.00221 & 2545 & 0.00281 & 271 & 0.03011 & 602 & 000 & 5786 & 522 & 0171 \\
\hline SP-Mn-3 & & & 963 & & 212 & 2043 & 270 & & 890 & & & & 501 & 64 \\
\hline SP-Na-1 & & 0.07642 & 0.01092 & 753 & 0.00240 & 0.13646 & .00306 & 295 & 0.03275 & 55 & 93 & 0.08000 & 0.00568 & 186 \\
\hline SP-Na-3 & & 0.06645 & 0.00949 & 0.00655 & 0.00209 & 866 & .00266 & & 0.02848 & & & 0.19999 & 0.00494 & 161 \\
\hline SPA-18 & 0.05999 & 0.08179 & 0.02000 & 0.00000 & 0.00300 & 0.13998 & 0.03889 & 0.00260 & 0.03789 & 0.00000 & 0.01000 & 0.15888 & 0.00500 & 0.0029 \\
\hline
\end{tabular}


Table 6.5. Compositions of 39 HLW Glasses (Mass Fractions of 25 Normalized Components) for Validating Spinel $\mathbf{T}_{1 \%}$ Models (continued).

\begin{tabular}{|c|c|c|c|c|c|c|c|c|c|c|c|c|c|}
\hline Glass ID & $\mathrm{Sb}_{2} \mathrm{O}_{3}$ & $\mathrm{SeO}_{2}$ & $\mathrm{SiO}_{2}$ & SrO & $\mathrm{ThO}_{2}$ & $\mathrm{TiO}_{2}$ & $\mathrm{Tl}_{2} \mathrm{O}$ & $\mathrm{UO}_{3}$ & $\mathrm{ZnO}$ & $\mathrm{ZrO}_{2}$ & Others & Sum $^{(\mathbf{a})}$ & Used for \\
\hline MS-7a & 0.00000 & 0.00000 & 0.45310 & 0.00000 & 0.00000 & 0.00000 & 0.00000 & 0.00000 & 0.00000 & 0.06000 & 0.00000 & 1.00000 & Yes \\
\hline MS-7d & 0.00000 & 0.00000 & 0.45310 & 0.00000 & 0.00000 & 0.00000 & 0.00000 & 0.00000 & 0.00000 & 0.06000 & 0.00000 & 1.00000 & Yes \\
\hline MS-7e & 0.00000 & 0.00000 & 0.45310 & 0.00000 & 0.00000 & 0.00000 & 0.00000 & 0.00000 & 0.00000 & 0.06000 & 0.00000 & 1.00000 & Yes \\
\hline MS7-H-Al & 0.00000 & 0.00000 & 0.43834 & 0.00000 & 0.00000 & 0.00000 & 0.00000 & 0.00000 & 0.00000 & 0.05801 & 0.00000 & 1.00000 & Yes \\
\hline MS7-L-Al & 0.00000 & 0.00000 & 0.46825 & 0.00000 & 0.00000 & 0.00000 & 0.00000 & 0.00000 & 0.00000 & 0.06201 & 0.00000 & 1.00000 & Yes \\
\hline MS7-H-Cr & 0.00000 & 0.00000 & 0.45260 & 0.00000 & 0.00000 & 0.00000 & 0.00000 & 0.00000 & 0.00000 & 0.05990 & 0.00000 & 1.00000 & Yes \\
\hline MS7-L-Cr & 0.00000 & 0.00000 & 0.45405 & 0.00000 & 0.00000 & 0.00000 & 0.00000 & 0.00000 & 0.00000 & 0.06011 & 0.00000 & 1.00000 & Yes \\
\hline MS7-L-Fe & 0.00000 & 0.00000 & 0.47095 & 0.00000 & 0.00000 & 0.00000 & 0.00000 & 0.00000 & 0.00000 & 0.06239 & 0.00000 & 1.00000 & Yes \\
\hline MS7-H-Li & 0.00000 & 0.00000 & 0.44616 & 0.00000 & 0.00000 & 0.00000 & 0.00000 & 0.00000 & 0.00000 & 0.05909 & 0.00000 & 1.00000 & Yes \\
\hline MS7-L-Li & 0.00000 & 0.00000 & 0.46035 & 0.00000 & & 0.00000 & 0.00000 & & & 0.06099 & & 1.00000 & Yes \\
\hline MS7-H-Mg & 0.00000 & 0.00000 & 0.44216 & 0.00000 & 0.00000 & 0.00000 & 0.00000 & 0.00000 & 0.00000 & 0.05859 & 0.00000 & 1.00000 & Yes \\
\hline MS7-L-Mg & 0.00000 & 0.00000 & 0.45580 & 0.00000 & 0.00000 & 0.00000 & 0.00000 & 0.00000 & 0.00000 & 0.06040 & 0.00000 & 1.00000 & Yes \\
\hline MS7-H-Na & 0.00000 & 0.00000 & & & & 0.00000 & 0.00000 & 0.00000 & 0.00000 & 0.05810 & 0.00000 & 1.00000 & Yes \\
\hline MS7-L-Na & 0.00000 & 0.00000 & 0.47080 & 0.00000 & 0.00000 & 0.00000 & 0.00000 & 0.00000 & 0.00000 & 0.06230 & 0.00000 & 1.00000 & Yes \\
\hline MS7-H-Ni & 0.00000 & 0.00000 & 0.44920 & 0.00000 & 0.00000 & 0.00000 & 0.00000 & 0.00000 & 0.00000 & 0.05950 & 0.00000 & 1.00000 & Yes \\
\hline MS7-L-Ni & 0.00000 & 0.00000 & 0.45610 & 0.00000 & 0.00000 & 0.00000 & 0.00000 & 0.00000 & 0.00000 & 0.06040 & 0.00000 & 1.00000 & Yes \\
\hline SP-Al-1 ${ }^{(a)}$ & 0.00073 & 0.00094 & 0.47998 & 0.00031 & 0.00000 & 0.00031 & 0.00000 & 0.00000 & 0.00042 & 0.01910 & 0.01642 & 1.00000 & Yes \\
\hline SP-Cr-1-o & 0.00070 & 0.00090 & 0.46100 & 0.00030 & 0.00000 & 0.00030 & 0.00000 & 0.00000 & 0.00040 & 0.01834 & 0.01577 & 1.00000 & Yes \\
\hline SP-Cr-1-r & 0.00070 & 0.00090 & 0.46100 & 0.00030 & 0.00000 & 0.00030 & 0.00000 & 0.00000 & 0.00040 & 0.01834 & 0.01577 & 1.00000 & Yes \\
\hline SP-Li-3-o & 0.00070 & 0.00090 & 0.45999 & 0.00030 & 0.00000 & 0.00030 & 0.00000 & 0.00000 & 0.00040 & 0.01830 & 0.01573 & 1.00000 & Yes \\
\hline SP-Li-3-r & 0.00070 & 0.00090 & 0.45999 & 0.00030 & 0.00000 & 0.00030 & 0.00000 & 0.00000 & 0.00040 & 0.01830 & 0.01573 & 1.00000 & Yes \\
\hline SP-Mg-1 & 0.00070 & 0.00090 & 0.45813 & 0.00030 & 0.00000 & 0.00030 & 0.00000 & 0.00000 & 0.00040 & 0.01823 & 0.01567 & 1.00000 & Yes \\
\hline SP-Mn-1 & 0.00070 & 0.00090 & 0.46165 & 0.00030 & 0.00000 & 0.00030 & 0.00000 & 0.00000 & 0.00040 & 0.01837 & 0.01579 & 1.00000 & Yes \\
\hline SP-Mn-3 & 0.00067 & 0.00087 & 0.44318 & 0.00029 & 0.00000 & 0.00029 & 0.00000 & 0.00000 & 0.00039 & 0.01763 & 0.01516 & 1.00000 & Yes \\
\hline SP-Na-1 & 0.00076 & 0.00098 & 0.50218 & 0.00033 & 0.00000 & 0.00033 & 0.00000 & 0.00000 & 0.00044 & 0.01998 & 0.01717 & 1.00000 & Yes \\
\hline SP-Na-3 & 0.00066 & 0.00085 & 0.43668 & 0.00028 & 0.00000 & 0.00028 & 0.00000 & 0.00000 & 0.00038 & 0.01737 & 0.01493 & 1.00000 & Yes \\
\hline SPA-18 & 0.00033 & 0.00060 & 0.35535 & 0.01420 & 0.00000 & 0.00000 & 0.00000 & 0.00000 & 0.00990 & 0.03000 & 0.02870 & 1.00000 & $\mathrm{No}^{(\mathrm{b})}$ \\
\hline
\end{tabular}

(a) The component mass fractions are normalized to sum to one over the 25 components listed in this table. The normalized component mass fractions listed in this table were rounded to five decimals, and may not sum exactly to 1.00000 as listed. However, complete compositions listed to more decimal places and summing to 1.0000 were used for property-composition modeling.

(b) This glass has nearly $0.09(9 \mathrm{wt} \%)$ of its composition involved in 9 components not varied as part of statistically designed test matries, and was also found to be a significant outlier in initial model development and validation work. Hence, it was excluded from the spinel $\mathrm{T}_{1 \%}$ validation dataset. 
Table 6.5. Compositions of 39 HLW Glasses (Mass Fractions of 25 Normalized Components) for Validating Spinel $\mathbf{T}_{1 \%}$ Models (continued).

\begin{tabular}{|c|c|c|c|c|c|c|c|c|c|c|c|c|c|c|}
\hline Glass ID & $\mathrm{Al}_{2} \mathrm{O}_{3}$ & $\mathbf{B}_{2} \mathbf{O}_{3}$ & $\mathrm{CaO}$ & $\mathrm{CdO}$ & $\mathrm{Cr}_{2} \mathrm{O}_{3}$ & $\mathrm{Fe}_{2} \mathrm{O}_{3}$ & $\mathrm{~K}_{2} \mathrm{O}$ & $\mathrm{La}_{2} \mathrm{O}_{3}$ & $\mathbf{L i}_{2} \mathbf{O}$ & MgO & MnO & $\mathrm{Na}_{2} \mathrm{O}$ & $\mathrm{NiO}$ & PbO \\
\hline SPA-38 & 0.08000 & 0.07000 & 0.01000 & 0.00700 & 0.00220 & 0.12500 & 0.00280 & 0.00270 & 0.03000 & 0.00600 & 0.00360 & 0.15730 & 0.00520 & 00170 \\
\hline WTP-TL-16 & 10999 & נח & 0 & 0 & 00 & 99 & 20 & 280 & 99 & 380 & 00 & 000 & 000 & 20 \\
\hline WTP-TL-17 & 10999 & 14999 & & 0.00000 & 500 & 0.06559 & 20 & 880 & 0.00000 & 380 & 000 & 999 & 01000 & \\
\hline WTP-TL-19 & 0.02000 & 14999 & 0.00 & 0.01000 & 0.00500 & 0.03000 & 0.00020 & 0.00280 & 0.00000 & 9380 & 0.05000 & 0.14999 & 0.01000 & 0.00120 \\
\hline WTP-TL-20 & 0.02000 & .04000 & 0.00380 & 0.01000 & 0.00500 & 0.12999 & 0.00020 & 0.0 & \begin{tabular}{|l|}
0.05999 \\
\end{tabular} & 380 & 0.00000 & 0.04000 & 0.01000 & 20 \\
\hline WTP-TL & & 04000 & 80 & 00 & 0.0 & & & & & & & & & \\
\hline WTP-TL-23 & 0.08749 & .06749 & 0.0 & 0.00750 & 0.00380 & 0.07929 & 0.0 & 0.0 & 0.04500 & 0.00380 & 0.03750 & 0.06749 & 0.00750 & 120 \\
\hline WTP-TL-24 & 0.04250 & 0.06749 & 0.00380 & 0.00250 & 0.00120 & 0.10499 & 0.00020 & 280 & 0.01500 & 0.00380 & 750 & 0.11179 & 0.00750 & 120 \\
\hline WTP-TL-27 & 0.08749 & 0.12249 & 0.0 & 0.0 & 0.0 & 0.10499 & 0.0 & 0.0 & 0.04500 & 380 & 750 & 0.06749 & 0.00250 & 120 \\
\hline WTP-TL-28 & 0.04250 & .06749 & .00 & 50 & 0.0 & 0.10499 & 0.0 & 0.0 & 0.04500 & 80 & 50 & 0.06749 & 0250 & 20 \\
\hline WTP-TL-29 & 0.04250 & 0.12249 & 0.00380 & 0.00750 & 0.00380 & 0.10499 & 0.00020 & 0.0 & 0.01500 & 0.00380 & 750 & 0.06749 & 0.00250 & 0.00120 \\
\hline WTP-TL-30 & 0.08749 & 0.12249 & 0.00380 & 0.00250 & 0.00380 & 0.05499 & 0.00020 & 0.00280 & 0.04500 & 0.00380 & 0.01580 & 0.06749 & 0.00750 & 0.00120 \\
\hline
\end{tabular}

\begin{tabular}{|c|c|c|c|c|c|c|c|c|c|c|c|c|c|}
\hline Glass ID & $\mathrm{Sb}_{2} \mathrm{O}_{3}$ & $\mathrm{SeO}_{2}$ & $\mathrm{SiO}_{2}$ & SrO & $\mathrm{ThO}_{2}$ & $\mathrm{TiO}_{2}$ & $\mathbf{T l}_{2} \mathbf{O}$ & $\mathbf{U O}_{3}$ & $\mathrm{ZnO}$ & $\mathrm{ZrO}_{2}$ & Others & $\operatorname{Sum}^{(a)}$ & $\begin{array}{c}\text { Used for } \\
\text { Validation } \\
\text { Analysis }\end{array}$ \\
\hline SPA-38 & 0.00078 & 0.00090 & 0.46011 & 0.00030 & 0.00000 & 0.00030 & 0.00000 & 0.00000 & 0.00040 & 0.01850 & 0.01520 & 1.00000 & Yes \\
\hline WTP-TL-16 & 0.00070 & 0.00120 & 0.40056 & 0.00000 & 0.00000 & 0.00040 & 0.00000 & 0.00000 & 0.02500 & 0.00000 & 0.00540 & 1.00000 & Yes \\
\hline WTP-TL-17 & 0.00070 & 0.00120 & 0.37996 & 0.08499 & 0.00000 & 0.00040 & 0.00000 & 0.00000 & 0.02500 & 0.00000 & 0.00540 & 1.00000 & Yes \\
\hline WTP-TL-19 & 0.00070 & 0.00120 & 0.49555 & 0.00000 & 0.00000 & 0.00040 & 0.00000 & 0.00000 & 0.00000 & 0.05999 & 0.00540 & 1.00000 & Yes \\
\hline WTP-TL-20 & 0.00070 & 0.00120 & 0.49555 & 0.08499 & 0.00000 & 0.00040 & 0.00000 & 0.00000 & 0.02500 & 0.05999 & 0.00540 & 1.00000 & Yes \\
\hline WTP-TL-21 & 0.00070 & 0.00120 & 0.52995 & 0.02040 & 0.00000 & 0.00040 & 0.00000 & 0.00000 & 0.02500 & 0.00000 & 0.00540 & 1.00000 & Yes \\
\hline WTP-TL-23 & 0.00070 & 0.00120 & 0.49245 & 0.06379 & 0.00000 & 0.00040 & 0.00000 & 0.00000 & 0.00620 & 0.01500 & 0.00540 & 1.00000 & Yes \\
\hline WTP-TL-24 & 0.00070 & 0.00120 & 0.49245 & 0.06379 & 0.00000 & 0.00040 & 0.00000 & 0.00000 & 0.01880 & 0.01500 & 0.00540 & 1.00000 & Yes \\
\hline WTP-TL-27 & 0.00070 & 0.00120 & 0.42436 & 0.02120 & 0.00000 & 0.00040 & 0.00000 & 0.00000 & 0.01880 & 0.04500 & 0.00540 & 1.00000 & Yes \\
\hline WTP-TL-28 & 0.00070 & 0.00120 & 0.48175 & 0.06379 & 0.00000 & 0.00040 & 0.00000 & 0.00000 & 0.01880 & 0.04500 & 0.00540 & 1.00000 & Yes \\
\hline WTP-TL-29 & 0.00070 & 0.00120 & 0.49245 & 0.05199 & 0.00000 & 0.00040 & 0.00000 & 0.00000 & 0.00620 & 0.02610 & 0.00540 & 1.00000 & Yes \\
\hline WTP-TL-30 & 0.00070 & 0.00120 & 0.48845 & 0.02120 & 0.00000 & 0.00040 & 0.00000 & 0.00000 & 0.01880 & 0.04500 & 0.00540 & 1.00000 & Yes \\
\hline
\end{tabular}

(a) The component mass fractions are normalized to sum to one over the 25 components listed in this table. The normalized component mass fractions listed in this table were rounded to five decimals, and may not sum exactly to 1.00000 as listed. However, complete compositions listed to more decimal places and summing to 1.0000 were used for property-composition modeling. 
Table 6.6. Temperature and Volume \%-Crystallinity Data for 39 HLW Glasses with Spinel as the Primary Crystalline Phase and Used in Validating Spinel $\mathbf{T}_{1 \%}$ Models.

\begin{tabular}{|l|r|r|}
\hline Glass ID & Vol\% & Temp \\
\hline MS-7a & 1.19 & 864 \\
\hline MS-7a & 1.13 & 893 \\
\hline MS-7a & 0.93 & 934 \\
\hline MS-7a & 0.7 & 971 \\
\hline MS-7a & 0.5 & 1014 \\
\hline MS-7a & 0.11 & 1062 \\
\hline MS-7d & 0.74 & 959 \\
\hline MS-7d & 0.52 & 1000 \\
\hline MS-7d & 0.33 & 1045 \\
\hline MS-7d & 0.51 & 1011 \\
\hline MS-7d & 0.62 & 985 \\
\hline MS-7d & 0.81 & 919 \\
\hline MS-7e & 1.83 & 734 \\
\hline MS-7e & 1.83 & 734 \\
\hline MS-7e & 1.91 & 750 \\
\hline MS-7e & 1.8 & 750 \\
\hline MS-7e & 1.75 & 801 \\
\hline MS-7e & 1.62 & 801 \\
\hline MS-7e & 1.56 & 801 \\
\hline MS-7e & 1.45 & 801 \\
\hline MS-7e & 1.42 & 801 \\
\hline MS-7e & 1.74 & 801 \\
\hline MS-7e & 1.39 & 853 \\
\hline MS-7e & 1.11 & 853 \\
\hline MS-7e & 1.17 & 853 \\
\hline MS-7e & 1.5 & 853 \\
\hline MS-7e & 1.49 & 853 \\
\hline MS-7e & 1.22 & 928 \\
\hline MS-7e & 0.85 & 950 \\
\hline MS-7e & 0.94 & 950 \\
\hline MS-7e & 0.68 & 977 \\
\hline MS-7e & 0.46 & 1005 \\
\hline MS-7e & 0.12 & 1039 \\
\hline MS-7e & 0.21 & 1052 \\
\hline MS7-H-Al & 3.24 & 730 \\
\hline MS7-H-Al & 2.68 & 839 \\
\hline MS7-H-Al & 2.4 & 946 \\
\hline MS7-H-Al & 1.62 & 987 \\
\hline MS7-H-Al & 1.43 & 997 \\
\hline MS7-H-Al & 1.14 & 1040 \\
\hline MS7-H-Al & 0.59 & 1092 \\
\hline MS7-H-Al & 0.36 & 1118 \\
\hline MS7-H-Cr & 2.83 & 730 \\
\hline MS7-H-Cr & 2.01 & 875 \\
\hline MS7-H-Cr & 1.74 & 905 \\
\hline
\end{tabular}

\begin{tabular}{|l|r|r|}
\hline Glass ID & Vol\% & Temp \\
\hline MS7-H-Cr & 1.49 & 949 \\
\hline MS7-H-Cr & 1.07 & 1000 \\
\hline MS7-H-Cr & 0.55 & 1047 \\
\hline MS7-H-Cr & 0.19 & 1096 \\
\hline MS7-H-Li & 2.95 & 705 \\
\hline MS7-H-Li & 1.72 & 839 \\
\hline MS7-H-Li & 1.28 & 905 \\
\hline MS7-H-Li & 0.85 & 925 \\
\hline MS7-H-Li & 0.97 & 942 \\
\hline MS7-H-Li & 0.56 & 987 \\
\hline MS7-H-Li & 0.11 & 1047 \\
\hline MS7-H-Mg & 2.89 & 808 \\
\hline MS7-H-Mg & 2.23 & 924 \\
\hline MS7-H-Mg & 1.92 & 946 \\
\hline MS7-H-Mg & 1.56 & 1000 \\
\hline MS7-H-Mg & 0.87 & 1060 \\
\hline MS7-H-Mg & 0.2 & 1133 \\
\hline MS7-H-Na & 2.37 & 750 \\
\hline MS7-H-Na & 1.36 & 860 \\
\hline MS7-H-Na & 0.92 & 905 \\
\hline MS7-H-Na & 0.32 & 969 \\
\hline MS7-H-Ni & 4.02 & 808 \\
\hline MS7-H-Ni & 4.01 & 812 \\
\hline MS7-H-Ni & 3.86 & 840 \\
\hline MS7-H-Ni & 3.86 & 870 \\
\hline MS7-H-Ni & 3.49 & 915 \\
\hline MS7-H-Ni & 3.61 & 930 \\
\hline MS7-H-Ni & 2.75 & 1000 \\
\hline MS7-H-Ni & 2.52 & 1041 \\
\hline MS7-H-Ni & 1.48 & 1047 \\
\hline MS7-H-Ni & 1.69 & 1060 \\
\hline MS7-H-Ni & 0.55 & 1133 \\
\hline MS7-H-Ni & 2.03 & 1000 \\
\hline MS7-H-Ni & 2.77 & 915 \\
\hline MS7-H-Ni & 3.42 & 808 \\
\hline MS7-L-Al & 1.72 & 798 \\
\hline MS7-L-Al & 1.0 & 875 \\
\hline MS7-L-Al & 0.98 & 919 \\
\hline MS7-L-Al & 0.39 & 964 \\
\hline MS7-L-Al & 0.17 & 1000 \\
\hline MS7-L-Cr & 2.71 & 730 \\
\hline MS7-L-Cr & 1.79 & 860 \\
\hline MS7-L-Cr & 1.3 & 905 \\
\hline MS7-L-Cr & 1.1 & 925 \\
\hline MS7-L-Cr & 0.59 & 969 \\
\hline
\end{tabular}

\begin{tabular}{|l|r|r|}
\hline Glass ID & Vol\% & Temp \\
\hline MS7-L-Cr & 0.22 & 1006 \\
\hline MS7-L-Fe & 1.76 & 808 \\
\hline MS7-L-Fe & 1.53 & 840 \\
\hline MS7-L-Fe & 0.76 & 919 \\
\hline MS7-L-Fe & 0.39 & 946 \\
\hline MS7-L-Fe & 0.39 & 960 \\
\hline MS7-L-Fe & 0.16 & 1000 \\
\hline MS7-L-Li & 2.63 & 750 \\
\hline MS7-L-Li & 1.94 & 875 \\
\hline MS7-L-Li & 1.65 & 919 \\
\hline MS7-L-Li & 1.77 & 949 \\
\hline MS7-L-Li & 1.34 & 964 \\
\hline MS7-L-Li & 1.09 & 1000 \\
\hline MS7-L-Li & 0.24 & 1096 \\
\hline MS7-L-Mg & 2.14 & 808 \\
\hline MS7-L-Mg & 1.96 & 854 \\
\hline MS7-L-Mg & 1.53 & 924 \\
\hline MS7-L-Mg & 1.03 & 997 \\
\hline MS7-L-Mg & 0.21 & 1046 \\
\hline MS7-L-Na & 3.7 & 728 \\
\hline MS7-L-Na & 3.37 & 860 \\
\hline MS7-L-Na & 2.94 & 905 \\
\hline MS7-L-Na & 2.75 & 919 \\
\hline MS7-L-Na & 1.93 & 969 \\
\hline MS7-L-Na & 1.35 & 1006 \\
\hline MS7-L-Na & 0.83 & 1092 \\
\hline MS7-L-Na & 0.79 & 1118 \\
\hline MS7-L-Na & 0.44 & 1155 \\
\hline MS7-L-Na & 2.11 & 949 \\
\hline MS7-L-Na & 1.68 & 1019 \\
\hline MS7-L-Ni & 1.32 & 750 \\
\hline MS7-L-Ni & 0.82 & 860 \\
\hline MS7-L-Ni & 0.43 & 919 \\
\hline MS7-L-Ni & 0.16 & 949 \\
\hline MS7-L-Ni & 0.19 & 964 \\
\hline MS7-L-Ni & 0.12 & 1006 \\
\hline SPA-18 ${ }^{\text {(a) }}$ & 0.99 & 875 \\
\hline SPA-18 ${ }^{(a)}$ & 0.69 & 900 \\
\hline SPA-18 ${ }^{(a)}$ & 0.59 & 926 \\
\hline SPA-18 ${ }^{(a)}$ & 0.24 & 951 \\
\hline SPA-38 & 1.05 & 851 \\
\hline SPA-38 & 0.65 & 901 \\
\hline SPA-38 & 0.32 & 951 \\
\hline SPA-38 & 0.21 & 975 \\
\hline SPA-38 & 0.15 & 1003 \\
\hline
\end{tabular}

(a) SPA-18 was not incuded in the validation dataset as explained in footnote (b) of Table 6.5. 
Table 6.6. Temperature and Volume \%-Crystallinity Data for 39 HLW Glasses with Spinel as the Primary Crystalline Phase and Used in Validating Spinel $\mathbf{T}_{1 \%}$ Models (continued).

\begin{tabular}{|l|c|c|}
\hline Glass ID & Vol\% & Temp \\
\hline SP-Al-1 & 0.1 & 952 \\
\hline SP-Al-1 & 0.19 & 898 \\
\hline SP-Al-1 & 0.33 & 854 \\
\hline SP-Al-1 & 0.6 & 808 \\
\hline SP-Al-1 & 0.82 & 717 \\
\hline SP-Cr-1-o & 0.18 & 897 \\
\hline SP-Cr-1-o & 0.38 & 848 \\
\hline SP-Cr-1-o & 0.59 & 797 \\
\hline SP-Cr-1-o & 0.92 & 744 \\
\hline SP-Cr-1-o & 0.83 & 701 \\
\hline SP-Cr-1-r & 0.29 & 897 \\
\hline SP-Cr-1-r & 0.61 & 848 \\
\hline SP-Cr-1-r & 0.95 & 797 \\
\hline SP-Cr-1-r & 1.5 & 744 \\
\hline SP-Cr-1-r & 1.34 & 701 \\
\hline SP-Li-3-o & 0.72 & 938 \\
\hline SP-Li-3-o & 0.77 & 892 \\
\hline SP-Li-3-o & 1.08 & 793 \\
\hline SP-Li-3-o & 1.71 & 740 \\
\hline SP-Li-3-r & 0.27 & 951 \\
\hline SP-Li-3-r & 0.47 & 897 \\
\hline SP-Li-3-r & 1.39 & 737 \\
\hline SP-Li-3-r & 1.35 & 701 \\
\hline SP-Mg-1 & 0.07 & 1028 \\
\hline SP-Mg-1 & 0.57 & 952 \\
\hline SP-Mg-1 & 0.96 & 898 \\
\hline SP-Mg-1 & 1.39 & 854 \\
\hline SP-Mg-1 & 1.81 & 808 \\
\hline SP-Mn-1 & 0.47 & 1028 \\
\hline SP-Mn-1 & 1.12 & 952 \\
\hline SP-Mn-1 & 0.78 & 943 \\
\hline SP-Mn-1 & 1.37 & 852 \\
\hline SP-Mn-1 & 1.66 & 808 \\
\hline SP-Mn-3 & 0.42 & 1028 \\
\hline SP-Mn-3 & 1.02 & 952 \\
\hline SP-Mn-3 & 1.29 & 900 \\
\hline SP-Mn-3 & 1.69 & 898 \\
\hline SP-Mn-3 & 2.17 & 854 \\
\hline SP-Mn-3 & 2.58 & 808 \\
\hline SP-Mn-3 & 2.84 & 736 \\
\hline SP-Na-1 & 1.19 & 1125 \\
\hline SP-Na-1 & 1.73 & 1028 \\
\hline SP-Na-1 & 2.84 & 952 \\
\hline SP-Na-1 & 3.74 & 898 \\
\hline SP-Na-1 & 4.57 & 808 \\
\hline
\end{tabular}

\begin{tabular}{|l|r|r|}
\hline Glass ID & Vol\% & Temp \\
\hline SP-Na-3 & 0.7 & 898 \\
\hline SP-Na-3 & 0.89 & 852 \\
\hline SP-Na-3 & 1.03 & 808 \\
\hline SP-Na-3 & 1.31 & 717 \\
\hline WTP-TL-16 & 2.35 & 1001 \\
\hline WTP-TL-16 & 1.55 & 1100 \\
\hline WTP-TL-16 & 0.93 & 1200 \\
\hline WTP-TL-16 & 0.46 & 1251 \\
\hline WTP-TL-16 & 0.36 & 1275 \\
\hline WTP-TL-17 & 0.56 & 894 \\
\hline WTP-TL-17 & 0.31 & 1002 \\
\hline WTP-TL-17 & 0.1 & 1100 \\
\hline WTP-TL-17 & 1.08 & 802 \\
\hline WTP-TL-17 & 0.05 & 1140 \\
\hline WTP-TL-19 & 0.87 & 894 \\
\hline WTP-TL-19 & 0.26 & 1002 \\
\hline WTP-TL-19 & 0.2 & 1025 \\
\hline WTP-TL-20 & 4.3 & 894 \\
\hline WTP-TL-20 & 2.2 & 1002 \\
\hline WTP-TL-20 & 0.72 & 1100 \\
\hline WTP-TL-20 & 0.26 & 1199 \\
\hline WTP-TL-21 & 0.62 & 901 \\
\hline WTP-TL-21 & 0.36 & 1002 \\
\hline WTP-TL-21 & 0.2 & 1100 \\
\hline WTP-TL-21 & 0.87 & 802 \\
\hline WTP-TL-23 & 1.4 & 901 \\
\hline WTP-TL-23 & 0.51 & 1000 \\
\hline WTP-TL-23 & 0.2 & 1100 \\
\hline WTP-TL-24 & 0.87 & 901 \\
\hline WTP-TL-24 & 0.2 & 1000 \\
\hline WTP-TL-24 & 0.1 & 1025 \\
\hline WTP-TL-27 & 3.14 & 899 \\
\hline WTP-TL-27 & 1.32 & 1001 \\
\hline WTP-TL-27 & 0.36 & 1101 \\
\hline WTP-TL-28 & 1.82 & 899 \\
\hline WTP-TL-28 & 0.67 & 1001 \\
\hline WTP-TL-28 & 0 & 1050 \\
\hline WTP-TL-29 & 1.51 & 899 \\
\hline WTP-TL-29 & 0.77 & 1001 \\
\hline WTP-TL-29 & 0.46 & 1101 \\
\hline WTP-TL-29 & 0.31 & 1200 \\
\hline WTP-TL-30 & 2.1 & 899 \\
\hline WTP-TL-30 & 1.02 & 1001 \\
\hline WTP-TL-30 & 0.41 & 1101 \\
\hline WTP-TL-30 & 0.15 & 1200 \\
\hline
\end{tabular}


Table 6.7. Intercepts, Slopes, Predicted Spinel $T_{1 \%}$ Values, Standard Deviations of Spinel $\mathbf{T}_{1 \%}$ Values, and Number of Temperature vs. Vol\%-Crystallinity Points for 39 HLW Glasses Used to Validate Spinel $\mathrm{T}_{1 \%}$ Models.

\begin{tabular}{|c|c|c|c|c|c|c|c|}
\hline Glass ID & $\begin{array}{l}\text { Primary/ } \\
\text { Secondary } \\
\text { Crystalline } \\
\text { Phase(s) }\end{array}$ & $\begin{array}{c}\text { Retained } \\
\text { for Spinel } \\
\mathbf{T}_{1 \%} \text { Model } \\
\text { Validation }\end{array}$ & $\begin{array}{c}\text { Number of } \\
\text { Points }^{(b)}\end{array}$ & Intercept $^{(\mathbf{b})}$ & Slope $^{(\mathbf{b})}$ & $\begin{array}{c}\text { Estimated } \\
\text { Spinel } \\
\mathbf{T}_{1 \%} \\
\left({ }^{\circ} \mathrm{C}\right)\end{array}$ & $\begin{array}{c}\mathrm{SD}\left(\mathrm{T}_{1 \%}\right) \\
\left({ }^{\circ} \mathrm{C}\right)\end{array}$ \\
\hline MS-7a & Spinel & Yes & 6 & $1092.68^{(\mathrm{c})}$ & $-179.41^{(\mathrm{c})}$ & $913.3^{(\mathrm{c})}$ & $5.75^{(\mathrm{c})}$ \\
\hline MS-7d & Spinel & Yes & 6 & 1131.49 & -246.44 & 885.0 & 10.90 \\
\hline MS-7e & Spinel & Yes & 22 & 1087.53 & -177.74 & 909.8 & 6.50 \\
\hline MS7-H-Al & Spinel & Yes & 8 & 1176.97 & -123.83 & 1053.1 & 14.87 \\
\hline MS7-L-Al & Spinel & Yes & 5 & 1019.89 & -127.58 & 892.3 & 8.16 \\
\hline MS7-H-Cr & Spinel & Yes & 7 & 1133.11 & -134.59 & 998.5 & 6.94 \\
\hline MS7-L-Cr & Spinel & Yes & 6 & 1038.80 & -108.66 & 930.1 & 5.52 \\
\hline MS7-L-Fe & Spinel & Yes & 6 & 1004.07 & -110.50 & 893.6 & 4.44 \\
\hline MS7-H-Li & Spinel & Yes & 7 & 1050.35 & -118.77 & 931.6 & 5.12 \\
\hline MS7-L-Li & Spinel & Yes & 7 & 1149.48 & -140.09 & 1009.4 & 12.78 \\
\hline MS7-H-Mg & Spinel & Yes & 6 & 1165.84 & -116.24 & 1049.6 & 8.42 \\
\hline MS7-L-Mg & Spinel & Yes & 5 & 1093.89 & -122.34 & 971.6 & 13.81 \\
\hline MS7-H-Na & Spinel & Yes & 4 & 1003.62 & -106.73 & 896.9 & 0.66 \\
\hline MS7-L-Na & Spinel & Yes & 11 & 1191.86 & -109.21 & 1082.7 & 13.18 \\
\hline MS7-H-Ni & Spinel & Yes & 14 & 1200.03 & -90.40 & 1109.6 & 23.49 \\
\hline MS7-L-Ni & Spinel & Yes & 6 & 1003.59 & -188.66 & 814.9 & 11.52 \\
\hline SP-Al-1 & Spinel & Yes & 5 & 966.51 & -295.85 & 670.7 & 19.98 \\
\hline SP-Cr-1-o & Spinel & Yes & 5 & 938.83 & -243.84 & 695.0 & 21.79 \\
\hline SP-Cr-1-r & Spinel & Yes & 5 & 937.30 & -149.15 & 788.2 & 12.41 \\
\hline SP-Li-3-o & Spinel & Yes & 4 & 1037.43 & -183.82 & 853.6 & 21.22 \\
\hline SP-Li-3-r & Spinel & Yes & 4 & 1000.20 & -205.41 & 794.8 & 11.89 \\
\hline SP-Mg-1 & Spinel & Yes & 5 & 1028.38 & -125.39 & 903.0 & 3.99 \\
\hline SP-Mn-1 & Spinel & Yes & 5 & 1107.36 & -176.63 & 930.7 & 13.76 \\
\hline SP-Mn-3 & Spinel & Yes & 7 & 1065.35 & -106.70 & 958.7 & 11.15 \\
\hline SP-Na-1 & Spinel & Yes & 5 & 1203.97 & -85.92 & 1118.1 & 18.24 \\
\hline SP-Na-3 & Spinel & Yes & 4 & 1113.18 & -299.67 & 813.5 & 3.27 \\
\hline SPA-18 & Spinel & No & 4 & 978.18 & -103.88 & 874.3 & 6.92 \\
\hline SPA-38 & Spinel & Yes & 5 & 1012.07 & -159.39 & 852.7 & 9.94 \\
\hline WTP-TL-16 & Spinel & Yes & 5 & 1320.38 & -137.15 & 1183.2 & 3.48 \\
\hline WTP-TL-17 & Spinel & Yes & 5 & 1124.04 & -324.85 & 799.2 & 32.58 \\
\hline WTP-TL-19 & Spinel & Yes & 3 & 1057.02 & -188.01 & 869.0 & 10.05 \\
\hline WTP-TL-20 & Spinel & Yes & 4 & 1179.15 & -69.73 & 1109.4 & 22.34 \\
\hline WTP-TL-21 & Spinel & Yes & 4 & 1173.72 & -434.09 & 739.6 & 16.33 \\
\hline WTP-TL-23 & Spinel & Yes & 3 & 1108.46 & -153.73 & 954.7 & 25.54 \\
\hline WTP-TL-24 & Spinel $+\mathrm{ZrSiO}_{4}$ & Yes & 3 & 1036.26 & -156.22 & 880.0 & 7.89 \\
\hline WTP-TL-27 & Spinel & Yes & 3 & 1113.58 & -70.49 & 1043.1 & 15.86 \\
\hline WTP-TL-28 & Spinel & Yes & 3 & 1052.71 & -83.59 & 969.1 & 3.15 \\
\hline WTP-TL-29 & Spinel & Yes & 4 & 1225.51 & -229.85 & 995.7 & 28.46 \\
\hline WTP-TL-30 & Spinel $+\mathrm{ZrSiO}_{4}$ & Yes & 4 & 1182.65 & -143.92 & 1038.7 & 21.30 \\
\hline
\end{tabular}

(a) Personal communication from Jarrod Crum at PNNL based on reviewing data records for these glasses.

(b) The number of points are the number of (temperature, vol\% crystallinity) data points for each glass used to fit Equation (E.1) in Appendix E. The intercept and slope are from fitting Equation (E.1) to the data in Table 6.6.

(b) Estimated $\mathrm{T}_{1 \%}$ values in this table have been rounded to one decimal place. Intercepts, slopes, and standard deviations have been rounded to two decimal places. 


\section{Table 6.8. Coefficients and Performance Summary for the 25-Component Full Linear Mixture Model on Spinel $\mathrm{T}_{1 \%}$ for HLW Glasses. ${ }^{(a)}$}

\begin{tabular}{|c|c|c|c|c|c|c|c|c|}
\hline $\begin{array}{l}\text { Spinel } \mathbf{T}_{1 \%} \\
\text { Model Term }\end{array}$ & $\begin{array}{c}\text { Coefficient } \\
\text { Estimate }\end{array}$ & $\begin{array}{l}\text { Coefficient } \\
\text { Standard } \\
\text { Deviation }\end{array}$ & $\begin{array}{l}\text { t-value }= \\
\text { Coeff } / \text { SD }\end{array}$ & p-value & \multicolumn{3}{|c|}{$\begin{array}{l}\text { Modeling Data Statistic, } \\
168 \text { Glasses }^{(b)}\end{array}$} & Value \\
\hline $\mathrm{Al}_{2} \mathrm{O}_{3}$ & 2948.0746 & 186.0618 & $\mathrm{NA}^{(\mathrm{c})}$ & NA & \multicolumn{3}{|c|}{$\mathrm{R}^{2}$} & 0.852 \\
\hline $\mathrm{B}_{2} \mathrm{O}_{3}$ & -119.8000 & 139.6647 & NA & NA & \multicolumn{3}{|c|}{$\mathrm{R}^{2}$ Adjusted $\left(\mathrm{R}_{\mathrm{A}}^{2}\right)$} & 0.827 \\
\hline $\mathrm{CaO}$ & 4078.8766 & 5361.9673 & NA & NA & \multicolumn{3}{|c|}{$\mathrm{R}^{2}$ Predicted $\left(\mathrm{R}_{\mathrm{P}}^{2}\right)$} & 0.783 \\
\hline $\mathrm{CdO}$ & 2624.5305 & 1016.7253 & NA & NA & \multicolumn{3}{|c|}{ RMSE } & 51.991 \\
\hline $\mathrm{Cr}_{2} \mathrm{O}_{3}$ & 12541.1620 & 3047.4673 & NA & NA & \multicolumn{3}{|c|}{ Model LOF p-value } & 0.001 \\
\hline $\mathrm{Fe}_{2} \mathrm{O}_{3}$ & 3362.1190 & \multirow{2}{*}{$\begin{array}{r}166.9466 \\
5718.8581\end{array}$} & NA & NA & \multirow{3}{*}{\multicolumn{3}{|c|}{\begin{tabular}{|l|} 
\\
Separate Validation Statistic, \\
38 Glasses $^{(b, d)}$ \\
\end{tabular}}} & \\
\hline $\mathrm{K}_{2} \mathrm{O}$ & 4043.1803 & & NA & NA & & & & \\
\hline $\mathrm{La}_{2} \mathrm{O}_{3}$ & -10726.2793 & 6363.2935 & NA & NA & & & & Value \\
\hline $\mathrm{Li}_{2} \mathrm{O}$ & -1310.4535 & 329.4567 & NA & NA & \multicolumn{3}{|c|}{$\mathrm{R}^{2}$ Validation $\left(\mathrm{R}_{\mathrm{V}}^{2}\right)$} & 0.353 \\
\hline $\mathrm{MgO}$ & 5954.3066 & 9853.4999 & NA & NA & \multicolumn{3}{|c|}{ RMSE Validation $\left(\mathrm{RMSE}_{\mathrm{V}}\right)$} & 94.771 \\
\hline $\mathrm{MnO}$ & 2660.8690 & 210.0607 & NA & NA & & & & \\
\hline $\mathrm{Na}_{2} \mathrm{O}$ & -1157.6661 & 140.5576 & NA & NA & Dat & tition Sta & & \\
\hline $\mathrm{NiO}$ & 12781.4215 & 1386.8183 & NA & NA & 124 & ling \& 4 & dation $^{(b, e)}$ & Value \\
\hline $\mathrm{PbO}$ & -8841.7278 & 3155.4546 & NA & NA & & & & 0.832 \\
\hline $\mathrm{Sb}_{2} \mathrm{O}_{3}$ & 8753.4500 & 5885.3603 & NA & NA & & usted $\left(\mathrm{R}^{2}\right.$ & & 0.791 \\
\hline $\mathrm{SeO}_{2}$ & 9481.1136 & 7522.8923 & NA & NA & & dicted $(\mathrm{R}$ & & $<0$ \\
\hline $\mathrm{SiO}_{2}$ & 413.6868 & 65.4055 & NA & NA & & & & 47.664 \\
\hline $\mathrm{SrO}$ & 2.5326 & 186.0193 & NA & NA & & idation (F & & $<0$ \\
\hline $\mathrm{ThO}_{2}$ & 1370.2792 & 320.3093 & NA & NA & & Validatic & $\left.\overline{\mathrm{MSE}} \mathrm{V}_{\mathrm{V}}\right)$ & 332.415 \\
\hline $\mathrm{TiO}_{2}$ & -3916.8767 & 12500.9145 & NA & NA & & & & \\
\hline $\mathrm{Tl}_{2} \mathrm{O}$ & 2119.8954 & 6666.3819 & NA & NA & & & & \\
\hline $\mathrm{UO}_{3}$ & 1154.1717 & 297.7606 & NA & NA & & & & \\
\hline $\mathrm{ZnO}$ & 3886.6258 & 509.2748 & NA & NA & & & & \\
\hline $\mathrm{ZrO}_{2}$ & 1821.2236 & 201.8524 & NA & NA & & & & \\
\hline Others $^{(\mathrm{g})}$ & 6081.2766 & 1201.6308 & NA & NA & & & & \\
\hline Data Splittin & $\operatorname{atistic}^{(b, f)}$ & DS & & DS2 & DS3 & DS4 & DS5 & Average \\
\hline $\mathrm{R}^{2}$ & & 0.8 & & 0.843 & 0.871 & 0.871 & 0.862 & 0.860 \\
\hline $\mathrm{R}^{2}$ Adjusted ( & & 0.8 & & 0.810 & 0.844 & 0.844 & 0.834 & 0.831 \\
\hline $\mathrm{R}^{2}$ Predicted ( & & 0.7 & & 0.751 & 0.781 & 0.795 & 0.782 & 0.773 \\
\hline RMSE & & 52.9 & & 4.008 & 48.989 & 49.872 & 51.509 & 51.470 \\
\hline $\mathrm{R}^{2}$ Validation & & 0.7 & & 0.847 & 0.739 & 0.668 & 0.714 & 0.750 \\
\hline RMSE Valida & $\left(\mathrm{RMSE}_{\mathrm{V}}\right)$ & 55.0 & & 0.432 & 66.234 & 67.555 & 62.641 & 60.387 \\
\hline
\end{tabular}

(a) Model results and summary statistics were generated using estimated spinel $\mathrm{T}_{1 \%}$ values calculated to many decimal places. Rounded versions of these spinel $\mathrm{T}_{1 \%}$ values are given in Table 6.3. Conducting modeling with the rounded versions of the estimated spinel $\mathrm{T}_{1 \%}$ values may result in slightly different model results and summary statistics.

(b) The model evaluation statistics are defined in Section C.3 of Appendix C. Model validation statistics are defined in Section C.5 of Appendix C. A negative value for $\mathrm{R}_{\mathrm{V}}^{2}$ means that the sum of squares of model prediction errors is larger than if the mean response value over the validation data set were used as the predicted value for each glass. In other words, the model predicts worse for the validation data than the mean response value does.

(c) NA denotes that it is not applicable to perform a statistical t-test on linear terms in a mixture model (see Section C.5.1).

(d) The 38 separate HLW glass compositions with spinel $\mathrm{T}_{1 \%}$ data for validation (mostly extrapolative) of spinel $\mathrm{T}_{1 \%}$ models are discussed in Section 6.1.4.

(e) The partition of the spinel $\mathrm{T}_{1 \%}$ modeling dataset into modeling and validation subsets is described in Section 6.1.3.

(f) The evaluation and validation statistics calculated for data-splits are defined the same as for separate modeling and validation sets. Section 6.1.2 describes how the data-splitting was accomplished.

(g) For the 25-component full linear mixture model, the "Others" component includes $\mathrm{Ag}_{2} \mathrm{O}, \mathrm{As}_{2} \mathrm{O}_{5}, \mathrm{BaO}, \mathrm{BeO}_{2} \mathrm{Bi}_{2} \mathrm{O}_{3}, \mathrm{Ce}_{2} \mathrm{O}_{3}$, $\mathrm{Cl}, \mathrm{CoO}, \mathrm{Cs}_{2} \mathrm{O}, \mathrm{CuO}, \mathrm{Dy}_{2} \mathrm{O}, \mathrm{Eu}_{2} \mathrm{O}, \mathrm{F}, \mathrm{Gd}_{2} \mathrm{O}_{3}, \mathrm{HfO}_{2}, \mathrm{HgO}, \mathrm{MoO}_{3}, \mathrm{Nd}_{2} \mathrm{O}_{3}, \mathrm{P}_{2} \mathrm{O}_{5}, \mathrm{PdO}, \mathrm{Pr}_{2} \mathrm{O}_{3}, \mathrm{Rb}_{2} \mathrm{O}, \mathrm{Re}_{2} \mathrm{O}_{7}, \mathrm{Rh}_{2} \mathrm{O}_{3}, \mathrm{RuO}_{2}$, $\mathrm{SO}_{3}, \mathrm{Sm}_{2} \mathrm{O}_{3}, \mathrm{SnO}_{2}, \mathrm{Tc}_{2} \mathrm{O}_{7}, \mathrm{TeO}_{2}, \mathrm{~V}_{2} \mathrm{O}_{5}, \mathrm{WO}_{3}$, and $\mathrm{Y}_{2} \mathrm{O}_{3}$. 


\section{Table 6.9. Coefficients and Performance Summary for the 15-Component Reduced Linear Mixture Model on Spinel $\mathbf{T}_{1 \%}$ for HLW Glasses. ${ }^{(\text {a) }}$}

\begin{tabular}{|c|c|c|c|c|c|c|c|c|}
\hline $\begin{array}{l}\text { Spinel } \mathbf{T}_{1 \%} \\
\text { Model Term }\end{array}$ & $\begin{array}{c}\text { Coefficient } \\
\text { Estimate }\end{array}$ & $\begin{array}{l}\text { Coefficient } \\
\text { Standard } \\
\text { Deviation } \\
\end{array}$ & $\begin{array}{l}\text { t-value }= \\
\text { Coeff/SD }\end{array}$ & p-value & \multicolumn{3}{|c|}{$\begin{array}{l}\text { Modeling Data Statistic, } \\
168 \text { Glasses }^{(b)}\end{array}$} & Value \\
\hline $\mathrm{Al}_{2} \mathrm{O}_{3}$ & 3088.0502 & 183.6295 & $\mathrm{NA}^{(\mathrm{c})}$ & NA & \multicolumn{3}{|c|}{$\mathrm{R}^{2}$} & 0.813 \\
\hline $\mathrm{B}_{2} \mathrm{O}_{3}$ & -26.6528 & 138.8054 & NA & NA & \multicolumn{3}{|c|}{$\mathrm{R}^{2}$ Adjusted $\left(\mathrm{R}_{\mathrm{A}}^{2}\right)$} & 0.796 \\
\hline $\mathrm{Cr}_{2} \mathrm{O}_{3}$ & 12080.4140 & 2913.1578 & NA & NA & \multicolumn{3}{|c|}{$\mathrm{R}^{2}$ Predicted $\left(\mathrm{R}_{\mathrm{P}}^{2}\right)$} & 0.766 \\
\hline $\mathrm{Fe}_{2} \mathrm{O}_{3}$ & 3338.0164 & 166.2722 & NA & NA & \multicolumn{3}{|c|}{ RMSE } & 56.417 \\
\hline $\mathrm{Li}_{2} \mathrm{O}$ & -1406.1516 & 320.4707 & NA & NA & \multicolumn{3}{|c|}{ Model LOF p-value } & $<0.0001$ \\
\hline $\mathrm{MnO}$ & 2922.0507 & 220.7946 & \multirow{2}{*}{$\begin{array}{l}\text { NA } \\
\text { NA }\end{array}$} & NA & \multirow{3}{*}{\multicolumn{3}{|c|}{ 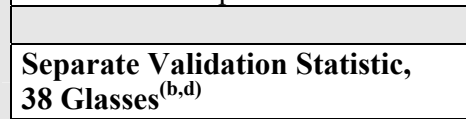 }} & \\
\hline $\mathrm{Na}_{2} \mathrm{O}$ & -1190.2964 & 144.2012 & & NA & & & & \\
\hline $\mathrm{NiO}$ & 12100.3042 & 1403.4436 & NA & NA & & & & Value \\
\hline $\mathrm{SiO}_{2}$ & 444.3234 & 63.0215 & NA & NA & \multicolumn{3}{|c|}{$\mathrm{R}^{2}$ Validation $\left(\mathrm{R}_{\mathrm{V}}^{2}\right)$} & 0.421 \\
\hline $\mathrm{SrO}$ & -78.6514 & 187.1833 & NA & NA & & 89.674 \\
\hline $\mathrm{ThO}_{2}$ & 1495.4475 & 330.7936 & NA & NA & \multicolumn{3}{|c|}{ RMSE Validation ( RMSE $_{V}$ ) } & \\
\hline $\mathrm{UO}_{3}$ & 1136.6640 & 276.3298 & \multirow{2}{*}{$\begin{array}{l}\text { NA } \\
\text { NA }\end{array}$} & NA & \multirow{2}{*}{\multicolumn{3}{|c|}{$\begin{array}{l}\text { Data Partition Statistic, } \\
124 \text { Modeling \& } 44 \text { Validation }{ }^{(\mathrm{b}, \mathrm{e})}\end{array}$}} & \\
\hline $\mathrm{ZnO}$ & 4205.4513 & 475.1240 & & NA & & & & Value \\
\hline $\mathrm{ZrO}_{2}$ & 1838.9129 & 208.0386 & \multirow{2}{*}{ NA } & NA & \multicolumn{3}{|c|}{$\mathrm{R}^{2}$} & 0.766 \\
\hline Others $^{(\mathrm{g})}$ & 2184.2478 & 304.8945 & & NA & \multicolumn{3}{|c|}{$\mathrm{R}^{2}$ Adjusted $\left(\mathrm{R}_{\mathrm{A}}^{2}\right)$} & 0.736 \\
\hline & & & & & \multicolumn{3}{|c|}{$\mathrm{R}^{2}$ Predicted $\left(\mathrm{R}_{\mathrm{P}}^{2}\right)$} & 0.668 \\
\hline & & & & & & & & 53.552 \\
\hline & & & & & & idation (l & & 0.794 \\
\hline & & & & & & Validati & $\left.\mathrm{SSE}_{\mathrm{V}}\right)$ & 76.235 \\
\hline Data Splitting & tistic $^{(b, f)}$ & DS & & DS2 & DS3 & DS4 & DS5 & Average \\
\hline $\mathrm{R}^{2}$ & & 0.8 & & .799 & 0.814 & 0.843 & 0.824 & 0.819 \\
\hline $\mathrm{R}^{2}$ Adjusted (I & & 0.7 & & .777 & 0.793 & 0.825 & 0.805 & 0.798 \\
\hline $\mathrm{R}^{2}$ Predicted ( & & 0.7 & & .734 & 0.752 & 0.800 & 0.770 & 0.762 \\
\hline RMSE & & 57.5 & & 3.590 & 56.389 & 52.814 & 55.792 & 56.235 \\
\hline $\mathrm{R}^{2}$ Validation & & 0.80 & & .855 & 0.802 & 0.585 & 0.719 & 0.752 \\
\hline RMSE Valida & $\left(\mathrm{RMSE}_{\mathrm{V}}\right)$ & 52.3 & & 9.043 & 57.721 & 75.562 & 62.142 & 59.364 \\
\hline
\end{tabular}

(a) Model results and summary statistics were generated using estimated spinel $\mathrm{T}_{1 \%}$ values calculated to many decimal places. Rounded versions of these spinel $\mathrm{T}_{1 \%}$ values are given in Table 6.3. Conducting modeling with the rounded versions of the estimated spinel $\mathrm{T}_{1 \%}$ values may result in slightly different model results and summary statistics.

(b) The model evaluation statistics are defined in Section C.3 of Appendix C. Model validation statistics are defined in Section C.5 of Appendix C. A negative value for $\mathrm{R}_{\mathrm{V}}^{2}$ means that the sum of squares of model prediction errors is larger than if the mean response value over the validation data set were used as the predicted value for each glass. In other words, the model predicts worse for the validation data than the mean response value does.

(c) NA denotes that it is not applicable to perform a statistical t-test on linear terms in a mixture model (see Section C.5.1).

(d) The 38 separate HLW glass compositions with spinel $\mathrm{T}_{1 \%}$ data for validation (mostly extrapolative) of spinel $\mathrm{T}_{1 \%}$ models are discussed in Section 6.1.4.

(e) The partition of the spinel $\mathrm{T}_{1 \%}$ modeling dataset into modeling and validation subsets is described in Section 6.1.3.

(f) The evaluation and validation statistics calculated for data-splits are defined the same as for separate modeling and validation sets. Section 6.1.2 describes how the data-splitting was accomplished.

(g) For the 15-component reduced linear mixture model, the "Others" component includes $\mathrm{Ag}_{2} \mathrm{O}, \mathrm{As}_{2} \mathrm{O}_{5}, \mathrm{BaO}, \mathrm{BeO}, \mathrm{Bi}_{2} \mathrm{O}_{3}$, $\mathrm{CaO}, \mathrm{CdO}, \mathrm{Ce}_{2} \mathrm{O}_{3}, \mathrm{Cl}, \mathrm{CoO}, \mathrm{Cs}_{2} \mathrm{O}, \mathrm{CuO}, \mathrm{Dy}_{2} \mathrm{O}, \mathrm{Eu}_{2} \mathrm{O}, \mathrm{F}, \mathrm{Gd}_{2} \mathrm{O}_{3}, \mathrm{HfO}_{2}, \mathrm{HgO}, \mathrm{K}_{2} \mathrm{O}, \mathrm{La}_{2} \mathrm{O}_{3}, \mathrm{MgO}, \mathrm{MoO}_{3}, \mathrm{Nd}_{2} \mathrm{O}_{3}, \mathrm{P}_{2} \mathrm{O}_{5}, \mathrm{PbO}$, $\mathrm{PdO}, \mathrm{Pr}_{2} \mathrm{O}_{3}, \mathrm{Rb}_{2} \mathrm{O}, \mathrm{Re}_{2} \mathrm{O}_{7}, \mathrm{Rh}_{2} \mathrm{O}_{3}, \mathrm{RuO}_{2}, \mathrm{SO}_{3}, \mathrm{Sb}_{2} \mathrm{O}_{3}, \mathrm{SeO}_{2}, \mathrm{Sm}_{2} \mathrm{O}_{3}, \mathrm{SnO}_{2}, \mathrm{Tc}_{2} \mathrm{O}_{7}, \mathrm{TeO}_{2}, \mathrm{TiO}_{2}, \mathrm{Tl}_{2} \mathrm{O}, \mathrm{V}_{2} \mathrm{O}_{5}, \mathrm{WO}_{3}$, and $\mathrm{Y}_{2} \mathrm{O}_{3}$. 
Table 6.10. Coefficients and Performance Summary for the First 20-Term Partial Quadratic Mixture Model (PQM1a) on Spinel T $_{1 \%}$ for HLW Glasses. ${ }^{(a)}$

\begin{tabular}{|c|c|c|c|c|c|c|c|c|}
\hline $\begin{array}{l}\text { Spinel } \mathbf{T}_{1 \%} \\
\text { Model Term }\end{array}$ & $\begin{array}{c}\text { Coefficient } \\
\text { Estimate }\end{array}$ & $\begin{array}{c}\text { Coefficient } \\
\text { Standard } \\
\text { Deviation }\end{array}$ & $\begin{array}{l}\text { t-value }= \\
\text { Coeff } / \text { SD }\end{array}$ & p-value & \multicolumn{3}{|c|}{$\begin{array}{l}\text { Modeling Data Statistic, } \\
168 \text { Glasses }^{(b)}\end{array}$} & Value \\
\hline $\mathrm{Al}_{2} \mathrm{O}_{3}$ & 4301.9031 & 301.7802 & $\mathrm{NA}^{(\mathrm{c})}$ & NA & \multicolumn{3}{|c|}{$\mathrm{R}^{2}$} & 0.880 \\
\hline $\mathrm{B}_{2} \mathrm{O}_{3}$ & 962.6031 & 334.9961 & NA & NA & \multicolumn{3}{|c|}{$\mathrm{R}^{2}$ Adjusted $\left(\mathrm{R}_{\mathrm{A}}^{2}\right)$} & 0.865 \\
\hline $\mathrm{Cr}_{2} \mathrm{O}_{3}$ & 8936.8818 & 2443.5932 & NA & NA & \multicolumn{3}{|c|}{$\mathrm{R}^{2}$ Predicted $\left(\mathrm{R}_{\mathrm{P}}^{2}\right)$} & 0.841 \\
\hline $\mathrm{Fe}_{2} \mathrm{O}_{3}$ & 4144.6963 & 296.7529 & NA & NA & \multicolumn{3}{|c|}{ RMSE } & 45.934 \\
\hline $\mathrm{Li}_{2} \mathrm{O}$ & -1947.5122 & 487.9694 & NA & NA & \multicolumn{3}{|c|}{ Model LOF p-value } & 0.006 \\
\hline $\mathrm{MnO}$ & -163.7335 & 886.6175 & NA & NA & & \\
\hline $\mathrm{Na}_{2} \mathrm{O}$ & -1146.0980 & \multirow{2}{*}{$\begin{array}{r}332.0013 \\
2014.7494\end{array}$} & NA & NA & & \\
\hline $\mathrm{NiO}$ & 21966.7988 & & \multirow{2}{*}{$\frac{\mathrm{NA}}{\mathrm{NA}}$} & NA & & & & Value \\
\hline $\mathrm{SiO}_{2}$ & -2566.0459 & 1043.4802 & & NA & \multicolumn{3}{|c|}{$\frac{38 \text { Glasses }^{(\mathbf{b}, \mathbf{d})}}{\mathrm{R}^{2} \text { Validation }\left(\mathrm{R}_{\mathrm{V}}^{2}\right)}$} & 0.255 \\
\hline $\mathrm{SrO}$ & 1474.0702 & 359.8276 & NA & NA & \multicolumn{3}{|c|}{ RMSE Validation $\left(\mathrm{RMSE}_{\mathrm{V}}\right)$} & 101.728 \\
\hline $\mathrm{ThO}_{2}$ & 2154.2912 & 397.5112 & NA & NA & & & & \\
\hline $\mathrm{UO}_{3}$ & 2591.2652 & 397.7276 & NA & NA & Data & ition Stati & & \\
\hline $\mathrm{ZnO}$ & 5028.5598 & 482.3861 & NA & NA & $124 \mathrm{~N}$ & ling \& 44 & $\operatorname{lation}^{(b, e}$ & Value \\
\hline $\mathrm{ZrO}_{2}$ & 466.9017 & 657.6080 & NA & NA & $\mathrm{R}^{2}$ & & & 0.852 \\
\hline Others $^{(\mathrm{g})}$ & 2842.9261 & 339.5348 & NA & NA & & isted $\left(\mathrm{R}_{\mathrm{A}}^{2}\right.$ & & 0.825 \\
\hline$\left(\mathrm{ZrO}_{2}\right)^{2}$ & 33632.6338 & 6855.0610 & 4.91 & 0.0000 & & icted $\left(\mathrm{R}_{\mathrm{P}}^{2}\right.$ & & 0.776 \\
\hline $\mathrm{MnO} \times \mathrm{Na}_{2} \mathrm{O}$ & 29256.3805 & 4928.1384 & 5.94 & 0.0000 & & & & 43.665 \\
\hline $\mathrm{Li}_{2} \mathrm{O} \times \mathrm{MnO}$ & 47617.3683 & 11745.2530 & 4.05 & 0.0001 & & dation $\left(\mathrm{R}^{2}\right.$ & & 0.881 \\
\hline $\mathrm{MnO} \times \mathrm{NiO}$ & -216741.7305 & 44154.0496 & -4.91 & 0.0000 & & Validation & $\left.\mathrm{SE}_{\mathrm{V}}\right)$ & 57.989 \\
\hline$\left(\mathrm{SiO}_{2}\right)^{2}$ & 4736.9006 & 1535.1562 & 3.09 & 0.0024 & & & & \\
\hline Data Splittins & tatistic $^{(\mathrm{b}, \mathrm{f})}$ & $\overline{D S 1}$ & & DS2 & DS3 & DS4 & DS5 & Average \\
\hline $\mathrm{R}^{2}$ & & 0.8 & 380 & 0.880 & 0.887 & 0.892 & 0.885 & 0.885 \\
\hline $\mathrm{R}^{2}$ Adjusted (I & & 0.8 & 361 & 0.861 & 0.869 & 0.875 & 0.867 & 0.866 \\
\hline $\mathrm{R}^{2}$ Predicted ( & & 0.8 & 329 & 0.832 & 0.836 & 0.850 & 0.836 & 0.837 \\
\hline RMSE & & 47.0 & & 46.336 & 44.918 & 44.715 & 46.029 & 45.810 \\
\hline $\mathrm{R}^{2}$ Validation & & 0.8 & 362 & 0.859 & 0.841 & 0.764 & 0.831 & 0.832 \\
\hline RMSE Valida & $\mathrm{n}\left(\mathrm{RMSE}_{\mathrm{V}}\right)$ & 43.4 & & 48.472 & 51.642 & 56.911 & 48.250 & 49.753 \\
\hline
\end{tabular}

(a) Model results and summary statistics were generated using estimated spinel $\mathrm{T}_{1 \%}$ values calculated to many decimal places. Rounded versions of these spinel $\mathrm{T}_{1 \%}$ values are given in Table 6.3. Conducting modeling with the rounded versions of the estimated spinel $\mathrm{T}_{1 \%}$ values may result in slightly different model results and summary statistics.

(b) The model evaluation statistics are defined in Section C.3 of Appendix C. Model validation statistics are defined in Section C.5 of Appendix C. A negative value for $\mathrm{R}_{\mathrm{V}}^{2}$ means that the sum of squares of model prediction errors is larger than if the mean response value over the validation data set were used as the predicted value for each glass. In other words, the model predicts worse for the validation data than the mean response value does.

(c) NA denotes that it is not applicable to perform a statistical t-test on linear terms in a mixture model (see Section C.5.1).

(d) The 38 separate HLW glass compositions with spinel $\mathrm{T}_{1 \%}$ data for validation (mostly extrapolative) of spinel $\mathrm{T}_{1 \%}$ models are discussed in Section 6.1.4.

(e) The partition of the spinel $\mathrm{T}_{1 \%}$ modeling dataset into modeling and validation subsets is described in Section 6.1.3.

(f) The evaluation and validation statistics calculated for data-splits are defined the same as for separate modeling and validation sets. Section 6.1.2 describes how the data-splitting was accomplished.

(g) For this 20-term partial quadratic mixture model, the "Others" component includes $\mathrm{Ag}_{2} \mathrm{O}, \mathrm{As}_{2} \mathrm{O}_{5}, \mathrm{BaO}, \mathrm{BeO}, \mathrm{Bi}{ }_{2} \mathrm{O}_{3}, \mathrm{CaO}$, $\mathrm{CdO}, \mathrm{Ce}_{2} \mathrm{O}_{3}, \mathrm{Cl}, \mathrm{CoO}, \mathrm{Cs}_{2} \mathrm{O}, \mathrm{CuO}, \mathrm{Dy}_{2} \mathrm{O}, \mathrm{Eu}_{2} \mathrm{O}, \mathrm{F}, \mathrm{Gd}_{2} \mathrm{O}_{3}, \mathrm{HfO}_{2}, \mathrm{HgO}, \mathrm{K}_{2} \mathrm{O}, \mathrm{La}_{2} \mathrm{O}_{3}, \mathrm{MgO}, \mathrm{MoO}_{3}, \mathrm{Nd}_{2} \mathrm{O}_{3}, \mathrm{P}_{2} \mathrm{O}_{5}, \mathrm{PbO}, \mathrm{PdO}$, $\mathrm{Pr}_{2} \mathrm{O}_{3}, \mathrm{Rb}_{2} \mathrm{O}, \mathrm{Re}_{2} \mathrm{O}_{7}, \mathrm{Rh}_{2} \mathrm{O}_{3}, \mathrm{RuO}_{2}, \mathrm{SO}_{3}, \mathrm{Sb}_{2} \mathrm{O}_{3}, \mathrm{SeO}_{2}, \mathrm{Sm}_{2} \mathrm{O}_{3}, \mathrm{SnO}_{2}, \mathrm{Tc}_{2} \mathrm{O}_{7}, \mathrm{TeO}_{2}, \mathrm{TiO}_{2}, \mathrm{Tl}_{2} \mathrm{O}, \mathrm{V}_{2} \mathrm{O}_{5}, \mathrm{WO}_{3}$, and $\mathrm{Y}_{2} \mathrm{O}_{3}$. 
Table 6.11. Coefficients and Performance Summary for the Second 20-Term Partial Quadratic Mixture Model (PQM1b) on Spinel T $_{1 \%}$ for HLW Glasses. ${ }^{(a)}$

\begin{tabular}{|c|c|c|c|c|c|c|c|c|}
\hline $\begin{array}{l}\text { Spinel } \mathbf{T}_{1 \%} \\
\text { Model Term }\end{array}$ & $\begin{array}{c}\text { Coefficient } \\
\text { Estimate }\end{array}$ & $\begin{array}{l}\text { Coefficient } \\
\text { Standard } \\
\text { Deviation }\end{array}$ & $\begin{array}{l}\text { t-value }= \\
\text { Coeff } / \text { SD }\end{array}$ & p-value & \multicolumn{3}{|c|}{$\begin{array}{l}\text { Modeling Data Statistic, } \\
168 \text { Glasses }^{(b)}\end{array}$} & Value \\
\hline $\mathrm{Al}_{2} \mathrm{O}_{3}$ & 2221.3073 & 262.1497 & $\mathrm{NA}^{(\mathrm{c})}$ & NA & \multicolumn{3}{|c|}{$\mathrm{R}^{2}$} & 0.870 \\
\hline $\mathrm{B}_{2} \mathrm{O}_{3}$ & -335.4916 & 151.7150 & NA & NA & \multicolumn{3}{|c|}{$\mathrm{R}^{2}$ Adjusted $\left(\mathrm{R}_{\mathrm{A}}^{2}\right)$} & 0.854 \\
\hline $\mathrm{Cr}_{2} \mathrm{O}_{3}$ & 81507.9184 & 18514.6071 & NA & NA & \multicolumn{3}{|c|}{$\mathrm{R}^{2}$ Predicted $\left(\mathrm{R}_{\mathrm{P}}^{2}\right)$} & 0.827 \\
\hline $\mathrm{Fe}_{2} \mathrm{O}_{3}$ & 3073.4785 & 161.3176 & NA & NA & \multicolumn{3}{|c|}{ RMSE } & 47.782 \\
\hline $\mathrm{Li}_{2} \mathrm{O}$ & -3064.1078 & 434.2131 & NA & NA & \multicolumn{3}{|c|}{ Model LOF p-value } & 0.004 \\
\hline $\mathrm{MnO}$ & -2776.0387 & 944.9658 & NA & NA & \multirow{3}{*}{\multicolumn{3}{|c|}{$\begin{array}{l}\text { Separate Validation Statistic, }_{\text {38 Glasses }^{(b, d)}} \\
\end{array}$}} & \\
\hline $\mathrm{Na}_{2} \mathrm{O}$ & 454.0952 & 714.6020 & NA & NA & & & & \\
\hline $\mathrm{NiO}$ & 12674.6141 & 1247.7440 & NA & NA & & & & Value \\
\hline $\mathrm{SiO}_{2}$ & 1174.1467 & 132.4537 & NA & NA & & dation $(\mathrm{R}$ & & 0.040 \\
\hline $\mathrm{SrO}$ & -114.5504 & 193.0381 & NA & NA & & Validatio & $\left.\mathrm{SE}_{\mathrm{V}}\right)$ & 115.453 \\
\hline $\mathrm{ThO}_{2}$ & 1656.2172 & 294.1268 & NA & NA & & & & \\
\hline $\mathrm{UO}_{3}$ & 810.2138 & 274.6447 & NA & NA & Data & ItIon Stat & & \\
\hline $\mathrm{ZnO}$ & 4291.8476 & 417.7870 & NA & NA & 124 & ling \& 44 & $\operatorname{ation}^{(\mathbf{b}, \mathrm{e})}$ & Value \\
\hline $\mathrm{ZrO}_{2}$ & 1534.3617 & 198.6207 & NA & NA & $\mathrm{R}$ & & & 0.837 \\
\hline Others $^{(\mathrm{g})}$ & 1289.7754 & 304.6075 & NA & NA & & isted $\left(\mathrm{R}^{2}\right.$ & & 0.808 \\
\hline $\mathrm{Cr}_{2} \mathrm{O}_{3} \times \mathrm{SiO}_{2}$ & -162465.3420 & 42869.8297 & -3.79 & 0.0002 & & licted $\left(\mathrm{R}^{2}\right.$ & & 0.759 \\
\hline $\mathrm{Al}_{2} \mathrm{O}_{3} \times \mathrm{MnO}$ & 18577.3054 & 5475.3910 & 3.39 & 0.0009 & & & & 45.725 \\
\hline $\mathrm{MnO} \times \mathrm{Na}_{2} \mathrm{O}$ & 23039.1649 & 4982.0570 & 4.62 & 0.0000 & & dation $(\mathrm{R}$ & & 0.862 \\
\hline $\mathrm{Li}_{2} \mathrm{O} \times \mathrm{MnO}$ & 49060.0711 & 12231.0034 & 4.01 & 0.0001 & & Validatio & $\left.\mathrm{SE}_{\mathrm{V}}\right)$ & 62.364 \\
\hline $\mathrm{Na}_{2} \mathrm{O} \times \mathrm{SiO}_{2}$ & -5934.6589 & 1809.5929 & -3.28 & 0.0013 & & & & \\
\hline Data Splitting & atistic $^{(b, f)}$ & DS1 & & DS2 & DS3 & DS4 & DS5 & Average \\
\hline $\mathrm{R}^{2}$ & & 0.8 & & 0.862 & 0.878 & 0.883 & 0.878 & 0.875 \\
\hline $\mathrm{R}^{2}$ Adjusted (I & & 0.8 & & 0.840 & 0.859 & 0.864 & 0.859 & 0.855 \\
\hline $\mathrm{R}^{2}$ Predicted ( & & 0.8 & & 0.808 & 0.821 & 0.838 & 0.829 & 0.823 \\
\hline RMSE & & 48.2 & & 49.619 & 46.501 & 46.565 & 47.384 & 47.669 \\
\hline $\mathrm{R}^{2}$ Validation & & 0.8 & & 0.879 & 0.823 & 0.749 & 0.796 & 0.817 \\
\hline RMSE Valida & $\mathrm{n}\left(\mathrm{RMSE}_{\mathrm{V}}\right)$ & 47.5 & & 44.881 & 54.492 & 58.692 & 52.977 & 51.715 \\
\hline
\end{tabular}

(a) Model results and summary statistics were generated using estimated spinel $\mathrm{T}_{1 \%}$ values calculated to many decimal places. Rounded versions of these spinel $\mathrm{T}_{1 \%}$ values are given in Table 6.3. Conducting modeling with the rounded versions of the estimated spinel $\mathrm{T}_{1 \%}$ values may result in slightly different model results and summary statistics.

(b) The model evaluation statistics are defined in Section C.3 of Appendix C. Model validation statistics are defined in Section C.5 of Appendix C. A negative value for $\mathrm{R}_{\mathrm{V}}^{2}$ means that the sum of squares of model prediction errors is larger than if the mean response value over the validation data set were used as the predicted value for each glass. In other words, the model predicts worse for the validation data than the mean response value does.

(c) NA denotes that it is not applicable to perform a statistical t-test on linear terms in a mixture model (see Section C.5.1).

(d) The 38 separate HLW glass compositions with spinel $\mathrm{T}_{1 \%}$ data for validation (mostly extrapolative) of spinel $\mathrm{T}_{1 \%}$ models are discussed in Section 6.1.4.

(e) The partition of the spinel $\mathrm{T}_{1 \%}$ modeling dataset into modeling and validation subsets is described in Section 6.1.3.

(f) The evaluation and validation statistics calculated for data-splits are defined the same as for separate modeling and validation sets. Section 6.1.2 describes how the data-splitting was accomplished.

(g) For this 20-term partial quadratic mixture model, the "Others" component includes $\mathrm{Ag}_{2} \mathrm{O}, \mathrm{As}_{2} \mathrm{O}_{5}, \mathrm{BaO}, \mathrm{BeO}, \mathrm{Bi}_{2} \mathrm{O}_{3}, \mathrm{CaO}$, $\mathrm{CdO}, \mathrm{Ce}_{2} \mathrm{O}_{3}, \mathrm{Cl}, \mathrm{CoO}, \mathrm{Cs}_{2} \mathrm{O}, \mathrm{CuO}, \mathrm{Dy}_{2} \mathrm{O}, \mathrm{Eu}_{2} \mathrm{O}, \mathrm{F}, \mathrm{Gd}_{2} \mathrm{O}_{3}, \mathrm{HfO}_{2}, \mathrm{HgO}, \mathrm{K} 2 \mathrm{O}, \mathrm{La}_{2} \mathrm{O}_{3}, \mathrm{MgO}, \mathrm{MoO}_{3}, \mathrm{Nd}_{2} \mathrm{O}_{3}, \mathrm{P}_{2} \mathrm{O}_{5}, \mathrm{PbO}, \mathrm{PdO}$, $\mathrm{Pr}_{2} \mathrm{O}_{3}, \mathrm{Rb}_{2} \mathrm{O}, \mathrm{Re}_{2} \mathrm{O}_{7}, \mathrm{Rh}_{2} \mathrm{O}_{3}, \mathrm{RuO}_{2}, \mathrm{SO}_{3}, \mathrm{Sb}_{2} \mathrm{O}_{3}, \mathrm{SeO}_{2}, \mathrm{Sm}_{2} \mathrm{O}_{3}, \mathrm{SnO}_{2}, \mathrm{Tc}_{2} \mathrm{O}_{7}, \mathrm{TeO}_{2}, \mathrm{TiO}_{2}, \mathrm{Tl}_{2} \mathrm{O}, \mathrm{V}_{2} \mathrm{O}_{5}, \mathrm{WO}_{3}$, and $\mathrm{Y}_{2} \mathrm{O}_{3}$. 

Table 6.12. Fit and Validation Statistics for Selected Spinel $T_{1 \%}$ Models Based on 144
Spinel-Only HLW Glasses ${ }^{(a)}$.

\begin{tabular}{|c|c|c|c|c|c|c|c|}
\hline $\begin{array}{c}\text { Statistics / } \\
\text { Model }\end{array}$ & $\begin{array}{c}\text { 25-Term } \\
\text { Full } \\
\text { LM }\end{array}$ & $\begin{array}{c}\text { 15-Term } \\
\text { Reduced } \\
\text { LM }\end{array}$ & $\begin{array}{c}\text { 13-Term } \\
\text { Reduced } \\
\text { LM }\end{array}$ & $\begin{array}{c}\text { 20-Term } \\
\text { PQM } \\
\text { (PQM1a) }\end{array}$ & $\begin{array}{c}\text { 20-Term } \\
\text { PQM } \\
\text { (PQM1b) }\end{array}$ & $\begin{array}{c}\text { 18-Term } \\
\text { PQM } \\
\text { (PQM2) }\end{array}$ & $\begin{array}{c}\text { 20-Term } \\
\text { PQM } \\
\text { (PQM1c) }\end{array}$ \\
\hline \multicolumn{8}{|c|}{ Statistics from 144-Glass Modeling Data } \\
\hline $\mathrm{R}^{2}$ & 0.866 & 0.829 & 0.821 & 0.875 & 0.884 & 0.877 & 0.890 \\
\hline $\mathrm{R}_{\mathrm{A}}^{2}$ & 0.839 & 0.810 & 0.804 & 0.856 & 0.867 & 0.861 & 0.873 \\
\hline $\mathrm{R}_{\mathrm{P}}^{2}$ & 0.786 & 0.774 & 0.770 & 0.824 & 0.838 & 0.832 & 0.848 \\
\hline RMSE & 46.621 & 50.650 & 51.466 & 44.182 & 42.450 & 43.383 & 41.393 \\
\hline \multicolumn{8}{|c|}{ Statistics from 24 Spinel $+X^{(\mathbf{b})}$ Data } \\
\hline $\mathrm{R}_{\mathrm{V}}^{2}$ & 0.487 & 0.387 & 0.348 & 0.659 & 0.573 & 0.604 & 0.423 \\
\hline $\mathrm{RMSE}_{\mathrm{V}}$ & 87.540 & 92.633 & 93.242 & 73.429 & 83.887 & 76.799 & 94.417 \\
\hline \multicolumn{8}{|c|}{ Statistics from 38 Separate Validation Data } \\
\hline $\mathrm{R}_{\mathrm{V}}^{2}$ & $<0^{(\mathrm{c})}$ & 0.239 & 0.327 & 0.235 & $<0$ & $<0$ & $<0$ \\
\hline $\mathrm{RMSE}_{\mathrm{V}}$ & 131.594 & 102.807 & 96.676 & 103.063 & 123.839 & 119.075 & 127.603 \\
\hline
\end{tabular}

(a) Summary statistics were generated using estimated $\mathrm{T}_{1 \%}$ values as the response. Rounded versions of these $\mathrm{T}_{1 \%}$ values are given in Table 6.3. Fitting the models with the rounded versions of the estimated $\mathrm{T}_{1 \%}$ values may result in slightly different summary statistic values.

(b) The ' $\mathrm{X}$ ' represents some other crystal form identified in the 24 'spinel plus other crystal' glasses discussed in Section 6.1.1.

(c) $\mathrm{R}^{2}$ statistics can take negative values for validation data, indicating that model predictions are worse than just using the mean of the validation response values ( spinel $\mathrm{T}_{1 \%}$ ) as the predicted value for all validation glasses. 
Table 6.13. Fit and Validation Statistics for Selected Spinel $T_{1 \%}$ Models Based on 168 HLW Glasses in the Modeling Dataset ${ }^{(\mathrm{a})}$.

\begin{tabular}{|c|c|c|c|c|c|c|}
\hline $\begin{array}{c}\text { Statistics/ } \\
\text { Model }\end{array}$ & $\begin{array}{l}\text { 25-Term } \\
\text { Full LM }\end{array}$ & $\begin{array}{c}\text { 15-Term } \\
\text { Reduced LM }\end{array}$ & $\begin{array}{c}\text { 13-Term } \\
\text { Reduced LM }\end{array}$ & $\begin{array}{c}\text { 20-Term } \\
\text { PQM } \\
\text { (PQM1a) }\end{array}$ & $\begin{array}{c}\text { 20-Term } \\
\text { PQM } \\
\text { (PQM1b) }\end{array}$ & $\begin{array}{c}\text { 18-Term } \\
\text { PQM } \\
\text { (PQM2) } \\
\end{array}$ \\
\hline \multicolumn{7}{|c|}{ Statistics from 168-Glass Modeling Dataset } \\
\hline $\mathrm{R}^{2}$ & 0.852 & 0.813 & 0.804 & 0.880 & 0.870 & 0.876 \\
\hline $\mathrm{R}_{\mathrm{A}}^{2}$ & 0.827 & 0.796 & 0.789 & 0.865 & 0.854 & 0.862 \\
\hline $\mathrm{R}_{\mathrm{P}}^{2}$ & 0.783 & 0.766 & 0.761 & 0.841 & 0.827 & 0.837 \\
\hline RMSE & 51.991 & 56.417 & 57.330 & 45.934 & 47.782 & 46.332 \\
\hline LOF p-value & 0.001 & $<0.0001$ & $<0.0001$ & 0.006 & 0.004 & 0.005 \\
\hline \multicolumn{7}{|c|}{ Average Statistics from Data Splitting } \\
\hline $\mathrm{R}^{2}$ & 0.860 & 0.819 & 0.811 & 0.885 & 0.875 & 0.881 \\
\hline $\mathrm{R}_{\mathrm{A}}^{2}$ & 0.831 & 0.798 & 0.793 & 0.866 & 0.855 & 0.865 \\
\hline $\mathrm{R}_{\mathrm{P}}^{2}$ & 0.773 & 0.762 & 0.759 & 0.837 & 0.823 & 0.834 \\
\hline RMSE & 51.470 & 56.235 & 56.981 & 45.810 & 47.669 & 46.067 \\
\hline $\mathrm{R}_{\mathrm{V}}^{2}$ & 0.750 & 0.752 & 0.743 & 0.832 & 0.817 & 0.820 \\
\hline $\mathrm{RMSE}_{\mathrm{V}}$ & 60.387 & 59.364 & 60.662 & 49.753 & 51.715 & 51.330 \\
\hline \multicolumn{7}{|c|}{ Statistics from Data Partitioning } \\
\hline $\mathrm{R}^{2}$ & 0.832 & 0.766 & 0.756 & 0.852 & 0.837 & 0.848 \\
\hline $\mathrm{R}_{\mathrm{A}}^{2}$ & 0.791 & 0.736 & 0.730 & 0.825 & 0.808 & 0.824 \\
\hline $\mathrm{R}_{\mathrm{P}}^{2}$ & $<0^{(\mathrm{b})}$ & 0.668 & 0.670 & 0.776 & 0.759 & 0.777 \\
\hline RMSE & 47.664 & 53.552 & 54.206 & 43.665 & 45.725 & 43.747 \\
\hline $\mathrm{R}_{\mathrm{V}}^{2}$ & $<0^{(\mathrm{b})}$ & 0.794 & 0.798 & 0.881 & 0.862 & 0.876 \\
\hline $\mathrm{RMSE}_{\mathrm{V}}$ & 332.415 & 76.235 & 75.358 & 57.989 & 62.364 & 59.026 \\
\hline \multicolumn{7}{|c|}{ Statistics from Separate Validation Data } \\
\hline $\mathrm{R}_{\mathrm{V}}^{2}$ & 0.353 & 0.421 & 0.509 & 0.255 & 0.040 & 0.117 \\
\hline $\mathrm{RMSE}_{\mathrm{V}}$ & 94.771 & 89.674 & 82.558 & 101.728 & 115.453 & 110.704 \\
\hline \multicolumn{7}{|c|}{ Statistics from Spinel-Only and Spinel $+X^{(\mathrm{c})}$ Glasses } \\
\hline $\mathrm{R}_{\mathrm{V}}^{2}$ Spinel & 0.834 & 0.785 & 0.775 & 0.849 & 0.856 & 0.852 \\
\hline $\mathrm{RMSE}_{\mathrm{V}}$ Spinel & 44.895 & 50.133 & 51.165 & 43.111 & 41.864 & 42.664 \\
\hline $\mathrm{R}_{\mathrm{V}}^{2}$ Spinel+X & 0.762 & 0.667 & 0.625 & 0.896 & 0.802 & 0.854 \\
\hline $\mathrm{RMSE}_{\mathrm{V}}$ Spinel+X & 63.342 & 72.188 & 74.297 & 43.124 & 59.699 & 49.953 \\
\hline
\end{tabular}

(a) Summary statistics were generated using estimated $\mathrm{T}_{1 \%}$ values as the response. Rounded versions of these $\mathrm{T}_{1 \%}$ values are given in Table 6.3. Conducting modeling with the rounded versions of the estimated $\mathrm{T}_{1 \%}$ values may result in slightly different summary statistic values.

(b) $\mathrm{R}^{2}$ statistics can take negative values for validation data, indicating that model predictions are worse than just using the mean of the validation response values (spinel $\mathrm{T}_{1 \%}$ ) as the predicted value for all validation glasses

(c) The ' $\mathrm{X}$ ' represents some other crystal form identified in the 24 'spinel plus other crystal' glasses discussed in Section 6.1.1. 
Table 6.14. HLW03-06 Composition in Formats Needed for Use in Spinel $\mathbf{T}_{1 \%}$ Models for HLW Glasses.

\begin{tabular}{|c|c|c|c|c|}
\hline Component & $\begin{array}{c}\text { HLW03-06 } \\
\text { 25-Component } \\
\text { Composition }^{(a)} \\
\text { (mass fractions) }\end{array}$ & $\begin{array}{c}\text { HLW03-06 } \\
\text { 15-Component } \\
\text { Composition }^{(b)} \\
\text { (mass fractions) } \\
\end{array}$ & $\begin{array}{c}\text { HLW03-06 } \\
\text { 20-Term PQM1a } \\
\text { Composition }^{(\mathrm{c})} \\
\text { (mass fractions) }^{\text {(mass }}\end{array}$ & $\begin{array}{c}\text { HLW03-06 } \\
\text { 20-Term PQM1b } \\
\text { Composition }^{(\mathrm{d})} \\
\text { (mass fractions) }^{\text {(mas }}\end{array}$ \\
\hline $\mathrm{Al}_{2} \mathrm{O}_{3}$ & 0.08344 & 0.08344 & 0.08344 & 0.08344 \\
\hline $\mathrm{B}_{2} \mathrm{O}_{3}$ & 0.04908 & 0.04908 & 0.04908 & 0.04908 \\
\hline $\mathrm{CaO}$ & 0.00500 & $\mathrm{NA}^{(\mathrm{e})}$ & NA & NA \\
\hline $\mathrm{CdO}$ & 0.01600 & NA & NA & NA \\
\hline $\mathrm{Cr}_{2} \mathrm{O}_{3}$ & 0.00491 & 0.00491 & 0.00491 & 0.00491 \\
\hline $\mathrm{Fe}_{2} \mathrm{O}_{3}$ & 0.01963 & 0.01963 & 0.01963 & 0.01963 \\
\hline $\mathrm{K}_{2} \mathrm{O}$ & 0.00060 & NA & NA & NA \\
\hline $\mathrm{La}_{2} \mathrm{O}_{3}$ & 0.00300 & NA & NA & NA \\
\hline $\mathrm{Li}_{2} \mathrm{O}$ & 0.05890 & 0.05890 & 0.05890 & 0.05890 \\
\hline $\mathrm{MgO}$ & 0.00120 & NA & NA & NA \\
\hline $\mathrm{MnO}$ & 0.06872 & 0.06872 & 0.06872 & 0.06872 \\
\hline $\mathrm{Na}_{2} \mathrm{O}$ & 0.03927 & 0.03927 & 0.03927 & 0.03927 \\
\hline $\mathrm{NiO}$ & 0.00982 & 0.00982 & 0.00982 & 0.00982 \\
\hline $\mathrm{PbO}$ & 0.00040 & NA & NA & NA \\
\hline $\mathrm{Sb}_{2} \mathrm{O}_{3}$ & 0.00020 & NA & NA & NA \\
\hline $\mathrm{SeO}_{2}$ & 0.00020 & NA & NA & NA \\
\hline $\mathrm{SiO}_{2}$ & 0.52031 & 0.52031 & 0.52031 & 0.52031 \\
\hline $\mathrm{SrO}$ & 0.05091 & 0.05091 & 0.05091 & 0.05091 \\
\hline $\mathrm{ThO}_{2}$ & 0.01416 & 0.01416 & 0.01416 & 0.01416 \\
\hline $\mathrm{TiO}_{2}$ & 0.00030 & NA & NA & NA \\
\hline $\mathrm{Tl}_{2} \mathrm{O}$ & 0.00019 & NA & NA & NA \\
\hline $\mathrm{UO}_{3}$ & 0.00000 & 0.00000 & 0.00000 & 0.00000 \\
\hline $\mathrm{ZnO}$ & 0.00000 & 0.00000 & 0.00000 & 0.00000 \\
\hline $\mathrm{ZrO}_{2}$ & 0.04095 & 0.04095 & 0.04095 & 0.04095 \\
\hline Others & 0.01281 & 0.03990 & 0.03990 & 0.03990 \\
\hline $\mathrm{ZrO}_{2} \times \mathrm{ZrO}_{2}$ & NA & NA & 0.0016769 & NA \\
\hline $\mathrm{MnO} \times \mathrm{Na}_{2} \mathrm{O}$ & NA & NA & 0.0026986 & 0.0026986 \\
\hline $\mathrm{Li}_{2} \mathrm{O} \times \mathrm{MnO}$ & NA & NA & 0.0040476 & 0.0040476 \\
\hline $\mathrm{MnO} \times \mathrm{NiO}$ & NA & NA & 0.0006748 & NA \\
\hline$\left(\mathrm{SiO}_{2}\right)^{2}$ & NA & NA & 0.2707225 & NA \\
\hline $\mathrm{Cr}_{2} \mathrm{O}_{3} \times \mathrm{SiO}_{2}$ & NA & NA & NA & 0.0025547 \\
\hline $\mathrm{Al}_{2} \mathrm{O}_{3} \times \mathrm{MnO}$ & NA & NA & NA & 0.0057340 \\
\hline $\mathrm{Na}_{2} \mathrm{O} \times \mathrm{SiO}_{2}$ & NA & NA & NA & 0.0204326 \\
\hline
\end{tabular}

(a) The composition in mass fractions is from Table 6.1 .

(b) The composition prepared for the model in Table 6.9.

(c) The composition prepared for the model in Table 6.10 .

(d) The composition prepared for the model in Table 6.11 .

(e) NA indicates components included in the Others component in reduced spinel $\mathrm{T}_{1 \%}$ models. 
Table 6.15. Predicted Spinel $T_{1 \%}$ Values and Corresponding $90 \%$ UCIs and $90 \%$ SUCIs for the HLW03-06 Composition Used in Spinel $\mathbf{T}_{1 \%}$ Models for HLW Glasses.

\begin{tabular}{|c|c|c|c|c|}
\hline Spinel T $_{1 \%}$ Model $^{(a)}$ & $\begin{array}{c}\text { Predicted } \\
\text { Spinel T }_{1 \%}{ }^{(b)} \\
\left({ }^{\circ} \mathrm{C}\right) \\
\end{array}$ & $\begin{array}{c}\text { Standard } \\
\text { Deviation of } \\
\text { Predicted } \\
\text { Spinel T } \\
\left.\text { ( }{ }^{\circ} \mathrm{C}\right)\end{array}$ & $\begin{array}{c}90 \% \text { UCI } \\
\text { on Mean } \\
\text { Spinel T }{ }_{1 \%} \\
\left({ }^{\circ} \mathrm{C}\right) \\
\end{array}$ & $\begin{array}{c}90 \% \text { SUCI on } \\
\text { Mean Spinel } \\
\mathbf{T}_{1 \%} \\
\left({ }^{\circ} \mathrm{C}\right) \\
\end{array}$ \\
\hline $\begin{array}{l}\text { 15-Component Reduced } \\
\text { LM Model }\end{array}$ & $982.1^{(\mathrm{c})}$ & 22.2 & 1010.7 & 1080.7 \\
\hline $\begin{array}{c}\text { 20-Term PQM Model } \\
\text { (PQM1a) }\end{array}$ & 943.4 & 22.0 & 971.7 & 1054.9 \\
\hline $\begin{array}{c}\text { 20-Term PQM Model } \\
\text { (PQM1b) }\end{array}$ & 974.3 & 25.2 & 1006.7 & 1101.6 \\
\hline
\end{tabular}

(a) The three spinel $\mathrm{T}_{1 \%}$ models are given in Tables 6.9,6.10, and 6.11. Note that $\mathrm{LM}=$ linear mixture and PQM= partial quadratic mixture.

(b) The estimated spinel $\mathrm{T}_{1 \%}$ value for HLW03-06 is $950^{\circ} \mathrm{C}$ (see Table 6.3). The recommended 20-term PQM1a model has predicted value closest to this estimated value.

(c) All calculations were performed using the HLW03-06 glass composition, model coefficients, and variancecovariance matrix values given in tables of this report. The calculated spinel $\mathrm{T}_{1 \%}$ values were rounded to one decimal place in this table. 
Table 7.1. HLW Glass Compositions with Data for Electrical Conductivity and Viscosity Having Outlying Values for One or More Components.

\begin{tabular}{|c|c|c|}
\hline Glass ID & Mass Fractions for Outlying Component Values & $\begin{array}{c}\text { Remove from Electrical } \\
\text { Conductivity and } \\
\text { Viscosity Modeling } \\
\text { Datasets? }\end{array}$ \\
\hline HLW98-96A & $\begin{array}{l}\left.\mathrm{Ce}_{2} \mathrm{O}_{3}=0.02585 \text { (most below } 0.004\right) \\
\left.\mathrm{Nd}_{2} \mathrm{O}_{3}=0.01657 \text { (most below } 0.003\right)\end{array}$ & Yes \\
\hline HLW98-96B & $\begin{array}{l}\mathrm{HfO}_{2}=0.03292 \text { (all others are zero) } \\
\left.\mathrm{Nd}_{2} \mathrm{O}_{3}=0.01645 \text { (most below } 0.003\right)\end{array}$ & Yes \\
\hline $\begin{array}{l}\text { HLW04-01,03, } \\
\quad \text { and } 06\end{array}$ & $\begin{array}{l}\mathrm{SnO}_{2}=0.00666,0.00685 \text {, and } 0.00685 \text { respectively } \\
\text { (most below } 0.003)\end{array}$ & $\mathrm{No}^{(\mathrm{a})}$ \\
\hline HLW06-02 & $\begin{array}{l}\mathrm{F}=0.00440 \text { (most below } 0.0015) \\
\left.\mathrm{K}_{2} \mathrm{O}=0.01640 \text { (most below } 0.007\right) \\
\left.\mathrm{TiO}_{2}=0.01000 \text { (most below } 0.0017\right)\end{array}$ & $\mathrm{No}^{(\mathrm{b})}$ \\
\hline HLW06-04 & $\begin{array}{l}\mathrm{F}=0.00440 \text { (most below } 0.0015) \\
\left.\mathrm{K}_{2} \mathrm{O}=0.01240 \text { (most below } 0.007\right) \\
\left.\mathrm{TiO}_{2}=0.00757 \text { (most below } 0.0017\right)\end{array}$ & $\mathrm{No}^{(\mathrm{b})}$ \\
\hline HLW06-22 & $\begin{array}{l}\mathrm{F}=0.00440(\text { most below } 0.0015) \\
\left.\mathrm{La}_{2} \mathrm{O}_{3}=0.01234 \text { (most at or below } 0.005\right)\end{array}$ & $\mathrm{No}^{(\mathrm{b})}$ \\
\hline HLW06-32 & $\mathrm{F}=0.00440($ most below 0.0015$)$ & $\mathrm{No}^{(\mathrm{b})}$ \\
\hline HLW06-34 & $\mathrm{F}=0.00440($ most below 0.0015$)$ & $\mathrm{No}^{(\mathrm{b})}$ \\
\hline
\end{tabular}

(a) $\mathrm{SnO}_{2}$ is not expected to significantly affect glass properties and hence these glasses will be retained for initial modeling work.

(b) Specific archived HLW06 glasses were selected for viscosity and electrical conductivity measurement to support model development. Therefore, they were to be retained in the modeling datasets unless they had extreme outliers in viscosity or electrical conductivity response. 
Table 7.2. Normalized $^{(\text {a) }}$ 22-Component Compositions (mass fractions) of 208 HLW Glasses Used for Electrical Conductivity Model Development.

\begin{tabular}{|c|c|c|c|c|c|c|c|c|c|c|c|c|c|c|c|c|c|c|c|c|c|c|c|}
\hline Glas & $\begin{array}{c}\text { Group } \\
\text { ID }^{(\mathbf{b})}\end{array}$ & $\mathrm{I}_{2} \mathrm{O}_{3}$ & $\mathbf{B}_{2} \mathbf{O}_{3}$ & $\mathrm{CaO}$ & CdO & $\mathrm{Cr}_{2} \mathrm{O}_{3}$ & $\mathrm{Fe}_{2} \mathrm{O}_{3}$ & $\mathbf{L i}_{2} \mathbf{O}$ & MgO & MnO & $\mathrm{Na}_{2} \mathrm{O}$ & $\mathrm{NiO}$ & PbO & $\left|\mathbf{S b}_{2} \mathbf{O}_{3}\right|$ & $\mathrm{SeO}_{2}$ & $\mathrm{SiO}_{2}$ & SrO & $\mathrm{ThO}_{2}$ & $\mathbf{T l}_{2} \mathbf{O}$ & $\mathbf{U O}_{3}$ & ZnO & $\mathrm{ZrO}_{2}$ & Others \\
\hline $2-01$ & HLW02 & 171 & 927 & 500 & 7771 & 108 & 0899 & 3996 & 0120 & 85 & 9957 & 5518 & 216 & 0110 & 0110 & 43612 & 2444 & 0000 & 0102 & 0000 & 02000 & 2974 & טת \\
\hline HLW02-02 & W02 & 3999 & 3996 & 5500 & 1500 & 0199 & 13996 & 55998 & 0120 & 0000 & \begin{tabular}{|l|l|}
.03999 \\
\end{tabular} & .00100 & .00400 & .00200 & .00020 & .50445 & .00000 & .00000 & .00019 & .00000 & 01999 & .00000 & 2509 \\
\hline HLW02-03 & W02 & 3999 & 13998 & 00500 & .01500 & .00199 & .07999 & .02000 & .00120 & .00000 & \begin{tabular}{|l|l|}
.14998 \\
\end{tabular} & \begin{tabular}{|l|l|}
.01000 \\
\end{tabular} & \begin{tabular}{|l|l|}
.00400 \\
\end{tabular} & .00020 & .00200 & .37994 & .04379 & .00000 & .00186 & .00000 & .02000 & .05999 & 2510 \\
\hline HLW02-04 & W02 & 4001 & 5001 & .00500 & .01500 & .00020 & .14002 & .02000 & .00120 & \begin{tabular}{|l|l|}
.00518 \\
\end{tabular} & \begin{tabular}{|l|l|}
.15002 \\
\end{tabular} & .00100 & .00040 & .00200 & .00200 & .52939 & .00000 & .00000 & .00186 & .00000 & .02000 & .00000 & 1671 \\
\hline HLW02-05 & W02 & .04000 & .05000 & .00500 & .00050 & .00020 & .08000 & .06000 & .00120 & .00000 & \begin{tabular}{|l|l|}
.13788 \\
\end{tabular} & .00100 & .00040 & .00020 & .00020 & .52652 & .00000 & .00000 & .00019 & .00000 & .02000 & .06000 & 1671 \\
\hline HLW02-06 & W02 & 8501 & .05001 & .00500 & 01500 & 0020 & .08001 & .04740 & .00120 & .05001 & .15002 & .01000 & .00040 & .00020 & .00200 & .40496 & .00000 & .00000 & .00186 & .00000 & .02000 & .06001 & 1671 \\
\hline HLW02-07 & W02 & .08499 & (04999 & .00500 & .00050 & 0199 & .07999 & .05999 & .00120 & .00000 & \begin{tabular}{|l|l|}
.11703 \\
\end{tabular} & .00100 & .00400 & .00200 & .00020 & .52992 & .00000 & .00000 & .00186 & .00000 & .02000 & .01525 & 2510 \\
\hline HLW02-08 & W02 & .04000 & 14000 & .00500 & .00050 & .00020 & .09205 & .03310 & .00120 & .05000 & .15000 & .00100 & .00040 & .00200 & .00020 & .38744 & .00000 & .00000 & .00019 & .00000 & .02000 & .06000 & 1671 \\
\hline HLW02-09 & W02 & .08500 & .11589 & .00500 & .00050 & 0020 & .14000 & .02271 & .00120 & .00000 & .15000 & .01000 & .00040 & .00200 & .00020 & 38000 & .05000 & .00000 & .00019 & .00000 & .02000 & .00000 & 71 \\
\hline HLW02-10 & W02 & .08500 & 14000 & .00500 & .01500 & 0020 & .08000 & .06000 & .00120 & .00000 & \begin{tabular}{|l|l|}
.10513 \\
\end{tabular} & .00100 & .00040 & .00020 & .00200 & 38000 & .02797 & .00000 & .00019 & .00000 & .02000 & .06000 & 71 \\
\hline HLW02-11 & W02 & .04001 & .14002 & .00500 & .00050 & 0020 & .08001 & .06001 & .00120 & .00000 & \begin{tabular}{|l|l|}
.10858 \\
\end{tabular} & .01000 & .00040 & .00200 & .00200 & .45149 & .00000 & .00000 & .00186 & .00000 & .02000 & .06001 & 71 \\
\hline HLW02-12 & W02 & |.03999 & (04999 & .00500 & .01500 & 0199 & .11382 & .05998 & .00120 & \begin{tabular}{|l|l|}
.04999 \\
\end{tabular} & \begin{tabular}{|l|l|}
.12757 \\
\end{tabular} & .01000 & . .00400 & .00020 & .00200 & .41402 & .00000 & .00000 & .00019 & .00000 & 01999 & .05998 & 09 \\
\hline HLW02-13 & W02 & |.03999 & (04999 & .00500 & .00050 & 0199 & .13998 & .05999 & .00120 & \begin{tabular}{|l|l|}
.04999 \\
\end{tabular} & \begin{tabular}{|l|}
.10425 \\
\end{tabular} & .00100 & . .00400 & .00020 & .00200 & 43114 & .04999 & .00000 & .00186 & .00000 & .02000 & 01182 & 510 \\
\hline HLW02-14 & W02 & .04001 & .05001 & .00500 & .01500 & 0020 & .08001 & .06001 & .00120 & \begin{tabular}{|l|l|}
.02490 \\
\end{tabular} & \begin{tabular}{|l|l|}
.04141 \\
\end{tabular} & .00100 & .00040 & .00200 & .00020 & .53007 & .05001 & .00000 & .00186 & .00000 & .02000 & .06001 & 771 \\
\hline HLW02-15 & W02 & .08499 & . 13998 & .00500 & .00050 & .00199 & .13998 & .02000 & .00120 & \begin{tabular}{|l|l|}
.04688 \\
\end{tabular} & \begin{tabular}{|l|l|}
.12539 \\
\end{tabular} & .00100 & . .00400 & .00020 & .00200 & .37994 & .00000 & .00000 & .00186 & .00000 & .02000 & .00000 & 510 \\
\hline HLW02-16 & W02 & .08498 & (04999 & .00500 & .01500 & .00199 & .07998 & .05998 & .00120 & \begin{tabular}{|l|l|}
.04999 \\
\end{tabular} & \begin{tabular}{|l|}
.09651 \\
\end{tabular} & \begin{tabular}{|l|l|}
.00100 \\
\end{tabular} & . .00400 & .00200 & .00200 & 39115 & .04999 & .00000 & .00019 & .00000 & 01999 & .05998 & 2509 \\
\hline HLW02-17 & W02 & .08500 & .05000 & .00500 & .01500 & .00020 & .13843 & .06000 & .00120 & \begin{tabular}{|l|l|}
.00000 \\
\end{tabular} & \begin{tabular}{|l|l|}
.07690 \\
\end{tabular} & \begin{tabular}{|l|l|}
.00100 \\
\end{tabular} & .00040 & .00020 & .00020 & .52958 & . 00000 & .00000 & .00019 & .00000 & .02000 & .00000 & 1671 \\
\hline HLW02-18 & W02 & . 03999 & . 04999 & .00500 & .00050 & .00199 & .11126 & .02013 & .00120 & \begin{tabular}{|l|l|}
.00000 \\
\end{tabular} & \begin{tabular}{|l|}
.14996 \\
\end{tabular} & \begin{tabular}{|l|l|}
.01000 \\
\end{tabular} & .00400 & .00200 & .00020 & .49852 & . 00000 & .00000 & .00019 & .00000 & .01999 & .05998 & 2509 \\
\hline HLW02-19 & W02 & .04000 & .14000 & .00500 & .01500 & .00020 & .10781 & .02000 & .00120 & \begin{tabular}{|l|l|}
.05000 \\
\end{tabular} & \begin{tabular}{|l|l|}
.08849 \\
\end{tabular} & \begin{tabular}{|l|l|}
.00100 \\
\end{tabular} & .00040 & .00200 & .00200 & .38000 & . 05000 & .00000 & .00019 & .00000 & .02000 & .06000 & 1671 \\
\hline HLW02-20 & W02 & .04000 & .14000 & .00500 & .00050 & .00020 & .14000 & .02000 & .00120 & .00000 & \begin{tabular}{|l|}
.06453 \\
\end{tabular} & \begin{tabular}{|l|l|}
.00100 \\
\end{tabular} & .00040 & .00020 & .00020 & .51734 & .03253 & .00000 & .00019 & .00000 & .02000 & .00000 & 1671 \\
\hline HLW02-21 & W02 & .08500 & .14000 & .00500 & .00050 & .00020 & .08000 & .02000 & .00120 & \begin{tabular}{|l|l|}
.00000 \\
\end{tabular} & \begin{tabular}{|l|l|}
.15000 \\
\end{tabular} & \begin{tabular}{|l|l|}
.00100 \\
\end{tabular} & \begin{tabular}{|l|l|}
.00040 \\
\end{tabular} & .00020 & .00020 & .46440 & .00000 & .00000 & .00019 & .00000 & .02000 & .01500 & 1671 \\
\hline HLW02-22 & W02 & .08500 & . 14000 & .00500 & .00050 & .00020 & .09500 & .06000 & .00120 & \begin{tabular}{|l|l|}
.00000 \\
\end{tabular} & \begin{tabular}{|l|l|}
.04000 \\
\end{tabular} & \begin{tabular}{|l|l|}
.00100 \\
\end{tabular} & \begin{tabular}{|l|l|}
.00040 \\
\end{tabular} & .00200 & .00200 & .53000 & . 00080 & .00000 & .00019 & .00000 & .02000 & .00000 & 1671 \\
\hline HLW02-23 & W02 & .08501 & 14002 & .00500 & .01500 & .00020 & .08001 & .06001 & .00120 & \begin{tabular}{|l|l|}
.05001 \\
\end{tabular} & \begin{tabular}{|l|l|}
.05591 \\
\end{tabular} & \begin{tabular}{|l|l|}
.01000 \\
\end{tabular} & .00040 & .00020 & .00020 & .39325 & . 05001 & .00000 & .00186 & .00000 & \begin{tabular}{|l|l|}
.02000 \\
\end{tabular} & .01500 & 1671 \\
\hline HLW02-24 & W02 & .08498 & |04999 & .00500 & .00050 & .00153 & .07998 & .02000 & .00120 & \begin{tabular}{|l|l|}
.04999 \\
\end{tabular} & \begin{tabular}{|l|}
.12195 \\
\end{tabular} & .00100 & .00307 & .00020 & .00200 & .47052 & .04999 & .00000 & .00019 & .00000 & .02000 & .01500 & 2292 \\
\hline HLW02-25 & W02 & .08501 & .14002 & .00500 & .01500 & .00020 & .09501 & .02000 & .00120 & .00355 & \begin{tabular}{|l|l|}
.06884 \\
\end{tabular} & .00100 & .00040 & .00200 & .00020 & \begin{tabular}{ll|l}
.47398 \\
\end{tabular} & .05001 & .00000 & .00186 & .00000 & .02000 & .00000 & 1671 \\
\hline HLW02-26 & W02 & |.03999 & (04999 & .00500 & .01500 & .00199 & .12498 & .02000 & .00120 & \begin{tabular}{|l|l|}
.04959 \\
\end{tabular} & \begin{tabular}{|l|l|}
.14998 \\
\end{tabular} & .00100 & . .00400 & .00020 & .00020 & .37994 & .04999 & .00000 & .00186 & .00000 & .02000 & .05999 & 2510 \\
\hline HLW02-27 & W02 & .04001 & .14002 & .00500 & .00050 & .00020 & .12502 & .06001 & .00120 & \begin{tabular}{|l|l|}
.03366 \\
\end{tabular} & \begin{tabular}{|l|l|}
.04275 \\
\end{tabular} & .00100 & .00040 & .00020 & .00200 & . 39946 & .05001 & .00000 & .00186 & .00000 & .02000 & .06001 & 1671 \\
\hline HLW02-28 & W02 & .07500 & .08000 & .00500 & .01000 & .00040 & .10451 & .02500 & .00120 & .01500 & \begin{tabular}{|l|}
.15001 \\
\end{tabular} & .00300 & .00080 & .00050 & .00050 & .41003 & .03500 & .00000 & . .00140 & .00000 & .02000 & .04500 & 1764 \\
\hline HLW02-29 & W02 & .07499 & . 12998 & .00500 & .00500 & .00133 & .09998 & .03749 & .00120 & .01500 & \begin{tabular}{|l|l|}
.08999 \\
\end{tabular} & .00300 & .00267 & .00050 & .00150 & .40994 & .03499 & .00000 & .00046 & .00000 & .02000 & .04499 & 2199 \\
\hline HLW02-30 & HLW02 & .05500 & .09721 & .00500 & .01000 & .00040 & .10000 & .05000 & .00120 & .03500 & \begin{tabular}{|l|l|}
.11228 \\
\end{tabular} & .00300 & .00080 & .00150 & .00050 & .41000 & .03500 & .00000 & \begin{tabular}{|l|l|}
.00047 \\
\end{tabular} & .00000 & .02000 & .04500 & .01764 \\
\hline
\end{tabular}

(a) Normalized to sum to 1.00000 over the 22 components listed in this table. The normalized component mass fractions listed in this table were rounded to five decimals, and may not sum exactly to 1.00000 as listed. However, complete compositions listed to more decimal places and summing to 1.00000 were used for property-composition modeling.

(b) The Group IDs are described in Sections 2.1.1 to 2.1.9. 
Table 7.2. Normalized $^{(\text {a) }}$ 22-Component Compositions (mass fractions) of 208 HLW Glasses Used for Electrical Conductivity Model Development (continued).

\begin{tabular}{|c|c|c|c|c|c|c|c|c|c|c|c|c|c|c|c|c|c|c|c|c|c|c|c|}
\hline G & $\begin{array}{l}\text { roup } \\
D^{(\mathbf{b})}\end{array}$ & $\mathbf{A l}_{2} \mathbf{O}_{3}$ & $\mathbf{B}_{2} \mathbf{O}_{3}$ & $\mathrm{CaO}$ & CdO & $D_{3}$ & $3_{3}$ & $\mathbf{O}$ & $\mathbf{O}$ & InO & $\mathrm{Na}_{2} \mathrm{O}$ & NiO & PbO & $\mathbf{S b}_{2} \mathbf{O}_{3}$ & $\mathrm{SeO}_{2}$ & $\mathrm{SiO}_{2}$ & SrO & $\mathrm{ThO}_{2}$ & $\mathbf{T l}_{2} \mathbf{O}$ & $\mathbf{U O}_{3}$ & $\mathrm{ZnO}$ & $\mathrm{ZrO}_{2}$ & Othe \\
\hline LW02-31 & & 500 & 001 & 500 & 00 & 040 & & & & 500 & 882 & 300 & 080 & 050 & 150 & 1003 & .01500 & 000 & .00140 & 000 & 2000 & 4369 & 704 \\
\hline HLWO & 102 & 7500 & 8000 & 0500 & 000 & 0040 & 0000 & 5000 & 120 & 1500 & 7733 & 300 & 0080 & 0150 & .00150 & .46117 & .03500 & .00000 & .00047 & .00000 & .02000 & .01500 & 1764 \\
\hline HLW02-33 & W02 & .06341 & .08000 & .00500 & .00500 & .00040 & 12000 & 2500 & 0120 & 3500 & 15000 & 0800 & .00080 & .00150 & .00150 & .41000 & .03500 & .00000 & .00047 & .00000 & .02000 & 02009 & 1764 \\
\hline HLW02-34 & $\mathrm{LW}$ & .05499 & .12998 & .00500 & .01000 & .00133 & 11998 & 3957 & .00120 & 01500 & \begin{tabular}{|l|l|}
.10891 \\
\end{tabular} & .00800 & .00267 & .00050 & .00050 & .40994 & \begin{tabular}{|l|l|}
.03499 \\
\end{tabular} & .00000 & . .00046 & .00000 & .02000 & 01500 & 2199 \\
\hline HLW02- & $\mathrm{LW}$ & .06488 & .12999 & .00500 & .00500 & .00133 & .11999 & 05000 & .00120 & 3500 & .09160 & .00800 & .00267 & .00150 & .00050 & .40996 & .01500 & .00000 & .00140 & $\mid .00000$ & .02000 & 01500 & 2199 \\
\hline HLW02-36 & LW & .05499 & .08667 & .00500 & .01000 & .00133 & .11998 & 02500 & .00120 & 01500 & \begin{tabular}{|l|l|}
.14998 \\
\end{tabular} & .00300 & .00267 & .00050 & .00150 & .45074 & .01500 & .00000 & |.00046 & $\mid .00000$ & $\mid .02000$ & .01500 & 2199 \\
\hline HLW02-3 & LV & .06762 & .13000 & .00500 & .00500 & .00040 & 10000 & .02500 & .00120 & 03500 & \begin{tabular}{|l|l|}
.1188 \\
\end{tabular} & .00800 & .00080 & .00150 & .00050 & .41000 & .01500 & .00000 & . & $\mid .00000$ & $\mid .02000$ & 04500 & 1764 \\
\hline HLW02-38 & $\mathrm{LV}$ & .06893 & .12998 & .00500 & .01000 & .00133 & .11998 & . 04255 & .00120 & 01500 & .08999 & . & .00267 & .00150 & .00150 & 40994 & .03499 & .00000 & .00046 & .00000 & .02000 & .01500 & 2199 \\
\hline HLW02-39 & ILW02 & .07500 & .08991 & .00500 & .01000 & .00040 & .10000 & .02500 & .00120 & 01500 & .11058 & .00800 & .00080 & .00050 & .00050 & .49000 & .01500 & .00000 & .00047 & .00000 & .02000 & .01500 & 1764 \\
\hline HLW02-40 & $\mathrm{LV}$ & .07499 & .09833 & .00500 & .01000 & .00133 & .09999 & .02632 & .00120 & .01500 & .09683 & .00300 & .00267 & .00150 & .00050 & .48996 & .01500 & .00000 & .00140 & .00000 & .02000 & .01500 & 2199 \\
\hline HLW02-41 & & .06500 & .13001 & .00500 & .00500 & .00040 & .10001 & .02500 & .00120 & .01500 & .09001 & .00300 & .00080 & .00050 & .00050 & .48953 & .01500 & .00000 & .00140 & .00000 & .02000 & .01500 & 1764 \\
\hline HLV & & .05500 & .13001 & .00500 & .00500 & .00040 & .10001 & .05000 & .00120 & .01500 & .09001 & .00300 & .00080 & .00050 & .00050 & .44453 & .03500 & .00000 & .00140 & .00000 & .02000 & .02500 & 1764 \\
\hline HLW02-43 & & .06500 & .13000 & .00500 & .01000 & .00040 & .10000 & .02500 & .00120 & .03500 & .12450 & .00300 & .00080 & .00150 & .00050 & . 41000 & .03500 & .00000 & .00047 & .00000 & .02000 & .01500 & 1764 \\
\hline HLW02-44 & & .05499 & .09069 & .00500 & .01000 & .00133 & .09998 & .02500 & .00120 & . .03499 & .14998 & .00300 & .00267 & .00150 & .00050 & .43673 & .01500 & .00000 & .00046 & .00000 & .02000 & .02500 & 2199 \\
\hline HLW02-45 & & .05500 & .08000 & .00500 & .01000 & .00040 & .11000 & .02500 & .00120 & .03500 & .09619 & .00300 & .00080 & .00050 & .00150 & . 48831 & .03500 & .00000 & .00047 & .00000 & .02000 & .01500 & 1764 \\
\hline HLW02-46 & HIL & .05500 & .09149 & .00500 & .00500 & .00040 & .10001 & .03701 & .00120 & .03500 & .09001 & .00800 & .00080 & .00050 & .00150 & .49003 & .01500 & .00000 & .00140 & .00000 & .02000 & .02500 & 1764 \\
\hline HLW02-47 & 02 & .05499 & .09806 & .00500 & .00500 & .00133 & .09999 & .02500 & .00120 & .03500 & .09443 & .00300 & .00267 & .00050 & .00050 & . 48996 & .01500 & .00000 & .00140 & .00000 & .02000 & .02500 & 2199 \\
\hline HLW02-48 & LW02 & .05999 & .07999 & . 00500 & .00500 & .00133 & .11999 & .03339 & .00120 & .01500 & .14999 & .00800 & .00267 & .00150 & .00150 & . 40996 & .01710 & .00000 & .00140 & .00000 & .02000 & 4500 & 2199 \\
\hline HLW02-49 & LW02 & .07500 & .08740 & . 00500 & .00500 & .00040 & .12001 & .05000 & .00120 & .03500 & .09001 & .00300 & .00080 & .00050 & .00050 & .44213 & .01500 & .00000 & .00140 & .00000 & .02000 & 3000 & 01764 \\
\hline HLW02-50 & HLW02 & .06000 & .13001 & .00500 & .00500 & .00040 & .12001 & .02500 & .00120 & .01500 & .09821 & .00300 & .00080 & .00150 & .00050 & .43532 & .01500 & .00000 & .00140 & .00000 & .02000 & 4500 & 01764 \\
\hline HLW02-51 & HLW02 & .07500 & .08000 & .00500 & .00500 & .00040 & .10501 & .04589 & .00120 & .01500 & .09001 & .00300 & .00080 & .00150 & .00150 & .45164 & .03500 & .00000 & .00140 & .00000 & .02000 & .04500 & 01764 \\
\hline HLW02-52 & HLW02 & .06171 & .09927 & .00500 & .00771 & .00108 & .10899 & .03996 & .00120 & .02385 & .10957 & .00518 & .00216 & .00110 & .00110 & .43612 & .02444 & .00000 & .00102 & .00000 & .02000 & .02974 & 02080 \\
\hline HLW02-53 & HLW02 & .08500 & .05000 & .00500 & .01500 & .00020 & .13843 & .06000 & .00120 & .00000 & .07690 & .00100 & .00040 & .00020 & .00020 & .52958 & .00000 & .00000 & .00019 & .00000 & .02000 & .00000 & 01671 \\
\hline HLW02-54 & HLW02 & .04001 & .05001 & .00500 & .01500 & .00020 & .14002 & .02000 & .00120 & .00518 & .15002 & .00100 & .00040 & .00200 & .00200 & .52939 & .00000 & .00000 & .00186 & .00000 & .02000 & .00000 & 01671 \\
\hline HLW02-55 & HLW02 & .05500 & .13001 & .00500 & .00500 & .00040 & .10001 & .05000 & .00120 & .01500 & .09001 & .00300 & .00080 & .00050 & .00050 & .44453 & .03500 & .00000 & .00140 & .00000 & .02000 & .02500 & 01764 \\
\hline HLW02-56 & HLW02 & .05499 & .09069 & .00500 & .01000 & .00133 & .09998 & .02500 & .00120 & .03499 & .14998 & .00300 & .00267 & .00150 & .00050 & .43673 & .01500 & .00000 & .00046 & .00000 & .02000 & .02500 & 02199 \\
\hline HLW02-57 & HLW02 & .04000 & .14000 & .00500 & .00050 & .00020 & .09205 & .03310 & .00120 & .05000 & .15000 & .00100 & .00040 & .00200 & .00020 & . 38744 & .00000 & .00000 & .00019 & .00000 & .02000 & .06000 & 01671 \\
\hline HLW03-01 & HLW03 & .08335 & .13727 & .00500 & .00050 & .00020 & .13727 & .05883 & .00120 & .06078 & .03922 & \begin{tabular}{|l|l|l|}
.00098 \\
\end{tabular} & .00400 & .00020 & .00200 & .35299 & .00000 & .02764 & .00307 & .00000 & .03059 & .02983 & .02510 \\
\hline HLW03-02 & HLW03 & .01951 & .13662 & .00500 & .01600 & .00488 & .13662 & .02473 & .00120 & .06832 & .11177 & .00976 & .00040 & .00300 & .00020 & .35132 & .00000 & .00000 & .00307 & .00000 & .00000 & .09088 & 01671 \\
\hline HLW03-03 & HLW03 & .01953 & $\begin{array}{ll}.04884 \\
\end{array}$ & . .00500 & .01600 & .00488 & .13677 & .02678 & .00120 & . & .10755 & |.00977 & . & .00020 & .00200 & .35169 & . & .00000 & . & $\mid .00000$ & .01946 & .06404 & . \\
\hline
\end{tabular}

(a) Normalized to sum to 1.00000 over the 22 components listed in this table. The normalized component mass fractions listed in this table were rounded to five decimals, and may not sum exactly to 1.00000 as listed. However, complete compositions listed to more decimal places and summing to 1.00000 were used for property-composition modeling.

(b) The Group IDs are described in Sections 2.1.1 to 2.1.9. 
Table 7.2. Normalized $^{(\text {a) }}$ 22-Component Compositions (mass fractions) of 208 HLW Glasses Used for Electrical Conductivity Model Development (continued).

\begin{tabular}{|c|c|c|c|c|c|c|c|c|c|c|c|c|c|c|c|c|c|c|c|c|c|c|c|}
\hline Glass ID & $\begin{array}{l}\text { roup } \\
D^{(\mathbf{b})}\end{array}$ & $\mathbf{A l}_{2} \mathbf{O}_{3}$ & $\mathbf{B}_{2} \mathbf{O}_{3}$ & $\mathrm{CaO}$ & CdO & $D_{3}$ & $3_{3}$ & $\mathbf{O}$ & $\mathbf{N}$ & $\operatorname{InO}$ & $\mathrm{Na}_{2} \mathrm{O}$ & NiO & PbO & $\mathbf{S b}_{2} \mathbf{O}_{3}$ & $\mathrm{SeO}_{2}$ & $\mathrm{SiO}_{2}$ & SrO & $\mathrm{ThO}_{2}$ & $\mathbf{T l}_{2} \mathbf{O}$ & $\mathbf{U O}_{3}$ & $\mathrm{ZnO}$ & $\mathrm{ZrO}_{2}$ & Others \\
\hline LW03-04 & & & 886 & 498 & & 488 & & & & & 442 & 098 & 399 & 020 & 199 & 2425 & \begin{tabular}{|l|l|}
.09771 \\
\end{tabular} & 000 & .00306 & 6210 & 0000 & 2932 & 501 \\
\hline HLW03-05 & V03 & 175 & 809 & 0500 & 600 & 0481 & 1924 & 1924 & 120 & 6733 & 4427 & 0096 & 0400 & 0300 & .00200 & .47837 & .00000 & .03812 & .00307 & .00000 & .03847 & 0000 & 2510 \\
\hline HLW03-06 & W03 & .08344 & .04908 & .00500 & .01600 & .00491 & .01963 & 5890 & 00120 & 6872 & 03927 & \begin{tabular}{|l|l|}
.00982 \\
\end{tabular} & .00040 & .00020 & .00020 & .52031 & .05091 & .01416 & |.00019 & .00000 & .00000 & 4095 & 1671 \\
\hline HLW03-07 & LW03 & .04961 & .04961 & .00498 & .00050 & .00496 & 13891 & 4750 & .00120 & 06945 & 11693 & .00100 & .00040 & .00020 & \begin{tabular}{|l|l|l|l|}
.00199 \\
\end{tabular} & .39825 & .00000 & .00000 & \begin{tabular}{|l|l|}
.00019 \\
\end{tabular} & .06306 & .03461 & 00000 & 1665 \\
\hline HLW03-08 & LW03 & .08031 & .04833 & .00500 & .01600 & .00483 & 01933 & 15151 & .00120 & .06766 & 14499 & \begin{tabular}{|l|l|}
.00097 \\
\end{tabular} & . .00400 & .00300 & .00020 & 34797 & .00000 & .04412 & .00019 & .00000 & .03866 & 9666 & 2509 \\
\hline HLW03-09 & LW03 & .07668 & .13695 & .00500 & .00050 & .00020 & .03486 & 01979 & .00120 & .00000 & 14848 & \begin{tabular}{|l|l|}
.00099 \\
\end{tabular} & .00040 & .00300 & .00200 & .52465 & .00000 & .02552 & .00307 & .00000 & .00000 & .00000 & 1671 \\
\hline HLW03-10 & $\mathrm{LW}$ & .08369 & .04924 & .00500 & .00050 & .00020 & .09982 & .05908 & .00120 & .06893 & .12851 & .00985 & .00400 & .00020 & .00020 & .35449 & .00000 & .02626 & .00019 & .01108 & .00000 & .07250 & 2508 \\
\hline HLW03-11 & $\mathrm{LV}$ & .01984 & .04961 & .00498 & .00050 & .00020 & .09538 & .01984 & .00120 & .00000 & .14883 & .00100 & .00040 & .00020 & .00199 & .52586 & .00000 & .05027 & .00019 & .06306 & .00000 & .00000 & 1665 \\
\hline HLW03-12 & LW03 & .01982 & .04956 & .00498 & .00050 & .00495 & .01982 & .05008 & .00120 & .06939 & .03965 & \begin{tabular}{|l|l|}
.00099 \\
\end{tabular} & .00040 & \begin{tabular}{|l|}
.00299 \\
\end{tabular} & .00020 & .44277 & \begin{tabular}{|l|l|}
.09912 \\
\end{tabular} & .03729 & \begin{tabular}{|l|l|}
.00019 \\
\end{tabular} & \begin{tabular}{|l|l|}
.06299 \\
\end{tabular} & .03965 & .03682 & 1665 \\
\hline HLW03-13 & LW03 & .08433 & .04961 & .00498 & .00050 & .00496 & .08633 & .05209 & .00120 & .06945 & .03969 & \begin{tabular}{|l|l|}
.00992 \\
\end{tabular} & .00040 & .00020 & .00199 & 35719 & \begin{tabular}{|l}
.09922 \\
\end{tabular} & .03836 & .00019 & .06306 & .01121 & .00846 & 01665 \\
\hline HLW03-14 & 3 & .01989 & .04973 & .00500 & .00050 & .00020 & .09047 & .02504 & .00120 & .06962 & .10425 & \begin{tabular}{|l|l}
.00994 \\
\end{tabular} & .00040 & .00020 & .00020 & .35806 & .09946 & .04115 & .00307 & .00000 & .03979 & .06511 & 1671 \\
\hline HLW & & .01951 & .13662 & .00500 & .01600 & .00020 & .13662 & .01951 & .00120 & .01348 & .05248 & \begin{tabular}{|l|l|}
.00098 \\
\end{tabular} & .00040 & .00300 & .00020 & .51722 & .00000 & .02441 & .00307 & .00000 & .03337 & .00000 & 01671 \\
\hline HLW03-16 & & .01955 & .04886 & .00498 & .00050 & .00020 & .07905 & .02862 & .00120 & .06840 & .03909 & .00977 & .00398 & .00299 & .00199 & .44240 & .09772 & .02568 & .00019 & .06210 & .02772 & .01001 & 2501 \\
\hline HLW03-17 & & .08352 & .13757 & .00499 & .00050 & .00020 & .01965 & .01965 & .00120 & . 06879 & .04461 & .00293 & .00399 & .00020 & .00020 & .46088 & .00000 & .02237 & .00019 & .04784 & .03930 & .01639 & 2503 \\
\hline HLW03-18 & & .01989 & .04973 & .00500 & .00050 & .00497 & .13924 & .05922 & .00120 & .00000 & .10533 & \begin{tabular}{|l|l|}
.00980 \\
\end{tabular} & .00040 & .00020 & .00020 & .52484 & .00000 & .05967 & .00307 & .00000 & .00000 & .00000 & 1671 \\
\hline HLW03-19 & 05 & .01963 & .04908 & .00500 & .01600 & .00491 & .09634 & .05890 & .00120 & .00197 & .10142 & \begin{tabular}{|r|r|}
.00982 \\
\end{tabular} & .00040 & .00020 & .00020 & .52030 & .00000 & .05846 & .00019 & .00000 & .03927 & .00000 & 01671 \\
\hline HLW03-20 & 003 & .01923 & .04808 & .00500 & .01600 & .00019 & .13462 & .05769 & .00120 & .00000 & .10097 & \begin{tabular}{|l|l|}
.00962 \\
\end{tabular} & .00400 & .00300 & .00200 & .50681 & .00145 & \begin{tabular}{|l|l|}
.05769 \\
\end{tabular} & .00307 & .00430 & .00000 & .00000 & 02509 \\
\hline HLW03-21 & LW03 & .04958 & .06941 & .00499 & .00300 & .00079 & .04958 & .02479 & .00120 & .04462 & .10828 & \begin{tabular}{|l|l|}
.00298 \\
\end{tabular} & .00080 & .00050 & .00050 & . 48587 & .01487 & .02975 & .00046 & .02100 & .00992 & .05949 & 01762 \\
\hline HLW03-22 & LW03 & .04915 & .06881 & .00499 & .00299 & .00079 & .09752 & .02458 & .00120 & .01474 & .11797 & .00295 & .00267 & .00050 & .00150 & .40304 & .04424 & .02949 & .00046 & .04165 & .00983 & 15898 & 2196 \\
\hline HLW03-23 & HLW03 & .04957 & .11897 & .00499 & .00100 & .00199 & .07733 & .02478 & .00120 & .01487 & .11897 & .00297 & .00080 & .00050 & .00150 & .40648 & .01487 & .02974 & .00046 & .04201 & .00992 & 15949 & 01760 \\
\hline HLW03-24 & HLW03 & .02975 & .06941 & .00499 & .00300 & .00079 & .04958 & .04958 & .00120 & \begin{tabular}{|l|l}
.04462 \\
\end{tabular} & .08151 & .00495 & .00080 & .00050 & .00050 & .48588 & .01487 & .02975 & .00046 & .02100 & .02975 & .05949 & .01762 \\
\hline HLW03-25 & HLW03 & .02956 & .11823 & .00499 & .00100 & .00079 & .04927 & .02463 & .00120 & .01478 & .11823 & \begin{tabular}{|r|r|}
.00492 \\
\end{tabular} & .00267 & .00050 & .00150 & .42090 & .04433 & .02956 & .00139 & .02087 & .02956 & .05912 & .02199 \\
\hline HLW03-26 & HLW03 & .04921 & .06889 & .00499 & .00100 & .00197 & .04921 & .04921 & .00120 & .01476 & .10431 & \begin{tabular}{|l|l}
.00492 \\
\end{tabular} & .00267 & .00150 & .00150 & .40345 & .04428 & .04428 & .00046 & . .04169 & .02953 & .05904 & .02196 \\
\hline HLW03-27 & HLW03 & .04926 & .06897 & .00499 & .00100 & .00197 & .09359 & .04040 & .00120 & .01478 & .11822 & \begin{tabular}{|l|l|}
.00492 \\
\end{tabular} & .00267 & .00150 & .00150 & .40393 & .01478 & .04433 & .00046 & .02087 & .02956 & .05911 & .02199 \\
\hline HLW03-28 & HLW03 & .03629 & .11911 & .00499 & .00100 & .00080 & .09926 & .04963 & .00120 & .01489 & .10486 & \begin{tabular}{|l|l|}
.00496 \\
\end{tabular} & .00080 & .00150 & .00050 & .40695 & .01489 & .02977 & .00046 & .02103 & .00993 & .05956 & .01762 \\
\hline HLW03-29 & HLW03 & .02971 & .06933 & .00499 & .00299 & .00199 & .04952 & .04952 & .00120 & .03518 & .11885 & \begin{tabular}{|l|l|}
.00297 \\
\end{tabular} & .00080 & .00050 & .00050 & .40606 & .01485 & .04456 & .00046 & .04196 & .02971 & .07674 & 01760 \\
\hline HLW03-30 & HLW03 & .02972 & .11888 & .00499 & .00100 & .00079 & .04953 & .04953 & .00120 & .04458 & .06934 & \begin{tabular}{|l|l|}
.00298 \\
\end{tabular} & .00080 & .00150 & .00150 & .43203 & .01486 & .04458 & .00139 & .02098 & .00991 & .08229 & 01762 \\
\hline HLW03-31 & HLW03 & .04953 & .06934 & .00499 & .00100 & .00198 & .04953 & .04953 & .00120 & .04458 & .08533 & 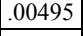 & .00080 & .00150 & .00150 & .45058 & .01486 & .02972 & .00139 & .02098 & .00991 & .08915 & .01762 \\
\hline HLW03-32 & HLW03 & .04921 & .06889 & .00499 & .00100 & .00079 & .04921 & .04921 & .00120 & .02925 & .09101 & .00492 & .00267 & .00150 & .00050 & .40348 & .01476 & .04428 & .00139 & .04170 & .02953 & .08857 & .02196 \\
\hline HLW03-33 & HLW03 & .04960 & .11902 & .00499 & .00100 & .00199 & .09919 & .03898 & .00120 & . & . .06943 & \begin{tabular}{|l|l|}
.00451 \\
\end{tabular} & . & .00150 & .00050 & .40667 & .01488 & .02975 & . & . & . .02975 & .05952 & . 01761 \\
\hline
\end{tabular}

(a) Normalized to sum to 1.00000 over the 22 components listed in this table. The normalized component mass fractions listed in this table were rounded to five decimals, and may not sum exactly to 1.00000 as listed. However, complete compositions listed to more decimal places and summing to 1.00000 were used for property-composition modeling.

(b) The Group IDs are described in Sections 2.1.1 to 2.1.9. 
Table 7.2. Normalized $^{(\text {a) }}$ 22-Component Compositions (mass fractions) of 208 HLW Glasses Used for Electrical Conductivity Model Development (continued).

\begin{tabular}{|c|c|c|c|c|c|c|c|c|c|c|c|c|c|c|c|c|c|c|c|c|c|c|c|}
\hline Glass ID & $\begin{array}{l}\text { roup } \\
D^{(\mathbf{b})}\end{array}$ & $\mathbf{A l}_{2} \mathbf{O}_{3}$ & $\mathbf{B}_{2} \mathbf{O}_{3}$ & $\mathrm{CaO}$ & CdO & $D_{3}$ & $\mathbf{F}$ & $\mathbf{O}$ & $\mathbf{O}$ & InO & $\mathrm{Na}_{2} \mathrm{O}$ & NiO & PbO & $\mathbf{S b}_{2} \mathbf{O}_{3}$ & $\mathrm{SeO}_{2}$ & $\mathrm{SiO}_{2}$ & SrO & $\mathrm{ThO}_{2}$ & $\mathbf{T l}_{2} \mathbf{O}$ & $\mathbf{U O}_{3}$ & $\mathrm{ZnO}$ & $\mathrm{ZrO}_{2}$ & Othe \\
\hline LW03-34 & & 956 & 397 & 499 & 100 & 197 & & & & 478 & 541 & 492 & 267 & 050 & 150 & 8278 & 1478 & 3858 & \begin{tabular}{|l|l|}
.00139 \\
\end{tabular} & 2087 & 0986 & 5912 & 199 \\
\hline HLW03-35 & V03 & 963 & 397 & 0499 & 100 & 0080 & 4963 & 2481 & 120 & 467 & 6948 & 496 & 0080 & 0050 & .00050 & .48639 & .01489 & .03176 & \begin{tabular}{|l|l|}
.00139 \\
\end{tabular} & \begin{tabular}{|l|l|}
.02103 \\
\end{tabular} & .01039 & 15956 & 1762 \\
\hline HLW03-36 & 103 & .04921 & 6889 & 0499 & .00300 & .00197 & 09507 & 2692 & 0120 & 1476 & 07961 & \begin{tabular}{|l|l|}
.00492 \\
\end{tabular} & .00267 & .00150 & .00050 & .48226 & .01476 & \begin{tabular}{|l|l|}
.03558 \\
\end{tabular} & . .00046 & .02085 & .00984 & .05905 & 2199 \\
\hline HLW03-37 & W03 & .02953 & .11809 & .00499 & .00100 & .00079 & .07222 & 04859 & .00120 & 1476 & 06889 & \begin{tabular}{|l|l|}
.00492 \\
\end{tabular} & .00267 & .00050 & .00150 & .40348 & .01476 & \begin{tabular}{|l|l|l|l}
.0428 \\
\end{tabular} & .00139 & .04170 & .02953 & 07325 & 2196 \\
\hline HLW03-38 & LW03 & .04915 & .06881 & .00499 & .00299 & .00197 & .09831 & 02458 & .00120 & 1474 & .09618 & \begin{tabular}{|l|l|}
.00295 \\
\end{tabular} & .00267 & .00050 & .00150 & .43156 & .01474 & .03875 & . .00046 & .04165 & .00983 & 07051 & 2196 \\
\hline HLW03-39 & LW03 & .02946 & .06875 & .00499 & .00300 & .00197 & .08502 & .04850 & .00120 & 1473 & .06875 & \begin{tabular}{|l|l|}
.00295 \\
\end{tabular} & .00267 & .00150 & .00150 & .48128 & .01473 & .04420 & |. & .02081 & .00982 & .07078 & 2199 \\
\hline HLW03-40 & $\mathrm{LW}$ & .04941 & .06919 & .00499 & .00299 & .00079 & .09390 & .04881 & .00120 & 01483 & .06919 & \begin{tabular}{|l|l|}
.00494 \\
\end{tabular} & .00080 & .00150 & .00150 & .42959 & .03279 & \begin{tabular}{|l|l|l|l|l|}
.0448 \\
\end{tabular} & |.00046 & \begin{tabular}{|l|l|}
.04188 \\
\end{tabular} & .00989 & .05930 & 1760 \\
\hline HLW03-41 & $\mathrm{LV}$ & .03888 & .08732 & .00499 & .00200 & .00140 & .06939 & .03710 & .00120 & 02698 & .09093 & .00395 & .00174 & .00100 & .00100 & .43059 & .02705 & .03658 & .00093 & .03032 & .01920 & .06767 & 1979 \\
\hline HLW03-42 & LLW03 & .05500 & .09150 & .00500 & .00500 & .00040 & .10001 & .03701 & .00120 & \begin{tabular}{|l|l|}
.03500 \\
\end{tabular} & \begin{tabular}{|l|l|}
.09001 \\
\end{tabular} & \begin{tabular}{|l|l|}
.00800 \\
\end{tabular} & .00080 & .00050 & .00150 & .49004 & \begin{tabular}{|l|l|}
.01500 \\
\end{tabular} & .00000 & \begin{tabular}{|l|l|}
.00140 \\
\end{tabular} & \begin{tabular}{|l|l|l|l}
.00000 \\
\end{tabular} & 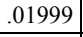 & .02500 & 1764 \\
\hline HLW03-43 & LW03 & .08344 & .04908 & .00500 & .01600 & .00491 & .01963 & .05890 & .00120 & .06872 & .03927 & .00982 & .00040 & .00020 & .00020 & .52031 & .05091 & .01416 & .00019 & .00000 & .00000 & . & 1671 \\
\hline HLW03-44 & J V & .01984 & .04961 & .00498 & .00050 & .00020 & .09538 & .01984 & .00120 & .00000 & .14883 & .00100 & .00040 & .00020 & .00199 & .52586 & .00000 & .05027 & .00019 & .06306 & .00000 & . 00000 & 1665 \\
\hline HLW & & .04921 & .06889 & .00499 & .00100 & .00197 & .04921 & .04921 & .00120 & .01476 & .10431 & \begin{tabular}{|l|l|}
.00492 \\
\end{tabular} & .00267 & .00150 & .00150 & . 40345 & .04428 & .04428 & .00046 & . .04169 & .02953 & . 05904 & 2196 \\
\hline HLW04-01 & & .04781 & .11258 & .00363 & .00011 & .00212 & .13088 & .02808 & .00113 & .02054 & .12251 & .00384 & .00465 & .00000 & .00000 & . 48507 & .00201 & .00000 & .00000 & .00000 & .01978 & . 00000 & 1528 \\
\hline HLW05-15 & & .02000 & .04500 & .00750 & .00050 & .00250 & .12000 & .00000 & .00100 & .00100 & .16670 & .00050 & .00150 & .00000 & .00000 & . 49000 & .01200 & .01500 & .00050 & .04380 & .01200 & . .04000 & 2050 \\
\hline HLW05-20 & & .13000 & .14000 & .00750 & .00500 & .00250 & .01500 & .00000 & .00100 & .01000 & .20000 & .00500 & .00150 & .00000 & .00000 & . 37750 & .01200 & .01500 & .00050 & .01000 & .01200 & . 03500 & 2050 \\
\hline HLW05-21 & \begin{tabular}{|lll} 
\\
\end{tabular} & .02000 & .14000 & .00750 & .00050 & .00250 & .12000 & .00000 & .00100 & .00100 & .19710 & .00050 & .00150 & .00000 & .00000 & . 34000 & .01200 & .06000 & .00050 & .01000 & .01200 & .05340 & 82050 \\
\hline HLW05-22 & $2=05$ & .13000 & .14000 & .00750 & .00050 & .00050 & .02500 & .03700 & .00100 & .00100 & .06500 & .00050 & .00150 & .00000 & .00000 & .44050 & .01200 & .01500 & .00050 & .06500 & .01200 & . 02500 & 02050 \\
\hline HLW05-27 & LW05 & .02000 & .04500 & .00750 & .00500 & .00050 & .12000 & .05950 & .00100 & .01000 & .10390 & .00500 & .00150 & .00000 & .00000 & .45610 & .01200 & .01500 & .00050 & .06500 & .01200 & 4000 & 2050 \\
\hline HLW06-02 & LW06 & .10390 & .11000 & .01000 & .00235 & .00250 & .07000 & .00250 & 01170 & .01000 & .20000 & .01000 & .00910 & .00000 & .00000 & .35000 & .01470 & .00250 & .00000 & .00750 & .01500 & 1500 & 53325 \\
\hline HLW06-04 & HLW06 & .08000 & .06500 & .00757 & .00706 & .00250 & .07000 & .00250 & .00886 & .01000 & .20000 & .00600 & .00689 & .00000 & .00000 & .35000 & . .04409 & .01500 & .00000 & .00750 & .02500 & 4000 & 05203 \\
\hline HLW06-22 & ILW06 & .13000 & .15000 & .00000 & .01646 & .00600 & .01400 & .06010 & .00000 & .00000 & .06840 & .00000 & .00000 & .00000 & .00000 & . 34560 & .10287 & .00000 & .00000 & .06500 & .00000 & . & .04156 \\
\hline HLW06-32 & HLW06 & .01880 & .15000 & .00000 & .00000 & .00600 & .15000 & .00000 & .00000 & .08000 & .20000 & .00000 & .00000 & .00000 & .00000 & .37430 & .00000 & .00000 & .00000 & .00000 & .00000 & . 00000 & .02090 \\
\hline HLW06-34 & HLW06 & .01880 & .15000 & .00000 & .00000 & .00600 & .01400 & .00000 & .00000 & .08000 & .20000 & .00000 & .00000 & .00000 & .00000 & .33030 & .00000 & .00000 & .00000 & .06500 & .00000 & .11500 & .02090 \\
\hline HLW07-01 & HLW07 & .07161 & .09206 & .00150 & .00237 & .00277 & .07993 & .01802 & .00000 & .03171 & .11287 & \begin{tabular}{|l|l|}
.00422 \\
\end{tabular} & .00240 & .00200 & .00000 & .41825 & .04260 & .02138 & .00000 & .02206 & .00983 & . .04300 & .02140 \\
\hline HLW07-02 & HLW07 & .05500 & .09149 & .00500 & .00500 & .00040 & .10001 & .03701 & .00120 & .03500 & .09001 & .00800 & .00080 & .00050 & .00150 & . 49003 & .01500 & .00000 & .00140 & .00000 & .02000 & . 02500 & 01764 \\
\hline HLW07-03 & HLW07 & .03888 & .08732 & .00499 & .00200 & .00140 & .06939 & .03710 & .00120 & .02698 & .09093 & .00395 & .00174 & .00100 & .00100 & .43059 & .02705 & .03658 & .00093 & .03032 & .01920 & .06767 & 01979 \\
\hline HLW07-04 & HLW07 & .08500 & .14000 & .00500 & .00050 & .00020 & .09500 & .06000 & .00120 & .00000 & .04000 & .00100 & .00040 & .00200 & .00200 & .53000 & .00080 & .00000 & .00019 & .00000 & .02000 & . 00000 & 01671 \\
\hline HLW07-05 & HLW07 & .04961 & .04961 & .00498 & .00050 & .00496 & .13891 & .04750 & .00120 & .06945 & .11693 & .00100 & .00040 & .00020 & .00199 & .39825 & .00000 & .00000 & .00019 & .06306 & .03461 & . 00000 & .01665 \\
\hline HLW07-06 & HLW07 & .11501 & .06001 & .00300 & .01000 & .00600 & .04000 & .00000 & .00000 & .06001 & .12530 & .00000 & .01010 & .00400 & .00000 & .35004 & .10001 & .00000 & .00000 & .04100 & .00000 & .02951 & .04601 \\
\hline HLW07-07 & HLW07 & .03000 & .06001 & .00300 & .01000 & .00050 & .14001 & .00000 & .00000 & . & . 17977 & \begin{tabular}{|l|l|l}
.01000 \\
\end{tabular} & . & .00400 & .00000 & .35059 & .10001 & .00000 & . & . & .00000 & . 01000 & . 04601 \\
\hline
\end{tabular}

(a) Normalized to sum to 1.00000 over the 22 components listed in this table. The normalized component mass fractions listed in this table were rounded to five decimals, and may not sum exactly to 1.00000 as listed. However, complete compositions listed to more decimal places and summing to 1.00000 were used for property-composition modeling.

(b) The Group IDs are described in Sections 2.1.1 to 2.1.9. 
Table 7.2. Normalized $^{(\text {a) }}$ 22-Component Compositions (mass fractions) of 208 HLW Glasses Used for Electrical Conductivity Model Development (continued).

\begin{tabular}{|c|c|c|c|c|c|c|c|c|c|c|c|c|c|c|c|c|c|c|c|c|c|c|c|}
\hline Glass ID & $\underset{\text { ID }^{\text {Group }}}{\text { Group }}$ & 3 & $\mathbf{O}_{3}$ & $\mathbf{O}$ & $\mathrm{CdO}$ & $\mathrm{Cr}_{2} \mathrm{O}_{3}$ & )$_{3}$ & $\mathbf{L}$ & 0 & MnO & $\mathbf{O}$ & $\mathbf{N i O}$ & PbO & $\mathbf{S b}_{2} \mathbf{O}_{3}$ & $\mathrm{SeO}_{2}$ & $\mathrm{SiO}_{2}$ & SrO & $\mathrm{ThO}_{2}$ & $\mathbf{T l}_{2} \mathbf{O}$ & $\mathbf{U O}_{3}$ & $\mathrm{ZnO}$ & $\mathrm{ZrO}_{2}$ & Oth \\
\hline & & & & & 000 & 50 & & & & 001 & & 000 & & 400 & 000 & 307 & & 400 & .00000 & & 000 & & \\
\hline & & 000 & 001 & 300 & 0000 & 600 & 459 & 500 & 000 & 0500 & 603 & .00000 & .00000 & 400 & 0000 & 5004 & 0001 & .04400 & .00000 & 0000 & 2500 & 9601 & 4130 \\
\hline $\mathrm{HLI}$ & & 000 & 867 & 300 & 1000 & 0600 & 4001 & 0000 & 00000 & 0500 & \begin{tabular}{|l|}
.09461 \\
\end{tabular} & \begin{tabular}{|l|l|}
.00114 \\
\end{tabular} & .01010 & 0400 & .00000 & 5004 & .10001 & 4400 & .00000 & .04100 & 00000 & 1.01000 & 3240 \\
\hline $\mathrm{HLI}$ & & .11501 & 6001 & 300 & .01000 & 0600 & 10495 & .04500 & 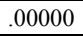 & .00500 & \begin{tabular}{|l|l|}
.17016 \\
\end{tabular} & .01000 & .01010 & 0400 & .00000 & 35004 & .02332 & .00000 & .00000 & .04100 & .00000 & 1.01000 & 3240 \\
\hline $\mathrm{HLI}$ & & .11501 & 06001 & 300 & .00000 & 0116 & .13191 & .04413 & .00000 & .00500 & \begin{tabular}{|l|l|}
.17903 \\
\end{tabular} & .00000 & .00000 & .00400 & .00000 & 55004 & . 000000 & .04400 & 1.00000 & 1.00000 & .02500 & .01000 & 2770 \\
\hline HLV & & .11501 & .06001 & 3300 & .00435 & 0600 & .04000 & .00790 & .00000 & 0500 & \begin{tabular}{|l|l|}
.18002 \\
\end{tabular} & .00000 & .00440 & .00400 & .00000 & 36494 & .00000 & .00000 & .00000 & .04100 & .02500 & .09601 & 3335 \\
\hline HLV & & .11501 & .06001 & .00300 & .01000 & 0050 & .04647 & .04284 & .00000 & 0500 & \begin{tabular}{|l|}
.06001 \\
\end{tabular} & .01000 & .01010 & .00400 & .00000 & 55004 & .10001 & .00000 & 1.00000 & .04100 & 00000 & 99601 & 4601 \\
\hline HLV & & .04400 & .06001 & .00300 & .00000 & 0050 & .04000 & .00000 & .00000 & \begin{tabular}{|l|}
.06001 \\
\end{tabular} & .18002 & \begin{tabular}{|l|}
.01000 \\
\end{tabular} & .00000 & .00400 & .00000 & 55004 & .10001 & .00000 & .00000 & .02470 & .00000 & 9601 & 2770 \\
\hline HLV & & . 04400 & .11569 & . .00300 & .00000 & 0600 & .04000 & .03853 & .00000 & \begin{tabular}{|l|}
.06001 \\
\end{tabular} & \begin{tabular}{|l|}
.18002 \\
\end{tabular} & \begin{tabular}{|l|}
.01000 \\
\end{tabular} & .00000 & \begin{tabular}{|l|}
.00400 \\
\end{tabular} & .00000 & 35004 & .00000 & .00000 & .00000 & .00000 & .02500 & 09601 & 2770 \\
\hline HLV & & .11501 & .13001 & . & .00000 & 0050 & .04000 & .04253 & . & .06001 & .18002 & .00000 & . .00000 & .00400 & .00000 & 35861 & . 00000 & .00000 & .00000 & .00000 & .00000 & .02500 & 4130 \\
\hline HLV & & . 09077 & .13001 & . & .00000 & 0600 & .07925 & .04500 & . & .00500 & .18002 & .00000 & . .00000 & .00400 & .00000 & 7524 & . 00000 & .04400 & .00000 & .00000 & .00000 & 01000 & 2770 \\
\hline & & .03000 & .06572 & 300 & .01000 & 0600 & .05401 & .04210 & .00000 & .00500 & \begin{tabular}{|l|}
.15061 \\
\end{tabular} & \begin{tabular}{|l|}
.00000 \\
\end{tabular} & .01010 & .00400 & .00000 & .35004 & .10001 & .00000 & .00000 & .04100 & .00000 & 09601 & 3240 \\
\hline & & .11501 & .13001 & . & .00000 & 0600 & .05501 & .04500 & . & .06001 & .06001 & .00000 & . .00000 & .00400 & .00000 & .46179 & . 00000 & .02246 & .00000 & .00000 & .00000 & .01000 & 2770 \\
\hline HLV & & . 03000 & . 06001 & . & .01000 & 0050 & 401 & .00000 & . & .00500 & .11335 & .00000 & 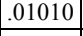 & .00400 & .00000 & .42700 & .10001 & .00000 & .00000 & .04100 & .00000 & .09601 & 4601 \\
\hline HLV & & .11501 & . 06073 & . & .01000 & 0050 & .04000 & .00000 & . & .00500 & \begin{tabular}{|l|l|} 
\\
\end{tabular} & .01000 & .01010 & .00400 & .00000 & .35004 & .10001 & .04400 & .00000 & .04100 & .02500 & .02500 & 3240 \\
\hline 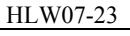 & & . & .13001 & 300 & .00000 & 0600 & .04000 & .01822 & . & .00500 & .06620 & .01000 & . .00000 & .00400 & .00000 & .41883 & . 06501 & .00000 & .00000 & .04100 & .02500 & .09601 & 2770 \\
\hline HLW & & .11501 & . 13001 & . & .00000 & .00600 & .05501 & .00000 & . & .00500 & .16120 & .01000 & $\mid .00000$ & .00400 & .00000 & .37445 & . 00000 & .04400 & .00000 & .04100 & .00000 & .01000 & 4130 \\
\hline HLW07-25 & & .11501 & . 06001 & . & .01000 & .00050 & .05501 & .00997 & . & .06001 & .11453 & .00000 & .01010 & .00400 & .00000 & .42662 & . 00000 & .04400 & .00000 & .04100 & .00384 & .01000 & 3240 \\
\hline HLW07-26 & 07 & .10001 & .08000 & .00150 & .00000 & .00150 & .06000 & .03460 & .00000 & \begin{tabular}{|l|}
.02500 \\
\end{tabular} & \begin{tabular}{|l|}
.10001 \\
\end{tabular} & .00650 & .00000 & .00200 & .00000 & .47002 & .02500 & .03500 & .00000 & .01500 & .00500 & .02500 & 1385 \\
\hline HLW07-27 & W07 & .10001 & .11001 & .00150 & .00000 & .00400 & .06000 & .03500 & .00000 & .02500 & .10001 & \begin{tabular}{|l|}
.00200 \\
\end{tabular} & .00000 & .00200 & .00000 & .40002 & .07000 & .01000 & .00000 & .03000 & .00500 & .02500 & 2045 \\
\hline HLW07-28 & W07 & .10001 & .08000 & .00150 & .00000 & .00150 & .06000 & .03500 & .00000 & .02500 & .14001 & .00650 & .00000 & .00200 & .00000 & .40002 & .03100 & .03500 & .00000 & .01500 & .01500 & .02500 & 2745 \\
\hline HLW07-29 & LW07 & .05000 & .11001 & .00150 & .00000 & .00150 & .11001 & .01000 & .00000 & .04000 & \begin{tabular}{|l|}
.10782 \\
\end{tabular} & \begin{tabular}{|l|}
.00650 \\
\end{tabular} & .00000 & .00200 & .00000 & .40002 & .05179 & .03500 & .00000 & .03000 & .00500 & .02500 & 1385 \\
\hline HLW07-30 & LW07 & .05000 & .08000 & .00150 & .00000 & .00400 & .11001 & .01000 & .00000 & \begin{tabular}{|l|}
.03687 \\
\end{tabular} & .12614 & \begin{tabular}{|l|}
.00200 \\
\end{tabular} & .00000 & .00200 & .00000 & .47002 & .02500 & .01000 & .00000 & .01500 & .00500 & .02500 & 2745 \\
\hline HLW07-31 & LW07 & .10001 & .11001 & .00150 & .00500 & .00400 & .06000 & .01357 & .00000 & \begin{tabular}{|l|}
.02500 \\
\end{tabular} & \begin{tabular}{|l|}
.10001 \\
\end{tabular} & \begin{tabular}{|l|}
.00403 \\
\end{tabular} & .00505 & .00200 & .00000 & .40002 & .07000 & .01000 & .00000 & .03000 & .00500 & .02500 & 2980 \\
\hline HLW07-32 & LW07 & .05000 & .08000 & .00150 & .00500 & .00150 & .11001 & .01000 & .00000 & \begin{tabular}{|l|}
.02500 \\
\end{tabular} & \begin{tabular}{|l|}
.14001 \\
\end{tabular} & .00650 & .00505 & .00200 & .00000 & .40002 & .03264 & .01000 & .00000 & .01500 & .01096 & .06500 & 2980 \\
\hline HLW07-33 & LW07 & .10001 & .08000 & .00150 & .00000 & .00400 & .06297 & .01000 & .00000 & .04000 & .12268 & \begin{tabular}{|l|}
.00650 \\
\end{tabular} & .00000 & .00200 & .00000 & .42207 & .06940 & .01000 & .00000 & .01500 & .01500 & .02500 & 1385 \\
\hline HLW07-34 & W07 & .10001 & .11001 & .00150 & .00000 & .00150 & .06000 & .02063 & .00000 & .04000 & \begin{tabular}{|l|}
.10001 \\
\end{tabular} & \begin{tabular}{|l|}
.00650 \\
\end{tabular} & .00000 & .00200 & .00000 & .41514 & .02905 & .01000 & .00000 & \begin{tabular}{|l|l|}
.01981 \\
\end{tabular} & .00500 & .06500 & 1385 \\
\hline HLW07-35 & W07 & .10001 & .09587 & .00150 & .00000 & .00400 & .06000 & .01347 & .00000 & .02500 & \begin{tabular}{|l|}
.10001 \\
\end{tabular} & \begin{tabular}{|l|}
.00200 \\
\end{tabular} & .00000 & .00200 & .00000 & .40002 & .07000 & .03500 & .00000 & .01500 & .01500 & .04727 & 1385 \\
\hline HLW07-36 & W07 & .09500 & .11001 & .00150 & .00000 & .00150 & .06000 & .01000 & .00000 & .02500 & .14001 & .00200 & .00000 & .00200 & .00000 & .40002 & . 06910 & .01000 & .00000 & .03000 & .00500 & .02500 & .01385 \\
\hline HLW07-37 & HLW07 & .05000 & . & . & .00500 & .00150 & .10501 & .03500 & . & \begin{tabular}{|l|l|}
.04000 \\
\end{tabular} & \begin{tabular}{|l|l|}
.13811 \\
\end{tabular} & \begin{tabular}{|l|l|}
.00200 \\
\end{tabular} & . & .00200 & .00000 & .40002 & . 02500 & .03500 & .00000 & .01500 & .00500 & .02500 & . 02980 \\
\hline
\end{tabular}

(a) Normalized to sum to 1.00000 over the 22 components listed in this table. The normalized component mass fractions listed in this table were rounded to five decimals, and may not sum exactly to 1.00000 as listed. However, complete compositions listed to more decimal places and summing to 1.00000 were used for property-composition modeling.

(b) The Group IDs are described in Sections 2.1.1 to 2.1.9. 
Table 7.2. Normalized $^{(\text {a) }}$ 22-Component Compositions (mass fractions) of 208 HLW Glasses Used for Electrical Conductivity Model Development (continued).

\begin{tabular}{|c|c|c|c|c|c|c|c|c|c|c|c|c|c|c|c|c|c|c|c|c|c|c|c|}
\hline & $\begin{array}{c}\text { Group } \\
\text { ID }^{(\mathbf{b})}\end{array}$ & $\mathrm{O}_{3}$ & $D_{3}$ & $\mathrm{CaO}$ & dO & $\mathrm{O}_{3}$ & 3 & $\mathbf{L i}_{2} \mathbf{O}$ & 0 & no & $\mathbf{O}$ & $\mathbf{N i O}$ & PbO & $\mathbf{S b}_{2} \mathbf{O}_{3}$ & $\mathrm{SeO}_{2}$ & $\mathrm{SiO}_{2}$ & SrO & $\mathrm{hO}_{2}$ & $\mathbf{T l}_{2} \mathbf{O}$ & $\mathbf{U O}_{3}$ & ZnO & $\mathrm{ZrO}_{2}$ & Oth \\
\hline & & & & & & & & & & & & & & & & & & & 00 & & & & \\
\hline & & 00 & 001 & 150 & 500 & 1400 & 000 & & 000 & 500 & 629 & 200 & 505 & 200 & 000 & 4794 & 2500 & 1000 & \begin{tabular}{|l|}
.00000 \\
\end{tabular} & 1500 & 500 & 6300 & 1620 \\
\hline & & 000 & 000 & 150 & 500 & 0400 & 0384 & 000 & 00000 & 2500 & 001 & .00200 & .00505 & 0200 & .00000 & 42803 & .07000 & 3500 & .00000 & .02119 & 1500 & 22617 & 1620 \\
\hline $\mathrm{HL}$ & & 1086 & 560 & 3331 & .00000 & .00501 & 9619 & .03329 & .00096 & 0000 & \begin{tabular}{|l|l|}
.17280 \\
\end{tabular} & .00000 & .00202 & .00000 & .00000 & .45286 & .00000 & .00000 & .00000 & .00000 & 1062 & 10000 & 0649 \\
\hline -ALG-02 & & 3001 & \begin{tabular}{|l|l|}
.11088 \\
\end{tabular} & .00350 & .00000 & .00278 & 7145 & .03550 & .00101 & 0000 & \begin{tabular}{|l|l|}
.15318 \\
\end{tabular} & \begin{tabular}{|l|l|}
.00522 \\
\end{tabular} & $\mid .00214$ & .00000 & .00000 & . 444674 & .00000 & .00000 & .00000 & .00000 & 1577 & 16495 & 6686 \\
\hline ALG-03 & & .01926 & .08621 & .00339 & .00000 & .00501 & .12650 & .03057 & .00098 & \begin{tabular}{|l|l|}
.02095 \\
\end{tabular} & \begin{tabular}{|l|l|}
.18966 \\
\end{tabular} & $\mid .01001$ & .00207 & .00000 & 00000 & 4365 & .00000 & .00000 & .00000 & .00000 & 0032 & 5433 & 7708 \\
\hline ALG-04 & & .01926 & .11134 & .00224 & .00000 & .00501 & .12639 & .02876 & .00066 & 0000 & \begin{tabular}{|l|l|}
.15980 \\
\end{tabular} & \begin{tabular}{|l|l|}
.01001 \\
\end{tabular} & 0135 & 0000 & .00000 & 1881 & .00000 & .00000 & .00000 & 00000 & 1226 & 0000 & 0409 \\
\hline ALG-05 & & .01927 & .04810 & .00521 & .01198 & \begin{tabular}{|l|}
.00415 \\
\end{tabular} & .12536 & . 04286 & .00149 & \begin{tabular}{|l|}
.06906 \\
\end{tabular} & .08937 & .00781 & .00320 & 0000 & .00000 & .46197 & .09891 & .00000 & .00000 & .00000 & 0050 & 0000 & 1077 \\
\hline LG-06 & & \begin{tabular}{|l|}
.09670 \\
\end{tabular} & .04807 & .00579 & .01322 & .00201 & 10620 & .02530 & .00164 & \begin{tabular}{|l|}
.04007 \\
\end{tabular} & .15635 & \begin{tabular}{|l|}
.00481 \\
\end{tabular} & .00357 & .00000 & .00000 & .37279 & .08015 & .01603 & \begin{tabular}{|l|l|}
.00000 \\
\end{tabular} & .00601 & 00055 & 0801 & 1272 \\
\hline $\mathrm{G}-07$ & & .08194 & .10704 & .00390 & .00000 & .00000 & .01928 & .03258 & .00114 & \begin{tabular}{|l|}
.02339 \\
\end{tabular} & \begin{tabular}{|l|}
.11777 \\
\end{tabular} & \begin{tabular}{|l|}
.00000 \\
\end{tabular} & .00239 & .00000 & .00000 & .44110 & .04113 & .04126 & $\begin{array}{l}.00000 \\
\end{array}$ & .00000 & 1675 & 6262 & 0771 \\
\hline & & \begin{tabular}{|l|}
.01926 \\
\end{tabular} & .04807 & .00591 & .01349 & .00471 & 318 & .02081 & .00167 & \begin{tabular}{|l|}
.03560 \\
\end{tabular} & .13943 & \begin{tabular}{|l|}
.00887 \\
\end{tabular} & .00364 & .00000 & .00000 & .36699 & .06267 & .04006 & $\begin{array}{l}.00000 \\
\end{array}$ & .04644 & 0056 & .09541 & 1323 \\
\hline & & 5480 & .04808 & .00560 & .00084 & 0211 & 3931 & .01987 & .00492 & \begin{tabular}{|l|}
.03916 \\
\end{tabular} & .15116 & \begin{tabular}{|l|}
.00189 \\
\end{tabular} & .00410 & .00000 & .00000 & .38868 & .07479 & .00603 & $\begin{array}{l}.00000 \\
\end{array}$ & .01360 & 0059 & .02565 & 1883 \\
\hline $\mathrm{s}-10$ & & \begin{tabular}{|l|}
.01926 \\
\end{tabular} & .09448 & .00332 & .00854 & .00501 & .10984 & .02020 & .00096 & \begin{tabular}{|l|}
.07010 \\
\end{tabular} & .17410 & \begin{tabular}{|l|}
.01001 \\
\end{tabular} & .00203 & .00000 & .00000 & .47112 & .00000 & .00228 & \begin{tabular}{|l|l|}
.00000 \\
\end{tabular} & .00000 & 0031 & 0159 & 685 \\
\hline & & .11886 & .12188 & .00565 & . & .00000 & .01928 & . 06013 & .00163 & .03408 & .06065 & .00000 & .00348 & .00000 & .00000 & 5076 & .05994 & .06013 & .00000 & . 00000 & 00054 & .09125 & 1174 \\
\hline $\mathrm{s}-12$ & & 5938 & 07 & .00586 & . 00406 & . 00285 & 2540 & . .02750 & .00166 & .02029 & \begin{tabular}{|l|l|}
15899 \\
\end{tabular} & .00812 & .00361 & .00000 & .00000 & .40350 & .06087 & .01623 & .00000 & . 01623 & 00056 & .02394 & 1288 \\
\hline $\mathrm{G}-13$ & & .06166 & .04808 & .00882 & . 00061 & .00000 & 16 & . 03354 & .00247 & .03063 & \begin{tabular}{|l|l}
.09504 \\
\end{tabular} & .00061 & .00545 & .00000 & .00000 & .35058 & .06125 & .05513 & .00000 & . 06125 & 00084 & .09188 & 1999 \\
\hline HLW-ALG-14 & WALG & .03543 & .04809 & .00507 & . 01486 & .00000 & .12562 & .06012 & .00146 & .06715 & .04804 & \begin{tabular}{|l|l|}
.00759 \\
\end{tabular} & .00311 & .00000 & .00000 & .47605 & \begin{tabular}{|l|l|}
.09618 \\
\end{tabular} & .00000 & .00000 & . .00000 & 0048 & .00000 & 1075 \\
\hline HLW-ALG-15 & WALG & .09731 & .14029 & .00424 & . .00000 & .00338 & .09780 & . 01928 & .00121 & .00000 & .17583 & \begin{tabular}{|l|l|}
.00636 \\
\end{tabular} & .00261 & .00000 & .00000 & .37449 & .00000 & .00000 & .00000 & . 00000 & 0040 & .06845 & 835 \\
\hline HLW-ALG-16 & WALG & .10329 & .13850 & .00363 & .00025 & .00501 & .04396 & .02021 & .00104 & \begin{tabular}{|l|}
.00000 \\
\end{tabular} & \begin{tabular}{|l|}
.17406 \\
\end{tabular} & \begin{tabular}{|l|}
.00751 \\
\end{tabular} & .00223 & .00000 & .00000 & .43773 & .00000 & .00000 & \begin{tabular}{|l|l}
.00000 \\
\end{tabular} & .00000 & 1786 & .03757 & 7714 \\
\hline HLW-ALG-17 & WALG & .01926 & .10338 & .00331 & .00000 & .00501 & .12515 & .02020 & .00095 & \begin{tabular}{|l|}
.06912 \\
\end{tabular} & .17414 & \begin{tabular}{|l|}
.00997 \\
\end{tabular} & .00202 & .00000 & .00000 & .45869 & .00000 & .00000 & \begin{tabular}{|l|l}
.00000 \\
\end{tabular} & .00000 & 00031 & .00159 & 889 \\
\hline HLW-ALG-18 & WALG & .11360 & .11109 & .00339 & .00000 & \begin{tabular}{|l|}
.00000 \\
\end{tabular} & .10369 & .03437 & .00098 & .00000 & .14807 & .00000 & .00207 & .00000 & .00000 & .45993 & .00000 & .00000 & \begin{tabular}{l|l|}
.00000 \\
\end{tabular} & .00000 & .01616 & .00000 & 0665 \\
\hline HLW-ALG-19 & WALG & \begin{tabular}{|l|}
.01926 \\
\end{tabular} & .09652 & .00340 & .00000 & .00501 & .12652 & .02659 & .00098 & \begin{tabular}{|l|}
.02096 \\
\end{tabular} & \begin{tabular}{|l|}
.16131 \\
\end{tabular} & \begin{tabular}{|l|}
.01001 \\
\end{tabular} & .00207 & .00000 & .00000 & .46563 & .00000 & .00000 & \begin{tabular}{|l|l|}
.00000 \\
\end{tabular} & .00000 & .00032 & .05434 & 0707 \\
\hline HLW-ALG-20 & WALG & \begin{tabular}{|l|}
.01926 \\
\end{tabular} & .07754 & .00340 & .00000 & .00501 & .12651 & .02926 & .00098 & \begin{tabular}{|l|}
.02095 \\
\end{tabular} & .17400 & \begin{tabular}{|l|}
.01001 \\
\end{tabular} & .00207 & .00000 & .00000 & .46929 & .00000 & .00000 & $\begin{array}{l}.00000 \\
\end{array}$ & .00000 & 00032 & .05434 & 0708 \\
\hline HLW-ALG-21 & WALG & \begin{tabular}{|l|}
.02619 \\
\end{tabular} & .04810 & .00642 & .00131 & .00493 & .09663 & .02475 & .00112 & \begin{tabular}{|l|}
.01186 \\
\end{tabular} & .17623 & \begin{tabular}{|l|}
.00542 \\
\end{tabular} & .00180 & .00000 & .00000 & .38986 & .00000 & .05894 & $\begin{array}{l}.00000 \\
\end{array}$ & .04502 & .00084 & .08915 & 1142 \\
\hline HLW-ALG-22 & HLWALG & \begin{tabular}{|l|}
.02588 \\
\end{tabular} & .06599 & .00635 & .00129 & .00487 & .09548 & .02407 & .00111 & \begin{tabular}{|l|}
.01172 \\
\end{tabular} & \begin{tabular}{|l|}
.16615 \\
\end{tabular} & \begin{tabular}{|l|}
.00535 \\
\end{tabular} & \begin{tabular}{|l|}
.00178 \\
\end{tabular} & .00000 & .00000 & .38701 & .00000 & .05824 & $\begin{array}{l}.00000 \\
\end{array}$ & .04449 & .00083 & .08809 & 1128 \\
\hline HLW-ALG-23 & HLWALG & .02492 & .04809 & .00611 & .00124 & .00469 & .09180 & .02069 & .00107 & \begin{tabular}{|l|}
.01127 \\
\end{tabular} & .19298 & \begin{tabular}{|l|}
.00515 \\
\end{tabular} & \begin{tabular}{|l|}
.00171 \\
\end{tabular} & .00000 & .00000 & .39517 & .00000 & .05599 & \begin{tabular}{|l|l|}
.00000 \\
\end{tabular} & .04278 & .00079 & .08469 & 1086 \\
\hline HLW-ALG-24 & HLWALG & .12589 & .04808 & .00902 & .00063 & .00000 & .01927 & .04265 & .00255 & .03134 & \begin{tabular}{|l|}
.09813 \\
\end{tabular} & \begin{tabular}{|l|}
.00063 \\
\end{tabular} & .00558 & .00000 & .00000 & .35060 & .04071 & .05637 & \begin{tabular}{|l|l|}
.00000 \\
\end{tabular} & .05637 & .00086 & .09082 & 2051 \\
\hline HLW-ALG-25 & HLWALG & \begin{tabular}{|l|}
.01926 \\
\end{tabular} & .10096 & .00332 & .00000 & .00501 & .11817 & .02020 & .00096 & \begin{tabular}{|l|}
.07012 \\
\end{tabular} & .17414 & \begin{tabular}{|l|}
.01002 \\
\end{tabular} & .00203 & .00000 & .00000 & .46478 & .00000 & .00228 & \begin{tabular}{|l|l|}
.00000 \\
\end{tabular} & .00000 & .00031 & .00159 & 0685 \\
\hline HLW-ALG-26 & HLWALG & .04632 & .07474 & .00661 & .00046 & .00000 & .05397 & .03024 & .00187 & .02289 & .09610 & .00046 & .00408 & .00000 & .00000 & .43210 & .04578 & .04120 & .00000 & . 04578 & .01427 & .06866 & .01451 \\
\hline HLW-ALG-27 & HLWALG & . 13025 & .14027 & .00387 & . & .00000 & .11905 & . 01928 & .00111 & . .00000 & \begin{tabular}{|l|l|l|l}
.17589 \\
\end{tabular} & . .00000 & . & .00000 & .00000 & .37713 & .00000 & .00000 & $\mid 00000$ & . & . 02316 & .00000 & .00762 \\
\hline
\end{tabular}

(a) Normalized to sum to 1.00000 over the 22 components listed in this table. The normalized component mass fractions listed in this table were rounded to five decimals, and may not sum exactly to 1.00000 as listed. However, complete compositions listed to more decimal places and summing to 1.00000 were used for property-composition modeling.

(b) The Group IDs are described in Sections 2.1.1 to 2.1.9. 
Table 7.2. Normalized $^{(\text {a) }}$ 22-Component Compositions (mass fractions) of 208 HLW Glasses Used for Electrical Conductivity Model Development (continued).

\begin{tabular}{|c|c|c|c|c|c|c|c|c|c|c|c|c|c|c|c|c|c|c|c|c|c|c|c|}
\hline Glass ID & $\mathbf{u p}_{\text {b) }}$ & ${ }_{2} \mathbf{O}_{3}$ & $\mathbf{O}_{3}$ & $\mathrm{aO}$ & $\mathrm{CdO}$ & )$_{3}$ & $\mathrm{Fe}_{2} \mathrm{O}_{3}$ & $\mathbf{L i}_{2} \mathbf{O}$ & $\mathbf{O}$ & [nO & $\mathbf{O}$ & NiO & bO & $\mathbf{S b}_{2} \mathbf{O}_{3}$ & $\mathrm{SeO}_{2}$ & $\mathrm{SiO}_{2}$ & SrO & $\mathbf{T h O}_{2}$ & $\mathbf{T l}_{2} \mathbf{O}$ & $\mathbf{U O}_{3}$ & $\mathrm{ZnO}$ & $\mathrm{ZrO}_{2}$ & Othe \\
\hline & & & & & & & & & & & & & & 000 & 000 & 956 & & & 000 & 00 & 037 & & \\
\hline & & 926 & 030 & 433 & 000 & 345 & 0002 & 926 & 123 & 000 & 7581 & 1045 & 266 & 0000 & 0000 & .36865 & .00000 & 0000 & 0000 & 00000 & 00041 & 8079 & 852 \\
\hline G-30 & & 250 & 597 & 4422 & 631 & 0141 & 1020 & 099 & 0102 & 0323 & 5321 & 0485 & 0073 & 0000 & .00000 & .44901 & .00153 & .00000 & .00000 & .00911 & 0654 & 3343 & 1574 \\
\hline G-31 & & 926 & 0888 & 0340 & 0000 & 0501 & .12650 & 3078 & .00098 & 2095 & 1711 & 1001 & 0207 & .00000 & .00000 & .47666 & .00000 & .00000 & .00000 & .00000 & .01699 & 5433 & 0706 \\
\hline LG-32 & G & 6000 & 4810 & 00529 & .01213 & . 00420 & .12753 & 3972 & .00151 & 6996 & 9317 & 0791 & 0324 & .00000 & .00000 & .41153 & .10020 & .00000 & .00000 & .00000 & .00404 & 0000 & 1146 \\
\hline HLW-ALG-33 & G & 1389 & 8006 & .00497 & .00000 & 然. 00396 & .11456 & 3783 & .00141 & 00000 & 7656 & 0746 & 00306 & .00000 & .00000 & .36552 & .00000 & .00000 & .00000 & .00000 & .00047 & 8019 & 1005 \\
\hline HLW-ALG-34 & G & 1926 & 8223 & .00331 & .00000 & . 00501 & .12515 & 2020 & .00096 & 6912 & 9002 & 0997 & .00202 & .00000 & .00000 & . 46396 & .00000 & .00000 & .00000 & .00000 & .00031 & 0159 & 0689 \\
\hline HLW-ALG-35 & LG & 5519 & 4808 & .00564 & .00085 & . 00212 & .14024 & 2801 & .00495 & 03942 & 10818 & 0190 & .00413 & .00000 & .00000 & .40921 & .07529 & .00607 & .00000 & .01369 & .01228 & 2582 & 1894 \\
\hline HLW-ALG-36 & HLV & 6536 & 6511 & .00645 & .00447 & . 00314 & .138 & 2903 & .00182 & .02236 & 12535 & .00894 & .00398 & .00000 & .00000 & .38173 & .06709 & .01789 & .00000 & .01789 & .00062 & 2639 & 1418 \\
\hline LG-37 & $\mathrm{HLW}$ & 6186 & .04808 & .00884 & .00062 & .00000 & .07 & 2580 & .00248 & 03072 & .09358 & .00061 & .00547 & .00000 & .00000 & .35059 & .06145 & .05530 & .00000 & .06145 & .00853 & 9217 & 2005 \\
\hline & HLWALG & 2661 & .07901 & .00652 & .00133 & .00501 & . & 380 & .00114 & .01204 & 10641 & .00550 & .00183 & .00000 & .00000 & .41588 & .00000 & .05983 & .00000 & .04570 & .00420 & 9050 & 1158 \\
\hline & $\mathrm{HLW}$ & 1927 & .10207 & .00468 & .00095 & .00358 & 07 & 10 & .00084 & .00860 & .11054 & .00393 & .00131 & .00000 & .00000 & .47962 & .00000 & .04274 & .00000 & .03265 & .01572 & 6465 & 0763 \\
\hline HLW-ALG-40 & HLWALG & 9195 & .08436 & .00535 & .00802 & .00179 & .14 & 54 & .00128 & .00411 & 14348 & .00616 & 00092 & .00000 & .00000 & .40399 & .00195 & .00000 & .00000 & .01158 & .00162 & 4250 & 2030 \\
\hline & HLW98 & .05192 & .08185 & .00278 & .00064 & . 00000 & 89 & 28 & .00107 & .00169 & .13447 & .00618 & .00036 & .00000 & .00000 & .47982 & .00000 & .00000 & .00000 & .00000 & .02018 & .03795 & 0894 \\
\hline & HLW98 & .05196 & .11908 & .00280 & .00064 & .00000 & 221 & & 06 & 0170 & .11659 & .00615 & 00034 & .00000 & .00000 & .47453 & .00032 & .00000 & .00000 & .00000 & .02016 & . 03806 & 0914 \\
\hline HLV & HLW98 & .05590 & 2529 & .00233 & .00114 & .00000 & 530 & & 73 & .00357 & .12033 & .00447 & .00070 & .00000 & .00000 & .48308 & .00000 & .00000 & .00000 & .00000 & .02012 & .01772 & 0672 \\
\hline HLV & HLW98 & .01428 & .11914 & .00668 & .00000 & .00045 & .12740 & . & .00565 & .03040 & .11738 & 00374 & .00252 & .00108 & .00212 & .50938 & .00000 & .00000 & .00000 & .00000 & . 02019 & .00127 & 1073 \\
\hline HLW98-84 & HLW98 & .05182 & .11163 & .00668 & .00000 & .00045 & .12746 & 755 & .00565 & .03040 & .11988 & \begin{tabular}{|l|l|}
.00374 \\
\end{tabular} & .00252 & .00108 & .00212 & . 47684 & .00000 & .00000 & .00000 & .00000 & . 02019 & 0127 & 1073 \\
\hline HLW98-86AG & HLW98 & .05297 & .09407 & .00300 & .00000 & .00078 & .12582 & . 03012 & .01168 & .03996 & .11859 & \begin{tabular}{|l|l|}
.00172 \\
\end{tabular} & .00145 & .00256 & .00370 & .47137 & .00918 & .00000 & .00000 & .00000 & . .02074 & 0259 & 0971 \\
\hline HLW98-88 & HLW98 & .07454 & .10599 & .00429 & .00654 & .00139 & .11413 & . 03759 & .00101 & .00335 & .11713 & .00502 & .00075 & .00000 & .00000 & .43966 & .00159 & .00000 & .00000 & .00944 & .02013 & 3465 & 22279 \\
\hline HLW98-89 & HLW98 & .03360 & .09096 & .00452 & .00000 & .00059 & .08947 & . 02843 & .00000 & .01425 & .10736 & .00438 & .00115 & .00000 & .00000 & .44571 & .00000 & .04051 & .00000 & .02573 & .02017 & . 08843 & 0476 \\
\hline HLW98-95 & HLW98 & .07317 & .10632 & .00425 & .00642 & .00143 & .11206 & . & .00099 & .00329 & .11925 & \begin{tabular}{|r|r|}
.00493 \\
\end{tabular} & .00074 & .00000 & .00000 & .44687 & .00156 & .00000 & .00000 & .00927 & .02012 & . 03402 & 01774 \\
\hline HLW98-96 & HLW98 & .03360 & .10096 & .00452 & .00000 & .00059 & .08947 & . 03093 & .00000 & .01425 & .10736 & .00438 & .00115 & .00000 & .00000 & .43322 & .00000 & .04051 & .00000 & .02573 & .02017 & .08843 & 0476 \\
\hline HLW98-96D & HLW98 & .03598 & .10812 & .00484 & .00000 & .00063 & .09581 & . 03313 & .00000 & .01526 & .11497 & \begin{tabular}{|l|l|l}
.00469 \\
\end{tabular} & .00123 & .00000 & .00000 & .46395 & .00000 & .00000 & .00000 & .00000 & .02160 & . 09470 & 0510 \\
\hline HLW98-97 & HLW98 & .09754 & .11050 & .00252 & .00679 & .00028 & .10947 & . 03877 & .00094 & .00126 & .12180 & .00622 & .00063 & .00000 & .00000 & .43002 & .00029 & .00000 & .00000 & .00000 & .02063 & . 03366 & 1869 \\
\hline HLW98-V19 & HLW98 & .05774 & .08816 & .00351 & .00000 & .00091 & .14687 & . 02814 & .01364 & .04665 & .11211 & .00201 & .00169 & .00299 & .00432 & .44496 & .01071 & .00000 & .00000 & .00000 & .01953 & .00302 & 01305 \\
\hline HLW98-V24 & HLW98 & .04732 & .10055 & .00242 & .00000 & .00063 & .10123 & .03230 & .00940 & .03216 & .12566 & .00139 & .00116 & .00206 & .00298 & .50023 & .00738 & .00000 & .00000 & .00000 & .02206 & .00208 & 00900 \\
\hline HLW98-T05 & HLW98 & . & . 11846 & .00451 & .00057 & .00022 & .12638 & . 03008 & .00319 & . & . 12010 & \begin{tabular}{|l|l|l|}
.00410 \\
\end{tabular} & .00161 & .00054 & .00106 & .47996 & .00000 & .00000 & . & . & .02015 & .00950 & .00873 \\
\hline
\end{tabular}

(a) Normalized to sum to 1.00000 over the 22 components listed in this table. The normalized component mass fractions listed in this table were rounded to five decimals, and may not sum exactly to 1.00000 as listed. However, complete compositions listed to more decimal places and summing to 1.00000 were used for property-composition modeling.

(b) The Group IDs are described in Sections 2.1.1 to 2.1.9. 
Table 7.3. Temperature and Electrical Conductivity Observations and DataSplitting Validation Sets for Each of the 208 HLW Glasses Used for Electrical Conductivity Model Development.

\begin{tabular}{|c|c|c|c|c|c|c|c|c|c|c|}
\hline Glass ID & $\begin{array}{l}\text { Group } \\
\text { ID }^{(\mathbf{a})}\end{array}$ & $\begin{array}{c}\text { Temp1 } \\
\left({ }^{\circ} \mathrm{C}\right)\end{array}$ & $\begin{array}{c}\text { EC1 } \\
(\mathrm{S} / \mathrm{cm})\end{array}$ & $\begin{array}{c}\text { Temp2 } \\
\left({ }^{\circ} \mathrm{C}\right)\end{array}$ & $\begin{array}{c}\text { EC2 } \\
(\mathrm{S} / \mathrm{cm})\end{array}$ & $\begin{array}{c}\text { Temp3 } \\
\left({ }^{\circ} \mathrm{C}\right)\end{array}$ & $\begin{array}{c}\mathrm{EC3} \\
(\mathrm{S} / \mathrm{cm})\end{array}$ & $\begin{array}{c}\text { Temp4 } \\
\left({ }^{\circ} \mathrm{C}\right)\end{array}$ & $\begin{array}{c}\mathrm{EC4} \\
(\mathrm{S} / \mathrm{cm})\end{array}$ & $\begin{array}{c}\text { EC Data Splitting } \\
\text { Validation Set }^{(\mathbf{b})}\end{array}$ \\
\hline HLW02-01 & HLW02 & 1260 & 0.480 & 1166 & 0.356 & 1071 & 0.252 & 978 & 0.157 & NA-Rep ${ }^{(\mathrm{c})}$ \\
\hline HLW02-02 & HLW02 & 1251 & 0.326 & 1155 & 0.240 & 1054 & 0.167 & 957 & 0.104 & 2 \\
\hline HLW02-03 & HLW02 & 1257 & 0.532 & 1165 & 0.402 & 1070 & 0.276 & 977 & 0.173 & 5 \\
\hline HLW02-04 & HLW02 & 1236 & 0.420 & 1145 & 0.321 & 1051 & 0.242 & 958 & 0.159 & NA-Rep \\
\hline HLW02-05 & HLW02 & 1245 & 0.618 & 1151 & 0.482 & 1056 & 0.367 & 962 & 0.241 & 5 \\
\hline HLW02-06 & HLW02 & 1250 & 0.624 & 1154 & 0.468 & 1057 & 0.333 & 960 & 0.220 & 1 \\
\hline HLW02-07 & HLW02 & 1245 & 0.628 & 1150 & 0.441 & 1054 & 0.309 & 959 & 0.205 & 4 \\
\hline HLW02-08 & HLW02 & 1245 & 0.525 & 1152 & 0.412 & 1057 & 0.295 & 963 & 0.187 & NA-Rep \\
\hline HLW02-09 & HLW02 & 1251 & 0.414 & 1151 & 0.350 & 1055 & 0.219 & 959 & 0.139 & 4 \\
\hline HLW02-10 & HLW02 & 1237 & 0.513 & 1143 & 0.370 & 1048 & 0.269 & 953 & 0.180 & 1 \\
\hline HLW02-11 & HLW02 & 1244 & 0.514 & 1149 & 0.405 & 1053 & 0.284 & 957 & 0.182 & 2 \\
\hline HLW02-12 & HLW02 & 1247 & 0.744 & 1152 & 0.567 & 1059 & 0.384 & 963 & 0.243 & 2 \\
\hline HLW02-13 & HLW02 & 1242 & 0.586 & 1148 & 0.454 & 1055 & 0.330 & 960 & 0.211 & 3 \\
\hline HLW02-14 & HLW02 & 1247 & 0.575 & 1151 & 0.426 & 1055 & 0.309 & 959 & 0.196 & 5 \\
\hline HLW02-15 & HLW02 & 1249 & 0.350 & 1155 & 0.262 & 1060 & 0.183 & 964 & 0.113 & 3 \\
\hline HLW02-16 & HLW02 & 1245 & 0.541 & 1154 & 0.402 & 1059 & 0.282 & 964 & 0.175 & 1 \\
\hline HLW02-17 & HLW02 & 1246 & 0.426 & 1151 & 0.311 & 1055 & 0.224 & 959 & 0.150 & NA-Rep \\
\hline HLW02-18 & HLW02 & 1249 & 0.368 & 1153 & 0.290 & 1052 & 0.195 & 956 & 0.123 & 3 \\
\hline HLW02-19 & HLW02 & 1250 & 0.221 & 1155 & 0.148 & 1060 & 0.095 & 964 & 0.052 & 5 \\
\hline HLW02-20 & HLW02 & 1245 & 0.118 & 1150 & 0.086 & 1054 & 0.057 & 957 & 0.034 & 1 \\
\hline HLW02-21 & HLW02 & 1247 & 0.370 & 1154 & 0.279 & 1059 & 0.198 & 963 & 0.130 & 4 \\
\hline HLW02-22 & HLW02 & 1246 & 0.287 & 1150 & 0.225 & 1054 & 0.164 & 958 & 0.101 & NA-Rep \\
\hline HLW02-23 & HLW02 & 1249 & 0.419 & 1154 & 0.314 & 1060 & 0.227 & 964 & 0.130 & 5 \\
\hline HLW02-24 & HLW02 & 1247 & 0.240 & 1151 & 0.174 & 1055 & 0.117 & 958 & 0.071 & 3 \\
\hline HLW02-25 & HLW02 & 1247 & 0.245 & 1152 & 0.174 & 1056 & 0.116 & 959 & 0.072 & 5 \\
\hline HLW02-26 & HLW02 & 1250 & 0.423 & 1154 & 0.289 & 1059 & 0.199 & 963 & 0.121 & 3 \\
\hline HLW02-27 & HLW02 & 1247 & 0.533 & 1154 & 0.347 & 1058 & 0.251 & 963 & 0.151 & 2 \\
\hline HLW02-28 & HLW02 & 1246 & 0.568 & 1152 & 0.417 & 1045 & 0.277 & 958 & 0.184 & 3 \\
\hline HLW02-29 & HLW02 & 1250 & 0.491 & 1155 & 0.364 & 1059 & 0.240 & 963 & 0.146 & 4 \\
\hline HLW02-30 & HLW02 & 1247 & 0.572 & 1158 & 0.425 & 1054 & 0.291 & 958 & 0.181 & 5 \\
\hline HLW02-31 & HLW02 & 1249 & 0.532 & 1152 & 0.388 & 1057 & 0.279 & 962 & 0.167 & 4 \\
\hline HLW02-32 & HLW02 & 1229 & 0.434 & 1141 & 0.337 & 1047 & 0.271 & 954 & 0.149 & 1 \\
\hline HLW02-33 & HLW02 & 1251 & 0.443 & 1150 & 0.322 & 1055 & 0.232 & 958 & 0.144 & 2 \\
\hline HLW02-34 & HLW02 & 1246 & 0.373 & 1150 & 0.282 & 1054 & 0.196 & 958 & 0.121 & 1 \\
\hline HLW02-35 & HLW02 & 1250 & 0.463 & 1151 & 0.403 & 1055 & 0.269 & 958 & 0.171 & 2 \\
\hline HLW02-36 & HLW02 & 1248 & 0.353 & \begin{tabular}{|l|}
1151 \\
\end{tabular} & 0.263 & 1055 & 0.188 & 958 & 0.122 & 2 \\
\hline HLW02-37 & HLW02 & 1243 & 0.422 & \begin{tabular}{|l|}
1149 \\
\end{tabular} & 0.316 & 1054 & 0.208 & 960 & 0.125 & 5 \\
\hline HLW02-38 & HLW02 & 1243 & 0.370 & \begin{tabular}{|l|}
1147 \\
\end{tabular} & 0.273 & 1052 & 0.185 & 956 & 0.117 & 3 \\
\hline HLW02-39 & HLW02 & 1251 & 0.246 & 1154 & 0.195 & 1057 & 0.132 & 960 & 0.077 & 5 \\
\hline HLW02-40 & HLW02 & 1252 & 0.202 & 1155 & 0.168 & 1059 & 0.114 & 957 & 0.066 & 1 \\
\hline
\end{tabular}

(a) The Group IDs are described in Sections 2.1.1 to 2.1.9.

(b) Numbers from 1 to 5 denote the five split validation subsets. NA denotes "not applicable", because these replicate glasses were forced into the modeling subsets, and thus were not parts of the validation subsets.

(c) NA-Rep indicates glasses that were not included in any of the validation splits because they were replicates. 
Table 7.3. Temperature and Electrical Conductivity Observations and DataSplitting Validation Sets for Each of the 208 HLW Glasses Used for Electrical Conductivity Model Development (continued).

\begin{tabular}{|c|c|c|c|c|c|c|c|c|c|c|}
\hline Glass ID & $\begin{array}{l}\text { Group } \\
\text { ID }^{(\mathbf{a})}\end{array}$ & $\begin{array}{c}\text { Temp1 } \\
\left({ }^{\circ} \mathrm{C}\right)\end{array}$ & $\begin{array}{c}\text { EC1 } \\
(\mathrm{S} / \mathrm{cm})\end{array}$ & $\begin{array}{c}\text { Temp2 } \\
\left({ }^{\circ} \mathrm{C}\right)\end{array}$ & \begin{tabular}{|c|} 
EC2 \\
$(\mathrm{S} / \mathrm{cm})$
\end{tabular} & $\begin{array}{c}\text { Temp3 } \\
\left({ }^{\circ} \mathrm{C}\right)\end{array}$ & $\begin{array}{c}\text { EC3 } \\
(\mathrm{S} / \mathrm{cm})\end{array}$ & $\begin{array}{c}\text { Temp4 } \\
\left({ }^{\circ} \mathrm{C}\right)\end{array}$ & $\begin{array}{c}\mathrm{EC4} \\
(\mathrm{S} / \mathrm{cm})\end{array}$ & $\begin{array}{l}\text { EC Data Splitting } \\
\text { Validation Set }^{(\mathbf{b})}\end{array}$ \\
\hline HLW02-41 & HLW02 & 1249 & 0.216 & 1154 & 0.174 & 1058 & 0.105 & 963 & 0.080 & 5 \\
\hline HLW02-42 & HLW02 & 1245 & 0.479 & 1151 & 0.37 & 1057 & 0.245 & 962 & 0.143 & NA-Rep $^{(\mathrm{c})}$ \\
\hline HLW02-43 & HLW02 & 1242 & 0.265 & 1147 & 0.181 & 1053 & 0.125 & 957 & 0.068 & 1 \\
\hline HLW02-44 & HLW02 & 1242 & 0.616 & 1148 & 0.449 & 1054 & 0.324 & 960 & 0.194 & NA-Rep \\
\hline HLW02-45 & HLW02 & 1249 & 0.243 & 1153 & 0.173 & 1057 & 0.130 & 961 & 0.078 & 2 \\
\hline HLW02-46 & HLW02 & 1249 & 0.324 & 1148 & 0.242 & 1053 & 0.146 & 957 & 0.090 & NA-Rep \\
\hline HLW02-47 & HLW02 & 1248 & 0.230 & 1153 & 0.168 & 1058 & 0.112 & 962 & 0.068 & 4 \\
\hline HLW02-48 & HLW02 & 1250 & 0.509 & 1154 & 0.408 & 1059 & 0.288 & 963 & 0.183 & 3 \\
\hline HLW02-49 & HLW02 & 1256 & 0.421 & 1160 & 0.308 & 1064 & 0.215 & 968 & 0.135 & 3 \\
\hline HLW02-50 & HLW02 & 1252 & 0.256 & 1156 & 0.187 & 1060 & 0.123 & 965 & 0.075 & 3 \\
\hline HLW02-51 & HLW02 & 1248 & 0.342 & 1153 & 0.246 & 1058 & 0.169 & 964 & 0.102 & 5 \\
\hline HLW02-52 & HLW02 & 1250 & 0.382 & 1153 & 0.288 & 1052 & 0.190 & 955 & 0.119 & NA-Rep \\
\hline HLW02-53 & HLW02 & 1251 & 0.475 & 1156 & \begin{tabular}{|l|}
0.369 \\
\end{tabular} & 1061 & 0.255 & 965 & 0.170 & NA-Rep \\
\hline HLW02-54 & HLW02 & 1246 & 0.416 & 1152 & 0.342 & 1057 & 0.220 & 962 & 0.145 & NA-Rep \\
\hline HLW02-55 & HLW02 & 1250 & 0.388 & 1150 & \begin{tabular}{|l|}
0.271 \\
\end{tabular} & 1054 & 0.194 & 958 & 0.119 & NA-Rep \\
\hline HLW02-56 & HLW02 & 1246 & 0.428 & 1151 & 0.325 & 1053 & 0.219 & 957 & 0.142 & NA-Rep \\
\hline HLW02-57 & HLW02 & 1249 & 0.422 & 1153 & 0.332 & 1056 & 0.230 & 959 & 0.156 & NA-Rep \\
\hline HLW03-01 & HLW03 & 1212 & 0.589 & 1124 & 0.377 & 1027 & 0.255 & 921 & 0.158 & 4 \\
\hline HLW03-02 & HLW03 & 1241 & 0.295 & 1146 & 0.215 & 1039 & 0.147 & 954 & 0.098 & 2 \\
\hline HLW03-03 & HLW03 & 1250 & 0.365 & 1153 & 0.246 & 1056 & 0.166 & 959 & 0.104 & 1 \\
\hline HLW03-04 & HLW03 & 1209 & 0.492 & 1130 & 0.353 & 1036 & 0.232 & 940 & 0.141 & 5 \\
\hline HLW03-05 & HLW03 & 1230 & 0.517 & 1139 & 0.354 & 1044 & 0.240 & 945 & 0.158 & 1 \\
\hline HLW03-06 & HLW03 & 1233 & 0.386 & 1140 & 0.302 & 1045 & 0.192 & 950 & 0.119 & NA-Rep \\
\hline HLW03-07 & HLW03 & 1230 & 0.835 & 1128 & 0.648 & 1041 & 0.466 & 944 & 0.285 & NA-Rep \\
\hline HLW03-08 & HLW03 & 1230 & 0.918 & 1137 & 0.786 & 1042 & 0.532 & 948 & 0.352 & 2 \\
\hline HLW03-09 & HLW03 & 1225 & 0.438 & 1131 & 0.317 & 1034 & 0.220 & 935 & 0.141 & 3 \\
\hline HLW03-10 & HLW03 & 1221 & 0.893 & 1128 & 0.725 & 1032 & 0.464 & 938 & 0.329 & 5 \\
\hline HLW03-11 & HLW03 & 1228 & 0.443 & 1133 & 0.384 & 1038 & 0.261 & 943 & 0.190 & NA-Rep \\
\hline HLW03-12 & HLW03 & 1219 & 0.418 & 1129 & 0.293 & 1035 & 0.174 & 939 & 0.090 & 4 \\
\hline HLW03-13 & HLW03 & 1213 & 0.400 & 1121 & 0.304 & 1022 & \begin{tabular}{|l|}
0.177 \\
\end{tabular} & 923 & 0.103 & 5 \\
\hline HLW03-14 & HLW03 & 1224 & 0.454 & 1132 & 0.302 & 1037 & 0.171 & 943 & 0.090 & 1 \\
\hline HLW03-15 & HLW03 & 1233 & 0.179 & 1141 & 0.121 & 1045 & \begin{tabular}{|l|}
0.077 \\
\end{tabular} & 951 & 0.047 & 2 \\
\hline HLW03-16 & HLW03 & 1217 & 0.193 & 1123 & 0.130 & 1029 & 0.074 & 932 & 0.037 & 5 \\
\hline HLW03-17 & HLW03 & 1230 & 0.178 & 1139 & 0.135 & 1043 & 0.074 & 947 & 0.042 & 1 \\
\hline HLW03-18 & HLW03 & 1214 & 0.623 & 1118 & 0.490 & 1014 & 0.318 & 908 & 0.180 & 3 \\
\hline HLW03-19 & HLW03 & 1212 & 0.653 & 1120 & 0.463 & 1024 & 0.335 & 920 & 0.195 & 5 \\
\hline HLW03-20 & HLW03 & 1218 & 0.648 & 1127 & 0.530 & 1032 & 0.342 & 933 & 0.214 & 2 \\
\hline HLW03-21 & HLW03 & 1230 & 0.313 & 1136 & 0.254 & 1041 & 0.155 & 944 & 0.093 & 5 \\
\hline HLW03-22 & HLW03 & 1217 & 0.444 & 1125 & 0.307 & 1029 & 0.199 & 935 & 0.110 & 4 \\
\hline HLW03-23 & HLW03 & 1224 & 0.432 & 1129 & 0.296 & 1034 & 0.212 & 937 & 0.122 & 3 \\
\hline
\end{tabular}

(a) The Group IDs are described in Sections 2.1.1 to 2.1.9.

(b) Numbers from 1 to 5 denote the five split validation subsets. NA denotes "not applicable", because these replicate glasses were forced into the modeling subsets, and thus were not parts of the validation subsets.

(c) NA-Rep indicates glasses that were not included in any of the validation splits because they were replicates. 
Table 7.3. Temperature and Electrical Conductivity Observations and DataSplitting Validation Sets for Each of the 208 HLW Glasses Used for Electrical Conductivity Model Development (continued).

\begin{tabular}{|c|c|c|c|c|c|c|c|c|c|c|}
\hline Glass ID & $\begin{array}{l}\text { Group } \\
\text { ID }^{(\text {a) }}\end{array}$ & $\begin{array}{c}\text { Temp1 } 1 \\
\left({ }^{\circ} \mathrm{C}\right)\end{array}$ & $\begin{array}{c}\text { EC1 } \\
(\mathrm{S} / \mathrm{cm})\end{array}$ & $\begin{array}{c}\text { Temp2 } \\
\left({ }^{\circ} \mathrm{C}\right)\end{array}$ & $\begin{array}{c}\text { EC2 } \\
(\mathbf{S} / \mathbf{c m})\end{array}$ & $\begin{array}{c}\text { Temp3 } 3 \\
\left({ }^{\circ} \mathrm{C}\right)\end{array}$ & $\begin{array}{c}\text { EC3 } \\
(\mathbf{S} / \mathbf{c m})\end{array}$ & $\begin{array}{c}\text { Temp4 } \\
\left({ }^{\circ} \mathrm{C}\right)\end{array}$ & $\begin{array}{c}\text { EC4 } \\
(\mathbf{S} / \mathbf{c m})\end{array}$ & $\begin{array}{c}\text { EC Data } \\
\text { Splitting } \\
\text { Validation } \\
\text { Set }^{(b)}\end{array}$ \\
\hline HLW03-24 & HLW03 & 1227 & 0.471 & 1132 & 0.352 & 1036 & 0.222 & 937 & 0.130 & 3 \\
\hline HLW03-25 & HLW03 & 1222 & 0.428 & 1131 & 0.329 & 1034 & 0.205 & 928 & \begin{tabular}{|l|}
0.107 \\
\end{tabular} & 1 \\
\hline HLW03-26 & HLW03 & 1212 & 0.622 & 1129 & 0.425 & 1034 & 0.298 & 937 & \begin{tabular}{|l|}
0.162 \\
\end{tabular} & NA-Rep ${ }^{(c)}$ \\
\hline HLW03-27 & HLW03 & 1219 & 0.582 & 1125 & 0.394 & 1029 & 0.253 & 930 & 0.159 & 2 \\
\hline HLW03-28 & HLW03 & 1229 & 0.718 & 1130 & 0.444 & 1033 & 0.295 & 936 & 0.188 & 5 \\
\hline HLW03-29 & HLW03 & 1227 & 0.690 & 1134 & 0.552 & 1037 & 0.368 & 941 & 0.220 & 4 \\
\hline HLW03-30 & HLW03 & 1227 & 0.406 & 1127 & 0.316 & 1024 & 0.213 & 919 & \begin{tabular}{|l|}
0.105 \\
\end{tabular} & 1 \\
\hline HLW03-31 & HLW03 & 1212 & 0.425 & 1121 & 0.327 & 1022 & 0.194 & 923 & \begin{tabular}{|l|}
0.099 \\
\end{tabular} & 5 \\
\hline HLW03-32 & HLW03 & 1211 & 0.523 & 1121 & 0.394 & 1022 & 0.248 & 920 & \begin{tabular}{|l|}
0.133 \\
\end{tabular} & 5 \\
\hline HLW03-33 & HLW03 & 1215 & 0.339 & 1125 & 0.247 & 1033 & $\mid 0.170$ & 941 & \begin{tabular}{|l|}
0.096 \\
\end{tabular} & 3 \\
\hline HLW03-34 & HLW03 & 1224 & 0.273 & 1129 & 0.199 & 1039 & 0.128 & 940 & \begin{tabular}{|l|}
0.080 \\
\end{tabular} & 3 \\
\hline HLW03-35 & HLW03 & 1217 & 0.189 & 1133 & 0.136 & 1039 & 0.088 & 942 & \begin{tabular}{|l|}
0.049 \\
\end{tabular} & 4 \\
\hline HLW03-36 & HLW03 & 1224 & 0.231 & 1132 & 0.179 & 1034 & 0.111 & 938 & \begin{tabular}{|l|}
0.071 \\
\end{tabular} & 1 \\
\hline HLW03-37 & HLW03 & 1217 & 0.443 & 1122 & 0.327 & 1026 & 0.207 & 927 & \begin{tabular}{|l|}
0.122 \\
\end{tabular} & 1 \\
\hline HLW03-38 & HLW03 & 1214 & 0.368 & 1128 & 0.288 & 1032 & 0.195 & 935 & \begin{tabular}{|l|}
0.107 \\
\end{tabular} & 4 \\
\hline HLW03-39 & HLW03 & 1226 & 0.302 & 1131 & 0.223 & 1036 & 0.124 & 934 & \begin{tabular}{|l|}
0.079 \\
\end{tabular} & 3 \\
\hline HLW03-40 & HLW03 & 1226 & 0.405 & 1132 & 0.310 & 1031 & 0.198 & 937 & 0.116 & 2 \\
\hline HLW03-41 & HLW03 & 1200 & 0.344 & 1120 & 0.278 & 1019 & 0.181 & 921 & \begin{tabular}{|l|}
0.111 \\
\end{tabular} & NA-Rep \\
\hline HLW03-42 & HLW03 & 1251 & 0.261 & 1152 & 0.182 & 1050 & 0.120 & 953 & 0.073 & NA-Rep \\
\hline HLW03-43 & HLW03 & 1223 & 0.407 & 1132 & 0.283 & 1038 & 0.185 & 943 & \begin{tabular}{|l|}
0.119 \\
\end{tabular} & NA-Rep \\
\hline HLW03-44 & HLW03 & 1226 & 0.465 & 1133 & 0.413 & 1038 & 0.281 & 941 & \begin{tabular}{|l|}
0.170 \\
\end{tabular} & NA-Rep \\
\hline HLW03-45 & HLW03 & 1224 & 0.594 & 1137 & 0.474 & 1043 & 0.335 & 945 & 0.191 & NA-Rep \\
\hline HLW04-01 & HLW04 & 1245 & 0.480 & 1146 & 0.360 & 1047 & 0.261 & 949 & 0.148 & 4 \\
\hline HLW05-15 & HLW05 & 1236 & 0.419 & 1139 & 0.338 & 1042 & 0.243 & 942 & \begin{tabular}{|l|}
0.158 \\
\end{tabular} & 3 \\
\hline HLW05-20 & HLW05 & 1225 & 0.504 & 1132 & 0.463 & 1029 & 0.285 & 928 & \begin{tabular}{|l|} 
\\
\end{tabular} & 5 \\
\hline HLW05-21 & HLW05 & 1231 & 0.638 & 1137 & 0.533 & 1041 & 0.369 & 943 & 0.225 & 5 \\
\hline HLW05-22 & HLW05 & 1225 & 0.261 & 1133 & 0.186 & 1037 & 0.134 & 938 & 0.080 & 2 \\
\hline HLW05-27 & HLW05 & 1221 & 0.712 & 1128 & 0.478 & 1032 & 0.364 & 933 & 0.228 & 1 \\
\hline HLW06-02 & HLW06 & 1231 & 0.697 & 1136 & 0.499 & 1040 & 0.363 & 939 & 0.244 & 3 \\
\hline HLW06-04 & HLW06 & 1228 & 0.687 & 1132 & 0.491 & 1033 & 0.385 & 932 & 0.268 & 5 \\
\hline HLW06-22 & HLW06 & 1226 & 0.592 & 1131 & 0.379 & 1033 & 0.259 & 933 & 0.163 & 3 \\
\hline HLW06-32 & HLW06 & 1223 & 0.699 & 1133 & 0.557 & 1043 & 0.398 & 954 & 0.277 & 3 \\
\hline HLW06-34 & HLW06 & 1220 & 0.650 & 1130 & 0.475 & 1033 & 0.333 & 932 & 0.214 & 2 \\
\hline HLW07-01 & HLW07 & 1231 & 0.276 & 1132 & 0.200 & 1035 & 0.150 & 933 & \begin{tabular}{|l|}
0.079 \\
\end{tabular} & 2 \\
\hline HLW07-02 & HLW07 & 1274 & 0.360 & 1177 & 0.264 & 1080 & 0.186 & 983 & 0.113 & NA-Rep \\
\hline HLW07-03 & HLW07 & 1239 & 0.442 & 1145 & 0.331 & 1048 & 0.227 & 950 & 0.133 & NA-Rep \\
\hline HLW07-04 & HLW07 & 1269 & 0.402 & 1170 & 0.310 & 1072 & 0.223 & 973 & 0.149 & NA-Rep \\
\hline HLW07-05 & HLW07 & 1253 & 0.894 & 1160 & 0.703 & 1062 & 0.496 & 965 & 0.308 & NA-Rep \\
\hline HLW07-06 & HLW07 & 1249 & 0.269 & 1154 & 0.192 & 1057 & 0.126 & 960 & 0.070 & 4 \\
\hline HLW07-07 & HLW07 & 1249 & 0.552 & 1155 & 0.419 & 1058 & 0.285 & 962 & \begin{tabular}{|l|}
0.178 \\
\end{tabular} & 1 \\
\hline
\end{tabular}

(a) The Group IDs are described in Sections 2.1.1 to 2.1.9.

(b) Numbers from 1 to 5 denote the five split validation subsets. NA denotes "not applicable", because these replicate glasses were forced into the modeling subsets, and thus were not parts of the validation subsets.

(c) NA-Rep indicates glasses that were not included in any of the validation splits because they were replicates. 
Table 7.3. Temperature and Electrical Conductivity Observations and DataSplitting Validation Sets for Each of the 208 HLW Glasses Used for Electrical Conductivity Model Development (continued).

\begin{tabular}{|c|c|c|c|c|c|c|c|c|c|c|}
\hline Glass ID & $\begin{array}{l}\text { Group } \\
\text { ID }^{(\mathbf{a})}\end{array}$ & $\begin{array}{c}\text { Temp1 } 1 \\
\left({ }^{\circ} \mathrm{C}\right)\end{array}$ & $\begin{array}{c}\text { EC1 } \\
(\mathrm{S} / \mathrm{cm})\end{array}$ & $\begin{array}{c}\text { Temp2 } 2 \\
\left({ }^{\circ} \mathrm{C}\right)\end{array}$ & $\begin{array}{c}\mathrm{EC2} \\
(\mathrm{S} / \mathrm{cm})\end{array}$ & $\begin{array}{c}\text { Temp3 } \\
\left({ }^{\circ} \mathrm{C}\right)\end{array}$ & $\begin{array}{c}\text { EC3 } \\
(\mathrm{S} / \mathrm{cm})\end{array}$ & $\begin{array}{c}\text { Temp4 } \\
\left({ }^{\circ} \mathrm{C}\right)\end{array}$ & $\begin{array}{c}\text { EC4 } \\
(\mathrm{S} / \mathrm{cm})\end{array}$ & $\begin{array}{c}\text { EC Data } \\
\text { Splitting } \\
\text { Validation } \\
\text { Set }^{(\mathbf{b})}\end{array}$ \\
\hline HLW07-08 & HLW07 & 1239 & 0.384 & 1144 & 0.341 & 1049 & 0.245 & 951 & 0.157 & 5 \\
\hline HLW07-09 & HLW07 & 1252 & 0.645 & 1153 & 0.446 & 1058 & 0.294 & 960 & 0.167 & 3 \\
\hline HLW07-10 & HLW07 & 1243 & 0.191 & 1149 & 0.122 & 1053 & \begin{tabular}{|l|}
0.072 \\
\end{tabular} & 956 & 0.039 & 4 \\
\hline HLW07-11 & HLW07 & 1240 & 0.683 & 1145 & 0.609 & 1048 & 0.432 & 950 & 0.289 & 1 \\
\hline HLW07-12 & HLW07 & 1249 & 0.901 & 1154 & 0.671 & 1057 & 0.523 & 960 & 0.324 & 1 \\
\hline HLW07-13 & HLW07 & 1245 & 0.550 & 1150 & 0.423 & 1055 & 0.273 & 958 & 0.181 & 4 \\
\hline HLW07-14 & HLW07 & 1219 & 0.295 & 1128 & 0.182 & 1033 & 0.133 & 937 & 0.072 & 1 \\
\hline HLW07-15 & HLW07 & 1233 & 0.612 & 1141 & 0.469 & 1045 & 0.305 & 948 & 0.175 & 1 \\
\hline HLW07-16 & HLW07 & 1270 & 1.376 & 1173 & 1.023 & 1076 & 0.780 & 981 & 0.524 & 1 \\
\hline HLW07-17 & HLW07 & 1277 & 1.035 & 1177 & 0.816 & 1078 & 0.618 & 979 & 0.424 & 5 \\
\hline HLW07-18 & HLW07 & 1245 & 0.867 & 1149 & 0.634 & 1052 & 0.492 & 954 & 0.335 & 3 \\
\hline HLW07-19 & HLW07 & 1251 & 1.046 & 1154 & 0.772 & 1059 & 0.549 & 964 & 0.347 & 3 \\
\hline HLW07-20 & HLW07 & 1237 & 0.312 & 1142 & 0.211 & 1046 & 0.141 & 946 & 0.082 & 5 \\
\hline HLW07-21 & HLW07 & 1239 & 0.167 & 1141 & 0.107 & 1043 & 0.064 & 943 & 0.034 & 2 \\
\hline HLW07-22 & HLW07 & 1232 & 0.187 & 1135 & 0.116 & 1039 & 0.078 & 941 & 0.038 & 3 \\
\hline HLW07-23 & HLW07 & 1250 & 0.191 & 1155 & 0.132 & 1058 & 0.076 & 961 & 0.044 & 3 \\
\hline HLW07-24 & HLW07 & 1197 & 0.418 & 1105 & 0.323 & 1010 & 0.225 & 911 & 0.140 & 2 \\
\hline HLW07-25 & HLW07 & 1259 & 0.239 & 1160 & 0.167 & 1063 & 0.112 & 965 & 0.074 & 2 \\
\hline HLW07-26 & HLW07 & 1256 & 0.330 & 1160 & 0.231 & 1061 & 0.155 & 962 & 0.095 & 4 \\
\hline HLW07-27 & HLW07 & 1210 & 0.425 & 1115 & 0.321 & 1020 & 0.185 & 923 & 0.121 & 5 \\
\hline HLW07-28 & HLW07 & 1248 & 0.254 & 1154 & 0.193 & 1058 & 0.115 & 959 & 0.062 & 4 \\
\hline HLW07-29 & HLW07 & 1247 & 0.274 & 1153 & 0.206 & 1057 & \begin{tabular}{|l|}
0.129 \\
\end{tabular} & 960 & 0.086 & 1 \\
\hline HLW07-30 & HLW07 & 1235 & \begin{tabular}{|l|}
0.274 \\
\end{tabular} & 1140 & 0.202 & 1046 & 0.141 & 946 & \begin{tabular}{|l|}
0.076 \\
\end{tabular} & 4 \\
\hline HLW07-31 & HLW07 & 1218 & \begin{tabular}{|l|}
0.227 \\
\end{tabular} & 1126 & 0.169 & 1031 & \begin{tabular}{|l|}
0.109 \\
\end{tabular} & 935 & 0.062 & 2 \\
\hline HLW07-32 & HLW07 & 1252 & 0.293 & 1154 & 0.236 & 1058 & 0.156 & 961 & 0.093 & 3 \\
\hline HLW07-33 & HLW07 & 1246 & \begin{tabular}{|l|}
0.339 \\
\end{tabular} & 1150 & 0.239 & 1054 & 0.156 & 958 & 0.094 & 1 \\
\hline HLW07-34 & HLW07 & 1223 & \begin{tabular}{|l|}
0.337 \\
\end{tabular} & 1118 & 0.208 & 1031 & 0.135 & 933 & 0.079 & 4 \\
\hline HLW07-35 & HLW07 & 1249 & 0.238 & 1152 & 0.159 & 1055 & 0.113 & 958 & 0.061 & 3 \\
\hline HLW07-36 & HLW07 & 1252 & \begin{tabular}{|l|}
0.437 \\
\end{tabular} & 1152 & 0.315 & 1057 & \begin{tabular}{|l|}
0.219 \\
\end{tabular} & 959 & 0.128 & 4 \\
\hline HLW07-37 & HLW07 & 1244 & 0.579 & 1150 & 0.438 & 1052 & 0.288 & 954 & 0.185 & 1 \\
\hline HLW07-38 & HLW07 & 1245 & 0.289 & 1150 & 0.205 & 1055 & 0.134 & 957 & 0.075 & 5 \\
\hline HLW07-39 & HLW07 & 1242 & 0.284 & 1144 & 0.216 & 1046 & \begin{tabular}{|l|l|}
0.147 \\
\end{tabular} & 946 & \begin{tabular}{|l|}
0.090 \\
\end{tabular} & 1 \\
\hline HLW07-40 & HLW07 & 1240 & 0.626 & 1147 & 0.527 & 1051 & 0.370 & 953 & 0.221 & 1 \\
\hline HLW98-72 & HLW98 & 1243 & 0.827 & 1142 & 0.582 & 1046 & 0.467 & 950 & 0.270 & 5 \\
\hline HLW98-77 & HLW98 & 1226 & 0.454 & 1131 & 0.351 & 1036 & \begin{tabular}{|l|}
0.219 \\
\end{tabular} & 942 & \begin{tabular}{|l|}
0.141 \\
\end{tabular} & 4 \\
\hline HLW98-80 & HLW98 & 1249 & 0.491 & 1151 & 0.370 & 1054 & 0.242 & 958 & 0.146 & 3 \\
\hline HLW98-83 & HLW98 & 1228 & 0.425 & 1135 & 0.323 & 1041 & 0.223 & 947 & 0.138 & 1 \\
\hline HLW98-84 & HLW98 & 1211 & 0.479 & 1118 & 0.348 & 1026 & 0.238 & 933 & 0.149 & 2 \\
\hline HLW98-86AG & HLW98 & 1228 & 0.462 & 1134 & 0.348 & 1040 & 0.239 & 952 & 0.158 & 3 \\
\hline HLW98-88 & HLW98 & 1228 & 0.441 & 1135 & 0.329 & 1037 & 0.223 & 943 & 0.138 & 5 \\
\hline
\end{tabular}

(a) The Group IDs are described in Sections 2.1.1 to 2.1.9.

(b) Numbers from 1 to 5 denote the five split validation subsets. NA denotes "not applicable", because these replicate glasses were forced into the modeling subsets, and thus were not parts of the validation subsets. 
Table 7.3. Temperature and Electrical Conductivity Observations and DataSplitting Validation Sets for Each of the 208 HLW Glasses Used for Electrical Conductivity Model Development (continued).

\begin{tabular}{|c|c|c|c|c|c|c|c|c|c|c|}
\hline Glass ID & $\begin{array}{l}\text { Group } \\
\text { ID }^{(\mathbf{a})}\end{array}$ & $\begin{array}{c}\text { Temp1 } \\
\left({ }^{\circ} \mathrm{C}\right)\end{array}$ & $\begin{array}{c}\text { EC1 } \\
(\mathrm{S} / \mathrm{cm})\end{array}$ & $\begin{array}{c}\text { Temp2 } \\
\left({ }^{\circ} \mathrm{C}\right)\end{array}$ & $\begin{array}{c}\mathrm{EC2} \\
(\mathrm{S} / \mathrm{cm})\end{array}$ & $\begin{array}{c}\text { Temp3 } \\
\left({ }^{\circ} \mathrm{C}\right)\end{array}$ & $\begin{array}{c}\mathbf{E C 3} \\
(\mathrm{S} / \mathrm{cm})\end{array}$ & $\begin{array}{c}\text { Temp4 } \\
\left({ }^{\circ} \mathrm{C}\right)\end{array}$ & $\begin{array}{c}\text { EC4 } \\
(\mathrm{S} / \mathrm{cm})\end{array}$ & $\begin{array}{c}\text { EC Data } \\
\text { Splitting } \\
\text { Validation } \\
\text { Set }^{(b)}\end{array}$ \\
\hline HLW98-89 & HLW98 & 1224 & 0.451 & 1129 & 0.332 & 1037 & 0.224 & 942 & 0.138 & 1 \\
\hline HLW98-95 & HLW98 & 1234 & 0.472 & 1137 & 0.350 & 1043 & 0.247 & 948 & 0.156 & 1 \\
\hline HLW98-96 & HLW98 & 1233 & 0.353 & 1138 & 0.266 & 1044 & 0.190 & 950 & 0.109 & 5 \\
\hline HLW98-96D & HLW98 & 1247 & 0.640 & 1154 & 0.479 & 1058 & 0.316 & 964 & 0.189 & 2 \\
\hline HLW98-97 & HLW98 & 1241 & 0.502 & 1147 & 0.365 & 1052 & 0.257 & 958 & 0.159 & 5 \\
\hline HLW98-T05 & HLW98 & 1240 & 0.464 & 1148 & 0.368 & 1054 & 0.237 & 961 & 0.156 & 5 \\
\hline HLW98-V19 & HLW98 & 1245 & 0.448 & 1153 & 0.354 & 1059 & 0.241 & 966 & 0.145 & 4 \\
\hline HLW98-V24 & HLW98 & 1240 & 0.508 & 1148 & 0.378 & 1054 & 0.273 & 962 & 0.169 & 3 \\
\hline HLW-ALG-01 & HLWALG & 1261 & 0.756 & 1162 & 0.587 & 1069 & 0.444 & 975 & 0.317 & 1 \\
\hline HLW-ALG-02 & HLWALG & 1254 & 0.584 & 1154 & 0.463 & 1062 & 0.349 & 969 & 0.236 & 3 \\
\hline HLW-ALG-03 & HLWALG & 1248 & 0.841 & 1155 & 0.694 & 1062 & 0.491 & 970 & 0.344 & 4 \\
\hline HLW-ALG-04 & HLWALG & 1248 & 0.568 & 1150 & 0.501 & 1059 & 0.345 & 967 & 0.229 & 4 \\
\hline HLW-ALG-05 & HLWALG & 1270 & 0.494 & 1174 & 0.374 & 1080 & 0.250 & 983 & 0.153 & 3 \\
\hline HLW-ALG-06 & HLWALG & 1229 & 0.555 & 1132 & 0.436 & 1036 & 0.298 & 937 & 0.189 & 2 \\
\hline HLW-ALG-07 & HLWALG & 1223 & 0.394 & 1128 & 0.288 & 1031 & 0.195 & 927 & 0.113 & 2 \\
\hline HLW-ALG-08 & HLWALG & 1236 & 0.501 & 1139 & 0.371 & 1041 & 0.243 & 943 & 0.141 & 2 \\
\hline HLW-ALG-09 & HLWALG & 1231 & 0.657 & 1137 & \begin{tabular}{|l|}
0.439 \\
\end{tabular} & 1042 & 0.294 & 946 & 0.187 & 2 \\
\hline HLW-ALG-10 & HLWALG & 1230 & 0.791 & 1142 & 0.627 & 1043 & 0.395 & 946 & 0.273 & 2 \\
\hline HLW-ALG-11 & HLWALG & 1239 & 0.547 & 1143 & 0.394 & 1047 & 0.317 & 950 & 0.180 & 4 \\
\hline HLW-ALG-12 & HLWALG & 1224 & 0.617 & 1130 & 0.518 & 1034 & 0.359 & 937 & 0.227 & 3 \\
\hline HLW-ALG-13 & HLWALG & 1231 & 0.484 & 1138 & 0.350 & 1042 & 0.229 & 944 & 0.134 & 2 \\
\hline HLW-ALG-14 & HLWALG & 1209 & 0.531 & 1120 & 0.382 & 1031 & 0.252 & 941 & 0.151 & 1 \\
\hline HLW-ALG-15 & HLWALG & 1213 & 0.632 & 1123 & 0.495 & 1034 & 0.351 & 943 & 0.226 & 5 \\
\hline HLW-ALG-16 & HLWALG & 1221 & 0.765 & 1129 & 0.494 & 1038 & 0.377 & 947 & 0.249 & 1 \\
\hline HLW-ALG-17 & HLWALG & 1214 & 0.571 & 1122 & 0.414 & 1031 & 0.307 & 940 & 0.202 & 4 \\
\hline HLW-ALG-18 & HLWALG & 1217 & 0.538 & 1125 & 0.403 & 1034 & 0.291 & 943 & 0.189 & 2 \\
\hline HLW-ALG-19 & HLWALG & 1215 & 0.582 & 1127 & 0.446 & 1040 & 0.329 & 952 & 0.217 & 4 \\
\hline HLW-ALG-20 & HLWALG & 1226 & 0.787 & 1136 & 0.602 & 1048 & 0.437 & 959 & 0.291 & 4 \\
\hline HLW-ALG-21 & HLWALG & 1217 & 0.610 & 1125 & 0.548 & 1030 & 0.366 & 933 & 0.233 & 2 \\
\hline HLW-ALG-22 & HLWALG & 1223 & 0.780 & 1127 & 0.612 & 1030 & 0.404 & 941 & 0.251 & 5 \\
\hline HLW-ALG-23 & HLWALG & 1235 & 0.951 & 1139 & 0.879 & 1042 & 0.579 & 942 & 0.380 & 4 \\
\hline HLW-ALG-24 & HLWALG & 1232 & 0.452 & 1134 & 0.360 & 1039 & 0.313 & 941 & 0.145 & 4 \\
\hline HLW-ALG-25 & HLWALG & 1231 & 0.623 & 1135 & 0.482 & 1039 & 0.388 & 941 & 0.213 & 1 \\
\hline HLW-ALG-26 & HLWALG & 1244 & 0.443 & 1148 & 0.300 & 1051 & 0.202 & 952 & 0.122 & 2 \\
\hline HLW-ALG-27 & HLWALG & 1247 & 0.752 & 1155 & 0.576 & 1066 & 0.442 & 973 & 0.288 & 3 \\
\hline HLW-ALG-28 & HLWALG & 1214 & 0.621 & 1129 & 0.490 & 1041 & 0.365 & 952 & 0.243 & 3 \\
\hline HLW-ALG-29 & HLWALG & 1237 & 0.688 & 1136 & 0.504 & 1055 & 0.364 & 963 & 0.222 & 4 \\
\hline HLW-ALG-30 & HLWALG & 1222 & 0.636 & 1128 & 0.514 & 1032 & 0.353 & 924 & 0.226 & 4 \\
\hline
\end{tabular}

(a) The Group IDs are described in Sections 2.1.1 to 2.1.9.

(b) Numbers from 1 to 5 denote the five split validation subsets. NA denotes "not applicable", because these replicate glasses were forced into the modeling subsets, and thus were not parts of the validation subsets. 
Table 7.3. Temperature and Electrical Conductivity Observations and DataSplitting Validation Sets for Each of the 208 HLW Glasses Used for Electrical Conductivity Model Development (continued).

\begin{tabular}{|c|c|c|c|c|c|c|c|c|c|c|}
\hline Glass ID & $\begin{array}{l}\text { Group } \\
\text { ID }^{(\mathbf{a})}\end{array}$ & $\begin{array}{c}\text { Temp1 } 1 \\
\left({ }^{\circ} \mathrm{C}\right)\end{array}$ & $\begin{array}{c}\text { EC1 } \\
(\mathrm{S} / \mathrm{cm})\end{array}$ & $\begin{array}{c}\text { Temp2 } \\
\left({ }^{\circ} \mathrm{C}\right)\end{array}$ & $\begin{array}{c}\text { EC2 } \\
(\mathrm{S} / \mathrm{cm})\end{array}$ & $\begin{array}{c}\text { Temp3 } \\
\left({ }^{\circ} \mathrm{C}\right)\end{array}$ & $\begin{array}{c}\text { EC3 } \\
(\mathbf{S} / \mathbf{c m})\end{array}$ & $\begin{array}{c}\text { Temp4 } \\
\left({ }^{\circ} \mathrm{C}\right)\end{array}$ & \begin{tabular}{|c|} 
EC4 \\
$(\mathrm{S} / \mathrm{cm})$
\end{tabular} & $\begin{array}{c}\text { EC Data } \\
\text { Splitting } \\
\text { Validation } \\
\text { Set }^{(b)}\end{array}$ \\
\hline HLW-ALG-31 & HLWALG & 1270 & 0.498 & 1173 & 0.329 & 1073 & 0.22 & 975 & 0.144 & 1 \\
\hline HLW-ALG-32 & HLWALG & 1243 & 0.572 & 1145 & 0.408 & 1048 & 0.254 & 950 & 0.152 & 5 \\
\hline HLW-ALG-33 & HLWALG & 1251 & 0.828 & 1154 & 0.637 & 1056 & 0.478 & 958 & 0.317 & 2 \\
\hline HLW-ALG-34 & HLWALG & 1225 & 0.787 & 1127 & 0.555 & 1028 & 0.404 & 930 & 0.265 & 4 \\
\hline HLW-ALG-35 & HLWALG & 1239 & 0.446 & 1144 & 0.323 & 1048 & 0.206 & 951 & 0.115 & 4 \\
\hline HLW-ALG-36 & HLWALG & 1248 & 0.667 & 1151 & 0.480 & 1055 & 0.320 & 956 & 0.177 & 1 \\
\hline HLW-ALG-37 & HLWALG & 1212 & 0.374 & 1120 & 0.279 & 1026 & 0.177 & 929 & 0.096 & 2 \\
\hline HLW-ALG-38 & HLWALG & 1243 & 0.332 & 1148 & 0.268 & 1052 & 0.155 & 955 & 0.101 & 4 \\
\hline HLW-ALG-39 & HLWALG & 1230 & 0.427 & 1135 & 0.318 & 1038 & 0.213 & 940 & 0.128 & 2 \\
\hline HLW-ALG-40 & HLWALG & 1231 & 0.626 & 1141 & 0.527 & 1046 & 0.370 & 949 & 0.221 & 2 \\
\hline
\end{tabular}

(a) The Group IDs are described in Sections 2.1.1 to 2.1.9.

(b) Numbers from 1 to 5 denote the five split validation subsets. NA denotes "not applicable", because these replicate glasses were forced into the modeling subsets, and thus were not parts of the validation subsets. 
Table 7.4. Variation in Electrical Conductivity Values for Replicate Glasses at Actual Temperature Measurements.

\begin{tabular}{|c|c|c|c|c|c|c|c|c|c|c|}
\hline \multirow{3}{*}{\begin{tabular}{|l|} 
Glass IDs of \\
Replicate \\
Glasses $^{\text {(a) }}$
\end{tabular}} & \multicolumn{8}{|c|}{ EC Values For Exact Temperatures Near Each Nominal Temperature ${ }^{(b)}$} & \multicolumn{2}{|c|}{ Pooled Over Temp. } \\
\hline & \multicolumn{2}{|c|}{$950^{\circ} \mathrm{C}$} & \multicolumn{2}{|c|}{$1050^{\circ} \mathrm{C}$} & \multicolumn{2}{|c|}{$1150^{\circ} \mathrm{C}$} & \multicolumn{2}{|c|}{$1250^{\circ} \mathrm{C}$} & \multirow{2}{*}{$\frac{\% \text { RSD }}{\text { S/cm }}$} & \multirow{2}{*}{$\frac{\text { SD }}{\ln (\mathrm{S} / \mathrm{cm})}$} \\
\hline & $\mathrm{T}\left({ }^{\circ} \mathrm{C}\right)$ & S/cm & $\mathbf{T}\left(\mathbf{}^{\circ} \mathbf{C}\right)$ & S/cm & $\mathbf{T}\left({ }^{\circ} \mathrm{C}\right)$ & S/cm & $\mathbf{T}\left({ }^{\circ} \mathrm{C}\right)$ & $\mathbf{S} / \mathbf{c m}$ & & \\
\hline HLW03-11 & 943 & 0.190 & 1038 & 0.261 & 1133 & 0.384 & 1228 & 0.443 & & \\
\hline HLW03-44 & 941 & 0.170 & 1038 & 0.281 & 1133 & 0.413 & 1226 & 0.465 & & \\
\hline$\% \mathrm{RSD}^{(\mathrm{c})}, \mathbf{S D}^{(\mathrm{d})}$ & (f) 7.857 & (f) 0.079 & 5.219 & 0.052 & 5.146 & 0.051 & $\mathbf{3 . 4 2 7}$ & $\mathbf{0 . 0 3 4}$ & 5.64 & 0.056 \\
\hline HLW03-41 & 921 & 0.111 & 1019 & 0.181 & 1120 & 0.278 & 1200 & 0.344 & & \\
\hline HLW07-03 & 950 & 0.133 & 1048 & 0.227 & 1145 & 0.331 & 1239 & 0.442 & & \\
\hline$\% \mathrm{RSD}^{(\mathrm{c})}, \mathrm{SD}^{(\mathrm{d})}$ & 12.751 & 0.128 & 15.945 & 0.160 & 12.308 & 0.123 & 17.633 & 0.177 & 14.83 & 0.149 \\
\hline HLW02-08 & 963 & 0.187 & 1057 & 0.295 & 1152 & 0.412 & 1245 & 0.525 & & \\
\hline HLW02-57 & 959 & 0.156 & 1056 & 0.230 & 1153 & 0.332 & 1249 & 0.422 & & \\
\hline$\% \mathrm{RSD}^{(\mathrm{c})}, \mathrm{SD}^{(\mathrm{d})}$ & 12.782 & 0.128 & \begin{tabular}{|l|l|}
17.509 \\
\end{tabular} & 0.176 & 15.207 & 0.153 & 15.382 & 0.154 & 15.31 & 0.154 \\
\hline HLW02-04 & 958 & 0.159 & 1051 & 0.242 & 1145 & 0.321 & 1236 & 0.420 & & \\
\hline HLW02-54 & 962 & 0.145 & 1057 & 0.220 & 1152 & 0.342 & 1246 & 0.416 & & \\
\hline$\% \mathrm{RSD}^{(\mathrm{c})}, \mathrm{SD}^{(\mathrm{d})}$ & 6.513 & 0.065 & 6.734 & 0.067 & 4.479 & 0.045 & $\mathbf{0 . 6 7 7}$ & 0.007 & 5.20 & 0.052 \\
\hline HLW03-26 & 937 & 0.162 & 1034 & 0.298 & 1129 & 0.425 & 1212 & 0.622 & & \\
\hline HLW03-45 & 945 & 0.191 & 1043 & 0.335 & 1137 & 0.474 & 1224 & 0.594 & & \\
\hline$\% \mathrm{RSD}^{(\mathrm{c})}, \mathbf{S D}^{(\mathrm{d})}$ & 11.618 & 0.116 & 8.266 & 0.083 & 7.708 & 0.077 & 3.256 & 0.033 & 8.27 & 0.083 \\
\hline HLW03-07 & 944 & 0.285 & 1041 & 0.466 & 1128 & 0.648 & 1230 & 0.835 & & \\
\hline HLW07-05 & 965 & 0.308 & 1062 & 0.496 & 1160 & 0.703 & 1253 & 0.894 & & \\
\hline$\% \mathrm{RSD}^{(\mathrm{c})}, \mathrm{SD}^{(\mathrm{d})}$ & 5.485 & 0.055 & 4.410 & 0.044 & 5.757 & 0.058 & 4.826 & 0.048 & 5.15 & 0.051 \\
\hline HLW02-44 & 960 & 0.194 & 1054 & 0.324 & 1148 & 0.449 & 1242 & 0.616 & & \\
\hline HLW02-56 & 957 & 0.142 & 1053 & 0.219 & 1151 & 0.325 & 1246 & 0.428 & & \\
\hline$\% \mathrm{RSD}^{(\mathrm{c})}, \mathrm{SD}^{(\mathrm{d})}$ & 21.887 & 0.221 & 27.347 & 0.277 & 22.657 & 0.229 & 25.467 & 0.257 & 24.44 & 0.247 \\
\hline HLW02-42 & 962 & 0.143 & 1057 & 0.245 & 1151 & 0.370 & 1245 & 0.479 & & \\
\hline HLW02-55 & 958 & 0.119 & 1054 & 0.194 & 1150 & 0.271 & 1250 & 0.388 & & \\
\hline$\% \mathrm{RSD}^{(\mathrm{c})}, \mathbf{S D}^{(\mathrm{d})}$ & 12.955 & 0.130 & \begin{tabular}{|l|l|}
16.429 \\
\end{tabular} & 0.165 & 21.842 & 0.220 & 14.844 & 0.149 & 16.85 & 0.169 \\
\hline HLW02-46 & 957 & 0.090 & 1053 & 0.146 & 1148 & 0.242 & 1249 & 0.324 & & \\
\hline HLW03-42 & 953 & 0.073 & 1050 & 0.120 & 1152 & 0.182 & 1251 & 0.261 & & \\
\hline HLW07-02 & 983 & 0.113 & 1080 & 0.186 & 1177 & 0.264 & 1274 & 0.360 & & \\
\hline$\% \mathrm{RSD}^{(\mathrm{c})}, \mathrm{SD}^{(\mathrm{d})}$ & 21.820 & 0.219 & 22.066 & 0.220 & 18.507 & 0.195 & 15.908 & 0.164 & 19.74 & 0.200 \\
\hline HLW02-01 & 978 & 0.157 & 1071 & 0.252 & 1166 & 0.356 & 1260 & 0.480 & & \\
\hline HLW02-52 & 955 & 0.119 & 1052 & 0.190 & 1153 & 0.288 & 1250 & 0.382 & & \\
\hline$\% \mathrm{RSD}^{(\mathrm{c})}, \mathrm{SD}^{(\mathrm{d})}$ & 19.471 & 0.196 & 19.837 & 0.200 & 14.933 & 0.150 & 16.078 & 0.161 & 17.71 & 0.178 \\
\hline HLW03-06 & 950 & 0.119 & 1045 & 0.192 & 1140 & 0.302 & 1233 & 0.386 & & \\
\hline HLW03-43 & 943 & 0.119 & 1038 & 0.185 & 1132 & 0.283 & 1223 & 0.407 & & \\
\hline$\% \mathrm{RSD}^{(\mathrm{c})}, \mathrm{SD}^{(\mathrm{d})}$ & 0.000 & 0.000 & 2.626 & 0.026 & 4.593 & 0.046 & 3.745 & 0.037 & 3.24 & 0.032 \\
\hline HLW02-17 & 959 & 0.150 & 1055 & 0.224 & 1151 & 0.311 & 1246 & 0.426 & & \\
\hline HLW02-53 & 965 & 0.170 & 1061 & 0.255 & 1156 & 0.369 & 1251 & 0.475 & & \\
\hline$\% \mathrm{RSD}^{(\mathrm{c})}, \mathrm{SD}^{(\mathrm{d})}$ & 8.839 & 0.089 & 9.153 & 0.092 & 12.062 & 0.121 & 7.691 & 0.077 & 9.57 & 0.096 \\
\hline HLW02-22 & 958 & 0.101 & 1054 & 0.164 & 1150 & 0.225 & 1246 & 0.287 & & \\
\hline HLW07-04 & 973 & 0.149 & 1072 & 0.223 & 1170 & 0.310 & 1269 & 0.402 & & \\
\hline$\%$ RSD $^{(\mathrm{c})}, \mathbf{S D}^{(\mathrm{d})}$ & 27.153 & 0.275 & 21.560 & 0.217 & 22.469 & 0.227 & 23.604 & 0.238 & 24.62 & 0.240 \\
\hline $\begin{array}{l}\text { Pooled Over } \\
\text { Replicates }\end{array}$ & 15.56 & 0.16 & 16.17 & 0.16 & 14.86 & 0.15 & 14.29 & 0.14 & 15.24 & 0.154 \\
\hline
\end{tabular}

(a) All replicates appear in pairs of HLW glasses except for HLW02-46, HLW03-42, and HLW07-02.

(b) Electrical conductivity values are listed at the exact temperatures near the nominal temperature values.

(c) $\% \mathrm{RSD}=100 *$ (Standard Deviation / Mean), calculated using the $\mathrm{S} / \mathrm{cm}$ values.

(d) Calculated using $\ln (\mathrm{S} / \mathrm{cm})$ values.

(e) The individual and pooled SDs estimate $\sqrt{\sigma_{G}^{2}+\sigma_{T}^{2}}$ in $\ln (\mathrm{S} / \mathrm{cm})$ units (see Section C.2.2 of Appendix C).

(f) The \%RSD and SD values are uncertainties of EC values, not temperature values. Because EC values at actual temperatures were used, temperature and EC columns are listed. The \%RSD and SD values are merely listed under these columns. 
The Catholic University of America

Vitreous State Laboratory
IHLW PCT, Spinel $T_{1 \%}$ Electrical Conductivity, and Viscosity Model Development

Final Report, VSL-07R1240-4, Rev. 0

Table 7.5. Variation in Electrical Conductivity Values for Replicate Glasses Interpolated at Nominal Temperatures.

\begin{tabular}{|c|c|c|c|c|c|c|c|c|c|c|}
\hline \multirow{3}{*}{\begin{tabular}{|l|} 
Glass IDs of \\
Replicate \\
Glasses $^{\text {(a) }}$
\end{tabular}} & \multicolumn{8}{|c|}{ Electrical Conductivity Values Interpolated at Nominal Temperatures ${ }^{(\mathbf{b})}$} & \multicolumn{2}{|c|}{ Pooled Over Temp. } \\
\hline & \multicolumn{2}{|c|}{$950^{\circ} \mathrm{C}$} & \multicolumn{2}{|c|}{$1050^{\circ} \mathrm{C}$} & \multicolumn{2}{|c|}{$1150^{\circ} \mathrm{C}$} & \multicolumn{2}{|c|}{$1250^{\circ} \mathrm{C}$} & \multirow{2}{*}{\begin{tabular}{|c|}
$\%$ RSD \\
S/cm \\
\end{tabular}} & \multirow{2}{*}{$\begin{array}{c}\text { SD } \\
\ln (\mathbf{S} / \mathbf{c m})\end{array}$} \\
\hline & $\mathbf{S} / \mathbf{c m}$ & $\ln (\mathbf{S} / \mathbf{c m})$ & S/cm & $\ln (\mathbf{S} / \mathbf{c m})$ & $\mathbf{S} / \mathbf{c m}$ & $\ln (\mathbf{S} / \mathbf{c m})$ & S/cm & $\ln (\mathbf{S} / \mathbf{c m})$ & & \\
\hline HLW03-11 & 0.195 & -1.636 & 0.282 & -1.267 & 0.378 & -0.973 & 0.479 & -0.735 & & \\
\hline HLW03-44 & 0.185 & -1.688 & 0.285 & -1.255 & 0.402 & -0.910 & 0.532 & -0.631 & & \\
\hline$\% \mathrm{RSD}^{(\mathrm{c})}, \mathbf{S D}^{(\mathrm{d})}$ & $\mathbf{3 . 6 4 2}$ & 0.036 & 0.856 & 0.009 & 4.438 & 0.044 & 7.334 & 0.073 & 4.68 & 0.047 \\
\hline HLW03-41 & 0.130 & -2.037 & 0.207 & -1.574 & 0.300 & -1.205 & 0.404 & -0.906 & & \\
\hline HLW07-03 & 0.135 & -2.002 & 0.224 & -1.497 & 0.335 & -1.095 & 0.464 & -0.769 & & \\
\hline$\% \mathrm{RSD}^{(\mathrm{c})}, \mathrm{SD}^{(\mathrm{d})}$ & 2.498 & 0.025 & 5.435 & 0.054 & 7.772 & 0.078 & 9.660 & 0.097 & 6.88 & 0.069 \\
\hline HLW02-08 & 0.178 & -1.726 & 0.281 & -1.270 & 0.404 & -0.907 & 0.542 & -0.613 & & \\
\hline HLW02-57 & 0.149 & -1.906 & 0.229 & -1.475 & 0.323 & -1.131 & 0.426 & -0.853 & & \\
\hline$\% \mathrm{RSD}^{(\mathrm{c})}, \mathrm{SD}^{(\mathrm{d})}$ & 12.709 & 0.127 & 14.439 & 0.145 & 15.814 & 0.159 & 16.926 & 0.170 & 15.05 & 0.151 \\
\hline HLW02-04 & 0.155 & -1.867 & 0.236 & -1.444 & 0.331 & -1.107 & 0.434 & -0.834 & & \\
\hline HLW02-54 & 0.136 & -1.993 & 0.219 & -1.518 & 0.320 & -1.139 & 0.435 & -0.833 & & \\
\hline$\% \mathrm{RSD}^{(\mathrm{c})}, \mathrm{SD}^{(\mathrm{d})}$ & 8.906 & 0.089 & 5.218 & 0.052 & 2.275 & 0.023 & 0.109 & 0.001 & 5.29 & 0.053 \\
\hline HLW03-26 & 0.178 & -1.726 & 0.311 & -1.169 & 0.485 & -0.725 & 0.694 & -0.365 & & \\
\hline HLW03-45 & 0.203 & -1.596 & 0.330 & -1.110 & 0.485 & -0.723 & 0.664 & -0.409 & & \\
\hline$\% \mathrm{RSD}^{(\mathrm{c})}, \mathbf{S D}^{(\mathrm{d})}$ & 9.209 & 0.092 & 4.162 & 0.042 & 0.132 & 0.001 & 3.131 & 0.031 & 5.29 & 0.053 \\
\hline HLW03-07 & 0.300 & -1.203 & 0.472 & -0.750 & 0.678 & -0.389 & 0.908 & -0.097 & & \\
\hline HLW07-05 & 0.290 & -1.238 & 0.462 & -0.772 & 0.670 & -0.401 & 0.905 & -0.100 & & \\
\hline$\% \mathrm{RSD}^{(\mathrm{c})}, \mathrm{SD}^{(\mathrm{d})}$ & 2.485 & 0.025 & 1.552 & 0.016 & 0.808 & 0.008 & 0.206 & 0.002 & 52 & 0. \\
\hline HLW02-44 & 0.187 & -1.679 & 0.308 & -1.179 & 0.458 & -0.780 & 0.633 & -0.457 & & \\
\hline HLW02-56 & 0.136 & $\begin{array}{l}-1.993 \\
\end{array}$ & 0.219 & -1.518 & 0.320 & -1.140 & 0.435 & -0.833 & & \\
\hline$\% \mathrm{RSD}^{(\mathrm{c})}, \mathrm{SD}$ & 22.054 & 0.222 & 23.796 & 0.240 & 25.179 & 0.255 & 26.295 & 0.266 & 24.38 & 0.246 \\
\hline HLW02-42 & 0.136 & -1.995 & 0.232 & -1.459 & 0.356 & -1.033 & 0.503 & -0.687 & & \\
\hline HLW02-55 & 0.114 & -2.170 & 0.187 & -1.674 & 0.278 & -1.279 & 0.383 & -0.959 & & \\
\hline$\% \mathrm{RSD}^{(\mathrm{c})}, \mathbf{S D}^{(\mathrm{d})}$ & 12.336 & 0.124 & 15.129 & 0.152 & 17.346 & 0.174 & 19.134 & 0.193 & 16.19 & 0.163 \\
\hline HLW02-46 & 0.086 & -2.459 & 0.149 & -1.903 & 0.232 & -1.461 & 0.332 & -1.102 & & \\
\hline HLW03-42 & 0.071 & -2.641 & 0.121 & -2.116 & 0.183 & -1.697 & 0.257 & -1.358 & & \\
\hline HLW07-02 & 0.095 & -2.355 & 0.159 & -1.836 & 0.241 & -1.423 & 0.337 & -1.089 & & \\
\hline$\% \mathrm{RSD}^{(\mathrm{c})}, \mathrm{SD}^{(\mathrm{d})}$ & 14.196 & 0.145 & 14.090 & 0.146 & 14.229 & 0.149 & 14.487 & 0.152 & 14.25 & 0.148 \\
\hline HLW02-01 & 0.136 & -1.996 & 0.226 & -1.489 & 0.338 & -1.086 & 0.468 & -0.759 & & \\
\hline HLW02-52 & 0.116 & -2.156 & 0.190 & -1.663 & 0.281 & -1.271 & 0.385 & -0.953 & & \\
\hline$\% \mathrm{RSD}^{(\mathrm{c})}, \mathrm{SD}^{(\mathrm{d})}$ & 11.296 & 0.113 & 12.284 & 0.123 & 13.071 & 0.131 & 13.708 & 0.138 & 12.62 & 0.127 \\
\hline HLW03-06 & 0.119 & -2.126 & 0.199 & -1.613 & 0.300 & -1.204 & 0.417 & -0.874 & & \\
\hline HLW03-43 & 0.121 & -2.114 & 0.203 & -1.593 & 0.308 & -1.178 & 0.431 & -0.842 & & \\
\hline$\% \mathrm{RSD}^{(\mathrm{c})}, \mathrm{SD}^{(\mathrm{d})}$ & 0.831 & 0.008 & 1.401 & 0.014 & 1.855 & 0.019 & 2.223 & 0.022 & 1.66 & 0.017 \\
\hline HLW02-17 & 0.142 & -1.953 & 0.222 & -1.506 & 0.317 & -1.150 & 0.422 & -0.862 & & \\
\hline HLW02-53 & 0.157 & -1.851 & 0.248 & -1.396 & 0.356 & -1.034 & 0.477 & -0.740 & & \\
\hline $\mathrm{FRSD}^{(\mathrm{c})}, \mathrm{SD}^{(\mathrm{d})}$ & 7.201 & 0.072 & 7.778 & 0.078 & 8.238 & 0.082 & 8.610 & 0.086 & 7.97 & 0.080 \\
\hline HLW02-22 & 0.099 & -2.308 & 0.156 & -1.860 & 0.222 & -1.503 & 0.297 & -1.214 & & \\
\hline HLW07-04 & 0.134 & -2.013 & 0.206 & -1.580 & 0.291 & -1.236 & 0.384 & -0.956 & & \\
\hline$\%$ RSD $^{(\mathrm{c})}, \mathbf{S D}^{(\mathrm{d})}$ & 20.687 & 0.208 & 19.647 & 0.198 & 18.816 & 0.189 & 18.143 & 0.182 & 19.35 & 0.195 \\
\hline $\begin{array}{l}\text { Pooled Over } \\
\text { Replicates }\end{array}$ & 11.96 & 0.12 & 12.18 & 0.12 & 12.74 & 0.13 & 13.41 & 0.14 & 12.58 & 0.127 \\
\hline
\end{tabular}

(a) All replicates appear in pairs of HLW glasses except for HLW02-46, HLW03-42, and HLW07-02.

(b) Electrical conductivity values were interpolated at the nominal temperature values using a T2-equation (see Section C.2.1) fit for each glass.

(c) $\% \mathrm{RSD}=100 *($ Standard Deviation / Mean), calculated using the $\mathrm{S} / \mathrm{cm}$ values.

(d) Calculated using $\ln (\mathrm{S} / \mathrm{cm})$ values.

(e) The individual and pooled SDs estimate $\sqrt{\sigma_{G}^{2}+\sigma_{T}^{2}}$ in $\ln (\mathrm{S} / \mathrm{cm})$ units (see Section C.2.2 of Appendix C). 
Table 7.6. Coefficients and Performance Summary for the 44-Term Truncated T2-Linear Mixture Model on the Natural Logarithm of Electrical Conductivity for HLW Glasses.

\begin{tabular}{|c|c|c|c|c|c|c|c|c|c|c|}
\hline $\begin{array}{l}\text { Mixture } \\
\text { Term } \\
\left(x_{i}\right)\end{array}$ & $\begin{array}{c}\text { Coefficient } \\
\text { Estimate }\end{array}$ & \multicolumn{2}{|c|}{$\begin{array}{l}\text { Coefficient } \\
\text { Standard } \\
\text { Deviation } \\
\end{array}$} & \begin{tabular}{|c|} 
Mixture-Temp. \\
Term \\
{$\left[x_{i} /(T / 1000)^{2}\right]$} \\
\end{tabular} & $\begin{array}{c}\text { Coefficient } \\
\text { Estimate }\end{array}$ & $\begin{array}{l}\text { Coefficient } \\
\text { Standard } \\
\text { Deviation } \\
\end{array}$ & $\begin{array}{l}\text { t-value }= \\
\text { Coeff } / \text { SD }\end{array}$ & p-value & $\begin{array}{l}\text { Modeling Data Statistic, } \\
208 \text { Glasses }^{(\text {a) }}\end{array}$ & Value \\
\hline $\mathrm{Al}_{2} \mathrm{O}_{3}$ & -1.0041 & \multicolumn{2}{|c|}{0.7434} & $\mathrm{Al}_{2} \mathrm{O}_{3} /(T / 1000)^{2}$ & -5.1911 & 0.8232 & -6.31 & $<0.0001$ & $\mathrm{R}^{2}$ & 0.899 \\
\hline $\mathrm{B}_{2} \mathrm{O}_{3}$ & 0.9132 & \multicolumn{2}{|c|}{0.5961} & $\mathrm{~B}_{2} \mathrm{O}_{3} /(T / 1000)^{2}$ & -6.6924 & 0.6617 & -10.11 & $<0.0001$ & SSE & 33.428 \\
\hline $\mathrm{CaO}$ & -21.5902 & \multicolumn{2}{|c|}{16.1655} & $\mathrm{CaO} /(T / 1000)^{2}$ & 30.8474 & 17.7660 & 1.74 & 0.0830 & RMSE & 0.206 \\
\hline $\mathrm{CdO}$ & -6.5608 & \multicolumn{2}{|c|}{4.1415} & $\mathrm{CdO} /(T / 1000)^{2}$ & 2.4219 & 4.5862 & 0.53 & 0.5976 & & \\
\hline $\mathrm{Cr}_{2} \mathrm{O}_{3}$ & 17.3795 & \multicolumn{2}{|c|}{11.3928} & $\mathrm{Cr}_{2} \mathrm{O}_{3} /(T / 1000)^{2}$ & 7.0469 & 12.6288 & 0.56 & 0.5770 & & \\
\hline $\mathrm{Fe}_{2} \mathrm{O}_{3}$ & 0.7316 & \multicolumn{2}{|c|}{0.6810} & $\mathrm{Fe}_{2} \mathrm{O}_{3} /(T / 1000)^{2}$ & -6.6012 & 0.7503 & -8.80 & $<0.0001$ & & \\
\hline $\mathrm{Li}_{2} \mathrm{O}$ & 15.2744 & \multicolumn{2}{|c|}{1.4317} & $\mathrm{Li}_{2} \mathrm{O} /(T / 1000)^{2}$ & 8.0533 & 1.5853 & 5.08 & $<0.0001$ & & \\
\hline $\mathrm{MgO}$ & 27.1901 & \multicolumn{2}{|c|}{13.7299} & $\mathrm{MgO} /(T / 1000)^{2}$ & 8.2623 & 15.3107 & 0.54 & 0.5896 & & \\
\hline $\mathrm{MnO}$ & 2.4645 & \multicolumn{2}{|c|}{0.8469} & $\mathrm{MnO} /(T / 1000)^{2}$ & -8.3015 & 0.9373 & -8.86 & $<0.0001$ & & \\
\hline $\mathrm{Na}_{2} \mathrm{O}$ & 6.1064 & \multicolumn{2}{|c|}{0.6048} & $\mathrm{Na}_{2} \mathrm{O} /(T / 1000)^{2}$ & 3.1596 & 0.6700 & 4.72 & $<0.0001$ & & \\
\hline $\mathrm{NiO}$ & 6.0189 & \multicolumn{2}{|c|}{5.7018} & $\mathrm{NiO} /(T / 1000)^{2}$ & -26.0519 & 6.3107 & -4.13 & $<0.0001$ & & \\
\hline $\mathrm{PbO}$ & 10.0861 & \multicolumn{2}{|c|}{10.2261} & $\mathrm{PbO} /(T / 1000)^{2}$ & -24.6562 & 11.2874 & -2.18 & 0.0293 & & \\
\hline $\mathrm{Sb}_{2} \mathrm{O}_{3}$ & -4.0927 & \multicolumn{2}{|c|}{19.7787} & $\mathrm{Sb}_{2} \mathrm{O}_{3} /(T / 1000)^{2}$ & -31.0137 & 21.8482 & -1.42 & 0.1563 & & \\
\hline $\mathrm{SeO}_{2}$ & -35.3938 & & 629 & $\mathrm{SeO}_{2} /(T / 1000)^{2}$ & -3.5503 & 33.3718 & -0.11 & 0.9153 & (a) & ix $C$ \\
\hline $\mathrm{SiO}_{2}$ & -0.3899 & & 551 & $\mathrm{SiO}_{2} /(T / 1000)^{2}$ & -6.3168 & 0.2825 & -22.36 & $<0.0001$ & & $\begin{array}{l}\mathrm{X} C \mathrm{C} \\
\text { ined in }\end{array}$ \\
\hline $\mathrm{SrO}$ & 4.6197 & & 258 & $\mathrm{SrO} /(T / 1000)^{2}$ & -13.1177 & 0.8019 & -16.36 & $<0.0001$ & i vallation st & ined in \\
\hline $\mathrm{ThO}_{2}$ & 2.7040 & & 705 & $\mathrm{ThO}_{2} /(T / 1000)^{2}$ & -7.4267 & 1.2850 & -5.78 & $<0.0001$ & (b) The "Others" comp & $\mathrm{Ag}_{2} \mathrm{O}$ \\
\hline $\mathrm{Tl}_{2} \mathrm{O}$ & 26.1682 & & 368 & $\mathrm{Tl}_{2} \mathrm{O} /(T / 1000)^{2}$ & -23.7724 & 32.1640 & -0.74 & 0.4601 & As $205, \mathrm{BaO}, \mathrm{BeO} \mathrm{Bi}$ & $\mathrm{Cl}_{2} \mathrm{U}$ \\
\hline $\mathrm{UO}_{3}$ & 2.8953 & & 948 & $\mathrm{UO}_{3} /(T / 1000)^{2}$ & -5.9054 & 1.4226 & -4.15 & $<0.0001$ & $\mathrm{CoO}, \mathrm{Cs}_{2} \mathrm{O}, \mathrm{CuO}, \mathrm{Dy}_{2}$ & \\
\hline $\mathrm{ZnO}$ & 6.8845 & & 840 & $\mathrm{ZnO} /(T / 1000)^{2}$ & -18.9414 & 2.1747 & -8.71 & $<0.0001$ & $\mathrm{Gd}_{2} \mathrm{O}_{3}, \mathrm{HfO}_{2}, \mathrm{HgO}, \mathrm{K}$ & $\mathrm{MoO}_{3}$ \\
\hline $\mathrm{ZrO}_{2}$ & 1.4040 & & 197 & $\mathrm{ZrO}_{2} /(T / 1000)^{2}$ & -8.8605 & 0.7933 & -11.17 & $<0.0001$ & $\mathrm{P}_{2} \mathrm{O}_{5}, \mathrm{PdO}, \mathrm{Pr}_{2} \mathrm{O}_{3}, \mathrm{Rb}_{2}$ & $\mathrm{Rh}_{2} \mathrm{O}_{3}$ \\
\hline Others $^{(b)}$ & -5.3026 & & 994 & Others $/(T / 1000)^{2}$ & -2.7053 & 3.4288 & -0.79 & 0.4304 & $\mathrm{RuO}_{2}, \mathrm{SO}_{3}, \mathrm{Sm}_{2} \mathrm{O}_{3}, \mathrm{Sn}$ & $\mathrm{TeO}_{2}$ \\
\hline & $\hat{\sigma}_{G}=0.20$ & & & & & $=0.0494$ & & & $\mathrm{TiO}_{2}, \mathrm{~V}_{2} \mathrm{O}_{5}, \mathrm{WO}_{3}$ and & \\
\hline Data Sp & ting Statisti & & DS & DS2 & DS3 & DS4 & DS5 & Average & c) The evaluation and va & tistics \\
\hline $\mathrm{R}^{2}$ & & & 0.90 & 0.909 & 0.893 & 0.910 & 0.894 & 0.901 & calculated for data-s & ied the \\
\hline SSE & & & 26.1 & 24.628 & 29.249 & 24.338 & 28.777 & 26.636 & vlidation cats Conti & \\
\hline RMSE & & & 0.20 & 0.196 & 0.213 & 0.194 & 0.211 & 0.203 & bow the dote snlitti & ribes \\
\hline $\mathrm{R}^{2}$ Valid & $\operatorname{tion}\left(\mathrm{R}_{\mathrm{V}}^{2}\right)$ & & 0.87 & 0.833 & 0.918 & 0.825 & 0.911 & 0.871 & & \\
\hline RMSE V & alidation (RM & $\left(\mathrm{E}_{\mathrm{V}}\right)$ & 0.24 & 0.262 & 0.182 & 0.268 & 0.191 & 0.229 & & \\
\hline
\end{tabular}


Table 7.7. Coefficients and Performance Summary for the 27-Term Truncated T2-Linear Mixture Model on the Natural Logarithm of Electrical Conductivity for HLW Glasses.

\begin{tabular}{|c|c|c|c|c|c|c|c|c|c|c|c|}
\hline $\begin{array}{l}\text { Mixture } \\
\text { Term } \\
\left(x_{i}\right)\end{array}$ & $\begin{array}{c}\text { Coefficient } \\
\text { Estimate }\end{array}$ & \multicolumn{2}{|c|}{$\begin{array}{c}\text { Coefficient } \\
\text { Standard } \\
\text { Deviation } \\
\end{array}$} & \multicolumn{2}{|c|}{$\begin{array}{c}\text { Mixture-Temp. } \\
\text { Term } \\
{\left[x_{i} /(T / 1000)^{2}\right]}\end{array}$} & $\begin{array}{c}\text { Coefficient } \\
\text { Estimate }\end{array}$ & $\begin{array}{l}\text { Coefficient } \\
\text { Standard } \\
\text { Deviation }\end{array}$ & $\begin{array}{l}\text { t-value }= \\
\text { Coeff } / \text { SD }\end{array}$ & p-value & $\begin{array}{l}\text { Modeling Data Statistic, } \\
208 \text { Glasses }^{(a)}\end{array}$ & Value \\
\hline $\mathrm{Al}_{2} \mathrm{O}_{3}$ & -1.5135 & \multicolumn{2}{|c|}{0.7019} & \multicolumn{2}{|c|}{$\mathrm{Al}_{2} \mathrm{O}_{3} /(T / 1000)^{2}$} & -4.8415 & 0.7746 & -6.25 & $<0.0001$ & $\mathrm{R}^{2}$ & 0.891 \\
\hline $\mathrm{B}_{2} \mathrm{O}_{3}$ & 1.0642 & \multicolumn{2}{|c|}{0.5839} & \multicolumn{2}{|c|}{$\mathrm{B}_{2} \mathrm{O}_{3} /(T / 1000)^{2}$} & -6.8301 & 0.6452 & -10.59 & $<0.0001$ & SSE & 36.038 \\
\hline $\mathrm{Fe}_{2} \mathrm{O}_{3}$ & 0.5676 & \multicolumn{2}{|c|}{0.6695} & \multicolumn{2}{|c|}{$\mathrm{Fe}_{2} \mathrm{O}_{3} /(T / 1000)^{2}$} & -6.4175 & 0.7331 & -8.75 & $<0.0001$ & RMSE & 0.212 \\
\hline $\mathrm{Li}_{2} \mathrm{O}$ & 15.1066 & \multicolumn{2}{|c|}{1.3684} & \multicolumn{2}{|c|}{$\mathrm{Li}_{2} \mathrm{O} /(T / 1000)^{2}$} & 9.0435 & 1.5108 & -6.25 & $<0.0001$ & & \\
\hline $\mathrm{MgO}$ & 23.1981 & \multicolumn{2}{|c|}{8.6743} & \multicolumn{2}{|c|}{$\mathrm{MgO} /(T / 1000)^{2}$} & $-^{(\mathrm{c})}$ & - & - & - & & \\
\hline $\mathrm{MnO}$ & 2.7824 & \multicolumn{2}{|c|}{0.8259} & \multicolumn{2}{|c|}{$\mathrm{MnO} /(T / 1000)^{2}$} & -8.2949 & 0.9096 & -9.12 & $<0.0001$ & & \\
\hline $\mathrm{Na}_{2} \mathrm{O}$ & 6.5580 & \multicolumn{2}{|c|}{0.5617} & \multicolumn{2}{|c|}{$\mathrm{Na}_{2} \mathrm{O} /(T / 1000)^{2}$} & 3.1740 & 0.6202 & 5.12 & $<0.0001$ & & \\
\hline $\mathrm{SiO}_{2}$ & -0.4703 & \multicolumn{2}{|c|}{0.2497} & \multicolumn{2}{|c|}{$\mathrm{SiO}_{2} /(T / 1000)^{2}$} & -6.2346 & 0.2757 & -22.61 & $<0.0001$ & & \\
\hline $\mathrm{SrO}$ & 4.8805 & \multicolumn{2}{|c|}{0.7268} & \multicolumn{2}{|c|}{$\mathrm{SrO} /(T / 1000)^{2}$} & -13.4287 & 0.8008 & -16.77 & $<0.0001$ & & \\
\hline $\mathrm{ThO}_{2}$ & 2.7632 & \multicolumn{2}{|c|}{1.1187} & \multicolumn{2}{|c|}{$\mathrm{ThO}_{2} /(T / 1000)^{2}$} & -7.2918 & 1.2202 & -5.98 & $<0.0001$ & & \\
\hline $\mathrm{UO}_{3}$ & 2.6756 & \multicolumn{2}{|c|}{1.1162} & \multicolumn{2}{|c|}{$\mathrm{UO}_{3} /(T / 1000)^{2}$} & -5.2594 & 1.2184 & -4.32 & $<0.0001$ & & \\
\hline $\mathrm{ZnO}$ & 4.4987 & \multicolumn{2}{|c|}{1.8903} & \multicolumn{2}{|c|}{$\mathrm{ZnO} /(T / 1000)^{2}$} & -17.1446 & 2.0572 & -8.33 & $<0.0001$ & & \\
\hline $\mathrm{ZrO}_{2}$ & 1.3457 & \multicolumn{2}{|c|}{0.7000} & \multicolumn{2}{|c|}{$\mathrm{ZrO}_{2} /(T / 1000)^{2}$} & -8.9179 & 0.7667 & -11.63 & $<0.0001$ & & \\
\hline Others $^{(b)}$ & -2.7925 & \multicolumn{2}{|c|}{1.4282} & \multicolumn{2}{|c|}{ Others/(T/1000) $)^{2}$} & -5.5824 & 1.5727 & -3.55 & 0.0004 & & \\
\hline \multicolumn{4}{|c|}{$\hat{\sigma}_{G}=0.2094$} & \multicolumn{6}{|c|}{$\hat{\sigma}_{T}=0.0501$} & & \\
\hline Data Sp & itting Statist & $c^{(a, d)}$ & DS & & DS2 & DS3 & DS4 & DS5 & Average & & \\
\hline $\mathrm{R}^{2}$ & & & 0.90 & & 0.885 & 0.884 & 0.900 & 0.887 & 0.892 & & \\
\hline SSE & & & 24.9 & & 31.349 & 31.571 & 27.147 & 30.680 & 29.138 & & \\
\hline RMSE & & & 0.19 & & 0.218 & 0.219 & 0.203 & 0.215 & 0.210 & & \\
\hline $\mathrm{R}^{2}$ Valid & tion $\left(\mathrm{R}_{\mathrm{V}}^{2}\right)$ & & 0.82 & & 0.915 & 0.917 & 0.842 & 0.903 & 0.879 & & \\
\hline RMSE V & alidation (RN & $\left.\mathrm{SE}_{\mathrm{V}}\right)$ & 0.28 & & 0.187 & 0.183 & 0.255 & 0.199 & 0.222 & & \\
\hline
\end{tabular}

(a) The model evaluation statistics are defined in Section C.3 of Appendix C. Model validation statistics are defined in Section C.5 of Appendix C.

(b) The "Others" component includes $\mathrm{Ag}_{2} \mathrm{O}, \mathrm{As} 2 \mathrm{O} 5, \mathrm{BaO}, \mathrm{BeO}, \mathrm{Bi}_{2} \mathrm{O}_{3}, \mathrm{Ce}_{2} \mathrm{O}_{3}, \mathrm{Cl}, \mathrm{CoO}, \mathrm{Cs}_{2} \mathrm{O}, \mathrm{CuO}_{2} \mathrm{Dy}_{2} \mathrm{O}_{3}, \mathrm{Eu}_{2} \mathrm{O}_{3}, \mathrm{~F}, \mathrm{Gd}_{2} \mathrm{O}_{3}, \mathrm{HfO}_{2}, \mathrm{HgO}_{2}, \mathrm{~K}_{2} \mathrm{O}, \mathrm{La}_{2} \mathrm{O}_{3}, \mathrm{MoO}_{3}$, $\mathrm{P}_{2} \mathrm{O}_{5}, \mathrm{PdO}, \mathrm{Pr}_{2} \mathrm{O}_{3}, \mathrm{Rb}_{2} \mathrm{O}, \mathrm{Re}_{2} \mathrm{O}_{7}, \mathrm{Rh}_{2} \mathrm{O}_{3}, \mathrm{RuO}_{2}, \mathrm{SO}_{3}, \mathrm{Sm}_{2} \mathrm{O}_{3}, \mathrm{SnO}_{2}, \mathrm{Tc}_{2} \mathrm{O}_{7}, \mathrm{TeO}_{2}, \mathrm{TiO}_{2}, \mathrm{~V}_{2} \mathrm{O}_{5}, \mathrm{WO}_{3}$ and $\mathrm{Y}_{2} \mathrm{O}_{3}$.

(c) A dash (-) indicates the term was not included in the model.

(d) The evaluation and validation statistics calculated for data-splits are defined the same as for separate modeling and validation sets. Section 7.1.2 describes how the data-splitting was accomplished. 


\section{Table 7.8. Summary Statistics for Various Models Fitted and Validated Using Electrical Conductivity Data for HLW Glasses.}

\begin{tabular}{|c|c|c|c|c|c|}
\hline \multicolumn{6}{|c|}{ Results Using all 208 HLW Glasses with Electrical Conductivity Data } \\
\hline Statistic & Model 1 & Model 2 & Model 3 & Model 4 & Model $5^{(a)}$ \\
\hline \# Model Terms & 44 & 27 & 28 & 27 & 22 \\
\hline $\mathrm{R}^{2}$ & 0.899 & 0.891 & 0.907 & 0.907 & 0.907 \\
\hline SSE & 33.428 & 36.038 & 30.698 & 30.717 & 30.899 \\
\hline RMSE & 0.206 & 0.212 & 0.195 & 0.195 & 0.195 \\
\hline \multicolumn{6}{|c|}{ Average Results Using Five Subsets Resulting from Data Splitting ${ }^{(b)}$} \\
\hline Statistic & Model 1 & Model 2 & Model 3 & Model 4 & Model 5 \\
\hline $\mathrm{R}^{2}$ & 0.901 & 0.892 & 0.909 & 0.909 & 0.908 \\
\hline SSE & 26.636 & 29.138 & 24.689 & 24.706 & 24.868 \\
\hline RMSE & 0.203 & 0.210 & 0.193 & 0.193 & 0.193 \\
\hline $\mathrm{R}_{\mathrm{V}}^{2}$ & 0.871 & 0.879 & 0.894 & 0.894 & 0.894 \\
\hline $\mathrm{RMSE}_{\mathrm{V}}$ & 0.229 & 0.222 & 0.209 & 0.209 & 0.210 \\
\hline
\end{tabular}

(a) Model 5 is the recommended model.

(b) The data-split validation subsets used to obtain the average values shown in this table contain EC data for $37 \mathrm{HLW}$ glasses (validation subset 1) and $36 \mathrm{HLW}$ glasses (for validations subsets 2 to 5). 
Table 7.9. Coefficients and Performance Summary for the 22-Term Truncated T2-Linear Mixture Model with One Crossproduct Term on the Natural Logarithm of Electrical Conductivity for HLW Glasses.

\begin{tabular}{|c|c|c|c|c|c|c|c|c|c|}
\hline $\begin{array}{l}\text { Mixture } \\
\text { Term } \\
\left(x_{i} \text { or } x_{i} x_{i}\right) \\
\end{array}$ & $\begin{array}{c}\text { Coefficient } \\
\text { Estimate }\end{array}$ & $\begin{array}{l}\text { Coefficient } \\
\text { Standard } \\
\text { Deviation }\end{array}$ & $\begin{array}{c}\text { Mixture-Temp. } \\
\text { Term } \\
{\left[x_{i} /(T / 1000)^{2}\right]}\end{array}$ & $\begin{array}{c}\text { Coefficient } \\
\text { Estimate }\end{array}$ & $\begin{array}{l}\text { Coefficient } \\
\text { Standard } \\
\text { Deviation }\end{array}$ & $\begin{array}{l}\text { t-value }= \\
\text { Coeff } / \text { SD }\end{array}$ & p-value & $\begin{array}{l}\text { Modeling Data Statistic, } \\
208 \text { Glasses }^{(a)}\end{array}$ & Value \\
\hline $\mathrm{Al}_{2} \mathrm{O}_{3}$ & -4.3754 & 0.5166 & $\mathrm{Al}_{2} \mathrm{O}_{3} /(T / 1000)^{2}$ & $-{ }^{(\mathrm{c})}$ & - & - & - & $\mathrm{R}^{2}$ & 0.907 \\
\hline $\mathrm{B}_{2} \mathrm{O}_{3}$ & 0.7852 & 0.5703 & $\mathrm{~B}_{2} \mathrm{O}_{3} /(T / 1000)^{2}$ & -7.7965 & 0.6450 & -12.09 & $<0.0001$ & SSE & 30.899 \\
\hline $\mathrm{Fe}_{2} \mathrm{O}_{3}$ & -2.9876 & 0.4931 & $\mathrm{Fe}_{2} \mathrm{O}_{3} /(T / 1000)^{2}$ & - & - & - & - & RMSE & 0.195 \\
\hline $\mathrm{Li}_{2} \mathrm{O}$ & 32.2034 & 2.2768 & $\mathrm{Li}_{2} \mathrm{O} /(T / 1000)^{2}$ & - & - & - & - & & \\
\hline $\mathrm{MgO}$ & 16.3440 & 8.0548 & $\mathrm{MgO} /(T / 1000)^{2}$ & - & - & - & - & & \\
\hline $\mathrm{MnO}$ & 1.5985 & 0.8216 & $\mathrm{MnO} /(T / 1000)^{2}$ & -7.3668 & 0.9937 & -7.41 & $<0.0001$ & & \\
\hline $\mathrm{Na}_{2} \mathrm{O}$ & 11.3872 & 0.6634 & $\mathrm{Na}_{2} \mathrm{O} /(T / 1000)^{2}$ & - & - & - & - & & \\
\hline $\mathrm{SiO}_{2}$ & -0.3215 & 0.2193 & $\mathrm{SiO}_{2} /(T / 1000)^{2}$ & -7.2800 & 0.1774 & -41.03 & $<0.0001$ & & \\
\hline $\mathrm{SrO}$ & 5.7863 & 0.6803 & $\mathrm{SrO} /(T / 1000)^{2}$ & -16.0518 & 0.7550 & -21.26 & $<0.0001$ & & \\
\hline $\mathrm{ThO}_{2}$ & -1.5427 & 0.8259 & $\mathrm{ThO}_{2} /(T / 1000)^{2}$ & - & - & - & - & & \\
\hline $\mathrm{UO}_{3}$ & 3.2523 & 1.0576 & $\mathrm{UO}_{3} /(T / 1000)^{2}$ & -7.2864 & 1.2025 & -6.06 & $<0.0001$ & & \\
\hline $\mathrm{ZnO}$ & 5.4527 & 1.8495 & $\mathrm{ZnO} /(T / 1000)^{2}$ & -16.5091 & 2.1792 & -7.58 & $<0.0001$ & & \\
\hline $\mathrm{ZrO}_{2}$ & 0.2269 & 0.6505 & $\mathrm{ZrO}_{2} /(T / 1000)^{2}$ & -7.2539 & 0.7239 & -10.02 & $<0.0001$ & & \\
\hline Others $^{(b)}$ & -7.1088 & 1.0699 & Others $/(T / 1000)^{2}$ & - & - & - & - & & \\
\hline $\mathrm{Na}_{2} \mathrm{O} \times \mathrm{Li}_{2} \mathrm{O}$ & -113.7300 & 19.0671 & & & & & & & \\
\hline \multicolumn{3}{|c|}{$\hat{\sigma}_{G}=0.1919$} & \multicolumn{5}{|c|}{$\hat{\sigma}_{T}=0.0553$} & & \\
\hline Data Splitt & ing Statistic & DS & DS2 & DS3 & DS4 & DS5 & Average & & \\
\hline $\mathrm{R}^{2}$ & & 0.92 & 0.903 & 0.901 & 0.913 & 0.903 & 0.908 & & \\
\hline SSE & & 20.7 & 26.359 & 27.037 & 23.674 & 26.535 & 24.868 & & \\
\hline RMSE & & 0.17 & 0.199 & 0.201 & 0.189 & 0.200 & 0.193 & & \\
\hline $\mathrm{R}^{2}$ Validatio & n $\left(\mathrm{R}_{\mathrm{V}}^{2}\right)$ & 0.83 & 0.916 & 0.924 & 0.870 & 0.922 & 0.894 & & \\
\hline RMSE Vali & dation (RMS & 0.2 & 0.185 & 0.175 & 0.231 & 0.179 & 0.210 & & \\
\hline
\end{tabular}

(a) The model evaluation statistics are defined in Section C.3 of Appendix C. Model validation statistics are defined in Section C.5 of Appendix C.

(b) The "Others" component includes $\mathrm{Ag}_{2} \mathrm{O}$, As2 $\mathrm{O} 5, \mathrm{BaO}, \mathrm{BeO}, \mathrm{Bi}_{2} \mathrm{O}_{3}, \mathrm{Ce}_{2} \mathrm{O}_{3}, \mathrm{Cl}, \mathrm{CoO}, \mathrm{Cs}_{2} \mathrm{O}, \mathrm{CuO}_{2} \mathrm{Dy}_{2} \mathrm{O}_{3}, \mathrm{Eu}_{2} \mathrm{O}_{3}, \mathrm{~F}, \mathrm{Gd}_{2} \mathrm{O}_{3}, \mathrm{HfO}_{2}, \mathrm{HgO}_{2} \mathrm{~K}_{2} \mathrm{O}, \mathrm{La}_{2} \mathrm{O}_{3}, \mathrm{MoO}_{3}$, $\mathrm{P}_{2} \mathrm{O}_{5}, \mathrm{PdO}, \mathrm{Pr}_{2} \mathrm{O}_{3}, \mathrm{Rb}_{2} \mathrm{O}, \mathrm{Re}_{2} \mathrm{O}_{7}, \mathrm{Rh}_{2} \mathrm{O}_{3}, \mathrm{RuO}_{2}, \mathrm{SO}_{3}, \mathrm{Sm}_{2} \mathrm{O}_{3}, \mathrm{SnO}_{2}, \mathrm{Tc}_{2} \mathrm{O}_{7}, \mathrm{TeO}_{2}, \mathrm{TiO}_{2}, \mathrm{~V}_{2} \mathrm{O}_{5}, \mathrm{WO}_{3}$ and $\mathrm{Y}_{2} \mathrm{O}_{3}$.

(c) A dash (-) indicates the term was not included in the model.

(d) The evaluation and validation statistics calculated for data-splits are defined the same as for separate modeling and validation sets. Section 7.1.2 describes how the data-splitting was accomplished.. 
Table 7.10. HLW03-06 Composition in Formats Needed for Use in Electrical Conductivity Models for HLW Glasses.

\begin{tabular}{|c|c|c|c|}
\hline Model Term $^{(a)}$ & $\begin{array}{c}\text { HLW03-06 } \\
\text { Composition }^{(b)} \\
\text { (mass fractions) }\end{array}$ & $\begin{array}{c}\text { HLW03-06 } \\
\text { Composition } \\
\text { (mass fractions) } \\
\text { for Use in 27-Term } \\
\text { EC Model }^{(\mathfrak{c})} \\
\end{array}$ & $\begin{array}{c}\text { HLW03-06 } \\
\text { Composition } \\
\text { (mass fractions) } \\
\text { for Use in 22-Term } \\
\text { EC Model }^{(\mathrm{d})} \\
\end{array}$ \\
\hline $\mathrm{Al}_{2} \mathrm{O}_{3}$ & 0.08344 & 0.08344 & 0.08344 \\
\hline $\mathrm{B}_{2} \mathrm{O}_{3}$ & 0.04908 & 0.04908 & 0.04908 \\
\hline $\mathrm{CaO}$ & 0.00500 & NA & NA \\
\hline $\mathrm{CdO}$ & 0.01600 & NA & NA \\
\hline $\mathrm{Cr} 2 \mathrm{O} 3$ & 0.00491 & NA & NA \\
\hline $\mathrm{Fe}_{2} \mathrm{O}_{3}$ & 0.01963 & 0.01963 & 0.01963 \\
\hline $\mathrm{Li}_{2} \mathrm{O}$ & 0.05890 & 0.05890 & 0.05890 \\
\hline $\mathrm{MgO}$ & 0.00120 & 0.00120 & 0.00120 \\
\hline $\mathrm{MnO}$ & 0.06872 & 0.06872 & 0.06872 \\
\hline $\mathrm{Na}_{2} \mathrm{O}$ & 0.03927 & 0.03927 & 0.03927 \\
\hline $\mathrm{NiO}$ & 0.00982 & NA & NA \\
\hline $\mathrm{PbO}$ & 0.00040 & NA & NA \\
\hline $\mathrm{Sb} 2 \mathrm{O} 3$ & 0.00020 & NA & NA \\
\hline $\mathrm{SeO}_{2}$ & 0.00020 & NA & NA \\
\hline $\mathrm{SiO}_{2}$ & 0.52031 & 0.52031 & 0.52031 \\
\hline $\mathrm{SrO}$ & 0.05091 & 0.05091 & 0.05091 \\
\hline $\mathrm{ThO}_{2}$ & 0.01416 & 0.01416 & 0.01416 \\
\hline $\mathrm{T} 12 \mathrm{O}$ & 0.00019 & NA & NA \\
\hline $\mathrm{UO}_{3}$ & 0.00000 & 0.00000 & 0.00000 \\
\hline $\mathrm{ZnO}$ & 0.00000 & 0.00000 & 0.00000 \\
\hline $\mathrm{ZrO}_{2}$ & 0.04095 & 0.04095 & 0.04095 \\
\hline Others & 0.01671 & 0.05343 & 0.05343 \\
\hline $\mathrm{Na}_{2} \mathrm{O} \times \mathrm{Li}_{2} \mathrm{O}$ & & $\mathrm{NA}^{(\mathrm{e})}$ & 0.00231 \\
\hline
\end{tabular}

(a) The electrical conductivity models contain $x_{i} /(T / 1000)^{2}$ terms in addition to the $x_{i}$ and $x_{i} x_{j}$ terms shown in this column. The purpose of this table is to show the compositional forms needed for model predictions, so the temperature-containing terms are not shown.

(b) The composition in mass fractions is from Table 7.2.

(c) See Table 7.7.

(d) See Table 7.9.

(e) NA = not applicable, because the model does not contain this term. 
Table 7.11. Predicted Electrical Conductivity, Standard Deviation, and Statistical Intervals for HLW03-06 Composition Used in IHLW Electrical Conductivity Models.

\begin{tabular}{|c|c|c|c|c|c|c|c|c|c|}
\hline Model $^{(a)}$ & $\begin{array}{c}\text { Predicted } \\
\ln (\mathrm{EC}) \\
{[\ln (\mathrm{S} / \mathrm{cm})]}\end{array}$ & $\begin{array}{c}\text { Predicted } \\
\text { EC }^{(c)} \\
{[\mathrm{S} / \mathrm{cm}]}\end{array}$ & $\begin{array}{c}\text { Standard } \\
\text { Deviation of } \\
\text { Predicted } \\
\ln (\mathrm{EC})^{(\mathbf{d})} \\
{[\ln (\mathrm{S} / \mathrm{cm})]}\end{array}$ & $\begin{array}{c}90 \% \mathrm{LCI}^{(\mathrm{e})} \\
\text { on Mean } \\
\ln (\mathrm{EC}) \\
{[\ln (\mathrm{S} / \mathrm{cm})]}\end{array}$ & $\begin{array}{c}90 \% \text { LCI }^{(\mathrm{e})} \\
\text { on Median } \\
\text { EC } \\
{[\mathrm{S} / \mathrm{cm}]}\end{array}$ & $\begin{array}{c}90 \% \mathrm{UCI}^{(\mathrm{e})} \\
\text { on Mean } \\
\ln (\mathrm{EC}) \\
{[\ln (\mathrm{S} / \mathrm{cm})]}\end{array}$ & $\begin{array}{c}90 \% \mathrm{UCI}^{(\mathrm{e})} \\
\text { on Median } \\
\text { EC } \\
{[\mathrm{S} / \mathrm{cm}]}\end{array}$ & $\begin{array}{c}90 \% \mathrm{CI}^{(\mathrm{e})} \text { on } \\
\text { Mean } \ln (\mathrm{EC}) \\
{[\ln (\mathrm{S} / \mathrm{cm})]}\end{array}$ & $\begin{array}{c}90 \% \mathrm{CI}^{(\mathrm{e})} \text { on } \\
\text { Median EC } \\
{[\mathrm{S} / \mathrm{cm}]}\end{array}$ \\
\hline $\begin{array}{l}\text { 22-Term } \\
\text { EC Model } \\
\text { at } 1140^{\circ} \mathrm{C}^{(\mathrm{b})}\end{array}$ & $-1.340^{(\mathrm{f})}$ & 0.262 & 0.071 & -1.431 & 0.239 & -1.248 & 0.287 & $(-1.457,-1.222)$ & $(0.233,0.295)$ \\
\hline $\begin{array}{l}\text { 27-Term } \\
\text { EC Model } \\
\text { at } 1140^{\circ} \mathrm{C}^{(\mathrm{b})}\end{array}$ & -1.488 & 0.226 & $0 . .073$ & -1.582 & 0.205 & -1.393 & 0.248 & $(-1.609,-1.367)$ & $(0.200,0.255)$ \\
\hline
\end{tabular}

(a) The two models in this column are given in Tables 7.9 and 7.7, respectively.

(b) The temperature of $1140^{\circ} \mathrm{C}$ was chosen because it was one of the temperatures at which the EC of HLW03-06 was measured. This facilitates comparison of the predicted and measured values.

(c) Of the two models, the one with the predicted EC value at $1140^{\circ} \mathrm{C}$ closest to the measured value of $0.302 \mathrm{~S} / \mathrm{cm}$ is the 22 -term EC model.

(d) The standard deviation is for the $\ln (\mathrm{EC})$ prediction at $1140^{\circ} \mathrm{C}$ considered to be the mean of such values for the HLW03-06 glass.

(e) $\mathrm{UCI}=$ upper confidence interval, LCI = lower confidence interval, and CI = two-sided confidence interval (see Section C.7 of Appendix C).

(f) All calculations were performed using the HLW03-06 glass composition, model coefficients, and variance-covariance matrix values given in tables of this report. The calculated $\ln (\mathrm{S} / \mathrm{cm})$ values were rounded to four decimal places in this table. The $\mathrm{S} / \mathrm{cm}$ values were calculated by exponentiating the $\ln (\mathrm{S} / \mathrm{cm})$ values before rounding, then rounding the resulting values to three decimal places in this table. 
Table 8.1. $\quad$ Normalized $^{(\text {a) }}$ 22-Component Compositions (mass fractions) of 197 HLW Glasses Used for Viscosity Model Development.

\begin{tabular}{|c|c|c|c|c|c|c|c|c|c|c|c|c|c|c|c|c|c|c|c|c|c|c|c|}
\hline Glas & $\begin{array}{c}\text { Group } \\
\text { ID }^{(\mathbf{b})}\end{array}$ & $\mathrm{I}_{2} \mathrm{O}_{3}$ & $\mathbf{B}_{2} \mathbf{O}_{3}$ & $\mathrm{CaO}$ & CdO & $\mathrm{Cr}_{2} \mathrm{O}_{3}$ & $\mathrm{Fe}_{2} \mathrm{O}_{3}$ & $\mathbf{L i}_{2} \mathbf{O}$ & MgO & MnO & $\mathrm{Na}_{2} \mathrm{O}$ & $\mathrm{NiO}$ & PbO & $\left|\mathbf{S b}_{2} \mathbf{O}_{3}\right|$ & $\mathrm{SeO}_{2}$ & $\mathrm{SiO}_{2}$ & SrO & $\mathrm{ThO}_{2}$ & $\mathbf{T l}_{2} \mathbf{O}$ & $\mathbf{U O}_{3}$ & ZnO & $\mathrm{ZrO}_{2}$ & Others \\
\hline $2-01$ & HLW02 & 171 & 927 & 500 & 7771 & 108 & 8999 & 3996 & 0120 & 85 & 9957 & 5518 & 216 & 0110 & 0110 & 43612 & 2444 & 0000 & 0102 & 0000 & 2000 & 2974 & 0 \\
\hline HLW02-02 & W02 & 9999 & 3996 & 5500 & 1500 & 0199 & 13996 & 55998 & 0120 & 0000 & \begin{tabular}{|l|l|}
.03999 \\
\end{tabular} & .00100 & .00400 & .00200 & 00020 & .50445 & .00000 & .00000 & .00019 & .00000 & 01999 & .00000 & 2509 \\
\hline HLW02-03 & W02 & 3999 & . 13998 & 00500 & .01500 & .00199 & .07999 & .02000 & .00120 & .00000 & \begin{tabular}{|l|l|}
.14998 \\
\end{tabular} & \begin{tabular}{|l|l|}
.01000 \\
\end{tabular} & \begin{tabular}{|l|l|}
.00400 \\
\end{tabular} & .00020 & .00200 & .37994 & .04379 & .00000 & .00186 & .00000 & .02000 & .05999 & 2510 \\
\hline HLW02-04 & W02 & 4001 & .05001 & .00500 & .01500 & .00020 & .14002 & .02000 & .00120 & \begin{tabular}{|l|l|}
.00518 \\
\end{tabular} & \begin{tabular}{|l|l|}
.15002 \\
\end{tabular} & .00100 & .00040 & .00200 & .00200 & .52939 & .00000 & .00000 & .00186 & .00000 & .02000 & .00000 & 1671 \\
\hline HLW02-05 & W02 & 4000 & .05000 & .00500 & .00050 & .00020 & .08000 & .06000 & .00120 & .00000 & \begin{tabular}{|l|l|}
.13788 \\
\end{tabular} & .00100 & .00040 & .00020 & .00020 & .52652 & .00000 & .00000 & .00019 & .00000 & .02000 & .06000 & 1671 \\
\hline HLW02-07 & W02 & .08499 & .04999 & .00500 & 00050 & 0199 & .07999 & .05999 & .00120 & .00000 & \begin{tabular}{|l|l|}
.11703 \\
\end{tabular} & .00100 & .00400 & .00200 & .00020 & .52992 & .00000 & .00000 & .00186 & .00000 & .02000 & .01525 & 2510 \\
\hline HLW02-08 & W02 & .04000 & .14000 & .00500 & .00050 & 0020 & .09205 & .03310 & .00120 & .05000 & .15000 & .00100 & .00040 & .00200 & .00020 & $\begin{array}{ll}.38744 \\
\end{array}$ & .00000 & .00000 & .00019 & .00000 & .02000 & .06000 & 1671 \\
\hline HLW02-09 & W02 & .08500 & .11589 & .00500 & .00050 & .00020 & .14000 & .02271 & .00120 & .00000 & .15000 & .01000 & .00040 & .00200 & .00020 & .38000 & .05000 & .00000 & .00019 & .00000 & .02000 & .00000 & 1671 \\
\hline HLW02-10 & W02 & .08500 & 14000 & .00500 & .01500 & 0020 & .08000 & .06000 & .00120 & .00000 & \begin{tabular}{|l|l|}
.10513 \\
\end{tabular} & .00100 & .00040 & .00020 & .00200 & .38000 & .02797 & .00000 & .00019 & .00000 & .02000 & .06000 & 771 \\
\hline HLW02-11 & W02 & .04001 & .14002 & .00500 & .00050 & 0020 & .08001 & .06001 & .00120 & .00000 & \begin{tabular}{|l|l|}
.10858 \\
\end{tabular} & .01000 & .00040 & .00200 & .00200 & .45149 & .00000 & .00000 & .00186 & .00000 & .02000 & .06001 & 71 \\
\hline HLW02-12 & W02 & .03999 & |04999 & .00500 & .01500 & 0199 & .11382 & .05998 & .00120 & \begin{tabular}{|l|l|}
.04999 \\
\end{tabular} & \begin{tabular}{|l|l|}
.12757 \\
\end{tabular} & .01000 & . .00400 & .00020 & .00200 & .41402 & .00000 & .00000 & .00019 & .00000 & 01999 & .05998 & 99 \\
\hline HLW02-13 & W02 & |.03999 & (04999 & .00500 & .00050 & 0199 & .13998 & .05999 & .00120 & \begin{tabular}{|l|l|}
.04999 \\
\end{tabular} & \begin{tabular}{|l|l|}
.10425 \\
\end{tabular} & .00100 & . .00400 & .00020 & .00200 & .43114 & .04999 & .00000 & .00186 & .00000 & .02000 & 01182 & 10 \\
\hline HLW02-15 & W02 & .08499 & . 13998 & .00500 & .00050 & 0199 & .13998 & .02000 & .00120 & \begin{tabular}{|l|l|}
.04688 \\
\end{tabular} & \begin{tabular}{|l|}
.12539 \\
\end{tabular} & .00100 & . .00400 & .00020 & .00200 & .37994 & .00000 & .00000 & .00186 & .00000 & .02000 & .00000 & 2510 \\
\hline HLW02-16 & W02 & .08498 & (04999 & .00500 & .01500 & 0199 & .07998 & .05998 & .00120 & \begin{tabular}{|l|l|}
.04999 \\
\end{tabular} & \begin{tabular}{|l|l|}
.09651 \\
\end{tabular} & .00100 & . .00400 & .00200 & .00200 & .39115 & .04999 & .00000 & .00019 & .00000 & .01999 & .05998 & 509 \\
\hline HLW02-17 & W02 & .08500 & .05000 & .00500 & .01500 & .00020 & .13843 & .06000 & .00120 & .00000 & \begin{tabular}{|l|l|}
.07690 \\
\end{tabular} & .00100 & .00040 & .00020 & .00020 & .52958 & .00000 & .00000 & .00019 & .00000 & .02000 & .00000 & 771 \\
\hline HLW02-18 & W02 & |.03999 & (04999 & .00500 & .00050 & .00199 & .11126 & .02013 & .00120 & .00000 & \begin{tabular}{|l|}
.14996 \\
\end{tabular} & \begin{tabular}{|l|l|}
.01000 \\
\end{tabular} & . .00400 & .00200 & .00020 & .49852 & .00000 & .00000 & .00019 & .00000 & 01999 & .05998 & 2509 \\
\hline HLW02-19 & W02 & .04000 & .14000 & .00500 & .01500 & .00020 & .10781 & .02000 & .00120 & \begin{tabular}{|l|}
.05000 \\
\end{tabular} & \begin{tabular}{|l|l|}
.08849 \\
\end{tabular} & \begin{tabular}{|l|l|}
.00100 \\
\end{tabular} & .00040 & .00200 & .00200 & .38000 & . 05000 & .00000 & .00019 & .00000 & .02000 & .06000 & 1671 \\
\hline HLW02-20 & W02 & .04000 & .14000 & .00500 & .00050 & .00020 & .14000 & .02000 & .00120 & \begin{tabular}{|l|l|}
.00000 \\
\end{tabular} & \begin{tabular}{|l|l|}
.06453 \\
\end{tabular} & \begin{tabular}{|l|l|}
.00100 \\
\end{tabular} & .00040 & .00020 & .00020 & .51734 & .03253 & .00000 & .00019 & .00000 & .02000 & .00000 & 1671 \\
\hline HLW02-21 & W02 & .08500 & .14000 & .00500 & .00050 & .00020 & .08000 & .02000 & .00120 & .00000 & .15000 & \begin{tabular}{|l|l|}
.00100 \\
\end{tabular} & .00040 & .00020 & .00020 & .46440 & . 00000 & .00000 & .00019 & .00000 & .02000 & .01500 & 1671 \\
\hline HLW02-22 & W02 & .08500 & .14000 & .00500 & .00050 & .00020 & .09500 & .06000 & .00120 & .00000 & \begin{tabular}{|l|l|}
.04000 \\
\end{tabular} & \begin{tabular}{|l|l|}
.00100 \\
\end{tabular} & .00040 & .00200 & .00200 & .53000 & .00080 & .00000 & .00019 & .00000 & .02000 & .00000 & 1671 \\
\hline HLW02-23 & W02 & .08501 & .14002 & .00500 & .01500 & .00020 & .08001 & .06001 & .00120 & \begin{tabular}{|l|}
.05001 \\
\end{tabular} & \begin{tabular}{|l|}
.05591 \\
\end{tabular} & \begin{tabular}{|l|l|}
.01000 \\
\end{tabular} & \begin{tabular}{|l|l|}
.00040 \\
\end{tabular} & .00020 & .00020 & .39325 & .05001 & .00000 & .00186 & .00000 & .02000 & .01500 & 1671 \\
\hline HLW02-24 & W02 & .08498 & . 04999 & .00500 & .00050 & .00153 & .07998 & .02000 & .00120 & \begin{tabular}{|l|l|}
.04999 \\
\end{tabular} & \begin{tabular}{|l|}
.12195 \\
\end{tabular} & \begin{tabular}{|l|l|}
.00100 \\
\end{tabular} & .00307 & .00020 & .00200 & .47052 & . 04999 & .00000 & .00019 & .00000 & .02000 & .01500 & 2292 \\
\hline HLW02-25 & W02 & .08501 & 14002 & .00500 & .01500 & .00020 & .09501 & .02000 & .00120 & \begin{tabular}{|l|l|}
.00355 \\
\end{tabular} & \begin{tabular}{|l|l|}
.06884 \\
\end{tabular} & \begin{tabular}{|l|l|}
.00100 \\
\end{tabular} & .00040 & .00200 & .00020 & .47398 & . 05001 & .00000 & .00186 & .00000 & \begin{tabular}{|l|l|}
.02000 \\
\end{tabular} & .00000 & 1671 \\
\hline HLW02-26 & W02 & .03999 & |04999 & .00500 & .01500 & .00199 & .12498 & .02000 & .00120 & \begin{tabular}{|l|l|}
.04959 \\
\end{tabular} & \begin{tabular}{|l|l|}
.14998 \\
\end{tabular} & .00100 & . .00400 & .00020 & .00020 & .37994 & .04999 & .00000 & .00186 & .00000 & .02000 & .05999 & 2510 \\
\hline HLW02-27 & W02 & .04001 & .14002 & .00500 & .00050 & .00020 & .12502 & .06001 & .00120 & \begin{tabular}{|l|l|}
.03366 \\
\end{tabular} & \begin{tabular}{|l|l|}
.04275 \\
\end{tabular} & .00100 & .00040 & .00020 & .00200 & .39946 & .05001 & .00000 & .00186 & .00000 & .02000 & .06001 & 1671 \\
\hline HLW02-28 & W02 & .07500 & .08000 & .00500 & .01000 & .00040 & .10451 & .02500 & .00120 & .01500 & \begin{tabular}{|l|}
.15001 \\
\end{tabular} & .00300 & . .00080 & .00050 & .00050 & .41003 & .03500 & .00000 & . .00140 & .00000 & .02000 & .04500 & 1764 \\
\hline HLW02-29 & W02 & .07499 & . 12998 & .00500 & .00500 & .00133 & .09998 & .03749 & .00120 & .01500 & \begin{tabular}{|l|l|}
.08999 \\
\end{tabular} & .00300 & \begin{tabular}{|l|}
.00267 \\
\end{tabular} & .00050 & .00150 & 40994 & .03499 & .00000 & .00046 & .00000 & .02000 & .04499 & 2199 \\
\hline HLW02-30 & W02 & .05500 & .09721 & .00500 & .01000 & .00040 & .10000 & .05000 & .00120 & .03500 & \begin{tabular}{|l|l|}
.11228 \\
\end{tabular} & .00300 & . .00080 & .00150 & .00050 & .41000 & .03500 & .00000 & .00047 & .00000 & .02000 & .04500 & 1764 \\
\hline $2-31$ & & .05500 & 13001 & .00500 & .00500 & .00040 & .10001 & .02500 & .00120 & .01500 & \begin{tabular}{|l|l|}
.14982 \\
\end{tabular} & .00300 & .00080 & .00050 & .00150 & .41003 & .01500 & .00000 & .00140 & .00000 & .02000 & .04369 & 1764 \\
\hline HLW02-32 & W02 & .07500 & .08000 & .00500 & .01000 & .00040 & .10000 & .05000 & .00120 & .01500 & \begin{tabular}{|l|l|}
.10733 \\
\end{tabular} & \begin{tabular}{|l|l|}
.00300 \\
\end{tabular} & \begin{tabular}{|l|l|}
.00080 \\
\end{tabular} & .00150 & .00150 & 46117 & .03500 & .00000 & .00047 & .00000 & .02000 & .01500 & .01764 \\
\hline
\end{tabular}

(a) Normalized to sum to 1.00000 over the 22 components listed in this table. The normalized component mass fractions listed in this table were rounded to five decimals, and may not sum exactly to 1.00000 as listed. However, complete compositions listed to more decimal places and summing to 1.00000 were used for property-composition modeling.

(b) The Group IDs are described in Sections 2.1.1 to 2.1.9. 
Table 8.1. $\quad$ Normalized $^{(\text {a) }}$ 22-Component Compositions (mass fractions) of 197 HLW Glasses Used for Viscosity Model Development (continued).

\begin{tabular}{|c|c|c|c|c|c|c|c|c|c|c|c|c|c|c|c|c|c|c|c|c|c|c|c|}
\hline Glass ID & $\underset{\text { ID }^{\text {Group }}}{\text { Group }}$ & $\mathbf{I}_{2} \mathbf{O}_{3}$ & $\mathbf{O}_{3}$ & $\mathrm{aO}$ & $\mathrm{CdO}$ & $\mathrm{Cr}_{2} \mathrm{O}_{3}$ & )$_{3}$ & $\mathbf{L}$ & 0 & InO & $\mathbf{O}$ & $\mathbf{N i O}$ & PbO & $\mathbf{S b}_{2} \mathbf{O}_{3}$ & $\mathrm{SeO}_{2}$ & $\mathrm{SiO}_{2}$ & SrO & $\mathrm{ThO}_{2}$ & $\mathbf{T l}_{2} \mathbf{O}$ & $\mathbf{U O}_{3}$ & $\mathrm{ZnO}$ & $\mathrm{ZrO}_{2}$ & Oth \\
\hline & & & & 500 & 500 & & & & & 00 & 000 & 800 & 080 & & & 000 & & .00000 & 047 & 0000 & 2000 & 2009 & \\
\hline HLV & & 499 & 998 & 500 & 1000 & 133 & 998 & 957 & 120 & 1500 & 891 & .00800 & .00267 & 050 & 050 & 9994 & 499 & .00000 & .00046 & 00000 & 2000 & 1500 & 2199 \\
\hline HLV & & .06488 & 2999 & 500 & 0500 & 0133 & 1999 & 5000 & 0120 & 3500 & \begin{tabular}{|l|l|}
.09160 \\
\end{tabular} & .00800 & .00267 & 0150 & .00050 & .40996 & .01500 & .00000 & .00140 & .00000 & 02000 & 1.01500 & 2199 \\
\hline HLV & & .05499 & .08667 & 5500 & 1000 & 133 & 1998 & 22500 & 0120 & 1500 & \begin{tabular}{|l|l|}
.14998 \\
\end{tabular} & .00300 & .00267 & .00050 & 00150 & 45074 & .01500 & .00000 & 1.00046 & .00000 & .02000 & 1.01500 & 2199 \\
\hline HLV & & .06762 & .13000 & .00500 & .00500 & 040 & 0000 & 12500 & 00120 & 3500 & \begin{tabular}{|l|l|}
.11188 \\
\end{tabular} & .00800 & .00080 & 0150 & 0050 & .41000 & .01500 & .00000 & .00047 & 1.00000 & .02000 & .04500 & 1764 \\
\hline HLV & & \begin{tabular}{|c|}
.06893 \\
\end{tabular} & 12998 & .00500 & .01000 & 133 & 1998 & 14255 & 00120 & 1500 & \begin{tabular}{|l|l|}
.08999 \\
\end{tabular} & .00800 & .00267 & 0150 & 00150 & .40994 & 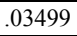 & .00000 & .00046 & 1.00000 & .02000 & .01500 & 2199 \\
\hline HLV & & .07500 & 08991 & .00500 & .01000 & 0040 & .10000 & 2500 & .00120 & 1500 & \begin{tabular}{|l|l|}
.11058 \\
\end{tabular} & .00800 & .00080 & .00050 & 0050 & 49000 & 1500 & .00000 & .00047 & .00000 & .02000 & .01500 & 1764 \\
\hline HLV & & .07499 & .09833 & .00500 & .01000 & 0133 & .09999 & .02632 & .00120 & 1500 & .09683 & .00300 & .00267 & .00150 & 0050 & 48996 & .01500 & .00000 & .00140 & .00000 & .02000 & 01500 & 2199 \\
\hline HLW & & .06500 & .13001 & .00500 & 0500 & 0040 & .10001 & .02500 & .00120 & \begin{tabular}{|l|l|}
.01500 \\
\end{tabular} & \begin{tabular}{|l|}
.09001 \\
\end{tabular} & .00300 & .00080 & \begin{tabular}{|l|}
.00050 \\
\end{tabular} & 0050 & .48953 & . 01500 & .00000 & .00140 & .00000 & .02000 & .01500 & 1764 \\
\hline HLV & & .05500 & .13001 & . .00500 & .00500 & 0040 & .10001 & .05000 & . 00120 & .01500 & .09001 & .00300 & .00080 & .00050 & 0050 & .44453 & . & .00000 & .00140 & .00000 & .02000 & .02500 & 1764 \\
\hline HLV & & .06500 & .13000 & .00500 & .01000 & 0040 & .10000 & 2500 & .00120 & .03500 & .12450 & .00300 & .00080 & .00150 & 0050 & .41000 & . 03500 & .00000 & .00047 & .00000 & .02000 & .01500 & 1764 \\
\hline HLV & & .05499 & .09069 & .00500 & .01000 & 0133 & .09998 & 2500 & .00120 & \begin{tabular}{|l|}
.03499 \\
\end{tabular} & \begin{tabular}{|l|}
.14998 \\
\end{tabular} & \begin{tabular}{|l|}
.00300 \\
\end{tabular} & \begin{tabular}{|l|}
.00267 \\
\end{tabular} & .00150 & 0050 & .43673 & .01500 & .00000 & .00046 & .00000 & .02000 & .02500 & 2199 \\
\hline & & .05500 & .08000 & .00500 & 1000 & 0040 & .11000 & 2500 & .00120 & .03500 & \begin{tabular}{|l|}
.09619 \\
\end{tabular} & \begin{tabular}{|l|}
.00300 \\
\end{tabular} & .00080 & .00050 & 0150 & .48831 & .03500 & .00000 & .00047 & .00000 & .02000 & .01500 & 1764 \\
\hline HLV & & .05500 & . 09149 & .00500 & 0500 & 0040 & .10001 & 3701 & . .00120 & .03500 & \begin{tabular}{|l|l|} 
\\
\end{tabular} & .00800 & . 00080 & 050 & 0150 & .49003 & . 01500 & .00000 & .00140 & .00000 & .02000 & .02500 & 1764 \\
\hline HLV & & . 05499 & . 09806 & .00500 & .00500 & 133 & .09999 & 2500 & . .00120 & .03500 & \begin{tabular}{|l|l|} 
\\
\end{tabular} & .00300 & .00267 & .00050 & 0050 & .48996 & . 01500 & .00000 & .00140 & .00000 & .02000 & .02500 & 2199 \\
\hline 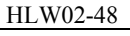 & & . 05999 & . & .00500 & .00500 & 0133 & .11999 & 3339 & . .00120 & .01500 & \begin{tabular}{|l|l|}
.14999 \\
\end{tabular} & .00800 & .00267 & 0150 & 0150 & .40996 & . 01710 & .00000 & .00140 & .00000 & .02000 & .04500 & 2199 \\
\hline HLW & & . .07500 & . 08740 & .00500 & .00500 & 0040 & .12001 & .05000 & .00120 & .03500 & .09001 & .00300 & $\mid .00080$ & 0050 & 0050 & .44213 & . 01500 & .00000 & .00140 & .00000 & .02000 & .03000 & 1764 \\
\hline HLW02-50 & & . .06000 & .13001 & . 00500 & .00500 & .00040 & .12001 & .02500 & .00120 & .01500 & .09821 & .00300 & .00080 & 0150 & 050 & .43532 & . 01500 & .00000 & .00140 & .00000 & .02000 & .04500 & 1764 \\
\hline HLW02-51 & 02 & .07500 & .08000 & .00500 & .00500 & .00040 & .10501 & .04589 & .00120 & \begin{tabular}{|l|}
.01500 \\
\end{tabular} & \begin{tabular}{|l|}
.09001 \\
\end{tabular} & .00300 & .00080 & .00150 & 0150 & .45164 & .03500 & .00000 & .00140 & .00000 & .02000 & .04500 & 1764 \\
\hline HLW02-52 & W02 & .06171 & .09927 & .00500 & .00771 & .00108 & .10899 & .03996 & .00120 & .02385 & \begin{tabular}{|l|}
.10957 \\
\end{tabular} & .00518 & .00216 & .00110 & 0110 & .43612 & .02444 & .00000 & .00102 & .00000 & .02000 & .02974 & 2080 \\
\hline HLW02-53 & W02 & .08500 & .05000 & .00500 & .01500 & .00020 & .13843 & .06000 & .00120 & .00000 & .07690 & .00100 & .00040 & .00020 & 0020 & .52958 & .00000 & .00000 & .00019 & .00000 & .02000 & .00000 & 1671 \\
\hline HLW02-54 & LW02 & .04001 & .05001 & .00500 & .01500 & .00020 & .14002 & .02000 & .00120 & \begin{tabular}{|l|}
.00518 \\
\end{tabular} & \begin{tabular}{|l|}
.15002 \\
\end{tabular} & \begin{tabular}{|l|}
.00100 \\
\end{tabular} & .00040 & .00200 & 0200 & .52939 & .00000 & .00000 & \begin{tabular}{|l|l|}
.00186 \\
\end{tabular} & .00000 & .02000 & .00000 & 1671 \\
\hline HLW02-55 & LW02 & .05500 & .13001 & .00500 & .00500 & .00040 & .10001 & .05000 & .00120 & .01500 & \begin{tabular}{|l|}
.09001 \\
\end{tabular} & \begin{tabular}{|l|}
.00300 \\
\end{tabular} & .00080 & .00050 & .00050 & .44453 & .03500 & .00000 & .00140 & .00000 & .02000 & .02500 & 1764 \\
\hline HLW02-56 & LW02 & .05499 & .09069 & .00500 & .01000 & .00133 & .09998 & .02500 & .00120 & \begin{tabular}{|l|}
.03499 \\
\end{tabular} & \begin{tabular}{|l|}
.14998 \\
\end{tabular} & \begin{tabular}{|l|}
.00300 \\
\end{tabular} & .00267 & .00150 & .00050 & .43673 & .01500 & .00000 & .00046 & .00000 & .02000 & .02500 & 2199 \\
\hline HLW02-57 & LW02 & .04000 & .14000 & .00500 & .00050 & .00020 & .09205 & .03310 & .00120 & \begin{tabular}{|l|}
.05000 \\
\end{tabular} & .15000 & \begin{tabular}{|l|}
.00100 \\
\end{tabular} & .00040 & .00200 & .00020 & .38744 & .00000 & .00000 & .00019 & .00000 & .02000 & .06000 & 1671 \\
\hline HLW03-02 & LW03 & .01951 & .13662 & .00500 & .01600 & .00488 & .13662 & .02473 & .00120 & .06832 & \begin{tabular}{|l|}
.11177 \\
\end{tabular} & \begin{tabular}{|l|}
.00976 \\
\end{tabular} & .00040 & .00300 & .00020 & .35132 & .00000 & .00000 & .00307 & .00000 & .00000 & .09088 & 1671 \\
\hline HLW03-03 & W03 & .01953 & .04884 & .00500 & .01600 & .00488 & .13677 & .02678 & .00120 & .06839 & \begin{tabular}{|l|}
.10755 \\
\end{tabular} & \begin{tabular}{|l|}
.00977 \\
\end{tabular} & .00040 & .00020 & .00200 & .35169 & .09769 & .00000 & .00307 & .00000 & .01946 & .06404 & 1671 \\
\hline HLW03-04 & W03 & .01954 & .04886 & .00498 & .00050 & .00488 & .13680 & .05862 & .00120 & \begin{tabular}{|l|}
.03161 \\
\end{tabular} & .04442 & \begin{tabular}{|l|}
.00098 \\
\end{tabular} & \begin{tabular}{|l|}
.00399 \\
\end{tabular} & .00020 & .00199 & .42425 & .09771 & .00000 & .00306 & .06210 & .00000 & .02932 & 2501 \\
\hline HLW03-05 & W03 & .08175 & .04809 & .00500 & .01600 & .00481 & .01924 & .01924 & .00120 & .06733 & .14427 & .00096 & .00400 & .00300 & .00200 & .47837 & .00000 & .03812 & .00307 & .00000 & .03847 & .00000 & .02510 \\
\hline HLW03-06 & HLW03 & . 08344 & . & .00500 & .01600 & .00491 & .01963 & .05890 & .00120 & \begin{tabular}{|l|l|}
.06872 \\
\end{tabular} & \begin{tabular}{|l|l|}
.03927 \\
\end{tabular} & \begin{tabular}{|l|l|}
.00982 \\
\end{tabular} & . & .00020 & .00020 & .52031 & . & .01416 & \begin{tabular}{|l|l|}
.00019 \\
\end{tabular} & .00000 & .00000 & .04095 & .01671 \\
\hline
\end{tabular}

(a) Normalized to sum to 1.00000 over the 22 components listed in this table. The normalized component mass fractions listed in this table were rounded to five decimals, and may not sum exactly to 1.00000 as listed. However, complete compositions listed to more decimal places and summing to 1.00000 were used for property-composition modeling.

(b) The Group IDs are described in Sections 2.1.1 to 2.1.9. 
Table 8.1. $\quad$ Normalized $^{(\text {a) }}$ 22-Component Compositions (mass fractions) of 197 HLW Glasses Used for Viscosity Model Development (continued).

\begin{tabular}{|c|c|c|c|c|c|c|c|c|c|c|c|c|c|c|c|c|c|c|c|c|c|c|c|}
\hline Glass ID & $\underset{\text { ID }^{\text {Group }}}{\text { Ge }}$ & $\mathbf{A l}_{2} \mathbf{O}_{3}$ & $\mathbf{B}_{2} \mathbf{O}_{3}$ & $\mathrm{CaO}$ & $\mathrm{CdO}$ & $\mathrm{Cr}_{2} \mathrm{O}_{3}$ & $\mathrm{Fe}_{2} \mathrm{O}_{3}$ & $\mathbf{L i}_{2} \mathbf{O}$ & MgO & MnO & $\mathrm{Na}_{2} \mathrm{O}$ & $\mathrm{NiO}$ & PbO & $\mathbf{S b}_{2} \mathbf{O}_{3}$ & $\mathrm{SeO}_{2}$ & $\mathrm{SiO}_{2}$ & SrO & $\mathrm{ThO}_{2}$ & $\mathrm{Tl}_{2} \mathrm{O}$ & $\mathbf{U O}_{3}$ & ZnO & $\mathrm{ZrO}_{2}$ & Others \\
\hline & & 961 & 961 & 498 & 050 & 496 & 3891 & 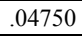 & 120 & 945 & 693 & .00100 & .00040 & 020 & \begin{tabular}{l|l|}
199 \\
\end{tabular} & 9825 & 000 & .00000 & 0019 & 6306 & 3461 & & 65 \\
\hline 0 & & 7668 & 695 & 500 & 0050 & 0020 & 3486 & 1979 & 0120 & 0000 & \begin{tabular}{|l|l|}
.14848 & \\
\end{tabular} & \begin{tabular}{|l|l|}
.00099 \\
\end{tabular} & .00040 & 0300 & 0200 & 52465 & 00000 & .02552 & .00307 & 00000 & 00000 & .00000 & 1671 \\
\hline HLV & & 984 & 961 & 498 & 0050 & 0020 & 538 & 1984 & 120 & 0000 & \begin{tabular}{|l|l|}
.14883 \\
\end{tabular} & .00100 & .00040 & 0020 & 1199 & 52586 & 0000 & 05027 & .00019 & 06306 & 0000 & .00000 & 1665 \\
\hline HLW03-1 & & .01982 & 956 & 498 & .00050 & 0495 & 1982 & .05008 & 120 & \begin{tabular}{|l|l|}
.06939 \\
\end{tabular} & \begin{tabular}{|l|l|}
.03965 \\
\end{tabular} & \begin{tabular}{|l|l|}
.00099 \\
\end{tabular} & .00040 & 0299 & 020 & 44277 & 09912 & 03729 & .00019 & 06299 & .03965 & .03682 & 1665 \\
\hline HLW & $\mathrm{I}$ & .01989 & .04973 & 500 & .00050 & 0020 & .09047 & .02504 & 120 & \begin{tabular}{|l|l|}
.06962 \\
\end{tabular} & 4425 & \begin{tabular}{|l|l|}
.00994 \\
\end{tabular} & .00040 & 0020 & 020 & 35806 & 09946 & 04115 & .00307 & 00000 & 03979 & .06511 & 1671 \\
\hline HLW & $\mathrm{I}$ & .01951 & 13662 & 500 & .01600 & 0020 & .13662 & .01951 & 120 & \begin{tabular}{|l|l|}
.01348 \\
\end{tabular} & \begin{tabular}{|l|l|}
.05248 \\
\end{tabular} & \begin{tabular}{|l|l|}
.00098 \\
\end{tabular} & .00040 & 0300 & 020 & 51722 & 0000 & .02441 & .00307 & 00000 & .03337 & .00000 & 671 \\
\hline HLW & $\mathrm{H}$ & .01955 & .04886 & .00498 & .00050 & .00020 & .07905 & .02862 & 0120 & \begin{tabular}{|l|l|}
.06840 \\
\end{tabular} & \begin{tabular}{|l|l|}
.03909 \\
\end{tabular} & \begin{tabular}{|l|l|}
.00977 \\
\end{tabular} & \begin{tabular}{|l|l|}
.00398 \\
\end{tabular} & .00299 & 0199 & 44240 & 9772 & .02568 & .00019 & .06210 & .02772 & .01001 & 01 \\
\hline HLW & WO & .08352 & 13757 & .00499 & .00050 & .00020 & .01965 & .01965 & .00120 & \begin{tabular}{|l|l|}
.06879 \\
\end{tabular} & \begin{tabular}{|l|l|}
.04461 \\
\end{tabular} & .00293 & \begin{tabular}{|l|l|}
.00399 \\
\end{tabular} & .00020 & .00020 & 46088 & .00000 & .02237 & .00019 & .04784 & .03930 & .01639 & 2503 \\
\hline HLW & Wo & .01989 & .04973 & .00500 & .00050 & .00497 & .13924 & .05922 & .00120 & .00000 & \begin{tabular}{|l|l|}
.10533 \\
\end{tabular} & \begin{tabular}{|l|l|}
.00980 \\
\end{tabular} & .00040 & .00020 & .00020 & 52484 & .00000 & .05967 & .00307 & .00000 & .00000 & .00000 & 1671 \\
\hline HLV & & .01963 & .04908 & .00500 & .01600 & 0491 & .09634 & .05890 & .00120 & \begin{tabular}{|l|}
.00197 \\
\end{tabular} & \begin{tabular}{|l|l|}
.10142 \\
\end{tabular} & \begin{tabular}{|l|}
.00982 \\
\end{tabular} & .00040 & .00020 & .00020 & 52030 & .00000 & .05846 & .00019 & .00000 & .03927 & .00000 & 1671 \\
\hline HLV & & 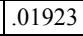 & 4808 & .00500 & .01600 & .00019 & .13462 & .05769 & .00120 & .00000 & \begin{tabular}{|l|l|}
.10097 \\
\end{tabular} & \begin{tabular}{|l|}
.00962 \\
\end{tabular} & .00400 & .00300 & .00200 & .50681 & .00145 & .05769 & .00307 & .00430 & .00000 & .00000 & 2509 \\
\hline HLV & & .04958 & .06941 & .00499 & .00300 & .00079 & .04958 & .02479 & .00120 & \begin{tabular}{|l|l|}
.04462 \\
\end{tabular} & \begin{tabular}{|l|l|}
.10828 \\
\end{tabular} & \begin{tabular}{|l|l|}
.00298 \\
\end{tabular} & .00080 & .00050 & .00050 & .48587 & .01487 & .02975 & .00046 & .02100 & .00992 & \begin{tabular}{|l}
.05949 \\
\end{tabular} & 1762 \\
\hline HLV & & .04915 & .06881 & .00499 & .00299 & .00079 & .09752 & .02458 & .00120 & \begin{tabular}{|l|l|}
.01474 \\
\end{tabular} & \begin{tabular}{|l|l|}
.11797 \\
\end{tabular} & .00295 & .00267 & .00050 & .00150 & .40304 & .04424 & \begin{tabular}{|l|l|}
.02949 \\
\end{tabular} & .00046 & .04165 & .00983 & .05898 & 2196 \\
\hline HLV & & \begin{tabular}{|l}
.04957 \\
\end{tabular} & .11897 & .00499 & .00100 & .00199 & .07733 & .02478 & .00120 & .01487 & \begin{tabular}{|l|}
.11897 \\
\end{tabular} & .00297 & .00080 & .00050 & .00150 & .40648 & .01487 & \begin{tabular}{|l|l|}
.02974 \\
\end{tabular} & .00046 & .04201 & .00992 & \begin{tabular}{|l|}
.05949 \\
\end{tabular} & 1760 \\
\hline HLV & & \begin{tabular}{|l}
.02975 \\
\end{tabular} & .06941 & .00499 & .00300 & .00079 & .04958 & .04958 & .00120 & \begin{tabular}{|l|l|}
.04462 \\
\end{tabular} & \begin{tabular}{|l|l|}
.08151 \\
\end{tabular} & .00495 & .00080 & .00050 & .00050 & .48588 & .01487 & .02975 & .00046 & .02100 & .02975 & .05949 & 1762 \\
\hline HLV & & \begin{tabular}{|l}
.02956 \\
\end{tabular} & .11823 & .00499 & .00100 & .00079 & .04927 & .02463 & .00120 & \begin{tabular}{|l|l|}
.01478 \\
\end{tabular} & \begin{tabular}{|l|l|}
.11823 \\
\end{tabular} & \begin{tabular}{|l|}
.00492 \\
\end{tabular} & .00267 & .00050 & .00150 & .42090 & .04433 & .02956 & .00139 & .02087 & .02956 & .05912 & 2199 \\
\hline HLV & & .04921 & .06889 & .00499 & .00100 & .00197 & .04921 & .04921 & .00120 & \begin{tabular}{|l|l|}
.01476 \\
\end{tabular} & \begin{tabular}{|l|l|}
.10431 \\
\end{tabular} & \begin{tabular}{|l|}
.00492 \\
\end{tabular} & .00267 & .00150 & .00150 & .40345 & .04428 & .04428 & .00046 & .04169 & .02953 & .05904 & 2196 \\
\hline HLV & & .04926 & .06897 & .00499 & .00100 & .00197 & .09359 & .04040 & .00120 & \begin{tabular}{|l|l|}
.01478 \\
\end{tabular} & \begin{tabular}{|l|l|}
.11822 \\
\end{tabular} & \begin{tabular}{|l|}
.00492 \\
\end{tabular} & .00267 & .00150 & .00150 & .40393 & .01478 & .04433 & .00046 & .02087 & .02956 & .05911 & 2199 \\
\hline HLW & & .03629 & .11911 & .00499 & .00100 & .00080 & .09926 & .04963 & .00120 & \begin{tabular}{|l|l|}
.01489 \\
\end{tabular} & \begin{tabular}{|l|}
.10486 \\
\end{tabular} & \begin{tabular}{|l|}
.00496 \\
\end{tabular} & .00080 & .00150 & .00050 & .40695 & .01489 & \begin{tabular}{|l|l|}
.02977 \\
\end{tabular} & .00046 & .02103 & .00993 & .05956 & 1762 \\
\hline HLW03-29 & & .02971 & .06933 & .00499 & .00299 & .00199 & .04952 & .04952 & .00120 & \begin{tabular}{|l|l|}
.03518 \\
\end{tabular} & \begin{tabular}{|l|l|}
.11885 \\
\end{tabular} & \begin{tabular}{|l|l|}
.00297 \\
\end{tabular} & .00080 & .00050 & .00050 & .40606 & 01485 & .04456 & .00046 & .04196 & .02971 & .07674 & 1760 \\
\hline HLW03-30 & & .02972 & .11888 & .00499 & .00100 & .00079 & .04953 & .04953 & .00120 & \begin{tabular}{|l|l|}
.04458 \\
\end{tabular} & \begin{tabular}{|l|l|}
.06934 \\
\end{tabular} & \begin{tabular}{|l|l|}
.00298 \\
\end{tabular} & .00080 & .00150 & .00150 & .43203 & .01486 & .04458 & .00139 & .02098 & .00991 & .08229 & 01762 \\
\hline HLW03-31 & 103 & .04953 & .06934 & .00499 & .00100 & .00198 & .04953 & .04953 & .00120 & \begin{tabular}{|l|l|}
.04458 \\
\end{tabular} & .08533 & \begin{tabular}{|l|}
.00495 \\
\end{tabular} & .00080 & .00150 & .00150 & .45058 & .01486 & .02972 & .00139 & .02098 & .00991 & .08915 & 01762 \\
\hline HLW03-33 & W03 & .04960 & .11902 & .00499 & .00100 & .00199 & .09919 & .03898 & .00120 & \begin{tabular}{|l|l|}
.01488 \\
\end{tabular} & \begin{tabular}{|l|}
.06943 \\
\end{tabular} & \begin{tabular}{|l|l|}
.00451 \\
\end{tabular} & .00080 & .00150 & .00050 & .40667 & .01488 & .02975 & .00046 & .03378 & .02975 & .05952 & 01761 \\
\hline HLW03-34 & HLW03 & .02956 & .06897 & .00499 & .00100 & .00197 & .09853 & .02463 & .00120 & \begin{tabular}{|l|l|l|l|l|l|} 
\\
\end{tabular} & \begin{tabular}{|l|l|}
.09541 \\
\end{tabular} & \begin{tabular}{|l|l|}
.00492 \\
\end{tabular} & .00267 & .00050 & .00150 & .48278 & .01478 & .03858 & .00139 & .02087 & .00986 & .05912 & 2199 \\
\hline HLW03-35 & HLW03 & .04963 & .10397 & .00499 & .00100 & .00080 & .04963 & .02481 & .00120 & \begin{tabular}{|l|l|}
.04467 \\
\end{tabular} & \begin{tabular}{|l|l|}
.06948 \\
\end{tabular} & \begin{tabular}{|l|l|}
.00496 \\
\end{tabular} & .00080 & .00050 & .00050 & .48639 & .01489 & .03176 & .00139 & .02103 & .01039 & .05956 & 1762 \\
\hline HLW03-36 & HLW03 & .04921 & .06889 & .00499 & .00300 & .00197 & .09507 & .02692 & .00120 & \begin{tabular}{|l|l|}
.01476 \\
\end{tabular} & \begin{tabular}{|l|l|}
.07961 \\
\end{tabular} & \begin{tabular}{|l|l|}
.00492 \\
\end{tabular} & .00267 & \begin{tabular}{|l|}
.00150 \\
\end{tabular} & .00050 & .48226 & .01476 & .03558 & .00046 & .02085 & .00984 & .05905 & 2199 \\
\hline HLW03-37 & HLW03 & .02953 & .11809 & .00499 & .00100 & .00079 & .07222 & .04859 & .00120 & \begin{tabular}{|l|}
.01476 \\
\end{tabular} & \begin{tabular}{|l|}
.06889 \\
\end{tabular} & \begin{tabular}{|l|l|}
.00492 \\
\end{tabular} & .00267 & .00050 & .00150 & .40348 & .01476 & .04428 & . 00139 & .04170 & .02953 & .07325 & 2196 \\
\hline HLW03-38 & HLW03 & .04915 & .06881 & .00499 & .00299 & .00197 & .09831 & .02458 & .00120 & \begin{tabular}{|l|}
.01474 \\
\end{tabular} & \begin{tabular}{|l|}
.09618 \\
\end{tabular} & .00295 & .00267 & .00050 & .00150 & .43156 & .01474 & .03875 & .00046 & .04165 & .00983 & .07051 & 2196 \\
\hline HLW03-39 & HLW03 & .02946 & .06875 & .00499 & .00300 & .00197 & .08502 & .04850 & .00120 & \begin{tabular}{|l|}
.01473 \\
\end{tabular} & \begin{tabular}{|l|}
.06875 \\
\end{tabular} & \begin{tabular}{|l|}
.00295 \\
\end{tabular} & .00267 & .00150 & .00150 & .48128 & .01473 & .04420 & .00139 & .02081 & .00982 & .07078 & .02199 \\
\hline HLW03-40 & HLW03 & .04941 & .06919 & .00499 & .00299 & .00079 & .09390 & .04881 & .00120 & \begin{tabular}{|l|}
.01483 \\
\end{tabular} & .06919 & \begin{tabular}{|l|l|}
.00494 \\
\end{tabular} & .00080 & .00150 & .00150 & .42959 & .03279 & .04448 & .00046 & .04188 & .00989 & .05930 & .01760 \\
\hline
\end{tabular}

(a) Normalized to sum to 1.00000 over the 22 components listed in this table. The normalized component mass fractions listed in this table were rounded to five decimals, and may not sum exactly to 1.00000 as listed. However, complete compositions listed to more decimal places and summing to 1.00000 were used for property-composition modeling.

(b) The Group IDs are described in Sections 2.1.1 to 2.1.9. 
Table 8.1. $\quad$ Normalized $^{(\text {a) }}$ 22-Component Compositions (mass fractions) of 197 HLW Glasses Used for Viscosity Model Development (continued).

\begin{tabular}{|c|c|c|c|c|c|c|c|c|c|c|c|c|c|c|c|c|c|c|c|c|c|c|c|}
\hline Glass ID & $\underset{\text { ID }^{\text {Group }}}{\text { Group }}$ & $\mathrm{I}_{2} \mathrm{O}_{3}$ & $\mathbf{O}_{3}$ & 10 & $\mathrm{CdO}$ & $\mathrm{Cr}_{2} \mathrm{O}_{3}$ & 3 & $\mathbf{L}$ & 0 & InO & $\mathbf{O}$ & $\mathbf{N i O}$ & PbO & $\mathbf{S b}_{2} \mathbf{O}_{3}$ & $\mathrm{SeO}_{2}$ & $\mathrm{SiO}_{2}$ & SrO & $\mathrm{hO}_{2}$ & $\mathbf{T l}_{2} \mathbf{O}$ & $\mathbf{U O}_{3}$ & $\mathrm{ZnO}$ & $\mathrm{ZrO}_{2}$ & Oth \\
\hline & & & & 499 & 200 & & & & & 698 & 093 & 395 & 174 & 100 & 100 & 559 & 705 & 658 & 0093 & & 920 & 5767 & \\
\hline $\mathrm{HLV}$ & & 500 & 50 & 500 & 0500 & 040 & 001 & - & 120 & 3500 & 0001 & .00800 & .00080 & 050 & 0150 & 9004 & 1500 & .00000 & .00140 & 0000 & 1999 & .02500 & 1764 \\
\hline HLW & & 3344 & 908 & 500 & 1600 & 491 & 1963 & 5890 & 0120 & 6872 & \begin{tabular}{|l|l|}
.03927 \\
\end{tabular} & \begin{tabular}{|l|l|}
.00982 \\
\end{tabular} & .00040 & 0020 & .00020 & .52031 & .05091 & .01416 & .00019 & .00000 & 00000 & 44095 & 1671 \\
\hline HLV & W03 & .01984 & 04961 & 498 & .00050 & 020 & 538 & 11984 & 0120 & 0000 & \begin{tabular}{|l|l|}
.14883 \\
\end{tabular} & .00100 & $.00040 \mathrm{~J}$ & .00020 & .00199 & .52586 & . & .05027 & .00019 & .06306 & 00000 & .00000 & 1665 \\
\hline $3-45$ & W03 & .04921 & .06889 & .00499 & .00100 & 197 & 921 & 4921 & 0120 & 1476 & \begin{tabular}{|l|l|}
.10431 \\
\end{tabular} & \begin{tabular}{|l|l|}
.00492 \\
\end{tabular} & .00267 & .00150 & 00150 & .40345 & .04428 & \begin{tabular}{|l|l|l}
.0428 \\
\end{tabular} & 1.00046 & .04169 & .02953 & .05904 & 2196 \\
\hline HLV & & .04781 & 1258 & 363 & .00011 & 0212 & .13088 & .02808 & 00113 & 2054 & \begin{tabular}{|l|l|}
.12251 \\
\end{tabular} & \begin{tabular}{|l|l|}
.00384 \\
\end{tabular} & - .00465 & .00000 & 00000 & - 48507 & .00201 & 1.00000 & .00000 & 1.00000 & 01978 & 1.00000 & 1528 \\
\hline HLV & & .04917 & 11088 & .00373 & .00011 & 0218 & .1 & .02770 & .00116 & \begin{tabular}{|l|l|}
.02112 \\
\end{tabular} & \begin{tabular}{|l|l|}
.12307 \\
\end{tabular} & \begin{tabular}{|l|l|}
.00395 \\
\end{tabular} & | & .00000 & 00000 & . & - & .00000 & 1.00000 & 1.00000 & 11949 & .00000 & 1571 \\
\hline HLW04-06 & & .04917 & .10358 & .00373 & .00011 & 218 & .1 & .02620 & .00116 & .02112 & .12287 & \begin{tabular}{|l|}
.00395 \\
\end{tabular} & .00478 & .00000 & 00000 & .48928 & .00207 & .00000 & .00000 & .00000 & 1949 & 00000 & 1571 \\
\hline HLW04-07 & wo4 & .04882 & .10368 & .00456 & .00011 & 223 & .14005 & .02643 & .00145 & \begin{tabular}{|l|}
.02821 \\
\end{tabular} & \begin{tabular}{|l|}
.12527 \\
\end{tabular} & \begin{tabular}{|l|}
.00412 \\
\end{tabular} & \begin{tabular}{|l|l|}
.00541 \\
\end{tabular} & .00037 & .00000 & .47445 & .00171 & .00000 & .00000 & .00000 & 1480 & .00463 & 1372 \\
\hline HLV & & .02000 & . & .00750 & .00050 & 0250 & .12000 & .00000 & . 00100 & .00100 & .16670 & .00050 & .00150 & .00000 & 0000 & .49000 & . 01200 & .01500 & .00050 & .04380 & 1200 & .04000 & 2050 \\
\hline HLV & & .13000 & .14000 & .00750 & .00500 & 0250 & .01500 & .00000 & . 00100 & .01000 & .20000 & .00500 & .00150 & .00000 & 0000 & .37750 & . 01200 & .01500 & .00050 & .01000 & 1200 & .03500 & 2050 \\
\hline HLV & & .02000 & .14000 & .00750 & .00050 & 0250 & 00 & .00000 & .00100 & .00100 & .19710 & \begin{tabular}{|l|}
.00050 \\
\end{tabular} & .00150 & .00000 & 0000 & .34000 & .01200 & .06000 & .00050 & .01000 & .01200 & .05340 & 2050 \\
\hline HLV & & .13000 & .14000 & .00750 & .00050 & 0050 & 00 & .03700 & .00100 & .00100 & .06500 & \begin{tabular}{|l|}
.00050 \\
\end{tabular} & .00150 & .00000 & 0000 & .44050 & .01200 & .01500 & .00050 & .06500 & .01200 & .02500 & 2050 \\
\hline HLV & & . 02000 & . 04500 & .00750 & .00500 & 0050 & 00 & .05950 & . 00100 & .01000 & .10390 & .00500 & .00150 & .00000 & 0000 & .45610 & . 01200 & .01500 & .00050 & .06500 & .01200 & .04000 & 2050 \\
\hline$\pi L w^{\prime}$ & & .10390 & .11000 & .01000 & .00235 & 0250 & 00 & .00250 & .01170 & .01000 & .20000 & .01000 & .00910 & .00000 & 0000 & .35000 & . 01470 & .00250 & .00000 & .00750 & .01500 & .01500 & 5325 \\
\hline กIL W00-2L & & .13000 & .15000 & .00000 & .01646 & .00600 & 100 & .06010 & . & .00000 & \begin{tabular}{|r|}
.06840 \\
\end{tabular} & .00000 & .00000 & .00000 & 0000 & .34560 & . 10287 & .00000 & .00000 & .06500 & .00000 & .00000 & 4156 \\
\hline HLW06-32 & & . 01880 & .15000 & . 00000 & .00000 & .00600 & .15000 & .00000 & . & .08000 & .20000 & .00000 & .00000 & .00000 & .00000 & .37430 & . .00000 & .00000 & .00000 & .00000 & 00000 & .00000 & 2090 \\
\hline HLW06-34 & & . 01880 & .15000 & . & .00000 & .00600 & .01 & .00000 & . & .08000 & .20000 & .00000 & .00000 & .00000 & 0000 & .33030 & . 00000 & .00000 & .00000 & .06500 & .00000 & .11500 & 2090 \\
\hline HLW07-01 & 07 & .07161 & .09206 & .00150 & .00237 & .00277 & .07993 & .01802 & .00000 & \begin{tabular}{|l|}
.03171 \\
\end{tabular} & \begin{tabular}{|l|}
.11287 \\
\end{tabular} & \begin{tabular}{|l|}
.00422 \\
\end{tabular} & .00240 & .00200 & 0000 & .41825 & .04260 & .02138 & .00000 & .02206 & .00983 & .04300 & 2140 \\
\hline HLW07-02 & LW07 & .05500 & .09149 & .00500 & .00500 & .00040 & .10001 & .03701 & .00120 & .03500 & \begin{tabular}{|l|}
.09001 \\
\end{tabular} & .00800 & .00080 & .00050 & .00150 & .49003 & .01500 & .00000 & .00140 & .00000 & .02000 & .02500 & 1764 \\
\hline HLW07-03 & W07 & .03888 & .08732 & .00499 & .00200 & .00140 & .06939 & .03710 & .00120 & .02698 & .09093 & .00395 & .00174 & .00100 & .00100 & .43059 & .02705 & .03658 & .00093 & .03032 & .01920 & .06767 & 1979 \\
\hline HLW07-04 & LW07 & .08500 & .14000 & .00500 & .00050 & .00020 & .09500 & .06000 & .00120 & \begin{tabular}{|l|}
.00000 \\
\end{tabular} & \begin{tabular}{|l|}
.04000 \\
\end{tabular} & \begin{tabular}{|l|}
.00100 \\
\end{tabular} & .00040 & .00200 & .00200 & .53000 & .00080 & .00000 & .00019 & .00000 & .02000 & .00000 & 1671 \\
\hline HLW07-05 & LW07 & .04961 & .04961 & .00498 & .00050 & .00496 & .13891 & .04750 & .00120 & .06945 & .11693 & \begin{tabular}{|l|}
.00100 \\
\end{tabular} & .00040 & .00020 & .00199 & .39825 & .00000 & .00000 & .00019 & .06306 & .03461 & .00000 & 1665 \\
\hline HLW07-06 & LW07 & .11501 & .06001 & .00300 & .01000 & .00600 & .04000 & .00000 & .00000 & \begin{tabular}{|l|}
.06001 \\
\end{tabular} & .12530 & \begin{tabular}{|l|}
.00000 \\
\end{tabular} & .01010 & .00400 & .00000 & .35004 & .10001 & .00000 & .00000 & .04100 & .00000 & .02951 & 4601 \\
\hline HLW07-07 & LW07 & .03000 & .06001 & .00300 & .01000 & .00050 & .14001 & .00000 & .00000 & .00500 & \begin{tabular}{|l|}
.17977 \\
\end{tabular} & \begin{tabular}{|l|}
.01000 \\
\end{tabular} & .01010 & .00400 & .00000 & .35059 & .10001 & .00000 & .00000 & .04100 & .00000 & .01000 & 4601 \\
\hline HLW07-09 & LW07 & .03000 & .06001 & .00300 & .00000 & .00600 & .10459 & .04500 & .00000 & .00500 & .08603 & \begin{tabular}{|l|}
.00000 \\
\end{tabular} & .00000 & .00400 & .00000 & .35004 & .10001 & .04400 & .00000 & .00000 & .02500 & .09601 & 4130 \\
\hline HLW07-10 & LW07 & .03000 & .11867 & .00300 & .01000 & .00600 & .14001 & .00000 & .00000 & .00500 & \begin{tabular}{|l|}
.09461 \\
\end{tabular} & \begin{tabular}{|l|}
.00114 \\
\end{tabular} & .01010 & .00400 & .00000 & .35004 & .10001 & .04400 & .00000 & .04100 & .00000 & .01000 & 3240 \\
\hline HLW07-11 & W07 & .11501 & .06001 & .00300 & .01000 & .00600 & .10495 & .04500 & .00000 & .00500 & .17016 & \begin{tabular}{|l|}
.01000 \\
\end{tabular} & .01010 & .00400 & .00000 & .35004 & .02332 & .00000 & .00000 & .04100 & .00000 & .01000 & 3240 \\
\hline HLW07-12 & W07 & .11501 & .06001 & .00300 & .00000 & .00116 & .13191 & .04413 & .00000 & .00500 & .17903 & .00000 & .00000 & .00400 & .00000 & .35004 & .00000 & .04400 & .00000 & .00000 & .02500 & .01000 & .02770 \\
\hline HLW07-13 & HLW07 & .11501 & . & .00300 & .00435 & .00600 & .04000 & .00790 & . & . .00500 & \begin{tabular}{|l|l|}
.18002 \\
\end{tabular} & . .00000 & |.00440 & .00400 & .00000 & .36494 & . & .00000 & .00000 & .04100 & .02500 & .09601 & .04335 \\
\hline
\end{tabular}

(a) Normalized to sum to 1.00000 over the 22 components listed in this table. The normalized component mass fractions listed in this table were rounded to five decimals, and may not sum exactly to 1.00000 as listed. However, complete compositions listed to more decimal places and summing to 1.00000 were used for property-composition modeling.

(b) The Group IDs are described in Sections 2.1.1 to 2.1.9. 
Table 8.1. $\quad$ Normalized $^{(\text {a) }}$ 22-Component Compositions (mass fractions) of 197 HLW Glasses Used for Viscosity Model Development (continued).

\begin{tabular}{|c|c|c|c|c|c|c|c|c|c|c|c|c|c|c|c|c|c|c|c|c|c|c|c|}
\hline D & $\underset{\text { ID }^{(\mathbf{b})}}{\text { Group }}$ & $\mathbf{I}_{2} \mathbf{O}_{3}$ & $\mathbf{B}_{2} \mathbf{O}_{3}$ & $\mathrm{aO}$ & $\mathrm{CdO}$ & $\mathbf{r}_{2} \mathrm{O}_{3}$ & $O_{3}$ & $\mathbf{O}$ & $\mathbf{O}$ & InO & $\mathbf{a}_{2} \mathrm{O}$ & NiO & PbO & $\mathbf{S b}_{2} \mathbf{O}_{3}$ & $\mathrm{SeO}_{2}$ & $\mathrm{SiO}_{2}$ & SrO & $\mathrm{ThO}_{2}$ & $\mathbf{T l}_{2} \mathbf{O}$ & $\mathbf{U O}_{3}$ & $\mathrm{ZnO}$ & $\mathrm{ZrO}_{2}$ & Othe \\
\hline & & 400 & 01 & & 000 & 050 & & & 00 & 01 & 002 & 000 & 000 & 400 & 000 & 5004 & 001 & 000 & .00000 & 2470 & 000 & 601 & \\
\hline HLV & 07 & 400 & 1569 & 300 & 0000 & 0600 & 1000 & 3853 & 0000 & 6001 & 3002 & 1000 & 0000 & 0400 & .00000 & .35004 & .00000 & .00000 & .00000 & .00000 & .02500 & 9601 & 2770 \\
\hline HLW07-17 & W07 & .11501 & .13001 & 0300 & .00000 & .00050 & 4000 & 4253 & .00000 & 06001 & 18002 & 0000 & 00000 & .00400 & .00000 & 35861 & .00000 & .00000 & .00000 & .00000 & .00000 & .02500 & 4130 \\
\hline HLW07-18 & HLW07 & .09077 & .13001 & 0300 & .00000 & .00600 & $0 / 925$ & 4500 & .00000 & 00500 & 18002 & .00000 & 00000 & .00400 & .00000 & .37524 & .00000 & .04400 & .00000 & .00000 & .00000 & 01000 & 2770 \\
\hline HLW07-19 & $\mathrm{H}$ & .03000 & .06572 & .00300 & .01000 & .00600 & 55401 & 84210 & .00000 & 00500 & .15061 & .00000 & .01010 & .00400 & .00000 & .35004 & .10001 & .00000 & .00000 & .04100 & .00000 & 09601 & 3240 \\
\hline HLW07. & $\mathrm{H}$ & .11501 & .13001 & .00300 & .00000 & .00600 & 15501 & .04500 & .00000 & .06001 & .06001 & .00000 & 00000 & .00400 & .00000 & .46179 & .00000 & .02246 & .00000 & .00000 & .00000 & .01000 & 2770 \\
\hline HLW07 & $\mathrm{H}$ & .03000 & .06001 & .00300 & .01000 & .00050 & 55401 & .00000 & .00000 & .00500 & .11335 & .00000 & .01010 & .00400 & .00000 & .42700 & .10001 & .00000 & .00000 & .04100 & .00000 & .09601 & 4601 \\
\hline HLW07-22 & $\mathrm{H}$ & .11501 & .06073 & .00300 & .01000 & .00050 & .04000 & .00000 & .00000 & .00500 & .12419 & .01000 & .01010 & .00400 & .00000 & 35004 & .10001 & .04400 & .00000 & .04100 & .02500 & .02500 & 3240 \\
\hline HLW07-23 & HLW07 & .04400 & .13001 & .00300 & .00000 & .00600 & .04000 & .01822 & .00000 & .00500 & .06620 & .01000 & .00000 & .00400 & .00000 & .41883 & .06501 & .00000 & .00000 & .04100 & .02500 & .09601 & 2770 \\
\hline \begin{tabular}{|l|} 
HLW07-24 \\
\end{tabular} & & .11501 & .13001 & .00300 & .00000 & .00600 & .05501 & .00000 & .00000 & .00500 & .16120 & \begin{tabular}{|l|}
.01000 \\
\end{tabular} & .00000 & .00400 & .00000 & .37445 & .00000 & .04400 & .00000 & .04100 & .00000 & .01000 & 4130 \\
\hline HLW & & .11501 & .06001 & .00300 & .01000 & .00050 & .05501 & .00997 & .00000 & .06001 & .11453 & .00000 & . 01010 & .00400 & .00000 & .42662 & .00000 & .04400 & .00000 & .04100 & .00384 & .01000 & 3240 \\
\hline HLV & & .10001 & .08000 & .00150 & .00000 & .00150 & .06000 & .03460 & .00000 & .02500 & .10001 & .00650 & .00000 & .00200 & .00000 & .47002 & .02500 & .03500 & .00000 & .01500 & .00500 & .02500 & 1385 \\
\hline $\mathrm{HLW}$ & & .10001 & .11001 & .00150 & .00000 & .00400 & .06000 & .03500 & . & .02500 & .10001 & .00200 & .00000 & .00200 & .00000 & .40002 & .07000 & .01000 & .00000 & .03000 & .00500 & .02500 & 2045 \\
\hline HLW07-29 & & .05000 & .11001 & .00150 & .00000 & .00150 & .11001 & .01000 & .00000 & . .04000 & .10782 & .00650 & .00000 & .00200 & .00000 & .40002 & .05179 & .03500 & .00000 & .03000 & .00500 & .02500 & 1385 \\
\hline HLW07-30 & H & .05000 & .08000 & .00150 & .00000 & .00400 & .11001 & .01000 & .00000 & .03687 & .12614 & .00200 & .00000 & .00200 & .00000 & .47002 & .02500 & .01000 & .00000 & .01500 & .00500 & .02500 & 2745 \\
\hline HLW07-31 & $\mathrm{H}$ & .10001 & .11001 & .00150 & .00500 & .00400 & .06000 & .01357 & .00000 & .02500 & .10001 & \begin{tabular}{|r|r|}
.00403 \\
\end{tabular} & .00505 & .00200 & .00000 & .40002 & .07000 & .01000 & .00000 & .03000 & .00500 & .02500 & 2980 \\
\hline HLW07-32 & HLWO & .05000 & .08000 & .00150 & .00500 & .00150 & .11001 & .01000 & .00000 & .02500 & .14001 & .00650 & .00505 & .00200 & .00000 & .40002 & .03264 & .01000 & .00000 & .01500 & .01096 & .06500 & 2980 \\
\hline HLW07-33 & HLW07 & .10001 & .08000 & .00150 & .00000 & .00400 & .06297 & .01000 & .00000 & .04000 & .12268 & .00650 & .00000 & .00200 & .00000 & . 42207 & .06940 & .01000 & .00000 & .01500 & .01500 & 2500 & 1385 \\
\hline HLW07-34 & HLW07 & .10001 & .11001 & .00150 & .00000 & .00150 & .06000 & .02063 & .00000 & .04000 & .10001 & .00650 & .00000 & .00200 & .00000 & .41514 & .02905 & .01000 & .00000 & .01981 & .00500 & .06500 & 1385 \\
\hline HLW07-35 & HLW07 & .10001 & .09587 & .00150 & .00000 & .00400 & .06000 & .01347 & .00000 & .02500 & .10001 & .00200 & .00000 & .00200 & .00000 & .40002 & .07000 & .03500 & .00000 & .01500 & .01500 & 4727 & 01385 \\
\hline HLW07-36 & HLW07 & .09500 & .11001 & .00150 & .00000 & .00150 & .06000 & .01000 & .00000 & .02500 & .14001 & .00200 & .00000 & .00200 & .00000 & .40002 & .06910 & .01000 & .00000 & .03000 & .00500 & .02500 & 01385 \\
\hline HLW07-37 & HLW07 & .05000 & .08000 & .00150 & .00500 & .00150 & .10501 & .03500 & .00000 & .04000 & .13811 & .00200 & .00505 & .00200 & .00000 & .40002 & .02500 & .03500 & .00000 & .01500 & .00500 & .02500 & .02980 \\
\hline HLW07-38 & HLW07 & .05000 & .11001 & .00150 & .00500 & .00400 & .06500 & .01000 & .00000 & .04000 & .10393 & .00200 & .00505 & .00200 & .00000 & .41670 & .02500 & .03500 & .00000 & .01500 & .01500 & .06500 & 02980 \\
\hline HLW07-39 & HLW07 & .05500 & .11001 & .00150 & .00500 & .00400 & .06000 & .01000 & .00000 & .02500 & .13629 & .00200 & .00505 & .00200 & .00000 & .44794 & .02500 & .01000 & .00000 & .01500 & .00500 & .06500 & 01620 \\
\hline HLW-ALG-01 & HLWALG & .11086 & .10560 & .00331 & .00000 & .00501 & .09619 & .03329 & .00096 & .00000 & .17280 & .00000 & \begin{tabular}{|l|l|l|}
.00202 \\
\end{tabular} & .00000 & .00000 & .45286 & .00000 & .00000 & .00000 & .00000 & .01062 & .00000 & 00649 \\
\hline HLW-ALG-02 & HLWALG & .08001 & .11088 & .00350 & .00000 & .00278 & .07145 & .03550 & .00101 & .00000 & .15318 & .00522 & .00214 & .00000 & .00000 & .44674 & .00000 & .00000 & .00000 & .00000 & .01577 & .06495 & .00686 \\
\hline HLW-ALG-03 & HLWALG & .01926 & .08621 & .00339 & .00000 & .00501 & .12650 & .03057 & .00098 & .02095 & .18966 & 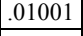 & .00207 & .00000 & .00000 & .44365 & .00000 & .00000 & .00000 & .00000 & .00032 & .05433 & 00708 \\
\hline HLW-ALG-04 & HLWALG & .01926 & .11134 & .00224 & .00000 & .00501 & .12639 & .02876 & .00066 & .00000 & .15980 & .01001 & .00135 & .00000 & .00000 & .51881 & .00000 & .00000 & .00000 & .00000 & .01226 & .00000 & .00409 \\
\hline HLW-ALG-05 & HLWALG & .01927 & .04810 & .00521 & .01198 & .00415 & .12536 & .04286 & .00149 & .06906 & .08937 & .00781 & .00320 & .00000 & .00000 & .46197 & .09891 & .00000 & .00000 & .00000 & .00050 & .00000 & .01077 \\
\hline HLW-ALG-06 & HLWALG & . & . & .00579 & .01322 & .00201 & .10620 & .02530 & .00164 & . & .15635 & \begin{tabular}{|l|l|l|}
.00481 \\
\end{tabular} & . & .00000 & .00000 & .37279 & . 08015 & .01603 & . & .00601 & .00055 & .00801 & .01272 \\
\hline
\end{tabular}

(a) Normalized to sum to 1.00000 over the 22 components listed in this table. The normalized component mass fractions listed in this table were rounded to five decimals, and may not sum exactly to 1.00000 as listed. However, complete compositions listed to more decimal places and summing to 1.00000 were used for property-composition modeling.

(b) The Group IDs are described in Sections 2.1.1 to 2.1.9. 
Table 8.1. $\quad$ Normalized $^{(\text {a) }}$ 22-Component Compositions (mass fractions) of 197 HLW Glasses Used for Viscosity Model Development (continued).

\begin{tabular}{|c|c|c|c|c|c|c|c|c|c|c|c|c|c|c|c|c|c|c|c|c|c|c|c|}
\hline & p & $\mathrm{O}_{3}$ & $D_{3}$ & $\mathrm{CaO}$ & dO & 3 & 3 & $\mathbf{L i}_{2} \mathbf{O}$ & 0 & no & $\mathbf{O}$ & $\mathbf{N i O}$ & PbO & $\mathbf{S b}_{2} \mathbf{O}_{3}$ & $\mathrm{SeO}_{2}$ & $\mathrm{SiO}_{2}$ & SrO & $\mathrm{hO}_{2}$ & $\mathbf{T l}_{2} \mathbf{O}$ & $\mathbf{U O}_{3}$ & $\mathrm{ZnO}$ & $\mathrm{ZrO}_{2}$ & Oth \\
\hline & & & 704 & & 00 & & & & & & 777 & & & & 0000 & & & & 00 & & & & \\
\hline-08 & & & 307 & 591 & 349 & 471 & & & & 560 & 943 & \begin{tabular}{|l|l|}
.00887 \\
\end{tabular} & 364 & 000 & 0000 & 6699 & 6267 & 4006 & .00000 & 4644 & 0056 & 9541 & 323 \\
\hline HLW-ALG-09 & & 480 & 4808 & 0560 & 0084 & 0211 & 31 & . & 92 & 3916 & 116 & \begin{tabular}{|l|l|}
.00189 \\
\end{tabular} & .00410 & 000 & .00000 & 38868 & 7479 & .00603 & .00000 & .01360 & 0059 & 2565 & 1883 \\
\hline LG-10 & & 926 & 448 & .00332 & .00854 & .00501 & .10984 & .02020 & .00096 & 7010 & \begin{tabular}{|l|l|}
.17410 \\
\end{tabular} & \begin{tabular}{|l|l|}
.01001 \\
\end{tabular} & . .00203 & 0000 & .00000 & 47112 & .00000 & .00228 & .00000 & .00000 & 0031 & 0159 & 0685 \\
\hline HLW-ALG-11 & & 1886 & 2188 & .00565 & . & .00000 & 1928 & .06013 & .00163 & 3408 & .06065 & .00000 & .00348 & 0000 & .00000 & 5076 & . 05994 & .06013 & .00000 & .00000 & 0054 & 9125 & 1174 \\
\hline ALG-12 & & 5938 & 4807 & .00586 & .00406 & .00285 & .12540 & . .02750 & .00166 & 2029 & \begin{tabular}{|l|l|}
.15899 \\
\end{tabular} & \begin{tabular}{|l|l|}
.00812 \\
\end{tabular} & .00361 & 0000 & .00000 & 0350 & . 06087 & .01623 & .00000 & .01623 & 0056 & 2394 & 1288 \\
\hline HLW-ALG-14 & & .03543 & .04809 & .00507 & . 01486 & .00000 & .12562 & .06012 & .00146 & .06715 & .04804 & \begin{tabular}{|l|l|}
.00759 \\
\end{tabular} & .00311 & .00000 & .00000 & . 47605 & . 09618 & .00000 & .00000 & .00000 & 0048 & 0000 & 1075 \\
\hline HLW-ALG-15 & & .09731 & .14029 & .00424 & . & .00338 & .09780 & . 01928 & .00121 & 00000 & .17583 & .00636 & .00261 & .00000 & .00000 & 37449 & . 00000 & .00000 & .00000 & .00000 & 00040 & 6845 & 0835 \\
\hline LG-16 & & .10329 & .13850 & .00363 & .00025 & .00501 & .04396 & .02021 & .00104 & \begin{tabular}{|l|}
.00000 \\
\end{tabular} & \begin{tabular}{|l|}
.17406 \\
\end{tabular} & \begin{tabular}{|l|}
.00751 \\
\end{tabular} & .00223 & .00000 & .00000 & .43773 & .00000 & .00000 & .00000 & .00000 & 01786 & 3757 & 7714 \\
\hline $\mathrm{G}-17$ & & .01926 & .10338 & .00331 & .00000 & .00501 & .12515 & .02020 & .00095 & .06912 & .17414 & \begin{tabular}{|l|}
.00997 \\
\end{tabular} & .00202 & .00000 & .00000 & .45869 & .00000 & .00000 & .00000 & .00000 & 00031 & 0159 & 889 \\
\hline & & .11360 & .11109 & .00339 & .00000 & .00000 & .10369 & .03437 & .00098 & \begin{tabular}{|l|}
.00000 \\
\end{tabular} & \begin{tabular}{|l|}
.14807 \\
\end{tabular} & \begin{tabular}{|l|}
.00000 \\
\end{tabular} & .00207 & .00000 & .00000 & .45993 & .00000 & .00000 & .00000 & .00000 & .01616 & 0000 & 665 \\
\hline & & .01926 & .09652 & .00340 & .00000 & .00501 & .12652 & .02659 & .00098 & \begin{tabular}{|l|}
.02096 \\
\end{tabular} & \begin{tabular}{|l|}
.16131 \\
\end{tabular} & \begin{tabular}{|l|}
.01001 \\
\end{tabular} & .00207 & .00000 & .00000 & .46563 & .00000 & .00000 & .00000 & .00000 & .00032 & 5434 & 0707 \\
\hline & & .01926 & .07754 & .00340 & .00000 & .00501 & .12651 & .02926 & .00098 & .02095 & .17400 & \begin{tabular}{|l|}
.01001 \\
\end{tabular} & .00207 & .00000 & .00000 & .46929 & .00000 & .00000 & .00000 & .00000 & .00032 & 5434 & 0708 \\
\hline $\mathrm{s}-21$ & & \begin{tabular}{|l|l|}
.02619 \\
\end{tabular} & .04810 & .00642 & . 00131 & .00493 & 53 & . 02475 & .00112 & \begin{tabular}{|l|l|l}
.0186 \\
\end{tabular} & .17623 & \begin{tabular}{|r|}
.00542 \\
\end{tabular} & .00180 & .00000 & .00000 & .38986 & . 00000 & .05894 & .00000 & .04502 & .00084 & 8915 & 1142 \\
\hline $\mathrm{s}-22$ & & .02588 & .06599 & .00635 & . & .00487 & 18 & . 02407 & .00111 & .01172 & .16615 & .00535 & .00178 & .00000 & .00000 & .38701 & . 00000 & .05824 & .00000 & .04449 & .00083 & .08809 & 1128 \\
\hline $\mathrm{G}-23$ & & .02492 & .04809 & .00611 & . 00124 & .00469 & 80 & . 02069 & .00107 & .01127 & \begin{tabular}{|l|l|}
.19298 \\
\end{tabular} & .00515 & .00171 & .00000 & .00000 & .39517 & . & .05599 & .00000 & .04278 & .00079 & .08469 & 1086 \\
\hline HLW-ALG-25 & & 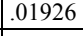 & .10096 & .00332 & . & .00501 & .11817 & . 02020 & .00096 & .07012 & .17414 & \begin{tabular}{|l|l|l}
.01002 \\
\end{tabular} & .00203 & .00000 & .00000 & .46478 & . .00000 & .00228 & .00000 & .00000 & .00031 & .00159 & 0685 \\
\hline HLW-ALG-26 & LG & .04632 & .07474 & .00661 & .00046 & .00000 & 7 & . 03024 & .00187 & \begin{tabular}{|l|l|}
.02289 \\
\end{tabular} & \begin{tabular}{|l|l|}
.09610 \\
\end{tabular} & \begin{tabular}{|l|l|}
.00046 \\
\end{tabular} & .00408 & .00000 & .00000 & .43210 & . 04578 & .04120 & .00000 & \begin{tabular}{|l|l|}
.04578 \\
\end{tabular} & \begin{tabular}{|l|l}
.01427 \\
\end{tabular} & 8866 & 1451 \\
\hline HLW-ALG-27 & WALG & .13025 & .14027 & .00387 & .00000 & .00000 & .11905 & .01928 & .00111 & \begin{tabular}{|l|}
.00000 \\
\end{tabular} & \begin{tabular}{|l|}
.17589 \\
\end{tabular} & .00000 & .00238 & .00000 & .00000 & .37713 & .00000 & .00000 & .00000 & .00000 & .02316 & 000 & 7762 \\
\hline HLW-ALG-28 & LWALG & .08839 & .14027 & .00388 & .00000 & .00322 & .12 & .01928 & .00111 & .02330 & .17589 & \begin{tabular}{|l|}
.00589 \\
\end{tabular} & .00238 & .00000 & .00000 & .39956 & .00000 & .00000 & .00000 & .00000 & .00037 & 0000 & 63 \\
\hline HLW-ALG-29 & LWALG & .09926 & .14030 & .00433 & .00000 & \begin{tabular}{|l|}
.00345 \\
\end{tabular} & .08882 & .01928 & .00123 & .00000 & .17581 & .00649 & \begin{tabular}{|l|}
.00266 \\
\end{tabular} & .00000 & .00000 & .36865 & .00000 & .00000 & .00000 & .00000 & .00041 & .08079 & 0852 \\
\hline HLW-ALG-30 & WALG & .07250 & .09597 & .00422 & .00631 & .00141 & .11020 & .03099 & .00102 & \begin{tabular}{|l|}
.00323 \\
\end{tabular} & \begin{tabular}{|l|}
.15321 \\
\end{tabular} & \begin{tabular}{|l|}
.00485 \\
\end{tabular} & \begin{tabular}{|l|}
.00073 \\
\end{tabular} & .00000 & .00000 & .44901 & .00153 & .00000 & .00000 & .00911 & .00654 & .03343 & 1574 \\
\hline HLW-ALG-31 & WALG & .01926 & .10888 & .00340 & .00000 & .00501 & .12650 & .03078 & .00098 & \begin{tabular}{|l|}
.02095 \\
\end{tabular} & \begin{tabular}{|l|}
.11711 \\
\end{tabular} & \begin{tabular}{|l|}
.01001 \\
\end{tabular} & .00207 & .00000 & .00000 & .47666 & .00000 & .00000 & .00000 & .00000 & .01699 & .05433 & 0706 \\
\hline HLW-ALG-32 & WALG & .06000 & .04810 & .00529 & .01213 & .00420 & .12753 & .03972 & .00151 & \begin{tabular}{|l|}
.06996 \\
\end{tabular} & \begin{tabular}{|l|}
.09317 \\
\end{tabular} & \begin{tabular}{|l|}
.00791 \\
\end{tabular} & .00324 & .00000 & .00000 & .41153 & .10020 & .00000 & .00000 & .00000 & .00404 & .00000 & 1146 \\
\hline HLW-ALG-33 & HLWALG & .11389 & .08006 & .00497 & .00000 & .00396 & .11456 & .03783 & .00141 & .00000 & .17656 & \begin{tabular}{|l|}
.00746 \\
\end{tabular} & .00306 & .00000 & .00000 & .36552 & .00000 & .00000 & .00000 & .00000 & .00047 & .08019 & 1005 \\
\hline HLW-ALG-34 & WALG & .01926 & .08223 & .00331 & .00000 & .00501 & .12515 & .02020 & .00096 & .06912 & \begin{tabular}{|l|}
.19002 \\
\end{tabular} & \begin{tabular}{|l|}
.00997 \\
\end{tabular} & .00202 & .00000 & .00000 & .46396 & .00000 & .00000 & .00000 & .00000 & .00031 & .00159 & 0689 \\
\hline HLW-ALG-35 & WALG & .05519 & .04808 & .00564 & .00085 & .00212 & .14024 & .02801 & .00495 & .03942 & .10818 & \begin{tabular}{|l|}
.00190 \\
\end{tabular} & .00413 & .00000 & .00000 & .40921 & .07529 & .00607 & .00000 & .01369 & .01228 & .02582 & 1894 \\
\hline HLW-ALG-36 & WALG & .06536 & .06511 & .00645 & .00447 & .00314 & .13819 & .02903 & .00182 & \begin{tabular}{|l|}
.02236 \\
\end{tabular} & .12535 & \begin{tabular}{|l|}
.00894 \\
\end{tabular} & \begin{tabular}{|l|}
.00398 \\
\end{tabular} & .00000 & .00000 & .38173 & .06709 & .01789 & .00000 & .01789 & .00062 & .02639 & 1418 \\
\hline HLW-ALG-37 & HLWALG & .06186 & .04808 & .00884 & .00062 & .00000 & .07240 & .02580 & .00248 & .03072 & .09358 & .00061 & .00547 & .00000 & .00000 & .35059 & .06145 & .05530 & .00000 & .06145 & .00853 & .09217 & .02005 \\
\hline HLW-ALG-39 & HLWALG & \begin{tabular}{|l|l|l|l|l|}
.0197 \\
\end{tabular} & .10207 & .00468 & . & .00358 & .07012 & . 03110 & .00084 & \begin{tabular}{|l|l|}
.00860 \\
\end{tabular} & \begin{tabular}{|l|l|l|l|l|l|} 
\\
\end{tabular} & \begin{tabular}{|l|l|l|}
.00393 \\
\end{tabular} & .00131 & .00000 & .00000 & .47962 & . & .04274 & .00000 & .03265 & .01572 & .06465 & .00763 \\
\hline
\end{tabular}

(a) Normalized to sum to 1.00000 over the 22 components listed in this table. The normalized component mass fractions listed in this table were rounded to five decimals, and may not sum exactly to 1.00000 as listed. However, complete compositions listed to more decimal places and summing to 1.00000 were used for property-composition modeling.

(b) The Group IDs are described in Sections 2.1.1 to 2.1.9. 
Table 8.1. $\quad$ Normalized $^{(\text {a) }}$ 22-Component Compositions (mass fractions) of 197 HLW Glasses Used for Viscosity Model Development (continued).

\begin{tabular}{|c|c|c|c|c|c|c|c|c|c|c|c|c|c|c|c|c|c|c|c|c|c|c|c|}
\hline Glass ID & $\underset{\text { ID }^{\text {Gr) }}}{\text { Group }}$ & ${ }_{2} \mathrm{O}_{3}$ & $\mathbf{B}_{2} \mathbf{O}_{3}$ & $\mathrm{aO}$ & CdO & $\mathbf{r}_{2} \mathrm{O}_{3}$ & $O_{3}$ & $\mathbf{L i}_{2} \mathbf{O}$ & IgO & InO & $\mathrm{Na}_{2} \mathrm{O}$ & $\mathrm{NiO}$ & PbO & $\mathbf{S b}_{2} \mathbf{O}_{3}$ & $\mathrm{SeO}_{2}$ & $\mathrm{SiO}_{2}$ & SrO & $\mathrm{ThO}_{2}$ & $\mathbf{T l}_{2} \mathbf{O}$ & $\mathbf{U O}_{3}$ & ZnO & $\mathrm{rO}_{2}$ & Others \\
\hline HLW-ALG-40 & & 95 & 36 & 35 & 802 & 179 & 008 & 154 & 28 & 411 & 348 & 616 & 092 & 000 & .00000 & 399 & 195 & .00000 & .00000 & 1158 & 162 & $\$ 250$ & 050 \\
\hline HLW98-72 & HLW98 & 192 & 185 & 278 & 0064 & 0000 & 2189 & 5028 & 0107 & 0169 & 3447 & \begin{tabular}{|l|l|}
.00618 \\
\end{tabular} & . .00036 & .00000 & .00000 & .47982 & .00000 & .00000 & .00000 & .00000 & .02018 & .03795 & 0894 \\
\hline $\mathrm{HLV}$ & HLWS & . .05196 & 908 & .00280 & .00064 & .00000 & .12221 & 3525 & .00106 & .00170 & 11659 & .00615 & .00034 & .00000 & .00000 & .47453 & .00032 & .00000 & .00000 & .00000 & .02016 & .03806 & 0914 \\
\hline HLV & $\mathrm{H}$ & .05590 & 2529 & .00233 & .00114 & .00000 & .12530 & .03260 & .00073 & .00357 & .12033 & \begin{tabular}{|l|l|}
.00447 \\
\end{tabular} & .00070 & .00000 & .00000 & .48308 & .00000 & .00000 & .00000 & .00000 & .02012 & .01772 & 0672 \\
\hline $\mathrm{HL}$ & $\mathrm{H}$ & .01428 & .11914 & . 00668 & . 00000 & .00045 & .12746 & . 02755 & .00565 & .03040 & .11738 & .00374 & .00252 & .00108 & .00212 & . 50938 & .00000 & .00000 & .00000 & .00000 & .02019 & .00127 & 01073 \\
\hline & $\mathrm{H}$ & .05182 & .11163 & . 00668 & . 00000 & .00045 & .12746 & . 02755 & .00565 & .03040 & .11988 & \begin{tabular}{|l|l|}
.00374 \\
\end{tabular} & .00252 & .00108 & .00212 & . 47684 & .00000 & .00000 & .00000 & .00000 & \begin{tabular}{|l|l}
.02019 \\
\end{tabular} & .00127 & 01073 \\
\hline$-86 \mathrm{AG}$ & & .05297 & .09407 & . 00300 & . 00000 & .00078 & .12582 & . 03012 & .01168 & .03996 & .11859 & \begin{tabular}{|l|l|}
.00172 \\
\end{tabular} & .00145 & .00256 & .00370 & .47137 & .00918 & .00000 & .00000 & .00000 & .02074 & .00259 & 00971 \\
\hline HLW98-87 & HLW98 & .07680 & .10102 & . & .00674 & .00143 & .11759 & . 03509 & .00104 & .00345 & .11076 & .00517 & .00078 & .00000 & .00000 & .44503 & .00164 & .00000 & .00000 & .00973 & .02014 & .03570 & 2348 \\
\hline HLW98-88 & HLW98 & .07454 & .10599 & .00429 & .00654 & .00139 & .11413 & .03759 & .00101 & .00335 & .11713 & \begin{tabular}{|l|}
.00502 \\
\end{tabular} & .00075 & .00000 & .00000 & .43966 & .00159 & .00000 & .00000 & .00944 & .02013 & .03465 & 02279 \\
\hline \begin{tabular}{|l|} 
HLW98-89 \\
\end{tabular} & HLW98 & .03360 & \begin{tabular}{|l|}
.09096 \\
\end{tabular} & .00452 & .00000 & .00059 & .08947 & .02843 & .00000 & .01425 & .10736 & \begin{tabular}{|l|}
.00438 \\
\end{tabular} & .00115 & .00000 & .00000 & .44571 & .00000 & .04051 & .00000 & .02573 & .02017 & .08843 & 00476 \\
\hline HLW98-95 & HLW98 & .07317 & .10632 & .00425 & . 00642 & .00143 & .11206 & . 03758 & .00099 & .00329 & .11925 & \begin{tabular}{|r|r|}
.00493 \\
\end{tabular} & .00074 & .00000 & .00000 & .44687 & .00156 & .00000 & .00000 & .00927 & .02012 & .03402 & 01774 \\
\hline HLW98-96 & HLW98 & .03360 & .10096 & . 00452 & . 00000 & .00059 & .08947 & . 03093 & .00000 & .01425 & .10736 & \begin{tabular}{|r|r|}
.00438 \\
\end{tabular} & .00115 & .00000 & .00000 & .43322 & .00000 & .04051 & .00000 & .02573 & .02017 & .08843 & 00476 \\
\hline HLW98-96D & HLW98 & .03598 & .10812 & . 00484 & . 00000 & .00063 & 09581 & . 03313 & .00000 & .01526 & .11497 & \begin{tabular}{|l|l|l}
.00469 \\
\end{tabular} & .00123 & .00000 & .00000 & .46395 & .00000 & .00000 & .00000 & .00000 & .02160 & .09470 & 00510 \\
\hline HLW98-97 & HLW98 & .09754 & .11050 & .00252 & . & .00028 & .10947 & . 03877 & .00094 & .00126 & .12180 & .00622 & .00063 & .00000 & .00000 & .43002 & .00029 & .00000 & .00000 & .00000 & .02063 & .03366 & 01869 \\
\hline HLW98-V19 & HLW98 & .05774 & .08816 & . 00351 & . 00000 & .00091 & .14687 & . 02814 & .01364 & .04665 & .11211 & .00201 & .00169 & .00299 & .00432 & .44496 & .01071 & .00000 & .00000 & .00000 & .01953 & .00302 & .01305 \\
\hline HLW98-V24 & HLW98 & .04732 & .10055 & .00242 & . 00000 & .00063 & .10123 & . 03230 & .00940 & .03216 & .12566 & \begin{tabular}{|l|l|l}
.00139 \\
\end{tabular} & .00116 & .00206 & .00298 & .50023 & .00738 & .00000 & .00000 & .00000 & .02206 & .00208 & .00900 \\
\hline HLW98-T05 & HLW98 & |.05386 & |.11846 & . & . & .00022 & .12638 & . 03008 & .00319 & |.01698 & .12010 & |.00410 & .00161 & .00054 & |.00106 & . & .00000 & .00000 & .00000 & .00000 & .02015 & .00950 & . 00873 \\
\hline
\end{tabular}

(a) Normalized to sum to 1.00000 over the 22 components listed in this table. The normalized component mass fractions listed in this table were rounded to five decimals, and may not sum exactly to 1.00000 as listed. However, complete compositions listed to more decimal places and summing to 1.00000 were used for property-composition modeling.

(b) The Group IDs are described in Sections 2.1.1 to 2.1.9. 
Table 8.2. Temperature and Viscosity Observations and Data-Splitting Validation Sets for Each of the 197 HLW Glasses Used for Viscosity Model Development.

\begin{tabular}{|c|c|c|c|c|c|c|c|c|c|c|}
\hline Glass ID & $\begin{array}{l}\text { Group } \\
\text { ID }^{\text {(a) }}\end{array}$ & $\begin{array}{c}\text { Temp1 } \\
\left({ }^{\circ} \mathbf{C}\right)\end{array}$ & $\begin{array}{c}\text { Vis1 } \\
\text { (P) }\end{array}$ & $\begin{array}{c}\text { Temp2 } \\
\left({ }^{\circ} \mathrm{C}\right)\end{array}$ & $\begin{array}{l}\text { Vis2 } \\
\text { (P) }\end{array}$ & $\begin{array}{c}\text { Temp3 } \\
\left({ }^{\circ} \mathbf{C}\right)\end{array}$ & $\begin{array}{l}\text { Vis3 } \\
\text { (P) }\end{array}$ & $\begin{array}{c}\text { Temp4 } \\
\left({ }^{\circ} \mathrm{C}\right)\end{array}$ & $\begin{array}{l}\text { Vis4 } \\
\text { (P) }\end{array}$ & $\begin{array}{c}\text { Visc. Data } \\
\text { Splitting } \\
\text { Validation } \\
\text { Set }^{(\mathbf{b})} \\
\end{array}$ \\
\hline HLW02-01 & HLW02 & 1245 & 15.13 & 1148 & 31.72 & 1050 & 75.25 & 952 & 235.47 & NA-Rep ${ }^{(c)}$ \\
\hline HLW02-02 & HLW02 & 1247 & 20.39 & 1146 & 40.63 & 1047 & 96.00 & 946 & 289.21 & 5 \\
\hline HLW02-03 & HLW02 & 1245 & 8.54 & 1148 & 19.03 & 1050 & 47.37 & 953 & 158.90 & 1 \\
\hline HLW02-04 & HLW02 & 1250 & 51.32 & 1151 & 114.25 & 1052 & 296.76 & 952 & 971.22 & NA-Rep \\
\hline HLW02-05 & HLW02 & 1251 & 26.99 & 1152 & 51.58 & 1053 & \begin{tabular}{|l|}
135.84 \\
\end{tabular} & 953 & 451.69 & 1 \\
\hline HLW02-07 & HLW02 & 1221 & 42.99 & 1125 & 84.95 & 1030 & 210.73 & 934 & 646.25 & 3 \\
\hline HLW02-08 & HLW02 & 1247 & 5.62 & 1149 & 11.58 & 1051 & 27.12 & 952 & 80.66 & NA-Rep \\
\hline HLW02-09 & HLW02 & 1234 & 9.70 & 1137 & 18.79 & 1040 & 40.70 & 943 & 114.33 & 3 \\
\hline HLW02-10 & HLW02 & 1251 & 7.05 & 1152 & 13.40 & 1054 & 29.16 & 955 & \begin{tabular}{|l|l|}
81.10 \\
\end{tabular} & 4 \\
\hline HLW02-11 & HLW02 & 1228 & 9.35 & 1132 & 18.21 & 1030 & 40.91 & 940 & 125.47 & 4 \\
\hline HLW02-12 & HLW02 & 1254 & 7.15 & 1155 & 13.51 & 1057 & 29.31 & 958 & 86.51 & 1 \\
\hline HLW02-13 & HLW02 & 1246 & 7.31 & 1149 & 12.94 & 1053 & 26.58 & 956 & 69.77 & 1 \\
\hline HLW02-15 & HLW02 & 1253 & 11.34 & 1154 & 23.10 & 1055 & \begin{tabular}{|l|l|}
54.80 \\
\end{tabular} & 956 & 170.21 & 3 \\
\hline HLW02-16 & HLW02 & 1252 & 11.66 & 1152 & 20.94 & 1053 & 49.58 & 953 & 170.26 & 5 \\
\hline HLW02-17 & HLW02 & 1227 & 45.80 & 1130 & 102.04 & 1034 & 257.92 & 936 & 822.82 & NA-Rep \\
\hline HLW02-18 & HLW02 & 1240 & 48.68 & 1142 & 123.06 & 1045 & \begin{tabular}{|l|}
376.83 \\
\end{tabular} & 946 & $\begin{array}{l}1573.09 \\
\end{array}$ & 2 \\
\hline HLW02-19 & HLW02 & 1250 & 10.29 & 1152 & 22.77 & 1053 & 61.62 & 957 & 229.73 & 5 \\
\hline HLW02-20 & HLW02 & 1239 & 73.19 & 1143 & 172.70 & 1047 & \begin{tabular}{|l|}
492.51 \\
\end{tabular} & 950 & 1799.91 & 4 \\
\hline HLW02-21 & HLW02 & 1249 & 27.95 & 1151 & 58.10 & 1053 & \begin{tabular}{|l|}
147.29 \\
\end{tabular} & 955 & 506.85 & 4 \\
\hline HLW02-22 & HLW02 & 1247 & 48.95 & 1147 & 106.91 & 1048 & 267.10 & 947 & \begin{tabular}{|l|}
919.37 \\
\end{tabular} & NA-Rep \\
\hline HLW02-23 & HLW02 & 1254 & 8.47 & 1154 & 14.46 & 1055 & \begin{tabular}{|l|}
29.26 \\
\end{tabular} & 955 & 78.63 & 3 \\
\hline HLW02-24 & HLW02 & 1244 & 48.74 & 1144 & 118.54 & 1044 & 353.91 & 943 & 1373.72 & 1 \\
\hline HLW02-25 & HLW02 & 1235 & 68.92 & 1138 & 164.70 & 1041 & \begin{tabular}{|l|}
512.65 \\
\end{tabular} & 944 & 1726.81 & 1 \\
\hline HLW02-26 & HLW02 & 1241 & 8.98 & 1141 & 20.26 & 1042 & 54.57 & 942 & 205.34 & 4 \\
\hline HLW02-27 & HLW02 & 1246 & 6.31 & 1149 & 13.75 & 1052 & 33.17 & 956 & 104.05 & 4 \\
\hline HLW02-28 & HLW02 & 1230 & 19.48 & 1135 & 42.53 & 1040 & \begin{tabular}{|l|}
115.74 \\
\end{tabular} & 944 & \begin{tabular}{|l|}
379.76 \\
\end{tabular} & 3 \\
\hline HLW02-29 & HLW02 & 1251 & 14.38 & 1151 & 31.02 & 1051 & 81.43 & 951 & 279.67 & 1 \\
\hline HLW02-30 & HLW02 & 1235 & 7.63 & 1138 & 15.11 & 1041 & 34.99 & 944 & 104.76 & 5 \\
\hline HLW02-31 & HLW02 & 1253 & 11.74 & 1154 & 24.58 & 1054 & 62.29 & 955 & 195.38 & 2 \\
\hline HLW02-32 & HLW02 & 1230 & 20.75 & 1135 & 41.77 & 1040 & \begin{tabular}{|l|}
100.67 \\
\end{tabular} & 945 & 293.48 & 2 \\
\hline HLW02-33 & HLW02 & 1238 & 11.69 & 1141 & 23.91 & 1044 & 57.54 & 947 & 176.67 & 5 \\
\hline HLW02-34 & HLW02 & 1229 & 9.22 & 1136 & 17.24 & 1044 & 38.12 & 951 & \begin{tabular}{l|l}
108.00 \\
\end{tabular} & 4 \\
\hline HLW02-35 & HLW02 & 1226 & 10.62 & 1133 & 19.05 & 1041 & 39.89 & 948 & 122.16 & 5 \\
\hline HLW02-36 & HLW02 & 1235 & 18.69 & 1138 & 39.39 & 1041 & 99.31 & 943 & 309.38 & 4 \\
\hline HLW02-37 & HLW02 & 1245 & 15.68 & 1143 & 36.74 & 1040 & 99.52 & 938 & \begin{tabular}{|l|}
367.45 \\
\end{tabular} & 2 \\
\hline HLW02-38 & HLW02 & 1244 & 10.13 & 1143 & 20.30 & 1042 & \begin{tabular}{|c|}
47.59 \\
\end{tabular} & 941 & \begin{tabular}{|l|l}
147.90 \\
\end{tabular} & 3 \\
\hline HLW02-39 & HLW02 & 1253 & 51.96 & 1152 & 122.69 & 1051 & 340.15 & 950 & 1221.48 & 3 \\
\hline HLW02-40 & HLW02 & 1239 & 72.24 & 1142 & 171.24 & 1045 & 482.91 & 948 & 1830.58 & 3 \\
\hline HLW02-41 & HLW02 & 1241 & 38.16 & 1141 & 85.81 & 1042 & 230.44 & 942 & 796.60 & 4 \\
\hline HLW02-42 & HLW02 & 1246 & 10.82 & 1148 & 21.57 & 1050 & 50.09 & 951 & 148.44 & NA-Rep \\
\hline
\end{tabular}

(a) The Group IDs are described in Sections 2.1.1 to 2.1.9.

(b) Numbers from 1 to 5 denote the five split validation subsets. NA denotes "not applicable", because these replicate glasses were forced into the modeling subsets, and thus were not parts of the validation subsets.

(c) NA-Rep indicates glasses that were not included in any of the validation splits because they were replicates. 
Table 8.2. Temperature and Viscosity Observations and Data-Splitting Validation Sets for Each of the 197 HLW Glasses Used for Viscosity Model Development (continued).

\begin{tabular}{|c|c|c|c|c|c|c|c|c|c|c|}
\hline Glass ID & $\begin{array}{l}\text { Group } \\
\text { ID }^{(\mathbf{a})}\end{array}$ & $\begin{array}{c}\text { Temp1 } 1 \\
\left({ }^{\circ} \mathrm{C}\right)\end{array}$ & $\begin{array}{c}\text { Vis1 } \\
\text { (P) }\end{array}$ & $\begin{array}{c}\text { Temp2 } \\
\left({ }^{\circ} \mathrm{C}\right)\end{array}$ & $\begin{array}{c}\text { Vis3 } \\
\text { (P) }\end{array}$ & $\begin{array}{c}\text { Temp3 } \\
\left({ }^{\circ} \mathrm{C}\right)\end{array}$ & $\begin{array}{c}\text { Vis3 } \\
\text { (P) }\end{array}$ & $\begin{array}{c}\text { Temp4 } \\
\left({ }^{\circ} \mathrm{C}\right)\end{array}$ & $\begin{array}{c}\text { Vis4 } \\
\text { (P) }\end{array}$ & $\begin{array}{c}\text { Visc. Data } \\
\text { Splitting } \\
\text { Validation } \\
\text { Set }^{(\mathbf{b})}\end{array}$ \\
\hline HLW02-43 & HLW02 & 1236 & 10.73 & 1139 & 20.96 & 1042 & 48.17 & 945 & 145.30 & 5 \\
\hline HLW02-44 & HLW02 & 1238 & 16.53 & 1137 & 37.07 & 1035 & 95.53 & 934 & 321.40 & NA-Rep ${ }^{(c)}$ \\
\hline HLW02-45 & HLW02 & 1233 & 35.18 & 1135 & 80.79 & 1038 & 222.26 & 941 & 783.14 & 2 \\
\hline HLW02-46 & HLW02 & 1244 & 25.35 & 1144 & 55.19 & 1044 & 143.78 & 944 & 491.02 & NA-Rep \\
\hline HLW02-47 & HLW02 & 1237 & 40.58 & 1138 & 92.22 & 1040 & 284.16 & 941 & 1046.42 & 2 \\
\hline HLW02-48 & HLW02 & 1236 & 10.54 & 1137 & 22.60 & 1038 & 56.18 & 940 & 178.91 & 1 \\
\hline HLW02-49 & HLW02 & 1247 & 16.26 & 1148 & 33.21 & 1049 & 81.95 & 949 & 260.62 & 3 \\
\hline HLW02-50 & HLW02 & 1241 & 24.43 & 1141 & 55.09 & 1042 & 153.69 & 943 & 514.45 & 3 \\
\hline HLW02-51 & HLW02 & 1243 & 23.43 & 1145 & 49.28 & 1047 & 134.39 & 948 & 470.53 & 3 \\
\hline HLW02-52 & HLW02 & 1255 & 14.43 & 1155 & 29.91 & 1055 & 73.74 & 955 & 238.39 & NA-Rep \\
\hline HLW02-53 & HLW02 & 1244 & 47.79 & 1145 & 106.56 & 1046 & 275.47 & 947 & 875.67 & NA-Rep \\
\hline HLW02-54 & HLW02 & 1242 & 50.75 & 1138 & 114.86 & 1035 & 306.81 & 931 & 1065.15 & NA-Rep \\
\hline HLW02-55 & HLW02 & 1239 & 9.66 & 1140 & 19.25 & 1042 & 44.07 & 943 & 130.06 & NA-Rep \\
\hline HLW02-56 & HLW02 & 1235 & 15.31 & 1138 & 32.29 & 1041 & 79.94 & 943 & 260.34 & NA-Rep \\
\hline HLW02-57 & HLW02 & 1231 & 7.56 & 1135 & 13.91 & 1039 & 30.45 & 943 & 92.93 & NA-Rep \\
\hline HLW03-02 & HLW03 & 1253 & 5.95 & 1154 & 13.40 & 1056 & 37.57 & 957 & 159.81 & 2 \\
\hline HLW03-03 & HLW03 & 1257 & 4.81 & 1157 & 10.64 & 1057 & 30.91 & 957 & 125.46 & 3 \\
\hline HLW03-04 & HLW03 & 1261 & 6.18 & 1163 & 11.31 & 1064 & 28.46 & 965 & 90.61 & 2 \\
\hline HLW03-05 & HLW03 & 1251 & 30.18 & 1155 & 64.07 & 1058 & 164.75 & 960 & 476.54 & 5 \\
\hline HLW03-06 & HLW03 & 1245 & 39.29 & 1146 & 93.53 & 1049 & 267.56 & 951 & 977.37 & NA-Rep \\
\hline HLW03-07 & HLW03 & 1281 & 5.08 & 1192 & 9.29 & 1104 & 21.11 & 1016 & 62.80 & NA-Rep \\
\hline HLW03-09 & HLW03 & 1278 & 35.95 & 1175 & 72.51 & 1073 & 175.89 & 970 & 561.84 & 2 \\
\hline HLW03-11 & HLW03 & 1261 & 44.28 & 1165 & 95.82 & 1069 & 252.03 & 972 & 788.90 & NA-Rep \\
\hline HLW03-12 & HLW03 & 1256 & 11.94 & 1157 & 26.08 & 1057 & 71.77 & 958 & 273.50 & 5 \\
\hline HLW03-14 & HLW03 & 1245 & 5.91 & 1148 & 13.12 & 1051 & 37.61 & 953 & 167.78 & 3 \\
\hline HLW03-15 & HLW03 & 1260 & 53.15 & 1166 & 120.97 & 1072 & 318.75 & 979 & 1198.38 & 2 \\
\hline HLW03-16 & HLW03 & 1248 & 17.92 & 1155 & 39.81 & 1062 & 115.98 & 969 & 461.19 & 5 \\
\hline HLW03-17 & HLW03 & 1254 & 71.47 & 1154 & 175.51 & 1055 & 555.02 & 955 & 2259.05 & 5 \\
\hline HLW03-18 & HLW03 & 1250 & 17.41 & 1153 & 31.32 & 1056 & 72.41 & 959 & 213.16 & 3 \\
\hline HLW03-19 & HLW03 & 1252 & 15.83 & 1153 & 31.44 & 1055 & 74.70 & 956 & 232.06 & 4 \\
\hline HLW03-20 & HLW03 & 1252 & 18.75 & 1152 & 31.44 & 1052 & 73.10 & 952 & 213.30 & 5 \\
\hline HLW03-21 & HLW03 & 1251 & 52.94 & 1152 & 127.49 & 1054 & 400.00 & 955 & 1725.10 & 3 \\
\hline HLW03-22 & HLW03 & 1255 & 18.97 & 1155 & 45.70 & 1055 & 136.42 & 955 & 570.39 & 2 \\
\hline HLW03-23 & HLW03 & 1250 & 18.78 & 1150 & 42.33 & 1052 & 117.18 & 953 & 444.89 & 2 \\
\hline HLW03-24 & HLW03 & 1254 & 19.96 & 1156 & 45.11 & 1060 & 124.37 & 963 & 437.95 & 4 \\
\hline HLW03-25 & HLW03 & 1252 & 12.48 & 1155 & 27.54 & 1059 & 75.02 & 964 & 279.19 & 1 \\
\hline HLW03-26 & HLW03 & 1259 & 9.67 & 1162 & 18.33 & 1066 & 49.49 & 971 & 167.66 & NA-Rep \\
\hline HLW03-27 & HLW03 & 1252 & 11.30 & 1155 & 23.43 & 1059 & 59.15 & 964 & 200.77 & 3 \\
\hline HLW03-28 & HLW03 & 1239 & 6.51 & 1142 & 13.10 & 1046 & 30.38 & 951 & 90.34 & 5 \\
\hline HLW03-29 & HLW03 & 1247 & 8.74 & 1150 & 19.18 & 1054 & 51.62 & 958 & 187.70 & 1 \\
\hline
\end{tabular}

(a) The Group IDs are described in Sections 2.1.1 to 2.1.9.

(b) Numbers from 1 to 5 denote the five split validation subsets. NA denotes "not applicable", because these replicate glasses were forced into the modeling subsets, and thus were not parts of the validation subsets.

(c) NA-Rep indicates glasses that were not included in any of the validation splits because they were replicates. 
Table 8.2. Temperature and Viscosity Observations and Data-Splitting Validation Sets for Each of the 197 HLW Glasses Used for Viscosity Model Development (continued).

\begin{tabular}{|c|c|c|c|c|c|c|c|c|c|c|}
\hline Glass ID & $\begin{array}{l}\text { Group } \\
\text { ID }^{(\mathbf{a})}\end{array}$ & $\begin{array}{c}\text { Temp1 } 1 \\
\left({ }^{\circ} \mathrm{C}\right)\end{array}$ & $\begin{array}{c}\text { Vis1 } \\
\text { (P) }\end{array}$ & $\begin{array}{c}\text { Temp2 } \\
\left({ }^{\circ} \mathrm{C}\right)\end{array}$ & $\begin{array}{c}\text { Vis2 } \\
\text { (P) }\end{array}$ & $\begin{array}{c}\text { Temp3 } \\
\left({ }^{\circ} \mathrm{C}\right)\end{array}$ & $\begin{array}{c}\text { Vis3 } \\
\text { (P) }\end{array}$ & $\begin{array}{c}\text { Temp4 } \\
\left({ }^{\circ} \mathrm{C}\right)\end{array}$ & $\begin{array}{c}\text { Vis4 } \\
\text { (P) }\end{array}$ & $\begin{array}{c}\text { Visc. Data } \\
\text { Splitting } \\
\text { Validation } \\
\text { Set }^{(\mathbf{b})}\end{array}$ \\
\hline HLW03-30 & HLW03 & 1249 & 12.54 & 1155 & 26.72 & 1062 & 72.04 & 969 & 243.50 & 3 \\
\hline HLW03-31 & HLW03 & 1244 & 24.22 & 1147 & 53.82 & 1051 & 158.48 & 954 & 635.13 & 2 \\
\hline HLW03-33 & HLW03 & 1250 & 14.39 & 1153 & 31.97 & 1056 & 90.15 & 960 & 329.48 & 1 \\
\hline HLW03-34 & HLW03 & 1249 & 46.31 & 1151 & 112.97 & 1054 & 353.32 & 957 & 1436.25 & 4 \\
\hline HLW03-35 & HLW03 & 1243 & 69.54 & 1146 & 177.42 & 1049 & 567.22 & 952 & 2645.67 & 1 \\
\hline HLW03-36 & HLW03 & 1246 & 68.84 & 1148 & 184.37 & 1049 & 636.30 & 951 & 3165.51 & 4 \\
\hline HLW03-37 & HLW03 & 1246 & 10.94 & 1147 & 22.71 & 1049 & 60.63 & 950 & 201.62 & 2 \\
\hline HLW03-38 & HLW03 & 1248 & 42.04 & 1151 & 104.95 & 1053 & 352.03 & 956 & 1741.64 & 5 \\
\hline HLW03-39 & HLW03 & 1250 & 28.09 & 1153 & 64.55 & 1056 & 184.89 & 959 & 728.10 & 5 \\
\hline HLW03-40 & HLW03 & 1255 & 17.42 & 1156 & 37.28 & 1058 & 106.40 & 959 & 408.01 & 4 \\
\hline HLW03-41 & HLW03 & 1244 & 17.13 & 1147 & 39.20 & 1049 & 110.91 & 952 & 442.89 & NA-Rep $^{(\mathrm{c})}$ \\
\hline HLW03-42 & HLW03 & 1244 & 29.97 & 1148 & 66.99 & 1052 & 172.22 & 956 & 594.67 & NA-Rep \\
\hline HLW03-43 & HLW03 & 1257 & 40.72 & 1161 & 94.67 & 1066 & 285.60 & 971 & 1081.87 & NA-Rep \\
\hline HLW03-44 & HLW03 & 1259 & 48.85 & 1161 & 104.35 & 1063 & 257.33 & 965 & 877.42 & NA-Rep \\
\hline HLW03-45 & HLW03 & 1257 & 9.30 & 1155 & 18.70 & 1054 & 48.24 & 952 & 201.02 & NA-Rep \\
\hline HLW04-01 & HLW04 & 1239 & 21.57 & 1139 & 41.59 & 1041 & 100.90 & 941 & 307.76 & 3 \\
\hline HLW04-03 & HLW04 & 1242 & 28.00 & 1144 & 58.74 & 1046 & 152.10 & 948 & 529.86 & 3 \\
\hline HLW04-06 & HLW04 & 1240 & 28.47 & 1142 & 59.27 & 1045 & 145.48 & 947 & 420.54 & 2 \\
\hline HLW04-07 & HLW04 & 1248 & 22.26 & 1149 & 44.24 & 1050 & 109.91 & 952 & 322.41 & 1 \\
\hline HLW05-15 & HLW05 & 1269 & 69.68 & 1170 & 185.68 & 1072 & 607.76 & 973 & 2992.31 & 3 \\
\hline HLW05-20 & HLW05 & 1259 & 33.35 & 1162 & 72.86 & 1061 & 196.96 & 965 & 732.91 & 5 \\
\hline HLW05-21 & HLW05 & 1265 & 6.14 & 1166 & 12.57 & 1067 & 30.90 & 967 & 104.40 & 2 \\
\hline HLW05-22 & HLW05 & 1260 & 67.15 & 1163 & 155.59 & 1066 & 434.28 & 968 & 1616.10 & 5 \\
\hline HLW05-27 & HLW05 & 1260 & 11.60 & 1162 & 23.57 & 1064 & 56.64 & 965 & 164.21 & 4 \\
\hline HLW06-02 & HLW06 & 1262 & 12.61 & 1163 & 25.72 & 1066 & 65.65 & 967 & 202.89 & 1 \\
\hline HLW06-22 & HLW06 & 1264 & 7.85 & 1159 & 14.30 & 1060 & 31.33 & 962 & 87.41 & 5 \\
\hline HLW06-32 & HLW06 & 1246 & 3.85 & 1151 & 7.27 & 1056 & 15.66 & 960 & 41.34 & 1 \\
\hline HLW06-34 & HLW06 & 1256 & 5.69 & 1158 & 12.49 & 1059 & 35.47 & 961 & 143.12 & 2 \\
\hline HLW07-01 & HLW07 & 1262 & 31.50 & 1166 & 67.03 & 1071 & 199.52 & 975 & 789.61 & 4 \\
\hline HLW07-02 & HLW07 & 1274 & 29.67 & 1173 & 62.41 & 1074 & 150.59 & 974 & 439.11 & NA-Rep \\
\hline HLW07-03 & HLW07 & 1260 & 16.94 & 1158 & 37.50 & 1056 & 80.62 & 956 & 359.53 & NA-Rep \\
\hline HLW07-04 & HLW07 & 1253 & 52.33 & 1151 & 109.69 & 1049 & 281.79 & 948 & 888.65 & NA-Rep \\
\hline HLW07-05 & HLW07 & 1247 & 7.51 & 1157 & 12.18 & 1067 & 31.76 & 979 & 92.23 & NA-Rep \\
\hline HLW07-06 & HLW07 & 1245 & 35.88 & 1155 & 96.44 & 1065 & 336.71 & 977 & 1679.68 & 4 \\
\hline HLW07-07 & HLW07 & 1255 & 9.19 & 1160 & 16.69 & 1066 & 36.07 & 971 & 107.57 & 1 \\
\hline HLW07-09 & HLW07 & 1252 & 6.56 & 1158 & 13.48 & 1064 & 35.05 & 972 & 121.42 & 4 \\
\hline HLW07-10 & HLW07 & 1257 & 12.42 & 1162 & 25.67 & 1067 & 73.75 & 974 & 285.30 & 3 \\
\hline HLW07-11 & HLW07 & 1256 & 8.84 & 1156 & 17.02 & 1056 & 37.73 & 956 & 119.30 & 5 \\
\hline HLW07-12 & HLW07 & 1255 & 9.67 & 1161 & 19.44 & 1067 & 56.58 & 975 & 162.44 & 2 \\
\hline HLW07-13 & HLW07 & 1259 & 66.85 & 1160 & 170.87 & 1062 & 531.96 & 1014 & 1063.25 & 4 \\
\hline
\end{tabular}

(a) The Group IDs are described in Sections 2.1.1 to 2.1.9.

(b) Numbers from 1 to 5 denote the five split validation subsets. NA denotes "not applicable", because these replicate glasses were forced into the modeling subsets, and thus were not parts of the validation subsets.

(c) NA-Rep indicates glasses that were not included in any of the validation splits because they were replicates. 
Table 8.2. Temperature and Viscosity Observations and Data-Splitting Validation Sets for Each of the 197 HLW Glasses Used for Viscosity Model Development (continued).

\begin{tabular}{|c|c|c|c|c|c|c|c|c|c|c|}
\hline Glass ID & $\begin{array}{l}\text { Group } \\
\text { ID }^{(\mathbf{a})}\end{array}$ & $\begin{array}{c}\text { Temp1 } \\
\left({ }^{\circ} \mathrm{C}\right)\end{array}$ & $\begin{array}{c}\text { Vis1 } \\
\text { (P) }\end{array}$ & $\begin{array}{c}\text { Temp2 } \\
\left({ }^{\circ} \mathrm{C}\right)\end{array}$ & $\begin{array}{l}\text { Vis2 } \\
\text { (P) }\end{array}$ & $\begin{array}{c}\text { Temp3 } \\
\left({ }^{\circ} \mathrm{C}\right)\end{array}$ & $\begin{array}{c}\text { Vis3 } \\
\text { (P) }\end{array}$ & $\begin{array}{c}\text { Temp4 } \\
\left({ }^{\circ} \mathrm{C}\right)\end{array}$ & $\begin{array}{c}\text { Vis4 } \\
\text { (P) }\end{array}$ & \begin{tabular}{|c|} 
Visc. Data \\
Splitting \\
$\begin{array}{c}\text { Validation } \\
\text { Set }^{(b)}\end{array}$ \\
\end{tabular} \\
\hline HLW07-15 & HLW07 & 1258 & 10.27 & 1162 & 24.35 & 1066 & 79.23 & 972 & 351.34 & 4 \\
\hline HLW07-16 & HLW07 & 1263 & 3.60 & 1160 & 7.49 & 1056 & 17.99 & 951 & 55.89 & 2 \\
\hline HLW07-17 & HLW07 & 1264 & 5.65 & 1170 & 10.45 & 1074 & 20.32 & 983 & 45.10 & 4 \\
\hline HLW07-18 & ILW07 & 1247 & 5.74 & 1153 & 9.77 & 1059 & 22.06 & 965 & 47.64 & 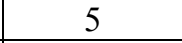 \\
\hline HLW07-19 & HLW07 & 1251 & 4.41 & 1159 & 8.19 & 1068 & 19.61 & 979 & 57.90 & 3 \\
\hline HLW07-20 & HLW07 & 1254 & 39.36 & 1158 & 80.72 & 1062 & 195.47 & 966 & 685.48 & 1 \\
\hline HLW07-21 & ILW07 & 1265 & 48.00 & 1165 & 224.06 & 1065 & 1051.18 & 1016 & 2575.48 & 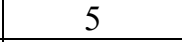 \\
\hline HLW07-22 & HLW07 & 1256 & 50.16 & 1155 & 142.90 & 1053 & 517.46 & 951 & 2718.95 & 2 \\
\hline HLW07-23 & HLW07 & 1258 & 39.65 & 1160 & 85.00 & 1062 & 261.17 & 966 & 1012.38 & 1 \\
\hline HLW07-24 & HLW07 & 1261 & 45.25 & 1164 & 101.86 & 1067 & 308.82 & 972 & 1252.75 & 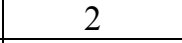 \\
\hline HLW07-25 & HLW07 & 1263 & 93.67 & 1165 & 229.41 & 1067 & 669.47 & 1020 & 1454.75 & 2 \\
\hline HLW07-26 & HLW07 & 1255 & 48.76 & 1157 & 106.99 & 1059 & 274.78 & 961 & 1004.53 & 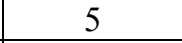 \\
\hline HLW07-27 & HLW07 & 1248 & 17.96 & 1158 & 35.69 & 1068 & 95.47 & 980 & 282.33 & 4 \\
\hline HLW07-29 & HLW07 & 1257 & 19.02 & 1159 & 38.29 & 1061 & 106.47 & 965 & 396.92 & 3 \\
\hline HLW07-30 & HLW07 & 1251 & 48.47 & 1156 & 109.12 & 1061 & 327.15 & 966 & 1247.92 & 5 \\
\hline HLW07-31 & HLW07 & 1252 & 41.41 & 1159 & 99.38 & 1066 & 292.47 & 975 & 1295.89 & 1 \\
\hline HLW07-32 & HLW07 & 1258 & 21.82 & 1156 & 51.14 & 1054 & 162.34 & 952 & 683.02 & 5 \\
\hline HLW07-33 & HLW07 & 1242 & 42.40 & 1152 & 98.44 & 1062 & 284.76 & 974 & 1187.56 & 4 \\
\hline HLW07-34 & HLW07 & 1248 & 42.20 & 1158 & 101.75 & 1068 & 322.18 & 980 & 1604.68 & 1 \\
\hline HLW07-35 & HLW07 & 1249 & 43.44 & 1156 & 98.02 & 1063 & 303.68 & 972 & 1396.56 & 3 \\
\hline HLW07-36 & HLW07 & 1253 & 25.02 & 1156 & 51.80 & 1059 & 135.80 & 964 & 476.70 & 5 \\
\hline HLW07-37 & HLW07 & 1256 & 9.26 & 1160 & 17.51 & 1066 & 37.93 & 970 & 104.93 & 3 \\
\hline HLW07-38 & HLW07 & 1252 & 29.54 & 1157 & 81.89 & 1062 & 262.90 & 969 & 1151.04 & 5 \\
\hline HLW07-39 & HLW07 & 1257 & 37.01 & 1163 & 86.34 & 1070 & 277.84 & 976 & 1502.00 & 3 \\
\hline HLW-ALG-01 & HLWALG & 1253 & 15.18 & 1156 & 28.96 & 1057 & 60.84 & 959 & 167.81 & 2 \\
\hline HLW-ALG-02 & HLWALG & 1259 & 16.77 & 1160 & 34.87 & 1059 & 88.47 & 959 & 289.17 & 3 \\
\hline HLW-ALG-03 & HLWALG & 1261 & 8.18 & 1161 & 16.08 & 1061 & 36.31 & 960 & 108.34 & 4 \\
\hline HLW-ALG-04 & HLWALG & 1262 & 14.78 & 1161 & 27.49 & 1060 & 59.35 & 958 & 170.17 & 4 \\
\hline HLW-ALG-05 & HLWALG & 1258 & 7.82 & 1159 & 14.95 & 1058 & 33.06 & 958 & 97.28 & 3 \\
\hline HLW-ALG-06 & HLWALG & 1273 & 12.71 & 1170 & 26.24 & 1067 & 62.52 & 964 & 198.59 & 5 \\
\hline HLW-ALG-07 & HLWALG & 1255 & 26.85 & 1156 & 58.72 & 1058 & 172.10 & 959 & 639.26 & 2 \\
\hline HLW-ALG-08 & HLWALG & 1254 & 8.86 & 1159 & 21.24 & 1065 & 64.77 & 970 & 273.63 & 1 \\
\hline HLW-ALG-09 & HLWALG & 1249 & 9.94 & 1153 & 20.60 & 1057 & 46.56 & 963 & 157.46 & 4 \\
\hline HLW-ALG-10 & HLWALG & 1267 & 9.19 & 1168 & 17.00 & 1070 & 36.23 & 971 & 95.80 & 5 \\
\hline HLW-ALG-11 & HLWALG & 1272 & 10.60 & 1172 & 21.96 & 1073 & 59.33 & 973 & 212.31 & 1 \\
\hline HLW-ALG-12 & HLWALG & 1249 & 11.84 & 1160 & 22.81 & 1071 & 52.12 & 984 & 172.35 & 2 \\
\hline HLW-ALG-14 & HLWALG & 1261 & 8.88 & 1158 & 17.78 & 1055 & 40.99 & 952 & 121.57 & 2 \\
\hline HLW-ALG-15 & HLWALG & 1251 & 15.15 & 1153 & 32.97 & 1054 & 86.45 & 955 & 293.00 & 5 \\
\hline HLW-ALG-16 & HLWALG & 1248 & 20.05 & 1151 & 43.02 & 1053 & 110.76 & 956 & 366.30 & 2 \\
\hline HLW-ALG-17 & HLWALG & 1264 & 10.02 & 1163 & 17.57 & 1063 & 35.68 & 963 & 95.36 & 2 \\
\hline
\end{tabular}

(a) The Group IDs are described in Sections 2.1.1 to 2.1.9.

(b) Numbers from 1 to 5 denote the five split validation subsets. NA denotes "not applicable", because these replicate glasses were forced into the modeling subsets, and thus were not parts of the validation subsets.

(c) NA-Rep indicates glasses that were not included in any of the validation splits because they were replicates. 
Table 8.2. Temperature and Viscosity Observations and Data-Splitting Validation Sets for Each of the 197 HLW Glasses Used for Viscosity Model Development (continued).

\begin{tabular}{|c|c|c|c|c|c|c|c|c|c|c|}
\hline Glass ID & $\begin{array}{l}\text { Group } \\
\text { ID }^{(a)}\end{array}$ & $\begin{array}{c}\text { Temp1 } 1 \\
\left({ }^{\circ} \mathrm{C}\right)\end{array}$ & $\begin{array}{c}\text { Vis1 } \\
\text { (P) }\end{array}$ & $\begin{array}{c}\text { Temp2 } \\
\left({ }^{\circ} \mathrm{C}\right)\end{array}$ & $\begin{array}{c}\text { Vis2 } \\
\text { (P) }\end{array}$ & $\begin{array}{c}\text { Temp3 } \\
\left({ }^{\circ} \mathrm{C}\right)\end{array}$ & $\begin{array}{c}\text { Vis3 } \\
\text { (P) }\end{array}$ & $\begin{array}{c}\text { Temp4 } \\
\left({ }^{\circ} \mathrm{C}\right)\end{array}$ & $\begin{array}{c}\text { Vis4 } \\
\text { (P) }\end{array}$ & \begin{tabular}{|c|} 
Visc. Data \\
Splitting \\
Validation \\
Set $^{\left({ }^{(b)}\right.}$ \\
\end{tabular} \\
\hline HLW-ALG-18 & HLWALG & 1263 & 28.57 & 1161 & 57.01 & 1060 & 131.16 & 959 & 368.15 & 4 \\
\hline HLW-ALG-19 & HLWALG & 1265 & 13.67 & 1164 & 29.04 & 1061 & 73.46 & 959 & 244.87 & 5 \\
\hline HLW-ALG-20 & HLWALG & 1262 & 11.83 & 1160 & 24.48 & 1058 & 59.48 & 956 & 192.43 & 4 \\
\hline HLW-ALG-21 & HLWALG & 1246 & 14.63 & 1156 & 34.93 & 1066 & 109.65 & 978 & 508.70 & 5 \\
\hline HLW-ALG-22 & HLWALG & 1264 & 12.29 & 1169 & 25.65 & 1074 & 77.13 & 981 & 251.52 & 1 \\
\hline HLW-ALG-23 & HLWALG & 1273 & 11.58 & 1173 & 27.14 & 1073 & 78.53 & 973 & 316.45 & 2 \\
\hline HLW-ALG-25 & HLWALG & 1271 & 8.27 & 1171 & 15.24 & 1072 & 32.69 & 972 & 85.72 & 1 \\
\hline HLW-ALG-26 & HLWALG & 1252 & 26.97 & 1155 & 58.10 & 1057 & 185.41 & 963 & 741.02 & 4 \\
\hline HLW-ALG-27 & HLWALG & 1264 & 15.05 & 1163 & 30.56 & 1060 & 69.76 & 958 & 193.88 & 2 \\
\hline HLW-ALG-28 & HLWALG & 1263 & 10.63 & 1163 & 20.77 & 1061 & 45.60 & 960 & 125.21 & 2 \\
\hline HLW-ALG-29 & HLWALG & 1262 & 15.59 & 1161 & 35.07 & 1059 & 96.19 & 957 & 346.36 & 5 \\
\hline HLW-ALG-30 & HLWALG & 1243 & 20.63 & 1148 & 40.42 & 1053 & 98.39 & 960 & 293.76 & 1 \\
\hline HLW-ALG-31 & HLWALG & 1260 & 16.93 & 1159 & 37.08 & 1060 & 98.75 & 960 & 350.08 & 3 \\
\hline HLW-ALG-32 & HLWALG & 1243 & 8.10 & 1144 & 16.62 & 1046 & 40.33 & 948 & 127.33 & 1 \\
\hline HLW-ALG-33 & HLWALG & 1249 & 15.69 & 1149 & 33.05 & 1050 & 83.43 & 951 & 273.94 & 4 \\
\hline HLW-ALG-34 & HLWALG & 1236 & 8.54 & 1141 & 16.30 & 1046 & 34.55 & 952 & 88.98 & 1 \\
\hline HLW-ALG-35 & HLWALG & 1264 & 13.23 & 1166 & 27.74 & 1068 & 70.12 & 972 & 234.45 & 4 \\
\hline HLW-ALG-36 & HLWALG & 1261 & 10.01 & 1163 & 20.33 & 1065 & 51.03 & 969 & 167.31 & 3 \\
\hline HLW-ALG-37 & HLWALG & 1255 & 23.55 & 1161 & 56.29 & 1067 & 200.99 & 975 & 760.01 & 3 \\
\hline \begin{tabular}{|l} 
HLW-ALG-39 \\
\end{tabular} & HLWALG & 1260 & 27.26 & 1162 & 59.39 & 1064 & 159.64 & 968 & 632.48 & 1 \\
\hline HLW-ALG-40 & HLWALG & 1258 & 20.38 & 1155 & 38.86 & 1052 & 107.47 & 951 & 369.89 & 4 \\
\hline HLW98-72 & HLW98 & 1277 & 12.06 & 1157 & 27.41 & 1057 & 64.22 & 957 & 176.20 & 3 \\
\hline \begin{tabular}{|l|} 
HLW98-77 \\
\end{tabular} & HLW98 & 1259 & 22.08 & 1159 & 45.50 & 1059 & 119.42 & 959 & 380.59 & 3 \\
\hline HLW98-80 & HLW98 & 1261 & 22.78 & 1160 & 46.80 & 1060 & 114.71 & 967 & 336.45 & 1 \\
\hline HLW98-83 & HLW98 & 1264 & 16.82 & 1164 & 33.42 & 1064 & 80.29 & 964 & 238.93 & 2 \\
\hline HLW98-84 & HLW98 & 1261 & 22.32 & 1161 & 44.56 & 1060 & 112.24 & 959 & 337.23 & 4 \\
\hline HLW98-86AG & HLW98 & 1264 & 18.62 & 1164 & 38.61 & 1063 & 96.93 & 963 & 292.35 & 1 \\
\hline HLW98-87 & HLW98 & 1268 & 25.34 & 1166 & 57.51 & 1063 & 159.92 & 960 & 562.36 & 1 \\
\hline HLW98-88 & HLW98 & 1266 & \begin{tabular}{|l|}
18.50 \\
\end{tabular} & 1164 & 40.90 & 1061 & 110.42 & 958 & 361.83 & 2 \\
\hline HLW98-89 & HLW98 & 1265 & 24.10 & 1162 & 61.74 & 1059 & 204.75 & 956 & 888.92 & 3 \\
\hline \begin{tabular}{|l} 
HLW98-95 \\
\end{tabular} & HLW98 & 1261 & 22.51 & 1161 & 48.55 & 1061 & 129.76 & 961 & 417.86 & 1 \\
\hline HLW98-96 & HLW98 & 1250 & 23.06 & 1152 & 55.11 & 1055 & 167.00 & 958 & 675.78 & 4 \\
\hline HLW98-96D & HLW98 & 1255 & 25.90 & 1149 & 58.70 & 1043 & 214.42 & 938 & 777.60 & 1 \\
\hline HLW98-97 & HLW98 & 1253 & 19.42 & 1154 & 41.58 & 1054 & 108.18 & 955 & 336.04 & 1 \\
\hline HLW98-T05 & HLW98 & 1245 & 22.92 & 1141 & 49.77 & 1036 & 125.61 & 932 & 408.10 & 5 \\
\hline HLW98-V19 & HLW98 & 1255 & 15.71 & 1152 & 34.18 & 1050 & 89.24 & 946 & 294.34 & 2 \\
\hline HLW98-V24 & HLW98 & 1256 & 22.28 & 1153 & 42.75 & 1048 & 107.38 & 945 & 325.76 & 5 \\
\hline
\end{tabular}

(a) The Group IDs are described in Sections 2.1.1 to 2.1.9.

(b) Numbers from 1 to 5 denote the five split validation subsets. NA denotes "not applicable", because these replicate glasses were forced into the modeling subsets, and thus were not parts of the validation subsets.

(c) NA-Rep indicates glasses that were not included in any of the validation splits because they were replicates. 
Table 8.3. Variation in Viscosity Values for Replicate Glasses at Actual Temperature Measurements.

\begin{tabular}{|c|c|c|c|c|c|c|c|c|c|c|}
\hline \multirow{3}{*}{\begin{tabular}{|l|} 
Glass IDs of \\
Replicate \\
Glasses $^{\text {(a) }}$
\end{tabular}} & \multicolumn{8}{|c|}{ Viscosity Values For Exact Temperatures Near Each Nominal Temperature ${ }^{(\mathbf{b})}$} & \multicolumn{2}{|c|}{ Pooled Over Temp. } \\
\hline & \multicolumn{2}{|c|}{$950^{\circ} \mathrm{C}$} & \multicolumn{2}{|c|}{$1050^{\circ} \mathrm{C}$} & \multicolumn{2}{|c|}{$1150^{\circ} \mathrm{C}$} & \multicolumn{2}{|c|}{$1250^{\circ} \mathrm{C}$} & \multirow{2}{*}{\begin{tabular}{|c|} 
\%RSD \\
Poise \\
\end{tabular}} & \multirow{2}{*}{\begin{tabular}{|c|} 
SD \\
$\ln$ (Poise)
\end{tabular}} \\
\hline & $\mathbf{T}\left({ }^{\circ} \mathrm{C}\right)$ & Poise & $\mathrm{T}\left({ }^{\circ} \mathrm{C}\right)$ & Poise & $\mathbf{T}\left({ }^{\circ} \mathrm{C}\right)$ & Poise & $\mathrm{T}\left({ }^{\circ} \mathrm{C}\right)$ & Poise & & \\
\hline HLW03-11 & 972 & 788.900 & 1069 & 252.030 & 1165 & 95.820 & 1261 & 44.280 & & \\
\hline HLW03-44 & 965 & 877.424 & 1063 & 257.330 & 1161 & 104.350 & 1259 & 48.850 & & \\
\hline$\%$ RSD $^{(\mathrm{c})}, \mathbf{S D}^{(\mathrm{d})}$ & 7.51 & 0.075 & 1.47 & 0.015 & 6.03 & 0.060 & 6.94 & 0.069 & 5.98 & 0.060 \\
\hline HLW03-41 & 952 & 442.889 & 1049 & 110.910 & 1147 & 39.200 & 1244 & 17.130 & & \\
\hline HLW07-03 & 956 & 359.531 & 1056 & 80.620 & 1158 & 37.500 & 1260 & 16.940 & & \\
\hline$\% \mathrm{RSD}^{(\mathrm{c})}, \mathrm{SD}^{(\mathrm{d})}$ & 14.69 & 0.147 & 22.37 & 0.226 & 3.13 & 0.031 & 0.79 & 0.008 & 13.48 & 0.136 \\
\hline HLW02-08 & 952 & 80.660 & 1051 & 27.120 & 1149 & 11.580 & 1247 & 5.620 & & \\
\hline HLW02-57 & 943 & 92.930 & 1039 & 30.450 & 1135 & 13.910 & 1231 & 7.560 & & \\
\hline$\% \mathrm{RSD}^{(\mathrm{c})}, \mathrm{SD}^{(\mathrm{d})}$ & 10.00 & 0.100 & 8.18 & 0.082 & 12.93 & 0.130 & 20.82 & 0.210 & 13.85 & 0.139 \\
\hline HLW02-04 & 952 & 971.217 & 1052 & 296.759 & 1151 & 114.250 & 1250 & 51.320 & & \\
\hline HLW02-54 & 931 & 1065.149 & 1035 & 306.810 & 1138 & 114.860 & 1242 & 50.750 & & \\
\hline$\% \mathrm{RSD}^{(\mathrm{c})}, \mathrm{SD}^{(\mathrm{d})}$ & 6.52 & 0.065 & 2.36 & 0.024 & 0.38 & 0.004 & 0.79 & 0.008 & 3.50 & 0.035 \\
\hline HLW03-26 & 971 & 167.660 & 1066 & 49.490 & 1162 & 18.330 & 1259 & 9.670 & & \\
\hline HLW03-45 & 952 & 201.019 & 1054 & 48.240 & 1155 & 18.700 & 1257 & 9.300 & & \\
\hline$\% \mathrm{RSD}^{(\mathrm{c})}, \mathbf{S D}^{(\mathrm{d})}$ & 12.80 & 0.128 & 1.81 & 0.018 & 1.41 & 0.014 & 2.76 & 0.028 & 6.64 & 0.067 \\
\hline HLW03-07 & 1016 & 62.800 & 1104 & 21.110 & 1192 & 9.290 & 1281 & 5.080 & & \\
\hline HLW07-05 & 979 & 92.230 & 1067 & 31.760 & 1157 & 12.180 & 1247 & 7.510 & & \\
\hline$\% \mathrm{RSD}^{(\mathrm{c})}, \mathrm{SD}^{(\mathrm{d})}$ & 26.85 & 0.272 & 28.49 & 0.289 & 19.04 & 0.192 & 27.30 & 0.276 & 25.69 & 0.260 \\
\hline HLW02-44 & 934 & 321.401 & 1035 & 95.530 & 1137 & 37.070 & 1238 & 16.530 & & \\
\hline HLW02-56 & 943 & 260.340 & 1041 & 79.940 & 1138 & 32.290 & 1235 & 15.310 & & \\
\hline$\% \mathrm{RSD}^{(\mathrm{c})}, \mathrm{SD}^{(\mathrm{d})}$ & 14.84 & 0.149 & 12.56 & 0.126 & 9.75 & 0.098 & 5.42 & 0.054 & 11.21 & 0.112 \\
\hline HLW02-42 & 951 & 148.440 & 1050 & 50.090 & 1148 & 21.570 & 1246 & 10.820 & & \\
\hline HLW02-55 & 943 & 130.061 & 1042 & 44.070 & 1140 & 19.250 & 1239 & 9.660 & & \\
\hline$\% \mathrm{RSD}^{(\mathrm{c})}, \mathbf{S D}^{(\mathrm{d})}$ & 9.33 & 0.093 & 9.04 & 0.091 & 8.04 & 0.080 & 8.01 & 0.080 & 8.63 & 0.086 \\
\hline HLW02-46 & 944 & 491.018 & 1044 & 143.779 & 1144 & 55.190 & 1244 & 25.350 & & \\
\hline HLW03-42 & 956 & 594.672 & 1052 & 172.220 & 1148 & 66.990 & 1244 & 29.970 & & \\
\hline HLW07-02 & 974 & 439.110 & 1074 & 150.590 & 1173 & 62.410 & 1274 & 29.670 & & \\
\hline$\% \mathrm{RSD}^{(\mathrm{c})}, \mathrm{SD}^{(\mathrm{d})}$ & 15.58 & 0.153 & 9.55 & 0.094 & 9.67 & 0.098 & 9.13 & 0.094 & 11.30 & 0.113 \\
\hline HLW02-01 & 952 & 235.469 & 1050 & 75.250 & 1148 & 31.720 & 1245 & 15.130 & & \\
\hline HLW02-52 & 955 & 238.390 & 1055 & 73.740 & 1155 & 29.910 & 1255 & 14.430 & & \\
\hline$\% \mathrm{RSD}^{(\mathrm{c})}, \mathbf{S D}^{(\mathrm{d})}$ & 0.87 & 0.009 & 1.43 & 0.014 & 4.15 & 0.042 & $\mathbf{3 . 3 5}$ & $\mathbf{0 . 0 3 3}$ & 2.80 & 0.028 \\
\hline HLW03-06 & 951 & 977.375 & 1049 & 267.559 & 1146 & 93.530 & 1245 & 39.290 & & \\
\hline HLW03-43 & 971 & 1081.874 & 1066 & 285.599 & 1161 & 94.670 & 1257 & 40.720 & & \\
\hline$\% \mathrm{RSD}^{(\mathrm{c})}, \mathrm{SD}^{(\mathrm{d})}$ & 7.18 & 0.072 & 4.61 & 0.046 & 0.86 & 0.009 & 2.53 & 0.025 & 4.47 & 0.045 \\
\hline HLW02-17 & 936 & 822.822 & 1034 & 257.920 & 1130 & 102.040 & 1227 & 45.800 & & \\
\hline HLW02-53 & 947 & 875.671 & 1046 & 275.470 & 1145 & 106.560 & 1244 & 47.790 & & \\
\hline$\% \mathrm{RSD}^{(\mathrm{c})}, \mathrm{SD}^{(\mathrm{d})}$ & 4.40 & 0.044 & 4.65 & 0.047 & 3.06 & 0.031 & 3.01 & 0.030 & 3.86 & 0.039 \\
\hline HLW02-22 & 947 & 919.371 & 1048 & 267.099 & 1147 & 106.910 & 1247 & 48.950 & & \\
\hline HLW07-04 & 948 & 888.647 & 1049 & 281.789 & 1151 & 109.690 & 1253 & 52.330 & & \\
\hline$\%$ RSD $^{(\mathrm{c})}, \mathbf{S D}^{(\mathrm{d})}$ & 2.40 & 0.024 & 3.78 & 0.038 & 1.82 & 0.018 & 4.72 & 0.047 & 3.63 & 0.034 \\
\hline $\begin{array}{l}\text { Pooled Over } \\
\text { Replicates }^{(\mathrm{e})}\end{array}$ & 12.45 & 0.12 & 11.56 & 0.12 & 8.26 & 0.08 & 10.50 & 0.11 & 10.81 & 0.109 \\
\hline
\end{tabular}

(a) All replicates appear in pairs of HLW glasses except for HLW02-46, HLW03-42, and HLW07-02.

(b) Viscosity values are listed at the exact temperatures near the nominal temperature values.

(c) $\% \mathrm{RSD}=100 *$ (Standard Deviation / Mean), calculated using the Poise values.

(d) Calculated using $\ln$ (Poise) values.

(e) The individual and pooled SDs estimate $\sqrt{\sigma_{G}^{2}+\sigma_{T}^{2}}$ in $\ln$ (Poise) units (see Section C.2.2 of Appendix C).

(f) The \%RSD and SD values are uncertainties of viscosity values, not temperature values. Because viscosity values at actual temperatures were used, temperature and viscosity columns are listed. The \%RSD and SD values are merely listed under these columns. 
Table 8.4. Variation in Viscosity Values for Replicate Glasses Interpolated at Nominal Temperatures.

\begin{tabular}{|c|c|c|c|c|c|c|c|c|c|c|}
\hline \multirow{3}{*}{\begin{tabular}{|l} 
Glass IDs of \\
Replicate \\
Glasses $^{(a)}$
\end{tabular}} & \multicolumn{8}{|c|}{ Viscosity Values Interpolated at Nominal Temperatures $^{(\mathbf{b})}$} & \multicolumn{2}{|c|}{ Pooled Over Temp. } \\
\hline & \multicolumn{2}{|c|}{$950^{\circ} \mathrm{C}$} & \multicolumn{2}{|c|}{$1050^{\circ} \mathrm{C}$} & \multicolumn{2}{|c|}{$1150^{\circ} \mathrm{C}$} & \multicolumn{2}{|c|}{$1250^{\circ} \mathrm{C}$} & \multirow{2}{*}{\begin{tabular}{|c|} 
\%RSD \\
Poise
\end{tabular}} & \multirow{2}{*}{\begin{tabular}{|c|} 
SD \\
$\ln$ (Poise) \\
\end{tabular}} \\
\hline & Poise & $\ln$ (Poise) & Poise & $\ln$ (Poise) & Poise & $\ln$ (Poise) & Poise & $\ln$ (Poise) & & \\
\hline HLW03-11 & 1086.609 & 6.991 & 303.720 & 5.716 & 110.007 & 4.701 & 48.345 & 3.878 & & \\
\hline HLW03-44 & 1056.303 & 6.963 & 306.566 & 5.725 & 114.415 & 4.740 & 51.517 & 3.942 & & \\
\hline$\% \mathrm{RSD}^{(\mathrm{c})}, \mathbf{S D}^{(\mathrm{d})}$ & 2.000 & 0.020 & 0.660 & 0.007 & 2.778 & 0.028 & 4.492 & 0.045 & 2.84 & 0.028 \\
\hline HLW03-41 & 445.126 & 6.098 & 113.890 & 4.735 & 38.445 & 3.649 & 15.959 & 2.770 & & \\
\hline HLW07-03 & 354.406 & 5.870 & 103.176 & 4.636 & 38.601 & 3.653 & 17.415 & 2.857 & & \\
\hline$\% \mathrm{RSD}^{(\mathrm{c})}, \mathbf{S D}^{(\mathrm{d})}$ & 16.047 & 0.161 & 6.981 & 0.070 & 0.288 & 0.003 & 6.172 & 0.062 & 9.28 & 0.093 \\
\hline HLW02-08 & 82.907 & 4.418 & 27.413 & 3.311 & 11.351 & 2.429 & 5.559 & 1.715 & & \\
\hline HLW02-57 & 82.314 & 4.411 & 29.055 & 3.369 & 12.674 & 2.540 & 6.474 & 1.868 & & \\
\hline$\% \mathrm{RSD}^{(\mathrm{c})}, \mathbf{S D}^{(\mathrm{d})}$ & 0.507 & 0.005 & 4.112 & 0.041 & 7.786 & 0.078 & 10.754 & 0.108 & 6.95 & 0.070 \\
\hline HLW02-04 & 1008.449 & 6.916 & 299.522 & 5.702 & 113.864 & 4.735 & 52.039 & 3.952 & & \\
\hline HLW02-54 & 831.957 & 6.724 & 259.886 & 5.560 & 102.848 & 4.633 & 48.558 & 3.883 & & \\
\hline$\% \mathrm{RSD}^{(\mathrm{c})}, \mathbf{S D}^{(\mathrm{d})}$ & $\mathbf{1 3 . 5 6 2}$ & 0.136 & 10.020 & 0.100 & 7.189 & 0.072 & 4.893 & 0.049 & 9.49 & 0.095 \\
\hline HLW03-26 & 216.810 & 5.379 & 60.685 & 4.106 & 22.004 & 3.091 & 9.679 & 2.270 & & \\
\hline HLW03-45 & 193.439 & 5.265 & 55.354 & 4.014 & 20.428 & 3.017 & 9.115 & 2.210 & & \\
\hline$\% \mathrm{RSD}^{(\mathrm{c})}, \mathbf{S D}^{(\mathrm{d})}$ & 8.057 & 0.081 & 6.497 & 0.065 & 5.253 & 0.053 & 4.245 & 0.042 & 6.18 & 0.062 \\
\hline HLW03-07 & 147.772 & 4.996 & 39.985 & 3.689 & 14.113 & 2.647 & 6.074 & 1.804 & & \\
\hline HLW07-05 & 129.667 & 4.865 & 38.505 & 3.651 & 14.636 & 2.683 & 6.688 & 1.900 & & \\
\hline$\% \mathrm{RSD}^{(\mathrm{c})}, \mathrm{SD}^{(\mathrm{d})}$ & 9.229 & 0.092 & 2.666 & 0.027 & 2.571 & 0.026 & 6.807 & 0.068 & 03 & 0.060 \\
\hline HLW02-44 & 260.761 & 5.564 & 81.936 & 4.406 & 32.577 & 3.484 & 15.439 & 2.737 & & \\
\hline HLW02-56 & 235.798 & 5.463 & 73.648 & 4.299 & 29.142 & 3.372 & 13.758 & 2.622 & & \\
\hline$\% \mathrm{RSD}^{(\mathrm{c})}, \mathrm{SD}$ & 7.109 & 0.071 & 7.533 & 0.075 & 7.870 & 0.079 & 8.144 & 0.082 & .67 & 0.077 \\
\hline HLW02-42 & 149.655 & 5.008 & 50.456 & 3.921 & 21.219 & 3.055 & 10.524 & 2.354 & & \\
\hline HLW02-55 & 118.893 & 4.778 & 41.307 & 3.721 & 17.792 & 2.879 & 8.997 & 2.197 & & \\
\hline$\% \mathrm{RSD}^{(\mathrm{c})}, \mathbf{S D}^{(\mathrm{d})}$ & 16.199 & 0.163 & 14.100 & 0.141 & 12.423 & 0.125 & 11.063 & 0.111 & 13.58 & 0.136 \\
\hline HLW02-46 & 450.309 & 6.110 & 136.031 & 4.913 & 52.415 & 3.959 & 24.218 & 3.187 & & \\
\hline HLW03-42 & 641.858 & 6.464 & 179.625 & 5.191 & 65.123 & & 28.642 & 3.355 & & \\
\hline HLW07-02 & 602.996 & 6.402 & 188.434 & 5.239 & 74.594 & 4.312 & 35.227 & 3.562 & & \\
\hline$\% \mathrm{RSD}^{(\mathrm{c})}, \mathrm{SD}^{(\mathrm{d})}$ & 17.919 & 0.189 & 16.699 & 0.176 & 17.377 & 0.178 & 18.867 & 0.188 & 17.73 & 0.183 \\
\hline HLW02-01 & 240.207 & 5.482 & 76.495 & 4.337 & 30.741 & 3.426 & 14.695 & 2.688 & & \\
\hline HLW02-52 & 251.772 & 5.529 & 78.857 & 4.368 & 31.273 & 3.443 & 14.791 & 2.694 & & \\
\hline$\%$ RSD $^{(\mathrm{c})}, \mathbf{S D}^{(\mathrm{d})}$ & 3.324 & 0.033 & 2.150 & 0.022 & 1.214 & 0.012 & 0.457 & 0.005 & 2.08 & 0.021 \\
\hline HLW03-06 & 998.389 & 6.906 & 261.619 & 5.567 & 90.008 & 4.500 & 37.943 & 3.636 & & \\
\hline HLW03-43 & 1506.561 & 7.318 & 349.150 & 5.856 & 108.924 & 4.691 & 42.420 & 3.748 & & \\
\hline$\% \mathrm{RSD}^{(\mathrm{c})}, \mathbf{S D}^{(\mathrm{d})}$ & 28.690 & 0.291 & 20.267 & 0.204 & 13.448 & 0.135 & 7.878 & 0.079 & 19.21 & 0.194 \\
\hline HLW02-17 & 691.294 & 6.539 & 214.653 & 5.369 & 84.542 & 4.437 & 39.761 & 3.683 & & \\
\hline HLW02-53 & 853.097 & 6.749 & 259.527 & 5.559 & 100.562 & 4.611 & 46.676 & 3.843 & & \\
\hline$\% \mathrm{RSD}^{(\mathrm{c})}, \mathbf{S D}^{(\mathrm{d})}$ & 14.816 & 0.149 & 13.383 & 0.134 & 12.240 & 0.123 & 11.313 & 0.113 & 13.00 & 0.130 \\
\hline HLW02-22 & 875.712 & 6.775 & 266.399 & 5.585 & 103.222 & 4.637 & 47.909 & 3.869 & & \\
\hline HLW07-04 & 868.323 & 6.767 & 276.846 & 5.623 & 111.358 & 4.713 & 53.274 & 3.975 & & \\
\hline$\%$ RSD $^{(\mathrm{c})}, \mathbf{S D}^{(\mathrm{d})}$ & 0.599 & 0.006 & 2.720 & 0.027 & 5.362 & 0.054 & 7.498 & 0.075 & 4.81 & 0.048 \\
\hline $\begin{array}{l}\text { Pooled Over } \\
\text { Replicates }^{(\mathrm{e})}\end{array}$ & 13.64 & 0.14 & 10.79 & 0.11 & 9.77 & 0.10 & 10.03 & 0.10 & 11.16 & 0.113 \\
\hline
\end{tabular}

(a) All replicates appear in pairs of HLW glasses except for HLW02-46, HLW03-42, and HLW07-02.

(b) Viscosity values were interpolated at the nominal temperature values using a T2-equation (see Section C.2.1) fit for each glass.

(c) $\% \mathrm{RSD}=100 *($ Standard Deviation / Mean), calculated using the Poise values.

(d) Calculated using $\ln$ (Poise) values.

(e) The individual and pooled SDs estimate $\sqrt{\sigma_{G}^{2}+\sigma_{T}^{2}}$ in $\ln$ (Poise) units (see Section C.2.2 of Appendix C). 
Table 8.5. Coefficients and Performance Summary for the 44-Term Truncated T2-Linear Mixture Model on the Natural Logarithm of Viscosity Fitted to Data on 197 HLW Glassses.

\begin{tabular}{|c|c|c|c|c|c|c|c|c|c|c|c|}
\hline $\begin{array}{l}\text { Mixture } \\
\text { Term } \\
\left(x_{i}\right) \\
\end{array}$ & $\begin{array}{c}\text { Coefficient } \\
\text { Estimate }\end{array}$ & \multicolumn{2}{|c|}{$\begin{array}{c}\text { Coefficient } \\
\text { Standard } \\
\text { Deviation } \\
\end{array}$} & \multicolumn{2}{|c|}{\begin{tabular}{|c|} 
Mixture-Temp. \\
Term \\
{$\left[x_{i} /(T / 1000)^{2}\right]$}
\end{tabular}} & $\begin{array}{c}\text { Coefficient } \\
\text { Estimate } \\
\end{array}$ & $\begin{array}{c}\text { Coefficient } \\
\text { Standard } \\
\text { Deviation } \\
\end{array}$ & $\begin{array}{l}\text { t-value }= \\
\text { Coeff/SD }\end{array}$ & p-value & $\begin{array}{l}\text { Modeling Data Statistic, } \\
197 \text { Glasses }^{(a)}\end{array}$ & Value \\
\hline $\mathrm{Al}_{2} \mathrm{O}_{3}$ & -0.7550 & \multicolumn{2}{|c|}{0.8834} & \multicolumn{2}{|c|}{$\mathrm{Al}_{2} \mathrm{O}_{3} /(T / 1000)^{2}$} & 31.1392 & 1.4034 & 22.19 & $<0.0001$ & $\mathrm{R}^{2}$ & 0.987 \\
\hline $\mathrm{B}_{2} \mathrm{O}_{3}$ & -3.9465 & \multicolumn{2}{|c|}{0.6779} & \multicolumn{2}{|c|}{$\mathrm{B}_{2} \mathrm{O}_{3} /(T / 1000)^{2}$} & -1.7832 & 1.0665 & -1.67 & 0.0951 & SSE & 19.479 \\
\hline $\mathrm{CaO}$ & 1.5546 & \multicolumn{2}{|c|}{18.6459} & \multicolumn{2}{|c|}{$\mathrm{CaO} /(T / 1000)^{2}$} & 15.9886 & 29.4748 & 0.54 & 0.5877 & RMSE & 0.162 \\
\hline $\mathrm{CdO}$ & -4.3780 & \multicolumn{2}{|c|}{4.6727} & \multicolumn{2}{|c|}{$\mathrm{CdO} /(T / 1000)^{2}$} & 14.5944 & 7.3277 & 1.99 & 0.0469 & & \\
\hline $\mathrm{Cr}_{2} \mathrm{O}_{3}$ & -45.6486 & \multicolumn{2}{|c|}{13.4313} & \multicolumn{2}{|c|}{$\mathrm{Cr}_{2} \mathrm{O}_{3} /(T / 1000)^{2}$} & 81.8385 & 21.4112 & 3.82 & 0.0001 & & \\
\hline $\mathrm{Fe}_{2} \mathrm{O}_{3}$ & -6.9754 & \multicolumn{2}{|c|}{0.7810} & \multicolumn{2}{|c|}{$\mathrm{Fe}_{2} \mathrm{O}_{3} /(T / 1000)^{2}$} & 16.5372 & 1.2365 & 13.37 & $<0.0001$ & & \\
\hline $\mathrm{Li}_{2} \mathrm{O}$ & 0.6416 & \multicolumn{2}{|c|}{1.6354} & \multicolumn{2}{|c|}{$\mathrm{Li}_{2} \mathrm{O} /(T / 1000)^{2}$} & -73.5742 & 2.5797 & -28.52 & $<0.0001$ & & \\
\hline $\mathrm{MgO}$ & -8.1241 & \multicolumn{2}{|c|}{15.5595} & \multicolumn{2}{|c|}{$\mathrm{MgO} /(T / 1000)^{2}$} & -1.1577 & 24.3751 & -0.05 & 0.9621 & & \\
\hline $\mathrm{MnO}$ & -9.4907 & \multicolumn{2}{|c|}{1.0092} & \multicolumn{2}{|c|}{$\mathrm{MnO} /(T / 1000)^{2}$} & 12.3983 & 1.6048 & 7.73 & $<0.0001$ & & \\
\hline $\mathrm{Na}_{2} \mathrm{O}$ & -3.4490 & \multicolumn{2}{|c|}{0.6874} & \multicolumn{2}{|c|}{$\mathrm{Na}_{2} \mathrm{O} /(T / 1000)^{2}$} & -11.9814 & 1.0846 & -11.05 & $<0.0001$ & & \\
\hline $\mathrm{NiO}$ & -1.1078 & \multicolumn{2}{|c|}{6.6737} & \multicolumn{2}{|c|}{$\mathrm{NiO} /(T / 1000)^{2}$} & -5.7345 & 10.5261 & -0.54 & 0.5861 & & \\
\hline $\mathrm{PbO}$ & -2.4825 & \multicolumn{2}{|c|}{11.6555} & \multicolumn{2}{|c|}{$\mathrm{PbO} /(T / 1000)^{2}$} & 7.3841 & 18.5595 & 0.40 & 0.6909 & & \\
\hline $\mathrm{Sb}_{2} \mathrm{O}_{3}$ & -11.9423 & \multicolumn{2}{|c|}{22.5659} & \multicolumn{2}{|c|}{$\mathrm{Sb}_{2} \mathrm{O}_{3} /(T / 1000)^{2}$} & 71.6156 & 35.5502 & 2.01 & 0.0444 & & \\
\hline $\mathrm{SeO}_{2}$ & 0.2872 & & 224 & $\mathrm{SeC}$ & $(T / 1000)^{2}$ & -35.9466 & 53.7911 & -0.67 & 0.5042 & (a) The model evaluation & \\
\hline $\mathrm{SiO}_{2}$ & 1.0395 & & 948 & $\mathrm{SiC}$ & $(T / 1000)^{2}$ & 21.6797 & 0.4663 & 46.49 & $<0.0001$ & defined in Section C.3 & $\operatorname{dix} \mathrm{C}$. \\
\hline $\mathrm{SrO}$ & -9.2692 & & 423 & $\mathrm{SrC}$ & $T / 1000)^{2}$ & 11.3064 & 1.3417 & 8.43 & $<0.0001$ & Model validation stati & fined in \\
\hline $\mathrm{ThO}_{2}$ & -9.0395 & & 738 & Th & $/(T / 1000)^{2}$ & 23.5370 & 2.1880 & 10.76 & $<0.0001$ & Section C. 5 of Appen & \\
\hline $\mathrm{Tl}_{2} \mathrm{O}$ & -13.5838 & & 092 & $\mathrm{Tl}_{2}$ & $(T / 1000)^{2}$ & -31.2720 & 51.9038 & -0.60 & 0.5471 & (b) The "Others" compon & $\mathrm{Ag}_{2} \mathrm{O}$ \\
\hline $\mathrm{UO}_{3}$ & -7.6473 & & 800 & $\mathrm{UO}$ & $(T / 1000)^{2}$ & 24.8928 & 2.3615 & 10.54 & $<0.0001$ & As2O5, $\mathrm{BaO}, \mathrm{BeO}, \mathrm{Bi}$ & $\mathrm{Cl}$ \\
\hline $\mathrm{ZnO}$ & -9.1568 & & 132 & $\mathrm{Zn}$ & $(T / 1000)^{2}$ & 15.2908 & 3.6744 & 4.16 & $<0.0001$ & $\mathrm{C}=\mathrm{C} \mathrm{C}=\mathrm{O}$ & \\
\hline $\mathrm{ZrO}_{2}$ & -15.4612 & & 330 & $\mathrm{ZrC}$ & $(T / 1000)^{2}$ & 48.6265 & 1.3180 & 36.90 & $<0.0001$ & $\mathrm{Gd}_{2} \mathrm{O}_{3}, \mathrm{HfO}_{2}, \mathrm{HgO}, \mathrm{K}$ & $\mathrm{MoO}_{3}$ \\
\hline Others $^{(b)}$ & -5.0691 & & 820 & Oth & $\mathrm{s} /(T / 1000)^{2}$ & 21.9094 & 5.8414 & 3.75 & 0.0002 & $\mathrm{P}_{2} \mathrm{O}_{5}, \mathrm{PdO}, \mathrm{Pr}_{2} \mathrm{O}_{3}, \mathrm{Rb}_{2}$ & $\mathrm{Rh}_{2} \mathrm{O}_{3}$ \\
\hline & $\hat{\sigma}_{G}=0.14$ & & & & & & $=0.0764$ & & & $\mathrm{TiO}_{2}, \mathrm{~V}_{2} \mathrm{O}_{5}, \mathrm{WO}_{3}$ anc & $\mathrm{eO}_{2}$ \\
\hline Data Spl & tting Statisti & & DS & & DS2 & DS3 & DS4 & DS5 & Average & (c) See Section 8.1.2. & \\
\hline $\mathrm{R}^{2}$ & & & 0.98 & & 0.988 & 0.988 & 0.987 & 0.988 & 0.988 & & \\
\hline SSE & & & 15.7 & & 14.522 & 15.387 & 16.723 & 14.552 & 15.393 & & \\
\hline RMSE & & & 0.16 & & 0.155 & 0.159 & 0.166 & 0.155 & 0.159 & & \\
\hline $\mathrm{R}^{2}$ Valid & $\operatorname{tion}\left(\mathrm{R}_{\mathrm{V}}^{2}\right)$ & & 0.98 & & 0.972 & 0.981 & 0.988 & 0.977 & 0.980 & & \\
\hline RMSE V & alidation (RM & $\left(E_{V}\right)$ & 0.18 & & 0.230 & 0.190 & 0.154 & 0.211 & 0.193 & & \\
\hline
\end{tabular}


Table 8.6. Coefficients and Performance Summary for the 27-Term Truncated T2-Linear Mixture Model on the Natural Logarithm of Viscosity Fitted to Data on 197 HLW Glasses.

\begin{tabular}{|c|c|c|c|c|c|c|c|c|c|c|c|}
\hline $\begin{array}{l}\text { Mixture } \\
\text { Term } \\
\left(x_{i}\right)\end{array}$ & $\begin{array}{c}\text { Coefficient } \\
\text { Estimate }\end{array}$ & \multicolumn{2}{|c|}{$\begin{array}{l}\text { Coefficient } \\
\text { Standard } \\
\text { Deviation } \\
\end{array}$} & \multicolumn{2}{|c|}{$\begin{array}{c}\text { Mixture-Temp. } \\
\text { Term } \\
{\left[x_{i} /(T / 1000)^{2}\right]}\end{array}$} & $\begin{array}{c}\text { Coefficient } \\
\text { Estimate }\end{array}$ & $\begin{array}{l}\text { Coefficient } \\
\text { Standard } \\
\text { Deviation }\end{array}$ & $\begin{array}{l}\text { t-value }= \\
\text { Coeff } / \text { SD }\end{array}$ & p-value & $\begin{array}{l}\text { Modeling Data Statistic, }_{197 \text { Glasses }^{(a)}}\end{array}$ & Value \\
\hline $\mathrm{Al}_{2} \mathrm{O}_{3}$ & -0.1569 & \multicolumn{2}{|c|}{0.8023} & \multicolumn{2}{|c|}{$\mathrm{Al}_{2} \mathrm{O}_{3} /(T / 1000)^{2}$} & 31.3260 & 1.2369 & 25.33 & $<0.0001$ & $\mathrm{R}^{2}$ & 0.986 \\
\hline $\mathrm{B}_{2} \mathrm{O}_{3}$ & -4.8536 & \multicolumn{2}{|c|}{0.3652} & \multicolumn{2}{|c|}{$\mathrm{B}_{2} \mathrm{O}_{3} /(T / 1000)^{2}$} & $-^{(\mathrm{c})}$ & - & - & - & SSE & 21.585 \\
\hline $\mathrm{CaO}$ & -2.4253 & \multicolumn{2}{|c|}{8.7310} & \multicolumn{2}{|c|}{$\mathrm{CaO} /(T / 1000)^{2}$} & - & - & - & - & RMSE & 0.168 \\
\hline $\mathrm{Fe}_{2} \mathrm{O}_{3}$ & -6.5880 & \multicolumn{2}{|c|}{0.7761} & \multicolumn{2}{|c|}{$\mathrm{Fe}_{2} \mathrm{O}_{3} /(T / 1000)^{2}$} & 15.6897 & 1.2081 & 12.99 & $<0.0001$ & & \\
\hline $\mathrm{Li}_{2} \mathrm{O}$ & -0.1582 & \multicolumn{2}{|c|}{1.5621} & \multicolumn{2}{|c|}{$\mathrm{Li}_{2} \mathrm{O} /(T / 1000)^{2}$} & -72.9785 & 2.4398 & -29.91 & $<0.0001$ & & \\
\hline $\mathrm{MgO}$ & -8.1438 & \multicolumn{2}{|c|}{7.3280} & \multicolumn{2}{|c|}{$\mathrm{MgO} /(T / 1000)^{2}$} & - & - & - & - & & \\
\hline $\mathrm{MnO}$ & -10.1862 & \multicolumn{2}{|c|}{0.9857} & \multicolumn{2}{|c|}{$\mathrm{MnO} /(T / 1000)^{2}$} & 13.1279 & 1.5527 & 8.45 & $<0.0001$ & & \\
\hline $\mathrm{Na}_{2} \mathrm{O}$ & -3.9947 & \multicolumn{2}{|c|}{0.6475} & \multicolumn{2}{|c|}{$\mathrm{Na}_{2} \mathrm{O} /(T / 1000)^{2}$} & -11.0190 & 1.0148 & -10.86 & $<0.0001$ & & \\
\hline $\mathrm{SiO}_{2}$ & 1.2193 & \multicolumn{2}{|c|}{0.2820} & \multicolumn{2}{|c|}{$\mathrm{SiO}_{2} /(T / 1000)^{2}$} & 21.2699 & 0.4332 & 49.10 & $<0.0001$ & & \\
\hline $\mathrm{SrO}$ & -9.2520 & \multicolumn{2}{|c|}{0.8435} & \multicolumn{2}{|c|}{$\mathrm{SrO} /(T / 1000)^{2}$} & 11.3963 & 1.3305 & 8.57 & $<0.0001$ & & \\
\hline $\mathrm{ThO}_{2}$ & -9.3364 & \multicolumn{2}{|c|}{1.3235} & \multicolumn{2}{|c|}{$\mathrm{ThO}_{2} /(T / 1000)^{2}$} & 24.4765 & 2.0802 & 11.77 & $<0.0001$ & & \\
\hline $\mathrm{UO}_{3}$ & -8.3279 & \multicolumn{2}{|c|}{1.2997} & \multicolumn{2}{|c|}{$\mathrm{UO}_{3} /(T / 1000)^{2}$} & 27.4787 & 2.0678 & 13.29 & $<0.0001$ & & \\
\hline $\mathrm{ZnO}$ & -6.9469 & \multicolumn{2}{|c|}{2.1813} & \multicolumn{2}{|c|}{$\mathrm{ZnO} /(T / 1000)^{2}$} & 12.0986 & 3.4027 & 3.56 & 0.0004 & & \\
\hline $\mathrm{ZrO}_{2}$ & -15.0817 & \multicolumn{2}{|c|}{0.8066} & \multicolumn{2}{|c|}{$\mathrm{ZrO}_{2} /(T / 1000)^{2}$} & 48.0253 & 1.2437 & 38.61 & $<0.0001$ & & \\
\hline Others $^{(\mathrm{b})}$ & -6.1644 & \multicolumn{2}{|c|}{1.6736} & \multicolumn{2}{|c|}{ Others/(T/1000) $)^{2}$} & 20.2064 & 2.6297 & 7.68 & $<0.0001$ & & \\
\hline & $\hat{\sigma}_{G}=0.153$ & & & & & & $=0.0773$ & & & & \\
\hline Data Spl & itting Statist & ,d) & D: & $\mathbf{S 1}$ & DS2 & DS3 & DS4 & DS5 & Average & & \\
\hline $\mathrm{R}^{2}$ & & & 0.9 & 85 & 0.987 & 0.986 & 0.985 & 0.987 & 0.986 & & \\
\hline SSE & & & 18. & 143 & 16.022 & 17.838 & 18.779 & 16.238 & 17.404 & & \\
\hline RMSE & & & 0.1 & 70 & 0.160 & 0.169 & 0.173 & 0.161 & 0.167 & & \\
\hline $\mathrm{R}^{2}$ Valida & tion $\left(\mathrm{R}_{\mathrm{V}}^{2}\right)$ & & 0.9 & 85 & 0.974 & 0.984 & 0.989 & 0.976 & 0.982 & & \\
\hline RMSE V & alidation (RN & $\left.\mathrm{SE}_{\mathrm{V}}\right)$ & 0.1 & & 0.224 & 0.173 & 0.148 & 0.214 & 0.186 & & \\
\hline
\end{tabular}

(a) The model evaluation statistics are defined in Section C.3 of Appendix C. Model validation statistics are defined in Section C.5 of Appendix C.

(b) The "Others" component includes $\mathrm{Ag}_{2} \mathrm{O}, \mathrm{As}_{2} \mathrm{O}_{5}, \mathrm{BaO}, \mathrm{BeO}, \mathrm{Bi}_{2} \mathrm{O}_{3}, \mathrm{CdO}, \mathrm{Cr}_{2} \mathrm{O}_{3}, \mathrm{Ce}_{2} \mathrm{O}_{3}, \mathrm{Cl}, \mathrm{CoO}_{2} \mathrm{Cs}_{2} \mathrm{O}, \mathrm{CuO}, \mathrm{Dy} \mathrm{O}_{3}, \mathrm{Eu}_{2} \mathrm{O}_{3}, \mathrm{~F}, \mathrm{Gd}_{2} \mathrm{O}_{3}, \mathrm{HfO} \mathrm{HgO}_{2}, \mathrm{Hg}_{2} \mathrm{O}$, $\mathrm{La}_{2} \mathrm{O}_{3}, \mathrm{MoO}_{3}, \mathrm{NiO}, \mathrm{P}_{2} \mathrm{O}_{5}, \mathrm{PbO}, \mathrm{PdO}, \mathrm{Pr}_{2} \mathrm{O}_{3}, \mathrm{Rb}_{2} \mathrm{O}, \mathrm{Re}_{2} \mathrm{O}_{7}, \mathrm{Rh}_{2} \mathrm{O}_{3}, \mathrm{RuO}_{2}, \mathrm{Sb}_{2} \mathrm{O}_{3}, \mathrm{SeO}_{2}, \mathrm{SO}_{3}, \mathrm{Sm}_{2} \mathrm{O}_{3}, \mathrm{SnO}_{2}, \mathrm{Tc}_{2} \mathrm{O}_{7}, \mathrm{TeO}_{2}, \mathrm{TiO}_{2}, \mathrm{Tl}_{2} \mathrm{O}, \mathrm{V}_{2} \mathrm{O}_{5}, \mathrm{WO}_{3}$ and $\mathrm{Y}_{2} \mathrm{O}_{3}$.

(c) A dash (-) indicates the term was not included in the model.

(d) The evaluation and validation statistics calculated for data-splits are defined the same as for separate modeling and validation sets. Section 8.1 .2 describes how the data-splitting was accomplished. 
Table 8.7. Coefficients and Performance Summary for the 24-Term Truncated T2-Linear Mixture Model on the Natural Logarithm of Viscosity Fitted to Data on 197 HLW Glasses.

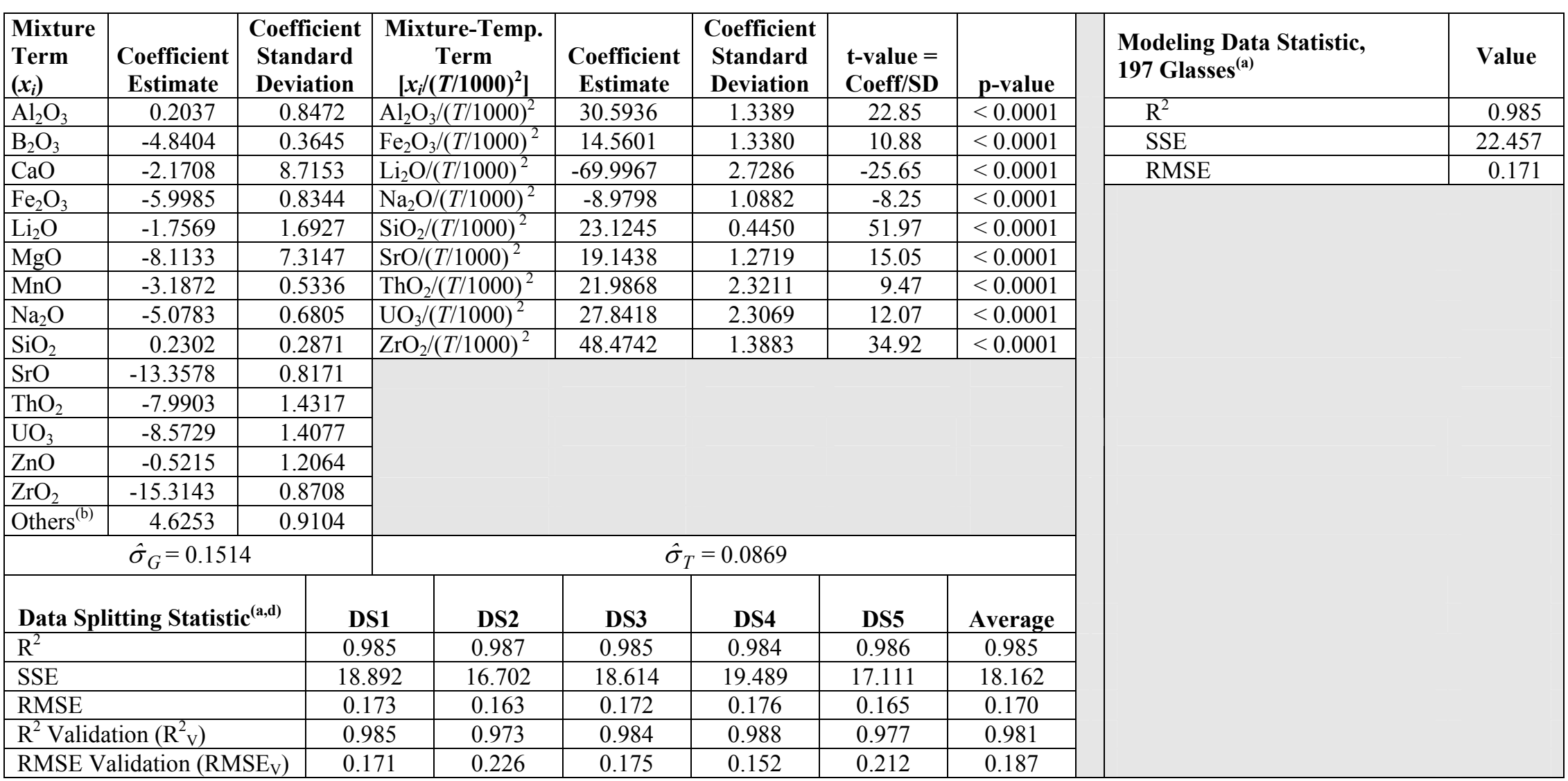

(a) The model evaluation statistics are defined in Section C.3 of Appendix C. Model validation statistics are defined in Section C.5 of Appendix C.

(b) The "Others" component includes $\mathrm{Ag}_{2} \mathrm{O}, \mathrm{As}_{2} \mathrm{O}_{5}, \mathrm{BaO}, \mathrm{BeO}, \mathrm{Bi}_{2} \mathrm{O}_{3}, \mathrm{CdO}, \mathrm{Cr}_{2} \mathrm{O}_{3}, \mathrm{Ce}_{2} \mathrm{O}_{3}, \mathrm{Cl}, \mathrm{CoO}_{2} \mathrm{Cs}_{2} \mathrm{O}, \mathrm{CuO}, \mathrm{Dy}_{2} \mathrm{O}_{3}, \mathrm{Eu}_{2} \mathrm{O}_{3}, \mathrm{~F}, \mathrm{Gd}_{2} \mathrm{O}_{3}, \mathrm{HfO} \mathrm{H}_{2}, \mathrm{HgO}_{2} \mathrm{~K}_{2} \mathrm{O}$, $\mathrm{La}_{2} \mathrm{O}_{3}, \mathrm{MoO}_{3}, \mathrm{NiO}, \mathrm{P}_{2} \mathrm{O}_{5}, \mathrm{PbO}, \mathrm{PdO}, \mathrm{Pr}_{2} \mathrm{O}_{3}, \mathrm{Rb}_{2} \mathrm{O}, \mathrm{Re}_{2} \mathrm{O}_{7}, \mathrm{Rh}_{2} \mathrm{O}_{3}, \mathrm{RuO}_{2}, \mathrm{Sb}_{2} \mathrm{O}_{3}, \mathrm{SeO}_{2}, \mathrm{SO}_{3}, \mathrm{Sm}_{2} \mathrm{O}_{3}, \mathrm{SnO}_{2}, \mathrm{Tc}_{2} \mathrm{O}_{7}, \mathrm{TeO}_{2}, \mathrm{TiO}_{2}, \mathrm{Tl}_{2} \mathrm{O}, \mathrm{V}_{2} \mathrm{O}_{5}, \mathrm{WO}_{3}$ and $\mathrm{Y}_{2} \mathrm{O}_{3}$.

(c) A dash (-) indicates the term was not included in the model. The evaluation and validation statistics calculated for data-splits are defined the same as for separate modeling and validation sets. Section 8.1.2 describes how the data-splitting was accomplished. 
Table 8.8. Coefficients and Performance Summary for the 29-Term Truncated T2-Linear Mixture Model With Five Quadratic Terms on the Natural Logarithm of Viscosity Fitted to Data on 197 HLW Glasses.

\begin{tabular}{|c|c|c|c|c|c|c|c|c|c|}
\hline $\begin{array}{l}\text { Mixture } \\
\text { Term }\left(x_{i}\right)\end{array}$ & $\begin{array}{c}\text { Coefficient } \\
\text { Estimate }\end{array}$ & $\begin{array}{l}\text { Coefficient } \\
\text { Standard } \\
\text { Deviation }\end{array}$ & $\begin{array}{c}\text { Mixture-Temp. } \\
\text { Term } \\
{\left[x_{i} /(T / 1000)^{2}\right]} \\
\end{array}$ & $\begin{array}{c}\text { Coefficient } \\
\text { Estimate }\end{array}$ & $\begin{array}{l}\text { Coefficient } \\
\text { Standard } \\
\text { Deviation } \\
\end{array}$ & $\begin{array}{l}\text { t-value }= \\
\text { Coeff } / \text { SD }\end{array}$ & p-value & $\begin{array}{l}\text { Modeling Data Statistic, } \\
\text { 197 Glasses }^{(a)}\end{array}$ & Value \\
\hline $\mathrm{Al}_{2} \mathrm{O}_{3}$ & 12.5333 & 2.8226 & $\mathrm{Al}_{2} \mathrm{O}_{3} /(T / 1000)^{2}$ & 30.5925 & 1.3388 & 22.85 & $<0.0001$ & $\mathrm{R}^{2}$ & 0.988 \\
\hline $\mathrm{B}_{2} \mathrm{O}_{3}$ & -3.1161 & 0.8768 & $\mathrm{Fe}_{2} \mathrm{O}_{3} /(T / 1000)^{2}$ & 14.5535 & 1.3379 & 10.88 & $<0.0001$ & SSE & 17.385 \\
\hline $\mathrm{CaO}$ & -3.7004 & 7.6447 & $\mathrm{Li}_{2} \mathrm{O} /(T / 1000)^{2}$ & -70.0777 & 2.7284 & -25.68 & $<0.0001$ & RMSE & 0.151 \\
\hline $\mathrm{Fe}_{2} \mathrm{O}_{3}$ & -6.7690 & 0.8304 & $\mathrm{Na}_{2} \mathrm{O} /(T / 1000)^{2}$ & -8.9510 & 1.0881 & -8.23 & $<0.0001$ & & \\
\hline $\mathrm{Li}_{2} \mathrm{O}$ & -13.4090 & 2.8847 & $\mathrm{SiO}_{2} /(T / 1000)^{2}$ & 23.1245 & 0.4449 & 51.98 & $<0.0001$ & & \\
\hline $\mathrm{MgO}$ & -6.8977 & 6.3479 & $\mathrm{SrO} /(T / 1000)^{2}$ & 19.1357 & 1.2718 & 15.05 & $<0.0001$ & & \\
\hline $\mathrm{MnO}$ & -2.8771 & 0.4744 & $\mathrm{ThO}_{2} /(T / 1000)^{2}$ & 22.0504 & 2.3209 & 9.50 & $<0.0001$ & & \\
\hline $\mathrm{Na}_{2} \mathrm{O}$ & -4.6897 & 1.0507 & $\mathrm{UO}_{3} /(T / 1000)^{2}$ & 27.8595 & 2.3066 & 12.08 & $<0.0001$ & & \\
\hline $\mathrm{SiO}_{2}$ & 1.3479 & 0.3883 & $\mathrm{ZrO}_{2} /(T / 1000)^{2}$ & 48.4524 & 1.3882 & 34.90 & $<0.0001$ & & \\
\hline $\mathrm{SrO}$ & -14.0315 & 0.7968 & & & & & & & \\
\hline $\mathrm{ThO}_{2}$ & -15.2911 & 2.2807 & & & & & & & \\
\hline $\mathrm{UO}_{3}$ & -10.3115 & 1.3898 & & & & & & & \\
\hline $\mathrm{ZnO}$ & -5.8582 & 2.5771 & & & & & & & \\
\hline $\mathrm{ZrO}_{2}$ & -15.2230 & 0.8548 & & & & & & & \\
\hline Others $^{(b)}$ & 2.3371 & 0.8797 & & & & & & & \\
\hline $\mathrm{Al}_{2} \mathrm{O}_{3} \times \mathrm{SiO}_{2}$ & -30.4134 & 6.6928 & & & & -4.54 & $<0.0001$ & & \\
\hline $\mathrm{B}_{2} \mathrm{O}_{3} \times \mathrm{Na}_{2} \mathrm{O}$ & -21.8792 & 7.2738 & & & & -3.01 & 0.0030 & & \\
\hline $\mathrm{Li}_{2} \mathrm{O} \times \mathrm{ZnO}$ & 165.7600 & 67.1844 & & & & 2.47 & 0.0146 & & \\
\hline $\mathrm{Na}_{2} \mathrm{O} \times \mathrm{ThO}_{2}$ & 52.6720 & 14.5725 & & & & 3.61 & 0.0004 & & \\
\hline$\left(\mathrm{Li}_{2} \mathrm{O}\right)^{2}$ & 127.0900 & 38.7202 & & & & 3.28 & 0.0012 & & \\
\hline & $\hat{\sigma}_{G}=0.1283$ & & & & $=0.0869$ & & & & \\
\hline Data Splitt & ng Statistic ${ }^{(a,}$ & D & DS2 & DS3 & DS4 & DS5 & Average & & \\
\hline $\mathrm{R}^{2}$ & & 0.9 & 0.989 & 0.989 & 0.988 & 0.989 & 0.989 & & \\
\hline SSE & & 14. & 13.893 & 13.940 & 14.577 & 13.106 & 14.046 & & \\
\hline RMSE & & 0.1 & 0.149 & 0.150 & 0.153 & 0.145 & 0.150 & & \\
\hline $\mathrm{R}^{2}$ Validatio & $n\left(\mathrm{R}_{\mathrm{V}}^{2}\right)$ & 0.9 & 0.983 & 0.986 & 0.987 & 0.980 & 0.985 & & \\
\hline RMSE Vali & dation (RMSE & 0.1 & 0.179 & 0.167 & 0.155 & 0.198 & 0.169 & & \\
\hline
\end{tabular}

(a) The model evaluation statistics are defined in Section C.3 of Appendix C. Model validation statistics are defined in Section C.5 of Appendix C.

(b) The "Others" component includes $\mathrm{Ag}_{2} \mathrm{O}, \mathrm{As}_{2} \mathrm{O}_{5}, \mathrm{BaO}, \mathrm{BeO}, \mathrm{Bi}_{2} \mathrm{O}_{3}, \mathrm{CdO}, \mathrm{Cr}_{2} \mathrm{O}_{3}, \mathrm{Ce}_{2} \mathrm{O}_{3}, \mathrm{Cl}, \mathrm{CoO}, \mathrm{Cs}_{2} \mathrm{O}, \mathrm{CuO}_{2} \mathrm{Dy}_{2} \mathrm{O}_{3}, \mathrm{Eu}_{2} \mathrm{O}_{3}, \mathrm{~F}, \mathrm{Gd}_{2} \mathrm{O}_{3}, \mathrm{HfO} \mathrm{O}_{2}, \mathrm{HgO}_{2} \mathrm{~K}_{2} \mathrm{O}$, $\mathrm{La}_{2} \mathrm{O}_{3}, \mathrm{MoO}_{3}, \mathrm{NiO}, \mathrm{P}_{2} \mathrm{O}_{5}, \mathrm{PbO}, \mathrm{PdO}, \mathrm{Pr}_{2} \mathrm{O}_{3}, \mathrm{Rb}_{2} \mathrm{O}, \mathrm{Re}_{2} \mathrm{O}_{7}, \mathrm{Rh}_{2} \mathrm{O}_{3}, \mathrm{RuO}_{2}, \mathrm{Sb}_{2} \mathrm{O}_{3}, \mathrm{SeO}_{2}, \mathrm{SO}_{3}, \mathrm{Sm}_{2} \mathrm{O}_{3}, \mathrm{SnO}_{2}, \mathrm{Tc}_{2} \mathrm{O}_{7}, \mathrm{TeO}_{2}, \mathrm{TiO}_{2}, \mathrm{Tl}_{2} \mathrm{O}, \mathrm{V}_{2} \mathrm{O}_{5}, \mathrm{WO}_{3}$ and $\mathrm{Y}_{2} \mathrm{O}_{3}$

(c) The evaluation and validation statistics calculated for data-splits are defined the same as for separate modeling and validation sets. Section 8.1 .2 describes how the data-splitting was accomplished. 
Table 8.9. Summary Statistics for Various Viscosity Models Fitted and Validated Using Data from HLW Glasses.

\begin{tabular}{|c|c|c|c|c|c|}
\hline \multicolumn{6}{|c|}{ Results Using all 197 HLW Glasses with Viscosity Data ${ }^{(a)}$} \\
\hline Statistic & Model 1 & Model 2 & Model 3 & Model 4 & Model 5 \\
\hline \# Model Terms & 44 & 27 & 32 & 24 & 29 \\
\hline $\mathrm{R}^{2}$ & 0.987 & 0.986 & 0.989 & 0.985 & 0.988 \\
\hline SSE & 19.479 & 21.5851 & 16.492 & 22.457 & 17.385 \\
\hline RMSE & 0.162 & 0.168 & 0.148 & 0.171 & 0.151 \\
\hline \multicolumn{6}{|c|}{$\begin{array}{c}\text { Average Results Over Five Modeling and Validation } \\
\text { Subsets from Data Splitting }\end{array}$} \\
\hline Statistic & Model 1 & Model 2 & Model 3 & Model 4 & Model 5 \\
\hline $\mathrm{R}^{2}$ & 0.988 & 0.986 & 0.989 & 0.985 & 0.989 \\
\hline SSE & 15.393 & 17.404 & 13.267 & 18.162 & 14.046 \\
\hline RMSE & 0.159 & 0.167 & 0.146 & 0.170 & 0.150 \\
\hline $\mathrm{R}_{\mathrm{V}}^{2}$ & 0.980 & 0.982 & 0.985 & 0.981 & 0.985 \\
\hline $\mathrm{RMSE}_{\mathrm{V}}$ & 0.193 & 0.186 & 0.167 & 0.187 & 0.169 \\
\hline
\end{tabular}

(a) Model 5 is the recommended model.

(b) The data-split modeling subsets contain viscosity data for $163 \mathrm{HLW}$ glasses each, while the validation subsets contain viscosity data for $34 \mathrm{HLW}$ glasses each. 
Table 8.10. HLW03-06 Composition in Formats Needed for Use in Viscosity Models for HLW Glasses.

\begin{tabular}{|c|c|c|c|}
\hline Model Term ${ }^{(a)}$ & $\begin{array}{c}\text { HLW03-06 } \\
\text { Composition }^{(b)} \\
\text { (mass fractions) }\end{array}$ & $\begin{array}{c}\text { HLW03-06 } \\
\text { Composition } \\
\text { (mass fractions) } \\
\text { for Use in 29-Term } \\
\text { Viscosity Model }^{(\mathbf{c})}\end{array}$ & $\begin{array}{c}\text { HLW03-06 } \\
\text { Composition } \\
\text { (mass fractions) } \\
\text { for Use in 24-Term } \\
\text { Viscosity Model }^{(\mathbf{d})}\end{array}$ \\
\hline $\mathrm{Al}_{2} \mathrm{O}_{3}$ & 0.08344 & 0.08344 & 0.08344 \\
\hline $\mathrm{B}_{2} \mathrm{O}_{3}$ & 0.04908 & 0.04908 & 0.04908 \\
\hline $\mathrm{CaO}$ & 0.00500 & 0.00500 & 0.00500 \\
\hline $\mathrm{CdO}$ & 0.01600 & NA & NA \\
\hline $\mathrm{Cr}_{2} \mathrm{O}_{3}$ & 0.00491 & NA & NA \\
\hline $\mathrm{Fe}_{2} \mathrm{O}_{3}$ & 0.01963 & 0.01963 & 0.01963 \\
\hline $\mathrm{Li}_{2} \mathrm{O}$ & 0.05890 & 0.05890 & 0.05890 \\
\hline $\mathrm{MgO}$ & 0.00120 & 0.00120 & 0.00120 \\
\hline $\mathrm{MnO}$ & 0.06872 & 0.06872 & 0.06872 \\
\hline $\mathrm{Na}_{2} \mathrm{O}$ & 0.03927 & 0.03927 & 0.03927 \\
\hline $\mathrm{NiO}$ & 0.00982 & NA & NA \\
\hline $\mathrm{PbO}$ & 0.00040 & NA & NA \\
\hline $\mathrm{Sb}_{2} \mathrm{O}_{3}$ & 0.00020 & NA & NA \\
\hline $\mathrm{SeO}_{2}$ & 0.00020 & NA & NA \\
\hline $\mathrm{SiO}_{2}$ & 0.52031 & 0.52031 & 0.52031 \\
\hline $\mathrm{SrO}$ & 0.05091 & 0.05091 & 0.05091 \\
\hline $\mathrm{ThO}_{2}$ & 0.01416 & 0.01416 & 0.01416 \\
\hline $\mathrm{UO}_{3}$ & 0.00000 & 0.00000 & 0.00000 \\
\hline $\mathrm{ZnO}$ & 0.00000 & 0.00000 & 0.00000 \\
\hline $\mathrm{ZrO}_{2}$ & 0.04095 & 0.04095 & 0.04095 \\
\hline Others & 0.04843 & 0.04843 & 0.04843 \\
\hline $\mathrm{Al}_{2} \mathrm{O}_{3} \times \mathrm{SiO}_{2}$ & 0.04341 & 0.04341 & $\mathrm{NA}^{(\mathrm{e})}$ \\
\hline $\mathrm{B}_{2} \mathrm{O}_{3} \times \mathrm{Na}_{2} \mathrm{O}$ & 0.00193 & 0.00193 & NA \\
\hline $\mathrm{Li}_{2} \mathrm{O} \times \mathrm{ZnO}$ & 0.00000 & 0.00000 & NA \\
\hline $\mathrm{Na}_{2} \mathrm{O} \times \mathrm{ThO}_{2}$ & 0.00056 & 0.00056 & NA \\
\hline$\left(\mathrm{Li}_{2} \mathrm{O}\right)^{2}$ & 0.00347 & 0.00347 & NA \\
\hline
\end{tabular}

(a) The viscosity models contain $x_{i} /(T / 1000)^{2}$ terms in addition to the $x_{i}$ and $x_{i} x_{j}$ terms shown in this column. The purpose of this table is to show the compositional forms needed for model predictions, so the temperature-containing terms are not shown.

(b) The composition in mass fractions is from Table 8.1.

(c) See Table 8.8.

(d) See Table 8.7.

(e) $\mathrm{NA}=$ not applicable, because the model does not contain this term. 
Table 8.11. Predicted Viscosity, Standard Deviation, and Statistical Intervals for HLW03-06 Composition Used in Viscosity Models for HLW Glasses.

\begin{tabular}{|c|c|c|c|c|c|c|c|c|c|}
\hline Model $^{(a)}$ & $\begin{array}{c}\text { Predicted } \\
\ln (\eta) \\
{[\ln (\text { Poise })]}\end{array}$ & $\begin{array}{c}\text { Predicted } \\
\text { Viscosity }^{(c)} \\
{[\text { Poise] }}\end{array}$ & $\begin{array}{c}\text { Standard } \\
\text { Deviation of } \\
\text { Predicted } \\
\ln (\eta)^{(d)} \\
{[\ln (\text { Poise })]}\end{array}$ & $\begin{array}{c}90 \% \text { LCI }^{(\mathrm{e})} \\
\text { on Mean } \\
\ln (\eta) \\
{[\ln (\text { Poise })]}\end{array}$ & $\begin{array}{c}90 \% \text { LCI }^{(e)} \\
\text { on Median } \\
\text { Viscosity } \\
\text { [Poise] }\end{array}$ & $\begin{array}{c}90 \% \mathrm{UCI}^{(\mathrm{e})} \\
\text { on Mean } \\
\ln (\boldsymbol{\eta}) \\
{[\ln (\text { Poise })]}\end{array}$ & $\begin{array}{c}90 \% \text { UCI }^{(e)} \\
\text { on Median } \\
\text { Viscosity } \\
\text { [Poise] }\end{array}$ & $\begin{array}{c}90 \% \mathrm{CI}^{(\mathrm{e})} \text { on } \\
\text { Mean } \ln (\eta) \\
{[\ln (\text { Poise })]} \\
\end{array}$ & $\begin{array}{c}90 \% \mathrm{CI}^{(\mathrm{e})} \text { on } \\
\text { Median Viscosity } \\
{[\text { Poise] }}\end{array}$ \\
\hline $\begin{array}{l}29-\text { Term } \\
\text { Viscosity } \\
\text { Model at } \\
1146^{\circ} \mathrm{C}^{(b)}\end{array}$ & $4.713^{(\mathrm{f})}$ & 111.367 & 0.058 & 4.638 & 103.367 & 4.787 & 119.986 & $(4.617,4.809)$ & $(101.190,122.567)$ \\
\hline $\begin{array}{l}\text { 24-Term } \\
\text { Viscosity } \\
\text { Model at } \\
1146^{\circ} \mathrm{C}^{(\mathrm{b})}\end{array}$ & 4.828 & 124.931 & 0.058 & 4.753 & 115.944 & 4.902 & 134.614 & $(4.732,4.924)$ & $(113.499,137.514)$ \\
\hline
\end{tabular}

(a) The two models in this column are given in Tables 8.7 (24-term model) and 8.8 (29-term model).

(b) The temperature of $1146^{\circ} \mathrm{C}$ was chosen because it was one of the temperatures at which the viscosity of HLW03-06 was measured. This facilitates comparison of the predicted and measured values.

(c) Of the two models, the one with the predicted viscosity value at $1146^{\circ} \mathrm{C}$ closest to the measured value of 93.53 Poise is the recommended 29 -term viscosity model.

(d) The standard deviation is for the $\ln (\eta)$ prediction at $1146^{\circ} \mathrm{C}$ considered to be the mean of such values for the HLW03-06 glass.

(e) $\mathrm{UCI}=$ upper confidence interval, LCI = lower confidence interval, and CI = two-sided confidence interval (see Section C.7 of Appendix C).

(f) All calculations were performed using the HLW03-06 glass composition, model coefficients, and variance-covariance matrix values given in tables of this report. The calculated $\ln (\mathrm{P})$ values were rounded to three decimal places in this table. The Poise values were calculated by exponentiating the $\ln (\mathrm{P})$ values before rounding, then rounding the resulting values to three decimal places in this table. 
Table 9.1. Minimums and Maximums of HLW Glass Components (in Mass Fractions) for Compositions in the Modeling Datasets for Each HLW Glass Property.

\begin{tabular}{|c|c|c|c|c|c|c|c|c|c|c|}
\hline $\begin{array}{l}\text { HLW } \\
\text { Glass } \\
\text { Property }\end{array}$ & \multicolumn{2}{|c|}{ PCT } & \multicolumn{2}{|c|}{ Spinel $\mathbf{T}_{1 \%}$} & \multicolumn{2}{|c|}{ Viscosity } & \multicolumn{2}{|c|}{$\begin{array}{c}\text { Electrical } \\
\text { Conductivity }\end{array}$} & \multicolumn{2}{|c|}{ TCLP-Cd } \\
\hline $\begin{array}{l}\text { Number of } \\
\text { Glasses in } \\
\text { Modeling }\end{array}$ & \multicolumn{2}{|c|}{$266^{(a)}$} & \multicolumn{2}{|c|}{168} & \multicolumn{2}{|c|}{197} & \multicolumn{2}{|c|}{208} & \multicolumn{2}{|c|}{$100^{(b)}$} \\
\hline $\begin{array}{l}\text { HLW } \\
\text { Glass } \\
\text { Component }\end{array}$ & $\begin{array}{l}\text { Min } \\
(\mathbf{m f})\end{array}$ & $\begin{array}{l}\text { Max } \\
\text { (mf) }\end{array}$ & $\begin{array}{l}\text { Min } \\
\text { (mf) }\end{array}$ & $\begin{array}{l}\text { Max } \\
\text { (mf) }\end{array}$ & $\begin{array}{l}\text { Min } \\
\text { (mf) }\end{array}$ & $\begin{array}{l}\text { Max } \\
\text { (mf) }\end{array}$ & $\begin{array}{l}\text { Min } \\
\text { (mf) }\end{array}$ & $\begin{array}{l}\text { Max } \\
\text { (mf) }\end{array}$ & $\begin{array}{l}\text { Min } \\
\text { (mf) }\end{array}$ & $\begin{array}{l}\text { Max } \\
\text { (mf) }\end{array}$ \\
\hline $\mathrm{Al}_{2} \mathrm{O}_{3}$ & 0.01428 & 0.13025 & 0.01800 & 0.13025 & 0.01428 & 0.13025 & 0.01428 & 0.13025 & 0.01923 & 0.08501 \\
\hline $\mathrm{B}_{2} \mathrm{O}_{3}$ & 0.03785 & 0.15000 & 0.04300 & 0.15000 & 0.04500 & 0.15000 & 0.04500 & 0.15000 & 0.04808 & 0.14002 \\
\hline $\mathrm{CaO}$ & 0 & 0.01000 & 0 & 0.01000 & 0 & 0.01000 & 0 & 0.01000 & 0.00498 & 0.00500 \\
\hline $\mathrm{CdO}$ & 0 & 0.01646 & 0 & 0.01600 & 0 & 0.01646 & 0 & 0.01646 & 0.00050 & 0.01600 \\
\hline $\mathrm{Cr}_{2} \mathrm{O}_{3}$ & 0 & 0.00600 & 0 & 0.00600 & 0 & 0.00600 & 0 & 0.00600 & 0.00019 & 0.00497 \\
\hline $\mathrm{Fe}_{2} \mathrm{O}_{3}$ & 0.01400 & 0.15052 & 0.01400 & 0.15000 & 0.01400 & 0.15000 & 0.01400 & 0.15000 & 0.01924 & 0.14002 \\
\hline $\mathrm{K}_{2} \mathrm{O}$ & 0 & 0.01640 & 0 & 0.01640 & 0 & 0.01640 & 0 & 0.01640 & 0.00060 & 0.00060 \\
\hline $\mathrm{La}_{2} \mathrm{O}_{3}$ & 0 & 0.01234 & 0 & 0.00529 & 0 & 0.01234 & 0 & 0.01234 & 0.00299 & 0.00300 \\
\hline $\mathrm{Li}_{2} \mathrm{O}$ & $0^{(\mathrm{c})}$ & 0.06013 & 0 & 0.06012 & 0 & 0.06013 & 0 & 0.06013 & 0.01924 & 0.06001 \\
\hline $\mathrm{MgO}$ & 0 & 0.01364 & 0 & 0.01170 & 0 & 0.01364 & 0 & 0.01364 & 0.00120 & 0.00120 \\
\hline $\mathrm{MnO}$ & 0 & $0.08000^{(\mathrm{d})}$ & 0 & 0.08000 & 0 & 0.08000 & 0 & 0.08000 & 0 & 0.06962 \\
\hline $\mathrm{Na}_{2} \mathrm{O}$ & 0.03700 & 0.20000 & 0.03700 & 0.20000 & 0.03909 & 0.20000 & 0.03909 & 0.20000 & 0.03909 & 0.15002 \\
\hline $\mathrm{NiO}$ & 0 & 0.01002 & 0 & 0.01002 & 0 & 0.01002 & 0 & 0.01002 & 0.00096 & 0.01000 \\
\hline $\mathrm{PbO}$ & 0 & 0.01010 & 0 & 0.01010 & 0 & 0.01010 & 0 & 0.01010 & 0.00040 & 0.00400 \\
\hline $\mathrm{Sb}_{2} \mathrm{O}_{3}$ & 0 & 0.00400 & 0 & 0.00400 & 0 & 0.00400 & 0 & 0.00400 & 0.00020 & 0.00300 \\
\hline $\mathrm{SeO}_{2}$ & 0 & 0.00432 & 0 & 0.00200 & 0 & 0.00432 & 0 & 0.00432 & 0.00020 & 0.00200 \\
\hline $\mathrm{SiO}_{2}$ & 0.33000 & 0.53100 & 0.35000 & 0.53000 & 0.33030 & 0.53000 & 0.33030 & 0.53007 & 0.35132 & 0.53007 \\
\hline $\mathrm{SrO}$ & 0 & 0.10287 & 0 & 0.10020 & 0 & 0.10287 & 0 & 0.10287 & 0 & 0.09946 \\
\hline $\mathrm{ThO}_{2}$ & 0 & 0.06013 & 0 & 0.05967 & 0 & 0.06013 & 0 & 0.06013 & 0 & 0.05967 \\
\hline $\mathrm{TiO}_{2}$ & 0 & 0.01000 & 0 & 0.01000 & 0 & 0.01000 & 0 & 0.01000 & 0.00030 & 0.00030 \\
\hline $\mathrm{Tl}_{2} \mathrm{O}$ & 0 & 0.00307 & 0 & 0.00307 & 0 & 0.00307 & 0 & 0.00307 & 0.00019 & 0.00307 \\
\hline $\mathrm{UO}_{3}$ & 0 & 0.06500 & 0 & 0.06500 & 0 & 0.06500 & 0 & 0.06500 & 0 & 0.06306 \\
\hline $\mathrm{ZnO}$ & 0 & 0.04000 & 0 & 0.04000 & 0 & 0.03979 & 0 & 0.03979 & 0 & 0.03979 \\
\hline $\mathrm{ZrO}_{2}$ & 0 & 0.11500 & 0 & 0.09601 & 0 & 0.11500 & 0 & 0.11500 & 0 & 0.09088 \\
\hline Others ${ }^{(\mathrm{e})}$ & 0.00220 & 0.05145 & 0.00421 & 0.03770 & 0.00220 & 0.03770 & 0.00220 & 0.03770 & 0.01276 & 0.02120 \\
\hline
\end{tabular}

(a) The results are given for the 266 glasses in the PCT-Na modeling dataset. Differences resulting from there being only 264 glasses in the PCT-B modeling dataset and 250 glasses in the PCT-Li dataset are noted via footnotes.

(b) Only 100 of the 102 HLW02 and HLW03 glasses (excluding HLW03-01 and HLW03-08) were used to develop TCLP-Cd models. Note that the summary statistics are based on the mass fractions before the normalization to the number of components in the TCLP-Cd models. See Kot et al. (2004).

(c) The minimum $\mathrm{Li}_{2} \mathrm{O}$ is 0 for the PCT-B and PCT-Na datasets. The minimum for the PCT-Li dataset is 0.0025 .

(d) The maximum $\mathrm{MnO}$ is 0.08000 for the PCT-B and PCT-Na datasets. The minimum for the PCT-Li dataset is 0.07012 .

(e) The mass fraction of the Others component was calculated as one minus the sum of the mass fractions of the 24 listed components. 
Table 9.2. Minimums and Maximums of HLW Glass Components (in Mass Fractions) Included in the Others Group in Table 9.1 for Compositions in the Modeling Datasets for Each HLW Glass Property.

\begin{tabular}{|c|c|c|c|c|c|c|c|c|c|c|}
\hline $\begin{array}{l}\text { HLW Glass } \\
\text { Property }\end{array}$ & \multicolumn{2}{|c|}{ PCT } & \multicolumn{2}{|c|}{ Spinel $\mathbf{T}_{1 \%}$} & \multicolumn{2}{|c|}{ Viscosity } & \multicolumn{2}{|c|}{$\begin{array}{c}\text { Electrical } \\
\text { Conductivity }\end{array}$} & \multicolumn{2}{|c|}{ TCLP-Cd } \\
\hline Glasses in & \multicolumn{2}{|c|}{$266^{(a)}$} & \multicolumn{2}{|c|}{168} & \multicolumn{2}{|c|}{197} & \multicolumn{2}{|c|}{208} & \multicolumn{2}{|c|}{$100^{(b)}$} \\
\hline $\begin{array}{l}\text { HLW Glass } \\
\text { Component } \\
\text { in Others }\end{array}$ & $\begin{array}{l}\text { Min } \\
\text { (mf) }\end{array}$ & $\begin{array}{l}\text { Max } \\
(\mathrm{mf})\end{array}$ & $\begin{array}{l}\text { Min } \\
\text { (mf) }\end{array}$ & $\begin{array}{l}\text { Max } \\
(\mathrm{mf})\end{array}$ & $\begin{array}{l}\text { Min } \\
\text { (mf) }\end{array}$ & $\begin{array}{l}\text { Max } \\
(\mathbf{m f})\end{array}$ & $\begin{array}{l}\text { Min } \\
(\mathrm{mf})\end{array}$ & $\begin{array}{l}\text { Max } \\
(\mathrm{mf})\end{array}$ & $\begin{array}{l}\text { Min } \\
(\mathrm{mf})\end{array}$ & $\begin{array}{l}\text { Max } \\
\text { (mf) }\end{array}$ \\
\hline $\mathrm{Ag}_{2} \mathrm{O}$ & 0 & 0.00236 & 0 & 0.00200 & 0 & 0.00200 & 0 & 0.00200 & 0.00020 & 0.00200 \\
\hline $\mathrm{As}_{2} \mathrm{O}_{5}$ & 0 & 0.00236 & 0 & 0.00232 & 0 & 0.00232 & 0 & 0.00232 & 0.00023 & 0.00232 \\
\hline $\mathrm{BaO}$ & 0 & 0.00300 & 0 & 0.00500 & 0 & 0.00500 & 0 & 0.00500 & 0.00030 & 0.00300 \\
\hline $\mathrm{BeO}$ & 0 & 0.00005 & 0 & 0 & 0 & 0 & 0 & 0 & 0 & 0 \\
\hline $\mathrm{Bi}_{2} \mathrm{O}_{3}$ & 0 & 0.00300 & 0 & 0.00300 & 0 & 0.00300 & 0 & 0.00300 & 0.00010 & 0.00010 \\
\hline $\mathrm{Ce}_{2} \mathrm{O}_{3}$ & 0 & 0.00405 & 0 & 0.00380 & 0 & 0.00405 & 0 & 0.02585 & 0.00047 & 0.00048 \\
\hline $\mathrm{Cl}$ & 0 & 0.00340 & 0 & 0.00340 & 0 & 0.00340 & 0 & 0.00340 & 0.00199 & 0.00200 \\
\hline $\mathrm{CoO}$ & 0 & 0.00230 & 0 & 0.00230 & 0 & 0.00230 & 0 & 0.00230 & 0.00010 & 0.00010 \\
\hline $\mathrm{Cs}_{2} \mathrm{O}$ & 0 & 0.00250 & 0 & 0.00250 & 0 & 0.00250 & 0 & 0.00250 & 0.00010 & 0.00010 \\
\hline $\mathrm{CuO}$ & 0 & 0.00240 & 0 & 0.00240 & 0 & 0.00240 & 0 & 0.00240 & 0.00010 & 0.00100 \\
\hline $\mathrm{Dy}_{2} \mathrm{O}_{3}$ & 0 & 0.00030 & 0 & 0 & 0 & 0 & 0 & 0 & 0 & 0 \\
\hline $\mathrm{F}$ & 0 & 0.00440 & 0 & 0.00440 & 0 & 0.00440 & 0 & 0.00440 & 0.00050 & 0.00050 \\
\hline $\mathrm{Gd}_{2} \mathrm{O}_{3}$ & 0 & 0.00010 & 0 & 0 & 0 & 0 & 0 & 0 & 0 & 0 \\
\hline $\mathrm{HfO}_{2}$ & 0 & 0.03292 & 0 & 0 & 0 & 0 & 0 & 0.03292 & 0 & 0 \\
\hline $\mathrm{MoO}_{3}$ & 0 & 0.00390 & 0 & 0.00390 & 0 & 0.00390 & 0 & 0.00390 & 0 & 0 \\
\hline $\mathrm{Nd}_{2} \mathrm{O}_{3}$ & 0 & 0.01645 & 0 & 0.00487 & 0 & 0.00802 & 0 & 0.01657 & 0 & 0 \\
\hline $\mathrm{P}_{2} \mathrm{O}_{5}$ & 0 & 0.00640 & 0 & 0.00640 & 0 & 0.00640 & 0 & 0.00640 & 0.00498 & 0.00500 \\
\hline $\mathrm{PdO}$ & 0 & 0.00128 & 0 & 0.00128 & 0 & 0.00128 & 0 & 0.00128 & 0.00120 & 0.00120 \\
\hline $\mathrm{Pr}_{2} \mathrm{O}_{3}$ & 0 & 0.00160 & 0 & 0.00160 & 0 & 0.00160 & 0 & 0.00160 & 0 & 0 \\
\hline $\mathrm{Rb}_{2} \mathrm{O}$ & 0 & 0.00080 & 0 & 0.00080 & 0 & 0.00080 & 0 & 0.00080 & 0 & 0 \\
\hline $\mathrm{Rh}_{2} \mathrm{O}_{3}$ & 0 & 0.00080 & 0 & 0.00080 & 0 & 0.00800 & 0 & 0.00800 & 0.00050 & 0.00050 \\
\hline $\mathrm{RuO}_{2}$ & 0 & 0.00130 & 0 & 0.00130 & 0 & 0.00130 & 0 & 0.00130 & 0.00080 & 0.00080 \\
\hline $\mathrm{SO}_{3}$ & 0 & 0.00330 & 0 & 0.00330 & 0 & 0.00330 & 0 & 0.00330 & 0.00100 & 0.00100 \\
\hline $\mathrm{SnO}_{2}$ & 0 & 0.00685 & 0 & 0.00230 & 0 & 0.00685 & 0 & 0.00685 & 0 & 0 \\
\hline $\mathrm{TeO}_{2}$ & 0 & 0.00010 & 0 & 0.00010 & 0 & 0.00010 & 0 & 0.00010 & 0.00010 & 0.00010 \\
\hline $\mathrm{V}_{2} \mathrm{O}_{5}$ & 0 & 0.00100 & 0 & 0.00101 & 0 & 0.00100 & 0 & 0.00100 & 0.00010 & 0.00100 \\
\hline $\mathrm{WO}_{3}$ & 0 & 0.00124 & 0 & 0.00120 & 0 & 0.00123 & 0 & 0.00124 & 0 & 0 \\
\hline $\mathrm{Y}_{2} \mathrm{O}_{3}$ & 0 & 0.00080 & 0 & 0.00080 & 0 & 0.00080 & 0 & 0.00080 & 0 & 0 \\
\hline
\end{tabular}

(a) The results are the same for the 264, 250, and 266 glasses in the PCT-B, PCT-Li, and PCT-Na modeling datasets, respectively.

(b) Only 100 of the 102 HLW02 and HLW03 glasses (excluding HLW03-01 and HLW03-08) were used to develop TCLP-Cd models. Note that the summary statistics are based on the mass fractions before the normalization to the number of components in the TCLP-Cd models. See Kot et al. (2004). 
Table 9.3. Lower and Upper Bounds on HLW Glass Components (in Mass Fractions) that Partially Define the Composition Validity Regions for IHLW Property Models. ${ }^{(a)}$

\begin{tabular}{|c|c|c|c|c|c|c|c|c|c|c|}
\hline $\begin{array}{l}\text { HLW } \\
\text { Glass } \\
\text { Property }\end{array}$ & \multicolumn{2}{|c|}{ PCT } & \multicolumn{2}{|c|}{ Spinel $T_{1 \%}$} & \multicolumn{2}{|c|}{ Viscosity } & \multicolumn{2}{|c|}{$\begin{array}{c}\text { Electrical } \\
\text { Conductivity }\end{array}$} & \multicolumn{2}{|c|}{ TCLP-Cd } \\
\hline $\begin{array}{l}\text { Number of } \\
\text { Glasses in } \\
\text { Modeling }\end{array}$ & \multicolumn{2}{|c|}{$266^{(b)}$} & \multicolumn{2}{|c|}{168} & \multicolumn{2}{|c|}{197} & \multicolumn{2}{|c|}{208} & \multicolumn{2}{|c|}{$100^{(c)}$} \\
\hline $\begin{array}{l}\text { HLW } \\
\text { Glass } \\
\text { Component }\end{array}$ & $\begin{array}{l}\text { Min } \\
\text { (mf) }\end{array}$ & $\begin{array}{l}\text { Max } \\
\text { (mf) }\end{array}$ & $\begin{array}{l}\text { Min } \\
\text { (mf) }\end{array}$ & $\begin{array}{l}\text { Max } \\
(\mathbf{m f})\end{array}$ & $\begin{array}{l}\text { Min } \\
(\mathbf{m f})\end{array}$ & $\begin{array}{l}\text { Max } \\
(\mathbf{m f})\end{array}$ & $\begin{array}{l}\text { Min } \\
(\mathbf{m f})\end{array}$ & $\begin{array}{l}\text { Max } \\
(\mathbf{m f})\end{array}$ & $\begin{array}{l}\text { Min } \\
\text { (mf) }\end{array}$ & $\begin{array}{l}\text { Max } \\
\text { (mf) }\end{array}$ \\
\hline $\mathrm{Al}_{2} \mathrm{O}_{3}$ & 0.014 & 0.131 & 0.0170 & 0.131 & 0.014 & 0.131 & 0.014 & 0.131 & 0.019 & 0.086 \\
\hline $\mathrm{B}_{2} \mathrm{O}_{3}$ & 0.037 & 0.151 & 0.042 & 0.151 & 0.044 & 0.151 & 0.044 & 0.151 & 0.048 & 0.141 \\
\hline $\mathrm{CaO}$ & 0 & 0.011 & 0 & 0.011 & 0 & 0.011 & 0 & 0.011 & $0^{(\mathrm{f})}$ & 0.006 \\
\hline $\mathrm{CdO}$ & 0 & 0.017 & 0 & 0.017 & 0 & 0.017 & 0 & 0.017 & 0 & 0.017 \\
\hline $\mathrm{Cr}_{2} \mathrm{O}_{3}$ & 0 & 0.007 & 0 & 0.007 & 0 & 0.007 & 0 & 0.007 & 0 & 0.005 \\
\hline $\mathrm{Fe}_{2} \mathrm{O}_{3}$ & 0.013 & 0.151 & 0.013 & 0.151 & 0.013 & 0.151 & 0.013 & 0.151 & 0.019 & 0.141 \\
\hline $\mathrm{K}_{2} \mathrm{O}$ & 0 & 0.017 & 0 & 0.017 & 0 & 0.017 & 0 & 0.017 & 0 & 0.001 \\
\hline $\mathrm{La}_{2} \mathrm{O}_{3}$ & 0 & 0.013 & 0 & 0.006 & 0 & 0.013 & 0 & 0.013 & $0^{(\mathrm{f})}$ & 0.004 \\
\hline $\mathrm{Li}_{2} \mathrm{O}$ & $0^{(\mathrm{d})}$ & 0.061 & 0 & 0.061 & 0 & 0.061 & 0 & 0.061 & 0.019 & 0.061 \\
\hline $\mathrm{MgO}$ & 0 & 0.014 & 0 & 0.012 & 0 & 0.014 & 0 & 0.014 & $0^{(\mathrm{f})}$ & 0.002 \\
\hline $\mathrm{MnO}$ & 0 & $0.081^{(\mathrm{e})}$ & 0 & 0.081 & 0 & 0.081 & 0 & 0.081 & 0 & 0.070 \\
\hline $\mathrm{Na}_{2} \mathrm{O}$ & 0.037 & 0.201 & 0.036 & 0.201 & 0.039 & 0.201 & 0.039 & 0.201 & 0.038 & 0.151 \\
\hline $\mathrm{NiO}$ & 0 & 0.011 & 0 & 0.011 & 0 & 0.011 & 0 & 0.011 & 0 & 0.011 \\
\hline $\mathrm{PbO}$ & 0 & 0.011 & 0 & 0.011 & 0 & 0.011 & 0 & 0.011 & 0 & 0.005 \\
\hline $\mathrm{Sb}_{2} \mathrm{O}_{3}$ & 0 & 0.005 & 0 & 0.005 & 0 & 0.005 & 0 & 0.005 & 0 & 0.004 \\
\hline $\mathrm{SeO}_{2}$ & 0 & 0.005 & 0 & 0.003 & 0 & 0.005 & 0 & 0.005 & 0 & 0.003 \\
\hline $\mathrm{SiO}_{2}$ & 0.330 & 0.532 & 0.350 & 0.531 & 0.330 & 0.531 & 0.330 & 0.531 & 0.351 & 0.531 \\
\hline $\mathrm{SrO}$ & 0 & 0.103 & 0 & 0.101 & 0 & 0.103 & 0 & 0.103 & 0 & 0.010 \\
\hline $\mathrm{ThO}_{2}$ & 0 & 0.061 & 0 & 0.060 & 0 & 0.061 & 0 & 0.061 & 0 & 0.060 \\
\hline $\mathrm{TiO}_{2}$ & 0 & 0.011 & 0 & 0.011 & 0 & 0.011 & 0 & 0.011 & 0 & 0.001 \\
\hline $\mathrm{Tl}_{2} \mathrm{O}$ & 0 & 0.004 & 0 & 0.004 & 0 & 0.004 & 0 & 0.004 & 0 & 0.004 \\
\hline $\mathrm{UO}_{3}$ & 0 & 0.066 & 0 & 0.066 & 0 & 0.066 & 0 & 0.066 & 0 & 0.064 \\
\hline $\mathrm{ZnO}$ & 0 & 0.041 & 0 & 0.041 & 0 & 0.040 & 0 & 0.040 & 0 & 0.040 \\
\hline $\mathrm{ZrO}_{2}$ & 0 & 0.116 & 0 & 0.097 & 0 & 0.116 & 0 & 0.116 & 0 & 0.040 \\
\hline Others ${ }^{(\mathrm{g})}$ & $0^{(\mathrm{f})}$ & 0.052 & $0^{(\mathrm{f})}$ & 0.038 & $0^{(\mathrm{f})}$ & 0.038 & $0^{(\mathrm{f})}$ & 0.038 & 0.012 & 0.022 \\
\hline
\end{tabular}

(a) The lower and upper bounds for these components are the minimum and maximum values from Table 9.1, with the lower bounds rounded down and the upper bounds rounded up, each to the third decimal place.

(b) The results are given for the 266 glasses in the PCT-Na modeling dataset. Differences resulting from there being only 264 glasses in the PCT-B modeling dataset and 250 glasses in the PCT-Li dataset are noted via footnotes.

(c) Only 100 of the 102 HLW02 and HLW03 glasses (excluding HLW03-01 and HLW03-08) were used to develop TCLP-Cd models. Note that the lower and upper bounds are based on the mass fractions before the normalization to the number of components in the TCLP-Cd models. See Kot et al. (2004).

(d) $\mathrm{The}_{\mathrm{Li}} \mathrm{O}$ lower bound is 0 for the PCT-B and PCT-Na datasets and is 0.002 for the PCT-Li dataset.

(e) The $\mathrm{MnO}$ upper bound is 0.081 for the PCT-B and PCT-Na datasets and is 0.071 for the PCT-Li dataset.

(f) The lower bound was set to zero even though the rounded value to three decimals was slightlylarger than zero.

(g) The components in Others are listed in the second half of the table on the following page. 
Table 9.3. Lower and Upper Bounds on HLW Glass Components (in Mass Fractions) that Partially Define the Composition Validity Regions for IHLW Property Models (continued). ${ }^{(a)}$

\begin{tabular}{|c|c|c|c|c|c|c|c|c|c|c|}
\hline $\begin{array}{l}\text { HLW Glass } \\
\text { Property }\end{array}$ & \multicolumn{2}{|c|}{ PCT } & \multicolumn{2}{|c|}{ Spinel $\mathbf{T}_{1 \%}$} & \multicolumn{2}{|c|}{ Viscosity } & \multicolumn{2}{|c|}{$\begin{array}{c}\text { Electrical } \\
\text { Conductivity }\end{array}$} & \multicolumn{2}{|c|}{ TCLP-Cd } \\
\hline & \multicolumn{2}{|c|}{$266^{(b)}$} & \multicolumn{2}{|c|}{168} & \multicolumn{2}{|c|}{197} & \multicolumn{2}{|c|}{208} & \multicolumn{2}{|c|}{$100^{(c)}$} \\
\hline $\begin{array}{l}\text { HLW Glass } \\
\text { Component } \\
\text { in Others }\end{array}$ & $\begin{array}{l}\text { Min } \\
(\mathrm{mf})\end{array}$ & $\begin{array}{l}\text { Max } \\
(\mathrm{mf})\end{array}$ & $\begin{array}{l}\text { Min } \\
(\mathrm{mf})\end{array}$ & $\begin{array}{l}\operatorname{Max} \\
(\mathrm{mf})\end{array}$ & $\begin{array}{l}\text { Min } \\
(\mathrm{mf})\end{array}$ & $\begin{array}{l}\text { Max } \\
(\mathbf{m f})\end{array}$ & $\begin{array}{l}\text { Min } \\
(\mathrm{mf})\end{array}$ & $\begin{array}{l}\text { Max } \\
(\mathrm{mf})\end{array}$ & $\begin{array}{l}\text { Min } \\
(\mathbf{m f})\end{array}$ & $\begin{array}{l}\text { Max } \\
\text { (mf) }\end{array}$ \\
\hline $\mathrm{Ag}_{2} \mathrm{O}$ & 0 & 0.003 & 0 & 0.003 & 0 & 0.003 & 0 & 0.003 & 0 & 0.003 \\
\hline $\mathrm{As}_{2} \mathrm{O}_{5}$ & 0 & 0.003 & 0 & 0.003 & 0 & 0.003 & 0 & 0.003 & 0 & 0.003 \\
\hline $\mathrm{BaO}$ & 0 & 0.004 & 0 & 0.006 & 0 & 0.006 & 0 & 0.006 & 0 & 0.004 \\
\hline $\mathrm{BeO}$ & 0 & 0.001 & 0 & 0 & 0 & 0 & 0 & 0 & 0 & 0 \\
\hline $\mathrm{Bi}_{2} \mathrm{O}_{3}$ & 0 & 0.004 & 0 & 0.004 & 0 & 0.004 & 0 & 0.004 & 0 & 0.001 \\
\hline $\mathrm{Ce}_{2} \mathrm{O}_{3}$ & 0 & 0.005 & 0 & 0.004 & 0 & 0.005 & 0 & 0.026 & 0 & 0.001 \\
\hline $\mathrm{Cl}$ & 0 & 0.004 & 0 & 0.004 & 0 & 0.004 & 0 & 0.004 & 0 & 0.003 \\
\hline $\mathrm{CoO}$ & 0 & 0.003 & 0 & 0.003 & 0 & 0.003 & 0 & 0.003 & 0 & 0.001 \\
\hline $\mathrm{Cs}_{2} \mathrm{O}$ & 0 & 0.003 & 0 & 0.003 & 0 & 0.003 & 0 & 0.003 & 0 & 0.001 \\
\hline $\mathrm{CuO}$ & 0 & 0.003 & 0 & 0.003 & 0 & 0.003 & 0 & 0.003 & 0 & 0.002 \\
\hline $\mathrm{Dy}_{2} \mathrm{O}_{3}$ & 0 & 0.001 & 0 & 0 & 0 & 0 & 0 & 0 & 0 & 0 \\
\hline $\mathrm{F}$ & 0 & 0.005 & 0 & 0.005 & 0 & 0.005 & 0 & 0.005 & 0 & 0.001 \\
\hline $\mathrm{Gd}_{2} \mathrm{O}_{3}$ & 0 & 0.001 & 0 & 0 & 0 & 0 & 0 & 0 & 0 & 0 \\
\hline $\mathrm{HfO}_{2}$ & 0 & 0.033 & 0 & 0 & 0 & 0 & 0 & 0.033 & 0 & 0 \\
\hline $\mathrm{MoO}_{3}$ & 0 & 0.004 & 0 & 0.004 & 0 & 0.004 & 0 & 0.004 & 0 & 0 \\
\hline $\mathrm{Nd}_{2} \mathrm{O}_{3}$ & 0 & 0.017 & 0 & 0.005 & 0 & 0.009 & 0 & 0.017 & 0 & 0 \\
\hline $\mathrm{P}_{2} \mathrm{O}_{5}$ & 0 & 0.007 & 0 & 0.007 & 0 & 0.007 & 0 & 0.007 & 0 & 0.006 \\
\hline $\mathrm{PdO}$ & 0 & 0.002 & 0 & 0.002 & 0 & 0.002 & 0 & 0.002 & 0 & 0.002 \\
\hline $\mathrm{Pr}_{2} \mathrm{O}_{3}$ & 0 & 0.002 & 0 & 0.002 & 0 & 0.002 & 0 & 0.002 & 0 & 0 \\
\hline $\mathrm{Rb}_{2} \mathrm{O}$ & 0 & 0.001 & 0 & 0.001 & 0 & 0.001 & 0 & 0.001 & 0 & 0 \\
\hline $\mathrm{Rh}_{2} \mathrm{O}_{3}$ & 0 & 0.001 & 0 & 0.001 & 0 & 0.009 & 0 & 0.009 & 0 & 0.001 \\
\hline $\mathrm{RuO}_{2}$ & 0 & 0.002 & 0 & 0.002 & 0 & 0.002 & 0 & 0.002 & 0 & 0.001 \\
\hline $\mathrm{SO}_{3}$ & 0 & 0.004 & 0 & 0.004 & 0 & 0.004 & 0 & 0.004 & 0 & 0.002 \\
\hline $\mathrm{SnO}_{2}$ & 0 & 0.007 & 0 & 0.003 & 0 & 0.007 & 0 & 0.007 & 0 & 0 \\
\hline $\mathrm{TeO}_{2}$ & 0 & 0.001 & 0 & 0.001 & 0 & 0.001 & 0 & 0.001 & 0 & 0.001 \\
\hline $\mathrm{V}_{2} \mathrm{O}_{5}$ & 0 & 0.002 & 0 & 0.002 & 0 & 0.002 & 0 & 0.002 & 0 & 0.002 \\
\hline $\mathrm{WO}_{3}$ & 0 & 0.002 & 0 & 0.002 & 0 & 0.002 & 0 & 0.002 & 0 & 0 \\
\hline $\mathrm{Y}_{2} \mathrm{O}_{3}$ & 0 & 0.001 & 0 & 0.001 & 0 & 0.001 & 0 & 0.001 & 0 & 0 \\
\hline
\end{tabular}

(a) The lower and upper bounds for these components are the minimum and maximum values from Table 9.2, with the lower bounds rounded down and the upper bounds rounded up, each to the third decimal place.

(b) The results are the same for the 264, 250, and 266 glasses in the PCT-B, PCT-Li, and PCT-Na modeling datasets, respectively.

(c) Only 100 of the 102 HLW02 and HLW03 glasses (excluding HLW03-01 and HLW03-08) were used to develop TCLP-Cd models. Note that the summary statistics are based on the mass fractions before the normalization to the number of components in the TCLP-Cd models. See Kot et al. (2004). 
Table 9.4. Minimum and Maximum Temperatures at Which Electrical Conductivity and Viscosity were Measured for HLW Glass Compositions in the Modeling Datasets Along with the Lower and Upper Bounds on Temperature that Partially Define the Validity Regions for IHLW Electrical Conductivity and Viscosity Models.

\begin{tabular}{|l|c|c|}
\hline Temperature for Glass Property & Minimum & Maximum \\
\hline$T\left({ }^{\circ} \mathrm{C}\right)$ for Electrical Conductivity & 908 & 1277 \\
\hline$T\left({ }^{\circ} \mathrm{C}\right)$ for Viscosity & 931 & 1281 \\
\hline \multicolumn{3}{|c|}{} \\
\hline Temperature for Glass Property & Lower Bound & Upper Bound \\
\hline$T\left({ }^{\circ} \mathrm{C}\right)$ for EC \& Viscosity & 900 & 1290 \\
\hline
\end{tabular}

Table 9.5. Minimums and Maximums of Measured Property Values for HLW Glass Compositions in the Modeling Dataset for Each HLW Glass Property.

\begin{tabular}{|l|c|c|}
\hline \multicolumn{1}{|c|}{ HLW Glass Property } & Minimum & Maximum \\
\hline PCT-B $(\mathrm{g} / \mathrm{L})$ & 0.104 & 21.903 \\
\hline PCT-Li $(\mathrm{g} / \mathrm{L})$ & 0.141 & 10.675 \\
\hline PCT-Na $(\mathrm{g} / \mathrm{L})$ & 0.050 & 11.819 \\
\hline Spinel $_{1 \%}\left({ }^{\circ} \mathrm{C}\right)$ & 635.7 & 1230.7 \\
\hline Electrical Conductivity $(\mathrm{S} / \mathrm{cm})$ & Functions of temperature, see Figure 9.1. \\
\hline Viscosity $($ poise $)$ & \multicolumn{2}{|c|}{ Functions of temperature, see Figure 9.2. } \\
\hline TCLP-Cd $^{(\mathrm{a})}(\mathrm{mg} / \mathrm{L})$ & 0.007 & 1.240 \\
\hline
\end{tabular}

(a) Based on the 100 of 102 HLW02 and HLW03 glasses used in the modeling dataset and the model summarized in Table 6.16 of Kot et al. (2004). 
Table 9.6. Multiple-Component and Multiple-Variable Constraints that Partially Define the Composition Validity Regions for IHLW Property Models.

\begin{tabular}{|l|c|c|}
\hline HLW Glass Property & La) & Upper Bound \\
\hline PCT-B $(\mathrm{g} / \mathrm{L})$ & None & $6.61^{(\mathrm{b})}$ \\
\hline PCT-Li $(\mathrm{g} / \mathrm{L})$ & None & $4.27^{(\mathrm{b})}$ \\
\hline PCT-Na $(\mathrm{g} / \mathrm{L})$ & None & $5.53^{(\mathrm{b})}$ \\
\hline Spinel $\mathrm{T}_{1 \%}\left({ }^{\circ} \mathrm{C}\right)$ & $630^{(\mathrm{c})}$ & $1240^{(\mathrm{d})}$ \\
\hline EC as $\mathrm{fct}\left(T,{ }^{\circ} \mathrm{C}\right)(\mathrm{S} / \mathrm{cm})$ & $\mathrm{EC} \geq \exp [1.45-4753.46(1 / T)]$ & $\mathrm{EC} \leq \exp [4.35-4753.46(1 / T)]$ \\
\hline Viscosity as fct $\left(T,{ }^{\circ} \mathrm{C}\right)($ poise $)$ & $\eta \geq \exp [-9.17+11944.20(1 / T)]$ & $\eta \leq \exp [-3.67+11944.20(1 / T)]$ \\
\hline TCLP-Cd $(\mathrm{mg} / \mathrm{L})$ & None & $0.80^{(\mathrm{d})}$ \\
\hline
\end{tabular}

(a) These constraints (lower and upper bounds) on HLW glass property values are implemented using the HLW glass property models recommended in Sections 5 to 8 for all of the properties except TCLP-Cd release. The recommended model for TCLP-Cd release is discussed in Section 6.5.2 of Kot et al. (2004). Thus, these property constraints are actually indirect constraints on HLW glass composition.

(b) See the discussion in Section 9.2.1 for how these upper bounds were determined.

(c) The spinel $\mathrm{T}_{1 \%}$ lower and upper bounds are rounded versions of the minimum and maximum estimated values from Table 9.5

(d) See the discussion in Section 9.2.1 for how this upper bound was determined. 
Table 9.7. Minimum and Maximum Values of Multi-Component Constraint Expressions Calculated for 302 HLW Glasses ${ }^{(a)}$

\begin{tabular}{|c|c|c|c|c|c|c|c|c|c|c|c|c|c|c|c|c|c|c|}
\hline \multirow{2}{*}{ 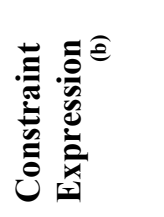 } & \multicolumn{2}{|c|}{ HLW02 } & \multicolumn{2}{|c|}{ HLW03 } & \multicolumn{2}{|c|}{ HLW04 } & \multicolumn{2}{|c|}{ HLW05 } & \multicolumn{2}{|c|}{ HLW06 } & \multicolumn{2}{|c|}{ HLW07 } & \multicolumn{2}{|c|}{ HLW-ALG } & \multicolumn{2}{|c|}{$\begin{array}{c}\text { HLW98 \& } \\
\text { Actual }\end{array}$} & \multicolumn{2}{|c|}{ All Studies } \\
\hline & $\equiv$ & $\stackrel{\Xi}{\Sigma}$ & $\Xi$ & 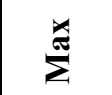 & $\sum$ & $\sum^{\grave{J}}$ & $\Xi$ & 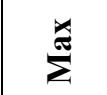 & $\equiv$ & $\stackrel{\grave{E}}{\Sigma}$ & $\equiv$ & $\sum_{\Sigma}^{\grave{\Xi}}$ & $\equiv$ & $\sum^{\grave{E}}$ & $\Xi$ & $\sum^{\grave{E}}$ & $\equiv$ & $\sum_{\Sigma}^{\grave{J}}$ \\
\hline TCLP B $^{(\mathrm{c})}$ & 0.007 & 0.162 & 0.007 & \begin{tabular}{|l|}
0.127 \\
\end{tabular} & 0.029 & 0.035 & 0.010 & 0.161 & 0.003 & 0.450 & 0.011 & 0.418 & 0.017 & 0.149 & 0.018 & 0.059 & 0.003 & $0.450^{(\mathrm{g})}$ \\
\hline $\mathrm{T}_{\mathrm{LS}}{ }^{(\mathrm{c})}$ & 1013.8 & 1114.0 & 960.7 & 1150.2 & 1054.1 & 1086.5 & 988.0 & 1076.5 & 961.4 & 1184.8 & 942.1 & 1185.1 & 1003.6 & 1112.2 & 1028.5 & 1118.5 & 942.1 & $1185.1^{(\mathrm{h})}$ \\
\hline $\mathrm{T}_{\mathrm{LZ}}{ }^{(\mathrm{c})}$ & 619.1 & 1200.5 & 497.7 & 1151.9 & 697.2 & 729.2 & 555.2 & 1294.4 & 480.4 & 1516.9 & 442.3 & 1393.0 & 472.7 & 1304.0 & 659.2 & 1129.3 & 442.3 & $1516.9^{(\mathrm{i})}$ \\
\hline $\mathrm{T}_{\text {LZO }}{ }^{\text {(d) }}$ & 576.8 & 1146.3 & 525.5 & 1229.8 & 646.8 & 701.1 & 753.9 & 1157.9 & 459.0 & 1359.4 & 587.3 & 1666.9 & 416.3 & 1588.1 & 510.8 & 1132.4 & 416.3 & $1666.9^{(\mathrm{j})}$ \\
\hline $\mathrm{AlFeZr} \mathrm{r}^{(\mathrm{f})}$ & 17.99 & 22.50 & 7.65 & 25.60 & 17.87 & 19.36 & 18.00 & 27.00 & 13.36 & 29.00 & 17.59 & 26.77 & 13.07 & 30.86 & 11.45 & 24.96 & $7.65^{(\mathrm{k})}$ & $30.86^{(\mathrm{k})}$ \\
\hline $\mathrm{AlFeZrTh}^{(\mathrm{f})}$ & 17.99 & 22.50 & 18.00 & 33.82 & 17.87 & 19.36 & 22.50 & 39.42 & 13.36 & 46.20 & 18.00 & 39.97 & 13.75 & 40.98 & 14.30 & 33.30 & $13.36^{(1)}$ & $46.20^{(\mathrm{II})}$ \\
\hline $\operatorname{LiNaTh}^{(\mathrm{f})}$ & 10.45 & 25.79 & -0.001 & 21.19 & 17.53 & 17.87 & -11.08 & 17.94 & -7.60 & 25.06 & -7.04 & 26.51 & -6.22 & 25.22 & 1.23 & 24.10 & $-11.08^{(\mathrm{m})}$ & 26.51 \\
\hline $\mathrm{LiNa}^{(\mathrm{f})}$ & 10.45 & 25.79 & 8.39 & 24.80 & 17.53 & 17.87 & 11.42 & 23.56 & 13.16 & 26.00 & 9.46 & 27.00 & 14.52 & 25.22 & 16.42 & 24.10 & 8.39 & $27.00^{(\mathrm{n})}$ \\
\hline
\end{tabular}

(a) The 302 HLW glasses are the ones having values for at least one of the four main properties (PCT, crystallinity, electrical conductivity, and viscosity) addressed in this report.

(b) In calculating the constraint expressions, revised oxides were substituted for original oxides (e.g., $\mathrm{UO}_{3}$ in place of $\left.\mathrm{UO}_{2}\right)$ in cases where the constraint expression involved original oxides.

(c) TCLP B = normalized boron release from the TCLP $(\mathrm{g} / \mathrm{L}) . \mathrm{T}_{\mathrm{LS}}=$ liquidus temperature of Cr-bearing spinel $\left({ }^{\circ} \mathrm{C}\right)$. Values were calculated using the model coefficients derived from constraint coefficients in Table 7 of Cooley et al. (2003).

(d) $\mathrm{T}_{\mathrm{LZ}}=$ liquidus temperature of zircon $\left({ }^{\circ} \mathrm{C}\right)$. Coefficients for the $\mathrm{T}_{\mathrm{LZ}}$ model are from the "TRU + CVS" column of Table 4 in Rao et al. (1997). The Others coefficient in that model was used as the coefficient for all components in the combined WTP HLW glass database without coefficents.

(e) $\mathrm{T}_{\mathrm{LZO}}=$ liquidus temperature of zirconia $\left({ }^{\circ} \mathrm{C}\right)$. Coefficients for the $\mathrm{T}_{\mathrm{LZO}}$ model are from the baddeleyite $(\mathrm{Z})$ column of Table II in Plaisted et al. $(2000)$. The Others coefficient in that model was used as the coefficient for all components in the combined WTP HLW glass database without coefficents. Note that this model was only 7 coefficeints fitted to 14 data points, with an $\mathrm{R}^{2}$ of only 0.548 . Hence, predictions with this model can be expected to have large uncertainties.

(f) $\mathrm{AlFeZr}=\mathrm{Al}_{2} \mathrm{O}_{3}+\mathrm{Fe}_{2} \mathrm{O}_{3}+\mathrm{ZrO}_{2}(\mathrm{wt} \%), \mathrm{AlFeZrTh}=\mathrm{Al}_{2} \mathrm{O}_{3}+\mathrm{Fe}_{2} \mathrm{O}_{3}+\mathrm{ZrO}_{2}+3 \mathrm{ThO}_{2}(\mathrm{wt} \%), \mathrm{LiNaTh}=2 \mathrm{Li}_{2} \mathrm{O}+\mathrm{Na}_{2} \mathrm{O}-3.75 \mathrm{ThO}$ (wt $\left.\%\right)$ to limit thorium crystallization, $\mathrm{LiNa}=\mathrm{Na}_{2} \mathrm{O}+2 \mathrm{Li}_{2} \mathrm{O}(\mathrm{wt} \%$ ). Values shown are mass fractions calculated using glass compositions expressed in the revised (new) oxide forms (see Table 2.10).

(g) The overall maximum TCLP B value exceeds the upper limit of $0.3 \mathrm{mg} / \mathrm{L}$ imposed for HLW02, HLW03, and HLW05, as shown in Table 2.6.

(h) The overall maximum $\mathrm{T}_{\mathrm{LS}}$ value exceeds the upper limit of $1150^{\circ} \mathrm{C}$ imposed for HLW03, as shown in Table 2.6.

(i) The overall maximum $\mathrm{T}_{\mathrm{LZ}}$ value exceeds the upper limits of $1150^{\circ} \mathrm{C}$ imposed for HLW03, as shown in Table 2.6 .

(j) The overall maximum $\mathrm{T}_{\mathrm{LZO}}$ value exceeds the upper limit of $1420^{\circ} \mathrm{C}$ imposed for HLW06, as shown in Table 2.6 .

(k) AlFeZr has values significantly below the lower limit of $18 \mathrm{wt} \%$ imposed for HLW02, HLW05, and HLW07, as shown in Table 2.6. AlFeZr also has values noticeably above the upper limit of $27 \mathrm{wt} \%$ imposed for HLW05.

(1) AlFeZrTh has values significantly outside the limits of 19 to $34 \mathrm{wt} \%$ imposed for HLW03, as shown in Table 2.6.

(m) LiNaTh has values below the lower limit of $0 \mathrm{wt} \%$ imposed for HLW03, as shown in Table 2.6.

(n) LiNa has values that exceed the upper limit of $24 \mathrm{wt} \%$ imposed for HLW05, as shown in Table 2.6. 
Table 9.8. Summary of Constraints Specifying the Model Validity Region for each HLW Glass Property.

\begin{tabular}{|c|c|c|c|c|c|c|c|}
\hline $\begin{array}{l}\text { Single-component } \\
\text { lower and upper } \\
\text { bounds }\end{array}$ & \multicolumn{7}{|c|}{ As listed for each property in Table 9.3} \\
\hline $\begin{array}{l}\text { Temperature } \\
\text { bounds }^{(b)}\end{array}$ & $\mathrm{N} / \mathrm{A}^{(\mathrm{a})}$ & $\mathrm{N} / \mathrm{A}$ & N/A & N/A & $900-1290^{\circ} \mathrm{C}$ & $900-1290^{\circ} \mathrm{C}$ & N/A \\
\hline Property bounds ${ }^{(c)}$ & $\leq 6.61 \mathrm{~g} / \mathrm{L}$ & $\leq 4.27 \mathrm{~g} / \mathrm{L}$ & $\leq 5.53 \mathrm{~g} / \mathrm{L}$ & $630-1260^{\circ} \mathrm{C}$ & See Table 9.6 & See Table 9.6 & $0.80 \mathrm{mg} / \mathrm{L}$ \\
\hline
\end{tabular}

(a) $\mathrm{N} / \mathrm{A}=$ not applicable.

(b) From Table 9.4

(c) From Table 9.6. The property bounds for PCT-B, PCT-Li, PCT-Na, and spinel $\mathrm{T}_{1 \%}$ are indirect multiple-component constraints on HLW glass composition. The property bounds for electrical conductivity and viscosity are indirect multiple-variable constraints on combinations of HLW glass composition and melt temperature. The property bounds are implemented using the recommended model for each property. 
The Catholic University of America Vitreous State Laboratory
IHLW PCT, Spinel $T_{1 \%}$, Electrical Conductivity, and Viscosity Model Development Final Report, VSL-07R1240-4, Rev. 0

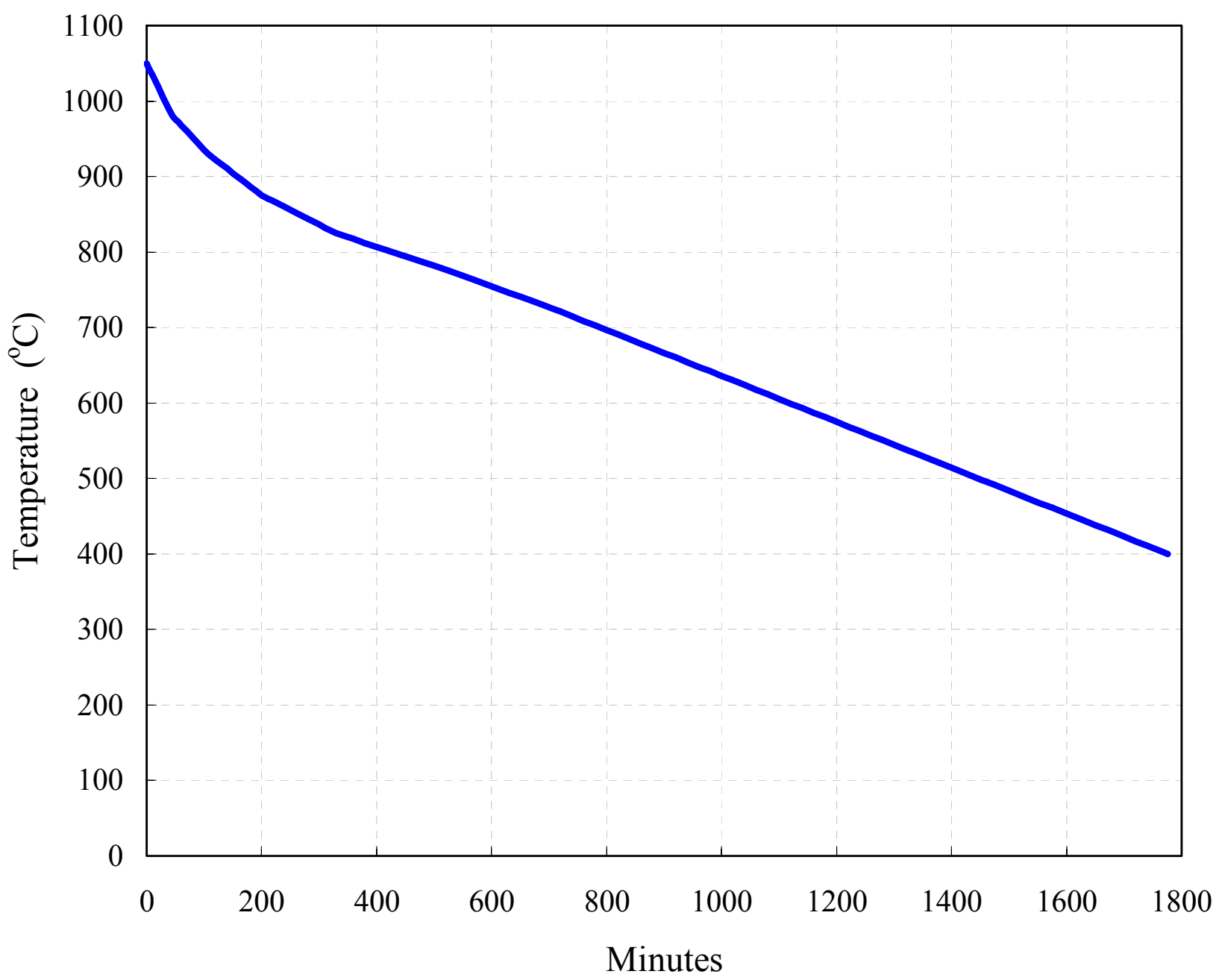

Figure 3.1. HLW Canister Centerline Cooling (CCC) Temperature Profile. 
The Catholic University of America Vitreous State Laboratory
IHLW PCT, Spinel $T_{1 \%}$, Electrical Conductivity, and Viscosity Model Development Final Report, VSL-07R1240-4, Rev. 0
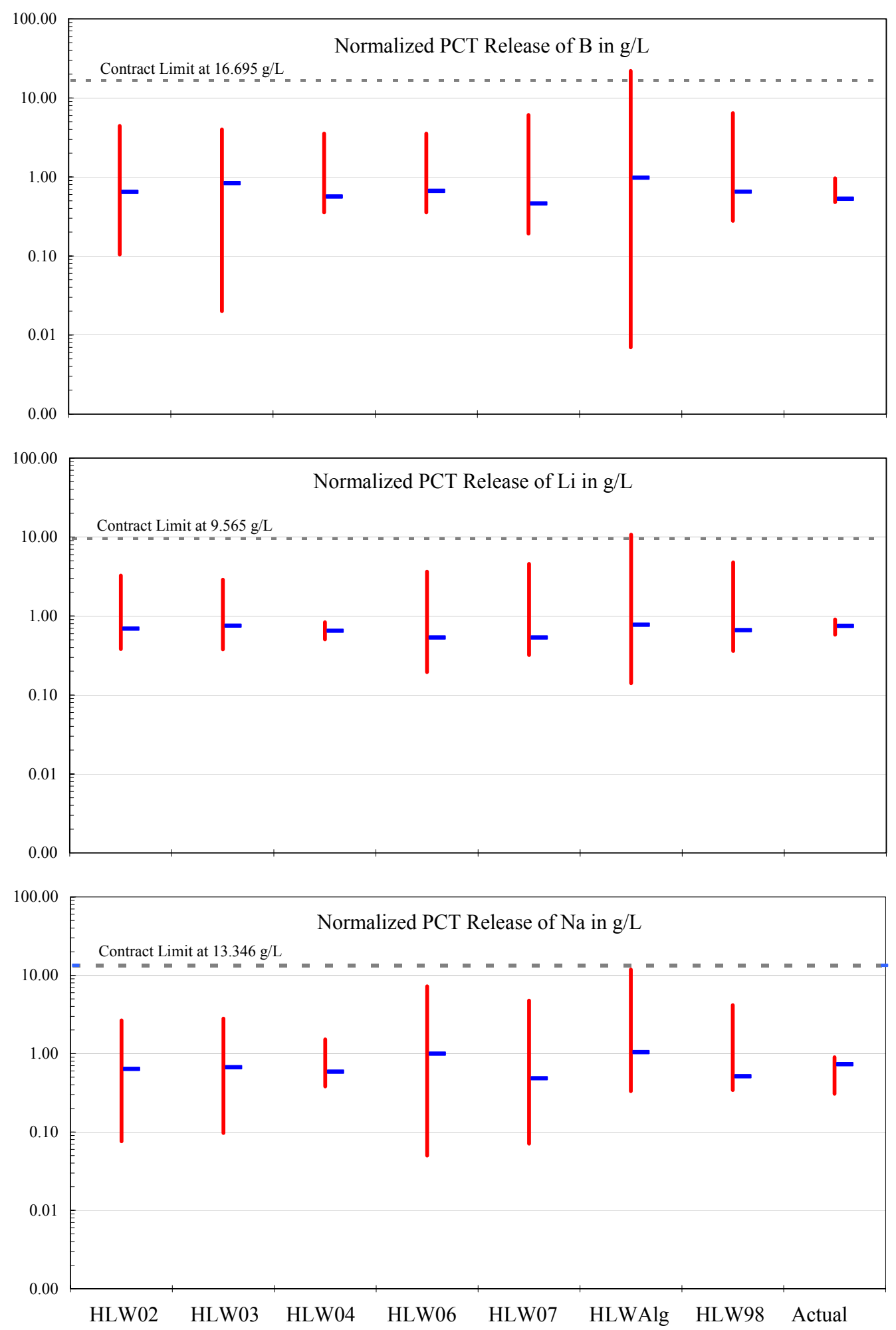

Figure 4.1. Ranges of Normalized PCT Releases (B, Li, and Na, in g/L) for the $268 \mathrm{HLW}$ Glasses with PCT Data, by Groups of Glasses. The median values are shown as blue bars. 


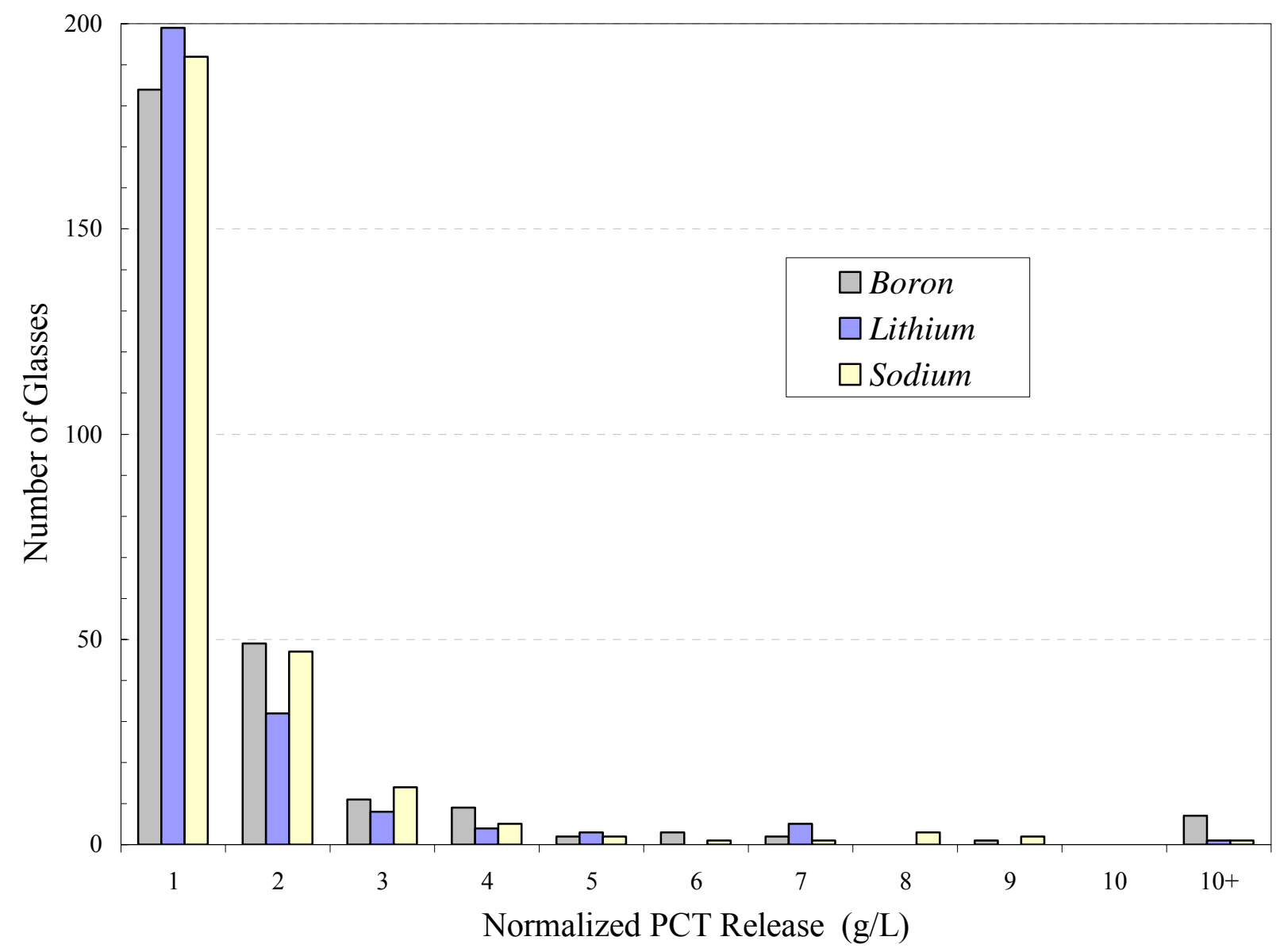

Figure 4.2. Distribution of Normalized PCT Releases of Boron, Lithium, and Sodium for the 268 HLW Glasses with PCT Data. 
The Catholic University of America Vitreous State Laboratory
IHLW PCT, Spinel $T_{1 \%}$, Electrical Conductivity, and Viscosity Model Development Final Report, VSL-07R1240-4, Rev. 0
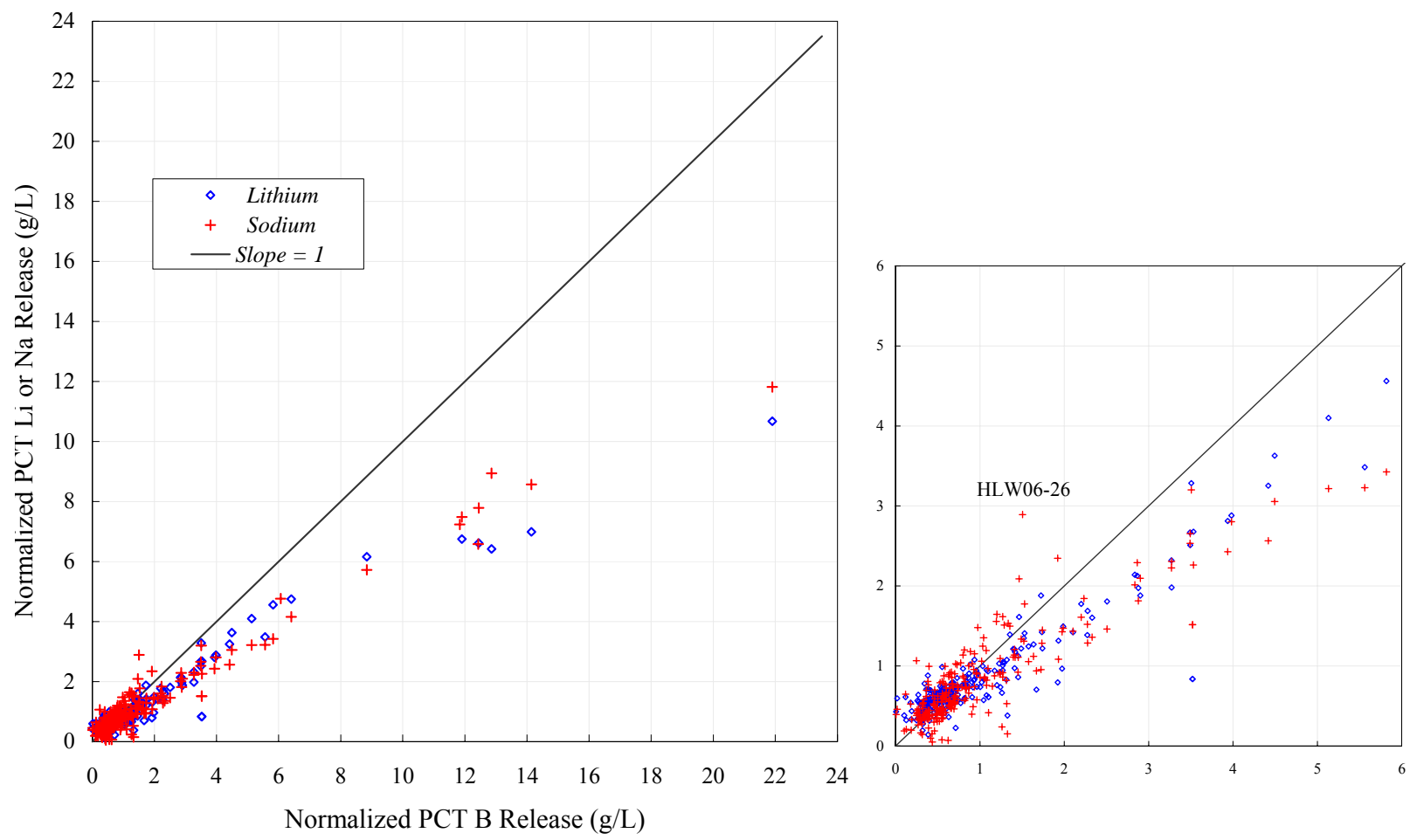

Figure 4.3. Comparison of Normalized PCT Releases of Sodium and Lithium with Normalized PCT Release of Boron for the 268 HLW Glasses with PCT Data. The figure on the right is a blow-up of the region of 0 to $6 \mathrm{~g} / \mathrm{L}$. 
The Catholic University of America Vitreous State Laboratory
IHLW PCT, Spinel $T_{1 \%}$, Electrical Conductivity, and Viscosity Model Development Final Report, VSL-07R1240-4, Rev. 0

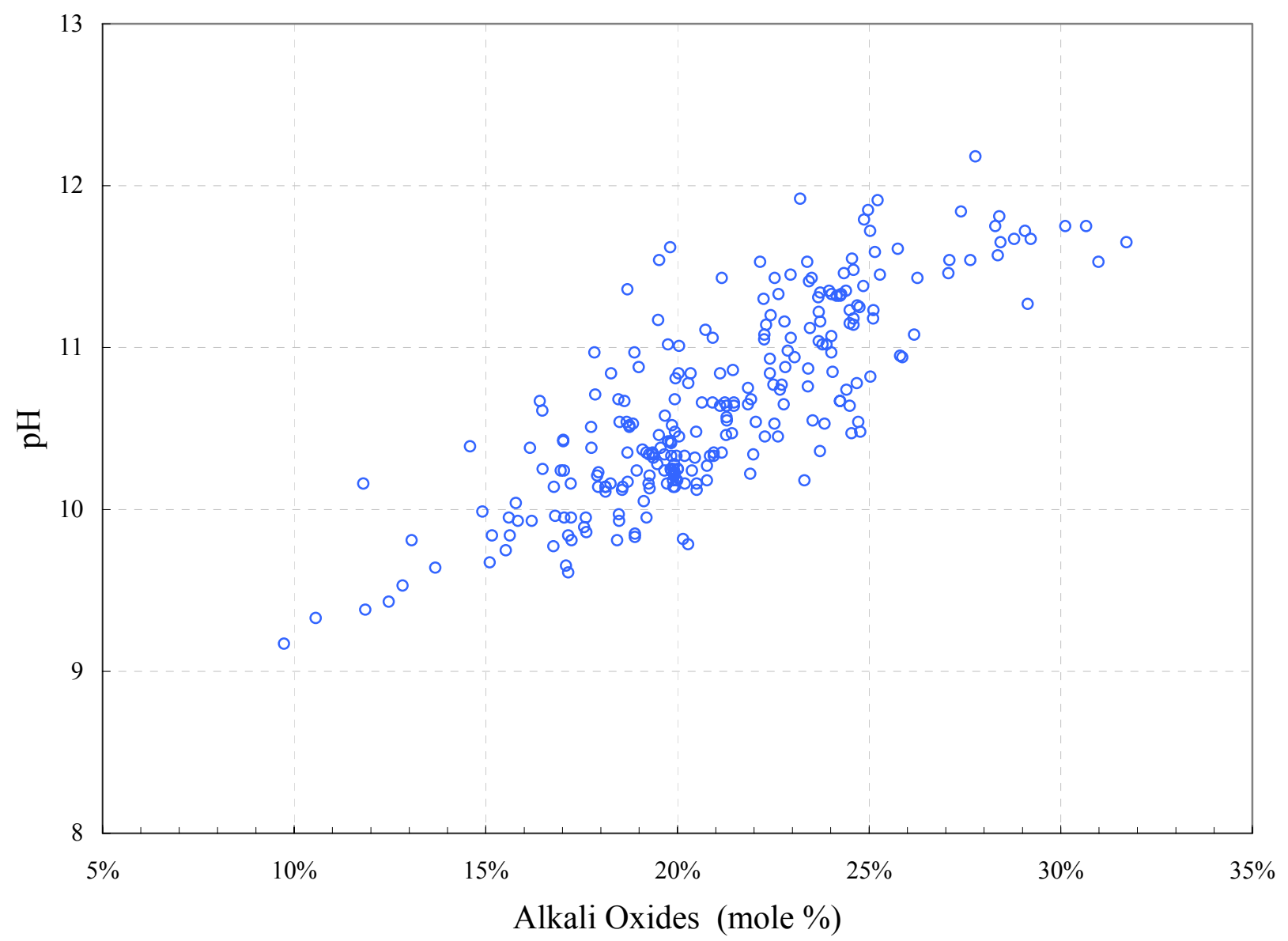

Figure 4.4. Measured pH of the PCT Leachates versus Alkali Oxides for the 268 HLW Glasses with PCT Data. 
The Catholic University of America Vitreous State Laboratory
IHLW PCT, Spinel $T_{1 \%}$, Electrical Conductivity, and Viscosity Model Development Final Report, VSL-07R1240-4, Rev. 0

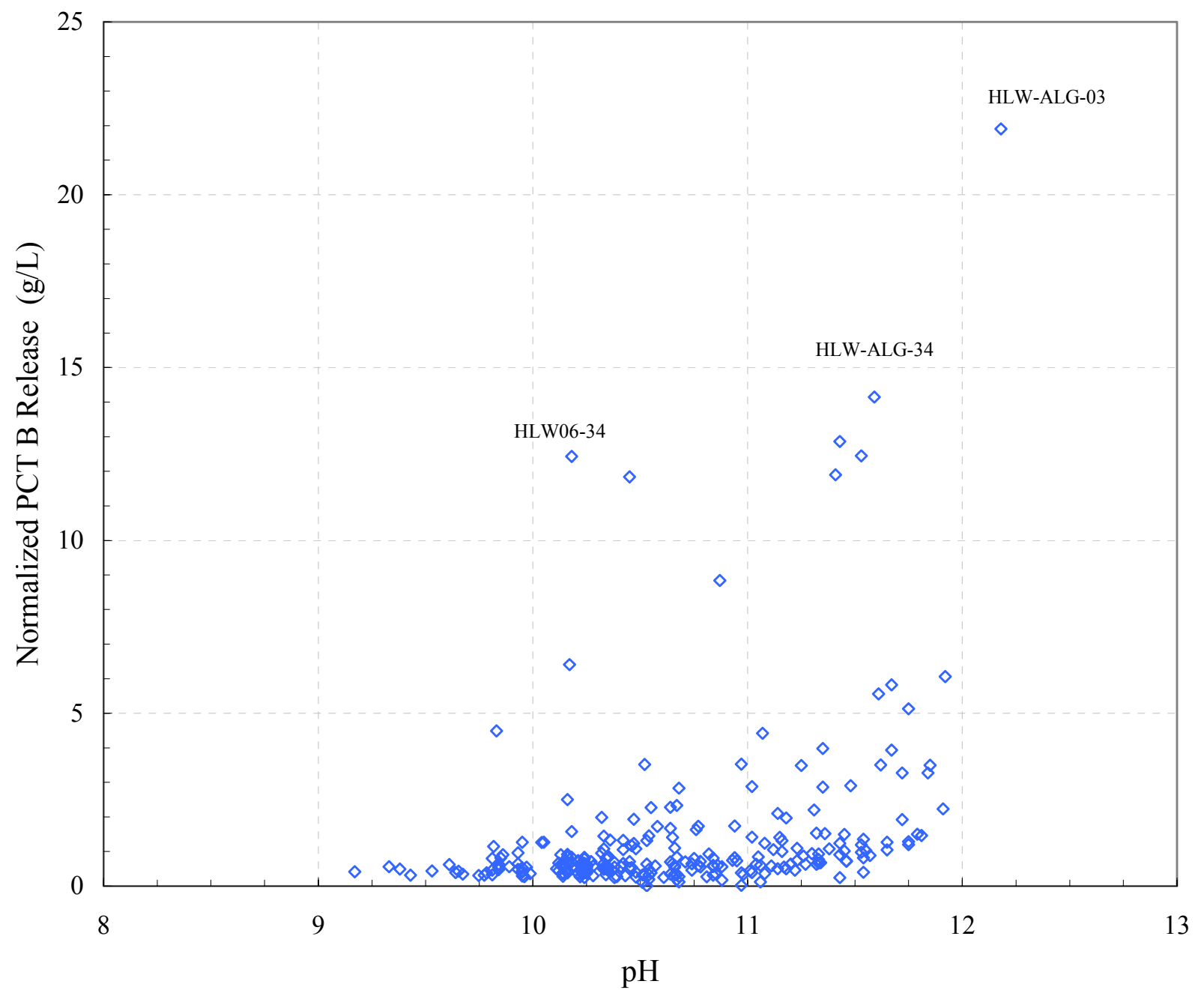

Figure 4.5. Normalized PCT Releases of Boron versus pH of PCT Leachates for the 268 HLW Glasses with PCT Data. 
The Catholic University of America Vitreous State Laboratory
IHLW PCT, Spinel $T_{1 \%}$, Electrical Conductivity, and Viscosity Model Development Final Report, VSL-07R1240-4, Rev. 0

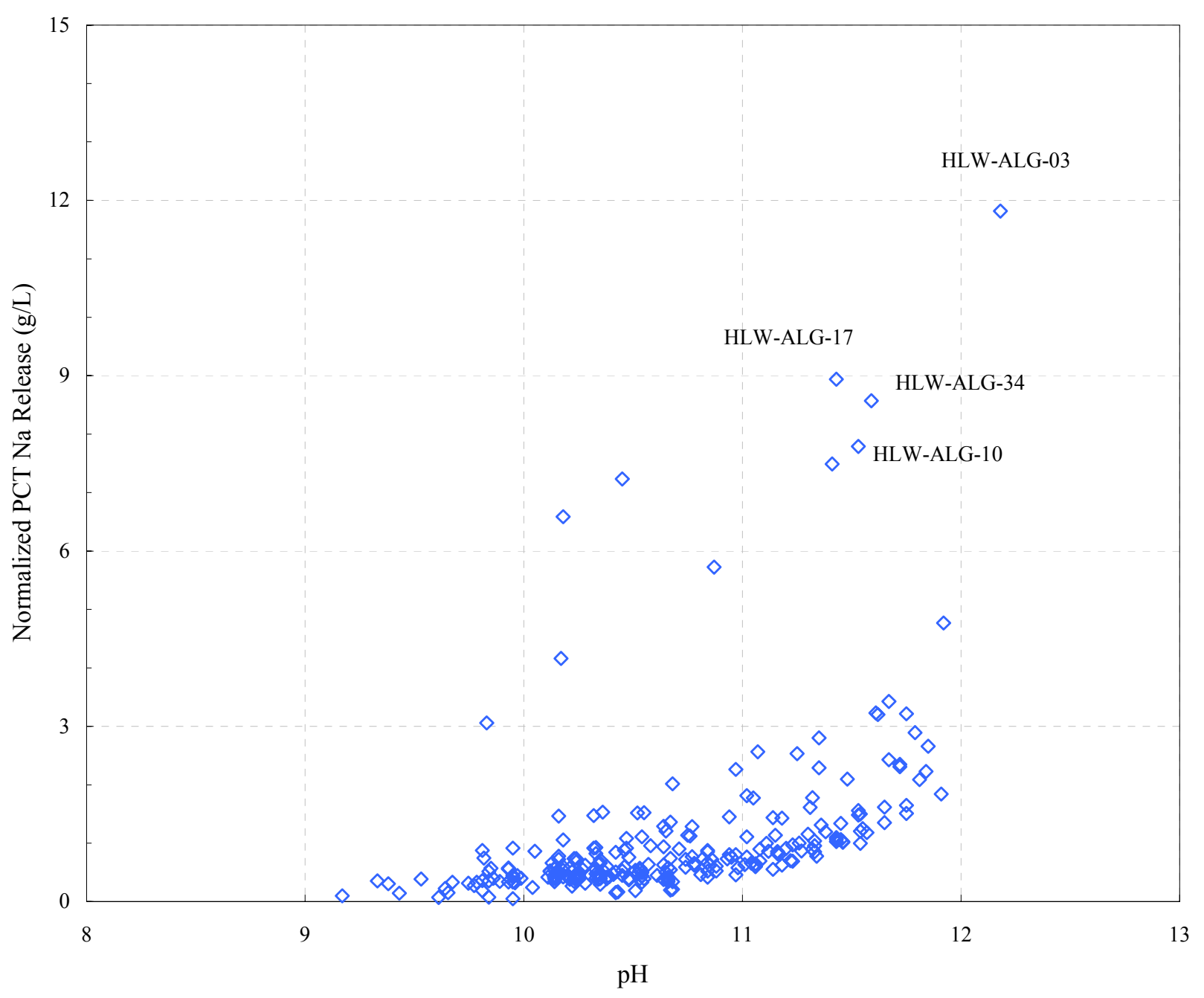

Figure 4.6. Normalized PCT Releases of Sodium versus pH of PCT Leachate for the 268 HLW Glasses with PCT Data. 
The Catholic University of America Vitreous State Laboratory
IHLW PCT, Spinel $T_{1 \%}$, Electrical Conductivity, and Viscosity Model Development Final Report, VSL-07R1240-4, Rev. 0

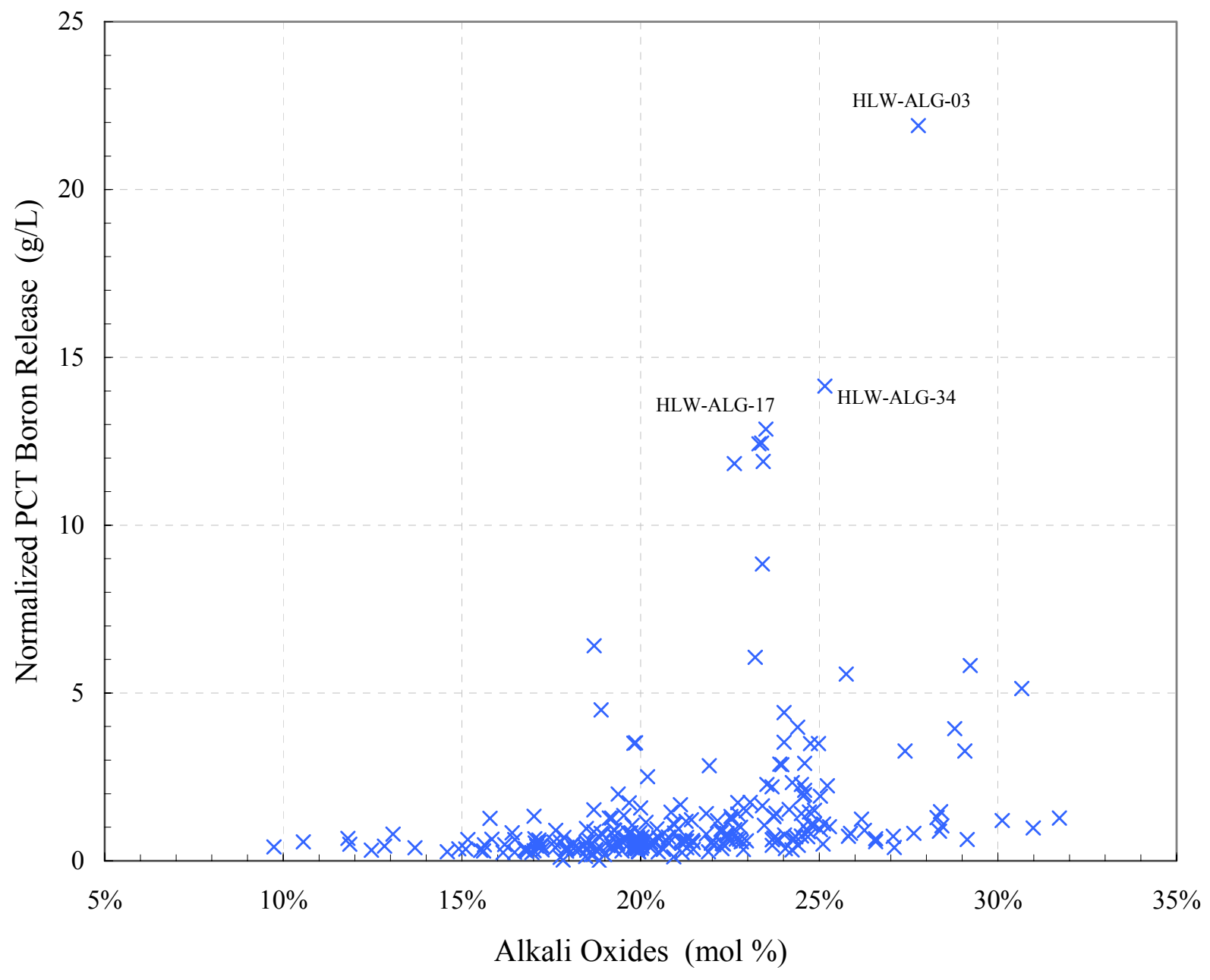

Figure 4.7. Normalized PCT Boron Release versus Alkali Content $\left(\mathrm{Na}_{2} \mathrm{O}+\mathrm{Li}_{2} \mathrm{O}+\mathrm{K}_{2} \mathrm{O}\right)$ for the 268 HLW Glasses with PCT Data. 
The Catholic University of America Vitreous State Laboratory
IHLW PCT, Spinel $T_{1 \%}$, Electrical Conductivity, and Viscosity Model Development Final Report, VSL-07R1240-4, Rev. 0

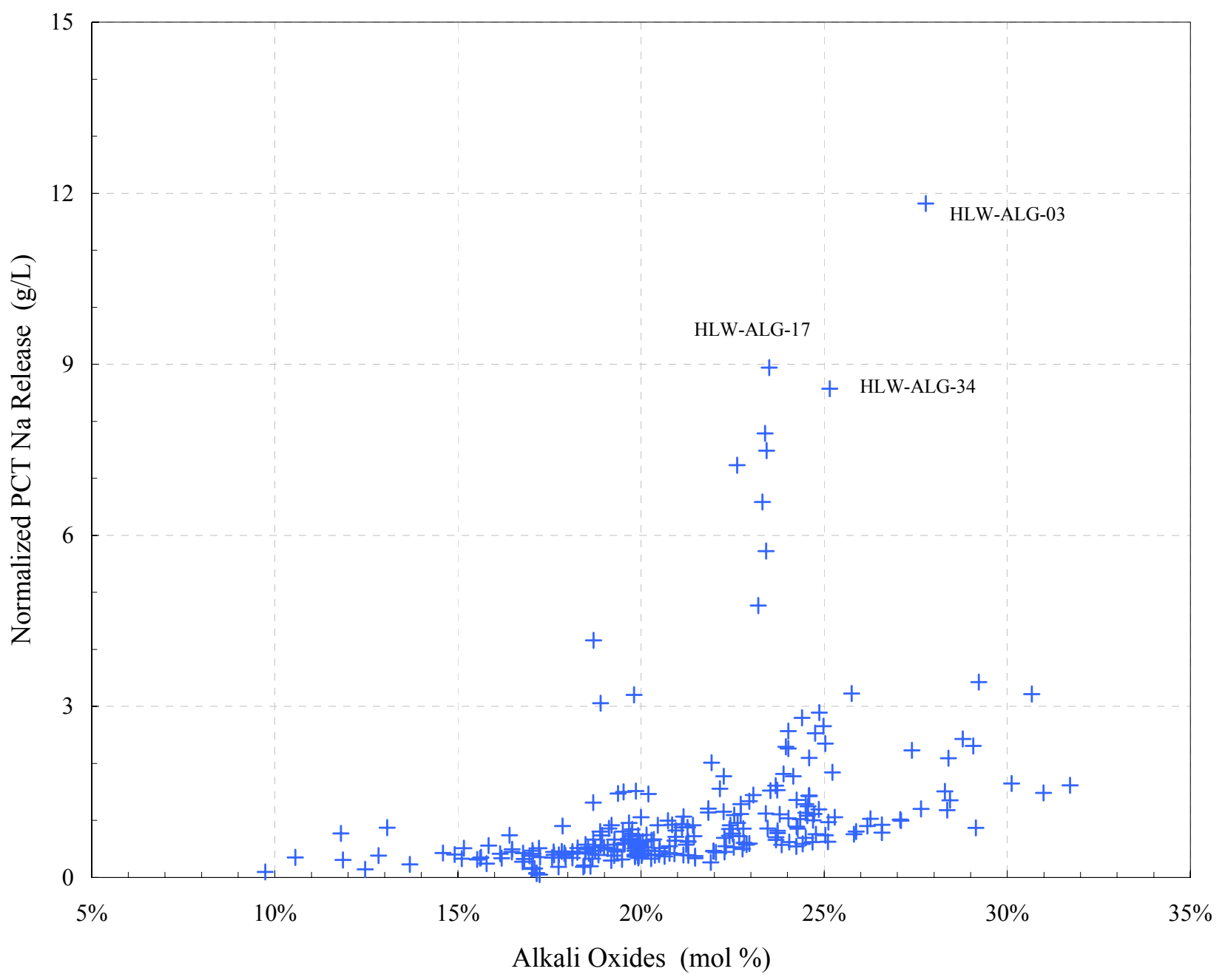

Figure 4.8. Normalized PCT Sodium Release versus Alkali Content $\left(\mathrm{Na}_{2} \mathrm{O}+\mathrm{Li}{ }_{2} \mathrm{O}+\mathrm{K}_{2} \mathrm{O}\right)$ for the 268 HLW Glasses with PCT Data. 


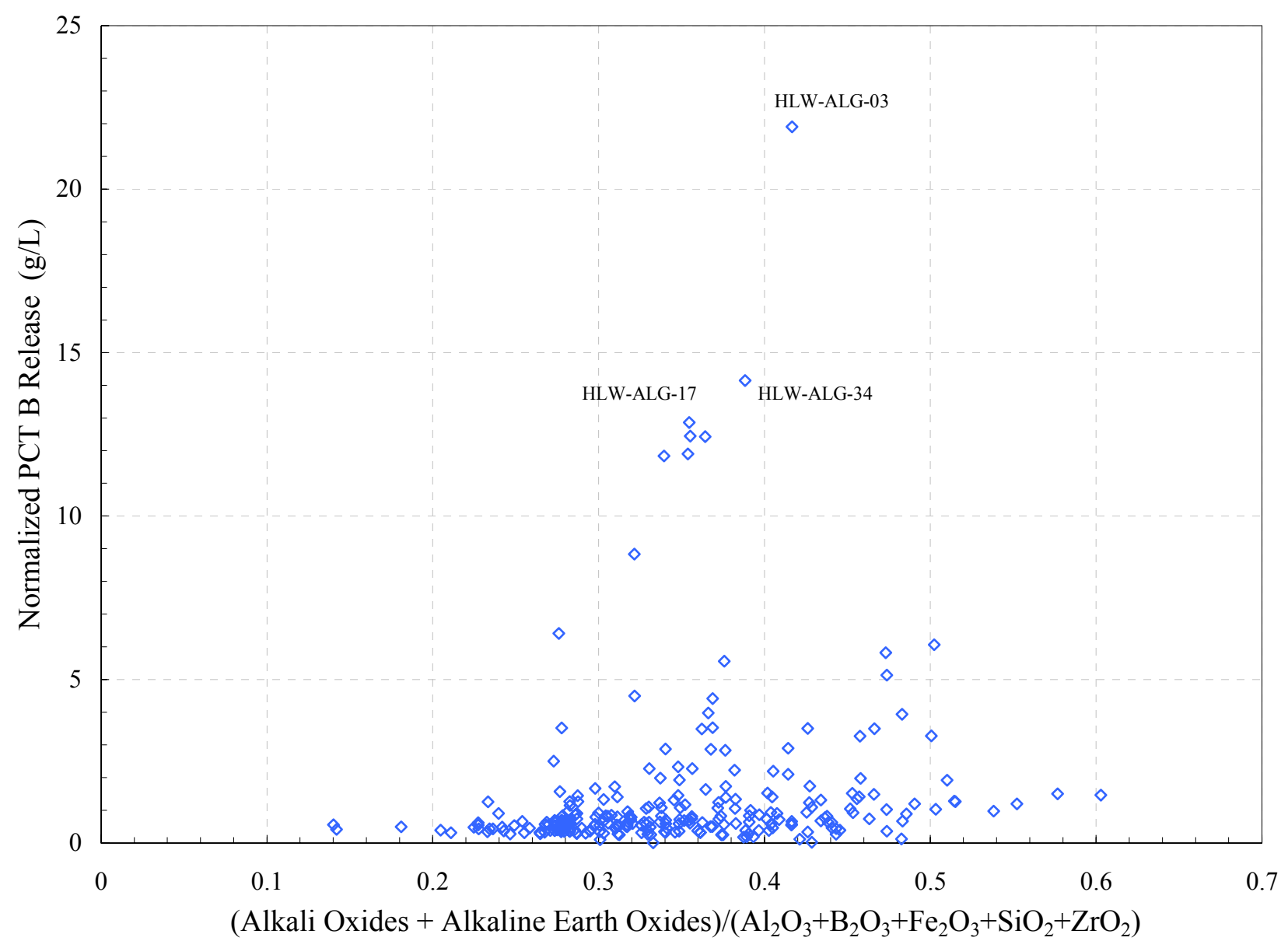

Figure 4.9. Normalized PCT Boron Release versus the Molar Ratio of (Alkali Oxides + Alkaline Earth Oxides) $/\left(\mathrm{Al}_{2} \mathrm{O}_{3}+\mathrm{B}_{2} \mathrm{O}_{3}+\mathrm{Fe}_{2} \mathrm{O}_{3}+\mathrm{SiO}_{2}+\mathrm{ZrO}_{2}\right.$ ) for the 268 HLW Glasses with PCT Data. 
The Catholic University of America Vitreous State Laboratory
IHLW PCT, Spinel $T_{1 \%}$, Electrical Conductivity, and Viscosity Model Development Final Report, VSL-07R1240-4, Rev. 0

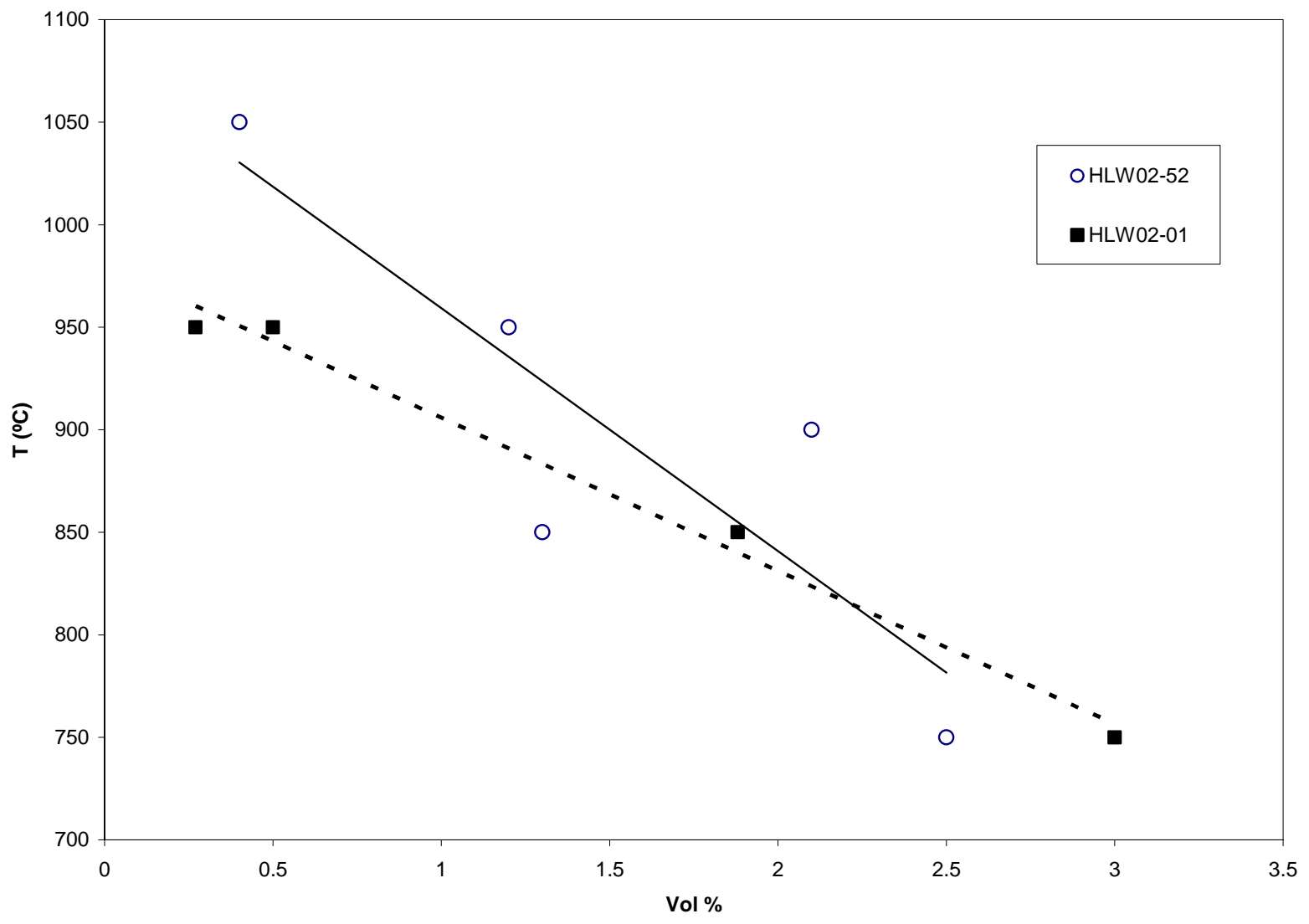

Figure 4.10. Volume \% of Crystalline (Spinel) Phase in Heat-Treated HLW Matrix Glass (HLW02-01) and Replicate (HLW02-52). 
The Catholic University of America Vitreous State Laboratory
IHLW PCT, Spinel $T_{1 \%}$, Electrical Conductivity, and Viscosity Model Development Final Report, VSL-07R1240-4, Rev. 0

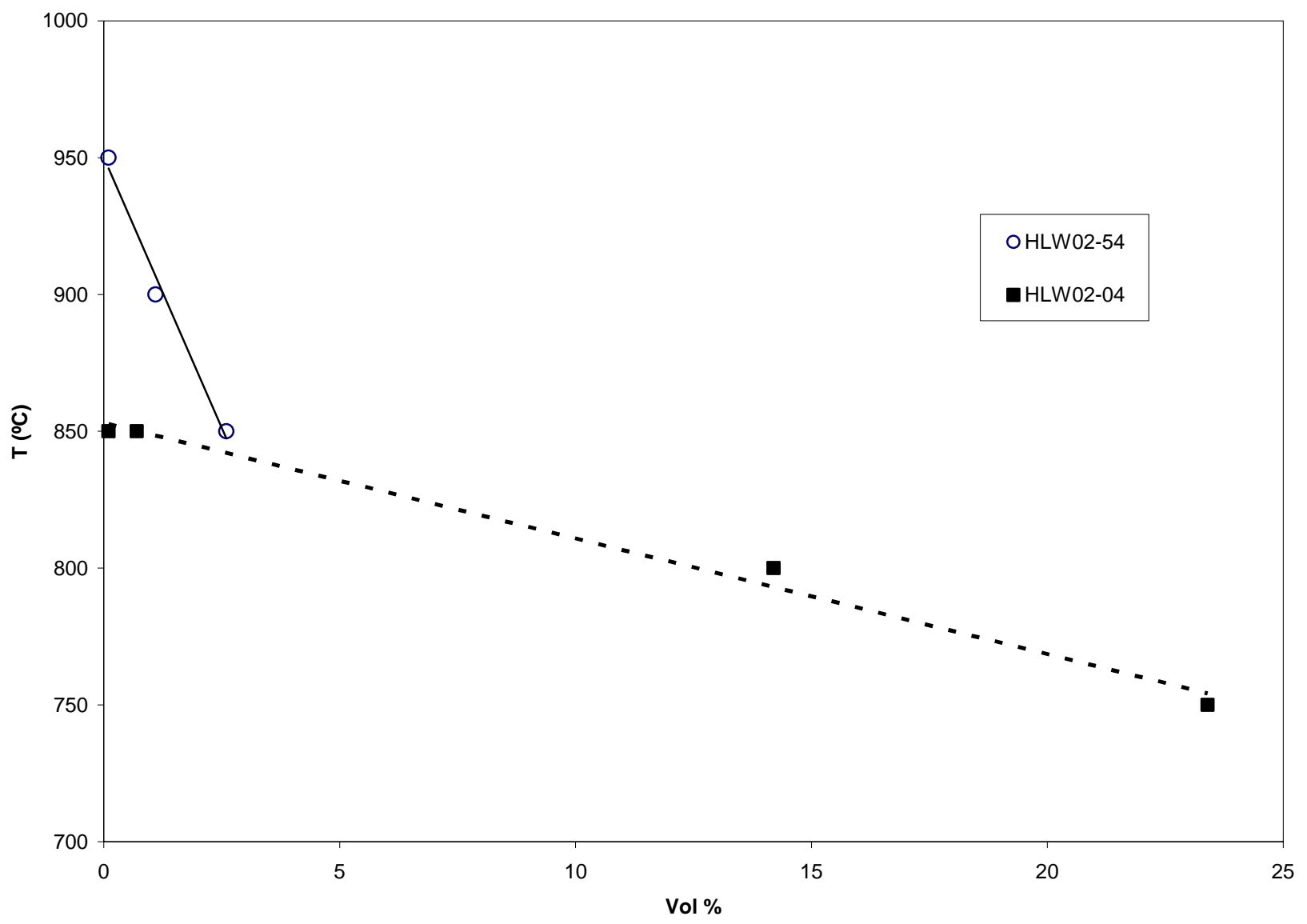

Figure 4.11. Volume \% of Crystalline Phase in Heat-Treated HLW Matrix Glass (HLW02-04) and Replicate (HLW02-54). 
The Catholic University of America Vitreous State Laboratory
IHLW PCT, Spinel $T_{1 \%}$, Electrical Conductivity, and Viscosity Model Development Final Report, VSL-07R1240-4, Rev. 0

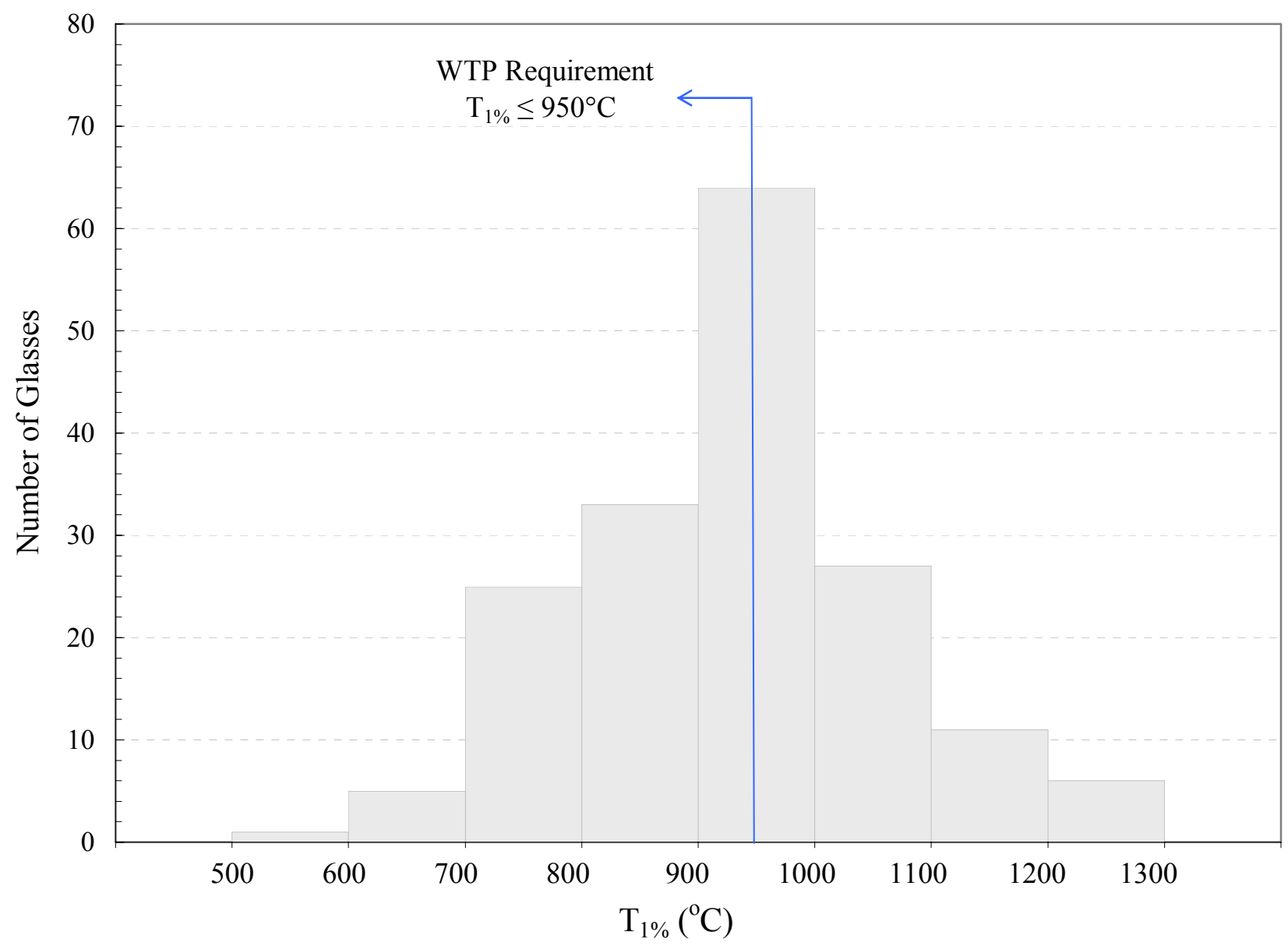

Figure 4.12. Distribution of Estimated One-Percent Crystal Fraction Temperature $\left(T_{1 \%}\right)$ for 172 HLW Glasses with Spinel as the Primary Crystalline Phase. 
The Catholic University of America Vitreous State Laboratory
IHLW PCT, Spinel $T_{1 \%}$, Electrical Conductivity, and Viscosity Model Development Final Report, VSL-07R1240-4, Rev. 0

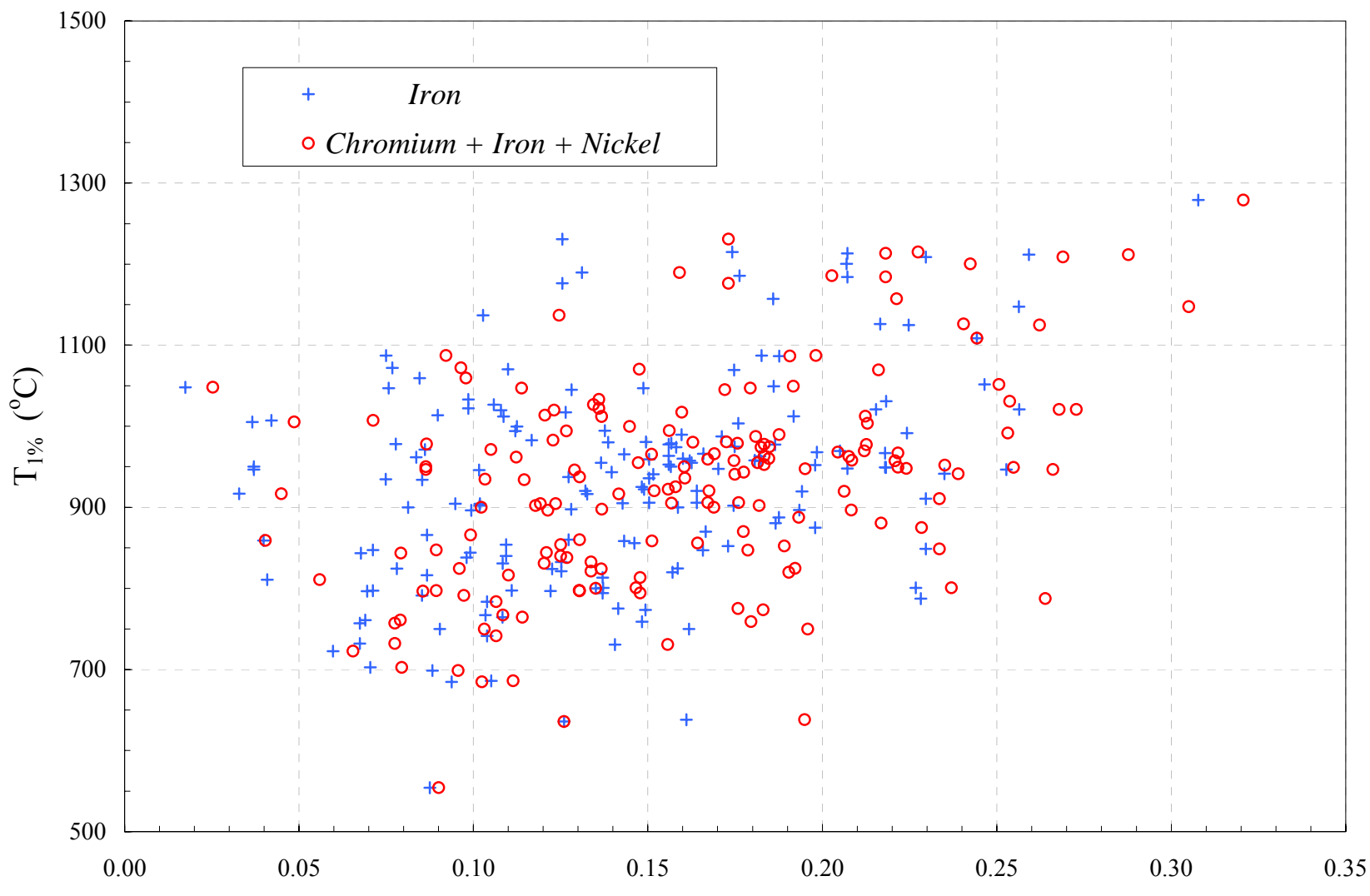

$\mathrm{Fe}_{2} \mathrm{O}_{3} /\left(\right.$ Alkali Oxides $\left.+\mathrm{B}_{2} \mathrm{O}_{3}\right)$ or $\left(\mathrm{Cr}_{2} \mathrm{O}_{3}+\mathrm{Fe}_{2} \mathrm{O}_{3}+\mathrm{NiO}\right) /\left(\right.$ Alkali Oxides $\left.+\mathrm{B}_{2} \mathrm{O}_{3}\right)$

Figure 4.13. Estimated $\mathrm{T}_{1 \%}$ versus Molar Ratios of $\mathrm{Fe}_{2} \mathrm{O}_{3}$ and $\left(\mathrm{Cr}_{2} \mathrm{O}_{3}+\mathrm{Fe}_{2} \mathrm{O}_{3}+\mathrm{NiO}\right)$ to (Alkali Oxides + Boron Oxide) for 172 HLW Glasses with Spinel as the Primary Crystalline Phase. 
The Catholic University of America Vitreous State Laboratory
IHLW PCT, Spinel $T_{1 \%}$, Electrical Conductivity, and Viscosity Model Development Final Report, VSL-07R1240-4, Rev. 0

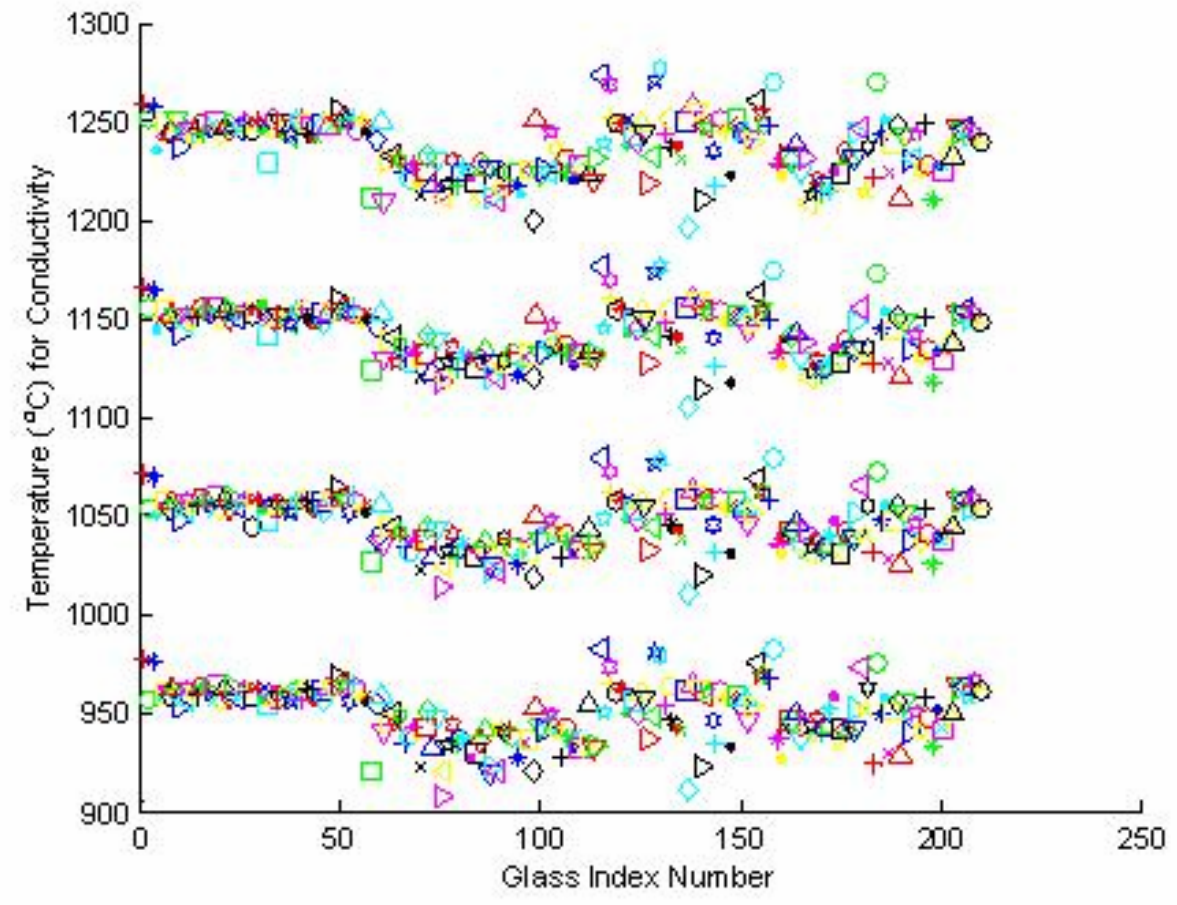

Figure 4.14. Distribution of Temperature Values for Each of 210 HLW Glasses with Electrical Conductivity Data.

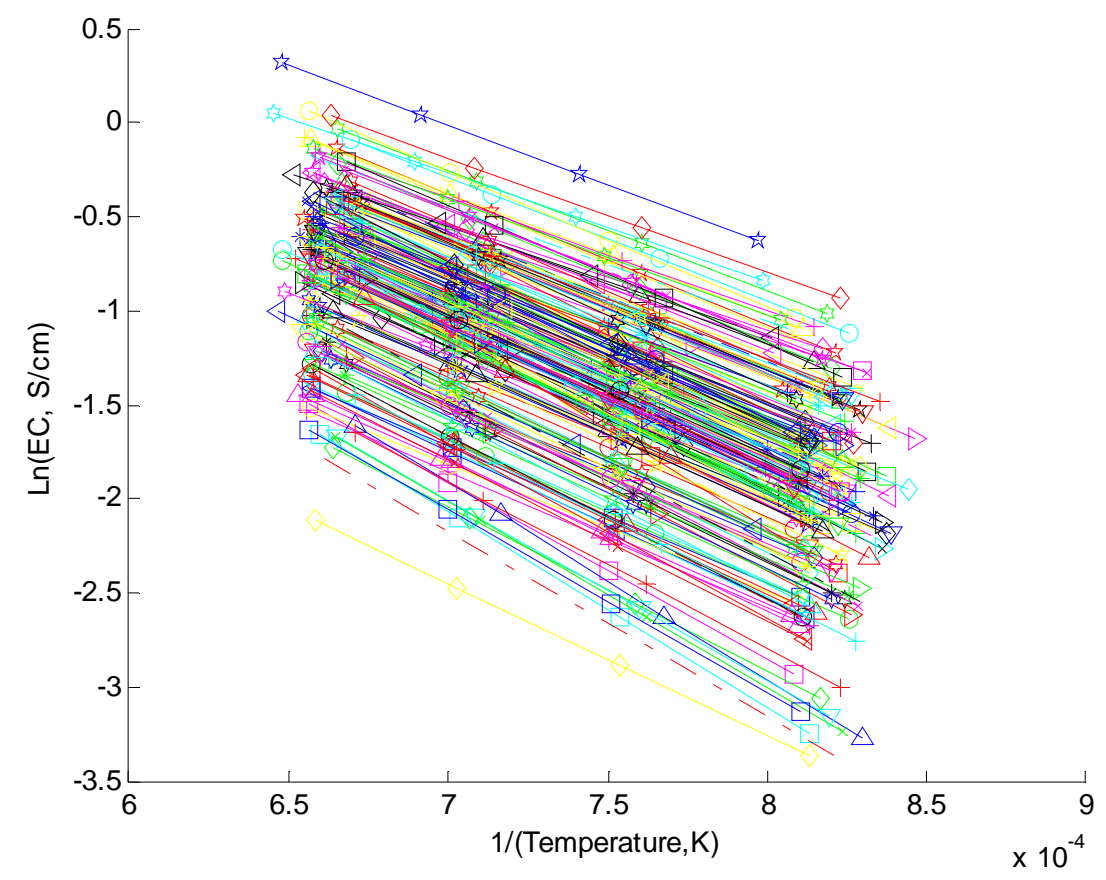

Figure 4.15. Temperature Dependence of Electrical Conductivity for Each of 210 HLW Glasses. Also shown is an Arrhenius equation fit for each glass for comparison purposes. 


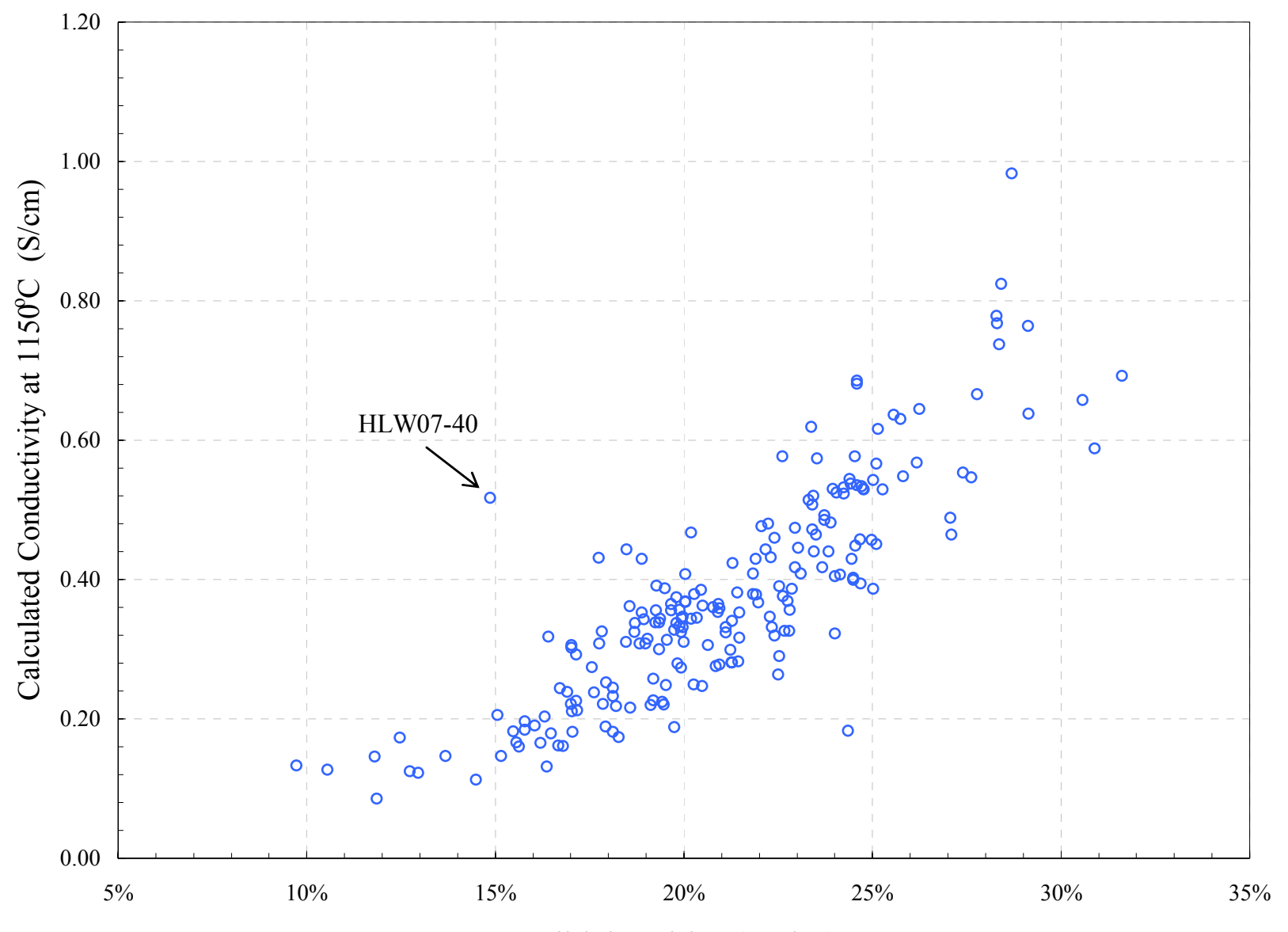

Alklai Oxides (mol\%)

Figure 4.16. Glass Melt Electrical Conductivity (in $\mathrm{S} / \mathrm{cm}$ ) at $1150^{\circ} \mathrm{C}$ Calculated by Vogel-Fulcher Equation Fit as a Function of the Sum of Major Alkali Oxides $\left(\mathrm{Li}_{2} \mathrm{O}+\mathrm{Na}_{2} \mathrm{O}+\mathrm{K}_{2} \mathrm{O}\right)$ for $210 \mathrm{HLW}$ Glasses with Electrical Conductivity Data. 


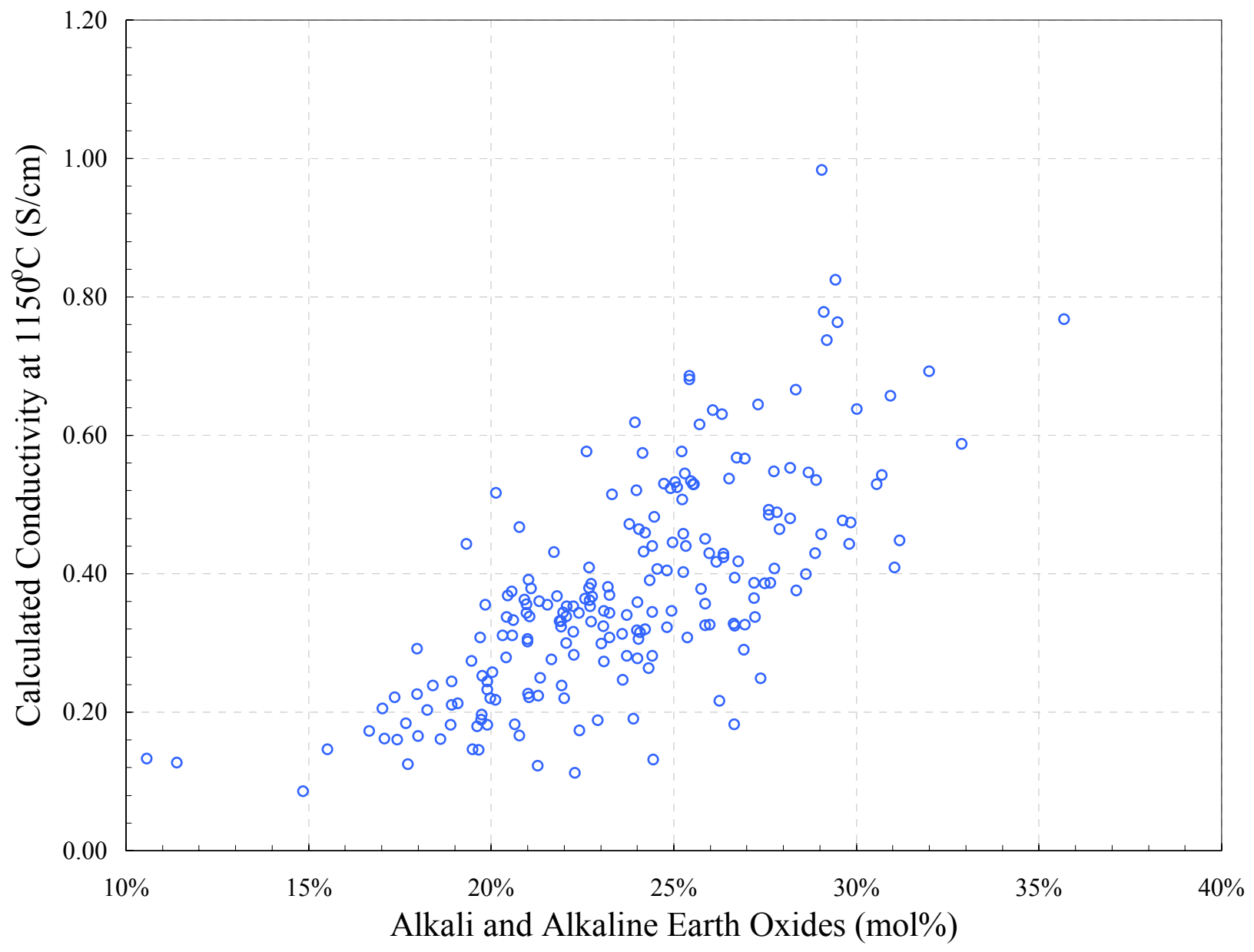

Figure 4.17. Glass Melt Electrical Conductivity (in $\mathrm{S} / \mathrm{cm}$ ) at $1150^{\circ} \mathrm{C}$ Calculated by Vogel-Fulcher Equation Fit as a Function of the Sum of Major Alkali Oxides and Alkaline Earth Oxides $\left(\mathrm{Li}_{2} \mathrm{O}+\mathrm{Na}_{2} \mathrm{O}+\mathrm{K}_{2} \mathrm{O}+\mathrm{CaO}+\mathrm{MgO}+\mathrm{SrO}\right)$ for 210 HLW Glasses with Electrical Conductivity Data. 
The Catholic University of America Vitreous State Laboratory
IHLW PCT, Spinel $T_{1 \%}$, Electrical Conductivity, and Viscosity Model Development Final Report, VSL-07R1240-4, Rev. 0

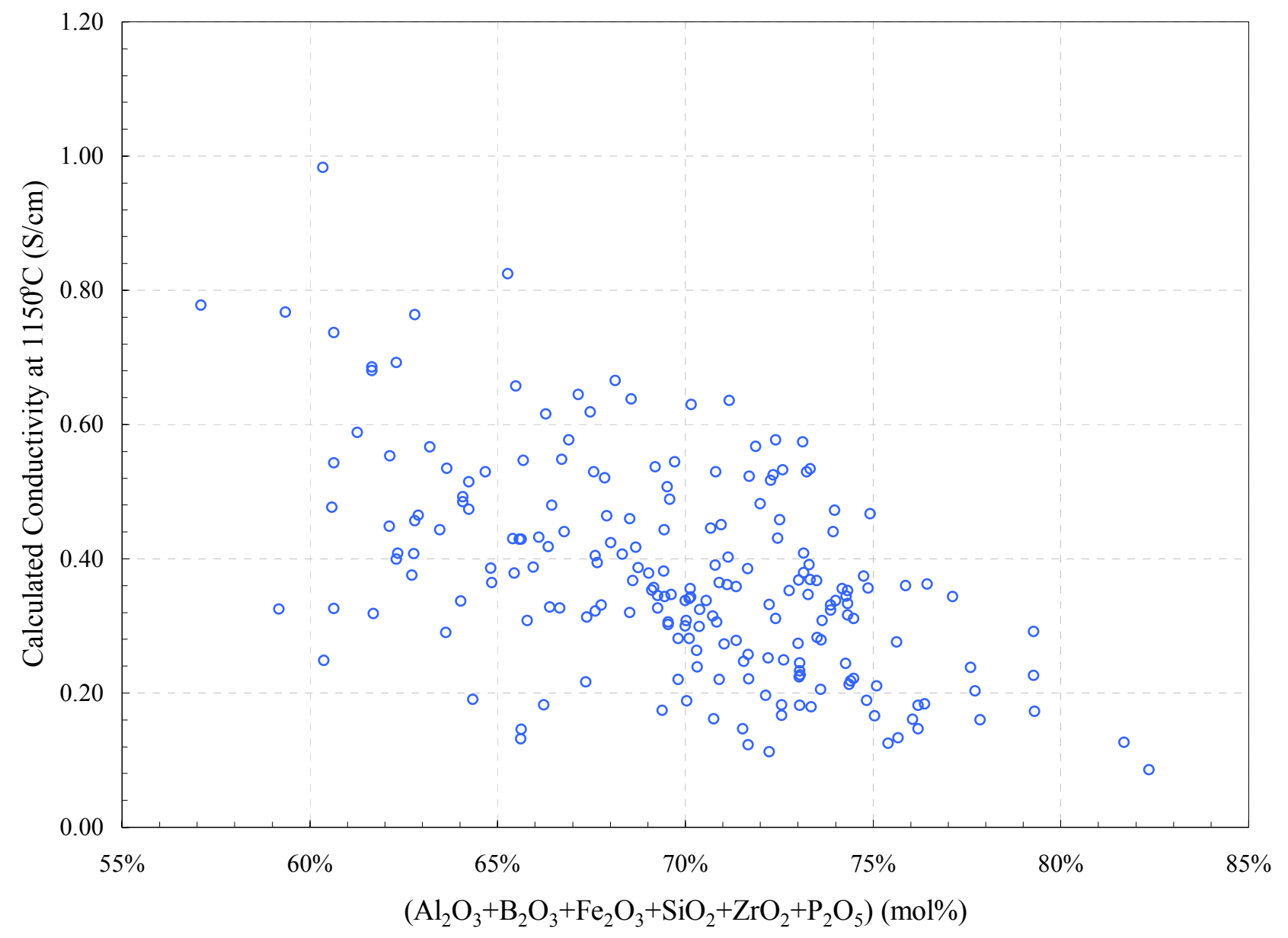

Figure 4.18. Glass Melt Electrical Conductivity (in $\mathrm{S} / \mathrm{cm}$ ) at $1150^{\circ} \mathrm{C}$ Calculated by Vogel-Fulcher Equation Fit as a Function of the Sum of Major Valence III, IV, and V Components $\left(\mathrm{Al}_{2} \mathrm{O}_{3}+\mathrm{B}_{2} \mathrm{O}_{3}+\mathrm{Fe}_{2} \mathrm{O}_{3}+\mathrm{SiO}_{2}+\mathrm{ZrO}_{2}+\mathrm{P}_{2} \mathrm{O}_{5}\right)$ for 210 HLW Glasses with Electrical Conductivity Data. 
The Catholic University of America Vitreous State Laboratory
IHLW PCT, Spinel $T_{1 \%}$, Electrical Conductivity, and Viscosity Model Development Final Report, VSL-07R1240-4, Rev. 0

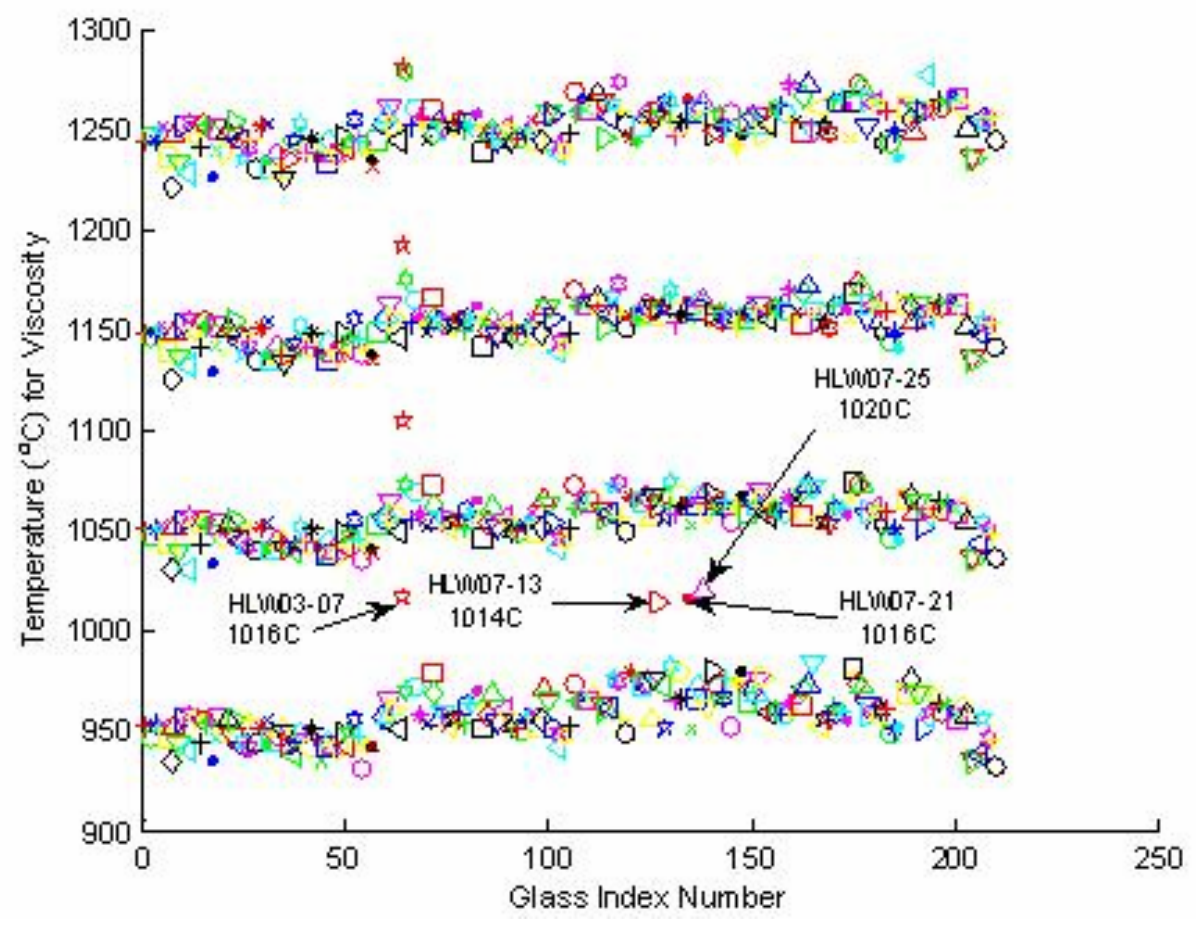

Figure 4.19. Distribution of Temperature Values for Each of 210 HLW Glasses with Viscosity Data.

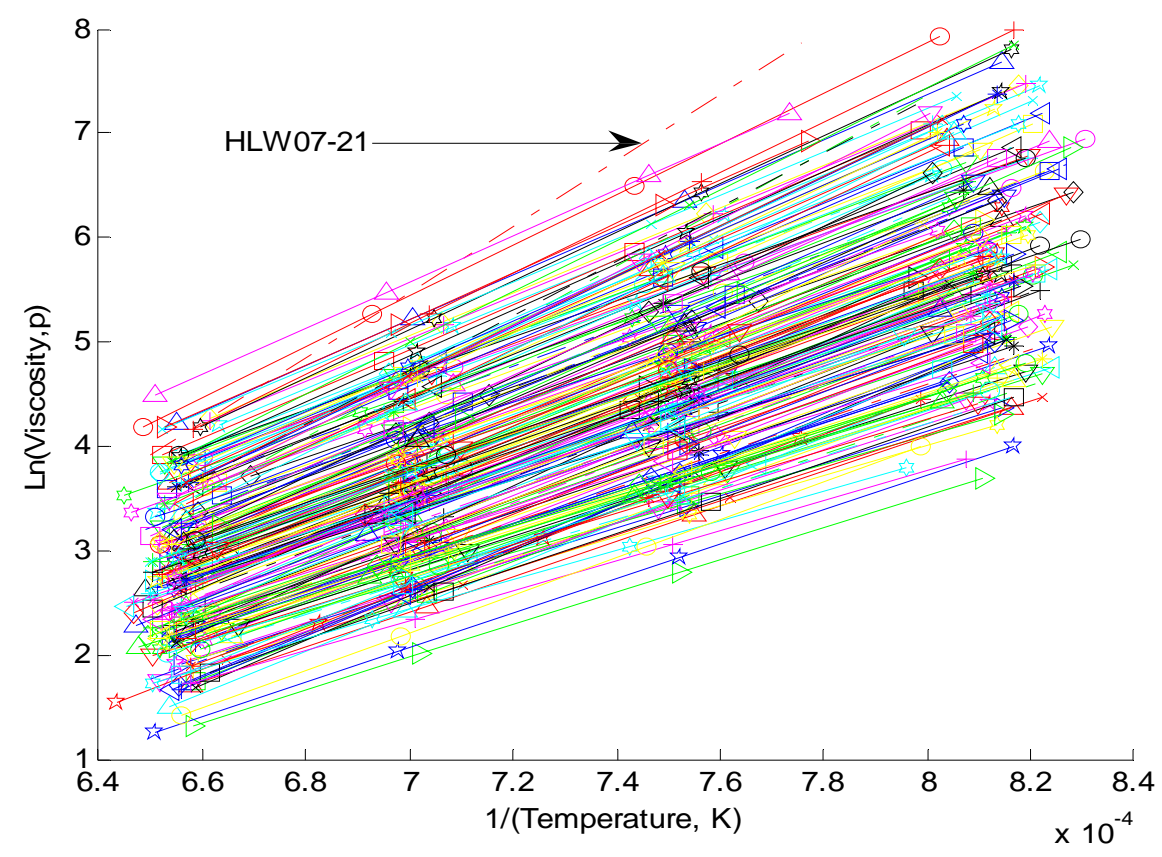

Figure 4.20. Temperature Dependence of Viscosity for Each of 210 HLW Glasses. Also shown is an Arrhenius equation fit for each glass for comparison purposes. 
The Catholic University of America Vitreous State Laboratory
IHLW PCT, Spinel $T_{1 \%}$, Electrical Conductivity, and Viscosity Model Development Final Report, VSL-07R1240-4, Rev. 0

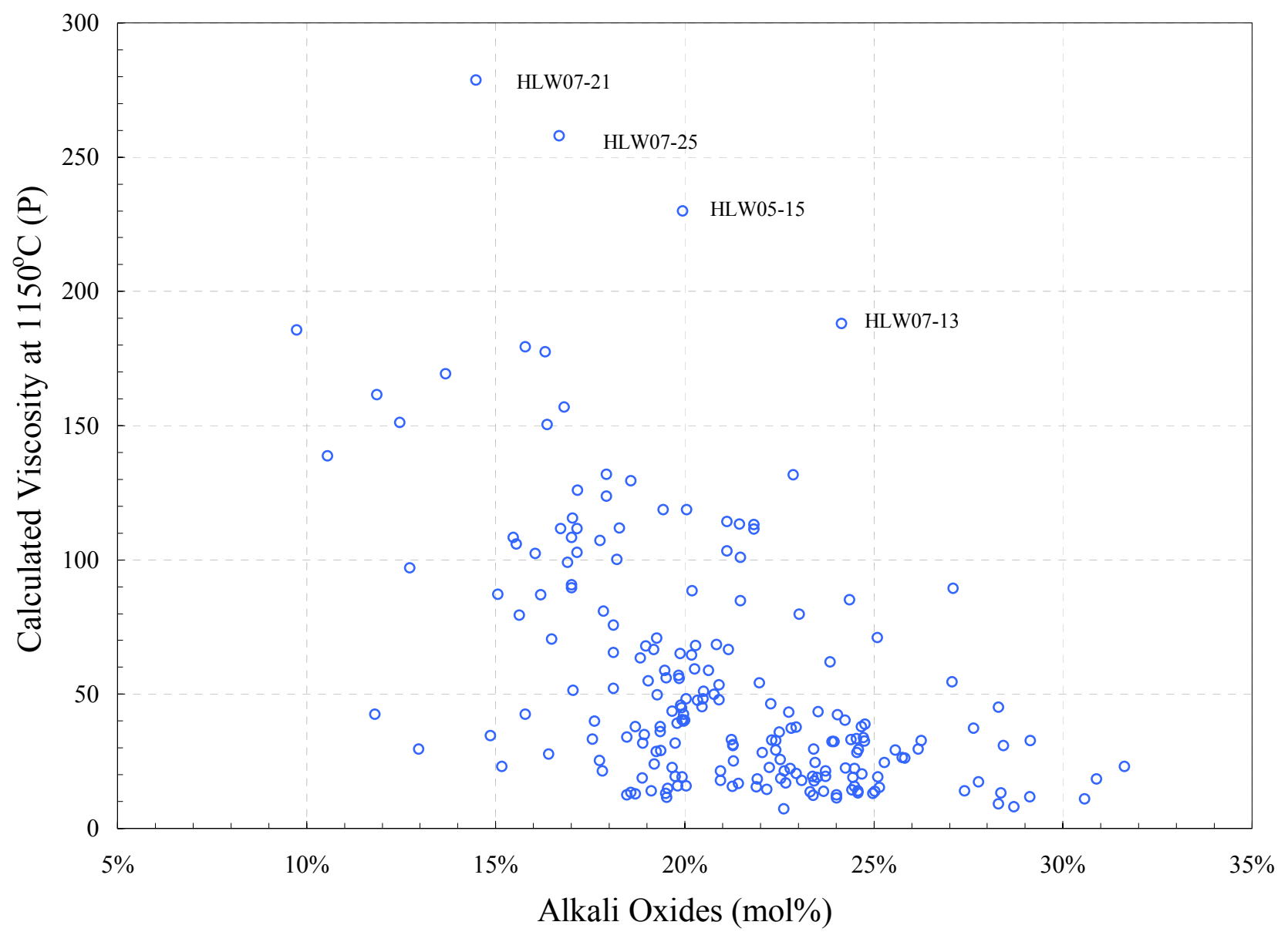

Figure 4.21. Glass Melt Viscosity (in P) at $1150^{\circ} \mathrm{C}$ Calculated by Vogel-Fulcher Equation Fit as a Function of the Sum of Major Alkali Oxides $\left(\mathrm{Li}_{2} \mathrm{O}+\mathrm{Na}_{2} \mathrm{O}+\mathrm{K}_{2} \mathrm{O}\right)$ for $210 \mathrm{HLW}$ Glasses with Melt Viscosity Data. 


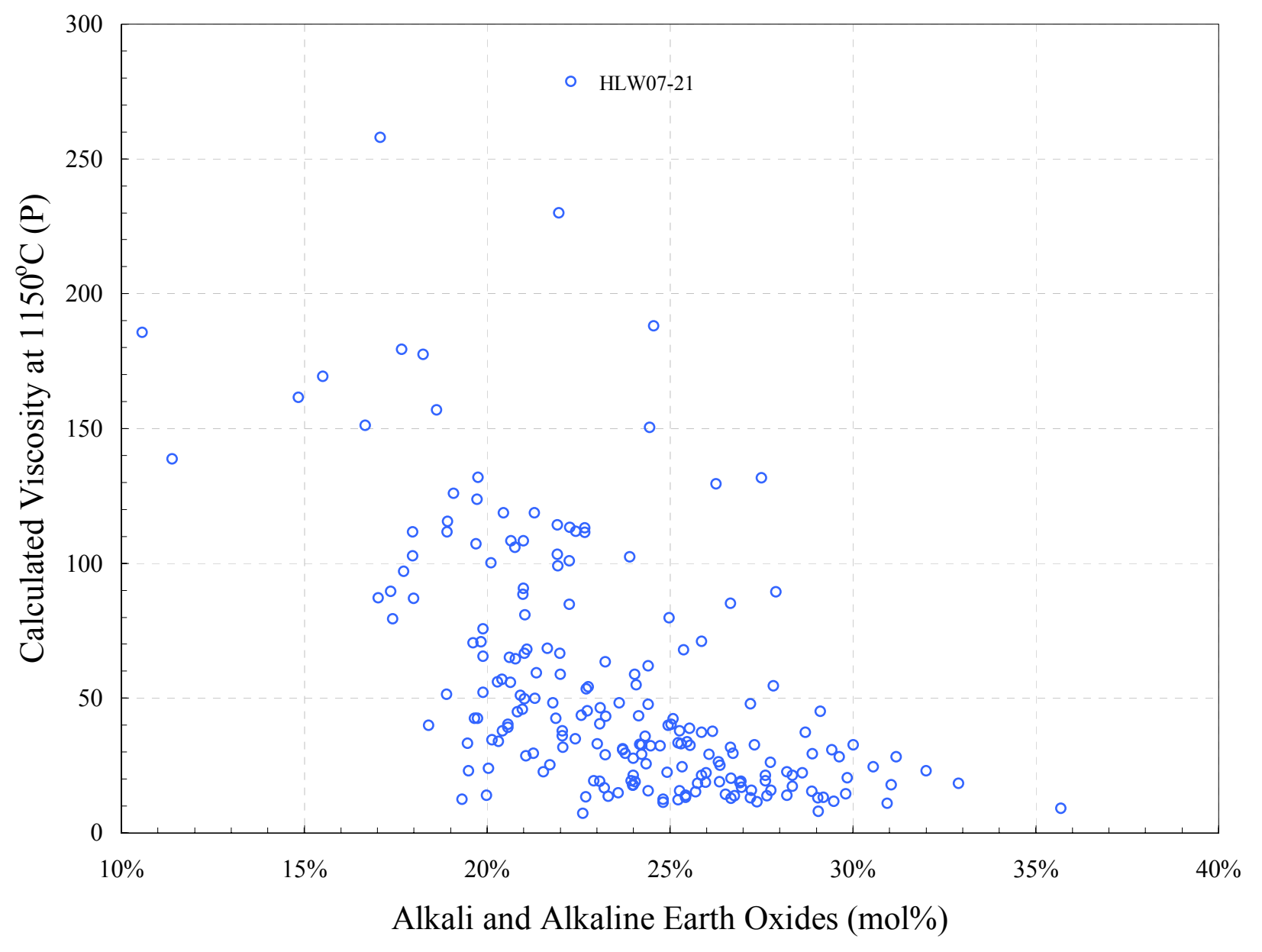

Figure 4.22. Glass Melt Viscosity (in P) at $1150^{\circ} \mathrm{C}$ Calculated by Vogel-Fulcher Equation Fit as a Function of the Sum of Major Alkali and Alkaline Earth Oxides $\left(\mathrm{Li}_{2} \mathrm{O}+\mathrm{Na}_{2} \mathrm{O}+\mathrm{K}_{2} \mathrm{O}+\mathrm{CaO}+\mathrm{MgO}+\mathrm{SrO}\right)$ for $210 \mathrm{HLW}$ Glasses with Melt Viscosity Data. 
The Catholic University of America Vitreous State Laboratory
IHLW PCT, Spinel $T_{1 \%}$, Electrical Conductivity, and Viscosity Model Development Final Report, VSL-07R1240-4, Rev. 0

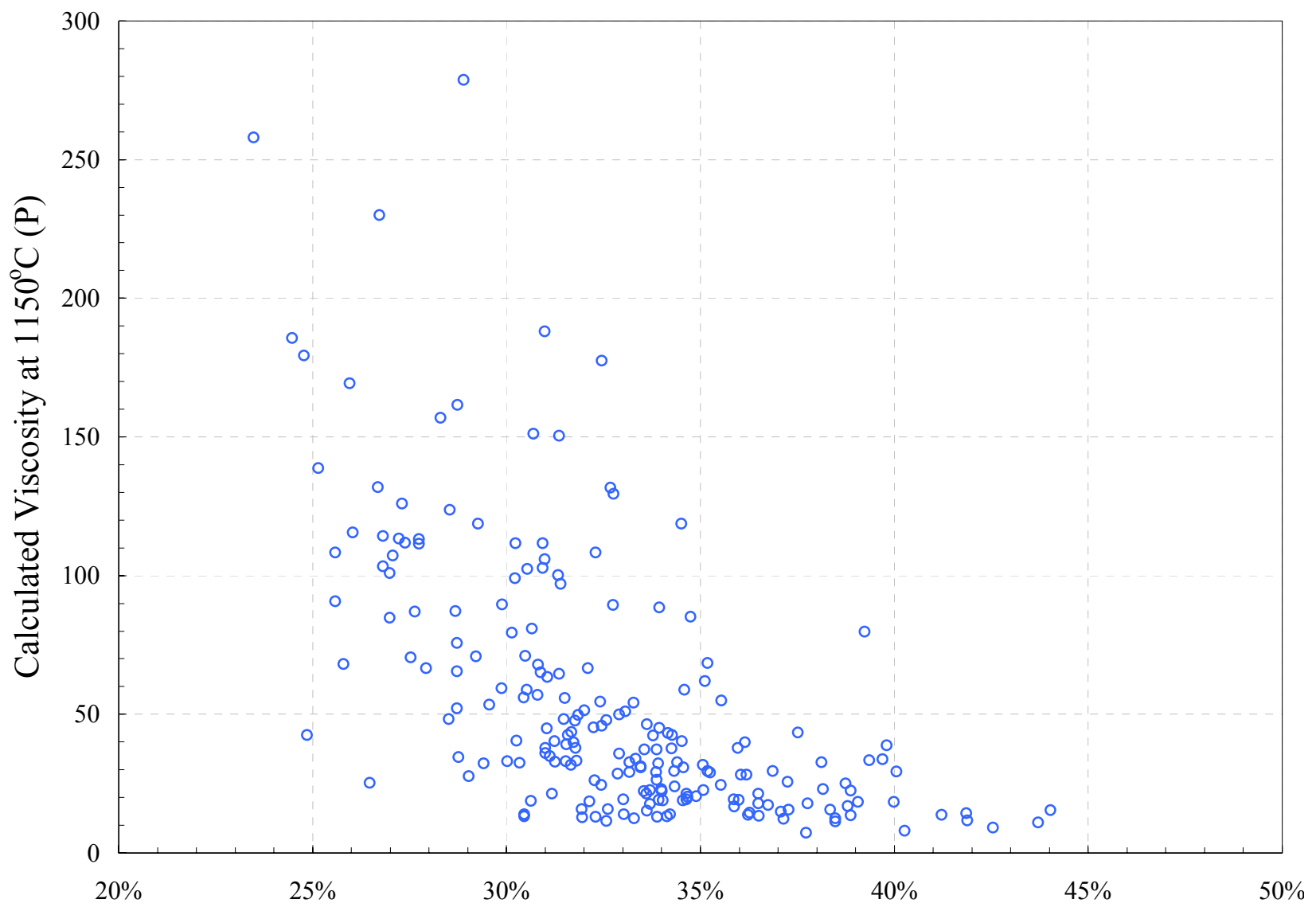

Alkali, Alkaline Earth and Boron Oxides (mol\%)

Figure 4.23. Glass Melt Viscosity (in P) at $1150^{\circ} \mathrm{C}$ Calculated by Vogel-Fulcher Equation Fit as a Function of the Sum of Major Alkali Oxides, Major Alkaline Earth Oxides and Boron Oxide $\left(\mathrm{Li}_{2} \mathrm{O}+\mathrm{Na}_{2} \mathrm{O}+\mathrm{K}_{2} \mathrm{O}+\mathrm{CaO}+\mathrm{MgO}+\mathrm{SrO}+\mathrm{B}_{2} \mathrm{O}_{3}\right)$ for 210 HLW Glasses with Melt Viscosity Data. 


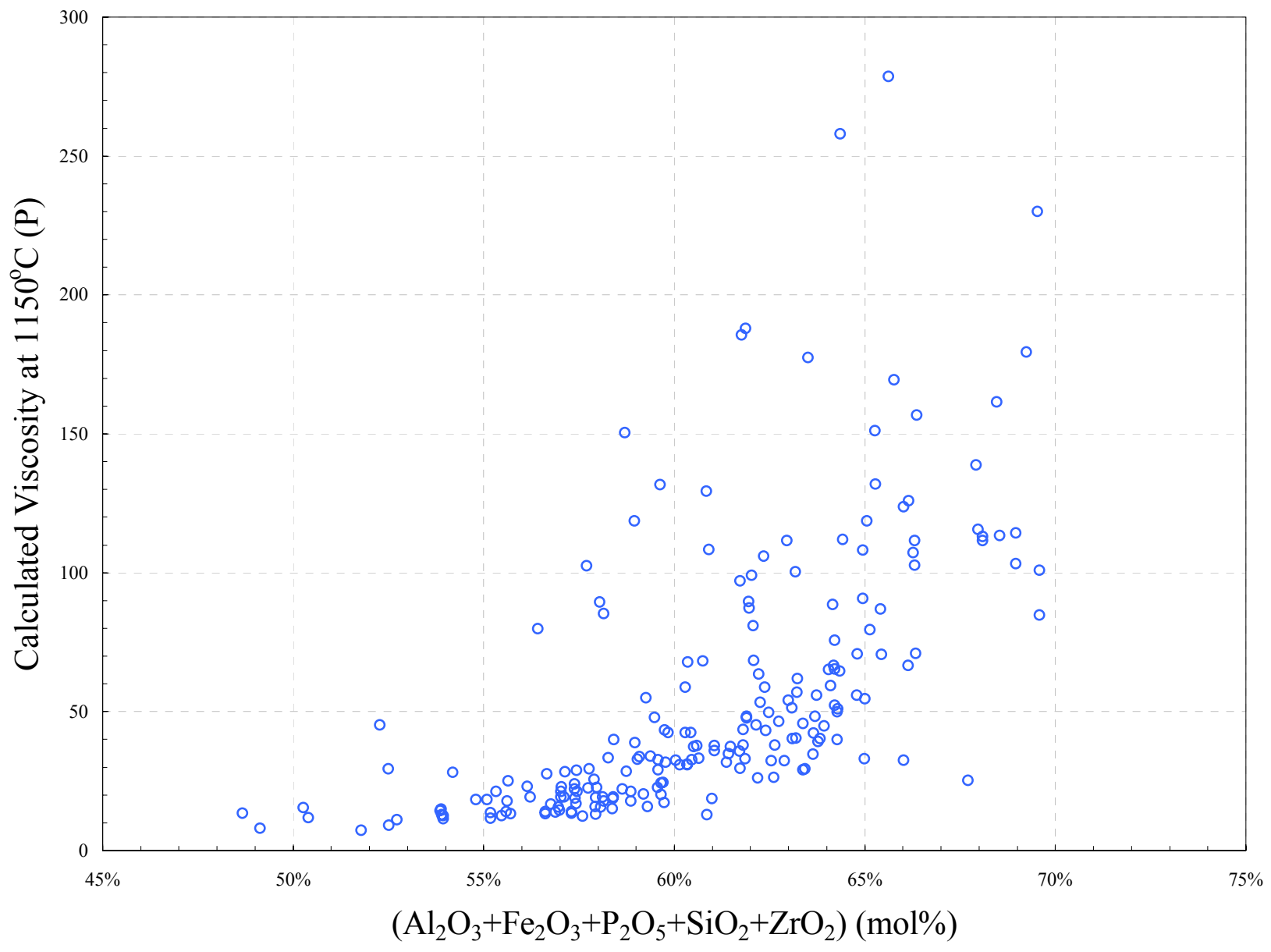

Figure 4.24. Glass Melt Viscosity (in $\mathrm{P}$ ) at $1150^{\circ} \mathrm{C}$ Calculated by Vogel-Fulcher Equation Fit as a Function of $\mathrm{Al}_{2} \mathrm{O}_{3}+\mathrm{Fe}_{2} \mathrm{O}_{3}+\mathrm{P}_{2} \mathrm{O}_{5}+\mathrm{SiO}_{2}+\mathrm{ZrO}_{2}$ for $210 \mathrm{HLW}$ Glasses with Melt Viscosity Data. 
The Catholic University of America Vitreous State Laboratory
IHLW PCT, Spinel $T_{1 \%}$, Electrical Conductivity, and Viscosity Model Development Final Report, VSL-07R1240-4, Rev. 0

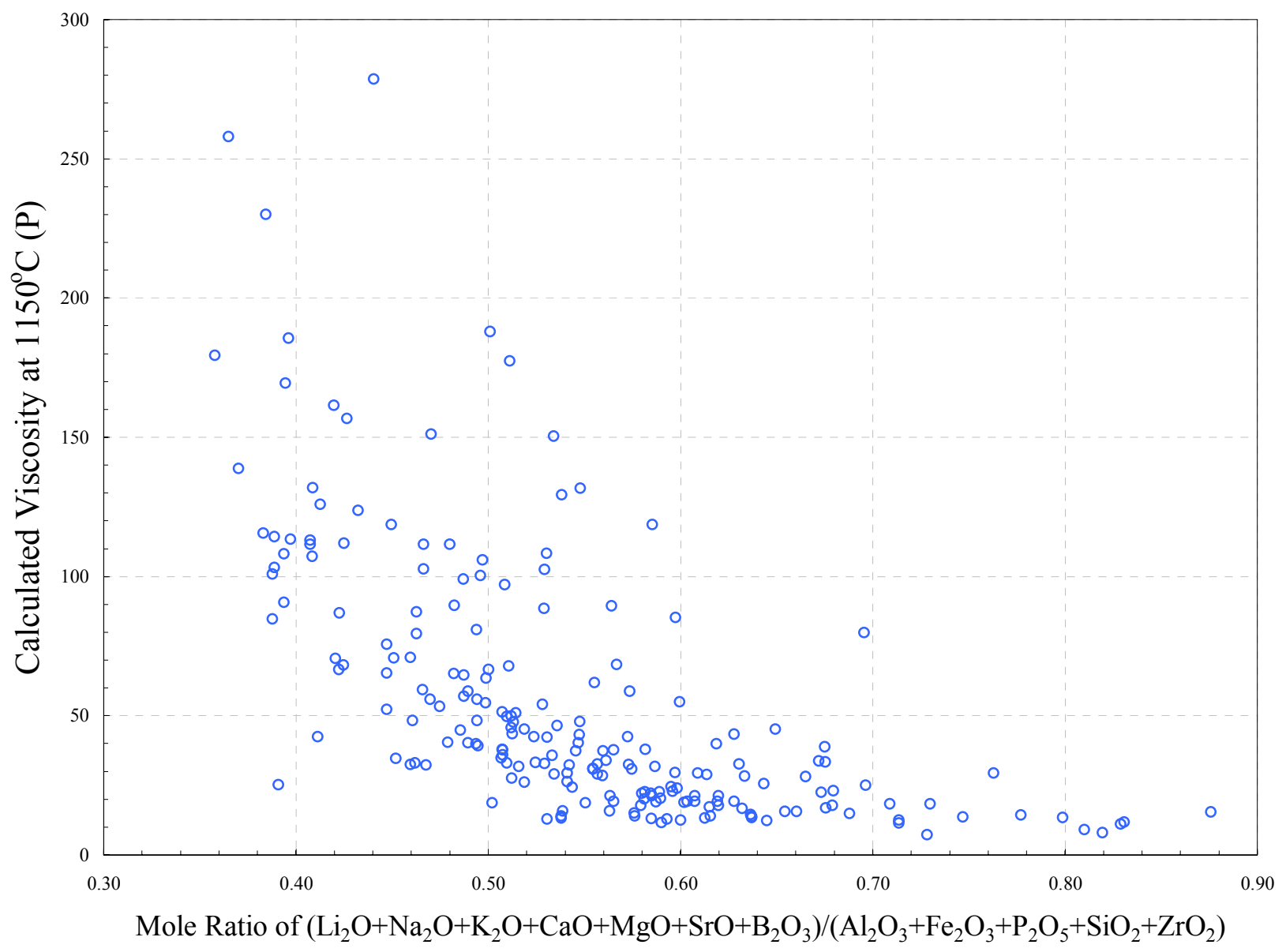

Figure 4.25. Glass Melt Viscosity (in P) at $1150^{\circ} \mathrm{C}$ Calculated by Vogel-Fulcher Equation Fit as a Function of the Molar Ratio of the Sum of Alkali Oxides, Alkaline Earth Oxides and Boron Oxides $\left(\mathrm{Li}_{2} \mathrm{O}+\mathrm{Na}_{2} \mathrm{O}+\mathrm{K}_{2} \mathrm{O}+\mathrm{CaO}+\mathrm{MgO}+\mathrm{SrO}+\mathrm{B}_{2} \mathrm{O}_{3}\right)$ to Glass Forming Oxides $\left(\mathrm{Al}_{2} \mathrm{O}_{3}+\mathrm{Fe}_{2} \mathrm{O}_{3}+\mathrm{P}_{2} \mathrm{O}_{5}+\mathrm{SiO}_{2}+\mathrm{ZrO}_{2}\right)$ for $210 \mathrm{HLW}$ Glasses with Melt Viscosity Data. 
The Catholic University of America Vitreous State Laboratory
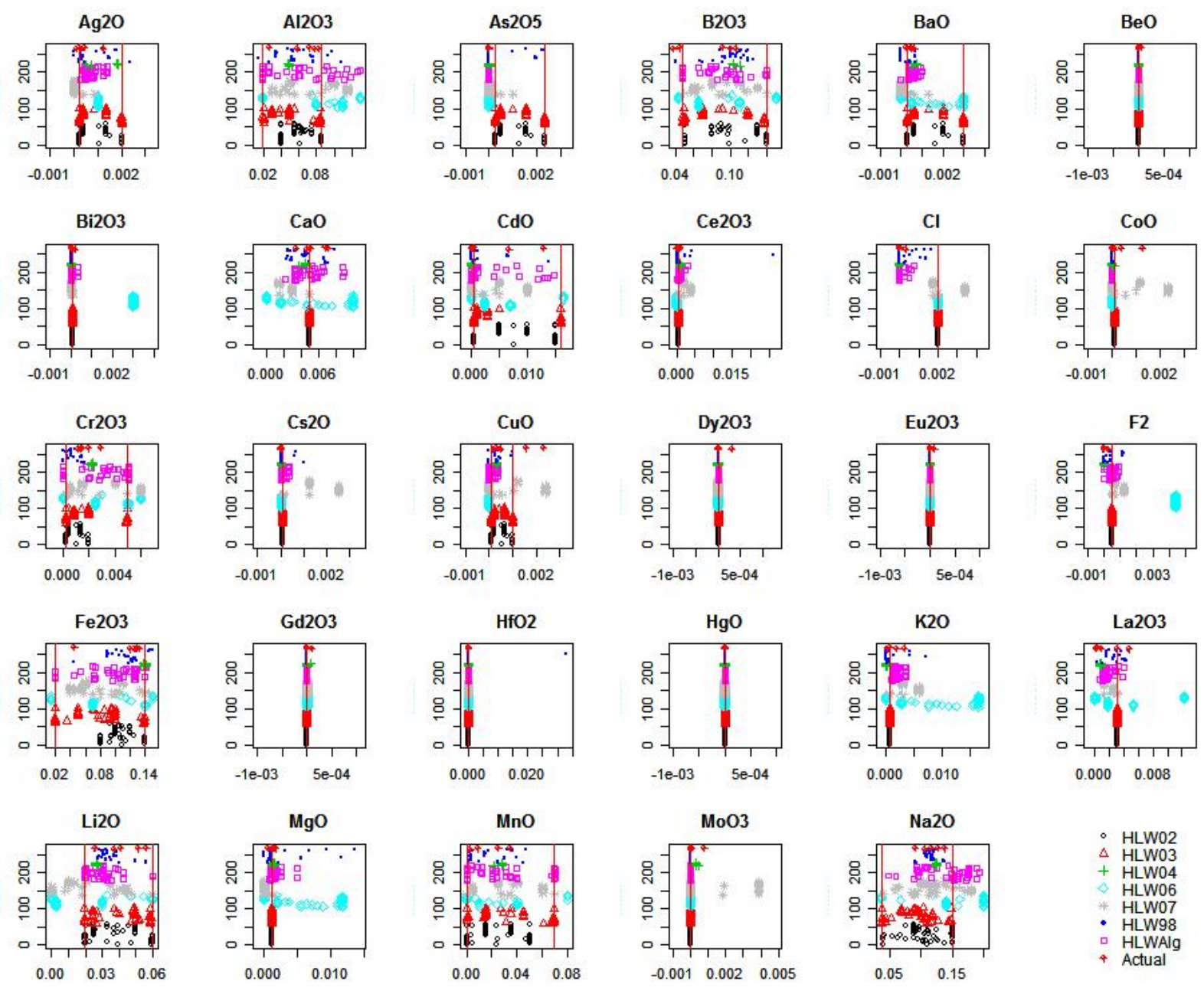

IHLW PCT, Spinel $T_{1 \%}$, Electrical Conductivity, and Viscosity Model Development Final Report, VSL-07R1240-4, Rev. 0
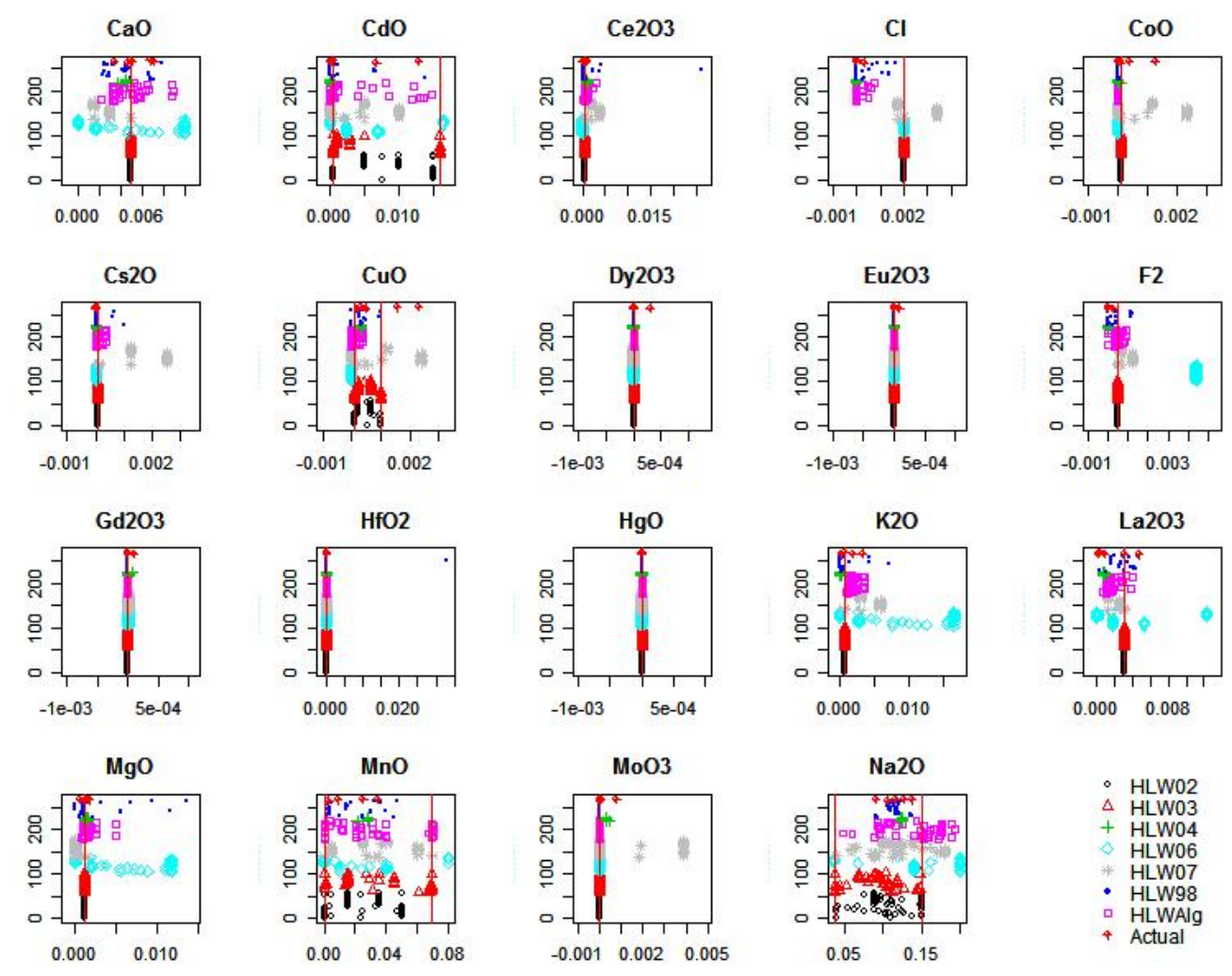

Figure 5.1. Ranges and Distributions of Component Mass Fractions (x-axes) for 268 HLW Glass Compositions with PCT Data. The vertical lines (when present) are the lower and upper limits for each component varied in statistically designed test matrices. 
The Catholic University of America Vitreous State Laboratory
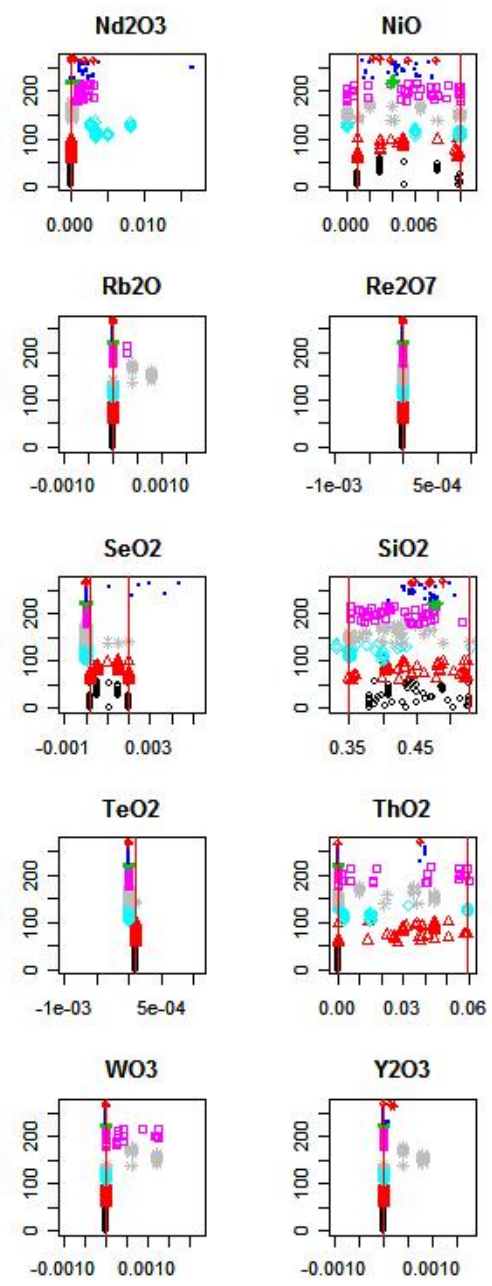

IHLW PCT, Spinel $T_{1 \%}$, Electrical Conductivity, and Viscosity Model Development Final Report, VSL-07R1240-4, Rev. 0
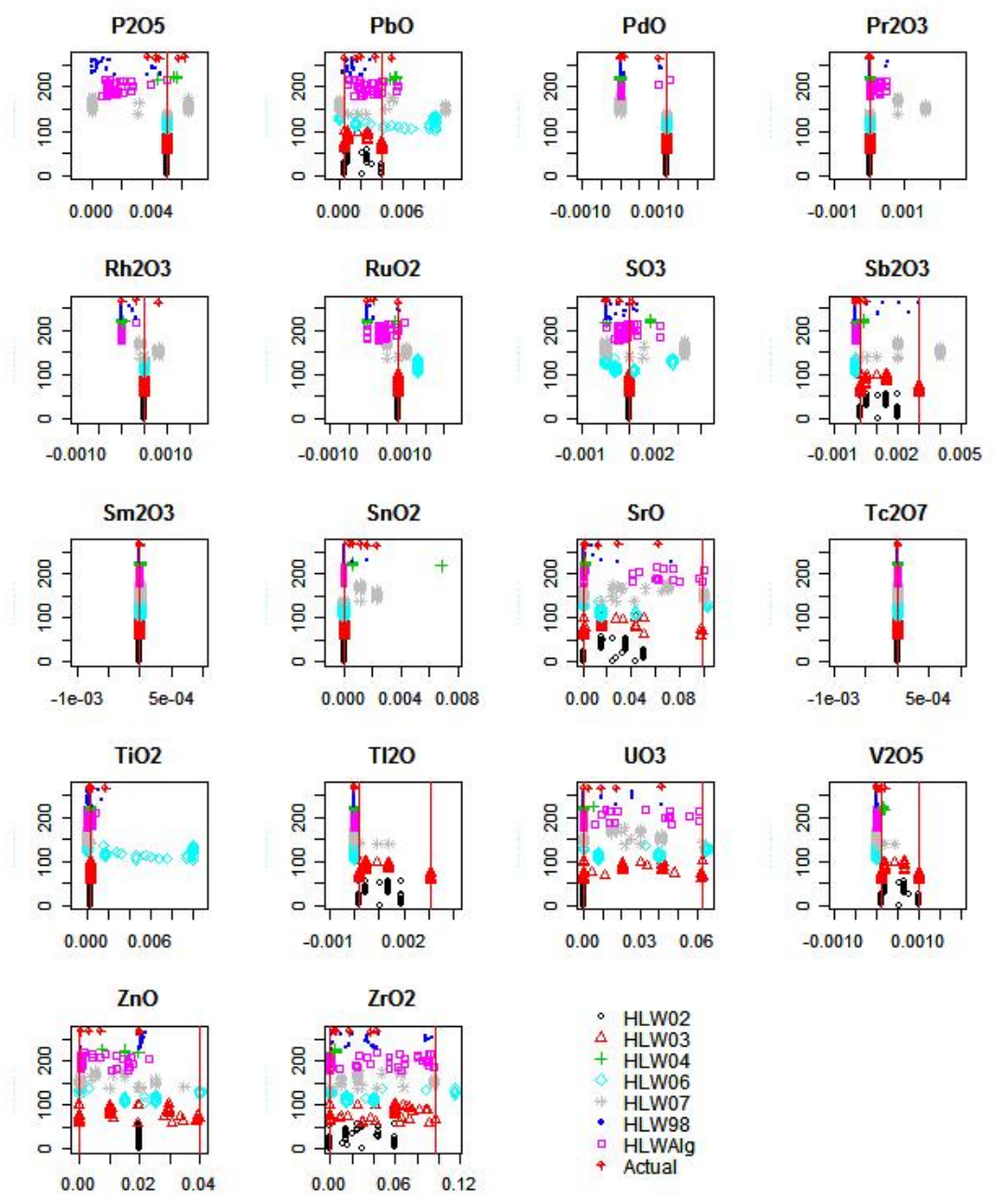

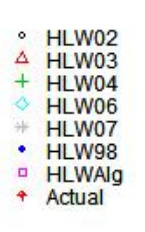

Figure 5.1. Ranges and Distributions of Component Mass Fractions (x-axes) for 268 HLW Glass Compositions with PCT Data. The vertical lines (when present) are the lower and upper limits for each component varied in statistically designed test matrices (continued). 
The Catholic University of America Vitreous State Laboratory
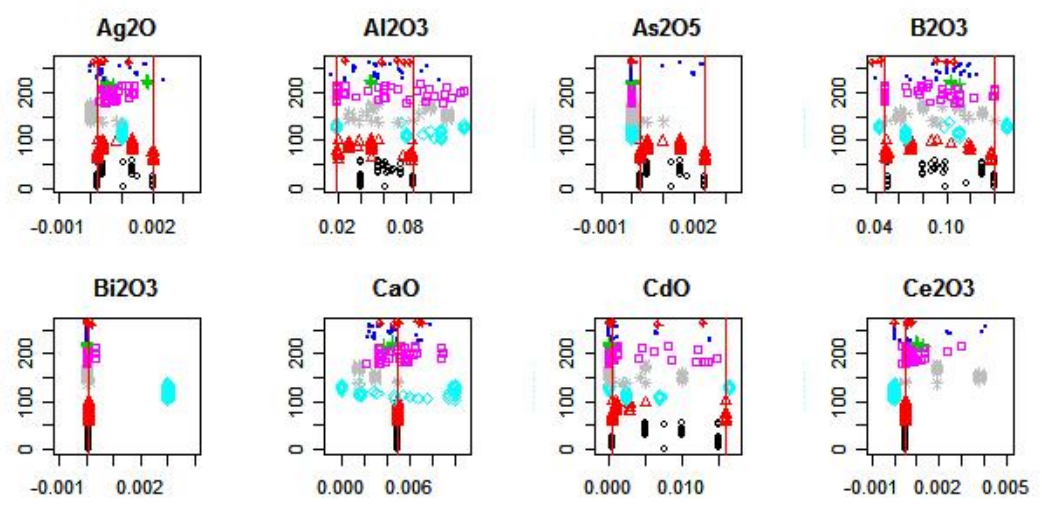

IHLW PCT, Spinel $T_{1 \%}$, Electrical Conductivity, and Viscosity Model Development Final Report, VSL-07R1240-4, Rev. 0
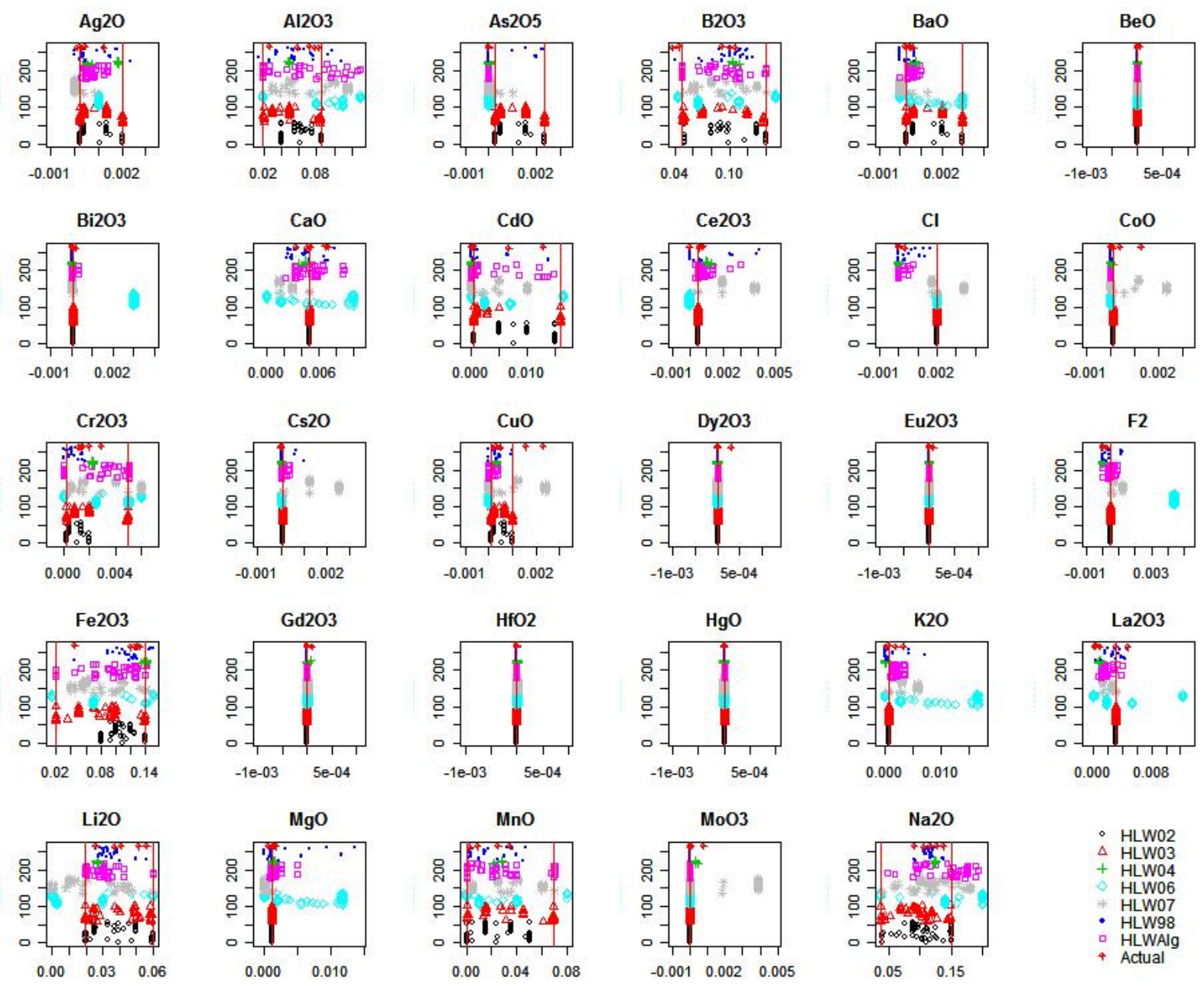

Figure 5.2. Ranges and Distributions of Component Mass Fractions (x-axes) for 266 HLW Glass Compositions with PCT Data after Removing Two Outliers. The vertical lines (when present) are the lower and upper limits for each component varied in statistically designed test matrices. 
The Catholic University of America Vitreous State Laboratory
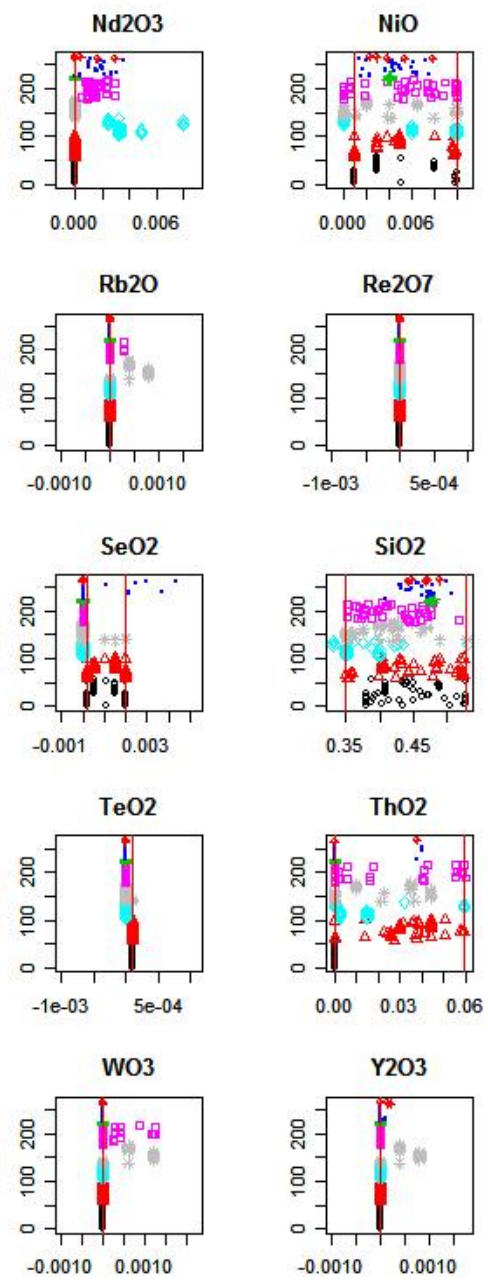

IHLW PCT, Spinel $T_{1 \%}$, Electrical Conductivity, and Viscosity Model Development Final Report, VSL-07R1240-4, Rev. 0
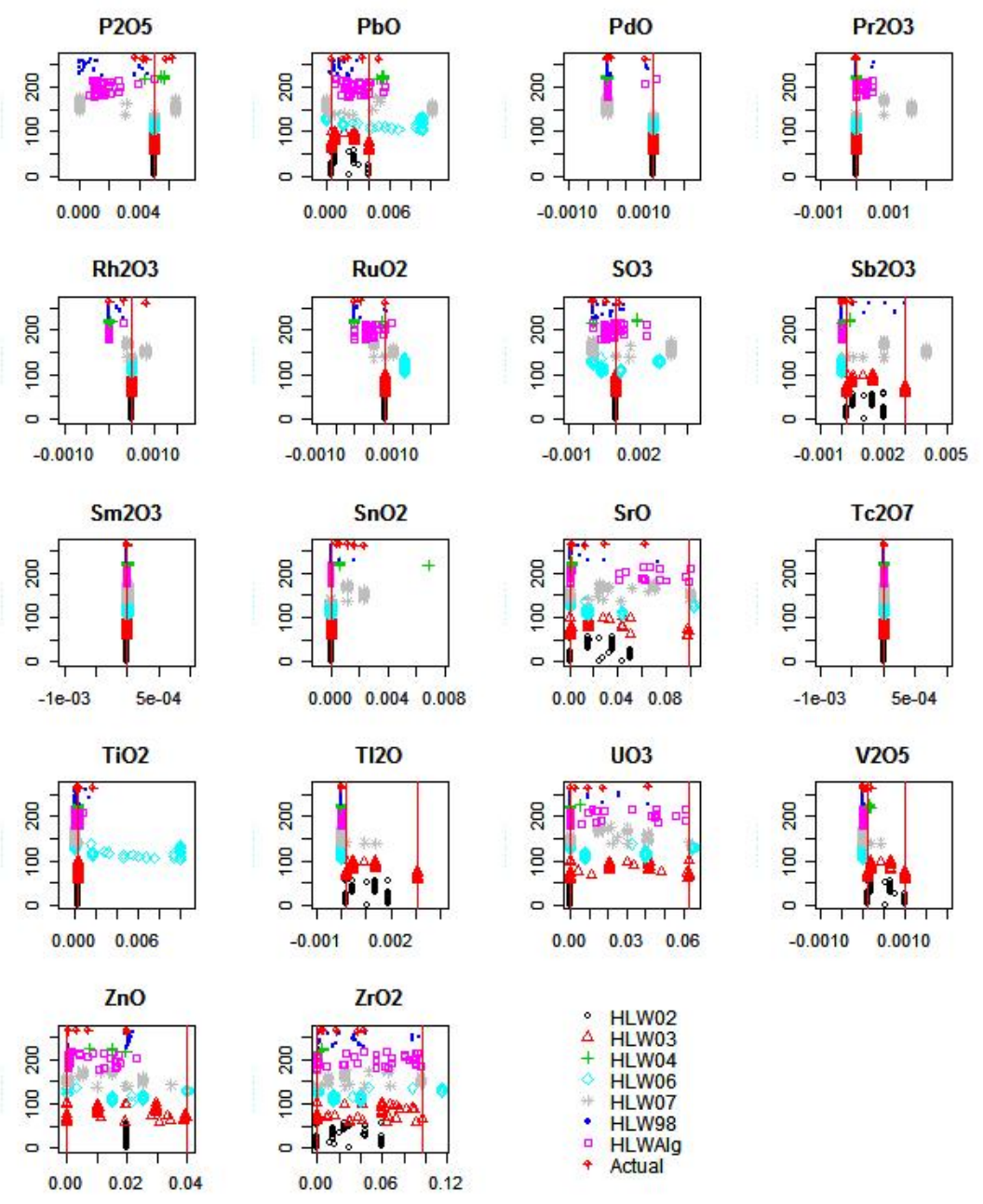

Figure 5.2. Ranges and Distributions of Component Mass Fractions (x-axes) for 266 HLW Glass Compositions with PCT Data after Removing Two Outliers. The vertical lines (when present) are the lower and upper limits for each component varied in statistically designed test matrices (continued). 


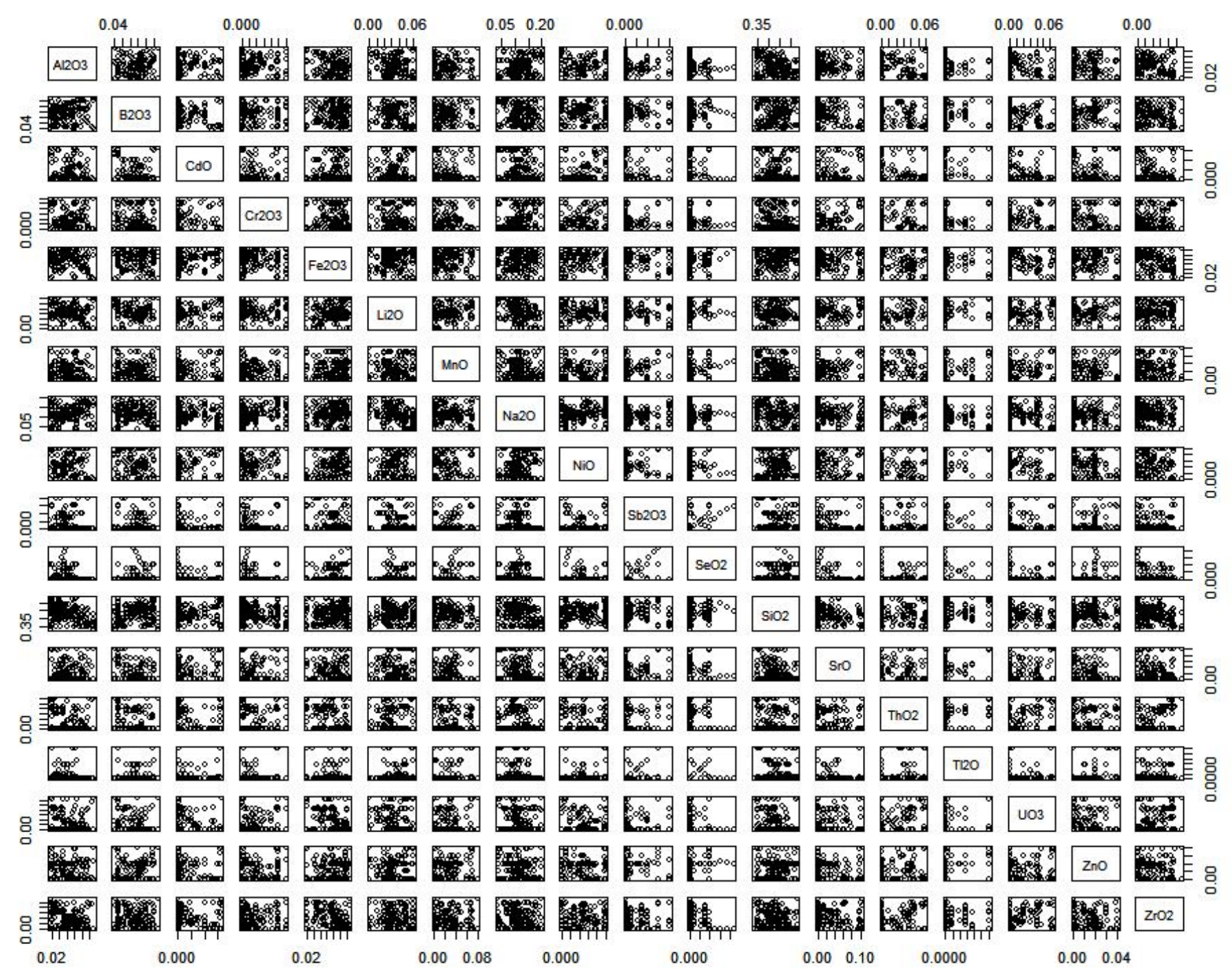

Figure 5.3. Scatterplot Matrix of 18 Components (mass fractions) for 266 HLW Glasses in the Initial PCT Modeling Data Set. 
The Catholic University of America Vitreous State Laboratory

$\ln (\mathrm{PCT}-\mathrm{B}, \mathrm{g} / \mathrm{L})$
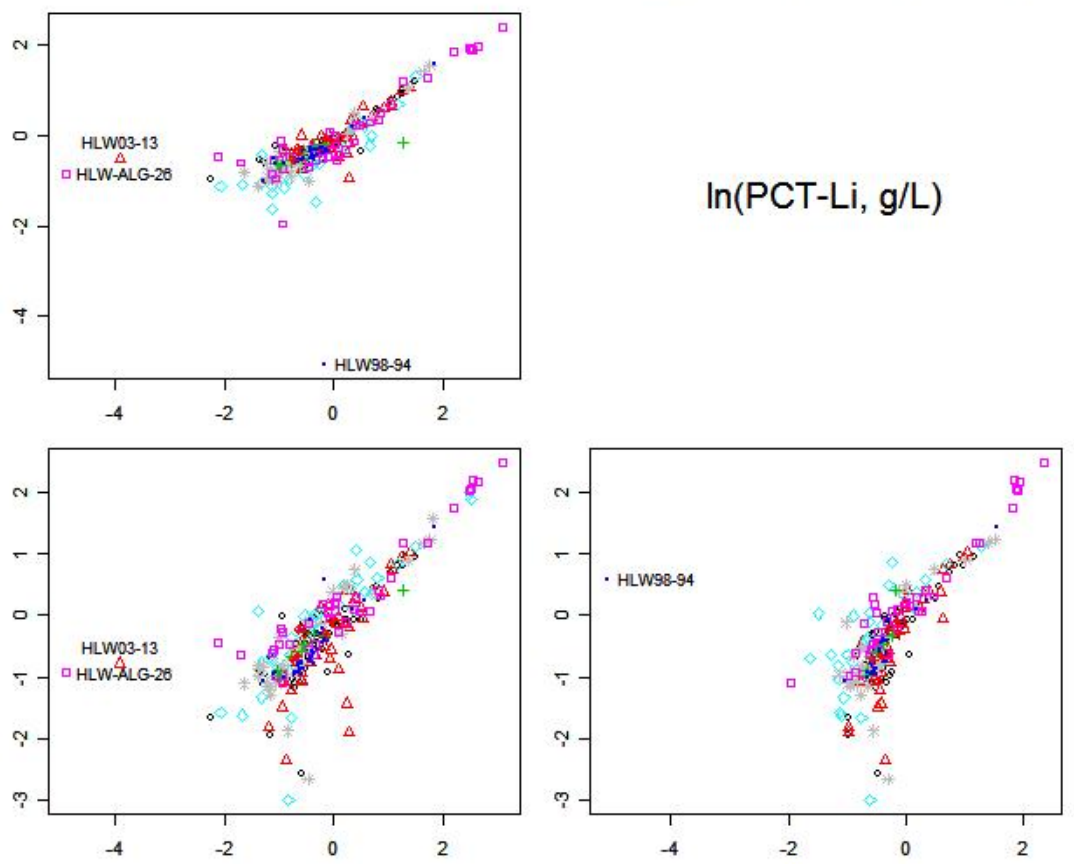

IHLW PCT, Spinel $T_{1 \%}$, Electrical Conductivity, and Viscosity Model Development Final Report, VSL-07R1240-4, Rev. 0
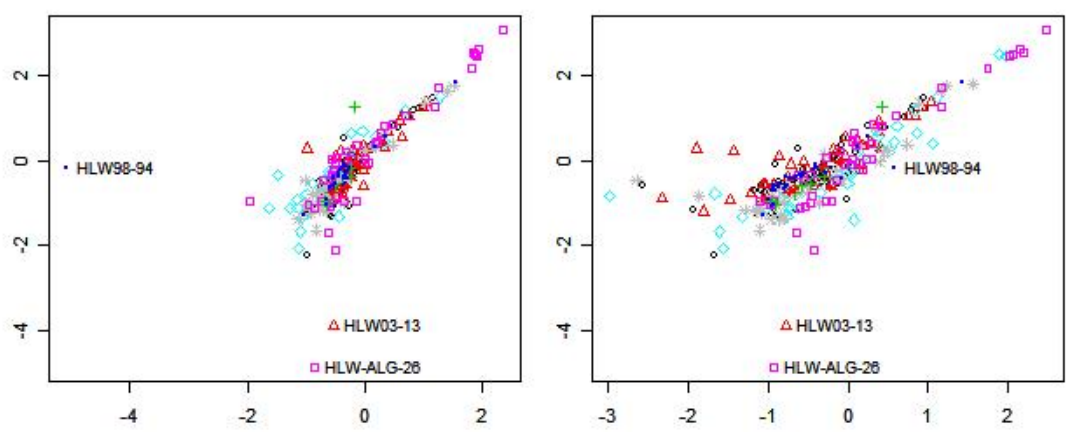

$\ln (\mathrm{PCT}-\mathrm{Li}, \mathrm{g} / \mathrm{L})$

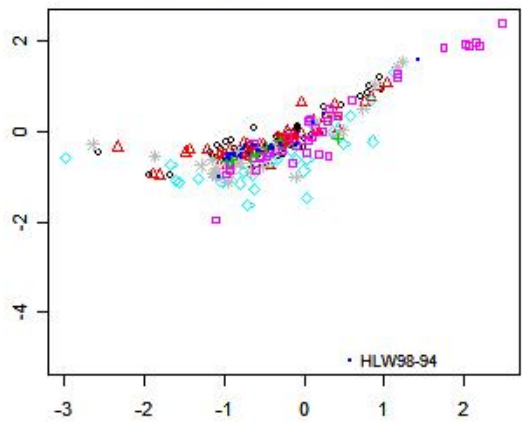

$\ln (\mathrm{PCT}-\mathrm{Na}, \mathrm{g} / \mathrm{L})$

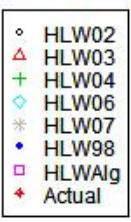

Figure 5.4. Scatterplot Matrix of Natural Logarithms of PCT-B, PCT-Li, and PCT-Na Normalized Releases (g/L) for Initial PCT Modeling Dataset of 266 HLW

Glasses. Glasses with low PCT-B releases are HLW03-13 and HLW-ALG-26. Glass with low PCT-Li release is HLW98-94. 
The Catholic University of America Vitreous State Laboratory
IHLW PCT, Spinel $T_{1 \%}$, Electrical Conductivity, and Viscosity Model Development Final Report, VSL-07R1240-4, Rev. 0

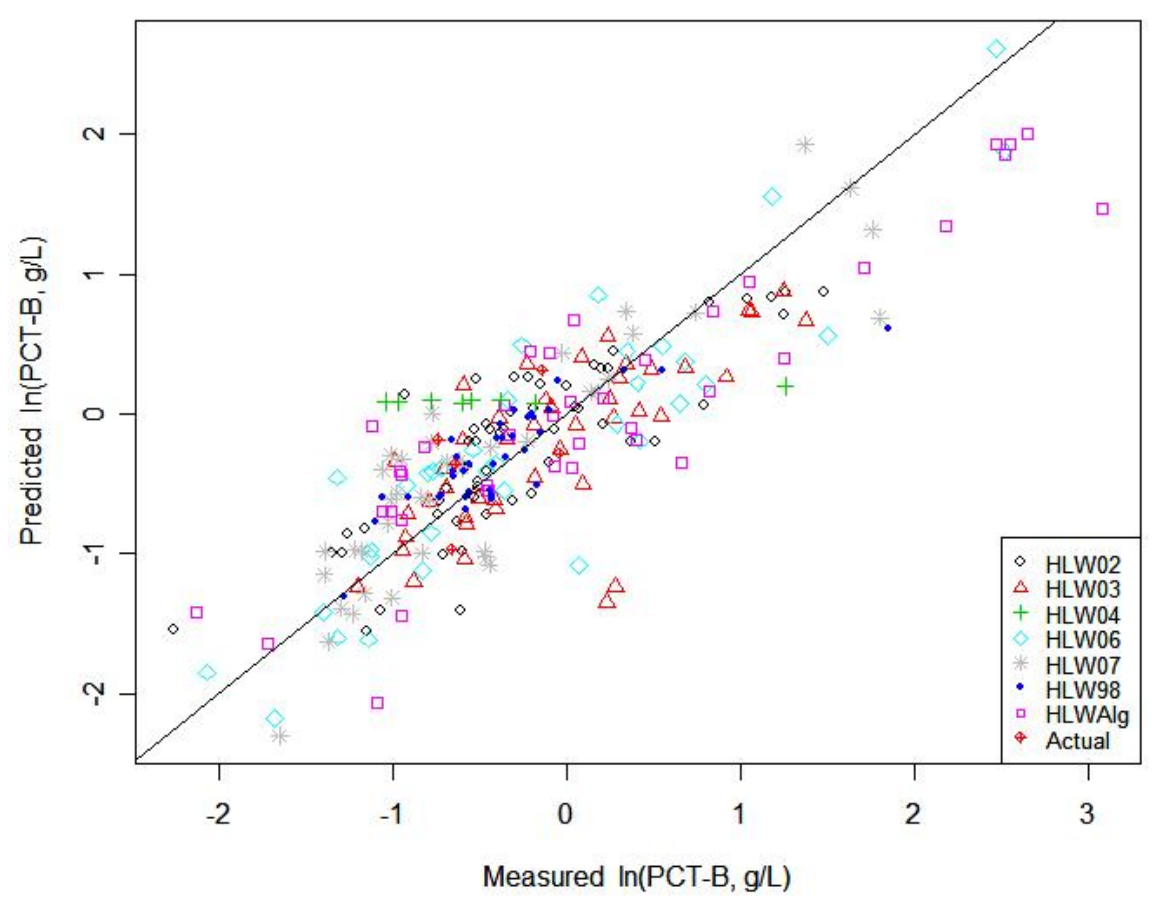

Figure 5.5. Predicted Versus Measured Plot for the 25-Component Full Linear Mixture Model for PCT-B Fitted to Data from 264 HLW Glasses.

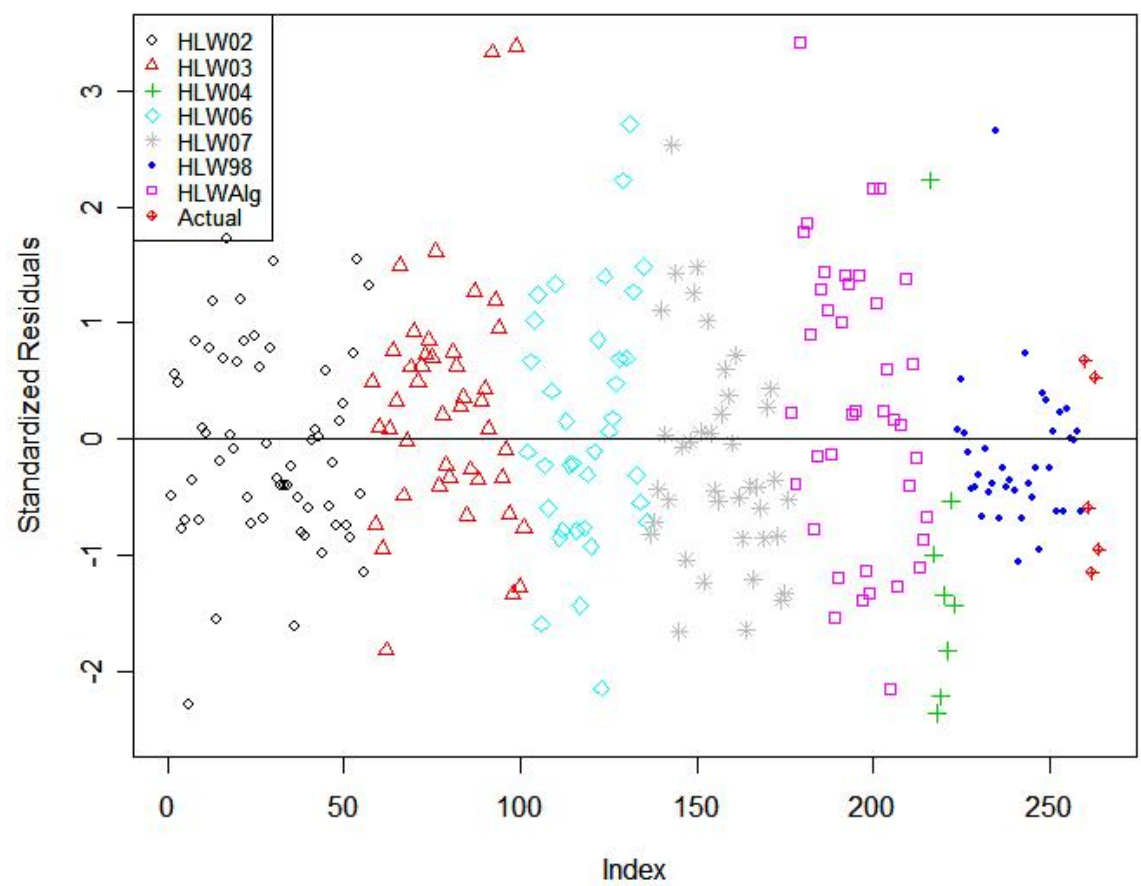

Figure 5.6. Standardized Residuals Plot for the 25-Component Full Linear Mixture Model for PCT-B Fitted to Data from 264 HLW Glasses. 


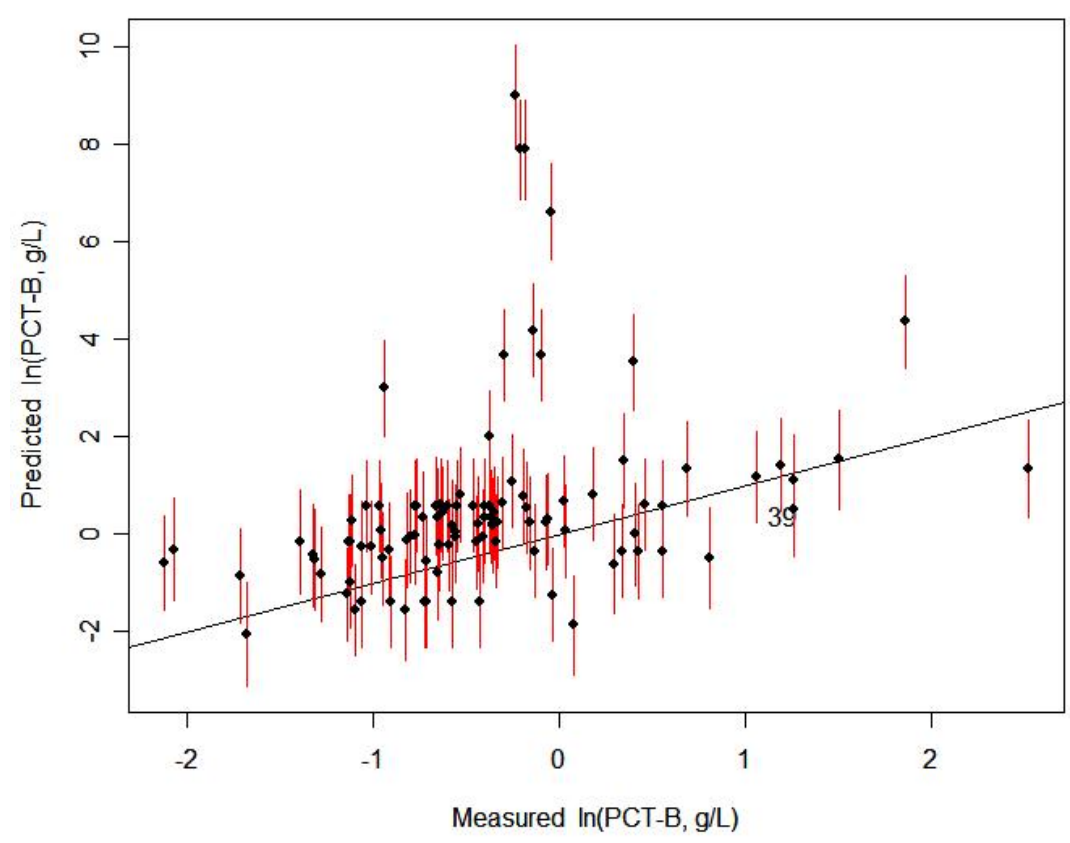

Figure 5.7. Predicted Versus Measured Plot for the 25-Component Full Linear Mixture Model on IHLW PCT-B Fitted to the Data-Partition Modeling Subset of 162 Glasses and Applied to the Validation Subset of 102 Glasses. Error bars are 95\% prediction intervals (PIs). The number of glasses whose $\mathbf{9 5 \%}$ PIs do not include the measured values (represented by the $45^{\circ}$ line) is shown.

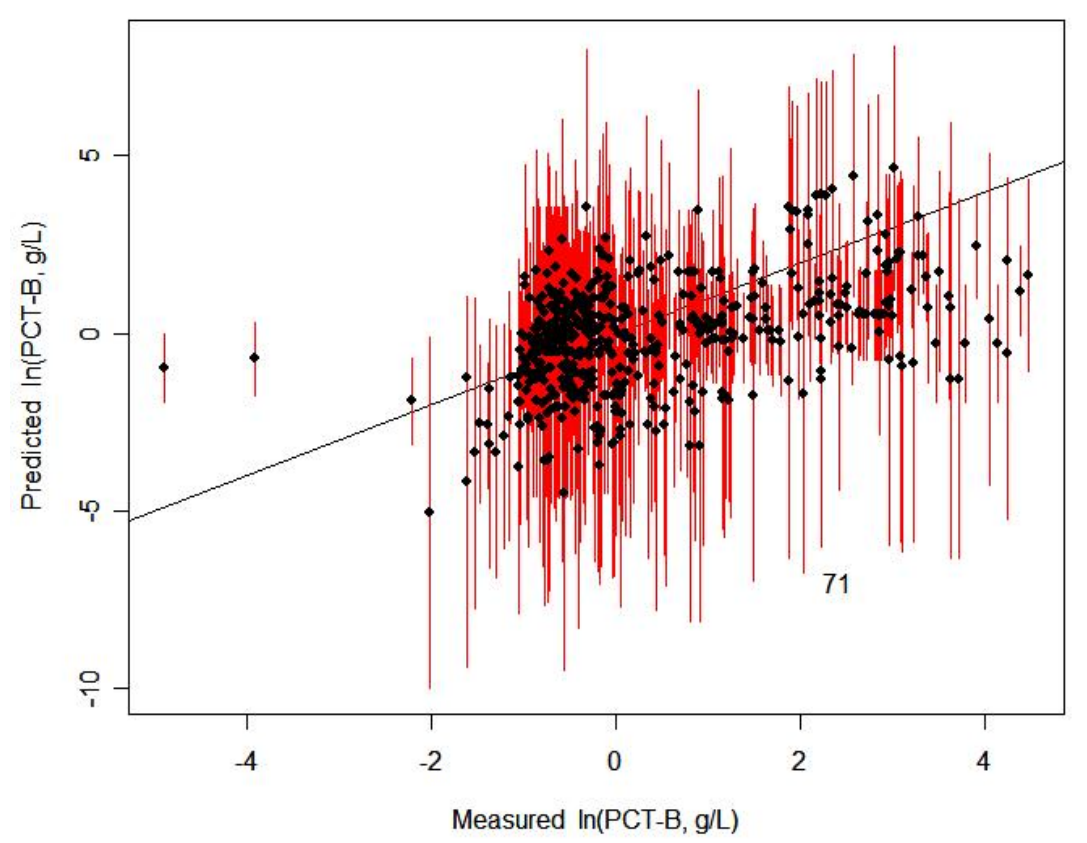

Figure 5.8. Predicted Versus Measured Plot for the 25-Component Full Linear Mixture Model for PCT-B Applied to the 556-Glass Separate Validation Set. Error bars are $95 \%$ prediction intervals (PIs). The number of glasses whose $95 \%$ PIs do not include the measured values (represented by the $45^{\circ}$ line) is shown. 
The Catholic University of America Vitreous State Laboratory
IHLW PCT, Spinel $T_{1 \%}$, Electrical Conductivity, and Viscosity Model Development Final Report, VSL-07R1240-4, Rev. 0

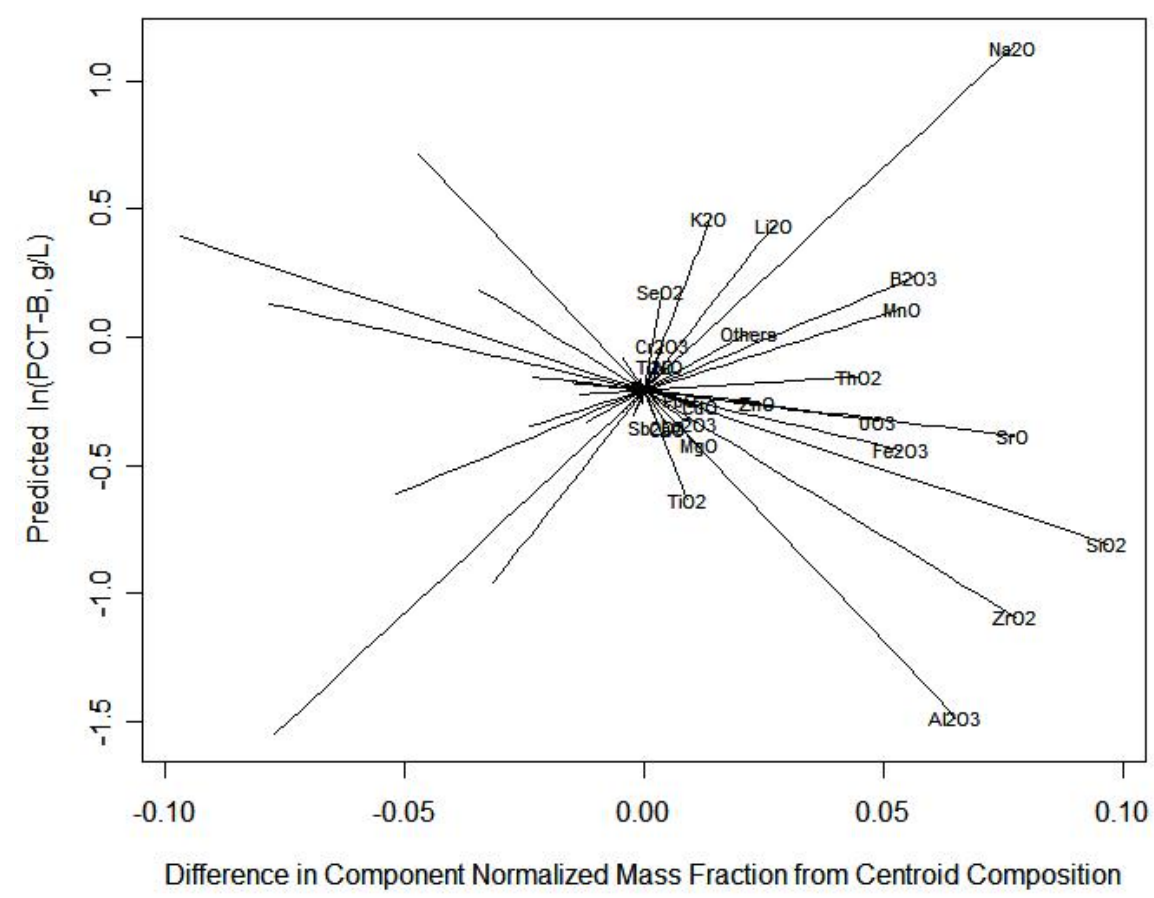

Figure 5.9. Response Trace Plot for the 25-Component Full Linear Mixture Model for PCT-B Fitted to Data from 264 HLW Glasses.

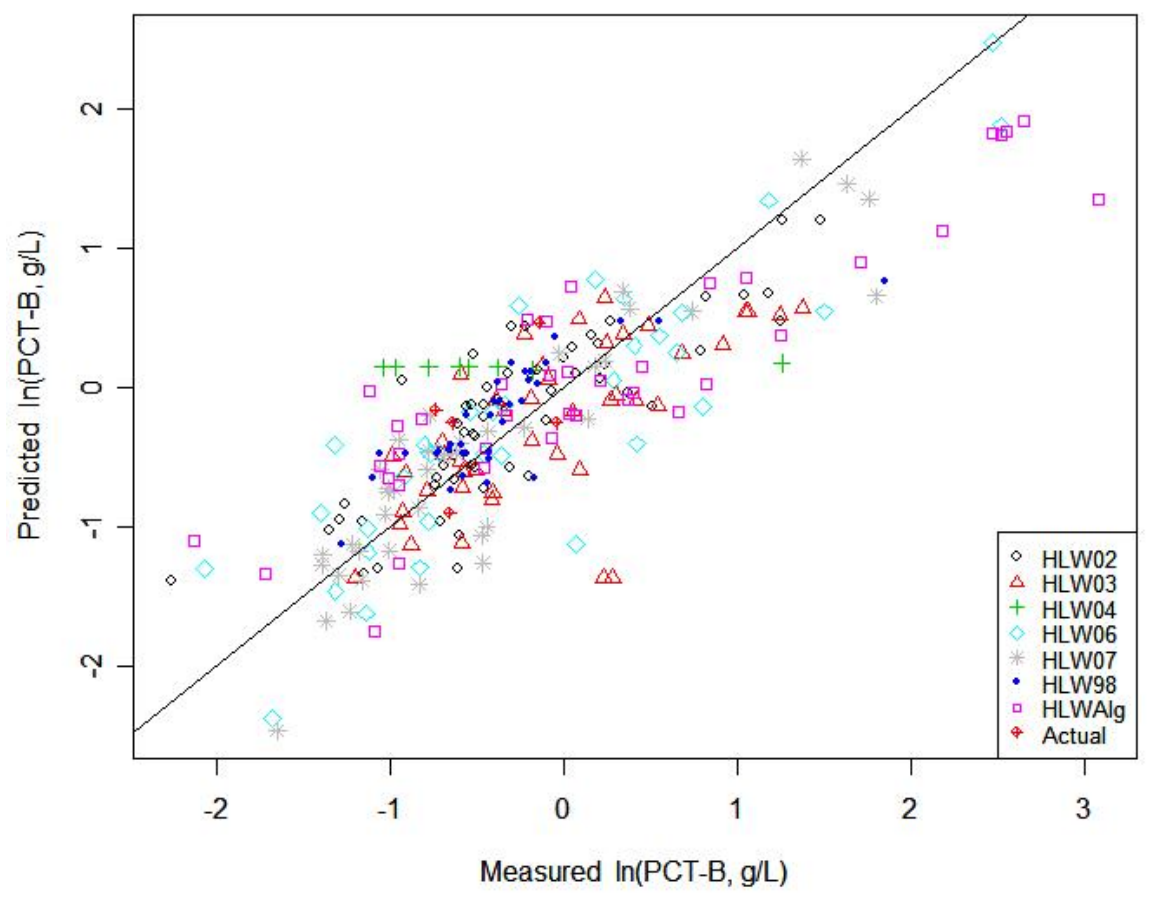

Figure 5.10. Predicted Versus Measured Plot for the 13-Component Reduced Linear Mixture Model for PCT-B Fitted to Data from 264 HLW Glasses. 
The Catholic University of America Vitreous State Laboratory
IHLW PCT, Spinel $T_{1 \%}$, Electrical Conductivity, and Viscosity Model Development Final Report, VSL-07R1240-4, Rev. 0

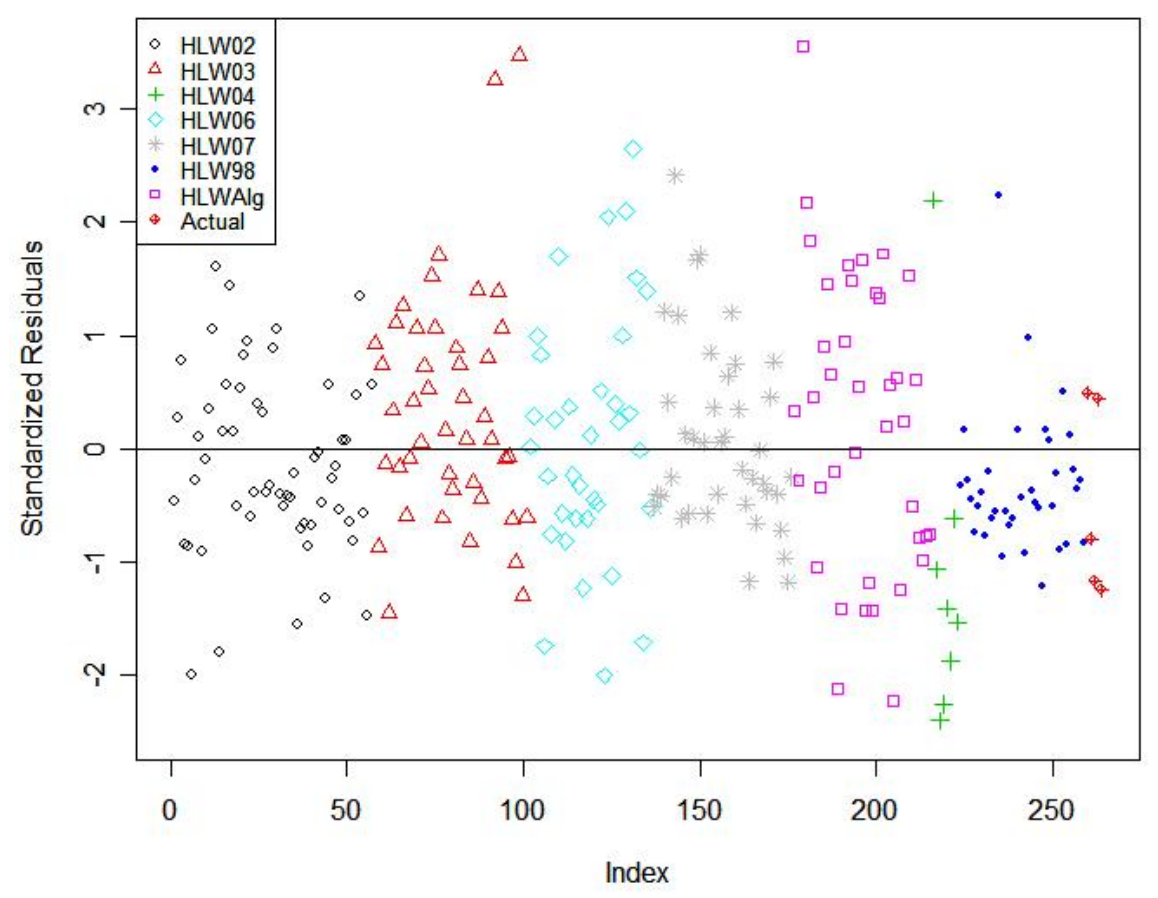

Figure 5.11. Standardized Residuals Plot for the 13-Component Reduced Linear Mixture Model for PCT-B Fitted to Data from 264 HLW Glasses.

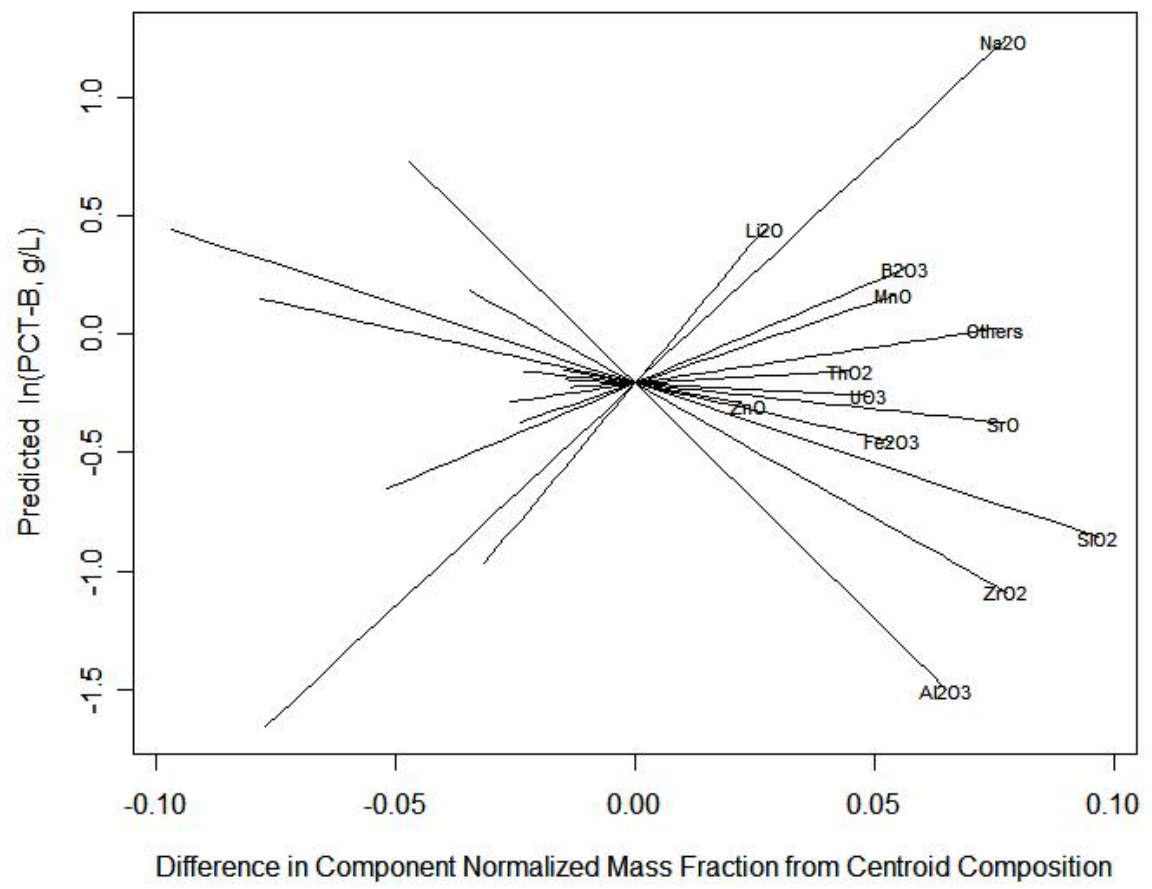

Figure 5.12. Response Trace Plot for the 13-Component Reduced Linear Mixture Model for PCT-B Fitted to Data from 264 HLW Glasses. 


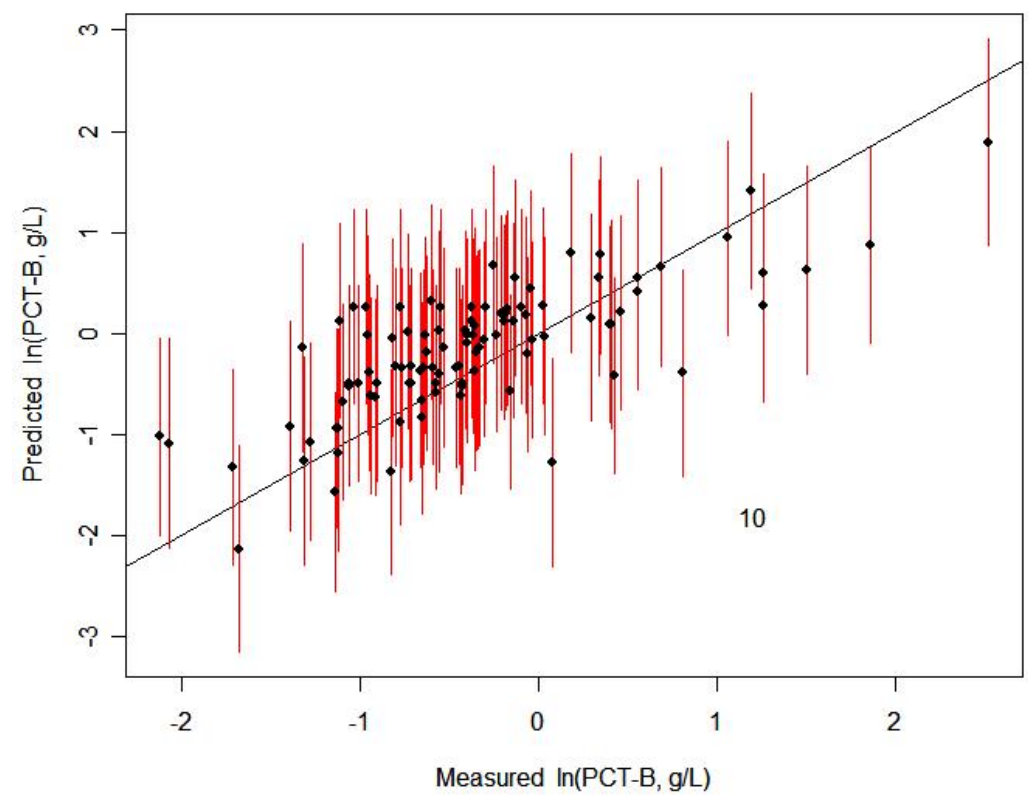

Figure 5.13. Predicted Versus Measured Plot for the 13-Component Reduced Linear Mixture Model on IHLW PCT-B Fitted to the Data-Partition Modeling Subset of 162 Glasses and Applied to the Validation Subset of 102 Glasses. Error bars are 95\% prediction intervals (PIs). The number of glasses whose 95\% PIs do not include the measured values (represented by the $45^{\circ}$ line) is shown.

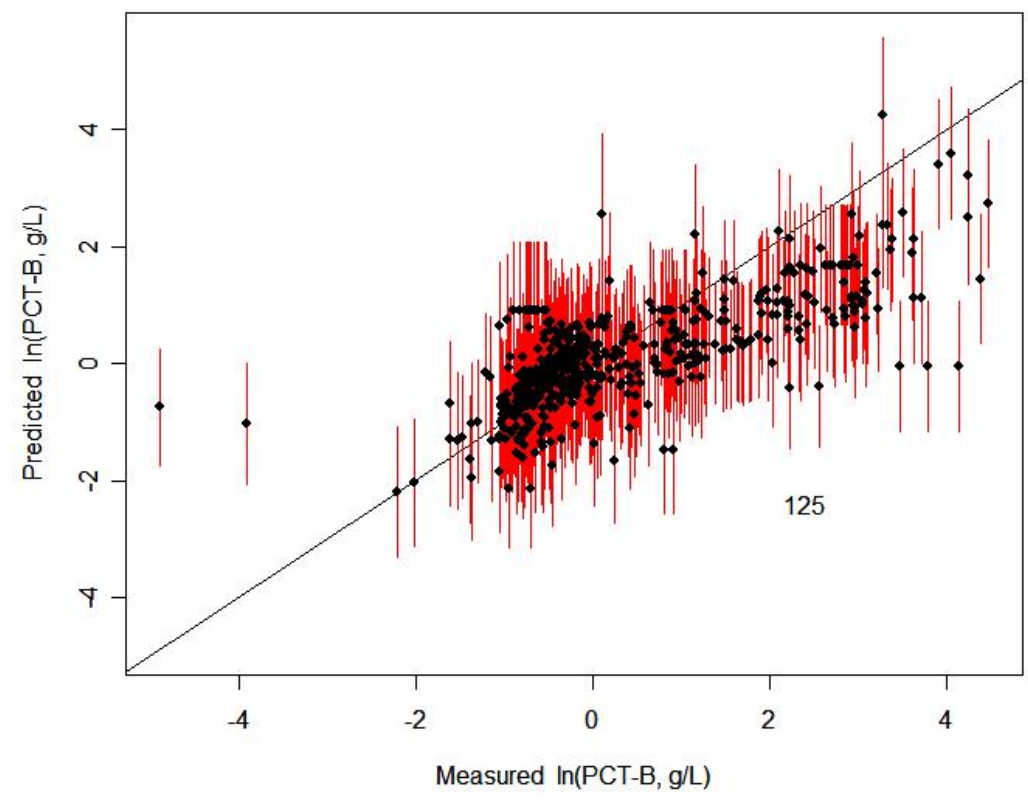

Figure 5.14. Predicted Versus Measured Plot for the 13-Component Reduced Linear Mixture Model for PCT-B Applied to the 556-Glass Separate Validation Set. Error bars are $95 \%$ prediction intervals (PIs). The number of glasses whose $95 \%$ PIs do not include the measured values (represented by the $45^{\circ}$ line) is shown. 
The Catholic University of America Vitreous State Laboratory
IHLW PCT, Spinel $T_{1 \%}$, Electrical Conductivity, and Viscosity Model Development Final Report, VSL-07R1240-4, Rev. 0

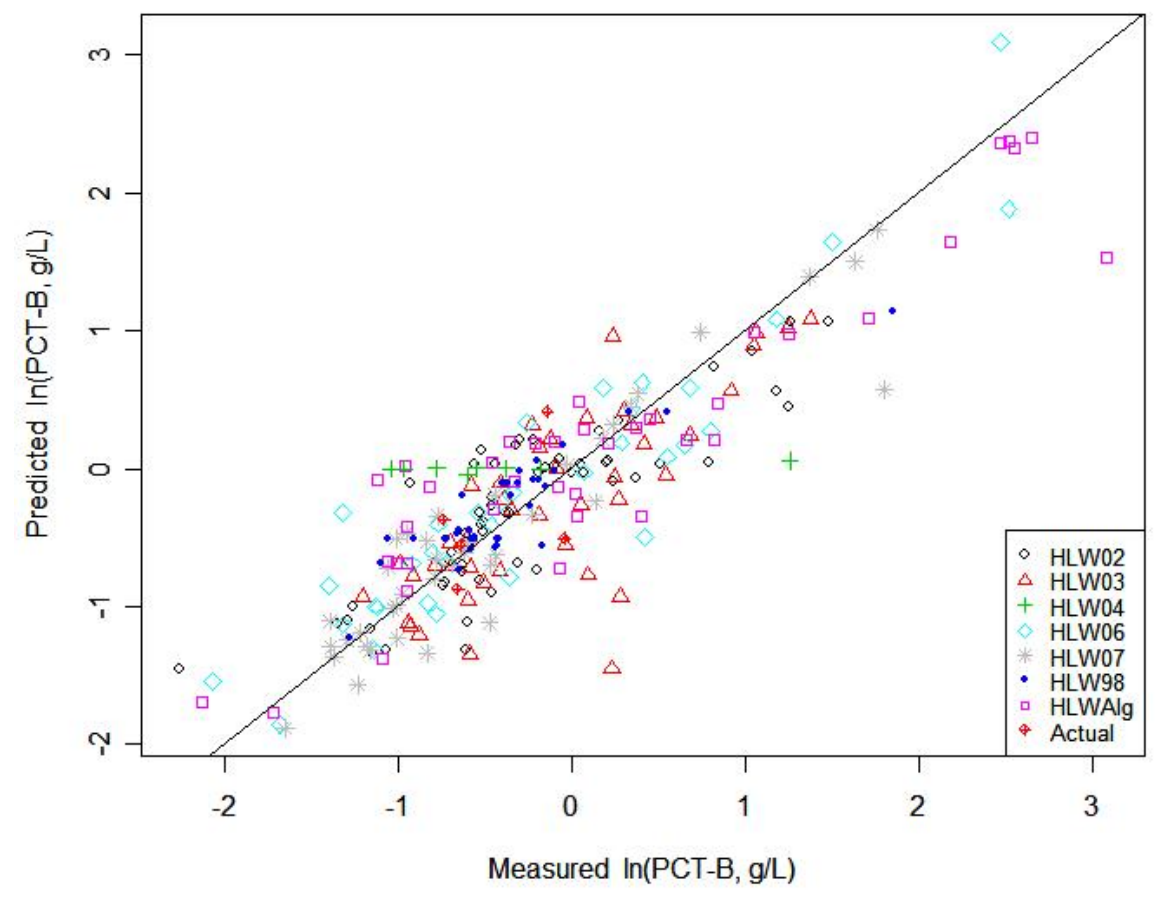

Figure 5.15. Predicted Versus Measured Plot for the 18-Term Partial Quadratic Mixture Model for PCT-B Fitted to Data from 264 HLW Glasses.

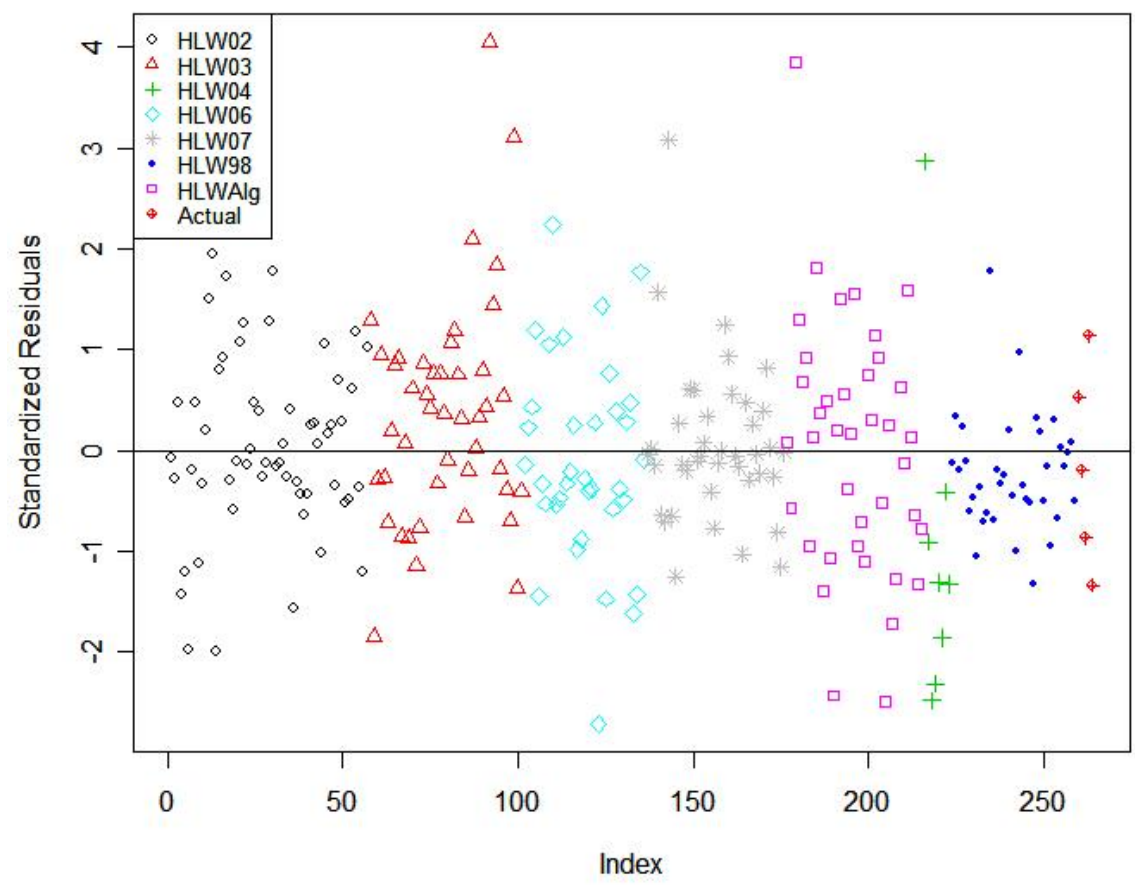

Figure 5.16. Standardized Residuals Plot for the 18-Term Partial Quadratic Mixture Model for PCT-B Fitted to Data from 264 HLW Glasses. 


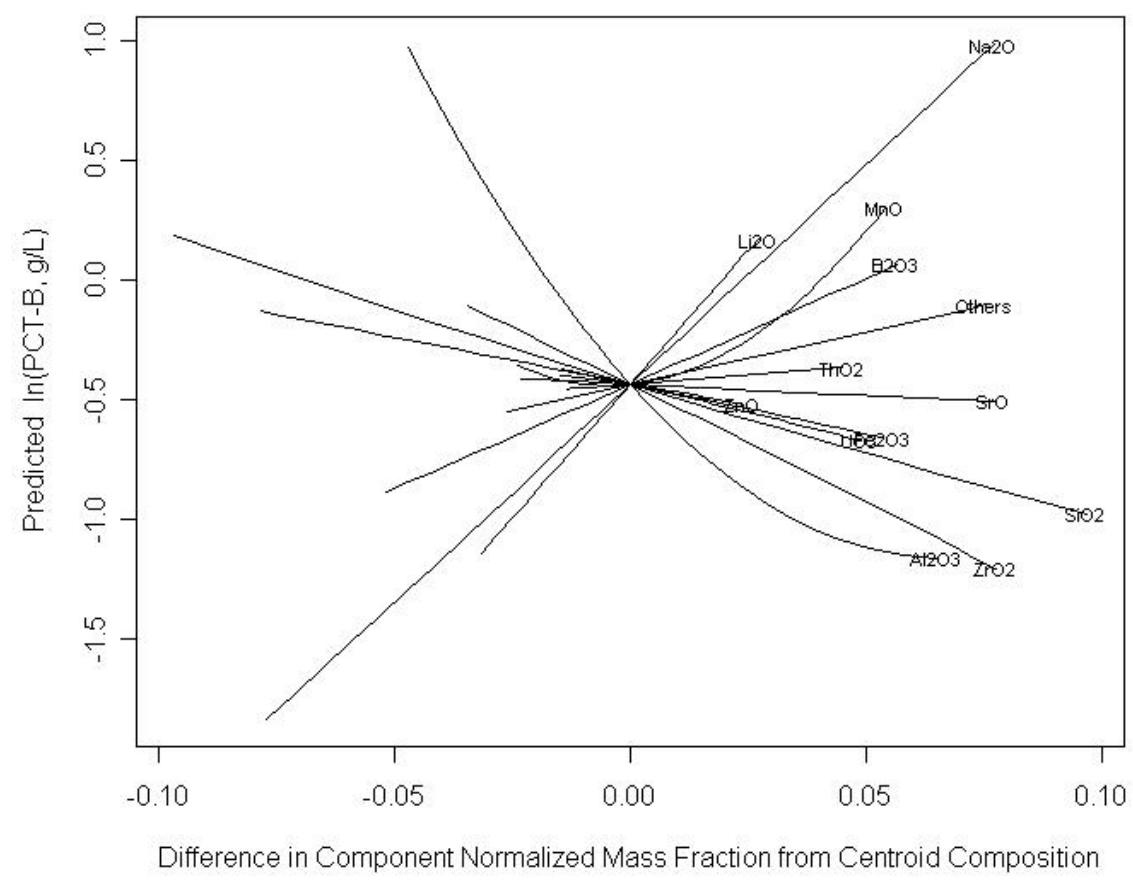

Figure 5.17. Response Trace Plot for the 18-Term Partial Quadratic Mixture Model for PCT-B Fitted to Data from 264 HLW Glasses.

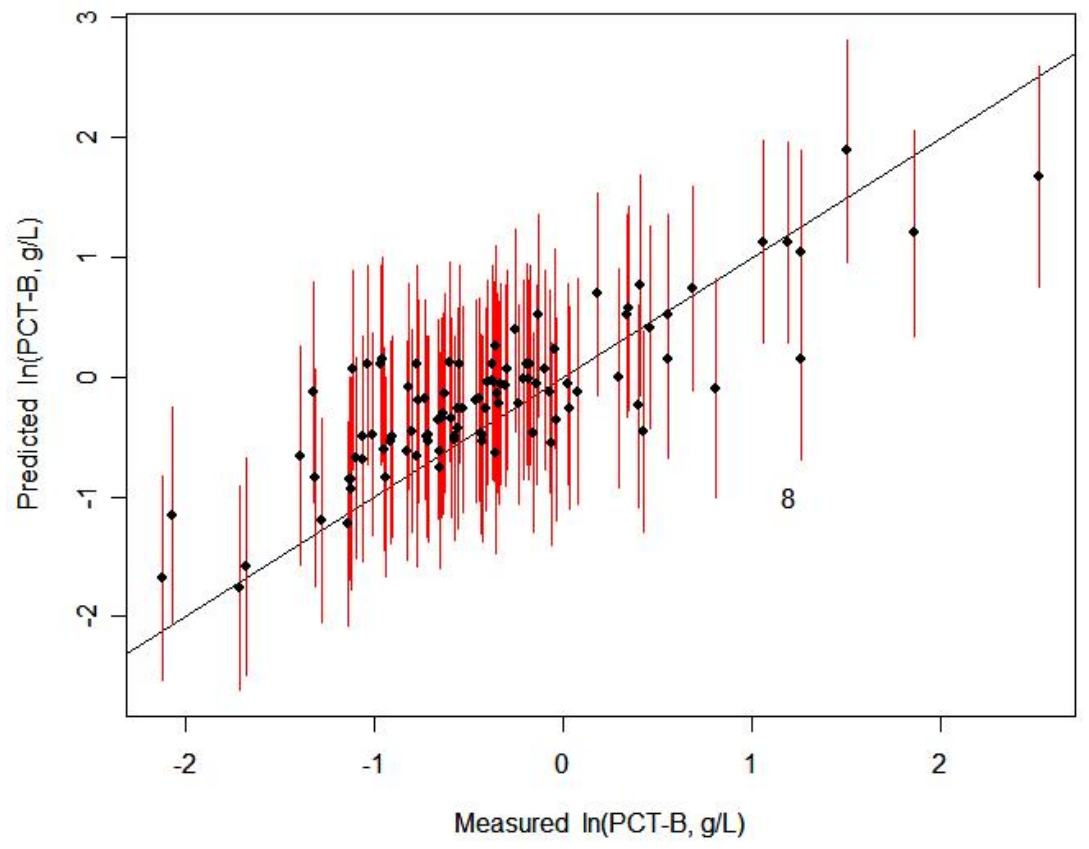

Figure 5.18. Predicted Versus Measured Plot for the 18-Term Partial Quadratic Mixture Model on IHLW PCT-B Fitted to the Data-Partition Modeling Subset of 162 Glasses and Applied to the Validation Subset of 102 Glasses. Error bars are 95\% prediction intervals (PIs). The number of glasses whose $95 \%$ PIs do not include the measured values (represented by the $45^{\circ}$ line) is shown. 


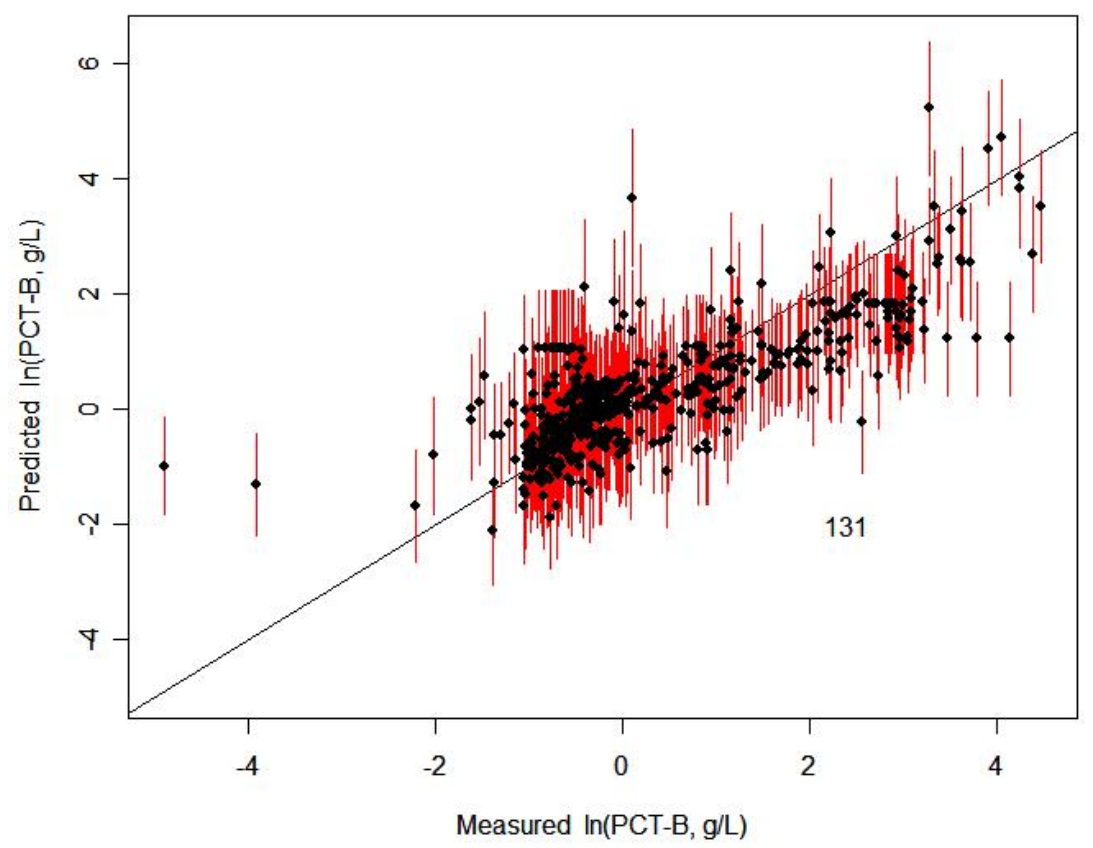

Figure 5.19. Predicted Versus Measured Plot for the 18-Term Partial Quadratic Mixture Model for PCT-B Applied to the 556-Glass Separate Validation Set. Error bars are $95 \%$ prediction intervals (PIs). The number of glasses whose $\mathbf{9 5 \%}$ PIs do not include the measured values (represented by the $45^{\circ}$ line) is shown.

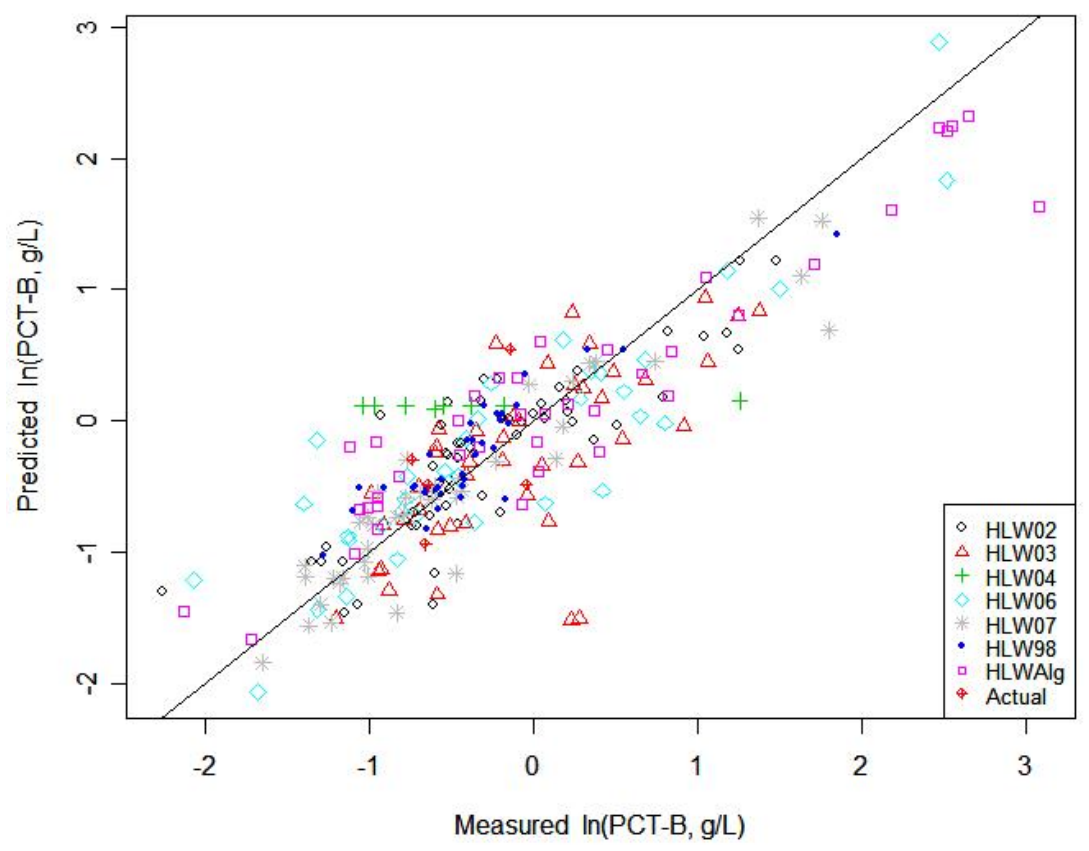

Figure 5.20. Predicted Versus Measured Plot for the 15-Term Partial Quadratic Mixture Model for PCT-B Fitted to Data from 264 HLW Glasses. 
The Catholic University of America Vitreous State Laboratory
IHLW PCT, Spinel $T_{1 \%}$, Electrical Conductivity, and Viscosity Model Development Final Report, VSL-07R1240-4, Rev. 0

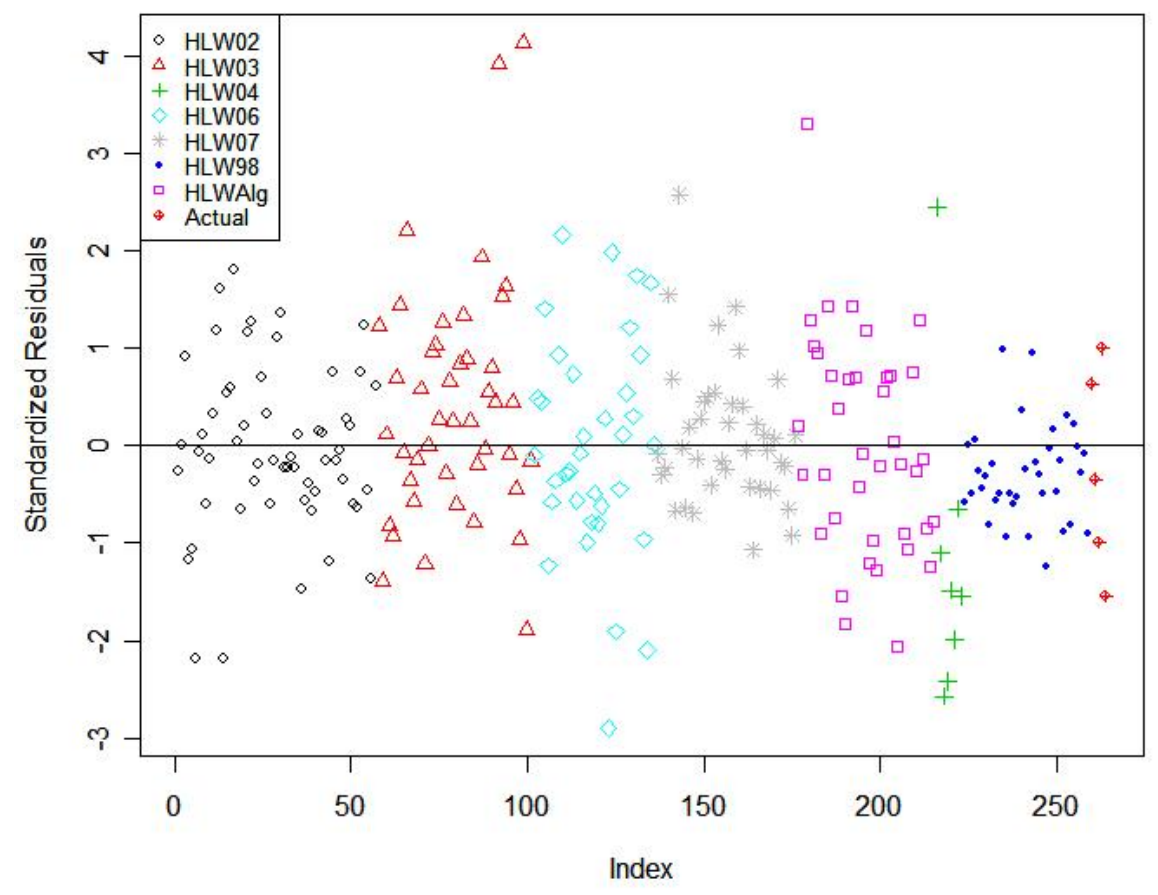

Figure 5.21. Standardized Residuals Plot for the 15-Term Partial Quadratic Mixture Model for PCT-B Fitted to Data from 264 HLW Glasses.

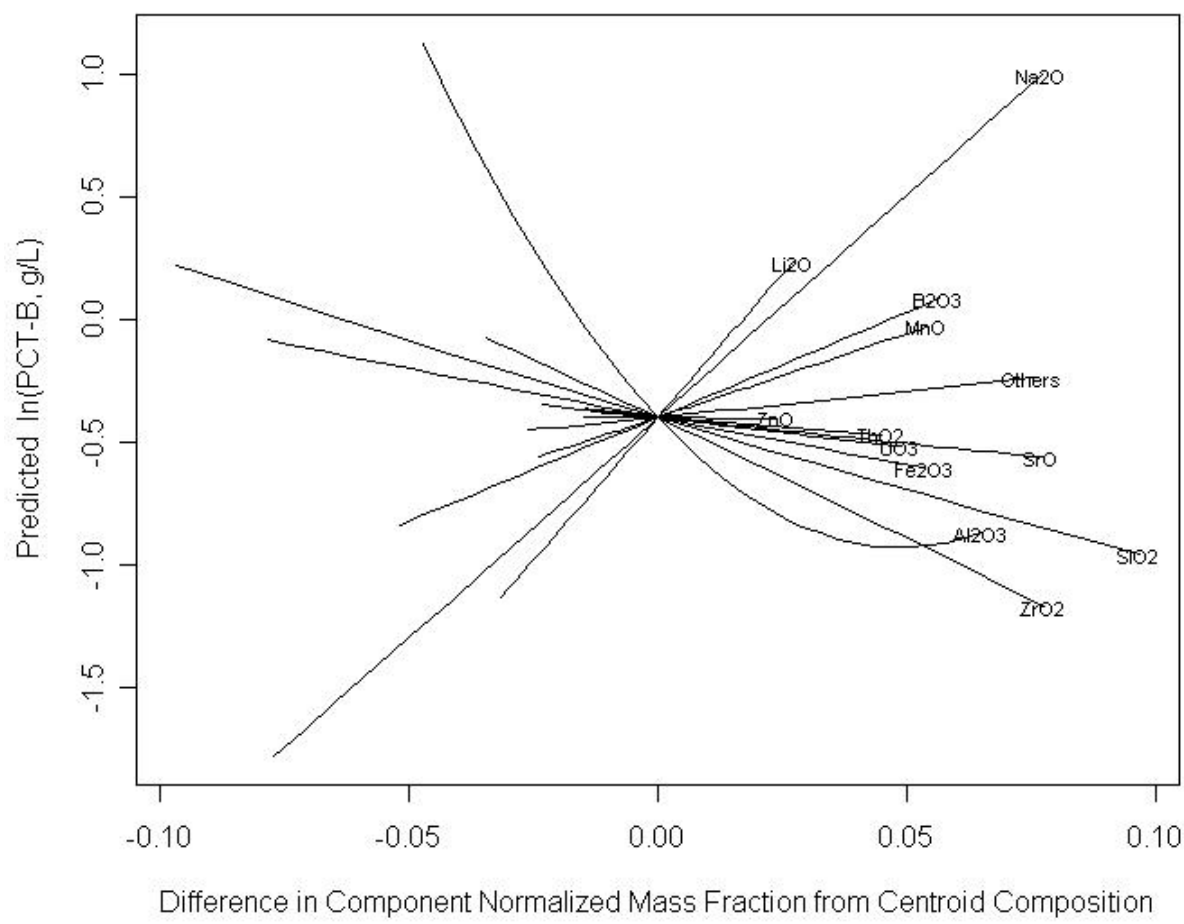

Figure 5.22. Response Trace Plot for the 15-Term Partial Quadratic Mixture Model for PCT-B Fitted to Data from 264 HLW Glasses. 


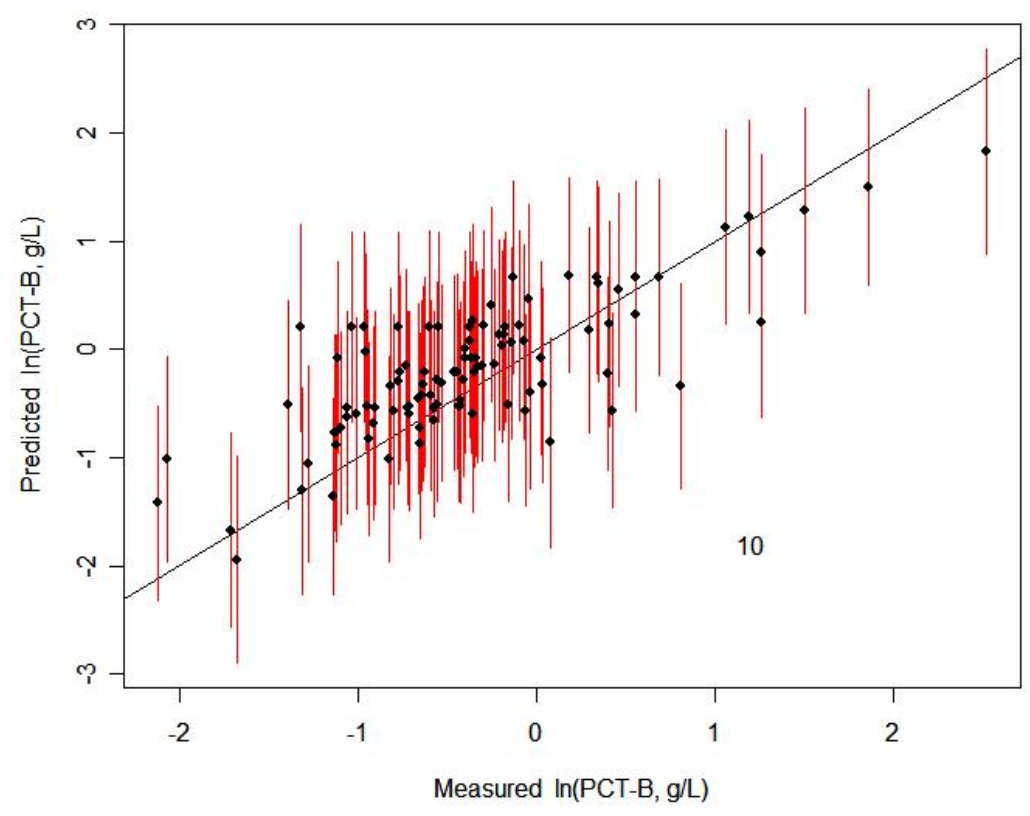

Figure 5.23. Predicted Versus Measured Plot for the 15-Term Partial Quadratic Mixture Model on IHLW PCT-B Fitted to the Data-Partition Modeling Subset of 162 Glasses and Applied to the Validation Subset of 102 Glasses. Error bars are 95\% prediction intervals (PIs). The number of glasses whose $95 \%$ PIs do not include the measured values (represented by the $45^{\circ}$ line) is shown.

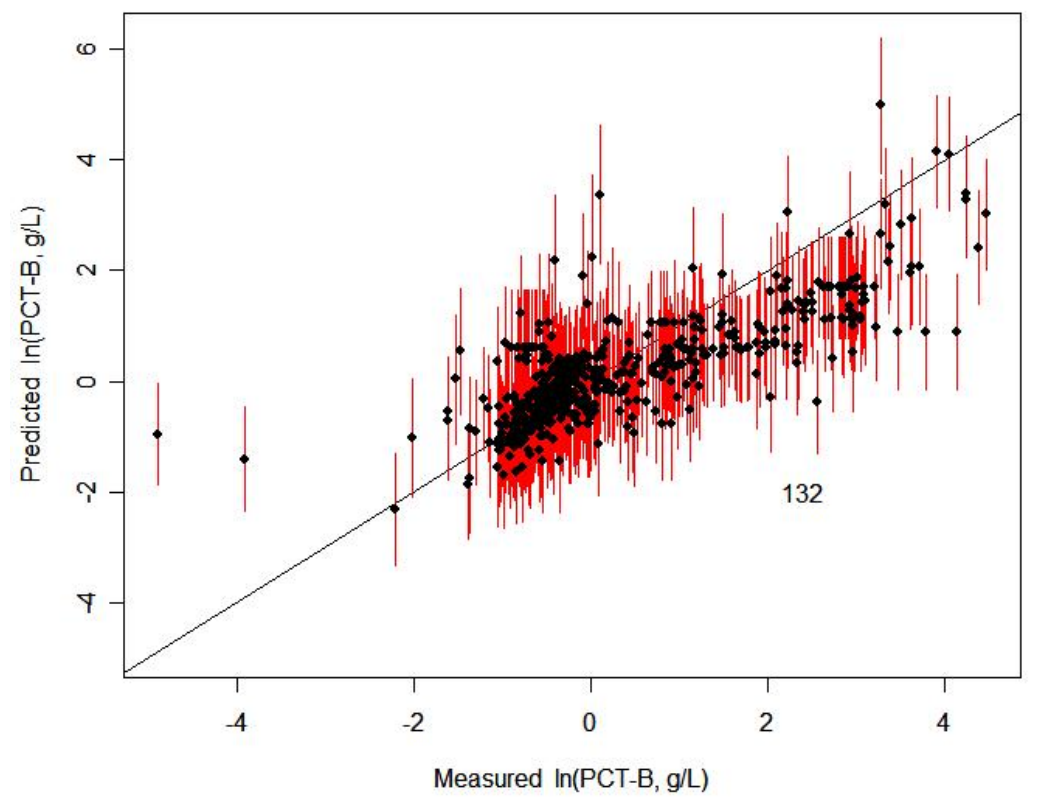

Figure 5.24. Predicted Versus Measured Plot for the 15-Term Partial Quadratic Mixture Model for PCT-B Applied to the 556-Glass Separate Validation Set. Error bars are $95 \%$ prediction intervals (PIs). The number of glasses whose $95 \%$ PIs do not include the measured values (represented by the $45^{\circ}$ line) is shown. 
The Catholic University of America Vitreous State Laboratory
IHLW PCT, Spinel $T_{1 \%}$, Electrical Conductivity, and Viscosity Model Development Final Report, VSL-07R1240-4, Rev. 0

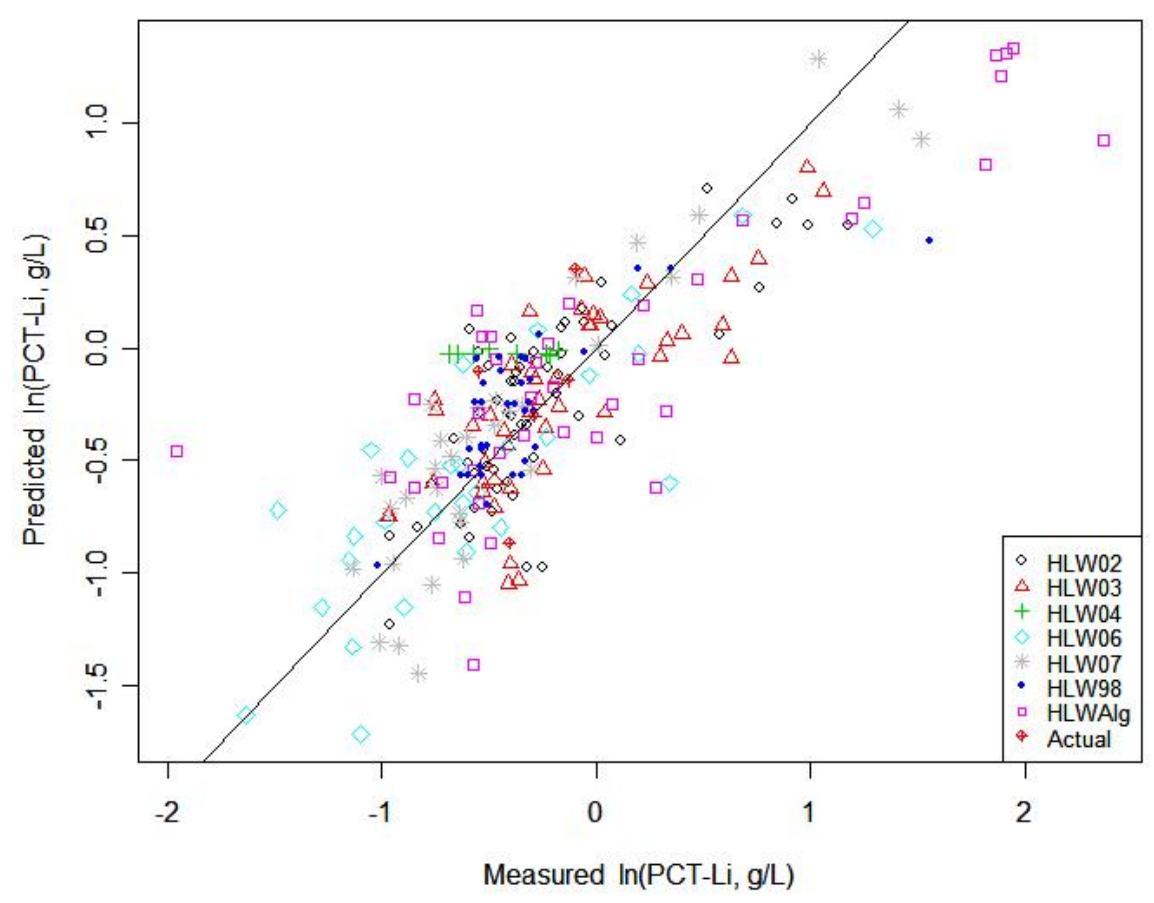

Figure 5.25. Predicted Versus Measured Plot for the 25-Component Full Linear Mixture Model for PCT-Li Fitted to Data from 250 HLW Glasses.

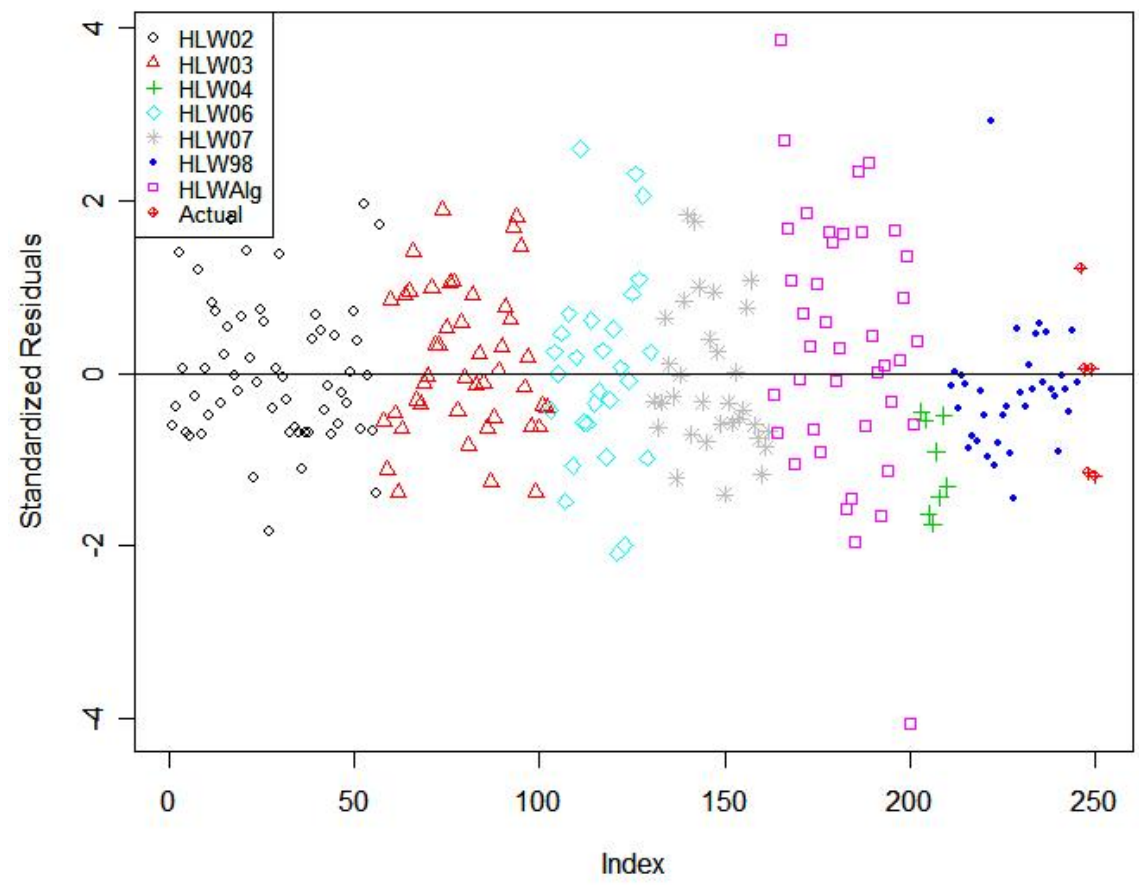

Figure 5.26. Standardized Residuals Plot for the 25-Component Full Linear Mixture Model for PCT-Li Fitted to Data from 250 HLW Glasses. 


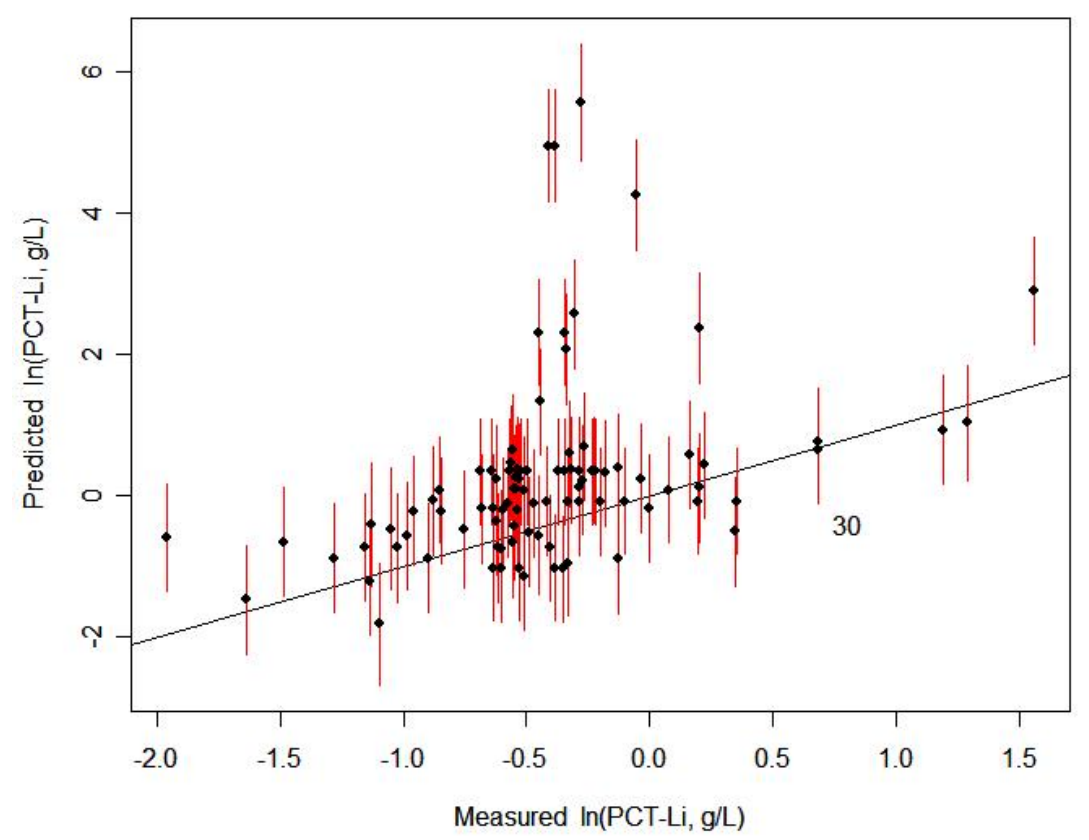

Figure 5.27. Predicted Versus Measured Plot for the 25-Component Full Linear Mixture Model on IHLW PCT-Li Fitted to the Data-Partition Modeling Subset of 154 Glasses and Applied to the Validation Subset of 96 Glasses. Error bars are 95\% prediction intervals (PIs). The number of glasses whose $\mathbf{9 5 \%}$ PIs do not include the measured values (represented by the $45^{\circ}$ line) is shown.

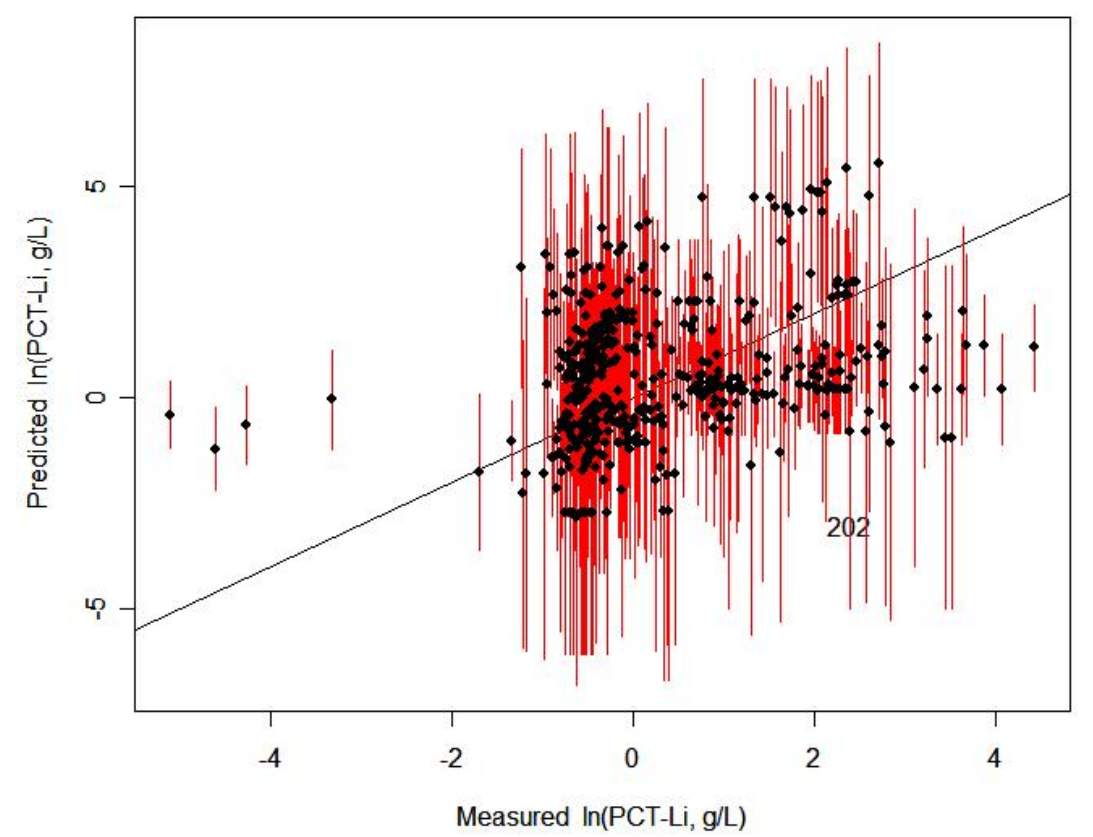

Figure 5.28. Predicted Versus Measured Plot for the 25-Component Full Linear Mixture Model for PCT-Li Applied to the 480-Glass Separate Validation Set. Error bars are $95 \%$ prediction intervals (PIs). The number of glasses whose $95 \%$ PIs do not include the measured values (represented by the $45^{\circ}$ line) is shown. 
The Catholic University of America Vitreous State Laboratory
IHLW PCT, Spinel $T_{1 \%}$, Electrical Conductivity, and Viscosity Model Development Final Report, VSL-07R1240-4, Rev. 0

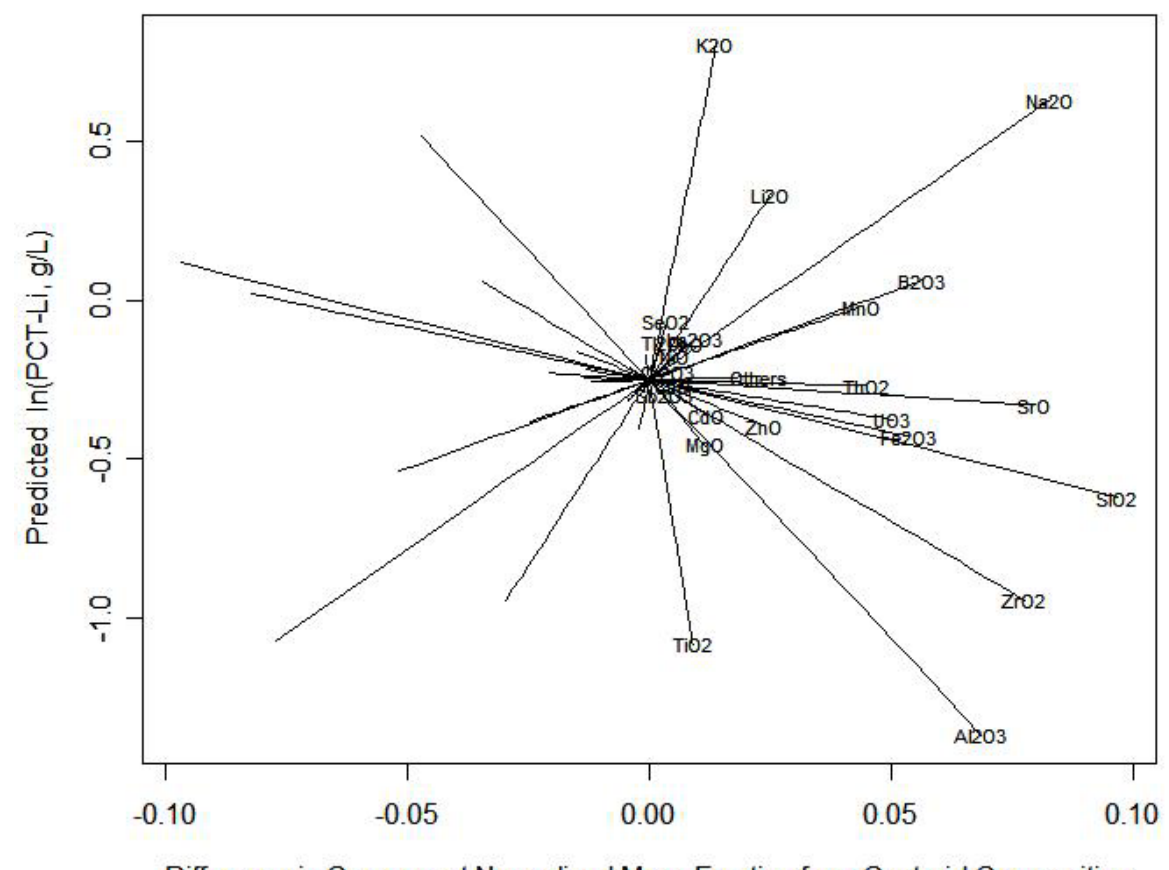

Difference in Component Normalized Mass Fraction from Centroid Composition

Figure 5.29. Response Trace Plot for the 25-Component Full Linear Mixture Model for PCT-Li Fitted to Data from 250 HLW Glasses.

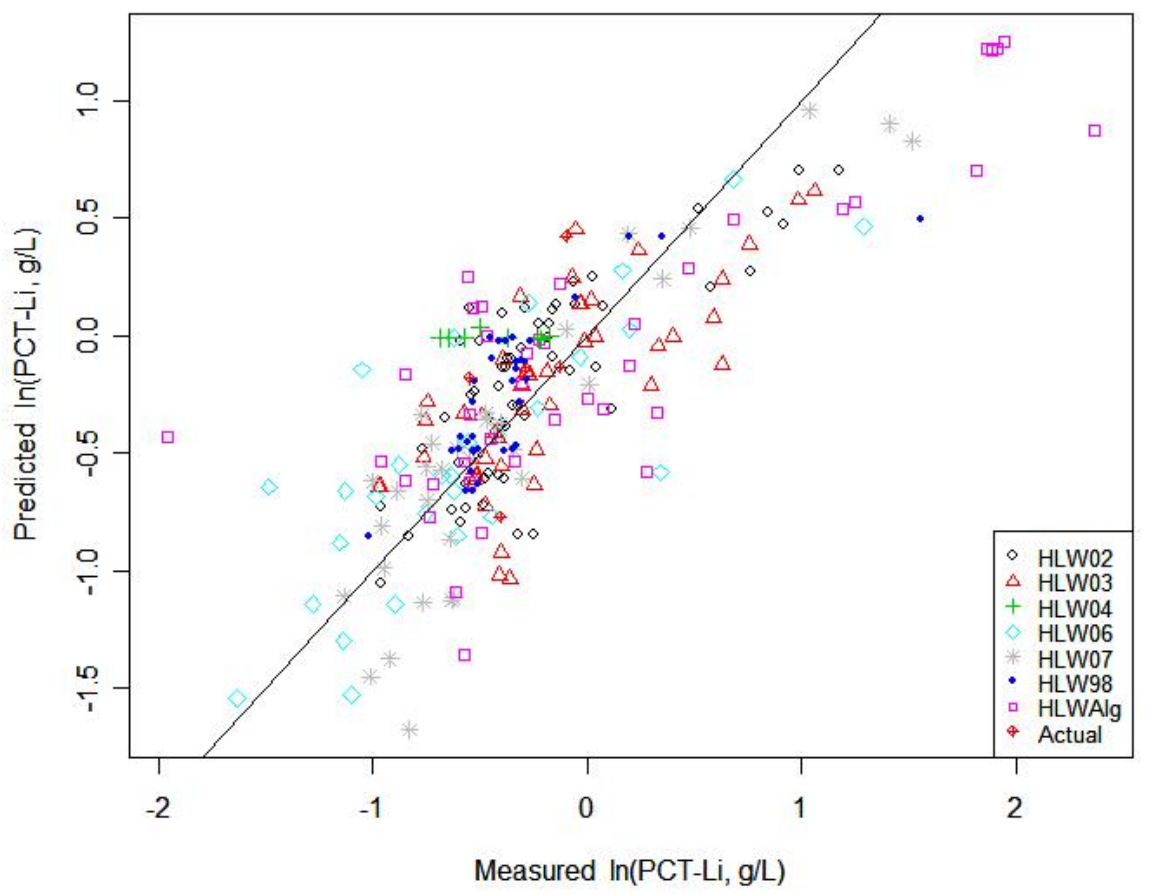

Figure 5.30. Predicted Versus Measured Plot for the 13-Component Reduced Linear Mixture Model for PCT-Li Fitted to Data from 250 HLW Glasses. 
The Catholic University of America Vitreous State Laboratory
IHLW PCT, Spinel $T_{1 \%}$, Electrical Conductivity, and Viscosity Model Development Final Report, VSL-07R1240-4, Rev. 0

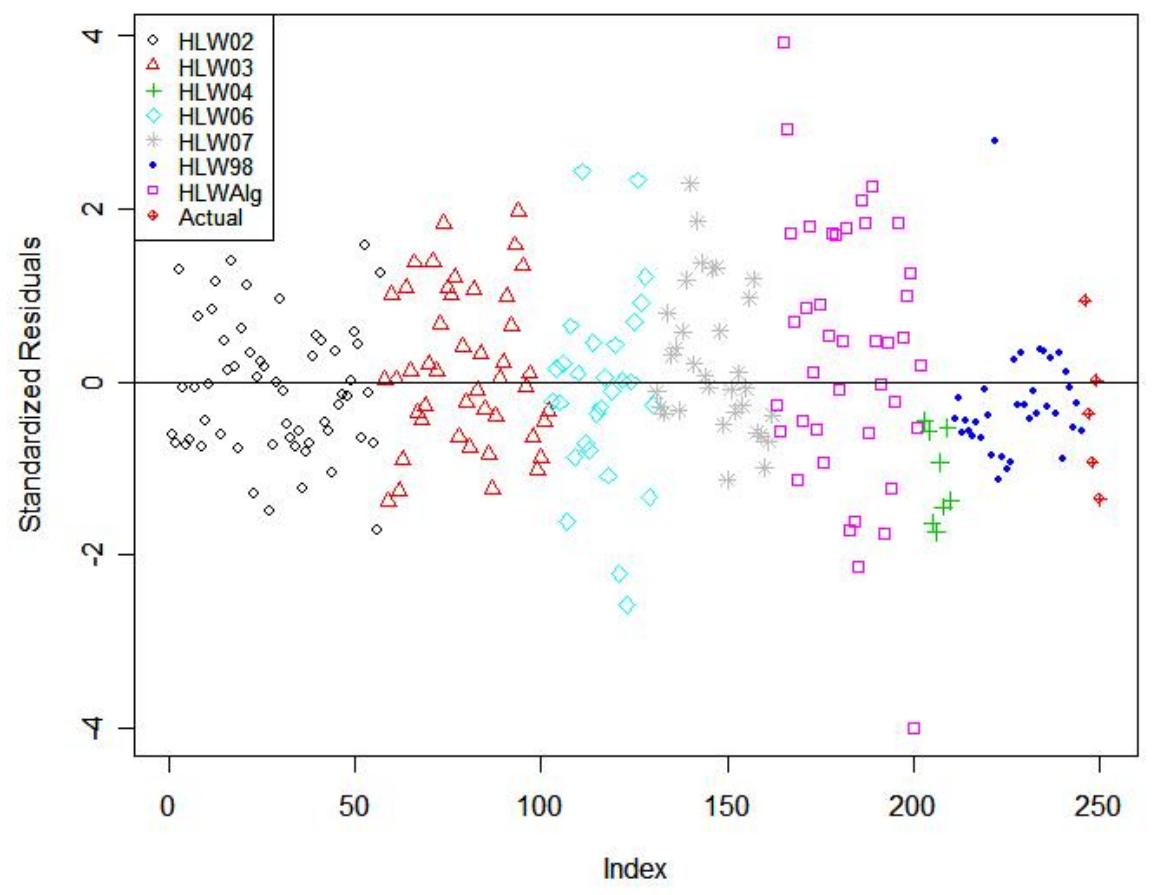

Figure 5.31. Standardized Residuals Plot for the 13-Component Reduced Linear Mixture Model for PCT-Li Fitted to Data from 250 HLW Glasses.

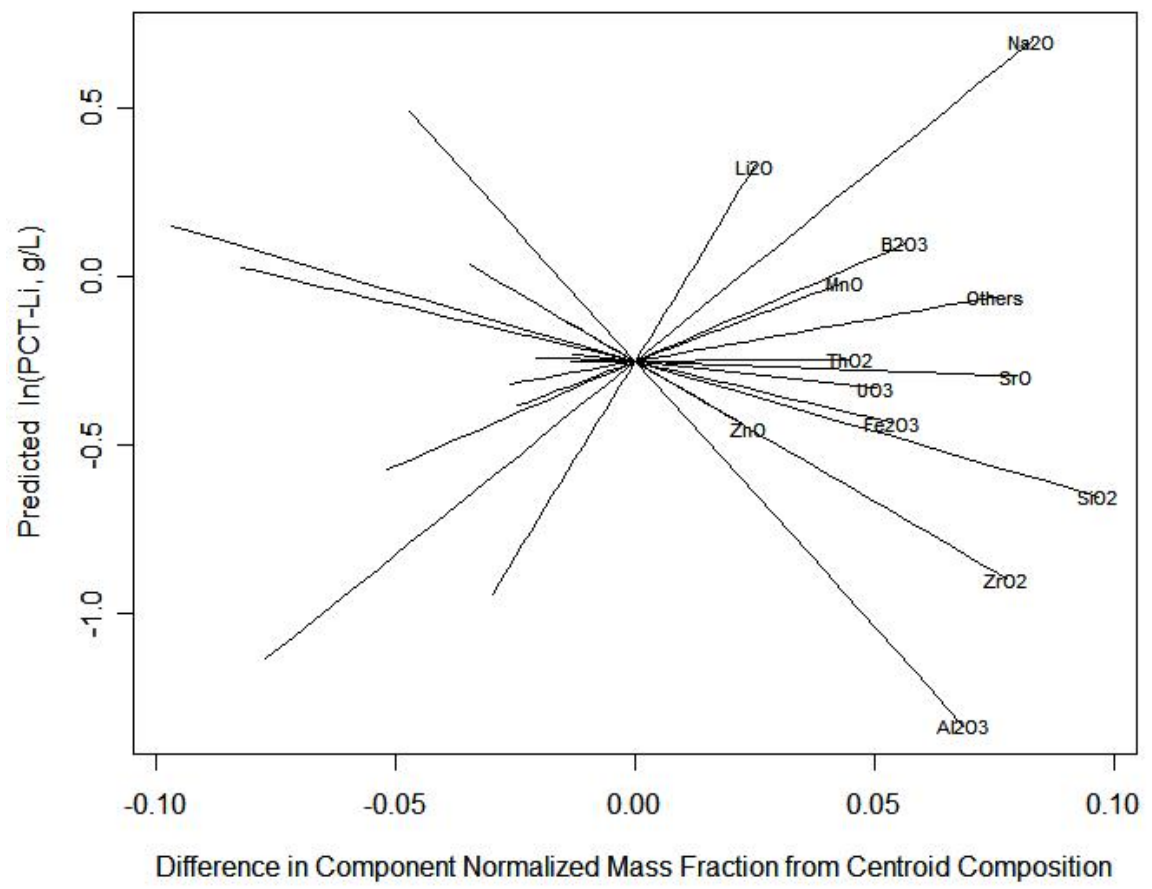

Figure 5.32. Response Trace Plot for the 13-Component Reduced Linear Mixture Model for PCT-Li Fitted to Data from 250 HLW Glasses. 


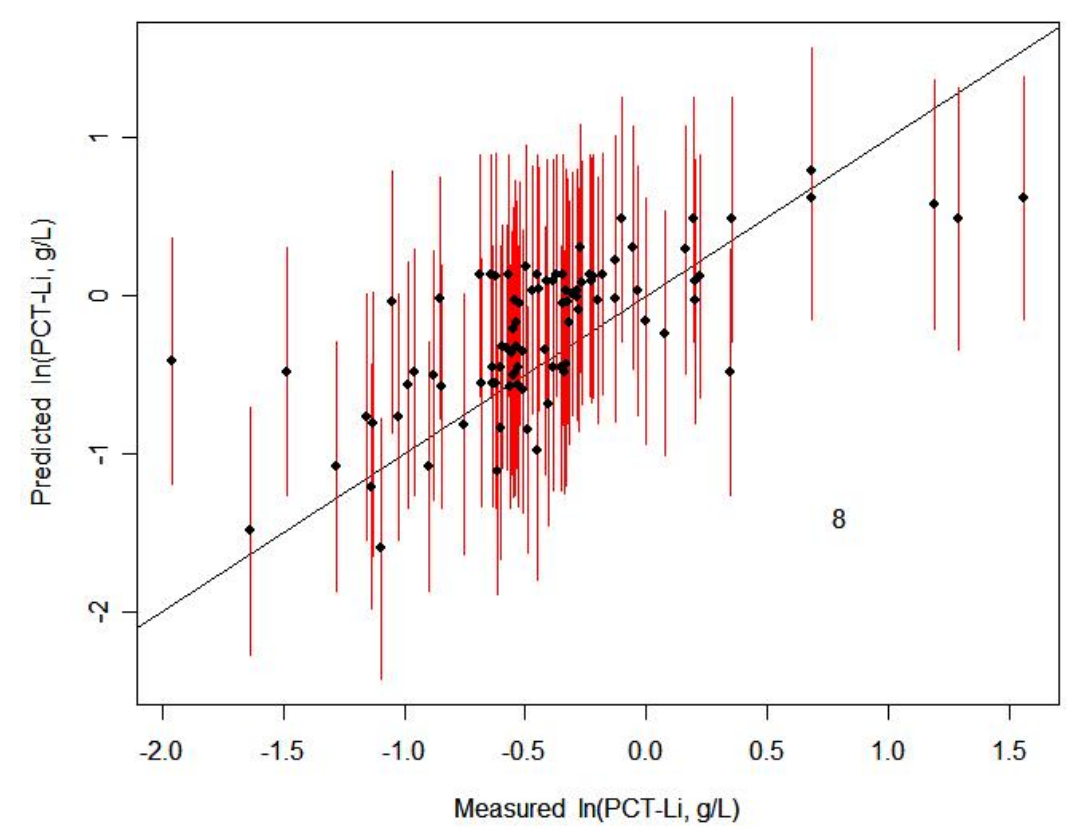

Figure 5.33. Predicted Versus Measured Plot for the 13-Component Reduced Linear Mixture Model on IHLW PCT-Li Fitted to the Data-Partition Modeling Subset of 154 Glasses and Applied to the Validation Subset of 96 Glasses. Error bars are $95 \%$ prediction intervals (PIs). The number of glasses whose $95 \%$ PIs do not include the measured values (represented by the $45^{\circ}$ line) is shown.

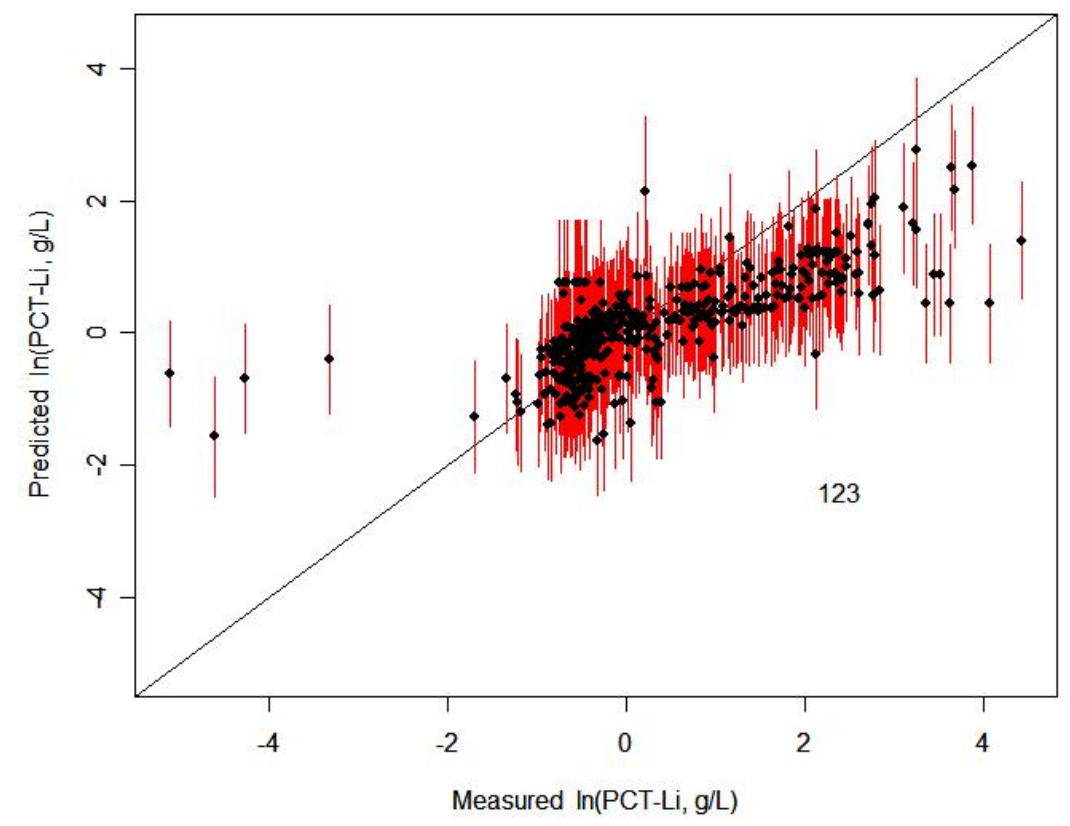

Figure 5.34. Predicted Versus Measured Plot for the 13-Component Reduced Linear Mixture Model for PCT-Li Applied to the 480-Glass Separate Validation Set. Error bars are $95 \%$ prediction intervals (PIs). The number of glasses whose 95\% PIs do not include the measured values (represented by the $45^{\circ}$ line) is shown. 
The Catholic University of America Vitreous State Laboratory
IHLW PCT, Spinel $T_{1 \%}$, Electrical Conductivity, and Viscosity Model Development Final Report, VSL-07R1240-4, Rev. 0

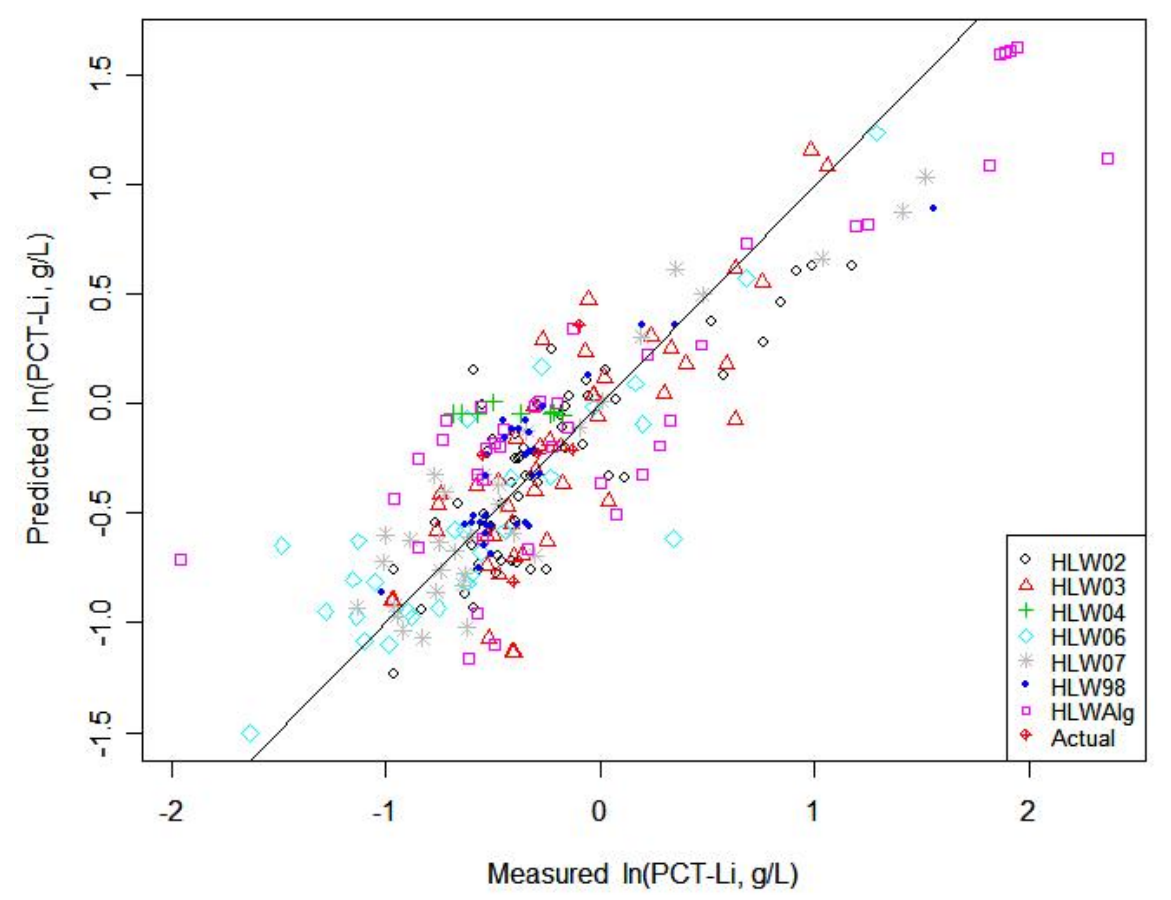

Figure 5.35. Predicted Versus Measured Plot for the 18-Term Partial Quadratic Mixture Model for PCT-Li Fitted to Data from 250 HLW Glasses.

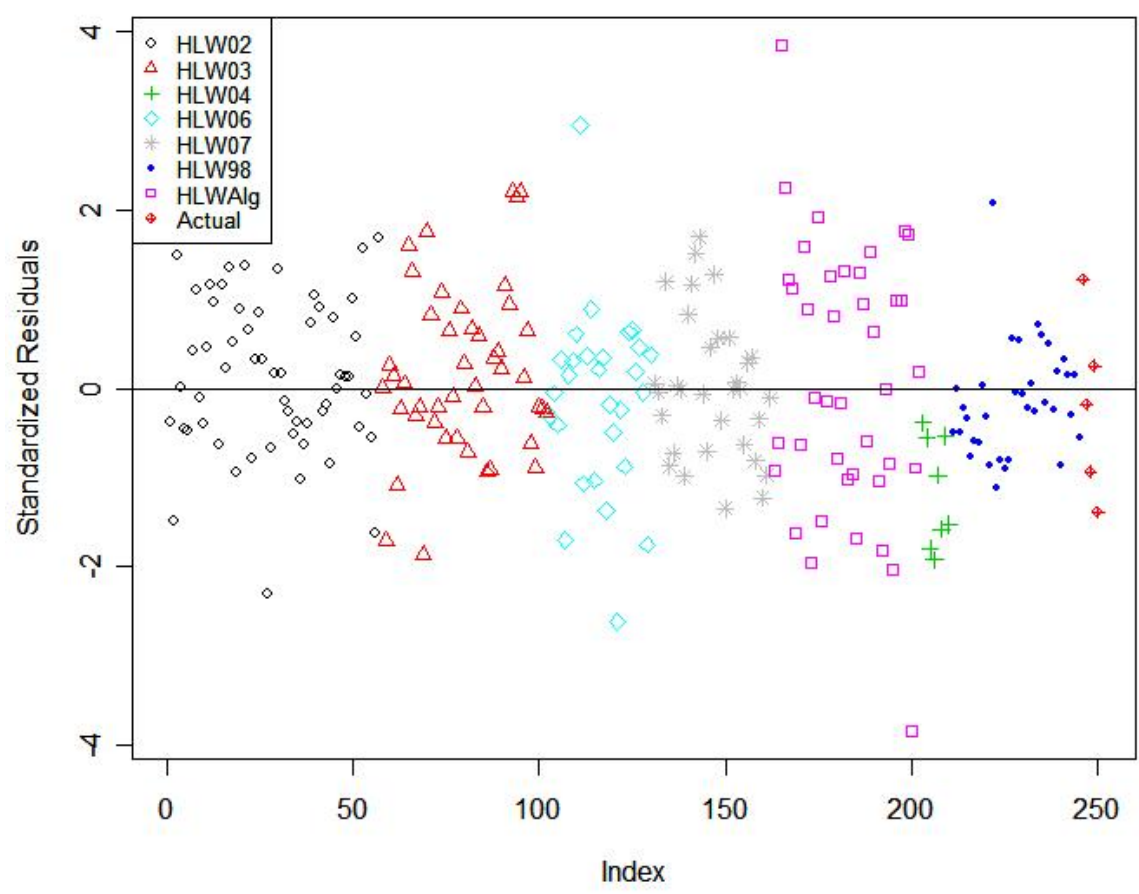

Figure 5.36. Standardized Residuals Plot for the 18-Term Partial Quadratic Mixture Model for PCT-Li Fitted to Data from 250 HLW Glasses. 


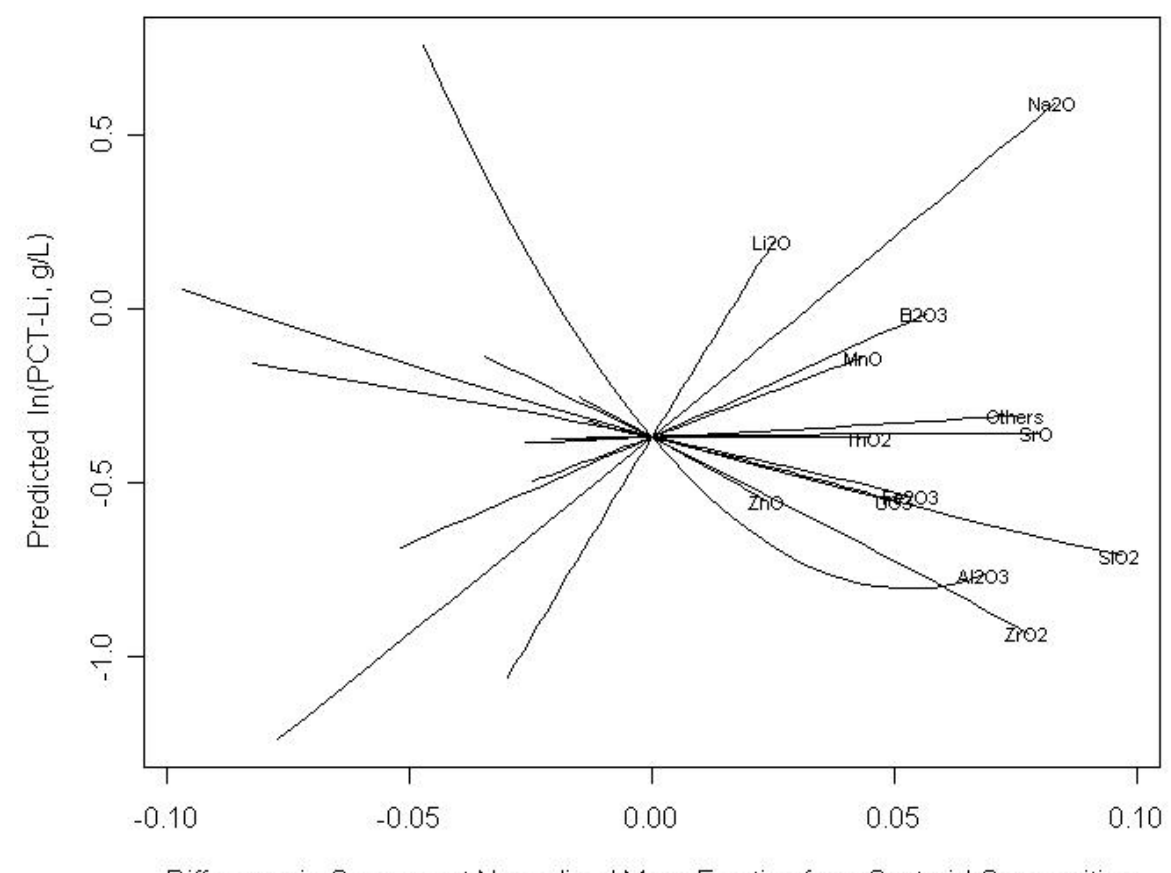

Difference in Component Normalized Mass Fraction from Centroid Composition

Figure 5.37. Response Trace Plot for the 18-Term Partial Quadratic Mixture Model for PCT-Li Fitted to Data from 250 HLW Glasses.

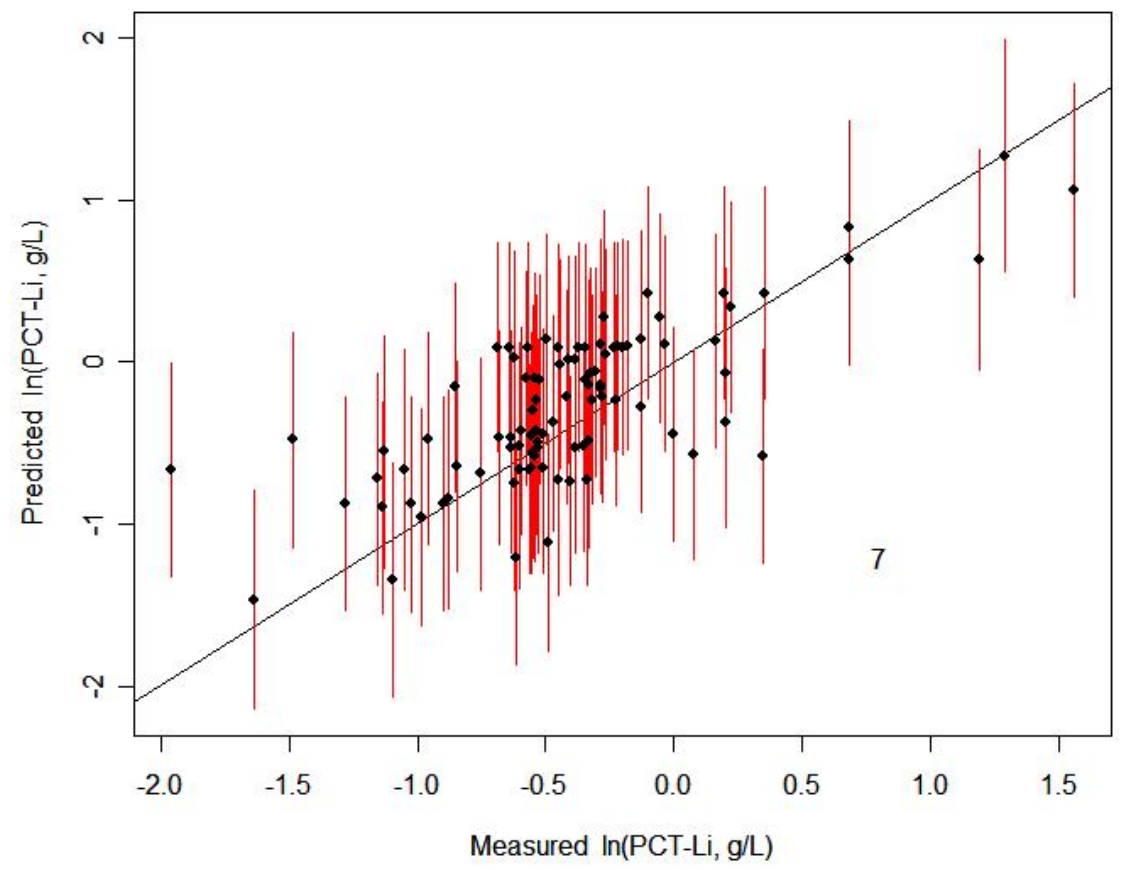

Figure 5.38. Predicted Versus Measured Plot for the 18-Term Partial Quadratic Mixture Model on IHLW PCT-Li Fitted to the Data-Partition Modeling Subset of 154 Glasses and Applied to the Validation Subset of 96 Glasses. Error bars are 95\% prediction intervals (PIs). The number of glasses whose $95 \%$ PIs do not include the measured values (represented by the $45^{\circ}$ line) is shown. 


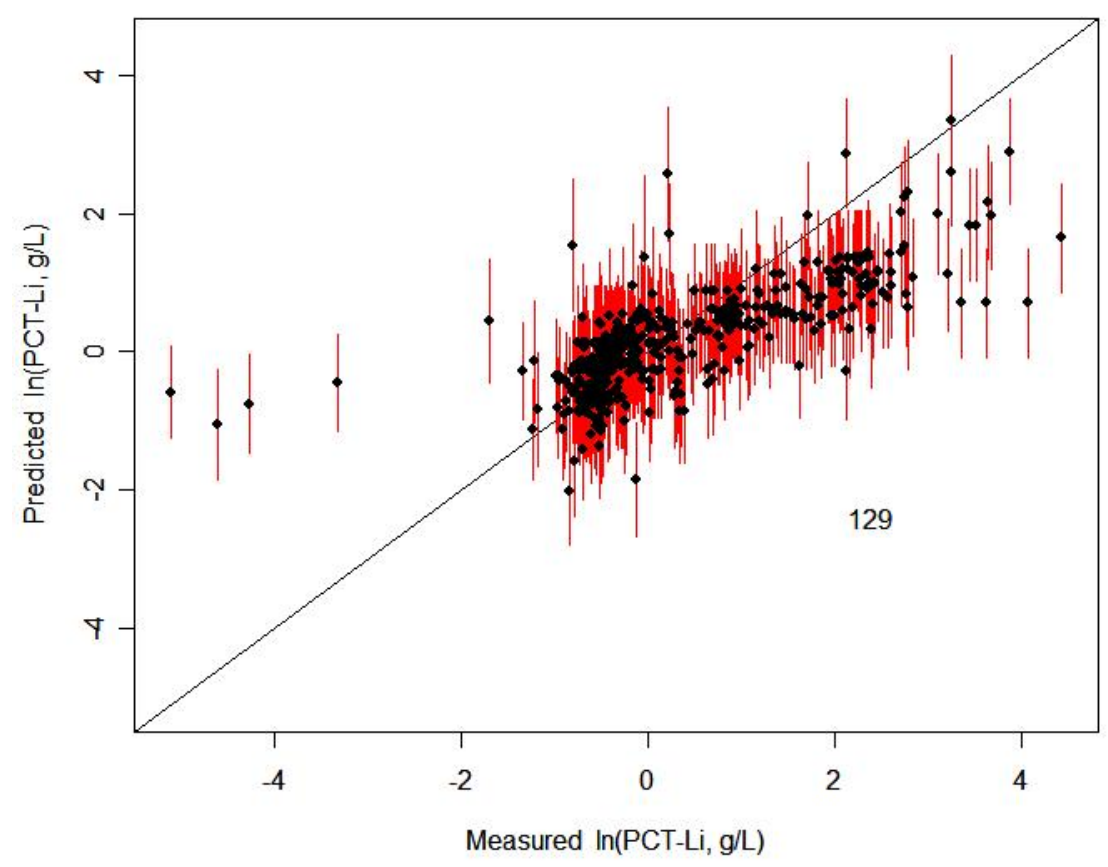

Figure 5.39. Predicted Versus Measured Plot for the 18-Term Partial Quadratic Mixture Model for PCT-Li Applied to the 480-Glass Separate Validation Set. Error bars are $95 \%$ prediction intervals (PIs). The number of glasses whose $95 \%$ PIs do not include the measured values (represented by the $45^{\circ}$ line) is shown.

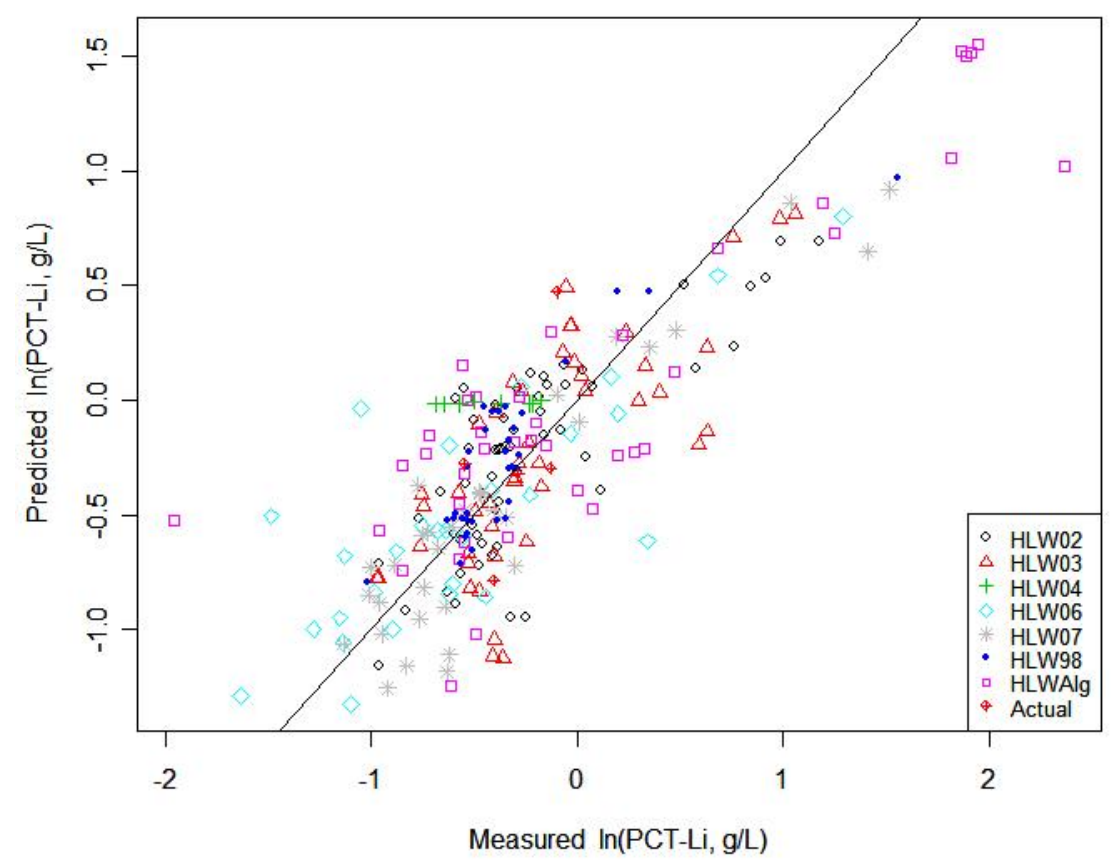

Figure 5.40. Predicted Versus Measured Plot for the 15-Term Partial Quadratic Mixture Model for PCT-Li Fitted to Data from 250 HLW Glasses. 
The Catholic University of America Vitreous State Laboratory
IHLW PCT, Spinel $T_{1 \%}$, Electrical Conductivity, and Viscosity Model Development Final Report, VSL-07R1240-4, Rev. 0

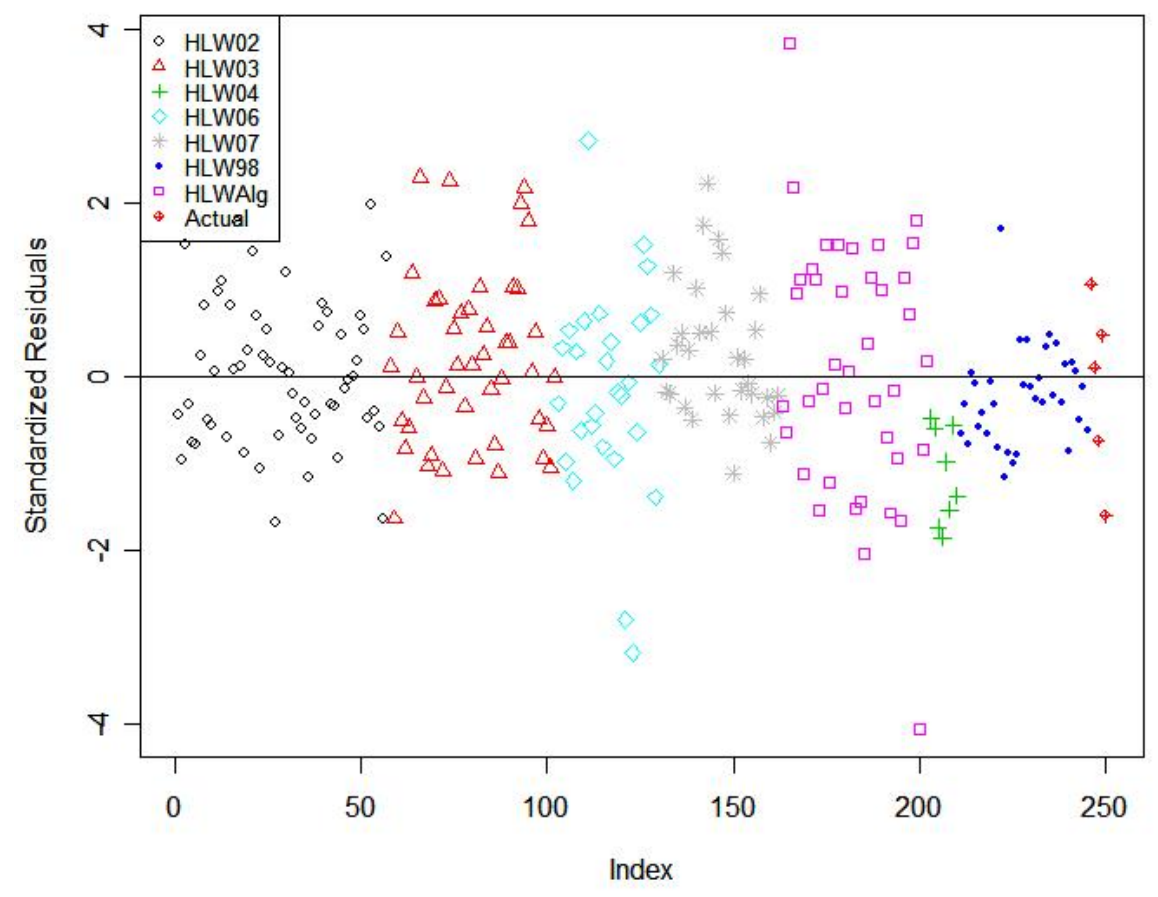

Figure 5.41. Standardized Residuals Plot for the 15-Term Partial Quadratic Mixture Model for PCT-Li Fitted to Data from 250 HLW Glasses.

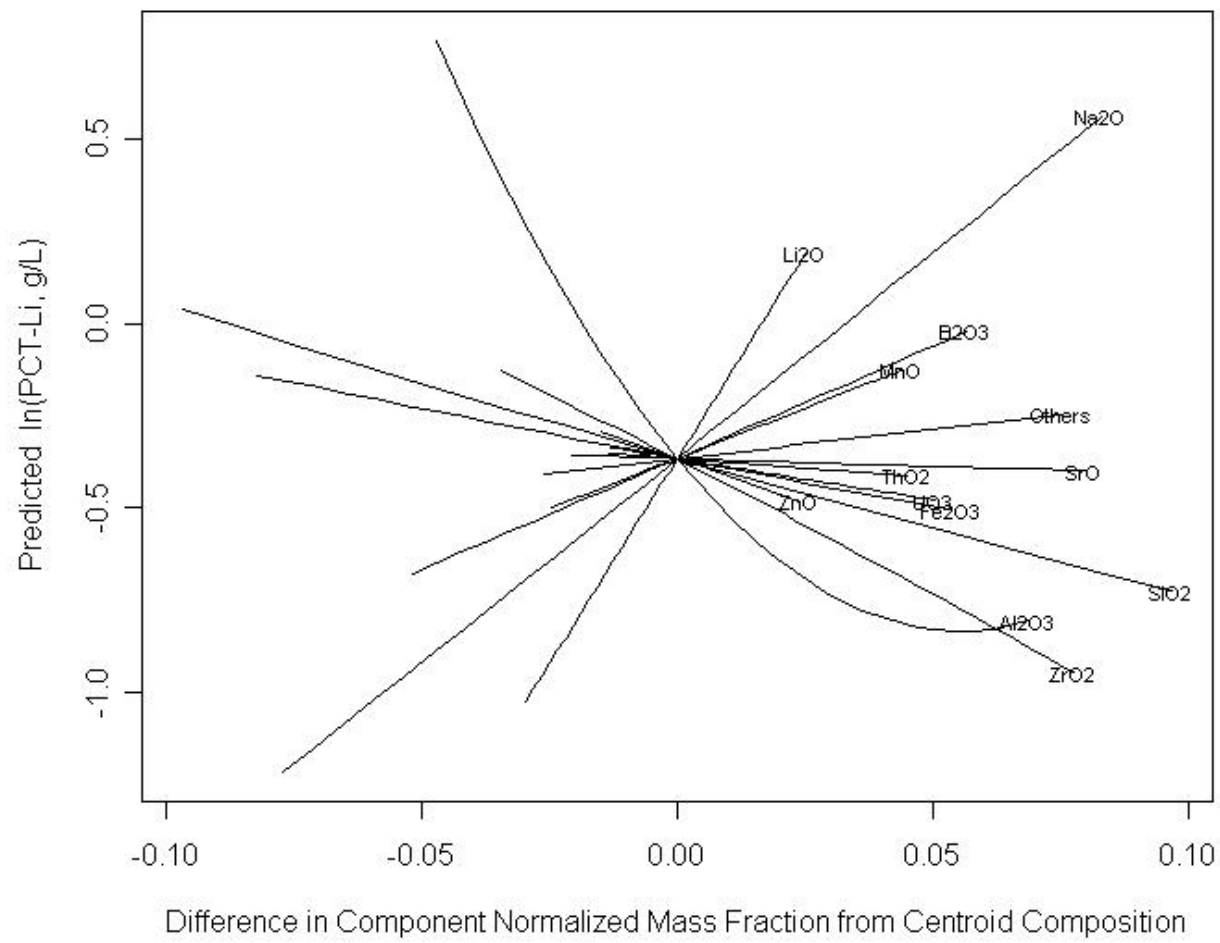

Figure 5.42. Response Trace Plot for the 15-Term Partial Quadratic Mixture Model for PCT-Li Fitted to Data from 250 HLW Glasses. 


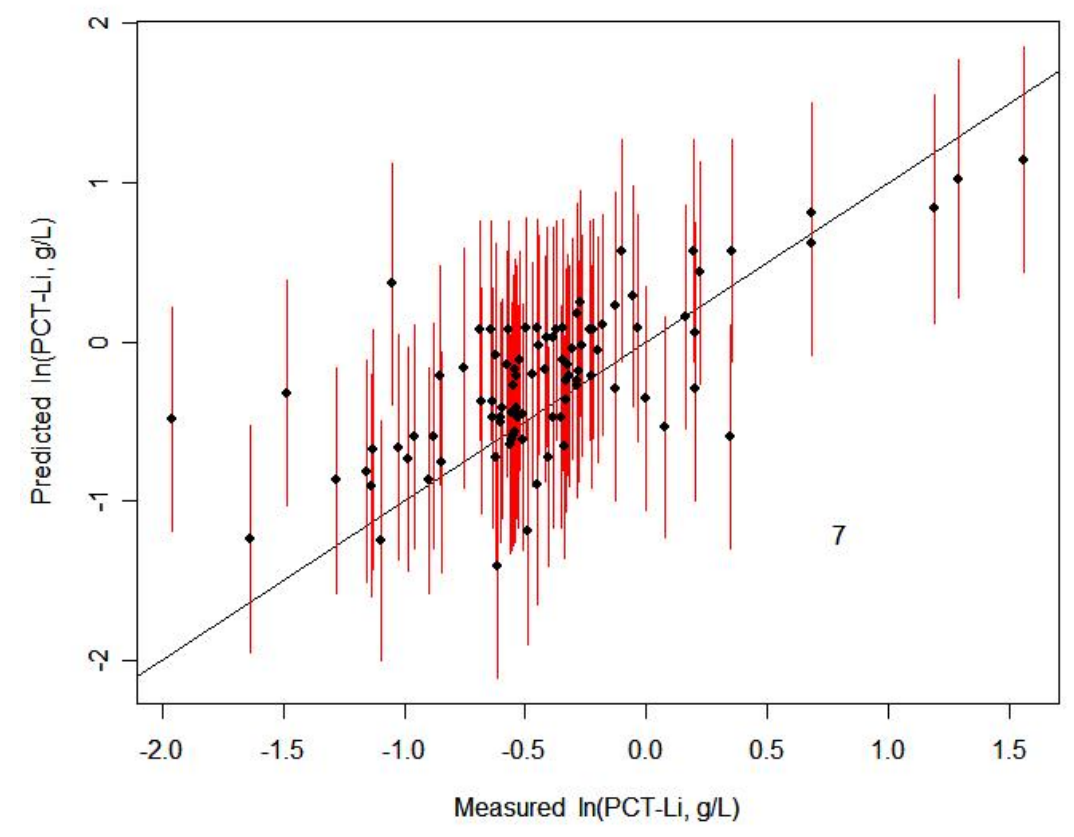

Figure 5.43. Predicted Versus Measured Plot for the 15-Term Partial Quadratic Mixture Model on IHLW PCT-Li Fitted to the Data-Partition Modeling Subset of 154 Glasses and Applied to the Validation Subset of 96 Glasses. Error bars are 95\% prediction intervals (PIs). The number of glasses whose $95 \%$ PIs do not include the measured values (represented by the $45^{\circ}$ line) is shown.

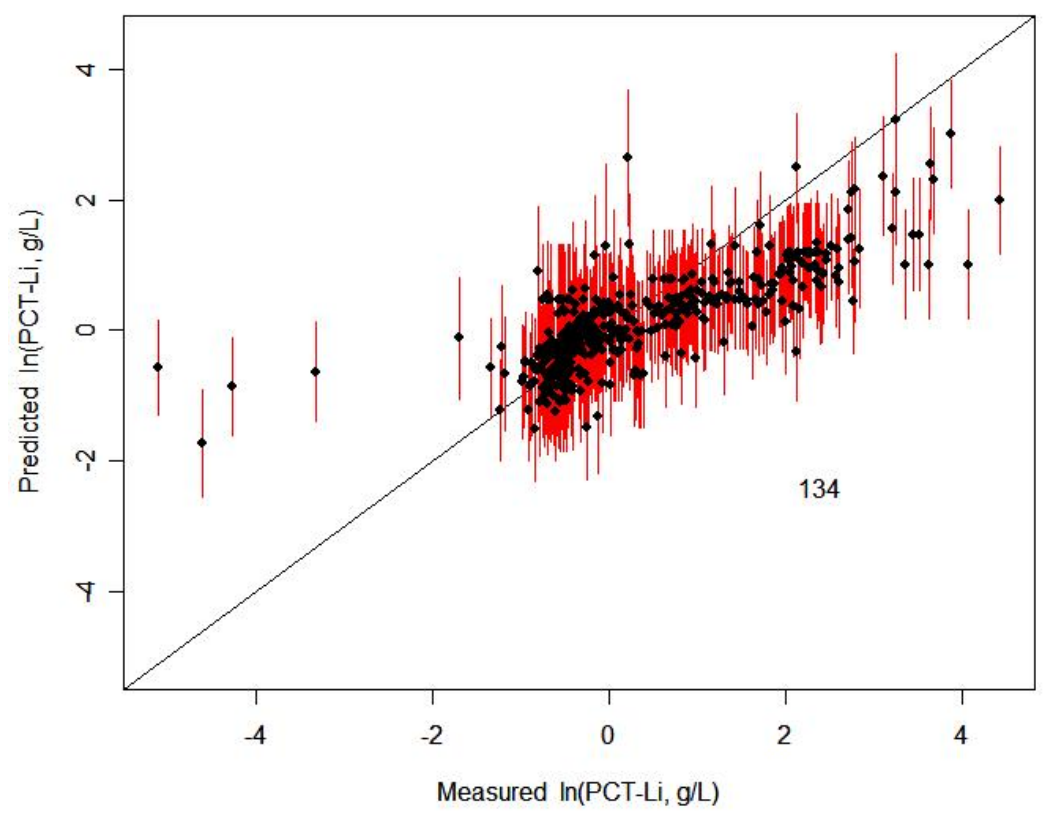

Figure 5.44. Predicted Versus Measured Plot for the 15-Term Partial Quadratic Mixture Model for PCT-Li Applied to the 480-Glass Separate Validation Set. Error bars are $95 \%$ prediction intervals (PIs). The number of glasses whose $95 \%$ PIs do not include the measured values (represented by the $45^{\circ}$ line) is shown. 
The Catholic University of America Vitreous State Laboratory
IHLW PCT, Spinel $T_{1 \%}$, Electrical Conductivity, and Viscosity Model Development Final Report, VSL-07R1240-4, Rev. 0

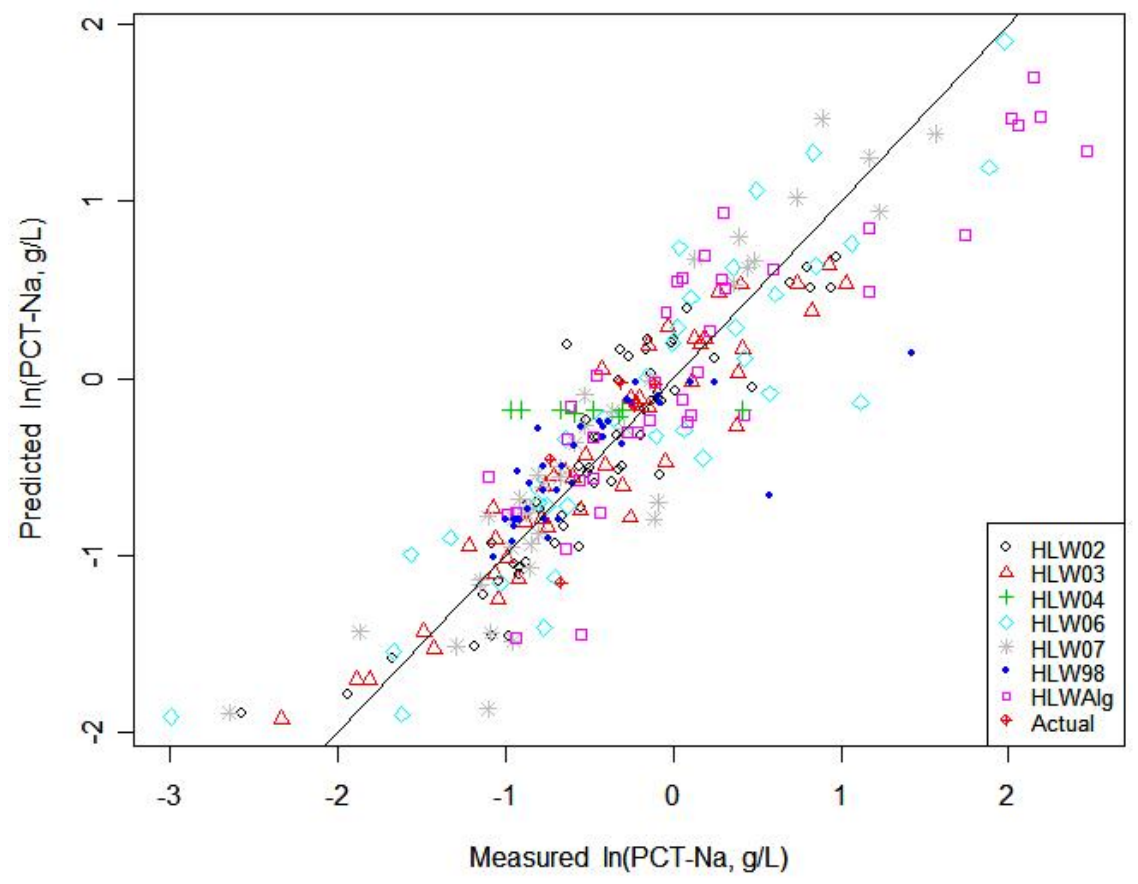

Figure 5.45. Predicted Versus Measured Plot for the 25-Component Full Linear Mixture Model for PCT-Na Fitted to Data from 266 HLW Glasses.

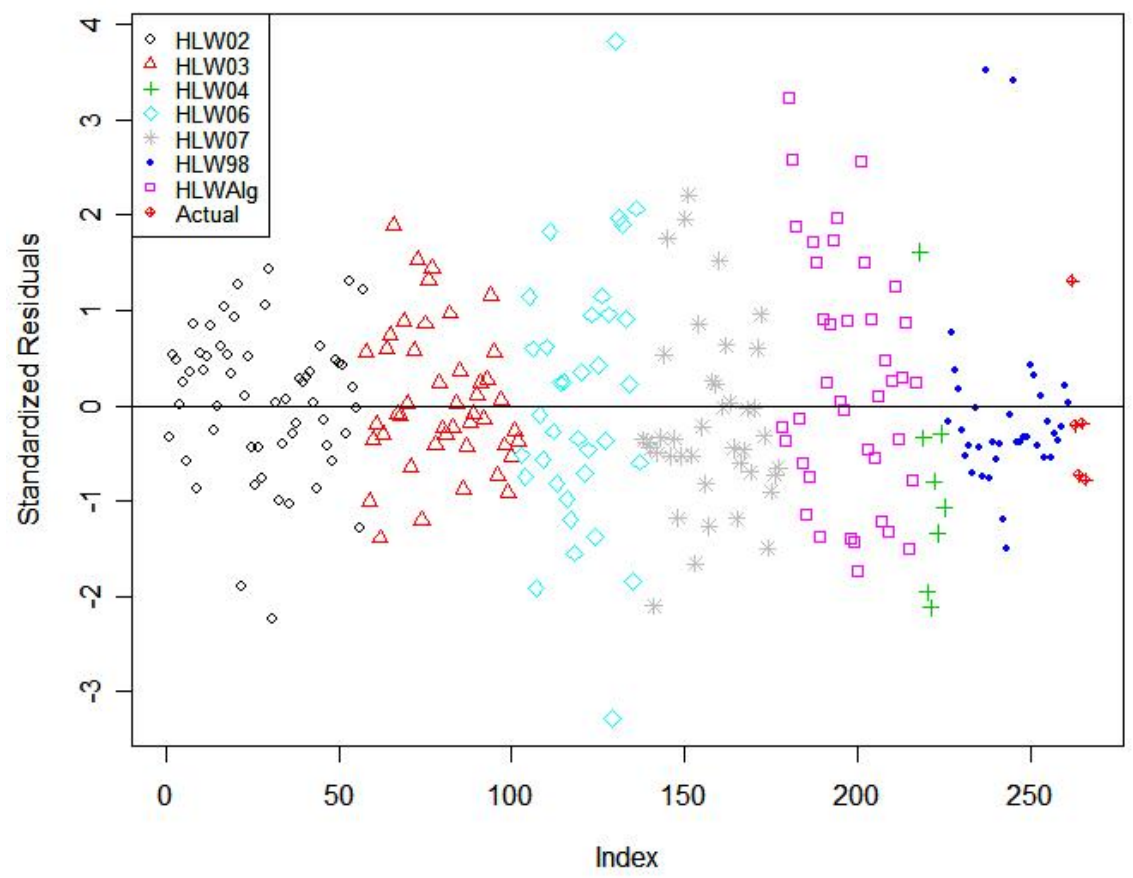

Figure 5.46. Standardized Residuals Plot for the 25-Component Full Linear Mixture Model for PCT-Na Fitted to Data from 266 HLW Glasses. 


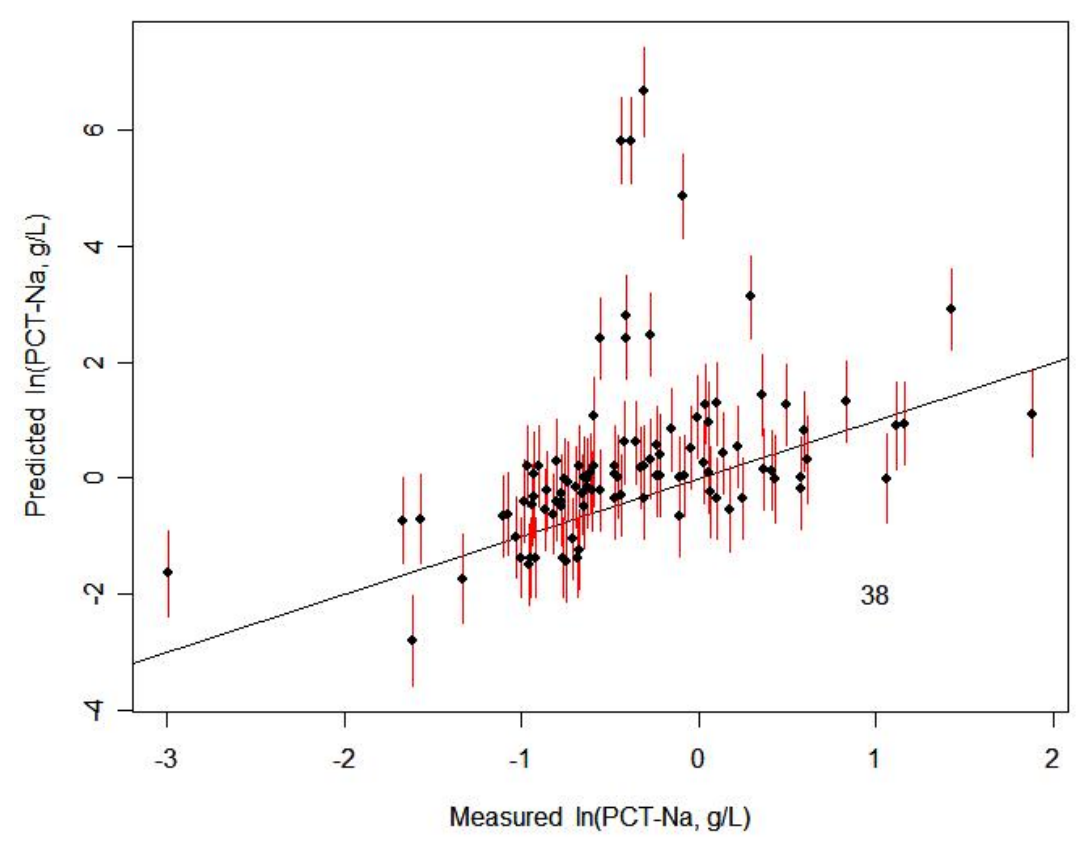

Figure 5.47. Predicted Versus Measured Plot for the 25-Component Full Linear Mixture Model on IHLW PCT-Na Fitted to the Data-Partition Modeling Subset of 163 Glasses and Applied to the Validation Subset of 103 Glasses. Error bars are $95 \%$ prediction intervals (PIs). The number of glasses whose $95 \%$ PIs do not include the measured values (represented by the $45^{\circ}$ line) is shown.

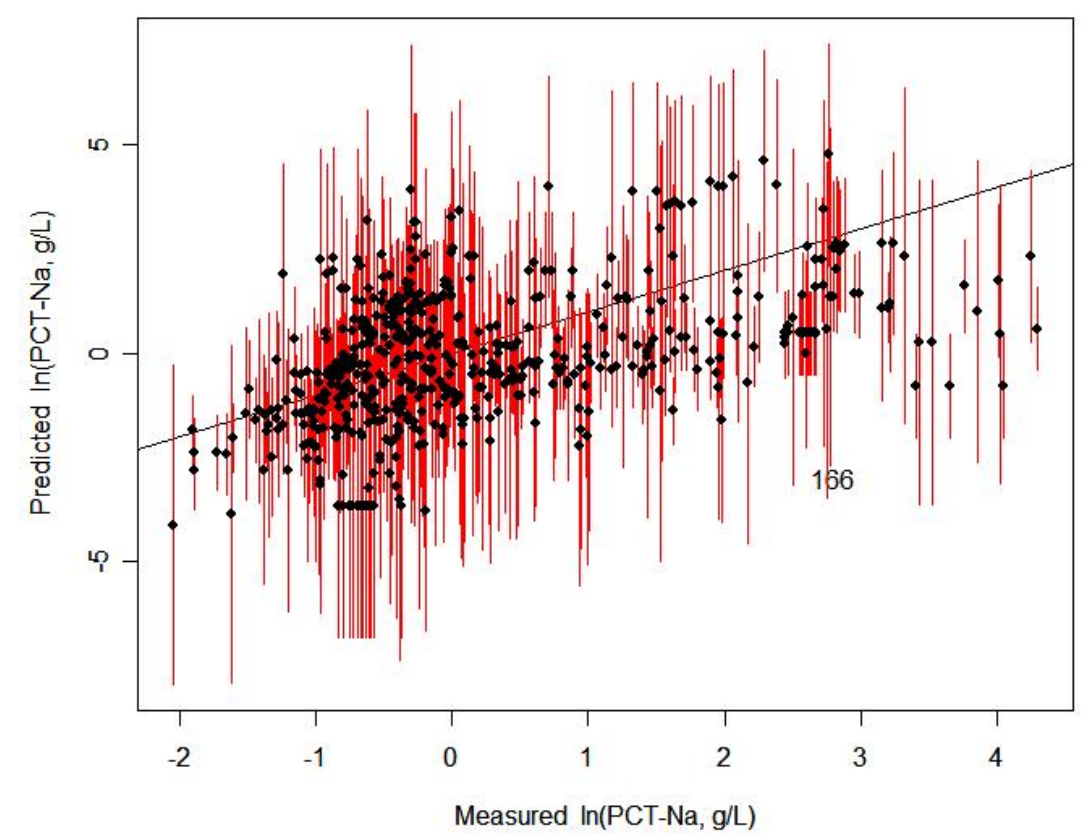

Figure 5.48. Predicted Versus Measured Plot for the 25-Component Full Linear Mixture Model for PCT-Na Applied to the 554-Glass Separate Validation Set. Error bars are $95 \%$ prediction intervals (PIs). The number of glasses whose $95 \%$ PIs do not include the measured values (represented by the $45^{\circ}$ line) is shown. 
The Catholic University of America Vitreous State Laboratory
IHLW PCT, Spinel $T_{1 \%}$, Electrical Conductivity, and Viscosity Model Development Final Report, VSL-07R1240-4, Rev. 0

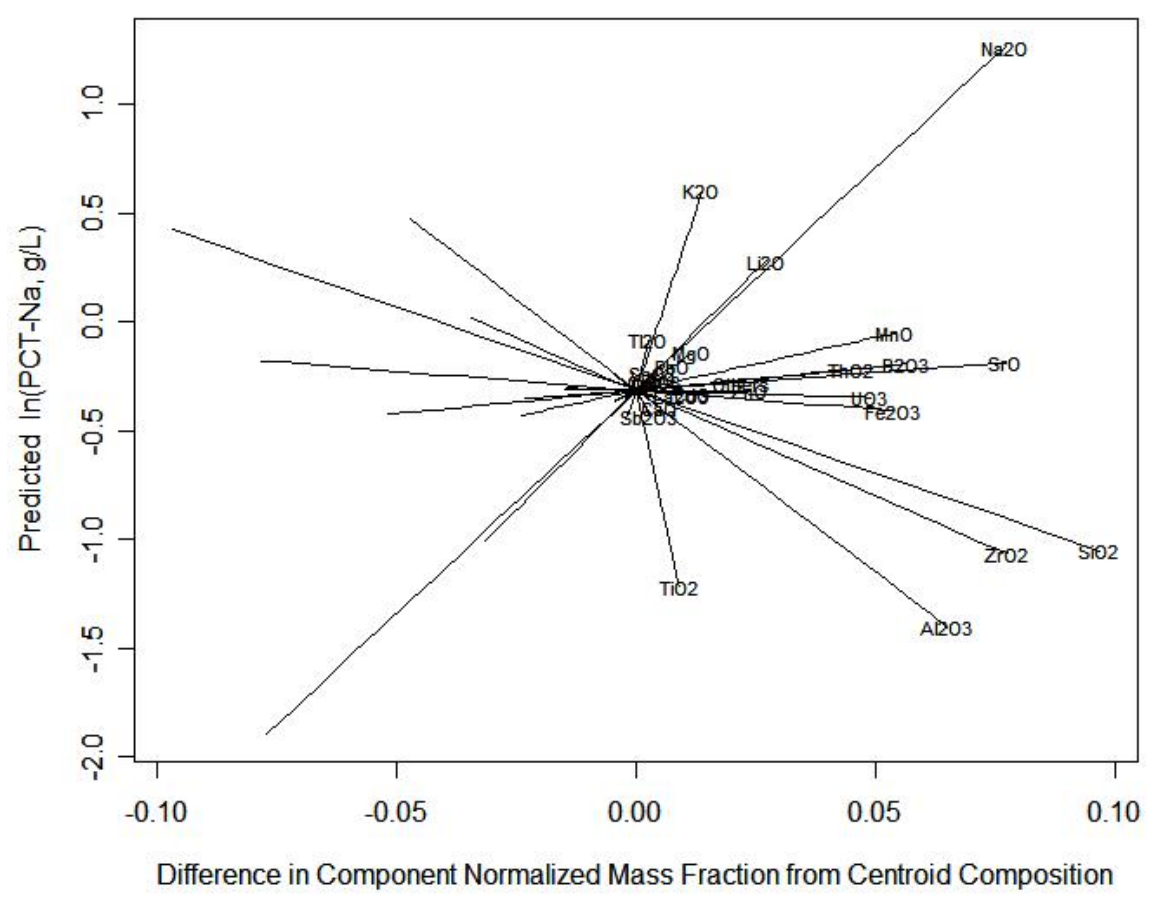

Figure 5.49. Response Trace Plot for the 25-Component Full Linear Mixture Model for PCT-Na Fitted to Data from 266 HLW Glasses.

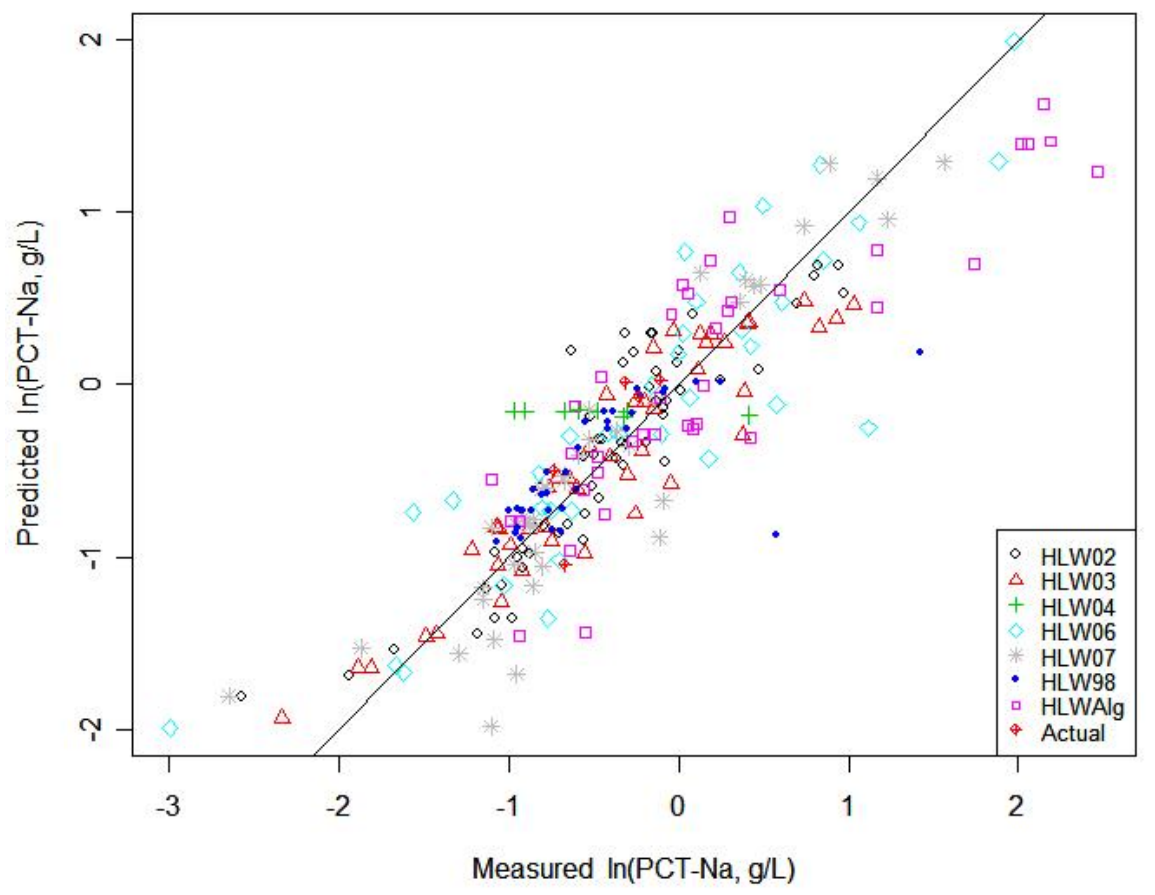

Figure 5.50. Predicted Versus Measured Plot for the 13-Component Reduced Linear Mixture Model for PCT-Na Fitted to Data from 266 HLW Glasses. 
The Catholic University of America Vitreous State Laboratory
IHLW PCT, Spinel $T_{1 \%}$, Electrical Conductivity, and Viscosity Model Development Final Report, VSL-07R1240-4, Rev. 0

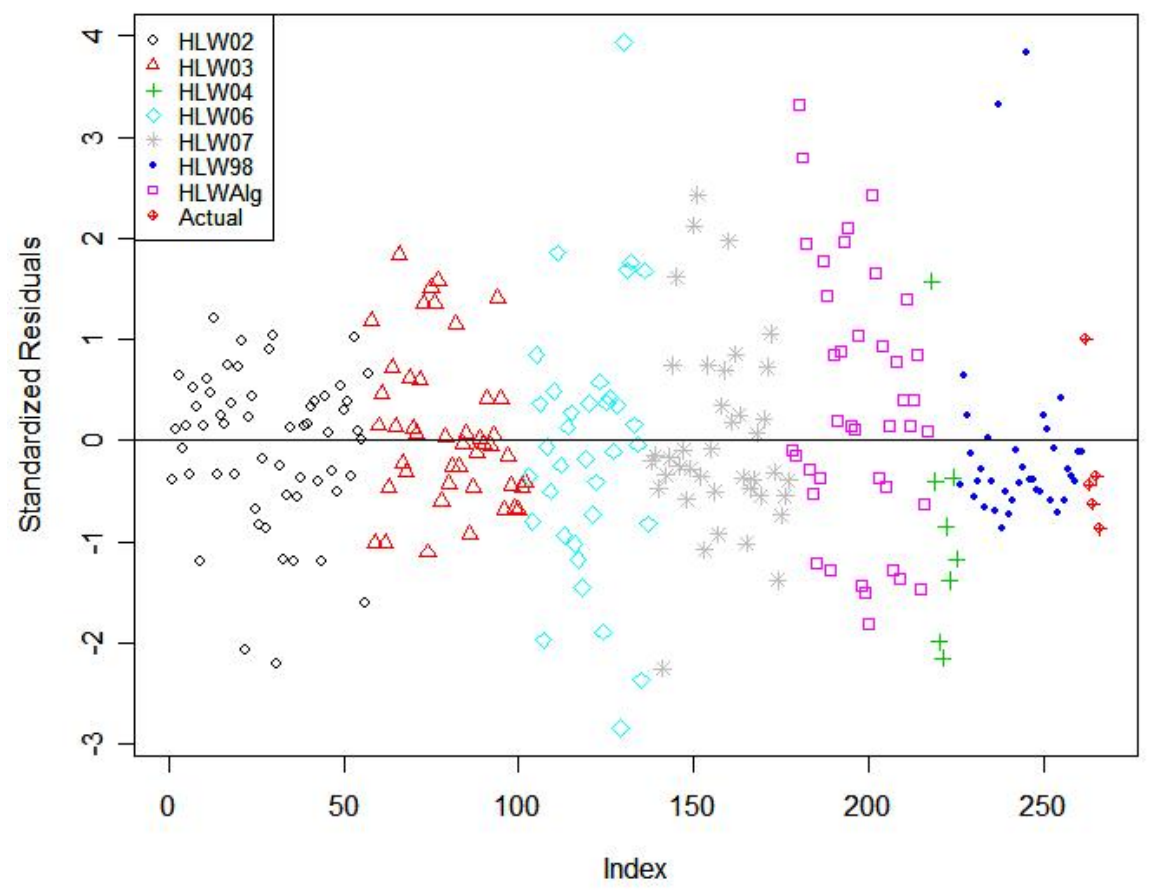

Figure 5.51. Standardized Residuals Plot for the 13-Component Reduced Linear Mixture Model for PCT-Na Fitted to Data from 266 HLW Glasses.

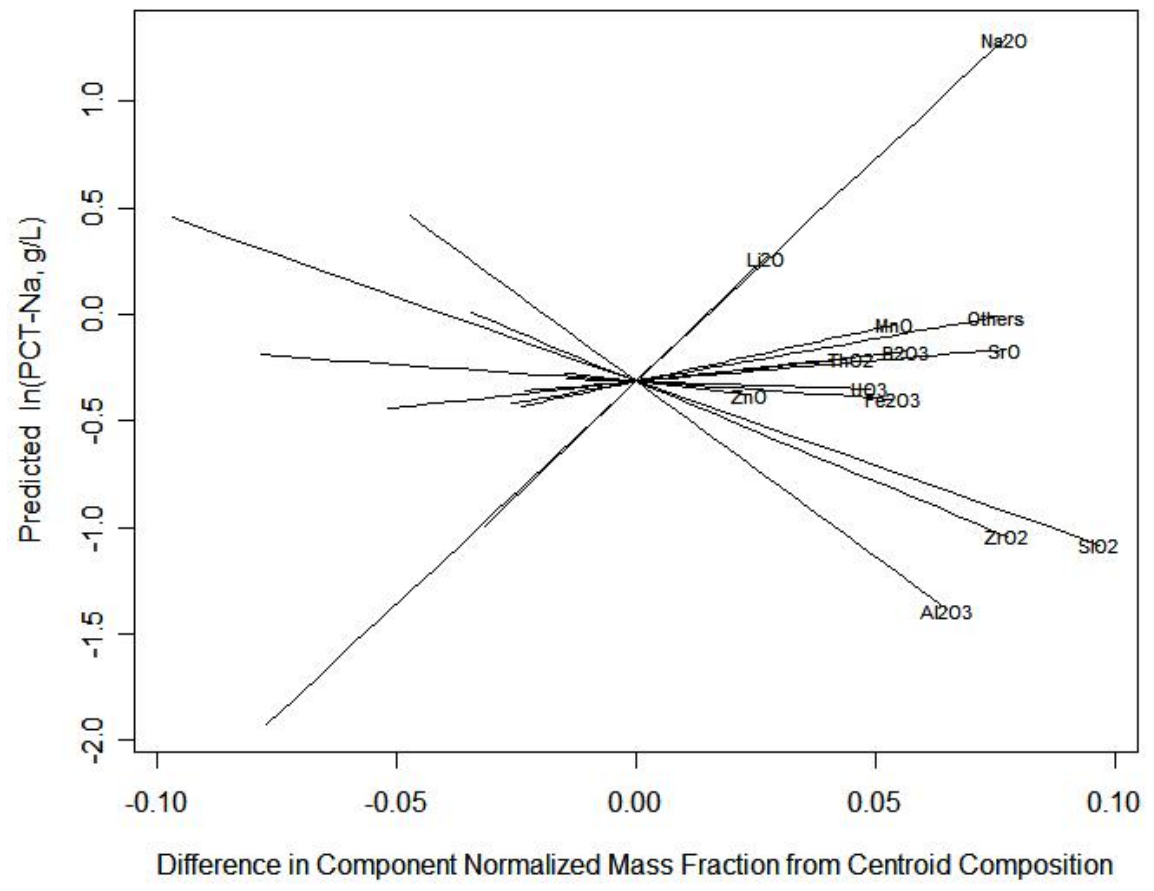

Figure 5.52. Response Trace Plot for the 13-Component Reduced Linear Mixture Model for PCT-Na Fitted to Data from 266 HLW Glasses. 


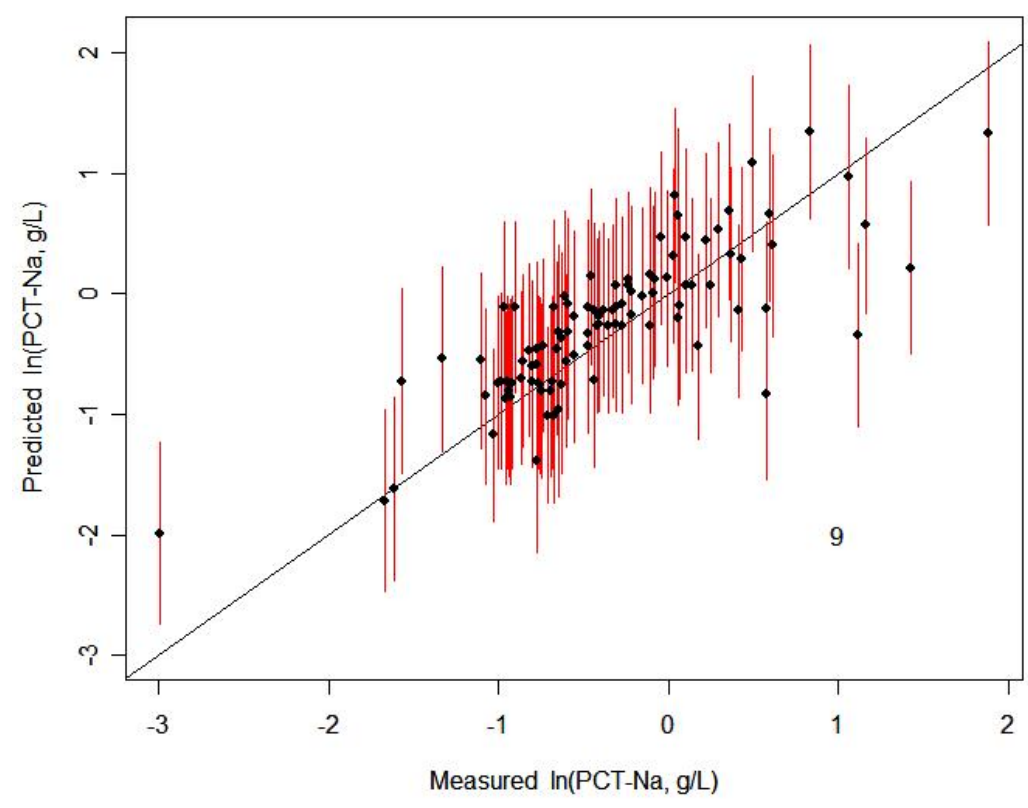

Figure 5.53. Predicted Versus Measured Plot for the 13-Component Reduced Linear Mixture Model on IHLW PCT-Na Fitted to the Data-Partition Modeling Subset of 163 Glasses and Applied to the Validation Subset of 103 Glasses. Error bars are $95 \%$ prediction intervals (PIs). The number of glasses whose $95 \%$ PIs do not include the measured values (represented by the $45^{\circ}$ line) is shown.

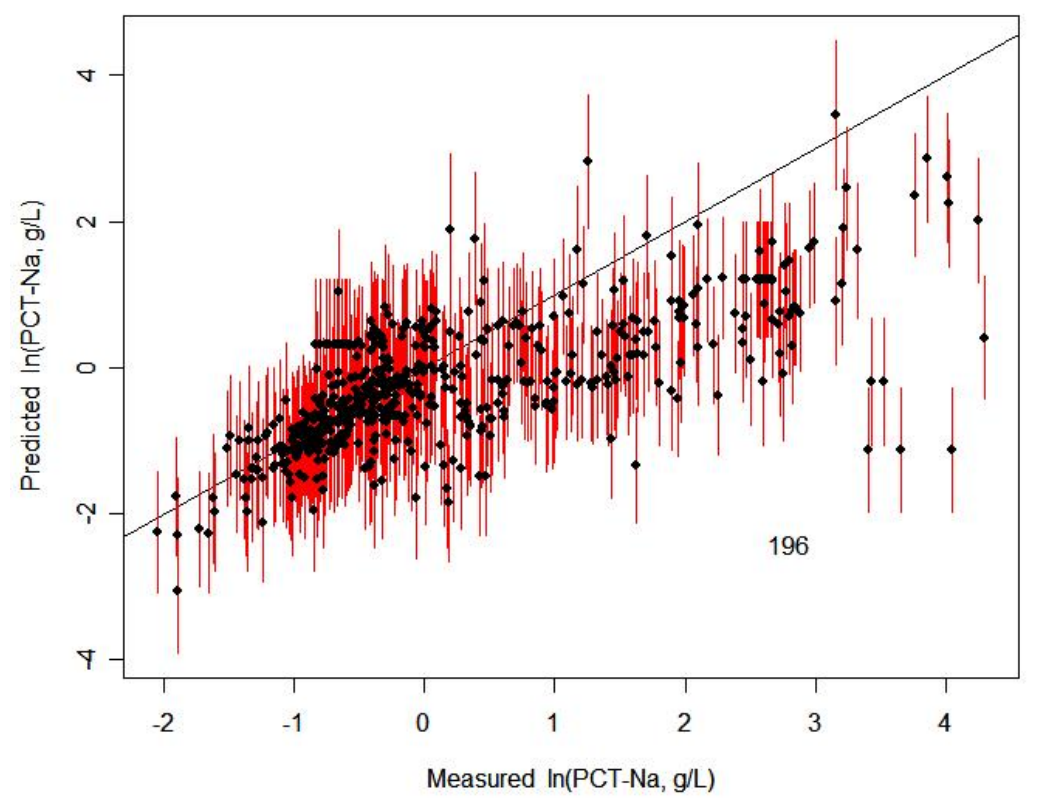

Figure 5.54. Predicted Versus Measured Plot for the 13-Component Reduced Linear Mixture Model for PCT-Na Applied to the 554-Glass Separate Validation Set. Error bars are $95 \%$ prediction intervals (PIs). The number of glasses whose $95 \%$ PIs do not include the measured values (represented by the $45^{\circ}$ line) is shown. 
The Catholic University of America Vitreous State Laboratory
IHLW PCT, Spinel $T_{1 \%}$, Electrical Conductivity, and Viscosity Model Development Final Report, VSL-07R1240-4, Rev. 0

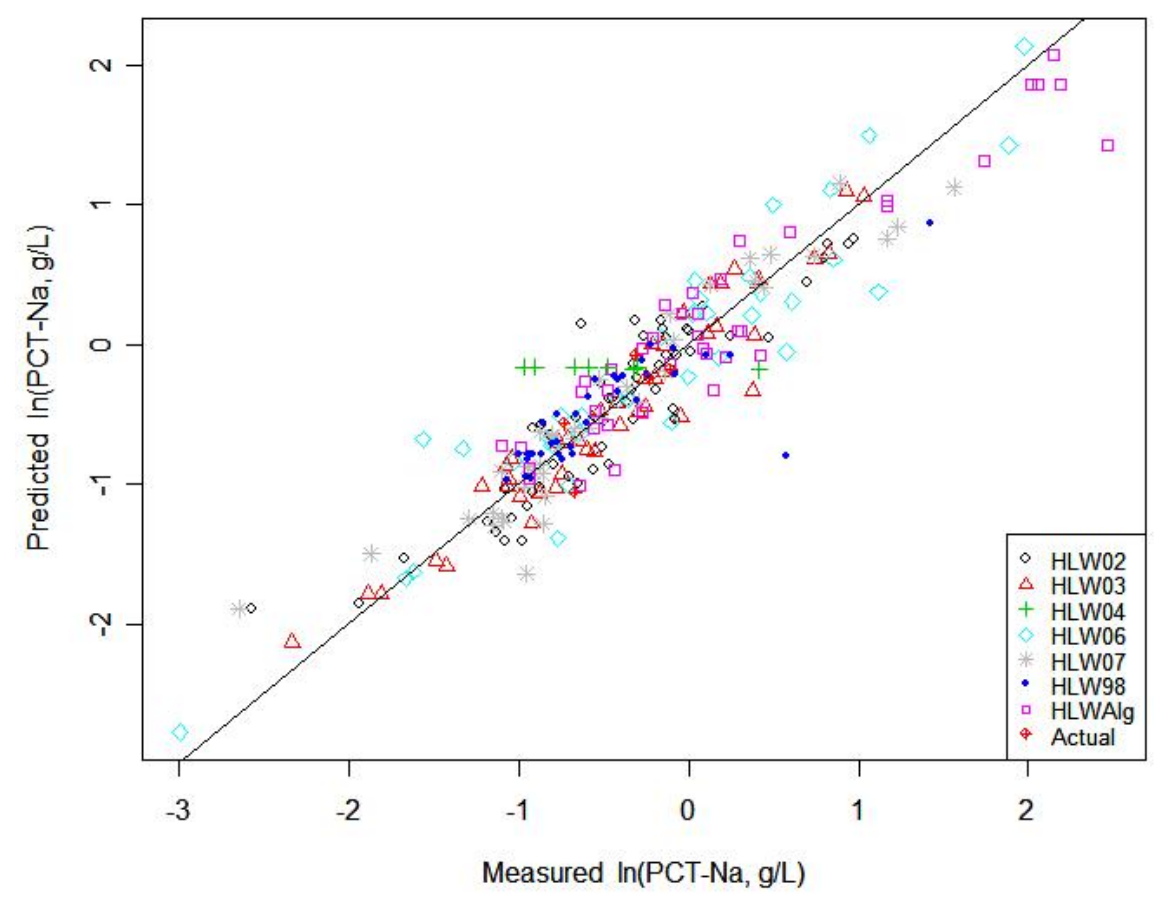

Figure 5.55. Predicted Versus Measured Plot for the 18-Term Partial Quadratic Mixture Model for PCT-Na Fitted to Data from 266 HLW Glasses.

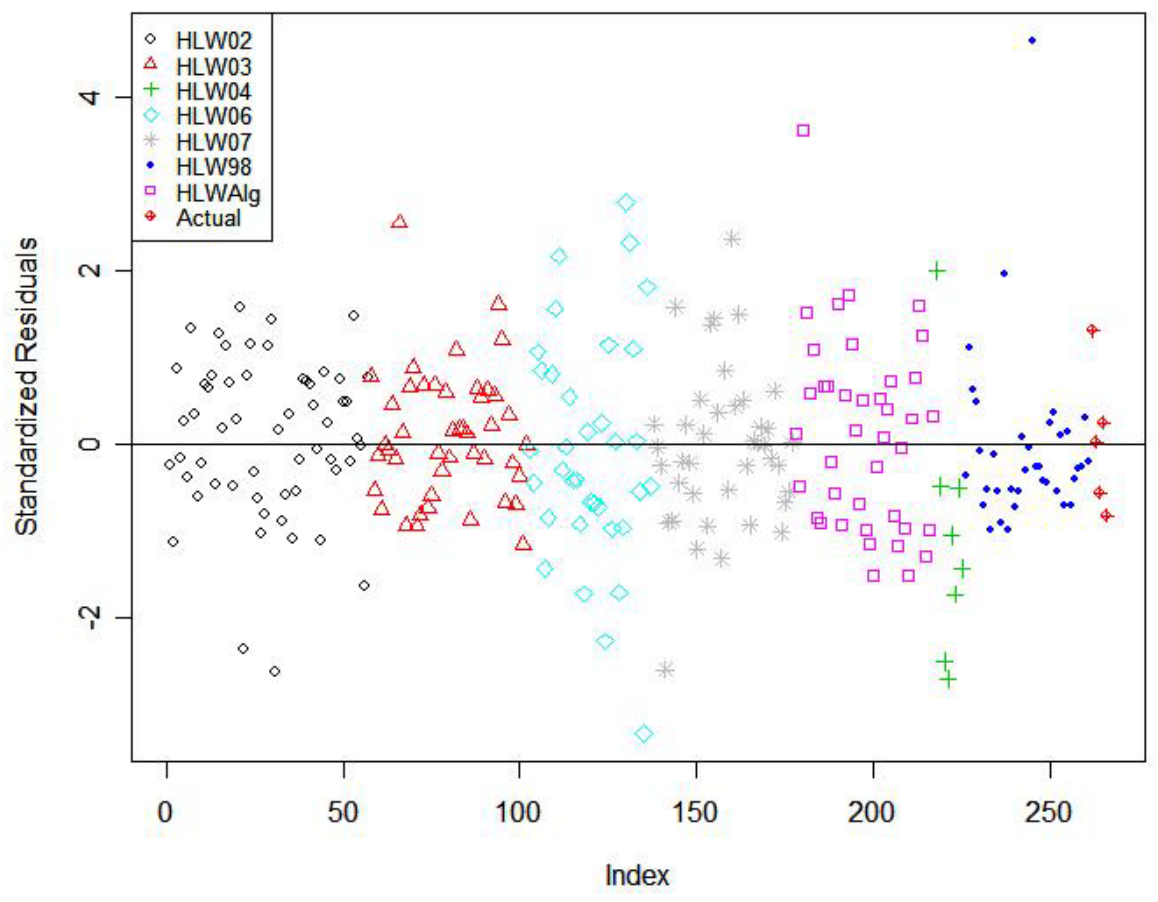

Figure 5.56. Standardized Residuals Plot for the 18-Term Partial Quadratic Mixture Model for PCT-Na Fitted to Data from 266 HLW Glasses. 


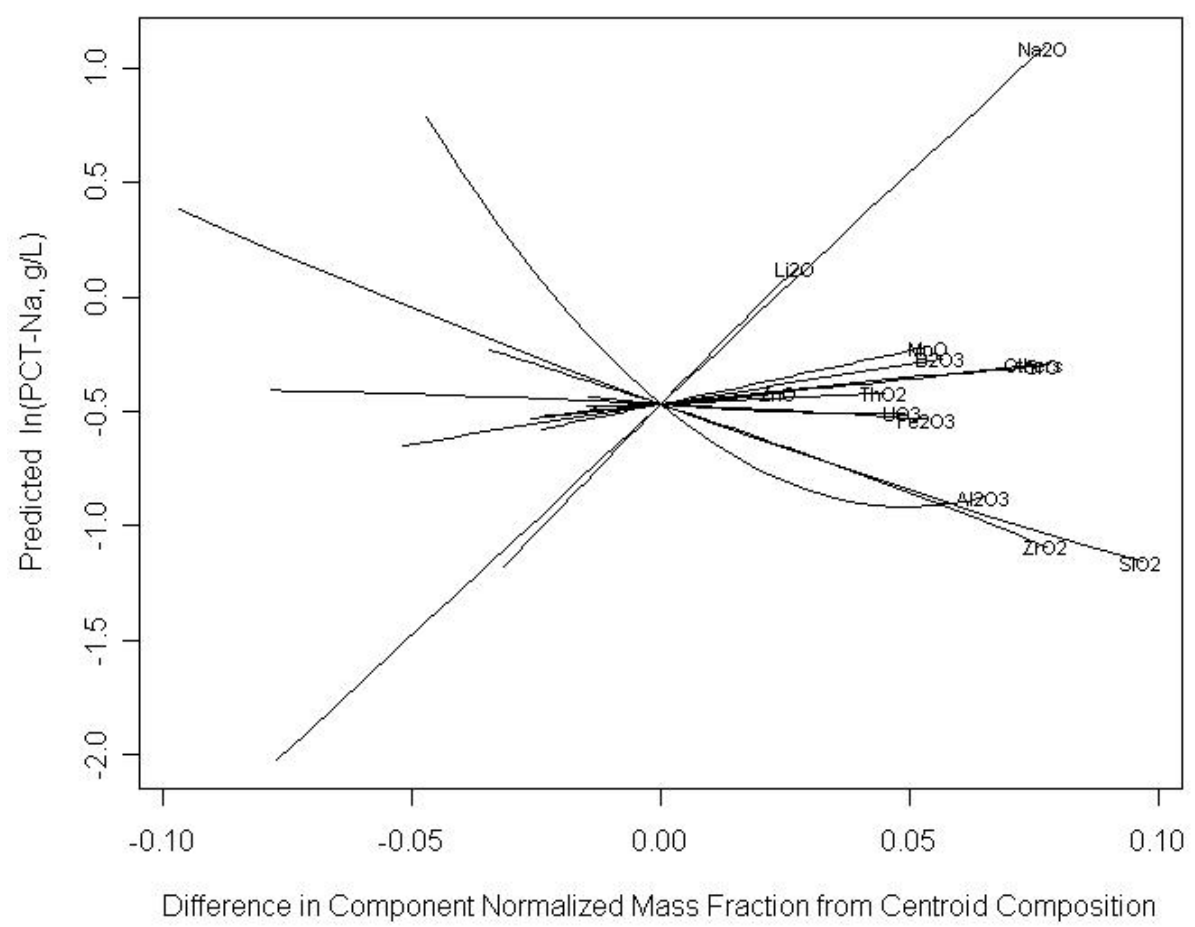

Figure 5.57. Response Trace Plot for the 18-Term Partial Quadratic Mixture Model for PCT-Na Fitted to Data from 266 HLW Glasses.

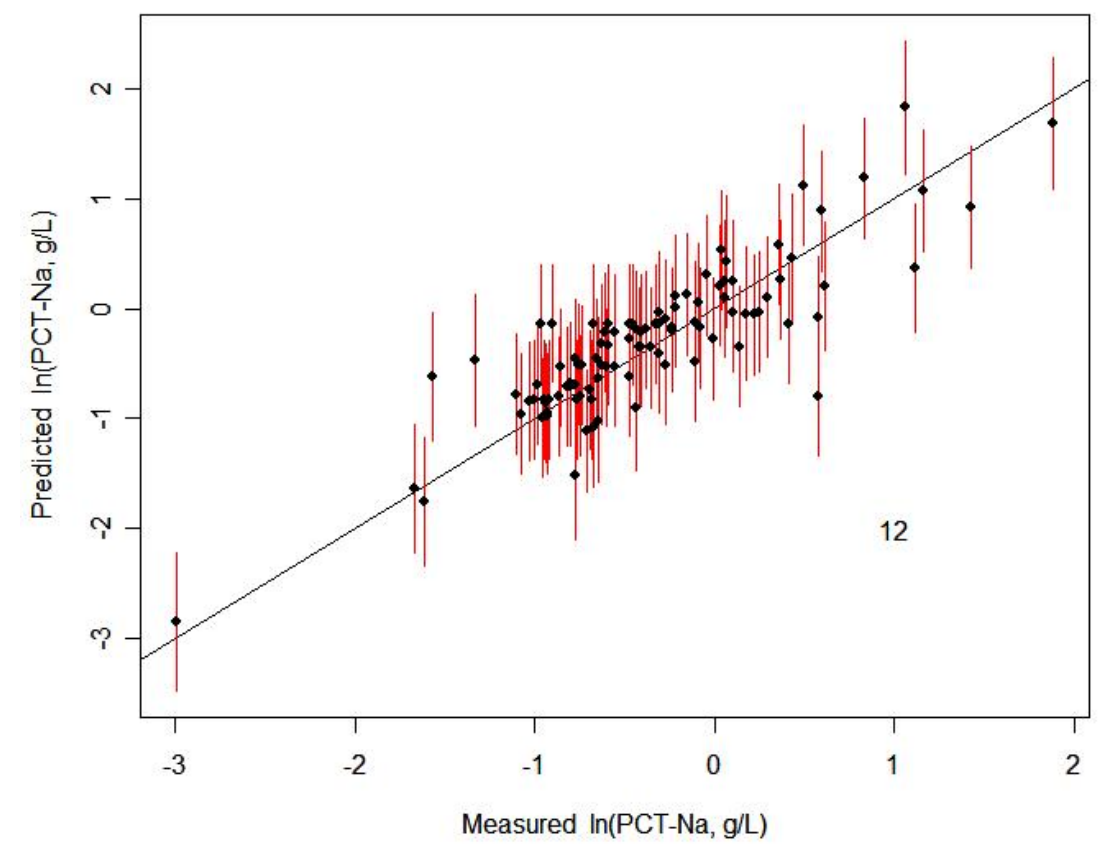

Figure 5.58. Predicted Versus Measured Plot for the 18-Term Partial Quadratic Mixture Model on IHLW PCT-Na Fitted to the Data-Partition Modeling Subset of 163 Glasses and Applied to the Validation Subset of 103 Glasses. Error bars are $\mathbf{9 5 \%}$ prediction intervals (PIs). The number of glasses whose $95 \%$ PIs do not include the measured values (represented by the $45^{\circ}$ line) is shown. 


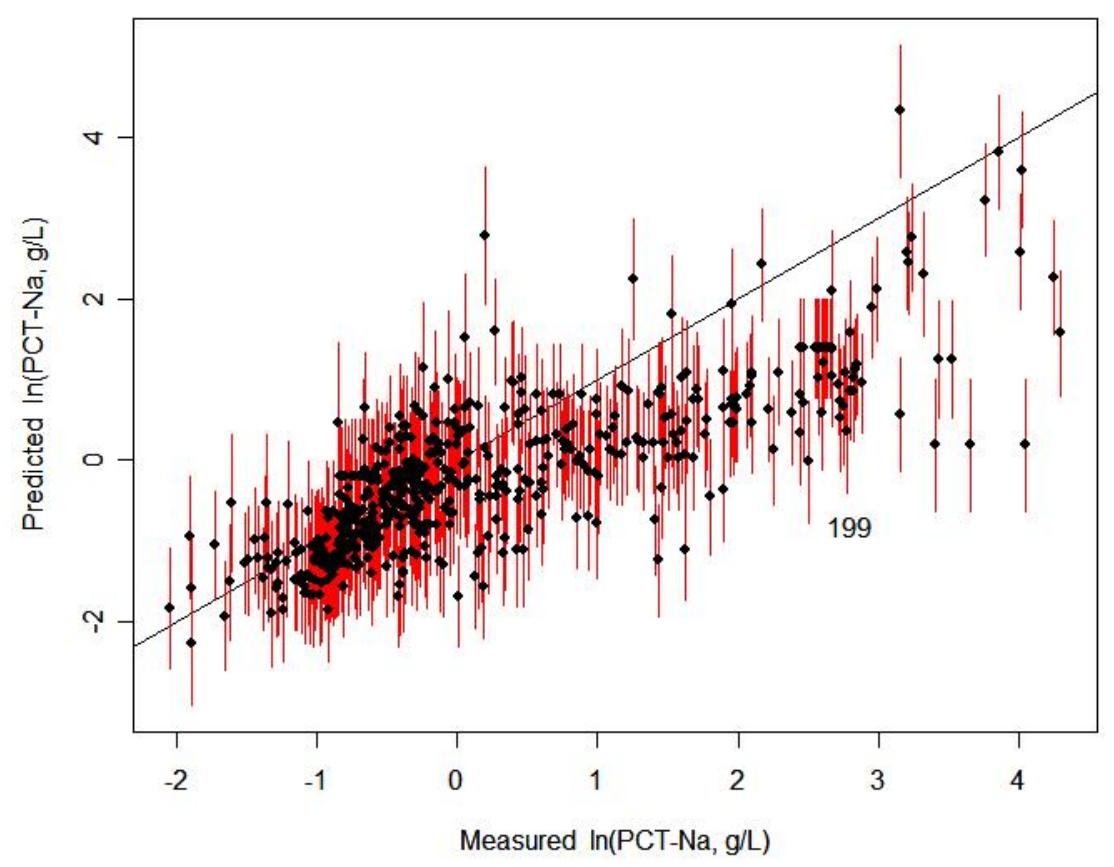

Figure 5.59. Predicted Versus Measured Plot for the 18-Term Partial Quadratic Mixture Model for PCT-Na Applied to the 554-Glass Separate Validation Set. Error bars are $95 \%$ prediction intervals (PIs). The number of glasses whose $95 \%$ PIs do not include the measured values (represented by the $45^{\circ}$ line) is shown.

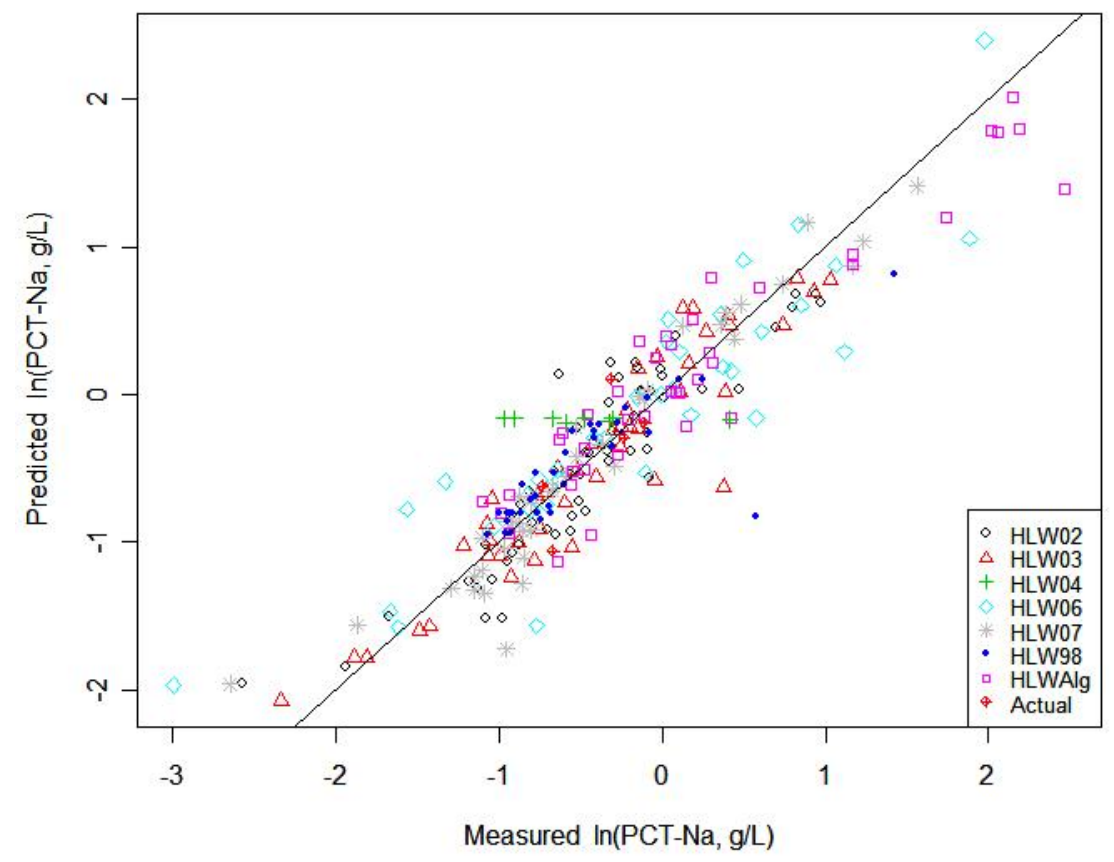

Figure 5.60. Predicted Versus Measured Plot for the 15-Term Partial Quadratic Mixture Model for PCT-Na Fitted to Data from 266 HLW Glasses. 
The Catholic University of America Vitreous State Laboratory
IHLW PCT, Spinel $T_{1 \%}$, Electrical Conductivity, and Viscosity Model Development Final Report, VSL-07R1240-4, Rev. 0

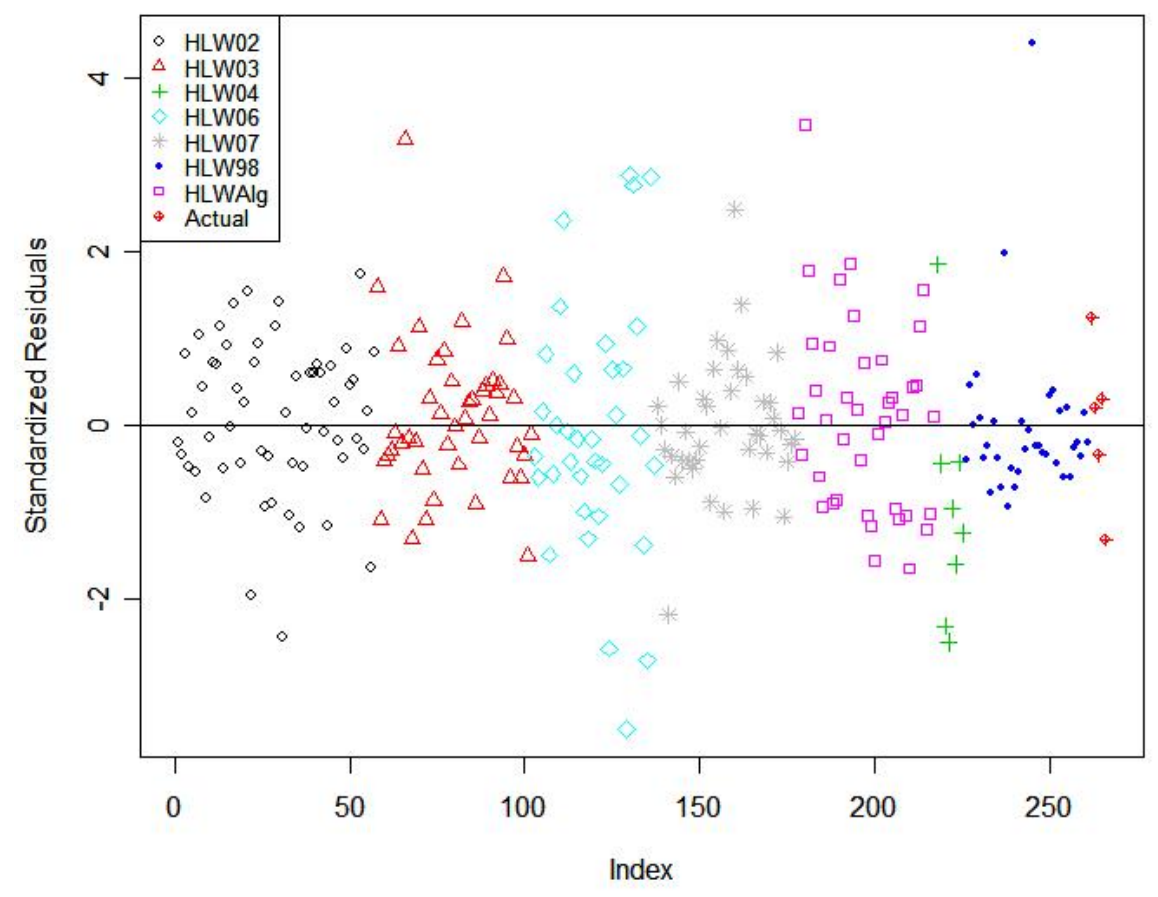

Figure 5.61. Standardized Residuals Plot for the 15-Term Partial Quadratic Mixture Model for PCT-Na Fitted to Data from 266 HLW Glasses.

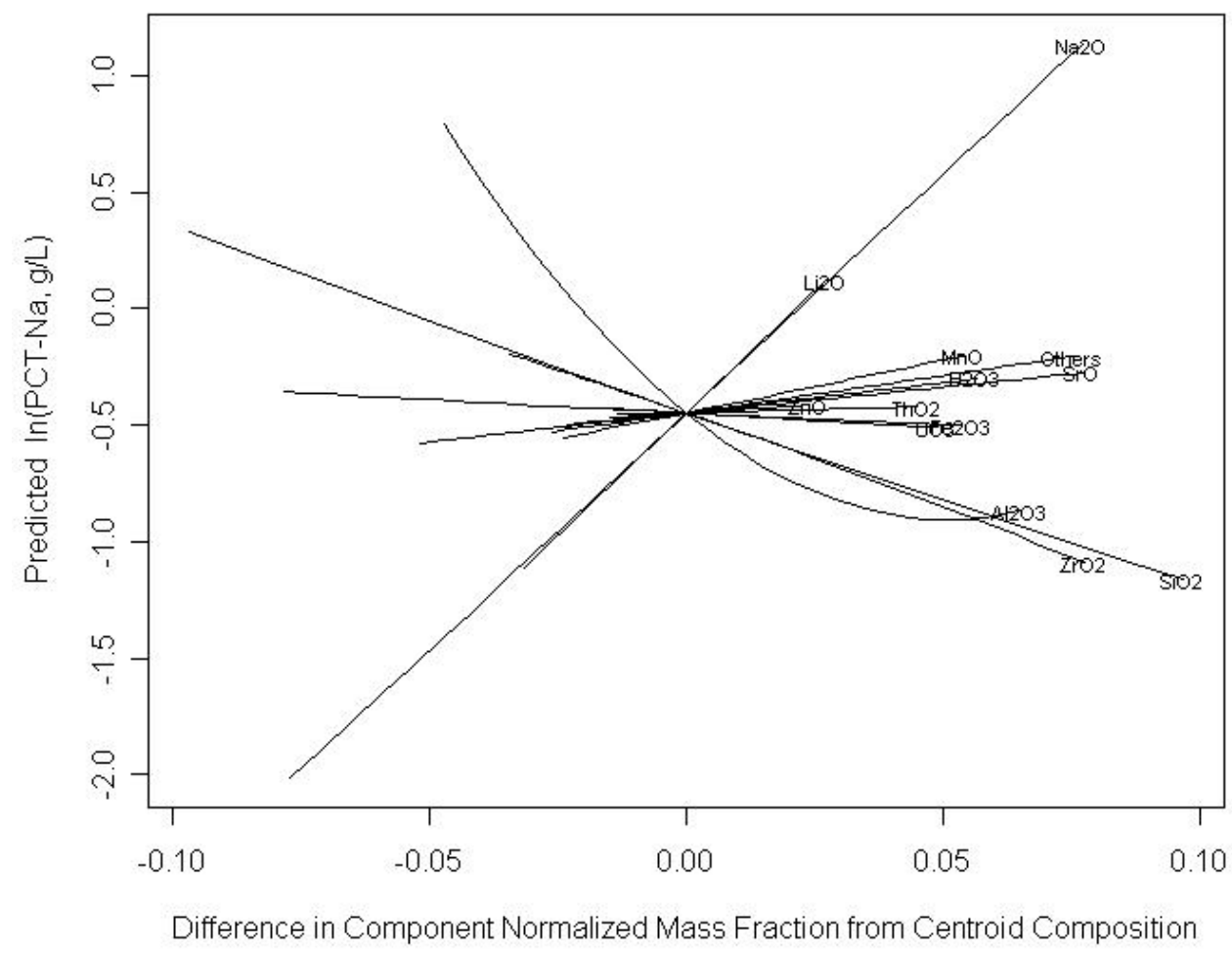

Figure 5.62. Response Trace Plot for the 15-Term Partial Quadratic Mixture Model for PCT-Na Fitted to Data from 266 HLW Glasses. 


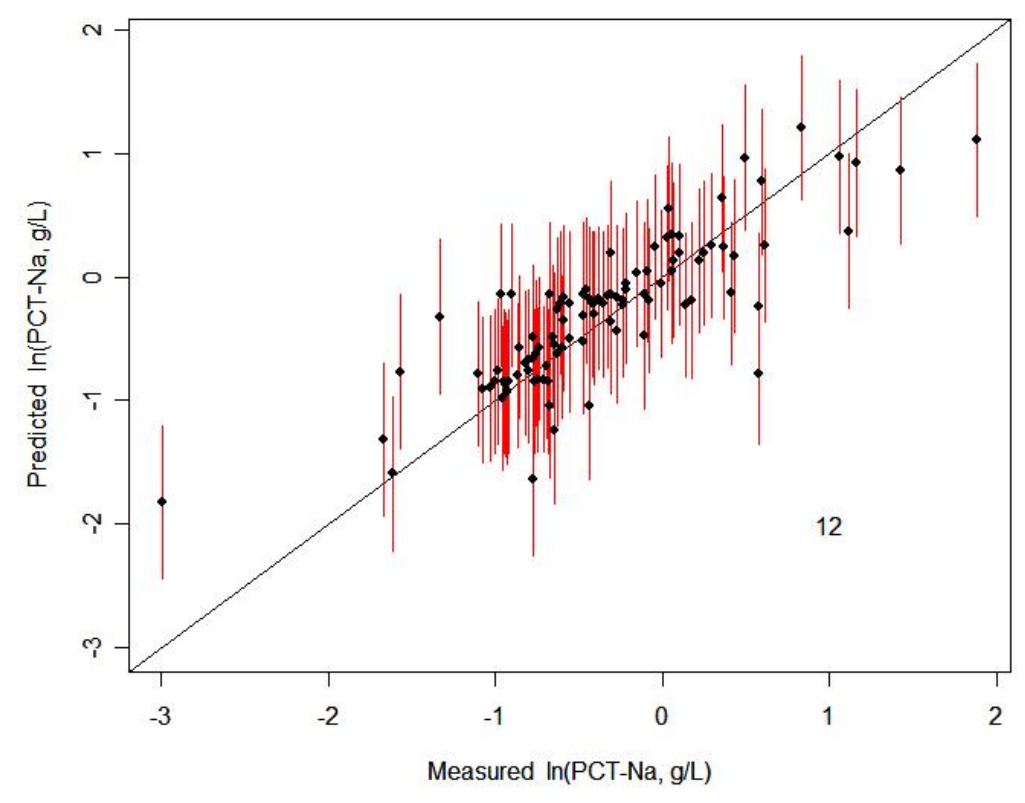

Figure 5.63. Predicted Versus Measured Plot for the 15-Term Partial Quadratic Mixture Model on IHLW PCT-Na Fitted to the Data-Partition Modeling Subset of 163 Glasses and Applied to the Validation Subset of 103 Glasses. Error bars are $\mathbf{9 5 \%}$ prediction intervals (PIs). The number of glasses whose $\mathbf{9 5 \%}$ PIs do not include the measured values (represented by the $45^{\circ}$ line) is shown.

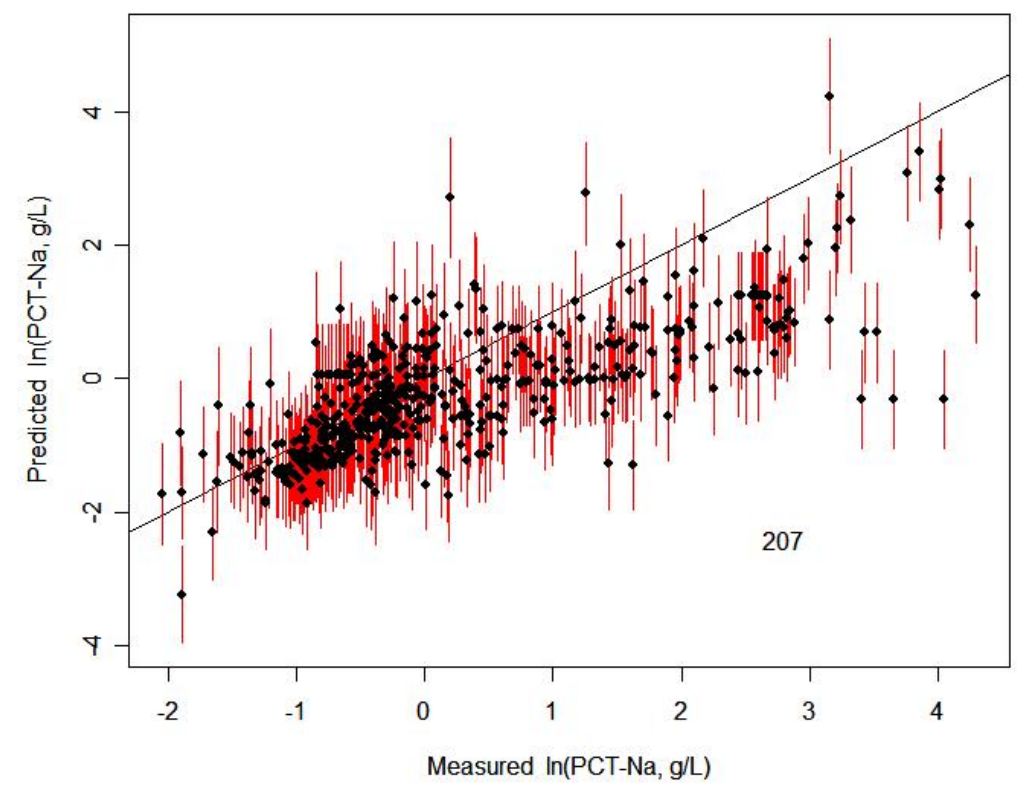

Figure 5.64. Predicted Versus Measured Plot for the 15-Term Partial Quadratic Mixture Model for PCT-Na Applied to the 554-Glass Separate Validation Set. Error bars are $95 \%$ prediction intervals (PIs). The number of glasses whose $95 \%$ PIs do not include the measured values (represented by the $45^{\circ}$ line) is shown. 


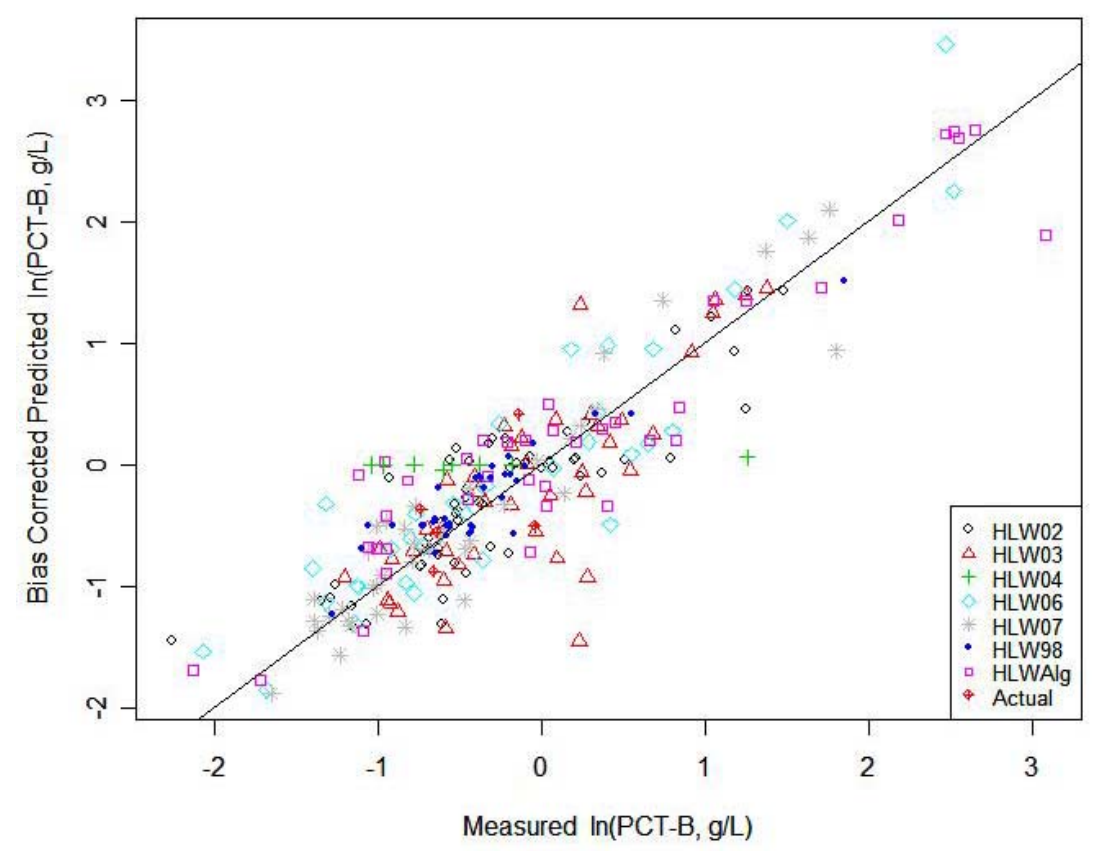

Figure 5.65. Predicted Versus Measured Plot for the Recommended 18-Term Partial Quadratic Mixture Model for PCT-B Fitted to Data from 264 HLW Glasses, With Bias-Correction for Predicted Values Above 0.5 $\ln (\mathrm{g} / \mathrm{L})$. Counting the bias-correction term, the model contains 19 terms.

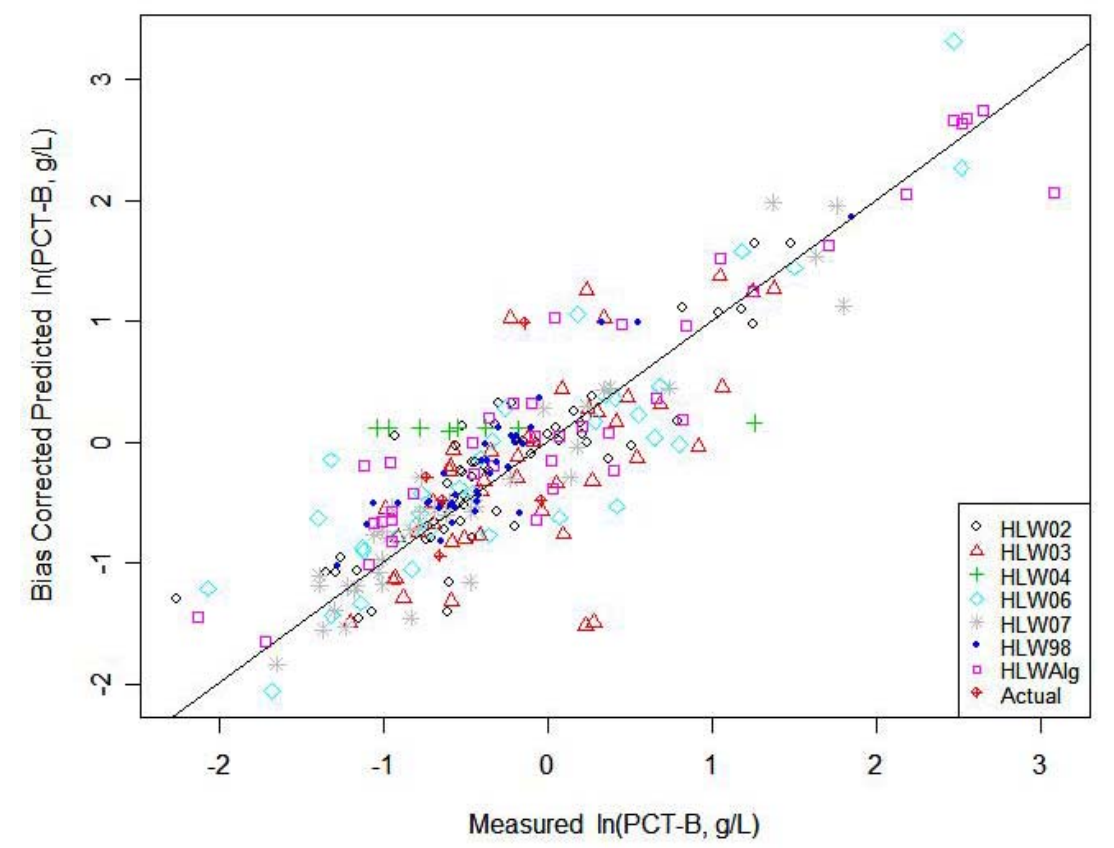

Figure 5.66. Predicted Versus Measured Plot for the Second-Choice 15-Term Partial Quadratic Mixture Model for PCT-B Fitted to Data from 264 HLW Glasses, With Bias-Correction for Predicted Values Above $0.5 \ln (\mathrm{g} / \mathrm{L})$. Counting the bias-correction term, the model contains 16 terms. 


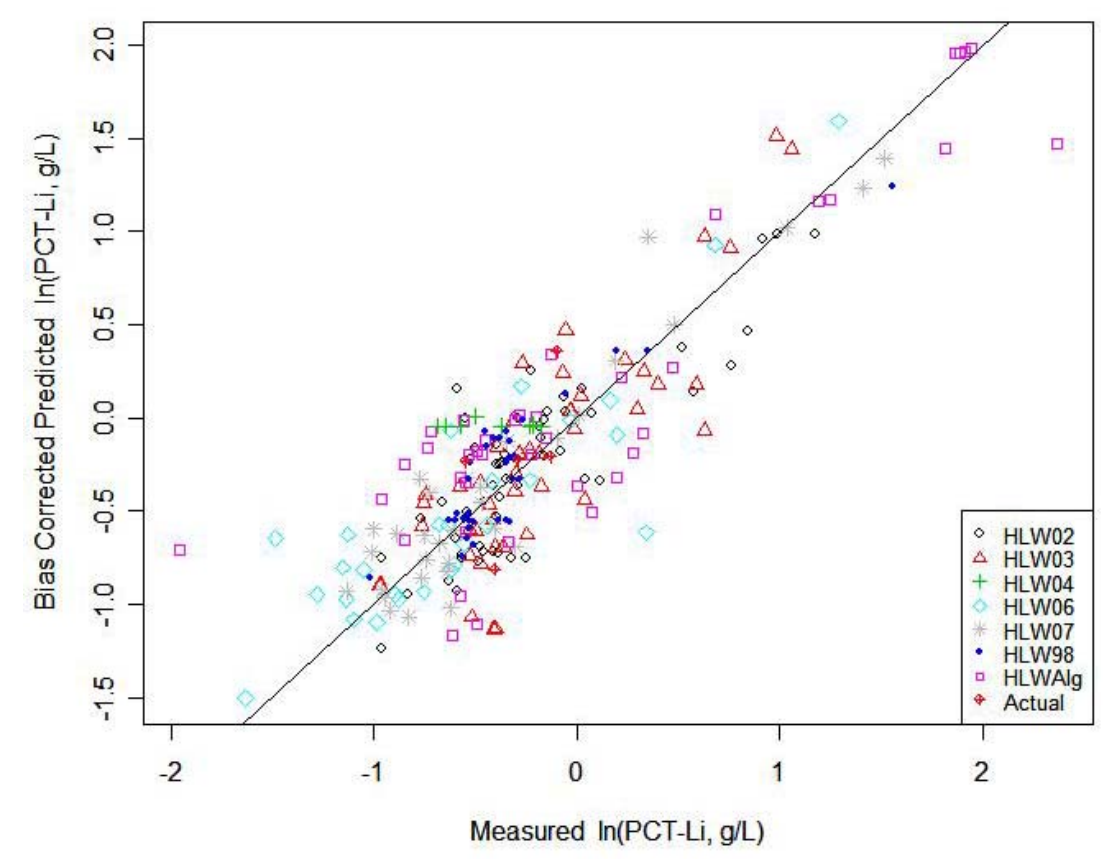

Figure 5.67. Predicted Versus Measured Plot for the Recommended 18-Term Partial Quadratic Mixture Model for PCT-Li Fitted to Data from 250 HLW Glasses, With Bias-Correction for Predicted Values Above $0.5 \ln (\mathrm{g} / \mathrm{L})$. Counting the bias-correction term, the model contains 19 terms.

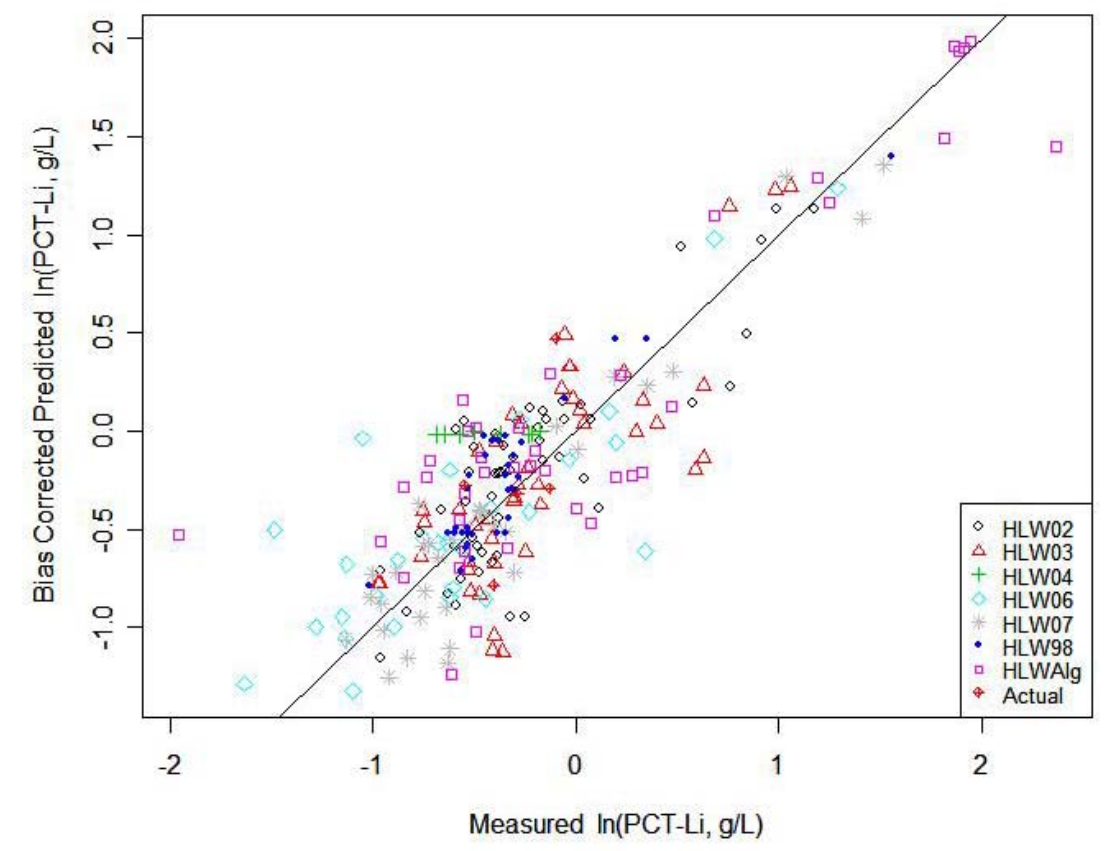

Figure 5.68. Predicted Versus Measured Plot for the Second-Choice 15-Term Partial Quadratic Mixture Model for PCT-Li Fitted to Data from 250 HLW Glasses, With Bias-Correction for Predicted Values Above $0.5 \ln (\mathrm{g} / \mathrm{L})$. Counting the bias-correction term, the model contains 16 terms. 


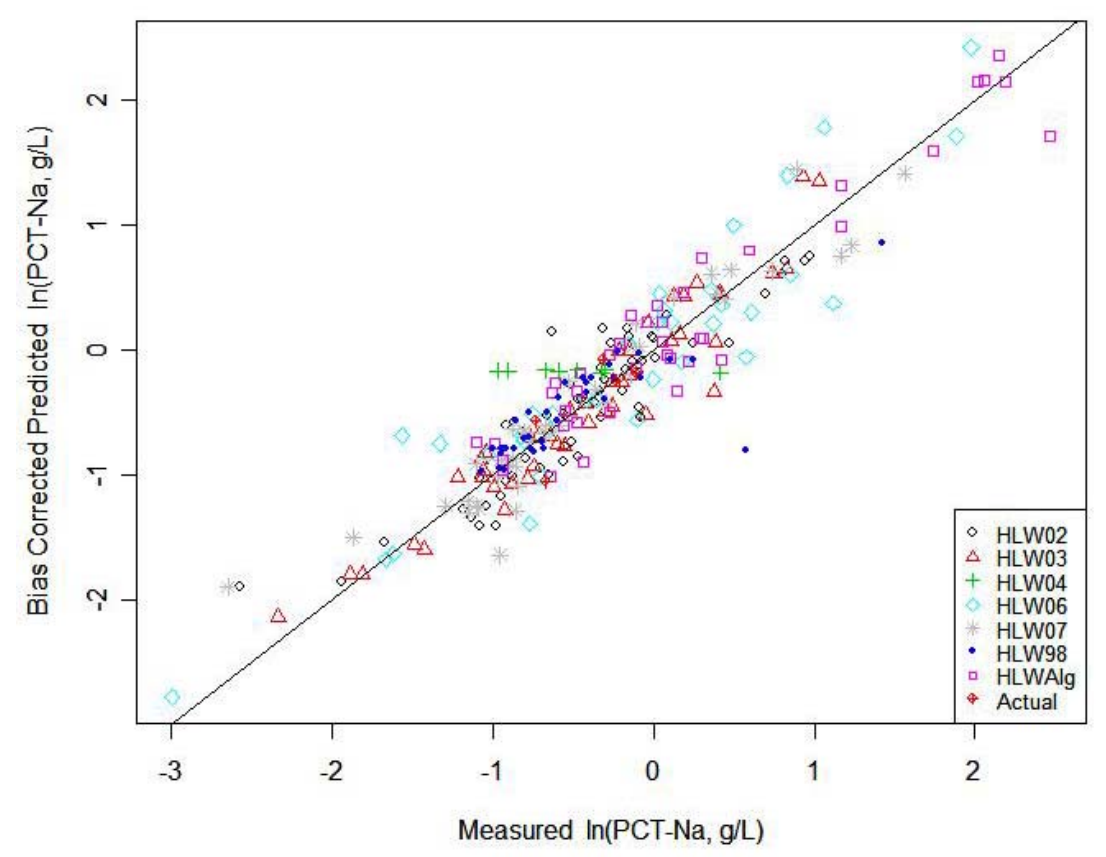

Figure 5.69. Predicted Versus Measured Plot for the Recommended 18-Term Partial Quadratic Mixture Model for PCT-Na Fitted to Data from 266 HLW Glasses, With Bias-Correction for Predicted Values Above $1.0 \ln (\mathrm{g} / \mathrm{L})$. Counting the bias-correction term, the model contains 19 terms.

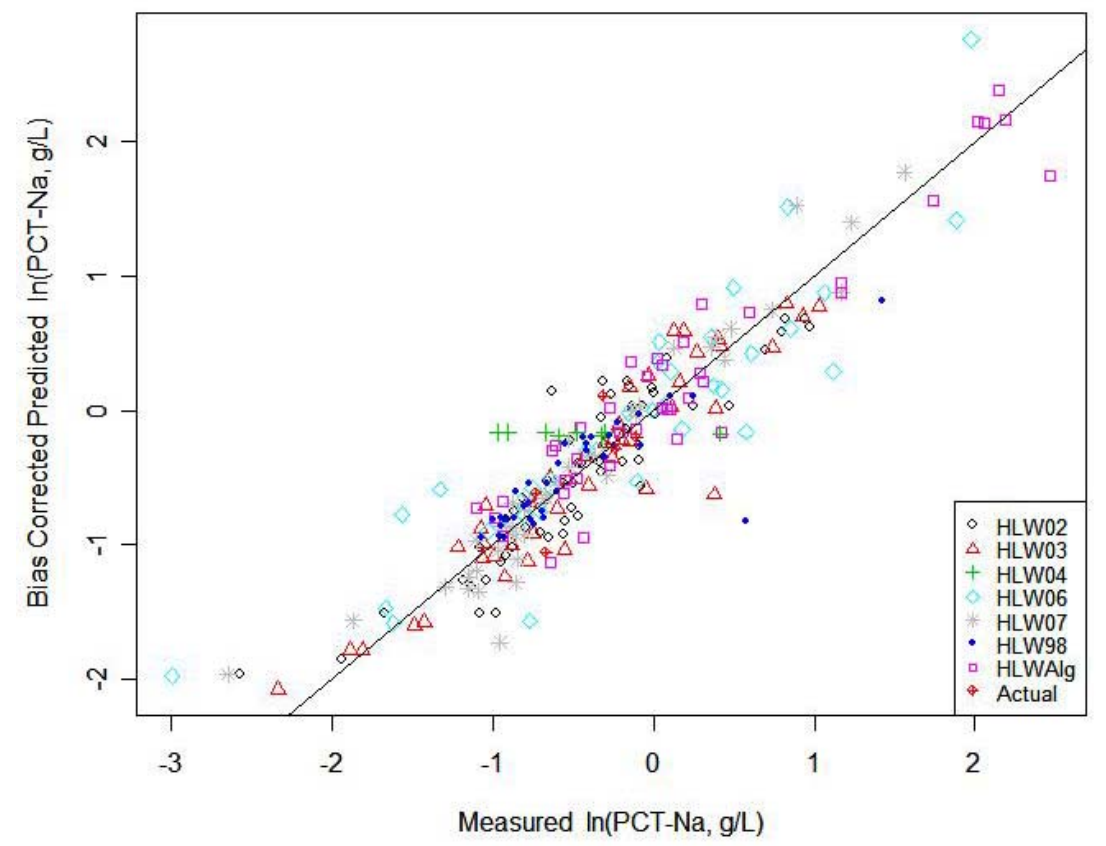

Figure 5.70. Predicted Versus Measured Plot for the Second-Choice 15-Term Partial Quadratic Mixture Model for PCT-Na Fitted to Data from 266 HLW Glasses, With Bias-Correction for Predicted Values Above $1.0 \ln (\mathrm{g} / \mathrm{L})$. Counting the bias-correction term, the model contains 16 terms. 


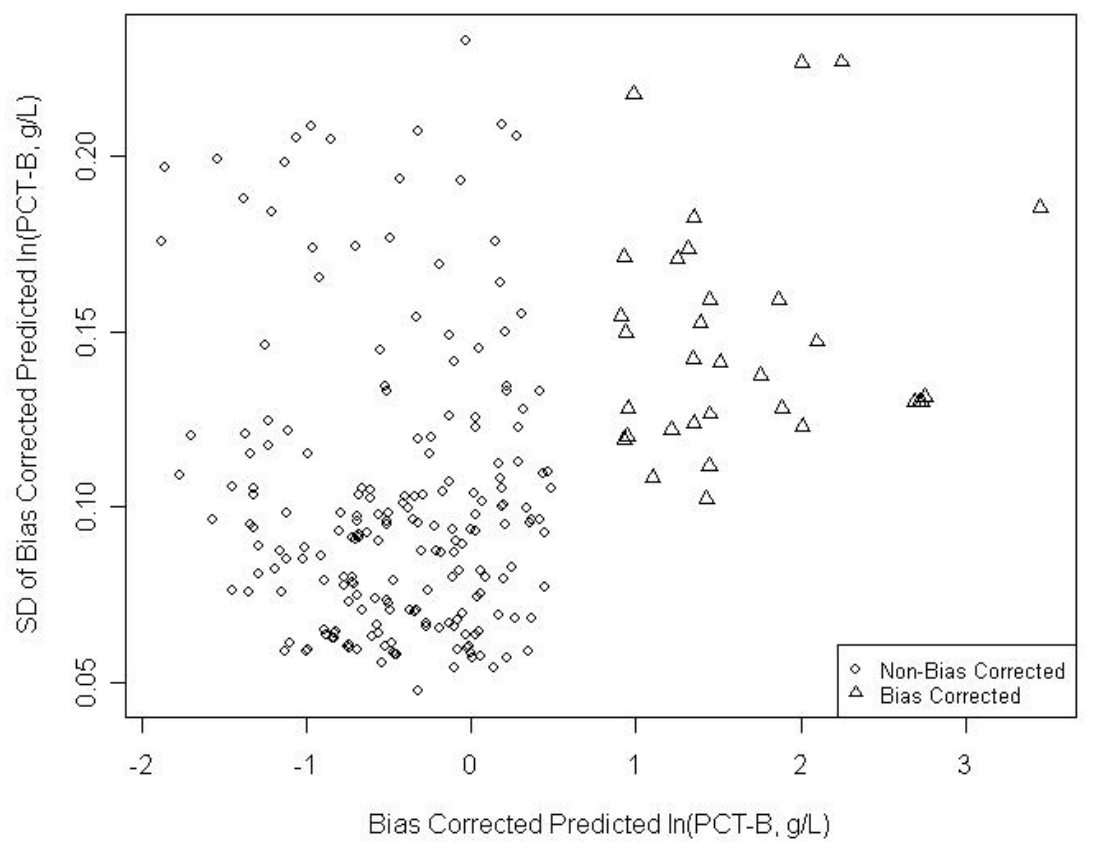

Figure 5.71. Standard Deviations of Predictions Considered as Mean Values versus Predicted Values over the HLW Glass Compositions in the PCT-B Modeling Dataset for the Recommended 19-Term Partial Quadratic Mixture Model with Bias-Correction Term.

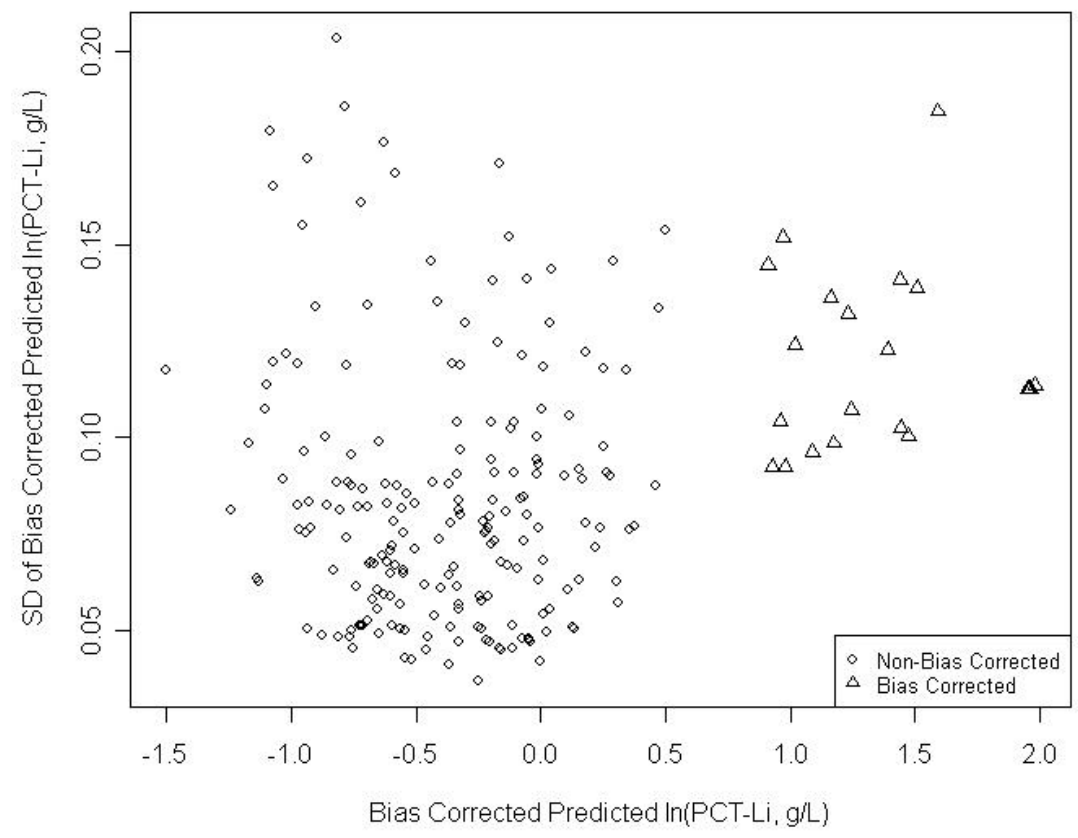

Figure 5.72. Standard Deviations of Predictions Considered as Mean Values versus Predicted Values over the HLW Glass Compositions in the PCT-Li Modeling Dataset for the Recommended 19-Term Partial Quadratic Mixture Model with Bias-Correction Term. 
The Catholic University of America Vitreous State Laboratory
IHLW PCT, Spinel $T_{1 \%}$, Electrical Conductivity, and Viscosity Model Development Final Report, VSL-07R1240-4, Rev. 0

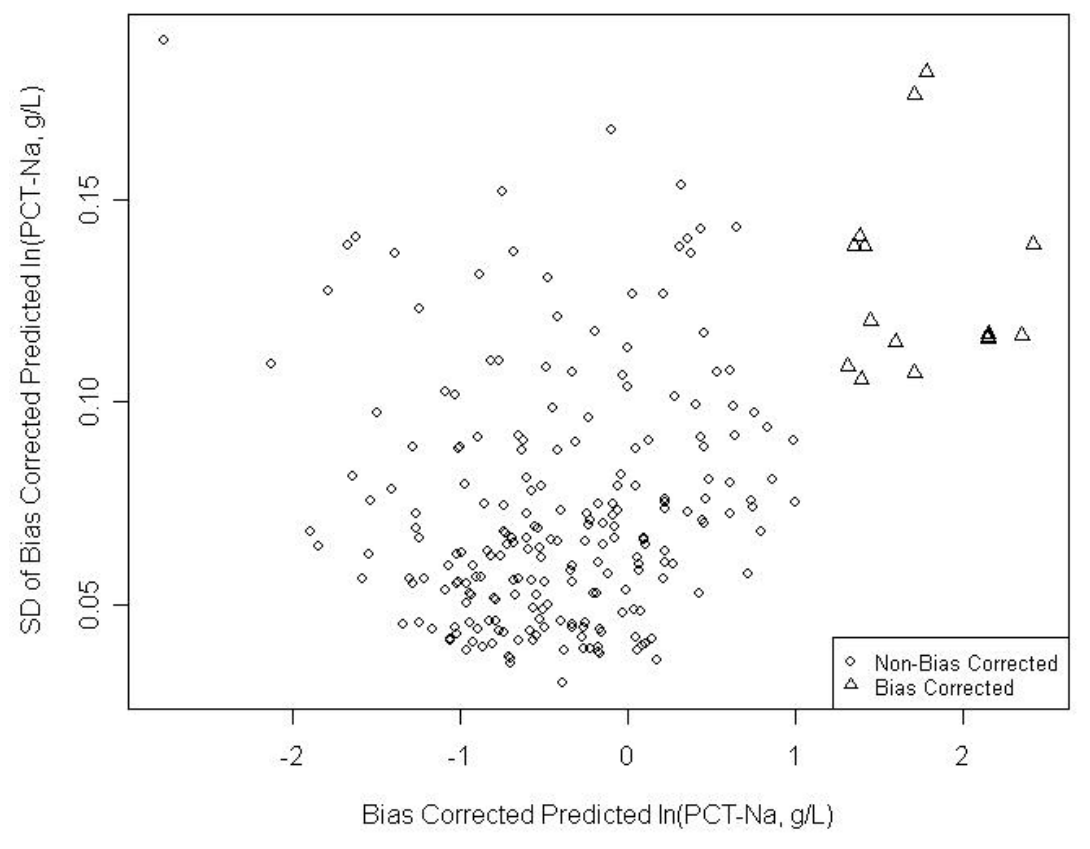

Figure 5.73. Standard Deviations of Predictions Considered as Mean Values versus Predicted Values over the HLW Glass Compositions in the PCT-Na Modeling Dataset for the Recommended 19-Term Partial Quadratic Mixture Model with Bias-Correction Term. 
The Catholic University of America Vitreous State Laboratory
IHLW PCT, Spinel $T_{1 \%}$, Electrical Conductivity, and Viscosity Model Development Final Report, VSL-07R1240-4, Rev. 0
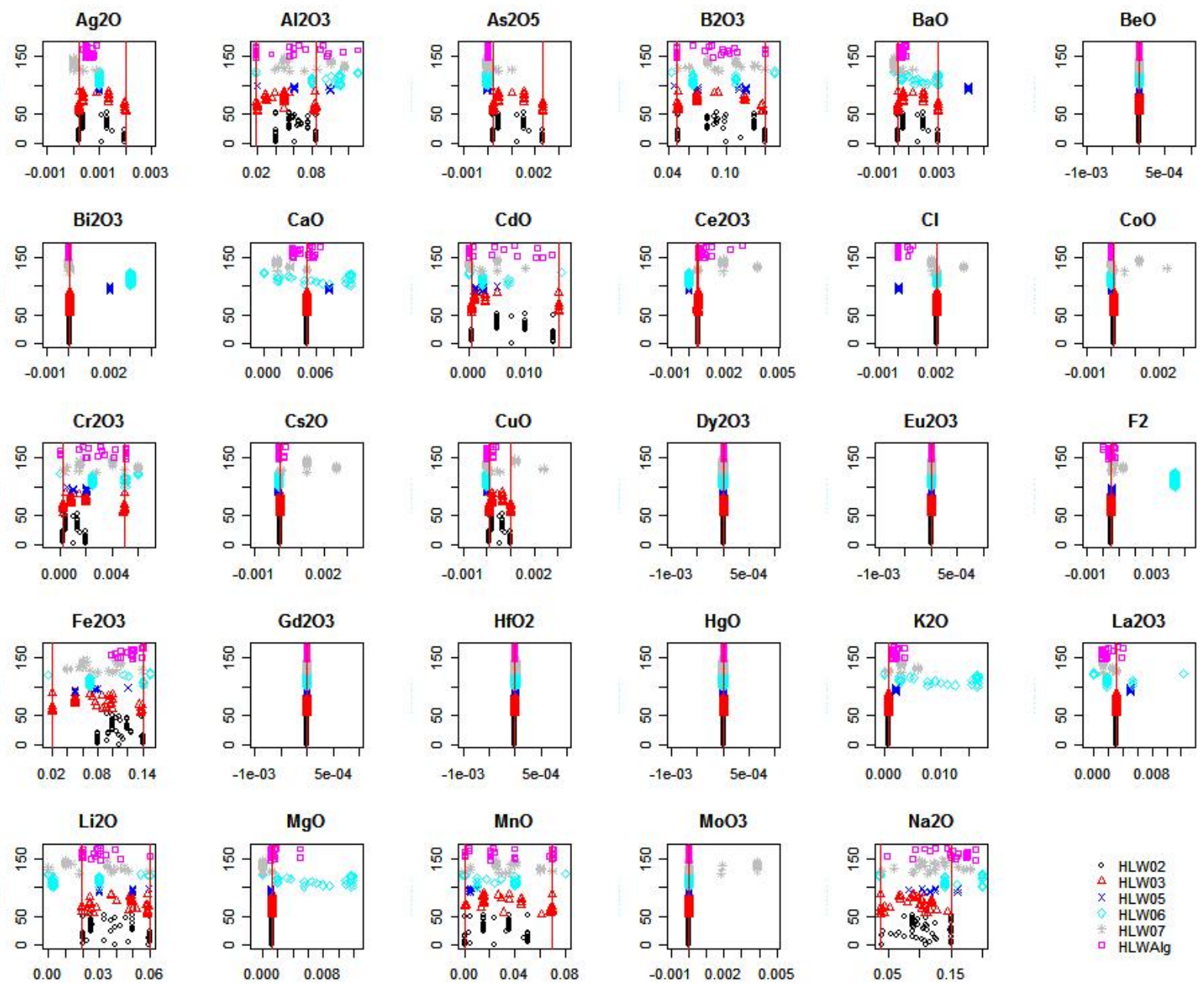

$$
\begin{array}{cc}
\circ & \text { HLW02 } \\
\triangle & H L W 03 \\
\times & H L W 05 \\
\nabla & \text { HLW06 } \\
* & \text { HLW07 } \\
\square & \text { HLWAlg }
\end{array}
$$

Figure 6.1. Ranges and Distributions of Component Mass Fractions (x-axes) for 169 HLW Glass Compositions with Spinel $\mathbf{T}_{1 \%}$ Values Judged Acceptable for Model Development. The vertical lines (when present) are the lower and upper limits for each component from the statistically designed glasses. 
The Catholic University of America Vitreous State Laboratory
IHLW PCT, Spinel $T_{1 \%}$, Electrical Conductivity, and Viscosity Model Development Final Report, VSL-07R1240-4, Rev. 0
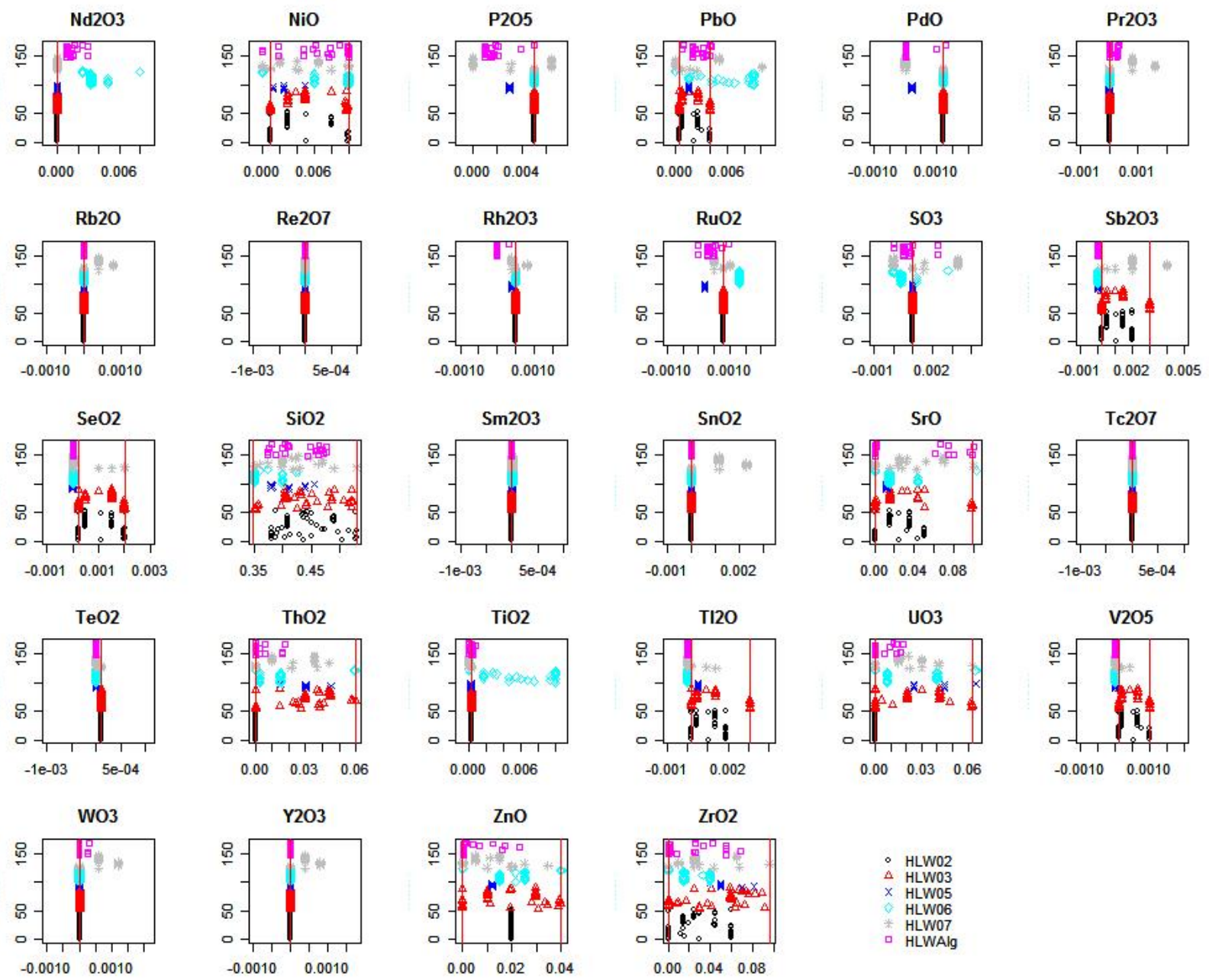

Figure 6.1. Ranges and Distributions of Component Mass Fractions (x-axes) for 169 HLW Glass Compositions with Spinel $\mathbf{T}_{1 \%}$ Values Judged Acceptable for Model Development. The vertical lines (when present) are the lower and upper limits for each component from statistically designed test matrices (continued). 
The Catholic University of America Vitreous State Laboratory
IHLW PCT, Spinel $T_{1 \%}$, Electrical Conductivity, and Viscosity Model Development Final Report, VSL-07R1240-4, Rev. 0
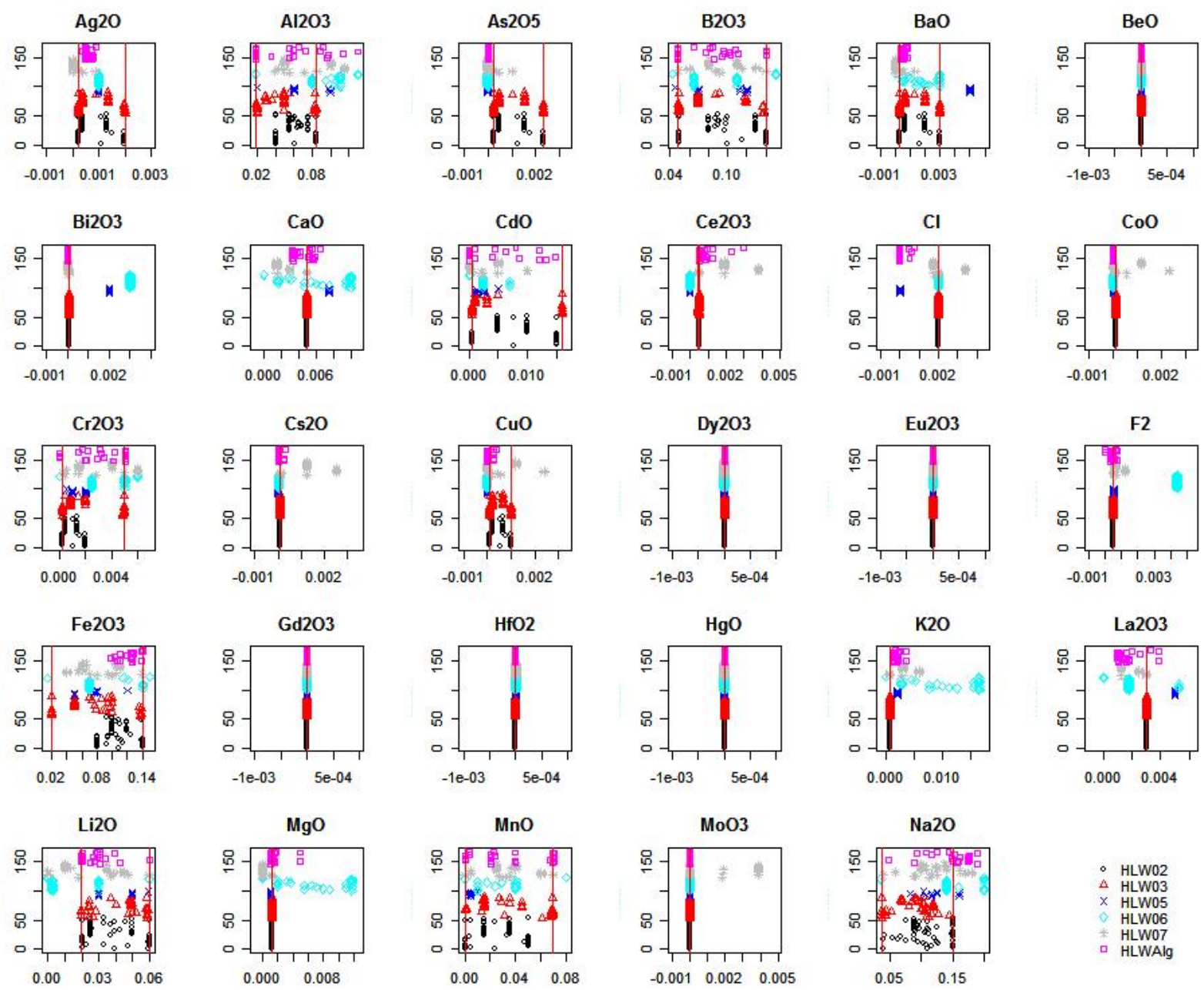

Figure 6.2. Ranges and Distributions of Component Mass Fractions (x-axes) for 168 HLW Glass Compositions with Spinel $\mathbf{T}_{1 \%}$ Values Selected for Model Development. The vertical lines (when present) are the lower and upper limits for each component from statistically designed test matrices. 
The Catholic University of America Vitreous State Laboratory
IHLW PCT, Spinel $T_{1 \%}$, Electrical Conductivity, and Viscosity Model Development Final Report, VSL-07R1240-4, Rev. 0
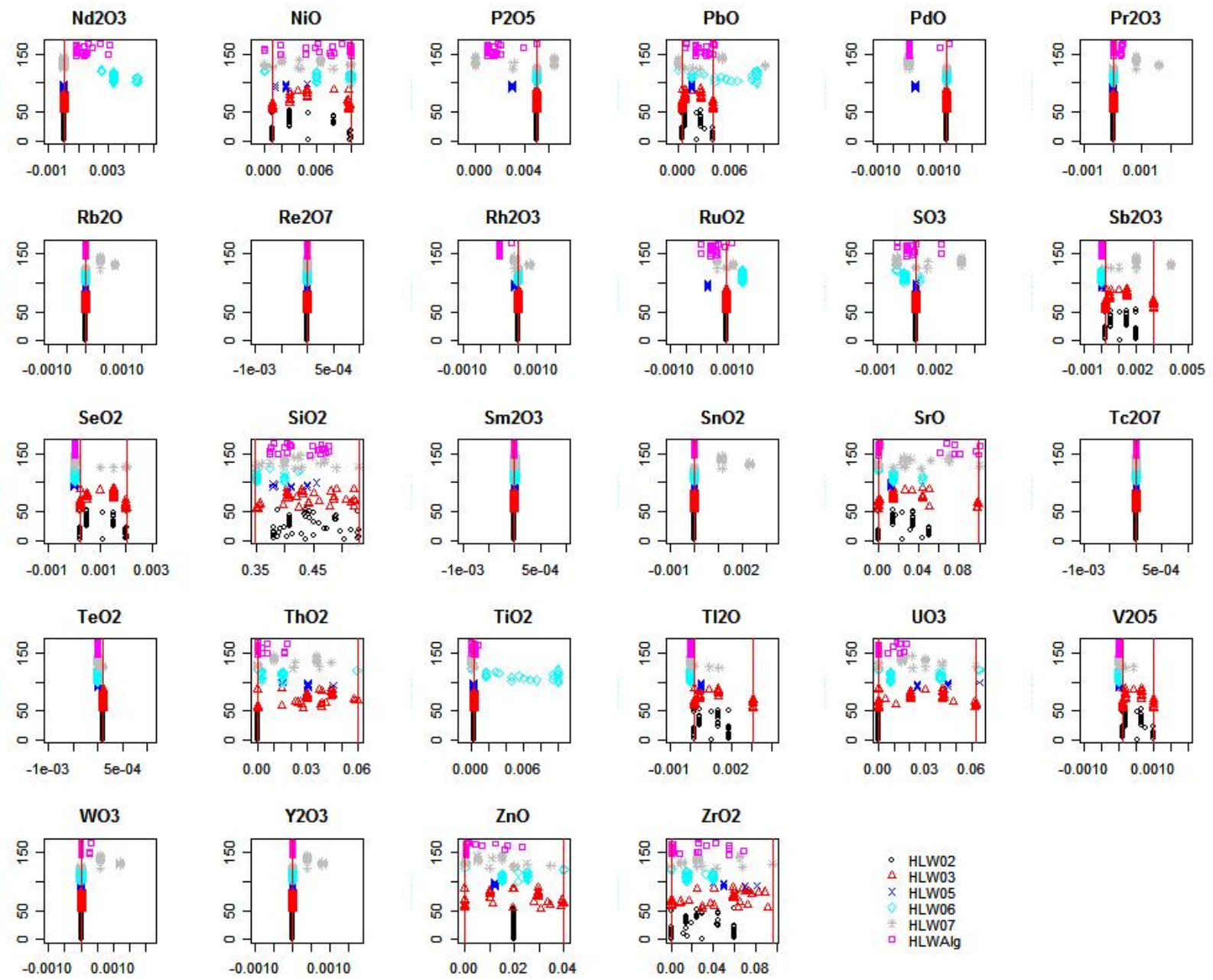

Figure 6.2. Ranges and Distributions of Component Mass Fractions (x-axes) for $168 \mathrm{HLW}$ Glass Compositions with Spinel $\mathbf{T}_{1 \%}$ Values Selected for Model Development. The vertical lines (when present) are the lower and upper limits for each component from the statistically designed test matrices (continued). 


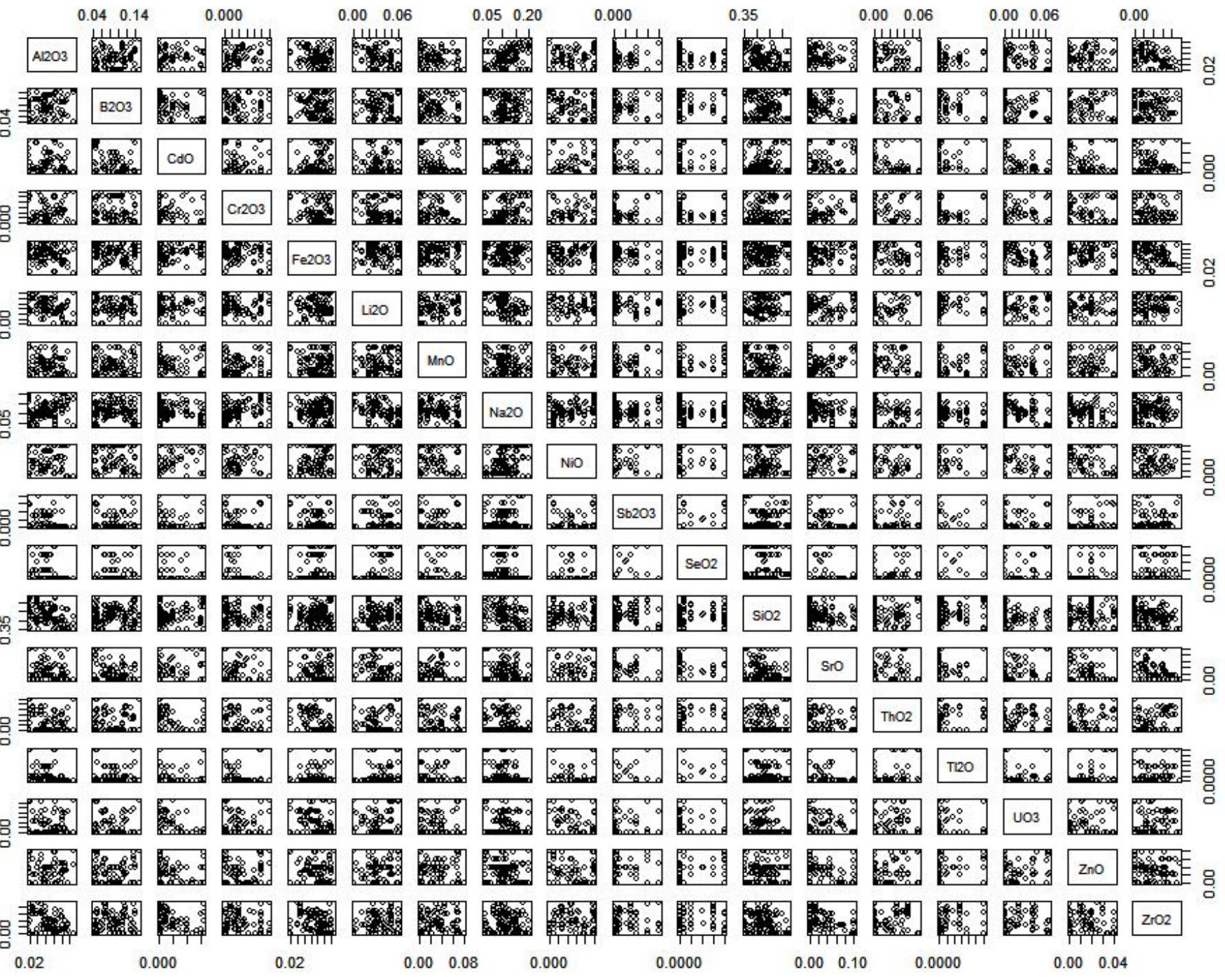

Figure 6.3. Scatterplot Matrix of 18 Components (mass fractions) for $168 \mathrm{HLW}$ Glasses with Spinel $\mathrm{T}_{1 \%}$ Data. 
The Catholic University of America Vitreous State Laboratory
IHLW PCT, Spinel $T_{1 \%}$, Electrical Conductivity, and Viscosity Model Development Final Report, VSL-07R1240-4, Rev. 0

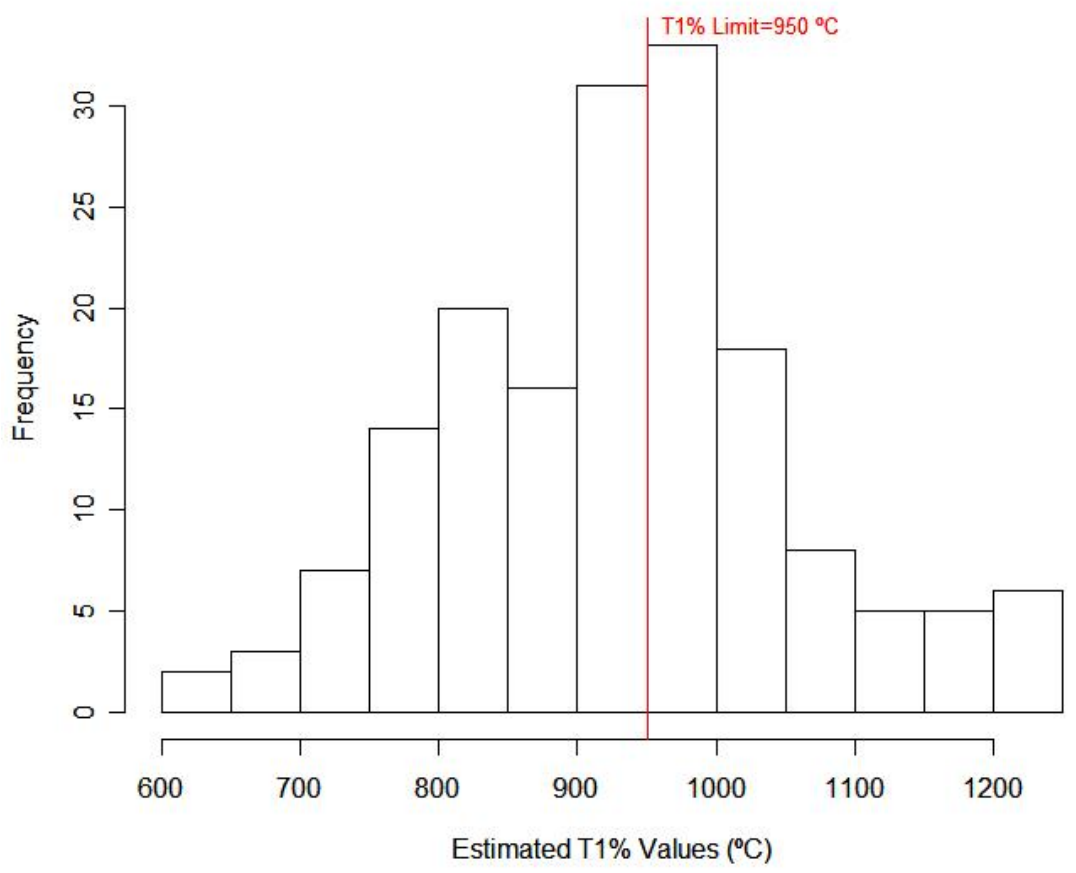

Figure 6.4. Histogram of Estimated Spinel $T_{1 \%}$ Values for 168 Model Development Glasses.

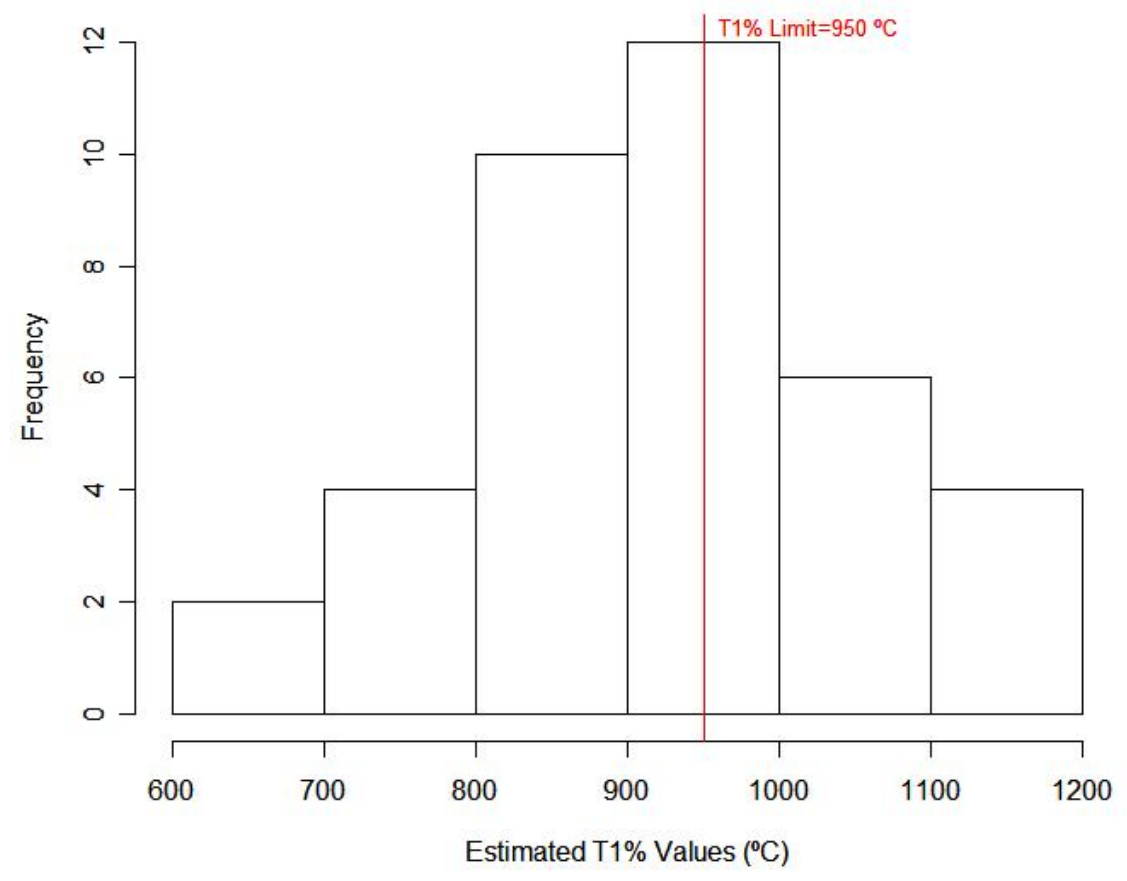

Figure 6.5. Histogram of Estimated Spinel $T_{1 \%}$ Values for 38 Validation Glasses. 
The Catholic University of America Vitreous State Laboratory
IHLW PCT, Spinel $T_{1 \%}$, Electrical Conductivity, and Viscosity Model Development Final Report, VSL-07R1240-4, Rev. 0

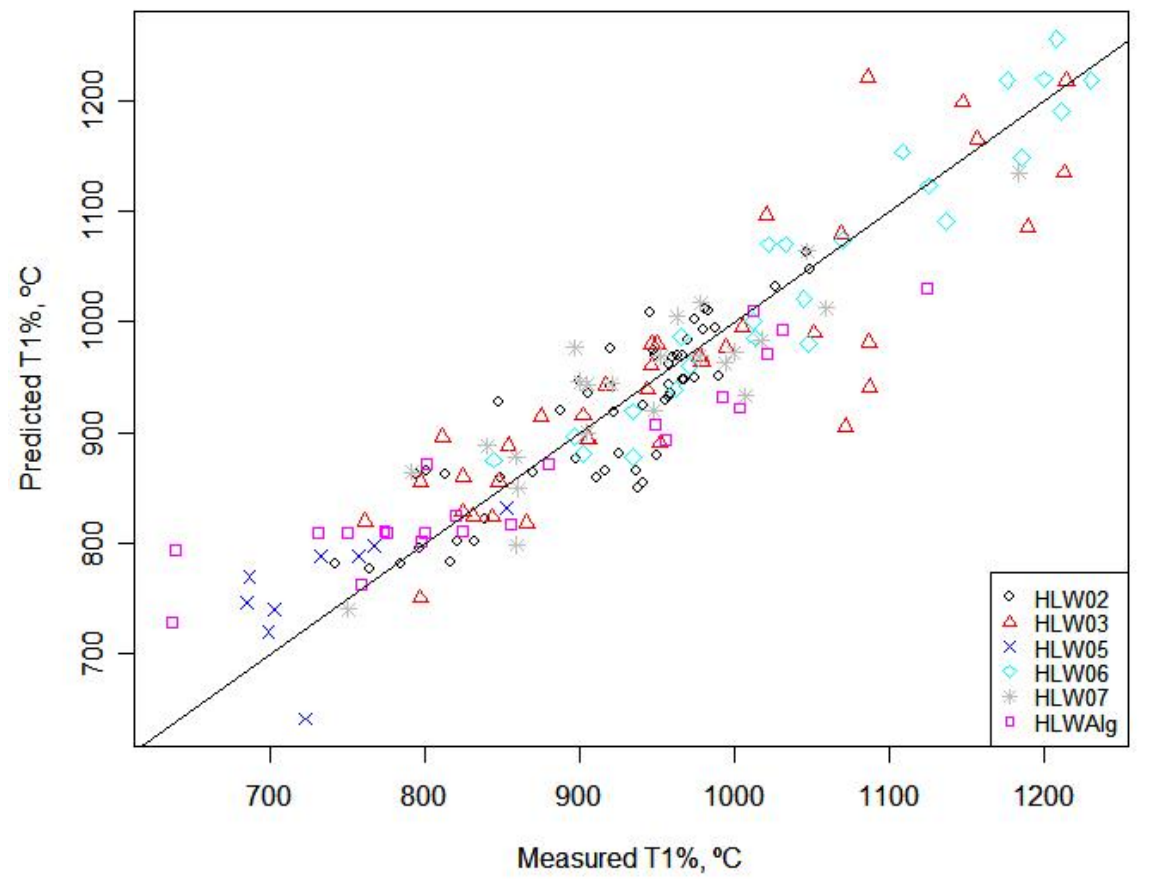

Figure 6.6. Predicted Versus Measured Plot for the 25-Component Full Linear Mixture Model for Spinel $\mathrm{T}_{1 \%}$ Fitted to Data from $168 \mathrm{HLW}$ Glasses.

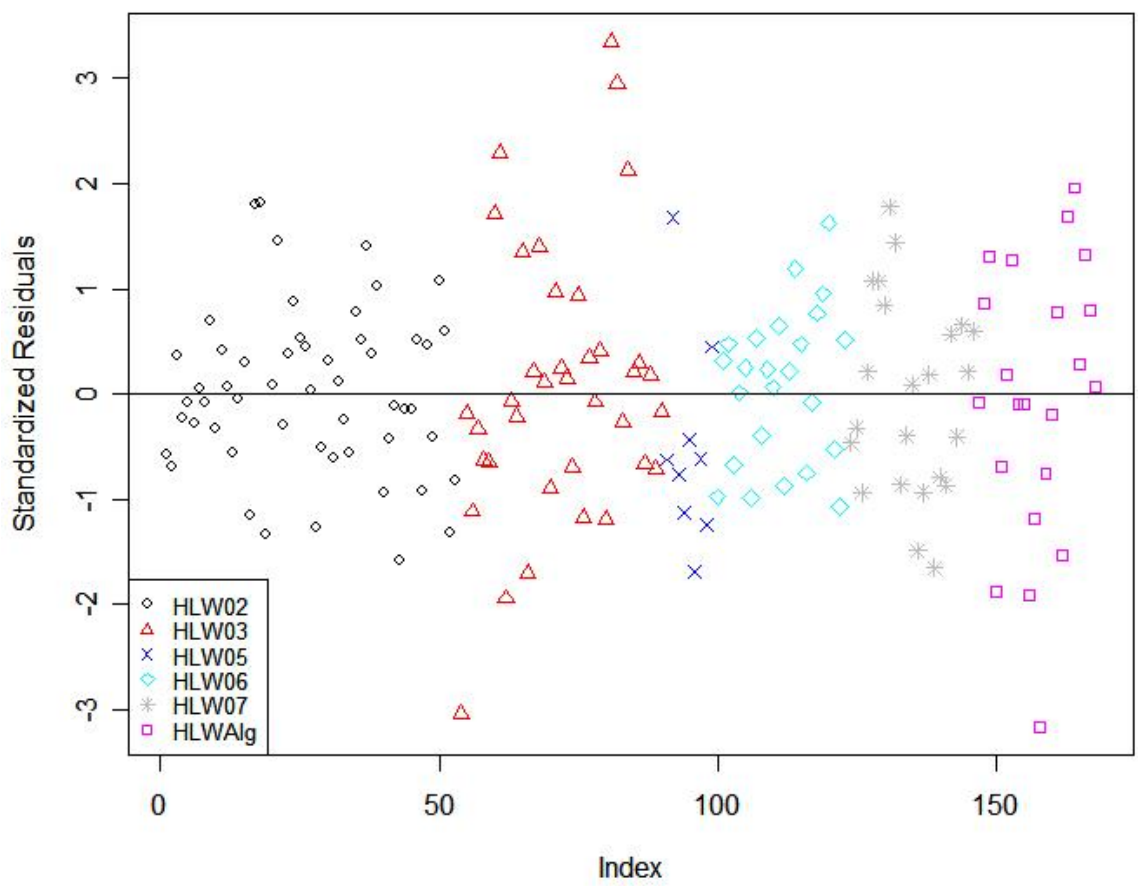

Figure 6.7. Standardized Residuals Plot for the 25-Component Full Linear Mixture Model for Spinel $\mathbf{T}_{1 \%}$ Fitted to Data from 168 HLW Glasses. 


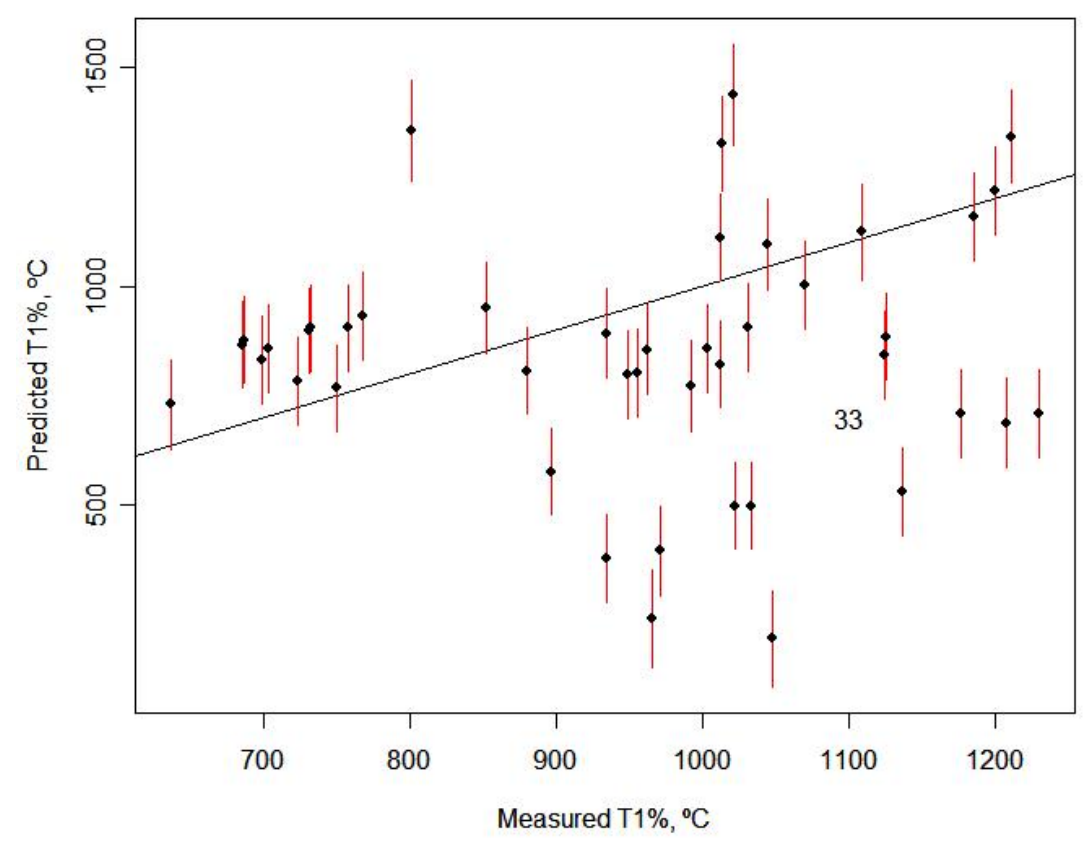

Figure 6.8. Predicted Versus Measured Plot for the 25-Component Full Linear Mixture Model on IHLW Spinel $T_{1 \%}$ Fitted to the Data-Partition Modeling Subset of 124 Glasses and Applied to the Validation Subset of 44 Glasses. Error bars are 95\% prediction intervals (PIs). The number of glasses whose $95 \%$ PIs do not include the measured values (represented by the $45^{\circ}$ line) is shown.

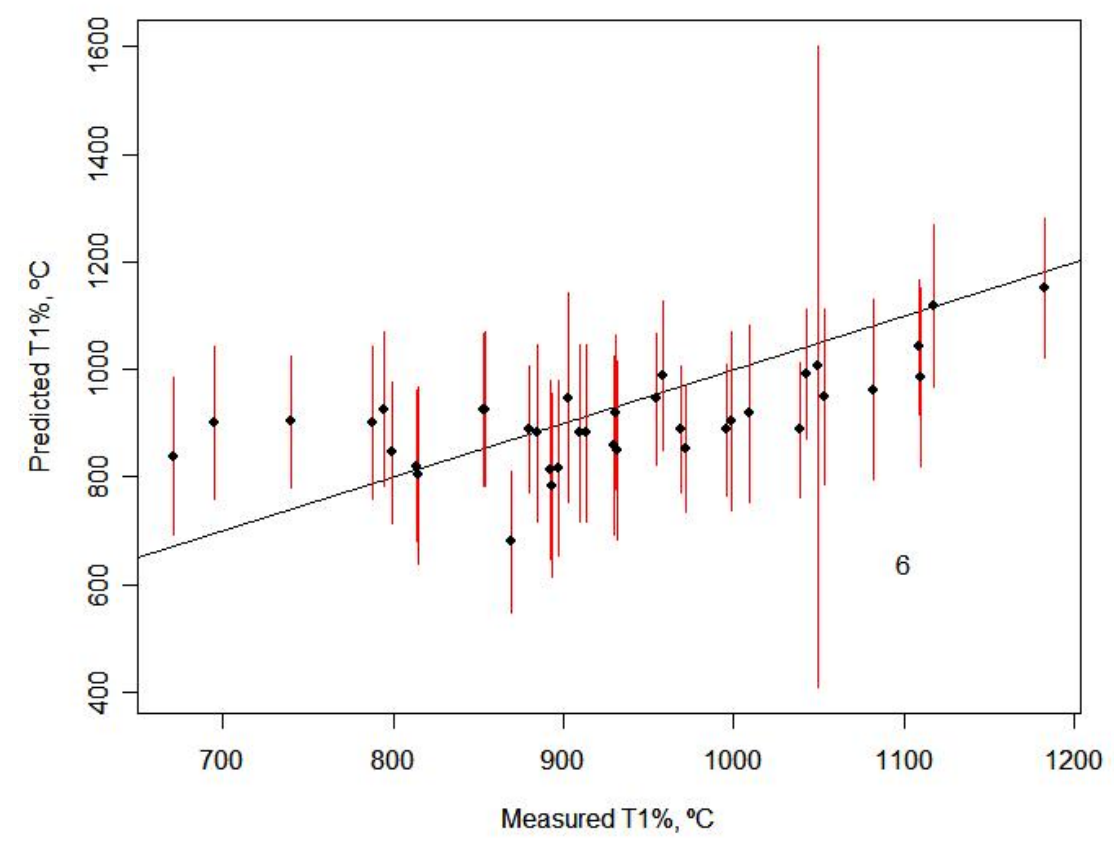

Figure 6.9. $\quad$ Predicted Versus Measured Plot for the 25-Component Full Linear Mixture Model for Spinel $\mathbf{T}_{\mathbf{1}}$ Applied to the 38-Glass Separate Validation Set. Error bars are $95 \%$ prediction intervals (PIs). The number of glasses whose $95 \%$ PIs do not include the measured values (represented by the $45^{\circ}$ line) is shown. 
The Catholic University of America Vitreous State Laboratory
IHLW PCT, Spinel $T_{1 \%}$, Electrical Conductivity, and Viscosity Model Development Final Report, VSL-07R1240-4, Rev. 0

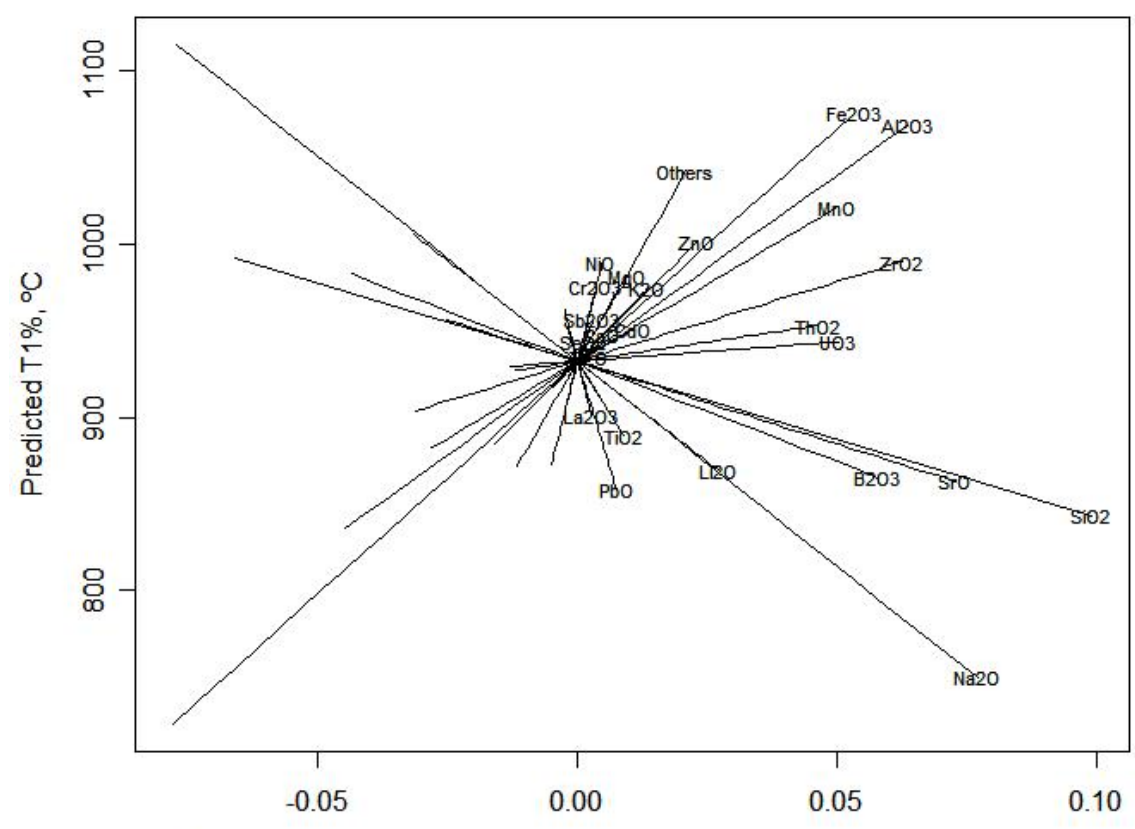

Difference in Component Normalized Mass Fraction from Centroid Composition

Figure 6.10. Response Trace Plot for the 25-Component Full Linear Mixture Model for Spinel $\mathrm{T}_{1 \%}$ Fitted to Data from 168 HLW Glasses.

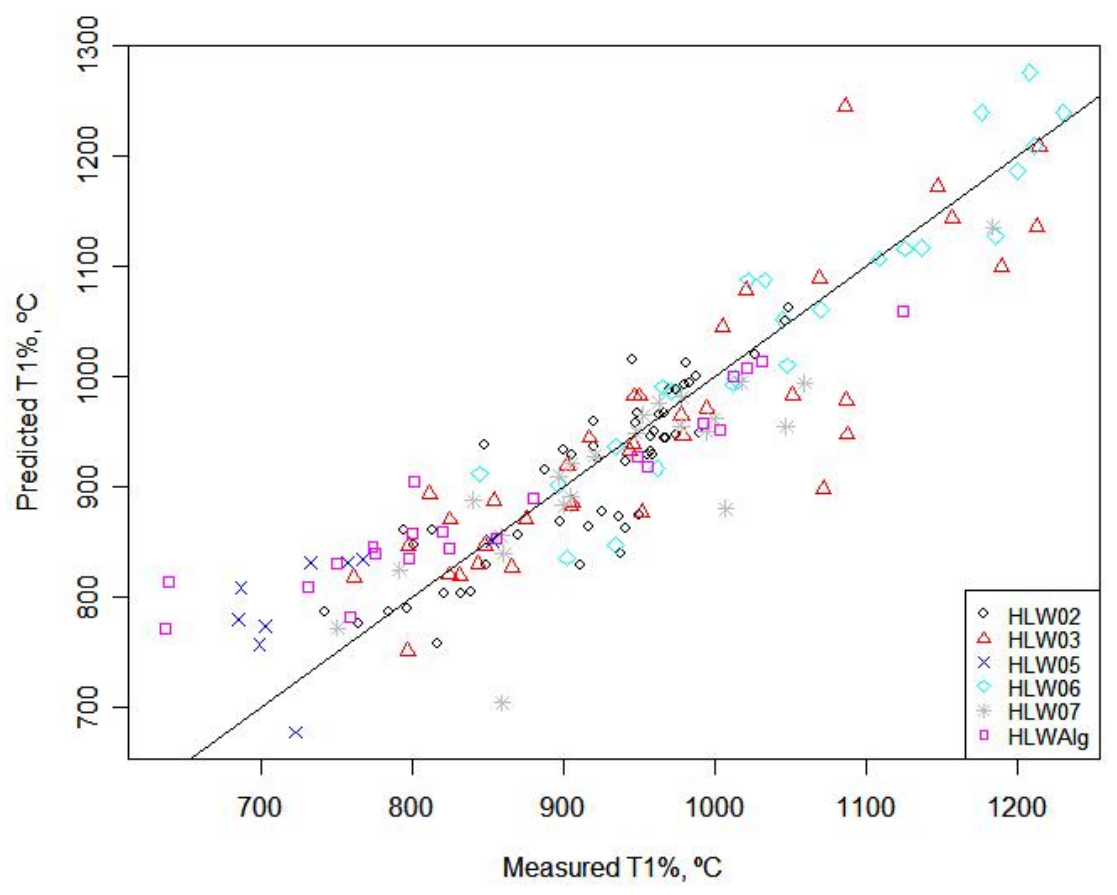

Figure 6.11. Predicted Versus Measured Plot for the 15-Component Reduced Linear Mixture Model for Spinel $T_{1 \%}$ Fitted to Data from 168 HLW Glasses. 
The Catholic University of America Vitreous State Laboratory
IHLW PCT, Spinel $T_{1 \%}$, Electrical Conductivity, and Viscosity Model Development Final Report, VSL-07R1240-4, Rev. 0

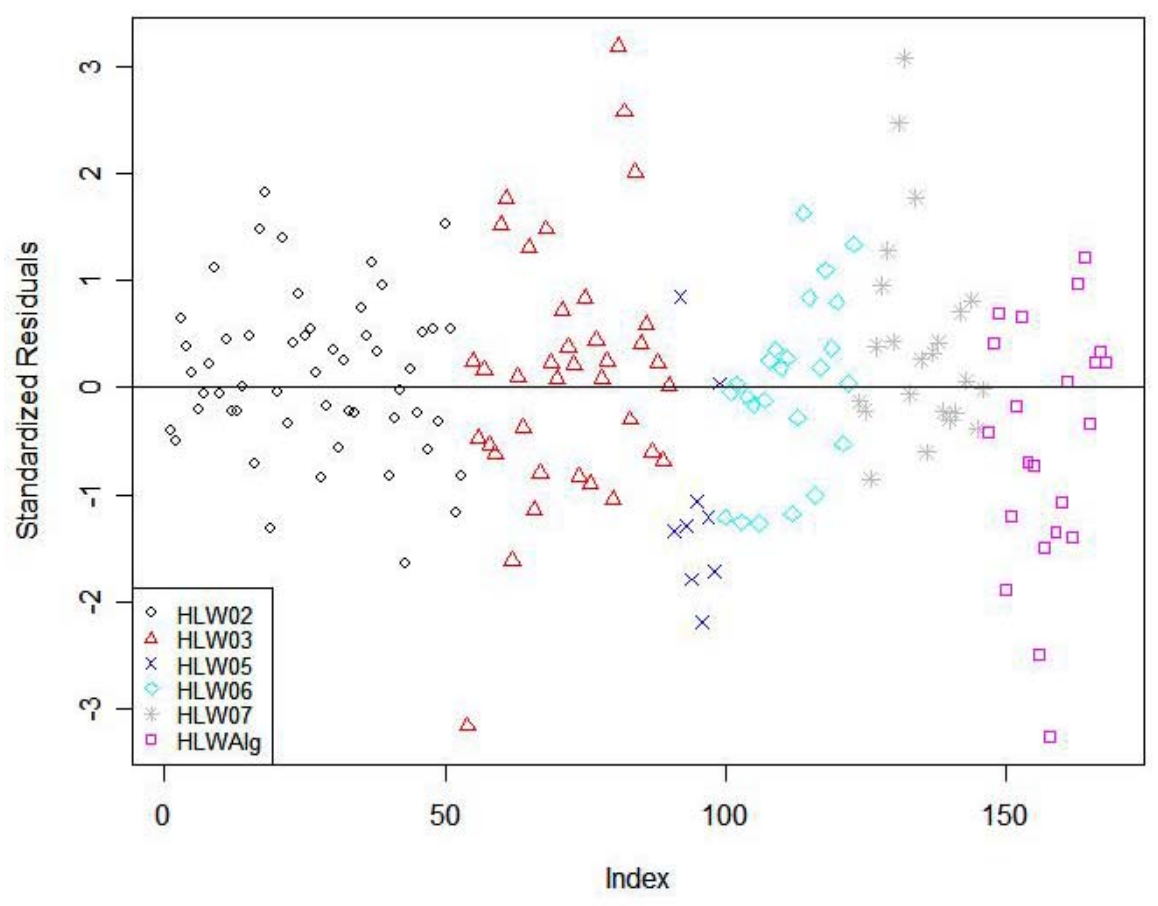

Figure 6.12. Standardized Residuals Plot for the 15-Component Reduced Linear Mixture Model for Spinel $\mathrm{T}_{1 \%}$ Fitted to Data from $168 \mathrm{HLW}$ Glasses.

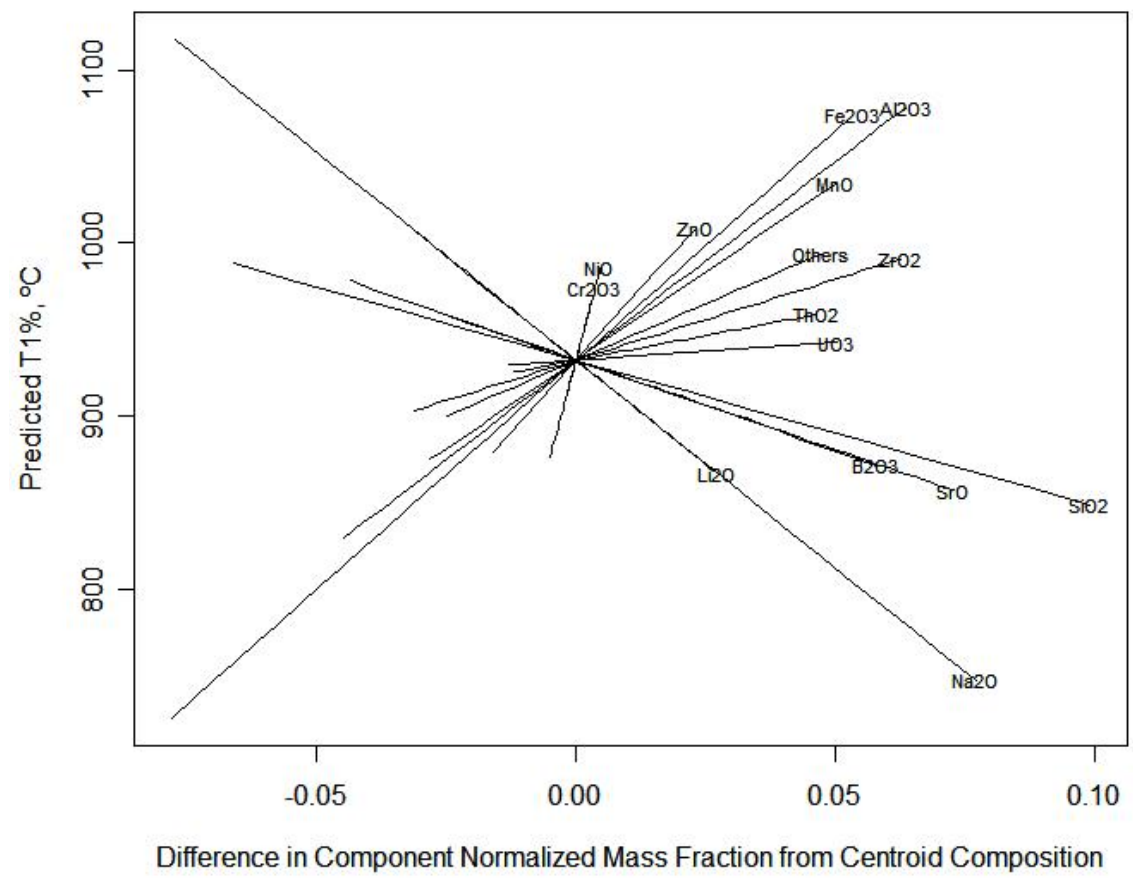

Figure 6.13. Response Trace Plot for the 15-Component Reduced Linear Mixture Model for Spinel $\mathbf{T}_{\mathbf{1} \%}$ Fitted to Data from $168 \mathrm{HLW}$ Glasses. 


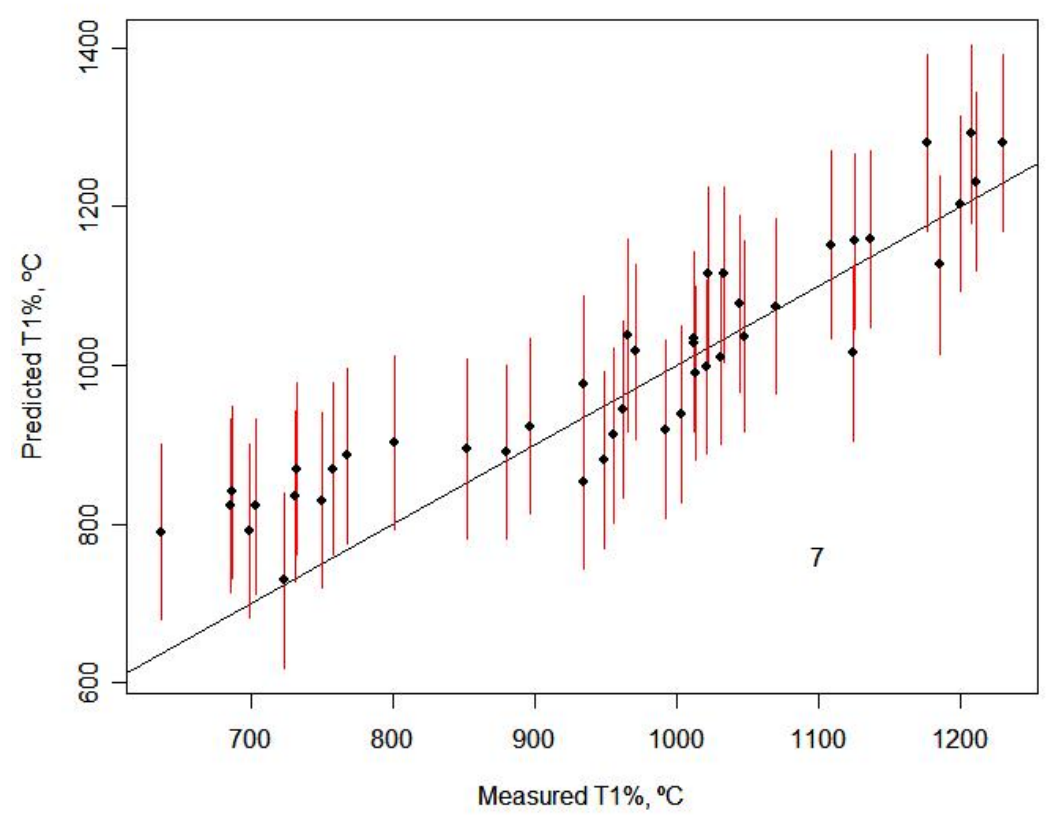

Figure 6.14. Predicted Versus Measured Plot for the 15-Component Reduced Linear Mixture Model on IHLW Spinel $\mathbf{T}_{1 \%}$ Fitted to the Data-Partition Modeling Subset of 124 Glasses and Applied to the Validation Subset of 44 Glasses. Error bars are $95 \%$ prediction intervals (PIs). The number of glasses whose 95\% PIs do not include the measured values (represented by the $45^{\circ}$ line) is shown.

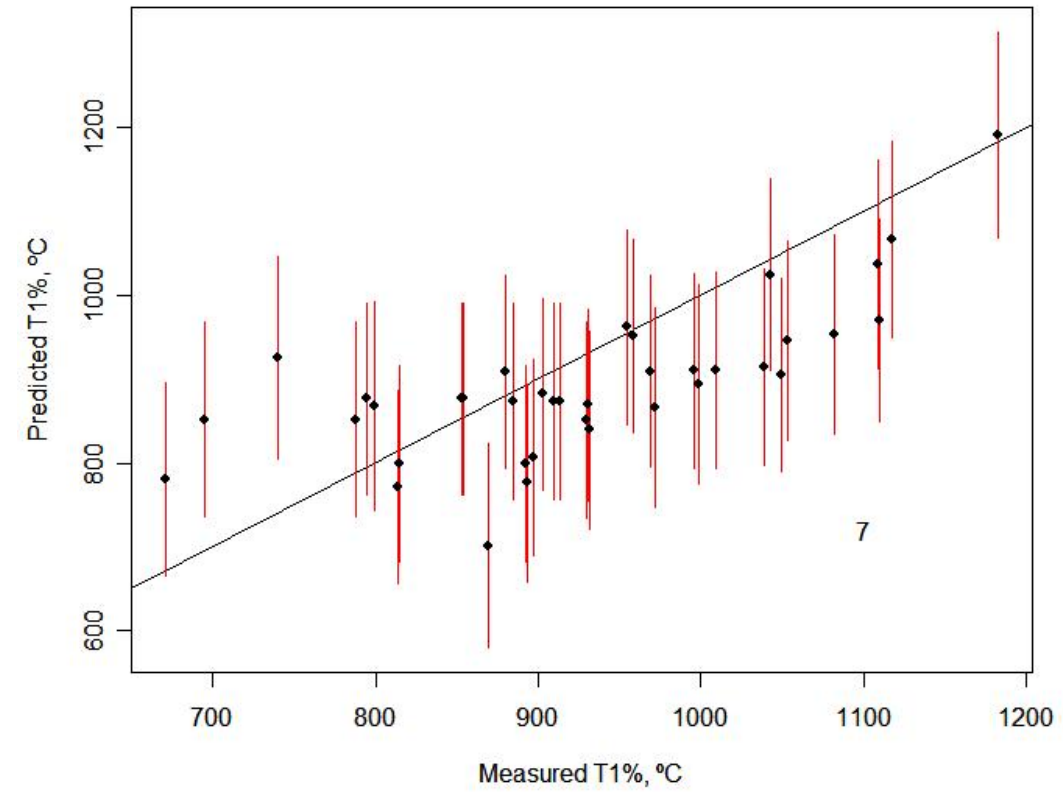

Figure 6.15. Predicted Versus Measured Plot for the 15-Component Reduced Linear Mixture Model for Spinel $\mathbf{T}_{1 \%}$ Applied to the 38-Glass Separate Validation Set. Error bars are $\mathbf{9 5 \%}$ prediction intervals (PIs). The number of glasses whose $95 \%$ PIs do not include the measured values (represented by the $45^{\circ}$ line) is shown. 
The Catholic University of America Vitreous State Laboratory
IHLW PCT, Spinel $T_{1 \%}$, Electrical Conductivity, and Viscosity Model Development Final Report, VSL-07R1240-4, Rev. 0

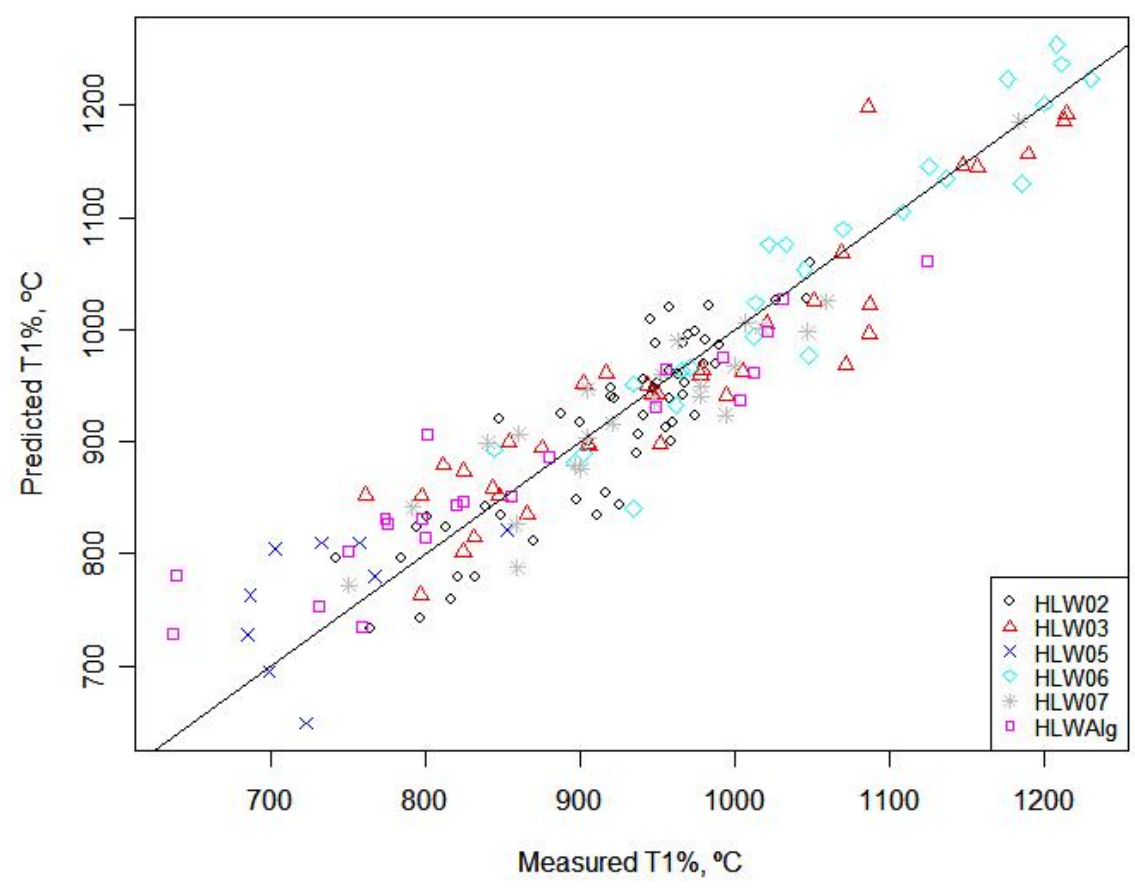

Figure 6.16. Predicted Versus Measured Plot for the 20-Term Partial Quadratic Mixture Model (PQM1a) for Spinel $\mathrm{T}_{1 \%}$ Fitted to Data from 168 HLW Glasses.

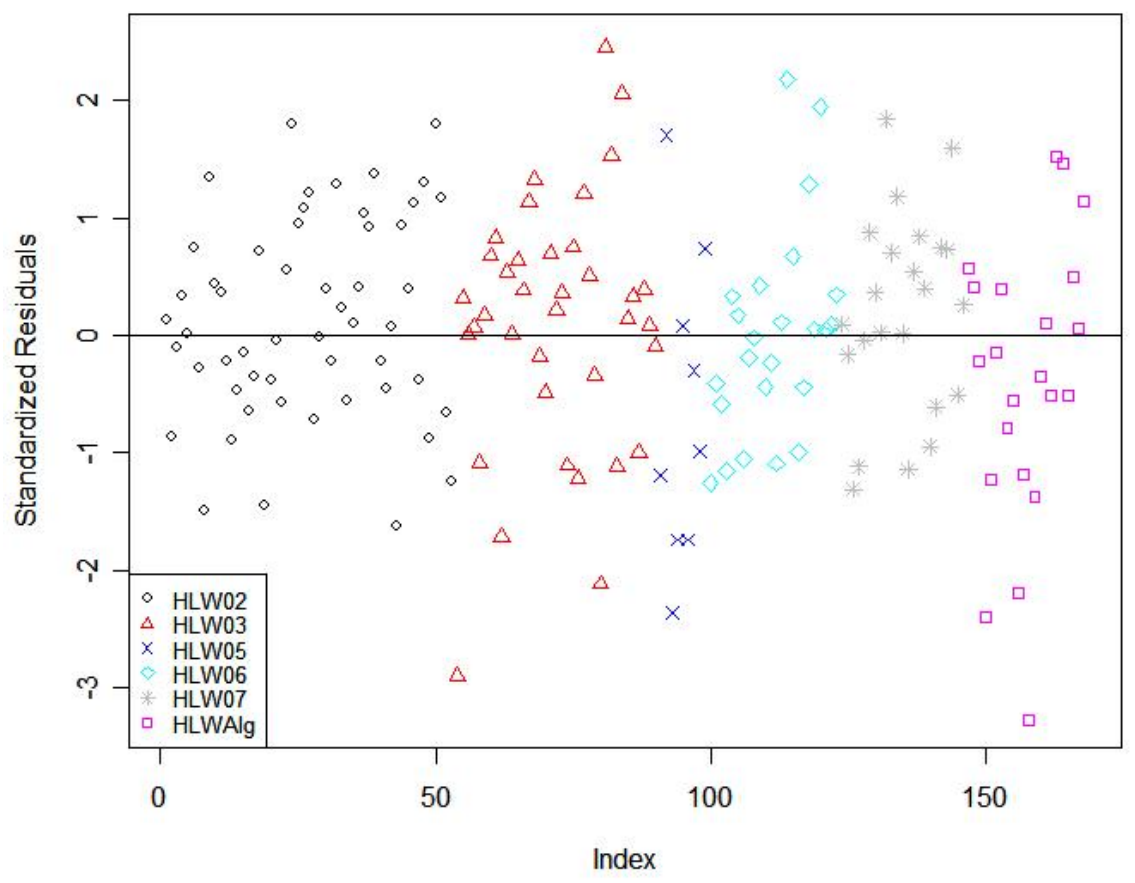

Figure 6.17. Standardized Residuals Plot for the 20-Term Partial Quadratic Mixture Model (PQM1a) for Spinel $\mathrm{T}_{1 \%}$ Fitted to Data from $168 \mathrm{HLW}$ Glasses. 


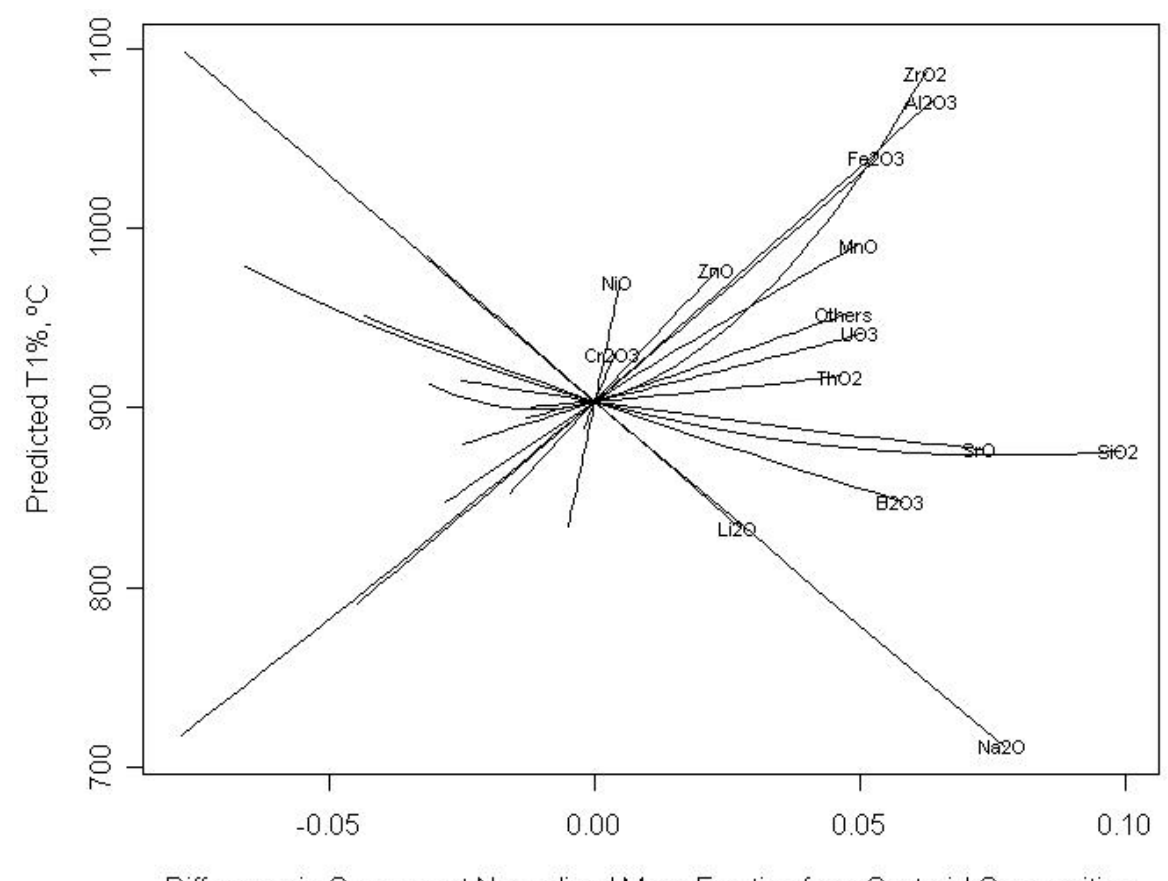

Difference in Component Normalized Mass Fraction from Centroid Composition

Figure 6.18. Response Trace Plot for the 20-Term Partial Quadratic Mixture Model (PQM1a) for Spinel $T_{1 \%}$ Fitted to Data from 168 HLW Glasses.

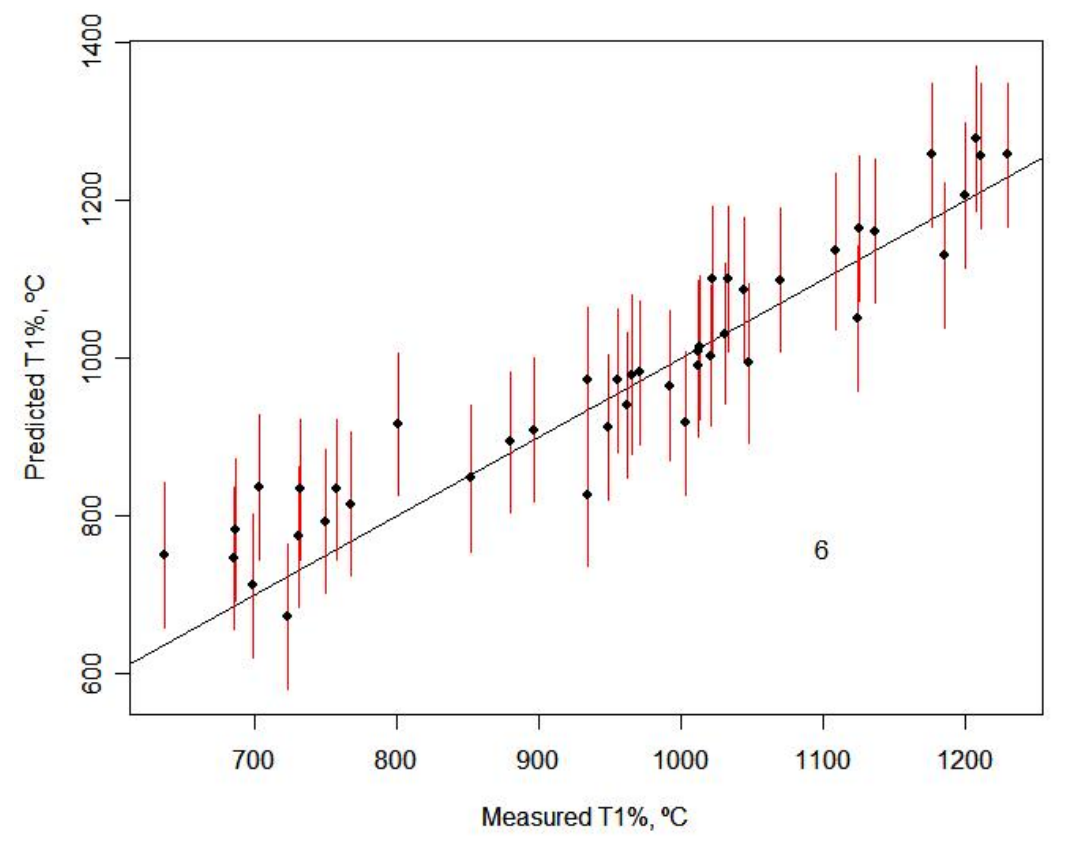

Figure 6.19. Predicted Versus Measured Plot for the 20-Term Partial Quadratic Mixture Model (PQM1a) on IHLW Spinel $\mathbf{T}_{1 \%}$ Fitted to the Data-Partition Modeling Subset of 124 Glasses and Applied to the Validation Subset of 44 Glasses. Error bars are $95 \%$ prediction intervals (PIs). The number of glasses whose 95\% PIs do not include the measured values (represented by the $45^{\circ}$ line) is shown. 


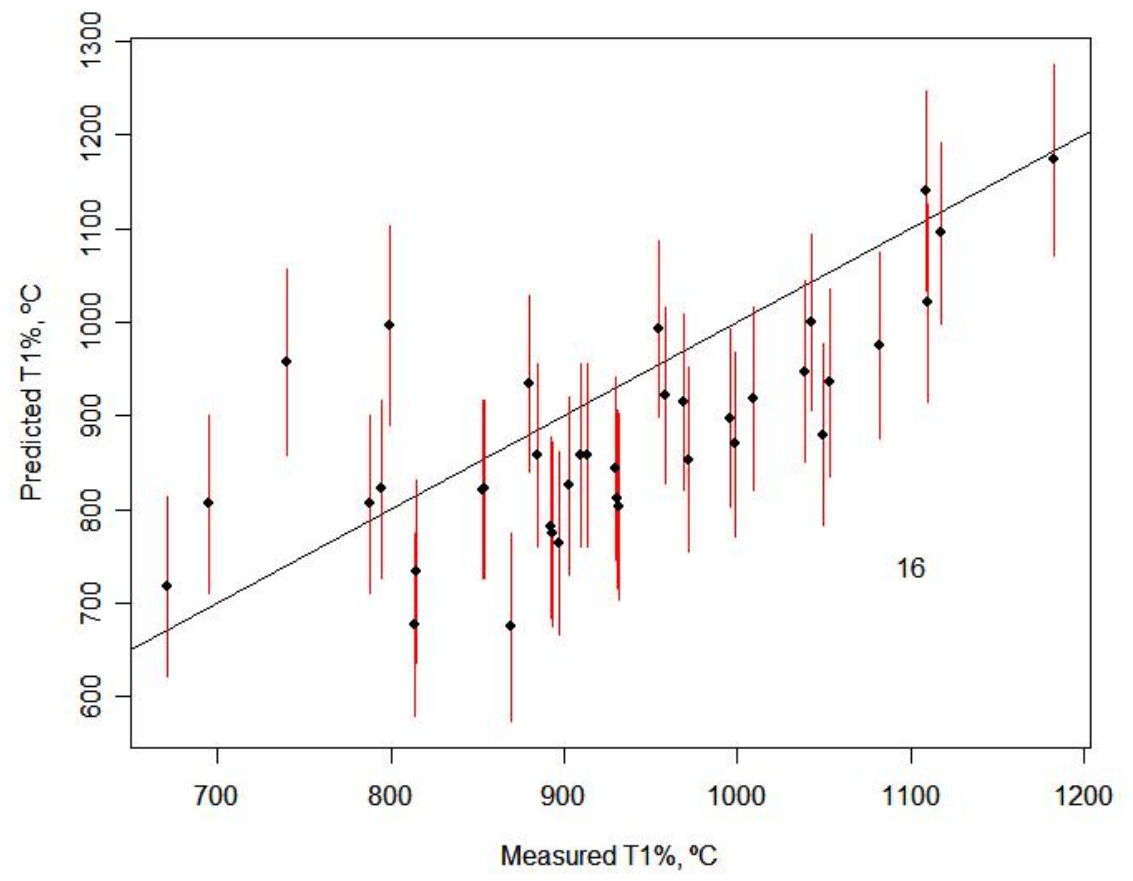

Figure 6.20. Predicted Versus Measured Plot for the 20-Term Partial Quadratic Mixture Model (PQM1a) for Spinel $T_{1 \%}$ Applied to the 38-Glass Separate Validation Set. Error bars are $95 \%$ prediction intervals (PIs). The number of glasses whose $95 \%$ PIs do not include the measured values (represented by the $45^{\circ}$ line) is shown.

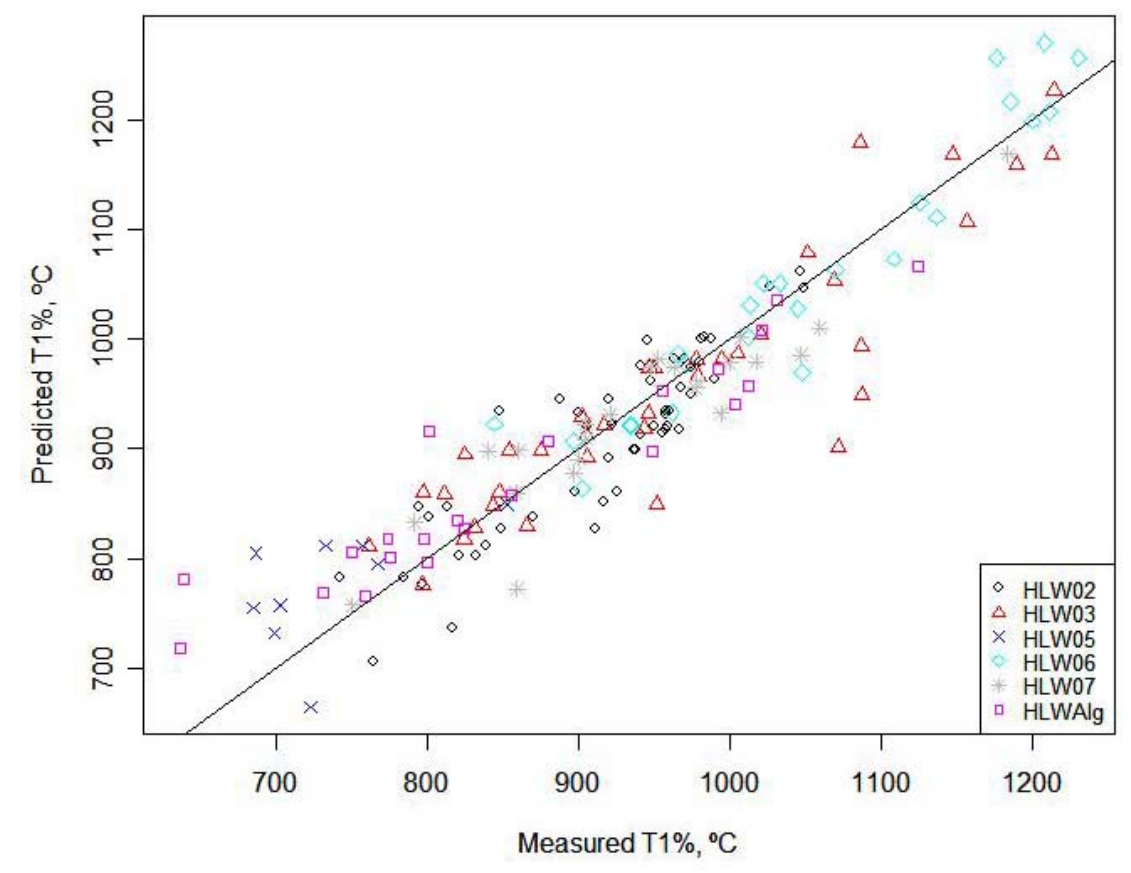

Figure 6.21. Predicted Versus Measured Plot for the 20-Term Partial Quadratic Mixture Model (PQM1b) for Spinel $\mathrm{T}_{1 \%}$ Fitted to Data from $168 \mathrm{HLW}$ Glasses. 
The Catholic University of America Vitreous State Laboratory
IHLW PCT, Spinel $T_{1 \%}$, Electrical Conductivity, and Viscosity Model Development Final Report, VSL-07R1240-4, Rev. 0

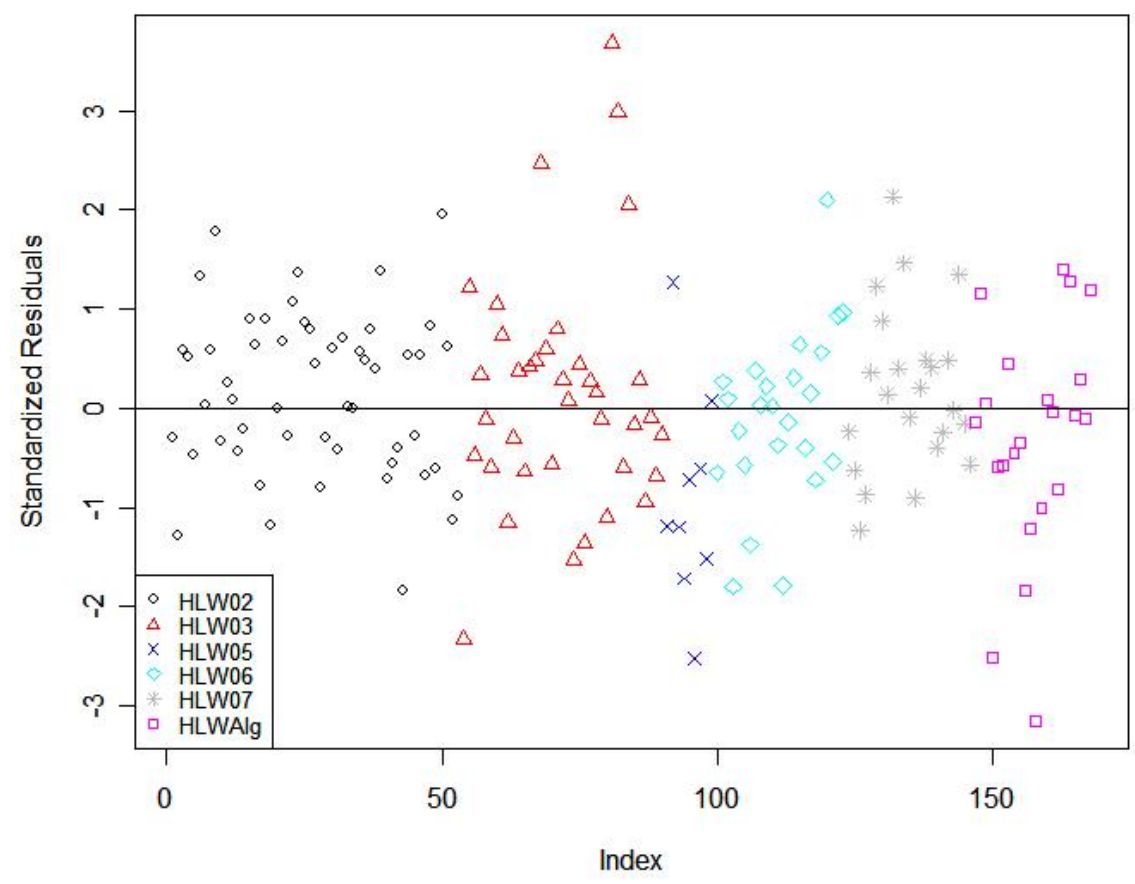

Figure 6.22. Standardized Residuals Plot for the 20-Term Partial Quadratic Mixture Model (PQM1b) for Spinel $\mathrm{T}_{1 \%}$ Fitted to Data from $168 \mathrm{HLW}$ Glasses.

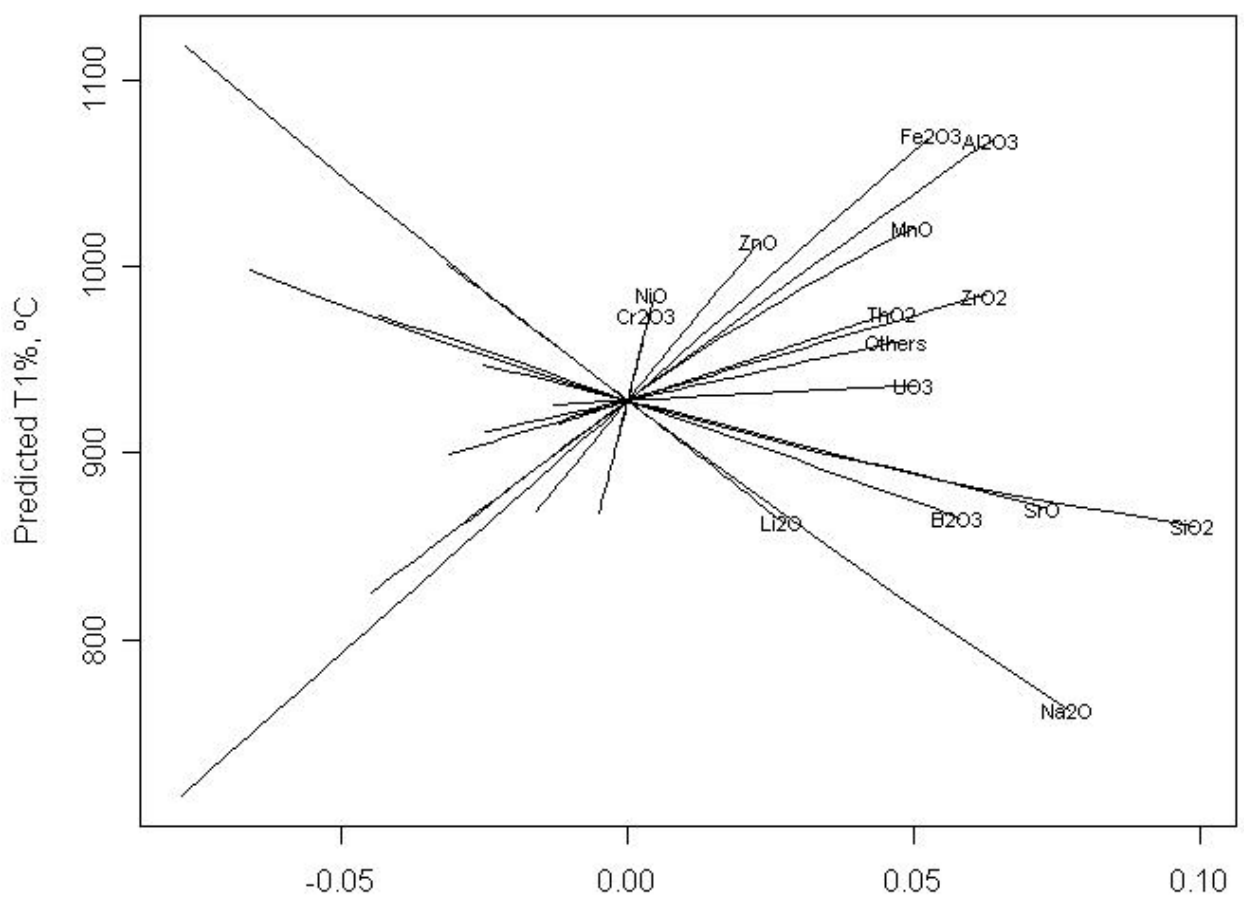

Difference in Component Normalized Mass Fraction from Centroid Composition

Figure 6.23. Response Trace Plot for the 20-Term Partial Quadratic Mixture Model (PQM1b) for Spinel $\mathrm{T}_{1 \%}$ Fitted to Data from 168 HLW Glasses. 


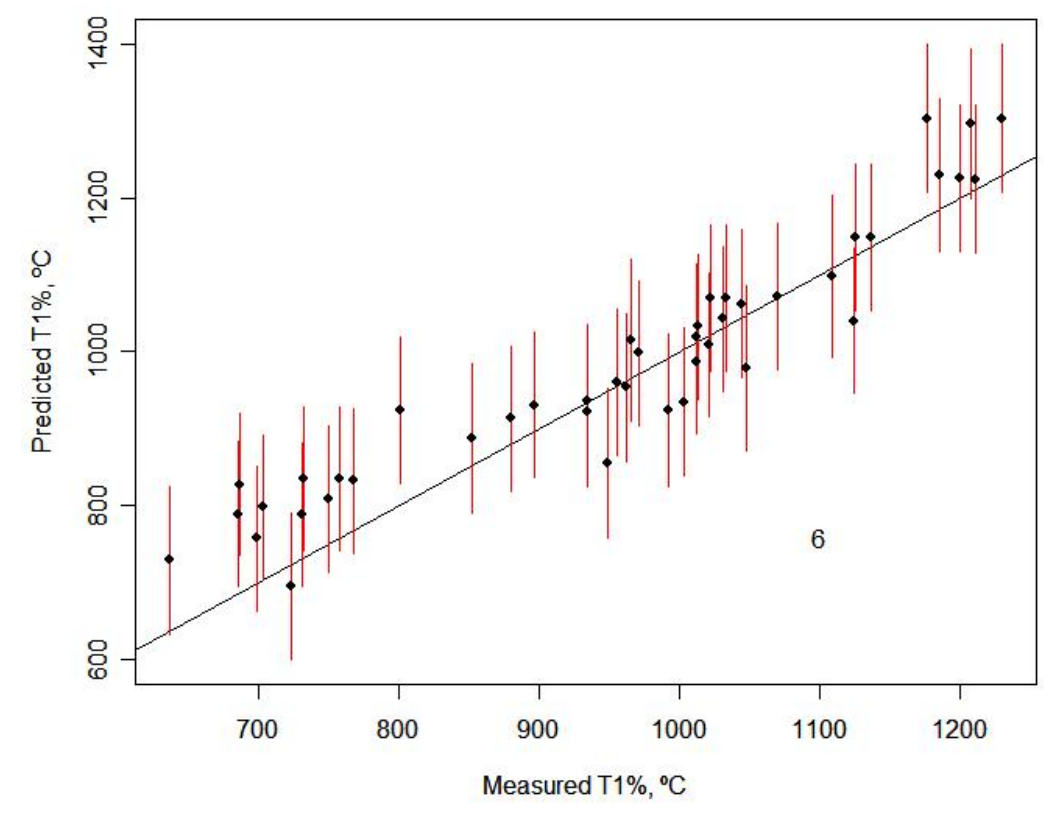

Figure 6.24. Predicted Versus Measured Plot for the 20-Term Partial Quadratic Mixture Model (PQM1b) on IHLW Spinel $T_{1 \%}$ Fitted to the Data-Partition Modeling Subset of 124 Glasses and Applied to the Validation Subset of 44 Glasses. Error bars are $95 \%$ prediction intervals (PIs). The number of glasses whose 95\% PIs do not include the measured values (represented by the $45^{\circ}$ line) is shown.

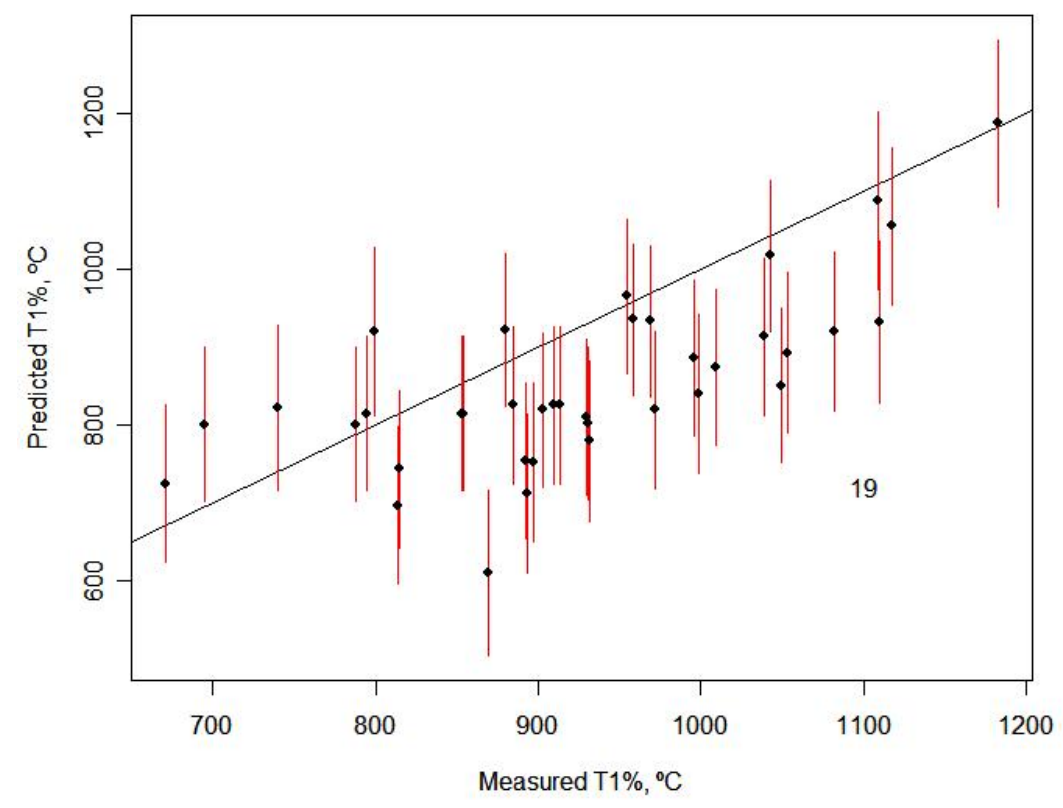

Figure 6.25. Predicted Versus Measured Plot for the 20-Term Partial Quadratic Mixture Model (PQM1b) for Spinel $\mathbf{T}_{1 \%}$ Applied to the 38-Glass Separate Validation Set. Error bars are 95\% prediction intervals (PIs). The number of glasses whose $95 \%$ PIs do not include the measured values (represented by the $45^{\circ}$ line) is shown. 


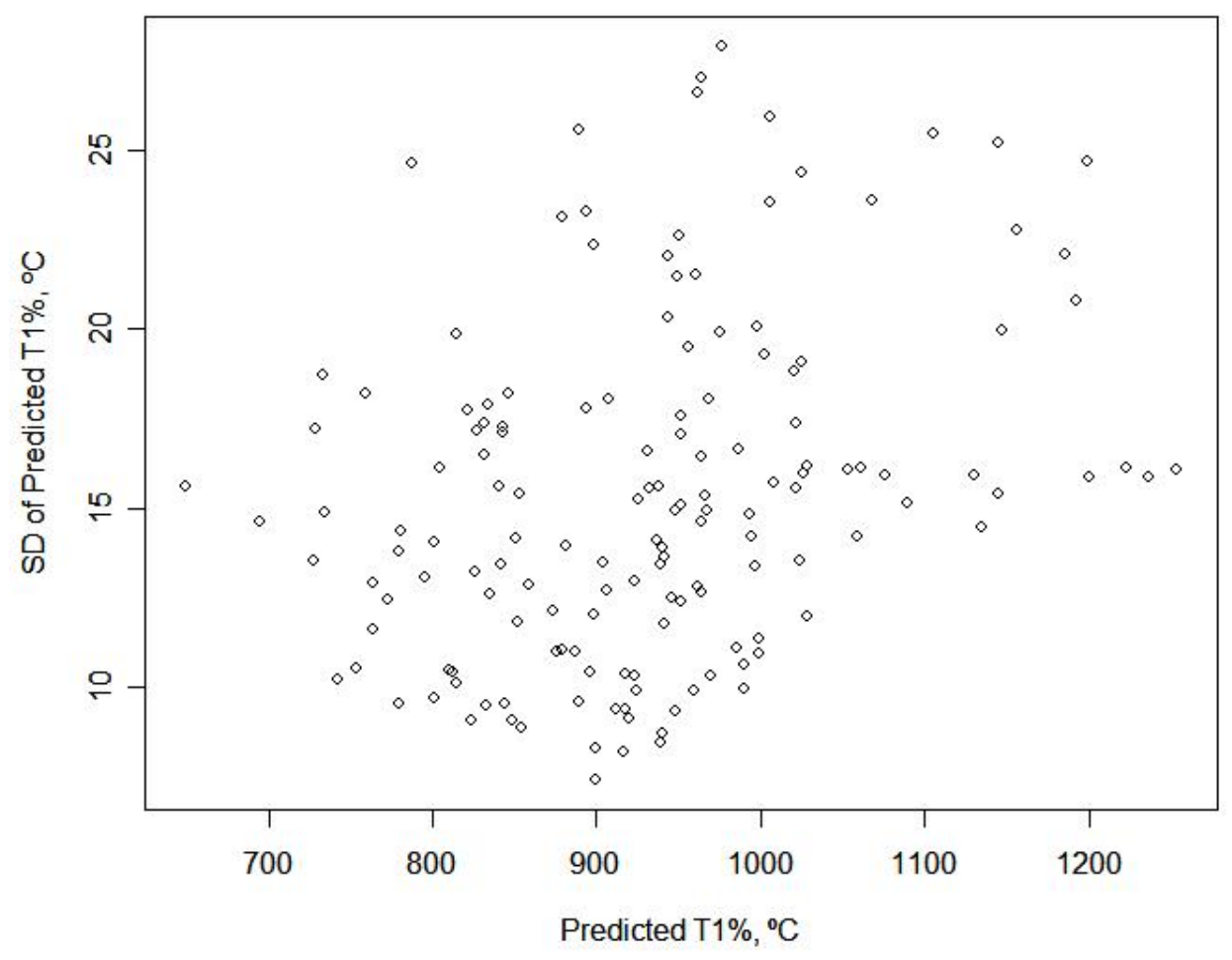

Figure 6.26. Prediction Standard Deviations versus Predicted Values over the HLW Glass Compositions in the Modeling Dataset for the Recommended 20-Term Partial Quadratic Mixture Model (PQM1a) on Spinel $\mathbf{T}_{1 \%}$. 
The Catholic University of America Vitreous State Laboratory
IHLW PCT, Spinel $T_{1 \%}$, Electrical Conductivity, and Viscosity Model Development Final Report, VSL-07R1240-4, Rev. 0
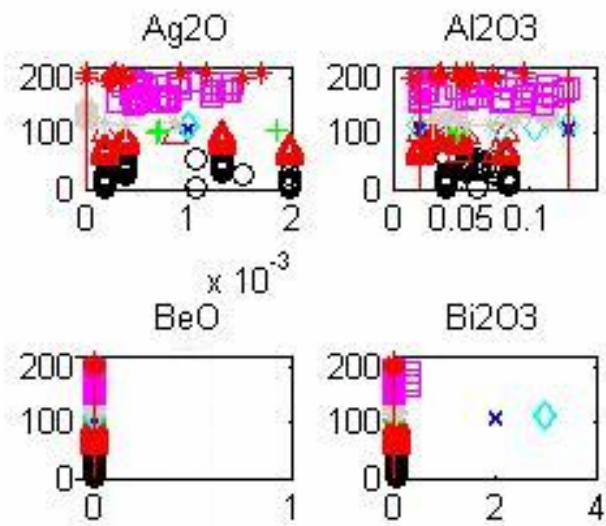

$\mathrm{Cl}$
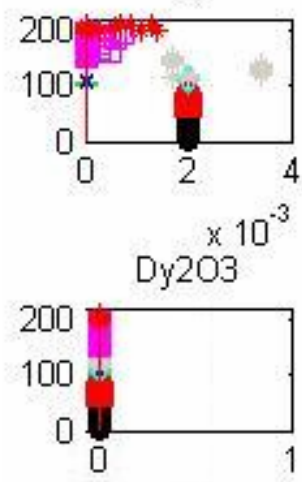

$\mathrm{HfO} 2$

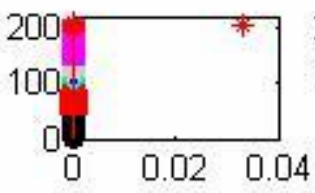

$\mathrm{MgO}$

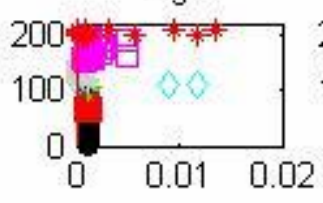

$\mathrm{Bi} 203$

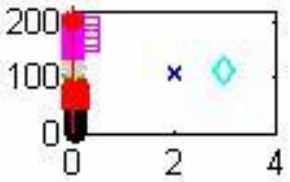

$\times 10^{-3}$
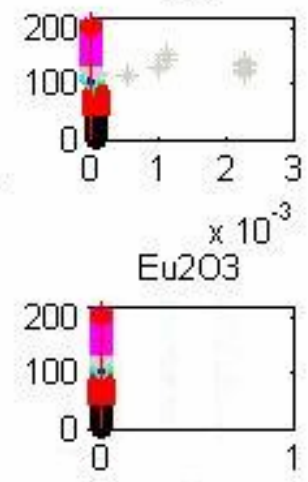

$\mathrm{HgO}$

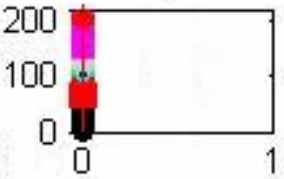

$\mathrm{MnO}$

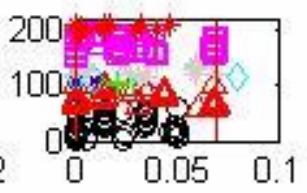

As205

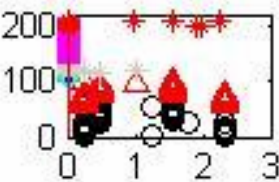

$\times 10^{-3}$

$\mathrm{CaO}$
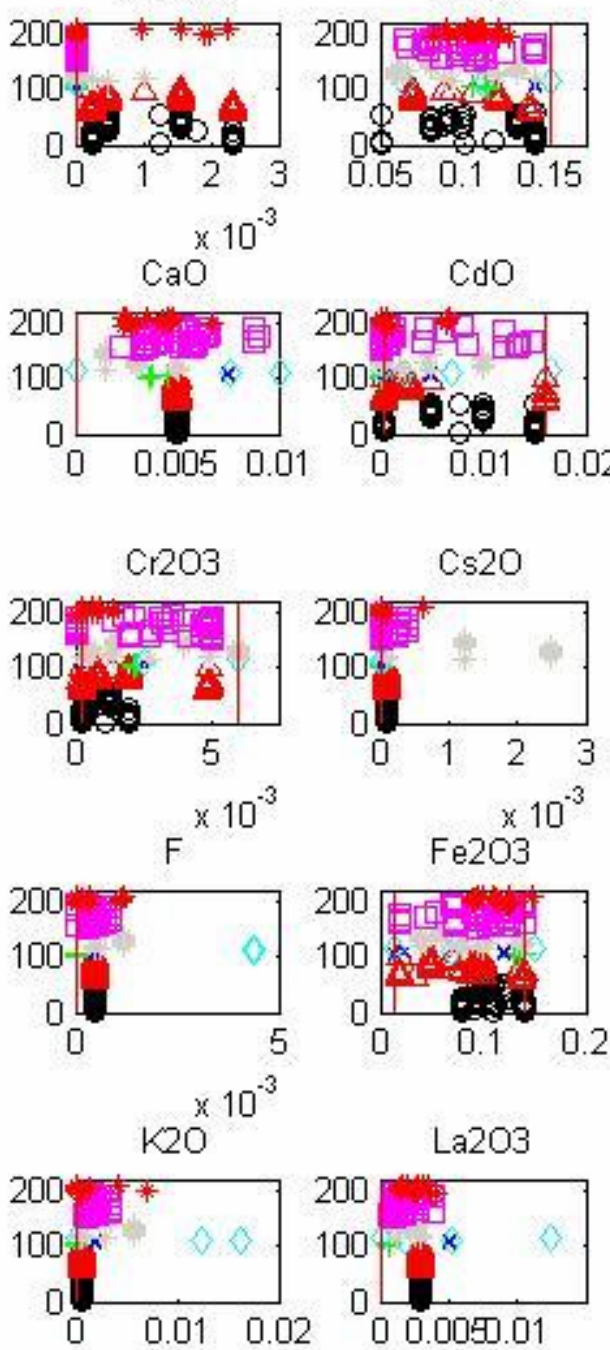

$\mathrm{CdO}$

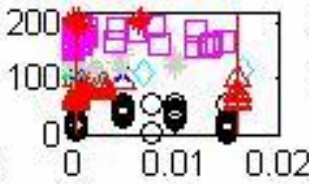

02
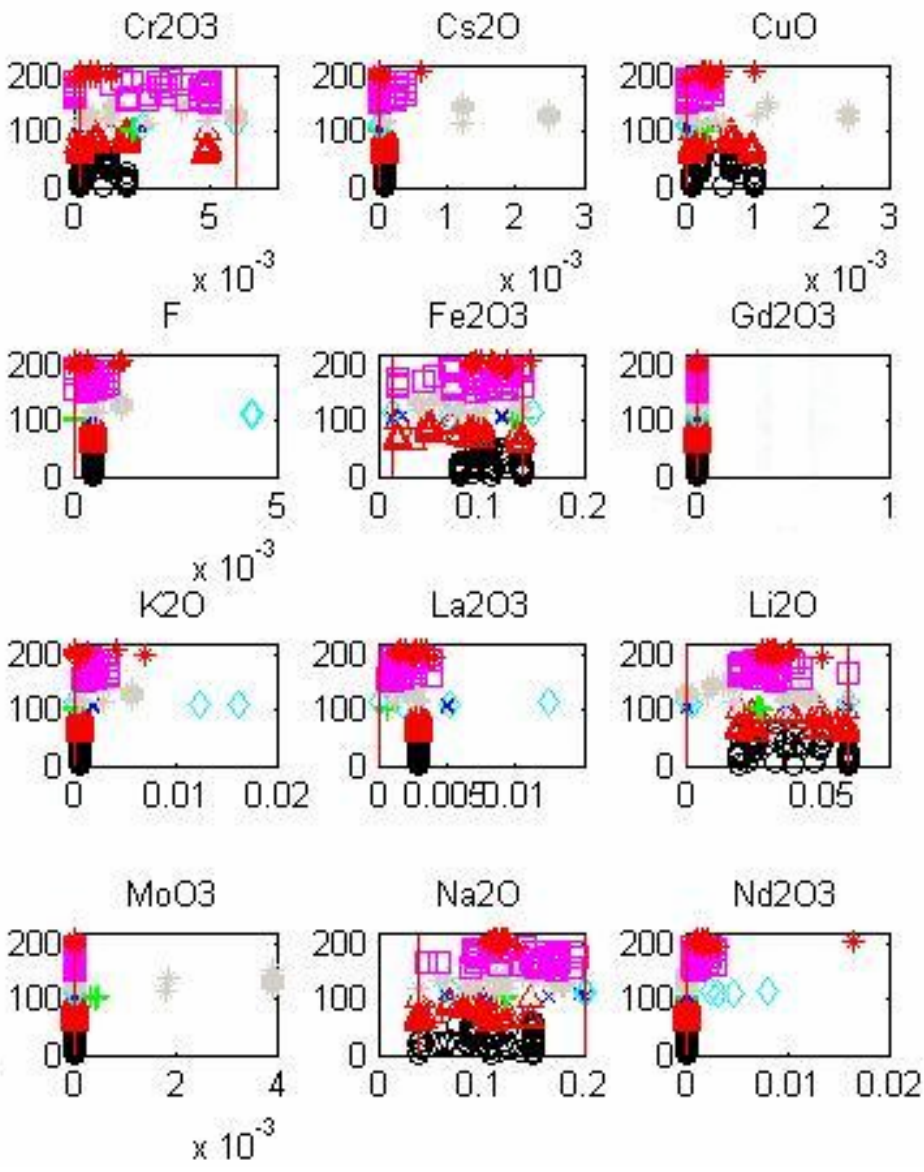

Figure 7.1. $\quad$ Ranges and Distributions of Component Mass Fractions (x-axes) for 210 HLW Glass Compositions with Electrical Conductivity Data. The vertical lines (when present) are the lower and upper limits for the components varied in statistically designed test matrices. 
The Catholic University of America

Vitreous State Laboratory
IHLW PCT, Spinel $T_{1 \%}$, Electrical Conductivity, and Viscosity Model Development Final Report, VSL-07R1240-4, Rev. 0
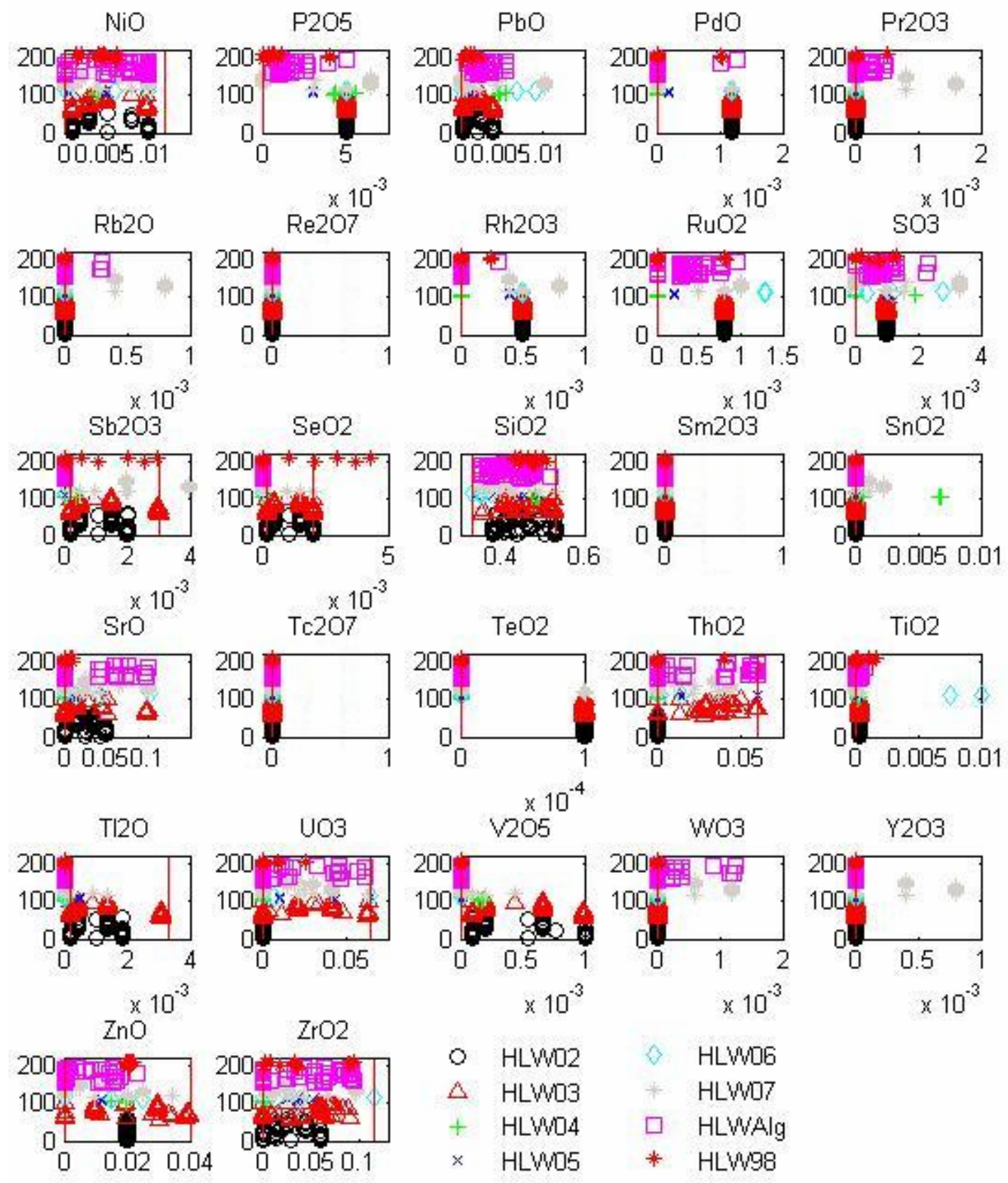

o HLWO2

$\times 10^{-3}$ $\times 10^{-3}$

$\triangle$ HLWO3

HLW06

+ HLWO4

$\times \quad$ HLMO5

HLWO7

HLWAlg

* HLW98

Figure 7.1. Ranges and Distributions of Component Mass Fractions (x-axes) for 210 HLW Glass Compositions with Electrical Conductivity Data. The vertical lines (when present) are the lower and upper limits for the components varied in statistically designed test matrices (continued). 
The Catholic University of America Vitreous State Laboratory
IHLW PCT, Spinel $T_{1 \%}$, Electrical Conductivity, and Viscosity Model Development Final Report, VSL-07R1240-4, Rev. 0
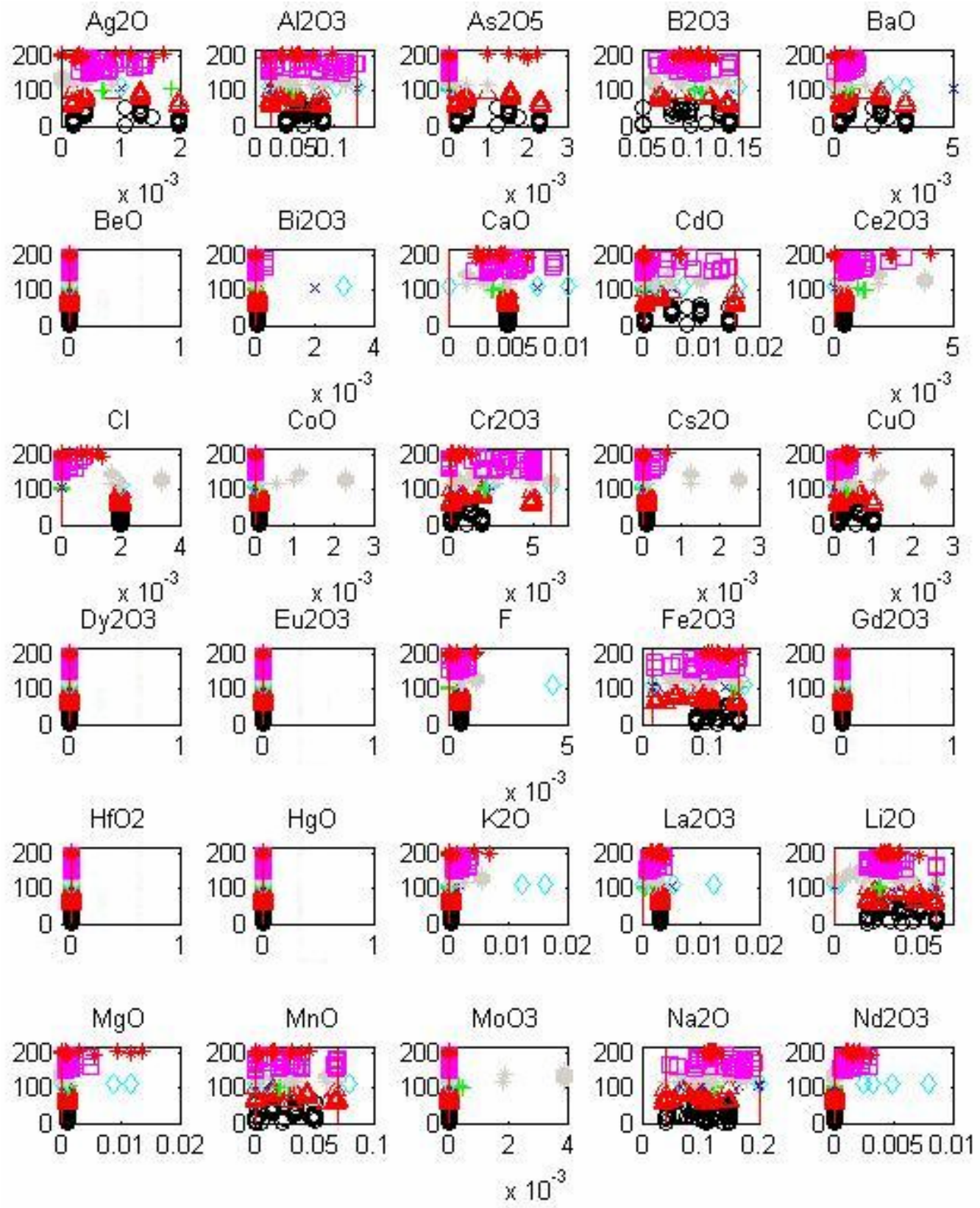

Figure 7.2. Ranges and Distributions of Component Mass Fractions (x-axes) for 208 HLW Glass Compositions with Electrical Conductivity Data After Deleting Two Outliers from the Initial 210 Glasses. The vertical lines (when present) are the lower and upper limits for the components varied in statistically designed test matrices. 
The Catholic University of America

Vitreous State Laboratory
IHLW PCT, Spinel $T_{1 \%}$, Electrical Conductivity, and Viscosity Model Development Final Report, VSL-07R1240-4, Rev. 0
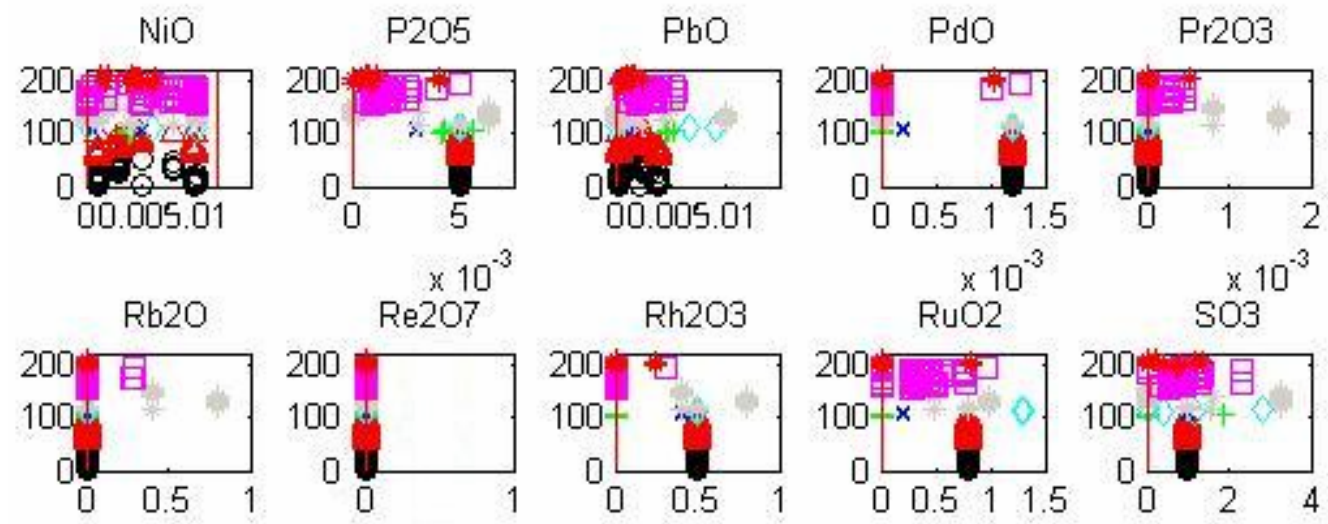

$\times 10^{-3}$
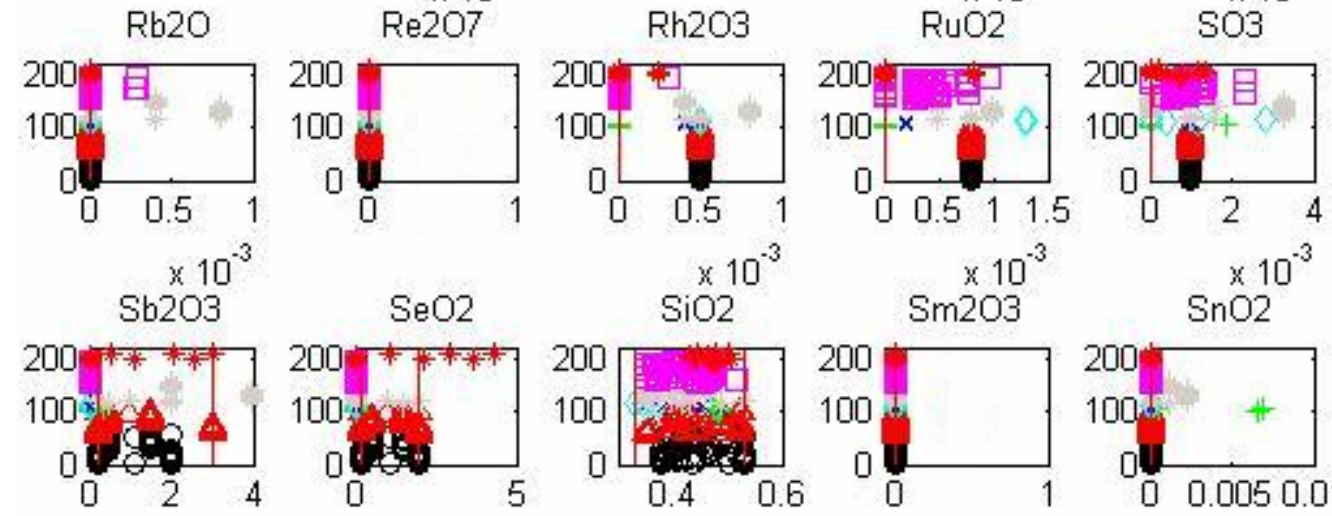

$\times 10^{-3}$
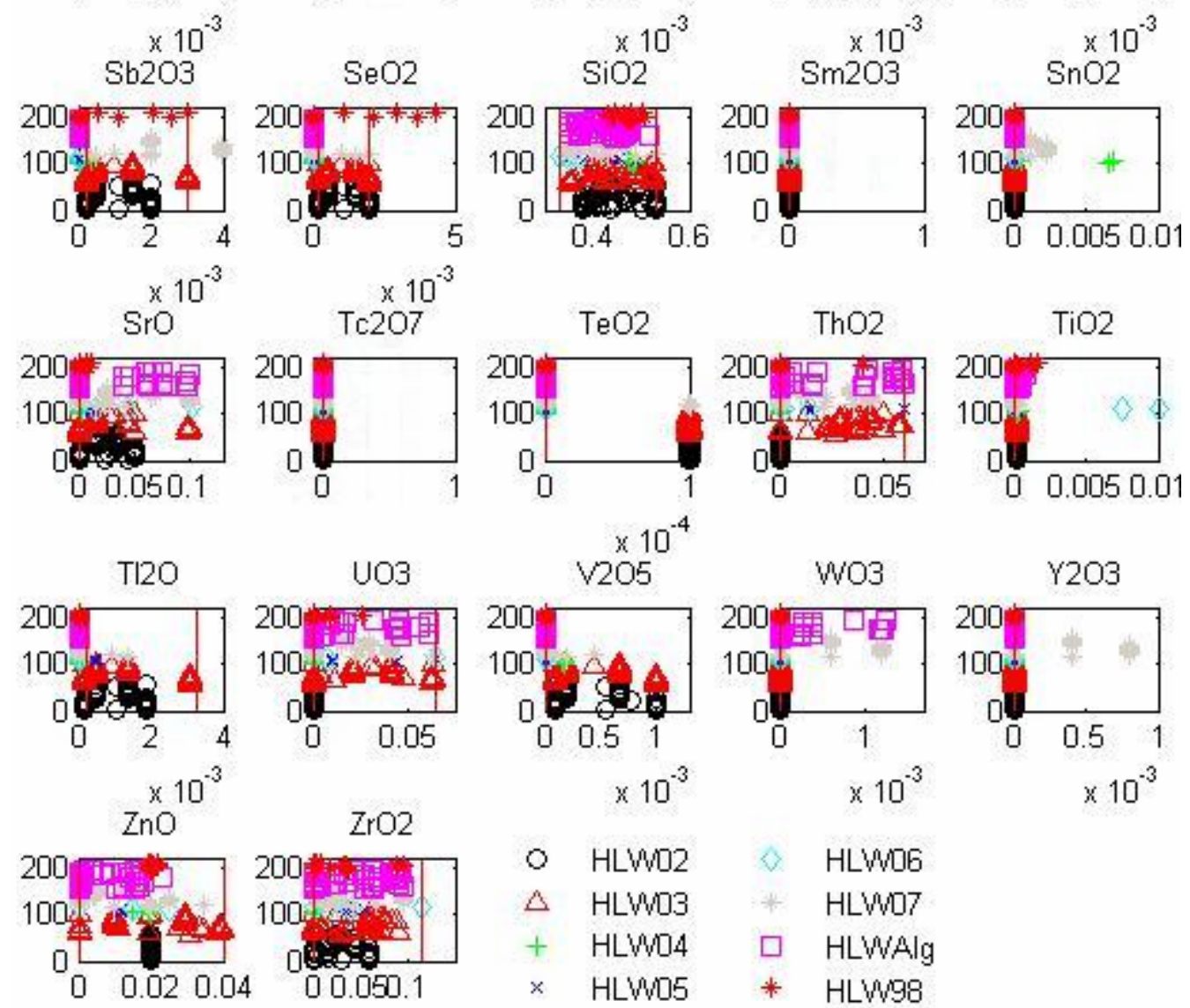

$\begin{array}{cr}\odot & \text { HLW02 } \\ \triangle & \text { HLW03 } \\ + & \text { HLW04 } \\ \times & \text { HLW05 }\end{array}$

HLW06

HLWO7

HLWAIg

* HLW98

Figure 7.2. Ranges and Distributions of Component Mass Fractions (x-axes) for 208 HLW Glass Compositions with Electrical Conductivity Data After Deleting Two Outliers from the Initial 210 Glasses. The vertical lines (when present) are the lower and upper limits for the components varied in statistically designed test matrices (continued). 


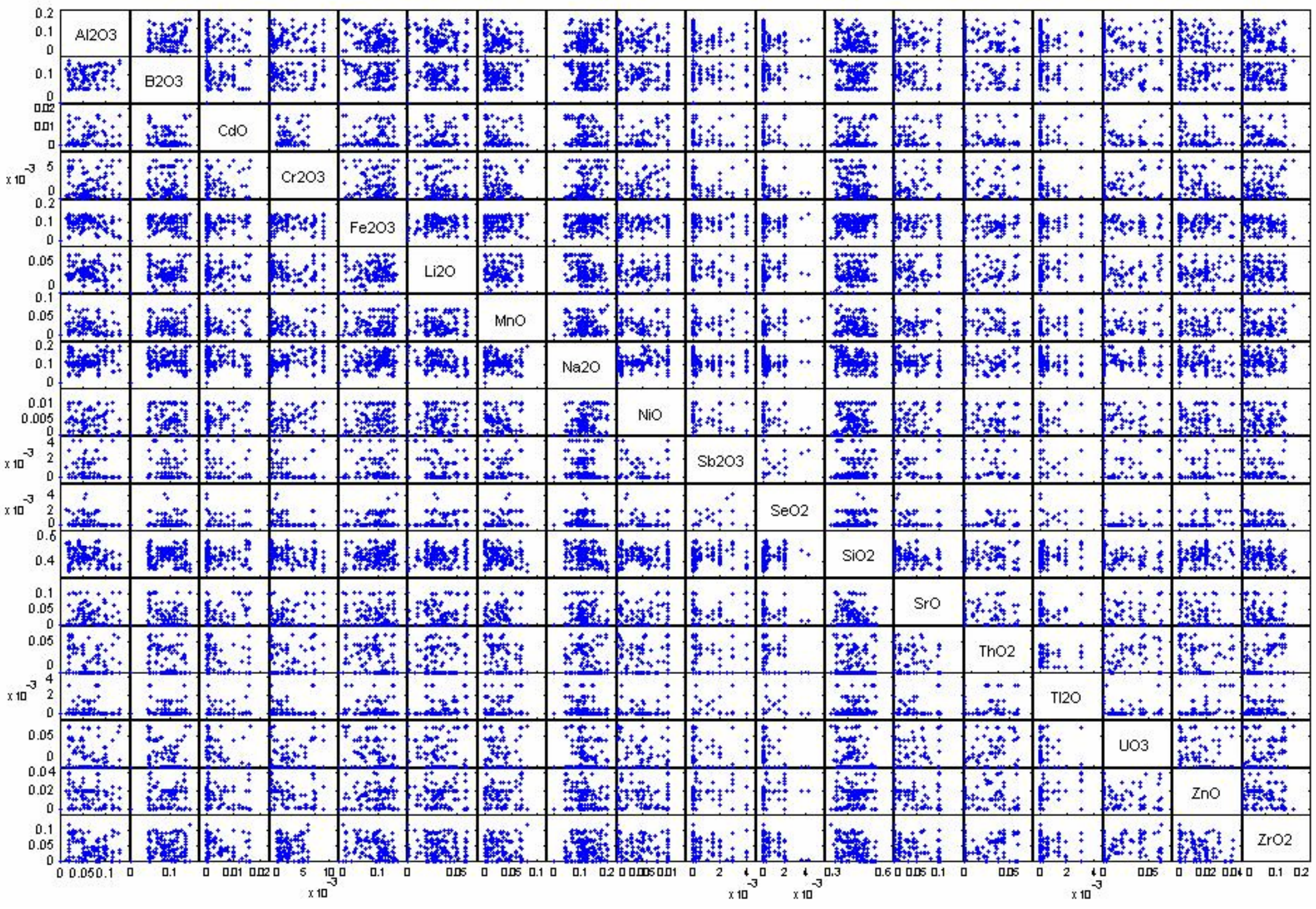

Figure 7.3. Scatterplot Matrix of 18 Component Mass Fractions for 208 HLW Glass Compositions with Electrical Conductivity Data After Deleting Two Outliers from the Initial 210 Glasses. 
The Catholic University of America Vitreous State Laboratory
IHLW PCT, Spinel $T_{1 \%}$, Electrical Conductivity, and Viscosity Model Development Final Report, VSL-07R1240-4, Rev. 0

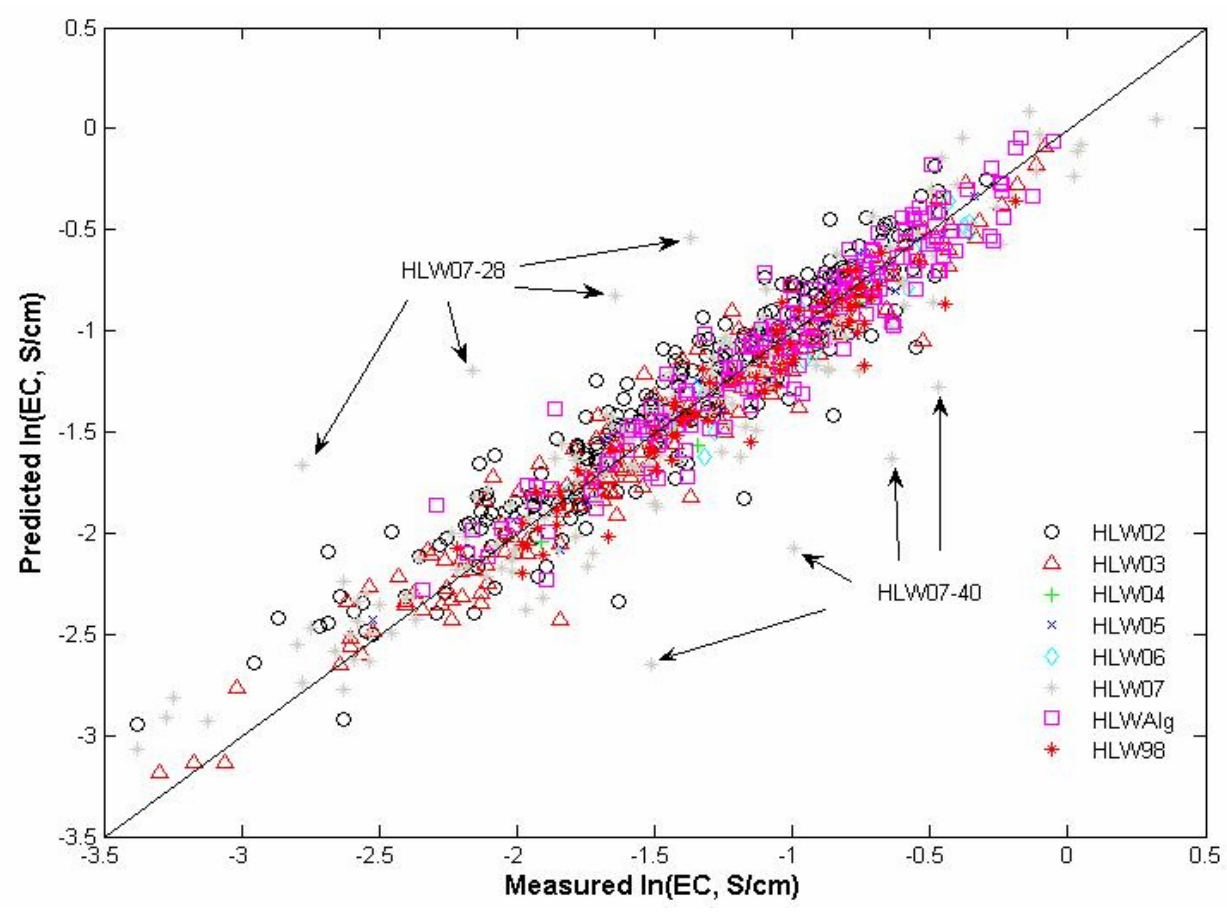

Figure 7.4. Predicted Versus Measured Plot for the 208 HLW Glasses in the Electrical Conductivity Modeling Dataset Constructed Using the 44-Term Truncated T2Linear Mixture Model.

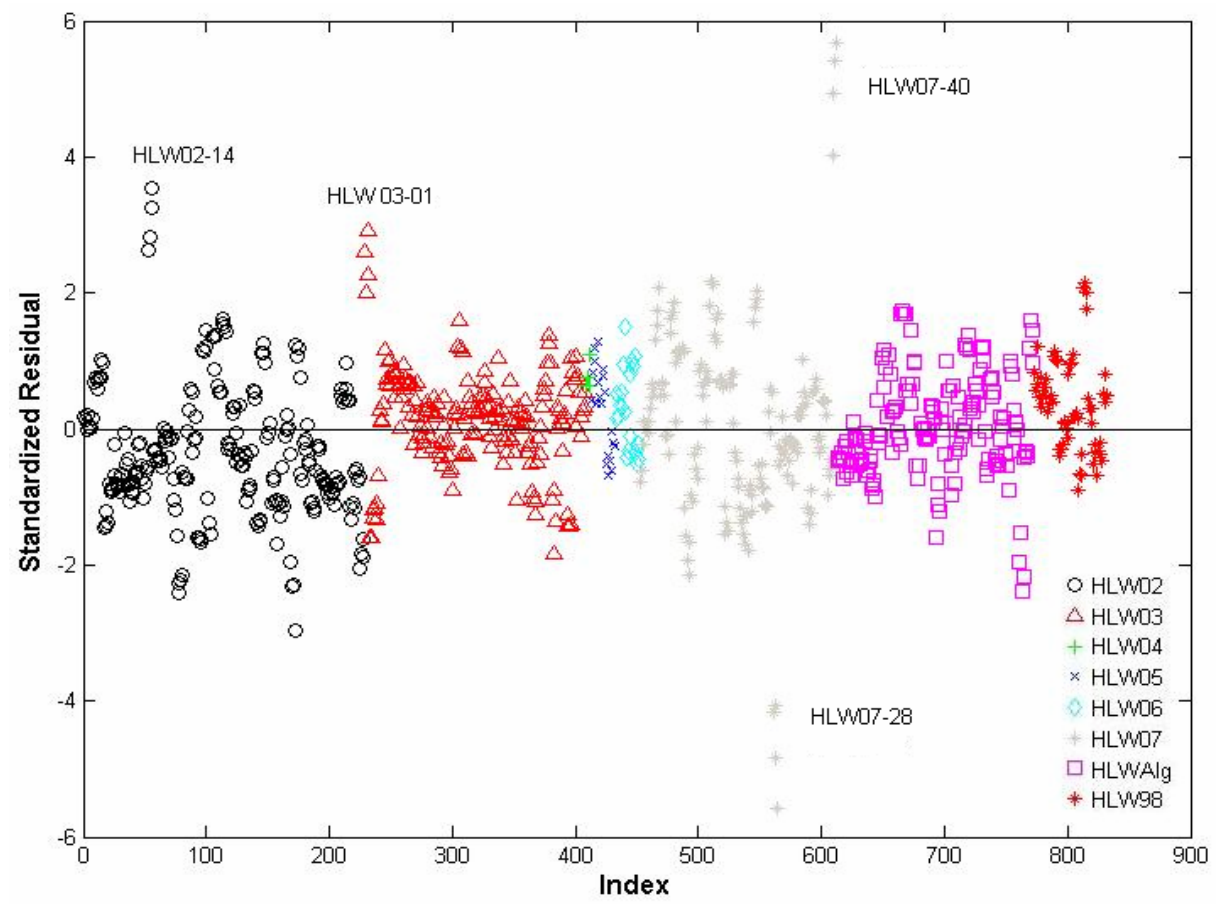

Figure 7.5. Standardized Residuals Plot for the 208 HLW Glasses in the Electrical Conductivity Modeling Dataset Constructed Using the 44-Term Truncated T2Linear Mixture Model. 


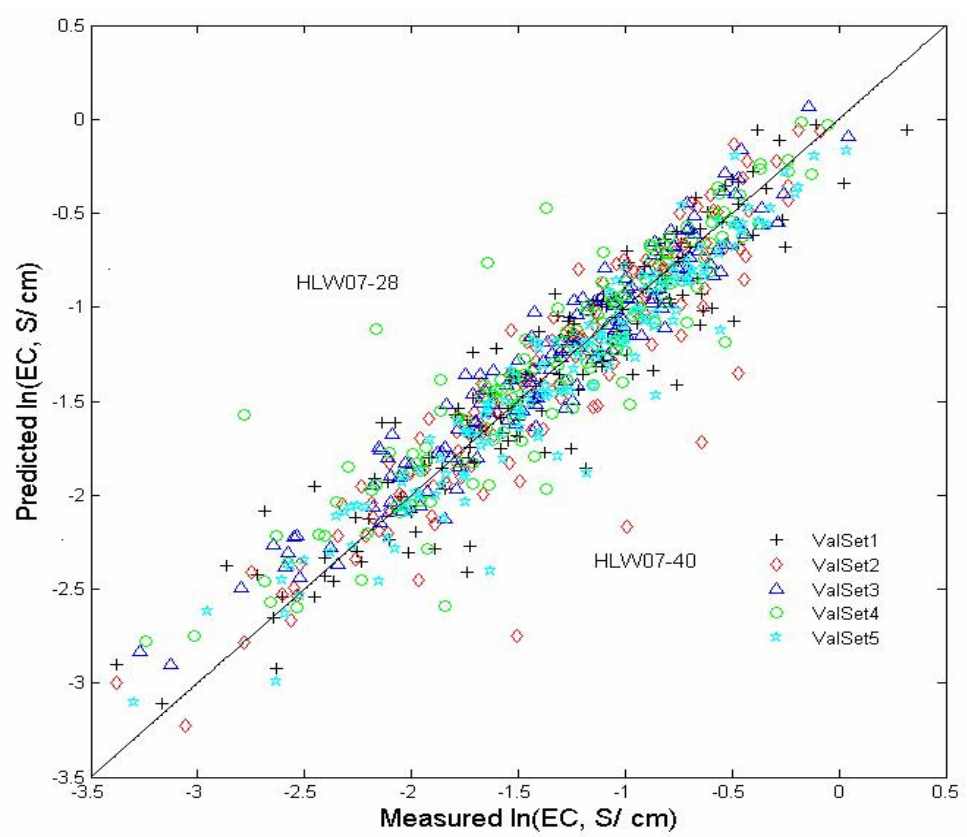

Figure 7.6. Predicted versus Measured $\ln (\mathrm{EC}, \mathrm{S} / \mathrm{cm})$ Values for each of the Five DataSplitting Validation Subsets of the 208 HLW Glasses in the Electrical Conductivity Modeling Dataset Constructed Using the 44-Term Truncated T2Linear Mixture Model.

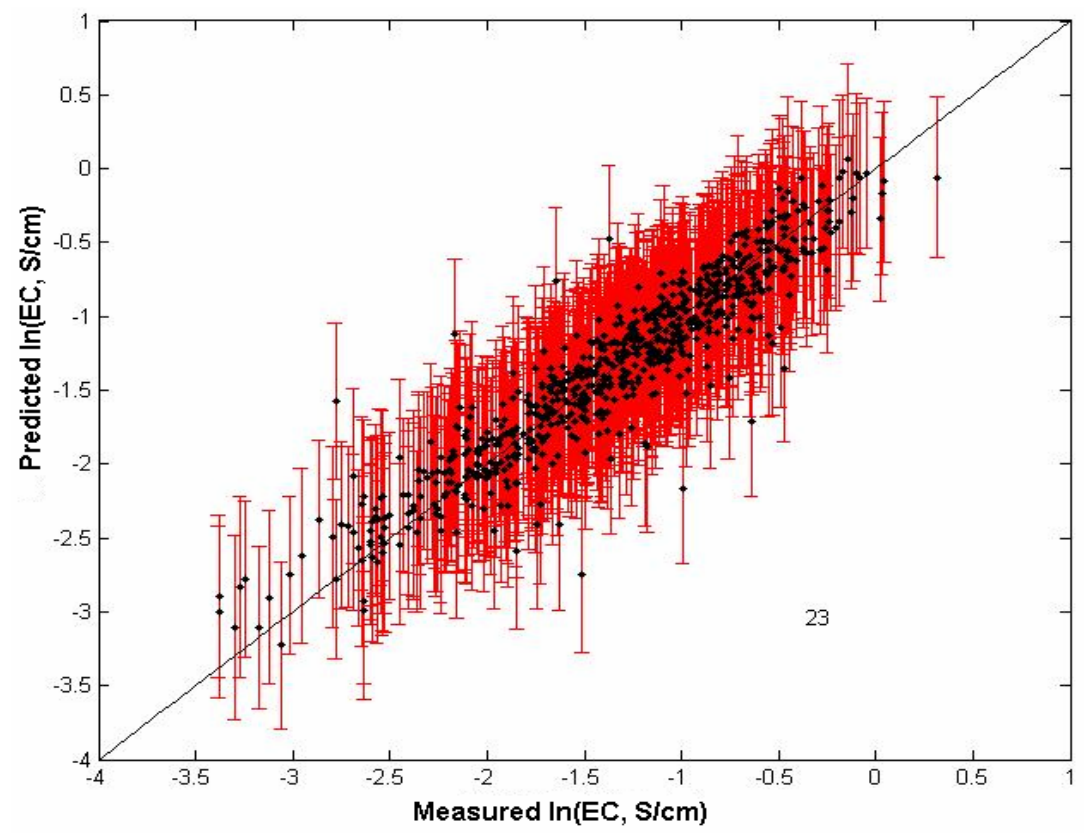

Figure 7.7. Predicted Versus Measured $\ln (\mathrm{EC}, \mathrm{S} / \mathrm{cm})$ Values for each of the Five DataSplitting Validation Subsets of the 208 HLW Glasses in the Electrical Conductivity Modeling Dataset Constructed Using the 44-Term Truncated T2Linear Mixture Model. Error bars are 95\% prediction intervals (PIs). The number of glasses whose $95 \%$ PIs do not include the measured values (represented by the $45^{\circ}$ line) is shown. 
The Catholic University of America Vitreous State Laboratory
IHLW PCT, Spinel $T_{1 \%}$, Electrical Conductivity, and Viscosity Model Development Final Report, VSL-07R1240-4, Rev. 0

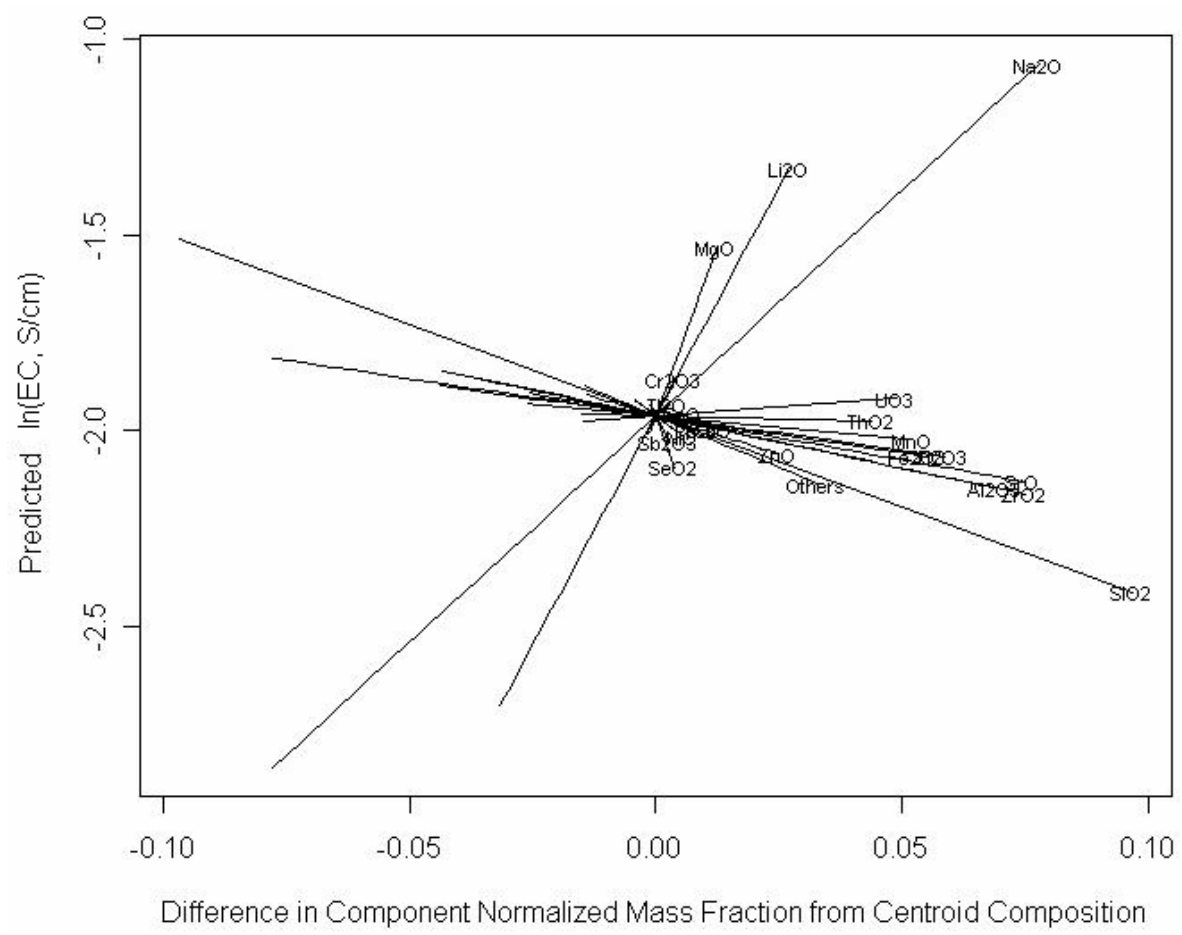

Figure 7.8a. Response Trace Plot for IHLW Electrical Conductivity at $950^{\circ} \mathrm{C}$ Constructed Using the 44-Term Truncated T2-Linear Mixture Model.

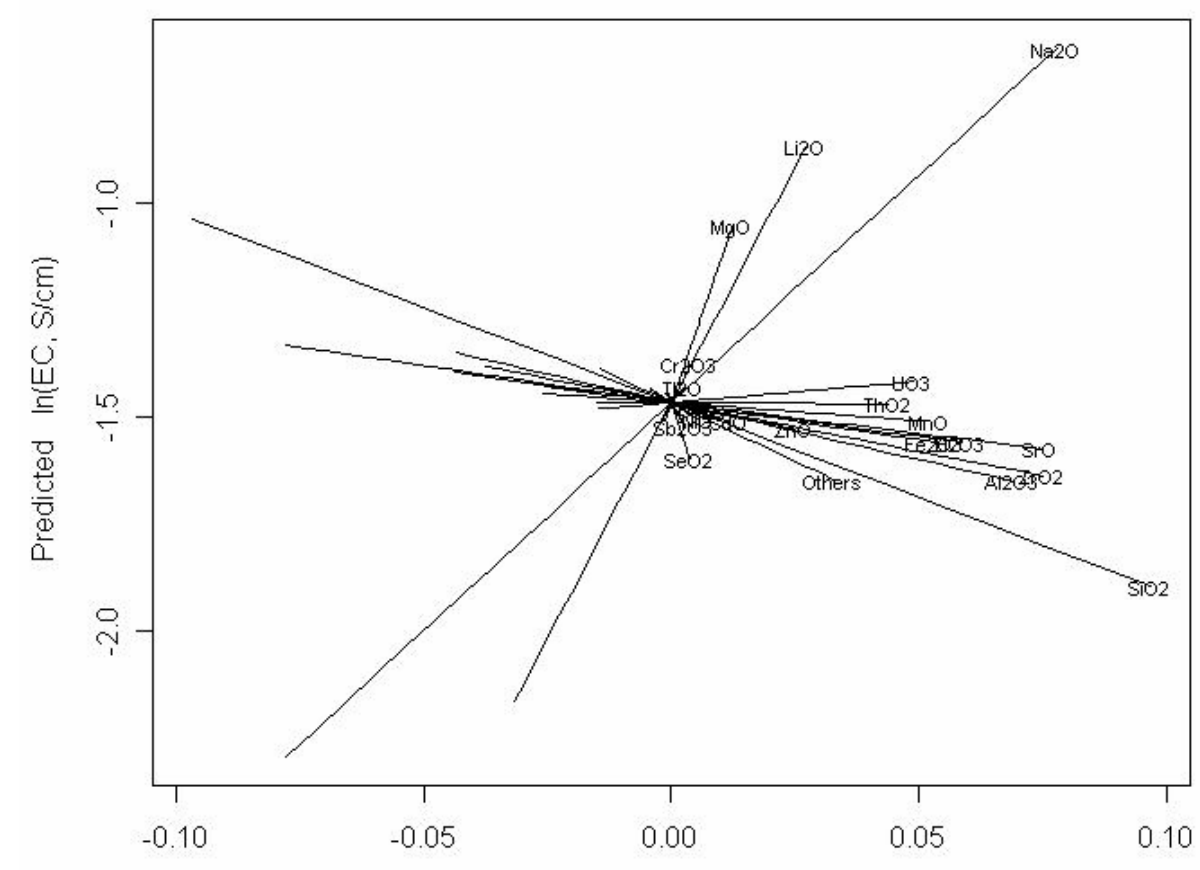

Difference in Component Normalized Mass Fraction from Centroid Composition

Figure 7.8b. Response Trace Plot for IHLW Electrical Conductivity at $1050^{\circ} \mathrm{C}$ Constructed Using the 44-Term Truncated T2-Linear Mixture Model. 
The Catholic University of America Vitreous State Laboratory
IHLW PCT, Spinel $T_{1 \%}$, Electrical Conductivity, and Viscosity Model Development Final Report, VSL-07R1240-4, Rev. 0

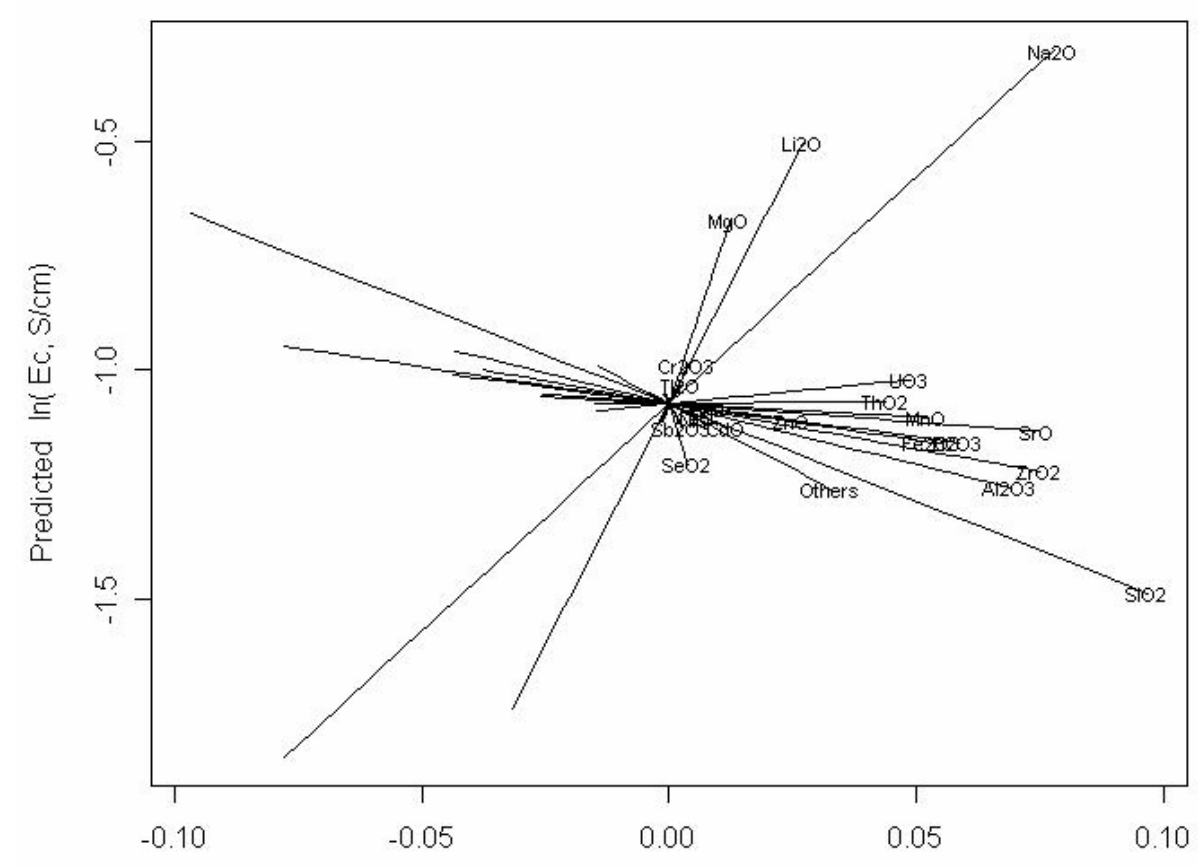

Difference in Component Normalized Mass Fraction from Centroid Composition

Figure 7.8c. Response Trace Plot for IHLW Electrical Conductivity at $1150^{\circ} \mathrm{C}$ Constructed Using the 44-Term Truncated T2-Linear Mixture Model.

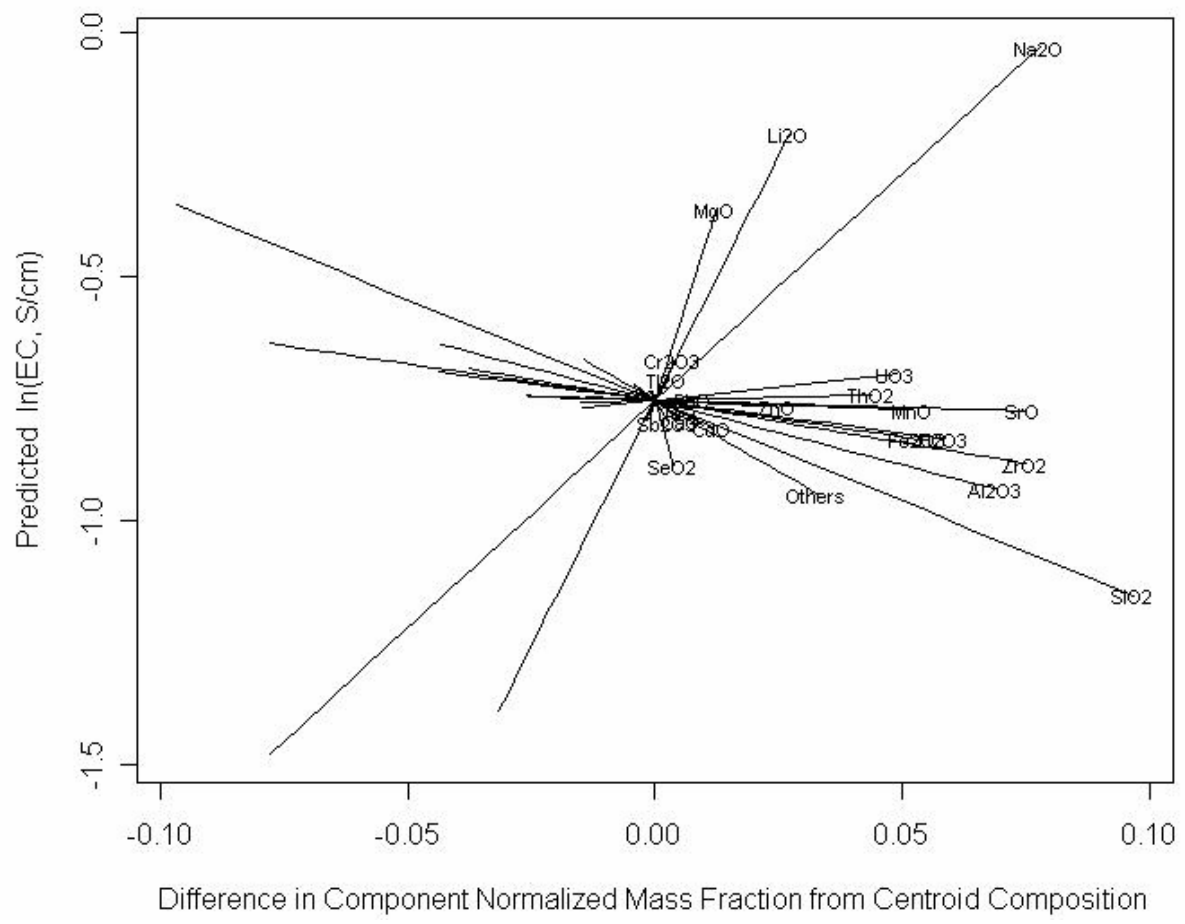

Figure 7.8d. Response Trace Plot for IHLW Electrical Conductivity at $1250^{\circ} \mathrm{C}$ Constructed Using the 44-Term Truncated T2-Linear Mixture Model. 
The Catholic University of America Vitreous State Laboratory
IHLW PCT, Spinel $T_{1 \%}$, Electrical Conductivity, and Viscosity Model Development Final Report, VSL-07R1240-4, Rev. 0

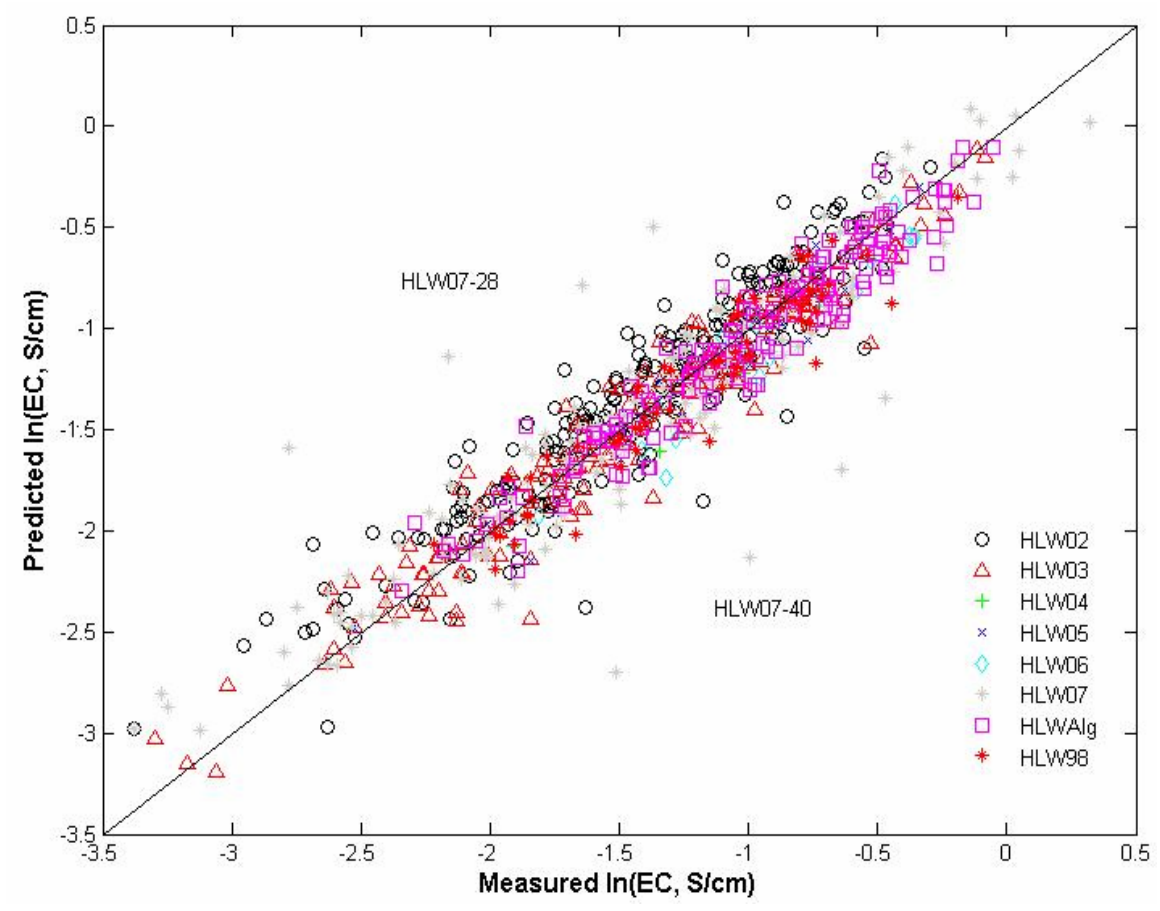

Figure 7.9. Predicted Versus Measured Plot for the 208 HLW Glasses in the Electrical Conductivity Modeling Dataset Constructed Using the 27-Term Truncated T2-Linear Mixture Model.

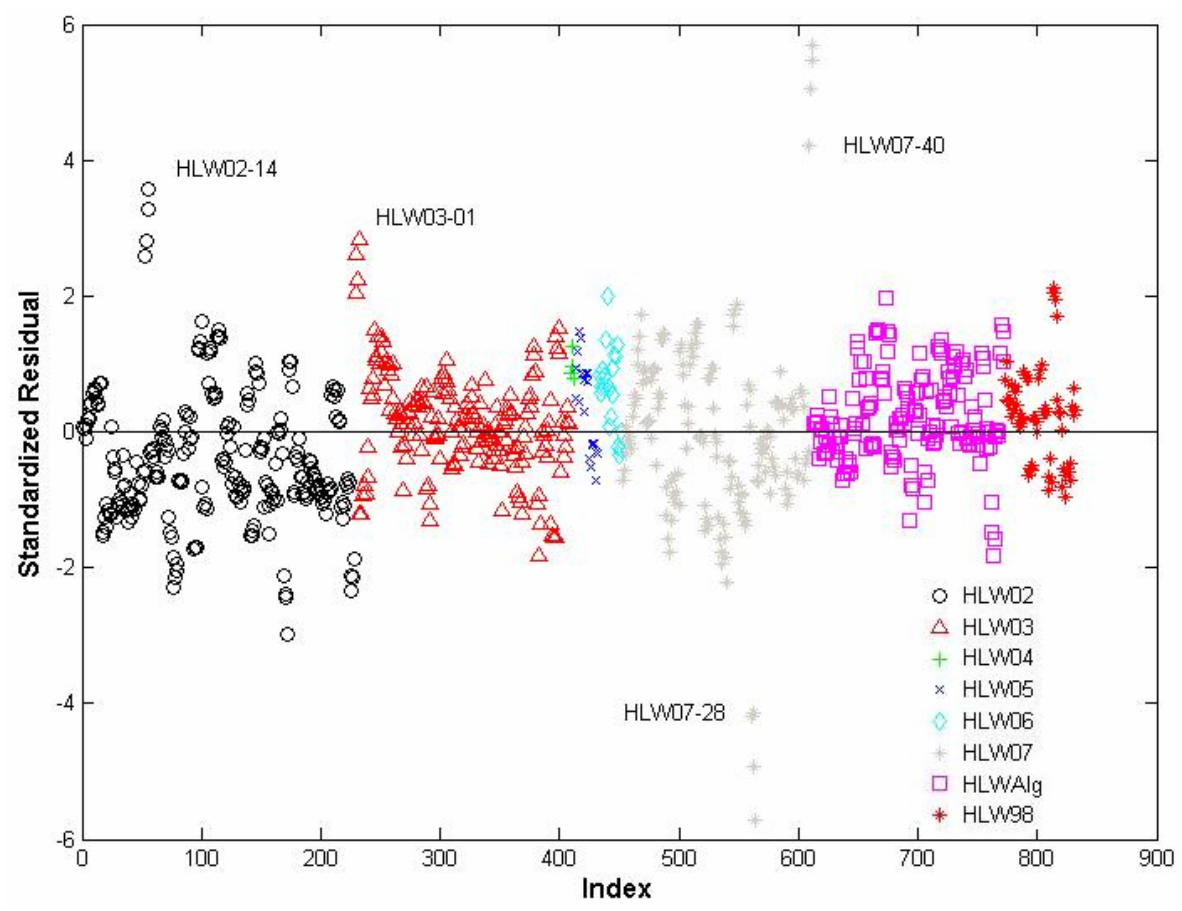

Figure 7.10. Standardized Residuals Plot for the 208 HLW Glasses in the Electrical Conductivity Modeling Dataset Constructed Using the 27-Term Truncated T2-Linear Mixture Model. 


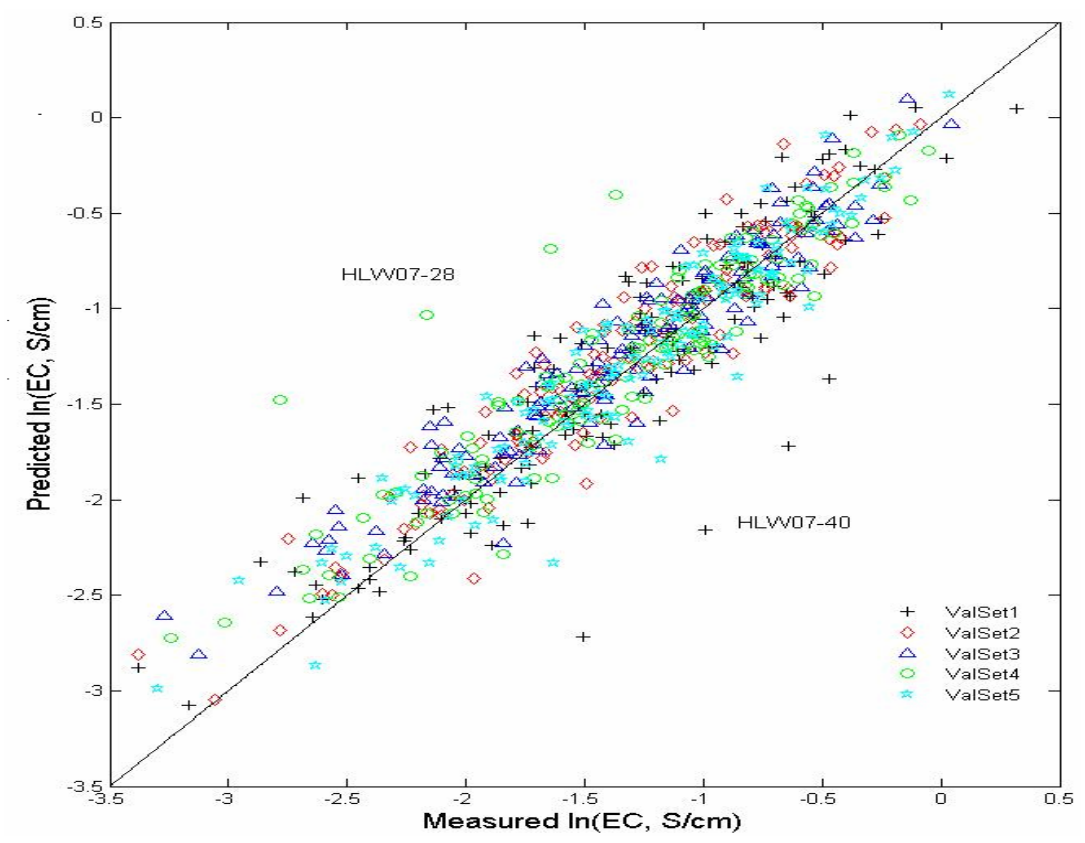

Figure 7.11. Predicted versus Measured $\ln (\mathrm{EC}, \mathrm{S} / \mathrm{cm})$ Values for each of the Five DataSplitting Validation Subsets of the 208 HLW Glasses in the Electrical Conductivity Modeling Dataset Constructed Using the 27-Term Truncated T2-Linear Mixture Model.

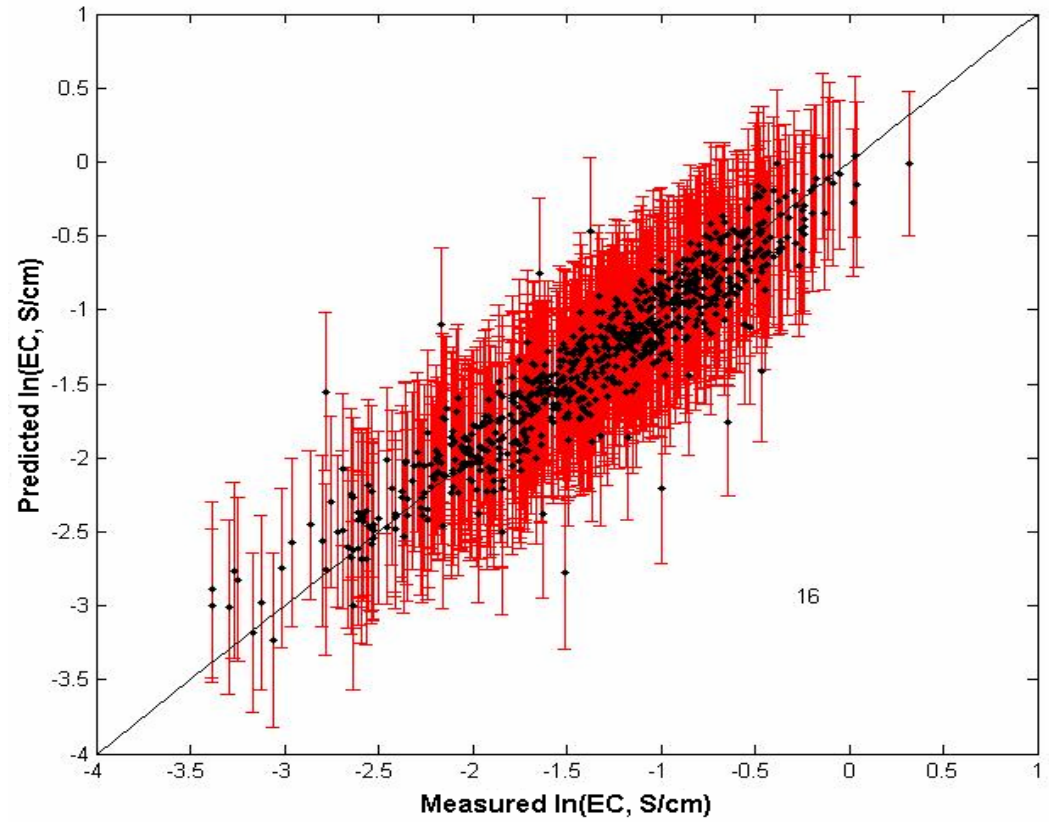

Figure 7.12. Predicted Versus Measured $\ln (\mathrm{EC}, \mathrm{S} / \mathrm{cm})$ Values for each of the Five Data-Splitting Validation Subsets of the 208 HLW Glasses in the Electrical Conductivity Modeling Dataset Constructed Using the 27-Term Truncated T2-Linear Mixture Model. Error bars are 95\% prediction intervals (PIs). The number of glasses whose $95 \%$ PIs do not include the measured values (represented by the $45^{\circ}$ line) is shown. 
The Catholic University of America Vitreous State Laboratory
IHLW PCT, Spinel $T_{1 \%}$, Electrical Conductivity, and Viscosity Model Development Final Report, VSL-07R1240-4, Rev. 0

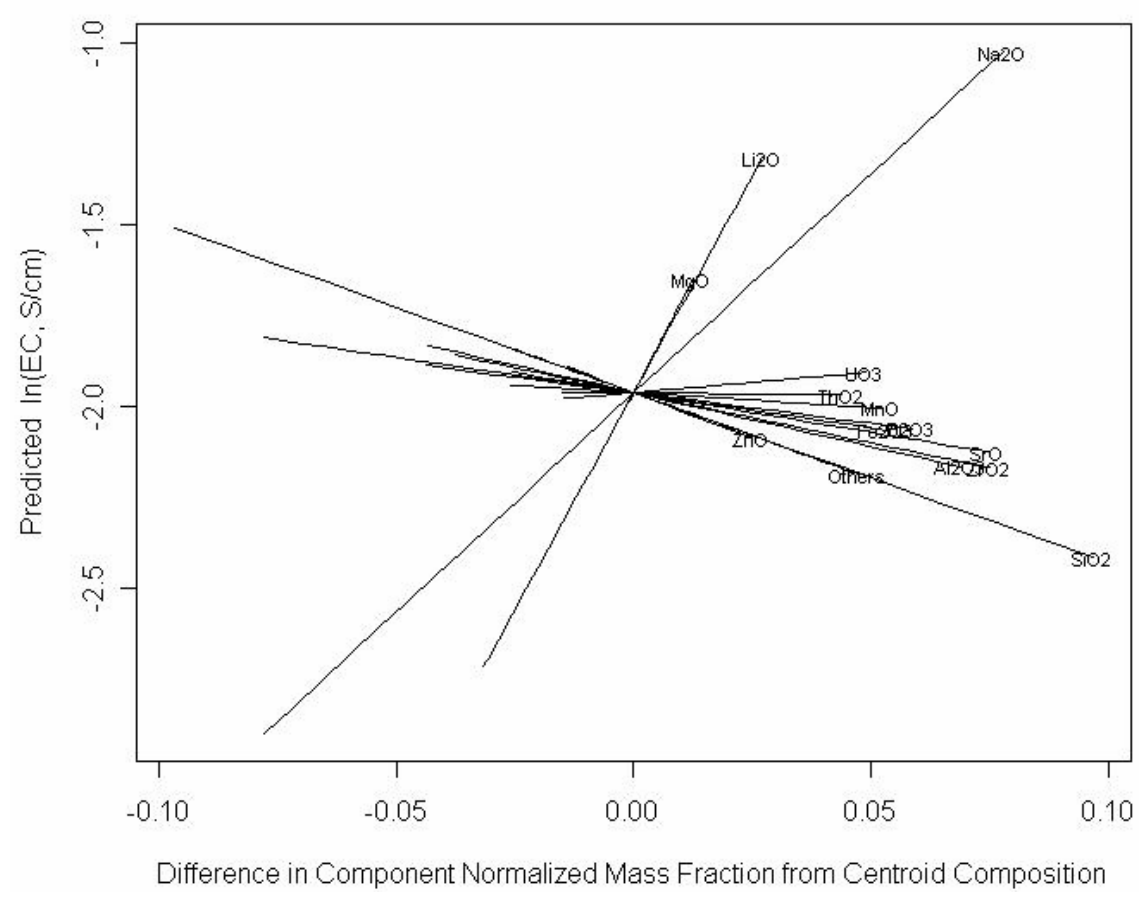

Figure 7.13a. Response Trace Plot for IHLW Electrical Conductivity at $950^{\circ} \mathrm{C}$ Constructed Using the 27-Term Truncated T2-Linear Mixture Model.

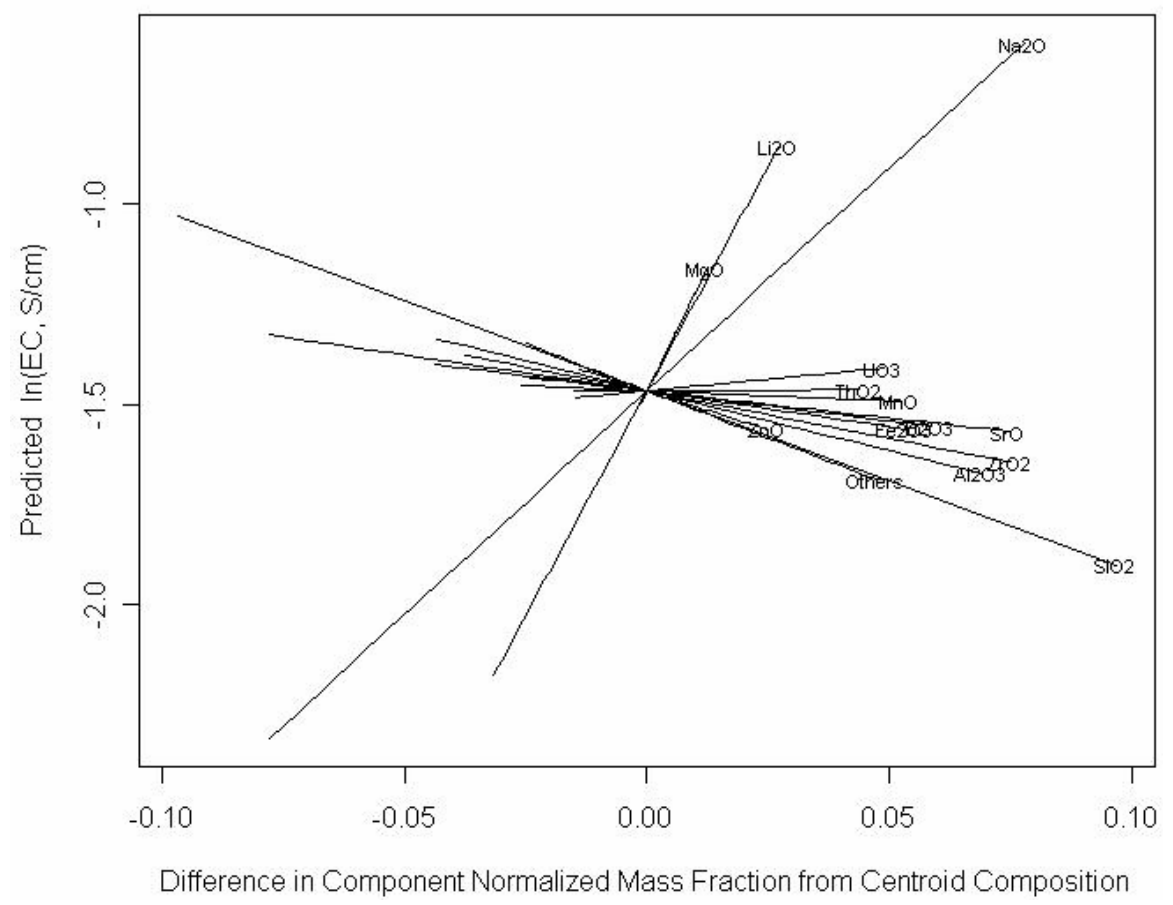

Figure 7.13b. Response Trace Plot for IHLW Electrical Conductivity at $1050^{\circ} \mathrm{C}$ Constructed Using the 27-Term Truncated T2-Linear Mixture Model. 
The Catholic University of America Vitreous State Laboratory
IHLW PCT, Spinel $T_{1 \%}$, Electrical Conductivity, and Viscosity Model Development Final Report, VSL-07R1240-4, Rev. 0

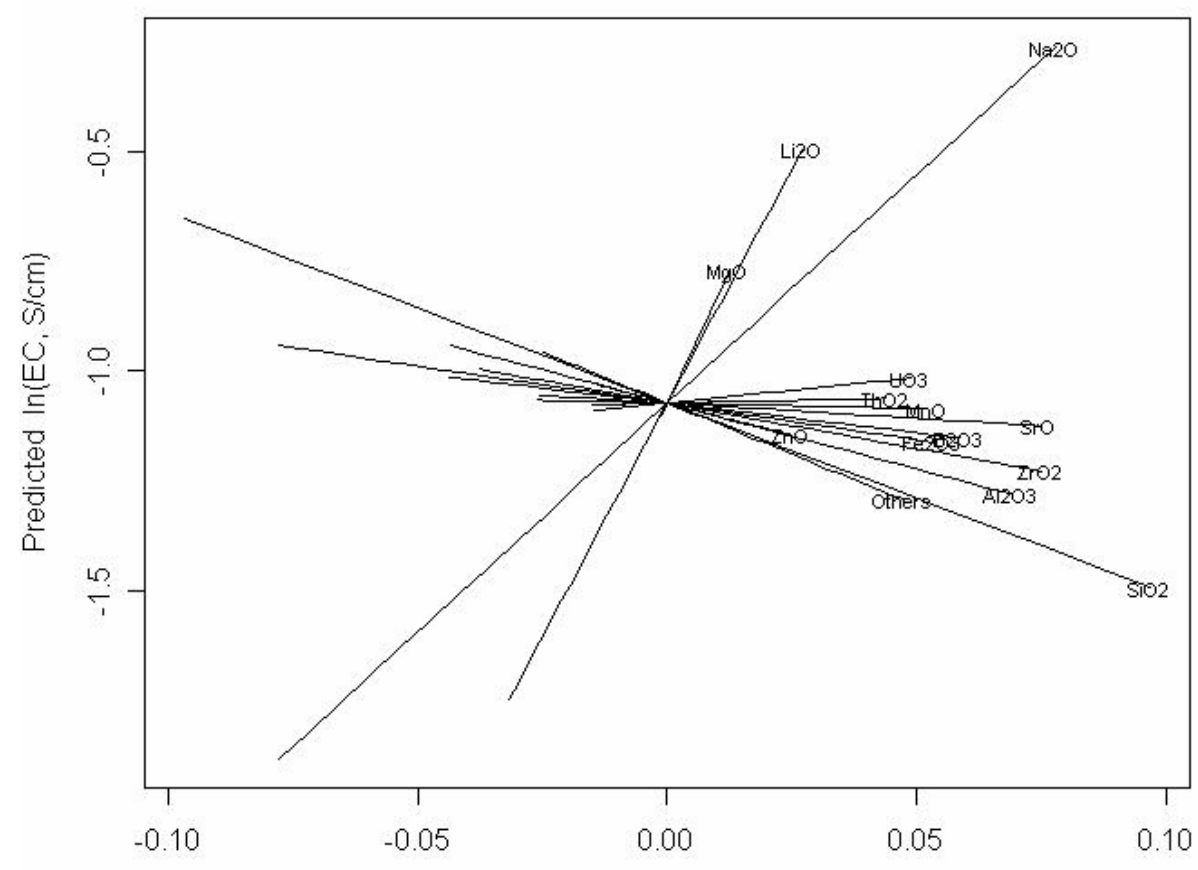

Difference in Component Normalized Mass Fraction from Centroid Composition

Figure 7.13c. Response Trace Plot for IHLW Electrical Conductivity at $1150^{\circ} \mathrm{C}$ Constructed Using the 27-Term Truncated T2-Linear Mixture Model.

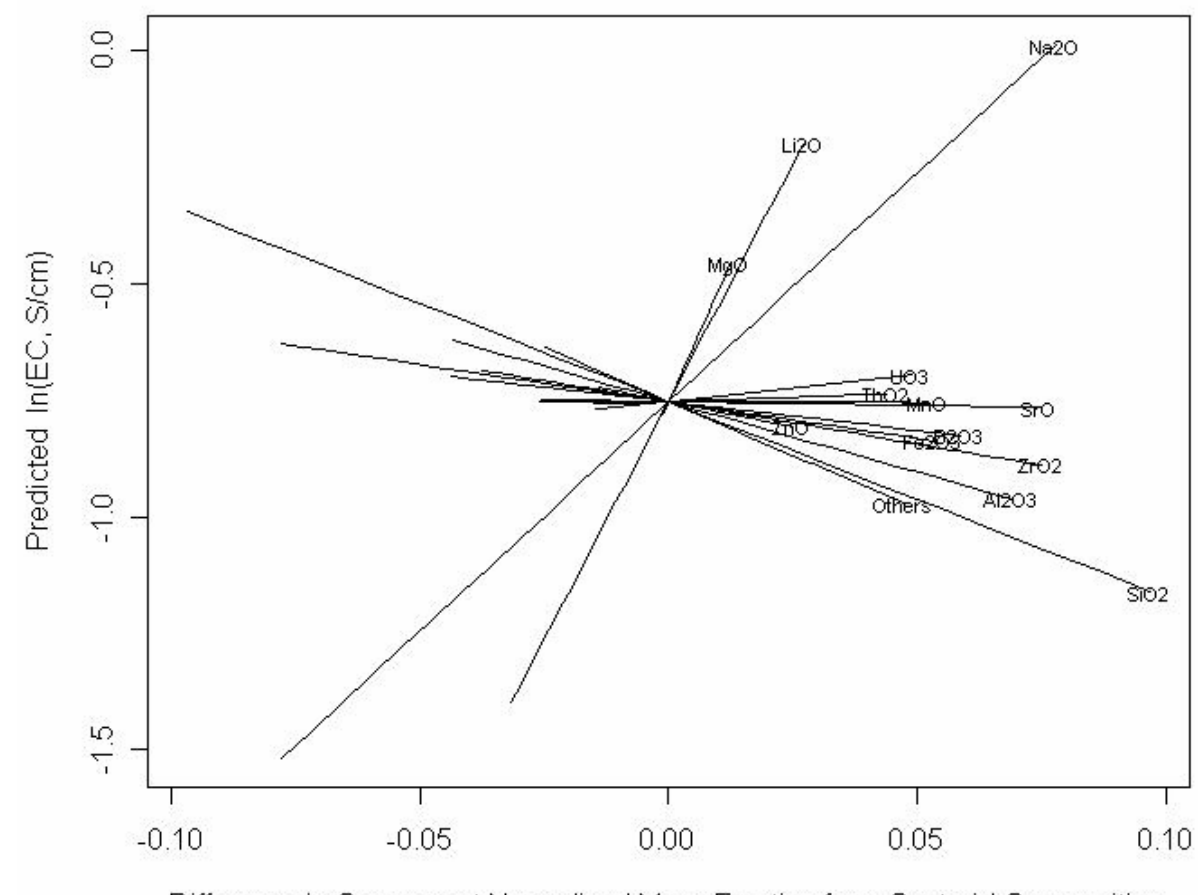

Difference in Component Normalized Mass Fraction from Centroid Composition

Figure 7.13d. Response Trace Plot for IHLW Electrical Conductivity at $1250^{\circ} \mathrm{C}$ Constructed Using the 27-Term Truncated T2-Linear Mixture Model. 


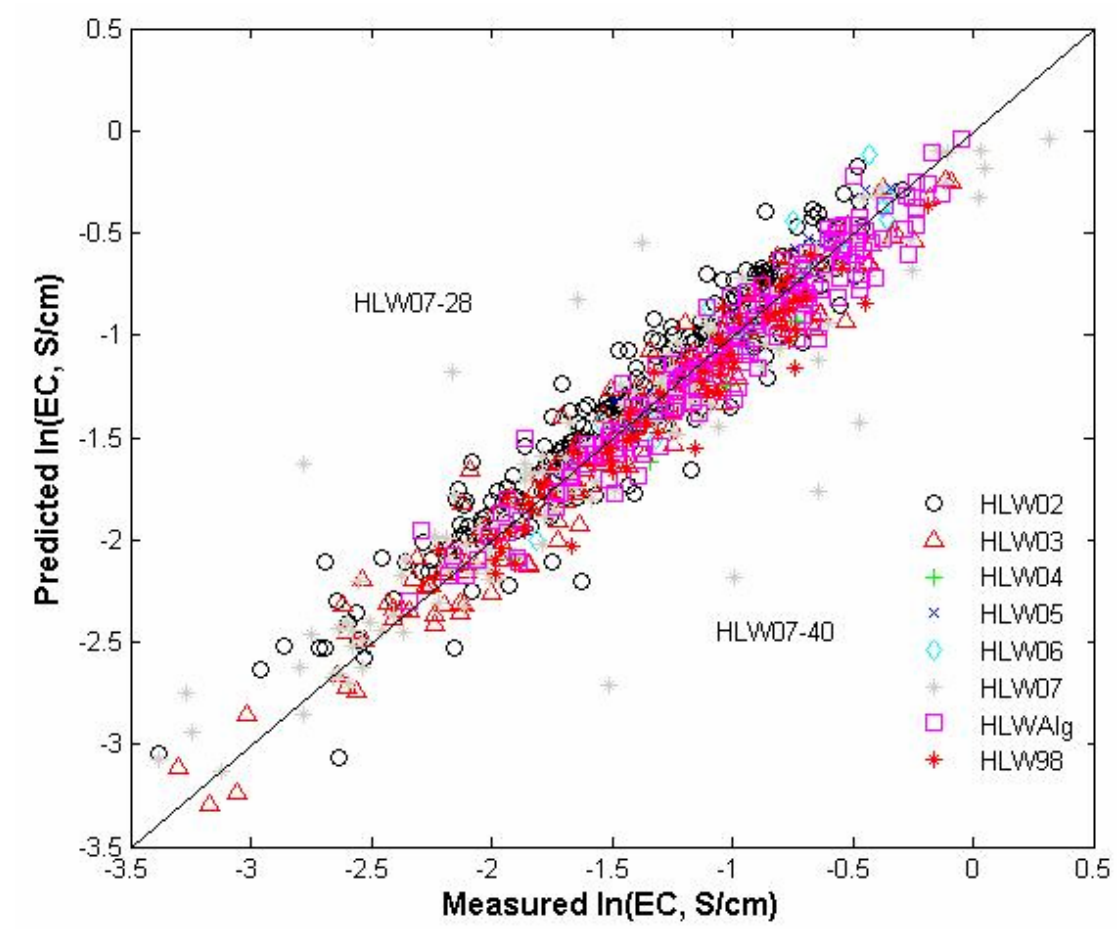

Figure 7.14. Predicted Versus Measured Plot for the 208 HLW Glasses in the Electrical Conductivity Modeling Dataset Constructed Using the 22-Term Truncated T2-Linear Mixture Model.

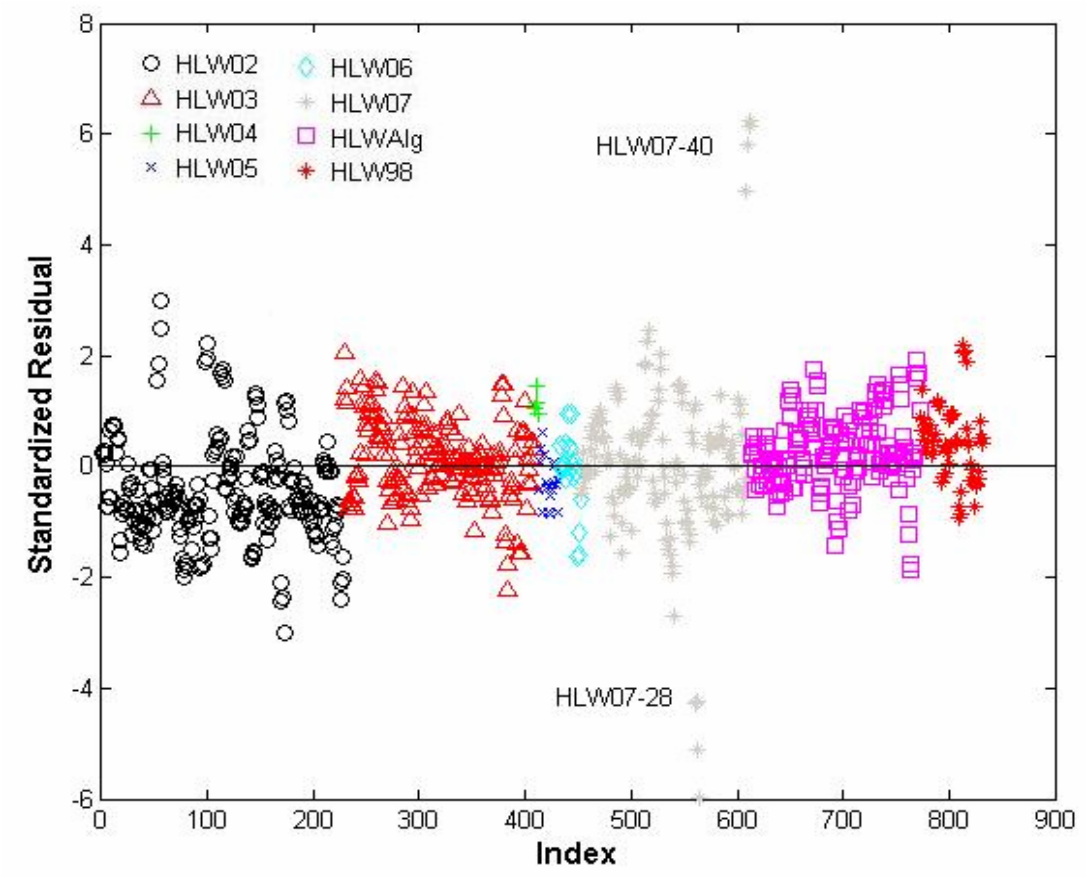

Figure 7.15. Standardized Residuals Plot for the 208 HLW Glasses in the Electrical Conductivity Modeling Dataset Constructed Using the 22-Term Truncated T2-Linear Mixture Model. 
The Catholic University of America Vitreous State Laboratory
IHLW PCT, Spinel $T_{1 \%}$, Electrical Conductivity, and Viscosity Model Development Final Report, VSL-07R1240-4, Rev. 0

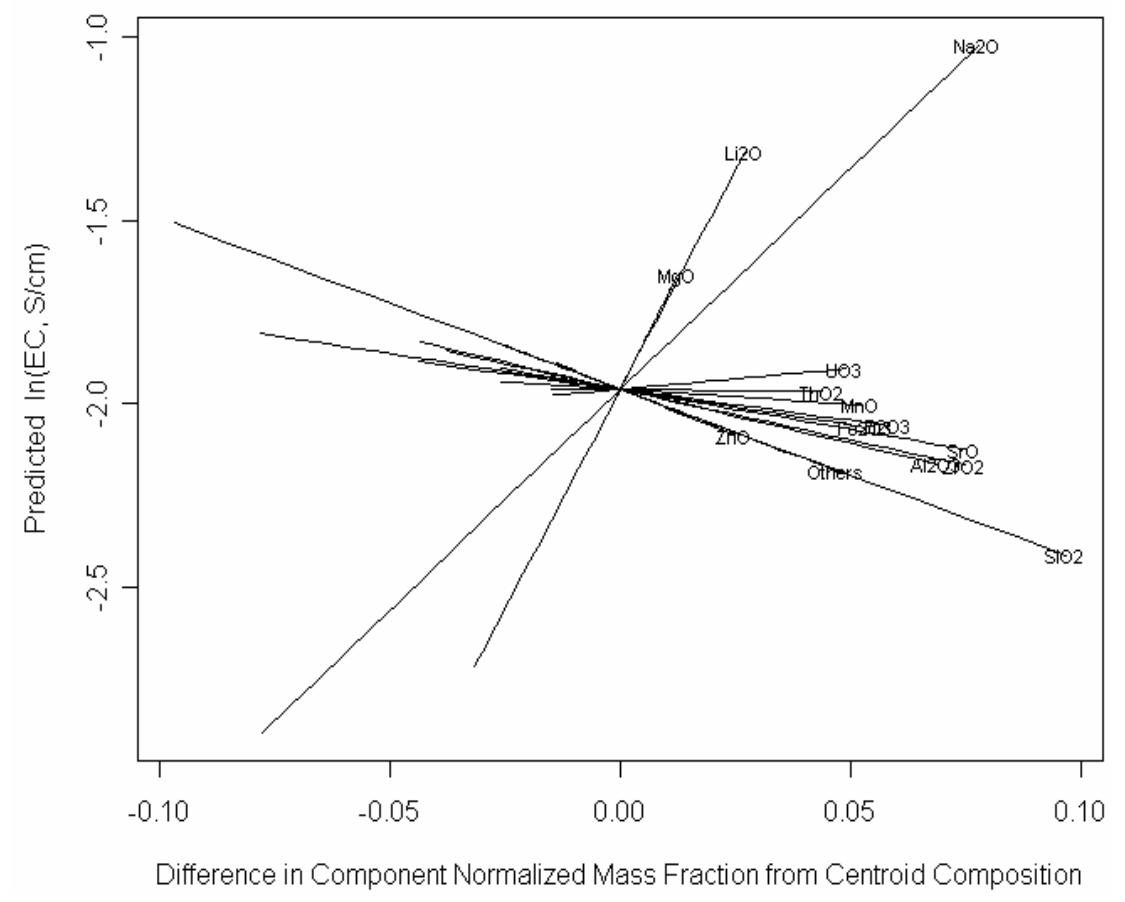

Figure 7.16a. Response Trace Plot for IHLW Electrical Conductivity at $950^{\circ} \mathrm{C}$ Constructed Using the 22-Term Truncated T2-Linear Mixture Model.

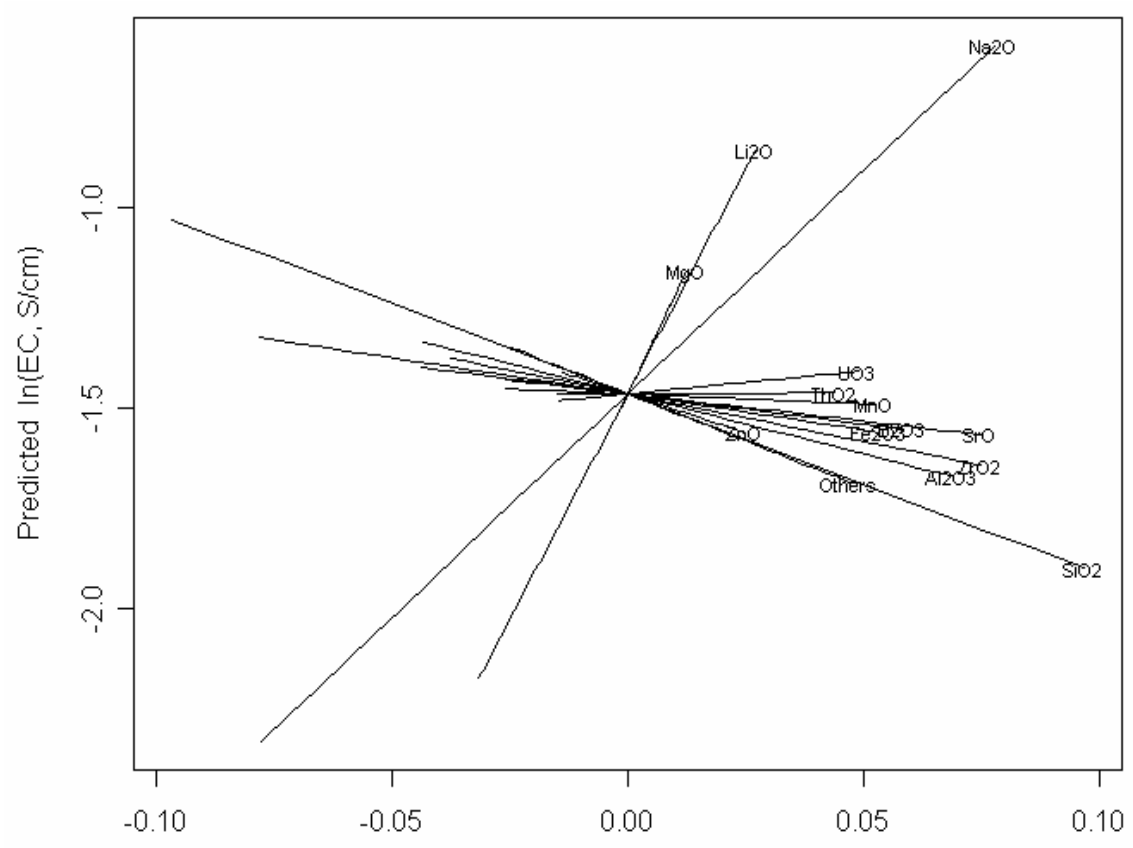

Difference in Component Normalized Mass Fraction from Centroid Composition

Figure 7.16b. Response Trace Plot for IHLW Electrical Conductivity at $1050^{\circ} \mathrm{C}$ Constructed Using the 22-Term Truncated T2-Linear Mixture Model. 
The Catholic University of America Vitreous State Laboratory
IHLW PCT, Spinel $T_{1 \%}$, Electrical Conductivity, and Viscosity Model Development Final Report, VSL-07R1240-4, Rev. 0

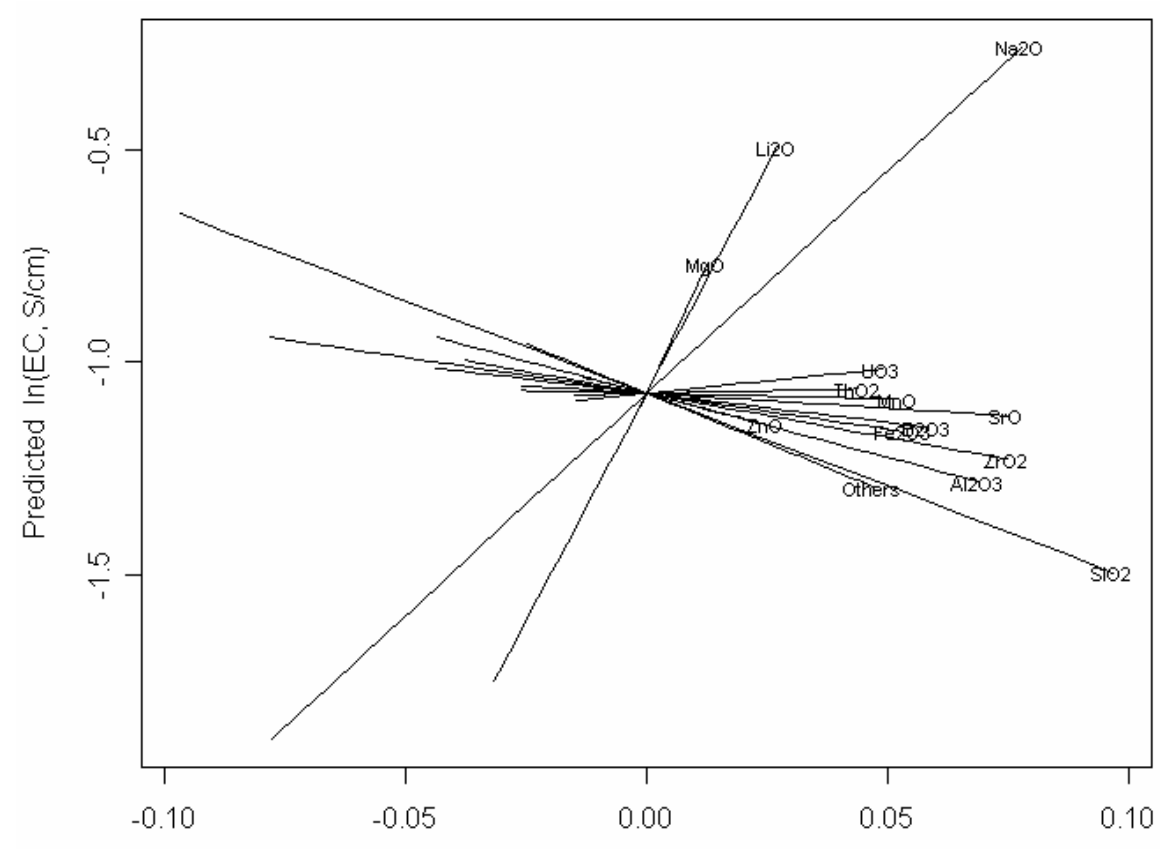

Difference in Component Normalized Mass Fraction from Centroid Composition

Figure 7.16c. Response Trace Plot for IHLW Electrical Conductivity at $1150^{\circ} \mathrm{C}$ Constructed Using the 22-Term Truncated T2-Linear Mixture Model.

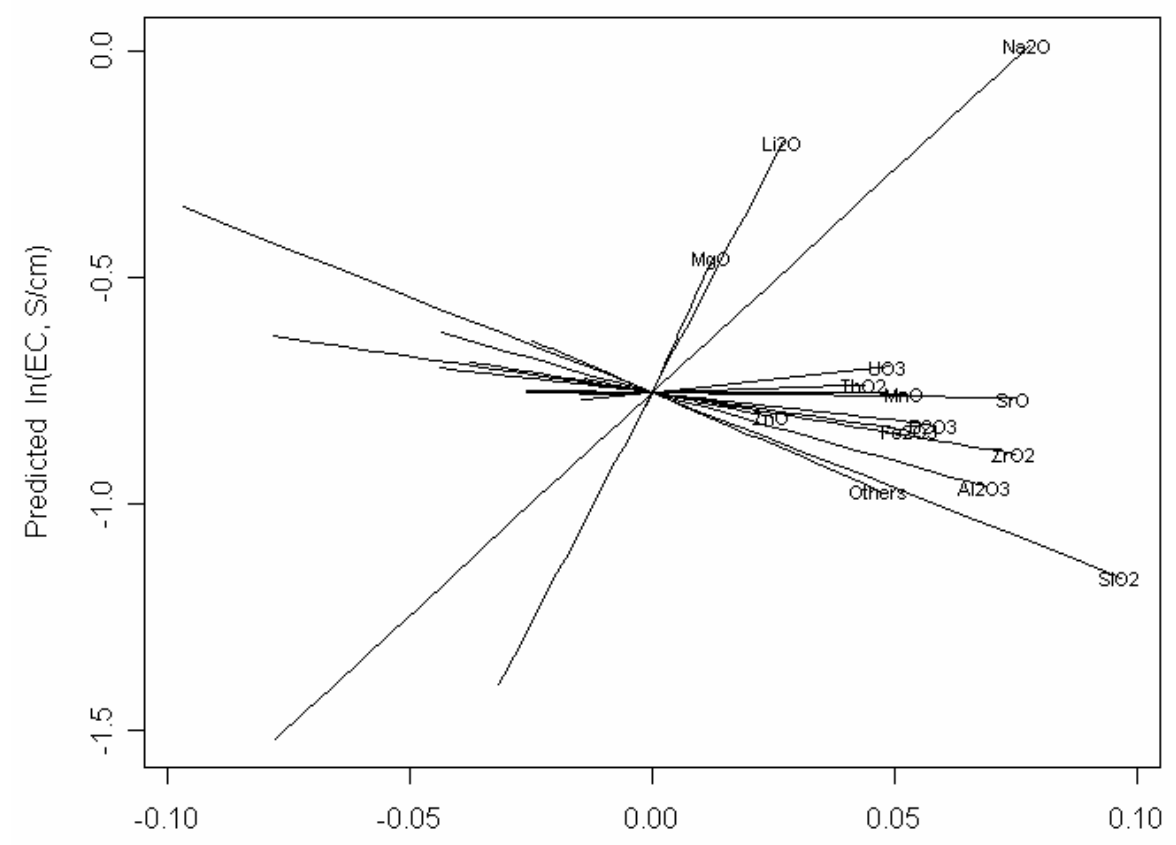

Difference in Component Normalized Mass Fraction from Centroid Composition

Figure 7.16d. Response Trace Plot for IHLW Electrical Conductivity at $1250^{\circ} \mathrm{C}$ Constructed Using the 22-Term Truncated T2-Linear Mixture Model. 


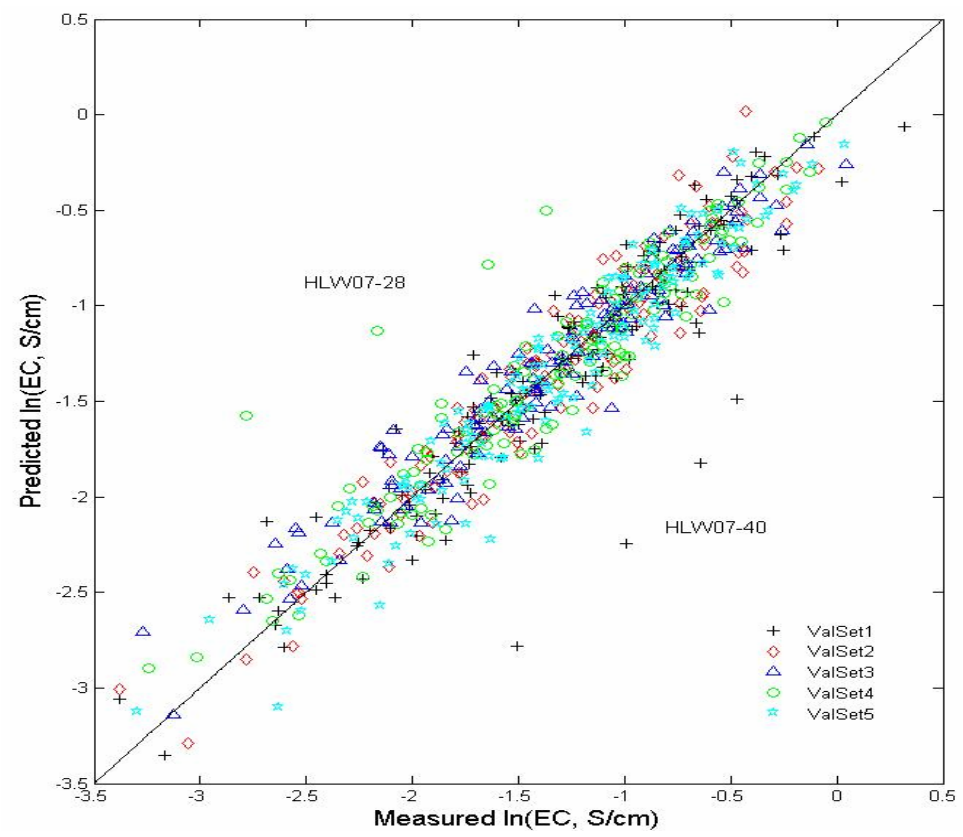

Figure 7.17. Predicted versus Measured $\ln (\mathrm{EC}, \mathrm{S} / \mathrm{cm})$ Values for each of the Five Data-Splitting Validation Subsets of the $208 \mathrm{HLW}$ Glasses in the Electrical Conductivity Modeling Dataset Constructed Using the 22-Term Truncated T2-Linear Mixture Model.

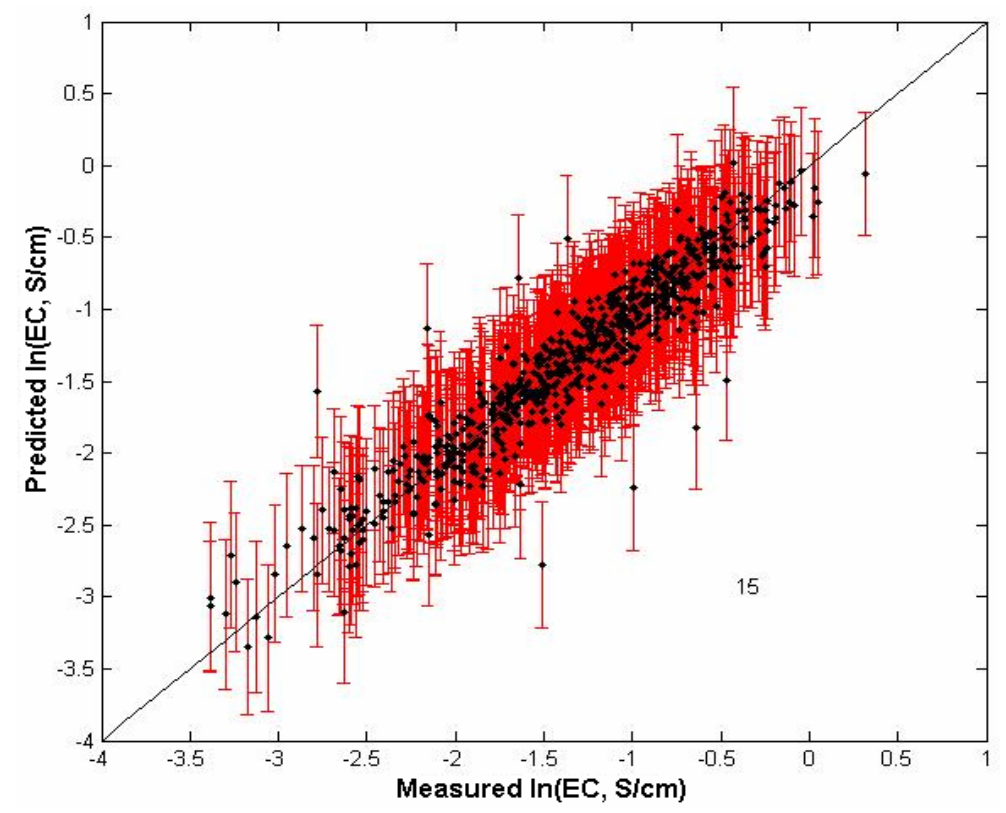

Figure 7.18. Predicted Versus Measured $\ln (\mathrm{EC}, \mathrm{S} / \mathrm{cm})$ Values for each of the Five DataSplitting Validation Subsets of the 208 HLW Glasses in the Electrical Conductivity Modeling Dataset Constructed Using the 22-Term Truncated T2-Linear Mixture Model. Error bars are 95\% prediction intervals (PIs). The number of glasses whose $95 \%$ PIs do not include the measured values (represented by the $45^{\circ}$ line) is shown. 


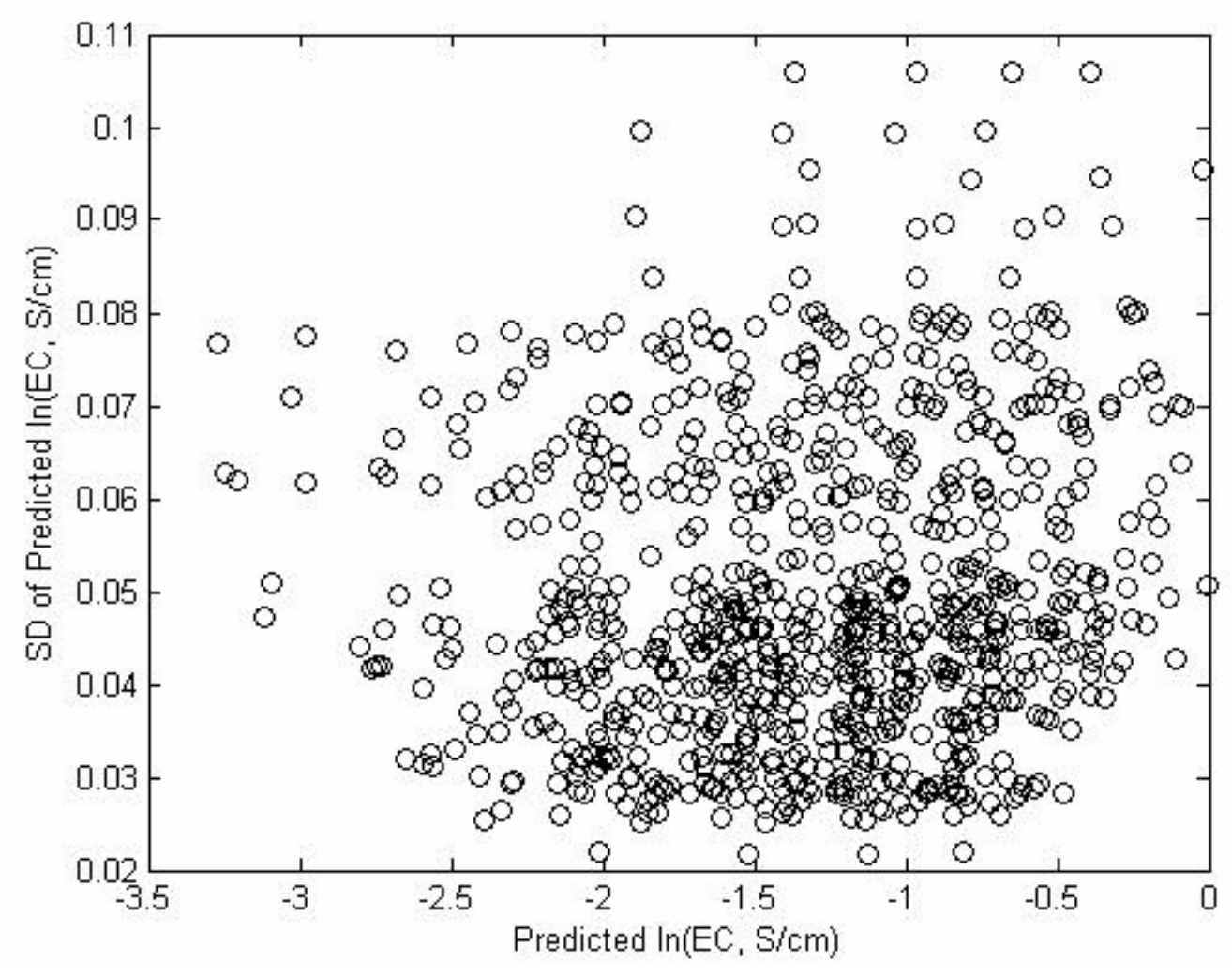

Figure 7.19. Prediction Standard Deviations versus Predicted $\ln (\mathrm{EC})$ Values over the HLW Glass Compositions in the Modeling Dataset and Temperatures 950, 1050,1150 , and $1250^{\circ} \mathrm{C}$, Obtained Using the Recommended 22-Term Electrical Conductivity Model. 
The Catholic University of America

Vitreous State Laboratory
IHLW PCT, Spinel $T_{1 \%}$, Electrical Conductivity, and Viscosity Model Development Final Report, VSL-07R1240-4, Rev. 0
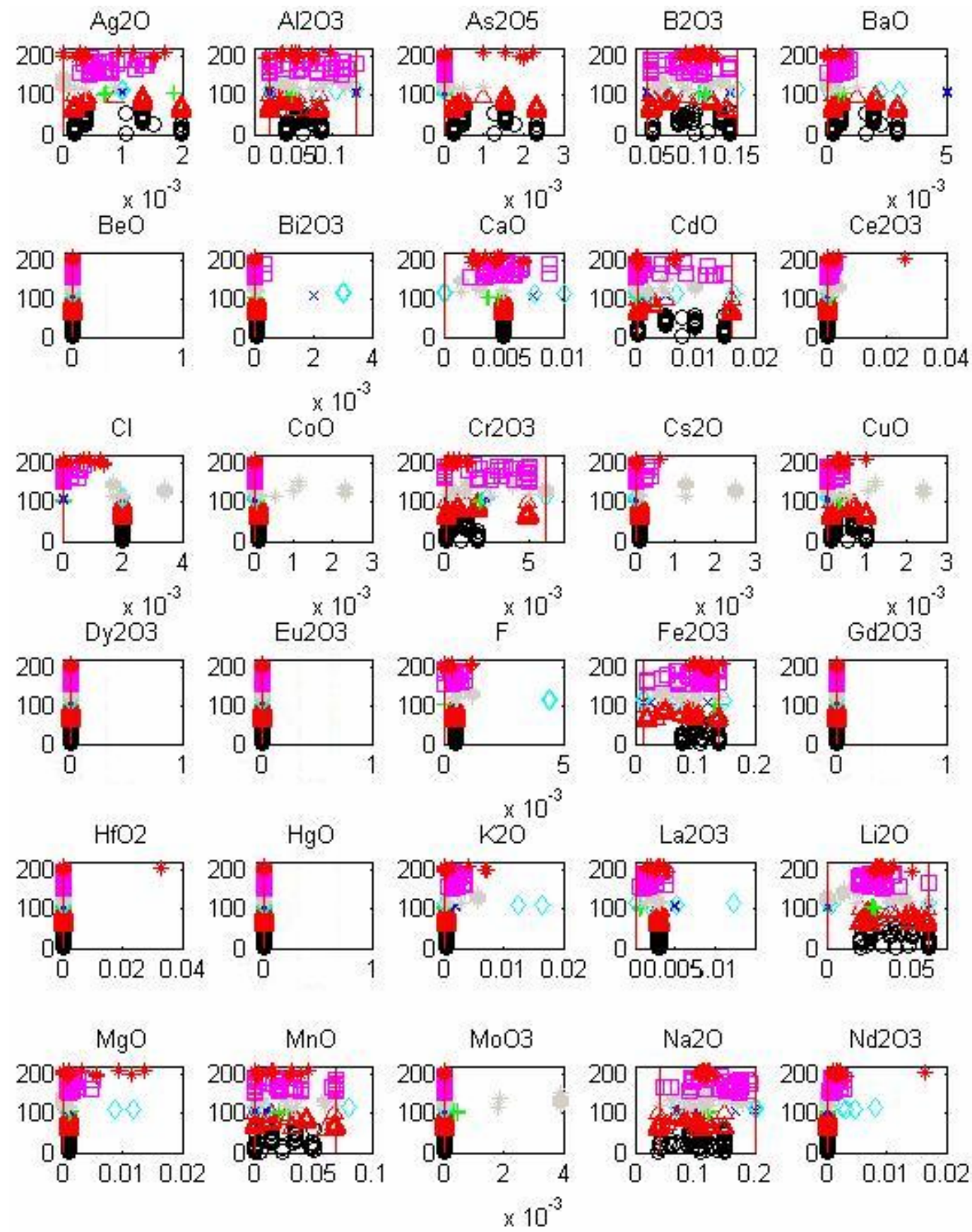

Figure 8.1. Ranges and Distributions of Component Mass Fractions (x-axes) for 210 HLW Glass Compositions with Viscosity Data. The vertical lines (when present) are the lower and upper limits for components varied in statistically designed test matrices. 
The Catholic University of America

Vitreous State Laboratory
IHLW PCT, Spinel $T_{1 \%}$, Electrical Conductivity, and Viscosity Model Development Final Report, VSL-07R1240-4, Rev. 0
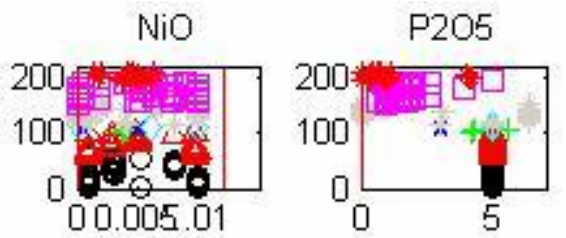

$\mathrm{Rb} 2 \mathrm{O}$

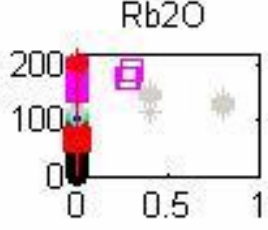

$\times 10^{-3}$

$\mathrm{Sb} 2 \mathrm{O} 3$
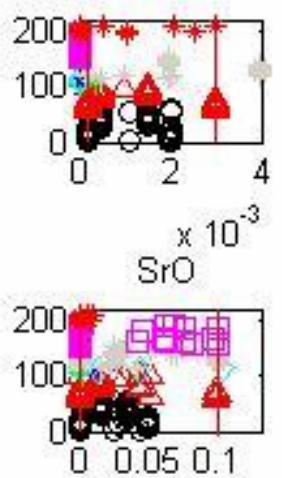

$\mathrm{T} 2 \mathrm{O}$

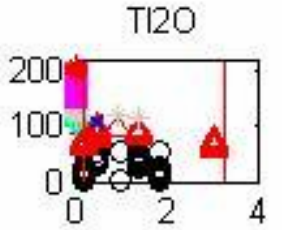

$\times 10^{-3}$
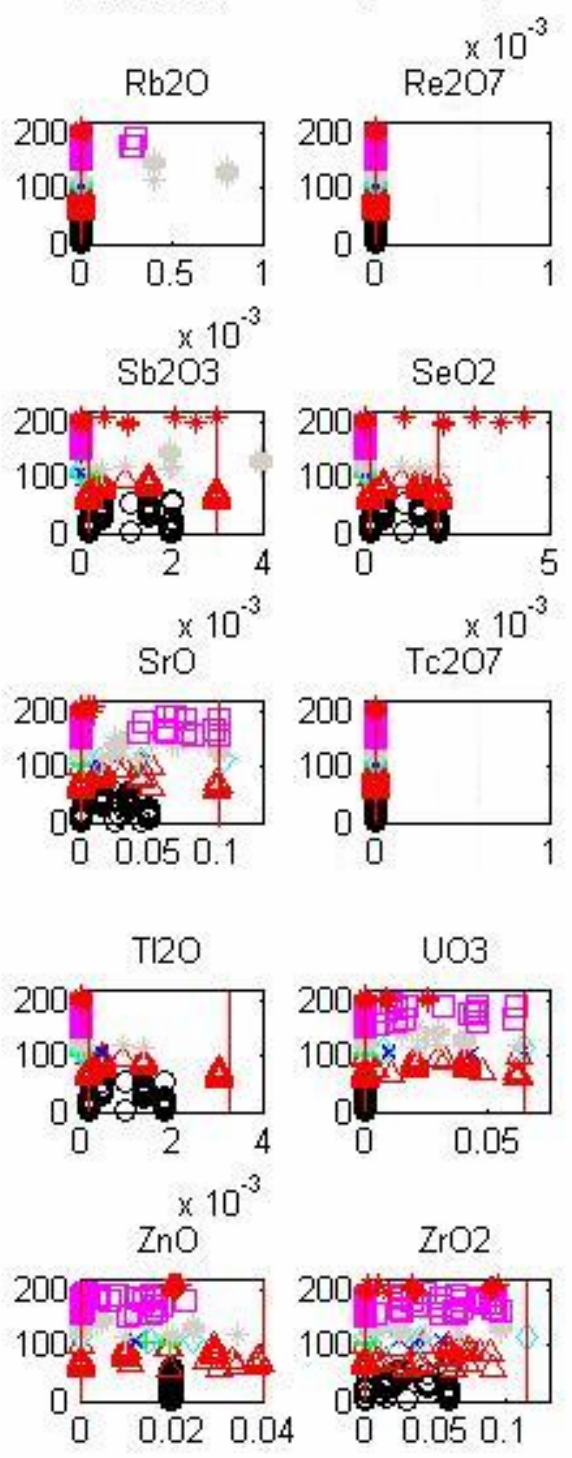
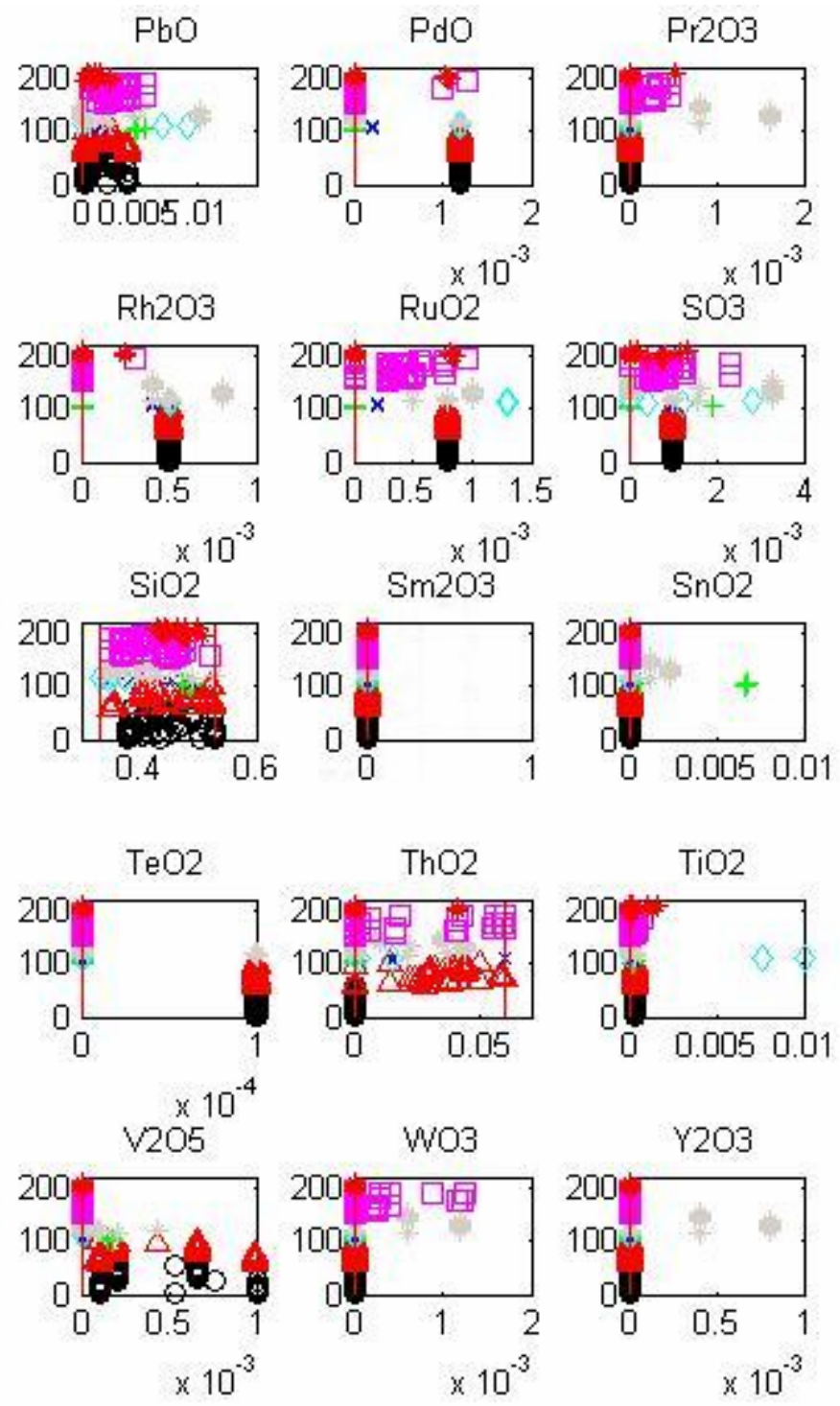

$$
\begin{array}{cr}
\times & \text { HLW02 } \\
\triangle & \text { HLW03 } \\
+ & \text { HLW04 } \\
\times & \text { HLW05 }
\end{array}
$$

HLW06

HLWO7

HLWAlg

* HLW98

Figure 8.1. Ranges and Distributions of Component Mass Fractions (x-axes) for 210 HLW Glass Compositions with Electrical Conductivity Data. The vertical lines (when present) are the lower and upper limits for the components varied in statistically designed test matrices (continued). 
The Catholic University of America

Vitreous State Laboratory
IHLW PCT, Spinel $T_{1 \%}$, Electrical Conductivity, and Viscosity Model Development Final Report, VSL-07R1240-4, Rev. 0
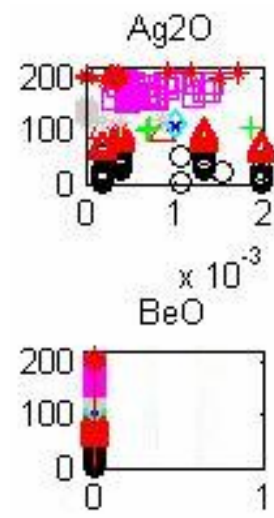

$\mathrm{Cl}$
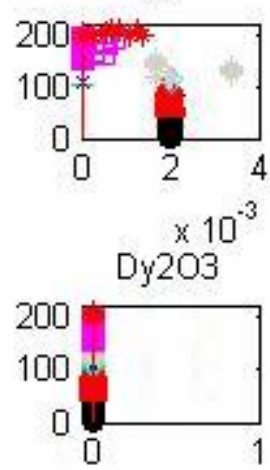

$\mathrm{HfO} 2$

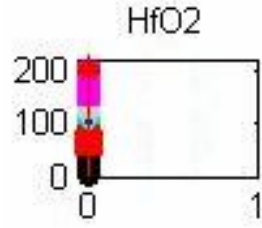

$\mathrm{MgO}$

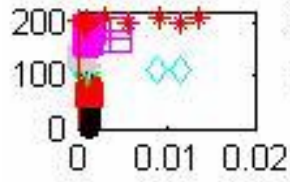

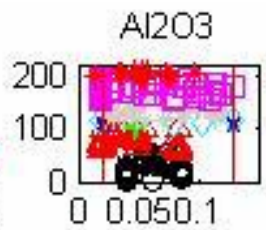

$\mathrm{Bi} 2 \mathrm{O} 3$
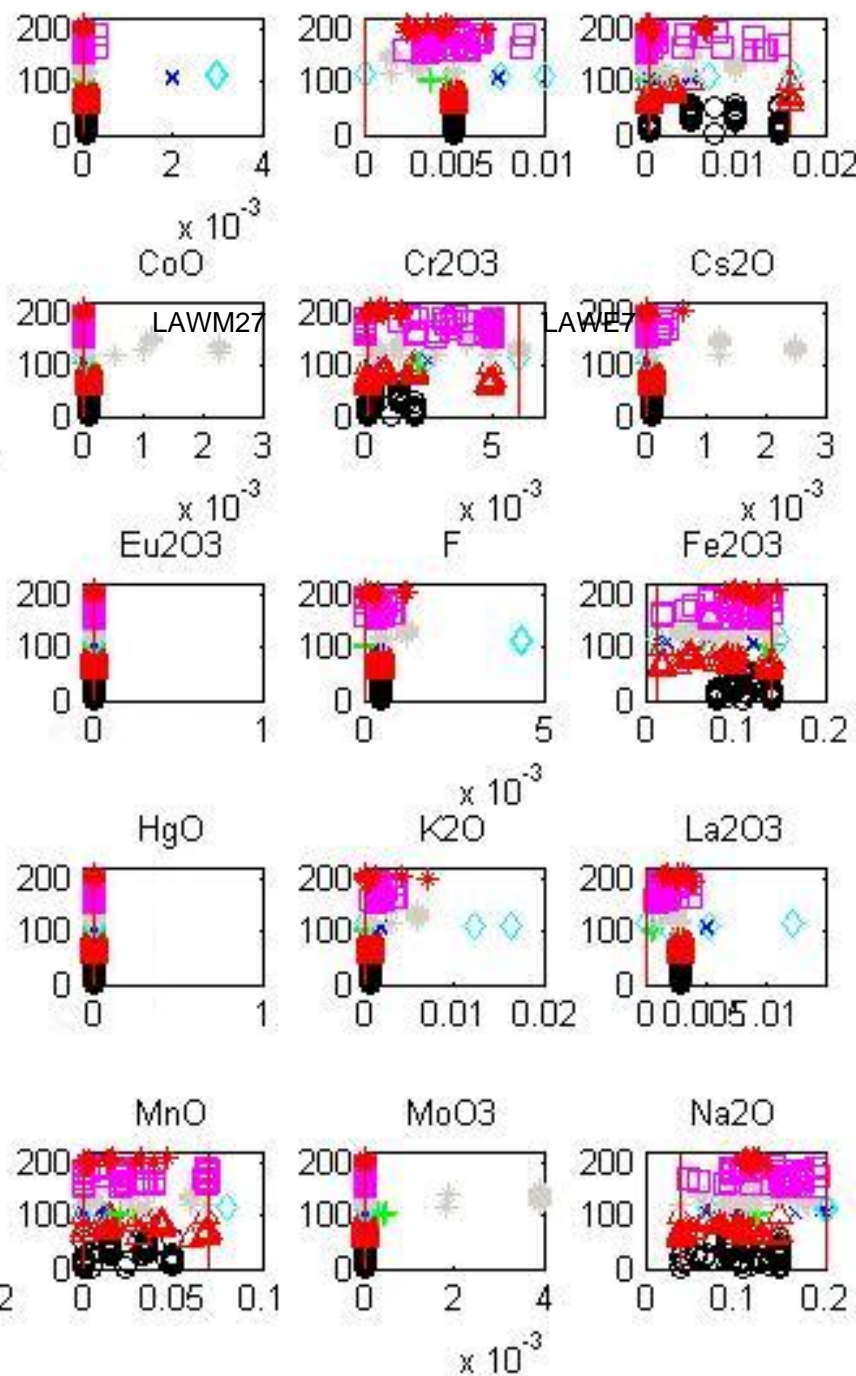
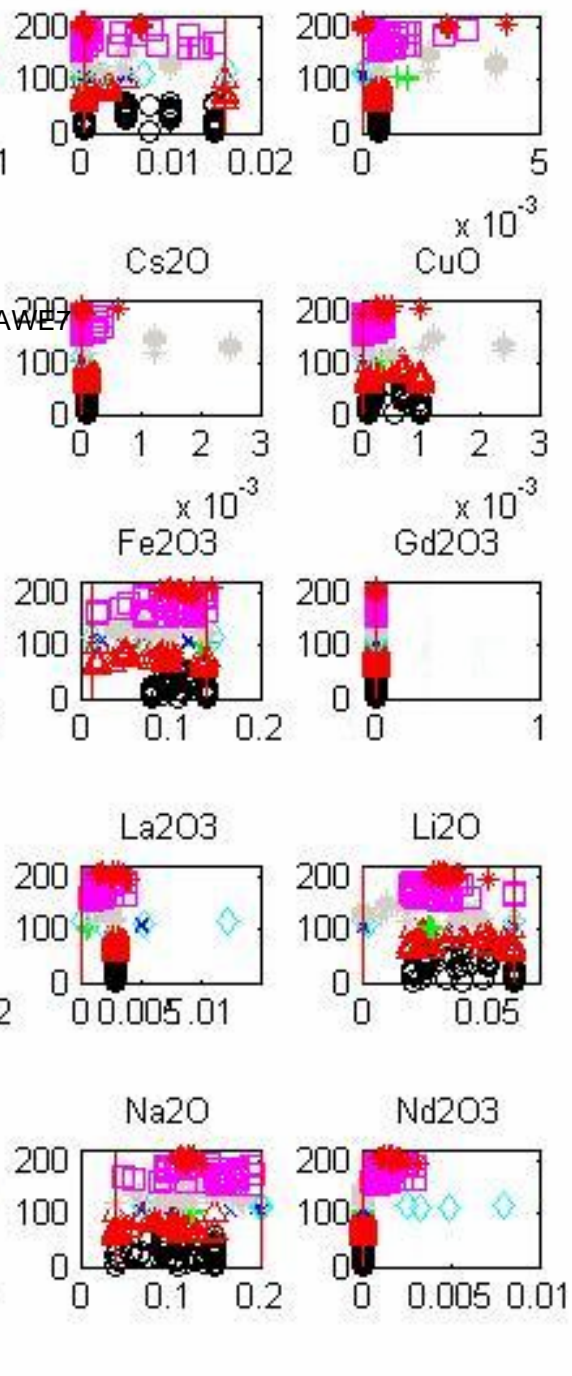

Figure 8.2. Ranges and Distributions of Component Mass Fractions (x-axes) for 208 HLW Glass Compositions with Viscosity Data After Deleting Two Outliers from the Initial 210 Glasses. The vertical lines (when present) are the lower and upper limits for the components varied in statistically designed test matrices. 
The Catholic University of America

Vitreous State Laboratory
IHLW PCT, Spinel $T_{1 \%}$, Electrical Conductivity, and Viscosity Model Development Final Report, VSL-07R1240-4, Rev. 0
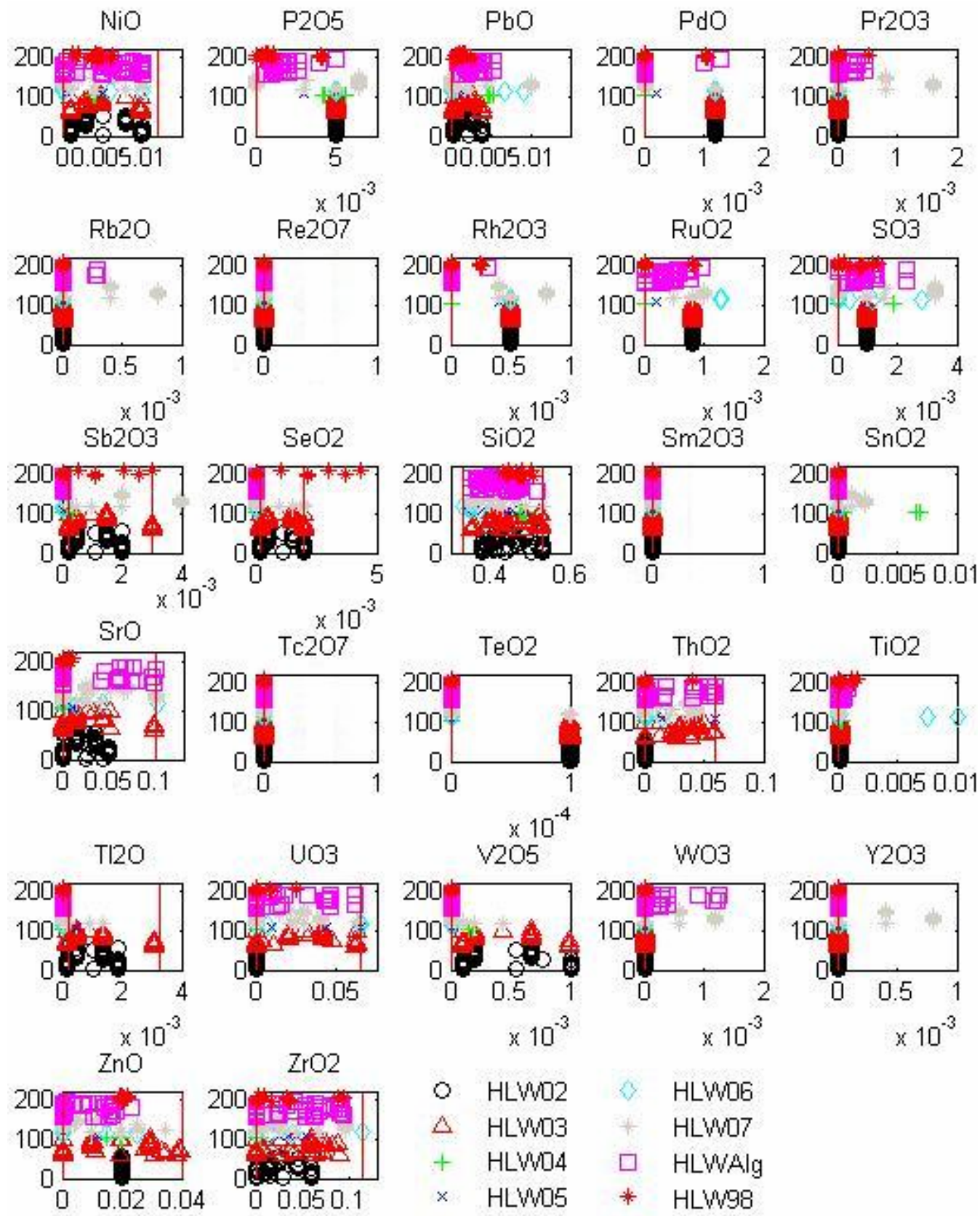

Figure 8.2. Ranges and Distributions of Component Mass Fractions (x-axes) for 208 HLW Glass Compositions with Viscosity Data After Deleting Two Outliers from the Initial 210 Glasses. The vertical lines (when present) are the lower and upper limits for the components varied in statistically designed test matrices (continued). 


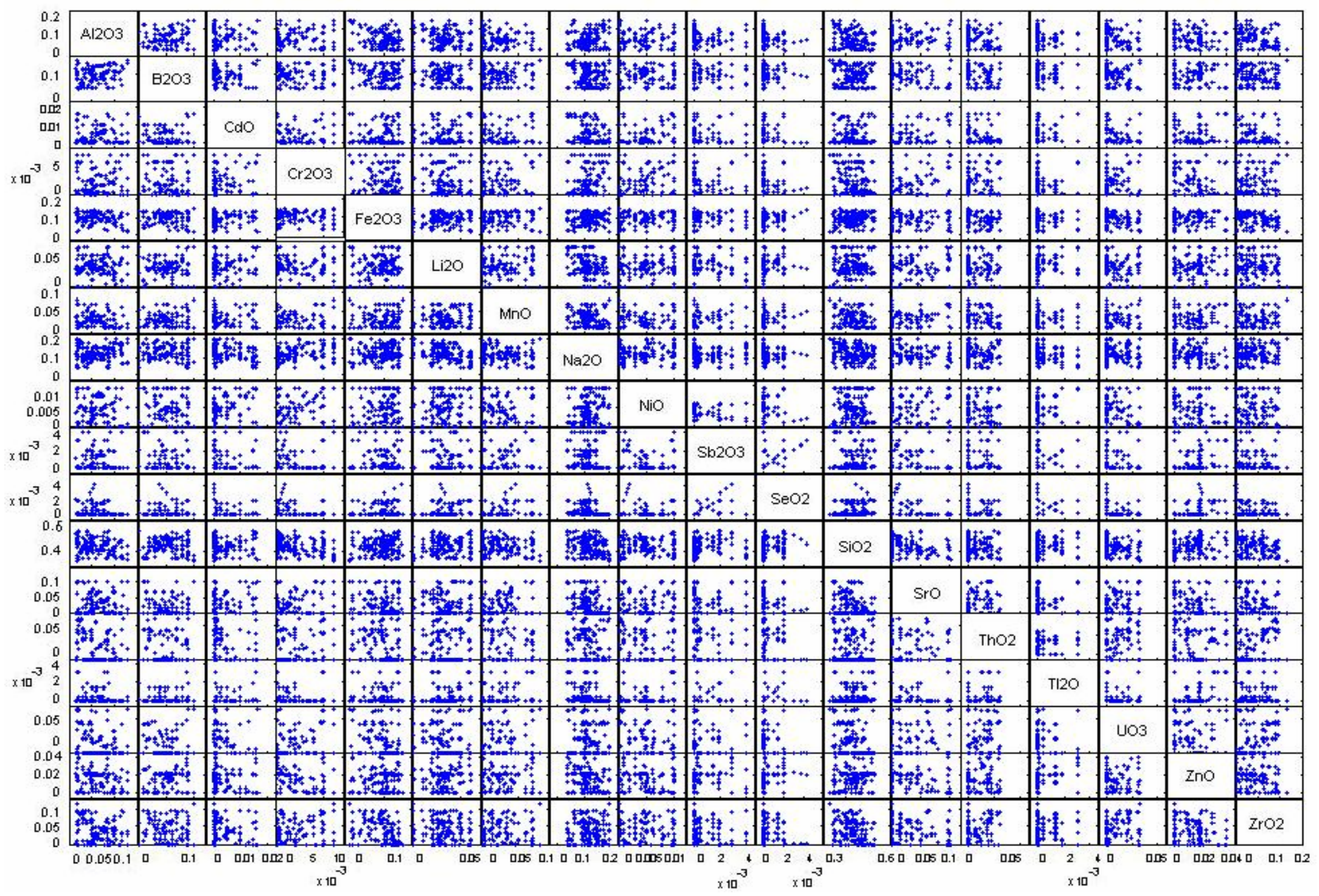

Figure 8.3. Scatterplot Matrix of 18 Component Mass Fractions for 208 HLW Glass Compositions with Viscosity Data After Deleting Two Outliers from the Initial 210 Glasses. 


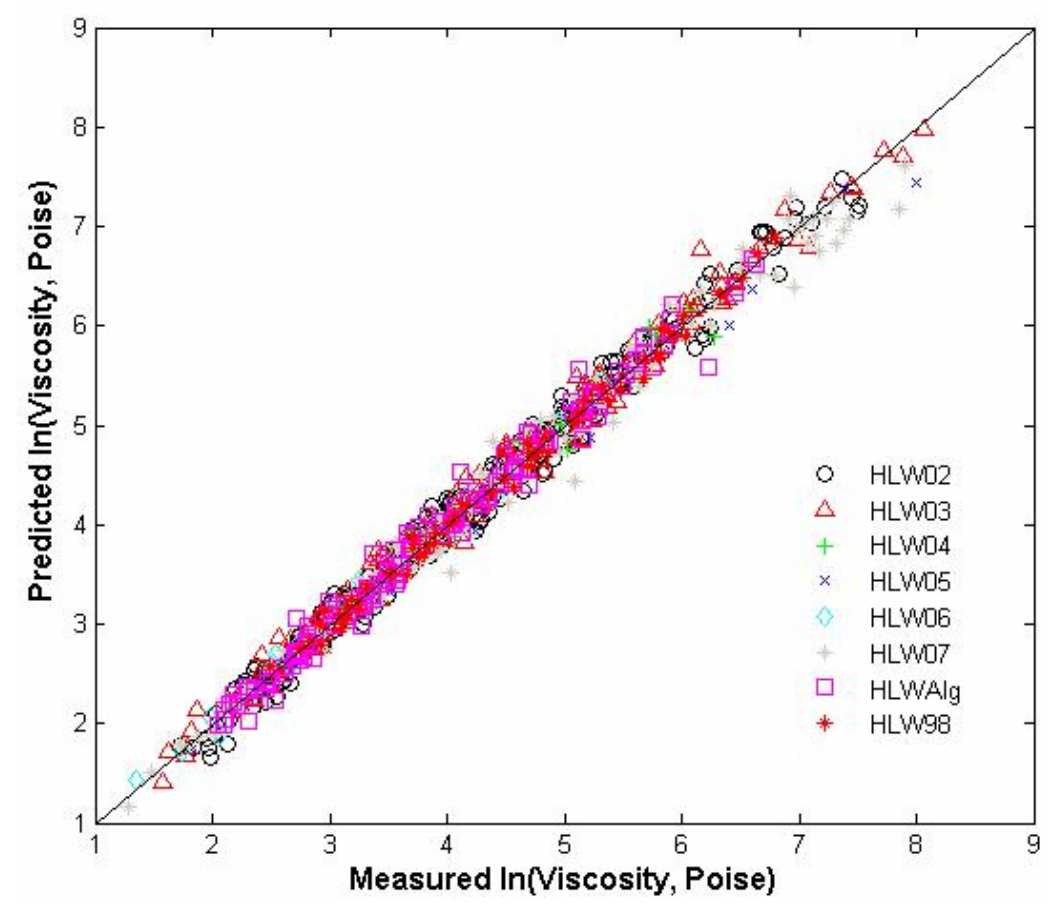

Figure 8.4. Predicted Versus Measured Plot for the 197 HLW Glasses in the Viscosity Modeling Dataset Constructed Using the 44-Term Truncated T2-Linear Mixture Model.

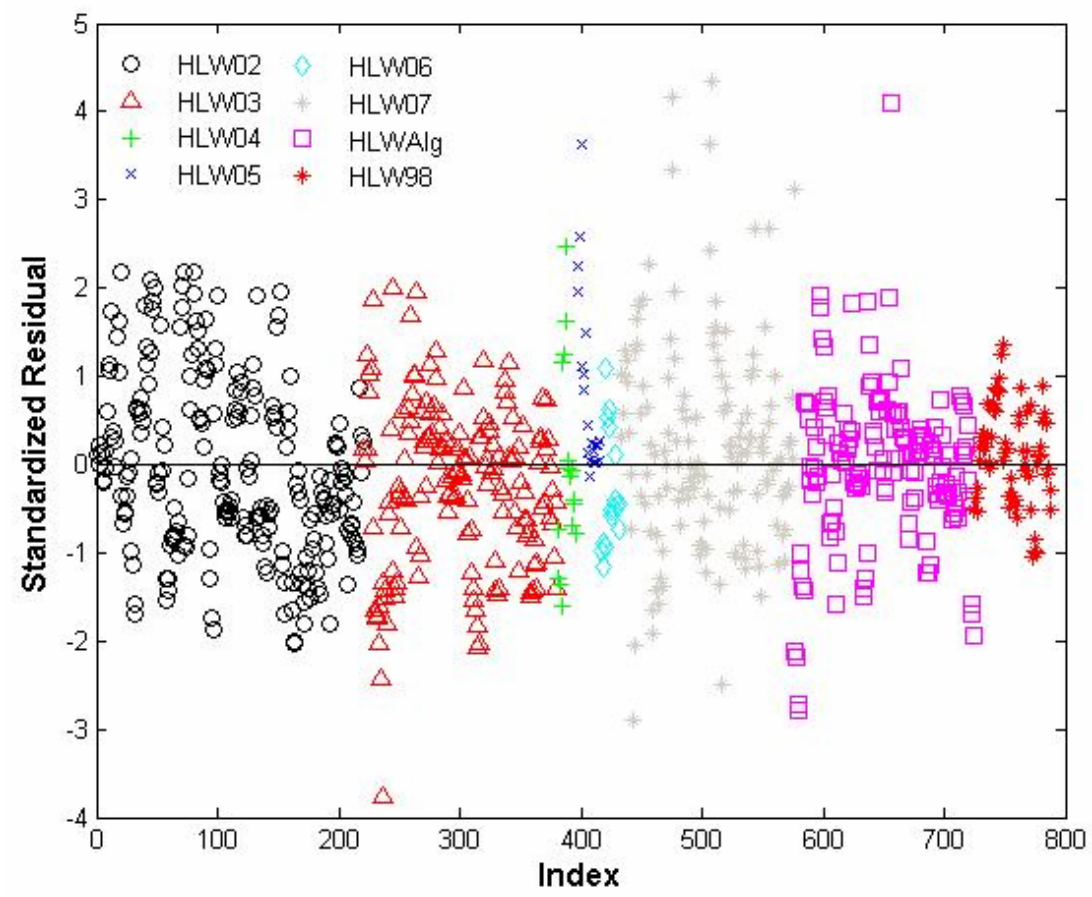

Figure 8.5. Standardized Residuals Plot for the 197 HLW Glasses in the Viscosity Modeling Dataset Constructed Using the 44-Term Truncated T2-Linear Mixture Model. 


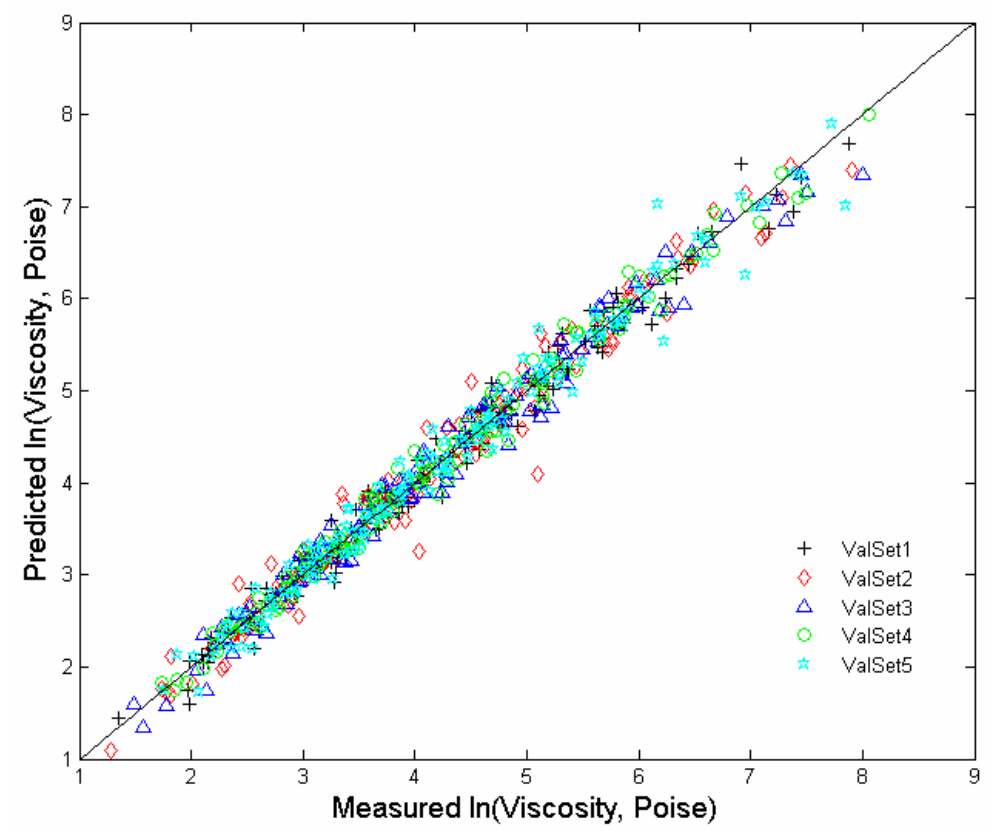

Figure 8.6. Predicted versus Measured $\ln ($ Viscosity, poise) Values for each of the Five Data-Splitting Validation Subsets of the 197 HLW Glasses in the Viscosity Modeling Dataset Constructed Using the 44-Term Truncated T2-Linear Mixture Model.

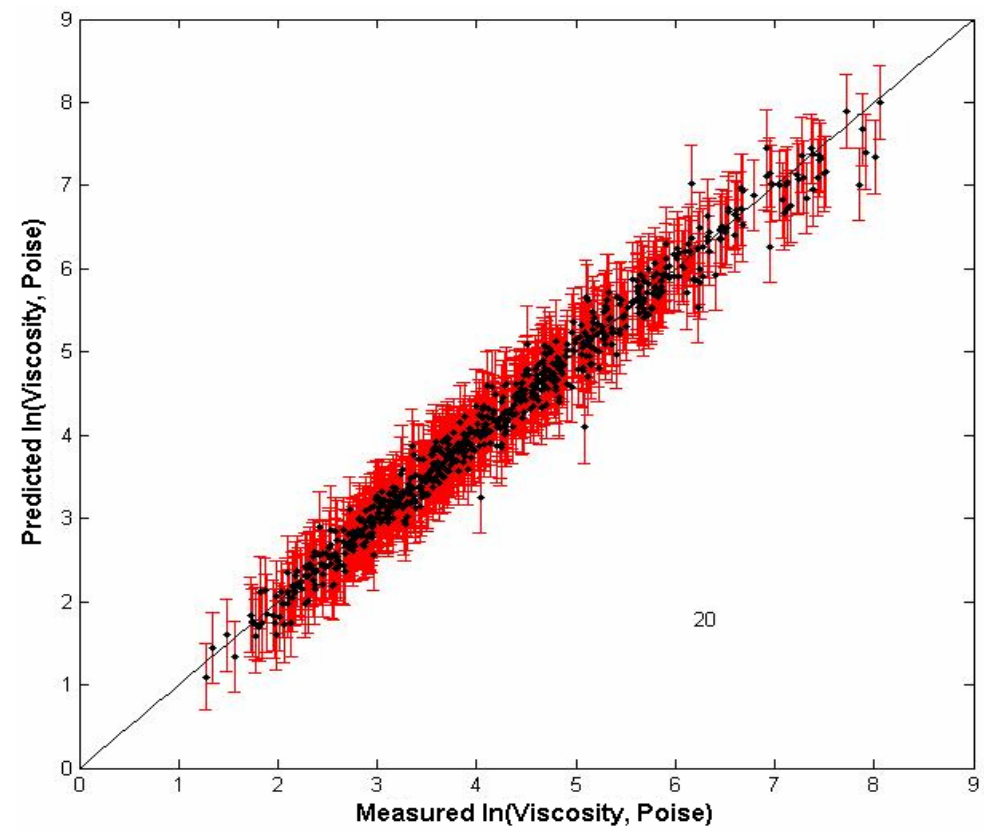

Figure 8.7. Predicted Versus Measured $\ln ($ Viscosity, poise) Values for each of the Five Data-Splitting Validation Subsets of the 197 HLW Glasses in the Viscosity Modeling Dataset Constructed Using the 44-Term Truncated T2-Linear Mixture Model. Error bars are 95\% prediction intervals (PIs). The number of glasses whose $95 \%$ PIs do not include the measured values (represented by the $45^{\circ}$ line) is shown. 
The Catholic University of America Vitreous State Laboratory
IHLW PCT, Spinel $T_{1 \%}$, Electrical Conductivity, and Viscosity Model Development Final Report, VSL-07R1240-4, Rev. 0

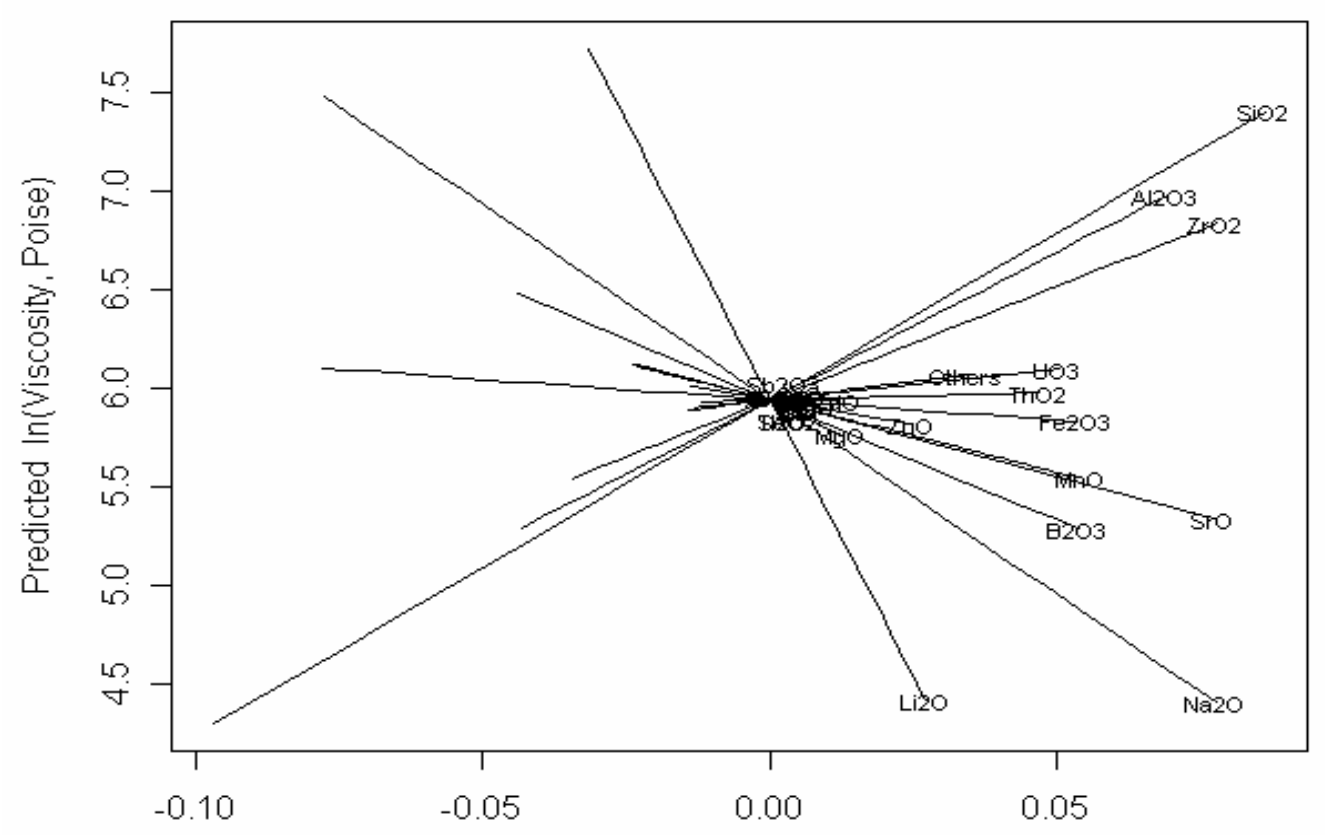

Difference in Component Normalized Mass Fraction from Centroid Composition

Figure 8.8a. Response Trace Plot for IHLW Viscosity at $950^{\circ} \mathrm{C}$ Constructed Using the 44-Term Truncated T2-Linear Mixture Model.

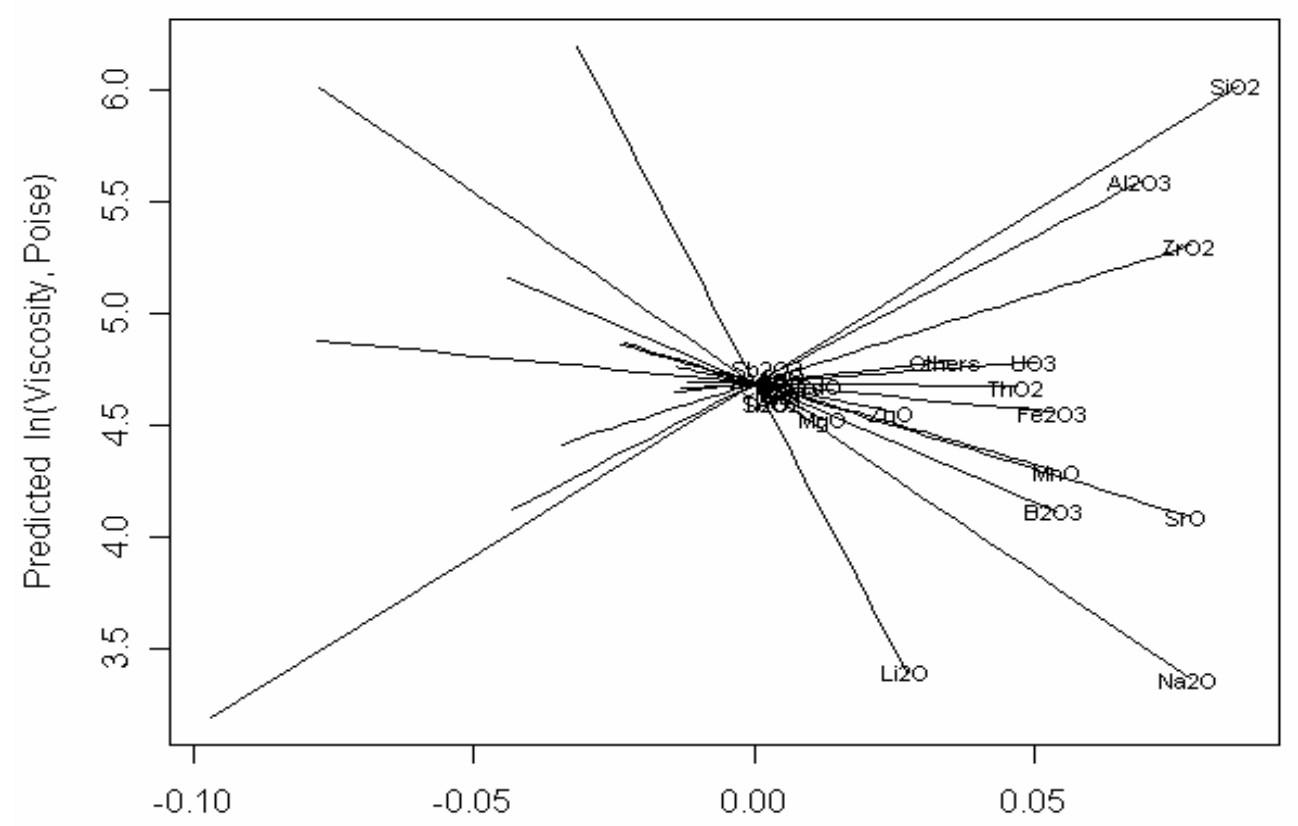

Difference in Component Normalized Mass Fraction from Centroid Composition

Figure 8.8b. Response Trace Plot for IHLW Viscosity at $1050^{\circ} \mathrm{C}$ Constructed Using the 44-Term Truncated T2-Linear Mixture Model. 
The Catholic University of America Vitreous State Laboratory
IHLW PCT, Spinel $T_{1 \%}$, Electrical Conductivity, and Viscosity Model Development Final Report, VSL-07R1240-4, Rev. 0

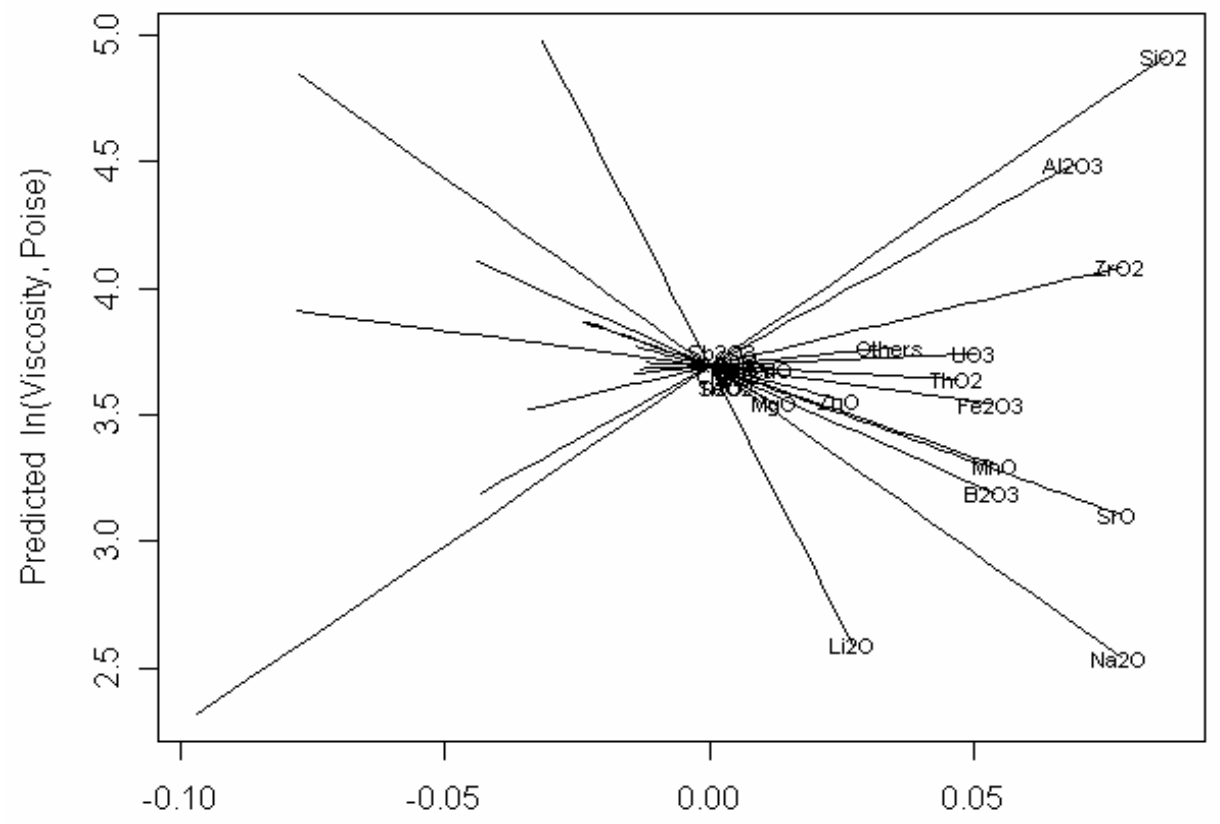

Difference in Component Normalized Mass Fraction from Centroid Composition

Figure 8.8c. Response Trace Plot for IHLW Viscosity at $\mathbf{1 1 5 0}^{\circ} \mathrm{C}$ Constructed Using the 44-Term Truncated T2-Linear Mixture Model.

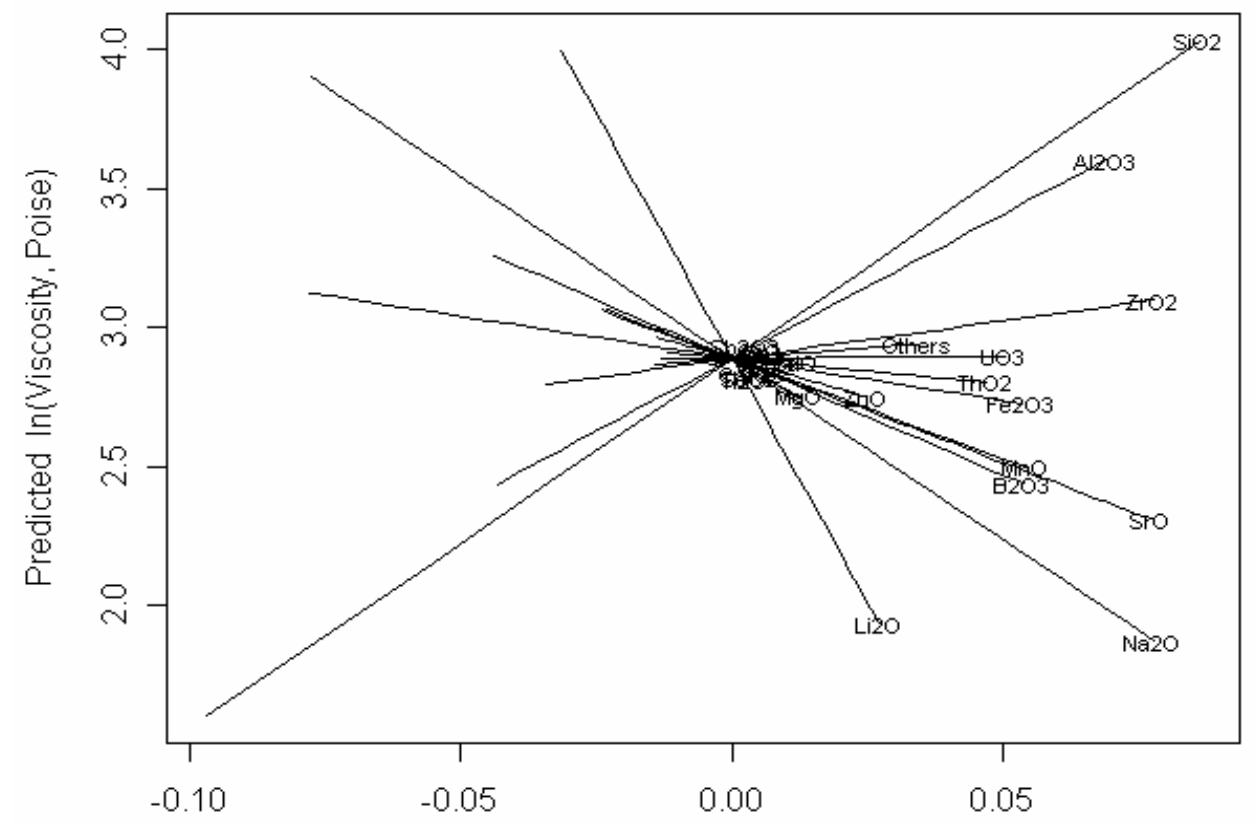

Difference in Component Normalized Mass Fraction from Centroid Composition

Figure 8.8d. Response Trace Plot for IHLW Viscosity at $1250^{\circ} \mathrm{C}$ Constructed Using the 44-Term Truncated T2-Linear Mixture Model. 


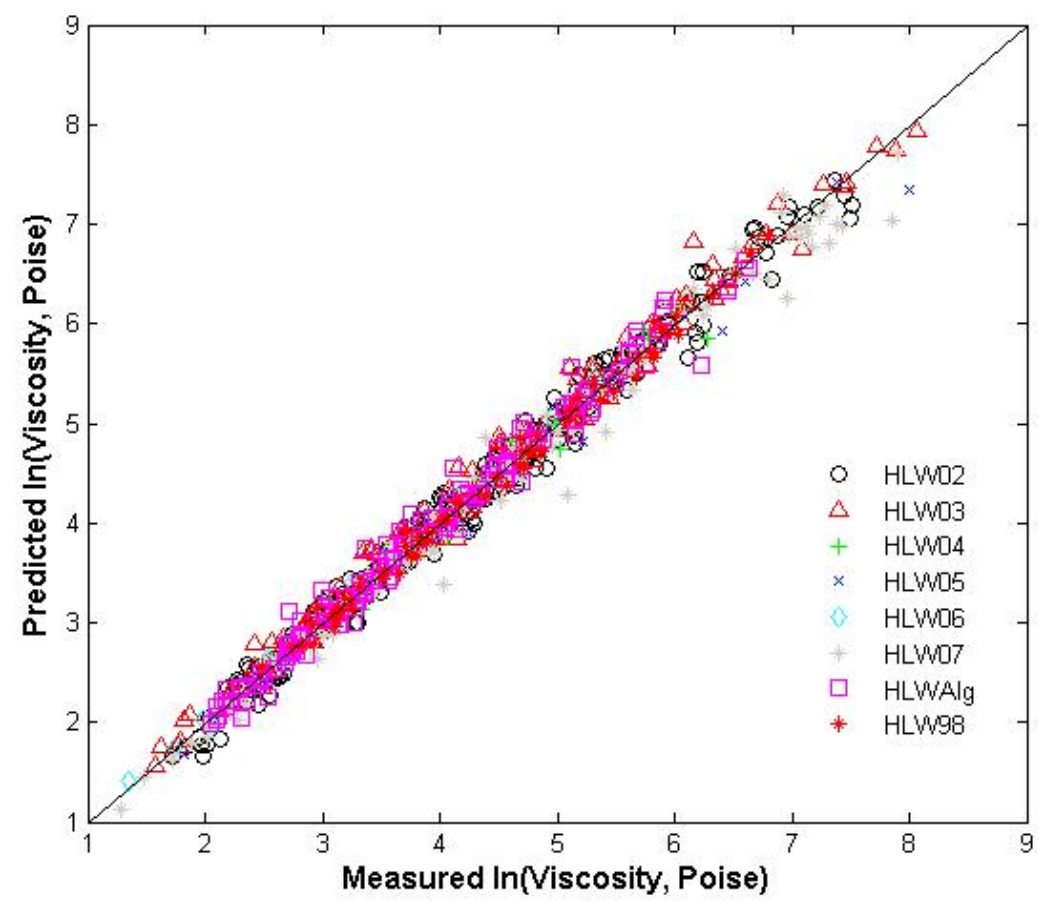

Figure 8.9. Predicted Versus Measured Plot for the 197 HLW Glasses in the Viscosity Modeling Dataset Constructed Using the 27-Term Truncated T2-Linear Mixture Model.

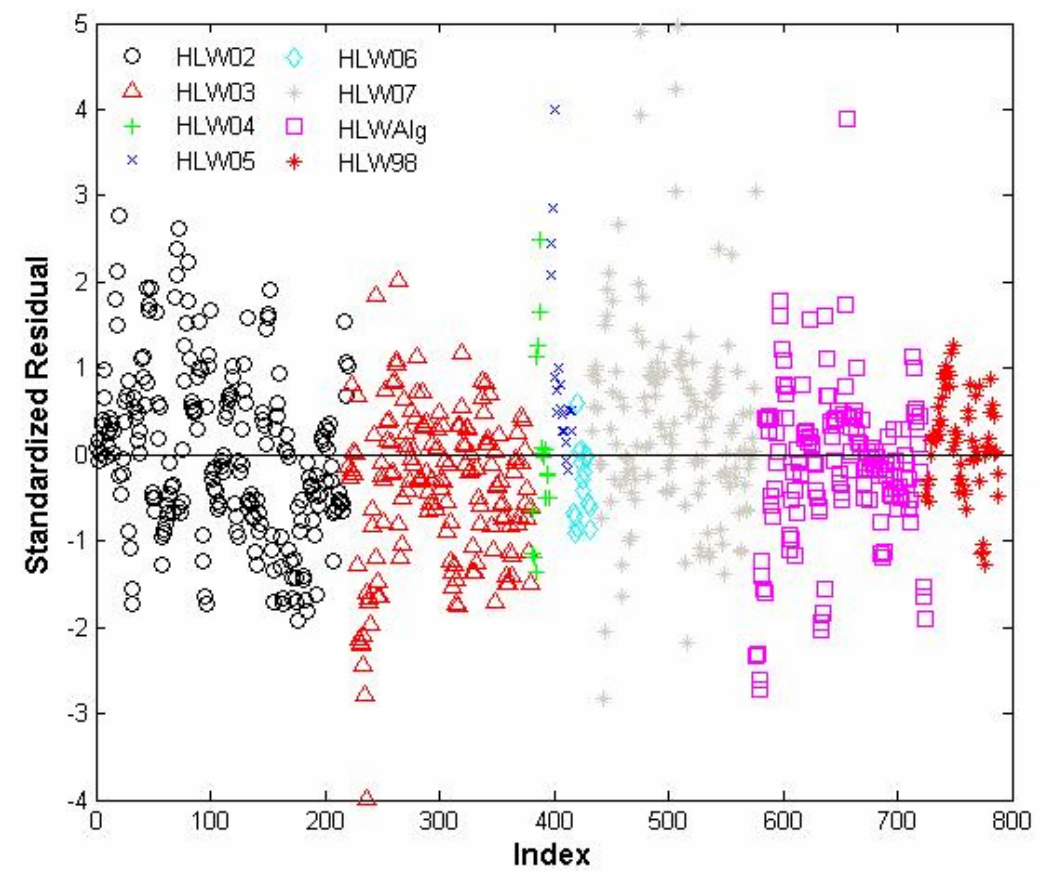

Figure 8.10. Standardized Residuals Plot for the 197 HLW Glasses in the Viscosity Modeling Dataset Constructed Using the 27-Term Truncated T2-Linear Mixture Model. 


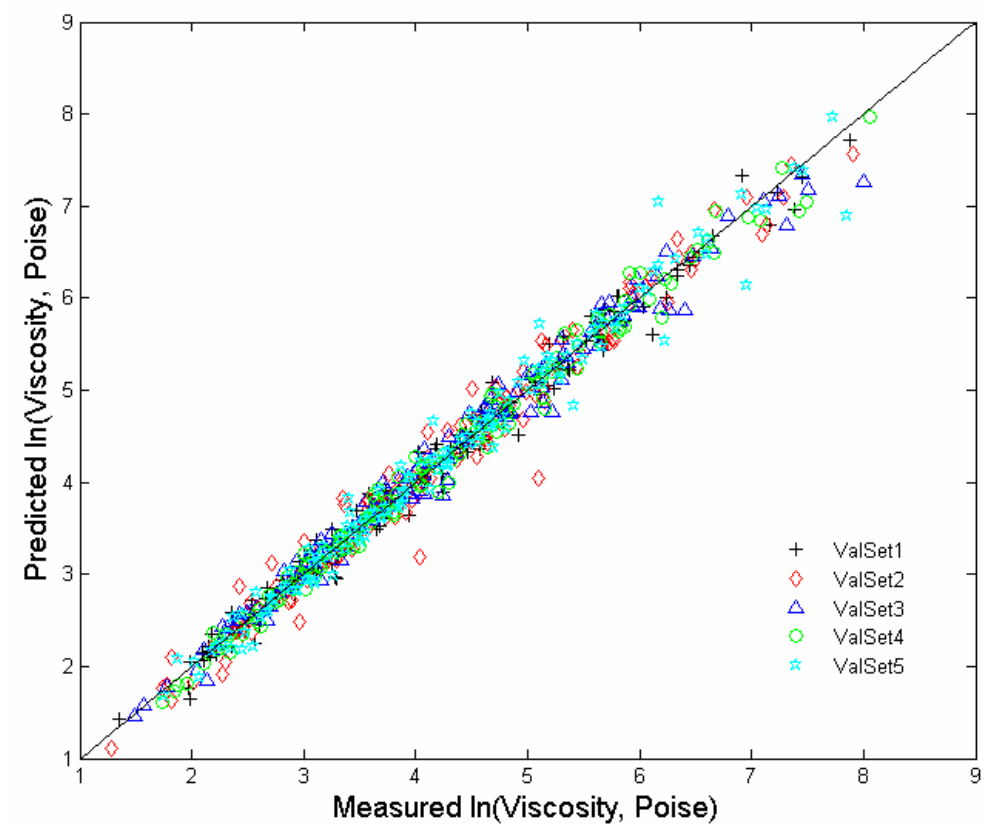

Figure 8.11. Predicted versus Measured $\ln$ (Viscosity, poise) Values for each of the Five Data-Splitting Validation Subsets of the $197 \mathrm{HLW}$ Glasses in the Viscosity Modeling Dataset Constructed Using the 27-Term Truncated T2-Linear Mixture Model.

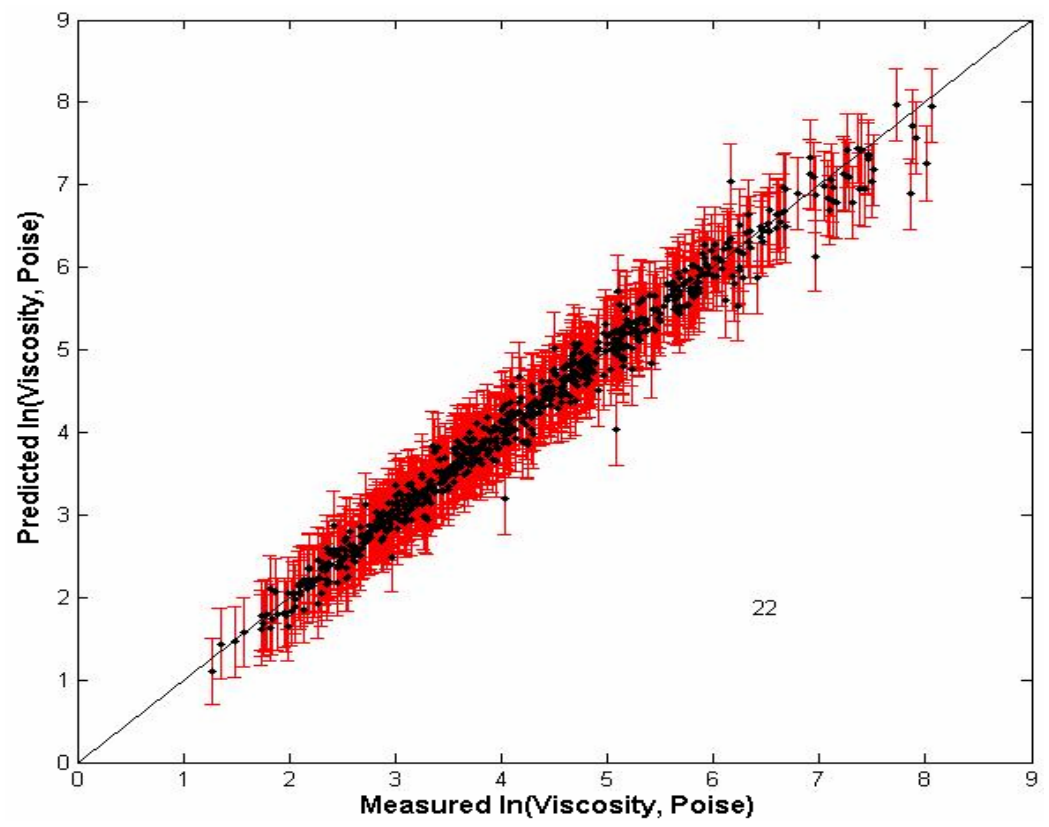

Figure 8.12. Predicted Versus Measured $\ln$ (Viscosity, poise) Values for each of the Five Data-Splitting Validation Subsets of the $197 \mathrm{HLW}$ Glasses in the Viscosity Modeling Dataset Constructed Using the 27-Term Truncated T2-Linear Mixture Model. Error bars are 95\% prediction intervals (PIs). The number of glasses whose $95 \%$ PIs do not include the measured values (represented by the $45^{\circ}$ line) is shown. 
The Catholic University of America Vitreous State Laboratory
IHLW PCT, Spinel $T_{1 \%}$, Electrical Conductivity, and Viscosity Model Development Final Report, VSL-07R1240-4, Rev. 0

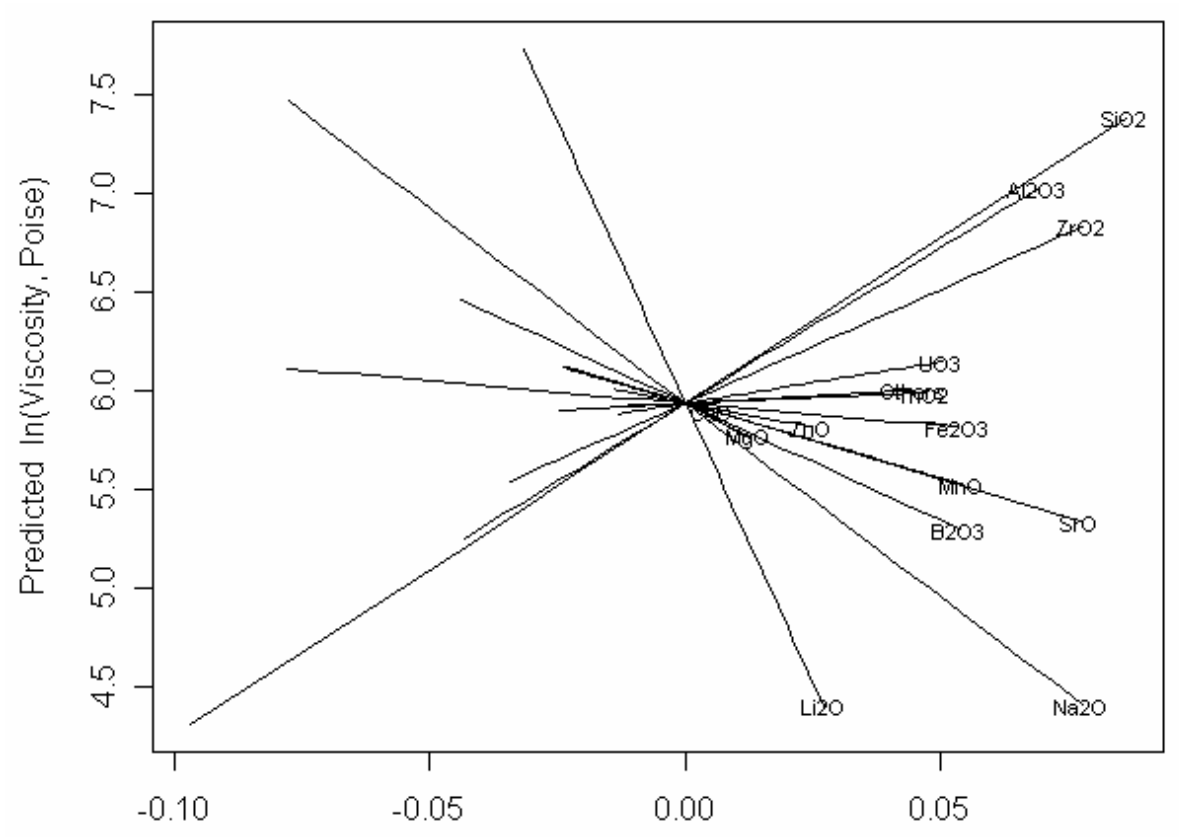

Difference in Component Normalized Mass Fraction from Centroid Composition

Figure 8.13a. Response Trace Plot for IHLW Viscosity at $950^{\circ} \mathrm{C}$ Constructed Using the 27-Term Truncated T2-Linear Mixture Model.

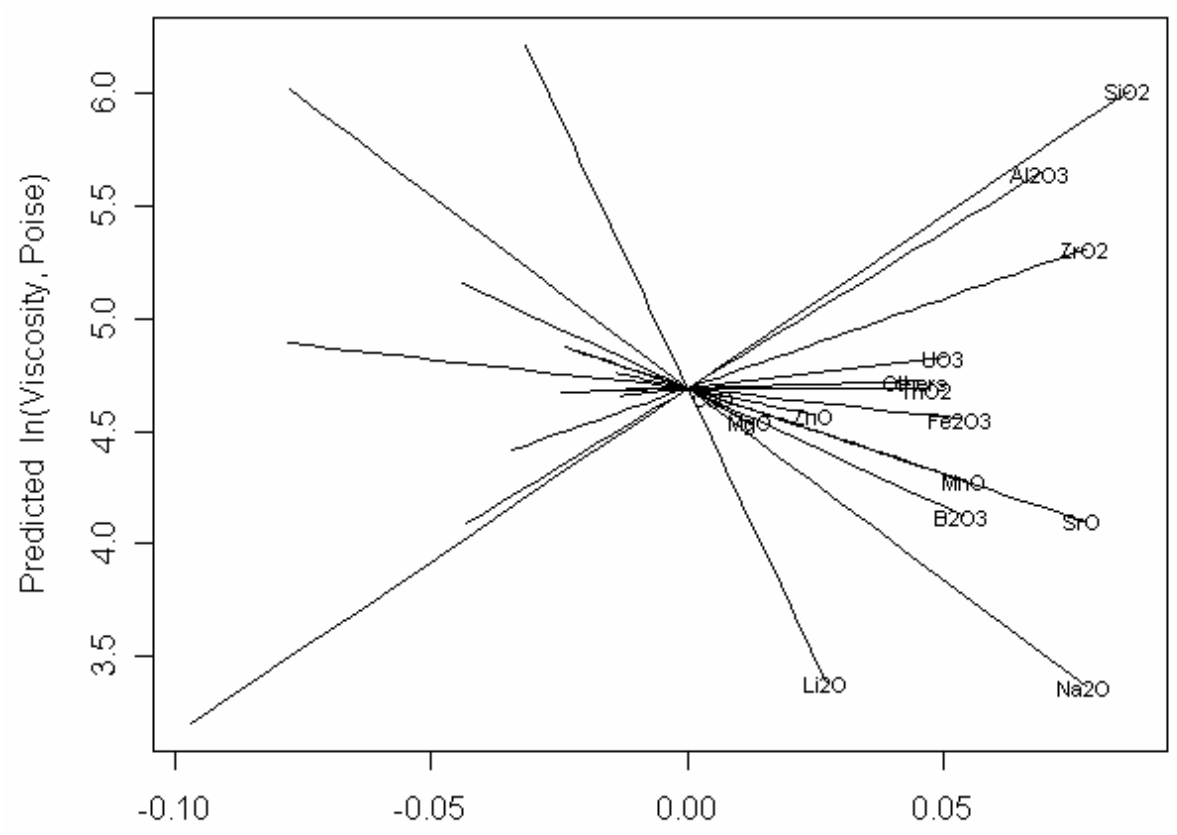

Difference in Component Normalized Mass Fraction from Centroid Composition

Figure 8.13b. Response Trace Plot for IHLW Viscosity at $1050^{\circ} \mathrm{C}$ Constructed Using the 27-Term Truncated T2-Linear Mixture Model. 
The Catholic University of America Vitreous State Laboratory
IHLW PCT, Spinel $T_{1 \%}$, Electrical Conductivity, and Viscosity Model Development Final Report, VSL-07R1240-4, Rev. 0

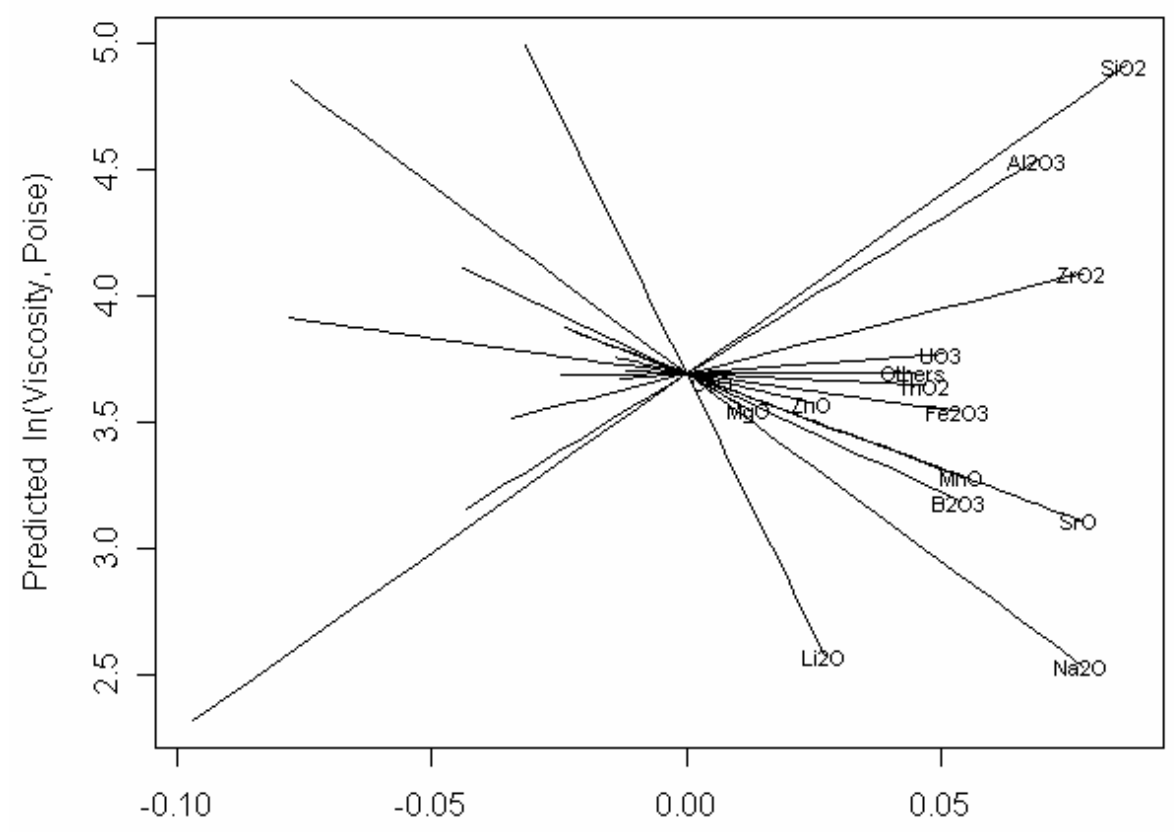

Difference in Component Normalized Mass Fraction from Centroid Composition

Figure 8.13c. Response Trace Plot for IHLW Viscosity at $1150^{\circ} \mathrm{C}$ Constructed Using the 27-Term Truncated T2-Linear Mixture Model.

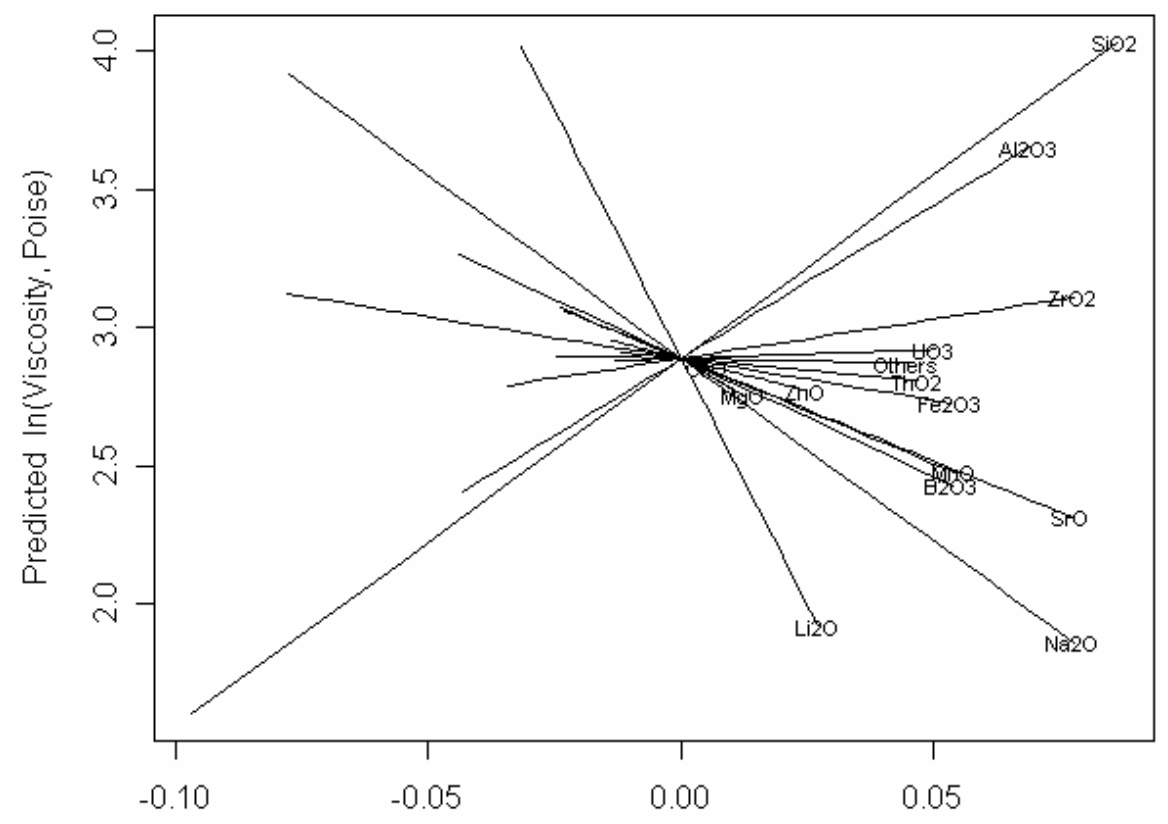

Difference in Component Normalized Mass Fraction from Centroid Composition

Figure 8.13d. Response Trace Plot for IHLW Viscosity at $1250^{\circ} \mathrm{C}$ Constructed Using the 27-Term Truncated T2-Linear Mixture Model. 


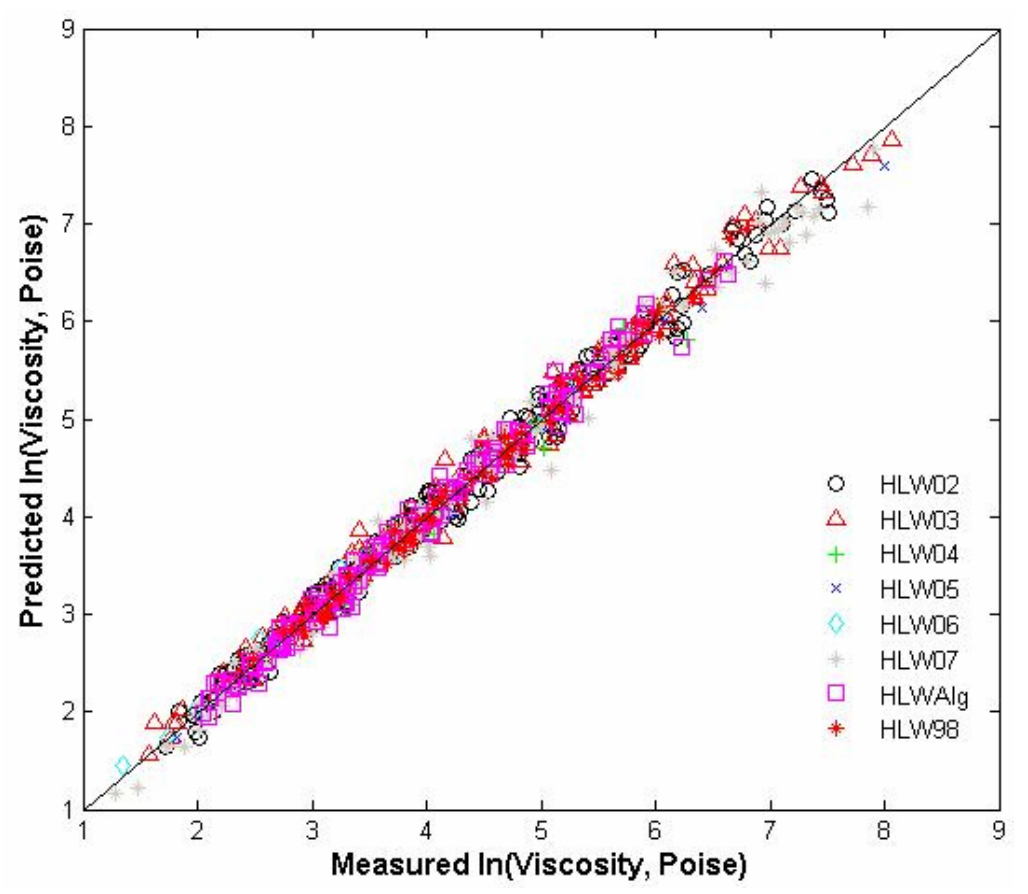

Figure 8.14. Predicted Versus Measured Plot for the 197 HLW Glasses in the Viscosity Modeling Dataset Constructed Using the 29-Term Truncated T2-Linear Mixture Model.

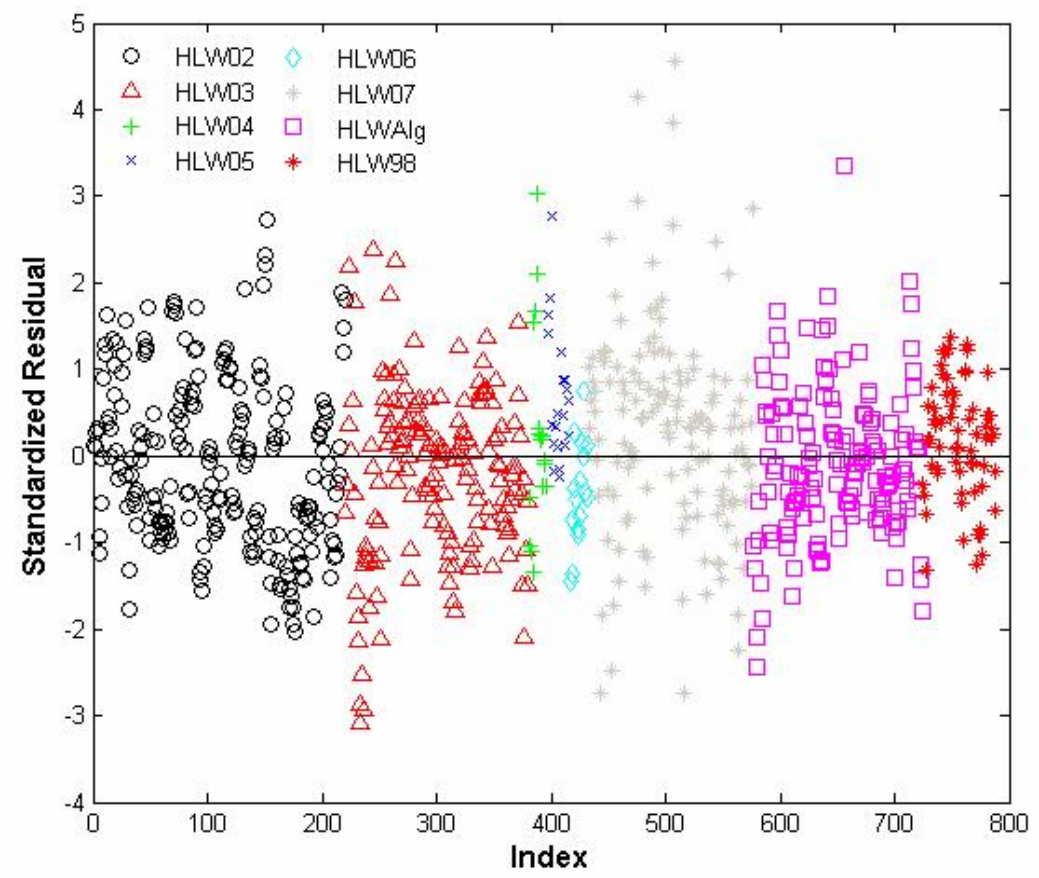

Figure 8.15. Standardized Residuals Plot for the 197 HLW Glasses in the Viscosity Modeling Dataset Constructed Using the 29-Term Truncated T2-Linear Mixture Model. 
The Catholic University of America Vitreous State Laboratory
IHLW PCT, Spinel $T_{1 \%}$, Electrical Conductivity, and Viscosity Model Development Final Report, VSL-07R1240-4, Rev. 0

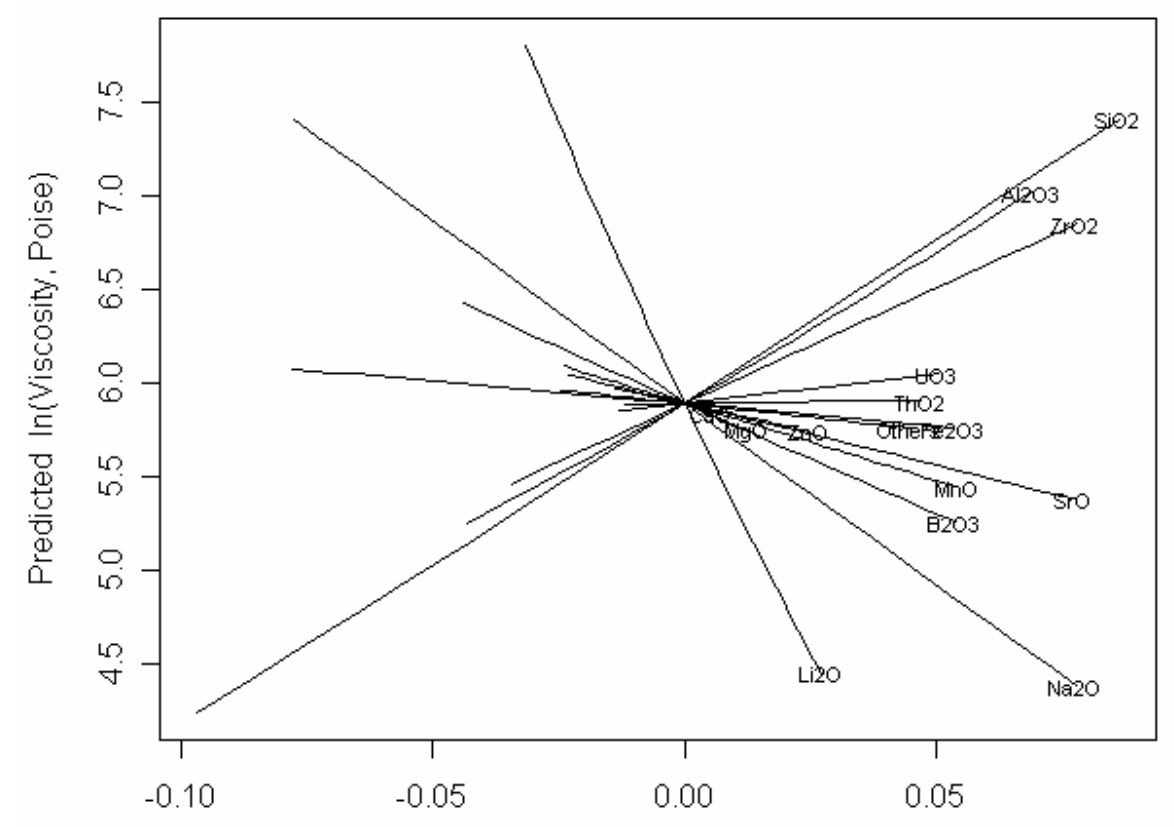

Difference in Component Normalized Mass Fraction from Centroid Composition

Figure 8.16a. Response Trace Plot for IHLW Viscosity at $950^{\circ} \mathrm{C}$ Constructed Using the 29-Term Truncated T2-Linear Mixture Model.

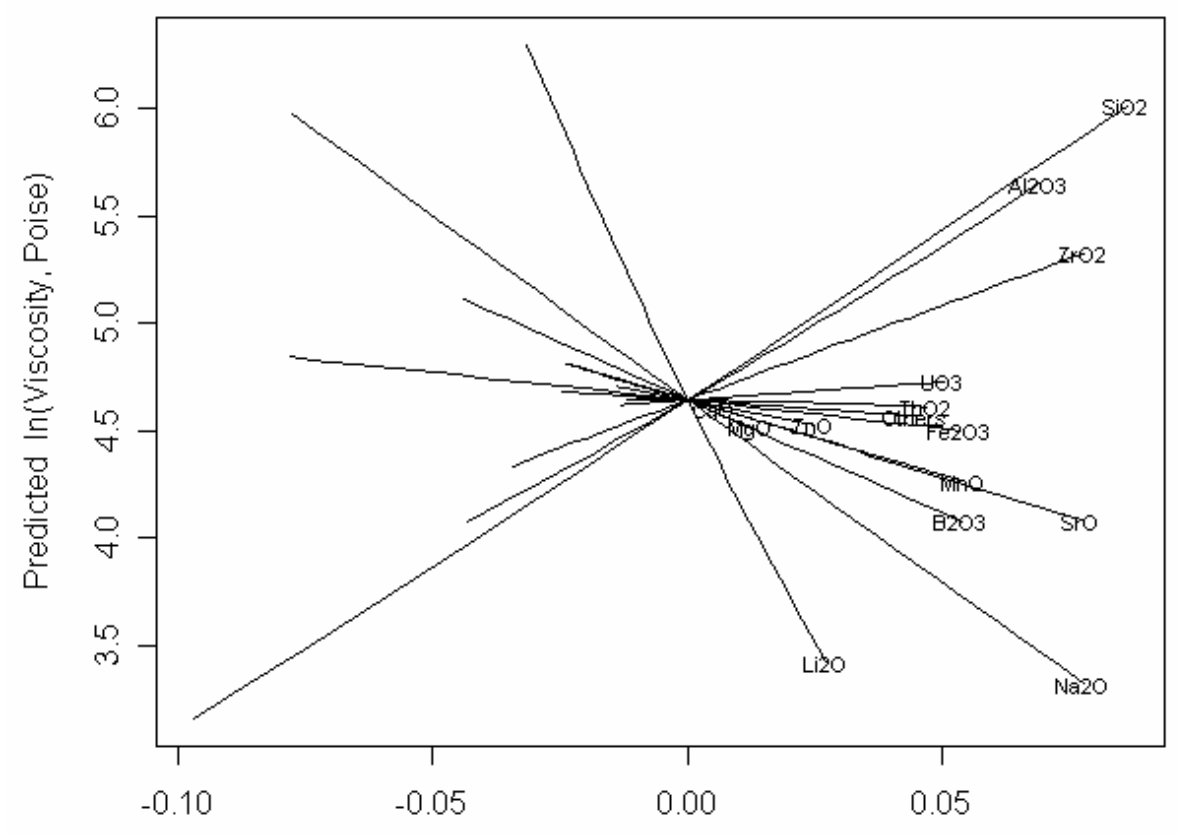

Difference in Component Normalized Mass Fraction from Centroid Composition

Figure 8.16b. Response Trace Plot for IHLW Viscosity at $1050^{\circ} \mathrm{C}$ Constructed Using the 29-Term Truncated T2-Linear Mixture Model. 
The Catholic University of America Vitreous State Laboratory
IHLW PCT, Spinel $T_{1 \%}$, Electrical Conductivity, and Viscosity Model Development Final Report, VSL-07R1240-4, Rev. 0

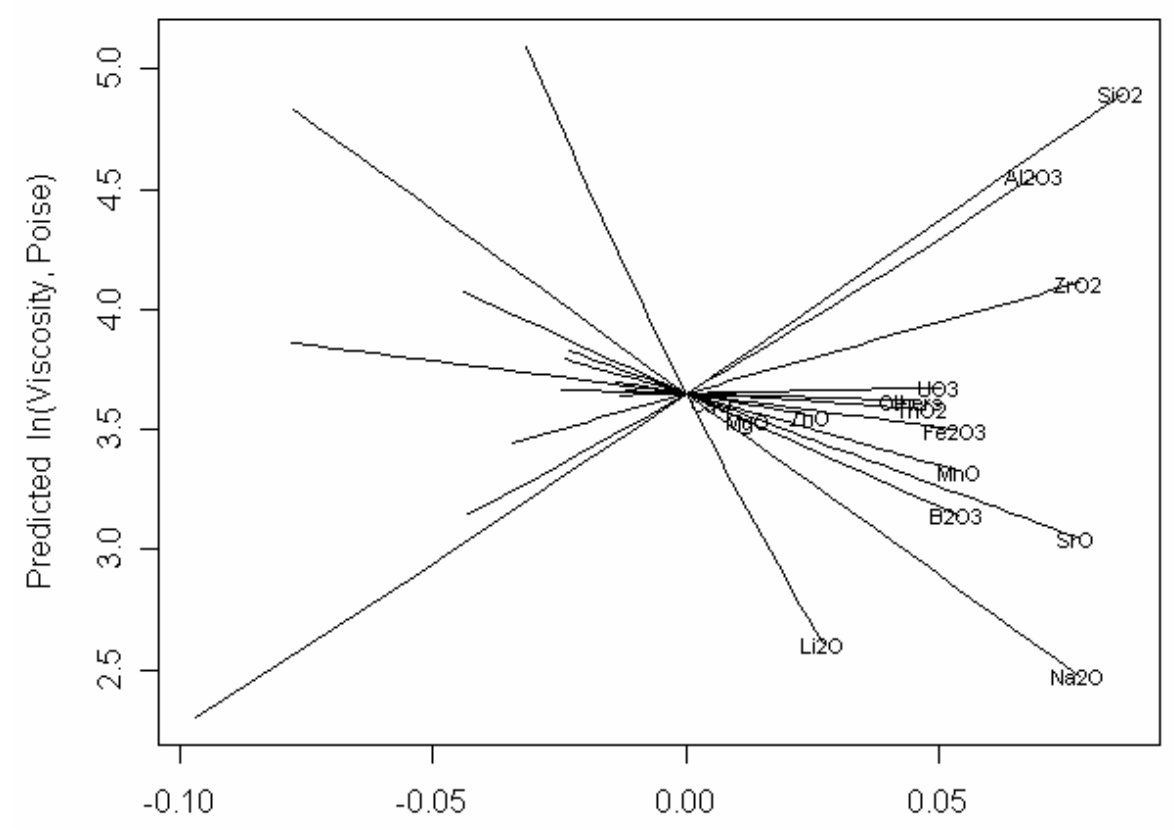

Difference in Component Normalized Mass Fraction from Centroid Composition

Figure 8.16c. Response Trace Plot for IHLW Viscosity at $1150^{\circ} \mathrm{C}$ Constructed Using the 29-Term Truncated T2-Linear Mixture Model.

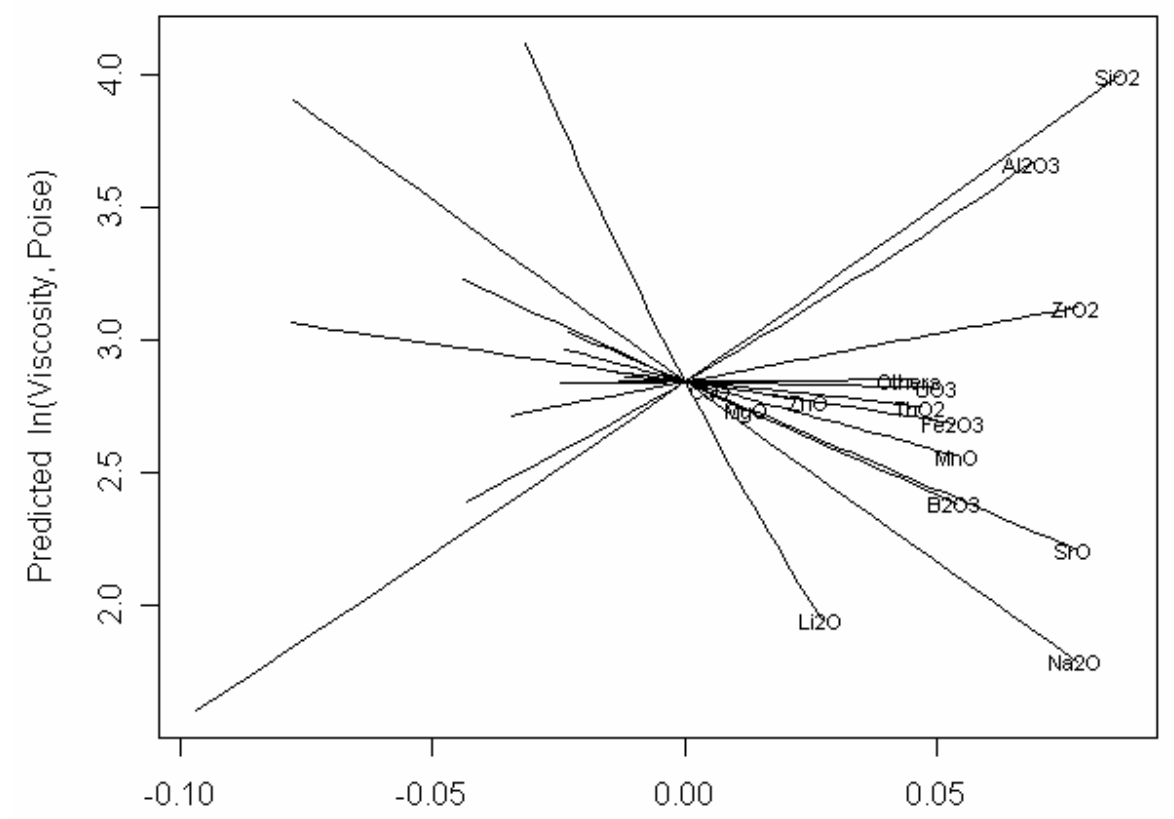

Difference in Component Normalized Mass Fraction from Centroid Composition

Figure 8.16d. Response Trace Plot for IHLW Viscosity at $1250^{\circ} \mathrm{C}$ Constructed Using the 29-Term Truncated T2-Linear Mixture Model. 


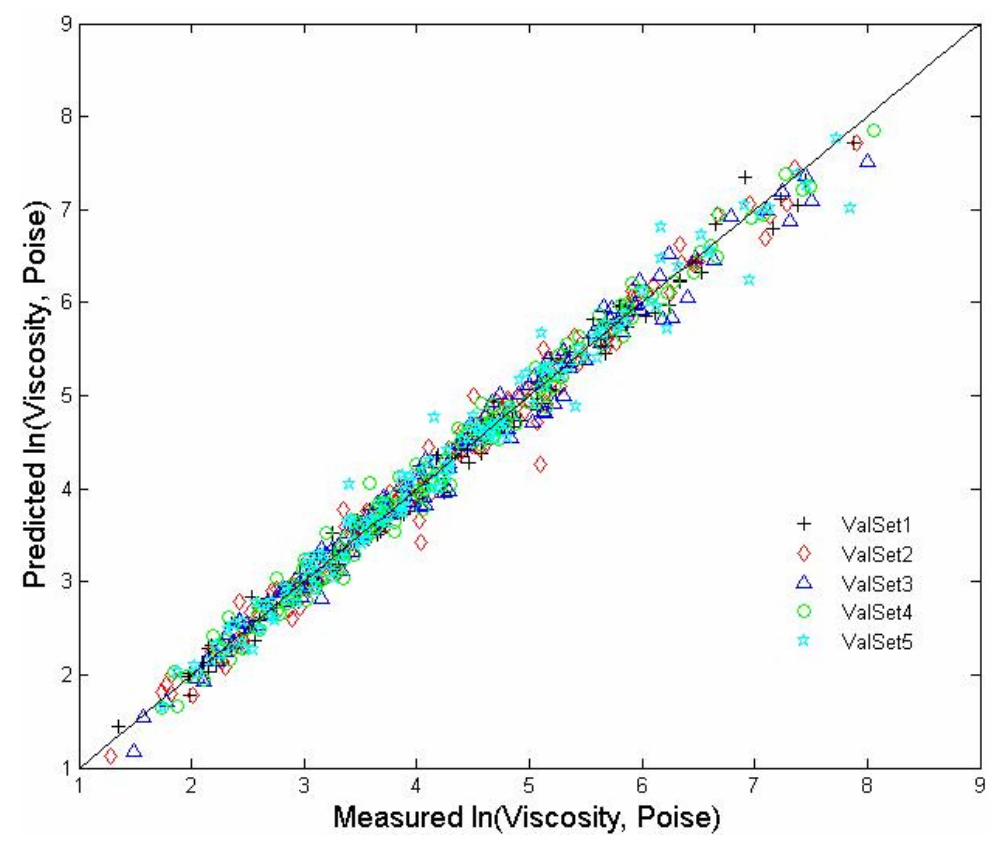

Figure 8.17. Predicted versus Measured $\ln$ (Viscosity, poise) Values for each of the Five Data-Splitting Validation Subsets of the 197 HLW Glasses in the Viscosity Modeling Dataset Constructed Using the 29-Term Truncated T2-Linear Mixture Model.

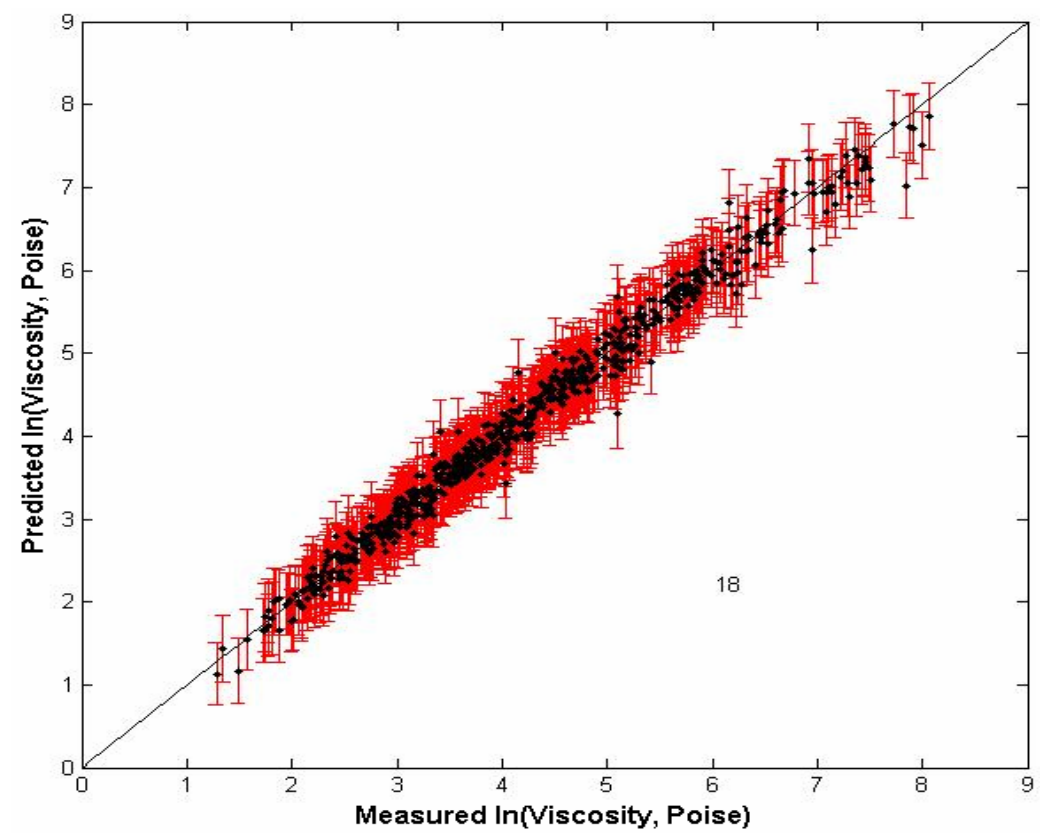

Figure 8.18. Predicted Versus Measured ln(Viscosity, poise) Values for each of the Five Data-Splitting Validation Subsets of the $197 \mathrm{HLW}$ Glasses in the Viscosity Modeling Dataset Constructed Using the 29-Term Truncated T2-Linear Mixture Model. Error bars are 95\% prediction intervals (PIs). The number of glasses whose $95 \%$ PIs do not include the measured values (represented by the $45^{\circ}$ line) is shown. 


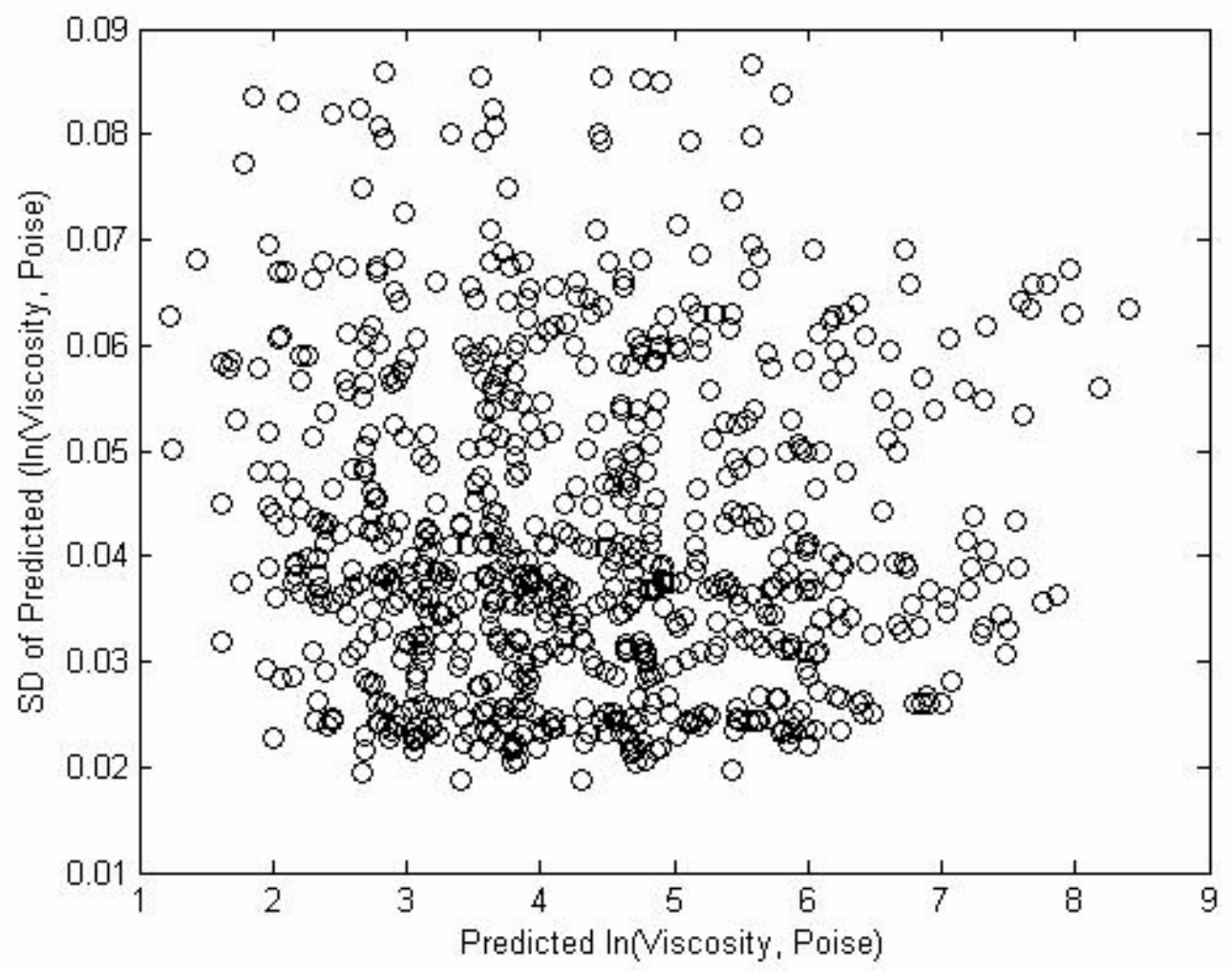

Figure 8.19. Prediction Standard Deviations Versus Predicted In(Viscosity, poise) Values over the HLW Glass Compositions in the Modeling Dataset and Temperatures 950, 1050, 1150 and $1250^{\circ} \mathrm{C}$, Obtained Using the Recommended 29-Term Viscosity Model. 


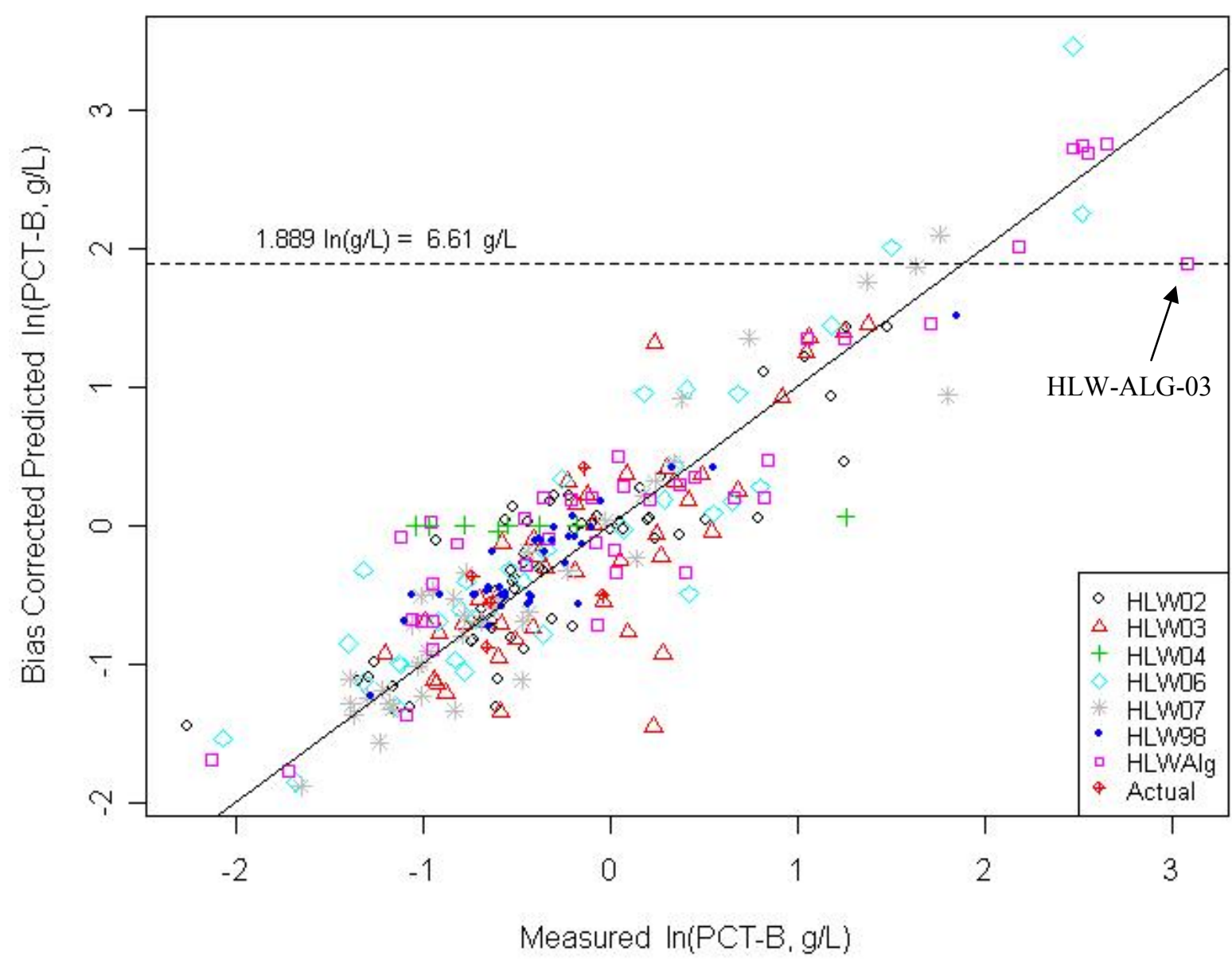

Figure 9.1. Illustration of How the PCT-B Model Validity Upper Bound was Determined for the Recommended 18-Term PQM Model with Bias Correction. The model validity upper bound is indicated by the dashed line and value. It was determined by the glass HLW-ALG-03, the only glass in the PCT-B modeling dataset with measured PCT-B release greater than the corresponding DWPFEA glass limit. 


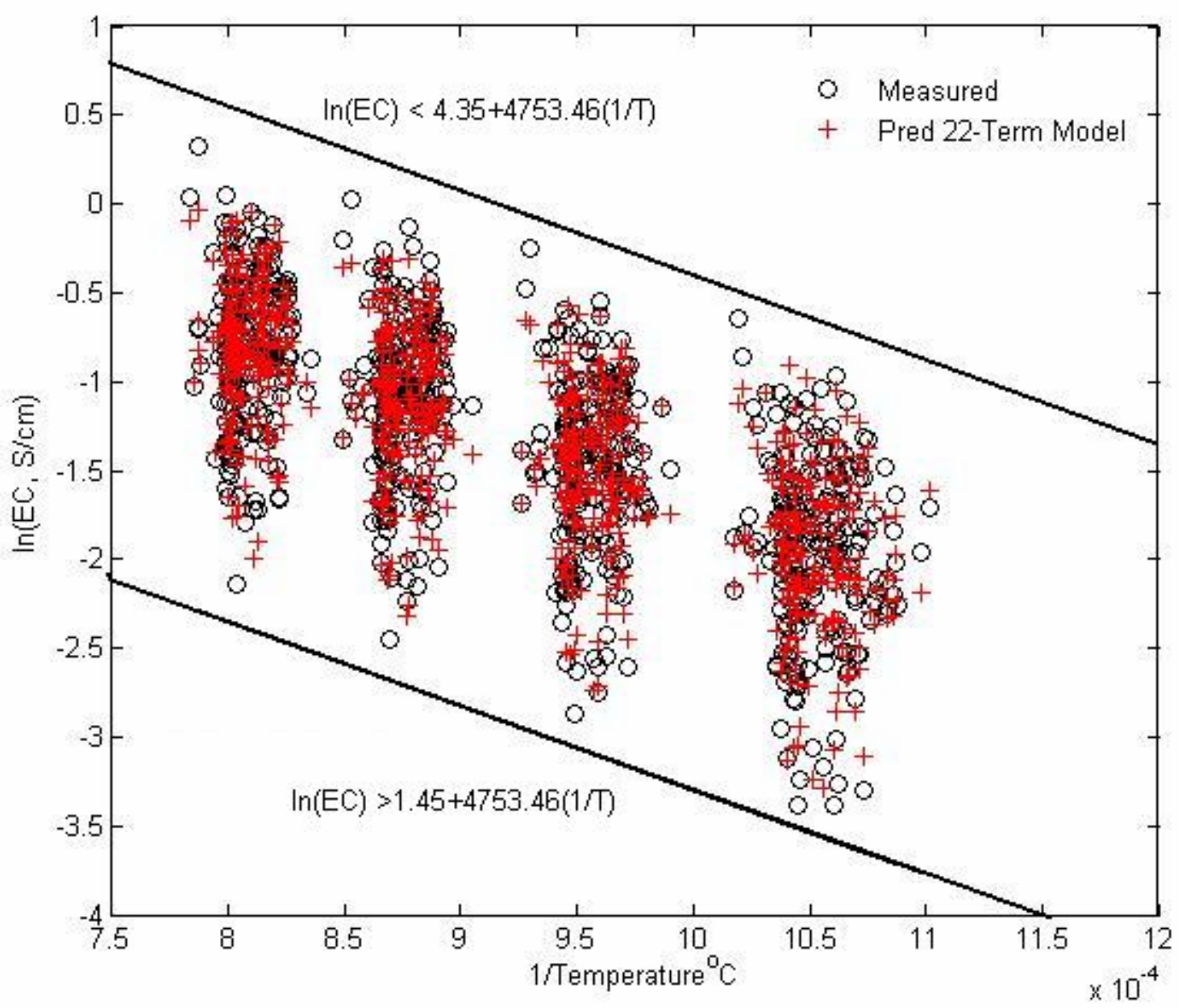

Figure 9.2. Model Validity Constraints on HLW Glass Electrical Conductivity as Functions of Temperature. The constraints were determined to include all measured and predicted electrical conductivity values for glasstemperature combinations in the electrical conductivity modeling dataset. 


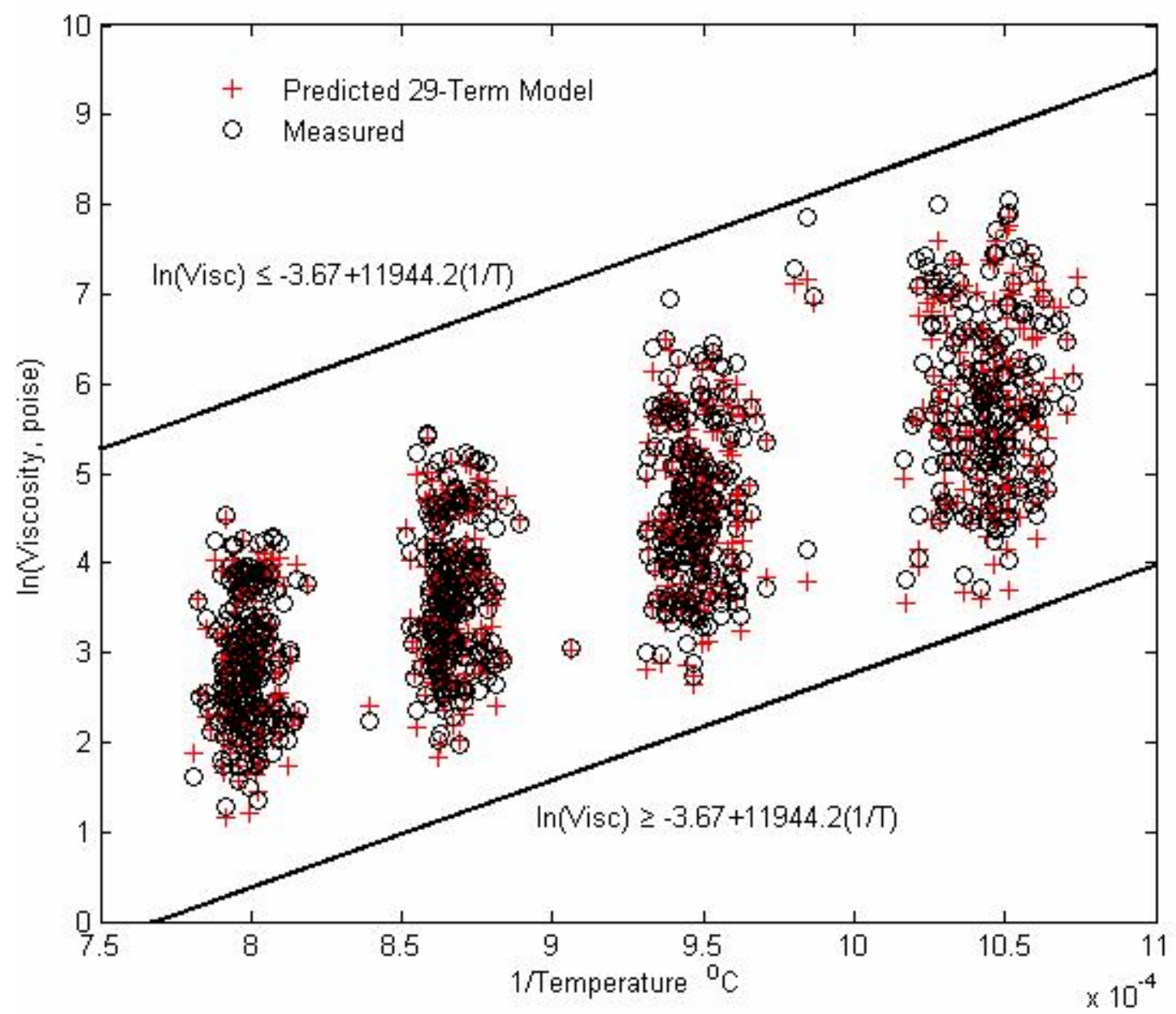

Figure 9.3. Model Validity Constraints on HLW Glass Viscosity as Functions of Temperature. The constraints were determined to include all measured and predicted viscosity values for glass-temperature combinations in the viscosity modeling dataset. 


\section{APPENDIX A}

\section{Selection of Test Matrices to Support Development of Phase 2 Property-Composition Models for WTP HLW Glasses}




\section{Appendix A}

\section{Selection of Test Matrices to Support Development of Phase 2 Property-Composition Models for WTP HLW Glasses}

This appendix summarizes the selection of two test matrices to provide additional data for Phase 2 of the work to develop property-composition models for Waste Treatment and Immobilization Plant (WTP) high-level waste (HLW) glasses. The appendix was written in early 2006 to document the test matrix development work performed in 2005 and 2006. The text refers to the testing and data generation in the future tense because it had not been performed at the time the appendix was originally written. Some revisions have been made to the original version of this appendix for clarity and consistency as part of this report. References to Battelle-Pacific Northwest Division (PNWD) rather than Pacific Northwest National Laboratory (PNNL) and to Duratek rather than Energy Solutions are used because those were the names of the entities who performed the work at the time.

Section A.1 presents relevant background and introduces the test matrix development work. Section A.2 discusses the optimal experimental design approach used to select the test matrices. Section A.3 describes the work to develop the first test matrix, which is a subset of 10 glasses from the HLW05 and HLW06 matrices for which viscosity and electrical conductivity will be measured. Section A.4 discusses the generation of the second test matrix (referred to as the HLW07 matrix), which consists of 40 HLW glasses selected to cover a newly defined experimental glass composition region (EGCR). Section A.5 discusses the Quality Assurance (QA) aspects of the work.

\section{A.1. Introduction}

This appendix is responsive to the Test Plans (Gan and Pegg 2002, Piepel and Cooley 2003), Test Specifications (Swanberg 2001, 2002), and Test Exceptions (Kelly 2002, Westsik 2003a, 2003b) to develop HLW glass property-composition models for the WTP project. The purpose of the work described in those documents is to develop data, mathematical models, and corresponding statistical uncertainty expressions that relate waste form performance and glass processing properties to the chemical composition of Immobilized High-Level Waste (IHLW) glasses. These property-composition models and uncertainty expressions will provide the basis for (1) qualifying waste forms, (2) defining viable operating envelopes, and (3) selecting target glass compositions for the range of possible HLW waste types to be treated in the WTP. During operation of the WTP HLW vitrification facility, the models and uncertainty expressions will also be used to make various operating decisions and to demonstrate that the resultant IHLW meets compliance requirements. 
In order to develop IHLW property-composition models, adequate property-composition data covering the EGCR of interest are required. This appendix addresses the generation of two test matrices to support the collection of the necessary data on four HLW glass properties:

1. Normalized releases $(\mathrm{g} / \mathrm{L})$ of $\mathrm{B}, \mathrm{Li}$, and $\mathrm{Na}$ from the Product Consistency Test (PCT)

2. The temperature $\left({ }^{\circ} \mathrm{C}\right.$ ) at which $1 \%$ (by volume) of a glass melt is comprised of spinel crystals, denoted by spinel $\mathrm{T}_{1 \%}$

3. Viscosity as a function of temperature (poise)

4. Electrical conductivity as a function of temperature $(\mathrm{S} / \mathrm{cm})$

Previous work developed the property-composition data and models for release of cadmium from HLW glass subjected to the Toxicity Characteristic Leaching Procedure (TCLP) (Piepel et al. 2002a, Cooley et al. 2003, Kot et al. 2004).

Property-composition data to develop models for WTP HLW glasses were developed in several test matrices prior to those discussed in this appendix (see Section 2.1). These test matrices are referred to by the prefixes used in the Glass IDs for glasses in the test matrices, namely HLW02, HLW03, HLW04, HLW05, HLW06, and HLWAlg. ${ }^{1}$. The HLW02 and HLW03 matrices were constructed in Phase 1 of the work to develop property-composition models for WTP HLW glasses.

Because HLW glasses are mixtures of oxide and halogen components, their mass fractions must sum to 1 (equivalently, their $w t \%$ values must sum to 100 ). Such problems are referred to as mixture experiments. Statistical experimental design, modeling, and data analysis methods for mixture experiments (Cornell 2002) are applicable for selecting the two test matrices and developing property-composition models.

\section{A.2 Optimal Experimental Design Approach}

An optimal experimental design approach was used to select the two test matrices described in Sections A.3 and A.4. This section describes in general terms the optimal experimental design approach used. The specifics for each of the two test matrices are described in Sections A.3 and A.4.

An optimal experimental design approach provides for selecting the points of an experimental design to optimize a specified mathematical criterion (referred to as an optimal design criterion). Many optimal design criteria are available in the statistical experimental design literature, but in general they quantify in a single number the goodness of an experimental design. Optimal design criteria often depend on the form of a mathematical model assumed to adequately represent the true form of the relationship between the response to be modeled (e.g., glass properties) and the predictor variables (e.g., mass fractions of glass components). Because

\footnotetext{
1 "HLWAlg" stands for HLW algorithm support glasses, which were developed by the WTP project to assess performance of the glass formulation algorithm being developed by the project.
} 
many mathematical functions can be adequately approximated by first- or second-order Taylor series expansions, often first-order (linear) or quadratic (second-order) polynomial models are used to construct optimal experimental designs. Finally, the optimal experimental design approach can be used to optimally augment existing data, or it can be used to build a design from scratch if there are no appropriate existing data.

The optimal experimental design approach used in Sections A.3 and A.4 consists of the following steps. The terminology of HLW glass test matrices is used.

1. Select the existing HLW glass compositions to be augmented.

2. Specify the property-composition model form assumed to provide an adequate approximation of the true property-composition relationships for the HLW glass properties of interest.

3. Specify the optimal design criterion to be used.

4. Select or generate the candidate set of glass compositions from which new design (test matrix) compositions are to be selected by the optimal experimental design software.

5. Use the optimal design software to select the glass compositions for the design (test matrix) from the candidate set to optimally (according to the assumed model form and optimality criterion selected) augment the existing glasses.

Three optimal design criteria commonly used to construct experimental designs are as follows, where $\boldsymbol{X}$ denotes the "model matrix" and $\boldsymbol{x}$ denotes a point from the EGCR. The model matrix is the design matrix (existing points plus new design points) expanded in the assumed model form.

- D-optimal: Minimize $\left|\left(\boldsymbol{X}^{\prime} \boldsymbol{X}\right)^{-1}\right|$, where the vertical bars denote a matrix determinant. The D-optimal criterion seeks to minimize the uncertainty in coefficients of models developed from the resulting data.

- $\underline{\text { G-optimal: }}$ Minimize $\underset{\boldsymbol{x}}{\max } \boldsymbol{x}^{\prime}\left(\boldsymbol{X}^{\prime} \boldsymbol{X}\right)^{-1} \boldsymbol{x}$. The G-optimal criterion seeks to minimize the maximum uncertainty (imprecision) in predictions made with the model developed from the resulting data.

- $\quad$-optimal: Minimize $\underset{\boldsymbol{x}}{\operatorname{avg}} \boldsymbol{x}^{\prime}\left(\boldsymbol{X}^{\prime} \boldsymbol{X}\right)^{-1} \boldsymbol{x}$. The V-optimal criterion seeks to minimize the average uncertainty (imprecision) in predictions made with the model developed from the resulting data.

In the $\mathrm{G}$ - and $\mathrm{V}$-optimal criteria, the maximum and average are ideally with respect to all glasses $\boldsymbol{x}$ in the constrained glass composition region to be covered by the design. However, in practice the maximum and average are often taken with respect to the set of candidate points as well as existing points if they exist, which is what was done for the designs presented in Sections A.3 and A.4. In general, the D-, G-, V-optimal criteria are appropriate for selecting the test matrices 
so that property-composition models developed from the resulting data have low prediction uncertainties.

The D-optimal criterion was used to select the test matrix in Section A.3, while all three optimal-design criteria were considered in selecting the test matrix in Section A.4. See those sections for the specifics of the optimal experimental design approach used in each case. See Atkinson and Donev (1992) and Cornell (2002) for more general discussion of optimal experimental design and its application to mixture experiments.

\section{A.3 Selecting a Subset of HLW05 and HLW06 Glasses for Viscosity and Electrical Conductivity Measurements}

As shown in Tables 2.1 to 2.4 of Section 2, the ranges of some components investigated in the HLW05 and HLW06 studies were expanded compared to the previous HLW02 and HLW03 studies. However, viscosity and electrical conductivity (EC) were not measured for HLW05 and HLW06 glasses. These two facts indicate that the composition region over which models could be developed and considered valid would be smaller for viscosity and EC than for PCT and spinel $\mathrm{T}_{1 \%}$. Thus, the WTP project decided that a subset of the HLW05 and HLW06 glasses should be selected for viscosity and EC measurement. The goal was to select the subset to expand the IHLW component ranges covered for viscosity and electrical conductivity to be similar to the component ranges covered for PCT and spinel $\mathrm{T}_{1 \%}$. Those component ranges are defined by the least restrictive of the component ranges for HLW02, HLW03, HLW05, and HLW06. As seen from Table 2.1, the component ranges for HLW06 are the least restrictive with one exception. For HLW06 the range of $\mathrm{ThO}_{2}$ is 0 to $5.94 \mathrm{wt} \%$, whereas the least-restrictive range is 0 to $6 \mathrm{wt} \%$. For convenience, the least-restrictive component ranges over the HLW02, HLW03, HLW05, and HLW06 studies are listed in Table 2.5. ${ }^{2}$

The Vitreous State Laboratory (VSL) checked archive materials of the 65 HLW05 and HLW06 glasses and confirmed there was sufficient material remaining to measure both viscosity and EC on any of the 65 glasses. However, VSL was concerned that glasses with high spinel $\mathrm{T}_{1 \%}$ values may show crystallization to various extents, which could compromise the viscosity and EC measurements. Therefore, VSL recommended conservatively excluding all glasses with spinel $\mathrm{T}_{1 \%}>950^{\circ} \mathrm{C}$, which left 25 of the $65 \mathrm{HLW} 05$ and HLW06 glasses. These glasses were HLW05-1, 2, 3, 4, 5, 7, 9, 10, 11, 13, 14, 15, 20, 21, 22, 27, and 30, and HLW06-2, 4, 5, 15, 22, $32,34,35$.

The number of glasses to select from the candidate set of 25 HLW05 and HLW06 glasses was not specified by the WTP project. It was decided to select subsets of 5, 10, and 15 glasses and to assess the relationship between the number of glasses selected and the extent to which the component ranges of interest were covered. Subsets of these sizes were selected from the 25 candidate HLW05 and HLW06 glasses using optimal experimental design software. The subsets

\footnotetext{
${ }^{2}$ Table 2.5 actually lists the least restrictive component limits for HLW02, HLW03, HLW05, HLW06, and HLW07. However, except for minor exceptions noted in footnotes of that table, all component ranges were achieved prior to HLW07.
} 
were selected to augment 143 "existing" glasses that had (or would have after scheduled testing) data for viscosity and EC. A linear mixture experiment model (see Section C.1.1 of Appendix C) was assumed for purposes of this optimal design augmentation. Most optimal experimental design software will select replicate points if that is what yields an optimal design. However, in this situation we did not want to select replicate glasses out of the 25 candidate HLW05 and HLW06 glasses. The ACED optimal design software (Welch 1987) that has been used for previous WTP work was too complicated to revise so that replicates would not be selected. Instead, modifications were made by the vendor to the D-optimal ${ }^{3}$ design routine DMAX in the MIXSOFT software (Piepel 2006a) to allow optimally selecting each candidate point only once.

The selected subsets of 5, 10, and 15 glasses were compared graphically to the set of 143 existing glasses as well as to the set of 25 candidate glasses. The goal was to cover the expanded component ranges in Table 2.5 with as few glasses as possible, and also obtain a good distribution of predicted viscosity and EC values. The subset of 10 glasses clearly did better covering the desired component ranges than did selecting 5 glasses, whereas selecting 15 didn't improve (compared to 10) the coverage of the desired component ranges. Based on (1) a telephone conference discussion of this topic with the WTP project, Duratek, and VSL, and (2) subsequent direction by the WTP project, the subset of 10 of the 25 HLW05 and HLW06 glasses was chosen. This decision was made based on the consideration that investigating subsets of between 5 and 10 glasses would be more time-consuming and costly than the little savings in less viscosity and EC testing work it would provide.

Table A.1 lists the Glass IDs of the 143 existing glasses that have data for viscosity and EC and meet applicable QA requirements. Also listed in Table A.1 are the Glass IDs of the 25 HLW05 and HLW06 candidate glasses. The IDs of the 10 glasses selected from the 25 candidates using the DMAX routine in MIXSOFT (Piepel 2006) are also identified in Table A.1. Tables A.2, A.3, and A.4 list the compositions of the 143 existing glasses having viscosity and EC data. Tables A.5, A.6, and A.7 list the compositions of the 10 of 25 HLW05 and HLW06 glasses selected to have viscosity and electrical conductivity measured. The HLW glass compositions in Table A.2 (143 existing) and Table A.5 (10 HLW05 and HLW06 glasses) are listed in terms of 14 individual components and 4 grouped components as defined for the HLW07 test matrix development (see Section A.4). Table A.3 (143 existing glasses) and Table A.6 (10 HLW05 and HLW06 glasses) list the expansions of the Others1, Others2, and Constant grouped components. Table A.4 (143 existing glasses) and Table A.7 (10 HLW05 and HLW06 glasses) list the expansions of the Remaining grouped component.

Figure A.1 displays component distributions (unnormalized mass fractions) for the 14 main components selected for study in Phase 2 property-composition modeling for HLW glasses (see Section A.4.2). This figure shows the 10 glasses selected from the HLW05 and HLW06 matrices as red triangles, and the 143 existing glasses as black circles. Because the HLW05 and HLW06 test matrices were constructed as layered designs (Piepel et al. 1993, Piepel et al. 2002b), they each contain glass compositions on outer and inner layers of their respective EGCRs. For comparison purposes in Figure A.1, the inner-layer single-component constraints from the HLW06 study are marked with blue dashed lines; the outer-layer single-component

\footnotetext{
${ }^{3}$ The D-optimal design criterion and other optimal design criteria are discussed in Section A.2.
} 
constraints from the HLW06 study are marked with red solid lines. The component mass fraction values are displayed along the x-axes, whereas the "index number" of each glass is displayed along the y-axis. Indices 1 to 143 correspond to the existing glasses, while indices 144 to 153 correspond to the 10 selected HLW05 and HLW06 glasses.

Figure A. 2 shows predicted property distributions for the 143 existing glasses and the 10 newly selected glasses (plotting symbols as before). The red solid lines represent the property constraint limits or values of interest: $1000^{\circ} \mathrm{C}$ for spinel $\mathrm{T}_{1 \%}$ (constraint limit); $4 \mathrm{~g} / \mathrm{L}$ for PCT-B release (value of interest); 10 and 100 poise for viscosity at $1150^{\circ} \mathrm{C}$ (constraint limits); and 0.2 and $0.7 \mathrm{~S} / \mathrm{cm}$ for $\mathrm{EC}$ at $1150^{\circ} \mathrm{C}$ (constraint limits).

Figure A.3 shows component distributions (unnormalized mass fractions for the 14 main components) for the selected 10 of 25 candidate HLW05 and HLW06 glasses. The 10 glasses selected from the HLW05 and HLW06 datasets are marked with red triangles, and the 15 not selected are marked with black circles. Figure A.3 better shows the choice of the 10 HLW05 and HLW06 glasses from the 25 candidate glasses. The plots in Figure A.3 show that there were no HLW05 and HLW06 candidate glasses with the lower limits of $\mathrm{Na}_{2} \mathrm{O}$ or the upper limits of $\mathrm{NiO}$, $\mathrm{SiO}_{2}$, and $\mathrm{ZnO}$. Also, there was only one candidate glass with the upper limit of $\mathrm{ZrO}_{2}$.

Figure A.4 shows the predicted property distributions for the selected 10 of 25 candidate HLW05 and HLW06 glasses (same plotting symbols as before). The properties include PCT-B release $(\mathrm{g} / \mathrm{L})$, spinel $\mathrm{T}_{1 \%}\left({ }^{\circ} \mathrm{C}\right)$, viscosity at $1150^{\circ} \mathrm{C}$ (poise); and $\mathrm{EC}$ at $1150^{\circ} \mathrm{C}(\mathrm{S} / \mathrm{cm})$.

\section{A.4 Construction of the HLW07 Test Matrix}

This section discusses how the HLW07 test matrix was constructed. Based on input from the WTP project, the principal objective for the HLW07 test matrix was to augment the existing HLW glass property-composition data to reflect the current understanding of the waste feed compositions to the WTP HLW vitrification facility. A secondary objective included filling in any composition subregions having limited data with respect to both composition coverage and property coverage. The purpose of these objectives was to ensure that the composite data set (existing data plus the HLW07 test matrix) provides an adequate region of validity for the final property-composition models for HLW glasses.

Section A.4.1 describes the experimental design approach used to construct the HLW07 test matrix. Section A.4.2 discusses the inputs considered by VSL (with input from the WTP project) in developing the HLW glass components and constraints that define the EGCR to be covered by the HLW07 test matrix. Section A.4.3 presents the glass components and singlecomponent constraints used to define the EGCR for the HLW07 study. Section A.4.4 discusses the waste-loading constraint chosen to help define the HLW Phase 2 EGCR. Section A.4.5 presents the glass property constraints and the property-composition models used to help define the EGCR for the HLW07 study. Section A.4.6 discusses how the outer and inner layers of the HLW07 EGCR were defined using the single-component and multi-component (waste loading and property-based) constraints. Section A.4.7 describes steps of the process and software used by PNWD to construct the HLW07 test matrix. Section A.4.8 describes the model form for glass 
property-composition relationships used in constructing the test matrix using optimality criteria described in Section A.2. Section A.4.9 presents graphical views of the 125 existing glasses and 40 HLW glasses in the HLW07 test matrix to assess how well the HLW07 EGCR of interest is covered.

\section{A.4.1 Experimental Design Approach for Generating the HLW07 Test Matrix}

The experimental design approach used to generate the HLW07 test matrix was to augment existing glasses (from the previous HLW studies: HLW02, HLW03, HLW05, and HLW06) with additional glass formulations within the HLW07 EGCR (described subsequently in Section A.4.6). A layered design approach (Piepel et al. 1993, Piepel et al. 2002b) was chosen to generate the HLW07 test matrix, with HLW glass compositions on one outer layer, one inner layer, and a center point. The layered design approach provides for collecting data on a larger glass composition region (the outer layer), a smaller glass composition region (the inner layer), and at the center of the EGCR. Each of the previous HLW glass test matrices (which provide the existing data to be augmented by the HLW07 test matrix) were constructed using a layered design approach.

A layered design approach is well-suited for constructing the HLW07 test matrix, because the objectives involve (1) augmenting existing data, (2) covering the glass composition region likely to be associated with the current understanding of the waste feed compositions to the WTP HLW vitrification facility, and (3) filling in any areas of limited data with respect to both composition coverage and property coverage. The HLW07 test matrix includes a center glass, glasses from the outer and inner layers of the HLW07 EGCR, and several replicate glass formulations. The outer- and inner-layer glasses were selected to optimally augment the existing glasses having values of the four properties discussed in Section A.1.

\section{A.4.2 Bases for the Components and Constraints Defining the HLW07 EGCR}

In order to select the HLW glass components and constraints to define the EGCR for the HLW07 test matrix, the following starting points were used:

1. Previous statistically-designed HLW glass test matrices (HLW02, HLW03, HLW05 and HLW06) that provide the existing data for developing property-composition models.

2. Property constraints employed in the previous test matrices and property-composition models developed during Phase 1.

3. Tank waste compositions and flow-sheet projections of glass composition ranges.

4. Glass component ranges spanned by existing data.

5. Contract waste loading requirements. 
The components, component constraints, and property constraints used to develop the previous statistically-designed HLW glass test matrices (HLW02, HLW03, HLW05, and HLW06) are summarized in Section 2.1. Data from these previous test matrices were graphically evaluated using

- Histograms of the distributions of major glass components and key properties.

- Selected pair-wise scatter plots of component vs. component or property vs. components.

The following paragraphs discuss the histogram results. The scatter plots were examined to identify subregions of composition or property space with little or no data. However, such areas are primarily determined by component and property constraints. The constraints were reviewed and determined to be what was desired, and so the scatter plot results are not presented in this appendix or discussed further.

Histograms for 14 glass components $\left(\mathrm{Al}_{2} \mathrm{O}_{3}, \mathrm{~B}_{2} \mathrm{O}_{3}, \mathrm{Cr}_{2} \mathrm{O}_{3}, \mathrm{Fe}_{2} \mathrm{O}_{3}, \mathrm{Li}_{2} \mathrm{O}, \mathrm{MnO}, \mathrm{Na}_{2} \mathrm{O}\right.$, $\mathrm{NiO}, \mathrm{SiO}_{2}, \mathrm{SrO}, \mathrm{ThO}_{2}, \mathrm{UO}_{3}, \mathrm{ZnO}$, and $\mathrm{ZrO}_{2}$ ) over all $167 \mathrm{HLW02}, \mathrm{HLW} 03, \mathrm{HLW} 05$, and HLW06 glasses are shown in Figures A.5 to A.18. As can be seen in the figures, the values of some components are reasonably well distributed over their ranges of interest $\left(\mathrm{Al}_{2} \mathrm{O}_{3}, \mathrm{~B}_{2} \mathrm{O}_{3}\right.$, $\mathrm{Li}_{2} \mathrm{O}, \mathrm{Na}_{2} \mathrm{O}, \mathrm{NiO}, \mathrm{SiO}_{2}, \mathrm{ZnO}$ ), while other components have at least one gap in their distribution of values $\left(\mathrm{Cr}_{2} \mathrm{O}_{3}, \mathrm{SrO}\right)$ or have noticeably skewed distributions $\left(\mathrm{MnO}, \mathrm{SrO}, \mathrm{ThO}_{2}, \mathrm{UO}_{3}\right)$. Even for some components listed as having reasonably well-distributed data, there are sub-ranges having limited data.

The histograms for key properties [spinel $\mathrm{T}_{1 \%}\left({ }^{\circ} \mathrm{C}\right)$, viscosity at $1150^{\circ} \mathrm{C}$ (poise), $\mathrm{EC}$ at $1150^{\circ} \mathrm{C}(\mathrm{S} / \mathrm{cm})$, and PCT-B release $\left.(\mathrm{g} / \mathrm{L})\right]$ are shown in Figures A.19 to A.22. Table A.8 summarizes some observations based on the histograms. These histograms and observations were subsequently used to select property constraints, which are discussed in Section A.4.5.

\section{A.4.3. HLW Glass Components and Single-Component Constraints}

This section discusses the HLW glass components included (individually or in grouped components) or excluded from defining the outer and inner layers of the EGCR for the HLW07 test matrix. It also presents the component lower and upper limits used to define the outer and inner layers of the HLW07 EGCR as a step toward constructing a layered design.

The HLW glass components used to define the HLW07 EGCR are given in Table A.9. The first 14 components listed in Table A.9 $\left(\mathrm{Al}_{2} \mathrm{O}_{3}, \mathrm{~B}_{2} \mathrm{O}_{3}, \ldots, \mathrm{ZrO}_{2}\right)$ are the main HLW glass components with the potential to affect at least one HLW glass property. The next two components, Others 1 and Others2, are each mixtures of minor HLW glass components (as defined in Table A.10 and Table A.11, respectively). Finally, Table A.9 lists the Constant component, which is a mixture of minor HLW glass components defined in Table A.12. Note in Table A.9 that the Constant component is constant only separately for the HLW07 outer layer and the HLW07 inner layer. The Constant component takes different values for each of the outer 
and inner layers, and hence is a component that varies across the HLW07 EGCR. Thus, Constant was treated as a varied component in developing the HLW07 test matrix. In summary, Table A.9 lists 17 HLW glass components that were to be varied in the HLW07 test matrix.

The component distributions for the existing HLW test matrix glasses (HLW02, HLW03, HLW05, and HLW06) are shown in Figures A.5 to A.18. These distributions of component values for the existing glasses were reviewed and used to select the lower and upper limits on the components for both outer and inner layers of the HLW07 EGCR. The limits were selected such that they tend to fall in the locations of gaps in the previous data. The single-component lower and upper limits for the outer and inner layers of the HLW07 EGCR are listed in Table A.9. These lower and upper limits are compared to the lower and upper limits for the outer and inner layers of previous WTP HLW glass studies in Table 2.1 of the main body of the report.

Because the grouped components (Others1, Others2, and Constant) vary, the individual components comprising each group also vary. Tables A.10, A.11, and A.12 respectively list, for Others1, Others2, and Constant, the maximum values (wt\%) of the individual components that can occur. The bases for the maximum values of each component are listed in the final columns of Tables A.10, A.11, and A.12. In some cases the maximum desired value of a minor component was achieved in a previous HLW test matrix, and it was decided to consider smaller, more realistic upper limits in the HLW07 test matrix. In the remaining cases the desired maximum values of minor components are achieved in the HLW07 test matrix. These maximum values either correspond to (1) limits in Specification 8.1 of the WTP contract (U. S. DOE-ORP 2003), or (2) calculations made with the WTP dynamic simulation flowsheet (Deng 2004, Vora 2004) for actual waste compositions.

Table A.13 lists the minor components that were excluded from the HLW07 study. These components were excluded because they had occurred in previous test matrix HLW glasses up to or approaching the maximum values of interest. Hence, the WTP project directed that these minor components should be omitted from the HLW07 study.

\section{A.4.4 Waste Loading Constraint}

Only a single waste-loading constraint

$$
X_{\mathrm{Al}_{2} \mathrm{O}_{3}}+X_{\mathrm{Fe}_{2} \mathrm{O}_{3}}+X_{\mathrm{ZrO}_{2}} \geq 18 \mathrm{wt} \%
$$

was selected to help define both the outer and inner layers of the EGCR for the HLW07 study. In (A.1), the $X_{i}$ are weight percents of the components included in the constraint. Note that the single-component constraints in Table A.9 allow $X_{\mathrm{Al}_{2} \mathrm{O}_{3}}+X_{\mathrm{Fe}_{2} \mathrm{O}_{3}}+X_{\mathrm{ZrO}_{2}}$ to go as low as $8 \mathrm{wt} \%$ on the outer layer and as low as $13.5 \mathrm{wt} \%$ on the inner layer. Hence, setting a lower limit of 18 $\mathrm{wt} \%$ does not allow all three of the components to take their lower limits at the same time.

No upper-limit constraint was employed because waste loading was implicitly limited by other EGCR constraints such as single-component limits and the spinel $\mathrm{T}_{1 \%}$ constraint. The 
Phase 1 spinel $\mathrm{T}_{1 \%}$ model was not available for the design of previous HLW studies, which instead made necessary the use of multiple waste-loading constraints.

\section{A.4.5 Glass Property Constraints}

Glass property constraints for the HLW07 EGCR were selected based on the histograms of property values for studies that had been completed at the time of the test matrix development work (HLW02, HLW03, HLW05, and HLW06). The property constraints and the models for implementing the constraints are listed in Table A.14 and Table A.15, respectively. Explanations of the property constraints are given in the following bullets.

- The spinel $\mathrm{T}_{1 \%}$ data are relatively well-distributed (see Figure A.19), so it was decided to focus the HLW07 study on glasses with spinel $\mathrm{T}_{1 \%}$ values around the limit of $950^{\circ} \mathrm{C}$. Consequently, an upper constraint of $1000^{\circ} \mathrm{C}$ was specified.

- No constraints on $\mathrm{T}_{1 \%}$ for Th- and Zr-containing phases were specified for two reasons. First, reliable property-composition models for $\mathrm{T}_{1 \%}$ of $\mathrm{Th}$ and $\mathrm{Zr}$ phases are not available to implement the constraints. Second, the relatively low limits of $\mathrm{ThO}_{2}$ and $\mathrm{ZrO}_{2}$ recommended in the composition constraints (see Table A.9) suggests that the number of glasses with Th- or Zr-containing primary phases should be small.

- Existing data for viscosity at $1150^{\circ}\left(\eta_{1150}\right)$ are heavily skewed to the right (see Figure A.20), with the majority of data below about 40 poise. Data from 40 poise to about 110 poise are relatively evenly scattered. Although additional data in the 50 to 70 poise range would be desirable, it was decided not to impose such tight constraints for the HLW07 study. Hence, lower and upper limits for $\eta_{1150}$ were maintained at the processing limits of 10 to 100 poise, the full range that has been used in previous WTP HLW glass studies.

- Existing data for EC at $1150^{\circ}\left(\varepsilon_{1150}\right)$ are relatively well distributed (see Figure A.21), although the data beyond about $0.55 \mathrm{~S} / \mathrm{cm}$ is limited. It was decided to maintain the lower and upper limits for $\varepsilon_{1150}$ at the processing limits of 0.2 to $0.7 \mathrm{~S} / \mathrm{cm}$, the full range that has been used in previous WTP HLW glass studies.

- None of the HLW02, HLW03, HLW05, and HLW06 glasses have exhibited PCT responses that exceed the Defense Waste Processing Facility Environmental Assessment (DWPF-EA) glass limits (Jantzen et al. 1993). This is illustrated in Figure A.22 for PCT-B release $[\ln (\mathrm{g} / \mathrm{L})]$. Hence, it appears that the combination of other constraints is sufficient to avoid exceeding the PCT limits. Conceptually it would be good to have more data on HLW glasses with PCT responses up to and somewhat past the limits for the DWPF-EA glass. With such data, the resulting PCT response models would be able to better predict higher PCT responses. However, it would be artificial to specify an EGCR subregion of HLW glasses with higher PCT responses in an attempt to fill the gap between the bulk of the data and the PCT 
values for the DWPF-EA glass. Also, it is relatively easy to make HLW glasses with PCT-B (and other) releases in the range for the bulk of the data in Figure A.22. Thus, it was decided that no PCT constraint would be imposed to define the EGCR for the HLW07 study.

It was decided to use the same property constraints for the outer and inner layers. This was because the lower- and upper-limits for both layers were previously selected to fill in the gaps in the existing data base. Hence, there were no obvious advantages to employ different constraints for the two layers in the HLW07 study.

Note that the property constraints in Table A.14 do not achieve all of the possible property-related objectives listed in the last column of Table A.8. Those objectives were considered secondary, and were not always jointly possible. Also, there was concern that too tightly restricting the HLW07 EGCR to obtain certain ranges of property values as well as composition values might result in too artificial of a data set.

\section{A.4.6 Outer and Inner Layers of the HLW07 EGCR}

The outer and inner layers of the EGCR for the HLW07 study are defined by the singlecomponent constraints in Table A.9 and the multi-component constraints in Table A.16. The multi-component constraints consist of the waste-loading constraint from Equation (A.1), and three constraints on glass properties (spinel $\mathrm{T}_{1 \%}, \eta_{1150}$, and $\varepsilon_{1150}$ ) constructed from the information in Table A.14 and Table A.15. The single- and multi-component constraints were expressed in terms of mass fractions of the 17 HLW glass components used to construct the HLW07 test matrix (see Section A.4.7). Because the mass fractions of these 17 HLW glass components must sum to one and the nature of the single- and multi-component constraints, the outer and inner layers of the EGCR are 16-dimensional irregularly-shaped polyhedrons.

We now describe how the three property-based constraints in Table A.16 were developed from the information in Table A.14 and Table A.15. To help define the outer and inner layers of the EGCR for the HLW07 study, the glass property constraints had to be rewritten in terms of the 17 HLW glass components to be varied in the HLW07 test matrix. Because the property constraints were the same for the outer and inner layers, they only had to be rewritten once. The steps of rewriting the three constraints (spinel $\mathrm{T}_{1 \%}$, viscosity at $1150^{\circ} \mathrm{C}$, and $\mathrm{EC}$ at $1150^{\circ} \mathrm{C}$ ) in terms of the mass fractions of the 17 components to be varied in HLW07 test matrix are described in the following paragraphs. 
$\underline{\text { Spinel } \mathrm{T}_{1 \%}} \underline{\underline{1}}$

The spinel $\mathrm{T}_{1 \%}$ constraint in Table A.14 implemented using the reduced linear mixture model in Table A.15 is given by

$$
\text { Spinel } \mathrm{T}_{1 \%}=\sum_{i=1}^{13} b_{i} x_{i}^{*} \leq 1000
$$

where the $b_{i}(i=1,2, \ldots, 13)$ are the Phase 1 spinel $\mathrm{T}_{1 \%}$ model coefficients in Table A.15 (from Table 6.8 of Kot et al. 2005a) and the

$$
x_{i}^{*}=\frac{x_{i}}{\sum_{j=1}^{13} x_{j}}, i=1,2, \ldots, 13
$$

are normalized mass fractions of the 13 components in the spinel $\mathrm{T}_{1 \%}$ model. Substituting Equation (A.3) into Equation (A.2) and collecting terms yields

$$
\begin{aligned}
& \sum_{i=1}^{13} b_{i}\left(\frac{x_{i}}{\sum_{j=1}^{13} x_{j}}\right) \leq 1000 \\
& \sum_{i=1}^{13} b_{i} x_{i} \leq 1000\left(\sum_{j=1}^{13} x_{j}\right) \\
& 0 \leq \sum_{i=1}^{13}\left(1000-b_{i}\right) x_{i} .
\end{aligned}
$$

The constraint is now expressed in terms of unnormalized mass fractions $x_{i}$ of 13 of the 17 HLW glass components for the HLW07 study. The missing four components are $\mathrm{UO}_{3}$, Others1, Others2, and Constant, which can be thought of as having zero coefficients in Equations (A.2) to (A.4).

\section{$\underline{\text { Viscosity at } 1150^{\circ} \mathrm{C}}$}

The lower and upper limit constraints on viscosity at $1150^{\circ} \mathrm{C}\left(\eta_{1150}\right)$ in Table A.14 were implemented using the model in Table A.15. That model was denoted Model 16 in Table 8 from Gan et al. (2004). The lower and upper constraints on $\eta_{1150}$ are given by

$$
\begin{gathered}
\ln (10) \leq \ln \left(\eta_{1150}\right) \leq \ln (100) \\
\ln (10) \leq a_{0}+\sum_{i=1}^{11} a_{i} \frac{X_{i}}{T^{2}}+a_{C d O} \frac{X_{C d O}}{T^{2}}+a_{S_{2} O_{3}} \frac{X_{S_{2} O_{3}}}{T^{2}}+a_{S_{e O} 2} \frac{X_{S_{2} O_{2}}}{T^{2}}+a_{T l_{2} O} \frac{X_{\mathrm{Tl}_{2} \mathrm{O}}}{T^{2}} \leq \ln (100)
\end{gathered}
$$




$$
\begin{gathered}
\ln (10) \leq a_{0}+\sum_{i=1}^{11} a_{i} \frac{X_{i}}{(1423.15)^{2}}+a_{\mathrm{CdO}} \frac{X_{\mathrm{CdO}}}{(1423.15)^{2}}+a_{\mathrm{Sb}_{2} \mathrm{O}_{3}} \frac{X_{\mathrm{Sb}_{2} \mathrm{O}_{3}}}{(1423.15)^{2}}+a_{\mathrm{SeO}_{2}} \frac{X_{\mathrm{SeO}_{2}}}{(1423.15)^{2}}+a_{\mathrm{Tl}_{2} \mathrm{O}} \frac{X_{\mathrm{Tl}_{2} \mathrm{O}}}{(1423.15)^{2}} \leq \ln (100) \\
\ln (10) \leq a_{0}+\sum_{i=1}^{11} a_{i} \frac{100 x_{i}}{(1423.15)^{2}}+a_{\mathrm{CdO}} \frac{100 x_{\mathrm{CdO}}}{(1423.15)^{2}}+a_{\mathrm{Sb}_{2} \mathrm{O}_{3}} \frac{100 x_{\mathrm{Sb}_{2} \mathrm{O}_{3}}}{(1423.15)^{2}} \\
+a_{\mathrm{SeO}_{2}} \frac{100 x_{\mathrm{SeO}_{2}}}{(1423.15)^{2}}+a_{\mathrm{Tl}_{2} \mathrm{O}} \frac{100 x_{\mathrm{Tl}_{2} \mathrm{O}}}{(1423.15)^{2}} \leq \ln (100)
\end{gathered}
$$

where the $a_{0}$ and $a_{i}$ are the coefficients for the $\ln \left(\eta_{1150}\right)$ model in Table A.15, the $X_{i}$ are weight percents of components included in the model, the $x_{i}$ are mass fractions of the components included in the model, and $T$ is temperature in Kelvin (so that $1150^{\circ} \mathrm{C}=1423.15 \mathrm{~K}$ ). Rewriting the constraints to simplify yields

$$
\frac{(1423.15)^{2}\left[\ln (10)-a_{0}\right]}{100} \leq \sum_{i=1}^{11} a_{i} x_{i}+a_{C d O} x_{C d O}+a_{S_{2} O_{3}} x_{S_{2} O_{3}}+a_{S O_{2}} x_{\mathrm{SeO}_{2}}+a_{T l_{2} \mathrm{O}} x_{T l_{2} \mathrm{O}} \leq \frac{(1423.15)^{2}\left[\ln (100)-a_{0}\right]}{100}
$$

Note that the mass fractions of components $\mathrm{SeO}_{2}$, and $\mathrm{Tl}_{2} \mathrm{O}$ are zero (i.e., $x_{\mathrm{SeO}_{2}}=x_{\mathrm{Tl}_{2} \mathrm{O}}=0$ ) in the HLW07 study per Table A.13. Rewriting the viscosity constraints to account for these substitutions yields

$$
\frac{(1423.15)^{2}\left[\ln (10)-a_{0}\right]}{100} \leq \sum_{i=1}^{11} a_{i} x_{i}+a_{C d O} x_{C d O}+a_{S b_{2} O_{3}} x_{S b_{2} O_{3}} \leq \frac{(1423.15)^{2}\left[\ln (100)-a_{0}\right]}{100}
$$

Two more substitutions are possible. First, per Table A.12, $x_{\mathrm{Sb}_{2} \mathrm{O}_{3}}=0.1149 x_{\text {Constant }}$. However, in rewriting the viscosity constraints, $x_{\mathrm{Sb}_{2} \mathrm{O}_{3}}=0$ was inadvertently used (which had been the case for the constraints before the final revisions). Second, note that $x_{C d O}=0.4032 x_{\text {Others } 2}$ per Table A.11. However, because $0 \leq x_{C d O} \leq 0.01$ for the outer layer of the EGCR, $x_{C d O}=0.005$ was inadvertently used as a substitution. Making these two modified substitutions yields the following lower and upper limit constraints on viscosity

$$
\begin{gathered}
\frac{(1423.15)^{2}\left[\ln (10)-a_{0}\right]}{100} \leq \sum_{i=1}^{11} a_{i} x_{i}+a_{C d O}(0.005) \leq \frac{(1423.15)^{2}\left[\ln (100)-a_{0}\right]}{100} \\
\frac{(1423.15)^{2}\left[\ln (10)-a_{0}\right]}{100}-a_{C d O}(0.005) \leq \sum_{i=1}^{11} a_{i} x_{i} \leq \frac{(1423.15)^{2}\left[\ln (100)-a_{0}\right]}{100}-a_{C d O}(0.005)
\end{gathered}
$$

Making the unmodified substitutions yields the following lower and upper limits constraints on viscosity

$$
\frac{(1423.15)^{2}\left[\ln (10)-a_{0}\right]}{100} \leq \sum_{i=1}^{11} a_{i} x_{i}+a_{C d O}\left(0.4032 x_{\text {Others } 2}\right)+a_{S b_{2} O_{3}}\left(0.1149 x_{\text {Constant }}\right) \leq \frac{(1423.15)^{2}\left[\ln (100)-a_{0}\right]}{100}
$$


The consequence of having used the viscosity modified constraints in Equation (A.6) instead of the unmodified constraints in Equation (A.7) was investigated. This was done by predicting for the 40 HLW07 test matrix glasses (discussed subsequently in Section A.4.7) the viscosity at $1150^{\circ} \mathrm{C}$, using the model in the center of the inequality in Equation (A.5) with

- $\underline{\text { Case 1: }} x_{\mathrm{Sb}_{2} \mathrm{O}_{3}}=0$ and $x_{\mathrm{CdO}}=0.005$

- Case 2: $x_{\mathrm{Sb}_{2} \mathrm{O}_{3}}=0.1149 x_{\text {Constant }}$ and $x_{C d O}=0.4032 x_{\text {Others } 2}$

substitutions. For Case 1, which was used to develop the HLW07 test matrix, $\eta_{1150}$ predictions varied between 10 and 100 poise per the lower and upper limit constraints in Table A.14. For Case $2, \eta_{1150}$ predictions varied between 9.84 and 103.5 poise. A plot of the Case 1 versus Case 2 predictions were tightly scattered about a $45^{\circ}$ line. Hence, there was negligible impact of having used Equation (A.6) rather than Equation (A.7) for implementing the viscosity constraints.

\section{Electrical Conductivity at $1150^{\circ} \mathrm{C}$}

The lower and upper limit constraints on $\mathrm{EC}$ at $1150^{\circ} \mathrm{C}\left(\varepsilon_{1150}\right)$ in Table A.14 were implemented using the model in Table A.15. That model was denoted Model 10 in Table 10 from Gan et al. (2004). The lower and upper constraints on EC are given by

$$
\begin{aligned}
& \ln (0.2) \leq \ln \left(\varepsilon_{1150}\right) \leq \ln (0.7) \\
& \ln (0.2) \leq \sum_{i=1}^{9} a_{i} X_{i}+c_{\mathrm{ZrO}_{2}} \frac{X_{\mathrm{ZrO}_{2}}}{T}+d_{\mathrm{B}_{2} \mathrm{O}_{3}} \frac{X_{\mathrm{B}_{2} \mathrm{O}_{3}}}{T^{2}}+d_{\mathrm{MnO}} \frac{X_{\mathrm{MnO}}}{T^{2}}+d_{\mathrm{SiO}_{2}} \frac{X_{\mathrm{SiO}_{2}}}{T^{2}}+d_{\mathrm{SrO}} \frac{X_{\mathrm{SrO}}}{T^{2}} \leq \ln (0.7) \\
& \ln (0.2) \leq \sum_{i=1}^{8} a_{i} X_{i}+a_{\mathrm{ZrO}_{2}} X_{\mathrm{ZrO}_{2}}+c_{\mathrm{ZrO}_{2}} \frac{X_{\mathrm{ZrO}_{2}}}{T}+d_{B_{2} \mathrm{O}_{3}} \frac{X_{\mathrm{B}_{2} \mathrm{O}_{3}}}{T^{2}}+d_{\mathrm{MnO}} \frac{X_{\mathrm{MnO}}}{T^{2}}+d_{\mathrm{SiO}_{2}} \frac{X_{\mathrm{SiO}_{2}}}{T^{2}}+d_{\mathrm{SrO} O} \frac{X_{\mathrm{SrO}^{2}}}{T^{2}} \leq \ln (0.7) \\
& \ln (0.2) \leq \sum_{i=1}^{8} a_{i} X_{i}+a_{\mathrm{ZrO}_{2}} X_{\mathrm{ZrO}_{2}}+c_{\mathrm{ZrO}_{2}} \frac{X_{\mathrm{ZrO}_{2}}}{1423.15}+d_{B_{2} \mathrm{O}_{3}} \frac{X_{B_{2} \mathrm{O}_{3}}}{(1423.15)^{2}}+d_{\mathrm{MnO}} \frac{X_{\mathrm{MnO}}}{(1423.15)^{2}} \\
& +d_{\mathrm{SiO}_{2}} \frac{X_{\mathrm{SiO}_{2}}}{(1423.15)^{2}}+d_{\mathrm{SrO}} \frac{X_{\mathrm{SrO}}}{(1423.15)^{2}} \leq \ln (0.7)
\end{aligned}
$$

where $X_{i}$ denotes the wt $\%$ of the $i^{\text {th }}$ HLW glass component, $T$ denotes temperature in Kelvin (so that $\left.1150^{\circ} \mathrm{C}=1423.15 \mathrm{~K}\right)$, and the $a_{i}, c_{i}$, and $d_{i}$ are the coefficients for the $\ln \left(\varepsilon_{1150}\right)$ model in Table A.15. Collecting terms yields

$$
\begin{gathered}
\ln (0.2) \leq a_{\mathrm{Al}_{2} \mathrm{O}_{3}} X_{\mathrm{Al}_{2} \mathrm{O}_{3}}+a_{\mathrm{Fe}_{2} \mathrm{O}_{3}} X_{\mathrm{Fe}_{2} \mathrm{O}_{3}}+a_{\mathrm{Li}_{2} \mathrm{O}} \mathrm{X}_{\mathrm{Li}_{2} \mathrm{O}}+a_{\mathrm{Na}_{2} \mathrm{O}} X_{\mathrm{Na}_{2} \mathrm{O}} \\
+\left(a_{\mathrm{ZrO}_{2}}+\frac{c_{\mathrm{ZrO}_{2}}}{1423.15}\right) X_{\mathrm{ZrO}_{2}}+\left[a_{\mathrm{B}_{2} \mathrm{O}_{3}}+\frac{d_{\mathrm{B}_{2} \mathrm{O}_{3}}}{(1423.15)^{2}}\right] X_{\mathrm{B}_{2} \mathrm{O}_{3}}+\left[a_{\mathrm{MnO}}+\frac{d_{\mathrm{MnO}}}{(1423.15)^{2}}\right] X_{\mathrm{MnO}} \\
+\left[a_{\mathrm{SiO}_{2}}+\frac{d_{\mathrm{SiO}_{2}}}{(1423.15)^{2}}\right] X_{\mathrm{SiO}_{2}}+\left[a_{\mathrm{SrO}}+\frac{d_{\mathrm{SrO}}}{(1423.15)^{2}}\right] X_{\mathrm{SrO}} \leq \ln (0.7)
\end{gathered}
$$


Converting from components expressed in $\mathrm{wt} \%\left(X_{i}\right)$ to components expressed in mass fractions $\left(x_{i}\right)$ yields

$$
\begin{gathered}
\ln (0.2) \leq 100 a_{\mathrm{Al}_{2} \mathrm{O}_{3}} x_{\mathrm{Al}_{2} \mathrm{O}_{3}}+100 a_{\mathrm{Fe}_{2} \mathrm{O}_{3}} x_{\mathrm{Fe}_{2} \mathrm{O}_{3}}+100 a_{\mathrm{Li}_{2} \mathrm{O}} x_{\mathrm{Li}_{2} \mathrm{O}}+100 a_{\mathrm{Na}_{2} \mathrm{O}} x_{\mathrm{Na}_{2} \mathrm{O}} \\
+100\left(a_{\mathrm{ZrO}_{2}}+\frac{c_{\mathrm{ZrO}_{2}}}{1423.15}\right) x_{\mathrm{ZrO}_{2}}+100\left[a_{\mathrm{B}_{2} \mathrm{O}_{3}}+\frac{d_{\mathrm{B}_{2} \mathrm{O}_{3}}}{(1423.15)^{2}}\right] x_{\mathrm{B}_{2} \mathrm{O}_{3}}+100\left[a_{\mathrm{MnO}}+\frac{d_{\mathrm{MnO}}}{(1423.15)^{2}}\right] x_{\mathrm{MnO}} \\
+100\left[a_{\mathrm{SiO}_{2}}+\frac{d_{\mathrm{SiO}_{2}}}{(1423.15)^{2}}\right] x_{\mathrm{SiO}_{2}}+100\left[a_{\mathrm{SrO}}+\frac{d_{\mathrm{SrO}}}{(1423.15)^{2}}\right] x_{\mathrm{SrO}} \leq \ln (0.7)
\end{gathered}
$$

Finally, dividing all sides by 100 yields

$$
\begin{gathered}
\frac{\ln (0.2)}{100} \leq a_{\mathrm{Al}_{2} \mathrm{O}_{3}} x_{\mathrm{Al}_{2} \mathrm{O}_{3}}+a_{\mathrm{Fe}_{2} \mathrm{O}_{3}} x_{\mathrm{Fe}_{2} \mathrm{O}_{3}}+a_{\mathrm{Li}_{2} \mathrm{O}} x_{\mathrm{Li}_{2} \mathrm{O}}+a_{\mathrm{Na}_{2} \mathrm{O}} x_{\mathrm{Na}_{2} \mathrm{O}} \\
+\left(a_{\mathrm{ZrO}_{2}}+\frac{c_{\mathrm{ZrO}_{2}}}{1423.15}\right) x_{\mathrm{ZrO}_{2}}+\left[a_{\mathrm{B}_{2} \mathrm{O}_{3}}+\frac{d_{\mathrm{B}_{2} \mathrm{O}_{3}}}{(1423.15)^{2}}\right] x_{\mathrm{B}_{2} \mathrm{O}_{3}}+\left[a_{\mathrm{MnO}}+\frac{d_{\mathrm{MnO}}}{(1423.15)^{2}}\right] x_{\mathrm{MnO}} \\
+\left[a_{\mathrm{SiO}_{2}}+\frac{d_{\mathrm{SiO}_{2}}}{(1423.15)^{2}}\right] x_{\mathrm{SiO}_{2}}+\left[a_{\mathrm{SrO}}+\frac{d_{\mathrm{SrO}}}{(1423.15)^{2}}\right] x_{\mathrm{SrO}} \leq \frac{\ln (0.7)}{100} .
\end{gathered}
$$

This expression then gives the constraints for $\mathrm{EC}$ at $1150^{\circ} \mathrm{C}$ expressed in the mass fractions of components to be varied in the HLW07 test matrix.

\section{$\underline{\text { Standardization of Constraint Coefficients }}$}

Finally, the coefficients of the re-expressed property constraints for spinel $\mathrm{T}_{1 \%}$ [in Equation (A.4)], $\ln \left(\eta_{1150}\right)$ [in Equation (A.6)], and $\ln \left(\varepsilon_{1150}\right)$ [in Equation (A.7)] were standardized so that, in absolute value, the largest coefficient would equal 1 . This was accomplished by dividing both sides of a property inequality constraint by the absolute value of the largest (in absolute value) coefficient. This process results in the largest (in absolute value) coefficient being either +1 or -1 depending on its original sign. Dividing both sides of an inequality by a positive value yields a mathematically equivalent constraint. Hence, the standardization process yielded mathematically equivalent constraints for the three HLW glass properties. Note that the waste-loading constraint already had its largest coefficient equal to 1 , and thus did not need to be standardized. Standardizing the coefficients of the property constraints was required so that the same criterion could be used to apply and check constraints in the software used to generate candidate design points for the outer and inner layers of the HLW07 EGCR. 


\section{A.4.7 HLW Phase 2 Test Matrix}

A 40-glass HLW07 layered design (test matrix) was constructed based on the HLW glass component lower and upper limits for outer and inner layers (as discussed in previous subsections). The 40-glass test matrix contains

- the center glass of the HLW07 inner layer (formed by averaging all of the vertices of the inner-layer constrained region)

- replicates of four glasses studied in previous phases (HLW02-22, HLW02-46, HLW03-07, and HLW03-41)

- 20 outer-layer glasses

- 15 inner-layer glasses

The outer- and inner-layer glasses were selected to optimally augment 125 existing HLW glasses (from previous testing performed by the WTP project) having data for all four of the properties of interest (PCT, spinel $\mathrm{T}_{1 \%}$, viscosity, and EC). The approach of only augmenting glasses having data for every property was chosen as providing an optimized common set of data to develop models for all four properties of interest. Of course, previously tested glasses that have data for fewer than all four properties will still be used for modeling. described.

The detailed steps of the process used to generate the HLW07 test matrix are now

Step 1. The 125 existing HLW glasses having data for all four properties of interest were identified. The Glass IDs and 18-component compositions of these 125 glasses are listed in Table A.17. Tables A.18 and A.19 list the compositions of the grouped components (Others1, Others2, Constant, and Remaining) for the 125 existing glasses. Note that the "Constant" component was not constant for these existing glasses. The "Remaining" group of components was required to account for components included in previous WTP HLW glass studies that were not included in any component of the HLW07 study. Note that only five of the ten HLW05 and HLW06 glasses selected as discussed in Section A.3 appear in the list of 125 glasses. Specifically, only the five HLW06 glasses (HLW06-2, HLW06-4, HLW06-22, HLW06-32, and HLW06-34) appear because the PCT was not performed for HLW05 glasses.

Step 2. The MCCVRT routine of MIXSOFT (Piepel 2003) was used to generate a set of 218,514 vertices for the constrained outer-layer region involving $17 \mathrm{HLW} 07$ glass components $\left(\mathrm{Al}_{2} \mathrm{O}_{3}, \mathrm{~B}_{2} \mathrm{O}_{3}, \mathrm{Cr}_{2} \mathrm{O}_{3}, \mathrm{Fe}_{2} \mathrm{O}_{3}, \mathrm{Li}_{2} \mathrm{O}, \mathrm{MnO}, \mathrm{Na}_{2} \mathrm{O}, \mathrm{NiO}, \mathrm{SiO}_{2}, \mathrm{SrO}, \mathrm{ThO}_{2}\right.$, $\mathrm{UO}_{3}, \mathrm{ZnO}, \mathrm{ZrO}_{2}$, Others1, Others2, and Constant). The mass fractions of these 17 components sum to 1 for each of the outer-layer vertices. To match the 18-component format of the 125 existing glasses, a "Remaining" component with value equal to 0 was appended to the end of every 17-component outer-layer vertex. All of the single- and multi-component constraints were necessary, meaning they all were active in defining the outer-layer boundary and calculating its vertices. 
Step 3. The MCCVRT routine of MIXSOFT (Piepel 2003) was used to generate a set of 178,438 vertices for the constrained inner-layer region involving the 17 HLW07 glass components. The mass fractions of these 17 components sum to 1 for each of the innerlayer vertices. To match the 18-component format of the 125 existing glasses, a "Remaining" component with value equal to 0 was appended to the end of every 17 component inner-layer vertex. All of the single- and multi-component constraints were necessary (meaning they all were active in defining the inner-layer boundary and calculating its vertices) except for two. The lower limit constraint on viscosity (10 poise) and the upper limit constraint on EC $(0.7 \mathrm{~S} / \mathrm{cm})$ were not necessary. Over the inner-layer vertices, the smallest predicted viscosity was 13.34 poise, while the largest predicted EC was $0.463 \mathrm{~S} / \mathrm{cm}$.

Step 4. Center points of the constrained regions defined by the outer layer and the inner layer were calculated by averaging the vertices in each set. The glass compositions of the outer-layer and inner-layer center points were graphically compared to each other and to the center points of previous WTP HLW studies. The inner-layer center point was the most different from previous center points, and was thus selected for inclusion in the HLW07 test matrix. This center point glass is listed as HLW07-01 in Tables A.20, A.21, and A.22.

Step 5. Replicates of four glasses tested in previous WTP HLW glass studies were included in the HLW07 test matrix. Including replicates of glasses tested in previous studies provides for assessing the longer-term sources of variation and uncertainty affecting property-composition data (including batching and melting of glasses, as well as property measurements). Most of the replicates included in previous test matrices of WTP HLW glasses were same-study replicates, and thus only provided for assessing short-term sources of uncertainty. The four replicate glasses were selected to be as spread apart as possible, both in terms of compositions and property values (PCT-B release, spinel $\mathrm{T}_{1 \%}$, viscosity at $1150^{\circ} \mathrm{C}$, and $\mathrm{EC}$ at $1150^{\circ} \mathrm{C}$ ). The glasses selected for replication were HLW02-46 (HLW02 inner layer), HLW03-41 (HLW03 center point), HLW02-22 (HLW02 outer layer), and HLW03-07 (HLW03 outer layer). These glasses are respectively listed as HLW07-02 to HLW07-05 in Tables A.20, A.21, and A.22.

Step 6. ACED (Welch 1987) was used to select 60 candidate subsets of 20 outer-layer glass compositions: 20 subsets each corresponding to the D-, G-, and V-optimal criteria ${ }^{4}$, to optimally augment 130 glasses (the 125 existing glass compositions from Step 1, the center point from Step 4, and the four replicates from Step 5). An 86-term partial quadratic mixture (PQM) model form was assumed to implement the optimality criteria. The model form consisted of linear terms for the 18 mixture components $\left(\mathrm{Al}_{2} \mathrm{O}_{3}, \mathrm{~B}_{2} \mathrm{O}_{3}, \mathrm{Cr}_{2} \mathrm{O}_{3}, \mathrm{Fe}_{2} \mathrm{O}_{3}, \mathrm{Li}_{2} \mathrm{O}, \mathrm{MnO}, \mathrm{Na}_{2} \mathrm{O}, \mathrm{NiO}, \mathrm{SiO}_{2}, \mathrm{SrO}, \mathrm{ThO}_{2}, \mathrm{UO}_{3}, \mathrm{ZnO}\right.$, $\mathrm{ZrO}_{2}$, Others1, Others2, Constant, and Remaining), 12 squared terms, and 56

\footnotetext{
${ }^{4}$ Optimal design software does not guarantee an optimal solution on any given try, so multiple tries must be made to increase the chances of finding the best design. Twenty tries were made with each of the D-, G-, and V-optimal design criteria. These design criteria are discussed in Section A.2. Typically, most or all of a set of 20 tries achieves very close to the same optimality properties.
} 
crossproduct terms for a total of 86 model terms. This model form is further described in Section A.4.8. The 86-term model form is not necessarily the one that will be fit to the resulting property-composition data. Rather, developing optimal designs based on such a model produces a test matrix that supports modeling nonlinear blending effects of important glass components if needed. Design summary statistics (i.e., D-, G-, and V-optimal measures) output by ACED were compared and used, together with plots of predicted property values produced by $\mathrm{R}$ (as described in Step 7), to select one of the best options among the available 60 subsets of 20 outer-layer glass compositions.

Step 7. R (Ihaka and Gentelman 1996) was used to plot predicted property values and visually inspect the predicted property distributions for each of the 60 candidate subsets of 20 outer-layer glass compositions. Of particular interest were the predicted $\mathrm{T}_{1 \%}$ and viscosity distributions, which differed dramatically among the 60 subsets of candidate outer-layer glasses, even though summary statistics for the optimality criteria used by ACED were very similar. ${ }^{5}$ Property constraints were included in the MIXSOFT MCCVRT runs used to calculate vertices for each layer. Thus, all candidate glass compositions satisfy property constraints, meaning that the predicted property values associated with each outer-layer vertex must fall within the limiting range for each property of interest. However, an even coverage of the predicted property space is desirable. Therefore, the 20 outer-layer design points that were ultimately selected in this step were chosen because they performed well in terms of the D-, G-, and Voptimal measures from ACED and had predicted property distributions that provided 'good' coverage of the specified property ranges. R was used to select a 'best' set of 20 outer-layer glass compositions to be used in the augmentation test matrix. The selected outer-layer glass compositions are listed as HLW07-06 to HLW07-25 in Tables A.20, A.21, and A.22.

Step 8. ACED was used to select 60 candidate subsets of 15 inner-layer glass compositions: 20 subsets, each corresponding to the D-, G-, and V-optimal criteria. These sets of 15 inner-layer glass compositions were chosen to optimally augment 150 glasses (the 125 existing glass compositions from Step 1, the center glass from Step 4, the four replicates from Step 5, and the 20 outer-layer glasses from Step 7). The same 86-term model (see Step 6 and Section A.4.8) was used to implement the optimality criteria for the inner-layer ACED run as was used for the outer-layer ACED run. Design summary statistics (i.e., D-, G-, and V-optimal measures) output by ACED were compared and used, together with plots of predicted property values produced by $\mathrm{R}$ (as described in Step 9), to select one of the best options among the available 60 subsets of 15 innerlayer glass compositions.

Step 9. R (Ihaka and Gentleman 1996) was used to plot predicted property values and visually inspect the predicted property distributions for each of the 60 candidate subsets of 15 inner-layer glass compositions. As with the outer-layer glass compositions, the

\footnotetext{
${ }^{5}$ Optimal experimental design software packages such as ACED only consider the distribution of design points in design variable space (i.e., glass compositions in this application), not property variable space. Hence, it was necessary to separately consider distributions of predicted property values as well as optimized distributions of compositions provided by ACED.
} 
predicted $\mathrm{T}_{1 \%}$ and viscosity distributions showed considerable differences among the 60 subsets of candidate inner-layer glass compositions. The 15 inner-layer glass compositions that were ultimately selected were chosen because they performed well in terms of the D-, G-, and V-optimal measures from ACED and had predicted property distributions that provided 'good' coverage of the property ranges. $\mathrm{R}$ was used to select a 'best' set of 15 inner-layer glass compositions to complete the HLW07 test matrix. The selected inner-layer glass compositions are listed as HLW07-26 to HLW07-40 in Tables A.20, A.21, and A.22.

In summary, the 40-glass HLW07 test matrix consists of a center point (HLW07-01), four replicates (HLW07-02 to HLW07-05), 20 outer-layer glasses (HLW07-06 to HLW07-25), and 15 inner-layer glasses (HLW07-26 to HLW07-40). The 18-component compositions of the glasses in the test matrix are given in Table A.20. Expansions of the Others1, Others2, and Constant components are given in Table A.21, while expansions of the Remaining component are given in Table A.22.

In preparing the list of expanded compositions of HLW07-01 and HLW07-06 to HLW0740, $\mathrm{Ta}_{2} \mathrm{O}_{5}$ in the "Constant" grouped component was inadvertently omitted from the expansion. $\mathrm{Ta}_{2} \mathrm{O}_{5}$ was intended to have occurred at $0.01 \mathrm{wt} \%$ in outer-layer glasses and $0.005 \mathrm{wt} \%$ in innerlayer glasses. The omission of $\mathrm{Ta}_{2} \mathrm{O}_{5}$ (plus minor round-off differences in the calculation of outer- and inner-layer vertices) led to renormalizing these glass compositions so their mass fractions would sum to exactly 1 (wt\% values would sum to 100). This renormalization led to minor impacts on the values of all glass components (not just those included in the "Constant" component). This issue was brought to the attention of the WTP project technical contacts for the test matrix development work at PNWD. It was concluded that the omission of $\mathrm{Ta}_{2} \mathrm{O}_{5}$ and the minor impacts of renormalization were not of practical technical impact. Hence, 18-component compositions of the HLW07 glasses in Table A.20 and the expansions of the grouped components in Tables A.21 and A.22 correspond to the actual compositions. The compositions of the 125 existing glasses listed in Tables A.17 to A.19 were not affected by this issue. Similarly, the compositions of the four replicate glasses in the HLW07 test matrix (HLW07-02, HLW07-03, HLW07-04, and HLW07-05) were not affected by this issue because they are replicates of existing glasses which did not contain $\mathrm{Ta}_{2} \mathrm{O}_{5}$.

\section{A.4.8 Model Form Used in Optimal Experimental Design Approach}

The 20 outer-layer and 15 inner-layer glasses of the HLW07 test matrix were selected using optimal experimental design methods as described in the previous subsection. The optimal experimental design approach requires specifying a model form that is assumed to be adequate to represent the linear as well as any nonlinear blending effects of the HLW07 glass components. The sets of 20 outer-layer glasses and 15 inner-layer glasses were optimally selected for a PQM model form consisting of 18 linear terms $\left(\mathrm{Al}_{2} \mathrm{O}_{3}, \mathrm{~B}_{2} \mathrm{O}_{3}, \mathrm{Cr}_{2} \mathrm{O}_{3}, \mathrm{Fe}_{2} \mathrm{O}_{3}, \mathrm{Li}_{2} \mathrm{O}, \mathrm{MnO}, \mathrm{Na}_{2} \mathrm{O}, \mathrm{NiO}\right.$, $\mathrm{SiO}_{2}, \mathrm{SrO}, \mathrm{ThO}_{2}, \mathrm{UO}_{3}, \mathrm{ZnO}, \mathrm{ZrO}_{2}$, Others1, Others2, Constant, and Remaining) along with: 
a) all pairwise crossproduct and squared terms of the five components included in the PQM model optimization of the HLW Phase $1 \mathrm{~b}$ augmentation test matrix $\left(\mathrm{Al}_{2} \mathrm{O}_{3}, \mathrm{~B}_{2} \mathrm{O}_{3}, \mathrm{Li}_{2} \mathrm{O}\right.$, $\left.\mathrm{Na}_{2} \mathrm{O}, \mathrm{SiO}_{2}\right)$ and the five components affecting spinel $\mathrm{T}_{1 \%}\left(\mathrm{Cr}_{2} \mathrm{O}_{3}, \mathrm{Fe}_{2} \mathrm{O}_{3}, \mathrm{MnO}, \mathrm{NiO}, \mathrm{ZnO}\right)$

b) all pairwise crossproduct and squared terms of the five components included in the PQM model optimization of the augmentation matrix $\left(\mathrm{Al}_{2} \mathrm{O}_{3}, \mathrm{~B}_{2} \mathrm{O}_{3}, \mathrm{Li}_{2} \mathrm{O}, \mathrm{Na}_{2} \mathrm{O}, \mathrm{SiO}_{2}\right)$ as well as $\mathrm{ThO}_{2}$ and $\mathrm{ZrO}_{2}$. These last two components were previously found to have statistically significant effects on HLW glass properties. Also, although generating additional glasses with primary $\mathrm{Th}$ and $\mathrm{Zr}$ crystalline phases was not a goal of this study, including crossproducts and squared terms of $\mathrm{ThO}_{2}$ and $\mathrm{ZrO}_{2}$ may generate some glasses with these primary crystalline phases. Such data would be useful in any future efforts to model $\mathrm{T}_{1 \%}$ for Th- or Zr-containing crystalline phases.

There are 10 squared and 45 crossproduct terms in a), plus 2 more squared terms and 11 more crossproduct terms in b) not in a). Thus, this PQM model form contains 18 linear terms, 12 squared terms, and 56 crossproduct terms for a total of 86 model terms. The 86 model terms are listed in Table A.23.

Sets of 20 outer-layer glasses (Step 6 of Section A.4.7) and 15 inner-layer glasses (Step 8 of Section A.4.7) were also constructed in a similar fashion as described above for (1) a linear mixture model form and (2) a 54-term PQM model from having 36 quadratic terms, fewer than the 68 in the selected 86-term model form. It was found that designs (i.e., sets of outer- or innerlayer glasses) optimized for the 86-term and 54-term PQM model forms, but evaluated using the linear mixture model form, had design statistics that were only marginally worse than the statistics of designs optimized for the linear mixture model. On the other hand, designs optimized for the linear mixture model but evaluated for the 86-term and 54-term PQM model forms had much worse design statistics than the designs optimized for the PQM models. There were only small differences between the statistics for designs selected based on the 86-term and 54-term PQM model forms. Thus, the selected HLW07 matrix glasses were optimized for the 86-term PQM model to so that the data would include more information on nonlinear blending effects of components, with only marginal loss in estimation efficiency if linear mixture models are ultimately fitted to the data.

\section{A.4.9 Graphical Assessment of Existing Glasses and HLW07 Test Matrix Glasses}

The 165 glasses obtained by combining the 125 existing glasses and the 40 HLW Phase 2 glasses were graphically assessed to confirm that they adequately cover the least-restrictive HLW glass composition region defined by the constraints in Table 2.5. Henceforth, this region is referred to as the modeling composition region. Good coverage of this region without strong correlations among components is needed to support developing property-composition models from the data. ${ }^{6}$ Recall that property-composition modeling will use all glasses having data for a

\footnotetext{
${ }^{6}$ Good coverage of the outer and inner portions of the EGCR defined by the constraints in Tables A.5 and A.12 is also desirable to verify the HLW07 test matrix. However, property-composition models will be developed and their validity determined over the least-restrictive modeling composition region.
} 
given property. Thus, the modeling database for some properties may contain more than the 165 glasses assessed by the plots in this subsection. However, if the 165 glasses provides good support for developing property models, then more glasses for some properties will also provide good support.

Figure A.23 shows single-component distribution plots for the 18 components used to represent the compositions of the 125 existing and 40 HLW07 test matrix glasses. In these plots, the black circles denote the 125 glasses from past studies: 97 HLW02 and HLW03 glasses, 5 HLW06 glasses, and 23 algorithm support glasses (see Section 2) that have or were planned to have property data for all four HLW glass properties of interest. The blue box with a cross inside represents the new HLW07 center point, the four blue $\times_{\text {s }}$ represent the four new replicates selected for the HLW07 glasses, the green crosses represent the 20 new HLW07 outer-layer glasses, and the red triangles represent the 15 new HLW07 inner-layer glasses. In Figure A.23, the component mass fraction values are displayed along the x-axes, whereas the "index number" of each glass is displayed along the y-axes. Indices 1-125 correspond to the existing glasses, while indices 126-165 correspond to the 40 HLW glasses in the HLW07 test matrix. Most components show good distributions consistent with the component lower and upper limits used in the various HLW glass studies. Exceptions are (1) the Others1 component, which is constant for all of the HLW02 and HLW03 glasses, (2) the Constant component (as defined for the HLW07 study) comprised a relatively consistent fraction of the HLW02 and HLW03 glasses, varied for the Algorithm HLW glasses, and then is constant at one of two values for the HLW07 outer- and inner-layer glasses, and (3) the Remaining component generally varies up to about 0.015 mass fraction (1.5 wt\%) for HLW02, HLW03, and the Algorithm HLW glasses and then is zero for the HLW07 outer- and inner-layer glasses. However, there are two HLW06 glasses with the Remaining component having mass fraction values near 0.03 (wt\% values near 3.0).

Figure A.24 shows predicted property plots for spinel $\mathrm{T}_{1 \%}\left({ }^{\circ} \mathrm{C}\right)$, PCT-B release $(\mathrm{g} / \mathrm{L})$, viscosity at $1150^{\circ} \mathrm{C}$ (poise), and $\mathrm{EC}$ at $1150^{\circ} \mathrm{C}(\mathrm{S} / \mathrm{cm})$. The same plotting symbols and colors are used as in Figure A.23. Note that many of the 40 HLW07 glasses have predicted property values (for spinel $\mathrm{T}_{1 \%}$, viscosity at $1150^{\circ} \mathrm{C}$, and $\mathrm{EC}$ at $1150^{\circ} \mathrm{C}$ ) at limiting values used in defining the outer and inner layers of the EGCR. This is expected because the glasses were selected from the sets of outer- and inner-layer vertices, which must satisfy at least 17 of the constraints defining the outer layer or the inner layer. However, in comparing the 60 subsets of 20 outer-layer glasses and subsequently the 60 subsets of 15 inner-layer glasses that were selected by optimal experimental design (see Section A.4.8), designs with fewer glasses "stacked up" at limiting values were preferred. The set of 20 outer-layer glasses selected gave a noticeably better distribution of property values than other options. The top few choices for subsets of 15 innerlayer glasses had trade-offs when considering the distribution of property values and the number of glasses stacked-up at limiting values. For example, one set of 15 inner-layer glasses considered had a slightly better distribution of PCT-B release values, but had a poorer distribution of spinel $\mathrm{T}_{1 \%}$ values with more of them stacked-up at the limit. The 15 inner-layer glasses selected were judged to be the best compromise of property and composition distributions among the top several of the 60 subsets generated.

One additional aspect of Figure A.24 requires a brief discussion. One of the replicate glasses selected (HLW03-07) is seen in the figure to have a predicted spinel $\mathrm{T}_{1 \%}$ value of 
approximately $1150^{\circ} \mathrm{C}$. The measured value originally was $1213^{\circ} \mathrm{C}$. Values of spinel $\mathrm{T}_{1 \%}$ this large raise questions about whether crystallinity in glass melts might be high enough to affect viscosity and EC measurements. This issue was considered in selecting replicate glasses. However, selecting at least one of the higher $\mathrm{T}_{1 \%}$ glasses as a replicate was the only way to achieve the desired separation of glass compositions and properties. Also, when tested the first time HLW03-07 did not exhibit indications of crystallinity affecting viscosity and EC measurements, so it is considered a "safe" choice for a replicate.

Figure A.25 is a scatterplot matrix showing scatterplots for all pairs of the 14 main components plus Others1 and Others2. The Constant and Remaining components were not included in the scatterplot matrix for space reasons and because they do not show any more than can be seen in the single-component distribution plots in Figure A.24. The same plotting symbols and colors are used in Figure A.25 as described previously. Although the individual scatterplots in the scatterplot matrix are small, they are sufficient for judging how well the composition space is covered (in two-dimensional projections), whether there are outlying data, or whether there are strong pairwise correlations. The plots show good coverage of the composition space by the 125 existing plus 40 new HLW07 glasses. In some cases there are uncovered subregions in individual scatterplots. However, those generally correspond to edges of component ranges that are included in the least-restrictive component ranges (see Table 2.5) but were not included in the EGCR for the HLW07 study. Further, it should be kept in mind that all glasses with values of a given property will be used to develop models for that property. Hence, plots such as Figure A.25 with all glasses having values for each glass property would contain additional points that may improve the coverage of the HLW07 and least-restrictive composition regions.

In summary, Figures A.23 to A.25 show that the 125 existing plus 40 new HLW07 glasses provide good coverage of the HLW glass composition region defined by the leastrestrictive constraints in Table 2.5. Hence, these glasses provide a good basis for developing property-composition models over the corresponding HLW glass composition region.

\section{A.5 Quality Assurance}

The test matrices described in Sections A.3 and A.4 of this appendix were constructed to support the development of HLW property-composition models, as described in Section A.1 and the Test Plans (Gan and Pegg 2002, Piepel and Cooley 2003). The properties to be modeled included PCT releases. Because the data and PCT models will be waste glass quality-affecting, software control procedures that meet DOE/RW-0333P (QARD) requirements (U. S. DOE-RW 2004) were implemented at PNWD for the software used to generate the test matrices discussed in Sections A.3 and A.4. The test matrices were generated using commercially available software packages that have undergone appropriate verification and validation. This work did not involve software development; rather existing software packages were used as tools to develop the test matrices.

PNWD addressed internal verification and validation requirements by conducting an Independent Technical Review of this appendix (when it was a separate letter report in early 2006) in accordance with the PNWD procedure QA-RPP-WTP-604 applicable at the time. This 
review verified that the reported results are traceable, that inferences and conclusions are soundly based, and the reported work satisfied the Test Plan objectives. This review procedure was part of PNWD's WTPSP Quality Assurance Requirements and Description Manual. See Section 12 of the report for a more general discussion of QA implementation. 
Table A.1. Existing 143 HLW Glasses with Viscosity and Electrical Conductivity Data, the 25 Candidate HLW05 and HLW06 Glasses, and the 10 Glasses Selected for Viscosity and Electrical Conductivity Measurement.

\begin{tabular}{|c|c|c|c|c|c|c|c|}
\hline Glass ID & Existing & Candidate & Selected & Glass ID & Existing & Candidate & Selected \\
\hline HLW98-72 & $X^{(a)}$ & -(a) & - & HLW03-11 & $\mathrm{X}$ & - & - \\
\hline HLW98-77 & $\mathrm{X}$ & - & - & HLW03-12 & $\mathrm{X}$ & - & - \\
\hline HLW98-80 & $X$ & - & - & HLW03-13 & $\mathrm{X}$ & - & - \\
\hline HLW98-83 & $\mathrm{X}$ & - & - & HLW03-14 & $\mathrm{X}$ & - & - \\
\hline HLW98-84 & $\mathrm{X}$ & - & - & HLW03-15 & $\mathrm{X}$ & - & - \\
\hline HLW98-86AG & $\mathrm{X}$ & - & - & HLW03-16 & $\mathrm{X}$ & - & - \\
\hline HLW98-88 & $\mathrm{X}$ & - & - & HLW03-17 & $\mathrm{X}$ & - & - \\
\hline HLW98-89 & $\mathrm{X}$ & - & - & HLW03-18 & $\mathrm{X}$ & - & - \\
\hline HLW98-95 & $\mathrm{X}$ & - & - & HLW03-19 & $\mathrm{X}$ & - & - \\
\hline HLW98-96 & $\mathrm{X}$ & - & - & HLW03-20 & $\mathrm{X}$ & - & - \\
\hline HLW98-96A & $\mathrm{X}$ & - & - & HLW03-21 & $\mathrm{X}$ & - & - \\
\hline HLW98-96B & $\mathrm{X}$ & - & - & HLW03-22 & $\mathrm{X}$ & - & - \\
\hline HLW98-96D & $\mathrm{X}$ & - & - & HLW03-23 & $\mathrm{X}$ & - & - \\
\hline HLW98-97 & $\mathrm{X}$ & - & - & HLW03-24 & $\mathrm{X}$ & - & - \\
\hline HLW98-V19 & $\mathrm{X}$ & - & - & HLW03-25 & $\mathrm{X}$ & - & - \\
\hline HLW98-V24 & $\mathrm{X}$ & - & - & HLW03-26 & $\mathrm{X}$ & - & - \\
\hline HLW98-T05 & $\mathrm{X}$ & - & - & HLW03-27 & $\mathrm{X}$ & - & - \\
\hline HLW02-01 & $\mathrm{X}$ & - & - & HLW03-28 & $\mathrm{X}$ & - & - \\
\hline HLW02-02 & $\mathrm{X}$ & - & - & HLW03-29 & $\mathrm{X}$ & - & - \\
\hline HLW02-03 & $\mathrm{X}$ & - & - & HLW03-30 & $\mathrm{X}$ & - & - \\
\hline HLW02-04 & $X$ & - & - & HLW03-31 & $X$ & - & - \\
\hline HLW02-05 & $X$ & - & - & HLW03-32 & $X$ & - & - \\
\hline HLW02-06 & $X$ & - & - & HLW03-33 & $X$ & - & - \\
\hline HLW02-07 & $X$ & - & - & HLW03-34 & $X$ & - & - \\
\hline HLW02-08 & $X$ & - & - & HLW03-35 & $X$ & - & - \\
\hline HLW02-09 & $X$ & - & - & HLW03-36 & $X$ & - & - \\
\hline HLW02-10 & $\mathrm{X}$ & - & - & HLW03-37 & $X$ & - & - \\
\hline HLW02-11 & $X$ & - & - & HLW03-38 & $X$ & - & - \\
\hline HLW02-12 & $\mathrm{X}$ & - & - & HLW03-39 & $X$ & - & - \\
\hline HLW02-13 & $\mathrm{X}$ & - & - & HLW03-40 & $X$ & - & - \\
\hline HLW02-14 & $\mathrm{X}$ & - & - & HLW03-41 & $X$ & - & - \\
\hline HLW02-15 & $\mathrm{X}$ & - & - & HLW03-42 & $X$ & - & - \\
\hline HLW02-16 & $\mathrm{X}$ & - & - & HLW03-43 & $X$ & - & - \\
\hline HLW02-17 & $X$ & - & - & HLW03-44 & $X$ & - & - \\
\hline HLW02-18 & $\mathrm{X}$ & - & - & HLW03-45 & $X$ & - & - \\
\hline HLW02-19 & $\mathrm{X}$ & - & - & HLW04-01 & $X$ & - & - \\
\hline HLW02-20R1 & $\mathrm{X}$ & - & - & HLW-ALG-01 & $\mathrm{X}$ & - & - \\
\hline HLW02-21R1 & $X$ & - & - & HLW-ALG-02 & $\mathrm{X}$ & - & - \\
\hline HLW02-22 & $\mathrm{X}$ & - & - & HLW-ALG-03 & $\mathrm{X}$ & - & - \\
\hline HLW02-23R1 & $\mathrm{X}$ & - & - & HLW-ALG-04 & $\mathrm{X}$ & - & - \\
\hline HLW02-24 & $X$ & - & - & HLW-ALG-05 & $\mathrm{X}$ & - & - \\
\hline HLW02-25R1 & $\mathrm{X}$ & - & - & HLW-ALG-06 & $\mathrm{X}$ & - & - \\
\hline HLW02-26 & $\mathrm{X}$ & - & - & HLW-ALG-07 & $\mathrm{X}$ & - & - \\
\hline HLW02-27 & $\mathrm{X}$ & - & - & HLW-ALG-08 & $\mathrm{X}$ & - & - \\
\hline HLW02-28 & $\mathrm{X}$ & - & - & HLW-ALG-09 & $\mathrm{X}$ & - & - \\
\hline
\end{tabular}

(a) An "X" indicates the glass is included in the set specified by the column, a "-" indicates that it is not included. 
Table A.1. Existing 143 HLW Glasses with Viscosity and Electrical Conductivity Data, the 25 Candidate HLW05 and HLW06 Glasses, and the 10 Glasses Selected for Viscosity and Electrical Conductivity Measurement (continued).

\begin{tabular}{|c|c|c|c|c|c|c|c|}
\hline Glass ID & Existing & Candidate & Selected & Glass ID & Existing & Candidate & Selected \\
\hline HLW02-29R1 & $X^{(a)}$ & - (a) & - & HLW-ALG-10 & $\mathrm{X}$ & - & - \\
\hline HLW02-30 & $\mathrm{X}$ & - & $\begin{array}{llll}- & \\
\end{array}$ & HLW-ALG-11 & $\mathrm{X}$ & - & - \\
\hline HLW02-31 & $\mathrm{X}$ & - & - & HLW-ALG-12 & $\mathrm{X}$ & - & $\begin{array}{ll}- \\
-\end{array}$ \\
\hline HLW02-32R1 & $\mathrm{X}$ & - & - & HLW-ALG-13 & $\mathrm{X}$ & - & - \\
\hline HLW02-33 & $\mathrm{X}$ & $\begin{array}{llll}- & \end{array}$ & $\begin{array}{llll}- & \end{array}$ & HLW-ALG-14 & $\mathrm{X}$ & - & $\begin{array}{llll}- & \end{array}$ \\
\hline HLW02-34R1 & $\mathrm{X}$ & - & - & HLW-ALG-15 & $\mathrm{X}$ & - & - \\
\hline HLW02-35 & $\mathrm{X}$ & - & - & HLW-ALG-16 & $\mathrm{X}$ & - & - \\
\hline HLW02-36 & $\mathrm{X}$ & - & - & HLW-ALG-17 & $\mathrm{X}$ & - & - \\
\hline HLW02-37 & $\mathrm{X}$ & - & - & HLW-ALG-18 & $\mathrm{X}$ & - & - \\
\hline HLW02-38 & $\mathrm{X}$ & - & - & HLW-ALG-19 & $\mathrm{X}$ & - & - \\
\hline HLW02-39 & $\mathrm{X}$ & - & - & HLW-ALG-20 & $\mathrm{X}$ & - & - \\
\hline HLW02-40 & $\mathrm{X}$ & - & - & HLW-ALG-21 & $\mathrm{X}$ & - & - \\
\hline HLW02-41 & $\mathrm{X}$ & - & - & HLW-ALG-22 & $\mathrm{X}$ & - & - \\
\hline HLW02-42 & $\mathrm{X}$ & - & - & HLW-ALG-23 & $\mathrm{X}$ & - & - \\
\hline HLW02-43 & $\mathrm{X}$ & - & - & HLW05-01 & - & $\mathrm{X}$ & - \\
\hline HLW02-44 & $\mathrm{X}$ & - & - & HLW05-02 & - & $\mathrm{X}$ & - \\
\hline HLW02-45 & $\mathrm{X}$ & - & - & HLW05-03 & - & $\mathrm{X}$ & - \\
\hline HLW02-46 & $\mathrm{X}$ & - & - & HLW05-04 & - & $\mathrm{X}$ & - \\
\hline HLW02-47 & $\mathrm{X}$ & - & - & HLW05-05 & - & $\mathrm{X}$ & - \\
\hline HLW02-48 & $\mathrm{X}$ & - & - & HLW05-07 & - & $\mathrm{X}$ & - \\
\hline HLW02-49 & $\mathrm{X}$ & - & - & HLW05-09 & - & $\mathrm{X}$ & - \\
\hline HLW02-50 & $\mathrm{X}$ & - & - & HLW05-10 & - & $\mathrm{X}$ & - \\
\hline HLW02-51R1 & $\mathrm{X}$ & - & - & HLW05-11 & - & $\mathrm{X}$ & - \\
\hline HLW02-52 & $\mathrm{X}$ & - & - & HLW05-13 & - & $\mathrm{X}$ & - \\
\hline HLW02-53 & $\mathrm{X}$ & - & - & HLW05-14 & - & $\mathrm{X}$ & - \\
\hline HLW02-54 & $\mathrm{X}$ & - & - & HLW05-15 & - & $\mathrm{X}$ & $\mathrm{X}$ \\
\hline HLW02-55 & $\mathrm{X}$ & - & - & HLW05-20 & - & $\mathrm{X}$ & $\mathrm{X}$ \\
\hline HLW02-56 & $\mathrm{X}$ & - & - & HLW05-21 & - & $\mathrm{X}$ & $\mathrm{X}$ \\
\hline HLW02-57 & $\mathrm{X}$ & - & - & HLW05-22 & - & $\mathrm{X}$ & $\mathrm{X}$ \\
\hline HLW03-01 & $\mathrm{X}$ & - & - & HLW05-27 & - & $\mathrm{X}$ & $\mathrm{X}$ \\
\hline HLW03-02 & $\mathrm{X}$ & - & - & HLW05-30 & - & $\mathrm{X}$ & - \\
\hline HLW03-03 & $\mathrm{X}$ & - & - & HLW06-02 & - & $\mathrm{X}$ & $\mathrm{X}$ \\
\hline HLW03-04 & $\mathrm{X}$ & - & - & HLW06-04 & - & $\mathrm{X}$ & $\mathrm{X}$ \\
\hline HLW03-05 & $X$ & - & - & HLW06-05 & - & $\mathrm{X}$ & - \\
\hline HLW03-06 & $\mathrm{X}$ & - & - & HLW06-15 & - & $\mathrm{X}$ & - \\
\hline HLW03-07 & $\mathrm{X}$ & - & - & HLW06-22 & - & $\mathrm{X}$ & $\mathrm{X}$ \\
\hline HLW03-08 & $\mathrm{X}$ & - & - & HLW06-32 & - & $\mathrm{X}$ & $\mathrm{X}$ \\
\hline HLW03-09 & $\mathrm{X}$ & - & - & HLW06-34 & - & $\mathrm{X}$ & $\mathrm{X}$ \\
\hline HLW03-10R1 & $\mathrm{X}$ & - & - & HLW06-35 & - & $\mathrm{X}$ & - \\
\hline
\end{tabular}

(a) An "X" indicates the glass is included in the set specified by the column, a "- " indicates that it is not included. 


\section{Table A.2. 18-Component Target Glass Compositions (wt\%) for the 143 Existing Glasses Having Viscosity and Electrical} Conductivity Data.

\begin{tabular}{|c|c|c|c|c|c|c|c|c|c|c|c|c|c|c|c|c|c|c|c|c|}
\hline Glass ID $^{(\mathrm{a})}$ & oint Type (b) $^{(b}$ & $\mathrm{Al}_{2} \mathbf{O}_{3}$ & $\mathbf{B}_{2} \mathbf{O}_{3}$ & $\mathrm{Cr}_{2} \mathrm{O}_{3}$ & $\mathrm{Fe}_{2} \mathbf{O}_{3}$ & $\mathbf{L i}_{2} \mathbf{O}$ & MnO & $\mathrm{Na}_{2} \mathrm{O}$ & $\mathrm{NiO}$ & $\mathrm{SiO}_{2}$ & SrO & $\mathrm{ThO}_{2}$ & $\mathrm{UO}_{3}$ & $\mathrm{ZnO}$ & $\mathrm{ZrO}_{2}$ & Others1 & Others2 & Constant & Remain & Sum ${ }^{(c)}$ \\
\hline HLW98-72 & 998.72 & 5.192 & 8.185 & 0.000 & 12.189 & 5.028 & 0.169 & 13.447 & (0.618 & 47.982 & 0.000 & 0.000 & 0.000 & 2.018 & 3.795 & 0.074 & 0.135 & 0.789 & 0.380 & 100.000 \\
\hline HLW98-77 & 98.77 & 196 & 11.908 & 0.000 & 12.221 & 3.525 & .170 & 11.659 & .615 & 47.453 & 0.032 & 0.000 & 0.000 & 2.016 & 3.806 & 0.075 & .128 & 0.757 & .438 & 100.000 \\
\hline HLW98-80 & 98.80 & 590 & 12.529 & 0.000 & 2.530 & 3.260 & 0.357 & 12.033 & $\begin{array}{l}0.447 \\
\end{array}$ & 48.308 & 0.000 & 0.000 & 0.000 & 2.012 & 1.772 & 0.066 & 184 & 0.641 & .272 & 100.000 \\
\hline HLW98-83 & 998.83 & 1.428 & 11.914 & 0.045 & 12.746 & 2.755 & 3.040 & 11.738 & 0.374 & 50.938 & 0.000 & 0.000 & 0.000 & 2.019 & 0.127 & 0.099 & 0.299 & 1.165 & 1.315 & 100.000 \\
\hline HLW98-84 & 998.84 & 5.182 & 11.163 & 0.045 & 12.746 & 2.755 & 3.040 & 11.988 & 0.374 & 47.684 & 0.000 & 0.000 & 0.000 & 2.019 & 0.127 & 0.099 & 0.299 & 1.165 & 1.315 & 100.000 \\
\hline HLW98-86AG & 1998.86AC & 5.301 & 9.392 & 0.080 & 12.583 & 3.011 & 4.001 & 11.862 & \begin{tabular}{l|l|}
0.170 \\
\end{tabular} & 47.149 & 0.920 & 0.000 & 0.000 & 2.070 & 0.260 & 0.090 & .180 & 0.910 & 020 & 0.000 \\
\hline $3-88$ & 1998 & 7.459 & 10.606 & 0.139 & 11.421 & 3.762 & 0.273 & 11.721 & 0.502 & 43.995 & 0.159 & 0.000 & 0.945 & 2.015 & 3.468 & 488 & 772 & 768 & 08 & 100.000 \\
\hline 39 & 1998 & 3.360 & 9.096 & 059 & 8.947 & 2.843 & 1.425 & 10.736 & 38 & 44.571 & 0.000 & 4.051 & 2.573 & 17 & 8.843 & 38 & 42 & 12 & 49 & 0.000 \\
\hline-95 & 95 & 7.317 & 10.633 & 143 & 11.206 & 3.758 & 329 & 11.925 & 493 & 44.689 & 0.156 & 0.000 & 0.927 & 013 & 3.402 & 19 & 746 & 35 & 10 & 000 \\
\hline $3-96$ & 98.96 & 356 & 10.097 & .060 & 8.949 & 3.096 & 1.428 & 10.737 & .439 & 43.316 & 0.000 & 4.055 & 2.571 & .017 & 8.839 & .040 & 140 & 709 & 150 & $\overline{000}$ \\
\hline HLW98-96A & 1998.96A & 3.440 & 10.351 & 060 & 9.171 & 3.170 & 1.460 & 11.011 & 450 & 44.424 & 0.000 & 0.000 & 0.000 & 2.070 & 9.071 & .040 & 150 & .430 & .700 & 100.000 \\
\hline HLW98-96B & 1998.96B & 3.420 & 10.291 & 0.060 & 9.121 & 3.150 & 1.450 & 10.941 & \begin{tabular}{l|l}
0.450 \\
\end{tabular} & 44.154 & 0.000 & 0.000 & 0.000 & 2.060 & 9.011 & 0.040 & .150 & 0.720 & 4.980 & 100.000 \\
\hline HLW98-96D & 1998.96D & 3.600 & 10.811 & 0.060 & 9.581 & 3.310 & 1.530 & 11.501 & \begin{tabular}{l|l|}
0.470 \\
\end{tabular} & 46.395 & 0.000 & 0.000 & 0.000 & 2.160 & 9.471 & 0.040 & .150 & 0.760 & .160 & 100.000 \\
\hline $98-97$ & 1998.97 & 9.752 & 11.052 & 0.030 & 10.942 & 3.881 & 0.150 & 12.182 & 0.620 & 42.999 & 0.030 & 0.000 & 0.000 & 2.060 & 3.361 & 0.130 & .840 & 1.590 & .380 & .000 \\
\hline $8-\mathrm{V} 19$ & 1998 & 5.771 & 8.821 & 0.090 & 14.691 & 2.810 & 4.670 & & $\begin{array}{l}0.200 \\
\end{array}$ & 44.504 & 1.070 & 0.000 & 0.000 & 1.950 & 0.300 & 10 & 20 & .060 & 520 & $\overline{000}$ \\
\hline$-\mathrm{V} 24$ & 1998 & 4.729 & 10.058 & 060 & 10.118 & 3.229 & 3.219 & 12.567 & \begin{tabular}{|l|l|}
0.140 \\
\end{tabular} & 50.010 & 0.740 & 0.000 & 0.000 & 2.210 & 0.210 & 80 & 60 & 730 & 40 & 000 \\
\hline -T05 & 1998 & 5.389 & 11.849 & 0.020 & 12.639 & 3.010 & 1.700 & 12.009 & $\begin{array}{l}0.410 \\
\end{array}$ & 47.995 & 0.000 & 0.000 & 0.000 & 2.020 & 0.950 & 0.080 & 240 & 900 & 90 & 000 \\
\hline $2-01$ & Ph1a & 6.171 & 9.927 & 108 & 10.899 & 3.996 & 2.385 & 10.957 & 0.518 & 43.612 & 2.444 & 0.000 & 0.000 & 2.000 & 2.974 & 0.600 & .051 & 1.407 & .951 & 000 \\
\hline-02 & $1 \mathrm{a}$ & 3.999 & 13.996 & 199 & 13.996 & 5.998 & 0.000 & 3.999 & \begin{tabular}{l|l|}
0.100 \\
\end{tabular} & 50.445 & 0.000 & 0.000 & 0.000 & 1.999 & 0.000 & 0.600 & .010 & 1.497 & .160 & 100.000 \\
\hline $2-03$ & Ph1a.OL02 & 3.999 & 13.998 & 0.199 & 7.999 & 2.000 & 0.000 & 14.998 & 1.000 & 37.994 & 4.379 & 0.000 & 0.000 & 2.000 & 5.999 & 0.600 & 2.011 & 1.317 & 1.508 & 100.000 \\
\hline HLW02-04 & Ph1a.OL03 & 4.001 & 5.001 & 0.020 & 14.002 & 2.000 & 0.518 & 15.002 & $\begin{array}{l}0.100 \\
\end{array}$ & 52.939 & 0.000 & 0.000 & 0.000 & 2.000 & 0.000 & 0.600 & .560 & 1.498 & .759 & 100.000 \\
\hline HLW02-05 & Ph1a.OL04 & 4.000 & 5.000 & 0.020 & 8.000 & 6.000 & 0.000 & 13.788 & 0.100 & 52.652 & 0.000 & 0.000 & 0.000 & 2.000 & 6.000 & 0.600 & .110 & 1.318 & .412 & 100.000 \\
\hline $2-06$ & Ph1a.OL05 & 8.501 & 5.001 & 0.020 & 8.001 & 4.740 & 5.001 & 15.002 & 1.000 & 40.496 & 0.000 & 0.000 & 0.000 & 2.000 & 6.001 & 0.600 & 1.560 & 1.318 & .759 & 100.000 \\
\hline-07 & Ph1a.OL06 & 8.499 & 4.999 & 0.199 & .999 & 5.999 & 0.000 & 11.703 & 0.100 & 52.992 & 0.000 & 0.000 & 0.000 & 2.000 & 1.525 & 0.600 & .561 & 1.497 & 328 & 100.000 \\
\hline & Ph1a. & 4.000 & 14.000 & 0.020 & 9.205 & 3.310 & 5.000 & 15.000 & \begin{tabular}{l|l|}
0.100 \\
\end{tabular} & 38.744 & 0.000 & 0.000 & 0.000 & 2.000 & 6.000 & 0.600 & 10 & 498 & 12 & $\overline{000}$ \\
\hline-09 & $\mathrm{Ph} 1 \mathrm{c}$ & 8.500 & 11.589 & 0.020 & 14.000 & 2.271 & 0.000 & 15.000 & 1.000 & 38.000 & 5.000 & 0.000 & 0.000 & 2.000 & 0.000 & 0.600 & 110 & .498 & 12 & 000 \\
\hline-10 & L09 & 8.500 & 14.000 & 0.020 & 8.000 & 6.000 & 0.000 & 10.513 & 0.100 & 38.000 & 2.797 & 0.000 & 0.000 & 2.000 & 6.000 & 0.600 & 1.560 & 1.318 & 592 & 100.000 \\
\hline $2-11$ & $\mathrm{~L} 10$ & 4.001 & 14.002 & 0.020 & 8.001 & 6.001 & 0.000 & 10.858 & 1.000 & 45.149 & 0.000 & 0.000 & 0.000 & 2.000 & 6.001 & 0.600 & 0.110 & 1.498 & 0.759 & 100.000 \\
\hline $2-12$ & $\mathrm{~J}$ & 3.999 & 4.999 & 199 & 11.382 & 5.998 & 4.999 & 12.757 & 1.000 & 41.402 & 0.000 & 0.000 & 0.000 & 1.999 & 5.998 & 0.600 & 2.010 & 1.317 & 1.340 & 100.000 \\
\hline HLW02-13 & Ph1a.OL12 & 3.999 & 4.999 & 0.199 & 13.998 & 5.999 & 4.999 & 10.425 & 0.100 & 43.114 & 4.999 & 0.000 & 0.000 & 2.000 & 1.182 & 0.600 & 0.561 & 1.317 & 1.508 & 100.000 \\
\hline HLW02-14 & Ph1a.OL13 & 4.001 & 5.001 & 020 & 8.001 & 6.001 & 2.490 & 4.141 & \begin{tabular}{|l|l|}
0.100 \\
\end{tabular} & 53.007 & 5.001 & 0.000 & 0.000 & 2.000 & 6.001 & 0.600 & 1.560 & 1.498 & 0.579 & 100.000 \\
\hline $2-15$ & Ph1a.OL14 & 8.499 & 13.998 & 0.199 & 13.998 & 2.000 & 4.688 & 12.539 & $\begin{array}{l}0.100 \\
\end{array}$ & 37.994 & 0.000 & 0.000 & 0.000 & 2.000 & 0.000 & 0.600 & 0.561 & 1.317 & 1.508 & 100.000 \\
\hline HLW02-16 & Ph1a.OL15 & 8.498 & 4.999 & 0.199 & 7.998 & 5.998 & 4.999 & 9.651 & 0.100 & 39.115 & 4.999 & 0.000 & 0.000 & 1.999 & 5.998 & 0.600 & 2.010 & 1.497 & 1.340 & 100.000 \\
\hline
\end{tabular}

(a) R1 after a Glass ID indicates the glass batching, melting, and testing was repeated.

(b) The "Point Type" notation begins with an abbreviation of the HLW study phase (e.g., Ph1a denotes Phase 1a). After a separating dot, the notation continues (when appropriate) with "Center", "OL", or "IL", denoting whether the glass was a center point, outer-layer point, or inner-layer point. The "Center", "OL", or "IL" designation is with respect to the given study phase. Next, "XX" denotes the number of each outer-layer, inner-layer, or other point with respect to the given study phase. Replicate points are denoted by "Rep.HLW02-xx" and "Rep.HLW03-xx", where the "xx" represents a specific ID number for a replicated glass.

(c) The wt\% values in the table are rounded to three decimal places and may not sum to 100.000 exactly, but the sum is achieved in the data base. 
Table A.2. 18-Component Target Glass Compositions (wt\%) for the 143 Existing Glasses Having Viscosity and Electrical Conductivity Data (continued).

\begin{tabular}{|c|c|c|c|c|c|c|c|c|c|c|c|c|c|c|c|c|c|c|c|c|}
\hline Glass ID $^{(\mathrm{a})}$ & Point Type $^{(\mathrm{b})}$ & $\mathbf{A l}_{2} \mathbf{O}_{3}$ & $\mathbf{B}_{2} \mathbf{O}_{3}$ & $\mathrm{Cr}_{2} \mathrm{O}_{3}$ & $\mathrm{Fe}_{2} \mathrm{O}_{3}$ & $\mathrm{Li}_{2} \mathbf{O}$ & MnO & $\mathrm{Na}_{2} \mathrm{O}$ & $\mathrm{NiO}$ & $\mathrm{SiO}_{2}$ & SrO & $\mathrm{ThO}_{2}$ & $\mathrm{UO}_{3}$ & $\mathrm{ZnO}$ & $\mathrm{ZrO}_{2}$ & \begin{tabular}{|l|} 
Others1 \\
\end{tabular} & \begin{tabular}{|l|} 
Others2 \\
\end{tabular} & Constant & Remain & Sum ${ }^{(c)}$ \\
\hline HLW02-17 & Ph1a.OL16 & 8.500 & 5.000 & 0.020 & $\mid 13.843$ & 6.000 & 0.000 & 7.690 & 0.100 & 52.958 & 0.000 & 0.000 & 0.000 & 2.000 & 0.000 & 0.600 & 1.560 & 1.318 & 0.412 & 100.000 \\
\hline HLW02-18 & Ph1a.OL17 & 3.999 & 4.999 & 0.199 & 11.126 & 2.013 & 0.000 & 14.996 & 1.000 & 49.852 & 0.000 & 0.000 & 0.000 & 1.999 & \begin{tabular}{|l|}
5.998 \\
\end{tabular} & 0.600 & 0.561 & 1.497 & 1.160 & 100.000 \\
\hline HLW02-19 & Ph1a.OL18 & 4.000 & 14.000 & 0.020 & 10.781 & 2.000 & 5.000 & 8.849 & 0.100 & 38.000 & 5.000 & 0.000 & 0.000 & 2.000 & 6.000 & 0.600 & 1.560 & 1.498 & 0.592 & 100.000 \\
\hline HLW02-20R1 & Phla.OL19 & 4.000 & 14.000 & 0.020 & \begin{tabular}{|l|}
14.000 \\
\end{tabular} & 2.000 & 0.000 & 6.453 & 0.100 & 51.734 & 3.253 & 0.000 & 0.000 & 2.000 & 0.000 & 0.600 & 0.110 & 1.318 & 0.412 & 100.000 \\
\hline HLW02-21 & Ph1a & 8.500 & 14.000 & 0.020 & 8.000 & 2.000 & 0.000 & 15.000 & 0.100 & 46.440 & 0.000 & 0.000 & 0.000 & 2.000 & 1.500 & 0.600 & 0.110 & 1.318 & .412 & 100.000 \\
\hline HLW02-22 & 21 & 500 & 14.000 & 0.020 & 9.500 & 6.000 & 0.000 & 4.000 & 0.100 & 53.000 & 0.080 & 0.000 & 0.000 & 2.000 & 0.000 & 0.600 & .110 & 1.498 & 592 & 100.000 \\
\hline $2-23 \mathrm{R} 1$ & Ph1a. & 501 & 14.002 & 0.020 & 8.001 & $\begin{array}{ll}6.001 \\
\end{array}$ & 5.001 & 5.591 & 1.000 & 39.325 & 5.001 & 0.000 & 0.000 & 2.000 & 1.500 & 0.600 & .560 & 1.318 & .579 & .000 \\
\hline HLW02-24 & Ph1a.OL23 & .498 & 4.999 & 0.153 & 7.998 & 2.000 & 999 & \begin{tabular}{|l|}
12.195 \\
\end{tabular} & 0.100 & 47.052 & 4.999 & 0.000 & 0.000 & 2.000 & 1.500 & 0.600 & .444 & 1.317 & .147 & 100.000 \\
\hline HLW02-25R1 & $\mathrm{Ph} 1$ & .501 & 14.002 & .020 & 9.501 & 2.000 & .355 & 6.884 & 0.100 & 47.398 & 5.001 & 0.000 & 0.000 & 2.000 & 0.000 & 0.600 & .560 & 1.498 & .579 & .000 \\
\hline HLW02-26 & $\mathrm{L} 25$ & 3.999 & 4.999 & 0.199 & \begin{tabular}{|l|}
12.498 \\
\end{tabular} & 2.000 & 4.959 & \begin{tabular}{|l|}
14.998 \\
\end{tabular} & 0.100 & 37.994 & 4.999 & 0.000 & 0.000 & 2.000 & 5.999 & 0.600 & 2.011 & 1.317 & 1.328 & 100.000 \\
\hline HLW02-27 & Ph1a.OL26 & 4.001 & 14.002 & 0.020 & 12.502 & 6.001 & 3.366 & 4.275 & 0.100 & 39.946 & 5.001 & 0.000 & 0.000 & 2.000 & 6.001 & 0.600 & 0.110 & 1.318 & 0.759 & 100.000 \\
\hline HLW02-28 & Ph1a.IL01 & 7.500 & 8.000 & 0.040 & 10.451 & 2.500 & 1.500 & 15.001 & 0.300 & 41.003 & 3.500 & 0.000 & 0.000 & 2.000 & 4.500 & 0.600 & 1.110 & 1.348 & 0.646 & 100.000 \\
\hline HLW02-29R1 & & 7.499 & 12.998 & 0.133 & 9.998 & 3.749 & 1.500 & 8.999 & 0.300 & 40.994 & 3.499 & 0.000 & 0.000 & 2.000 & \begin{tabular}{l|}
4.499 \\
\end{tabular} & 0.600 & 0.844 & 1.347 & 1.041 & 100.000 \\
\hline HLV & $\mathrm{Ph} 1$ & 5.500 & 9.721 & 0.040 & 10.000 & 5.000 & 3.500 & \begin{tabular}{|l|}
11.228 \\
\end{tabular} & 0.300 & 41.000 & 3.500 & 0.000 & 0.000 & 2.000 & 4.500 & 0.600 & 110 & 1.448 & 53 & 000 \\
\hline $\mathrm{HLV}$ & $\mathrm{Ph}$ & 5.500 & 13.001 & 0.040 & 10.001 & 2.500 & 1.500 & 14.982 & .300 & 41.003 & 1.500 & 0.000 & 0.000 & 2.000 & \begin{tabular}{l|}
4.369 \\
\end{tabular} & 0.600 & .610 & 1.348 & 746 & .000 \\
\hline $32 \mathrm{R} 1$ & $\mathrm{P}$ & 7.500 & 8.000 & 0.040 & 10.000 & 5.000 & 1.500 & 10.733 & 0.300 & 46.117 & 3.500 & 0.000 & 0.000 & 2.000 & 1.500 & 0.600 & 110 & 1.448 & .653 & 000 \\
\hline HLV & Ph1a. & 341 & 8.000 & 0.040 & \begin{tabular}{|l|}
12.000 \\
\end{tabular} & 2.500 & .500 & 15.000 & 0.800 & 41.000 & 3.500 & 0.000 & 0.000 & 2.000 & 2.009 & 0.600 & .610 & 1.448 & .653 & 100.000 \\
\hline HLW02-34R1 & Ph1a. & 5.499 & 12.998 & 0.133 & \begin{tabular}{|l|}
11.998 \\
\end{tabular} & 3.957 & 1.500 & 10.891 & 0.800 & 40.994 & 3.499 & 0.000 & 0.000 & 2.000 & 1.500 & 0.600 & .344 & 1.347 & .941 & 100.000 \\
\hline HLW02-35 & Ph1a.IL08 & 6.488 & 12.999 & 0.133 & \begin{tabular}{|l|}
11.999 \\
\end{tabular} & 5.000 & 3.500 & 9.160 & 0.800 & 40.996 & 1.500 & 0.000 & 0.000 & 2.000 & 1.500 & 0.600 & 0.844 & 1.448 & 1.034 & 100.000 \\
\hline HLW02-36 & Ph1a.IL09 & 5.499 & 8.667 & 0.133 & \begin{tabular}{|l|}
11.998 \\
\end{tabular} & 2.500 & 1.500 & \begin{tabular}{|l|}
14.998 \\
\end{tabular} & 0.300 & 45.074 & 1.500 & 0.000 & 0.000 & 2.000 & 1.500 & 0.600 & 1.344 & 1.347 & 1.041 & 100.000 \\
\hline HLW & $\mathrm{Ph} 1$ & 6.762 & 13.000 & 0.040 & 10.000 & 2.500 & 3.500 & 11.188 & 0.800 & 41.000 & 1.500 & 0.000 & 0.000 & 2.000 & 4.500 & 0.600 & 0.610 & 1.448 & .553 & 100.000 \\
\hline HLV & & 6.893 & 12.998 & 0.133 & \begin{tabular}{|l|}
11.998 \\
\end{tabular} & \begin{tabular}{l|}
4.255 \\
\end{tabular} & 1.500 & 8.999 & 0.800 & 40.994 & 3.499 & 0.000 & 0.000 & 2.000 & 1.500 & 0.600 & 344 & 1.447 & 041 & 0.000 \\
\hline & & 500 & 8.991 & 0.040 & \begin{tabular}{|l|}
10.000 \\
\end{tabular} & 2.500 & 1.500 & \begin{tabular}{|l|}
11.058 \\
\end{tabular} & 0.800 & 49.000 & 1.500 & 0.000 & 0.000 & 2.000 & 1.500 & 0.600 & 10 & 1.348 & 553 & 000 \\
\hline 40 & & 7.499 & 9.833 & .133 & 9.999 & 2.632 & 1.500 & 9.683 & .300 & 48.996 & 1.500 & 0.000 & 0.000 & 2.000 & 1.500 & 0.600 & 344 & 1.448 & 034 & 000 \\
\hline-41 & & 500 & 13.001 & .040 & 10.001 & 2.500 & 1.500 & 9.001 & .300 & 48.953 & 1.500 & 0.000 & 0.000 & 2.000 & 1.500 & 0.600 & .610 & 1.348 & 0.646 & 100.000 \\
\hline HLW & $\mathrm{Pl}$ & 5.500 & 13.001 & .040 & \begin{tabular}{|l|}
10.001 \\
\end{tabular} & 5.000 & 1.500 & 9.001 & 0.300 & 44.453 & 3.500 & 0.000 & 0.000 & 2.000 & 2.500 & 0.600 & 0.610 & 1.348 & 0.646 & 100.000 \\
\hline HLW02-43 & Ph1a.IL16 & 6.500 & 13.000 & 0.040 & \begin{tabular}{|l|}
10.000 \\
\end{tabular} & 2.500 & 3.500 & 12.450 & 0.300 & 41.000 & 3.500 & 0.000 & 0.000 & 2.000 & 1.500 & 0.600 & 1.110 & 1.448 & 0.553 & 100.000 \\
\hline HLW02-44 & Ph1a.IL17 & 5.499 & 9.069 & 0.133 & 9.998 & 2.500 & 3.499 & \begin{tabular}{|l|}
14.998 \\
\end{tabular} & 0.300 & 43.673 & 1.500 & 0.000 & 0.000 & 2.000 & 2.500 & 0.600 & 1.344 & 1.447 & 0.941 & 100.000 \\
\hline HLW02-45 & Ph1a.IL18 & 5.500 & 8.000 & 0.040 & 11.000 & 2.500 & 3.500 & 9.619 & 0.300 & 48.831 & 3.500 & 0.000 & 0.000 & 2.000 & 1.500 & 0.600 & 1.110 & 1.348 & 0.653 & 100.000 \\
\hline HLW02-46 & Ph1a.IL19 & 5.500 & 9.149 & 0.040 & 10.001 & 3.701 & 3.500 & 9.001 & 0.800 & 49.003 & 1.500 & 0.000 & 0.000 & 2.000 & 2.500 & 0.600 & 0.610 & 1.348 & 0.746 & 100.000 \\
\hline HLW02-47 & Ph1a.IL20 & 5.499 & 9.806 & 0.133 & 9.999 & 2.500 & 3.500 & 9.443 & 0.300 & 48.996 & 1.500 & 0.000 & 0.000 & 2.000 & 2.500 & 0.600 & 0.844 & 1.348 & 1.034 & 100.000 \\
\hline HLV & Ph1a.IL21 & 5.999 & 7.999 & 0.133 & 11.999 & 3.339 & 1.500 & 14.999 & 0.800 & 40.996 & 1.710 & 0.000 & 0.000 & 2.000 & 4.500 & 0.600 & 0.844 & 1.448 & 1.134 & 100.000 \\
\hline HLW02-49 & Ph1a.IL22 & 7.500 & 8.740 & 0.040 & 12.001 & 5.000 & 3.500 & 9.001 & 0.300 & 44.213 & 1.500 & 0.000 & 0.000 & 2.000 & 3.000 & 0.600 & 0.610 & 1.348 & 0.646 & 100.000 \\
\hline
\end{tabular}

(a) R1 after a Glass ID indicates the glass batching, melting, and testing was repeated.

(b) The "Point Type" notation begins with an abbreviation of the HLW study phase (e.g., Ph1a denotes Phase 1a). After a separating dot, the notation continues (when appropriate) with "Center", "OL", or "IL", denoting whether the glass was a center point, outer-layer point, or inner-layer point. The "Center", "OL", or "IL" designation is with respect to the given study phase. Next, "XX" denotes the number of each outer-layer, inner-layer, or other point with respect to the given study phase. Replicate points are denoted by "Rep.HLW02-xx" and "Rep.HLW03-xx", where the "xx" represents a specific ID number for a replicated glass.

(c) The wt\% values in the table are rounded to three decimal places and may not sum to 100.000 exactly, but the sum is achieved in the data base. 
Table A.2. 18-Component Target Glass Compositions (wt\%) for the 143 Existing Glasses Having Viscosity and Electrical Conductivity Data (continued).

\begin{tabular}{|c|c|c|c|c|c|c|c|c|c|c|c|c|c|c|c|c|c|c|c|c|}
\hline Glass ID $^{(\mathbf{a})}$ & oint Type ${ }^{(b)}$ & $\mathbf{A l}_{2} \mathbf{O}_{3}$ & $\mathbf{B}_{2} \mathbf{O}_{3}$ & $\mathrm{Cr}_{2} \mathrm{O}_{3}$ & $\mathrm{Fe}_{2} \mathbf{O}_{3}$ & $\mathbf{L i}_{2} \mathbf{O}$ & MnO & $\mathrm{Na}_{2} \mathrm{O}$ & $\mathrm{NiO}$ & $\mathrm{SiO}_{2}$ & SrO & $\mathrm{ThO}_{2}$ & $\mathrm{UO}_{3}$ & $\mathrm{ZnO}$ & $\mathrm{ZrO}_{2}$ & Others1 & Others2 & Constant & Remain & Sum ${ }^{(c)}$ \\
\hline HLW02-50 & h1a.IL23 & 6.000 & 13.001 & 0.040 & 12.001 & 2.500 & 1.500 & 9.821 & 0.300 & \begin{tabular}{|l|}
43.532 \\
\end{tabular} & 1.500 & 0.000 & 0.000 & 2.000 & 4.500 & 0.600 & 0.610 & 1.448 & 0.646 & 100.000 \\
\hline HLW02-51R1 & 11a.IL24 & 7.500 & 8.000 & 0.040 & 10.501 & 4.589 & 1.500 & 9.001 & 0.300 & 45.164 & 3.500 & 0.000 & 0.000 & 2.000 & 4.500 & 0.600 & 0.610 & 1.448 & 0.746 & 100.000 \\
\hline HLW02-52 & ep.HLW02-01 & 6.171 & 9.927 & 0.108 & 10.899 & 3.996 & 2.385 & 10.957 & 0.518 & 43.612 & 2.444 & 0.000 & 0.000 & 2.000 & 2.974 & 0.600 & 1.051 & 1.407 & 0.951 & 100.000 \\
\hline HLW02-53 & ep.HLW02-17 & 8.500 & 5.000 & 0.020 & 13.843 & 6.000 & 0.000 & 7.690 & 0.100 & 52.958 & 0.000 & 0.000 & 0.000 & 2.000 & 0.000 & 0.600 & 1.560 & 1.318 & 0.412 & 100.000 \\
\hline HLW02-54 & ep.HLW02-4 & 4.001 & 5.001 & 0.020 & 14.002 & 2.000 & 0.518 & 15.002 & 0.100 & 52.939 & 0.000 & 0.000 & 0.000 & 2.000 & 0.000 & 0.600 & 1.560 & 1.498 & 0.759 & 100.000 \\
\hline HLW02-55 & Rep.HLW02-42 & 5.500 & 13.001 & 0.040 & 10.001 & $\begin{array}{l}5.000 \\
\end{array}$ & 1.500 & 9.001 & 0.300 & 44.453 & 3.500 & 0.000 & 0.000 & 2.000 & 2.500 & 0.600 & 0.610 & 1.348 & 0.646 & 100.000 \\
\hline HLW02-56 & p.HLW02-44 & 5.499 & 9.069 & 0.133 & 9.998 & 2.500 & 3.499 & 14.998 & 0.300 & \begin{tabular}{|l|}
43.673 \\
\end{tabular} & 1.500 & 0.000 & 0.000 & 2.000 & 2.500 & 0.600 & 1.344 & 1.447 & 941 & 100.000 \\
\hline HLW02-57 & V02-8 & 4.000 & 14.000 & 0.020 & 9.205 & 3.310 & 5.000 & 15.000 & 0.100 & 38.744 & 0.000 & 0.000 & 0.000 & 2.000 & 6.000 & .600 & 0.110 & 1.498 & 412 & 100.000 \\
\hline HLW03-01 & $1 \mathrm{~b} . \mathrm{OL} 01$ & 8.335 & \begin{tabular}{|l|}
13.727 \\
\end{tabular} & 0.020 & 13.727 & $\begin{array}{ll}5.883 \\
\end{array}$ & 6.078 & 3.922 & 0.098 & \begin{tabular}{|l|}
35.299 \\
\end{tabular} & 0.000 & 2.764 & 0.000 & 3.059 & 2.983 & 0.600 & 0.560 & 1.318 & 629 & 100.000 \\
\hline HLW03-02 & $11 \mathrm{~b} . \mathrm{OL} 02$ & 1.951 & 13.662 & 0.488 & 13.662 & 2.473 & 6.832 & 11.177 & 0.976 & 35.132 & 0.000 & 0.000 & 0.000 & 0.000 & 9.088 & 0.600 & 1.660 & 1.598 & 0.700 & 100.000 \\
\hline HLW03-03 & Ph1b.OL03 & 1.953 & 4.884 & 0.488 & 13.677 & 2.678 & 6.839 & 10.755 & 0.977 & \begin{tabular}{|l|}
35.169 \\
\end{tabular} & 9.769 & 0.000 & 0.000 & 1.946 & 6.404 & 0.600 & 1.660 & 1.318 & 0.880 & 100.000 \\
\hline HLW03-04 & Ph1b.OL04 & 1.954 & 4.886 & 0.488 & 13.680 & \begin{tabular}{l|l|}
5.862 \\
\end{tabular} & 3.161 & 4.442 & 0.098 & 42.425 & 9.771 & 0.000 & 6.210 & 0.000 & 2.932 & 0.598 & 0.558 & 1.313 & 1.623 & 100.000 \\
\hline HLW03-05 & h1b.OL05 & 8.175 & 4.809 & 0.481 & 1.924 & 1.924 & 6.733 & 14.427 & 0.096 & \begin{tabular}{|l|}
47.837 \\
\end{tabular} & 0.000 & 3.812 & 0.000 & 3.847 & 0.000 & 0.600 & 2.110 & 1.598 & 1.629 & 100.000 \\
\hline HLI & & 8.344 & 4.908 & 0.491 & 1.963 & 5.890 & 6.872 & 3.927 & 0.982 & \begin{tabular}{|l|}
52.031 \\
\end{tabular} & 5.091 & 1.416 & 0.000 & 0.000 & 4.095 & 0.600 & 1.660 & 1.318 & 412 & 100.000 \\
\hline HLV & & 4.961 & 4.961 & 0.496 & 13.891 & 4.750 & 6.945 & 11.693 & 0.100 & 39.825 & 0.000 & 0.000 & 6.306 & 3.461 & 0.000 & 0.598 & 0.110 & 1.313 & 590 & 100.000 \\
\hline HLI & OL08 & 8.031 & 4.833 & 0.483 & 1.933 & 5.151 & 6.766 & 14.499 & 0.097 & 34.797 & 0.000 & 4.412 & 0.000 & 3.866 & 9.666 & 0.600 & 2.109 & 1.597 & 161 & 100.000 \\
\hline HLW03-09 & 1b.OL09 & 7.668 & 13.695 & 0.020 & 3.486 & 1.979 & 0.000 & 14.848 & 0.099 & \begin{tabular}{|l|}
52.465 \\
\end{tabular} & 0.000 & 2.552 & 0.000 & 0.000 & 0.000 & 0.600 & 0.110 & 1.598 & 0.880 & 100.000 \\
\hline HLW03-10R & 210 & 8.369 & 4.924 & 0.020 & 9.982 & 5.908 & 6.893 & 12.851 & 0.985 & 35.449 & 0.000 & 2.626 & 1.108 & 0.000 & 7.250 & 0.599 & 0.559 & 1.316 & 1.160 & 100.000 \\
\hline HLW03-11 & 1b.OL11 & 1.984 & 4.961 & 0.020 & 9.538 & 1.984 & 0.000 & 14.883 & 0.100 & 52.586 & 0.000 & 5.027 & 6.306 & 0.000 & 0.000 & 0.598 & 0.110 & 1.313 & 0.590 & 100.000 \\
\hline HLW03-12 & Ph1b.OL12 & 1.982 & 4.956 & 0.495 & 1.982 & 5.008 & 6.939 & 3.965 & 0.099 & \begin{tabular}{|l|}
44.277 \\
\end{tabular} & 9.912 & 3.729 & 6.299 & 3.965 & 3.682 & 0.598 & 0.110 & 1.592 & 0.410 & 100.000 \\
\hline HLW03-13 & Ph1b.OL13 & 8.433 & 4.961 & 0.496 & 8.633 & 5.209 & 6.945 & 3.969 & 0.992 & 35.719 & 9.922 & 3.836 & 6.306 & 1.121 & 0.846 & 0.598 & 0.110 & 1.313 & 0.590 & 100.000 \\
\hline $\mathrm{HL}$ & & 1.989 & 4.973 & 0.020 & 9.047 & 2.504 & 6.962 & 10.425 & 0.994 & 35.806 & 9.946 & 4.115 & 0.000 & 3.979 & 6.511 & 0.600 & 0.110 & 1.318 & 700 & 100.000 \\
\hline HLW03-15 & 15 & 1.951 & 13.662 & 0.020 & 13.662 & 1.951 & 1.348 & 5.248 & 0.098 & 51.722 & 0.000 & 2.441 & 0.000 & 3.337 & 0.000 & 0.600 & 1.660 & 1.598 & 700 & 100.000 \\
\hline HLV & & 1.955 & 4.886 & 0.020 & 7.905 & 2.862 & 6.840 & 3.909 & 0.977 & 44.240 & 9.772 & 2.568 & 6.210 & 2.772 & 1.001 & 0.598 & 0.558 & 1.592 & 336 & 100.000 \\
\hline $3-17$ & Ph1b & 8.352 & 13.757 & 0.020 & 1.965 & 1.965 & 6.879 & 4.461 & 0.293 & 46.088 & 0.000 & 2.237 & 4.784 & 3.930 & 1.639 & 0.598 & 0.558 & 1.314 & 158 & 100.000 \\
\hline HLW03-18 & Ph1b.OL18 & 1.989 & 4.973 & 0.497 & 13.924 & 5.922 & 0.000 & 10.533 & 0.980 & \begin{tabular}{|l|}
52.484 \\
\end{tabular} & 0.000 & 5.967 & 0.000 & 0.000 & 0.000 & 0.600 & 0.110 & 1.318 & 0.700 & 100.000 \\
\hline HLW03-19 & Ph1b.OL19 & 1.963 & 4.908 & 0.491 & 9.634 & 5.890 & 0.197 & 10.142 & 0.982 & 52.030 & 0.000 & 5.846 & 0.000 & 3.927 & 0.000 & 0.600 & 1.660 & 1.318 & 0.412 & 100.000 \\
\hline HLW03-20 & Ph1b.OL20 & 1.923 & 4.808 & 0.019 & 13.462 & 5.769 & 0.000 & 10.097 & 0.962 & \begin{tabular}{|l|}
50.681 \\
\end{tabular} & 0.145 & 5.769 & 0.430 & 0.000 & 0.000 & 0.600 & 2.109 & 1.597 & 1.629 & 100.000 \\
\hline HLW03-21 & Ph1b.IL01 & 4.958 & 6.941 & 0.079 & 4.958 & 2.479 & 4.462 & 10.828 & 0.298 & 48.587 & 1.487 & 2.975 & 2.100 & 0.992 & 5.949 & 0.599 & 0.410 & 1.346 & 0.552 & 100.000 \\
\hline HLW03-22 & Ph1b.IL02 & 4.915 & 6.881 & 0.079 & 9.752 & 2.458 & 1.474 & 11.797 & 0.295 & 40.304 & 4.424 & 2.949 & 4.165 & 0.983 & 5.898 & 0.599 & 0.643 & 1.344 & 1.041 & 100.000 \\
\hline HLW03-23 & Ph1b.IL03 & 4.957 & 11.897 & 0.199 & 7.733 & 2.478 & 1.487 & 11.897 & 0.297 & 40.648 & 1.487 & 2.974 & 4.201 & 0.992 & 5.949 & 0.599 & 0.210 & 1.345 & 0.651 & 100.000 \\
\hline HLW03-24 & Ph1b.IL04 & 2.975 & 6.941 & 0.079 & 4.958 & 4.958 & 4.462 & 8.151 & 0.495 & 48.588 & 1.487 & 2.975 & 2.100 & 2.975 & 5.949 & 0.599 & 0.410 & 1.346 & 0.552 & 100.000 \\
\hline HLW03-25 & Ph1b.IL05 & 2.956 & 11.823 & 0.079 & 4.927 & 2.463 & 1.478 & 11.823 & 0.492 & 42.090 & 4.433 & 2.956 & 2.087 & 2.956 & 5.912 & 0.599 & 0.444 & 1.346 & 1.135 & 100.000 \\
\hline
\end{tabular}

(a) R1 after a Glass ID indicates the glass batching, melting, and testing was repeated.

(b) The "Point Type" notation begins with an abbreviation of the HLW study phase (e.g., Ph1a denotes Phase 1a). After a separating dot, the notation continues (when appropriate) with "Center", "OL", or "IL", denoting whether the glass was a center point, outer-layer point, or inner-layer point. The "Center", "OL", or "IL" designation is with respect to the given study phase. Next, "XX" denotes the number of each outer-layer, inner-layer, or other point with respect to the given study phase. Replicate points are denoted by "Rep.HLW02-xx" and "Rep.HLW03-xx", where the "xx" represents a specific ID number for a replicated glass.

(c) The wt\% values in the table are rounded to three decimal places and may not sum to 100.000 exactly, but the sum is achieved in the data base. 
Table A.2. 18-Component Target Glass Compositions (wt\%) for the 143 Existing Glasses Having Viscosity and Electrical Conductivity Data (continued).

\begin{tabular}{|c|c|c|c|c|c|c|c|c|c|c|c|c|c|c|c|c|c|c|c|c|}
\hline Glass ID $^{(\mathbf{a})}$ & oint Type ${ }^{(b)}$ & $\mathbf{A l}_{2} \mathbf{O}_{3}$ & $\mathbf{B}_{2} \mathbf{O}_{3}$ & $\mathrm{Cr}_{2} \mathrm{O}_{3}$ & $\mathbf{F e}_{2} \mathbf{O}_{3}$ & $\mathbf{L i}_{2} \mathbf{O}$ & MnO & $\mathrm{Na}_{2} \mathrm{O}$ & $\mathrm{NiO}$ & $\mathrm{SiO}_{2}$ & SrO & $\mathrm{ThO}_{2}$ & $\mathrm{UO}_{3}$ & $\mathrm{ZnO}$ & $\mathrm{ZrO}_{2}$ & Others1 & Others2 & Constant & Remain & Sum ${ }^{(c)}$ \\
\hline HLW03-26 & Ph1b.IL06 & 4.921 & 6.889 & 0.197 & 4.921 & 4.921 & 1.476 & 10.431 & 0.492 & 40.345 & 4.428 & 4.428 & 4.169 & 2.953 & 5.904 & 0.598 & 0.443 & 1.444 & 1.041 & 100.000 \\
\hline HLW03-27 & h1b.IL07 & 926 & 6.897 & 0.197 & 9.359 & 4.040 & 1.478 & 11.822 & 0.492 & 0.393 & 1.478 & 4.433 & 2.087 & 2.956 & 5.911 & 0.599 & .444 & 1.446 & 1.042 & 100.000 \\
\hline HLW03-28 & 1b.IL08 & 629 & 11.911 & 0.080 & 9.926 & 4.963 & 1.489 & 10.486 & 0.496 & 40.695 & 1.489 & 2.977 & 2.103 & 0.993 & 5.956 & 0.599 & .210 & 1.446 & 0.552 & 100.000 \\
\hline HLW03-29 & 11b.IL09 & 2.971 & 6.933 & 0.199 & 4.952 & 4.952 & 3.518 & 11.885 & 0.297 & 40.606 & 1.485 & 4.456 & $\begin{array}{l}4.196 \\
\end{array}$ & 2.971 & 7.674 & 0.599 & 0.409 & 1.345 & 0.552 & 100.000 \\
\hline HLW03-30 & 11b.IL10 & 2.972 & 11.888 & 0.079 & 4.953 & 4.953 & 4.458 & 6.934 & 0.298 & 43.203 & 1.486 & 4.458 & 2.098 & 0.991 & 8.229 & 0.599 & 0.210 & 1.446 & 0.745 & 100.000 \\
\hline HLW03-31 & .IL11 & 4.953 & 6.934 & 0.198 & 4.953 & 4.953 & 4.458 & 8.533 & 0.495 & 45.058 & 1.486 & 2.972 & 2.098 & 0.991 & 8.915 & 0.599 & 0.210 & 1.446 & 745 & 00.000 \\
\hline HLW03-32 & & 4.921 & 6.889 & 0.079 & 4.921 & 4.921 & 2.925 & 9.101 & 0.492 & 40.348 & 1.476 & 4.428 & 4.170 & 2.953 & 8.857 & .599 & 444 & 1.444 & 34 & 100.000 \\
\hline-33 & & 960 & 11.902 & 199 & 9.919 & 3.898 & 488 & 943 & 0.451 & 40.667 & 1.488 & 2.975 & 3.378 & 2.975 & 5.952 & 99 & 210 & .445 & 52 & 100.000 \\
\hline-34 & 14 & 2.956 & 6.897 & 197 & 9.853 & 2.463 & 478 & 541 & 0.492 & 8.278 & 1.478 & 3.858 & 2.087 & 0.986 & 5.912 & 599 & 444 & .346 & 35 & .000 \\
\hline-35 & 15 & 963 & 10.397 & .080 & 4.963 & 2.481 & .467 & 948 & 0.496 & 48.639 & 1.489 & 3.176 & 2.103 & 1.039 & 5.956 & .599 & 210 & 1.346 & 545 & .000 \\
\hline HLW03-36 & 16 & 921 & 6.889 & .197 & 9.507 & 2.692 & 1.476 & 7.961 & 0.492 & 8.226 & 1.476 & 3.558 & 2.085 & 0.984 & 5.905 & .599 & 644 & 1.446 & .942 & 100.000 \\
\hline HLW03-37 & Ph1b.IL17 & 2.953 & 11.809 & 0.079 & 7.222 & 4.859 & 1.476 & 6.889 & 0.492 & 40.348 & 1.476 & 4.428 & 4.170 & 2.953 & 7.325 & 0.599 & .444 & 1.344 & 1.134 & 100.000 \\
\hline HLW03-38 & 18 & 4.915 & 6.881 & 0.197 & 9.831 & 2.458 & 1.474 & 9.618 & 0.295 & 43.156 & 1.474 & 3.875 & 4.165 & 0.983 & 7.051 & 0.599 & .643 & 1.344 & 1.041 & 100.000 \\
\hline HLW03-39 & & 2.946 & 6.875 & 0.197 & 8.502 & 4.850 & 1.473 & 6.875 & 0.295 & 48.128 & 1.473 & 4.420 & 2.081 & 0.982 & 7.078 & 0.599 & .644 & 1.446 & 1.135 & 100.000 \\
\hline-40 & & 4.941 & 6.919 & 0.079 & 9.390 & 4.881 & 1.483 & 6.919 & 0.494 & 42.959 & 3.279 & 4.448 & $\begin{array}{ll}4.188 \\
\end{array}$ & 0.989 & 5.930 & 0.599 & 409 & 1.444 & 651 & 100.000 \\
\hline-41 & & 3.888 & 8.732 & 140 & 6.939 & 3.710 & 698 & 093 & 0.395 & 43.059 & 2.705 & 3.658 & 3.032 & 1.920 & 6.767 & 0.599 & 427 & .395 & 343 & 000 \\
\hline-42 & 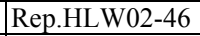 & 5.500 & 9.150 & 0.040 & \begin{tabular}{|l|}
10.001 \\
\end{tabular} & 3.701 & 3.500 & .001 & 0.800 & 49.004 & 1.500 & \begin{tabular}{|c|}
0.000 \\
\end{tabular} & 0.000 & 1.999 & 2.500 & 0.600 & 610 & 1.348 & 746 & 000 \\
\hline-43 & U & 8.344 & 4.908 & 0.491 & 1.963 & 5.890 & 6.872 & 3.927 & 0.982 & 52.031 & 5.091 & 1.416 & 0.000 & 0.000 & 4.095 & 0.600 & .660 & 1.318 & .412 & 100.000 \\
\hline $3-44$ & epHLW03-11 & 1.984 & 4.961 & 0.020 & 9.538 & 1.984 & 0.000 & 14.883 & 0.100 & 52.586 & 0.000 & 5.027 & 6.306 & 0.000 & 0.000 & 0.598 & .110 & 1.313 & .590 & 100.000 \\
\hline HLW03-45 & ep.HLW03-26 & 4.921 & 6.889 & 0.197 & 4.921 & 4.921 & 1.476 & 10.431 & 0.492 & 40.345 & 4.428 & 4.428 & 4.169 & 2.953 & 5.904 & 0.598 & .443 & 1.444 & 1.041 & 100.000 \\
\hline HLW04-01 & .01 & 4.780 & 11.259 & 0.210 & 13.089 & 2.810 & 2.050 & 12.249 & 0.380 & 48.505 & 0.200 & 0.000 & 0.000 & 1.980 & 0.000 & 0.470 & .520 & 1.220 & 0.280 & 100.000 \\
\hline HLW-ALG-01 & g.01 & 11.086 & 10.560 & 0.501 & 9.619 & 3.329 & 0.000 & 17.280 & 0.000 & 45.286 & 0.000 & 0.000 & 0.000 & 1.062 & 0.000 & 0.148 & .202 & 0.666 & .261 & 100.000 \\
\hline HLW-ALG-02 & $\lg .02$ & 8.001 & 11.088 & 0.278 & 7.145 & 3.550 & 0.000 & 15.318 & 0.522 & 44.674 & 0.000 & 0.000 & 0.000 & 1.577 & 6.495 & 0.156 & 0.214 & 0.705 & .276 & 100.000 \\
\hline HLW-ALG-03 & A & 1.926 & 8.621 & 0.501 & 12.650 & 3.057 & 2.095 & 18.966 & 1.001 & 44.365 & 0.000 & 0.000 & 0.000 & 0.032 & 5.433 & 0.152 & 0.207 & 0.683 & 310 & 100.000 \\
\hline LG-04 & & 1.926 & 11.134 & 0.501 & 12.639 & 2.876 & 0.000 & 15.980 & 1.001 & 51.881 & 0.000 & 0.000 & 0.000 & 1.226 & 0.000 & 0.100 & 0.135 & 0.408 & 92 & $\overline{000}$ \\
\hline LG-05 & & 1.927 & 4.810 & 0.415 & 12.536 & 4.286 & 6.906 & 8.937 & 0.781 & 46.197 & 9.891 & 0.000 & 0.000 & 0.050 & 0.000 & 0.231 & 1.518 & 1.079 & 0.437 & 000 \\
\hline LG-06 & & 9.670 & 4.807 & 0.201 & 10.620 & 2.530 & 4.007 & 15.635 & 0.481 & 37.279 & 8.015 & 1.603 & 0.601 & 0.055 & 0.801 & 0.257 & 1.705 & 1.251 & 0.481 & 100.000 \\
\hline HLW-ALG-07 & 7 & 8.194 & 10.704 & 0.000 & 1.928 & 3.258 & 2.339 & 11.777 & 0.000 & 44.110 & 4.113 & 4.126 & 0.000 & 1.675 & 6.262 & 0.179 & 0.239 & 0.786 & 0.310 & 100.000 \\
\hline HLW-ALG-08 & $\mathrm{\sigma} 08$ & 1.926 & 4.807 & .471 & 7.318 & 2.081 & 3.560 & 13.943 & 0.887 & 36.699 & 6.267 & 4.006 & 4.644 & 0.056 & 9.541 & 0.261 & 1.739 & 1.277 & 0.517 & 100.000 \\
\hline HLW-ALG-09 & g.09 & 5.480 & 4.808 & 0.211 & 13.931 & 1.987 & 3.916 & 15.116 & 0.189 & 38.868 & 7.479 & 0.603 & 1.360 & 0.059 & 2.565 & 0.433 & 0.495 & 1.579 & 0.923 & 100.000 \\
\hline HLW-ALG-10 & $\lg .1$ & 1.926 & 9.448 & 0.501 & 10.984 & 2.020 & 7.010 & 17.410 & 1.001 & 47.112 & 0.000 & 0.228 & 0.000 & 0.031 & 0.159 & 0.147 & 1.056 & 0.668 & 0.298 & 100.000 \\
\hline HLW-ALG-11 & Alg.11 & 11.886 & 12.188 & 0.000 & 1.928 & 6.013 & 3.408 & 6.065 & 0.000 & 35.076 & 5.994 & 6.013 & 0.000 & 0.054 & 9.125 & 0.258 & 0.348 & 1.197 & 0.448 & 100.000 \\
\hline HLW-ALG-12 & Alg.12 & 5.938 & 4.807 & 0.285 & 12.540 & 2.750 & 2.029 & 15.899 & 0.812 & 40.350 & 6.087 & 1.623 & 1.623 & 0.056 & 2.394 & 0.260 & 0.793 & 1.267 & 0.488 & 100.000 \\
\hline
\end{tabular}

(a) R1 after a Glass ID indicates the glass batching, melting, and testing was repeated.

(b) The "Point Type" notation begins with an abbreviation of the HLW study phase (e.g., Phla denotes Phase 1a). After a separating dot, the notation continues (when appropriate) with "Center", "OL", or "IL", denoting whether the glass was a center point, outer-layer point, or inner-layer point. The "Center", "OL", or "IL" designation is with respect to the given study phase. Next, "XX" denotes the number of each outer-layer, inner-layer, or other point with respect to the given study phase. Replicate points are denoted by "Rep.HLW02-xx" and "Rep.HLW03-xx", where the "xx" represents a specific ID number for a replicated glass.

(c) The wt\% values in the table are rounded to three decimal places and may not sum to 100.000 exactly, but the sum is achieved in the data base. 


\section{Table A.2. 18-Component Target Glass Compositions (wt\%) for the 143 Existing Glasses Having Viscosity and Electrical} Conductivity Data (continued).

\begin{tabular}{|c|c|c|c|c|c|c|c|c|c|c|c|c|c|c|c|c|c|c|c|c|}
\hline Glass ID $^{(\mathrm{a})}$ & Point Type $^{(\mathrm{b})}$ & $\mathrm{Al}_{2} \mathbf{O}_{3}$ & $\mathbf{B}_{2} \mathbf{O}_{3}$ & $\mathrm{Cr}_{2} \mathrm{O}_{3}$ & $\mathrm{Fe}_{2} \mathrm{O}_{3}$ & $\mathrm{Li}_{2} \mathrm{O}$ & MnO & $\mathrm{Na}_{2} \mathrm{O}$ & $\mathrm{NiO}$ & $\mathrm{SiO}_{2}$ & SrO & $\mathrm{ThO}_{2}$ & $\mathrm{UO}_{3}$ & $\mathrm{ZnO}$ & $\mathrm{ZrO}_{2}$ & Others1 & Others2 & \begin{tabular}{|l|} 
Constant \\
\end{tabular} & Remain & Sum ${ }^{(\mathrm{c})}$ \\
\hline \begin{tabular}{|l} 
HLW-ALG-13 \\
\end{tabular} & Alg.13 & 6.166 & 4.808 & 0.000 & 7.216 & 3.354 & 3.063 & 9.504 & 0.061 & 35.058 & 6.125 & 5.513 & 6.125 & 0.084 & 9.188 & 0.388 & 0.645 & 1.938 & 0.763 & 100.000 \\
\hline HLW-ALG-14 & Alg.14 & 3.543 & 4.809 & 0.000 & 12.562 & 6.012 & 6.715 & 4.804 & 0.759 & 47.605 & 9.618 & 0.000 & 0.000 & 0.048 & 0.000 & 0.225 & 1.798 & 1.050 & 0.453 & 100.000 \\
\hline HLW-ALG-15 & Alg.15 & 9.731 & 14.029 & 0.338 & 9.780 & 1.928 & 0.000 & 17.583 & 0.636 & 37.449 & 0.000 & 0.000 & 0.000 & 0.040 & 6.845 & 0.188 & 0.261 & 0.857 & 0.335 & 100.000 \\
\hline \begin{tabular}{|l} 
HLW-ALG-16 \\
\end{tabular} & Alg.16 & 10.329 & 13.850 & 0.501 & 4.396 & 2.021 & 0.000 & \begin{tabular}{|l|}
17.406 \\
\end{tabular} & 0.751 & 43.773 & 0.000 & 0.000 & 0.000 & 1.786 & 3.757 & 0.162 & 0.248 & 0.733 & 0.287 & 100.000 \\
\hline HLW-ALG-17 & Alg.17 & 1.926 & 10.338 & 0.501 & 12.515 & 2.020 & 6.912 & 17.414 & 0.997 & 45.869 & 0.000 & 0.000 & 0.000 & 0.031 & 0.159 & 0.146 & 0.202 & 0.665 & 0.303 & 100.000 \\
\hline \begin{tabular}{|l|} 
HLW-ALG-18 \\
\end{tabular} & Alg.18 & 11.360 & 11.109 & 0.000 & 10.369 & 3.437 & 0.000 & \begin{tabular}{|l|}
14.807 \\
\end{tabular} & 0.000 & 45.993 & 0.000 & 0.000 & 0.000 & 1.616 & 0.000 & 0.151 & 0.207 & 0.682 & 0.268 & 100.000 \\
\hline HLW-ALG-19 & Alg.19 & 1.926 & 9.652 & 0.501 & 12.652 & 2.659 & 2.096 & 16.131 & 1.001 & 46.563 & 0.000 & 0.000 & 0.000 & 0.032 & 5.434 & 0.151 & 0.207 & 0.683 & 0.311 & 100.000 \\
\hline HLW-ALG-20 & Alg.20 & 1.926 & 7.754 & 0.501 & 12.651 & 2.926 & 2.095 & 17.400 & 1.001 & 46.929 & 0.000 & 0.000 & 0.000 & 0.032 & 5.434 & 0.151 & 0.207 & 0.683 & 0.311 & 100.000 \\
\hline HLW-ALG-21 & Alg. 21 & 2.619 & 4.810 & 0.493 & 9.663 & 2.475 & 1.186 & 17.623 & 0.542 & 38.986 & 0.000 & 5.894 & 4.502 & 0.084 & 8.915 & 0.240 & 0.345 & 1.193 & 0.431 & 100.000 \\
\hline HLW-ALG-22 & Alg.22 & 2.588 & 6.599 & 0.487 & 9.548 & 2.407 & 1.172 & 16.615 & 0.535 & 38.701 & 0.000 & 5.824 & 4.449 & 0.083 & 8.809 & 0.237 & 0.341 & 1.179 & 0.426 & 100.000 \\
\hline HLW-ALG-23 & Alg.23 & 2.492 & 4.809 & 0.469 & 9.180 & 2.069 & 1.127 & 19.298 & 0.515 & 39.517 & 0.000 & 5.599 & 4.278 & 0.079 & 8.469 & 0.228 & 0.327 & 1.134 & 0.410 & 100.000 \\
\hline
\end{tabular}

(a) R1 after a Glass ID indicates the glass batching, melting, and testing was repeated.

(b) The "Point Type" notation begins with an abbreviation of the HLW study phase (e.g., Phla denotes Phase 1a). After a separating dot, the notation continues (when appropriate) with "Center", "OL", or "IL", denoting whether the glass was a center point, outer-layer point, or inner-layer point. The "Center", "OL", or "IL" designation is with respect to the given study phase. Next, "XX" denotes the number of each outer-layer, inner-layer, or other point with respect to the given study phase. Replicate points are denoted by "Rep.HLW02-xx" and "Rep.HLW03-xx", where the "xx" represents a specific ID number for a replicated glass.

(c) The wt\% values in the table are rounded to three decimal places and may not sum to 100.000 exactly, but the sum is achieved in the data base. 
Table A.3. Composition Expansions of Others1, Others2, and Constant Components for the 143 Existing Glasses in Table A.2 Having Viscosity and Electrical Conductivity Data.

\begin{tabular}{|c|c|c|c|c|c|c|c|c|c|c|c|c|c|c|c|c|c|c|c|c|c|c|}
\hline \multirow[t]{2}{*}{ Glass ID $^{(\mathbf{a})}$} & \multicolumn{3}{|c|}{\begin{tabular}{|c|}
$\begin{array}{c}\text { Others1 Components } \\
\text { (wt\%) }\end{array}$ \\
\end{tabular}} & \multicolumn{4}{|c|}{$\begin{array}{c}\text { Others2 Components } \\
(\mathrm{wt} \%)^{(\mathrm{b})}\end{array}$} & \multicolumn{15}{|c|}{ Constant Components (wt\%) ${ }^{(\mathbf{b})}$} \\
\hline & $\mathrm{MoO}_{3}$ & $\mathbf{P}_{2} \mathbf{O}_{5}$ & $\mathrm{SO}_{3}$ & CdO & $\mathrm{CoO}$ & $\mathrm{CuO}$ & PbO & $\mathbf{a O}$ & $\mathrm{Ce}_{2} \mathrm{O}_{3}$ & $\mathbf{C l}$ & $\mathrm{Cs}_{2} \mathrm{O}$ & $F$ & $\mathrm{~K}_{2} \mathrm{O}$ & $\mathrm{La}_{2} \mathbf{O}_{3}$ & $\mathbf{P r}_{2} \mathbf{O}_{3}$ & $\mathbf{R} \mathbf{b}_{2} \mathbf{O}$ & $\mathbf{R h}_{2} \mathbf{O}_{3}$ & $\mathrm{RuO}_{2}$ & $\mathrm{Sb}_{2} \mathbf{O}_{3}$ & $\mathrm{SnO}_{2}$ & $\mathbf{W O}_{3}$ & $\mathbf{Y}_{2} \mathbf{O}_{3}$ \\
\hline $98-72$ & .000 & 0.000 & 0.074 & 0.064 & 0.000 & 0.036 & 0.036 & 0.278 & 0.000 & 0.000 & 0.008 & 0.036 & 0.06 & 0.406 & 0.000 & 0.000 & 0.000 & 0.000 & 0.000 & 0.000 & 0.000 & 0.000 \\
\hline-77 & 00 & 000 & .075 & 064 & 0.000 & 030 & 0.034 & 280 & $\begin{array}{l}0.000 \\
\end{array}$ & 0.000 & 0.000 & 0.037 & 0.033 & 0.407 & 0.000 & 0.000 & 0.000 & 0.000 & 0.000 & 0.000 & 0.000 & .000 \\
\hline HLW98-80 & 000 & .024 & .041 & .114 & 0.000 & 0.000 & 0.070 & 0.233 & \begin{tabular}{|l|}
0.000 \\
\end{tabular} & 0.000 & 0.000 & 0.000 & 0.032 & 0.376 & 0.000 & 0.000 & 0.000 & 0.000 & 0.000 & 0.000 & 0.000 & 0.000 \\
\hline HLW98-83 & 000 & 0.099 & .000 & .000 & 0.000 & 0.047 & 0.252 & 0.668 & 0.000 & 0.139 & 0.000 & 0.000 & 0.000 & 0.249 & 0.000 & 0.000 & 0.000 & 0.000 & 0.108 & 0.000 & 0.000 & 0.000 \\
\hline \begin{tabular}{|l} 
HLW98-84 \\
\end{tabular} & of & t & 000 & 000 & 0.000 & & 252 & 668 & .000 & 139 & 0.000 & 0.000 & 0.000 & .249 & 0.000 & 0.000 & 0.000 & 0.000 & .108 & 0.000 & 0.000 & 0.000 \\
\hline HLW & & if & 00 & 0 & & & 140 & & 000 & 110 & & .000 & & & 00 & & 00 & 000 & & & 000 & 000 \\
\hline 88 & 00 & 7 & 080 & 4 & 000 & & 075 & 429 & 242 & 028 & 00 & 0.000 & 0.696 & 269 & 000 & 00 & 25 & 78 & 000 & 000 & 000 & .00 \\
\hline HLV & 000 & 03 & 000 & 000 & 000 & 28 & 115 & 152 & 000 & 000 & 00 & .111 & .000 & 49 & .000 & 000 & .000 & 000 & .000 & .000 & 000 & .0 \\
\hline HLV & 0 & 0 & 119 & 642 & 000 & 20 & 074 & 425 & 238 & 056 & 00 & .016 & 0.136 & 64 & .000 & .000 & .024 & .077 & 0.000 & .000 & 0.000 & 00 \\
\hline HLV & ot & 0406 & 000 & 000 & 0.000 & 020 & .110 & 449 & 000 & 000 & & 0.110 & 0.000 & 150 & 0.000 & 0.000 & 0.000 & 000 & 0.000 & 0.000 & 000 & 000 \\
\hline$-96 \mathrm{~A}$ & 000 & 0.040 & 0.000 & 0.000 & 0.000 & 0030 & 0.120 & 0.460 & .710 & 0.000 & 0.000 & 0.110 & 0.000 & 0.150 & 0.000 & 0.000 & 0.000 & .000 & 0.000 & 0.000 & 0.000 & 0.000 \\
\hline HLW98-96B & .000 & 0.040 & 0.000 & 0.000 & 0.000 & 0.030 & 0.120 & 0.460 & 0.000 & 0.000 & 0.000 & 0.110 & 0.000 & 0.150 & 0.000 & 0.000 & 0.000 & 0.000 & 0.000 & 0.000 & 0.000 & 0.000 \\
\hline HLW98-96D & & & 0.000 & 0.000 & 0.000 & & 0.120 & 0.480 & .000 & 0.000 & 0.000 & 0.120 & 0.000 & 160 & 0.000 & 0.000 & 0.000 & 0.000 & 0.000 & 0.000 & 0.000 & 0.000 \\
\hline HL & & & & & & & & & & & & 040 & 30 & & 50 & 00 & 00 & 00 & 00 & 00 & 000 & 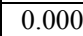 \\
\hline HL & & & 000 & j & a & & 70 & 50 & 0 & 30 & & 0.000 & .000 & & 00 & 00 & 00 & 00 & 300 & 00 & 000 & $\overline{00}$ \\
\hline 4 & 0 & 0 & 000 & 000 & 0.000 & & 20 & 40 & 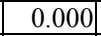 & .090 & 0 & 0.000 & 0.000 & 90 & .000 & 000 & .000 & 000 & .210 & 000 & 0.000 & $\overline{0.0 c}$ \\
\hline HLV & 00 & 060 & 020 & 060 & 000 & 02 & 160 & 450 & 000 & .070 & 000 & 0.000 & 0.020 & 310 & .000 & .000 & .000 & .000 & 0.050 & .000 & 0.000 & 0.00 \\
\hline $\mathrm{HLI}$ & & & 100 & 71 & 010 & & It & 00 & & 200 & 10 & 0.050 & .060 & 00 & 000 & 000 & 050 & .080 & 0.110 & .000 & 0.000 & $\overline{0.000}$ \\
\hline HLW02-02 & 0.000 & 0.500 & 0.100 & 1.500 & 0.010 & 0.100 & 0.400 & 0.500 & 0.048 & 0.200 & 0.010 & 0.050 & 0.060 & 0.300 & 0.000 & 0.000 & 0.050 & 0.080 & 0.200 & 0.000 & 0.000 & 0.000 \\
\hline HLW02-03 & 000 & 0.500 & 0.100 & 1.500 & 0.010 & 0.100 & 0.400 & 0.500 & 0.048 & 0.200 & 0.010 & 0.050 & 0.060 & 0.300 & 0.000 & 0.000 & 0.050 & 0.080 & 0.020 & 0.000 & 0.000 & 0.000 \\
\hline HLW & 000 & 0.500 & 0.100 & 1.500 & 0.010 & 0.010 & 0.040 & 0.500 & 0.048 & 0.200 & 0.010 & 0.050 & 0.060 & 0.300 & 0.000 & 0.000 & 0.050 & 0.080 & 0.200 & 0.000 & 0.000 & 0.000 \\
\hline HLV & & 0.500 & 0.100 & 0.050 & 0.010 & 0.010 & 0.040 & 0.500 & .048 & 0.200 & .010 & 0.050 & 0.060 & .300 & 0.000 & 0.000 & 0.050 & .080 & 0.020 & .000 & 0.000 & 0.000 \\
\hline $\mathrm{HLV}$ & & & 0.100 & 1.500 & 010 ( & & 0.040 & 500 & 048 & 200 & & 0.050 & 0.060 & 300 & 000 & 000 & 050 & 080 & 020 & 000 & 000 & 0.000 \\
\hline & & & 01 & & & & of & & & & & & 60 & & & 00 & & & & & 0.000 & \\
\hline & 00 & & 0 & 050 & 10 & & 40 & 0 & 0.0 & 00 & & 0.050 & 0.060 & 00 & 000 & 000 & 050 & 080 & .200 & .000 & 0.000 & 0.0 \\
\hline HLV & & & 100 & 050 & 10 & & 40 & 00 & & 00 & 10 & 0.050 & 0.060 & 300 & 000 & 0.000 & .050 & .080 & 0.200 & 0.000 & 0.000 & 0.000 \\
\hline $\mathrm{HLV}$ & U & & 100 & 500 & 10 & & 040 & 500 & 48 & 200 & 010 & .050 & .060 & 300 & 000 & 000 & 050 & 080 & .020 & .000 & 0.000 & 0.000 \\
\hline HLW02-11 & 0.000 & 0.500 & 0.100 & 0.050 & 0.010 & 0.010 & 0.040 & 500 & 0.048 & 0.200 & 0.010 & 0.050 & 0.060 & 0.300 & 0.000 & 0.000 & 0.050 & 0.080 & 0.200 & 0.000 & 0.000 & 0.000 \\
\hline HLW02-12 & 0.000 & 0.500 & 0.100 & 1.500 & 0.010 & 0.100 & 0.400 & 0.500 & 0.048 & 0.200 & 0.010 & 0.050 & 0.060 & 0.300 & 0.000 & 0.000 & 0.050 & 0.080 & 0.020 & 0.000 & 0.000 & 0.000 \\
\hline HLW02-13 & 0.000 & 0.500 & 0.100 & 0.050 & 0.010 & 0.100 & 0.400 & 0.500 & 0.048 & .200 & 0.010 & 0.050 & 0.060 & 0.300 & 0.000 & 0.000 & 0.050 & 080 & 0.020 & 0.000 & 0.000 & 0.000 \\
\hline HLW & 0.000 & 0.500 & 0.100 & 1.500 & 0.010 & 0.010 & 0.040 & 500 & 0.048 & .200 & 0.010 & 0.050 & 0.060 & 0.300 & 0.000 & 0.000 & 0.050 & .080 & 0.200 & 0.000 & 0.000 & 0.000 \\
\hline $\mathrm{HLV}$ & 0.000 & 0.500 & 0.100 & 0.050 & 0.010 & & 0.400 & 0.500 & 0.048 & 0.200 & 0.010 & 0.050 & 0.060 & 0.300 & 0.000 & 0.000 & 0.050 & 0.080 & 0.020 & 0.000 & 0.000 & 0.000 \\
\hline HLW02-16 & 0.000 & 0.500 & 0.100 & 1.500 & 0.010 & 0.100 & 0.400 & 0.500 & 0.048 & 0.200 & 0.010 & 0.050 & 0.060 & 0.300 & 0.000 & 0.000 & .050 & .080 & 0.200 & 0.000 & 0.000 & 0.000 \\
\hline
\end{tabular}

(a) R1 after a Glass ID indicates the glass batching, melting, and testing was repeated.

(b) For each glass, the sum of the wt\% values for the components comprising Others1, Others 2 , and Constant equal the wt $\%$ values listed in the Others1, Others 2 , and Constant columns of Table A.2, except for any differences resulting from rounding wt $\%$ values to three decimal places. The equalities are exact to the additional decimal places contained in the data base. 
Table A.3. Composition Expansions of Others1, Others2, and Constant Components for the 143 Existing Glasses in Table A.2 Having Viscosity and Electrical Conductivity Data (continued).

\begin{tabular}{|c|c|c|c|c|c|c|c|c|c|c|c|c|c|c|c|c|c|c|c|c|c|c|}
\hline \multirow[t]{2}{*}{ Glass ID $^{(a)}$} & \multicolumn{3}{|c|}{\begin{tabular}{|c|}
$\begin{array}{c}\text { Others1 Components } \\
(\mathrm{wt} \%)^{(\mathbf{b})}\end{array}$ \\
\end{tabular}} & \multicolumn{4}{|c|}{$\begin{array}{c}\text { Others2 Components } \\
\text { (wt\%) }\end{array}$} & \multicolumn{15}{|c|}{ Constant Components (wt \%) $)^{(b)}$} \\
\hline & $\mathrm{MoO}_{3}$ & $\mathbf{P}_{2} \mathbf{O}_{5}$ & $\mathrm{SO}_{3}$ & dO & $\mathrm{CoO}$ & $\mathrm{CuO}$ & PbO & $\mathrm{CaO}$ & $\mathrm{Ce}_{2} \mathrm{O}_{3}$ & $\mathrm{Cl}$ & $\mathrm{Cs}_{2} \mathrm{O}$ & $\mathbf{F}$ & $\mathrm{K}_{2} \mathrm{O}$ & $\mathbf{L a}_{2} \mathbf{O}_{3}$ & \begin{tabular}{|l|}
$\mathrm{Pr}_{2} \mathbf{O}_{3}$ \\
\end{tabular} & $\mathbf{R b}_{2} \mathbf{O}$ & $\mathbf{R \mathbf { h } _ { 2 } \mathbf { O } _ { 3 }}$ & $\mathrm{RuO}_{2}$ & \begin{tabular}{|l|}
$\mathrm{Sb}_{2} \mathrm{O}_{3}$ \\
\end{tabular} & $\mathrm{SnO}_{2}$ & $\mathbf{W O}_{3}$ & $\mathbf{Y}_{2} \mathbf{O}_{3}$ \\
\hline W02-17 & .000 & 500 & & 1.500 & 010 ( & .010 & 0.040 & 0.500 & 0.048 & .200 & 0.010 & 0.050 & 0.060 & 0.300 & 0.000 & 0.000 & 0.050 & 0.080 & 0.020 & 0.000 & 0.000 & \\
\hline & & & & & & & & 500 & 048 & 200 & 010 & 050 & 060 & 300 & 000 & 000 & 050 & 080 & 200 & 000 & 000 & 0000 \\
\hline & & & & 00 & & & 40 & 500 & 048 & 200 & 10 & 050 & 060 & 300 & 000 & .000 & 050 & .080 & 200 & 000 & 000 & 0.00 \\
\hline HLV & 00 & 0 & 100 & & & & & & & & & & & & & & & & & & 000 & \\
\hline HLW & 000 & 500 & 100 & 0.050 & .010 & 0.010 & 0.040 & 0.500 & 0.048 & 0.200 & $\begin{array}{l}0.010 \\
\end{array}$ & 0.050 & 0.060 & 0.300 & 0.000 & 0.000 & 0.050 & 0.080 & 0.020 & .000 & .000 & 0.000 \\
\hline HLW0 & 000 & 0.500 & 0.100 & 0.050 & 0.010 & 0.010 & 0.040 & 0.500 & 0.048 & 0.200 & 0.010 & 0.050 & 0.060 & 0.300 & 0.000 & 0.000 & 0.050 & 0.080 & 0.200 & .000 & .000 & 0.000 \\
\hline HLW0 & 000 & 0 & 00 & 1.500 & t & & 0.040 & 0.500 & 0.048 & 0.200 & 0.010 & 0.050 & 0.060 & 300 & 0.000 & 0.000 & .050 & .080 & .020 & .000 & .000 & 0.000 \\
\hline HLI & & & & & & & & & & 200 & & 0.050 & 0.060 & & 00 & & 050 & 080 & 020 & 00 & 000 & 0.000 \\
\hline & & & & & & & 40 & 00 & & 200 & & 0.050 & 0.060 & & 00 & & & 080 & 200 & & 000 & 0.00 \\
\hline $\mathrm{HI}$ & & & & & & & 0 & 00 & .0 & 200 & & 0.050 & 0.060 & 300 & 00 & 000 & 050 & 080 & 020 & & 000 & 0.00 \\
\hline $\mathrm{HI}$ & & & 50 & 050 & & & .040 & 500 & .04 & 200 & 10 & 0.050 & 0.060 & 300 & 000 & 00 & .050 & .080 & .020 & & & 0.000 \\
\hline & & & & 000 & & & (2) & 500 & & 2004 & & 0.050 & 0.060 & 00 & 00 & .000 & 050 & .080 & .050 & & 000 & 0.000 \\
\hline HLV & 00 & 500 & 100 & 0.500 & 0. & & 0.267 & 0.500 & 0.048 & 0.200 & & 0.050 & 0.060 & 300 & 0.000 & 0.000 & .050 & .080 & .050 & 000 & .000 & 0.000 \\
\hline HLV & 000 & 0.500 & 100 & .000 & 00100 & 00206 & 0.080 & 0.500 & 0.048 & 0.200 & & 0.050 & 0.060 & 0.300 & 0.000 & 0.000 & .050 & .080 & .150 & .000 & .000 & 0.000 \\
\hline HLW & & 00 & 00 & .500 & 10 & & 0.080 & 0.500 & 0.048 & 0.200 & 0.010 & 0.050 & 0.060 & 0.300 & 0.000 & 0.000 & 0.050 & 0.080 & .050 & .000 & .000 & 0.000 \\
\hline HLV & & & & 000 & & & 0.080 & 500 & & 0.200 & & 0.050 & 0.060 & 300 & 000 & 000 & 050 & 080 & & & 000 & 0.000 \\
\hline & & & & & & & & 00 & & & & & 60 & & & & & 80 & & & 000 & 0.000 \\
\hline & & & & 0 & & & 67 & 500 & 00 & .200 & & 0.050 & .060 & 00 & 00 & 00 & & 080 & 50 & & 000 & 0.000 \\
\hline HL & & & & 500 & & & 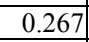 & 500 & $\overline{00}$ & 200 & ) & 0.050 & 060 & 300 & 000 & .000 & .050 & .080 & .150 & 00 & .000 & 0.000 \\
\hline HL & & & & 000 & & & ( & 500 & 0.0 & 200 & at & 0.050 & 0.060 & 300 & 000 & .000 & .050 & .080 & .050 & 000 & 0.000 & 0.000 \\
\hline $\mathrm{HLV}$ & & & & 500 & & & 0.080 & 0.500 & \begin{tabular}{|l|l|}
0.048 \\
\end{tabular} & 0.200 & & 0.050 & 0.060 & 300 & 0.000 & 0.000 & .050 & 0.080 & .150 & 000 & 0.000 & 0.000 \\
\hline HLWO & 000 & 0.500 & 0.100 & 1.000 & 0.010 & 0.067 & 0.267 & 0.500 & 0.048 & 0.200 & 0.010 & 0.050 & 0.060 & 0.300 & 0.000 & 0.000 & 0.050 & 0.080 & 0.150 & .000 & 0.000 & 0.000 \\
\hline HLW & 000 & 0.500 & 0.100 & 1.000 & 0.010 & & 0.080 & 0.500 & 0.048 & 0.200 & 0.010 & 0.050 & 0.060 & 0.300 & 0.000 & 0.000 & 0.050 & 0.080 & .050 & .000 & 0.000 & 0.000 \\
\hline HLV & & & & 1.000 & & & 0.267 & .500 & 0.048 & 0.200 & & 0.050 & 0.060 & 0.300 & 0.000 & 0.000 & .050 & .080 & 150 & 00 & .000 & 0.000 \\
\hline & & & & 00 & & & & 500 & & 200 & & 0.050 & 0.060 & 300 & 000 & 000 & 050 & 80 & .050 & & .000 & 0.000 \\
\hline & & & & & & & & 500 & & .200 & & 0.050 & 0.060 & 00 & & & & 80 & & & .000 & 0.000 \\
\hline & & & & & & & & 500 & & 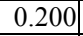 & & 0.050 & 060 & & 00 & 00 & & 80 & & & 000 & 0.00 \\
\hline & & & 0 & 000 & & & 267 & 500 & & .200 & a & 0.050 & 0.060 & 300 & .000 & .000 & 050 & .080 & .150 & 000 & 0.000 & 0.000 \\
\hline $\mathrm{HLV}$ & & & & & & & .080 & 500 & 0.0 & 0.200 & & & 0.060 & & & 0.000 & .050 & .080 & .050 & .000 & 0.000 & 0.000 \\
\hline HLW & 000 & 0.500 & 100 & 500 & 0.010 & 0020 & 0.080 & 0.500 & 0.048 & 0.200 & 0.010 & 0.050 & 0.060 & 0.300 & 0.000 & 0.000 & .050 & 0.080 & .050 & .000 & 0.000 & 0.000 \\
\hline HLW0 & 0.000 & 0.500 & 0.100 & 0.500 & 0.010 & 0.067 & 0.267 & 0.500 & 0.048 & 0.200 & 0.010 & 0.050 & 0.060 & 0.300 & 0.000 & 0.000 & 0.050 & 0.080 & 0.050 & .000 & 0.000 & 0.000 \\
\hline HLW & 0.000 & 0.500 & 0.100 & 0.500 & 0.010 & .067 & 0.267 & 0.500 & 0.048 & 0.200 & 0.010 & 0.050 & 0.060 & 0.300 & 0.000 & 0.000 & 0.050 & 0.080 & 0.150 & .000 & 0.000 & 0.000 \\
\hline HLW02-49 & 0.000 & 0.500 & 0.100 & 0.500 & 0.010 & 0.020 & 0.080 & 0.500 & 0.048 & 0.200 & 0.010 & 0.050 & 0.060 & 0.300 & \begin{tabular}{l|l}
0.000 \\
\end{tabular} & 0.000 & 0.050 & 0.080 & 0.050 & 0.000 & 0.000 & 0.000 \\
\hline
\end{tabular}

(a) R1 after a Glass ID indicates the glass batching, melting, and testing was repeated.

(b) For each glass, the sum of the $\mathrm{wt} \%$ values for the components comprising Others 1 , Others 2 , and Constant equal the wt $\%$ values listed in the Others 1 , Others 2 , and Constant columns of Table A.2, except for any differences resulting from rounding wt $\%$ values to three decimal places. The equalities are exact to the additional decimal places contained in the data base. 
Table A.3. Composition Expansions of Others1, Others2, and Constant Components for the 143 Existing Glasses in Table A.2 Having Viscosity and Electrical Conductivity Data (continued).

\begin{tabular}{|c|c|c|c|c|c|c|c|c|c|c|c|c|c|c|c|c|c|c|c|c|c|c|}
\hline \multirow[t]{2}{*}{ Glass ID $^{(\mathbf{a})}$} & \multicolumn{3}{|c|}{$\begin{array}{c}\text { Others1 Components } \\
\text { (wt \%) }^{(\mathbf{b})}\end{array}$} & \multicolumn{4}{|c|}{$\begin{array}{c}\text { Others2 Components } \\
(\mathrm{wt} \%)^{(\mathrm{b})}\end{array}$} & \multicolumn{15}{|c|}{ Constant Components (wt\%) ${ }^{(\mathbf{b})}$} \\
\hline & $\mathrm{MoO}_{3}$ & $\mathbf{P}_{2} \mathbf{O}_{5}$ & $\mathrm{SO}_{3}$ & dO & $\mathrm{CoO}$ & $\mathrm{CuO}$ & PbO & $\mathrm{aO}$ & $\mathrm{Ce}_{2} \mathrm{O}_{3}$ & $\mathbf{C l}$ & $\mathrm{Cs}_{2} \mathrm{O}$ & $F$ & $\mathbf{K}_{2} \mathbf{O}$ & $\mathrm{La}_{2} \mathbf{O}_{3}$ & $\mathbf{P r}_{2} \mathbf{O}_{3}$ & $\mathbf{R} \mathbf{b}_{2} \mathbf{O}$ & $\mathbf{R h}_{2} \mathbf{O}_{3}$ & $\mathrm{RuO}_{2}$ & $\mathrm{Sb}_{2} \mathbf{O}_{3}$ & $\mathrm{SnO}_{2}$ & $\mathbf{W O}_{3}$ & $\mathbf{Y}_{2} \mathbf{O}_{3}$ \\
\hline $02-50$ & .000 & 0.500 & 0.100 & 0.500 & 0.010 & 0.020 & 0.080 & 0.500 & 0.048 & 0.200 & 0.010 & 0.050 & 0.060 & 0.300 & 0.000 & 0.000 & 0.050 & 0.080 & 0.150 & 0.000 & 0.000 & 0.000 \\
\hline -51R1 & 000 & 500 & 100 & 500 & 010 & 020 & 0.080 & 500 & \begin{tabular}{|l|}
0.048 \\
\end{tabular} & 0.200 & 0.010 & 0.050 & 0.060 & 0.300 & 0.000 & 0.000 & 0.050 & 0.080 & 0.150 & 0.000 & 0.000 & .000 \\
\hline ALW02-52 & 000 & .500 & .100 & .771 & 0.010 & 0.054 & 0.216 & 0.500 & \begin{tabular}{|l|}
0.048 \\
\end{tabular} & 0.200 & 0.010 & 0.050 & 0.060 & 0.300 & 0.000 & 0.000 & 0.050 & 0.080 & 0.110 & 0.000 & 0.000 & 0.000 \\
\hline HLW02-53 & 000 & 0.500 & .100 & 1.500 & 0.010 & 0.010 & 0.040 & 0.500 & \begin{tabular}{|l|}
0.048 \\
\end{tabular} & 0.200 & 0.010 & 0.050 & 0.060 & 0.300 & 0.000 & 0.000 & 0.050 & 0.080 & 0.020 & 0.000 & 0.000 & 0.000 \\
\hline HLW02-54 & of & $500 t$ & 100 & 500 & t & & 0.040 & 500 & \begin{tabular}{|l|}
0.048 \\
\end{tabular} & 200 & 0.010 & 0.050 & 0.060 & .300 & 0.000 & 0.000 & 0.050 & 0.080 & 0.200 & 0.000 & 0.000 & 0.000 \\
\hline$\overline{L V}$ & & & 100 & (20 & & & 080 & 00 & \begin{tabular}{|l|}
0.048 \\
\end{tabular} & 200 & & .050 & 0.060 & & 00 & & 50 & & & & 000 & 000 \\
\hline 56 & 0 & t & 100 & 000 & 0 (1 & & 267 & 500 & .048 & 200 & & 0.050 & 0.060 & 00 & 000 & 00 & 050 & 80 & 150 & 000 & 000 & .00 \\
\hline $\mathrm{HLV}$ & 0 & 500 & 100 & 050 & D10 & 它 & 040 & 500 & .048 & 200 & & .050 & 0.060 & 300 & .000 & 000 & .050 & 080 & 200 & .000 & 0.000 & .0 \\
\hline HL & 0 & t & 100 & 050 & 010 & & 400 & 500 & & 200 & & .050 & 0.060 & 300 & .000 & .000 & .050 & .080 & .020 & .000 & 0.000 & 00 \\
\hline HLV & ot & 500 & 100 & 600 & 0.010 & 01 & .040 & 500 & & 200 & 0 & 0.050 & 0.060 & 00 & 00 & 0.000 & 050 & 080 & 0.300 & 0.000 & 000 & 000 \\
\hline HLV & 000 & .500 & 100 & 1.600 & 0.010 & 0.010 & 0.040 & 500 & 048 & 0.200 & 0.010 & 0.050 & 0.060 & 0.300 & 0.000 & 0.000 & .050 & .080 & 0.020 & 0.000 & 0.000 & 0.000 \\
\hline HLW03-04 & 000 & 0.498 & $\begin{array}{l}0.100 \\
\end{array}$ & 0.050 & 0.010 & 0.100 & 0.399 & 0.498 & 0.048 & 0.199 & 0.010 & 0.050 & 0.060 & 0.299 & 0.000 & 0.000 & 0.050 & 0.080 & 0.020 & 0.000 & 0.000 & 0.000 \\
\hline HLW03-05 & & 0500 & 0.100 & 1.600 & & & 0.400 & 0.500 & 048 & 200 & .010 & 0.050 & 0.060 & .300 & 0.000 & 0.000 & 0.050 & 0.080 & 0.300 & 0.000 & 0.000 & .000 \\
\hline $\mathrm{HLI}$ & & & & & & & 40 & & & 00 & & 0.050 & 0.060 & & & 00 & 50 & 80 & 20 & 00 & 000 & 000 \\
\hline HL & & 8 & 100 & 050 & & & 0.040 & 498 & 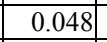 & 199 & & 0.050 & 0.060 & 99 & 00 & 00 & 550 & 80 & 20 & 00 & 000 & .00 \\
\hline 8 & T & 500 & 100 & 600 & 0 & & 400 & 500 & 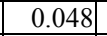 & 200 & 0 & 0.050 & 0.060 & 00 & .000 & 000 & 050 & .080 & 300 & 000 & 0.000 & 0.00 \\
\hline HLV & 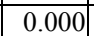 & 00 & 100 & 050 & 010 & 010 & .040 & 500 & + & 200 & 0 & 0.050 & 0.060 & 300 & .000 & .000 & .050 & 0.080 & 0.300 & .000 & 0.000 & 0.00 \\
\hline$\overline{\mathrm{HLI}}$ & & 些 & 100 & 550 & & & 400 & 500 & & 200 & 10 & 0.050 & 0.060 & 00 & 000 & 000 & .050 & 0.080 & 0.020 & .000 & 0.000 & $\overline{0.000}$ \\
\hline HLW03-11 & 0.000 & 0.498 & 0.100 & 0.050 & 0.010 & 0.010 & 0.040 & 0.498 & 0.048 & 0.199 & 0.010 & 0.050 & 0.060 & 0.299 & 0.000 & 0.000 & 0.050 & 0.080 & 0.020 & 0.000 & 0.000 & 0.000 \\
\hline HLW03-12 & 000 & 0.498 & 0.100 & 0.050 & 0.010 & 0.010 & 0.040 & 0.498 & 0.048 & 0.199 & 0.010 & 0.050 & 0.060 & 0.299 & 0.000 & 0.000 & 0.050 & 0.080 & 0.299 & 0.000 & 0.000 & 0.000 \\
\hline HLWC & 000 & .498 & 0.100 & 0.050 & 0.010 & 0.010 & 0.040 & 0.498 & 0.048 & 0.199 & 0.010 & 0.050 & 0.060 & 0.299 & 0.000 & 0.000 & 0.050 & 0.080 & 0.020 & 0.000 & 0.000 & 0.000 \\
\hline HLV & & .500 & 0.100 & 0.050 & 0.010 & 0.010 & 0.040 & 0.500 & .048 & 0.200 & .010 & 0.050 & 0.060 & 300 & 0.000 & 0.000 & 0.050 & 0.080 & 0.020 & .000 & 0.000 & 0.000 \\
\hline $\mathrm{HLV}$ & & 5006 & 0.100 & 1.600 & 0.010 & & 0.040 & 500 & & 200 & & 0.050 & 0.060 & 300 & 000 & 000 & 050 & 080 & 300 & 00 & 000 & 0.000 \\
\hline & & & & & & & 80 & 98 & & 20 & & & 0.060 & & & 00 & & & & & 000 & \\
\hline & 00 & & 0 & 050 & 0.010 & & 399 & 499 & & 99 & & 0.050 & 0.060 & 99 & 000 & 000 & 050 & 080 & .020 & .000 & 0.000 & 0.00 \\
\hline HLV & & & 100 & 050 & & & 040 & 300 & & 200 & 10 & 0.050 & 0.060 & 300 & 0.000 & 0.000 & .050 & .080 & .020 & 0.000 & 0.000 & 0.000 \\
\hline $\mathrm{HLV}$ & U & 00 & 100 & 500 & 10 & 10 & 040 & 500 & & 200 & 010 & 0.050 & 0.060 & 300 & 000 & 000 & 050 & .080 & .020 & .000 & 0.000 & 0.000 \\
\hline HLW03-20 & 0.000 & 0.500 & 0.100 & 1.600 & 0.010 & 0.100 & 0.400 & 0.500 & 048 & .200 & 0.010 & 0.050 & 0.060 & 0.300 & 0.000 & 0.000 & 0.050 & 0.080 & 0.300 & 0.000 & 0.000 & 0.000 \\
\hline HLW03-21 & 0.000 & 0.499 & 0.100 & 0.300 & 0.010 & 0.020 & 0.080 & 0.499 & 0.048 & 0.200 & 0.010 & 0.050 & 0.060 & 0.300 & 0.000 & 0.000 & 0.050 & 0.080 & 0.050 & 0.000 & 0.000 & 0.000 \\
\hline HLWC & 0.000 & 0.499 & 0.100 & 0.299 & 0.010 & 0.067 & 0.267 & 0.499 & .048 & .200 & 0.010 & 0.050 & 0.060 & 0.299 & 0.000 & 0.000 & 0.050 & 0.080 & 0.050 & 0.000 & 0.000 & 0.000 \\
\hline HLW03-23 & 0.000 & 0.499 & 0.100 & 0.100 & 0.010 & 0.020 & 0.080 & 0.499 & 0.048 & .200 & 0.010 & 0.050 & 0.060 & 0.299 & 0.000 & 0.000 & 0.050 & 0.080 & 0.050 & 0.000 & 0.000 & 0.000 \\
\hline HLW03-24 & 000 & 0.499 & 0.100 & 0.300 & 0.010 & 0.020 & 0.080 & 0.499 & 0.048 & 0.200 & 0.010 & 0.050 & 0.060 & 0.300 & 0.000 & 0.000 & 0.050 & 0.080 & 0.050 & 0.000 & 0.000 & 0.000 \\
\hline HLW03-25 & 0.000 & 0.499 & 0.100 & 0.100 & 0.010 & 0.067 & 0.267 & 0.499 & 0.048 & 0.200 & 0.010 & 0.050 & 0.060 & 0.300 & 0.000 & 0.000 & .050 & 0.080 & 0.050 & 0.000 & 0.000 & 0.000 \\
\hline
\end{tabular}

(a) R1 after a Glass ID indicates the glass batching, melting, and testing was repeated.

(b) For each glass, the sum of the $\mathrm{wt} \%$ values for the components comprising Others 1 , Others 2 , and Constant equal the wt $\%$ values listed in the Others 1 , Others 2 , and Constant columns of Table A.2, except for any differences resulting from rounding wt $\%$ values to three decimal places. The equalities are exact to the additional decimal places contained in the data base. 
Table A.3. Composition Expansions of Others1, Others2, and Constant Components for the 143 Existing Glasses in Table A.2 Having Viscosity and Electrical Conductivity Data (continued).

\begin{tabular}{|c|c|c|c|c|c|c|c|c|c|c|c|c|c|c|c|c|c|c|c|c|c|c|}
\hline \multirow[t]{2}{*}{ Glass ID $^{(\mathbf{a})}$} & \multicolumn{3}{|c|}{\begin{tabular}{|c|}
$\begin{array}{c}\text { Others1 Components } \\
(\mathrm{wt} \%)^{(\mathbf{b})}\end{array}$ \\
\end{tabular}} & \multicolumn{4}{|c|}{$\begin{array}{c}\text { Others2 Components } \\
(\mathrm{wt} \%)^{(\mathrm{b})}\end{array}$} & \multicolumn{15}{|c|}{ Constant Components (wt\%) ${ }^{(\mathbf{b})}$} \\
\hline & $\mathrm{MoO}_{3}$ & $\mathbf{P}_{2} \mathbf{O}_{5}$ & $\mathrm{SO}_{3}$ & dO & $\mathrm{CoO}$ & $\mathrm{CuO}$ & PbO & $\mathbf{a O}$ & $\mathrm{Ce}_{2} \mathrm{O}_{3}$ & $\mathbf{C l}$ & $\mathrm{Cs}_{2} \mathrm{O}$ & $\mathbf{F}$ & $\mathrm{K}_{2} \mathrm{O}$ & $\mathrm{La}_{2} \mathbf{O}_{3}$ & $\mathbf{P r}_{2} \mathbf{O}_{3}$ & $\mathbf{R} \mathbf{b}_{2} \mathbf{O}$ & $\mathbf{R h}_{2} \mathbf{O}_{3}$ & $\mathrm{RuO}_{2}$ & $\mathrm{Sb}_{2} \mathbf{O}_{3}$ & $\mathrm{SnO}_{2}$ & $\mathbf{W O}_{3}$ & $\mathbf{Y}_{2} \mathbf{O}_{3}$ \\
\hline $3-26$ & .000 & 0.499 & 0.100 & 0.100 & 0.010 & 0.067 & 0.267 & 0.499 & 0.048 & 0.199 & 0.010 & 0.050 & 0.060 & 0.299 & 0.000 & 0.000 & 0.050 & 0.080 & 0.150 & 0.000 & 0.000 & 0.000 \\
\hline 27 & 000 & .499 & 0.100 & 100 & 0.010 & 067 & 0.267 & 0.499 & 0.048 & 0.200 & 0.010 & 0.050 & 0.060 & 0.300 & 0.000 & 0.000 & 0.050 & 0.080 & 0.150 & 0.000 & 0.000 & .000 \\
\hline HLW03-28 & 000 & .499 & .100 & .100 & 0.010 & 0.020 & 0.080 & 0.499 & 0.048 & 0.200 & 0.010 & 0.050 & 0.060 & 0.300 & 0.000 & 0.000 & 0.050 & 0.080 & 0.150 & 0.000 & 0.000 & 0.000 \\
\hline HLW03-29 & 000 & .499 & .100 & 299 & 0.010 & 0.020 & 0.080 & 0.499 & 0.048 & 0.200 & 0.010 & 0.050 & 0.060 & 0.299 & 0.000 & 0.000 & 0.050 & 0.080 & 0.050 & 0.000 & 0.000 & 0.000 \\
\hline ILW03-30 & tot & 些 & 100 & 100 & & & 080 & 499 & 0.048 & 200 & .010 & .050 & 0.060 & 300 & 0.000 & 0.000 & 0.050 & 0.080 & 150 & .000 & 0.000 & 0.000 \\
\hline 1 & & & 0 & & & & 080 & 499 & 048 & 200 & & .050 & 060 & & & & & & & & 000 & 000 \\
\hline 32 & & t & 0 & 0 & & & 267 & 499 & 048 & 200 & & 0.050 & 0.060 & 99 & 000 & 00 & 050 & 80 & 150 & 000 & 000 & .00 \\
\hline $\mathrm{HLV}$ & 0 & 7 & 0 & 10 & 010 & 021 & 080 & 499 & 048 & 200 & & .050 & 0.060 & 299 & .000 & 000 & .050 & .080 & 150 & .000 & .000 & .00 \\
\hline & & & 100 & & & & 267 & 99 & & 200 & & .050 & .060 & 300 & .000 & .000 & .050 & .080 & .050 & .000 & 0.000 & 00 \\
\hline $\mathrm{HL}$ & t & 0 & 100 & in & & & 080 & & & 200 & 0 & 0.050 & 0.060 & 300 & 00 & 0.000 & 050 & 080 & 0.050 & 0.000 & 000 & 000 \\
\hline HLV & 000 & 0,499 & .100 & .300 & 0.010 & 0.067 & 0.267 & 0.499 & .048 & 0.200 & 0.010 & 0.050 & 0.060 & 0.300 & 0.000 & 0.000 & .050 & .080 & 0.150 & 0.000 & 0.000 & 0.000 \\
\hline HLW03-37 & 000 & 0.499 & 0.100 & 0.100 & 0.010 & 0.067 & 0.267 & 0.499 & 0.048 & 0.200 & 0.010 & 0.050 & 0.060 & 0.299 & 0.000 & 0.000 & 0.050 & 0.080 & .050 & 0.000 & 0.000 & 0.000 \\
\hline HLW0 & & & 0.100 & & & & 0.267 & 499 & & 200 & .010 & 0.050 & 0.060 & 299 & 0.000 & 0.000 & 0.050 & 0.080 & .050 & .000 & 0.000 & .000 \\
\hline $\mathrm{HI}$ & & & & & & & 267 & & & & & 0.050 & 0.060 & & & & 50 & 80 & & 00 & 000 & 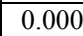 \\
\hline 0 & & & 0 & 7 & & & .080 & 9 & 0.0 & 00 & & 0.050 & 0.060 & 99 & 00 & 00 & 50 & 80 & 50 & 00 & 000 & $\overline{00}$ \\
\hline $\mathrm{HLV}$ & T & 0 & 0 & 200 & 0.0 & 0.043 & 174 & 9 & 0.04 & 200 & 0 & 0.050 & 0.060 & 299 & .000 & 000 & 050 & .080 & 100 & 000 & 0.000 & $\overline{0.00}$ \\
\hline HLV & 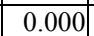 & 0 & 0 & 500 & 0.010 & .020 & .080 & 500 & 048 & 200 & 0 & 0.050 & 0.060 & 300 & .000 & .000 & .050 & 0.080 & .050 & .000 & 0.000 & 0.00 \\
\hline $\mathrm{HLI}$ & & & s & 600 & & & 040 & 0 & & 200 & & 0.050 & 0.060 & 00 & 000 & 000 & 050 & 0.080 & .020 & .000 & 0.000 & 0.000 \\
\hline HLW03-44 & 000 & 0.498 & 0.100 & 0.050 & 0.010 & 0.010 & 0.040 & 0.498 & 0.048 & 0.199 & 0.010 & 0.050 & 0.060 & 0.299 & 0.000 & 0.000 & 0.050 & 0.080 & 0.020 & 0.000 & 0.000 & 0.000 \\
\hline HLW03-45 & 000 & 0.499 & 0.100 & 0.100 & 0.010 & 0.067 & 0.267 & 0.499 & 0.048 & 0.199 & 0.010 & 0.050 & 0.060 & 0.299 & 0.000 & 0.000 & 0.050 & 0.080 & 0.150 & 0.000 & 0.000 & 0.000 \\
\hline HLW04-01 & 050 & 0.420 & 0.000 & 0.010 & 0.010 & 0.030 & 0.470 & 0.360 & 0.130 & 0.000 & 0.000 & 0.000 & 0.000 & 0.060 & 0.000 & 0.000 & 0.000 & 0.000 & 0.000 & .670 & 0.000 & 0.000 \\
\hline \begin{tabular}{|l|} 
HLW-ALG-01 \\
\end{tabular} & 000 & 0.096 & 0.052 & 0.000 & 0.000 & 0.000 & 0.202 & 0.331 & 050 & 0.000 & 0.000 & 0.032 & 0.124 & 0.101 & 0.000 & 0.000 & 0.000 & .028 & .000 & .000 & 0.000 & 0.000 \\
\hline HLV & 000 & & 5 & 0.000 & & & 214 & & & .000 & & 0.033 & 0.132 & 107 & 000 & 000 & 000 & 30 & 000 & 00 & 000 & 0.000 \\
\hline & & & 4 & & & & 0.207 & & & 00 & & & 7 & & & 00 & 00 & & & & 000 & \\
\hline 4 & 00 & & 36 & 000 & & & 35 & 24 & & 00 & 0 & 0.000 & .083 & 67 & 00 & 000 & 000 & 000 & 000 & .000 & 0.000 & 0.00 \\
\hline HLV & 0 & & 30 & 198 & & & 320 & & & 000 & 00 & 0.050 & .197 & 160 & 027 & 000 & .000 & .045 & .000 & 0.000 & 0.000 & 0.000 \\
\hline HLW- & 0 & & 88 & 22 & 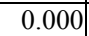 & 25 & 357 & 79 & 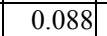 & 000 & 025 & .056 & 219 & 178 & 030 & 000 & .000 & .050 & .000 & .000 & 0.026 & 0.000 \\
\hline HLW-ALG-07 & 000 & 0.118 & 0.061 & 0.000 & 0.000 & 0.000 & 0.239 & 390 & 059 & 0.000 & 0.000 & 0.037 & 0.147 & 0.119 & 0.000 & 0.000 & 0.000 & 0.034 & 0.000 & 0.000 & 0.000 & 0.000 \\
\hline HLW-ALG-08 & 000 & 0.172 & 0.089 & 1.349 & 0.000 & 0.026 & 0.364 & 0.591 & 0.090 & 0.000 & 0.026 & 0.057 & 0.224 & 0.182 & 0.031 & 0.000 & 0.000 & 0.051 & 0.000 & 0.000 & 0.026 & 0.000 \\
\hline HLW-ALG-09 & .000 & 0.204 & 0.229 & 0.084 & 0.000 & 0.000 & 0.410 & 0.560 & 0.124 & 0.050 & 0.000 & 0.076 & 0.354 & 0.387 & 0.028 & 0.000 & 0.000 & 0.000 & .000 & 0.000 & 0.000 & 0.000 \\
\hline HLW-ALG-10 & 0.000 & 0.096 & 0.051 & 0.854 & 0.000 & 0.000 & 0.203 & 0.332 & 0.050 & 0.000 & 0.000 & 0.032 & 0.125 & 0.101 & 0.000 & 0.000 & 0.000 & 0.028 & .000 & 0.000 & 0.000 & 0.000 \\
\hline LG-11 & 0.000 & & 0.088 & 0.000 & 0.000 & 000 & 0.348 & 0.565 & 0.086 & 0.000 & 0.000 & 0.054 & 0.214 & 0.174 & 0.029 & 0.000 & 0.000 & 0.049 & 0.000 & 0.000 & 0.025 & 0.000 \\
\hline HLW-ALG-12 & 0.000 & 0.171 & 0.089 & 0.406 & 0.000 & .026 & 0.361 & 0.586 & .089 & 0.000 & 0.025 & 0.056 & 0.222 & 0.180 & 0.031 & 0.000 & 0.000 & 0.051 & 0.000 & 0.000 & 0.026 & 0.000 \\
\hline
\end{tabular}

(a) R1 after a Glass ID indicates the glass batching, melting, and testing was repeated.

(b) For each glass, the sum of the $\mathrm{wt} \%$ values for the components comprising Others1, Others 2 , and Constant equal the wt $\%$ values listed in the Others 1 , Others 2 , and Constant columns of Table A.2, except for any differences resulting from rounding wt $\%$ values to three decimal places. The equalities are exact to the additional decimal places contained in the data base. 
Table A.3. Composition Expansions of Others1, Others2, and Constant Components for the 143 Existing Glasses in Table A.2 Having Viscosity and Electrical Conductivity Data (continued).

\begin{tabular}{|c|c|c|c|c|c|c|c|c|c|c|c|c|c|c|c|c|c|c|c|c|c|c|}
\hline \multirow{2}{*}{ Glass ID $^{\text {(a) }}$} & \multicolumn{3}{|c|}{\begin{tabular}{|c|}
$\begin{array}{c}\text { Others1 Components } \\
(\mathrm{wt} \%)^{(\mathbf{b})}\end{array}$ \\
\end{tabular}} & \multicolumn{4}{|c|}{$\begin{array}{c}\text { Others2 Components } \\
\left(w \mathrm{w}^{(\mathrm{b})}\right)\end{array}$} & \multicolumn{15}{|c|}{ Constant Components (wt\%) ${ }^{(\mathbf{b})}$} \\
\hline & \begin{tabular}{|l|}
$\mathbf{M o O}_{3}$ \\
\end{tabular} & $\mathrm{P}_{2} \mathrm{O}_{5}$ & $\mathrm{SO}_{3}$ & CdO & $\mathrm{CoO}$ & $\mathrm{CuO}$ & PbO & $\mathrm{aO}$ & 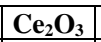 & $\mathrm{Cl}$ & $\mathrm{Cs}_{2} \mathrm{O}$ & $\mathbf{F}$ & ${ }_{2} \mathrm{O}$ & $\mathbf{L a}_{2} \mathbf{O}_{3}$ & $\mathrm{Pr}_{2} \mathrm{O}_{3}$ & $\mathrm{Rb}_{2} \mathrm{O}$ & $\mathbf{R h}_{2} \mathbf{O}_{3}$ & \begin{tabular}{|l|}
$\mathrm{RuO}_{2}$ \\
\end{tabular} & $\mathrm{Sb}_{2} \mathbf{O}_{3}$ & $\mathrm{SnO}_{2}$ & $\mathrm{WO}_{3}$ & $\mathbf{Y}_{2} \mathbf{O}_{3}$ \\
\hline G-13 & 0.000 & 0.258 & 0.130 & 0.061 & .000 & .039 & 0.545 & 1.882 & .135 & 0.028 & 0.038 & 0.085 & 0.335 & 0.272 & 0.046 & 0.000 & 0.000 & 0.077 & 0.000 & 0.000 & 0.040 & 0.000 \\
\hline HLW-ALG-14 & 0.000 & 0.147 & 0.078 & 1.486 & 0.000 & 0.000 & 0.311 & 0.507 & 0.077 & 0.000 & 0.000 & 0.048 & 0.191 & 0.155 & 0.026 & 0.000 & 0.000 & 0.044 & 0.000 & 0.000 & 0.000 & 0.000 \\
\hline HLW-ALG-15 & 0.000 & 0.124 & 0.065 & 0.000 & 0.000 & 0.000 & 0.261 & 0.424 & 0.065 & 0.000 & 0.000 & 0.041 & 0.161 & 0.130 & 0.000 & 0.000 & 0.000 & 0.037 & 0.000 & 0.000 & 0.000 & 0.000 \\
\hline \begin{tabular}{|l|} 
HLW-ALG-16 \\
\end{tabular} & 0.000 & 0.106 & 0.056 & 0.025 & 0.000 & 0.000 & 0.223 & 0.363 & 0.055 & 0.000 & 0.000 & 0.035 & 0.137 & .111 & .000 & .000 & 0.000 & .031 & 0.000 & .000 & 0.000 & 0.000 \\
\hline & & & & & & & & & & & & & & & & & & & & 00 & 00 & \\
\hline$\overline{\mathrm{HL}}$ & 0.000 & 0.09 & .053 & 0.000 & 0.000 & 0.000 & 207 & 39 & 0.051 & 0.000 & 0.000 & 0.032 & 0 & & 0.000 & 0.000 & 0.000 & 29 & 0. & .000 & 0.000 & 0.000 \\
\hline $\mathrm{HLV}$ & .000 & 0 & 00 & .000 & 0.000 & 00 & .207 & 40 & 00 & 0.000 & 0 & 0.032 & 21 & 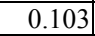 & 0.000 & 0.000 & 0.000 & 0.029 & 0.000 & 0.000 & 0.000 & 0.000 \\
\hline HLV & 000 & $\overline{09}$ & 053 & 000 & 000 & 0 & 207 & 40 & 0.051 & 0.000 & 0.000 & 0.032 & 27 & 3 & 0.000 & 000 & 0.000 & 0.029 & 0.000 & 0.000 & 0.000 & 0.000 \\
\hline \begin{tabular}{|l|} 
HLW-ALG-21 \\
\end{tabular} & 0.000 & 118 & 121 & .131 & 0.000 & 0.034 & 0.180 & 0.642 & 0.049 & 0.000 & 0.000 & 0.039 & 0.174 & 0.136 & 0.000 & 0.030 & 0.000 & 0.000 & 0.000 & 0.000 & 0.123 & 0.000 \\
\hline HLW-ALG-22 & 0.000 & 0.117 & 0.120 & 0.129 & 0.000 & 0.033 & 0.178 & 0.635 & 0.049 & 0.000 & 0.000 & 0.038 & 0.172 & 0.135 & 0.000 & 0.029 & 0.000 & 0.000 & 0.000 & 0.000 & 0.121 & 0.000 \\
\hline HLW-ALG-23 & 0.000 & 0.112 & 0.116 & 0.124 & 0.000 & 0.032 & 0.171 & 0.611 & 0.047 & 0.000 & 0.000 & 0.037 & 0.165 & 0.130 & 0.000 & 0.028 & 0.000 & 0.000 & 0.000 & 0.000 & 0.116 & 0.000 \\
\hline
\end{tabular}

(a) R1 after a Glass ID indicates the glass batching, melting, and testing was repeated.

(b) For each glass, the sum of the wt $\%$ values for the components comprising Others 1 , Others 2 , and Constant equal the wt $\%$ values listed in the Others 1 , Others 2 , and Constant columns of Table A.2, except for any differences resulting from rounding wt\% values to three decimal places. The equalities are exact to the additional decimal places contained in the data base. 
Table A.4. Composition Expansions of Remaining Components for the 143 Existing Glasses in Table A.2 Having Viscosity and Electrical Conductivity Data.

\begin{tabular}{|c|c|c|c|c|c|c|c|c|c|c|c|c|}
\hline \multirow{2}{*}{ Glass ID $^{(\mathrm{a})}$} & \multicolumn{12}{|c|}{ Remaining Components (wt \%) ${ }^{(\mathrm{b})}$} \\
\hline & $\mathrm{g}_{2} \mathrm{O}$ & ${ }_{2} \mathbf{O}_{5}$ & BaO & $\mathbf{B i}_{2} \mathbf{O}_{3}$ & MgO & $\mathrm{Nd}_{2} \mathrm{O}_{3}$ & PdO & $\mathrm{SeO}_{2}$ & $\mathrm{TeO}_{2}$ & $\mathrm{TiO}_{2}$ & $\mathrm{Tl}_{2} \mathrm{O}$ & $\mathbf{V}_{2} \mathbf{O}_{5}$ \\
\hline 72 & 23 & & 000 & & 107 & & & 0.000 & & 0.000 & 0.000 & \\
\hline & & & & & & & & & & & & 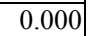 \\
\hline & 4 & 000 & 000 & .000 & 73 & & 000 & 000 & .000 & .000 & 000 & $\overline{00}$ \\
\hline & 53 & 200 & 0 & 0.000 & & & 000 & 212 & 0.000 & 0.028 & .000 & \\
\hline & 153 & 200 & 0.000 & 0.000 & .565 & & 0.000 & 212 & 0.000 & 0.028 & 0.000 & 0.000 \\
\hline & 000 & 190 & 0.000 & 0.000 & .170 & & 000 & 370 & 0.000 & 0.140 & .000 & 0.000 \\
\hline & 38 & 00 & 067 & 000 & & & 04 & 00 & 0.000 & 00 & 00 & 0.0 \\
\hline & & & & 8 & & & & & & & & .000 \\
\hline & & & 619 & 000 & & & & & 000 & & 00 & .000 \\
\hline & & & 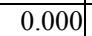 & $\overline{000}$ & & & & & .000 & & 00 & .000 \\
\hline & 0 & & 0 & 000 & & & 00 & 00 & .000 & 20 & .000 & .0 \\
\hline & & & & 0 & & & & & .000 & & & \\
\hline & 030 & 000 & 0.000 & 0.000 & 0.000 & & 0.000 & .000 & 0.000 & 0.020 & 0.000 & 0.000 \\
\hline & 000 & 000 & 0.070 & 0.000 & 0.090 & & 0.000 & 0.000 & 0.000 & 0.000 & 0.000 & 0.000 \\
\hline & 170 & 220 & 0.000 & 0.000 & & & & 430 & 0.000 & 0.160 & & 0.000 \\
\hline & & & & a & & & & & & & & 0.000 \\
\hline & 0 & & 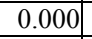 & 0.00 & & & & & 0.000 & & & .000 \\
\hline & & & 2 & 0 & & & & & 0.010 & & & .05 \\
\hline & & & & 0 & & & & & 10 & 30 & 19 & .100 \\
\hline & & & & 0 & & & & 200 & .010 & 30 & & .100 \\
\hline & $0_{1}$ & & 0 & 010 & & & & 200 & 0.010 & 0.030 & 0.186 & 0.010 \\
\hline & 20 & & 0.030 & 0.010 & 0.120 & 00 & 20 & .020 & $\begin{array}{ll}0.010 \\
\end{array}$ & 0.030 & 0.019 & 0.010 \\
\hline & 020 & & 0.030 & 0.010 & 20 & & 20 & 200 & 0.010 & 0.030 & 0.186 & 0.010 \\
\hline & & & & 0.010 & & & & 020 & 0.010 & 0.030 & 0.186 & 0.100 \\
\hline & & & & 0.0 & & & & & & & & 0.010 \\
\hline & & & & 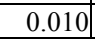 & & & & & 0.010 & & & 0.010 \\
\hline & & & & & & & & & & & & 0,0 \\
\hline & & & & & & & & & 0 & 0.030 & 0.186 & 01 \\
\hline & 19 & & 0 & 0 & & & .120 & 200 & 0.010 & 0.030 & 0.019 & 0100 \\
\hline & 199 & 2 & 0.300 & 0.010 & 20 & & 20 & 200 & 0.010 & 0.030 & 0.186 & 0.100 \\
\hline & 20 & 3 & 0.030 & 0.010 & 0.120 & 00 & 0.120 & .020 & 0.010 & 0.030 & 0.186 & 0.010 \\
\hline & 199 & & 0.300 & 0.010 & 0.120 & & 0.120 & 200 & 0.010 & 0.030 & 0.186 & 0.100 \\
\hline $600-10$ & \begin{tabular}{|c|}
0.199 \\
\end{tabular} & 0.232 & 0.300 & 0.010 & 0.120 & 0.000 & 0.120 & 0.200 & 0.010 & 0.030 & 0.019 & 0.100 \\
\hline
\end{tabular}

(a) R1 after a Glass ID indicates the glass batching, melting, and testing was repeated.

(b) For each glass, the sum of the wt\% values for the components comprising Remaining equals the $\mathrm{wt} \%$ value listed in the Remaining column of Table A.2, except for any differences resulting from rounding $\mathrm{wt} \%$ values to three decimal places. 
Table A.4. Composition Expansions of Remaining Components for the 143 Existing Glasses in Table A.2 Having Viscosity and Electrical Conductivity Data (continued).

\begin{tabular}{|c|c|c|c|c|c|c|c|c|c|c|c|c|}
\hline \multirow{2}{*}{ Glass ID $^{(a)}$} & \multicolumn{12}{|c|}{ Remaining Components (wt\%) } \\
\hline & $\mathrm{Ag}_{2} \mathrm{O}$ & $\mathbf{A s}_{2} \mathbf{O}_{5}$ & BaO & $\mathrm{Bi}_{2} \mathbf{O}_{3}$ & MgO & $\mathrm{Nd}_{2} \mathrm{O}_{3}$ & PdO & $\mathrm{SeO}_{2}$ & $\mathrm{TeO}_{2}$ & $\mathrm{TiO}_{2}$ & $\mathrm{Tl}_{2} \mathrm{O}$ & $\mathrm{V}_{2} \mathrm{O}_{5}$ \\
\hline & 020 & 0.023 & 030 & .010 & 120 & 0.000 & 0.120 & 0.020 & 0.010 & 0.030 & 0.019 & 00 \\
\hline & & 232 & & & & & & & 010 & 030 & & $x$ \\
\hline & 20 & 023 & 030 & 010 & 20 & 000 & & 200 & 10 & 30 & & \\
\hline $\mathbf{y}$ & 020 & 0.023 & 0.030 & 0.010 & 20 & 000 & 120 & 020 & 010 & .030 & & 0.010 \\
\hline & 20 & 0.023 & 0.030 & 0010 & & & & 020 & & & & \\
\hline & & .0 & & & & & & & & & & \\
\hline & & & & & & & & & & & & \\
\hline & & & & & & & & & & 30 & & \\
\hline & 0 & 3 & of & & & & & 20 & & & & \\
\hline & 99 & 0. & 300 & 0.010 & & 000 & 120 & 020 & 010 & .030 & 186 & \\
\hline & 020 & 0.023 & 0.030 & 0.010 & 120 & 000 & 120 & 200 & .010 & .030 & .186 & .010 \\
\hline & 040 & 0.046 & .060 & 0.010 & & 0.000 & 20 & 050 & .010 & .030 & 140 & .020 \\
\hline & 133 & 0.154 & 0.200 & & & 000 & & 150 & 10 & 30 & & \\
\hline & & & & & & & & & & & & \\
\hline & & & & & & & & & & & & \\
\hline & & & & & & & & & & & & \\
\hline & 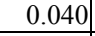 & & 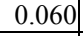 & & & & & & & & & \\
\hline & & & the & & & & & & & & & \\
\hline & 33 & 4 & 200 & 0.010 & 20 & 000 & 20 & 050 & 010 & .030 & 140 & 667 \\
\hline & 33 & 154 & 200 & 10 & 20 & 000 & 20 & 150 & 10 & .030 & 46 & \\
\hline & 40 & 16 & 060 & & & 000 & & 050 & 10 & .030 & 47 & \\
\hline & 33 & 154 & 0.200 & 10 & & 000 & 20 & 150 & .010 & $\begin{array}{l}.030 \\
\end{array}$ & 446 & 67 \\
\hline & & & & & & & & 50 & & 30 & 47 & \\
\hline & & & & & & & & & & & & \\
\hline & & & & & & & & & & 30 & & \\
\hline & & & 50 & & & 00 & & 050 & 10 & 30 & & \\
\hline & & & 60 & & & 00 & & 050 & .010 & .030 & 477 & \\
\hline & & 4 & 00 & & & 00 & & 050 & 10 & .030 & 46 & \\
\hline & 40 & 46 & 060 & 0 & & 000 & & 150 & 10 & .030 & 47 & \\
\hline & 040 & 046 & 060 & 10 & 20 & 000 & 20 & 150 & .010 & 0.030 & 140 & 020 \\
\hline & 133 & 0.154 & 0.200 & 0.010 & 120 & 0.000 & 120 & 0.050 & 0.010 & 0.030 & .140 & 57 \\
\hline & & 0.154 & 0.200 & 0.010 & & 0.000 & 0.120 & 0.150 & 0.010 & 0.030 & 0.140 & 67 \\
\hline$-1000-49$ & .040 & 0.046 & 0.060 & 0.010 & 0.120 & 0.000 & 0.120 & 0.050 & 0.010 & 0.030 & 0.140 & 0.021 \\
\hline
\end{tabular}

(a) R1 after a Glass ID indicates the glass batching, melting, and testing was repeated.

(b) For each glass, the sum of the $\mathrm{wt} \%$ values for the components comprising Remaining equals the $\mathrm{wt} \%$ value listed in the Remaining column of Table A.2, except for any differences resulting from rounding $\mathrm{wt} \%$ values to three decimal places. 
Table A.4. Composition Expansions of Remaining Components for the 143 Existing Glasses in Table A.2 Having Viscosity and Electrical Conductivity Data (continued).

\begin{tabular}{|c|c|c|c|c|c|c|c|c|c|c|c|c|}
\hline \multirow{2}{*}{ Glass ID $^{(a)}$} & \multicolumn{12}{|c|}{ Remaining Components (wt\%) } \\
\hline & $\mathrm{Ag}_{2} \mathrm{O}$ & $\mathbf{A s}_{2} \mathbf{O}_{5}$ & BaO & $\mathrm{Bi}_{2} \mathbf{O}_{3}$ & MgO & $\mathbf{N d}_{2} \mathrm{O}_{3}$ & PdO & $\mathrm{SeO}_{2}$ & $\mathrm{TeO}_{2}$ & $\mathrm{TiO}_{2}$ & $\mathrm{Tl}_{2} \mathrm{O}$ & $\mathbf{V}_{2} \mathbf{O}_{5}$ \\
\hline-50 & 0.040 & 0.046 & .060 & 0.010 & .120 & 0.000 & .120 & 0.050 & 0.010 & 0.030 & 0.140 & 000 \\
\hline & & & & & & & & & & 30 & & \\
\hline & 108 & 0.125 & 0.162 & 10 & & 000 & & 110 & 10 & .030 & 02 & 0.054 \\
\hline & 020 & 0.023 & 0.030 & 0.010 & 0.120 & 0.000 & & 0.020 & 0.010 & 0.030 & 019 & 0.010 \\
\hline & 020 & 0.023 & 0.030 & 0.010 & & 0.000 & & 200 & .010 & .030 & & 0.010 \\
\hline & 40 & 0.046 & & 0.0 & & & & & & & & 0.02 \\
\hline & & & & & & & & & & & & \\
\hline & 20 & 23 & & & & & & 020 & & & 19 & .010 \\
\hline & 200 & & & & & & & 200 & & 30 & & 0.100 \\
\hline & 20 & 023 & 0 & & & & & 020 & 010 & .030 & 307 & 0.010 \\
\hline & 020 & 0.023 & 030 & 0.010 & 120 & 00 & 20 & 200 & 010 & .030 & 307 & 0.010 \\
\hline & 199 & .232 & 0.299 & 0.010 & 0.120 & 000 & & .199 & .010 & 0.030 & .306 & 0.100 \\
\hline & 200 & 0.232 & 0.300 & 0.010 & 0.120 & .000 & 0.120 & 0.200 & 0.010 & 0.030 & .307 & 0.100 \\
\hline & & & & & & & & .020 & & & & 0.010 \\
\hline & & & & & & & & & & & & 510 \\
\hline & & & & & & & & 20 & & & & 100 \\
\hline & 20 & & & & & & & 00 & & 30 & & .010 \\
\hline & 200 & & & & & & & & & 30 & & .10 \\
\hline & 020 & 0 & 030 & 0 & 20 & 00 & 20 & 199 & 010 & .030 & $\begin{array}{l}019 \\
\end{array}$ & 0.010 \\
\hline & 20 & .023 & 030 & & & 000 & & .020 & .010 & .030 & .019 & 0.010 \\
\hline & 020 & 0.023 & 0.030 & 0.010 & 0.120 & 0.000 & 0.120 & 0.199 & 0.010 & 0.030 & .019 & 0.010 \\
\hline & 020 & 0.023 & 0.030 & 0.010 & 0.120 & 0.000 & 0.120 & 0.020 & 0.010 & 0.030 & .307 & 0.010 \\
\hline & & & & & & & & 0.020 & & 30 & 07 & 0.010 \\
\hline & & & & & & & & 99 & & & & \\
\hline & & & & & & & & 20 & & 30 & & \\
\hline & & & & & & & & 20 & & 30 & 07 & 0.010 \\
\hline & & & & & & & & 020 & 10 & .030 & 019 & 0.010 \\
\hline & & & & & & & & 200 & & 30 & 307 & 0.100 \\
\hline & 40 & & 60 & & 0.120 & 00 & 20 & 0.050 & 0.010 & 0.030 & .046 & 0.020 \\
\hline & 0.134 & 0.155 & 0.200 & 0.010 & 0.120 & 0.000 & 0.120 & 0.150 & 0.010 & 0.030 & .046 & 0.067 \\
\hline & 0.040 & 0.046 & 0.060 & 0.010 & 0.120 & 0.000 & 0.120 & 0.150 & 0.010 & 0.030 & .046 & 0.020 \\
\hline & 040 & & 0.060 & & 0.120 & 0.000 & 20 & 0.050 & 0.010 & 0.030 & .046 & 0.020 \\
\hline 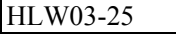 & 0.134 & 0.155 & 0.201 & 0.010 & 0.120 & 0.000 & 0.120 & 0.150 & 0.010 & 0.030 & 0.139 & 0.06 \\
\hline
\end{tabular}

(a) R1 after a Glass ID indicates the glass batching, melting, and testing was repeated.

(b) For each glass, the sum of the wt\% values for the components comprising Remaining equals the $\mathrm{wt} \%$ value listed in the Remaining column of Table A.2, except for any differences resulting from rounding $\mathrm{w} t \%$ values to three decimal places. 
Table A.4. Composition Expansions of Remaining Components for the 143 Existing Glasses in Table A.2 Having Viscosity and Electrical Conductivity Data (continued).

\begin{tabular}{|c|c|c|c|c|c|c|c|c|c|c|c|c|}
\hline \multirow{2}{*}{ Glass ID } & \multicolumn{12}{|c|}{ Remaining Components (wt\%) } \\
\hline & $\mathbf{g}_{2} \mathrm{O}$ & $\mathbf{A s}_{2} \mathbf{O}_{5}$ & $\mathbf{B a O}$ & $\mathbf{B i}_{2} \mathbf{O}_{3}$ & MgO & $\mathbf{N d}_{2} \mathrm{O}_{3}$ & PdO & $\mathrm{SeO}_{2}$ & $\mathrm{TeO}_{2}$ & $\mathrm{TiO}_{2}$ & $\mathrm{Tl}_{2} \mathrm{O}$ & $\mathbf{V}_{2} \mathbf{O}_{5}$ \\
\hline & 134 & & 0.200 & 0.010 & 0.120 & 0.000 & 0.120 & 0.150 & 0.010 & 0.030 & 0.046 & 0.06 \\
\hline & & 5 & 200 & 010 & 120 & 000 & 120 & 150 & 010 & .030 & 0.046 & \\
\hline & 40 & 046 & 060 & 010 & 120 & 00 & 0 & 50 & 0.010 & & 0.046 & $\overline{5}+2+$ \\
\hline & 40 & 046 & 060 & 010 & & & & & & & 0.046 & 00 \\
\hline & 40 & & & & & & & & & & & \\
\hline & & & & & & & & & & & & \\
\hline & & & & & & & & & & & & \\
\hline & & & 0 & & & & & & & & & .0 \\
\hline & & & 1 & & & & & & & & & \\
\hline & 40 & 046 & 0.060 & 0.010 & 20 & 0 & 0 & 050 & 0.0 & 0.030 & 39 & 0.020 \\
\hline & 34 | & 155 & .201 & 0.010 & 0.120 & 0.000 & 120 & & & & 0.046 & \\
\hline & 4 & & 200 & 010 & 0.120 & 00 & & 0.150 & & & 39 & 0.067 \\
\hline & & & 0.200 & 0 & & & & & & & 46 & \\
\hline & & & & & & & & & & & & 0.067 \\
\hline & & & & & & & & & & & & .020 \\
\hline & & & & & & & & & & & & .043 \\
\hline & & & 0 & & & & & & & & & 020 \\
\hline & & & & & & & & & & & & 010 \\
\hline & 20 & t & 030 & 0.01 & 20 & 0 & & 199 & & 0.030 & 19 & .010 \\
\hline & & & 0 & & & 00 & 20 & 50 & 0.010 & 0.030 & 0.046 & 0.067 \\
\hline & & & & & & & & 00 & & 0.030 & 00 & 0.020 \\
\hline & & & & & & & & & & & 50 & .000 \\
\hline & & & & & & & & & & & & .000 \\
\hline & & & & & & & & & & & & \\
\hline & & & & & & & & & & & & .000 \\
\hline & & & 6 & & 49 & & & 00 & & .026 & 00 & 000 \\
\hline & & & 52 & & & & & 000 & & .025 & .000 & .000 \\
\hline & 054 & & 0.042 & f & & f & & .000 & & .000 & 00 & .000 \\
\hline & 082 & 00 & 4 & 0 & & & 00 & 000 & 0.000 & 0.052 & .000 & 0.000 \\
\hline & & & 80 & 0 & 492 & & 00 & 00 & & 0.000 & 00 & 0.000 \\
\hline & STy & & 0.035 & 0.0 & 0.096 & & & & & 0.036 & 000 & 0.000 \\
\hline & & & & & & & & & & & 00 & .000 \\
\hline WTILU 12 & 081 & 0.000 & 063 & 0.000 & 0.166 & 0.1. & 0.000 & 0.000 & 0.0 & 0.026 & 0.000 & 0.0 \\
\hline
\end{tabular}

(a) R1 after a Glass ID indicates the glass batching, melting, and testing was repeated.

(b) For each glass, the sum of the wt\% values for the components comprising Remaining equals the $\mathrm{wt} \%$ value listed in the Remaining column of Table A.2, except for any differences resulting from rounding $\mathrm{w} t \%$ values to three decimal places. 
Table A.4. Composition Expansions of Remaining Components for the 143 Existing Glasses in Table A.2 Having Viscosity and Electrical Conductivity Data (continued).

\begin{tabular}{|c|c|c|c|c|c|c|c|c|c|c|c|c|}
\hline \multirow{2}{*}{ Glass ID $^{(a)}$} & \multicolumn{12}{|c|}{ emaining Components (wt\%) } \\
\hline & $\mathrm{g}_{2} \mathrm{O}$ & $\mathrm{S}_{2} \mathbf{O}_{5}$ & $\mathrm{BaO}$ & $\mathrm{Bi}_{2} \mathrm{O}_{3}$ & MgO & $\mathrm{Nd}_{2} \mathrm{O}_{3}$ & PdO & $\mathrm{SeO}_{2}$ & $\mathrm{TeO}_{2}$ & $\mathrm{TiO}_{2}$ & $\mathrm{Tl}_{2} \mathrm{O}$ & $\mathbf{V}_{2} \mathbf{O}_{5}$ \\
\hline & 0.123 & .000 & 0.095 & 0.033 & & & 0.000 & 0.000 & 0.000 & 0.036 & 0.000 & \\
\hline & & & & & & & & & & & & \\
\hline & & & & & & & & & & & & \\
\hline & & & & & & & & & & & & \\
\hline & & & & & & & & & & & & .0 \\
\hline & 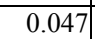 & 7 & 36 & 000 & & & & 000 & 00 & .00 & .000 & .00 \\
\hline & & 000 & 36 & & & & & & .000 & 43 & .000 & .000 \\
\hline & .047 & 0.000 & 0.036 & 0.000 & 0.098 & & 0.000 & 0.000 & 0.000 & 0.043 & 0.000 & 0.000 \\
\hline & 140 & 0.000 & 0.048 & 0.000 & 0.112 & & 0.000 & 0.000 & 0.000 & 0.027 & 0.000 & 0.000 \\
\hline & 138 & 0.000 & 0.048 & 0.000 & & & 0.000 & 0.000 & 0.000 & 0.027 & 0.000 & 0.000 \\
\hline$-A L U-\angle 3$ & 0.133 & 0.000 & 0.046 & 0.000 & 0.107 & 0.097 & 0.000 & 0.000 & 0.000 & 0.026 & 0.000 & 0.00 \\
\hline
\end{tabular}

(a) R1 after a Glass ID indicates the glass batching, melting, and testing was repeated.

(b) For each glass, the sum of the wt\% values for the components comprising Remaining equals the $w t \%$ value listed in the Remaining column of Table A.2, except for any differences resulting from rounding $\mathrm{wt} \%$ values to three decimal places. 
Table A.5. 18-Component Target Glass Compositions (wt \%) for the Ten HLW05 and HLW06 Glasses Selected to Have Viscosity and Electrical Conductivity Data Collected.

\begin{tabular}{|c|c|c|c|c|c|c|c|c|c|c|c|c|c|c|c|c|c|c|c|c|}
\hline Glass ID $^{(\mathbf{a})}$ & Point Type $^{(b)}$ & $\mathbf{A l}_{2} \mathbf{O}_{3}$ & $\mathbf{B}_{2} \mathbf{O}_{3}$ & $\mathrm{Cr}_{2} \mathrm{O}_{3}$ & $\mathrm{Fe}_{2} \mathrm{O}_{3}$ & $\mathbf{L i}_{2} \mathbf{O}$ & MnO & $\mathrm{Na}_{2} \mathrm{O}$ & $\mathrm{NiO}$ & $\mathrm{SiO}_{2}$ & SrO & $\mathrm{ThO}_{2}$ & $\mathrm{UO}_{3}$ & $\mathrm{ZnO}$ & $\mathrm{ZrO}_{2}$ & Others1 & Others2 & Constant & Remain & Sum $^{(c)}$ \\
\hline HLW05-15 & 05. OL15 & 2.000 & 4.500 & 0.250 & 12.000 & 0.000 & 0.100 & 16.670 & .050 & 49.000 & 1.200 & 1.500 & 4.380 & 1.200 & 4.000 & 0.400 & 0.200 & 1.560 & 0.990 & 100.000 \\
\hline HLW05-20 & OL20 & 13.000 & 14.000 & 250 & 1.500 & 0.000 & 1.000 & 20.000 & .500 & 37.750 & 1.200 & 1.500 & 1.000 & 1.200 & 3.500 & .400 & .650 & 1.560 & 0.990 & 0.000 \\
\hline HLW05-21 & 05.OL21 & 2.000 & 14.000 & 0.250 & 12.000 & 0.000 & 0.100 & 19.710 & 0.050 & 34.000 & 1.200 & 6.000 & 1.000 & 1.200 & 5.340 & 0.400 & 0.200 & 1.560 & 0.990 & 100.000 \\
\hline HLW05-22 & 05.OL22 & 13.000 & 14.000 & 0.050 & 2.500 & 3.700 & 0.100 & 6.500 & 0.050 & 44.050 & 1.200 & 1.500 & 6.500 & 1.200 & 2.500 & 0.400 & 0.200 & 1.560 & 0.990 & 100.000 \\
\hline HLW05-27 & 05.OL27 & 2.000 & 4.500 & 0.050 & 12.000 & 5.950 & 1.000 & 10.390 & 0.500 & 45.610 & 1.200 & 1.500 & 6.500 & 1.200 & 4.000 & 0.400 & 0.650 & 1.560 & .990 & 0.000 \\
\hline HLV & & 10.390 & 11.000 & 0.250 & 7.000 & 0.250 & 1.000 & 20.000 & 1.000 & 35.000 & 1.470 & 0.250 & 0.750 & 1.500 & 1.500 & .540 & .145 & 3.636 & .319 & 0.000 \\
\hline $\mathrm{HLV}$ & & 8.000 & 6.500 & 0.250 & 7.000 & 0.250 & 1.000 & 20.000 & 0.600 & 35.000 & $\begin{array}{ll}4.409 \\
\end{array}$ & 1.500 & 0.750 & 2.500 & 4.000 & 0.620 & 1.395 & 3.349 & 878 & 100.000 \\
\hline HLV & & 13.000 & 15.000 & 0.600 & 1.400 & 6.010 & 0.000 & 6.840 & 0.000 & 34.560 & 10.287 & 0.000 & 6.500 & 0.000 & 0.000 & 0.780 & 1.646 & 2.054 & 1.322 & 100.000 \\
\hline HLV & & 1.880 & 15.000 & 0.600 & 15.000 & 0.000 & 8.000 & 20.000 & 0.000 & 37.430 & 0.000 & 0.000 & 0.000 & 0.000 & 0.000 & 0.500 & 0.000 & 0.820 & 0.770 & 100.000 \\
\hline HLW06-34 & 06.OL34 & 1.880 & 15.000 & 0.600 & 1.400 & 0.000 & 8.000 & 20.000 & 0.000 & 33.030 & 0.000 & 0.000 & 6.500 & 0.000 & 11.500 & 0.500 & 0.000 & 0.820 & 0.770 & 100.00 \\
\hline
\end{tabular}

(a) R1 after a Glass ID indicates the glass batching, melting, and testing was repeated.

(b) The "Point Type" notation begins with an abbreviation of the HLW study phase (e.g., Ph1a denotes Phase 1a). After a separating dot, the notation continues (when appropriate) with "Center", "OL", or "IL", denoting whether the glass was a center point, outer-layer point, or inner-layer point. The "Center", "OL", or "IL" designation is with respect to the given study phase. Next, "XX" denotes the number of each outer-layer, inner-layer, or other point with respect to the given study phase. Replicate points are denoted by "Rep.HLW02-xx" and "Rep.HLW03-xx", where the "xx" represents a specific ID number for a replicated glass.

(c) The $\mathrm{wt} \%$ values in the table are rounded to three decimal places and may not sum to 100.000 exactly, but the sum is achieved in the data base. 
Table A.6. Composition Expansions of Others1, Others2, and Constant Components for the Ten HLW05 and HLW06 Glasses in Table A.5 Selected to Have Viscosity and Electrical Conductivity Data Collected.

\begin{tabular}{|c|c|c|c|c|c|c|c|c|c|c|c|c|c|c|c|c|c|c|c|c|c|c|}
\hline \multirow[t]{2}{*}{ Glass ID $^{(a)}$} & \multicolumn{3}{|c|}{\begin{tabular}{|c|}
$\begin{array}{c}\text { Others1 Components } \\
(\mathrm{wt} \%)^{(\mathbf{b})}\end{array}$ \\
\end{tabular}} & \multicolumn{4}{|c|}{$\begin{array}{c}\text { Others2 Components } \\
\text { (wt\%) }^{(\mathbf{b})}\end{array}$} & \multicolumn{15}{|c|}{ Constant Components (wt\%) $)^{(b)}$} \\
\hline & \begin{tabular}{|l|}
$\mathrm{MoO}_{3}$ \\
\end{tabular} & $\mathbf{P}_{2} \mathbf{O}_{5}$ & $\mathrm{SO}_{3}$ & CdO & $\mathrm{CoO}$ & $\mathrm{CuO}$ & PbO & $\mathrm{CaO}$ & $\mathrm{Ce}_{2} \mathrm{O}_{3}$ & $\mathrm{Cl}$ & $\mathrm{Cs}_{2} \mathrm{O}$ & $\mathbf{F}$ & $\mathbf{K}_{2} \mathbf{O}$ & \begin{tabular}{|l|}
$\mathbf{L a}_{2} \mathbf{O}_{3}$ \\
\end{tabular} & \begin{tabular}{|l|}
$\mathbf{P r}_{2} \mathbf{O}_{3}$ \\
\end{tabular} & \begin{tabular}{|l|}
$\mathbf{R} \mathbf{b}_{2} \mathbf{O}$ \\
\end{tabular} & $\mid \mathbf{R h}_{2} \mathbf{O}_{3}$ & $\mathbf{R u O}_{2}$ & \begin{tabular}{|l|}
$\mathbf{S b}_{2} \mathbf{O}_{3}$ \\
\end{tabular} & $\mathrm{SnO}_{2}$ & $\mathbf{W O}_{3}$ & $\mathbf{Y}_{2} \mathbf{O}_{3}$ \\
\hline-15 & 0.000 & 0.300 & 0.100 & 0.050 & 0.000 & 0.000 & 0.150 & 0.750 & 0.000 & 0.000 & 0.000 & 0.050 & 0.200 & 0.500 & 0.000 & 0.000 & 0.040 & 0.020 & 0.000 & 0.000 & 0.000 & 0.000 \\
\hline \begin{tabular}{|l} 
HLW05-20 \\
\end{tabular} & 000 & 0.300 & 0.100 & 0.500 & 0.000 & 0.000 & 0.150 & 0.750 & 0.000 & 0.000 & .000 & 0.050 & 200 & .500 & .000 & .000 & 0.040 & .020 & 0.000 & .000 & .000 & 0.000 \\
\hline & & & & & 0.000 & & & & 0.000 & 0 & & 50 & & & & & & & & & 00 & 0.000 \\
\hline & & 0 & 100 & 050 & 0.000 & 0.00 & 50 & 07 & 0.000 & 0.000 & 0.000 & 0.050 & 0.200 & 00 & 0.000 & 00 & 0.040 & 20 & 0.000 & 00 & 000 & 0.000 \\
\hline & 0 & 30 & 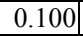 & 0 & .000 & 0.00 & 0 & 0 & 0.000 & 0.000 & 0 & 0.050 & 0.200 & 00 & 0 & 00 & 040 & 20 & 0 & 00 & 000 & 0.0 \\
\hline HLI & 00 & 500 & .040 & .235 & 0.000 & .000 & 910 & 1.000 & 0.000 & 0.200 & 0.0 & 0.440 & 1.640 & 176 & 0.000 & .000 & 0.050 & 130 & 0.000 & .000 & 0.000 & 0.00 \\
\hline HLW06-04 & 000 & .500 & .120 & 0.706 & 0.000 & .000 & 0.689 & 0.757 & 0.000 & 0.200 & 0.000 & 0.440 & 1.242 & 0.529 & 0.000 & 0.000 & 0.050 & 0.130 & 0.000 & 0.000 & 0.000 & 0.000 \\
\hline HLW06-22 & 0.000 & 0.500 & 0.280 & 1.646 & 0.000 & 0.000 & 0.000 & 0.000 & 0.000 & 0.200 & 0.000 & 0.440 & 0.000 & 1.234 & 0.000 & 0.000 & 0.050 & 0.130 & 0.000 & 0.000 & 0.000 & 0.000 \\
\hline HLW06-32 & 0.000 & 0.500 & 0.000 & 0.000 & 0.000 & 0.000 & 0.000 & 0.000 & 0.000 & 0.200 & 0.000 & 0.440 & 0.000 & 0.000 & 0.000 & 0.000 & 0.050 & 0.130 & 0.000 & 0.000 & 0.000 & 0.000 \\
\hline HLW06-34 & 0.000 & 0.500 & 0.000 & 0.000 & 0.000 & 0.000 & 0.000 & 0.000 & 0.000 & 0.200 & 0.000 & 0.440 & 0.000 & 0.000 & 0.000 & 0.000 & 0.050 & 0.130 & 0.000 & 0.000 & 0.000 & 0.000 \\
\hline
\end{tabular}

(a) R1 after a Glass ID indicates the glass batching, melting, and testing was repeated.

(b) For each glass, the sum of the wt\% values for the components comprising Others1, Others2, and Constant equal the wt\% values listed in the Others1, Others 2 , and Constant columns of Table A.5, except for any differences resulting from rounding wt $\%$ values to three decimal places. The equalities are exact to the additional decimal places contained in the data base. 
Table A.7. Composition Expansions of Remaining Components for the Ten HLW05 and HLW06 Glasses in Table A.5 Selected to Have Viscosity and Electrical Conductivity Data Collected.

\begin{tabular}{|c|c|c|c|c|c|c|c|c|c|c|c|c|}
\hline \multirow{2}{*}{ Glass ID $^{(a)}$} & \multicolumn{12}{|c|}{ Remaining Components (wt \%) ${ }^{(b)}$} \\
\hline & $\mathrm{Ag}_{2} \mathrm{O}$ & $\mathbf{A s}_{2} \mathbf{O}_{5}$ & BaO & $\mathbf{B i}_{2} \mathbf{O}_{3}$ & MgO & $\mathbf{N d}_{2} \mathrm{O}_{3}$ & PdO & $\mathrm{SeO}_{2}$ & $\mathrm{TeO}_{2}$ & $\mathrm{TiO}_{2}$ & $\mathrm{Tl}_{2} \mathrm{O}$ & $\mathbf{V}_{2} \mathbf{O}_{5}$ \\
\hline $\mathrm{HI}$ & 0.100 & 0.000 & 0.500 & 0.200 & 0.100 & 0.000 & 0.020 & 0.000 & 0.000 & 0.020 & 0.050 & 0.000 \\
\hline & 100 & 0.000 & 0.500 & 0.200 & 0.100 & 0.000 & .020 & 0.000 & 0.000 & 0.020 & 0.050 & \\
\hline & 100 & 0.000 & 0.500 & 0.200 & 0.100 & 000 & 0.020 & 0.000 & 0.000 & 0.020 & 0.050 & .000 \\
\hline & 100 & 000 & 0.500 & 0.200 & 100 & 00 & 0.020 & 0.000 & 0.000 & 0.020 & 0.050 & \\
\hline & & & & & & & & & & & & 0.000 \\
\hline & & 0 & 0 & 0 & & & & .000 & 0.000 & 1.000 & 0.000 & .000 \\
\hline & & 0 & 227 & 0 & & & & .000 & 0.000 & 0.757 & 0.000 & 0.000 \\
\hline & 0 & 000 & 0.000 & 300 & 000 & 2 & & 0.000 & 0.000 & 0.000 & 0.000 & 0.000 \\
\hline & 00 & 0.000 & 0.000 & 0.300 & 000 & 0.250 & 20 & 0.000 & 0.000 & 0.000 & 0.000 & 0.000 \\
\hline $600-54$ & 100 & .000 & 0.000 & .300 & 0.000 & & .120 & 0.000 & .000 & 0.000 & .000 & $.0 t$ \\
\hline
\end{tabular}

(a) R1 after a Glass ID indicates the glass batching, melting, and testing was repeated.

(b) For each glass, the sum of the wt $\%$ values for the components comprising Remaining equals the $\mathrm{wt} \%$ value listed in the Remaining column of Table A.5, except for any differences resulting from rounding $\mathrm{wt} \%$ values to three decimal places. 
Table A.8. Observations on Distributions of Property Values for HLW Glasses in Studies HLW02, HLW03, HLW05, and HLW06.

\begin{tabular}{|l||l|l|l||}
\hline \hline Property & $\begin{array}{l}\text { Distribution Peak, } \\
\text { (Range) }\end{array}$ & $\begin{array}{l}\text { Data Deficient } \\
\text { Location }\end{array}$ & $\begin{array}{l}\text { Data Useful for Better } \\
\text { Coverage of Property Values }\end{array}$ \\
\hline $\begin{array}{l}\mathrm{T}_{1 \%} \text { of Spinel } \\
\text { (HLW02, HLW03, } \\
\text { HLW05, HLW06) }\end{array}$ & $\sim 950^{\circ} \mathrm{C},\left(650-1300^{\circ} \mathrm{C}\right)$ & None apparent & Not specific \\
\hline $\begin{array}{l}\mathrm{T}_{1 \%} \text { of Zr- Th- } \\
\text { related (HLW02, } \\
\text { HLW03, HLW05, } \\
\text { HLW06) }\end{array}$ & $\begin{array}{l}\text { Data scattered }(750- \\
\left.1500^{\circ} \mathrm{C}\right)\end{array}$ & Around $950^{\circ} \mathrm{C}$ & $\begin{array}{l}\text { Additional data around } 850, \\
950 \text { and } 1000^{\circ} \mathrm{C}\end{array}$ \\
\hline $\begin{array}{l}\text { Viscosity } \\
\text { (HLW02, HLW03) }\end{array}$ & $\begin{array}{l}\sim 10 \text { to } 20 \text { most } \\
\text { concentrated, }(10-190 \\
\text { poise) }\end{array}$ & $\begin{array}{l}\text { Around } 50 \text { to } 80 \\
\text { poise }\end{array}$ & $\begin{array}{l}\text { Additional data around } 50,60, \\
70,80 \text { poise }\end{array}$ \\
\hline $\begin{array}{l}\text { Electrical } \\
\text { conductivity } \\
\text { (HLW02, HLW03) }\end{array}$ & $\sim 0.3,(0.1$ to $0.8 \mathrm{~S} / \mathrm{cm})$ & $\begin{array}{l}\text { Around } 0.4 \text { to } \\
0.55 \mathrm{~S} / \mathrm{cm}\end{array}$ & $\begin{array}{l}\text { Additional data around } 0.4 \text { and } \\
0.5 \mathrm{~S} / \mathrm{cm}\end{array}$ \\
\hline $\begin{array}{l}\text { PCT-B } \text { (g/L) } \\
\text { (HLW02, HLW03, } \\
\text { HLW06) }\end{array}$ & $\begin{array}{l}\sim 0.5,(0.02-4.5, \text { two } \\
\text { around } 12)\end{array}$ & 5 to $16.7 \mathrm{~g} / \mathrm{L}$ & $\begin{array}{l}\text { Additional data around } 5 \text { to } 11 \\
\mathrm{~g} / \mathrm{L}\end{array}$ \\
\hline \hline
\end{tabular}


Table A.9. Components and Their Lower and Upper Bounds Defining the Inner and Outer Layers of the EGCR for the HLW07 Study.

\begin{tabular}{|c|c|c|c|c|c|c|}
\hline \multirow[b]{2}{*}{ Component } & \multicolumn{2}{|c|}{ Inner Layer } & \multicolumn{2}{|c|}{ Outer Layer } & \multicolumn{2}{|c|}{ Existing Glasses $^{(\mathbf{a})}$} \\
\hline & $\begin{array}{c}\text { Lower Limit } \\
\text { (wt \%) }\end{array}$ & $\begin{array}{l}\text { Upper Limit } \\
\text { (wt\%) }\end{array}$ & $\begin{array}{c}\text { Lower Limit } \\
\text { (wt\%) }\end{array}$ & \begin{tabular}{|c|} 
Upper Limit \\
(wt\%)
\end{tabular} & $\begin{array}{l}\text { Minimum } \\
\text { (wt\%) }\end{array}$ & $\begin{array}{c}\text { Maximum } \\
(w t \%)\end{array}$ \\
\hline $\mathrm{Al}_{2} \mathrm{O}_{3}$ & 5 & 10 & 3 & 11.5 & 1.88 & 13 \\
\hline $\mathrm{B}_{2} \mathrm{O}_{3}$ & 8 & 11 & 6 & 13 & 4.3 & 15 \\
\hline $\mathrm{Cr}_{2} \mathrm{O}_{3}$ & 0.15 & 0.4 & 0.05 & 0.6 & 0 & 0.6 \\
\hline $\mathrm{Fe}_{2} \mathrm{O}_{3}$ & 6 & 11 & 4 & 14 & 1.4 & 15 \\
\hline $\mathrm{Li}_{2} \mathrm{O}$ & 1 & 3.5 & 0 & 4.5 & 0 & 6.01 \\
\hline $\mathrm{MnO}$ & 2.5 & 4 & 0.5 & 6 & 0 & 8 \\
\hline $\mathrm{Na}_{2} \mathrm{O}$ & 10 & 14 & 6 & 18 & 3.7 & 20 \\
\hline $\mathrm{NiO}$ & 0.2 & 0.65 & 0 & 1 & 0 & 1 \\
\hline $\mathrm{SiO}_{2}$ & 40 & 47 & 35 & 51 & 33 & 53.1 \\
\hline $\mathrm{SrO}$ & 2.5 & 7 & 0 & 10 & 0 & 10.29 \\
\hline $\mathrm{ThO}_{2}$ & 1 & 3.5 & 0 & 4.4 & 0 & 6 \\
\hline$\overline{\mathrm{UO}_{3}}$ & 1.5 & 3 & 0 & 4.1 & 0 & 6.5 \\
\hline $\mathrm{ZnO}$ & 0.5 & 1.5 & 0 & 2.5 & 0 & 4 \\
\hline $\mathrm{ZrO}_{2}$ & 2.5 & 6.5 & 1 & 9.6 & 0 & 11.5 \\
\hline Others1 & 0 & 1.36 & 0 & 1.36 & $0.40^{(\mathrm{b})}$ & $0.78^{(\mathrm{b})}$ \\
\hline Others2 & 0 & 1.24 & 0 & 2.48 & $0.00^{(\mathrm{b})}$ & $2.56^{(\mathrm{b})}$ \\
\hline Constant & 1.74 & 1.74 & 3.48 & 3.48 & $0.82^{(\mathrm{b})}$ & $4.69^{(\mathrm{b})}$ \\
\hline
\end{tabular}

(a) The existing glasses in this case refer to all 167 glasses from the HLW02, HLW03, HLW05 and HLW06 studies.

(b) The minimum and maximum values listed are for Others1, Others2, and Constant, which are defined for the existing glasses in the same way they are defined for the HLW07 glasses in Tables A.10, A.11, and A.12, respectively.

Table A.10. Definition of "Others1" Component for the HLW07 Study.

\begin{tabular}{|l||c|c|c|}
\hline Oxide & $\begin{array}{c}\text { Composition } \\
\text { (wt \%) }\end{array}$ & $\begin{array}{c}\text { Maximum in } \\
\text { Glass (wt \%) }\end{array}$ & $\begin{array}{c}\text { Basis for } \\
\text { Maximum in Glass }\end{array}$ \\
\hline \hline $\mathrm{MoO}_{3}$ & 28.68 & 0.39 & $\mathrm{~S}^{\text {(a) }}{ }^{\text {(a) }}$ \\
\hline $\mathrm{P}_{2} \mathrm{O}_{5}$ & 47.06 & 0.64 & $\mathrm{G} 2 \&$ actual waste \\
\hline $\mathrm{SO}_{3}$ & 24.26 & 0.33 & $\mathrm{G} 2 \&$ actual waste \\
\hline \hline $\mathrm{Sum}$ & 100.00 & 1.36 & (c) \\
\hline
\end{tabular}

(a) S8.1 refers to Specification 8.1 in Section C of the WTP Contract (DOE-ORP 2003).

(b) "G2 and actual waste" refers to calculations made with the WTP dynamic simulation

flowsheet (G2) for actual waste compositions.

(c) Not applicable. 
Table A.11. Definition of “Others2” Component for the HLW07 Study.

\begin{tabular}{|c|c|c|c|}
\hline Oxide & $\begin{array}{c}\text { Composition } \\
\text { (wt } \%)\end{array}$ & $\begin{array}{c}\text { Maximum in } \\
\text { Glass (wt\%) }\end{array}$ & $\begin{array}{c}\text { Basis for } \\
\text { Maximum in Glass }\end{array}$ \\
\hline $\mathrm{CdO}$ & 40.32 & 1 & Max (1.39) hit previously ${ }^{(\mathrm{a})}$ \\
\hline $\mathrm{CoO}$ & 9.27 & 0.23 & $\mathrm{~S} 8.1^{(\mathrm{b})}$ \\
\hline $\mathrm{CuO}$ & 9.68 & 0.24 & S8.1 \\
\hline $\mathrm{PbO}$ & 40.73 & 1.01 & G2 \& actual waste ${ }^{(\mathrm{c})}$ \\
\hline Sum & 100.00 & 2.48 & (d) \\
\hline
\end{tabular}

(a) The maximum value of interest was achieved in a previous WTP HLW study.

(b) S8.1 refers to Specification 8.1 in Section C of the WTP Contract (DOE-ORP 2003).

(c) "G2 and actual waste" refers to calculations made with the WTP dynamic simulation flowsheet (G2) for actual waste compositions.

(d) Not applicable.

Table A.12. Definition of “Constant” Component for the HLW07 Study.

\begin{tabular}{|c|c|c|c|c|c|}
\hline Oxide & $\begin{array}{c}\begin{array}{c}\text { Intended } \\
\text { Composition } \\
\text { (wt\%) }\end{array} \\
\end{array}$ & $\begin{array}{c}\text { Intended } \\
\text { Maximum in } \\
\text { Glass on Outer } \\
\text { Layer (wt\%) }\end{array}$ & $\begin{array}{c}\text { Actual }^{(\mathrm{d})} \\
\text { Composition }^{(\mathbf{w t} \%)} \\
\end{array}$ & $\begin{array}{c}\text { Actual }^{(\mathrm{d})} \\
\text { Maximum in } \\
\text { Glass on } \\
\text { Outer Layer } \\
\text { (wt\%) }\end{array}$ & $\begin{array}{c}\text { Basis for } \\
\text { Maximum in Glass } \\
\end{array}$ \\
\hline $\mathrm{CaO}$ & 8.62 & 0.3 & 8.65 & 0.3 & max (0.8) hit previously ${ }^{(a)}$ \\
\hline $\mathrm{Ce}_{2} \mathrm{O}_{3}$ & 10.92 & 0.38 & 10.95 & 0.38 & $\mathrm{~S} 8.1^{(\mathrm{b})}$ \\
\hline $\mathrm{Cl}$ & 9.77 & 0.34 & 9.80 & 0.34 & G2 \& actual waste ${ }^{(\mathrm{c})}$ \\
\hline $\mathrm{Cs}_{2} \mathrm{O}$ & 7.18 & 0.25 & 7.20 & 0.25 & S8.1 \\
\hline $\mathrm{F}$ & 3.45 & 0.12 & 3.46 & 0.12 & G2 \& actual waste \\
\hline $\mathrm{K}_{2} \mathrm{O}$ & 16.67 & 0.58 & 16.71 & 0.58 & G2 \& actual waste \\
\hline $\mathrm{La}_{2} \mathrm{O}_{3}$ & 7.18 & 0.25 & 7.20 & 0.25 & $\max (1.22)$ hit previously ${ }^{(\mathrm{a})}$ \\
\hline $\mathrm{Pr}_{2} \mathrm{O}_{3}$ & 4.60 & 0.16 & 4.61 & 0.16 & S8.1 \\
\hline $\mathrm{Rb}_{2} \mathrm{O}$ & 2.30 & 0.08 & 2.31 & 0.08 & S8.1 \\
\hline $\mathrm{Rh}_{2} \mathrm{O}_{3}$ & 2.30 & 0.08 & 2.31 & 0.08 & G2 \& actual waste \\
\hline $\mathrm{RuO}_{2}$ & 2.87 & 0.1 & 2.88 & 0.1 & G2 \& actual waste \\
\hline $\mathrm{Sb}_{2} \mathrm{O}_{3}$ & 11.49 & 0.4 & 11.53 & 0.4 & S8.1 \\
\hline $\mathrm{SnO}_{2}$ & 6.61 & 0.23 & 6.63 & 0.23 & G2 \& actual waste \\
\hline $\mathrm{Ta}_{2} \mathrm{O}_{5}$ & 0.29 & 0.01 & $0.00^{(\mathrm{d})}$ & $0.00^{(\mathrm{d})}$ & S8.1 \\
\hline $\mathrm{WO}_{3}$ & 3.45 & 0.12 & 3.46 & 0.12 & S8.1 \\
\hline $\mathrm{Y}_{2} \mathrm{O}_{3}$ & 2.30 & 0.08 & 2.30 & 0.08 & S8.1 \\
\hline Sum & 100.00 & 3.48 & 100.00 & 3.47 & (e) \\
\hline
\end{tabular}

(a) The maximum value of interest was achieved in a previous WTP HLW study.

(b) S8.1 refers to Specification 8.1 in Section C of the WTP Contract (DOE-ORP 2003).

(c) "G2 and actual waste" refers to calculations made with the WTP dynamic simulation flowsheet (G2) for actual waste compositions.

(d) $\mathrm{Ta}_{2} \mathrm{O}_{5}$ was inadvertently omitted from the compositions of the test matrix glasses, and thus was not included when the glasses were batched and melted.

(e) Not applicable. 
Table A.13. Glass Components Excluded from the HLW07 Study.

\begin{tabular}{|c|c|c|}
\hline Oxide & $\begin{array}{c}\text { Composition } \\
\text { (wt \%) }\end{array}$ & Basis for Exclusion $^{(a)}$ \\
\hline $\mathrm{Ag}_{2} \mathrm{O}$ & 0 & max (0.2) hit previously \\
\hline $\mathrm{As}_{2} \mathrm{O}_{5}$ & 0 & $\max (0.22)$ hit previously \\
\hline $\mathrm{BaO}$ & 0 & $\max (0.1)$ hit previously \\
\hline $\mathrm{Bi}_{2} \mathrm{O}_{3}$ & 0 & $\max (0.05)$ hit previously \\
\hline $\mathrm{MgO}$ & 0 & $\max (1.39)$ approached (1.36) previously \\
\hline $\mathrm{Nd}_{2} \mathrm{O}_{3}$ & 0 & $\max (0.79)$ hit previously \\
\hline $\mathrm{PdO}$ & 0 & $\max (0.11)$ hit previously \\
\hline $\mathrm{SeO}_{2}$ & 0 & $\max (0.4)$ hit previously \\
\hline $\mathrm{TeO}_{2}$ & 0 & $\max (0.07)$ hit previously \\
\hline $\mathrm{TiO}_{2}$ & 0 & $\max (0.15)$ hit previously \\
\hline $\mathrm{Tl}_{2} \mathrm{O}$ & 0 & $\max (0.19)$ hit previously \\
\hline $\mathrm{V}_{2} \mathrm{O}_{5}$ & 0 & $\max (0.03)$ hit previously \\
\hline
\end{tabular}

(a) The maximum value of interest for each component was achieved or approached in a previous WTP HLW study.

Table A.14. Property Constraints Used to Define Both the Outer and Inner Layers of the EGCR for the HLW07 Study.

\begin{tabular}{|l||c|c|c|c||}
\hline \multicolumn{1}{|l||}{ Property } & \multicolumn{1}{|c|}{$\begin{array}{c}\text { Property-Composition } \\
\text { Model }\end{array}$} & $\begin{array}{c}\text { Lower } \\
\text { Limit }\end{array}$ & $\begin{array}{c}\text { Upper } \\
\text { Limit }\end{array}$ \\
\hline \hline Spinel $\mathrm{T}_{1 \%}\left(\mathrm{~T}_{1 \%}\right)$ & Model in Table 6.8 of Kot et al. $(2005 \mathrm{a})$ & ${ }^{\circ} \mathrm{C}$ & None & $1000^{\circ} \mathrm{C}$ \\
\hline Viscosity at $1150^{\circ} \mathrm{C}\left(\eta_{1150}\right)$ & Model 16 in Table 8 of Gan et al. $(2004)$ & poise & $10^{(\mathrm{a})}$ & 100 \\
\hline $\begin{array}{l}\text { Electrical Conductivity at } \\
1150^{\circ} \mathrm{C}\left(\varepsilon_{1150}\right)\end{array}$ & Model 5 in Table 10 of Gan et al. $(2004)$ & $\mathrm{S} / \mathrm{cm}$ & 0.2 & $0.7^{(\mathrm{b})}$ \\
\hline
\end{tabular}

(a) On the inner layer of the HLW07 EGCR, this lower limit on viscosity could not be achieved. The minimum model-predicted viscosity value over all vertices of the inner layer was 13.34 poise.

(b) On the inner layer of the HLW07 EGCR, this upper limit on electrical conductivity could not be achieved. The maximum model-predicted electrical conductivity value over all vertices of the inner layer was $0.463 \mathrm{~S} / \mathrm{cm}$. 
Table A.15. Property-Composition Models Used to Implement the Property Constraints in Table A.12 for the HLW07 Study.

\begin{tabular}{|c|c|c|c|c|c|}
\hline \multicolumn{6}{|c|}{$\begin{array}{c}\text { Property } \\
\text { Modeled Property } \\
\text { Units }\end{array}$} \\
\hline \multicolumn{2}{|c|}{$\mathrm{T}_{1 \%}$} & \multicolumn{2}{|c|}{$\eta_{1150}$} & \multicolumn{2}{|c|}{$\varepsilon_{1150}$} \\
\hline \multicolumn{2}{|c|}{$\mathrm{T}_{1 \%}$} & \multicolumn{2}{|c|}{$\ln \left(\eta_{1150}\right)$} & \multicolumn{2}{|c|}{$\ln \left(\varepsilon_{1150}\right)$} \\
\hline \multicolumn{2}{|c|}{${ }^{\circ} \mathrm{C}$} & \multicolumn{2}{|c|}{$\ln$ (poise) } & \multicolumn{2}{|c|}{$\ln (\mathrm{S} / \mathrm{cm})$} \\
\hline Model Term $^{(a)}$ & Coefficient & Model Term $^{(b)}$ & Coefficient & Model Term $^{(\mathrm{c})}$ & Coefficient \\
\hline Constant & $\mathrm{N} / \mathrm{A}^{(\mathrm{d})}$ & Constant & -2.37916 & Constant & $\mathrm{N} / \mathrm{A}^{(\mathrm{d})}$ \\
\hline $\mathrm{Al}_{2} \mathrm{O}_{3}$ & 3139.3911 & $\mathrm{Al}_{2} \mathrm{O}_{3} / \mathrm{T}^{2}$ & 309980.228 & $\mathrm{Al}_{2} \mathrm{O}_{3}$ & -0.035719 \\
\hline $\mathrm{B}_{2} \mathrm{O}_{3}$ & 16.8471 & $\mathrm{~B}_{2} \mathrm{O}_{3} / \mathrm{T}^{2}$ & -25524.485 & $\mathrm{~B}_{2} \mathrm{O}_{3}$ & 0.014964 \\
\hline $\mathrm{Cr}_{2} \mathrm{O}_{3}$ & 17827.9333 & $\mathrm{CdO} / \mathrm{T}^{2}$ & 101859.606 & $\mathrm{Fe}_{2} \mathrm{O}_{3}$ & -0.023870 \\
\hline $\mathrm{Fe}_{2} \mathrm{O}_{3}$ & 3616.2420 & $\mathrm{Cr}_{2} \mathrm{O}_{3} / \mathrm{T}^{2}$ & 1054196.628 & $\mathrm{Li}_{2} \mathrm{O}$ & 0.177034 \\
\hline $\mathrm{Li}_{2} \mathrm{O}$ & -1982.3832 & $\mathrm{Fe}_{2} \mathrm{O}_{3} / \mathrm{T}^{2}$ & 45087.363 & $\mathrm{MnO}$ & 0.017739 \\
\hline $\mathrm{MnO}$ & 2182.6998 & $\mathrm{Li}_{2} \mathrm{O} / \mathrm{T}^{2}$ & -603321.997 & $\mathrm{Na}_{2} \mathrm{O}$ & 0.053575 \\
\hline $\mathrm{Na}_{2} \mathrm{O}$ & -1177.8694 & $\mathrm{MnO} / \mathrm{T}^{2}$ & -1862.382 & $\mathrm{SiO}_{2}$ & 0.001441 \\
\hline $\mathrm{NiO}$ & 11230.9464 & $\mathrm{Na}_{2} \mathrm{O} / \mathrm{T}^{2}$ & -128973.946 & $\mathrm{SrO}$ & 0.045768 \\
\hline $\mathrm{SiO}_{2}$ & 573.8247 & $\mathrm{NiO} / \mathrm{T}^{2}$ & -34606.026 & $\mathrm{ZrO}_{2}$ & 0.041137 \\
\hline $\mathrm{SrO}$ & -164.6976 & $\mathrm{Sb}_{2} \mathrm{O}_{3} / \mathrm{T}^{2}$ & -80395.215 & $\mathrm{ZrO}_{2} / \mathrm{T}$ & -82.81435 \\
\hline $\mathrm{ThO}_{2}$ & 1659.3672 & $\mathrm{SeO}_{2} / \mathrm{T}^{2}$ & 423261.260 & $\mathrm{~B}_{2} \mathrm{O}_{3} / \mathrm{T}^{2}$ & -87316.319 \\
\hline $\mathrm{ZnO}$ & 3948.6108 & $\mathrm{SiO}_{2} / \mathrm{T}^{2}$ & 287011.241 & $\mathrm{MnO} / \mathrm{T}^{2}$ & -121107.017 \\
\hline \multirow[t]{3}{*}{$\mathrm{ZrO}_{2}$} & 2029.1022 & $\mathrm{SrO} / \mathrm{T}^{2}$ & 3437.917 & $\mathrm{SiO}_{2} / \mathrm{T}^{2}$ & -70295.405 \\
\hline & & $\mathrm{Tl}_{2} \mathrm{O} / \mathrm{T}^{2}$ & -145158.299 & $\mathrm{SrO} / \mathrm{T}^{2}$ & -120757.126 \\
\hline & & $\mathrm{ZrO}_{2} / \mathrm{T}^{2}$ & 228749.388 & & \\
\hline
\end{tabular}

(a) The spinel $\mathrm{T}_{1 \%}$ model is a reduced linear mixture model in which the components are expressed in normalized mass fraction values. The normalized mass fractions of the components for a given glass are obtained by dividing the original mass fractions of the components by the sum of the mass fractions of components in the model. This model is from Table 6.8 in Kot et al. (2005a).

(b) The $\ln \left(\eta_{1150}\right)$ model has a nonmixture-temperature form in which the components are expressed in original (unnormalized) wt $\%$ values. This model is from Gan et al. (2004)

(c) The $\ln \left(\varepsilon_{1150}\right)$ model has a mixture-temperature form in which the components are expressed in original (unnormalized) $\mathrm{wt} \%$ values. This model is from Gan et al. (2004)

(d) $\mathrm{N} / \mathrm{A}=$ not applicable, because a mixture-temperature model form was used. 
Table A.16. Multi-Component Constraints Used in Defining the Outer and Inner Layers of the EGCR for the HLW07 Test Matrix. ${ }^{(a)}$

\begin{tabular}{|c|c|c|c|c|c|}
\hline \multirow{3}{*}{$\begin{array}{c}\text { HLW07 } \\
\text { Component }\end{array}$} & Property & Waste Loading & $\mathbf{T}_{\mathbf{1} \%}$ & $\eta_{1150}$ & $\varepsilon_{1150}$ \\
\hline & $\begin{array}{l}\text { Modeled } \\
\text { Response }\end{array}$ & N/A & $\mathrm{T}_{1 \%}{ }^{(\mathbf{b})}$ & $\ln \left(\eta_{1150}\right)^{(b)}$ & $\ln \left(\varepsilon_{1150}\right)^{(b)}$ \\
\hline & Units & Mass Fraction & ${ }^{\circ} \mathbf{C}^{(\mathbf{b})}$ & $\ln (\text { poise })^{(\mathbf{b})}$ & $\ln (\mathrm{S} / \mathrm{cm})^{(\mathbf{b})}$ \\
\hline \multicolumn{2}{|l|}{$\mathrm{Al}_{2} \mathrm{O}_{3}$} & 1 & -0.12713332 & 0.29404403 & -0.20176350 \\
\hline \multicolumn{2}{|l|}{$\mathrm{B}_{2} \mathrm{O}_{3}$} & $-{ }^{(\mathrm{c})}$ & 0.05842386 & -0.02421226 & -0.15899545 \\
\hline \multicolumn{2}{|l|}{$\mathrm{Cr}_{2} \mathrm{O}_{3}$} & - & -1.00000000 & 1.00000000 & - \\
\hline \multicolumn{2}{|l|}{$\mathrm{Fe}_{2} \mathrm{O}_{3}$} & 1 & -0.15547019 & 0.04276941 & -0.13483286 \\
\hline \multicolumn{2}{|l|}{$\mathrm{Li}_{2} \mathrm{O}$} & - & 0.17722813 & -0.57230594 & 1.00000000 \\
\hline \multicolumn{2}{|l|}{$\mathrm{MnO}$} & - & -0.07028194 & -0.00176664 & -0.23756115 \\
\hline \multicolumn{2}{|l|}{$\mathrm{Na}_{2} \mathrm{O}$} & - & 0.12941990 & -0.12234335 & 0.30262548 \\
\hline \multicolumn{2}{|l|}{$\mathrm{NiO}$} & - & -0.60797403 & -0.03282692 & - \\
\hline \multicolumn{2}{|l|}{$\mathrm{SiO}_{2}$} & - & 0.02532547 & 0.27225589 & -0.18791136 \\
\hline \multicolumn{2}{|l|}{$\mathrm{SrO}$} & - & 0.06921216 & 0.00326117 & -0.07826011 \\
\hline \multicolumn{2}{|l|}{$\mathrm{ThO}_{2}$} & - & -0.03918290 & - & - \\
\hline \multicolumn{2}{|l|}{$\mathrm{UO}_{3}$} & - & - & - & - \\
\hline \multicolumn{2}{|l|}{$\mathrm{ZnO}$} & - & -0.17522121 & - & - \\
\hline \multicolumn{2}{|l|}{$\mathrm{ZrO}_{2}$} & 1 & -0.06115440 & 0.21698930 & -0.09633121 \\
\hline \multicolumn{2}{|l|}{ Others1 } & - & - & - & - \\
\hline \multicolumn{2}{|l|}{ Others2 } & - & - & - & - \\
\hline \multicolumn{2}{|l|}{ Constant } & - & - & - & - \\
\hline & $\begin{array}{c}\text { Lower } \\
\text { Limit }\end{array}$ & 0.18 & None & 0.08946405 & -0.09091135 \\
\hline & $\begin{array}{l}\text { Upper } \\
\text { Limit }\end{array}$ & None & 0 & 0.13370210 & -0.02014698 \\
\hline
\end{tabular}

(a) The multi-component constraints listed in this table are expressed using mass fractions of the HLW glass components. In cases where these constraints were previously expressed using $\mathrm{wt} \%$ values, the appropriate conversions were made.

(b) Constraints implemented from the inputs in Tables A.14 and A.15 were re-expressed and normalized by dividing all constraint coefficients by the largest (in absolute value) constraint. This process resulted in equivalent constraints with the largest (in absolute value) coefficient being one. See Section A.4.6 for detailed discussion. Also, note that the large number of decimal places in coefficients of the constraints is to maintain the equivalency between the constraints before and after the re-expression and normalization.

(c) A "-“" indicates that the component was not involed in the constraint (i.e., the component's coefficient in the constraint is zero). 
Table A.17. 18-Component Target Glass Compositions (wt\%) for the 125 Existing HLW Glasses Augmented by the HLW07 Test Matrix.

\begin{tabular}{|c|c|c|c|c|c|c|c|c|c|c|c|c|c|c|c|c|c|c|c|c|}
\hline Glass ID $^{(a)}$ & Point Type ${ }^{(\mathrm{b})}$ & \begin{tabular}{|l|}
$\mathbf{A l}_{2} \mathbf{O}_{3}$ \\
\end{tabular} & $\mathbf{B}_{2} \mathbf{O}_{3}$ & $\mathrm{Cr}_{2} \mathrm{O}_{3}$ & $\mathrm{Fe}_{2} \mathrm{O}_{3}$ & $\mathbf{L i}_{2} \mathbf{O}$ & MnO & $\mathrm{Na}_{2} \mathrm{O}$ & $\mathrm{NiO}$ & $\mathrm{SiO}_{2}$ & SrO & $\mathrm{ThO}_{2}$ & $\mathrm{UO}_{3}$ & $\mathrm{ZnO}$ & $\mathrm{ZrO}_{2}$ & Others1 & Others2 & Constant & Remain & Sum ${ }^{(\mathrm{c})}$ \\
\hline \begin{tabular}{|l} 
HLW02-01 \\
\end{tabular} & Ph1a.Center & 6.171 & 9.927 & 0.108 & \begin{tabular}{|l|}
10.899 \\
\end{tabular} & 3.996 & 2.385 & 10.957 & 0.518 & \begin{tabular}{|l|}
43.612 \\
\end{tabular} & 2.444 & 0.000 & 0.000 & 2.000 & 2.974 & 0.600 & 1.051 & 1.407 & 0.951 & 100.000 \\
\hline HLW02-02 & Ph1a.OL01 & 3.999 & 13.996 & 0.199 & \begin{tabular}{|l|}
13.996 \\
\end{tabular} & 5.998 & 0.000 & 3.999 & 0.100 & \begin{tabular}{|l|}
50.445 \\
\end{tabular} & 0.000 & 0.000 & 0.000 & 1.999 & 0.000 & 0.600 & 2.010 & 1.497 & 1.160 & 100.000 \\
\hline HLW02-03 & Ph1a.OL02 & 3.999 & 13.998 & 0.199 & 7.999 & 2.000 & 0.000 & 14.998 & 1.000 & \begin{tabular}{|l|}
37.994 \\
\end{tabular} & 4.379 & 0.000 & 0.000 & 2.000 & 5.999 & 0.600 & 2.011 & 1.317 & 1.508 & 100.000 \\
\hline $\begin{array}{l}\text { HLW02-04 } \\
\end{array}$ & Ph1a.OL03 & 4.001 & 5.001 & 0.020 & 14.002 & 2.000 & 0.518 & 15.002 & 0.100 & \begin{tabular}{|l|}
52.939 \\
\end{tabular} & 0.000 & 0.000 & 0.000 & 2.000 & 0.000 & 0.600 & 1.560 & 1.498 & 0.759 & 100.000 \\
\hline \begin{tabular}{|l} 
HLW02-06 \\
\end{tabular} & $\mathrm{Ph} 1$ & 8.501 & 5.001 & 0.020 & 8.001 & 4.740 & 5.001 & 15.002 & 1.000 & \begin{tabular}{|l|}
40.496 \\
\end{tabular} & 0.000 & 0.000 & 0.000 & 2.000 & 6.001 & 0.600 & 1.560 & 1.318 & 0.759 & 100.000 \\
\hline HLV & & .499 & 4.999 & .199 & 7.999 & 5.999 & 0.000 & 11.703 & 0.100 & 52.992 & 0.000 & 0.000 & 0.000 & 2.000 & 1.525 & .600 & 0.561 & 1.497 & 328 & 100.000 \\
\hline HLV & $\mathrm{P}$ & 4.000 & 14.000 & 0.020 & 9.205 & 3.310 & 5.000 & 15.000 & 0.100 & \begin{tabular}{|l|}
38.744 \\
\end{tabular} & 0.000 & 0.000 & 0.000 & 2.000 & 6.000 & 0.600 & .110 & 1.498 & 412 & .000 \\
\hline HLW & $\mathrm{P}$ & 8.500 & 11.589 & 020 & 14.000 & 2.271 & 0.000 & 15.000 & 1.000 & 38.000 & 5.000 & 0.000 & 0.000 & 2.000 & 0.000 & 0.600 & .110 & 1.498 & .412 & 0.000 \\
\hline HLW & & 8.500 & 14.000 & 0.020 & 8.000 & 6.000 & 0.000 & 10.513 & 0.100 & 38.000 & 2.797 & 0.000 & 0.000 & 2.000 & 6.000 & 0.600 & .560 & 1.318 & 592 & .000 \\
\hline \begin{tabular}{|l} 
HLW02-11 \\
\end{tabular} & $\mathrm{Ph} 1$ & 4.001 & 14.002 & 0.020 & 8.001 & 6.001 & 0.000 & 10.858 & 1.000 & \begin{tabular}{|l|}
45.149 \\
\end{tabular} & 0.000 & 0.000 & 0.000 & 2.000 & 6.001 & 0.600 & 0.110 & 1.498 & 0.759 & 100.000 \\
\hline HLW02-12 & \begin{tabular}{|l} 
Ph1a.OL11 \\
\end{tabular} & 3.999 & 4.999 & 0.199 & \begin{tabular}{|l|}
11.382 \\
\end{tabular} & 5.998 & 4.999 & 12.757 & 1.000 & \begin{tabular}{|l|}
41.402 \\
\end{tabular} & 0.000 & 0.000 & 0.000 & 1.999 & 5.998 & 0.600 & 2.010 & 1.317 & 1.340 & 100.000 \\
\hline HLW02-13 & Ph1a.OL12 & 3.999 & 4.999 & 0.199 & 13.998 & 5.999 & 4.999 & 10.425 & 0.100 & 43.114 & 4.999 & 0.000 & 0.000 & 2.000 & 1.182 & 0.600 & 0.561 & 1.317 & 1.508 & 100.000 \\
\hline \begin{tabular}{|l|} 
HLW02-14 \\
\end{tabular} & & 4.001 & 5.001 & 0.020 & 8.001 & 6.001 & 2.490 & 4.141 & 0.100 & \begin{tabular}{|l|}
53.007 \\
\end{tabular} & 5.001 & 0.000 & 0.000 & 2.000 & 6.001 & 0.600 & 1.560 & 1.498 & 0.579 & 100.000 \\
\hline$\overline{\mathrm{HL}}$ & $\mathrm{Pl}$ & 8.499 & 13.998 & 0.199 & \begin{tabular}{|l|}
13.998 \\
\end{tabular} & 2.000 & 4.688 & 12.539 & 0.100 & \begin{tabular}{|l|}
37.994 \\
\end{tabular} & 0.000 & 0.000 & 0.000 & 2.000 & 0.000 & .600 & .561 & 1.317 & 508 & 000 \\
\hline HL & & .498 & 4.999 & 199 & 7.998 & 5.998 & 4.999 & 9.651 & 0.100 & 39.115 & 4.999 & 0.000 & 0.000 & 1.999 & 5.998 & 0.600 & 2.010 & 1.497 & 340 & .000 \\
\hline-17 & $\mathrm{P}$ & 8.500 & 5.000 & 020 & 13.843 & 6.000 & 0.000 & 7.690 & 0.100 & \begin{tabular}{|l|}
52.958 \\
\end{tabular} & 0.000 & 0.000 & 0.000 & 2.000 & 0.000 & .600 & .560 & 1.318 & 112 & 000 \\
\hline HLV & $\mathrm{Pl}$ & 3.999 & 4.999 & 199 & 11.126 & 2.013 & 0.000 & 14.996 & 1.000 & \begin{tabular}{|l|}
49.852 \\
\end{tabular} & 0.000 & 0.000 & 0.000 & 1.999 & 5.998 & .600 & .561 & 1.497 & .160 & .000 \\
\hline HLW02-19 & Ph1a & 4.000 & 14.000 & 0.020 & 10.781 & 2.000 & 5.000 & 8.849 & 0.100 & 38.000 & 5.000 & 0.000 & 0.000 & 2.000 & 6.000 & 0.600 & 1.560 & 1.498 & .592 & 100.000 \\
\hline \begin{tabular}{|l|} 
HLW02-20R1 \\
\end{tabular} & Ph1a.OL19 & 4.000 & 14.000 & 0.020 & 14.000 & 2.000 & 0.000 & 6.453 & 0.100 & \begin{tabular}{|l|}
51.734 \\
\end{tabular} & 3.253 & 0.000 & 0.000 & 2.000 & 0.000 & 0.600 & 0.110 & 1.318 & 0.412 & 100.000 \\
\hline HLW02-22 & Ph1a.OL21 & 8.500 & 14.000 & 0.020 & 9.500 & 6.000 & 0.000 & 4.000 & 0.100 & 53.000 & 0.080 & 0.000 & 0.000 & 2.000 & 0.000 & 0.600 & 0.110 & 1.498 & 0.592 & 100.000 \\
\hline HLW02-23R1 & $\mathrm{Ph} 1$ & 8.501 & 14.002 & 0.020 & 8.001 & 6.001 & 5.001 & 5.591 & 1.000 & 39.325 & 5.001 & 0.000 & 0.000 & 2.000 & 1.500 & 0.600 & 1.560 & 1.318 & .579 & 100.000 \\
\hline HLV & $\mathrm{Ph} 1$ & 8.498 & 4.999 & 3 & 7.998 & 2.000 & 4.999 & 12.195 & 0.100 & \begin{tabular}{|l|}
47.052 \\
\end{tabular} & 4.999 & 0.000 & 0.000 & 2.000 & 1.500 & 0.600 & .444 & 317 & 147 & 0.000 \\
\hline $25 \mathrm{R} 1$ & & 501 & 14.002 & 0.020 & 9.501 & 2.000 & .355 & 6.884 & 0.100 & \begin{tabular}{|l|}
47.398 \\
\end{tabular} & 5.001 & 0.000 & 0.000 & 2.000 & 0.000 & 0.600 & 1.560 & 1.498 & 579 & 000 \\
\hline 26 & & .999 & 4.999 & 199 & 12.498 & 2.000 & 959 & 14.998 & 0.100 & 37.994 & 4.999 & 0.000 & 0.000 & 2.000 & 5.999 & 0.600 & 2.011 & 1.317 & 328 & 000 \\
\hline 27 & $\mathrm{P}$ & .001 & 14.002 & 020 & 12.502 & 6.001 & 3.366 & 4.275 & 0.100 & 39.946 & 5.001 & 0.000 & 0.000 & 2.000 & 6.001 & .600 & .110 & 1.318 & .759 & .000 \\
\hline HLW & $\mathrm{P}$ & 7.500 & 8.000 & 0.040 & \begin{tabular}{|l|}
10.451 \\
\end{tabular} & 2.500 & 1.500 & 15.001 & 0.300 & \begin{tabular}{|l|}
41.003 \\
\end{tabular} & 3.500 & 0.000 & 0.000 & 2.000 & 4.500 & 0.600 & 1.110 & 1.348 & .646 & 100.000 \\
\hline HLW02-29R1 & Ph1a.IL02 & 7.499 & 12.998 & 0.133 & 9.998 & 3.749 & 1.500 & 8.999 & 0.300 & 40.994 & 3.499 & 0.000 & 0.000 & 2.000 & 4.499 & 0.600 & 0.844 & 1.347 & 1.041 & 100.000 \\
\hline HLW02-30 & Ph1a.IL03 & 5.500 & 9.721 & 0.040 & 10.000 & 5.000 & 3.500 & 11.228 & 0.300 & 41.000 & 3.500 & 0.000 & 0.000 & 2.000 & 4.500 & 0.600 & 1.110 & 1.448 & 0.553 & 100.000 \\
\hline HLW02-31 & Ph1a.IL04 & 5.500 & 13.001 & 0.040 & 10.001 & 2.500 & 1.500 & 14.982 & 0.300 & 41.003 & 1.500 & 0.000 & 0.000 & 2.000 & 4.369 & 0.600 & 0.610 & 1.348 & 0.746 & 100.000 \\
\hline HLW02-32R1 & Ph1a.IL05 & 7.500 & 8.000 & 0.040 & 10.000 & 5.000 & 1.500 & 10.733 & 0.300 & \begin{tabular}{|l|}
46.117 \\
\end{tabular} & 3.500 & 0.000 & 0.000 & 2.000 & 1.500 & 0.600 & 1.110 & 1.448 & 0.653 & 100.000 \\
\hline \begin{tabular}{|l|} 
HLW02-33 \\
\end{tabular} & Ph1a.IL06 & 6.341 & 8.000 & 0.040 & 12.000 & 2.500 & 3.500 & 15.000 & 0.800 & 41.000 & 3.500 & 0.000 & 0.000 & 2.000 & 2.009 & 0.600 & 0.610 & 1.448 & 0.653 & 100.000 \\
\hline HLV & Ph1a.IL07 & 5.499 & 12.998 & 0.133 & 11.998 & 3.957 & 1.500 & 10.891 & 0.800 & 40.994 & 3.499 & 0.000 & 0.000 & 2.000 & 1.500 & 0.600 & 1.344 & 1.347 & 0.941 & 100.000 \\
\hline HLW02-35 & Ph1a.IL08 & 6.488 & 12.999 & 0.133 & 11.999 & 5.000 & 3.500 & 9.160 & 0.800 & 40.996 & 1.500 & 0.000 & 0.000 & 2.000 & 1.500 & 0.600 & 0.844 & 1.448 & 1.034 & 100.000 \\
\hline
\end{tabular}

(a) R1 after a Glass ID indicates the glass batching, melting, and testing was repeated.

(b) The "Point Type" notation begins with an abbreviation of the HLW study phase (e.g., Ph1a denotes Phase 1a). After a separating dot, the notation continues (when appropriate) with "Center", "OL", or "IL", denoting whether the glass was a center point, outer-layer point, or inner-layer point. The "Center", "OL", or "IL" designation is with respect to the given study phase. Next, "XX" denotes the number of each outer-layer, inner-layer, or other point with respect to the given study phase. Replicate points are denoted by "Rep.HLW02-xx" and "Rep.HLW03-xx", where the "xx" represents a specific ID number for a replicated glass.

(c) The wt\% values in the table are rounded to three decimal places and may not sum to 100.000 exactly, but the sum is achieved in the data base. 
Table A.17. 18-Component Target Glass Compositions (wt\%) for the 125 Existing HLW Glasses Augmented by the HLW07 Test Matrix (continued).

\begin{tabular}{|c|c|c|c|c|c|c|c|c|c|c|c|c|c|c|c|c|c|c|c|c|}
\hline Glass ID $^{(\mathrm{a})}$ & Point Type $^{(b)}$ & $\mathbf{A l}_{2} \mathbf{O}_{3}$ & $\mathbf{B}_{2} \mathbf{O}_{3}$ & $\mathrm{Cr}_{2} \mathrm{O}_{3}$ & $\mathrm{Fe}_{2} \mathbf{O}_{3}$ & $\mathbf{L i}_{2} \mathbf{O}$ & MnO & $\mathrm{Na}_{2} \mathrm{O}$ & $\mathrm{NiO}$ & $\mathrm{SiO}_{2}$ & SrO & $\mathrm{ThO}_{2}$ & $\mathrm{UO}_{3}$ & $\mathrm{ZnO}$ & $\mathrm{ZrO}_{2}$ & Others1 & \begin{tabular}{|l|} 
Others2 \\
\end{tabular} & Constant & Remain & Sum ${ }^{(c)}$ \\
\hline HLW02-36 & Ph1a.IL09 & 5.499 & 8.667 & 0.133 & 11.998 & 2.500 & 1.500 & 14.998 & 0.300 & 45.074 & 1.500 & 0.000 & 0.000 & 2.000 & 1.500 & 0.600 & 1.344 & 1.347 & 1.041 & 100.000 \\
\hline $02-37$ & Ph1a.IL10 & 762 & 13.000 & 040 & 10.000 & 2.500 & 3.500 & 11.188 & 800 & 41.000 & 1.500 & 0.000 & 0.000 & 2.000 & 4.500 & 0.600 & 610 & 1.448 & .553 & 100.000 \\
\hline $02-38$ & $\mathrm{Phl}$ & 893 & 12.998 & 133 & 11.998 & 4.255 & 1.500 & 8.999 & .800 & 40.994 & 3.499 & 0.000 & 0.000 & 2.000 & 1.500 & 0.600 & 344 & 1.447 & .041 & 100.000 \\
\hline HLW02-39 & Ph1a.IL12 & .500 & 8.991 & 0.040 & 10.000 & 2.500 & 1.500 & 11.058 & 0.800 & 49.000 & 1.500 & 0.000 & 0.000 & $\begin{array}{l}2.000 \\
\end{array}$ & 1.500 & 0.600 & .110 & 1.348 & 0.553 & 100.000 \\
\hline HLW02-40 & Ph1a.IL13 & .499 & 9.833 & 0.133 & 9.999 & 2.632 & 1.500 & 9.683 & 0.300 & 48.996 & 1.500 & 0.000 & 0.000 & 2.000 & 1.500 & 0.600 & 1.344 & 1.448 & 1.034 & 100.000 \\
\hline HLW02-41 & & .500 & 13.001 & 0.040 & 10.001 & 2.500 & 1.500 & 9.001 & 0.300 & 48.953 & 1.500 & 0.000 & 0.000 & 2.000 & 1.500 & 0.600 & 0.610 & 1.348 & 0.646 & 0.000 \\
\hline-42 & & 500 & 13.001 & 0.040 & 10.001 & 5.000 & 500 & 9.001 & 0.300 & 44.453 & 3.500 & 0.000 & 0.000 & 2.000 & 2.500 & 600 & 610 & 348 & 646 & 0.000 \\
\hline 43 & & 00 & 13.000 & .040 & 10.000 & 500 & 500 & 2.450 & 00 & 41.000 & 00 & .000 & 000 & \begin{tabular}{|l|}
2.000 \\
\end{tabular} & 1.500 & 00 & 10 & 448 & 53 & .000 \\
\hline-44 & & 499 & 9.069 & 0.133 & 9.998 & 2.500 & 499 & 14.998 & .300 & 43.673 & 1.500 & 0.000 & 0.000 & 2.000 & 2.500 & 00 & 44 & .447 & 941 & 000 \\
\hline $2-45$ & & 500 & 8.000 & 0.040 & 11.000 & 2.500 & 500 & .619 & 0.300 & 48.831 & 3.500 & 0.000 & 0.000 & 2.000 & 1.500 & .600 & 110 & .348 & \begin{tabular}{l|l}
653 \\
\end{tabular} & 100 \\
\hline $2-46$ & $\mathrm{Ph} 1$ & 500 & 9.149 & 0.040 & 10.001 & 3.701 & 500 & .001 & 0.800 & 49.003 & 1.500 & .000 & 0.000 & 2.000 & 2.500 & 0.600 & 610 & 1.348 & .746 & 000 \\
\hline HLW02-47 & $\mathrm{Ph} 1$ & .499 & 9.806 & 0.133 & 9.999 & 2.500 & 3.500 & 9.443 & 0.300 & 48.996 & 1.500 & 0.000 & 0.000 & 2.000 & 2.500 & 0.600 & 844 & 1.348 & .034 & 100.000 \\
\hline $02-48$ & & 999 & 7.999 & 0.133 & 11.999 & 3.339 & 1.500 & 14.999 & 0.800 & 40.996 & 1.710 & 0.000 & 0.000 & \begin{tabular}{|l|}
2.000 \\
\end{tabular} & 4.500 & 0.600 & 844 & 1.448 & .134 & 100.000 \\
\hline $2-49$ & & 500 & 8.740 & 0.040 & 12.001 & 5.000 & 3.500 & 9.001 & 0.300 & 44.213 & 1.500 & 0.000 & 0.000 & 2.000 & 3.000 & 0.600 & 610 & 1.348 & .646 & 100.000 \\
\hline & & .000 & 13.001 & .040 & 12.001 & 2.500 & 1.500 & 9.821 & 0.300 & 43.532 & 1.500 & 0.000 & 0.000 & 2.000 & $\begin{array}{l}4.500 \\
\end{array}$ & 00 & 10 & 448 & 646 & 000 \\
\hline $51 \mathrm{R} 1$ & & 500 & 8.000 & 0 & 10.501 & 4.589 & 500 & 001 & 00 & 45.164 & 3.500 & 0.000 & 00 & 2.000 & 4.500 & & 10 & .448 & 746 & 00 \\
\hline 52 & $\mathrm{R}$ & 171 & 9.927 & .108 & 10.899 & 3.996 & 385 & 10.957 & 0.518 & 43.612 & 2.444 & 0.000 & 0.000 & \begin{tabular}{|l|}
2.000 \\
\end{tabular} & 2.974 & 600 & 51 & 407 & 951 & 000 \\
\hline-53 & $\mathrm{R}$ & 500 & 5.000 & 020 & 13.843 & 6.000 & .000 & 7.690 & .100 & 52.958 & 0.000 & 0.000 & 0.000 & 2.000 & 0.000 & 0.600 & 560 & .318 & 412 & 000 \\
\hline-54 & $\mathrm{R}$ & 001 & 5.001 & 0.020 & 14.002 & 2.000 & 518 & 15.002 & .100 & 52.939 & 0.000 & 0.000 & 0.000 & 2.000 & 0.000 & 0.600 & .560 & 1.498 & .759 & 100.000 \\
\hline $2-55$ & No & 5.500 & 13.001 & 0.040 & 10.001 & 5.000 & 1.500 & 9.001 & 0.300 & 44.453 & 3.500 & 0.000 & 0.000 & 2.000 & 2.500 & 0.600 & .610 & 1.348 & .646 & 100.000 \\
\hline HLW02-56 & $\mathrm{VO}$ & 5.499 & 9.069 & 0.133 & 9.998 & 2.500 & 3.499 & 14.998 & 0.300 & 43.673 & 1.500 & 0.000 & 0.000 & 2.000 & 2.500 & 0.600 & .344 & 1.447 & .941 & 100.000 \\
\hline HLW02-57 & W02-8 & .000 & 14.000 & .020 & 9.205 & 3.310 & 5.000 & 15.000 & 0.100 & 38.744 & 0.000 & 0.000 & 0.000 & 2.000 & 6.000 & 0.600 & .110 & 1.498 & .412 & 100.000 \\
\hline 3-01 & 1 & 8.335 & 13.727 & 0.020 & 13.727 & 5.883 & 6.078 & 3.922 & 0.098 & 35.299 & 0.000 & 2.764 & 0.000 & 3.059 & 2.983 & 0.600 & .560 & 1.318 & 1.629 & 100.000 \\
\hline-02 & & 1.951 & 13.662 & 488 & 13.662 & 2.473 & 6.832 & 11.177 & 0.976 & 35.132 & 0.000 & 0.000 & 0.000 & 0.000 & 9.088 & 600 & 660 & .598 & 700 & 100.000 \\
\hline & & 953 & 4.884 & 0.488 & 13.677 & 2.678 & .839 & 10.755 & 0.977 & 35.169 & 9.769 & 0.000 & 0.000 & 1.946 & 6.404 & 0.600 & 60 & 18 & 880 & 000 \\
\hline & & 954 & 4.886 & 38 & 13.680 & 5.862 & 3.161 & 4.442 & 0.098 & 42.425 & 9.771 & 0.000 & 6.210 & 0.000 & 2.932 & 0.598 & 58 & 13 & \begin{tabular}{l|l}
623 \\
\end{tabular} & 000 \\
\hline-05 & & 175 & 4.809 & 81 & 1.924 & 1.924 & .733 & 14.427 & 0.096 & 47.837 & 0.000 & 3.812 & 0.000 & 3.847 & 0.000 & 0.600 & 2.110 & 1.598 & 1.629 & 100.000 \\
\hline $3-06$ & & 344 & 4.908 & 491 & 1.963 & 5.890 & 872 & 3.927 & 0.982 & 52.031 & 5.091 & 1.416 & 0.000 & 0.000 & 4.095 & 0.600 & 1.660 & 1.318 & 0.412 & 100.000 \\
\hline 3-07 & $\mathrm{P}$ & 961 & 4.961 & 496 & 13.891 & 4.750 & 945 & 11.693 & 0.100 & 39.825 & 0.000 & 0.000 & 6.306 & 3.461 & 0.000 & 0.598 & 0.110 & 1.313 & 0.590 & 100.000 \\
\hline W03-08 & 08 & 031 & 4.833 & 0.483 & 1.933 & 5.151 & 6.766 & 14.499 & 0.097 & 34.797 & 0.000 & 4.412 & 0.000 & 3.866 & 9.666 & 0.600 & 2.109 & 1.597 & 1.161 & 100.000 \\
\hline HLW03-10R1 & Ph1b.OL10 & 369 & 4.924 & 0.020 & 9.982 & 5.908 & 6.893 & 12.851 & 0.985 & 35.449 & 0.000 & 2.626 & 1.108 & 0.000 & 7.250 & 0.599 & 0.559 & 1.316 & 1.160 & 100.000 \\
\hline HLW03-12 & Ph1b.OL12 & 1.982 & 4.956 & 0.495 & 1.982 & 5.008 & 6.939 & 3.965 & 0.099 & 44.277 & 9.912 & 3.729 & 6.299 & 3.965 & 3.682 & 0.598 & 0.110 & 1.592 & \begin{tabular}{l|l|}
0.410 \\
\end{tabular} & 100.000 \\
\hline HLW03-13 & Ph1b.OL13 & 8.433 & 4.961 & 0.496 & 8.633 & 5.209 & 6.945 & 3.969 & 0.992 & 35.719 & 9.922 & 3.836 & 6.306 & 1.121 & 0.846 & 0.598 & 0.110 & 1.313 & 0.590 & 100.000 \\
\hline
\end{tabular}

(a) R1 after a Glass ID indicates the glass batching, melting, and testing was repeated.

(b) The "Point Type" notation begins with an abbreviation of the HLW study phase (e.g., Phla denotes Phase 1a). After a separating dot, the notation continues (when appropriate) with "Center", "OL", or "IL", denoting whether the glass was a center point, outer-layer point, or inner-layer point. The "Center", "OL", or "IL" designation is with respect to the given study phase. Next, "XX" denotes the number of each outer-layer, inner-layer, or other point with respect to the given study phase. Replicate points are denoted by "Rep.HLW02-xx" and "Rep.HLW03-xx", where the "xx" represents a specific ID number for a replicated glass.

(c) The wt $\%$ values in the table are rounded to three decimal places and may not sum to 100.000 exactly, but the sum is achieved in the data base. 
Table A.17. 18-Component Target Glass Compositions (wt\%) for the 125 Existing HLW Glasses Augmented by the HLW07 Test Matrix (continued).

\begin{tabular}{|c|c|c|c|c|c|c|c|c|c|c|c|c|c|c|c|c|c|c|c|c|}
\hline Glass ID $^{(\mathrm{a})}$ & Point Type $^{(\text {b) }}$ & $\mathbf{A l}_{2} \mathbf{O}_{3}$ & $\mathbf{B}_{2} \mathbf{O}_{3}$ & $\mathrm{Cr}_{2} \mathrm{O}_{3}$ & $\mathbf{F e}_{2} \mathrm{O}_{3}$ & $\mathbf{L i}_{2} \mathbf{O}$ & MnO & $\mathrm{Na}_{2} \mathrm{O}$ & $\mathrm{NiO}$ & $\mathrm{SiO}_{2}$ & SrO & $\mathrm{ThO}_{2}$ & $\mathrm{UO}_{3}$ & $\mathrm{ZnO}$ & $\mathrm{ZrO}_{2}$ & \begin{tabular}{|l|} 
Others1 \\
\end{tabular} & \begin{tabular}{|l|} 
Others2 \\
\end{tabular} & Constant & Remain & Sum $^{(\mathbf{c})}$ \\
\hline HLW03-14 & h1b.OL14 & 1.989 & 4.973 & 0.020 & 9.047 & 2.504 & 6.962 & 10.425 & 0.994 & 35.806 & 9.946 & 4.115 & 0.000 & 3.979 & 6.511 & 0.600 & 0.110 & 1.318 & 0.700 & 100.000 \\
\hline HLW03-15 & $11 \mathrm{~b} . \mathrm{OL} 15$ & 951 & 13.662 & 020 & 13.662 & 1.951 & 1.348 & 5.248 & 0.098 & 51.722 & 0.000 & 2.441 & 0.000 & 3.337 & 0.000 & 0.600 & 1.660 & 1.598 & 0.700 & 100.000 \\
\hline HLW03-16 & 16 & 955 & 4.886 & 0.020 & 7.905 & 2.862 & .840 & 3.909 & 0.977 & 44.240 & 9.772 & 2.568 & 6.210 & 2.772 & 1.001 & 0.598 & .558 & 1.592 & 1.336 & 100.000 \\
\hline HLW03-17 & $11 \mathrm{~b} . \mathrm{OL} 17$ & 8.352 & 13.757 & 0.020 & 1.965 & 1.965 & 6.879 & 4.461 & 0.293 & 46.088 & 0.000 & 2.237 & 4.784 & \begin{tabular}{|l|}
3.930 \\
\end{tabular} & 1.639 & 0.598 & 0.558 & 1.314 & 1.158 & 100.000 \\
\hline ALW03-18 & 1b.OL18 & 1.989 & 4.973 & 0.497 & 13.924 & 5.922 & 0.000 & 10.533 & 0.980 & 52.484 & 0.000 & 5.967 & 0.000 & 0.000 & 0.000 & 0.600 & 0.110 & 1.318 & 0.700 & 100.000 \\
\hline $03-19$ & 1b.OL19 & 1.963 & 4.908 & 0.491 & 9.634 & 5.890 & 0.197 & 10.142 & 0.982 & 52.030 & 0.000 & 5.846 & 0.000 & 3.927 & 0.000 & 0.600 & 1.660 & 1.318 & 0.412 & 00.000 \\
\hline & & 1.923 & 4.808 & 0.019 & 13.462 & 5.769 & 0.000 & 10.097 & 0.962 & 50.681 & 0.145 & 5.769 & 0.430 & $\begin{array}{l}0.000 \\
\end{array}$ & 0.000 & 0.600 & 109 & 597 & 529 & 100.000 \\
\hline $\mathrm{HL}$ & & 958 & 6.941 & .079 & 4.958 & 2.479 & 4.462 & 10.828 & 0.298 & 48.587 & 1.487 & 2.975 & 2.100 & \begin{tabular}{l|l|}
0.992 \\
\end{tabular} & 5.949 & 99 & 410 & 346 & 52 & 0.000 \\
\hline 22 & & 915 & 6.881 & 0.079 & 9.752 & 2.458 & 1.474 & 11.797 & 0.295 & 40.304 & 4.424 & 2.949 & 4.165 & 0.983 & 5.898 & 99 & 643 & 344 & 41 & 000 \\
\hline 23 & $\mathrm{P}$ & 957 & 11.897 & 0.199 & 7.733 & 2.478 & 1.487 & 11.897 & .297 & 40.648 & 1.487 & 2.974 & 4.201 & .992 & 5.949 & 599 & 210 & 345 & 651 & 000 \\
\hline $33-24$ & 4 & 975 & 6.941 & 0.079 & 4.958 & 4.958 & 4.462 & 8.151 & 0.495 & 48.588 & 1.487 & 2.975 & 2.100 & \begin{tabular}{|l|l|}
2.975 \\
\end{tabular} & 5.949 & 0.599 & 410 & 1.346 & 552 & 100.000 \\
\hline HLW03-25 & 5 & 2.956 & 11.823 & 0.079 & 4.927 & 2.463 & 1.478 & 11.823 & 0.492 & 42.090 & 4.433 & 2.956 & 2.087 & 2.956 & 5.912 & 0.599 & .444 & 1.346 & 1.135 & 100.000 \\
\hline HLW03-26 & & 4.921 & 6.889 & 0.197 & 4.921 & 4.921 & 1.476 & 10.431 & 0.492 & 40.345 & 4.428 & 4.428 & 4.169 & \begin{tabular}{|l|}
2.953 \\
\end{tabular} & 5.904 & .598 & 443 & 1.444 & 1.041 & 100.000 \\
\hline $3-27$ & & 4.926 & 6.897 & 0.197 & 9.359 & 4.040 & 1.478 & 11.822 & 0.492 & 40.393 & 1.478 & 4.433 & 2.087 & 2.956 & 5.911 & 0.599 & .444 & 1.446 & 1.042 & 100.000 \\
\hline & & 3.629 & 11.911 & 0.080 & 9.926 & 4.963 & 1.489 & 10.486 & 0.496 & 40.695 & 1.489 & 2.977 & 2.103 & 0.993 & 5.956 & 599 & 210 & 446 & 552 & .000 \\
\hline & & 971 & 6.933 & 199 & 4.952 & 4.952 & 3.518 & 11.885 & 0.297 & 40.606 & 1.485 & 4.456 & 4.196 & 2.971 & 7.674 & 99 & 409 & 345 & 52 & 000 \\
\hline 30 & & 972 & 11.888 & 0.079 & 4.953 & 4.953 & 4.458 & 6.934 & 0.298 & 43.203 & 1.486 & 4.458 & 2.098 & $\mid$ & 8.229 & 599 & 210 & .446 & 745 & 000 \\
\hline 31 & $\mathrm{Ph} 1$ & 953 & 6.934 & .198 & 4.953 & 4.953 & 4.458 & 8.533 & 0.495 & 45.058 & 1.486 & 2.972 & 2.098 & 0.991 & 8.915 & 0.599 & 210 & 1.446 & .745 & 100.000 \\
\hline-32 & Ph11 & 921 & 6.889 & 0.079 & 4.921 & 4.921 & 2.925 & 9.101 & 0.492 & 40.348 & 1.476 & 4.428 & 4.170 & 2.953 & 8.857 & 0.599 & 444 & 1.444 & .034 & 100.000 \\
\hline $3-33$ & Ph1b.IL13 & 4.960 & 11.902 & 0.199 & 9.919 & 3.898 & 1.488 & 6.943 & 0.451 & 40.667 & 1.488 & 2.975 & 3.378 & 2.975 & 5.952 & 0.599 & .210 & 1.445 & 0.552 & 100.000 \\
\hline HLW03-34 & Ph1b.IL14 & 2.956 & 6.897 & 0.197 & 9.853 & 2.463 & 1.478 & 9.541 & 0.492 & 48.278 & 1.478 & 3.858 & 2.087 & 0.986 & 5.912 & 0.599 & .444 & 1.346 & 1.135 & 100.000 \\
\hline HLW03-35 & h1b.IL15 & 4.963 & 10.397 & 0.080 & 4.963 & 2.481 & 4.467 & 6.948 & 0.496 & 48.639 & 1.489 & 3.176 & 2.103 & 1.039 & 5.956 & 0.599 & .210 & 1.346 & .645 & 100.000 \\
\hline HLW03-36 & & 4.921 & 6.889 & 0.197 & 9.507 & 2.692 & 1.476 & 7.961 & 0.492 & 48.226 & 1.476 & 3.558 & 2.085 & 0.984 & 5.905 & 0.599 & 0.644 & 1.446 & 0.942 & 100.000 \\
\hline $33-37$ & & 2.953 & 11.809 & 0.079 & 7.222 & 4.859 & 1.476 & 6.889 & 0.492 & 40.348 & 1.476 & 4.428 & 4.170 & 2.953 & 7.325 & 599 & 0.444 & 1.344 & 1.134 & 100.000 \\
\hline & & 4.915 & 6.881 & 0.197 & 9.831 & 2.458 & 1.474 & 9.618 & 0.295 & 43.156 & 1.474 & 3.875 & 4.165 & 0.983 & 7.051 & \begin{tabular}{|l|}
599 \\
\end{tabular} & 0.643 & 44 & 41 & 000 \\
\hline & & 946 & 6.875 & .197 & 8.502 & 4.850 & 1.473 & 6.875 & 0.295 & 48.128 & 1.473 & 4.420 & 2.081 & 0.982 & 7.078 & 599 & 0.644 & .446 & 35 & 000 \\
\hline & & 4.941 & 6.919 & 0.079 & 9.390 & 4.881 & 1.483 & 6.919 & 0.494 & 42.959 & 3.279 & 4.448 & 4.188 & 0.989 & 5.930 & 599 & 0.409 & .444 & 0.651 & 100.000 \\
\hline $03-41$ & & 3.888 & 8.732 & 0.140 & 6.939 & 3.710 & 2.698 & 9.093 & 0.395 & 43.059 & 2.705 & 3.658 & 3.032 & 1.920 & 6.767 & 0.599 & 0.427 & 1.395 & 0.843 & 100.000 \\
\hline $3-42$ & $02-4$ & 5.500 & 9.150 & .040 & 10.001 & 3.701 & 3.500 & 9.001 & 0.800 & 49.004 & 1.500 & 0.000 & 0.000 & 1.999 & 2.500 & 0.600 & 0.610 & 1.348 & 0.746 & 100.000 \\
\hline HLW03-43 & W03-06 & 8.344 & 4.908 & 0.491 & 1.963 & 5.890 & 6.872 & 3.927 & 0.982 & 52.031 & 5.091 & 1.416 & 0.000 & 0.000 & 4.095 & 0.600 & 1.660 & 1.318 & 0.412 & 100.000 \\
\hline HLW03-45 & Rep.HLW03-26 & 4.921 & 6.889 & 0.197 & 4.921 & 4.921 & 1.476 & 10.431 & 0.492 & 40.345 & 4.428 & 4.428 & 4.169 & 2.953 & 5.904 & .598 & 0.443 & 1.444 & 1.041 & 100.000 \\
\hline HLW06-02 & 06.02 & 10.390 & 11.000 & 0.250 & 7.000 & 0.250 & 1.000 & 20.000 & 1.000 & 35.000 & 1.470 & 0.250 & 0.750 & $\begin{array}{l}1.500 \\
\end{array}$ & 1.500 & 0.540 & 1.145 & 3.636 & 3.319 & 100.000 \\
\hline HLW06-04 & 06.04 & 8.000 & 6.500 & 0.250 & 7.000 & 0.250 & 1.000 & 20.000 & 0.600 & 35.000 & 4.409 & 1.500 & 0.750 & 2.500 & 4.000 & 0.620 & 1.395 & 3.349 & 2.878 & 100.000 \\
\hline
\end{tabular}

(a) R1 after a Glass ID indicates the glass batching, melting, and testing was repeated.

(b) The "Point Type" notation begins with an abbreviation of the HLW study phase (e.g., Ph1a denotes Phase 1a). After a separating dot, the notation continues (when appropriate) with "Center", "OL", or "IL", denoting whether the glass was a center point, outer-layer point, or inner-layer point. The "Center", "OL", or "IL" designation is with respect to the given study phase. Next, "XX" denotes the number of each outer-layer, inner-layer, or other point with respect to the given study phase. Replicate points are denoted by "Rep.HLW02-xx" and "Rep.HLW03-xx", where the "xx" represents a specific ID number for a replicated glass.

(c) The $\mathrm{wt} \%$ values in the table are rounded to three decimal places and may not sum to 100.000 exactly, but the sum is achieved in the data base. 
Table A.17. 18-Component Target Glass Compositions (wt\%) for the 125 Existing HLW Glasses Augmented by the HLW07 Test Matrix (continued).

\begin{tabular}{|c|c|c|c|c|c|c|c|c|c|c|c|c|c|c|c|c|c|c|c|c|}
\hline Glass ID $^{(a)}$ & Point Type $^{(\mathrm{b})}$ & $\mathrm{Al}_{2} \mathbf{O}_{3}$ & $\mathrm{~B}_{2} \mathbf{O}_{3}$ & $\mathrm{Cr}_{2} \mathrm{O}_{3}$ & $\mathrm{Fe}_{2} \mathrm{O}_{3}$ & $\mathrm{Li}_{2} \mathrm{O}$ & MnO & $\mathrm{Na}_{2} \mathrm{O}$ & $\mathrm{NiO}$ & $\mathrm{SiO}_{2}$ & SrO & $\mathrm{ThO}_{2}$ & $\mathrm{UO}_{3}$ & $\mathrm{ZnO}$ & $\mathrm{ZrO}_{2}$ & Others1 & Others2 & Constant & Remain & Sum ${ }^{(\mathrm{c})}$ \\
\hline HLW06-22 & 06.22 & 13.000 & 15.000 & 0.600 & 1.400 & 6.010 & 0.000 & 6.840 & 0.000 & 34.560 & 10.287 & 0.000 & 6.500 & 0.000 & 0.000 & 0.780 & 1.646 & 2.054 & 1.322 & 100.000 \\
\hline HLW06-32 & 06.32 & 1.880 & 15.000 & 0.600 & 15.000 & 0.000 & 8.000 & 20.000 & 0.000 & 37.430 & 0.000 & 0.000 & 0.000 & 0.000 & 0.000 & 0.500 & 0.000 & 0.820 & 0.770 & 100.000 \\
\hline HLW06-34 & 6.34 & 1.880 & 15.000 & 0.600 & 1.400 & 0.000 & 8.000 & 20.000 & 0.000 & 33.030 & 0.000 & 0.000 & 6.500 & 0.000 & 11.500 & 0.500 & 0.000 & 0.820 & 0.770 & 100.000 \\
\hline \begin{tabular}{|l|} 
HLW-ALG-01 \\
\end{tabular} & lg.01 & \begin{tabular}{|l|}
11.086 \\
\end{tabular} & 10.560 & 0.501 & 9.619 & 3.329 & 0.000 & \begin{tabular}{|l|}
17.280 \\
\end{tabular} & 0.000 & \begin{tabular}{|l|}
45.286 \\
\end{tabular} & 0.000 & 0.000 & 0.000 & 1.062 & 0.000 & 0.148 & 0.202 & 0.666 & 0.261 & 100.000 \\
\hline \begin{tabular}{|l} 
HLW-ALG-02 \\
\end{tabular} & Alg.02 & 8.001 & 11.088 & 0.278 & 7.145 & 3.550 & 0.000 & 15.318 & 0.522 & 44.674 & 0.000 & 0.000 & 0.000 & 1.577 & 6.495 & 0.156 & 0.214 & 0.705 & 0.276 & 100.000 \\
\hline \begin{tabular}{|l|} 
HLW-ALG-03 \\
\end{tabular} & lg. & 1.926 & 8.621 & 0.501 & 12.650 & 3.057 & 095 & \begin{tabular}{|l|}
18.966 \\
\end{tabular} & .001 & 44.365 & 0.000 & 0.000 & 0.000 & .032 & 5.433 & .152 & 207 & 0.683 & 310 & 100.000 \\
\hline LG-04 & lg.04 & 1.926 & 11.134 & 0.501 & \begin{tabular}{|l|}
12.639 \\
\end{tabular} & 2.876 & 0.000 & 15.980 & .001 & 51.881 & 0.000 & 0.000 & 0.000 & 1.226 & 0.000 & 100 & 135 & 0.408 & 192 & 100.000 \\
\hline LG-05 & lg.05 & 1.927 & 4.810 & 0.415 & 12.536 & 4.286 & 6.906 & 8.937 & .781 & \begin{tabular}{|l|}
46.197 \\
\end{tabular} & 9.891 & 0.000 & 0.000 & 0.050 & 0.000 & 231 & .518 & 1.079 & 437 & 100.000 \\
\hline HLW-ALG-06 & $\lg .06$ & 9.670 & 4.807 & 0.201 & 10.620 & .530 & 4.007 & 15.635 & 481 & 37.279 & 8.015 & 1.603 & 0.601 & 0.055 & 0.801 & 257 & 705 & 1.251 & 481 & .000 \\
\hline \begin{tabular}{|l|} 
HLW-ALG-07 \\
\end{tabular} & $\lg .07$ & 8.194 & 10.704 & 0.000 & 1.928 & .258 & 2.339 & \begin{tabular}{|l|}
11.777 \\
\end{tabular} & 0.000 & 44.110 & 4.113 & 4.126 & 0.000 & 1.675 & 6.262 & 179 & .239 & 0.786 & .310 & .000 \\
\hline \begin{tabular}{|l|} 
HLW-ALG-08 \\
\end{tabular} & Alg.08 & 1.926 & 4.807 & 0.471 & 7.318 & 2.081 & 3.560 & 13.943 & 0.887 & \begin{tabular}{|l|}
36.699 \\
\end{tabular} & 6.267 & 4.006 & 4.644 & 0.056 & 9.541 & 0.261 & 1.739 & 1.277 & 0.517 & 100.000 \\
\hline HLW-ALG-09 & Alg.09 & 5.480 & 4.808 & 0.211 & 13.931 & 1.987 & 3.916 & 15.116 & 0.189 & 38.868 & 7.479 & 0.603 & 1.360 & 0.059 & 2.565 & 0.433 & 0.495 & 1.579 & 0.923 & 100.000 \\
\hline \begin{tabular}{|l} 
HLW-ALG-10 \\
\end{tabular} & Alg.10 & 1.926 & 9.448 & 0.501 & 10.984 & 2.020 & 7.010 & \begin{tabular}{|l|}
17.410 \\
\end{tabular} & 1.001 & \begin{tabular}{|l|}
47.112 \\
\end{tabular} & 0.000 & 0.228 & 0.000 & 0.031 & 0.159 & 0.147 & 1.056 & 0.668 & 0.298 & 100.000 \\
\hline \begin{tabular}{|l|} 
HLW-ALG-11 \\
\end{tabular} & Alg.11 & \begin{tabular}{|l|}
11.886 \\
\end{tabular} & 12.188 & 0.000 & 1.928 & 6.013 & 3.408 & 6.065 & 0.000 & 35.076 & 5.994 & 6.013 & 0.000 & 0.054 & 9.125 & .258 & 0.348 & 1.197 & .448 & 100.000 \\
\hline ALG-12 & 2 & 5.938 & 4.807 & 0.285 & 12.540 & 2.750 & 2.029 & 15.899 & 0.812 & 40.350 & 6.087 & 1.623 & 1.623 & 0.056 & 2.394 & .260 & 0.793 & 1.267 & 0.488 & 100.000 \\
\hline HLV & lo 13 & .166 & 4.808 & 0.000 & 7.216 & 3.354 & 3.063 & 9.504 & 0.061 & 35.058 & 6.125 & 5.513 & 6.125 & 0.084 & 9.188 & .388 & 0.645 & 1.938 & 0.763 & 000 \\
\hline HLW-ALG-14 & $\lg .14$ & 3.543 & 4.809 & 0.000 & 12.562 & 6.012 & 6.715 & 4.804 & 0.759 & 47.605 & 9.618 & 0.000 & 0.000 & 0.048 & 0.000 & .225 & 1.798 & 1.050 & .453 & 100.000 \\
\hline HLW-ALG-15 & $\lg .15$ & 9.731 & 14.029 & 0.338 & 9.780 & 1.928 & 0.000 & 17.583 & .636 & 37.449 & 0.000 & 0.000 & 0.000 & 0.040 & 6.845 & .188 & 0.261 & 0.857 & 0.335 & 100.000 \\
\hline \begin{tabular}{|l|} 
HLW-ALG-16 \\
\end{tabular} & $\lg .16$ & \begin{tabular}{|l|}
10.329 \\
\end{tabular} & 13.850 & 0.501 & 4.396 & 2.021 & 0.000 & 17.406 & 0.751 & \begin{tabular}{|l|}
43.773 \\
\end{tabular} & 0.000 & 0.000 & 0.000 & 1.786 & 3.757 & 0.162 & 0.248 & 0.733 & 0.287 & 100.000 \\
\hline HLW-ALG-17 & Alg.17 & 1.926 & 10.338 & 0.501 & 12.515 & 2.020 & 6.912 & \begin{tabular}{|l|}
17.414 \\
\end{tabular} & 0.997 & 45.869 & 0.000 & 0.000 & 0.000 & 0.031 & 0.159 & 0.146 & 0.202 & 0.665 & 0.303 & 100.000 \\
\hline HLW-ALG-18 & Alg.18 & 11.360 & 11.109 & 0.000 & 10.369 & 3.437 & 0.000 & 14.807 & 0.000 & 45.993 & 0.000 & 0.000 & 0.000 & 1.616 & 0.000 & 0.151 & 0.207 & 0.682 & 0.268 & 100.000 \\
\hline HLW-ALG-19 & Alg.19 & 1.926 & 9.652 & 0.501 & 12.652 & 2.659 & 2.096 & 16.131 & 1.001 & 46.563 & 0.000 & 0.000 & 0.000 & 0.032 & 5.434 & 0.151 & 0.207 & 0.683 & 0.311 & 100.000 \\
\hline \begin{tabular}{|l|} 
HLW-ALG-20 \\
\end{tabular} & Alg.20 & 1.926 & 7.754 & 0.501 & \begin{tabular}{|l|}
12.651 \\
\end{tabular} & 2.926 & 2.095 & 17.400 & 1.001 & \begin{tabular}{|l|}
46.929 \\
\end{tabular} & 0.000 & 0.000 & 0.000 & 0.032 & 5.434 & 0.151 & 0.207 & 0.683 & 0.311 & 100.000 \\
\hline HLW-ALG-21 & Alg.21 & 2.619 & 4.810 & 0.493 & 9.663 & 2.475 & 1.186 & 17.623 & 0.542 & 38.986 & 0.000 & 5.894 & 4.502 & 0.084 & 8.915 & 0.240 & 0.345 & 1.193 & 0.431 & 100.000 \\
\hline HLW-ALG-22 & Alg.22 & 2.588 & 6.599 & 0.487 & 9.548 & 2.407 & 1.172 & 16.615 & 0.535 & 38.701 & 0.000 & 5.824 & 4.449 & 0.083 & 8.809 & 0.237 & 0.341 & 1.179 & 0.426 & 100.000 \\
\hline HLW-ALG-23 & Alg.23 & 2.492 & 4.809 & 0.469 & 9.180 & 2.069 & 1.127 & \begin{tabular}{|l|}
19.298 \\
\end{tabular} & 0.515 & 39.517 & 0.000 & 5.599 & 4.278 & 0.079 & 8.469 & 0.228 & 0.327 & 1.134 & 0.410 & 100.000 \\
\hline
\end{tabular}

(a) R1 after a Glass ID indicates the glass batching, melting, and testing was repeated.

(b) The "Point Type" notation begins with an abbreviation of the HLW study phase (e.g., Ph1a denotes Phase 1a). After a separating dot, the notation continues (when appropriate) with "Center", "OL", or "IL", denoting whether the glass was a center point, outer-layer point, or inner-layer point. The "Center", "OL", or "IL" designation is with respect to the given study phase. Next, "XX" denotes the number of each outer-layer, inner-layer, or other point with respect to the given study phase. Replicate points are denoted by "Rep.HLW02-xx" and "Rep.HLW03-xx", where the "xx" represents a specific ID number for a replicated glass.

(c) The wt\% values in the table are rounded to three decimal places and may not sum to 100.000 exactly, but the sum is achieved in the data base. 
Table A.18. Composition Expansions of Others1, Others2, and Constant Components for the 125 Existing HLW Glasses in Table A.17.

\begin{tabular}{|c|c|c|c|c|c|c|c|c|c|c|c|c|c|c|c|c|c|c|c|c|c|c|c|}
\hline \multirow[t]{2}{*}{ Glass ID $^{(\mathbf{a})}$} & \multicolumn{3}{|c|}{\begin{tabular}{|c|}
$\begin{array}{c}\text { Others1 Components } \\
(\mathrm{wt} \%)^{(\mathbf{b})}\end{array}$ \\
\end{tabular}} & \multicolumn{4}{|c|}{$\begin{array}{c}\text { Others2 Components } \\
(\mathrm{wt} \%)^{(\mathbf{b})}\end{array}$} & \multicolumn{16}{|c|}{$\begin{array}{c}\begin{array}{c}\text { Constant Components } \\
(\mathrm{wt} \%)^{(b)}\end{array} \\
\end{array}$} \\
\hline & $\mathbf{M o O}_{3}$ & $\mathbf{P}_{2} \mathbf{O}_{5}$ & $\mathrm{SO}_{3}$ & CdO & $\mathrm{CoO}$ & $\mathrm{CuO}$ & PbO & $\mathrm{CaO}$ & $\mathrm{Ce}_{2} \mathrm{O}_{3}$ & Cl & $\mathrm{Cs}_{2} \mathrm{O}$ & $\mathbf{F}$ & $\mathbf{K}_{2} \mathbf{O}$ & $\mathbf{L a}_{2} \mathbf{O}_{3}$ & $\mathbf{P r}_{2} \mathbf{O}_{3}$ & $\mathbf{R b}_{2} \mathbf{O}$ & $\mathbf{R h _ { 2 } \mathbf { O } _ { 3 }}$ & $\mathbf{R u O}_{2}$ & \begin{tabular}{|l|}
$\mathbf{S b}_{2} \mathbf{O}_{3}$ \\
\end{tabular} & $\mathrm{SnO}_{2}$ & $\mathbf{T a}_{2} \mathbf{O}_{5}$ & $\mathrm{WO}_{3}$ & $\mathbf{Y}_{2} \mathbf{O}_{3}$ \\
\hline LW02-01 & 0.000 & 0.500 & 0.100 & 0.771 & 0.010 & 0.054 & 0.216 & 0.500 & 0.048 & 0.200 & 0.010 & 0.050 & 0.060 & 0.300 & 0.000 & 0.000 & 0.050 & 0.080 & 0.110 & 0.000 & 0.000 & 0.000 & 0.000 \\
\hline HLW02-02 & 000 & 0.500 & 0.100 & 1.500 & 0.010 & 0.100 & 0.400 & 0.500 & 0.048 & 0.200 & 0.010 & 0.050 & 0.060 & 0.300 & 0.000 & 0.000 & 0.050 & 0.080 & 0.200 & 0.000 & 0.000 & 0.000 & 0.000 \\
\hline HLW02-03 & 0.000 & 0.500 & 0.100 & 1.500 & 0.010 & 0.100 & 0.400 & 0.500 & 0.048 & 0.200 & 0.010 & .050 & 0.060 & 0.300 & 0.000 & 0.000 & .050 & 0.080 & 0.020 & 0.000 & 0.000 & 0.000 & 0.00 \\
\hline 04 & 00 & 500 & 100 & 1.500 & 0.010 & 10 & .040 & & 0.048 & 0.200 & 0.010 & & 0.060 & 0.300 & & 0.000 & .050 & 0.080 & 200 & 0.000 & .000 & 000 & \\
\hline & 00 & 500 & 100 & 1.500 & .010 & 010 & .040 & 500 & 0.048 & 0.200 & 0.010 & 50 & 0.060 & 0.300 & 000 & 0.000 & .050 & .080 & .020 & 0.000 & 0.000 & .000 & \\
\hline $\mathrm{HLV}$ & 00 & 500 & 100 & 0.050 & 010 & 100 & .400 & 500 & 0.048 & 0.200 & 0.010 & .050 & 0.060 & 0.300 & 0.000 & 0.000 & .050 & 0.080 & 200 & 0.000 & 0.000 & .000 & \\
\hline & 000 & 500 & 100 & 0.050 & 010 & .010 & .040 & 500 & 0.048 & 0.200 & 0.010 & .050 & 0.060 & 0.300 & .000 & 0.000 & .050 & 0.080 & 0.200 & 0.000 & 0.000 & .000 & \\
\hline & 00 & 500 & 100 & 0.050 & 010 & .010 & .040 & 0 & 0.048 & 0.200 & 0.010 & .050 & 0.060 & 0.300 & .000 & .000 & .050 & 0.080 & 200 & 0.000 & 0.000 & .000 & 0 \\
\hline 10 & 000 & 0.500 & 0.100 & 1.500 & 0.010 & 0.010 & 0.040 & 0.500 & 0.048 & 0.200 & 0.010 & 0.050 & 0.060 & 0.300 & 0.000 & 0.000 & .050 & 0.080 & 0.020 & 0.000 & 0.000 & 0.000 & 0.000 \\
\hline HLW02-11 & 0.000 & 0.500 & 0.100 & 0.050 & 0.010 & 0.010 & 0.040 & 0.500 & 0.048 & 0.200 & 0.010 & .050 & 0.060 & 0.300 & 0.000 & 0.000 & 0.050 & 0.080 & 0.200 & 0.000 & 0.000 & 0.000 & .000 \\
\hline & 0.000 & 0.500 & 0.100 & 1.500 & 0.010 & 0.100 & 400 & 500 & 0.048 & 0.200 & 0.010 & .050 & 0.060 & 0.300 & 0.000 & 0.000 & .050 & 0.080 & 0.020 & 0.000 & .000 & .000 & .00 \\
\hline & & 500 & & 0.050 & & & 400 & & 0.048 & 0.200 & 0.010 & 0.050 & 0.060 & 0.300 & & 0. & 050 & 0.080 & 20 & 0.000 & .000 & .000 & 0.00 \\
\hline & & 0.500 & 0.100 & 1.500 & 10 & 0 & 0.040 & 0 & 0.048 & 0.200 & 0.010 & 0.0 & 0.060 & 0.300 & & 0. & 050 & 0.080 & 200 & 0.000 & 000 & 000 & 0.0 \\
\hline & 000 & 0.500 & 00 & 0.050 & 0.010 & 0 & 400 & 0 & 0.048 & 0.200 & 0.010 & $\underline{0}$ & 0.060 & 0.300 & & 0.000 & 050 & 0.080 & .020 & 0.000 & 00 & .000 & 0.0 \\
\hline 16 & 00 & 500 & 0.100 & 1.500 & 010 & 0.100 & 400 & 500 & 0.048 & 0.200 & 0.010 & 0.050 & 0.060 & 0.300 & 00 & 0.000 & .050 & 0.080 & 0.200 & 0.000 & .000 & .000 & .0 \\
\hline $2-17$ & 000 & 0.500 & 0.100 & 1.500 & .010 & 0.010 & .040 & 500 & 0.048 & 0.200 & 0.010 & 0.050 & .060 & 0.300 & 00 & 0.000 & .050 & 0.080 & 0.020 & 0.000 & .000 & .000 & 0.00 \\
\hline LW02-18 & 000 & 0.500 & 0.100 & 0.050 & 0.010 & 0.100 & 0.400 & 0.500 & 0.048 & 0.200 & 0.010 & 0.050 & 0.060 & 0.300 & 0.000 & 0.000 & 0.050 & 0.080 & 0.200 & 0.000 & 0.000 & 0.000 & 0.000 \\
\hline HLW02-19 & 0.000 & 0.500 & 0.100 & 1.500 & 0.010 & 0.010 & 0.040 & 0.500 & 0.048 & 0.200 & 0.010 & 0.050 & 0.060 & 0.300 & 0.000 & 0.000 & 0.050 & 0.080 & 0.200 & 0.000 & 0.000 & 0.000 & 0.00 \\
\hline HLW02-20R1 & 0.000 & 0.500 & 0.100 & 0.050 & 0.010 & 0.010 & 0.040 & 0.500 & 0.048 & 0.200 & 0.010 & 0.050 & 0.060 & 0.300 & 0.000 & 0.000 & 0.050 & 0.080 & 0.020 & 0.000 & 0.000 & .000 & 0.000 \\
\hline & & 0.500 & & 0.050 & & & 040 & 500 & 0.048 & 0.200 & 0.010 & & 060 & 0.300 & & 00 & 50 & 0.080 & 200 & 0.000 & 0.000 & 0.000 & 0. \\
\hline & & 0 & & 1.500 & & & 40 & & 0.048 & 0 & & & 060 & 300 & & & 50 & 0.080 & 20 & 0.000 & 00 & 0.000 & 0 \\
\hline & 000 & 500 & 01 & 0.050 & 00 & 0 & 07 & 500 & 0.048 & 0.200 & 0.010 & 80 & 0.060 & 0.300 & 0 & 0.1 & 050 & 0.080 & 020 & 0.000 & 0.000 & 0.000 & 0 \\
\hline & 00 & 0.500 & 00 & 1.500 & 10 & 0 & 040 & 00 & 0.048 & 0.200 & 0.010 & 0.050 & 0.060 & 0.300 & 000 & 0.000 & .050 & 0.080 & 0.200 & 0.000 & .000 & 0.000 & .0 \\
\hline & 00 & 0.500 & 0.100 & 1.500 & 10 & 100 & 400 & 00 & 0.048 & 0.200 & 0.010 & 050 & .060 & 0.300 & 00 & 0.000 & .050 & 0.080 & 0.020 & 0.000 & .000 & 0.000 & 0.0 \\
\hline-27 & 0.000 & 0.500 & 0.100 & 0.050 & 0.010 & .010 & 0.040 & 500 & 0.048 & 0.200 & 0.010 & 0.050 & 0.060 & 0.300 & 0.000 & 0.000 & 0.050 & 0.080 & 0.020 & 0.000 & 0.000 & 0.000 & 0.000 \\
\hline HLW02-28 & 0.000 & 0.500 & 0.100 & 1.000 & 0.010 & 0.020 & 0.080 & 0.500 & 0.048 & 0.200 & 0.010 & 0.050 & 0.060 & 0.300 & 0.000 & 0.000 & 0.050 & 0.080 & 0.050 & 0.000 & 0.000 & 0.000 & 0.000 \\
\hline HLW02-29R1 & 0.000 & 0.500 & 0.100 & 0.500 & 0.010 & 0.067 & 0.267 & 0.500 & 0.048 & 0.200 & 0.010 & 0.050 & 0.060 & 0.300 & 0.000 & 0.000 & 0.050 & 0.080 & 0.050 & 0.000 & 0.000 & 0.000 & 0.000 \\
\hline HLW02-30 & 0.000 & 0.500 & 0.100 & 1.000 & 0.010 & 0.020 & 0.080 & 0.500 & 0.048 & 0.200 & 0.010 & 0.050 & 0.060 & 0.300 & 0.000 & 0.000 & 0.050 & 0.080 & 0.150 & 0.000 & 0.000 & 0.000 & 0.000 \\
\hline & 0.000 & 0.500 & 0.100 & 0.500 & 0.010 & 0.020 & 0.080 & 0.500 & 0.048 & 0.200 & 0.010 & 0.050 & 0.060 & 0.300 & 0.000 & 0.000 & 0.050 & 0.080 & 0.050 & 0.000 & 0.000 & 0.000 & 0.000 \\
\hline 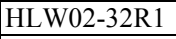 & 0.000 & 0.500 & 0.100 & 1.000 & 0.010 & 0.020 & 0.080 & 0.500 & 0.048 & 0.200 & 0.010 & 0.050 & 0.060 & 0.300 & 0.000 & 0.000 & 0.050 & 0.080 & 0.150 & 0.000 & 0.000 & 0.000 & 0 \\
\hline-33 & 000 & 0.500 & 0.100 & 0.500 & 0.010 & .020 & .080 & 500 & 0.048 & 0.200 & 0.010 & 0.050 & 0.060 & 0.300 & 0.000 & 0.000 & 0.050 & 0.080 & 0.150 & 0.000 & 0.000 & 0.000 & 0.00 \\
\hline & & 0.500 & 00 & 1.000 & 0.010 & 0.001 & $26 / 4$ & 00 & 0.040 & 0.200 & 0.010 & 0.000 & 060 & 0.300 & & & .050 & 080 & .050 & 0.000 & .000 & 00 & \\
\hline $02-35$ & 0.000 & 0.500 & 0.100 & 0.500 & 0.010 & 0.067 & 267 & 500 & 0.048 & 0.200 & 0.010 & 0.050 & .060 & 0.300 & 0.000 & 0.000 & .050 & 0.080 & 0.150 & 0.000 & 0.000 & 0.000 & 0.000 \\
\hline
\end{tabular}

(a) R1 after a Glass ID indicates the glass batching, melting, and testing was repeated.

(b) For each glass, the sum of the wt $\%$ values for the components comprising Others 1 , Others 2 , and Constant equal the wt $\%$ values listed in the Others 1 , Others2, and Constant columns of Table A.17, except for any differences resulting from rounding wt $\%$ values to three decimal places. The equalities are exact to the additional decimal places contained in the data base. 
Table A.18. Composition Expansions of Others1, Others2, and Constant Components for the 125 Existing HLW Glasses in Table A.17 (continued).

\begin{tabular}{|c|c|c|c|c|c|c|c|c|c|c|c|c|c|c|c|c|c|c|c|c|c|c|c|}
\hline \multirow[t]{2}{*}{ Glass ID $^{(a)}$} & \multicolumn{3}{|c|}{\begin{tabular}{|c|}
$\begin{array}{c}\text { Others1 Components } \\
(\mathrm{wt} \%)^{(\mathbf{b})}\end{array}$ \\
\end{tabular}} & \multicolumn{4}{|c|}{$\begin{array}{c}\text { Others2 Components } \\
\left(^{(w t \%)^{(b)}}\right.\end{array}$} & \multicolumn{16}{|c|}{$\begin{array}{c}\begin{array}{c}\text { Constant Components } \\
(\mathrm{wt} \%)^{(\mathbf{b})}\end{array} \\
\end{array}$} \\
\hline & $\mathrm{MoO}_{3}$ & $\mathbf{P}_{2} \mathbf{O}_{5}$ & $\mathrm{SO}_{3}$ & CdO & $\mathrm{CoO}$ & $\mathrm{CuO}$ & PbO & $\mathrm{CaO}$ & $\mathrm{Ce}_{2} \mathrm{O}_{3}$ & $\mathbf{C l}$ & $\mathrm{Cs}_{2} \mathrm{O}$ & $\mathbf{F}$ & $\mathrm{K}_{2} \mathrm{O}$ & $\mathrm{La}_{2} \mathrm{O}_{3}$ & $\mathrm{Pr}_{2} \mathrm{O}_{3}$ & $\mathbf{R} \mathbf{b}_{2} \mathbf{O}$ & $\mathbf{R h}_{2} \mathbf{O}_{3}$ & $\mathrm{RuO}_{2}$ & \begin{tabular}{|l|}
$\mathbf{S b}_{2} \mathbf{O}_{3}$ \\
\end{tabular} & $\mathrm{SnO}_{2}$ & $\mathbf{T a}_{2} \mathbf{O}_{5}$ & $\mathrm{WO}_{3}$ & $\mathbf{Y}_{2} \mathbf{O}_{3}$ \\
\hline HLW02-36 & 0.000 & 0.500 & 0.100 & 1.000 & 0.010 & 0.067 & 0.267 & 0.500 & \begin{tabular}{|l|}
0.048 \\
\end{tabular} & 0.200 & 0.010 & 0.050 & 0.060 & 0.300 & 0.000 & 0.000 & 0.050 & 0.080 & 0.050 & 0.000 & 0.000 & 0.000 & 0.000 \\
\hline HLW02-37 & 000 & 0.500 & 0.100 & 0.500 & 0.010 & 0.020 & 0.080 & 0.500 & \begin{tabular}{|l|}
0.048 \\
\end{tabular} & 0.200 & 0.010 & 0.050 & 0.060 & 0.300 & 0.000 & 0.000 & 0.050 & 0.080 & 0.150 & 0.000 & 0.000 & 0.000 & 0.000 \\
\hline \begin{tabular}{|l|} 
HLW02-38 \\
\end{tabular} & 00 & 0.500 & 0.100 & 1.000 & 0.010 & 0.067 & 0.267 & 500 & \begin{tabular}{|l|}
0.048 \\
\end{tabular} & 0.200 & 0.010 & 0.050 & 0.060 & 0.300 & 0.000 & 0.000 & .050 & 0.080 & 150 & 0.000 & 0.000 & 000 & 000 \\
\hline HLW02-39 & & .500 & 0.100 & 1.000 & 010 & 0.020 & .080 & 00 & 0.048 & 0.200 & 0.010 & 0.050 & 0.060 & 0.300 & 0.000 & 0.000 & 050 & 0.080 & 050 & 0.000 & 0.000 & .000 & .000 \\
\hline W02-40 & 00 & 500 & 100 & 1.000 & 010 & 067 & 267 & 00 & 0.048 & 200 & 0.010 & 0.050 & 0.060 & 300 & 000 & 00 & 050 & 0.080 & 150 & 0.000 & 000 & 000 & 0.000 \\
\hline HLW0 & 0 & 500 & 100 & 0.500 & 010 & .020 & 080 & 00 & 0.048 & 200 & 0.010 & 0.050 & 0.060 & 0.300 & 000 & 0.000 & 050 & 0.080 & 050 & 0.000 & 0.000 & .000 & \\
\hline HLW02-42 & 00 & 500 & 100 & 0.500 & 0.010 & .020 & .080 & 500 & 0.048 & 200 & 0.010 & 0.050 & 0.060 & 0.300 & .000 & 0.000 & .050 & 0.080 & 050 & 0.000 & 0.000 & .000 & .00 \\
\hline HLV & 000 & 0.500 & 0.100 & 1.000 & 0.010 & 0.020 & 0.080 & 00 & 048 & 0.200 & 0.010 & 0.050 & 0.060 & 300 & 0.000 & 0.000 & .050 & .080 & 150 & 0.000 & 0.000 & 00 & 000 \\
\hline HLW02-44 & 000 & 0.500 & 0.100 & 1.000 & 0.010 & 0.067 & 0.267 & 0.500 & 0.048 & 0.200 & 0.010 & 0.050 & 0.060 & 0.300 & 0.000 & 0.000 & 0.050 & 0.080 & 0.150 & 0.000 & 0.000 & 0.000 & 0.000 \\
\hline HLW02-45 & 000 & 0.500 & 0.100 & 1.000 & 0.010 & 0.020 & 0.080 & 0.500 & 0.048 & 0.200 & 0.010 & 0.050 & 0.060 & 0.300 & 0.000 & 0.000 & 0.050 & 0.080 & 0.050 & 0.000 & 0.000 & 0.000 & 0.000 \\
\hline HLW02-46 & & 0.500 & 0.100 & 0.500 & 0.010 & 0.020 & 0.080 & 0.500 & 0.048 & 0.200 & 0.010 & 0.050 & 0.060 & 0.300 & 0.000 & 0.000 & .050 & 0.080 & 050 & 0.000 & 0.000 & .000 & .000 \\
\hline HLV & & 0 & & 0.500 & 0 & 0.0 & 267 & 0 & 0.048 & 0.200 & 0.010 & 0.050 & 0.060 & 300 & & & 50 & .080 & 50 & 00 & 00 & 000 & .000 \\
\hline $\mathrm{HLV}$ & 0 & 0500 & 0.100 & 0.500 & .010 & 0.067 & 0.267 & 0 & 0.048 & 0.200 & 0.010 & 0.050 & 0.060 & 0.300 & 00 & & 50 & 0.080 & 50 & 00 & 00 & 000 & .00 \\
\hline HLI & t & .500 & 100 & 0.500 & 0.010 & 0.020 & .080 & 0 & 0.0 & 200 & 0.010 & 0.050 & 0.060 & 300 & 00 & & 50 & 0.080 & 050 & 00 & 00 & .000 & .0 \\
\hline HLV & 00 & 0.500 & 0.100 & 0.500 & 010 & 0.020 & 0.080 & 500 & 0.0 & 200 & 0.010 & 0.050 & 0.060 & 300 & 0.000 & 0.00 & .050 & 0.080 & 150 & 0.000 & .000 & .000 & 0.00 \\
\hline HLV & 00 & 0.500 & 0.100 & 0.500 & 0.010 & 0.020 & .080 & 500 & .048 & 200 & 0.010 & 0.050 & 0.060 & 300 & 000 & 00 & .050 & 0.080 & 150 & 0.000 & 0.000 & .000 & $\overline{0.00}$ \\
\hline HLW02-52 & 0.000 & 0.500 & 0.100 & 0.771 & 0.010 & 0.054 & 0.216 & 0.500 & 0.048 & 0.200 & 0.010 & 0.050 & 0.060 & 0.300 & 0.000 & 0.000 & 0.050 & 0.080 & 0.110 & 0.000 & 0.000 & 0.000 & 0.000 \\
\hline HLW02-53 & 000 & 0.500 & 0.100 & 1.500 & 0.010 & 0.010 & 0.040 & 0.500 & 0.048 & 0.200 & 0.010 & 0.050 & 0.060 & 0.300 & 0.000 & 0.000 & 0.050 & 0.080 & 0.020 & 0.000 & 0.000 & 0.000 & 0.000 \\
\hline HLW02-54 & 000 & 0.500 & 0.100 & 1.500 & 0.010 & 0.010 & 0.040 & 0.500 & 0.048 & 0.200 & 0.010 & 0.050 & 0.060 & 0.300 & 0.000 & 0.000 & .050 & 0.080 & 0.200 & 0.000 & 0.000 & 0.000 & 0.000 \\
\hline HLV & & 0.500 & 0.100 & 0.500 & & 0.020 & 0.080 & 0.500 & 0.048 & 0.200 & 0.010 & 0.050 & 0.060 & 0.300 & 0.000 & & .050 & .080 & 050 & 0.000 & 00 & 0.000 & 0.000 \\
\hline & & 0 & 0 & 1.000 & & & 67 & & & & 0.010 & & & 00 & & & 50 & 80 & 50 & & & 00 & $\overline{0.00}$ \\
\hline HLI & & 0500 & $\Omega$ & 0.050 & 0 & 0.010 & 0.040 & 0.500 & 4 & 0.200 & 0.010 & 0.050 & 0.060 & 0.300 & 0.000 & & 0.050 & 0.080 & 200 & 0.000 & 0.000 & 0.000 & $\overrightarrow{0.0}$ \\
\hline $\mathrm{HI}$ & & 0.500 & 00 & 0.050 & 10 & 0.100 & 0.400 & 00 & 0.048 & 0.200 & 0.010 & 0.050 & 0.060 & 300 & 0.000 & 0 & .050 & 0.080 & .020 & 0.000 & 0.000 & 0.000 & $0.0 \mathrm{c}$ \\
\hline HLV & 00 & 500 & 100 & 1.600 & 10 & 0.010 & .040 & 00 & 8 & 200 & 0.010 & 0.050 & 060 & 300 & 000 & & 050 & 0.080 & 300 & 0.000 & 0.000 & .000 & 0.00 \\
\hline HLW03-03 & 0.000 & 0.500 & 0.100 & 1.600 & 0.010 & 0.010 & 0.040 & 0.500 & 0.048 & 0.200 & 0.010 & 0.050 & 0.060 & 0.300 & 0.000 & 0.000 & 0.050 & 0.080 & 0.020 & 0.000 & 0.000 & 0.000 & 0.000 \\
\hline HLW03-04 & 0.000 & 0.498 & 0.100 & 0.050 & 0.010 & 0.100 & 0.399 & 0.498 & 0.048 & 0.199 & 0.010 & 0.050 & 0.060 & 0.299 & 0.000 & 0.000 & 0.050 & 0.080 & 0.020 & 0.000 & 0.000 & 0.000 & 0.000 \\
\hline HLW03-05 & 0.000 & 0.500 & 0.100 & 1.600 & 0.010 & 0.100 & 0.400 & 0.500 & 0.048 & 0.200 & 0.010 & 0.050 & 0.060 & 0.300 & 0.000 & 0.000 & 0.050 & 0.080 & 0.300 & 0.000 & 0.000 & 0.000 & 0.000 \\
\hline HLW03-06 & 0.000 & 0.500 & 0.100 & 1.600 & 0.010 & 0.010 & 0.040 & 0.500 & 0.048 & 0.200 & 0.010 & 0.050 & 0.060 & 0.300 & 0.000 & 0.000 & 0.050 & 0.080 & 0.020 & 0.000 & 0.000 & 0.000 & 0.000 \\
\hline HLW03-07 & 0.000 & 0.498 & 0.100 & 0.050 & 0.010 & 0.010 & 0.040 & 0.498 & 0.048 & 0.199 & 0.010 & 0.050 & 0.060 & 0.299 & 0.000 & 0.000 & 0.050 & 0.080 & 0.020 & 0.000 & 0.000 & 0.000 & 0.000 \\
\hline HLV & 000 & 0.500 & 0.100 & 1.600 & 0.010 & 0.100 & 0.400 & 0.500 & 0.048 & 0.200 & 0.010 & 0.050 & 0.060 & 0.300 & 0.000 & 0.000 & 0.050 & 0.080 & 0.300 & 0.000 & 0.000 & 0.000 & 0.000 \\
\hline HLW & 000 & 0.500 & 0.100 & 0.050 & 0.010 & 0.100 & 0.400 & 0.500 & 0.048 & 0.200 & 0.010 & 0.050 & 0.060 & 0.300 & 0.000 & 0.000 & 0.050 & 0.080 & 0.020 & 0.000 & 0.000 & 0.000 & 0.000 \\
\hline & 000 & 0.498 & 0.100 & 0.050 & .010 & 0.010 & 0.040 & 0.498 & 0.040 & 0.199 & 0.010 & 0.050 & 0.060 & 0.299 & 0.000 & 0.000 & .050 & 0.080 & 0.299 & .000 & 0.000 & 0.000 & 0.000 \\
\hline HLW03-13 & 000 & 0.498 & 0.100 & 0.050 & 0.010 & 0.010 & 0.040 & 0.498 & 0.048 & 0.199 & 0.010 & 0.050 & 0.060 & 0.299 & 0.000 & $0.0 \mathrm{C}$ & 0.050 & 0.080 & 0.020 & 0.000 & 0.000 & 0.000 & 0.0 \\
\hline
\end{tabular}

(a) R1 after a Glass ID indicates the glass batching, melting, and testing was repeated.

(b) For each glass, the sum of the wt $\%$ values for the components comprising Others 1 , Others 2 , and Constant equal the wt $\%$ values listed in the Others 1 , Others2, and Constant columns of Table A.17, except for any differences resulting from rounding wt $\%$ values to three decimal places. The equalities are exact to the additional decimal places contained in the data base. 
Table A.18. Composition Expansions of Others1, Others2, and Constant Components for the 125 Existing HLW Glasses in Table A.17 (continued).

\begin{tabular}{|c|c|c|c|c|c|c|c|c|c|c|c|c|c|c|c|c|c|c|c|c|c|c|c|}
\hline \multirow[t]{2}{*}{ Glass ID $^{(a)}$} & \multicolumn{3}{|c|}{$\begin{array}{c}\text { Others1 Components } \\
(\mathrm{wt} \%)^{(\mathbf{b})}\end{array}$} & \multicolumn{4}{|c|}{$\begin{array}{c}\text { Others2 Components } \\
\text { (wt\%) }^{(\mathbf{b})}\end{array}$} & \multicolumn{16}{|c|}{$\begin{array}{c}\begin{array}{c}\text { Constant Components } \\
(\mathrm{wt} \%)^{(\mathbf{b})}\end{array} \\
\end{array}$} \\
\hline & $\mathrm{MoO}_{3}$ & $\mathbf{P}_{2} \mathbf{O}_{5}$ & $\mathrm{SO}_{3}$ & CdO & $\mathrm{CoO}$ & $\mathrm{CuO}$ & PbO & $\mathrm{CaO}$ & $\mathrm{Ce}_{2} \mathrm{O}_{3}$ & $\mathrm{Cl}$ & $\mathrm{Cs}_{2} \mathrm{O}$ & $\mathbf{F}$ & $\mathbf{K}_{2} \mathbf{O}$ & $\mathbf{L a}_{2} \mathbf{O}_{3}$ & $\mathbf{P r}_{2} \mathbf{O}_{3}$ & $\mathbf{R \mathbf { b } _ { 2 } \mathbf { O }}$ & $\mathbf{R h}_{2} \mathbf{O}_{3}$ & $\mathrm{RuO}_{2}$ & $\mathbf{S b}_{2} \mathbf{O}_{3}$ & $\mathrm{SnO}_{2}$ & $\mathbf{T a}_{2} \mathbf{O}_{5}$ & $\mathbf{W O}_{3}$ & $\mathbf{Y}_{2} \mathbf{O}_{3}$ \\
\hline LW03-14 & 0.000 & 0.500 & 0.100 & 0.050 & 0.010 & 0.010 & 0.040 & 0.500 & \begin{tabular}{|l|}
0.048 \\
\end{tabular} & 0.200 & 0.010 & 0.050 & 0.060 & 0.300 & 0.000 & 0.000 & 0.050 & 0.080 & 0.020 & 0.000 & 0.000 & 0.000 & 0.000 \\
\hline HLW03-15 & 0.000 & 0.500 & 0.100 & 1.600 & 0.010 & 0.010 & 0.040 & 0.500 & \begin{tabular}{|l|}
0.048 \\
\end{tabular} & 0.200 & 0.010 & 0.050 & 0.060 & 0.300 & 0.000 & 0.000 & 0.050 & 0.080 & 0.300 & 0.000 & 0.000 & 0.000 & 0.000 \\
\hline LW03-16 & 0.000 & 0.498 & 0.100 & 0.050 & 0.010 & 0.100 & 0.398 & 0.498 & 0.047 & 0.199 & 0.010 & 0.050 & 0.060 & 0.299 & 0.000 & 0.000 & 0.050 & 0.080 & 0.299 & 0.000 & 0.000 & 0.000 & 0.000 \\
\hline W03-17 & 000 & 0.499 & .100 & .050 & 0.010 & 0100 & 0.399 & 0.499 & 0.048 & 0.199 & 0.010 & 0.050 & 0.060 & 0.299 & 0.000 & 0.000 & 0.050 & 0.080 & 0.020 & 0.000 & 0.000 & 0.000 & 0.000 \\
\hline $33-18$ & 000 & 0.500 & 00 & .050 & 010 & 010 & 0.040 & 0.500 & 0.048 & 0.200 & 0.010 & 0.050 & 0.060 & 0.300 & 0.000 & 0.000 & 0.050 & 0.080 & 0.020 & 0.000 & 000 & 0.000 & 0.000 \\
\hline-19 & 000 & 0.500 & 100 & .600 & .010 & 010 & .040 & 0.500 & 0.048 & 0.200 & 0.010 & 0.050 & 0.060 & 0.300 & 0.000 & .000 & 0.050 & 0.080 & 0.020 & 0.000 & 0.000 & 0.000 & 0.000 \\
\hline-20 & 000 & 0.500 & 100 & 1.600 & 0.010 & 1006 & .400 & 0.500 & 0.048 & 0.200 & 0.010 & 0.050 & 0.060 & 0.300 & 0.000 & 0.000 & 0.050 & 0.080 & 0.300 & 0.000 & 0.000 & 0.000 & 0.000 \\
\hline $\mathrm{HLV}$ & 0.000 & 0.499 & 0.100 & 0.300 & 0.010 & 0.020 & 0.080 & 0.499 & (048 & 0.200 & 0.010 & 0.050 & .060 & 0.300 & 0.000 & 0.000 & 0.050 & 0.080 & 0.050 & .000 & 0.000 & 0.000 & 0.000 \\
\hline HLW03-22 & 0.000 & 0.499 & 0.100 & 0.299 & 0.010 & 0.067 & 0.267 & 0.499 & 0.048 & 0.200 & 0.010 & 0.050 & 0.060 & 0.299 & 0.000 & 0.000 & 0.050 & 0.080 & 0.050 & 0.000 & 0.000 & 0.000 & 0.000 \\
\hline HLW03-23 & 0.000 & 0.499 & 0.100 & 0.100 & 0.010 & 0.020 & 0.080 & 0.499 & 0.048 & 0.200 & 0.010 & 0.050 & 0.060 & 0.299 & 0.000 & 0.000 & 0.050 & 0.080 & 0.050 & 0.000 & 0.000 & 0.000 & 0.000 \\
\hline HLW03-24 & 0.000 & 0.499 & 0.100 & 0.300 & 0.010 & 0.020 & 0.080 & 0.499 & .048 & 0.200 & 0.010 & 0.050 & 0.060 & 0.300 & 0.000 & 0.000 & 0.050 & 0.080 & 0.050 & 0.000 & 0.000 & 0.000 & 0.000 \\
\hline & 00 & 0.499 & 0.100 & 0.100 & 0.010 & & 0.267 & 0.499 & .048 & 0.200 & 0.010 & 0.050 & 0.060 & 0.300 & 00 & & 0.050 & 80 & 0.050 & .000 & 000 & 0.000 & 0.000 \\
\hline & 000 & 0.499 & 0.100 & 0.100 & 0.010 & $\overline{00}$ & 0.267 & 0.499 & 0.048 & 0.199 & 0.010 & 0.050 & 0.060 & 0.299 & 000 & 0 & 0.050 & 0.080 & 0.150 & 0.000 & 0.000 & 0.000 & 0.000 \\
\hline & 00 & 0.499 & 0 & 0.100 & 0.010 & 0.0 & 0.267 & 0.499 & .048 & 0.200 & 0.010 & 0.050 & 0.060 & 0.300 & 00 & 0.000 & 0.050 & 0.080 & 50 & 0.000 & 0.000 & 0.000 & 0.000 \\
\hline & 00 & 0.499 & 100 & 0.100 & 0.010 & 0 & 080 & 0.499 & .048 & 0.200 & 0.010 & 0.050 & .060 & 0.300 & 000 & 00 & 0.050 & 0.080 & 50 & .000 & 0.000 & 0.000 & 0.000 \\
\hline $3-29$ & 0.000 & 0.499 & 0.100 & 0.299 & 0.010 & 0.020 & 0.080 & 0.499 & 0.048 & 0.200 & 0.010 & 0.050 & 0.060 & 0.299 & 0.000 & 0.000 & 0.050 & 0.080 & 0.050 & 0.000 & 0.000 & 0.000 & 0.000 \\
\hline HLW03-30 & 0.000 & 0.499 & 0.100 & 0.100 & 0.010 & 0.020 & 0.080 & 0.499 & 0.048 & 0.200 & 0.010 & 0.050 & 0.060 & 0.300 & 0.000 & 0.000 & 0.050 & 0.080 & 0.150 & 0.000 & 0.000 & 0.000 & 0.000 \\
\hline HLW03-31 & 0.000 & 0.499 & 0.100 & 0.100 & 0.010 & 0.020 & 0.080 & 0.499 & 0.048 & 0.200 & 0.010 & 0.050 & 0.060 & 0.300 & 0.000 & 0.000 & 0.050 & 0.080 & 0.150 & 0.000 & 0.000 & 0.000 & 0.000 \\
\hline HLW03-32 & 0.000 & 0.499 & 0.100 & 0.100 & 0.010 & 0.067 & 0.267 & 0.499 & 0.048 & 0.200 & 0.010 & 0.050 & 0.060 & 0.299 & 0.000 & 0.000 & 0.050 & 0.080 & 0.150 & 0.000 & 0.000 & 0.000 & 0.000 \\
\hline & 0.000 & 0.499 & .100 & 0.100 & 0.010 & & 0.080 & 0.499 & .048 & 0.200 & 0.010 & 0.050 & 0.060 & 0.299 & 0.000 & 0.000 & 0.050 & 080 & 0.150 & 0.000 & 0.000 & 0.000 & 0.000 \\
\hline & 00 & 0.499 & 0.100 & 0.100 & 0010 & & \begin{tabular}{l|}
0.267 \\
\end{tabular} & 0.499 & 048 & 0.200 & & 0.050 & 0.060 & 0.300 & & & 0.050 & & 50 & 0.000 & 0.000 & 0.000 & 0.000 \\
\hline & 000 & 0.499 & 0.100 & 0.100 & 0.010 & $\overline{00}$ & 0.080 & 0.499 & 0.048 & 0.200 & 0.010 & 0.05 & 0.060 & 0.300 & 0.000 & 0.000 & 0.050 & 0.080 & 0.050 & 0.000 & 0.000 & 0.000 & 0.000 \\
\hline & 000 & 0.499 & 0 & .300 & 0.010 & r & 0.267 & 0.499 & .048 & 0.200 & 0.010 & 0.050 & .060 & 0.300 & 0.000 & 0.000 & 0.050 & 0.080 & 0.150 & 0.000 & 0.000 & 0.000 & 0.000 \\
\hline & 00 & 0.499 & 100 & .100 & 0.010 & 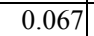 & 267 & 499 & .048 & 0.200 & 0.010 & 0.050 & .060 & 0.299 & 0.000 & 0.000 & 0.050 & 0.080 & 0.050 & 0.000 & 0.000 & 0.000 & 0.000 \\
\hline HLW03-38 & 0.000 & 0.499 & 0.100 & 0.299 & 0.010 & 0.067 & 0.267 & 0.499 & 0.048 & 0.200 & 0.010 & 0.050 & 0.060 & 0.299 & 0.000 & 0.000 & 0.050 & 0.080 & 0.050 & 0.000 & 0.000 & 0.000 & 0.000 \\
\hline HLW03-39 & 0.000 & 0.499 & 0.100 & 0.300 & 0.010 & 0.067 & 0.267 & 0.499 & 0.048 & 0.200 & 0.010 & 0.050 & 0.060 & 0.300 & 0.000 & 0.000 & 0.050 & 0.080 & 0.150 & 0.000 & 0.000 & 0.000 & 0.000 \\
\hline HLW03-40 & 0.000 & 0.499 & 0.100 & 0.299 & 0.010 & 0.020 & 0.080 & 0.499 & 0.048 & 0.200 & 0.010 & 0.050 & 0.060 & 0.299 & 0.000 & 0.000 & 0.050 & 0.080 & 0.150 & 0.000 & 0.000 & 0.000 & 0.000 \\
\hline HLW03-41 & 0.000 & 0.499 & 0.100 & 0.200 & 0.010 & 0.043 & 0.174 & 0.499 & 0.048 & 0.200 & 0.010 & 0.050 & 0.060 & 0.299 & 0.000 & 0.000 & 0.050 & 0.080 & 0.100 & 0.000 & 0.000 & 0.000 & 0.000 \\
\hline HLW03-42 & 0.000 & 0.500 & 0.100 & 0.500 & 0.010 & 0.020 & 0.080 & 0.500 & 0.048 & 0.200 & 0.010 & 0.050 & 0.060 & 0.300 & 0.000 & 0.000 & 0.050 & 0.080 & 0.050 & 0.000 & 0.000 & 0.000 & 0.000 \\
\hline $03-43$ & 0.000 & 0.500 & 0.100 & 1.600 & 0.010 & 0.010 & 0.040 & 0.500 & 0.048 & 0.200 & 0.010 & 0.050 & 0.060 & 0.300 & 0.000 & 0.000 & 0.050 & 0.080 & 0.020 & 0.000 & 0.000 & 0.000 & 0.000 \\
\hline $03-45$ & 0.000 & 0.499 & 0.100 & .100 & 0.010 & 0.067 & 0.267 & 0.499 & 0.048 & 0.199 & 0.010 & 0.050 & 0.060 & 0.299 & 0.000 & 0.000 & 0.050 & 0.080 & 0.150 & 0.000 & 0.000 & 0.000 & 0.000 \\
\hline & 0.000 & 0.500 & 0.040 & 0.235 & 0.000 & 0.000 & 0.910 & 1.000 & 0.000 & 0.200 & 0.000 & 0.440 & 1.640 & 0.176 & 0.000 & 0.000 & 0.050 & 0.130 & 0.000 & 0.000 & 0.000 & 0.000 & 0.000 \\
\hline $6-04$ & 0.000 & 0.500 & 0.120 & 0.706 & 0.000 & 0.000 & 0.689 & 0.757 & 0.000 & 0.200 & 0.000 & 0.440 & 1.242 & 0.529 & 0.000 & 0.000 & 0.050 & 0.130 & 0.000 & 0.000 & 0.000 & 0.000 & 0.000 \\
\hline
\end{tabular}

(a) R1 after a Glass ID indicates the glass batching, melting, and testing was repeated.

(b) For each glass, the sum of the $\mathrm{wt} \%$ values for the components comprising Others 1 , Others 2 , and Constant equal the wt $\%$ values listed in the Others 1 , Others2, and Constant columns of Table A.17, except for any differences resulting from rounding wt $\%$ values to three decimal places. The equalities are exact to the additional decimal places contained in the data base. 
Table A.18. Composition Expansions of Others1, Others2, and Constant Components for the 125 Existing HLW Glasses in Table A.17 (continued).

\begin{tabular}{|c|c|c|c|c|c|c|c|c|c|c|c|c|c|c|c|c|c|c|c|c|c|c|c|}
\hline \multirow[t]{2}{*}{ Glass ID ${ }^{(a)}$} & \multicolumn{3}{|c|}{$\begin{array}{c}\begin{array}{c}\text { Others1 Components } \\
(\mathrm{wt} \%)^{(\mathbf{b})}\end{array} \\
\end{array}$} & \multicolumn{4}{|c|}{$\begin{array}{c}\text { Others2 Components } \\
(\mathrm{wt} \%)^{(\mathbf{b})}\end{array}$} & \multicolumn{16}{|c|}{$\begin{array}{c}\begin{array}{c}\text { Constant Components } \\
(\mathrm{wt} \%)^{(b)}\end{array} \\
\end{array}$} \\
\hline & $\mathrm{MoO}_{3}$ & $\mathbf{P}_{2} \mathbf{O}_{5}$ & $\mathrm{SO}_{3}$ & CdO & $\mathrm{CoO}$ & $\mathrm{CuO}$ & PbO & $\mathrm{CaO}$ & $C_{2} U_{3}$ & $\mathrm{Cl}$ & $\mathrm{Cos}_{2} \mathrm{U}$ & $\mathbf{F}$ & $\mathrm{K}_{2} \mathrm{O}$ & $\mathrm{La}_{2} \mathrm{O}_{3}$ & $\mathrm{Pr}_{2} \mathbf{O}_{3}$ & $\mathbf{R b}_{2} \mathbf{O}$ & $\mathbf{R h _ { 2 } \mathbf { O } _ { 3 }}$ & $\mathbf{R u O}_{2}$ & $\mathbf{S b}_{2} \mathbf{O}_{3}$ & $\mathrm{nO}_{2}$ & $\mathbf{T a}_{2} \mathbf{O}_{5}$ & $\mathrm{NO}_{3}$ & \begin{tabular}{|l|}
$\mathbf{Y}_{2} \mathbf{O}_{3}$ \\
\end{tabular} \\
\hline 2 & 0.000 & 500 & 0.280 & 1.646 & 0.000 & 000 & 0.000 & 0.000 & 0.000 & 0.200 & 0.000 & 0.440 & 0.000 & 1.234 & 0.000 & 0.000 & 0.050 & 0.130 & 0.000 & 0.000 & 0.000 & 0.000 & 0.0 \\
\hline 58 & 000 & 500 & 000 & .000 & .000 & .000 & .000 & .000 & .000 & 0.200 & 0.000 & & 0.000 & .000 & & .000 & 0.050 & & 0.000 & .000 & 0.000 & 0.000 & .000 \\
\hline & & & & onget & & & & & & & & & & & & & & & & & & & \\
\hline 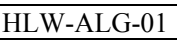 & & & & 000 & & & & & & 00 & & & & & & & 00 & & 00 & 000 & 000 & & \\
\hline & & & & 000 & & & & & & 000 & & & & & & & & & & 000 & & & \\
\hline & & & 554 & 000 & 000 & & 207 & & & 000 & 000 & 32 & 127 & & & & 00 & & & & & & \\
\hline & & & & 000 & (2) & & & & & 000 & & & 083 & & & & 00 & & & & & & \\
\hline & 00 & & 80 & 198 & 000 & & 20 & 521 & & 0.000 & 0.000 & & & 60 & & & 000 & 45 & 00 & 000 & 000 & 00 & 0.000 \\
\hline $\mathrm{G}-06$ & 000 & & .088 & .322 & 0.000 & 0.025 & .357 & 579 & 088 & 0.000 & 0.025 & .056 & 219 & 0.178 & & 00 & 000 & 050 & .000 & .000 & 000 & 26 & .000 \\
\hline & & & .061 & .000 & 0.000 & & & 390 & & 0.000 & 0.000 & .037 & 0.147 & 0.119 & & & 0.000 & 0.034 & .000 & .000 & .000 & 00 & 0.000 \\
\hline & & & & 349 & & & & & & & & & & & & & & & 00 & 00 & & 26 & .0 \\
\hline & & & & 084 & & & & & & & & & & & & & & & 00 & 000 & 000 & 00 & .00 \\
\hline & & & & 854 & 00 & & & 32 & & 0.000 & 0 & 2 & 25 & & & & 00 & 28 & 00 & 000 & 00 & 00 & .00 \\
\hline & & & 088 & 000 & .000 & & 348 & 65 & & 000 & 00 & A & 214 & 74 & & & 000 & & 00 & 000 & & & .0( \\
\hline & & & 089 & 406 & - & & 51 & 586 & & 0.000 & 025 & .056 & 222 & & & & .000 & 051 & .000 & .000 & 00 & 026 & 0.00 \\
\hline HLW-ALG-13 & 0.000 & .258 & 0.130 & 0.061 & 0.000 & 0.039 & 0.545 & 0.882 & .135 & 0.028 & 0.038 & 0.085 & 0.335 & 0.272 & 0.046 & 00 & 0.000 & 0.077 & 0.000 & 0.000 & 0.000 & 0.040 & 0.00 \\
\hline LG-14 & 000 & 7 & .078 & 1.486 & 0.000 & 0.000 & .311 & 0.507 & 0.077 & 0.000 & 0.000 & 0.048 & 0.191 & 0.155 & 0.026 & 0.000 & 0.000 & 0.044 & 0.000 & 0.000 & 0.000 & 0.000 & 0.000 \\
\hline & 000 & & .065 & 0.000 & 0.000 & 0.000 & 261 & 424 & 65 & 0.000 & 0.000 & 41 & 0.161 & 0.130 & 00 & 00 & 0.000 & .037 & .000 & .000 & .000 & .000 & 0.000 \\
\hline & & & $\overline{n e}$ & .025 & 0.000 & & 223 & 363 & & 0.000 & 0.000 & 0.035 & .137 & .111 & 00 & 00 & 0.000 & 0.031 & 0.000 & .000 & 0.000 & 000 & 0.00 \\
\hline & & & & 0.000 & 50 & & & & & 0.000 & 0.000 & 0.1 & 124 & & & & 00 & & .000 & 000 & 000 & 00 & 0.00 \\
\hline & & & & & & & & & & & 00 & & & & & & & & 000 & 00 & & & \\
\hline & & & 3 & 000 & 0.000 & & & 440 & & 0.000 & 0.000 & 0.0 & 127 & 03 & & & 000 & 029 & .000 & 000 & 000 & 000 & 0.00 \\
\hline & & & & 000 & 0.000 & & & 340 & & 0.000 & .000 & & 127 & 03 & & & .000 & 029 & .000 & .000 & 000 & 000 & 000 \\
\hline & & & & 131 & 00 & & & 42 & & & 0.000 & & 74 & & & & & & .000 & .000 & .000 & 23 & 0.00 \\
\hline-22 & 0.000 & 0. & 120 & 0.129 & 0.000 & 0.033 & 0.178 & 0.635 & 0.049 & 0.000 & 0.000 & 0.038 & 0.172 & 0.135 & 0.000 & 29 & 0.000 & 0.000 & 0.000 & .000 & 0.000 & 0.121 & 0.00 \\
\hline HLW-ALG-23 & 0.000 & 0.112 & 0.116 & 0.124 & 0.000 & 0.032 & 0.171 & 0.611 & 0.047 & 0.000 & 0.000 & 0.037 & 0.165 & 0.130 & 0.000 & 0.028 & 0.000 & 0.000 & 0.000 & 0.000 & 0.000 & 0.116 & 0.000 \\
\hline
\end{tabular}

(a) R1 after a Glass ID indicates the glass batching, melting, and testing was repeated.

(b) For each glass, the sum of the wt $\%$ values for the components comprising Others 1 , Others 2 , and Constant equal the wt $\%$ values listed in the Others 1 , Others2, and Constant columns of Table A.17, except for any differences resulting from rounding wt $\%$ values to three decimal places. The equalities are exact to the additional decimal places contained in the data base. 
Table A.19. Composition Expansions of Remaining Components for the 125 Existing HLW Glasses in Table A.17.

\begin{tabular}{|c|c|c|c|c|c|c|c|c|c|c|c|c|}
\hline \multirow{2}{*}{ Glass ID (a) $^{(1)}$} & \multicolumn{12}{|c|}{ Remaining Components (wt\%) $)^{(b)}$} \\
\hline & $\mathrm{Ag}_{2} \mathrm{O}$ & \begin{tabular}{|l|}
$\mathbf{A s}_{2} \mathbf{O}_{5}$ \\
\end{tabular} & $\mathbf{B a O}$ & $\mathrm{Bi}_{2} \mathbf{O}_{3}$ & MgO & $\mathrm{Nd}_{2} \mathrm{O}_{3}$ & PdO & $\mathrm{SeO}_{2}$ & $\mathrm{TeO}_{2}$ & $\mathrm{TiO}_{2}$ & $\mathrm{Tl}_{2} \mathbf{O}$ & $\mathbf{V}_{2} \mathbf{O}_{5}$ \\
\hline W02-01 & 0.108 & 0.125 & 162 & 0.010 & .120 & 0.000 & 0.120 & 0.110 & 0.010 & 0.030 & 0.102 & \\
\hline 07 & 199 & 232 & 300 & & & 000 & & 020 & & & 019 & \\
\hline & 99 & 232 & 300 & & & & & & & & & \\
\hline & 020 & 023 & 030 & 0.010 & & 000 & & 00 & .010 & 0.030 & 0.186 & .010 \\
\hline & 020 & 0.023 & 0.030 & & & 000 & & 200 & & & 0.186 & 0.010 \\
\hline 77 & 199 & 0.232 & 0.300 & 0.010 & & 0.000 & 120 & 0.020 & 0.010 & 0.030 & 0.186 & 0.100 \\
\hline $5 \times 0$ & 020 & 0.023 & 0.030 & 0.010 & & 0.000 & 120 & .020 & 0.010 & 0.030 & 0.019 & 0.010 \\
\hline & 20 & 23 & 0.030 & & & & & & & & 0.019 & .010 \\
\hline & & & & & & & & & & & 019 & \\
\hline & & & 0 & & & & & & & & & \\
\hline & 9 & 2 & 0 & & & & & & & & 0.019 & \\
\hline & 199 & 232 & 0 & 0 & & t & & & & 0 & 86 & \\
\hline & & & 030 & & & 00 & & & & & .186 & \\
\hline & 99 & 232 & 0.300 & 0.010 & & 0.000 & & 200 & & & 0.186 & \\
\hline $\mathrm{Ex}$ & 199 & .232 & 0.300 & 0.010 & 0.120 & 0.000 & 20 & 0.200 & 0.010 & 0.030 & 0.019 & 0.100 \\
\hline & 020 & .023 & 0.030 & 0.010 & & 000 & & & & & 0.019 & 010 \\
\hline & & & & & & & & & & & & \\
\hline & & & & & & & & & & & 0.019 & \\
\hline & & & & & & & & & & & 0.019 & \\
\hline & 0 & 23 & 0.030 & 0.010 & & 000 & & & & 0. & 0.019 & .010 \\
\hline & 20 & 23 & 030 & 0 & & 000 & & 220 & v & 0.030 & 0.186 & 0.010 \\
\hline & 53 & 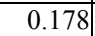 & 230 & & & 000 & & 200 & .010 & 0.030 & 0.019 & 0.077 \\
\hline $\mathrm{LW0}$ & 0.020 & 0.023 & 0.030 & 0.010 & 120 & 0.000 & 120 & 0.020 & 0.010 & 0.030 & 0.186 & 0.010 \\
\hline HLWO & 0.199 & 0.232 & 0.300 & 0.010 & 0.120 & 0.000 & .120 & 0.020 & 0.010 & 0.030 & 0.186 & 0.100 \\
\hline & .020 & .023 & 0.030 & 0.010 & & 0.000 & & 00 & & & 0.186 & 0.010 \\
\hline & n & & 0.060 & & & & & & & & 0.140 & 0.020 \\
\hline & & & 0 & & & & & & & & & \\
\hline & & & & & & & & & & & & \\
\hline & & & 0.060 & 0010 & & 0.000 & & & & 0.030 & 0.140 & 007 \\
\hline & & & 060 & & & .000 & & & & 0.030 & 0.047 & 002 \\
\hline & 040 & 046 & 0.060 & 000 & & 0.000 & 0.120 & 0.150 & 0.010 & 0.030 & 0.047 & 0.020 \\
\hline$-34 \mathrm{~F}$ & 0.133 & 0.154 & 0.200 & 0.010 & 0.120 & 0.000 & 0.120 & 0.050 & 0.010 & 0.030 & 0.046 & 0.067 \\
\hline HLW02-35 & 0.133 & 0.154 & 0.200 & 0.010 & 0.120 & 0.000 & 0.120 & 0.050 & 0.010 & 0.030 & 0.140 & 0.067 \\
\hline
\end{tabular}

(a) R1 after a Glass ID indicates the glass batching, melting, and testing was repeated.

(b) For each glass, the sum of the $\mathrm{wt}_{\mathrm{t}} \%$ values for the components comprising Remaining equals the $w t \%$ value listed in the Remaining column of Table A.17, except for any differences resulting from rounding $w t \%$ values to three decimal places. 
Table A.19. Composition Expansions of Remaining Components for the 125 Existing HLW Glasses in Table A.17 (continued).

\begin{tabular}{|c|c|c|c|c|c|c|c|c|c|c|c|c|}
\hline \multirow{2}{*}{ Glass ID (a) $^{(1)}$} & \multicolumn{12}{|c|}{ Remaining Components (wt\%) $)^{(b)}$} \\
\hline & $\mathrm{Ag}_{2} \mathrm{O}$ & $\mathbf{A s}_{2} \mathbf{O}_{5}$ & $\mathrm{BaO}$ & $\mathbf{B i}_{2} \mathbf{O}_{3}$ & MgO & $\mathrm{Nd}_{2} \mathrm{O}_{3}$ & PdO & $\mathrm{SeO}_{2}$ & $\mathrm{TeO}_{2}$ & $\mathrm{TiO}_{2}$ & $\mathbf{T l}_{2} \mathbf{O}$ & $\mathbf{V}_{2} \mathbf{O}_{5}$ \\
\hline $\mathrm{W} 02-36$ & .133 & 0.154 & 200 & 0.010 & .120 & 0.000 & 0.120 & 0.150 & 0.010 & 0.030 & 0.046 & \\
\hline 37 & 440 & 046 & 060 & & & 000 & & 050 & 210 & & .047 & \\
\hline$\overline{\text { HLW }}$ & 133 & 154 & 200 & & & & & & & & .046 & \\
\hline & 040 & 046 & 060 & 0.010 & 20 & 000 & 20 & 50 & .010 & 0.030 & \begin{tabular}{|c|}
0.047 \\
\end{tabular} & 0.020 \\
\hline 40 & 133 & 0.154 & 0.200 & 0.010 & & .000 & 120 & & 0.010 & 0.030 & 0.140 & 0.067 \\
\hline 41 & 040 & 0.046 & 0.060 & 0.010 & 0.120 & 0.000 & 120 & 0.050 & 0.010 & 0.030 & 0.140 & 0.020 \\
\hline 580 & .040 & 0.046 & 0.060 & 0.010 & & 0.000 & 120 & .050 & 0.010 & 0.030 & 0.140 & 0.020 \\
\hline & 840 & 0.046 & 0.060 & & & & & & & & 0.047 & 0.020 \\
\hline & & & 0.200 & & & & & & & & 0.046 & .067 \\
\hline & a & 6 & 0.060 & & & & & & & & 0.047 & .020 \\
\hline & 040 & 6 & 0.060 & & & & & & & & 0.140 & .020 \\
\hline & 133 & 4 & 200 & 0 & & t & & & & 0 & .140 & $0.06 /$ \\
\hline & & 54 & 0.200 & & & 000 & & & & & 0.140 & \\
\hline & 40 & 046 & 0.060 & 0.010 & & 0.000 & & 50 & & & 0.140 & \\
\hline$\overline{\mathrm{IW}}$ & 040 & 0.046 & 0.060 & 0.010 & 0.120 & 0.000 & 20 & 0.050 & 0.010 & 0.030 & 0.140 & 0.020 \\
\hline & .040 & 0.046 & 0.060 & & & 000 & & & & & 0.140 & 0.020 \\
\hline & & & & & & & & & & & 02 & \\
\hline & & & 0.030 & & & & & & & & 0.019 & $=$ \\
\hline & & & 30 & & & & & & & & 0.186 & 0.0 \\
\hline & 0 & 46 & 0.060 & 0.010 & & 000 & & & & 0. & 0.140 & 0.02 \\
\hline & 列 & 54 & 0.200 & 0.010 & & 000 & & 50 & 0 & 0.030 & 0.046 & $0.06^{\prime}$ \\
\hline & 20 & 223 & 0.030 & & & 000 & 20 & 020 & .010 & 0.030 & \begin{tabular}{|c|}
0.019 \\
\end{tabular} & 0.010 \\
\hline W0 & 200 & 0.232 & 0.300 & 0.010 & 0.120 & 0.000 & 120 & 0.200 & 0.010 & 0.030 & 0.307 & 0.100 \\
\hline HLW0 & 0.020 & 0.023 & 0.030 & 0.010 & 0.120 & 0.000 & .120 & 0.020 & 0.010 & 0.030 & 0.307 & 0.010 \\
\hline & 020 & .023 & 0.030 & 0.010 & & 000 & & .200 & & & 0.307 & 0.010 \\
\hline & 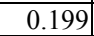 & & 0.299 & & & & & & & & 0.306 & 0.100 \\
\hline & & & & & & & & & & & & \\
\hline & & & & & & & & & & & 0.019 & 0.010 \\
\hline & & & .030 & 0010 & & 0.000 & & & 0.010 & 0.030 & 0.019 & 001 \\
\hline & 200 & & 300 & & & .000 & & 0.020 & & 0.030 & 0.019 & 010 \\
\hline$\overline{\mathrm{H}}$ & 200 & 233 & 300 & 0010 & & 0.000 & 0.120 & 0.020 & 0.010 & 0.030 & \begin{tabular}{|c|}
0.019 \\
\end{tabular} & 0.100 \\
\hline$\overline{\mathrm{H}}$ & 0.020 & 0.023 & 0.030 & 0.010 & 0.120 & 0.000 & 0.120 & 0.020 & 0.010 & 0.030 & \begin{tabular}{|l|}
0.019 \\
\end{tabular} & 0.010 \\
\hline HLW03-13 & 0.020 & 0.023 & 0.030 & 0.010 & 0.120 & 0.000 & 0.120 & 0.199 & 0.010 & 0.030 & 0.019 & 0.010 \\
\hline
\end{tabular}

(a) R1 after a Glass ID indicates the glass batching, melting, and testing was repeated.

(b) For each glass, the sum of the $\mathrm{wt}_{\mathrm{t}} \%$ values for the components comprising Remaining equals the $\mathrm{wt} \%$ value listed in the Remaining column of Table A.17, except for any differences resulting from rounding $w t \%$ values to three decimal places. 
Table A.19. Composition Expansions of Remaining Components for the 125 Existing HLW Glasses in Table A.17 (continued).

\begin{tabular}{|c|c|c|c|c|c|c|c|c|c|c|c|c|}
\hline \multirow{2}{*}{ Glass ID $^{(a)}$} & \multicolumn{12}{|c|}{ Remaining Components $(w t \%)^{(b)}$} \\
\hline & $\mathrm{Ag}_{2} \mathrm{O}$ & $\mathrm{As}_{2} \mathbf{O}_{5}$ & BaO & $\mathbf{B i}_{2} \mathbf{O}_{3}$ & MgO & $\mathbf{N d}_{2} \mathrm{O}_{3}$ & PdO & $\mathrm{SeO}_{2}$ & $\mathrm{TeO}_{2}$ & $\mathrm{TiO}_{2}$ & $\mathbf{T l}_{2} \mathrm{O}$ & $V_{2} \mathbf{O}_{5}$ \\
\hline . & 0.020 & 0.023 & 0.030 & 0.010 & 0.120 & & & 0.020 & 0.010 & 0.030 & 0.307 & 0.010 \\
\hline & & 023 & 0 & & & & & & & & & \\
\hline & 99 & 231 & 299 & & & & & & & & 19 & \\
\hline & 99 & 232 & 299 & & & & & & & & & \\
\hline & 020 & & 030 & & & & & & & & 307 & .010 \\
\hline & 20 & 23 & 0.030 & & 20 & & & 020 & 010 & 030 & .019 & .010 \\
\hline & 200 & 0.232 & 0.300 & 0.010 & 0.120 & & 20 & 00 & 10 & 030 & 0.307 & 0.100 \\
\hline & 040 & 0.046 & 0.060 & 0.010 & 0.120 & & & & & .030 & 0.046 & 020 \\
\hline & 134 & & 0.200 & & & & & & & & .046 & \\
\hline & & & 0.060 & & & & & & & & 0.046 & \\
\hline & 40 & & 0.060 & & & & & & & 30 & 46 & \\
\hline & 34 & 5 & 201 & & & & & & & & 39 & \\
\hline & 34 & 5 & 200 & & & & & & & 50 & 46 & .001 \\
\hline & 34 & 155 & 0.200 & 10 & 0.120 & 00 & 20 & 150 & & .030 & .046 & \\
\hline & 040 & 0.046 & 0.060 & 0.010 & 0.120 & 50 & & 050 & 0.010 & 0.030 & 0.046 & 0.020 \\
\hline & 040 & 0.046 & 0.060 & 0.010 & 0.120 & 0.000 & & .050 & 0.010 & 0.030 & 0.046 & 0.020 \\
\hline & 40 & 0.046 & 0.060 & & 0.120 & & & 150 & & 30 & 39 & 020 \\
\hline & & & 0.060 & & & & & & & 30 & 39 & \\
\hline & & & & & & & & & & 30 & 0.139 & \\
\hline & & & 0.060 & & & & & & & 30 & 46 & \\
\hline & & & 1 & & & & & & & .030 & 139 & \\
\hline & & & 0 & & 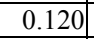 & & & 50 & & 030 & .139 & .02 \\
\hline & 34 & 55 & 0.201 & & 0.120 & & 20 & 050 & & .030 & .046 & 0.067 \\
\hline & 34 & 0.155 & 0.200 & 0.010 & 0.120 & 0.000 & 120 & 0.150 & 0.010 & 0.030 & 0.139 & 0.067 \\
\hline & 34 & 0.155 & 0.200 & 0.010 & 0.120 & 0.000 & 120 & .150 & .010 & 0.030 & 0.046 & 0.067 \\
\hline & 134 & .155 & 0.201 & & 0.120 & 0.000 & 120 & 0.150 & 010 & 0.030 & 0.139 & 0.067 \\
\hline & & & 0.060 & & 0.120 & & & 0.150 & & 0.030 & 0.046 & 0 \\
\hline & & & & & & & & & & & .093 & \\
\hline & & & 0.060 & & 0.120 & & 20 & 150 & & 0.030 & 0.140 & 0.0 \\
\hline & & & & & & & & & & .030 & 0.019 & \\
\hline & & & & & & & & 50 & & 0.030 & 0.046 & $\overline{00}$ \\
\hline & & & 300 & & 1.170 & & 0.120 & 0.000 & 0.000 & 1.000 & 0.000 & 0.000 \\
\hline HLW06-0 & 0.100 & 0.000 & 0.227 & 0.300 & 0.886 & 0.487 & 0.120 & 0.000 & 0.000 & 0.757 & 0.000 & 0.000 \\
\hline
\end{tabular}

(a) R1 after a Glass ID indicates the glass batching, melting, and testing was repeated.

(b) For each glass, the sum of the wt\% values for the components comprising Remaining equals the $\mathrm{wt} \%$ value listed in the Remaining column of Table A.17, except for any differences resulting from rounding $w t \%$ values to three decimal places. 
Table A.19. Composition Expansions of Remaining Components for the 125 Existing HLW Glasses in Table A.17 (continued).

\begin{tabular}{|c|c|c|c|c|c|c|c|c|c|c|c|c|}
\hline \multirow{2}{*}{ Glass ID $^{(a)}$} & \multicolumn{12}{|c|}{ Remaining Components (wt\%) $)^{(\mathbf{b})}$} \\
\hline & $\mathrm{g}_{2} \mathrm{O}$ & ${ }_{2} \mathrm{O}_{5}$ & $\mathbf{B a O}$ & $\mathbf{B i}_{2} \mathbf{O}_{3}$ & MgO & $\mathrm{Nd}_{2} \mathrm{O}_{3}$ & PdO & $\mathrm{SeO}_{2}$ & $\mathrm{eO}_{2}$ & $\mathrm{iO}_{2}$ & $\mathrm{I}_{2} \mathrm{O}$ & $\bar{J}_{2} \mathbf{O}_{5}$ \\
\hline & & 000 & 000 & & 000 t & & & & & & & \\
\hline & & & & & & & & & & & & \\
\hline & & & & & & & & & & & & \\
\hline & & & & & & & & & & & & \\
\hline & & & & & & & & & & & & \\
\hline & 47 & & 0.036 & & & & & & & & .000 & 00 \\
\hline & & 000 & 0.000 & 0.000 & & & & & 000 & & 000 & .000 \\
\hline & & & & & & & & & & & & 8 \\
\hline & & & & & & & & & & & & \\
\hline & & & & & & & & & & & 00 & 000 \\
\hline & & & & & & & & & & & 00 & 00 \\
\hline & & & & & & & & & & & 000 & 00 \\
\hline & & & 5 & & & & & & & & 00 & \\
\hline & & & 0.061 & & & & & & 000 & 00 & 0.000 & 0.000 \\
\hline & 81 & 0.000 & 0.063 & 0.000 & 0.166 & & & .000 & 0.000 & 0.026 & 0.000 & 0.000 \\
\hline & & 000 & 0.095 & 0.033 & 247 & & & 000 & 000 & .036 & 0.000 & 0.000 \\
\hline & & & & & & & & & & 052 & .000 & 0.000 \\
\hline & & & & & & & & & & & 500 & $\overline{000}$ \\
\hline & & & & & & & & & & & & \\
\hline & & & & & & & & & & & .000 & 00 \\
\hline & & & & & & & & & & & 000 & 0.00 \\
\hline & & & & & & & & & & & .000 & 00 \\
\hline & & & & & & & & & 00 & & .000 & 0.00 \\
\hline & & & 0. & 0 & & & & 00 & 0.000 & 27 & 0.000 & 0.000 \\
\hline & & & 0.048 & & & & & 00 & 0.000 & 0.027 & 0.000 & 0.000 \\
\hline LW-ALG-23 & 133 & .000 & 0.046 & 0.000 & 0.107 & $0.09^{\prime}$ & 0.000 & 0.000 & 0.000 & 0.026 & 0.000 & 0.00 \\
\hline
\end{tabular}

(a) R1 after a Glass ID indicates the glass batching, melting, and testing was repeated.

(b) For each glass, the sum of the $\mathrm{wt} \%$ values for the components comprising Remaining equals the wt\% value listed in the Remaining column of Table A.17, except for any differences resulting from rounding $\mathrm{wt} \%$ values to three decimal places. 
Table A.20. 18-Component Target Glass Compositions (wt\%) for the 40-Glass HLW07 Test Matrix.

\begin{tabular}{|c|c|c|c|c|c|c|c|c|c|c|c|c|c|c|c|c|c|c|c|c|}
\hline Slass ID & pint Type $^{(a)}$ & $\mathbf{A l}_{2} \mathbf{O}_{3}$ & $\mathbf{B}_{2} \mathbf{O}_{3}$ & $\mathrm{Cr}_{2} \mathrm{O}_{3}$ & $\mathrm{Fe}_{2} \mathbf{O}_{3}$ & $\mathbf{L i}_{2} \mathbf{O}$ & MnO & $\mathrm{Na}_{2} \mathrm{O}$ & $\mathrm{NiO}$ & $\mathrm{SiO}_{2}$ & SrO & $\mathrm{ThO}_{2}$ & $\mathrm{UO}_{3}$ & ZnO & $\mathrm{ZrO}_{2}$ & Others1 & Others2 & Constant & Remain & Sum \\
\hline HLW07-01 & h2.Center & 7.161 & 9.206 & 0.277 & 7.993 & 1.802 & 3.171 & 11.287 & 0.422 & 41.825 & 4.260 & 2.138 & 2.206 & 0.983 & 4.300 & 0.644 & 0.588 & 1.735 & 0.000 & 100.000 \\
\hline HLW07-02 & 12.Rep.HLI & .500 & 149 & 040 & 10.001 & 3.701 & 3.500 & 9.001 & 800 & 499.003 & 500 & .000 & .000 & 2.000 & .500 & 0.600 & 610 & 1.348 & 0.746 & 00.000 \\
\hline HLW07-03 & 2.Rep.HLW03-41 & .888 & 8.732 & 140 & 6.939 & 3.710 & .698 & 9.093 & 395 & 43.059 & 705 & 658 & .032 & 1.920 & .767 & .599 & 427 & 1.395 & 843 & 0.000 \\
\hline HLW07-04 & HLW02-22 & 8.500 & 14.000 & 020 & .500 & 6.000 & .000 & 4.000 & .100 & 53.000 & 0.080 & 000 & .000 & 2.000 & .000 & .600 & .110 & 1.498 & .592 & 0.000 \\
\hline HLW07-05 & HLW03-07 & 4.961 & 4.961 & 496 & 13.891 & 4.750 & 945 & 11.693 & 0.100 & 39.825 & 0.000 & 0.000 & 5.306 & 3.461 & .000 & 0.598 & 110 & 1.313 & 590 & 0.000 \\
\hline HLW07-06 & $\mathrm{P}$ & 11.501 & 6.001 & .600 & 4.000 & 0.000 & 001 & 2.530 & 0.000 & 35.004 & 10.001 & 0.000 & 4.100 & 0.000 & .951 & 1.360 & 480 & 3.470 & 000 & 0.000 \\
\hline $\mathrm{HLV}$ & & 3.000 & 6.001 & 050 & .001 & .000 & & .977 & & 35.059 & 01 & 0.000 & 100 & 00 & 00 & & & 70 & 00 & .000 \\
\hline 08 & & 501 & 1 & & 67 & 00 & & 3.002 & & \begin{tabular}{|l|}
35.307 \\
\end{tabular} & & 00 & 00 & & 01 & & & 70 & 00 & .000 \\
\hline 09 & & 000 & .001 & 600 & 459 & 500 & 00 & 8.603 & & 35.004 & 01 & 400 & 00 & 00 & 01 & 60 & & 170 & 00 & 000 \\
\hline 10 & & 000 & .867 & 600 & \begin{tabular}{|l|}
14.001 \\
\end{tabular} & .000 & 0 & 9.461 & 14 & 35.004 & 10.001 & 400 & 00 & 50 & 1.000 & 00 & 80 & 70 & 000 & 000 \\
\hline HLW07-11 & $\mathrm{P}$ & 501 & 6.001 & 600 & 10.495 & 500 & 500 & 7.016 & 1.000 & 35.004 & 2.332 & .000 & .100 & .000 & .000 & .000 & 480 & 470 & .000 & .000 \\
\hline HLW07-12 & $\mathrm{P}$ & .501 & 6.001 & .116 & 13.191 & 413 & 500 & 7.903 & 0.000 & 35.004 & 0.000 & 4.400 & 0.000 & 2.500 & .000 & .000 & 0.000 & .470 & .000 & .000 \\
\hline $7-13$ & & .501 & 6.001 & 600 & 4.000 & 0.790 & 500 & 8.002 & 0.000 & 36.494 & 0.000 & 0.000 & 4.100 & 2.500 & .601 & 360 & 80 & & .000 & .000 \\
\hline $\mathrm{HLV}$ & & 11.501 & 6.001 & .050 & 4.647 & 284 & 500 & 6.001 & 1.000 & \begin{tabular}{|l|}
35.004 \\
\end{tabular} & 10.001 & 0.000 & 4.100 & 0.000 & 601 & 360 & 480 & 470 & .000 & .000 \\
\hline HLV & & 4.400 & 6.001 & & 4.000 & .000 & & 8.002 & 00 & & 01 & 00 & 470 & 00 & 001 & 00 & & 70 & & \\
\hline$\underline{\mathrm{HL}}$ & & 4.400 & & & & 3 & & & & & & & & & 01 & & & & & \\
\hline 17 & & .501 & 1 & 0 & 000 & 253 & 01 & 8.002 & & 35. & 0. & 0 & 00 & 0.000 & $\overline{00}$ & 60 & & & 00 & 000 \\
\hline 18 & & 9.077 & 13.001 & 600 & 925 & 500 & 00 & 8.002 & 00 & \begin{tabular}{|l|}
37.524 \\
\end{tabular} & 00 & 400 & 000 & 00 & .000 & 000 & 00 & 70 & 000 & 000 \\
\hline 19 & & 000 & .572 & 600 & 401 & 210 & 00 & 15.061 & 000 & 35.004 & 10.001 & 000 & 100 & 00 & 001 & 000 & 480 & 470 & .000 & .000 \\
\hline $7-20$ & 1 & .501 & 13.001 & 0.600 & .501 & .500 & .001 & 6.001 & 0.000 & \begin{tabular}{|l|}
46.179 \\
\end{tabular} & 0.000 & 2.246 & 0.000 & .000 & 1.000 & .000 & 0.000 & .470 & 0.000 & 00.000 \\
\hline HLW07-21 & $\mathrm{P}$ & 3.000 & 6.001 & .050 & .401 & .000 & 500 & 1.335 & 0.000 & 42.700 & .001 & 0.000 & 4.100 & 0.000 & .601 & 360 & 2.480 & 470 & .000 & .000 \\
\hline HLW07-22 & $2 . \mathrm{OL} 17$ & 11.501 & 6.073 & .050 & .000 & .000 & 500 & 12.419 & 1.000 & 35.004 & 10.001 & 4.400 & .100 & 2.500 & .500 & .000 & 2.480 & 470 & .000 & 0.000 \\
\hline $\mathrm{HLV}$ & & 4.400 & 13.001 & .600 & 4.000 & 1.822 & .500 & 6.620 & 1.000 & 41.883 & 6.501 & 0.000 & 4.100 & 2.500 & 9.601 & .000 & 0.000 & .470 & .000 & 00.000 \\
\hline $\mathrm{HLV}$ & & .501 & 13.001 & .600 & 5.501 & 0.000 & 500 & 6.120 & 000 & 37.445 & 0.000 & 4.400 & 4.100 & 0.000 & 1.000 & 360 & .000 & 470 & .000 & 000 \\
\hline $7-25$ & & 1.501 & 6.001 & .050 & 5.501 & 0.997 & .001 & 11.453 & 0.000 & 42.662 & 0.000 & 400 & 4.100 & 0.384 & 1.000 & 000 & .480 & 470 & 000 & 000 \\
\hline & & .001 & 8.000 & 150 & 000 & 3.460 & & 0.001 & & 47.002 & .000 & 00 & 500 & 00 & 2.500 & 000 & 000 & & 000 & \\
\hline & & 001 & 11.001 & 400 & 000 & 3.500 & 00 & 0.001 & 200 & 40.002 & 000 & & 000 & 000 & 2.500 & 660 & .000 & 735 & 000 & .000 \\
\hline & & .001 & & 150 & 00 & 3.500 & 500 & 14.001 & 650 & & 00 & & 500 & .500 & .500 & 360 & 000 & 735 & .000 & 100.000 \\
\hline & & 5.000 & 11.001 & & & 000 & 000 & & & & & 500 & 000 & 500 & 00 & 000 & & & .000 & 000 \\
\hline ILW07-30 & 2.IL5 & 5.000 & 8.000 & 0.400 & 1.001 & 1.000 & 3.687 & 12.614 & 0.200 & 7.002 & 2.500 & 1.000 & 1.500 & 0.500 & 2.500 & 1.360 & 0.000 & 1.735 & 0.000 & 100.00 \\
\hline
\end{tabular}

(a) The "Point Type" notation begins with Ph2 to denote HLW Phase 2. After a separating dot, "Center", "OL", or "IL", denotes whether the glass was a center point, outer-layer point, or inner-layer point. Next, "XX" denotes the number of each outer-layer, inner-layer, or other point with respect to the given study phase. Replicate points are denoted by "Rep.HLW02-xx" and "Rep.HLW03-xx", where the "xx" represents a specific ID number for a replicated glass.

(b) The $\mathrm{wt} \%$ values in the table are rounded to three decimal places and may not sum to 100.000 exactly, but the sum is achieved in the data base. 
Table A.20. 18-Component Target Glass Compositions (wt\%) for the 40-Glass HLW07 Test Matrix (continued).

\begin{tabular}{|c|c|c|c|c|c|c|c|c|c|c|c|c|c|c|c|c|c|c|c|c|}
\hline Glass ID & Point Type $^{(\mathrm{a})}$ & $\mathrm{Al}_{2} \mathrm{O}_{3}$ & $\mathbf{B}_{2} \mathbf{O}_{3}$ & $\mathrm{Cr}_{2} \mathrm{O}_{3}$ & $\mathrm{Fe}_{2} \mathrm{O}_{3}$ & $\mathrm{Li}_{2} \mathrm{O}$ & MnO & $\mathrm{Na}_{2} \mathrm{O}$ & $\mathrm{NiO}$ & $\mathrm{SiO}_{2}$ & SrO & $\mathrm{ThO}_{2}$ & $\mathrm{UO}_{3}$ & $\mathrm{ZnO}$ & $\mathrm{ZrO}_{2}$ & Others1 & \begin{tabular}{|l|} 
Others2 \\
\end{tabular} & \begin{tabular}{|l|} 
Constant \\
\end{tabular} & Remain & Sum ${ }^{(b)}$ \\
\hline HLW07-31 & Ph2.IL6 & 10.001 & 11.001 & 0.400 & 6.000 & 1.357 & 2.500 & 10.001 & 0.403 & 40.002 & 7.000 & 1.000 & 3.000 & 0.500 & 2.500 & 1.360 & 1.240 & 1.735 & 0.000 & 100.000 \\
\hline HLW07-32 & Ph2.IL7 & 5.000 & 8.000 & 0.150 & $\mid 11.001$ & 1.000 & 2.500 & \begin{tabular}{|l|}
14.001 \\
\end{tabular} & 0.650 & \begin{tabular}{|l|}
40.002 \\
\end{tabular} & 3.264 & 1.000 & 1.500 & 1.096 & 6.500 & 1.360 & 1.240 & 1.735 & 0.000 & 100.000 \\
\hline HLW07-33 & Ph2.IL8 & 10.001 & 8.000 & 0.400 & 6.297 & 1.000 & 4.000 & 12.268 & 0.650 & 42.207 & 6.940 & 1.000 & 1.500 & 1.500 & 2.500 & 0.000 & 0.000 & 1.735 & 0.000 & 100.000 \\
\hline HLW07-34 & Ph2.IL9 & 10.001 & \begin{tabular}{|l|}
11.001 \\
\end{tabular} & 0.150 & 6.000 & 2.063 & 4.000 & \begin{tabular}{|l|}
10.001 \\
\end{tabular} & 0.650 & 41.514 & 2.905 & 1.000 & 1.981 & 0.500 & 6.500 & 0.000 & 0.000 & 1.735 & 0.000 & 100.000 \\
\hline HLW07-35 & Ph2.IL10 & 10.001 & 9.587 & 0.400 & 6.000 & 1.347 & 2.500 & 10.001 & 0.200 & 40.002 & 7.000 & 3.500 & 1.500 & 1.500 & 4.727 & 0.000 & 0.000 & 1.735 & 0.000 & 100.000 \\
\hline HLW07-36 & Ph2.IL11 & 9.500 & 11.001 & 0.150 & 6.000 & 1.000 & 2.500 & 14.001 & 0.200 & 40.002 & 6.910 & 1.000 & 3.000 & 0.500 & 2.500 & 0.000 & 0.000 & 1.735 & 0.000 & 100.000 \\
\hline-37 & $\mathrm{Ph} 2$. & 5.000 & 8.000 & 0.150 & 10.501 & 3.500 & 4.000 & 13.811 & 200 & 40.002 & .500 & 3.500 & 1.500 & 0.500 & 2.500 & .360 & 1.240 & .735 & 000 & 100.000 \\
\hline-38 & $\mathrm{Ph} 2$ & 5.000 & \begin{tabular}{|l|}
11.001 \\
\end{tabular} & 0.400 & 6.500 & 1.000 & 4.000 & \begin{tabular}{|l|}
10.393 \\
\end{tabular} & 200 & \begin{tabular}{|l|}
41.670 \\
\end{tabular} & 2.500 & 3.500 & 1.500 & 1.500 & 6.500 & 1.360 & 1.240 & 1.735 & 0.000 & 100.000 \\
\hline $7-39$ & Ph2.IL14 & 5.500 & 11.001 & 0.400 & 6.000 & 1.000 & 2.500 & 13.629 & 0.200 & 44.794 & 2.500 & 1.000 & 1.500 & 0.500 & 6.500 & 0.000 & 1.240 & 1.735 & 0.000 & 100.000 \\
\hline HLW07-40 & Ph2.IL15 & 5.000 & 8.000 & 0.400 & \begin{tabular}{|l|}
10.384 \\
\end{tabular} & 1.000 & 2.500 & \begin{tabular}{|l|}
10.001 \\
\end{tabular} & 0.200 & \begin{tabular}{|l|}
42.803 \\
\end{tabular} & 7.000 & 3.500 & 2.119 & 1.500 & 2.617 & 0.000 & 1.240 & 1.735 & 0.000 & 100.00 \\
\hline
\end{tabular}

(a) The "Point Type" notation begins with Ph2 to denote HLW Phase 2. After a separating dot, "Center", "OL", or "IL", denotes whether the glass was a center point, outer-layer point, or inner-layer point. Next, "XX" denotes the number of each outer-layer, inner-layer, or other point with respect to the given study phase. Replicate points are denoted by "Rep.HLW02-xx" and "Rep.HLW03-xx", where the "xx" represents a specific ID number for a replicated glass.

(b) The $\mathrm{wt} \%$ values in the table are rounded to three decimal places and may not sum to 100.000 exactly, but the sum is achieved in the data base 
Table A.21. Composition Expansions of Others1, Others2, and Constant Components for the HLW07 Test Matrix in Table A.20.

\begin{tabular}{|c|c|c|c|c|c|c|c|c|c|c|c|c|c|c|c|c|c|c|c|c|c|c|c|}
\hline \multirow[t]{2}{*}{ Glass ID } & \multicolumn{3}{|c|}{ 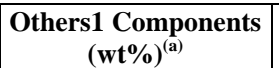 } & \multicolumn{4}{|c|}{$\begin{array}{c}\text { Others2 Components } \\
(\mathrm{wt} \%)^{\mathrm{a} a)}\end{array}$} & \multicolumn{16}{|c|}{$\begin{array}{c}\text { Constant Components } \\
(w t \%)^{(a)}\end{array}$} \\
\hline & \begin{tabular}{|l|}
$\mathrm{MoO}_{3}$ \\
\end{tabular} & $\mathbf{P}_{2} \mathbf{O}_{5}$ & $\mathrm{SO}_{3}$ & dO & $\mathrm{CoO}$ & $\mathrm{CuO}$ & PbO & $\mathrm{aO}$ & ${ }_{2} \mathrm{O}_{3}$ & 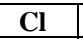 & $\mathrm{s}_{2} \mathrm{O}$ & $\mathbf{F}$ & ${ }_{2} \mathrm{O}$ & $\mathbf{L a}_{2} \mathbf{O}_{3}$ & $\mathrm{Pr}_{2} \mathrm{O}_{3}$ & $\mathbf{R b}_{2} \mathbf{O}$ & $\mathbf{R h}_{2} \mathbf{O}_{3}$ & \begin{tabular}{|l|}
$\mathrm{RuO}_{2}$ \\
\end{tabular} & $\mathrm{Sb}_{2} \mathbf{O}_{3}$ & $\mathrm{nO}_{2}$ & $\mathbf{T a}_{2} \mathbf{O}_{5}$ & $\mathrm{VO}_{3}$ & $\mathbf{Y}_{2} \mathbf{O}_{3}$ \\
\hline 7-01 & 5 & 303 & 156 & .237 & $5=$ & .057 & .240 & .150 & 0.190 & 0.170 & .125 & 0.060 & .290 & 0.125 & 0.080 & 0.040 & 0.040 & 0.050 & 0.200 & 0.115 & 0.000 & 0.060 & \\
\hline & 00 & 500 & 100 & 500 & 10 & 020 & 880 & 500 & 0.048 & 200 & 010 & 0.050 & 0.060 & 300 & .000 & .000 & .050 & 0.080 & 0.050 & .000 & 0.000 & 0.000 & .000 \\
\hline $7-03$ & 000 & .499 & .100 & 200 & 010 & 0.043 & .174 & .499 & 0.048 & 200 & .010 & 0.050 & 0.060 & 0.299 & 0.000 & .000 & .050 & 0.080 & 0.100 & .000 & 0.000 & 000 & .0 \\
\hline LW07-04 & 000 & 0.500 & .100 & .050 & 010 & 0.010 & 0.040 & .500 & 0.048 & 200 & 010 & 0.050 & 0.060 & 0.300 & 0.000 & .000 & .050 & 0.080 & 0.200 & 0.000 & 0.000 & 0.000 & .000 \\
\hline & & & & & & & & 498 & & & & & & & & & 050 & 80 & 020 & 000 & 0.000 & & 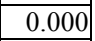 \\
\hline & & & & & & & & 300 & & & & & & & & & & & 400 & 30 & 000 & & \\
\hline & & 0 & & & & & & 00 & & & & & & 50 & & & 80 & & 400 & 30 & 000 & & \\
\hline & & 00 & & & & & t & & & & & 20 & 580 & 250 & & & 080 & & 400 & 30 & 0.000 & & \\
\hline & & & & & & & & & & & & & & 50 & & & 80 & & on & & $\mathrm{ng}$ & & \\
\hline & & 0 & 00 & & & 0. & 1.010 & & & & & & 580 & 0.250 & & & 80 & 00 & 400 & 230 & 0.000 & & \\
\hline & . & 0.000 & 0.000 & .000 & & 0.240 & 1010 & .300 & 0.380 & 340 & & 120 & 0.580 & 0.250 & 60 & & 080 & 100 & 400 & 230 & 0.000 & & \\
\hline & & 0.000 & 0.000 & 0000 & & 0.000 & 0.000 & 0.300 & .380 & .340 & & .120 & 0.580 & 0.250 & 160 & & 080 & .100 & .400 & 230 & 0.000 & & 100 \\
\hline & & 640 & 0.330 & & & & 0.440 & & & & & & 0.580 & & & & .080 & 100 & 400 & & \begin{tabular}{|l|}
0.000 \\
\end{tabular} & & \\
\hline & & & & & & & & & & & & & & & & & & & 00 & & 00 & & \\
\hline & & 0.0 & 0 & & & & .000 & 0 & & & & 20 & 580 & 250 & & & 80 & 00 & .400 & 30 & .000 & & \\
\hline & & 0.00 & 0 & 00 & & 0 & 1 & 0 & & 340 & & 20 & 0.580 & 250 & & & 80 & 00 & .400 & 30 & 0.000 & & 0. \\
\hline & & 0 & & & & & 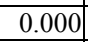 & 0 & & & & 20 & 0.580 & 250 & & & 80 & 00 & .400 & 30 & 0.000 & & \\
\hline & & & 0 & & & & & 0 & & & & & 580 & 50 & & & 80 & 00 & 400 & & 0.000 & & \\
\hline V07-19 & 000 & 0.000 & 0.000 & 1.000 & 0.230 & 0.240 & 1.010 & 0.300 & 0.380 & .340 & 250 & 0.120 & 0.580 & 0.250 & 0.160 & 0.080 & 0.080 & 0.100 & 0.400 & 0.230 & 0.000 & 0.120 & 0.08 \\
\hline $77-20$ & 000 & 0.000 & 0.000 & 0.000 & 0.000 & 0.000 & 0.000 & 0.300 & 0.380 & .340 & 0.250 & 0.120 & 0.580 & 0.250 & 0.160 & 0.080 & 0.080 & 0.100 & 0.400 & 0.230 & \begin{tabular}{|l|}
0.000 \\
\end{tabular} & 0.120 & 0.08 \\
\hline & 390 & 0.640 & 0.330 & 1.000 & & \begin{tabular}{l|}
0.240 \\
\end{tabular} & 1.010 & .300 & 0.380 & 340 & & 0.120 & 0.580 & 0.250 & 0.160 & 80 & .080 & .100 & .400 & 230 & 0.000 & 20 & 0.08 \\
\hline & & 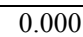 & 000 & 1.000 & & 0.240 & .0 & 300 & 0 & 340 & 250 & 120 & 580 & 250 & 160 & & 0.080 & .100 & 0.400 & 230 & 0.000 & & 0.08 \\
\hline & & 0.00 & 0 & & & & 9 & & & & & 20 & 0.580 & 250 & & & 0.080 & 00 & 400 & 30 & 0.000 & & 0.08 \\
\hline & & & & & & & - & & & & & & 580 & & & & 80 & & 00 & 30 & 0.000 & & \\
\hline & & 0 & & 1.000 & & & 0 & 00 & & 340 & 50 & 120 & 580 & 250 & & & .080 & 100 & 400 & 230 & 0.000 & & 0.0 \\
\hline & & 0 & 0 & t & & 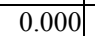 & t & 150 & & $170 \mathrm{~d}$ & 25 & .060 & 0.290 & .125 & & & .040 & .050 & 200 & & 0.000 & 60 & \\
\hline & & 311 & 160 & & & 0.000 & & 150 & & & & & 0.290 & 0.125 & & & .040 & .050 & 200 & 15 & 0.000 & & 0.04 \\
\hline & 390 & 640 & 0.330 & 0.000 & 0.000 & 0.000 & 0.000 & 150 & 0.190 & .170 & 25 & 0.060 & 0.290 & 0.125 & 0.080 & \begin{tabular}{|c|}
0.040 \\
\end{tabular} & 0.040 & .050 & .200 & 115 & \begin{tabular}{|l|}
0.000 \\
\end{tabular} & 0.060 & 0.04 \\
\hline & .000 & 0.000 & 0.000 & 0.000 & 0.000 & 0.000 & 0.000 & 0.150 & 0.190 & $\begin{array}{l}0.170 \\
\end{array}$ & 0.125 & 0.060 & 0.290 & 0.125 & 0.080 & 0.040 & 0.040 & .050 & 0.200 & 115 & 0.000 & 0.060 & 0.04 \\
\hline LW07-30 & 0.390 & 0.640 & 0.330 & 0.000 & 0.000 & 0.000 & 0.000 & 0.150 & 0.190 & 0.170 & .125 & 0.060 & 0.290 & 0.125 & 0.080 & 0.040 & 0.040 & 0.050 & 0.200 & 0.115 & \begin{tabular}{|l|}
0.000 \\
\end{tabular} & 0.060 & 0.04 \\
\hline
\end{tabular}

(a) For each glass, the sum of the wt\% values for the components comprising Others 1 , Others 2 , and Constant equal the wt $\%$ values listed in the Others 1 , Others2, and Constant columns of Table A.20, except for any differences resulting from rounding wt $\%$ values to three decimal places. The equalities are exact to the additional decimal places contained in the data base. 
Table A.21. Composition Expansions of Others1, Others2, and Constant Components for the HLW07 Test Matrix in Table A.20 (continued).

\begin{tabular}{|c|c|c|c|c|c|c|c|c|c|c|c|c|c|c|c|c|c|c|c|c|c|c|c|}
\hline \multirow[b]{2}{*}{ Glass ID } & \multicolumn{3}{|c|}{$\begin{array}{c}\text { Others1 Components } \\
\text { (wt\%) }^{(\mathrm{a})}\end{array}$} & \multicolumn{4}{|c|}{$\begin{array}{c}\text { Others2 Components } \\
(\mathrm{wt} \%)^{\mathrm{a})}\end{array}$} & \multicolumn{16}{|c|}{$\begin{array}{c}\text { Constant Components } \\
(\mathrm{wt} \%)^{(\mathrm{a})}\end{array}$} \\
\hline & $\mathrm{MoO}_{3}$ & $\mathbf{P}_{2} \mathbf{O}_{5}$ & $\mathrm{SO}_{3}$ & CdO & $\mathrm{CoO}$ & $\mathrm{CuO}$ & PbO & $\mathrm{aO}$ & ${ }_{2} \mathbf{O}_{3}$ & $\mathrm{Cl}$ & $\mathrm{s}_{2} \mathrm{O}$ & $\mathbf{F}$ & $\mathrm{K}_{2} \mathrm{O}$ & $\mathrm{a}_{2} \mathrm{O}_{3}$ & $\mathrm{Pr}_{2} \mathrm{O}_{3}$ & \begin{tabular}{|l|}
$\mathbf{R} \mathbf{b}_{2} \mathbf{O}$ \\
\end{tabular} & $\mathbf{R h}_{2} \mathbf{O}_{3}$ & $\mathrm{RuO}_{2}$ & $\mathrm{Sb}_{2} \mathrm{O}_{3}$ & $\mathrm{nO}_{2}$ & $\mathbf{T a}_{\mathbf{2}} \mathbf{O}_{5}$ & $\mathbf{W O}_{3}$ & $\mathbf{Y}_{2} \mathbf{O}_{3}$ \\
\hline HLW07-31 & & 640 & 33 & 50 & & & & .150 & 100 & .17 & & 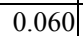 & 0 & \begin{tabular}{|l|}
0.125 \\
\end{tabular} & 0.080 & 0.040 & \begin{tabular}{|l|}
0.040 \\
\end{tabular} & 0.050 & 0.200 & 0.115 & 0.000 & 0.060 & 0040 \\
\hline $\mathrm{HLI}$ & & 0 & ( & 000 & & 20 & & & 190 & 70 & & .060 & 290 & & 80 & 40 & 040 & 050 & 200 & 15 & & 060 & 40 \\
\hline $\mathrm{HL}$ & 000 & .000 & .000 & .000 & 0.000 & 0.000 & , & 150 & 0.190 & 170 & .125 & .060 & 290 & 25 & & .040 & 0.040 & .050 & 200 & .115 & .000 & 0.060 & 0.040 \\
\hline HLW & 0 & .000 & 000 & .000 & 000 & 0.000 & 0.000 & 150 & 0.190 & .170 & 125 & 0.060 & 0.290 & 0.125 & 0.080 & 0.040 & 0.040 & 0.050 & 0.200 & 115 & 0.000 & 0.060 & 0.040 \\
\hline HLWC & 0.000 & 0.000 & 0.000 & .000 & 0.000 & 0.000 & 0.000 & 0.150 & 0.190 & 0.170 & 0.125 & 0.060 & 0.290 & 0.125 & 0.080 & 0.040 & 0.040 & 0.050 & 0.200 & .115 & 0.000 & 0.060 & 0.040 \\
\hline HLW07-36 & 0.000 & .000 & 0.000 & 0.000 & 0.000 & 0.000 & 0.000 & 0.150 & 0.190 & 0.170 & 0.125 & 0.060 & 0.290 & 0.125 & 0.080 & 0.040 & .040 & 0.050 & 0.200 & .115 & 0.000 & 0.060 & 0.040 \\
\hline $\mathrm{HLW}$ & & 640 & 330 & 500 & & & & & 0.190 & .170 & & 0.060 & 0.290 & 125 & & 0.040 & .040 & .050 & .200 & .115 & .000 & .060 & 0.040 \\
\hline & & & & 500 & & & & & 190 & & & .060 & 0.290 & & & & .040 & 50 & 0.200 & 15 & 000 & & 0.04 \\
\hline & & & & 300 & & & & & & & & 0.060 & 290 & & & & .040 & 050 & 0.200 & .115 & .000 & .060 & 0.04 \\
\hline 40 & 0.000 & 0.000 & 0.000 & .500 & 115 & 0.120 & 0.505 & 0.150 & .190 & 0.170 & .125 & 0.060 & 0.290 & 0.125 & 0.080 & 0.040 & 0.040 & 0.050 & 0.200 & 0.115 & 0.000 & 0.060 & 0.04 \\
\hline
\end{tabular}

(a) For each glass, the sum of the wt $\%$ values for the components comprising Others 1 , Others 2 , and Constant equal the wt $\%$ values listed in the Others 1 , Others2, and Constant columns of Table A.20, except for any differences resulting from rounding wt $\%$ values to three decimal places. The equalities are exact to the additional decimal places contained in the data base. 
Table A.22. Composition Expansions of Remaining Components for the HLW07 Test Matrix in Table A.20.

\begin{tabular}{|c|c|c|c|c|c|c|c|c|c|c|c|c|}
\hline \multirow{2}{*}{ Glass ID } & \multicolumn{12}{|c|}{ Remaining Components (wt \%) $)^{(a)}$} \\
\hline & $\mathrm{Ig}_{2} \mathrm{O}$ & \begin{tabular}{|l|}
$\mathbf{A s}_{2} \mathbf{O}_{5}$ \\
\end{tabular} & BaO & $\mathbf{B i}_{2} \mathbf{O}_{3}$ & MgO & $\mathrm{Nd}_{2} \mathrm{O}_{3}$ & PdO & $\mathrm{SeO}_{2}$ & $\mathrm{TeO}_{2}$ & $\mathrm{TiO}_{2}$ & $\mathrm{Tl}_{2} \mathrm{O}$ & $\mathbf{V}_{2} \mathbf{O}_{5}$ \\
\hline 01 & 0.000 & 0.000 & 000 & 0.000 & 0.000 & 0.000 & .000 & 0.000 & 0.000 & 0.000 & 0.000 & 0.000 \\
\hline & & 046 & 060 & & & & & & 110 & 30 & 140 & \\
\hline & 887 & 101 & 130 & & & & & & & & .093 & .043 \\
\hline & 020 & 023 & 0.030 & & & & & & 010 & 030 & .019 & .010 \\
\hline & 20 & & 0.030 & & & & & & 10 & 30 & .019 & .010 \\
\hline & .000 & 0.000 & 0.000 & 0.000 & 0.000 & & & & .000 & 0.000 & 0.000 & 0.000 \\
\hline & .000 & 0.000 & 0.000 & 0.000 & 0.000 & 00 & 000 & .000 & .000 & .000 & 0.000 & 0.000 \\
\hline & & & 0.000 & & & & & & & .000 & .000 & .000 \\
\hline & & & .000 & & & & & & & & 000 & .000 \\
\hline & 00 & 0 & 0.000 & 0 & & & & & & 00 & .000 & .000 \\
\hline & 000 & .000 & 0.000 & 00 & Jo & & & & 00 & 00 & .000 & .000 \\
\hline & 000 & .000 & 0.000 & 00 & 0 & & & & 00 & 00 & .000 & .000 \\
\hline & 000 & 000 & 0.000 & 00 & 00 & & & & .000 & .000 & .000 & .000 \\
\hline & 000 & .000 & 0.000 & 0.000 & 0.000 & & & .000 & .000 & 0.000 & 0.000 & 0.000 \\
\hline & 000 & 0.000 & 0.000 & 0.000 & 0.000 & 0.000 & 00 & .000 & .000 & 0.000 & 0.000 & 0.000 \\
\hline & & 000 & 0.000 & 0.000 & & & & & 00 & 00 & 0.000 & .000 \\
\hline & & & 0.000 & & & & & & & 00 & 000 & 000 \\
\hline & & & 0.000 & 0 & & & & & 00 & .000 & 0.000 & 0.000 \\
\hline & 000 & 0 & 0.000 & 0 & 0 & & & 00 & 00 & .000 & 0.000 & 0.000 \\
\hline & 000 & 000 & 0.000 & 000 & 00 & & & 000 & .000 & .000 & 0.000 & 0.000 \\
\hline & 000 & 000 & 0.000 & 000 & 000 & & & .000 & .000 & .000 & 0.000 & 0.000 \\
\hline & .000 & 0.000 & 0.000 & 0.000 & 0.000 & 0.000 & 000 & 0.000 & 0.000 & 0.000 & 0.000 & 0.000 \\
\hline HLW0 & 0.000 & 0.000 & 0.000 & 0.000 & 0.000 & 0.000 & 0.000 & 0.000 & 0.000 & 0.000 & 0.000 & 0.000 \\
\hline & 0.000 & 0.000 & 0.000 & 0.000 & 0.000 & 0.000 & 0.000 & 0.000 & 0.000 & 0.000 & 0.000 & 0.000 \\
\hline & & & 0.000 & & 0.000 & & & 00 & & .000 & 000 & 0.000 \\
\hline & & 000 & 0.000 & .000 & 0.000 & & & 0.000 & .000 & 0.000 & 0.000 & 0.000 \\
\hline & & & .000 & & 0.000 & & & .000 & & .000 & 0.000 & 0.000 \\
\hline & & & .000 & & & & & & & 00 & .000 & .00 \\
\hline & & & & & & & & & & 00 & .000 & 0.00 \\
\hline HL & .000 & 0.000 & 0.000 & 0.000 & 0.000 & 0.000 & 0.000 & 0.000 & 0.000 & 0.000 & 0.000 & 0.000 \\
\hline
\end{tabular}

(a) For each glass, the sum of the $\mathrm{wt} \%$ values for the components comprising Remaining equals the $\mathrm{wt} \%$ value listed in the Remaining column of Table A.20, except for any differences resulting from rounding $\mathrm{wt} \%$ values to three decimal places. 
Table A.22. Composition Expansions of Remaining Components for the HLW07 Test Matrix in Table A.20 (continued).

\begin{tabular}{|c|c|c|c|c|c|c|c|c|c|c|c|c|}
\hline \multirow{2}{*}{ Glass ID } & \multicolumn{12}{|c|}{ Remaining Components (wt\%) ${ }^{(\mathrm{a})}$} \\
\hline & $\mathrm{Ag}_{2} \mathbf{O}$ & $\mathbf{A s}_{2} \mathbf{O}_{5}$ & $\mathbf{B a O}$ & $\mathrm{Bi}_{2} \mathbf{O}_{3}$ & MgO & $\mathrm{Nd}_{2} \mathrm{O}_{3}$ & PdO & $\mathrm{SeO}_{2}$ & $\mathrm{TeO}_{2}$ & $\mathrm{TiO}_{2}$ & $\mathrm{Tl}_{2} \mathrm{O}$ & $\mathbf{V}_{2} \mathbf{O}_{5}$ \\
\hline & 0.000 & 0.000 & 0.000 & 0.000 & 0.000 & 0.000 & 0.000 & 0.000 & 0.000 & 0.000 & 0.000 & 0.000 \\
\hline & 000 & 000 & .000 & 0.000 & 0.000 & & & 0.000 & 0.000 & .000 & .000 & .000 \\
\hline & & & & & & & & & & & & .000 \\
\hline & & & 0 & 0 & & & & & $\overline{0}$ & 00 & .000 & .000 \\
\hline & & 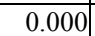 & 0.0 & .000 & & & & & 0 & 00 & 0.000 & .00 \\
\hline & 00 & 00 & $\overline{00}$ & 000 & 50 & 00 & & .000 & 0.000 & .000 & 0.000 & 0.000 \\
\hline & 000 & 000 & $\overline{00}$ & 0.000 & 0.000 & 0.000 & & 0.000 & 0.000 & 0.000 & 0.000 & 0.000 \\
\hline$\overline{\mathrm{H}}$ & .000 & 0.000 & 0.000 & 0.000 & 0.000 & 0.000 & 0.000 & 0.000 & 0.000 & 0.000 & 0.000 & 0.000 \\
\hline CW0/-39 & 0.000 & 0.000 & 0.000 & 0.000 & 0.000 & 0.000 & 0.000 & 0.000 & 0.000 & 0.000 & 0.000 & 0.00 \\
\hline ILW07-40 & 0.000 & 0.000 & 0.000 & 0.000 & 0.000 & 0.000 & 0.000 & 0.000 & 0.000 & 0.000 & 0.000 & .0 \\
\hline
\end{tabular}

(a) For each glass, the sum of the $\mathrm{wt} \%$ values for the components comprising Remaining equals the $\mathrm{wt} \%$ value listed in the Remaining column of Table A.20, except for any differences resulting from rounding $\mathrm{wt} \%$ values to three decimal places. 
Table A.23. The 86 Terms Included in the Partial Quadratic Mixture Model Form Used to Select the Outer-Layer and Inner-Layer Glasses of the HLW07 Test Matrix by Optimal Experimental Design.

\begin{tabular}{|c|c|c|c|c|c|}
\hline $\begin{array}{l}\text { Linear } \\
\text { Terms } \\
\end{array}$ & $\begin{array}{l}\text { Squared } \\
\text { Terms }\end{array}$ & \multicolumn{4}{|c|}{ Crossproduct Terms } \\
\hline $\mathrm{Al}_{2} \mathrm{O}_{3}$ & $\left(\mathrm{Al}_{2} \mathrm{O}_{3}\right)^{2}$ & $\left(\mathrm{Al}_{2} \mathrm{O}_{3}\right)\left(\mathrm{B}_{2} \mathrm{O}_{3}\right)$ & $\left(\mathrm{B}_{2} \mathrm{O}_{3}\right)\left(\mathrm{ThO}_{2}\right)$ & \begin{tabular}{|l}
$\left(\mathrm{Li}_{2} \mathrm{O}\right)(\mathrm{NiO})$ \\
\end{tabular} & $\left(\mathrm{SiO}_{2}\right)\left(\mathrm{ZrO}_{2}\right)$ \\
\hline $\mathrm{B}_{2} \mathrm{O}_{3}$ & $\left(\mathrm{~B}_{2} \mathrm{O}_{3}\right)^{2}$ & $\left(\mathrm{Al}_{2} \mathrm{O}_{3}\right)\left(\mathrm{Cr}_{2} \mathrm{O}_{3}\right)$ & $\left(\mathrm{B}_{2} \mathrm{O}_{3}\right)(\mathrm{ZnO})$ & $\left(\mathrm{Li}_{2} \mathrm{O}\right)\left(\mathrm{SiO}_{2}\right)$ & $\left(\mathrm{ThO}_{2}\right)\left(\mathrm{ZrO}_{2}\right)$ \\
\hline $\mathrm{Cr}_{2} \mathrm{O}_{3}$ & $\left(\mathrm{Cr}_{2} \mathrm{O}_{3}\right)^{2}$ & $\left(\mathrm{Al}_{2} \mathrm{O}_{3}\right)\left(\mathrm{Fe}_{2} \mathrm{O}_{3}\right)$ & $\left(\mathrm{B}_{2} \mathrm{O}_{3}\right)\left(\mathrm{ZrO}_{2}\right)$ & $\left(\mathrm{Li}_{2} \mathrm{O}\right)\left(\mathrm{ThO}_{2}\right)$ & \\
\hline $\mathrm{Fe}_{2} \mathrm{O}_{3}$ & $\left(\mathrm{Fe}_{2} \mathrm{O}_{3}\right)^{2}$ & $\left(\mathrm{Al}_{2} \mathrm{O}_{3}\right)\left(\mathrm{Li}_{2} \mathrm{O}\right)$ & $\left(\mathrm{Cr}_{2} \mathrm{O}_{3}\right)\left(\mathrm{Fe}_{2} \mathrm{O}_{3}\right)$ & $\left(\mathrm{Li}_{2} \mathrm{O}\right)(\mathrm{ZnO})$ & \\
\hline $\mathrm{Li}_{2} \mathrm{O}$ & $\left(\mathrm{Li}_{2} \mathrm{O}\right)^{2}$ & $\left(\mathrm{Al}_{2} \mathrm{O}_{3}\right)(\mathrm{MnO})$ & $\left(\mathrm{Cr}_{2} \mathrm{O}_{3}\right)\left(\mathrm{Li}_{2} \mathrm{O}\right)$ & $\left(\mathrm{Li}_{2} \mathrm{O}\right)\left(\mathrm{ZrO}_{2}\right)$ & \\
\hline $\mathrm{MnO}$ & $(\mathrm{MnO})^{2}$ & $\left(\mathrm{Al}_{2} \mathrm{O}_{3}\right)\left(\mathrm{Na}_{2} \mathrm{O}\right)$ & $\left(\mathrm{Cr}_{2} \mathrm{O}_{3}\right)(\mathrm{MnO})$ & $(\mathrm{MnO})\left(\mathrm{Na}_{2} \mathrm{O}\right)$ & \\
\hline $\mathrm{Na}_{2} \mathrm{O}$ & $\left(\mathrm{Na}_{2} \mathrm{O}\right)^{2}$ & $\left(\mathrm{Al}_{2} \mathrm{O}_{3}\right)(\mathrm{NiO})$ & $\left(\mathrm{Cr}_{2} \mathrm{O}_{3}\right)\left(\mathrm{Na}_{2} \mathrm{O}\right)$ & $(\mathrm{MnO})(\mathrm{NiO})$ & \\
\hline $\mathrm{NiO}$ & $(\mathrm{NiO})^{2}$ & $\left(\mathrm{Al}_{2} \mathrm{O}_{3}\right)\left(\mathrm{SiO}_{2}\right)$ & $\left(\mathrm{Cr}_{2} \mathrm{O}_{3}\right)(\mathrm{NiO})$ & $(\mathrm{MnO})\left(\mathrm{SiO}_{2}\right)$ & \\
\hline $\mathrm{SiO}_{2}$ & $\left(\mathrm{SiO}_{2}\right)^{2}$ & $\left(\mathrm{Al}_{2} \mathrm{O}_{3}\right)\left(\mathrm{ThO}_{2}\right)$ & $\left(\mathrm{Cr}_{2} \mathrm{O}_{3}\right)\left(\mathrm{SiO}_{2}\right)$ & $(\mathrm{MnO})(\mathrm{ZnO})$ & \\
\hline $\mathrm{SrO}$ & $\left(\mathrm{ThO}_{2}\right)^{2}$ & $\left(\mathrm{Al}_{2} \mathrm{O}_{3}\right)(\mathrm{ZnO})$ & $\left(\mathrm{Cr}_{2} \mathrm{O}_{3}\right)(\mathrm{ZnO})$ & $\left(\mathrm{Na}_{2} \mathrm{O}\right)(\mathrm{NiO})$ & \\
\hline $\mathrm{ThO}_{2}$ & $(\mathrm{ZnO})^{2}$ & $\left(\mathrm{Al}_{2} \mathrm{O}_{3}\right)\left(\mathrm{ZrO}_{2}\right)$ & $\left(\mathrm{Fe}_{2} \mathrm{O}_{3}\right)\left(\mathrm{Li}_{2} \mathrm{O}\right)$ & $\left(\mathrm{Na}_{2} \mathrm{O}\right)\left(\mathrm{SiO}_{2}\right)$ & \\
\hline $\mathrm{UO}_{3}$ & $\left(\mathrm{ZrO}_{2}\right)^{2}$ & $\left(\mathrm{~B}_{2} \mathrm{O}_{3}\right)\left(\mathrm{Cr}_{2} \mathrm{O}_{3}\right)$ & $\left(\mathrm{Fe}_{2} \mathrm{O}_{3}\right)(\mathrm{MnO})$ & $\left(\mathrm{Na}_{2} \mathrm{O}\right)\left(\mathrm{ThO}_{2}\right)$ & \\
\hline $\mathrm{ZnO}$ & & $\left(\mathrm{B}_{2} \mathrm{O}_{3}\right)\left(\mathrm{Fe}_{2} \mathrm{O}_{3}\right)$ & $\left(\mathrm{Fe}_{2} \mathrm{O}_{3}\right)\left(\mathrm{Na}_{2} \mathrm{O}\right)$ & $\left(\mathrm{Na}_{2} \mathrm{O}\right)(\mathrm{ZnO})$ & \\
\hline $\mathrm{ZrO}_{2}$ & & $\left(\mathrm{~B}_{2} \mathrm{O}_{3}\right)\left(\mathrm{Li}_{2} \mathrm{O}\right)$ & $\left(\mathrm{Fe}_{2} \mathrm{O}_{3}\right)(\mathrm{NiO})$ & $\left(\mathrm{Na}_{2} \mathrm{O}\right)\left(\mathrm{ZrO}_{2}\right)$ & \\
\hline Others1 & & $\left(\mathrm{B}_{2} \mathrm{O}_{3}\right)(\mathrm{MnO})$ & $\left(\mathrm{Fe}_{2} \mathrm{O}_{3}\right)\left(\mathrm{SiO}_{2}\right)$ & $(\mathrm{NiO})\left(\mathrm{SiO}_{2}\right)$ & \\
\hline Others2 & & $\left(\mathrm{B}_{2} \mathrm{O}_{3}\right)\left(\mathrm{Na}_{2} \mathrm{O}\right)$ & $\left(\mathrm{Fe}_{2} \mathrm{O}_{3}\right)(\mathrm{ZnO})$ & $(\mathrm{NiO})(\mathrm{ZnO})$ & \\
\hline Constant & & $\left(\mathrm{B}_{2} \mathrm{O}_{3}\right)(\mathrm{NiO})$ & $\left(\mathrm{Li}_{2} \mathrm{O}\right)(\mathrm{MnO})$ & $\left(\mathrm{SiO}_{2}\right)\left(\mathrm{ThO}_{2}\right)$ & \\
\hline Remaining & & $\left(\mathrm{B}_{2} \mathrm{O}_{3}\right)\left(\mathrm{SiO}_{2}\right)$ & $\left(\mathrm{Li}_{2} \mathrm{O}\right)\left(\mathrm{Na}_{2} \mathrm{O}\right)$ & $\left(\mathrm{SiO}_{2}\right)(\mathrm{ZnO})$ & \\
\hline
\end{tabular}



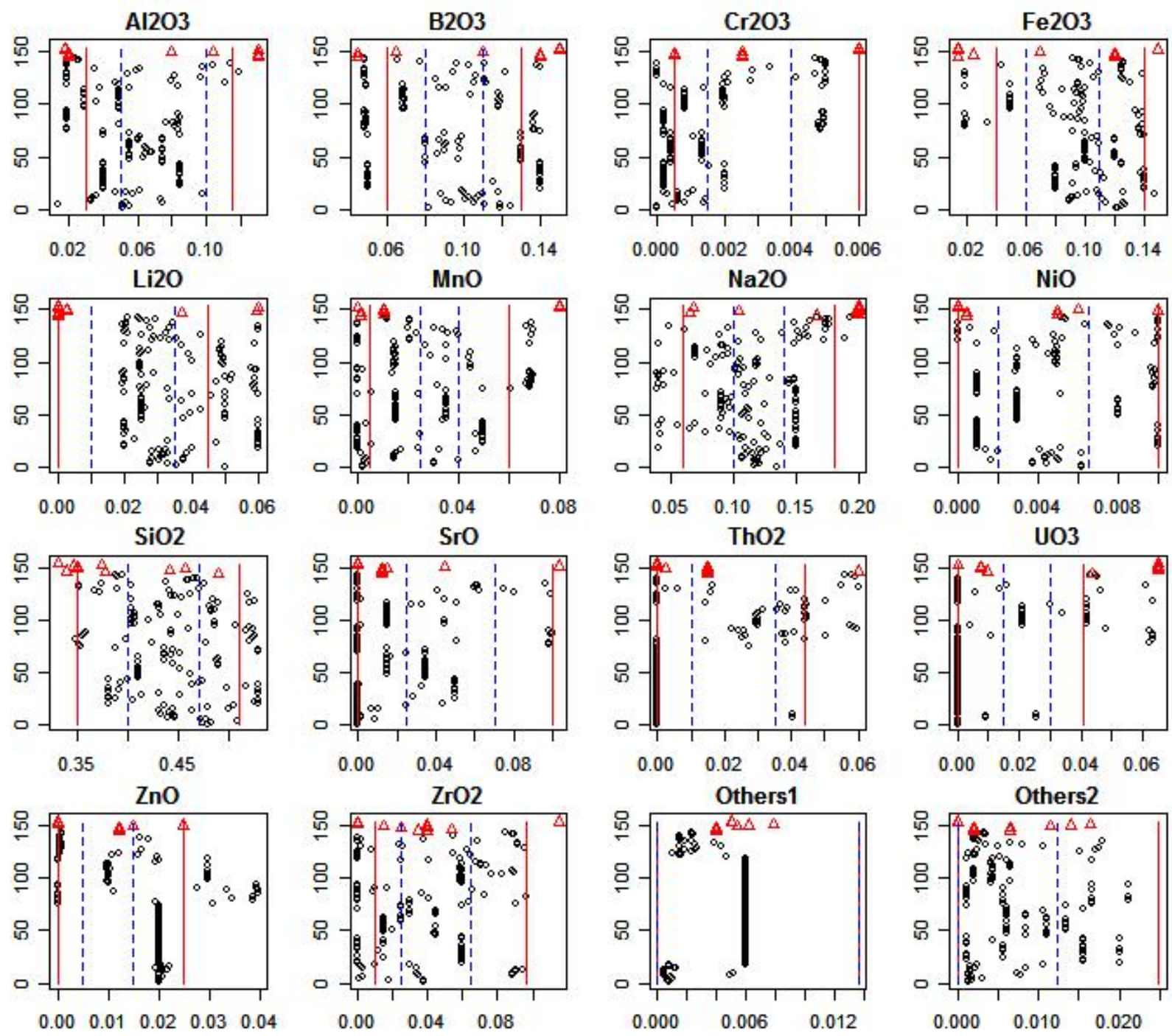

Figure A.1. Mass Fraction Distributions of 14 Components for the 143 Existing HLW Glasses (black circles) with Viscosity and Electrical Conductivity Data and the 10 Selected HLW05 and HLW06 Glasses (red triangles) for Which Viscosity and Electrical Conductivity will be Measured. For reference purposes, the inner-layer component constraints from the HLW06 study are marked with blue dashed lines, while the outer-layer component constraints from the HLW06 study are marked with red solid lines. 
Spinel T1\%

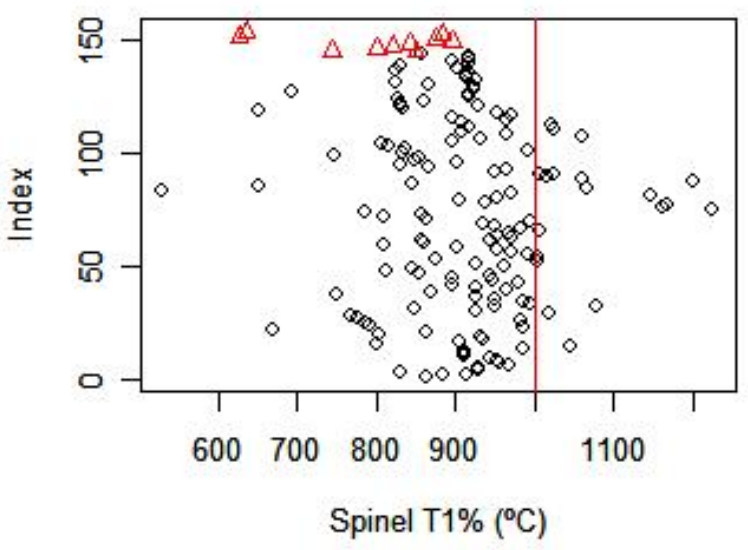

Viscosity

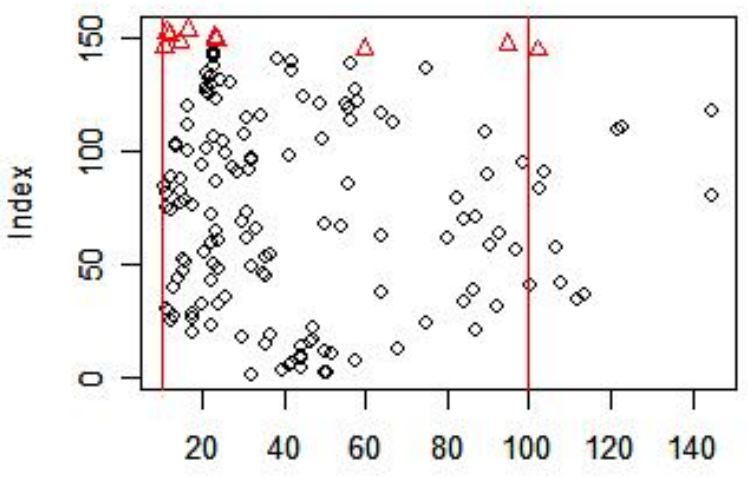

Viscosity at $1150^{\circ} \mathrm{C}$ (poise)
РСТ B Release

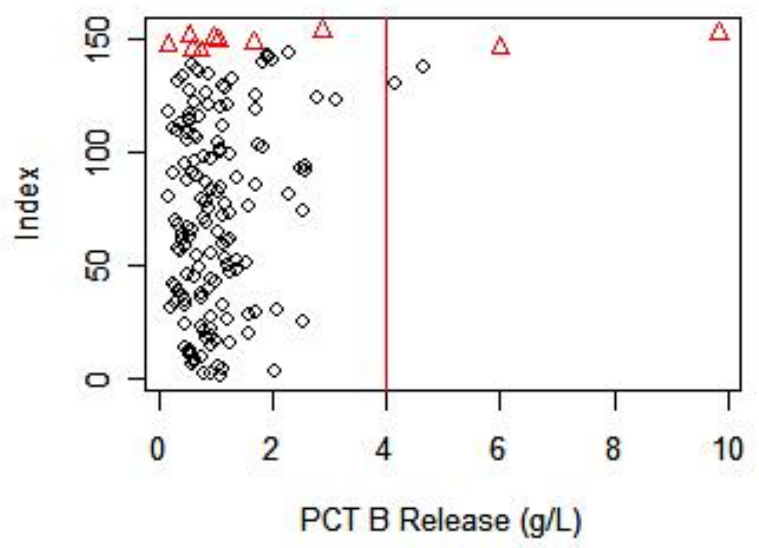

Electrical Conductivity

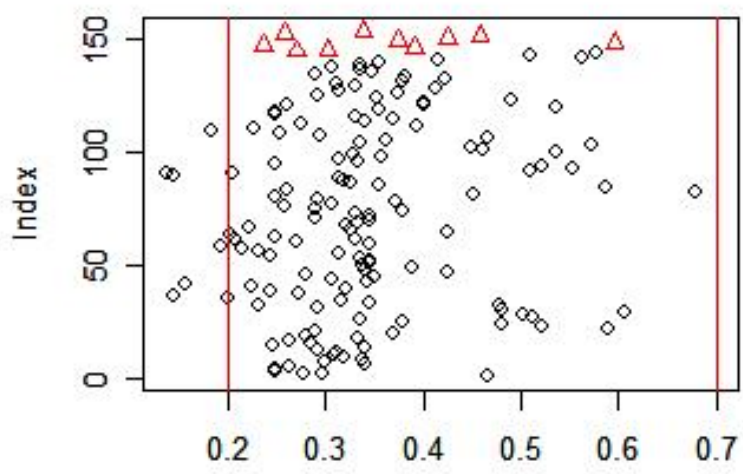

Electrical Conductivity at $1150^{\circ} \mathrm{C}(\mathrm{S} / \mathrm{cm})$

Figure A.2. Distributions of Model-Predicted Properties for the 143 Existing HLW Glasses (black circles) with Viscosity and Electrical Conductivity Data and the 10 Selected HLW05 and HLW06 Glasses (red triangles) for Which Viscosity and Electrical Conductivity will be Measured. For reference purposes, property limits (spinel $\mathbf{T}_{1 \%}$, viscosity, and electrical conductivity) or reference values (PCT-B release) are marked with red solid lines. 

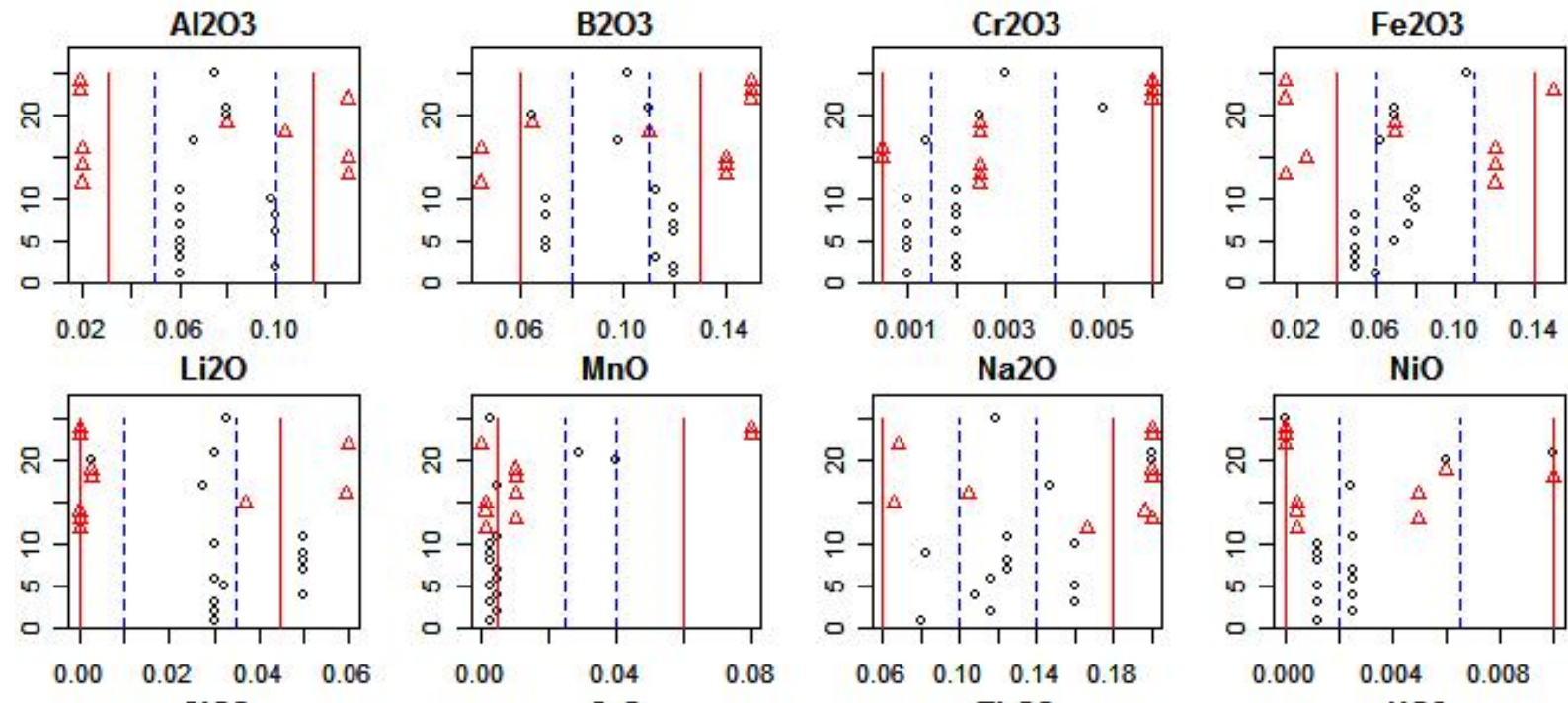

$\mathrm{NiO}$
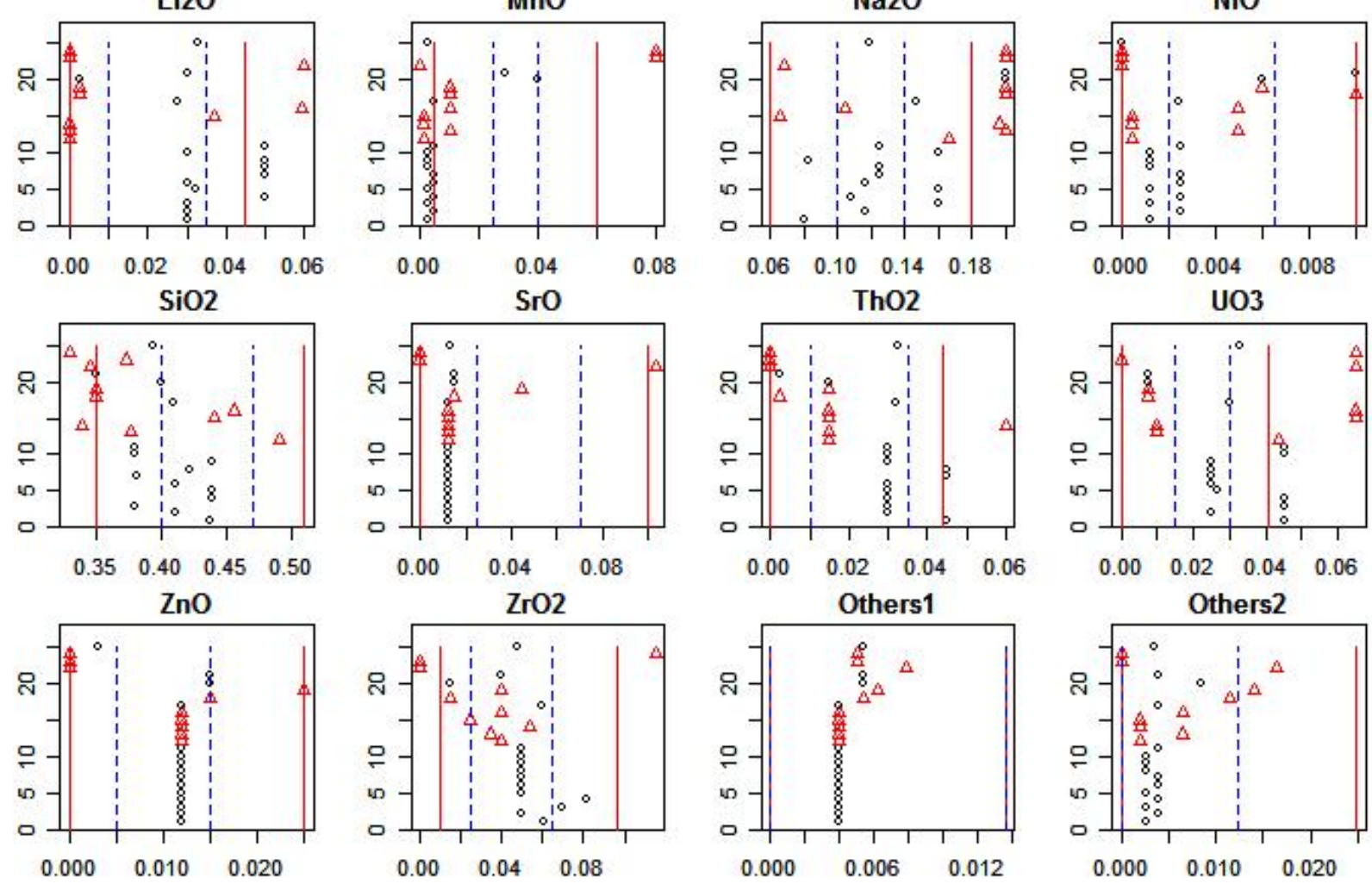

Figure A.3. Mass Fraction Distributions of 14 Components for the 25 Candidate HLW05 and HLW06 Glasses (black circles) and 10 Selected HLW05 and HLW06 Glasses (red triangles) for Which Viscosity and Electrical Conductivity will be Measured. For reference purposes, the inner-layer component constraints from the HLW06 study are marked with blue dashed lines, while the outerlayer component constraints from the HLW06 study are marked with red solid lines. 
Spinel T1\%

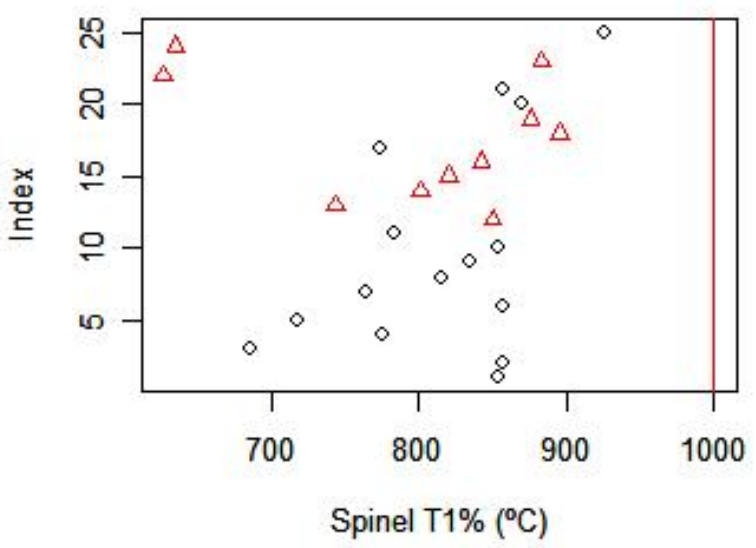

Viscosity

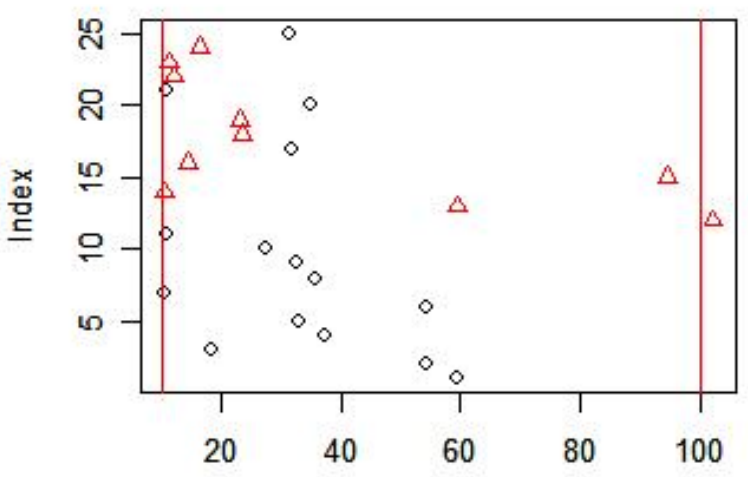

Viscosity at $1150^{\circ} \mathrm{C}$ (poise)
PCT B Release

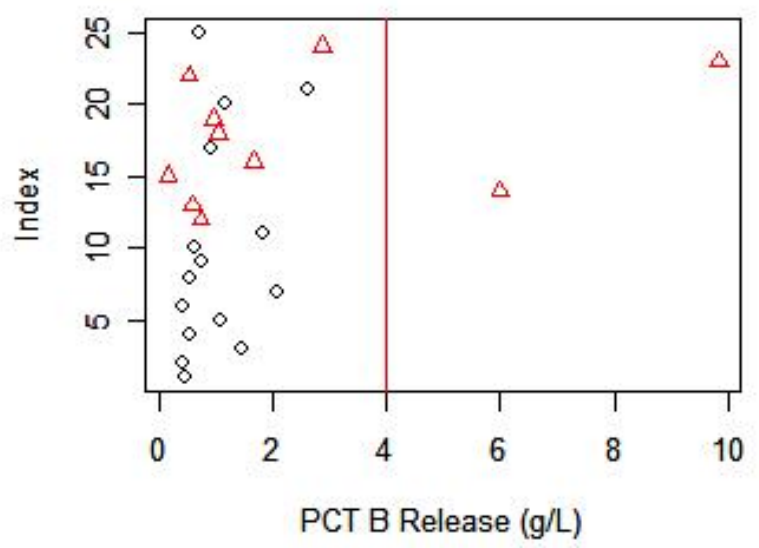

Electrical Conductivity

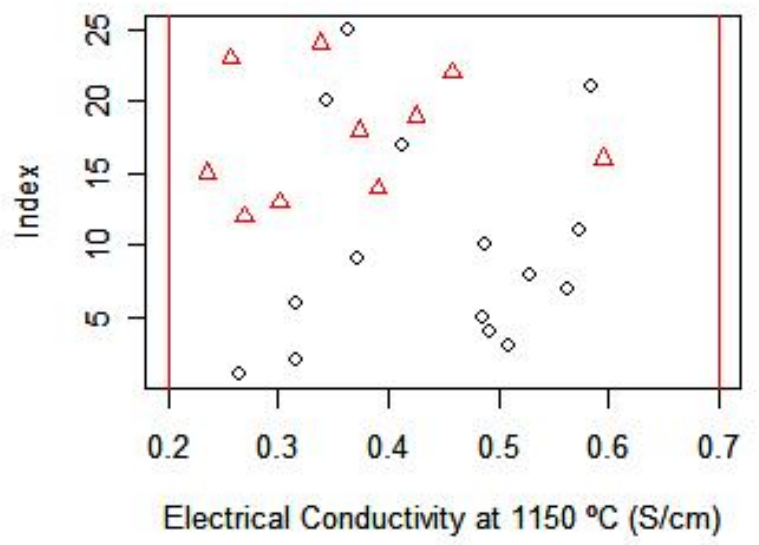

Figure A.4. Distributions of Model-Predicted Properties for the 25 Available HLW Glasses (black diamonds) and 10 Selected HLW05 and HLW06 Glasses (red triangles) for Which Viscosity and Electrical Conductivity will be Measured. For reference purposes, property limits (spinel $T_{1 \%}$, viscosity, and electrical conductivity) or reference values (PCT-B release) are marked with red solid lines. 
The Catholic University of America Vitreous State Laboratory
IHLW PCT, Spinel $T_{1 \%}$ Electrical Conductivity, and Viscosity Model Development Final Report, VSL-07R1240-4, Rev. 0

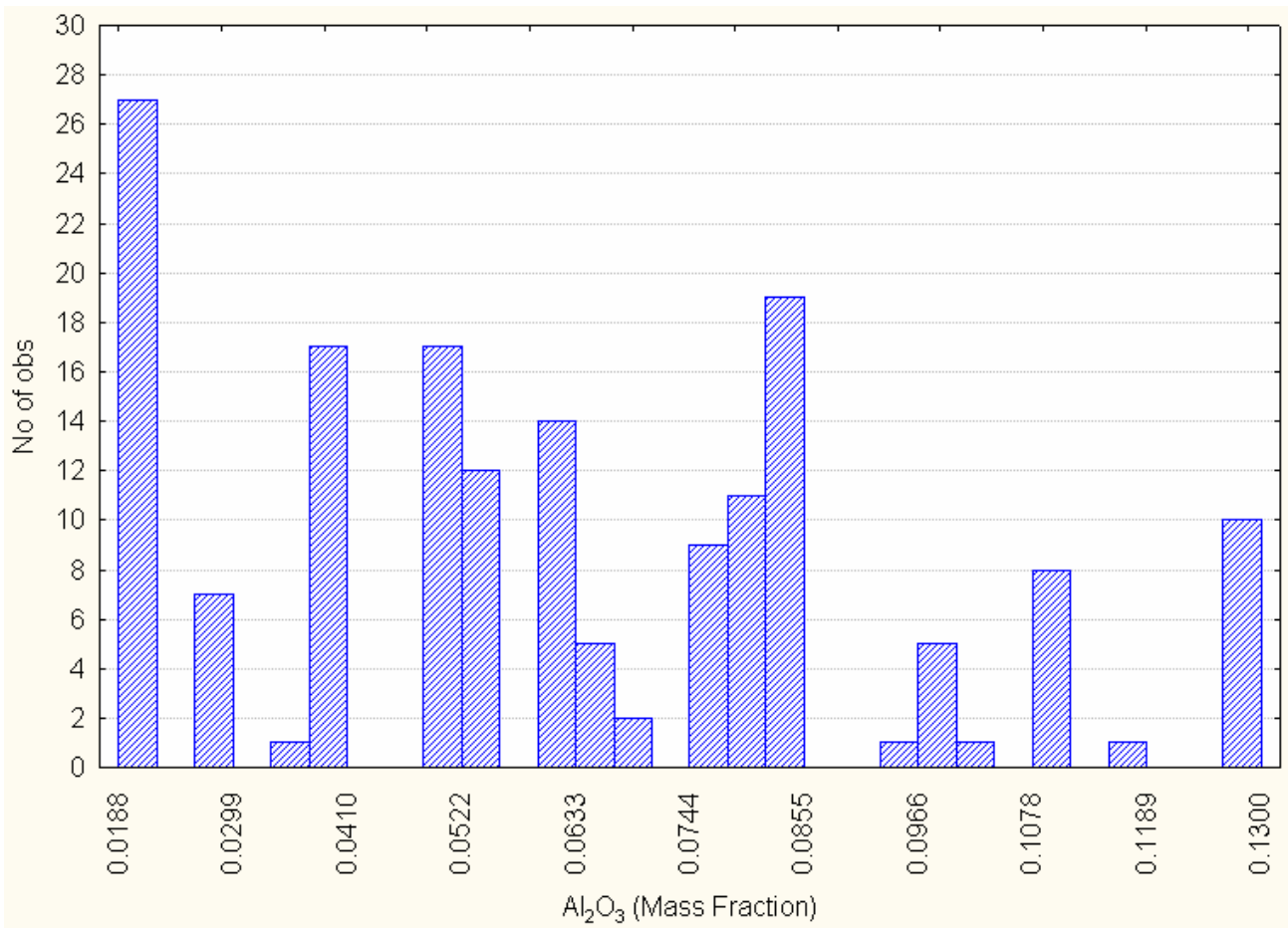

Figure A.5. Distribution of $\mathrm{Al}_{2} \mathrm{O}_{3}$ Mass Fractions for the HLW02, HLW03, HLW05, and HLW06 Glasses.

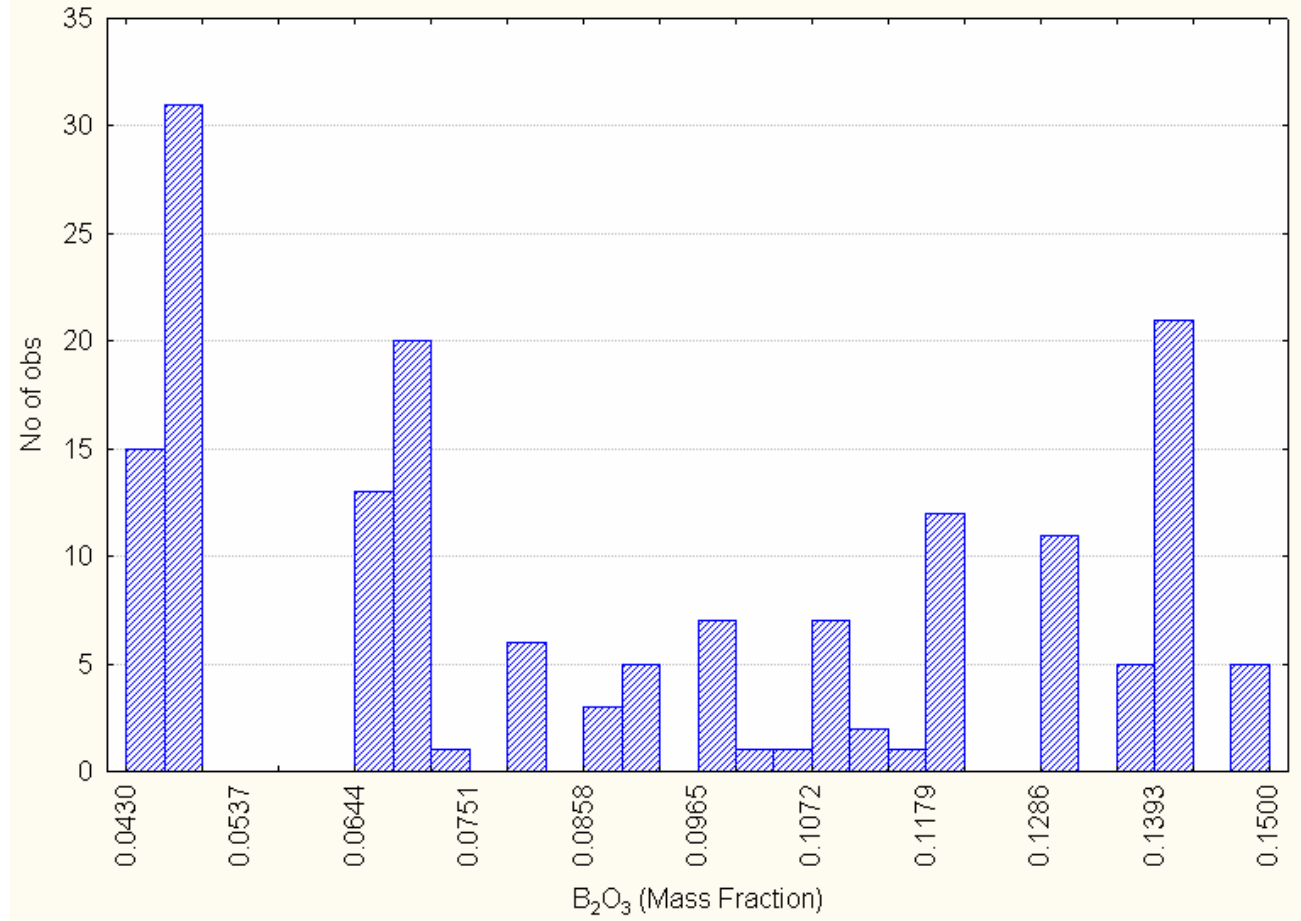

Figure A.6. Distribution of $\mathrm{B}_{2} \mathrm{O}_{3}$ Mass Fractions for the HLW02, HLW03, HLW05, and HLW06 Glasses. 
The Catholic University of America Vitreous State Laboratory
IHLW PCT, Spinel $T_{1 \%}$ Electrical Conductivity, and Viscosity Model Development Final Report, VSL-07R1240-4, Rev. 0

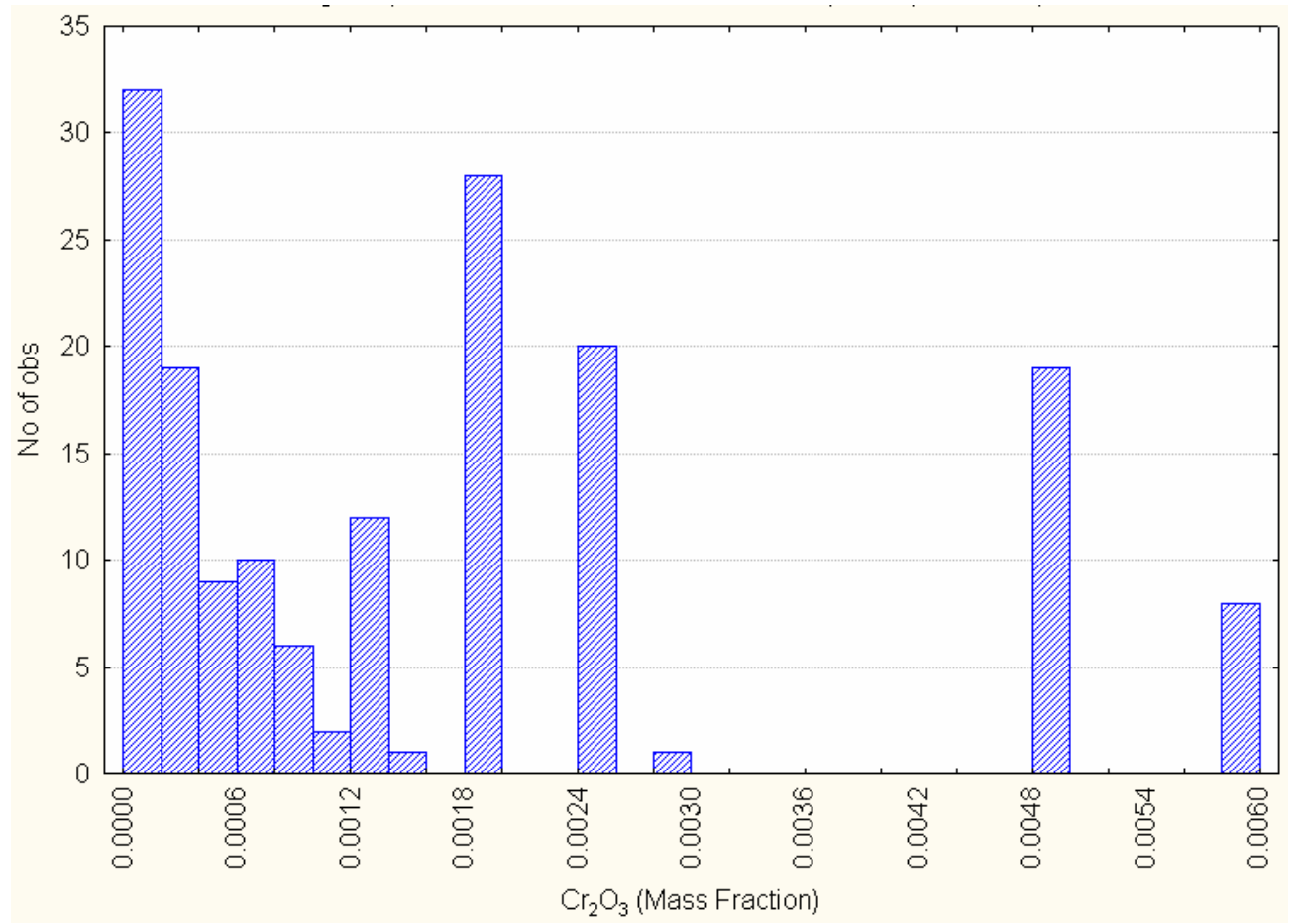

Figure A.7. Distribution of $\mathrm{Cr}_{2} \mathrm{O}_{3}$ Mass Fractions for the HLW02, HLW03, HLW05, and HLW06 Glasses.

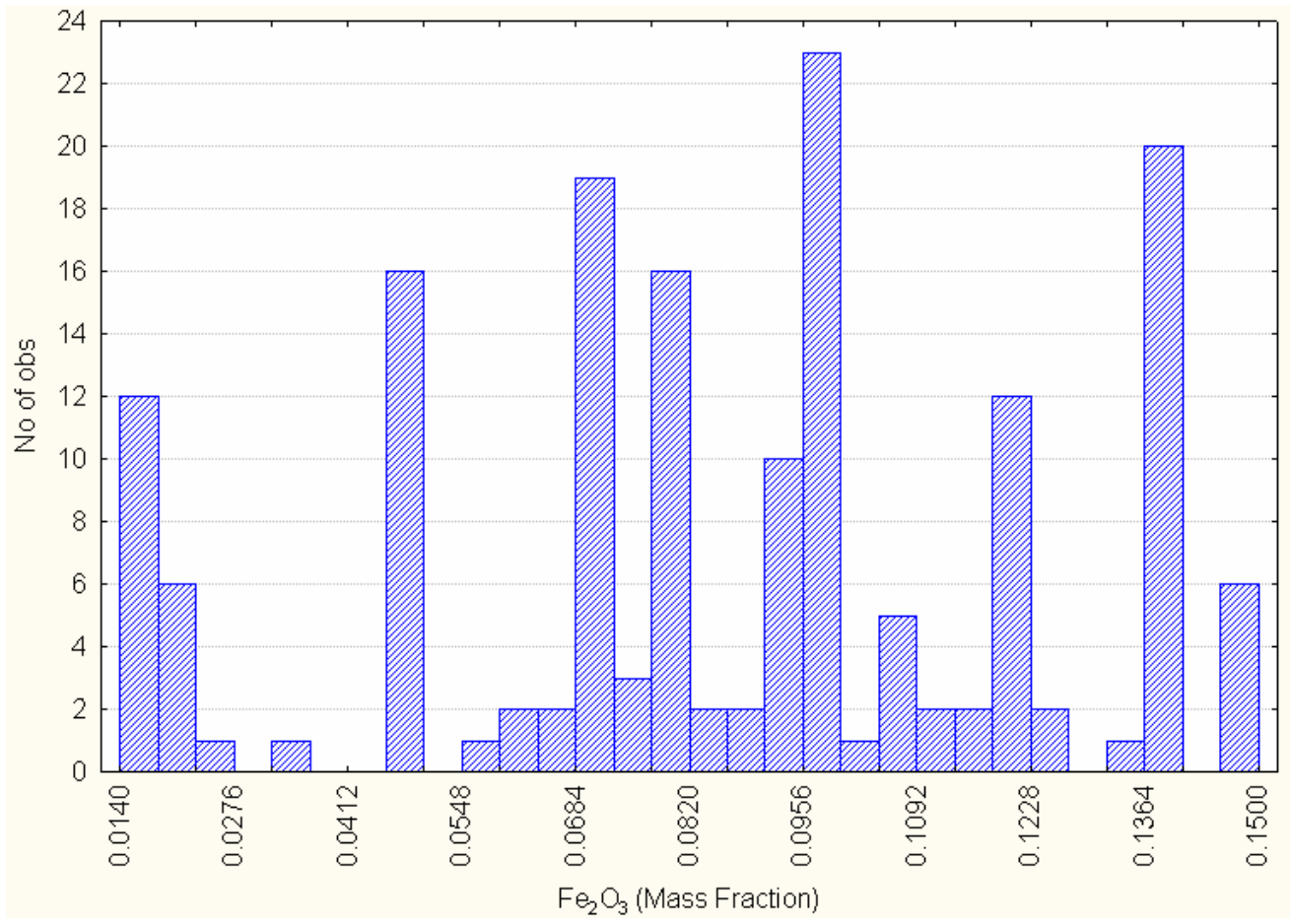

Figure A.8. Distribution of $\mathrm{Fe}_{2} \mathrm{O}_{3}$ Mass Fractions for the HLW02, HLW03, HLW05, and HLW06 Glasses. 
The Catholic University of America Vitreous State Laboratory
IHLW PCT, Spinel $T_{1 \%}$ Electrical Conductivity, and Viscosity Model Development Final Report, VSL-07R1240-4, Rev. 0

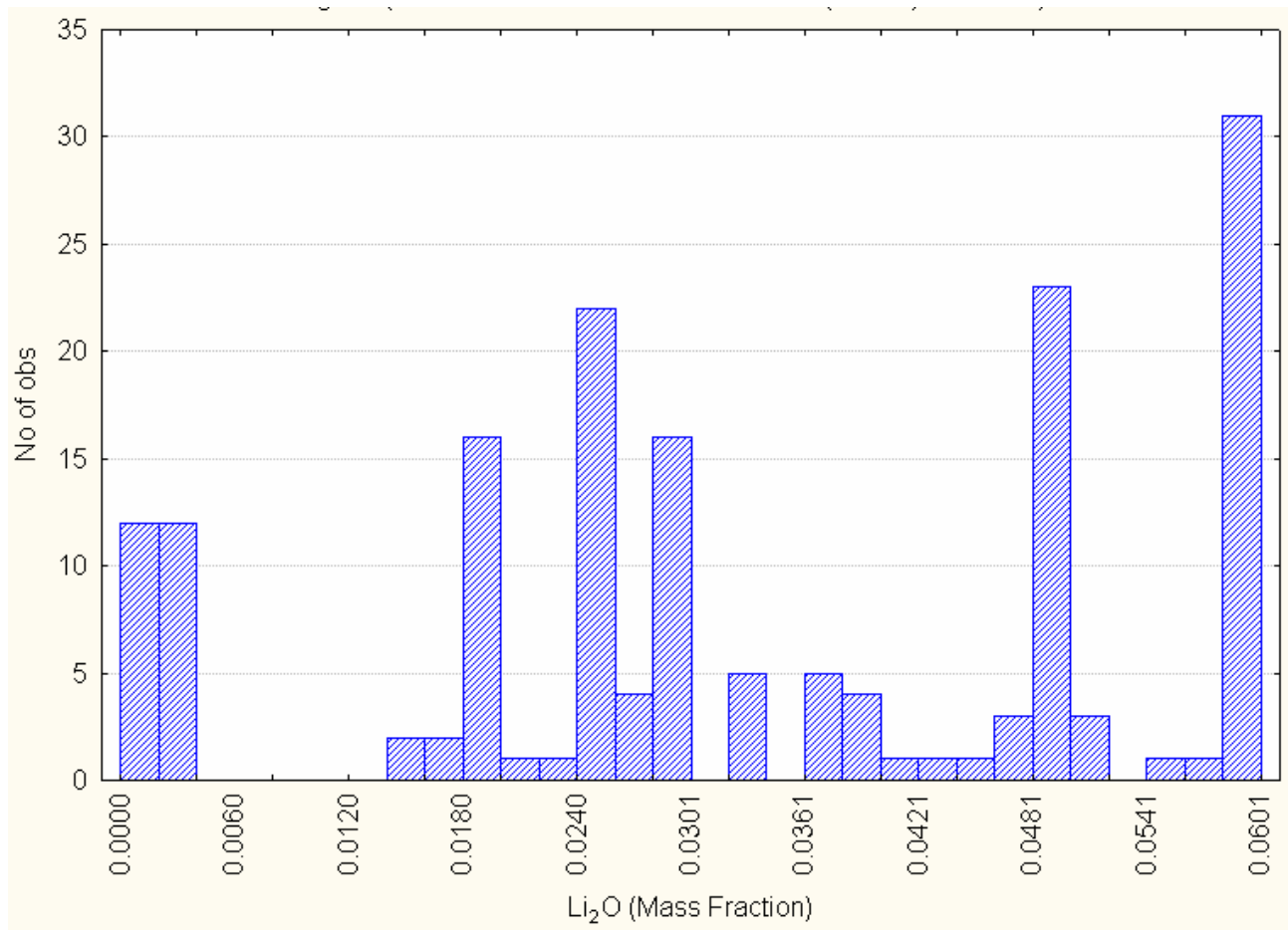

Figure A.9. Distribution of $\mathrm{Li}_{2} \mathrm{O}$ Mass Fractions for the HLW02, HLW03, HLW05, and HLW06 Glasses.

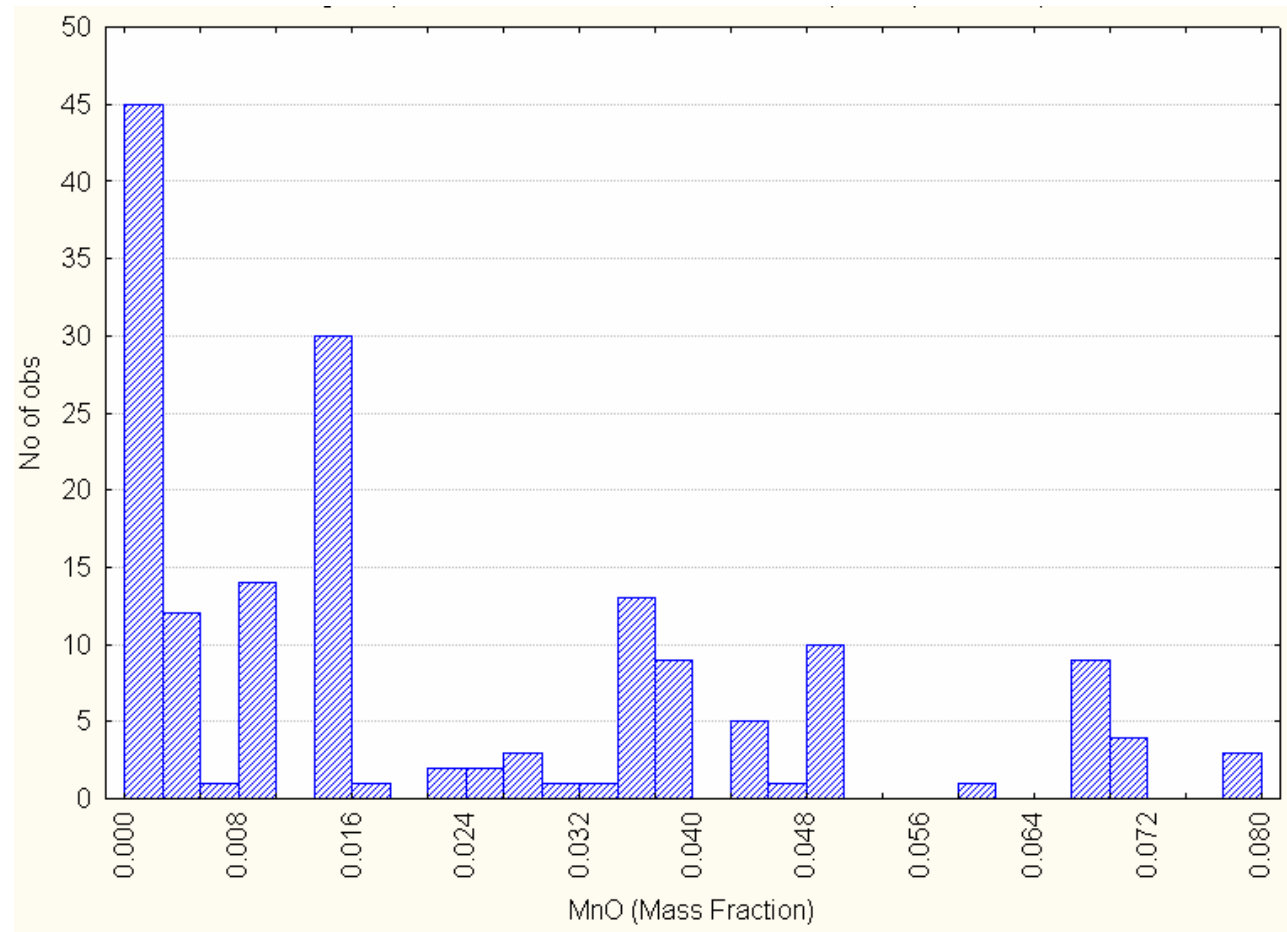

Figure A.10. Distribution of MnO Mass Fractions for the HLW02, HLW03, HLW05, and HLW06 Glasses. 
The Catholic University of America Vitreous State Laboratory
IHLW PCT, Spinel $T_{1 \%}$ Electrical Conductivity, and Viscosity Model Development Final Report, VSL-07R1240-4, Rev. 0

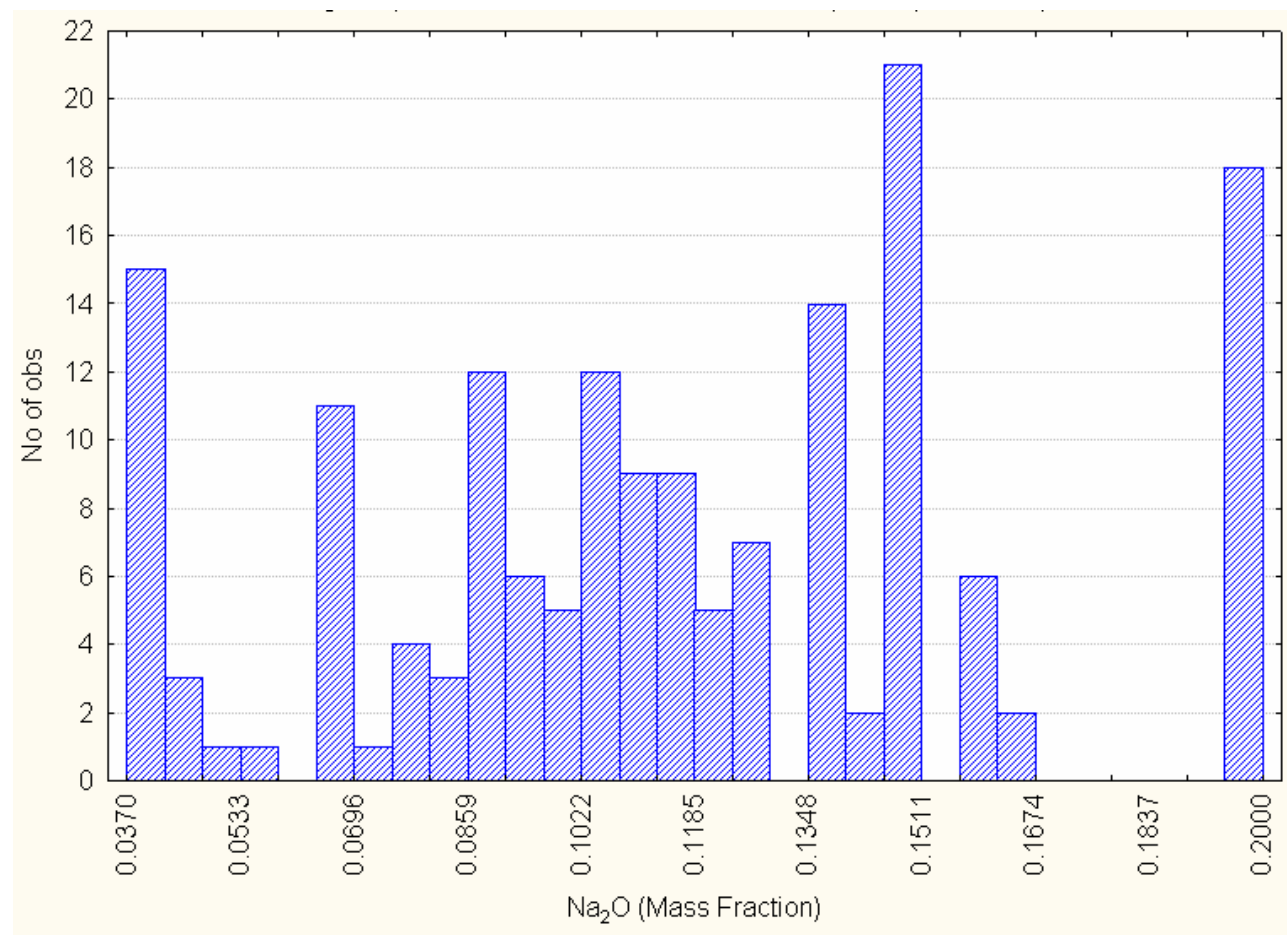

Figure A.11. Distribution of $\mathrm{Na}_{2} \mathrm{O}$ Mass Fractions for the HLW02, HLW03, HLW05, and HLW06 Glasses.

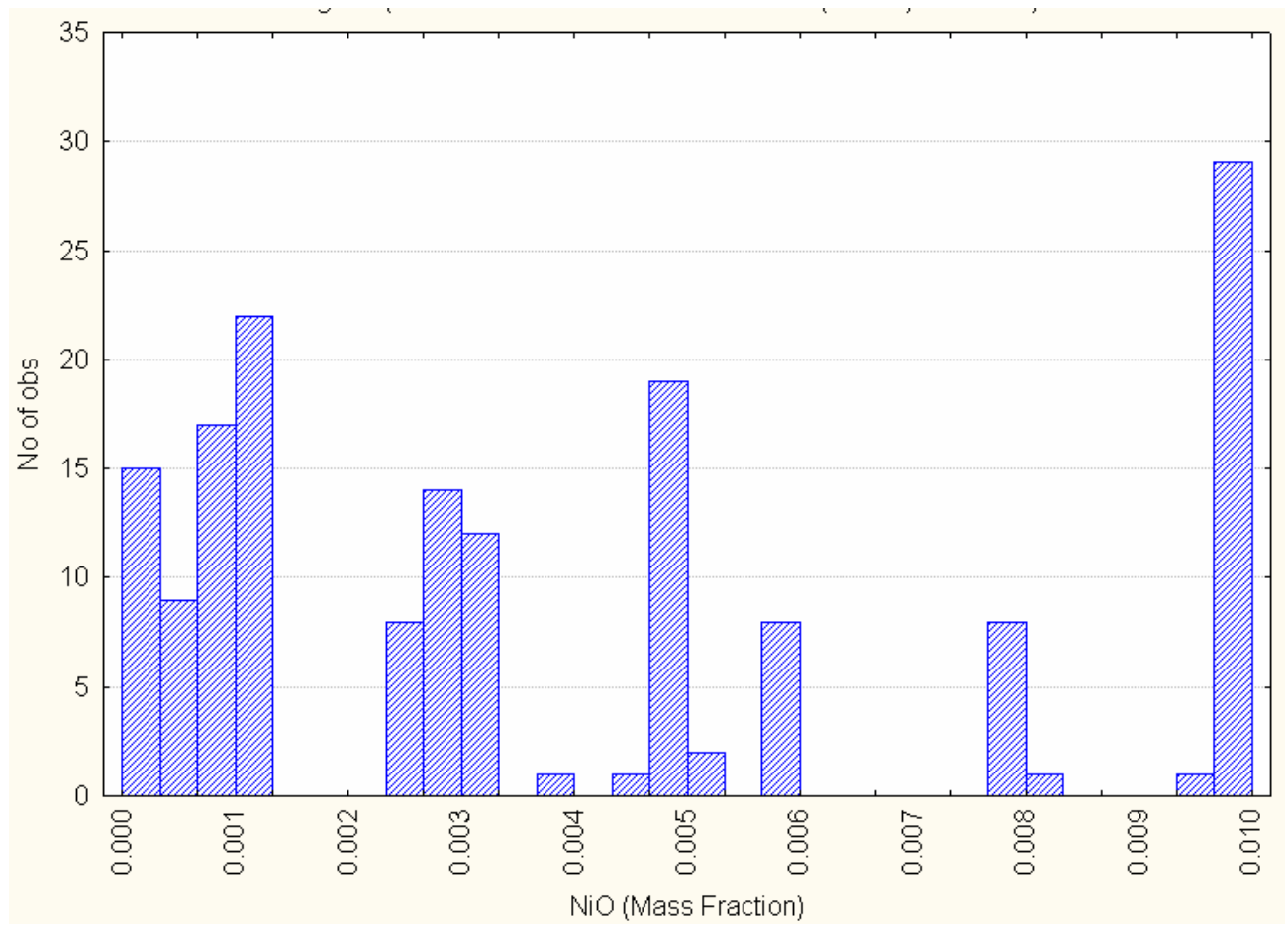

Figure A.12. Distribution of NiO Mass Fractions for the HLW02, HLW03, HLW05, and HLW06 Glasses. 
The Catholic University of America Vitreous State Laboratory
IHLW PCT, Spinel $T_{1 \%}$ Electrical Conductivity, and Viscosity Model Development Final Report, VSL-07R1240-4, Rev. 0

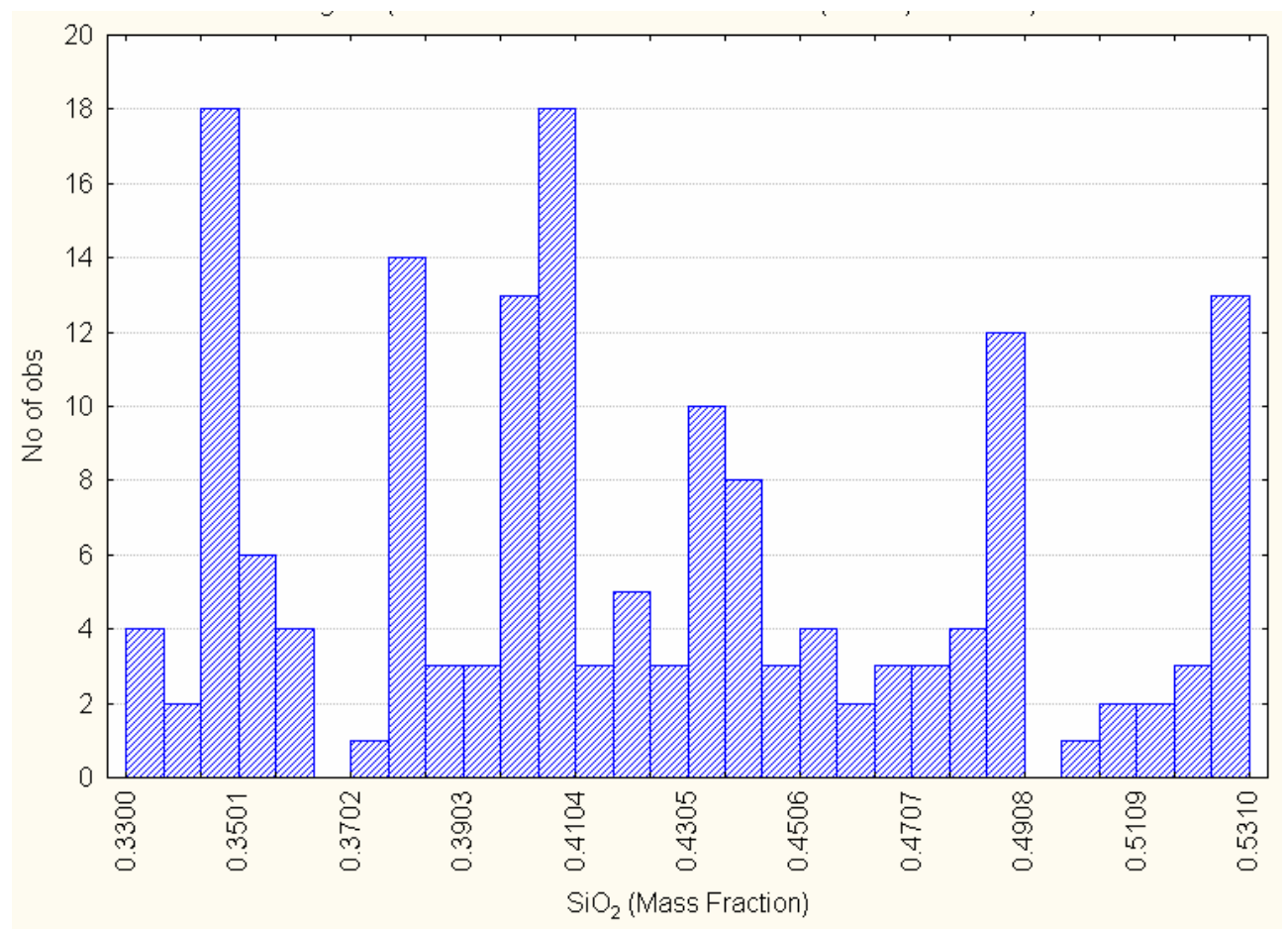

Figure A.13. Distribution of $\mathrm{SiO}_{2}$ Mass Fractions for the HLW02, HLW03, HLW05, and HLW06 Glasses.

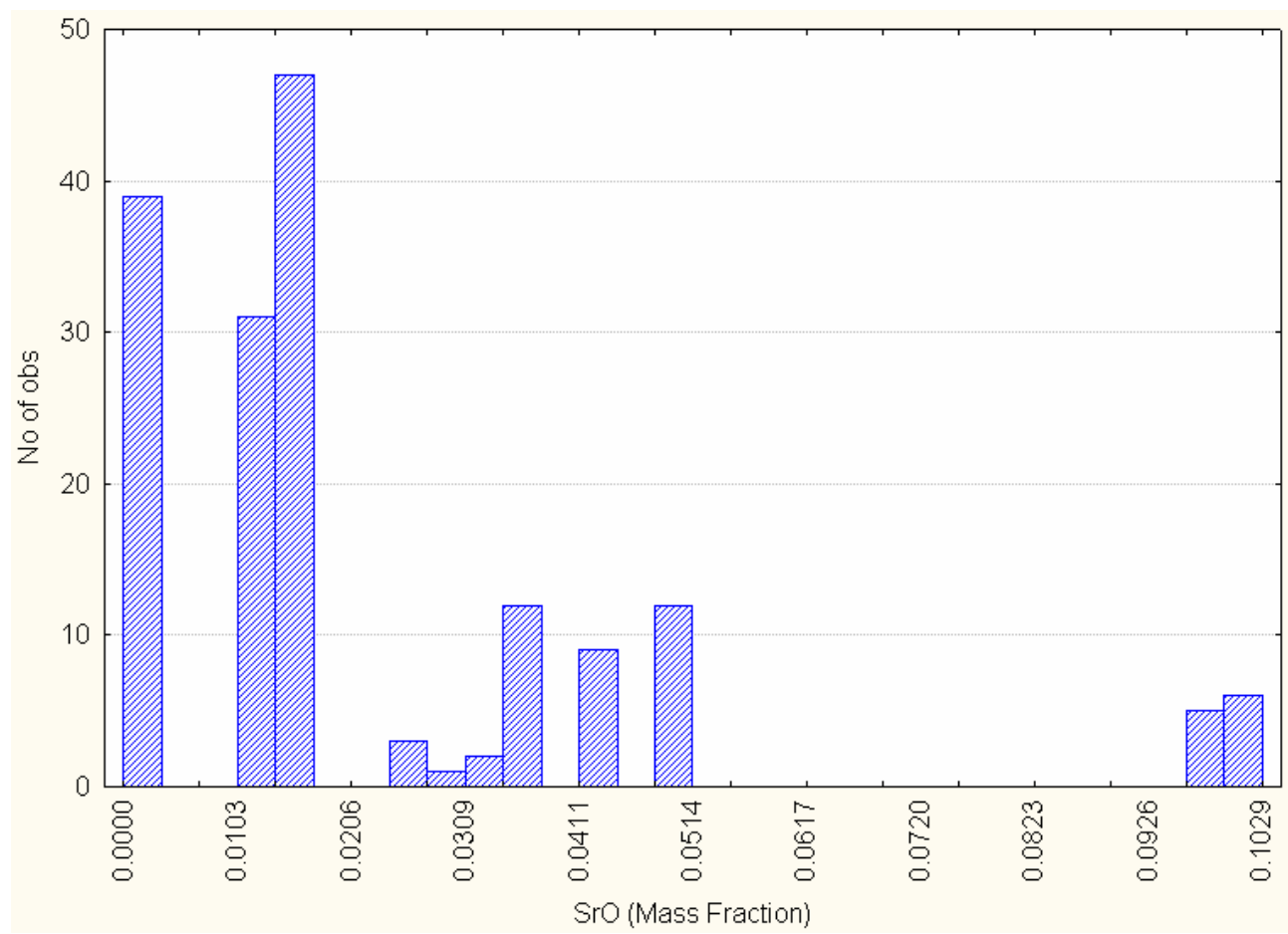

Figure A.14. Distribution of SrO Mass Fractions for the HLW02, HLW03, HLW05, and HLW06 Glasses. 
The Catholic University of America Vitreous State Laboratory
IHLW PCT, Spinel $T_{1 \%}$ Electrical Conductivity, and Viscosity Model Development Final Report, VSL-07R1240-4, Rev. 0

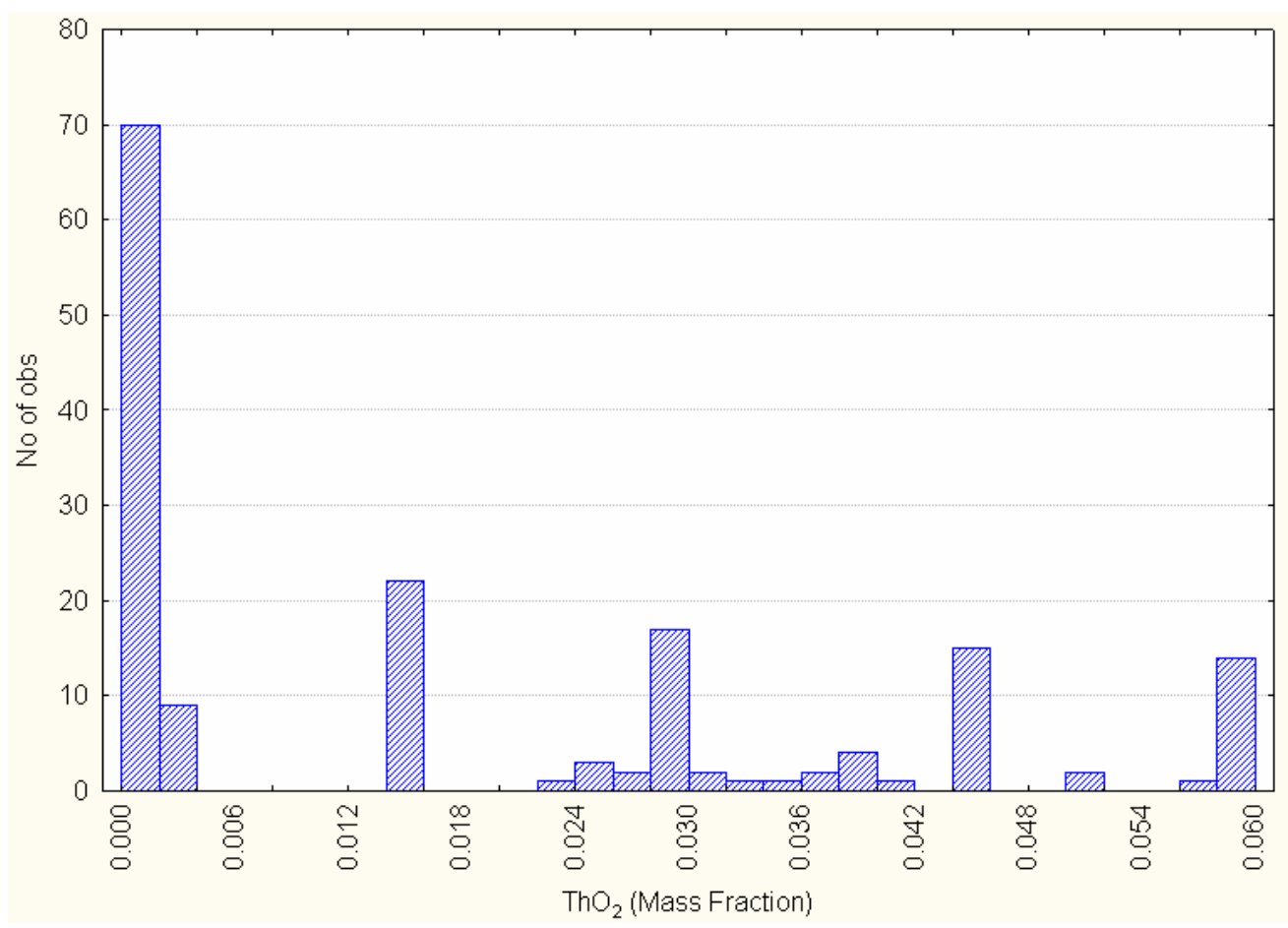

Figure A.15. Distribution of $\mathrm{ThO}_{2}$ Mass Fractions for the HLW02, HLW03, HLW05, and HLW06 Glasses.

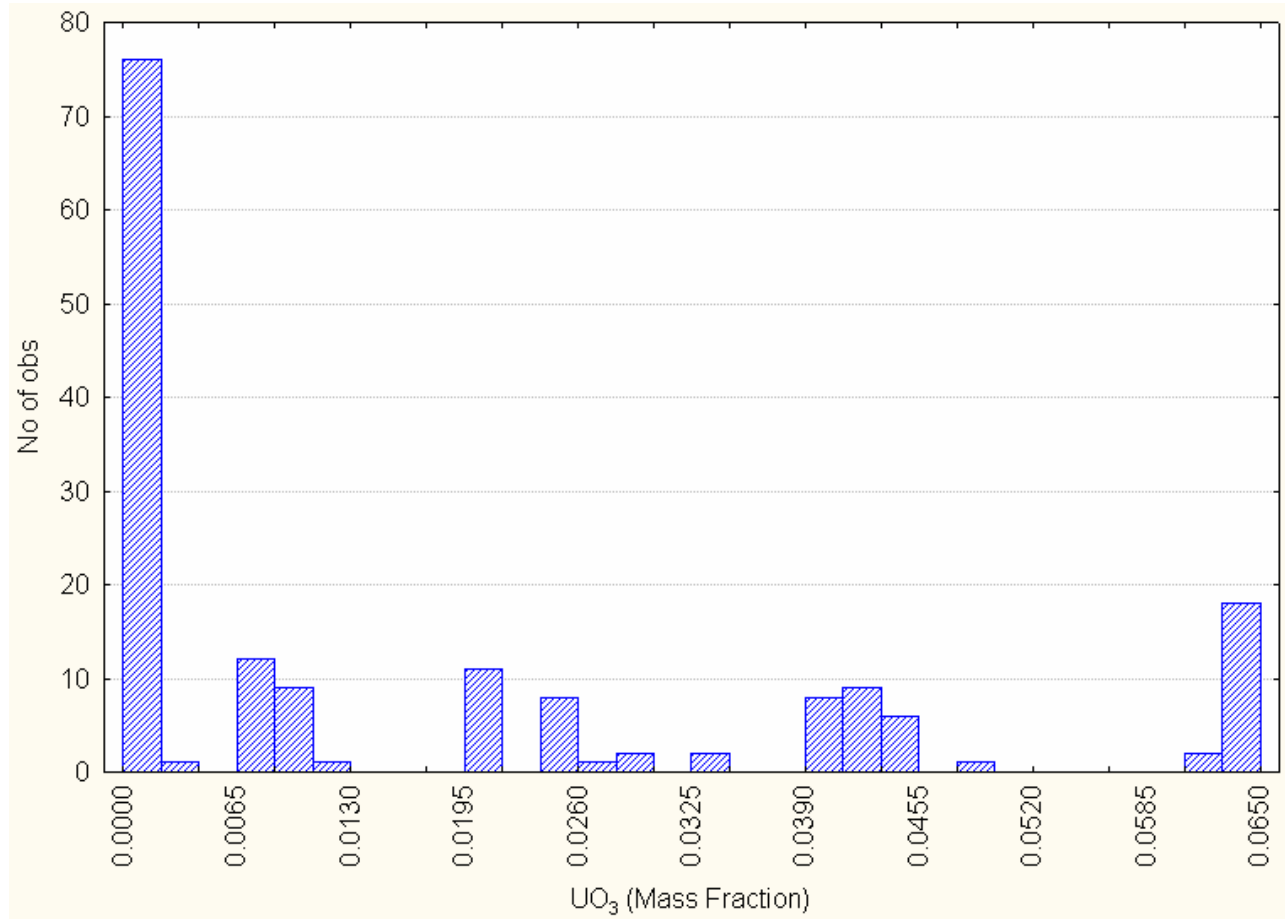

Figure A.16. Distribution of $\mathrm{UO}_{3}$ Mass Fractions for the HLW02, HLW03, HLW05, and HLW06 Glasses. 
The Catholic University of America Vitreous State Laboratory
IHLW PCT, Spinel $T_{1 \%}$ Electrical Conductivity, and Viscosity Model Development Final Report, VSL-07R1240-4, Rev. 0

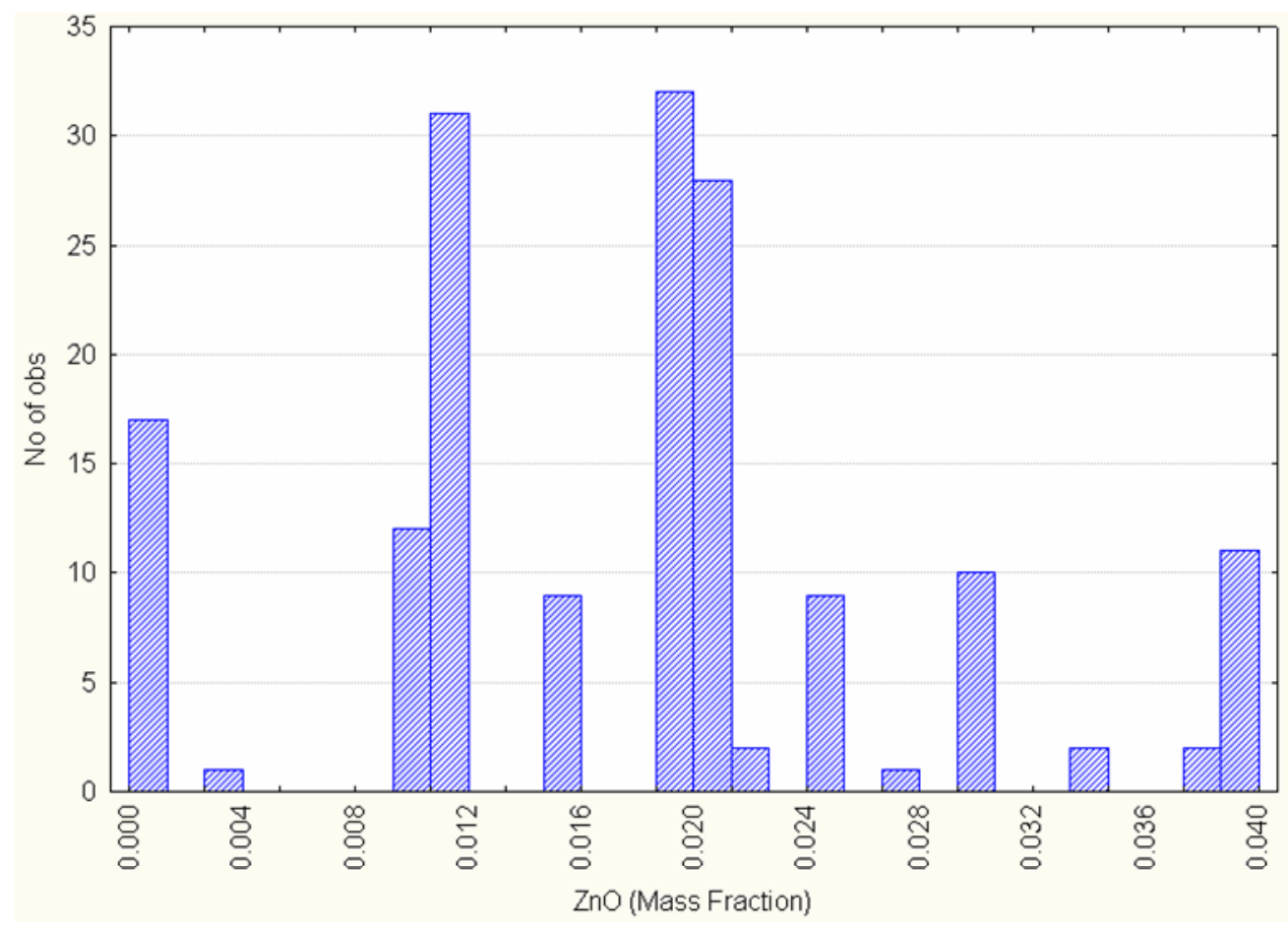

Figure A.17. Distribution of ZnO Mass Fractions for the HLW02, HLW03, HLW05, and HLW06 Glasses.

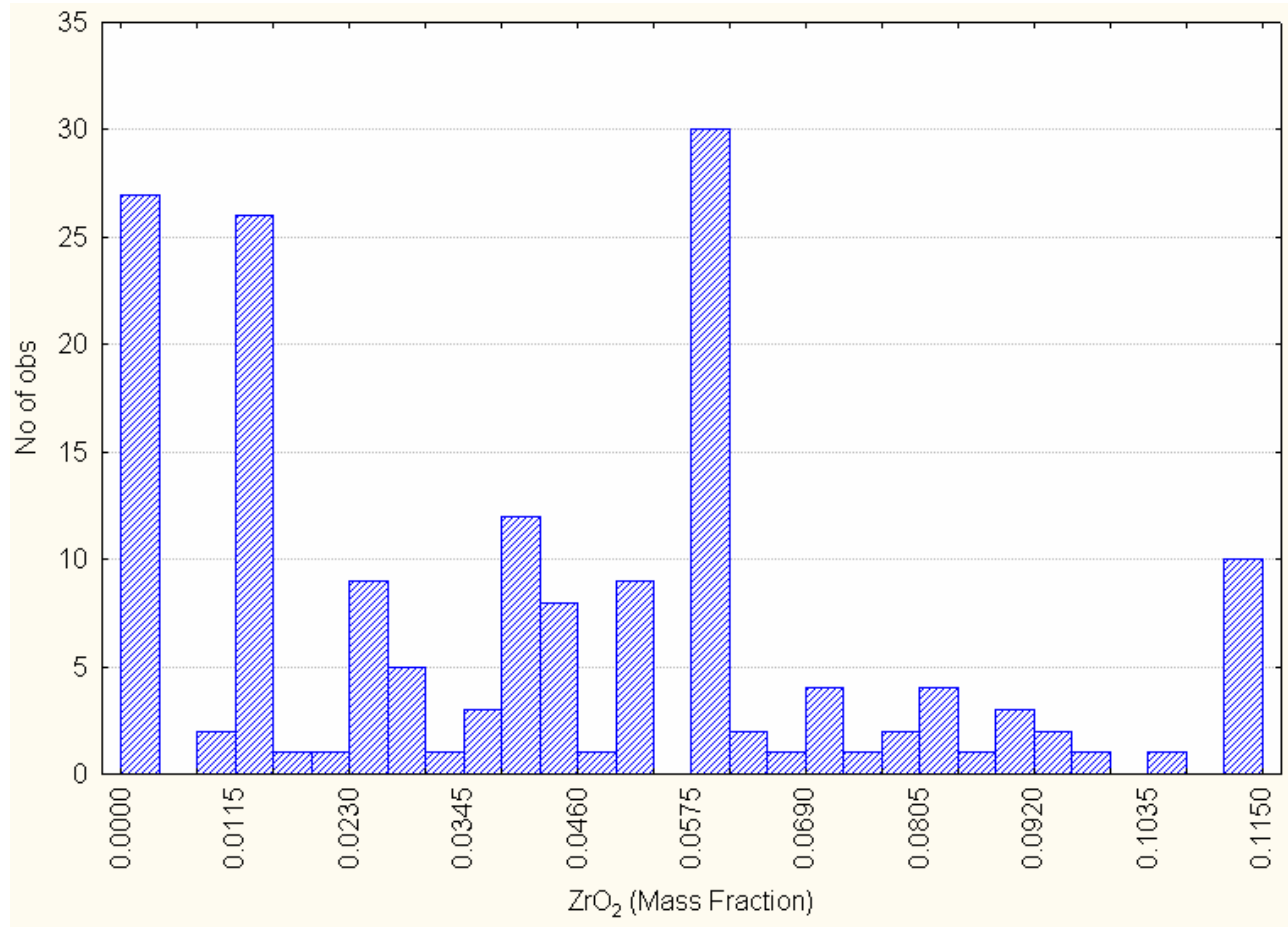

Figure A.18. Distribution of $\mathrm{ZrO}_{2}$ Mass Fractions for the HLW02, HLW03, HLW05, and HLW06 Glasses. 
The Catholic University of America Vitreous State Laboratory
IHLW PCT, Spinel $T_{1 \%}$ Electrical Conductivity, and Viscosity Model Development Final Report, VSL-07R1240-4, Rev. 0

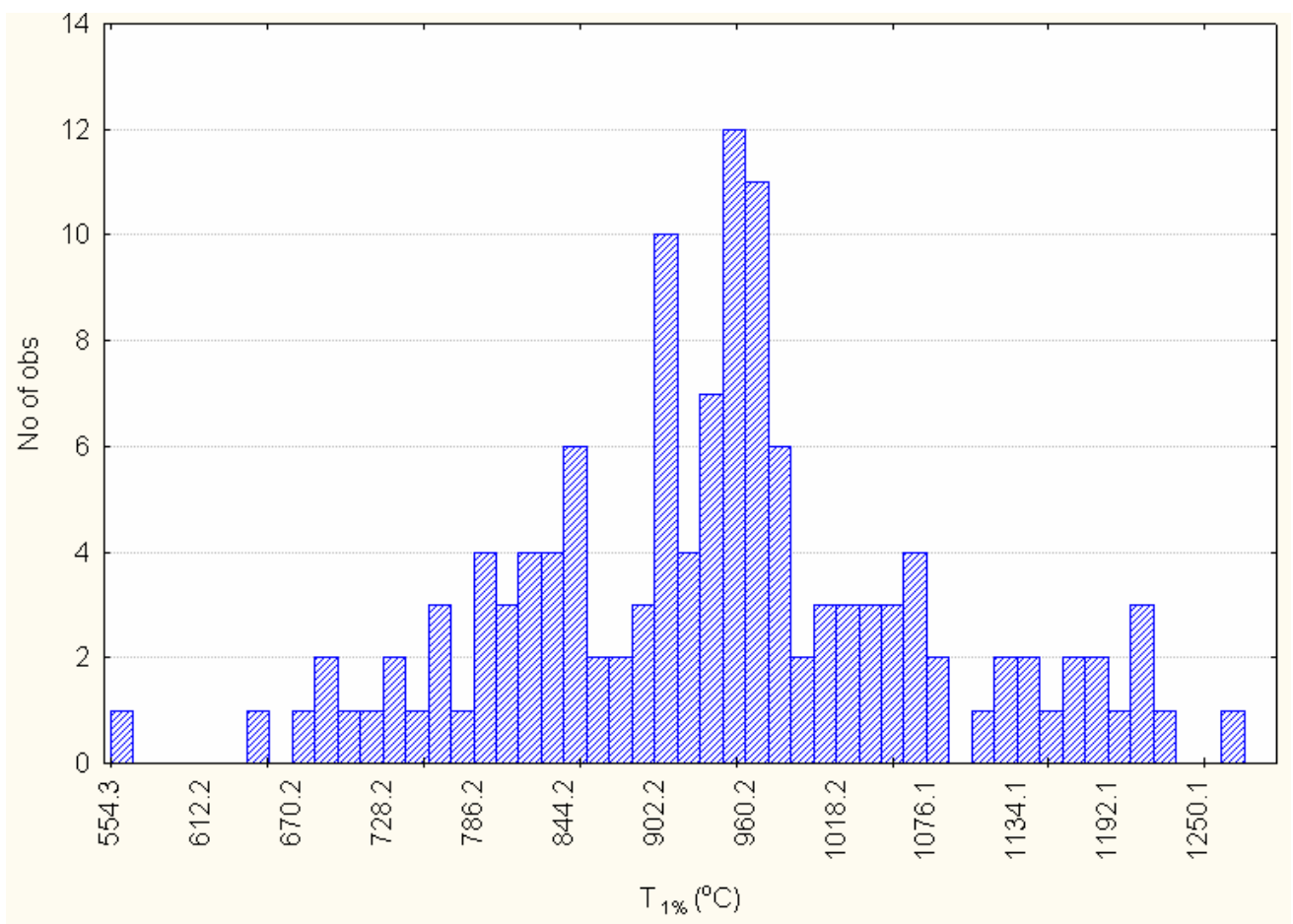

Figure A.19. Distribution of Spinel $T_{1 \%}$ for the HLW02, HLW03, HLW05, and HLW06 Glasses.

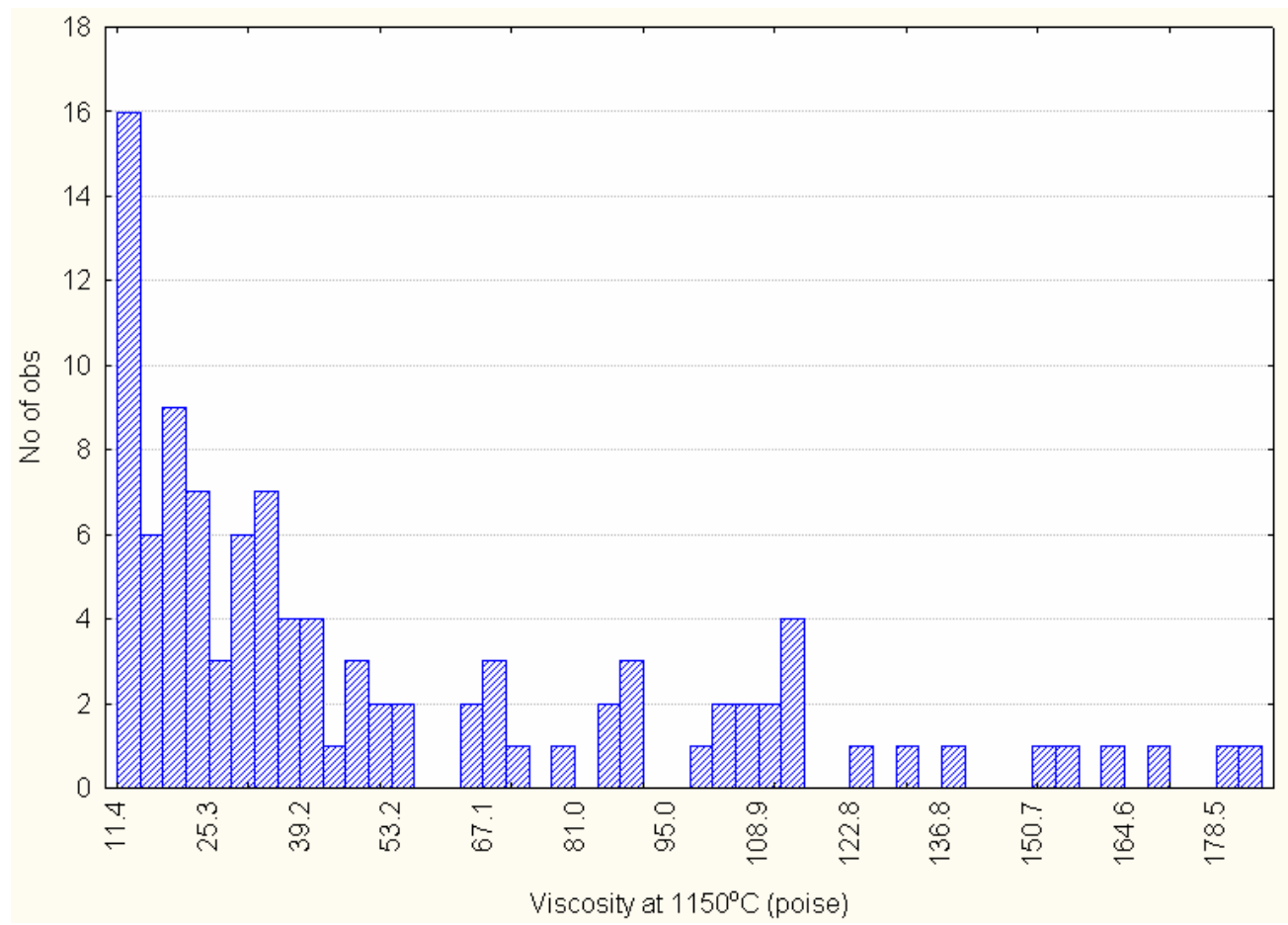

Figure A.20. Distribution of Viscosity at $1150^{\circ} \mathrm{C}$ (Poise) for the HLW02 and HLW03 Glasses (Viscosity was not measured for the HLW05 and HLW06 glasses). 


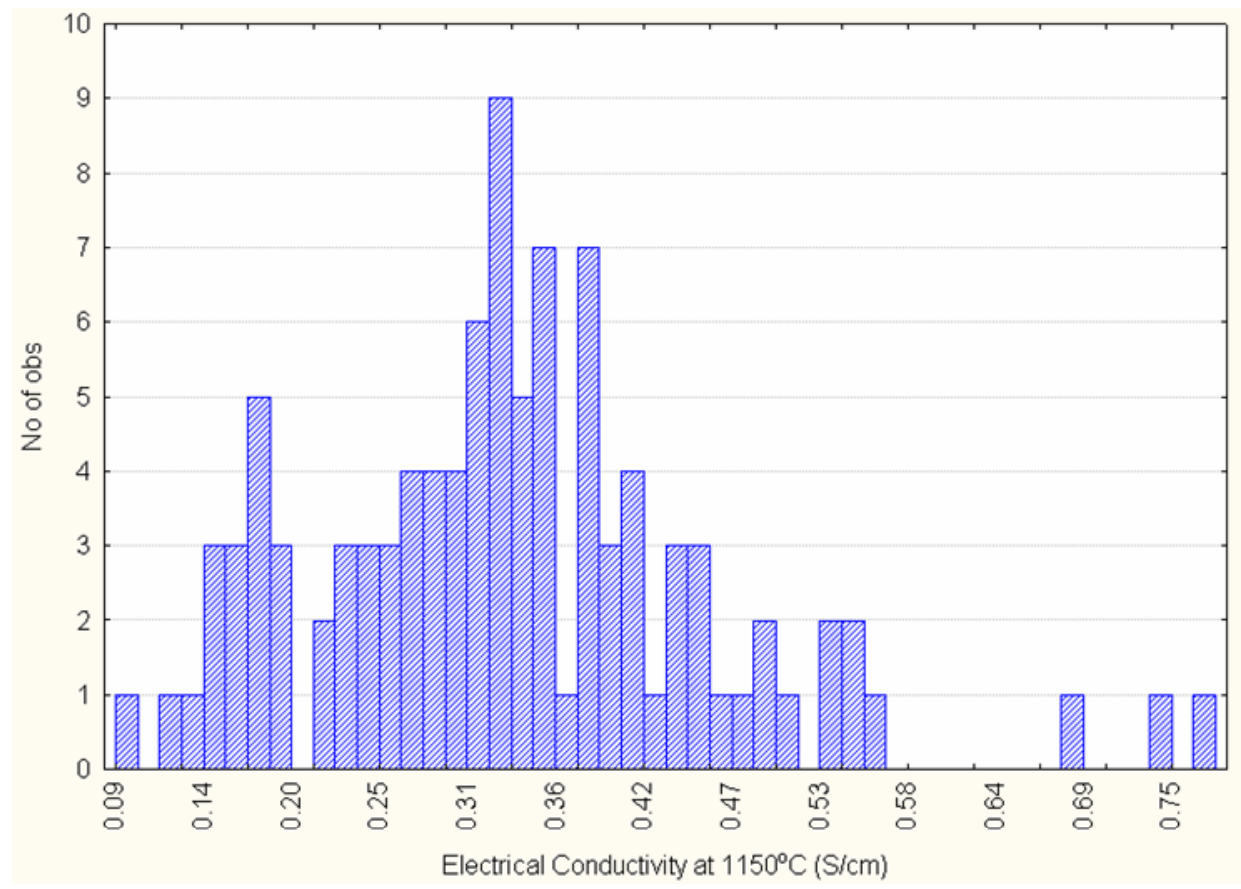

Figure A.21. Distribution of Electrical Conductivity at $1150^{\circ} \mathrm{C}(\mathrm{S} / \mathrm{cm})$ for the $\mathrm{HLW02}$ and HLW03 HLW Glasses (Electrical conductivity was not measured for the HLW05 and HLW06 glasses).

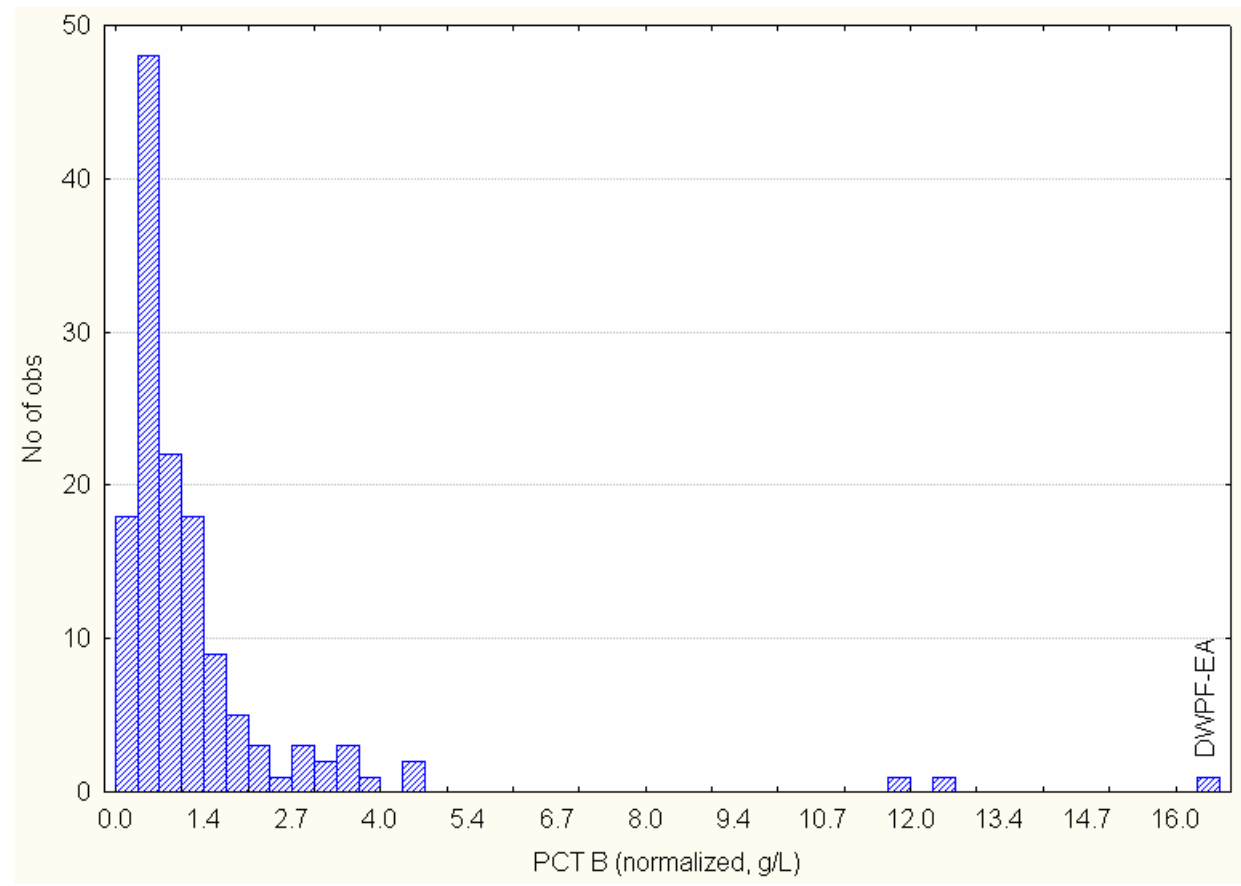

Figure A.22. Distribution of PCT-B Release (g/L) for the HLW02, HLW03, and HLW06 Glasses, with the Limit Corresponding to the DWPF-EA Glass Shown (PCT was not performed on the HLW05 glasses). 

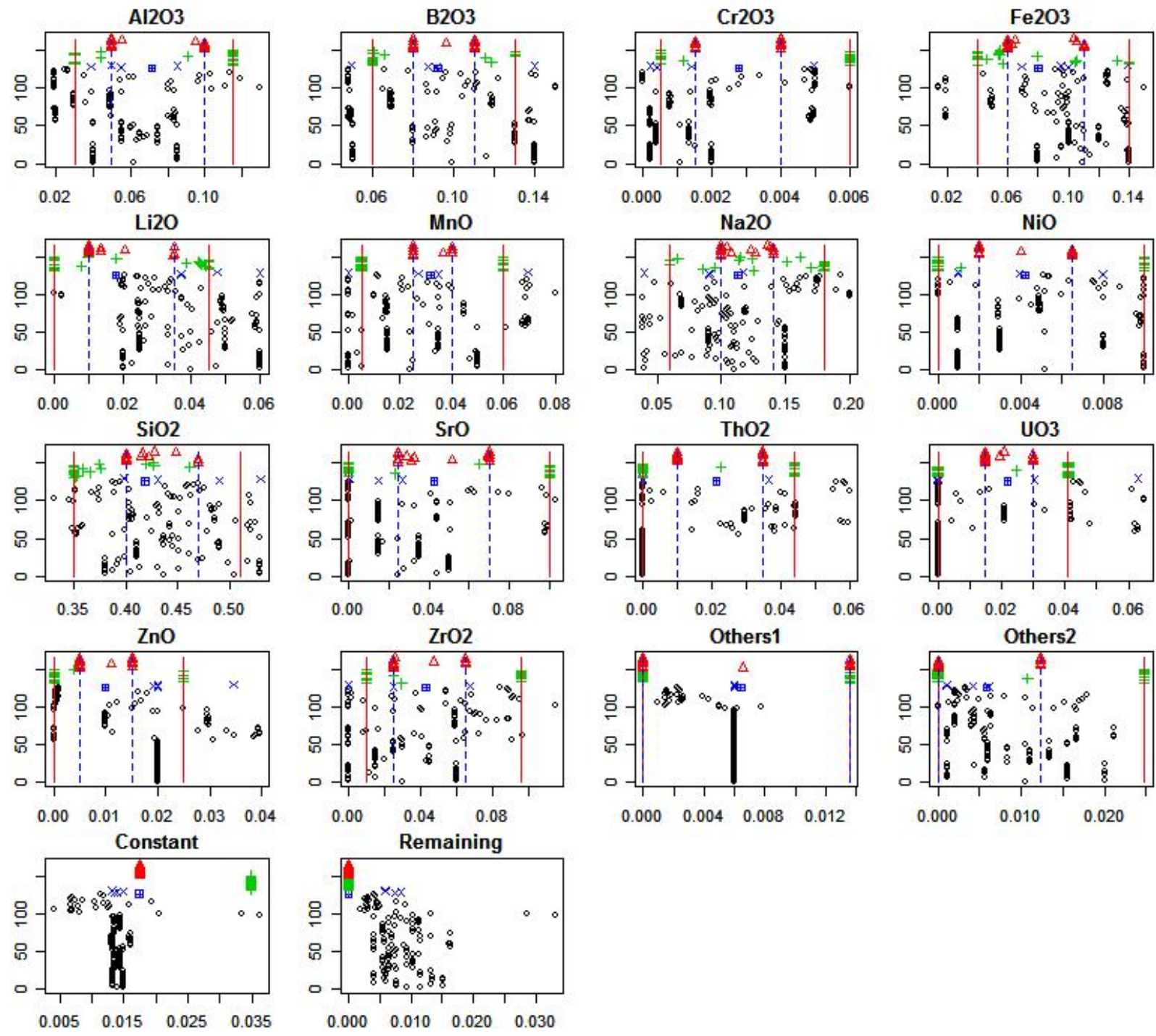

Legend: The black circles denote existing glasses. The blue box with a cross inside denotes the HLW07 center point. The blue $\times_{\mathrm{S}}$ represent the four new HLW07 replicates. The green crosses represent the 20 new HLW07 outer-layer glasses, and the red triangles represent the 15 new HLW07 inner-layer glasses. For reference purposes, the inner-layer component constraints from the HLW06 study are marked with blue dashed lines, while the outer-layer component constraints from the HLW06 study are marked with red solid lines.

Figure A.23. Single-Component Mass-Fraction Distributions for the 40-Glass HLW07 Test Matrix and the 125 Existing HLW Glasses that were Augmented. 


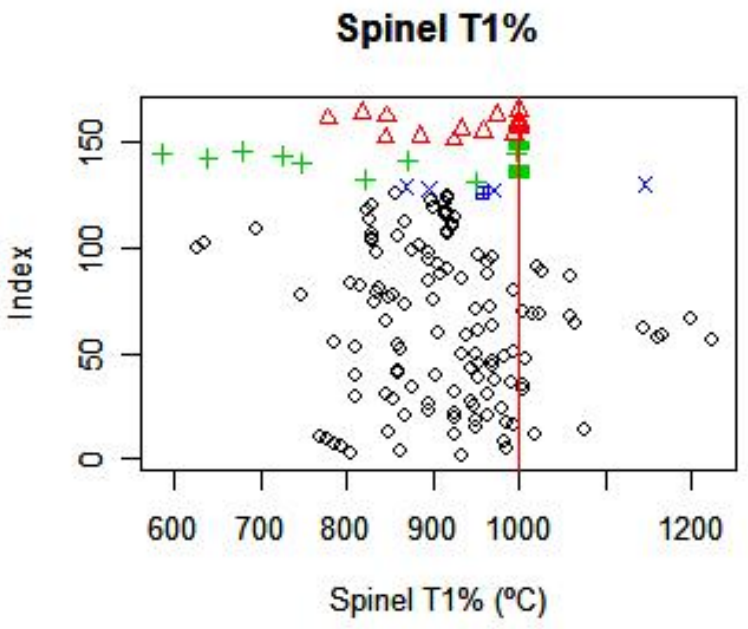

Viscosity

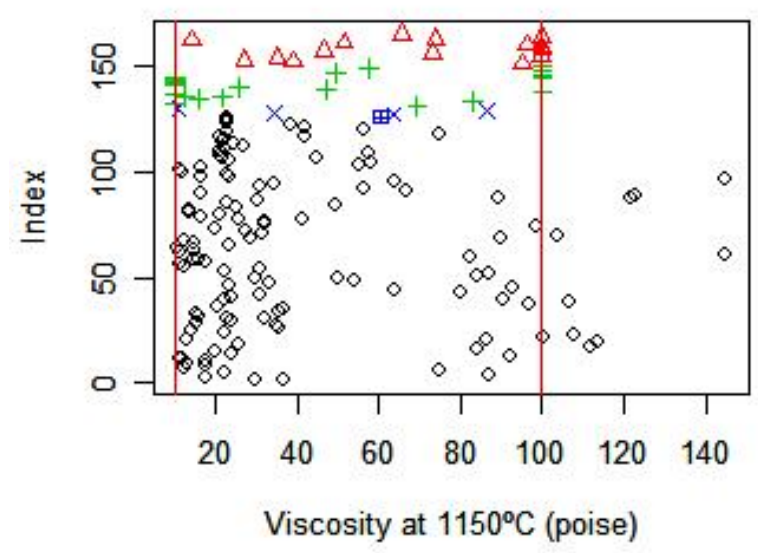

РСТ B Release

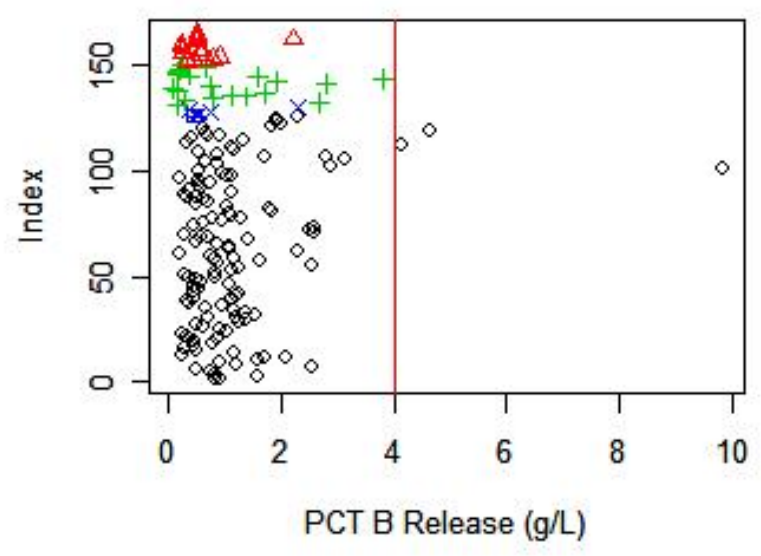

Electrical Conductivity

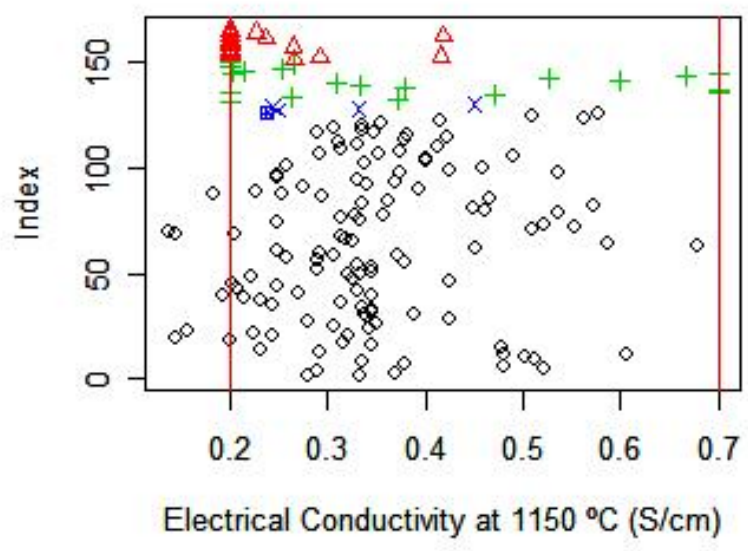

Legend: The black circles denote existing glasses. The blue box with a cross inside denotes the HLW07 center point. The blue $\times_{\mathrm{S}}$ represent the four new HLW07 replicates. The green crosses represent the 20 new HLW07 outer-layer glasses, and the red triangles represent the 15 new HLW07 inner-layer glasses. For reference purposes, property limits (spinel $\mathrm{T}_{1 \%}$, viscosity, and electrical conductivity) or reference values (PCT-B release) are marked with red solid lines.

Figure A.24. Predicted IHLW Property Plots for the 40-Glass HLW07 Test Matrix and the 125 Existing HLW Glasses that were Augmented. 


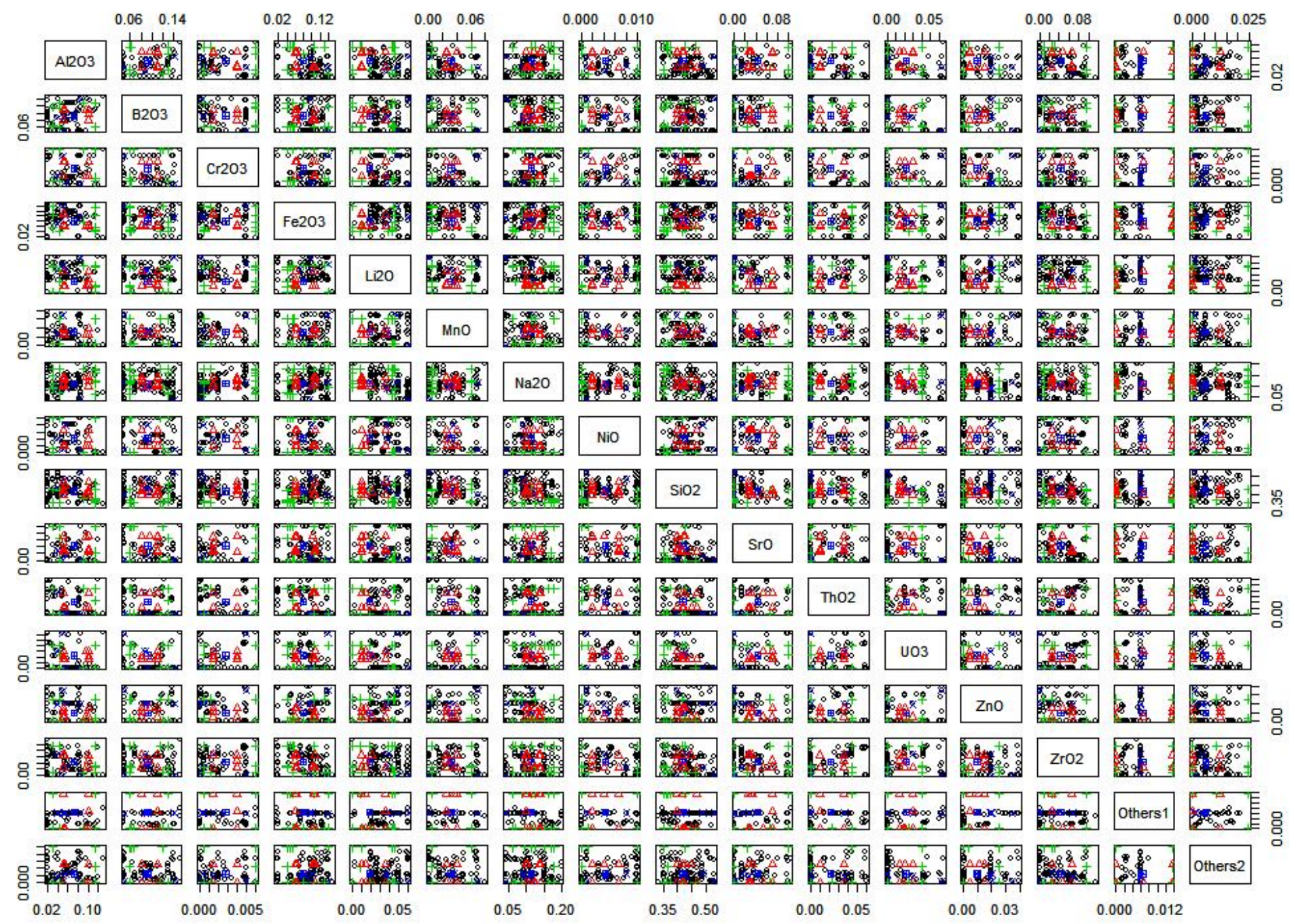

Legend: The black circles denote existing glasses. The blue box with a cross inside denotes the HLW07 center point. The blue $\times$ s represent the four new HLW07 replicates. The green crosses represent the 20 new HLW07 outer-layer glasses, and the red triangles represent the 15 new HLW07 inner-layer glasses.

Figure A.25. Scatterplot Matrix of Pairwise Distributions of Component Mass Fractions for the 40-Glass HLW07 Test Matrix and the 125 Existing HLW Glasses. 
The Catholic University of America

Vitreous State Laboratory
IHLW PCT, Spinel $T_{1 \%}$, Electrical Conductivity, and Viscosity Model Development Final Report, VSL-07R1240-4, Rev. 0

\section{APPENDIX B}

\section{Compositions and PCT Release Data for HLW Glasses Used to Validate PCT Models}




\section{APPENDIX B}

\section{Compositions and PCT Release Data for HLW Glasses Used to Validate PCT Models}

This appendix contains the compositions and corresponding PCT release data for 554 glasses used to validate the Immobilized High Level Waste (IHLW) PCT property-composition models considered in this report. The 554 validation glasses are a subset of 574 glasses described and presented in the report (and appendix) by Vienna et al. (2002). That report actually contains data for 576 glasses. However, two of the glasses (WVDG-40 and WVDG-46) were listed twice in the summary tables. Hence, there are data for 574 unique glasses in the Vienna et al. (2002) report. Of the 574 glasses, 20 glasses (designated HLW98 glasses) were included in the PCT modeling dataset of 266 glasses (see Section 5.1.1). This left 554 of the 574 glasses available for validating the PCT models developed in this report. However, 75 of these glasses did not contain $\mathrm{Li}_{2} \mathrm{O}$, and thus did not have PCT-Lithium (PCT-Li) releases. Thus, out of 574 glasses in Vienna et al. (2002), there were 554 glasses that could be used to validate PCT-Boron (PCT-B) and PCT-Sodium (PCT-Na) models, and $554-75=479$ glasses that could be used to validate PCTLi models.

In addition, glasses initially included in the 266-glass PCT modeling dataset but eventually excluded as outliers based on initial modeling work (see Section 5.1.1) were also used as validation data. Specifically, two glasses (HLW03-13 and HLW-ALG-26) with very low PCT-B releases were excluded from the PCT-B modeling dataset, but were included in the PCT$\mathrm{B}$ validation dataset. Thus, there were $554+2=556$ glasses in the final PCT-B validation dataset. Also, one glass (HLW98-94) with very low PCT-Li release was excluded from the PCTLi modeling dataset. Thus, there were $479+1=480$ glasses in the final PCT-Li validation dataset. Initial modeling work for PCT-Na did not identify any outliers to exclude from the PCT$\mathrm{Na}$ modeling dataset, so there were 554 glasses in the final PCT-Na validation dataset.

Compositions for the three glasses originally in the PCT model development dataset but moved to the model validation sets (HLW03-13, HLW-ALG-26, and HLW98-94) are given in Table 5.2. PCT release data for these three glasses are given in Table 5.3.

Table B.1 gives the compositions of the 554 validation glasses previously described. The compositions are given in mass fractions, normalized to sum to 1.0 over the 25 components identified in Section 5.1.1 as having sufficient data in the modeling dataset to support separate model terms. These components are $\mathrm{Al}_{2} \mathrm{O}_{3}, \mathrm{~B}_{2} \mathrm{O}_{3}, \mathrm{CaO}, \mathrm{CdO}, \mathrm{Cr}_{2} \mathrm{O}_{3}, \mathrm{Fe}_{2} \mathrm{O}_{3}, \mathrm{~K}_{2} \mathrm{O}, \mathrm{La}_{2} \mathrm{O}_{3}, \mathrm{Li}_{2} \mathrm{O}$, $\mathrm{MgO}, \mathrm{MnO}, \mathrm{Na}_{2} \mathrm{O}, \mathrm{NiO}, \mathrm{PbO}, \mathrm{Sb}_{2} \mathrm{O}_{3}, \mathrm{SeO}_{2}, \mathrm{SiO}_{2}, \mathrm{SrO}, \mathrm{ThO}_{2}, \mathrm{TiO}_{2}, \mathrm{Tl}_{2} \mathrm{O}, \mathrm{UO}_{3}, \mathrm{ZnO}, \mathrm{ZrO}_{2}$, and Others (the sum of the remaining components). The compositions for these glasses presented in the report by Vienna et al. (2002) were given in terms of 66 components. In cases where Vienna et al. (2002) listed glass compositions in original (old) oxide forms, the compositions were converted to the revised (new) oxide forms (see Table 2.10 in this report). In cases where the sum of the $\mathrm{wt} \%$ values of the 25 components was not exactly $100 \mathrm{wt} \%$, the compositons were normalized to sum to $100 \mathrm{wt} \%$. Because the property models for HLW glasses were developed using mass fractions of components, the validation compositions were converted to mass fractions that sum to 1 for each glass. 
Table B.2 contains PCT data on the elemental releases of boron PCT-B), lithium (PCT$\mathrm{Li}$ ), and sodium (PCT-Na) for the 554 validation glasses. PCT releases are given in unnormalized units of ppm and in normalized units of $\mathrm{g} / \mathrm{L}$. The normalized releases are based on HLW glass compositions expressed in the revised (new) oxides given in Table 2.10. Thus, the normalized releases may differ slightly from those listed in older reports that had been normalized based on glass compositions expressed in the original (old) oxides. Table B.2 contains columns that identify which of the 554 separate validation glasses were ultimately used for validation of PCT-B, PCT-Li, and PCT-Na models. 
Table B.1. Normalized 25-Component Compositions (mass fractions) of 554 HLW Glasses Used for PCT Model Validation.

\begin{tabular}{|c|c|c|c|c|c|c|c|c|c|c|c|c|c|c|c|}
\hline D & $\mathrm{Al}_{2} \mathrm{O}_{3}$ & $\mathbf{B}_{2} \mathbf{O}_{3}$ & & 10 & $\mathbf{r}_{2} \mathbf{O}_{3}$ & $\mathrm{Fe}_{2} \mathrm{O}_{3}$ & $\mathbf{K}_{2} \mathbf{O}$ & $\mathbf{L a}_{2} \mathbf{O}_{3}$ & $\mathbf{L i}_{\mathbf{2}} \mathbf{O}$ & $\operatorname{IgO}$ & & $\mathrm{Na}_{2} \mathrm{O}$ & $\mathrm{NiO}$ & PbO & $\mathrm{Sb}_{2} \mathrm{O}_{3}$ \\
\hline 22 & 88 & 988 & 13 & 52 & 30 & 101 & 00441 & 0.00170 & 02015 & 13 & 326 & 13504 & 0441 & 31 & \\
\hline & & & & & & & & & & & & & & & \\
\hline & & & & & & & & & & & & & & & \\
\hline & & 08 & & & & & & & 1501 & & & 390 & & & \\
\hline 21 & & 006 & & & & & & & & & & & & & \\
\hline & & & & & & & & & & & & & & & \\
\hline & & & & & & & & & & & & & & & \\
\hline $7 B$ & & 20 & & & & & & & & & & 423 & 573 & & \\
\hline $\mathrm{HL}$ & 85 & 04 & & & & & & & & & & & & & 306 \\
\hline & & & & & & & & & & & & & & & \\
\hline & & & & & & & & & & & & & & & \\
\hline $1 \mathrm{R}$ & & 82 & & 60 & & & & & 9990 & & & 83 & 230 & & \\
\hline$-53 \mathrm{~A}$ & .08111 & 07251 & & & & & 060 & & \begin{tabular}{|l|}
0.06001 \\
\end{tabular} & & 490 & 921 & 0710 & 070 & 0324 \\
\hline-56 & 0.07553 & 06993 & 0.00579 & \begin{tabular}{|l|}
0.01369 \\
\end{tabular} & 0.00090 & 0.11778 & 0000 & & \begin{tabular}{|l|}
0.06993 \\
\end{tabular} & & 260 & 531 & \begin{tabular}{|l|l|}
0.00769 \\
\end{tabular} & 0000 & 000 \\
\hline & & & & & & & & & & & & 745 & & & \\
\hline 60 & 0.07595 & 0.03998 & 0.00590 & 0.01369 & 0.00100 & 0.11 & 0.00030 & 0.00 & 0.04997 & \begin{tabular}{|l|}
0.00120 \\
\end{tabular} & 0.00610 & 0.13242 & 0.00770 & 0.00010 & 8 \\
\hline
\end{tabular}

\begin{tabular}{|l|c|c|c|c|c|c|c|c|c|c|c|}
\hline Glass ID & $\mathbf{S e O}_{2}$ & $\mathbf{S i O}_{2}$ & $\mathbf{S r O}$ & $\mathbf{T h O}_{2}$ & $\mathbf{T i O}_{2}$ & $\mathbf{T l}_{\mathbf{2}} \mathbf{O}$ & $\mathbf{U O}_{3}$ & $\mathbf{Z n O}$ & $\mathbf{Z r O}_{2}$ & $\mathbf{O t h e r s}^{\text {Sum }}$ \\
\hline HLW98-02 & 0.00201 & 0.33264 & 0.02717 & 0.00000 & 0.00130 & 0.00420 & 0.00000 & 0.02015 & 0.03028 & 0.03263 & 1.00000 \\
\hline HLW98-04 & 0.00050 & 0.39457 & 0.01181 & 0.00000 & 0.00050 & 0.00047 & 0.00000 & 0.02001 & 0.03773 & 0.03039 & 1.00000 \\
\hline HLW98-12 & 0.00210 & 0.41023 & 0.01751 & 0.00000 & 0.00090 & 0.00558 & 0.00530 & 0.02002 & 0.03883 & 0.02076 & 1.00000 \\
\hline HLW98-20 & 0.00000 & 0.43630 & 0.01161 & 0.00000 & 0.00000 & 0.00000 & 0.00000 & 0.02001 & 0.00320 & 0.01921 & 1.00000 \\
\hline HLW98-21 & 0.00190 & 0.50935 & 0.01251 & 0.00000 & 0.00080 & 0.00000 & 0.00000 & 0.02002 & 0.03503 & 0.01755 & 1.00000 \\
\hline HLW98-22 & 0.00000 & 0.40279 & 0.10135 & 0.00000 & 0.00000 & 0.00000 & 0.00000 & 0.02001 & 0.00190 & 0.01151 & 1.00000 \\
\hline HLW98-23 & 0.00000 & 0.44309 & 0.09174 & 0.00000 & 0.00000 & 0.00000 & 0.00000 & 0.02001 & 0.00170 & 0.01040 & 1.00000 \\
\hline HLW98-27B & 0.00151 & 0.43240 & 0.02463 & 0.00000 & 0.00070 & 0.00000 & 0.00000 & 0.02010 & 0.02804 & 0.00877 & 1.00000 \\
\hline HLW98-32A & 0.00060 & 0.45518 & 0.02261 & 0.00000 & 0.00000 & 0.00000 & 0.00000 & 0.02001 & 0.01461 & 0.00335 & 1.00000 \\
\hline HLW98-34 & 0.00000 & 0.40891 & 0.07350 & 0.00000 & 0.00040 & 0.00000 & 0.00000 & 0.02000 & 0.00120 & 0.00649 & 1.00000 \\
\hline HLW98-50 & 0.00000 & 0.45332 & 0.00010 & 0.04619 & 0.00020 & 0.00000 & 0.04311 & 0.01995 & 0.05447 & 0.00715 & 1.00000 \\
\hline HLW98-51R & 0.00000 & 0.47734 & 0.03393 & 0.04092 & 0.00020 & 0.00000 & 0.03827 & 0.01996 & 0.04840 & 0.00715 & 1.00000 \\
\hline HLW98-53A & 0.00060 & 0.46385 & 0.02380 & 0.00000 & 0.00000 & 0.00000 & 0.00000 & 0.02000 & 0.01540 & 0.00414 & 1.00000 \\
\hline HLW98-56 & 0.00000 & 0.49671 & 0.00000 & 0.00000 & 0.00010 & 0.00000 & 0.01820 & 0.00040 & 0.01648 & 0.00466 & 1.00000 \\
\hline HLW98-58 & 0.00000 & 0.47818 & 0.01359 & 0.00010 & 0.00010 & 0.00000 & 0.01831 & 0.00050 & 0.01658 & 0.00516 & 1.00000 \\
\hline HLW98-60 & 0.00000 & 0.47622 & 0.00680 & 0.00000 & 0.00010 & 0.00000 & 0.01831 & 0.02039 & 0.01659 & 0.00486 & 1.00000 \\
\hline
\end{tabular}

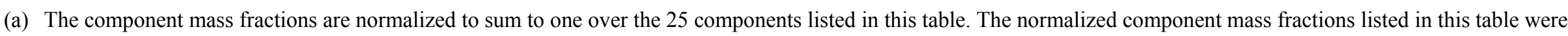

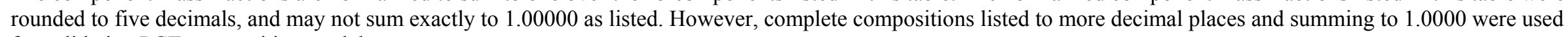
for validating PCT-composition models. 
Table B.1. Normalized 25-Component Compositions (mass fractions) of 554 HLW Glasses Used for PCT Model Validation (continued).

\begin{tabular}{|c|c|c|c|c|c|c|c|c|c|c|c|c|c|c|c|}
\hline D & $\mathbf{A l}_{2} \mathbf{O}_{3}$ & $\mathbf{B}_{2} \mathbf{O}_{3}$ & & $\mathbf{O}$ & $\mathrm{Cr}_{2} \mathrm{O}_{3}$ & $\mathbf{e}_{2} \mathrm{O}_{3}$ & $\mathrm{~K}_{2} \mathrm{O}$ & $\mathbf{L a}_{2} \mathbf{O}_{3}$ & $\mathbf{L}_{2} \mathbf{O}$ & D & & $\mathrm{Na}_{2} \mathrm{O}$ & $\mathbf{N}$ & 0 & $\mathrm{Sb}_{2} \mathbf{O}_{3}$ \\
\hline & & 2000 & & 60 & 40 & & 080 & & 000 & & & 640 & 50 & & 0000 \\
\hline & & & & & & & & & & & & & & & \\
\hline & & & & & & & & & & & & & & & \\
\hline & & & & & & & & & & & & & & & \\
\hline & & & & & & & & & & & & & & & \\
\hline & & & & & & & & & & & & & & & \\
\hline & & & & & & & & & & & & & & & \\
\hline & & & & & & & & & & & & & & & \\
\hline & & & & & & & & & & & & & & & \\
\hline & & & & & & & & & & & & & & & \\
\hline & & & & & & & & & & & & & & & \\
\hline & & & & & & & & & & & & & & & \\
\hline & & & & & & & & & & & & & & & 000 \\
\hline & & & & 0.00010 & & & & & & & & & & & \\
\hline & & & & & & & & & & & & & & & \\
\hline HLWD1-14R & .03771 & 0.16020 & 0.00000 & 0.00000 & 0.00000 & 0.07541 & 0.00000 & 0.01786 & 0.03112 & 0.00000 & 0.00000 & 0.14134 & 0.00170 & 0.00000 & 0.0000 \\
\hline
\end{tabular}

\begin{tabular}{|l|c|c|c|c|c|c|c|c|c|c|c|}
\hline Glass ID & $\mathbf{S e O}_{2}$ & $\mathbf{S i O}_{2}$ & $\mathbf{S r O}$ & $\mathbf{T h O}_{2}$ & $\mathbf{T i O}_{\mathbf{2}}$ & $\mathbf{T l}_{\mathbf{2}} \mathbf{O}$ & $\mathbf{U O}_{3}$ & $\mathbf{Z n O}$ & $\mathbf{Z r O}_{2}$ & $\mathbf{\text { Others }}$ & $\mathbf{S u m}^{(\mathbf{a})}$ \\
\hline HLW98-62 & 0.00000 & 0.42550 & 0.02080 & 0.00000 & 0.00000 & 0.00000 & 0.00000 & 0.02010 & 0.08080 & 0.00410 & 1.00000 \\
\hline HLW99-15 & 0.00200 & 0.31015 & 0.00200 & 0.00000 & 0.01000 & 0.00186 & 0.00000 & 0.02001 & 0.00000 & 0.08327 & 1.00000 \\
\hline HLW99-27 & 0.00200 & 0.30014 & 0.00200 & 0.00000 & 0.01000 & 0.00186 & 0.00000 & 0.02001 & 0.00000 & 0.08327 & 1.00000 \\
\hline HLW99-52 & 0.00200 & 0.37018 & 0.00200 & 0.00000 & 0.01000 & 0.00186 & 0.00000 & 0.02001 & 0.00000 & 0.08327 & 1.00000 \\
\hline HLWD1-01 & 0.00000 & 0.36369 & 0.00180 & 0.00000 & 0.00621 & 0.00000 & 0.04735 & 0.00000 & 0.05833 & 0.05581 & 1.00000 \\
\hline HLWD1-02 & 0.00000 & 0.30938 & 0.00180 & 0.00000 & 0.00622 & 0.00000 & 0.04694 & 0.00000 & 0.05775 & 0.06406 & 1.00000 \\
\hline HLWD1-03 & 0.00000 & 0.30941 & 0.00180 & 0.00000 & 0.00622 & 0.00000 & 0.04694 & 0.00000 & 0.05775 & 0.06407 & 1.00000 \\
\hline HLWD1-04 & 0.00000 & 0.30938 & 0.00180 & 0.00000 & 0.00622 & 0.00000 & 0.04694 & 0.00000 & 0.05775 & 0.06406 & 1.00000 \\
\hline HLWD1-05 & 0.00000 & 0.32987 & 0.00180 & 0.00000 & 0.00622 & 0.00000 & 0.04694 & 0.00000 & 0.05775 & 0.06407 & 1.00000 \\
\hline HLWD1-07 & 0.00000 & 0.32274 & 0.03094 & 0.00000 & 0.00897 & 0.00000 & 0.06801 & 0.00000 & 0.00000 & 0.09656 & 1.00000 \\
\hline HLWD1-08 & 0.00000 & 0.32251 & 0.03085 & 0.00000 & 0.00877 & 0.00000 & 0.06632 & 0.00000 & 0.00000 & 0.09444 & 1.00000 \\
\hline HLWD1-09 & 0.00000 & 0.32248 & 0.03085 & 0.00000 & 0.00877 & 0.00000 & 0.06631 & 0.00000 & 0.00000 & 0.09443 & 1.00000 \\
\hline HLWD1-10 & 0.00000 & 0.30119 & 0.03057 & 0.00000 & 0.00822 & 0.00000 & 0.06200 & 0.00000 & 0.00000 & 0.08946 & 1.00000 \\
\hline HLWD1-11 & 0.00000 & 0.28596 & 0.02583 & 0.00000 & 0.00271 & 0.00000 & 0.00277 & 0.00000 & 0.00181 & 0.01690 & 1.00000 \\
\hline HLWD1-13 & 0.00000 & 0.30024 & 0.01848 & 0.00000 & 0.00000 & 0.00000 & 0.00000 & 0.00000 & 0.00000 & 0.00826 & 1.00000 \\
\hline HLWD1-14R & 0.00000 & 0.27331 & 0.01795 & 0.00349 & 0.00000 & 0.00000 & 0.09604 & 0.00000 & 0.12249 & 0.02137 & 1.00000 \\
\hline
\end{tabular}

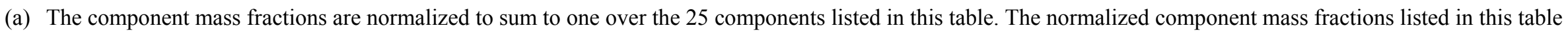
were rounded to five decimals, and may not sum exactly to 1.00000 as listed. However, complete compositions listed to more decimal places and summing to 1.0000 were used for validating PCT-composition models. 
Table B.1. Normalized 25-Component Compositions (mass fractions) of 554 HLW Glasses Used for PCT Model Validation (continued).

\begin{tabular}{|c|c|c|c|c|c|c|c|c|c|c|c|c|c|c|c|}
\hline Gl & $\mathrm{I}_{2} \mathrm{O}_{3}$ & $\mathbf{B}_{2} \mathbf{O}_{3}$ & $\mathrm{AO}$ & do & $\mathrm{Cr}_{2} \mathrm{O}_{3}$ & $\mathbf{e}_{2} \mathrm{O}_{3}$ & $\mathbf{K}_{2} \mathbf{O}$ & $\mathbf{a}_{2} \mathbf{O}_{3}$ & $\mathbf{L i}_{2} \mathbf{O}$ & o & $\mathbf{0}$ & $\mathrm{Na}_{2} \mathrm{O}$ & $\mathrm{NiO}$ & PbO & $\mathrm{Sb}_{2} \mathrm{O}_{3}$ \\
\hline $17 \mathrm{R}$ & 770 & 16018 & 0000 & 00000 & 0000 & 558 & 00000 & 85 & 3112 & 00 & 00 & .09425 & 70 & 00 & 00000 \\
\hline & & & & & & & & & & & & & & & \\
\hline $\mathrm{HL}$ & & 53 & & 0 & 45 & & & & 98 & & 00 & 766 & & & \\
\hline & & & & & & & & & & & & & & & \\
\hline & & & & \begin{tabular}{|l|}
0.00010 \\
\end{tabular} & 120 & & & & & & & & & & 000 \\
\hline & & 39 & 324 & \begin{tabular}{|l|}
0.00662 \\
\end{tabular} & & & & & & & & & & & \\
\hline & 259 & 696 & & \begin{tabular}{|l|}
0.00797 \\
\end{tabular} & 367 & 225 & 535 & 210 & \begin{tabular}{|l|}
0.02098 \\
\end{tabular} & 535 & 37 & 375 & 35 & 73 & 42 \\
\hline & & & & & & & & & & & & & & & \\
\hline & & 33 & 25 & & & 72 & 82 & & & & & 186 & 956 & 272 & 0.00000 \\
\hline & & 0.06036 & 000 & \begin{tabular}{|l|}
0.01915 \\
\end{tabular} & 0.00736 & 0.24327 & 0.00010 & & 23 & 0.00000 & & 0.07095 & & & 0.00000 \\
\hline & 16020 & 0.06593 & & \begin{tabular}{|l|}
0.00000 \\
\end{tabular} & 0.00000 & & & & & 0.00000 & & & & & \\
\hline & & & & & & & & & & & & & & & \\
\hline HLW & 38 & 0.06711 & 7675 & \begin{tabular}{|l|}
0.00000 \\
\end{tabular} & 0.00660 & 0.08 & 0.01056 & 0.00000 & 0.0 & 0.02 & 517 & 188 & 162 & 000 & 0.00000 \\
\hline HLW & 99166 & 0.11984 & 05637 & \begin{tabular}{|l|}
0.00330 \\
\end{tabular} & 0.00560 & 0.17022 & 0.00220 & 0.00090 & 0.02989 & 0.00220 & 0.00179 & 0.11355 & 0.01159 & 0.00110 & 0.00063 \\
\hline & 8365 & 0.07109 & 0.02051 & \begin{tabular}{|l|}
0.01036 \\
\end{tabular} & 0.00201 & 0.09753 & 0.02111 & 0.00613 & 0.00060 & 0.00704 & 0.0 & 576 & 003 & 41 & 0.00000 \\
\hline HLWD3-02 & 0.04683 & 0.07176 & \begin{tabular}{|l|}
0.00040 \\
\end{tabular} & \begin{tabular}{|l|}
0.01327 \\
\end{tabular} & 0.00251 & 0.11808 & 0.01538 & 0.00774 & 0.00000 & 0.00000 & 0.02173 & 0.15919 & 0.00754 & 0.00301 & 0.00000 \\
\hline
\end{tabular}

\begin{tabular}{|l|c|c|c|c|c|c|c|c|c|c|c|}
\hline Glass ID & $\mathbf{S e O}_{\mathbf{2}}$ & $\mathbf{S i O}_{\mathbf{2}}$ & $\mathbf{S r O}$ & $\mathbf{T h O}_{\mathbf{2}}$ & $\mathbf{T i O}_{\mathbf{2}}$ & $\mathbf{T l}_{\mathbf{2}} \mathbf{O}$ & $\mathbf{U O}_{\mathbf{3}}$ & $\mathbf{Z n O}$ & $\mathbf{Z r O}_{\mathbf{2}}$ & $\mathbf{O t h e r s}^{\text {Sum }}$ \\
\hline HLWD1-17R & 0.00000 & 0.28276 & 0.01795 & 0.00349 & 0.00000 & 0.00000 & 0.09604 & 0.00000 & 0.00000 & 0.02137 & 1.00000 \\
\hline HLWD1-18 & 0.00000 & 0.23950 & 0.01827 & 0.00000 & 0.00000 & 0.00000 & 0.00000 & 0.00000 & 0.12457 & 0.00826 & 1.00000 \\
\hline HLWD1- & 0.00487 & 0.23453 & 0.02621 & 0.00000 & 0.01688 & 0.00351 & 0.00000 & 0.00407 & 0.00000 & 0.06887 & 1.00000 \\
\hline HLWD1-20R & 0.00492 & 0.27485 & 0.02287 & 0.00000 & 0.01705 & 0.00354 & 0.00000 & 0.00411 & 0.12318 & 0.06958 & 1.00000 \\
\hline HLWD1-21R & 0.00000 & 0.30823 & 0.02068 & 0.00000 & 0.00231 & 0.00000 & 0.00234 & 0.00040 & 0.00151 & 0.01594 & 1.00000 \\
\hline HLWD1-23 & 0.00150 & 0.32101 & 0.02759 & 0.00110 & 0.00140 & 0.00429 & 0.02805 & 0.00090 & 0.00090 & 0.03185 & 1.00000 \\
\hline HLWD1-25 & 0.00189 & 0.32739 & 0.03304 & 0.00000 & 0.00000 & 0.00000 & 0.00000 & 0.00000 & 0.00000 & 0.03690 & 1.00000 \\
\hline HLWD1-27 & 0.00131 & 0.33374 & 0.02771 & 0.00110 & 0.00141 & 0.00411 & 0.02818 & 0.00090 & 0.00090 & 0.03158 & 1.00000 \\
\hline HLWD2-01 & 0.00000 & 0.32146 & 0.02939 & 0.00000 & 0.00503 & 0.00000 & 0.03806 & 0.00000 & 0.04690 & 0.05466 & 1.00000 \\
\hline HLWD2-02 & 0.00000 & 0.30192 & 0.03154 & 0.00000 & 0.00796 & 0.00000 & 0.06052 & 0.00000 & 0.00000 & 0.08700 & 1.00000 \\
\hline HLWD2-03 & 0.00000 & 0.27331 & 0.01795 & 0.00349 & 0.00000 & 0.00000 & 0.09604 & 0.00000 & 0.00000 & 0.02137 & 1.00000 \\
\hline HLWD2-04 & 0.00000 & 0.23689 & 0.01805 & 0.00000 & 0.00000 & 0.00000 & 0.00000 & 0.00000 & 0.00000 & 0.09447 & 1.00000 \\
\hline HLWD2-05R & 0.00000 & 0.23980 & 0.01827 & 0.00000 & 0.00000 & 0.00000 & 0.00000 & 0.00000 & 0.12467 & 0.00816 & 1.00000 \\
\hline HLWD2-06 & 0.00080 & 0.33784 & 0.01349 & 0.00050 & 0.00070 & 0.00204 & 0.01376 & 0.00040 & 0.00050 & 0.01912 & 1.00000 \\
\hline HLWD3-01 & 0.00000 & 0.30345 & 0.02504 & 0.00000 & 0.00432 & 0.00000 & 0.03280 & 0.00000 & 0.04052 & 0.05239 & 1.00000 \\
\hline HLWD3-02 & 0.00000 & 0.40239 & 0.01960 & 0.00151 & 0.00553 & 0.00000 & 0.04184 & 0.00000 & 0.00010 & 0.06160 & 1.00000 \\
\hline
\end{tabular}

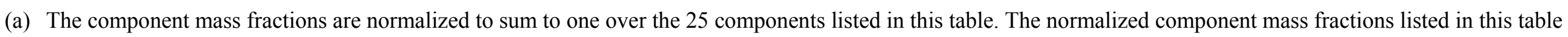
were rounded to five decimals, and may not sum exactly to 1.00000 as listed. However, complete compositions listed to more decimal places and summing to 1.0000 were used for validating PCT-composition models. 
Table B.1. Normalized 25-Component Compositions (mass fractions) of 554 HLW Glasses Used for PCT Model Validation (continued).

\begin{tabular}{|c|c|c|c|c|c|c|c|c|c|c|c|c|c|c|c|}
\hline & $\mathbf{l}_{2} \mathrm{O}_{3}$ & $\mathbf{B}_{2} \mathbf{O}_{3}$ & D & $\mathbf{O}$ & $\mathrm{Cr}_{2} \mathrm{O}_{3}$ & $\mathbf{e}_{2} \mathrm{O}_{3}$ & $\mathrm{~K}_{2} \mathrm{O}$ & $\mathbf{L a}_{2} \mathbf{O}_{3}$ & $\mathbf{i}_{2} \mathbf{O}$ & o & & $\mathrm{Na}_{2} \mathrm{O}$ & $\mathbf{N}$ & $\mathbf{P}$ & $\mathrm{Sb}_{2} \mathrm{O}_{3}$ \\
\hline 5 & & 651 & & 1 & & 19 & 0000 & 00000 & 03159 & 0 & 00 & 9567 & 70 & 0 & 00000 \\
\hline & & & & & & & & & & & & & & & \\
\hline & & & & & & & & & & & & & & & \\
\hline & & & & & & & & & & & & & & & \\
\hline & & & & & & & & & & & & & & & \\
\hline & & & & & & & & & & & & & & & \\
\hline & & & & & & & & & & & & & & & \\
\hline & & & & & & & & & & & & & & & \\
\hline & & & & & & & & & & & & & & & \\
\hline & & & & & & & & & & & & & & & \\
\hline & & & & & & & & & & & & & & & \\
\hline & & & & & & & & & & & & & & & \\
\hline & & & 000 & & & & & & & & & 003 & & 00 & 0000 \\
\hline & 000 & \begin{tabular}{|l|}
0.05000 \\
\end{tabular} & 0001 & \begin{tabular}{|l|}
0.00134 \\
\end{tabular} & & & & & & & & & & & \\
\hline & & & & & & & & & & & & & & & \\
\hline $\begin{array}{l}\text { CVS1-9 } \\
\end{array}$ & 00000 & \begin{tabular}{|l|}
0.19633 \\
\end{tabular} & \begin{tabular}{|l|}
0.00000 \\
\end{tabular} & 0.01344 & 0.00224 & 0.14009 & 0.00000 & 0.01120 & \begin{tabular}{|l|}
0.01001 \\
\end{tabular} & 0.08005 & 0.00220 & 0.05383 & 0.01031 & 0.00000 & 0.00000 \\
\hline
\end{tabular}

\begin{tabular}{|l|c|c|c|c|c|c|c|c|c|c|c|}
\hline Glass ID & $\mathbf{S e O}_{2}$ & $\mathbf{S i O}_{2}$ & $\mathbf{S r O}$ & $\mathbf{T h O}_{2}$ & $\mathbf{T i O}_{\mathbf{2}}$ & $\mathbf{T l}_{\mathbf{2}} \mathbf{O}$ & $\mathbf{U O}_{3}$ & $\mathbf{Z n O}$ & $\mathbf{Z r O}_{2}$ & $\mathbf{\text { Others }}$ & $\mathbf{S u m}^{(\mathbf{a})}$ \\
\hline HLWD3-03 & 0.00000 & 0.29653 & 0.01825 & 0.00000 & 0.00000 & 0.00000 & 0.00000 & 0.00000 & 0.00000 & 0.09537 & 1.00000 \\
\hline HLWD3-04 & 0.00571 & 0.23669 & 0.02285 & 0.00000 & 0.01704 & 0.00373 & 0.00000 & 0.00411 & 0.00000 & 0.06951 & 1.00000 \\
\hline HLWD3-06 & 0.00000 & 0.29375 & 0.01805 & 0.00000 & 0.00000 & 0.00000 & 0.00000 & 0.00000 & 0.10420 & 0.09447 & 1.00000 \\
\hline HLWD3-07 & 0.00000 & 0.29372 & 0.01805 & 0.00000 & 0.00000 & 0.00000 & 0.00000 & 0.00000 & 0.00000 & 0.00140 & 1.00000 \\
\hline HLWD3-08 & 0.00090 & 0.28641 & 0.02271 & 0.00080 & 0.00100 & 0.00298 & 0.02003 & 0.00080 & 0.00160 & 0.02445 & 1.00000 \\
\hline HLW98-96A & 0.00000 & 0.44595 & 0.00000 & 0.00000 & 0.00021 & 0.00000 & 0.00000 & 0.02076 & 0.09102 & 0.04464 & 1.00000 \\
\hline HLW98-96B & 0.00000 & 0.44270 & 0.00000 & 0.00000 & 0.00021 & 0.00000 & 0.00000 & 0.02061 & 0.09036 & 0.05159 & 1.00000 \\
\hline CVS1-1 & 0.00000 & 0.48023 & 0.00073 & 0.00000 & 0.00000 & 0.00000 & 0.00000 & 0.00000 & 0.04291 & 0.02370 & 1.00000 \\
\hline CVS1-2 & 0.00000 & 0.55004 & 0.00018 & 0.00000 & 0.00000 & 0.00000 & 0.00000 & 0.00000 & 0.00000 & 0.00582 & 1.00000 \\
\hline CVS1-3 & 0.00000 & 0.42003 & 0.00018 & 0.00000 & 0.00000 & 0.00000 & 0.00000 & 0.00000 & 0.01000 & 0.00582 & 1.00000 \\
\hline CVS1-4 & 0.00000 & 0.57004 & 0.00018 & 0.00000 & 0.00000 & 0.00000 & 0.00000 & 0.00000 & 0.00000 & 0.00582 & 1.00000 \\
\hline CVS1-5 & 0.00000 & 0.57004 & 0.00018 & 0.00000 & 0.00000 & 0.00000 & 0.00000 & 0.00000 & 0.00000 & 0.00582 & 1.00000 \\
\hline CVS1-6 & 0.00000 & 0.44028 & 0.00179 & 0.00000 & 0.00000 & 0.00000 & 0.00000 & 0.00000 & 0.12008 & 0.05825 & 1.00000 \\
\hline CVS1-7 & 0.00000 & 0.57004 & 0.00018 & 0.00000 & 0.00000 & 0.00000 & 0.00000 & 0.00000 & 0.13001 & 0.00582 & 1.00000 \\
\hline CVS1-8 & 0.00000 & 0.53633 & 0.00018 & 0.00000 & 0.00000 & 0.00000 & 0.00000 & 0.00000 & 0.08001 & 0.00582 & 1.00000 \\
\hline CVS1-9 & 0.00000 & 0.42027 & 0.00179 & 0.00000 & 0.00000 & 0.00000 & 0.00000 & 0.00000 & 0.00000 & 0.05825 & 1.00000 \\
\hline
\end{tabular}

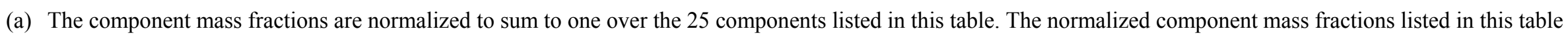
were rounded to five decimals, and may not sum exactly to 1.00000 as listed. However, complete compositions listed to more decimal places and summing to 1.0000 were used for validating PCT-composition models. 
Table B.1. Normalized 25-Component Compositions (mass fractions) of 554 HLW Glasses Used for PCT Model Validation (continued).

\begin{tabular}{|c|c|c|c|c|c|c|c|c|c|c|c|c|c|c|c|}
\hline & $\mathrm{Al}_{2} \mathrm{O}_{3}$ & ${ }_{2} \mathbf{O}_{3}$ & & & $\mathbf{r}_{2} \mathbf{O}_{3}$ & $\mathrm{Fe}_{2} \mathrm{O}_{3}$ & $\mathbf{K}_{2} \mathbf{O}$ & $\mathbf{L a}_{2} \mathbf{O}_{3}$ & $\mathbf{L i}_{2} \mathbf{O}$ & & & $\mathrm{Na}_{2} \mathrm{O}$ & D & PbO & $\mathbf{b}_{2} \mathbf{O}_{3}$ \\
\hline & & & 00 & & & & 0 & 20 & 1 & & & & 31 & & \\
\hline & & & & & & & & & & & & & & & \\
\hline & & & & & & & & & & & & & & & \\
\hline & & & & & & & & & & & & & & & \\
\hline & & & & & & & & & & & & & & & \\
\hline & & & & & & & & & & & & & & & \\
\hline & & & & & & & & & & & & & & & \\
\hline & & & & & & & & & & & & & & & \\
\hline & & & & & & & & & & & & & & & \\
\hline & & & & & & & & & & & & & & & \\
\hline & & & & & & & & & & & & & & & \\
\hline & & & & & & & & & & & & & & & \\
\hline & & & & & & & & & & & & & & & 000 \\
\hline & 04561 & 562 & 2891 & 528 & & & & & & & & & & & 0000 \\
\hline & & & & & & & & & & & & & & & \\
\hline & 11002 & 0.07001 & 0.07001 & 0.00336 & 0.00056 & 0.04501 & 0.00000 & 0.00280 & 0.06001 & 0.00000 & 0.00055 & 0.08851 & 0.00258 & 0.00000 & 0.00000 \\
\hline
\end{tabular}

\begin{tabular}{|l|c|c|c|c|c|c|c|c|c|c|c|}
\hline Glass ID & $\mathbf{S e O}_{2}$ & $\mathbf{S i O}_{2}$ & $\mathbf{S r O}$ & $\mathbf{T h O}_{2}$ & $\mathbf{T i O}_{2}$ & $\mathbf{T l}_{\mathbf{2}} \mathbf{O}$ & $\mathbf{U O}_{3}$ & $\mathbf{Z n O}$ & $\mathbf{Z r O}_{2}$ & $\mathbf{O t h e r s}^{\text {Sum }}$ \\
\hline CVS1-10 & 0.00000 & 0.57037 & 0.00179 & 0.00000 & 0.00000 & 0.00000 & 0.00000 & 0.00000 & 0.00000 & 0.05825 & 1.00000 \\
\hline CVS1-11 & 0.00000 & 0.42022 & 0.00143 & 0.00000 & 0.00000 & 0.00000 & 0.00000 & 0.00000 & 0.00000 & 0.04659 & 1.00000 \\
\hline CVS1-12 & 0.00000 & 0.42003 & 0.00018 & 0.00000 & 0.00000 & 0.00000 & 0.00000 & 0.00000 & 0.00000 & 0.00582 & 1.00000 \\
\hline CVS1-13 & 0.00000 & 0.57004 & 0.00018 & 0.00000 & 0.00000 & 0.00000 & 0.00000 & 0.00000 & 0.00000 & 0.00582 & 1.00000 \\
\hline CVS1-14 & 0.00000 & 0.42003 & 0.00018 & 0.00000 & 0.00000 & 0.00000 & 0.00000 & 0.00000 & 0.13001 & 0.00582 & 1.00000 \\
\hline CVS1-15 & 0.00000 & 0.55926 & 0.00179 & 0.00000 & 0.00000 & 0.00000 & 0.00000 & 0.00000 & 0.00000 & 0.05825 & 1.00000 \\
\hline CVS1-16 & 0.00000 & 0.43273 & 0.00018 & 0.00000 & 0.00000 & 0.00000 & 0.00000 & 0.00000 & 0.00000 & 0.00582 & 1.00000 \\
\hline CVS1-17 & 0.00000 & 0.45479 & 0.00179 & 0.00000 & 0.00000 & 0.00000 & 0.00000 & 0.00000 & 0.00000 & 0.05825 & 1.00000 \\
\hline CVS1-18 & 0.00000 & 0.42165 & 0.00161 & 0.00000 & 0.00000 & 0.00000 & 0.00000 & 0.00000 & 0.13008 & 0.05242 & 1.00000 \\
\hline CVS1-19 & 0.00000 & 0.48023 & 0.00073 & 0.00000 & 0.00000 & 0.00000 & 0.00000 & 0.00000 & 0.04291 & 0.02370 & 1.00000 \\
\hline CVS1-20 & 0.00000 & 0.48023 & 0.00073 & 0.00000 & 0.00000 & 0.00000 & 0.00000 & 0.00000 & 0.04291 & 0.02370 & 1.00000 \\
\hline CVS1-21 & 0.00000 & 0.57004 & 0.00018 & 0.00000 & 0.00000 & 0.00000 & 0.00000 & 0.00000 & 0.00000 & 0.00582 & 1.00000 \\
\hline CVS1-22 & 0.00000 & 0.53633 & 0.00018 & 0.00000 & 0.00000 & 0.00000 & 0.00000 & 0.00000 & 0.08001 & 0.00582 & 1.00000 \\
\hline CVS1-23 & 0.00000 & 0.51543 & 0.00070 & 0.00000 & 0.00000 & 0.00000 & 0.00000 & 0.00000 & 0.00630 & 0.02288 & 1.00000 \\
\hline CVS2-1 & 0.00000 & 0.52287 & 0.00143 & 0.00000 & 0.00000 & 0.00000 & 0.00000 & 0.00000 & 0.01001 & 0.04659 & 1.00000 \\
\hline CVS2-2 & 0.00000 & 0.50178 & 0.00045 & 0.00000 & 0.00000 & 0.00000 & 0.00000 & 0.00000 & 0.03000 & 0.01455 & 1.00000 \\
\hline
\end{tabular}

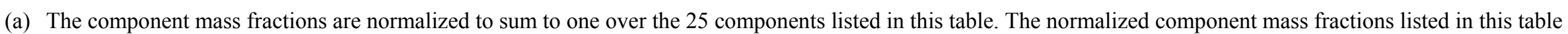
were rounded to five decimals, and may not sum exactly to 1.00000 as listed. However, complete compositions listed to more decimal places and summing to 1.0000 were used for validating PCT-composition models. 
Table B.1. Normalized 25-Component Compositions (mass fractions) of 554 HLW Glasses Used for PCT Model Validation (continued).

\begin{tabular}{|c|c|c|c|c|c|c|c|c|c|c|c|c|c|c|c|}
\hline & $\mathrm{Al}_{2} \mathbf{O}_{3}$ & $\mathbf{B}_{2} \mathbf{O}_{3}$ & & o & $\mathbf{r}_{2} \mathbf{O}_{3}$ & $\mathrm{Fe}_{2} \mathrm{O}_{3}$ & $\mathbf{K}_{2} \mathbf{O}$ & $\mathbf{L a}_{2} \mathbf{O}_{3}$ & $\mathbf{L i}_{2} \mathbf{O}$ & & & $\mathrm{Na}_{2} \mathrm{O}$ & 0 & & $\mathbf{b}_{2} \mathbf{O}_{3}$ \\
\hline & & & 01 & & 6 & & 0 & & 51 & 0 & 55 & & $00 ?$ & 0 & \\
\hline & & & & & & & & & & & & & & & \\
\hline & & & & & & & & & & & & & & & \\
\hline & & & & & & & & & & & & & & & \\
\hline & & & & & & & & & & & & & & & \\
\hline & & & & & & & & & & & & & & & \\
\hline & & & & & & & & & & & & & & & \\
\hline & & & & & & & & & & & & & & & \\
\hline & & & & & & & & & & & & & & & \\
\hline & & & & & & & & & & & & & & & \\
\hline & & & & & & & & & & & & & & & \\
\hline & & & & & & & & & & & & & & & \\
\hline & & & & & & & & & & & & & 824 & & 000 \\
\hline-16 & & & & 0795 & & & & & & & & & & & 0000 \\
\hline & & & & & & & & & & & & & & & \\
\hline-18 & 02311 & 0.10534 & 0.00830 & 0.00795 & 0.00153 & 0.07193 & 0.00000 & 0.00663 & 0.03751 & 0.00840 & 0.00130 & 0.11254 & 0.00610 & 0.00000 & 0.00000 \\
\hline
\end{tabular}

\begin{tabular}{|l|c|c|c|c|c|c|c|c|c|c|c|}
\hline Glass ID & $\mathbf{S e O}_{2}$ & $\mathbf{S i O}_{2}$ & $\mathbf{S r O}$ & $\mathbf{T h O}_{2}$ & $\mathbf{T i O}_{2}$ & $\mathbf{T l}_{\mathbf{2}} \mathbf{O}$ & $\mathbf{U O}_{3}$ & $\mathbf{Z n O}$ & $\mathbf{Z r O}_{2}$ & $\mathbf{O t h e r s}^{\text {Sum }}$ \\
\hline CVS2-3 & 0.00000 & 0.46458 & 0.00045 & 0.00000 & 0.00000 & 0.00000 & 0.00000 & 0.00000 & 0.03681 & 0.01455 & 1.00000 \\
\hline CVS2-4 & 0.00000 & 0.56009 & 0.00045 & 0.00000 & 0.00000 & 0.00000 & 0.00000 & 0.00000 & 0.01000 & 0.01455 & 1.00000 \\
\hline CVS2-5 & 0.00000 & 0.47545 & 0.00143 & 0.00000 & 0.00000 & 0.00000 & 0.00000 & 0.00000 & 0.01001 & 0.04659 & 1.00000 \\
\hline CVS2-6 & 0.00000 & 0.53742 & 0.00115 & 0.00000 & 0.00000 & 0.00000 & 0.00000 & 0.00000 & 0.01000 & 0.03733 & 1.00000 \\
\hline CVS2-7 & 0.00000 & 0.48160 & 0.00116 & 0.00000 & 0.00000 & 0.00000 & 0.00000 & 0.00000 & 0.01000 & 0.03774 & 1.00000 \\
\hline CVS2-8 & 0.00000 & 0.51158 & 0.00045 & 0.00000 & 0.00000 & 0.00000 & 0.00000 & 0.00000 & 0.01000 & 0.01455 & 1.00000 \\
\hline CVS2-9 & 0.00000 & 0.54329 & 0.00045 & 0.00000 & 0.00000 & 0.00000 & 0.00000 & 0.00000 & 0.10002 & 0.01455 & 1.00000 \\
\hline CVS2-10 & 0.00000 & 0.46949 & 0.00052 & 0.00000 & 0.00000 & 0.00000 & 0.00000 & 0.00000 & 0.01000 & 0.01677 & 1.00000 \\
\hline CVS2-11 & 0.00000 & 0.49181 & 0.00119 & 0.00000 & 0.00000 & 0.00000 & 0.00000 & 0.00000 & 0.09354 & 0.03873 & 1.00000 \\
\hline CVS2-12 & 0.00000 & 0.46838 & 0.00045 & 0.00000 & 0.00000 & 0.00000 & 0.00000 & 0.00000 & 0.01000 & 0.01455 & 1.00000 \\
\hline CVS2-13 & 0.00000 & 0.49378 & 0.00045 & 0.00000 & 0.00000 & 0.00000 & 0.00000 & 0.00000 & 0.01000 & 0.01455 & 1.00000 \\
\hline CVS2-14 & 0.00000 & 0.46014 & 0.00082 & 0.00000 & 0.00000 & 0.00000 & 0.00000 & 0.00000 & 0.10003 & 0.02661 & 1.00000 \\
\hline CVS2-15 & 0.00000 & 0.47314 & 0.00143 & 0.00000 & 0.00000 & 0.00000 & 0.00000 & 0.00000 & 0.01001 & 0.04659 & 1.00000 \\
\hline CVS2-16 & 0.00000 & 0.53550 & 0.00106 & 0.00000 & 0.00000 & 0.00000 & 0.00000 & 0.00000 & 0.03851 & 0.03447 & 1.00000 \\
\hline CVS2-17 & 0.00000 & 0.48023 & 0.00073 & 0.00000 & 0.00000 & 0.00000 & 0.00000 & 0.00000 & 0.04291 & 0.02370 & 1.00000 \\
\hline CVS2-18 & 0.00000 & 0.53550 & 0.00106 & 0.00000 & 0.00000 & 0.00000 & 0.00000 & 0.00000 & 0.03851 & 0.03447 & 1.00000 \\
\hline
\end{tabular}

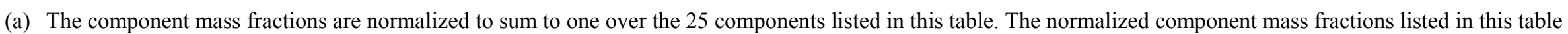
were rounded to five decimals, and may not sum exactly to 1.00000 as listed. However, complete compositions listed to more decimal places and summing to 1.0000 were used for validating PCT-composition models. 
Table B.1. Normalized 25-Component Compositions (mass fractions) of 554 HLW Glasses Used for PCT Model Validation (continued).

\begin{tabular}{|c|c|c|c|c|c|c|c|c|c|c|c|c|c|c|c|}
\hline & $\mathrm{Al}_{2} \mathrm{O}_{3}$ & $\mathbf{B}_{2} \mathbf{O}_{3}$ & & & $\mathbf{r}_{2} \mathbf{O}_{3}$ & $\mathrm{Fe}_{2} \mathrm{O}_{3}$ & $\mathbf{K}_{2} \mathbf{O}$ & $\mathbf{L a}_{2} \mathbf{O}_{3}$ & $\mathbf{L i}_{2} \mathbf{O}$ & & & $\mathrm{Na}_{2} \mathrm{O}$ & $\mathrm{NiO}$ & PbO & $\mathbf{b}_{2} \mathbf{O}_{3}$ \\
\hline & & & & & & & 0 & 46 & 03731 & & & 94 & 006 & & \\
\hline & & & & & & & & & & & & & & & \\
\hline & & & & & & & & & & & & & & & \\
\hline & & & & & & & & & & & & & & & \\
\hline & & & & & & & & & & & & & & & \\
\hline & & & & & & & & & & & & & & & \\
\hline & & & & & & & & & & & & & & & \\
\hline & & & & & & & & & & & & & & & \\
\hline & & & & & & & & & & & & & & & \\
\hline & & & & & & & & & & & & & & & \\
\hline & & & & & & & & & & & & & & & \\
\hline & & & & & & & & & & & & & & & \\
\hline & & & & & & & & & & & & & & & 000 \\
\hline & 00270 & 000 & .00000 & 0134 & & & & & & & & & & & 0000 \\
\hline & & & & & & & & & & & & & & & \\
\hline-34 & 0.13881 & 0.17431 & 0.00000 & 0.00134 & 0.00022 & 0.02000 & 0.00000 & 0.00112 & 0.03690 & 0.00000 & 0.00022 & 0.20001 & 0.00103 & 0.00000 & 0.00000 \\
\hline
\end{tabular}

\begin{tabular}{|l|c|c|c|c|c|c|c|c|c|c|c|}
\hline Glass ID & $\mathbf{S e O}_{2}$ & $\mathbf{S i O}_{2}$ & $\mathbf{S r O}$ & $\mathbf{T h O}_{2}$ & $\mathbf{T i O}_{2}$ & $\mathbf{T l}_{\mathbf{2}} \mathbf{O}$ & $\mathbf{U O}_{3}$ & $\mathbf{Z n O}$ & $\mathbf{Z r O}_{2}$ & $\mathbf{O t h e r s}^{\text {Sum }}$ \\
\hline CVS2-19 & 0.00000 & 0.53299 & 0.00000 & 0.00000 & 0.00000 & 0.00000 & 0.00000 & 0.00492 & 0.03921 & 0.02375 & 1.00000 \\
\hline CVS2-20 & 0.00000 & 0.57004 & 0.00018 & 0.00000 & 0.00000 & 0.00000 & 0.00000 & 0.00000 & 0.13001 & 0.00582 & 1.00000 \\
\hline CVS2-21 & 0.00000 & 0.57004 & 0.00018 & 0.00000 & 0.00000 & 0.00000 & 0.00000 & 0.00000 & 0.00000 & 0.00582 & 1.00000 \\
\hline CVS2-22 & 0.00000 & 0.57037 & 0.00179 & 0.00000 & 0.00000 & 0.00000 & 0.00000 & 0.00000 & 0.00000 & 0.05825 & 1.00000 \\
\hline CVS2-23 & 0.00000 & 0.57004 & 0.00018 & 0.00000 & 0.00000 & 0.00000 & 0.00000 & 0.00000 & 0.00000 & 0.00582 & 1.00000 \\
\hline CVS2-24 & 0.00000 & 0.44667 & 0.00168 & 0.00000 & 0.00000 & 0.00000 & 0.00000 & 0.00000 & 0.00000 & 0.05469 & 1.00000 \\
\hline CVS2-25 & 0.00000 & 0.50609 & 0.00102 & 0.00000 & 0.00000 & 0.00000 & 0.00000 & 0.00000 & 0.00000 & 0.03302 & 1.00000 \\
\hline CVS2-26 & 0.00000 & 0.44313 & 0.00018 & 0.00000 & 0.00000 & 0.00000 & 0.00000 & 0.00000 & 0.10001 & 0.00582 & 1.00000 \\
\hline CVS2-27 & 0.00000 & 0.54634 & 0.00018 & 0.00000 & 0.00000 & 0.00000 & 0.00000 & 0.00000 & 0.00000 & 0.00582 & 1.00000 \\
\hline CVS2-28 & 0.00000 & 0.56226 & 0.00179 & 0.00000 & 0.00000 & 0.00000 & 0.00000 & 0.00000 & 0.00000 & 0.05825 & 1.00000 \\
\hline CVS2-29 & 0.00000 & 0.43938 & 0.00179 & 0.00000 & 0.00000 & 0.00000 & 0.00000 & 0.00000 & 0.08345 & 0.05825 & 1.00000 \\
\hline CVS2-30 & 0.00000 & 0.51903 & 0.00018 & 0.00000 & 0.00000 & 0.00000 & 0.00000 & 0.00000 & 0.00000 & 0.00582 & 1.00000 \\
\hline CVS2-31 & 0.00000 & 0.57004 & 0.00018 & 0.00000 & 0.00000 & 0.00000 & 0.00000 & 0.00000 & 0.00000 & 0.00582 & 1.00000 \\
\hline CVS2-32 & 0.00000 & 0.54454 & 0.00018 & 0.00000 & 0.00000 & 0.00000 & 0.00000 & 0.00000 & 0.13001 & 0.00582 & 1.00000 \\
\hline CVS2-33 & 0.00000 & 0.42027 & 0.00179 & 0.00000 & 0.00000 & 0.00000 & 0.00000 & 0.00000 & 0.00000 & 0.05825 & 1.00000 \\
\hline CVS2-34 & 0.00000 & 0.42003 & 0.00018 & 0.00000 & 0.00000 & 0.00000 & 0.00000 & 0.00000 & 0.00000 & 0.00582 & 1.00000 \\
\hline
\end{tabular}

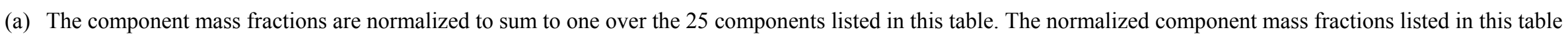
were rounded to five decimals, and may not sum exactly to 1.00000 as listed. However, complete compositions listed to more decimal places and summing to 1.0000 were used for validating PCT-composition models. 
Table B.1. Normalized 25-Component Compositions (mass fractions) of 554 HLW Glasses Used for PCT Model Validation (continued).

\begin{tabular}{|c|c|c|c|c|c|c|c|c|c|c|c|c|c|c|c|}
\hline & $\mathrm{Al}_{2} \mathrm{O}_{3}$ & ${ }_{2} \mathbf{O}_{3}$ & & & $\mathbf{r}_{2} \mathbf{O}_{3}$ & $\mathrm{Fe}_{2} \mathrm{O}_{3}$ & $\mathbf{K}_{2} \mathbf{O}$ & $\mathbf{L a}_{2} \mathbf{O}_{3}$ & $\mathbf{L i}_{2} \mathbf{O}$ & & & $\mathrm{Na}_{2} \mathrm{O}$ & $\mathrm{NiO}$ & PbO & $\mathbf{b}_{2} \mathbf{O}_{3}$ \\
\hline & & & & & 2 & & 0 & 112 & 0 & & & 01 & & 0 & \\
\hline & & & & & & & & & & & & & & & \\
\hline & & & & & & & & & & & & & & & \\
\hline & & & & & & & & & & & & & & & \\
\hline & & & & & & & & & & & & & & & \\
\hline & & & & & & & & & & & & & & & \\
\hline & & & & & & & & & & & & & & & \\
\hline & & & & & & & & & & & & & & & \\
\hline & & & & & & & & & & & & & & & \\
\hline & & & & & & & & & & & & & & & \\
\hline & & & & & & & & & & & & & & & \\
\hline & & & & & & & & & & & & & & & \\
\hline & & & & & & & & & & & & & & & 000 \\
\hline-48 & 5543 & & 002 & 0734 & & & & & & & & & & & 0000 \\
\hline & & & & & & & & & & & & & & & \\
\hline-50 & 06362 & 0.11423 & 0.02751 & 0.00547 & 0.00091 & 0.05681 & 0.00000 & 0.00456 & 0.03761 & 0.03631 & 0.00089 & 0.10033 & 0.00419 & 0.00000 & 0.00000 \\
\hline
\end{tabular}

\begin{tabular}{|l|c|c|c|c|c|c|c|c|c|c|c|}
\hline Glass ID & $\mathbf{S e O}_{2}$ & $\mathbf{S i O}_{2}$ & $\mathbf{S r O}$ & $\mathbf{T h O}_{2}$ & $\mathbf{T i O}_{2}$ & $\mathbf{T l}_{\mathbf{2}} \mathbf{O}$ & $\mathbf{U O}_{3}$ & $\mathbf{Z n O}$ & $\mathbf{Z r O}_{2}$ & $\mathbf{O t h e r s}$ & $\mathbf{S u m}^{(\mathbf{a})}$ \\
\hline CVS2-35 & 0.00000 & 0.42003 & 0.00018 & 0.00000 & 0.00000 & 0.00000 & 0.00000 & 0.00000 & 0.00000 & 0.00582 & 1.00000 \\
\hline CVS2-36 & 0.00000 & 0.54214 & 0.00018 & 0.00000 & 0.00000 & 0.00000 & 0.00000 & 0.00000 & 0.00000 & 0.00582 & 1.00000 \\
\hline CVS2-37 & 0.00000 & 0.57004 & 0.00018 & 0.00000 & 0.00000 & 0.00000 & 0.00000 & 0.00000 & 0.00000 & 0.00582 & 1.00000 \\
\hline CVS2-38 & 0.00000 & 0.51473 & 0.00018 & 0.00000 & 0.00000 & 0.00000 & 0.00000 & 0.00000 & 0.00000 & 0.00582 & 1.00000 \\
\hline CVS2-39 & 0.00000 & 0.48383 & 0.00018 & 0.00000 & 0.00000 & 0.00000 & 0.00000 & 0.00000 & 0.07000 & 0.00582 & 1.00000 \\
\hline CVS2-40 & 0.00000 & 0.50410 & 0.00054 & 0.00000 & 0.00000 & 0.00000 & 0.00000 & 0.00000 & 0.02000 & 0.01747 & 1.00000 \\
\hline CVS2-41 & 0.00000 & 0.53260 & 0.00054 & 0.00000 & 0.00000 & 0.00000 & 0.00000 & 0.00000 & 0.02000 & 0.01747 & 1.00000 \\
\hline CVS2-42 & 0.00000 & 0.56761 & 0.00054 & 0.00000 & 0.00000 & 0.00000 & 0.00000 & 0.00000 & 0.02000 & 0.01747 & 1.00000 \\
\hline CVS2-43 & 0.00000 & 0.50710 & 0.00054 & 0.00000 & 0.00000 & 0.00000 & 0.00000 & 0.00000 & 0.07001 & 0.01747 & 1.00000 \\
\hline CVS2-44 & 0.00000 & 0.57011 & 0.00054 & 0.00000 & 0.00000 & 0.00000 & 0.00000 & 0.00000 & 0.02000 & 0.01747 & 1.00000 \\
\hline CVS2-45 & 0.00000 & 0.53014 & 0.00125 & 0.00000 & 0.00000 & 0.00000 & 0.00000 & 0.00000 & 0.02001 & 0.04076 & 1.00000 \\
\hline CVS2-46 & 0.00000 & 0.52662 & 0.00117 & 0.00000 & 0.00000 & 0.00000 & 0.00000 & 0.00000 & 0.02001 & 0.03808 & 1.00000 \\
\hline CVS2-47 & 0.00000 & 0.52964 & 0.00125 & 0.00000 & 0.00000 & 0.00000 & 0.00000 & 0.00000 & 0.05002 & 0.04076 & 1.00000 \\
\hline CVS2-48 & 0.00000 & 0.47017 & 0.00098 & 0.00000 & 0.00000 & 0.00000 & 0.00000 & 0.00000 & 0.02001 & 0.03179 & 1.00000 \\
\hline CVS2-49 & 0.00000 & 0.50740 & 0.00054 & 0.00000 & 0.00000 & 0.00000 & 0.00000 & 0.00000 & 0.02000 & 0.01747 & 1.00000 \\
\hline CVS2-50 & 0.00000 & 0.48023 & 0.00073 & 0.00000 & 0.00000 & 0.00000 & 0.00000 & 0.00000 & 0.04291 & 0.02370 & 1.00000 \\
\hline
\end{tabular}

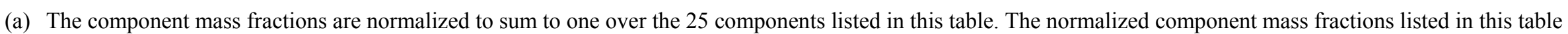
were rounded to five decimals, and may not sum exactly to 1.00000 as listed. However, complete compositions listed to more decimal places and summing to 1.0000 were used for validating PCT-composition models. 
Table B.1. Normalized 25-Component Compositions (mass fractions) of 554 HLW Glasses Used for PCT Model Validation (continued).

\begin{tabular}{|c|c|c|c|c|c|c|c|c|c|c|c|c|c|c|c|}
\hline & $\mathrm{Al}_{2} \mathbf{O}_{3}$ & $\mathbf{B}_{2} \mathbf{O}_{3}$ & & & $\mathbf{r}_{2} \mathbf{O}_{3}$ & $\mathrm{Fe}_{2} \mathrm{O}_{3}$ & $\mathbf{K}_{2} \mathbf{O}$ & $\mathbf{L a}_{2} \mathbf{O}_{3}$ & $\mathbf{L i}_{2} \mathbf{O}$ & & & $\mathrm{Na}_{2} \mathrm{O}$ & $\mathrm{NiO}$ & PbO & $\mathbf{b}_{2} \mathbf{O}_{3}$ \\
\hline & & & & & & & 0 & 46 & 03731 & & & 94 & 006 & 0 & \\
\hline & & & & & & & & & & & & & & & \\
\hline & & & & & & & & & & & & & & & \\
\hline & & & & & & & & & & & & & & & \\
\hline & & & & & & & & & & & & & & & \\
\hline & & & & & & & & & & & & & & & \\
\hline & & & & & & & & & & & & & & & \\
\hline & & & & & & & & & & & & & & & \\
\hline & & & & & & & & & & & & & & & \\
\hline & & & & & & & & & & & & & & & \\
\hline & & & & & & & & & & & & & & & \\
\hline & & & & & & & & & & & & & & & \\
\hline & & & & & & & & & & & & & & & 000 \\
\hline-64 & 880 & 5091 & 250 & 1294 & & & & & & & & & & & 0000 \\
\hline & & & & & & & & & & & & & & & \\
\hline-66 & 11832 & 0.09195 & 0.00973 & 0.00000 & $0.010 / 9$ & 0.03890 & 0.00000 & 0.00427 & 0.05244 & 0.00612 & 0.01188 & 0.12142 & 0.00525 & 0.00000 & 0.00000 \\
\hline
\end{tabular}

\begin{tabular}{|l|c|c|c|c|c|c|c|c|c|c|c|}
\hline Glass ID & $\mathbf{S e O}_{2}$ & $\mathbf{S i O}_{2}$ & $\mathbf{S r O}$ & $\mathbf{T h O}_{2}$ & $\mathbf{T i O}_{2}$ & $\mathbf{T l}_{\mathbf{2}} \mathbf{O}$ & $\mathbf{U O}_{3}$ & $\mathbf{Z n O}$ & $\mathbf{Z r O}_{2}$ & $\mathbf{O t h e r s}^{\text {Sum }}$ \\
\hline CVS2-51 & 0.00000 & 0.53299 & 0.00000 & 0.00000 & 0.00000 & 0.00000 & 0.00000 & 0.00492 & 0.03921 & 0.02375 & 1.00000 \\
\hline CVS2-52 & 0.00000 & 0.60023 & 0.00106 & 0.00000 & 0.00000 & 0.00000 & 0.00000 & 0.00000 & 0.03851 & 0.03436 & 1.00000 \\
\hline CVS2-53 & 0.00000 & 0.52232 & 0.00143 & 0.00000 & 0.00000 & 0.00000 & 0.01871 & 0.00000 & 0.00999 & 0.02888 & 1.00000 \\
\hline CVS2-54 & 0.00000 & 0.53281 & 0.00000 & 0.00000 & 0.00000 & 0.00000 & 0.00606 & 0.00492 & 0.03920 & 0.01802 & 1.00000 \\
\hline CVS2-55 & 0.00000 & 0.53556 & 0.00000 & 0.00000 & 0.00000 & 0.00000 & 0.00000 & 0.00000 & 0.03940 & 0.02277 & 1.00000 \\
\hline CVS2-56 & 0.00000 & 0.53740 & 0.00000 & 0.00000 & 0.00000 & 0.00000 & 0.00000 & 0.00000 & 0.03954 & 0.00601 & 1.00000 \\
\hline CVS2-57 & 0.00000 & 0.53280 & 0.00000 & 0.00000 & 0.00000 & 0.00000 & 0.00000 & 0.00000 & 0.03920 & 0.05424 & 1.00000 \\
\hline CVS2-58 & 0.00000 & 0.39003 & 0.00018 & 0.00000 & 0.00000 & 0.00000 & 0.00000 & 0.00000 & 0.01000 & 0.00582 & 1.00000 \\
\hline CVS2-59 & 0.00000 & 0.43803 & 0.00018 & 0.00000 & 0.00000 & 0.00000 & 0.00000 & 0.00000 & 0.00750 & 0.00594 & 1.00000 \\
\hline CVS2-60 & 0.00000 & 0.52814 & 0.00019 & 0.00000 & 0.00000 & 0.00000 & 0.00000 & 0.00000 & 0.00750 & 0.00623 & 1.00000 \\
\hline CVS2-61 & 0.00000 & 0.52814 & 0.00022 & 0.00000 & 0.00000 & 0.00000 & 0.00000 & 0.00000 & 0.01750 & 0.00728 & 1.00000 \\
\hline CVS2-62 & 0.00000 & 0.55793 & 0.00017 & 0.00000 & 0.00000 & 0.00000 & 0.00000 & 0.00000 & 0.00750 & 0.00553 & 1.00000 \\
\hline CVS2-63 & 0.00000 & 0.32322 & 0.00018 & 0.00000 & 0.00000 & 0.00000 & 0.00000 & 0.00000 & 0.00000 & 0.00582 & 1.00000 \\
\hline CVS2-64 & 0.00000 & 0.56977 & 0.00000 & 0.00000 & 0.00278 & 0.00000 & 0.00000 & 0.00146 & 0.04311 & 0.03162 & 1.00000 \\
\hline CVS2-65 & 0.00000 & 0.53440 & 0.00000 & 0.00000 & 0.00000 & 0.00000 & 0.00000 & 0.00000 & 0.15480 & 0.00633 & 1.00000 \\
\hline CVS2-66 & 0.00000 & 0.51889 & 0.00000 & 0.00000 & 0.00000 & 0.00000 & 0.00000 & 0.00000 & 0.00261 & 0.00745 & 1.00000 \\
\hline
\end{tabular}

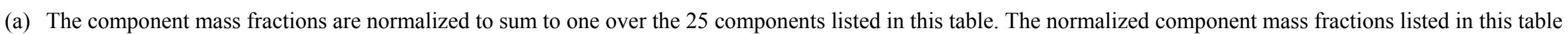
were rounded to five decimals, and may not sum exactly to 1.00000 as listed. However, complete compositions listed to more decimal places and summing to 1.0000 were used for validating PCT-composition models. 
Table B.1. Normalized 25-Component Compositions (mass fractions) of 554 HLW Glasses Used for PCT Model Validation (continued).

\begin{tabular}{|c|c|c|c|c|c|c|c|c|c|c|c|c|c|c|c|}
\hline & $\mathrm{Al}_{2} \mathbf{O}_{3}$ & $\mathbf{B}_{2} \mathbf{O}_{3}$ & & & $\mathbf{r}_{2} \mathbf{O}_{3}$ & $\mathrm{Fe}_{2} \mathrm{O}_{3}$ & $\mathbf{K}_{2} \mathbf{O}$ & $\mathbf{L a}_{2} \mathbf{O}_{3}$ & $\mathbf{L i}_{2} \mathbf{O}$ & & & $\mathrm{Na}_{2} \mathrm{O}$ & $\mathrm{NiO}$ & & $\mathbf{b}_{2} \mathbf{O}_{3}$ \\
\hline & & 0 & 40 & & & & 0 & 00 & 0 & & & 50 & 000 & & \\
\hline & & & & & & & & & & & & & & & \\
\hline & & & & & & & & & & & & & & & \\
\hline & & & & & & & & & & & & & & & \\
\hline & & & & & & & & & & & & & & & \\
\hline & & & & & & & & & & & & & & & \\
\hline & & & & & & & & & & & & & & & \\
\hline & & & & & & & & & & & & & & & \\
\hline & & & & & & & & & & & & & & & \\
\hline & & & & & & & & & & & & & & & \\
\hline & & & & & & & & & & & & & & & \\
\hline & & & & & & & & & & & & & & & \\
\hline & & & & & & & & & & & & & 28 & & 000 \\
\hline-80 & 2000 & 6002 & 500 & 269 & & & & & & & & & & & 0000 \\
\hline & & & & & & & & & & & & & & & \\
\hline-82 & .02000 & 0.09501 & 0.00500 & 0.00269 & 0.00045 & 0.00500 & 0.00000 & 0.00224 & 0.07001 & 0.04001 & 0.00044 & 0.18002 & 0.00206 & 0.00000 & 0.00000 \\
\hline
\end{tabular}

\begin{tabular}{|l|c|c|c|c|c|c|c|c|c|c|c|}
\hline Glass ID & $\mathbf{S e O}_{2}$ & $\mathbf{S i O}_{2}$ & $\mathbf{S r O}$ & $\mathbf{T h O}_{2}$ & $\mathbf{T i O}_{2}$ & $\mathbf{T l}_{\mathbf{2}} \mathbf{O}$ & $\mathbf{U O}_{3}$ & $\mathbf{Z n O}$ & $\mathbf{Z r O}_{2}$ & $\mathbf{O t h e r s}^{\text {Sum }}$ \\
\hline CVS2-67 & 0.00000 & 0.45960 & 0.00000 & 0.00000 & 0.00000 & 0.00000 & 0.00000 & 0.00000 & 0.00000 & 0.00625 & 1.00000 \\
\hline CVS2-68 & 0.00000 & 0.50425 & 0.00000 & 0.00000 & 0.00000 & 0.00000 & 0.00000 & 0.00121 & 0.00010 & 0.00645 & 1.00000 \\
\hline CVS2-69 & 0.00358 & 0.56756 & 0.00000 & 0.00000 & 0.00000 & 0.00000 & 0.00000 & 0.00000 & 0.00050 & 0.04689 & 1.00000 \\
\hline CVS2-70 & 0.00353 & 0.48566 & 0.00000 & 0.00000 & 0.00000 & 0.00000 & 0.00000 & 0.00000 & 0.00050 & 0.00892 & 1.00000 \\
\hline CVS2-71 & 0.00000 & 0.56994 & 0.00119 & 0.00000 & 0.00000 & 0.00000 & 0.00000 & 0.00000 & 0.04312 & 0.03861 & 1.00000 \\
\hline CVS2-72 & 0.00000 & 0.51764 & 0.00076 & 0.00000 & 0.00000 & 0.00000 & 0.00000 & 0.00000 & 0.00260 & 0.02457 & 1.00000 \\
\hline CVS2-73 & 0.00000 & 0.50414 & 0.00074 & 0.00000 & 0.00000 & 0.00000 & 0.00000 & 0.00000 & 0.00010 & 0.02422 & 1.00000 \\
\hline CVS2-74 & 0.00000 & 0.56634 & 0.00164 & 0.00000 & 0.00000 & 0.00000 & 0.00000 & 0.00000 & 0.00050 & 0.05335 & 1.00000 \\
\hline CVS2-75 & 0.00000 & 0.48550 & 0.00055 & 0.00000 & 0.00000 & 0.00000 & 0.00000 & 0.00000 & 0.00050 & 0.01776 & 1.00000 \\
\hline CVS2-76 & 0.00000 & 0.50186 & 0.00036 & 0.00000 & 0.00000 & 0.00000 & 0.00000 & 0.00000 & 0.00500 & 0.01164 & 1.00000 \\
\hline CVS2-77 & 0.00000 & 0.45526 & 0.00161 & 0.00000 & 0.00000 & 0.00000 & 0.00000 & 0.00000 & 0.11006 & 0.05242 & 1.00000 \\
\hline CVS2-78 & 0.00000 & 0.56007 & 0.00036 & 0.00000 & 0.00000 & 0.00000 & 0.00000 & 0.00000 & 0.04971 & 0.01164 & 1.00000 \\
\hline CVS2-79 & 0.00000 & 0.54822 & 0.00161 & 0.00000 & 0.00000 & 0.00000 & 0.00000 & 0.00000 & 0.00500 & 0.05242 & 1.00000 \\
\hline CVS2-80 & 0.00000 & 0.50747 & 0.00036 & 0.00000 & 0.00000 & 0.00000 & 0.00000 & 0.00000 & 0.07501 & 0.01164 & 1.00000 \\
\hline CVS2-81 & 0.00000 & 0.44023 & 0.00146 & 0.00000 & 0.00000 & 0.00000 & 0.00000 & 0.00000 & 0.00500 & 0.04752 & 1.00000 \\
\hline CVS2-82 & 0.00000 & 0.56007 & 0.00036 & 0.00000 & 0.00000 & 0.00000 & 0.00000 & 0.00000 & 0.00500 & 0.01164 & 1.00000 \\
\hline
\end{tabular}

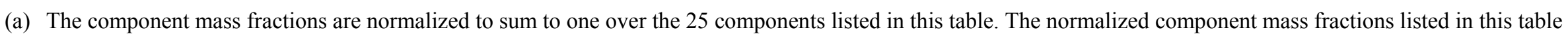
were rounded to five decimals, and may not sum exactly to 1.00000 as listed. However, complete compositions listed to more decimal places and summing to 1.0000 were used for validating PCT-composition models. 
Table B.1. Normalized 25-Component Compositions (mass fractions) of 554 HLW Glasses Used for PCT Model Validation (continued).

\begin{tabular}{|c|c|c|c|c|c|c|c|c|c|c|c|c|c|c|c|}
\hline & $\mathrm{Al}_{2} \mathrm{O}_{3}$ & ${ }_{2} \mathbf{O}_{3}$ & & & $\mathbf{r}_{2} \mathbf{O}_{3}$ & $\mathrm{Fe}_{2} \mathrm{O}_{3}$ & $\mathbf{K}_{2} \mathbf{O}$ & $\mathbf{L a}_{2} \mathbf{O}_{3}$ & $\mathbf{L i}_{2} \mathbf{O}$ & & & $\mathrm{Na}_{2} \mathrm{O}$ & $\mathrm{NiO}$ & PbO & $\mathbf{b}_{2} \mathbf{O}_{3}$ \\
\hline & & & & & & 00 & 0 & & 4 & & & 10 & (חת & & \\
\hline & & & & & & & & & & & & & & & \\
\hline & & & & & & & & & & & & & & & \\
\hline & & & & & & & & & & & & & & & \\
\hline & & & & & & & & & & & & & & & \\
\hline & & & & & & & & & & & & & & & \\
\hline & & & & & & & & & & & & & & & \\
\hline & & & & & & & & & & & & & & & \\
\hline & & & & & & & & & & & & & & & \\
\hline & & & & & & & & & & & & & & & \\
\hline & & & & & & & & & & & & & & & \\
\hline & & & & & & & & & & & & & & & \\
\hline & & & & & & & & & & & & & & & 000 \\
\hline-96 & 362 & & 751 & 0547 & & & & & & & & & & & 0000 \\
\hline & & & & & & & & & & & & & & & \\
\hline-98 & 81 & 31 & .00000 & 00134 & 22 & 000 & .00000 & 0. & .03690 & 00 & 22 & 01 & 0.00 & 0.00000 & 0.0000 \\
\hline
\end{tabular}

\begin{tabular}{|l|c|c|c|c|c|c|c|c|c|c|c|}
\hline Glass ID & $\mathbf{S e O}_{2}$ & $\mathbf{S i O}_{2}$ & $\mathbf{S r O}$ & $\mathbf{T h O}_{2}$ & $\mathbf{T i O}_{2}$ & $\mathbf{T l}_{\mathbf{2}} \mathbf{O}$ & $\mathbf{U O}_{3}$ & $\mathbf{Z n O}$ & $\mathbf{Z r O}_{2}$ & $\mathbf{O t h e r s}^{\text {Sum }}$ \\
\hline CVS2-83 & 0.00000 & 0.49029 & 0.00161 & 0.00000 & 0.00000 & 0.00000 & 0.00000 & 0.00000 & 0.00500 & 0.05242 & 1.00000 \\
\hline CVS2-84 & 0.00000 & 0.45506 & 0.00036 & 0.00000 & 0.00000 & 0.00000 & 0.00000 & 0.00000 & 0.08001 & 0.01164 & 1.00000 \\
\hline CVS2-85 & 0.00000 & 0.44013 & 0.00081 & 0.00000 & 0.00000 & 0.00000 & 0.00000 & 0.00000 & 0.00500 & 0.02620 & 1.00000 \\
\hline CVS2-86 & 0.00000 & 0.47654 & 0.00081 & 0.00000 & 0.00000 & 0.00000 & 0.00000 & 0.00000 & 0.00500 & 0.02620 & 1.00000 \\
\hline CVS2-87 & 0.00000 & 0.49836 & 0.00036 & 0.00000 & 0.00000 & 0.00000 & 0.00000 & 0.00000 & 0.06131 & 0.01164 & 1.00000 \\
\hline CVS2-88 & 0.00000 & 0.45976 & 0.00036 & 0.00000 & 0.00000 & 0.00000 & 0.00000 & 0.00000 & 0.07501 & 0.01164 & 1.00000 \\
\hline CVS2-89 & 0.00000 & 0.44006 & 0.00036 & 0.00000 & 0.00000 & 0.00000 & 0.00000 & 0.00000 & 0.06291 & 0.01164 & 1.00000 \\
\hline CVS2-90 & 0.00000 & 0.56007 & 0.00036 & 0.00000 & 0.00000 & 0.00000 & 0.00000 & 0.00000 & 0.00500 & 0.01164 & 1.00000 \\
\hline CVS2-91 & 0.00000 & 0.56033 & 0.00161 & 0.00000 & 0.00000 & 0.00000 & 0.00000 & 0.00000 & 0.00500 & 0.05242 & 1.00000 \\
\hline CVS2-92 & 0.00000 & 0.44026 & 0.00161 & 0.00000 & 0.00000 & 0.00000 & 0.00000 & 0.00000 & 0.07004 & 0.05242 & 1.00000 \\
\hline CVS2-93 & 0.00000 & 0.44026 & 0.00161 & 0.00000 & 0.00000 & 0.00000 & 0.00000 & 0.00000 & 0.00500 & 0.05242 & 1.00000 \\
\hline CVS2-94 & 0.00000 & 0.44006 & 0.00036 & 0.00000 & 0.00000 & 0.00000 & 0.00000 & 0.00000 & 0.00500 & 0.01164 & 1.00000 \\
\hline CVS2-95 & 0.00000 & 0.48950 & 0.00000 & 0.00000 & 0.00708 & 0.00000 & 0.00000 & 0.00000 & 0.00410 & 0.00000 & 1.00000 \\
\hline CVS2-96 & 0.00000 & 0.48023 & 0.00073 & 0.00000 & 0.00000 & 0.00000 & 0.00000 & 0.00000 & 0.04291 & 0.02370 & 1.00000 \\
\hline CVS2-97 & 0.00000 & 0.53299 & 0.00000 & 0.00000 & 0.00000 & 0.00000 & 0.00000 & 0.00492 & 0.03921 & 0.02375 & 1.00000 \\
\hline CVS2-98 & 0.00000 & 0.42003 & 0.00018 & 0.00000 & 0.00000 & 0.00000 & 0.00000 & 0.00000 & 0.00000 & 0.00582 & 1.00000 \\
\hline
\end{tabular}

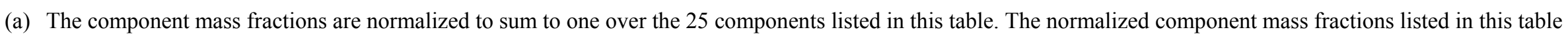
were rounded to five decimals, and may not sum exactly to 1.00000 as listed. However, complete compositions listed to more decimal places and summing to 1.0000 were used for validating PCT-composition models. 
Table B.1. Normalized 25-Component Compositions (mass fractions) of 554 HLW Glasses Used for PCT Model Validation (continued).

\begin{tabular}{|c|c|c|c|c|c|c|c|c|c|c|c|c|c|c|c|}
\hline Glass ID & $\mathbf{A l}_{2} \mathbf{O}_{3}$ & $\mathbf{B}_{2} \mathbf{O}_{3}$ & $\mathrm{aO}$ & CdO & $\mathbf{r}_{2} \mathbf{O}_{3}$ & $\mathbf{e}_{2} \mathrm{O}_{3}$ & $\mathbf{K}_{2} \mathbf{O}$ & $\mathbf{L a}_{2} \mathbf{O}_{3}$ & $\mathbf{L i}_{2} \mathbf{O}$ & $\mathbf{O}$ & 10 & $\mathrm{Na}_{2} \mathrm{O}$ & $\mathrm{NiO}$ & PbO & $\mathrm{Sb}_{2} \mathrm{O}_{3}$ \\
\hline & 235 & 99700 & 971 & 0300 & 00200 & 0201 & 0.02122 & 00140 & 03564 & \begin{tabular}{|l|}
0.00771 \\
\end{tabular} & 92 & 0.09810 & 00291 & 0.00200 & 00000 \\
\hline 100 & & 07403 & & & & & & & & & & & & & \\
\hline $\mathrm{CV}$ & 03670 & 20 & & 00000 & 000 & 970 & 0.0 & 00409 & 0.04280 & \begin{tabular}{|l|}
0.01660 \\
\end{tabular} & 36 & \begin{tabular}{|l|}
0.16710 \\
\end{tabular} & 00608 & 00 & 000 \\
\hline & 02311 & 0.10 & & 95 & 33 & 193 & & 663 & 51 & & & & 0610 & & \\
\hline CVS2-103 & 0.02934 & 0.13376 & 0.01055 & \begin{tabular}{|l|}
0.01010 \\
\end{tabular} & \begin{tabular}{|l|}
0.00168 \\
\end{tabular} & 0.09134 & 0.00000 & 0.00841 & 0.04763 & 0.01067 & & & 0.00775 & 0000 & 0.00000 \\
\hline CVS2-104 & 0.02735 & 0.12466 & 0.00982 & \begin{tabular}{|l|}
0.00941 \\
\end{tabular} & 0.00157 & 0.08514 & 0.00000 & 0.00784 & 0.04440 & 0.00994 & 54 & \begin{tabular}{|l|}
0.13321 \\
\end{tabular} & 0.00722 & 0.00000 & 0.00000 \\
\hline $\mathrm{CVs}$ & 02536 & 0.11561 & 0.00911 & 0.00873 & 0.00146 & 0.07894 & 0.00000 & 0.00727 & 0.04118 & 0.00922 & 43 & 0.12352 & 0.00669 & 0000 & 000 \\
\hline & & 47 & 68 & 736 & 123 & 655 & 0.00000 & 613 & 471 & 777 & & & 564 & 00 & 0. \\
\hline 107 & 0.02454 & 0.05002 & 0.0 & 845 & 141 & 0.07637 & 0.00000 & 0.00704 & 0.03984 & 892 & 138 & 0.11950 & 0.00648 & 0.00000 & 0.00000 \\
\hline CVS2-108 & 0.02196 & 0.15005 & 0.00789 & \begin{tabular}{|l|}
0.00756 \\
\end{tabular} & 0.00126 & 0.06833 & 0.00000 & 0.00630 & 0.03564 & \begin{tabular}{|l|}
0.00798 \\
\end{tabular} & 0.00123 & 0.10692 & 0.00579 & 0.00000 & 0.00000 \\
\hline CVS2-109 & 0.02066 & 0.20007 & 0.00742 & \begin{tabular}{|l|}
0.00711 \\
\end{tabular} & \begin{tabular}{|l|}
0.00119 \\
\end{tabular} & 0.06431 & 0.00000 & 0.00593 & 0.03354 & \begin{tabular}{|l|}
0.00751 \\
\end{tabular} & 0.00116 & 0.10063 & 0.00545 & 0.00000 & \\
\hline & 474 & & & & & .07699 & & & 0.0 & 899 & & & 653 & 00 & \\
\hline CVS2 & \begin{tabular}{|l|}
0.02213 \\
\end{tabular} & \begin{tabular}{|l}
0.10089 \\
\end{tabular} & 0.00795 & \begin{tabular}{|l|}
0.00762 \\
\end{tabular} & \begin{tabular}{|l|}
0.00127 \\
\end{tabular} & \begin{tabular}{|l|}
0.06889 \\
\end{tabular} & 0.00000 & 0.00635 & 0.03593 & 0.00805 & \begin{tabular}{|l|}
0.00124 \\
\end{tabular} & \begin{tabular}{|l|}
0.15005 \\
\end{tabular} & 0.00584 & 0.00000 & 0.00000 \\
\hline CVS2-112 & \begin{tabular}{|l|}
0.02083 \\
\end{tabular} & \begin{tabular}{|l|}
0.09495 \\
\end{tabular} & 0.00748 & \begin{tabular}{|l|}
0.00717 \\
\end{tabular} & 0.00120 & 0.06483 & 0.00000 & 0.00597 & 0.03381 & 0.00757 & 0.00117 & 0.20007 & 0.00550 & 0.00000 & 0.00000 \\
\hline CVS2-113 & 0.02377 & 0.10835 & 0.00854 & 0.00818 & 0.00136 & 0.07398 & 0.00000 & 0.00682 & 0.01000 & 0.00864 & 0.00134 & 0.11576 & 0.00627 & 0.00000 & 0.00000 \\
\hline CVS2-114 & 0.02257 & 0.10288 & 0.00811 & \begin{tabular}{|l|}
0.00777 \\
\end{tabular} & \begin{tabular}{|l|}
0.00130 \\
\end{tabular} & 0.07025 & 0.00000 & 0.00647 & 0.06002 & 0.00821 & 0.00127 & \begin{tabular}{|l|}
0.10991 \\
\end{tabular} & 0.00596 & 0.00000 & 0.00000 \\
\hline
\end{tabular}

\begin{tabular}{|l|c|c|c|c|c|c|c|c|c|c|c|}
\hline Glass ID & $\mathbf{S e O}_{2}$ & $\mathbf{S i O}_{2}$ & $\mathbf{S r O}$ & $\mathbf{T h O}_{2}$ & $\mathbf{T i O}_{2}$ & $\mathbf{T l}_{\mathbf{2}} \mathbf{O}$ & $\mathbf{U O}_{3}$ & $\mathbf{Z n O}$ & $\mathbf{Z r O}_{2}$ & $\mathbf{O t h e r s}$ & $\mathbf{S u m}^{(\mathbf{a})}$ \\
\hline CVS2-99 & 0.00000 & 0.52084 & 0.00040 & 0.00000 & 0.00120 & 0.00000 & 0.00000 & 0.00050 & 0.01992 & 0.01815 & 1.00000 \\
\hline CVS2-100 & 0.00000 & 0.53311 & 0.00050 & 0.00000 & 0.00080 & 0.00000 & 0.00000 & 0.00020 & 0.04432 & 0.02922 & 1.00000 \\
\hline CVS2-101 & 0.00000 & 0.48950 & 0.00000 & 0.00000 & 0.00708 & 0.00000 & 0.00000 & 0.00000 & 0.00410 & 0.00000 & 1.00000 \\
\hline CVS2-102 & 0.00000 & 0.53550 & 0.00106 & 0.00000 & 0.00000 & 0.00000 & 0.00000 & 0.00000 & 0.03851 & 0.03447 & 1.00000 \\
\hline CVS2-103 & 0.00000 & 0.41020 & 0.00135 & 0.00000 & 0.00000 & 0.00000 & 0.00000 & 0.00000 & 0.04890 & 0.04377 & 1.00000 \\
\hline CVS2-104 & 0.00000 & 0.45022 & 0.00125 & 0.00000 & 0.00000 & 0.00000 & 0.00000 & 0.00000 & 0.04559 & 0.04081 & 1.00000 \\
\hline CVS2-105 & 0.00000 & 0.49021 & 0.00116 & 0.00000 & 0.00000 & 0.00000 & 0.00000 & 0.00000 & 0.04227 & 0.03783 & 1.00000 \\
\hline CVS2-106 & 0.00000 & 0.57020 & 0.00098 & 0.00000 & 0.00000 & 0.00000 & 0.00000 & 0.00000 & 0.03564 & 0.03190 & 1.00000 \\
\hline CVS2-107 & 0.00000 & 0.56862 & 0.00113 & 0.00000 & 0.00000 & 0.00000 & 0.00000 & 0.00000 & 0.04090 & 0.03660 & 1.00000 \\
\hline CVS2-108 & 0.00000 & 0.50873 & 0.00101 & 0.00000 & 0.00000 & 0.00000 & 0.00000 & 0.00000 & 0.03659 & 0.03275 & 1.00000 \\
\hline CVS2-109 & 0.00000 & 0.47881 & 0.00095 & 0.00000 & 0.00000 & 0.00000 & 0.00000 & 0.00000 & 0.03443 & 0.03082 & 1.00000 \\
\hline CVS2-110 & 0.00000 & 0.57323 & 0.00113 & 0.00000 & 0.00000 & 0.00000 & 0.00000 & 0.00000 & 0.04123 & 0.03690 & 1.00000 \\
\hline CVS2-111 & 0.00000 & 0.51287 & 0.00102 & 0.00000 & 0.00000 & 0.00000 & 0.00000 & 0.00000 & 0.03688 & 0.03302 & 1.00000 \\
\hline CVS2-112 & 0.00000 & 0.48270 & 0.00096 & 0.00000 & 0.00000 & 0.00000 & 0.00000 & 0.00000 & 0.03471 & 0.03107 & 1.00000 \\
\hline CVS2-113 & 0.00000 & 0.55081 & 0.00109 & 0.00000 & 0.00000 & 0.00000 & 0.00000 & 0.00000 & 0.03962 & 0.03546 & 1.00000 \\
\hline CVS2-114 & 0.00000 & 0.52298 & 0.00104 & 0.00000 & 0.00000 & 0.00000 & 0.00000 & 0.00000 & 0.03761 & 0.03367 & 1.00000 \\
\hline
\end{tabular}

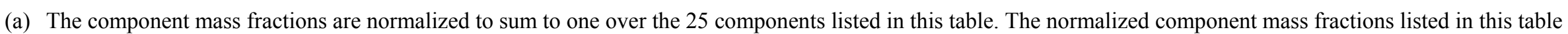
were rounded to five decimals, and may not sum exactly to 1.00000 as listed. However, complete compositions listed to more decimal places and summing to 1.0000 were used for validating PCT-composition models. 
Table B.1. Normalized 25-Component Compositions (mass fractions) of 554 HLW Glasses Used for PCT Model Validation (continued).

\begin{tabular}{|c|c|c|c|c|c|c|c|c|c|c|c|c|c|c|c|}
\hline Glass ID & $\mathbf{A l}_{2} \mathbf{O}_{3}$ & $\mathbf{B}_{2} \mathbf{O}_{3}$ & $\mathrm{aO}$ & CdO & $\mathrm{Cr}_{2} \mathrm{O}_{3}$ & $\mathbf{e}_{2} \mathrm{O}_{3}$ & $\mathbf{K}_{2} \mathbf{O}$ & $\mathbf{L a}_{2} \mathbf{O}_{3}$ & $\mathbf{L i}_{2} \mathbf{O}$ & $\mathbf{0}$ & $\mathbf{O}$ & $\mathrm{Na}_{2} \mathrm{O}$ & $\mathrm{NiO}$ & PbO & $\mathrm{Sb}_{2} \mathrm{O}_{3}$ \\
\hline-115 & 02233 & 10178 & 0802 & 00768 & 00128 & 06950 & 0.00000 & 00640 & 07003 & 0812 & 0126 & 10874 & 00589 & 0.00000 & 00000 \\
\hline & 02284 & & & & & & & & & & & & & & \\
\hline $\mathrm{CV}$ & 31 & 3 & 37 & 2 & 34 & 254 & 0.0 & 00668 & 0.03783 & 00 & & 49 & 00615 & 000 & 000 \\
\hline & 02284 & 11 & & & 31 & & & & 07 & 01 & & 22 & & & \\
\hline CVS2-119 & 0.00000 & 0.10783 & 0.00850 & 0.00814 & 0.00136 & 0.07363 & 0.00000 & 0.00678 & 0.03840 & 0.00860 & 133 & 0.11520 & 0.00624 & 0.00000 & 0.00000 \\
\hline CVS2-120 & 0.05002 & 0.10244 & 0.00807 & 0.00773 & 129 & 0.06995 & 0.00000 & 0.00644 & 0.03648 & 0.00817 & 126 & \begin{tabular}{|l|}
0.10944 \\
\end{tabular} & 0.00593 & 0.00000 & 0.00000 \\
\hline $\mathrm{CVs}$ & 10004 & 0.09704 & 0.00765 & 0.00733 & 0.00122 & 0.06626 & 0.00000 & 0.00611 & 0.03456 & 0.00774 & 120 & \begin{tabular}{|l|}
0.10368 \\
\end{tabular} & 0.00562 & 0000 & 000 \\
\hline & 5005 & 0.09165 & 722 & 0.00692 & 115 & 258 & 0.00000 & 577 & 264 & 731 & 13 & 792 & & 00 & 0. \\
\hline $\mathrm{CVS}$ & 0.02351 & 0.10484 & 0.00820 & 0.00653 & 0.0 & \begin{tabular}{|l|}
0.07333 \\
\end{tabular} & 0.00000 & 0.01546 & 0.03731 & 840 & 129 & \begin{tabular}{|l|}
0.11294 \\
\end{tabular} & 0.00602 & 0.00000 & 0.00000 \\
\hline HG-1-1-7 & 0.05349 & 0.06901 & 0.01300 & 0.00000 & 0.00348 & 0.12761 & 0.02629 & 0.00000 & 0.04343 & \begin{tabular}{|l|}
0.01512 \\
\end{tabular} & 131 & 0.09017 & 0.00843 & 0.00102 & 0.00000 \\
\hline HG-1-2-7 & 0.04992 & 0.06720 & 0.01045 & 0.00000 & 0.00328 & 0.11654 & 0.02973 & 0.00000 & 0.04476 & \begin{tabular}{|l|}
0.01471 \\
\end{tabular} & 217 & \begin{tabular}{|l|}
0.08492 \\
\end{tabular} & 0.00759 & 0.00206 & \\
\hline & 889 & & & 000 & & & & 000 & & & & 656 & 728 & & \\
\hline HG-2-1-7 & \begin{tabular}{|l|}
0.05017 \\
\end{tabular} & 0.06648 & 0.01064 & 0.00000 & 0.00328 & \begin{tabular}{|l|}
0.11898 \\
\end{tabular} & 0.02398 & 0.00000 & 0.04494 & \begin{tabular}{|l|}
0.01467 \\
\end{tabular} & \begin{tabular}{|l|}
0.02243 \\
\end{tabular} & \begin{tabular}{|l|}
0.08614 \\
\end{tabular} & 0.00761 & 0.00172 & 0.00000 \\
\hline HG-2-2-7 & 0.05354 & 0.05937 & 0.01082 & 0.00000 & 0.00279 & 0.12616 & 0.01774 & 0.00000 & 0.04323 & 0.01345 & \begin{tabular}{|l|}
0.02389 \\
\end{tabular} & \begin{tabular}{|l|}
0.10153 \\
\end{tabular} & 0.00755 & 0.00239 & 0.00000 \\
\hline HG-2-3-7 & 0.05266 & 0.05917 & 0.01077 & 0.00000 & 0.00304 & 0.12420 & 0.01766 & 0.00000 & 0.04359 & 0.01350 & 0.02355 & \begin{tabular}{|l|}
0.10212 \\
\end{tabular} & 0.00746 & 0.00172 & 0.00000 \\
\hline HG-3-1-7 & \begin{tabular}{|l|}
0.05487 \\
\end{tabular} & 0.06014 & 0.01115 & 0.00000 & 0.00325 & 0.12818 & 0.01973 & 0.00000 & 0.04262 & \begin{tabular}{|l|}
0.01337 \\
\end{tabular} & \begin{tabular}{|l|}
0.02419 \\
\end{tabular} & 0.09874 & 0.00777 & 0.00239 & 0.00000 \\
\hline
\end{tabular}

\begin{tabular}{|l|c|c|c|c|c|c|c|c|c|c|c|}
\hline Glass ID & $\mathbf{S e O}_{2}$ & $\mathbf{S i O}_{2}$ & $\mathbf{S r O}$ & $\mathbf{T h O}_{2}$ & $\mathbf{T i O}_{2}$ & $\mathbf{T l}_{\mathbf{2}} \mathbf{O}$ & $\mathbf{U O}_{3}$ & $\mathbf{Z n O}$ & $\mathbf{Z r O}_{2}$ & $\mathbf{O t h e r s}$ & $\mathbf{S u m}^{(\mathbf{a})}$ \\
\hline CVS2-115 & 0.00000 & 0.51742 & 0.00102 & 0.00000 & 0.00000 & 0.00000 & 0.00000 & 0.00000 & 0.03721 & 0.03331 & 1.00000 \\
\hline CVS2-116 & 0.00000 & 0.52918 & 0.00105 & 0.00000 & 0.00000 & 0.00000 & 0.00000 & 0.00000 & 0.03806 & 0.03407 & 1.00000 \\
\hline CVS2-117 & 0.00000 & 0.54004 & 0.00107 & 0.00000 & 0.00000 & 0.00000 & 0.00000 & 0.00000 & 0.03884 & 0.03476 & 1.00000 \\
\hline CVS2-118 & 0.00000 & 0.52924 & 0.00105 & 0.00000 & 0.00000 & 0.00000 & 0.00000 & 0.00000 & 0.03806 & 0.03407 & 1.00000 \\
\hline CVS2-119 & 0.00000 & 0.54817 & 0.00109 & 0.00000 & 0.00000 & 0.00000 & 0.00000 & 0.00000 & 0.03943 & 0.03529 & 1.00000 \\
\hline CVS2-120 & 0.00000 & 0.52075 & 0.00103 & 0.00000 & 0.00000 & 0.00000 & 0.00000 & 0.00000 & 0.03745 & 0.03352 & 1.00000 \\
\hline CVS2-121 & 0.00000 & 0.49333 & 0.00098 & 0.00000 & 0.00000 & 0.00000 & 0.00000 & 0.00000 & 0.03548 & 0.03176 & 1.00000 \\
\hline CVS2-122 & 0.00000 & 0.46592 & 0.00092 & 0.00000 & 0.00000 & 0.00000 & 0.00000 & 0.00000 & 0.03351 & 0.02999 & 1.00000 \\
\hline CVS2-123 & 0.00000 & 0.53299 & 0.00000 & 0.00000 & 0.00000 & 0.00000 & 0.00000 & 0.00492 & 0.03921 & 0.02375 & 1.00000 \\
\hline HG-1-1-7 & 0.00000 & 0.51320 & 0.00016 & 0.00000 & 0.00451 & 0.00000 & 0.00000 & 0.00310 & 0.00150 & 0.00518 & 1.00000 \\
\hline HG-1-2-7 & 0.00000 & 0.53485 & 0.00032 & 0.00000 & 0.00271 & 0.00000 & 0.00000 & 0.00376 & 0.00095 & 0.00409 & 1.00000 \\
\hline HG-1-3-7 & 0.00000 & 0.53928 & 0.00032 & 0.00000 & 0.00260 & 0.00000 & 0.00000 & 0.00365 & 0.00000 & 0.00411 & 1.00000 \\
\hline HG-2-1-7 & 0.00000 & 0.53860 & 0.00032 & 0.00000 & 0.00259 & 0.00000 & 0.00000 & 0.00377 & 0.00000 & 0.00367 & 1.00000 \\
\hline HG-2-2-7 & 0.00000 & 0.52546 & 0.00032 & 0.00000 & 0.00220 & 0.00000 & 0.00000 & 0.00399 & 0.00208 & 0.00348 & 1.00000 \\
\hline HG-2-3-7 & 0.00000 & 0.53073 & 0.00032 & 0.00000 & 0.00209 & 0.00000 & 0.00000 & 0.00375 & 0.00076 & 0.00292 & 1.00000 \\
\hline HG-3-1-7 & 0.00000 & 0.52177 & 0.00032 & 0.00000 & 0.00220 & 0.00000 & 0.00000 & 0.00435 & 0.00170 & 0.00327 & 1.00000 \\
\hline
\end{tabular}

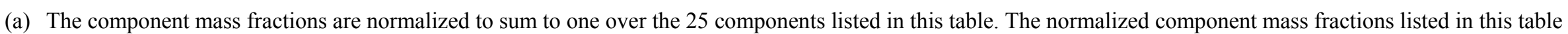
were rounded to five decimals, and may not sum exactly to 1.00000 as listed. However, complete compositions listed to more decimal places and summing to 1.0000 were used for validating PCT-composition models. 
Table B.1. Normalized 25-Component Compositions (mass fractions) of 554 HLW Glasses Used for PCT Model Validation (continued).

\begin{tabular}{|c|c|c|c|c|c|c|c|c|c|c|c|c|c|c|c|}
\hline ID & $\mathbf{A l}_{2} \mathbf{O}_{3}$ & $\mathbf{B}_{2} \mathbf{O}_{3}$ & $\mathrm{CaO}$ & CdO & $\mathbf{r}_{2} \mathbf{O}_{3}$ & $\mathrm{Fe}_{2} \mathrm{O}_{3}$ & $\mathbf{K}_{2} \mathbf{O}$ & $\mathbf{L a}_{2} \mathbf{O}_{3}$ & $\mathbf{L i}_{2} \mathbf{O}$ & $\mathbf{O}$ & $\mathbf{O}$ & $\mathrm{Na}_{2} \mathrm{O}$ & $\mathrm{NiO}$ & PbO & $\mathrm{Sb}_{2} \mathrm{O}_{3}$ \\
\hline-7 & 5573 & 06106 & 01144 & 00000 & 00278 & 13300 & .02180 & 00000 & 04177 & 19 & 517 & 09579 & 00762 & 00238 & 0.00000 \\
\hline & 5603 & 06228 & & & & & & & & & & & & & \\
\hline Al-7 & 09 & 96 & 17 & 00000 & 0.0 & 878 & 0.00000 & 0.00000 & 4234 & 667 & 2638 & 581 & 00677 & 00 & 000 \\
\hline $\mathrm{AV}-7$ & 0.0 & 06596 & & 0000 & 0.0 & & & 000 & & & & & & & \\
\hline 5 FE-7 & 0.01432 & 0.07323 & 0.01409 & 0.00000 & 0.00000 & 7110 & 0.00000 & 0.00000 & 0.04076 & 0.00654 & 074 & 0766 & 985 & 0000 & 0.00000 \\
\hline AH-131 Al-7 & 0.13512 & 0.10816 & 0.00383 & 0.00000 & 0.00000 & 0.04689 & 0.00000 & 0.00354 & 0.04094 & 384 & 2513 & 0.14116 & 627 & 0.00000 & 0.00000 \\
\hline AH-131 AV-7 & 0.04432 & 0.07674 & 0.00766 & 0.00000 & 0.00000 & 12012 & 0.00000 & 0.00000 & 0.04296 & 676 & 2621 & 959 & 055 & 0000 & 0.0 \\
\hline FE-7 & .02264 & 379 & 017 & 0000 & 0.00000 & 514 & 0.00000 & 0.00000 & 4083 & 662 & 932 & 69 & 581 & 000 & \\
\hline $8 \mathrm{Al}-7$ & 0.06734 & 0.13736 & 38 & 0000 & 0.00000 & 453 & 0.00000 & 0.00000 & 0.05356 & 894 & 095 & 1832 & 0.00331 & 0.00000 & 0.00000 \\
\hline \begin{tabular}{|l} 
AH-168 AV-7 \\
A
\end{tabular} & 0.05627 & 0.10697 & 0.00685 & 0.00000 & 0.00000 & 0.11306 & 0.00000 & 0.00000 & 0.04277 & 0.00748 & 0.02665 & 0.10194 & 0.01028 & 0.00000 & 0.00000 \\
\hline \begin{tabular}{|l|} 
AH-168 FE-7 \\
\end{tabular} & 0.02464 & 0.11411 & 0.01355 & 0.00000 & 0.00000 & 0.16315 & 0.00000 & 0.00000 & 0.04125 & 0.00712 & 0.00978 & & & 0.00000 & \\
\hline $0 \mathrm{Al}-7$ & & & & 000 & 0.0 & 486 & & 000 & 664 & & 499 & & & 000 & \\
\hline \begin{tabular}{|l} 
AH-200 AV-7 \\
\end{tabular} & 0.05169 & 0.10369 & 0.00631 & 0.00000 & 0.00000 & \begin{tabular}{|l}
0.11976 \\
\end{tabular} & 0.03207 & 0.00000 & 0.02698 & 0.01251 & \begin{tabular}{|l|}
0.02564 \\
\end{tabular} & 0.09835 & 0.01031 & 0.00000 & 0.00000 \\
\hline $\begin{array}{l}\text { AH-200 FE-7 } \\
\end{array}$ & 0.02078 & 0.10122 & 0.00923 & 0.00000 & 0.00000 & 0.16432 & 0.03157 & 0.00000 & 0.02599 & 0.01211 & 0.00953 & 0.10631 & 0.02571 & 0.00000 & 0.00000 \\
\hline AH-202 Al-7 & 0.13972 & 0.07459 & 0.00408 & 0.00000 & 0.00000 & 0.04426 & 0.03340 & 0.00000 & 0.04201 & 0.01286 & 0.02526 & 0.07370 & 0.00625 & 0.00000 & 0.00000 \\
\hline \begin{tabular}{|l}
$\mathrm{AH}-202-\mathrm{AV}-7$ \\
\end{tabular} & 0.04980 & 0.07475 & 0.00724 & 0.00000 & 0.00000 & 0.11946 & 0.03342 & 0.00000 & 0.04292 & 0.01306 & 0.02604 & 0.06578 & 0.01010 & 0.00000 & 0.00000 \\
\hline
\end{tabular}

\begin{tabular}{|l|c|c|c|c|c|c|c|c|c|c|c|}
\hline Glass ID & $\mathbf{S e O}_{2}$ & $\mathbf{S i O}_{2}$ & $\mathbf{S r O}$ & $\mathbf{T h O}_{2}$ & $\mathbf{T i O}_{2}$ & $\mathbf{T l}_{\mathbf{2}} \mathbf{O}$ & $\mathbf{U O}_{3}$ & $\mathbf{Z n O}$ & $\mathbf{Z r O}_{2}$ & $\mathbf{O t h e r s}$ & $\mathbf{S u m}^{(\mathbf{a})}$ \\
\hline HG-3-2-7 & 0.00000 & 0.51672 & 0.00032 & 0.00000 & 0.00231 & 0.00000 & 0.00000 & 0.00384 & 0.00169 & 0.00340 & 1.00000 \\
\hline HG-3-3-7 & 0.00000 & 0.51760 & 0.00032 & 0.00000 & 0.00244 & 0.00000 & 0.00000 & 0.00422 & 0.00150 & 0.00297 & 1.00000 \\
\hline AH-165 Al-7 & 0.00000 & 0.54014 & 0.00000 & 0.00000 & 0.00000 & 0.00000 & 0.00000 & 0.00000 & 0.00789 & 0.00000 & 1.00000 \\
\hline AH-165 AV-7 & 0.00000 & 0.55478 & 0.00000 & 0.00000 & 0.00000 & 0.00000 & 0.00000 & 0.00000 & 0.00772 & 0.000000 & 1.00000 \\
\hline AH-165 FE-7 & 0.00000 & 0.52325 & 0.00000 & 0.00000 & 0.00000 & 0.00000 & 0.00000 & 0.00000 & 0.00846 & 0.00000 & 1.00000 \\
\hline AH-131 Al-7 & 0.00000 & 0.46448 & 0.00000 & 0.00000 & 0.00720 & 0.00000 & 0.00000 & 0.00000 & 0.00345 & 0.00000 & 1.00000 \\
\hline AH-131 AV-7 & 0.00000 & 0.55567 & 0.00000 & 0.00000 & 0.00062 & 0.00000 & 0.00000 & 0.00000 & 0.00880 & 0.00000 & 1.00000 \\
\hline AH-131 FE-7 & 0.00000 & 0.51721 & 0.00000 & 0.00000 & 0.00012 & 0.00000 & 0.00000 & 0.00000 & 0.00867 & 0.00000 & 1.00000 \\
\hline AH-168 Al-7 & 0.00000 & 0.56560 & 0.00000 & 0.00000 & 0.00000 & 0.00000 & 0.00000 & 0.00000 & 0.00870 & 0.000000 & 1.00000 \\
\hline AH-168 AV-7 & 0.00000 & 0.52069 & 0.00000 & 0.00000 & 0.00000 & 0.00000 & 0.00000 & 0.00000 & 0.00705 & 0.00000 & 1.00000 \\
\hline AH-168 FE-7 & 0.00000 & 0.48337 & 0.00000 & 0.00000 & 0.00000 & 0.00000 & 0.00000 & 0.00000 & 0.00668 & 0.00000 & 1.00000 \\
\hline AH-200 Al-7 & 0.00000 & 0.48669 & 0.00000 & 0.00000 & 0.01711 & 0.00000 & 0.00000 & 0.00000 & 0.00037 & 0.00000 & 1.00000 \\
\hline AH-200 AV-7 & 0.00000 & 0.49836 & 0.00000 & 0.00000 & 0.01414 & 0.00000 & 0.00000 & 0.00000 & 0.00018 & 0.00000 & 1.00000 \\
\hline AH-200 FE-7 & 0.00000 & 0.47518 & 0.00000 & 0.00000 & 0.01785 & 0.00000 & 0.00000 & 0.00000 & 0.00019 & 0.000000 & 1.00000 \\
\hline AH-202 Al-7 & 0.00000 & 0.52648 & 0.00000 & 0.00000 & 0.01720 & 0.00000 & 0.00000 & 0.00000 & 0.00019 & 0.00000 & 1.00000 \\
\hline AH-202-AV-7 & 0.00000 & 0.54350 & 0.00000 & 0.00000 & 0.01375 & 0.00000 & 0.00000 & 0.00000 & 0.00019 & 0.00000 & 1.00000 \\
\hline
\end{tabular}

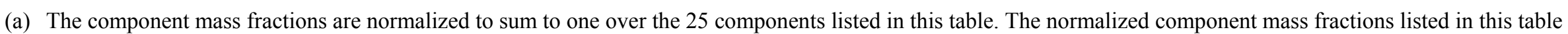
were rounded to five decimals, and may not sum exactly to 1.00000 as listed. However, complete compositions listed to more decimal places and summing to 1.0000 were used for validating PCT-composition models. 
Table B.1. Normalized 25-Component Compositions (mass fractions) of 554 HLW Glasses Used for PCT Model Validation (continued).

\begin{tabular}{|c|c|c|c|c|c|c|c|c|c|c|c|c|c|c|c|}
\hline Glass ID & $\mathbf{A l}_{2} \mathbf{O}_{3}$ & $\mathbf{B}_{2} \mathbf{O}_{3}$ & $\mathrm{aO}$ & CdO & $\mathrm{Cr}_{2} \mathrm{O}_{3}$ & $\mathbf{e}_{2} \mathbf{O}_{3}$ & $\mathrm{~K}_{2} \mathrm{O}$ & $\mathbf{L a}_{2} \mathbf{O}_{3}$ & $\mathbf{L i}_{2} \mathbf{O}$ & $\operatorname{IgO}$ & MnO & $\mathrm{Na}_{2} \mathrm{O}$ & $\mathrm{NiO}$ & PbO & $\mathrm{Sb}_{2} \mathrm{O}_{3}$ \\
\hline$[-202$ & 01360 & 07053 & 00957 & 00000 & 00000 & 16539 & \begin{tabular}{|l|}
0.03259 \\
\end{tabular} & 00000 & 04251 & 01257 & 0947 & \begin{tabular}{|l|}
0.07587 \\
\end{tabular} & 02724 & 0.00000 & .00000 \\
\hline & & 10293 & 00961 & & 00023 & & & & & & & & & & \\
\hline & & 0.13 & 15 & 0.0 & 23 & 427 & \begin{tabular}{|l|}
0.03110 \\
\end{tabular} & \begin{tabular}{|l|}
0.00000 \\
\end{tabular} & 0.03768 & 584 & & 10315 & \begin{tabular}{|l|}
0.00926 \\
\end{tabular} & 00 & 00000 \\
\hline & & $0.0^{7}$ & & 0.0 & 947 & 31 & 74 & .00000 & 15 & 32 & & 26 & 0977 & & 000 \\
\hline AH-5-7 & 522 & 0.07001 & 0.00665 & 0.00000 & 0.00000 & 11491 & 0.03181 & 0.00000 & 0.03796 & 0.00607 & 655 & \begin{tabular}{|l|}
0.09307 \\
\end{tabular} & 0.00966 & 0.0 & 0.00000 \\
\hline AH-6-7 & 5603 & 0.09395 & 0.00681 & 0.00000 & 0.00000 & \begin{tabular}{|l|}
0.11879 \\
\end{tabular} & 0.03160 & 0.00000 & 0.04622 & 0.00606 & 735 & \begin{tabular}{|l|}
0.10576 \\
\end{tabular} & 0.00941 & 0.00000 & 0.00000 \\
\hline AH-7-7 & 290 & 0.11529 & 0.00638 & 0.00000 & 0.00000 & 11333 & 0.03159 & 0.00000 & 0.03159 & 0.00591 & 2623 & \begin{tabular}{|l|}
0.09271 \\
\end{tabular} & 0.00951 & 00 & 0.00000 \\
\hline $8-7$ & & \begin{tabular}{|l|}
0.10146 \\
\end{tabular} & 592 & 0.00000 & 0.00023 & 649 & 88 & 0.00000 & 186 & 206 & & 806 & 9977 & & 0.00000 \\
\hline AH-9-7 & 079 & 0.08805 & 692 & 0.00000 & 0.00023 & 662 & 0.03149 & 0.00000 & 0.03491 & 583 & 660 & \begin{tabular}{|l|}
0.09257 \\
\end{tabular} & 0.00979 & 0.00000 & 0.00000 \\
\hline AH-10-7 & 0.05167 & 0.07636 & 0.00682 & 0.00000 & 0.00000 & 0.11365 & 0.03105 & 0.00000 & 0.04469 & 0.01118 & 0.02688 & 0.06874 & 0.00967 & 0.00000 & 0.00000 \\
\hline AH-11-7 & 0.05763 & 0.12143 & 0.00654 & 0.00000 & 0.00023 & \begin{tabular}{|l|}
0.11132 \\
\end{tabular} & 0.03026 & 0.00000 & 0.03663 & 0.01124 & 0.02655 & \begin{tabular}{|l|}
0.06490 \\
\end{tabular} & 0.00940 & & 0.00000 \\
\hline $2-7$ & & 0.08 & & & 0.00000 & & & 0.00000 & & & & 259 & \begin{tabular}{|l|}
0.00979 \\
\end{tabular} & & 0.00000 \\
\hline AH-13-7 & \begin{tabular}{|l}
0.06598 \\
\end{tabular} & \begin{tabular}{|l|}
0.06526 \\
\end{tabular} & 0.01271 & 0.00000 & 0.00000 & \begin{tabular}{|l|}
0.13858 \\
\end{tabular} & \begin{tabular}{|l|}
0.03111 \\
\end{tabular} & 0.00000 & 0.03381 & 0.00501 & \begin{tabular}{|l|}
0.03309 \\
\end{tabular} & \begin{tabular}{|l|}
0.08958 \\
\end{tabular} & \begin{tabular}{|l|}
0.01162 \\
\end{tabular} & 0.00000 & 0.00000 \\
\hline AH-14-7 & 0.07148 & 0.08322 & 0.01258 & 0.00000 & 0.00000 & 0.14023 & 0.03114 & 0.00000 & 0.03978 & 0.00535 & 0.03371 & \begin{tabular}{|l|}
0.09851 \\
\end{tabular} & 0.01136 & 0.00000 & 0.00000 \\
\hline AH-15-7 & 0.06958 & 0.09318 & 0.01284 & 0.00000 & 0.00022 & \begin{tabular}{|l|}
0.13781 \\
\end{tabular} & 0.03138 & 0.00000 & 0.02837 & 0.01035 & 0.03300 & \begin{tabular}{|l|}
0.09533 \\
\end{tabular} & 0.01140 & 0.00000 & 0.00000 \\
\hline AH-16-7 & 0.06427 & \begin{tabular}{|l|}
0.07283 \\
\end{tabular} & 0.01271 & 0.00000 & 0.00068 & \begin{tabular}{|l|}
0.13542 \\
\end{tabular} & 0.03096 & 0.00000 & 0.04108 & 0.01010 & 0.03258 & 0.06614 & 0.01110 & 0.00000 & 0.00000 \\
\hline
\end{tabular}

\begin{tabular}{|l|c|c|c|c|c|c|c|c|c|c|c|}
\hline Glass ID & $\mathbf{S e O}_{2}$ & $\mathbf{S i O}_{2}$ & $\mathbf{S r O}$ & $\mathbf{T h O}_{2}$ & $\mathbf{T i O}_{2}$ & $\mathbf{T l}_{\mathbf{2}} \mathbf{O}$ & $\mathbf{U O}_{3}$ & $\mathbf{Z n O}$ & $\mathbf{Z r O}_{2}$ & $\mathbf{O t h e r s}$ & $\mathbf{S u m}^{(\mathbf{a})}$ \\
\hline AH-202 FE-7 & 0.00000 & 0.52336 & 0.00000 & 0.00000 & 0.01711 & 0.00000 & 0.00000 & 0.00000 & 0.00019 & 0.00000 & 1.00000 \\
\hline AH-1-7 & 0.00000 & 0.44055 & 0.00031 & 0.00000 & 0.01333 & 0.00000 & 0.00000 & 0.00000 & 0.00666 & 0.00085 & 1.00000 \\
\hline AH-2-7 & 0.00000 & 0.44629 & 0.00046 & 0.00000 & 0.01301 & 0.00000 & 0.00000 & 0.00000 & 0.00626 & 0.00042 & 1.00000 \\
\hline AH-4-7 & 0.00000 & 0.53679 & 0.00048 & 0.00000 & 0.01303 & 0.00000 & 0.00000 & 0.00000 & 0.00000 & 0.00043 & 1.00000 \\
\hline AH-5-7 & 0.00000 & 0.53465 & 0.00000 & 0.00000 & 0.01325 & 0.00000 & 0.00000 & 0.00000 & 0.00019 & 0.00000 & 1.00000 \\
\hline AH-6-7 & 0.00000 & 0.47631 & 0.00047 & 0.00000 & 0.01407 & 0.00000 & 0.00000 & 0.00000 & 0.00673 & 0.00043 & 1.00000 \\
\hline AH-7-7 & 0.00000 & 0.49146 & 0.00000 & 0.00000 & 0.01292 & 0.00000 & 0.00000 & 0.00000 & 0.00018 & 0.00000 & 1.00000 \\
\hline AH-8-7 & 0.00000 & 0.49223 & 0.00047 & 0.00000 & 0.01322 & 0.00000 & 0.00000 & 0.00000 & 0.00000 & 0.00042 & 1.00000 \\
\hline AH-9-7 & 0.00000 & 0.51196 & 0.00047 & 0.00000 & 0.01335 & 0.00000 & 0.00000 & 0.00000 & 0.00000 & 0.00042 & 1.00000 \\
\hline AH-10-7 & 0.00000 & 0.54533 & 0.00048 & 0.00000 & 0.01305 & 0.00000 & 0.00000 & 0.00000 & 0.00000 & 0.00043 & 1.00000 \\
\hline AH-11-7 & 0.00000 & 0.50989 & 0.00047 & 0.00000 & 0.01308 & 0.00000 & 0.00000 & 0.00000 & 0.00000 & 0.00043 & 1.00000 \\
\hline AH-12-7 & 0.00000 & 0.51212 & 0.00047 & 0.00000 & 0.01336 & 0.00000 & 0.00000 & 0.00000 & 0.00000 & 0.00042 & 1.00000 \\
\hline AH-13-7 & 0.00000 & 0.49890 & 0.00061 & 0.00000 & 0.01313 & 0.00000 & 0.00000 & 0.00000 & 0.00018 & 0.00042 & 1.00000 \\
\hline AH-14-7 & 0.00000 & 0.45206 & 0.00061 & 0.00000 & 0.01332 & 0.00000 & 0.00000 & 0.00000 & 0.00582 & 0.000083 & 1.00000 \\
\hline AH-15-7 & 0.00000 & 0.46190 & 0.00061 & 0.00000 & 0.01360 & 0.00000 & 0.00000 & 0.00000 & 0.00000 & 0.00041 & 1.00000 \\
\hline AH-16-7 & 0.00000 & 0.50772 & 0.00078 & 0.00000 & 0.01319 & 0.00000 & 0.00000 & 0.00000 & 0.00000 & 0.00042 & 1.00000 \\
\hline
\end{tabular}

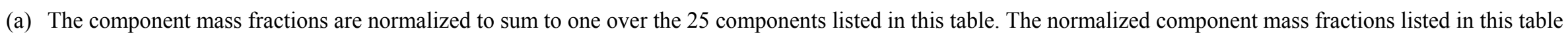
were rounded to five decimals, and may not sum exactly to 1.00000 as listed. However, complete compositions listed to more decimal places and summing to 1.0000 were used for validating PCT-composition models. 
Table B.1. Normalized 25-Component Compositions (mass fractions) of 554 HLW Glasses Used for PCT Model Validation (continued).

\begin{tabular}{|c|c|c|c|c|c|c|c|c|c|c|c|c|c|c|c|}
\hline Glass ID & $\mathbf{A l}_{2} \mathbf{O}_{3}$ & $\mathbf{B}_{2} \mathbf{O}_{3}$ & $\mathrm{CaO}$ & EdO & $\mathbf{r}_{2} \mathbf{O}_{3}$ & $\mathrm{Fe}_{2} \mathrm{O}_{3}$ & $\mathbf{K}_{2} \mathbf{O}$ & $\mathbf{L a}_{2} \mathbf{O}_{3}$ & $\mathbf{L i}_{2} \mathbf{O}$ & MgO & MnO & $\mathrm{Na}_{2} \mathrm{O}$ & $\mathrm{NiO}$ & PbO & $\mathrm{Sb}_{2} \mathrm{O}_{3}$ \\
\hline $7-7$ & 05777 & 88197 & .00659 & 0000 & 00093 & 0.11510 & 33093 & 0.00000 & 04732 & 0.00585 & 0.02730 & 0.06673 & 0.00924 & 00000 & 0.00000 \\
\hline SFRIT1 & 04619 & 08548 & 0.01 & 0.00000 & .00091 & 0.14278 & .02709 & 0.00000 & .03264 & 0.00847 & 0.01945 & 0.11582 & 0.01 & 0.00000 & 00000 \\
\hline \begin{tabular}{|l} 
SFRIT2 \\
\end{tabular} & 04619 & 08548 & 0.01479 & 0.00000 & 0.00091 & 0.14278 & .02709 & 0.00000 & .03264 & 0.00847 & 0.01945 & 0.11582 & & 0.00000 & 0.00000 \\
\hline$\widehat{S F I}$ & 04619 & 08548 & 0.01 & 0.00000 & 0.00 & 278 & 02709 & 0.00000 & 3264 & 47 & 45 & 582 & & 00 & \\
\hline /o Mn-7 & 285 & 575 & & 0.00000 & 070 & 680 & 707 & 0.0 & \begin{tabular}{|l|}
0.03410 \\
\end{tabular} & & 000 & 174 & 99 & 000 & \\
\hline o Mn-7 & 611 & 926 & & & & & 737 & & 0.03766 & & & & & 000 & \\
\hline \begin{tabular}{|l|}
$200 \mathrm{R}-7$ \\
\end{tabular} & 0.04776 & 0.09793 & & 0.00000 & 0.00000 & 0.1 & 0.03617 & 0.00000 & 0.03114 & & & 0.13749 & & 0.00000 & $\overline{000}$ \\
\hline NBS SRM 623-7 & 0.06300 & 0.10710 & 0.00704 & 0.00000 & 0.00000 & 0.00000 & 0.00606 & 0.00000 & 0.00000 & 0000 & & 0.06405 & & 0000 & \\
\hline 165 CGW STD-7 & 0.04203 & 0.06728 & 0.01541 & 0.00000 & 0.00000 & 0.12965 & 0.00000 & 0.00000 & 0.05015 & 0.01026 & 0.02569 & 0.10470 & 0.00968 & 0.00000 & 00 \\
\hline \begin{tabular}{|ll} 
ARM-1-7 (4/88) \\
\end{tabular} & & 11285 & & 0.00000 & 0.00000 & 0.00000 & 0000 & 0.00000 & 074 & 000 & & 0.09661 & & 0000 & \\
\hline \begin{tabular}{|ll} 
ARM-1-7 & $(5 / 89)$ \\
\end{tabular} & 0.05580 & 0.11285 & 0.0 & 0.00000 & 0.00000 & 0.00000 & 0.00000 & 0.00000 & 0.05074 & 0.00000 & 0.00000 & 0.09661 & 0.00000 & 0.00000 & 0.00000 \\
\hline $\begin{array}{|ll|}\text { ARM-1-7 } & (7 / 90) \\
\end{array}$ & 0.05580 & 0.11285 & 0.02229 & 0.00000 & 0.00000 & 0.00000 & 0.00000 & 0.00000 & 0.05074 & 0.00000 & 0.00000 & 0.09661 & 0.00000 & 0.00000 & 0.00000 \\
\hline \begin{tabular}{|ll} 
ARM-1-7 & $(12 / 90)$
\end{tabular} & 0.05580 & 0.11285 & 0.02229 & 0.00000 & 0.00000 & 0.00000 & 0.00000 & 0.00000 & 0.05074 & 0.00000 & 0.00000 & 0.09661 & 0.00000 & 0.00000 & \\
\hline \begin{tabular}{|ll} 
ARM-1-7 & $(5 / 91)$ \\
\end{tabular} & & 0.11285 & 0.02229 & & 0.0 & 0.0 & & 0.0 & 0.05074 & & & 0.0 & & & \\
\hline \begin{tabular}{|ll} 
ARM-1-7 (10/91) \\
\end{tabular} & 0.05580 & 0.11285 & \begin{tabular}{|l}
0.02229 \\
\end{tabular} & 0.00000 & 0.00000 & 0.00000 & 0.00000 & 0.00000 & \begin{tabular}{|l|}
0.05074 \\
\end{tabular} & 0.00000 & 0.00000 & 0.09661 & 0.00000 & 0.00000 & \\
\hline $\begin{array}{ll}\text { ARM-1-7 (10/92) } \\
\end{array}$ & 0.05580 & 0.11285 & 0.02229 & 0.00000 & 0.00000 & 0.00000 & 0.00000 & 0.00000 & 0.05074 & 0.00000 & 0.00000 & 0.09661 & 0.00000 & 0.00000 & 0.00000 \\
\hline
\end{tabular}

\begin{tabular}{|l|c|c|c|c|c|c|c|c|c|c|c|}
\hline Glass ID & $\mathbf{S e O}_{2}$ & $\mathbf{S i O}_{2}$ & $\mathbf{S r O}$ & $\mathbf{T h O}_{2}$ & $\mathbf{T i O}_{2}$ & $\mathbf{T l}_{\mathbf{2}} \mathbf{O}$ & $\mathbf{U O}_{3}$ & $\mathbf{Z n O}$ & $\mathbf{Z r O}_{2}$ & $\mathbf{O t h e r s ~}^{\text {Sum }}$ \\
\hline AH-17-7 & 0.00000 & 0.52978 & 0.00032 & 0.00000 & 0.01318 & 0.00000 & 0.00000 & 0.00000 & 0.00659 & 0.00043 & 1.00000 \\
\hline SFRIT1 & 0.00000 & 0.48134 & 0.00000 & 0.00000 & 0.01191 & 0.00000 & 0.00000 & 0.00000 & 0.00110 & 0.00091 & 1.00000 \\
\hline SFRIT2 & 0.00000 & 0.48134 & 0.00000 & 0.00000 & 0.01191 & 0.00000 & 0.00000 & 0.00000 & 0.00110 & 0.00091 & 1.00000 \\
\hline SFRIT3 & 0.00000 & 0.48134 & 0.00000 & 0.00000 & 0.01191 & 0.00000 & 0.00000 & 0.00000 & 0.00110 & 0.00091 & 1.00000 \\
\hline 202P w/o Mn-7 & 0.00000 & 0.51059 & 0.00000 & 0.00000 & 0.01238 & 0.00000 & 0.00000 & 0.00000 & 0.00000 & 0.00977 & 1.00000 \\
\hline 202G w/o Mn-7 & 0.00000 & 0.56025 & 0.00000 & 0.00000 & 0.00683 & 0.00000 & 0.00000 & 0.00000 & 0.00000 & 0.00606 & 1.00000 \\
\hline 200R-7 & 0.00000 & 0.46664 & 0.00000 & 0.00000 & 0.00000 & 0.00000 & 0.00000 & 0.00000 & 0.00000 & 0.00000 & 1.00000 \\
\hline NBS SRM 623- & 0.00000 & 0.73063 & 0.00000 & 0.00000 & 0.00000 & 0.00000 & 0.00000 & 0.00000 & 0.00000 & 0.02212 & 1.00000 \\
\hline 165 CGW STD- & 0.00000 & 0.54015 & 0.00000 & 0.00000 & 0.00000 & 0.00000 & 0.00000 & 0.00000 & 0.00500 & 0.00000 & 1.00000 \\
\hline ARM-1-7 & 0.00000 & 0.46452 & 0.00446 & 0.00000 & 0.03211 & 0.00000 & 0.00000 & 0.01460 & 0.01791 & 0.12812 & 1.00000 \\
\hline ARM-1-7 & 0.00000 & 0.46452 & 0.00446 & 0.00000 & 0.03211 & 0.00000 & 0.00000 & 0.01460 & 0.01791 & 0.12812 & 1.00000 \\
\hline ARM-1-7 & 0.00000 & 0.46452 & 0.00446 & 0.00000 & 0.03211 & 0.00000 & 0.00000 & 0.01460 & 0.01791 & 0.12812 & 1.00000 \\
\hline ARM-1-7 & 0.00000 & 0.46452 & 0.00446 & 0.00000 & 0.03211 & 0.00000 & 0.00000 & 0.01460 & 0.01791 & 0.12812 & 1.00000 \\
\hline ARM-1-7 & 0.00000 & 0.46452 & 0.00446 & 0.00000 & 0.03211 & 0.00000 & 0.00000 & 0.01460 & 0.01791 & 0.12812 & 1.00000 \\
\hline ARM-1-7 & 0.00000 & 0.46452 & 0.00446 & 0.00000 & 0.03211 & 0.00000 & 0.00000 & 0.01460 & 0.01791 & 0.12812 & 1.00000 \\
\hline ARM-1-7 & 0.00000 & 0.46452 & 0.00446 & 0.00000 & 0.03211 & 0.00000 & 0.00000 & 0.01460 & 0.01791 & 0.12812 & 1.00000 \\
\hline
\end{tabular}

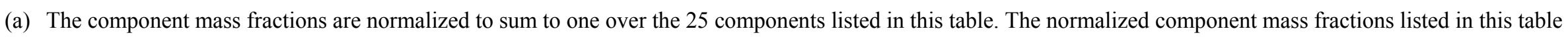
were rounded to five decimals, and may not sum exactly to 1.00000 as listed. However, complete compositions listed to more decimal places and summing to 1.0000 were used for validating PCT-composition models. 
Table B.1. Normalized 25-Component Compositions (mass fractions) of 554 HLW Glasses Used for PCT Model Validation (continued).

\begin{tabular}{|c|c|c|c|c|c|c|c|c|c|c|c|c|c|c|c|}
\hline & $\mathbf{A l}_{2} \mathbf{O}_{3}$ & $\mathbf{B}_{2} \mathbf{O}_{3}$ & & dO & $\mathrm{Cr}_{2} \mathrm{O}_{3}$ & $\mathrm{Fe}_{2} \mathrm{O}_{3}$ & $\mathbf{K}_{2} \mathbf{O}$ & $\mathbf{L a}_{2} \mathbf{O}_{3}$ & $\mathbf{L i}_{\mathbf{2}} \mathbf{O}$ & 0 & & $\mathrm{Na}_{2} \mathrm{O}$ & $\mathrm{NiO}$ & כ & $\mathrm{Sb}_{2} \mathrm{O}_{3}$ \\
\hline ARM-1-7 (4/93) & 5580 & 11285 & 29 & 0000 & 00000 & 00000 & 0000 & 00000 & 05074 & 00 & 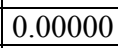 & 9661 & 00 & 0 & 20 \\
\hline 1-1-7 (6/93) & & & & & & & & & & & & & & & \\
\hline $1-7 \quad(8 / 93)$ & & & & & & & & & & & & & & & \\
\hline & & & & & & & & & & & & & & & \\
\hline & & & & 00 & & & & & & & & & & & \\
\hline & & & & & & & & & & & & & & & \\
\hline & & & & & & & & & & & & & & & \\
\hline & & & & & & & & & & & & & & 000 & \\
\hline & & & & & & & & & & & & & & 000 & \\
\hline & & & & & & & & & & & & & & & \\
\hline & & & & & & & & & & & & & & & \\
\hline & & & & 00 & 00 & & & & & & & & & 000 & \\
\hline & & & & & 000 & & 045 & & & 718 & & 6778 & 570 & 000 & 000 \\
\hline & 3698 & 1283 & & 0.00000 & 0.00000 & 0.0 & 0.00045 & & 4254 & & & & & 0000 & \\
\hline & & & & 0.00000 & & & & & & & & & & 000 & \\
\hline$-2-7$ & 03698 & .11283 & 15 & 0.00000 & .00000 & 0.08979 & 0.00045 & 0.00 & 0.04254 & 718 & 0.0 & 0.16778 & 0.00570 & 0.00000 & 0 \\
\hline
\end{tabular}

\begin{tabular}{|c|c|c|c|c|c|c|c|c|c|c|c|}
\hline Glass ID & $\mathrm{SeO}_{2}$ & $\mathrm{SiO}_{2}$ & SrO & $\mathrm{ThO}_{2}$ & $\mathrm{TiO}_{2}$ & $\mathrm{Tl}_{2} \mathrm{O}$ & $\mathbf{U O}_{3}$ & $\mathrm{ZnO}$ & $\mathrm{ZrO}_{2}$ & \begin{tabular}{|l|} 
Others \\
\end{tabular} & sum \\
\hline ARM-1-7 & 00000 & 0.46452 & 00446 & .00000 & 0.03211 & 00000 & 00000 & 01460 & 01791 & & .00000 \\
\hline & & 46452 & 0446 & 0000 & & & & & & & \\
\hline $\mathrm{AR}$ & & & & & & & & & & & \\
\hline ARM-1-7 & 00000 & 0.46452 & & 0.00000 & 0.03211 & .00000 & 0.00000 & 0.01460 & & & 1.00000 \\
\hline T-ARM-1 & 0000 & 46452 & 0.00446 & 00000 & 0.03211 & .00000 & 0.00000 & 0.01460 & 791 & 312 & 00 \\
\hline & & & & & & & & & & & \\
\hline & & & & & & & & 460 & & & \\
\hline & & & & & & & & & & & \\
\hline & & 0.48653 & 0.00000 & 000 & 0.0 & 0000 & 00 & 000 & & & 0000 \\
\hline EA & 000 & 0.48653 & 0.00000 & 0000 & 0.00699 & .00000 & 0.00000 & 0.00000 & 451 & 000 & 0000 \\
\hline EA & & & & 000 & & 0000 & & 000 & & & \\
\hline$\overline{T-1}$ & 000 & 653 & 000 & 000 & 0.0 & 000 & 00 & 000 & 451 & 000 & 1.00000 \\
\hline SS-EA-19 & 00000 & 0.48653 & 0.00000 & \begin{tabular}{|l|l|}
0.00000 \\
\end{tabular} & \begin{tabular}{|l}
0.00699 \\
\end{tabular} & \begin{tabular}{|l|}
0.00000 \\
\end{tabular} & \begin{tabular}{|l|}
0.00000 \\
\end{tabular} & 0.00000 & \begin{tabular}{|l|l|}
0.00451 \\
\end{tabular} & \begin{tabular}{|l|l|}
0.00000 \\
\end{tabular} & \begin{tabular}{|l|}
1.00000 \\
\end{tabular} \\
\hline SS-EA-15 & 00000 & 0.48653 & 0.00000 & 0.00000 & 0.00699 & 0.00000 & 0.00000 & 0.00000 & 0.00451 & 0.00000 & 1.00000 \\
\hline & & & & & & & & & & & 000 \\
\hline \begin{tabular}{|l} 
SS-EA-2-7 \\
\end{tabular} & .00000 & 0.48653 & 0.00000 & 0.00000 & 0.00699 & 0.00000 & 0.00000 & 0.00000 & 0.00451 & 0.00000 & 1.00000 \\
\hline
\end{tabular}

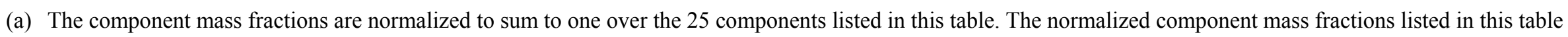
were rounded to five decimals, and may not sum exactly to 1.00000 as listed. However, complete compositions listed to more decimal places and summing to 1.0000 were used for validating PCT-composition models. 
Table B.1. Normalized 25-Component Compositions (mass fractions) of 554 HLW Glasses Used for PCT Model Validation (continued).

\begin{tabular}{|c|c|c|c|c|c|c|c|c|c|c|c|c|c|c|c|}
\hline Glass ID & $\mathbf{A l}_{2} \mathbf{O}_{3}$ & $\mathbf{B}_{2} \mathbf{O}_{3}$ & $\mathrm{CaO}$ & CdO & $\mathrm{Cr}_{2} \mathrm{O}_{3}$ & $\mathrm{Fe}_{2} \mathrm{O}_{3}$ & $\mathbf{K}_{2} \mathbf{O}$ & $\mathbf{L a}_{2} \mathbf{O}_{3}$ & $\mathbf{L i}_{2} \mathbf{O}$ & MgO & MnO & $\mathrm{Na}_{2} \mathrm{O}$ & $\mathrm{NiO}$ & FUO & $\mathrm{Sb}_{2} \mathrm{O}_{3}$ \\
\hline $\mathrm{A}-7$ & 03698 & 11283 & 5 & 0000 & 00000 & 0.08979 & 00045 & \begin{tabular}{|l|}
0.00415 \\
\end{tabular} & .04254 & \begin{tabular}{|l|}
0.01718 \\
\end{tabular} & .01343 & 16778 & 70 & 0 & 000 \\
\hline$-\mathrm{B}-7$ & & & & & & & & & & & & & & & \\
\hline A-A-7 & 03698 & 11283 & 0.01115 & 0.00000 & 0.00000 & 0.08979 & .00045 & 0.00415 & 0.04254 & 0.01718 & 0.01343 & 0.16778 & 0.00570 & 0.00000 & .00000 \\
\hline CUASEA-B-7 & 03698 & 11283 & 0.01 & 0.00000 & 0.00000 & 0.08979 & .00045 & & 0.04254 & & & & 0.00570 & & \\
\hline 131 & 4 & & 0.0 & 0 & 0. & & 3 & 45 & 789 & & & 475 & 33 & & 000 \\
\hline & & & & & & & & & 183 & & & & & & \\
\hline $\mathrm{BL}$ & 81 & & & & & & & & & & & & & & \\
\hline $7(2)$ & 181 & 0.08092 & & & & & & & & & & & & & 000 \\
\hline & & 0.08092 & & 0.00000 & & & & 0.00000 & 0.04463 & & & & & & \\
\hline & & & & & & & & & & & & & & & \\
\hline $7(2)$ & 10 & 40 & 0.0 & 000 & 0.0 & 22 & 59 & 00 & \begin{tabular}{|l|}
0.04462 \\
\end{tabular} & 31 & 730 & \begin{tabular}{|l|}
0.09067 \\
\end{tabular} & 751 & \begin{tabular}{|l|}
0.00000 \\
\end{tabular} & 0000 \\
\hline-1.6 & 0.04910 & 0.07840 & 0.01 & 0.00000 & 0.00116 & 0.12922 & 0.03359 & 0.00000 & 0.04462 & 431 & 0.01730 & 0.09067 & 0.00751 & 0.00000 & 0.00000 \\
\hline BAT & 0.04653 & 0.07911 & \begin{tabular}{|l|}
0.01081 \\
\end{tabular} & 0.00000 & 0.00141 & 0.11154 & 0.03398 & 0.00000 & 0.04515 & 0.01423 & 0.01411 & 0.09241 & 0.00898 & 0.00000 & 0.00000 \\
\hline $\mathrm{BA}$ & & 0.07911 & & & & & & & & & & & & & 0.00000 \\
\hline & & \begin{tabular}{|l|}
0.07911 \\
\end{tabular} & & 0.00000 & 0.00141 & & & 0.0 & 0.0 & & & & & & 000 \\
\hline BATCH 3-7 & 0.03465 & 0.07753 & 0.00996 & 0.00000 & 0.00141 & 0.11815 & 0.03434 & 0.00000 & 0.04546 & 0.01432 & 0.01534 & 0.09085 & 0.01061 & 0.00000 & 0.00000 \\
\hline
\end{tabular}

\begin{tabular}{|l|c|c|c|c|c|c|c|c|c|c|c|}
\hline Glass ID & $\mathbf{S e O}_{2}$ & $\mathbf{S i O}_{2}$ & $\mathbf{S r O}$ & $\mathbf{T h O}_{2}$ & $\mathbf{T i O}_{2}$ & $\mathbf{T l}_{\mathbf{2}} \mathbf{O}$ & $\mathbf{U O}_{3}$ & $\mathbf{Z n O}$ & $\mathbf{Z r O}_{2}$ & $\mathbf{O t h e r s}$ & $\mathbf{S u m}^{(\mathbf{a})}$ \\
\hline SRS-SEA-A-7 & 0.00000 & 0.48653 & 0.00000 & 0.00000 & 0.00699 & 0.00000 & 0.00000 & 0.00000 & 0.00451 & 0.00000 & 1.00000 \\
\hline SRS-SEA-B-7 & 0.00000 & 0.48653 & 0.00000 & 0.00000 & 0.00699 & 0.00000 & 0.00000 & 0.00000 & 0.00451 & 0.00000 & 1.00000 \\
\hline CUASEA-A-7 & 0.00000 & 0.48653 & 0.00000 & 0.00000 & 0.00699 & 0.00000 & 0.00000 & 0.00000 & 0.00451 & 0.00000 & 1.00000 \\
\hline CUASEA-B-7 & 0.00000 & 0.48653 & 0.00000 & 0.00000 & 0.00699 & 0.00000 & 0.00000 & 0.00000 & 0.00451 & 0.000000 & 1.00000 \\
\hline 131-TDS-EA-7 & 0.00000 & 0.39465 & 0.00000 & 0.00000 & 0.00917 & 0.00000 & 0.00000 & 0.00000 & 0.00428 & 0.00000 & 1.00000 \\
\hline 131-TDS-3A- & 0.00000 & 0.45904 & 0.00000 & 0.00000 & 0.00736 & 0.00000 & 0.00000 & 0.00000 & 0.00340 & 0.00000 & 1.00000 \\
\hline BLEND 1-7 & 0.00000 & 0.52146 & 0.00000 & 0.00000 & 0.00899 & 0.00000 & 0.00000 & 0.00000 & 0.00133 & 0.01080 & 1.00000 \\
\hline BLEND 1-7 (2) & 0.00000 & 0.52146 & 0.00000 & 0.00000 & 0.00899 & 0.00000 & 0.00000 & 0.00000 & 0.00133 & 0.01080 & 1.00000 \\
\hline BLEND 1.6-7 & 0.00000 & 0.52146 & 0.00000 & 0.00000 & 0.00899 & 0.00000 & 0.00000 & 0.00000 & 0.00133 & 0.01080 & 1.00000 \\
\hline BATCH 1-7 & 0.00000 & 0.50559 & 0.00000 & 0.00000 & 0.00682 & 0.00000 & 0.00000 & 0.00000 & 0.00094 & 0.00847 & 1.00000 \\
\hline BATCH 1-7 (2) & 0.00000 & 0.50559 & 0.00000 & 0.00000 & 0.00682 & 0.00000 & 0.00000 & 0.00000 & 0.00094 & 0.00847 & 1.00000 \\
\hline BATCH 1-1.6 & 0.00000 & 0.50559 & 0.00000 & 0.00000 & 0.00682 & 0.00000 & 0.00000 & 0.00000 & 0.00094 & 0.00847 & 1.00000 \\
\hline BATCH 2-7 & 0.00000 & 0.52294 & 0.00000 & 0.00000 & 0.00690 & 0.00000 & 0.00000 & 0.00000 & 0.00171 & 0.01019 & 1.00000 \\
\hline BATCH 2-7 (2) & 0.00000 & 0.52294 & 0.00000 & 0.00000 & 0.00690 & 0.00000 & 0.00000 & 0.00000 & 0.00171 & 0.01019 & 1.00000 \\
\hline BATCH 2-1.6 & 0.00000 & 0.52294 & 0.00000 & 0.00000 & 0.00690 & 0.00000 & 0.00000 & 0.00000 & 0.00171 & 0.01019 & 1.00000 \\
\hline BATCH 3-7 & 0.00000 & 0.53028 & 0.00000 & 0.00000 & 0.00691 & 0.00000 & 0.00000 & 0.00000 & 0.00114 & 0.00906 & 1.00000 \\
\hline
\end{tabular}

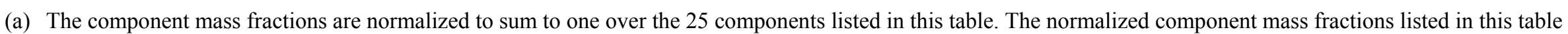
were rounded to five decimals, and may not sum exactly to 1.00000 as listed. However, complete compositions listed to more decimal places and summing to 1.0000 were used for validating PCT-composition models. 
Table B.1. Normalized 25-Component Compositions (mass fractions) of 554 HLW Glasses Used for PCT Model Validation (continued).

\begin{tabular}{|c|c|c|c|c|c|c|c|c|c|c|c|c|c|c|c|}
\hline Gla & $\mathbf{A l}_{2} \mathbf{O}_{3}$ & $\mathbf{B}_{2} \mathbf{O}_{3}$ & $\mathrm{CaO}$ & dO & $\mathrm{Cr}_{2} \mathrm{O}_{3}$ & $\mathrm{Fe}_{2} \mathrm{O}_{3}$ & $\mathbf{K}_{2} \mathbf{O}$ & $\mathbf{L a}_{2} \mathbf{O}_{3}$ & $\mathbf{L i}_{2} \mathbf{O}$ & MgO & $\mathbf{0}$ & $\mathrm{Na}_{2} \mathrm{O}$ & $\mathrm{NiO}$ & PbO & $\mathrm{Sb}_{2} \mathrm{O}_{3}$ \\
\hline BATCH 3-7 (2) & 03465 & 07753 & 00996 & 00000 & 0.00141 & 0.11815 & 03434 & 0.00000 & 04546 & 0.01432 & 01534 & 0.09085 & \begin{tabular}{|l|}
0.01061 \\
\end{tabular} & 00000 & 0.00000 \\
\hline BATCH 3-7 (3) & 3465 & 77753 & 00996 & 00000 & & \begin{tabular}{|l|}
0.11815 \\
\end{tabular} & 03434 & \begin{tabular}{|l|}
0.00000 \\
\end{tabular} & 04546 & & 534 & 0.09085 & & & \\
\hline CH 4-7 & 54 & & 47 & 0000 & & & & 00 & 4318 & & 555 & & & 00000 & 000 \\
\hline BATCH 4-7 (2) & 0.03454 & .08191 & 0.00847 & 0.00000 & 0.00139 & 0.11795 & 0.03881 & 0.00000 & 0.04318 & & 555 & 0.09222 & & 0.00000 & 0.00000 \\
\hline H 4-7(3) & 3454 & 08191 & .00847 & 0.00000 & 00139 & 0.11795 & 03881 & 0.00000 & 0.04318 & & 555 & 0.09222 & & 0.00000 & 0.00000 \\
\hline $\mathrm{HM}$ & 146 & 07030 & 11 & 0.00000 & 95 & 87 & 215 & 00 & 620 & 91 & 57 & 561 & 10 & 000 & 00 \\
\hline & & & & 0.00000 & 95 & 87 & 215 & 00 & \begin{tabular}{|l|}
0.04620 \\
\end{tabular} & & 57 & 561 & & 000 & 000 \\
\hline $\mathrm{HN}$ & 146 & 030 & 11 & 0.00000 & 0.00095 & 87 & 215 & 000 & 0.04620 & & 757 & 561 & & 0.00000 & 000 \\
\hline X 1-7 & 0.03005 & \begin{tabular}{|l|}
0.10394 \\
\end{tabular} & \begin{tabular}{|l|}
0.01096 \\
\end{tabular} & 0.00000 & 0.00160 & 0.13326 & 0.03428 & 0.00000 & 0.03239 & 0.01418 & 696 & 0.12702 & 202 & 0.00000 & 0.00000 \\
\hline PUREX 1-7 (2) & 0.03005 & \begin{tabular}{|l|}
0.10394 \\
\end{tabular} & 0.01096 & 0.00000 & & & 0.03428 & 0.00000 & 0.03239 & & & 0.12702 & & 0.00000 & 0.00000 \\
\hline $1.6-7$ & & & & 0.00000 & & & 03428 & & 0.03239 & & & 0.12702 & & 0000 & \\
\hline X SRSS 1.6 & 03005 & 394 & 0.01096 & 0.00000 & 0.00160 & 0.1 & 3428 & 0.00000 & 0.03239 & 18 & 696 & 0.12702 & 0. & 0.00000 & 0.00000 \\
\hline PUREX SRST-4.0 & 0.03005 & \begin{tabular}{|l|}
0.10394 \\
\end{tabular} & 0.01096 & 0.00000 & 0.00160 & 0.13326 & 0.03428 & 0.00000 & 0.03239 & 0.01418 & 0.01696 & 0.12702 & \begin{tabular}{|l|}
0.01202 \\
\end{tabular} & 0.00000 & 0.00000 \\
\hline PUREX CUA & 0.03005 & \begin{tabular}{|l|}
0.10394 \\
\end{tabular} & 0.01096 & 0.00000 & 0.00160 & 0.13326 & 0.03428 & 0.00000 & 0.03239 & 0.01418 & 0.01696 & 0.12702 & 0.01202 & 0.00000 & 0.00000 \\
\hline D 1-3457 & & \begin{tabular}{|l|}
0.07029 \\
\end{tabular} & 0.01122 & 0.00000 & 0.00232 & 0.1 & \begin{tabular}{|l|}
0.02561 \\
\end{tabular} & 0.00000 & 0.04286 & & 0.02156 & 0.10253 & 0.00 & 0.00000 & 0.00000 \\
\hline BLEND 1-3479 & 0.05378 & 0.07078 & 0.01089 & 0.00000 & 0.00232 & 0.12879 & 0.02621 & 0.00000 & 0.04308 & 0.01294 & 0.02202 & 0.10158 & 0.00868 & 0.00000 & 0.00000 \\
\hline
\end{tabular}

\begin{tabular}{|l|c|c|c|c|c|c|c|c|c|c|c|}
\hline Glass ID & $\mathbf{S e O}_{2}$ & $\mathbf{S i O}_{2}$ & $\mathbf{S r O}$ & $\mathbf{T h O}_{2}$ & $\mathbf{T i O}_{2}$ & $\mathbf{T l}_{\mathbf{2}} \mathbf{O}$ & $\mathbf{U O}_{\mathbf{3}}$ & $\mathbf{Z n O}$ & $\mathbf{Z r O}_{2}$ & $\mathbf{O t h e r s ~}^{\mathbf{S u m}}$ \\
\hline BATCH 3-7 & 0.00000 & 0.53028 & 0.00000 & 0.00000 & 0.00691 & 0.00000 & 0.00000 & 0.00000 & 0.00114 & 0.00906 & 1.00000 \\
\hline BATCH 3-7 & 0.00000 & 0.53028 & 0.00000 & 0.00000 & 0.00691 & 0.00000 & 0.00000 & 0.00000 & 0.00114 & 0.00906 & 1.00000 \\
\hline BATCH 4-7 & 0.00000 & 0.50422 & 0.00000 & 0.00000 & 0.01036 & 0.00000 & 0.00000 & 0.00000 & 0.00226 & 0.01401 & 1.00000 \\
\hline BATCH 4-7 (2) & 0.00000 & 0.50422 & 0.00000 & 0.00000 & 0.01036 & 0.00000 & 0.00000 & 0.00000 & 0.00226 & 0.01401 & 1.00000 \\
\hline BATCH 4-7 (3) & 0.00000 & 0.50422 & 0.00000 & 0.00000 & 0.01036 & 0.00000 & 0.00000 & 0.00000 & 0.00226 & 0.01401 & 1.00000 \\
\hline HM-1-7 & 0.00000 & 0.55817 & 0.00000 & 0.00000 & 0.00564 & 0.00000 & 0.00000 & 0.00000 & 0.00328 & 0.01167 & 1.00000 \\
\hline HM-1-7 (2) & 0.00000 & 0.55817 & 0.00000 & 0.00000 & 0.00564 & 0.00000 & 0.00000 & 0.00000 & 0.00328 & 0.01167 & 1.00000 \\
\hline HM-1.6-7 & 0.00000 & 0.55817 & 0.00000 & 0.00000 & 0.00564 & 0.00000 & 0.00000 & 0.00000 & 0.00328 & 0.01167 & 1.00000 \\
\hline PUREX 1-7 & 0.00000 & 0.46806 & 0.00000 & 0.00000 & 0.00685 & 0.00000 & 0.00000 & 0.00000 & 0.00037 & 0.00806 & 1.00000 \\
\hline PUREX 1-7 (2) & 0.00000 & 0.46806 & 0.00000 & 0.00000 & 0.00685 & 0.00000 & 0.00000 & 0.00000 & 0.00037 & 0.00806 & 1.00000 \\
\hline PUREX 1.6-7 & 0.00000 & 0.46806 & 0.00000 & 0.00000 & 0.00685 & 0.00000 & 0.00000 & 0.00000 & 0.00037 & 0.00806 & 1.00000 \\
\hline PUREX SRSS & 0.00000 & 0.46806 & 0.00000 & 0.00000 & 0.00685 & 0.00000 & 0.00000 & 0.00000 & 0.00037 & 0.00806 & 1.00000 \\
\hline PUREX SRST- & 0.00000 & 0.46806 & 0.00000 & 0.00000 & 0.00685 & 0.00000 & 0.00000 & 0.00000 & 0.00037 & 0.00806 & 1.00000 \\
\hline PUREX CUA & 0.00000 & 0.46806 & 0.00000 & 0.00000 & 0.00685 & 0.00000 & 0.00000 & 0.00000 & 0.00037 & 0.00806 & 1.00000 \\
\hline BLEND 1-3457 & 0.00000 & 0.51302 & 0.00000 & 0.00000 & 0.00244 & 0.00000 & 0.00000 & 0.00000 & 0.00000 & 0.00312 & 1.00000 \\
\hline BLEND 1-3479 & 0.00000 & 0.51386 & 0.00000 & 0.00000 & 0.00232 & 0.00000 & 0.00000 & 0.00000 & 0.00000 & 0.00276 & 1.00000 \\
\hline
\end{tabular}

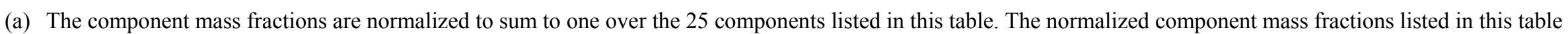
were rounded to five decimals, and may not sum exactly to 1.00000 as listed. However, complete compositions listed to more decimal places and summing to 1.0000 were used for validating PCT-composition models. 
Table B.1. Normalized 25-Component Compositions (mass fractions) of 554 HLW Glasses Used for PCT Model Validation (continued).

\begin{tabular}{|c|c|c|c|c|c|c|c|c|c|c|c|c|c|c|c|}
\hline & ${ }_{2} \mathbf{O}_{3}$ & $\mathbf{B}_{2} \mathbf{O}_{3}$ & & $\mathbf{O}$ & $\mathbf{r}_{2} \mathbf{O}_{3}$ & $\mathrm{Fe}_{2} \mathrm{O}_{3}$ & $\mathrm{~K}_{2} \mathrm{O}$ & $\mathbf{L a}_{2} \mathbf{O}_{3}$ & $\mathbf{i}_{2} \mathbf{O}$ & & & $\mathrm{Na}_{2} \mathrm{O}$ & $\mathrm{NiO}$ & & $\mathrm{Sb}_{2} \mathbf{O}_{3}$ \\
\hline 498 & & 06 & 1 & 00 & & 13064 & 770 & 0 & 4 & & & 00 & 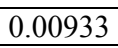 & & 0000 \\
\hline & & & & & & & & & & & & & & & \\
\hline & & & & & & & & & & & & & & & \\
\hline & & & & & & & & & & & & & & & \\
\hline & & & & & & & & & & & & & & & \\
\hline & & & & & & & & & & & & & & & \\
\hline & & & & & & & & & & & & & & & \\
\hline & & & & & & & & & & & & & & & \\
\hline & & & & & & & & & & & & & & & \\
\hline & & & & & & & & & & & & & & & \\
\hline & & & & & & & & & & & & & & & \\
\hline & & & & & & & & & & & & & & & \\
\hline $3802 \mathrm{~B}$ & & & & & & & & & & & & & 88 & & 000 \\
\hline & & 6956 & & 00000 & & & & & & & & & & & \\
\hline & & & & & & & & & & & & & & & \\
\hline 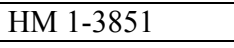 & +3 & 06692 & 9935 & .00000 & 37 & 22 & 53 & 0.0 & 562 & 64 & 0.0 & 20 & 0.007 & 0.00000 & 0.070 \\
\hline
\end{tabular}

\begin{tabular}{|l|c|c|c|c|c|c|c|c|c|c|c|}
\hline Glass ID & $\mathbf{S e O}_{2}$ & $\mathbf{S i O}_{2}$ & $\mathbf{S r O}$ & $\mathbf{T h O}_{2}$ & $\mathbf{T i O}_{2}$ & $\mathbf{T l}_{\mathbf{2}} \mathbf{O}$ & $\mathbf{U O}_{\mathbf{3}}$ & $\mathbf{Z n O}$ & $\mathbf{Z r O}_{2}$ & $\mathbf{O t h e r s ~}^{\text {Sum }}$ \\
\hline BLEND 1-3498 & 0.00000 & 0.50125 & 0.00000 & 0.00000 & 0.00207 & 0.00000 & 0.00000 & 0.00000 & 0.00000 & 0.00287 & 1.00000 \\
\hline BLEND 1-3510 & 0.00000 & 0.49853 & 0.00000 & 0.00000 & 0.00194 & 0.00000 & 0.00000 & 0.00000 & 0.00000 & 0.00287 & 1.00000 \\
\hline BLEND 1-3526 & 0.00000 & 0.50241 & 0.00000 & 0.00000 & 0.00183 & 0.00000 & 0.00000 & 0.00000 & 0.00000 & 0.00276 & 1.00000 \\
\hline BLEND 2-3611 & 0.00000 & 0.52298 & 0.00000 & 0.00000 & 0.00172 & 0.00000 & 0.00000 & 0.00000 & 0.00000 & 0.00265 & 1.00000 \\
\hline BLEND 2-3622 & 0.00000 & 0.52635 & 0.00000 & 0.00000 & 0.00160 & 0.00000 & 0.00000 & 0.00000 & 0.00000 & 0.00266 & 1.00000 \\
\hline BLEND 2-3635 & 0.00000 & 0.52762 & 0.00000 & 0.00000 & 0.00173 & 0.00000 & 0.00000 & 0.00000 & 0.00000 & 0.00267 & 1.00000 \\
\hline BLEND 2-3654 & 0.00000 & 0.52642 & 0.00000 & 0.00000 & 0.00148 & 0.00000 & 0.00000 & 0.00000 & 0.00000 & 0.00267 & 1.00000 \\
\hline BLEND 2-3666 & 0.00000 & 0.52565 & 0.00000 & 0.00000 & 0.00148 & 0.00000 & 0.00000 & 0.00000 & 0.00000 & 0.00267 & 1.00000 \\
\hline BLEND 2-3676 & 0.00000 & 0.52958 & 0.00000 & 0.00000 & 0.00148 & 0.00000 & 0.00000 & 0.00000 & 0.00000 & 0.00267 & 1.00000 \\
\hline BLEND 3-3768 & 0.00000 & 0.51975 & 0.00000 & 0.00000 & 0.00136 & 0.00000 & 0.00000 & 0.00000 & 0.00057 & 0.00315 & 1.00000 \\
\hline BLEND 3-3789 & 0.00000 & 0.50404 & 0.00000 & 0.00000 & 0.00135 & 0.00000 & 0.00000 & 0.00000 & 0.00038 & 0.00348 & 1.00000 \\
\hline BLEND 3-3793 & 0.00000 & 0.49454 & 0.00000 & 0.00000 & 0.00122 & 0.00000 & 0.00000 & 0.00000 & 0.00037 & 0.00370 & 1.00000 \\
\hline BLEND 3- & 0.00000 & 0.49693 & 0.00000 & 0.00000 & 0.00121 & 0.00000 & 0.00000 & 0.00000 & 0.00037 & 0.00358 & 1.00000 \\
\hline HM 1-3824 & 0.00000 & 0.53257 & 0.00000 & 0.00000 & 0.00087 & 0.00000 & 0.00000 & 0.00000 & 0.00019 & 0.00244 & 1.00000 \\
\hline HM 1-3829 & 0.00000 & 0.53470 & 0.00000 & 0.00000 & 0.00099 & 0.00000 & 0.00000 & 0.00000 & 0.00038 & 0.00244 & 1.00000 \\
\hline HM 1-3851 & 0.00000 & 0.53414 & 0.00000 & 0.00000 & 0.00087 & 0.00000 & 0.00000 & 0.00000 & 0.00038 & 0.00244 & 1.00000 \\
\hline
\end{tabular}

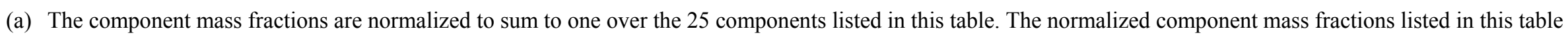
were rounded to five decimals, and may not sum exactly to 1.00000 as listed. However, complete compositions listed to more decimal places and summing to 1.0000 were used for validating PCT-composition models. 
Table B.1. Normalized 25-Component Compositions (mass fractions) of 554 HLW Glasses Used for PCT Model Validation (continued).

\begin{tabular}{|c|c|c|c|c|c|c|c|c|c|c|c|c|c|c|c|}
\hline Gla & $\mathbf{A l}_{2} \mathbf{O}_{3}$ & $\mathbf{B}_{2} \mathbf{O}_{3}$ & $\mathrm{CaO}$ & dO & $\mathrm{Cr}_{2} \mathrm{O}_{3}$ & $\mathrm{Fe}_{2} \mathrm{O}_{3}$ & $\mathbf{K}_{2} \mathbf{O}$ & $\mathbf{L a}_{2} \mathbf{O}_{3}$ & $\mathbf{L i}_{2} \mathbf{O}$ & 0 & 0 & $\mathrm{Na}_{2} \mathrm{O}$ & $\mathrm{NiO}$ & PbO & $\mathrm{Sb}_{2} \mathrm{O}_{3}$ \\
\hline HM 1-3855 & 06640 & .06615 & 860 & 00000 & .00214 & 10137 & 01386 & 0.00000 & 04612 & 01653 & 02687 & 10207 & 0690 & 0000 & .00000 \\
\hline HM-2-1 (39 & & 6640 & & 0000 & 0494 & & & 0.00000 & & & & 10173 & & 0.00069 & \\
\hline HM-2-2 (4099A) & 88 & 58 & & 00 & & 0 & & 00 & & & & & & 0069 & \\
\hline HM-2-3 (4120B) & 07479 & 0.06744 & 00699 & 0.00000 & 00402 & 0.09376 & 936 & 0.00000 & 0.04630 & 32 & 662 & 521 & 0.00605 & 0.00070 & 00000 \\
\hline HM-3-1 (4176) & 07740 & 0.06458 & 0685 & 0.00000 & \begin{tabular}{|l|}
0.00399 \\
\end{tabular} & 0.0 & 2170 & 0.00000 & & 83 & 555 & 818 & & 0.00035 & 00000 \\
\hline HM-3-2 (4225) & 81 & 693 & 41 & 0.0 & 97 & 0. & 13 & 0. & 63 & 41 & 00 & 75 & 85 & 334 & \\
\hline HM-3-3 (4357) & 75 & 696 & 779 & 0.00000 & 118 & 0.1 & 58 & 0.00000 & 206 & 75 & 35 & 077 & 504 & 034 & 00 \\
\hline HM-4-1 (5260) & 0.05285 & 0.0 & 498 & 0.00000 & 149 & & 346 & 0.00000 & 0.04456 & 85 & 02 & 464 & 0.00616 & 104 & 000 \\
\hline HM-4-2 (5641) & \begin{tabular}{|l|}
0.06259 \\
\end{tabular} & 0.09186 & 0.00497 & 0.00000 & 0.00661 & 0.0 & 0.02694 & 0.00000 & 0.04314 & 52 & 554 & 0.09276 & 975 & 0.00069 & 0.00000 \\
\hline HM-4-3 (5748) & \begin{tabular}{|l}
0.05656 \\
\end{tabular} & \begin{tabular}{|l|}
0.08799 \\
\end{tabular} & 0.00495 & 0.00000 & & \begin{tabular}{|l|}
0.07273 \\
\end{tabular} & \begin{tabular}{|l|}
0.02791 \\
\end{tabular} & & & & & & & 0035 & \\
\hline PX 1-1 (4643) & & \begin{tabular}{|l|}
0.07422 \\
\end{tabular} & & 0.00000 & 468 & & 927 & & & & & & 20 & 172 & \\
\hline PX 1-2 (4726) & \begin{tabular}{|l|}
0.04897 \\
\end{tabular} & 0.07265 & 01480 & 0.00000 & \begin{tabular}{|l|}
0.00536 \\
\end{tabular} & \begin{tabular}{|l|}
0.11028 \\
\end{tabular} & 02992 & 0.00000 & 0.04283 & 23 & 22 & \begin{tabular}{|l|}
0.09892 \\
\end{tabular} & 0.0 & 0.00171 & 0000 \\
\hline PX 1-3 (4776) & 0.04349 & 0.07272 & 0.01327 & 0.00000 & \begin{tabular}{|l|}
0.00521 \\
\end{tabular} & \begin{tabular}{|l|}
0.09994 \\
\end{tabular} & 0.02771 & \begin{tabular}{|l|}
0.00000 \\
\end{tabular} & \begin{tabular}{|l|}
0.04503 \\
\end{tabular} & 0.01474 & \begin{tabular}{|l|}
0.02838 \\
\end{tabular} & \begin{tabular}{|l|}
0.09581 \\
\end{tabular} & 0.01570 & 0.00174 & 0.00000 \\
\hline PX 2-1 (4455) & \begin{tabular}{|l|}
0.08464 \\
\end{tabular} & \begin{tabular}{|l|}
0.06821 \\
\end{tabular} & 0.00787 & 0.00000 & 0.00399 & 0.09462 & 0.02137 & 0.00000 & 0.04307 & 0.01580 & 0.02813 & \begin{tabular}{|l|}
0.10377 \\
\end{tabular} & 0.00634 & 0.00034 & 0.00000 \\
\hline PX 2-2 (4509) & & \begin{tabular}{|l|}
0.07193 \\
\end{tabular} & 0.01142 & \begin{tabular}{|l|}
0.00000 \\
\end{tabular} & \begin{tabular}{|l|}
0.00465 \\
\end{tabular} & 0.1 & \begin{tabular}{|l|}
0.02480 \\
\end{tabular} & \begin{tabular}{|l|}
0.00000 \\
\end{tabular} & 0.04318 & 555 & 40 & \begin{tabular}{|l|}
0.09553 \\
\end{tabular} & 0.01178 & 0.00102 & \\
\hline PX 2-3 (4566) & 0.06009 & 0.07438 & 0.01459 & 0.00000 & 0.00465 & 0.10951 & 0.03028 & 0.00000 & 0.04313 & 0.01511 & 0.03257 & 0.09885 & 0.01521 & 0.00137 & 0.00000 \\
\hline
\end{tabular}

\begin{tabular}{|l|c|c|c|c|c|c|c|c|c|c|c|}
\hline Glass ID & $\mathbf{S e O}_{2}$ & $\mathbf{S i O}_{2}$ & $\mathbf{S r O}$ & $\mathbf{T h O}_{2}$ & $\mathbf{T i O}_{2}$ & $\mathbf{T l}_{\mathbf{2}} \mathbf{O}$ & $\mathbf{U O}_{3}$ & $\mathbf{Z n O}$ & $\mathbf{Z r O}_{2}$ & $\mathbf{O t h e r s}$ & $\mathbf{S u m}^{(\mathbf{a})}$ \\
\hline HM 1-3855 & 0.00000 & 0.53959 & 0.00000 & 0.00000 & 0.00088 & 0.00000 & 0.00000 & 0.00000 & 0.00019 & 0.00233 & 1.00000 \\
\hline HM-2-1 & 0.00000 & 0.52889 & 0.00144 & 0.00000 & 0.00087 & 0.00000 & 0.00000 & 0.00101 & 0.00076 & 0.00230 & 1.00000 \\
\hline HM-2-2 & 0.00000 & 0.52351 & 0.00160 & 0.00000 & 0.00123 & 0.00000 & 0.00000 & 0.00101 & 0.00057 & 0.00242 & 1.00000 \\
\hline HM-2-3 & 0.00000 & 0.52701 & 0.00145 & 0.00000 & 0.00100 & 0.00000 & 0.00000 & 0.00089 & 0.00077 & 0.00232 & 1.00000 \\
\hline HM-3-1 & 0.00000 & 0.52809 & 0.00144 & 0.00000 & 0.00099 & 0.00000 & 0.00000 & 0.00088 & 0.00057 & 0.00219 & 1.00000 \\
\hline HM-3-2 & 0.00000 & 0.50934 & 0.00143 & 0.00000 & 0.00098 & 0.00000 & 0.00000 & 0.00087 & 0.00057 & 0.00253 & 1.00000 \\
\hline HM-3-3 & 0.00000 & 0.50265 & 0.00158 & 0.00000 & 0.00098 & 0.00000 & 0.00000 & 0.00087 & 0.00075 & 0.00251 & 1.00000 \\
\hline HM-4-1 & 0.00000 & 0.54140 & 0.00081 & 0.00000 & 0.00249 & 0.00000 & 0.00000 & 0.00114 & 0.01189 & 0.00214 & 1.00000 \\
\hline HM-4-2 & 0.00000 & 0.53964 & 0.00081 & 0.00000 & 0.00261 & 0.00000 & 0.00000 & 0.00114 & 0.00689 & 0.00312 & 1.00000 \\
\hline HM-4-3 & 0.00000 & 0.56311 & 0.00082 & 0.00000 & 0.00252 & 0.00000 & 0.00000 & 0.00103 & 0.00447 & 0.00259 & 1.00000 \\
\hline PX 1-1 (4643) & 0.00000 & 0.50025 & 0.00032 & 0.00000 & 0.00172 & 0.00000 & 0.00000 & 0.00163 & 0.00076 & 0.00495 & 1.00000 \\
\hline PX 1-2 (4726) & 0.00000 & 0.49948 & 0.00032 & 0.00000 & 0.00368 & 0.00000 & 0.00000 & 0.00175 & 0.00076 & 0.00527 & 1.00000 \\
\hline PX 1-3 (4776) & 0.00000 & 0.52557 & 0.00016 & 0.00000 & 0.00361 & 0.00000 & 0.00000 & 0.00165 & 0.00077 & 0.00452 & 1.00000 \\
\hline PX 2-1 (4455) & 0.00000 & 0.51530 & 0.00144 & 0.00000 & 0.00099 & 0.00000 & 0.00000 & 0.00100 & 0.00057 & 0.00254 & 1.00000 \\
\hline PX 2-2 (4509) & 0.00000 & 0.50197 & 0.00079 & 0.00000 & 0.00171 & 0.00000 & 0.00000 & 0.00137 & 0.00057 & 0.00372 & 1.00000 \\
\hline PX 2-3 (4566) & 0.00000 & 0.49065 & 0.00048 & 0.00000 & 0.00220 & 0.00000 & 0.00000 & 0.00149 & 0.00075 & 0.00468 & 1.00000 \\
\hline
\end{tabular}

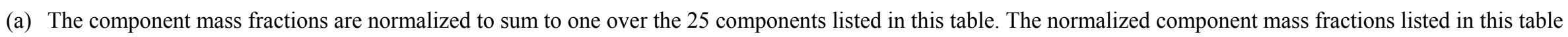
were rounded to five decimals, and may not sum exactly to 1.00000 as listed. However, complete compositions listed to more decimal places and summing to 1.0000 were used for validating PCT-composition models. 
Table B.1. Normalized 25-Component Compositions (mass fractions) of 554 HLW Glasses Used for PCT Model Validation (continued).

\begin{tabular}{|c|c|c|c|c|c|c|c|c|c|c|c|c|c|c|c|}
\hline D & $\mathbf{A l}_{2} \mathbf{O}_{3}$ & $\mathbf{B}_{2} \mathbf{O}_{3}$ & & & $\mathrm{Cr}_{2} \mathrm{O}_{3}$ & $\mathbf{e}_{2} \mathbf{O}_{3}$ & ${ }_{2} \mathrm{O}$ & $\mathbf{L a}_{2} \mathbf{O}_{3}$ & $\mathbf{i}_{2} \mathbf{O}$ & & & $\mathrm{Ja}_{2} \mathrm{O}$ & $\mathbf{N}$ & & $\mathrm{Sb}_{2} \mathrm{O}_{3}$ \\
\hline 3-1 & & 9 & & 0 & & & 36 & 0 & 1 & 2 & & 08 & 8 & & $\overline{00}$ \\
\hline PX 3-2 & & & & & & & & & & & & & & & \\
\hline $3-3$ & & & & & & & & & & & & & & & \\
\hline PX 4-1 (63 & & & & & & & & & & & & & & & \\
\hline PX 4-2 (643 & & & & & & & & & & & & & & & \\
\hline PX 4-3 (64 & & & & & & & & & & & & & & & \\
\hline $5-1 \quad 67$ & & & & & & & & & & & & & & & \\
\hline PX 5-2 (67 & & & & & & & & & & & & & & & \\
\hline $\begin{array}{l}\text { PX 5-3 } \quad(68 \\
\end{array}$ & & & & & & & & & & & & & & & \\
\hline PX 5-4 (6820) & & & & & & & & & & & & & & & \\
\hline $\begin{array}{ll}\text { PX 5-5 } & (68 \\
\end{array}$ & & & & & & & & & & & & & & & \\
\hline PX 5-6 (68 & & & & & & & & & & & & & & & 00 \\
\hline PX 5-7 (6871) & & & & & & & & & & & & & & & 000 \\
\hline PX 5-8 (6884) & 787 & 0.09482 & 823 & 0000 & & & & & & & & & & & \\
\hline PX 5-9 (696 & & & & & & & & & & & & & & & \\
\hline X 5-10 (6972) & 655 & 10955 & 00748 & 00000 & 53 & 18 & 0.0 & 0.00000 & 0.0 & 54 & 91 & 35 & 13 & 0.0 & 0.00000 \\
\hline
\end{tabular}

\begin{tabular}{|c|c|c|c|c|c|c|c|c|c|c|c|}
\hline Slass ID & $\mathrm{SeO}_{2}$ & $\mathrm{SiO}_{2}$ & rO & $\mathrm{ThO}_{2}$ & $\mathrm{TiO}_{2}$ & $\mathrm{Tl}_{2} \mathrm{O}$ & $\mathbf{U O}_{3}$ & 2110 & $\mathrm{ZrO}_{2}$ & 0 & \\
\hline X 3-1 ( & 0000 & 57624 & & 00000 & 00227 & 0000 & & & & & \\
\hline $3-2 \quad(5818)$ & & & & & & & & & & & \\
\hline $3-3 \quad(58$ & & & & & & & & & & & \\
\hline \begin{tabular}{|ll} 
PX 4-1 & $(63$ \\
\end{tabular} & & & & & & & & & & & \\
\hline \begin{tabular}{|ll} 
PX 4-2 & $(643$ \\
\end{tabular} & & & & & & & & & & & \\
\hline 42 & & & & & & & & & & & \\
\hline$-1 \quad(67$ & & & & & & & & & & & \\
\hline$-2 \quad 67$ & & 79 & & & & & & & & & \\
\hline $5-3 \quad 68$ & & & & & & & & & & & \\
\hline $\begin{array}{ll}5-4 & (6820) \\
\end{array}$ & & & & & & & & & & & \\
\hline $5-5 \quad(683$ & & & & & & & & & & & \\
\hline $5-6 \quad 68$ & & & & & & & & & & & \\
\hline $5-7 \quad 68$ & & & & & & & & & & & \\
\hline $\begin{array}{|ll|}\text { PX 5-8 (6884) } \\
\end{array}$ & & 9712 & & & & & & & & & \\
\hline$(69$ & & & & & & & & & & & \\
\hline PX 5-10 & 0000 & 49997 & 0.00000 & .00000 & 3 & 0.00000 & 0.00000 & 0.00089 & 715 & 0.00571 & 1.00000 \\
\hline
\end{tabular}

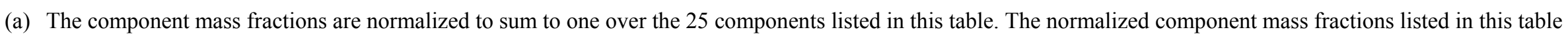
were rounded to five decimals, and may not sum exactly to 1.00000 as listed. However, complete compositions listed to more decimal places and summing to 1.0000 were used for validating PCT-composition models. 
Table B.1. Normalized 25-Component Compositions (mass fractions) of 554 HLW Glasses Used for PCT Model Validation (continued).

\begin{tabular}{|c|c|c|c|c|c|c|c|c|c|c|c|c|c|c|c|}
\hline Gl & $\mathrm{Al}_{2} \mathrm{O}_{3}$ & $\mathbf{B}_{2} \mathbf{O}_{3}$ & $\mathrm{CaO}$ & dO & $\mathrm{Cr}_{2} \mathrm{O}_{3}$ & $\mathrm{Fe}_{2} \mathrm{O}_{3}$ & $\mathbf{K}_{2} \mathbf{O}$ & $\mathbf{L a}_{2} \mathbf{O}_{3}$ & $\mathbf{L i}_{2} \mathbf{O}$ & MgO & $\mathrm{O}$ & $\mathrm{Na}_{2} \mathrm{O}$ & $\mathrm{NiO}$ & bO & $\mathrm{Sb}_{2} \mathrm{O}_{3}$ \\
\hline PX 6-1 (7340) & 02072 & 0.08633 & 00839 & 0.00000 & \begin{tabular}{|l|}
0.00383 \\
\end{tabular} & \begin{tabular}{|l|}
0.09914 \\
\end{tabular} & 0.02805 & 0.00000 & 04873 & 0.01588 & \begin{tabular}{|l|}
0.01721 \\
\end{tabular} & 0.10898 & 0.01142 & 00141 & 0.00000 \\
\hline BATCH 1 STUDY & 2555 & 11416 & 31 & 00000 & 00049 & 0.04399 & 0.07701 & 0.00000 & .04660 & 72 & & 108 & 76 & 36 & \\
\hline BATCH 1 STUDY-10B-7 & 95 & 88 & 57 & 0.00000 & 0050 & 10 & 4207 & 0.00000 & 0.05255 & & 34 & 12 & 0258 & 0.00000 & 0000 \\
\hline 1 STUDY-15-7 & 0.02553 & 0.08089 & 0.00562 & 0.00000 & 0.00025 & 0.04439 & 0.02249 & 0.00000 & 0.05622 & 0.01696 & 0.00722 & 0.07222 & 0.00274 & 0.00000 & 0.00000 \\
\hline H-GLAS-0112 & \begin{tabular}{|l|}
0.04074 \\
\end{tabular} & 0.08257 & 0.01330 & 0.00000 & \begin{tabular}{|l|}
0.00451 \\
\end{tabular} & \begin{tabular}{|l|}
0.09844 \\
\end{tabular} & 0.01588 & 0.00051 & 0.04622 & 0.01365 & 0.02546 & 0.09383 & 0.01446 & 0.00209 & 0.00000 \\
\hline $\mathrm{H}-\mathrm{G}$ & 03863 & 99450 & & 0.00000 & 0.00428 & 13 & 622 & 0.0 & 0.04711 & 61 & 44 & \begin{tabular}{|l|}
0.08869 \\
\end{tabular} & 10 & 210 & 000 \\
\hline $\mathrm{H}-\mathrm{C}$ & & 606 & & 0.00000 & 427 & 16 & 823 & 54 & 0.04790 & 85 & 94 & \begin{tabular}{|l|}
0.07993 \\
\end{tabular} & 02 & 0.00174 & 000 \\
\hline $\mathrm{H}-\mathrm{C}$ & 348 & 0.09400 & 0.01002 & 0.00000 & \begin{tabular}{|l|}
0.00374 \\
\end{tabular} & 0.11064 & 0.01436 & 100 & 0.04527 & 99 & 791 & 0.09275 & 0.00909 & 0.00172 & 0.00000 \\
\hline 0254 & \begin{tabular}{|l|}
0.03189 \\
\end{tabular} & 0.12159 & 0.00684 & 0.00000 & \begin{tabular}{|l|}
0.00380 \\
\end{tabular} & 0.08265 & 0.00663 & 255 & 0.04859 & 0.00592 & 131 & 0.07685 & 0.00923 & 0.00175 & 0.00000 \\
\hline $\mathrm{H}-\mathrm{G}$ & 0.03218 & 0.11874 & 0.00567 & 0.00000 & \begin{tabular}{|l|}
0.00378 \\
\end{tabular} & 0.08889 & 0.00600 & & 0.04725 & 0.00539 & 0.00993 & 0.07632 & 0.00848 & 0.00174 & 0.00000 \\
\hline $\mathrm{H}-\mathrm{C}$ & & & 0.00561 & 0.00000 & 0.00 & 0.0 & 0.00633 & & 0.04800 & & 998 & 0.08126 & 0.00852 & 0.00174 & 0.00000 \\
\hline $\mathrm{H}-\mathrm{G}$ & 03099 & 0.12642 & 0.00577 & 0.00000 & \begin{tabular}{|l|}
0.00521 \\
\end{tabular} & 0.0 & 0.00514 & 0.0 & 0.05030 & 0.00465 & \begin{tabular}{|l|}
0.00973 \\
\end{tabular} & 0.07912 & 13 & 0.00174 & 0.00000 \\
\hline \begin{tabular}{|l|}
$\mathrm{H}-\mathrm{GL}$ \\
\end{tabular} & 0.03065 & 0.12957 & 0.00515 & 0.00000 & \begin{tabular}{|l|}
0.00450 \\
\end{tabular} & 0.09675 & 0.00469 & 0.00254 & 0.04924 & 0.00427 & \begin{tabular}{|l|}
0.00906 \\
\end{tabular} & 0.08051 & 0.00931 & 0.00174 & 0.00000 \\
\hline H-GLAS-0352 & 0.02903 & 0.13184 & 0.00469 & 0.00000 & \begin{tabular}{|l|}
0.00400 \\
\end{tabular} & \begin{tabular}{|l|}
0.09315 \\
\end{tabular} & 0.00408 & 0.00252 & 0.04938 & 0.00343 & 0.00790 & 0.07911 & 0.00948 & 0.00173 & 0.00000 \\
\hline H-G & 02833 & 0.13604 & 0.00403 & 0.00000 & \begin{tabular}{|l|}
0.00403 \\
\end{tabular} & 0.08050 & 0.00323 & 0.00203 & 0.04995 & 0.00289 & 0.00698 & 0.07642 & 0.00804 & 0.00174 & 0.00000 \\
\hline \begin{tabular}{|l|} 
H-GLAS-0421 \\
\end{tabular} & 0.03035 & 0.13763 & 0.00430 & 0.00000 & \begin{tabular}{|l|}
0.00452 \\
\end{tabular} & 0.08906 & 0.00295 & 0.00204 & 0.05079 & 0.00278 & 0.00700 & 0.07971 & 0.00854 & 0.00175 & 0.00000 \\
\hline
\end{tabular}

\begin{tabular}{|l|c|c|c|c|c|c|c|c|c|c|c|}
\hline Glass ID & $\mathbf{S e O}_{\mathbf{2}}$ & $\mathbf{S i O}_{\mathbf{2}}$ & $\mathbf{S r O}$ & $\mathbf{T h O}_{\mathbf{2}}$ & $\mathbf{T i O}_{\mathbf{2}}$ & $\mathbf{T l}_{\mathbf{2}} \mathbf{O}$ & $\mathbf{U O}_{\mathbf{3}}$ & $\mathbf{Z n O}$ & $\mathbf{Z r O}_{\mathbf{2}}$ & $\mathbf{O t h e r s}^{\text {Sum }}$ \\
\hline PX 6-1 (7340) & 0.00000 & 0.53357 & 0.00000 & 0.00000 & 0.00151 & 0.00000 & 0.00000 & 0.00103 & 0.01010 & 0.00371 & 1.00000 \\
\hline BATCH 1 & 0.00000 & 0.54225 & 0.00017 & 0.00000 & 0.01527 & 0.00000 & 0.00000 & 0.00026 & 0.00158 & 0.01180 & 1.00000 \\
\hline BATCH 1 & 0.00000 & 0.60278 & 0.00000 & 0.00000 & 0.01036 & 0.00000 & 0.00000 & 0.00053 & 0.00202 & 0.00864 & 1.00000 \\
\hline BATCH 1 & 0.00000 & 0.65200 & 0.00000 & 0.00000 & 0.00520 & 0.00000 & 0.00000 & 0.00054 & 0.00185 & 0.00587 & 1.00000 \\
\hline H-GLAS-0112 & 0.00000 & 0.52953 & 0.00032 & 0.00000 & 0.00387 & 0.00000 & 0.00000 & 0.00330 & 0.00615 & 0.00517 & 1.00000 \\
\hline H-GLAS-0130 & 0.00000 & 0.53733 & 0.00032 & 0.00000 & 0.00275 & 0.00000 & 0.00000 & 0.00280 & 0.00617 & 0.00525 & 1.00000 \\
\hline H-GLAS-0162 & 0.00000 & 0.54579 & 0.00032 & 0.00000 & 0.00212 & 0.00000 & 0.00000 & 0.00444 & 0.02613 & 0.00433 & 1.00000 \\
\hline H-GLAS-0244 & 0.00000 & 0.52359 & 0.00032 & 0.00000 & 0.00197 & 0.00000 & 0.00000 & 0.00288 & 0.01328 & 0.00398 & 1.00000 \\
\hline H-GLAS-0254 & 0.00000 & 0.55289 & 0.00032 & 0.00000 & 0.00187 & 0.00000 & 0.00000 & 0.00267 & 0.02832 & 0.00431 & 1.00000 \\
\hline H-GLAS-0278 & 0.00000 & 0.55426 & 0.00032 & 0.00000 & 0.00174 & 0.00000 & 0.00000 & 0.00329 & 0.02931 & 0.00418 & 1.00000 \\
\hline H-GLAS-0293 & 0.00000 & 0.55582 & 0.00032 & 0.00000 & 0.00175 & 0.00000 & 0.00000 & 0.00280 & 0.01579 & 0.00417 & 1.00000 \\
\hline H-GLAS-0308 & 0.00000 & 0.54172 & 0.00032 & 0.00000 & 0.00174 & 0.00000 & 0.00000 & 0.00342 & 0.03227 & 0.00439 & 1.00000 \\
\hline H-GLAS-0334 & 0.00000 & 0.54567 & 0.00032 & 0.00000 & 0.00162 & 0.00000 & 0.00000 & 0.00304 & 0.01746 & 0.00391 & 1.00000 \\
\hline H-GLAS-0352 & 0.00000 & 0.53556 & 0.00032 & 0.00000 & 0.00161 & 0.00000 & 0.00000 & 0.00302 & 0.03527 & 0.00389 & 1.00000 \\
\hline H-GLAS-0387 & 0.00000 & 0.54962 & 0.00032 & 0.00000 & 0.00150 & 0.00000 & 0.00000 & 0.00343 & 0.03712 & 0.00380 & 1.00000 \\
\hline H-GLAS-0421 & 0.00000 & 0.55101 & 0.00032 & 0.00000 & 0.00150 & 0.00000 & 0.00000 & 0.00280 & 0.01911 & 0.00381 & 1.00000 \\
\hline
\end{tabular}

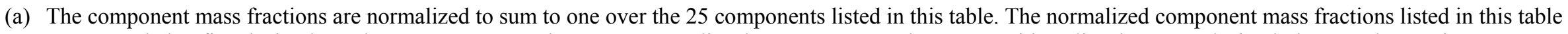
were rounded to five decimals, and may not sum exactly to 1.00000 as listed. However, complete compositions listed to more decimal places and summing to 1.0000 were used for validating PCT-composition models. 
Table B.1. Normalized 25-Component Compositions (mass fractions) of 554 HLW Glasses Used for PCT Model Validation (continued).

\begin{tabular}{|c|c|c|c|c|c|c|c|c|c|c|c|c|c|c|c|}
\hline Glass ID & $\mathbf{A l}_{2} \mathbf{O}_{3}$ & $\mathbf{B}_{2} \mathbf{O}_{3}$ & $\mathrm{CaO}$ & CdO & $\mathrm{Cr}_{2} \mathrm{O}_{3}$ & $\mathrm{Fe}_{2} \mathrm{O}_{3}$ & $\mathbf{K}_{2} \mathbf{O}$ & $\mathbf{L a}_{2} \mathbf{O}_{3}$ & $\mathbf{L i}_{2} \mathbf{O}$ & MgO & MnO & $\mathrm{Na}_{2} \mathrm{O}$ & $\mathrm{NiO}$ & PbO & $\mathrm{Sb}_{2} \mathbf{O}_{3}$ \\
\hline \begin{tabular}{|l|} 
H-GLAS-0466 \\
\end{tabular} & 0.02854 & 0.13727 & 0.00390 & 0.00000 & 0.00376 & 0.09211 & 0.00320 & 0.00252 & 0.05023 & 0.00237 & 0.00658 & 0.07888 & 0.00751 & 0.00207 & 0.00000 \\
\hline \begin{tabular}{|l|} 
FRIT-202-CLEAR \\
\end{tabular} & 0.00394 & 0.07756 & 0.00098 & 0.00000 & 0.00000 & 0.00000 & 0.00116 & 0.00000 & 0.06559 & 0.01888 & 0.00000 & 0.05763 & 0.00000 & 0.00000 & 0.00000 \\
\hline FRIT-202-INT & 0.00394 & 0.07756 & 0.00098 & 0.00000 & 0.00000 & 0.00000 & 0.00116 & 0.00000 & 0.06559 & 0.01888 & 0.00000 & 0.05763 & 0.00000 & 0.00000 & 0.00000 \\
\hline \begin{tabular}{|l|} 
FRIT-202-WHITE \\
\end{tabular} & 0.00394 & 0.07756 & 0.00098 & 0.00000 & 0.00000 & 0.00000 & 0.00116 & 0.00000 & 0.06559 & 0.01888 & 0.00000 & 0.05763 & 0.00000 & 0.00000 & 0.00000 \\
\hline \begin{tabular}{|l|} 
FRIT-165-7 \\
\end{tabular} & 0.00000 & 0.09392 & 0.00000 & 0.00000 & 0.00000 & 0.00000 & 0.00000 & 0.00000 & 0.07009 & 0.00997 & 0.00000 & 0.12243 & 0.00000 & 0.00000 & 0.00000 \\
\hline FRIT-131-7 & 0.00365 & 0.15110 & 0.00086 & 0.00000 & 0.00000 & 0.00054 & 0.00193 & 0.00000 & 0.05386 & 0.01778 & 0.00145 & 0.19766 & 0.00102 & 0.00000 & 0.00000 \\
\hline \begin{tabular}{|l|} 
MG 9-7 \\
\end{tabular} & 0.00202 & 0.05633 & 0.09251 & 0.00000 & 0.00000 & 0.00000 & 0.00000 & 0.00000 & 0.00000 & 0.00000 & 0.00000 & 0.25973 & 0.00000 & 0.00000 & 0.00000 \\
\hline \begin{tabular}{|l|} 
MG $18-7$ \\
\end{tabular} & 0.00941 & 0.16097 & 0.09325 & 0.00000 & 0.00000 & 0.00000 & 0.00000 & 0.00000 & 0.00000 & 0.00000 & 0.00000 & 0.25851 & 0.00000 & 0.00000 & 0.00000 \\
\hline \begin{tabular}{|l|} 
MG 25-7 \\
\end{tabular} & \begin{tabular}{|l|}
0.12947 \\
\end{tabular} & \begin{tabular}{|l|}
0.13694 \\
\end{tabular} & 0.03008 & 0.00000 & 0.00000 & 0.09503 & \begin{tabular}{|l|l|}
0.0000 \\
\end{tabular} & \begin{tabular}{|l|}
0.00000 \\
\end{tabular} & 0.00000 & 0.00000 & 0.00000 & 0.15453 & \begin{tabular}{|l|l|}
0.00000 \\
\end{tabular} & 0.00000 & 0.00000 \\
\hline \begin{tabular}{|l|} 
MG 28-7 \\
\end{tabular} & 0.14599 & 0.09213 & 0.00000 & 0.00000 & 0.00000 & \begin{tabular}{|l|}
0.13548 \\
\end{tabular} & 0.00000 & 0.00000 & 0.00000 & 0.00000 & 0.00000 & 0.16814 & 0.00000 & 0.00000 & 0.00000 \\
\hline \begin{tabular}{|l|} 
PNL 1 \\
\end{tabular} & 0.07710 & 0.16560 & 0.00480 & 0.00000 & 0.00140 & 0.15450 & 0.03130 & 0.00000 & 0.02320 & 0.00890 & 0.00820 & 0.05720 & 0.00250 & 0.00000 & 0.00000 \\
\hline \begin{tabular}{|l|} 
PNL 2 \\
\end{tabular} & \begin{tabular}{|l|l|}
0.04290 \\
\end{tabular} & \begin{tabular}{|l|l|}
0.16560 \\
\end{tabular} & 0.00480 & 0.00000 & 0.00140 & 0.08590 & \begin{tabular}{|l|l|}
0.06880 \\
\end{tabular} & \begin{tabular}{|l|}
0.00000 \\
\end{tabular} & 0.02320 & 0.00890 & 0.00820 & \begin{tabular}{|l|l|}
0.10280 \\
\end{tabular} & \begin{tabular}{|l|l|}
0.00250 \\
\end{tabular} & 0.00000 & 0.00000 \\
\hline \begin{tabular}{|l|} 
PNL 3 \\
\end{tabular} & 0.07710 & \begin{tabular}{|l|l|}
0.16560 \\
\end{tabular} & 0.00480 & 0.00000 & 0.00140 & 0.08590 & \begin{tabular}{|l|}
0.06880 \\
\end{tabular} & \begin{tabular}{|l|l|}
0.00000 \\
\end{tabular} & 0.05100 & 0.00890 & 0.00820 & 0.10280 & 0.00250 & 0.00000 & 0.00000 \\
\hline \begin{tabular}{|l|} 
PNL 4 \\
\end{tabular} & 0.04290 & 0.09220 & 0.00480 & 0.00000 & 0.00140 & 0.15450 & 0.06880 & 0.00000 & 0.02320 & 0.00890 & 0.00820 & 0.05720 & 0.00250 & 0.00000 & 0.00000 \\
\hline \begin{tabular}{|l|} 
PNL 5 \\
\end{tabular} & 0.04290 & 0.16560 & 0.00480 & 0.00000 & 0.00140 & 0.08590 & 0.03130 & 0.00000 & 0.05100 & 0.00890 & 0.00820 & 0.05720 & 0.00250 & 0.00000 & 0.00000 \\
\hline PNL 6 & 0.07710 & 0.09220 & 0.00480 & 0.00000 & 0.00140 & 0.08590 & 0.03130 & 0.00000 & 0.04320 & 0.00890 & 0.00820 & 0.10280 & 0.00250 & 0.00000 & 0.00000 \\
\hline
\end{tabular}

\begin{tabular}{|l|c|c|c|c|c|c|c|c|c|c|c|}
\hline Glass ID & $\mathbf{S e O}_{2}$ & $\mathbf{S i O}_{2}$ & $\mathbf{S r O}$ & $\mathbf{T h O}_{2}$ & $\mathbf{T i O}_{2}$ & $\mathbf{T l}_{\mathbf{2}} \mathbf{O}$ & $\mathbf{U O}_{3}$ & $\mathbf{Z n O}$ & $\mathbf{Z r O}_{2}$ & $\mathbf{\text { Others }}$ & Sum \\
\hline H-GLAS-0466 & 0.00000 & 0.53445 & 0.00032 & 0.00000 & 0.00161 & 0.00000 & 0.00000 & 0.00264 & 0.03792 & 0.00411 & 1.00000 \\
\hline FRIT-202- & 0.00000 & 0.76536 & 0.00000 & 0.00000 & 0.00000 & 0.00000 & 0.00000 & 0.00000 & 0.00000 & 0.00890 & 1.00000 \\
\hline FRIT-202-INT & 0.00000 & 0.76536 & 0.00000 & 0.00000 & 0.00000 & 0.00000 & 0.00000 & 0.00000 & 0.00000 & 0.00890 & 1.00000 \\
\hline FRIT-202- & 0.00000 & 0.76536 & 0.00000 & 0.00000 & 0.00000 & 0.00000 & 0.00000 & 0.00000 & 0.00000 & 0.00890 & 1.00000 \\
\hline FRIT-165-7 & 0.00000 & 0.69366 & 0.00000 & 0.00000 & 0.00000 & 0.00000 & 0.00000 & 0.00000 & 0.00994 & 0.00000 & 1.00000 \\
\hline FRIT-131-7 & 0.00000 & 0.54732 & 0.00000 & 0.00000 & 0.00994 & 0.00000 & 0.00000 & 0.00000 & 0.00483 & 0.00807 & 1.00000 \\
\hline MG 9-7 & 0.00000 & 0.58942 & 0.00000 & 0.00000 & 0.00000 & 0.00000 & 0.00000 & 0.00000 & 0.00000 & 0.00000 & 1.00000 \\
\hline MG 18-7 & 0.00000 & 0.47786 & 0.00000 & 0.00000 & 0.00000 & 0.00000 & 0.00000 & 0.00000 & 0.00000 & 0.00000 & 1.00000 \\
\hline MG 25-7 & 0.00000 & 0.45395 & 0.00000 & 0.00000 & 0.00000 & 0.00000 & 0.00000 & 0.00000 & 0.00000 & 0.00000 & 1.00000 \\
\hline MG 28-7 & 0.00000 & 0.45826 & 0.00000 & 0.00000 & 0.00000 & 0.00000 & 0.00000 & 0.00000 & 0.00000 & 0.00000 & 1.00000 \\
\hline PNL 1 & 0.00000 & 0.39490 & 0.00250 & 0.01780 & 0.00800 & 0.00000 & 0.00630 & 0.00260 & 0.01320 & 0.02000 & 1.00000 \\
\hline PNL 2 & 0.00000 & 0.41460 & 0.00250 & 0.01780 & 0.00800 & 0.00000 & 0.00630 & 0.00260 & 0.01320 & 0.02000 & 1.00000 \\
\hline PNL 3 & 0.00000 & 0.35260 & 0.00250 & 0.01780 & 0.00800 & 0.00000 & 0.00630 & 0.00260 & 0.01320 & 0.02000 & 1.00000 \\
\hline PNL 4 & 0.00000 & 0.46500 & 0.00250 & 0.01780 & 0.00800 & 0.00000 & 0.00630 & 0.00260 & 0.01320 & 0.02000 & 1.00000 \\
\hline PNL 5 & 0.00000 & 0.46990 & 0.00250 & 0.01780 & 0.00800 & 0.00000 & 0.00630 & 0.00260 & 0.01320 & 0.02000 & 1.00000 \\
\hline PNL 6 & 0.00000 & 0.47130 & 0.00250 & 0.01780 & 0.00800 & 0.00000 & 0.00630 & 0.00260 & 0.01320 & 0.02000 & 1.00000 \\
\hline
\end{tabular}

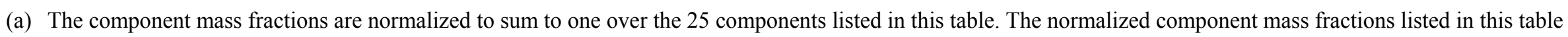
were rounded to five decimals, and may not sum exactly to 1.00000 as listed. However, complete compositions listed to more decimal places and summing to 1.0000 were used for validating PCT-composition models. 
Table B.1. Normalized 25-Component Compositions (mass fractions) of 554 HLW Glasses Used for PCT Model Validation (continued).

\begin{tabular}{|c|c|c|c|c|c|c|c|c|c|c|c|c|c|c|c|}
\hline & $\mathrm{Al}_{2} \mathbf{O}_{3}$ & $\mathbf{B}_{2} \mathbf{O}_{3}$ & & D & $\mathbf{r}_{2} \mathbf{O}_{3}$ & $\mathbf{e}_{2} \mathrm{O}_{3}$ & $\mathrm{~K}_{2} \mathrm{O}$ & $\mathbf{L a}_{2} \mathbf{O}_{3}$ & $\mathbf{L i}_{2} \mathbf{O}$ & O & & $\mathrm{J}_{2} \mathbf{O}$ & $\mathrm{NiO}$ & D & $\mathbf{b}_{2} \mathbf{O}_{3}$ \\
\hline & 10 & & & & 40 & 90 & 0 & 0 & 20 & & 20 & 20 & & & \\
\hline & & & & & & & & & & & & & & & \\
\hline & & & & & & & & & & & & & & & \\
\hline & & & & & & & & & & & & & & & \\
\hline & & & & & & & & & & & & & & & \\
\hline & & & & & & & & & & & & & & & \\
\hline & & & & & & & & & & & & & & & \\
\hline & & & & & & & & & & & & & & & \\
\hline & & & & & & & & & & & & & & & \\
\hline & & & & & & & & & & & & & & & \\
\hline & & & & & & & & & & & & & & & \\
\hline & & & & & & & & & & & & & & & \\
\hline & & & & & & & & & & & & & & 000 & 000 \\
\hline $\mathrm{Qtr}$ & 000 & & & & & & & & & & & & & & \\
\hline & & & & & & & & & & & & & & & \\
\hline DG-2 & 3637 & 12208 & .00833 & 00000 & 0.0 & 756 & 0.00 & 0.00040 & 1765 & 04 & 80 & 0.05 & 271 & 000 & 00 \\
\hline
\end{tabular}

\begin{tabular}{|l|c|c|c|c|c|c|c|c|c|c|c|}
\hline Glass ID & $\mathbf{S e O}_{2}$ & $\mathbf{S i O}_{2}$ & $\mathbf{S r O}$ & $\mathbf{T h O}_{2}$ & $\mathbf{T i O}_{2}$ & $\mathbf{T l}_{\mathbf{2}} \mathbf{O}$ & $\mathbf{U O}_{3}$ & $\mathbf{Z n O}$ & $\mathbf{Z r O}_{2}$ & $\mathbf{O t h e r s}$ & $\mathbf{S u m}^{(\mathbf{a})}$ \\
\hline PNL 7 & 0.00000 & 0.46380 & 0.00250 & 0.05340 & 0.00800 & 0.00000 & 0.00630 & 0.00260 & 0.01320 & 0.02000 & 1.00000 \\
\hline PNL 8 & 0.00000 & 0.34830 & 0.00250 & 0.05340 & 0.00800 & 0.00000 & 0.00630 & 0.00260 & 0.01320 & 0.02000 & 1.00000 \\
\hline PNL 9 & 0.00000 & 0.34830 & 0.00250 & 0.05340 & 0.00800 & 0.00000 & 0.00630 & 0.00260 & 0.01320 & 0.02000 & 1.00000 \\
\hline PNL 10 & 0.00000 & 0.46210 & 0.00250 & 0.05340 & 0.00800 & 0.00000 & 0.00630 & 0.00260 & 0.01320 & 0.02000 & 1.00000 \\
\hline Alkali1 & 0.00000 & 0.42760 & 0.00250 & 0.04000 & 0.00800 & 0.00000 & 0.00630 & 0.00260 & 0.01450 & 0.02000 & 1.00000 \\
\hline Alkali2 & 0.00000 & 0.38800 & 0.00250 & 0.04020 & 0.00800 & 0.00000 & 0.00630 & 0.00260 & 0.01440 & 0.02000 & 1.00000 \\
\hline Alkali3 & 0.00000 & 0.40000 & 0.00250 & 0.03300 & 0.00800 & 0.00000 & 0.00630 & 0.00260 & 0.01520 & 0.02000 & 1.00000 \\
\hline Alkali4 & 0.00000 & 0.43500 & 0.00250 & 0.03700 & 0.00800 & 0.00000 & 0.00630 & 0.00260 & 0.01530 & 0.02000 & 1.00000 \\
\hline Alkali5 & 0.00000 & 0.40430 & 0.00250 & 0.03850 & 0.00800 & 0.00000 & 0.00630 & 0.00260 & 0.01250 & 0.02000 & 1.00000 \\
\hline Alkali6 & 0.00000 & 0.40250 & 0.00250 & 0.03450 & 0.00800 & 0.00000 & 0.00630 & 0.00260 & 0.01390 & 0.02000 & 1.00000 \\
\hline Alkali7 & 0.00000 & 0.39000 & 0.00250 & 0.04130 & 0.00800 & 0.00000 & 0.00630 & 0.00260 & 0.01600 & 0.02000 & 1.00000 \\
\hline Alkali8 & 0.00000 & 0.40700 & 0.00250 & 0.03940 & 0.00800 & 0.00000 & 0.00630 & 0.00260 & 0.01440 & 0.02000 & 1.00000 \\
\hline Alkali9 & 0.00000 & 0.42150 & 0.00250 & 0.04190 & 0.00800 & 0.00000 & 0.00630 & 0.00260 & 0.01620 & 0.02000 & 1.00000 \\
\hline Ref6Qtr2 & 0.00000 & 0.40980 & 0.00250 & 0.03560 & 0.00800 & 0.00000 & 0.00630 & 0.00260 & 0.01320 & 0.02000 & 1.00000 \\
\hline WVDG-1 & 0.00000 & 0.43398 & 0.00030 & 0.02870 & 0.00963 & 0.00000 & 0.00574 & 0.00000 & 0.00592 & 0.03147 & 1.00000 \\
\hline WVDG-2 & 0.00000 & 0.43734 & 0.00030 & 0.02809 & 0.00963 & 0.00000 & 0.00563 & 0.00000 & 0.00562 & 0.03264 & 1.00000 \\
\hline
\end{tabular}

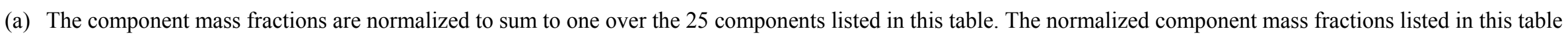
were rounded to five decimals, and may not sum exactly to 1.00000 as listed. However, complete compositions listed to more decimal places and summing to 1.0000 were used for validating PCT-composition models. 
Table B.1. Normalized 25-Component Compositions (mass fractions) of 554 HLW Glasses Used for PCT Model Validation (continued).

\begin{tabular}{|c|c|c|c|c|c|c|c|c|c|c|c|c|c|c|c|}
\hline Gl & $\mathbf{A l}_{2} \mathbf{O}_{3}$ & $\mathbf{B}_{2} \mathbf{O}_{3}$ & O & dO & $\mathrm{Cr}_{2} \mathrm{O}_{3}$ & $\mathbf{e}_{2} \mathbf{O}_{3}$ & $\mathrm{~K}_{2} \mathrm{O}$ & $\mathbf{L a}_{2} \mathbf{O}_{3}$ & $\mathbf{L i}_{2} \mathbf{O}$ & D & & $\mathbf{T}_{2} \mathbf{O}$ & $\mathrm{NiO}$ & PbO & $\mathrm{Sb}_{2} \mathrm{O}_{3}$ \\
\hline & 94 & 374 & 33 & 0 & 91 & 1 & 9 & 550 & 02351 & 08 & 3 & 6 & 2 & 0 & 0000 \\
\hline & & & & & & & & & & & & & & & \\
\hline & & & & & & & & & & & & & & & \\
\hline & & & & & & & & & & & & & & & \\
\hline & & & & & & & & & & & & & & & \\
\hline & & & & & & & & & & & & & & & \\
\hline & & & & & & & & & & & & & & & \\
\hline $2 \mathrm{R}$ & & & & & & & & & & & & & & & \\
\hline & & & & & & & & & & & & & & & \\
\hline$-14 R$ & & & & & & & & & & & & & & & \\
\hline & & & & & & & & & & & & & & & \\
\hline & & & & & & & & & & & & & & & \\
\hline & & & & & & & & & & 297 & & & & 000 & 000 \\
\hline & 484 & 10635 & 5541 & 00000 & \begin{tabular}{|l|}
0.00080 \\
\end{tabular} & 461 & & 20 & & 441 & & & & & 000 \\
\hline & & & & & & & & & & & & & & & \\
\hline WVDG-20 & 12264 & 0.10641 & 0.01343 & 0.00000 & \begin{tabular}{|l|}
0.00261 \\
\end{tabular} & 0.08767 & 0.02234 & 0.00070 & 0.02044 & \begin{tabular}{|l|}
0.01423 \\
\end{tabular} & 0.00425 & 0.08647 & 0.00581 & 0.00000 & 0.00000 \\
\hline
\end{tabular}

\begin{tabular}{|l|c|c|c|c|c|c|c|c|c|c|c|}
\hline Glass ID & $\mathbf{S e O}_{2}$ & $\mathbf{S i O}_{2}$ & $\mathbf{S r O}$ & $\mathbf{T h O}_{2}$ & $\mathbf{T i O}_{2}$ & $\mathbf{T l}_{\mathbf{2}} \mathbf{O}$ & $\mathbf{U O}_{3}$ & $\mathbf{Z n O}$ & $\mathbf{Z r O}_{2}$ & $\mathbf{O t h e r s}^{\text {Sum }}$ \\
\hline WVDG-3 & 0.00000 & 0.45674 & 0.00040 & 0.02743 & 0.01226 & 0.00000 & 0.00575 & 0.00000 & 0.00643 & 0.03038 & 1.00000 \\
\hline WVDG-4 & 0.00000 & 0.42088 & 0.00030 & 0.02950 & 0.00903 & 0.00000 & 0.00574 & 0.00000 & 0.00542 & 0.03097 & 1.00000 \\
\hline WVDG-5 & 0.00000 & 0.44329 & 0.00030 & 0.03103 & 0.00968 & 0.00000 & 0.00602 & 0.00000 & 0.00599 & 0.03208 & 1.00000 \\
\hline WVDG-6 & 0.00000 & 0.43556 & 0.00030 & 0.02759 & 0.00933 & 0.00000 & 0.00563 & 0.00000 & 0.00562 & 0.04110 & 1.00000 \\
\hline WVDG-7 & 0.00000 & 0.43157 & 0.00030 & 0.03841 & 0.00963 & 0.00000 & 0.00489 & 0.00000 & 0.00622 & 0.03055 & 1.00000 \\
\hline WVDG-8 & 0.00000 & 0.45979 & 0.00030 & 0.02759 & 0.01013 & 0.00000 & 0.00616 & 0.00050 & 0.00572 & 0.03385 & 1.00000 \\
\hline WVDG-11R & 0.00000 & 0.40721 & 0.00030 & 0.02206 & 0.00953 & 0.00000 & 0.00669 & 0.00020 & 0.00461 & 0.03193 & 1.00000 \\
\hline WVDG-12R & 0.00000 & 0.40256 & 0.00030 & 0.02536 & 0.00942 & 0.00000 & 0.00690 & 0.00060 & 0.00541 & 0.03222 & 1.00000 \\
\hline WVDG-13R & 0.00000 & 0.40307 & 0.00030 & 0.02488 & 0.00963 & 0.00000 & 0.00733 & 0.00000 & 0.00522 & 0.03244 & 1.00000 \\
\hline WVDG-14R & 0.00000 & 0.40319 & 0.00030 & 0.02598 & 0.00963 & 0.00000 & 0.00680 & 0.00000 & 0.00732 & 0.03247 & 1.00000 \\
\hline WVDG-15 & 0.00000 & 0.40005 & 0.00030 & 0.01669 & 0.01448 & 0.00000 & 0.00980 & 0.00020 & 0.00694 & 0.03841 & 1.00000 \\
\hline WVDG-16 & 0.00000 & 0.40099 & 0.00010 & 0.01606 & 0.00442 & 0.00000 & 0.00138 & 0.00020 & 0.00211 & 0.04298 & 1.00000 \\
\hline WVDG-17 & 0.00000 & 0.39793 & 0.00040 & 0.04716 & 0.01589 & 0.00000 & 0.00085 & 0.00060 & 0.00754 & 0.03956 & 1.00000 \\
\hline WVDG-18 & 0.00000 & 0.43262 & 0.00010 & 0.01963 & 0.00461 & 0.00000 & 0.00095 & 0.00000 & 0.00220 & 0.02365 & 1.00000 \\
\hline WVDG-19 & 0.00000 & 0.36387 & 0.00010 & 0.05295 & 0.00445 & 0.00000 & 0.00995 & 0.00000 & 0.00212 & 0.02417 & 1.00000 \\
\hline WVDG-20 & 0.00000 & 0.40028 & 0.00040 & 0.01874 & 0.01573 & 0.00000 & 0.01008 & 0.00020 & 0.00751 & 0.06007 & 1.00000 \\
\hline
\end{tabular}

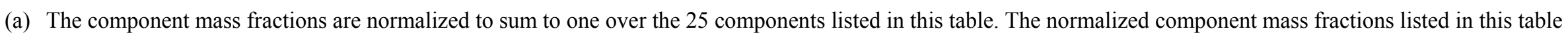
were rounded to five decimals, and may not sum exactly to 1.00000 as listed. However, complete compositions listed to more decimal places and summing to 1.0000 were used for validating PCT-composition models. 
Table B.1. Normalized 25-Component Compositions (mass fractions) of 554 HLW Glasses Used for PCT Model Validation (continued).

\begin{tabular}{|c|c|c|c|c|c|c|c|c|c|c|c|c|c|c|c|}
\hline ID & $\mathrm{Al}_{2} \mathrm{O}_{3}$ & $\mathbf{B}_{2} \mathbf{O}_{3}$ & $\mathrm{aO}$ & CdO & $\mathrm{Cr}_{2} \mathrm{O}_{3}$ & $\mathbf{e}_{2} \mathrm{O}_{3}$ & $\mathbf{K}_{2} \mathbf{O}$ & $\mathbf{L a}_{2} \mathbf{O}_{3}$ & $\mathbf{L i}_{2} \mathbf{O}$ & $\mathbf{O}$ & O & $\mathrm{Na}_{2} \mathrm{O}$ & $\mathrm{NiO}$ & PbO & $\mathrm{Sb}_{2} \mathrm{O}_{3}$ \\
\hline WVDG-21 & 12553 & 10085 & 00502 & 00000 & 00080 & 14721 & 0.01234 & 00020 & 02318 & 32 & 47 & .10496 & 0171 & 00 & 00000 \\
\hline WVDG-22 & & & & & & & & & & & & & & & \\
\hline WVDG-23 & 28 & 91 & 00 & 0.0 & 00080 & 253 & \begin{tabular}{|l|}
0.01862 \\
\end{tabular} & 00020 & \begin{tabular}{|l|}
0.01802 \\
\end{tabular} & 540 & & .08237 & 80 & 00 & 00 \\
\hline WVDG-24 & 75 & 79 & & 0.0 & & & & & & & & & & & \\
\hline WVDG-25 & 0.09346 & 0.10954 & 0.00502 & 0.00000 & 0.00080 & 0.08713 & & \begin{tabular}{|l|}
0.00020 \\
\end{tabular} & 0.02040 & 533 & & 0.09135 & 191 & & 0.00000 \\
\hline WVDG-26 & 0.12283 & 0.13394 & 0.01341 & 0.00000 & 0.00090 & 679 & 43 & \begin{tabular}{|l|}
0.00030 \\
\end{tabular} & 02 & & 149 & 0.09100 & 190 & 00 & 0.00000 \\
\hline WVDG-27 & 0.12189 & 0.12600 & 0491 & 0.00000 & 0.00280 & 0.08694 & 454 & \begin{tabular}{|l|}
0.00080 \\
\end{tabular} & 0.02284 & 621 & 17 & 0.10156 & 621 & 00 & 000 \\
\hline-28 & 91 & 672 & 81 & 0 & 270 & 124 & & \begin{tabular}{|l|}
0.00080 \\
\end{tabular} & & & & 870 & & & 00 \\
\hline $\mathrm{j}-29$ & 09294 & 0.11467 & 32 & 0.0 & 080 & 753 & 43 & 020 & 0.02574 & 362 & 109 & 0.10756 & 190 & 0.00000 & 0.00000 \\
\hline WVDG-30 & 0.10093 & 0.11907 & 0.00842 & 0.00000 & 0.00160 & 0.11506 & 0.01814 & \begin{tabular}{|l|}
0.00040 \\
\end{tabular} & 0.02105 & 0.01012 & 0.00981 & 0.09652 & 0.00351 & 0.00000 & 0.00000 \\
\hline WVDG-33 & 0.08238 & 0.09050 & 0.00401 & 0.00000 & 0.00130 & 0.11475 & & & & 0.00982 & & 0.10533 & 0.00291 & & 0.00000 \\
\hline $\mathrm{S}-34$ & 188 & & & 0.0 & & & & & & & & 109 & & & 000 \\
\hline WVDG-35 & 0.10098 & 0.07206 & \begin{tabular}{|l|}
0.00705 \\
\end{tabular} & 0.00000 & 0.00060 & \begin{tabular}{|l|}
0.15097 \\
\end{tabular} & \begin{tabular}{|l|}
0.03739 \\
\end{tabular} & \begin{tabular}{|l|}
0.00020 \\
\end{tabular} & 0.03164 & 0.01754 & 604 & 0.11428 & \begin{tabular}{|l|}
0.00141 \\
\end{tabular} & \begin{tabular}{|l|}
0.00000 \\
\end{tabular} & 0.00000 \\
\hline WVDG-36 & 0.05697 & 0.10812 & 0.00160 & 0.00000 & 0.00370 & 0.14677 & 0.02543 & 0.00100 & 0.02152 & 0.00400 & 0.00098 & 0.07759 & 0.00811 & 0.00000 & 0.00000 \\
\hline WVDG-37 & 0.09991 & 0.07788 & 0.00140 & 0.00000 & 0.00360 & \begin{tabular}{|l|}
0.09780 \\
\end{tabular} & 0.03904 & \begin{tabular}{|l|}
0.00100 \\
\end{tabular} & \begin{tabular}{|l}
0.03303 \\
\end{tabular} & 0.00360 & 0.00106 & 0.11923 & 0.00801 & 0.00000 & 0.00000 \\
\hline WVDG-38 & 0.10318 & 0.07637 & 0.00161 & 0.00000 & 0.00373 & 0.09743 & 0.03285 & \begin{tabular}{|l|}
0.00111 \\
\end{tabular} & 0.02781 & 0.00393 & 0.01324 & 0.10025 & 0.00836 & 0.00000 & 0.00000 \\
\hline
\end{tabular}

\begin{tabular}{|l|c|c|c|c|c|c|c|c|c|c|c|}
\hline Glass ID & $\mathbf{S e O}_{2}$ & $\mathbf{S i O}_{\mathbf{2}}$ & $\mathbf{S r O}$ & $\mathbf{T h O}_{2}$ & $\mathbf{T i O}_{2}$ & $\mathbf{T l}_{\mathbf{2}} \mathbf{O}$ & $\mathbf{U O}_{3}$ & $\mathbf{Z n O}$ & $\mathbf{Z r O}_{2}$ & $\mathbf{O t h e r s}^{\text {Sum }}$ & $\mathbf{S u m}^{(\mathbf{a})}$ \\
\hline WVDG-21 & 0.00000 & 0.37670 & 0.00010 & 0.01595 & 0.00462 & 0.00000 & 0.00978 & 0.00060 & 0.00221 & 0.04246 & 1.00000 \\
\hline WVDG-22 & 0.00000 & 0.37613 & 0.00040 & 0.01761 & 0.01550 & 0.00000 & 0.00117 & 0.00020 & 0.00735 & 0.03870 & 1.00000 \\
\hline WVDG-23 & 0.00000 & 0.39345 & 0.00010 & 0.04954 & 0.00500 & 0.00000 & 0.00986 & 0.00020 & 0.00240 & 0.04134 & 1.00000 \\
\hline WVDG-24 & 0.00000 & 0.42287 & 0.00010 & 0.01888 & 0.00472 & 0.00000 & 0.00989 & 0.00020 & 0.00221 & 0.02241 & 1.00000 \\
\hline WVDG-25 & 0.00000 & 0.45225 & 0.00010 & 0.04382 & 0.00513 & 0.00000 & 0.00106 & 0.00000 & 0.00241 & 0.04009 & 1.00000 \\
\hline WVDG-26 & 0.00000 & 0.40994 & 0.00010 & 0.03804 & 0.00531 & 0.00000 & 0.00106 & 0.00020 & 0.00250 & 0.02731 & 1.00000 \\
\hline WVDG-27 & 0.00000 & 0.36778 & 0.00040 & 0.03465 & 0.01683 & 0.00000 & 0.00117 & 0.00060 & 0.00801 & 0.06170 & 1.00000 \\
\hline WVDG-28 & 0.00000 & 0.43430 & 0.00040 & 0.01722 & 0.01612 & 0.00000 & 0.01018 & 0.00060 & 0.00771 & 0.04118 & 1.00000 \\
\hline WVDG-29 & 0.00000 & 0.44746 & 0.00010 & 0.01933 & 0.00511 & 0.00000 & 0.00106 & 0.00020 & 0.00240 & 0.04355 & 1.00000 \\
\hline WVDG-30 & 0.00000 & 0.40150 & 0.00020 & 0.03267 & 0.00942 & 0.00000 & 0.00626 & 0.00030 & 0.00451 & 0.04051 & 1.00000 \\
\hline WVDG-33 & 0.00000 & 0.42593 & 0.00020 & 0.03377 & 0.00782 & 0.00000 & 0.00531 & 0.00030 & 0.00371 & 0.03746 & 1.00000 \\
\hline WVDG-34 & 0.00000 & 0.40140 & 0.00050 & 0.01927 & 0.02238 & 0.00000 & 0.01945 & 0.00080 & 0.01064 & 0.05336 & 1.00000 \\
\hline WVDG-35 & 0.00000 & 0.38296 & 0.00010 & 0.02802 & 0.00383 & 0.00000 & 0.02562 & 0.00010 & 0.00181 & 0.00740 & 1.00000 \\
\hline WVDG-36 & 0.00000 & 0.41147 & 0.00050 & 0.05817 & 0.02193 & 0.00000 & 0.00138 & 0.00080 & 0.01041 & 0.03954 & 1.00000 \\
\hline WVDG-37 & 0.00000 & 0.42044 & 0.00050 & 0.02092 & 0.02162 & 0.00000 & 0.00148 & 0.00080 & 0.01031 & 0.03834 & 1.00000 \\
\hline WVDG-38 & 0.00000 & 0.41210 & 0.00050 & 0.04161 & 0.02267 & 0.00000 & 0.00096 & 0.00081 & 0.01078 & 0.04069 & 1.00000 \\
\hline
\end{tabular}

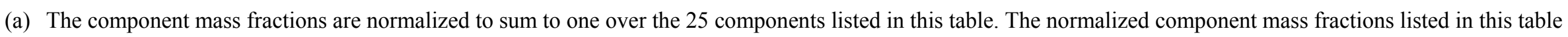
were rounded to five decimals, and may not sum exactly to 1.00000 as listed. However, complete compositions listed to more decimal places and summing to 1.0000 were used for validating PCT-composition models. 
Table B.1. Normalized 25-Component Compositions (mass fractions) of 554 HLW Glasses Used for PCT Model Validation (continued).

\begin{tabular}{|c|c|c|c|c|c|c|c|c|c|c|c|c|c|c|c|}
\hline ID & $\mathrm{Al}_{2} \mathrm{O}_{3}$ & $\mathbf{B}_{2} \mathbf{O}_{3}$ & $\mathrm{aO}$ & CdO & $\mathrm{Cr}_{2} \mathrm{O}_{3}$ & $\mathbf{e}_{2} \mathbf{O}_{3}$ & $\mathbf{K}_{2} \mathbf{O}$ & $\mathbf{L a}_{2} \mathbf{O}_{3}$ & $\mathbf{L i}_{2} \mathbf{O}$ & $\mathbf{O}$ & $\mathbf{O}$ & $\mathrm{Na}_{2} \mathrm{O}$ & $\mathrm{NiO}$ & PbO & $\mathrm{Sb}_{2} \mathrm{O}_{3}$ \\
\hline WVDG-39 & 10056 & 11227 & 00660 & 00000 & 00100 & 99285 & 03622 & 00030 & 03062 & 541 & 90 & .11047 & 20 & 00 & 00000 \\
\hline WVDG-40 & & 527 & & & & & & & & & & & & & \\
\hline WVDG-41 & 15 & 54 & 00 & 000 & 00090 & 99472 & 47 & 00030 & \begin{tabular}{|l|}
0.03167 \\
\end{tabular} & 510 & 98 & 11431 & 10 & 00 & 00 \\
\hline WVD & 60 & 84 & & 00 & 67 & & & & & & & 810 & & & 000 \\
\hline WVDG-43 & 0.10067 & 0.12464 & \begin{tabular}{|l|}
0.00201 \\
\end{tabular} & \begin{tabular}{|l|}
0.00000 \\
\end{tabular} & 0.00080 & 556 & 687 & \begin{tabular}{|l|}
0.00020 \\
\end{tabular} & 0.02276 & 491 & & 0.08192 & 180 & & 0.00000 \\
\hline WVDG-44 & 0.08315 & \begin{tabular}{|l|}
0.11494 \\
\end{tabular} & \begin{tabular}{|l|}
0.00190 \\
\end{tabular} & \begin{tabular}{|l|}
0.00000 \\
\end{tabular} & 0.00080 & 801 & 528 & \begin{tabular}{|l|}
0.00020 \\
\end{tabular} & 0.0 & 480 & 06 & 0.10784 & 0170 & 00 & 0.00000 \\
\hline WVDG-45 & 0.10269 & \begin{tabular}{|l|}
0.07171 \\
\end{tabular} & 0161 & \begin{tabular}{|l|}
0.00000 \\
\end{tabular} & 0.00080 & \begin{tabular}{|l|}
0.15599 \\
\end{tabular} & 862 & \begin{tabular}{|l|}
0.00020 \\
\end{tabular} & 0.03269 & 402 & 50 & 0.11797 & 181 & 00 & 0000 \\
\hline-46 & 25 & 274 & 882 & \begin{tabular}{|l|}
0.00000 \\
\end{tabular} & 070 & 428 & 382 & \begin{tabular}{|l|}
0.00020 \\
\end{tabular} & 0.02870 & 576 & & 337 & & & 00 \\
\hline WVDG-47 & 0.05710 & \begin{tabular}{|l|}
0.11249 \\
\end{tabular} & 161 & 00 & 070 & 992 & 679 & 020 & 0.02268 & 401 & 588 & 0.08209 & 0151 & 0000 & 0.00000 \\
\hline WVDG-48 & 0.09431 & 0.10561 & \begin{tabular}{|l|}
0.00680 \\
\end{tabular} & 0.00000 & 0.00400 & 0.09241 & 0.02680 & \begin{tabular}{|l|}
0.00110 \\
\end{tabular} & 0.02270 & 0.01670 & 0.00098 & 0.08181 & 0.00880 & 0.00000 & 0.00000 \\
\hline FY92-5 & 0.07140 & \begin{tabular}{|l|}
0.10440 \\
\end{tabular} & \begin{tabular}{|l|}
0.00480 \\
\end{tabular} & \begin{tabular}{|l|}
0.00000 \\
\end{tabular} & 0.00140 & 0.14300 & & 0.00000 & & & & 0.08750 & & & \\
\hline & & & & & & & & 000 & & & & 280 & & & 000 \\
\hline FY92-7 & 0.04860 & \begin{tabular}{|l|}
0.10440 \\
\end{tabular} & \begin{tabular}{|l|}
0.00480 \\
\end{tabular} & \begin{tabular}{|l|}
0.00000 \\
\end{tabular} & 0.00140 & 0.14300 & \begin{tabular}{|l|}
0.06880 \\
\end{tabular} & \begin{tabular}{|l|}
0.00000 \\
\end{tabular} & 0.02320 & 0.00890 & 0.00820 & 0.05720 & \begin{tabular}{|l|}
0.00250 \\
\end{tabular} & \begin{tabular}{|l|}
0.00000 \\
\end{tabular} & 0.00000 \\
\hline FY92-9 & 0.04860 & \begin{tabular}{|l|}
0.10440 \\
\end{tabular} & \begin{tabular}{|l|}
0.00480 \\
\end{tabular} & \begin{tabular}{|l|}
0.00000 \\
\end{tabular} & 0.00140 & 0.14300 & 0.03130 & 0.00000 & 0.05100 & 0.00890 & 0.00820 & 0.05720 & 0.00250 & 0.00000 & 0.00000 \\
\hline FY92-10 & 0.07140 & \begin{tabular}{|l|l|}
0.15340 \\
\end{tabular} & \begin{tabular}{|l|}
0.00480 \\
\end{tabular} & \begin{tabular}{|l|}
0.00000 \\
\end{tabular} & 0.00140 & 0.09740 & 0.06880 & \begin{tabular}{|l|}
0.00000 \\
\end{tabular} & 0.02320 & 0.00890 & 0.0 & 0.05720 & 0.00250 & 0.00000 & 0.00000 \\
\hline FY92Ref5 & 0.06447 & 0.12884 & \begin{tabular}{|l|}
0.00680 \\
\end{tabular} & \begin{tabular}{|l|}
0.00000 \\
\end{tabular} & 0.00140 & 0.12014 & 0.03178 & \begin{tabular}{|l|}
0.00040 \\
\end{tabular} & 0.02709 & 0.00890 & 0.00824 & 0.09815 & 0.00250 & 0.00000 & 0.00000 \\
\hline
\end{tabular}

\begin{tabular}{|l|c|c|c|c|c|c|c|c|c|c|c|}
\hline Glass ID & $\mathbf{S e O}_{2}$ & $\mathbf{S i O}_{2}$ & $\mathbf{S r O}$ & $\mathbf{T h O}_{2}$ & $\mathbf{T i O}_{2}$ & $\mathbf{T l}_{\mathbf{2}} \mathbf{O}$ & $\mathbf{U O}_{3}$ & $\mathbf{Z n O}$ & $\mathbf{Z r O}_{2}$ & $\mathbf{O t h e r s}$ & $\mathbf{S u m}^{(\mathbf{a})}$ \\
\hline WVDG-39 & 0.00000 & 0.38022 & 0.00010 & 0.05113 & 0.00600 & 0.00000 & 0.00106 & 0.00020 & 0.00280 & 0.04808 & 1.00000 \\
\hline WVDG-40 & 0.00000 & 0.44340 & 0.00010 & 0.04188 & 0.00490 & 0.00000 & 0.01927 & 0.00020 & 0.00230 & 0.01429 & 1.00000 \\
\hline WVDG-41 & 0.00000 & 0.44963 & 0.00010 & 0.05266 & 0.00560 & 0.00000 & 0.02106 & 0.00020 & 0.00270 & 0.04683 & 1.00000 \\
\hline WVDG-42 & 0.00000 & 0.40793 & 0.00051 & 0.05099 & 0.02203 & 0.00000 & 0.00130 & 0.00082 & 0.01050 & 0.07211 & 1.00000 \\
\hline WVDG-43 & 0.00000 & 0.42115 & 0.00010 & 0.04151 & 0.00481 & 0.00000 & 0.02039 & 0.00020 & 0.00231 & 0.03149 & 1.00000 \\
\hline WVDG-44 & 0.00000 & 0.37979 & 0.00010 & 0.03708 & 0.00470 & 0.00000 & 0.02276 & 0.00020 & 0.00220 & 0.01360 & 1.00000 \\
\hline WVDG-45 & 0.00000 & 0.38218 & 0.00010 & 0.01800 & 0.00483 & 0.00000 & 0.00107 & 0.00020 & 0.00231 & 0.04669 & 1.00000 \\
\hline WVDG-46 & 0.00000 & 0.45163 & 0.00010 & 0.02168 & 0.00422 & 0.00000 & 0.00117 & 0.00020 & 0.00211 & 0.01357 & 1.00000 \\
\hline WVDG-47 & 0.00000 & 0.45157 & 0.00010 & 0.01957 & 0.00421 & 0.00000 & 0.00128 & 0.00020 & 0.00201 & 0.04609 & 1.00000 \\
\hline WVDG-48 & 0.00000 & 0.38003 & 0.00060 & 0.02060 & 0.02390 & 0.00000 & 0.02013 & 0.00090 & 0.01140 & 0.08042 & 1.00000 \\
\hline FY92-5 & 0.00000 & 0.36880 & 0.00250 & 0.02670 & 0.00800 & 0.00000 & 0.00630 & 0.00260 & 0.01320 & 0.02000 & 1.00000 \\
\hline FY92-6 & 0.00000 & 0.44970 & 0.00250 & 0.02670 & 0.00800 & 0.00000 & 0.00630 & 0.00260 & 0.01320 & 0.02000 & 1.00000 \\
\hline FY92-7 & 0.00000 & 0.44970 & 0.00250 & 0.02670 & 0.00800 & 0.00000 & 0.00630 & 0.00260 & 0.01320 & 0.02000 & 1.00000 \\
\hline FY92-9 & 0.00000 & 0.44160 & 0.00250 & 0.04450 & 0.00800 & 0.00000 & 0.00630 & 0.00260 & 0.01320 & 0.02000 & 1.00000 \\
\hline FY92-10 & 0.00000 & 0.40570 & 0.00250 & 0.04450 & 0.00800 & 0.00000 & 0.00630 & 0.00260 & 0.01320 & 0.02000 & 1.00000 \\
\hline FY92Ref5 & 0.00000 & 0.41140 & 0.00250 & 0.03558 & 0.00800 & 0.00000 & 0.00625 & 0.00020 & 0.00320 & 0.03418 & 1.00000 \\
\hline
\end{tabular}

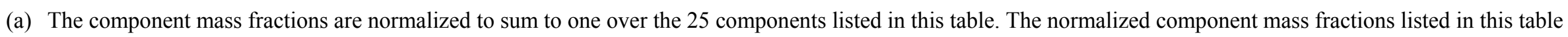
were rounded to five decimals, and may not sum exactly to 1.00000 as listed. However, complete compositions listed to more decimal places and summing to 1.0000 were used for validating PCT-composition models. 
Table B.1. Normalized 25-Component Compositions (mass fractions) of 554 HLW Glasses Used for PCT Model Validation (continued).

\begin{tabular}{|c|c|c|c|c|c|c|c|c|c|c|c|c|c|c|c|}
\hline ID & $\mathbf{A l}_{2} \mathbf{O}_{3}$ & $\mathbf{B}_{2} \mathbf{O}_{3}$ & & $\mathbf{O}$ & $\mathrm{Cr}_{2} \mathrm{O}_{3}$ & $\mathrm{Fe}_{2} \mathrm{O}_{3}$ & $\mathbf{K}_{2} \mathbf{O}$ & $-\mathbf{a}_{2} \mathbf{O}_{3}$ & $\mathbf{L i}_{\mathbf{2}} \mathbf{O}$ & 0 & & $\mathrm{Na}_{2} \mathrm{O}$ & $N$ & D & $\mathrm{Sb}_{2} \mathrm{O}_{3}$ \\
\hline & 87 & 1028 & 1 & 00 & 140 & 16100 & 5514 & 00000 & 9 & 22 & 2 & 822 & 51 & 0 & 00000 \\
\hline & & & & & & & & & & & & & & & \\
\hline & & & & & & & & & & & & & & & \\
\hline & & & & & & & & & & & & & & & \\
\hline & & & & & & & & & & & & & & & \\
\hline & & & & & & & & & & & & & & & \\
\hline & & & & & & & & & & & & & & & \\
\hline & & & & & & & & & & & & & & & \\
\hline & & & & & & & & & & & & & & & \\
\hline & & & & & & & & & & & & & & & \\
\hline & & & & & & & & & & & & & & & \\
\hline & & & & 00 & & & & & & & & & & 00 & \\
\hline & & & & & & & & & & & & & & 000 & 0000 \\
\hline $3-4$ & 0.04290 & 09220 & 0480 & 0.00000 & 140 & & & 0.00000 & & 890 & 0.0 & & & 0000 & \\
\hline & & & & & & & & & & & & & & & \\
\hline FY93-6 & 07710 & 0.09220 & 0.00480 & 0.00000 & 0.00140 & 0.08590 & 0.03130 & 0.00000 & 0.04320 & 0.00890 & 0.00820 & 0.10280 & 0.00250 & 0.00000 & 0.00000 \\
\hline
\end{tabular}

\begin{tabular}{|l|c|c|c|c|c|c|c|c|c|c|c|}
\hline Glass ID & $\mathbf{S e O}_{2}$ & $\mathbf{S i O}_{2}$ & $\mathbf{S r O}$ & $\mathbf{T h O}_{2}$ & $\mathbf{T i O}_{2}$ & $\mathbf{T l}_{\mathbf{2}} \mathbf{O}$ & $\mathbf{U O}_{3}$ & $\mathbf{Z n O}$ & $\mathbf{Z r O}_{2}$ & $\mathbf{O t h e r s}^{\text {Sum }}$ \\
\hline Ratio2 & 0.00000 & 0.39098 & 0.00251 & 0.01303 & 0.00802 & 0.00000 & 0.00632 & 0.00261 & 0.01203 & 0.02005 & 1.00000 \\
\hline Ratio4 & 0.00000 & 0.43400 & 0.00250 & 0.04300 & 0.00800 & 0.00000 & 0.00630 & 0.00260 & 0.01900 & 0.02000 & 1.00000 \\
\hline Ratio5 & 0.00000 & 0.38800 & 0.00250 & 0.02800 & 0.00800 & 0.00000 & 0.00630 & 0.00260 & 0.01000 & 0.02000 & 1.00000 \\
\hline LoTh2 & 0.00000 & 0.42500 & 0.00250 & 0.01400 & 0.00800 & 0.00000 & 0.00630 & 0.00260 & 0.01350 & 0.02000 & 1.00000 \\
\hline LoTh4 & 0.00000 & 0.43100 & 0.00250 & 0.01800 & 0.00800 & 0.00000 & 0.00630 & 0.00260 & 0.01200 & 0.02000 & 1.00000 \\
\hline LoTh5 & 0.00000 & 0.41700 & 0.00250 & 0.02400 & 0.00800 & 0.00000 & 0.00630 & 0.00260 & 0.01150 & 0.02000 & 1.00000 \\
\hline HiFe2 & 0.00000 & 0.39260 & 0.00250 & 0.03040 & 0.00800 & 0.00000 & 0.00630 & 0.00260 & 0.01140 & 0.02000 & 1.00000 \\
\hline HiFe3 & 0.00000 & 0.38790 & 0.00250 & 0.02900 & 0.00800 & 0.00000 & 0.00630 & 0.00260 & 0.01120 & 0.02000 & 1.00000 \\
\hline HiFe4 & 0.00000 & 0.38800 & 0.00250 & 0.03200 & 0.00800 & 0.00000 & 0.00630 & 0.00260 & 0.00930 & 0.02000 & 1.00000 \\
\hline PNL190 & 0.00000 & 0.40400 & 0.00250 & 0.04500 & 0.00800 & 0.00000 & 0.00630 & 0.00260 & 0.01300 & 0.02000 & 1.00000 \\
\hline FY93-1 & 0.00000 & 0.39490 & 0.00250 & 0.01780 & 0.00800 & 0.00000 & 0.00630 & 0.00260 & 0.01320 & 0.02000 & 1.00000 \\
\hline FY93-2 & 0.00000 & 0.41460 & 0.00250 & 0.01780 & 0.00800 & 0.00000 & 0.00630 & 0.00260 & 0.01320 & 0.02000 & 1.00000 \\
\hline FY93-3 & 0.00000 & 0.35260 & 0.00250 & 0.01780 & 0.00800 & 0.00000 & 0.00630 & 0.00260 & 0.01320 & 0.02000 & 1.00000 \\
\hline FY93-4 & 0.00000 & 0.46500 & 0.00250 & 0.01780 & 0.00800 & 0.00000 & 0.00630 & 0.00260 & 0.01320 & 0.02000 & 1.00000 \\
\hline FY93-5 & 0.00000 & 0.46990 & 0.00250 & 0.01780 & 0.00800 & 0.00000 & 0.00630 & 0.00260 & 0.01320 & 0.02000 & 1.00000 \\
\hline FY93-6 & 0.00000 & 0.47130 & 0.00250 & 0.01780 & 0.00800 & 0.00000 & 0.00630 & 0.00260 & 0.01320 & 0.02000 & 1.00000 \\
\hline
\end{tabular}

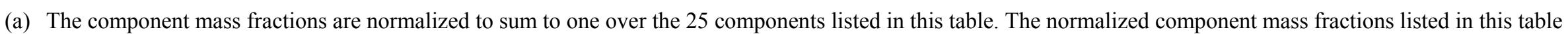
were rounded to five decimals, and may not sum exactly to 1.00000 as listed. However, complete compositions listed to more decimal places and summing to 1.0000 were used for validating PCT-composition models. 
Table B.1. Normalized 25-Component Compositions (mass fractions) of 554 HLW Glasses Used for PCT Model Validation (continued).

\begin{tabular}{|c|c|c|c|c|c|c|c|c|c|c|c|c|c|c|c|}
\hline ID & ${ }_{2} \mathrm{O}_{3}$ & ${ }_{2} \mathbf{O}_{3}$ & & $\mathbf{O}$ & $\mathbf{r}_{2} \mathrm{O}_{3}$ & $\mathrm{Fe}_{2} \mathrm{O}_{3}$ & ${ }_{2} \mathrm{O}$ & $\mathbf{a}_{2} \mathbf{O}_{3}$ & $\mathbf{L i}_{2} \mathbf{O}$ & & & $\mathrm{Na}_{2} \mathrm{O}$ & $\mathbf{O}$ & o & $\mathrm{Sb}_{2} \mathrm{O}_{3}$ \\
\hline & & & & & & & & & & & & 20 & & 0 & \\
\hline & & & & & & & & & & & & & & & \\
\hline & & & & & & & & & & & & & & & \\
\hline & & & & & & & & & & & & & & & \\
\hline & & & & & & & & & & & & & & & \\
\hline & & 90 & & & & & & & & & & & & & \\
\hline & & & & & & & & & & & & & & & \\
\hline & & & & & & & & & & & & & & & \\
\hline & & & & & & & & & & & & & & & \\
\hline & & & & & & & & & & & & & & & \\
\hline & & & & & & & & & & & & & & & \\
\hline & & & & & & & & & & & & & & & \\
\hline $4-9$ & 0 & & 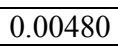 & 00 & & 00 & & & 00 & 90 & & 20 & & 00 & \\
\hline FY94-10 & 06120 & 690 & & 0.00000 & & & 30 & & & & & & & 000 & 000 \\
\hline na1 & & & & 000 & & & & & & & & & & & \\
\hline $1 \mathrm{a} 2$ & 04290 & 0.18690 & 0.00480 & 0.00000 & 140 & 0.07410 & 0.06880 & 0.00000 & 0.05100 & 890 & 0.0 & 0.11000 & 250 & 0.00000 & \\
\hline
\end{tabular}

\begin{tabular}{|l|c|c|c|c|c|c|c|c|c|c|c|}
\hline Glass ID & $\mathbf{S e O}_{2}$ & $\mathbf{S i O}_{2}$ & $\mathbf{S r O}$ & $\mathbf{T h O}_{2}$ & $\mathbf{T i O}_{2}$ & $\mathbf{T l}_{\mathbf{2}} \mathbf{O}$ & $\mathbf{U O}_{3}$ & $\mathbf{Z n O}$ & $\mathbf{Z r O}_{2}$ & $\mathbf{O t h e r s}$ & $\mathbf{S u m}^{(\mathbf{a})}$ \\
\hline FY93-7 & 0.00000 & 0.46380 & 0.00250 & 0.05340 & 0.00800 & 0.00000 & 0.00630 & 0.00260 & 0.01320 & 0.02000 & 1.00000 \\
\hline FY93-8 & 0.00000 & 0.34830 & 0.00250 & 0.05340 & 0.00800 & 0.00000 & 0.00630 & 0.00260 & 0.01320 & 0.02000 & 1.00000 \\
\hline FY93-9 & 0.00000 & 0.34830 & 0.00250 & 0.05340 & 0.00800 & 0.00000 & 0.00630 & 0.00260 & 0.01320 & 0.02000 & 1.00000 \\
\hline FY93-10 & 0.00000 & 0.46210 & 0.00250 & 0.05340 & 0.00800 & 0.00000 & 0.00630 & 0.00260 & 0.01320 & 0.02000 & 1.00000 \\
\hline FY94-1 & 0.00000 & 0.47740 & 0.00250 & 0.04800 & 0.00800 & 0.00000 & 0.00630 & 0.00260 & 0.00730 & 0.02000 & 1.00000 \\
\hline FY94-2 & 0.00000 & 0.43000 & 0.00250 & 0.02730 & 0.00800 & 0.00000 & 0.00630 & 0.00260 & 0.00730 & 0.02000 & 1.00000 \\
\hline FY94-3 & 0.00000 & 0.37000 & 0.00250 & 0.02000 & 0.00800 & 0.00000 & 0.00630 & 0.00260 & 0.00730 & 0.02000 & 1.00000 \\
\hline FY94-4 & 0.00000 & 0.34500 & 0.00250 & 0.00900 & 0.00800 & 0.00000 & 0.00630 & 0.00260 & 0.00730 & 0.02000 & 1.00000 \\
\hline FY94-5 & 0.00000 & 0.47700 & 0.00250 & 0.03100 & 0.00800 & 0.00000 & 0.00630 & 0.00260 & 0.01730 & 0.02000 & 1.00000 \\
\hline FY94-6 & 0.00000 & 0.39280 & 0.00250 & 0.05160 & 0.00800 & 0.00000 & 0.00630 & 0.00260 & 0.01910 & 0.02000 & 1.00000 \\
\hline FY94-7 & 0.00000 & 0.43500 & 0.00250 & 0.04700 & 0.00800 & 0.00000 & 0.00630 & 0.00260 & 0.01840 & 0.02000 & 1.00000 \\
\hline FY94-8 & 0.00000 & 0.34500 & 0.00250 & 0.01100 & 0.00800 & 0.00000 & 0.00630 & 0.00260 & 0.01910 & 0.02000 & 1.00000 \\
\hline FY94-9 & 0.00000 & 0.41260 & 0.00250 & 0.02400 & 0.00800 & 0.00000 & 0.00630 & 0.00260 & 0.01800 & 0.02000 & 1.00000 \\
\hline FY94-10 & 0.00000 & 0.42000 & 0.00250 & 0.03600 & 0.00800 & 0.00000 & 0.00630 & 0.00260 & 0.00730 & 0.02000 & 1.00000 \\
\hline Sigma1 & 0.00000 & 0.34220 & 0.00250 & 0.00890 & 0.00800 & 0.00000 & 0.00630 & 0.00260 & 0.00730 & 0.02000 & 1.00000 \\
\hline Sigma2 & 0.00000 & 0.34220 & 0.00250 & 0.05160 & 0.00800 & 0.00000 & 0.00630 & 0.00260 & 0.00730 & 0.02000 & 1.00000 \\
\hline
\end{tabular}

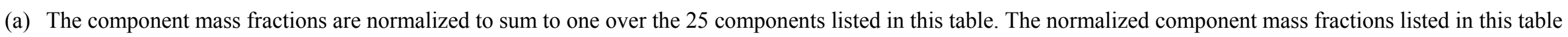
were rounded to five decimals, and may not sum exactly to 1.00000 as listed. However, complete compositions listed to more decimal places and summing to 1.0000 were used for validating PCT-composition models. 
Table B.1. Normalized 25-Component Compositions (mass fractions) of 554 HLW Glasses Used for PCT Model Validation (continued).

\begin{tabular}{|c|c|c|c|c|c|c|c|c|c|c|c|c|c|c|c|}
\hline & $\mathbf{O}_{3}$ & $\mathbf{O}_{3}$ & & & $\mathrm{D}_{3}$ & ${ }_{2} \mathbf{O}_{3}$ & $\mathbf{O}$ & $\mathbf{a}_{2} \mathbf{O}_{3}$ & $\mathbf{L i}_{2} \mathbf{O}$ & & & $\mathbf{a}_{2} \mathrm{O}$ & $\mathbf{O}$ & $\mathbf{O}$ & $\mathrm{Sb}_{2} \mathrm{O}_{3}$ \\
\hline & & & & & & & & & & & & & & & \\
\hline & & & & & & & & & & & & & & & \\
\hline & & & & & & & & & & & & & & & \\
\hline & & & & & & & & & & & & & & & \\
\hline & & & & & & & & & & & & & & & \\
\hline & & & & & & & & & & & & & & & \\
\hline & & & & & & & & & & & & & & & \\
\hline & & & & & & & & & & & & & & & \\
\hline & & & & & & & & & & & & & & & \\
\hline & & & & & & & & & & & & & & & \\
\hline & & & & & & & & & & & & & & & \\
\hline & & & & & & & & & & & & & & & \\
\hline & & & & & & & & & & & & & 000 & & 000 \\
\hline A46 & & & & & & & & & & & & & & & 000 \\
\hline & & & & & & & & & & & & & & & \\
\hline IA48 & .06201 & 08902 & 0.00000 & 0.00000 & 0.00020 & 0.06981 & 0.02999 & 0.00000 & 0.00000 & 477 & 0.00000 & 0.20000 & 0.00000 & 001 & 0. \\
\hline
\end{tabular}

\begin{tabular}{|l|c|c|c|c|c|c|c|c|c|c|c|}
\hline Glass ID & $\mathbf{S e O}_{2}$ & $\mathbf{S i O}_{2}$ & $\mathbf{S r O}$ & $\mathbf{T h O}_{\mathbf{2}}$ & $\mathbf{T i O}_{2}$ & $\mathbf{T l}_{\mathbf{2}} \mathbf{O}$ & $\mathbf{U O}_{3}$ & $\mathbf{Z n O}$ & $\mathbf{Z r O}_{2}$ & $\mathbf{O t h e r s}^{\text {Sum }}$ \\
\hline Sigma3 & 0.00000 & 0.36720 & 0.00250 & 0.03840 & 0.00800 & 0.00000 & 0.00630 & 0.00260 & 0.00780 & 0.02000 & 1.00000 \\
\hline Sigma4 & 0.00000 & 0.35500 & 0.00250 & 0.01000 & 0.00800 & 0.00000 & 0.00630 & 0.00260 & 0.00810 & 0.02000 & 1.00000 \\
\hline Sigma5 & 0.00000 & 0.35000 & 0.00250 & 0.00900 & 0.00800 & 0.00000 & 0.00630 & 0.00260 & 0.00800 & 0.02000 & 1.00000 \\
\hline Sigma6 & 0.00000 & 0.36500 & 0.00250 & 0.02200 & 0.00800 & 0.00000 & 0.00630 & 0.00260 & 0.00820 & 0.02000 & 1.00000 \\
\hline Sigma7 & 0.00000 & 0.36000 & 0.00250 & 0.01100 & 0.00800 & 0.00000 & 0.00630 & 0.00260 & 0.00780 & 0.02000 & 1.00000 \\
\hline Sigma8 & 0.00000 & 0.37000 & 0.00250 & 0.01000 & 0.00800 & 0.00000 & 0.00630 & 0.00260 & 0.00840 & 0.02000 & 1.00000 \\
\hline Sigma9 & 0.00000 & 0.37500 & 0.00250 & 0.04300 & 0.00800 & 0.00000 & 0.00630 & 0.00260 & 0.00850 & 0.02000 & 1.00000 \\
\hline Sigma10 & 0.00000 & 0.38000 & 0.00250 & 0.05000 & 0.00800 & 0.00000 & 0.00630 & 0.00260 & 0.00830 & 0.02000 & 1.00000 \\
\hline LAWA41 & 0.00009 & 0.43410 & 0.00000 & 0.00000 & 0.01995 & 0.00000 & 0.00000 & 0.02993 & 0.02995 & 0.00795 & 1.00000 \\
\hline LAWA42 & 0.00009 & 0.38000 & 0.00000 & 0.00000 & 0.02402 & 0.00000 & 0.00000 & 0.03604 & 0.03607 & 0.00799 & 1.00000 \\
\hline LAWA43 & 0.00009 & 0.38001 & 0.00000 & 0.00000 & 0.01965 & 0.00000 & 0.00000 & 0.02948 & 0.02951 & 0.00799 & 1.00000 \\
\hline LAWA44 & 0.00000 & 0.44552 & 0.00000 & 0.00000 & 0.01994 & 0.00000 & 0.00000 & 0.02965 & 0.02992 & 0.00904 & 1.00000 \\
\hline LAWA45 & 0.00000 & 0.44552 & 0.00000 & 0.00000 & 0.01994 & 0.00000 & 0.00000 & 0.02477 & 0.02992 & 0.00904 & 1.00000 \\
\hline LAWA46 & 0.00000 & 0.44552 & 0.00000 & 0.00000 & 0.01994 & 0.00000 & 0.00000 & 0.02477 & 0.02992 & 0.03903 & 1.00000 \\
\hline LAWA47 & 0.00000 & 0.44552 & 0.00000 & 0.00000 & 0.01994 & 0.00000 & 0.00000 & 0.02477 & 0.02992 & 0.03903 & 1.00000 \\
\hline LAWA48 & 0.00000 & 0.44552 & 0.00000 & 0.00000 & 0.01994 & 0.00000 & 0.00000 & 0.02477 & 0.02992 & 0.01405 & 1.00000 \\
\hline
\end{tabular}

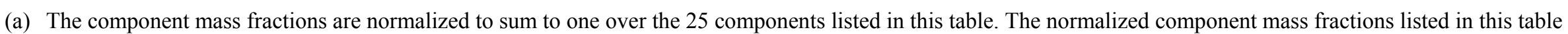
were rounded to five decimals, and may not sum exactly to 1.00000 as listed. However, complete compositions listed to more decimal places and summing to 1.0000 were used for validating PCT-composition models. 
Table B.1. Normalized 25-Component Compositions (mass fractions) of 554 HLW Glasses Used for PCT Model Validation (continued).

\begin{tabular}{|c|c|c|c|c|c|c|c|c|c|c|c|c|c|c|c|}
\hline ID & $\mathbf{A l}_{2} \mathbf{O}_{3}$ & $\mathbf{B}_{2} \mathbf{O}_{3}$ & $\mathrm{CaO}$ & CdO & $\mathbf{r}_{2} \mathbf{O}_{3}$ & $\mathrm{Fe}_{2} \mathrm{O}_{3}$ & $\mathbf{K}_{2} \mathbf{O}$ & $\mathbf{L a}_{2} \mathbf{O}_{3}$ & $\mathbf{L i}_{2} \mathbf{O}$ & MgO & MnO & $\mathrm{Na}_{2} \mathrm{O}$ & $\mathrm{NiO}$ & PbO & $\mathrm{Sb}_{2} \mathbf{O}_{3}$ \\
\hline \begin{tabular}{|l|} 
LAWA49 \\
\end{tabular} & 06201 & 08902 & .00000 & 00000 & 0.00020 & 09980 & .00000 & .00000 & 0.00000 & .01477 & 00000 & 0.20000 & 0.00000 & 00001 & 0.00000 \\
\hline \begin{tabular}{|l} 
LAWA50 \\
\end{tabular} & 06201 & & 00000 & 00000 & & 11982 & 00000 & & & & & & & & \\
\hline \begin{tabular}{|l}
$\mathrm{LAY}$ \\
\end{tabular} & \begin{tabular}{|l|}
0.06202 \\
\end{tabular} & 11974 & 0.00 & 00000 & 0.00018 & \begin{tabular}{|l|}
0.06997 \\
\end{tabular} & 0.00000 & 0.00000 & 0.00000 & \begin{tabular}{|l|}
0.01484 \\
\end{tabular} & 00000 & \begin{tabular}{|l|l|}
0.17999 \\
\end{tabular} & 0.00000 & 0001 & 0.00000 \\
\hline$\overline{L A}$ & 0.06179 & 0.06191 & $0.0^{\prime}$ & 0.00000 & 0.0 & 505 & 0501 & 000 & 0.00000 & 477 & 0000 & 0.20000 & 0000 & 00 & \\
\hline \begin{tabular}{|l|} 
LAWA60 \\
\end{tabular} & 0.08528 & 0.11229 & 0.04321 & 0.00000 & 0.00020 & 0.00000 & 0.00501 & 0.00000 & 0.00000 & 0.01994 & 0.00000 & 0.20000 & 0.00000 & 0.00000 & 0.00000 \\
\hline \begin{tabular}{|l} 
LAWA64 \\
\end{tabular} & 0.06179 & 0.06191 & 0.00000 & 0.00000 & 0.00020 & 0.07505 & 0.00501 & 0.00000 & 0.00000 & 0.01477 & 0.00000 & 0.20000 & 0.00000 & 0.00000 & 0.00000 \\
\hline \begin{tabular}{|l|} 
LAWA76 \\
\end{tabular} & 0.06097 & 0.10863 & 0.07779 & 0.00000 & 0.00020 & 0.07409 & 0.00491 & 0.00000 & 0.04956 & 0.01462 & 0.00000 & 0.10042 & 0.00000 & 0000 & 0.00000 \\
\hline \begin{tabular}{|l|} 
LAWA81 \\
\end{tabular} & \begin{tabular}{|l|}
0.06201 \\
\end{tabular} & 0.08902 & 0.03989 & 0.00000 & 0.00020 & 0.06981 & 0.00501 & 0.00000 & 0.00000 & 994 & 0000 & 0.20000 & 0.00000 & 0000 & 0.00000 \\
\hline \begin{tabular}{|l|} 
LAWA82 \\
\end{tabular} & 0.06201 & 0.08902 & 0.00000 & 0.00000 & 0.00020 & 0.06981 & 0.00501 & 0.00000 & 0.00000 & 994 & 0.00000 & 0.20000 & 0.00000 & 0.00000 & 0.00000 \\
\hline \begin{tabular}{|l|} 
LAWA83 \\
\end{tabular} & 0.06201 & 0.08902 & 0.01994 & 0.00000 & 0.00020 & 0.04986 & 0.00501 & 0.00000 & 0.00000 & 0.01994 & 0.00000 & 0.20000 & 0.00000 & 0.00000 & 0.00000 \\
\hline \begin{tabular}{|l} 
LAWA84 \\
\end{tabular} & 0.06201 & 0.08902 & 0.01994 & 0.00000 & 0.00020 & 0.02992 & 0.00501 & 0.00000 & 0.00000 & 0.01994 & 0.00000 & 0.20000 & 0.00000 & 0.00000 & 0.00000 \\
\hline$\overline{\text { LAV }}$ & 0.06201 & 0.08902 & 0.00000 & 000 & 0.0 & 0.04986 & 0.00501 & 0.0 & 0.00000 & & 0.00000 & 0.20000 & 0.00000 & 000 & 000 \\
\hline \begin{tabular}{|l} 
LAWA86 \\
\end{tabular} & \begin{tabular}{|l|}
0.06201 \\
\end{tabular} & 0.08902 & 0.00000 & 0.00000 & 0.00020 & 0.02992 & 0.00501 & 0.00000 & 0.00000 & 0.01994 & \begin{tabular}{|l|}
0.00000 \\
\end{tabular} & 0.20000 & 0.00000 & 0.00000 & 0.00000 \\
\hline \begin{tabular}{|l|} 
LAWA87 \\
\end{tabular} & 0.04480 & 0.08871 & 0.01991 & 0.00000 & 0.00009 & 0.06968 & 0.02583 & 0.00000 & 0.00000 & 0.01991 & 0.00000 & 0.19998 & 0.00000 & 0.00000 & 0.00000 \\
\hline \begin{tabular}{|l|} 
LAWA88 \\
\end{tabular} & 0.06079 & 0.09697 & 0.01991 & 0.00000 & 0.00009 & 0.05530 & 0.02583 & 0.00000 & 0.00000 & 0.01475 & 0.00000 & 0.19998 & 0.00000 & 0.00000 & 0.00000 \\
\hline \begin{tabular}{|l|} 
LAWA89 \\
\end{tabular} & 0.06079 & 0.09697 & 0.00000 & 0.00000 & 0.00009 & 0.05530 & 0.02583 & 0.00000 & 0.00000 & 0.01475 & 0.00000 & 0.19998 & 0.00000 & 0.00000 & 0.00000 \\
\hline
\end{tabular}

\begin{tabular}{|l|c|c|c|c|c|c|c|c|c|c|c|}
\hline Glass ID & $\mathbf{S e O}_{2}$ & $\mathbf{S i O}_{2}$ & $\mathbf{S r O}$ & $\mathbf{T h O}_{2}$ & $\mathbf{T i O}_{2}$ & $\mathbf{T l}_{\mathbf{2}} \mathbf{O}$ & $\mathbf{U O}_{3}$ & $\mathbf{Z n O}$ & $\mathbf{Z r O}_{2}$ & $\mathbf{O t h e r s}$ & $\mathbf{S u m}^{(\mathbf{a})}$ \\
\hline LAWA49 & 0.00000 & 0.44552 & 0.00000 & 0.00000 & 0.01994 & 0.00000 & 0.00000 & 0.02477 & 0.02992 & 0.01405 & 1.00000 \\
\hline LAWA50 & 0.00000 & 0.42550 & 0.00000 & 0.00000 & 0.01994 & 0.00000 & 0.00000 & 0.02477 & 0.02992 & 0.01405 & 1.00000 \\
\hline LAWA51 & 0.00000 & 0.46569 & 0.00000 & 0.00000 & 0.01996 & 0.00000 & 0.00000 & 0.02488 & 0.02998 & 0.01275 & 1.00000 \\
\hline LAWA52 & 0.00000 & 0.42248 & 0.00000 & 0.00000 & 0.01108 & 0.00000 & 0.00000 & 0.02994 & 0.02992 & 0.00904 & 1.00000 \\
\hline LAWA60 & 0.00000 & 0.44553 & 0.00000 & 0.00000 & 0.01994 & 0.00000 & 0.00000 & 0.02965 & 0.02992 & 0.00904 & 1.00000 \\
\hline LAWA64 & 0.00000 & 0.42248 & 0.07882 & 0.00000 & 0.01108 & 0.00000 & 0.00000 & 0.02994 & 0.02992 & 0.00904 & 1.00000 \\
\hline LAWA76 & 0.00000 & 0.41710 & 0.00000 & 0.00000 & 0.01091 & 0.00000 & 0.00000 & 0.02954 & 0.02954 & 0.02173 & 1.00000 \\
\hline LAWA81 & 0.00000 & 0.44552 & 0.00000 & 0.00000 & 0.00000 & 0.00000 & 0.00000 & 0.02965 & 0.02992 & 0.00904 & 1.00000 \\
\hline LAWA82 & 0.00000 & 0.44552 & 0.00000 & 0.00000 & 0.03989 & 0.00000 & 0.00000 & 0.02965 & 0.02992 & 0.00904 & 1.00000 \\
\hline LAWA83 & 0.00000 & 0.44553 & 0.00000 & 0.00000 & 0.01994 & 0.00000 & 0.00000 & 0.02965 & 0.02992 & 0.02898 & 1.00000 \\
\hline LAWA84 & 0.00000 & 0.44553 & 0.00000 & 0.00000 & 0.01994 & 0.00000 & 0.00000 & 0.02965 & 0.02992 & 0.04893 & 1.00000 \\
\hline LAWA85 & 0.00000 & 0.44553 & 0.01994 & 0.00000 & 0.01994 & 0.00000 & 0.00000 & 0.02965 & 0.02992 & 0.02898 & 1.00000 \\
\hline LAWA86 & 0.00000 & 0.44553 & 0.01994 & 0.00000 & 0.01994 & 0.00000 & 0.00000 & 0.02965 & 0.02992 & 0.04893 & 1.00000 \\
\hline LAWA87 & 0.00000 & 0.44451 & 0.00000 & 0.00000 & 0.01991 & 0.00000 & 0.00000 & 0.02957 & 0.02987 & 0.00725 & 1.00000 \\
\hline LAWA88 & 0.00000 & 0.43986 & 0.00000 & 0.00000 & 0.01991 & 0.00000 & 0.00000 & 0.02950 & 0.02987 & 0.00725 & 1.00000 \\
\hline LAWA89 & 0.00000 & 0.43986 & 0.00000 & 0.00000 & 0.03982 & 0.00000 & 0.00000 & 0.02950 & 0.02987 & 0.00725 & 1.00000 \\
\hline
\end{tabular}

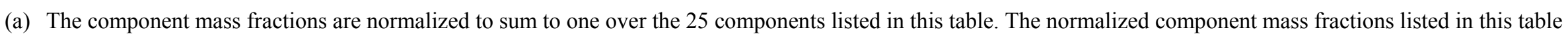
were rounded to five decimals, and may not sum exactly to 1.00000 as listed. However, complete compositions listed to more decimal places and summing to 1.0000 were used for validating PCT-composition models. 
Table B.1. Normalized 25-Component Compositions (mass fractions) of 554 HLW Glasses Used for PCT Model Validation (continued).

\begin{tabular}{|c|c|c|c|c|c|c|c|c|c|c|c|c|c|c|c|}
\hline D & $\mathbf{A l}_{2} \mathbf{O}_{3}$ & $\mathbf{B}_{2} \mathbf{O}_{3}$ & 0 & dO & $\mathrm{Cr}_{2} \mathrm{O}_{3}$ & $\mathrm{Fe}_{2} \mathrm{O}_{3}$ & $\mathbf{K}_{2} \mathbf{O}$ & $\mathbf{L a}_{2} \mathbf{O}_{3}$ & $\mathbf{L i}_{2} \mathbf{O}$ & & D & $\mathrm{Na}_{2} \mathrm{O}$ & $\mathrm{NiO}$ & ) & $\mathrm{Sb}_{2} \mathrm{O}_{3}$ \\
\hline 0 & 6079 & 9697 & 82 & 00000 & 00009 & 05530 & 2583 & 00000 & 00000 & 75 & 0000 & 9998 & 000 & 00 & 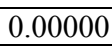 \\
\hline & & & & & & & & & & & & & & & \\
\hline & & & & & & & & & & & & & & & \\
\hline LA & & 667 & & 0000 & & & & & & & 000 & & 00 & 000 & 000 \\
\hline LAY & 5866 & 653 & & 0000 & & & & & 00 & & 000 & & & 0001 & \\
\hline LA & & & & & & & & & & & 00 & 20 & 00 & 001 & \\
\hline & & & & & & & & & & & & & & & \\
\hline LA & 033 & 60 & & 00 & & & & & 91 & & & & & 000 & \\
\hline $\mathrm{LA}$ & 0.06613 & 590 & & 00 & & & & & 00 & & 000 & & & 002 & 000 \\
\hline & & & & & & & & & & & & & & & \\
\hline LA & & & & & & & & & & & & & & 00 & \\
\hline & & 91 & 31 & \begin{tabular}{|l|}
0.00000 \\
\end{tabular} & 88 & & 19 & 0.0 & 56 & & 000 & 899 & 00 & 000 & 00 \\
\hline LA & 6157 & 15092 & 4031 & \begin{tabular}{|l|}
0.00000 \\
\end{tabular} & 088 & 0.0 & 319 & & 0.02956 & & \begin{tabular}{|l|}
0.00000 \\
\end{tabular} & 7899 & 0.00000 & 0.00000 & 0.00000 \\
\hline LA & 06157 & 0.12091 & 04031 & 0.00000 & 00088 & 0.05150 & 0.00319 & 0.00000 & 0.02956 & 39 & 0.00000 & \begin{tabular}{|l|}
0.07899 \\
\end{tabular} & 0.00000 & 0000 & 00000 \\
\hline & 58 & 091 & 46 & 0.00000 & & & & & & & & 899 & & 000 & \\
\hline LAW & 06157 & .12091 & 04031 & 0.00000 & 0.00088 & 0.05150 & 0.00319 & 0.00000 & 0.02956 & 255 & 0.00000 & 0.07899 & 0.00000 & 0.00000 & 0.00000 \\
\hline
\end{tabular}

\begin{tabular}{|l|c|c|c|c|c|c|c|c|c|c|c|}
\hline Glass ID & $\mathbf{S e O}_{2}$ & $\mathbf{S i O}_{2}$ & $\mathbf{S r O}$ & $\mathbf{T h O}_{2}$ & $\mathbf{T i O}_{2}$ & $\mathbf{T l}_{\mathbf{2}} \mathbf{O}$ & $\mathbf{U O}_{\mathbf{3}}$ & $\mathbf{Z n O}$ & $\mathbf{Z r O}_{2}$ & $\mathbf{O t h e r s ~}^{\mathbf{S u m}}$ \\
\hline LAWA90 & 0.00000 & 0.43986 & 0.00000 & 0.00000 & 0.00000 & 0.00000 & 0.00000 & 0.02950 & 0.02987 & 0.00725 & 1.00000 \\
\hline LAWA93 & 0.00000 & 0.42248 & 0.00000 & 0.00000 & 0.01108 & 0.00000 & 0.00000 & 0.02994 & 0.02992 & 0.00904 & 1.00000 \\
\hline LAWA96 & 0.00000 & 0.43555 & 0.00000 & 0.00000 & 0.01994 & 0.00000 & 0.00000 & 0.02965 & 0.02992 & 0.04893 & 1.00000 \\
\hline LAWA98S & 0.00000 & 0.42723 & 0.00000 & 0.00000 & 0.01122 & 0.00000 & 0.00000 & 0.03046 & 0.03005 & 0.01328 & 1.00000 \\
\hline LAWA99S & 0.00000 & 0.42667 & 0.00000 & 0.00000 & 0.01120 & 0.00000 & 0.00000 & 0.03042 & 0.03001 & 0.04417 & 1.00000 \\
\hline LAWA100S & 0.00000 & 0.42765 & 0.00000 & 0.00000 & 0.01123 & 0.00000 & 0.00000 & 0.03049 & 0.03008 & 0.01230 & 1.00000 \\
\hline LAWA101S & 0.00000 & 0.42761 & 0.00000 & 0.00000 & 0.01123 & 0.00000 & 0.00000 & 0.03049 & 0.03007 & 0.01240 & 1.00000 \\
\hline LAWA102S & 0.00000 & 0.46407 & 0.00000 & 0.00000 & 0.01139 & 0.00000 & 0.00000 & 0.03051 & 0.03011 & 0.01279 & 1.00000 \\
\hline LAWA104 & 0.00000 & 0.42986 & 0.00000 & 0.00000 & 0.01924 & 0.00000 & 0.00000 & 0.02860 & 0.02886 & 0.00983 & 1.00000 \\
\hline LAWA105 & 0.00000 & 0.41419 & 0.00000 & 0.00000 & 0.01854 & 0.00000 & 0.00000 & 0.02756 & 0.02781 & 0.01062 & 1.00000 \\
\hline LAWB30 & 0.00000 & 0.42716 & 0.00000 & 0.00000 & 0.00000 & 0.00000 & 0.00000 & 0.04114 & 0.03120 & 0.00457 & 1.00000 \\
\hline LAWB31 & 0.00000 & 0.46909 & 0.00000 & 0.00000 & 0.00000 & 0.00000 & 0.00000 & 0.03090 & 0.03090 & 0.03967 & 1.00000 \\
\hline LAWB32 & 0.00000 & 0.46909 & 0.00000 & 0.00000 & 0.00000 & 0.00000 & 0.00000 & 0.03090 & 0.03090 & 0.03967 & 1.00000 \\
\hline LAWB33 & 0.00000 & 0.46909 & 0.00000 & 0.00000 & 0.00000 & 0.00000 & 0.00000 & 0.03090 & 0.03090 & 0.05982 & 1.00000 \\
\hline LAWB34 & 0.00000 & 0.46909 & 0.00000 & 0.00000 & 0.00000 & 0.00000 & 0.00000 & 0.03090 & 0.03090 & 0.03967 & 1.00000 \\
\hline LAWB35 & 0.00000 & 0.46909 & 0.00000 & 0.00000 & 0.00000 & 0.00000 & 0.00000 & 0.03090 & 0.03090 & 0.03967 & 1.00000 \\
\hline
\end{tabular}

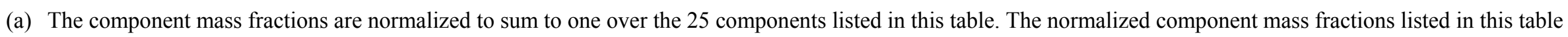
were rounded to five decimals, and may not sum exactly to 1.00000 as listed. However, complete compositions listed to more decimal places and summing to 1.0000 were used for validating PCT-composition models. 
Table B.1. Normalized 25-Component Compositions (mass fractions) of 554 HLW Glasses Used for PCT Model Validation (continued).

\begin{tabular}{|c|c|c|c|c|c|c|c|c|c|c|c|c|c|c|c|}
\hline Glass ID & $\mathbf{A l}_{2} \mathbf{O}_{3}$ & $\mathbf{B}_{2} \mathbf{O}_{3}$ & $\mathbf{O}$ & dO & $\mathrm{Cr}_{2} \mathrm{O}_{3}$ & $\mathrm{Fe}_{2} \mathrm{O}_{3}$ & $\mathbf{K}_{2} \mathbf{O}$ & $\mathbf{L a}_{2} \mathbf{O}_{3}$ & $\mathbf{L i}_{2} \mathbf{O}$ & $U$ & $\mathbf{0}$ & $\mathrm{Na}_{2} \mathrm{O}$ & $\mathrm{NiO}$ & PbO & $\mathrm{Sb}_{2} \mathrm{O}_{3}$ \\
\hline & & 12091 & 3 & & & 0.05150 & 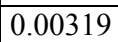 & & 02956 & & & 07899 & & & \\
\hline & & & & & & & & & & & & & & & \\
\hline & & & & & & & & & & & & & & & \\
\hline & & 12091 & & \begin{tabular}{|c|}
0.00000 \\
\end{tabular} & & & & & & & & & & & \\
\hline & & 91 & & 0.00000 & & & & & & & & & & & \\
\hline & & & & & & & & & & & & 199 & & & \\
\hline & & & & & & & & & 715 & & 00 & 987 & & 000 & \\
\hline & & & & & & & & & & & & & & & \\
\hline & 06075 & 09985 & 0.06719 & 0.00000 & & 0.0 & 226 & 0.0 & 832 & & 000 & 985 & & 000 & 000 \\
\hline & & & & & & & & & & & & & & & \\
\hline & & & & & & & & & & & & & & & \\
\hline & 17 & 157 & 0.0 & 00 & 23 & 0.0 & 46 & 0.0 & 000 & & 002 & 998 & 25 & 000 & 000 \\
\hline LAWC15* & 0.06226 & 0.08936 & 0.02008 & 0.00004 & 0.00003 & 0.07012 & 0142 & 0.00000 & 0.00000 & 10 & 0.00000 & 0.19978 & 0.00035 & 0.00004 & 0.00000 \\
\hline & 06106 & 0056 & 0.06346 & 0.00000 & 0.00020 & 0.07488 & 0150 & & 0.03954 & & 0.00003 & 0.11754 & 0.00000 & 0.00000 & \\
\hline & & & & & & & & & & & & & & & \\
\hline $\mathrm{LA}$ & 06103 & 10052 & 0.07331 & 0.00000 & 0.00020 & 0.07485 & .00150 & 0.00000 & 0.02964 & 503 & 0.00003 & 0.11749 & 0.00000 & 0.00000 & 0 \\
\hline
\end{tabular}

\begin{tabular}{|l|c|c|c|c|c|c|c|c|c|c|c|}
\hline Glass ID & $\mathbf{S e O}_{2}$ & $\mathbf{S i O}_{2}$ & $\mathbf{S r O}$ & $\mathbf{T h O}_{2}$ & $\mathbf{T i O}_{2}$ & $\mathbf{T l}_{\mathbf{2}} \mathbf{O}$ & $\mathbf{U O}_{\mathbf{3}}$ & $\mathbf{Z n O}$ & $\mathbf{Z r O}_{2}$ & $\mathbf{O t h e r s ~}^{\mathbf{S u m}} \mathbf{( a )}^{(\mathbf{a})}$ \\
\hline LAWB37 & 0.00000 & 0.46909 & 0.00000 & 0.00000 & 0.00000 & 0.00000 & 0.00000 & 0.03090 & 0.03090 & 0.04639 & 1.00000 \\
\hline LAWB38 & 0.00000 & 0.46909 & 0.00000 & 0.00000 & 0.00000 & 0.00000 & 0.00000 & 0.03090 & 0.03090 & 0.04415 & 1.00000 \\
\hline LAWB39 & 0.00000 & 0.46909 & 0.00000 & 0.00000 & 0.00000 & 0.00000 & 0.00000 & 0.03090 & 0.03090 & 0.04639 & 1.00000 \\
\hline LAWB40 & 0.00000 & 0.46909 & 0.00000 & 0.00000 & 0.00000 & 0.00000 & 0.00000 & 0.03090 & 0.03090 & 0.01280 & 1.00000 \\
\hline LAWB41 & 0.00000 & 0.46910 & 0.00000 & 0.00000 & 0.00000 & 0.00000 & 0.00000 & 0.03091 & 0.03091 & 0.01275 & 1.00000 \\
\hline LAWB45 & 0.00000 & 0.47853 & 0.00000 & 0.00000 & 0.00000 & 0.00000 & 0.00000 & 0.03153 & 0.03153 & 0.01074 & 1.00000 \\
\hline LAWB51S & 0.00000 & 0.48747 & 0.00000 & 0.00000 & 0.00000 & 0.00000 & 0.00000 & 0.03174 & 0.03174 & 0.01249 & 1.00000 \\
\hline LAWB52S & 0.00000 & 0.48747 & 0.00000 & 0.00000 & 0.00000 & 0.00000 & 0.00000 & 0.03174 & 0.03174 & 0.01249 & 1.00000 \\
\hline LAWB53S & 0.00000 & 0.48728 & 0.00000 & 0.00000 & 0.01400 & 0.00000 & 0.00000 & 0.03172 & 0.03172 & 0.01288 & 1.00000 \\
\hline LAWC12 for & 0.00000 & 0.39373 & 0.00000 & 0.00000 & 0.03416 & 0.00000 & 0.00000 & 0.04273 & 0.02458 & 0.00356 & 1.00000 \\
\hline LAWC13 & 0.00000 & 0.42333 & 0.00000 & 0.00000 & 0.01539 & 0.00000 & 0.00000 & 0.03079 & 0.03079 & 0.06898 & 1.00000 \\
\hline LAWC14 & 0.00000 & 0.42333 & 0.00000 & 0.00000 & 0.01539 & 0.00000 & 0.00000 & 0.03079 & 0.03079 & 0.06898 & 1.00000 \\
\hline LAWC15* & 0.00000 & 0.44748 & 0.00001 & 0.00000 & 0.02002 & 0.00000 & 0.00000 & 0.02993 & 0.03008 & 0.00891 & 1.00000 \\
\hline LAWC16S & 0.00000 & 0.44363 & 0.00000 & 0.00000 & 0.01118 & 0.00000 & 0.00000 & 0.03008 & 0.03011 & 0.01119 & 1.00000 \\
\hline LAWC17S & 0.00000 & 0.44386 & 0.00000 & 0.00000 & 0.01118 & 0.00000 & 0.00000 & 0.03010 & 0.03013 & 0.04079 & 1.00000 \\
\hline LAWC18S & 0.00000 & 0.44345 & 0.00000 & 0.00000 & 0.01117 & 0.00000 & 0.00000 & 0.03007 & 0.03010 & 0.01158 & 1.00000 \\
\hline
\end{tabular}

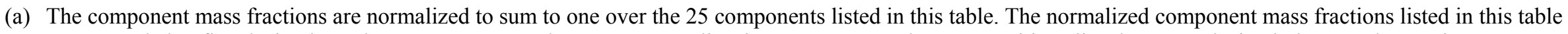
were rounded to five decimals, and may not sum exactly to 1.00000 as listed. However, complete compositions listed to more decimal places and summing to 1.0000 were used for validating PCT-composition models. 
Table B.1. Normalized 25-Component Compositions (mass fractions) of 554 HLW Glasses Used for PCT Model Validation (continued).

\begin{tabular}{|c|c|c|c|c|c|c|c|c|c|c|c|c|c|c|c|}
\hline Gl: & $\mathbf{A l}_{2} \mathbf{O}_{3}$ & $\mathbf{B}_{2} \mathbf{O}_{3}$ & $\mathrm{aO}$ & CdO & $\mathrm{Cr}_{2} \mathrm{O}_{3}$ & $\mathrm{Fe}_{2} \mathbf{O}_{3}$ & $\mathbf{K}_{2} \mathbf{O}$ & $\mathbf{L a}_{2} \mathbf{O}_{3}$ & $\mathbf{L i}_{2} \mathbf{O}$ & MgO & MnO & $\mathrm{Na}_{2} \mathrm{O}$ & $\mathrm{NiO}$ & PbO & $\mathrm{Sb}_{2} \mathrm{O}_{3}$ \\
\hline LAW & 5 & 0.10054 & 1 & 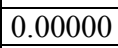 & 0.00020 & .07487 & 0.00150 & 0.00000 & 01977 & 1504 & 3 & 0.11751 & 0000 & 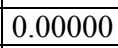 & 000000 \\
\hline & & & & & & & & & & & & & & & \\
\hline & & & & & & & & & & & & & 00 & & \\
\hline & & & & & & & & & & & & & & & \\
\hline & & 10067 & 94 & 0000 & 20 & & 78 & 000 & 00 & & & 345 & 0000 & & \\
\hline & & & & & & & & & & & & & & & \\
\hline & & & & & & & & & & & & & 0000 & & \\
\hline & & 0.0 & 000 & 0.0 & & & & 0.0 & 0.0 & & & 000 & 0000 & 00 & 0000 \\
\hline \begin{tabular}{|l|l|} 
PNLI \\
\end{tabular} & 12000 & 0.05000 & 0.04000 & 0.00000 & 0.00040 & 0.00003 & 0.01460 & 0.00000 & 0.00000 & 0003 & 0.00002 & 0.20000 & 0.00000 & 0.00000 & 0.00000 \\
\hline \begin{tabular}{|l|} 
TFA-BASE (HLP-01) \\
\end{tabular} & 07007 & 0.10010 & 0.00000 & 0.00000 & 0.00080 & 0.05506 & 0.00410 & 0.00000 & 0.00000 & 0.01502 & 0.00000 & 0.20020 & 0.00000 & 0.00000 & 0.00000 \\
\hline
\end{tabular}

\begin{tabular}{|l|c|c|c|c|c|c|c|c|c|c|c|}
\hline Glass ID & $\mathbf{S e O}_{2}$ & $\mathbf{S i O}_{2}$ & $\mathbf{S r O}$ & $\mathbf{T h O}_{2}$ & $\mathbf{T i O}_{2}$ & $\mathbf{T l}_{\mathbf{2}} \mathbf{O}$ & $\mathbf{U O}_{3}$ & $\mathbf{Z n O}$ & $\mathbf{Z r O}_{2}$ & $\mathbf{O t h e r s}^{\text {Sum }}$ & $\mathbf{S u}^{(\mathbf{a})}$ \\
\hline LAWC19S & 0.00000 & 0.44354 & 0.00000 & 0.00000 & 0.01117 & 0.00000 & 0.00000 & 0.03008 & 0.03010 & 0.01138 & 1.00000 \\
\hline LAWC20S & 0.00000 & 0.44434 & 0.00000 & 0.00000 & 0.01119 & 0.00000 & 0.00000 & 0.03013 & 0.03016 & 0.03974 & 1.00000 \\
\hline LAWC21S & 0.00000 & 0.46548 & 0.00000 & 0.00000 & 0.01117 & 0.00000 & 0.00000 & 0.03006 & 0.03009 & 0.01108 & 1.00000 \\
\hline LAWC22** & 0.00000 & 0.46610 & 0.00015 & 0.00000 & 0.01143 & 0.00000 & 0.00000 & 0.03069 & 0.03026 & 0.00942 & 1.00000 \\
\hline LAWC23 & 0.00000 & 0.46717 & 0.00000 & 0.00000 & 0.01119 & 0.00000 & 0.00000 & 0.03011 & 0.03014 & 0.00851 & 1.00000 \\
\hline LAWC24 & 0.00000 & 0.45389 & 0.00000 & 0.00000 & 0.01089 & 0.00000 & 0.00000 & 0.02932 & 0.02935 & 0.00818 & 1.00000 \\
\hline LAWC25 & 0.00000 & 0.44170 & 0.00000 & 0.00000 & 0.01060 & 0.00000 & 0.00000 & 0.02853 & 0.02856 & 0.00796 & 1.00000 \\
\hline LAWABP1 & 0.00000 & 0.41890 & 0.00000 & 0.00000 & 0.02490 & 0.00000 & 0.00000 & 0.02600 & 0.05250 & 0.00800 & 1.00000 \\
\hline PNLREF (LD6- & 0.00000 & 0.55911 & 0.00110 & 0.00000 & 0.00000 & 0.00000 & 0.00000 & 0.00000 & 0.00000 & 0.01470 & 1.00000 \\
\hline TFA-BASE & 0.00000 & 0.49119 & 0.00000 & 0.00000 & 0.03003 & 0.00000 & 0.00000 & 0.01502 & 0.01502 & 0.00340 & 1.00000 \\
\hline
\end{tabular}

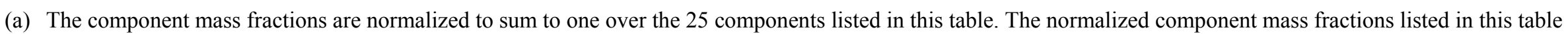
were rounded to five decimals, and may not sum exactly to 1.00000 as listed. However, complete compositions listed to more decimal places and summing to 1.0000 were used for validating PCT-composition models. 
Table B.2. PCT Release Data for 554 Validation Glasses.

\begin{tabular}{|c|c|c|c|c|c|c|c|}
\hline Glass & $\begin{array}{l}\text { PCT-B } \\
\text { (ppm) }\end{array}$ & $\begin{array}{c}\text { PCT-Li } \\
\text { (ppm) }\end{array}$ & $\begin{array}{c}\text { PCT-Na } \\
\text { (ppm) }\end{array}$ & $\begin{array}{c}\text { PCT-B } \\
\text { (g/L) }\end{array}$ & $\begin{array}{c}\text { PCT-Li } \\
\text { (g/L) }\end{array}$ & $\begin{array}{l}\text { PCT-Na } \\
\text { (g/L) }\end{array}$ & $\begin{array}{c}\text { In Validation Set } \\
\text { for Which PCT } \\
\text { Releases }\end{array}$ \\
\hline HLW98-02 & 24.030 & 6.040 & 66.840 & 0.704 & 0.646 & 0.668 & All \\
\hline HLW98-04 & 18.340 & $-{ }^{\text {(a) }}$ & 40.220 & 0.454 & - & 0.460 & PCT-B, PCT-Na \\
\hline HLW98-12 & 26.690 & 18.520 & 6.853 & 0.572 & 0.570 & 0.316 & All \\
\hline HLW98-20 & 21.870 & 3.120 & 53.160 & 0.586 & 0.448 & 0.498 & All \\
\hline HLW98-21 & 12.130 & 16.260 & 13.110 & 0.558 & 0.582 & 0.266 & All \\
\hline HLW98-22 & 16.150 & 6.467 & 27.750 & 0.434 & 0.464 & 0.434 & All \\
\hline HLW98-23 & 16.400 & 6.590 & 23.850 & 0.440 & 0.472 & 0.410 & All \\
\hline HLW98-27B & 9.833 & 13.230 & 82.430 & 0.788 & 0.630 & 0.770 & All \\
\hline HLW98-32A & 13.850 & 13.510 & 3.987 & 0.496 & 0.416 & 0.150 & All \\
\hline HLW98-34 & 10.100 & 8.047 & 27.190 & 0.464 & 0.434 & 0.392 & All \\
\hline HLW98-50 & 120.700 & 47.100 & 221.200 & 3.534 & 2.534 & 2.194 & All \\
\hline HLW98-51R & 75.850 & 50.260 & 116.800 & 2.714 & 2.164 & 1.830 & All \\
\hline HLW98-53A & 19.070 & 22.700 & 52.280 & 0.846 & 0.814 & 0.710 & All \\
\hline HLW98-56 & 30.300 & 28.810 & 64.670 & 1.394 & 0.886 & 0.914 & All \\
\hline HLW98-58 & 11.760 & 25.660 & 137.300 & 0.946 & 1.104 & 1.346 & All \\
\hline HLW98-60 & 12.010 & 23.440 & 115.800 & 0.966 & 1.008 & 1.178 & All \\
\hline HLW98-62 & 21.190 & 14.270 & 33.070 & 0.568 & 0.614 & 0.462 & All \\
\hline HLW99-15 & 1648.000 & 120.100 & 3511.000 & 26.516 & 25.838 & 23.650 & All \\
\hline HLW99-27 & 55.010 & 40.020 & 45.350 & 1.106 & 1.230 & 1.222 & All \\
\hline HLW99-52 & 1169.000 & 0.807 & 1713.000 & 18.810 & - & 14.424 & PCT-B, PCT-Na \\
\hline HLWD1-01 & 6.630 & 0.180 & 15.590 & 0.252 & 0.428 & 0.266 & All \\
\hline HLWD1-02 & 20.500 & 0.250 & 65.050 & 0.786 & 0.594 & 0.674 & All \\
\hline HLWD1-03 & 14.950 & 0.190 & 20.310 & 0.356 & 0.452 & 0.348 & All \\
\hline HLWD1-04 & 9.060 & 0.370 & 22.170 & 0.348 & 0.880 & 0.380 & All \\
\hline HLWD1-05 & 17.130 & 8.940 & 31.690 & 0.656 & 0.608 & 0.544 & All \\
\hline HLWD1-07 & 22.180 & 14.300 & 53.870 & 1.038 & 1.044 & 1.012 & All \\
\hline HLWD1-08 & 19.710 & 9.140 & 17.960 & 0.646 & 0.668 & 0.572 & All \\
\hline HLWD1-09 & 14.980 & 13.010 & 66.690 & 0.982 & 0.950 & 0.984 & All \\
\hline HLWD1-10 & 21.040 & 0.120 & 21.800 & 0.730 & - & 0.738 & PCT-B, PCT-Na \\
\hline HLWD1-11 & 30.210 & 18.620 & 137.500 & 1.594 & 1.324 & 1.260 & All \\
\hline HLWD1-13 & 8.060 & 7.330 & 40.940 & 0.382 & 0.494 & 0.518 & All \\
\hline HLWD1-14R & 123.700 & 27.490 & 162.300 & 2.474 & 1.892 & 1.540 & All \\
\hline HLWD1-17R & 121.800 & 29.260 & 111.100 & 2.436 & 2.014 & 1.580 & All \\
\hline HLWD1-18 & 60.760 & 15.490 & 66.810 & 1.276 & 1.056 & 0.940 & All \\
\hline HLWD1-19RW & 65.040 & 45.580 & 490.000 & 3.186 & 3.162 & 3.514 & All \\
\hline HLWD1-20R & 25.130 & 16.370 & 207.300 & 1.218 & 1.124 & 1.472 & All \\
\hline HLWD1-21R & 57.640 & 19.530 & 72.240 & 1.212 & 1.022 & 0.860 & All \\
\hline HLWD1-23 & 239.900 & 75.110 & 341.900 & 4.964 & 3.994 & 3.374 & All \\
\hline HLWD1-25 & 135.800 & 28.950 & 352.900 & 3.738 & 2.970 & 2.904 & All \\
\hline HLWD1-27 & 75.120 & 18.970 & 216.100 & 2.174 & 2.030 & 2.122 & All \\
\hline HLWD2-01 & 9.630 & 6.880 & 22.580 & 0.460 & 0.500 & 0.422 & All \\
\hline HLWD2-02 & 17.660 & 12.240 & 45.160 & 0.938 & 0.868 & 0.854 & All \\
\hline HLWD2-03 & 9.300 & 9.900 & 147.600 & 0.452 & 0.682 & 1.050 & All \\
\hline HLWD2-04 & 150.400 & 86.140 & 776.900 & 7.306 & 5.926 & 5.524 & All \\
\hline HLWD2-05R & 235.300 & 118.000 & 1159.000 & 11.290 & 8.018 & 8.142 & All \\
\hline HLWD2-06 & 17.340 & 6.650 & 40.810 & 0.466 & 0.478 & 0.484 & All \\
\hline HLWD3-01 & 35.670 & 0.390 & 226.000 & 1.612 & 1.388 & 1.552 & All \\
\hline HLWD3-02 & 19.980 & 0.070 & 102.800 & 0.894 & - & 0.868 & PCT-B, PCT-Na \\
\hline HLWD3-03 & 5.170 & 4.320 & 21.190 & 0.218 & 0.294 & 0.298 & All \\
\hline HLWD3-04 & 27.860 & 8.630 & 39.500 & 0.556 & 0.594 & 0.562 & All \\
\hline HLWD3-06 & 55.980 & 14.850 & 75.030 & 1.120 & 1.022 & 1.068 & All \\
\hline
\end{tabular}

(a) NA indicates the data are not available. The dash "-" indicates the glass did not contain $\mathrm{Li}_{2} \mathrm{O}$ and thus no PCT-Li release was recorded. 
The Catholic University of America Vitreous State Laboratory
IHLW PCT, Spinel $T_{1 \%}$, Electrical Conductivity, and Viscosity Model Development

Final Report, VSL-07R1240-4, Rev. 0

Table B.2. PCT Release Data for 554 Validation Glasses (continued).

\begin{tabular}{|c|c|c|c|c|c|c|c|}
\hline Glass ID & $\begin{array}{l}\text { PCT-B } \\
\text { (ppm) }\end{array}$ & $\begin{array}{c}\text { PCT-Li } \\
\text { (ppm) }\end{array}$ & $\begin{array}{c}\text { PCT-Na } \\
(\mathrm{ppm})\end{array}$ & $\begin{array}{c}\text { PCT-B } \\
\text { (g/L) }\end{array}$ & $\begin{array}{c}\text { PCT-Li } \\
(\mathrm{g} / \mathrm{L})\end{array}$ & $\begin{array}{c}\text { PCT-Na } \\
\text { (g/L) }\end{array}$ & $\begin{array}{c}\text { In Validation Set } \\
\text { for Which PCT } \\
\text { Releases }\end{array}$ \\
\hline HLWD3-07 & 48.670 & 13.480 & 163.200 & 1.378 & 0.928 & 1.160 & All \\
\hline HLWD3-08 & 256.500 & 0.620 & 814.900 & 9.300 & $--^{\text {(a) }}$ & 4.980 & PCT-B, PCT-Na \\
\hline HLW98-96A & 18.330 & 8.780 & 38.070 & 0.568 & 0.594 & 0.464 & All \\
\hline HLW98-96B & 17.250 & 8.800 & 35.350 & 0.538 & 0.600 & 0.434 & All \\
\hline CVS1-1 & $\mathrm{NA}^{(\mathrm{a})}$ & NA & NA & 1.042 & 1.058 & 0.806 & All \\
\hline CVS1-2 & NA & $\mathrm{NA}$ & $\mathrm{NA}$ & 0.132 & 0.308 & 0.128 & All \\
\hline CVS1-3 & NA & NA & NA & 1.728 & 1.582 & 1.160 & All \\
\hline CVS1-4 & NA & NA & NA & 41.278 & 33.870 & 34.068 & All \\
\hline CVS1-5 & NA & $\mathrm{NA}$ & $\mathrm{NA}$ & 0.710 & 0.924 & 0.382 & All \\
\hline CVS1-6 & NA & NA & NA & 12.226 & 9.784 & 6.092 & All \\
\hline CVS1-7 & NA & NA & NA & 0.574 & 0.662 & 0.678 & All \\
\hline CVS1-8 & NA & NA & NA & 2.476 & 1.488 & 1.610 & All \\
\hline CVS1-9 & NA & $\mathrm{NA}$ & $\mathrm{NA}$ & 21.986 & 17.204 & 15.794 & All \\
\hline CVS1-10 & NA & NA & NA & 0.254 & 0.772 & 0.190 & All \\
\hline CVS1-11 & NA & NA & NA & 0.198 & 0.374 & 0.198 & All \\
\hline CVS1-12 & NA & NA & NA & 9.324 & 8.342 & 8.790 & All \\
\hline CVS1-13 & NA & $\mathrm{NA}$ & NA & 28.144 & 25.806 & 24.826 & All \\
\hline CVS1-14 & NA & $\mathrm{NA}$ & $\mathrm{NA}$ & 19.694 & 16.022 & 11.580 & All \\
\hline CVS1-15 & NA & NA & NA & 37.556 & 22.396 & 27.990 & All \\
\hline CVS1-16 & NA & NA & NA & 1.046 & 0.532 & 1.080 & All \\
\hline CVS1-17 & NA & NA & NA & 4.470 & 4.150 & 4.608 & All \\
\hline CVS1-18 & NA & NA & NA & 22.476 & 16.130 & 16.080 & All \\
\hline CVS1-19 & NA & $\mathrm{NA}$ & NA & 1.046 & 1.066 & 0.866 & All \\
\hline CVS1-20 & NA & $\mathrm{NA}$ & NA & 0.910 & 0.936 & 0.792 & All \\
\hline CVS1-21 & NA & NA & NA & 37.700 & 31.182 & 31.072 & All \\
\hline CVS1-22 & NA & NA & NA & 2.238 & 1.408 & 1.520 & All \\
\hline CVS1-23 & NA & $\mathrm{NA}$ & $\mathrm{NA}$ & 1.050 & 1.070 & 0.974 & All \\
\hline CVS2-1 & NA & $\mathrm{NA}$ & $\mathrm{NA}$ & 0.624 & 0.738 & 0.416 & All \\
\hline CVS2-2 & NA & NA & NA & 0.256 & 0.552 & 0.376 & All \\
\hline CVS2-3 & NA & NA & NA & 0.274 & 0.444 & 0.250 & All \\
\hline CVS2-4 & NA & $\mathrm{NA}$ & $\mathrm{NA}$ & 0.316 & 0.600 & 0.364 & All \\
\hline CVS2-5 & NA & NA & NA & 0.568 & 0.764 & 0.568 & All \\
\hline CVS2-6 & NA & NA & NA & 2.370 & 2.606 & 2.568 & All \\
\hline CVS2-7 & NA & NA & $\mathrm{NA}$ & 1.480 & 1.624 & 0.686 & All \\
\hline CVS2-8 & NA & NA & NA & 0.968 & 1.046 & 0.890 & All \\
\hline CVS2-9 & NA & $\mathrm{NA}$ & $\mathrm{NA}$ & 1.120 & 1.240 & 0.748 & All \\
\hline CVS2-10 & NA & NA & NA & 2.664 & 2.644 & 1.656 & All \\
\hline CVS2-11 & NA & NA & NA & 3.174 & 3.128 & 2.740 & All \\
\hline CVS2-12 & NA & NA & NA & 0.388 & 0.524 & 0.368 & All \\
\hline CVS2-13 & NA & NA & NA & 0.720 & 0.724 & 0.956 & All \\
\hline CVS2-14 & NA & NA & NA & 3.312 & 2.936 & 2.536 & All \\
\hline CVS2-15 & NA & $\mathrm{NA}$ & $\mathrm{NA}$ & 0.662 & 0.902 & 1.216 & All \\
\hline CVS2-16 & NA & $\mathrm{NA}$ & $\mathrm{NA}$ & 5.874 & 4.698 & 4.364 & All \\
\hline CVS2-17 & NA & NA & NA & 0.990 & 1.142 & 0.948 & All \\
\hline CVS2-18 & NA & NA & NA & 5.156 & 4.188 & 3.772 & All \\
\hline CVS2-19 & NA & NA & NA & 3.980 & 3.308 & 2.962 & All \\
\hline CVS2-20 & NA & NA & NA & 0.694 & 0.772 & 0.558 & All \\
\hline CVS2-21 & NA & $\mathrm{NA}$ & $\mathrm{NA}$ & 7.708 & 5.068 & 4.178 & All \\
\hline CVS2-22 & NA & $\mathrm{NA}$ & $\mathrm{NA}$ & 19.292 & 10.906 & 12.194 & All \\
\hline CVS2-23 & NA & NA & NA & 0.346 & 1.208 & 1.618 & All \\
\hline CVS2-24 & NA & NA & NA & 9.044 & 6.452 & 4.120 & All \\
\hline
\end{tabular}

(a) NA indicates the data are not available. The dash "-" indicates the glass did not contain $\mathrm{Li}_{2} \mathrm{O}$ and thus no PCT-Li release was recorded. 
Table B.2. PCT Release Data for 554 Validation Glasses (continued).

\begin{tabular}{|c|c|c|c|c|c|c|c|}
\hline Glass ID & $\begin{array}{l}\text { PCT-B } \\
\text { (ppm) }\end{array}$ & $\begin{array}{c}\text { PCT-Li } \\
\text { (ppm) }\end{array}$ & $\begin{array}{c}\text { PCT-Na } \\
\text { (ppm) }\end{array}$ & $\begin{array}{c}\text { PCT-B } \\
\text { (g/L) }\end{array}$ & $\begin{array}{c}\text { PCT-Li } \\
\text { (g/L) }\end{array}$ & $\begin{array}{c}\text { PCT-Na } \\
\text { (g/L) }\end{array}$ & $\begin{array}{c}\text { In Validation Set } \\
\text { for Which PCT } \\
\text { Releases }\end{array}$ \\
\hline CVS2-25 & $\mathrm{NA}^{(\mathrm{a})}$ & NA & NA & 9.324 & 5.530 & 7.052 & All \\
\hline CVS2-26 & NA & NA & NA & 3.256 & 2.872 & 2.698 & All \\
\hline CVS2-27 & NA & NA & NA & 6.540 & 3.670 & 4.684 & All \\
\hline CVS2-28 & NA & NA & NA & 10.288 & 7.364 & 7.076 & All \\
\hline CVS2-29 & NA & NA & NA & 2.572 & 2.710 & 2.546 & All \\
\hline CVS2-30 & NA & NA & NA & 13.024 & 8.388 & 5.104 & All \\
\hline CVS2-31 & NA & NA & NA & 0.822 & 0.920 & 0.636 & All \\
\hline CVS2-32 & NA & NA & NA & 19.292 & 11.054 & 11.792 & All \\
\hline CVS2-33 & NA & NA & $\mathrm{NA}$ & 3.446 & 2.876 & 3.216 & All \\
\hline CVS2-34 & NA & NA & NA & 8.680 & 6.936 & 5.400 & All \\
\hline CVS2-35 & NA & NA & NA & 0.640 & 1.160 & 1.820 & All \\
\hline CVS2-36 & NA & NA & NA & 0.960 & 1.260 & 1.308 & All \\
\hline CVS2-37 & NA & NA & NA & 0.492 & 0.600 & 0.354 & All \\
\hline CVS2-38 & NA & NA & NA & 2.238 & 1.452 & 1.614 & All \\
\hline CVS2-39 & NA & NA & NA & 25.402 & 13.056 & 15.336 & All \\
\hline CVS2-40 & NA & NA & NA & 0.674 & 0.656 & 0.798 & All \\
\hline CVS2-41 & NA & NA & NA & 0.354 & 0.520 & 0.376 & All \\
\hline CVS2-42 & NA & NA & NA & 3.388 & 2.440 & 2.674 & All \\
\hline CVS2-43 & NA & NA & NA & 1.534 & 1.394 & 0.902 & All \\
\hline CVS2-44 & NA & NA & NA & 0.510 & 0.588 & 0.388 & All \\
\hline CVS2-45 & NA & NA & NA & 1.000 & 0.956 & 0.748 & All \\
\hline CVS2-46 & NA & NA & NA & 0.634 & 0.692 & 0.376 & All \\
\hline CVS2-47 & NA & NA & NA & 2.318 & 2.248 & 2.110 & All \\
\hline CVS2-48 & NA & NA & NA & 0.614 & 0.636 & 0.568 & All \\
\hline CVS2-49 & NA & NA & NA & 0.606 & 0.668 & 0.434 & All \\
\hline CVS2-50 & NA & NA & NA & 0.884 & 0.852 & 0.736 & All \\
\hline CVS2-51 & NA & NA & NA & 3.528 & 2.992 & 2.566 & All \\
\hline CVS2-52 & NA & NA & NA & 1.114 & 1.108 & 0.520 & All \\
\hline CVS2-53 & NA & NA & NA & 0.608 & 0.610 & 0.404 & All \\
\hline CVS2-54 & NA & NA & NA & 5.522 & 3.430 & 3.224 & All \\
\hline CVS2-55 & NA & NA & NA & 2.684 & 2.254 & 1.760 & All \\
\hline CVS2-56 & NA & NA & NA & 2.838 & 2.436 & 1.892 & All \\
\hline CVS2-57 & NA & NA & NA & 2.328 & 2.162 & 1.684 & All \\
\hline CVS2-58 & NA & NA & NA & 1.556 & 1.272 & 1.240 & All \\
\hline CVS2-59 & NA & NA & NA & 3.182 & 2.574 & 2.444 & All \\
\hline CVS2-60 & NA & NA & NA & 3.248 & 2.316 & 3.046 & All \\
\hline CVS2-61 & NA & NA & NA & 0.444 & 0.560 & 0.460 & All \\
\hline CVS2-62 & NA & NA & NA & 2.004 & 1.724 & 1.856 & All \\
\hline CVS2-63 & NA & NA & NA & 0.664 & 0.444 & 0.780 & All \\
\hline CVS2-64 & NA & NA & NA & 0.758 & 0.752 & 0.684 & All \\
\hline CVS2-65 & NA & NA & NA & 0.670 & 0.710 & 0.400 & All \\
\hline CVS2-66 & NA & NA & NA & 0.420 & 0.494 & 0.446 & All \\
\hline CVS2-67 & NA & NA & NA & 1.024 & 0.960 & 0.428 & All \\
\hline CVS2-68 & NA & NA & NA & 0.616 & 0.680 & 0.254 & All \\
\hline CVS2-69 & NA & NA & NA & 0.452 & 0.604 & 0.224 & All \\
\hline CVS2-70 & NA & NA & NA & 0.624 & 0.762 & 0.256 & All \\
\hline CVS2-71 & NA & NA & NA & 0.822 & 0.854 & 0.700 & All \\
\hline CVS2-72 & NA & NA & NA & 0.420 & 0.452 & 0.456 & All \\
\hline CVS2-73 & NA & NA & NA & 0.488 & 0.602 & 0.148 & All \\
\hline CVS2-74 & NA & NA & NA & 0.452 & 0.558 & 0.294 & All \\
\hline CVS2-75 & NA & NA & NA & 0.556 & 0.668 & 0.200 & All \\
\hline
\end{tabular}

(a) NA indicates the data are not available. The dash "-" indicates the glass did not contain $\mathrm{Li}_{2} \mathrm{O}$ and thus no PCT-Li release was recorded. 
Table B.2. PCT Release Data for 554 Validation Glasses (continued).

\begin{tabular}{|c|c|c|c|c|c|c|c|}
\hline Glass ID & $\begin{array}{l}\text { PCT-B } \\
\text { (ppm) }\end{array}$ & $\begin{array}{c}\text { PCT-Li } \\
\text { (ppm) }\end{array}$ & $\begin{array}{c}\text { PCT-Na } \\
\text { (ppm) }\end{array}$ & $\begin{array}{c}\text { PCT-B } \\
\text { (g/L) }\end{array}$ & $\begin{array}{c}\text { PCT-Li } \\
(\mathrm{g} / \mathrm{L})\end{array}$ & $\begin{array}{c}\text { PCT-Na } \\
(\mathrm{g} / \mathrm{L})\end{array}$ & $\begin{array}{c}\text { In Validation Set } \\
\text { for Which PCT } \\
\text { Releases }\end{array}$ \\
\hline CVS2-76 & $\mathrm{NA}^{(\mathrm{a})}$ & NA & NA & 29.742 & 15.142 & 25.082 & All \\
\hline CVS2-77 & NA & NA & NA & 19.024 & 12.442 & 13.104 & All \\
\hline CVS2-78 & NA & $\mathrm{NA}$ & NA & 1.868 & 1.396 & 1.186 & All \\
\hline CVS2-79 & NA & NA & NA & 1.488 & 1.368 & 1.320 & All \\
\hline CVS2-80 & NA & NA & NA & 1.528 & 1.344 & 1.200 & All \\
\hline CVS2-81 & NA & $\mathrm{NA}$ & NA & 33.226 & 16.128 & 25.648 & All \\
\hline CVS2-82 & NA & $\mathrm{NA}$ & NA & 88.000 & 39.938 & 70.754 & All \\
\hline CVS2-83 & NA & NA & NA & 69.312 & 38.456 & 55.780 & All \\
\hline CVS2-84 & NA & NA & $\mathrm{NA}$ & 24.920 & 13.364 & 16.472 & All \\
\hline CVS2-85 & NA & $\mathrm{NA}$ & NA & 0.912 & 0.844 & 1.498 & All \\
\hline CVS2-86 & NA & NA & NA & 0.230 & 0.182 & 0.508 & All \\
\hline CVS2-87 & NA & NA & NA & 0.356 & 0.262 & 0.572 & All \\
\hline CVS2-88 & NA & $\mathrm{NA}$ & NA & 0.616 & 0.752 & 0.946 & All \\
\hline CVS2-89 & NA & NA & NA & 3.432 & 2.472 & 2.696 & All \\
\hline CVS2-90 & NA & NA & NA & 11.154 & 7.528 & 6.962 & All \\
\hline CVS2-91 & NA & NA & NA & 17.284 & 13.548 & 13.476 & All \\
\hline CVS2-92 & NA & NA & NA & 37.180 & 24.884 & 23.584 & All \\
\hline CVS2-93 & NA & $\mathrm{NA}$ & NA & 26.454 & 15.514 & 20.020 & All \\
\hline CVS2-94 & NA & NA & NA & 8.140 & 6.132 & 6.700 & All \\
\hline CVS2-95 & NA & NA & NA & 19.952 & 8.542 & 14.518 & All \\
\hline CVS2-96 & NA & $\mathrm{NA}$ & NA & 0.986 & 0.858 & 0.820 & All \\
\hline CVS2-97 & NA & NA & NA & 2.868 & 2.104 & 2.268 & All \\
\hline CVS2-98 & NA & NA & NA & 9.040 & 6.994 & 5.592 & All \\
\hline CVS2-99 & NA & NA & NA & 0.464 & 0.492 & 0.398 & All \\
\hline CVS2-100 & NA & $\mathrm{NA}$ & NA & 0.652 & 0.686 & 0.452 & All \\
\hline CVS2-101 & NA & NA & NA & 17.288 & 7.662 & 13.172 & All \\
\hline CVS2-102 & NA & $\mathrm{NA}$ & NA & 5.344 & 3.842 & 3.354 & All \\
\hline CVS2-103 & NA & $\mathrm{NA}$ & NA & 12.146 & 8.132 & 8.164 & All \\
\hline CVS2-104 & NA & NA & NA & 11.096 & 7.266 & 7.336 & All \\
\hline CVS2-105 & NA & NA & NA & 9.180 & 6.264 & 5.948 & All \\
\hline CVS2-106 & NA & NA & NA & 3.302 & 2.696 & 2.330 & All \\
\hline CVS2-107 & NA & $\mathrm{NA}$ & NA & 1.576 & 1.324 & 1.240 & All \\
\hline CVS2-108 & NA & NA & NA & 4.288 & 3.292 & 2.774 & All \\
\hline CVS2-109 & NA & NA & NA & 11.414 & 8.988 & 7.168 & All \\
\hline CVS2-110 & NA & $\mathrm{NA}$ & NA & 0.628 & 0.804 & 0.236 & All \\
\hline CVS2-111 & NA & $\mathrm{NA}$ & NA & 12.270 & 7.788 & 8.086 & All \\
\hline CVS2-112 & NA & NA & NA & 28.800 & 15.588 & 19.206 & All \\
\hline CVS2-113 & NA & NA & NA & 1.224 & 1.260 & 1.020 & All \\
\hline CVS2-114 & NA & $\mathrm{NA}$ & NA & 14.232 & 9.856 & 9.198 & All \\
\hline CVS2-115 & NA & NA & NA & 18.812 & 11.674 & 11.530 & All \\
\hline CVS2-116 & NA & NA & NA & 6.024 & 4.406 & 4.060 & All \\
\hline CVS2-117 & NA & $\mathrm{NA}$ & NA & 3.180 & 2.674 & 2.198 & All \\
\hline CVS2-118 & NA & $\mathrm{NA}$ & NA & 7.260 & 5.218 & 4.788 & All \\
\hline CVS2-119 & NA & NA & NA & 7.606 & 5.376 & 5.148 & All \\
\hline CVS2-120 & NA & NA & NA & 0.582 & 0.648 & 0.462 & All \\
\hline CVS2-121 & NA & $\mathrm{NA}$ & NA & 0.398 & 0.622 & 0.274 & All \\
\hline CVS2-122 & NA & NA & NA & 0.386 & 0.726 & 0.178 & All \\
\hline CVS2-123 & NA & $\mathrm{NA}$ & NA & 2.946 & 2.250 & 2.150 & All \\
\hline HG-1-1-7 & NA & $\mathrm{NA}$ & NA & 0.680 & 0.660 & 0.670 & All \\
\hline HG-1-2-7 & NA & NA & NA & 0.730 & 0.670 & 0.690 & All \\
\hline HG-1-3-7 & NA & NA & NA & 0.680 & 0.620 & 0.650 & All \\
\hline
\end{tabular}

(a) NA indicates the data are not available. The dash "-" indicates the glass did not contain $\mathrm{Li}_{2} \mathrm{O}$ and thus no PCT-Li release was recorded. 
Table B.2. PCT Release Data for 554 Validation Glasses (continued).

\begin{tabular}{|c|c|c|c|c|c|c|c|}
\hline Glass ID & $\begin{array}{l}\text { PCT-B } \\
\text { (ppm) }\end{array}$ & $\begin{array}{c}\text { PCT-Li } \\
\text { (ppm) }\end{array}$ & $\begin{array}{c}\text { PCT-Na } \\
\text { (ppm) }\end{array}$ & $\begin{array}{c}\text { PCT-B } \\
(\mathrm{g} / \mathrm{L})\end{array}$ & $\begin{array}{c}\text { PCT-Li } \\
\text { (g/L) }\end{array}$ & $\begin{array}{c}\text { PCT-Na } \\
(\mathrm{g} / \mathrm{L})\end{array}$ & $\begin{array}{c}\text { In Validation Set } \\
\text { for Which PCT } \\
\text { Releases }\end{array}$ \\
\hline HG-2-1-7 & $\mathrm{NA}^{(\mathrm{a})}$ & NA & NA & 0.690 & 0.640 & 0.670 & All \\
\hline HG-2-2-7 & NA & NA & NA & 0.770 & 0.730 & 0.800 & All \\
\hline HG-2-3-7 & NA & $\mathrm{NA}$ & NA & 0.790 & 0.720 & 0.790 & All \\
\hline HG-3-1-7 & NA & NA & NA & 0.750 & 0.720 & 0.770 & All \\
\hline HG-3-2-7 & NA & NA & NA & 0.780 & 0.730 & 0.770 & All \\
\hline HG-3-3-7 & NA & $\mathrm{NA}$ & NA & 0.730 & 0.680 & 0.740 & All \\
\hline AH-165 Al-7 & NA & $\mathrm{NA}$ & NA & 0.520 & 0.630 & 0.360 & All \\
\hline AH-165 AV-7 & NA & NA & NA & 0.640 & 0.660 & 0.530 & All \\
\hline AH-165 FE-7 & NA & NA & NA & 4.760 & 3.930 & 4.180 & All \\
\hline AH-131 Al-7 & NA & $\mathrm{NA}$ & NA & 0.720 & 0.700 & 0.690 & All \\
\hline AH-131 AV-7 & NA & NA & NA & 0.680 & 0.730 & 0.610 & All \\
\hline AH-131 FE-7 & NA & NA & NA & 3.580 & 3.200 & 3.090 & All \\
\hline AH-168 Al-7 & NA & $\mathrm{NA}$ & NA & 10.250 & 8.640 & 6.700 & All \\
\hline AH-168 AV-7 & NA & NA & NA & 0.800 & 0.750 & 0.590 & All \\
\hline AH-168 FE-7 & NA & NA & NA & 5.130 & 4.420 & 3.900 & All \\
\hline AH-200 Al-7 & NA & NA & NA & 0.460 & 0.570 & 0.440 & All \\
\hline AH-200 AV-7 & NA & NA & NA & 0.580 & 0.620 & 0.590 & All \\
\hline AH-200 FE-7 & NA & $\mathrm{NA}$ & NA & 5.100 & 4.380 & 4.380 & All \\
\hline AH-202 Al-7 & NA & NA & NA & 0.350 & 0.480 & 0.290 & All \\
\hline AH-202-AV-7 & NA & NA & NA & 0.520 & 0.590 & 0.510 & All \\
\hline AH-202 FE-7 & NA & $\mathrm{NA}$ & NA & 3.160 & 2.550 & 2.710 & All \\
\hline AH-1-7 & NA & NA & NA & 0.580 & 0.710 & 0.730 & All \\
\hline AH-2-7 & NA & NA & NA & 0.950 & 0.950 & 0.870 & All \\
\hline AH-4-7 & NA & NA & NA & 0.530 & 0.610 & 0.630 & All \\
\hline AH-5-7 & NA & NA & NA & 0.420 & 0.520 & 0.490 & All \\
\hline AH-6-7 & NA & NA & NA & 0.690 & 0.730 & 0.700 & All \\
\hline AH-7-7 & NA & $\mathrm{NA}$ & NA & 0.440 & 0.490 & 0.450 & All \\
\hline AH-8-7 & NA & $\mathrm{NA}$ & NA & 0.500 & 0.550 & 0.490 & All \\
\hline AH-9-7 & NA & NA & NA & 0.440 & 0.510 & 0.460 & All \\
\hline AH-10-7 & NA & NA & NA & 0.430 & 0.520 & 0.430 & All \\
\hline AH-11-7 & NA & $\mathrm{NA}$ & NA & 0.470 & 0.570 & 0.450 & All \\
\hline AH-12-7 & NA & NA & NA & 0.850 & 0.610 & 0.730 & All \\
\hline AH-13-7 & NA & NA & NA & 0.430 & 0.520 & 0.470 & All \\
\hline AH-14-7 & NA & NA & NA & 0.520 & 0.580 & 0.610 & All \\
\hline AH-15-7 & NA & $\mathrm{NA}$ & NA & 0.430 & 0.480 & 0.450 & All \\
\hline AH-16-7 & NA & $\mathrm{NA}$ & NA & 0.420 & 0.480 & 0.440 & All \\
\hline AH-17-7 & NA & NA & NA & 0.360 & 0.450 & 0.370 & All \\
\hline SFRIT1 & NA & NA & NA & 0.750 & 0.690 & 0.710 & All \\
\hline SFRIT2 & NA & NA & NA & 0.730 & 0.700 & 0.700 & All \\
\hline SFRIT3 & NA & NA & NA & 0.760 & 0.820 & 0.870 & All \\
\hline $202 \mathrm{P}$ w/o Mn-7 & NA & NA & NA & 0.640 & 0.510 & 0.740 & All \\
\hline 202G w/o Mn-7 & NA & $\mathrm{NA}$ & NA & 0.390 & 0.390 & 0.520 & All \\
\hline $200 \mathrm{R}-7$ & NA & NA & NA & 1.150 & 0.970 & 1.010 & All \\
\hline NBS SRM 623-7 & NA & NA & NA & 0.110 & 0.010 & 0.150 & All \\
\hline 165 CGW STD-7 & NA & $\mathrm{NA}$ & NA & 0.840 & 0.730 & 0.820 & All \\
\hline ARM-1-7 (4/88) & NA & $\mathrm{NA}$ & NA & 0.580 & 0.750 & 0.690 & All \\
\hline ARM-1-7 (5/89) & NA & NA & NA & 0.590 & 0.560 & 0.470 & All \\
\hline ARM-1-7 (7/90) & NA & $\mathrm{NA}$ & NA & 0.480 & 0.570 & 0.510 & All \\
\hline ARM-1-7 (12/90) & NA & $\mathrm{NA}$ & NA & 0.500 & 0.590 & 0.520 & All \\
\hline ARM-1-7 (5/91) & NA & $\mathrm{NA}$ & NA & 0.540 & 0.630 & 0.540 & All \\
\hline ARM-1-7 (10/91) & NA & NA & NA & 0.510 & 0.600 & 0.540 & All \\
\hline
\end{tabular}

(a) NA indicates the data are not available. The dash "-" indicates the glass did not contain $\mathrm{Li}_{2} \mathrm{O}$ and thus no PCT-Li release was recorded. 
Table B.2. PCT Release Data for 554 Validation Glasses (continued).

\begin{tabular}{|c|c|c|c|c|c|c|c|}
\hline Glass ID & $\begin{array}{l}\text { PCT-B } \\
\text { (ppm) }\end{array}$ & $\begin{array}{c}\text { PCT-Li } \\
\text { (ppm) }\end{array}$ & $\begin{array}{c}\text { PCT-Na } \\
\text { (ppm) }\end{array}$ & $\begin{array}{c}\text { PCT-B } \\
\text { (g/L) }\end{array}$ & $\begin{array}{c}\text { PCT-Li } \\
\text { (g/L) }\end{array}$ & $\begin{array}{c}\text { PCT-Na } \\
\text { (g/L) }\end{array}$ & $\begin{array}{c}\text { In Validation Set } \\
\text { for Which PCT } \\
\text { Releases }\end{array}$ \\
\hline ARM-1-7 (10/92) & $\mathrm{NA}^{(\mathrm{a})}$ & NA & NA & 0.440 & 0.500 & 0.450 & All \\
\hline ARM-1-7 (4/93) & NA & NA & NA & 0.480 & 0.580 & 0.500 & All \\
\hline ARM-1-7 (6/93) & NA & $\mathrm{NA}$ & NA & 0.470 & 0.520 & 0.480 & All \\
\hline ARM-1-7 (8/93) & NA & NA & NA & 0.410 & 0.470 & 0.430 & All \\
\hline ARM-1-7 & NA & NA & NA & 0.510 & 0.600 & 0.510 & All \\
\hline T-ARM-1 & NA & $\mathrm{NA}$ & NA & 0.490 & 0.600 & 0.530 & All \\
\hline SS-ARM-1 & NA & NA & NA & 0.530 & 0.630 & 0.550 & All \\
\hline SS-ARM-1 & NA & NA & NA & 0.540 & 0.640 & 0.560 & All \\
\hline EA-1-7 & NA & NA & NA & 14.000 & 7.850 & 11.520 & All \\
\hline EA-1-7 & NA & NA & NA & 16.790 & 10.690 & 14.490 & All \\
\hline EA-2-7 & NA & NA & NA & 15.210 & 9.430 & 12.780 & All \\
\hline EA-7 & NA & NA & NA & 17.720 & 9.890 & 13.890 & All \\
\hline T-EA & NA & NA & NA & 14.750 & 8.520 & 11.820 & All \\
\hline SS-EA-19 & NA & NA & NA & 16.410 & 9.120 & 13.090 & All \\
\hline SS-EA-15 & NA & NA & NA & 16.790 & 9.740 & 13.600 & All \\
\hline SS-EA-1-7 & NA & NA & NA & 18.500 & 10.280 & 14.330 & All \\
\hline SS-EA-2-7 & NA & $\mathrm{NA}$ & NA & 17.760 & 9.770 & 13.720 & All \\
\hline SRS-SEA-A-7 & NA & $\mathrm{NA}$ & NA & 16.450 & 9.340 & 12.850 & All \\
\hline SRS-SEA-B-7 & NA & $\mathrm{NA}$ & NA & 16.990 & 9.120 & 13.510 & All \\
\hline CUASEA-A-7 & NA & NA & NA & 16.850 & 9.670 & 12.950 & All \\
\hline CUASEA-B-7 & NA & $\mathrm{NA}$ & NA & 16.460 & 9.210 & 13.420 & All \\
\hline 131-TDS-EA-7 & NA & NA & NA & 4.430 & 3.850 & 4.280 & All \\
\hline 131-TDS-3A-SOPER-7 & NA & NA & NA & 2.810 & 2.450 & 2.300 & All \\
\hline BLEND 1-7 & NA & NA & NA & 0.720 & 0.810 & 0.780 & All \\
\hline BLEND 1-7 (2) & NA & NA & NA & 0.780 & 0.800 & 0.790 & All \\
\hline BLEND 1.6-7 & NA & NA & NA & 0.720 & 0.760 & 0.750 & All \\
\hline BATCH 1-7 & NA & NA & NA & 0.730 & 0.810 & 0.800 & All \\
\hline BATCH 1-7 (2) & NA & NA & NA & 0.730 & 0.760 & 0.750 & All \\
\hline BATCH 1-1.6 & NA & NA & NA & 0.710 & 0.760 & 0.740 & All \\
\hline BATCH 2-7 & NA & NA & NA & 0.660 & 0.770 & 0.730 & All \\
\hline BATCH 2-7 (2) & NA & NA & NA & 0.670 & 0.720 & 0.690 & All \\
\hline BATCH 2-1.6 & $\mathrm{NA}$ & NA & NA & 0.640 & 0.710 & 0.670 & All \\
\hline BATCH 3-7 & NA & NA & NA & 0.860 & 0.900 & 0.890 & All \\
\hline BATCH 3-7 (2) & NA & NA & NA & 0.890 & 0.850 & 0.850 & All \\
\hline BATCH 3-7 (3) & NA & $\mathrm{NA}$ & NA & 0.850 & 0.850 & 0.830 & All \\
\hline BATCH 4-7 & NA & NA & NA & 0.970 & 1.000 & 1.000 & All \\
\hline BATCH 4-7 (2) & NA & NA & NA & 0.900 & 0.890 & 0.870 & All \\
\hline BATCH 4-7 (3) & NA & NA & NA & 0.940 & 0.940 & 0.940 & All \\
\hline HM-1-7 & NA & NA & NA & 0.460 & 0.620 & 0.490 & All \\
\hline HM-1-7 (2) & NA & NA & NA & 0.460 & 0.570 & 0.460 & All \\
\hline HM-1.6-7 & NA & NA & NA & 0.430 & 0.560 & 0.440 & All \\
\hline PUREX 1-7 & NA & $\mathrm{NA}$ & NA & 2.190 & 1.860 & 2.090 & All \\
\hline PUREX 1-7 (2) & NA & $\mathrm{NA}$ & NA & 1.970 & 1.650 & 1.760 & All \\
\hline PUREX 1.6-7 & NA & NA & NA & 4.460 & 3.250 & 4.260 & All \\
\hline PUREX SRSS 1.6 & NA & NA & NA & 2.380 & 2.040 & 2.080 & All \\
\hline PUREX SRST-4.0 & NA & $\mathrm{NA}$ & NA & 2.260 & 1.960 & 1.990 & All \\
\hline PUREX CUA & NA & NA & NA & 2.850 & 2.370 & 2.420 & All \\
\hline BLEND 1-3457 & NA & NA & NA & 0.600 & 0.670 & 0.650 & All \\
\hline BLEND 1-3479 & NA & $\mathrm{NA}$ & NA & 0.580 & 0.640 & 0.630 & All \\
\hline BLEND 1-3498 & NA & NA & NA & 0.630 & 0.700 & 0.670 & All \\
\hline BLEND 1-3510 & NA & NA & NA & 0.680 & 0.740 & 0.730 & All \\
\hline
\end{tabular}

(a) NA indicates the data are not available. The dash "-" indicates the glass did not contain $\mathrm{Li}_{2} \mathrm{O}$ and thus no PCT-Li release was recorded. 
Table B.2. PCT Release Data for 554 Validation Glasses (continued).

\begin{tabular}{|c|c|c|c|c|c|c|c|}
\hline Glass ID & $\begin{array}{l}\text { PCT-B } \\
\text { (ppm) }\end{array}$ & $\begin{array}{c}\text { PCT-Li } \\
\text { (ppm) }\end{array}$ & $\begin{array}{c}\text { PCT-Na } \\
\text { (ppm) }\end{array}$ & $\begin{array}{c}\text { PCT-B } \\
(\mathrm{g} / \mathrm{L})\end{array}$ & $\begin{array}{c}\text { PCT-Li } \\
(\mathrm{g} / \mathrm{L})\end{array}$ & $\begin{array}{c}\text { PCT-Na } \\
(\mathrm{g} / \mathrm{L})\end{array}$ & $\begin{array}{c}\text { In Validation Set } \\
\text { for Which PCT } \\
\text { Releases }\end{array}$ \\
\hline BLEND 1-3526 & $\mathrm{NA}^{(\mathrm{a})}$ & NA & NA & 0.670 & 0.740 & 0.720 & All \\
\hline BLEND 2-3611 & NA & NA & NA & 0.610 & 0.670 & 0.670 & All \\
\hline BLEND 2-3622 & NA & NA & $\mathrm{NA}$ & 0.610 & 0.660 & 0.660 & All \\
\hline BLEND 2-3635 & NA & NA & NA & 0.610 & 0.650 & 0.660 & All \\
\hline BLEND 2-3654 & NA & NA & NA & 0.600 & 0.650 & 0.640 & All \\
\hline BLEND 2-3666 & NA & NA & NA & 0.600 & 0.650 & 0.640 & All \\
\hline BLEND 2-3676 & NA & NA & NA & 0.590 & 0.640 & 0.630 & All \\
\hline BLEND 3-3768 & NA & NA & NA & 0.600 & 0.640 & 0.660 & All \\
\hline BLEND 3-3789 & NA & NA & NA & 0.630 & 0.660 & 0.700 & All \\
\hline BLEND 3-3793 & NA & NA & NA & 0.630 & 0.660 & 0.710 & All \\
\hline BLEND 3-3802B & NA & NA & NA & 0.700 & 0.710 & 0.770 & All \\
\hline HM 1-3824 & NA & NA & NA & 0.590 & 0.630 & 0.620 & All \\
\hline HM 1-3829 & NA & NA & NA & 0.570 & 0.630 & 0.610 & All \\
\hline HM 1-3851 & NA & NA & NA & 0.520 & 0.600 & 0.550 & All \\
\hline HM 1-3855 & NA & NA & NA & 0.530 & 0.600 & 0.550 & All \\
\hline $\begin{array}{ll}\text { HM-2-1 (3979C) } \\
\end{array}$ & NA & NA & NA & 0.530 & 0.610 & 0.540 & All \\
\hline HM-2-2 (4099A) & NA & NA & NA & 0.550 & 0.630 & 0.560 & All \\
\hline HM-2-3 (4120B) & NA & NA & NA & 0.530 & 0.620 & 0.540 & All \\
\hline HM-3-1 (4176) & NA & NA & NA & 0.560 & 0.650 & 0.530 & All \\
\hline HM-3-2 (4225) & NA & NA & NA & 0.550 & 0.640 & 0.520 & All \\
\hline HM-3-3 (4357) & NA & NA & NA & 0.510 & 0.590 & 0.530 & All \\
\hline $\begin{array}{ll}\text { HM-4-1 } & (5260) \\
\end{array}$ & NA & NA & NA & 0.750 & 0.760 & 0.640 & All \\
\hline HM-4-2 (5641) & NA & NA & NA & 0.530 & 0.570 & 0.520 & All \\
\hline HM-4-3 (5748) & NA & NA & NA & 0.700 & 0.710 & 0.650 & All \\
\hline $\begin{array}{ll}\text { PX 1-1 (4643) } \\
\end{array}$ & NA & NA & NA & 0.720 & 0.780 & 0.730 & All \\
\hline PX 1-2 (4726) & NA & NA & NA & 0.710 & 0.760 & 0.720 & All \\
\hline $\begin{array}{ll}\text { PX 1-3 } & \text { (4776) } \\
\end{array}$ & NA & NA & NA & 0.790 & 0.830 & 0.770 & All \\
\hline PX 2-1 (4455) & NA & NA & NA & 0.480 & 0.570 & 0.480 & All \\
\hline PX 2-2 (4509) & NA & NA & NA & 0.580 & 0.650 & 0.610 & All \\
\hline $\begin{array}{ll}\text { PX 2-3 } & (4566)\end{array}$ & NA & NA & NA & 0.730 & 0.780 & 0.730 & All \\
\hline $\begin{array}{ll}\text { PX 3-1 } & (5780) \\
\end{array}$ & NA & NA & NA & 0.840 & 0.820 & 0.670 & All \\
\hline PX 3-2 (5818) & NA & NA & NA & 1.080 & 1.010 & 0.850 & All \\
\hline PX 3-3 (5880) & NA & NA & NA & 1.350 & 1.210 & 1.040 & All \\
\hline $\begin{array}{ll}\text { PX 4-1 (6390) } \\
\end{array}$ & NA & NA & NA & 2.270 & 1.970 & 1.840 & All \\
\hline $\begin{array}{ll}\text { PX 4-2 (6434) } \\
\end{array}$ & NA & NA & NA & 4.540 & 3.630 & 3.600 & All \\
\hline $\begin{array}{ll}\text { PX 4-3 } & (6458)\end{array}$ & NA & NA & NA & 4.370 & 3.490 & 3.650 & All \\
\hline 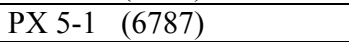 & NA & NA & NA & 1.070 & 1.050 & 1.060 & All \\
\hline $\begin{array}{ll}\text { PX 5-2 } & \text { (6795) }\end{array}$ & NA & NA & NA & 9.160 & 6.190 & 8.170 & All \\
\hline $\begin{array}{ll}\text { PX 5-3 (6812) } \\
\end{array}$ & NA & NA & NA & 19.200 & 10.610 & 16.470 & All \\
\hline $\begin{array}{ll}\text { PX 5-4 } & (6820) \\
\end{array}$ & NA & NA & NA & 21.000 & 11.290 & 17.880 & All \\
\hline PX 5-5 (6839) & NA & NA & NA & 21.030 & 11.400 & 16.970 & All \\
\hline PX 5-6 (6862) & NA & NA & NA & 18.970 & 10.810 & 15.120 & All \\
\hline $\begin{array}{ll}\text { PX 5-7 } & (6871)\end{array}$ & NA & NA & NA & 18.580 & 10.420 & 14.430 & All \\
\hline $\begin{array}{ll}\text { PX 5-8 (6884) } \\
\end{array}$ & NA & NA & NA & 21.580 & 11.800 & 17.150 & All \\
\hline PX 5-9 $(6960)$ & NA & NA & NA & 17.140 & 9.580 & 13.700 & All \\
\hline $\begin{array}{ll}\text { PX 5-10 (6972) } \\
\end{array}$ & NA & NA & NA & 21.900 & 9.490 & 17.370 & All \\
\hline PX 6-1 (7340) & NA & NA & NA & 15.120 & 9.610 & 16.830 & All \\
\hline BATCH 1 STUDY-6-7 & NA & NA & NA & 17.190 & 13.620 & 15.450 & All \\
\hline BATCH 1 STUDY-10B-7 & NA & NA & NA & 10.530 & 8.990 & 9.530 & All \\
\hline BATCH 1 STUDY-15-7 & NA & NA & NA & 1.660 & 1.520 & 1.420 & All \\
\hline H-GLAS-0112 & NA & NA & NA & 0.880 & 0.830 & 0.750 & All \\
\hline
\end{tabular}

(a) NA indicates the data are not available. The dash "_" indicates the glass did not contain $\mathrm{Li}_{2} \mathrm{O}$ and thus no PCT-Li release was recorded. 
Table B.2. PCT Release Data for 554 Validation Glasses (continued).

\begin{tabular}{|c|c|c|c|c|c|c|c|}
\hline Glass ID & $\begin{array}{l}\text { PCT-B } \\
\text { (ppm) }\end{array}$ & $\begin{array}{l}\text { PCT-Li } \\
(\mathrm{ppm})\end{array}$ & $\begin{array}{c}\text { PCT-Na } \\
\text { (ppm) }\end{array}$ & $\begin{array}{c}\text { PCT-B } \\
(\mathrm{g} / \mathrm{L})\end{array}$ & $\begin{array}{c}\text { PCT-Li } \\
(\mathrm{g} / \mathrm{L}) \\
\end{array}$ & $\begin{array}{c}\text { PCT-Na } \\
(\mathrm{g} / \mathrm{L})\end{array}$ & $\begin{array}{c}\text { In Validation Set } \\
\text { for Which PCT } \\
\text { Releases } \\
\end{array}$ \\
\hline H-GLAS-0130 & $\mathrm{NA}^{(\mathrm{a})}$ & NA & NA & 1.160 & 1.030 & 0.920 & All \\
\hline H-GLAS-0162 & NA & NA & NA & 2.010 & 1.670 & 1.380 & All \\
\hline H-GLAS-0244 & NA & NA & NA & 2.950 & 2.170 & 1.380 & All \\
\hline H-GLAS-0254 & NA & NA & NA & 2.100 & 1.820 & 1.430 & All \\
\hline H-GLAS-0278 & NA & NA & NA & 2.500 & 2.120 & 1.540 & All \\
\hline H-GLAS-0293 & NA & NA & NA & 3.080 & 2.580 & 1.850 & All \\
\hline H-GLAS-0308 & NA & NA & NA & 2.020 & 1.730 & 1.320 & All \\
\hline H-GLAS-0334 & NA & NA & NA & 2.410 & 2.150 & 1.550 & All \\
\hline H-GLAS-0352 & NA & NA & NA & 2.660 & 2.360 & 1.670 & All \\
\hline H-GLAS-0387 & NA & NA & $\mathrm{NA}$ & 2.580 & 2.310 & 1.570 & All \\
\hline H-GLAS-0421 & NA & NA & NA & 2.280 & 2.080 & 1.370 & All \\
\hline H-GLAS-0466 & NA & NA & NA & 2.790 & 2.410 & 1.660 & All \\
\hline FRIT-202-CLEAR & NA & NA & NA & 31.960 & 28.890 & 30.380 & All \\
\hline FRIT-202-INT & NA & NA & NA & 43.900 & 37.270 & 39.080 & All \\
\hline FRIT-202-WHITE & NA & NA & NA & 63.070 & 58.260 & 57.440 & All \\
\hline FRIT-165-7 & NA & NA & NA & 80.320 & 84.310 & 74.160 & All \\
\hline FRIT-131-7 & NA & NA & NA & 50.300 & 48.600 & 43.130 & All \\
\hline MG 9-7 & NA & NA & NA & 70.240 & $-^{(\mathrm{a})}$ & 56.420 & PCT-B, PCT-Na \\
\hline MG 18-7 & NA & NA & NA & 57.820 & - & 47.770 & PCT-B, PCT-Na \\
\hline MG 25-7 & NA & NA & NA & 0.830 & - & 0.790 & PCT-B, PCT-Na \\
\hline MG 28-7 & NA & NA & NA & 0.630 & - & 0.720 & PCT-B, PCT-Na \\
\hline PNL 1 & NA & NA & NA & 1.088 & 1.008 & 0.656 & All \\
\hline PNL 2 & NA & NA & NA & 8.088 & 5.404 & 4.852 & All \\
\hline PNL 3 & NA & NA & NA & 6.532 & 4.530 & 3.794 & All \\
\hline PNL 4 & NA & NA & NA & 0.478 & 0.500 & 0.380 & All \\
\hline PNL 5 & NA & NA & NA & 2.534 & 1.762 & 1.316 & All \\
\hline PNL 6 & NA & NA & NA & 0.538 & 0.532 & 0.450 & All \\
\hline PNL 7 & NA & NA & NA & 0.372 & 0.400 & 0.290 & All \\
\hline PNL 8 & NA & NA & NA & 3.150 & 2.394 & 1.924 & All \\
\hline PNL 9 & NA & NA & NA & 0.862 & 0.770 & 0.754 & All \\
\hline PNL 10 & NA & NA & NA & 1.514 & 0.990 & 0.934 & All \\
\hline Alkali1 & NA & NA & NA & 0.502 & 0.434 & 0.560 & All \\
\hline Alkali2 & NA & NA & $\mathrm{NA}$ & 1.294 & 0.860 & 0.948 & All \\
\hline Alkali3 & NA & NA & NA & 0.908 & 0.632 & 0.710 & All \\
\hline Alkali4 & NA & NA & NA & 0.548 & 0.390 & 0.514 & All \\
\hline Alkali5 & NA & NA & NA & 1.272 & 0.842 & 0.954 & All \\
\hline Alkali6 & NA & NA & NA & 0.656 & 0.480 & 0.604 & All \\
\hline Alkali7 & NA & NA & NA & 1.778 & 1.134 & 1.172 & All \\
\hline Alkali8 & NA & NA & NA & 0.936 & 0.700 & 0.824 & All \\
\hline Alkali9 & NA & NA & NA & 0.568 & 0.416 & 0.542 & All \\
\hline Ref6Qtr2 & NA & NA & NA & 0.830 & 0.706 & 0.634 & All \\
\hline WVDG-1 & NA & NA & NA & 0.360 & 0.500 & 0.318 & All \\
\hline WVDG-2 & NA & NA & NA & 0.414 & 0.622 & 0.362 & All \\
\hline WVDG-3 & NA & NA & $\mathrm{NA}$ & 0.476 & 0.582 & 0.466 & All \\
\hline WVDG-4 & NA & NA & $\mathrm{NA}$ & 0.522 & 0.606 & 0.532 & All \\
\hline WVDG-5 & NA & NA & NA & 0.428 & 0.570 & 0.396 & All \\
\hline WVDG-6 & NA & NA & NA & 0.398 & 0.606 & 0.338 & All \\
\hline WVDG-7 & NA & NA & NA & 0.360 & 0.534 & 0.338 & All \\
\hline WVDG-8 & NA & NA & NA & 0.346 & 0.546 & 0.348 & All \\
\hline WVDG-11R & NA & NA & $\mathrm{NA}$ & 0.410 & 0.492 & 0.408 & All \\
\hline WVDG-12R & NA & NA & NA & 0.434 & 0.526 & 0.428 & All \\
\hline
\end{tabular}

(a) NA indicates the data are not available. The dash "-" indicates the glass did not contain $\mathrm{Li}_{2} \mathrm{O}$ and thus no PCT-Li release was recorded. 
Table B.2. PCT Release Data for 554 Validation Glasses (continued).

\begin{tabular}{|c|c|c|c|c|c|c|c|}
\hline Glass ID & $\begin{array}{l}\text { PCT-B } \\
\text { (ppm) }\end{array}$ & $\begin{array}{c}\text { PCT-Li } \\
\text { (ppm) }\end{array}$ & $\begin{array}{c}\text { PCT-Na } \\
\text { (ppm) }\end{array}$ & $\begin{array}{c}\text { PCT-B } \\
\text { (g/L) }\end{array}$ & $\begin{array}{c}\text { PCT-Li } \\
(\mathrm{g} / \mathrm{L})\end{array}$ & $\begin{array}{c}\text { PCT-Na } \\
\text { (g/L) }\end{array}$ & $\begin{array}{c}\text { In Validation Set } \\
\text { for Which PCT } \\
\text { Releases }\end{array}$ \\
\hline WVDG-13R & $\mathrm{NA}^{(\mathrm{a})}$ & NA & NA & 0.474 & 0.558 & 0.486 & All \\
\hline WVDG-14R & NA & NA & NA & 0.576 & 0.666 & 0.604 & All \\
\hline WVDG-15 & NA & NA & NA & 0.592 & 0.600 & 0.528 & All \\
\hline WVDG-16 & NA & NA & NA & 0.378 & 0.470 & 0.330 & All \\
\hline WVDG-17 & NA & NA & NA & 0.584 & 0.584 & 0.546 & All \\
\hline WVDG-18 & NA & NA & NA & 0.450 & 0.538 & 0.438 & All \\
\hline WVDG-19 & NA & NA & NA & 0.428 & 0.564 & 0.414 & All \\
\hline WVDG-20 & NA & NA & NA & 0.320 & 0.484 & 0.278 & All \\
\hline WVDG-21 & NA & NA & NA & 0.450 & 0.504 & 0.444 & All \\
\hline WVDG-22 & NA & NA & NA & 0.420 & 0.600 & 0.358 & All \\
\hline WVDG-23 & NA & NA & NA & 0.506 & 0.614 & 0.374 & All \\
\hline WVDG-24 & NA & NA & NA & 0.426 & 0.572 & 0.346 & All \\
\hline WVDG-25 & NA & NA & NA & 0.376 & 0.506 & 0.328 & All \\
\hline WVDG-26 & NA & NA & NA & 0.370 & 0.514 & 0.312 & All \\
\hline WVDG-27 & NA & NA & NA & 0.618 & 0.654 & 0.486 & All \\
\hline WVDG-28 & NA & NA & NA & 0.402 & 0.578 & 0.338 & All \\
\hline WVDG-29 & NA & NA & NA & 0.434 & 0.036 & 0.428 & All \\
\hline WVDG-30 & NA & NA & NA & 0.418 & 0.014 & 0.392 & All \\
\hline WVDG-33 & NA & NA & NA & 0.494 & 0.526 & 0.490 & All \\
\hline WVDG-34 & NA & NA & NA & 0.834 & 0.776 & 0.726 & All \\
\hline WVDG-35 & NA & NA & NA & 0.800 & 0.788 & 0.798 & All \\
\hline WVDG-36 & NA & NA & NA & 0.488 & 0.502 & 0.328 & All \\
\hline WVDG-37 & NA & NA & NA & 0.462 & 0.534 & 0.534 & All \\
\hline WVDG-38 & NA & NA & NA & 0.394 & 0.480 & 0.394 & All \\
\hline WVDG-39 & NA & NA & NA & 0.542 & 0.498 & 0.494 & All \\
\hline WVDG-40 & NA & NA & NA & 0.610 & 0.610 & 0.578 & All \\
\hline WVDG-41 & NA & $\mathrm{NA}$ & NA & 0.628 & 0.598 & 0.738 & All \\
\hline WVDG-42 & NA & $\mathrm{NA}$ & NA & 0.760 & 0.710 & 0.728 & All \\
\hline WVDG-43 & NA & NA & NA & 0.416 & 0.514 & 0.276 & All \\
\hline WVDG-44 & NA & NA & NA & 0.714 & 0.716 & 0.662 & All \\
\hline WVDG-45 & NA & NA & NA & 0.520 & 0.530 & 0.600 & All \\
\hline WVDG-46 & NA & NA & NA & 0.744 & 0.634 & 0.598 & All \\
\hline WVDG-47 & NA & NA & NA & 0.448 & 0.466 & 0.312 & All \\
\hline WVDG-48 & NA & NA & NA & 0.358 & 0.412 & 0.258 & All \\
\hline FY92-5 & NA & $\mathrm{NA}$ & NA & 1.388 & 1.168 & 1.058 & All \\
\hline FY92-6 & NA & $\mathrm{NA}$ & NA & 0.556 & 0.714 & 0.534 & All \\
\hline FY92-7 & NA & NA & NA & 0.422 & 0.528 & 0.416 & All \\
\hline FY92-9 & NA & NA & NA & 0.524 & 0.590 & 0.392 & All \\
\hline FY92-10 & NA & NA & NA & 1.644 & 1.422 & 1.138 & All \\
\hline FY92Ref5 & NA & NA & NA & 0.392 & 0.550 & 0.512 & All \\
\hline Ratio2 & NA & NA & NA & 3.092 & 2.258 & 1.818 & All \\
\hline Ratio4 & NA & $\mathrm{NA}$ & $\mathrm{NA}$ & 0.522 & 0.580 & 0.510 & All \\
\hline Ratio5 & NA & $\mathrm{NA}$ & $\mathrm{NA}$ & 0.488 & 0.610 & 0.594 & All \\
\hline LoTh2 & NA & NA & NA & 0.786 & 0.566 & 0.458 & All \\
\hline LoTh4 & NA & NA & NA & 1.288 & 1.154 & 0.974 & All \\
\hline LoTh5 & NA & NA & $\mathrm{NA}$ & 0.484 & 0.866 & 0.770 & All \\
\hline $\mathrm{HiFe} 2$ & NA & NA & NA & 1.176 & 1.110 & 0.996 & All \\
\hline $\mathrm{HiFe} 3$ & NA & $\mathrm{NA}$ & $\mathrm{NA}$ & 0.836 & 0.846 & 0.764 & All \\
\hline HiFe4 & NA & $\mathrm{NA}$ & NA & 1.482 & 1.304 & 1.144 & All \\
\hline PNL190 & NA & NA & NA & 2.454 & 2.138 & 2.028 & All \\
\hline FY93-1 & NA & NA & NA & 1.088 & 0.656 & 1.008 & All \\
\hline
\end{tabular}

(a) NA indicates the data are not available. The dash "-" indicates the glass did not contain $\mathrm{Li}_{2} \mathrm{O}$ and thus no PCT-Li release was recorded. 
Table B.2. PCT Release Data for 554 Validation Glasses (continued).

\begin{tabular}{|c|c|c|c|c|c|c|c|}
\hline Glass ID & $\begin{array}{l}\text { PCT-B } \\
\text { (ppm) }\end{array}$ & $\begin{array}{c}\text { PCT-Li } \\
\text { (ppm) }\end{array}$ & $\begin{array}{c}\text { PCT-Na } \\
\text { (ppm) }\end{array}$ & $\begin{array}{c}\text { PCT-B } \\
(\mathrm{g} / \mathrm{L})\end{array}$ & $\begin{array}{c}\text { PCT-Li } \\
\text { (g/L) }\end{array}$ & $\begin{array}{c}\text { PCT-Na } \\
\text { (g/L) }\end{array}$ & $\begin{array}{c}\text { In Validation Set } \\
\text { for Which PCT } \\
\text { Releases }\end{array}$ \\
\hline FY93-2 & $\mathrm{NA}^{(\mathrm{a})}$ & NA & NA & 8.088 & 4.852 & 5.404 & All \\
\hline FY93-3 & NA & NA & NA & 6.532 & 3.794 & 4.530 & All \\
\hline FY93-4 & NA & NA & NA & 0.478 & 0.380 & 0.500 & All \\
\hline FY93-5 & NA & NA & NA & 2.534 & 1.316 & 1.762 & All \\
\hline FY93-6 & NA & NA & NA & 0.538 & 0.450 & 0.532 & All \\
\hline FY93-7 & NA & NA & $\mathrm{NA}$ & 0.372 & 0.290 & 0.400 & All \\
\hline FY93-8 & NA & NA & NA & 3.150 & 1.924 & 2.394 & All \\
\hline FY93-9 & NA & NA & NA & 0.862 & 0.754 & 0.770 & All \\
\hline FY93-10 & NA & NA & NA & 1.514 & 0.934 & 0.990 & All \\
\hline FY94-1 & NA & NA & NA & 0.372 & 0.506 & 0.416 & All \\
\hline FY94-2 & NA & NA & NA & 0.430 & 0.594 & 0.444 & All \\
\hline FY94-3 & NA & NA & NA & 8.114 & 7.118 & 5.106 & All \\
\hline FY94-4 & NA & NA & NA & 6.672 & 5.210 & 4.592 & All \\
\hline FY94-5 & NA & NA & NA & 0.906 & 1.064 & 0.990 & All \\
\hline FY94-6 & NA & NA & NA & 0.576 & 0.728 & 0.532 & All \\
\hline FY94-7 & NA & NA & NA & 2.094 & 1.898 & 1.386 & All \\
\hline FY94-8 & NA & NA & NA & 4.484 & 3.840 & 3.130 & All \\
\hline FY94-9 & NA & NA & NA & 0.870 & 0.894 & 0.736 & All \\
\hline FY94-10 & NA & NA & NA & 6.770 & 5.770 & 4.302 & All \\
\hline Sigma1 & NA & NA & NA & 13.218 & 10.624 & 9.840 & All \\
\hline Sigma2 & NA & NA & NA & 20.556 & 15.070 & 15.930 & All \\
\hline Sigma3 & NA & NA & NA & 15.484 & 8.142 & 10.858 & All \\
\hline Sigma4 & NA & NA & NA & 9.310 & 7.678 & 7.102 & All \\
\hline Sigma5 & NA & NA & NA & 10.536 & 8.524 & 7.860 & All \\
\hline Sigma6 & NA & NA & NA & 9.842 & 7.938 & 7.366 & All \\
\hline Sigma7 & NA & NA & NA & 8.858 & 7.090 & 6.652 & All \\
\hline Sigma8 & NA & NA & NA & 6.814 & 5.460 & 5.118 & All \\
\hline Sigma9 & NA & NA & NA & 7.084 & 5.666 & 4.970 & All \\
\hline Sigma10 & NA & NA & NA & 8.056 & 6.490 & 5.826 & All \\
\hline LAWA41 & NA & NA & NA & 0.940 & $-{ }^{\text {(a) }}$ & 1.040 & PCT-B, PCT-Na \\
\hline LAWA42 & NA & NA & NA & 1.560 & - & 1.400 & PCT-B, PCT-Na \\
\hline LAWA43 & NA & NA & NA & 0.760 & - & 0.860 & PCT-B, PCT-Na \\
\hline LAWA44 & NA & NA & NA & 0.740 & - & 0.720 & PCT-B, PCT-Na \\
\hline LAWA45 & NA & NA & NA & 1.540 & - & 1.020 & PCT-B, PCT-Na \\
\hline LAWA46 & NA & NA & NA & 0.860 & - & 0.700 & PCT-B, PCT-Na \\
\hline LAWA47 & NA & NA & NA & 0.760 & - & 0.660 & PCT-B, PCT-Na \\
\hline LAWA48 & NA & NA & NA & 0.780 & - & 0.660 & PCT-B, PCT-Na \\
\hline LAWA49 & NA & NA & NA & 0.620 & - & 0.580 & PCT-B, PCT-Na \\
\hline LAWA50 & NA & NA & NA & 0.620 & - & 0.600 & PCT-B, PCT-Na \\
\hline LAWA51 & NA & NA & NA & 0.700 & - & 0.520 & PCT-B, PCT-Na \\
\hline LAWA52 & NA & NA & NA & 0.860 & - & 1.100 & PCT-B, PCT-Na \\
\hline LAWA60 & NA & NA & NA & 0.580 & - & 0.620 & PCT-B, PCT-Na \\
\hline LAWA64 & NA & NA & NA & 0.760 & - & 1.000 & PCT-B, PCT-Na \\
\hline LAWA76 & NA & NA & NA & 1.420 & - & 1.320 & PCT-B, PCT-Na \\
\hline LAWA81 & NA & NA & NA & 0.780 & - & 0.840 & PCT-B, PCT-Na \\
\hline LAWA82 & NA & NA & NA & 0.680 & - & 0.660 & PCT-B, PCT-Na \\
\hline LAWA83 & NA & NA & NA & 0.620 & - & 0.680 & PCT-B, PCT-Na \\
\hline LAWA84 & NA & NA & NA & 0.600 & - & 0.660 & PCT-B, PCT-Na \\
\hline LAWA85 & NA & NA & NA & 0.680 & - & 0.700 & PCT-B, PCT-Na \\
\hline LAWA86 & NA & NA & NA & 0.780 & - & 0.780 & PCT-B, PCT-Na \\
\hline LAWA87 & NA & NA & NA & 1.200 & - & 1.100 & PCT-B, PCT-Na \\
\hline
\end{tabular}

(a) NA indicates the data are not available. The dash "-" indicates the glass did not contain $\mathrm{Li}_{2} \mathrm{O}$ and thus no PCT-Li release was recorded. 
The Catholic University of America Vitreous State Laboratory
IHLW PCT, Spinel $T_{1 \%}$, Electrical Conductivity, and Viscosity Model Development Final Report, VSL-07R1240-4, Rev. 0

Table B.2. PCT Release Data for 554 Validation Glasses (continued).

\begin{tabular}{|c|c|c|c|c|c|c|c|}
\hline Glass ID & $\begin{array}{l}\text { PCT-B } \\
\text { (ppm) }\end{array}$ & $\begin{array}{c}\text { PCT-Li } \\
\text { (ppm) }\end{array}$ & $\begin{array}{c}\text { PCT-Na } \\
\text { (ppm) }\end{array}$ & $\begin{array}{c}\text { PCT-B } \\
\text { (g/L) }\end{array}$ & $\begin{array}{c}\text { PCT-Li } \\
(\mathrm{g} / \mathrm{L})\end{array}$ & $\begin{array}{c}\text { PCT-Na } \\
\text { (g/L) }\end{array}$ & $\begin{array}{c}\text { In Validation Set } \\
\text { for Which PCT } \\
\text { Releases }\end{array}$ \\
\hline LAWA88 & $\mathrm{NA}^{(\mathrm{a})}$ & NA & NA & 0.860 & -(a) & 0.860 & PCT-B, PCT-Na \\
\hline LAWA89 & NA & NA & NA & 1.160 & - & 0.940 & PCT-B, PCT-Na \\
\hline LAWA90 & NA & NA & $\mathrm{NA}$ & 0.980 & - & 0.980 & PCT-B, PCT-Na \\
\hline LAWA93 & NA & NA & $\mathrm{NA}$ & 1.060 & - & 1.080 & PCT-B, PCT-Na \\
\hline LAWA96 & NA & NA & $\mathrm{NA}$ & 0.620 & - & 0.760 & PCT-B, PCT-Na \\
\hline LAWA98S & NA & NA & NA & 0.720 & - & 0.560 & PCT-B, PCT-Na \\
\hline LAWA99S & NA & NA & NA & 1.480 & - & 1.080 & PCT-B, PCT-Na \\
\hline LAWA100S & NA & NA & $\mathrm{NA}$ & 1.080 & - & 0.760 & PCT-B, PCT-Na \\
\hline LAWA101S & NA & $\mathrm{NA}$ & $\mathrm{NA}$ & 0.860 & - & 0.640 & PCT-B, PCT-Na \\
\hline LAWA102S & NA & $\mathrm{NA}$ & $\mathrm{NA}$ & 0.540 & - & 0.440 & PCT-B, PCT-Na \\
\hline LAWA104 & NA & NA & $\mathrm{NA}$ & 1.160 & - & 1.060 & PCT-B, PCT-Na \\
\hline LAWA105 & NA & $\mathrm{NA}$ & $\mathrm{NA}$ & 1.920 & - & 1.580 & PCT-B, PCT-Na \\
\hline LAWB30 & NA & NA & NA & 0.480 & - & 0.480 & PCT-B, PCT-Na \\
\hline LAWB31 & NA & NA & $\mathrm{NA}$ & 0.420 & - & 0.220 & PCT-B, PCT-Na \\
\hline LAWB32 & NA & NA & NA & 0.500 & - & 0.280 & PCT-B, PCT-Na \\
\hline LAWB33 & NA & $\mathrm{NA}$ & NA & 0.380 & - & 0.240 & PCT-B, PCT-Na \\
\hline LAWB34 & NA & $\mathrm{NA}$ & $\mathrm{NA}$ & 0.440 & - & 0.260 & PCT-B, PCT-Na \\
\hline LAWB35 & NA & NA & NA & 1.000 & - & 0.680 & PCT-B, PCT-Na \\
\hline LAWB37 & NA & NA & $\mathrm{NA}$ & 0.520 & - & 0.360 & PCT-B, PCT-Na \\
\hline LAWB38 & NA & NA & NA & 0.500 & - & 0.360 & PCT-B, PCT-Na \\
\hline LAWB39 & NA & NA & NA & 1.000 & - & 0.800 & PCT-B, PCT-Na \\
\hline LAWB40 & NA & NA & NA & 3.180 & - & 2.340 & PCT-B, PCT-Na \\
\hline LAWB41 & NA & NA & NA & 1.700 & - & 1.400 & PCT-B, PCT-Na \\
\hline LAWB45 & NA & NA & $\mathrm{NA}$ & 1.060 & - & 0.880 & PCT-B, PCT-Na \\
\hline LAWB51S & NA & NA & NA & 0.960 & - & 0.660 & PCT-B, PCT-Na \\
\hline LAWB52S & NA & NA & NA & 0.980 & - & 0.680 & PCT-B, PCT-Na \\
\hline LAWB53S & NA & NA & NA & 0.840 & - & 0.540 & PCT-B, PCT-Na \\
\hline LAWC12 for AN107 & NA & $\mathrm{NA}$ & NA & 0.840 & - & 0.818 & PCT-B, PCT-Na \\
\hline LAWC13 & NA & $\mathrm{NA}$ & $\mathrm{NA}$ & 0.708 & - & 0.740 & PCT-B, PCT-Na \\
\hline LAWC14 & NA & $\mathrm{NA}$ & NA & 1.080 & - & 7.218 & PCT-B, PCT-Na \\
\hline LAWC15 & NA & NA & $\mathrm{NA}$ & 0.658 & - & 0.670 & PCT-B, PCT-Na \\
\hline LAWC16S & NA & NA & $\mathrm{NA}$ & 1.168 & - & 0.816 & PCT-B, PCT-Na \\
\hline LAWC17S & NA & NA & $\mathrm{NA}$ & 0.798 & - & 0.588 & PCT-B, PCT-Na \\
\hline LAWC18S & NA & NA & $\mathrm{NA}$ & 0.826 & - & 0.590 & PCT-B, PCT-Na \\
\hline LAWC19S & NA & NA & $\mathrm{NA}$ & 0.464 & - & 0.450 & PCT-B, PCT-Na \\
\hline LAWC20S & NA & $\mathrm{NA}$ & $\mathrm{NA}$ & 0.488 & - & 0.378 & PCT-B, PCT-Na \\
\hline LAWC21S & NA & NA & NA & 0.300 & - & 0.344 & PCT-B, PCT-Na \\
\hline LAWC22 & NA & NA & NA & 1.036 & - & 0.938 & PCT-B, PCT-Na \\
\hline LAWC23 & NA & NA & $\mathrm{NA}$ & 0.478 & - & 0.546 & PCT-B, PCT-Na \\
\hline LAWC24 & NA & NA & $\mathrm{NA}$ & 0.442 & - & 0.564 & PCT-B, PCT-Na \\
\hline LAWC25 & NA & NA & NA & 0.640 & - & 0.770 & PCT-B, PCT-Na \\
\hline LAWABP1 & NA & NA & $\mathrm{NA}$ & 0.580 & - & 0.620 & PCT-B, PCT-Na \\
\hline PNLREF (LD6-5412) & NA & NA & $\mathrm{NA}$ & 0.200 & - & 0.540 & PCT-B, PCT-Na \\
\hline TFA-BASE (HLP-01) & NA & NA & $\mathrm{NA}$ & 0.780 & - & 0.660 & PCT-B, PCT-Na \\
\hline
\end{tabular}

(a) NA indicates the data are not available. The dash “-” indicates the glass did not contain $\mathrm{Li}_{2} \mathrm{O}$ and thus no PCT-Li release was recorded.. 
The Catholic University of America

Vitreous State Laboratory
IHLW PCT, Spinel $T_{1 \%}$ Electrical Conductivity, and Viscosity Model Development Final Report, VSL-07R1240-4, Rev. 0

\section{Appendix C}

\section{Statistical Methods Used to Develop, Evaluate, and Validate Property-Composition Models}




\section{Appendix C}

\section{Statistical Methods Used to Develop, Evaluate, and Validate Property-Composition Models}

This appendix presents various statistical methods used for developing, evaluating, and validating waste glass property-composition models. Section C.1 discusses mixture experiments, introduces two general forms of mixture experiment models, and two variants of one of the model forms appropriate for assessing the presence of "block effects". Section C.2 discusses mixture-temperature model forms appropriate for glass properties such as viscosity and electrical conductivity (EC) that depend on temperature as well as composition. Section C.3 discusses the least squares regression methods used to fit models to data and corresponding assumptions. Section C.4 discusses the statistical methods and summary statistics used for model evaluation based on the data used to fit a model. Section C.5 discusses statistical methods for model augmentation (i.e., adding terms to a model) and model reduction (i.e., removing unneeded terms from a model). Section C.6 discusses the statistical methods and summary statistics used for model validation based on data not used to fit a model. Section C.7 discusses several statistical intervals used to quantify uncertainties in model predictions.

\section{C.1 Mixture Experiments, Model Forms, and Assessing Block Effects}

A mixture experiment involves mixing two or more components in various proportions, and then measuring one or more response variables for the resulting end-product mixtures. If the proportions of $q$ mixture components are denoted $x_{i}, i=1,2, \ldots, q$, then these proportions are subject to the basic mixture constraints

$$
0 \leq x_{i} \leq 1 \text { and } \sum_{i=1}^{q} x_{i}=1
$$

Often in practice, the component proportions will be subject to additional single-component constraints

$$
0 \leq L_{i} \leq x_{i} \leq U_{i} \leq 1
$$

and/or multiple-component constraints that can be written in the general form

$$
\sum_{i=1}^{q} A_{k i} x_{i}+A_{k 0} \geq 0, \quad k=1,2, \ldots, K
$$

In Equation (C.2) $L_{i}$ and $U_{i}$ denote, respectively, the lower and upper constraints on the $i^{\text {th }}$ component $(i=1,2, \ldots, q)$. In Equation (C.3), the $A_{k i}(i=1,2, \ldots, q)$ and $A_{k 0}$ denote the coefficients of the $k^{\text {th }}$ multiple-component constraint. Cornell (2002) provides a comprehensive 
discussion of statistical methods for the design, modeling, and data analysis of mixture experiments.

Section C.1.1 introduces the linear mixture (LM) model, partial quadratic mixture (PQM) model, and partial cubic mixture (PCM) model forms for mixture experiment data. Section C.1.2 discusses two variations of the LM model that can be used to assess modeling data collected in two or more blocks (e.g., at different times or under different conditions) for "block effects".

\section{C.1.1 Linear, Partial Quadratic, and Partial Cubic Mixture Model Forms}

The LM model form is given by

$$
f(y)=\sum_{i=1}^{q} b_{i} x_{i}+E
$$

the PQM model form is given by

$$
f(y)=\sum_{i=1}^{q} b_{i} x_{i}+\text { Selected }\left\{\sum_{i=1}^{q} b_{i i} x_{i}^{2}+\sum_{i<j}^{q-1} \sum_{j}^{q} b_{i j} x_{i} x_{j}\right\}+E,
$$

and the PCM model form is given by

$$
f(y)=\sum_{i=1}^{q} b_{i} x_{i}+\text { Selected }\left\{\begin{array}{l}
\sum_{i=1}^{q} b_{i i} x_{i}^{2}+\sum_{i=1}^{q-1} \sum_{j=i+1}^{q} b_{i j} x_{i} x_{j}+\sum_{i=1}^{q} b_{i i i} x_{i}^{3} \\
+\sum_{i=1}^{q-1} \sum_{j=i+1}^{q} b_{i j} x_{i}^{2} x_{j}+\sum_{i=1}^{q-2} \sum_{j=i+1}^{q-1} \sum_{k=j+1}^{q} b_{i j k} x_{i} x_{j} x_{k}
\end{array}\right\}+E
$$

In Equations (C.4) to (C.6), $y$ is a property or response variable that can be measured for each end-product mixture; $f(y)$ is some mathematical transformation of $y$ (which could be the identity transformation); the $x_{i}(i=1,2, \ldots, q)$ are proportions of $q$ components subject to the constraints in Equation (C.1) and possibly constraints of the forms in Equations (C.2) and/or (C.3); the $b_{i}(i$ $=1,2, \ldots, q)$ and the $b_{i i}, b_{i j}, b_{i i i}, b_{i i j}$, and $b_{i i k}$ (selected) are coefficients to be estimated from data; and $E$ is a random experimental and property measurement error for each data point. Many statistical methods exist for the case where the $E$ are independent (i.e., not correlated) and normally distributed with mean 0 and standard deviation $\sigma$. In Equations (C.5) and (C.6), "Selected" means that only some of the terms in curly brackets are included in the model. The subset is selected using standard stepwise regression or related methods (Draper and Smith 1998; Montgomery et al. 2001). LM models and PQM models are discussed in more detail and illustrated, respectively, by Cornell (2002) and Piepel et al. (2002).

Cornell (2002) discusses many other empirical mixture model forms that can be more appropriate than models of the forms in Equations (C.4) to (C.6) in certain specialized conditions. However, models of the form in Equations (C.4) and (C.5) are widely used in many 
application areas (including waste glass property modeling) and have been shown to perform very well. Equation (C.6) is a natural extension of Equation (C.5) to allow the inclusion of cubic terms as well as quadratic terms.

\section{C.1.2 Variants of the Linear Mixture Model for Assessing Block Effects}

Two variants of the LM model, useful in assessing the presence or absence of "block effects" in a modeling dataset comprised of two subsets of data collected at different times and/or locations (i.e., "blocks"), are presented in this section. These LM model variants can easily be extended for use with modeling datasets comprised of three or more subsets of data.

The following model form is applicable if: (1) the LM model accounts for the majority of the compositional dependence of $f(y)$ and (2) there is a constant difference in $f(y)$ values for one subset of data (i.e., block) compared to the other:

$$
f(y)=b_{0} B+\sum_{i=1}^{q} b_{i} x_{i}+E
$$

where $B=0$ for one of the two subsets of modeling data and $B=1$ for the other subset. The remaining notation is as described previously. If there is a reason to believe one subset is unbiased and the other biased, then $B=0$ should be used for the subset believed to be unbiased. In Equation (C.7), $b_{0}$ is a coefficient estimated from the modeling data that gives the estimated magnitude of the constant difference in $f(y)$ values between the two subsets. If the $b_{0}$ coefficient is statistically different from zero, then that is an indication there is a significant constant difference between the $f(y)$ values for one subset of the modeling data compared to the other.

The following model form is applicable if: (1) the LM model accounts for the majority of the compositional dependence of $f(y)$ and (2) the difference in $f(y)$ values for one subset of data compared to the other depends on the composition of the mixture:

$$
f(y)=\sum_{i=1}^{q} b_{i}^{0} x_{i}+\sum_{i=1}^{q} b_{i}^{1} x_{i} B+E
$$

where the choice of $B=0$ or $B=1$ and the remaining notation is the same as previously discussed. In Equation (C.8), the $b_{i}^{0}$ coefficient represents the linear blending effect of the $i^{\text {th }}$ component for the subset of modeling data represented by $B=0$. The $b_{i}^{1}$ coefficient represents the change or bias in the linear blending effect of the $i^{\text {th }}$ component for the subset of modeling data represented by $B=1$. If any of the $b_{i}^{1}$ coefficients $(i=1,2, \ldots, q)$ are statistically different from zero, that is an indication that there are compositionally-dependent differences in the $f(y)$ values for one subset of the modeling data compared to the other.

The model forms in Equations (C.7) and (C.8) are intended for use in assessing whether data collected at different times, locations, or conditions are subject to effects (biases) related to 
the change in time, location, or conditions of data collection. If significant bias is indicated by such models, it should ideally be confirmed by other means (e.g., results on a standard collected at different times, locations, and conditions). It is beyond the scope of this discussion to address what to do when biased data are detected and confirmed. The appropriate steps will depend on the specific situation, the intended use of the data, and any requirements or limitations regarding the use of biased (or bias-corrected) data.

Equations (C.7) and (C.8) are for cases where a LM model accounts for the majority of the compositional dependence of $f(y)$. This will usually be the case for most waste glass property models. It is possible to include block effect terms similar to those in Equations (C.7) and (C.8) in cases where there is substantial non-linear compositional dependence. However, doing this can have added complications for some waste glass property-composition databases, and so is not discussed further.

Ultimately, investigation of block effects was not performed in conjunction with property-composition modeling work discussed in this report. The use of Equations (C.7) and (C.8) to assess block effects is complicated if different glass components vary, or vary over different ranges for groups of data in the property-composition modeling dataset. These factors can cause block effects to appear significant even though there is no systematic bias in property values across groups. Hence, investigation of block effects is often not performed in such cases. Further, because (i) procedures for batching, melting, and testing of waste glasses are well established, (ii) no block effects have been identified in previous phases of the WTP propertycomposition modeling work, and (iii) assessment of replicate data over groups showed no sign of block effects, investigation of block effects was deemed unnecessary for the propertycomposition modeling work discussed in this report.

\section{C.2 Mixture-Temperature Models for Viscosity and Electrical Conductivity}

Viscosity and EC of glass melts depend on the melt temperatures as well as the compositions of the glasses. Equations for representing the temperature dependence of viscosity or EC for a given glass composition are discussed in Section C.2.1. Then, Section C.2.2 discusses using the temperature-dependence equations as a basis for developing propertycomposition-temperature model forms for viscosity and EC.

\section{C.2.1 Equations for Temperature Dependence of Viscosity and Electrical Conductivity}

The temperature dependence for a given glass can be represented by the Arrhenius equation

$$
\ln (y)=A+\frac{B}{T}+E
$$


where $y=$ viscosity or EC for a given glass, $\ln (y)$ denotes the natural logarithm of $y, A$ and $B$ are coefficients specific to a given glass, and $T$ is temperature in Kelvin. Sometimes there is curvature in the relationship between $\ln (y)$ and $1 / T$, which can be represented by the $T 2$ equation

$$
\ln (y)=A+\frac{B}{T}+\frac{C}{T^{2}}+E
$$

or the truncated-T2 equation

$$
\ln (y)=A+\frac{C}{T^{2}}+E
$$

In these two equations, $B$ and $C$ represent coefficients specific to a given glass. The T2 equation is a second-order Taylor series expansion of the Vogel-Fulcher equation

$$
\ln (y)=A+\frac{B}{T-T_{0}}+E
$$

with coefficients $A, B$, and $T_{0}$. However, the Vogel-Fulcher equation is non-linear in its coefficients (specifically $T_{0}$ ). Hence, iterative nonlinear least squares methods are required to fit the Vogel-Fulcher equation to data rather than the single-step solution of linear least squares methods. Feng et al. (2004) showed that the T2 and truncated-T2 equations can provide adequate approximations of the Vogel-Fulcher equation, while requiring only linear least squares fitting methods.

In each of Equations (C.9) to (C.12), the $E$ denotes a random error for each data point. When these errors are independent (i.e., not correlated) and have equal variance across the data set, ULS regression can be used to fit the equation.

\section{C.2.2 Models for Temperature and Compositions Dependence of Viscosity and Electrical Conductivity}

The equations for temperature dependence in Section C.2.1 are applicable to specific glasses, with the equation coefficients differing from glass to glass. Hence, the temperature dependence equations can be converted to models representing the effects of both temperature and glass composition on viscosity or EC by writing the coefficients as functions of glass composition. For viscosity and EC, linear functions of glass composition (specifically, linear mixture models) may be sufficient. Thus, expanding the coefficients of the Arrhenius equation using LM models yields

$$
\ln (y)=\sum_{i=1}^{q} a_{i} x_{i}+E_{G}+\sum_{i=1}^{q} b_{i} \frac{x_{i}}{T}+E_{T},
$$


where $a_{i}$ and $b_{i}$ are coefficients for the $i^{\text {th }}$ glass component estimated from data, $x_{i}$ is the mass fraction of the $i^{\text {th }}$ glass component such that $\Sigma x_{i}=1, E_{G}$ is a random error associated with determining $y$ for each glass, and $E_{T}$ is a random error associated with determining $y$ at the temperature values for a given glass. The random errors $E_{G}$ and $E_{T}$ are assumed to be normally distributed with zero means and standard deviations $\sigma_{G}$ and $\sigma_{T}$. Further, the $\mathrm{E}_{\mathrm{G}}$ and $\mathrm{E}_{\mathrm{T}}$ are assumed to be statistically independent (i.e., not correlated).

In a similar manner, expanding the coefficients of the T2 equation using LM models yields

$$
\ln (y)=\sum_{i=1}^{q} a_{i} x_{i}+E_{G}+\sum_{i=1}^{q} b_{i} \frac{x_{i}}{T}+\sum_{i=1}^{q} c_{i} \frac{x_{i}}{T^{2}}+E_{T}
$$

while expanding the coefficients of the truncated-T2 equation yields

$$
\ln (y)=\sum_{i=1}^{q} a_{i} x_{i}+E_{G}+\sum_{i=1}^{q} c_{i} \frac{x_{i}}{T^{2}}+E_{T}
$$

where $c_{i}$ is the coefficient of the corresponding component-temperature model term for the $i^{\text {th }}$ glass component, and all other notations have been defined previously. In some cases it may be required to expand one or more coefficients in a temperature-dependence equation using a PQM model. Such models for viscosity or EC are discussed in the main body of the report where appropriate.

The two error terms, $E_{G}$ and $E_{T}$, in Equations (C.12) to (C.15) are a result of a "restriction on randomization" in measuring $y$ (viscosity or EC). Specifically, the property $y$ is measured at multiple temperatures on each glass before moving on to the next glass. This is a natural way to measure viscosity or EC, because glass is a "hard-to-change" factor while temperature is an "easy-to-change" factor. Thus, it is infeasible to completely randomize all combinations of glass composition and temperature in measuring viscosity or EC. Hence, the way in which viscosity or EC is measured is a "restriction on randomization" that requires a proper analysis of the data. Experiments with this sort of restriction are referred to as split-plot experiments in the statistical literature, because of their early use in agricultural experiments. However, this type of restrictedrandomization data collection is common in engineering and other experiments where there is at least one hard-to-change factor and at least one easy-to-change factor. The main consequence of the split-plot nature of the data is that there are two uncertainty standard deviations, one related to whole plots (WPs) and one related to sub-plots (SPs). For viscosity and EC, glasses are the WP "treatments" and the associated uncertainty standard deviation is denoted $\sigma_{G}$. Temperature values are the SP "treatments" and the associated uncertainty standard deviation is denoted $\sigma_{T}$. The observations within a WP (e.g., $y$ values at four temperatures) are correlated. Thus, it is improper to use ordinary least squares (OLS) regression, which has only one uncertainty standard deviation and assumes observations are uncorrelated. Generalized least squares (GLS) regression modeling is needed for the split-plot data structure present with viscosity and EC data. 
GLS regression modeling simultaneously estimates the model coefficients as well as $\sigma_{G}$ and $\sigma_{T}$. See Section C.3.3 for further discussion and references on these topics.

Investigation of block effects by adding block effect terms to the models in Equations (C.13) to (C.15) is an added complication on top of the split-plot structure of the data for such models. Assessing block effects is further complicated if different glass components vary, or vary over different ranges for groups of data in the property-composition-temperature modeling dataset. These factors can cause block effects to appear significant even though there is no systematic bias in property values across groups. Hence, investigation of block effects is often not performed in such cases. Further, because (i) procedures for batching, melting, and testing of waste glasses are well established, (ii) no block effects have been identified in previous phases of the WTP property-composition modeling work, and (iii) assessment of replicate data over groups showed no sign of block effects, investigation of block effects was deemed unnecessary for the property-composition-temperature modeling work discussed in this report.

\section{C.3 Least Squares Regression Methods and Assumptions for Fitting Models}

Empirical or semi-empirical property-composition models are typically fitted to data sets using unweighted least squares (ULS) or weighted least squares (WLS) regression. However, in some cases generalized least squares (GLS) regression is required. Section C.3.1 discusses ULS and WLS regression, while Section C.3.2 discusses GLS regression. Section C.3.3 discusses the case of GLS regression for data with a split-plot structure such as occurs when measuring viscosity and EC of glasses at various temperatures. Draper and Smith (1998) and Montgomery et al. (2001) provide additional discussion of the ULS, WLS, and GLS topics.

\section{C.3.1 Unweighted and Weighted Least Squares Regression}

The underlying assumptions of ULS and WLS regression are:

(i) The predictor variable values (e.g., mass fractions of glass components) are known or measured without uncertainty, or at least that the uncertainty is small relative to the uncertainty in response variable (glass property) values

(ii) The testing and/or measurement errors in a response variable (glass property) over a model development data set are independently distributed (i.e., the errors are not correlated). For ULS regression, the additional assumption is made that the errors are identically distributed (i.e., with zero mean and the same variance). For WLS regression, the errors are also assumed to have zero mean, but the variance can be different for different data points.

(iii) The errors from (ii) are normally (Gaussian) distributed. 
Regarding assumption (i), the true composition of glasses in a model development data set are generally not known, and so any representation of glass composition selected (e.g., target compositions, analyzed compositions, or adjusted and normalized versions of analyzed compositions) will be subject to uncertainty. Weier and Piepel (2003) discuss a procedure for performing adjustments and weighted normalization of analyzed glass compositions that corrects for biases and reduces uncertainties in analyzed glass compositions. As long as representations of glass composition do not have significant biases (or those biases are appropriately corrected), it is generally expected that uncertainties will be small compared to uncertainties in glass property values. Further, uncertainties in glass compositions are expected to be small compared to errors in using empirical or semi-empirical model forms to approximate the true (but unknown) property-composition relationships. Hence, assumption (i) is sufficiently satisfied for most waste glass property-composition modeling situations.

The portion of assumption (ii) having to do with the independence of errors in testing and measuring properties may not be completely satisfied when model development data sets are comprised of subsets of data generated at different times or locations (e.g., different laboratories). There is the potential for errors in testing and measuring properties to vary for different subsets of data, and be more alike within the same subset of data. However, this issue has generally not been a problem in many past property-composition modeling efforts. If needed, GLS methods that account for correlations among data points could be applied.

The "identically distributed" portion of assumption (ii) for ULS regression is not valid for some properties, because the variance of errors in testing and measurement of properties depends on the value of the property. For example, the variances of viscosity and durability results for waste glasses tend to increase as the values of these properties increase. In cases where the identically distributed (equal variance) assumption is violated, it can often be remedied by applying an appropriate mathematical transformation to the property values (e.g., a logarithmic transformation). The Box-Cox family of transformations contains transformations (including the logarithmic transformation) appropriate for many models (see Draper and Smith 1998). Such transformations also often yield better fitting empirical or semi-empirical property-composition models. In some cases, a property transformation used in a particular model form may be preferred for some reason (e.g., provides a better fit), but does not satisfy the constant variance assumption of (ii). Or, it may be that the difference in variances across response values in the modeling data set cannot be rectified by a response transformation. In such cases, other regression methods such as WLS regression or generalized linear models (Myers et al. 2002) could be applied.

The assumption of normally distributed measurement and testing errors in the measured response variable values allows the use of normal theory regression tests and uncertainty equations associated with the fitted regression model. For example, normal theory confidence intervals and prediction intervals can be used (see Section C.7).

As discussed in preceding text, ULS regression requires that all response values for the modeling data have constant variance (i.e., uncertainty). WLS regression accounts for response values having different variations by using a weight for each data point $\left(w_{i}\right)$. Often, $w_{i}$ is chosen 
to be proportional to the reciprocal of the variance (squared standard deviation) of the response for the $i^{\text {th }}$ data point $\left(y_{i}\right)$.

$$
w_{i}=\frac{\lambda}{\operatorname{Var}\left(y_{i}\right)}=\frac{\lambda}{\left[S D\left(y_{i}\right)\right]^{2}}
$$

where $\lambda$ is a proportionality constant (which could be 1). Thus, in such a WLS regression the weighted response values $\sqrt{w_{i}} y_{i}$ then have equal variance. However, other methods for selecting weights can be applicable for various situations.

In summary, assumptions of ULS regression may not be completely satisfied for typical property-composition data sets and models. Violations of the constant variance assumption for property values over a modeling data set can sometimes be addressed by appropriate property transformations so that ULS regression may be used. Other violations may be small enough that ULS regression methods can still be used without significant consequence. However, if there are large enough differences in variances of property values across a modeling data set that cannot be addressed by a property transformation, then WLS regression methods should be used. If there are correlations among data points in a regression set, GLS methods are needed as discussed in the following subsection.

\section{C.3.2 Generalized Least Squares Regression}

The underlying assumptions of GLS regression are:

(i) The predictor variable values (e.g., mass fractions of glass components) are known or measured without uncertainty, or at least that the uncertainty is small relative to the uncertainty in response variable (glass property) values

(ii) The testing and/or measurement errors in a response variable (glass property) over a model development data set are normally distributed with a mean vector of zeros and a variance-covariance matrix $\boldsymbol{V}$. 
Under these assumptions, the data to be modeled by GLS regression can be written in the general form

$$
\boldsymbol{y} \sim N(\boldsymbol{\mu}(\boldsymbol{x}, \boldsymbol{\beta}), \boldsymbol{V})
$$

which denotes that the vector of property values $\boldsymbol{y}$ is normally distributed with mean vector $\boldsymbol{\mu}(\boldsymbol{x}, \boldsymbol{\beta})$ and variance-covariance matrix $\boldsymbol{V}$. The mean vector is a function of the vector of predictor variables $\boldsymbol{x}$ and the unknown model parameter vector $\boldsymbol{\beta}$. Most commonly, functions linear in the parameters $\boldsymbol{\mu}(\boldsymbol{x}, \boldsymbol{\beta})=\boldsymbol{\beta}^{\prime} \boldsymbol{a}$ are used, where $\boldsymbol{a}$ is an expansion of $\boldsymbol{x}$ in the form of the model. Note that such functions can still be linear as well as nonlinear in the predictor variables. If the variance-covariance matrix $\boldsymbol{V}$ is known, the estimate of the parameter vector obtained by GLS can be written as

$$
\hat{\boldsymbol{\beta}}=\left(\boldsymbol{A}^{\prime} \boldsymbol{V}^{-1} \boldsymbol{A}\right)^{-1} \boldsymbol{A}^{\prime} \boldsymbol{V}^{-1} \boldsymbol{y}
$$

with the variance of the parameter estimates denoted by

$$
\operatorname{Var}(\hat{\boldsymbol{\beta}})=\left(\boldsymbol{A}^{\prime} \boldsymbol{V}^{-1} \boldsymbol{A}\right)^{-1}
$$

(see Montgomery et al. 2001, Section 5.5.1). In both of these equations, $\boldsymbol{A}$ is the matrix of data used to fit the model, expanded in the form of the model. If the variance-covariance matrix $V$ is not known in advance, for some problems it can be estimated at the same time as the model parameters are estimated (see Section C.3.3 for further discussion). In such a case, Equation (C.19) is only approximate.

Note that ULS and WLS regression are special cases of GLS regression. ULS applies when the diagonal elements of $\boldsymbol{V}$ (the variances of the data points) are all the same, and the offdiagonal elements (covariances) are all zero. WLS applies when the diagonal elements of $\boldsymbol{V}$ differ and the off-diagonal elements are all zero.

\section{C.3.3 Generalized Least Squares Regression for Split-Plot Data Structures}

Viscosity and EC are examples of glass properties for which GLS regression is required when data are collected using the approach typical for those properties. Specifically, viscosity (or EC) is measured at each of several temperatures for one glass, then another glass, etc. This is referred to in the statistical literature as a "restriction on randomization" because the property is not measured on composition-temperature combinations in a completely random order. The glass composition is referred to as a hard-to-change factor, and temperature is referred to as an easyto-change factor. It is easier to make viscosity or EC measurements at various temperatures for one glass, then the next glass, etc., but it results in a restriction on randomization. Experimental data collected in this way are referred to as having a split-plot structure. The terminology originally came from agricultural experiments with restrictions on randomization, where fields 
were split into "whole plots" and "sub plots". However, this terminology is also used for experiments in various non-agricultural application areas.

Every viscosity (or EC)-at-temperature data point is subject to one uncertainty related to batching and melting a glass, as well as the uncertainty associated with the set-up and property measurement of a given glass. The associated standard deviation is denoted $\sigma_{G}$. The data points for a given glass are also subject to a second uncertainty related to measuring the property at various temperatures. The associated standard deviation is denoted $\sigma_{T}$. The property-attemperature values for each given glass are correlated. The variance-covariance matrix for the split-plot structure typical for viscosity or electrical conductivity data on several glasses is given by

$$
\boldsymbol{V}=\left[\begin{array}{ccccc}
\boldsymbol{T}_{1} & 0 & \cdots & \cdots & 0 \\
0 & \boldsymbol{T}_{2} & 0 & \cdots & 0 \\
0 & 0 & \ddots & \cdots & 0 \\
\vdots & \vdots & \vdots & \ddots & \vdots \\
0 & 0 & 0 & \cdots & \boldsymbol{T}_{g}
\end{array}\right]
$$

where $g$ denotes the number of glasses in a modeling dataset and a $\boldsymbol{T}_{i}$ matrix is given by

$$
\boldsymbol{T}_{i}=\left[\begin{array}{cccc}
\sigma_{G}^{2}+\sigma_{T}^{2} & \sigma_{G}^{2} & \sigma_{G}^{2} & \sigma_{G}^{2} \\
\sigma_{G}^{2} & \sigma_{G}^{2}+\sigma_{T}^{2} & \sigma_{G}^{2} & \sigma_{G}^{2} \\
\sigma_{G}^{2} & \sigma_{G}^{2} & \sigma_{G}^{2}+\sigma_{T}^{2} & \sigma_{G}^{2} \\
\sigma_{G}^{2} & \sigma_{G}^{2} & \sigma_{G}^{2} & \sigma_{G}^{2}+\sigma_{T}^{2}
\end{array}\right]
$$

These equations are based on ones given by Myers and Montgomery (1995, Section 9.6.3). This form of $\boldsymbol{T}_{i}$ assumes viscosity or EC is measured at four temperatures for each glass. The $\boldsymbol{T}_{i}$ matrix would expand or contract accordingly if the number of temperatures at which a property is measured for a given glass would increase or decrease.

If $\sigma_{G}$ and $\sigma_{T}$ were known, then $\boldsymbol{V}$ in (C.20) could be used in Equations (C.18) and (C.19) to estimate viscosity or EC model coefficients and their uncertainties. However, $\sigma_{G}$ and $\sigma_{T}$ generally are not known and must be estimated from data. Statistical software is available for fitting so-called mixed models, that is, models that require simultaneous estimation of data uncertainties (e.g., $\sigma_{G}$ and $\sigma_{T}$ ) and model coefficients. The PROC MIXED routine in SAS (2005) was used to fit the viscosity and EC models presented in this report.

\section{C.4 Statistical Methods for Model Evaluation}

There are many statistical methods (both numerical and graphical) for assessing models. Evaluation methods assess a model with the data used to develop the model. Such data are 
referred to as model development data. The goals of model evaluation are to assess: (1) how well a model fits the data used to develop it, (2) how well the least squares or other regression method assumptions are satisfied (see Section C.3), and (3) whether there are any outlying or influential data points that significantly affect the fitted model. Problems detected by model evaluation such as violation of assumptions, detection of outlying data points, or detection of model inadequacy require implementing various remedies in the model development process until the problem(s) are corrected. When the model being evaluated acceptably fits the data used to develop the model, model validation methods should be applied using data not used to develop the model. Such data are referred to as model validation data. If model validation data are not available, crossvalidation methods can be applied using the model development data. Crossvalidation methods leave out one or more data points at a time, so that some of the data are used for model development and some for model validation. Such methods are also referred to as data-splitting validation methods, where part of the data is used for model development and evaluation, while the other part is used for validation. Draper and Smith (1998) and Montgomery et al. (2001) discuss statistical methods for evaluating and validating models.

Model evaluation techniques include predicted versus measured (PvM) property plots, standardized residual plots, outlier diagnostics, three $R^{2}$ statistics, root mean squared error $(R M S E)$, and statistical lack-of-fit (LOF) tests. Each of these is explained briefly below. The following notation is used in the subsequent descriptions and definitions:

$$
\begin{aligned}
& n=\text { the number of data points used to fit a model, } \\
& p=\text { the number of parameters (coefficients) in a model form estimated via } \\
& \text { regression on the data, } \\
& y_{i}=\text { the measured property value (mathematically transformed, if } \\
& \text { appropriate for the model form used) for the } i^{\text {th }} \text { data point, } \\
& \hat{y}_{i}=\text { the predicted property value (mathematically transformed, if } \\
& \text { appropriate for the model form used) for the } i^{\text {th }} \text { data point made using } \\
& \text { the model fitted to all } n \text { data points, } \\
& r_{i}=\text { the residual for the } i^{t h} \text { data point }=y_{i}-\hat{y}_{i} \text {, } \\
& \hat{y}_{(i)}=\text { the predicted property value (mathematically transformed, if } \\
& \text { appropriate for the model form used) for the } i^{\text {th }} \text { data point made using a } \\
& \text { model fitted to all } n \text { data points except the } i^{\text {th }} \text {, } \\
& w_{i}=\text { the weight applied to the } i^{\text {th }} \text { data point in cases where WLS regression } \\
& \text { is used. Typically, } w_{i} \text { is proportional to the reciprocal of the variance } \\
& \text { of the response variable for the } i^{\text {th }} \text { data point, }
\end{aligned}
$$


$\bar{y} \quad=\quad$ the unweighted average (mean) of the $n$ measured property values

(mathematically transformed, if appropriate for the model form used),

$\bar{y}_{w} \quad=$ the weighted average (mean) of the $n$ measured property values

(mathematically transformed, if appropriate for the model form used)

$$
\bar{y}_{w}=\frac{\sum_{i=1}^{n} w_{i} y_{i}}{\sum_{i=1}^{n} w_{i}}
$$

The model evaluation methods are now briefly described.

- $\quad$ Predicted versus measured ( $P v M)$ property plots show how well model predicted values $\hat{y}_{i}$ compare to the measured values $y_{i}$ for the glasses in the model development data set. Predicted property values $\hat{y}_{i}$ are plotted on the $y$-axis and measured property values $y_{i}$ are plotted on the $x$-axis. A line with slope one is included in the plot for reference purposes, and represents the ideal of predicted values equaling measured values. Plotted points falling above this line correspond to glasses for which the model over-predicts the property, while plotted points falling below this line represent glasses for which the model under-predicts the property. A preponderance of plotted points in a portion of the plot falling above or below the line indicates that the model tends to yield biased predictions for that range of property values. Plotted points far from the line are outlying or potentially influential data points.

For WLS regression, an ordinary (unweighted) PvM plot of $\hat{y}_{i}$ versus $y_{i}$ could be viewed as is done for ULS regression. Or, a weighted PvM plot of $\sqrt{w_{i}} \hat{y}_{i}$ versus $\sqrt{w_{i}} y_{i}$ could be viewed. The ordinary (unweighted) PvM plot has the advantage of retaining the units of the response (or its transformation), but the disadvantage that points with smaller weights (i.e., higher uncertainties) may appear farther from the line with slope one. However, rather than considering this a disadvantage, it may be better thought of as showing the penalty paid in obtaining predictions having more uncertainty for modeling data points with smaller weights (i.e., higher uncertainty). The weighted PvM plot would show the model predictive performance for the modeling data points after accounting for (i.e., removing the scatter due to) the differing weights (i.e., uncertainties).

For GLS regression, an ordinary PvM plot could be viewed as is done for ULS regression. Or, a modified version could be viewed that accounts for the variancecovariance structure of the data. Because such modified PvM plots are more complicated, they are not discussed or used in this report. In this report, ordinary PvM plots are viewed regardless of whether ULS, WLS, or GLS regression is employed to fit models.

- $\underline{R M S E}$ is given by 


$$
R M S E_{U}=\sqrt{\frac{\sum_{i=1}^{n}\left(\hat{y}_{i}-y_{i}\right)^{2}}{n-p}}
$$

for ULS regression, and by

$$
R M S E_{W}=\sqrt{\frac{\sum_{i=1}^{n} w_{i}\left(\hat{y}_{i}-y_{i}\right)^{2}}{n-p}}
$$

for WLS regression. If the fitted model is adequate and does not have a statistically significant lack-of-fit, this statistic provides an estimate of the experimental and measurement uncertainty standard deviation associated with melting glasses and measuring the associated property. The statistic RMSE is included as standard output in most regression software, and has units the same as the property values $y_{i}$ (including any mathematical transformation of the property in the model form) for ULS regression and the units of $\sqrt{w_{i}} y_{i}$ for WLS regression.

RMSE values are not traditionally calculated and reported by software implementing GLS regression because of the more complicated uncertainty structure of the data. In this report we have opted for using $\mathrm{RMSE}_{\mathrm{U}}$ to provide an overall summary measure of GLS fitted models. Note that $\mathrm{RMSE}_{\mathrm{U}}$ will not directly give proper estimates of $\sigma_{G}, \sigma_{T}$, or $\sqrt{\sigma_{G}^{2}+\sigma_{T}^{2}}$ and should not be interpreted as such.

- $\quad$ Standardized residual plots display standardized residuals $\left(s_{i}\right.$, differences in predicted and measured property values divided by their standard deviations) versus various quantities, such as: glass component mass fractions $\left(x_{i}\right)$, predicted property values $\left(\hat{y}_{i}\right)$, or an index associated with each data point. The formula for a standardized residual is given by

$$
s_{i}=\frac{r_{i}}{\operatorname{RMSE}_{U}\left[1-\boldsymbol{a}_{i}^{T}\left(\boldsymbol{A}^{T} \boldsymbol{A}\right)^{-1} \boldsymbol{a}_{i}\right]^{0.5}}
$$

for ULS regression, by

$$
s_{i}=\frac{\sqrt{w_{i}} r_{i}}{\operatorname{RMSE}_{W}\left[1-w_{i} \boldsymbol{a}_{i}^{T}\left(\boldsymbol{A}^{T} \boldsymbol{W} \boldsymbol{A}\right)^{-1} \boldsymbol{a}_{i}\right]^{0.5}}
$$

for WLS regression, and by 


$$
s_{i}=\frac{r_{i}}{\left[1-\boldsymbol{a}_{i}^{T}\left(\boldsymbol{A}^{T} \boldsymbol{V}^{-1} \boldsymbol{A}\right)^{-1} \boldsymbol{a}_{i}\right]^{0.5}}
$$

for GLS regression. In Equations (C.24a), (C.24b), and (C.24c): $s_{i}, w_{i}$, and $r_{i}$ are as previously described; $R M S E_{U}$ and $R M S E_{W}$ are respectively given by Equations (C.23a) and (C.23b); $\boldsymbol{a}_{i}$ is the composition (column) vector for the $i^{\text {th }}$ modeling data point expanded in the form of the model; $\boldsymbol{A}$ is an $n \times p$ matrix of the compositions (and temperatures in the case of viscosity or EC) in the modeling data set expanded in the form of the model; $\boldsymbol{W}$ is an $n \times n$ matrix with the weights $w_{i}$ along the main diagonal, and zeros elsewhere; and $\boldsymbol{V}$ is an $n \times n$ matrix representing the variance-covariance structure of the modeling dataset.

Patterns in the $s_{i}$ versus $\hat{y}_{i}$ plot can indicate a violation of the least squares regression assumptions and suggest a property transformation to remedy the situation. Patterns in the $s_{i}$ versus $x_{i}$ plots can indicate inadequacies of the model or least squares assumptions. Patterns in $s_{i}$ versus data indices can indicate subsets of the data for which a model may be inadequate. Standardized residuals are typically used in residual plots because the majority should fall within the range of \pm 2.0 and almost all should fall within \pm 3.0 . Comparing standardized residuals to such a range provides an easy criterion for judging whether a data point is outlying.

- Normality plots display normal scores versus the ordered (from smallest to largest) standardized residuals (from Equations (C.24a), (C.24b), or (C.24c) for ULS, WLS, and GLS regression, respectively) for the $n$ data points used to fit the model being assessed. Normal scores are the expected values of a sample of size $n$ from standard normal distribution (with mean 0 and standard deviation 1). The plotted points are compared to the ideal of a straight line corresponding to a normal distribution. A straight middle portion of the plot with curved "tails" on each end of the plot indicate the presence of outlying data points, which cause a heavier-tailed distribution than the normal distribution.

- Outlier diagnostics and plots indicate data points that are outlying or influential with respect to property value or composition. There are too many of these diagnostics and plots to discuss here, but several produced by the R software (Ihaka and Gentleman 1996, R Core Development Team 2006) and the SAS software (2005) were considered in this work. Draper and Smith (1998) and Montgomery et al. (2001) discuss outlier diagnostics and plots for ULS regression, but software such as R and SAS produce the appropriate versions of diagnostics and plots for WLS and GLS as well as ULS regression.

- $\underline{R}^{2}$ statistics quantify the proportion of variation in the property values $y_{i}$ (for ULS regression) or weighted property values $\sqrt{w_{i}} y_{i}$ (for WLS regression) accounted for by the fitted model. Three $\mathrm{R}^{2}$ statistics are used, as discussed later in this section. Typically $\mathrm{R}^{2}$ type statistics are not calculated and reported by software that performs GLS regression. This is because of the more complicated uncertainty structure of the data. It may be possible to develop such statistics for GLS regression, but the interpretations would be modified. 
- A statistical lack-of-fit (LOF) test checks whether the differences (for ULS regression) or weighted differences (for WLS regression) between measured and predicted property values from a fitted model are larger than expected based on the experimental and measurement uncertainty in the data. If the predicted versus measured differences are larger than data uncertainty at a high enough statistical confidence (e.g., greater than 90\%), the model is said to have a statistically significant LOF. Replicate data points containing all applicable sources of experimental and measurement uncertainty ${ }^{1}$ are required to perform statistical LOF tests. This process is conducted using a LOF F-test given by

$$
\begin{aligned}
F & =\frac{(\mathrm{SSE}-\mathrm{SSPE}) /(n-p-f)}{\mathrm{SSPE} / f} \\
& =\frac{\left[\left(\sum_{i=1}^{n}\left(\hat{y}_{i}-y_{i}\right)^{2}-\sum_{k=1}^{K} \sum_{j=1}^{m_{k}}\left(y_{k j}-\bar{y}_{k}\right)^{2}\right) /(n-p-f)\right]}{\sum_{k=1}^{K} \sum_{j=1}^{m_{k}}\left(y_{k j}-\bar{y}_{k}\right)^{2} / f}
\end{aligned}
$$

for ULS regression, and by

$$
\begin{aligned}
F & =\frac{(\mathrm{SSE}-\mathrm{SSPE}) /(n-p-f)}{\mathrm{SSPE} / f} \\
& =\frac{\left[\left(\sum_{i=1}^{n} w_{i}\left(\hat{y}_{i}-y_{i}\right)^{2}-\sum_{k=1}^{K} \sum_{j=1}^{m_{k}} w_{j}\left(y_{k j}-\bar{y}_{k}\right)^{2}\right) /(n-p-f)\right]}{\sum_{k=1}^{K} \sum_{j=1}^{m_{k}} w_{j}\left(y_{k j}-\bar{y}_{k}\right)^{2} / f}
\end{aligned}
$$

for WLS regression. In Equations (C.25a) and C.25b): SSE = sum of squares error; SSPE = sum of squared pure error (i.e., from replicates); $n$ and $p$ are as described previously such that $n-p$ is the degrees of freedom for SSE; and the degrees of freedom for pure error is given by $f=\sum_{k=1}^{K}\left(m_{k}-1\right)$, where $m_{k}$ is the number of replicate data points in the $k^{\text {th }}$ replicate set, $k=1,2, \ldots, K$. In practice, if the F-test is statistically significant at a significance level (often referred to as a $p$-value) of 0.05 or smaller (i.e., $95 \%$ confidence or higher), then it would be concluded that the fitted model has a statistically significant LOF for the modeling dataset. See Draper and Smith (1998) or Montgomery et al. (2001) for additional discussion of the statistical test for model LOF.

\footnotetext{
1 To be appropriate replicate data points, two or more glass samples of the same composition must be batched and melted at different times, and have their properties measured at different times. It is insufficient, for example, to batch and melt a glass once, and measure its properties several times (because the batching and melting sources of uncertainty are not included in the data). Similarly, replicate samples should not be measured at the same time (or close in time) because all sources of measurement uncertainty will not be included in the data.
} 
Statistical tests of LOF for GLS-fitted models have not been provided in the statistics literature. An ad hoc assessment of LOF for GLS-fitted viscosity and EC models (see Section C.3.3) is provided by considering

$$
\frac{\hat{\sigma}_{G}^{2}+\hat{\sigma}_{T}^{2}}{\text { Pure Error Estimate of } \sigma_{G}^{2}+\sigma_{T}^{2}}
$$

where $\hat{\sigma}_{G}^{2}$ and $\hat{\sigma}_{T}^{2}$ are estimates of the whole-plot (glasses) and sub-plot (temperatures) variance components that are outputs of the GLS software used to fit viscosity and EC models. The denominator of Equation (C.25c) is a "pure error" estimate of $\sigma_{G}^{2}+\sigma_{T}^{2}$ based on viscosity or EC data on replicate glasses. Developing the theory for the ratio in Equation (C.25c) was beyond the scope of the work in this report. However, a ratio as large as 1.5 to 2.0 provides evidence of a possible model LOF.

Even when a fitted model has a statistically significant LOF, the LOF may not be "practically significant". An example of such a situation is when a fitted model yields biased predictions for higher and/or lower values of a property or in a particular subregion of compositions, but the model will not be applied to such areas in practice. Another example is when the model fits the data very well (e.g., $\left.R^{2}>0.95\right)$ without bias over the model's region of validity, but the LOF is statistically significant because the experimental and measurement uncertainty is very small (e.g., because glasses can be batched, melted, and properties measured with excellent repeatability). Finally, a statistically significant LOF may not be practically significant if the uncertainty in model predictions is considerably smaller than uncertainty that can be tolerated and still meet requirements.

The model evaluation techniques discussed in the preceding bullets are included in, or can be obtained from, the output of the R software (Ihaka and Gentleman 1996, R Core Development Team) and SAS software (2005). See Draper and Smith (1998) or Montgomery et al. (2001) for further discussion of the concepts.

Three different $R^{2}$ statistics are useful in evaluating models fitted to glass propertycomposition data. These are denoted as $R^{2}, R_{A}^{2}$, and $R_{P}^{2}$, which are discussed subsequently. Formulas for these statistics are given when models are fitted by ULS or WLS. It may be possible to develop formulas for these statistics in the case of GLS regression, but doing so was beyond the scope of work in this report. Hence, only $R^{2}$ values as calculated by the ULS formula are given in this report for models fitted by GLS. 
The (ordinary) $R^{2}$ statistic is given by

$$
R^{2}=1-\frac{\sum_{i=1}^{n}\left(\hat{y}_{i}-y_{i}\right)^{2}}{\sum_{i=1}^{n}\left(y_{i}-\bar{y}\right)^{2}}
$$

for ULS regression, and by

$$
R^{2}=1-\frac{\sum_{i=1}^{n} w_{i}\left(\hat{y}_{i}-y_{i}\right)^{2}}{\sum_{i=1}^{n} w_{i}\left(y_{i}-\bar{y}_{w}\right)^{2}}
$$

for WLS regression, where $\bar{y}_{w}$ in Equation (C.26b) is the weighted mean whose formula is given in Equation (C.22). $R^{2}$ is interpreted as the fraction of variability in the unweighted (for ULS regression) or weighted (for WLS regression) property data (transformed if appropriate) accounted for by the fitted model. The adjusted $R^{2}$ statistic is given by

$$
R_{A}^{2}=1-\frac{\sum_{i=1}^{n}\left(\hat{y}_{i}-y_{i}\right)^{2} /(n-p)}{\sum_{i=1}^{n}\left(y_{i}-\bar{y}\right)^{2} /(n-1)}
$$

for ULS regression, and by

$$
R_{A}^{2}=1-\frac{\sum_{i=1}^{n} w_{i}\left(\hat{y}_{i}-y_{i}\right)^{2} /(n-p)}{\sum_{i=1}^{n} w_{i}\left(y_{i}-\bar{y}_{w}\right)^{2} /(n-1)}
$$

for WLS regression. $R_{A}^{2}$ is interpreted as the adjusted fraction of variability in the unweighted or weighted property data (transformed if appropriate) accounted for by the fitted model. The adjustment is for the number of parameters $(p)$ and number of data points $(n)$ used in fitting the model. A version of $R_{A}^{2}$ for GLS regression has not been proposed in the literature, and so this statistic is not calculated and reported for models fitted by GLS regression.

The predicted $R^{2}$ statistic is given by

for ULS regression, and by

$$
R_{P}^{2}=1-\frac{\sum_{i=1}^{n}\left(\hat{y}_{(i)}-y_{i}\right)^{2}}{\sum_{i=1}^{n}\left(y_{i}-\bar{y}\right)^{2}}
$$




$$
R_{P}^{2}=1-\frac{\sum_{i=1}^{n} w_{i}\left(\hat{y}_{(i)}-y_{i}\right)^{2}}{\sum_{i=1}^{n} w_{i}\left(y_{i}-\bar{y}_{w}\right)^{2}},
$$

for WLS regression. $R_{P}^{2}$ is interpreted as the leave-one-out crossvalidation fraction of variability in the unweighted or weighted property data (transformed if appropriate) accounted for by the fitted model. This statistic is calculated by a method equivalent to leaving each data point out of the model fit, and then evaluating how well the model predicts the property for that data point. $R_{P}^{2}$ estimates the fraction of variability that would be explained in predicting new observations drawn from the same composition space. However, computational simplifications for ULS and WLS regression do not require re-fitting a model with each data point removed. Unfortunately, no such simplification exists for GLS regression. Thus, $R_{P}^{2}$ is not calculated in this report for models fitted by GLS.

Generally $R^{2}$ statistics take values between 0 and 1 . However, $R_{A}^{2}$ and $R_{P}^{2}$ can take negative values for a poor fitting model, a model that contains many more terms than needed to fit the data, or a model fitted to data with one or more very influential data points. Among the three $R^{2}$ statistics, typically $R^{2}>R_{A}^{2}>R_{P}^{2}$. More than a minor difference between $R^{2}$ and $R_{A}^{2}$ indicates that the model may contain more terms than needed to achieve the same goodness of fit. A substantial difference between $R^{2}$ and $R_{P}^{2}$ is indicative of one or more data points being very influential in determining the fit of the model. Some reduction from $R^{2}$ to $R_{P}^{2}$ is expected because $R^{2}$ corresponds to using all data to fit the model, whereas $R_{P}^{2}$ corresponds to leaving each data point out of the fit when evaluating the performance of the model for that point. In general, a model will tend to predict better for data used to fit it than for data not used to fit it. $R_{P}^{2}$ is a crossvalidation evaluation method.

\section{C.5 Statistical Methods for Model Reduction and Augmentation}

Section C.5.1 discusses methods for identifying and removing unnecessary terms from mixture experiment models. Section C.5.2 discusses methods for augmenting linear mixture models with quadratic terms or other nonlinear blending terms.

\section{C.5.1 Statistical Methods for Reducing Mixture Experiment Models}

In evaluating a fitted regression model, it may often be determined that there are unnecessary terms in the model. Such terms may not improve, and can even degrade, the predictive performance of the model in applications to data not used to develop the model. 
The most basic statistical method to identify unnecessary terms in a model is a $t$-test to perform a hypothesis test of whether the coefficient of a model term is statistically different from zero. The t-test computes a t-statistic equal to a model coefficient divided by the standard deviation of the coefficient. The t-statistic is then compared to the Student-t probability distribution to determine the probability of getting a t-statistic at least that large. The resulting probability is referred to as a p-value, and represents the probability of incorrectly deciding a coefficient is significantly different than zero. Most regression software outputs estimated model coefficients, coefficient standard deviations, t-statistics, and p-values. Typically, practitioners require a p-value to be smaller than 0.05 or 0.01 as strong evidence that the coefficient is significantly different than zero, and thus that the corresponding model term is needed. If there are not too many potentially unnecessary terms in a model, a practitioner can assess the tstatistics and p-values for the coefficients in a "full" model, and remove the model term whose coefficient is least statistically significant. Then, the model would be refitted without that term, and the t-statistics and p-values again considered, deleting the model term with the least statistically significant coefficient. This process continues until all terms in the model have pvalues lower than 0.05, say. Backward elimination (Draper and Smith 1998, Montgomery et al. 2001 ) is a widely used statistical method for removing unneeded terms from a model. This method basically automates the process just described, where the practitioner sets a stopping criterion.

Unfortunately, there are some model forms for which the model reduction methods just described are inappropriate. In general, these are model forms where a model coefficient being small (e.g., near zero) does not imply the corresponding model term is unneeded. That is, some model forms may have terms with significant effects even though the coefficients of those terms are small. One class of models in this category relevant to this work is the class of mixture experiment models (Cornell 2002), of which LM, PQM, and PCM models are given in Section C.1.1. The LM model (or the linear blending portion of a PQM model or a PCM model) is of the form $\sum_{i=1}^{q} b_{i} x_{i}$, where the $b_{i}$ are coefficients and the $x_{i}$ are proportions of the mixture components (e.g., mass fractions of waste glass components) that must sum to one (i.e., $\sum_{i=1}^{q} x_{i}=1$ ). When each $x_{i}$ can vary from zero to one, the coefficient $b_{i}$ represents the estimated response variable value for pure component $i$ [i.e., when $x_{i}=1$ and $x_{j}=0(j \neq i)$ ]. When the ranges of the mixture component proportions $x_{i}$ are constrained, each $b_{i}$ represents extrapolated response values for pure component $i$. Because hypotheses concerning LM model coefficients (or the coefficients of linear terms in PQM or PCM models) equaling zero are not related to the importance or nonimportance of a given component, it is inappropriate to use t-tests or the standard backward elimination method to reduce the linear portion of a mixture experiment model. However, mixture models can contain nonlinear terms in the components (such as in the PQM and PCM model forms discussed in Section C.1.1), and it is appropriate to use t-tests or the standard stepwise, forward, or backward elimination variable selection methods (see Draper and Smith 1998 or Montgomery et al. 2001) on such terms. 


\section{Component Response Trace Plots}

Component response trace plots (Cornell 2002) provide for graphically assessing the effects of mixture components on a response variable of interest. These plots are generally produced using a fitted mixture model. The model is used to predict, for each component, the response for a series of compositions lying along an effect direction for that component. The most commonly used effect direction corresponds to subtracting or adding a component to a reference (or baseline) mixture. Along such a direction, the component of interest is varied within the allowable composition region of interest. The changes in the component of interest are offset by changes in the remaining components, such that they remain in the same relative proportions as in the reference mixture. The predicted response values along the effect direction for a given component form a component response trace. The response traces for the components varied in a mixture experiment plotted together form the component response trace plot. The predicted response values are plotted on the y-axis and changes in each component from its reference mixture value are plotted on the x-axis. Components with steeper response traces have stronger effects on the response. A response trace that is nearly horizontal indicates the corresponding component has little or no effect on the response. Components whose response traces are very close may have similar effects on the response. Thus, component response trace plots can be used to guide the reduction of components appearing in a mixture experiment model (e.g., see Piepel and Redgate 1997).

\section{$\underline{\text { Component Slope Linear Mixture Model }}$}

Piepel $(2006 \mathrm{~b}, 2007)$ discusses a re-parameterization of the linear mixture model in Equation (C.4) referred to as the component slope linear mixture (CSLM) model. The details of the model form are not given here, but it suffices to say that the coefficients of the CSLM model are slopes of the component response traces produced using a fitted linear mixture model. It is appropriate to perform t-tests that determine whether the slopes are significantly different from zero. Hence, this approach can be used to identify components that do not significantly affect the response variable.

\section{$\underline{\text { Backward Elimination Algorithm for Reducing Linear Mixture Models }}$}

A special backward elimination method for mixture experiments has been developed to reduce linear mixture models and linear portions of mixture models (Piepel and Cooley 2006). The reduction method is performed in stages. In general at the end of each stage, either (i) a mixture component is dropped and the remaining components are renormalized, or (ii) two components are combined. As an option, model reductions of the form (i) can be skipped and only reductions of the form (ii) considered. For each stage, the process occurs as follows.

- If reductions of the form (i) are allowed, each mixture component still in the model is in turn dropped from the model, the remaining mixture component proportions are renormalized to sum to one. Then a linear mixture model without the dropped component is fitted to the data. The dropped mixture component that causes the smallest increase in the error sums of squares (the quantity being minimized in ULS regression) is then the component permanently dropped from the model at the current stage. After each 
component is dropped, the remaining components are renormalized according to the mixture experiment definition that a response variable depends only on the relative proportions of the mixture components that affect the response variable (Cornell 2002).

- For reductions of the form (ii), each allowable pair of components is combined and the corresponding reduced linear mixture model is fitted. The pair of components causing the smallest increase in the error sum of squares is then permanently combined at the current stage.

Similar stages continue, with either one component dropped [option (i)] or one pair of components combined [option (ii)], until the stage in which a model reduction causes the fullreduced model F-test (Draper and Smith 1998, Montgomery et al. 2001) to declare a statistically significant increase in the error sum of squares. This then signals the stopping point for the backward elimination algorithm. Note that the algorithm allows for the user specifying the components (if any) that can be dropped, and components that can be combined. These options provide for incorporating glass science knowledge into the model reduction process.

\section{C.5.2 Statistical Methods for Adding Terms to Models}

It is often of interest to add additional terms onto a starting model in the hopes of improving the predictive performance of the starting model. For example, a linear mixture model may be considered as a starting model. However, if it has a significant LOF, adding nonlinear composition terms may be considered in hopes of improving the predictive performance of the model. Stepwise regression is the most commonly used method to add terms to an existing starting model. In stepwise regression, certain terms can be forced into the model, and a candidate list of possible terms to add is identified. The procedure identifies the term from the candidate list that, if added to the model, would yield the greatest reduction in the error sum of squares (i.e., the sum of squared differences in measured and model-predicted values across the modeling data set). If the reduction is statistically significant, that term is added to the model. Stepwise regression proceeds in stages, with one additional term being added at each stage unless the user-selected stopping criterion is reached. After adding a term, stepwise regression checks all other terms in the model to assess if they are still statistically significant. If not, a term can be removed during a stage.

The stepwise regression algorithm requires that a significance level be specified for terms to enter the model, and that a significance level be specified for terms to remain in the model. In each iteration of a stepwise regression application, t-tests are conducted for each term already in the model and for terms being considered for inclusion in the model. To describe the results of these t-tests, a p-value is calculated for each of the terms. Loosely speaking, the p-values represent the probability that the respective model terms do not make a significant contribution to the predictive ability of the model. Terms whose corresponding p-values are small (often $<0.05$ is considered sufficiently small) are considered important in the model. The significance levels specified for the stepwise regression algorithm indicate how small p-values must be for the corresponding terms to be included in the model. The statistical literature generally indicates that the stepwise algorithm is somewhat liberal in allowing terms into models. Yet, models 
containing unnecessary terms are undesirable because they tend to have inflated prediction variance. Thus, it is typically advisable to use tight significance levels such as 0.05 or 0.01 when applying the stepwise regression algorithm.

One particular variation of stepwise regression that can be used to select terms for model building is what the SAS statistical software package (SAS 2005) refers to as the Maximum Rsquared Improvement (MAXR) selection method. For the MAXR criterion (as with other criteria for stepwise regression), terms can enter and leave (being replaced by another term) the model. Sequential changes to the model are based on maximal increases to the model's $\mathrm{R}^{2}$ value, and MAXR tries to find the "best" model having a specified numbers of terms. However, MAXR is not the same as the "best subsets" algorithm because it does not consider all possible models with a given number of terms. Therefore, MAXR is not guaranteed to find the model with the highest $\mathrm{R}^{2}$ value among all models having a given number of terms. This method tends to have a better chance of finding more nearly optimal models than does the stepwise selection method using other criteria (Freund and Littell 1995). The MAXR method does not require significance levels to control term selection, but does require the user to identify any terms to force into the model and to specify the number of terms to include in models being considered.

The standard stepwise regression procedure (regardless of the criterion used for model term selection) is not appropriate for linear mixture models or linear portions of other mixture experiment models for similar reasons as described previously with regard to the standard backward elimination method. However, it is appropriate for adding nonlinear mixture terms or non-mixture terms to mixture models.

\section{C.6 Statistical Methods for Model Validation}

Model validation methods assess how well a fitted model predicts property values for glasses not used in fitting the model. A validation dataset could be separate from the modeling dataset, or it could be a subset obtained by splitting or partitioning the modeling dataset into modeling and validation subsets.

The glasses used for validation ideally should be in the same composition region as the data used to fit the property-composition models, because (in general) fitted empirical and semiempirical models should not be used to extrapolate much beyond the region covered by the modeling data. Also, ideally the validation data should be evenly distributed over the region of model validity ${ }^{2}$ to properly assess predictive ability over the region. These ideals can generally be achieved when splitting or partitioning the modeling dataset into modeling and validation subsets. However, they can difficult to achieve in practice for a separate validation dataset because such data are typically not designed, but often consists of whatever extra data are available.

\footnotetext{
${ }^{2}$ A model validity region is a composition region for models that are functions of composition, whereas it is a composition-temperature region for models that are functions of composition and temperature.
} 
Validation generally consists of using a fitted model to predict property values for a set of validation data, and then comparing the predicted property values to the measured values from the validation database. The following subsections describe several methods for comparing predicted and measured values of properties.

\section{C.6.1 Validation $\mathbf{R}^{2}$}

Statistical summary comparisons of predicted and measured property values are also useful to see if differences are larger than their expected uncertainties. One such comparison is the validation $R^{2}\left(R_{V}^{2}\right)$ statistic, which in general is given by

$$
R_{V}^{2}=1-\frac{\sum_{i=1}^{n}\left(\hat{y}_{i}-y_{i}\right)^{2}}{\sum_{i=1}^{n}\left(y_{i}-\bar{y}\right)^{2}} .
$$

However, in cases where WLS regression is used to fit the model and corresponding weights are available for the validation dataset, a weighted version of the validation $R^{2}$ statistics is given by

$$
R_{V}^{2}=1-\frac{\sum_{i=1}^{n} w_{i}\left(\hat{y}_{i}-y_{i}\right)^{2}}{\sum_{i=1}^{n} w_{i}\left(y_{i}-\bar{y}_{w}\right)^{2}}
$$

If weights are not available for the validation dataset in the WLS case, then weights $w_{i}=1$ can be used, which is equivalent to using Equation (C.29a) instead of Equation (C.29b). $R_{V}^{2}$ is interpreted as the fraction of variability in the unweighted or weighted property values (transformed if appropriate) in the validation data accounted for by the fitted model. Note that $R_{V}^{2}$ is defined exactly the same as the ordinary $R^{2}$ defined in Equations (C.26a) and (C.26b), except that model validation data are used to assess model predictive performance instead of the model development data. Hence, the $y_{i}, \hat{y}_{i}, \bar{y}, w_{i}$, and $\bar{y}_{w}$ values in Equations (C.29a) and (C.29b) correspond to the model validation data. Because it was beyond the scope of the work in this report to develop formulas for validation statistics on models fitted by GLS regression, the ULS formulas are used for such models in this report.

Generally $R_{V}^{2} \leq R_{P}^{2} \leq R_{A}^{2} \leq R^{2} \leq 1$. However, $R_{V}^{2}$ can take negative values (when a model predicts a validation set very poorly) and can take values larger than $R_{P}^{2}, R_{A}^{2}$, or $R^{2}$ (when a model predicts a particular validation dataset better than estimated by these statistics based on the modeling data). 


\section{C.6.2 Validation RMSE}

Another useful summary statistic for model validation is validation RMSE $\left(\mathrm{RMSE}_{\mathrm{V}}\right)$.

This statistic is calculated by

$$
\operatorname{RMSE}_{V}=\sqrt{\frac{\sum_{i=1}^{n}\left(\hat{y}_{i}-y_{i}\right)^{2}}{n_{V}}}
$$

for ULS-fitted models and by

$$
R M S E_{V}=\sqrt{\frac{\sum_{i=1}^{n} w_{i}\left(\hat{y}_{i}-y_{i}\right)^{2}}{n_{V}}}
$$

for WLS-fitted models. For the WLS case, if weights are not available for the validation dataset, then weights $w_{i}=1$ are used. This is equivalent to using Equation (C.30a) instead of Equation (C.30b). For GLS-fitted models, the ULS formula is used in this report.

In Equations (C.30a) and (C.30b), the denominator $n_{V}$ is the number of observations in the validation dataset. The denominator is different than the $n-p$ denominator for the modeling RMSE given in Equations (C.23a) and (C.23b), where $n$ is the number of observations in the modeling dataset and $p$ is the number of model coefficients estimated using the modeling dataset. In Equations (C.23a) and (C.23b), the $n-p$ denominator accounts for estimating the $p$ model coefficients using the $n$ observations in the modeling dataset. However, because no model coefficients are estimated from a validation dataset, the denominator in Equations (C.30a) and (C.30b) is $n_{V}$ rather than $n-p$.

In general, $\mathrm{RMSE}_{\mathrm{V}}$ calculated by Equations (C.30a) and (C.30b) is expected to be larger than RMSE calculated by Equations (C.23a) and (C.23b) because of not using the validation subset to fit the model. The difference can be larger when the validation dataset is small relative to the modeling dataset, so that $n_{V}$ is much smaller than $n-p$. The difference between RMSE and $\mathrm{RMSE}_{V}$ depends not only on how well a model predicts for the validation dataset, but also on the distribution of points in the validation dataset relative to the distribution in the modeling dataset. The non-representativeness of a smaller validation dataset can thus cause a larger difference between RMSE and RMSE .

\section{C.6.3 Predicted Versus Measured Plots}

Predicted and measured values for a model validation data set can be compared by plotting the predicted versus the measured property values for each data point. Such predicted versus measured plots are the same as described in Section C.4, except model validation data are used instead of model development data. Also, similarly as described in Section C.4, unweighted 
PvM plots or weighted PvM plots may be produced and viewed to validate models fitted by WLS regression.

Optionally, error bars consisting of $95 \%$ two-sided prediction intervals (95\% PIs) on the predicted values can be included in the predicted versus measured plot for validation. Then, if the error bar for a given validation data point overlaps a line with slope one superimposed on the PvM plot, the model is validated for that data point. Draper and Smith (1998) and Montgomery et al. (2001) provide additional discussion of 95\% PIs for regression models. The formulas for a 95\% two-sided PI in the ULS, WLS, and GLS cases are given in Section C.7.3 following.

\section{C.7 Statistical Intervals for Describing Uncertainties in Model Predictions}

Several types of statistical intervals are available to describe the uncertainty associated with model predictions. Each type of statistical interval has a particular interpretation. A common assumption for all statistical intervals based on regression models is that the model represents the true underlying response surface (property-composition or property-compositiontemperature relationship for waste glasses) without a statistically significant lack-of-fit.

The following subsections present the formulas for one-sided upper (or lower) confidence intervals (Section C.7.1), two-sided confidence intervals (Section C.7.2), and two-sided prediction intervals (Section C.7.3). These types of statistical intervals are used to describe the uncertainty associated with model predictions at a single specific composition, or at single specific composition and temperature for properties such as viscosity and EC that depend on temperature as well as composition. Section C.7.4 presents the formulas for simultaneous upper confidence intervals, which are used to describe the uncertainty associated with model predictions at many glass compositions, or at many composition-temperature combinations for properties such as viscosity and EC. The formulas for these types of statistical intervals are given in each subsection for the ULS, WLS, and GLS cases. Section C.7.5 presents equations for the various statistical intervals for bias-corrected PCT models. Section C.7.6 discusses aspects of using the statistical intervals.

\section{C.7.1 One-Sided Confidence Interval}

A $100(1-\alpha) \%$ upper confidence interval (UCI) for the true mean response value for a given glass composition $\boldsymbol{x}=\left(x_{1}, x_{2}, \ldots, x_{\mathrm{q}}\right)$ is given by

$$
\begin{aligned}
\hat{y}(\boldsymbol{x})+t_{1-\alpha}(n-p) \sqrt{\boldsymbol{a}^{T} \boldsymbol{C}_{U} \boldsymbol{a}} & =\hat{y}(\boldsymbol{x})+t_{1-\alpha}(n-p) \sqrt{\boldsymbol{a}^{T}\left[\left(\boldsymbol{A}^{T} \boldsymbol{A}\right)^{-1} M S E_{U}\right] \boldsymbol{a}} \\
& =\hat{y}(\boldsymbol{x})+t_{1-\alpha}(n-p) R M S E_{U} \sqrt{\boldsymbol{a}^{T}\left(\boldsymbol{A}^{T} \boldsymbol{A}\right)^{-1} \boldsymbol{a}},
\end{aligned}
$$

for ULS regression, and by 


$$
\begin{aligned}
\hat{y}(\boldsymbol{x})+t_{1-\alpha}(n-p) \sqrt{\boldsymbol{a}^{T} \boldsymbol{C}_{W} \boldsymbol{a}} & =\hat{y}(\boldsymbol{x})+t_{1-\alpha}(n-p) \sqrt{\boldsymbol{a}^{T}\left[\left(\boldsymbol{A}^{T} \boldsymbol{W} \boldsymbol{A}\right)^{-1} M S E_{W}\right] \boldsymbol{a}} \\
& =\hat{y}(\boldsymbol{x})+t_{1-\alpha}(n-p) R M S E_{W} \sqrt{\boldsymbol{a}^{T}\left(\boldsymbol{A}^{T} \boldsymbol{W} \boldsymbol{A}\right)^{-1} \boldsymbol{a}},
\end{aligned}
$$

for WLS regression. The formula is similar for properties such as viscosity and EC that depend on glass composition and melt temperature and have models fitted by GLS regression. A $100(1-\alpha) \%$ UCI for the true mean response value for a given glass composition $\boldsymbol{x}=\left(x_{1}, x_{2}, \ldots\right.$, $x_{\mathrm{q}}$ ) and temperature $T$ (in Kelvin) is given by

$$
\begin{aligned}
\hat{y}(\boldsymbol{x}, T)+t_{1-\alpha}\left(n_{g}-p_{g}\right) \sqrt{\boldsymbol{a}^{T} \boldsymbol{C}_{G} \boldsymbol{a}} & =\hat{y}(\boldsymbol{x}, T)+t_{1-\alpha}\left(n_{g}-p_{g}\right) \sqrt{\boldsymbol{a}^{T}\left[\left(\boldsymbol{A}^{T} \hat{\boldsymbol{V}}^{-1} \boldsymbol{A}\right)^{-1}\right] \boldsymbol{a}} \\
& =\hat{y}(\boldsymbol{x}, T)+t_{1-\alpha}\left(n_{g}-p_{g}\right) \sqrt{\boldsymbol{a}^{T}\left(\boldsymbol{A}^{T} \hat{\boldsymbol{V}}^{-1} \boldsymbol{A}\right)^{-1} \boldsymbol{a}}
\end{aligned}
$$

In Equations (C.31a), (C.31b), and (C.31c), the superscript $T$ notation indicates a vector or matrix transpose, not temperature. Only the $T$ appearing in $\hat{y}(\boldsymbol{x}, T)$ denotes temperature. Otherwise, the vector $\boldsymbol{a}$ is a function of both composition and temperature as explained following. The other notations in Equations (C.31a), (C.31b), and (C.31c) are defined as follows.

$$
\begin{aligned}
& \hat{y}(\boldsymbol{x}) \quad=\text { model predicted value at composition } \boldsymbol{x}, \\
& \hat{y}(\boldsymbol{x}, T)=\text { model predicted value at composition } \boldsymbol{x} \text { and temperature } T, \\
& 100(1-\alpha)=\text { desired confidence (e.g., 90\%) for the confidence interval, where } \alpha \\
& \text { denotes the significance level (e.g., } \alpha=0.10 \text { for } 90 \% \text { confidence), } \\
& t_{1-\alpha}(n-p)=100(1-\alpha) \text {-percentile of the Student's } t \text {-distribution with } n-p \text { degrees } \\
& \text { of freedom, } \\
& t_{1-\alpha}\left(n_{g}-p_{g}\right)=100(1-\alpha) \text {-percentile of the Student's } t \text {-distribution with } n_{g}-p_{g} \text { degrees } \\
& \text { of freedom, } \\
& n \quad=\text { number of data points used to fit the model, } \\
& p \quad=\text { number of parameters estimated in the model, } \\
& n_{g} \quad=\text { number of glasses used to fit a viscosity or EC model, } \\
& p_{g} \quad=\text { number of parameters estimated in the composition-only portion of the } \\
& \text { model (as differentiated from the composition-temperature portion of } \\
& \text { the model). } \\
& \boldsymbol{C}_{\boldsymbol{U}} \quad=\text { estimated variance-covariance matrix for the estimated coefficients of } \\
& \text { a model fitted by ULS regression }=\left(\boldsymbol{A}^{T} \boldsymbol{A}\right)^{-1} M S E_{U} \text {, } \\
& \boldsymbol{C}_{W} \quad=\text { estimated variance-covariance matrix for the estimated coefficients of } \\
& \text { a model fitted by WLS regression }=\left(\boldsymbol{A}^{T} \boldsymbol{W} \boldsymbol{A}\right)^{-1} M S E_{W} \text {, }
\end{aligned}
$$


$\boldsymbol{C}_{G} \quad=$ estimated variance-covariance matrix for the estimated coefficients of a model fitted by GLS regression, which is approximated by $\left(\boldsymbol{A}^{T} \hat{\boldsymbol{V}}^{-1} \boldsymbol{A}\right)^{-1}$,

$\boldsymbol{a}^{\boldsymbol{T}} \quad=$ the vector transpose of the glass composition vector $\boldsymbol{x}$ and temperature (if involved in the model) expanded in the form of the model,

$\boldsymbol{A}^{\boldsymbol{T}} \quad=$ the matrix transpose of the data matrix (consisting of glass compositions and temperatures, if involved in the model) expanded in the form of the model,

$\boldsymbol{W}=$ an $n \times n$ diagonal weight matrix with entries $w_{i}, i=1,2, \ldots, n$ (i.e., the weights associated with the model development set of $n$ data points),

MSE $\quad=$ mean squared error, which is obtained from the ULS $\left(M S E_{U}\right)$ or WLS $\left(M S E_{W}\right)$ regression fit of the model,

RMSE $\quad=$ the root mean squared error $=\sqrt{M S E}$, with $R M S E_{U}$ and $R M S E_{W}$ resulting from ULS and WLS regression fits of a model, respectively.

A $100(1-\alpha) \%$ UCI, as given by Equations (C.31a), (C.31b), and (C.31c) is appropriate when an uncertainty statement is desired about the true mean response for a given composition $\boldsymbol{x}$ and temperature $T$ (for properties that also depend on temperature).

Equation (C.31c) is approximate because of using an estimate $\hat{\boldsymbol{V}}$ of $\boldsymbol{V}$ (the variancecovariance matrix for the vector of viscosity- or EC-at-temperature data used to fit the modelsee Sections C.3.2 and C.3.3). Further, the number of degrees of freedom $\left(n_{g}-p_{g}\right)$ associated with the t-distribution multiplier is approximate. However, there is no practical consequence to using this approximate number of degrees of freedom because of the large number of glasses used to develop viscosity and EC models. In such cases, the t-distribution multiplier will essentially be a z-distribution (standard normal) multiplier, and thus there is no practical consequence.

The formulas for a one-sided lower confidence interval are the same as in Equations (C.31a), (C.31b), and (C.31c) except the plus signs following $\hat{y}(\boldsymbol{x})$ and $\hat{y}(\boldsymbol{x}, T)$ are changed to minus signs. Thus, a $100(1-\alpha) \%$ lower confidence interval (LCI) for the true mean response value for a given glass composition $\boldsymbol{x}=\left(x_{1}, x_{2}, \ldots, x_{\mathrm{q}}\right)$ is given by

$$
\begin{aligned}
\hat{y}(\boldsymbol{x})-t_{1-\alpha}(n-p) \sqrt{\boldsymbol{a}^{T} \boldsymbol{C}_{U} \boldsymbol{a}} & =\hat{y}(\boldsymbol{x})-t_{1-\alpha}(n-p) \sqrt{\boldsymbol{a}^{T}\left[\left(\boldsymbol{A}^{T} \boldsymbol{A}\right)^{-1} M S E_{U}\right] \boldsymbol{a}} \\
& =\hat{y}(\boldsymbol{x})-t_{1-\alpha}(n-p) R M S E_{U} \sqrt{\boldsymbol{a}^{T}\left(\boldsymbol{A}^{T} \boldsymbol{A}\right)^{-1} \boldsymbol{a}},
\end{aligned}
$$

for ULS regression, and by 


$$
\begin{aligned}
\hat{y}(\boldsymbol{x})-t_{1-\alpha}(n-p) \sqrt{\boldsymbol{a}^{T} \boldsymbol{C}_{W} \boldsymbol{a}} & =\hat{y}(\boldsymbol{x})-t_{1-\alpha}(n-p) \sqrt{\boldsymbol{a}^{T}\left[\left(\boldsymbol{A}^{T} \boldsymbol{W} \boldsymbol{A}\right)^{-1} M S E_{W}\right] \boldsymbol{a}}, \\
& =\hat{y}(\boldsymbol{x})-t_{1-\alpha}(n-p) R M S E_{W} \sqrt{\boldsymbol{a}^{T}\left(\boldsymbol{A}^{T} \boldsymbol{W} \boldsymbol{A}\right)^{-1} \boldsymbol{a}},
\end{aligned}
$$

for WLS regression. The formula is similar for properties such as viscosity and EC that depend on glass composition and melt temperature and have models fitted by GLS regression. A $100(1-\alpha) \%$ LCI for the true mean response value for a given glass composition $\boldsymbol{x}=\left(x_{1}, x_{2}, \ldots\right.$, $x_{\mathrm{q}}$ ) and temperature $T$ is given by

$$
\begin{aligned}
\hat{y}(\boldsymbol{x}, T)-t_{1-\alpha}\left(n_{g}-p_{g}\right) \sqrt{\boldsymbol{a}^{T} \boldsymbol{C}_{G} \boldsymbol{a}} & =\hat{y}(\boldsymbol{x}, T)-t_{1-\alpha}\left(n_{g}-p_{g}\right) \sqrt{\boldsymbol{a}^{T}\left[\left(\boldsymbol{A}^{T} \hat{\boldsymbol{V}}^{-1} \boldsymbol{A}\right)^{-1}\right] \boldsymbol{a}} \\
& =\hat{y}(\boldsymbol{x}, T)-t_{1-\alpha}\left(n_{g}-p_{g}\right) \sqrt{\boldsymbol{a}^{T}\left(\boldsymbol{A}^{T} \hat{\boldsymbol{V}}^{-1} \boldsymbol{A}\right)^{-1} \boldsymbol{a}}
\end{aligned}
$$

where the notation is as previously defined. Equation (C.32c) is approximate for the same reasons given following Equation (C.31c).

\section{C.7.2 Two-Sided Confidence Interval}

A $100(1-\alpha) \%$ two-sided confidence interval (CI) for the true mean response value for a given glass composition $\boldsymbol{x}=\left(x_{1}, x_{2}, \ldots, x_{\mathrm{q}}\right)$ is given by

$$
\begin{aligned}
\hat{y}(\boldsymbol{x}) \mp t_{1-\alpha / 2}(n-p) \sqrt{\boldsymbol{a}^{T} \boldsymbol{C}_{U} \boldsymbol{a}} & =\hat{y}(\boldsymbol{x}) \mp t_{1-\alpha / 2}(n-p) \sqrt{\boldsymbol{a}^{T}\left[\left(\boldsymbol{A}^{T} \boldsymbol{A}\right)^{-1} M S E_{U}\right] \boldsymbol{a}} \\
& =\hat{y}(\boldsymbol{x}) \mp t_{1-\alpha / 2}(n-p) R M S E_{U} \sqrt{\boldsymbol{a}^{T}\left(\boldsymbol{A}^{T} \boldsymbol{A}\right)^{-1} \boldsymbol{a}},
\end{aligned}
$$

for ULS regression, and by

$$
\begin{aligned}
\hat{y}(\boldsymbol{x}) \mp t_{1-\alpha / 2}(n-p) \sqrt{\boldsymbol{a}^{T} \boldsymbol{C}_{W} \boldsymbol{a}} & =\hat{y}(\boldsymbol{x}) \mp t_{1-\alpha / 2}(n-p) \sqrt{\boldsymbol{a}^{T}\left[\left(\boldsymbol{A}^{T} \boldsymbol{W A}\right)^{-1} M S E_{W}\right] \boldsymbol{a}} \\
& =\hat{y}(\boldsymbol{x}) \mp t_{1-\alpha / 2}(n-p) R M S E_{W} \sqrt{\boldsymbol{a}^{T}\left(\boldsymbol{A}^{T} \boldsymbol{W} \boldsymbol{A}\right)^{-1} \boldsymbol{a}}
\end{aligned}
$$

for WLS regression. The formula is similar for properties such as viscosity and EC that depend on glass composition and melt temperature and have models fitted by GLS regression. A $100(1-\alpha) \%$ CI for the true mean response value for a given glass composition $\boldsymbol{x}=\left(x_{1}, x_{2}, \ldots, x_{\mathrm{q}}\right)$ and temperature $T$ is given by

$$
\begin{aligned}
\hat{y}(\boldsymbol{x}, T) \mp t_{1-\alpha / 2}\left(n_{g}-p_{g}\right) \sqrt{\boldsymbol{a}^{T} \boldsymbol{C}_{G} \boldsymbol{a}} & =\hat{y}(\boldsymbol{x}, T) \mp t_{1-\alpha / 2}\left(n_{g}-p_{g}\right) \sqrt{\boldsymbol{a}^{T}\left[\left(\boldsymbol{A}^{T} \hat{\boldsymbol{V}}^{-1} \boldsymbol{A}\right)^{-1}\right] \boldsymbol{a}} \\
& =\hat{y}(\boldsymbol{x}, T) \mp t_{1-\alpha / 2}\left(n_{g}-p_{g}\right) \sqrt{\boldsymbol{a}^{T}\left(\boldsymbol{A}^{T} \hat{\boldsymbol{V}}^{-1} \boldsymbol{A}\right)^{-1} \boldsymbol{a}}
\end{aligned}
$$

In Equations (C.33a), (C.33b), and (C.33c), the notation is all the same as described in Section C.7.1, except that $t_{1-\alpha / 2}(n-p)$ denotes the $100(1-\alpha / 2)$-percentile of the Student's $t$-distribution 
with $n-p$ degrees of freedom. Similarly, $t_{1-\alpha / 2}\left(n_{g}-p_{g}\right)$ denotes the 100(1- $\left.\alpha / 2\right)$-percentile of the Student's $t$-distribution with $n_{g}-p_{g}$ degrees of freedom. Equation (C.33c) is approximate for the same reasons given following Equation (C.31c).

\section{C.7.3 Two-Sided Prediction Interval}

A $100(1-\alpha) \%$ two-sided prediction interval (PI) for an individual response value for a given composition $\boldsymbol{x}$ is given by

$$
\begin{aligned}
& \hat{y}(\boldsymbol{x}) \mp t_{1-\alpha / 2}(n-p) \sqrt{M S E_{U}+\boldsymbol{a}^{T} \boldsymbol{C}_{U} \boldsymbol{a}} \\
& \quad=\hat{y}(\boldsymbol{x}) \mp t_{1-\alpha / 2}(n-p) R M S E_{U} \sqrt{1+\boldsymbol{a}^{T}\left(\boldsymbol{A}^{T} \boldsymbol{A}\right)^{-1} \boldsymbol{a}},
\end{aligned}
$$

for ULS regression, and by

$$
\begin{aligned}
& \hat{y}(\boldsymbol{x}) \mp t_{1-\alpha / 2}(n-p) \sqrt{\frac{M S E_{W}}{w_{i}}+\boldsymbol{a}^{T} \boldsymbol{C}_{W} \boldsymbol{a}} \\
& \quad \hat{y}(\boldsymbol{x}) \mp t_{1-\alpha / 2}(n-p) R M S E_{W} \sqrt{\frac{1}{w_{i}}+\boldsymbol{a}^{T}\left(\boldsymbol{A}^{T} \boldsymbol{W} \boldsymbol{A}\right)^{-1} \boldsymbol{a}}
\end{aligned}
$$

for WLS regression. The formula is similar for properties such as viscosity and EC that depend on glass composition and melt temperature and have models fitted by GLS regression. A $100(1-\alpha) \%$ two-sided PI for an individual response value for a given composition $\boldsymbol{x}$ and temperature $T$ is given by

$$
\begin{aligned}
& \hat{y}(\boldsymbol{x}, T) \mp t_{1-\alpha / 2}\left(n_{g}-p_{g}\right) \sqrt{\hat{\sigma}_{y}^{2}+\boldsymbol{a}^{T} \boldsymbol{C}_{G} \boldsymbol{a}} \\
& \quad=\hat{y}(\boldsymbol{x}, T) \mp t_{1-\alpha / 2}\left(n_{g}-p_{g}\right) \sqrt{\left(\hat{\sigma}_{G}^{2}+\hat{\sigma}_{T}^{2}\right)+\boldsymbol{a}^{T}\left(\boldsymbol{A}^{T} \hat{\boldsymbol{V}}^{-1} \boldsymbol{A}\right)^{-1} \boldsymbol{a}} .
\end{aligned}
$$

where

$$
\begin{aligned}
\hat{\sigma}_{y}^{2}= & \text { estimate of the variance of a response variable observation } y \text {. For the split-plot } \\
& \text { structure associated with viscosity and EC data, as discussed in Sections C.2.2 } \\
& \text { and C.3.3, } \hat{\sigma}_{y}^{2}=\hat{\sigma}_{G}^{2}+\hat{\sigma}_{T}^{2} .
\end{aligned}
$$

The remaining notations in Equations (C.34a), (C.34b), and (C.34c) are defined as given following the UCI formulas in Section C.7.1. Equation (C.34c) is approximate for the same reasons given following Equation (C.31c). 
The preceding equations for $100(1-\alpha) \%$ two-sided PIs are easily converted to

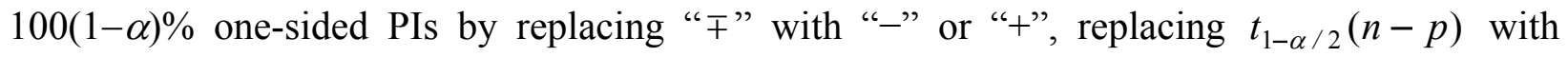
$t_{1-\alpha}(n-p)$, and replacing $t_{1-\alpha / 2}\left(n_{g}-p_{g}\right)$ with $t_{1-\alpha}\left(n_{g}-p_{g}\right)$.

Note in Equation (C.34b) that the $w_{i}$ under the square root applies when PIs are calculated for modeling data, validation data, or application data (i.e., data used in applying the models and PIs) with weights. In situations where validation or application data do not have weights, $w_{i}$ should be set to 1 .

A $100(1-\alpha) \%$ PI is appropriately used when comparing a model predicted response value for a given composition to an individual measurement of the response for that composition. This type of application arises in validating the predictive performance of a model for one or more glass compositions not used to fit the model. Specifically, Equations (C.34a), (C.34b), and (C.34c) can be used to produce 95\% PIs displayed as error bars in PvM plots for validation data, as described at the end of Section C.6.

\section{C.7.4 Simultaneous Upper Confidence Intervals}

At times it is desirable to describe the uncertainty associated with predictions obtained for a specified group of compositions. For example, a statement may be desired that indicates with high confidence that the predicted response value for every composition $\boldsymbol{x}$ in a specified group of compositions (or composition region) is below a particular regulatory limit. Such a confidence statement requires a statistical interval called a simultaneous upper confidence interval. The formula for a $100(1-\alpha) \%$ simultaneous upper confidence interval (SUCI) associated with predictions on an unlimited number of compositions $\boldsymbol{x}$ is given by

$$
\begin{aligned}
& \hat{y}(\boldsymbol{x})+\sqrt{p F_{1-2 \alpha}(p, n-p)} \sqrt{\boldsymbol{a}^{T} \boldsymbol{C}_{U} \boldsymbol{a}} \\
& \quad=\hat{y}(\boldsymbol{x})+R M S E_{U} \sqrt{p F_{1-2 \alpha}(p, n-p)} \sqrt{\boldsymbol{a}^{T}\left(\boldsymbol{A}^{T} \boldsymbol{A}\right)^{-1} \boldsymbol{a}}
\end{aligned}
$$

for ULS regression, and by

$$
\begin{aligned}
& \hat{y}(\boldsymbol{x})+\sqrt{p F_{1-2 \alpha}(p, n-p)} \sqrt{\boldsymbol{a}^{T} \boldsymbol{C}_{W} \boldsymbol{a}} \\
& \quad=\hat{y}(\boldsymbol{x})+R M S E_{W} \sqrt{p F_{1-2 \alpha}(p, n-p)} \sqrt{\boldsymbol{a}^{T}\left(\boldsymbol{A}^{T} \boldsymbol{W A}\right)^{-1} \boldsymbol{a}}
\end{aligned}
$$

for WLS regression. The formula is similar for properties such as viscosity and EC that depend on glass composition and melt temperature and have models fitted by GLS regression. The formula for a $100(1-\alpha) \%$ SUCI associated with predictions on an unlimited number of combinations of composition $\boldsymbol{x}$ and temperature $T$ is given by 


$$
\begin{aligned}
& \hat{y}(\boldsymbol{x}, T)+\sqrt{p F_{1-2 \alpha}\left(p, n_{g}-p_{g}\right)} \sqrt{\boldsymbol{a}^{T} \boldsymbol{C}_{G} \boldsymbol{a}} \\
& \quad=\hat{y}(\boldsymbol{x}, T)+\sqrt{p F_{1-2 \alpha}\left(p, n_{g}-p_{g}\right)} \sqrt{\boldsymbol{a}^{T}\left(\boldsymbol{A}^{T} \hat{\boldsymbol{V}}^{-1} \boldsymbol{A}\right)^{-1} \boldsymbol{a}}
\end{aligned}
$$

In Equations (C.35a) and (C.35b)

$$
\begin{aligned}
F_{1-2 \alpha}(p, n-p)= & 100(1-2 \alpha) \text {-percentile of the } F \text {-distribution with } p \text { and } n-p \\
& \text { degrees of freedom }
\end{aligned}
$$

while in Equation (C.35c)

$$
\begin{aligned}
\sqrt{p F_{1-2 \alpha}\left(p, n_{g}-p_{g}\right)}= & 100(1-2 \alpha) \text {-percentile of the } F \text {-distribution with } p_{g} \text { and } n_{g}-p_{g} \\
& \text { degrees of freedom. }
\end{aligned}
$$

The remaining notations are the same as defined previously. Equation (C.35c) is approximate because of using an estimate $\hat{\boldsymbol{V}}$ of $\boldsymbol{V}$ (the variance-covariance matrix for the vector of viscosity or EC-at-temperature data used to fit the model-see Sections C.3.2 and C.3.3). Further, the numbers of degrees of freedom for the numerator $\left(p_{g}\right)$ and denominator $\left(n_{g}-p_{g}\right)$ of the F-distribution multiplier are approximate.

\section{C.7.5 Statistical Intervals for Bias-Corrected PCT Models}

Section 5.7 discusses bias-corrected versions of the recommended and second-choice PCT-B, PCT-Li, and PCT-Na models, where a constant bias-correction is applied if the predicted release from a given model is above the cutoff value specified in Equation (5.7). Equation (5.9) gives the form of the bias-corrected PCT models, which consists of the base-portion (PQM model terms) plus a bias-correction constant $\left(a_{0}\right)$ applied when needed.

The statistical literature does not provide equations for statistical intervals when biascorrections of the nature applied to the PCT models are used. While the statistical theory may provide for developing such equations, the work would be non-trivial. Hence, doing that work was not possible given that the decision to bias-correct the PCT models came late in the preparation of this report. Instead, the following adaptations of statistical interval equations presented in previous subsections are given. These adaptations account for the uncertainty in the base-portion of a PCT model as well as the uncertainty in the bias-correction constant. The statistical confidence values for the following equations may only be approximate because of the adaptations made to the multipliers for the statistical intervals. Finally, note that only equations for models fit by ULS are provided, because that is how the base-portions of PCT models were developed. 
The formula for a $100(1-\alpha) \%$ UCI for the true mean PCT release value for a given glass composition $\boldsymbol{x}=\left(x_{1}, x_{2}, \ldots, x_{\mathrm{q}}\right)$ is given by

$$
\begin{array}{ll}
\hat{y}(\boldsymbol{x})+t_{1-\alpha}(n-p) \sqrt{\boldsymbol{a}^{T} \boldsymbol{C}_{U} \boldsymbol{a}} & \text { if } \hat{y}(\boldsymbol{x}) \leq \mathrm{cutoff} \\
\hat{y}(\boldsymbol{x})+a_{0}+t_{1-\alpha}(n-p-1) \sqrt{\boldsymbol{a}^{T} \boldsymbol{C}_{U} \boldsymbol{a}+\hat{\sigma}_{a_{0}}^{2}} & \text { if } \hat{y}(\boldsymbol{x})>\text { cutoff }
\end{array},
$$

where $\hat{y}(\boldsymbol{x})$ denotes the PCT-B, PCT-Li, or PCT-Na prediction in $\ln (\mathrm{g} / \mathrm{L})$ units before the biascorrection is applied, "cutoff" denotes the value from Equation (5.7) that determines whether a PCT-B, PCT-Li, or PCT-Na bias-correction is applied, and $\hat{\sigma}_{a_{0}}^{2}$ denotes the estimated standard deviation of the bias-correction constant $a_{0}$. Tables containing the $a_{0}$ and $\hat{\sigma}_{a_{0}}$ (note this is the standard deviation) values for the PCT models are referenced in Section 5.7. All other notation is as defined in Section C.7.1. Note that this equation is an adaptation of Equation (C.31a). For PCT, $100(1-\alpha) \%$ LCIs and $100(1-\alpha) \%$ CIs are not needed, so adaptations of Equations (C.32a) and (C.33a) are not provided.

The formula for a $100(1-\alpha) \%$ PI for an individual PCT release value for a given composition $\boldsymbol{x}$ is given by

$$
\begin{array}{ll}
\hat{y}(\boldsymbol{x})+t_{1-\alpha / 2}(n-p) \sqrt{M S E_{U}+\boldsymbol{a}^{T} \boldsymbol{C}_{U} \boldsymbol{a}} & \text { if } \hat{y}(\boldsymbol{x}) \leq \mathrm{cutoff} \\
\hat{y}(\boldsymbol{x})+a_{0}+t_{1-\alpha / 2}(n-p-1) \sqrt{M S E_{U}+\boldsymbol{a}^{T} \boldsymbol{C}_{U} \boldsymbol{a}+\hat{\sigma}_{a_{0}}^{2}} & \text { if } \hat{y}(\boldsymbol{x})>\text { cutoff }
\end{array},
$$

where all notation is as previously defined in this section and in Section C.7.3. Note that this equation is an adaptation of Equation (C.34a). Adaptations for one-sided lower or upper prediction intervals could be made to Equation (C.37) similar to the discussion at the end of Section C.7.3.

The formula for a $100(1-\alpha) \%$ SUCI associated with PCT release predictions on an unlimited number of compositions $\boldsymbol{x}$ is given by

$$
\begin{array}{ll}
\hat{y}(\boldsymbol{x})+\sqrt{p F_{1-2 \alpha}(p, n-p)} \sqrt{\boldsymbol{a}^{T} \boldsymbol{C}_{U} \boldsymbol{a}} & \text { if } \hat{y}(\boldsymbol{x}) \leq \mathrm{cutoff} \\
\hat{y}(\boldsymbol{x})+a_{0}+\sqrt{(p+1) F_{1-2 \alpha}(p+1, n-p-1)} \sqrt{\boldsymbol{a}^{T} \boldsymbol{C}_{U} \boldsymbol{a}+\hat{\sigma}_{a_{0}}^{2}} & \text { if } \hat{y}(\boldsymbol{x})>\text { cutoff }
\end{array}
$$

where all notation is as previously defined in this section and in Section C.7.4. Note that this equation is an adaptation of Equation (C.35a). 


\section{C.7.6 Statistical Intervals in Transformed and Untransformed Units}

Equations (C.31) to (C.38) yield statistical intervals in transformed units when a transformed property is modeled. For example, a natural logarithm transformation of a response $y$ [i.e., $\ln (y)]$ is often used for property-composition models. Hence, the statistical intervals calculated using the preceding equations would be in $\ln (y)$ units. The statistical intervals can be transformed back to the original units of $y$ by exponentiating the endpoint(s) of the statistical interval. However, the process of back-transforming (exponentiating) a statistical interval can change its interpretation. For example, if a $90 \%$ UCI in $\ln (y)$ units has the value "v", the backtransformed $90 \%$ UCI in the original units of $y$ is given by $\mathrm{e}^{\mathrm{v}}$. The $90 \% \mathrm{UCI}$ in units of $\ln (y)$ is a statement about the true mean response in $\ln (y)$ units for a given glass composition $\boldsymbol{x}$ (at a given temperature for properties that also depend on temperature). However, the resulting backtransformed interval is a $90 \%$ UCI on the true median response value for the given composition $\boldsymbol{x}$ (and temperature, if applicable), under the assumption that experimental errors in the data used to develop the model are lognormally distributed. This assumption corresponds to the assumption of the natural-log-transformed response data being normally distributed. This change in interpretation occurs because the mean and median of a normal distribution are the same, but the mean of a lognormal distribution is larger than the median of a lognormal distribution.

Hence, back-transforming a $100(1-\alpha) \%$ UCI on a mean response for a given composition $\underline{\boldsymbol{x} \text { and temperature (if applicable) in In-units (see Sections C.7.1 and C.7.5) yields a } 100(1-\alpha) \%}$ UCI on the median response for a given composition $\boldsymbol{x}$ in original units. This then underestimates a $100(1-\alpha) \%$ UCI on the mean response for a given composition $\boldsymbol{x}$ and temperature (if applicable) in original units. Similar interpretations hold for $100(1-\alpha) \%$ LCIs (see Section C.7.1) and CIs (see Section C.7.2). Back-transforming 100(1- $\alpha) \%$ SUCIs (see Sections C.7.4 and C.7.5) given in log-transformed units has a similar change in interpretation. Whereas the original $100(1-\alpha) \%$ SUCIs are statements about the true mean values of responses in log-transformed response units for multiple compositions $\boldsymbol{x}$ and temperatures (if applicable), the backtransformed $100(1-\alpha) \%$ SUCIs are statements about the true median values of responses in original response units for multiple compositions $\boldsymbol{x}$ and temperatures (if applicable). However, a $100(1-\alpha) \%$ PI (see Sections C.7.3 and C.7.5) in log-transformed units does not have a change in interpretation when back-transforming, because the original statement (in log-transformed units) and the back-transformed statement (in original units) are both about a true individual response value.

Alternatives exist to using normal-theory-based Equations (C.31) to (C.38) and backtransforming them when a transformed response variable is modeled. One alternative is to modify the statistical interval equations so that the statistical statement is about the true mean response value in the original units for a given composition $\boldsymbol{x}$ and temperature (where applicable) [e.g., Equation C.31) for an UCI] or a set of compositions $\boldsymbol{x}$ and temperature combinations (where applicable) [e.g., Equation (C.35) for a SUCI]. Although this type of alternative is discussed in the literature for non-regression problems (e.g., Gilbert 1987), no references were found for the regression context. Another alternative, the generalized linear model regression approach (Myers et al. 2002), avoids directly transforming the response variable and instead uses 
the transformation indirectly. These alternative approaches were not pursued in this work. However, the interested reader may refer to the references given.

Note that Equations (C.31) to (C.38) require knowledge of the variance-covariance matrix $\boldsymbol{C}_{\boldsymbol{U}}=M S E_{U}\left(\boldsymbol{A}^{T} \boldsymbol{A}\right)^{-1}$ for ULS regression, $\boldsymbol{C}_{W}=M S E_{W}\left(\boldsymbol{A}^{T} \boldsymbol{W A}\right)^{-1}$ for WLS regression, and $\boldsymbol{C}_{G}=\left(\boldsymbol{A}^{T} \hat{\boldsymbol{V}}^{-1} \boldsymbol{A}\right)^{-1}$ for GLS regression. The $M S E_{U}$ and $M S E_{W}$ are mean squared errors equal to the squares of $R M S E_{U}$ and $R M S E_{W}$ given by Equations (C.23a) and (C.23b). This information is included in the ULS, WLS, or GLS regression software output that comes with the estimates of the $p$ model coefficients. A variance-covariance matrix is a $p \times p$ matrix with coefficient variances along the diagonal, and covariances between coefficient pairs in the off-diagonal entries. 
The Catholic University of America Vitreous State Laboratory
IHLW PCT, Spinel $T_{1 \%}$, Electrical Conductivity, and Viscosity Model Development Final Report, VSL-07R1240-4, Rev. 0

\section{APPENDIX D}

\section{Variance-Covariance Matrices Associated with the Coefficients of PCT, Spinel $T_{1 \%}$, Electrical Conductivity, and Viscosity Models for HLW Glasses}




\section{APPENDIX D}

\section{Variance-Covariance Matrices Associated with the Coefficients of PCT, Spinel $\mathrm{T}_{1 \%}$, Electrical Conductivity, and Viscosity Models for HLW Glasses}

This appendix contains the variance-covariance matrices of selected property models for HLW glasses discussed in this report. Included are variance-covariance matrices for PCT and spinel $\mathrm{T}_{1 \%}$ models, which are functions of HLW glass composition. Also included are variancecovariance matrices for electrical conductivity (EC) and viscosity models, which are functions of HLW glass composition and glass melt temperature.

Tables D.1, D.2, and D.3, respectively, contain the variance-covariance matrices for three $\ln (\mathrm{PCT}-\mathrm{B}, \mathrm{g} / \mathrm{L}$ ) models for HLW glasses: (1) the 13-component reduced linear mixture (LM) model given in Table 5.6, (2) the 18-term partial quadratic mixture (PQM) model given in Table 5.7, and (3) the 15-term PQM model given in Table 5.8. The variance-covariance matrix in Table D.2 also applies to the coefficients of the 18 PQM terms in the 19-term recommended PCT-B model with bias-correction given in Table 5.19. The standard deviation associated with the biascorrection term is also given in Table 5.19. The variance-covariance matrix in Table D.3 also applies to the coefficients of the 15 PQM terms in the 16-term second-choice PCT-B model with bias-correction given in Table 5.20. The standard deviation associated with the bias-correction term is also given in Table 5.20. The 13-component reduced LM model for PCT-B was judged inferior to the two PQM models and was not bias-corrected, but it provides a baseline for comparison.

Tables D.4, D.5, and D.6, respectively, contain the variance-covariance matrices for three In(PCT-Li, g/L) models for HLW glasses: (1) the 13-component reduced LM model given in Table 5.10, (2) the 18-term PQM model given in Table 5.11, and (3) the 15-term PQM model given in Table 5.12. The variance-covariance matrix in Table D.5 also applies to the coefficients of the 18 PQM terms in the 19-term recommended PCT-Li model with bias-correction given in Table 5.21. The standard deviation associated with the bias-correction term is also given in Table 5.21. The variance-covariance matrix in Table D.6 also applies to the coefficients of the 15 PQM terms in the 16-term second-choice PCT-Li model with bias-correction given in Table 5.22. The standard deviation associated with the bias-correction term is also given in Table 5.22. The 13component reduced LM model for PCT-Li was judged inferior to the two PQM models and was not bias-corrected, but provides a baseline for comparison.

Tables D.7, D.8, and D.9, respectively, contain the variance-covariance matrices for three In(PCT-Na, g/L) models for HLW glasses: (1) the 13-component reduced LM model given in Table 5.14, (2) the 18-term PQM model given in Table 5.15, and (3) the 15-term PQM model given in Table 5.16. The variance-covariance matrix in Table D.8 also applies to the coefficients of the 18 PQM terms in the 19-term recommended PCT-Na model with bias-correction given in Table 5.23. The standard deviation associated with the bias-correction term is also given in Table 5.23. The variance-covariance matrix in Table D.9 also applies to the coefficients of the 15 PQM terms in the 16-term second-choice PCT-Na model with bias-correction given in Table 5.24. The standard deviation associated with the bias-correction term is also given in Table 5.24. The 13- 
component reduced LM model for PCT-Na was judged inferior to the two PQM models and was not bias-corrected, but provides a baseline for comparison.

Tables D.10, D.11 and D.12, respectively, contain the variance-covariance matrices for three spinel $\mathrm{T}_{1 \%}\left({ }^{\circ} \mathrm{C}\right)$ models for HLW glasses: (1) the 15-component reduced LM model given in Table 6.9, (2) the recommended 20-term PQM model given in Table 6.10, and (3) the secondchoice 20-term PQM model given in Table 6.11. The 15-component reduced LM was judged as inadequate for predicting spinel $\mathrm{T}_{1 \%}$, but provides a baseline for comparison to the other two models.

Tables D.13 and D.14, respectively, contain the variance-covariance matrices for two ln(EC, S/cm) models: (1) the 27-term truncated T2-LM model given in Table 7.7, and (2) the 22term truncated T2-LM model with one quadratic composition term given in Table 7.9. The 22term model is the one recommended for use, while the 27-term model is a second-choice model without the quadratic composition term and with fewer of the composition-temperature terms removed.

Tables D.15 and D.16, respectively, contain the variance-covariance matrices for two ln(Viscosity, poise) models: (1) the 24-term truncated T2-LM model given in Table 8.8 and (2) the 29-term truncated T2-LM model with five quadratic crossproduct terms given in Table 8.9. The 29-term model is the one recommended for use, while the 24-term model serves as a secondchoice model without quadratic composition terms. 
Table D.1. Variance-Covariance Matrix Associated With the Estimated Coefficients of the 13-Component Reduced Linear Mixture Model for $\ln (\mathrm{PCT}-\mathrm{B}, \mathrm{g} / \mathrm{L})$ of HLW Glasses.

\begin{tabular}{|c|c|c|c|c|c|c|c|c|c|c|c|c|c|}
\hline Term & $\mathrm{Al}_{2} \mathrm{O}_{3}$ & $\mathbf{B}_{2} \mathbf{O}_{3}$ & $\mathbf{F e}_{2} \mathbf{O}_{3}$ & $\mathbf{L i}_{2} \mathbf{O}$ & MnO & $\mathrm{Na}_{2} \mathrm{O}$ & $\mathrm{SiO}_{2}$ & SrO & $\mathrm{ThO}_{2}$ & $\mathrm{UO}_{3}$ & $\mathrm{ZnO}$ & $\mathrm{ZrO}_{2}$ & \\
\hline $\mathbf{A l}_{2} \mathbf{O}_{3}$ & 1.3064 & -0.2968 & 0.3263 & -0.5340 & 0.1595 & -0.4267 & 0.0101 & -0.1963 & -0.1218 & 0.1301 & 0.0177 & 0.3881 & -0.6208 \\
\hline $\mathrm{B}_{2} \mathrm{O}_{3}$ & -0.2968 & 1.0152 & -0.0470 & 0.2328 & 0.0062 & 0.0555 & -0.1964 & 0.1476 & 0.3244 & 0.0977 & -0.3589 & -0.2198 & 484 \\
\hline $\mathrm{Fe}_{2} \mathrm{O}_{3}$ & 0.3263 & -0.0470 & 0.9973 & -0.3528 & 0.1948 & -0.3014 & -0.1808 & -0.0998 & 0.2838 & 0.2624 & 0.1776 & 0.2667 & 2074 \\
\hline $\mathbf{L i}_{2}$ & 340 & 0.2328 & -0 . & 5.1704 & -0 . & 1.0 & 95 & 13 & 40 & 32 & 83 & 342 & 81 \\
\hline MnO & 1595 & 0.0062 & 0.1948 & -0.1362 & 2.0 & -0.2219 & -0.1006 & -0.3486 & 624 & 0.0753 & 338 & 0.0761 & 34 \\
\hline $\mathrm{Na}_{2} \mathrm{O}$ & .4267 & 0.0555 & 14 & 1.0682 & -0.2 & & -0.1493 & 49 & 307 & -0.0838 & & -0.3648 & \\
\hline $\mathrm{SiO}_{2}$ & .0101 & -0.1964 & -0.1808 & -0.5095 & -0.1 & -0.1 & 0.1925 & -0.0 & -0.1780 & -0.0926 & -0.2338 & 0.0220 & \\
\hline SrO & .1963 & 0.1476 & -0.0998 & 0.2213 & -0.3486 & 0.2749 & -0.0459 & 1.3 & 0.1589 & -0.4120 & 0.4265 & -0.2223 & 977 \\
\hline $\mathrm{ThO}_{2}$ & -0.1218 & 0.3244 & 0.2838 & -0.0740 & 0.0624 & 0.0807 & -0.1780 & 0.1589 & 3.2677 & -0.9394 & 0.1574 & -0.4953 & 381 \\
\hline $\mathrm{UO}_{3}$ & 0.1301 & 0.0977 & 0.2624 & 0.3632 & 0.0753 & -0.0838 & -0.0926 & -0.4120 & 394 & 3.2292 & -0.0429 & -0.3230 & 899 \\
\hline ZnO & 0.0177 & -0.3589 & 0.1776 & -0.2983 & 0.1038 & 0.1855 & -0.2338 & 0.4265 & 0.1574 & -0.0429 & 8.6910 & -0.1229 & -0.9757 \\
\hline $\mathrm{ZrO}_{2}$ & 0.3881 & -0.2198 & 0.2667 & -0.6842 & 0.0761 & -0.3648 & 0.0220 & -0.2223 & -0.4953 & -0.3230 & -0.1229 & 1.2597 & -0.0573 \\
\hline Others & -0.6208 & 0.1484 & -0.2074 & -0.0781 & -0.0934 & -0.2159 & -0.0336 & -0.6977 & -0.0381 & -0.3899 & -0.9757 & -0.0573 & 3.0853 \\
\hline
\end{tabular}


The Catholic University of America Vitreous State Laboratory
IHLW PCT, Spinel $T_{1 \%}$, Electrical Conductivity, and Viscosity Model Development

Final Report, VSL-07R1240-4, Rev. 0

Table D.2. Variance-Covariance Matrix Associated With the Estimated Coefficients of the 18-Term Partial Quadratic Mixture Model for $\ln ($ PCT-B, g/L) of HLW Glasses.

\begin{tabular}{|c|c|c|c|c|c|c|c|c|c|c|}
\hline Term & $\mathbf{A l}_{2} \mathbf{O}_{3}$ & $\mathbf{B}_{2} \mathbf{O}_{3}$ & $\mathrm{Fe}_{2} \mathrm{O}_{3}$ & $\mathbf{L i}_{2} \mathbf{O}$ & MnO & $\mathrm{Na}_{2} \mathrm{O}$ & $\mathrm{SiO}_{2}$ & SrO & $\mathrm{ThO}_{2}$ & $\mathbf{U O}_{3}$ \\
\hline $\mathbf{A l}_{2} \mathbf{O}_{3}$ & 21.5775 & -0.6081 & -0.4040 & -0.9414 & -7.1047 & $\begin{array}{l}-0.5091 \\
\end{array}$ & -0.7193 & -0.4055 & 1.5309 & -0.3785 \\
\hline $\mathbf{B}_{2} \mathbf{O}_{3}$ & -0.6081 & 0.7531 & -0.0758 & 0.1813 & -0.0210 & 0.0635 & -0.1189 & 0.1438 & 0.2673 & -0.0615 \\
\hline $\mathrm{Fe}_{2} \mathrm{O}_{3}$ & -0.4040 & -0.0758 & 1.6455 & -0.4662 & 0.1646 & \begin{tabular}{|c|}
-0.3869 \\
\end{tabular} & \begin{tabular}{|l|}
-0.1916 \\
\end{tabular} & -0.2631 & -0.1650 & 0.7393 \\
\hline $\mathbf{L i}_{2} \mathbf{O}$ & -0.9414 & 0.1813 & -0.4662 & 3.8457 & 0.7850 & 0.8289 & \begin{tabular}{|l|}
-0.3411 \\
\end{tabular} & 0.1877 & $\begin{array}{l}-0.0608 \\
\end{array}$ & 0.3975 \\
\hline MnO & -7.1047 & -0.0210 & 0.1646 & 0.7850 & 17.2688 & 0.0502 & 0.0136 & -0.5977 & -0.9703 & 0.2186 \\
\hline $\mathrm{Na}_{2} \mathrm{O}$ & -0.5091 & 0.0635 & -0.3869 & 0.8289 & 0.0502 & 0.6508 & \begin{tabular}{|l|}
-0.0863 \\
\end{tabular} & 0.2493 & 0.1371 & -0.1940 \\
\hline $\mathrm{SiO}_{2}$ & -0.7193 & -0.1189 & -0.1916 & -0.3411 & 0.0136 & \begin{tabular}{|l|}
-0.0863 \\
\end{tabular} & 0.1749 & 0.0036 & -0.1396 & -0.1739 \\
\hline SrO & -0.4055 & 0.1438 & -0.2631 & 0.1877 & -0.5977 & 0.2493 & 0.0036 & 1.0646 & 0.2393 & -0.5911 \\
\hline $\mathrm{ThO}_{2}$ & 1.5309 & 0.2673 & -0.1650 & -0.0608 & $\begin{array}{l}-0.9703 \\
\end{array}$ & 0.1371 & \begin{tabular}{|l|}
-0.1396 \\
\end{tabular} & 0.2393 & 2.7658 & -1.4342 \\
\hline $\mathbf{U O}_{3}$ & -0.3785 & -0.0615 & 0.7393 & 0.3975 & 0.2186 & \begin{tabular}{|l|}
-0.1940 \\
\end{tabular} & \begin{tabular}{|l|}
-0.1739 \\
\end{tabular} & -0.5911 & -1.4342 & 6.0350 \\
\hline $\mathrm{ZnO}$ & -2.8319 & -0.6835 & 5.5369 & -1.0602 & 1.0572 & \begin{tabular}{|l|}
-0.9048 \\
\end{tabular} & -0.6806 & -1.1153 & -2.7577 & 8.0124 \\
\hline $\mathrm{ZrO}_{2}$ & 1.4180 & -0.2726 & 0.0731 & -0.6212 & 0.0421 & $\begin{array}{l}-0.4027 \\
\end{array}$ & 0.0081 & -0.2826 & -0.5346 & -0.8209 \\
\hline Others & -0.3262 & 0.1538 & -0.5847 & 0.0218 & -0.1393 & $\begin{array}{l}-0.0564 \\
\end{array}$ & 0.0204 & -0.3706 & 0.2323 & -0.9431 \\
\hline$\left(\mathrm{Al}_{2} \mathrm{O}_{3}\right)^{2}$ & -147.8742 & 2.2957 & 5.5961 & 3.2255 & 54.3075 & 0.5780 & 5.1057 & 1.0391 & $\begin{array}{l}-13.3849 \\
\end{array}$ & 1.5565 \\
\hline $\mathrm{UO}_{3} \times \mathrm{ZnO}$ & 45.2010 & 7.3551 & -26.2878 & -7.6071 & -2.5420 & 7.7196 & 4.4581 & 15.6425 & 44.1775 & -201.4758 \\
\hline$(\mathrm{MnO})^{2}$ & 101.4370 & 0.2023 & 1.2255 & -13.5535 & -239.8868 & $\begin{array}{l}-3.6850 \\
\end{array}$ & \begin{tabular}{|l|l|}
-1.1558 \\
\end{tabular} & 4.7593 & 13.2235 & 2.2825 \\
\hline $\mathrm{Fe}_{2} \mathrm{O}_{3} \times \mathrm{ZnO}$ & -4.2651 & 3.9181 & -55.6168 & 12.6364 & -12.1847 & 10.7436 & 5.7330 & 13.5138 & 21.0334 & -37.5810 \\
\hline $\mathrm{Al}_{2} \mathrm{O}_{3} \times \mathrm{ZrO}_{2}$ & -37.4922 & 2.5227 & 3.2942 & 1.9919 & -3.7554 & 2.4918 & 0.8474 & 2.7253 & 2.2851 & 9.3288 \\
\hline
\end{tabular}

\begin{tabular}{|c|c|c|c|c|c|c|c|c|}
\hline Term & $\mathrm{ZnO}$ & $\mathrm{ZrO}_{2}$ & Others & $\left(\mathrm{Al}_{2} \mathrm{O}_{3}\right)^{2}$ & $\mathrm{UO}_{3} \times \mathrm{ZnO}$ & $(\mathrm{MnO})^{2}$ & $\mathrm{Fe}_{2} \mathrm{O}_{3} \times \mathrm{ZnO}$ & $\mathrm{Al}_{2} \mathbf{O}_{3} \times \mathrm{ZrO}_{2}$ \\
\hline $\mathrm{Al}_{2} \mathrm{O}_{3}$ & -2.8319 & 1.4180 & -0.3262 & -147.8742 & 45.2010 & 101.4370 & -4.2651 & -37.4922 \\
\hline $\mathrm{B}_{2} \mathrm{O}_{3}$ & -0.6835 & -0.2726 & 0.1538 & 2.2957 & 7.3551 & 0.2023 & 3.9181 & 2.5227 \\
\hline $\mathrm{Fe}_{2} \mathrm{O}_{3}$ & 5.5369 & 0.0731 & -0.5847 & 5.5961 & -26.2878 & 1.2255 & -55.6168 & 3.2942 \\
\hline $\mathrm{Li}_{2} \mathrm{O}$ & -1.0602 & -0.6212 & 0.0218 & 3.2255 & -7.6071 & -13.5535 & 12.6364 & 1.9919 \\
\hline MnO & 1.0572 & 0.0421 & -0.1393 & 54.3075 & -2.5420 & -239.8868 & -12.1847 & -3.7554 \\
\hline $\mathrm{Na}_{2} \mathrm{O}$ & -0.9048 & -0.4027 & -0.0564 & 0.5780 & 7.7196 & -3.6850 & 10.7436 & 2.4918 \\
\hline $\mathrm{SiO}_{2}$ & -0.6806 & 0.0081 & 0.0204 & 5.1057 & 4.4581 & -1.1558 & 5.7330 & 0.8474 \\
\hline SrO & -1.1153 & -0.2826 & -0.3706 & 1.0391 & 15.6425 & 4.7593 & 13.5138 & 2.7253 \\
\hline $\mathrm{ThO}_{2}$ & -2.7577 & -0.5346 & 0.2323 & -13.3849 & 44.1775 & 13.2235 & 21.0334 & 2.2851 \\
\hline $\mathrm{UO}_{3}$ & 8.0124 & -0.8209 & -0.9431 & 1.5565 & -201.4758 & 2.2825 & -37.5810 & 9.3288 \\
\hline $\mathrm{ZnO}$ & 44.7952 & -1.5359 & -3.8263 & 22.6510 & -415.5353 & -0.8867 & -334.6201 & 28.4580 \\
\hline $\mathrm{ZrO}_{2}$ & -1.5359 & 2.8376 & -0.0860 & 0.5058 & 17.9261 & 1.8804 & 4.5249 & -35.4485 \\
\hline Others & -3.8263 & -0.0860 & 2.4862 & -1.7791 & 35.5010 & -0.2668 & 27.2897 & 0.7058 \\
\hline$\left(\mathrm{Al}_{2} \mathrm{O}_{3}\right)^{2}$ & 22.6510 & 0.5058 & -1.7791 & 1101.9958 & -287.8425 & -754.1419 & -35.8347 & 114.0686 \\
\hline $\mathrm{UO}_{3} \times \mathrm{ZnO}$ & -415.5353 & 17.9261 & 35.5010 & -287.8425 & 11120.4615 & -253.6193 & 1755.7687 & -279.0188 \\
\hline$(\mathrm{MnO})^{2}$ & -0.8867 & 1.8804 & -0.2668 & -754.1419 & -253.6193 & 3665.9189 & 104.5419 & 34.8856 \\
\hline $\mathrm{Fe}_{2} \mathrm{O}_{3} \times \mathrm{ZnO}$ & -334.6201 & 4.5249 & 27.2897 & -35.8347 & 1755.7687 & 104.5419 & 3478.0346 & -94.9453 \\
\hline $\mathrm{Al}_{2} \mathrm{O}_{3} \times \mathrm{ZrO}_{2}$ & 28.4580 & -35.4485 & 0.7058 & 114.0686 & -279.0188 & 34.8856 & -94.9453 & 673.0366 \\
\hline
\end{tabular}


The Catholic University of America Vitreous State Laboratory
IHLW PCT, Spinel $T_{1 \%}$, Electrical Conductivity, and Viscosity Model Development

Final Report, VSL-07R1240-4, Rev. 0

Table D.3. Variance-Covariance Matrix Associated With the Estimated Coefficients of the 15-Term Partial Quadratic Mixture Model for $\ln (\mathrm{PCT}-\mathrm{B}, \mathrm{g} / \mathrm{L})$ of HLW Glasses.

\begin{tabular}{|c|c|c|c|c|c|c|c|c|c|c|}
\hline Term & $\mathbf{A l}_{2} \mathbf{O}_{3}$ & $\mathbf{B}_{2} \mathbf{O}_{3}$ & $\mathrm{Fe}_{2} \mathbf{O}_{3}$ & $\mathbf{L i}_{2} \mathbf{O}$ & MnO & $\mathrm{Na}_{2} \mathrm{O}$ & $\mathrm{SiO}_{2}$ & SrO & $\mathrm{ThO}_{2}$ & $\mathrm{UO}_{3}$ \\
\hline $\mathrm{Al}_{2} \mathbf{O}_{3}$ & 21.2556 & -0.7317 & -0.6493 & -0.5261 & -0.4471 & -0.4556 & -0.7873 & -0.6450 & 1.1730 & 0.5503 \\
\hline $\mathrm{B}_{2} \mathrm{O}_{3}$ & -0.7317 & 0.8593 & -0.0164 & 0.2020 & 0.0079 & 0.0582 & -0.1453 & 0.1424 & 0.2593 & 0.0885 \\
\hline $\mathrm{Fe}_{2} \mathrm{O}_{3}$ & -0.6493 & -0.0164 & 0.8680 & -0.2881 & 0.1872 & -0.2445 & -0.1143 & -0.0603 & 0.1780 & 0.1981 \\
\hline $\mathrm{Li}_{2} \mathbf{O}$ & -0.5261 & 0.2020 & -0.2881 & 4.2906 & -0.1224 & 0.8957 & -0.4203 & 0.1945 & -0.0437 & 0.3186 \\
\hline MnO & -0.4471 & 0.0079 & 0.1872 & -0.1224 & 1.7703 & -0.1971 & -0.0586 & -0.2891 & -0.0202 & 0.0194 \\
\hline $\mathrm{Na}_{2} \mathrm{O}$ & -0.4556 & 0.0582 & -0.2445 & 0.8957 & -0.1971 & 0.7060 & -0.1218 & 0.2426 & 0.0913 & -0.0452 \\
\hline $\mathrm{SiO}_{2}$ & -0.7873 & -0.1453 & -0.1143 & -0.4203 & -0.0586 & -0.1218 & 0.1898 & -0.0213 & -0.2012 & -0.0977 \\
\hline SrO & -0.6450 & 0.1424 & -0.0603 & 0.1945 & -0.2891 & 0.2426 & -0.0213 & 1.1505 & 0.1284 & -0.3285 \\
\hline $\mathrm{ThO}_{2}$ & 1.1730 & 0.2593 & 0.1780 & -0.0437 & -0.0202 & 0.0913 & -0.2012 & 0.1284 & 2.8547 & -0.6922 \\
\hline $\mathbf{U O}_{3}$ & 0.5503 & 0.0885 & 0.1981 & 0.3186 & 0.0194 & -0.0452 & -0.0977 & -0.3285 & -0.6922 & 2.7340 \\
\hline $\mathrm{ZnO}$ & -2.4787 & -0.2040 & 0.2623 & -0.2010 & 0.1026 & 0.2144 & -0.1045 & 0.4552 & 0.0782 & -0.0001 \\
\hline $\mathrm{ZrO}_{2}$ & 1.4848 & -0.3296 & 0.1623 & -0.7000 & 0.2275 & -0.4814 & -0.0012 & -0.3645 & -0.7159 & -0.5666 \\
\hline Other: & -0.4389 & 0.1287 & -0.1749 & -0.0569 & -0.0921 & -0.1682 & -0.0323 & -0.5700 & -0.0027 & -0.3007 \\
\hline$\left(\mathrm{Al}_{2} \mathrm{O}_{3}\right)^{2}$ & -144.2541 & 2.9135 & 6.5493 & -0.0033 & 5.0704 & -0.0823 & 5.6900 & 2.7334 & -10.8882 & -4.6873 \\
\hline $\mathrm{Al}_{2} \mathrm{O}_{3} \times \mathrm{ZrO}_{2}$ & -43.0958 & 3.1670 & 2.0639 & 2.4678 & -2.2890 & 3.3065 & 1.2097 & 3.7492 & 4.0349 & 4.8376 \\
\hline
\end{tabular}

\begin{tabular}{|c|c|c|c|c|c|}
\hline Term & $\mathrm{ZnO}$ & $\mathrm{ZrO}_{2}$ & Others & $\left(\mathrm{Al}_{2} \mathrm{O}_{3}\right)^{2}$ & $\mathrm{Al}_{2} \mathrm{O}_{3} \times \mathrm{ZrO}_{2}$ \\
\hline $\mathbf{A l}_{2} \mathbf{O}_{3}$ & -2.4787 & 1.4848 & -0.4389 & -144.2541 & -43.0958 \\
\hline $\mathbf{B}_{2} \mathbf{O}_{3}$ & -0.2040 & -0.3296 & 0.1287 & 2.9135 & 3.1670 \\
\hline $\mathrm{Fe}_{2} \mathrm{O}_{3}$ & 0.2623 & 0.1623 & $\begin{array}{l}-0.1749 \\
\end{array}$ & 6.5493 & 2.0639 \\
\hline $\mathrm{Li}_{2} \mathrm{O}$ & -0.2010 & -0.7000 & -0.0569 & -0.0033 & 2.4678 \\
\hline MnO & 0.1026 & 0.2275 & -0.0921 & 5.0704 & -2.2890 \\
\hline $\mathrm{Na}_{2} \mathrm{O}$ & 0.2144 & -0.4814 & -0.1682 & -0.0823 & 3.3065 \\
\hline $\mathrm{SiO}_{2}$ & -0.1045 & -0.0012 & -0.0323 & 5.6900 & 1.2097 \\
\hline SrO & 0.4552 & -0.3645 & -0.5700 & 2.7334 & 3.7492 \\
\hline $\mathrm{ThO}_{2}$ & 0.0782 & -0.7159 & -0.0027 & -10.8882 & 4.0349 \\
\hline $\mathrm{UO}_{3}$ & -0.0001 & -0.5666 & -0.3007 & -4.6873 & 4.8376 \\
\hline ZnO & 7.6703 & -0.8350 & -0.7800 & 15.0636 & 15.8287 \\
\hline $\mathrm{ZrO}_{2}$ & -0.8350 & 3.2332 & -0.1779 & 1.6424 & -40.3105 \\
\hline Others & -0.7800 & -0.1779 & 2.5643 & -1.1708 & 2.2407 \\
\hline$\left(\mathrm{Al}_{2} \mathrm{O}_{3}\right)^{2}$ & 15.0636 & 1.6424 & -1.1708 & 1078.2561 & 130.6648 \\
\hline $\mathrm{Al}_{2} \mathrm{O}_{3} \times \mathrm{ZrO}_{2}$ & 15.8287 & -40.3105 & 2.2407 & 130.6648 & 766.0704 \\
\hline
\end{tabular}


Table D.4. Variance-Covariance Matrix Associated With the Estimated Coefficients of the 13-Component Reduced Linear Mixture Model for $\ln ($ PCT-Li, g/L) of HLW Glasses.

\begin{tabular}{|c|c|c|c|c|c|c|c|c|c|c|c|c|c|}
\hline Term & $\mathbf{A l}_{2} \mathbf{O}_{3}$ & $\mathbf{B}_{2} \mathbf{O}_{3}$ & $\mathrm{Fe}_{2} \mathrm{O}_{3}$ & $\mathbf{L i}_{2} \mathbf{O}$ & MnO & $\mathrm{Na}_{2} \mathrm{O}$ & $\mathrm{SiO}_{2}$ & SrO & $\mathrm{ThO}_{2}$ & $\mathbf{U O}_{3}$ & $\mathrm{ZnO}$ & $\mathrm{ZrO}_{2}$ & \\
\hline $\mathrm{Al}_{2} \mathbf{O}_{3}$ & 0.9901 & -0.2640 & 0.2418 & -0.3809 & 0.1445 & -0.3081 & -0.0001 & -0.2311 & -0.0145 & 0.0982 & 0.1009 & 0.2530 & -0.5093 \\
\hline $\mathrm{B}_{2} \mathrm{O}_{3}$ & 0.2640 & 0.7381 & -0.0384 & 0.1729 & 0.0487 & 0.0388 & -0.1328 & 0.0873 & 0.2120 & 0.0933 & -0.4720 & \begin{tabular}{|c|c|}
-0.1773 \\
\end{tabular} & 0.1676 \\
\hline $\mathrm{Fe}_{2} \mathrm{O}_{3}$ & 0.2418 & 0.0384 & 0.7265 & -0.2232 & 0.1146 & -0.2108 & -0.1293 & -0.1194 & 0.2502 & 0.1601 & 43 & 743 & \\
\hline $\mathbf{L i}_{2}$ & 3809 & 0.1729 & 0.2232 & 3.5636 & 0.0496 & 0.6334 & -0.3221 & -0.0069 & 1727 & 0.2016 & 337 & -0.4454 & 784 \\
\hline MnO & 0.1445 & 0.0487 & 0.1146 & -0.0496 & 1.5826 & -0.1437 & -0.0653 & -0.4014 & -0.0178 & 0.1120 & -0.2882 & 0.0884 & 682 \\
\hline $\mathrm{Na}_{2} \mathrm{O}$ & 0.3081 & 0.0388 & -0.2108 & 0.6334 & -0.1437 & 0.5817 & -0.1017 & 0.2308 & 0.0447 & -0.0083 & 281 & \begin{tabular}{|l|}
-0.2392 \\
\end{tabular} & 397 \\
\hline $\mathrm{SiO}_{2}$ & .0001 & -0.1328 & -0.1293 & -0.3221 & -0.0653 & -0.1017 & 0.1276 & -0.0 & -0.1346 & -0.0608 & -0.1755 & 0.0208 & \\
\hline SrC & 2311 & 0.0873 & -0.1194 & -0.0069 & -0.4 & 0.2308 & -0.0194 & 1.0664 & 0.1000 & -0.3401 & 0.4386 & -0.1564 & \\
\hline $\mathrm{ThO}_{2}$ & -0.0145 & 0.2120 & 0.2502 & -0.1727 & -0.0178 & 0.0447 & -0.1346 & 0.1000 & 2.5299 & -0.8423 & 0.2689 & $\begin{array}{l}-0.4095 \\
\end{array}$ & 418 \\
\hline $\mathbf{U O}_{3}$ & 0.0982 & 0.0933 & 0.1601 & 0.2016 & 0.1120 & -0.0083 & -0.0608 & -0.3401 & -0.8423 & 2.4108 & -0.1535 & -0.2256 & -0.3629 \\
\hline $\mathrm{ZnO}$ & 0.1009 & -0.4720 & 0.1943 & -0.2637 & -0.2882 & 0.2281 & -0.1755 & 0.4386 & 0.2689 & -0.1535 & 6.8726 & -0.0522 & -0.7942 \\
\hline $\mathrm{ZrO}_{2}$ & 0.2530 & -0.1773 & 0.1743 & -0.4454 & & -0.2392 & 0.0208 & -0.1564 & -0.4095 & -0.2256 & -0.0522 & 0.9096 & \\
\hline Other & 0.5093 & 0.1676 & -0.2022 & -0.0784 & -0.1682 & -0.1397 & -0.0102 & -0.2893 & 0.0418 & -0.3629 & -0.7942 & \begin{tabular}{|l|}
-0.0959 \\
\end{tabular} & 2.1709 \\
\hline
\end{tabular}


The Catholic University of America Vitreous State Laboratory
IHLW PCT, Spinel $T_{1 \%}$, Electrical Conductivity, and Viscosity Model Development

Final Report, VSL-07R1240-4, Rev. 0

Table D.5. Variance-Covariance Matrix Associated With the Estimated Coefficients of the 18-Term Partial Quadratic Mixture Model for $\ln (\mathrm{PCT}-\mathrm{Li}, \mathrm{g} / \mathrm{L})$ of HLW Glasses.

\begin{tabular}{|c|c|c|c|c|c|c|c|c|c|c|}
\hline Term & $\mathbf{I}_{2} \mathrm{O}_{3}$ & $\mathbf{B}_{2} \mathbf{O}_{3}$ & $\mathbf{e}_{2} \mathbf{O}_{3}$ & $\mathrm{Li}_{2} \mathbf{O}$ & MnO & $\mathrm{Na}_{2} \mathrm{O}$ & $\mathrm{SiO}_{2}$ & SrO & $\mathrm{ThO}_{2}$ & $\mathrm{UO}_{3}$ \\
\hline $\mathbf{A l}_{2} \mathbf{O}_{3}$ & 12.9605 & -0.4453 & 0.0015 & 1.0725 & -0.5106 & -0.4008 & -0.4714 & -0.7838 & 0.6486 & -0.5884 \\
\hline $\mathrm{B}_{2} \mathrm{O}_{3}$ & -0.4453 & 5961 & -0.2793 & -0.5384 & 0.0792 & 0.0698 & \begin{tabular}{|l|}
-0.0648 \\
\end{tabular} & 0.1252 & 0.1842 & 0.1087 \\
\hline 5 & 0015 & -0.2793 & 2369 & 4.0732 & 2122 & .3697 & 22467 & .2863 & 0969 & .1453 \\
\hline $\mathbf{L i}_{2} \mathbf{O}$ & 0725 & 0.5384 & 732 & 13.5546 & & \begin{tabular}{|l|}
-0.1177 \\
\end{tabular} & \begin{tabular}{|l|}
-0.7014 \\
\end{tabular} & & & 0037 \\
\hline & 0510 & 00707 & & & & -0.0687 & & & & 1600 \\
\hline & & r & & & & & & & & \\
\hline $\mathrm{SiC}$ & 714 & -0.0648 & & 14 & & \begin{tabular}{|l|}
-0.0458 \\
\end{tabular} & & & & 570 \\
\hline SrO & 7838 & 0.1252 & -0.2 & 3 & & 0.1983 & & 468 & & .2326 \\
\hline Th & & 1842 & & 12 & & 84 & & & & 0464 \\
\hline $\mathrm{UO}$ & 5884 & 1087 & 3 & 20 & & \begin{tabular}{|l|}
-0.0435 \\
\end{tabular} & & 26 & 64 & 4.5187 \\
\hline $\mathbf{Z n}$ & -2.8385 & -0.2366 & -0.2 & -0.8041 & 31 & 0.1694 & & 37 & -0.3 & 3.0843 \\
\hline $\mathbf{Z r}$ & & -0.2256 & & 30 & & & & & -0.5 & 2977 \\
\hline & 72 & 1313 & & & & -0.1 & & & & 4239 \\
\hline$\left(\mathbf{A l}_{2}\right.$ & 9.3333 & 1.3978 & 0.1529 & -13.4207 & 341 & 1.2451 & 3.6895 & 2.5892 & -5.9859 & 3.0018 \\
\hline $\mathbf{U O}_{3} \times$ & 40.6030 & -0.9308 & 7.8024 & -8.7867 & $\begin{array}{l}-20.5319 \\
\end{array}$ & 3.1630 & 1.2326 & -0.7753 & 25.8077 & 155.3408 \\
\hline $\mathrm{Fe}_{2} \mathrm{O}$ & \begin{tabular}{|l|}
-12.7074 \\
\end{tabular} & 7.8252 & -49.3653 & 126.4231 & 9.2363 & 6.7309 & 5.2296 & 5.5530 & 2.5887 & 4.3596 \\
\hline $\mathrm{SrO} \times 2$ & 7.8824 & -0.3769 & -0.0252 & -2.2446 & 3.4726 & 0.3761 & 0.3093 & -18.8704 & 1.6238 & -6.8387 \\
\hline $\mathrm{Al}_{2} \mathrm{O}_{3}$ & -24.5475 & 2.5341 & 2.1133 & 2.9728 & -1.8039 & 0.9935 & 0.4373 & 5.6802 & 4.0233 & 3.6558 \\
\hline
\end{tabular}

\begin{tabular}{|c|c|c|c|c|c|c|c|c|}
\hline Term & ZnO & $\mathrm{ZrO}_{2}$ & \begin{tabular}{|l|} 
Others \\
\end{tabular} & $\left(\mathrm{Al}_{2} \mathrm{O}_{3}\right)^{2}$ & $\mathrm{UO}_{3} \times \mathrm{ZnO}$ & $\mathrm{Fe}_{2} \mathrm{O}_{3} \times \mathrm{Li}_{2} \mathrm{O}$ & $\mathrm{SrO} \times \mathrm{ZrO}_{2}$ & $\mathrm{Al}_{2} \mathrm{O}_{3} \times \mathrm{ZrO}_{2}$ \\
\hline $\mathbf{A l}_{2} \mathbf{O}_{3}$ & -2.8385 & 0.6566 & \begin{tabular}{|l|}
-0.0872 \\
\end{tabular} & -89.3333 & 40.6030 & -12.7074 & 7.8824 & -24.5475 \\
\hline $\mathbf{B}_{2} \mathbf{O}_{3}$ & -0.2366 & -0.2256 & 0.1313 & 1.3978 & -0.9308 & 7.8252 & -0.3769 & 2.5341 \\
\hline $\mathrm{Fe}_{2} \mathrm{O}_{3}$ & $\begin{array}{l}-0.2023 \\
\end{array}$ & \begin{tabular}{|l|}
-0.1303 \\
\end{tabular} & \begin{tabular}{|l|}
-0.1265 \\
\end{tabular} & 0.1529 & 7.8024 & -49.3653 & -0.0252 & 2.1133 \\
\hline $\mathbf{L i}_{2} \mathbf{O}$ & -0.8041 & -0.9380 & 0.0309 & -13.4207 & -8.7867 & -126.4231 & -2.2446 & 2.9728 \\
\hline MnO & 0.3131 & 0.1477 & $\mid-0.2222$ & 5.4841 & -20.5319 & 9.2363 & 3.4726 & -1.8039 \\
\hline $\mathrm{Na}_{2} \mathrm{O}$ & 0.1694 & $\begin{array}{l}-0.2045 \\
\end{array}$ & \begin{tabular}{|l|}
-0.1024 \\
\end{tabular} & 1.2451 & 3.1630 & 6.7309 & 0.3761 & 0.9935 \\
\hline $\mathrm{SiO}_{2}$ & -0.0531 & 0.0306 & \begin{tabular}{|l|}
-0.0241 \\
\end{tabular} & 3.6895 & 1.2326 & 5.2296 & 0.3093 & 0.4373 \\
\hline SrO & 0.5237 & -0.0018 & \begin{tabular}{|l|}
-0.0154 \\
\end{tabular} & 2.5892 & -0.7753 & 5.5530 & -18.8704 & 5.6802 \\
\hline $\mathrm{ThO}_{2}$ & -0.3771 & \begin{tabular}{|l|}
-0.5712 \\
\end{tabular} & 0.1017 & -5.9859 & 25.8077 & 2.5887 & 1.6238 & 4.0233 \\
\hline $\mathbf{U O}_{3}$ & 3.0843 & \begin{tabular}{|l|}
-0.2977 \\
\end{tabular} & \begin{tabular}{|l|}
-0.4239 \\
\end{tabular} & 3.0018 & -155.3408 & 4.3596 & -6.8387 & 3.6558 \\
\hline $\mathrm{ZnO}$ & 9.1515 & -0.3185 & \begin{tabular}{|l|}
-0.7847 \\
\end{tabular} & 18.7897 & -180.6513 & 9.5224 & -10.5812 & 10.0004 \\
\hline $\mathrm{ZrO}_{2}$ & -0.3185 & 2.2325 & \begin{tabular}{|l|}
-0.1677 \\
\end{tabular} & 3.2092 & 4.2334 & 5.0805 & -4.6194 & -26.3679 \\
\hline Others & -0.7847 & \begin{tabular}{|l|}
-0.1677 \\
\end{tabular} & 1.6839 & -3.2673 & 9.1880 & -1.0205 & -4.8026 & 3.2017 \\
\hline$\left(\mathrm{Al}_{2} \mathrm{O}_{3}\right)^{2}$ & 18.7897 & 3.2092 & -3.2673 & 690.5741 & -206.3990 & 124.3437 & -9.8794 & 46.9424 \\
\hline $\mathrm{UO}_{3} \times \mathrm{ZnO}$ & \begin{tabular}{|l|}
-180.6513 \\
\end{tabular} & 4.2334 & 9.1880 & -206.3990 & 8817.1795 & -38.4103 & 411.5527 & -149.1727 \\
\hline $\mathrm{Fe}_{2} \mathrm{O}_{3} \times \mathrm{Li}_{2} \mathrm{O}$ & 9.5224 & 5.0805 & -1.0205 & 124.3437 & -38.4103 & 1467.1276 & 34.2128 & -6.6871 \\
\hline $\mathrm{SrO} \times \mathrm{ZrO}_{2}$ & -10.5812 & -4.6194 & -4.8026 & -9.8794 & 411.5527 & 34.2128 & 512.8649 & -101.6170 \\
\hline $\mathrm{Al}_{2} \mathbf{O}_{3} \times \mathrm{ZrO}{ }_{2}$ & 10.0004 & -26.3679 & 3.2017 & 46.9424 & -149.1727 & $\begin{array}{l}-6.6871 \\
\end{array}$ & -101.6170 & 529.4615 \\
\hline
\end{tabular}


The Catholic University of America Vitreous State Laboratory
IHLW PCT, Spinel $T_{1 \%}$, Electrical Conductivity, and Viscosity Model Development

Final Report, VSL-07R1240-4, Rev. 0

Table D.6. Variance-Covariance Matrix Associated With the Estimated Coefficients of the 15-Term Partial Quadratic Mixture Model for $\ln ($ PCT-Li, g/L) of HLW Glasses.

\begin{tabular}{|c|c|c|c|c|c|c|c|c|c|c|}
\hline Term & $\mathbf{A l}_{2} \mathbf{O}_{3}$ & $\mathbf{B}_{2} \mathbf{O}_{3}$ & $\mathrm{Fe}_{2} \mathrm{O}_{3}$ & $\mathbf{L i}_{2} \mathbf{O}$ & $\mathrm{MnO}$ & $\mathrm{Na}_{2} \mathrm{O}$ & $\mathrm{SiO}_{2}$ & SrO & $\mathrm{ThO}_{2}$ & $\mathrm{UO}_{3}$ \\
\hline $\mathbf{A l}_{2} \mathbf{O}_{3}$ & 14.6817 & -0.4286 & \begin{tabular}{|l|l|}
-0.5440 \\
\end{tabular} & 0.0192 & $\begin{array}{l}-0.4569 \\
\end{array}$ & -0.4182 & -0.5061 & -0.5721 & 0.6396 & 0.1800 \\
\hline $\mathbf{B}_{2} \mathbf{O}_{3}$ & -0.4286 & 0.6459 & -0.0170 & 0.1589 & 0.0382 & 0.0399 & -0.1079 & 0.0879 & 0.2017 & 0.0852 \\
\hline $\mathrm{Fe}_{2} \mathrm{O}_{3}$ & -0.5440 & -0.0170 & 0.6646 & -0.2028 & 0.1243 & -0.1700 & -0.0839 & -0.0785 & 0.1917 & 0.1347 \\
\hline $\mathrm{Li}_{2} \mathrm{O}$ & 0.0192 & 0.1589 & $\begin{array}{l}-0.2028 \\
\end{array}$ & 3.0805 & $\begin{array}{l}-0.0738 \\
\end{array}$ & 0.5445 & -0.2906 & -0.0044 & -0.0893 & 0.1845 \\
\hline MnO & -0.4569 & 0.0382 & 0.1243 & -0.0738 & 1.3913 & -0.1212 & -0.0328 & -0.3359 & -0.0743 & 0.0847 \\
\hline $\mathrm{Na}_{2} \mathrm{O}$ & -0.4182 & 0.0399 & $\begin{array}{l}-0.1700 \\
\end{array}$ & 0.5445 & -0.1212 & 0.5013 & -0.0821 & 0.2047 & 0.0428 & -0.0055 \\
\hline $\mathrm{SiO}_{2}$ & -0.5061 & -0.1079 & \begin{tabular}{|l|}
-0.0839 \\
\end{tabular} & -0.2906 & $\begin{array}{l}-0.0328 \\
\end{array}$ & $\begin{array}{l}-0.0821 \\
\end{array}$ & 0.1279 & -0.0041 & -0.1436 & -0.0566 \\
\hline SrO & -0.5721 & 0.0879 & -0.0785 & -0.0044 & -0.3359 & 0.2047 & -0.0041 & 0.9279 & 0.0882 & -0.2891 \\
\hline $\mathrm{ThO}_{2}$ & 0.6396 & 0.2017 & 0.1917 & -0.0893 & -0.0743 & 0.0428 & -0.1436 & 0.0882 & 2.2745 & -0.6984 \\
\hline $\mathrm{UO}_{3}$ & 0.1800 & 0.0852 & 0.1347 & 0.1845 & 0.0847 & -0.0055 & -0.0566 & -0.2891 & -0.6984 & 2.0676 \\
\hline ZnO & -2.2184 & -0.3555 & 0.2977 & -0.2625 & -0.1655 & 0.2267 & -0.0681 & 0.4477 & 0.1602 & -0.1386 \\
\hline $\mathrm{ZrO}_{2}$ & 0.8676 & -0.3004 & 0.0533 & -0.5617 & 0.1959 & $\begin{array}{l}-0.2670 \\
\end{array}$ & 0.0152 & -0.2461 & -0.6876 & -0.2715 \\
\hline Others & -0.0832 & 0.1539 & $\begin{array}{l}-0.1854 \\
\end{array}$ & -0.0362 & $\begin{array}{l}-0.1753 \\
\end{array}$ & -0.1173 & -0.0240 & -0.2465 & 0.0937 & -0.2988 \\
\hline$\left(\mathrm{Al}_{2} \mathrm{O}_{3}\right)^{2}$ & \begin{tabular}{|l|}
-101.8199 \\
\end{tabular} & 0.8334 & 5.2402 & -3.4718 & 4.9714 & 0.8773 & 3.8246 & 2.3073 & -6.5402 & -1.0992 \\
\hline $\mathrm{Al}_{2} \mathrm{O}_{3} \times \mathrm{ZrO}_{2}$ & -26.4987 & 2.8657 & 2.5150 & 2.8404 & -1.5154 & 1.2747 & 0.5926 & 2.4004 & 5.2972 & 1.2923 \\
\hline
\end{tabular}

\begin{tabular}{|c|c|c|c|c|c|}
\hline Term & $\mathrm{ZnO}$ & $\mathrm{ZrO}_{2}$ & Others & $\left(\mathrm{Al}_{2} \mathrm{O}_{3}\right)^{2}$ & $\mathrm{Al}_{2} \mathrm{O}_{3} \times \mathrm{ZrO}_{2}$ \\
\hline $\mathrm{Al}_{2} \mathbf{O}_{3}$ & \begin{tabular}{|l|}
-2.2184 \\
\end{tabular} & 0.8676 & -0.0832 & -101.8199 & -26.4987 \\
\hline $\mathbf{B}_{2} \mathbf{O}_{3}$ & -0.3555 & -0.3004 & 0.1539 & 0.8334 & 2.8657 \\
\hline $\mathrm{Fe}_{2} \mathrm{O}_{3}$ & 0.2977 & 0.0533 & -0.1854 & 5.2402 & 2.5150 \\
\hline $\mathrm{Li}_{2} \mathbf{O}$ & $\begin{array}{l}-0.2625 \\
\end{array}$ & -0.5617 & -0.0362 & -3.4718 & 2.8404 \\
\hline MnO & -0.1655 & 0.1959 & -0.1753 & 4.9714 & -1.5154 \\
\hline $\mathrm{Na}_{2} \mathrm{O}$ & 0.2267 & -0.2670 & -0.1173 & 0.8773 & 1.2747 \\
\hline $\mathrm{SiO}_{2}$ & \begin{tabular}{|l|}
-0.0681 \\
\end{tabular} & 0.0152 & -0.0240 & 3.8246 & 0.5926 \\
\hline SrO & 0.4477 & -0.2461 & -0.2465 & 2.3073 & 2.4004 \\
\hline $\mathrm{ThO}_{2}$ & 0.1602 & -0.6876 & 0.0937 & -6.5402 & 5.2972 \\
\hline $\mathrm{UO}_{3}$ & \begin{tabular}{|l|}
-0.1386 \\
\end{tabular} & -0.2715 & -0.2988 & -1.0992 & 1.2923 \\
\hline ZnO & 6.2837 & -0.3335 & -0.7181 & 16.1094 & 7.6227 \\
\hline $\mathrm{ZrO}_{2}$ & -0.3335 & 2.5233 & -0.2577 & 3.3203 & -31.7502 \\
\hline Others & $\begin{array}{l}-0.7181 \\
\end{array}$ & -0.2577 & 1.8882 & -3.5045 & 2.7458 \\
\hline$\left(\mathrm{Al}_{2} \mathrm{O}_{3}\right)^{2}$ & 16.1094 & 3.3203 & -3.5045 & 787.7772 & 50.6727 \\
\hline $\mathrm{Al}_{2} \mathrm{O}_{3} \times \mathrm{ZrO}_{2}$ & 7.6227 & -31.7502 & 2.7458 & 50.6727 & 593.5028 \\
\hline
\end{tabular}


Table D.7. Variance-Covariance Matrix Associated With the Estimated Coefficients of the 13-Component Reduced Linear Mixture Model for $\ln ($ PCT-Na, g/L) of HLW Glasses.

\begin{tabular}{|c|c|c|c|c|c|c|c|c|c|c|c|c|c|}
\hline Term & $\mathbf{A l}_{2} \mathbf{O}_{3}$ & $\mathbf{B}_{2} \mathbf{O}_{3}$ & $\mathrm{Fe}_{2} \mathrm{O}_{3}$ & $\mathbf{L i}_{2} \mathbf{O}$ & MnO & $\mathrm{Na}_{2} \mathrm{O}$ & $\mathrm{SiO}_{2}$ & SrO & $\mathrm{ThO}_{2}$ & $\mathbf{U O}_{3}$ & $\mathrm{ZnO}$ & $\mathrm{ZrO}_{2}$ & 50 \\
\hline $\mathrm{Al}_{2} \mathbf{O}_{3}$ & 0.7600 & -0.1738 & 0.1865 & -0.3218 & 0.0835 & -0.2474 & -0.0040 & -0.1205 & -0.0763 & 0.0623 & 0.0087 & 0.2322 & -0.3559 \\
\hline $\mathrm{B}_{2} \mathrm{O}_{3}$ & 0.1738 & 0.5945 & -0.0276 & 0.1362 & 0.0037 & 0.0324 & -0.1149 & 0.0867 & 0.1903 & 0.0579 & -0.2101 & -0.1287 & 0.0863 \\
\hline $\mathrm{Fe}_{2} \mathrm{O}_{3}$ & 0.1865 & -0.0276 & 0.5796 & -0.2154 & 0.1049 & -0.1745 & -0.1038 & -0.0627 & 0.1626 & 0.1428 & 26 & 609 & \\
\hline $\mathbf{L i}_{2}$ & 3218 & 0.1362 & 0.2154 & 3.0109 & 79 & 0.6298 & -0.2945 & 0.1208 & 509 & 0.1902 & 775 & 915 & 345 \\
\hline MnO & 0.0835 & 0.0037 & 0.1049 & -0.0979 & 1.2073 & -0.1252 & -0.0550 & -0.2146 & 0.0273 & 0.0178 & 575 & 543 & 407 \\
\hline $\mathrm{Na}_{2} \mathrm{O}$ & 0.2474 & 0.0324 & -0.1745 & 0.6298 & -0.1252 & 0.4875 & -0.0883 & 0.1640 & 0.0501 & -0.0416 & 95 & \begin{tabular}{|c|}
-0.2160 \\
\end{tabular} & 309 \\
\hline $\mathrm{SiO}_{2}$ & .0040 & -0.1149 & -0.1038 & -0.2945 & -0.0550 & -0.0883 & 0.1118 & -0.0253 & -0.1031 & -0.0501 & 64 & 0.0109 & \\
\hline SrC & 1205 & 0.0867 & -0.0627 & 0.1208 & -0.2146 & 0.1640 & -0.0253 & 0.7902 & 0.0860 & -0.2592 & 0.2476 & -0.1253 & \\
\hline $\mathrm{ThO}_{2}$ & -0.0763 & 0.1903 & 0.1626 & -0.0509 & 0.0273 & 0.0501 & -0.1031 & 0.0860 & 1.9067 & -0.5673 & 0.0901 & \begin{tabular}{|l|}
-0.2859 \\
\end{tabular} & 112 \\
\hline $\mathbf{U O}_{3}$ & 0.0623 & 0.0579 & 0.1428 & 0.1902 & 0.0178 & -0.0416 & -0.0501 & -0.2592 & -0.5673 & 1.8475 & -0.0305 & -0.1768 & -0.2015 \\
\hline $\mathrm{ZnO}$ & 0.0087 & -0.2101 & 0.1026 & -0.1775 & 0.0575 & 0.1095 & -0.1364 & 0.2476 & 0.0901 & -0.0305 & 5.0891 & -0.0704 & -0.5681 \\
\hline $\mathrm{ZrO}_{2}$ & 0.2322 & -0.1287 & 0.1609 & -0.3915 & & -0.2160 & 0.0109 & -0.1253 & -0.2859 & -0.1768 & -0. & 0.7328 & \\
\hline Others & -0.3559 & 0.0863 & -0.1162 & -0.0345 & -0.0407 & -0.1309 & -0.0214 & -0.3974 & -0.0112 & -0.2015 & -0.5681 & -0.0399 & 1.7891 \\
\hline
\end{tabular}


The Catholic University of America Vitreous State Laboratory
IHLW PCT, Spinel $T_{1 \%}$, Electrical Conductivity, and Viscosity Model Development

Final Report, VSL-07R1240-1, Rev. 0

Table D.8. Variance-Covariance Matrix Associated With the Estimated Coefficients of the 18-Term Partial Quadratic Mixture Model for $\ln (\mathrm{PCT}-\mathrm{Na}, \mathrm{g} / \mathrm{L})$ of HLW Glasses.

\begin{tabular}{|c|c|c|c|c|c|c|c|c|c|c|}
\hline Term & $\mathbf{A l}_{2} \mathbf{O}_{3}$ & $\mathbf{B}_{2} \mathbf{O}_{3}$ & $\mathrm{Fe}_{2} \mathrm{O}_{3}$ & $\mathbf{L i}_{2} \mathbf{O}$ & MnO & $\mathrm{Na}_{2} \mathrm{O}$ & $\mathrm{SiO}_{2}$ & SrO & $\mathrm{ThO}_{2}$ & $\mathrm{UO}_{3}$ \\
\hline $\mathbf{A l}_{2} \mathbf{O}_{3}$ & 9.3009 & \begin{tabular}{|l|}
-0.3050 \\
\end{tabular} & -0.0965 & 0.1419 & -0.1696 & -0.1021 & $\begin{array}{l}-0.4522 \\
\end{array}$ & -0.2382 & 0.5242 & -1.3483 \\
\hline $\mathbf{B}_{2} \mathbf{O}_{3}$ & -0.3050 & 0.4178 & -0.1050 & -0.2651 & 0.0497 & 0.0788 & -0.0930 & 0.1113 & 0.1637 & -0.5104 \\
\hline $\mathrm{Fe}_{2} \mathrm{O}_{3}$ & -0.0965 & \begin{tabular}{|l|}
-0.1050 \\
\end{tabular} & 0.9488 & 1.4734 & 0.0445 & -0.1229 & \begin{tabular}{|l|}
-0.1478 \\
\end{tabular} & -0.0577 & 0.0252 & -0.4104 \\
\hline $\mathrm{Li}_{2} \mathbf{O}$ & 0.1419 & \begin{tabular}{|l|}
-0.2651 \\
\end{tabular} & 1.4734 & 6.6471 & -0.2826 & 0.1902 & \begin{tabular}{|l|}
-0.3129 \\
\end{tabular} & -0.1427 & \begin{tabular}{|l|}
-0.2772 \\
\end{tabular} & 1.2315 \\
\hline MnO & -0.1696 & 0.0497 & 0.0445 & -0.2826 & 0.8376 & 0.0060 & -0.0947 & -0.0586 & 0.0738 & -0.6472 \\
\hline $\mathrm{Na}_{2} \mathrm{O}$ & \begin{tabular}{|l|}
-0.1021 \\
\end{tabular} & 0.0788 & -0.1229 & 0.1902 & 0.0060 & 0.4220 & \begin{tabular}{|l|}
-0.1512 \\
\end{tabular} & 0.2000 & 0.1527 & -0.8784 \\
\hline $\mathrm{SiO}_{2}$ & -0.4522 & \begin{tabular}{|l|}
-0.0930 \\
\end{tabular} & -0.1478 & -0.3129 & -0.0947 & -0.1512 & 0.1885 & -0.0847 & \begin{tabular}{|l|}
-0.1658 \\
\end{tabular} & 1.0238 \\
\hline SrO & -0.2382 & 0.1113 & -0.0577 & -0.1427 & -0.0586 & 0.2000 & -0.0847 & 0.5793 & 0.1288 & -1.1857 \\
\hline $\mathrm{ThO}_{2}$ & 0.5242 & 0.1637 & 0.0252 & -0.2772 & 0.0738 & 0.1527 & \begin{tabular}{|l|}
-0.1658 \\
\end{tabular} & 0.1288 & 1.4073 & 0.3551 \\
\hline $\mathrm{UO}_{3}$ & \begin{tabular}{|l|}
-1.3483 \\
\end{tabular} & \begin{tabular}{|l|}
-0.5104 \\
\end{tabular} & -0.4104 & 1.2315 & -0.6472 & $\begin{array}{l}-0.8784 \\
\end{array}$ & 1.0238 & -1.1857 & 0.3551 & 48.7335 \\
\hline $\mathrm{ZnO}$ & -4.7045 & -1.3959 & -1.9826 & -1.0364 & -2.9733 & -3.8344 & 3.7386 & -2.7247 & -4.3971 & 11.5812 \\
\hline $\mathrm{ZrO}_{2}$ & 0.7517 & \begin{tabular}{|l|}
-0.1219 \\
\end{tabular} & 0.1398 & -0.2288 & 0.1534 & -0.1444 & \begin{tabular}{|l|}
-0.0775 \\
\end{tabular} & -0.1008 & \begin{tabular}{|c|}
-0.2701 \\
\end{tabular} & -1.3797 \\
\hline Others & -0.0425 & 0.0869 & -0.0036 & 0.0361 & 0.0310 & 0.0088 & \begin{tabular}{|l|}
-0.1102 \\
\end{tabular} & -0.1706 & 0.0578 & -1.6256 \\
\hline$\left(\mathrm{Al}_{2} \mathrm{O}_{3}\right)^{2}$ & -62.5624 & 1.3906 & 1.8865 & -2.6245 & 2.4101 & -0.1679 & 2.6787 & 1.3478 & \begin{tabular}{|l|l|}
-4.5698 \\
\end{tabular} & -1.2739 \\
\hline $\mathrm{Al}_{2} \mathbf{O}_{3} \times \mathrm{ZrO}_{2}$ & $\begin{array}{l}-19.4908 \\
\end{array}$ & 1.5599 & -0.8404 & -3.3939 & -1.0136 & 1.2381 & 1.0435 & 1.5540 & 1.8642 & 8.7683 \\
\hline $\mathrm{Fe}_{2} \mathrm{O}_{3} \times \mathrm{Li}_{2} \mathrm{O}$ & -4.0857 & 4.5515 & -18.9078 & -57.4722 & 3.2277 & 3.2498 & 0.8203 & 3.3051 & 3.7575 & -19.8178 \\
\hline $\mathrm{SiO}_{2} \times \mathrm{ZnO}$ & 8.8126 & 3.3084 & 4.7414 & 1.0993 & 7.5089 & 9.7430 & -9.2924 & 7.2633 & 11.0579 & -27.3463 \\
\hline $\mathrm{SiO}_{2} \times \mathrm{UO}_{3}$ & 3.7857 & 1.4113 & 1.1269 & -3.1089 & 1.6372 & 2.1986 & -2.6670 & 2.6122 & -1.6335 & -118.9243 \\
\hline
\end{tabular}

\begin{tabular}{|c|c|c|c|c|c|c|c|c|}
\hline Term & ZnO & $\mathrm{ZrO}_{2}$ & Others & $\left(\mathrm{Al}_{2} \mathrm{O}_{3}\right)^{2}$ & $\mathrm{Al}_{2} \mathrm{O}_{3} \times \mathrm{ZrO} \mathrm{O}_{2}$ & $\mathrm{Fe}_{2} \mathrm{O}_{3} \times \mathrm{Li}_{2} \mathrm{O}$ & $\mathrm{SiO}_{2} \times \mathrm{ZnO}$ & $\mathrm{SiO}_{2} \times \mathrm{UO}_{3}$ \\
\hline $\mathbf{A l}_{2} \mathbf{O}_{3}$ & -4.7045 & 0.7517 & -0.0425 & -62.5624 & -19.4908 & -4.0857 & 8.8126 & 3.7857 \\
\hline $\mathbf{B}_{2} \mathbf{O}_{3}$ & -1.3959 & -0.1219 & 0.0869 & 1.3906 & 1.5599 & 4.5515 & 3.3084 & 1.4113 \\
\hline $\mathrm{Fe}_{2} \mathrm{O}_{3}$ & -1.9826 & 0.1398 & -0.0036 & 1.8865 & -0.8404 & -18.9078 & 4.7414 & 1.1269 \\
\hline $\mathrm{Li}_{2} \mathrm{O}$ & -1.0364 & -0.2288 & 0.0361 & -2.6245 & $\begin{array}{l}-3.3939 \\
\end{array}$ & -57.4722 & 1.0993 & -3.1089 \\
\hline MnO & -2.9733 & 0.1534 & 0.0310 & 2.4101 & -1.0136 & 3.2277 & 7.5089 & 1.6372 \\
\hline $\mathrm{Na}_{2} \mathrm{O}$ & -3.8344 & -0.1444 & 0.0088 & -0.1679 & 1.2381 & 3.2498 & 9.7430 & 2.1986 \\
\hline $\mathrm{SiO}_{2}$ & 3.7386 & -0.0775 & -0.1102 & 2.6787 & 1.0435 & 0.8203 & -9.2924 & -2.6670 \\
\hline SrO & -2.7247 & -0.1008 & -0.1706 & 1.3478 & 1.5540 & 3.3051 & 7.2633 & 2.6122 \\
\hline $\mathrm{ThO}_{2}$ & -4.3971 & -0.2701 & 0.0578 & -4.5698 & 1.8642 & 3.7575 & 11.0579 & -1.6335 \\
\hline $\mathbf{U O}_{3}$ & 11.5812 & -1.3797 & -1.6256 & $\begin{array}{l}-1.2739 \\
\end{array}$ & 8.7683 & -19.8178 & -27.3463 & -118.9243 \\
\hline ZnO & 163.4296 & -2.7961 & -3.2960 & 14.1083 & 20.3726 & -17.9160 & -395.3236 & -29.9360 \\
\hline $\mathrm{ZrO}_{2}$ & -2.7961 & 1.4752 & -0.0081 & 0.4867 & -18.1050 & -0.3696 & 5.9509 & 2.8486 \\
\hline Others & -3.2960 & -0.0081 & 1.2058 & -0.9616 & 0.4528 & 0.0086 & 7.2361 & 3.7886 \\
\hline$\left(\mathrm{Al}_{2} \mathrm{O}_{3}\right)^{2}$ & 14.1083 & 0.4867 & -0.9616 & 467.6615 & 58.9902 & 32.4175 & -17.9420 & -0.6660 \\
\hline $\mathrm{Al}_{2} \mathrm{O}_{3} \times \mathrm{ZrO}_{2}$ & 20.3726 & -18.1050 & 0.4528 & 58.9902 & 341.7350 & 51.8237 & -31.8149 & -16.0606 \\
\hline $\mathrm{Fe}_{2} \mathrm{O}_{3} \times \mathrm{Li}_{2} \mathrm{O}$ & -17.9160 & -0.3696 & 0.0086 & 32.4175 & 51.8237 & 697.4878 & 59.1573 & 53.8727 \\
\hline $\mathrm{SiO}_{2} \times \mathrm{ZnO}$ & $\begin{array}{l}-395.3236 \\
\end{array}$ & 5.9509 & 7.2361 & -17.9420 & -31.8149 & 59.1573 & 976.7308 & 70.9144 \\
\hline $\mathrm{SiO}_{2} \times \mathrm{UO}_{3}$ & -29.9360 & 2.8486 & 3.7886 & $\begin{array}{l}-0.6660 \\
\end{array}$ & -16.0606 & 53.8727 & 70.9144 & 297.3792 \\
\hline
\end{tabular}


The Catholic University of America Vitreous State Laboratory
IHLW PCT, Spinel $T_{1 \%}$, Electrical Conductivity, and Viscosity Model Development

Final Report, VSL-07R1240-1, Rev. 0

Table D.9. Variance-Covariance Matrix Associated With the Estimated Coefficients of the 15-Term Partial Quadratic Mixture Model for $\ln (\mathrm{PCT}-\mathrm{Na}, \mathrm{g} / \mathrm{L})$ of HLW Glasses.

\begin{tabular}{|c|c|c|c|c|c|c|c|c|c|c|}
\hline Term & $\mathbf{A l}_{2} \mathbf{O}_{3}$ & $\mathbf{B}_{2} \mathbf{O}_{3}$ & $\mathrm{Fe}_{2} \mathrm{O}_{3}$ & $\mathbf{L i}_{2} \mathbf{O}$ & MnO & $\mathrm{Na}_{2} \mathrm{O}$ & $\mathrm{SiO}_{2}$ & SrO & $\mathrm{ThO}_{2}$ & $\mathbf{U O}_{3}$ \\
\hline $\mathbf{A l}_{2} \mathbf{O}_{3}$ & 10.4882 & -0.3625 & -0.3359 & -0.3006 & -0.2632 & -0.2155 & -0.3828 & \begin{tabular}{|l|}
-0.3523 \\
\end{tabular} & 0.5468 & 0.1948 \\
\hline $\mathrm{B}_{2} \mathrm{O}_{3}$ & -0.3625 & 0.4319 & -0.0082 & 0.1023 & 0.0048 & 0.0289 & -0.0733 & 0.0724 & 0.1316 & 0.0467 \\
\hline $\mathrm{Fe}_{2} \mathrm{O}_{3}$ & .3359 & 0082 & 0.4342 & 1496 & 0895 & 1219 & -0.0560 & -0.0318 & 0.0880 & .0950 \\
\hline $\mathrm{Li}_{2} \mathbf{O}$ & -0.3006 & 0.1023 & $\begin{array}{l}-0.1496 \\
\end{array}$ & 2.1457 & -0.0734 & 0.4535 & -0.2075 & 0.0925 & -0.0288 & 0.1442 \\
\hline MnO & -0.2632 & 0.0048 & 0.0895 & -0.0734 & 0.8781 & -0.0958 & -0.0256 & \begin{tabular}{|l|}
-0.1510 \\
\end{tabular} & -0.0176 & -0.0072 \\
\hline $\mathrm{Na}_{2} \mathrm{O}$ & 2155 & 0.0289 & -0.1219 & 0.4535 & -0.0958 & 0.3540 & -0.0623 & $\overline{0.1}$ & 0.0487 & 0.0169 \\
\hline $\mathrm{SiO}_{2}$ & -0.3828 & -0.0733 & -0.0560 & -0.2075 & -0.0256 & -0.0623 & 0.0942 & \begin{tabular}{|l|}
-0.0088 \\
\end{tabular} & -0.0986 & -0.0434 \\
\hline SrO & -0.3523 & 0.0724 & -0.0318 & 0.0925 & -0.1510 & 0.1239 & -0.0088 & 0.5745 & 0.0586 & -0.1768 \\
\hline ThC & 4468 & 0.1 & & -0.0288 & -0.0176 & 0.0487 & -0.0986 & 0.0586 & 1.4260 & -0.3655 \\
\hline $\mathbf{U O}_{3}$ & 1948 & 0.0467 & 0.0950 & 0.1442 & -0.0072 & -0.0169 & -0.0434 & \begin{tabular}{|l|}
-0.1768 \\
\end{tabular} & -0.3655 & 1.3408 \\
\hline $\mathrm{ZnO}$ & -1.2352 & -0.1029 & 0.1324 & -0.0990 & 0.0538 & 0.1070 & -0.0533 & 0.2305 & 0.0417 & 0.0045 \\
\hline $\mathrm{ZrO}_{2}$ & 0.7606 & -0.1660 & 0.0829 & -0.3484 & 0.1180 & -0.2431 & -0.0018 & \begin{tabular}{|l|}
-0.1813 \\
\end{tabular} & -0.3572 & -0.2789 \\
\hline Other & .1723 & 0.0633 & -0.0862 & -0.0209 & -0.0379 & -0.0877 & -0.0191 & \begin{tabular}{|l|}
-0.2799 \\
\end{tabular} & 0.0092 & -0.1316 \\
\hline$\left(\mathrm{Al}_{2} \mathrm{O}_{3}\right)^{2}$ & -71.2559 & 1.4290 & 3.3400 & 0.2057 & 2.7738 & -0.1254 & 2.7840 & 1.5526 & -5.1954 & -1.8379 \\
\hline $\mathrm{Al}_{2} \mathrm{O}_{3} \times \mathrm{ZrO}_{2}$ & -21.3622 & 1.5855 & 1.0686 & 1.3243 & -1.0654 & 1.6378 & 0.5803 & 1.9297 & 2.0902 & 2.5655 \\
\hline
\end{tabular}

\begin{tabular}{|c|c|c|c|c|c|}
\hline Term & $\mathrm{ZnO}$ & $\mathrm{ZrO}_{2}$ & \begin{tabular}{|l|} 
Others \\
\end{tabular} & $\left(\mathrm{Al}_{2} \mathrm{O}_{3}\right)^{2}$ & $\mathrm{Al}_{2} \mathrm{O}_{3} \times \mathrm{ZrO}_{2}$ \\
\hline $\mathbf{A l}_{2} \mathbf{O}_{3}$ & -1.2352 & 0.7606 & \begin{tabular}{|l|}
-0.1723 \\
\end{tabular} & -71.2559 & -21.3622 \\
\hline $\mathbf{B}_{2} \mathbf{O}_{3}$ & -0.1029 & -0.1660 & 0.0633 & 1.4290 & 1.5855 \\
\hline $\mathrm{Fe}_{2} \mathrm{O}_{3}$ & 0.1324 & 0.0829 & \begin{tabular}{|l|}
-0.0862 \\
\end{tabular} & 3.3400 & 1.0686 \\
\hline $\mathrm{Li}_{2} \mathbf{O}$ & -0.0990 & -0.3484 & \begin{tabular}{|l|}
-0.0209 \\
\end{tabular} & 0.2057 & 1.3243 \\
\hline MnO & 0.0538 & 0.1180 & \begin{tabular}{|l|}
-0.0379 \\
\end{tabular} & 2.7738 & -1.0654 \\
\hline $\mathrm{Na}_{2} \mathrm{O}$ & 0.1070 & -0.2431 & \begin{tabular}{|l|}
-0.0877 \\
\end{tabular} & -0.1254 & 1.6378 \\
\hline $\mathrm{SiO}_{2}$ & -0.0533 & $\begin{array}{l}-0.0018 \\
\end{array}$ & \begin{tabular}{|l|}
-0.0191 \\
\end{tabular} & 2.7840 & 0.5803 \\
\hline SrO & 0.2305 & -0.1813 & \begin{tabular}{|l|}
-0.2799 \\
\end{tabular} & 1.5526 & 1.9297 \\
\hline $\mathrm{ThO}_{2}$ & 0.0417 & -0.3572 & 0.0092 & -5.1954 & 2.0902 \\
\hline $\mathbf{U O}_{3}$ & 0.0045 & -0.2789 & \begin{tabular}{|l|}
-0.1316 \\
\end{tabular} & -1.8379 & 2.5655 \\
\hline ZnO & 3.8562 & -0.4206 & \begin{tabular}{|l|}
-0.3949 \\
\end{tabular} & 7.5035 & 7.9417 \\
\hline $\mathrm{ZrO}_{2}$ & -0.4206 & 1.6246 & \begin{tabular}{|l|}
-0.0926 \\
\end{tabular} & 0.7409 & -20.2961 \\
\hline Others & -0.3949 & -0.0926 & 1.2775 & -0.9032 & 1.0576 \\
\hline$\left(\mathrm{Al}_{2} \mathrm{O}_{3}\right)^{2}$ & 7.5035 & 0.7409 & \begin{tabular}{|l|}
-0.9032 \\
\end{tabular} & 533.8824 & 63.8584 \\
\hline $\mathrm{Al}_{2} \mathbf{O}_{3} \times \mathrm{ZrO}_{2}$ & 7.9417 & -20.2961 & 1.0576 & 63.8584 & 384.5749 \\
\hline
\end{tabular}


The Catholic University of America Vitreous State Laboratory
IHLW PCT, Spinel $T_{1 \%}$, Electrical Conductivity, and Viscosity Model Development

Final Report, VSL-07R1240-1, Rev. 0

\section{Table D.10. Variance-Covariance Matrix Associated With the Estimated Coefficients of the 15-Component Reduced Linear Mixture Model for Spinel $T_{1 \%}\left({ }^{\circ} \mathrm{C}\right)$ of HLW Glasses.}

\begin{tabular}{|c|c|c|c|c|c|c|c|c|}
\hline Term & $\mathrm{Al}_{2} \mathrm{O}_{3}$ & $\mathrm{~B}_{2} \mathbf{O}_{3}$ & $\mathrm{Cr}_{2} \mathrm{O}_{3}$ & $\mathrm{Fe}_{2} \mathrm{O}_{3}$ & $\mathbf{L i}_{2} \mathbf{O}$ & $\mathrm{MnO}$ & $\mathrm{Na}_{2} \mathrm{O}$ & $\mathrm{NiO}$ \\
\hline $\mathrm{Al}_{2} \mathrm{O}_{3}$ & 33719.811 & -7054.649 & 58012.597 & 10665.722 & -9114.130 & 4980.235 & -11833.658 & 16957.221 \\
\hline $\mathrm{B}_{2} \mathrm{O}_{3}$ & -7054.649 & 19266.943 & -36625.186 & -3385.374 & 4182.118 & 368.739 & 1801.138 & 20008.045 \\
\hline $\mathrm{Cr}_{2} \mathrm{O}_{3}$ & 8012.597 & -36625.186 & 486488.289 & 71119.632 & 13107.055 & 185541.258 & -81899.491 & -805792.254 \\
\hline $\mathrm{Fe}_{2} \mathrm{O}_{3}$ & 10665.722 & -338 & 7111 & 27646.432 & 10724 & 342 & $-10 t$ & -10 \\
\hline $\mathbf{L i}_{2} \mathbf{O}$ & -9114.130 & 4182.118 & 13107.055 & -10724.082 & 02701.463 & -6532.730 & 2280 & 669 \\
\hline & 4980.235 & 368.739 & 85541.258 & 3421.870 & -6532.730 & 48750.271 & -342 & -13049.248 \\
\hline & & 8 & -818 & 10 & 228 & -34 & & .691 \\
\hline $\mathrm{Ni}$ & 16957.221 & 45 & 80579 & -10758.437 & -4138 & -13049.248 & -487 & 1969654.034 \\
\hline $\mathrm{SiO}_{2}$ & -1480.807 & -2956.774 & -16892.546 & -4420.695 & -9553.807 & -1546.687 & -212 & 319.527 \\
\hline $\mathrm{Sr}$ & -6695.693 & 4825.755 & 19562.671 & -6427.120 & 10061.227 & -15010.432 & 669 & -25849.579 \\
\hline $\mathrm{ThO}_{2}$ & 5937.989 & 1869.295 & -45752.425 & 18631.883 & -10220.461 & 998 & 16 & -34363.273 \\
\hline $\mathrm{UO}_{3}$ & -7116.075 & 5538.801 & -225120.072 & -5628.435 & -157.388 & 3595.674 & 31.858 & 69119.606 \\
\hline $\mathrm{ZnO}$ & 5503.653 & -8467.127 & 405902.261 & 4250.750 & -8408.605 & -9332.427 & -697.209 & 50734.163 \\
\hline $\mathrm{ZrO}_{2}$ & 12331.674 & -8199.117 & 136029.551 & 10741.676 & -17007.435 & -2417.058 & -12087.890 & -28974.618 \\
\hline Others & -21466.733 & 2439.855 & -198773.807 & -3094.752 & 4322.862 & 3056.568 & 666.388 & -64768.874 \\
\hline
\end{tabular}

\begin{tabular}{|c|c|c|c|c|c|c|c|}
\hline Term & $\mathrm{SiO}_{2}$ & SrO & $\mathrm{ThO}_{2}$ & $\mathbf{U O}_{3}$ & $\mathrm{ZnO}$ & $\mathrm{ZrO}_{2}$ & Others \\
\hline $\mathrm{Al}_{2} \mathrm{O}_{3}$ & -1480.807 & -6695.693 & 5937.989 & -7116.075 & 5503.653 & 12331.674 & -21466.733 \\
\hline $\mathrm{B}_{2} \mathrm{O}_{3}$ & -2956.774 & 4825.755 & 1869.295 & 5538.801 & -8467.127 & -8199.117 & 2439.855 \\
\hline $\mathrm{Cr}_{2} \mathrm{O}_{3}$ & -16892.546 & 19562.671 & -45752.425 & -225120.072 & 405902.261 & 136029.551 & -198773.807 \\
\hline $\mathrm{Fe}_{2} \mathrm{O}_{3}$ & -4420.695 & -6427.120 & 18631.883 & -5628.435 & 4250.750 & 10741.676 & -3094.752 \\
\hline $\mathrm{Li}_{2} \mathbf{O}$ & -9553.807 & 10061.227 & -10220.461 & -157.388 & -8408.605 & -17007.435 & 4322.862 \\
\hline MnO & -1546.687 & -15010.432 & 9984.001 & 3595.674 & -9332.427 & -2417.058 & 3056.568 \\
\hline $\mathrm{Na}_{2} \mathrm{O}$ & -2126.817 & 8667.669 & 905.116 & 31.858 & -697.209 & -12087.890 & 666.388 \\
\hline $\mathrm{NiO}$ & 319.527 & -25849.579 & -34363.273 & 69119.606 & 50734.163 & -28974.618 & -64768.874 \\
\hline $\mathrm{SiO}_{2}$ & 3971.703 & -1784.319 & -6065.526 & 2032.734 & -5123.238 & -147.945 & -1387.375 \\
\hline SrO & -1784.319 & 35037.598 & -514.756 & -8152.284 & 7981.222 & -5677.527 & -4198.373 \\
\hline $\mathrm{ThO}_{2}$ & -6065.526 & -514.756 & 109424.393 & -33704.168 & -1166.701 & -10026.835 & -2065.870 \\
\hline $\mathrm{UO}_{3}$ & 2032.734 & -8152.284 & -33704.168 & 76358.138 & -27782.101 & -10491.146 & 714.646 \\
\hline $\mathrm{ZnO}$ & -5123.238 & 7981.222 & -1166.701 & -27782.101 & 225742.778 & 6412.135 & -51350.068 \\
\hline $\mathrm{ZrO}_{2}$ & -147.945 & -5677.527 & -10026.835 & -10491.146 & 6412.135 & 43280.077 & -4399.767 \\
\hline Others & -1387.375 & -4198.373 & -2065.870 & 714.646 & -51350.068 & -4399.767 & 92960.634 \\
\hline
\end{tabular}


Table D.11. Variance-Covariance Matrix Associated With the Estimated Coefficients of the Recommended 20-Term Partial Quadratic Mixture Model for Spinel $\mathrm{T}_{1 \%}$ of HLW Glasses.

\begin{tabular}{|c|c|c|c|c|c|c|c|c|c|c|}
\hline Term & $\mathbf{A l}_{2} \mathbf{O}_{3}$ & $\mathbf{B}_{2} \mathbf{O}_{3}$ & $\mathrm{Cr}_{2} \mathrm{O}_{3}$ & $\mathrm{Fe}_{2} \mathrm{O}_{3}$ & $\mathrm{Li}_{2} \mathbf{O}$ & MnO & $\mathrm{Na}_{2} \mathrm{O}$ & $\mathrm{NiO}$ & $\mathrm{SiO}_{2}$ & SrO \\
\hline $\mathbf{A l}_{2} \mathbf{O}_{3}$ & 91071.269 & 73937.953 & 49965.589 & 73939.274 & 60517.858 & 32069.811 & 53888.252 & 174929.352 & -263291.592 & 80008.799 \\
\hline $\mathbf{B}_{2} \mathbf{O}_{3}$ & 73937.953 & 112222.385 & 39830.230 & 80696.259 & 78632.936 & 49405.767 & 88076.735 & 126775.554 & -328839.057 & 103374.151 \\
\hline $\mathrm{Cr}_{2} \mathrm{O}_{3}$ & 49965.589 & 39830.230 & 5971147.797 & 96639.646 & 31346.374 & -90152.235 & 36774.056 & -1157045.737 & -199895.706 & 41793.869 \\
\hline $\mathrm{Fe}_{2} \mathrm{O}_{3}$ & 73939.274 & 80696.259 & 96639.646 & 88062.262 & 60072.594 & 43558.100 & 64081.586 & 94867.526 & -277169.134 & 79811.395 \\
\hline $\mathbf{L i}_{2} \mathbf{O}$ & 60517.858 & 78632.936 & 31346.374 & 60072.594 & 238114.123 & 272769.808 & 108229.635 & 31374.568 & -289764.572 & 79932.918 \\
\hline MnO & 32069.811 & 49405.767 & -90152.235 & 43558.100 & 272769.808 & 786090.583 & 142719.504 & 82390.601 & -233355.794 & 14543.906 \\
\hline $\mathrm{Na}_{2} \mathrm{O}$ & 53888.252 & 88076.735 & 36774.056 & 64081.586 & 108229.635 & 142719.504 & 110224.886 & -32508.769 & -292095.910 & 85998.446 \\
\hline $\mathrm{NiO}$ & 174929.352 & 126775.554 & -1157045.737 & 94867.526 & 31374.568 & 82390.601 & -32508.769 & 4059214.991 & -421873.291 & 160501.037 \\
\hline $\mathrm{SiO}_{2}$ & -263291.592 & -328839.057 & -199895.706 & -277169.134 & -289764.572 & -233355.794 & -292095.910 & -421873.291 & 1088850.978 & -330804.932 \\
\hline SrO & 80008.799 & 103374.151 & 41793.869 & 79811.395 & 79932.918 & 14543.906 & 85998.446 & 160501.037 & -330804.932 & 129475.928 \\
\hline $\mathrm{ThO}_{2}$ & 73301.555 & 91382.287 & 52139.625 & 87782.785 & 53992.488 & 22513.691 & 77012.274 & 25470.831 & -297240.805 & 88580.126 \\
\hline $\mathrm{UO}_{3}$ & 80257.291 & 104712.887 & -114460.870 & 81484.151 & 73026.917 & 22574.032 & 79479.121 & 234655.007 & -331517.538 & 100907.272 \\
\hline $\mathrm{ZnO}$ & 76313.904 & 83331.676 & 325770.447 & 78229.542 & 65333.679 & 19311.638 & 72687.741 & 123057.158 & -297149.934 & 95897.053 \\
\hline $\mathrm{ZrO}_{2}$ & 101810.022 & 122465.709 & 319023.197 & 120133.068 & 98082.983 & 12940.883 & 94618.764 & -59540.054 & -426162.250 & 107687.250 \\
\hline Others & 40011.399 & 73441.055 & -72520.831 & 56971.704 & 52157.622 & 34637.538 & 65918.613 & -4299.289 & -233973.903 & 68311.388 \\
\hline$\left(\mathrm{ZrO}_{2}\right)^{2}$ & -208552.164 & -467305.631 & -2605490.555 & -460722.490 & -392707.297 & 454956.750 & -332246.745 & 2528790.464 & 1559333.325 & -194296.669 \\
\hline $\mathrm{MnO} \times \mathrm{Na}_{2} \mathrm{O}$ & 417508.895 & 238448.740 & -913188.994 & 242318.154 & -743866.498 & -3495303.097 & -485532.328 & 2910961.856 & -589583.674 & 484871.910 \\
\hline $\mathrm{Li}_{2} \mathrm{O} \times \mathbf{M n O}$ & 298794.677 & 677547.096 & 1550185.824 & 440383.039 & -3341594.731 & -8020322.269 & -354713.905 & 1556084.423 & -1060529.532 & 765764.515 \\
\hline $\mathrm{MnO} \times \mathrm{NiO}$ & -2727716.128 & -1714759.757 & 14987897.173 & -1480536.320 & -372771.504 & -5389277.420 & 288981.759 & -71381715.604 & 6819006.166 & -2911295.222 \\
\hline$\left(\mathrm{SiO}_{2}\right)^{2}$ & 388094.416 & 482324.784 & 271092.646 & 404534.882 & 404890.235 & 306334.019 & 423121.850 & 645872.140 & -1599248.273 & 488327.678 \\
\hline
\end{tabular}


Table D.11. Variance-Covariance Matrix Associated With the Estimated Coefficients of the Recommended 20-Term Partial Quadratic Mixture Model for Spinel T $_{1 \%}$ of HLW Glasses (continued).

\begin{tabular}{|c|c|c|c|c|c|c|c|c|c|c|}
\hline Term & $\mathrm{ThO}_{2}$ & $\mathrm{UO}_{3}$ & $\mathrm{ZnO}$ & $\mathrm{ZrO}_{2}$ & Others & $\left(\mathrm{ZrO}_{2}\right)^{2}$ & $\mathrm{MnO} \times \mathrm{Na}_{2} \mathrm{O}$ & $\mathrm{Li}_{2} \mathrm{O} \times \mathrm{MnO}$ & $\mathrm{MnO} \times \mathrm{NiO}$ & $\left(\mathrm{SiO}_{2}\right)^{2}$ \\
\hline $\mathbf{A l}_{2} \mathbf{O}_{3}$ & 73301.555 & 80257.291 & 76313.904 & 101810.022 & 40011.399 & -208552.164 & 417508.895 & 298794.677 & -2727716.128 & 388094.416 \\
\hline $\mathbf{B}_{2} \mathbf{O}_{3}$ & 91382.287 & 104712.887 & 83331.676 & 122465.709 & 73441.055 & -467305.631 & 238448.740 & 677547.096 & -1714759.757 & 482324.784 \\
\hline$\overline{\mathrm{Cr}_{2} \mathrm{O}_{3}}$ & 52139.625 & -114460.870 & 325770.447 & 319023.197 & -72520.831 & -2605490.555 & -913188.994 & 1550185.824 & 14987897.173 & 271092.646 \\
\hline $\mathrm{Fe}_{2} \mathrm{O}_{3}$ & 87782.785 & 81484.151 & 78229.542 & 120133.068 & 56971.704 & -460722.490 & 242318.154 & 440383.039 & -1480536.320 & 404534.882 \\
\hline MnO & 22513.691 & 22574.032 & 19311.638 & 12940.883 & 34637.538 & 454956.750 & -3495303.097 & -8020322.269 & -5389277.420 & 306334.019 \\
\hline $\mathrm{Na}_{2} \mathrm{O}$ & 77012.274 & 79479.121 & 72687.741 & 94618.764 & 65918.613 & -332246.745 & -485532.328 & 3.905 & 288981.759 & 850 \\
\hline $\mathrm{NiO}$ & 25470.831 & 234655.007 & 12305 & -59540.054 & -4299.289 & 2528790.464 & 61.856 & 4.423 & 15.604 & 2.140 \\
\hline $\mathrm{SiO}_{2}$ & 297240.805 & -331517.538 & -297149.934 & -426162.250 & -233973.903 & 1559333.325 & -589583.674 & -1060529.532 & 6.166 & -1599248.273 \\
\hline SrO & 88580.126 & 100907.272 & 95897.053 & 107687.250 & 68311.388 & -194296.669 & 484871.910 & 765764.515 & -2911295.222 & 488327.678 \\
\hline $\mathrm{ThO}_{2}$ & 158015.148 & 68655.545 & 81890.682 & 133196.672 & 64007.993 & -762787.654 & 310530.512 & 926655.090 & -43125.632 & 433317.388 \\
\hline $\mathrm{UO}_{3}$ & 68655.545 & 158187.249 & 74060.833 & 120810.137 & 71377.957 & -403636.794 & 533202.474 & 824327.043 & -3216858.527 & 493208.869 \\
\hline $\mathrm{ZnO}$ & 81890.682 & 74060.833 & 232696.385 & 138032.710 & 28673.526 & -653492.760 & 377552.874 & 530945.175 & -802733.181 & 433849.570 \\
\hline $\mathrm{ZrO}_{2}$ & 133196.672 & 120810.137 & 138032.710 & 432448.307 & 81645.978 & -3853221.469 & 624532.180 & 41.606 & 7720.119 & 625728.386 \\
\hline Other & 6400 & 71377.957 & 2867 & 81645.978 & 11528 & -257 & 5.727 & 1.046 & 159.804 & 343872.087 \\
\hline$\left(\mathrm{ZrO}_{2}\right)^{2}$ & -762787.654 & -403636.794 & -653492.760 & -3853221.469 & -257807.719 & 46991860.827 & -3863109.294 & -7084411.401 & -69478634.452 & -2259873.815 \\
\hline $\mathrm{MnO} \times \mathrm{Na}_{2} \mathrm{O}$ & 310530.512 & 533202.474 & 377552.874 & 624532.180 & 90855.727 & -3863109.294 & 24286548.558 & 34241522.289 & -43243496.782 & 1067679.310 \\
\hline $\mathrm{Li}_{2} \mathbf{O} \times \mathbf{M n O}$ & 926655.090 & 824327.043 & 530945.175 & 844541.606 & 664521.046 & -7084411.401 & 34241522.289 & 137950967.499 & -39128224.321 & 2021560.536 \\
\hline $\mathrm{MnO} \times \mathrm{NiO}$ & -43125.632 & -3216858.527 & -802733.181 & 2870720.119 & -260159.804 & -69478634.452 & -43243496.782 & -39128224.321 & 1949580096.286 & -10514377.302 \\
\hline$\left(\mathrm{SiO}_{2}\right)^{2}$ & 433317.388 & 493208.869 & 433849.570 & 625728.386 & 343872.087 & -2259873.815 & 1067679.310 & 2021560.536 & -10514377.302 & 2356704.709 \\
\hline
\end{tabular}


Table D.12. Variance-Covariance Matrix Associated With the Estimated Coefficients of the Second-Choice 20-Term Partial Quadratic Mixture Model for Spinel $\mathrm{T}_{1 \%}$ of HLW Glasses.

\begin{tabular}{|c|c|c|c|c|c|c|c|c|c|c|}
\hline Term & $\mathrm{Al}_{2} \mathrm{O}_{3}$ & $\mathrm{~B}_{2} \mathrm{O}_{3}$ & $\mathrm{Cr}_{2} \mathrm{O}_{3}$ & $\mathrm{Fe}_{2} \mathrm{O}_{3}$ & $\mathbf{L i}_{2} \mathbf{O}$ & MnO & $\mathrm{Na}_{2} \mathrm{O}$ & $\mathrm{NiO}$ & $\mathrm{SiO}_{2}$ & SrO \\
\hline $\mathbf{A l}_{2} \mathbf{O}_{3}$ & 68722.443 & 4316.857 & -1213273.392 & 16247.491 & 5280.488 & 28241.623 & -101381.032 & 52689.913 & -17228.546 & 7081.215 \\
\hline $\mathbf{B}_{2} \mathbf{O}_{3}$ & 4316.857 & 23017.434 & -342009.810 & 4559.263 & 2802.656 & -14954.669 & -57500.244 & 25416.169 & -12071.384 & 12214.390 \\
\hline $\mathrm{Cr}_{2} \mathrm{O}_{3}$ & 213273.392 & 342009.810 & 342790674.382 & -572705.730 & -609132.633 & 1077955.031 & -1777486.544 & -2124588.128 & 578794.725 & -492760.599 \\
\hline $\mathrm{Fe}_{2} \mathrm{O}_{3}$ & 16247.491 & 4559.263 & -572705.730 & 26023.368 & -3842.080 & -10268.816 & -51182.480 & 8403.980 & -11313.816 & 3238.970 \\
\hline $\mathbf{L i}_{2} \mathbf{O}$ & 5280.488 & 2802.656 & -609132.633 & -3842.080 & 188541.009 & 243050.045 & -14749.564 & -16874.270 & -25952.007 & 3683.687 \\
\hline MnO & 28241.623 & -14954.669 & -1077955.031 & -10268.816 & 243050.045 & 892960.381 & 68298.140 & -164205.198 & -35606.819 & -62361.483 \\
\hline $\mathrm{Na}_{2} \mathrm{O}$ & 101381.032 & -57500.244 & -1777486.544 & -51182.480 & -14749.564 & 68298.140 & 510656.037 & -163625.007 & 68826.995 & -55851.875 \\
\hline $\mathrm{NiO}$ & 52689.913 & 25416.169 & -2124588.128 & 8403.980 & -16874.270 & -164205.198 & -163625.007 & 1556865.187 & -12672.946 & 13231.780 \\
\hline $\mathrm{SiO}_{2}$ & 228.546 & -12071.384 & 578794.725 & -11313.816 & -25952.007 & -35606.819 & 68826.995 & -12672.946 & 17543.986 & -9780.737 \\
\hline SrO & & 12214.390 & -492760.599 & 3238.970 & 3683.687 & & -55851.875 & .780 & -9780.737 & 37263.702 \\
\hline $\mathrm{ThO}_{2}$ & & & 909 & 241 & -2045 & & .479 & -214 & -7628.469 & 7.540 \\
\hline $\mathrm{UO}_{3}$ & 15025.630 & 200 & -16423 & 6406.260 & -1284.030 & -42907.903 & 1.716 & 88419.769 & -10571.715 & 8854.467 \\
\hline ZnO & & & 350 & 346 & & & 644 & & -10859.253 & 16507.408 \\
\hline $\mathrm{ZrO}_{2}$ & 70 & 82 & -677 & 411 & -348 & & -578 & 598 & -8999.008 & .917 \\
\hline Others & 10799.699 & 14115.545 & -1502481.555 & 7274.101 & 2988.049 & 481 & -75509.350 & -37023.105 & -16852.083 & 7272.145 \\
\hline $\mathrm{Cr}_{2} \mathrm{O}_{3} \times \mathrm{SiO}_{2}$ & 2796619.167 & 756780.698 & -786431837.942 & 1459805.782 & 1359326.822 & 2167615.505 & 4145963.241 & 3366216.660 & 1376359.776 & 1166442.619 \\
\hline $\mathrm{Al}_{2} \mathrm{O}_{3} \times \mathrm{MnO}$ & -861217.848 & 43321.363 & 14032499.641 & 55262.790 & -20633.622 & -1758935.186 & 387943.174 & 65791.964 & 95470.044 & 90100.422 \\
\hline $\mathrm{MnO} \times \mathrm{Na}_{2} \mathrm{O}$ & 329738.339 & 75698.302 & -10729819.712 & 107814.648 & -918979.304 & -3926354.758 & -865803.352 & 1461838.443 & 82089.137 & 344128.090 \\
\hline $\mathrm{Li}_{2} \mathrm{O} \times \mathrm{MnO}$ & -39506.185 & 309365.925 & 35007543.773 & 67276.174 & -3971809.004 & -8917237.521 & -1293425.909 & -114166.606 & 326016.470 & 394505.604 \\
\hline $\mathrm{Na}_{2} \mathrm{O} \times \mathrm{SiO}_{2}$ & 212919.152 & 154228.813 & 4803146.285 & 110411.485 & 134217.400 & 55277.321 & -1248956.366 & 228102.751 & -192905.032 & 142682.957 \\
\hline
\end{tabular}


Table D.12. Variance-Covariance Matrix Associated With the Estimated Coefficients of the Second-Choice 20-Term Partial Quadratic Mixture Model for Spinel T $_{1 \%}$ of HLW Glasses (continued).

\begin{tabular}{|c|c|c|c|c|c|c|c|c|c|c|}
\hline Term & $\mathrm{ThO}_{2}$ & $\mathrm{UO}_{3}$ & $\mathrm{ZnO}$ & $\mathrm{ZrO}_{2}$ & Others & $\mathrm{Cr}_{2} \mathrm{O}_{3} \times \mathrm{SiO}_{2}$ & $\mathrm{Al}_{2} \mathrm{O}_{3} \times \mathrm{MnO}$ & $\mathrm{MnO} \times \mathrm{Na}_{2} \mathrm{O}$ & $\mathrm{Li}_{2} \mathrm{O} \times \mathrm{MnO}$ & $\mathrm{Na}_{2} \mathrm{O} \times \mathrm{SiO}_{2}$ \\
\hline $\mathbf{A l}_{2} \mathbf{O}_{3}$ & 7445.309 & 15025.630 & 6037.332 & 23572.370 & 10799.699 & 2796619.167 & -861217.848 & 329738.339 & -39506.185 & 212919.152 \\
\hline $\mathbf{B}_{2} \mathbf{O}_{3}$ & 6624.545 & 14816.200 & 1804.184 & 602.782 & 14115.545 & 756780.698 & 43321.363 & 75698.302 & 309365.925 & 154228.813 \\
\hline $\mathrm{Cr}_{2} \mathrm{O}_{3}$ & 901417.909 & 642345.119 & 148923.350 & $\begin{array}{l}-677700.872 \\
\end{array}$ & 502481.555 & -786431837.942 & 14032499.641 & -10729819.712 & 35007543.773 & 4803146.285 \\
\hline $\mathrm{Fe}_{2} \mathrm{O}_{3}$ & 15773.241 & 6406.260 & 10196.346 & 14177.411 & 7274.101 & 1459805.782 & 55262.790 & 107814.648 & 67276.174 & 110411.485 \\
\hline MnO & -29555.482 & -42907.903 & -54827.841 & -9972.693 & 16369.481 & 2167615.505 & -1758935.186 & -3926354.758 & -8917237.521 & 55277.321 \\
\hline $\mathrm{Na}_{2} \mathrm{O}$ & -44748.479 & -69221.716 & -53303.644 & -57872.824 & & 4145963.241 & 387943.174 & $\begin{array}{l}-865803.352 \\
\end{array}$ & -12934 & -1248956.366 \\
\hline $\mathrm{NiO}$ & $-214 !$ & 769 & 633 & 372 & -37 & 3366 & & & -11 & 2.751 \\
\hline $\mathrm{SiO}_{2}$ & -7628.469 & -10571.715 & -10859.253 & -8999.008 & -16852.083 & -1376359.776 & 95470.044 & 82089.137 & 326016.470 & -192905.032 \\
\hline SrO & 4527.540 & 8854.467 & 16507.408 & 4751.917 & 2.145 & 1166442.619 & 0.422 & 344128.090 & 5.604 & 32.957 \\
\hline $\mathrm{ThO}_{2}$ & 86510.603 & -21018.503 & 3588.930 & -5709.355 & 3227.616 & -2170157.454 & 24824.162 & 127485.471 & 712384.307 & 112619.063 \\
\hline $\mathrm{UO}_{3}$ & -21018.503 & 75429.725 & -8653.763 & 4829.204 & 17657.818 & 3429665.338 & -48983.119 & 396148.796 & 329968.256 & 158389.348 \\
\hline $\mathrm{ZnO}$ & 3588.930 & -8653.763 & 174545.936 & 11475.060 & -32359.674 & 343580.678 & 361293.200 & 233094.290 & 166288.928 & 128058.845 \\
\hline $\mathrm{ZrO}_{2}$ & -5709.355 & 4829.204 & 11475.060 & 39450.189 & 7175.849 & 1774834.393 & -72449.300 & 191295.534 & -107880.802 & 116323.176 \\
\hline Others & 3227.616 & 17657.818 & -32359.674 & 7175.849 & 92785.758 & 3174330.751 & -414322.051 & 54233.484 & 393705.067 & 199652.293 \\
\hline $\mathrm{Cr}_{2} \mathrm{O}_{3} \times \mathrm{SiO}_{2}$ & 2170157.454 & 3429665.338 & 343580.678 & 1774834.393 & 3174330.751 & 1837822296.181 & -29713915.571 & 22835931.161 & -78671072.979 & 11325107.863 \\
\hline $\mathrm{Al}_{2} \mathrm{O}_{3} \times$ & 24824.162 & -48983.119 & 361293.200 & -72449.300 & -414322.051 & -29713915.571 & 29979906.691 & -296528.929 & -515764.079 & -657946.058 \\
\hline $\mathrm{MnO} \times \mathrm{Na}_{2} \mathrm{O}$ & 127485.471 & 396148.796 & 233094.290 & 191295.534 & 54233.484 & 22835931.161 & -296528.929 & 24820892.376 & 33883874.219 & 520329.245 \\
\hline $\mathbf{L i}_{2} \mathbf{O} \times$ & 712384.307 & 329968.256 & 166288.928 & -107880.802 & 3937 & -78671 & -5157 & 3388 & 149597444.423 & 1525282.971 \\
\hline $\mathrm{Na}_{2} \mathrm{O} \times \mathrm{SiO}_{2}$ & 112619.063 & 158389.348 & 128058.845 & 116323.176 & 199652.293 & -11325107.863 & -657946.058 & 520329.245 & 1525282.971 & 3274626.419 \\
\hline
\end{tabular}


Table D.13. Variance-Covariance Matrix Associated With the Estimated Coefficients of the 27-Term Truncated T2-Linear Mixture Model for In(Electrical Conductivity, S/cm) of HLW Glasses.

\begin{tabular}{|c|c|c|c|c|c|c|c|c|c|c|c|c|c|}
\hline Term & $\mathbf{A l}_{2} \mathbf{O}_{3}$ & $\mathbf{B}_{2} \mathbf{O}_{3}$ & $\mathrm{Fe}_{2} \mathrm{O}_{3}$ & $\mathbf{L i}_{2} \mathbf{O}$ & MgO & $\mathrm{MnO}$ & $\mathrm{Na}_{2} \mathrm{O}$ & $\mathrm{SiO}_{2}$ & SrO & $\mathrm{ThO}_{2}$ & $\mathrm{UO}_{3}$ & $\mathrm{ZnO}$ & $\mathrm{ZrO}_{2}$ \\
\hline $\mathbf{A l}_{2} \mathbf{O}_{3}$ & & -0.1418 & 0.1942 & -0.2830 & -0.1060 & 0.0567 & -0.1428 & & 0.0895 & & & 0.0504 & \\
\hline $\mathrm{B}_{2} \mathrm{O}_{3}$ & -0.1418 & 0.3409 & -0.0467 & 0.1200 & 2594 & 0.0055 & 0.0027 & .0545 & & 943 & 30 & & \\
\hline $\mathrm{Fe}_{2} \mathrm{O}_{3}$ & 1942 & -0.0467 & 0.4483 & -0.2509 & 0.4909 & 0.0508 & 0.1568 & 0.0633 & 0.0843 & 0.0893 & 0.0819 & 0.0259 & 548 \\
\hline $\mathbf{L i}_{2} \mathbf{O}$ & 2830 & 0.1200 & -0.2509 & 1.8724 & 0.2824 & 0.1072 & 0.3897 & 0.1384 & & & .1151 & -0.2609 & \\
\hline & & & & & 75.2 & & & & & & & & \\
\hline Mn & & 55 & & -0 . & 18 & & & 233 & & & 90 & 444 & \\
\hline $\mathrm{Na}_{2} \mathrm{O}$ & 28 & 0.0027 & -0.1 & 0.3897 & 22 & 0.0538 & & 419 & & & 0.0023 & 715 & 570 \\
\hline SiO & 134 & -0.0545 & -0.0633 & -0.1384 & 744 & 0.0233 & -0.0419 & 0.0624 & & 69 & 0.0372 & -0.0989 & 085 \\
\hline SrC & & 0.0402 & -0.0 & 0.1515 & 0.0825 & 47 & & 51 & & 97 & 69 & 84 & 310 \\
\hline Th & & & & 75 & & & & 69 & & & 80 & & \\
\hline $\mathrm{UO}_{3}$ & & & & & 39 & & & 772 & & & 59 & & \\
\hline $\mathrm{ZnO}$ & & -0.1344 & 0.0259 & -0.2609 & 74 & 44 & 15 & \begin{tabular}{|l|}
-0.0989 \\
\end{tabular} & & & 0.1590 & 732 & 699 \\
\hline $\mathrm{ZrO}_{2}$ & & 20 & 48 & -0.2 & 69 & 01 & & 0.0085 & & & 05 & & \\
\hline Otl & & & & & & & & & & & & & \\
\hline $\mathbf{A l}_{2}$ & & & & & & & & & & & 34 & & \\
\hline $\mathbf{B}_{2} \mathbf{O}_{3} /$ & 947 & -0.2264 & 283 & -0.0771 & 023 & \begin{tabular}{|l|}
-0.0043 \\
\end{tabular} & 26 & 363 & 75 & 34 & 95 & 344 & 550 \\
\hline $\mathrm{Fe}_{2} \mathrm{O}$ & 280 & 0.0283 & -0.2939 & 0.1676 & 0.0034 & -0.0312 & & 0421 & 547 & 502 & 559 & 997 & 029 \\
\hline & & -0.0771 & & & & & & & & & & & \\
\hline Mn & & & & 703 & & 17 & & 0.0157 & & -0. & 83 & & \\
\hline $\mathrm{Na}_{2} \mathrm{C}$ & 947 & -0.0026 & 0.1041 & -0.2622 & -0.0051 & \begin{tabular}{|l|}
0.0357 \\
\end{tabular} & 994 & 0.0285 & 393 & 044 & 023 & 084 & 222 \\
\hline $\mathrm{SiO}_{2} /$ & .0085 & 0.0363 & 0.0421 & 0.0918 & 0.0017 & 0.0157 & 0.0285 & \begin{tabular}{|l|}
-0.0414 \\
\end{tabular} & 035 & 379 & 0.0242 & 0.0664 & -0.0059 \\
\hline $\mathrm{SrO} /$ & 0609 & -0.0275 & 0.0547 & -0.1019 & .0013 & 0.0893 & \begin{tabular}{|l|}
-0.0893 \\
\end{tabular} & 0.0035 & 498 & -0.0475 & 0.1316 & -0.0955 & 0.0539 \\
\hline $\mathrm{ThO}_{2}$ & -0.0161 & -0.0634 & -0.0602 & 0.0482 & 20 & -0.0218 & 044 & 0.0379 & 475 & -0.8164 & 0.3272 & 109 & 0.1060 \\
\hline $\mathbf{U O}_{3} / \mathbf{(}$ & -0.0134 & -0.0195 & -0.0559 & -0.0741 & 0.0024 & -0.0184 & -0.0023 & 0.0242 & & 0.3272 & -0.8157 & -0.1117 & 0.0632 \\
\hline $\mathrm{ZnO} /$ & -0.0345 & 0.0844 & -0.0096 & 0.1659 & -0.0106 & \begin{tabular}{|l|}
0.0373 \\
\end{tabular} & \begin{tabular}{|l|}
-0.1085 \\
\end{tabular} & 0.0665 & -0.0956 & -0.0108 & -0.1117 & -2.3239 & 0.0407 \\
\hline $\mathrm{ZrO}_{2} /$ & .0874 & 0.0549 & -0.1029 & 0.1841 & -0.0023 & 0.0083 & 0.1023 & \begin{tabular}{|l|}
-0.0059 \\
\end{tabular} & 0.0539 & 0.1060 & 0.0632 & 0.0409 & -0.3218 \\
\hline Others/(T/1000) $)^{2}$ & 0.1357 & -0.0489 & 0.0375 & 0.0885 & -0.0248 & 0.0289 & 0.1188 & 0.0345 & 0.2772 & -0.0154 & 0.0806 & 0.2296 & 0.0430 \\
\hline
\end{tabular}


Table D.13. Variance-Covariance Matrix Associated With the Estimated Coefficients of the 27-Term Truncated T2-Linear Mixture Model for $\ln ($ Electrical Conductivity, S/cm) of HLW Glasses (continued).

\begin{tabular}{|c|c|c|c|c|c|c|c|}
\hline Term & \begin{tabular}{|l|} 
Others \\
\end{tabular} & $\mathrm{Al}_{2} \mathrm{O}_{3} /(T / 1000)^{2}$ & $\mathrm{~B}_{2} \mathrm{O}_{3} /(\mathrm{T} / 1000)^{2}$ & $\mathrm{Fe}_{2} \mathrm{O}_{3} /(\mathrm{T} / 1000)^{2}$ & $\mathrm{Li}_{2} \mathrm{O} /(T / 1000)^{2}$ & $\mathrm{MnO} /(\mathrm{T} / 1000)^{2}$ & $\mathrm{Na}_{2} \mathrm{O} /(\mathrm{T} / 1000)^{2}$ \\
\hline $\mathrm{Al}_{2} \mathrm{O}_{3}$ & -0.2016 & -0.3273 & 0.0947 & -0.1280 & 0.1874 & -0.0355 & 0.0947 \\
\hline $\mathrm{B}_{2} \mathrm{O}_{3}$ & 0.0742 & 0.0947 & -0.2264 & 0.0283 & -0.0771 & -0.0043 & -0.0026 \\
\hline $\mathrm{Fe}_{2} \mathrm{O}_{3}$ & -0.0541 & -0.1280 & 0.0283 & -0.2939 & 0.1675 & -0.0312 & 0.1041 \\
\hline $\mathrm{Li}_{2} \mathbf{O}$ & -0.1336 & 0.1874 & -0.0771 & 0.1676 & -1.2422 & 0.0703 & -0.2622 \\
\hline MgO & -0.0945 & -0.0022 & 0.0023 & 0.0034 & 0.0016 & 0.0058 & -0.0051 \\
\hline MnO & -0.0519 & -0.0355 & -0.0043 & -0.0312 & 0.0703 & -0.4517 & 0.0357 \\
\hline $\mathrm{Na}_{2} \mathrm{O}$ & -0.1764 & 0.0947 & -0.0026 & 0.1041 & -0.2622 & 0.0356 & -0.2094 \\
\hline $\mathrm{SiO}_{2}$ & -0.0522 & 0.0086 & 0.0363 & 0.0421 & 0.0917 & 0.0157 & 0.0285 \\
\hline SrO & -0.4222 & 0.0609 & -0.0275 & 0.0547 & -0.1019 & 0.0893 & -0.0893 \\
\hline $\mathrm{ThO}_{2}$ & 0.0319 & -0.0160 & -0.0634 & -0.0602 & 0.0482 & -0.0218 & 0.0044 \\
\hline $\mathrm{UO}_{3}$ & -0.1247 & -0.0134 & -0.0195 & -0.0559 & -0.0741 & -0.0183 & -0.0023 \\
\hline $\mathrm{ZnO}$ & -0.3439 & -0.0345 & 0.0844 & -0.0097 & 0.1658 & 0.0370 & -0.1084 \\
\hline $\mathrm{ZrO}_{2}$ & -0.0723 & -0.0874 & 0.0550 & -0.1029 & 0.1842 & 0.0083 & 0.1022 \\
\hline Others & 2.0399 & 0.1356 & -0.0488 & 0.0373 & 0.0888 & 0.0288 & 0.1187 \\
\hline $\mathrm{Al}_{2} \mathrm{O}_{3} /(\mathrm{T} / \mathbf{1 0 0 0})^{2}$ & 0.1356 & 0.6000 & -0.1751 & 0.2342 & -0.3438 & 0.0654 & -0.1730 \\
\hline $\mathrm{B}_{2} \mathrm{O}_{3} /(T / 1000)^{2}$ & -0.0488 & -0.1751 & 0.4162 & -0.0517 & 0.1428 & 0.0075 & 0.0048 \\
\hline $\mathrm{Fe}_{2} \mathrm{O}_{3} /(T / 1000)^{2}$ & 0.0373 & 0.2342 & -0.0517 & 0.5374 & -0.3095 & 0.0565 & -0.1906 \\
\hline $\mathrm{Li}_{2} \mathrm{O} /(\mathrm{T} / 1000)^{2}$ & 0.0888 & -0.3438 & 0.1428 & -0.3095 & 2.2827 & -0.1285 & 0.4841 \\
\hline $\mathrm{MnO} /(T / 1000)^{2}$ & 0.0288 & 0.0654 & 0.0075 & 0.0565 & -0.1285 & 0.8274 & -0.0648 \\
\hline $\mathrm{Na}_{2} \mathrm{O} /(T / 1000)^{2}$ & 0.1187 & -0.1730 & 0.0048 & -0.1906 & 0.4841 & -0.0648 & 0.3846 \\
\hline $\mathrm{SiO}_{2} /(\mathrm{T} / 1000)^{2}$ & 0.0345 & -0.0151 & -0.0669 & -0.0766 & -0.1692 & -0.0291 & -0.0529 \\
\hline $\mathrm{SrO} /(T / 1000)^{2}$ & 0.2773 & -0.1129 & 0.0516 & -0.0993 & 0.1861 & -0.1648 & 0.1636 \\
\hline $\mathrm{ThO}_{2} /(\mathrm{T} / 1000)^{2}$ & -0.0154 & 0.0323 & 0.1173 & 0.1113 & -0.0923 & 0.0423 & -0.0089 \\
\hline $\mathrm{UO}_{3} /(T / 1000)^{2}$ & 0.0806 & 0.0246 & 0.0339 & 0.1021 & 0.1331 & 0.0330 & 0.0046 \\
\hline $\mathrm{ZnO} /(\mathrm{T} / 1000)^{2}$ & 0.2291 & 0.0656 & -0.1551 & 0.0210 & -0.3050 & -0.0692 & 0.1974 \\
\hline $\mathrm{ZrO}_{2} /(T / 1000)^{2}$ & 0.0431 & 0.1582 & -0.1006 & 0.1871 & -0.3367 & -0.0164 & -0.1865 \\
\hline Others/(T/1000) $)^{2}$ & -1.3500 & -0.2509 & 0.0901 & -0.0690 & -0.1618 & -0.0484 & -0.2172 \\
\hline
\end{tabular}


Table D.13. Variance-Covariance Matrix Associated With the Estimated Coefficients of the 27-Term Truncated T2-Linear Mixture Model for In(Electrical Conductivity, S/cm) of HLW Glasses (continued).

\begin{tabular}{|c|c|c|c|c|c|c|c|}
\hline Term & $\mathrm{SiO}_{2} /(\mathrm{T} / 1000)^{2}$ & $\mathrm{SrO} /(T / 1000)^{2}$ & $\mathrm{ThO}_{2} /(\mathrm{T} / \mathbf{1 0 0 0})^{2}$ & $\mathrm{UO}_{3} /(T / 1000)^{2}$ & $\mathrm{ZnO} /(T / 1000)^{2}$ & $\mathrm{ZrO}_{2} /(\mathrm{T} / \mathbf{1 0 0 0})^{2}$ & Others/(T/1000) ${ }^{2}$ \\
\hline $\mathrm{Al}_{2} \mathrm{O}_{3}$ & 0.0085 & 0.0609 & -0.0161 & -0.0134 & -0.0345 & -0.0874 & 0.1357 \\
\hline $\mathrm{B}_{2} \mathrm{O}_{3}$ & 0.0363 & -0.0275 & -0.0634 & -0.0195 & 0.0844 & 0.0549 & -0.0489 \\
\hline $\mathrm{Fe}_{2} \mathrm{O}_{3}$ & 0.0421 & 0.0547 & -0.0602 & -0.0559 & -0.0096 & -0.1029 & 0.0375 \\
\hline $\mathbf{L i}_{2} \mathbf{O}$ & 0.0918 & -0.1019 & 0.0482 & -0.0741 & 0.1659 & 0.1841 & 0.0885 \\
\hline MgO & 0.0017 & 0.0013 & 0.0020 & 0.0024 & -0.0106 & -0.0023 & -0.0248 \\
\hline $\mathrm{MnO}$ & 0.0157 & 0.0893 & -0.0218 & -0.0184 & 0.0373 & 0.0083 & 0.0289 \\
\hline $\mathrm{Na}_{2} \mathrm{O}$ & 0.0285 & -0.0893 & 0.0044 & -0.0023 & -0.1085 & 0.1023 & 0.1188 \\
\hline $\mathrm{SiO}_{2}$ & -0.0414 & 0.0035 & 0.0379 & 0.0242 & 0.0665 & -0.0059 & 0.0345 \\
\hline SrO & 0.0035 & -0.3498 & -0.0475 & 0.1316 & -0.0956 & 0.0539 & 0.2772 \\
\hline $\mathrm{ThO}_{2}$ & 0.0379 & -0.0475 & -0.8164 & 0.3272 & -0.0108 & 0.1060 & -0.0154 \\
\hline $\mathrm{UO}_{3}$ & 0.0242 & 0.1316 & 0.3272 & -0.8157 & -0.1117 & 0.0632 & 0.0806 \\
\hline $\mathrm{ZnO}$ & 0.0664 & -0.0955 & -0.0109 & -0.1117 & -2.3239 & 0.0409 & 0.2296 \\
\hline $\mathrm{ZrO}_{2}$ & -0.0059 & 0.0539 & 0.1060 & 0.0632 & 0.0407 & -0.3218 & 0.0430 \\
\hline Others & 0.0345 & 0.2773 & -0.0154 & 0.0806 & 0.2291 & 0.0431 & -1.3500 \\
\hline $\mathrm{Al}_{2} \mathrm{O}_{3} /(T / 1000)^{2}$ & -0.0151 & -0.1129 & 0.0323 & 0.0246 & 0.0656 & 0.1582 & -0.2509 \\
\hline $\mathrm{B}_{2} \mathrm{O}_{3} /(T / 1000)^{2}$ & -0.0669 & 0.0516 & 0.1173 & 0.0339 & -0.1551 & -0.1006 & 0.0901 \\
\hline $\mathrm{Fe}_{2} \mathrm{O}_{3} /(T / 1000)^{2}$ & -0.0766 & -0.0993 & 0.1113 & 0.1021 & 0.0210 & 0.1871 & -0.0690 \\
\hline $\mathrm{Li}_{2} \mathrm{O} /(T / 1000)^{2}$ & -0.1692 & 0.1861 & -0.0923 & 0.1331 & -0.3050 & -0.3367 & -0.1618 \\
\hline $\mathrm{MnO} /(T / 1000)^{2}$ & -0.0291 & -0.1648 & 0.0423 & 0.0330 & -0.0692 & -0.0164 & -0.0484 \\
\hline $\mathrm{Na}_{2} \mathrm{O} /(T / 1000)^{2}$ & -0.0529 & 0.1636 & -0.0089 & 0.0046 & 0.1974 & -0.1865 & -0.2172 \\
\hline $\mathrm{SiO}_{2} /(\mathrm{T} / 1000)^{2}$ & 0.0760 & -0.0067 & -0.0696 & -0.0439 & -0.1209 & 0.0110 & -0.0634 \\
\hline $\mathrm{SrO} /(T / 1000)^{2}$ & -0.0067 & 0.6413 & 0.0894 & -0.2426 & 0.1711 & -0.0981 & -0.5064 \\
\hline $\mathrm{ThO}_{2} /(\mathrm{T} / \mathbf{1 0 0 0})^{2}$ & -0.0696 & 0.0894 & 1.4889 & -0.5940 & 0.0151 & -0.1934 & 0.0211 \\
\hline $\mathrm{UO}_{3} /(T / 1000)^{2}$ & -0.0439 & -0.2426 & -0.5940 & 1.4845 & 0.2046 & -0.1169 & -0.1446 \\
\hline $\mathrm{ZnO} /(T / 1000)^{2}$ & -0.1209 & 0.1711 & 0.0151 & 0.2046 & 4.2319 & -0.0725 & -0.4181 \\
\hline $\mathrm{ZrO}_{2} /(T / 1000)^{2}$ & 0.0110 & -0.0981 & -0.1934 & -0.1169 & -0.0725 & 0.5878 & -0.0764 \\
\hline Others/(T/1000) $)^{2}$ & -0.0634 & -0.5064 & 0.0211 & -0.1446 & -0.4181 & -0.0764 & 2.4735 \\
\hline
\end{tabular}


The Catholic University of America

Vitreous State Laboratory
IHLW PCT, Spinel $T_{1 \%}$, Electrical Conductivity, and Viscosity Model Development

Final Report, VSL-07R1240-4, Rev. 0

Table D.14. Variance-Covariance Matrix Associated With the Estimated Coefficients of the 22-Term Truncated T2-Linear Mixture Model with One Quadratic Composition Term for $\ln ($ Electrical Conductivity, S/cm) of HLW Glasses.

\begin{tabular}{|c|c|c|c|c|c|c|c|c|c|c|c|}
\hline Term & $\mathrm{Al}_{2} \mathbf{O}_{3}$ & $\mathbf{B}_{2} \mathbf{O}_{3}$ & $\mathrm{Fe}_{2} \mathrm{O}_{3}$ & $\mathbf{L i}_{2} \mathbf{O}$ & MgO & MnO & $\mathrm{Na}_{2} \mathrm{O}$ & $\mathrm{SiO}_{2}$ & SrO & $\mathrm{ThO}_{2}$ & $\mathrm{UO}_{3}$ \\
\hline $\mathrm{Al}_{2} \mathrm{O}_{3}$ & 0.2669 & -0.0710 & 0.1053 & -0.2292 & -0.0481 & 0.0358 & -0.0964 & \begin{tabular}{|l|}
-0.0048 \\
\end{tabular} & -0.0438 & 0.0114 & 0.0141 \\
\hline $\mathbf{B}_{2} \mathbf{O}_{3}$ & -0.0710 & 0.3253 & -0.0252 & -0.2076 & 0.3723 & 0.0247 & -0.0684 & \begin{tabular}{|l|}
-0.0449 \\
\end{tabular} & 0.0416 & 0.0568 & 0.0640 \\
\hline $\mathrm{Fe}_{2} \mathrm{O}_{3}$ & 0.1053 & -0.0252 & 0.2431 & -0.1532 & -0.4034 & 0.0296 & \begin{tabular}{|l|}
-0.0889 \\
\end{tabular} & -0.0334 & 0452 & 0.0484 & 0439 \\
\hline $\mathrm{Li}_{2} \mathrm{O}$ & \begin{tabular}{|l|}
-0.2292 \\
\end{tabular} & \begin{tabular}{|l|}
-0.2076 \\
\end{tabular} & -0.1532 & 5.1837 & \begin{tabular}{|l|}
-2.0830 \\
\end{tabular} & \begin{tabular}{|l|}
-0.2895 \\
\end{tabular} & 1.2705 & \begin{tabular}{|l|}
-0.2209 \\
\end{tabular} & -0.1025 & -0.1356 & -0.1226 \\
\hline MgO & \begin{tabular}{|l|}
-0.0481 \\
\end{tabular} & 0.3723 & -0.4034 & -2.0830 & 64.8804 & \begin{tabular}{|l|}
-0.2028 \\
\end{tabular} & -0.7808 & \begin{tabular}{|l|l|}
0.0194 \\
\end{tabular} & 0.1748 & 0.1057 & 0.3019 \\
\hline MnO & \begin{tabular}{|l|}
0.0358 \\
\end{tabular} & 0.0247 & 0.0296 & -0.2895 & \begin{tabular}{|l|}
-0.2028 \\
\end{tabular} & 0.6750 & -0.0878 & -0.0179 & -0.1165 & 0.0186 & 0.0420 \\
\hline $\mathrm{Na}_{2} \mathrm{O}$ & \begin{tabular}{|l|}
-0.0964 \\
\end{tabular} & -0.0684 & -0.0889 & 1.2705 & -0.7808 & \begin{tabular}{|l|}
-0.0878 \\
\end{tabular} & 0.4401 & -0.0596 & 0.0262 & $\begin{array}{l}-0.0298 \\
\end{array}$ & -0.6 \\
\hline $\mathrm{SiO}_{2}$ & \begin{tabular}{|l|}
-0.0048 \\
\end{tabular} & \begin{tabular}{|l|}
-0.0449 \\
\end{tabular} & -0.0334 & -0.2209 & 0.0194 & \begin{tabular}{|l|}
-0.0179 \\
\end{tabular} & -0.0596 & 0.0481 & -0.0020 & -0.0265 & -0.0268 \\
\hline SrO & -0.0438 & 0.0416 & \begin{tabular}{|l|}
-0.0452 \\
\end{tabular} & -0.1025 & 0.1748 & -0.1165 & 0.0262 & \begin{tabular}{|l|}
-0.0020 \\
\end{tabular} & 0.4628 & 0.0416 & -0.1755 \\
\hline $\mathrm{ThO}_{2}$ & \begin{tabular}{|l|}
0.0114 \\
\end{tabular} & \begin{tabular}{|l|}
0.0568 \\
\end{tabular} & 0.0484 & $\begin{array}{l}-0.1356 \\
\end{array}$ & 0.1057 & \begin{tabular}{|l|}
0.0186 \\
\end{tabular} & -0.0298 & -0.0265 & 0.0416 & 0.6821 & -0.2730 \\
\hline $\mathrm{UO}_{3}$ & \begin{tabular}{|l|}
0.0141 \\
\end{tabular} & 0.0640 & 0.0439 & -0.1226 & 0.3019 & 0.0420 & -0.0464 & -0.0268 & -0.1755 & -0.2730 & 1.1185 \\
\hline $\mathrm{ZnO}$ & 0.0187 & -0.1316 & 0.0154 & 0.2950 & -1.8728 & -0.0677 & 0.2065 & -0.1106 & 0.0828 & -0.0060 & 0.1377 \\
\hline $\mathrm{ZrO}_{2}$ & 0.0733 & -0.0578 & 0.0837 & -0.2224 & 0.3853 & -0.0207 & -0.1035 & 0.0024 & -0.0487 & -0.0866 & -0.1269 \\
\hline Others & -0.1006 & 0.0680 & -0.0268 & -0.4978 & 0.1457 & -0.0075 & -0.2025 & \begin{tabular}{|l|}
-0.0131 \\
\end{tabular} & -0.2103 & 0.0292 & -0.0484 \\
\hline $\mathbf{N a}_{2} \mathbf{O} \times \mathbf{L i}_{2} \mathbf{O}$ & 0.7126 & 2.5485 & 0.1660 & -38.9483 & 21.6781 & 2.1556 & -9.9054 & 1.3647 & 1.7150 & 1.0102 & 1.7410 \\
\hline $\mathrm{B}_{2} \mathrm{O}_{3} /(\mathrm{T} / 100$ & \begin{tabular}{|l|}
-0.0010 \\
\end{tabular} & -0.2263 & 0.0001 & -0.0028 & 0.0021 & -0.0124 & -0.0009 & 0.0462 & -0.0150 & 0.0019 & -0.0599 \\
\hline $\mathrm{MnO} /(\mathrm{T} / \mathbf{1 0 0 0})^{2}$ & 0.0003 & -0.0120 & -0.0004 & -0.0085 & 0.0105 & -0.5384 & -0.0019 & 0.0249 & 0.0991 & 0.0016 & -0.0291 \\
\hline $\mathrm{SiO}_{2} / \mathrm{(}$ & 0.0003 & \begin{tabular}{|l|}
0.0460 \\
\end{tabular} & 0.0000 & 0.0008 & -0.0008 & \begin{tabular}{|l|}
0.0249 \\
\end{tabular} & 0.0002 & -0.0172 & 0.0105 & -0.0006 & 0.0240 \\
\hline $\mathrm{SrO} /(\mathrm{T} / \mathbf{1 0 0 0})^{2}$ & \begin{tabular}{|l|}
-0.0014 \\
\end{tabular} & -0.0151 & 0.0004 & 0.0002 & -0.0045 & 0.0991 & 0.0002 & 0.0105 & -0.3109 & 0.0013 & 0.1426 \\
\hline $\mathrm{UO}_{3} /(\mathrm{T} / \mathbf{1 0 0 0})^{2}$ & 0.0009 & -0.0596 & 0.0004 & -0.0052 & 0.0028 & -0.0284 & -0.0009 & 0.0239 & 0.1431 & 0.0017 & -0.7939 \\
\hline $\mathrm{ZnO}$ & \begin{tabular}{|l|}
0.0010 \\
\end{tabular} & 0.0510 & 0.0017 & 0.0012 & \begin{tabular}{|l|}
-0.0105 \\
\end{tabular} & 0.0426 & -0.0001 & 0.0770 & -0.0387 & -0.0043 & -0.1346 \\
\hline 000) & -0.0010 & 0.0340 & -0.0007 & 0.0009 & -0.0064 & 0.0366 & 0.0007 & 0.0083 & 0.0150 & -0.0010 & 0.1513 \\
\hline
\end{tabular}

\begin{tabular}{|c|c|c|c|c|c|c|c|}
\hline Term & $\mathrm{ZnO}$ & ZrO2 & Others & $\mathrm{Na}_{2} \mathrm{O} \times \mathrm{Li}_{2} \mathrm{O}$ & $\mathrm{B}_{2} \mathrm{O}_{3} /(\mathrm{T} / 1000)^{2}$ & $\mathrm{MnO} /(T / 1000)^{2}$ & $\mathrm{SiO}_{2} /(\mathrm{T} / 1000)^{2}$ \\
\hline $\mathbf{A l}_{2} \mathbf{O}_{3}$ & 0.0187 & 0.0733 & -0.1006 & 0.7126 & $\begin{array}{l}-0.0010 \\
\end{array}$ & 0.0003 & 0.0003 \\
\hline $\mathbf{B}_{2} \mathbf{O}_{3}$ & -0.1316 & -0.0578 & 0.0680 & 2.5485 & -0.2263 & -0.0120 & 0.0460 \\
\hline $\mathrm{Fe}_{2} \mathrm{O}_{3}$ & 0.0154 & 0.0837 & -0.0268 & 0.1660 & 0.0001 & -0.0004 & 0.0000 \\
\hline $\mathbf{L i}_{2} \mathbf{O}$ & 0.2950 & -0.2224 & -0.4978 & -38.9483 & -0.0028 & -0.0085 & 0.0008 \\
\hline MgO & -1.8728 & 0.3853 & 0.1457 & 21.6781 & 0.0021 & 0.0105 & -0.0008 \\
\hline MnO & -0.0677 & -0.0207 & -0.0075 & 2.1556 & -0.0124 & -0.5384 & 0.0249 \\
\hline $\mathrm{Na}_{2} \mathrm{O}$ & 0.2065 & -0.1035 & -0.2025 & -9.9054 & -0.0009 & -0.0019 & 0.0002 \\
\hline $\mathrm{SiO}_{2}$ & -0.1106 & 0.0024 & -0.0131 & 1.3647 & 0.0462 & 0.0249 & -0.0172 \\
\hline SrO & 0.0828 & -0.0487 & -0.2103 & 1.7150 & -0.0150 & 0.0991 & 0.0105 \\
\hline $\mathrm{ThO}_{2}$ & $\begin{array}{l}-0.0060 \\
\end{array}$ & -0.0866 & 0.0292 & 1.0102 & 0.0019 & 0.0016 & -0.0006 \\
\hline $\mathrm{UO}_{3}$ & 0.1377 & -0.1269 & -0.0484 & 1.7410 & -0.0599 & -0.0291 & 0.0240 \\
\hline $\mathrm{ZnO}$ & 3.4206 & -0.0663 & -0.2297 & -4.0928 & 0.0511 & 0.0414 & 0.0774 \\
\hline $\mathrm{ZrO}_{2}$ & -0.0663 & 0.4232 & -0.0342 & 0.6505 & 0.0335 & 0.0363 & 0.0085 \\
\hline Others & -0.2297 & -0.0342 & 1.1446 & 3.9754 & 0.0008 & 0.0041 & -0.0006 \\
\hline $\mathbf{N a}_{2} \mathbf{O} \times \mathbf{L i}_{2} \mathbf{O}$ & -4.0928 & 0.6505 & 3.9754 & 363.5500 & 0.0386 & 0.0855 & -0.0107 \\
\hline $\mathrm{B}_{2} \mathrm{O}_{3} /(T / 1000)^{2}$ & 0.0511 & 0.0335 & 0.0008 & 0.0386 & 0.4160 & 0.0226 & -0.0847 \\
\hline $\mathrm{MnO} /(T / 1000)^{2}$ & 0.0414 & 0.0363 & 0.0041 & 0.0855 & 0.0226 & 0.9874 & -0.0455 \\
\hline $\mathrm{SiO}_{2} /(T / 1000)^{2}$ & 0.0774 & 0.0085 & -0.0006 & -0.0107 & -0.0847 & -0.0455 & 0.0315 \\
\hline $\mathrm{SrO} /(\mathrm{T} / \mathbf{1 0 0 0})^{2}$ & -0.0373 & 0.0147 & 0.0009 & -0.0088 & 0.0288 & -0.1824 & -0.0193 \\
\hline $\mathrm{UO}_{3} /(\mathrm{T} / \mathbf{1 0 0 0})^{2}$ & -0.1362 & 0.1512 & 0.0003 & 0.0232 & 0.1075 & 0.0532 & -0.0432 \\
\hline $\mathrm{ZnO} /(T / 1000)^{2}$ & -2.6087 & 0.0348 & 0.0009 & -0.0251 & -0.0937 & -0.0795 & -0.1400 \\
\hline $\mathrm{ZrO}_{2} /(\mathrm{T} / \mathbf{1 0 0 0})^{2}$ & 0.0338 & -0.2866 & 0.0013 & 0.0051 & -0.0618 & -0.0673 & -0.0154 \\
\hline
\end{tabular}


The Catholic University of America Vitreous State Laboratory
IHLW PCT, Spinel $T_{1 \%}$, Electrical Conductivity, and Viscosity Model Development Final Report, VSL-07R1240-4, Rev. 0

Table D.14. Variance-Covariance Matrix Associated With the Estimated Coefficients of the 22-Term Truncated T2-Linear Mixture Model with One Quadratic Composition Term for $\ln ($ Electrical Conductivity, S/cm) of HLW Glasses (continued).

\begin{tabular}{|c|c|c|c|c|}
\hline Term & $\mathrm{SrO} /(T / 1000)^{2}$ & $\mathrm{UO}_{3} /(T / 1000)^{2}$ & $\mathrm{ZnO} /(T / 1000)^{2}$ & $\mathrm{ZrO}_{2} /(\mathrm{T} / 1000)^{2}$ \\
\hline $\mathrm{Al}_{2} \mathrm{O}_{3}$ & -0.0014 & 0.0009 & 0.0010 & -0.0010 \\
\hline $\mathbf{B}_{2} \mathbf{O}_{3}$ & -0.0151 & -0.0596 & 0.0510 & 0.0340 \\
\hline $\mathrm{Fe}_{2} \mathrm{O}_{3}$ & 0.0004 & 0.0004 & 0.0017 & -0.0007 \\
\hline $\mathbf{L i}_{2} \mathbf{O}$ & 0.0002 & -0.0052 & 0.0012 & 0.0009 \\
\hline MgO & -0.0045 & 0.0028 & -0.0105 & -0.0064 \\
\hline MnO & 0.0991 & -0.0284 & 0.0426 & 0.0366 \\
\hline $\mathrm{Na}_{2} \mathrm{O}$ & 0.0002 & -0.0009 & -0.0001 & 0.0007 \\
\hline $\mathrm{SiO}_{2}$ & 0.0105 & 0.0239 & 0.0770 & 0.0083 \\
\hline SrO & -0.3109 & 0.1431 & -0.0387 & 0.0150 \\
\hline $\mathrm{ThO}_{2}$ & 0.0013 & 0.0017 & -0.0043 & -0.0010 \\
\hline $\mathrm{UO}_{3}$ & 0.1426 & -0.7939 & -0.1346 & 0.1513 \\
\hline $\mathrm{ZnO}$ & -0.0373 & -0.1362 & -2.6087 & 0.0338 \\
\hline $\mathrm{ZrO}_{2}$ & 0.0147 & 0.1512 & 0.0348 & -0.2866 \\
\hline Others & 0.0009 & 0.0003 & 0.0009 & 0.0013 \\
\hline $\mathrm{Na}_{2} \mathrm{O} \times \mathrm{Li}_{2} \mathrm{O}$ & -0.0088 & 0.0232 & -0.0251 & 0.0051 \\
\hline $\mathrm{B}_{2} \mathrm{O}_{3} /(T / 1000)^{2}$ & 0.0288 & 0.1075 & -0.0937 & -0.0618 \\
\hline $\mathrm{MnO} /(T / 1000)^{2}$ & -0.1824 & 0.0532 & -0.0795 & -0.0673 \\
\hline $\mathrm{SiO}_{2} /(T / 1000)^{2}$ & -0.0193 & -0.0432 & -0.1400 & -0.0154 \\
\hline $\mathrm{SrO} /(T / 1000)^{2}$ & 0.5700 & -0.2631 & 0.0661 & -0.0264 \\
\hline $\mathrm{UO}_{3} /(T / 1000)^{2}$ & -0.2631 & 1.4459 & 0.2456 & -0.2773 \\
\hline $\mathrm{ZnO} /(T / 1000)^{2}$ & 0.0661 & 0.2456 & 4.7488 & -0.0613 \\
\hline $\mathrm{ZrO}_{2} /(\mathrm{T} / 1000)^{2}$ & -0.0264 & -0.2773 & -0.0613 & 0.5240 \\
\hline
\end{tabular}


The Catholic University of America

Vitreous State Laboratory
IHLW PCT, Spinel $T_{1 \%}$, Electrical Conductivity, and Viscosity Model Development

Final Report, VSL-07R1240-4, Rev. 0

Table D.15. Variance-Covariance Matrix Associated With the Estimated Coefficients of the 24-Term Truncated T2-Linear Mixture Model for $\ln ($ Viscosity, poise) of HLW Glasses.

\begin{tabular}{|c|c|c|c|c|c|c|c|c|c|c|c|}
\hline Term & $\mathbf{A l}_{2} \mathbf{O}_{3}$ & $\mathbf{B}_{2} \mathbf{O}_{3}$ & $\mathrm{CaO}$ & $\mathrm{Fe}_{2} \mathrm{O}_{3}$ & $\mathbf{L i}_{2} \mathbf{O}$ & MgO & MnO & $\mathrm{Na}_{2} \mathrm{O}$ & $\mathrm{SiO}_{2}$ & SrO & $\mathrm{ThO}_{2}$ \\
\hline $\mathbf{A l}_{2} \mathbf{O}_{3}$ & \begin{tabular}{|l}
0.7178 \\
\end{tabular} & -0.0610 & -0.2301 & 0.2932 & -0.3503 & 0.0073 & 0.0450 & -0.2358 & -0.0646 & -0.1563 & 0.1610 \\
\hline $\mathbf{B}_{2} \mathbf{O}_{3}$ & -0.0610 & 0.1329 & 0.1984 & -0.0156 & 0.0400 & 0.0496 & \begin{tabular}{|l}
-0.0041 \\
\end{tabular} & -0.0002 & \begin{tabular}{|l}
-0.0204 \\
\end{tabular} & 0189 & 0.0275 \\
\hline $\mathrm{CaO}$ & \begin{tabular}{|l|}
-0.2301 \\
\end{tabular} & 0.1984 & 75.9557 & \begin{tabular}{|l|}
-0.6970 \\
\end{tabular} & \begin{tabular}{|l|}
-1.0995 \\
\end{tabular} & -20.9211 & 0.2674 & -0.0788 & -0.2650 & 0.0174 & -1.1463 \\
\hline $\mathrm{Fe}_{2} \mathrm{O}_{3}$ & 0.2932 & 0156 & -0.6970 & 0.6962 & $\mid-0.3231$ & -0.1434 & 0.0332 & -0.2585 & -0.1106 & -0.1307 & 0.2249 \\
\hline $\mathrm{Li}_{2} \mathbf{O}$ & & 5400 & 95 & 231 & 2.8652 & 4242 & & 0.5666 & & & .1024 \\
\hline MgO & \begin{tabular}{|l|l}
0.0073 \\
\end{tabular} & 0.0496 & -20.9211 & -0.1434 & 0.4242 & 53.5046 & -0.4274 & -0.0793 & -0.0009 & -0.0229 & 0.3741 \\
\hline MnO & \begin{tabular}{|l|}
0.0450 \\
\end{tabular} & -0.0041 & 0.2674 & 0.0332 & -0.0333 & -0.4274 & 0.2847 & -0.0239 & \begin{tabular}{|l|}
-0.0164 \\
\end{tabular} & -0.0643 & 0.0368 \\
\hline $\mathrm{Na}_{2}$ & -0.2358 & .0002 & -0.0788 & 0.2585 & 0.5666 & 93 & \begin{tabular}{|l|}
-0.0239 \\
\end{tabular} & 0.4630 & \begin{tabular}{|l|}
-0.0599 \\
\end{tabular} & 0.1365 & \\
\hline $\mathrm{SiO}$ & \begin{tabular}{|l|}
-0.0646 \\
\end{tabular} & 0204 & -0.2650 & -0.1106 & -0 & -0.0009 & -0.0164 & -0.0599 & 0.0824 & -0.0010 & \\
\hline SrO & \begin{tabular}{|l|}
-0.1563 \\
\end{tabular} & 0.0189 & 0.0174 & .1307 & 99 & -0.1 & -0.0643 & 0.1365 & -0.0010 & 0.6677 & \\
\hline ThC & \begin{tabular}{|l}
0.1610 \\
\end{tabular} & 0.0275 & -1.1463 & 0.2249 & -0.1024 & 0.3741 & \begin{tabular}{|l|l}
0.0368 \\
\end{tabular} & -0.0168 & \begin{tabular}{|l|}
-0.0859 \\
\end{tabular} & 0.0394 & 2.0497 \\
\hline UO & \begin{tabular}{|l|}
0.0433 \\
\end{tabular} & 0.0215 & -0.3415 & 0.1597 & 0.2148 & 0.2859 & 0.0009 & \begin{tabular}{|l|}
-0.0399 \\
\end{tabular} & \begin{tabular}{|l|}
-0.0509 \\
\end{tabular} & -0.3041 & -0.7971 \\
\hline $\mathrm{ZnO}$ & \begin{tabular}{|l|}
-0.0013 \\
\end{tabular} & .0485 & -1.8604 & 0.0008 & \begin{tabular}{|l|}
-0.0596 \\
\end{tabular} & -0.5392 & \begin{tabular}{|l|}
-0.0118 \\
\end{tabular} & 0.0874 & \begin{tabular}{|l|}
-0.0337 \\
\end{tabular} & 0.0562 & 0.0534 \\
\hline $\mathrm{ZrO}_{2}$ & \begin{tabular}{|l|l}
0.2008 \\
\end{tabular} & .0411 & -0.7536 & 0.2390 & -0.3925 & 0.4799 & & -0.2520 & 098 & -0.1457 & \\
\hline Oth & \begin{tabular}{|l|}
-0.0678 \\
\end{tabular} & 34 & -0.6087 & .0135 & \begin{tabular}{|c|}
-0.0158 \\
\end{tabular} & 469 & -0.0303 & -0.0591 & \begin{tabular}{|c|}
-0.0196 \\
\end{tabular} & -0.1686 & 0.0237 \\
\hline $\mathbf{A l}_{2} \mathbf{O}$ & \begin{tabular}{|l}
-0.9552 \\
\end{tabular} & .0006 & -0.0220 & .3874 & 0.4703 & 0.0046 & 0.0031 & 0.3286 & \begin{tabular}{|l|l|}
0.1039 \\
\end{tabular} & 0.2107 & -0.2393 \\
\hline $\mathbf{F e}_{2} \mathbf{O}_{3} /$ & \begin{tabular}{|l}
-0.3869 \\
\end{tabular} & -0.0018 & 0.0019 & -0.9564 & 0.4496 & -0.0082 & 0.0017 & 0.3582 & 0.1619 & 0.1741 & -0.3060 \\
\hline & \begin{tabular}{|l|l|l}
0.472 \\
\end{tabular} & -0.0008 & & 0.4514 & \begin{tabular}{|l|}
-3.9846 \\
\end{tabular} & -0. & & \begin{tabular}{|l|}
-0.7956 \\
\end{tabular} & & 0.1073 & 714 \\
\hline & 03287 & 0.0004 & .0252 & 75 & \begin{tabular}{|l|}
-0.7964 \\
\end{tabular} & 30 & & \begin{tabular}{|l|}
-0.6339 \\
\end{tabular} & 852 & 0.1601 & 0.0224 \\
\hline SiO & \begin{tabular}{|l|l}
0.1037 \\
\end{tabular} & 0.0006 & -0.0083 & 0.1618 & 0.3116 & 0.0045 & \begin{tabular}{|l|}
-0.0007 \\
\end{tabular} & 0.0851 & -0.1058 & 0.0049 & 0.1151 \\
\hline $\mathrm{SrO} /$ & \begin{tabular}{|l}
0.2108 \\
\end{tabular} & 0.0009 & -0.0308 & 0.1736 & -0.1068 & 0.0268 & -0.0051 & -0.1604 & 0.0055 & -0.8626 & -0.0603 \\
\hline ThC & .2411 & 0.0026 & 0.0740 & .3069 & 0.1714 & .0144 & -0.0005 & 0.0229 & 147 & -0.0588 & -2.8668 \\
\hline UO & -0.0640 & .0052 & & \begin{tabular}{|l}
-0.2288 \\
\end{tabular} & -0.2926 & -0.0647 & & 0.0620 & 704 & 0.4567 & 1.1616 \\
\hline $\mathrm{ZrO}_{2} /(\mathrm{T} / \mathbf{1 0 0 0})^{2}$ & \begin{tabular}{|l|}
-0.2475 \\
\end{tabular} & -0.0017 & -0.0319 & -0.3145 & 0.5580 & 0.0148 & -0.0038 & 0.3488 & 0.0261 & 0.1859 & 0.2324 \\
\hline
\end{tabular}

\begin{tabular}{|c|c|c|c|c|c|c|c|}
\hline Term & $\mathbf{U O}_{3}$ & $\mathrm{ZnO}$ & $\mathrm{ZrO}_{2}$ & Others & $\mathrm{Al}_{2} \mathrm{O}_{3} /(T / 1000)^{2}$ & $\mathrm{Fe}_{2} \mathrm{O}_{3} /(\mathrm{T} / 1000)^{2}$ & $\mathrm{Li}_{2} \mathrm{O} /(\mathrm{T} / \mathbf{1 0 0 0})^{2}$ \\
\hline $\mathbf{A l}_{2} \mathbf{O}_{3}$ & 0.0433 & -0.0013 & 0.2008 & $\begin{array}{l}-0.0678 \\
\end{array}$ & -0.9552 & -0.3869 & 0.4727 \\
\hline $\mathbf{B}_{2} \mathbf{O}_{3}$ & 0.0215 & -0.0485 & -0.0411 & 0.0164 & -0.0006 & -0.0018 & -0.0008 \\
\hline $\mathrm{CaO}$ & -0.3415 & -1.8604 & -0.7536 & -0.6087 & -0.0220 & 0.0019 & 0.0350 \\
\hline $\mathrm{Fe}_{2} \mathrm{O}_{3}$ & 0.1597 & 0.0008 & 0.2390 & -0.0135 & -0.3874 & -0.9564 & 0.4514 \\
\hline $\mathrm{Li}_{2} \mathrm{O}$ & 0.2148 & -0.0596 & -0.3925 & -0.0158 & 0.4703 & 0.4496 & -3.9846 \\
\hline MgO & 0.2859 & -0.5392 & 0.4799 & 0.6469 & 0.0046 & -0.0082 & -0.0228 \\
\hline MnO & 0.0009 & -0.0118 & 0.0070 & -0.0303 & 0.0031 & 0.0017 & 0.0073 \\
\hline $\mathrm{Na}_{2} \mathrm{O}$ & -0.0399 & 0.0874 & -0.2520 & -0.0591 & 0.3286 & 0.3582 & -0.7956 \\
\hline $\mathrm{SiO}_{2}$ & -0.0509 & -0.0337 & -0.0098 & -0.0196 & 0.1039 & 0.1619 & 0.3107 \\
\hline SrO & -0.3041 & 0.0562 & -0.1457 & -0.1686 & 0.2107 & 0.1741 & -0.1073 \\
\hline $\mathrm{ThO}_{2}$ & $\begin{array}{l}-0.7971 \\
\end{array}$ & 0.0534 & -0.1634 & 0.0237 & -0.2393 & -0.3060 & 0.1714 \\
\hline $\mathrm{UO}_{3}$ & 1.9815 & 0.0191 & -0.1307 & -0.0610 & -0.0667 & -0.2296 & -0.2875 \\
\hline $\mathrm{ZnO}$ & 0.0191 & 1.4553 & -0.0325 & -0.0635 & 0.0035 & 0.0083 & 0.0093 \\
\hline $\mathrm{ZrO}_{2}$ & -0.1307 & -0.0325 & 0.7583 & -0.0007 & -0.2473 & -0.3142 & 0.5575 \\
\hline Others & -0.0610 & -0.0635 & -0.0007 & 0.8288 & 0.0021 & -0.0029 & -0.0138 \\
\hline $\mathrm{Al}_{2} \mathrm{O}_{3} /(\mathrm{T} / \mathbf{1 0 0 0})^{2}$ & -0.0667 & 0.0035 & -0.2473 & 0.0021 & 1.7926 & 0.7242 & -0.8780 \\
\hline $\mathrm{Fe}_{2} \mathrm{O}_{3} /(\mathrm{T} / \mathbf{1 0 0 0})^{2}$ & -0.2296 & 0.0083 & -0.3142 & -0.0029 & 0.7242 & 1.7902 & -0.8364 \\
\hline $\mathrm{Li}_{2} \mathrm{O} /(T / 1000)^{2}$ & -0.2875 & 0.0093 & 0.5575 & -0.0138 & -0.8780 & -0.8364 & 7.4453 \\
\hline $\mathrm{Na}_{2} \mathrm{O} /(T / 1000)^{2}$ & 0.0615 & -0.0046 & 0.3485 & -0.0004 & -0.6142 & -0.6682 & 1.4883 \\
\hline $\mathrm{SiO}_{2} /(\mathrm{T} / 1000)^{2}$ & 0.0708 & -0.0021 & 0.0256 & 0.0013 & -0.1955 & -0.3036 & -0.5829 \\
\hline $\mathrm{SrO} /(T / 1000)^{2}$ & 0.4587 & -0.0099 & 0.1860 & 0.0026 & -0.3977 & -0.3269 & 0.1997 \\
\hline $\mathrm{ThO}_{2} /(T / 1000)^{2}$ & 1.1625 & -0.0085 & 0.2316 & -0.0046 & 0.4556 & 0.5750 & -0.3233 \\
\hline $\mathrm{UO}_{3} /(T / 1000)^{2}$ & -2.8194 & 0.0200 & 0.1852 & -0.0003 & 0.1235 & 0.4362 & 0.5494 \\
\hline $\mathrm{ZrO}_{2} /(T / 1000)^{2}$ & 0.1847 & 0.0011 & -1.0296 & 0.0021 & 0.4630 & 0.5859 & -1.0465 \\
\hline
\end{tabular}


The Catholic University of America Vitreous State Laboratory
IHLW PCT, Spinel $T_{1 \%}$, Electrical Conductivity, and Viscosity Model Development

Final Report, VSL-07R1240-4, Rev. 0

Table D.15. Variance-Covariance Matrix Associated With the Estimated Coefficients of the 24-Term Truncated T2-Linear Mixture Model for $\ln ($ Viscosity, poise) of HLW Glasses (continued).

\begin{tabular}{|c|c|c|c|c|c|c|}
\hline Term & $\mathrm{Na}_{2} \mathrm{O} /(T / 1000)^{2}$ & $\mathrm{SiO}_{2} /(\mathrm{T} / \mathbf{1 0 0 0})^{2}$ & $\mathrm{SrO} /(T / 1000)^{2}$ & $\mathrm{ThO}_{2} /(\mathrm{T} / \mathbf{1 0 0 0})^{2}$ & $\mathrm{UO}_{3} /(T / 1000)^{2}$ & $\mathrm{ZrO}_{2} /(\mathrm{T} / \mathbf{1 0 0 0})^{2}$ \\
\hline $\mathbf{A l}_{2} \mathbf{O}_{3}$ & 0.3287 & 0.1037 & 0.2108 & -0.2411 & -0.0640 & -0.2475 \\
\hline $\mathbf{B}_{2} \mathbf{O}_{3}$ & 0.0004 & 0.0006 & 0.0009 & 0.0026 & -0.0052 & -0.0017 \\
\hline $\mathrm{CaO}$ & 0.0252 & -0.0083 & -0.0308 & 0.0740 & 0.0487 & -0.0319 \\
\hline $\mathrm{Fe}_{2} \mathrm{O}_{3}$ & 0.3575 & 0.1618 & 0.1736 & -0.3069 & -0.2288 & $\begin{array}{l}-0.3145 \\
\end{array}$ \\
\hline $\mathbf{L i}_{2} \mathbf{O}$ & -0.7964 & 0.3116 & -0.1068 & 0.1714 & -0.2926 & 0.5580 \\
\hline MgO & -0.0030 & 0.0045 & 0.0268 & -0.0144 & -0.0647 & 0.0148 \\
\hline MnO & -0.0003 & -0.0007 & -0.0051 & -0.0005 & 0.0067 & $\begin{array}{l}-0.0038 \\
\end{array}$ \\
\hline $\mathrm{Na}_{2} \mathrm{O}$ & -0.6339 & 0.0851 & -0.1604 & 0.0229 & 0.0620 & 0.3488 \\
\hline $\mathrm{SiO}_{2}$ & 0.0852 & -0.1058 & 0.0055 & 0.1147 & 0.0704 & 0.0261 \\
\hline SrO & -0.1601 & 0.0049 & -0.8626 & -0.0588 & 0.4567 & 0.1859 \\
\hline $\mathrm{ThO}_{2}$ & 0.0224 & 0.1151 & -0.0603 & -2.8668 & 1.1616 & 0.2324 \\
\hline $\mathrm{UO}_{3}$ & 0.0615 & 0.0708 & 0.4587 & 1.1625 & -2.8194 & 0.1847 \\
\hline $\mathrm{ZnO}$ & $\begin{array}{l}-0.0046 \\
\end{array}$ & -0.0021 & $\begin{array}{l}-0.0099 \\
\end{array}$ & -0.0085 & 0.0200 & 0.0011 \\
\hline $\mathrm{ZrO}_{2}$ & 0.3485 & 0.0256 & 0.1860 & 0.2316 & 0.1852 & -1.0296 \\
\hline Others & -0.0004 & 0.0013 & 0.0026 & -0.0046 & -0.0003 & 0.0021 \\
\hline $\mathrm{Al}_{2} \mathrm{O}_{3} /(\mathrm{T} / \mathbf{1 0 0 0})^{2}$ & $\begin{array}{l}-0.6142 \\
\end{array}$ & -0.1955 & -0.3977 & 0.4556 & 0.1235 & 0.4630 \\
\hline $\mathrm{Fe}_{2} \mathrm{O}_{3} /(T / \mathbf{1 0 0 0})^{2}$ & -0.6682 & -0.3036 & -0.3269 & 0.5750 & 0.4362 & 0.5859 \\
\hline $\mathrm{Li}_{2} \mathrm{O} /(T / 1000)^{2}$ & 1.4883 & -0.5829 & 0.1997 & -0.3233 & 0.5494 & $\begin{array}{l}-1.0465 \\
\end{array}$ \\
\hline $\mathrm{Na}_{2} \mathrm{O} /(T / 1000)^{2}$ & 1.1842 & -0.1590 & 0.2980 & -0.0434 & -0.1136 & -0.6527 \\
\hline $\mathrm{SiO}_{2} /(\mathrm{T} / \mathbf{1 0 0 0})^{2}$ & -0.1590 & 0.1980 & -0.0083 & -0.2156 & -0.1339 & -0.0472 \\
\hline $\mathrm{SrO} /(\mathrm{T} / \mathbf{1 0 0 0})^{2}$ & 0.2980 & -0.0083 & 1.6177 & 0.1104 & -0.8644 & $\begin{array}{l}-0.3435 \\
\end{array}$ \\
\hline $\mathrm{ThO}_{2} /(\mathrm{T} / \mathbf{1 0 0 0})^{2}$ & -0.0434 & -0.2156 & 0.1104 & 5.3874 & -2.2012 & -0.4343 \\
\hline $\mathrm{UO}_{3} /(\mathrm{T} / \mathbf{1 0 0 0})^{2}$ & -0.1136 & -0.1339 & -0.8644 & -2.2012 & 5.3219 & -0.3523 \\
\hline $\mathrm{ZrO}_{2} /(\mathrm{T} / \mathbf{1 0 0 0})^{2}$ & -0.6527 & -0.0472 & -0.3435 & $\begin{array}{l}-0.4343 \\
\end{array}$ & -0.3523 & 1.9275 \\
\hline
\end{tabular}


Table D.16. Variance-Covariance Matrix Associated With the Estimated Coefficients of the Recommended 29-Term Truncated T2-Linear Mixture Model with Five Quadratic Composition Terms for ln(Viscosity, P) of HLW Glasses.

\begin{tabular}{|c|c|c|c|c|c|c|c|c|c|c|c|c|c|c|c|}
\hline Term & $\mathbf{A l}_{2} \mathbf{O}_{3}$ & $\mathbf{B}_{2} \mathbf{O}_{3}$ & $\mathrm{CaO}$ & $\mathrm{Fe}_{2} \mathrm{O}_{3}$ & $\mathbf{L i}_{2} \mathbf{O}$ & MgO & $\mathrm{MnO}$ & $\mathrm{Na}_{2} \mathrm{O}$ & $\mathrm{SiO}_{2}$ & SrO & $\mathrm{ThO}_{2}$ & $\mathbf{U O}_{3}$ & ZnO & $\mathrm{ZrO}_{2}$ & Others \\
\hline $\mathbf{A l}_{2} \mathbf{O}_{3}$ & 7.9668 & -0.8835 & -0.1646 & -0.0751 & -0.8011 & -1.3053 & -0.1258 & -1.3455 & 0.6377 & -0.4855 & -1.8077 & -0.5264 & -1.6812 & 0.1244 & -0.4437 \\
\hline $\mathbf{B}_{2} \mathbf{O}_{3}$ & -0.8835 & 0.7688 & 0.2340 & -0.0648 & -0.2239 & 0.1636 & 0.0226 & 0.6473 & -0.1532 & 0.0075 & 0.4314 & -0.0288 & 0.0981 & -0.1080 & -0.1117 \\
\hline $\mathrm{CaO}$ & -0.1646 & 0.2340 & 58.4418 & -0.5260 & -1.3424 & -15.8103 & 0.1048 & 0.1726 & \begin{tabular}{|l|}
-0.2157 \\
\end{tabular} & 0.0163 & 1.1468 & -0.3915 & -3.5957 & -0.6454 & $\begin{array}{l}-0.4099 \\
\end{array}$ \\
\hline $\mathrm{Fe}_{2} \mathrm{O}_{3}$ & -0.0751 & -0.0648 & -0.5260 & 0.6896 & -0.4580 & -0.0281 & 0.0360 & -0.2656 & -0.1265 & -0.0983 & 0.3044 & 0.1957 & 0.1683 & 0.2439 & 0.0071 \\
\hline $\mathbf{L i}_{2} \mathbf{O}$ & -0.8011 & -0.2239 & -1.3424 & -0.4580 & 8.3215 & -0.1447 & -0.1583 & 0.2371 & -0.2745 & 0.1343 & -0.6056 & 0.3241 & -0.4173 & -0.4996 & 0.7090 \\
\hline MgO & -1.3053 & 0.1636 & -15.8103 & -0.0281 & -0.1447 & 40.2953 & -0.2260 & 0.0185 & -0.0921 & 0.0682 & -0.2543 & 2952 & -0.6735 & 0.4393 & 0.5528 \\
\hline $\mathrm{MnO}$ & -0.1258 & 0.0226 & 0.1048 & 0.0360 & -0.1583 & -0.2260 & 0.2251 & 0.0017 & -0.0238 & -0.0382 & -0.0541 & 0.0115 & 0.0670 & 0.0180 & $\overline{308}$ \\
\hline $\mathrm{Na}_{2} \mathrm{O}$ & -1.3455 & 0.6473 & 0.1726 & -0.2656 & 0.2371 & 0.0185 & 0.0017 & 1.1039 & -0.2219 & 0.1289 & 0.7342 & -0.0472 & 0.3710 & -0.3145 & -0.1562 \\
\hline $\mathrm{SiO}_{2}$ & 0.6377 & -0.1532 & -0.2157 & -0.1265 & -0.2745 & -0.0921 & -0.0238 & -0.2219 & 0.1508 & -0.0280 & -0.3337 & -0.0931 & -0.2223 & -0.0030 & -0.0374 \\
\hline SrO & -0.4855 & \begin{tabular}{|l|}
0.0075 \\
\end{tabular} & 0.0163 & -0.0983 & 0.1343 & 0.0682 & -0.0382 & \begin{tabular}{l|l|}
0.1289 \\
\end{tabular} & -0.0280 & \begin{tabular}{|l|}
0.6350 \\
\end{tabular} & 0.0763 & -0.2564 & 0.0459 & -0.1220 & -0.0874 \\
\hline $\mathrm{ThO}_{2}$ & -1.8077 & 0.4314 & 1.1468 & 0.3044 & -0.6056 & -0.2543 & -0.0541 & 0.7342 & -0.3337 & 0.0763 & 018 & 559 & 144 & 908 & 154 \\
\hline $\mathrm{UO}_{3}$ & -0.5264 & \begin{tabular}{|l|}
-0.0288 \\
\end{tabular} & -0.3915 & 0.1957 & 0.3241 & 0.2952 & 0.0115 & -0.0472 & \begin{tabular}{|l|}
-0.0931 \\
\end{tabular} & -0.2564 & -0.6559 & 1.9314 & 0.3979 & -0.1020 & 0.0048 \\
\hline $\mathrm{ZnO}$ & -1.6812 & 0.0981 & -3.5957 & 0.1683 & -0.4173 & -0.6735 & 0.0670 & 0.3710 & -0.2223 & 0.0459 & 0.2144 & 0.3979 & 6.6416 & 0.0086 & -0.3371 \\
\hline $\mathrm{ZrO}_{2}$ & 0.1244 & -0.1080 & -0.6454 & 0.2439 & -0.4996 & 0.4393 & 0.0180 & -0.3145 & -0.0030 & -0.1220 & -0.2908 & -0.1020 & 0.0086 & 0.7307 & 0.0101 \\
\hline Others & -0.4437 & -0.1117 & -0.4099 & 0.0071 & 0.7090 & 0.5528 & -0.0308 & -0.1562 & -0.0374 & -0.0874 & -0.0154 & 0.0048 & -0.3371 & 101 & 0.7739 \\
\hline $\mathrm{Al}_{2} \mathrm{O}_{3} \times \mathrm{SiO}_{2}$ & -18.0627 & 1.8832 & 0.0871 & 0.8951 & 0.9398 & 3.3789 & 0.4029 & 2.5964 & -1.7017 & 0.8666 & 4.7166 & 1.4188 & 3.8006 & 0.1915 & 1.0202 \\
\hline $\mathrm{B}_{2} \mathrm{O}_{3} \times \mathrm{Na}_{2} \mathrm{O}$ & 3.9629 & -5.8522 & -0.8342 & 0.6929 & 2.4376 & -0.3677 & -0.1418 & -5.5031 & 0.9306 & 0.2493 & -2.9795 & 0.7188 & -0.5774 & 0.7809 & 1.3717 \\
\hline $\mathbf{L i}_{2} \mathbf{O} \times \mathbf{Z n O}$ & 45.6008 & -6.2806 & 61.3201 & -3.7651 & -0.5317 & 11.4410 & -1.5858 & -11.1072 & 5.9252 & 0.3309 & -8.4407 & -10.4225 & -157.5900 & 0.1578 & 7.9266 \\
\hline $\mathrm{Na}_{2} \mathrm{O} \times \mathrm{ThO}$ & 11.5929 & -3.2844 & -16.3624 & -0.4856 & 3.9734 & 5.5329 & 0.7951 & -5.8915 & 1.7238 & -0.0548 & -26.2277 & -0.3795 & -1.1583 & 1.2759 & 0.6295 \\
\hline$\left(\mathrm{Li}_{2} \mathrm{O}\right)^{2}$ & -11.1465 & 5.8540 & -5.0365 & 3.6141 & -84.9332 & 6.5510 & 2.5664 & 7.7552 & -0.9550 & -0.2981 & 11.1086 & 0.9894 & 39.9423 & 2.1272 & -11.9445 \\
\hline $\mathrm{Al}_{2} \mathrm{O}_{3} /(\mathrm{T} / \mathbf{1 0 0 0})^{2}$ & -0.9444 & 0.0002 & -0.0178 & -0.3878 & 0.4636 & -0.0007 & 0.0026 & 0.3298 & 0.1045 & \begin{tabular}{|l|}
0.2098 \\
\end{tabular} & -0.2327 & -0.0677 & 0.0068 & -0.2480 & -0.0002 \\
\hline $\mathrm{Fe}_{2} \mathrm{O}_{3} /(\mathrm{T} / \mathbf{1 0 0 0})^{2}$ & -0.3984 & 0.0000 & -0.0001 & -0.9553 & 0.4398 & -0.0041 & 0.0024 & 0.3602 & 0.1608 & 0.1746 & -0.3049 & -0.2285 & 0.0138 & -0.3137 & -0.0037 \\
\hline $\mathrm{Li}_{2} \mathrm{O} /(\mathrm{T} / \mathbf{1 0 0 0})^{2}$ & 0.4798 & -0.0014 & 0.0155 & 0.4486 & -3.9152 & -0.0388 & 0.0052 & -0.7959 & 0.3100 & -0.1085 & 0.1671 & -0.2855 & 0.0425 & 0.5546 & -0.0095 \\
\hline $\mathrm{Na}_{2} \mathrm{O} /(T / 1000)^{2}$ & 0.3289 & \begin{tabular}{|l|}
0.0012 \\
\end{tabular} & 0.0190 & 0.3570 & -0.7930 & 0.0017 & 0.0003 & -0.6345 & 0.0854 & \begin{tabular}{|l|}
-0.1599 \\
\end{tabular} & 0.0103 & 0.0612 & -0.0103 & 0.3488 & 0.0002 \\
\hline $\mathrm{SiO}_{2} /(T / 1000)^{2}$ & 0.1069 & -0.0005 & -0.0053 & 0.1618 & 0.3099 & 0.0035 & -0.0009 & 0.0842 & -0.1054 & 0.0048 & 0.1169 & 0.0705 & -0.0052 & 0.0256 & 0.0012 \\
\hline $\mathrm{SrO} /(T / 1000)^{2}$ & 0.2034 & 0.0016 & -0.0190 & 0.1741 & -0.1154 & 0.0282 & -0.0052 & -0.1588 & 0.0049 & -0.8619 & -0.0496 & 0.4583 & -0.0215 & 0.1860 & 0.0029 \\
\hline $\mathrm{ThO}_{2} /(T / 1000)^{2}$ & -0.2526 & 0.0084 & 0.0671 & -0.3072 & 0.1688 & -0.0041 & 0.0008 & 0.0266 & 0.1136 & \begin{tabular}{|l|}
-0.0581 \\
\end{tabular} & -2.8796 & 1.1617 & -0.0179 & 0.2321 & -0.0042 \\
\hline $\mathrm{UO}_{3} /(\mathrm{T} / \mathbf{1 0 0 0})^{2}$ & -0.0651 & -0.0055 & 0.0368 & -0.2285 & -0.2930 & -0.0595 & 0.0075 & 0.0604 & 0.0706 & \begin{tabular}{|l|}
0.4567 \\
\end{tabular} & 1.1467 & -2.8181 & 0.0246 & 0.1859 & -0.0002 \\
\hline $\mathrm{ZrO}_{2} /(\mathrm{T} / 1000)^{2}$ & -0.2593 & 0.0009 & -0.0338 & -0.3134 & 0.5444 & 0.0165 & -0.0032 & 0.3523 & 0.0249 & 0.1861 & 0.2382 & 0.1857 & 0.0146 & -1.0291 & 0.0002 \\
\hline
\end{tabular}


Table D.16. Variance-Covariance Matrix Associated With the Estimated Coefficients of the Recommended 29-Term Truncated T2-Linear Mixture Model with Five Quadratic Composition Terms for ln(Viscosity, P) of HLW Glasses (continued).

\begin{tabular}{|c|c|c|c|c|c|c|c|c|c|}
\hline Term & $\mathrm{Al}_{2} \mathrm{O}_{3} \times \mathrm{SiO}_{2}$ & $\mathrm{~B}_{2} \mathrm{O}_{3} \times \mathrm{Na}_{2} \mathrm{O}$ & $\mathbf{L i}_{2} \mathbf{O} \times \mathbf{Z n O}$ & $\mathrm{Na}_{2} \mathrm{O} \times \mathrm{ThO}_{2}$ & $\left(\mathbf{L i}_{2} \mathbf{O}\right)^{2}$ & $\mathrm{Al}_{2} \mathrm{O}_{3} /(T / 1000)^{2}$ & $\mathrm{Fe}_{2} \mathrm{O}_{3} /(T / 1000)^{2}$ & $\mathrm{Li}_{2} \mathrm{O} /(T / 1000)^{2}$ & $\mathrm{Na}_{2} \mathrm{O} /(\mathrm{T} / \mathbf{1 0 0 0})^{2}$ \\
\hline $\mathrm{Al}_{2} \mathrm{O}_{3}$ & -18.0627 & 3.9629 & 45.6008 & 11.5929 & -11.1465 & -0.9444 & -0.3984 & 0.4798 & 0.3289 \\
\hline $\mathrm{B}_{2} \mathrm{O}_{3}$ & 1.8832 & -5.8522 & -6.2806 & -3.2844 & 5.8540 & 0.0002 & 0.0000 & -0.0014 & 0.0012 \\
\hline $\mathrm{CaO}$ & 0.0871 & -0.8342 & 61.3201 & -16.3624 & -5.0365 & -0.0178 & -0.0001 & 0.0155 & 0.0190 \\
\hline $\mathrm{Fe}_{2} \mathrm{O}_{3}$ & 0.8951 & 0.6929 & -3.7651 & -0.4856 & 3.6141 & -0.3878 & -0.9553 & 0.4486 & 0.3570 \\
\hline $\mathrm{Li}_{2} \mathrm{O}$ & 0.9398 & 2.4376 & -0.5317 & 3.9734 & -84.9332 & 0.4636 & 0.4398 & -3.9152 & -0.7930 \\
\hline MgO & 3.3789 & -0.3677 & 11.4410 & 5.5329 & 6.5510 & -0.0007 & -0.0041 & -0.0388 & 0.0017 \\
\hline MnO & 0.4029 & -0.1418 & -1.5858 & 0.7951 & 2.5664 & 0.0026 & 0.0024 & 0.0052 & 0.0003 \\
\hline $\mathrm{Na}_{2} \mathrm{O}$ & 2.5964 & -5.5031 & -11.1072 & -5.8915 & 7.7552 & 0.3298 & 0.3602 & -0.7959 & -0.6345 \\
\hline $\mathrm{SiO}_{2}$ & -1.7017 & 0.9306 & 5.9252 & 1.7238 & -0.9550 & 0.1045 & 0.1608 & 0.3100 & 0.0854 \\
\hline SrO & 0.8666 & 0.2493 & 0.3309 & -0.0548 & -0.2981 & 0.2098 & 0.1746 & -0.1085 & -0.1599 \\
\hline $\mathrm{ThO}_{2}$ & 4.7166 & -2.9795 & -8.4407 & -26.2277 & 11.1086 & -0.2327 & -0.3049 & 0.1671 & 0.0103 \\
\hline $\mathrm{UO}_{3}$ & 1.4188 & 0.7188 & -10.4225 & -0.3795 & 0.9894 & -0.0677 & -0.2285 & -0.2855 & 0.0612 \\
\hline $\mathrm{ZnO}$ & 3.8006 & -0.5774 & -157.5900 & -1.1583 & 39.9423 & 0.0068 & 0.0138 & 0.0425 & -0.0103 \\
\hline $\mathrm{ZrO}_{2}$ & 0.1915 & 0.7809 & 0.1578 & 1.2759 & 2.1272 & -0.2480 & -0.3137 & 0.5546 & 0.3488 \\
\hline Others & 1.0202 & 1.3717 & 7.9266 & 0.6295 & -11.9445 & -0.0002 & -0.0037 & -0.0095 & 0.0002 \\
\hline $\mathrm{Al}_{2} \mathrm{O}_{3} \times \mathrm{SiO}_{2}$ & 44.7941 & -7.9693 & -100.7100 & -27.3300 & 28.8522 & -0.0275 & 0.0292 & -0.0256 & -0.0003 \\
\hline $\mathrm{B}_{2} \mathrm{O}_{3} \times \mathrm{Na}_{2} \mathrm{O}$ & -7.9693 & 52.9077 & 41.6790 & 26.0936 & -47.3966 & -0.0140 & -0.0104 & -0.0032 & -0.0069 \\
\hline $\mathbf{L i}_{2} \mathbf{O} \times \mathbf{Z n O}$ & -100.7100 & 41.6790 & 4513.7400 & 67.5881 & -968.3600 & -0.1110 & -0.1260 & -1.1280 & 0.1729 \\
\hline $\mathrm{Na}_{2} \mathrm{O} \times \mathrm{ThO}_{2}$ & -27.3300 & 26.0936 & 67.5881 & 212.3600 & -82.1514 & -0.0634 & -0.0002 & 0.0123 & 0.1011 \\
\hline$\left(\mathrm{Li}_{2} \mathrm{O}\right)^{2}$ & 28.8522 & -47.3966 & -968.3600 & -82.1514 & 1499.2500 & 0.1055 & 0.1895 & -0.8160 & -0.0811 \\
\hline $\mathrm{Al}_{2} \mathrm{O}_{3} /(\mathrm{T} / 1000)^{2}$ & -0.0275 & -0.0140 & -0.1110 & -0.0634 & 0.1055 & 1.7923 & 0.7240 & -0.8779 & -0.6141 \\
\hline $\mathrm{Fe}_{2} \mathrm{O}_{3} /(T / 1000)^{2}$ & 0.0292 & -0.0104 & -0.1260 & -0.0002 & 0.1895 & 0.7240 & 1.7899 & -0.8365 & -0.6680 \\
\hline $\mathrm{Li}_{2} \mathrm{O} /(T / 1000)^{2}$ & -0.0256 & -0.0032 & -1.1280 & 0.0123 & -0.8160 & -0.8779 & -0.8365 & 7.4442 & 1.4878 \\
\hline $\mathrm{Na}_{2} \mathrm{O} /(T / 1000)^{2}$ & -0.0003 & -0.0069 & 0.1729 & 0.1011 & -0.0811 & -0.6141 & -0.6680 & 1.4878 & 1.1840 \\
\hline $\mathrm{SiO}_{2} /(\mathrm{T} / \mathbf{1 0 0 0})^{2}$ & -0.0075 & 0.0086 & 0.0915 & -0.0166 & 0.0000 & -0.1955 & -0.3036 & -0.5827 & -0.1589 \\
\hline $\mathrm{SrO} /(T / 1000)^{2}$ & 0.0196 & -0.0019 & 0.3466 & -0.0806 & 0.0658 & -0.3976 & -0.3268 & 0.1996 & 0.2980 \\
\hline $\mathrm{ThO}_{2} /(\mathrm{T} / 1000)^{2}$ & 0.0290 & -0.0468 & 0.2849 & 0.1190 & -0.0064 & 0.4554 & 0.5749 & -0.3232 & -0.0432 \\
\hline $\mathrm{UO}_{3} /(T / 1000)^{2}$ & 0.0034 & 0.0043 & -0.1015 & 0.1230 & 0.0369 & 0.1234 & 0.4359 & 0.5488 & -0.1135 \\
\hline $\mathrm{ZrO}_{2} /(T / 1000)^{2}$ & 0.0288 & -0.0182 & -0.3609 & -0.0416 & 0.2917 & 0.4629 & 0.5859 & -1.0463 & -0.6526 \\
\hline
\end{tabular}


Table D.16. Variance-Covariance Matrix Associated With the Estimated Coefficients of the Recommended 29-Term Truncated T2-Linear Mixture Model with Five Quadratic Composition Terms for In(Viscosity, P) of HLW Glasses (continued).

\begin{tabular}{|c|c|c|c|c|c|}
\hline Term & $\mathrm{SiO}_{2} /(T / 1000)^{2}$ & $\mathrm{SrO} /(T / 1000)^{2}$ & $\mathrm{ThO}_{2} /(\mathrm{T} / 1000)^{2}$ & $\mathrm{UO}_{3} /(\mathrm{T} / 1000)^{2}$ & $\mathrm{ZrO}_{2} /(\mathrm{T} / \mathbf{1 0 0 0})^{2}$ \\
\hline $\mathbf{A l}_{2} \mathbf{O}_{3}$ & 0.1069 & 0.2034 & -0.2526 & -0.0651 & -0.2593 \\
\hline $\mathbf{B}_{2} \mathbf{O}_{3}$ & -0.0005 & 0.0016 & 0.0084 & -0.0055 & 0.0009 \\
\hline $\mathrm{CaO}$ & -0.0053 & -0.0190 & 0.0671 & 0.0368 & -0.0338 \\
\hline $\mathrm{Fe}_{2} \mathrm{O}_{3}$ & 0.1618 & 0.1741 & -0.3072 & -0.2285 & -0.3134 \\
\hline $\mathbf{L i}_{2} \mathbf{O}$ & 0.3099 & -0.1154 & 0.1688 & -0.2930 & 0.5444 \\
\hline MgO & 0.0035 & 0.0282 & -0.0041 & -0.0595 & 0.0165 \\
\hline MnO & -0.0009 & -0.0052 & 0.0008 & 0.0075 & -0.0032 \\
\hline $\mathrm{Na}_{2} \mathrm{O}$ & 0.0842 & -0.1588 & 0.0266 & 0.0604 & 0.3523 \\
\hline $\mathrm{SiO}_{2}$ & -0.1054 & 0.0049 & 0.1136 & 0.0706 & 0.0249 \\
\hline SrO & 0.0048 & -0.8619 & -0.0581 & 0.4567 & 0.1861 \\
\hline $\mathrm{ThO}_{2}$ & 0.1169 & -0.0496 & -2.8796 & 1.1467 & 0.2382 \\
\hline $\mathrm{UO}_{3}$ & 0.0705 & 0.4583 & 1.1617 & -2.8181 & 0.1857 \\
\hline $\mathrm{ZnO}$ & -0.0052 & -0.0215 & -0.0179 & 0.0246 & 0.0146 \\
\hline $\mathrm{ZrO}_{2}$ & 0.0256 & 0.1860 & 0.2321 & 0.1859 & -1.0291 \\
\hline Others & 0.0012 & 0.0029 & -0.0042 & -0.0002 & 0.0002 \\
\hline $\mathrm{Al}_{2} \mathrm{O}_{3} \times \mathrm{SiO}_{2}$ & -0.0075 & 0.0196 & 0.0290 & 0.0034 & 0.0288 \\
\hline $\mathrm{B}_{2} \mathrm{O}_{3} \times \mathrm{Na}_{2} \mathrm{O}$ & 0.0086 & -0.0019 & -0.0468 & 0.0043 & -0.0182 \\
\hline $\mathbf{L i}_{2} \mathbf{O} \times \mathbf{Z n O}$ & 0.0915 & 0.3466 & 0.2849 & -0.1015 & -0.3609 \\
\hline $\mathrm{Na}_{2} \mathrm{O} \times \mathrm{ThO}_{2}$ & -0.0166 & -0.0806 & 0.1190 & 0.1230 & -0.0416 \\
\hline$\left(\mathbf{L i}_{2} \mathbf{O}\right)^{2}$ & 0.0000 & 0.0658 & -0.0064 & 0.0369 & 0.2917 \\
\hline $\mathrm{Al}_{2} \mathrm{O}_{3} /(T / 1000)^{2}$ & -0.1955 & -0.3976 & 0.4554 & 0.1234 & 0.4629 \\
\hline $\mathrm{Fe}_{2} \mathrm{O}_{3} /(\mathrm{T} / 1000)^{2}$ & -0.3036 & -0.3268 & 0.5749 & 0.4359 & 0.5859 \\
\hline $\mathrm{Li}_{2} \mathrm{O} /(\mathrm{T} / \mathbf{1 0 0 0})^{2}$ & -0.5827 & 0.1996 & -0.3232 & 0.5488 & -1.0463 \\
\hline $\mathrm{Na}_{2} \mathrm{O} /(\mathrm{T} / \mathbf{1 0 0 0})^{2}$ & -0.1589 & 0.2980 & -0.0432 & -0.1135 & -0.6526 \\
\hline $\mathrm{SiO}_{2} /(\mathrm{T} / \mathbf{1 0 0 0})^{2}$ & 0.1980 & -0.0083 & -0.2156 & -0.1338 & -0.0472 \\
\hline $\mathrm{SrO} /(T / 1000)^{2}$ & -0.0083 & 1.6174 & 0.1103 & -0.8640 & -0.3435 \\
\hline $\mathrm{ThO}_{2} /(\mathrm{T} / 1000)^{2}$ & -0.2156 & 0.1103 & 5.3866 & -2.2005 & -0.4343 \\
\hline $\mathrm{UO}_{3} /(\mathrm{T} / \mathbf{1 0 0 0})^{2}$ & -0.1338 & -0.8640 & -2.2005 & 5.3202 & -0.3520 \\
\hline $\mathrm{ZrO}_{2} /(T / 1000)^{2}$ & -0.0472 & -0.3435 & -0.4343 & -0.3520 & 1.9271 \\
\hline
\end{tabular}


The Catholic University of America Vitreous State Laboratory
IHLW PCT, Spinel $T_{1 \%}$, Electrical Conductivity, and Viscosity Model Development Final Report, VSL-07R1240-4, Rev. 0

\title{
Appendix E
}

\author{
Calculating Estimated $T_{1 \%}$ Values \\ and Corresponding Standard Deviations
}




\section{Appendix E}

\section{Calculating Estimated $\mathbf{T}_{1 \%}$ Values and Corresponding Standard Deviations}

The high-level waste (HLW) glasses considered in this report were heat-treated at various temperatures and then samples of the heat-treated glass were analyzed to determine the volume percent (vol\%) crystallinity as well as the primary and any secondary crystalline phases. Section E.1 describes how the (temperature, vol\% crystallinity) data for each HLW glass was used to calculate the temperature at which the equilibrium crystal fraction is one volume percent of the molten glass $\left(\mathrm{T}_{1 \%}\right)$. Section E.2 illustrates using the equations to calculate $\mathrm{T}_{1 \%}$ and its uncertainty.

\section{E.1 Equations for Calculating Estimated $T_{1 \%}$ and It's Standard Deviation}

For each HLW glass, the temperature and volume \%-crystallinity data were used to fit a separate regression equation of the form

$$
T=a_{0}+a_{1} v
$$

where $v$ is the volume \% crystallinity at a given temperature $T\left({ }^{\circ} \mathrm{C}\right)$, and $a_{0}$ and $a_{1}$ are the fitted intercept and slope of the $T$ vs. $X$ model for that glass. Equations of the form (E.1) were fit for each HLW glass having sufficient (temperature, vol\%) data using unweighted least squares (ULS) regression. Substituting $v=1$ vol\% into the fitted equation for a given glass yields an estimate of $\mathrm{T}_{1 \%}$ for that glass. Using statistical regression theory and equations, the standard deviation of the $\mathrm{T}_{1 \%}$ value, denoted $\mathrm{SD}\left(\mathrm{T}_{1 \%}\right)$, can also be calculated.

In Equation (E.1), temperature ( $T$ ) was used as the response variable, and vol\% crystals (v) was used as the explanatory variable. This assignment of variables is considered an inverse regression approach. In the classical regression approach, the explanatory variable should have no uncertainty, or uncertainty that is small relative to the uncertainty in the response variable. Hence, with the classical approach, $T$ would be the explanatory variable and $v$ would be the response variable. However, the classical approach presents problems for calculating the uncertainty of $\mathrm{T}_{1 \%}$ values. Also, statistical research (Shukla 1972) has shown that if the number of data points is small, it is better to use the inverse regression approach.

Equations involving matrix algebra can be used to calculate the $\mathrm{SD}\left(\mathrm{T}_{1 \%}\right)$ values mentioned above. However, because simple linear regression is used to relate temperature to 
volume \%-crystallinity in Equation (E.1), a simpler equation can be used to calculate the $\mathrm{SD}\left(\mathrm{T}_{1 \%}\right)$ values. This equation is

$$
S D\left(T_{1 \%}\right)=\sqrt{M S E \times\left(\frac{1}{n}+\frac{\left(v_{0}-\bar{v}\right)^{2}}{\sum_{i=1}^{n}\left(v_{i}-\bar{v}\right)^{2}}\right)}
$$

where $n$ is the number of temperature versus volume \%-crystallinity data points used in the simple linear regression to calculate the slope, intercept, estimated $\mathrm{T}_{1 \%}$ value, and $\mathrm{SD}\left(\mathrm{T}_{1 \%}\right)$ for a particular glass; $v_{0}$ is 1 volume $\%$-crystallinity; $v_{i}$ is the $i^{\text {th }}$ volume $\%$-crystallinity value among the $n$ data points; $\bar{v}$ is the mean volume \%-crystallinity value for the $n$ data points; and MSE is the mean squared error for the simple linear regression involving the $n$ data points. The MSE is calculated using

$$
M S E=\frac{S S E}{n-2}=\frac{\sum_{i=1}^{n}\left(T_{i}-\hat{T}_{i}\right)^{2}}{n-2},
$$

where $T_{i}\left({ }^{\circ} \mathrm{C}\right)$ is the measured temperature for the $i^{\text {th }}$ data point among the $n$ data points used in the simple linear regression, and $\hat{T}_{i}\left({ }^{\circ} \mathrm{C}\right)$ is the predicted temperature corresponding to the $i^{\text {th }}$ volume \%-crystallinity value among the $n$ data points. Section E.2 contains an example that illustrates the use of Equations (E.1) through (E.3) to calculate estimated $\mathrm{T}_{1 \%}$ values and their corresponding standard deviations.

\section{E.2 Example Illustrating the Use of $\mathbf{T}_{1 \%}$ Equations}

This section illustrates the use of Equations (E.1) to (E.3) for calculating the estimated $\mathrm{T}_{1 \%}$ value and corresponding standard deviation for one HLW glass, namely HLW02-52. The temperature versus volume \%-crystallinity data for HLW02-52 are given in Table 4.3 and Table 6.2 , but are listed again here for convenience.

\begin{tabular}{|c|c|c|c|c|c|}
\hline Temperature $\left({ }^{\circ} \mathrm{C}\right)$ & 750 & 850 & 900 & 950 & 1050 \\
\hline $\begin{array}{c}\text { Volume \%- } \\
\text { Crystallinity }\end{array}$ & 2.5 & 1.3 & 2.1 & 1.2 & 0.4 \\
\hline
\end{tabular}

Simple linear regression using the above data with temperature as the response results in the regression line

$$
\hat{T}=1077.78-118.52 v,
$$


where $v$ is the volume \%-crystallinity and $\hat{T}$ is the corresponding temperature estimate. As explained in Section E.1, this regression equation form can be considered an inverse regression because temperature would typically be the more suitable predictor variable. For a volume \%crystallinity value of 1, the above regression line in Equation (E.4) produces an estimated $\mathrm{T}_{1 \%}$ value of

$$
\hat{T}=1077.78-118.52(1)=1077.78-118.52=959.3^{\circ} \mathrm{C}
$$

Note that the intercept (1077.78), slope (-118.52), and estimated $T_{1 \%}$ value (959.3) for HLW02-52 are given in Table 6.3.

A graphical depiction of the temperature versus volume \%-crystallinity data for HLW02-52, together with the calculated regression line in Equation (E.4) is shown in Figure E.1. The black diagonal line in Figure E. 1 is the regression line used to obtain the estimated $\mathrm{T}_{1 \%}$ value for HLW02-52. The dashed line in Figure E.1 represents using the regression line to calculate the estimated $\mathrm{T}_{1 \%}$ value for HLW02-52. As depicted in Figure E.1, the dashed red line corresponds to a volume \%-crystallinity value of 1.0 , and results in an estimated temperature of $959.3^{\circ} \mathrm{C}$.

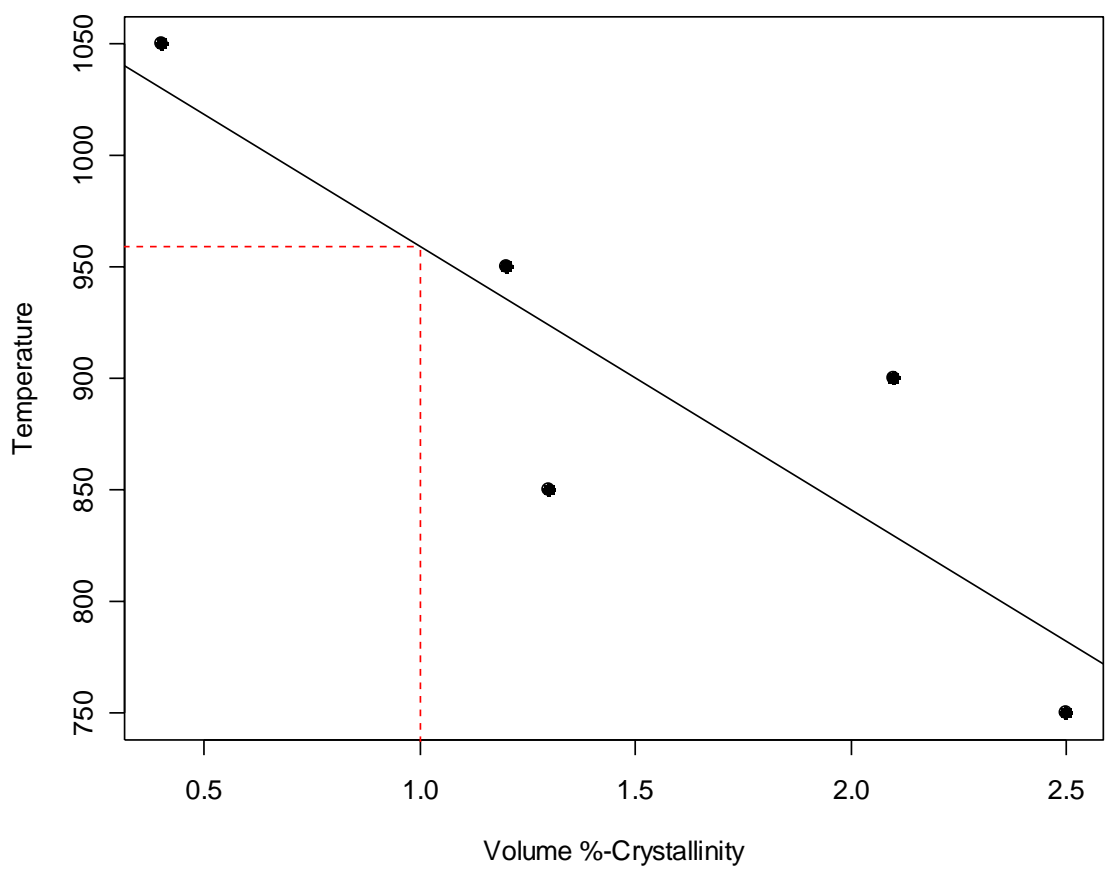

Figure E.1. Temperature versus Volume \%-Crystallinity Data, Regression Line, and Estimated $\mathrm{T}_{1 \%}$ Value for HLW02-52. 
The standard deviation associated with the estimated $\mathrm{T}_{1 \%}$ value for HLW02-52 is calculated using Equations (E.2) and (E.3). Equation (E.3) is used first to calculate the mean squared error $(M S E)^{1}$, which is then substituted into Equation (E.2) to calculate $\operatorname{SD}\left(\mathrm{T}_{1 \%}\right)$ value for HLW02-52. As indicated in Equation (E.3), estimated $T_{i}$ (i.e., $\hat{T}_{i}$ ) values are needed for each of the five temperature versus volume \%-crystallinity data points available for HLW02-52. These estimated $\hat{T}_{i}$ values are obtained by applying the regression Equation (E.4) to each of the five volume \%-crystallinity values for HLW02-52. The estimated temperature calculations are shown below.

\begin{tabular}{|c|c|}
\hline Volume \%-Crystallinity & Estimated Temperature $\left(\hat{T}_{i}\right)^{\text {(a) }}$ \\
\hline 2.5 & $1077.7778-118.5185(2.5)=781.482$ \\
\hline 1.3 & $1077.7778-118.5185(1.3)=923.704$ \\
\hline 2.1 & $1077.7778-118.5185(2.1)=828.889$ \\
\hline 1.2 & $1077.7778-118.5185(1.2)=935.556$ \\
\hline 0.4 & $1077.7778-118.5185(0.4)=1030.370$ \\
\hline
\end{tabular}

(a) Intercepts, slopes, and estimated $\mathrm{T}_{1 \%}$ values are given in greater decimal accuracy here than were used in Table 6.3 in order to ensure two decimal accuracy in the calculated standard deviation below.

Thus, using Equation (E.3) yields

$$
\begin{aligned}
& \text { MSE }=\frac{\sum_{i=1}^{n}\left(T_{i}-\hat{T}_{i}\right)^{2}}{n-2} \\
& =\frac{(750-781.482)^{2}+(850-923.704)^{2}+(900-828.889)^{2}+(950-935.556)^{2}+(1050-1030.370)^{2}}{5-2} \\
& =\frac{991.116+5432.280+5056.774+208.629+385.337}{3} \\
& =\frac{12074.136}{3}=4024.712
\end{aligned}
$$

Prior to using Equation (E.2) to calculate SD( $\mathrm{T}_{1 \%}$ ) value for HLW02-52, the mean volume \%crystallinity value is needed. This is calculated as

$$
\bar{v}=\frac{\sum_{i=1}^{n} v_{i}}{n}=\frac{2.5+1.3+2.1+1.2+0.4}{5}=1.5
$$

\footnotetext{
${ }^{1}$ Although Equation (E.3) can be used to calculate the MSE, it (or its square root, known as RMSE) is typically included in the output of many regression software routines.
} 
Substituting MSE and $\bar{v}$ into Equation (E.2), and using $v_{0}=1$, the standard deviation associated with the estimated $T_{1 \%}$ value for HLW02-52 is calculated as follows

$$
\begin{aligned}
S D\left(T_{1 \%}\right) & =\sqrt{M S E\left(\frac{1}{n}+\frac{\left(v_{0}-\bar{v}\right)^{2}}{\sum_{i=1}^{n}\left(v_{i}-\bar{v}\right)^{2}}\right)} \\
& =\sqrt{4024.712\left(\frac{1}{5}+\frac{(2.5-1.5)^{2}+(1.3-1.5)^{2}+(2.1-1.5)^{2}+(1.2-1.5)^{2}+(0.4-1.5)^{2}}{(1-1.5)^{2}}\right)} \\
& =\sqrt{4024.712\left(0.2+\frac{0.25}{2.7}\right)} \\
& =34.32
\end{aligned}
$$

This calculated standard deviation is as given in Table 6.3.

The process described in Section E.1 and illustrated in Section E.2 was used, where possible, to calculate estimated $\mathrm{T}_{1 \%}$ values and their corresponding standard deviations for both modeling and validation glasses. See Section 4.2 for additional discussion. 
The Catholic University of America

Vitreous State Laboratory
IHLW PCT, Spinel $T_{1 \%}$, Electrical Conductivity, and Viscosity Model Development Final Report, VSL-07R1240-4, Rev. 0

\section{Appendix F}

Normalized Target Compositions (in mol\%) of 305 HLW Simulated and Actual Glasses 
The Catholic University of America Vitreous State Laboratory
IHLW PCT, Spinel $T_{1 \%}$, Electrical Conductivity, and Viscosity Model Development Final Report, VSL-07R1240-4, Rev. 0

\section{Appendix F}

\section{Normalized Target Compositions (in mol\%) of 305 HLW Simulated and Actual Glasses}

This appendix contains a table of normalized compositions in mole percent (mol\%) of $300 \mathrm{HLW}$ simulated glasses and 5 HLW actual waste glasses calculated from the normalized target compositions in weight percent (wt\%). The normalized wt\% compositions are given in Tables 2.11 to 2.23 . 
Table F.1. Normalized Target Compositions (mol\%) of 305 HLW Simulated and Actual Waste Glasses.

\begin{tabular}{|c|c|c|c|c|c|c|c|c|c|c|c|c|c|c|c|c|c|c|c|c|}
\hline Glass ID & $\mathbf{A l}_{2} \mathbf{O}_{3}$ & $\mathbf{B}_{2} \mathbf{O}_{3}$ & $\mathrm{CaO}$ & $\mathrm{Cr}_{2} \mathrm{O}_{3}$ & $\mathrm{Fe}_{2} \mathbf{O}_{3}$ & $\mathbf{K}_{2} \mathbf{O}$ & $\mathbf{L i}_{2} \mathbf{O}$ & MgO & MnO & $\mathrm{Na}_{2} \mathrm{O}$ & $\mathrm{NiO}$ & $\mathbf{P}_{2} \mathbf{O}_{5}$ & $\mathrm{SiO}_{2}$ & SrO & $\mathrm{ThO}_{2}$ & $\mathbf{U O}_{3}$ & ZnO & $\mathrm{ZrO}_{2}$ & Others & Sum \\
\hline HLW02-01 & 4.14 & 9.75 & 0.61 & 0.05 & 4.67 & 0.04 & 9.15 & 0.20 & 2.30 & 12.09 & 0.47 & 0.24 & 49.65 & 1.61 & 0.00 & 0.00 & 1.68 & 1.65 & 1.68 & 100.0 \\
\hline HLW02-02 & 2.60 & 13.32 & 0.59 & 0.09 & 5.81 & 0.04 & 13.30 & 0.20 & 0.00 & 4.28 & 0.09 & 0.23 & 55.63 & 0.00 & 0.00 & 0.00 & 1.63 & 0.00 & 2.19 & 100.0 \\
\hline HLW02-03 & 2.78 & 14.24 & 0.63 & 0.09 & 3.55 & 0.05 & 4.74 & 0.21 & 0.00 & 17.13 & 0.95 & 0.25 & 44.77 & 2.99 & 0.00 & 0.00 & 1.74 & 3.45 & 2.44 & 100.0 \\
\hline HLW02-04 & 2.68 & 4.90 & 0.61 & 0.01 & 5.98 & 0.04 & 4.56 & 0.20 & 0.50 & 16.51 & 0.09 & 0.24 & 60.07 & 0.00 & 0.00 & 0.00 & 1.68 & 0.00 & 1.93 & 100.0 \\
\hline HLW02-05 & 2.51 & 4.59 & 0.57 & 0.01 & 3.20 & 0.04 & 12.82 & 0.19 & 0.00 & 14.21 & 0.09 & 0.22 & 55.96 & 0.00 & 0.00 & 0.00 & 1.57 & 3.11 & 0.92 & 100.0 \\
\hline HLW02-06 & 5.63 & 4.85 & 0.60 & 0.01 & 3.38 & 0.04 & 10.71 & 0.20 & 4.76 & 16.34 & 0.90 & 0.24 & 45.51 & 0.00 & 0.00 & 0.00 & 1.66 & 3.29 & 1.87 & 100.0 \\
\hline HLW02-07 & 5.36 & 4.62 & 0.57 & 0.08 & 3.22 & 0.04 & 12.92 & 0.19 & 0.00 & 12.15 & 0.09 & 0.23 & 56.73 & 0.00 & 0.00 & 0.00 & 1.58 & 0.80 & 1.42 & 100.0 \\
\hline HLW02-08 & 2.67 & 13.66 & 0.61 & 0.01 & 3.92 & 0.04 & 7.53 & 0.20 & 4.79 & 16.44 & 0.09 & 0.24 & 43.81 & 0.00 & 0.00 & 0.00 & 1.67 & 3.31 & 1.02 & 100.0 \\
\hline HLW02-09 & 5.93 & 11.84 & 0.63 & 0.01 & 6.24 & 0.05 & 5.41 & 0.21 & 0.00 & 17.22 & 0.95 & 0.25 & 45.00 & 3.43 & 0.00 & 0.00 & 1.75 & 0.00 & 1.07 & 100.0 \\
\hline HLW02-10 & 5.62 & 13.56 & 0.60 & 0.01 & 3.38 & 0.04 & 13.54 & 0.20 & 0.00 & 11.44 & 0.09 & 0.24 & 42.66 & 1.82 & 0.00 & 0.00 & 1.66 & 3.28 & 1.84 & 100.0 \\
\hline HLW02-11 & 2.55 & 13.08 & 0.58 & 0.01 & 3.26 & 0.04 & 13.06 & 0.19 & 0.00 & 11.39 & 0.87 & 0.23 & 48.86 & 0.00 & 0.00 & 0.00 & 1.60 & 3.17 & 1.11 & 100.0 \\
\hline HLW02-12 & 2.64 & 4.83 & 0.60 & 0.09 & 4.80 & 0.04 & 13.51 & 0.20 & 4.74 & 13.85 & 0.90 & 0.24 & 46.36 & 0.00 & 0.00 & 0.00 & 1.65 & 3.28 & 2.29 & 100.0 \\
\hline HLW02-13 & 2.65 & 4.85 & 0.60 & 0.09 & 5.92 & 0.04 & 13.57 & 0.20 & 4.76 & 11.37 & 0.09 & 0.24 & 48.48 & 3.26 & 0.00 & 0.00 & 1.66 & 0.65 & 1.56 & 100.0 \\
\hline HLW02-14 & 2.60 & 4.75 & 0.59 & 0.01 & 3.31 & 0.04 & 13.28 & 0.20 & 2.32 & 4.42 & 0.09 & 0.23 & 58.35 & 3.19 & 0.00 & 0.00 & 1.63 & 3.22 & 1.77 & 100.0 \\
\hline HLW02-15 & 5.93 & 14.30 & 0.63 & 0.09 & 6.23 & 0.05 & 4.76 & 0.21 & 4.70 & 14.39 & 0.10 & 0.25 & 44.97 & 0.00 & 0.00 & 0.00 & 1.75 & 0.00 & 1.64 & 100.0 \\
\hline HLW02-16 & 5.72 & 4.92 & 0.61 & 0.09 & 3.44 & 0.04 & 13.77 & 0.20 & 4.83 & 10.68 & 0.09 & 0.24 & 44.65 & 3.31 & 0.00 & 0.00 & 1.69 & 3.34 & 2.38 & 100.0 \\
\hline HLW02-17 & 5.50 & 4.74 & 0.59 & 0.01 & 5.72 & 0.04 & 13.25 & 0.20 & 0.00 & 8.18 & 0.09 & 0.23 & 58.14 & 0.00 & 0.00 & 0.00 & 1.62 & 0.00 & 1.70 & 100.0 \\
\hline HLW02-18 & 2.71 & 4.97 & 0.62 & 0.09 & 4.82 & 0.04 & 4.66 & 0.21 & 0.00 & 16.74 & 0.93 & 0.24 & 57.40 & 0.00 & 0.00 & 0.00 & 1.70 & 3.37 & 1.50 & 100.0 \\
\hline HLW02-19 & 2.83 & 14.49 & 0.64 & 0.01 & 4.87 & 0.05 & 4.82 & 0.21 & 5.08 & 10.29 & 0.10 & 0.25 & 45.58 & 3.48 & 0.00 & 0.00 & 1.77 & 3.51 & 2.01 & 100.0 \\
\hline HLW02-20 & 2.71 & 13.89 & 0.62 & 0.01 & 6.05 & 0.04 & 4.62 & 0.21 & 0.00 & 7.19 & 0.09 & 0.24 & 59.46 & 2.17 & 0.00 & 0.00 & 1.70 & 0.00 & 1.00 & 100.0 \\
\hline HLW02-21 & 5.61 & 13.54 & 0.60 & 0.01 & 3.37 & 0.04 & 4.51 & 0.20 & 0.00 & 16.30 & 0.09 & 0.24 & 52.04 & 0.00 & 0.00 & 0.00 & 1.65 & 0.82 & 0.97 & 100.0 \\
\hline HLW02-22 & 5.38 & 12.97 & 0.57 & 0.01 & 3.84 & 0.04 & 12.95 & 0.19 & 0.00 & 4.16 & 0.09 & 0.23 & 56.87 & 0.05 & 0.00 & 0.00 & 1.58 & 0.00 & 1.07 & 100.0 \\
\hline HLW02-23 & 5.59 & 13.49 & 0.60 & 0.01 & 3.36 & 0.04 & 13.47 & 0.20 & 4.73 & 6.05 & 0.90 & 0.24 & 43.88 & 3.24 & 0.00 & 0.00 & 1.65 & 0.82 & 1.75 & 100.0 \\
\hline HLW02-24 & 5.76 & 4.96 & 0.62 & 0.07 & 3.46 & 0.04 & 4.63 & 0.21 & 4.87 & 13.60 & 0.09 & 0.24 & 54.12 & 3.33 & 0.00 & 0.00 & 1.70 & 0.84 & 1.45 & 100.0 \\
\hline HLW02-25 & 5.82 & 14.04 & 0.62 & 0.01 & 4.15 & 0.04 & 4.67 & 0.21 & 0.35 & 7.75 & 0.09 & 0.25 & 55.05 & 3.37 & 0.00 & 0.00 & 1.72 & 0.00 & 1.87 & 100.0 \\
\hline HLW02-26 & 2.86 & 5.23 & 0.65 & 0.10 & 5.70 & 0.05 & 4.87 & 0.22 & 5.09 & 17.62 & 0.10 & 0.26 & 46.04 & 3.51 & 0.00 & 0.00 & 1.79 & 3.54 & 2.39 & 100.0 \\
\hline HLW02-27 & 2.69 & 13.81 & 0.61 & 0.01 & 5.38 & 0.04 & 13.79 & 0.20 & 3.26 & 4.74 & 0.09 & 0.24 & 45.65 & 3.31 & 0.00 & 0.00 & 1.69 & 3.34 & 1.13 & 100.0 \\
\hline HLW02-28 & 5.17 & 8.08 & 0.63 & 0.02 & 4.60 & 0.04 & 5.89 & 0.21 & 1.49 & 17.03 & 0.28 & 0.25 & 48.00 & 2.38 & 0.00 & 0.00 & 1.73 & 2.57 & 1.63 & 100.0 \\
\hline HLW02-29 & 5.12 & 13.00 & 0.62 & 0.06 & 4.36 & 0.04 & 8.74 & 0.21 & 1.47 & 10.11 & 0.28 & 0.25 & 47.50 & 2.35 & 0.00 & 0.00 & 1.71 & 2.54 & 1.63 & 100.0 \\
\hline HLW02-30 & 3.66 & 9.47 & 0.60 & 0.02 & 4.25 & 0.04 & 11.35 & 0.20 & 3.35 & 12.28 & 0.27 & 0.24 & 46.26 & 2.29 & 0.00 & 0.00 & 1.67 & 2.48 & 1.58 & 100.0 \\
\hline
\end{tabular}


Table F.1. Normalized Target Compositions (mol\%) of 305 HLW Simulated and Actual Waste Glasses (continued).

\begin{tabular}{|c|c|c|c|c|c|c|c|c|c|c|c|c|c|c|c|c|c|c|c|c|}
\hline Glass ID & $\mathbf{A l}_{2} \mathbf{O}_{3}$ & $\mathbf{B}_{2} \mathbf{O}_{3}$ & $\mathrm{CaO}$ & $\mathrm{Cr}_{2} \mathrm{O}_{3}$ & $\mathrm{Fe}_{2} \mathrm{O}_{3}$ & $\mathbf{K}_{2} \mathbf{O}$ & $\mathbf{L i}_{2} \mathbf{O}$ & MgO & MnO & $\mathrm{Na}_{2} \mathrm{O}$ & $\mathrm{NiO}$ & $\mathbf{P}_{2} \mathbf{O}_{5}$ & $\mathrm{SiO}_{2}$ & SrO & $\mathrm{ThO}_{2}$ & $\mathbf{U O}_{3}$ & ZnO & $\mathrm{ZrO}_{2}$ & Others & Sum \\
\hline HLW02-31 & 3.73 & 12.90 & 0.62 & 0.02 & 4.33 & 0.04 & 5.78 & 0.21 & 1.46 & 16.70 & 0.28 & 0.24 & 47.15 & 1.00 & 0.00 & 0.00 & 1.70 & 2.45 & 1.40 & 100.0 \\
\hline HLW02-32 & 4.92 & 7.68 & 0.60 & 0.02 & 4.19 & 0.04 & 11.19 & 0.20 & 1.41 & 11.58 & 0.27 & 0.24 & 51.33 & 2.26 & 0.00 & 0.00 & 1.64 & 0.81 & 1.62 & 100.0 \\
\hline HLW02-33 & 4.34 & 8.03 & 0.62 & 0.02 & 5.25 & 0.04 & 5.84 & 0.21 & 3.45 & 16.90 & 0.75 & 0.25 & 47.66 & 2.36 & 0.00 & 0.00 & 1.72 & 1.14 & 1.42 & 100.0 \\
\hline HLW02-34 & 3.71 & 12.86 & 0.61 & 0.06 & 5.17 & 0.04 & 9.12 & 0.21 & 1.46 & 12.10 & 0.74 & 0.24 & 46.99 & 2.33 & 0.00 & 0.00 & 1.69 & 0.84 & 1.82 & 100.0 \\
\hline HLW02-35 & 4.32 & 12.67 & 0.60 & 0.06 & 5.10 & 0.04 & 11.35 & 0.20 & 3.35 & 10.03 & 0.73 & 0.24 & 46.28 & 0.98 & 0.00 & 0.00 & 1.67 & 0.83 & 1.57 & 100.0 \\
\hline HLW02-36 & 3.72 & 8.59 & 0.61 & 0.06 & 5.18 & 0.04 & 5.77 & 0.21 & 1.46 & 16.69 & 0.28 & 0.24 & 51.73 & 1.00 & 0.00 & 0.00 & 1.69 & 0.84 & 1.89 & 100.0 \\
\hline HLW02-37 & 4.63 & 13.03 & 0.62 & 0.02 & 4.37 & 0.04 & 5.84 & 0.21 & 3.44 & 12.59 & 0.75 & 0.25 & 47.60 & 1.01 & 0.00 & 0.00 & 1.71 & 2.55 & 1.36 & 100.0 \\
\hline HLW02-38 & 4.67 & 12.91 & 0.62 & 0.06 & 5.20 & 0.04 & 9.85 & 0.21 & 1.46 & 10.04 & 0.74 & 0.24 & 47.17 & 2.34 & 0.00 & 0.00 & 1.70 & 0.84 & 1.92 & 100.0 \\
\hline HLW02-39 & 5.02 & 8.81 & 0.61 & 0.02 & 4.27 & 0.04 & 5.71 & 0.20 & 1.44 & 12.18 & 0.73 & 0.24 & 55.65 & 0.99 & 0.00 & 0.00 & 1.68 & 0.83 & 1.57 & 100.0 \\
\hline HLW02-40 & 5.05 & 9.69 & 0.61 & 0.06 & 4.30 & 0.04 & 6.04 & 0.20 & 1.45 & 10.72 & 0.28 & 0.24 & 55.95 & 0.99 & 0.00 & 0.00 & 1.69 & 0.84 & 1.85 & 100.0 \\
\hline HLW02-41 & 4.34 & 12.71 & 0.61 & 0.02 & 4.26 & 0.04 & 5.70 & 0.20 & 1.44 & 9.89 & 0.27 & 0.24 & 55.47 & 0.99 & 0.00 & 0.00 & 1.67 & 0.83 & 1.32 & 100.0 \\
\hline HLW02-42 & 3.61 & 12.49 & 0.60 & 0.02 & 4.19 & 0.04 & 11.19 & 0.20 & 1.41 & 9.71 & 0.27 & 0.24 & 49.48 & 2.26 & 0.00 & 0.00 & 1.64 & 1.36 & 1.29 & 100.0 \\
\hline HLW02-43 & 4.42 & 12.94 & 0.62 & 0.02 & 4.34 & 0.04 & 5.80 & 0.21 & 3.42 & 13.92 & 0.28 & 0.24 & 47.27 & 2.34 & 0.00 & 0.00 & 1.70 & 0.84 & 1.62 & 100.0 \\
\hline HLW02-44 & 3.71 & 8.95 & 0.61 & 0.06 & 4.30 & 0.04 & 5.75 & 0.20 & 3.39 & 16.62 & 0.28 & 0.24 & 49.93 & 0.99 & 0.00 & 0.00 & 1.69 & 1.39 & 1.84 & 100.0 \\
\hline HLW02-45 & 3.71 & 7.91 & 0.61 & 0.02 & 4.74 & 0.04 & 5.76 & 0.20 & 3.39 & 10.68 & 0.28 & 0.24 & 55.92 & 2.32 & 0.00 & 0.00 & 1.69 & 0.84 & 1.64 & 100.0 \\
\hline HLW02-46 & 3.62 & 8.83 & 0.60 & 0.02 & 4.21 & 0.04 & 8.32 & 0.20 & 3.31 & 9.76 & 0.72 & 0.24 & 54.79 & 0.97 & 0.00 & 0.00 & 1.65 & 1.36 & 1.36 & 100.0 \\
\hline HLW02-47 & 3.69 & 9.64 & 0.61 & 0.06 & 4.29 & 0.04 & 5.73 & 0.20 & 3.38 & 10.43 & 0.27 & 0.24 & 55.80 & 0.99 & 0.00 & 0.00 & 1.68 & 1.39 & 1.56 & 100.0 \\
\hline HLW02-48 & 4.10 & 8.01 & 0.62 & 0.06 & 5.24 & 0.04 & 7.79 & 0.21 & 1.47 & 16.86 & 0.75 & 0.25 & 47.53 & 1.15 & 0.00 & 0.00 & 1.71 & 2.54 & 1.68 & 100.0 \\
\hline HLW02-49 & 4.99 & 8.51 & 0.60 & 0.02 & 5.09 & 0.04 & 11.35 & 0.20 & 3.35 & 9.85 & 0.27 & 0.24 & 49.88 & 0.98 & 0.00 & 0.00 & 1.67 & 1.65 & 1.31 & 100.0 \\
\hline HLW02-50 & 4.13 & 13.11 & 0.63 & 0.02 & 5.28 & 0.04 & 5.88 & 0.21 & 1.48 & 11.13 & 0.28 & 0.25 & 50.87 & 1.02 & 0.00 & 0.00 & 1.73 & 2.56 & 1.38 & 100.0 \\
\hline HLW02-51 & 5.03 & 7.86 & 0.61 & 0.02 & 4.50 & 0.04 & 10.51 & 0.20 & 1.45 & 9.94 & 0.27 & 0.24 & 51.42 & 2.31 & 0.00 & 0.00 & 1.68 & 2.50 & 1.41 & 100.0 \\
\hline HLW02-52 & 4.14 & 9.75 & 0.61 & 0.05 & 4.67 & 0.04 & 9.15 & 0.20 & 2.30 & 12.09 & 0.47 & 0.24 & 49.65 & 1.61 & 0.00 & 0.00 & 1.68 & 1.65 & 1.68 & 100.0 \\
\hline HLW02-53 & 5.50 & 4.74 & 0.59 & 0.01 & 5.72 & 0.04 & 13.25 & 0.20 & 0.00 & 8.18 & 0.09 & 0.23 & 58.14 & 0.00 & 0.00 & 0.00 & 1.62 & 0.00 & 1.70 & 100.0 \\
\hline HLW02-54 & 2.68 & 4.90 & 0.61 & 0.01 & 5.98 & 0.04 & 4.56 & 0.20 & 0.50 & 16.51 & 0.09 & 0.24 & 60.07 & 0.00 & 0.00 & 0.00 & 1.68 & 0.00 & 1.93 & 100.0 \\
\hline HLW02-55 & 3.61 & 12.49 & 0.60 & 0.02 & 4.19 & 0.04 & 11.19 & 0.20 & 1.41 & 9.71 & 0.27 & 0.24 & 49.48 & 2.26 & 0.00 & 0.00 & 1.64 & 1.36 & 1.29 & 100.0 \\
\hline HLW02-56 & 3.71 & 8.95 & 0.61 & 0.06 & 4.30 & 0.04 & 5.75 & 0.20 & 3.39 & 16.62 & 0.28 & 0.24 & 49.93 & 0.99 & 0.00 & 0.00 & 1.69 & 1.39 & 1.84 & 100.0 \\
\hline HLW02-57 & 2.67 & 13.66 & 0.61 & 0.01 & 3.92 & 0.04 & 7.53 & 0.20 & 4.79 & 16.44 & 0.09 & 0.24 & 43.81 & 0.00 & 0.00 & 0.00 & 1.67 & 3.31 & 1.02 & 100.0 \\
\hline HLW03-01 & 5.79 & 13.97 & 0.63 & 0.01 & 6.09 & 0.05 & 13.95 & 0.21 & 6.07 & 4.48 & 0.09 & 0.25 & 41.62 & 0.00 & 0.74 & 0.00 & 2.66 & 1.72 & 1.66 & 100.0 \\
\hline HLW03-02 & 1.39 & 14.23 & 0.65 & 0.23 & 6.20 & 0.05 & 6.00 & 0.22 & 6.98 & 13.08 & 0.95 & 0.26 & 42.39 & 0.00 & 0.00 & 0.00 & 0.00 & 5.35 & 2.04 & 100.0 \\
\hline HLW03-03 & 1.42 & 5.19 & 0.66 & 0.24 & 6.34 & 0.05 & 6.63 & 0.22 & 7.13 & 12.84 & 0.97 & 0.26 & 43.32 & 6.98 & 0.00 & 0.00 & 1.77 & 3.85 & 2.13 & 100.0 \\
\hline
\end{tabular}


Table F.1. Normalized Target Compositions (mol\%) of 305 HLW Simulated and Actual Waste Glasses (continued).

\begin{tabular}{|c|c|c|c|c|c|c|c|c|c|c|c|c|c|c|c|c|c|c|c|c|}
\hline Glass ID & $\mathbf{A l}_{2} \mathbf{O}_{3}$ & $\mathbf{B}_{2} \mathbf{O}_{3}$ & $\mathrm{CaO}$ & $\mathrm{Cr}_{2} \mathrm{O}_{3}$ & $\mathrm{Fe}_{2} \mathrm{O}_{3}$ & $\mathbf{K}_{2} \mathbf{O}$ & $\mathbf{L i}_{2} \mathbf{O}$ & MgO & MnO & $\mathrm{Na}_{2} \mathrm{O}$ & $\mathrm{NiO}$ & $\mathbf{P}_{2} \mathbf{O}_{5}$ & $\mathrm{SiO}_{2}$ & SrO & $\mathrm{ThO}_{2}$ & $\mathbf{U O}_{3}$ & ZnO & $\mathrm{ZrO}_{2}$ & Others & Sum \\
\hline HLW03-04 & 1.39 & 5.10 & 0.65 & 0.23 & 6.22 & 0.05 & 14.25 & 0.22 & 3.24 & 5.20 & 0.09 & 0.25 & 51.27 & 6.85 & 0.00 & 1.58 & 0.00 & 1.73 & 1.69 & 100.0 \\
\hline HLW03-05 & 5.46 & 4.70 & 0.61 & 0.22 & 0.82 & 0.04 & 4.39 & 0.20 & 6.46 & 15.86 & 0.09 & 0.24 & 54.23 & 0.00 & 0.98 & 0.00 & 3.22 & 0.00 & 2.48 & 100.0 \\
\hline HLW03-06 & 5.33 & 4.59 & 0.58 & 0.21 & 0.80 & 0.04 & 12.85 & 0.19 & 6.31 & 4.13 & 0.86 & 0.23 & 56.43 & 3.20 & 0.35 & 0.00 & 0.00 & 2.17 & 1.73 & 100.0 \\
\hline HLW03-07 & 3.44 & 5.03 & 0.63 & 0.23 & 6.14 & 0.04 & 11.22 & 0.21 & 6.91 & 13.32 & 0.09 & 0.25 & 46.79 & 0.00 & 0.00 & 1.56 & 3.00 & 0.00 & 1.13 & 100.0 \\
\hline HLW03-08 & 5.48 & 4.83 & 0.62 & 0.22 & 0.84 & 0.04 & 11.98 & 0.21 & 6.63 & 16.26 & 0.09 & 0.24 & 40.26 & 0.00 & 1.16 & 0.00 & 3.30 & 5.45 & 2.37 & 100.0 \\
\hline HLW03-09 & 4.96 & 12.96 & 0.59 & 0.01 & 1.44 & 0.04 & 4.37 & 0.20 & 0.00 & 15.79 & 0.09 & 0.23 & 57.53 & 0.00 & 0.64 & 0.00 & 0.00 & 0.00 & 1.17 & 100.0 \\
\hline HLW03-10 & 5.74 & 4.94 & 0.62 & 0.01 & 4.37 & 0.04 & 13.82 & 0.21 & 6.79 & 14.49 & 0.92 & 0.25 & 41.24 & 0.00 & 0.70 & 0.27 & 0.00 & 4.11 & 1.47 & 100.0 \\
\hline HLW03-11 & 1.38 & 5.07 & 0.63 & 0.01 & 4.25 & 0.05 & 4.72 & 0.21 & 0.00 & 17.07 & 0.09 & 0.25 & 62.21 & 0.00 & 1.35 & 1.57 & 0.00 & 0.00 & 1.14 & 100.0 \\
\hline HLW03-12 & 1.37 & 5.03 & 0.63 & 0.23 & 0.88 & 0.04 & 11.84 & 0.21 & 6.91 & 4.52 & 0.09 & 0.25 & 52.05 & 6.76 & 1.00 & 1.56 & 3.44 & 2.11 & 1.08 & 100.0 \\
\hline HLW03-13 & 6.17 & 5.32 & 0.66 & 0.24 & 4.03 & 0.05 & 13.01 & 0.22 & 7.31 & 4.78 & 0.99 & 0.26 & 44.35 & 7.14 & 1.08 & 1.64 & 1.03 & 0.51 & 1.19 & 100.0 \\
\hline HLW03-14 & 1.44 & 5.29 & 0.66 & 0.01 & 4.19 & 0.05 & 6.20 & 0.22 & 7.26 & 12.45 & 0.98 & 0.26 & 44.09 & 7.10 & 1.15 & 0.00 & 3.62 & 3.91 & 1.12 & 100.0 \\
\hline HLW03-15 & 1.34 & 13.76 & 0.63 & 0.01 & 6.00 & 0.04 & 4.58 & 0.21 & 1.33 & 5.94 & 0.09 & 0.25 & 60.34 & 0.00 & 0.65 & 0.00 & 2.87 & 0.00 & 1.97 & 100.0 \\
\hline HLW03-16 & 1.42 & 5.19 & 0.66 & 0.01 & 3.66 & 0.05 & 7.09 & 0.22 & 7.14 & 4.67 & 0.97 & 0.26 & 54.49 & 6.98 & 0.72 & 1.61 & 2.52 & 0.60 & 1.75 & 100.0 \\
\hline HLW03-17 & 5.76 & 13.90 & 0.63 & 0.01 & 0.87 & 0.04 & 4.63 & 0.21 & 6.82 & 5.06 & 0.28 & 0.25 & 53.96 & 0.00 & 0.60 & 1.18 & 3.40 & 0.94 & 1.48 & 100.0 \\
\hline HLW03-18 & 1.31 & 4.79 & 0.60 & 0.22 & 5.85 & 0.04 & 13.30 & 0.20 & 0.00 & 11.41 & 0.88 & 0.24 & 58.62 & 0.00 & 1.52 & 0.00 & 0.00 & 0.00 & 1.01 & 100.0 \\
\hline HLW03-19 & 1.28 & 4.67 & 0.59 & 0.21 & 4.00 & 0.04 & 13.06 & 0.20 & 0.18 & 10.85 & 0.87 & 0.23 & 57.39 & 0.00 & 1.47 & 0.00 & 3.20 & 0.00 & 1.76 & 100.0 \\
\hline HLW03-20 & 1.29 & 4.72 & 0.61 & 0.01 & 5.77 & 0.04 & 13.21 & 0.20 & 0.00 & 11.14 & 0.88 & 0.24 & 57.70 & 0.10 & 1.49 & 0.10 & 0.00 & 0.00 & 2.49 & 100.0 \\
\hline HLW03-21 & 3.38 & 6.92 & 0.62 & 0.04 & 2.16 & 0.04 & 5.76 & 0.21 & 4.37 & 12.13 & 0.28 & 0.24 & 56.15 & 1.00 & 0.78 & 0.51 & 0.85 & 3.35 & 1.22 & 100.0 \\
\hline HLW03-22 & 3.59 & 7.36 & 0.66 & 0.04 & 4.55 & 0.05 & 6.13 & 0.22 & 1.55 & 14.17 & 0.29 & 0.26 & 49.95 & 3.18 & 0.83 & 1.08 & 0.90 & 3.56 & 1.63 & 100.0 \\
\hline HLW03-23 & 3.53 & 12.39 & 0.64 & 0.09 & 3.51 & 0.05 & 6.01 & 0.22 & 1.52 & 13.92 & 0.29 & 0.25 & 49.05 & 1.04 & 0.82 & 1.06 & 0.88 & 3.50 & 1.22 & 100.0 \\
\hline HLW03-24 & 1.96 & 6.70 & 0.60 & 0.03 & 2.09 & 0.04 & 11.16 & 0.20 & 4.23 & 8.84 & 0.45 & 0.24 & 54.36 & 0.97 & 0.76 & 0.49 & 2.46 & 3.25 & 1.18 & 100.0 \\
\hline HLW03-25 & 2.05 & 12.01 & 0.63 & 0.04 & 2.18 & 0.05 & 5.83 & 0.21 & 1.47 & 13.50 & 0.47 & 0.25 & 49.56 & 3.03 & 0.79 & 0.52 & 2.57 & 3.39 & 1.46 & 100.0 \\
\hline HLW03-26 & 3.43 & 7.04 & 0.63 & 0.09 & 2.19 & 0.05 & 11.71 & 0.21 & 1.48 & 11.97 & 0.47 & 0.25 & 47.75 & 3.04 & 1.19 & 1.04 & 2.58 & 3.41 & 1.47 & 100.0 \\
\hline HLW03-27 & 3.47 & 7.12 & 0.64 & 0.09 & 4.21 & 0.05 & 9.71 & 0.21 & 1.50 & 13.70 & 0.47 & 0.25 & 48.28 & 1.02 & 1.21 & 0.52 & 2.61 & 3.45 & 1.49 & 100.0 \\
\hline HLW03-28 & 2.48 & 11.92 & 0.62 & 0.04 & 4.33 & 0.04 & 11.57 & 0.21 & 1.46 & 11.79 & 0.46 & 0.25 & 47.18 & 1.00 & 0.79 & 0.51 & 0.85 & 3.37 & 1.14 & 100.0 \\
\hline HLW03-29 & 2.04 & 6.98 & 0.62 & 0.09 & 2.17 & 0.04 & 11.62 & 0.21 & 3.48 & 13.45 & 0.28 & 0.25 & 47.39 & 1.01 & 1.18 & 1.03 & 2.56 & 4.37 & 1.23 & 100.0 \\
\hline HLW03-30 & 2.02 & 11.81 & 0.62 & 0.04 & 2.15 & 0.04 & 11.47 & 0.21 & 4.35 & 7.74 & 0.28 & 0.24 & 49.73 & 0.99 & 1.17 & 0.51 & 0.84 & 4.62 & 1.21 & 100.0 \\
\hline HLW03-31 & 3.34 & 6.85 & 0.61 & 0.09 & 2.13 & 0.04 & 11.40 & 0.20 & 4.32 & 9.47 & 0.46 & 0.24 & 51.56 & 0.99 & 0.77 & 0.50 & 0.84 & 4.98 & 1.20 & 100.0 \\
\hline HLW03-32 & 3.45 & 7.07 & 0.64 & 0.04 & 2.20 & 0.05 & 11.77 & 0.21 & 2.95 & 10.49 & 0.47 & 0.25 & 47.99 & 1.02 & 1.20 & 1.04 & 2.59 & 5.14 & 1.43 & 100.0 \\
\hline HLW03-33 & 3.51 & 12.35 & 0.64 & 0.09 & 4.49 & 0.05 & 9.43 & 0.21 & 1.52 & 8.09 & 0.44 & 0.25 & 48.90 & 1.04 & 0.81 & 0.85 & 2.64 & 3.49 & 1.18 & 100.0 \\
\hline
\end{tabular}


Table F.1. Normalized Target Compositions (mol\%) of 305 HLW Simulated and Actual Waste Glasses (continued).

\begin{tabular}{|c|c|c|c|c|c|c|c|c|c|c|c|c|c|c|c|c|c|c|c|c|}
\hline Glass ID & $\mathbf{A l}_{2} \mathbf{O}_{3}$ & $\mathbf{B}_{2} \mathbf{O}_{3}$ & $\mathrm{CaO}$ & $\mathrm{Cr}_{2} \mathrm{O}_{3}$ & $\mathrm{Fe}_{2} \mathrm{O}_{3}$ & $\mathbf{K}_{2} \mathbf{O}$ & $\mathbf{L i}_{2} \mathbf{O}$ & MgO & MnO & $\mathrm{Na}_{2} \mathrm{O}$ & $\mathrm{NiO}$ & $\mathbf{P}_{2} \mathbf{O}_{5}$ & $\mathrm{SiO}_{2}$ & SrO & $\mathrm{ThO}_{2}$ & $\mathbf{U O}_{3}$ & ZnO & $\mathrm{ZrO}_{2}$ & Others & Sum \\
\hline HLW03-34 & 2.08 & 7.12 & 0.64 & 0.09 & 4.44 & 0.05 & 5.93 & 0.21 & 1.50 & 11.07 & 0.47 & 0.25 & 57.75 & 1.03 & 1.05 & 0.52 & 0.87 & 3.45 & 1.48 & 100.0 \\
\hline HLW03-35 & 3.40 & 10.44 & 0.62 & 0.04 & 2.17 & 0.04 & 5.80 & 0.21 & 4.40 & 7.83 & 0.46 & 0.25 & 56.57 & 1.00 & 0.84 & 0.51 & 0.89 & 3.38 & 1.13 & 100.0 \\
\hline HLW03-36 & 3.47 & 7.12 & 0.64 & 0.09 & 4.29 & 0.05 & 6.49 & 0.21 & 1.50 & 9.25 & 0.47 & 0.25 & 57.78 & 1.03 & 0.97 & 0.52 & 0.87 & 3.45 & 1.54 & 100.0 \\
\hline HLW03-37 & 2.08 & 12.16 & 0.64 & 0.04 & 3.24 & 0.05 & 11.66 & 0.21 & 1.49 & 7.97 & 0.47 & 0.25 & 48.14 & 1.02 & 1.20 & 1.05 & 2.60 & 4.26 & 1.47 & 100.0 \\
\hline HLW03-38 & 3.59 & 7.37 & 0.66 & 0.10 & 4.59 & 0.05 & 6.13 & 0.22 & 1.55 & 11.57 & 0.29 & 0.26 & 53.56 & 1.06 & 1.09 & 1.09 & 0.90 & 4.27 & 1.63 & 100.0 \\
\hline HLW03-39 & 2.02 & 6.92 & 0.62 & 0.09 & 3.73 & 0.04 & 11.37 & 0.21 & 1.45 & 7.77 & 0.28 & 0.25 & 56.11 & 1.00 & 1.17 & 0.51 & 0.85 & 4.02 & 1.57 & 100.0 \\
\hline HLW03-40 & 3.50 & 7.19 & 0.64 & 0.04 & 4.25 & 0.05 & 11.81 & 0.21 & 1.51 & 8.07 & 0.48 & 0.25 & 51.70 & 2.29 & 1.22 & 1.06 & 0.88 & 3.48 & 1.36 & 100.0 \\
\hline HLW03-41 & 2.72 & 8.94 & 0.63 & 0.07 & 3.10 & 0.05 & 8.85 & 0.21 & 2.71 & 10.46 & 0.38 & 0.25 & 51.07 & 1.86 & 0.99 & 0.76 & 1.68 & 3.91 & 1.37 & 100.0 \\
\hline HLW03-42 & 3.62 & 8.83 & 0.60 & 0.02 & 4.21 & 0.04 & 8.32 & 0.20 & 3.31 & 9.76 & 0.72 & 0.24 & 54.79 & 0.97 & 0.00 & 0.00 & 1.65 & 1.36 & 1.36 & 100.0 \\
\hline HLW03-43 & 5.33 & 4.59 & 0.58 & 0.21 & 0.80 & 0.04 & 12.85 & 0.19 & 6.31 & 4.13 & 0.86 & 0.23 & 56.43 & 3.20 & 0.35 & 0.00 & 0.00 & 2.17 & 1.73 & 100.0 \\
\hline HLW03-44 & 1.38 & 5.07 & 0.63 & 0.01 & 4.25 & 0.05 & 4.72 & 0.21 & 0.00 & 17.07 & 0.09 & 0.25 & 62.21 & 0.00 & 1.35 & 1.57 & 0.00 & 0.00 & 1.14 & 100.0 \\
\hline HLW03-45 & 3.43 & 7.04 & 0.63 & 0.09 & 2.19 & 0.05 & 11.71 & 0.21 & 1.48 & 11.97 & 0.47 & 0.25 & 47.75 & 3.04 & 1.19 & 1.04 & 2.58 & 3.41 & 1.47 & 100.0 \\
\hline HLW05-01 & 4.29 & 12.55 & 0.97 & 0.05 & 2.76 & 0.15 & 7.31 & 0.18 & 0.26 & 9.40 & 0.12 & 0.15 & 53.03 & 0.84 & 1.24 & 1.15 & 1.07 & 3.59 & 0.88 & 100.0 \\
\hline HLW05-02 & 6.97 & 12.25 & 0.95 & 0.09 & 2.23 & 0.15 & 7.14 & 0.18 & 0.50 & 13.40 & 0.24 & 0.15 & 48.65 & 0.82 & 0.81 & 0.62 & 1.05 & 2.88 & 0.92 & 100.0 \\
\hline HLW05-03 & 4.23 & 11.66 & 0.96 & 0.09 & 2.25 & 0.15 & 7.21 & 0.18 & 0.25 & 18.54 & 0.12 & 0.15 & 45.42 & 0.83 & 0.82 & 1.13 & 1.06 & 4.08 & 0.86 & 100.0 \\
\hline HLW05-04 & 4.12 & 7.04 & 0.94 & 0.05 & 2.19 & 0.15 & 11.72 & 0.17 & 0.49 & 12.15 & 0.23 & 0.15 & 51.30 & 0.81 & 0.80 & 1.10 & 1.03 & 4.63 & 0.91 & 100.0 \\
\hline HLW05-05 & 4.12 & 7.04 & 0.94 & 0.05 & 3.07 & 0.15 & 7.62 & 0.17 & 0.25 & 18.08 & 0.12 & 0.15 & 51.28 & 0.81 & 0.80 & 0.65 & 1.03 & 2.84 & 0.84 & 100.0 \\
\hline HLW05-06 & 4.31 & 7.43 & 0.98 & 0.10 & 3.67 & 0.16 & 7.36 & 0.18 & 0.52 & 18.91 & 0.25 & 0.15 & 46.33 & 0.85 & 1.25 & 0.64 & 1.08 & 4.90 & 0.95 & 100.0 \\
\hline HLW05-07 & 6.97 & 12.25 & 0.95 & 0.09 & 2.23 & 0.15 & 7.14 & 0.18 & 0.50 & 13.40 & 0.24 & 0.15 & 48.65 & 0.82 & 0.81 & 0.62 & 1.05 & 2.88 & 0.92 & 100.0 \\
\hline HLW05-08 & 4.13 & 12.11 & 0.94 & 0.05 & 2.20 & 0.15 & 11.75 & 0.17 & 0.25 & 13.48 & 0.12 & 0.15 & 44.41 & 0.81 & 0.80 & 0.61 & 1.04 & 5.98 & 0.84 & 100.0 \\
\hline HLW05-09 & 4.14 & 12.13 & 0.94 & 0.05 & 3.38 & 0.15 & 11.77 & 0.17 & 0.50 & 14.19 & 0.24 & 0.15 & 44.76 & 0.81 & 1.20 & 0.61 & 1.04 & 2.85 & 0.91 & 100.0 \\
\hline HLW05-10 & 6.84 & 7.01 & 0.93 & 0.09 & 2.18 & 0.15 & 11.67 & 0.17 & 0.25 & 14.06 & 0.12 & 0.15 & 49.08 & 0.81 & 1.19 & 0.61 & 1.03 & 2.83 & 0.84 & 100.0 \\
\hline HLW05-11 & 4.09 & 11.97 & 0.93 & 0.09 & 3.48 & 0.15 & 11.62 & 0.17 & 0.24 & 9.30 & 0.12 & 0.15 & 50.83 & 0.80 & 0.79 & 0.61 & 1.02 & 2.82 & 0.83 & 100.0 \\
\hline HLW05-12 & 4.31 & 7.43 & 0.98 & 0.10 & 3.67 & 0.16 & 7.36 & 0.18 & 0.52 & 18.91 & 0.25 & 0.15 & 46.33 & 0.85 & 1.25 & 0.64 & 1.08 & 4.90 & 0.95 & 100.0 \\
\hline HLW05-13 & 7.01 & 7.35 & 0.98 & 0.05 & 3.50 & 0.16 & 7.34 & 0.18 & 0.26 & 18.88 & 0.12 & 0.15 & 46.26 & 0.85 & 0.83 & 1.15 & 1.08 & 2.97 & 0.88 & 100.0 \\
\hline HLW05-14 & 4.17 & 11.50 & 0.95 & 0.09 & 3.55 & 0.15 & 11.86 & 0.18 & 0.50 & 14.29 & 0.24 & 0.15 & 44.80 & 0.82 & 0.80 & 1.11 & 1.04 & 2.87 & 0.92 & 100.0 \\
\hline HLW05-15 & 1.44 & 4.76 & 0.98 & 0.12 & 5.53 & 0.16 & 0.00 & 0.18 & 0.10 & 19.79 & 0.05 & 0.16 & 60.01 & 0.85 & 0.42 & 1.13 & 1.09 & 2.39 & 0.84 & 100.0 \\
\hline HLW05-16 & 3.63 & 14.55 & 0.97 & 0.12 & 0.68 & 0.15 & 14.53 & 0.18 & 0.10 & 8.66 & 0.05 & 0.15 & 43.51 & 0.84 & 1.64 & 1.64 & 1.07 & 6.69 & 0.83 & 100.0 \\
\hline HLW05-17 & 8.10 & 14.00 & 0.93 & 0.02 & 3.13 & 0.15 & 13.98 & 0.17 & 0.10 & 12.07 & 0.05 & 0.15 & 39.39 & 0.81 & 0.40 & 0.24 & 1.03 & 4.49 & 0.80 & 100.0 \\
\hline HLW05-18 & 1.47 & 15.11 & 1.00 & 0.02 & 3.04 & 0.16 & 0.00 & 0.19 & 1.06 & 13.84 & 0.50 & 0.16 & 52.55 & 0.87 & 1.71 & 0.26 & 1.11 & 5.82 & 1.12 & 100.0 \\
\hline
\end{tabular}


Table F.1. Normalized Target Compositions (mol\%) of 305 HLW Simulated and Actual Waste Glasses (continued).

\begin{tabular}{|c|c|c|c|c|c|c|c|c|c|c|c|c|c|c|c|c|c|c|c|c|}
\hline Glass ID & $\mathbf{A l}_{2} \mathbf{O}_{3}$ & $\mathbf{B}_{2} \mathbf{O}_{3}$ & $\mathrm{CaO}$ & $\mathrm{Cr}_{2} \mathrm{O}_{3}$ & $\mathrm{Fe}_{2} \mathbf{O}_{3}$ & $\mathbf{K}_{2} \mathbf{O}$ & $\mathbf{L i}_{2} \mathbf{O}$ & MgO & MnO & $\mathrm{Na}_{2} \mathrm{O}$ & $\mathrm{NiO}$ & $\mathbf{P}_{2} \mathbf{O}_{5}$ & $\mathrm{SiO}_{2}$ & SrO & $\mathrm{ThO}_{2}$ & $\mathbf{U O}_{3}$ & ZnO & $\mathrm{ZrO}_{2}$ & Others & Sum \\
\hline HLW05-19 & 9.82 & 4.98 & 1.03 & 0.03 & 2.85 & 0.16 & 3.74 & 0.19 & 0.11 & 24.85 & 0.05 & 0.16 & 44.06 & 0.89 & 1.75 & 1.75 & 1.14 & 1.56 & 0.88 & 100.0 \\
\hline HLW05-20 & 9.04 & 14.26 & 0.95 & 0.12 & 0.67 & 0.15 & 0.00 & 0.18 & 1.00 & 22.88 & 0.47 & 0.15 & 44.55 & 0.82 & 0.40 & 0.25 & 1.05 & 2.01 & 1.06 & 100.0 \\
\hline HLW05-21 & 1.50 & 15.34 & 1.02 & 0.13 & 5.73 & 0.16 & 0.00 & 0.19 & 0.11 & 24.26 & 0.05 & 0.16 & 43.17 & 0.88 & 1.73 & 0.27 & 1.12 & 3.31 & 0.87 & 100.0 \\
\hline HLW05-22 & 9.01 & 14.21 & 0.95 & 0.02 & 1.11 & 0.15 & 8.75 & 0.18 & 0.10 & 7.41 & 0.05 & 0.15 & 51.81 & 0.82 & 0.40 & 1.61 & 1.04 & 1.43 & 0.81 & 100.0 \\
\hline HLW05-23 & 8.44 & 4.37 & 0.90 & 0.11 & 0.63 & 0.14 & 13.57 & 0.17 & 0.95 & 10.90 & 0.45 & 0.14 & 52.58 & 0.78 & 1.54 & 0.24 & 1.00 & 2.07 & 1.01 & 100.0 \\
\hline HLW05-24 & 1.62 & 4.92 & 1.02 & 0.13 & 4.26 & 0.16 & 3.80 & 0.19 & 1.07 & 24.57 & 0.51 & 0.16 & 45.18 & 0.88 & 0.43 & 1.73 & 1.12 & 7.11 & 1.14 & 100.0 \\
\hline HLW05-25 & 1.34 & 7.27 & 0.91 & 0.11 & 3.89 & 0.14 & 13.67 & 0.17 & 0.10 & 7.14 & 0.05 & 0.14 & 55.52 & 0.79 & 0.39 & 0.24 & 1.00 & 6.35 & 0.78 & 100.0 \\
\hline HLW05-26 & 3.36 & 4.43 & 0.92 & 0.02 & 0.64 & 0.15 & 4.09 & 0.17 & 0.10 & 22.13 & 0.05 & 0.14 & 54.18 & 0.79 & 0.39 & 0.24 & 1.01 & 6.40 & 0.78 & 100.0 \\
\hline HLW05-27 & 1.37 & 4.52 & 0.94 & 0.02 & 5.26 & 0.15 & 13.94 & 0.17 & 0.99 & 11.73 & 0.47 & 0.15 & 53.13 & 0.81 & 0.40 & 1.59 & 1.03 & 2.27 & 1.05 & 100.0 \\
\hline HLW05-28 & 1.47 & 15.11 & 1.00 & 0.02 & 3.04 & 0.16 & 0.00 & 0.19 & 1.06 & 13.84 & 0.50 & 0.16 & 52.55 & 0.87 & 1.71 & 0.26 & 1.11 & 5.82 & 1.12 & 100.0 \\
\hline HLW05-29 & 3.36 & 4.43 & 0.92 & 0.02 & 0.64 & 0.15 & 4.09 & 0.17 & 0.10 & 22.13 & 0.05 & 0.14 & 54.18 & 0.79 & 0.39 & 0.24 & 1.01 & 6.40 & 0.78 & 100.0 \\
\hline HLW05-30 & 4.63 & 10.12 & 0.96 & 0.07 & 2.80 & 0.15 & 6.65 & 0.18 & 0.49 & 16.96 & 0.23 & 0.15 & 48.72 & 0.83 & 0.87 & 0.75 & 1.05 & 3.48 & 0.93 & 100.0 \\
\hline HLW06-01 & 7.44 & 6.43 & 1.23 & 0.23 & 3.02 & 1.20 & 6.92 & 2.00 & 0.97 & 15.57 & 0.92 & 0.24 & 45.88 & 0.98 & 0.39 & 0.18 & 1.81 & 0.84 & 3.75 & 100.0 \\
\hline HLW06-02 & 7.19 & 11.15 & 1.26 & 0.12 & 3.09 & 1.23 & 0.59 & 2.05 & 0.99 & 22.77 & 0.94 & 0.25 & 41.11 & 1.00 & 0.07 & 0.19 & 1.30 & 0.86 & 3.84 & 100.0 \\
\hline HLW06-03 & 8.23 & 7.12 & 0.64 & 0.13 & 6.69 & 0.62 & 0.64 & 1.03 & 1.08 & 17.23 & 0.61 & 0.27 & 44.44 & 3.25 & 0.07 & 0.20 & 1.41 & 2.48 & 3.87 & 100.0 \\
\hline HLW06-04 & 5.70 & 6.79 & 0.98 & 0.12 & 3.19 & 0.96 & 0.61 & 1.60 & 1.02 & 23.46 & 0.58 & 0.26 & 42.35 & 3.09 & 0.41 & 0.19 & 2.23 & 2.36 & 4.08 & 100.0 \\
\hline HLW06-05 & 5.50 & 6.54 & 0.84 & 0.12 & 3.07 & 0.82 & 0.59 & 1.37 & 3.95 & 22.62 & 0.56 & 0.25 & 46.65 & 0.99 & 0.40 & 0.18 & 1.29 & 0.85 & 3.39 & 100.0 \\
\hline HLW06-06 & 8.07 & 6.98 & 1.25 & 0.25 & 3.28 & 1.22 & 0.63 & 2.04 & 4.22 & 16.90 & 1.00 & 0.26 & 43.57 & 1.06 & 0.42 & 1.05 & 1.38 & 2.43 & 3.99 & 100.0 \\
\hline HLW06-07 & 5.77 & 6.86 & 1.31 & 0.12 & 6.44 & 1.28 & 0.61 & 2.13 & 4.14 & 18.84 & 0.98 & 0.26 & 42.80 & 1.04 & 0.07 & 0.19 & 2.26 & 0.89 & 4.00 & 100.0 \\
\hline HLW06-08 & 5.72 & 6.81 & 0.79 & 0.12 & 3.20 & 0.77 & 0.61 & 1.29 & 4.11 & 16.47 & 0.98 & 0.26 & 48.55 & 3.10 & 0.07 & 1.02 & 1.34 & 0.89 & 3.89 & 100.0 \\
\hline HLW06-09 & 5.76 & 6.85 & 0.22 & 0.12 & 6.43 & 0.21 & 7.37 & 0.35 & 2.49 & 16.58 & 0.98 & 0.26 & 42.74 & 1.04 & 0.07 & 1.03 & 2.25 & 2.38 & 2.86 & 100.0 \\
\hline HLW06-10 & 5.70 & 11.48 & 0.60 & 0.24 & 3.19 & 0.59 & 0.61 & 0.98 & 1.02 & 16.42 & 0.58 & 0.26 & 48.38 & 1.03 & 0.07 & 1.02 & 2.23 & 2.36 & 3.24 & 100.0 \\
\hline HLW06-11 & 5.97 & 12.02 & 0.75 & 0.13 & 6.67 & 0.73 & 0.64 & 1.21 & 1.07 & 17.19 & 0.61 & 0.27 & 44.33 & 1.08 & 0.43 & 1.06 & 1.40 & 0.93 & 3.51 & 100.0 \\
\hline HLW06-12 & 6.47 & 11.07 & 0.21 & 0.12 & 3.07 & 0.20 & 7.03 & 0.34 & 3.95 & 15.82 & 0.94 & 0.25 & 40.81 & 2.98 & 0.40 & 0.18 & 2.15 & 0.85 & 3.17 & 100.0 \\
\hline HLW06-13 & 8.07 & 6.98 & 1.25 & 0.25 & 3.28 & 1.22 & 0.63 & 2.04 & 4.22 & 16.90 & 1.00 & 0.26 & 43.57 & 1.06 & 0.42 & 1.05 & 1.38 & 2.43 & 3.99 & 100.0 \\
\hline HLW06-14 & 5.43 & 10.93 & 1.23 & 0.11 & 3.03 & 1.20 & 6.95 & 2.01 & 3.90 & 15.63 & 0.56 & 0.24 & 40.31 & 0.98 & 0.39 & 0.18 & 1.28 & 1.85 & 3.77 & 100.0 \\
\hline HLW06-15 & 5.35 & 10.78 & 0.20 & 0.22 & 2.99 & 0.20 & 6.85 & 0.33 & 2.80 & 22.02 & 0.91 & 0.24 & 39.75 & 0.97 & 0.06 & 0.18 & 1.26 & 2.22 & 2.66 & 100.0 \\
\hline HLW06-16 & 6.89 & 6.56 & 0.40 & 0.12 & 3.08 & 0.39 & 7.06 & 0.65 & 1.73 & 22.68 & 0.94 & 0.25 & 40.93 & 1.00 & 0.40 & 0.98 & 2.16 & 0.86 & 2.94 & 100.0 \\
\hline HLW06-17 & 7.44 & 6.43 & 1.23 & 0.23 & 3.02 & 1.20 & 6.92 & 2.00 & 0.97 & 15.57 & 0.92 & 0.24 & 45.88 & 0.98 & 0.39 & 0.18 & 1.81 & 0.84 & 3.75 & 100.0 \\
\hline HLW06-18 & 7.78 & 11.39 & 0.35 & 0.12 & 3.16 & 0.35 & 0.60 & 0.58 & 1.02 & 16.29 & 0.97 & 0.25 & 48.00 & 1.02 & 0.41 & 0.19 & 2.22 & 2.34 & 2.96 & 100.0 \\
\hline
\end{tabular}


Table F.1. Normalized Target Compositions (mol\%) of 305 HLW Simulated and Actual Waste Glasses (continued).

\begin{tabular}{|c|c|c|c|c|c|c|c|c|c|c|c|c|c|c|c|c|c|c|c|c|}
\hline Glass ID & $\mathbf{A l}_{2} \mathbf{O}_{3}$ & $\mathbf{B}_{2} \mathbf{O}_{3}$ & $\mathrm{CaO}$ & $\mathrm{Cr}_{2} \mathrm{O}_{3}$ & $\mathrm{Fe}_{2} \mathbf{O}_{3}$ & $\mathbf{K}_{2} \mathbf{O}$ & $\mathbf{L i}_{2} \mathbf{O}$ & MgO & MnO & $\mathrm{Na}_{2} \mathrm{O}$ & $\mathrm{NiO}$ & $\mathbf{P}_{2} \mathbf{O}_{5}$ & $\mathrm{SiO}_{2}$ & SrO & $\mathrm{ThO}_{2}$ & $\mathbf{U O}_{3}$ & ZnO & $\mathrm{ZrO}_{2}$ & Others & Sum \\
\hline HLW06-19 & 7.86 & 6.81 & 0.22 & 0.24 & 5.51 & 0.21 & 0.61 & 0.35 & 4.11 & 23.52 & 0.59 & 0.26 & 42.46 & 1.03 & 0.07 & 0.19 & 2.24 & 0.89 & 2.84 & 100.0 \\
\hline HLW06-20 & 7.62 & 6.59 & 1.26 & 0.12 & 3.22 & 1.23 & 7.09 & 2.05 & 3.98 & 15.95 & 0.57 & 0.25 & 41.14 & 1.00 & 0.07 & 0.99 & 2.17 & 0.86 & 3.84 & 100.0 \\
\hline HLW06-21 & 9.37 & 4.54 & 0.00 & 0.00 & 0.64 & 0.00 & 0.00 & 0.00 & 8.29 & 23.72 & 0.00 & 0.26 & 47.43 & 0.00 & 1.65 & 1.67 & 0.00 & 0.00 & 2.41 & 100.0 \\
\hline HLW06-22 & 8.96 & 15.15 & 0.00 & 0.28 & 0.62 & 0.00 & 14.14 & 0.00 & 0.00 & 7.76 & 0.00 & 0.25 & 40.44 & 6.98 & 0.00 & 1.60 & 0.00 & 0.00 & 3.83 & 100.0 \\
\hline HLW06-23 & 1.44 & 4.83 & 0.00 & 0.31 & 7.34 & 0.00 & 0.00 & 0.00 & 0.00 & 25.22 & 0.00 & 0.28 & 45.12 & 0.00 & 1.76 & 0.00 & 3.84 & 7.30 & 2.56 & 100.0 \\
\hline HLW06-24 & 9.65 & 4.67 & 1.35 & 0.00 & 0.66 & 1.32 & 0.00 & 2.20 & 0.00 & 19.84 & 0.00 & 0.27 & 41.57 & 7.51 & 1.70 & 0.00 & 3.72 & 0.00 & 5.53 & 100.0 \\
\hline HLW06-25 & 8.44 & 14.27 & 1.18 & 0.26 & 0.58 & 1.15 & 13.32 & 1.92 & 0.00 & 3.95 & 0.00 & 0.23 & 46.55 & 0.00 & 1.49 & 0.00 & 3.25 & 0.00 & 3.40 & 100.0 \\
\hline HLW06-26 & 1.42 & 4.76 & 0.00 & 0.30 & 0.68 & 0.00 & 0.00 & 0.00 & 0.79 & 24.87 & 0.00 & 0.27 & 42.32 & 7.65 & 0.00 & 1.75 & 3.79 & 7.19 & 4.20 & 100.0 \\
\hline HLW06-27 & 1.22 & 9.31 & 0.00 & 0.00 & 0.58 & 0.00 & 13.28 & 0.00 & 0.00 & 3.94 & 0.00 & 0.23 & 58.36 & 0.00 & 0.00 & 1.50 & 3.25 & 6.16 & 2.16 & 100.0 \\
\hline HLW06-28 & 1.25 & 14.63 & 1.21 & 0.27 & 4.88 & 1.18 & 13.66 & 1.97 & 0.00 & 4.05 & 0.00 & 0.24 & 48.28 & 0.00 & 0.00 & 1.54 & 3.34 & 0.00 & 3.49 & 100.0 \\
\hline HLW06-29 & 1.32 & 4.43 & 1.28 & 0.00 & 6.73 & 1.25 & 14.42 & 2.08 & 0.00 & 4.28 & 0.00 & 0.25 & 51.97 & 0.00 & 1.61 & 0.00 & 0.00 & 6.69 & 3.68 & 100.0 \\
\hline HLW06-30 & 9.82 & 4.76 & 0.00 & 0.00 & 7.23 & 0.00 & 0.00 & 0.00 & 0.00 & 24.85 & 0.00 & 0.27 & 45.00 & 0.00 & 0.00 & 1.75 & 3.79 & 0.00 & 2.52 & 100.0 \\
\hline HLW06-31 & 9.75 & 4.72 & 0.00 & 0.30 & 7.18 & 0.00 & 14.05 & 0.00 & 0.00 & 4.57 & 0.00 & 0.27 & 45.67 & 7.59 & 1.72 & 0.00 & 0.00 & 0.00 & 4.17 & 100.0 \\
\hline HLW06-32 & 1.29 & 15.10 & 0.00 & 0.28 & 6.59 & 0.00 & 0.00 & 0.00 & 7.91 & 22.62 & 0.00 & 0.25 & 43.67 & 0.00 & 0.00 & 0.00 & 0.00 & 0.00 & 2.30 & 100.0 \\
\hline HLW06-33 & 1.45 & 4.84 & 1.40 & 0.00 & 7.36 & 1.37 & 12.41 & 2.28 & 0.00 & 4.68 & 0.00 & 0.28 & 43.06 & 7.78 & 0.00 & 1.78 & 0.00 & 5.59 & 5.73 & 100.0 \\
\hline HLW06-34 & 1.33 & 15.57 & 0.00 & 0.29 & 0.63 & 0.00 & 0.00 & 0.00 & 8.15 & 23.31 & 0.00 & 0.25 & 39.71 & 0.00 & 0.00 & 1.64 & 0.00 & 6.74 & 2.37 & 100.0 \\
\hline HLW06-35 & 5.30 & 10.59 & 0.20 & 0.14 & 4.82 & 0.20 & 7.94 & 0.33 & 0.30 & 13.91 & 0.00 & 0.25 & 47.48 & 0.93 & 0.89 & 0.83 & 0.28 & 2.82 & 2.78 & 100.0 \\
\hline HLW07-01 & 5.11 & 9.62 & 0.19 & 0.13 & 3.64 & 0.22 & 4.39 & 0.00 & 3.25 & 13.25 & 0.41 & 0.16 & 50.63 & 2.99 & 0.59 & 0.56 & 0.88 & 2.54 & 1.44 & 100.0 \\
\hline HLW07-02 & 3.62 & 8.83 & 0.60 & 0.02 & 4.21 & 0.04 & 8.32 & 0.20 & 3.31 & 9.76 & 0.72 & 0.24 & 54.79 & 0.97 & 0.00 & 0.00 & 1.65 & 1.36 & 1.36 & 100.0 \\
\hline HLW07-03 & 2.72 & 8.94 & 0.63 & 0.07 & 3.10 & 0.05 & 8.85 & 0.21 & 2.71 & 10.46 & 0.38 & 0.25 & 51.07 & 1.86 & 0.99 & 0.76 & 1.68 & 3.91 & 1.37 & 100.0 \\
\hline HLW07-04 & 5.38 & 12.97 & 0.57 & 0.01 & 3.84 & 0.04 & 12.95 & 0.19 & 0.00 & 4.16 & 0.09 & 0.23 & 56.87 & 0.05 & 0.00 & 0.00 & 1.58 & 0.00 & 1.07 & 100.0 \\
\hline HLW07-05 & 3.44 & 5.03 & 0.63 & 0.23 & 6.14 & 0.04 & 11.22 & 0.21 & 6.91 & 13.32 & 0.09 & 0.25 & 46.79 & 0.00 & 0.00 & 1.56 & 3.00 & 0.00 & 1.13 & 100.0 \\
\hline HLW07-06 & 8.69 & 6.64 & 0.41 & 0.30 & 1.93 & 0.47 & 0.00 & 0.00 & 6.52 & 15.58 & 0.00 & 0.35 & 44.89 & 7.44 & 0.00 & 1.10 & 0.00 & 1.85 & 3.83 & 100.0 \\
\hline HLW07-07 & 2.29 & 6.72 & 0.42 & 0.03 & 6.84 & 0.48 & 0.00 & 0.00 & 0.55 & 22.62 & 1.04 & 0.35 & 45.50 & 7.53 & 0.00 & 1.12 & 0.00 & 0.63 & 3.88 & 100.0 \\
\hline HLW07-08 & 8.49 & 6.49 & 0.40 & 0.02 & 2.67 & 0.46 & 0.00 & 0.00 & 6.37 & 21.87 & 0.00 & 0.00 & 44.25 & 0.00 & 1.25 & 0.00 & 0.00 & 5.87 & 1.84 & 100.0 \\
\hline HLW07-09 & 2.21 & 6.46 & 0.40 & 0.30 & 4.91 & 0.46 & 11.30 & 0.00 & 0.53 & 10.41 & 0.00 & 0.34 & 43.69 & 7.24 & 1.25 & 0.00 & 2.30 & 5.84 & 2.35 & 100.0 \\
\hline HLW07-10 & 2.40 & 13.91 & 0.44 & 0.32 & 7.16 & 0.50 & 0.00 & 0.00 & 0.58 & 12.46 & 0.12 & 0.00 & 47.54 & 7.88 & 1.36 & 1.17 & 0.00 & 0.66 & 3.50 & 100.0 \\
\hline HLW07-11 & 8.08 & 6.17 & 0.38 & 0.28 & 4.71 & 0.44 & 10.79 & 0.00 & 0.50 & 19.66 & 0.96 & 0.00 & 41.72 & 1.61 & 0.00 & 1.03 & 0.00 & 0.58 & 3.07 & 100.0 \\
\hline HLW07-12 & 8.06 & 6.16 & 0.38 & 0.05 & 5.90 & 0.44 & 10.55 & 0.00 & 0.50 & 20.63 & 0.00 & 0.00 & 41.61 & 0.00 & 1.19 & 0.00 & 2.19 & 0.58 & 1.75 & 100.0 \\
\hline HLW07-13 & 8.43 & 6.44 & 0.40 & 0.30 & 1.87 & 0.46 & 1.98 & 0.00 & 0.53 & 21.71 & 0.00 & 0.34 & 45.41 & 0.00 & 0.00 & 1.07 & 2.30 & 5.83 & 2.94 & 100.0 \\
\hline
\end{tabular}


Table F.1. Normalized Target Compositions (mol\%) of 305 HLW Simulated and Actual Waste Glasses (continued).

\begin{tabular}{|c|c|c|c|c|c|c|c|c|c|c|c|c|c|c|c|c|c|c|c|c|}
\hline Glass ID & $\mathbf{A l}_{2} \mathbf{O}_{3}$ & $\mathbf{B}_{2} \mathbf{O}_{3}$ & $\mathrm{CaO}$ & $\mathrm{Cr}_{2} \mathrm{O}_{3}$ & $\mathrm{Fe}_{2} \mathrm{O}_{3}$ & $\mathbf{K}_{2} \mathbf{O}$ & $\mathbf{L i}_{2} \mathbf{O}$ & MgO & MnO & $\mathrm{Na}_{2} \mathrm{O}$ & $\mathrm{NiO}$ & $\mathbf{P}_{2} \mathbf{O}_{5}$ & $\mathrm{SiO}_{2}$ & SrO & $\mathrm{ThO}_{2}$ & $\mathbf{U O}_{3}$ & ZnO & $\mathrm{ZrO}_{2}$ & Others & Sum \\
\hline HLW07-14 & 8.51 & 6.50 & 0.40 & 0.02 & 2.19 & 0.46 & 10.81 & 0.00 & 0.53 & 7.30 & 1.01 & 0.34 & 43.93 & 7.28 & 0.00 & 1.08 & 0.00 & 5.88 & 3.75 & 100.0 \\
\hline HLW07-15 & 3.21 & 6.41 & 0.40 & 0.02 & 1.86 & 0.46 & 0.00 & 0.00 & 6.29 & 21.60 & 1.00 & 0.00 & 43.32 & 7.18 & 0.00 & 0.64 & 0.00 & 5.79 & 1.82 & 100.0 \\
\hline HLW07-16 & 2.91 & 11.21 & 0.36 & 0.27 & 1.69 & 0.42 & 8.70 & 0.00 & 5.70 & 19.59 & 0.90 & 0.00 & 39.28 & 0.00 & 0.00 & 0.00 & 2.07 & 5.25 & 1.65 & 100.0 \\
\hline HLW07-17 & 7.49 & 12.39 & 0.36 & 0.02 & 1.66 & 0.41 & 9.45 & 0.00 & 5.61 & 19.28 & 0.00 & 0.30 & 39.61 & 0.00 & 0.00 & 0.00 & 0.00 & 1.35 & 2.08 & 100.0 \\
\hline HLW07-18 & 6.09 & 12.77 & 0.37 & 0.27 & 3.39 & 0.42 & 10.30 & 0.00 & 0.48 & 19.86 & 0.00 & 0.00 & 42.69 & 0.00 & 1.14 & 0.00 & 0.00 & 0.55 & 1.67 & 100.0 \\
\hline HLW07-19 & 2.14 & 6.85 & 0.39 & 0.29 & 2.45 & 0.45 & 10.22 & 0.00 & 0.51 & 17.63 & 0.00 & 0.00 & 42.27 & 7.00 & 0.00 & 1.04 & 0.00 & 5.65 & 3.11 & 100.0 \\
\hline HLW07-20 & 7.57 & 12.52 & 0.36 & 0.26 & 2.31 & 0.41 & 10.10 & 0.00 & 5.67 & 6.49 & 0.00 & 0.00 & 51.54 & 0.00 & 0.57 & 0.00 & 0.00 & 0.54 & 1.64 & 100.0 \\
\hline HLW07-21 & 2.26 & 6.61 & 0.41 & 0.03 & 2.59 & 0.47 & 0.00 & 0.00 & 0.54 & 14.02 & 0.00 & 0.35 & 54.46 & 7.40 & 0.00 & 1.10 & 0.00 & 5.97 & 3.81 & 100.0 \\
\hline HLW07-22 & 8.94 & 6.91 & 0.42 & 0.03 & 1.99 & 0.49 & 0.00 & 0.00 & 0.56 & 15.88 & 1.06 & 0.00 & 46.17 & 7.65 & 1.32 & 1.14 & 2.44 & 1.61 & 3.40 & 100.0 \\
\hline HLW07-23 & 3.16 & 13.67 & 0.39 & 0.29 & 1.83 & 0.45 & 4.46 & 0.00 & 0.52 & 7.82 & 0.98 & 0.00 & 51.03 & 4.59 & 0.00 & 1.05 & 2.25 & 5.70 & 1.79 & 100.0 \\
\hline HLW07-24 & 8.49 & 14.06 & 0.40 & 0.30 & 2.59 & 0.46 & 0.00 & 0.00 & 0.53 & 19.58 & 1.01 & 0.34 & 46.92 & 0.00 & 1.25 & 1.08 & 0.00 & 0.61 & 2.36 & 100.0 \\
\hline HLW07-25 & 8.39 & 6.41 & 0.40 & 0.02 & 2.56 & 0.46 & 2.48 & 0.00 & 6.29 & 13.74 & 0.00 & 0.00 & 52.80 & 0.00 & 1.24 & 1.07 & 0.35 & 0.60 & 3.19 & 100.0 \\
\hline HLW07-26 & 6.80 & 7.97 & 0.19 & 0.07 & 2.61 & 0.21 & 8.03 & 0.00 & 2.44 & 11.19 & 0.60 & 0.00 & 54.25 & 1.67 & 0.92 & 0.36 & 0.43 & 1.41 & 0.85 & 100.0 \\
\hline HLW07-27 & 6.96 & 11.20 & 0.19 & 0.19 & 2.66 & 0.22 & 8.31 & 0.00 & 2.50 & 11.44 & 0.19 & 0.16 & 47.21 & 4.79 & 0.27 & 0.74 & 0.44 & 1.44 & 1.10 & 100.0 \\
\hline HLW07-28 & 6.90 & 8.09 & 0.19 & 0.07 & 2.64 & 0.22 & 8.25 & 0.00 & 2.48 & 15.90 & 0.61 & 0.32 & 46.86 & 2.11 & 0.93 & 0.37 & 1.30 & 1.43 & 1.34 & 100.0 \\
\hline HLW07-29 & 3.68 & 11.85 & 0.20 & 0.07 & 5.17 & 0.23 & 2.51 & 0.00 & 4.23 & 13.05 & 0.65 & 0.00 & 49.93 & 3.75 & 0.99 & 0.79 & 0.46 & 1.52 & 0.92 & 100.0 \\
\hline HLW07-30 & 3.51 & 8.22 & 0.19 & 0.19 & 4.93 & 0.22 & 2.39 & 0.00 & 3.72 & 14.55 & 0.19 & 0.32 & 55.94 & 1.73 & 0.27 & 0.38 & 0.44 & 1.45 & 1.36 & 100.0 \\
\hline HLW07-31 & 7.23 & 11.65 & 0.20 & 0.19 & 2.77 & 0.23 & 3.35 & 0.00 & 2.60 & 11.90 & 0.40 & 0.33 & 49.09 & 4.98 & 0.28 & 0.77 & 0.45 & 1.50 & 2.08 & 100.0 \\
\hline HLW07-32 & 3.64 & 8.52 & 0.20 & 0.07 & 5.11 & 0.23 & 2.48 & 0.00 & 2.61 & 16.76 & 0.65 & 0.33 & 49.38 & 2.34 & 0.28 & 0.39 & 1.00 & 3.91 & 2.10 & 100.0 \\
\hline HLW07-33 & 7.07 & 8.29 & 0.19 & 0.19 & 2.84 & 0.22 & 2.41 & 0.00 & 4.07 & 14.27 & 0.63 & 0.00 & 50.65 & 4.83 & 0.27 & 0.38 & 1.33 & 1.46 & 0.88 & 100.0 \\
\hline HLW07-34 & 7.02 & 11.31 & 0.19 & 0.07 & 2.69 & 0.22 & 4.94 & 0.00 & 4.04 & 11.55 & 0.62 & 0.00 & 49.47 & 2.01 & 0.27 & 0.50 & 0.44 & 3.78 & 0.88 & 100.0 \\
\hline HLW07-35 & 7.28 & 10.22 & 0.20 & 0.20 & 2.79 & 0.23 & 3.35 & 0.00 & 2.62 & 11.98 & 0.20 & 0.00 & 49.43 & 5.02 & 0.98 & 0.39 & 1.37 & 2.85 & 0.91 & 100.0 \\
\hline HLW07-36 & 6.76 & 11.47 & 0.19 & 0.07 & 2.73 & 0.22 & 2.43 & 0.00 & 2.56 & 16.39 & 0.19 & 0.00 & 48.31 & 4.84 & 0.27 & 0.76 & 0.45 & 1.47 & 0.89 & 100.0 \\
\hline HLW07-37 & 3.50 & 8.19 & 0.19 & 0.07 & 4.69 & 0.22 & 8.35 & 0.00 & 4.02 & 15.88 & 0.19 & 0.32 & 47.45 & 1.72 & 0.94 & 0.37 & 0.44 & 1.45 & 2.01 & 100.0 \\
\hline HLW07-38 & 3.62 & 11.65 & 0.20 & 0.19 & 3.00 & 0.23 & 2.47 & 0.00 & 4.16 & 12.36 & 0.20 & 0.33 & 51.12 & 1.78 & 0.98 & 0.39 & 1.36 & 3.89 & 2.08 & 100.0 \\
\hline HLW07-39 & 3.83 & 11.22 & 0.19 & 0.19 & 2.67 & 0.22 & 2.38 & 0.00 & 2.50 & 15.62 & 0.19 & 0.00 & 52.94 & 1.71 & 0.27 & 0.37 & 0.44 & 3.75 & 1.52 & 100.0 \\
\hline HLW07-40 & 3.68 & 8.63 & 0.20 & 0.20 & 4.88 & 0.23 & 2.51 & 0.00 & 2.65 & 12.12 & 0.20 & 0.00 & 53.49 & 5.07 & 1.00 & 0.56 & 1.38 & 1.59 & 1.61 & 100.0 \\
\hline HLW-ALG-01 & 7.27 & 10.14 & 0.39 & 0.22 & 4.03 & 0.09 & 7.45 & 0.16 & 0.00 & 18.64 & 0.00 & 0.05 & 50.39 & 0.00 & 0.00 & 0.00 & 0.87 & 0.00 & 0.31 & 100.0 \\
\hline HLW-ALG-02 & 5.27 & 10.70 & 0.42 & 0.12 & 3.01 & 0.09 & 7.98 & 0.17 & 0.00 & 16.60 & 0.47 & 0.05 & 49.95 & 0.00 & 0.00 & 0.00 & 1.30 & 3.54 & 0.32 & 100.0 \\
\hline HLW-ALG-03 & 1.28 & 8.39 & 0.41 & 0.22 & 5.37 & 0.09 & 6.94 & 0.16 & 2.00 & 20.75 & 0.91 & 0.05 & 50.05 & 0.00 & 0.00 & 0.00 & 0.03 & 2.99 & 0.35 & 100.0 \\
\hline
\end{tabular}


Table F.1. Normalized Target Compositions (mol\%) of 305 HLW Simulated and Actual Waste Glasses (continued).

\begin{tabular}{|c|c|c|c|c|c|c|c|c|c|c|c|c|c|c|c|c|c|c|c|c|}
\hline Glass ID & $\mathbf{A l}_{2} \mathbf{O}_{3}$ & $\mathbf{B}_{2} \mathbf{O}_{3}$ & $\mathrm{CaO}$ & $\mathrm{Cr}_{2} \mathrm{O}_{3}$ & $\mathrm{Fe}_{2} \mathrm{O}_{3}$ & $\mathbf{K}_{2} \mathbf{O}$ & $\mathbf{L i}_{2} \mathbf{O}$ & MgO & MnO & $\mathrm{Na}_{2} \mathrm{O}$ & NiO & $\mathbf{P}_{2} \mathbf{O}_{5}$ & $\mathrm{SiO}_{2}$ & SrO & $\mathrm{ThO}_{2}$ & $\mathbf{U O}_{3}$ & ZnO & $\mathrm{ZrO}_{2}$ & Others & Sum \\
\hline HLW-ALG-04 & 1.25 & 10.55 & 0.26 & 0.22 & 5.22 & 0.06 & 6.35 & 0.11 & 0.00 & 17.00 & 0.88 & 0.03 & 56.94 & 0.00 & 0.00 & 0.00 & 0.99 & 0.00 & 0.14 & 100.0 \\
\hline HLW-ALG-05 & 1.29 & 4.72 & 0.63 & 0.19 & 5.37 & 0.14 & 9.81 & 0.25 & 6.66 & 9.86 & 0.71 & 0.07 & 52.56 & 6.53 & 0.00 & 0.00 & 0.04 & 0.00 & 1.16 & 100.0 \\
\hline HLW-ALG-06 & 6.86 & 5.00 & 0.75 & 0.10 & 4.81 & 0.17 & 6.13 & 0.29 & 4.09 & 18.26 & 0.47 & 0.09 & 44.90 & 5.60 & 0.44 & 0.15 & 0.05 & 0.47 & 1.39 & 100.0 \\
\hline HLW-ALG-07 & 5.52 & 10.56 & 0.48 & 0.00 & 0.83 & 0.11 & 7.49 & 0.19 & 2.26 & 13.05 & 0.00 & 0.06 & 50.40 & 2.73 & 1.07 & 0.00 & 1.41 & 3.49 & 0.37 & 100.0 \\
\hline HLW-ALG-08 & 1.44 & 5.26 & 0.80 & 0.24 & 3.49 & 0.18 & 5.31 & 0.32 & 3.82 & 17.14 & 0.90 & 0.09 & 46.53 & 4.61 & 1.16 & 1.24 & 0.05 & 5.90 & 1.52 & 100.0 \\
\hline HLW-ALG-09 & 3.93 & 5.05 & 0.73 & 0.10 & 6.37 & 0.27 & 4.86 & 0.89 & 4.03 & 17.82 & 0.18 & 0.10 & 47.26 & 5.27 & 0.17 & 0.35 & 0.05 & 1.52 & 1.03 & 100.0 \\
\hline HLW-ALG-10 & 1.26 & 9.07 & 0.40 & 0.22 & 4.60 & 0.09 & 4.52 & 0.16 & 6.61 & 18.78 & 0.90 & 0.05 & 52.41 & 0.00 & 0.06 & 0.00 & 0.03 & 0.09 & 0.78 & 100.0 \\
\hline HLW-ALG-11 & 8.24 & 12.37 & 0.71 & 0.00 & 0.85 & 0.16 & 14.22 & 0.28 & 3.39 & 6.91 & 0.00 & 0.08 & 41.24 & 4.09 & 1.61 & 0.00 & 0.05 & 5.23 & 0.57 & 100.0 \\
\hline HLW-ALG-12 & 4.20 & 4.97 & 0.75 & 0.13 & 5.66 & 0.17 & 6.63 & 0.30 & 2.06 & 18.48 & 0.78 & 0.09 & 48.37 & 4.23 & 0.44 & 0.41 & 0.05 & 1.40 & 0.88 & 100.0 \\
\hline HLW-ALG-13 & 4.70 & 5.37 & 1.22 & 0.00 & 3.51 & 0.28 & 8.72 & 0.48 & 3.35 & 11.92 & 0.06 & 0.14 & 45.34 & 4.59 & 1.62 & 1.66 & 0.08 & 5.79 & 1.16 & 100.0 \\
\hline HLW-ALG-14 & 2.34 & 4.65 & 0.61 & 0.00 & 5.29 & 0.14 & 13.53 & 0.24 & 6.37 & 5.21 & 0.68 & 0.07 & 53.29 & 6.24 & 0.00 & 0.00 & 0.04 & 0.00 & 1.30 & 100.0 \\
\hline HLW-ALG-15 & 6.74 & 14.24 & 0.53 & 0.16 & 4.33 & 0.12 & 4.56 & 0.21 & 0.00 & 20.04 & 0.60 & 0.06 & 44.03 & 0.00 & 0.00 & 0.00 & 0.04 & 3.92 & 0.41 & 100.0 \\
\hline HLW-ALG-16 & 6.81 & 13.38 & 0.44 & 0.22 & 1.85 & 0.10 & 4.55 & 0.17 & 0.00 & 18.89 & 0.68 & 0.05 & 48.99 & 0.00 & 0.00 & 0.00 & 1.48 & 2.05 & 0.35 & 100.0 \\
\hline HLW-ALG-17 & 1.27 & 9.97 & 0.40 & 0.22 & 5.26 & 0.09 & 4.54 & 0.16 & 6.54 & 18.87 & 0.90 & 0.05 & 51.27 & 0.00 & 0.00 & 0.00 & 0.03 & 0.09 & 0.34 & 100.0 \\
\hline HLW-ALG-18 & 7.48 & 10.71 & 0.41 & 0.00 & 4.36 & 0.09 & 7.72 & 0.16 & 0.00 & 16.03 & 0.00 & 0.05 & 51.36 & 0.00 & 0.00 & 0.00 & 1.33 & 0.00 & 0.31 & 100.0 \\
\hline HLW-ALG-19 & 1.29 & 9.45 & 0.41 & 0.22 & 5.40 & 0.09 & 6.06 & 0.17 & 2.01 & 17.74 & 0.91 & 0.05 & 52.81 & 0.00 & 0.00 & 0.00 & 0.03 & 3.01 & 0.36 & 100.0 \\
\hline HLW-ALG-20 & 1.28 & 7.55 & 0.41 & 0.22 & 5.37 & 0.09 & 6.64 & 0.17 & 2.00 & 19.03 & 0.91 & 0.05 & 52.93 & 0.00 & 0.00 & 0.00 & 0.03 & 2.99 & 0.35 & 100.0 \\
\hline HLW-ALG-21 & 1.92 & 5.17 & 0.86 & 0.24 & 4.53 & 0.14 & 6.20 & 0.21 & 1.25 & 21.29 & 0.54 & 0.06 & 48.58 & 0.00 & 1.67 & 1.18 & 0.08 & 5.42 & 0.65 & 100.0 \\
\hline HLW-ALG-22 & 1.90 & 7.10 & 0.85 & 0.24 & 4.48 & 0.14 & 6.03 & 0.21 & 1.24 & 20.08 & 0.54 & 0.06 & 48.25 & 0.00 & 1.65 & 1.17 & 0.08 & 5.36 & 0.64 & 100.0 \\
\hline HLW-ALG-23 & 1.82 & 5.13 & 0.81 & 0.23 & 4.27 & 0.13 & 5.15 & 0.20 & 1.18 & 23.15 & 0.51 & 0.06 & 48.88 & 0.00 & 1.58 & 1.11 & 0.07 & 5.11 & 0.61 & 100.0 \\
\hline HLW-ALG-24 & 9.27 & 5.18 & 1.21 & 0.00 & 0.91 & 0.27 & 10.71 & 0.47 & 3.32 & 11.88 & 0.06 & 0.14 & 43.79 & 2.95 & 1.60 & 1.48 & 0.08 & 5.53 & 1.15 & 100.0 \\
\hline HLW-ALG-25 & 1.27 & 9.71 & 0.40 & 0.22 & 4.96 & 0.09 & 4.53 & 0.16 & 6.62 & 18.81 & 0.90 & 0.05 & 51.79 & 0.00 & 0.06 & 0.00 & 0.03 & 0.09 & 0.34 & 100.0 \\
\hline HLW-ALG-26 & 3.30 & 7.81 & 0.86 & 0.00 & 2.46 & 0.19 & 7.36 & 0.34 & 2.35 & 11.28 & 0.04 & 0.10 & 52.31 & 3.21 & 1.13 & 1.16 & 1.28 & 4.05 & 0.77 & 100.0 \\
\hline HLW-ALG-27 & 8.96 & 14.13 & 0.48 & 0.00 & 5.23 & 0.11 & 4.53 & 0.19 & 0.00 & 19.91 & 0.00 & 0.06 & 44.03 & 0.00 & 0.00 & 0.00 & 2.00 & 0.00 & 0.38 & 100.0 \\
\hline HLW-ALG-28 & 6.01 & 13.96 & 0.48 & 0.15 & 5.59 & 0.11 & 4.47 & 0.19 & 2.28 & 19.67 & 0.55 & 0.06 & 46.09 & 0.00 & 0.00 & 0.00 & 0.03 & 0.00 & 0.37 & 100.0 \\
\hline HLW-ALG-29 & 6.89 & 14.27 & 0.55 & 0.16 & 3.94 & 0.12 & 4.57 & 0.22 & 0.00 & 20.08 & 0.62 & 0.06 & 43.43 & 0.00 & 0.00 & 0.00 & 0.04 & 4.64 & 0.42 & 100.0 \\
\hline HLW-ALG-30 & 4.89 & 9.48 & 0.52 & 0.06 & 4.75 & 0.10 & 7.14 & 0.17 & 0.31 & 17.01 & 0.45 & 0.19 & 51.41 & 0.10 & 0.00 & 0.22 & 0.55 & 1.87 & 0.78 & 100.0 \\
\hline HLW-ALG-31 & 1.29 & 10.66 & 0.41 & 0.22 & 5.40 & 0.09 & 7.02 & 0.17 & 2.01 & 12.88 & 0.91 & 0.05 & 54.09 & 0.00 & 0.00 & 0.00 & 1.42 & 3.01 & 0.35 & 100.0 \\
\hline HLW-ALG-32 & 4.13 & 4.85 & 0.66 & 0.19 & 5.61 & 0.15 & 9.34 & 0.26 & 6.93 & 10.56 & 0.74 & 0.08 & 48.10 & 6.79 & 0.00 & 0.00 & 0.35 & 0.00 & 1.25 & 100.0 \\
\hline HLW-ALG-33 & 7.87 & 8.11 & 0.62 & 0.18 & 5.06 & 0.14 & 8.92 & 0.25 & 0.00 & 20.08 & 0.70 & 0.07 & 42.87 & 0.00 & 0.00 & 0.00 & 0.04 & 4.59 & 0.49 & 100.0 \\
\hline
\end{tabular}


Table F.1. Normalized Target Compositions (mol\%) of 305 HLW Simulated and Actual Waste Glasses (continued).

\begin{tabular}{|c|c|c|c|c|c|c|c|c|c|c|c|c|c|c|c|c|c|c|c|c|}
\hline Glass ID & $\mathbf{A l}_{2} \mathbf{O}_{3}$ & $\mathbf{B}_{2} \mathbf{O}_{3}$ & $\mathrm{CaO}$ & $\mathrm{Cr}_{2} \mathrm{O}_{3}$ & $\mathrm{Fe}_{2} \mathrm{O}_{3}$ & $\mathbf{K}_{2} \mathbf{O}$ & $\mathbf{L i}_{2} \mathbf{O}$ & MgO & MnO & $\mathrm{Na}_{2} \mathrm{O}$ & $\mathrm{NiO}$ & $\mathbf{P}_{2} \mathbf{O}_{5}$ & $\mathrm{SiO}_{2}$ & SrO & $\mathrm{ThO}_{2}$ & $\mathbf{U O}_{3}$ & ZnO & $\mathrm{ZrO}_{2}$ & Others & Sum \\
\hline HLW-ALG-34 & 1.27 & 7.91 & 0.39 & 0.22 & 5.25 & 0.09 & 4.53 & 0.16 & 6.53 & 20.54 & 0.89 & 0.05 & 51.72 & 0.00 & 0.00 & 0.00 & 0.03 & 0.09 & 0.34 & 100.0 \\
\hline HLW-ALG-35 & 3.93 & 5.01 & 0.73 & 0.10 & 6.38 & 0.27 & 6.81 & 0.89 & 4.03 & 12.67 & 0.18 & 0.10 & 49.45 & 5.28 & 0.17 & 0.35 & 1.10 & 1.52 & 1.02 & 100.0 \\
\hline HLW-ALG-36 & 4.72 & 6.89 & 0.85 & 0.15 & 6.37 & 0.19 & 7.16 & 0.33 & 2.32 & 14.90 & 0.88 & 0.10 & 46.79 & 4.77 & 0.50 & 0.46 & 0.06 & 1.58 & 0.99 & 100.0 \\
\hline HLW-ALG-37 & 4.78 & 5.44 & 1.24 & 0.00 & 3.57 & 0.28 & 6.80 & 0.48 & 3.41 & 11.90 & 0.06 & 0.14 & 45.97 & 4.67 & 1.65 & 1.69 & 0.83 & 5.89 & 1.18 & 100.0 \\
\hline HLW-ALG-38 & 1.96 & 8.52 & 0.87 & 0.25 & 4.61 & 0.14 & 7.24 & 0.21 & 1.27 & 12.89 & 0.55 & 0.06 & 51.96 & 0.00 & 1.70 & 1.20 & 0.39 & 5.51 & 0.66 & 100.0 \\
\hline HLW-ALG-39 & 1.32 & 10.27 & 0.58 & 0.17 & 3.08 & 0.09 & 7.29 & 0.15 & 0.85 & 12.50 & 0.37 & 0.04 & 55.93 & 0.00 & 1.13 & 0.80 & 1.35 & 3.68 & 0.39 & 100.0 \\
\hline HLW-ALG-40 & 6.46 & 8.69 & 0.68 & 0.08 & 6.29 & 0.13 & 7.33 & 0.23 & 0.41 & 16.59 & 0.59 & 0.25 & 48.19 & 0.13 & 0.00 & 0.29 & 0.14 & 2.47 & 1.03 & 100.0 \\
\hline HLW04-01 & 3.18 & 10.98 & 0.44 & 0.09 & 5.57 & 0.00 & 6.38 & 0.19 & 1.97 & 13.42 & 0.35 & 0.20 & 54.82 & 0.13 & 0.00 & 0.00 & 1.65 & 0.00 & 0.62 & 100.0 \\
\hline HLW04-02 & 3.19 & 12.22 & 0.44 & 0.09 & 5.58 & 0.00 & 6.39 & 0.19 & 1.97 & 13.45 & 0.35 & 0.20 & 53.51 & 0.13 & 0.00 & 0.00 & 1.65 & 0.00 & 0.62 & 100.0 \\
\hline HLW04-03 & 3.29 & 10.86 & 0.45 & 0.10 & 5.75 & 0.00 & 6.32 & 0.20 & 2.03 & 13.54 & 0.36 & 0.21 & 54.50 & 0.14 & 0.00 & 0.00 & 1.63 & 0.00 & 0.64 & 100.0 \\
\hline HLW04-04 & 3.05 & 10.47 & 0.42 & 0.09 & 5.32 & 0.00 & 6.36 & 0.18 & 1.88 & 13.69 & 0.33 & 0.19 & 55.54 & 0.13 & 0.00 & 0.10 & 1.66 & 0.00 & 0.59 & 100.0 \\
\hline HLW04-05 & 3.09 & 11.05 & 0.43 & 0.09 & 5.40 & 0.00 & 6.42 & 0.18 & 1.91 & 13.59 & 0.34 & 0.19 & 54.92 & 0.13 & 0.00 & 0.00 & 1.66 & 0.00 & 0.60 & 100.0 \\
\hline HLW04-06 & 3.29 & 10.15 & 0.45 & 0.10 & 5.75 & 0.00 & 5.98 & 0.20 & 2.03 & 13.52 & 0.36 & 0.21 & 55.55 & 0.14 & 0.00 & 0.00 & 1.63 & 0.00 & 0.64 & 100.0 \\
\hline HLW04-07 & 3.28 & 10.21 & 0.56 & 0.10 & 6.01 & 0.01 & 6.06 & 0.25 & 2.73 & 13.85 & 0.38 & 0.27 & 54.11 & 0.11 & 0.00 & 0.00 & 1.25 & 0.26 & 0.57 & 100.0 \\
\hline HLW04-07NRE9 & 3.28 & 10.21 & 0.56 & 0.10 & 6.01 & 0.01 & 6.06 & 0.25 & 2.73 & 13.85 & 0.38 & 0.27 & 54.11 & 0.11 & 0.00 & 0.00 & 1.25 & 0.26 & 0.57 & 100.0 \\
\hline HLW04-07NRE9CCC & 3.28 & 10.21 & 0.56 & 0.10 & 6.01 & 0.01 & 6.06 & 0.25 & 2.73 & 13.85 & 0.38 & 0.27 & 54.11 & 0.11 & 0.00 & 0.00 & 1.25 & 0.26 & 0.57 & 100.0 \\
\hline HLW04-07RE39 & 3.28 & 10.21 & 0.56 & 0.10 & 6.01 & 0.01 & 6.06 & 0.25 & 2.73 & 13.85 & 0.38 & 0.27 & 54.11 & 0.11 & 0.00 & 0.00 & 1.25 & 0.26 & 0.57 & 100.0 \\
\hline HLW04-07RE39CCC & 3.28 & 10.21 & 0.56 & 0.10 & 6.01 & 0.01 & 6.06 & 0.25 & 2.73 & 13.85 & 0.38 & 0.27 & 54.11 & 0.11 & 0.00 & 0.00 & 1.25 & 0.26 & 0.57 & 100.0 \\
\hline HLW04-08 & 3.20 & 10.17 & 0.54 & 0.10 & 5.86 & 0.01 & 6.04 & 0.24 & 2.66 & 13.68 & 0.37 & 0.26 & 54.70 & 0.11 & 0.00 & 0.00 & 1.24 & 0.25 & 0.56 & 100.0 \\
\hline HLW04-09 & 3.29 & 10.14 & 0.56 & 0.10 & 6.03 & 0.01 & 6.08 & 0.25 & 2.73 & 13.89 & 0.38 & 0.27 & 54.59 & 0.11 & 0.00 & 0.13 & 0.62 & 0.26 & 0.58 & 100.0 \\
\hline HLW98-34CG & 7.37 & 7.02 & 0.89 & 0.07 & 5.12 & 0.02 & 9.34 & 0.38 & 4.36 & 10.54 & 0.14 & 0.07 & 47.48 & 4.95 & 0.00 & 0.00 & 1.72 & 0.07 & 0.44 & 100.0 \\
\hline HLW98-51AW & 1.75 & 8.94 & 0.81 & 0.06 & 1.92 & 0.04 & 12.79 & 0.10 & 2.33 & 9.89 & 0.22 & 0.18 & 52.89 & 1.91 & 0.97 & 0.97 & 1.65 & 2.33 & 0.25 & 100.0 \\
\hline HLW98-51AWCG & 1.75 & 8.94 & 0.81 & 0.06 & 1.92 & 0.04 & 12.79 & 0.10 & 2.33 & 9.89 & 0.22 & 0.18 & 52.89 & 1.91 & 0.97 & 0.97 & 1.65 & 2.33 & 0.25 & 100.0 \\
\hline HLW98-61 & 5.12 & 3.89 & 0.59 & 0.05 & 5.20 & 0.02 & 11.34 & 0.20 & 0.98 & 15.21 & 0.69 & 0.22 & 53.10 & 0.98 & 0.00 & 0.41 & 0.03 & 0.81 & 1.14 & 100.0 \\
\hline HLW98-61CG1 & 5.12 & 3.89 & 0.59 & 0.05 & 5.20 & 0.02 & 11.34 & 0.20 & 0.98 & 15.21 & 0.69 & 0.22 & 53.10 & 0.98 & 0.00 & 0.41 & 0.03 & 0.81 & 1.14 & 100.0 \\
\hline HLW98-72 & 3.37 & 7.79 & 0.33 & 0.00 & 5.06 & 0.04 & 11.15 & 0.18 & 0.16 & 14.38 & 0.55 & 0.00 & 52.91 & 0.00 & 0.00 & 0.00 & 1.64 & 2.04 & 0.40 & 100.0 \\
\hline HLW98-74 & 3.60 & 7.86 & 0.35 & 0.00 & 5.40 & 0.05 & 11.24 & 0.19 & 0.17 & 14.58 & 0.59 & 0.00 & 51.69 & 0.02 & 0.00 & 0.00 & 1.66 & 2.18 & 0.43 & 100.0 \\
\hline HLW98-75 & 3.59 & 6.41 & 0.35 & 0.00 & 5.39 & 0.05 & 11.22 & 0.19 & 0.17 & 14.55 & 0.58 & 0.00 & 53.24 & 0.02 & 0.00 & 0.00 & 1.65 & 2.17 & 0.43 & 100.0 \\
\hline HLW98-77 & 3.45 & 11.60 & 0.34 & 0.00 & 5.19 & 0.02 & 8.00 & 0.18 & 0.16 & 12.75 & 0.56 & 0.00 & 53.54 & 0.02 & 0.00 & 0.00 & 1.68 & 2.09 & 0.42 & 100.0 \\
\hline HLW98-77CG & 3.45 & 11.60 & 0.34 & 0.00 & 5.19 & 0.02 & 8.00 & 0.18 & 0.16 & 12.75 & 0.56 & 0.00 & 53.54 & 0.02 & 0.00 & 0.00 & 1.68 & 2.09 & 0.42 & 100.0 \\
\hline
\end{tabular}


Table F.1. Normalized Target Compositions (mol\%) of 305 HLW Simulated and Actual Waste Glasses (continued).

\begin{tabular}{|c|c|c|c|c|c|c|c|c|c|c|c|c|c|c|c|c|c|c|c|c|}
\hline Glass ID & $\mathbf{A l}_{2} \mathbf{O}_{3}$ & $\mathbf{B}_{2} \mathbf{O}_{3}$ & $\mathrm{CaO}$ & $\mathrm{Cr}_{2} \mathrm{O}_{3}$ & $\mathrm{Fe}_{2} \mathrm{O}_{3}$ & $\mathbf{K}_{2} \mathbf{O}$ & $\mathbf{L i}_{2} \mathbf{O}$ & MgO & MnO & $\mathrm{Na}_{2} \mathrm{O}$ & NiO & $\mathbf{P}_{2} \mathbf{O}_{5}$ & $\mathrm{SiO}_{2}$ & SrO & $\mathrm{ThO}_{2}$ & $\mathbf{U O}_{3}$ & ZnO & $\mathrm{ZrO}_{2}$ & Others & Sum \\
\hline HLW98-80 & 3.70 & 12.16 & 0.28 & 0.00 & 5.30 & 0.02 & 7.37 & 0.12 & 0.34 & 13.11 & 0.40 & 0.01 & 54.30 & 0.00 & 0.00 & 0.00 & 1.67 & 0.97 & 0.24 & 100.0 \\
\hline HLW98-80CG & 3.70 & 12.16 & 0.28 & 0.00 & 5.30 & 0.02 & 7.37 & 0.12 & 0.34 & 13.11 & 0.40 & 0.01 & 54.30 & 0.00 & 0.00 & 0.00 & 1.67 & 0.97 & 0.24 & 100.0 \\
\hline HLW98-83 & 0.93 & 11.36 & 0.79 & 0.02 & 5.30 & 0.00 & 6.12 & 0.93 & 2.85 & 12.58 & 0.33 & 0.05 & 56.29 & 0.00 & 0.00 & 0.00 & 1.65 & 0.07 & 0.73 & 100.0 \\
\hline HLW98-84 & 3.43 & 10.82 & 0.80 & 0.02 & 5.39 & 0.00 & 6.22 & 0.95 & 2.89 & 2.89 & 13.05 & 0.05 & 53.55 & 0.00 & 0.00 & 0.00 & 1.67 & 0.07 & 0.74 & 100.0 \\
\hline HLW98-84CG & 3.43 & 10.82 & 0.80 & 0.02 & 5.39 & 0.00 & 6.22 & 0.95 & 2.89 & 2.89 & 13.05 & 0.05 & 53.55 & 0.00 & 0.00 & 0.00 & 1.67 & 0.07 & 0.74 & 100.0 \\
\hline HLW98-86 & 3.50 & 9.09 & 0.36 & 0.03 & 5.30 & 0.00 & 6.78 & 1.95 & 3.79 & 3.79 & 12.88 & 0.04 & 52.79 & 0.60 & 0.00 & 0.00 & 1.72 & 0.14 & 0.87 & 100.0 \\
\hline HLW98-86AG & 3.50 & 9.10 & 0.36 & 0.03 & 5.30 & 0.00 & 6.79 & 1.95 & 3.79 & 3.79 & 12.88 & 0.04 & 52.81 & 0.60 & 0.00 & 0.00 & 1.72 & 0.14 & 0.82 & 100.0 \\
\hline HLW98-86CG & 3.50 & 9.09 & 0.36 & 0.03 & 5.30 & 0.00 & 6.78 & 1.95 & 3.79 & 3.79 & 12.88 & 0.04 & 52.79 & 0.60 & 0.00 & 0.00 & 1.72 & 0.14 & 0.87 & 100.0 \\
\hline HLW98-87 & 5.25 & 10.11 & 0.55 & 0.07 & 5.13 & 0.53 & 8.18 & 0.18 & 0.34 & 0.34 & 12.45 & 0.21 & 51.58 & 0.11 & 0.00 & 0.24 & 1.72 & 2.02 & 0.87 & 100.0 \\
\hline HLW98-88 & 5.06 & 10.53 & 0.53 & 0.06 & 4.94 & 0.51 & 8.70 & 0.17 & 0.33 & 0.33 & 13.07 & 0.20 & 50.61 & 0.11 & 0.00 & 0.23 & 1.71 & 1.95 & 0.84 & 100.0 \\
\hline HLW98-89 & 2.37 & 9.38 & 0.58 & 0.03 & 4.02 & 0.00 & 6.83 & 0.00 & 1.44 & 1.44 & 12.43 & 0.02 & 53.24 & 0.00 & 1.10 & 0.65 & 1.78 & 5.15 & 0.56 & 100.0 \\
\hline HLW98-94 & 6.29 & 11.31 & 0.30 & 0.01 & 4.51 & 0.30 & 8.86 & 0.15 & 0.12 & 0.12 & 13.08 & 0.00 & 50.03 & 0.02 & 0.00 & 0.00 & 1.73 & 1.80 & 0.94 & 100.0 \\
\hline HLW98-95 & 4.94 & 10.50 & 0.52 & 0.06 & 4.83 & 0.10 & 8.65 & 0.17 & 0.32 & 0.32 & 13.23 & 0.19 & 51.15 & 0.10 & 0.00 & 0.22 & 1.70 & 1.90 & 0.96 & 100.0 \\
\hline HLW98-95CG-1 & 4.94 & 10.50 & 0.52 & 0.06 & 4.83 & 0.10 & 8.65 & 0.17 & 0.32 & 0.32 & 13.23 & 0.19 & 51.15 & 0.10 & 0.00 & 0.22 & 1.70 & 1.90 & 0.96 & 100.0 \\
\hline HLW98-96 & 2.36 & 10.39 & 0.58 & 0.03 & 4.02 & 0.00 & 7.42 & 0.00 & 1.44 & 1.44 & 12.42 & 0.02 & 51.68 & 0.00 & 1.10 & 0.64 & 1.78 & 5.14 & 0.56 & 100.0 \\
\hline HLW98-96A & 2.38 & 10.49 & 0.58 & 0.03 & 4.05 & 0.00 & 7.49 & 0.00 & 1.45 & 1.45 & 12.53 & 0.02 & 52.13 & 0.00 & 0.00 & 0.00 & 1.79 & 5.19 & 1.45 & 100.0 \\
\hline HLW98-96B & 2.37 & 10.43 & 0.58 & 0.03 & 4.03 & 0.00 & 7.44 & 0.00 & 1.44 & 1.44 & 12.46 & 0.02 & 51.85 & 0.00 & 0.00 & 0.00 & 1.78 & 5.16 & 1.99 & 100.0 \\
\hline HLW98-96CG & 2.36 & 10.39 & 0.58 & 0.03 & 4.02 & 0.00 & 7.42 & 0.00 & 1.44 & 1.44 & 12.42 & 0.02 & 51.68 & 0.00 & 1.10 & 0.64 & 1.78 & 5.14 & 0.56 & 100.0 \\
\hline HLW98-96D & 2.40 & 10.58 & 0.59 & 0.03 & 4.09 & 0.00 & 7.55 & 0.00 & 1.46 & 1.46 & 12.64 & 0.02 & 52.60 & 0.00 & 0.00 & 0.00 & 1.81 & 5.24 & 0.57 & 100.0 \\
\hline HLW98-96NRE4 & 2.36 & 10.39 & 0.58 & 0.03 & 4.01 & 0.00 & 7.42 & 0.00 & 1.44 & 1.44 & 12.41 & 0.02 & 51.66 & 0.00 & 1.10 & 0.64 & 1.78 & 5.14 & 0.60 & 100.0 \\
\hline HLW98-96NRE4CCC & 2.36 & 10.39 & 0.58 & 0.03 & 4.01 & 0.00 & 7.42 & 0.00 & 1.44 & 1.44 & 12.41 & 0.02 & 51.66 & 0.00 & 1.10 & 0.64 & 1.78 & 5.14 & 0.60 & 100.0 \\
\hline HLW98-96RE7 & 2.36 & 10.39 & 0.58 & 0.03 & 4.02 & 0.00 & 7.42 & 0.00 & 1.44 & 1.44 & 12.42 & 0.02 & 51.68 & 0.00 & 1.10 & 0.64 & 1.78 & 5.14 & 0.56 & 100.0 \\
\hline HLW98-96RE7CCC & 2.36 & 10.39 & 0.58 & 0.03 & 4.02 & 0.00 & 7.42 & 0.00 & 1.44 & 1.44 & 12.42 & 0.02 & 51.68 & 0.00 & 1.10 & 0.64 & 1.78 & 5.14 & 0.56 & 100.0 \\
\hline HLW98-97 & 6.58 & 10.92 & 0.31 & 0.01 & 4.72 & 0.31 & 8.93 & 0.16 & 0.12 & 0.12 & 13.52 & 0.00 & 49.23 & 0.02 & 0.00 & 0.00 & 1.74 & 1.88 & 0.98 & 100.0 \\
\hline HLW98-T05 & 3.57 & 11.49 & 0.54 & 0.01 & 5.34 & 0.01 & 6.80 & 0.53 & 1.62 & 1.62 & 13.08 & 0.03 & 53.93 & 0.00 & 0.00 & 0.00 & 1.67 & 0.52 & 0.49 & 100.0 \\
\hline HLW98-V01 & 4.17 & 11.23 & 0.41 & 0.00 & 6.26 & 0.03 & 7.73 & 0.22 & 0.20 & 0.20 & 12.61 & 0.00 & 51.79 & 0.03 & 0.00 & 0.00 & 1.62 & 2.53 & 0.51 & 100.0 \\
\hline HLW98-V07 & 4.47 & 11.87 & 0.34 & 0.00 & 6.40 & 0.03 & 7.13 & 0.15 & 0.41 & 0.41 & 12.88 & 0.01 & 52.75 & 0.00 & 0.00 & 0.00 & 1.62 & 1.17 & 0.29 & 100.0 \\
\hline HLW98-V13 & 3.53 & 10.46 & 0.97 & 0.02 & 6.49 & 0.00 & 6.00 & 1.14 & 3.48 & 3.48 & 12.70 & 0.06 & 52.16 & 0.00 & 0.00 & 0.00 & 1.62 & 0.08 & 0.90 & 100.0 \\
\hline HLW98-V19 & 3.90 & 8.72 & 0.43 & 0.04 & 6.33 & 0.00 & 6.48 & 2.33 & 4.53 & 4.53 & 12.45 & 0.05 & 50.98 & 0.71 & 0.00 & 0.00 & 1.65 & 0.17 & 1.03 & 100.0 \\
\hline HLW98-V24 & 3.05 & 9.50 & 0.28 & 0.03 & 4.17 & 0.00 & 7.11 & 1.53 & 2.98 & 2.98 & 13.34 & 0.04 & 54.78 & 0.47 & 0.00 & 0.00 & 1.78 & 0.11 & 0.68 & 100.0 \\
\hline
\end{tabular}


Table F.1. Normalized Target Compositions (mol\%) of 305 HLW Simulated and Actual Waste Glasses (continued).

\begin{tabular}{|c|c|c|c|c|c|c|c|c|c|c|c|c|c|c|c|c|c|c|c|c|}
\hline Glass ID & $\mathbf{A l}_{2} \mathbf{O}_{3}$ & $\mathbf{B}_{2} \mathbf{O}_{3}$ & $\mathrm{CaO}$ & $\mathrm{Cr}_{2} \mathrm{O}_{3}$ & $\mathrm{Fe}_{2} \mathrm{O}_{3}$ & $\mathrm{~K}_{2} \mathrm{O}$ & $\mathbf{L i}_{2} \mathbf{O}$ & $\mathrm{Na}_{2} \mathrm{O}$ & MgO & MnO & $\mathrm{NiO}$ & $\mathbf{P}_{2} \mathbf{O}_{5}$ & $\mathrm{SiO}_{2}$ & SrO & $\mathrm{ThO}_{2}$ & $\mathbf{U O}_{3}$ & ZnO & $\mathrm{ZrO}_{2}$ & Others & Sum \\
\hline AZ101 Actual & 5.62 & 10.09 & 0.58 & 0.06 & 5.24 & 0.01 & 8.70 & 0.19 & 0.29 & 11.89 & 0.50 & 0.22 & 51.36 & 0.13 & 0.00 & 0.22 & 1.70 & 2.11 & 1.07 & 100.0 \\
\hline AZ-102 Actual & 5.21 & 3.70 & 0.41 & 0.05 & 5.28 & 0.02 & 11.81 & 0.30 & 0.87 & 15.04 & 0.72 & 0.27 & 53.03 & 0.81 & 0.00 & 0.41 & 0.03 & 0.97 & 1.07 & 100.0 \\
\hline C-104 Actual & 1.75 & 8.94 & 0.81 & 0.06 & 1.92 & 0.04 & 12.79 & 0.10 & 2.33 & 9.89 & 0.22 & 0.18 & 52.88 & 1.91 & 0.97 & 0.97 & 1.65 & 2.33 & 0.26 & 100.0 \\
\hline C-106 Actual & 4.85 & 4.33 & 0.88 & 0.13 & 5.52 & 0.23 & 9.49 & 0.26 & 3.31 & 14.14 & 0.27 & 0.30 & 51.02 & 4.11 & 0.00 & 0.00 & 0.25 & 0.28 & 0.64 & 100.0 \\
\hline $\begin{array}{l}\text { AY-102/C- } \\
106 \text { Actual }\end{array}$ & 3.52 & 14.52 & 0.58 & 0.08 & 6.06 & 0.16 & 6.23 & 0.22 & 2.78 & 8.76 & 0.37 & 0.18 & 54.81 & 0.13 & 0.00 & 0.12 & 0.62 & 0.24 & 0.60 & 100.0 \\
\hline
\end{tabular}




\section{Appendix G}

\section{Glass Melt Electrical Conductivity and Viscosity Values at a Temperature of $1150^{\circ} \mathrm{C}$ Calculated Using Vogel-Fulcher Equation Fits}




\section{Appendix G}

\section{Glass Melt Electrical Conductivity and Viscosity Values at a Temperature of $1150^{\circ} \mathrm{C}$ Calculated Using Vogel-Fulcher Equation Fits}

This appendix lists electrical conductivity (EC) and viscosity values of high-level waste (HLW) simulated glasses calculated at a temperature of $1150^{\circ} \mathrm{C}$ using Vogel-Fulcher fits to the property-temperature data for each HLW glass. Specifically, the Vogel-Fulcher equation (Equation 4.1 in Section 4.3.1) was fitted to the EC-at-temperature and viscosity-at-temperature data collected for each of 214 simulated HLW glasses having data for EC and/or viscosity. The fitted Vogel-Fulcher equation for each HLW glass was then used to calculate the EC or viscosity at $1150^{\circ} \mathrm{C}$ for that HLW glass. Out of the 214 glasses, 210 have EC data while a different subset of 210 have viscosity data. 
Table G.1. Glass Melt Electrical Conductivity (S/cm) and Viscosity (P) at a Temperature of $1150^{\circ} \mathrm{C}$ Calculated Using Vogel-Fulcher Equation Fits.

\begin{tabular}{|c|c|c|c|c|c|}
\hline Glass ID & $\begin{array}{c}\text { Electrical } \\
\text { Conductivity } \\
\text { at } 1150^{\circ} \mathrm{C}\end{array}$ & $\begin{array}{l}\text { Viscosity at } \\
1150^{\circ} \mathrm{C}\end{array}$ & Glass ID & $\begin{array}{c}\text { Electrical } \\
\text { Conductivity } \\
\text { at } 1150^{\circ} \mathrm{C}\end{array}$ & $\begin{array}{l}\text { Viscosity at } \\
1150^{\circ} \mathrm{C}\end{array}$ \\
\hline HLW02-01 & 0.340 & 30.84 & HLW02-37 & 0.310 & 33.92 \\
\hline HLW02-02 & 0.238 & 39.86 & HLW02-38 & 0.273 & 19.16 \\
\hline HLW02-03 & 0.378 & 18.27 & HLW02-39 & 0.189 & 123.62 \\
\hline HLW02-04 & 0.331 & 114.28 & HLW02-40 & 0.161 & 156.79 \\
\hline HLW02-05 & 0.488 & 54.56 & HLW02-41 & 0.160 & 79.38 \\
\hline HLW02-06 & 0.465 & 89.36 & HLW02-42 & 0.358 & 21.28 \\
\hline HLW02-07 & 0.450 & 70.98 & HLW02-43 & 0.188 & 19.30 \\
\hline HLW02-08 & 0.405 & 11.39 & HLW02-44 & 0.459 & 32.68 \\
\hline HLW02-09 & 0.326 & 16.86 & HLW02-45 & 0.179 & 70.53 \\
\hline HLW02-10 & 0.387 & 13.65 & HLW02-46 & 0.232 & 52.16 \\
\hline HLW02-11 & 0.402 & 15.56 & HLW02-47 & 0.165 & 86.93 \\
\hline HLW02-12 & 0.553 & 13.90 & HLW02-48 & 0.394 & 20.17 \\
\hline HLW02-13 & 0.456 & 13.06 & HLW02-49 & 0.299 & 33.06 \\
\hline HLW02-14 & 0.431 & 25.13 & HLW02-50 & 0.181 & 51.32 \\
\hline HLW02-15 & 0.258 & 23.91 & HLW02-51 & 0.247 & 48.26 \\
\hline HLW02-16 & 0.399 & 22.19 & HLW02-52 & 0.281 & 31.10 \\
\hline HLW02-17 & 0.316 & 84.75 & HLW02-53 & 0.353 & 100.90 \\
\hline HLW02-18 & 0.282 & 113.36 & HLW02-54 & 0.324 & 103.18 \\
\hline HLW02-19 & 0.146 & 22.91 & HLW02-55 & 0.278 & 17.72 \\
\hline HLW02-20 & 0.085 & 161.47 & HLW02-56 & 0.319 & 29.03 \\
\hline HLW02-21 & 0.276 & 68.41 & HLW02-57 & 0.322 & 12.45 \\
\hline HLW02-22 & 0.226 & 102.69 & HLW03-01 & 0.443 & 12.46 \\
\hline HLW02-23 & 0.313 & 14.82 & HLW03-02 & 0.220 & 13.98 \\
\hline HLW02-24 & 0.174 & 111.89 & HLW03-03 & 0.249 & 11.52 \\
\hline HLW02-25 & 0.173 & 151.10 & HLW03-04 & 0.387 & 12.89 \\
\hline HLW02-26 & 0.290 & 18.62 & HLW03-05 & 0.379 & 68.14 \\
\hline HLW02-27 & 0.361 & 13.39 & HLW03-06 & 0.302 & 90.73 \\
\hline HLW02-28 & 0.417 & 37.65 & HLW03-07 & 0.685 & 13.16 \\
\hline HLW02-29 & 0.353 & 31.71 & HLW03-08 & 0.778 & Not Fitted $^{(\mathrm{a})}$ \\
\hline HLW02-30 & 0.418 & 13.74 & HLW03-09 & 0.343 & 88.44 \\
\hline HLW02-31 & 0.390 & 25.58 & HLW03-10 & 0.737 & 13.18 \\
\hline HLW02-32 & 0.357 & 37.33 & HLW03-11 & 0.379 & 111.46 \\
\hline HLW02-33 & 0.326 & 22.16 & HLW03-12 & 0.318 & 27.57 \\
\hline HLW02-34 & 0.281 & 15.58 & HLW03-13 & 0.326 & 21.26 \\
\hline HLW02-35 & 0.381 & 16.71 & HLW03-14 & 0.325 & 12.88 \\
\hline HLW02-36 & 0.263 & 35.77 & HLW03-15 & 0.127 & 138.72 \\
\hline
\end{tabular}

(a) Heavy crystallization observed during measurements. No data were collected. 
Table G.1. Glass Melt Electrical Conductivity (S/cm) and Viscosity (P) at a Temperature of $1150^{\circ} \mathrm{C}$ Calculated Using Vogel-Fulcher Equation Fits.

\begin{tabular}{|c|c|c|c|c|c|}
\hline Glass ID & $\begin{array}{c}\text { Electrical } \\
\text { Conductivity } \\
\text { at } 1150^{\circ} \mathrm{C}\end{array}$ & $\begin{array}{l}\text { Viscosity at } \\
1150^{\circ} \mathrm{C}\end{array}$ & Glass ID & $\begin{array}{c}\text { Electrical } \\
\text { Conductivity } \\
\text { at } 1150^{\circ} \mathrm{C}\end{array}$ & $\begin{array}{l}\text { Viscosity at } \\
1150^{\circ} \mathrm{C}\end{array}$ \\
\hline HLW03-16 & 0.146 & 42.40 & HLW05-21 & 0.537 & 14.27 \\
\hline HLW03-17 & 0.133 & 185.51 & HLW05-22 & 0.203 & 177.46 \\
\hline HLW03-18 & 0.530 & 32.52 & HLW05-27 & 0.548 & 26.15 \\
\hline HLW03-19 & 0.530 & 32.28 & HLW06-02 & 0.535 & 29.34 \\
\hline HLW03-20 & 0.544 & 33.06 & HLW06-04 & 0.542 & Not Fitted ${ }^{(b)}$ \\
\hline HLW03-21 & 0.252 & 131.82 & HLW06-22 & 0.430 & 15.39 \\
\hline HLW03-22 & 0.345 & 47.70 & HLW06-32 & 0.577 & 7.31 \\
\hline HLW03-23 & 0.332 & 42.49 & HLW06-34 & 0.514 & 13.48 \\
\hline HLW03-24 & 0.368 & 48.24 & HLW07-01 & 0.221 & 80.92 \\
\hline HLW03-25 & 0.343 & 28.92 & HLW07-02 & 0.245 & 75.62 \\
\hline HLW03-26 & 0.485 & 21.25 & HLW07-03 & 0.338 & 35.97 \\
\hline HLW03-27 & 0.440 & 24.39 & HLW07-04 & 0.292 & 111.59 \\
\hline HLW03-28 & 0.507 & 12.25 & HLW07-05 & 0.680 & 14.00 \\
\hline HLW03-29 & 0.566 & 19.16 & HLW07-06 & 0.190 & 102.42 \\
\hline HLW03-30 & 0.338 & 28.48 & HLW07-07 & 0.409 & 17.84 \\
\hline HLW03-31 & 0.353 & 53.41 & HLW07-08 & 0.331 & Not Fitted $^{(\mathrm{c})}$ \\
\hline HLW03-32 & 0.432 & 32.76 & HLW07-09 & 0.443 & 14.51 \\
\hline HLW03-33 & 0.274 & 33.20 & HLW07-10 & 0.123 & 29.43 \\
\hline HLW03-34 & 0.211 & 115.48 & HLW07-11 & 0.588 & 18.27 \\
\hline HLW03-35 & 0.146 & 169.35 & HLW07-12 & 0.692 & 23.03 \\
\hline HLW03-36 & 0.184 & 179.32 & HLW07-13 & 0.407 & 187.94 \\
\hline HLW03-37 & 0.355 & 22.65 & HLW07-14 & 0.216 & Not Fitted $^{(\mathrm{c})}$ \\
\hline HLW03-38 & 0.308 & 107.20 & HLW07-15 & 0.477 & 28.15 \\
\hline HLW03-39 & 0.227 & 66.63 & HLW07-16 & 0.983 & 8.04 \\
\hline HLW03-40 & 0.324 & 40.40 & HLW07-17 & 0.763 & 11.76 \\
\hline HLW03-41 & 0.300 & 37.79 & HLW07-18 & 0.657 & 11.02 \\
\hline HLW03-42 & 0.181 & 65.36 & HLW07-19 & 0.767 & 9.00 \\
\hline HLW03-43 & 0.305 & 108.19 & HLW07-20 & 0.221 & 89.59 \\
\hline HLW03-44 & 0.409 & 113.04 & HLW07-21 & 0.112 & 278.64 \\
\hline HLW03-45 & 0.492 & 19.31 & HLW07-22 & 0.132 & 150.39 \\
\hline HLW04-01 & 0.374 & 39.12 & HLW07-23 & 0.125 & 97.03 \\
\hline HLW04-03 & Not Fitted $^{(a)}$ & 55.84 & HLW07-24 & 0.368 & 118.61 \\
\hline HLW04-06 & Not Fitted $^{(\text {a) }}$ & 55.94 & HLW07-25 & 0.162 & 257.91 \\
\hline HLW04-07 & Not Fitted ${ }^{(a)}$ & 44.85 & HLW07-26 & 0.224 & 118.68 \\
\hline HLW05-15 & 0.344 & 229.91 & HLW07-27 & 0.346 & 39.90 \\
\hline HLW05-20 & 0.445 & 79.78 & HLW07-28 & 0.182 & 85.17 \\
\hline
\end{tabular}

(a) Measurements of electrical conductivity were not performed.

(b) Non-Newtonian behavior observed at measurement temperatures $\leq 1066^{\circ} \mathrm{C}$.

(c) Non-Newtonian behavior observed at all measurement temperatures. 
Table G.1. Glass Melt Electrical Conductivity (S/cm) and Viscosity (P) at a Temperature of $1150^{\circ} \mathrm{C}$ Calculated Using Vogel-Fulcher Equation Fits.

\begin{tabular}{|c|c|c|c|c|c|}
\hline Glass ID & $\begin{array}{c}\text { Electrical } \\
\text { Conductivity } \\
\text { at } 1150^{\circ} \mathrm{C} \\
\end{array}$ & $\begin{array}{c}\text { Viscosity at } \\
1150^{\circ} \mathrm{C}\end{array}$ & Glass ID & $\begin{array}{c}\text { Electrical } \\
\text { Conductivity } \\
\text { at } 1150^{\circ} \mathrm{C} \\
\end{array}$ & $\begin{array}{c}\text { Viscosity at } \\
1150^{\circ} \mathrm{C}\end{array}$ \\
\hline HLW07-29 & 0.196 & 42.46 & HLW-ALG-24 & 0.386 & Not Fitted $^{(\mathrm{b})}$ \\
\hline HLW07-30 & 0.212 & 125.87 & HLW-ALG-25 & 0.520 & 17.69 \\
\hline HLW07-31 & 0.182 & 108.31 & HLW-ALG-26 & 0.308 & 63.43 \\
\hline HLW07-32 & 0.220 & 58.79 & HLW-ALG-27 & 0.577 & 33.42 \\
\hline HLW07-33 & 0.239 & 99.10 & HLW-ALG-28 & 0.523 & 22.53 \\
\hline HLW07-34 & 0.244 & 111.55 & HLW-ALG-29 & 0.529 & 38.78 \\
\hline HLW07-35 & 0.166 & 105.87 & HLW-ALG-30 & 0.532 & 40.18 \\
\hline HLW07-36 & 0.315 & 54.92 & HLW-ALG-31 & 0.311 & 40.20 \\
\hline HLW07-37 & 0.429 & 18.83 & HLW-ALG-32 & 0.408 & 15.81 \\
\hline HLW07-38 & 0.205 & 87.22 & HLW-ALG-33 & 0.638 & 32.56 \\
\hline HLW07-39 & 0.218 & 100.21 & HLW-ALG-34 & 0.616 & 15.14 \\
\hline HLW07-40 & 0.517 & 34.57 & HLW-ALG-35 & 0.328 & 31.68 \\
\hline HLW-ALG-01 & 0.567 & 29.55 & HLW-ALG-36 & 0.480 & 22.63 \\
\hline HLW-ALG-02 & 0.458 & 37.88 & HLW-ALG-37 & 0.308 & 67.88 \\
\hline HLW-ALG-03 & 0.665 & 17.26 & HLW-ALG-38 & 0.249 & 59.34 \\
\hline HLW-ALG-04 & 0.472 & 29.46 & HLW-ALG-39 & 0.333 & 65.13 \\
\hline HLW-ALG-05 & 0.337 & 15.74 & HLW-ALG-40 & 0.525 & 42.26 \\
\hline HLW-ALG-06 & 0.448 & 28.25 & HLW98-72 & 0.636 & 29.05 \\
\hline HLW-ALG-07 & 0.306 & 58.70 & HLW98-77 & 0.360 & 49.87 \\
\hline HLW-ALG-08 & 0.376 & 21.29 & HLW98-80 & 0.362 & 50.92 \\
\hline HLW-ALG-09 & 0.474 & 20.30 & HLW98-83 & 0.338 & 37.85 \\
\hline HLW-ALG-10 & 0.619 & 19.30 & HLW98-84 & 0.391 & 49.70 \\
\hline HLW-ALG-11 & 0.424 & 25.06 & HLW98-86AG & 0.364 & 43.53 \\
\hline HLW-ALG-12 & 0.529 & 24.45 & HLW98-87 & Not Fitted $^{(\text {a) }}$ & 66.50 \\
\hline HLW-ALG-13 & 0.364 & 47.83 & HLW98-88 & 0.346 & 46.37 \\
\hline HLW-ALG-14 & 0.429 & 18.73 & HLW98-89 & 0.355 & 70.77 \\
\hline HLW-ALG-15 & 0.534 & 33.82 & HLW98-95 & 0.367 & 54.08 \\
\hline HLW-ALG-16 & 0.574 & 43.30 & HLW98-96 & 0.279 & 56.90 \\
\hline HLW-ALG-17 & 0.464 & 18.98 & HLW98-96A & 0.335 & 45.35 \\
\hline HLW-ALG-18 & 0.440 & 61.92 & HLW98-96B & 0.387 & 59.24 \\
\hline HLW-ALG-19 & 0.482 & 32.34 & HLW98-96D & 0.467 & 64.61 \\
\hline HLW-ALG-20 & 0.630 & 26.30 & HLW98-97 & 0.369 & 43.16 \\
\hline HLW-ALG-21 & 0.546 & 37.30 & HLW98-T05 & 0.356 & 45.75 \\
\hline HLW-ALG-22 & 0.644 & 32.54 & HLW98-V19 & 0.343 & 34.85 \\
\hline HLW-ALG-23 & 0.825 & 30.83 & HLW98-V24 & 0.385 & 45.18 \\
\hline
\end{tabular}

(a) Measurements of electrical conductivity were not performed.

(b) Non-Newtonian behavior observed at all measurement temperatures. 